\title{
INTERNATIONAL GONFERENGE ON EURASIAN ECONOMIES 2015
}




\title{
INTERNATIONAL CONFERENCE ON EURASIAN ECONOMIES \\ 2015
}

\author{
Editors: \\ Selahattin Sarı \\ Alp H. Gencer \\ İlyas Sözen
}

\author{
Copyright (C) 2015 \\ Eurasian Economists Association
}

\begin{abstract}
ALL RIGHTS RESERVED.
This book contains material protected under International and Federal Copyright Laws and Treaties. Any unauthorized reprint or use of this material is prohibited. No part of this book may be reproduced or transmitted in any form or by any means, electronic or mechanical, including photocopying, recording, or by any information storage and retrieval system without express written permission from the publisher.
\end{abstract}

ISBN: 978-975-6319-24-6

Typesetting: Alp H. Gencer 


\title{
INTERNATIONAL CONFERENGE ON EURASIAN EBONOMIES 2015
}

\author{
Kazan - Russia \\ 9-11 September 2015
}




\section{FOREWORD}

The International Conference on Eurasian Economies 2015, organized by Beykent University in collaboration with the Federal University of Kazan and Manas University was held between 9-11 September in Kazan-Tatarstan-Russia.

This year's conference was the sixth andhas provoked as much interest as in the previous years. However, due to the feasibility of the conference, as well as the editability of the content of the applications evaluated by the referees, we regret to say that it was impossible to invite all the applicants.

On the other hand, on the behalf of the organizing committee, we are very glad to announce that the highly academic level of the participants and their duscussions was as pleasing as in the previous conferences. We had received 259 abstracts, from Indonesia to China, from Europe to Russia, from the United States to the all Turkic Republics. There were abstracts sent from 16 countries and from almost every university in Turkey. In the preliminary assessment 188 abstracts were accepted, only 123 of which, alongside with their full papers were found eligible for presentation. As in the every conference, the papers presented in the Kazan Conference are also published as a book. Ascribed to the conference rules, only those papers that were presented at the conference took place in the conference book. We are indepted to our distinguished referees and the members of the scientific committee who evaluated the double-blind refereeing papers for their hard work and devotion.

Preference was given to the papers that dwelt on the problems and solutions of the Eurasian countries, their resources and wealth in respect to their integration and contribution to the world economy. Hence, topics on the position of the Eurasian economy in the financial markets, financial crisis, along with the environmental factors and sectors such as tourism, energy, natural resources and agriculture, as well as topics on problems and solutions through growth and development models, public policy, legal and bureaucratic infrastructure arrangements took place. Presented papers were in Turkish, English and Russian.

The most significant facet in organizing the International Conference on Eurasian Economies has been the enormous support of the Beykent University Board of Trustees, the University Rector, General Secretary, staff of the Public Relations Department and all the administrative staff. Therefore, we would like to express our innermost gratitude to them all.

We are grateful to our organising partner Kazan Federal University vice-rectors, Dr. Linar Latypov and Prof. Dr. Nailya Bagautdinova and the staff of the Foreign Relations Department for their support and devotion. Also, many thanks to the Rector of Manas University and Jusup Primbaev, the head of the Department of Economics.

There was a need of financial support for the conference. Therefore, we are most grateful to the Governor, the Managers and the Specialists of the Central Bank of Turkey for their valuable support and encouragement from the very first day. We would also like to thank to the President and the specialists of the Turkish Cooperation and Development Agency.

As can be imagined, organizing and holding a conference, as well as preparing a conference book, all require an enormous effort and pedantic work. Thus, working with no hesitation and no time limit was the motto of the organizing committee, and therefore, the most deserved thank you and appriciation goes for them.

And last, but not least, undoubtedly, the biggest thank you goes to all the participants, academicians and researchers from all around the world, without whom the conference would not have been realized.

We do hope the conference would be of a great asset to the Eurasian countries and the world of science. We hope to see you all again in another Eurasian country.

\section{Prof. Dr. Selahattin Sarı}

Conference Chair 


\section{ÖNSÖZ}

Beykent Üniversitesi, Kazan Federal Üniversitesi ve Manas Üniversitesi'nin birlikte düzenlediği "Uluslararas1 Avrasya Ekonomileri 2015" konferans1 Kazan-Tataristan/Rusya'da 9-11 Eylül 2015 tarihlerinde gerçekleştirilmiştir. Bu sene Altıncısı düzenlenen konferansa daha öncekilerde olduğu gibi çok yoğun bir talep olmuştur. Ancak; başvuruların tamamını gerek konferansın düzenlenebilirliği, gerekse başvuruların içerik ve sunulabilirliği açısında hakem değerlendirmeleri sonuçları itibariyle tamamını davet etme imkanımız olamamıştır.

Daha önceki konferanslarda olduğu gibi, bu sene de katılımc1ların kariyerleri itibariyle üst seviyede olması ve oturumların ciddi olarak takibi ve konuların üst düzeyde tartış1ması organizasyon komitesi olarak bizleri mutlu etmiştir. Konferansa Endonezya'dan-Çin'e, Avrupa ülkelerinden-Rusya'ya, Amerika'dan Türk Cumhuriyetlerinin tamamı olmak üzere 16 ülkeden ve nerdeyse Türkiye'den her üniversiteden gönderilen bildiri özeti 259 adet olup yapılan ön değerlendirme sonucunda 188 bildiriye kabul verilmiştir. Konferansa gönderilen bildiri tam metinlerinden 123 adedi konferansta sunulabilir bulunmuştur. Her konferansta olduğu gibi Kazan Konferansı da kitap haline getirilmiştir. Konferans kuralları gereği sadece sunulan bildiriler kitaba alınmaktadır. Çift hakem tarafından değerlendirilen bildirilerin değerlendirilmesinde çok değerli Hakemlerimiz ve bilim kurulu üyelerine özverili çalışma ve katkıları nedeniyle sonsuz teşekkürlerimizi arz ediyoruz.

Konferansta sunulan bildirilerde Avrasya bölgesini ilgilendiren bildirilere öncelik verilerek, bölge ülkelerinin ekonomileriyle ilgili, iktisadi büyüme ve kalkınma stratejileri, finans, dış ticaret, enerji, çevre, tarım, bölgeselleşme, küreselleşme, kamu politikaları, turizm alanlarına yönelik problemler, çözüm yollarına ilişkin konular yer almıştır. Sunulan bildiriler Türkçe, İngilizce ve Rusça dillerinde olup, ağırlıklı olarak Türkçe ve İngilizcedir.

Uluslararası Avrasya Ekonomileri konferansı'nın başarılı olarak düzenlenmesinde Beykent Üniversitesi Mütevelli Heyetinin, Üniversite Rektörünün, Genel Sekreter ve başta Halkla ilişkiler olmak üzere diğer idari birimlerin sonsuz destekleri en önemli faktördür. Bu nedenle kendilerine teşekkürlerimizi arz ediyoruz.

Konferansı birlikte düzenlediğimiz Kazan Federal Üniversitesinin Rektör yardımcısı Dr.Linar Latypov ve Prof. Dr. Nailya Bagautdinova olmak üzere büyük bir özveri ile destek veren tüm dış ilişkiler departmanı görevlilerine, Organizasyonda her türlü desteği veren Manas Üniversitesi Rektörü ve İktisat Bölüm Başkanı Yusuf Primbaev'e, ilgili personele teşekkür ediyoruz.

Konferansın gerçekleştirilmesi için önemli ölçüde finans desteğine ihtiyaç duyulmaktadır. $\mathrm{Bu}$ noktada ilk konferanstan itibaren destek vererek bizleri cesaretlendiren Türkiye Cumhuriyeti Merkez Bankası başkanı başta olmak üzere ilgili tüm yönetici ve uzmanlarına teşekkürlerimizi sunuyoruz. Türkiye İşbirliği ve Kalkınma Ajansının Başkan ve ilgili yönetici, uzmanlarına teşekkür ediyoruz.

Konferansın gerçekleştirilmesi başlangıcından bu kitabın hazırlanmasına kadar çok titiz ve özverili bir çalışma istiyor. Dolayısıyla, zaman kavramını dikkate almadan çalışarak emek veren ve organizasyonu başarılı olarak gerçekleştiren organizasyon komitesine sonsuz teşekkürler. En büyük teşekkürümüz ise; konferansın oluşmasını sağlayan dünyanın her tarafından gelen akademisyen, araştırmacı ve katılımcılara...Konferansın bilim dünyasına ve Avrasya ülkelerine katkı sağlayacağı inanc1 ve bir başka Avrasya ülkesinde buluşma dileğiyle...

\section{Prof. Dr. Selahattin Sarı}

Organizasyon Kurulu Başkanı 


\section{ADVISORY BOARD}

- Prof. Dr. Mehmet Emin Karahan (Rector, Beykent University, Turkey)

- Prof. Dr. Velimir Stojkovski (Rector, Ss. Cyril and Methodius University, Macedonia)

- Prof. Dr. Rahman Alshanov (Rector, Turan University, Kazakhstan)

- Prof. Dr. Sebahattin Balcı (Rector, Kyrgyzstan-Turkey Manas University, Kyrgyzstan)

- Dr. Linar Latypov (Vice Rector, Kazan Federal University, Russia)

- Prof. Dr. Nailya Bagautdinova (Director of the Institute of Management, Economics and Finance, Kazan Federal University, Russia)

- Prof. Dr. Selahattin Sarı (Dean, Faculty of Economic and Administrative Sciences, Beykent University, Turkey)

\section{ORGANIZING COMMITTEE}

- Assoc. Prof. Dr. Ayşen Hiç Gencer (Istanbul Aydın University, Turkey)

- Assoc. Prof. Dr. İlyas Sözen (Beykent University, Turkey)

- Asst. Prof. Dr. Aynura Turdalieva (Kyrgyzstan-Turkey Manas University, Kyrgyzstan)

- Mrs. Elmira Galyautdinova (Kazan Federal University, Russia)

- Assoc. Prof. Dr. Yuliya Gorelova (Kazan Federal University, Russia)

- Assoc. Prof. Dr. Özgür Ömer Ersin (Beykent University, Turkey)

- Asst. Prof. Dr. Mustafa Ercilasun (Beykent University, Turkey)

- Mrs. Meltem Gören (Eurasian Economists Association, Turkey)

\section{WEB \& PRINT DESIGN}

- Dr. Alp Gencer 


\section{SCIENTIFIC BOARD}

- Prof. Dr. Sudi Apak (Beykent University, Turkey)

- Prof. Dr. Ahmet Ay (Selçuk University, Turkey)

- Prof. Dr. Harun Bal (Çukurova University, Turkey)

- Prof. Dr. Mehmet Balcilar (Eastern Mediterranean University, Cyprus)

- Prof. Dr. Viktor Barhatov (Chelyabinsk State University, Russia)

- Prof. Dr. Tansu Barker (Brock University, Canada)

- Prof. Dr. Faik Bilgili (Erciyes University, Turkey)

- Prof. Dr. Ersan Bocutoğlu (Karadeniz Technical University, Turkey)

- Prof. Dr. Cihan Çobanoğlu (University of South Florida, United States of America)

- Prof. Dr. Mustafa Kemal Değer (Karadeniz Technical University, Turkey)

- Prof. Dr. Ljubomir Drakulevski (Ss. Cyril and Methodius University, Macedonia)

- Prof. Dr. Dzhumabek Dzhailov (Ministry of Agriculture, Kyrgyzstan)

- Prof. Dr. Hüseyin Avni Egeli (Dokuz Eylül University, Turkey)

- Prof. Dr. Ömer Selçuk Emsen (Atatürk University, Turkey)

- Prof. Dr. Cevat Gerni (Doğuş University, Turkey)

- Prof. Dr. Nuray Gökçek Karaca (Anadolu University, Turkey)

- Prof. Dr. Ahmet Incekara (Istanbul University, Turkey)

- Prof. Dr. Danijela Jacimovic (University of Montenegro, Montenegro)

- Prof. Dr. Gani Kaliev (Academy of Agricultural Sciences, Kazakhstan)

- Prof. Dr. S. Ridvan Karluk (Turgut Özal University, Turkey)

- Prof. Dr. Nuriddin Kayumov (Tajikistan Academy of Sciences, Tajikistan)

- Prof. Dr. Recep Kök (Dokuz Eylül University, Turkey)

- Assoc. Prof. Dr. Igor Kokh (Kazan Federal University, Russia)

- Prof. Dr. Turar Koychuev (National Academy of Sciences, Kyrgyzstan)

- Prof. Dr. Fevzi Okumuş (University of Central Florida, United States of America)

- Prof. Dr. Zekai Özdemir (Istanbul University, Turkey)

- Prof. Dr. Mikhail Panasyuk (Kazan Federal University, Russia)

- Prof. Dr. Jusup Pirimbaev (Kyrgyzstan-Turkey Manas University, Kyrgyzstan)

- Prof. Dr. Tatiana Pyshkina (Academy of Economic Studies of Moldova (ASEM), Moldova)

- Prof. Dr. Alisher Rasulev (Institute of Economics, Uzbekistan)

- Prof. Dr. Orazaly Sabden (Institute of Economics, Kazakhstan)

- Prof. Dr. Azat Safuillin (Kazan Federal University, Russia)

- Prof. Dr. Lenar Safuillin (Kazan Federal University, Russia)

- Prof. Dr. Mehmet Sarışık (Sakarya University, Turkey)

- Prof. Dr. Euphrasia Susy Suhendra (Gunadarma University, Indonesia)

- Prof. Dr. Muammer Tekeoğlu (Çukurova University, Turkey)

- Prof. Dr. Mustafa Topaloğlu (Beykent University, Turkey)

- Dr. Iuri Tsuladze (State Committee for Science and Technologies, Georgia)

- Prof. Dr. Khodjamakhmad Umarov (Institute of Economics, Tajikistan)

- Prof. Dr. Bahadir Umurzakov (G.V. Plekhanov Russian University of Economics in Tashkent, Uzbekistan)

- Prof. Dr. Venera Vagizova (Kazan Federal University, Russia) 


\section{Contents}

SESSION 1A: Keynote session

Session Chair: Prof. Dr. Selahattin Sar1

\#1446: Savings and Incomes of Households and Inclusive Growth

- Prof. Dr. Ercan Uygur (Turkish Economic Association, Turkey)

\#1287: О неэкономических факторах воздействия на Евразийское экономическое сотрудничество ..........2

- Prof. Dr. Turar Koychuev (National Academy of Sciences, Kyrgyzstan)

- Prof. Dr. Merim Koichueva (Kyrgyz-Russian Slavic University, Kyrgyzstan)

\#1445: The Power of Interdisciplinary Research: $1+1>2$ .5

- Prof. Dr. Cihan Çobanoğlu (University of South Florida, United States of America)

SESSION 2A: Macroeconomics

Session Chair: Assoc. Prof. Dr. Özlen Hiç

\#1288: Governance Aspect of Foreign-Exchange Policy in Indonesia

- Dr. Ferry Syarifuddin (Bank Indonesia, Indonesia)

\#1285: Fiscal Policy Shocks and the Dynamics of Asset Prices in Turkey 16

- Ph.D. Candidate Evrim Tören (Eastern Mediterranean University, Cyprus)

- Prof. Dr. Mehmet Balcılar (Eastern Mediterranean University, Cyprus)

\#1373: Trade Openness and Macroeconomic Policy in OECD Countries

- Asst. Prof. Dr. Naime İrem Koşan (Beykent University, Turkey)

- Prof. Dr. Sudi Apak (Beykent University, Turkey)

\section{SESSION 3A: Finance}

Session Chair: Prof. Dr. Sudi Apak

\#1238: Have Credit Rating Agencies Got a Role in Triggering 2007 Global Financial Crisis?

- Prof. Dr. Ersan Bocutoğlu (Karadeniz Technical University, Turkey)

\#1395: Effects of Sale of Non-Performing Loans to Asset Management Companies on Stock Performance of

Banks

- Asst. Prof. Dr. Sitk1 Sönmezer (Beykent University, Turkey)

\#1350: The Interaction between Stock Prices and Commodity Prices: East Europe and Central Asia Countries 41

- Asst. Prof. Dr. Mustafa Ildırar (Çukurova University, Turkey)

- Asst. Prof. Dr. Erhan İşcan (Çukurova University, Turkey)

\#1272: Financial Performance of Commercial Banks: The Case of Kyrgyz Republic . .48

- Ph.D. Candidate Adilya Yamaltdinova (Kyrgyzstan-Turkey Manas University, Kyrgyzstan)

- Ph.D. Candidate Burulcha Sulaimanova (Kyrgyzstan-Turkey Manas University, Kyrgyzstan)

\#1192: The Influence of Intellectual Capital on Firm Value towards Manufacturing Performance in Indonesia 54

- Prof. Dr. Euphrasia Susy Suhendra (Gunadarma University, Indonesia)

SESSION 4A: Growth and Development

Session Chair: Prof. Dr. Ersan Bocutoğlu

\#1404: Economic Growth: Types and Factors

- Mr. Aleksey Poliduts (Chelyabinsk State University, Russia)

- Assoc. Prof. Dr. Yuner Kapkaev (Chelyabinsk State University, Russia)

\#1420: Sustainable Development in Russia: Specific Features of Transition Procedure

- Ph.D. Candidate Ekaterina Grigoreva (Kazan Federal University, Russia) 
\#1384: Efficient and Effective Public Spending for Sustainable Economic Growth

- Ph.D. Candidate Asel Azhykulova (International Ataturk Alatoo University, Kyrgyzstan)

\#1261: Corruption, Poverty and Economic Performance: Eastern Europe and Central Asia (ECA) Countries ..81

- Asst. Prof. Dr. Mustafa Ildırar (Çukurova University, Turkey)

- Asst. Prof. Dr. Erhan İşcan (Çukurova University, Turkey)

SESSION 5A: Trade and Growth

Session Chair: Assoc. Prof. Dr. Ayşen Hiç Gencer

\#1374: The Effect of Globalization on International Trade: The Black Sea Economic Cooperation Case 88

- Dr. Mesut Savrul (Çanakkale Onsekiz Mart University, Turkey)

- Prof. Dr. Ahmet Incekara (Istanbul University, Turkey)

\#1385: Knowledge Economy and Turkey In Terms Of Innovation and Education 95

- Ph.D. Candidate Burcu Sakız (Istanbul Aydın University, Turkey)

- Mr. Semih Sakız (Garanti Technology, Turkey)

\#1176: Remittances as a Shield to Socially-Vulnerable Households in Macedonia: The Case When the Instrument is Not Strictly Exogenous

- Dr. Marjan Petreski (University American College, Macedonia)

- Dr. Blagica Petreski (Finance Think, Macedonia)

- Mrs. Despina Petreska (Finance Think, Macedonia)

\#1255: Foreign Direct Investment Strategy in International Marketing: The Case of Turkey

- Asst. Prof. Dr. Mustafa Ercilasun (Beykent University, Turkey)

- Asst. Prof. Dr. Ayşen Akyüz (Beykent University, Turkey)

- Asst. Prof. Dr. Ayşe Saime Döner (Beykent University, Turkey)

SESSION 6A: International Relations

Session Chair: Prof. Dr. Saulesh Kalenova

\#1187: Economic Expectations for Turkey, Central Asia and Caucasus Beyond 2050

- Dr. Ahmet Salih İkiz (Muğla University, Turkey)

\#1410: The European Union's Attitude towards Russia between Values and Interests

- Asst. Prof. Dr. Armağan Gözkaman (Beykent University, Turkey)

\#1243: The Resource Potential of the Participating Countries of the Eurasian Economic Union

- Prof. Dr. Saulesh Kalenova (Turan University, Kazakhstan)

- Prof. Dr. Rahman Alshanov (Turan University, Kazakhstan)

- Prof. Dr. Ali Abishev (Kazakh Economics University, Kazakhstan)

- Prof. Dr. Valentina Gerasimenko (Moscow State Lomonosov University, Russia)

\#1182: Changes in the World Power: The United States within the New Balance of Power

- Ph.D. Candidate Paulo Duarte (Université Catholique de Louvain, Portugal)

SESSION 7A: Sectoral Analysis

Session Chair: Prof. Dr. Euphrasia Susy Suhendra

\#1358: Gender Differences in Work Experiences and Work and Learning Outcomes among Employees in the Manufacturing Sector in Turkey: An Exploratory Study

- Prof. Dr. Mustafa Koyuncu (Çanakkale Onsekiz Mart University, Turkey)

- Asst. Prof. Dr. Fusun Tekin Acar (Erciyes University, Turkey)

- Prof. Dr. Ronald J Burke (York University, Canada)

- Mr. Kadife Koyuncu (Çanakkale Onsekiz Mart University, Turkey) 
\#1231: What are the New Functions of Agriculture Cooperatives in the Progress of Globalization? The Case of Agriculture Cooperatives of Kastamonu ..... 160

- Mr. Mustafa Yücel (Kastamonu University, Turkey)

- Prof. Dr. Yaşar Aktaş (Kastamonu University, Turkey)

- Mrs. Neslişah Taner (Kastamonu University, Turkey)

\#1252: Pivotal Points in Utilizing Cloud Services in Turkey 170

- Asst. Prof. Dr. Ediz Şaykol (Beykent University, Turkey)

- Mrs. Ayşe Seçil Avcı (Nişantaşı University, Turkey)

SESSION 2B: Microeconomics

Session Chair: Prof. Dr. Cihan Çobanoğlu

\#1412: The Impact of Microfinance on Entrepreneurship in Kyrgyzstan 176

- Asst. Prof. Dr. Kamalbek Karymshakov (Kyrgyzstan-Turkey Manas University, Kyrgyzstan)

- Ph.D. Candidate Kadyrbek Sultakeev (Kyrgyzstan-Turkey Manas University, Kyrgyzstan)

- Ph.D. Candidate Burulcha Sulaimanova (Kyrgyzstan-Turkey Manas University, Kyrgyzstan)

\#1344: Workplace Learning Cultures, Learning Potential and Important Work Outcomes among Managerial

Employees in Five-Star Turkish Hotels

- Mr. Kadife Koyuncu (Çanakkale Onsekiz Mart University, Turkey)

- Dr. Bekir Esitti (Çanakkale Onsekiz Mart University, Turkey)

- Prof. Dr. Ronald J Burke (York University, Canada)

- Prof. Dr. Mustafa Koyuncu (Çanakkale Onsekiz Mart University, Turkey)

\#1241: Comparative Analysis of Central Asian Tourism Product from Point of View of Turkish Travelers: A

Case of Kyrgyzstan, Kazakhstan, Tajikistan, Uzbekistan and Turkmenistan

- Prof. Dr. Kemal Kantarcı (Alanya Alaaddin Keykubat University, Turkey)

- Assoc. Prof. Dr. Murat Alper Basaran (Alanya Alaaddin Keykubat University, Turkey)

- Ph.D. Candidate Paşa Mustafa Özyurt (Akdeniz University, Turkey)

\#1381: Reverse Innovation Strategy: Local Technology Production Management Performance Booster Demand

Trend Analysis 202

- Prof. Dr. Ahmet Incekara (Istanbul University, Turkey)

- Assoc. Prof. Dr. Elif Haykır Hobikoğlu (Istanbul University, Turkey)

SESSION 3B: Makroekonomi

Session Chair: Prof. Dr. Hüseyin Avni Egeli

\#1213: Avrasya Ülkelerinde Zamanlararası Bütçe Kısıtının Göstergeleri .209

- Assoc. Prof. Dr. Sabri Azgün (Ataturk University, Turkey)

\#1178: Keynesgil Sistem, Keynesgil Politikalar ve Keynes’in Gözünden Günümüzün Bir Değerlendirmesi ..215

- Assoc. Prof. Dr. Özlen Hiç (Istanbul University, Turkey)

\#1379: Türki Cumhuriyeti Ülkelerinde Dış Borçların Sürdürülebilirliği

- Prof. Dr. Haluk Egeli (Dokuz Eylül University, Turkey)

- Mrs. Pınar Egeli (Dokuz Eylül University, Turkey)

\#1260: Türkiye Ekonomisinin Orta Gelir Tuzağına Düşüp Düşmediğine Dair Tartışma: Kur Değerlenmesi

Çerçevesinde Bir Bakış ....

- Prof. Dr. Murat Nişancı (Erzincan University, Turkey)

- Prof. Dr. Mine Gerni (Marmara University, Turkey)

- Ph.D. Candidate Adem Türkmen (Erzincan University, Turkey)

- Prof. Dr. Ömer Selçuk Emsen (Atatürk University, Turkey) 
SESSION 4B: Tarım Ekonomisi

Session Chair: Prof. Dr. Selim Başar

\#1341: Türkiye'de Tahıl Üreticilerinin Tarımsal Amaçları ve Üretimlerini Sürdürme Eğilimleri

- Dr. Gonca Gül Yavuz (Agricultural Economy and Policy Development Institute, Turkey)

- Prof. Dr. Bülent Miran (Ege University, Turkey)

- Dr. Tijen Özüdoğru (Agricultural Economy and Policy Development Institute, Turkey)

\#1405: Türkiye'de Baklagil Üretiminde Sürdürülebilirlik Açısından Etkili Faktörlerin Analizi

- Dr. Mehmet Hasdemir (Ministry of Food, Agriculture and Livestock, Turkey)

- Prof. Dr. Bülent Miran (Ege University, Turkey)

- Mrs. Mine Hasdemir (Agricultural Economy and Policy Development Institute, Turkey)

- Dr. Tijen Özüdoğru (Agricultural Economy and Policy Development Institute, Turkey)

\#1327: Öğrencilerin Beslenme Alışkanlıklarına Dair Kısıtlar Nelerdir? Yükseköğrenim Öğrencileri Üzerine Bir Araştırma

- Prof. Dr. Orhan Batman (Sakarya University, Turkey)

- Prof. Dr. Mehmet Sarışık (Sakarya University, Turkey)

- Ph.D. Candidate Akif Gökçe (Sakarya University, Turkey)

\#1444: Türkiye'de Tarımsal Destekleme Politikaları

- Assoc. Prof. Dr. Sibel Tan (Çanakkale Onsekiz Mart University, Turkey)

- Dr. Mehmet Hasdemir (Ministry of Food, Agriculture and Livestock, Turkey)

- Dr. Bengü Everest (Çanakkale Onsekiz Mart University, Turkey)

SESSION 5B: Bölgesel Ekonomiler I

Session Chair: Prof. Dr. Mustafa Kemal Değer

\#1413: Kırgızistan Ekonomisi İçin İkiz Açık Hipotezinin Test Edilmesi

- Dr. Damira Baigonushova (Kyrgyzstan-Turkey Manas University, Kyrgyzstan)

\#1211: Türki Cumhuriyetlerin İş Yapılabilirlik Potansiyeli Açısından Değerlendirilmesi

- Assoc. Prof. Dr. Serkan Dilek (Kastamonu University, Turkey)

- Asst. Prof. Dr. Ali Konak (Karabük University, Turkey)

\#1329: Orta Asya Türk Devletleri ile Türkiye Arasındaki Turizm Potansiyeli ve Ekonomi Açısından İncelenmesi

- Mr. Muhammet Fatih Sancar (Siirt University, Turkey)

- Prof. Dr. Said Kingır (Bartın University, Turkey)

- Mr. Mesut Soyalın (Siirt University, Turkey)

\#1362: Petrol Fiyatlarındaki Oynaklığın Dış Ticaret ve Milli Gelir Üzerindeki Etkisi: Seçilmiş Bazı Avrasya

Ekonomileri Üzerine Bir İnceleme

- Dr. Müjgan Hacıŏlu Deniz (Istanbul University, Turkey)

- Assoc. Prof. Dr. Kutluk Kağan Sümer (Istanbul University, Turkey)

SESSION 6B: Bölgesel Ekonomiler II

Session Chair: Prof. Dr. Ercan Uygur

\#1253: Türk Cumhuriyetlerinin Bulanık Kümeleme Analizi ile Belirlenen Ekonomik Göstergelerle

Siniflandirılması

- Asst. Prof. Dr. Necati Alp Erilli (Cumhuriyet University, Turkey)

- Asst. Prof. Dr. Çağatay Karaköy (Cumhuriyet University, Turkey)

\#1234: Bölgesel Dengesizliklerin Giderilmesinde Yatırım Teşviklerinin Rolü ve Başarı Kriteri Olarak Yakınsama Analizleri: Türkiye Örneği

- Prof. Dr. Cevat Gerni (Doğuş University, Turkey)

- Prof. Dr. Selahattin Sarı (Beykent University, Turkey)

- Asst. Prof. Dr. Haktan Sevinç (Ağrı İbrahim Çeçen University, Turkey)

- Prof. Dr. Ömer Selçuk Emsen (Atatürk University, Turkey) 
\#1270: Orta Asya Türk Cumhuriyetlerinin Ekonomik Performanslarının TOPSIS Metodu ile Karşılaştırılması 321

- Prof. Dr. Ziya Gökalp Göktolga (Cumhuriyet University, Turkey)

- Ph.D. Candidate Engin Karakış (Cumhuriyet University, Turkey)

- Asst. Prof. Dr. Hakan Türkay (Cumhuriyet University, Turkey)

\#1330: Türkiye Kazakistan İlişkilerinin Dış Ticaret Verileri ve Kurumlar Perspektifinden İncelenmesi 330

- Mr. İlker Salih Ebrem (Siirt University, Turkey)

SESSION 7B: Bölgesel Ekonomiler III

Session Chair: Prof. Dr. Feyzullah Eroğlu

\#1343: Avrasya Gümrük Birliği ve Türkiye’nin Üyeliği

- Prof. Dr. S. Ridvan Karluk (Turgut Özal University, Turkey)

\#1269: Ortak Para Otoritesine Giden Yol: Ekonomik Entegrasyon Sürecinde Avrasya Ekonomik Birliği

Ülkelerinin Bankacılık Sektörleri Üzerine Bir Değerlendirme

- Asst. Prof. Dr. Fatma Gündoğdu Odabaşığlu (Atatürk University, Turkey)

\#1262: Ukrayna Krizi'nin Türkiye ve Ukrayna Ekonomik İlişkilerine Etkileri

- Prof. Dr. Sudi Apak (Beykent University, Turkey)

- Ph.D. Candidate Selin Kozan (Doğuş University, Turkey)

\#1317: Geçişin 25. Y1lında Orta Asya Türk Cumhuriyetlerinde Dönüşüm Sürecini Özelleştirme ve İktisadi

Özgürlükler Açısından Değerlendirme 360

- Asst. Prof. Dr. Volkan Yurdadoğ (Çukurova University, Turkey)

- Assoc. Prof. Dr. Haşim Akça (Çukurova University, Turkey)

- Assoc. Prof. Dr. İlter Ünlükaplan (Çukurova University, Turkey)

\section{SESSION 2C: Finansal Krizler}

Session Chair: Prof. Dr. Ahmet Incekara

\#1267: Küresel Finans Krizi Sonrasında Sermaye Piyasalarında Şeffaflığın Arttırılması: Türkiye Örneği .370

- Ph.D. Candidate Cüneyd Ebrar Levent (Istanbul Aydın University, Turkey)

\#1353: 2000-2014 Y1lları Arasında Türkiye ve Rusya'da Finansal Risklerin Temel Ekonomik Veriler Üzerine

Etkilerinin Analizi

- Dr. Yusuf Ziya Tengiz (Kadir Has University, Turkey)

- Assoc. Prof. Dr. Emine Şule Aydeniz (Yeditepe University, Turkey)

\#1363: Avrupa Borç Krizinin Makroekonomik Etkileri ve Türkiye

- Prof. Dr. Ahmet Ulusoy (Karadeniz Technical University, Turkey)

- Ph.D. Candidate Mehmet Ela (Karadeniz Technical University, Turkey)

\#1369: Regülasyon Teorilerinin Finansal Krizler Üzerindeki Etkileri

- Assoc. Prof. Dr. Kamil Uslu (Marmara University, Turkey)

- Ph.D. Candidate Mustafa Batuhan Tufaner (Marmara University, Turkey)

SESSION 3C: Uluslararası Ticaret I

Session Chair: Prof. Dr. Zekai Özdemir

\#1300: Türkiye ile Rusya Federasyonu Serbest Ticaret Anlaşmasının İki Ülke Ticaretine Olası Etkileri ve Vergisel Yansimaları 406

- Mr. Raşit Gültekin (Trakya University, Turkey)

- Assoc. Prof. Dr. Mustafa Erkan Üyümez (Anadolu University, Turkey)

\#1438: İhracat Ve Ekonomik Büyüme Arasındaki Nedensellik İlişkisi: Rusya Örneği

- Asst. Prof. Dr. Özgür Uysal (Alanya Alaaddin Keykubat University, Turkey)

- Mrs. Sultan Sat (Alanya Alaaddin Keykubat University, Turkey) 
\#1364: Türkiye'nin Avrupa Birliği Ülkeleri ile Endüstri-içi Ticaretinin Belirleyicileri: Çekim Modeli Sonuçları (1996-2013)

- Prof. Dr. Mustafa Kemal Değer (Karadeniz Technical University, Turkey)

- Mr. Muharrem Akın Doğanay (Karadeniz Technical University, Turkey)

- Asst. Prof. Dr. Osman Murat Telatar (Karadeniz Technical University, Turkey)

\#1210: Türkiye-Rusya Diş Ticaretinin Sektörel Düzeyde Analizi

- Ph.D. Candidate Gizem Akbulut (Gümüşhane University, Turkey)

- Mrs. Candan Yılmaz (Gümüşhane University, Turkey)

\section{SESSION 4C: Uluslararası Ticaret II}

Session Chair: Prof. Dr. Ahmet Ay

\#1380: Telafi Hipotezi Türkiye İçin Geçerli midir? 437

- Asst. Prof. Dr. Murat Can Genç (Karadeniz Technical University, Turkey)

- Asst. Prof. Dr. Osman Murat Telatar (Karadeniz Technical University, Turkey)

\#1219: İthalatta Haksız Rekabet ve Türkiye'de Anti-damping Uygulamaları

- Asst. Prof. Dr. Hülya Göktepe (Anadolu University, Turkey)

\#1365: Kırgızistan'da Dış Ticaret ve Yurtdışından Transferlerin Gayri Safi Yurtiçi Hasılaya Etkisi: ARDL Sınır

Testi Yaklaşımı

- Asst. Prof. Dr. Junus Ganiev (Kyrgyzstan-Turkey Manas University, Kyrgyzstan)

\#1207: Küçük ve Orta Ölçekli İşletmelerde Dış Ticaret Politikalarının Önemi

- Asst. Prof. Dr. İlkay Noyan Yalman (Cumhuriyet University, Turkey)

- Ph.D. Candidate Mutlu Türkoğlu (Cumhuriyet University, Turkey)

- Dr. Yalçın Yalman (Cumhuriyet University, Turkey)

SESSION 5C: Uluslararası İlişkiler

Session Chair: Prof. Dr. S. Ridvan Karluk

\#1227: Kırımda Rus İşgalinden Sonra Rusya’ya Karşı Yaptırımların Ekonomik Sonuçları 469

- Assoc. Prof. Dr. Kutluk Kağan Sümer (Istanbul University, Turkey)

\#1297: Rus D1ş Politikasında Sibirya Faktörü: Ekonomik Araçlar ve Jeopolitik Oyunlar

- Prof. Dr. Erhan Büyükakıncı (Galatasaray University, Turkey)

\#1400: Türkiye'de Uygulanan AB Hibe Destekli Projelerin İncelenmesi (2000-2015)

- Ph.D. Candidate Hilal Abacı (Çankırı Karatekin University, Turkey)

- Ph.D. Candidate Gizem Saray (Çankırı Karatekin University, Turkey)

- Prof. Dr. Hasan Akça (Çankırı Karatekin University, Turkey)

- Asst. Prof. Dr. Levent Şahin (Çankırı Karatekin University, Turkey)

\#1419: Avrupa Birliğinde Malların Serbest Dolaşımının İlkesinin Analizi

- Prof. Dr. Ahmet Ay (Selçuk University, Turkey)

- Ph.D. Candidate Fatih Ayhan (Selçuk University, Turkey)

- Ph.D. Candidate Mustafa Gerçeker (Selçuk University, Turkey)

\section{SESSION 6C: Finans}

Session Chair: Prof. Dr. Murat Nişanc1

\#1278: Dolar Kuru’nun Borsa İstanbul-30 Endeksi Üzerindeki Etkisi ve Aralarındaki Nedensellik İlişkisinin İncelenmesi .505

- Assoc. Prof. Dr. Selçuk Kendirli (Hitit University, Turkey)

- Ph.D. Candidate Muhammet Çankaya (Hitit University, Turkey)

\#1435: Türkiye'de Bireysel Emeklilik Fonlarının Performansı ve Temel Yatırım Araçları ile Karşılaştırılması

- Prof. Dr. Turgut Özkan (Beykent University, Turkey)

- Ph.D. Candidate Özge Demirkale (Beykent University, Turkey) 
\#1360: Konsolide Finansal Tabloların Finansal Kuruluşların Performansı Üzerine Etkisi: Türkiye'deki

Kuruluşlar Üzerine Uygulamalı Bir Çalışma

- Prof. Dr. Turgut Çürük (Çukurova University, Turkey)

- Mrs. Ayşe Tanyeri (Çukurova University, Turkey)

\#1324: Mali Kurallar, Yaratıcı Muhasebe ve Mali Saydamlık: Geçiş Ekonomileri Üzerine Bir Değerlendirme

- Assoc. Prof. Dr. İlter Ünlükaplan (Çukurova University, Turkey)

- Asst. Prof. Dr. Volkan Yurdadoğ (Çukurova University, Turkey)

- Ph.D. Candidate Ebru Canıkalp (Çukurova University, Turkey)

SESSION 7C: Girişimcilik

Session Chair: Prof. Dr. Ahmet Incekara

\#1307: Toplumsal Kalkınma ve Kadın Girişimciliği Üzerine Bir Araştırma

- Prof. Dr. Feyzullah Eroğlu (Pamukkale University, Turkey)

- Mrs. Hatice Çoban (Pamukkale University, Turkey)

- Mr. Mustafa Koç (Pamukkale University, Turkey)

\#1224: Eğitim ve Kültürün Girişimciliğge Etkisi: Geçiş Ekonomilerinden Kırgızistan’da Üniversite Öğrencilerine Yönelik Saha Araştırması .544

- Asst. Prof. Dr. Çağatay Karaköy (Cumhuriyet University, Turkey)

- Asst. Prof. Dr. Necati Alp Erilli (Cumhuriyet University, Turkey)

- Asst. Prof. Dr. Sema Babayiğit (Melikşah University, Turkey)

- Emine Rabia Ersoy (Cumhuriyet University, Turkey)

\#1191: Küreselleşme Sürecinde Küçük ve Orta Büyüklükteki İşletmeler ve İstihdam Yapıları: Yalova Örneği .551

- Assoc. Prof. Dr. Orhan Koçak (Yalova University, Turkey)

- Prof. Dr. Eyüp Zengin (Istanbul University, Turkey)

- Mrs. Hande Oğuz Karademir (Yalova University, Turkey)

\#1254: Değişim Mühendisliği Temelinde Muhasebe Bürolarının Reorganizasyonu: İstanbul'daki Serbest

Muhasebeci Mali Müşavirliklerde Bir Araştırma 561

- Asst. Prof. Dr. Cihat Kartal (Kirıkkale University, Turkey)

- Assoc. Prof. Dr. Recep Yücel (Kırıkkale University, Turkey)

- Prof. Dr. Mustafa Kara (Abant İzzet Baysal University, Turkey)

SESSION 2D: Hukuk I

Session Chair: Prof. Dr. Sabahat Binnur Çelik

\#1220: Fiyatları Etkileme Suçu

- Prof. Dr. Çetin Arslan (Hacettepe University, Turkey)

- Ph.D. Candidate Didar Özdemir (Hacettepe University, Turkey)

\#1314: Türkiye'de Devletin Vergilerle Ekonomiye Müdahalesinin Sınırları 576

- Prof. Dr. Sabahat Binnur Çelik (Beykent University, Turkey)

\#1228: Türkiye'de Kadına Karşı Şiddetin Önlenmesinde Devletin Sorumluluğu

- Asst. Prof. Dr. Ebru Karaman (Beykent University, Turkey)

\#1366: Uluslararası Ekonomi Hukuku Kavramı ve Uluslararası Ekonomi Hukukunun Kaynakları

- Prof. Dr. Şaban Kayıhan (Hasan Kalyoncu University, Turkey)

- Mr. Mehmet Eski (İstanbul Ticaret University, Turkey)

\section{SESSION 3D: Hukuk II}

Session Chair: Prof. Dr. Mustafa Topaloğlu

\#1190: Maden İşyerlerinde İş Sağlığı ve Güvenliği Önlemleri ve Zorunlu Sendikalaşma 601

- Prof. Dr. Faruk Andaç (Çă̆ University, Turkey) 
\#1265: Milletlerarası Mal Satımına İlişkin Sözleşmeler Hakkında Birleşmiş Milletler Antlaşmasının (CISG)

Uygulama Alanı .606

- Prof. Dr. Adnan Deynekli (Bahçeşehir University, Turkey)

\#1217: Milletlerarası Mal Satımına İlişkin Sözleşmeler Hakkında Birleşmiş Milletler Antlaşması Çerçevesinde Satıcının Kötü İfadan Doğan Sorumluluğu 610

- Prof. Dr. Çağlar Özel (Hacettepe University, Turkey)

- Ph.D. Candidate Dila Okyar (Hacettepe University, Turkey)

\#1258: Milletlerarası Mal Satımlarında Sözleşmeden Dönme

- Prof. Dr. Mustafa Topaloğlu (Beykent University, Turkey)

SESSION 4D: Çevre ve Enerji

Session Chair: Prof. Dr. Ayşe İrmiş

\#1393: Küresel İklim Değişikliği Sorununun Çözümü İçin Yeni Bir Sürdürülebilir Kalkınma Anlayış1

- Prof. Dr. Serdar Altınok (Gazi University, Turkey)

- Asst. Prof. Dr. Emine Frrat (Aksaray University, Turkey)

- Mrs. Esra Soyu (Aksaray University, Turkey)

\#1284: Yenilenebilir Enerji Tüketimi, İktisadi Büyüme ve Karbondioksit Emisyonu Arasındaki Nedensel İlişki:

Orta Doğu ve Kuzey Afrika Ülkeleri Örneği

- Prof. Dr. Ebru Çağlayan Akay (Marmara University, Turkey)

- Asst. Prof. Dr. Raziiakhan Abdieva (Kyrgyzstan-Turkey Manas University, Kyrgyzstan)

- Dr. Zamira Oskonbaeva (Kyrgyzstan-Turkey Manas University, Kyrgyzstan)

\#1415: İnşaat Endüstrisinde Geri Dönüşüm Çalıșmalarının Geliștirilmesi ve Ekonomi Üzerine Etkileri

- Asst. Prof. Dr. Fatih Kürşat Frrat (Aksaray University, Turkey)

- Mr. Fahri Akbaş (Aksaray University, Turkey)

\#1426: Nükleer Enerji Türkiye İçin Doğru Bir Tercih mi?

- Asst. Prof. Dr. İsmail Güneş (Çukurova University, Turkey)

\#1237: Çevre Ekonomisi ve Sürdürülebilir Kalkınma Açısından E-Atık Yönetiminin Önemi

- Prof. Dr. Mehmet Marangoz (Muğla Sitkı Koçman University, Turkey)

- Prof. Dr. Asım Günal Önce (Dokuz Eylül University, Turkey)

- Ph.D. Candidate Ali Emre Aydın (Muğla Sitkı Koçman University, Turkey)

SESSION 5D: Mikroekonomi I

Session Chair: Prof. Dr. Mehmet Sarışık

\#1437: Alanya’yı Ziyaret Eden Yabancı Turistlerin Ülke Gruplarına Göre Güvenlik Algılarının Analizi

- Asst. Prof. Dr. Muharrem Aksu (Alanya Alaaddin Keykubat University, Turkey)

- Asst. Prof. Dr. Ali Rıza Aktaş (Alanya Alaaddin Keykubat University, Turkey)

- Asst. Prof. Dr. Mehmet Özer Demir (Alanya Alaaddin Keykubat University, Turkey)

- Asst. Prof. Dr. Faruk Kerem Şentürk (Düzce University, Turkey)

\#1440: Yükselen Bir Değer Olan Medikal Turizmin; Türkiye Ekonomisine Katkısı

- Ph.D. Candidate Vedat Moloğlu (Istanbul Aydın University, Turkey)

\#1423: Bişkek’te Faaliyet Gösteren Türk İşletmelerinde İnsan Kaynakları Yönetimi Sorunları

- Mr. Ömer Faruk Karaman (Kyrgyzstan-Turkey Manas University, Kyrgyzstan)

\#1325: Bir Kırsal Kalkınma Modeli Olarak Geleneksel Üretimi Yeniden Canlandırma Örneği: Yeşilyuva Ayakkabı Üretimi

- Prof. Dr. Ayşe İrmiş (Pamukkale University, Turkey)

- Dr. Şeyma Gün Eroğlu (Pamukkale University, Turkey) 
SESSION 6D: Mikroekonomi II

Session Chair: Assoc. Prof. Dr. Kutluk Kağan Sümer

\#1407: Türk İmalat Sanayinde Performans, İnovasyon ve Rekabet Arasındaki İlişki

- Asst. Prof. Dr. Aykut Karakaya (Recep Tayyip Erdogan University, Turkey)

- Assoc. Prof. Dr. Seymur Ağazade (Recep Tayyip Erdogan University, Turkey)

- Prof. Dr. Selçuk Perçin (Karadeniz Technical University, Turkey)

\#1 198: Kalite Kontrol Çemberleri Üzerine Kavramsal Bir Araştırma

- Dr. Gülçin Özbay (Sakarya University, Turkey)

- Prof. Dr. Mehmet Sarışık (Sakarya University, Turkey)

\#1408: Türk İmalat Sanayinde İhracat ve İnovasyon Arasındaki İlişki

- Prof. Dr. Selçuk Perçin (Karadeniz Technical University, Turkey)

- Asst. Prof. Dr. Aykut Karakaya (Recep Tayyip Erdogan University, Turkey)

- Assoc. Prof. Dr. Seymur Ağazade (Recep Tayyip Erdogan University, Turkey)

\#1235: İş Görenlerin İş Yaşam Dengesine Yönelik Tutumlarının Örgütsel Bağlılık Üzerindeki Etkisi

- Prof. Dr. Ufuk Durna (Akdeniz University, Turkey)

- Mr. Ali Babayiğit (Akdeniz University, Turkey)

\#1428: Hasta Yatış Süreleri Açısından Cerrahpaşa Tıp Fakültesi Hastanesi Çocuk Nefroloji Servisi'nin 2012 Yılı Analizi

- Asst. Prof. Dr. Volkan Öngel (Beykent University, Turkey)

- Mrs. Emel Duran (Beykent University, Turkey)

\section{SESSION 7D: Sektörel Analizler}

Session Chair: Prof. Dr. Ömer Selçuk Emsen

\#1216: Neoliberal Politikalar Sonucunda Medya Alanında Tekelleşme Eğilimleri ve Türkiye Örneğinde Son Yarım Yüzyıla Bakış

- Assoc. Prof. Dr. Hüseyin Çelik (Istanbul Arel University, Turkey)

\#1418: Türk Spor Sektöründe Kurumsallaşma: Futbol Kulüpleri Örneği

- Asst. Prof. Dr. Yeter Aytül Dağlı Ekmekçi (Pamukkale University, Turkey)

- Prof. Dr. Ayşe İrmiş (Pamukkale University, Turkey)

\#1432: İnternet'ten Alışverişte Tüketiciler Tarafından Algılanan Riskler ve Risk Azaltma Çabaları

- Ph.D. Candidate Çetin Kalburan (Pamukkale University, Turkey)

- Assoc. Prof. Dr. Selçuk Burak Haşıloğlu (Pamukkale University, Turkey)

SESSION 2E: Международная торговля

Session Chair: Prof. Dr. Lenar Safuillin

\#1443: Предпосылки вхождения Кыргызстана в Евразийский экономический союз .755

- Prof. Dr. Jusup Pirimbaev (Kyrgyzstan-Turkey Manas University, Kyrgyzstan)

\#1181: Региональный анализ российской внешней торговли в целях содействия развитию международной кооперации и импортозамещения

- Assoc. Prof. Dr. Rinas Kashbrasiev (Kazan Federal University, Russia)

- Assoc. Prof. Dr. Anatoly Stepin (Kazan Federal University, Russia)

\#1441: Торгово-экономические связи раннесредневекового Кыргызского государства

- Assoc. Prof. Dr. Muratbek Kozhobekov (Kyrgyzstan-Turkey Manas University, Kyrgyzstan)

\#1240: Внешнеторговая деятельность индивидуального предпринимательства в Кыргызской Республике и общие проблемы его развития

- Assoc. Prof. Dr. Khicheza Fynchina (Kyrgyz-Russian Slavic University, Kyrgyzstan) 
SESSION 3E: Макроэкономика

Session Chair: Assoc. Prof. Dr. Igor Kokh

\#1439: Государственный маркетинг как фактор, влияющий на укрепление макроэкономических показателей страны

- Prof. Dr. Anara Kamalova (Academy of Management, Kyrgyzstan)

\#1256: Аудит и его влияние на формирование национального капитала

- Asst. Prof. Dr. Kylychbek Supataev (Kyrgyz-Russian Slavyan University, Kyrgyzstan)

\#1383: Особенности Российской Безработицы и Безработных: 2000-2014гг

- Mrs. Alexandra Salatova (Kazan Federal University, Russia)

\#1389: Легализация платных услуг - источник повышения заработной платы медицинских работников .795

- Assoc. Prof. Dr. Damira Japarova (Kyrgyzstan-Turkey Manas University, Kyrgyzstan)

SESSION 4E: Региональные экономики

Session Chair: Prof. Dr. Mikhail Panasyuk

\#1282: Факторы, Определяющие Роста Микрокредитного Сектора в Кыргызстане .801

- Assoc. Prof. Dr. Turusbek Asanov (Kyrgyzstan-Turkey Manas University, Kyrgyzstan)

- Ph.D. Candidate Kadyrbek Sultakeev (Kyrgyzstan-Turkey Manas University, Kyrgyzstan)

\#1221: Интеграционные инициативы в Каспийском регионе: тенденции и перспективы .805

- Mrs. Lidiya Parkhomchik (Eurasian Research Institute, Kazakhstan)

\#1281: Экономика мусульманской повседневности: религиозные и экономические практики мусульман

Республики Татарстан

- Alsou Garaeva (Kazan Federal University, Russia)

SESSION 5E: Büyüme

Session Chair: Prof. Dr. Süleyman Karaçor

\#1296: Rekabet Gücü ve Ekonomik Büyüme İlişkisi: Seçilmiş Ülkeler Üzerine Panel Veri Analizi

- Asst. Prof. Dr. Ziya Çağlar Yurttançıkmaz (Atatürk University, Turkey)

- Prof. Dr. Ömer Selçuk Emsen (Atatürk University, Turkey)

- Asst. Prof. Dr. Ahmet Fatih Aydemir (Atatürk University, Turkey)

- Assoc. Prof. Dr. Ahmet Alkan Çelik (Beykent University, Turkey)

\#1368: Seçilmiş Bazı Geçiş Ekonomilerinde İktisadi Özgürlükler ve İktisadi Büyüme İlişkisi: Bir Panel Veri Analizi

- Asst. Prof. Dr. Hakan Türkay (Cumhuriyet University, Turkey)

\#1251: Türkiye Ekonomisinde Orta Gelir Tuzağı ve Ödemeler Bilançosu Kısıtı

- Asst. Prof. Dr. Zekayi Kaya (Çankırı Karatekin University, Turkey)

- Assoc. Prof. Dr. Erkan Tokucu (Kafkas University, Turkey)

- Murat Aykırı (Kafkas University, Turkey)

- Cahit Durmuş (Office of the Prime Ministry, Turkey)

\#1386: Kazakistan Ekonomisinde Ekonomik Büyümenin Kaynakları: Girdi-Çıktı Analizi Yaklaşımıyla Bir İnceleme . .841

- Assoc. Prof. Dr. Tuncer Özdil (Celal Bayar University, Turkey)

- Asst. Prof. Dr. Aynura Turdalieva (Kyrgyzstan-Turkey Manas University, Kyrgyzstan)

\section{SESSION 6E: Kalkınma I}

\section{Session Chair: Prof. Dr. Cevat Gerni}

\#1244: Ülkelerin İnsani Gelişmişlik Endeksi Değişkenlerine Göre Etkinliklerinin İncelenmesi .846

- Prof. Dr. Selim Başar (Atatürk University, Turkey)

- Ph.D. Candidate Murat Eren (Atatürk University, Turkey)

- Dr. Miraç Eren (Atatürk University, Turkey) 
\#1266: Beşeri Sermaye Harcamaları: Türkiye'de Yaşanan Gelişmeler ve Sonuçlar Üzerine Bir İnceleme .855

- Assoc. Prof. Dr. Haşim Akça (Çukurova University, Turkey)

\#1225: Bilgi Ekonomisi Sendikal Hareketin Sonu Mu? .864

- Prof. Dr. Adem Kalça (Karadeniz Technical University, Turkey)

\#1179: Kuznet Eğrisi Bağlamında Türkiye’de Finansal Gelişme ve Gelir Eşitsizliği İlişkisinin Analizi 871

- Asst. Prof. Dr. Utku Altunöz (Sinop University, Turkey)

SESSION 7E: Kalkınma II

Session Chair: Prof. Dr. Süreyya Hiç

\#1411: Kalkınma ve Eğitim İlişkisi: İnsani Gelişme Endeksine Göre Türkiye’nin Eğitim Düzeyinin

Değerlendirilmesi

- Asst. Prof. Dr. Emine Firat (Aksaray University, Turkey)

- Mr. Emre Ürün (Aksaray University, Turkey)

- Mr. Aytaç Aydın (Aksaray University, Turkey)

\#1271: Ekonomik Özgürlükler ve Ekonomik Büyüme: Yükselen Piyasa Ekonomileri Üzerine Bir İnceleme .884

- Prof. Dr. Bedriye Tunçsiper (Balıkesir University, Turkey)

- Ph.D. Candidate Ömer Faruk Biçen (Balıkesir University, Turkey)

\#1398: Kalkınma Ajansları Aracılığıyla Dağıtılan Hibelerin PESTLE Yöntemi İle Analizi: Türkiye'de KUZKA

Örneği 890

- Ph.D. Candidate Gizem Saray (Çankırı Karatekin University, Turkey)

- Ph.D. Candidate Hilal Abacı (Çankırı Karatekin University, Turkey)

- Prof. Dr. Hasan Akça (Çankırı Karatekin University, Turkey)

- Asst. Prof. Dr. Levent Şahin (Çankırı Karatekin University, Turkey)

\#1429: Üniversite Öğrencilerinin Başarılarını Etkileyen Demografik Faktörler

- Asst. Prof. Dr. Raziiakhan Abdieva (Kyrgyzstan-Turkey Manas University, Kyrgyzstan)

\#1299: Ekonomik Kriz Döneminde Turizm Pazarlaması 902

- Prof. Dr. Süleyman Karaçor (Selçuk University, Turkey)

- Asst. Prof. Dr. Betül Garda (Selçuk University, Turkey) 


\title{
Savings and Incomes of Households and Inclusive Growth
}

\author{
Prof. Dr. Ercan Uygur (Turkish Economic Association, Turkey)
}

\begin{abstract}
This paper has three aims. The first is to explore the savings behavior of different income groups of households, with an emphasis on those with low incomes. This is achieved by going through the Household Budget Surveys (HBS) in some developing and developed countries. The HBSs reveal that the majority of poor sections of the societies do not save or have negative savings. The second aim of the paper is to explain the economic and social aspects of the savings behaviour of income groups, particularly those with low incomes. The paper explains that the "no saving/dissaving" behaviour of the low income groups and the resultant factors create economic and social problems. In this context, the paper also dwells on wealth distribution and issues of inclusive growth. The third aim of this paper is to examine policies implemented to encourage savings in general and savings of the low income groups in particular. To this end, policies pursued in some developing and developed countries are evaluated with reference to inclusive growth.
\end{abstract}

The author has requested that the full text of the paper to be withheld from the proceedings. 


\title{
О неэкономических факторах воздействия на Евразийское экономическое сотрудничество \\ On the Non-Economic Factors of Impact on the Eurasian Economic Cooperation
}

\author{
Prof. Dr. Turar Koychuev (National Academy of Sciences, Kyrgyzstan) \\ Prof. Dr. Merim Koichueva (Kyrgyz-Russian Slavic University, Kyrgyzstan)
}

\begin{abstract}
Treat the entire Asia and Europe as a geo-economic space is impossible and counterproductive. In our opinion, Eurasian geo-economic space can be considered as a geographical area, which is the junction between Europe and Asia. Geographically, it is - the Urals, the Volga region, the Caspian Sea region of Russia, post-Soviet Central Asia, the Caucasus and the territory where Turkey and Xinjiang is located. The economic interests of the Eurasian countries for "unity" can be the same, but there are non-economic conditions (state and political system, the mode of government - authoritarian, democratic, way of life of the state - secular, religious, moral and cultural values, ideological differences, and historical features of interethnic relations) that as factors may influence positively or negatively.

Principles of formation of the Eurasian Economic Cooperation shall include economic feasibility and mutual benefit, political loyalty, ideological, philosophical and ethnic tolerance, peer contacts, peace-loving nature and solving conflict with a positive decision.
\end{abstract}

Азия и Европа - два важнейших, исторически, политически и экономически, шире-вообще цивилизационно значимых континента в мире со своими особенностями, традициями, темпами, масштабами и уровнями развития и в формировании государственно-политических преобразований и экономических систем. Разные численности населения, уровни их жизни, этнические составы и их ценностные ориентации. Поэтому рассматривать целиком Азию и Европу как единое геоэкономическое пространство немыслимо и непродуктивно. И такой попытки нет, хотя проблемы обеспечения их позитивного взаимовлияния всегда присутствуют.

Евразийским геоэкономическим пространством, на наш взгляд, может считаться географическое пространство, которое представляет собой стык между Европой и Азией. Если следовать географически строго, то это - Урал, Поволжье, Прикаспий РФ, Постсоветская Центральная Азия, Закавказье и территории, где расположены Турция, СУАР КНР. Возможно, мы ошибаемся, но приблизительно так.

Но, поскольку евразийские российские территории являются территориями Российской Федерации, а СУАР - территорией КНР, то эти две великие державы могут быть «представлены» в евразийском пространстве как «представители» своих обозначенных территорий.

Постсоветская Центральная Азия своими западными границами составляет часть евразийского стыка, а остальные ее части больше примыкают туда же, чем к другим частям Азии.

Скажем, пока геоэкономически в «Евразийское экономическое объединение» (формально или неформально) могут войти Россия, КНР, Казахстан, Кыргызстан, Таджикистан, Турция.

Экономические интересы евразийских стран для «объединения» могут совпадать, но есть неэкономические условия (государственно-политические устройства, режим власти - авторитарный, демократический; образ жизни государства - светский, конфессиональный; нравственные и культурные ценности, мировоззренческие различия, исторические особенности межэтнических отношений, которые как факторы могут влиять позитивно, либо негативно.

Поэтому в межстрановое евразийское сотрудничество не все соответствующие государства включаются активно. Отсюда, при организации международного евразийского экономического формирования всесторонне должно быть продумано, в каком составе оно будет позитивным, жизнеспособным. Желания будут приветствоваться, но двери не могут быть открытыми сразу для всех. При необдуманном «открытии двери в дом» каждому оправданному участнику сотрудничества могут «войти» чуждая идеология, неприемлемые мировоззренческие ценности, агрессия к образу жизни, ломающие стабильность и мир. Голая «экономическая выгода» может разрушить общественный позитивный уклад. Это будет непростительной ошибкой выбора...

Учет влияния неэкономических факторов на экономическое сотрудничество особенно стало ясным сегодня, когда: в мире участились и возросли теракты, берущие начало в конфликтных странах и проникающие в относительно спокойные страны; исходя из гегемонистических целей монополизировать 
мировую политику отдельными государствами стали приниматься экономические санкции в пользу своих совсем неэкономических, а политических целей мирового господства.

По каким критериям надо выбирать экономического партнера и какому экономическому партнеру доверять? Украинские события 2014-2015 года, когда «дружественные» миру западные страны - США, Англия, Канада и члены Европейского Союза применили экономические санкции против России, показали истинные лица «друзей». Они поддержали не установление мира и стабильности в Украине, не гражданские свободы и права русскоязычного населения, а преступные действия украинских националистов и радикалов и опирающейся на них официальной власти. «Цивилизованные» государственные власти показывают свою гегемонистическую, корыстную, агрессивную сущность. А Россия была связана с ними значительными экономическими договорами. Такая экономически мощного потенциала Россия должна была прежде всего интенсивно развивать, осваивать свое, надеяться на себя, а не на поставки со стороны. «Партнеры» раскрыли свою антироссийскую сущность, а не дружеские чувства. Отсюда вывод: с кем заключать экономический союз? Но прежде всего нужно надеяться на собственные силы и ресурсы, талант и ум, опыт и знания. Президент Российской Федерации Влаимир Путин дал обоснованную ориентацию на наращивание собственных усилий для покрытия потребностей, которые сегодня удовлетворяются импортом, что ставит Россию в зависимость перед «дружественными» партнерами.

Разумеется, в экономическом союзе могут оказаться государства с различными политическими ориентациями, ценностными ориентациями, но выбор должен быть селективным в рамках взаимопонимания и взаимоуважения различий без покушения на них. Экономические союзы могут образовываться как между государствами, так и между частными компаниями разных государств, но без государственного участия. Но государства должны признать и дать «добро» только при соблюдении требований экономической и национальной безопасности. И это вполне правомерно. Государство поощряет сотрудничество, не мешает, но контролирует «чистоту» и защищает честь и достоинство, интересы собственной страны. Идеологический и нравственный разгул, потеря культурных и моральных ценностей - опасное явление, не менее чем экономические потери! Непростительно, чтобы экономическое сотрудничество вносило в страну коррупцию, терроризм, криминал.

Характеризуя политические ценности стран, которые могли бы составить соответствующей опорой возможному Евразийскому экономическому и политическому союзу, мы бы отметили одну из них межэтническое единство, утвердившее себя в качестве формирования единых наций многонациональных государств. Так, органичную часть российской нации составляют, вместе с русскими и другими народами, татары, башкиры и калмыки, представляющие соответствующие республики, расположенные на евразийском стыке. В экономике РФ, будучи в Татарской Республике, хотелось бы отметить то значимое место, которое занимает она в экономическом, историческом, культурном, образовательном, научном развитии России. Значение Казани весомо и в общероссийском масштабе! Экономический и социальный «взлет» Татарстана вызывает восхищение.

В СУАР КНР образованы Илийский Казахский автономный и Кызылсуйский Кыргызский автономный округа. В Казахстане дружно проживают казахи, русские, уйгуры, узбеки, кыргызы и т.д; в Кыргызской Республике - кыргызы, узбеки, русские, дунгане, уйгуры, казахи и т.д.; в Таджикистане - таджики, узбеки, кыргызы, русские, туркмены и т.д.; в Туркменистане - туркмены, узбеки, таджики, русские и т.д.; в Узбекистане - узбеки, кыргызы, таджики, казахи, русские, татары и т.д. Никто не ущемлен в правах. Бытовые межэтнические вопросы возникают, но они решаются и конфликты погашаются. Политические, экономические, культурные права соблюдаются и для всех созданы равные условия развития. Из болезненных ситуаций прошлого извлечены поучительные уроки. Дискриминации со стороны властей нет.

В Украине, что трагично, украинские националисты открыли войну против братского народа - русских, живущих на юго-востоке Украины. Погибли дети и старики, мирные жители. Разрушены Донбасс, Луганск, города, поселки и села. Такому преступлению нет прощения!

Постсоветские Центрально-Азиатские республики реальные претенденты возможного евразийского экономического объединения более широкого, чем того союза, что уже стало фактом (включающий Россия, Белоруссию, Казахстан, Кыргызстан и Армению), в которое могли бы войти и КНР, Турция. Конечно, при этом важно разрешить спорные между ними межгосударственные вопросы. Скажем, вызывает недоумение, что вот уже 24 года (со дня обретения суверенитета) республики постсоветской Центральной Азии до сих пор не могут мудро и взвешенно разрешить пограничные проблемы: это между Кыргызстаном и Узбекистаном, между Кыргызстаном и Таджикистаном, между Узбекистаном и Таджикистаном. Нередки стычки. Гибнут пограничники и мирные жители. А, ведь, гибель даже одного человека - трагедия. В рамках возможно евразийского экономического объединения, может быть, они могли бы положительно разрешиться. Россия, КНР и Турция стали бы надежными гарантами устойчивости, прочности продолжительной формы сотрудничества, которая утверждает согласие и толерантность. Из «украинских» событий надо извлекать уроки в смысле того, от чего надо защищаться и 
против чего надо бороться, что надо отстаивать и утверждать. Позитивно воспринимается сообщение, что лидер курдской оппозиции в Турции призвал своих сторонников к национальному примирению. Это тоже положительный фактор для экономического сотрудничества.

Экономическую дружбу тоже надо заводить с теми, кто политически вызывает доверие, мировоззренчески позитивен, относится как равный к равному, образ жизни идентичен или близок и где государственно-политическое развитие устойчиво и демократично! Евразийский экономический «дом» должен стать не домом для выяснения отношений, раздоров и разногласий, а домом утверждения согласия и приложения совместных усилий для благополучия всех!

Принципы формирования Евразийского экономического сотрудничества должны включать экономическую целесообразность и взаимную выгоду, политическую лояльность, идеологическую, мировоззренческую и этническую толерантность, равноправные контакты, миролюбивый характер и исключение конфликтов позитивным решением.

\section{Литература}

- Койчуев T, 2015. Размышления на волнующие проблемы. Бишкек.

- К Койчуев Т. и др., 2015. Кыргызстан - выбор пути развития в цивилизационном мире. Варианты моделей развития. Бишкек. 


\title{
The Power of Interdisciplinary Research: $1+1>2$
}

\author{
Prof. Dr. Cihan Çobanoğlu (University of South Florida, United States of \\ America)
}

\begin{abstract}
National Academies defines interdisciplinary research as "a mode of research by teams or individuals that integrates information, data, techniques, tools, perspectives, concepts, and/or theories from two or more disciplines or bodies of specialized knowledge to advance fundamental understanding or to solve problems whose solutions are beyond the scope of a single discipline or area of research practice." This presentation will outline the power of interdisciplinary research in the context of tourism research. Today's problems are so complex that it requires different brains, approaches, knowledge sets, methods to work together and explore what has never been seen before. However, conducting interdisciplinary research has many challenges from adopting to work with different styles to finding a reputable outlet to publish the outcomes.
\end{abstract}

The author has requested that the full text of the paper to be withheld from the proceedings. 


\title{
Governance Aspect of Foreign-Exchange Policy in Indonesia
}

\author{
Dr. Ferry Syarifuddin (Bank Indonesia, Indonesia)
}

\begin{abstract}
While most recent central bank's foreign-exchange interventions have been directed at mitigating speculative currency pressures and reducing risks to price instability, as well as curbing volatility in capital flows, the good governance implementation plays significant role in making the foreign-exchange operations done in efficient and effective way. For Bank Indonesia, the implementation of foreign exchange policy strategy followed governance principle is essential and geared toward price and financial system stability. In practice, the objective is reached through foreign-exchange intervention policy combined with other monetary and macroprudential policy called policy mix.
\end{abstract}

\section{Introduction}

As a consequency of adopting floating foreign-exchange regime, a country would face rapid cross border capital flows. The excessive flows of foreign currencies put pressure on domestic exchange rate tend to be volatile and move to undesired direction (misaligned exchange rate movements). This conition is not good for the economy as it will disrupt international trade and capital flow performances, threaten price stability, as well as reduce business confidence. Thus, exchange-rate should be directed to its fundamental value in order to boost sustainable domestic economic growth. In many countries foreign-exchange interventions has been played more in order to mitigate those issues. The implementation of such policy have been followed by the concern on how this policy is implemented in a govern way to achieve its goal more effectively and efficiently (Figure 1). Furthermore, most of financial crisis around the world are erupted not only ignited by speculation motive but also lack of prudential and governance principle implementation. Without governance implementation, the objectives of corporates would face potential failure. On the other hand, governance principles implementation would help their objectives efficiently and effectively in a sustained basis.

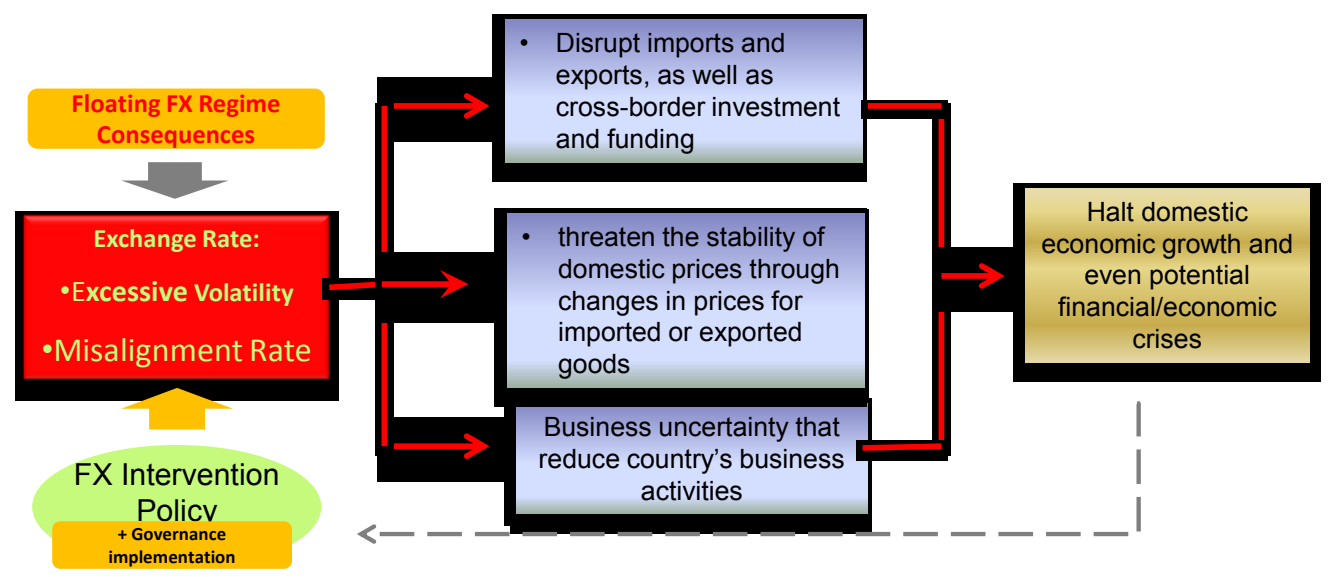

Figure 1. The Impact of volatility and misalignment FX Source: BIS (2013) modified

In good governance principle, all activities within organizations are needed to conduct in good manner and follow the commiteed regulations. Besides, it should be monitored continuously by the governing members of an organization in order to ensure it works based on the regulation that has been made. Generally, corporate governance is defined as a framework of rules and practices by which member of director ensures the implementation of accountability, fairness, and transparency in a company's relationship with its all stakeholders. In central banks, governance principles are implemented in every aspect of their activities included in the process of monetary policy formulations, decision makings, and operations to avoid price or financial instability in the future.

With regard to exchange rate policy governance, there are several argues concerning the role of foreignexchange intervention by the central bank. One argue assumes in a unfavorable economic condition, a central bank has to let the exchange rate to fluctuate in order to adjust unbalanced economy and inflation back to its equilibrium or target level. However, this is not always done moreover in developing countries where their exchange rates fluctuate more volatile or overshoot. In the emerging economies, the exchange rates tend to be more sensitive to exchange rate changes both directly 'because of pass-through effects on domestic inflation', and indirectly 'because the exchange rate appears as an objective functions of monetary policy in the respective countries (Domac and Mendoza, 2002). This excessive exchange-rate volatility would not adjust current unbalanced economy to its equilibrium automatically. Therefore, this unfavorable condition pushes many central 
banks in emerging countries mostly often implement foreign-exchange interventions in order to contain the negative impact of pass-through effects on domestic inflation and minimize exchange-rate volatility even though the economy is still unbalanced.

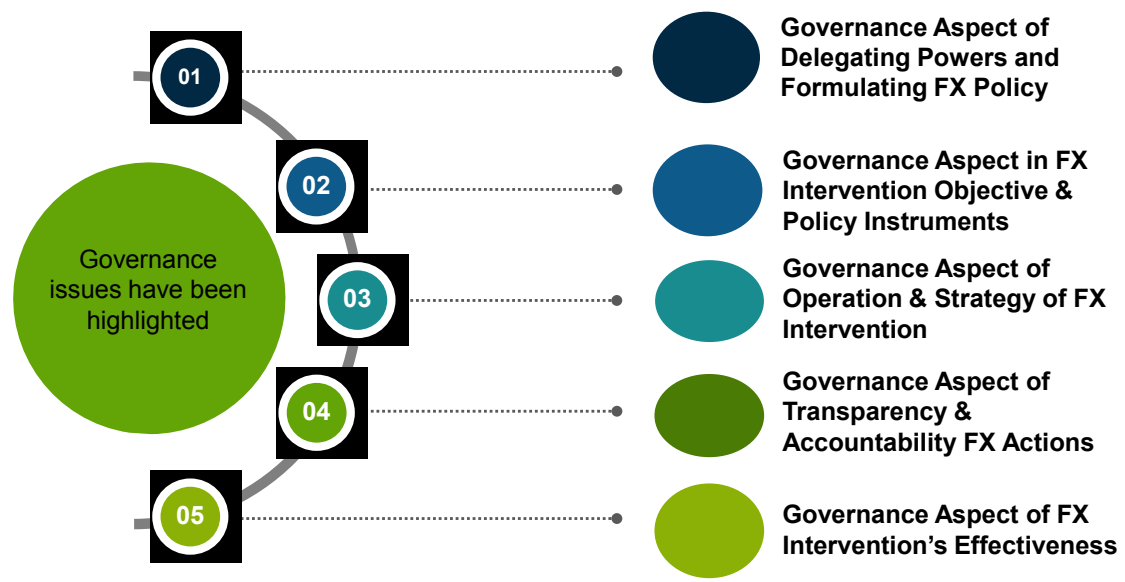

Figure 2. The Element of Governance in FX Intervention Source: BIS (2013) modified

Concerning foreign exchange intervention operation by most modern central banks, there are at least three governance issues have been highlighted as mentioned by Moser-Boehm, 2005. The first governance issue concerns the allocation of powers between central bank and the government in decision making of monetary policy and for exchange rate policy. This is the regulation of power and the mechanisms required among members within organizations which concern accountability. This issue concerns on which party within an organization, has the authority to make strategic decision on the foreign-exchange policy such as formulating the ultimate objectives decisions, and the role of central banks or the government in formulating strategic policy. The issue should clearly mention whether the power is delegated to the central banks or to the governments before decision is made and stated in the respected act or regulation. The second issue is about the standard operating procedure when implementing the decisions made, included the possibility of whether the decision is made solely by the central bank/monetary authority or should consult before with the governments. The last crucial issue with regard to the governance principles concern transparency and accountability. Even though, transparency and accountability should also be implemented by most institutions, central banks need modified rules with regard to transparency and accountability rule when implementing the governance aspect to ensure their effectiveness in achieving its policy objectives. It is because, most foreign-exchange interventions should be carried out in secret to have good result as desired (Figure 2).

According to the governance principle, Bank Indonesia has also the authority to conduct foreign currency intervention at both strategic policy and operational levels. Foreign-exchange intervention policies are mainly intended to support exchange-rate stability, at all times or curbing undesired short-term capital flows. The exchange rate policy such as foreign-exchange intervention is implemented which has function to smooth out the volatility of day-to-day exchange-rate movements. Consequently, Bank Indonesia should monitor exchange-rate development regularly and closely monitor foreign currency transaction activities, either indirectly via on-screen figures and broker's information (off-site supervision), or directly (on-site supervision). Beyond on that, BI exchange-rate policy supported by other monetary policies as designed to achieve BI's ultimate objective such as domestic inflation and financial stability in the medium to long run horizon.

Beyond on those issues, another important issue regarding to governance principles in foreign-exchange intervention is whether the objective to conduct such policy to meet a certain target of exchange-rate level or to lessen the exchange-rate fluctuations, or to meet both objectives. The other is whether the foreign-exchange policy is also a measure to accumulate foreign-exchange reserve to raise central bank's credibility. With regard to foreign reserve accumulation objective, BIS survey (2013), concludes that most central banks agree that reserve accumulation main objective is to protect the economy from adverse future shocks and to enhance central bank's credibility. The adequate level of official foreign reserves (OFRs) can increase considerably over time, particularly in boom periods. The accumulation of reserves is possible during periods of large inflows. Within this context, Bank Indonesia conducts foreign currency intervention at both policy and operational levels to reduce exchange rate volatility as well as managing rupiah domestic liquidity. Foreign currency intervention policies are mainly intended to support exchange-rate stability and drive it to support domestic inflation, at all times. Moreover, it is undertaken whenever moral suasion is not working in influencing foreign-exchange expectation and curbing excessive exchange rate movements. 


\section{Delegating and Formulating Foreign-Exchange Policy}

As mentioned before, many central banks implement governance principles in order to achieve their own objective efficiently and effectively. In strategic part, it is crucial for a central bank to state explicitly who will set operational objectives of foreign exchange. Moser-Boehm (2005) suggests the central bank or the government may have this task to set exchange rate objectives. Once it is decided, it should be clearly defined in the central bank law. Indonesia and most modern central banks have legal aspect as an independent monetary institution apart from government. The law may also regulate the power distribution between the government and the central bank to decide those objectives which may include exchange rate regime. In many circumstances, central bank has autonomy to set goal or even operational aspect of foreign exchange. Meanwhile, in some countries, the government has also strategic power in giving mandate to achieve specific target in implementation regularly. In the case of Indonesia, the central bank objectives are ruled out by the central bank law where Bank Indonesia has task to maintain Rupiah stability. In implementation, the government set the objective more specific to be reached yearly.

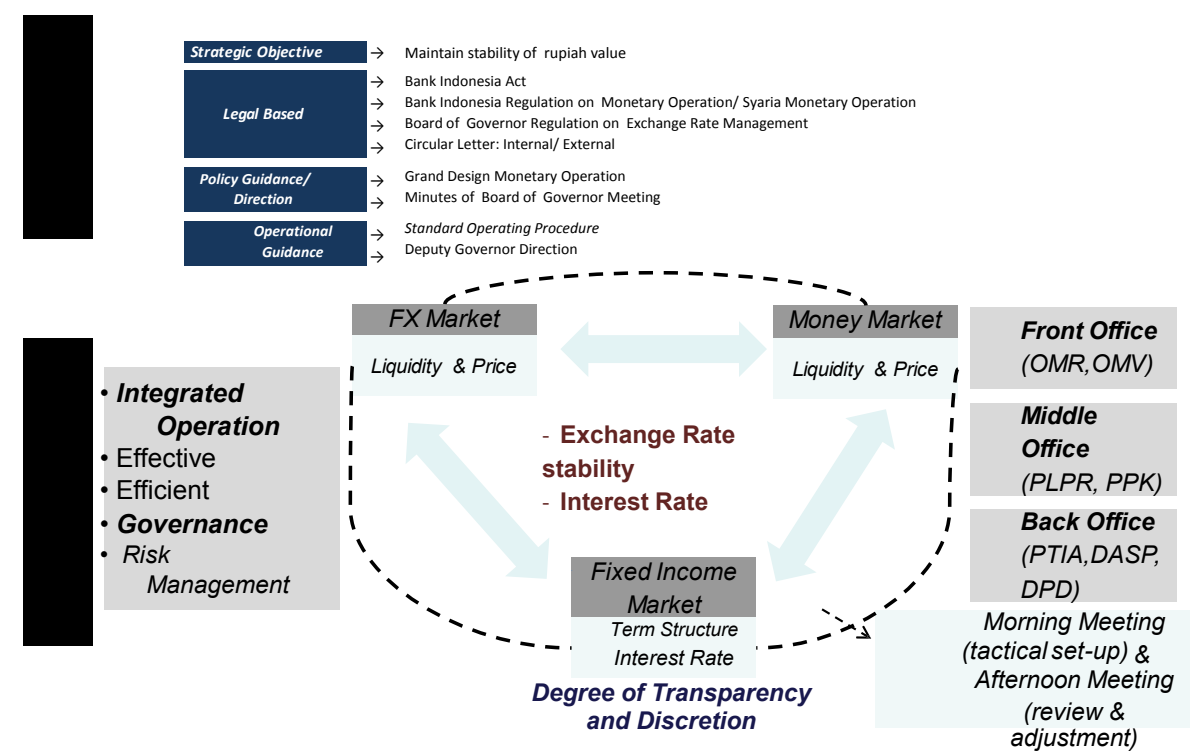

Figure 3. The Governance in Delegating \& Formulating FX Policy Source: BIS (2013) modified

As illustrated in the Figure 3, Bank Indonesia as the central bank of Indonesia is authorized to formulate and implement monetary policy to support achieving its ultimate objective i.e. price stability. The monetary policy which is designed to achieve price stability is divided in two main parts. The first one to achieve domestic liquidity in short term and price stability in the long-run is conducted through open monetary operation by setting appropriate policy interest rate. Meanwhile the second part to mitigate exchange rate volatility is conducted through exchange-rate intervention policy. To achieve its objective efficiently and effectively, Bank Indonesia set up foreign-exchange policy decision making process and dealing guidelines which are needed in policy implementation.

Thus, BI foreign-exchange intervention policy is divided in two parts i.e. strategic and operational level. The first part includes foreign-exchange intervention objective, legal based, policy guidance and direction, and operational guidance. Meanwhile, in the second part includes the method and strategy of foreign-exchange policy implementation depending on foreign-exchange market condition conducted by dedicated divisions (Front office, Middle office, and back-office/settlement divisions).

The legislation for the last decades has given many modern central banks greater operational independence in conducting monetary policy included foreign-exchange interventions even though in some cases the government has been involved moreover in setting specific objective target annually. According to BIS Survey (2005), exchange rate policy is a joint responsibility of the government and the RBI in India, BOK in Korea and Reserve Bank of New Zealand. Meanwhile, in the case of Mexico, the central bank has power to implement exchange rate policy itself as long as it is matched within guidelines set previously by the government and the central bank. On the other hand, in Malaysia, the regulation has given the government to set the objectives, after consulting the central bank. In the case of Indonesia, Bank Indonesia has full authority to conduct foreign currency intervention at both policy and operational levels. However, it should be harmonized with inflation stability policy in the strategic and operational level to avoid inefficiency. 


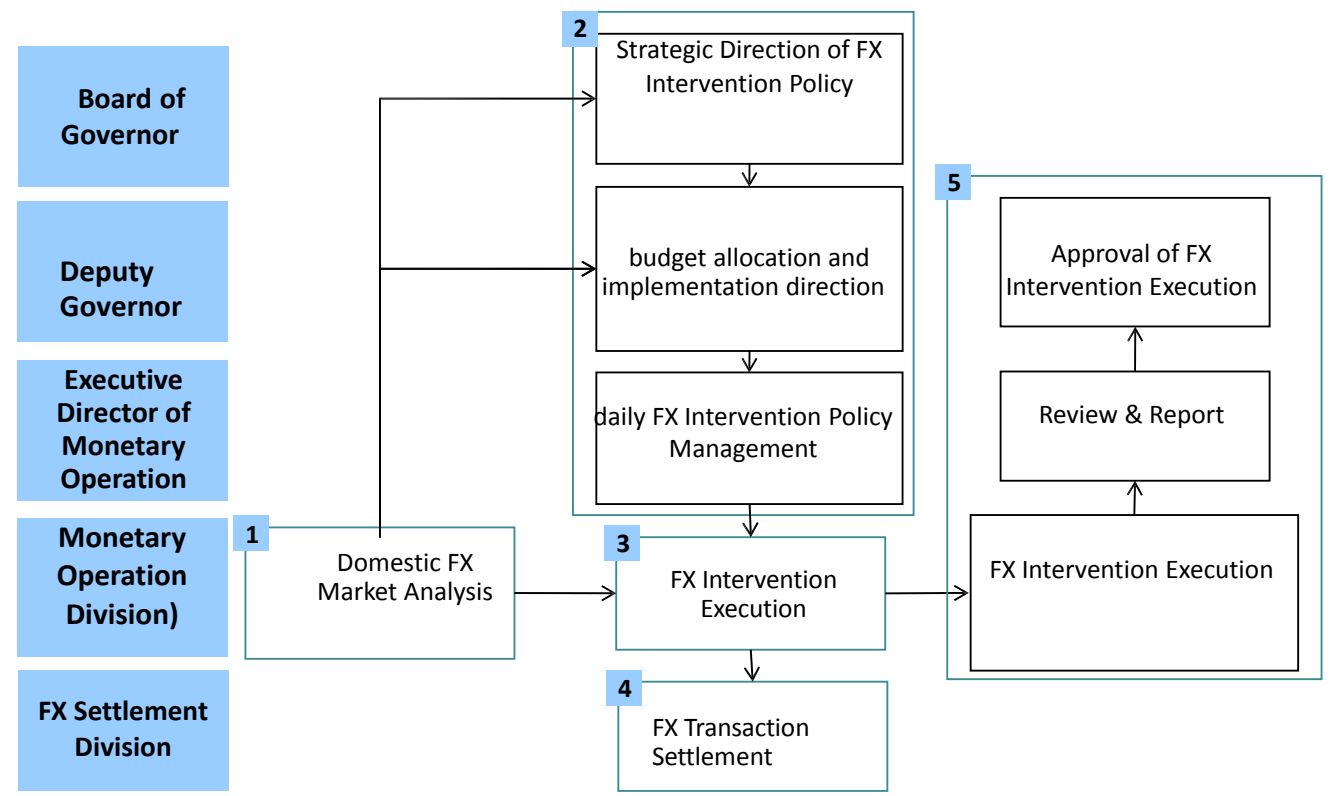

Figure 4. The Steps of FX Policy and Execution Source: BIS (2013) modified

Another governance issue is about the authority to make foreign exchange decision and to which department who will have the duty to execute the foreign exchange decision made by the authority. The decision may be set in the board of governor meeting or delegated to dealing room (monetary operation division) which also has a function as executing department, depending on various aspect to consider. In the case of Indonesia, BI has set up foreign-exchange policy decision making process guideline from formulating/directing policy until execution of the policy. The strategic plan of policy is made through board of governor meeting based on deep research regarding to exchange-rate development and its main determinants. The strategic decision is then implemented by the department/division in charge (Figure 4 and 5).

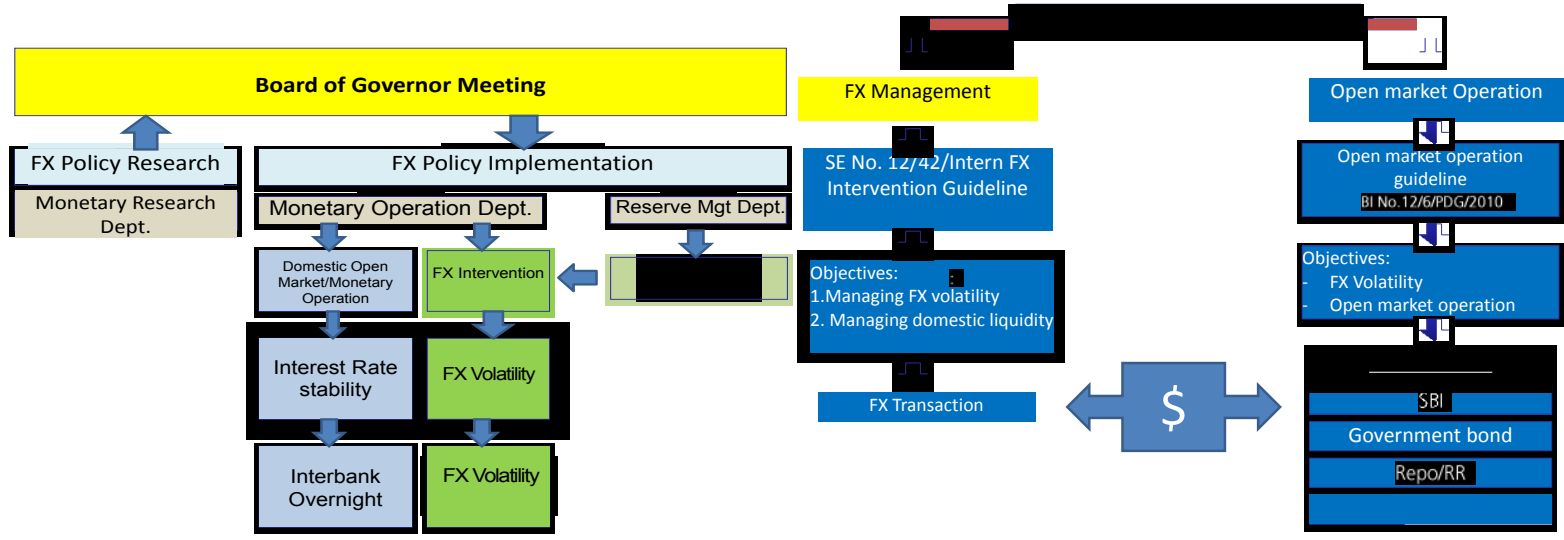

Figure 5. The Monetary Policy Decision Making Process \& Execution Source: BIS (2013) modified

\section{Foreign-exchange Intervention's Objectives and Policy Instruments}

In the case of Indonesia, foreign exchange policy conducted by Bank Indonesia has two main objectives. Firstly, in the short horizon, this such a policy has task to maintain exchange-rate stability. Secondly, in the medium and longer term, the policy should drive the exchange-rate movements along its fundamental path which is consistent with the inflation and macroeconomic forecast over the policy horizon. In addition to that, BI has been implementing various monetary instruments so called monetary and macro-prudential policy mix which recently consists of the following several policy instruments such as BI Rate, capital flows management, macro prudential policy, and monetary policy communication (Figure 6). As Bank Indonesia has been implementing ITF, the short-term interest rate policy 'BI Rate' is the main instrument supported by other monetary policy instruments to achieve the inflation target. In this case, the BI rate is a policy rate which has function as a monetary signal made so as to ensure that the inflation forecast over the policy horizon without disturbing business activities. Other supported monetary policy such as window facility, it has objective to ensure the adequacy of banking liquidity daily. 


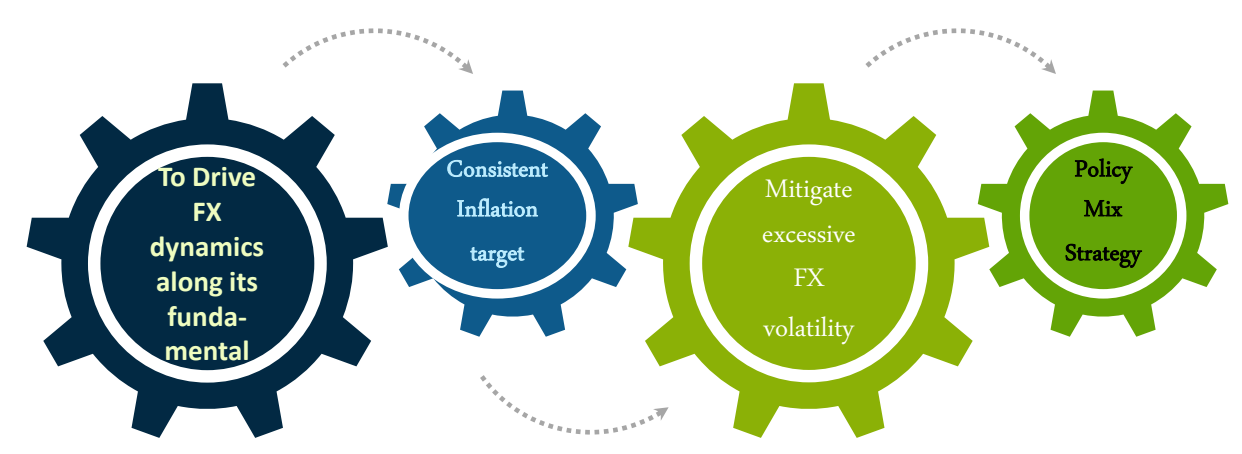

Figure 6. The Governance Aspect in FX Intervention Objectives Source: BIS (2013) modified

Meanwhile, to curb short-term undesired capital flows and mitigate the risks of capital reversal and financial system instability, BI has been conducting capital flow management. The implementation of this kind policy so far such as applying a longer maturity of SBI Certificate 'six-month holding period for BI's certificates', limiting on short-term bank off-shore borrowing, and foreign exchange reserve requirements is effective to curb shortterm capital flows as the foreign portfolio in domestic securities (SBI central bank bill 'SBI' and government bill 'SUN') showing decreasing. With regard to maintain financial stability, another measure concerns to macro prudential policy which is designed to strengthen the resilience of the financial system, including its ability to withstand exchange rate risk, to mitigate the pro-cyclicality of the intermediation function, and to enhance the efficiency of the financial system. This policy applies mostly in banking sector for example by regulating loanto-value ratio to contain excessive lending in the real estate and automotive sectors and pro-cyclical capital adequacy ratio. Besides, to support above policies, BI has also been implementing monetary policy communication especially to manage inflation expectations so that they are in line with the inflation and macroeconomic forecast.

\section{Operation and Strategy of Foreign Exchange Intervention}

With regard to foreign exchange policy implementation, most central banks included Bank Indonesia conduct foreign-exchange interventions in the spot market mostly and small portion in forward market as foreignexchange market transactions was dominated by foreign exchange spot instrument. In term of currency, USD/IDR is still the most active traded currency, but the proportion of other currencies pair transaction such as EUR/IDR, JPY/IDR, and Asian Currencies tend to increase. To support foreign exchange liquidity, since mid2012, BI has been offering foreign exchange term deposits (through weekly auctions) to those banks that are experiencing a temporary excess of foreign-exchange liquidity. In order to maintain domestic liquidity adequacy is consistent to support inflation target achievement, the implementation of foreign exchange intervention is supported with monetary operations for example interest rate corridor. This kind of monetary operation is called sterilized intervention which is designed to ensure that the objectives of maintaining price stability, exchange rate stability and financial system stability can be attained.

In conducting foreign-exchange intervention policy, a central bank will choose between open or closed method as its strategy (Figure 7). This strategy would be selected depending on the interconnectedness of financial markets between domestically and cross-border issue. In fact, most central banks conduct foreignexchange policy in a closed method as it may improve its effectiveness. This closed method of course may be contradictive with one of governance principle (transparency issue). Others prefer open method whenever conducting foreign-exchange intervention policy to give signal to foreign-exchange players that the central banks is concerned to maintain exchange-rate stability. With regard to exchange-rate policy, as outlined from BI foreign-exchange dealing guideline, Bank Indonesia has two methods of conducting foreign-exchange intervention. First, the foreign-exchange intervention altered directly with the market without using an intermediary, called open method. The second type of intervention is using intermediaries (an agent bank/financial institutions), which is called the closed method. In the case of Indonesia, BI conducts foreignexchange interventions through agent banks to trade foreign currency (mostly US dollars) depending on excess liquidity conditions in the market. The objective is to smooth out the volatility of exchange rate movements along the chosen fundamental path. According to Dealing Room Guideline, Bank Indonesia chooses between the open and closed method, considering some aspects such as market psychology, kinds of market sentiments, exchange-rate forecast calculated from technical analysis, liquidity condition of domestic foreign exchange market, and Foreign-exchange reserve adequacy. 
- Open method:

- Direct Dealing to Banks or indirect through money broker

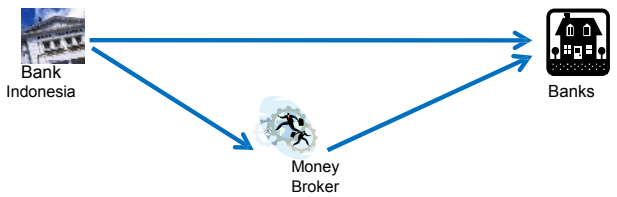

- Closed Method:

- Indirect Dealing through agent

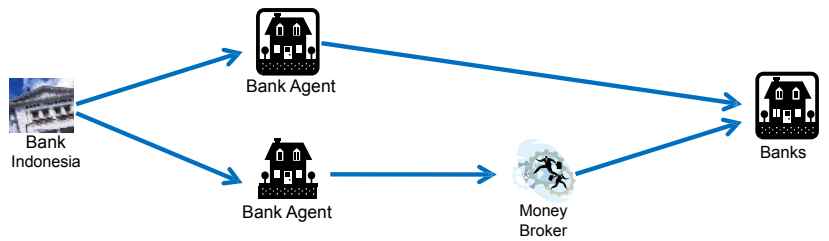

Figure 7. The Methods of Conducting FX Intervention Source: BIS (2013) modified

Supply and demand conditions in the foreign currency market are always taken into account when Bank Indonesia plans to enter foreign-exchange market or setting new policy directions caused by external shocks. Several factors such as global/regional/domestic financial market conditions/perception, potential mover (fundamental or speculative based foreign-exchange transactions), domestic market liquidity conditions and transaction turnovers are taken into account whenever foreign currency interventions are undertaken through appropriate FX management and implementation, as stated in internal Bank Indonesia guidelines and regulations. As illustrated in Figure 8, a comprehensive market coordination analysis is formulated to decide how (with respect to monitoring, moral suasion, intervention, match maker), when (with regard to timing of intervention execution), and whom (with regard to what institution the intervention is implemented trough) regarding to FX intervention implementation.

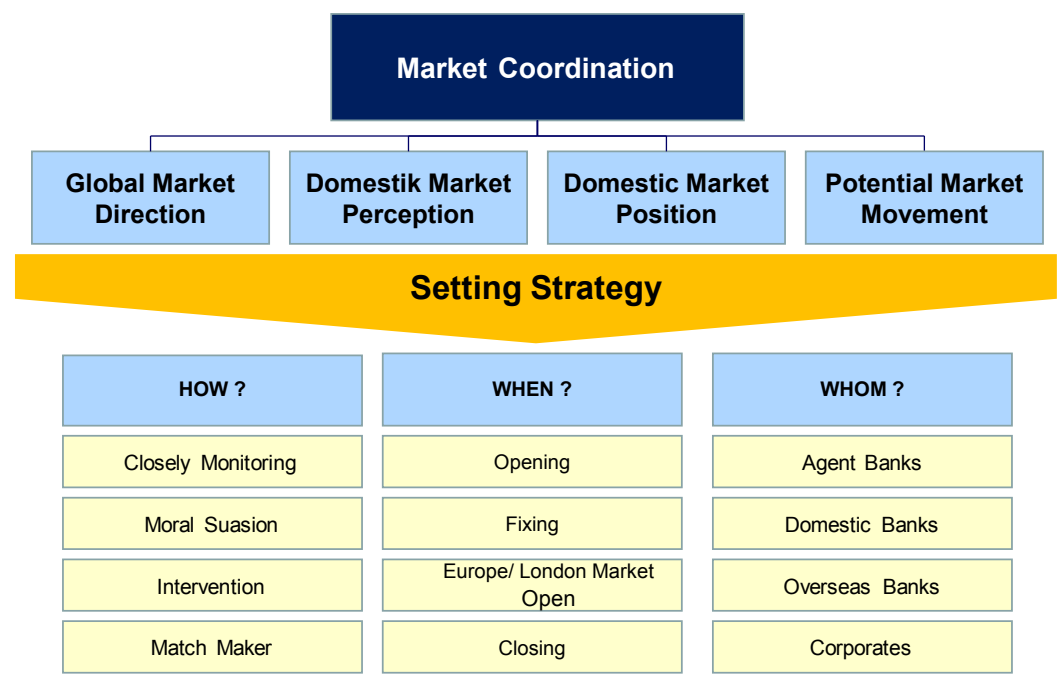

Figure 8. The Market Coordination \& Implementation FX Intervention's Strategy Source: BIS (2013) modified

The implementation of foreign currency intervention policy also considers timing, in order to avoid predictability and magnitude by the foreign-exchange players. The exchange-rate intervention in the domestic foreign exchange market is structured so as to provide a resistance level for the currency, with the objective of reducing the probability of exchange rate movements beyond that level. In addition, the foreign exchange intervention in the foreign exchange market by the central bank is conducted by entailing selling and buying of domestic currency, which directly affects the central bank's liabilities. Such policies are financed by official foreign reserves (OFRs), which are assets on the central bank's balance sheet. In this case, the central banks has also task to manage their portfolios of Official Foreign Reserves (OFRs) as their exchange rate management. As defined by IMF, central bank's official foreign exchange reserves (OFR) are official public sector assets reflecting the capacity to intervene in support of the national or union currency which are controlled by the monetary authorities to support and maintain confidence in conducting monetary and exchange rate policies. OFRs is designed to absorb external shocks during period of crisis. Moreover OFRs can improve central bank's 
credibility to stake holders to meet its external obligations, government foreign obligations and for some extend to guard debt obligations as well as maintain a reserve for national disaster or emergencies.

\section{Transparency and Accountability of Foreign-Exchange Intervention Policy}

Another interesting issue of governance implementation on exchange-rate policy concerns transparency and accountability. Transparency and accountability are other important aspects as part of governance principles. Most government institutions and private corporations, implement this aspect rigorously, as it will impact indirectly to its performance. According to this, to ensure the desired result upon exchange-rate expectation of foreign-exchange market participants, foreign-exchange policy implementation should be based on transparent mechanism and should be applied sparingly (Domac and Mendoza, 2002). However, this is not the case for central banks when conducting foreign-exchange interventions. The hypothesis predicts that central bank may influence exchange rate movements, under certain circumstances, secretly use volatility-changing strategies to manage exchange-rate levels. This is strongly supported by the fact that central banks frequently intervenes covertly in the foreign-exchange market.

As explained previously, it may be commonly accepted recently that a good central bank is a transparent central bank. However, it is different when discussing foreign-exchange intervention by the central banks. Transparency may halt the effectiveness of foreign-exchange intervention. In fact, foreign exchange interventions by most central banks are conducted secretly instead of transparency that in general this is well accepted in markets and compliant with central bank laws as well as with codes of common practice. This is because transparency about operations in the foreign exchange market may reduce their effectiveness in achieving their objectives. Moreover, the exchange-rate interventions are applied to mitigate the misaligned exchange-rate movements or when exchange-rate movements are inconsistent with the goals of monetary policy. Hence, the effectiveness of foreign-exchange interventions would be reached as they are implemented secretly as supported by Volcker (1995). He argues the further the actual exchange rate has departed from the fundamental equilibrium, the more damage the misalignment will do, the more confident the central banks can be that they will be acting as profitable stabilizing speculators, and the greater likelihood of success of any foreign-exchange intervention on the part of central banks. Several studies by Dominguez and Frankel (1993), Neely (2000), Sarno and Taylor (2001), argue that central banks conduct secret interventions to maximize the impact on the exchange rate. While Archer (2005) concludes the transparent intervention is preferable because it increases the power of the signaling and coordination channels. According to this aspect of governance, Bank Indonesia's foreign exchange interventions are done secrecy mostly. BI has not been announcing foreign currency intervention to the public, reserving to itself information regarding volume, strategy, and timing.

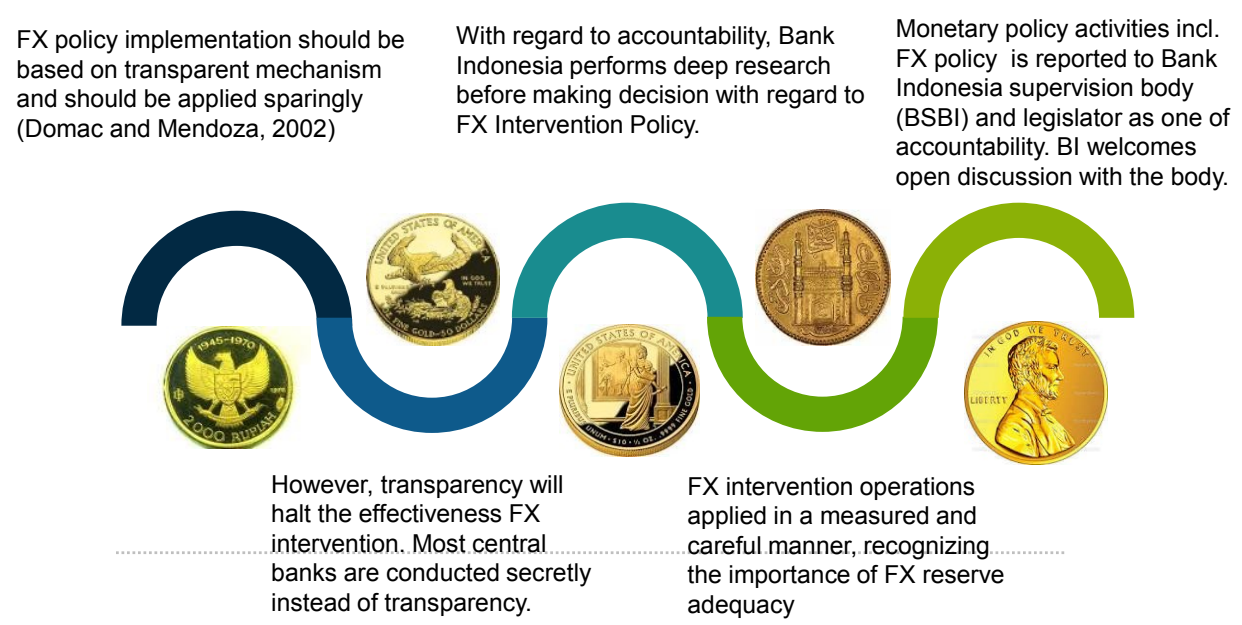

Figure 9. The Governance of Transperancy \& Accountability in FX Intervention Source: BIS (2013) modified

With regard to governance aspect of accountability, it is hard to be implemented as foreign exchange intervention for a central bank than one for the conduct of monetary policy as interventions are actions to mitigate exchange-rate volatility or misalignment within short or longer horizon. Moreover, exchange-rate adjustment is probably only effective in short-run not in the medium or longer run. Beyond on that, Bank Indonesia always perform deep research before making decision with regard to exchange rate policy. Many factors including global/regional/domestic financial markets are playing significant role in determining or formulating foreign-exchange policy in term of foreign-exchange market management or policy direction from the board of governor. As a consequence, foreign-exchange intervention operations by BI are applied in a measured and careful manner, recognizing the importance of foreign exchange reserve adequacy. Furthermore, 
BI always makes a regular report of its monetary policy activities included foreign-exchange policy implementation to Bank Indonesia supervision body (BSBI) as one of accountability implementation. BI also welcomes open discussion with the body to explain it more comprehensively. Regularly, a legislator will review a central bank's performance reported in the banks' annual reports (Figure 9).

\section{Foreign Exchange Intervention Effectiveness}

Obviously, it is hard to conclude that central bank's foreign exchange per se, is able to stabilize exchange rate due to several other monetary policy instruments are applied at the same time. However, central banks can measure the applied policy effectiveness by how far the policy's objectives reflected by economic indicators development are achieved. In the case of Indonesia, applied foreign-exchange intervention policy by BI, can stabilize rupiah volatility reflected by lower exchange-rate volatility comparing to its condition before foreignexchange intervention done. A research by Bank of Thailand (2005) suggests that the Bank of Thailand (BOT) manages the exchange rate by intervening in the foreign exchange market regularly in order to prevent excessive Thai Baht volatility, while fundamental trends are accommodated. Specifically, BOT focuses on containing excessive and persistent exchange rate volatility and intervenes when exchange-rate movements appear to be inconsistent with fundamental changes. Meanwhile, short-term exchange-rate volatility is not a major concern for BOT unless the volatility persists and becomes a threat to stability.

However, there are some circumstances that foreign-exchange intervention is not gain good results. Therefore, to assess the effectiveness of foreign exchange intervention, one should examine a number of aspects that are in line with the central bank's overall objective of maintaining price stability as well as monetary and financial system stability. There should be clear enough whether the objective of the exchange rate policy is merely smoothing volatility, or also managing the path of exchange rate movement. There should also considered the condition of the depth and behavior of the microstructure of the foreign exchange market, e.g. the number of players, volume of transactions, availability and variety of financial instruments, liquidity conditions and distribution across players, counter-party risks, and the infrastructure needed for efficient market functioning. Another interesting issue concerns the predictability of exchange-rate movements. A study by LeBaron in US (1999) reveals that the absent of exchange-rate interventions by the Fedres, make exchange-rate predictability is reduced as the market players still wait Fedres presents as done before. Conversely, a study by Uribe and Toro (2005) reveal that exchange-rate call volatility options implemented by the central bank in Colombia, have contributed to curb acute exchange-rate deviations, thus helping to reduce market uncertainty. Similar study by Domac and Mendoza (2002) in Mexico and Turkey find that both the amount and frequency of FX interventions have decreased the exchange-rate volatility in both countries.

Another important aspect regarding to the effectiveness of foreign exchange intervention is central banks credibility reflected by the adequacy of international reserves relative to the depth of the markets and the country's external vulnerability. A study by Disyatat and Galati (2005) reveal that in fact Asian Central Banks have accumulated large foreign reserves as a consequence of their foreign-exchange buying intervention policy and incomplete sterilization. They also suggest that several factors such as exchange-rate regime pursued, history of policy actions, the depth and sophistication of the foreign-exchange market, and regulatory controls on foreign-exchange transactions, have significant influence to support foreign-exchange intervention. Commonly, the more reserves, the more confidence the central bank does its monetary policy, and the more effective foreignexchange intervention would be. Bank Indonesia's findings firm the views that Rupiah exchange rate movement is not always reflecting the economic fundamentals. Thus, foreign-exchange intervention is conducted in order to be consistent with the overall objective of achieving price stability and supporting financial system stability. Thus, as stated above, the objective of foreign exchange intervention is to stabilize the exchange rate along its fundamental path and to ensure a path that is consistent with achieving the inflation target and supporting financial stability.

In shorter horizon, the effectiveness of intervention in influencing foreign-exchange market expectations is more difficult to assess, since the exchange rate is more sensitive to speculative foreign-exchange attacks driven by global shocks pronounced by financial or political news and market responses on them. The global shocks may overshoot exchange rate from its fundamental value within a short horizon. Exchange rate overshooting in the short horizon may also occur ignited by a number of factors, e.g. volatile capital flows, irrational behavior of market players, and the microstructure conditions of the market, as well as influence from offshore markets. In this case, the effectiveness of intervention will also depend on the central bank's ability to influence foreignexchange participant's expectations to central bank's desired. As explained by Bank Indonesia, the microstructure of the domestic foreign exchange market also influences the effectiveness of intervention in the case of Indonesia. Under these conditions, USD/IDR movements are prone to changes in perceptions and market conditions, both domestically and offshore. Therefore, it is important for central bank to identify the foreign exchange market player whether fundamentalists or chartists. The thinness of the market makes the banks heavily dependent on the central bank to absorb any excess supply in the market (during current account surplus 
and/or large capital inflow periods) and to supply any excess demand in the market during current account deficit or capital outflow periods.

The exchange-rate is crucial factor in determining future economic growth especially for the open economies. Apart from being the price of money in terms of other currency, exchange-rate dynamics can affect domestic price stability as well as financial stability. In term of price stability, for example, a country that heavily depends on imports, would suffer significantly when price of the import products increase or its exchange rate depreciates. This phenomenon could lead to a significant increase in foreign-exchange demand as well as domestic goods price depending on is power of exchange-rate pass through to inflation. Meanwhile, regarding to financial system stability, in a country that has huge foreign debt, for example, excessive exchangerate depreciation will increase foreign debt value in term of domestic currency rapidly. If the country cannot increase its foreign exchange sources accordingly, this will affect the country's ability to repay its foreign debt, which could lead to an episode of financial crises. As explained in the first part of this paper, the success of foreign exchange intervention in Indonesia will be judged on its contribution to achieving the inflation target and supporting financial system stability as they are explicitly stated as a mandatory in the central bank law. However, the effectiveness of foreign exchange intervention policy cannot be ruled out without other policies implementation such as macro prudential policy and fiscal policy. In the context of capital flows, the macro prudential policy by BI for managing capital flows apply to both residents and non-residents, has been working well supported by monitoring ad mitigating short-term and speculative capital flows (Figure 10).

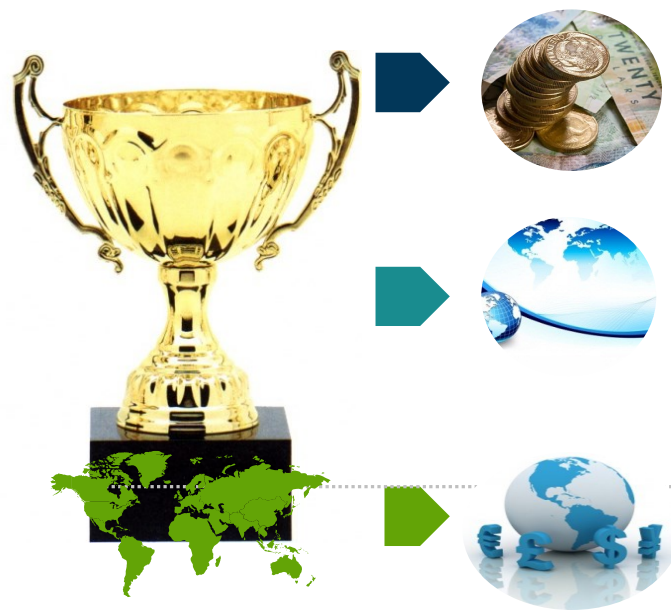

Figure 10. The Governance in FX Intervention's Effectiveness Source: BIS (2013) modified
The success of FX intervention in Indonesia will be judged on its contribution to achieving the inflation target and supporting financial system stability as they are explicitly stated as a mandatory in the central bank law

However, the effectiveness of FX intervention policy cannot be ruled out without other policies contribution such as macro prudential policy and fiscal policy.

In the context of capital flows, the macro prudential policy by $\mathrm{Bl}$ for managing capital flows apply to both residents and non-residents, has been working well supported by monitoring ad mitigating short-term and speculative capital flows.

With regard to ITF objective, exchange rate policy should be able to maintain domestic price stability stemming from external shocks such as foreign commodity prices an oil price (imported inflation). Summarized from BI economic reports, rupiah exchange appreciation in 2009, 2010, and 2011 (up to August) in the period of both the current account surplus and huge capital inflows during which help to reduce imported inflation during these periods of high commodity prices. The policy has been able to reduce the inflation pass-through effects of rupiah depreciation in the price decline of global commodity in 2012. Although recently, the rupiah experienced more than $10 \%$ depreciation in nominal terms, the inflaton is still below the target $4.5 \%$ in 2015 as demand is decreasing.

In the last several years of periods, BI efforts in supporting financial system stability, has been successfully managed through dual interventions of the central bank in both the foreign exchange and bond markets - called 'operation twist'. The operation twist has been able to ensure that domestic liquidity is sufficient and consistent with managing monetary and financial system stability (Warjiyo 2013). This can be illustrated for example when financial global crises happened in 2008 and recenlt, BI heavy foreign exchange intervention to defend the rupiah from the impacts of the global crisis caused a shortage of domestic liquidity and put pressures on conditions for banks, especially smaller banks. Thus BI encounter it by injecting domestic rupiah liquidty by several expansionary monetary policy including building governmet bond up from secondary market. The mentioned central bank purchases of government bonds in the secondary market not only have been able to stabilize government bond price and to stabilize the financial markets but also solving liquidity shortage.

\section{Conclusion}

Governance implementation is a must for the authority in achieving its objectives effectively and efficiently. In the context of foreign exchange intervention, the main objective of foreign exchange intervention is to 
stabilize the exchange rate along its fundamental. Exchange-rate policy in Indonesia is also geared toward price and financial system stability. Bank Indonesia applies the policy with measured and careful manner according to governance principles. Tactically, this has been done through various strategies includes operation strategy and presenting new instruments applied side by side with conventional monetary policies. The most recent policies called 'operation twist' combining dual intervention (in the foreign exchange market in addition to the central bank's operations in the secondary government bond market) augmented with macro-prudential policy, have been admitted as new powerful instruments in achieving Bank Indonesia's objectives.

Bank Indonesia regards exchange rate policy as an integral part of an overall monetary and macro-prudential policy mix designed to achieve price stability while paying due attention to economic growth as well as monetary and financial system stability. For a small open economy like Indonesia, exchange rate movement does not always reflect fundamental value. Increasing exchange rate volatility often occurs as a result of volatile capital flows, irrational behavior of market players, the microstructure conditions of the market, and offshore market influence. In this case, relying solely on interest rate policy to achieve the inflation target and maintain stability is not always sufficient. Thus, the central bank's strategy is to include exchange rate policy in the monetary and macro-prudential policy mix. BI Foreign-exchange intervention policy combined with other monetary policies especially during unfavorable global economic condition, are effective to support USD/IDR exchange-rate stability as well as to maintain domestic financial stability.

\section{References}

- Archer, 2005. "Foreign Exchange Market Intervention: Methods and Tactics". Paper Foreign Exchange Market Intervention in Emerging Markets: Motives, Techniques and Implication. BIS Papers, 24.

- Bank for International Settlements, 2013. "Market Volatility And Foreign Exchange Intervention In Emes: What Has Changed?" BIS Papers, 73.

- Bank for International Settlements, 2005. "Foreign Exchange Market Intervention In Emerging Markets: Motives, Techniques And Implications", BIS Papers, 24.

- Bank Indonesia, Various Years. Economic Report on Indonesia. Jakarta (ID): Bank Indonesia

- Bank Indonesia, 2014. Dealing Room Guideline. Jakarta (ID): Bank Indonesia

- Bank of Thailand, 2005. "Foreign Exchange Policy and Intervention in Thailand". BIS Papers, 24.

- Disyatat, Galati, 2005. "The Effectiveness of Foreign Exchange Intervention in Emerging Market Countries: Evidence from the Czech Koruna”. BIS Working Papers, 172.

- Domac, Mendoza, 2002. "Is there room for forex interventions under inflation targeting framework? Evidence from Mexico and Turkey. Research and Monetary Policy Department, Central Bank of the Republic of Turkey". Discussion Papers, 0206.

- Dominguez, Frankel, 1993. "Does Foreign-Exchange Intervention Matter? The Portfolio Effect", The American Economic Review, 83(5), p.1356-1369.

- LeBaron, 1999. "Technical Trading Rule Profitability And Foreign Exchange Intervention". Journal of International Economics, 49, p. 125 - 143.

- Moentjak T, 2014. Central Banking: Theory and Practice in Sustaining Monetary and Financial Stability. Wiley Finance Series.

- Neely, 2000. "The Practice of Central Bank Intervention: Looking under the Hood", the Regional Economist, Federal Reserve Bank of St Louis.

- Moser-Boehm, 2005. “Governance Aspects of Foreign Exchange Intervention”, BIS Papers, 24.

- Sarno, Taylor, 2001. "Official intervention in the foreign exchange market: is it effective, and if so, does it work?” Journal of Economic Literature, 39(3).

- Uribe, Toro, 2005. "Foreign exchange market intervention in Colombia". BIS Papers, 24.

- Volcker, 1995, "The quest for exchange rate stability: realistic or quixotic?", The Stamp 50th Anniversary Lecture: University of London.

- Warjiyo, 2013. "Stabilizing the exchange rate along its fundamental". BIS Paper, 73. 


\title{
Fiscal Policy Shocks and the Dynamics of Asset Prices in Turkey
}

\author{
Prof. Dr. Mehmet Balc1lar (Eastern Mediterranean University, Cyprus) \\ Ph. D. Candidate Evrim Tören (Eastern Mediterranean University, Cyprus)
}

\begin{abstract}
Asset markets and the asset prices affect financial institutions, consumers, producers and policy makers while they are making decisions. There is an important relationship not only between the financial market and banking system but also between the housing market and the credit market. Therefore, the study analyzes the impact of fiscal policy on asset prices by using beyasian vector autoregressive models. The sample data has been gathered from the Central Bank of the Republic of Turkey. The aim is to demonstrate the effects of fiscal policy shocks on stock prices and housing prices. The data covers the period between 1988:Q1 and 2014:Q2. Overall, the results confirm that the spending shocks coming from fiscal policy have a greater influence on the stock prices. In addition, the government revenue shocks are more influential on the house prices compared to the stock prices in Turkey.
\end{abstract}

\section{Introduction}

There are two different cycles in asset prices. These cycles are called the boom cycle and the bust cycle, respectively. They influence the macroeconomic stability in many countries. The boom cycle is defined as a period of great prosperity or rapid economic growth. It favorably affects output and price stability in the economy. In contrast, the bust cycle is a depression, which dramatically influences output and price stability. Due to the existence of the boom and bust cycles, the global financial crisis has existed recently. Hence, this event makes the macroeconomists aware of the business cycle because there is a decline in the economic, business and financial markets.

Although the signals from the stock market are sometimes interpreted falsely; the housing sector and stock market affect the business cycle movements. For example, the higher interest rates have resulted in in a temporary problem for the housing sector and stock markets in World War II period (Stock and Watson 2003). Thus, the researchers analyze the reasons for continuous loss of economic activity.

The studies based on the relationship between economic policy and asset markets generally examine the monetary policy because this policy is represented as an important factor influencing the business cycle in the economy (Bjornlord and Leitama 2009; Sousa 2010, 2012). However, fiscal policy is also influential when the zero interest rate lower bound is experienced. Schuknecht von Hagen and Wolswijk (2009) contend that the persistent incentives belonging to fiscal policy cause unsustainable conditions for government bond markets. Therefore, the researchers have started to carry out the connection between monetary policy and fiscal stability by ecamining business cycle fluctuations. Their aim is to identify the reasons for the resent financial crisis (Sousa 2010; Castro 2011).

Since producers, consumers, financial experts and government officials take into consideration the properties of asset markets and their prices, the nexus between the financial market and the banking system should be analyzed comprehensively. According to Afonso and Sousa (2011), this linkage creates strong influences in the state of financial disturbance and uncertainty. In addition, the relationship between the credit market and the housing sector also presents important effects, too. Therefore, there are crucial studies, which focus on the connection between the variables that belong to macroeconomics, wealth and asset returns in the literature (Sousa 2010; Afonso and Sousa 2011).

Aye, Balcilar, et al. (2013) state that there are limited studies, which show the process of transmitting innovations of fiscal policy to asset markets. The studies generally focus on the European and the U.S. markets (Afonso and Sousa 2011, 2012; Agnello and Sousa 2011).

For Afonso and Sousa (2011, 2012), the distinct channels coming from fiscal policy have an impact on the stock markets and housing sector. Hence, it is obvious that fiscal policy influences risk spreads in the stock markets. According to the researches on the effect of fiscal policy on the housing sector, the researchers claim that there are direct and indirect impacts of fiscal policy on the housing markets. The direct influences exist through taxes and subsidies on homeowners whereas the indirect effect of fiscal policy replaces through changes in macroeconomic variables. In this respect, the researchers should take into account the importance of fiscal policy properly, if they aim to reveal relevant facts about the development of housing sector and the changes in the stock market.

As stated above, the studies mostly examine the macroeconomic influences of fiscal policy and the effects of stock markets on the business cycle in the developed countries. In other words, the studies don't analyze the relationship between the actions of fiscal policy and improvements in asset prices for small-open economies in the literature. 
For Mountford and Uhlig (2009), the deficit financed tax cuts lead to beneficial consequences to improve gross domestic product (GDP) for the U.S. economy when they have worked on the effects of fiscal policy by using vector autoregressions for the quarterly data from 1955 to 2000. In addition, Afonso and Sousa (2011, 2012) notice that there is a small effect of government spending shocks on GDP but a varied impact on housing prices and a fall in stock prices. Afonso and Sousa (2012) also notice that there is a mixed influence of government revenue shocks on housing prices and a positive and small influence on stock prices. When the quarterly data from 1966:Q1 to 2011:Q2 in South Africa is analyzed, the results confirm that fiscal spending shocks have a greater effect on stock prices than the house prices. By contrast, the revenue shocks are more influential than the spending shocks in case of the house prices in South Africa (Aye, Balcilar, et al. 2013).

In this study, Turkish economy is examined because Turkey has experienced an extraordinary period of economic growth since 2003. For Coskun (2011), Turkey has this economic growth for several reasons such as the full membership candidacy for European Union (EU), the developments in political and economic stability and the increase in liquidity coming from direct and portfolio investments. Where Turkey is concerned, there are limited studies, which examine the effects of fiscal policy shocks specified in the vector autogressive models (VAR). There are some researches which address the effects of fiscal policy and macroeconomic alternatives on wealth, stock and housing returns in Turkey (Caporole and Sousa 2015; Yeldan 1997; Voyvoda and Erinc 2005; Berument and Tasci 2004; Ertugrul and Selcuk 2001; and Anand and van Wijnbergen 1989). The results of these studies generally conclude that fiscal and monetary policies have a positive influence on stock and house prices when they are adapted in a truthful way for the Turkish economy.

However, in the literature, there have been studies examining a disturbance that leads to instability in an economy. For the researches, the disturbance generally replaces because of the drawbacks in monetary policy, fiscal policy and business cycle. Sims $(1972,1980)$ indicates the usefulness of VAR method while analyzing the influences of monetary policy and fiscal policy. Many researchers use this method to show the dynamics of monetary policy shock. In their models VAR models, the monetary aggregate and interest rate are included for research findings.

After the identification of the VAR models by Sims (1972, 1980), Uhlig (2005) proposes a monetary policy shock. In Uhlig's (2005) model, sign restrictions are specified on impulse responses of determined variables for particular periods after the shock. Then, Mountford and Uhlig (2009) use Uhlig (2005) and determine fiscal policy shocks in their models. These shocks are specified as revenue or spending shocks by the government. In Mountford and Uhlig (2009), the sign restrictions are specified while determining the behavior of fiscal policy shocks. In this respect, this study includes the method of Mountford and Uhlig (2009) to analyze the influence of fiscal policy shocks on the stock prices and house prices for Turkey including the period between 1988:Q1 and 2014:Q4.

The variables in the VAR method are converted into real values. The variables in the model are stock prices, house prices, consumption, nonresidential investment, GDP, government expenditure, government revenue, interest rate and consumer price index (CPI) for the analyses. While defining the shocks of fiscal policy, this study also focuses on Afonso and Sousa (2011), Agnello, Castro and Sousa (2012) and Agnello and Sousa (2013). Through the use of sign restrictions proposed by Mountford and Uhlig (2009), this study provides the understanding of fiscal policy scenarios for Turkey.

The study covers a wider emphasis on fiscal policy shocks in Turkey. Throughout the study, the aim is to demonstrate the influences of these shocks concurrently on the stock prices, house prices and macroeconomic variables. The study consists of five sections. Section 2 introduces the particular econometric procedure identified by Mountford and Uhlig (2009). Section 3 reveals the properties of the data used. Section 4 provides the research findings based on the reactions of impulse responses of the series to the government spending and government revenue shocks. Finally, section 5 presents a brief conclusion of the important concerns in the study.

\section{Methodology}

The methodology of the study is based on the analyses of fiscal policy shocks because this issue is very important in the economic literature. When the researchers use Mountford and Uhlig (2009) in their studies, they can easily analyze the influences of fiscal policy on the stock prices and housing prices at the same time. Through the use of Mountford and Uhlig (2009), the study combines the effects of exogenous policy shocks and endogenous responses to the shocks concurrently. The study also uses the approach of Mountford and Uhlig (2009) to determine the shocks of fiscal policy as government revenue and government spending shocks, respectively. In this study, there is a standard procedure to obtain the VAR system while identifying the shocks with the help of sign restrictions.

According to the Uhlig's (2005) sign restrictions for monetary policy shocks, there is a positive restriction on the interest rate. However, there exists a negative restriction on the interest rate and the price level. In addition, the business cycle shock acts together with output, government revenue, consumption and investment in the same direction positively. 
The study includes the orthogonality assumption. This assumption enables the government revenue to avoid the process of being linked for unexpected tax cuts. An increase in taxes lead to the correlated and similar movements of government revenue and output in the model. Hence, the strength of fiscal policy is avoided by the orthogonality assumption in order to obtain beneficial results for the effects of fiscal policy shocks.

As noted before, the study adopts the sign restrictions, which are identified by Mountford and Uhlig (2009). The sign restrictions specify the limitations for the conditions of the sign on the impulse responses for each shock. There are ten variables in the VAR model of the study. According to the Mountford and Uglig (2009), there is a positive restriction on the impulse responses of the variables such as government revenue and government spending. This response is positive for four quarters after the shock. In simpler terms, the fiscal policy shocks, which are government revenue and government spending shocks re determined by the positive restrictions on the impulse responses of fiscal variables. These shocks present a positive limit on four quarters after the shock.

\section{Data}

The study focuses on the data for Turkey. The sample data is gathered from the Central Bank of the Republic of Turkey. The analyses are made for the period between 1988:Q1 and 2014:Q2. The aim is to demonstrate the relationship between asset prices and fiscal policy shocks in Turkey through B-VAR models. The sample data consists of important variables that are government revenue, government spending, GDP, consumption, investment, interest rate, wage rate, CPI and asset prices. All variables -except interest rate in the sample are determined in real per capita terms. The real per capita terms are calculated by dividing the nominal values of the variables by the CPI.

According to Schwartz Bayesian Information Criterion, the model is acquired on 4 lags. The model does not include a time trend and a constant value. Since this model uses sign restrictions, the government spending and government revenue shocks are determined for each draw from the posterior by plotting the 16th, 50th and 84th quantiles in the study.

\section{Empirical Results}

This section is devoted to illustrate four figures. In these figures, the aim is to show the impulse responses of the sample data for the period between 1988:Q1 and 2014:Q4. Each figure demonstrates the changing responses of ten variables. As noted before, the fiscal policy shocks, business cycle shocks and monetary policy shocks are determined are determined according to the sign restrictions.

The impulse responses for the fiscal policy shocks, monetary policy shocks and business cycle shocks are presented for then variables in four different figures. In each figure, the graphs show the 16th, 50th and 84th quantiles of the impulse responses. In order to illustrate the impulse responses properly, the calculation is made at each horizon by specifying the quarters between zero and twenty-four after the shock replaces.

\section{The Analysis of Government Revenue Shock}

Due to the orthogonality assumption, the government revenue shock is constructed as a resting position orthogonally to the business cycle shocks and monetary policy shocks. Therefore, there is an increase in government revenue for a period after the shock exists. Figure 1 presents the outcomes of the analyses of ten variables in the VAR. The graphs exhibit the impulse responses for the discussion. 

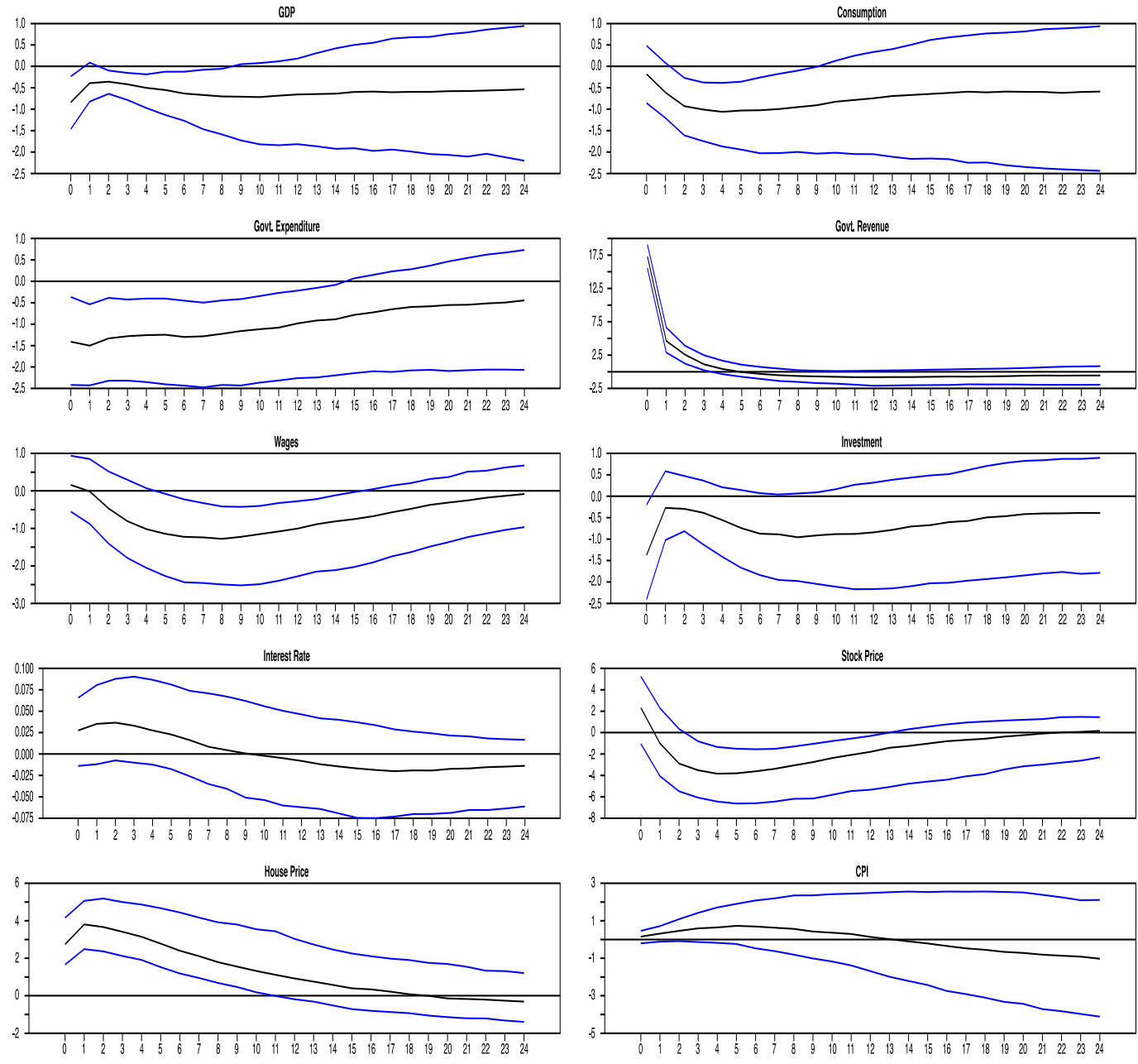

Figure 1. The Impulse Responses of Ten Variables: Government Revenue Shock

For example, when there is a positive government revenue shock, there exists a contractionary impact of this shock on the economy. There are significant and negative responses of GDP, consumption, wages and nonresidential investment to the government revenue shock. This shock adversely influences GDP and the consumption of households. In addition, the initial responses of the real house prices and stock prices are significant and positive. After the shock exists, the real house prices and stock prices start to fall significantly for the sample.

The government revenue shock leads to a decline in the deficit of fiscal policy. This influence automatically reduces the treasury bill price and increases the interest rate. Thus, Figure 1 illustrates a positive response of interest rate and CPI to the government revenue shock. As noted before, there is a decline in GDP. This decline results in a decrease in stock prices while nonresidential investment is responding negatively to the government revenue shock. In other words, the performance of the stock market is influenced adversely due to the negative responses of the stock prices.

\section{The Analysis of Government Spending Shock}

In order to express the influence of government spending shock, the outcomes of the impulse responses of ten variables are illustrated in Figure 2. As stated before, government spending shock is defined as a fiscal spending shock. Government spending shock is also constructed to remain orthogonal to the business cycle and monetary policy shocks. Therefore, the government spending shows a persistent increase for a year after the shock exists. 

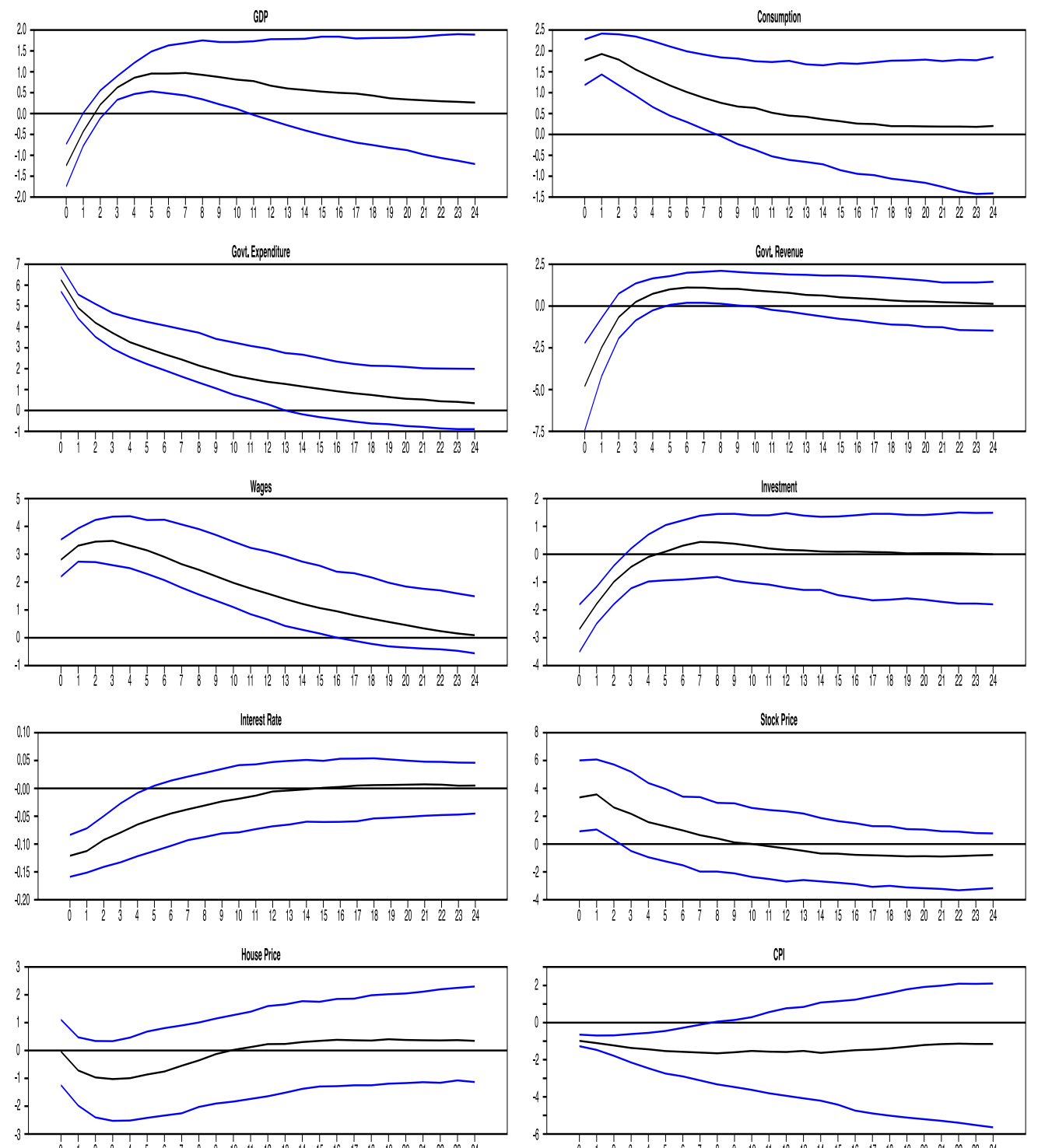

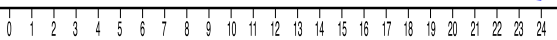

Figure 2. The Impulse Responses of Ten Variables: Government Spending Shock

When there is a positive shock to the government spending, there is an expansionary influence on the economy. Due to the existence of government spending shock, consumption and wages respond significantly and positively. The initial response of GDP to the government spending shock is significant and negative, but then it starts to respond positively for the entire sample.

\section{The Analyses of Business Cycle Shock and Monetary Policy Shock}

The impulse responses of the ten variables are analyzed in this section of the study. It is seen that in Figure 3, the stock prices respond significantly and positively for the entire sample if there is a positive business cycle shock. There is also a positive impact of a business cycle shock on the real house prices. The CPI also exhibits a significant and positive response because the demand increases in a small-open economy. 


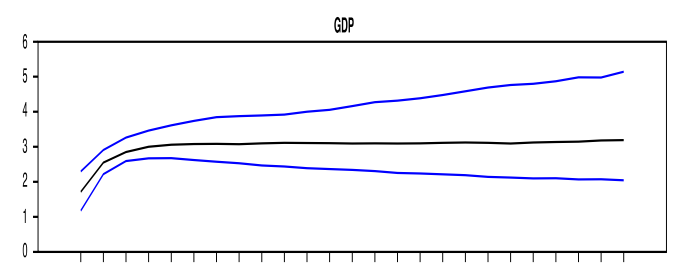

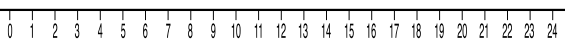

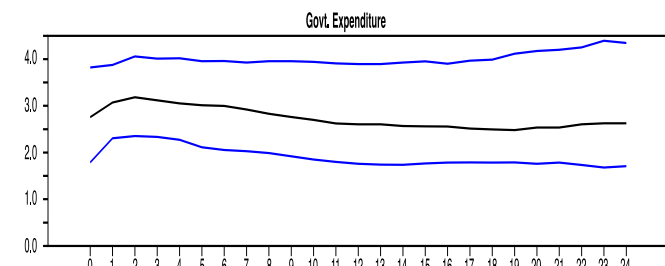

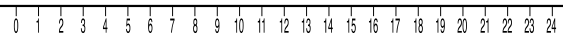

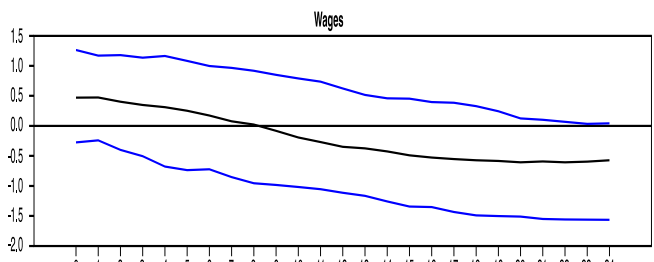

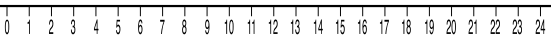

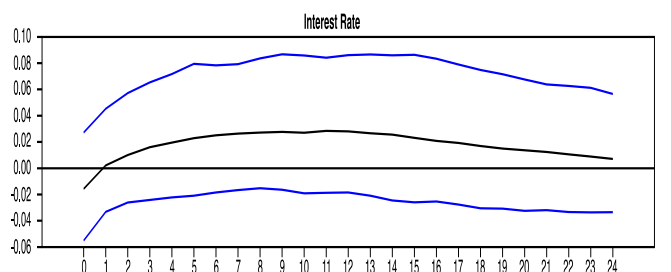

House Price

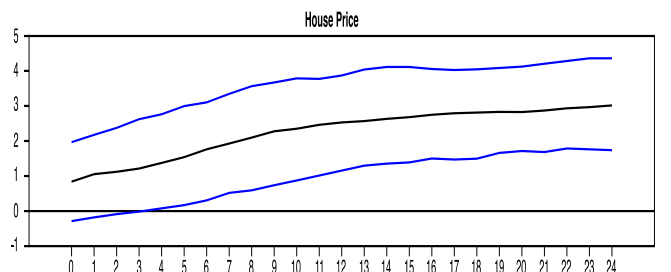

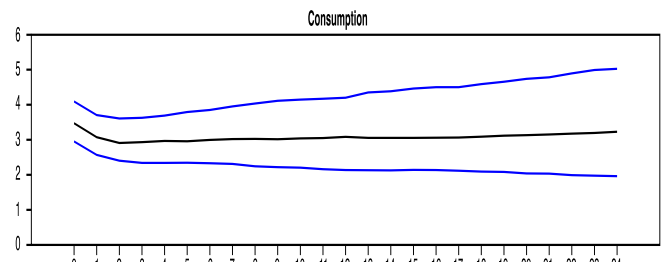

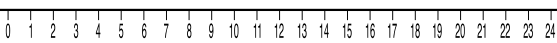

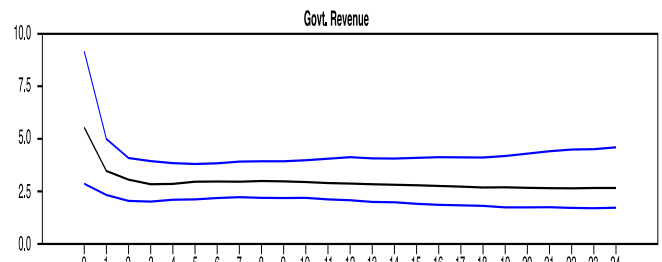

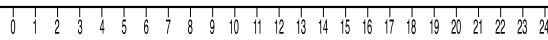

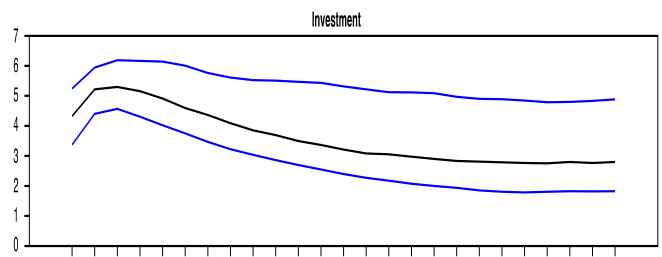

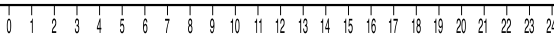
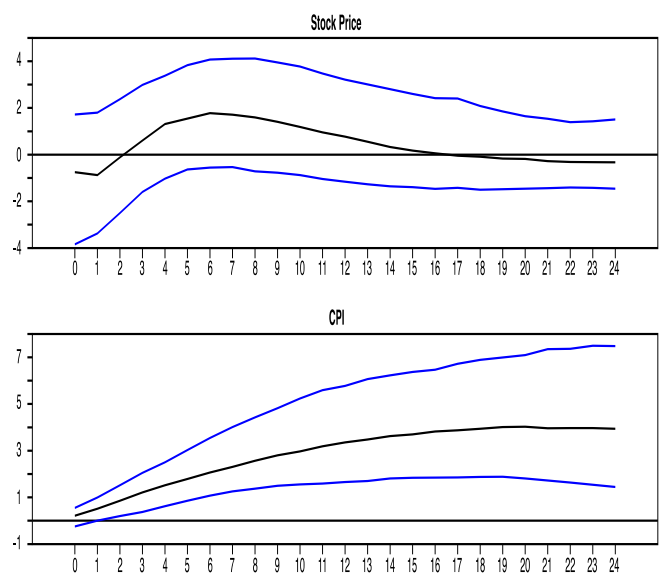

Figure 3. The Impulse Responses of Ten Variables: Business Cycle Shock

In addition, the impulse responses of ten variables in the VAR are presented in Figure 4. The real stock prices respond negatively and significantly to the monetary policy shock. In Figure 4, the real house prices exhibit a significant and positive response to the monetary policy shock.

However, the nonresidential investment and CPI respond significantly and negatively. The responses to the monetary policy shock of GDP, consumption, wages and interest rate, are significant and positive. It is also seen that the effect of the monetary policy shock on government expenditure and government revenue is examined, their responses are significant and positive. 

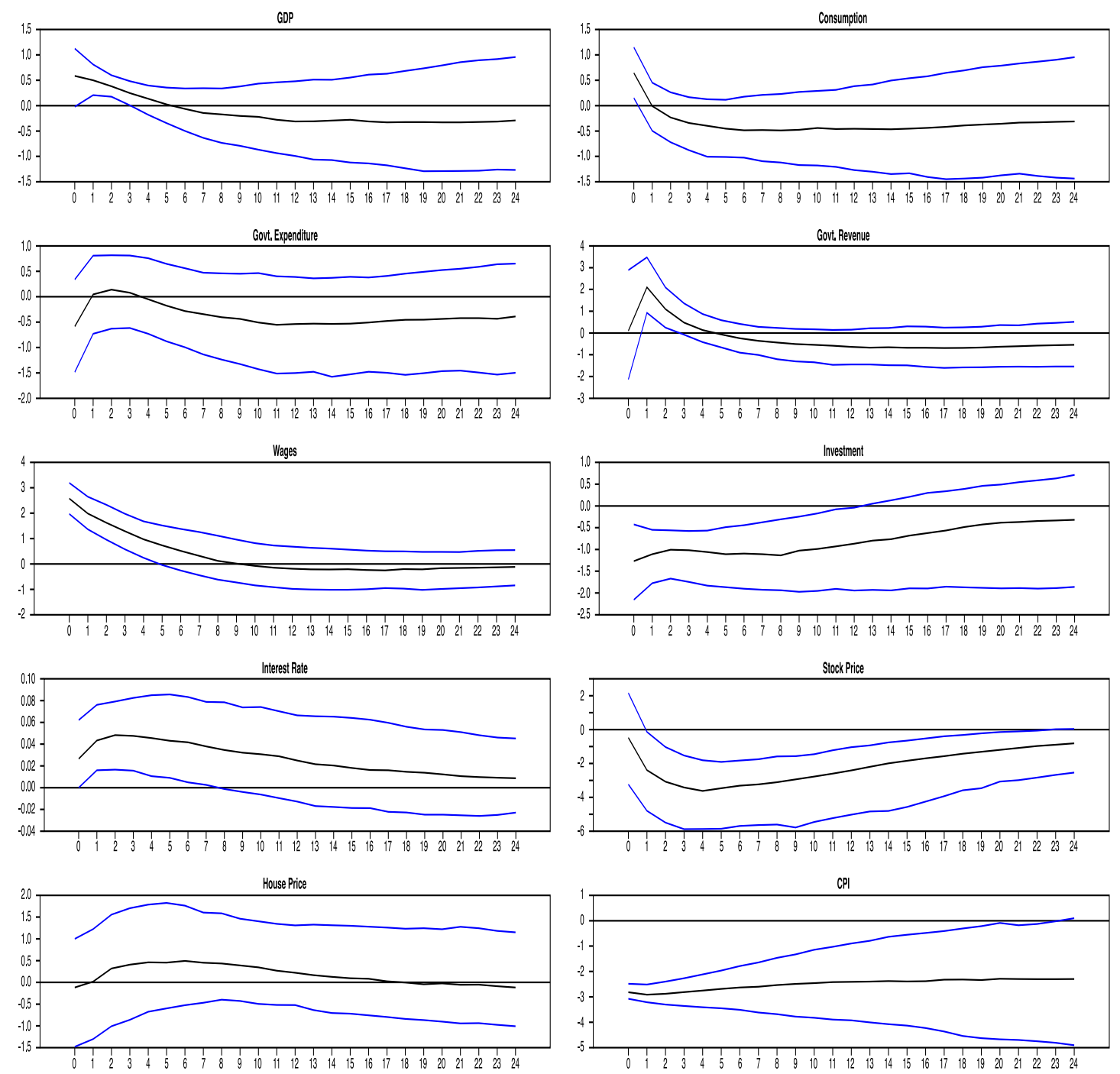

Figure 4. The Impulse Responses of Ten Variables: Monetary Policy Shock

\section{Conclusion}

In this study, the B-VAR models are used to examine the impact of fiscal policy shocks on stock prices and house prices. The VAR system includes ten variables, which are government revenue, government consumption, GDP, wages and nonresidential investment, stock prices, house prices and interest rate. The approach of Uhlig (2005) and Mountford and Uhlig (2009) is used to obtain outcomes. The sign restrictions are determined in order to get the beneficial results in the econometric method of the study.

According to the research findings, if there is a positive government revenue shock, this fact adversely influences the stock prices and house prices, respectively. On the other hand, where there is a positive shock to government spending, the stock prices have a significant and positive response whereas the house prices don't respond significantly. The results confirm that the spending shocks affect stock prices more than the house prices. In addition, the government revenue shock is more influential than the government spending shock when the responses of real house prices are taken into consideration. In this respect, it is very hard to provide a balance for policy makers because the responses of the stock prices and house prices vary when the fiscal policy shocks are examined. The study also shows that a positive monetary shock results in a contraction in Turkey. When there is a positive business cycle shock, the real stock prices and house prices respond significantly and positively. In conclusion, this study provides beneficial results for business cycle shocks, monetary policy shocks and fiscal policy shocks in Turkey. 


\section{References}

- Afonso, Antonio, and Ricardo M. Sousa. 2011. "What Are the Effects of Fiscal Policy on Asset Markets?" Economic Modelling 28:1871-90.

- Afonso, Antonio, and Ricardo M. Sousa. 2012. “The Macroeconomic Effects of Fiscal Policy.” Applied Economics 44:4439-54.

- Agnello, Luca, Vitor Castro, and Ricardo M. Sousa. 2012. "How Does Fiscal Policy React to Wealth Composition and Asset Prices?" Journal of Macroeconomics 34:874-90.

- $\quad$ Anand, Ritu, and Sweder Van Wijnbergen. 1989. "Inflation and the financing of government expenditure: an introductory analysis with an application to Turkey." The World Bank Economic Review 3(1): 17-38.

- Aye, Balcilar et al. 2013. "Fiscal Policy Shocks and the Dynamics of Asset Prices: The South African Experience.” Public Finance review 00(0):1-21.

- Bjørnland, Hilde C., and Kai Leitemo. 2009. "Identifying the Interdependence between US Monetary Policy and the Stock Market." Journal of Monetary Economics 56:275-82.

- Caporale, Guglielmo Maria, and Ricardo M. Sousa. 2015. "Consumption, wealth, stock and housing returns: evidence from emerging markets." Research in International Business and Finance.

- Castro, Vitor. 2011. “Can Central Banks' Monetary Policy be Described by a Linear (Augmented) Taylor Rule or by a Nonlinear Rule?” Journal of Financial Stabi- lity 7:228-46.

- Coskun, Yener. 2011. "Global Financial Crisis and Turkish Housing Market: Is There A Success Story?" Housing Finance International 25(3):6-14.

- Ertuğrul, Ahmet, and Faruk Selçuk. 2001. "A brief account of the Turkish economy, 1980-2000." Russian and East European Finance and Trade 1:6-30.

- Mountford, Andrew, and Harald Uhlig. 2009. "What are the Effects of Fiscal Policy Shocks?” Journal of Applied Econometrics 24:960-92.

- Schuknecht, Ludger, Jurgen von Hagen, and Guido Wolswijk. 2009. "Government Risk Premiums in the Bond Market: EMU and Canada.” European Journal of Political Economy 25:371-84.

- Sims, Christopher A. 1972. "Money, Income and Causality.” American Economic Review 62:540-52.

- Sims, Christopher A. 1980. "Macroeconomics and Reality." Econometrica 48:1-48.

- Sousa, Ricardo M. 2010. "Housing Wealth, Financial Wealth, Money Demand andPolicy Rule: Evidence from the Euro Area." The North American Journal ofEconomics and Finance 21:88-105.

- Stock, James H., and Mark W. Watson. 2003. "Understanding Changes in Interna-tional Business Cycle Dynamics.” National Bureau of Economic ResearchWorking Papers, Cambridge, MA.

- Uhlig, Harald. 2005. "What are the Effects of Monetary Policy on Output? Resultsfrom an Agnostic Identification Procedure.” Journal of Monetary Economics 52:381-419.

- Voyvoda, Ebru and Erinc Yeldan 2005. Turkish Macroeconomics under the IMF Program: Stangulation of the Twin-Targets, Lopsided Growth and Persistent Fragilities. Bağımsız Sosyal Bilimciler Working Paper.

- Yeldan, Erinc A. 1997. "Financial Liberalization and Fiscal Repression in Turkey: Policy Analysis in a CGE Model with Financial Markets. Journal of Policy Modeling 19(1): 79-117. 


\title{
Trade Openness and Macroeconomic Policy in OECD Countries
}

\author{
Asst. Prof. Dr. Naime İrem Koşan (Beykent University, Turkey) \\ Prof. Dr. Sudi Apak (Beykent University, Turkey)
}

\begin{abstract}
Trade openness has been subject to an important issue many studies in literature. It allows us to analyze potential trade as a percentage of gross domestic product. Total value of international trade in goods and services shows the countries' integration into the world economy. Generally, small countries are more integrated because of their dependency on imports. On the other hand, there many variables which effects trade integration. Our study focuses on to analyze the effects on trade openness and make inferences for OECD countries.

In this paper we aim to examine the relationship between trade openness and macro-economic indicators in OECD countries. To analyze the relationship, we used panel data regression analysis. Data obtained from World Bank, The Heritage Foundation and United Nations Conference on Trade and Development (UNCTAD). The panel data covers $2000-2013$ periods and 33 countries. The analysis made through the Stata econometric packet program. We predicted pooled, fixed effects and random effects panel data models and analyzed them.

It has been found that gross domestic savings, investment freedom, and unemployment rate are statistically significant. The results found in this paper show that investment freedom and gross domestic savings have positive effect on trade openness as we expected. On the other hand, unemployment rate has positive effect on trade openness. These findings have important policy implications for OECD countries. Our interpretation of these findings is that, integration to world economy has generally positive effects for macroeconomic factors in OECD countries, but it should be limited.
\end{abstract}

\section{Introduction}

The analysis of trade openness and macroeconomic policy has been a popular area of interest for a very long time. Trade openness is an indicator which allows us to analyze potential trade as a percentage of gross domestic product. Total value of international trade in goods and services shows the countries' integration into the world economy. Also there are many variables which effects trade integration.

In this paper in order to examine the relationship between trade openness and macro-economic indicators, panel data analysis has been used. The data covers 2000-2013 periods and 33 OECD countries Data obtained from World Bank, The Heritage Foundation and United Nations Conference on Trade and Development (UNCTAD).

\section{Literature Review}

Sachsida, et. al, (2003), discussed the impact of trade openness on inflation. The sample consists of 152 countries for the 1950-1992 period. They estimated the relation between inflation and trade openness with the use of panel data methods. The results show that there is a negative relation between inflation and trade openness. And the authors indicate this relation can be generalized for all countries for every period (Sachsida, et. al, 2003: 318).

Bowdler and Nunzata (2006), investigated impact of trade openness on the probability of such an event. The data set consists of 19 OECD countries covering the period 1961-93. Panel data regression results indicate that trade openness reduces the probability of an inflation start (Bowdler and Nunzata 2006:553).

Manole and Spataraneu (2010), investigated the relationship between trade policy and level of income. They used OLS regression and instrumental variables method with 131 countries between 1990 and 2004. The results suggested that higher trade protection is associated with lower per capita income (Manole and Spataraneu, 2010:3).

Kim, et. al (2010), discussed in their paper, the dynamic effects of trade openness on financial development. The data set consists of 88 countries covering the period 1960-2005. They run ARDL model and they evaluated the coefficients for long-term and short-term. The results shows while that trade openness and financial development has a positive relationship in the long term, has a negative relationship in the short term. Also they find that the trade-finance relationship differs along with inflation (Kim, et al 2010:254).

Kim et. al, (2013) examined the impacts of trade and foreign direct investment on domestic investment. The authors run instrumental variable regression approach the data set which consists of 85 countries over the period 1975-2010. The results suggested that trade has negative effects on domestic investment in under-developed countries but positive effects in developed countries which have better financial sectors, or low corruption (Kim, et. al, 2013:57). 
Gosh (2014), discussed in his paper the impact of openness and exchange rate regimes on inflation with using dynamic panel GMM method. The data set consist of 137 countries from 1999-2002. The regression analysis shows that there is no clear evidence of a significant negative effect of trade openness on inflation except for nations with low trade openness and high inflation rates. Also, the author found that higher capital account openness as well as a movement towards a fixed regime to lower inflation (Ghosh, 2014: 190-191).

Nasreen and Anwar (2014), investigated the causal relationship between economic growth, trade openness and energy consumption. The study covers the period of 1980-2011 using 15 Asian countries. Firstly they applied panel unit root tests to check the stationary properties of the variables. Secondly, they used the panel cointegration tests applied for long-run examination. The results confirm that the presence of cointegration between variables. The impact of economic growth and trade openness on energy consumption is found to be positive. And also the analysis indicate that there is a biddirectional causality between economic growth and energy consumption, trade openness and energy consumption (Nasreen and Anwar, 2014: 82).

Sbia, et. al (2014) examined the relationship between foreign direct investment, clean energy, trade openness and economic growth in United Arab Emirates covering the period of 1975-2011. Granger causality analysis applied the data series. The results show that foreign direct investment, trade openness and carbon emissions decline energy demand (Sbia, et. al, 2014:191).

Menyah et. al, (2014) investigated the causal relationship between financial development and economic growth. In order to examine the author used panel bootstrap approach to Granger causality. The data set covers 21 African countries during the period 1965-2006. The results show that financial development and trade liberalization don't have a significant effect on growth (Menyah, et al 2014:386).

Le (2014), examined impacts of trade openness and institutional reforms on household welfare. The data set includes Vietnam Household Living Standarts Surveys of 2006 and 2010. The results show that trade openness and institutional reforms have positive impact on household welfare in provinces (Le, 2014:68).

Musila and Yiheyis (2015), examined the relationship between trade openness on level of investments and the economic growth for Kenya. The data consists of the period 1982-2009. According to the results, trade openness is found to have positively impact the level of investment .On the other hand Granger Causality tests indicate that there is a long-term relationship between economic growth and trade openness (Musila and Yiheyis 2015:342-354).

\section{Data Source}

Data set comprises 2000-2013 period of 33 OECD countries. Trade openness is selected as dependent variable and Gross Domestic Savings, investment freedom of countries and unemployment rate are selected as independent variables in the study.

Trade openness used as a dependent variable in our models shows sum of exports and imports as a percentage of nominal gross domestic product. Trade openness data is downloaded from the database of the United Nations Conference on Trade and Development (UNCTAD).

Gross Domestic Savings is obtained by subtracting the final consumption expenditures from the Gross Domestic Product. Domestic savings is one of the most important variables when economy is analyzed in its entirety. According to the tendency to saving in a country, the rate of external savings to be made, the field where the investment will be made and the way of position to be taken in that country will be determined. Data of Gross Domestic Savings are obtained from the database of the World Bank. In our study, the numbers of gross domestic savings are taken as the percentage in the gross domestic product.

Unemployment rate shows the percentage of the total labor force that is unemployed but available and seeking employment. Unemployment rate data is downloaded from the database of the Worldbank.

Investment freedom index, on the other hand, is an index which shows the freedom of the investors in a country to use the investment capital in an unlimited manner as they desire. Many countries have different limitations in the application. Considering these limitations, an index is created for the countries. Data of the investment freedom index are also downloaded from the web site of the heritage foundation broadcasting the index of economic freedom.

\section{Empirical Results}

Pooled regression model, fixed effects panel regression model and random effects panel regression model are used in the model prediction. The results for every three models are presented in the following table. 


\begin{tabular}{|c|l|l|l|}
\hline & Pooled OLS & Fixed Effects & Random Effects \\
\hline $\mathrm{c}$ & $\mathbf{- 8 7 . 1 4 * * *}$ & $\mathbf{4 0 . 3 2} * * *$ & $\mathbf{3 3 . 6 5} * * *$ \\
& $(-7.91)$ & $(4.52)$ & $(3.25)$ \\
\hline Unemployment & $\mathbf{3 . 0 6} * * *$ & $\mathbf{0 . 7 0} * * *$ & $\mathbf{0 . 7 5} * * *$ \\
Rate & $(7.30)$ & $(3.32)$ & $(3.55)$ \\
\hline Gross Domestic & $\mathbf{3 . 4 5} * * *$ & $\mathbf{1 . 2 8} * * *$ & $\mathbf{1 . 4 4} * * *$ \\
Savings & $(12.77)$ & $(5.14)$ & $(5.93)$ \\
\hline Investment & $\mathbf{0 . 9 3} * * *$ & $\mathbf{0 . 1 4} * * *$ & $\mathbf{0 . 1 8} * * *$ \\
Freedom & $(7.32)$ & $(1.97)$ & $(2.39)$ \\
\hline F stat & $94.73 * * *$ & $137.48^{* * *}$ & $43.13 * * *$ \\
\hline
\end{tabular}

Table 1: Effect of unemployment rate, gross domestic savings and investment freedom on trade openness

Note: Terms on brackets denote $t$-stat based on robust standard errors. ***,*** indicate significances at the \%10, \%5 and $\% 1$ levels. The coefficients in bold are the ones that are statistically significant.

With respect to the pooled panel regression model, index of unemployment, gross domestic savings and investment freedom is observed to be statistically significant according to the 5\% significance level. According to these results, while one unit of increase in the index of investment freedom increases the trade openness 0.93 unit, one unit of increase in unemployment rates leads to a 3.06 unit increase in the trade openness. One unit of increase in the percentage of gross domestic savings in gross domestic product, however, leads to a 3.45 unit of increase in trade openness. Signs of the coefficients are suitable to our financial expectations. When fixed effects panel regression model is predicted, however, coefficients of every three variables are observed to be suitable to our financial expectations as in pooled model and to be significant in a 5\% significance level. One unit of increase in unemployment rate increases the trade openness about 0.70 unit while one unit of increase in the percentage of domestic savings in gross domestic product increases the trade openness 1.28 unit. One unit of increase of the investment freedom, on the other hand, increases the trade openness 0.14 unit.

Finally, random effects panel regression model is predicted. In this model all the coefficients are economically significant. While one unit of increase in the investment freedom increases the trade openness 0.18 unit, one unit of increase in the unemployment rate increases the trade openness 0.75 unit. One unit of increase in the percentage of gross domestic savings in gross domestic product, however, leads to a 1.44 unit of increase in trade openness.

After the coefficients for the three models are interpreted, model comparison is performed. $F$ test can be applied for the comparison of pooled model and one way fixed effects model. The hypothesis where all the unit effects are equal to zero is tested in F test. To carry out this test, fixed effects model is predicted and F statistics calculated here is compared with the table value. F statistics value obtained here is tested by being compared with $\mathrm{F}$ distribution table with $33-1=32$ and $(\mathrm{N}(\mathrm{T}-1)-\mathrm{K})=426$ degree of freedom. According to the obtained $\mathrm{F}(32$, $426=137.48$ and Prob $>\mathrm{F}=0.0000$ result, the hypothesis that the unit effects are equal to 0 is rejected and thus, it is understood that unit effects are present. Pooled model is not suitable. Hausman test is conducted for the comparison of fixed effects and random effects models. Hausman test results are given in the table. As known, Hausman test shows which of the fixed effects model and random effects model predictors are consistent. Actually in this test the significance of the difference between the fixed effects model parameter predictors and random effects model parameter predictors is examined. The biggest difference between the fixed effects and random effects models is that while unit effects are allowed to be correlated with independent variables in the fixed effects model, this correlation is not at stake and is random in the random effects model. If there is no correlation between the unit effects and explanatory variables, the use of random effects model predictors will be suitable. The main hypothesis of Hausman test is as the following: "No correlation is available between explanatory variables and unit effects" and the alternative hypothesis thereof, however, is as the following: "Explanatory variables and unit effects are correlated".

Test results are given in the table 2. Zero hypothesis could not be rejected according to the Hausman test results. In conclusion, it was determined that random effects model predictor is valid for this model. 


\begin{tabular}{|l|c|c|c|c|}
\hline & Fixed Effects & Random Effects & Difference & Standard Error \\
\hline Unemployment Rate & 0.70 & 0.75 & -0.05 & $\cdot$ \\
\hline Gross Domestic Savings & 1.28 & 1.44 & -.166 & 0.0512 \\
\hline Investment Freedom & 0.145 & 0.175 & -0.30 & 0.0024 \\
\hline chi2(3)= & \multicolumn{3}{|c|}{0.2767} \\
\hline Prob $>$ chi2 & \multicolumn{4}{|c|}{} \\
\hline
\end{tabular}

Table 2: Hausman Test's results

\section{Concluding Remarks}

Macroeconomic variables affecting the trade openness of OECD countries were analyzed in our study. When pool panel regression model, fixed effects and random effects models are predicted, it has been determined that unemployment rate, investment freedom and gross domestic savings variables are statistically significant for every three model. Every three variables are positively correlated with the trade openness. Thus, as the domestic savings and investment freedom increase, trade openness increases as well in the OECD countries; external integration of the country has been observed to positively affect these macroeconomic variables. Besides, positive correlation between unemployment rate and trade openness shows us that as the external openness of the countries increases, they need less labor especially thanks to the technological developments. Then, it may be concluded that the increase in the trade openness is generally positive for the countries, but it should be kept in a certain limit.

\section{References}

- Bowdler and Nunziata, 2006, "Trade Openness and Inflation Episodes in OECD ", Journal of Money, Credit and Banking, 38, pp: 553-563.

- Ghosh, 2014. "How do openness and exchange-rate regimes affect inflation ", International Review of Economics and Finance, 34, pp:190-202

- $\quad$ Kim, Lin and Suen 2010. "Dynamics effects of trade openness on financial development", Economic Modelling, 27, pp: 254-261.

- $\quad$ Kim, Lin and Suen, 2013. "Investments, trade openness and foreign direct investment: Social capability matters ", International Review of Economics and Finance, 26, pp: 56-69.

- Le, 2014. "Trade openness and household welfare within in a country : A microeconomic analysis of Vietnamese Households", Journal of Asian Economics, 33, pp: 56-70.

- Manole and Spatarenau, 2010. "Trade Openness and income-A re-examination ", Economics Letters, 106, pp: 1-2.

- Menyah, Nazlioglu and Wolde-Rufael ,2014. "Financial Development, trade openness and economic growth in African Countries: New insights from a panel causality approach", Economic Modelling, 37, pp 386-394.

- Musila and Yiheyis, 2015. "The Impact of trade openness on growth: The case of Kenya", Journal of Policy Modelling, 37, pp: 342-354.

- Nasreen and Anwar, 2014. "Causal Relationship between trade openness, economic growth and energy consumption: " Causal Relationship between trade openness, economic growth and energy consumption: A panel data analysis of Asian countries", Energy Policy, 69, pp: 82-91.

- Sachside, Carneiro and Loureiro, 2003. "Does Greater Trade Openness Reduce Inflation? Further evidence using panel data techniques", Economics Letters, 81, pp: 315-319.

- Sbia, Shahbaz and Hamdi, 2014. "A Contribution of foreign direct investment, clean energy, trade openness, carbon emissions and economic growth to energy demand in UAE", Economic Modelling, 36, pp:191-197.

- The Heritage Foundation 2015, Economic Freedom Statistics, http://www.heritage.org/index/explore

- Unctad 2015, Trade Indicators Statistics http://unctadstat.unctad.org/wds/TableViewer/tableView.aspx?ReportId=16419

- Vehabi, Sadiku and Petkovski, 2015. "Emprical Analysis of the Effects of Trade Openness on Economic Growth: An Evidence for South East European Countries", Economic Modelling, 37, pp. 386-394.

- World Bank 2015, Unemployment Rate Statistics http://databank.worldbank.org/data//reports.aspx . source=2\&country=\&series=SL.UEM.TOTL.NE.ZS\&peri $\underline{\mathrm{od}}=$ 


\title{
Have Credit Rating Agencies Got a Role in Triggering 2007 Global Financial Crisis?
}

\author{
Prof. Dr. Ersan Bocutoğlu (Karadeniz Technical University, Turkey)
}

\begin{abstract}
The efforts for understanding the 2007 Global Financial Crisis requires more elaborated studies on the institutions, processes and other micro foundations of financial services industry instead of studies solely on mainstream business cycles theories that have obviously failed in understanding, explaining and predicting the crisis. This paper attempts to investigate whether or not credit rating agencies had played a triggering role in 2007 Global Financial Crisis. It is a study of parties, institutions and processes within financial services market. It is well documented that the credit rating agencies whose main function is to provide investors with information about the credit-worthiness of securities on which they plan to invest had hardly ever performed that function properly during the crisis. By changing their business models from 'investor pays model' to 'issuer pays model', they paved the way to conflict of interest and inevitably created chaos in financial services industry. Credit rating agencies doubtlessly are responsible for triggering the 2007 Global Financial Crisis. However it should be fair to emphasize also the responsibility of the US regulatory processes in emerging the conflict of interest in credit rating industry by giving some credit rating agencies an oligopoly power in the credit rating market and taking their credit ratings as the basic points of reference for regulatory purposes. It is obvious that the credit rating industry needs a reform.
\end{abstract}

\section{Introduction}

Among other factors, the role credit rating agencies (CRAs) played in 2007 Global Financial Crisis has been extensively investigated (Bocutoğlu, 2014). The attention has been attracted recently to CRAs by the fact that the US Security and Exchange Commission (SEC) suspended the activities of Standard and Poor's (SફP) in the Commercial Mortgage Based Securities market for one year during January 21, 2015- January 21, 2016 because of that it caused loses to the investors by slackening secretly the assumptions of its credit rating model it announced publicly and therefore supplying fake - inflated - credit scores (Whitehouse, 2015).

While CRAs are criticized because of lack of competition, lack of accountability, lack of independence, lack of timeliness and pro-cyclical behavior, and rating triggers (McVea, 2010, Ryan, 2012), the main attack to them is for that their credit rating process proceeds under heavy conflict of interest. According to critics CRAs produce credit ratings with low quality of information about credibility of asset backed mortgages that are of extremely complex structures, their sudden downgrades of credit ratings do not contribute to the stability of the market but produce chaos and they are in lack of unaccountability in financial services industry despite the market power they have (McVea, 2010).

From the end of 2007 summer onwards CRAs had downgraded tremendously the credit ratings of assets backed mortgages and carried on this practice up to 2008 fall. On September 15, 2008 the big three consisting of S§P, Moody's and the Fitch downgraded the credit ratings of AIG, the biggest insurance company in the US due to the loss of stock value of AIG at the rate of $61 \%$. On the very day, Lehman Brothers and Merill Lynch went bankrupt. A while ego Bear Stern declared that it became insolvent and could not fulfill its obligations. After a couple of days Chairman of the Fed Bernanke and Treasury Secretary Paulson asked the Congress whether or not the Congress could buy subprime bed debt of 700 billion dollars. President Bush warned that the American economy as a whole would be in danger of collapse without immediate bail out support of the Congress.

Although CRAs' downgrading the credit ratings is not solely a cause of the crisis, it reveals that CRAs have produced inflated credit ratings. When taking into account of the given incentive system it is not surprising to see that issuers, investors, CRAs and regulators made fatal mistakes. The regulations in 1936 and 1973 implemented by the US Office of the Comptroller of the Currency (OCC) and the SEC respectively depended upon the credit ratings produced by the CRAs. Due to these regulations, a very limited number of CRAs were allowed to take part in credit rating market, the credit rating models and methodologies that CRAs adopted were accepted sufficient and therefore large-scale potential risks were born in financial services industry.

The malfunctioning of CRAs increased the need for international cooperation on a reform in credit rating industry. Financial Stability Commission that was set up in 2009 by D-20 to provide financial stability issued a report calling governments for reducing dependency on CRAs (Ryan, 2012).

This paper attempts to investigate whether or not CRAs had played a triggering role in 2007 Global Financial Crisis. It is a study of parties, institutions and processes within financial services market. 


\section{Credit Rating Agencies}

\subsection{Definition and the Scope of Credit Rating Agencies}

Credit rating agencies can be simply defined as institutions that are specialized in supplying information on credibility of securities or bonds issued by firms, municipalities and states. The credibility is possibility whether or not principal and interest of a certain security or bond are paid when due. Credit ratings can be executed both on debts of the issuers, namely general financial health of the issuers and on the assets that form a financial package as is the case of structured asset-backed securities (Ekins and Calabria, 2012). Credit rating agencies produce ratings by using certain letters and the letters symbolize the opinion of CRAs about credibility of securities or bonds at a certain date. It is important to state that these opinions are subjective and not necessarily represent the accurate forecasts. CRAs' functions can be grouped under three general headings: (i) providing information and assessment for investors, (ii) enabling issuers to access capital markets, (iii) helping regulators to regulate (Ryan, 2012).

It is estimated that there are about 130 CRAs across the world differed in scales, scope of interests and methodologies they use. Among them Standard and Poor's, Moody's and the Fitch are the biggest and they effectively operate globally mainly in financial services industries of the US and the United Kingdom (McVea 2010).

Changes in credit ratings are at stake when there is possibility of large-scale delinquencies but not small-scale credit risk changes in the short run. The rating method of a CRA is 'evaluation in conjuncture' and not 'evaluation at a point'. This means that CRAs do not continuously renew the information about the securities once they rated. They assume that the evaluations they made remain relatively stable in time (Ekins and Calabria, 2012). As a matter of fact the parties that intent to hold securities for longer period of time are not interested in short-term volatility of risk in the financial markets. Frequent changes in credit ratings of a financial instrument make the instrument more costly in that they increase the volatility and assurance of the instrument, and call for quick repayment. The performance of credit ratings represents the reputation of a CRA that performs the ratings and it is expected that changes in the reputation have substantial effects on general performance and profitability of the CRAs.

\subsection{How is the Credit Rating Services Financed?}

There are two business models to price the credit rating services: 'investors pay model' and 'issuers pay model'. In investors pay model, CRAs evaluate the financial instruments and sell the credit ratings to their investor subscribers. The main clients in this model are investors. CRAs have to produce correct information for their clients about the creditworthiness of securities under rating so as to be able to keep them in subscription list and to make money. In issuers pay model, CRAs evaluate the financial instruments upon issuers' request and sell the credit ratings to the issuers. The main clients in this model are issuers. Then the issuers use the credit ratings as some kind of certification that shows the quality and soundness of the financial product they have issued, and sell them to the investors. It is clear that this certification gives confidence to the investors. In the second model, the issuers benefit substantially from the higher credit ratings given by the CRAs. On the other hand, investors take into account the reputation of the CRA that has made the rating and the probability that the credit rating reflects the correct information about the financial instruments.

The issuers typically buy two credit ratings produced by different CRAs for each instrument they have issued. If the difference between two credit ratings are great than the issuers try a third rating. On the contrary, the investors generally rely on one credit rating. If investor is a commercial bank and its same security has different credit ratings, principally the lower rating is depended on calculating the risk that the security may have. In the decision of keeping a certain security at hand, only one credit rating is relied. If a certain security has more than one credit rating, the higher rate is considered (Ekins and Calabria, 2012, Hunt, without date).

\subsection{Brief History of Credit Rating Agencies}

Although the first credit reporting firm The Mercantile Agency was set up in 1841 for eliminating the asymmetric information that had given way to 1837 financial crisis, modern credit rating industry is the artifact of John Moody and Henry Poor who had collected information on railway bonds market and conveyed them to their subscribers by $20^{\text {th }}$ century. Moody's Analyses Publishing Company in 1909, H.V. And H.V. Poor Company in 1906, Standard Statistic Company in 1922 and Fitch Publishing Company in 1924 appeared. As the newcomers were increasing in the industry, an information infrastructure necessary for bonds market was developed.

The firms John Moody's and Henry Poor's were recognized across the financial services industry with their correct forecasts during 1929 Great Depression and this made them gain higher reputation in the market. As the 1945-1970 period was fairly stable, the demand for credit ratings started to increase through 1970s.

There are basically three reasons why CRAs have grown in importance in due course. First of all since Regulation Q of 1933 Glass-Steagall Act banned commercial banks to pay interest for checking accounts, the deposits of commercial banks had almost dried out and therefore their loans capacity was severely restricted 
(Ekins and Calabria, 2012). Together with this new state of affairs, demand for loans had tended to turn from commercial banking to non-commercial credit institutions. Since non-commercial credit institutions did not have credit rating infrastructure that commercial banks had, they turned their faces to the big CRAs. As a matter of course the demand for credit ratings increased. Secondly the fact that the firms departed away from commercial banks due to the higher inflations during the 1975-1980 period fostered the non-financial commercial paper market to grow by $\% 300$. By the same token higher demand for structured financial instruments such as commercial mortgage-backed securities increased the demand for credit ratings. The fact that the SEC and Basel II framework referenced credit ratings as a benchmark in regulations and banks' capital requirements respectively increased the importance of the credit rating agencies. Finally globalization also increased the demand for credit ratings since the new financial products require credit ratings.

\section{Oligopoly in Credit Rating Industry}

In the USA financial services industry and credit rating industry have been working in closely interrelated manner since 1975. The SEC allowed solely credit rating agencies with Nationally Recognized Statistical Rating Organizations designation to operate in credit rating industry. The restrictions imposed by the SEC on credit rating agencies to enter the industry have created an oligopoly in credit rating market dominated by the big tree, consisting of Standard and Poor's, Moody's and Fitch (Ekins and Calabria, 2012). The fact that the SEC and Basel II framework referenced credit ratings as a benchmark in regulations and banks' capital requirements respectively increased the importance of the credit rating agencies. The decision that the big three changed their business model from 'investors pay' to 'issuer pay' model led to the dominance of the security issuers over credit rating agencies and consequently it forced credit rating agencies to produce high credit ratings with low informative quality related to credit risk assessments. It is the starting point of conflict of interest in credit rating industry.

The SEC that is responsible for regulating the credit rating industry in the US set up an institution as Nationally Recognized Statistical Rating Organization (NRSRO) that covers the credit rating agencies that are selected eligible for credit rating business in the industry. It is mandatory that only credit rating agencies selected as NRSROs are allowed to produce -in some sense official- credit rating.

The SEC had granted that permission to a handful of credit rating agencies up to the crisis including Moody's, Standard and Poor's and the Fitch out of more than hundred credit rating agencies and this practice of the SEC gave way to a certain kind of oligopoly in credit rating industry dominated by the big three. The fact that the SEC had lengthened the evaluation process of other credit rating agencies applied for NRSRO status and prevented them from taking part in the industry strengthened the oligopolistic status of the big three in the credit rating market (Roubini and Mihm, 2012). Therefore it is the SEC that is responsible for creating oligopoly in credit rating industry.

The factors such as globalization of capital, the SEC's taking as proxy in regulations the credit ratings provided by the agencies with NRSRO status and the very fact that the Basel II framework has referenced to NRSRO credit ratings in determining the capital requirements of the banks worldwide increased the importance of credit ratings and henceforth that of credit rating agencies with NRSRO status that provide those credit ratings.

This dependence of global financial services industry on credit ratings and the oligopolistic status of credit rating agencies in the market had forced them to change their business model in financing the services they provided. Credit rating agencies gave up old 'investors pay business model' in which investors had paid for the credit ratings services and adopted new 'issuers pay business model' in which security issuers had paid for the credit rating services that is obviously more profitable and promises potential business opportunity.

The new 'issuers pay business model' adopted by credit rating agencies that aim at increasing their market share and prospective business opportunities provided by the issuers had paved the way to conflict of interest in credit rating industry. By the new model stemming from the dominance of issuers on credit rating market and the captivity of credit rating agencies to the issuers, credit rating agencies hardly hesitated to provide the securities of the issuers with high credit ratings whose informative quality is extremely poor, and consequently the securities with inflated credit ratings invaded the market.

During the process galloping to the crisis, credit rating agencies kept giving inflated credit ratings to the securities of their customer issuers on the one hand, they gave sudden downgrades to these securities on the other. The turmoil and herd psychology that these sudden downgrades had created in the financial services industry should be taken into consideration in assessing the causes of the crisis.

\section{On the Causes of 2007 Global Financial Crisis}

The causes of 2007 Global Financial Crisis have been profoundly debated in financial and academic circles and examined by the US Congress (Bocutoğlu, 2014, Kuttner, 2013, Roubini and Mihm, 2010, The National 
Commission, 2011). To Soros the crisis is not the result of external shocks but the result of the shocks that are produced by the dynamics within the financial services industry (see Soros, 2014). The Financial Crisis Inquiry Commission that was created by the Congress to examine the causes of the current financial and economic crisis in the United State issued a report. In this report, the Commission presents to the President, the Congress, and the American people the results of its examination and its conclusions as to the causes of the crisis. The majority view of the Commission in the report concluded that "(i) this financial crisis was avoidable, (ii) widespread failures in financial regulation and supervision proved devastating to the stability of the nation's financial markets, (ii) dramatic failures of corporate governance and risk management at many systemically important financial institutions were a key cause of this crisis, (iv) a combination of excessive borrowing, risky investments, and lack of transparency put the financial system on a collision course with crisis, (v) the government was ill prepared for the crisis, and its inconsistent response added to the uncertainty and panic in the financial markets, (vi) there was a systemic breakdown in accountability and ethics, (vii) collapsing mortgagelending standards and the mortgage securitization pipeline lit and spread the flame of contagion and crisis, (viii) over-the-counter derivatives contributed significantly to this crisis and finally (ix) the failures of credit rating agencies were essential cogs in the wheel of financial destruction (The National Commission, 2011).

According to the report, "the three credit rating agencies were key enablers of the financial meltdown. The mortgage-related securities at the heart of the crisis could not have been marketed and sold without their seal of approval. Investors relied on them, often blindly. In some cases, they were obligated to use them, or regulatory capital standards were hinged on them. This crisis could not have happened without the rating agencies. Their ratings helped the market soar and their downgrades through 2007 and 2008 wreaked havoc across markets and firms" (The National Commission, 2011).

\section{Assessments and Conclusions}

During the process tending to crisis, steps are summarized below and the role that CRAs have played can be seen in certain steps:

1. Fed's expansionary monetary policy since 1996 and global financial funds flowing to the USA financial markets such as sovereign state funds increased the money supply and reduced interest rate on the one hand and increased housing prices on the other.

2. Cheap money boosted demand for housing and consequently increasing housing prices gave way to huge housing constructions and created 'malinvestment' in housing sector (see Bocutoğlu and Ekinci, 2010, 2015).

3. Debt claims on mortgage, automobile and student credits were pooled and repacked by the financial institutions and a new financial instrument was born, Collateralized Debt Obligations (CDOs).

4. The CRAs entered the scene at this step during the process. Since the issuers of CDOs needed higher credit ratings for these financial instruments to market them easily, they applied CRAs for higher credit ratings.

5. The oligopolistic structure of credit rating industry and 'issuers pay model' adopted by the CRAs created conflict of interest in the industry. It is the SEC that is responsible for creating oligopoly in credit rating industry.

6. The conflict of interest forced CRAs to produce high credit ratings with low informative quality for CDOs just because CRAs want to make more profit and enjoy the potential business opportunity supplied by their customer issuers.

7. During the process galloping to the crisis, CRAs kept giving inflated credit ratings to the securities of their customer issuers on the one hand they gave sudden downgrades to these securities on the other. The turmoil and herd psychology that the downgrades had created in the financial services industry played a triggering role in 2007 Global Financial Crisis.

8. As the National Commission Report states, the three credit rating agencies were key enablers of the financial meltdown. The mortgage-related securities at the heart of the crisis could not have been marketed and sold without their seal of approval. Investors relied on them, often blindly. In some cases, they were obligated to use them, or regulatory capital standards were hinged on them. This crisis could not have happened without the rating agencies. Their ratings helped the market soar and their downgrades through 2007 and 2008 wreaked havoc across markets and firms.

The key concepts and cases that manifest the role of CRAs in 2007 Global Financial Crisis are (i) increase in importance of CRAs in regulations, determining banks' capital requirements due to Basel II accords and credit ratings of CDOs, (ii) oligopoly in credit rating market created by the SEC, (iii) issuers pay business model, (iv) conflict of interest and dominance of issuers over CRAs, (v) higher credit ratings with lower informative quality about financial assets, (vi) sudden downgrades, (vii) turmoil and herd psychology in financial services industry, and finally (viii) financial meltdown.

The FED, the SEC, issuers and CRAs are responsible as a whole for 2007 Global Financial Crisis. The responsibility of the FED is due to prolonged expansionary monetary policy, that of the SEC is due to oligopoly 
in the credit rating industry, that of the issuers is due to CDOs and conflict of interest and finally that of CRAs is due to conflict of interest and higher credit ratings with lower informative quality about CDOs and sudden downgrades.

As a consequence, D-20 Financial Stability Report (2009) calling governments for reducing dependency on CRAs, National Commission Report (2011) stating that the crisis could not have happened without the rating agencies because their ratings helped the market soar and their downgrades through 2007 and 2008 wreaked havoc across markets and firms, and the fact that the US Security and Exchange Commission (SEC) suspended the activities of Standard and Poor's (S§P) in the Commercial Mortgage Based Securities market for one year during January 21, 2015- January 21, 2016 because of that it caused loses to the investors by slackening secretly the assumptions of its credit rating model it announced publicly and therefore supplying fake - inflated - credit scores are evidence that underlines the responsibility of CRAs in the crisis.

It is obvious that the credit rating industry needs a global reform.

\section{References}

- Benmelech and Dlugosz, 2010. "The Credit Rating Crisis”, National Bureau of Economic Research.

- Bocutoğlu and Ekinci, 2010. "Austrian Business Cycles Theory and Global Crisis", Ludwig von Mises Institute, Daily.

- Bocutoğlu and Ekinci, 2011. "Austrian Business Cycles Theory and Global Financial Crisis: Some Lessons for Macroeconomic Risk and Financial Stability", Ludwig von Mises Institute, Working Paper.

- Bocutoğlu, 2014. ”ABD’de 1933 Glass-Steagall Yasasının Yürürlükten Kaldırılması 2007 Küresel Finansal Krizini Tetikledi mi?: Karşılaştırmalı Bir Değerlendirme”,(Did the Repeal of 1933 Glass-Steagall Act in the USA Trigger the 2007 Global Financial Crisis?: A Comparative Evaluations), Bankacilar Dergisi, Say1:90, pp. 88-100.

- Bocutoğlu and Ekinci, 2015. “A Suggestion: The Malinvestment Index”, George Mason University Working Papers in Economics, No: 15-27.

- Darcy, 2009. "Credit Rating Agencies and the Credit Crisis: How the 'Issuer Pays' Conflict Contributed and What Regulators Might Do About It”, Columbia Business Law Review, 605 (2009).

- Ekins and Calabria, 2012. "Regulation, Market Structure, and Role of Credit Rating Agencies", Policy Analysis, No: 704. August 1, 2012, pp.3-8

- Gudzowski, 2010. "Mortgage Credit Ratings and the Financial Crisis: The Need for a State-Run Mortgage Security Credit Rating Agency”, Columbia Business Law Review, 1 (2010).

- Hunt, (without date), Credit Rating Agencies and the 'Worldwide Credit Crisis': The Limits of Reputation, the Insufficiency of Reforms and a Proposal for Improvement, www2.wiwi.hu-berlin.de/institute /finanz/ scriptsemfin/t12.pdf. pp. 4-13

- Kindleberger and Aliber, 2013. Finansal Krizler Tarihi, Çılgınlık, Panik ve Çöküş, Türkiye İş Bankası Genel Yayın No: 2819, İstanbul.

- Kuttner, 2013. "Seven Deadly Sins of Deregulation and Three Necessary Reforms", The American Prospect, prospect.org/article/seven-deadly-sins-deregulation-and-three-necessary-reforms, pp. 1-4.

- McVea, 2010. "Credit Rating Agencies, Subprime Mortgage Debacle and Global Governance: The EU Strikes Back”, International and Comparative Law Quarterly, 59, pp.702-708.

- Mian and Sufi, 2009. "The Consequences of Mortgage Credit Expansions: Evidence from the US Mortgage Default Crisis", The Quarterly Journal of Economics, 2009, 124 (4).

- The National Commission, 2011. The Financial Crisis Inquiry Report, Official Government Edition, FCIC Website, pp. xvii-417-719.

- Partney, 1999. "The Siskel and Ebert of Financial Markets?: Two Thumbs Down For the Credit Rating Agencies", Washington University Law Quarterly, Vol:77, No: 3 (1999).

- Roubini and Mihm, S., (2012), Kriz Ekonomisi, Finansın Geleceğine Dair Hızlandırılmış Bir Kurs, (Crisis Economics: A Crash Course in the Future of Finance), Pegasus Yayınları: 442, Ekonomi:3, İstanbul, pp.69207.

- Ryan, J., (2012), “The Negative Impact of Credit Rating Agencies and Proposals for Better Regulation”, Working Paper, FG 1, No: 01, Research Division EU Integration, German Institute for International and Security Affairs, SWP Berlin, pp. 6-12.

- Soros, G., (2014), “Anatomy of a Crisis”, www.georgesoros.com/interview. 22.08.2014.

- Whitehouse, K., (2015), “SEC Charges Ratings Agency S§P over Ratings”, USA Today, 21 January 2015 


\title{
Effects of Sale of Non-Performing Loans to Asset Management Companies on Stock Performance of Banks
}

\author{
Asst. Prof. Dr. S1tkı Sönmezer (Beykent University, Turkey)
}

\begin{abstract}
Asset management Companies, starting from 2006, have a critical role in the banking sector of Turkey in terms of liquidating Non-performing loans into cash. Sale of bad debts enable banks to transfer receivables to asset management firms at a substantial discount and obtain liquidity so that they have more robust financials and their ability to focus on their core businesses which may increase productivity. The objective of this study is to determine the immediate impact of the announcement of recent sales on stock prices of banks. This study provides evidence that 22 statistically significant positive announcements versus 21 negative announcements out of 69 deals broken down by bank. Results indicate that particular deals are overpriced resulting in stock price increases and some are underpriced resulting in losses in the market. It can be inferred that information regarding with the structure and asset quality of deals are accessible.
\end{abstract}

\section{Introduction}

Asset management Companies (AMC) buy non-performing loans (NPL) from banks with a tender offer at a substantial discount and then they try to collect as much as they can via contacting customers to convince them to pay back loans and negotiate with them by pressuring them with laws to be enforced. Typically, they buy loans at $12.39 \%$, on average in our sample period, of the face value in Turkey which enables them to negotiate much better with customers than bank lawyers. Bank lawyers' drawback is that they don't have a benchmark rate to base the negotiations and it is hard for banks to authorize a lawyer to settle deals and reach an optimum solution. Selling loans to asset management firms enables them to bundle high quality debts with lower quality debts and get rid of the bad debts and also to write off the losses which brings tax advantage. They also save collection efforts and they may reduce costs in terms of employment, intelligence and suing fees that doesn't lead to collection.

This study aims to shed light to an additional effect of these firms; impact on share prices of the particular bank upon an announcement of a sold deal. When an announcement is made and there is a consequent price increase, this study assumes the sale as a positive sale on behalf of the bank from the presumption that market knows how to price the best. A decline in the stock market upon an announcement may be inferred as a negative sale indicating an inefficient sale by that particular bank.

This study has a unique data set of Turkish Vulture Market and it is the first study up to our knowledge in this realm. The constraint of this study is that it is limited with Turkish market as other countries' data set couldn't be reached.

Even though asset management firms have started their operations in the recent decade, their profitability has increased attention and People's Republican Party (CHP) has announced to eliminate them in their party program in 2015 elections. However, the advantages of these firms are clear as well as disadvantages. The assessment of the tradeoff is important.

\section{Non-Performing Loans}

Louzis, Vouldis and Metaxas (2012) have classified the determinants of NPLs in three classes. Mainly macroeconomic factors, debt and bank specific factors determine NPLs. Regarding with bank specific factors there are numerous hypothesis widely tested in the literature and relevant ones are listed here below:

Bad Management Hypothesis - bad management arising from collateral appraisals, investigating and monitoring borrowers and inability to score the credibility of the borrowers may be led by low cost efficiency which is directly proportional with increases in NPLs in the future. Berger and DeYoung (1997), Podpiera and Weili (2008) and Louzis et al, (2012) provide evidence supporting Bad Management Hypothesis. Bad management may be due to sales and time pressures to meet targets and NPLs may be inevitable the outcomes.

Skimping Hypothesis - less effort given to seek higher loan quality affects the decrease in costs and amount of NPLs positively. The tradeoff has not been supported by Louzis et al, 2012).

Moral hazard Hypothesis - Bank managers increase the riskiness of their loan portfolio on the owners' expense which leads to increases in NPLs. Berger and DeYoung (1997) and Louzis Et al, (2012) provide conflicting empirical evidences regarding with the hypotheses. Louzis et al,

Diversification Hypothesis - There is a negative relationship between diversification and NPLs. Credit risk decreases as diversification increase therefore NPLs, by intuition, shall decrease. Salas and Saurina (2002) use bank size instead of diversification opportunities and have found a negative relationship. 
Too Big to Fail Hypothesis - Bank managers may consider themselves too big to fail and assume the government will save them in case of financial crises. This presumption may lead to excess risk taking and have a positive impact on the increasing NPLs. Louzis et al, (2012) have found no significant relationship regarding with the hypothesis at the consumer group but they have provided empirical evidence at the business and mortgage sub-groups.

Tight Control Hypothesis - NPLs may be negatively related with ownership concentration. When the concentration is high, loans can be closely monitored as the controlling party is assumed to be more risk averse.

Reinhart and Rogoff (2010) claim that it is possible to deduce a banking crisis by examining NPLs. Determinants of NPLs are widely analyzed and there are even more hypotheses that have been analyzed but that is beyond the scope of this study.

Table 1 is presented to shed light to the legal grounds of NPLs in Turkish Jurisdiction. Once an NPL is considered as Group 3, Group 4 or Group 5, they are eligible for sale to AMCs.

\begin{tabular}{|l|l|}
\hline 1. Group & Standard loans and other receivables \\
\hline 2. Group & Closely Monitored loans and other receivables \\
\hline 3. Group & Low collection possibility loans and other receivables \\
\hline 4. Group & Bad debts and other receivables \\
\hline 5. Group & Loss equivalent loans and other receivables \\
\hline
\end{tabular}

Table 1. Classification of Non-Performing Loans in Turkish Legislation

\section{Asset Management Companies}

Asset Management Companies are one of the structural methods that banks use in restructuring their financials by solving their Non-performing Loans (NPL). This method enables banks to transfer NPLs to specialists in asset management and collection rather than finding solutions within the bank (Ersoy, 2007). These sales can either be a direct sale or in a form of revenue sharing. The former one is the more favored method in Turkey.

\begin{tabular}{|c|c|}
\hline Company & Year of Foundation \\
\hline Bebek Varlık Yönetimi A.Ş. & 2003 \\
\hline Girişim Varlık Yönetimi A.Ş. & 2005 \\
\hline RCT Varlık Yönetim A.Ş. & 2005 \\
\hline Anadolu Varlık Yönetim A.Ş. & 2006 \\
\hline LBT Varlık Yönetim A.Ş. & 2008 \\
\hline İstanbul Varlık Yönetimi A.Ş. & 2009 \\
\hline Efes Varlık Yönetim A.Ş. & 2010 \\
\hline Final Varlık Yönetim A.Ş. & 2011 \\
\hline Vera Varlık Yönetim A.Ş. & 2013 \\
\hline Turkasset Varlık Yönetim A.Ş. & 2013 \\
\hline Sümer Varlık Yönetim A.Ş. & 2015 \\
\hline Güven Varlık Yönetim A.Ş. & 2015 \\
\hline
\end{tabular}

Table 2. Asset Management Companies in Turkey Source: BDDK

Asset management companies are relatively young in Turkey as shown in Table 2. These companies are exempt from all taxes within the first five years since inception by law. The most recent companies may be founded to circumvent these regulations.

\begin{tabular}{|c|c|c|c|}
\hline Year & $\begin{array}{c}\text { Portfolio } \\
\text { (Million TL) }\end{array}$ & Sale Price (Million TL) & $\%$ \\
\hline 2010 & 2,139 & 246 & 11,5 \\
\hline 2011 & 2,656 & 198 & 7,45 \\
\hline 2012 & 2,527 & 359 & 14,2 \\
\hline 2013 & 2,570 & 370 & 14,4 \\
\hline 2014 & 4,305 & 586 & 13,61 \\
\hline Total & 14,197 & 1,759 & 12,39 \\
\hline
\end{tabular}

Table 3. Sales of Portfolio of Non-performing Loans by Banks between 2010-2014 Source: BDDK 
Table 3 indicates that the interest in asset sales have increased slightly as AMCs have increased their bids on average. It may be reasonable to assume shrinking profits margins for AMCs or market may be saturating. Sharp increase in 2014 may arise from increased awareness of banks about advantages of these NPL sales. Herding may even be the reason of this substantial increase.

\subsection{Advantages of Asset Management Companies}

Asset management companies provide numerous advantages to the banking system. Some advantages are vital and some are handy, this study aims to add another effects of these sales to the banking sector. Some of the advantages of these sales are addressed here below;

It can be argued that they help restructuring of the financial system in a way that when financial institutions sell out their bad debts, they obtain robustness, liquidity and trust. Moreover, written losses may bring credit discipline for further deals. Banks transfer risks to AMCs.

These firms also provide rapid solutions to liquidation sales, they provide high returns in liquidation process of bad debts, they also help asset prices to normalize; book value of debts and market value of them differs significantly which may mislead investors, creditors and stakeholders.

Economies of scale and economies of scope may be achieved when deals are pooled and sold to an entity. Increase in financial leverage and improved management conditions do also favor these sales (Selimler, 2006).

\subsection{Disadvantages of Asset Management Companies}

Banks generally have more accurate information about customers and transfer of loans may result in loss of information. AMCs may obtain information at a cost or may not even get the necessary information (Mesutoglu, 2001) as AMCs lack the essential information about the collateral and customer's ability and willingness, they have a tendency to underprice deals which results as a loss in the banking industry. The profits made by AMCs are the loss of the society. In other words, if the bank could sell the deal to the borrower at the sale price of the $\mathrm{AMC}$, borrowers would save the profit amount of the AMC. This inefficiency raise concerns about these deals.

Similarly, when AMCs obtain underpriced deals, they are inclined to sell the loans at below optimum prices as their profit margins are excessive. The profit margin of the AMC could be transferred to bank. Some banks elect to open up their own subsidiary AMCs to keep the profits but they don't necessarily sell to their subsidiaries but pursue best price in the market.

Either public or private these sales may not be detached from political pressures. Especially, in the former one, the system may convert into a loss transfer mechanism. Regulations may not be adequate and it may be hard to closely monitor side deals. When banks sell the loans on their own, moral hazard may also be lower.

\section{Data and Methodology}

Data is consisted of 97 deals sold by 11 banks to various AMCs in the period of 2010-2014. However, some of them are sold on the same date with different structures however, their price impact cannot be differentiated therefore, 69 announcement dates are present in the sample. This study utilizes VAR analysis by finding excess returns of each banks under study over market index returns. The study aims to provide evidence by obtaining results indicating that announcement day returns are statistically different than average returns.

\section{Findings}

Deals and their impact on prices are analyzed for each bank. Generally, it is evident that there is a price impact of announced deals but how the sale is perceived determines the direction of prices. Sales amount, portfolio amount, the structure of the portfolio, and the buyer may play a role in the price shifts but the announcement date effect is obvious; out of 69 deals 22 positive, 21 negative and 26 inconclusive 1-day statistically significant stock returns are found. The results are presented for each bank in order to present NPL management styles, pricing ability and market capitalization of these banks.

AKBANK have enjoyed four substantial increases and have had one significant negative return out of 6 deals. Interestingly, the price of the stock had not moved significantly when the bank had sold the best deal percentage wise, $88.57 \%$, which is highly over the industry averages. This may be due to the structure of that particular deal, market may have the information about how well the deal is collateralized; there should be an increase otherwise. This may indicate that market has access to detailed information about NPL sales. 


\begin{tabular}{|c|c|c|c|c|c|c|c|}
\hline BANK & Portfolio Amount & Sales Price & Ratio & Date & Structure & $\begin{array}{l}\text { 1-day return } \\
\text { of stock }\end{array}$ & $\begin{array}{l}\text { 1-day } \\
\text { return of } \\
\text { BIST } 100\end{array}$ \\
\hline AKBANK & 250.546 .000 & 41.000 .000 & $16,36 \%$ & 23.12 .2014 & $\begin{array}{l}\text { Cr. Cards } \\
\text { Consumer }\end{array}$ & $-0,0159 * * *$ & 0,0017 \\
\hline AKBANK & 248.540 .000 & 40.300 .000 & $16,21 \%$ & 23.12 .2014 & Consumer & & \\
\hline AKBANK & 252.153 .221 & 44.000 .000 & $17,45 \%$ & 14.03 .2014 & Consumer & $0,0034 * *$ & $-0,0094$ \\
\hline AKBANK & 250.465 .000 & 58.300 .000 & $23,28 \%$ & 14.05 .2013 & Corporate & $0,0180 * *$ & 0,0099 \\
\hline AKBANK & 1.242 .000 & 1.100 .000 & $88,57 \%$ & 03.05 .2013 & Consumer & 0,0102 & 0,0184 \\
\hline AKBANK & 499.183 .576 & 85.000 .000 & $17,03 \%$ & 14.09 .2012 & $\begin{array}{l}\text { Trade } \\
\text { Consumer }\end{array}$ & $0,0112 * * *$ & 0,0024 \\
\hline AKBANK & 323.388 .221 & 38.500 .000 & $11,91 \%$ & 04.01 .2010 & $\begin{array}{l}\text { Trade SME } \\
\text { Consumer }\end{array}$ & $0,0106 * * *$ & $-0,0088$ \\
\hline
\end{tabular}

$* * * \% 1$ level of significance **\%5 level of significance *\%10 level of significance

Table 4. Announcement day effect of AKBANK (TL)

Denizbank had significant negative returns after NPL sales announcements are made, 5 out of 9 deals has brought daily losses whereas in one deal excess return over the market had significantly helped her investors by storing stocks value when the market was substantially down. These results indicate that market believes the portfolios should be sold to a higher price.

\begin{tabular}{|c|c|c|c|c|c|c|c|}
\hline BANK & $\begin{array}{l}\text { Portfolio } \\
\text { Amount }\end{array}$ & Sales Price & Ratio & Date & Structure & $\begin{array}{l}\text { 1-day return } \\
\text { of stock }\end{array}$ & $\begin{array}{l}\text { 1-day return } \\
\text { of BIST } 100\end{array}$ \\
\hline DENIZBANK & 125.800 .000 & 19.050 .000 & $15,14 \%$ & 01.12 .2014 & SME-micro & 0,0077 & 0,0139 \\
\hline DENIZBANK & 125.800 .000 & 19.100 .000 & $15,18 \%$ & 01.12 .2014 & Consumer & & \\
\hline DENIZBANK & 88.800 .000 & 7.100 .000 & $8,00 \%$ & 01.12 .2014 & SME & & \\
\hline DENIZBANK & 51.332 .638 & 6.005 .919 & $11,70 \%$ & 12.12 .2013 & Trade & $-0,0044$ & $-0,0120$ \\
\hline DENIZBANK & 122.579 .295 & 25.104 .240 & $20,48 \%$ & 12.12 .2013 & Trade & & \\
\hline DENIZBANK & 31.417 .000 & 950.000 & $3,02 \%$ & 28.09 .2012 & $\begin{array}{l}\text { Consumer - } \\
\text { Trade }\end{array}$ & $-0,0188 * * *$ & $-0,0049$ \\
\hline DENIZBANK & 36.523 .567 & 6.250 .000 & $17,11 \%$ & 28.09 .2012 & Trade & & \\
\hline DENIZBANK & 60.788 .376 & 7.550 .000 & $12,42 \%$ & 02.07 .2012 & $\begin{array}{l}\text { Consumer } \\
\text { Trade }\end{array}$ & $0.000 * * *$ & $-0,0599$ \\
\hline DENIZBANK & 43.680 .000 & 7.000 .000 & $16,03 \%$ & 28.06 .2012 & Trade & $-0,0088^{*} *$ & 0,0007 \\
\hline DENIZBANK & 118.324 .000 & 14.950 .000 & $12,63 \%$ & 27.09 .2011 & Trade & 0,0170 & 0,0175 \\
\hline DENIZBANK & 32.979 .210 & 1.850 .000 & $5,61 \%$ & 25.03 .2011 & Trade & $-0,0132 * * *$ & 0,0232 \\
\hline DENIZBANK & 17.552 .681 & 1.600 .000 & $9,12 \%$ & 30.09 .2010 & Trade & - & $-0,0001$ \\
\hline DENIZBANK & 32.170 .000 & 3.206 .000 & $9,97 \%$ & 29.09 .2010 & Consumer & $-0,0081^{*}$ & 0,0062 \\
\hline DENIZBANK & 50.200 .000 & 4.900 .000 & $9,76 \%$ & 25.01 .2010 & Consumer & $-0,0244 * * *$ & $-0,0055$ \\
\hline
\end{tabular}

Table 5. Announcement day effect of DENIZBANK (TL)

Finansbank's announcements had two positive and two negative statistically significant impact on her stock price out of seven deals. Strikingly, the stock has enjoyed the highest return when sales to portfolio amount ratio is at $6.20 \%$. market may speculate regarding with the transaction as bank converting junk loans into cash. 


\begin{tabular}{|c|c|c|c|c|c|c|c|}
\hline BANK & $\begin{array}{l}\text { Portfolio } \\
\text { Amount }\end{array}$ & Sales Price & Ratio & Date & Structure & $\begin{array}{c}\text { 1-day return } \\
\text { of stock }\end{array}$ & $\begin{array}{c}\text { 1-day } \\
\text { return of } \\
\text { BIST } \\
100\end{array}$ \\
\hline FINANSBANK & 109.000 .000 & 22.890 .000 & $21,00 \%$ & 09.12 .2014 & & $-0,0097 * *$ & $-0,005$ \\
\hline FINANSBANK & 109.000 .000 & 21.800 .000 & $20,00 \%$ & 09.12 .2014 & & & \\
\hline FINANSBANK & 109.000 .000 & 20.710 .000 & $19,00 \%$ & 09.12 .2014 & & & \\
\hline FINANSBANK & 150.318 .753 & 4.800 .000 & $3,19 \%$ & 09.06 .2014 & & $0,0032 * * *$ & 0,0131 \\
\hline FINANSBANK & 95.281 .370 & 6.700 .000 & $7,03 \%$ & 09.06 .2014 & & & \\
\hline FINANSBANK & 37.437 .550 & 750.000 & $2,00 \%$ & 09.06 .2014 & & & \\
\hline FINANSBANK & 180.652 .909 & 33.000 .000 & $18,27 \%$ & 20.05 .2014 & & $-0,0032$ & $-0,0020$ \\
\hline FINANSBANK & 180.509 .013 & 34.600 .000 & $19,17 \%$ & 20.05 .2014 & & & \\
\hline FINANSBANK & 180.547 .743 & 35.600 .000 & $19,72 \%$ & 20.05 .2014 & & & \\
\hline FINANSBANK & 153.455 .084 & 20.000 .000 & $13,03 \%$ & 20.05 .2014 & & & \\
\hline FINANSBANK & 39.213 .252 & 4.400 .000 & $11,22 \%$ & 20.05 .2014 & & & \\
\hline FINANSBANK & 182.918 .000 & 35.000 .000 & $19,13 \%$ & 25.06 .2013 & & $0,0168^{* * *}$ & $-0,0065$ \\
\hline FINANSBANK & 182.888 .000 & 32.600 .000 & $17,83 \%$ & 14.06 .2013 & & 0,0126 & 0,0140 \\
\hline FINANSBANK & 182.909 .000 & 32.500 .000 & $17,77 \%$ & 14.06 .2013 & & & \\
\hline FINANSBANK & 95.900 .000 & 5.950 .000 & $6,20 \%$ & 29.09 .2011 & & $0,0311 * * *$ & 0,0142 \\
\hline FINANSBANK & 187.800 .000 & 11.500 .000 & $6,12 \%$ & 25.08 .2011 & Trade & 0,0028 & 0,0093 \\
\hline
\end{tabular}

Table 6. Announcement day effect of FINANSBANK (TL)

Garanti Bank has inconclusive results as well. Two significant increases and two significant decrease have occurred in six deals. A massive portfolio amount was sold to its $3.40 \%$ and this write off has probably deteriorated its financials. This reality seems rapidly adjusted by the market. Tax advantage generated by a sale of 1.478.137.000 TL, which is roughly 547 million USD as of 1 July 2015; Provisions are solved etc. yet there is a price to take into account by managers.

\begin{tabular}{|c|r|r|r|r|r|c|c|}
\hline BANK & \multicolumn{1}{|c|}{$\begin{array}{c}\text { Portfolio } \\
\text { Amount }\end{array}$} & Sales Price & Ratio & Date & Structure & $\begin{array}{c}\text { 1-day return } \\
\text { of stock }\end{array}$ & $\begin{array}{c}1 \text {-day } \\
\text { return of } \\
\text { BIST } 100\end{array}$ \\
\hline GARANTI & 106.598 .905 & 18.700 .000 & $17,54 \%$ & 21.08 .2014 & & 0,0048 & 0,0031 \\
\hline GARANTI & 75.000 .000 & 12.000 .000 & $16,00 \%$ & 21.05 .2014 & & $0,0320^{* * *}$ & 0,0185 \\
\hline GARANTI & 76.806 .000 & 11.911 .000 & $15,51 \%$ & 21.05 .2014 & & & \\
\hline GARANTI & 314.200 .000 & 56.400 .000 & $17,95 \%$ & 14.06 .2013 & & $0,0548^{* * *}$ & 0,0140 \\
\hline GARANTI & 200.654 .023 & 32.600 .000 & $16,25 \%$ & 13.06 .2012 & & $-0,0062 *$ & 0,0071 \\
\hline GARANTI & 1.478 .137 .000 & 50.267 .000 & $3,40 \%$ & 07.02 .2011 & & $-0,0185^{* * *}$ & 0,0345 \\
\hline GARANTI & 51.804 .000 & 3.900 .000 & $7,53 \%$ & 01.12 .2010 & & 0,0288 & 0,0217 \\
\hline
\end{tabular}

\footnotetext{
$* * * \% 1$ level of significance **\%5 level of significance *\%10 level of significance
}

Table 7. Announcement day effect of GARANTIBANK (TL)

NPL sales have had negative impact on Isbank stock, four significant decreases and one increase out of 9 deals was the case in the period under study. The heaviest decline, $4.04 \%$, was when the portfolio is sold to $9 \%$ of its face value. 


\begin{tabular}{|c|r|r|r|r|r|r|c|}
\hline & \multicolumn{1}{|c|}{$\begin{array}{l}\text { Portfolio } \\
\text { Amount }\end{array}$} & Sales Price & Ratio & Date & Structure & $\begin{array}{c}\text { 1-day } \\
\text { 1-day return } \\
\text { of stock }\end{array}$ & $\begin{array}{c}\text { return of } \\
\text { BIST } \\
100\end{array}$ \\
\hline ISBANK & 245.000 .000 & 22.050 .000 & $9,00 \%$ & 06.11 .2014 & & $-0,0404 * * *$ & $-0,0201$ \\
\hline ISBANK & 272.517 .432 & 44.016 .816 & $16,15 \%$ & 26.05 .2014 & & 0,0210 & 0,0280 \\
\hline ISBANK & 163.865 .085 & 32.041 .368 & $19,55 \%$ & 08.10 .2013 & & $-0,0113 * * *$ & 0,0016 \\
\hline ISBANK & 285.600 .000 & 50.200 .000 & $17,58 \%$ & 29.11 .2012 & & $-0,0069$ & 0,0050 \\
\hline ISBANK & 137.328 .434 & 28.800 .000 & $20,97 \%$ & 13.06 .2012 & & 0,0049 & 0,0071 \\
\hline ISBANK & 220.149 .000 & 42.200 .000 & $19,17 \%$ & 18.11 .2011 & & $-0,0051^{* *}$ & $-0,0148$ \\
\hline ISBANK & 88.464 .000 & 13.905 .000 & $15,72 \%$ & 23.06 .2011 & & $0,0148 * * *$ & $-0,0150$ \\
\hline ISBANK & 304.097 .000 & 51.500 .000 & $16,94 \%$ & 29.12 .2010 & & $-0,0036$ & $-0,0087$ \\
\hline ISBANK & 41.900 .000 & 6.500 .000 & $15,51 \%$ & 28.12 .2010 & & $-0,0030 * * *$ & 0,0178 \\
\hline
\end{tabular}

$* * * \% 1$ level of significance $* * \% 5$ level of significance *\%10 level of significance

Table 8. Announcement day effect of ISBANK (TL)

Out of twelve deals YKB had five positive announcements and 4 negative announcements stock price wise.

\begin{tabular}{|c|c|c|c|c|c|c|c|}
\hline BANK & $\begin{array}{l}\text { Portfolio } \\
\text { Amount }\end{array}$ & Sales Price & Ratio & Date & Structure & $\begin{array}{l}\text { 1-day return } \\
\text { of stock }\end{array}$ & $\begin{array}{c}\text { 1-day } \\
\text { return of } \\
\text { BIST } \\
100\end{array}$ \\
\hline YKB & 30.561 .000 & 4.150 .000 & $13,58 \%$ & 11.12 .2014 & & $0,0020 * *$ & 0,0158 \\
\hline YKB & 30.559 .000 & 4.150 .000 & $13,58 \%$ & 11.12 .2014 & & & \\
\hline YKB & 169.833 .000 & 23.430 .000 & $13,80 \%$ & 22.09 .2014 & & $0,0089 * *$ & $-0,009$ \\
\hline YKB & 56.393 .000 & 2.500 .000 & $4,43 \%$ & 22.09 .2014 & & & \\
\hline YKB & 56.128 .000 & 2.500 .000 & $4,45 \%$ & 22.09 .2014 & & & \\
\hline YKB & 54.314 .875 & 8.230 .000 & $15,15 \%$ & 20.06 .2014 & & $-0,0108 * *$ & $-0,0061$ \\
\hline YKB & 49.490 .282 & 7.310 .000 & $14,77 \%$ & 20.06 .2014 & & & \\
\hline YKB & 11.213 .000 & 10.652 .350 & $95,00 \%$ & 11.02 .2014 & & 0,0089 & 0,0094 \\
\hline YKB & 107.704 .808 & 20.230 .000 & $18,78 \%$ & 20.12 .2013 & & $0,0052 * * *$ & $-0,0217$ \\
\hline YKB & 53.822 .012 & 9.795 .606 & $18,20 \%$ & 20.12 .2013 & & & \\
\hline YKB & 53.287 .754 & 9.698 .371 & $18,20 \%$ & 20.12 .2013 & & & \\
\hline YKB & 59.946 .600 & 11.900 .000 & $19,85 \%$ & 05.12 .2012 & & 0,0101 & 0,0150 \\
\hline YKB & 59.783 .142 & 12.105 .000 & $20,25 \%$ & 05.12 .2012 & & & \\
\hline YKB & 73.711 .000 & 15.058 .000 & $20,43 \%$ & 05.12 .2012 & & & \\
\hline YKB & 372.600 .000 & 16.000 .000 & $4,29 \%$ & 05.12 .2012 & & & \\
\hline YKB & 60.022 .000 & 11.750 .000 & $19,58 \%$ & 21.11 .2012 & & 0,0089 & 0,0028 \\
\hline YKB & 290.276 .000 & 45.800 .000 & $15,78 \%$ & 05.12 .2011 & & $0,0228^{* *}$ & 0,0139 \\
\hline YKB & 88.717 .973 & 14.375 .000 & $16,20 \%$ & 26.11 .2010 & & $-0,0375 * * *$ & $-0,0120$ \\
\hline YKB & 82.149 .445 & 10.060 .000 & $12,25 \%$ & 26.11 .2010 & & & \\
\hline YKB & 256.900 .000 & 31.604 .000 & $12,30 \%$ & 26.11 .2010 & & & \\
\hline YKB & 224.400 .000 & 18.000 .000 & $8,02 \%$ & 18.03 .2010 & & $-0,0222 * * *$ & $-0,0085$ \\
\hline YKB & 74.606 .000 & 6.450 .000 & $8,65 \%$ & 17.03 .2010 & & $0,0405^{* *}$ & 0,0266 \\
\hline YKB & 382.107 .021 & 32.435 .000 & $8,49 \%$ & 01.03 .2010 & & $0,0120 * *$ & 0,0285 \\
\hline
\end{tabular}

$* * * \% 1$ level of significance $* * \% 5$ level of significance *\%10 level of significance

Table 9. Announcement day effect of YAPI VE KREDI BANK (TL)

Other banks also had similar results as banks mentioned above; six positive and four negative announcements out of nineteen deals. Relatively smaller cap banks react differently when an information is disseminated. It's worth to note that Tekstilbank didn't had a great sale, just around $6 \%$ of the portfolio amount, but enjoyed almost a return of $6 \%$. Investors may use announcements to speculate especially in inefficient markets where depth is low. 


\begin{tabular}{|c|c|c|c|c|c|c|c|}
\hline BANK & $\begin{array}{l}\text { Portfolio } \\
\text { Amount }\end{array}$ & Sales Price & Ratio & Date & Structure & $\begin{array}{l}\text { 1-day return } \\
\text { of stock }\end{array}$ & $\begin{array}{c}\text { 1-day } \\
\text { return of } \\
\text { BIST } 100\end{array}$ \\
\hline ABANK & 91.738 .986 & 19.200 .000 & $20,93 \%$ & 25.06 .2013 & MIXED & $-0,0075$ & $-0,0065$ \\
\hline ABANK & 92.800 .000 & 18.000 .000 & $19,40 \%$ & 20.06 .2013 & MIXED & $-0,0076 * * *$ & $-0,0414$ \\
\hline ABANK & 58.433 .761 & 7.750 .000 & $13,26 \%$ & 12.12 .2012 & CONSUMER & $-0,0001$ & $-0,0060$ \\
\hline ABANK & 34.535 .000 & 1.250 .000 & $3,62 \%$ & 29.12 .2010 & CONSUMER & $0,0181 * * *$ & $-0,0087$ \\
\hline ABANK & 59.605 .000 & 11.525 .000 & $19,34 \%$ & 10.11 .2010 & $\begin{array}{c}\text { CREDIT } \\
\text { CARD }\end{array}$ & $-0,0059$ & $-0,0008$ \\
\hline ASYAB & 371.158 .000 & 600.000 & $0,16 \%$ & 24.06 .2014 & TRADE & $-0,0126 * * *$ & 0,0156 \\
\hline ASYAB & 180.800 .000 & 36.600 .000 & $20,24 \%$ & 12.05 .2014 & $\begin{array}{l}\text { CREDIT } \\
\text { CARD }\end{array}$ & $0.0^{* *}$ & 0,0101 \\
\hline ASYAB & 140.000 .000 & 8.200 .000 & $5,86 \%$ & 21.06 .2013 & CONSUMER & $-0,0222$ & $-0,0247$ \\
\hline ASYAB & 461.236 .000 & 18.100 .000 & $3,92 \%$ & 05.06 .2013 & TRADE & $-0,0225 * * *$ & 0,0077 \\
\hline ŞEKER & 172.642 .882 & 16.000 .000 & $9,27 \%$ & 24.12 .2012 & & 0,0058 & 0,0083 \\
\hline ŞEKER & 23.961 .000 & 5.050 .000 & $21,08 \%$ & 21.12 .2012 & & $-0,0057$ & $-0,0083$ \\
\hline ŞEKER & 144.228 .597 & 12.000 .000 & $8,32 \%$ & 24.03 .2011 & & $0,0120 * * *$ & $-0,0264$ \\
\hline TEB & 117.000 .000 & 13.757 .000 & $11,76 \%$ & 27.06 .2013 & & $0,0619 * * *$ & 0,0294 \\
\hline TEB & 188.700 .000 & 22.222 .222 & $11,78 \%$ & 30.11 .2012 & & 0,0054 & $-0,0021$ \\
\hline TEB & 124.050 .420 & 16.900 .000 & $13,62 \%$ & 04.04 .2012 & & $0.00^{* * *}$ & $-0,0130$ \\
\hline TEB & 75.008 .000 & 6.500 .000 & $8,67 \%$ & 28.06 .2010 & & $0,0316^{* * *}$ & 0,0118 \\
\hline TEB & 39.957 .000 & 4.125 .000 & $10,32 \%$ & 12.04 .2010 & & $-0,0078^{* *}$ & 0,0060 \\
\hline TEKST & 22.623 .250 & 1.500 .000 & $6,63 \%$ & 10.03 .2014 & & $0,0598 * * *$ & $-0,0157$ \\
\hline TEKST & 60.489 .325 & 200.000 & $0,33 \%$ & 10.03 .2014 & & & \\
\hline
\end{tabular}

Table 10. Announcement day effect of Other Banks (TL)

\section{Conclusion}

Asset management firms are relatively young institutions in emerging markets but yet their advantages and disadvantages for the market are heavily debated. Despite drawbacks, these firms provide agility, liquidity, tax advantage and robustness to the banking sector.

In the sample period, results show that there is a struggle between AMCs and banks in terms of pricing the tenders. Some deals are found to be over priced; this may arise from the increased competition in the asset management sector. Announcement of overpriced deals are welcome in the financial market.

Some deals are underpriced; AMCs may assess the deals highly risky and may refrain from bidding up. When that is the case, investors start selling stock markets as the financial ratios are affected adversely. The asset management sector itself may face the problem of obtaining deal flow in the future as banks have emptied their sack of non-performing loans of years; building up new sums may take time and mergers and acquisitions in the sector seems likely.

Currently, banks are relatively more experienced with these deals and they are more keen on pricing, bundling and detaching particular deals out of the bundle. AMCs will be more cautious in the future to avoid losses and the market is expected to shrink with mergers and acquisitions. Yet, the appetite for these firms are clear in the growing number of them within a short period of time. The need for them may be speculated but for the countries that lack the legislation for these companies.

Turkish example may help to Eurasian markets even though, they differ in terms of credit card usage, nonperforming loans, laws and legislations but they may find a similar country that has the most suitable regulations in place. AMCs may exist or not in Eurasian markets but their effects on the banking system may be of interest as their vitality may be questioned in these markets as well. Further study will aim to determine the factors affecting non-performing loan sales.

\section{References}

- Aslan, E. 2002, “Türkiye'de VYŞ Kuruluşuna İlişkin Gelişmeler”, BDDK Bankacılık Sektörünün Yeniden Yapılandırılması Programı. 
- Berger, A., DeYoung, R., 1997. "Problem loans and Cost Efficiency in Commercial Banks." Journal of Banking and Finance 21, p. 849-870

- Claudia, D., 1998, “Market-Based Policy Instruments for Systemic Bank Restructuring”, International Monetary Fund Working Paper, WP/98/113.

- Ersoy, H., 2007, "Finansal Krizlerin Çözümleme Süreçleri ve Yöntemleri (Türkiye-Kore-Meksika Deneyimlerinin Karşılaştırmalı Analizi)", Marmara Üniversitesi, Bankacılık ve Sigortacılık Enstitüsü, Bankacılık Anabilim Dalı, İstanbul

- Klingebiel, D., 2000, "The Use of Asset Management Companies In The Resolution of Banking Crisis", World Bank Policy Research Working Paper, WPS/2284,

- Louzis D. P., Vouldis A. T., Metaxas V.1., 2012 "Macroeconomic and bank-specific determinants of nonperforming loans in Greece: A comparative study of mortgage, business and consumer loan portfolios" Journal of Banking \& Finance, Vol 36, Issue 4, p. 1012-1027.

- Mesutoğlu, B., 2001, "Sorunlu Aktiflerin Varlık Yönetimi Şirketlerince Tasfiyesi - Ülke Örnekleri", Bankacılık Düzenleme ve Denetleme Kurumu, MSPD Report.

- $\quad$ Podpiera, J., Weill, L., 2008. "Bad luck or bad management? “ Emerging Banking Market Experience. Journal of Financial Stability 4, p. 135-148.

- Reinhart, C., Rogoff, K., 2010. “From Financial Crash to Debt Crisis”. NBER Working Paper 15795.

- Salas, V., Saurina, J., 2002. "Credit risk in two institutional regimes: Spanish commercial and savings banks.” Journal of Financial Services Research 22, p. 203-224.

- Selimler, H., 2006, "Türk Bankacılık Sektöründe Sorunlu Kredilerin Varlık Yönetim Şirketlerince Tasfiyesi, Seçilmiş Ülkeler ve Türkiye Uygulaması”, Marmara Üniversitesi, Bankacılık ve Sigortacılık Enstitüsü, Bankacılık Anabilim Dalı (Unpublished Phd thesis), İstanbul.

- Woo D, 2000, “Two Approaches to Resolving Nonperforming Asset During Financial Crises”, IMF Working Paper No: WP/00/33, p. 6-7 


\title{
The Interaction between Stock Prices and Commodity Prices: East Europe and Central Asia Countries
}

\author{
Asst. Prof. Dr. Mustafa Ildırar (Çukurova University, Turkey) \\ Asst. Prof. Dr. Erhan İşcan (Çukurova University, Turkey)
}

\begin{abstract}
The sharp increase in commodity prices since 2000s has important effects on many economic variables. Especially the upward trend in commodity prices had substantial effects on stock prices. The literature has continuing and growing interest to the dynamics of commodity price and their significant impact on economic and financial developments. There is growing evidence that commodity prices, stock prices moved together, and that the correlations between them have increased. Many studies investigated the interaction between stock prices and real and commodity prices and find strong interaction for developed countries. However, the effect of the commodity prices on stock markets in relatively less investigated for ECA countries. The purpose of this study is to investigate the long-run relationship between commodity prices and stock prices in ECA countries can by using a panel cointegration test.
\end{abstract}

\section{Introduction}

The commodities especially oil, wheat, iron and rubber have an important role in economics because of they are the main components of many common goods in our lives. Especially an increases or a decrease in the commodity prices affects all of the economies in the world. In the last decade, the prices of many commodities volatility, with simultaneous and alternating phases of rising and falling trends. As shown in Figure $1 \& 2$ which displays All Commodity Price Index and Food Price Index indicates 2008 financial crisis and the decrease in last 12 months. Because of this, the prices of many commodities are the central issue for the world economy. Therefore, G20 emphasizes on volatility of commodity prices in its September 2009 Pittsburgh summit.

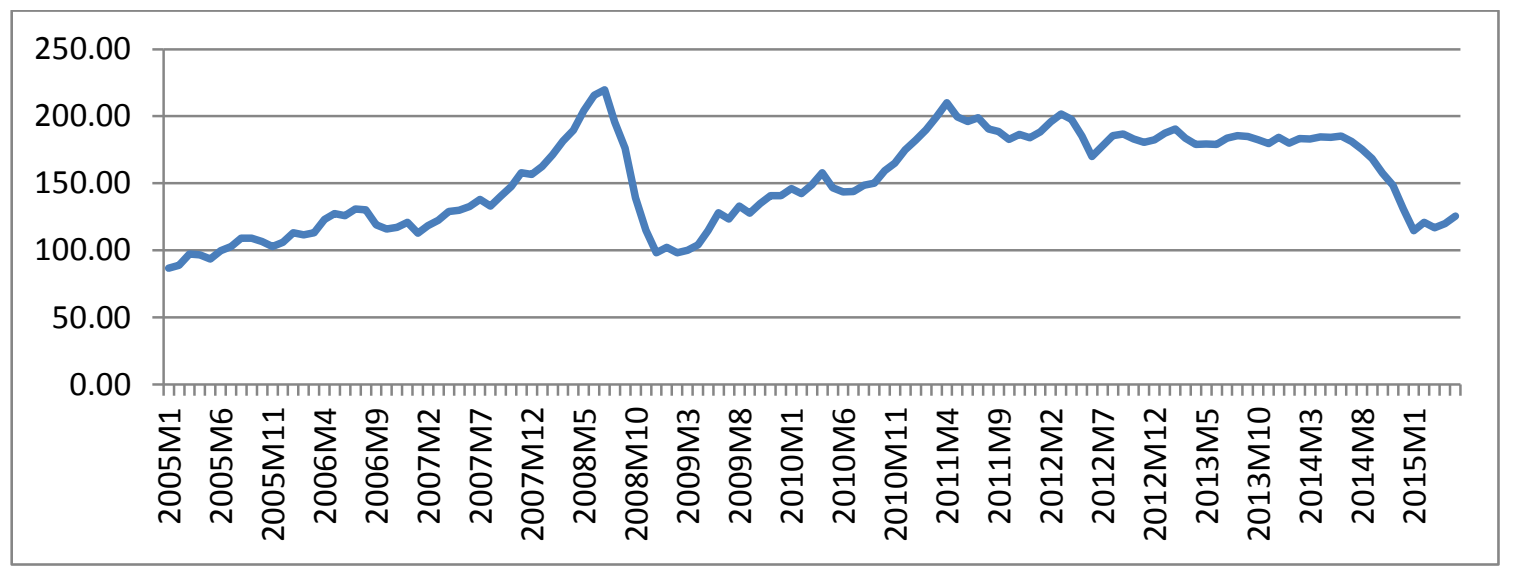

Table1. All Commodity Price Index, $2005=100$, includes both Fuel and Non-Fuel Price Indices Source: IMF

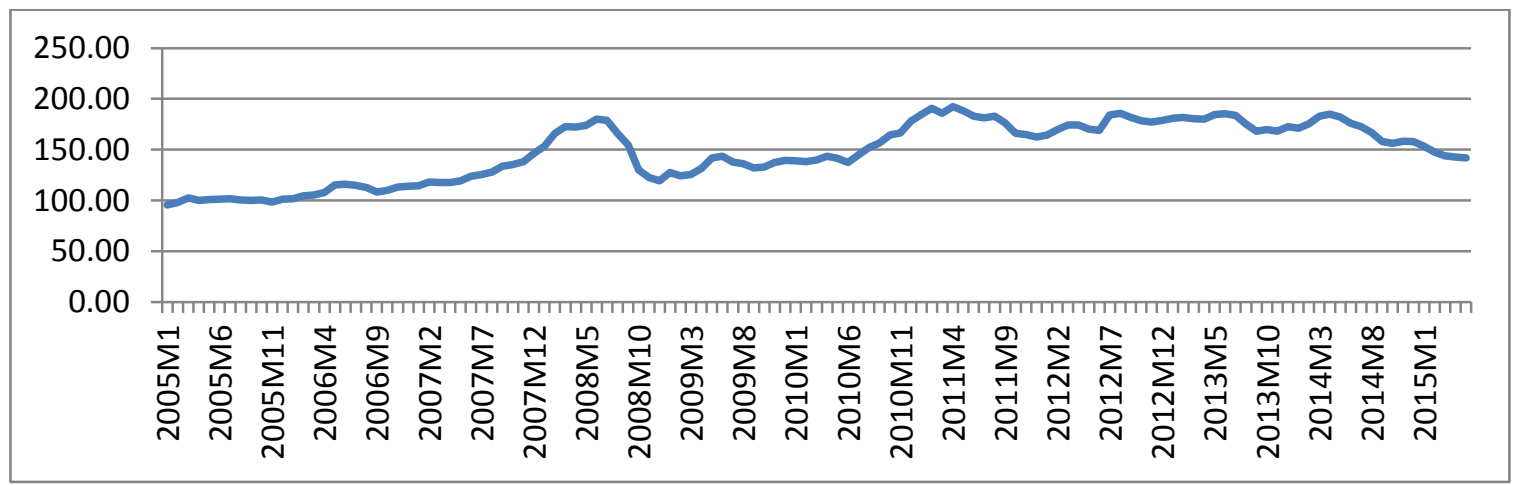

Table 2. Food Price Index, $2005=100$, includes Cereal, Vegetable Oils, Meat, Seafood, Sugar, Bananas, and Oranges Price Indices Source: IMF

Commodities are traded every day in commodity market as a financial instrument and a raw material for all commodities that we use in daily life. Commodity prices are important for the economy because they directly affect the prices. Moreover, commodities have effects on stock market as they are used as financial instrument 
and because of the effect on profitability of the corporate business. Therefore, analyzing the links between commodity and stock markets is very important for the investors, investment environment, economists, and economies.

Consequently, commodities influence world economy by affecting prices in fact. These prices may be commodity prices or share prices. Therefore, there will be a shock -negative or positive- to stock market that drags to an expansion or a recession the economy. The globalization causes the commodity price and stock markets in the world become more integrated. It was believed that the performance of stock markets would be affected by global commodity price.

This study contributes to the empirical literature about the relationships between stock and commodity markets. In addition, this is an additional study to the empirical literature, which focused on the dynamics of the relation between commodity and stock markets. These findings also help us assess the macroeconomic implications of commodity price shocks for the ECA countries. The paper is organized as follows: Definitions of the markets and interaction is reviewed in section 2, literature is reviewed in section 3, Methodology and data is presented and results are given in section 4, and results are concluded in section 5.

\section{Commodity Markets, Stock Markets and Interactions between Commodity Prices and Stock Prices}

Commodities consist of the basic materials and natural resources used in virtually all production and manufacturing processes. Commodity market is a market where the commodities are traded. There are various types of commodities include "hard commodities" and "soft commodities" in the market. Hard commodities are those resources exist naturally and must be extracted for example gold, oil, copper, etc. While soft commodities are products mostly from agricultural such as corn, wheat, sugar, soybeans, etc. (Keong et al., 2014). On the other the commodity market enables the investors to trade goods. In commodity markets buy or sell the shares of raw materials that are the components of our daily life.

Commodities are classified in different way by Farooki and Kaplinsky (2012) as follows.

\begin{tabular}{|c|c|c|c|}
\hline Primary Sector & Category & Major Use & Examples \\
\hline \multirow{5}{*}{ Soft Commodities } & Industrial Crops & Input in manufacturers & Timber \\
\hline & Fisheries & \multirow{4}{*}{$\begin{array}{l}\text { Final Consumption } \\
\text { (with limited processing) }\end{array}$} & Prawns, cod \\
\hline & Cereals & & Rice, wheat \\
\hline & Beverages & & Tea, Coffee, Cocoa \\
\hline & Livestock & & Cattle, Dairy products \\
\hline \multirow{4}{*}{ Hard Commodities } & Precious Metals & Input in manufactures & Gold, Silver, Platinum \\
\hline & Ferrous Metals & Infrastructure and Construction & Iron Ore and Steel \\
\hline & Non-Ferrous Metals & Input in manufacturers & Copper, Zinc, Lead, \\
\hline & Rare earths and metals & Input in manufacturers & Cerium Plutonium \\
\hline \multirow{4}{*}{ Energy } & Petroleum products & Fuel for industrial usage & Oil, Naturel Gas and \\
\hline & Coal & \multirow{3}{*}{ Final consumption } & Coal. \\
\hline & Nuclear & & Nuclear power \\
\hline & Renewables & & Renewable power \\
\hline
\end{tabular}

Table 3.Three Primary Commodity Families and Their Sector of Use Source: Farooki and Kaplinsky, 2011

Stocks represent individual shares of ownership in corporate businesses. Stocks can be purchased directly from corporate business or they can be bought from and sold to stock investors on stock exchanges around the world. These markets that stocks are traded between investors called as stock markets. Stock market which is part of the financial markets, perform the following functions in an economy: 1) Raising capital for business 2) Mobilizing savings for investment 3) Facilitate company growth 4) Redistribution of wealth 5) Corporate governance 6) Creates investment opportunities for small investors 7) Government raise capital for development projects 8) Barometer of the economy.

Both stocks and commodities are bought and sold on physical trading floors and through electronic trading networks without physical goods ever being exchanged. On the other hand, the fundamental differences between the stock market and the commodities market are the products they deal with, and thus the manner in which they work. The stock market deals in ownership shares of a company. In addition, while a share of stock represents an actual ownership in the company, it is essentially in electronic form but Commodities are actual iron, oil, wheat, or rubber and these are the components of the daily life commodities. Moreover, futures market contracts for commodities are like stocks, but they do not indicate ownership of a commodity; they indicate a right to own it from a contract. In the Table 4, we can see the economic indicators of major stock exchanges. 


\begin{tabular}{|c|c|c|c|}
\hline Stock Exchange & Headquarter & $\begin{array}{c}\text { Market Capitalization } \\
\text { (USD bn) }\end{array}$ & $\begin{array}{c}\text { Monthly Trade } \\
\text { Volume (USD bn) }\end{array}$ \\
\hline New York Stock Exchange & New York City & 19.223 & 1.520 \\
\hline NASDAQ OMX & New York City & 6.831 & 1.183 \\
\hline London Stock Exchange & London & 6.187 & 465 \\
\hline Japan Exchange Group & Tokyo & 4.485 & 1.278 \\
\hline Shanghai Stock Exchange & Shanghai & 3.986 & 155 \\
\hline Hong Kong Stock Exchange & Hong Kong & 3.328 & 184 \\
\hline Euronext & $\begin{array}{c}\text { Amsterdam-Brussels- } \\
\text { Lisbon-Paris }\end{array}$ & 3.321 & 800 \\
\hline Shenzhen Stock Exchange & Shenzhen & 2.285 & 120 \\
\hline TMX Group & Toronto & 1.939 & 142 \\
\hline Deutsche Börse & Frankfurt & 1.762 & \\
\hline
\end{tabular}

Table 4. Major stock exchanges of issued shares of domestic companies (as 30 January 2015) Resource: World Federation Exchange Monthly Reports

Table 5, reports stock market indicators for the some selected ECA countries examined. These ratios are also used in the work of Demirgüc et all. (1996) and Levine et all (1996) measure the role of stock market in economic growth.

Demirgüc et all. (1996) expressed that the ratio of stock market capitalization to GDP reflects the degree of activity with the liquidity and the turnover ratios. So that if we analyze the data we understand that the stock markets of ECA countries are quite large in terms of market capitalization, also these countries are considerable in terms of number of listed companies. The liquidity ratios are relatively very high in Turkey and Russian Federation while the other countries are low. This means that financial deepening is low in many ECA countries.

\begin{tabular}{|c|c|c|c|c|c|c|c|c|}
\hline \multirow[b]{2}{*}{ Country } & \multicolumn{2}{|c|}{$\begin{array}{c}\text { Stock Market } \\
\text { Capitalization } \\
\% \text { of GDP }\end{array}$} & \multicolumn{2}{|c|}{$\begin{array}{l}\text { Market Liquidity } \\
\text { Ratio \% of GDP }\end{array}$} & \multicolumn{2}{|c|}{$\begin{array}{c}\text { Turnover Ratio to } \\
\text { market } \\
\text { capitalization }\end{array}$} & \multicolumn{2}{|c|}{$\begin{array}{c}\text { Number of Listed } \\
\text { Domestic } \\
\text { Companies }\end{array}$} \\
\hline & 2005 & 2012 & 2005 & 2012 & 2005 & 2012 & 2005 & 2012 \\
\hline Armenia & 0.9 & 1.3 & 0.0 & 0.0 & 3.7 & 0.8 & 198 & 12 \\
\hline Georgia & 5.5 & 6.0 & 0.6 & 0.0 & 13.6 & 0.2 & 257 & 133 \\
\hline Kazakhstan & 18.4 & 11.5 & 1.9 & 0.5 & 14.9 & 3.3 & 62 & 74 \\
\hline Kyrgyzstan & 1.7 & 2.5 & 0.5 & 0.1 & 34.1 & 3.4 & 8 & 18 \\
\hline FRY Macedonia & 10.8 & 5.8 & 1.6 & 0.3 & 18.3 & 5.4 & 57 & 32 \\
\hline Montenegro & 46.5 & 94.6 & 4.6 & 1.1 & 14.8 & 1.2 & 19 & 33 \\
\hline Rus.Federation & 71.8 & 43.4 & 20.9 & 36.3 & 39 & 87.6 & 296 & 276 \\
\hline Serbia & 20.6 & 18.3 & 2.5 & 0.7 & 15.3 & 3.7 & 864 & 1086 \\
\hline Turkey & 33.4 & 39.1 & 41.7 & 44.2 & 154.9 & 136.5 & 302 & 405 \\
\hline Ukraine & 29.0 & 11.7 & 0.8 & 0.7 & 3.6 & 5.2 & 221 & 198 \\
\hline Uzbekistan & 0.3 & n.a & 0.3 & 0.2 & 184.7 & n.a & 114 & 132 \\
\hline
\end{tabular}

Table 5. Some Selected ECA Countries'Stock Market Indicators Resource: WorldBank, 2014

\section{Literature Review}

Over the last decade, increases in the commodity prices have an unexpected volatility. For the policymakers commodity prices and its significance of correlations with stock markets are at central issue in the world of economics. Furthermore, the analysis of relationships between commodity and stock markets is a topic of interest for financial players because many investment portfolios are included raw materials together with stock classes.

Sadorsky (1999) studied the relation between oil prices and stock prices by using a VAR model that includes a short-term interest rate and industrial production. They found that there is a relation between oil price and other variables (Sadorsky, 1999).

Hamilton (2003), Jimenez et all. (2005) and Kilian (2008) studied impact of oil prices on economic growth. They find that a shock on oil prices have an impact on economic growth.

Gorton and Rouwenhorst (2004) showed that commodity market price have a large impact on the stock price. 
Chiou and Lee (2009) studied the WTI daily oil prices on S\&P 500 stock returns data from 1992 to 2006 using a model with oil price fluctuations. They found that fluctuations in oil prices have impact on stock returns.

Choi and Hammoudeh (2010) studied the relation between commodity prices of Brent oil, WTI oil, copper, gold and silver, and the S\&P 500 index and found that commodity prices have effected portfolios in stock markets.

Filis et al. (2011) analyze the interaction between oil prices and stock markets by differentiating oil-importing and oil-exporting countries. Their study showed that there is an interaction between oil and stock prices for oilimporting and oil-exporting economies.

Killian and Vigfusson (2011) found that an unexpected increase in real price of oil affected economic growth.

To sum up, the commodity prices increasingly important role in explaining equity markets Wen et al. 2012, Büyükşahin and Robe, 2010, Tang and Xiong, 2010 revealed the financialization of commodities have complex relations between different commodities or the interactions between commodities and financial assets. Even further, Buyuksahin et al. (2010) found that commodity and stock markets could move like a "market of one" in times of fluctuations.

As this literature, review indicates that the interaction between commodity prices and stock prices needs new empirical findings about the interaction within the different countries.

\section{Model and Data}

This section defines variables and describes data. We collect a set of panel data from 10 of ECA countries over the period 2012M01-2015M05. Data frequency is the most important issue in examining the interaction between the stock prices and commodity prices. Data for 10 countries captures interaction between the commodities and the stock prices. Therefore, the monthly data is used in this study. The datas for all countries obtained from IMF International Financial Statistics (IFS) iLibrary system.

The datas are as follows:

\begin{tabular}{|l|l|}
\hline Data & Contents \\
\hline Stock Prices (SP) & Share Prices as index for every country \\
\hline Oil Price (OIL) & $\begin{array}{l}\text { Crude Oil (petroleum), Dated Brent, light blend 38 API, fob U.K., } \\
\text { US\$ per barrel }\end{array}$ \\
\hline Iron Price (IRON) & $\begin{array}{l}\text { China import Iron Ore Fines 62\% FE spot (CFR Tianjin port), US } \\
\text { dollars per metric ton }\end{array}$ \\
\hline Rubber Price (RUBBER) & $\begin{array}{l}\text { Rubber, Singapore Commodity Exchange, No. 3 Rubber Smoked } \\
\text { Sheets, 1st contract, US cents per pound }\end{array}$ \\
\hline Wheat Price (WHEAT) & $\begin{array}{l}\text { Wheat, No.1 Hard Red Winter, ordinary protein, FOB Gulf of } \\
\text { Mexico, US\$ per metric ton }\end{array}$ \\
\hline
\end{tabular}

Table 6. Data definitions

We consider the stock market prices as dependent variables for the stock market indicator. Due to the data restrictions, we use only four main commodity prices as independent variable. We selected oil, iron, rubber and wheat prices as commodity prices that affects the stock prices. These four commodities are the main commodities for the whole goods and services. Therefore, this selection of the variables is reasonable.

\subsection{Methods and Findings}

In this section, we will introduce the methods that used in the study and the resulting empirical findings. This study contributes to the empirical literature about the relationships between stock and commodity markets for the ECA countries. Panel unit root tests of Levin, Lin and Chu test is applied to test if there are unit roots in panel data sets. In the second step, Pedroni's panel cointegration test is used to examine the cointegrating relationship.

\subsection{Panel Unit Root Analysis}

Main issue before estimating the model is to test if the variables are stationary or not. We performed panel unit root test on the dependent and independent variables. We follow the approach of Levin, Lin \& Chu panel unit root test. Results of this test in levels and differences are reported in the Table 5. The LLC panel unit root test results in Table 5 suggests that both stock prices, oil prices, iron prices and rubber prices are I(1) variables. 


\begin{tabular}{|l|l|}
\hline Variables & Levin, Lin \& Chu \\
\hline Individual Intercept & \\
\hline SP & 0.97354 \\
\hline OIL & 2.30423 \\
\hline IRON & 2.15372 \\
\hline RUBBER & -1.29921 \\
\hline WHEAT & -1.59650 \\
\hline Individual Intercept and Trend & \\
\hline SP & 0.36339 \\
\hline OIL & 5.05918 \\
\hline IRON & 2.98896 \\
\hline RUBBER & 6.17715 \\
\hline WHEAT & -1.39116 \\
\hline Individual Intercept & \\
\hline$\Delta$ SP & $-16.7527^{* * *}$ \\
\hline$\Delta$ OIL & $-6.44536^{* * *}$ \\
\hline$\Delta$ IRON & $-7.22967^{* * *}$ \\
\hline$\Delta$ RUBBER & $-3.48752^{* * *}$ \\
\hline$\Delta$ WHEAT & $-3.78984^{* * *}$ \\
\hline Individual Intercept and Trend & \\
\hline$\Delta$ SP & $-15.6122^{* * *}$ \\
\hline$\Delta$ OIL & $-8.08513^{* * *}$ \\
\hline$\Delta$ IRON & $-7.62236^{* * *}$ \\
\hline$\Delta$ RUBBER & $-1.54904^{*}$ \\
\hline$\Delta$ WHEAT & $-3.39474^{* * *}$ \\
\hline
\end{tabular}

Table 7. Results for panel unit root test. The choice of lag levels is based on the Schwarz Information Criterion. The LLC tests were computed using the Bartlett kernel with automatic bandwidth selection. ***, ** and * indicate significance at the $1 \%, 5 \%$ and $10 \%$ levels.

\subsection{Empirical Results}

All of the variables under investigation are integrated of order one so we can examine whether a long-run relationship exists. We examined the long-run relationship between the variables. Pedroni at his pioneer study in 2000 and 2004 developed cointegrated panels illustrated by heterogeneity and fixed effects. Pedroni proposed seven statistics to test long-run relationship. The results of Pedroni's panel cointegration test are reported in Table 8. Pedroni panel cointegration tests have no any evidence of cointegration. For the six of seven statistics significantly we cannot reject the null of no cointegration. Thus, stock, oil, iron, rubber and wheat prices do not move together in the long run.

\begin{tabular}{|l|l|l|}
\hline Dependent Variable: Stock Prices \\
\hline \multicolumn{2}{|l|}{ Independent Variables: Oil Prices, Iron Prices, Rubber Prices, Wheat Prices } \\
\hline Intercept & \multicolumn{1}{|l|}{ Statistic } & \\
\hline Panel v-Statistic & 1.264224 & Prob. \\
\hline Panel rho-Statistic & -0.088014 & 0.1031 \\
\hline Panel PP-Statistic & -1.305742 & 0.4649 \\
\hline Panel ADF-Statistic & -0.203417 & 0.0958 \\
\hline & Statistic & 0.4194 \\
\hline Group rho-Statistic & 0.224497 & Prob. \\
\hline Group PP-Statistic & -1.830245 & 0.5888 \\
\hline Group ADF-Statistic & -0.212380 & 0.0336 \\
\hline Intercept and Trend & & 0.4159 \\
\hline Panel v-Statistic & Statistic & \\
\hline Panel rho-Statistic & -0.056683 & Prob. \\
\hline Panel PP-Statistic & 0.689856 & 0.5226 \\
\hline Panel ADF-Statistic & -1.372621 & 0.7549 \\
\hline & -0.207832 & 0.0849 \\
\hline Group rho-Statistic & Statistic & 0.4177 \\
\hline Group PP-Statistic & 0.742869 & Prob. \\
\hline Group ADF-Statistic & -2.185683 & 0.7712 \\
\hline
\end{tabular}

Table 8. Pedroni's panel cointegration tests. The null hypothesis is that there is no cointegration. Under the null hypothesis all the statistics are distributed as standard normal distributions. 


\section{Conclusion}

In this paper, we have examined the relationship between stock market and commodity prices in a panel cointegration. The interaction during the entire sample period (January 2012-May 2015) is investigated. Using Pedroni's panel cointegration test to investigate the relationships between the commodity price variables and stock variables shows important results. Our results show that there is no relation between commodity and stock markets. Estimates indicate that the interaction between commodity market and stock market is uncertain. We need to expand the study a wide area. On the other hand, this result is expected because of the stock market indicators. In the Section 2 we said that the liquidity ratios are relatively very high in Turkey and Russian Federation while the other countries are low. Therefore, we may expect that if the ratios there will be no relation between the commodity prices and the stock prices.

\section{Acknowledgments}

This study was supported by Research Fund of the Cukurova University.

\section{References}

- Avalos, F. (2011)-“Commodity prices: Microeconomic drivers and emerging risks for Latin America”, Papers and Proceedings of the VI International Conference, Challenges of macroeconomic policy in emerging and developing economies, Fondo Latinoamericano de Reservas, October, https://www.flar.net/documentos/4369_Fernando_Avalos.pdf.

- Black, A. et al. (2014)-“Forecasting Stock Returns: Do Commodity Prices Help?”, Journal of Forecasting,33(8)

- Büyükşahin, B. Et al. (2010)-“Commodities and Equities: Ever a "Market of One?" The Journal of Alternative Investments, Winter 2010, Vol. 12, No. 3: p. 76.

- Cooray, A. (2010)- “Do stock markets lead to economic growth?”, Journal of Policy Modelling, 32 (2010), p. 448.

- Creti, A. et al. (2012)- "On the links between stock and commodity markets' volatility”, CEP II, Working Paper No:2012-20

- Chiou, Jer-Shiou; Lee, Yen-Hsien. (2009) "Jump dynamics and volatility: Oil and the stock markets", Energy, 34.6: 788-796.

- Demiralay, S. and Ulusoy, V. (2014)- "Links Between Commodity Futures And Stock Market: Diversification Benefits, Financialization And Financial Crises”, MPRA Paper No. 59727

- Demirgüç-Kunt, Asli; Levine, Ross, (1996), "Stock markets, corporate finance, and economic growth: an overview”, The World Bank Economic Review, 223-239.

- Farooki, M. Z. and R. Kaplinsky (2011)- The Impact of China on Global Commodities: The Disruption of the World's Resource Sector, London: Routledge

- Filis, George; Degiannakis, Stavros; Floros, Christos, (2011), "Dynamic correlation between stock market and oil prices: The case of oil-importing and oil-exporting countries", International Review of Financial Analysis, 20.3: 152-164.

- Gorton, Gary; Rouwenhorst, K. Geert, (2006), "Facts and fantasies about commodity futures", Financial Analysts Journal, 2006, 62.2: 47-68.

- Hamilton, James D.,(2003), “What is an oil shock?”. Journal of econometrics, 113.2: 363-398.

- Choi, Kyongwook; Hammoudeh, Shawkat, (2010), "Volatility behavior of oil, industrial commodity and stock markets in a regime-switching environment” Energy Policy, 2010, 38.8: 4388-4399.

- Jiménez-Rodrìguez, Rebeca; Sànchez, Marcelo, (2005), “Oil price shocks and real GDP growth: empirical evidence for some OECD countries”, Applied economics, 37.2: 201-228.

- Johnson, R., Soenen, L. (2009)- "Commodity Prices and Stock Market Behavior in South American Countries in the Short Run”, Emerging Markets Finance and Trade, 45:4, p. 69.

- Keong, C.M, et al. (2014)- Relationship Between Commodities Market and Stock Market: Evidence From Malaysia and China, Universiti Tunku Abdul Rahman Research Project

- Kilian, Lutz, (2008) "Exogenous oil supply shocks: how big are they and how much do they matter for the US economy?", The Review of Economics and Statistics, 90.2: 216-240.

- Kilian, Lutz; Vigfusson, Robert J.(2011), “Are the responses of the US economy asymmetric in energy price increases and decreases?", Quantitative Economics, 2011, 2.3: 419-453.

- Lombardi, M., Ravazzolo, F. (2013)- On the correlation between commodity and equity returns: implications for portfolio allocation, BIS Working Papers No 420 
- Nangolo, C., and Musingwini (2012)-“Emprical correlation of mineral commodity prices with Exchangetraded mining stock prices”, JSAIMM,111(7), p. 459.

- Pedroni, Peter, (2004), "Panel cointegration: asymptotic and finite sample properties of pooled time series tests with an application to the PPP hypothesis", Econometric theory, 20.03: 597-625.

- Pedroni, Peter, (2000), "Fully Modified OLS for Heterogeneous Cointegrated Panels," Department of Economics Working Papers 2000-03, Department of Economics, Williams College.

- Sadorsky, P. (1999)-“'Oil pice shocks and stock market activity”, Energy Economics 21, p. 449.

- Soucek, Michael (2013)-“Crude oil, equity and gold futures open interest co movements”, Energy Economics 40 (2013), p.306.

- Tang, K., Xiong, W. (2012)-“Index Investment and the Financialization of Commodities”, Financial Analysts Journal, Volume:68, Number: 6, p. 54.

- Thuraisamy, K., et all. (2012)-“The ralationship between Asian equity and commodity futures market”, Financial Econometric Series, SWP 2012/07

- Zapata, H., et all (2012)- "Historical Performance of Commodity and Stock Markets", Journal of Agricultural and Applied Economics, 44,3 (August 2012), p. 339. 


\title{
Financial Performance of Commercial Banks: The Case of Kyrgyz Republic
}

\author{
Ph. D. Candidate Adilya Yamaltdinova (Kyrgyzstan-Turkey Manas University, Kyrgyzstan) \\ Ph. D. Candidate Burulcha Sulaimanova (Kyrgyzstan-Turkey Manas University, Kyrgyzstan)
}

\begin{abstract}
The banking sector of Kyrgyz Republic is mainly presented by commercial banks and increase of their financial performance will lead to improve their functions and activities. For this reason, the aim of this research is set as to empirically investigate the financial performance of commercial banks of Kyrgyz Republic for the period of 2008-2014. The financial performance measured by using one indicator, this is Return on Assets. This indicator will be estimated by multiple regression analysis, with explanatory variables, such as bank size, credit risk, operational efficiency and asset management. The model is checked for goodness-of-fit and classical linear model assumptions.
\end{abstract}

\section{Introduction}

The banking system of the Kyrgyz Republic consists of two levels: the first level - is the National Bank of the Kyrgyz Republic, the second one is the commercial banks of the Kyrgyz Republic. The Central Bank of the Kyrgyz Republic takes over the role of the banking sector regulator. Until to date, the regulatory basis for the functioning and development of the banking system is the Law of the Kyrgyz Republic "The National Bank of the Kyrgyz Republic" dated 07.29.1997, "On banks and banking activity" from 29.07.1997.

The banking system has gone through several stages in its development (Omorov, 2013):

The first stage (from 1992 to 1996) was characterized by the transition to market relations, and accompanied by high rates of inflation and imbalances associated with the restructuring of the economy. This stage can be called the stage of active reform and lay the foundation of the legislative, regulatory, institutional framework of the banking system.

The second stage (1997-2000) is characterized by the implementation of a program of restructuring the financial system of Kyrgyzstan (FINSAC), which is supported by the World Bank. Implementation of the program has helped to completely reorganize commercial banks. In this stage there was a system of laws and regulations, which amounted to a regulatory framework for banking and banking supervision in the Kyrgyz Republic.

The third stage (2000-2005) is characterized by a decrease in the stability of banks against the background of the external and internal factors. Since the beginning of the 2000 year the National Bank and the government took various measures to strengthen the banking sector, including providing financial support to banks to restructure bad debts. This situation is under the influence of macro-economic destabilization caused by the crisis neighboring countries.

In the fourth stage, from 2005 until now, are carried out the structural reforms on market relations in the banking sector. This stage can be called the stage of stabilization of the banking sector.

In 2005 the banking system continued its positive development, despite the political situation the end of March. However, the sharp economic downturn did not happen, the commercial banks have not only maintained its stability, but also continued to rise (Ayupova, 2008: 52). According to Ayupova one of the main problems that impeded spending development of the banking system remains high proportion of cash payments between legal entities and individuals inside Kyrgyz Republic. It slowed down the process of attracting foreign investment in the financial sector of the economy. Growing demand for international banking services such as trade finance and documentary operations. Nevertheless, many banking products actively used worldwide will remain unused within the country.

After 2005, Kyrgyz banking sector has begun to developing. But the global financial crisis that began in 2008 had a negative impact on the banking sector of Kyrgyzstan. Commercial banks have suspended development of credit products at the beginning of the year, in connection with which noted and some deterioration of the loan portfolio, due to the deteriorating financial condition of borrowers. This contributed to the fact that banks have shifted to risk-free commission operations (Kachkeev, 2010).

In 2010 year, the revolution of Kyrgyzstan has begun. In Kyrgyzstan every sector has effect of this revolution. Of course the banking sector has effect also from this revolution. At this time, banks in Kyrgyzstan along with other countries experienced a credit boom. However, the political instability of the banking system stopped the growth, which resumed only in 2011. Kyrgyz banking sector has felt the global crises of the financial sector during this revolution also. The impact of the global crisis and domestic political events of 2010 proved to be 
essential in reducing the solvency of borrowers of banks led to an increase in problem credits and deductions for losses and damages.

Growth of basic indicators of the banking sector was observed by the end of 2014, in particular, growth of assets, a loans portfolio, a resource base, and a net profit. Kyrgyz banking sectors of the level of capital adequacy of the banking sector is high, suggesting that there is some potential to further improve financial intermediation, enhance efficiency of the banking sector, and ensure a "safety cushion" in the future.

After the regulating of the Kyrgyz Republic of Central Bank, systemic risks in the banking sector are moderate. After all the regulator of the sector, nevertheless the banking sector is still poorly integrated into international financial markets.

By the end of 2014 are operated 24 commercial banks, including the Bishkek Branch of the National Bank of Pakistan and 292 branches of commercial banks operated in the Kyrgyz Republic. Among the commercial banks, 16 banks are noted for foreign participation in the capital (Annual Report of the NBKR for 2014). At the end of 2014, the share of foreign capital accounted for 35.8 percent of banks' capital (in 2013 - 36.5 percent). During the reporting period the total assets of the banking sector increased by 23.9 percent and amounted to 137.6 billion Kyrgyz Soms.

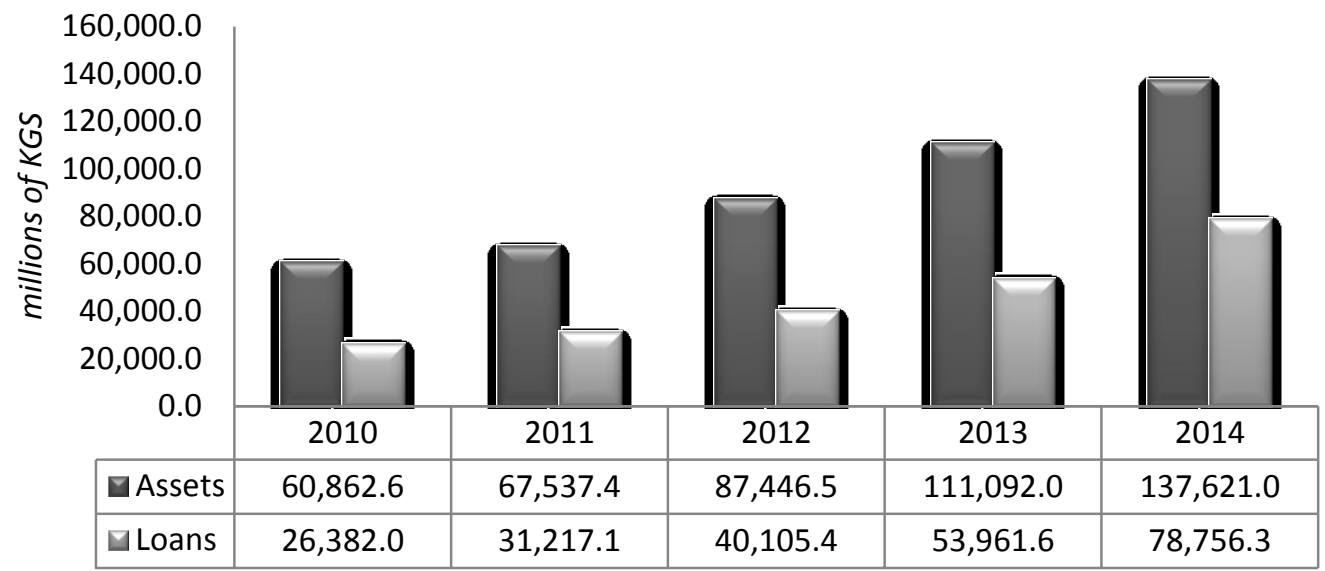

Figure 1. Pattern of Assets and Loan Portfolio of Banks; Source: Annual Report of the NBKR, 2014

The main share of the banks' assets $56.7 \%$ accounted for the loans issued. The volume of loans to customers of the banking system by the end of 2014 grew by 67 percent and reached 78.8 billion soms.

Assets of Kyrgyz banking sector has increased from 60 billion Kyrgyz Soms to 137.6 billion Kyrgyz Soms between of 2010-2014. It has increased really considerable for banking sector.

Loans to clients of Kyrgyz banking sector has increased from 26.4 billion Kyrgyz Soms to 78.8 billion Kyrgyz Soms between of 2010-2014. It has increased nearly 67\% during this time. The assets have increased $56 \%$ by this period. In the future, this situation would bring some risks to Kyrgyz banking sector.

The share of the loan portfolio in the assets of the banking sector increased by 8.6 percentage points compared with 2013 and made up 57.2 percent. The number of borrowers of banks at the end of 2014 increased in comparison with 2013 by 35.6 percent to 226,881 people.

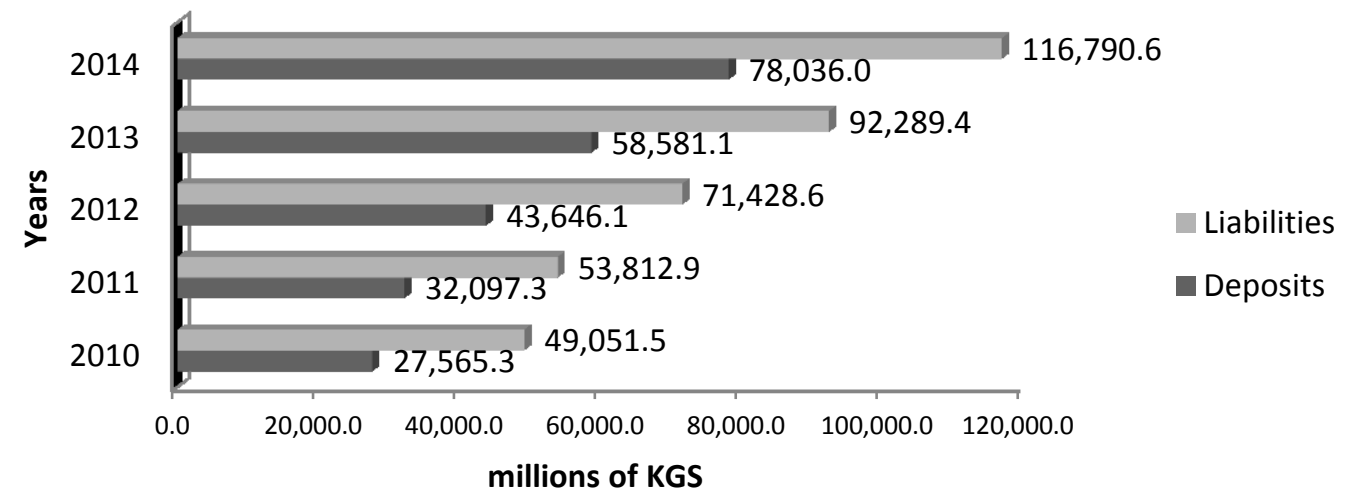

Figure 2. Pattern of Liabilities and Deposit Base of Banks between 2010-2014; Source: Annual Report of the NBKR, 2014 
In figure 4, the deposit base of banks could be seen. In the figure it has explained the deposit bases of banks have become 78 billion Kyrgyz Soms from 27.6 billion Kyrgyz Soms during the 2010 to 2014. It has increased $64 \%$ percentage. It is increasing faster than loans to clients. There is the better indicator for Kyrgyz banking sector.

By the end of 2014, the volume of liabilities of commercial banks increased by 26.5 percent to KGS 116.8 billion. The share of the deposit base in the gross volume of liabilities developed at the rate of 66.8 percent. For the reporting period, growth of the deposit base of the banking sector amounted to 22.3 percent.

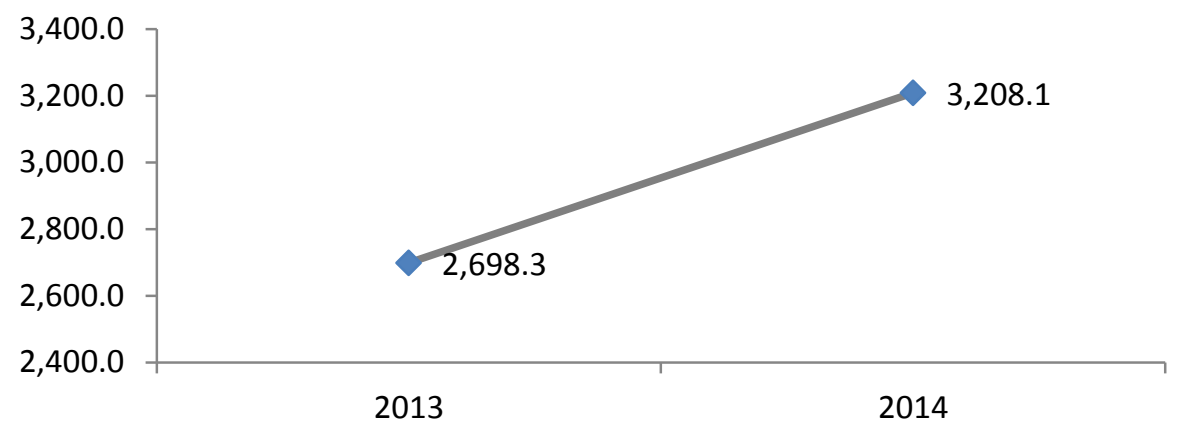

Figure 3. Net Profit of Kyrgyzstan Banking Sector between 2013-2014; Source: Annual Report of the NBKR for 2014

By the end of 2014, the net profit of the banking system amounted to 3.2 billion Kyrgyz Soms, having increased by 0.5 billion Kyrgyz Soms or by 18.5 percent compared to the previous year. Annual growth of deposits indicates maintaining public confidence in the banking system.

The paper is organized as follows: in section two, the empirical studies on financial performance are reviewed; in section three and four, the methodology with data description and empirical results are given respectively; in the final section conclusion is provided.

\section{Literature Review}

Empirical studies investigating the financial performance of commercial banks in general conclude that bank performance is conditional economic fluctuations, macro indicators, ownership characteristics, electronic banking operations. Thus, according to Boyd et al. (2001) there are a significant, and economically important, negative relationship between inflation and both banking sector development and equity market activity. While, there exist positive relationship between e-banking and bank performance (Aduda \& Kingoo, 2012).

The commercial bank efficiency in transition economies influenced by foreign ownership and this leads to more efficient banks (Grigorian \& Manole, 2002; Bonin et al., 2005). While findings of Verbrugge et al. (1999 suggest that, continued significant government ownership of banks raises serious problems for establishing market-oriented governance and decision-making systems in the banks.

DeYoung \& Rice (2004) demonstrated a number of empirical links between bank noninterest income, business strategies, market conditions, technological change, and financial performance between 1989 and 2001. The results indicate that well-managed banks expand more slowly into noninterest activities, and that marginal increases in noninterest income are associated with poorer risk-return tradeoffs on average. These findings suggest that noninterest income is co-existing with, rather than replacing, interest income from the intermediation activities that remain banks' core financial services function.

However, the empirical literature that investigates the financial performance of banks by efficiency ratios, shows that ranking of banks differ as the financial ratio changes, that capital adequacy, asset quality, management efficiency and liquidity had weak relationship with financial performance, while earnings had a strong relationship with financial performance ( Alam et al., 2011; Fredrick, 2012).

Hernando \& Nieto (2007) estimated the impact of the adoption of a transactional web site on financial performance using a sample of 72 Spanish commercial banks over the period 1994-2002. Since brokerage is one of the main drivers used for banks for acquiring new customers on-line, the paper also analyzes the impact on the performance of the multichannel banks of the provision of on-line brokerage. The impact on banks' performance of transactional web adoption (or the broker on line business model) seems to vary over time. The adoption of the Internet as a delivery channel has a positive impact on banks' profitability (ROA and ROE) after one and a half years, mainly explained by the lower overhead expenses and, in particular, staff and IT costs after the same period. The paper also concludes that the Internet is used as a complementary mean of transacting rather than a substitute for physical branches/ATMs. 
Jha \& Hui (2012) compared the financial performance of different ownership structured commercial banks in Nepal based on their financial characteristics and identify the determinants of performance exposed by the financial ratios, which were based on CAMEL Model. Eighteen commercial banks for the period 2005 to 2010 were financially analyzed. In addition, econometric model (multivariate regression analysis) by formulating two regression models was used to estimate the impact of capital adequacy ratio, non-performing loan ratio, interest expenses to total loan, net interest margin ratio and credit to deposit ratio on the financial profitability namely return on assets and return on equity of these banks. The results show that public sector banks are significantly less efficient than their counterpart are; however domestic private banks are equally efficient to foreign-owned (joint venture) banks. Furthermore, the estimation results reveal that return on assets was significantly influenced by capital adequacy ratio, interest expenses to total loan and net interest margin, while capital adequacy ratio had considerable effect on return on equity.

Nazir (2010) evaluated the financial performance of the two major banks operating in northern India. This evaluation has been done by using CAMEL Parameters, the latest model of financial analysis. Through this model, it is highlighted that the position of the banks under study is sound and satisfactory so far as their capital adequacy, asset quality, Management capability and liquidity is concerned.

Ongore \& Kusa (2013) used linear multiple regression model and Generalized Least Square on panel data to estimate the determinants of financial performance of commercial banks. The findings showed that bank specific factors significantly affect the performance of commercial banks in Kenya, except for liquidity variable. But the overall effect of macroeconomic variables was inconclusive at 5\% significance level. The moderating role of ownership identity on the financial performance of commercial banks was insignificant. Thus, it can be concluded that the financial performance of commercial banks in Kenya is driven mainly by board and management decisions, while macroeconomic factors have insignificant contribution.

Said \&Tumin (2011) investigated the impact of bank-specific factors which include the liquidity, credit, capital, operating expenses and the size of commercial banks on their performance, which is measured by return on average assets (ROAA) and return on average equity (ROAE). The results imply that ratios employed in this study have different effects on the performance of banks in both countries, except credit and capital ratios. Operating ratios influence performance of banks in China, but this influence is not true for Malaysian banks regardless of the measure of performance.

\section{Methodology and Data Description}

The financial performance is measured by using one indicator; this is Return on Assets (ROA). In general, financial literature suggests using not only ROA indicator, but also to use the Tobin's Q model and Economic Value add indicators. But in case of Kyrgyzstan's banking sector, there is a data limitation on these indicators. For this reason we do not include Tobin's Q and Economic Value add indictors to our investigations.

The sample of the study consists of the all commercial banks of Kyrgyz Republic. Annual Time series data for independent - dependent variables were extracted from Bulletin of the National Bank of the Kyrgyz Republic for the period 2008-2014.

To assess the financial performance of the Kyrgyz commercial banks, we estimated multiple regression model, which consists of dependent variable and four independent variables, where the ROA is used as an internal financial performance indicator.

The variables used for model represented below:

Dependent variable:

ROA $=$ Net Income / Total Assets

Independent variables:

Bank Size $=$ LOG (Total Assets)

Credit Risk $(\mathrm{CR})=$ Reserves for doubtful loans / credit facilities

Operational Efficiency $(\mathrm{OE})=$ Total operating expense $/$ net interest income

Asset management $(\mathrm{AM})=$ Operating income $/$ total assets

\section{Data Analysis and Empirical Results}

In table 1, the multiple regression model results are given, which were estimated with least squares method. The parameters estimated have expected signs and statistically significant. The model is checked for goodness of fit, where the adjusted R-square is $97 \%$, so we can conclude that $97 \%$ of the variation in the dependent variable (ROA) is explained by the independent variables. This implies that there is strong explanatory power of independent variables. The test for normal distribution, autocorrelation, heteroscedasticity of residuals show that in general there is no autocorrelation and heteroscedasticity in the residuals, and that they are normally 
distributed. F-statistics results show that there exist a significant impact of asset size, operational efficiency and asset management on ROA of commercial banks. While we could not find significant impact of credit risk on ROA, and did not include it to the estimation.

\begin{tabular}{|c|c|c|c|c|}
\hline Variable & Coefficient & Std. Error & t-Statistic & Prob. \\
\hline C & 103.1425 & 10.01395 & 10.29988 & 0.0093 \\
\hline LOG(ASSETS) & -6.690830 & 0.634739 & -10.54107 & 0.0089 \\
\hline AM & -0.806880 & 0.256685 & -3.143460 & 0.0880 \\
\hline EFFICIENCY & -0.192390 & 0.034383 & -5.595505 & 0.0305 \\
\hline DUMMY & -2.938533 & 0.425222 & -6.910584 & 0.0203 \\
\hline R-squared & 0.990153 & Mean dependent var & & 3.542857 \\
\hline Adjusted R-squared & 0.970460 & S.D. dependent var & & 1.624661 \\
\hline S.E. of regression & 0.279236 & Akaike info criterion & & 0.462287 \\
\hline Sum squared resid & 0.155945 & Schwarz criterion & & 0.423651 \\
\hline Log likelihood & 3.381996 & Hannan-Quinn criter. & & -0.015242 \\
\hline F-statistic & 50.27795 & Durbin-Watson stat & & 3.182984 \\
\hline Prob(F-statistic) & 0.019597 & & & \\
\hline \multirow{3}{*}{\multicolumn{2}{|c|}{$\begin{array}{l}\text { Breusch-Godfrey Serial Correlation LM Test: } \\
\text { Heteroskedasticity Test: Breusch-Pagan-Godfrey } \\
\text { Jarque-Bera Normality Test }\end{array}$}} & \multicolumn{2}{|c|}{ Obs*R-squared } & 2.829108 \\
\hline & & \multirow{2}{*}{\multicolumn{2}{|c|}{$\begin{array}{l}\text { Obs*R-squared } \\
\text { Jarque-Bera stat. }\end{array}$}} & 4.478302 \\
\hline & & & & 1.278971 \\
\hline
\end{tabular}

Table 1. Demographic Data for the Study (Efficient ROA with Independent Variables)

The empirical results show that with increase of asset for 1\% the ROA decreases for 6.69 point, which means that if the net income is constant and do not change, then the increase in asset the efficiency of the commercial bank decreases. The other explanatory variable of efficiency, the asset management is not statistically significant. While with increase in operational efficiency the ROA decreases for 0.19 points, this could be explained by the increase in expenditure level in operational efficiency variable, which has negative effect on net income level, which is in ROA indicator. The dummy variable for 2008-2009 years is included for model to adjust the structural break effect of financial crisis in 2008 and its impact in 2009. The result for this variable show that in general return on assets is higher in 2010-2014 period than in 2008-2009.

\section{Conclusion}

This paper's aim is set to empirically investigate the financial performance of commercial banks of Kyrgyz Republic for the period of 2008-2014. There are a lot of methods for measuring the performance of the banks, such as graphical application, mathematical applications and the others. We have used statistical method on explaining the Kyrgyz Banking system performance. Thus we used Return on Assets as indictor of efficiency of commercial banks, and estimated by multiple regression analysis with explanatory variables, such as bank size, credit risk, operational efficiency and asset management. The model has checked for goodness-of-fit and classical linear model assumptions.

According to results, we find that all the indicators have negative impact and in general return on assets is influenced by assets amount and operational efficiency of commercial banks. This can be due to many reasons. The most important one is, the increasing of profitability may be lower than the growth rate of total assets. In other words, banks are investing more their earned profits. The other one is, profit of the banks is stable but the assets of banks are increasing.

This study contributes to the literature by empirically investigating the determinants of efficiency in commercial banks of Kyrgyzstan. But limitation on data availability for all efficiency indicators, and short period of investigation suggest on further researches to focus for the longer period and include more efficiency indicators to justify the results of this study.

\section{References}

- Aduda, J., \& Kingoo, N. (2012). The relationship between electronic banking and financial performance among commercial banks in Kenya. Journal of Finance and Investment Analysis, 1(3), 99-118.

- Alam, H. M., Raza, A., \& Akram, M. (2011). A financial performance comparison of public vs private banks: The case of commercial banking sector of Pakistan. International Journal of Business and Social Science, 2(11), 56-64.

- Аюпова Р.А. (2008) Концепции развития банковской системы Кыргызской Республики. Вестник КРСУ. Том 8. № 3, 50-53. 
- Bonin, J. P., Hasan, I., \& Wachtel, P. (2005). Bank performance, efficiency and ownership in transition countries. Journal of Banking \& Finance, 29(1), 31-53.

- Boyd, J. H., Levine, R., \& Smith, B. D. (2001). The impact of inflation on financial sector performance. Journal of Monetary Economics, 47(2), 221-248.

- DeYoung, R., \& Rice, T. (2004). Noninterest income and financial performance at US commercial banks. Financial Review, 39(1), 101-127.

- Fredrick, O. (2012). The Impact of Credit Risk Management on Financial Performance of Commercial Banks in Kenya. Africa Management Review, 3(1), 22-37.

- Grigorian, D., \& Manole, V. (2002). Determinants of commercial bank performance in transition: An application of data envelopment analysis. World Bank Policy Research Working Paper, (2850).

- Hernando, I., \& Nieto, M. J. (2007). Is the Internet delivery channel changing banks' performance? The case of Spanish banks. Journal of Banking \& Finance, 31(4), 1083-1099.

- Jha, S., \& Hui, X. (2012). A comparison of financial performance of commercial banks: A case study of Nepal. African Journal of Business Management, 6(25), 7601.

- Kachkeev, "Bankovskiy vestnik”, NBKR, 2010

- Nazir, T. (2010). Analyzing Financial Performance of Commercial Banks in India: Application of CAMEL Model. Pakistan Journal of Commerce \& Social Sciences, 4(1).

- $\quad$ Ongore, V. O., \& Kusa, G. B. (2013). Determinants of financial performance of commercial banks in Kenya. International Journal of Economics and Financial Issues, 3(1), 237-252.

- Оморов К.А. Этапы развития банковской системы Кыргызской Республики в период трансформации экономики.

- Said, R. M., \&Tumin, M. H. (2011). Performance and financial ratios of commercial banks in Malaysia and China. International Review of Business Research Papers, 7(2), 157-169.

- Verbrugge, J., Megginson, W. L., \& Owens, W. L. (1999, March). State ownership and the financial performance of privatized banks: An empirical analysis. In conference Proceedings of a Policy research Workshop held at the World Bank.

- Annual Report of the NBKR for 2014

- Bulletins of the National Bank of the Kyrgyz Republic, 2008 and 2014.

- http://www.nbkr.kg/printver.jsp?item=1436\&lang=RUS\&material=29671 


\title{
The Influence of Intellectual Capital on Firm Value towards Manufacturing Performance in Indonesia
}

\author{
Prof. Dr. Euphrasia Susy Suhendra (Gunadarma University, Indonesia)
}

\begin{abstract}
The aim of this study is to analyse the influence of intellectual capital on firm value through firm performance (profitability, productivity, market valuation and growth). Intellectual capital is measured by using a Value Added Intellectual Coefficient (VAIC ${ }^{\mathrm{TM}}$ ). Firm value is measured by Tobin's Q. The financial performance consists of Return on assets (ROA), Asset turn over (ATO), Market to Book Value (MB) and Earnings per Share (EPS).

Data from this study was obtained from financial statements and annual reports of manufacturing companies that are taken from the Indonesia Stock Exchange. The sample of this study is manufacturing companies listed on the Indonesia Stock Exchange during the year of 2011-2013 for 37 companies. The types of data used are secondary data in the form of annual reports by the manufacturing companies. Empirical analysis is conducted by using Structural Equation Modelling (SEM).

The results of this study indicate that Intellectual capital has a significant effect on profitability, market valuation and growth. Intellectual capital does not significantly affect productivity and firm value. Market valuation significantly affects the firm value. Profitability, productivity and growth do not significantly affect firm value. Furthermore, Intellectual capital which is intervened by the firm performance has a positive effect on firm value.
\end{abstract}

\section{Introduction}

The emergence of "new economy", which in principle is driven by developments in information technology and science also trigger the growth of interest in intellectual capital (IC) (Petty and Guthrie, 2000). One area of interest to both academics and practitioners are related to the usefulness of the IC as an instrument for determining the value of the company (Stewart 1997; Edvinsson and Malone 1997; Sveiby 2001). It has become a vexed issue, which some authors have ensured that the management and reporting systems that have been established during this ongoing basis lost its relevance because it is not able to present information that is essential for executives to manage knowledge-based processes and intangible resources (Bornemann and Leitner, 2002).

The expansion of foreign company into the Indonesian market requires domestic companies to further improve its value and performance. Company need to have the strength of market value as value added, company must corrected its internal condition. One of them is the intellectual ability of the company or intangible capital which can enhance the performance and competitiveness of company (Arifin et al., 2014).

However, it is difficult to measure IC since it is intangible and non-physical in nature. The traditional accounting model, which is conceived for companies operating in an industrial economy, remains focused on physical and financial assets and ignores most IC assets. Interestingly, even the International Accounting Standards/International Financial Reporting Standards (IAS/IFRS), including the ones recently modified by the International Accounting Standards Board, did not contribute to redefining many of the concepts, principles and valuation methods of IC assets. The relative lack of IC accounting recognition and its growing role in the value creation process, imply that financial statements have lost some of their value for shareholders and many other users (Canibano et al., 2000).

Limitations of financial statements in explaining the value of the company pointed to the fact that the economy is no longer a source of value in the form of raw material production, but the creation of the IC. IC includes human capital and structural packed in customer, process, database, brand and system (Edvinsson and Malone, 1997 in Ulum, 2008), and has played an increasingly important role in creating a sustainable competitive advantage for the company (Kaplan and Norton, 2004).

The development of economy increasingly complex, raise the issue in the research field of intellectual capital. One of them is regarding the disclosure of intellectual capital. Intellectual capital disclosures need to be disclosed by a company. According to Goh and Lim (2004) in Wadhikorin (2010) in the presence of an increasing demand for transparency in the capital markets, intellectual capital information helps investors assess the ability of the company to be better.

Taking into consideration the increasing importance of the role played by IC in value creation, Pulic (1998, 2004), with colleagues at the Austrian IC Research Centre, developed a new method to measure companies' IC which they called the "value added intellectual coefficient" (VAIC ${ }^{\mathrm{TM}}$ ). This method is very important since it allows us to measure the contribution of every resource - human, structural, physical and financial - to create VA by the company. 
Pulic (in Solikhah, 2010) states that the VAIC TM deemed to comply the basic needs of the contemporary economy from "measurement system" that shows the true value and performance of a company, because the main objective in the knowledge-based economy is to create value added. Meanwhile, in order to create value added needed right size of physical capital (i.e. monetary funds) and intellectual potential (represented by the employee with all the potential and the ability attached to them). Furthermore (Pulic in Ulum, 2008) states that the intellectual ability (later called the VAIC TM) shows how both of these resources (physical capital and intellectual potential) has been efficiently utilized by the company.

The relationship between intellectual capital to the company's financial performance has been proved by several researchers in Indonesia as well as abroad. In Indonesia, including Ulum (2008) and Kuryanto (2008). Whereas studies abroad, among others, performed by Firrer and William (2003), Chen et al (2005), and Tan et al. (2007). From these studies, it was found mixed results regarding the relationship of intellectual capital to the company's financial performance.

The research by Firrer and William (2003) using the company's performance, the profitability of which is described by return on assets (ROA), productivity is described to the ratio of sales divided by total assets (ATO), and the market value represented by the market to book value ratio (MB). The results suggest that there is no positive effect between intellectual capital and corporate performance.

While the studies by Chen et al (2005) using a variable market to book value ratio on equity (MB) and the company's financial performance is proxied by return on equity (ROE), return on assets (ROA), revenue growth (GR) and employee productivity (EP). The samples used were 4,254 public companies in Taiwan Stock Exchange. Chen et al (2005) proved that intellectual capital affect the value of markets and corporate performance. Similar to the studies of Chen et al (2005), Tan et al (2007) proved that intellectual capital is positively related to financial performance of the company and the company's financial performance in the future.

While the research conducted by Ulum (2008) examine the effect of intellectual capital on the financial performance of 130 banking companies with the Partial Least Square (PLS) method, the company's financial performance in the future, and also examine the effect of the average growth of intellectual capital (ROGIG) on the performance of financial companies in the future. Comparable with the results of Tan et al (2007), the results of studies by Ulum (2008) proved that the intellectual capital affect the company's financial performance and financial performance in the future, but the average growth of intellectual capital (ROGIG) does not affect the performance financial companies in the future.

Furthermore, research conducted by Arifin et al. (2014) who studied the corporate governance and intellectual capital affects the financial performance and firm value. The result indicates Disclosure of Intellectual Capital has significant effect on the Financial Performance and Firm Value. Financial Performance has a significant effect on Firm Value.

Based on previous studies, this research tries to examine the relationship of Intellectual Capital (IC) to firm value through the firm performance. Intellectual capital will be measured using the method developed by Pulic VAIC $^{\mathrm{TM}}$ (1998). Financial performance in this study will use a variable Return on Assets (ROA) to measure the profitability of the company and Asset Turnover (ATO) to measure the productivity of the company. Stock market performance will be using variables Market to Book Value (MB) to measure the market valuation and Earnings per Share (EPS) to measure the growth. Furthermore, the firm value in this study will be measured using Tobin's Q.

\section{Literature}

Intellectual capital is a broad-based term considered synonymous with firm intangible assets. Consensus is lacking on a clear definition of intellectual capital. However, one widely recognized definition describes intellectual capital as: 'material that has been formalized, captured, and leveraged to produce a higher-valued asset' (Stewart, 1997 in Tseng and Goo, 2005). From the definition, it can be concluded that intellectual capital is a resource of knowledge available on the company that eventually bring future economic benefit to the company. So the core of the existence of intellectual capital is the knowledge itself that supported the process of information to establish contact with outsiders.

Of the various kinds of intellectual capital measurement techniques should be selected one measurement. Sveiby (2001) view that "No single method can fulfill all purposes; one must select the method depending on purpose, situation and audience". In this research, intellectual capital measurement technique used is the measurement technique of Pulic models. Intellectual capital in the model Pulic measured by value added (value added) which was created by the physical capital / capital employed (VACA), human capital (VAHU), and structural capital (STVA). The combination of these three value added is symbolized by the name VAIC ${ }^{\mathrm{TM}}$, developed by Pulic (1998; 2004). 
Value Added Capital Employed (VACA) shows the contribution made by each unit of capital employed to value added organization (Ulum, 2008). Value Added Capital Employed is a company's ability to manage resources in the form of capital assets which, if managed properly will improve the financial performance of the company.

Value Added Human Capital (VAHU) shows the contribution made by each dollar invested in the human capital of the organization's human capital value added individually represent knowledge stock of an organization which is represented by its employees (Bontis et al in Ulum, 2008). Human capital is the knowledge, skill, and experience are taken when the employee leaves the company (Starovic and Mark in Astuti, 2005) which includes the individual's knowledge of an organization that is on the employees (Bontis, Crossan and Hulland in Astuti, 2005) generated through competence, attitude, and intelligence (Roos, Edvinson and Dragonetti in Astuti, 2005).

Structural Capital Value Added (STVA), the amount of structural capital needed to produce 1 rupiah of VA and is an indication of how the success of structural capital in the creation of value (Ulum, 2008). Structural capital (capital organization) is an organization or a company's ability to meet the routine process of the company and the structure that supports the efforts of employees to produce optimal intellectual performance and overall business performance, for example: the company's operating systems, manufacturing processes, organizational culture, management philosophy and all forms of intellectual property owned by the company (Sawarjuwono, 2003).

Performance becomes an important thing for management, because the performance is the result of work that can be accomplished by a person or group of people in an organization, in accordance with the authority and responsibilities of each in order to achieve the goals of the organization in question legally, do not violate the law and in accordance with morals and ethics. Performance is a function of the organization's ability to obtain and use resources in a variety of ways to develop a competitive advantage. Performance can be divided into financial performance and non-financial (Hansen and Mowen, 2005).

\section{Methodology Research}

The independent variables in this study using the method of Value Added Intellectual Coefficient (VAIC TM) developed by Pulic (1998) in (Ulum, 2009). VAIC TM is a fundamental measurement basis for independent variable in this study. In this research, intellectual capital is a form of knowledge resources such as customer, employee competence, and where companies can use technology in the process of value creation (Ulum, 2009). Intellectual capital performance as measured by the value added created by physical capital, human capital and structural capital. VAIC TM is a combination of three indicators of value added which can be expressed as follows: (1) Physical Capital (VACA - Value Added Capital Employed). VACA is the ratio between the value added (VA) to the company's equity (CE), this ratio shows the contribution made by each unit of CE to the value added organization. (2) Human Capital (VAHU - Value Added Human Capital). VAHU shows the contribution made by every rupiah invested in $\mathrm{HC}$ against value added organization. The relationship between VA and HC indicates the ability of $\mathrm{HC}$ to create value for the company. (3) Human Capital (VAHU - Value Added Human Capital) VAHU shows the contribution made by every rupiah invested in $\mathrm{HC}$ against value added organization. The relationship between VA and $\mathrm{HC}$ indicates the ability of $\mathrm{HC}$ to create value for the company.

Intervening variable in this study is the financial performance of companies and stock market performance. This variable is a combination of Bontis et al (2000), Firer and Williams (2003), Chen et al study (2005), Zeghal and Maaloul (2010), Tan et al. (2007) and Arifin et al. (2012), as follows (1) Return on Assets (ROA) Profitability ratio that measures the ability of the capital invested in all of its assets to generate profit companies, (2) Asset Turnover (ATO), This ratio measures the overall efficiency of the use of assets to generate income. (3) Market to book value (MB). Market to book value is used as a proxy for the stock market performance, (4) Earnings per Share (EPS) is a ratio that shows how investors can profit earned per share owned.

Dependent variable in this study is the value of a company is measured using Tobin's Q. A modified version of the Tobin q by Chung \& Pruitt (1994) in Wolfe \& Sauaia (2003) was used for consistency between the games Because of their simplified balance sheets. This modified version closely approximates Tobin's original statistic and produces a $96.6 \%$ approximation of the original formulation used by Lindenberg \& Ross (1981) in Wolfe \& Sauaia (2003).

Population and sample in a study needs to be set in order for the research done really get the data as expected. The population in this study is all companies listed on the Stock Exchange in 2011-2013, while the sample is used throughout the manufacturing companies. Manufacturing companies selected for the manufacturing industry has a broad scope. The period of observation in this study is 2011-2013. This year's selection is based on the limitations of the data sources in the form of annual reports in 2014 so it is not possible to be extended study period to 2014 .

The model used in this study is a model of causality or relationships effect. To test the hypothesis that will be proposed in this study, the technique of analysis that will be used is Structural Equation Modeling SEM or 
operated by AMOS. Modeling studies by SEM allows a researcher to answer the research questions that are dimensionally (i.e. measure what the indicators of a concept) and regression (to measure the effect or the degree of relationship between the factors that have been identified dimensions).

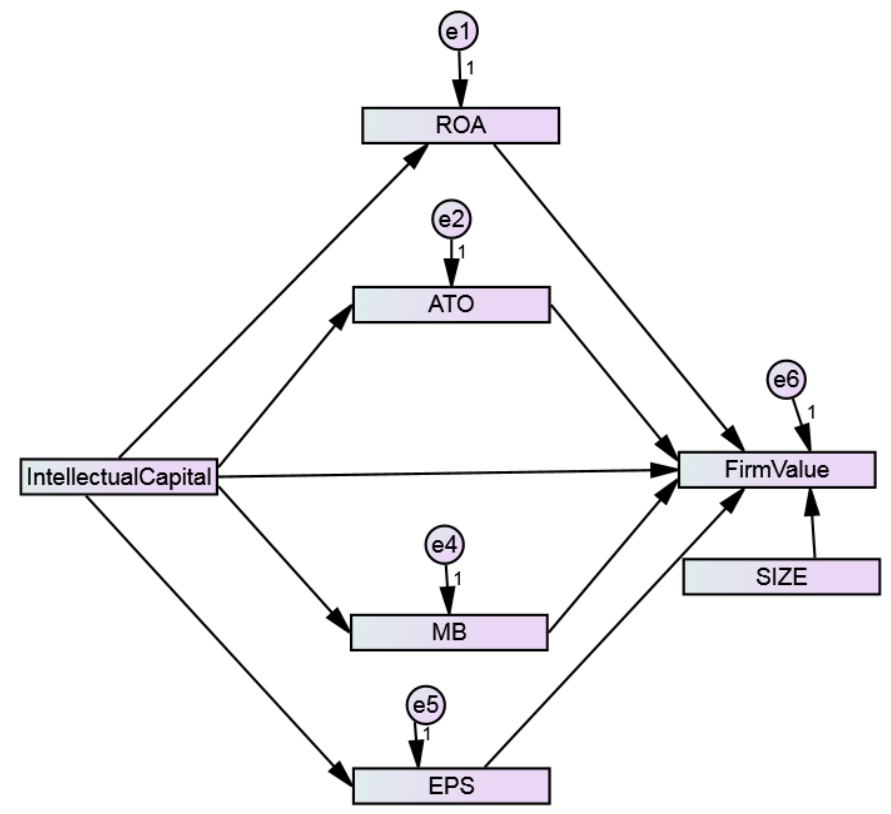

Picture 1. Research Model

\section{Result and Discussion}

Descriptive statistics aims to provide a picture or a description of the data that is seen from the number of samples, the minimum value, maximum value, average value (mean), and standard deviation of each variable. Descriptive statistical analysis was done with the statistical program SPSS version 16. The following describes the research data statistics:

\begin{tabular}{|l|c|c|c|c|c|}
\hline & $\mathbf{N}$ & Minimum & Maximum & Mean & Std. Deviation \\
\hline VAIC & 111 & 1.5788 & 8.3674 & $3.352934 \mathrm{E} 0$ & 1.4756444 \\
\hline ROA & 111 & .0117 & .3120 & .102751 & .0654814 \\
\hline ATO & 111 & .6503 & 2.9577 & $1.327892 \mathrm{E} 0$ & .4575532 \\
\hline MB & 111 & .3540 & 10.4789 & $2.438912 \mathrm{E} 0$ & 2.0366903 \\
\hline EPS & 111 & 2.6569 & $1.6515 \mathrm{E} 4$ & $6.946491 \mathrm{E} 2$ & $2.2116669 \mathrm{E} 3$ \\
\hline a & 111 & .0247 & 6.3750 & $1.226866 \mathrm{E} 0$ & 1.2985313 \\
\hline SIZE & 111 & 25.4942 & 30.9122 & $2.803793 \mathrm{E} 1$ & 1.3145745 \\
\hline
\end{tabular}

Table 1. Descriptive Statistics Source: Secondary data were processed

Based on Table 1 above shows the minimum value of the variable VAIC which is a proxy for the intellectual capital is 1.5788 and the maximum value is 8.3674 as well as the mean is 3.3529 , while the standard deviation is 1.4756. The minimum value of ROA (Return on Assets) is $0.0117(1.17 \%)$ and a maximum value is 0.3120 $(31.2 \%)$ as well as the mean is 0.1027 , while the standard deviation is 0.06548 . The minimum value of Variable ATO (Asset Turnover) is 0.6503 and the maximum value is 2.9577 as well as the mean is 1.3278 , while the standard deviation is 0.4575 . The minimum value of the variable $\mathrm{MB}$ is 0.3540 and the maximum value is 10.4789 as well as the mean is 2.4389 , while the standard deviation is 2.0366 . The minimum value of variable EPS of 2.6569 and the maximum value is 16515.00 as well as the mean is 694.6491, while the standard deviation is 2211.6669. The minimum value of variable $\mathrm{q}$ which is a proxy for firm value measured using Tobin's $\mathrm{Q}$ is 0.0247 and the maximum value is 6.3750 as well as the mean is 1.2268, while the standard deviation is 1.2985. Furthermore, the minimum value of the size of company proxied by the natural logarithm of the book value of total assets is the maximum value is 25.4942 and 30.9122 as well as the mean is 28.0379 while the standard deviation of 1.3145745 .

Analysis of Structural Equation Model (SEM) was performed to test the suitability and statistical tests. The results of data processing for a full analysis of SEM models shown in the figure below: 


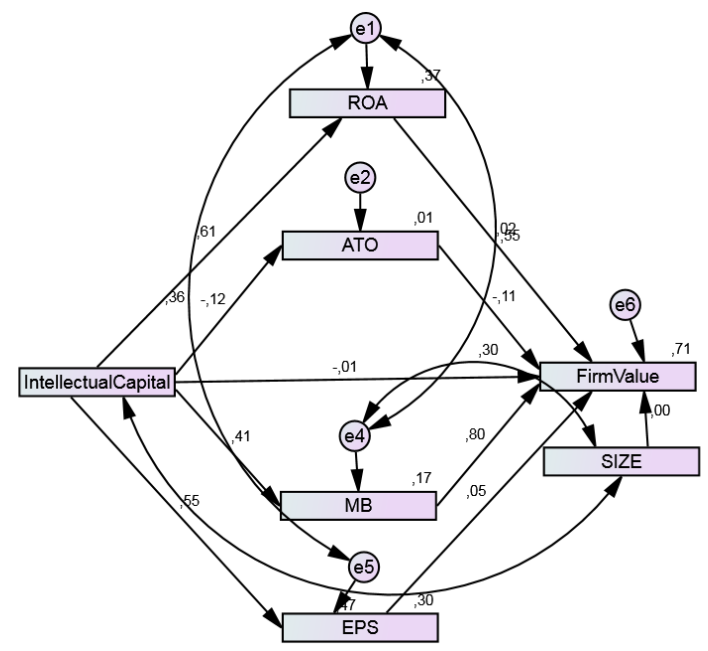

Figure 2. The Results of Structural Equation Model (SEM) Testing

Based on Figure 4.3 indicates that our model has the goodness of fit is good, so that the model deserves. Testing the suitability of the model is summarized in Table 4.12. Based on calculations by the AMOS program for SEM models in this study, resulting indexes of goodness of fit as follows:

\begin{tabular}{|c|c|c|c|}
\hline Goodness of Fit Index & Cut-off Value & The Results Of The Analysis & Evaluation Models \\
\hline Chi-Square & $<24,32$ & 8,570 & Good \\
\hline Probability & $\geq 0,05$ & 0,285 & Good \\
\hline RMSEA & $\leq 0,08$ & 0,045 & Good \\
\hline GFI & $\geq 0,09$ & 0,979 & Good \\
\hline AGFI & $\geq 0,09$ & 0,915 & Good \\
\hline CMIN/DF & $\leq 2,00$ & 1,224 & Good \\
\hline TLI & $\geq 0,95$ & 0,987 & Good \\
\hline CFI & $\geq 0,95$ & 0,996 & Good \\
\hline
\end{tabular}

Table 2. Goodness of Fit Criteria Source: Secondary data were processed

Parameter estimation for testing VAIC (Intellectual Capital) on ROA (Return on Assets) shows the CR value at 8.065 and the probability is 0,001 . Both values are obtained qualify for acceptance $\mathrm{H}_{1}$. CR value is greater than 1.96 and the probability is less than 0.05 . It can be concluded Intellectual Capital has significant effect on return on assets (ROA). It supports research conducted by Chen et al. (2005) and Ulum (2008) which shows that intellectual capital has significant effect on the profitability of the company. ROA illustrates the company's ability to generate profits by using the available resources. Use of company resources efficiently so as to minimize the cost will increase its profit. It also indicates that if a company has a high level of intellectual capital it will have an impact on the profitability rate.

Parameter estimation for testing VAIC (Intellectual Capital) on ATO (Asset Turnover) shows the CR value at -1.272 and probability equal to 0.203 . Both values are obtained do not qualify for acceptance $\mathrm{H}_{2}$ because the smaller CR value of 1.96 and a probability of greater than 0.05 . It can be concluded Intellectual Capital is no significantly effecting on the ATO (Asset Turnover). This is contrary to the research conducted by Chen et al. (2005) and Ulum (2008) which prove that the intellectual capital has significant effect on asset turnover. This might be due to the sample used in this research is a manufacturing company which is to boost the productivity not only human resources needed but also the magnitude of the production capacity of the machine, plant owned and many more.

Parameter estimation for testing VAIC (Intellectual Capital) on MB (Market to Book Value) shows the CR value at 4.719 and the probability is 0.001 . Both values are obtained qualify for acceptance $\mathrm{H}_{3}, \mathrm{CR}$ value is more than 1.96 and the probability is less than 0.05. It can be concluded Intellectual Capital has affect the MB (Market to Book Value). It supports research conducted by Chen et al. (2005) which shows that intellectual capital has significant effect on the market to book ratio (MB). MB reflected the investors about the company's management, liquidity, and future prospects of the company. Therefore, the high level of intellectual capital of the company will increase the level of investor confidence in the company's management, liquidity, and future prospects of the company.

Parameter estimation for testing VAIC (Intellectual Capital) on EPS (Earnings per Share) shows the CR value at 6.826 and the probability is 0.001 . Both values are obtained qualify for acceptance $\mathrm{H}_{4} \mathrm{CR}$ value is more 
than 1.96 and the probability is less than 0.05 . It can be concluded Intellectual Capital has significant effect on EPS (Earning per Share). It supports research conducted by Tan et.al (2007), which states that the intellectual capital significantly affects EPS in manufacturing companies. EPS provides a measure of profitability that combines the decisions from operating, investing and financing. The role of intellectual capital will certainly affect the decision from operating, investing and financing of the company.

Parameter estimation for testing VAIC (Intellectual Capital) on q (Firm Value) shows the CR value at -0.075 and with probability equal to 0.940 . Both values are obtained do not qualify for acceptance $\mathrm{H}_{5}$ because CR value less than 1.96 and a probability more than 0.05 . It can be concluded Intellectual Capital is not significantly effecting on the Firm Value. This is contrary to the research conducted by Arifin et al. (2012) which prove that intellectual capital has positive effect on firm value. This may occur because the creation of a value on the company needed more than just intellectual capital.

Parameter estimation for testing ROA (Return on Assets) on q (Firm Value) shows the CR value at 0.267 and the probability at 0.789 . Both values are obtained do not qualify for acceptance $\mathrm{H}_{6}$ because CR value less than 1.96 and a probability more than 0.05 . It can be concluded Return on Assets is not significantly effects on Firm Value. This indicates that the higher level of profitability of the company does not mean that the value of the company will increase. This is contrary to the research conducted by Arifin et al. (2012) which proved that the return on assets has positive effect on firm value.

Parameter estimation for testing ATO (Asset Turnover) on q (Firm Value) shows the CR value at -2.144 and the probability at 0.032 . Both values are obtained do not qualify for acceptance $\mathrm{H}_{7}$ because although the probability is less than 0.05 but CR value less than 1.96. It can be concluded Asset Turnover is no significantly effecting on Firm Value. This indicates that the high level of productivity does not guarantee the value of the company increased because high productivity without quality control of produced goods would create a bad image of the company.

Parameter estimation for testing MB (Market to Book Value) on q (Firm Value) shows the CR value at 10.258 and the probability at 0.001 . Both values are obtained qualify for acceptance $\mathrm{H}_{8}$ because CR value more than 1.96 and the probability is less than 0.05. It can be concluded that the Market to Book Value has significant effect on Firm Value. This is because the value of the company's market performance can be reflected using the company's stock price. Ratio of market to book value (MB) is to divide the total market capitalization (share price multiplied by the number of outstanding common shares) with a book value of equity owned companies.

Parameter estimation for testing EPS (Earnings per Share) on q (Firm Value) shows the CR value at 0.780 and the probability at 0.435 . Both values are obtained do not qualify for acceptance $\mathrm{H}_{9}$ because CR value less than 1.96 and a probability more than 0.05 . Thus we can conclude that the Asset Turnover is not significantly effecting on Firm Value. This is because EPS information shows the amount of a company's net profit company that is ready to be distributed to all shareholders of the company.

Analysis of the effect intended to see how strong the effect of a variable with other variables either directly, or indirectly. Interpretation of these results will have important meaning to get a clear election strategy. In accordance with the theoretical study and the results of the previous hypothesis testing, intellectual capital will have a direct or indirect effect on firm value. Indirect effect of these variables is to first pass through company's performance, which in turn affect the Firm Value

From these results it turns direct effect of Intellectual Capital to Retun on assets at 0.610, Earning Per Share at 0.545 and Market to Book Value at 0.410. Intellectual Capital turns out to have a negative influence on the Asset Turnover and Value Company. Then highest direct effect occurs in the firm value to Market to Book Value at 0.797 . These results support the regression weights analysis was conducted to the hypothesis test.

Although on results of direct analysis, intellectual capital has a negative effect on the Firm Value but based on the results of the analysis of the indirect effect was found that there was a positive effect of Intellectual Capital on Firm Value at 0,385. This means that, intellectual capital will affect well on Firm Value with the support of good firm performance. High intellectual capital without showing good company performance will not affect the value of the company. Then, good corporate performance will not necessarily increase the value of the company, proved to be only market to book value that significantly affects the firm value.

Total effect analysis is the sum of direct effects and indirect effects that have been done. From the analysis of the total effect turned out that Intellectual Capital effect on Return on Assets, Earnings per Share, Market to Book Value and the Firm Value at $0.610 ; 0.545 ; 0.410$ and 0.380 . Intellectual Capital has a negative influence on the Asset Turnover at -0.120 . The results show that the biggest total effect is in relation of Market to Book Value and Firm Value at 0.797 and the smallest in relation of Intellectual Capital and Asset Turnover at -0120.

\section{Conclusion}

The role of Intellectual capital to improve firm performance and firm value is no doubt. Although direct, intellectual capital has negative impact on firm value, but if it is supported by the firm performance will generate positive results. So, intellectual will affect the firm performance and then will affect firm value.

Based on the analysis has been done in this study conclude that: 
1. Intellectual capital has significant effect on profitability, market valuation and growth.

2. Intellectual capital has no significant effect on productivity and firm value.

3. Market valuation has significant effect on the firm value.

4. Profitability, productivity and growth are not significantly effecting on firm value.

5. Firm performance as intervening variables could affect the relationship between intellectual capital and firm value. This can be seen in the analysis of the effect of direct and indirect.

\section{References}

- Anatan, L., 2005. "E-business Adoption in Small and Medium Enterprises: Opportunities and Challenges in Service-Driven Economy”. 2nd UBAYA Annual Symposium on Management, March 16th-17th, 123-33.

- Arifin et al. 2014. "The Influence of Corporate Governance, Intellectual Capital on Financial Performance and Firm Value of Bank Sub-Sector Companies Listed at Indonesia Stock Exchange in Period 2008-2012". European Journal of Business and Management. Vol. 6 No. 26. pp. 159-167.

- Astuti, Partiwi Dwi. 2005. "Hubungan Intellectual Capital dan Business Performance.” Jurnal MAKSI. Vol 5, 34-58.

- Bontis, N., W.C.C. Keow, S. Richardson. 2000. "Intellectual capital and business performance in Malaysian industries". Journal of Intellectual Capital. Vol. 1 No. 1. pp. 85-100.

- $\quad$ Bornemann, M. and Leitner, K.H. 2002. "Measuring and reporting intellectual capital: the case of a research technology organisation”, Singapore Management Review, Vol. 24 No. 3, pp. 7-19.

- Canibano, L., Garcia-Ayuso, M. and Sanchez, P. 2000. “Accounting for intangibles: a literature review”, Journal of Accounting Literature, Vol. 19, pp. 102-30.

- Chen et al. 2005. "An empirical investigation of the relationship between intellectual capital and firm's market value and financial performance”. Journal of Intellectual Capital, Vol. 6, Issue 2.

- Chen, J., Zhu, Z. and Xie, H.Y. 2004. "Measuring intellectual capital: a new model and empirical study". Journal of Intellectual Capital, Vol. 5 No. 1, pp. 195-212.

- $\quad$ Euis dan Taswan. 2002. "Pengaruh Kebijakan Hutang Terhadap Nilai Perusahaan Serta Beberapa Faktor Yang Mempengaruhinya”. Jurnal Bisnis dan Ekonomi.

- $\quad$ Ferdinand, Augusty. 2006. Metode Penelitian Manajemen. Edisi 2. BP Universitas Diponegoro. Semarang.

- Guthrie, J., Petty, R., Yongvanich, K. and Ricceri, F. 2004. "Using content analysis as a research method to inquire into intellectual capital reporting”. Journal of Intellectual Capital, Vol. 5 No. 2, pp. 282-93.

- Hair, Joseph, F. Anderson, Rolph E. Anderson, R.L. Tatham and W.C. Black. 1998. Multivariate Data Analysis. $5^{\text {th }}$ edition. Upper Saddle River. Prentice-Hal International, Inc. New Jersey.

- Hansen, Don R., and Maryanne M. Mowen. 2005. Management Accounting, 7th Edition. Singapore: SouthWestern, a Division of Thomson Learning Inc.

- Harrison, S., and Sullivan, P.H. 2000. "Profitting form intellectual capital; Learning from leading companies". Journal of Intellectual Capital Vol. 1 No. 1. pp. 33-46.

- Husnan, S., 2000. Manajemen Keuangan-Teori dan Penerapan (Keputusan Jangka Panjeng, BPFE Yogyakarta, pp.7.

- Indriantoro dan Supomo. 2002. Metodologi Penelitian Bisnis. Yogyakarta: BPFE UGM.

- Indriantoro, N., dan B. Supomo. 1999. Metodologi Penelitian Bisnis (Untuk Akuntansi \& Manajemen), edisi pertama, Yogyakarta : BPFE

- Iswati, Sri. 2007. "Memprediksi Kinerja Keuangan dengan Modal Intelektual Pada Perusahaan Perbankan Terbuka di Bursa Efek Jakarta”. Jurnal Ekuitas, Maret, Vol. 11, No. 2, halaman 159-174.

- Iswatia, S. dan Anshoria M. 2007. "The Influence of Intellectual Capital to Financial Performance at Insurance Companies in Jakarta Stock Exchange (JSE)". Proceedings of the 13th Asia Pacific Management Conference, Melbourne, Australia, pp.1393-1399.

- Joia, L.A. 2000. "Measuring intangible corporate assets-linking business strategy with intellectual capital". Journal of Intellectual Capital, Vol.1, No. 1, pp. 68-84

- $\quad$ Kaplan, R.S. dan Northon, D.P. 2004. Strategy maps: Converting intangible assets into tangible outcomes. Boston, MA: Harvard Business School Press.

- Keown. 2004. Manajemen Keuangan : Prinsip-Prinsip dan Aplikasi. Edisi 9, Indeks. Jakarta.

- Kristandl, G. and Bontis, N. 2007. "The impact of voluntary disclosure on cost of equity capital estimates in a temporal setting". Journal of Intellectual Capital, Vol. 8 No. 4, pp. 577-94. 
- Lev, B., Thomas, J. and Nissim, D. 2007. On the informational usefulness of R\&D capitalization and amortization. working paper, available at: www.ssrn.com.

- Maknun, L. 2010. Analisis Pengaruh Frekuensi Perdagangan, Volume Perdagangan, Kapitalisasi Pasar, Dan Trading Day Terhadap Return Saham Pada Perusahaan Manufaktur Yang Terdaftar Di BEI Periode Tahun 2006-2008. Universitas Diponegoro.

- O'Donnell, D. and O'Regan, P. 2000. “The structural dimensions of intellectual capital: emerging challenges for management and accounting”. Southern African Business Review: Special Issue on Information Technology, 4, 2, 14-20.

- OECD. 2008. Intellectual Assets and Value Creation - Synthesis Report, OECD, Paris.

- $\quad$ Petty, R. and J. Guthrie. .2000. "Intellectual capital literature review: measurement, reporting and management". Journal of Intellectual Capital, Vol. 1 No. 2/3, pp. 155-76.

- $\quad$ Pulic, A. 1998. Measuring the performance of intellectual potential in knowledge economy. available at: www.vaic-on.net.

- Pulic, A. 2004. "Intellectual capital-does it create or destroy value?" Measuring Business Excellence, Vol. 8 No. 1, pp. 62-8.

- Riahi-Belkaoui, A. 2003. "Intellectual capital and firm performance of US multinational firms", Journal of Intellectual Capital, Vol. 4 No. 2, pp. 215-26.

- $\quad$ Roos, G., Kristine Jacobsen, and Anna Rylander, 2000. “Towards Improved Information Disclosure on Intellectual Capital”. International Journal of Technology Management, 20 (5/6/7/8), London, United Kingdom.

- Salvatore, Dominick. 2005. Ekonomi Manajerial dalam Perekonomian Global. Salemba Empat: Jakarta.

- Sari, Desfita; Mariso, Muchtar; dan Sjahruddin. 2012. "Pengaruh Assets turnover dan Profit Margin Terhadap Return On Assets Pada Perusahaan Farmasi yang Listing di Bursa Efek Indonesia Tahun 20062010". Repository University of Riau (http://repository.unri.ac.id:80/handle/123456789/1003). Downloaded at December $28^{\text {th }} 2014$

- Sawarjuwono, T. dan Kadir A. 2003. Intellectual Capital: Perlakuan, Pengukuran dan Pelaporan (Sebuah Library Research). Jurnal Akuntansi \& Keuangan Vol. 5, No. 1, Mei 2003: 35 - 57.

- Sawarjuwono, Tjiptohadi dan Agustine Prihatin Kadir. 2003. "Intellectual Capital: Perlakuan, Pengukuran dan Pelaporan (Sebuah Library Research).” Jurnal Akuntansi dan Keuangan. Vol 5, No. 1, 31-51.

- Solikhah, B. 2010. Pengaruh Intellectual Capital terhadap Kinerja Keuangan, Pertumbuhan dan Nilai Pasar pada Perusahaan yang Tercatat di Bursa Efek Indonesia.Universitas Diponegoro.

- Stewart, Thomas A. 2002. Modal Intelektual: Kekayaan Baru Organisasi. Jakarta: PT Elex Media komputindo.

- $\quad$ Sugeng, Imam. 2000. "Mengukur dan Mengelola Intellectual Capital.” Jurnal Ekonomi dan Bisnis Indonesia. Vol 15, No.2, 247-256.

- Sukamulja, Sukmawati. 2004. "Good corporate governance di sektor keuangan. Dampak good corporate governance terhadap kinerja perusahaan”. Benefit, Vol.8, No.1, h.1-25.

- Sveiby 2001. “A Knowledge-based Theory of the Firm to guide Strategy Formulation”. Journal of Intellectual Capital. Vol. 2, No. 4. Pp. 344-358.

- Syamsuddin, Lukman. 2009. Manajemen Keuangan Perusahaan. Edisi Baru. Jakarta: Raja Grafindo Persada.

- $\quad$ Tseng, C.Y. and Goo, Y.J. J. 2005. "Intellectual capital and corporate value in an emerging economy: empirical study of Taiwanese manufacturers". R\&D Management. Vol. 35 No. 2. pp. 187-201.

- Ulum, I. 2007. Pengaruh Intellectual Capital Terhadap Kinerja Keuangan Perusahaan Perbankan Di Indonesia. Tesis Universitas Diponegoro, Semarang.

- Ulum, I; I. Gozhali; dan A. Chariri. 2008. Intellectual Capital dan Kinerja Keuangan Perusahaan; Suatu Analisis dengan Pendekatan Partial Least Squares. Simposium Nasional Akuntansi XI. Pontianak: 23-24 Juli.

- Wahdikorin, A. 2010. Pengaruh Modal Intelektual Terhadap Kinerja Keuangan Perusahaan Perbankan Yang Terdaftar Di Bursa Efek Indonesia (BEI) Tahun 2007-2009. Universitas Diponegoro.

- Ze'ghal, D. 2000. "New assets for the new economy”. FMI Journal, Vol. 11 No. 2, pp. 35-40 (Financial Management Institute of Canada).

- Zeghal, M. dan Maaloul, A. 2010. “Analyzing value added as an indicator of intellectual capital and its consequences on company performance”. Journal of Intellectual Capital, Vol. 11, No. 1, pp. 39-60. 


\title{
Economic Growth: Types and Factors
}

\author{
Mr. Aleksey Poliduts (Chelyabinsk State University, Russia) \\ Assoc. Prof. Dr. Yuner Kapkaev (Chelyabinsk State University, Russia)
}

\begin{abstract}
The article deals with the content of economic growth as an economic category through determining its type, indicators and factors. It proposed grading factors based on the various existing theoretical approaches. With all the variety of growth factors and options for sorting the basic separation occurs in the direct and indirect factors, internal and external, intensive and extensive, the factors of supply, demand and distribution, controlled and uncontrolled factors, factors of economic and non-economic, interchangeable and supplemented growth factors.

The author points out the main trends and features of economic growth, determining the pace and quality of economic growth in Russia at the present stage of development. The methodological basis of the study is the dialectical method of knowledge, which allows to study economic phenomena and processes in their constant interaction and development. Sources of data in the study is an analytical and statistical materials the IMF, the World Bank and the Federal State Statistics Service.

Formulate a set of restrictions for sustainable economic growth in Russia, due to the influence of various kinds of factors. As highlighted in its basic elements: the raw structure of Russian exports, weak competitiveness of downstream industries, the economic sanctions imposed in 2014 by the Western countries, reducing the purchasing power of the ruble against the reserve currencies. The results may help to improve the efficiency of stimulating the development and maintenance of high economic growth in the implementation of measures of state regulation both in Russia and in other countries.
\end{abstract}

\section{Introduction}

The conception of modern economic growth has been introduced into scientific circulation by the laureate of the Nobel Prize, American scientist Simon Kuznets, who noted the occurrence of this process in the end of 18th century. However, there is another point of view, and it is supported by the majority of modern researchers. They are sure that it started in 20 s of the 19 th century. From this position, obviously, we can consider economic growth originated in Europe as a response to the devastating Napoleonic Wars.

Modern economic growth is an incomplete process in its continuation which often changes the dominant trends. The current trends reflect such fundamental civilization changes that they, according to the opinion of scientists, can lead to the emergence of a fundamentally new society.

Economic growth is characterized by direction, social necessity, and also by government regulation.

Scientific sources offer different definitions of "economic growth" category, a lot of them claim to be a complete reflection of its essence. It is necessary to show two main points: firstly, such conceptions as "economic growth" and "economic development" should be distinguished, and secondly, in a variety of definitions of growth, as a rule, one or another essential characteristic of that category is reflected.

According to J. Tinbergen, economic development and economic growth "are compatible with each other, but not identical" (Tinbergen, 1980). An important feature of the development is in improving the welfare of all groups of the population, so that its financial security increases. But economic growth does not mean the equal financial security improvement of all groups of population.

The economic development of society is a controversial and difficult in measurement process, also it is characterized by irregular flow, structural shifts in economy, improvement of conditions and increase of life quality of the population. Differentiation between the concepts of "economic growth" and "economic development" was introduced in economics by the American economist Joseph Schumpeter: "You can place in a row as many mail coaches as you wish, but you will not receive the railway by this" (Schumpeter, 2001). The reason is that the essence of economic growth is in increase production and consumption of the same goods and services, in this example, mail coaches. Economic development is, mainly, in creating something new, unknown previously, in our case, the railways. Economic development involves both the emergence of some new (or in a new quality) benefit and implementation of new production methods, development of new markets, receiving new sources of raw materials, appropriate restructuring and so on.

\section{Methodology and Results}

Different interpretations of the "economic growth" concept provide both quantitative and qualitative characteristics. Quantitative characteristic shows us changes in the amount of produced goods and services, reflects the dynamics of these changes; qualitative characteristic points to the possibilities of economic system in meeting the new growing needs of society. Due to the fact that it is non-static, moving and changing process, it has always a numerical index for a certain date. Economic growth is characterized by the dynamics of such 
absolute macroeconomic indicators as gross domestic product (GDP), gross national product (GNP), national income, and others. The relative indicators of economic growth which characterize it from the quantitative side are the value of GDP per capita, disposable income of the population per capita, and also attributable to per capita indicators of consumption, savings and investments. The rates of industrial production growth in whole and for the main sectors and types of products, indicators of economic efficiency, for example, labor productivity, are also being considered.

Economic growth is reflected by the positive dynamics of the considered indicators. Considering recent trends, the world practice offers to view the rates of $4 \%$ per year as "favorable" economic growth. The rates of growth more than 4\%, which India and China display, for example, are considered to be forced, and they are connected with the activities for the withdrawal of the country's economy from the crisis or emergency escalating of economic potential. For example, GDP dynamics of Russia this year went into the negative plane and by the end of 2015 it is projected to decline by $2.8 \%$. According to the estimation of the Ministry of Economic Development, Russian economy can return to positive growth of $2.3 \%$ already in 2016 .

The qualitative aspect of economic growth is determined by living standards and quality of life indicators. The living standard is estimated by consumer basket, cost of living, GDP structure by use; level of services development (the number of doctors per 10 thousand people, the number of hospital beds per 1 thousand people, etc.); state of the labor forces (average life expectancy, level of education, share of education expenditure in GDP, etc.), and others. The quality of life is reflected by the content of labor and leisure activities, level of labor and life comfort, environment, functioning of social institutions, etc.

The most completely features of the process of economic growth are expressed in its type. Several key points of view on the types of economic growth are distinguished in economic literature. The first point of view gives us an idea of the types of economic growth from the perspective of quantitative or qualitative changes in the factors of production, the so-called factorial approach. There are two types of economic growth allocated in economic theory - intensive and extensive, in addition, as a part of an intensive, there is an innovative type of economic growth. Extensive type of growth is characterized by quantitative increase of use of one or more factors of production. Accordingly, there are capital, labor and resource subtypes of extensive economic growth. When there is a qualitative improvement in the factors of production, such as use of ultra-precise modern equipment in goods production, cost-effective non-waste technologies and more skilled workforce, we can talk about the intensive, or qualitative, type of economic growth. Here it must be said that these two types of growth are interrelated, they should not be contraposed to each other.

The second point of view is determined by the needs and possibilities of the society, and also by the rates of population growth. The essence of this approach is contained in the works of British scientist and economist Roy Harrod, who introduced the concept of natural, guaranteed and actual types of economic growth. Natural economic growth is caused primarily by population growth, increase in the needs of this population, and also by desire of every individual to satisfy their material and spiritual needs as fully as possible, while using all potential opportunities for economic growth. R. Harrod defines guaranteed economic growth as some predicted line of development, «...on which the entrepreneurs are disposed and are satisfied with what they are doing. Actual growth is the real level of economic growth as a result of the combined action of natural and guaranteed economic growth» (Harrod, 1959).

The third point of view considers the economic growth from the perspective that it is determined by productive forces, equipment and production technologies. In this context, economists distinguish pre-industrial (traditional society stage), industrial and post-industrial types of economic growth. Pre-industrial type of growth takes place in those national economies where the main industry is agriculture and its part in GDP exceeds $50 \%$. In developed capitalist countries pre-industrial stage of agricultural development was finished in the 19th century, while some of the economically backward countries are being in it today. Pre-industrial type of economic growth is characterized, as a rule, by very low rates of economic growth. Industrial type of growth is characterized by overturn in the material basis of production, as a result the industry follows the agriculture and begins to play a decisive role across the national economy. Historically, industrial growth in modern developed countries has started at the beginning of 19th century and it is still going on. It brought both significant quantitative and qualitative changes in the national economies of these countries. As none of the economies at the present stage of development yet belong to the post-industrial type of economic growth and there are only preconditions for postindustrial economic society, scientists such as E. Pestel, suggest that the central place in the economy will again take the man and his life quality, but at a higher level compared to traditional society. «High level of industry will provide also a high level of social welfare in whole, new needs and requirements will be met relatively quickly. Dangerous technologies will be curtailed, and the environment will be maintained in proper condition» (Pestel, 1988).

By the level of economic criminalization there are distinguished legal and shadow types of economic growth. Both of them are inherent to immature economic systems, and they usually exist in them in parallel. Shadow growth is the result of functioning of the so-called shadow economy segment, in which management, business and resources use acquire a distorted form and develop outside the legal field. According to various estimates, 
the volume of the shadow segment in Russian economy varies from 20 to 50\% of GDP. The Security Council's report says that the informal segment of national economy involves about 10 million people, and the largest part of its turnover is generated by service sector. For comparison, the same indicator in Japanese economy is only $4.5 \%$ of GDP (Savchenko, 2005).

From the position of national economic interaction with the world economy there are distinguished importsubstitution and export-oriented types of economic growth. These types of growth show how differently external factors influence on the national economy and determine the level of that influence. However, they are purely theoretical because they do not occur in pure form. As a rule, while one determines the type of growth in a particular country, he can observe the features inherent to several types of economic growth.

Identification of factors takes a key position in the process of economic growth research. Factors of economic growth are the foundation of the growth process, which determines the level and dynamics of change, directly affects the magnitude of increase in real output, increases its efficiency, causes different types of growth. Economic theory defines the factors of economic growth as the processes and facts that determine the ability to increase real output, thus improve the efficiency and quality of growth.

It is obvious that the main drivers of economic growth for both developed and developing countries are the same, which are labor and reproductive factors. These factors have predominantly reproductive nature, and they are capital, territory, labor, scientific and technological progress, innovation and productivity, efficiency of productive unit, and so on. The factors both can directly and indirectly, positively and negatively effect on the rates and quality of growth. There is an important clarification: as a rule, economy in a given time and place is influenced not by all known and existing growth factors, but only by their definite set. Therefore, we analyze the sampling from the main factors that largely determine economic growth.

Economic literature mostly offers us the following gradation of growth factors: direct and indirect, extensive and intensive; factors of supply, demand and distribution; controllable and uncontrollable; substituted and complemented; economic and non-economic. Such a variety of factor sorting can be attributed to the difference in views of researchers in relation to the problems of economic growth.

For example, V. D. Kamaev has identified the following groups of growth factors: general, or permanent, and special, or momentary, and also controllable and uncontrollable. The degree of controllability by factors of economic growth in short and long terms shows the real capacity of the economy to achieve adjusted growth rates. For example, such factors as demographic situation, internal migration, energy intensity of production, social differentiation and some others due to objective reasons possess limited controllability in short and medium terms. Controllable factors which, if necessary, are relatively easy to control, include such factors as inflation, natural monopolies rates, level of taxation, government costs, fixed capital investments, money supply (Kamaev, 2001).

American scientists K. R. McConnell and S. L. Brue offered to distinguish the factors of supply, demand and use, or distribution, by functional features. Supply factors are quantity and quality of natural and human resources, fixed capital, level of scientific and technological progress and technologies, level of prices of productive resources, credits availability and so on. Demand factors are consumer expenses, investment and state costs, increased export, etc. Factors of distribution can include the order of income distribution between business entities, distribution of productive resources between industries, businesses and regions.

Roy Harrod distinguished from the variety of factors international, state and industry factors; scientific, technical and resource factors; structural, organizational and administrative factors; extensive and intensive factors; material and non-material factors; economical, political, social factors; subjective and objective factors.

Some researchers segregate economic and non-economic factors of growth. Non-economic factors of economic growth include military-political, geographical, climatic, demographic, social, cultural and other conditions.

Robert J. Barro and J. Sala-i-Martin examined 62 factors of economic growth and segregated 25 of them increasingly affecting it. They are GDP of initial period, investment, share of raw materials in exports, share of extractive industry in GDP, openness of economy, distortion of the exchange rate, share of primary education, profitability of shadow economy segment, expected duration of life, confessional structure of population and others.

According to the IMF experts' analytical review there are such positively correlated with economic growth factors as share of investment in GDP, primary education coverage, health indicators, openness of the global economy, share of non-primary goods in export.

According to position of the Russian Federation's Government, economic growth is one of the main strategic purposes of the national economy. It is reflected in the "Main activities of the Government of the Russian Federation for the Period up to 2018", in the Decrees of the President of the Russian Federation from May 7 , 2012 No 596 - 606, in the Concept of Long-term Socio-Economic Development of the Russian Federation for the Period up to 2020, in the Annual Presidential Addresses. These documents declare the following long-term 
priority of modern Russian society development - the creation of a socially-oriented innovative type system by achieving the sustained economic growth in the long term as the strategic purpose.

The previous six-year period can be characterized by global economic and financial crisis of 2008-2009 and by the subsequent restoration. Due to the high dependence on the sector of energy resources, the accumulated imbalances and disparities, the economy of Russia was exposed to the crisis factors more than the economies of other countries. In 2014, economic growth has slowed down, GDP growth, according to the Federal State Statistics Service, was only $0.6 \%$, inflation dynamics and the growth of the budget deficit sharply accelerated. It was caused by growth-constraining factors.

Firstly a serious decline in prices for traditional resource commodities should be mentioned. Thus, prices for industrial metals began active reduction in 2011 - 2012, natural gas price - in 2012 - 2013, and oil prices - in the second half of 2014. According to experts, these changes on the resource commodities market are long-term, and reduction in the price level leads to attenuation of Russia's payments balance and reduction of budget revenue.

The second growth-constraining factor is geopolitical escalation, it increased economic and political uncertainty and closed debt financing in foreign markets and modern technology inflow for many national companies.

The third factor is reduction of the working-age population in spite of the general stabilization of the demographic situation. The reason is in birth reduction in the 90 -ies of the last century. Annually the workingage population is reduced by approximately 1 million people, and this fact seriously restricts potential growth rates of the economy and increases the burden on the pension system.

In addition to these factors, there are some accumulated structural problems in economy like the imbalances of economic development (reduction of investment share in GDP, growth of economic dependence from instable oil and gas income, decline of quality and quantity indicators of the budgetary system costs), the high share of state presence in economy with low efficiency of its participation in it, the necessity of improving the efficiency of state costs, the gap from the world rates of technological development. It is necessary to form a new technological base of long-term growth, increase the costs in such high-tech areas as nanotechnology and information technology, pharmaceutics and biotechnology, microelectronics, engineering systems, nanophotonics, innovative technology in education and health. At the state level it is also important to help in increase and diversification of export, to reduce the share of consumer goods and services in total import, to evolve competition in domestic markets, to improve investment and business attractiveness of the Russian economy. As the main reason why investors and investment funds aimed at implementation of long-term projects restrict their activity, experts and businessmen designate political risks which, in their opinion, significantly increased in recent years in Russia. The results of opinion poll of 50 top executives of large foreign companies and funds point to the fact that corruption, rule of law and respect for property rights are still ignored in Russia.

Formation of a new growth model is also based on the need for "bottlenecks relieve", we should develop transport and energy infrastructure using pension funds and other extra-budgetary sources of long-term investment resources, create conditions and attract private investment to development projects of transport networks and energy, housing and engineering infrastructure.

\section{Conclusion}

Today the problems of sustainable economic growth achievement are important for all countries of the world, either developing or developed. This is largely due to population growth and resource exhaustion, economic shocks. Appreciation of resources, in turn, leads to decrease in production profitability. On the other hand, industrialization, growth of industrial production and technological progress leading to economic growth negatively impact the environment, pollute air, soil and water, that is harmful to population health.

The growth in GDP and national wealth does not imply equitable distribution of wealth among the population, because many factors affecting economic growth, such as the means of production and capital, are privately owned. Existing high income differentiation of society does not solve the problem of poverty. In this context, the aim of society is not only economic growth, its aim is sustainable economic development, which increases the level and quality of life, reduces the share of food expenses and income inequality in society.

\section{References}

- Barhatov, Kapkaev, Pletnev, 2004. The Development and Economic Growth in the Region. The South Urals State University's Publishing House, Chelyabinsk.

- Barhatov, Zhuravleva, Gorshkov, 2007. The Economic Theory: textbook. Finance and Statistics, Moscow.

- Barro, Sala-i-Martin, 2014. The Economic Growth. BINOM. The Knowledge Laboratory, Moscow.

- Bethell, 2008. The Property and Prosperity. IRISEN, Moscow. 
- $\quad$ Blaug, 2009. «Kuznets, Simon. Great Economists since Keynes: An introduction to the lifes \& works of one hundred great economists of the past», Library of "Economic School", 42, p. 131-134.

- Denison, 1975. The Evaluation of Sources of Economic Growth as the Basis of Long-time Forecasts, in the book Long-time planning and forecasting. Progress, Moscow.

- Harrod, 1959. Towards a Dynamic Economics. Some Recent Developments of Economic Theory and Their Application to Policy. Foreign Literature Publishing House, Moscow.

- Kamaev, 2001. The Economic Theory. VLADOS, Moscow.

- Keynes, 2007. The General Theory of Employment, Interest and Money. Selected. Eksmo, Moscow.

- Kuznetsova, 2001. The Economic Growth: History and Modernity: Textbook. University Book, Moscow.

- Lucas, 2013. Lectures on Economic Growth. Publishing House of the Gaidar Institute, Moscow.

- Mau, 2003. «The Economic Growth and Post-industrial Challenges», Problems of the Theory and Practice of Forecasting, 1, p. 32.

- McConnell, Brue, 1997. The Economics: Principles, Problems and Policies. Volume 1. Moscow.

- Pestel, 1988. Beyond the Limits to Growth. Progress, Moscow.

- Sachs, 1996. Macroeconomics. The Global Approach. Delo, Moscow.

- Savchenko, 2005. «The Exogenous Factors of Sustainable Economic Growth in Russia: the scientific research». The Kuban State University, p. 197.

- Schumpeter, 2001. The History of Economic Analysis: In 3 vol. Economic School, Moscow.

- Sharaev, 2006. The Theory of the Economic Growth. GU-VESh, Moscow.

- Spence, 2013. The Next Convergence: the Future of Economic Growth in a Multispeed World. Publishing House of the Gaidar Institute, Moscow.

- Solow, 2002. Growth Theory. Companion to Contemporary Economic Thought. The School of Economics, Moscow.

- Tarakanov, 2008. «The Factors of Economic Growth Accelerating: a Comparative Analysis: the scientific research». The Institute of World Economy and International Relations RAS, p. 202.

- Tarasevich, Grebennikov, Leussky, 2006. Macroeconomics: A Textbook. High Education, Moscow.

- $\quad$ "The Main Activities of the Government of the Russian Federation for the Period till 2018" // the Text of a Legal Act

- Tinbergen, 1980. The Review of the International Order. Progress, Moscow.

- Uskova, Lukin, Vorontsova, Smirnova, 2013. The Problems of Economic Growth in the Territory. ISERT Russian Academy of Sciences, Vologda.

- Voronin, 2004. Russia: The Economic Growth. Financial Control, Moscow. 


\title{
Sustainable Development in Russia: Specific Features of Transition Procedure
}

\author{
Ph. D. Candidate Ekaterina Grigoreva (Kazan Federal University, Russia)
}

\begin{abstract}
Current issues on economic security, preventing new challenges and threats to its strength and stability along with sustainable development of the regions require scientific background and scientific justification. New conceptual approaches to the mechanisms and methods are being searched for the purpose of the Russian Federation, as well as its constituent entities', enterprises' and organizations', public and entrepreneurship activity spheres' economic interests protection, which is reflected in the strategy of socio-economic development of the Russian regions.

The article considers conceptual frameworks of sustainable ecological and economic development at a global level. It defines the concept of sustainable development in terms of economic science and the range of its problems. It also discusses debating points of experts and volunteer environmentalists concerning the transition procedure to sustainable development models in Russia.
\end{abstract}

\section{Introduction}

The laws of ecological and economic balance are realized within the concept of 'sustainable development', which received public recognition, particularly at an international level, at the beginning of the 1980s. The necessity and background to establishment of the 'sustainable development' concept date back to the beginning of the $\mathrm{XX}^{\text {th }}$ century. Notably, in 1907 Theodore Roosevelt in his message to the US Congress declared the following: "To waste, to destroy our natural resources, to skin and exhaust the land instead of using it so as to increase its usefulness, will result in undermining in the days of our children the very prosperity which we ought by right to hand down to them amplified and developed". This assumption has been justified nowadays, since humanity is facing two major global problems: economic decline and environmental crisis.

It is at the global level where in the early 1990s, environmental impact on economic development has been defined as the concept of 'sustainable development', which in turn was immediately recognized by major industrialized countries. The basic idea was outlined in the report of the secretary general of the UN Conference on Environment and Development, Maurice Strong (Brazil): "The concentration of population growth in developing countries and economic growth in the industrialized countries has deepened, creating imbalances which are unsustainable, in either environmental or economic terms. Sustainable development - development that does not destroy or undermine the ecological, economic or social basis on which continued development depends/- is the only viable pathway to a more secure and hopeful future for rich and poor alike" (Strong, 1992).

\section{Theoretical Background}

There are various usages of the term "sustainable development". However the very first implementation of the concept was registered in the "Reviewing the International Order (RIO)" report to the Club of Rome, prepared by a group of researchers under the supervision of J. Tinbergen. The scholars came to the conclusion that there was a great necessity in a new social development strategy foundation. That strategy had to be determined for the entire humanity and was necessarily bound to take into account all the significant social impacts (employment, environmental status, etc.) in the process of economic growth efficiency calculation.

The term 'sustainable development' is quite controversial. Moreover, even recent academic publications devoted to the issues of eco-economic balance do not have one universally recognized interpretation of this concept in terms of economic category. Some Russian scientists claim that the English word "sustainable» doesn't inevitably imply to something which is "steady" and can also be defined as - "long, continuous, longterm, supportive" (Ursul, 1995). Others believe that it would be better to translate the term as a "valid development, inexhaustible development or development that preserves the integrity" (Rosenberg, et al., 1995). Some researchers support the idea of referring to "sustainable development" as "sustained development" (Gorshkov, et al., 1992).

Defining the concept of 'sustainable development' in terms of categories in economic science, it should be noted that the process of scientific research in this field for Russian scholars was hampered over a long period of time due to the low level of the academic community awareness in the field of international experience on sustainable development conceptual foundations design as well as its basic principles realization. The greatest interest in this sense are such basic documents as the Declaration of Principles, developing and supplementing a similar document of the UN Conference in Stockholm (1972) and Nairobi (1982), global conventions and Agenda 21. 
Within the framework of economics the category of 'sustainable development' is primarily considered by us as a qualitatively new stage in the evolution of ecological and economic relations, reflected in new patterns of interaction between economic development and environmental status in the context of the economic and ecological crisis. We are emphasizing the fact that the major premise of a new stage emergence in the development of ecological and economic relations reasonably belongs to the processes associated with certain quantitative changes in the eco-economic system, the accumulation of which in modern times has resulted in serious qualitative changes.

One of the most common and generally accepted definition of 'sustainable development' is reflected in the report of the World Commission on Environment and Development ("Brundtland Commission", established with the participation of the United Nations): Our Common Future: "Sustainable development is development that meets the needs of the present without compromising the ability of future generations to meet their own needs. It contains within it two key concepts: the concept of 'needs', in particular the essential needs of the world's poor, to which overriding priority should be given; and the idea of limitations imposed by the state of technology and social organisation on the environment's ability to meet present and future needs" (Report of the WCED, 1987). Thus, sustainable development is associated with a self-sufficient, non-self-disruptive development. Therefore, we underline the fact that sustainable development of the country can be achieved only within the system ensuring satisfaction of the people's needs, retaining the same opportunities for future generations. This interpretation is general, declarative and therefore requires clarification and specification through apparatus criticus of economic theory.

The essence of the definitions and interpretations mentioned above reduces itself to the principle of natural resources as well as natural conditions of equitable distribution between the generations with the development focus on the population's welfare improvement rather than on consumption expansion.

\section{Results and Discussions}

Sustainable development in Russia within the existing economic, political and institutional frameworks presupposes its advancing motion along the set path. This type of strategic development will enable the achievement of objectively progressive social purposes system. From this, we may deduce that the change of emphasis in social development towards the natural along with the labour potential effective development and preservation plays a vital role, since any human being acts as a main consumer of public benefits, as well as a main participant of eco-economic system evolution. This development is principally aimed at preservation and improvement of a human being together with the qualitative parameters of his life, at creation of all the indispensable frameworks for his creativity and spirituality realization (Grigoreva, 2013).

The report of the United Nations Conference on Environment and Development in Rio de Janeiro, defines 'sustainable development' as a number of target areas including: the human right to a healthy and productive life in harmony with nature, protection of the environment as an integral element of the social development process, decrease of the disparities in standards of living and the needs satisfaction of the majority of people of the world (UN report on ED, 1992). Sustainable development in these documents, is considered in the perspective of anthropogenic approach, that is, the basic principles are the survival and the possibility of an extended development of civilization.

The decisive factor in the mankind development at this time is the biosphere frontiers, whereas the sustainable development of mankind, the world system and the countries worldwide is the development taking place in the conditions of a sustainable biosphere. This is a type of economic development that fully corresponds to the biota capabilities to protect the environment and preserve its enabling characteristics. From now on we assume that 'sustainable development' (Voznyak, 1995; Fedotov, 1995) is a deliberate anthropogenic shift in the natural environment and social position, aimed at assisting the society in the overcoming process of the limitations of its existence within the biosphere conditions.

As can be vivid from the definitions outlined above, sustainable development is presented from the point of biosphere-centered approach, which is focused on the environment and sustainability preservation as well as possibility of the biosphere evolution.

Orientation towards the noosphere approach lies at the basis of the sustainable development model transition concept. This approach is focused on the progress within society itself, particularly on economic relations, acceptable for the human being ecological niche preservation, and hence the conditions for the civilization development. Painstaking attention should be paid at the practical implementation of the 'sustainable development' concept.

Thereby, there are strong debates on the topic of 'sustainable development' among domestic scholars, practitioners, social activists as well as environmentalists (Tisyachnyuk, 1999). In particular, the author of the alternative "Concept of Sustainable Development in Russia", the leader of the Socio-Ecological Union, S. Zabelin, criticizes the provisions adopted within the framework of the UN Conference on Environment and Development in Rio de Janeiro. He denies the fact that the introduction of innovative legislation system together 
with innovative environmental policies will lead to the world depopulation as well as consumption standards reduction processes. We support the author's viewpoint on the country's resources policy: the land and natural resources cannot be privately owned, since they belong not only to the present but also to the future generations. Natural resources should be in public ownership, whereas resources management should be primarily carried out by the constituent entities of the Russian Federation.

New concept has been devised from the perspectives of ecocentrism. The author is certainly accurate in outlining the following propositions: economic policy should be developed with the purpose of benefits provision for all those who preserve the nature; tax policy should be flexible, take into account all the reserves available and consider the biosphere economic capacity and its ability to assimilate the pollution arising due to the resource withdrawal from the soil. However, there seems to be no compelling reason to argue that there's a great necessity in the world economy reorganization in terms of the economy development intensification at a local level, leaving only the information flow functioning at a global one. We should not detract from the advantages of international division of labor and the development of international relations in the various fields of the nation's social and economic life. Natural resources' and finished goods' international exchange should become a constant procedure which has to be mutually beneficial for both parties in the national economy specialization processes within the context of global economic integration.

The ecological system acts as a resource base for the efficient functioning of the economy. Wasteful attitude to the nature usually leads to the depletion of natural resources. It is the natural resources which perform constituent basis for the ecological and economic systems development. Another key thing to remember is that any developed economy lives not at the expense of the basic capital but at the expense of dividends from it. Thus, in this paper we put forward the claim that sustainable development involves a specific pattern of the economy management, which expends not the basic natural capital but the interest gained from it (Gubaidullina, 2000).

The concept of sustainable development implicates that one has to apply to the economic development criteria, rather than to the categories of economic growth, since the model of sustainable development implies to a new stage of ecological and economic interaction, which is characterized by an innovative approach to the ecological and economic problems solution.

The concept of 'sustainable development', based on the trends and patterns of ecological and economic balance, is intended to create necessary conditions for ensuring economic methods of environmental safety at the macro- and microeconomic levels.

The problems of sustainable development are analyzed and investigated by many scholars and prominent public organizations. To give an illustration of sustainable development strategy relevance, let's examine the following principles, determined by the Organisation for Economic Cooperation and Development (OECD):

- $\quad$ population growth rate control;

- technological and scientific development of all action programmes grouped under the title of "Green Accounting";

- efficient management of the resources and their value determination;

- environmental problems exacerbated by poverty-linked population pressure such as over-exploitation of natural resources, and inadequate technological capabilities;

- $\quad$ sustainable and equitable development of widespread participation in the productive and decision-making processes, in access to education, health and other public services and in access to the benefits of development;

- $\quad$ shift in operating mode as well as consumption patterns for preserving scarce reserves and equal access maintenance (OECD, 1990).

The concept of 'sustainable development' in Russia was officially declared in the Presidential Decree № 236, February, 4, 1994, "On State Strategy of the Russian Federation on environmental protection and sustainable development". It goes without saying that in terms of the Russian Federation geographical position and vast natural resources potential, the development of this concept seems to us particularly relevant.

\section{Conclusions}

A complex approach to the study of the concept of 'sustainable development' in Russia allowed us not only to analyze precisely the materials but also to reach specific conclusions. The macro aim of ecological and economic system sustainability should be focused on the stable and balanced economic development with a glance to the ecological restrictions of a given region by means of balanced interaction between various economic entities of ecological and economic relations. In contrast to the traditional approaches to the investigation of acute economic issues, the concept of 'sustainable development' should maintain direct relation of the economic growth objectives to the environmental status of a given region. This requires a certain shift in the key points of 
social-economic development: the emphasis should be put not only upon the quantitative criteria of a human well-being, but also upon the qualitative characteristics such as quality of life, life expectancy, and primarily prevention of the negative impact of environmental factors on the health of present and future generations as an essential factor in the labour force reproduction procedure under the conditions of economic and ecological crisis.

\section{References}

- "The problem of sustainable development in Russia in the light of V.I. Vernadskiy's scientific heritage", in Proceedings of an International symposium 1997, Moscow, 155p.

- Fedotov, 1995. "Earth, mankind, economics", Economist, 11, p. 43-56.

- Gorshkov, Kotlyakov, Losev, 1994. "Economic growth, environmental status, wealth and poverty", Izvestiya RAN: Seriya Geographicheskaya, 1, p.12.

- Grigoreva, 2013. "Conceptual framework of sustainable ecological and economic development", in Proceedings of International research-to-practice conference, 2013, p. 188.

- Gubaidullina, 2000. Ecological and economic system's sustainable development: issues of theory and methodology. KFU press, Kazan, p.96.

- Maurice Strong, 1992. Speech to UNEP-UK Committee. London.

- Organisation for Economic Cooperation and Development, 1990. The Economics of Sustainable Development. Paris, p. 7

- Rosenberg, Gelashvili, Krasnoschekov, 1996. "Tricky steps of transition to sustainable development", Vestnik RAN, 66 (5), p.436.

- Tisyachnyuk, 1999. "Sustainable development: Moscow NGO CEOs' viewpoint", Green World, 5, p.5.

- Ursul, 1995. "Noospheric strategy of the RF transition procedure to the sustained development model", Scientific and technical aspects of environmental protection: background information of VINITI, 10, p.4.

- Voznyak, 1995. "Social development and ecology: interdependence, antagonisms, crisises", Voprosy economiki, 2, p. 129-138.

- World Commission on Environment and Development, 1987. Our common future. Progress, Moscow, 1989, p.50. 


\title{
Efficient and Effective Public Spending for Sustainable Economic Growth
}

\author{
Ph. D. Candidate Asel Azhykulova (International Ataturk Alatoo University, Kyrgyzstan)
}

\begin{abstract}
Nowadays, governments are more careful with the use of resources and attempt to be efficient and effective to achieve sustainable economic development. This paper contrasts the efficiency and effectiveness of public spending of developed and developing countries in current conditions and their impact on economic growth.

The author analyses efficiency and effectiveness measures of public spending applied by prominent crosscountry empirical studies. The critical success factors for the effective performance of government through World Bank indicator of government effectiveness highlights the role of effective public budget policy. In addition, the Public Sector Performance Index and Public Sector Efficiency Index introduced by Vito Tanzi and other measures of Livio di Matteo, Konstantinos Angelopoulos are examined. Based on these approaches the author proposes several suggestions for the current condition of public budget policies of Central Asian countries and ways of improving the effectiveness and efficiency levels of their public sector.

The author argues that the assumption that developing countries are less efficient than developed countries are based on several efficiency variations: the size of government expenditure, a government budget composition, aid dependency, and weak institutions. What is more, findings suggest that countries with relatively small governments that use resources more efficiently tend to achieve higher levels of economic growth that is not always the case for all developed countries. These findings have important implications for assessing the government performance on economic growth.
\end{abstract}

\section{Introduction}

Today governments play a different role than before. Starting with the classic theory of Adam Smith's limited intervention, and Keynes anti-crisis instruments of substantial intervention, and Buchanan's theory of public choice of reasonable intervention government's role changed. Nowadays, governments are more careful with the use of resources and attempt to be efficient and effective to achieve sustainable economic development. They pay more attention to performance measurement and evaluation in the public sector because of several developments over recent decades. The financial crisis of 2008-2009, debt crisis, and a tremendous fall of GDP, all has shown that governments are not effective. What's more, it has shown that problems of governance is actual for not only developing and transition countries, but for the highly developed parts of the world (Rothstein, 2011). The international organizations, such as IMF, World Bank, OECD, etc. with governments are for the sound public finance that allows for sustainable and effective budget policy in especially the time of globalization when borders are widely open and opportunity for economic growth is restrained by tough competition and pressure on government's revenue base.

The rest of the paper is as follows. Section 2 explains the concept of public sector performance. Section 3 analyses efficiency measures of prominent empirical cross-country studies. Section 4 analyses the efficiency variations and proposes suggestions for Central Asian countries. Section 5 concludes.

\section{Public Sector Performance}

It is often believed that countries with more effective governments tend to have economy that is more effective. Many empirical researches suggest that, it is true, and that countries with more effective government tend to achieve higher levels of economic growth by obtaining better credit ratings and attracting more investment, offering higher quality public services and encouraging higher levels of human capital accumulation, putting foreign aid resources to better use, accelerating technological innovation, and increasing the productivity of government spending (Rajkumar and Swaroop, 2002). Old scholars strongly believed that effective government can boost economic growth. Old exogenous Neo-classical growth theory (Solow, 1956) and new endogenous growth theory (e.g. Lucas, 1988). Jan S. Hogendorn (Hogendorn, 1996) highlights significance of an efficient government in group of six important factors of economic development: "An economic system that allows for efficient allocation, including increases in the efficiency of government". Marc Holzer (Holzer, 1992) proposes "productive government", highlighting the role of fiscal policy: "... no government can remain fiscally sound if it is inefficient and ineffective". Also he suggests for public agencies to improve their capacities to be productive, to apply those capacities to the efficient and effective delivery of services, and to convince the public that such actions are occurring. The author suggests measuring productivity through efficiency, effectiveness, impact, and performance, particularly by total quality management tools. Prominent study of Vito Tanzi also suggests the significant role of government in economic growth, suggesting more efficient use of public resources (Tanzi, 2005). More recent research is drawing attention to enhance the government effectiveness 
through sound public finance management. Research done by World Bank suggests that economic development can be achieved through implementing the principles of sound public finance. According to approaches in "Public Finance for Sustainable Development" research, there are three main goals of public expenditure management systems: fiscal discipline, allocative efficiency and cost-effectiveness.

Fiscal discipline - implementing constraints on the aggregate level of spending and deficits over the medium term;

Allocative efficiency - prioritizing competing claims of different social objectives on scarce resources in the best possible way using cost-benefit analysis and incidence analysis tools.

Cost-effectiveness is defined simply as that "public finance schemes should achieve their goals at a minimum costs".

What's more, as Rothstein, Allen Schick also highlights the fact that sustainable public budget policy is just a problem of developing countries but a core issue of developed countries, mainly because of aging population of OECD countries causing surge in public spending on pension and healthcare. He suggests four dimensions of sustainable public budget policy (Schick, 2005):

- Solvency - the ability of government to pay its financial obligations.

- Growth - fiscal policy that sustains economic growth.

- Stability - the capacity of government to meet future obligations with existing tax burdens.

- Fairness - the capacity of government to pay current obligations without shifting the cost to future generations.

Here we should pay attention to new important pillar of the economic development that compels to consider equity dimensions in attempts to grow sustainably. Starting with Joseph Stiglitz there is a tradeoff between efficiency and equity dimensions. Moreover, recent studies strongly highlights the role of fair distribution of national wealth among people in the way of growing.

Thus, sustainable growth is possible with balanced budget with expenditures that brings efficiency and effectiveness and fair allocation of the achievements of economic development. This study will concentrate on the ways how efficiency and effectiveness dimensions are measured and what policy implications can be suggested for Central Asian countries.

We have to start with identifying when government is effective. How we define "effective government"? Certainly, there is no common definition. It is a subset of the relatively new concept of "good governance" (Roshtein and Teorell, 2012). World Bank Governance Indicator (WGI) suggests it is one of the six composite indicators: Voice and Accountability, Political Stability, Government Effectiveness, Control of Corruption, Rule of Law, and Regulatory Quality. It utilizes 37 measures from 15 sources: "Government effectiveness captures perceptions of the quality of public services, the quality of the civil service and the degree of its independence from political pressures, the quality of policy formulation and implementation, and the credibility of the government's commitment to such policies" (Worldwide Governance Indicators, 2013). Certainly, this is qualitybased indicator, widespread and comprehensive cross-country analysis.

Another way of determining the government effectiveness is through evaluating efficiency and effectiveness of public sector performance. As clarified by Worthington and Dollery (Worthington and Dollery, 2000), efficiency and effectiveness is two different parts of performance.

$$
\begin{array}{ll}
\text { Efficiency } & \text { Performance } \\
\text { Resource Management } & \text { Outcomes Accessibility } \\
\text { Quality Appropriateness }
\end{array}
$$

In conceptual framework of efficiency and effectiveness (Ulrike Mandl et al., 2008) the relationship of inputs, outputs and outcomes is analyzed. The input-output ratio is measurement of efficiency, outcome is effectiveness. Input-output relates to outcome, meaning by efficiency we can achieve effectiveness. For example education spending as input gives educated people as output and it will affect economic growth as an outcome. Thus, as more efficient or productive public spending is used, the better result is achieved, enhanced economic growth in particular.

Thus, the public sector performance of any government can be evaluated through analyzing its public budget policy, efficiency and effectiveness of public spending particularly. Today many states define the public sector performance as the use of the least resources in achieving maximum results.

In IMF publications two conditions mentioned for public expenditure programs to be efficient or "productive": lowest possible cost (cost-effective) and appropriate mix of outputs and sustainable levels of aggregate expenditure (the mix of public sector outputs should be optimal and consistent with a sustainable 
macroeconomic framework). "In the simple case of one public good, the optimum provision of that good is achieved when the marginal social benefit derived from the good is equal to the marginal social cost of providing it" (Chu et al., 1995).

Important step to take is getting rid of first of all unnecessary spending. According to Baumol (Baumol and Bradford, 1970), government spending should be used more efficiently than in the private sector, as they were originally removed from the scope of certain inefficient private sector. So, only spending in those areas where government is really efficient. "This can be achieved by reducing unproductive expenditures while shifting budgetary resources toward areas that support the development of essential physical infrastructure and human capital, including basic health and primary education. Barro (Barro, 1990) study distinguishes between productive and non-productive government spending categories and between distortionary and non-distortionary taxes.

The methods of measuring efficiency is represented by contemporary econometric analysis methods, such as parametric and non-parametric methods. Various cross-country studies are built on these methods and they do not give certain results. They are rather contradictory.

In this study, we will analyse the Central Asian countries' public sector performance based on the approaches used by the comprehensive cross-country comparison of four important studies of World Bank, Livio di Matteo, and Vito Tanzi et al. and Konstantinos Angelopoulos et al. to compare public sector performance of countries of Central Asia. To find a good comprehensive data for Central Asian countries, namely Armenia, Azerbaijan, Georgia, Kazakhstan, Kyrgyz Republic, Tajikistan, Turkmenistan, and Uzbekistan is a difficult task. The author spent a lot of time researching World Development Indicator, IMF World Economic Outlook, ADB database, Global Competitiveness Index, IRIS-3 dataset, etc., unfortunately, it is impossible at least for now. This is a main cause of almost no empirical study for Central Asian countries on this most significant subject in recent conditions. This study marks the beginning of a new empirical study and will contribute to enhancement of the public sector performance and its impact on sustainable growth of Central Asian countries.

\section{Efficiency Measures of Prominent Empirical Studies}

\subsection{Worldwide Governance Indicator (WGI)}

The WGI project, a research dataset produced by Daniel Kaufmann, Aart Kraay, Massimo Mastruzzi reports aggregate and individual governance indicators for 215 economies over the period 1996-2013.

Important conclusions:

1. Improving governance indicators help fight poverty and improve living standards.

2. Good governance is not an exclusive prerogative of the rich countries.

3. Where there is commitment to reform, improvements in governance can and do occur.

4. Significant improvements in governance can and do happen.

5. However, in general, there is no evidence of a significant improvement in the quality of governance in the world over the past decade.

6. Assessment of governance is difficult enough, and all management measures are absolutely accurate, requiring careful interpretation.

Government effectiveness of 212 countries are compared in a study that range from -2.5 to +2.5 . The lowest line is occupied by countries of Africa, North Korea, and Afghanistan. Close to the middle of the chart are Central Asian countries Turkmenistan (-1.3) Tajikistan (-1.1), Uzbekistan (-0.9), Kyrgyzstan (-0.7), Kazakhstan $(-0,5)$, and Russia (- 0.4), India (-0.2), Brazil (-0.1). Right in the middle are China (0), Armenia (0.1), Saudi Arabia (0.1), Thailand (0.2), Mexico (0.3), Greece (0.4), Turkey (0.4), Georgia (0.5), Italy (0.5). And leaders are EU countries, the Asian tigers, Japan, USA, Canada. The first three are Finland, Singapore and Denmark.

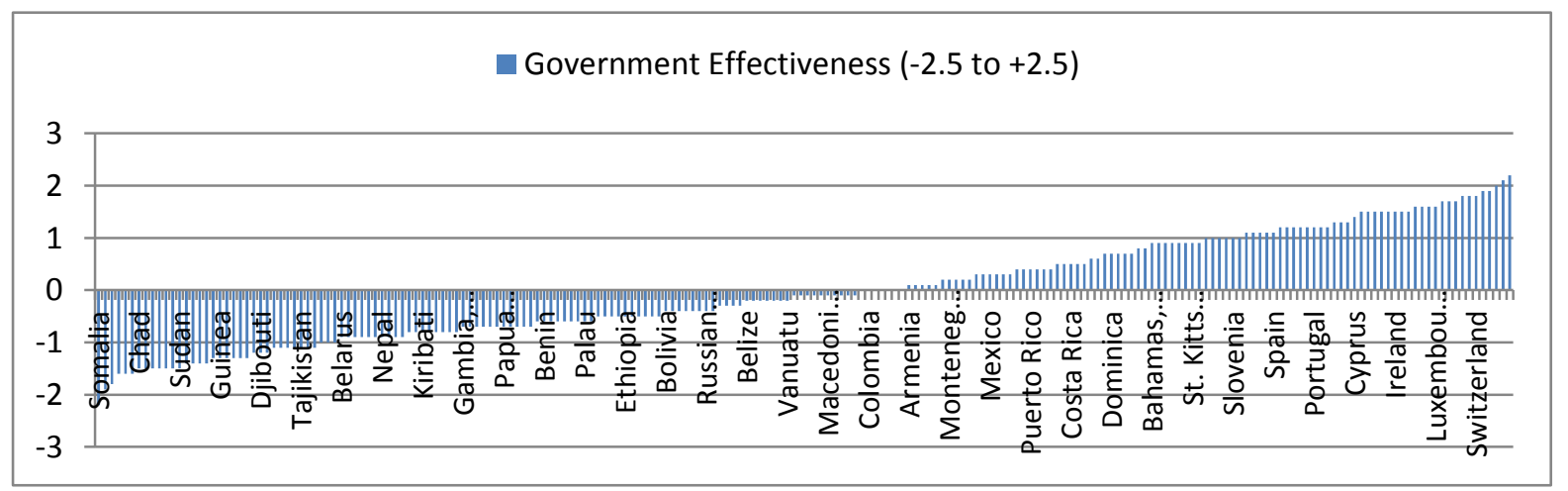

Figure 1 Government Effectiveness scores across countries, WDI. 


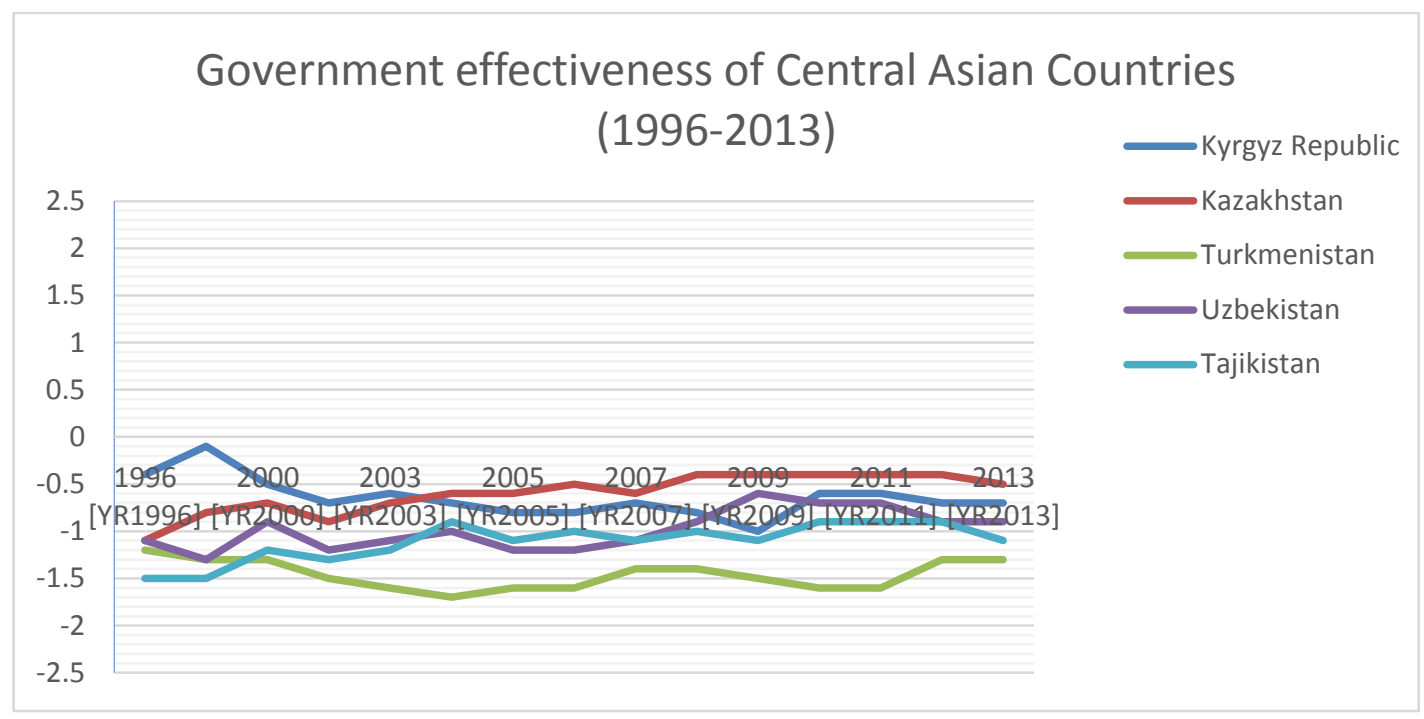

Figure 2. Government Effectiveness score for Central Asian countries, WDI.

Central Asian countries Kazakhstan, Uzbekistan, Tajikistan, Kyrgyzstan, and Turkmenistan government effectiveness levels are lying near to each other. Kazakhstan improved its level and is the best performing among others, followed by Kyrgyz Republic, whose level decreased and now second in list. Uzbekistan is the third and a slight up and downs. Tajikistan level is improving, but decreased to the fourth place. Turkmenistan started good but gradually fall to last place in the list.

\subsection{Livio di Matteo}

The second cross-country study of 34 OECD countries for years of 2000-2011 by Livio di Matteo presents an index of efficiency. An international overview of the size and efficiency of public spending named "Measuring government in 21st century" by Livio di Matteo (Matteo, 2013a) analyzed the role of government in influencing economic growth and specifically study on examining the theories relating the size of the public sector and economic growth. This index is computed by using OECD data by combining a set of outcome indicators with government size data. 20 indicators are chosen: 4 economic performance indicators (inflation, unemployment rate, level of per capita GDP, real per capita GDP growth rate); 2 health outcome performance indicators (life expectancy, infant mortality); 5 social outcome performance indicators (tertiary education, PISA reading score proportion, Gini coefficient, homicide rate, burglary rate); and 9 better life indicators (rooms per person, household net adjusted disposable income, household net financial wealth, life satisfaction, self-reported health status, voter turnout, air pollution, water quality).

Total performance index score and government expenditure to GDP ratio clearly shows the most efficient public sector is currently that of South Korea followed by Luxembourg, Switzerland, Australia, and Norway: "They illustrate that the goal is not a smaller public sector per se, but a smaller public sector given a performance level". In order to understand this conclusion we should compare the highest cost-effective countries (South Korea, Luxembourg, and Switzerland) with the least cost-effective countries (Greece, Hungary and Turkey). Luxembourg's performance index (7.5) is higher than Korea's (5.8). But the government expenditure to GDP ratio of Luxembourg is 40.5 percent, and Korea's 27.4, which means that Luxembourg has a public sector of $48 \%$ larger than Korea, but performing for only 29 percent better than Korea. Turkey as the least cost-effective country has a public sector of 36 percent and performance index score is only 2.5. Hungary and Greece public sectors are close to 50 percent while performance index is just 4 .

The important conclusion the authors made is that the relationship between the government expenditure to GDP ratio and the growth rate of per capita GDP has a hump-shaped Scully curve. "All other things given, annual per capita GDP growth is maximized at 3.1 percent at a government expenditure to GDP ratio of 26 percent; beyond this ratio, economic growth rates decline. This demonstrates that there is an optimal size for the public sector when it comes solely to the effect on economic growth. Naturally, what size the public sector should be is also about broader societal outcomes but, even then, the evidence suggests that there are few additional benefits once the public sector reaches 30 to 35 percent of GDP" (Matteo, 2013b).

\subsection{Vito Tanzi et al.}

Prominent scholars, Vito Tanzi et al. particularly explores the changing role of the government and highlights the importance of government effectiveness through enhancing public spending effectiveness and efficiency (Tanzi, 2011). Vito Tanzi suggests, “Achieving multiple objectives of stabilization, growth and equity requires not only reducing expenditures, where necessary, but improving the efficiency and composition of public expenditures" (Tanzi, 1997). "A fundamental role of the state would be to make markets work well by becoming 
more efficient and more transparent. This, in fact, should be seen as the most fundamental role of the state in a market economy. The government should be ruthless in the pursuit of that objective" (Tanzi, 2005). In addition, the author defines the effective government such as, when the focus of public expenditure is on agreed activities (genuine public goods, significant externalities, the creation of social institutions and the rule of law that protect individuals and property) suggested by Adam Smith, Pigou, Musgrave, Samuelson and others, than it is carried out in an efficient manner, the public sector remains small and efficient.

Recent research of Vito Tanzi et al., on "Public sector efficiency: evidence for new EU member states and emerging markets" core question is "... whether there is a positive, identifiable relationship between higher public spending and higher social welfare" (Tanzi et al., 2010). Two indicators, the Public Sector Performance (PSP) index and the Public Sector Efficiency (PSE) index are used for comparative analysis. Seven indicators of public sector performance are used in the calculation of the index and are broadly classified into two groups: opportunity indicators (administrative performance, education performance, health performance, public infrastructure outcomes) and Musgravian indicators (income distribution, economic stabilization, resource allocation). Opportunity indicators can show government's performance in promoting equal opportunities and Musgravian indicators can show how government is performing three main functions of public finance.

\begin{tabular}{lcccc} 
& Rank & PSE score & PSP score & $\begin{array}{c}\text { Government expenditure } \\
\text { to GDP ratio }\end{array}$ \\
\hline Singapore & 1 & 2.39 & 1.53 & 21.0 \\
Thailand & 2 & 1.83 & 1.07 & 17.8 \\
Korea & 3 & 1.65 & 1.14 & 24.4 \\
Mauritius & 4 & 1.56 & 1.05 & 24.7 \\
Chile & 5 & 1.38 & 0.94 & 24.4 \\
Ireland & 6 & 1.37 & 1.24 & 33.0 \\
Mexico & 7 & 1.31 & 0.84 & 25.3 \\
Cyprus & 8 & 1.08 & 1.33 & 40.0 \\
Greece & 9 & 0.96 & 1.09 & 48.6 \\
South Africa & 10 & 0.95 & 0.81 & 26.3 \\
Slovak Republic & 11 & 0.92 & 1.03 & 43.8 \\
Latvia & 12 & 0.91 & 0.95 & 36.6 \\
Estonia & 12 & 0.91 & 0.97 & 36.4 \\
Slovenia & 14 & 0.88 & 1.12 & 42.1 \\
Romania & 15 & 0.86 & 0.78 & 33.7 \\
Lithuania & 16 & 0.86 & 0.90 & 33.3 \\
Czech Republic & 17 & 0.85 & 0.97 & 40.6 \\
Hungary & 17 & 0.85 & 1.05 & 50.2 \\
Poland & 19 & 0.83 & 0.96 & 43.2 \\
Portugal & 20 & 0.83 & 1.04 & 46.2 \\
Malta & 21 & 0.78 & 1.15 & 45.0 \\
Bulgaria & 22 & 0.77 & 0.74 & 38.6 \\
Brazil & 23 & 0.69 & 0.75 & 46.6 \\
Turkey & 24 & 0.63 & 0.74 & 42.7 \\
\hline
\end{tabular}

Table 1. Ranked PSE and PSP scores and government expenditure to GDP rations.

The authors concluded that: "The results of our analysis show that expenditure efficiency across new EU member states is rather diverse especially compared to the group of top performing emerging markets in Asia. From the analysis of composite PSP and PSE scores, we find that countries with lean public sectors and public expenditure ratios not far from $30 \%$ of GDP tend to be most efficient. PSE scores of the most efficient countries are more than twice as high as those of the poorest performers".

\subsection{Konstantinos Angelopoulos et al.}

A rather different cross-country study exists that of Konstantinos Angelopoulos et al. (Angelopoulos et al. 2008) which was built on Vito Tanzi et al. study. This study compares the performance of governments in 64 developed and developing countries for 1980-2000 years. It differs from other studies in that it examines the relationship between fiscal size and economic growth that explicitly depends on the efficiency of the public sector. In order to find Public Sector Efficiency (PSE) index, they used a measure of Public Sector Performance index (PSP) and a measure of Public Sector Expenditure (PEX) index based on the assumption that particular activity expenditure is allocated to achieve this particular performance. They constructed PSE not on 7 indicators as Vito Tanzi et al., but four indicators of Education, Administration, Infrastructure, and Stabilization due to limited data for 64 countries. In the policy area of education they measure the Secondary School Enrollment and Public Spending in Education; In the policy area of administration they measure Corruption in Government and Bureaucratic Quality; In the policy area of infrastructure they measure Diesel Locomotives in Use and Electric 
Power Transmission and Distribution Losses; In the policy area of stabilization, the PSP is measured by the average of the inverse of the variables Inflation Rate and Unemployment Rate.

It is basically the ratio of performance indicators to associated expenditures: PSE = PSP / PEX

The authors concluded: "The policy implication is that what matters to growth is not the size per se, but the size-efficiency mix. Of course, improving the efficiency of the public sector is not an easy task. It requires, among other things, the reallocation of government resources, as well as the effective and efficient use of those resources towards identified and transparent strategic priorities".

\subsection{Other Studies}

Most comprehensive empirical research has been done by Slemrod in 1995, a cross-country study that "evaluates the evidence about the influence of government tax and expenditures on economic prosperity and growth" (Slemrod, 1995). The author attempted to analyze this impact by assessing two sides of government intervention. First, was to assess the different services of government: provision of public goods, maintenance of full employment, insurance against social risks, income maintenance, and adequate provision of certain basic goods and services. Second, was to assess the cost, in terms of a lower average standard of living, of the programs designed to achieve this goal. He used two approaches to measuring these costs: bottom-up and topdown approaches. As a result of this study authors concluded: "This review of the existing cross-country literature suggests that there is no persuasive evidence that the extent of government has either a positive or a negative impact on either the level or the growth rate of per capita income, largely because the fundamental problems of identification have not yet been adequately addressed".

Another comprehensive study of Nijkamp, P. and J. Poot (2004), in a meta-analysis of 41 studies, the author found that only 17 percent of studies show positive relationship between different measures of fiscal policy and economic growth; 29 percent showed negative relationships; and 54 percent were inconclusive. There is no certain evidence of government revenue and expenditures impact on long-term growth and suggesting that majority of study finds the growth enhancing impact of specific government expenditures like education and infrastructure.

Handler et al. (2005) suggested more efficiency to smaller, rather than larger, government.

By analyzing much of the prominent research work Lee and Whithford "... find that much of the variation in effectiveness is explained by the relative position of countries in the worldwide income distribution, with wealthier countries experience greater perceptions of effectiveness and those in the lower parts of the distribution being perceived as being less effective" (Lee and Whithford, 2009).

\section{Why Contradictory Results?}

One explanation to all above-mentioned contradictions gives Bergh and Henrekson who suggests the variation in definitions and countries studies is one of the reasons for the contradictory results in the studies that relate government size to economic growth (Bergh and Henrekson, 2011).

Livio di Matteo (Matteo, 2013c) suggested three important lessons:

1. The studies demonstrate that it is important to explicitly set out and adhere to consistent definitions of government size and economic growth.

2. The studies show that the analysis needs to be consistent in terms of the countries and economies being compared.

3. The studies show that even if there is a negative empirical relationship between government size and economic growth, the relationship may simply be due to reverse causality - that is, lower economic growth reduces resources for government and therefore leads to a smaller public sector.

These important lessons directs us to differentiate the efficiency measures used between public spending in developed and developing countries. All cross-country studies can only guide us in general terms, but no specific policies to implement. We should take for consideration top performing countries and conduct an in-depth study of their public budget policy. Here we can recommend emerging Asian countries, such as Singapore and South Korea, which were evaluated as top performing in both WGI government effectiveness index and Vito Tanzi PSE and PSP indexes for being the most efficient and effective in use of limited resources.

What is more, it is very important to mention the distinct variations inherent in countries. Another crosscountry study of 140 developing countries for 1996-2002 years in health and education spending found very interesting results and identified the main factors of efficiency variations in developing countries (Herrera and Pang, 2005a):

- The size of government expenditure

- A government budget composition variable

- Per-capita GDP

- Urbanization 
- Prevalance of AIDS

- Income distribution inequality

- Share of public sector in the provision of service

- External Aid

- Institutional Variables

"Results show that countries with higher expenditure levels register lower efficiency scores, as well as countries where the wage bill is a larger share of the government's budget. Similarly, countries with higher ratios of public to private financing of the service provision score lower efficiency, as do countries plagued by the HIV/AIDS epidemic and those with higher income inequality. Countries with higher aid-dependency ratios also tend to score lower in efficiency, probably due to the volatility of this type of funding that impedes medium term planning and budgeting".

Here, we will consider four variations most prevalent and of paramount importance in Central Asian countries: the size of government expenditure, a government budget composition variable, aid dependency and institutional variables.

First, if we compare overall level of public spending to GDP ratios of countries, we can see that this level in OECD developed countries may range from $30.2 \%$ of GDP in South Korea to $57.7 \%$ of GDP in Denmark as of 2011 (OECD, 2011). Public spending in developing countries range from $15 \%$ of GDP to $30 \%$ of GDP (Herrera and Pang, 2005b). This difference in levels of public spending of countries suggest that we cannot treat recommendations made for developed countries as definitive.

Second, the composition of government expenditures. "There is a strong evidence that as GDP rises the structure of public spending progressively shifts more heavily towards social outlays" (Palazzi, 1990). Developed countries' public spending is concentrated more on social expenditures. Actually all countries aim is economic growth that will ultimately bring human development. It suggests that social spending is significant component of overall public spending. The Paolo Palazzi introduced the concept of a sustainable level of development as the level of development characterized by an optimal ratio of GDP to social development. Corresponding to this theory developed countries really spend more on social facilities. In developing countries, it is found that agricultural spending, irrigation, education, and roads contributed strongly to growth, which means that governments should reduce their spending in unproductive sectors such as defense, that will help fight poverty (Fan and Rao, 2003). Therefore, developing countries should concentrate more on these types of public spending and work on improving efficiency and effectiveness of these expenditures.

Third, it is important to mention the international aid dependency of developing countries. Volatility of this type of funding hinders the sustainable fiscal policy planning and management thus negatively affect the efficiency and effectiveness of public spending.

Forth, institutions in Central Asian countries tend to be relatively weak than in developed countries. Consequently, we have higher corruption levels, which again hinders efficient and effective use of limited resources.

\subsection{Central Asian Countries' Public Spending}

Public spending in Central Asian countries range from in average terms in 1992-2000 it was $18.81 \%$, in 20012010 it was $25.02 \%$, and in $2011-2020$ it is $28.27 \%$. We can observe gradual growth of public expenditures, except for Turkmenistan and Uzbekistan. Uzbekistan public spending is far larger than other countries' before 2000 , and decreased from $41.55 \%$ to $33.88 \%$. Turkmenistan took the way of cutting public spending from $22.60 \%$ to $14.30 \%$. Other countries' spending is gradually growing except for Kazakhstan, which keeps the same level of $22.5 \%$. 


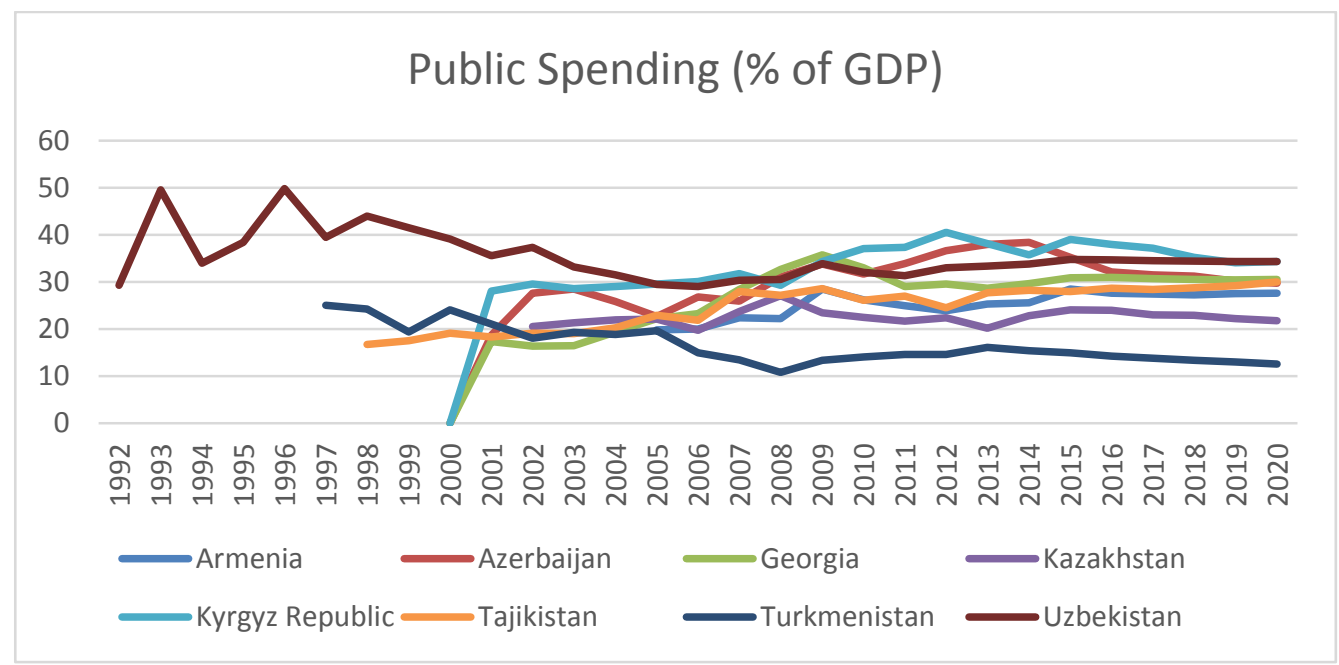

Figure 3. Public Spending of Central Asian Countries, IMF World Economic Outlook Database, April 2015.

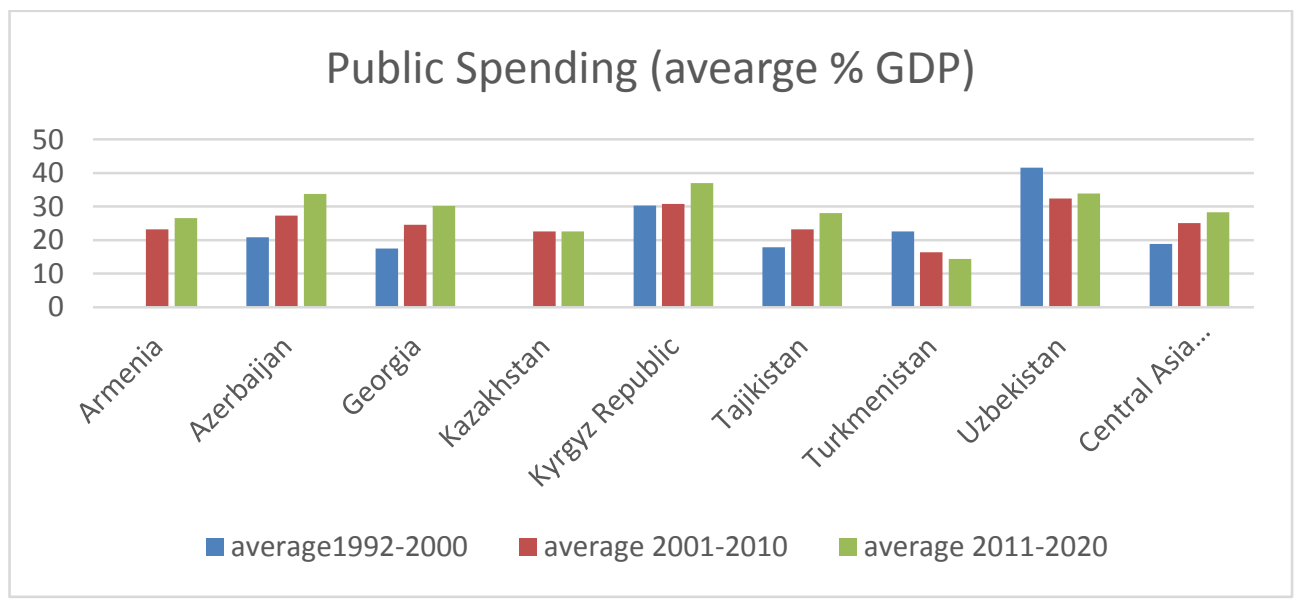

Figure 4. Public Spending of Central Asian Countries, IMF World Economic Outlook Database, April 2015.

The statistical data being collected are far from adequate. Therefore, we cannot apply the methods used for developed countries mentioned above. For available data, we can show correlation between variables of GDP growth and public spending in these countries. With basic correlation method used to determine whether or not GDP growth and growing public spending are correlated.

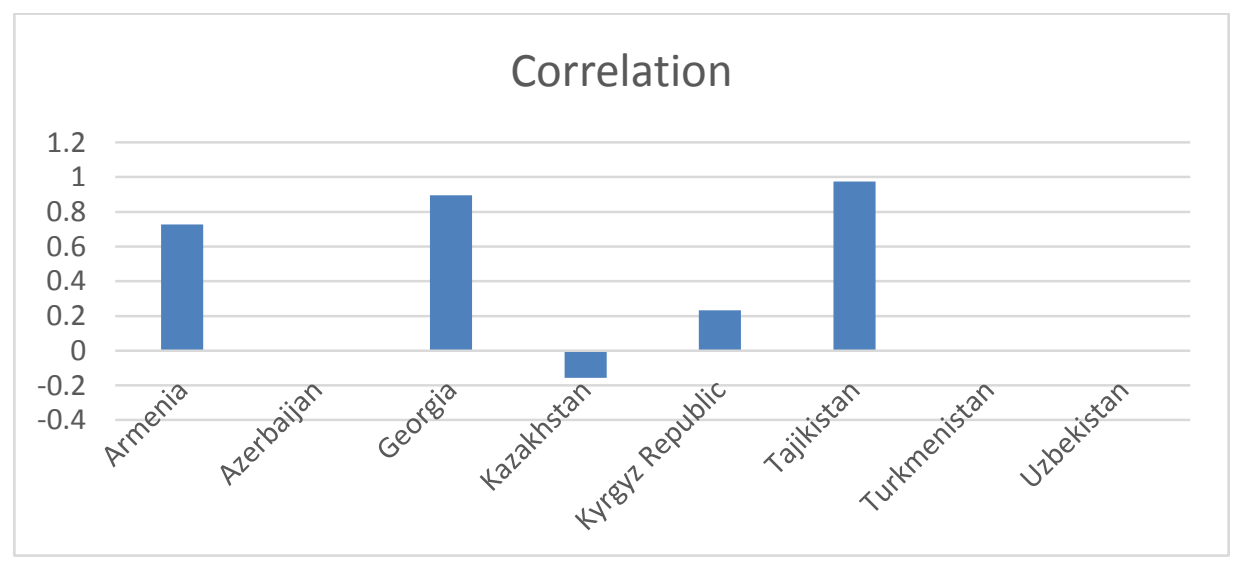

Figure 5. Correlation of GDP Growth and Change in Public Spending of Central Asian countries, WDI.

Relative high positive correlation is seen in Armenia (0.72), Georgia (0.89), and Tajikistan (0.97), Kyrgyz Republic (0.23), a negative correlation is in Azerbaijan (-0.01), and Kazakhstan (-0.15). For Turkmenistan and Uzbekistan data is not available.

If we look at composition of public spending in these countries, the dramatic change in composition of public spending in last decades in developed countries from government consumption, defence, direct spending on 
housing towards spending on social security, personal social services, health and education according Crawford and Johnson (Crawford and Johnson, 2011) leaves only two options. First is to increase the total public spending to adjust to growing demography. Many studies has shown a negative correlation between growing public spending and economic growth. Second is to implement reforms to reduce social spending. The second option is more viable and it points out the immediate and serious actions towards enhancing public sector performance through more productive use of public resources. Obviously, Central Asian countries way is not straightly following developed countries in changing composition of spending, but to take actions now, towards efficient use of public spending. There is no best fiscal policy, but certainly there is a way to be more productive. It is a way possible to have a small public sector but to be more efficient and rapidly prosper. Emerging Asian economies proved it and can guide us in how to achieve sustainable economic growth with limited resources in an efficient and effective way. Striclty dividing spending into productive and non-productive also will not guarantee economic growth. As S. Devarajan et al. (Devarajan et al, 1996) stated “... our empirical results suggest that expenditures which are normally considered productive could become unproductive if there is an excessive amount of them. In particular, capital expenditures - often thought to be the mainstay of development - may have been excessive in developing countries, rendering them unproductive at the margin”. Developing countries should avoid misallocating their limited resources in the recent conditions of lower commodity prices and tightening financial conditions.

\section{Concluding Remarks}

Today government's role changed towards reasonable intervention and careful use of limited resources. They search for the ways to enhance overall public sector performance. In this study, we analysed various methods used to evaluate the efficiency and effectiveness of public spending in developed and developing countries. Those methods suggested by Vito Tanzi et al., Livio di Matteo, Konstantinos Angelopoulos et al. are of significant econometric analysis methods and indicators evaluated are of high significance for efficiency measures. Overall, these authors suggested small-sized governments whose public spending is up to $30 \%$ of GDP are relatively more efficient. However, it does not speak for the current similar levels of Central Asian countries. In addition, there are contradictory results that enforces to differentiate efficiency measures used for developed and developing countries.

Due to the lack of data for Central Asian countries recently it is impossible to evaluate the comprehensive level of efficiency of public spending. The simple correlation method applied to eight countries of Central Asia shows diverse results, and it does not give any certain suggestions. Nevertheless, it is possible to suggest important points to consider. First of all, any developing country should not straightly follow any developed country and decrease or increase its public spending. The second thing is to think over the composition of public expenditures. At last, pay attention to factors of variations in efficiency: the size of government expenditure, a government budget composition variables, per-capita GDP, urbanization, prevalence of AIDS, income distribution inequality, share of public sector in the provision of service, external aid, and institutional variables. The author concludes that Central Asian countries are less efficient than developed countries because of four distinct problems: the size of government expenditure, a government budget composition, aid dependency, and weak institutions.

\section{References}

- Rothstein, 2011. "The Quality of Government: Corruption, Social Trust and Inequality in a Comparative Perspective", Chicago: University of Chicago Press.

- Rajkumar and Swaroop, 2002. “Public Spending and Outcomes: Does Governance Matter?”, Policy Research Working Paper, World Bank, http://dx.doi.org/10.1596/1813-9450-2840

- Solow, 1956. “A Contribution to the Theory of Economic Growth”, The Quarterly Journal of Economics, 70 (1), pp. 65-94.

- Lucas, 1988. "On the Mechanics of Economic Development”, Journal of Monetary Economics, 22, pp. 342.

- Hogendorn, 1996. Economic Development. Harper Collins College Publishers, Inc., New York, p56-64.

- Holzer, 1992. Public Finance. Soros Fund, Bishkek, pp. 323-350.

- Tanzi, 2005. "The Economic Role of the State in 21st Century”, Cato Journal, 25 (3), pp. 617-638.

- Schick, 2005. "Sustainable Budget Policy: Concepts and Approaches", OECD Journal on Budgeting, 5 (1), pp. 107-126.

- United Nations, 2002. "Finance for Sustainable Development: Testing New Policy Approaches: Proceedings of the Fifth Expert Group Meeting on Finance for Sustainable Development”, Nairobi, Kenya, 1-4 December 1999. 
- Rothstein and Teorell, 2012. "Defining and measuring quality of government", http://iisdb.stanford.edu/docs/623/Rothstein\%26Teorell2012.pdf

- Worldwide Governance Indicators, 2013. http://info.worldbank.org/governance/wgi/index.aspx\#home

- Worthington and Dollery, 2000. “An Empirical Survey of Frontier Efficiency Measurement Techniques in Local Government”, Local Government Studies, 26 (2), pp. 23-52.

- Ulrike Mandl et al., 2008. The Effectiveness and Efficiency of Public Spending, Economic Papers 301.

- Chu et al., 1995. "Unproductive Public Expenditures, A Pragmatic Approach To Policy Analysis", IMF Pamphlet Series No. 48.

- Baumol and Bradford, 1970. "Optimal Departures from Marginal Cost Pricing", The American Economic Review, 60, pp. 265-283.

- Barro, 1990. "Government Spending in a Simple Model of Endogeneous Growth", The Journal of Political Economy, 98 (S5), pp. 103-125.

- Matteo, 2013. Measuring Government in the Twenty-first Century: An International Overview of the Size and Efficiency of Public Spending, Fraser Institure, Canada.

- Tanzi, 2011. Government versus Markets: The Changing Economic Role of the State, Cambridge University Press, New York.

- Tanzi, 1997. "The Changing Role of Fiscal Policy in Fund Policy Advice", https://www.imf.org/external/np/apd/asia/TANZI.HTM

- Tanzi et al., 2010. "Public sector efficiency: evidence for new EU member states and emerging markets", Applied Economics, 42: 2147-2164.

- Baumol, 1970. "On the Discount Rate of Public Projects”, in Public Expenditures and Policy Analysis, Chicago: Markham, p. 274.

- Slemrod, 1995. "What Do Cross-Country Studies Teach about Government Involvement, Prosperity, and Economic Growth?”, William Easterly, Brookings Papers on Economic Activity.

- Angelopoulos et al., 2008. "Does public sector efficiency matter? Revisiting the relation between fiscal size and economic growth in a world sample", Athens University of Economics \& Business, University of Glasgow, and CESifo.

- Nijkamp, P. and J. Poot, 2004. "Meta-Analysis of the Effect of Fiscal Policies on Long-Run Growth", European Journal of Political Economy, 20, pp. 91-124.

- Lee and Whithford, 2009. "Government Effectiveness in Comparative Perspective", Journal of Comparative Policy Analysis, 11(2), pp. 249-281.

- Bergh and Henrekson, 2011. "Government Size and Growth: A Survey and Interpretation of the Evidence", IFN Working Paper No. 858

- Herrera and Pang, 2005. "Efficiency of Public Spending in Developing Countries: An Efficiency Frontier Approach 1", World Bank Policy Research Working Paper 3645.

- OECD, 2011. General government spending, https://data.oecd.org/gga/general-government-spending.htm

- Palazzi, 1990, “The Structure of Public Spending and Development”, Dipartimento di Scienze Economiche Universita' "la Sapienza", Roma.

- Fan and Rao, 2003. "Public Spending in Developing Countries", Environment and Production Technology Division International Food Policy Research Institute, N.W. Washington, D.C.

- IMF, 2015. World Economic Outlook Database, https://www.imf.org/external/pubs/ft/weo/2015/01/weodata/index.aspx

- Crawford and Johnson, 2011. "The changing composition of public spending”, IFS Briefing Note 119, Institute for Fiscal Studies.

- Devarajan et al., 1996. "The Composition of Public Expenditure and Economic Growth ”, Journal of Monetary Economics, 37, pp. 313-344. 


\title{
Corruption, Poverty and Economic Performance: Eastern Europe and Central Asia (ECA) Countries
}

\author{
Asst. Prof. Dr. Mustafa Ildırar (Çukurova University, Turkey) \\ Asst. Prof. Dr. Erhan İşcan (Çukurova University, Turkey)
}

\begin{abstract}
Corruption, defined as "the misuse of public power for private benefit." The World Bank describes corruption as one of the greatest obstacles to economic and social development. It undermines development by distorting the rule of law and weakening the institutional foundation on which economic performance depends. In past decades, many theoretical and empirical studies have presented corruption hinders investment, reduces economic growth, restricts trade, distorts government expenditures and strengthens the underground economy. In addition, they have shown a strong connection between corruption and poverty and income inequality. On the other hand, the literature on corruption points to the conclusion that corruption by itself does not lead to poverty. Rather, corruption has direct consequences on economic and governance factors, intermediaries that in turn produce poverty. Although corruption is seen in many countries in the world, it is higher and widespread in developing countries. This study investigates relation between corruption, poverty, and economic performance by using a panel consisting of countries in the Eastern Europe and Central Asia countries. It was shown that corruption affected directly economic performance and low economic performance leads to poverty. Additionally, results imply that rules against corruption could affect economic growth indirectly through their impact on the level of corruption.
\end{abstract}

\section{Introduction}

The term "corruption" can be identified and classified in several ways, since it contains types of human actions, as it is explained "as the misuse of entrusted power for personal or private gain" by World Bank (WB, 2007), whilst "the abuse of public or private office for personal gain....the active or passive misuse of the powers of public officials for private financial or other benefits" (by OECD, 2008). On the other hand, it can be seen that corruption is considered "misuse of entrusted power for private gain. It hurts everyone who depends on the integrity of people in position of authority" by The Transparency International (TI).

There are many types of corruption. The most widely known is bribery. The other types of corruption include fraud, embezzlement, nepotism, extortion, and kickbacks. On the other hand, categorization of the term corruption in a variety of ways facilitates the perception of its influence on economic performance, as the most featured categories are listed below:

\section{Supply versus Demand Corruption}

Having both "demand" and "supply" aspects, the term is used to define proposal of an illicit pay or anomalous benefit on supply aspect, whilst on the demand aspect it defines accepted or exacted a direct or indirect pay by the state employees.

\section{Conventional versus Unconventional Corruption}

The situation when government authorities misuse its powers in an illegal way to abuse state agency for personal benefit arises "conventional corruption", while an "unconventional" one arises from the making decisions disregarding public welfare by elected civil servants, such as abuse of confidence, pilferage, defalcation, and breach of trust. The conventional corruption is divided into two sub-categories, namely "grand" and "petty", which contains considerable amount of money and actions of top-level authorities, such as presidents, prime ministers, members of senate of parliament, and relatively smaller amounts and up and midlevel officials, respectively.

\section{Administrative versus Political Corruption}

Administrative corruption refers to actions of mid-level officials, arise from receive money and gift, etc. from individuals and companies, in return for policy implements, such as granting of a license in spite of being ineligible. Besides, political corruption is sometimes considered to be a grand one, as it arises from the actions of top-level authorities of executive, legislative and judiciary branches.

\section{Public versus Private Corruption}

While a state official is a party in a corrupt action refers to "public corruption", if any of private sector staff, from an ordinary employee to manager, takes part in an action within a private sector, such as being effective and influential by using certain power on fulfill of a duty or responsibility, it is called "private corruption" (Argandona,2003). 


\section{Systemic (Endemic) versus Occasional (Incidental) Corruption}

If a corrupt action is considered to be an integrated and fundamental course of political, social and economic system, in which being honest is deemed irrational, we can make a mention of a "systemic corruption". Although this action arises in irregular forms and in conditions, it can also have negative effects on morale and economic resources (Igwe, 2012).

\section{Centralized versus Decentralized Corruption}

Centralized corruption shows more estimative path than the decentralized one, thus it decreases the uncertain processes and misjudgments. However, if the transactions are not coordinated within the public administration, it can be suggested that the decentralized corruption will predominate (OECD, 2015).

On the other hand, the fact that the concept 'poverty' is a complex one requires extensive policies aimed at poverty eradication. Due to its sophisticated and complex nature, it is quite difficult to define poverty. Moreover, researchers with differing visions of world approach to this concept from diversified angles, and therefore reaching an agreement on its definition becomes much more troublesome. Some of the researchers consider the poverty as a consequence of imbalances of wealth and power, as caused by the structure and functioning of the prevailing system, while some others define the poor as a group of people who are not able to take advantage of the opportunities they get by virtue of lack of education and of personal skills such as competence, capability and personal qualifications. No matter how it is defined, it is clear that almost half of the world population lives in poverty, of whom 1 billion are children and 29.000 children, die of starvation every day. Poverty, in local terms, originates in a variety of reasons including unfair distribution of income, unemployment, inflation, rent economics, natural disasters, globalizations, etc. However, one of the important factors leading to poverty or impeding alleviation of the same is poverty. Fighting against poverty requires combating the corruption. In fact, there is an interrelation between these two variables. As a matter of fact,

- Corruption is a cause of poverty and impedes alleviation of poverty;

- Poverty is a cause of corruption and impedes combating the corruption;

- Corruption and inequality, one of its potential consequences, would become inevitable in the societies governed by the authorities that do not negotiate with the public opinion while establishing policies and budgets and that do not follow the principle of accountability;

- Notably in the poorest countries, successful outcome can be obtained if and only if a simultaneous fight is organized against poverty and corruption, thanks to which a coordinated struggle can be ensured (Erkan and Kara, 2007).

Poverty is an ongoing awaiting people's help from around the world. This issue is especially severe in developing countries. The region of ECA consists of 19 countries with the total population of about 380 million people, of whom 19.6 percent live below the national poverty line. Today corruption is the main obstacle for the development in ECA countries for the some organizations such as WB, IMF, UN. Because of corruption, ineffective distribution of welfare causes poverty and inequality.

There are a few studies, which research causal relationship between corruption and poverty especially for ECA countries. This study is intended to fill this gap in this area. We are concerned with the effects of corruption on economic performance and the consequences for the poverty in Eastern Europe and Central Asia (ECA) countries.

\section{Theoretical Framework and Some Empirical Findings from the Literature}

Studies on corruption's effect on economic performance have been increased rapidly since early 1990s. The debate on whether corruption has direct effect on poverty has led to two types of models. First, one is "Economic Model", the other one is "Governance Model". Economic model argue that corruption causes to poverty through by damage market conditions, disrupt competition, reduce domestic and foreign investment, increasing the cost of doing business and increasing income inequality. On the other hand, governance model claimed that corruption affect poverty by the channel reducing governance capacity such as hinders governance practices, reduces the services that are provided by the government, and reduces the credibility of the rule of law. In addition, corruption affects the institutional and infrastructure improvement negatively. This is especially observed in the health and education sectors.

The channels through which corruption lower economic performance and cause poverty, have been examined with different perspectives. All of these channels can be summarized in the following way (Gupta et.al.,1998; Rose-Ackerman,1997; Chetwynd et. al., 2003):

a. Lower economic growth rates-corruption impedes economic growth by deterrence for foreign and domestic investment, discouraging doing by business, decreasing direct or indirect tax revenues, , leading to violation of property rights

b. Hits the poor hardest-poor receive smaller share in economic growth because of corruption. It causes income inequality, destroy market competition, and also affect small sized firms 
c. Damaged access to public services-corruption impairs access and quality of public services, increase cost of basic public services to the poor, especially education and health sector and it lower quality of public services

d. Lower social services - corruption distorts the allocation of public expenditures, social services gets smaller share of budget, poor targeting social programs

After 1990s, most of the empirical studies on this topic presents that corruption has a negative impact on the economic performance of countries is emphasized. A large part of empirical studies proofed that there is a negative relationship between corruption and economic performance indicators such as growth rate of gross domestic products (GDP), GDP per capita, Consumer Price Index (CPI), labor productivity, etc. In other words there is broad consensus on the cost of corruption on economic performance. This negative relationship called in literature as "sand the wheels hypothesis". Some of the empirical studies that support this hypothesis can be summarized in the following way.

Firstly, Mauro (1995) who is the leader of the econometric studies of the effect of corruption on economic growth and investment across countries. He is finding that a significant negative relationship between corruption and the average annual economic growth rate for 1960-85 period. Rahman et al. (2000) test the relationship between the corruption and average per capita growth rates for 1990-97 for Bangladesh. They find that an increase of corruption by one standard deviation reduces economic growth by $0.79 . \%$. Mo (2000) analyzed the effect of corruption on economic growth and its transmission channels such as the investment, human capital, and political stability. He found that a one-unit increase on the corruption index leads to reduce growth rate by $0.54 \%$. Of this effect, $53 \%$ is explained by the effect of corruption on political instability, and, in turn on economic growth. Dreher and Herzfeld (2005) investigate economic cost of corruption that a \%1 increase in corruption index reduces economic growth by $0.13 \%$. Their estimate includes indirect effect through government expenditures, investment, foreign aid and inflation as well as the direct effect of corruption on growth. Gyimah and et al. (2006) uses panel data and research the effect of corruption on growth for some OECD, Latin American, and Asian Countries. They assert that $10 \%$ decrease in corruption increases the growth rate of income by about $1.7 \%$ in OECD and some Asian countries, $2.6 \%$ in some Latin American countries, and by $2.8 \%$ in some African countries. Swaleheen (2011) analyzed relationship between economic growth rate and corruption with the cross-country dynamic panel data regression analysis for the 1984-2007 period. He concluded that a one standard deviation increase in corruption reduces economic growth rates by $0.12 \%$. According to the results obtained by Algan and et. al. (2014), which was conducted on corruption-economic growth relationship of the Turkish Economy for the period 1980-2011 by using vector error correction model, corruption conducted by those with low level of education has a negative impact on growth, whereas corruption diminishes the level of education rises. Because of this phenomenon, a positive relationship between corruption and economic growth is brought forward in the light of elementary school and higher education graduates who were sentenced of corruption.

However, corruption's effect on economic performance remains still unclear, and studies has a different results across different countries, region and the periods. Some former economist such as Leff (1964), Huntington (1968), Leys (1970), Lull (1985) etc. claimed that corruption has a positive effects on economic performance of countries which governed weakly and less institutional quality by the facilitates doing by business, promotes efficiency, overcome bureaucracy. This approach is called such as "greasing the wheels hypothesis". Some of empirical studies support this hypothesis. (Vaal and Ebben, 2011; Mendez and Sepulveda, 2006; Egger and Vinner, 2005, Meon and Weill, 2010 etc.). In addition, the argument that there is a positive correlation between corruption and economic growth in some Asian Countries (called Asian Paradox ) is supported by the many empirical studies. (Capmpos,et. al., 2010). On the other hand, there is some empirical studies emphasized that there is no relationship between corruption economic growth. According to Drury et al. (2005) corruption has no significant effect on economic growth rate in democratic countries while it hurts economy in non-democratic countries. In other study, Aidt (2009) conclude that no effects of corruption on GDP growth rate while strong inverse relation with real wealth per capita.

\section{Corruption Effects on Economic Performance of ECA Countries}

Academic research and studies are suggesting that corruption is a negative influence on some macroeconomic indicators such as domestic and foreign investment level, employment level, economic growth rate, per capita income, international trade volume and price stability. In addition, corruption distorts market mechanism prevents fair competition and cause shadow market and inefficient allocation resources. On the other hand, although there are many causes of poverty, are being affected by these indicators by directly or indirectly.

The cost of corruption is quite high for global economy, private companies, and people in the world. According to latest data of World Bank, this cost at a macro level, more than $5 \%$ of global GDP. In addition, it adds unnecessary cost of doing business by $10 \%$. Furthermore, countries with high level of corruption have a one third of average income of low corruption countries. 
Poverty is a very complex theme in ECA countries where 80 million people live on less than $\$ 5$ per day and try to meet even basic needs. Unemployment and low wages rates are seen as major contributors to poverty. However, corruption is seen as indirect contributors to poverty. Poverty is still main obstacle for development in ECA countries at the national levels shows disparities. However, the figure concludes that there is a declining trend in poverty except 1990s.

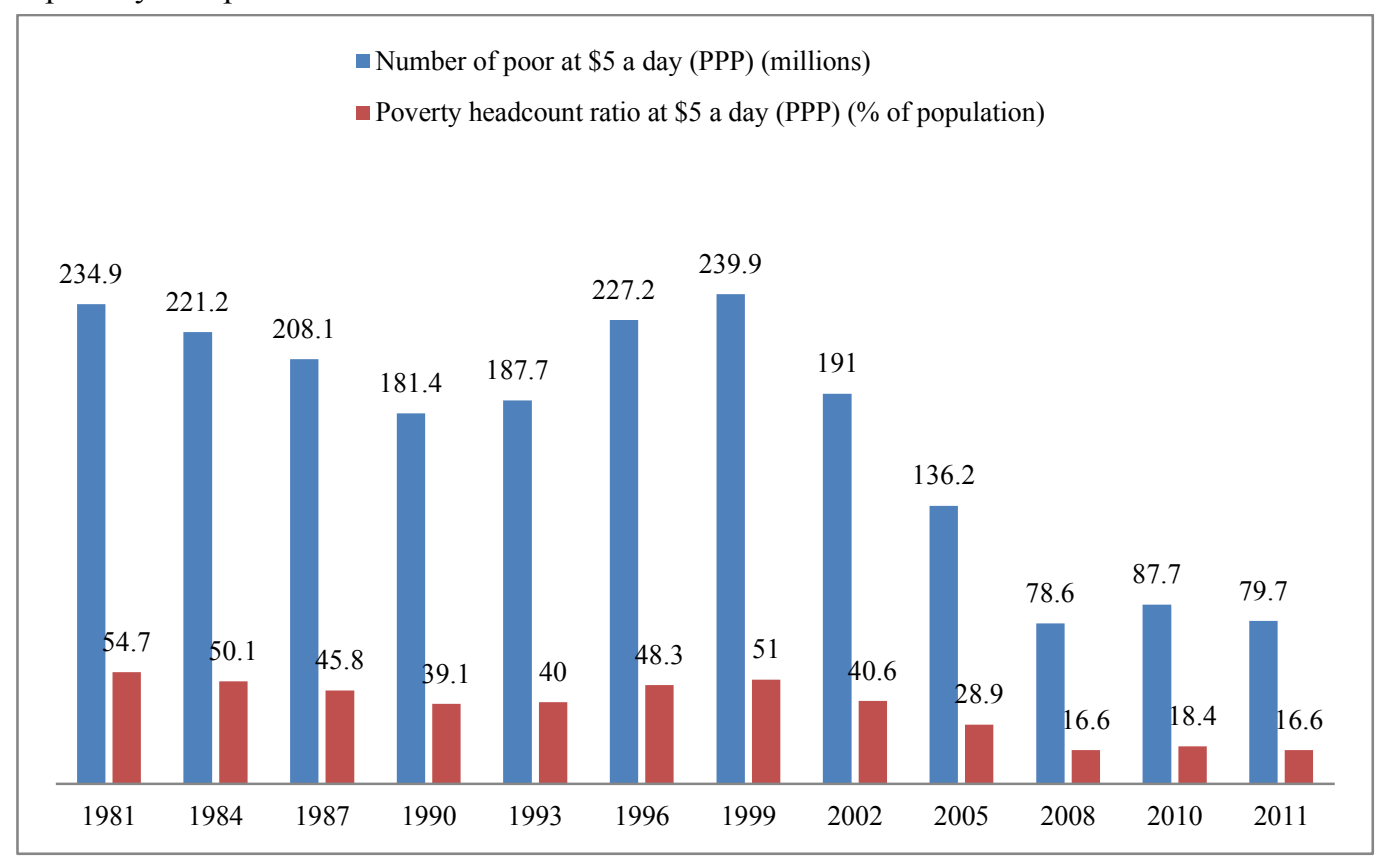

Figure 1. Poverty Trends in ECA Countries Resource: WB, IMF Poverty Indicators

Despite significant progress occurring in ECA countries since early 1980s, the figure shows concerning poverty in the ECA region. The data show disturbingly very high poverty levels in ECA region even in some upper middle-income countries.

The corruption perceptions index (CPI), which is announced by the Transparency International, the institution making important researches about corruption, sorts 175 countries by the level of perception over corruptions committed in the public sector. Covering expert assessments and opinions from the business world, Corruption Perceptions Index (CPI) is considered as one of the leading global indicators for corruptions in the public sector. The CPI currently ranks 175 countries "on a scale from 100 (very clean) to 0 (highly corrupt). We see that $95 \%$ of ECA countries score below 50 out of 100 while global average score is 43 .

In Economist, study shows that in countries ranked below 40 on the Corruption Perception Index (CPI) meaning the most corrupt countries, the correlation is quite weak but there is a strong connection between higher levels of human development and lower levels of perceived corruption for the countries scoring above 40 on the CPI. There are some disparities in CPI values. Uzbekistan, Turkmenistan, Tajikistan has a lowest CPI-1n other words-most corrupt countries in the region, while Georgia, Macedonia and Turkey is the highest value of CPI. Tajikistan also with the lowest level of per capita GDP in ECA countries.

Countries which ranked below 40 on the CPI such as Armenia, Bosnia\&Herzigova, Inflation rate in Armenia averaged 719.90 percent from 1993 until 2015, this is the highest ratio in ECA countries. On the other hand, Bosnia\&Herzigova has a worst performance in employment level in ECA countries. Unemployment rate in Bosnia\&Herzigova averaged 43.13 percent from 2007 until 2015. In addition, the poverty headcount ratio (HCR) at national poverty line (\% of population) in Tajikistan is 85.1 . It notes that income poverty remains serious problem in former Soviet republic not only Tajikistan. In Armenia, Georgia and Kyrgyzstan more than thirdquarter of population live in extreme poverty.

Some empirical studies demonstrates that the correlation between poverty levels and control of corruption is relatively weak but it is reinforced by strong correlation between control of corruption and GDP per capita, and Human Development Index, as well as between control of corruption and the levels of poverty. Briefly, the correlation between poverty levels and the control of corruption is relatively weak but it is reinforced by the strong correlation between control of corruption and GDP per capita. The control of corruption is 4.3 out of 100 , Turkmenistan only ranked in the 4.th percentile for control of corruption, lower than ECA average of 43.7. After Turkmenistan, Uzbekistan is not only the control of corruption, but also lowest value of GDP per capita. 


\begin{tabular}{|c|c|c|c|c|c|c|c|c|}
\hline Country & $\begin{array}{c}\text { Gross } \\
\text { National } \\
\text { Income } \\
\text { Per } \\
\text { Capita } \\
(2011) \\
\text { \$-PPP }\end{array}$ & $\begin{array}{l}\text { Annual } \\
\text { Average GDP } \\
\text { Growth Rate } \\
\text { (\%) Time } \\
\text { Period }\end{array}$ & $\begin{array}{c}\text { Averaged } \\
\text { Unemployment } \\
\text { Rate (\%) } \\
\text { Time Period }\end{array}$ & $\begin{array}{c}\text { Averaged } \\
\text { Inflation } \\
\text { Rate (\%) } \\
\text { Time Period }\end{array}$ & $\begin{array}{c}\text { Human } \\
\text { Development } \\
\text { Index } \\
\text { (HDI)/Rank } \\
\text { (2013) }\end{array}$ & $\begin{array}{l}\text { Head } \\
\text { count } \\
\text { Ratios } \\
\text { (HCR) } \\
\text { (\$5/day } \\
\text { below) } \\
(2012)\end{array}$ & $\begin{array}{c}\text { Corruption } \\
\text { Perception } \\
\text { Index/Rank } \\
\quad(2014)\end{array}$ & $\begin{array}{c}\text { Control of } \\
\text { Corruption } \\
\text { (World } \\
(2013) \\
\text { out of } 100\end{array}$ \\
\hline Albania & 9.225 & $5.08(96-14)$ & $15.07(93-15)$ & $3.22(95-15)$ & $0.716(95)$ & 47.5 & $33(110)$ & 25.84 \\
\hline Armenia & 7.952 & $7.81(96-14)$ & $10.97(98-15)$ & $719.9(93-15)$ & $0.730(87)$ & 79.7 & $37(94)$ & 39.71 \\
\hline Azerbaijan & 15.725 & $11.2(01-15)$ & $6.83(00-13)$ & $7.01(07-15)$ & $0.747(76)$ & 40.4 & $29(126)$ & 18.66 \\
\hline Belarus & 16.403 & $2.29(11-15)$ & $1.73(95-14)$ & $278.5(92-15)$ & $0.786(53)$ & 6.3 & $31(119)$ & 37.32 \\
\hline Bos.\&Herz. & 9.430 & $1.18(04-15)$ & $43.13(07-15)$ & $1.06(11-15)$ & $0.731(86)$ & 3.8 & $39(80)$ & 52.15 \\
\hline Georgia & 6.889 & $4.37(06-15)$ & $13.56(98-14)$ & $7.88(96-15)$ & $0.744(79)$ & 77.9 & $52(50)$ & 66.51 \\
\hline Kazakhstan & 19.440 & $5.49(95-15)$ & $6.02(03-15)$ & $62.52(92-15)$ & $0.757(70)$ & 34.7 & $29(126)$ & 20.10 \\
\hline Kyrgyzstan & 3.021 & $3.93(94-15)$ & $2.89(00-13)$ & $8.45(03-15)$ & $0.628(125)$ & 79.0 & $27(136)$ & 11.48 \\
\hline Kosovo & 9.446 & $3.51(06-14)$ & $44.10(01-13)$ & $2.44(03-15)$ & $0.786(53)$ & 29.7 & $33(110)$ & 30.62 \\
\hline FRYMac & 11.744 & $3.28(04-15)$ & $31.63(93-15)$ & $2.30(06-15)$ & $0.732(84)$ & 34.8 & $45(64)$ & 59.33 \\
\hline Moldova & 5.041 & $3.24(96-15)$ & $6.58(00-15)$ & $6.83(07-15)$ & $0.663(114)$ & 45.4 & $35(103)$ & 23.92 \\
\hline Montonegro & 14.710 & $2.21(01-15)$ & $16.91(02-15)$ & $5.44(01-15)$ & $0.789(51)$ & 17.3 & $42(76)$ & 51.20 \\
\hline Russian Fed. & 22.616 & $3.51(96-15)$ & $7.93(93-15)$ & $140.9(91-15)$ & $0.778(57)$ & 10.7 & $27(136)$ & 16.75 \\
\hline Serbia & 11.300 & $2.87(97-15)$ & $19.45(08-15)$ & $7.33(07-15)$ & $0.745(77)$ & 15.1 & $41(78)$ & 50.72 \\
\hline Tajikistan & 2.424 & $3.36(92-15)$ & $2.43(00-15)$ & $13.91(99-15)$ & $0.607(113)$ & 85.1 & $23(152)$ & 10.5 \\
\hline Turkey & 18.391 & $3.88(99-15)$ & $9.88(05-15)$ & $36.67(65-15)$ & $0.759(69)$ & 21.9 & $45(64)$ & 61.7 \\
\hline Turkmen. & 11.533 & $5.91(94-14)$ & $10.89(91-13)$ & $12.89(97-14)$ & $0.698(103)$ & n.a. & $17(169)$ & 4.31 \\
\hline Ukraine & 8.214 & $3.06(00-15)$ & $8.56(03-15)$ & $42.35(92-15)$ & $0.734(83)$ & 6 & $26(142)$ & 11.96 \\
\hline Uzbekistan & 5.227 & $8.06(06-15)$ & $4.80(2012)$ & $4.33(06-14)$ & $0.661(116)$ & 16 & $18(166)$ & 8.13 \\
\hline
\end{tabular}

Table 1. Economic Performance and Corruption Relationship in ECA Countries Source: WB, IMF Poverty Indicators

\section{Model and Data}

This section defines variables and describes data. We collect a set of panel data from 16 of ECA countries over the period 2003-2014. The annual data is used in this study. The data ranging from 2003 to 2014 for all countries obtained from Transparency International, United Nations, and IMF International Financial Statistics (IFS) iLibrary system. The data's are as follows. Annual Corruption Perceptions Index (known as CPI but we use as COR) is the best-known corruption index. It ranks countries by their perceived levels of corruption, The Human Development Index (HDI) measures poverty with three areas: first, as a long and healthy life second, is knowledge and third, as standard of living. The HDI focuses on the "progress in a community as a whole" (United Nations 1997: 20). The HDI is a useful indicator to compare nations for poverty. Consumer Price Index (CPI) is a well-known macroeconomic indicator. We use CPI as a proxy for macroeconomic stability.

\subsection{Methods and Findings}

This paper examines the link between poverty, corruption, and macroeconomic performance. We use an econometric model to study this relationship. Our empirical test investigates whether; poverty is correlated with corruption and macroeconomic performance or not. With this aim, we analyze within some selected ECA countries using panel data and estimating the following model:

$$
y_{i, t}=\beta_{1} y_{i, t-1}+\beta_{2} \alpha_{i, t}+\beta_{1} \rho_{i, t}
$$

\subsection{Panel Unit Root Analysis}

Main issue before estimating the model is to test if the variables are stationary or not. We carry out panel unit root tests on the dependent and independent variables. We follow the approach of Levin, Lin \& Chu panel unit root test and Choi unit root test (Fisher PP). Results of this test applied on our time series in levels are reported in the table below. The lag length are chosen by the result of Schwarz Information Criterion and shown in the parenthesis. Table illustrates that all variables are stationary. 


\begin{tabular}{|l|l|l|}
\hline Variables & Levin, Lin \& Chu & Choi (Fisher PP) \\
\hline Individual Intercept & & \\
\hline HDI & $-14.9029^{* * *}$ & $-6.54471 * * *$ \\
\hline COR & $-4.66606^{* * *}$ & $-2.07940^{* * *}$ \\
\hline CPI & $-6.05969^{*}$ & $-3.57378^{*}$ \\
\hline Individual Intercept and Trend & & \\
\hline HDI & $-65.0860^{* * *}$ & $-3.50424 * * *$ \\
\hline COR & $-4.16852^{* * *}$ & $-3.97568^{* * *}$ \\
\hline CPI & $-2.78963 *$ & $-3.00440^{*}$ \\
\hline
\end{tabular}

Table 2. Results for panel unit root test. The choice of lag levels is based on the Schwarz Information Criterion. The LLC tests were computed using the Bartlett kernel with automatic bandwidth selection. ***, ** and * indicate significance at the $1 \%, 5 \%$ and $10 \%$ levels.

\subsection{Empirical Results}

We now proceed to estimate the dynamic model specified here which has the logarithm of HDI as the dependent variable. Table 2 presents GMM first difference estimates with corruption measured by the Corruption Perception Index by Transparency International and macroeconomic performance measured by consumer price index. The coefficients have the expected sign.

The coefficients for corruption and consumer price index are both significant. The negative and significant impact of corruption on poverty is consistent with the results of many empirical studies. These studies lend support "sand to the wheels" hypothesis. The positive and significant impact of consumer price index on poverty is an interesting result in our model. This suggests that higher consumer prices decreases poverty. In other words, an increase in prices will cause a decrease in poverty.

\begin{tabular}{|l|c|c|c|c|}
\hline Variable & Coefficient & Std. Error & t-Statistic & Prob. \\
\hline HDI(-1) & 0.3259 & 0.00408 & 79.750251 & 0.0000 \\
\hline COR & -0.0342 & 0.00746 & -4.584012 & 0.0000 \\
\hline CPI & 0.0373 & 0.00639 & 5.839725 & 0.0000 \\
\hline
\end{tabular}

Table 3. Results of Dynamic Panel Data Analysis. This table reports estimation results for the dynamic panel data model, estimated using the Arellano-Bond GMM estimation method.

Three diagnostic tests are run for validity of the empirical models. First, the Sargan test is used to identifying restrictions under the null hypothesis of the validity of the instruments (Arellano and Bond, 1991). The second test is proposed by Arellano and Bond (1991) and examines the hypothesis that the residual from the estimated regressions is not correlated at second order. Third test is the Wald test indicates the goodness of fit. All of the diagnostics tests run and results reported below.

\begin{tabular}{|l|c|}
\hline Diagnostic Tests & Test Statistics \\
\hline Hansen J-Statistics & 15.82867 \\
\hline Arellano-Bond test of $1^{\text {st }}$ order autocorrelation & -3.266144 \\
\hline Arellano-Bond test of $2^{\text {nd }}$ order autocorrelation & -1.551839 \\
\hline Wald chi2 (prob) & 0.0000 \\
\hline No. of observations & 192 \\
\hline No. of countries & 16 \\
\hline
\end{tabular}

Table 4. Diagnostic Tests

\section{Conclusion}

One of the most important conclusions to be drawn from empirical studies is that corruption, in itself, does not lead to poverty, rather it gives rise to poverty through indirect channels by affecting social-economic, political and administrative conditions. Corruption usually affects economic growth and thus affects employment levels and income distribution, which might to lead to poverty. In addition, corruption affects the quality of government services and the shape of public expenditures which mainly the poor.

In the mainstream literature, it is concluded that corruption has an effect on poverty. Our aim is to extend the literature by using a well-known dynamic panel data estimation method to test our model for ECA countries. We present evidence that corruption has a direct effect on poverty. In addition, our results show that consumer prices index -as proxy for macroeconomic performance- have positive effect on poverty. This result is expected but quite interesting. This positive effect shows that price increases means that demand-pull inflation is the sign of a reducing in poverty. There is a simple rationale behind this case. An increase in income will cause simply demand-pull inflation. This increase in income also affects Human Development Index, a decrease in poverty.

As a result, corruption has a significant effect on the poverty in ECA countries. If a country wants to decrease its poverty it should improve factors such as laws and controls, as well as good governance. 


\section{Acknowledgments}

This work was supported by Research Fund of the Cukurova University.

\section{References}

- Aidt, 2009. "Corruption, Institutions and Economic Development", Oxford Review Of Economy Policy, 25(2), p.292

- Algan, N. et. al. (2014)-“Toplumsal Bir Mesele Olarak Yolsuzluk ve Büyüme İlişkisi”, http://avekon.org/papers/996.pdf (01.07.2015)

- Arellano, M. and Bond, S. (1991). Some tests of specification for panel data: Monte Carlo evidence and an application to employment equations, Review of Economic Studies, 58, 277-297.

- Campos et all., 2010 "Whither Corruption? A Quantitative Survey of the Literature on Corruption and Growth", IZA Discussion Paper No:5334

- Castro et all, 2012. "Does Corruption Sand the Wheels in the Public Works Execution?", Economia Informale, Evasione Fiscale e Corruzione, Preliminary Draft

- Chetwynd et all., 2003 “Corruption and Poverty: A Review of Recent Literature”, Management Systems International, Final Report, Washington, DC.

- Dinçer and Günalp, 2008. "Corruption, Income Inequality, and Poverty in the United States”, $\underline{\text { FEEM }}$ Working Paper No. 54.2008.

- Diridi, 2013. "Corruption and Economic Growth: The Transmission Channels", Journal of Business Studies Quarterly, Volume 4, Number 4,p.121.

- Erkan,B., Kara, O. "Yolsuzluk ve Yoksulluk Göstergeleri Arasındaki İlişsi:Türkiye Örneği”, http://www.oguzkara.com/ypksulluk\%20yolsuzluk.pdf (01.07.2015)

- Gökçekuş et all.,2015. "Level and quality of openness and corruption in ECA coutries", Applied Economic Letters, June, p.37.

- Gupta et all., 1998. "Does Corruption Affect Income Equality and Poverty”,IMF Working Paper Series, WP:9/76

- Johnson et all., 2013. "Corruption, Regulation, and Growth: An Emprical Study of the United States", Econoomics Of Governance, Volume 15, Issue 1, p.51

- Kato and Sato, 2014. "Greasing the Wheels? The Effect of Corruption in Regulated Manufacturing Sectors of India", Kobe University, Research Institute for Economics and Business Administration, Discussion Paper Series:2014-07.

- Kibet, 2013, "Effect of budget deficit and corruption on private investment in developing countries: A panel data analysis", African Journal of Business Management, Vol.7 (27), p.2720.

- Knack and Kisunko, 2011. "Trends in Corruption and Regulatory Burden in Eastern Europe and Central Asia", The International Bank for Reconstruction and Development/The World Bank

- Meon and Sekkat, 2005. "Does corruption Grease or sand the wheels of growth?”, Public Choice,122, p.69

- Negin et all., 2010. "The Causal Relationship between Corruption and Poverty:A Panel Data Analysis", MPR Paper No:24871

- Mallik and Saha, 2012. "Growth and corruption: a complex relationship" In: 8th Annual Conference on Economic Growth and Development, Indian Statistical Institute, December 17-19, 2012, Indian Statistical Institute, New Delhi, India

- Rothstein and Holdberg, 2011. "Correlates of Corruption", The Quality of Government Institute (QOG) Workng Paper Series: 2011/12.

- Treisman, 2000. "The causes of corruption: a cross national study", Journal of International Economics,35, 1-22.

- Ugur and Dasgupta, 2011. "Evidence on the economic growth impacts of corruption in low-income countries and a beyond: a systematic review", EPPI-Centre, Social Science Research Unit, Institute of Education, University of London.

- UNDP,2007. Human Development Report 1997. Oxford University Press, New York

- Walter and Bettina, 2004. "Fighting Poverty and Corruption", Deutsche Gesellschaft für Technische Zusammenarbeit (GTZ) GmbH, Division:42. 


\title{
The Effect of Globalization on International Trade: The Black Sea Economic Cooperation Case
}

\author{
Dr. Mesut Savrul (Çanakkale Onsekiz Mart University, Turkey) \\ Prof. Dr. Ahmet Incekara (Istanbul University, Turkey)
}

\begin{abstract}
Globalization including political, social and economic processes is frequently associated with multinational companies and investment, international trade and regionalism, global finance and money. While globalization process reduced activity and control of national governments on their economy and trade their place is substituted by international companies. The national economies on the other hand try to keep pace with the change in economic system by deregulating their international trade barriers via regional trade agreements and economic integrations.

Based on the assumption that the globalization has liberalized their infrastructure of trade, this study investigates the balance of trade in the member countries of The Black Sea Economic Cooperation Organization (BSEC). The data is collected from international trade database of UNCTAD and globalization index of KOF Swiss Economic Institute. The variables are evaluated using panel data analysis and the results have shown that globalization has a significant impact on international trade and the globalization process had a positive effect on the liberalization of trade in the member countries of the BSEC.
\end{abstract}

\section{Introduction}

One of the widespread definitions of globalization takes it as an irreversible force, which is being imposed upon the world by some countries and institutions through which an increasingly free flow of ideas, people, goods, services, and capital leads to the integration of economies and societies (IMF, 2002). Economic aspect of the phenomenon refers to the increasing interdependence of world economies as a result of the growing scale of cross-border trade of commodities and services, flow of international capital and wide and rapid spread of technologies. It reflects the continuing expansion and mutual integration of market frontiers, and is an irreversible trend for the economic development in the whole world at the turn of the millennium (Shangquan, 2000: 1).

As an inevitable result of this process the global trade flows benefited from this process substantially. According to the data from WTO merchandise exports grew more than $8 \%$ a year by 1950s. Although fluctuations and recession were experienced in this expansion period the increase went on to a degree and the average expansion of world merchandise exports averaged $6 \%$ by $2000 \mathrm{~s}$. Although the global figures seems appealing, individual performances of the countries aren't so clear because of the deepening in the globalization process which resulted in national governments' losing control over their economy and trade which they tried to keep pace with the change in economic system by deregulating their international trade barriers through regional trade agreements and economic integrations.

Regional integration includes a multitude of steps that increase the competitiveness of participating countries, not just preferential trade access and helps small and remote countries scale up supply capacity in regional production networks which in turn, allows these countries to access global markets (Deichmann and Gill, 2008: 45). However the consequences of the globalization and joining free trade agreements or economic integration are varies from country to country due to their geographical position, the natural resources they have, their level of economic development, etc. In this framework considering that it is formed completely by developing economies, how the globalization process affected international trade performance of BSEC member states is questioned in this study.

\section{Globalization and Trade}

A radical transformation of economic life is presented with the process of globalization which resulted in the generalization of market economy, increase in production, circulation of information, products, people and capital, implementation of technical systems becomes more efficient (Dăianu, 2009: 211). Nations are no longer self-sufficient in the global economy and they are included in trade at different levels to sell what they produce to obtain what they are in need. The countries usually produce more efficiently in some economic sectors than its trade partners. As supported by conventional economic theory, eventually trade promotes economic efficiency and it can be concluded that the globalization of production is contributing to the globalization of trade (Rodrigue et.al., 2006: 144).

The increase and expansion of the globalisation process were the result of a number of factors. These include the advances in the liberalisation of world trade and capital movements, technological progress that implied a 
significant decrease in transport and communication and co-ordination costs. The growing openness of developing and emerging market economies with special emphasis on large economies such as China and India and countries of Central and Eastern Europe is also reflected by the acceleration in globalisation process. The strong increases in both activity and international trade flows practiced the developing and emerging economies reflected this phenomenon to global level (Manteu 2008: 73-74).

In the last period three trends in world economy can be mentioned to shape globalization flows. The value of international trade has grown by a factor of 16 times since the late 1970s. In this regards ongoing growth of international trade, both in absolute terms and in relation to global national income can be taken as the first trend. The growing role of multinational corporations is the next since they are taking the lead in international trade particularly in terms of the share of trade taking place within corporations. And the last is higher relative growth of trade in Pacific Asia as many economies developed an export-oriented development strategy that has been associated with imbalances in commercial relations (Rodrigue et.al., 2013: 19). Empirical evidence suggests that globalization has significantly boosted economic growth in East Asian economies such as China, the Republic of Korea, and Singapore. However not all developing countries are equally engaged in globalization and it can't be said that all of them are benefitting from it equally. In fact, except for most countries in East Asia and some in Latin America, developing countries have been rather slow to integrate with the world economy (Soubbotina, 2000: 66). Regarding that the inequalities between the developed, developing and less developed countries the influence of globalization can be questioned.

Current globalization literature cites that pressure of capital mobility, technological progress and intense market competition describes an irreversible force beyond the influence of domestic policy makers. In this policy context globalization is often used as a synonym for greater openness and closely linked to the liberalization of domestic and foreign transactions (Bairoch and Wright, 1996: 3-4). Trade between the countries considering comparative advantage promotes growth, which is attributed to a strong correlation between the openness to trade flows and the effect on economic growth and economic performance. Likewise capital flows and their impact on economic growth adhere to each other with a significant relationship (Pologeorgis, 2010).

International trade is regarded as the engine of growth for long, even going back at least to Adam Smith. However, during the 20th century, it has not been a very popular one and instead protectionist theories became dominant and the majority of the developing countries implemented industrialization policies based on a very limited degree of international openness for a long time (Edwards, 1993: 1358). Conversely after the end of the Second World War international trade get into a new era in which world merchandise exports grew more than $8 \%$ a year. By 1973 this expansion slowed down a little bit due to the oil price shocks, the burst of inflation caused by monetary expansion and inadequate macroeconomic adjustment policies, By 1990s the developments in information technology sector led world trade to a second expansion period. The average expansion of world merchandise exports averaged 6\% in 2000 - 2007 period (WTO, 2008: 15).

\section{Black Sea Economic Integration}

Although globalization influence world economy both direct and indirect ways, some of the most common impression of it is related with international trade. Rodrigue et.al., (2006: 145) summarizes these impressions as follows;

- Production systems are more flexible and embedded, which encourages exchanges of commodities and services. Foreign direct investments are commonly linked with the globalization of production as corporations invest abroad in search of lower production costs and new markets.

- There is a growing availability of goods and services that can be traded on the global market.

- Transport efficiency has increased significantly because of innovations and improvements in the modes and infrastructures. As a result, the transferability of commodities has improved.

- Integration processes, such as the emergence of economic blocs and the decrease of tariffs at a global scale, promoted trade. The higher the level of economic integration, the more likely the concerned elements are to trade. The transactional capacity is consequently facilitated with the development of transportation networks and the adjustment of trade flows that follows increased integration.

Taken collectively it is clear that globalization is triggering formation of economic integrations. A vast amount of capital is circulated within the investment system in the globalizing market system in a relatively short amount of time. Because states lose control over exchanges and economic development, they hold a reduced its role in its own economy. Regional trade agreements help nations gradually work towards global free trade through allowing countries to increase the level of competition slowly and give domestic industries time to adjust. The increasing membership of less economically developed countries within the European Union, Southern Common Market, and Asia-Pacific Economic Cooperation is testament to the economic stability offered by regional 
economic integrations (Collins, 2010). Another good example for this progress is the establishment of Black Sea Economic Cooperation (BSEC).

The Black Sea region which hosts crossroads between Asia and Europe, people of different nationalities, trades, cultures and religions has been the cradle of different civilizations since ancient times. Being on a specific geography periods of peace and tranquillity were followed by protracted conflicts and wars in the region. However even in that climate the Black Sea area was well-known for its developed trade relations and contacts (Coutsoukis, 2013). Collapse of the Soviet Union due to particularly globalization, beside political structure, economic concept is also changed rapidly and these relations turned into more realistic attempts. BSEC is found in 1992 and The BSEC Headquarters - the Permanent International Secretariat of the Organization of the Black Sea Economic Cooperation was established in 1994. Aiming at fostering interaction and harmony among its members, as well as to ensure peace, stability and prosperity, encouraging friendly and good-neighbourly relations in the Black Sea region, today BSEC serves as a forum for cooperation in a wide range of areas such as agriculture and agro-industry, banking and finance, combating organized crime, culture, customs matters, education, emergency assistance, energy, environmental protection, exchange of statistical data and economic information, healthcare and pharmaceutics, information and communication technologies, institutional renewal and good governance, science and technology, SMEs, tourism, trade and economic development and transport for its 12 Member States: Albania, Armenia, Azerbaijan, Bulgaria, Georgia, Greece, Moldova, Romania, Russia, Serbia, Turkey and Ukraine (BSEC, 1992).

In the establishment phase establishment of a free trade zone in BSEC was projected which would eventually evolve the organization into a stronger form of integration. However the uncertainties encountered by the exSoviet Bloc members and newly independent states, the BSEC did not start off by requiring strong commitments from its members towards any kind of economic integration and it was later agreed that the BSEC would lead to the formation of a regional organization for economic cooperation in a loosely defined sense. Keeping in view that many of the member states were centrally planned economies with practically no private sector development at the time the BSEC was formed and with no well-established links to global markets, this could be considered natural (Sayan, 2005: 336). On the other hand regarding the deepening in globalization and the current economic structure of the region much can be expected.

Although the aims set by the BSEC is comprehensive and appealing whether it fulfils them is questionable. At this point some basic assumptions lying behind economic integration theory may be helpful. Incekara (1995) summarized the common impact of economic integrations on national economies under two main categories as static and dynamic effects;

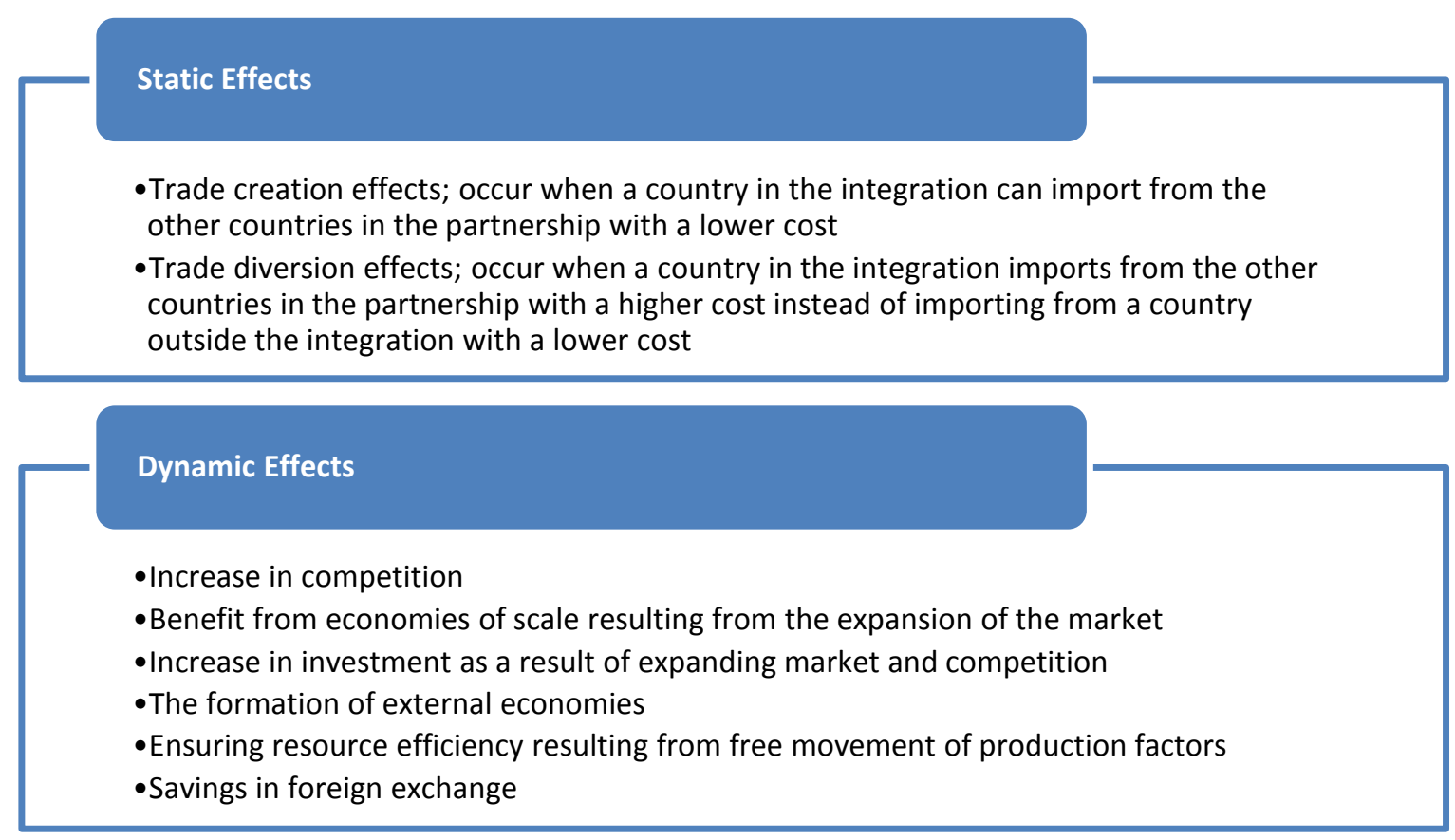

Figure 1. The Impact of Economic Integrations on National Economies

Taking the assumptions into consideration, it is evident that the BSEC countries are benefitting from the organization however the degree of it is controversial since there are significant differences between the economies of the members of BSEC. However the main motivation behind the establishment of the organization is regional proximity, which would in turn lead to gains from trade. The production capabilities of the member states are divergent both in manufacturing and service sectors, and factors of production to enjoy such gains as 
well as the natural resources that are unevenly distributed among them. There are cases where the basic need of a member country can be met by the factors owned by another member country (Dikkaya and Orhan, 2004: 67).

The private sector is regarded to play a major role in the development of the member economies of the BSEC and so that it aims provide a favourable economic environment for business. Economically, BSEC countries had more than $5 \%$ of total world trade amounting to US $\$ 300$ billion in 2000 . Strategically, over $5 \%$ of the world population lives in the BSEC countries and many of them, such as Turkey, are geo-politically important given their proximity to Europe, the Middle East and Asia. The countries of BSEC are also rich in strategic resources such as oil, coal and natural gas (Sriram and Bilgin, 2002: 140).

A short summary presents that emergence and deepening of globalization contribute to world trade on a large scale. Evidences show that although the developed economies with sophisticated economic infrastructure were benefited from globalization process well enough, the status of developing and less developed ones is variable. The same point is eligible for economic integrations which is already a consequence of globalization. In this framework although it is clear that establishment of BSEC is beneficial for its member states to a degree, considering that it is formed completely by developing economies, how the process of globalization affected BSEC can be questioned.

\section{Literature Review}

Kim and Hangshin (2002) investigated the consequences of globalization and regionalization on world economy. They used longitudinal data on international commodity trade using the social network approach in their study. The result of their study presented that the world became increasingly globalized between 1959 and 1996 and countries joined trade partnerships in this period further that the previous periods. As a result the world trade network became denser. On the other hand another finding of the study presented that all countries weren't integrated into the world economy equally. While developed and developing countries integrated to each other more and more the less developed one stayed behind of the process.

In their study Sriram and Bilgin (2002) investigated foreign trade flows between Turkey-BSEC and TurkeyEU covering the 1991-2001 periods. Their study presents that although fluctuations occurs in general Turkey's both imports and exports towards BSEC is in a rising trend while the volume of trade with EU is more constant.

Mukherjee (2008) investigated the impact of globalization on international trade taking historical perspectives of global economic integration into consideration. The study presents that the trend is towards free trade among all over the world, driven primarily by international trade which is an outcome of competitive liberalization. In this framework globalization plays an important role in enhancing cross-border trades by reducing or removing international trade barriers.

Karagoz Kadir and Karagoz Murat (2009) studied how the gravitational factors affected bilateral trade in BSEC covering a period of 16 years. The study they conducted using panel gravity model introduced that economic size and population of the importer countries have a positive impact on trade volume, where as the distance between them works on the opposite way.

Akram Ch. et. al (2011) investigated the impact of globalization on the world using the international trade, FDI and economic development data. The study they conducted particularly focused on the impact of the globalization process on the fastest growing industries of world. The results of the study showed that while USA was dominant in world export before the globalization process is dense Germany, Japan, South Korea and China have seriously challenged the position of USA in the following period.

Regarding the studies covered in this section it can be concluded that the impact of globalization on world economy is dealt within the framework of particularly international trade from various aspects and this study provides a different perspective of the subject.

\section{Model}

This study aims to analyze both time dimension with cross-sectional dimensions of various countries. Due to the presence of time and cross-sectional dimensions of the data set covered in the study, use of panel regression analysis is found eligible for the study.

\subsection{Data Set}

The analysis of the study uses globalization indexes and trade volume data of 12 BSEC Countries covering 1992-2014 period. While the globalization data is collected from KOF Swiss Institute, International Trade in Goods and Services Statistics is collected from UNCTAD database as an index of trade. Although data sets including international trade can go back to beginning of the century regarding the establishment of the BSEC and limitation in globalization index, 1992 is taken as the beginning year. 


\subsection{Method}

In order to avoid spurious relationships between the variables, the variables used in the study should be stationary. Stationary of the variables has been tested with common unit root process developed by Levin, Lin and Chu (LLC) (2002) and assume individual unit root process developed by Im, Pesaran and Shin (IPS) (2003) are performed. The results are summarized in Table 1.

\begin{tabular}{|l|l|c|c|}
\hline Method & Variable & TRADE & GLOB \\
\hline \multirow{2}{*}{ Levin, Lin \& Chu } & stat & -9.8783 & -5.1614 \\
\cline { 2 - 4 } & p-value & 0.0000 & 0.0000 \\
\hline & & & -6.4657 \\
\hline \multirow{2}{*}{ Im, Peseran \& Shin } & stat & -8.5500 & 0.0000 \\
\cline { 2 - 4 } & p-value & 0.0000 & 0.000 \\
\hline
\end{tabular}

Table 1. Panel Unit Root Test

The results of LLC and IPS tests show that displayed that all levels of variables are stationary at $1 \%$ significance level in their first difference and they can be used in panel data analysis. In the current analysis countries form the cross section dimension while years are the period dimension. Individual effects of both countries and the years should be estimated. These effects is summarized in equation below in which "i" units are individual and "t"s are the periods.

$$
T R A D E_{i t}=\beta_{1} G L O B_{i t}
$$

\begin{tabular}{|c|c|c|c|}
\hline \multirow{2}{*}{ Cross-section F } & Statistic & d.f. & Prob. \\
\hline & 1.088568 & $(11,251)$ & 0.3708 \\
\hline \multirow{2}{*}{ Breusch and Pagan LM Test } & \multicolumn{2}{|c|}{ chibar2(01) } & Prob $>$ chibar 2 \\
\hline & \multicolumn{2}{|l|}{0.00} & 0.4986 \\
\hline
\end{tabular}

Table 2. F and LM Tests

The equation is estimated using FE and LM tests respectively to determine the appropriate model. Because of the $p>0.5$ value in the Fixed Effects Test the analysis went along with the LM Test. As the LM test is also resulted in $\mathrm{p}>0.5$ Pooled EGLS model is found appropriate for the current data set.

\begin{tabular}{|c|c|c|c|c|}
\hline Variable & Coefficient & Std. Error & t-Statistic & Prob. \\
\hline $\mathrm{C}$ & 104.8612 & 35.22378 & 2.976999 & 0.0032 \\
\hline GLOB & 66980.28 & 32372.66 & 2.069038 & 0.0395 \\
\hline R-squared & 0.016077 & \multicolumn{2}{|c|}{ Mean dependent var } & 70.22043 \\
\hline Adjusted R-squared & 0.012321 & \multicolumn{2}{|l|}{ S.D. dependent var } & 506.6657 \\
\hline S.E. of regression & 503.5347 & \multicolumn{2}{|c|}{ Akaike info criterion } & 15.28873 \\
\hline Sum squared resid & 66429354 & \multicolumn{2}{|c|}{ Schwarz criterion } & 15.31582 \\
\hline Log likelihood & -2016.112 & \multicolumn{2}{|c|}{ Hannan-Quinn criterion } & 15.29961 \\
\hline F-statistic & 4.280919 & \multicolumn{2}{|c|}{ Durbin-Watson stat } & 2.210660 \\
\hline Prob(F-statistic) & 0.039523 & & & \\
\hline
\end{tabular}

Table 3. Pooled EGLS

The results Pooled EGLS Test presented in Table 3 show that the estimated relationship between globalization (GLOB) and international trade (TRADE) is significant $(\mathrm{p}<0.5)$ and the direction of this relationship is positive. Finally autocorrelation and heteroscedasticity tests should be implemented to finalize the analysis.

\begin{tabular}{|l|l|l|}
\hline \multirow{2}{*}{ Wooldridge test for autocorrelation } & $\mathrm{F}(1,11)$ & Prob $>\mathrm{F}$ \\
\cline { 2 - 3 } & 2.283 & 0.1590 \\
\hline \multirow{2}{*}{ White's test for heteroscedasticity } & chi2(2) & Prob > chi2 \\
\cline { 2 - 3 } & 1.87 & 0.3928 \\
\hline
\end{tabular}

Table 4. Correlation and Heteroskedasticity Tests

Wooldridge test for autocorrelation and White's test for heteroscedasticity tests were carried out to test the reliability of the analysis results. The tests rejected both heteroscedasticity and autocorrelation problems and proved that the results generated by the analysis are reliable.

\section{Conclusion}

Although globalization phenomenon is not new, it's clear that it reasonably expanded its domain after 1980s. The economic outcome of this process set increasing interdependence of world economies forth and scale of cross-border trade of commodities and services increased remarkably. However reflection of these developments on all economies is not the same. While the developed economies with sophisticated economic infrastructure 
were benefited from globalization process well enough, the status of developing and less developed ones varies from better to worse. The same topic is eligible for economic integrations which is already a consequence of globalization. In this framework although it is clear that establishment of BSEC is beneficial for its member states to a degree, considering that it is formed completely by developing economies, the impact of globalization process international trade volume of BSEC member states is investigated in this study.

The data collected from UNCTAD and KOF Swiss Economic Institute databases is analyzed using panel regression and the results of the study presented that as it is anticipated according as the economic theory the estimated relationship between globalization on international trade is significant $(p<0.5)$ and the direction of this relationship is positive. In this context it can be concluded that although many of the BSEC member states have limitations such as their being ex-Soviet Bloc members and newly independent states, globalization had positive effect on the liberalization of trade barriers in the member countries of the BSEC and the organization benefits from the process in a favourable way in the sense of international trade.

\section{References}

- Akram Ch., Muhammad, Faheem, Muhammad Asim, Bin Dost, Muhammad Khyzer, Abdullah, Iqra, 2011. "Globalization and Its Impacts on the World Economic Development", International Journal of Business and Social Science, Vol. 2 No. 23, pp. 291-297.

- Bairoch, Paul and Kozul-Wright, Richard, 1996. Globalization Myths: Some Historical Reflections on Integration, Industrialization and Growth in the World Economy, UNCTAD/OSG/DP/113.

- BSEC, 1992. "BSEC at a Glance”, http://www.bsec-organization.org/Information/Pages/bsec.aspx.

- Collins, Bennett, 2010. "Does Regionalism Challenge Globalization or Build Upon It?", E-International Relations, http:/www.e-ir.info/2010/07/29/does-regionalism-challenge-globalization-or-build-upon-it.

- Coutsoukis, Photius, 1999. "Why BSEC", http://www.photius.com/bsec/bsec.html\#about.

- Dăianu, Dana-Codruţa Dudă, 2009. “The Impact of Globalization through International Trade, Annals. Economic Science Series", International Conference, The Knowledge Society in the Space of United Europe, May 29th -30th 2009, Vol. XV/2009, pp. 211-215.

- Deichmann, Uwe and Gill, Indermit, 2008. “The Economic Geography of Regional Integration”, Finance and Development, Vol.45, No.4, 45-47.

- Dikkaya, Mehmet and Orhan, Mehmet, 2004. "Economies of the Black Sea Economic Cooperation (BSEC) Countries and their Bilateral Trade", Journal of Economic and Social Research, 6 (2), pp. 63-86.

- Edwards, Sebastian, 1993. “Openness, Trade Liberalization, and Growth in Developing Countries”, Journal of Economic Literature, Vol. 31, No. 3, pp. 1358-1393.

- IMF, 2002. Globalization: A Framework for IMF Involvement, 02/01, https://www.imf.org/external/np/exr/ib/2002/031502.htm.

- Incekara, Ahmet, 1995. Globalleşme ve Bölgeselleşme Sürecinde NAFTA ve Etkileri, İTO Yayınları, Yay. No: 1995-14, Istanbul.

- Karagöz, Kadir and Karagöz, Murat, 2009. "Determining Factors of Trade Flows Blacksea Economic Cooperation (BSEC) Region: A Panel Gravity Model”, Akademik Araştırmalar ve Çalışmalar Dergisi, Cilt 1, Sayı 1 (2009), pp. 63-75.

- Kim, Sangmoon and Hangshin, Eui, 2002. "A Longitudinal Analysis of Globalization and Regionalization in International Trade: A Social Network Approach”, Social Forces, 81 (2), pp. 445-468.

- KOF, 2015. KOF Index of Globalization, Zurich.

- $\quad$ Lupu, Gratian, 2006. "EU, BSEC and Energy Co Operation", Sfera Politicii, 125/2006,134-140.

- Manteu, Cristina, 2008. "Economic Effects of Globalisation: Lessons from Trade Models", Economic Bulletin, Banco de Portuga.

- Mukherjee, Ishita, 2008. "Impact of Globalization on International Trade", The ICFAI Journal of International Business, Vol. III, No. 1, pp. 28-45.

- OECD, 2005. Measuring Globalisation, OECD Handbook on Economic Globalisation Indicators, OECD Publishing, Paris.

- Pologeorgis, Nicolas, 2010. “How Globalization Affects Developed Countries”,http://www.invest opedia.com/articles/economics/10/globalization-developed-countries.asp 
- $\quad$ Rodrigue, Jean-Paul, Comtois, Claude and Slack, Brian, 2006. The Geography of Transport Systems, Routledge, Newyork.

- $\quad$ Rodrigue, Jean-Paul, Notteboom, Theo and Shaw, Jon, 2013. The SAGE Handbook of Transport Studies, SAGE Publications, London.

- Sayan, Serdar, 2005. "The Effects of the BSEC on Regional Trade Flows", Agora without Frontiers, Vol. 10 (4), pp. 334-347.

- Shangquan, Gao, 2000. "Economic Globalization: Trends, Risks and Risk Prevention”, Economic \& Social Affairs, CDP Background Paper No. 1, ST/ESA/2000/CDP/1, United Nations.

- Soubbotina, Tatyana P., 2000. Beyond Economic Growth an Introduction to Sustainable Development, The World Bank, Washington, D.C.

- $\quad$ Sriram, Ven and Bilgin, Zeynep, 2002. "Regionalism and Emerging Markets: An Analysis of Turkey's Trade with the BSEC and the EU”, Marmara Journal of European Studies, Vol: 10, No: 1, pp. 137-161.

- UNCTAD, 2015. International Trade in Goods and Services Statistics, Switzerland.

- WTO, 2008. "World Trade Report 2008, Trade in a Globalizing World", https://www.wto.org/ english/res_e/booksp_e/anrep_e/world_trade_report08_e.pdf. 


\title{
Knowledge Economy and Turkey In Terms Of Innovation and Education
}

\author{
Ph. D. Candidate Burcu Sakız (Istanbul Aydın University, Turkey) \\ Semih Sakız (Garanti Technology, Turkey)
}

\begin{abstract}
Communication and information technologies have started to emerge since the 40s resulting major changes in the way business has been conducted and effected global economy. Transitions to knowledge-intensive business models become popular since late 1950s. Additionally intellectual capabilities become more important than physical inputs. Having sufficient national production and technology to create a welfare society similar to developed countries is crucial for any modern nation. One of the main developmental leverages for the globalization becomes the knowledge based economic approach. Developed by World Bank "Knowledge Assessment Methodology" is very important methodology in order to measure the progress of countries towards having a knowledge based economy. World Bank's four Knowledge Economy pillars: economic and institutional regime, education, innovation, and Information and Communication Technologies (ICTs) developed for countries to make basic assessment of countries' readiness for the knowledge economy and help them the transition to a Knowledge Economy. In this study, knowledge economy concept and its properties are presented. Furthermore this paper introduces the analysis of knowledge economy from Turkey's perspective especially for the role of innovation and education pillars in the development of Turkey.
\end{abstract}

\section{Introduction}

According to Alvin Toffler, one of the most important management scholars of our age, history should be held in three segments and by his saying these segments should be called as waves. These waves are first wave: Agricultural Society; second wave: Industrial Society; third wave: Knowledge Society (Toffler, 1984). Since the first stage of history, agriculture has been in satisfying human needs and societies that could be able to use it most effectively have created a power field over other societies. Then comes industrial revolution. Mechanization has been the mainstay of Industrial Society. In the knowledge society that we are in service/knowledge technologies have come into prominence. Weight of input from natural sources and physical capital to industry will go towards qualitative human beings in the first period of information in the later periods. A requirement for computers triggered a new wave which can do calculations needed by simulations within the context of The Manhattan Project which was started with the aim of making atomic bomb in The United States of America during The Second World War. It can be said that knowledge age has started with the improvement of first programmable computer ENIAC in 1945. Use of computer in academic and business world and in personal life has increased over time, major changes have been observed in social and economic structure. Knowledge Society has witnessed to alteration and transformation of societies. Knowledge brings speed and effectiveness. Therefore, it plays the key role for the economy. Relations of production and business connections have been transforming, the resulting velocity, provided efficiency support each other with technological improvements.

Today's global competitive environment, becoming successful and increasing the productivity will be possible not only by structure-process and technological changes but also and the most important by teaching and developing of high quality human sources and by preparing them for the future. To measure how intense countries use their knowledge and communication technologies and contributions do these technologies provide has become a must to be able to make a comparative analysis. In this process which can be named as modernization of economic and social life, Turkey has been reconstructing certain things in order to keep pace with alterations and to be competitive benefiting from advantages of the process (Çirasun, 2011). These improvements and evaluating these improvements by measuring them are crucial to compare Turkey to other countries in the world with regards to Turkey's progress.

\section{Literature Review}

The first study we focused on is Gür's (2001) study about constructing a new framework which is to be utilized for the assessment of possible strategies which can be applied during the transition to a knowledge-based economy. He developed mixed integer programming model in order to determine the required levels of human resources and information and communications technology investments for given levels of R\&D investment of the country that determines most significant characteristic of the phenomenon. The results indicate that Turkish government should increase R\&D to considerable levels in order to trigger the transition to a knowledge-based economy. Second important finding is transformation towards a knowledge-based economy with an inefficient innovation system may require considerable amounts of additional resources compared to transforming with a more efficient system. 
Salduz (2005) studied that Turkey's position as a candidate country in adaptation to the Lisbon Strategy. She gives general information concerning knowledge economy and EU's activities aiming to reach Lisbon strategy and EU-Turkey comparison with using knowledge economy indicators. Also she examined Turkey's EU (European Union) adaptation process. Study reveals that Turkish economy has many disadvantages both for knowledge production and using information technologies and economy needs reconstruction to close this gap. Furthermore for knowledge economy that reconstruction requires renovations in science and technology policies, education policy and industrial policy needs reconstruction, too.

Özcan (2007) studied organizations in Turkey in terms of their extent to be knowledge-based by making a comparative analysis between Turkey and UK. Top 500 organizations in terms of owning most total assets to the parameters of knowledge economy in London and Istanbul are compared. The results indicate that organizations in Turkey has capability to compete with organization in top knowledge economies in terms of awareness on strategic importance of knowledge, but in terms of innovation organizations in Turkey are behind organizations in the UK.

Düzgün (2008) studied the shift of employment towards knowledge intensive industries, knowledge occupations and ICT utilization in Turkey. Results show that although there is an increase in knowledge and services employment, manufacturing employment also continues to grow in Turkey and middle knowledge intensity sectors shows the largest employment growth over the analyzed period. Also according to the ranking of Turkey in basic ICT indexes despite the increase in utilization of main ICTs, Turkey is still behind usage level in developed countries.

Kaynak (2008) studied that the meaning of knowledge economy and the economic effects of knowledge economy for Turkey. He used World Bank's Knowledge Assessment Methodology and used in analysis of knowledge economy performances of the countries. To accomplish this, he analyzed Basic Scorecard, the Knowledge Economy Index and Custom Scorecards for Turkey with 83 parameters. The results indicates that Turkey had a moderate performance according to the Basic Scorecard.

Arıkan (2008) examined the dynamics of the innovation construct in Turkey with 122 firms from a wide variety of sectors, through exploring the characteristics of organizations in terms of their openness to innovations. The results show that innovation leads to better business performance. An organization's market orientation, learning orientation, and entrepreneurial orientation lead to more openness to innovations.

Kaynak (2011) studied Turkey's science and technology situation and did a benchmark with EU. Result of his work stated that EU-27 member countries perform better than Turkey in terms of the variables as R\&D expenditures, patents adopted by United States Trademark Office (USPTO), total researchers working at R\&D, advanced technology patents, exports of advanced technology products, patent applications to European Patent Office (EPO), human resources in science and technology, doctorate students at science and technology, but Turkey perform better only in terms of woman researcher rate.

Memişoglu (2012) studied major determinants of knowledge based economy that are based on World Bank Knowledge Assessment Framework, on economic performance indicators such as GDP, GDP per capita and economic growth rate in Brazil, Russia, China, India, South Africa and Turkey (BRICST) between years 20002010 by using Panel Data Model. In the BRICST countries ICT infrastructure and secondary education are found to be important infrastructure channels that affect GDP per capita positively. Also it is indicated that R\&D personnel number as an indicator for innovation potential has positive influence on the GDP. Additionally country's ability to innovate, benefit from ICT and enhance economic performance can be affected by accumulation of educated people in R\&D. The major factors that affect economic performance in the BRICST countries found as ICT infrastructure expansion together with educated R\&D personnel.

Işık (2012) studied effects of R\&D, Innovation, Patent, Information Technologies for Turkey in years between 1990-2010. The competitive advantage factors in knowledge economies are analyzed by various methods. As a result of theoretical and empirical analyses, it is determined that the factors of competitive advantage in knowledge economies, contribute to the economic growth and the development of our country's position in the world in respect to knowledge economy.

Özmusul (2013) studied school policies and practices and also their effects on the learning outcomes (reading scores) at upper secondary schools in Turkey according to the PISA test results for year 2009. This research was performed as a descriptive study and examined 150 school principals and 4859 students at upper secondary schools. One of the result of this study is when students are admitted to the school; the high Socio-Economic Degree (SED) schools consider more the student's academic achievement and preference given to family members of current or former students than middle and low SED schools do.

\section{Economy based on Knowledge}

In the past for industrial society physical capital was important. But for knowledge society; information is important besides productivity and innovation are the most basic factors of growth. The current conditions of the 
information society have created the knowledge economy. In knowledge economy, capacity of producing, using, managing knowledge has become the major determinant of productivity and competitiveness. Knowledge economy is a global economy and it is a web economy. It is emerged because of intensive knowledge in economic activities, improvements in information and communication technologies, and globalization of economic activities. Organisation for Economic Cooperation and Development (OECD) defines knowledge economy as "Economy in which knowledge is being used in production and distribution." (OECD, 1996).

One of the most frequent features of knowledge based economies is that firms tend to produce as firm assemblages not by themselves. Many small and medium sized companies are clustering and are in joint production under the management of a large company. In the long term economies of scales are replaced with economies of scope. The second feature is tendency of using less energy in production. As increasing returns strengthen in the short term, firm assemblages increase the tendency of emerging field economies and increasing returns. In addition, a small number of experts working in coordination with each other and qualified manpower utilization lead to increased productivity by strengthening the effectiveness of labor on fixed facilities. Besides, emerging technologies and changes in the production structure have changed the demand structure significantly (Acar, 2000). Information society will be the society of increasing efficiency, increasing returns and field economies.

Features of knowledge economy have been determined by Don Tapscott (1998) as follows: Knowledge is the basic production factor, Knowledge economy is a digital economy, Virtualization plays an important role in the knowledge economy. Developments in information and communication technologies affect all economic units. The economic structure becomes very dynamic, complex and difficult to predict. Production, consumption, distribution relationships and market structure which are described as the three main elements of the economy are being restructured based on knowledge. From the perspective of the consumer, the consumers may take goods and services more quickly, without being limited by time and space; consumer behavior can be analyzed better in digital environments. Economy is guided by consumers. Barriers to market entry and exit reduce and information becomes a function of competition (Kara, 2005). Only innovative and entrepreneur, knowledge based corporations which can adapt market place quickly, manage change, take part not only in local market but global market can be successful. Because borders have removed, producing innovative products and services that can compete with global firms have become an obligation. The economic effects of physical distance and the cost of access to information are reduced through information and communication technologies. Thus, new business start-up costs are decreasing and the chance to compete in new markets is rising. While in industry based economies success of firms is measured by "profit" physically, now "market value" has become the measure. While financial capital is seen as a formerly scarce resource, now qualified human resources become scarce resources (Taşç1, 2007). An increase is observed in labor demand that can be defined as knowledge workers. Besides, it also creates collaboration opportunities for information and communication technologies to conceive high qualified products with low costs (European Commission, 2001). It is possible to say that the economic model in which knowledge comes into prominence, forces existing business processes and professions to be more qualified (Meçik, 2013). Especially in the second term of the 20th century by the increase in technological researches and in the usage of the technical tools and equipments, there had been a knowledge explosion because of new inventions.

\section{Four Pillars of Knowledge Economy}

Knowledge itself is difficult component to quantify and calculate its market value. The reason is knowledge has no fixed capacity, shows more rapid change in that sense and tends to be obsolete in a short period of time. The first attempt for the development of a framework in order to interpret of data relating to science, technology and innovation has been made by OECD. OECD has prepared manuals for measuring knowledge inputs mostly emphasis on input measures of R\&D expenditures and human resources and aimed at informing policy makers about the scope and limitations of innovation activities and allow countries to conduct international comparisons on knowledge based economy.

\begin{tabular}{|l|l|}
\hline Knowledge Economy Indicators & Manuals \\
\hline R\&D expenditures & Frascati Manual (1993) \\
\hline Technology balance of payments & TBP Manual 1990 \\
\hline Innovation & Oslo Manual 1992 (revised in 2005) \\
\hline Patent & Patent Manual 1994 \\
\hline Human Resources & Canberra Manual 1995 \\
\hline
\end{tabular}

Table 1. List of OECD Manuals Source: OECD, 1996

Along with OECD, many other institutions such as UNESCO, World Bank, ITU (International Telecommunication Union), Eurostat and United Nations have introduced a range of indicators are widely use to analyze country's potential for knowledge-based economy. Decision makers should evaluate their situation in terms of information and communication of their countries when determining the target for knowledge economy 
and knowledge society. They build several indexes in this regard. Such sample institutions which develop these indexes are McConnell International (MI) a global technology policy and management consulting firm, Harvard University International Development Center, The Economist Intelligent Unit, The United Nations Conference on Trade and Development (UNCTAD), The United Nations Development Program (with its Technology Achievement Index), World Economic Forum, The Mosaic Group and The World Bank (Beig, et.al, 2007).

Education, economic incentives and institutional regime, innovation, information and communication technologies are held as main pillars of knowledge economy by World Bank (World Bank, 2010). Knowledge Assessment Methodology-KAM is a method built by WB that aims to provide identifying problems and opportunities countries may face towards transition to knowledge economy. World Bank Institute started program in 1999. KAM has 69 structural/qualitative variables to benchmark performance on 4 pillars and variables normalized from 0 (worst) to 10 (best) for 100 countries. The unique strength of the KAM lies in its cross-sectoral approach that allows a holistic view of the wide spectrum of factors relevant to the knowledge economy. These pillars are briefly summed up as follows:

\begin{tabular}{|l|l|}
\hline Pillars & Indicators \\
\hline Economic and institutional regime & $\begin{array}{l}\text { - Tariff and non-tariff barriers } \\
\text { - Regulatory quality } \\
\text { - Rule of law }\end{array}$ \\
\hline Education and skill of population & $\begin{array}{l}\text { - Adult literacy rate } \\
\text { - Gross secondary enrollment rate } \\
\text { - Gross tertiary enrollment rate }\end{array}$ \\
\hline Information infrastructure & $\begin{array}{l}\text { - Telephones per } 1,000 \text { people } \\
\text { - Computers per } 1,000 \text { people }\end{array}$ \\
\hline & - Internet users per 1.000 people \\
\hline Innovation system & $\begin{array}{l}\text { - Royalty payments and receipts, US\$ per person } \\
\text { - Technical journal articles per million people }\end{array}$ \\
\hline
\end{tabular}

Table 2. Pillars of Knowledge Economy. Source: WorldBank

Knowledge Economy Index is used to produce economic performance and to possibility of making comparisons through knowledge based indicators. Performance of the knowledge economy is measured by using the basic score card, the knowledge economy index and specific score card models of knowledge assessment methodology. Basic score card determines the performance by using four basic factors of knowledge economy. Knowledge Economy Index shows a country's or a region's overall level of development in the knowledge economy. Specific score card is used while making a more flexible comparison.

\section{Knowledge Economy and Turkey}

According to the Turkey Prime Ministry Investment Support and Promotion Agency, Turkey is aware that role of information and communication technologies will be more important in the future compared to present. This development and search for solutions that appropriate for age's requirements which growth brought along and today's economic and social life's access to the most current and fast solutions as soon as possible underlie the information and communication technologies. In this respect, Turkey has increased the interest in information and communication technologies in recent years and has started working to have a voice in this sector. The most obvious ones in this study are new incentives for investors and R\&D Law. Predictions for future are as follows:

- As the young population and the online market grow, the number of mobile phone subscribers is expected to reach 75 million by 2017 .

- In Turkey, expenditures for hardware, software, information and communication services and telecommunication services are expected to rise to $\$ 25$ billion by 2016 .

- In Turkey, expenditures for information and communication technologies are expected to grow faster than average of the world. When potential and large domestic market is taken into account, sector is expected to grow with a 7\% compound rate of growth during 2012-2017.

- Computers with internet access are available in more than half of the households in Turkey; this rate is expected to rise by $65.6 \%$ in next five years.

- $\quad$ Rate of Internet users in Turkey is about 42\%; this rate is expected to rise over 47\% in 2017.

In accordance with Turkey's challenging vision for 2023 when Turkish Republic's 100th year will be celebrated, information and communication sector is expected on higher goals. These goals includes as follows:

- Increasing the number of broadband subscribers to 30 million.

- $\quad$ Providing 14 million households Internet connection at $1000 \mathrm{Mbps}$. 
- Increasing the share of sector in GDP from $2.9 \%$ to $8 \%$.

- Becoming one of ten biggest countries in e-transformation.

- To have $80 \%$ of population gained ability of computer using.

- Increasing the number of companies which operates in Technology Development Zones to 5500; increasing the number of employers to 65000 ; increasing the export to $\$ 10$ million.

- To make size of Information and communication technologies sector reach $\$ 160$ billion with a market growth by about $15 \%$ every year.

- Increasing the share of R\&D expenditures in GDP from $0.85 \%$ to 3\% (Turkey Prime Ministry Investment Support and Promotion Agency, 2014).

We can see that Toffler's first, second and third waves are all available at same time for Turkey. Turkey could be a young industrial country by the courtesy of policies such as protectionism and incentives. Turkey owes partial change to the law of diminishing returns. Law of diminishing returns, gives developing countries a chance to learn producing goods with high added value. However, law of increasing returns is valid in knowledge society. Thus, specialization in the production of goods with high added value and making production more efficient through knowledge are required (Acar, 2000). In this regard, according to the "Information and Communication Technologies toward 2023 Goals" report of International Investors Association, it is expected that impact of 1 unit of growth in information and communication sector will be 1.8 units of growth in whole economy. In 2011, information and communication sector size at the global level has reached \$4.1 trillion. And the size of the sector in Turkey is estimated to be $\$ 30,3$ billion. Although share of our country whose economy is the 17 th economy of the world as economical size, is about $1 \%$, country's share in global information and communication sector remaining at $0.75 \%$ indicates the sector's growth potential. When the sub-sectors of the market in Turkey are analyzed, it is seen that the growth potential of the information technologies industry whose share is $0.4 \%$ in global market, is much higher. In case of reaching targeted $8 \%$ share of Information and Communication Technologies in \$2 billions GDP, merely to be provided contribution through total factor productivity growth is estimated to be over $\$ 71$ billion (YASED International Investors Association, 2014).

Economical development and knowledge are highly related to each other. The relationship between the Knowledge Economy Index (KEI) and per capita GDP is positive. According to our regression test in the figure below, the relationship between KEI and economical performance is about $85 \%$.

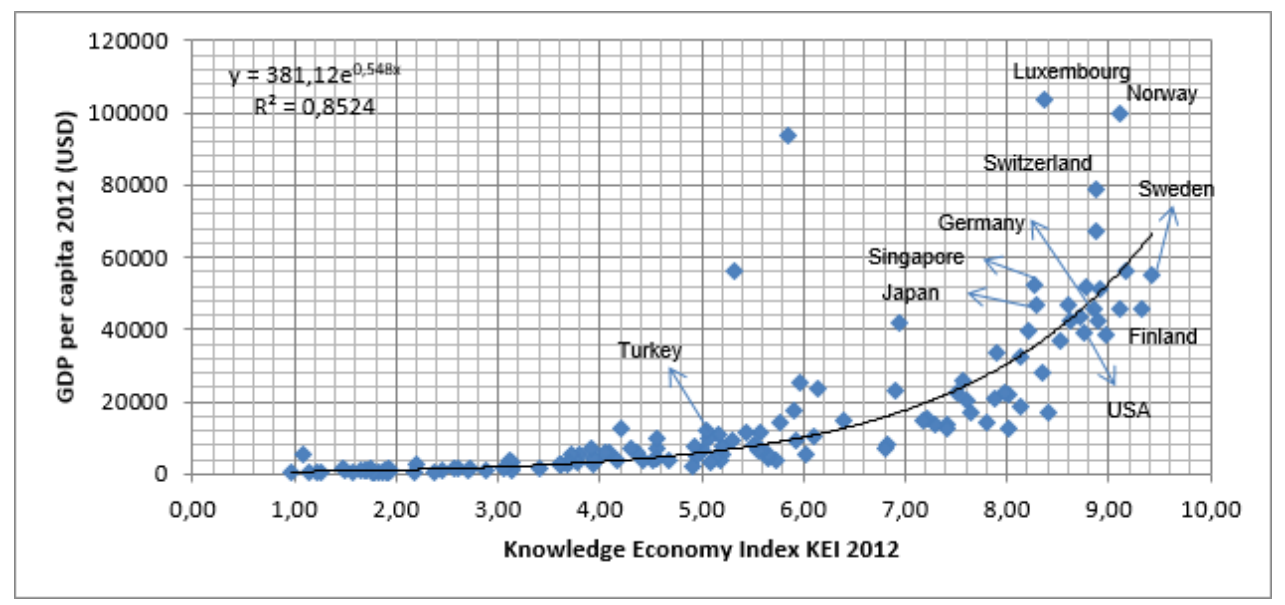

Figure 1. GDP per Capita \& KEI relation. Source: World Bank, 2014.

\subsection{Turkey and World Knowledge Economy Benchmarks}

The underlying reasons behind differences in countries' long-term growth performances are grouped under four main headings such as investment (fixed capital, and information and communication technology sector), non-formal education, innovation and structural change. When we consider Turkey according to these headings, it is observed that: Both fixed capital investment and the information and communication sector investments are not sufficient; R\&D expenditures remained behind the fast developing countries but increase in production efficiency by innovating could be achieved; It couldn't be achieved yet to develop the educational level of human capital, Tendency to high-tech products in the structure of production remained limited and structure of production based on low-technology continues. Knowledge Economy Index of Turkey pillars graphic and KEI table are given below. 


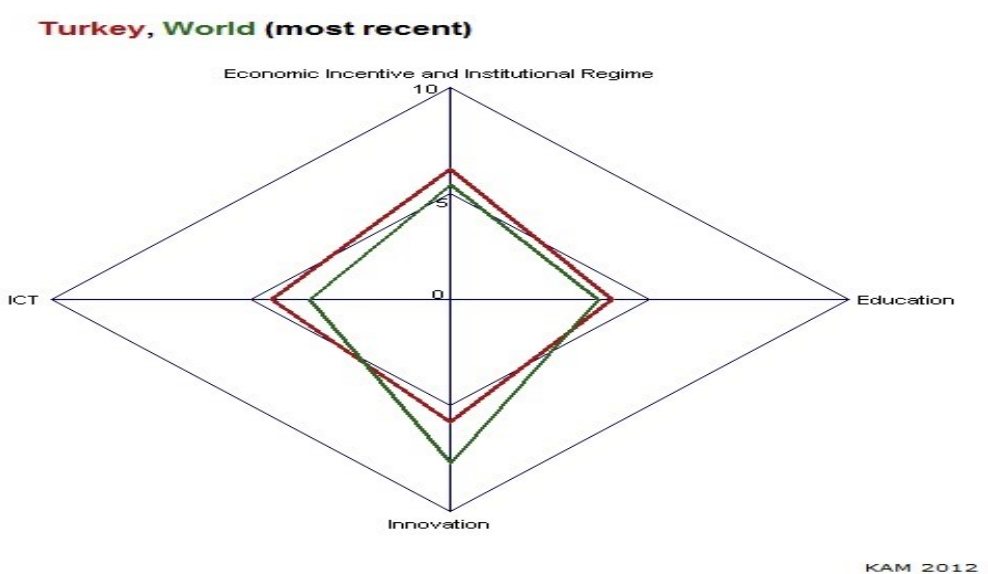

Figure 2. Turkey and World KEI graph Source: World Bank, 2014.

\begin{tabular}{|l|c|c|}
\hline Index & Turkey & World \\
\hline KEI & 5,16 & 5,12 \\
\hline KI & 4,81 & 5,01 \\
\hline Economic Incentives and Institutional Regime & 6,19 & 5,45 \\
\hline Education & 4,11 & 3,72 \\
\hline Innovation & 5,83 & 7,72 \\
\hline ICT & 4,5 & 3,58 \\
\hline
\end{tabular}

Table 3. Turkey and World knowledge indexes Source: World Bank, 2014.

\subsection{Innovation and Education Pillars}

Knowledge has always been important for development. We are in the midst of "knowledge revolution" which significantly increased importance of education, innovations and also updated skills for sustainable economic performance and improvement. An educated and skilled population that can create and use knowledge and an effective innovation system consisting of research centers, universities, think tanks, and other organizations that can create knowledge are two drivers for development. Educated, creative and skilled people and effective national innovation system are two important factors. For innovation system, KAM uses three variables: R\&D per million population, patent applications granted by the US Patent and Trademark Office (USPTO) per million population, and scientific and technical journal articles per million population. In summary KAM's innovation pillar aims to measure country's innovation system-firms, research centers, universities, think tanks, consultants, and other organizations - must be capable of tapping the growing stock of global knowledge, assimilating and adapting it to local needs, and creating new technology.

According to Innovation Union Score Board which is used to measure innovativeness by Europe Union Commission and is compiled through 25 indicators, even Turkey displays an increasing performance since 2006; she is still between countries that categorized as low in terms of innovation. In below figure, rankings of Turkey and other countries can be seen. Also we get application data from European Patent Office to compare European countries with Turkey. Turkey still has a lot of potential to grow its performance compared to its population. Moreover according to Turkish Patent Institute's data, Turkey's patent application numbers are increasing since 20 years.

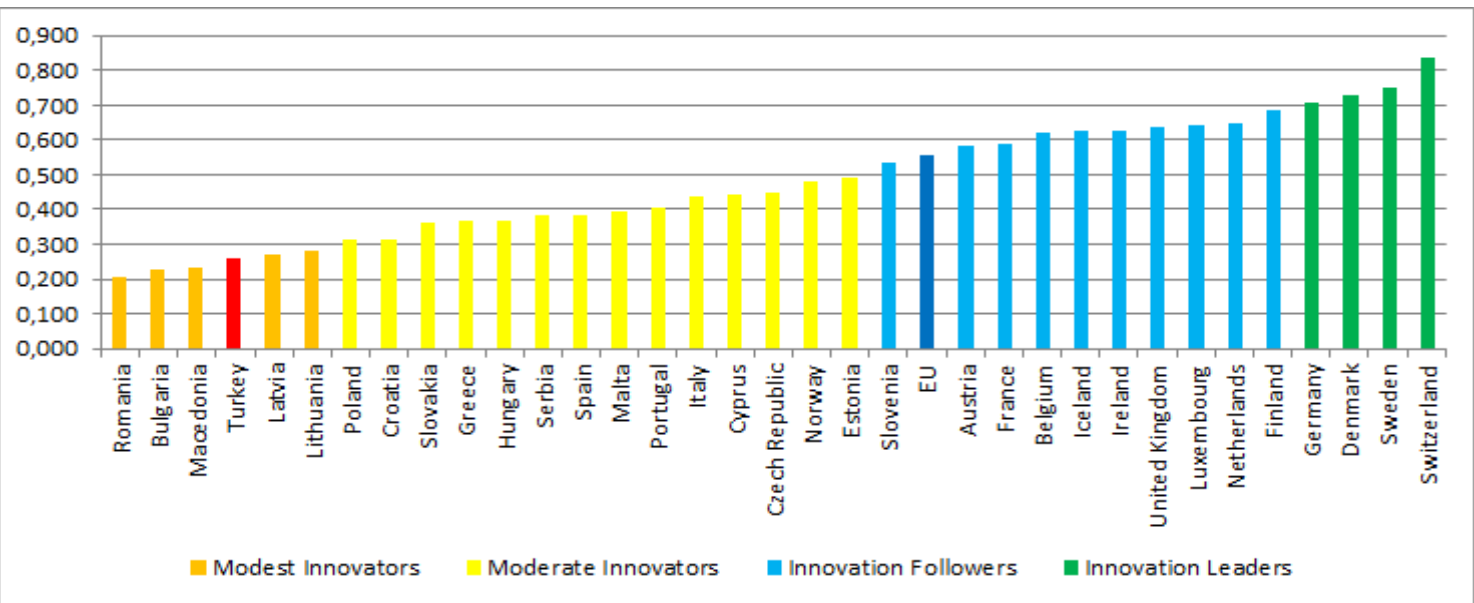

Figure 3. Innovation Union Scoreboard 2015 Source: European Commission, 2015. 


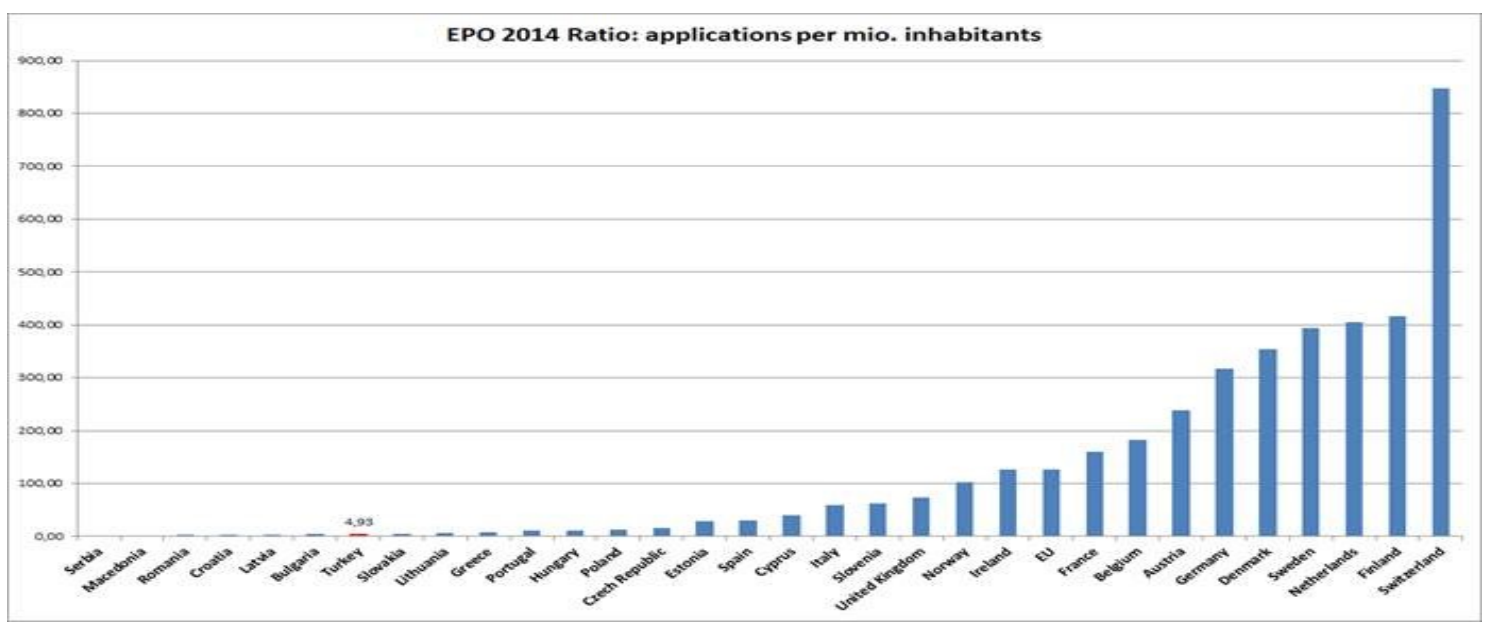

Figure 4. European Patent Office applications per mio. inhabitants Source: EPO, 2015.

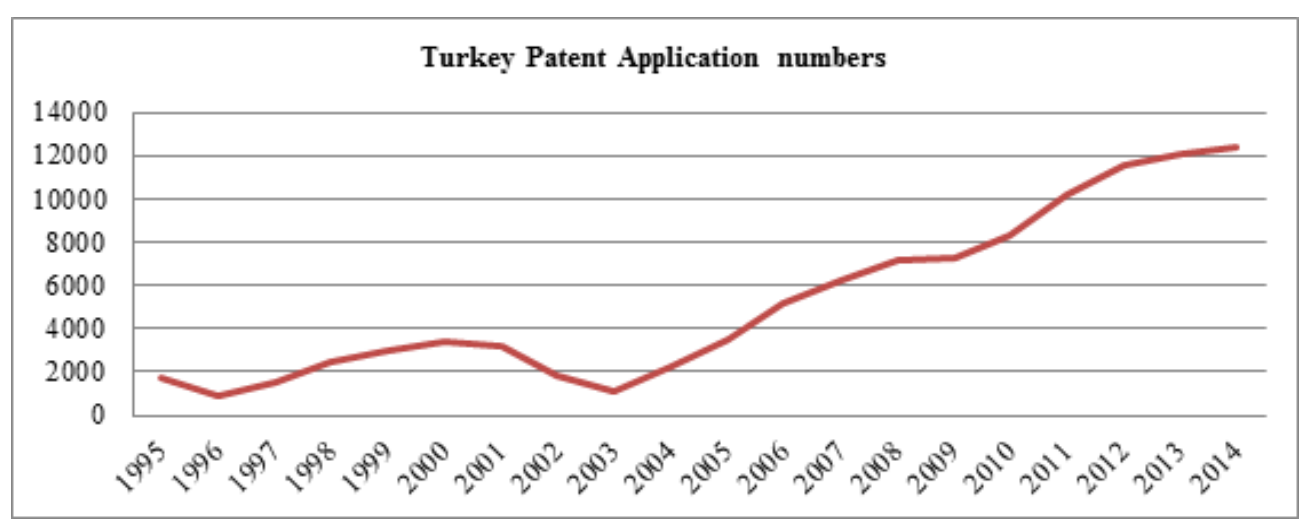

Figure 5. Turkey's Patent Application numbers Source: TPE, 2015

The knowledge economy is transforming the demands of the labor market in economies throughout the world. In industrial countries, where knowledge based industries are expanding rapidly, labor market demands are changing accordingly (World Bank, 2003: 1).World Bank's KAM methodology "education and skills" pillar aims to measure country's people needs education and skills that enables them to create and share, and to use it well. Education has a significant role to play that goes beyond input/ investment models to a finessed output set of specifications. For education pillar, three variables are used: the adult literacy rate (percentage of population aged 15 and above) gives a very broad stock measure of educated population, gross secondary enrollment rate and gross tertiary enrollment rates provide a flow rate. Experiences of developed countries shows that national innovation system, human development, effective education system and information-delivery technologies and business environments should affect each other satisfyingly and they should develop parallel to each other in order to have a successful knowledge economy (World Bank, 2004). Literacy rate, adult total (\% of people ages 15 and above) in Turkey was 94.92 as of 2012 and 95, 5 for 2015 as an estimation. Also Turkey's secondary and tertiary school enrollment percentages since 2010 has an increasing trend.

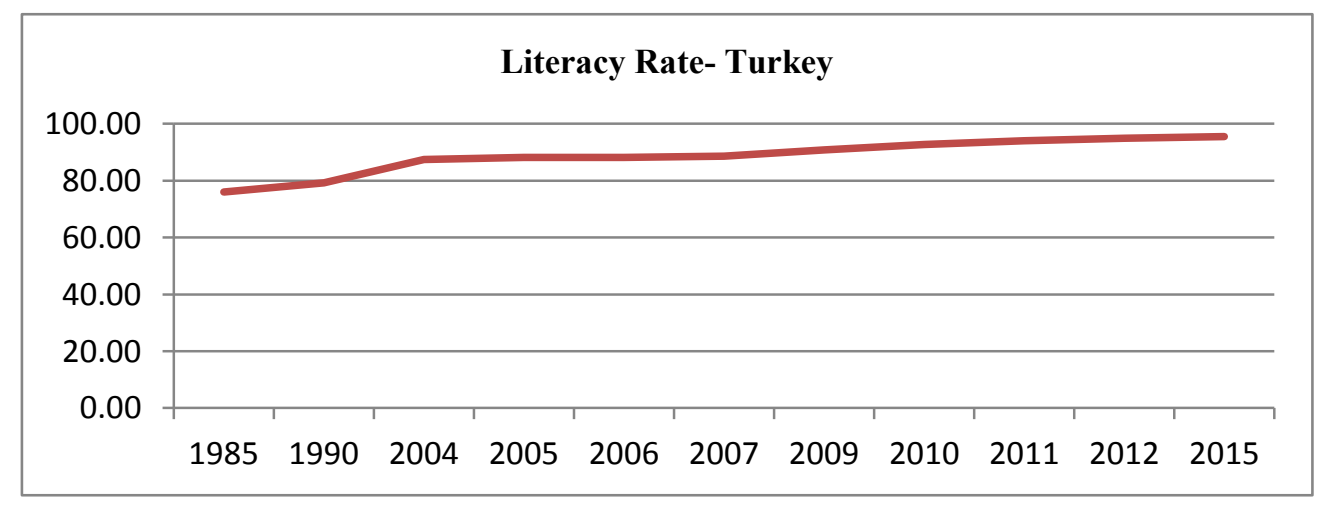

Figure 6. Turkey's Adult literacy rate for last 30 years Source: Unesco, 2015 (year 2015 is * UIS estimation) 


\begin{tabular}{|c|c|c|}
\hline Year & $\begin{array}{c}\text { School enrollment, } \\
\text { secondary (\% net) }\end{array}$ & $\begin{array}{c}\text { School enrollment, } \\
\text { tertiary (\% gross) }\end{array}$ \\
\hline 2010 & 81 & 56 \\
\hline 2011 & 85 & 61 \\
\hline 2012 & 82 & 69 \\
\hline 2013 & 88 & 79 \\
\hline
\end{tabular}

Table 4. Turkey's secondary school enrollment \% Source: World Bank, 2015.

According to OECD, the ongoing economic crisis has only increased the urgency of investing in the acquisition and development of citizens' skills - both through the education system and in the workplace. Investing in structural reforms to boost productivity, such as education and skills development, is key to future growth. Success is no longer measured against national standards alone, but against the best-performing and most rapidly improving education systems in a global economy. Over the past decade, the OECD Programme for International Student Assessment, PISA, has become the world's premier yardstick for evaluating the quality, equity and efficiency of school systems. PISA evaluates education systems worldwide by testing in key subjects' critical thinking in math, science, and reading to 15 year olds (OECD, 2012). It conducts research on the 65 countries that make up 90 percent of the world's economies. The OECD Directorate for Education has found that student achievement in math and science are a sound indicator for future economic health. Namely, nations or cities with good schools can expect a healthy economy (Asia Society, 2015). Turkey has involved this test since 2003. As of 2015, they revealed 2012 PISA test results. According to PISA 2012 results, Turkey is ranked 42nd for math, 41st for reading skills and 45th for science skills. Turkey had low PISA scores in 2003 and recorded an average four-point improvement in all three skills in 2012.
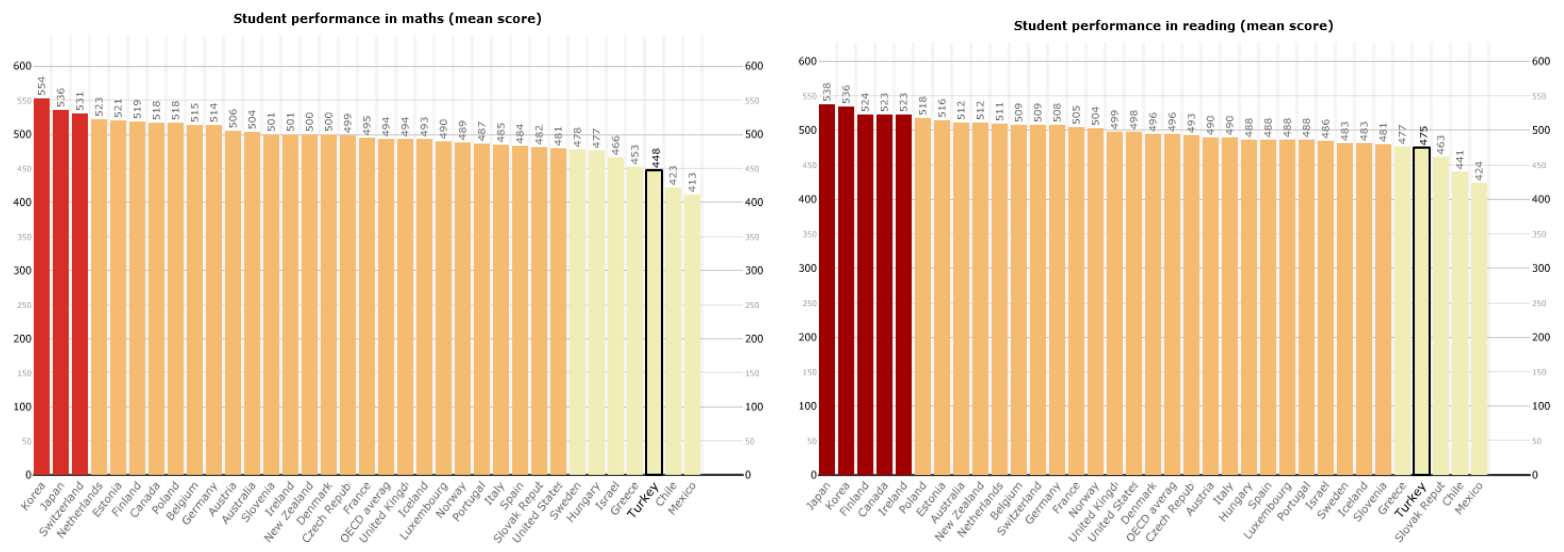

Figure 7. Figure 8. Student performance in math and reading means by countries Source: OECD, 2015

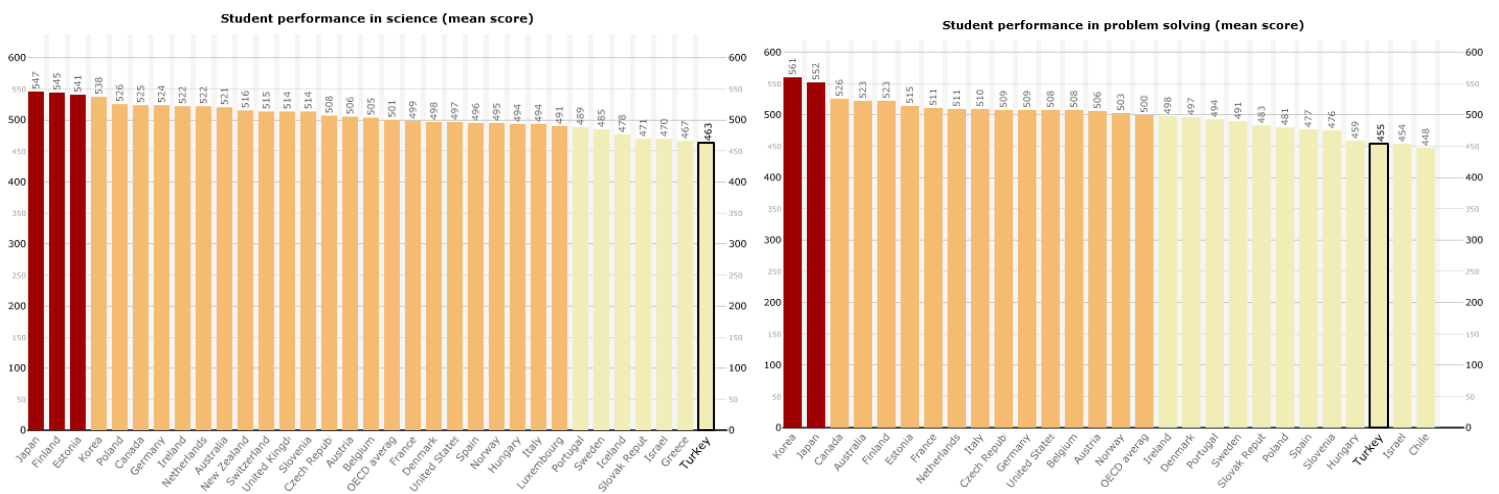

Figure 9. Figure 10. Student performance in science and problem solving means by countries Source: OECD, 2015 


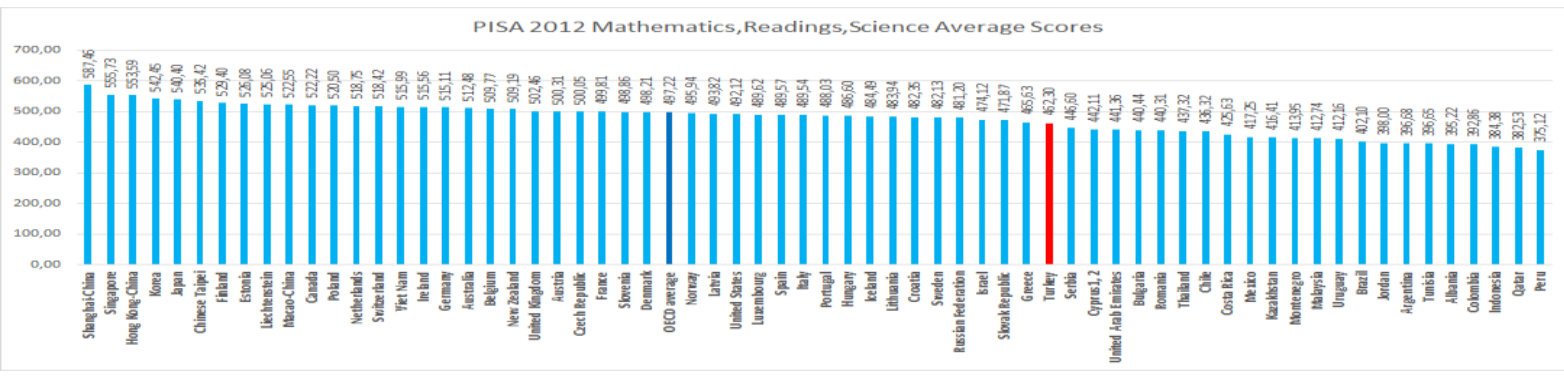

Figure 11. PISA 2012 math, reading, science average scores Source: OECD, 2015

\section{Conclusion}

As we see, knowledge economy relies primarily on the use of ideas rather than physical abilities and on the application of technology rather than the transformation of raw materials or the exploitation of cheap labor. It is an economy in which knowledge is created, acquired, transmitted and used more effectively by organizations, individuals, enterprises, and communities and that's why it promotes economic and social development. We can assume that knowledge-producing institutions are the most important institutions in knowledge era society which is considered as the era the humanity is in. And these institutions are universities and research related institutions. In recent years the growing number of universities In Turkey, can be regarded as one of the signs of being an information society. In his book "Rethinking the Future", Toffler says, "The illiterate of the 21 st century will not be those who cannot read and write, but those who cannot learn, unlearn, and relearn". From this perspective, it is very important for humans who are the main sources to be open and eager to learn and they should be promoted and provided the required environment. Turkey should give special attention to innovation, education, cultural and intellectual production in order to develop in knowledge society and to be able to have competitive advantage. Since states which make their citizens well-educated, specialized, creative, skilled to solve problems will be the ruler of the new era, Turkey needs to reduce the uneducated workforce. Innovation, science and education policies are critical for her progress. According to the Knowledge Economy Index pillars, Turkey should speed up the investments in ICT, increase R\&D expenditures, increase productivity in production by innovating, upgrade the level of education to have the required qualified human resources and should be directed to high-tech products in the production structure.

\section{References}

- $\quad$ Acar, 2000. "Bilgi Çağı ekonomisine Teorik Bir Yaklaşım", Dokuz Eylül Üniversitesi İ.İ.B.F Dergisi, 15, s $87-101$.

- Acar, 2000. Uluslararası Reel Ticaret, Teori, Politika, Dokuz Eylül Üniversitesi yayınları, İzmir.

- Arikan, 2008. Evaluating the dynamics of innovation in Turkey: The impact of innovation on business performance, Boğaziçi University, Business Administration, PhD Thesis, İstanbul.

- Asia Society, 2015. http://asiasociety.org/education/learning-world/what-pisa-and-why-does-it-matter

- Beig, vd, 2007. "Adoption a Proper Tool for E-Readiness Assessment in Developing Countries; Case Studies: Iran, Turkey and Malaysia", Journal of Knowledge Economy \& Knowledge Management Volume II Spring, s.54.

- CCirasun, 2011. "Enformasyon Toplumu ve Bilgi Çağında Türkiye'nin Gelişim Süreci", Marmara Üniversitesi, Sosyal Bilimler Enstitüsü, İktisat Politikası Bilim Dalı, Master Thesis, İstanbul.

- David ve Foray, 2002. "Economic Fundamentals of the Knowledge Society", Stanford University SIEPR Discussion Paper No.01-14.

- Düzgün 2008, Knowledge sector dimension of Turkish economy, Marmara University Social Sciences Institute, Economics, Master's thesis, İstanbul.

- European Comission, 2001. The Impact of the E-Economy on European Enterprises: Economic Analysis and Policy Implications, Brussels.

- European Commission, 2014. Innovation Union Scoreboard, http://ec.europa.eu/enterprise/policies/innovation/files/ius/ius-2014_en.pdf

- European Patent Office, 2015. http://www.epo.org/about-us/annual-reports-statistics/annualreport/2014/statistics/patent-applications.html

- Gür, 2001. Assessment of possible effective strategies in the transition process to a knowledge-based economy: The case of Turkey, Middle East Technical University Industrial Engineering Department, Master's Thesis, Ankara. 
- Iş1k 2012, The economic analysis of R\&D, innovation, patent and information technologies which influence the establishment of competitive advantage in knowledge economies: An application on Turkey's Economy, Atatürk University Social Sciences, Economics, PhD Thesis, Erzurum.

- Kara, 2005. Bilgi Ekonomisi'nin Olası Mikro Ekonomik Etkilerinin Teorik Analizi, http://oguzkara.com/Bilgi\%20Ekonomisi'nin\%20Olasi\%20Mikro\%20Ekonomik\%20Etkilerinin\%20Teorik \%20Analizi.pdf .

- Kaynak, 2011. "Avrupa Birliği Yolunda Bilim Ve Teknoloji Bağlamında Türkiye’nin Ab-27 Ülkeleri Karşısındaki Mevcut Durumu", Bilgi Ekonomisi ve Yönetimi Dergisi, Cilt: VI Sayı: II

- Meçik, 2013. "Türkiye İçin 2010-2012 Dönemi Karşılaştırmalı Bilgi Ekonomisi Analizi", Eskişehir Osmangazi Üniversitesi İktisadi ve İdari Bilimler Fakültesi Dergisi,2013, 8(2), s. 115-139.

- Memişoğlu, 2012. Knowledge-based economy and economic growth: Empirical analysis of BRICST Countries, Boğaziçi University Social Sciences International Trade Depaortment, Economics, Master's Thesis, İstanbul

- $\quad$ OECD, 1996. OECD, The Knowledge Based Economy, No. General Distribution OECD/GD(96)102, Paris.

- OECD, 2015. http://www.oecd.org/pisa/keyfindings/pisa-2012-results-overview.pdf

- Özcan, 2007. The case of organizations in Turkey from the perspective of knowledge economy, Afyon Kocatepe Üniversity, International Trade Department, Business Administration, Phd Thesis, Afyon

- Rondo, 2002. A Concise Economic History of the World (from paleolithic times to thepresent), Oxford Uni. Press, London.

- Tapscott, 1998. Dijital Ekonomi, Hora Matbaas1, İstanbul.

- Taşçı, 2007. "Teorik Çerçevesi ve Uygulama Örnekleriyle Dünyada ve Türkiye'deYazılım Endüstrisi”, Devlet Planlama Teşkilatı Müsteşarlığı, Planlama Uzmanlığı Tezi (yayımlanmamış eser), Ankara.

- T.C Başbakanlık Türkiye Yatırım Destek ve Tanıtım Ajansı, 2014, http://www.invest.gov.tr/trtr/sectors/Pages/ICT.aspx .

- $\quad$ Toffler, 1984. The Third Wave, Bantam Books, New York.

- TPE, 2015. http://www.tpe.gov.tr/TurkPatentEnstitusu/statistics/

- UNESCO, 2015. http://www.uis.unesco.org/Education/Documents/literacy-statistics-trends-1985-2015.pdf

- World Bank, 2003. Lifelong Learning for a Global Knowledge Economy, Washington, DC

- World Bank, 2004. "Turkey Knowledge Economy Assessment Study", http://wwwwds.worldbank.org/external/default/WDSContentServer/WDSP/IB/2007/04/06/000310607_2007040611350 1/Rendered/PDF/393650TR0Knowledge0economy01PUBLIC1.pdf .

- World Bank, 2010. Knowledge Assessment Methodology, http://www.worldbank.org/kam .

- World Bank, 2015. http://data.worldbank.org/indicator/SE.SEC.NENR/countries

- YASED International Investors Association,2014, http://www.yased.org.tr/webportal/Turkish/Yayinlar/Pages/YASED2023HedefleriYolundaBIT.aspx 


\title{
Remittances as a Shield to Socially-Vulnerable Households in Macedonia: The Case When the Instrument is Not Strictly Exogenous
}

\author{
Dr. Marjan Petreski (University American College, Macedonia) \\ Dr. Blagica Petreski (Association for Economic Research, Advocacy and Policymaking \\ "Finance Think", Macedonia) \\ Despina Petreska ("Finance Think", Macedonia)
}

\begin{abstract}
The objective of the paper is to investigate if remittances sent to Macedonia have a role to play for shielding socially-vulnerable households. To that end, we devise an index of social vulnerability, comprehending income poverty, unemployment of both spouses, single parents, as well conditions of impaired health, undernourishment, material deprivation and insufficient clothing, so as to capture non-income vulnerability conditions. Remittances then are allowed to determine the index of vulnerability. As remittances are likely endogenous to vulnerability, we use the noneconomic motive to migrate as instrument, as it is likely correlated with remittances, since any migrant is likely to send remittances irrespective of his migration motive; while uncorrelated with the shocks onto vulnerability. We use the Remittances Survey 2008 and conditional mixed process (CMP) estimator. Results suggest that remittance-receiving households have, on average $6 \%$ higher probability to report zero-vulnerability, suggesting that they indeed could act as social protection. However, as the assumption of noneconomic motive for migration being a good instrument may be easily dismantled, we further pursue Conley et al.'s (2012) method, allowing for a direct link between noneconomic motive and vulnerability. Results suggest that if we have a reasonable belief that they are determined simultaneously, or directly correlated due to the existence of a third unobservable factor, then it is reasonable to consider that this influence slightly reduces the effect of remittances on vulnerability.
\end{abstract}

\section{Introduction}

Poor households in Macedonia, as elsewhere, face risks from different origin, but the most prominent being the lack of or limited access to formal social insurance and formal credit finance. On the other hand, Macedonia receives about $20 \%$ of its GDP in private transfers per year, out of which it is estimated that at least half are pure cash remittances directly contributing to the livelihoods of (poor) households of Macedonian citizens (Petreski and Jovanovic, eds., 2013). Petreski and Jovanovic (2014) find that remittances sent to Macedonia significantly reduce poverty and increase income equity, while Petreski and Mojsoska (2014) find that while they could overall deter people from investing, the opposite holds for youth in households receiving remittances. Hence, the available studies for Macedonia document large developmental potential of remittances.

On the other hand, the economy is still diving into flagrant unemployment of $29 \%$ and a poverty of $27 \%$ in 2014. Only $9 \%$ of households receive formal social assistance from the government, and it reduces the incidence of poverty by only 3 percentage points. In addition, Mojsoska et al. (2013) argue that the assistance triggers inactivity and laziness. So, it is likely that the formal social assistance does not exert (large) positive role in Macedonia. However, these figures reflecting facets of economic development do not take into account the effect of remittances. Remittances are not a part of the official regular surveys and policies. They are frequently channelled through unofficial-unregistered channels (at least half of them; Petreski and Jovnanovic, 2013). Hence, the bold question emerging is the extent to which remittances serve informal social-protection agreements in handling social risks (Dercon, 2002) and potentially prevent social unrest.

The theory behind the role of remittances and migration as informal social protection for receivers dates back to the new economics of labour migration (Stark, 1978, 1991). This strand of theoretical underpinnings link the causes and consequences of migration explicitly, so that both positive and negative development effects are possible. Particularly, this strand of literature puts the household, not the individual as the decision-making unit with regard to the migration decisions (Taylor, 1999). Hence, if the households is exposed to social risks and income shocks, it will opt for diversification of its labour resources so as to minimize these risks (Stark and Levhari, 1982). This is done by sending a migrant abroad, so that the incidence of income shocks and hence falling into poverty is minimized by diversification of income sources and remittances serve as (informal) social insurance at origin (Lucas and Stark, 1985). Therefore, this approach adds the household-level decisions to the individual-level decisions, as the latter are mainly driven by the self-interest, i.e. the objective to maximize personal income. At the empirical front, the consumption and investment effects of remittances have been widely investigated: some papers date back to 1987, like Lucas, while others are quite recent, e.g. Javid et al. (2012), suggesting that the topic of remittances has not lost of its warmth over the decades. However, the potential of remittances to act as informal social protection and insurance mechanisms in a broader sense has been rarely 
investigated (Sabates-Wheeler and Waite, 2003). Essentially, bulk of the literature relates migration and formal social protection only from the migrants' perspective and the protection options they have in different stages of the migration process. On the other hand, as Sabates-Wheeler and Waite (2003) clearly point out (p.17), migration and hence, remittances have only informal protective role for migrant's family at origin, if not framed by the government in a specific policy. This is also the highlight of De la Briere et al.'s (1997) models of remittances' role: “...migration may be conceptualized as an informal preventive social protection strategy used by migrant households for insurance and risk diversification” (Sabates-Wheeler and Waite, 2003, p.19). However, to the best of our knowledge, remittances have not been framed by governments in specific formal social-protection mechanisms.

The objective of the paper is to investigate if remittances sent to Macedonia have a role to play for shielding socially-vulnerable households. To that end, we devise an index of social vulnerability, comprehending income poverty, unemployment of both spouses, single parents, as well conditions of impaired health, undernourishment, material deprivation and insufficient clothing, so as to capture non-income vulnerability conditions. We regress the index on a standard set of household and community characteristics, adding an indicator of if the households is a recipient of remittances. As remittances are likely endogenous to vulnerability, we use an instrumental variable approach and the conditional mixed process estimator. An indicator of a noneconomic motive to migrate is proposed as instrument, as it is likely correlated with remittances, since any migrant is likely to send remittances irrespective of his migration motive; while uncorrelated with the shocks onto vulnerability. We use the Remittances Survey 2008.

Results suggest that remittance-receiving households have, on average $6 \%$ higher probability to report zerovulnerability, suggesting that they indeed could act as social protection. However, as the assumption of noneconomic motive for migration being a good instrument may be easily dismantled, we further pursue Conley et al.'s (2012) method, allowing for a direct link between noneconomic motive and vulnerability. Results suggest that if we have a reasonable belief that they are determined simultaneously, or correlated due to the existence of a third unobservable factor, then it is reasonable to consider that this influence slightly reduces the effect of remittances on vulnerability.

The next section discusses the index of vulnerability and the economic model used. Section 3 reviews the data and methodology. Section 4 presents the data and offers a discussion. The last section concludes.

\section{Index of Vulnerability and Economic Model}

The most important task in vulnerability assessment is the identification of suitable vulnerability indicators and the construction of an overall vulnerability index. There is no consensus in the literature on the indicators defining vulnerability at the individual or household level. The micro-triggers of vulnerability (i.e. those affecting wellbeing negatively) could be loss of job (and hence income), illness, death and the like. In their effort to construct a vulnerability index, Rygel et al. (2005) used the following vulnerability indicators: poverty, gender, race and ethnicity, age, and disabilities. They argued that the most important manifestation of vulnerability is the income shortfall and hence took poverty as indicator of vulnerability. They argued that poor people have less money to spend on preventative measures, emergency supplies, and recovery efforts (Clark et al. 1998). However, a large strand of the literature goes beyond poverty in measuring vulnerability, although many of them refer to country and not the household level. For example, Adger et al. (2004) defined a couple of categories of vulnerability indicators, out of which the following refer to the household vulnerability: economic wellbeing - income and employment; health and nutrition. Given these notions, this paper is based on a vulnerability index which is composed of the following facets of vulnerability:

1. Income poverty, as the most direct measure of the well-being and being the only direct income-based vulnerability indicator;

2. Unemployment of two spouses in households with at least one child;

3. Single (lone) parents;

4. Households with bad health conditions;

5. Households with bad housing conditions;

6. Households who are undernourished;

7. Households with endangered health condition of members;

8. Households without availability of different forms of leisure.

Devised through these components, Table 1 presents the distribution of the Vulnerability index for Macedonia. It suggests that more than one third of the households in Macedonia, 37.6\% do not reveal any of the vulnerability condition. Nearly one third, $30.9 \%$, revealed only one condition of vulnerability. The shares significantly decline as we progress up the vulnerability scale: very vulnerable households, which could be arbitrarily taken those with an index of above 5 are only few: $2.3 \%$ of all households. 


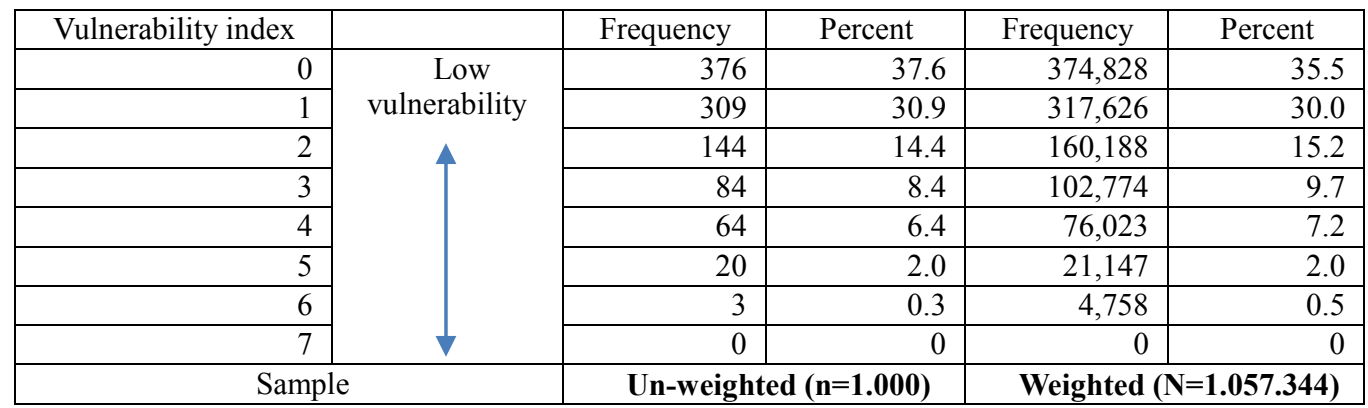

Table 1 - Distribution of the overall Vulnerability index for Macedonia Source: Authors' calculations.

We use this index obtained as a dependent variable in a fairly standard model in order to identify how different personal and household characteristics affect vulnerability. As our analysis is at the household level, any personal characteristic refers to that of the household head. We will write the model in the following generic form:

$V I_{i}=\alpha+\sum \beta_{1 i}$ Head_ch $_{i}+\sum \beta_{2 i}$ Household $_{i}+\sum \beta_{3 i}$ Community $_{i}+\gamma *$ Remit $_{i}+\varepsilon_{i}$

Whereby $V I_{i}$ stands for the Vulnerability Index of household i, as defined above; Head_ch $i$ captures a bunch of personal characteristics of the household head; Household $i$ captures a set of household-level characteristics, ${\text { while } \text { Community }_{i} \text { some community/regional level characteristics. The central variable of interest, Remit }}_{i}$ measures remittances and is expressed as a dummy variable by separating receiving from non-receiving households, so as any measurement issues (underreporting) of remittances is avoided. $\varepsilon_{i}$ is the error term which is assumed to be well behaved.

The explanatory variables that enter equation 1 are based on the literature. Gender affects vulnerability: women are more vulnerable than men, mainly because women - especially divorced mothers and never-married mothers - are more likely to live in poverty (Bianchi and Spain, 1996). Hence, being married or not may be also affecting vulnerability. Ethnicity may matter also: Fothergill et al. (1999) argued that racial minorities in the US are more vulnerable than whites because minorities are more likely to be poor. Discrimination also plays a major role in increasing the vulnerability of racial and ethnic groups. Further, both young and old people may be unable to respond to shocks on their own. Children who lack adequate family support are at a major disadvantage for disaster response. The elderly are more likely to lack the necessary physical and economic resources to respond effectively to a disaster (Morrow, 1999). Adger et al. (2004) inter alia identified less education and less endowed with social capital households as more prone to shocks and hence more vulnerable. Hence, in (1) we use the following explanatory variables: the age of the head and its square, gender, marriage, ethnicity (where available), education of the head (measured on an ordered scale from 1 - no education to 9 - holding a PhD), number of household members and its square, dependency ratio (measured as the share of children, students and persons older than 64 in the total number of household members) and an indicator of whether the household lives in an urban or rural area.

\section{Data and Methodological Concerns}

We use the Remittances Survey 2012. The Survey has been collected by the University American College Skopje within a previous effort to analyze poverty and inequality nexus with remittances (see, Petreski and Jovanovic, 2014). The survey comprehends about 60 questions specifically focused on remittances and little to migration. It also captures the socio-economic and demographic variables, making it suitable for the analysis we conduct herein.

We have two econometric challenges. The first econometric challenge in estimating (1) is the endogeneity of our variable of interest - remittances. Remittances could suffer endogeneity from two sources: reverse causality; and unobserved factors affecting both remittances and vulnerability. More vulnerable households may be more willing, but less able to send migrants abroad (reversed causality). Or, persons who belong to more vulnerable households may feel larger inclination to emigrate, in which case the unobserved factor - inclination to emigrate, determined both remittances and vulnerability. As remittances are probably measured with error, the OLS estimator will be biased towards zero (the so-called 'attenuation bias'). If we do not observe all facets of household wealth and personal characteristics, there would be omitted variables correlated with both remittances (which are the 'product' of migration) and vulnerability. For instance, households with higher innate 'ability' could be at the same less vulnerable and more likely to attract remittances intended for investment in the local economy, so that vulnerability and remittances would be negatively correlated without a causal relationship. Hence, remittances would tend to be correlated with the unobserved determinants of vulnerability, biasing any OLS estimate (Hanson and Woodruff, 2003). The endogeneity stemming from simultaneity, measurement error, and omitted variables (unobserved variables) is well documented in the literature (see, e.g. Wooldridge, 2002). Hence, the endogeneity between remittances and vulnerability is a major methodological concern. 
Instrumental variable estimators have been widely documented and applied for resolution of this problem (e.g. Amuedo-Dorantes and Pozo, 2006; Hanson and Woodruff, 2003; Cameron and Trivedi, 2005). The instrumental variables used to correct the remittances' endogeneity should not affect vulnerability of the household other than through their effect on the remittance income (see Wooldridge, 2002, pp.621). Perfect instruments are rare, though. However, as Petreski et al. (2014) argue, the noneconomic motive to migrate may well sure our purpose.

The variable is a dummy created from the question where the respondent was able to choose (multiple) options from the following: economic reasons, political reasons (including war and conflict), education, marriage/family reunion, and other. The dummy takes a value of one for those households who have not selected economic reasons as any of the possible choices. Thus, this variable should not be correlated with the vulnerability of the household, following an assumption that the economic reasons for migrating are uncorrelated with the other reasons.

The second econometric challenge in estimating (1) is that our dependent variable is an ordered variable (as we discussed in Section 2), while our suspected endogenous variable (remittances) is binary variable. From that viewpoint, using any form of IV is problematic: to our knowledge, there is no straightforward application of IV ordered probit; in addition, any genuine IV estimation treats endogenous variables as continuous, which is not the case here. This renders estimates biased and inefficient (Wooldridge, 2007). Roodman (2011) proposed the so called Conditional Mixed Process (CMP) estimator which allows mixing the standard limited dependent variable models in multi-equation systems. The CMP method is a parametric one, meaning that distributional assumptions are imposed on the model which leads to higher efficiency. The standard IV approach, however, does not; there is an implied trade-off between both estimators. The CMP method is appropriate for two broad types of estimation situations: 1) those in which a truly recursive data-generating process is posited and fully modeled; and 2) those in which there is simultaneity but instruments allow the construction of a recursive set of equations, as in two-stage least squares (2SLS) (Roodman, 2011). In the first case, CMP is a full-information maximum likelihood (FIML) estimator, all estimated parameters being structural. In the latter, it is a limitedinformation (LIML) estimator, and only the final stage's (or stages') parameters are structural, the rest being reduced-form.

So, given we have grounds for concern that both simultaneity (i.e. reverse causation), measurement error, and the omitted variables (due to unobserved variability) probably make remittances endogenous in our framework; and, in addition, due to the IV's disadvantages in dealing with ordered dependent variable and continuous endogenous regressors, we will proceed with the CMP approach. Hence, we will estimate the following system of equations:

$\operatorname{Pr}\left(\right.$ Remit $\left._{i}\right)=\alpha_{1}+\sum \beta_{11 i}$ Head_ch $_{i}+\sum \beta_{12 i}$ Household $_{i}+\sum \beta_{13 i}$ Community $_{i}+\sum \delta_{i}$ Inst $_{i}+\varepsilon_{1 i}$ $\operatorname{Pr}\left(V_{i}\right)=\alpha_{2}+\sum \beta_{21 i}$ Head_ch $_{i}+\sum \beta_{22 i}$ Household $_{i}+\sum \beta_{23 i}$ Community $_{i}+\gamma *$ Remit $_{i}+\varepsilon_{2 i}$

Whereby Inst $_{i}$ is the instrumental variable used in the first-stage regression (2) in which the probability that the household gets remittances is regressed on the same bunch of variables explained above and the instruments; while the second-stage regression (3) is the same (1) except that remittances enter after 'purging' from their potential endogeneity in (2).

\section{Results and Discussion}

\subsection{Baseline Results}

Table 2 presents the baseline results. The table is organized so that we first present the estimates for the overall vulnerability index and then we split the index on its income component, which reduces to relative poverty, and on its non-income components, which is all the remaining components. Each time, we first present the first-stage regression (equation 2), and then the second-stage regression (equation 3 ).

The first result to be noted is that only ethnicity and household size significant in the first-stage regression. This suggests that there are systematic differences in who receives remittances only in terms of these two observed characteristics. Macedonians have lower probability than Albanians, while smaller households higher probability to get remittances. Our instrument used - the non-economic motive to migrate is significant. The coefficient suggests that those who migrated for a non-economic reason have, on average, lower probability to send remittances by a large $86 \%$. We turn our attention to the second-stage regression. We start with column (2), whereby the total vulnerability index is used as a dependent variable. Ethnicity, education, the number of household members, dependency ratio and remittances are found significant in determining vulnerability. Ethnic Macedonians are less vulnerable, on average, than compared to ethnic Albanians. Higher education of the household head leads to lower vulnerability. Households which are larger in size are more vulnerable than those which are smaller, while the larger the share of dependent members, the higher the household vulnerability. These results are almost entirely replicated when vulnerability is split on income (column 4) and non-income vulnerability (column 6).

The central variable of interest - remittances - is found significant when considering the overall index and its income component. Households who receive remittances have on average lower vulnerability than those who do 
not. To quantify the effect of remittances on vulnerability, Table 3 gives the marginal effects for the seven outcomes of the vulnerability index. Remittance-receiving households have, on average $6 \%$ higher probability to report zero-vulnerability, i.e. that none of the vulnerability conditions we identified in Section 2 prevailed. This is very strong and, probably, the most important result of this study, suggesting that remittances indeed could act as social protection for remittance-receiving households. Remittance-receiving households have lower probability by, on average, $1.8 \%$ to report two vulnerability conditions than compared to non-receiving households. Afterwards, the effect diminishes to $1.7 \%$ and $1.5 \%$ for prevalence of three and four vulnerability conditions, respectively, and fully vanishes for the largest vulnerability conditions. The main driver of the finding is poverty / income vulnerability, and not non-income vulnerability. Results suggest that households who get remittances have lower probability of falling into poverty by, on average, $27 \%$ than compared to nonreceiving households. The result is similar, but still slightly lower than the one found in Petreski and Jovanovic, eds. (2013). Remittances are found insignificant for each outcome of the non-income vulnerability index (not shown, but available on request).

\begin{tabular}{|c|c|c|c|c|c|c|}
\hline & \multicolumn{2}{|c|}{ Vulnerability index } & \multicolumn{2}{|c|}{ Income vulnerability } & \multicolumn{2}{|c|}{ Non-income vulnerability } \\
\hline & $\begin{array}{c}\text { First stage: } \\
\text { Remittances }\end{array}$ & $\begin{array}{l}\text { Second stage: } \\
\text { Vulnerability }\end{array}$ & $\begin{array}{c}\text { First stage: } \\
\text { Remittances } \\
\end{array}$ & $\begin{array}{l}\text { Second stage: } \\
\text { Vulnerability }\end{array}$ & $\begin{array}{l}\text { First stage: } \\
\text { Remittances }\end{array}$ & $\begin{array}{l}\text { Second stage: } \\
\text { Vulnerability }\end{array}$ \\
\hline & (1) & (2) & (3) & (4) & (5) & (6) \\
\hline \multirow[t]{2}{*}{ Age of the head } & -0.0261 & 0.0366 & -0.0349 & 0.0088 & -0.0255 & 0.0357 \\
\hline & $(0.041)$ & $(0.023)$ & $(0.041)$ & $(0.033)$ & $(0.042)$ & $(0.023)$ \\
\hline \multirow[t]{2}{*}{ Age squared } & 0.0002 & $-0.0005 * *$ & 0.0003 & -0.0001 & 0.0002 & $-0.0005 * *$ \\
\hline & $(0.0000)$ & $(0.0000)$ & $(0.0000)$ & $(0.0000)$ & $(0.0000)$ & $(0.0000)$ \\
\hline \multirow[t]{2}{*}{ Gender $(1=$ male $)$} & -0.1518 & -0.1351 & -0.1497 & 0.0571 & -0.152 & -0.1426 \\
\hline & $(0.202)$ & $(0.102)$ & $(0.202)$ & $(0.155)$ & $(0.203)$ & $(0.104)$ \\
\hline \multirow[t]{2}{*}{$\begin{array}{l}\text { Marital status } \\
(1=\text { married })\end{array}$} & -0.3165 & -0.1616 & -0.3387 & 0.3418 & -0.3255 & -0.2563 \\
\hline & $(0.341)$ & $(0.200)$ & $(0.341)$ & $(0.276)$ & $(0.342)$ & $(0.215)$ \\
\hline \multirow[t]{2}{*}{$\begin{array}{l}\text { Ethnicity } \\
\text { (1=Macedonian) }\end{array}$} & $-0.8548 * * *$ & $-0.1866^{*}$ & $-0.8396 * * *$ & $-0.5587 * * *$ & $-0.8583 * * *$ & -0.0742 \\
\hline & $(0.168)$ & $(0.097)$ & $(0.166)$ & $(0.130)$ & $(0.166)$ & $(0.097)$ \\
\hline \multirow[t]{2}{*}{$\begin{array}{l}\text { Education of the } \\
\text { head (ordered scale) }\end{array}$} & -0.0091 & $-0.1999 * * *$ & -0.0043 & $-0.2321 * * *$ & -0.0101 & $-0.1686^{* * *}$ \\
\hline & $(0.055)$ & $(0.031)$ & $(0.054)$ & $(0.044)$ & $(0.055)$ & $(0.032)$ \\
\hline \multirow[t]{2}{*}{$\begin{array}{l}\text { Number of hh } \\
\text { members }\end{array}$} & $-0.5153 * * *$ & $0.2795 * * *$ & $-0.5190 * * *$ & $0.4580 * * *$ & $-0.5182 * * *$ & $0.2070^{* *}$ \\
\hline & $(0.153)$ & $(0.092)$ & $(0.150)$ & $(0.133)$ & $(0.155)$ & $(0.095)$ \\
\hline \multirow[t]{2}{*}{$\begin{array}{l}\text { Number of hh } \\
\text { members squared }\end{array}$} & $0.0435 * * *$ & -0.0128 & $0.0445 * * *$ & $-0.0207 *$ & $0.0436 * * *$ & -0.0095 \\
\hline & $(0.015)$ & $(0.008)$ & $(0.015)$ & $(0.012)$ & $(0.015)$ & $(0.009)$ \\
\hline \multirow[t]{2}{*}{ Dependency ratio } & -0.3302 & $1.2053 * * *$ & -0.3362 & 0.3054 & -0.324 & $1.2812 * * *$ \\
\hline & $(0.328)$ & $(0.167)$ & $(0.326)$ & $(0.252)$ & $(0.330)$ & $(0.171)$ \\
\hline \multirow[t]{2}{*}{$\begin{array}{l}\text { Geography } \\
\text { (1=urban) }\end{array}$} & 0.2277 & 0.0052 & 0.2247 & -0.125 & 0.2217 & 0.0434 \\
\hline & $(0.174)$ & $(0.082)$ & $(0.176)$ & $(0.114)$ & $(0.174)$ & $(0.084)$ \\
\hline \multirow[t]{2}{*}{$\begin{array}{l}\text { Non-economic } \\
\text { motive to migrate }\end{array}$} & $-0.8611 * * *$ & & $-0.8611 * * *$ & & $-0.8611 * * *$ & \\
\hline & $(0.018)$ & & $(0.018)$ & & $(0.018)$ & \\
\hline \multirow[t]{2}{*}{$\begin{array}{l}\text { Remittances }(1=\text { the } \\
\text { household receives } \\
\text { remittances) }\end{array}$} & & $-0.1629 *$ & & $-0.2658^{*}$ & & -0.1189 \\
\hline & & $(0.095)$ & & $(0.144)$ & & $(0.097)$ \\
\hline \multirow[t]{2}{*}{ Constant } & 0.9647 & & 1.1258 & -0.8993 & 0.9837 & \\
\hline & $(1.051)$ & & $(1.047)$ & $(0.878)$ & $(1.057)$ & \\
\hline Observations & 991 & 991 & 991 & 991 & 991 & 991 \\
\hline
\end{tabular}

Table 2 - Baseline results for Macedonia Source: Authors' calculations. *** and *** denote statistical significance at the 10, 5 and 1\% level, respectively. Standard errors given below each coefficient. 


\subsection{Second Relaxing the Assumption of Strictly Exogenous Instruments}

Despite our argumentation in Section 3, still the main criticism one could throw on our results is, actually, the validity of the instrument used, i.e. its strict exogeneity. In other words, our inference in Section 4.1 assumes that the IV exclusion restriction holds exactly. But, this may not be true. The first step is to think of the potential existence of direct links between the noneconomic motive to migrate and the vulnerability of the sending household. One example is persons leaving in deprivation who may be more inclined to conclude marriage with non-residents. This is not so uncommon for Macedonians, especially given the inclination of children from the diaspora (Macedonians born abroad) to marry Macedonians. Another example is the case of wars and conflicts: they financially and materially deprive households, increasing their inclination to emigrate in order to escape the perils of the war. While this has not been that usual for Macedonia, the war in Bosnia in the 1990s may serve as a good example. Both cases suggest that the direct link between the non-economic motive to migrate and vulnerability may not be so uncommon, though.

Recently, Conley et al. (2012) presented practical methods for performing inference while relaxing the exclusion restriction assumption. They presented "alternative approaches to inference that do not impose the assumption that instruments exactly satisfy an exclusion restriction; they need only be plausibly exogenous" (p.270). The approaches involve using prior information regarding the extent of deviations from the exact exclusion restriction. The argument we use here to justify exclusion restriction - migrants from more vulnerable households may have a tendency to emigrate for a non-economic reason - is providing information about prior beliefs about the violation of this restriction. The contribution of Conley et al. (2012) provides a tool for drawing inference about remittances when noneconomic motive to migrate is an imperfect instrument.

In what follows, hence, we relax the strong exogeneity assumption for our instrument and estimate the remittances impact onto vulnerability with only a plausibly exogenous instrument. The method consists of estimating a modified version of the model given in (2) and (3), and consists of estimating $\gamma$ in the following equation:

$$
\operatorname{Pr}\left(V_{i}\right)=\alpha_{3}+\sum \beta_{31 i} \text { Head_ch }_{i}+\sum \beta_{32 i} H_{H}+\sum \beta_{33 i} \text { Community }_{i}+\gamma * \text { Remit }_{i}+\delta * \text { Inst }_{i}+\varepsilon_{3 i}
$$

where $\delta$ is a measure of the direct relationship of the instrument with the household vulnerability. In the previous estimations, $\delta$ was assumed to equal zero, which could result in a biased estimate of $\gamma$ in case of a direct relationship between the instrument and the dependent variable.

We use an arbitrary span/magnitude of this direct influence of between $0 \%$ and $35 \%$, since we have no other prior information, except that it may be positive (i.e. more vulnerable households may be correlated with higher inclination to emigrate for noneconomic reason). Results are presented in Table 4 and suggest when no direct influence between noneconomic motive and vulnerability is allowed, households receiving remittances have lower chances to be vulnerable. Then, for increasing direct influence between the plausibly exogenous instrument and the dependent variable, the remittances' effect on vulnerability is retained significant up to the $6^{\text {th }}$ percentile, with decreasing magnitude. In other words, results suggest that there is still a significant effect of remittances on vulnerability, even with substantial departures from perfect instruments.

\begin{tabular}{|c|c|c|c|c|c|c|c|c|}
\hline 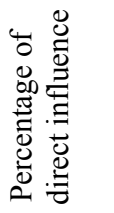 & 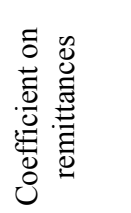 & 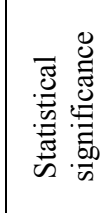 & 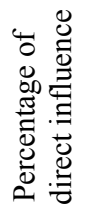 & 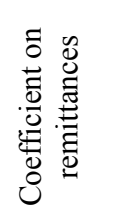 & 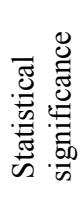 & 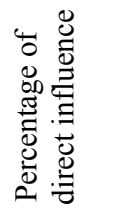 & 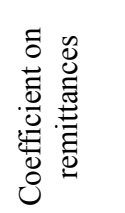 & 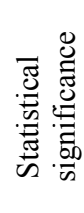 \\
\hline 0 & -0.21488 & $* * *$ & 12 & -0.14521 & & 24 & -0.07554 & \\
\hline 1 & -0.20907 & $* * *$ & 13 & -0.1394 & & 25 & -0.06973 & \\
\hline 2 & -0.20327 & $* * *$ & 14 & -0.1336 & & 26 & -0.06392 & \\
\hline 3 & -0.19746 & $* * *$ & 15 & -0.12779 & & 27 & -0.05812 & \\
\hline 4 & -0.19165 & $* * *$ & 16 & -0.12198 & & 28 & -0.05231 & \\
\hline 5 & -0.18585 & $* * *$ & 17 & -0.11618 & & 29 & -0.04651 & \\
\hline 6 & -0.18004 & & 18 & -0.11037 & & 30 & -0.0407 & \\
\hline 7 & -0.17424 & & 19 & -0.10457 & & 31 & -0.0349 & \\
\hline 8 & -0.16843 & & 20 & -0.09876 & & 32 & -0.02909 & \\
\hline 9 & -0.16262 & & 21 & -0.09295 & & 33 & -0.02328 & \\
\hline 10 & -0.15682 & & 22 & -0.08715 & & 34 & -0.01748 & \\
\hline 11 & -0.15101 & & 23 & -0.08134 & & 35 & -0.01167 & \\
\hline
\end{tabular}

Table 4 - Significance of remittances under the assumption of plausibly exogenous instrument Source: Authors' calculations. * denotes statistical significance at the 5\% level. Confidence intervals not reported to preserve space, but available on request. 
The idea is that if we have a reasonable belief that vulnerability and noneconomic motive are determined simultaneously, or correlated due to the existence of a third unobservable factor, then it is reasonable to consider that this influence slightly reduces the effect of remittances on vulnerability. This makes sense: if migrants originating from more vulnerable households have a tendency to leave for noneconomic reason and send remittances, then remittances may have weaker effect on vulnerability reduction, since those who depart for noneconomic reason likely generate income at destination with a slower pace than those who head for job. However, for medium to large direct influence, remittances are found not to affect vulnerability.

\section{Conclusions}

The objective of the paper is to investigate if remittances sent to Macedonia have a role to play for shielding socially-vulnerable households. To that end, we devise an index of social vulnerability, comprehending income poverty, unemployment of both spouses, single parents, as well conditions of impaired health, undernourishment, material deprivation and insufficient clothing, so as to capture non-income vulnerability conditions.

We regress the index on a standard set of household and community characteristics, adding an indicator of if the households is a recipient of remittances. As remittances are likely endogenous to vulnerability, we use an instrumental variable approach and the conditional mixed process estimator. An indicator of a noneconomic motive to migrate is proposed as instrument, as it is likely correlated with remittances, since any migrant is likely to send remittances irrespective of his migration motive; while uncorrelated with the shocks onto vulnerability. We use the Remittances Survey 2008.

Results suggest that remittance-receiving households have, on average $6 \%$ higher probability to report zerovulnerability, suggesting that they indeed could act as social protection. However, as the assumption of noneconomic motive for migration being a good instrument may be easily dismantled, we further pursue Conley et al.'s (2012) method, allowing for a direct link between noneconomic motive and vulnerability. Results suggest that if we have a reasonable belief that they are determined simultaneously, or correlated due to the existence of a third unobservable factor, then it is reasonable to consider that this influence slightly reduces the effect of remittances on vulnerability.

\section{References}

- $\quad$ Adger, W.N., Brooks, N., Bentham, G., Agnew, M. and Eriksen, S. (2004). New indicators of vulnerability and adaptive capacity. Tyndall Centre Technical Report 7, Tyndall Centre for Climate Change Research Norwich, UK

- Amuedo-Dorantes, C. and Pozo, S. (2006) Migration, Remittances, and Male and Female Employment Patterns. The American Economic Review, 96(2), p.222-226.

- Bianchi, S.M. and Spain, D. (1996). Women, work, and family in America. Population Bulletin 51(3), Population Reference Bureau.

- $\quad$ Clark, G., Moser, S., Ratick, S., Dow, K., Meyer, W., Emani, S., Jin, W., Kasperson, J., Kasperson, R. and Schwarz, H.E. (1998). Assessing the vulnerability of coastal communities to extreme storms: The case of Revere, MA., USA. Mitigation and Adaptation Strategies for Global Change 3, 59-82

- Conley, T.G., Hansen, C.B. and Rossi, P.E. (2012) Plausibly exogenous. The Review of Economics and Statistics, 94(1): 260-272.

- De la Briere, B., De Janvry, A., Lambert, S. and Sadoulet, E. (1997) Why Do Migrants Remit? An Analysis for the Dominican Sierra, International Food Policy Research Institute, Food Consumption and Nutrition Division, Discussion Paper No. 37.

- Dercon, S. (2002) Income Risk, Coping Strategies, and Safety Nets. World Bank Research Observer, Oxford University Press, vol. 17(2), pages 141-166, September.

- $\quad$ Fothergill, A., Maestas, E.G.M. and Darlington, J.D. (1999). Race, ethnicity and disasters in the United States: A review of the literature. Disasters 23(2), 156-173

- Hanson, G.H. and Woodruff, C. (2003) Emigration and Educational Attainment in Mexico. UCSD working paper, 2003.

- Javid, M., Arif, U. and Qayyum, A. (2012) Impact of remittances on economic growth and poverty. Academic Research International, Vol. 2, No. 1.

- $\quad$ Lucas, R. and Stark, O. (1985). Motivations to remit: Evidence from Botswana. Journal of Political Economy 93, 901-918.

- Mojsoska-Blazevski, N., Petreski, M. and Petreska, D. (2013) Increasing labour market activity of poor and female: Let's make work pay in Macedonia. EUROMOD Working Paper Series, EM16/13.

- $\quad$ Morrow, B.H. (1999). Identifying and mapping community vulnerability. Disasters 23, 1-18 
- $\quad$ Petreski, M. and Jovanovic, B. (2014) Do Remittances Reduce Poverty and Inequality in the Western Balkans? Evidence from Macedonia. MPRA Paper 51413.

- $\quad$ Petreski, M. and Jovanovic, B. eds. (2013). Remittances and Development in the Western Balkans: The cases of Macedonia, Kosovo and Bosnia-Herzegovina. Scholars' Press.

- Petreski, M. and Mojsoska, N. (2014) Youth self-employment in households receiving remittances in Macedonia. PEP report.

- Roodman, D. (2011) Fitting fully observed recursive mixed-process models with cmp. The Stata Journal, 11(2), p.159-206.

- Rygel, L., Sullivan, D. and Yarnal, B. (2006). A method for constructing a social vulnerability index: an application to hurricane storm surges in developed countries. Mitigation and adaptation strategies for global change 11, 741-764

- Sabates-Wheeler, R. and Waite, M. (2003) Migration and Social Protection: A Concept Paper. Working Paper of the Institute of Development Studies, Sussex.

- Stark, O. (1978) Economic-Demographic Interactions in Agricultural Development: The Case of Rural-to Urban Migration. Food and Agriculture Organization of the United Nations, Rome.

- Stark, O. (1991) The Migration of Labor. Blackwell, Cambridge and Oxford.

- $\quad$ Stark, O. and Levhari, d. (1982) On Migration and Risk n LDCs. Economic Development and Cultural Change, 31(1), p.191-196.

- Taylor, J.E. (1999) The New Economics of Labor Migration and the Role of Remittances in the Migration Process. International Migration, 37(1), p.63-88.

- Wooldridge, J.M. (2002) Econometric Analysis of Cross Section and Panel Data. London: The MIT Press.

- Wooldridge, J.M. (2007) Introductory Econometrics: A Modern Approach. London: The MIT Press. 


\title{
Foreign Direct Investment Strategy in International Marketing: The Case of Turkey
}

\author{
Asst. Prof. Dr. Mustafa Ercilasun (Beykent University, Turkey) \\ Asst. Prof. Dr. Ayşen Akyüz (Beykent University, Turkey) \\ Asst. Prof. Dr. Ayşe Saime Döner (Beykent University, Turkey)
}

\begin{abstract}
In recent years the role of foreign direct investments (FDIs) in economic development became very important for emerging economies. Thus, the competition to attract FDIs intensified. Turkey, being an emerging economy, needs to apply correct strategies to attract FDIs. This paper will consider competitive environment for FDIs around the world and evaluates steps taken by Turkey since the year 2000. In doing so, changing rules and regulations will be evaluated. After the experience of 2001 economic crisis, in 2003, Turkey passed Foreign Direct Investment Law and taken other actions to stimulate FDI's coming to the country. Changes in economic environment, political situation, legal framework and financial stability play roles in bringing inflow of FDIs. This paper will focus on the case of Turkey and will provide policy recommendations to increase the competitiveness in attracting FDIs.
\end{abstract}

\section{Introduction}

In order to understand how to attract FDIs it is important to understand factors influencing behaviors of existing corporations or corporations elevated to become international in selecting target countries and business environments they prefer to work. In this regard, doing business in particular country, preferred environment and business climate in a country is very important. In addition to economic factors such as cheap labor, location advantage general business climate is the most important for corporations selecting target countries. If Turkey, would like to attract FDIs it must evaluate all of these factors carefully and improve its business climate for foreigners. These improvements will reduce country risks of doing business abroad. Appropriate legal framework, rules and regulations, stable environments are a must to bring in FDIs.

Foreign direct investments by its nature are long run. Therefore stability helps to foresee the future with clarity. If political and business conditions are stable, not subject to change drastically over time, it helps to formulate business plans to succeed. Business plans need not be modified over and over. Stability is also important if it can provide security and guarantee. For example, governments may take over foreign-owned businesses, or may put some restrictions on expropriation of profits to home country. Countries with such an experience are not welcomed by potential FDI providers. The legal framework, need to provide guarantees for FDIs.

Turkey starting in 1980s changed its trade policies away from import substitution in favor of export promotion and moved toward trade liberalization. This drastic change in economic policy helped to accelerate its attractiveness for FDIs. Although economic policy shift happened in early 80s, rules and regulations changed slowly. During the adjustment process for development policy Turkey experienced some economic stagnations. Excluding the impact of latest global financial crisis, Turkey experienced its worst economic crisis in 2001. The collapse of some banks caused to take prudential measures to strengthening banking sector such as higher capital requirements. Since then, foreign banks percentage in Turkish banking sector increased. At the same time Turkey accelerated its privatization process. Some sizeable government enterprises such as Turk Telecom privatized. Privatization of state enterprises did not only brought in government revenues, but at the same time called for FDIs.

\section{Foreign Direct Investment}

Çavuşgil, Knight and Reisenberger (2012, p:434) defined foreign direct investment (FDI) as "an internationalization strategy where the firm establishes a physical presence abroad through direct ownership of productive assets such as capital, technology, labor, land, plant and equipment".

Foreign Direct Investment is the most convoluted and advanced market entry strategy entailing establishment of manufacturing plants, branches, etc. in target countries. Since, to establish physical presence, the company has to invest substantial amount of resources, FDI is riskier than other strategies like exporting or franchising (Çavuşgil, et. al., 2012)

There are numerous examples from Turkey that illustrate the examples of inward and outward FDI; such as Y1ldı Holding, Turkey's leading confectionary company acquired Belgium based chocolatier Godiva from American Campbell Soup Company which had earlier acquired Godiva or Russian Sberbank acquired Denizbank, a Turkish private bank, in 2012, since then Denizbank is controlled by Syberbank. 
When we look at the trends in the global economy we see that, companies from advanced and emerging markets are active in FDI and the target countries for such investments cover both the advanced and emerging markets. Companies from all types of sectors, services included, are taking a share from the FDI. For example major retailers began to perform activities across national borders in the 1970s including Carrefour (France), Metro AG (Germany) (Çavuşgil, et. al., 2012). Advanced economies such as United Kingdom, Japan and the United States have been popular destinations for FDI because they have strong GDP per capita; high GDP growth rates and density of knowledge workers in those countries are high.

Cavusgil et al (2012) states that managers pursue FDI strategies for different and complex reasons. Thus, they classified these reasons in three groups as "market-seeking motives", "resource/asset-seeking motives" and "efficiency-seeking motives". If we examine these motives in detail:

Market-seeking Motives: Focal companies may look for new opportunities abroad as a result of unfavorable local market conditions or they may be favorable opportunities in the foreign markets. So they may seek to gain access to new markets, they may follow their key customers abroad to prevent other suppliers from selling goods or service to them or to compete current or potential rivals directly in their home market.

Resource/asset-seeking motives: Some companies may desire to attain the resources or assets such as raw materials, knowledge, and technological and managerial know-how.

Efficiency-seeking motives: Some focal companies may seek to increase efficiency via FDI in operations and production by reducing sourcing and production costs by allocating cheap labor and other inputs to the production; by locating the plant facilities and assembly operations near the key customers, by taking advantage of the foreign government incentives and by avoiding trade barriers such as tariffs as these usually are applied only to exporting.

FDI activities can be classified by nature of the ownership (wholly owned direct investment, joint venture or equity participation) or by the form (greenfield investment, acquisition and merger).

Foreign direct investors choose their degree of control. This is accomplished through full -wholly owned direct investment in which the investor secures complete managerial control over its operations by assuming 100 percent ownership of the business or equity joint venture in which a separate firm is created through the investment by two or more parent firms- and partial -equity participation- ownership. On the other hand, when examining the classification by the form; Greenfield investment is a form of direct investment where a focal company starts a new venture in a foreign country by building new manufacturing plant or a new marketing or administrative facility from the ground up. An acquisition is the process of acquiring a company or facility. And a merger is a type of acquisition in which two companies join to form a new and a larger company (Cavusgil et al, 2012).

Hill (2009) states that, the majority of cross-border investment is in the form of acquisitions and mergers rather than greenfield investments. He indicates some reasons for that: First, mergers and acquisitions are quicker to execute compared to greenfield investment. Second, foreign companies are acquired because those firms have valuable assets such as strong brand loyalty, patents or distribution systems. Hence, it is simple and possibly less risky for a company to acquire those assets than to build them from the ground up. Third, companies involve in acquisitions because they believe that by transferring capital, management skills and technology, they can increase the efficiency of the acquired unit. FDI is expensive since a company must bear the costs of establishing production facilities across borders or of acquiring a foreign enterprise. It is risky because of the problems associated with different cultures and a focal company undertaking FDI in a foreign country for the first time is more likely to make mistakes.

Table 1 shows the top 10 non-financial multinational companies ranked by foreign assets dated 2013.

\begin{tabular}{|c|l|l|l|r|r|r|r|}
\hline Ranking by: & & & & \multicolumn{3}{|c|}{ Assets } & \multicolumn{2}{|c|}{$\begin{array}{c}\text { Sales } \\
\text { Industry }\end{array}$} & $\begin{array}{c}\text { Foreign } \\
\text { (millions } \\
\text { of } \\
\text { foreign } \\
\text { assets }\end{array}$ & \multicolumn{1}{|c|}{ Corporation } & Home economy & $\begin{array}{c}\text { Total } \\
\text { (millions } \\
\text { of } \\
\text { dollars) }\end{array}$ & $\begin{array}{c}\text { Foreign } \\
\text { (millions } \\
\text { of } \\
\text { dollars) }\end{array}$ & $\begin{array}{c}\text { Total } \\
\text { (millions } \\
\text { of } \\
\text { dollars) }\end{array}$ \\
\hline 1 & General Electric Co & United States & Electrical \& electronic equipment & 331160 & 656560 & 74382 & 142937 \\
\hline 2 & Royal Dutch Shell plc & United Kingdom & Petroleum expl./ref./distr. & 301898 & 357512 & 275651 & 451235 \\
\hline 3 & Toyota Motor Corporation & Japan & Motor vehicles & 274380 & 403088 & 171231 & 256381 \\
\hline 4 & Exxon Mobil Corporation & United States & Petroleum expl./ref./distr. & 231033 & 346808 & 237438 & 390247 \\
\hline 5 & Total SA & France & Petroleum expl./ref./distr. & 226717 & 238870 & 175703 & 227901 \\
\hline 6 & BP plc & United Kingdom & Petroleum expl./ref./distr. & 202899 & 305690 & 250372 & 379136 \\
\hline 7 & Vodafone Group Plc & United Kingdom & Telecommunications & 182837 & 202763 & 59059 & 69276 \\
\hline 8 & Volkswagen Group & Germany & Motor vehicles & 176656 & 446555 & 211488 & 261560 \\
\hline 9 & Chevron Corporation & United States & Petroleum expl./ref./distr. & 175736 & 253753 & 122982 & 211664 \\
\hline 10 & Eni SpA & Italy & Petroleum expl./ref./distr. & 141021 & 190125 & 109886 & 152313 \\
\hline
\end{tabular}

Table 1: Top 10 Non Financial Multinational Companies ranked by foreign assets Source: Adapted from UNCTAD website 
Czinkota et al (2005) mentions about the positive impacts of FDI on host countries. According to Czinkota et al (2005), capital flows are beneficial to the host countries with little indigenous sources and restricted opportunities to raise capital in the world markets. Technology and management skills transfer are two other reasons why the host countries are welcoming inward investments. At the company level, FDI may increase competition and this, ultimately may be beneficial to the economy as well as to consumers by increased productivity and possibly with lower prices. Besides, import substitution, export earnings and etc. all help the host country on the trade account side of the balance of payments. Job opportunities and salary payments over the market rates are the other important advantages of the FDI on host country.

On the other hand, FDI has some possible negative impacts too. Investors usually want to concentrate their research and development efforts and especially their fundamental research. With the technological expertise, the investor can assist the host nation's economic development; however it may leave the host country contingent upon the multinational company, on flows of new technology. Also the multinational company may attract highly skilled local employees from the host country to its central research facility and engage in the brain drain. Czinkota et al (2005), also remarks that the economic benefits of FDI may be questionable as well. Capital inflows may be followed by outflows in a higher degree. Governments also see the foreign investors as a disturbance to their economic planning. Host nations do not look approvingly on an investor that may want to keep the import content high. And the cultural factors may create negative impact on the host country.

The positive and negative impacts that concern the host countries also apply to the home country. FDI means a contribution to the focal company's home market's GDP from profits, royalties and fees sent from affiliates. It could lead to expanding export markets and it could serve for political motives as well. The major critical issue is concerning employment, not only job losses are in question but also effects on export and imports. Another negative issue is that of technological advantage. For instance, sharing the technological expertise with foreign entities could lead the home country to a loss of its competitive position in world market place. Arguments for and against FDI are countless. Costs and benefits must be put in the balance. Only the host and home countries can assess benefits against cost. (Czinkota et al, 2005). Hill (2009) mentions that when doing the assessment for the home country, we should take international trade theory into consideration. According to international trade theory, home country's anxiety about the unfavorable negative effects of offshore production may be positioned wrongly. Offshore production states the FDI is undertaken to serve the home market. Such FDI may stimulate economic growth and employment in the home country by setting the home country resources free to concentrate on activities that the home country has comparative advantage about. Besides, home country citizens could benefit if the price of a product falls due to the FDI.

Many countries implement policies to attract foreign direct investment. Incentives to promote such investments are fiscal, financial and non-financial. Fiscal incentives are specific tax deals that typically consist of tax rebates, special deductions for capital expenditures, special depreciation allowances, designed to attract the foreign investor. Financial incentives offer financial support by providing assets such as a land or loan. And nonfinancial incentives can cover special promotion through tariffs, quotas, and local content requirements and investments in infrastructure facilities (Czinkota et al, 2005).

\section{FDI Regulations in the World and in Turkey}

Host countries apply policies both to restrict and to support inward FDI. Government incentives such as tax concessions or subsidies are offered to foreign companies to attract investment. On the other hand, host nation's governments use a wide range of controls to restrict inward FDI. Ownership restraint is one way of control and can take several forms. Governments exclude foreign investors from certain industries related to national security or competition. They may do that also for protecting infant industries. Besides, they help maximize the resource transfer effect and employment benefits that are associated with FDI. In Japan for example, until the early 1980s, most FDI was prohibited unless the foreign firm had valuable technology. Then, the foreign firm was allowed to form a joint venture with a Japanese company because the Japanese government believed that such an arrangement would speed up the diffusion of the technology throughout the Japanese economy.

Performance requirement is also used to restrict FDI and can also take several forms like ownership restraint. The most prevalent performance requirements are related to exports, technology transfer and the local participation in top management. Besides, performance requirements are used to maximize the benefits and minimize the costs of FDI for the host country. Many countries apply some form of performance requirements but they tend to be common in less developed countries (Hill, 2009).

In considering political system of a country for doing business political stability of selected country appears to be the most important. Political system defined by the form of a government. Two extreme cases are democracies and dictatorships. However, more than the form of government, stability and being able to create influence to change regulations via special interest groups that exists come forward. Thus, existences of special interest groups are very helpful. Trade associations, environmental consumer groups, civil groups for liberalization and freedom are examples of some special interest groups. These groups do not only serve to 
promote improved trade and FDIs but also serve as a source for market information and facilitator to market entry.

During the early period of Turkish Republic, following the İzmir Economics conference, liberal economic policies adopted. In1924, Turkey passed a law allowing foreigners to acquire property. Until about mid-thirties number of multi-national corporations increased, particularly in banking, finance and insurance fields (Tezel 2002). However, the levels of domestic and foreign investments were not satisfactory. Thus, government changed its course toward Étatism, and engaged directly with economic activities. Up until 1950s, public state enterprises founded and operated by government and railroad projects implemented. During this period foreign investments declined significantly, partly due to World War II. After the war is over and Turkey transitioned to multi-party system incentives to stimulate foreign investments considered. In 1954, with the acceptance of Foreign Capital Law, foreigners allowed to enter into private sector, provided that they will not have monopoly power and special privileges as long as their investments considered contributing to the economic development of a country (Erçakar and Karagöl, 2011, p9). Although FDIs increased, this particular law was open to conflicting interpretations and was not clear. Foreign investors came in via partnership, in the areas of food processing, automotive, pharmaceutical and appliances. In 1963, with the establishment of State Planning Organization, Turkey entered into planned economic development era. Order number 17 declared. With this declaration, except petroleum area, foreigners can establish joint partnerships provided that they bring in primary capital as a foreign exchange. However, they were not allowed to transfer profits abroad. In practice, from time to time, governments got around this particular decree with other decrees.

The level FDIs coming in Turkey is shown in figures 1-3. It's obvious from Figure 1 that in early periods FDIs coming in Turkey did not reached to significant levels although we observed increasing trend with transition to planned economy era after 1963. Figure -2 shows that during 1970s FDIs were at low levels and impacted negatively from 1974 and 1979 recessions. After 1979, it jumped to above 100 million dollars.

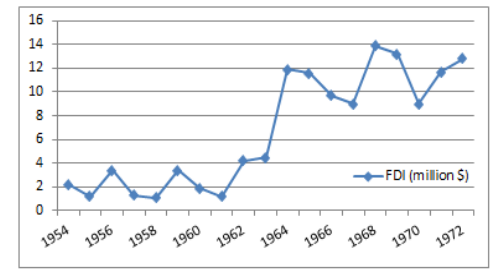

Figure 1: FDIs Period: 1954-1972

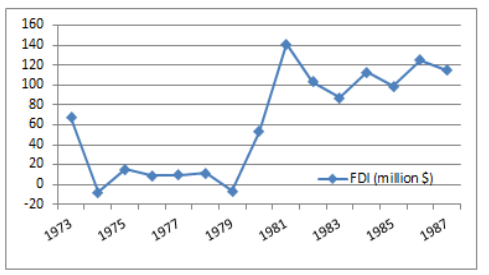

Figure 2: FDIs Period: 1973-1987

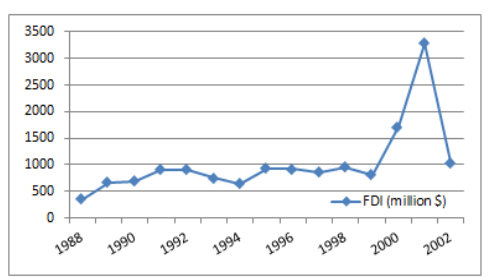

Figure 3: FDIs Period: 1988-2002

\begin{tabular}{|l|r|r|r|r|r|r|r|r|r|r|r|r|r|r|r|r|}
\hline Year & 1954 & 1955 & 1956 & 1957 & 1958 & 1959 & 1960 & 1961 & 1962 & 1963 & 1964 & 1965 & 1966 & 1967 & 1968 & 1969 \\
\hline FDI (million \$) & 2,2 & 1,2 & 3,4 & 1,3 & 1,1 & 3,4 & 1,9 & 1,2 & 4,2 & 4,5 & 11,9 & 11,6 & 9,7 & 9 & 13,9 & 13,2 \\
\hline Year & 1970 & 1971 & 1972 & 1973 & 1974 & 1975 & 1976 & 1977 & 1978 & 1979 & 1980 & 1981 & 1982 & 1983 & 1984 & 1985 \\
\hline FDI (million \$) & 9 & 11,7 & 12,8 & 67,3 & $-7,7$ & 15,1 & 8,9 & 9,2 & 11,7 & $-6,4$ & 53 & 141 & 103 & 87 & 113 & 99 \\
\hline Year & 1986 & 1987 & 1988 & 1989 & 1990 & 1991 & 1992 & 1993 & 1994 & 1995 & 1996 & 1997 & 1998 & 1999 & 2000 & 2001 \\
\hline FDI (million \$) & 125 & 115 & 354 & 663 & 684 & 907 & 911 & 746 & 636 & 934 & 914 & 852 & 953 & 813 & 1707 & 3288 \\
\hline
\end{tabular}

Table 2: FDI Inflows During 1954-2001 Source: Treasure Department of Turkey

After 1980, liberalization and export promotion periods, Turkey observed increased FDI levels. However, FDI levels did not increased significantly, despite new mode of trade and accession to Customs Union with European Union in 1995. As Turkey approached to year 2000 it observed significant increase in FDI levels, but this jump hampered by 2001 economic crisis. During 1990s the collapse of Eastern Block, China and Far Eastern countries become potential destinations for FDIs along with some emerging Latin American countries. Turkey was not in a position to compete with these countries both on economic and regulatory fronts. 1980 with the new decree Foreign Capital Directorate established. This was a significant turning point.

With the passage of Foreign Direct Investment Law in 2003 (FDIL-2003), Turkey experienced significant increase in FDI inflows till 2006. Some of this increase could be attributed to expansionary economic policies of western countries, particularly United States. After 2007 as the world entered global economic crisis FDIs flowing out of these countries declined. Turkey also took its share from this declining trend of FDIs as it is shown by Figure 4. 


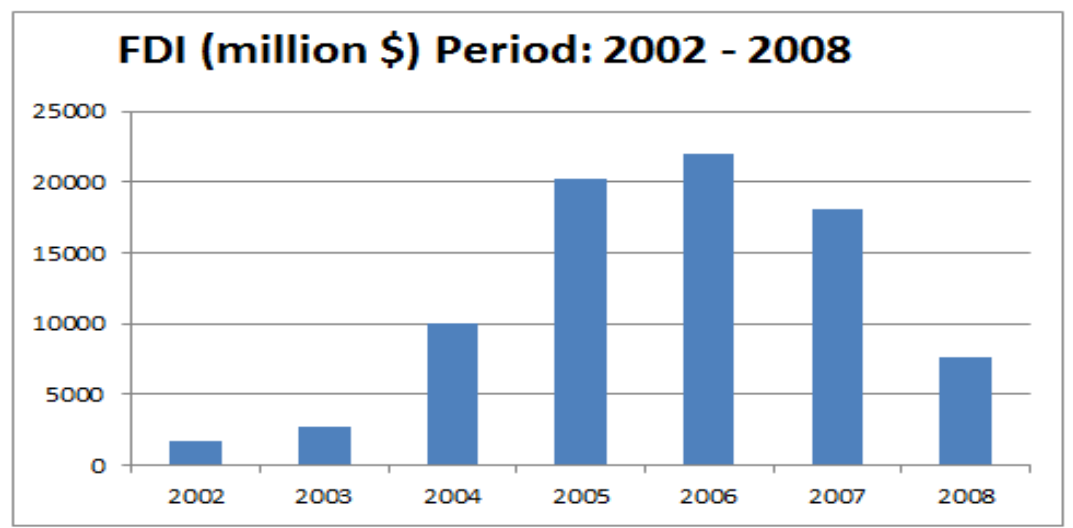

Figure 4: Foreign Direct Investments 2002-2008 Source: Ernst \& Young, 2013.

According to with FDIL-2003 foreign investors are subject to equal treatment with domestic investors and protected against expropriation and nationalization. Furthermore, they can freely transfer profits, dividends and other payments received as a result of their activities in Turkey. Additionally foreign investors were no longer required to obtain pre-license to business in Turkey. Instead of granting permission to foreign operations in Turkey, monitoring their activities is chosen as a new strategy.

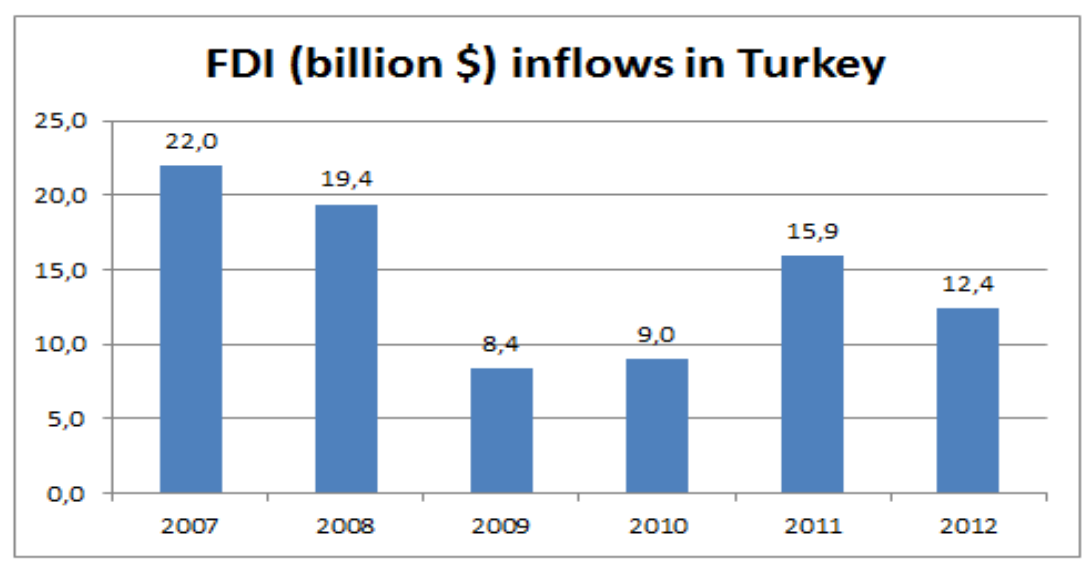

Figure 5: Foreign Direct Investments 2007 - 2012 Source: Ernst \& Young, 2013

Figure 5 adopted from Ernst \& Young's Attentiveness Survey. It shows that Turkey improved its FDI inflow situation after the global economic crisis. In 2011 FDIs increased by 76 percent against the prior year. However, in 2012 FDI declined again due to cross-border decline in merger \& acquisitions (Ernst \& Young, 2013). According to the same survey respondents asked the following question. In your opinion, where should Turkey concentrate its efforts to increase its attractiveness in global competition? Reduced government bureaucracy with $38 \%$ was the highest scored attribute. Other important attributes that come forward support SMEs, reduce taxation, increase tax benefits \& incentives, facilitate access to credit, and increase flexibility of labor regulations (Ernst \& Young, 2013).

FDI inflows coming in Turkey for years of 2013-14 differs depending upon the sources considered. According to Investment Support \& Promotion Agency of Turkey for 2013 expected FDI inflow was $\$ 13.7$ billion (Bloomberg, 2014). International net direct investments in Turkey totaled $\$ 8.6$ billion in the first eight months of 2014, a 9.8 percent increase from the same period of the previous year, the Economy Ministry announced on Oct. 27 (Hürriyet Daily News, 2014).

In 2012, Turkey declared new investment incentive scheme. These incentives used various support instruments:

$\checkmark \quad$ VAT Exemption

$\checkmark$ Customs Duty Exemptions

$\checkmark$ Tax Reduction

$\checkmark$ Social Security Premium Support (both employer \& employee shares)

$\checkmark \quad$ Income Tax Withholding

$\checkmark$ Interest Rate Support

$\checkmark$ Land Allocation

$\checkmark \quad$ VAT Refund

Different levels of incentives provided depending upon the region where the FDIs are directed. Turkey is divided into six regions from 1 through 6, where region 1 receives lowest level of incentive. As the region 
number increased the level of incentive also increases. For example tax reduction rate for region 1 is 50 percent and for region 6 it is 90 percent (invest.gov.tr).

Figure 6 shows FDIs as percentage of GDP for Turkey and how it stands with comparable countries. Compared to other emerging markets (Brazil, Mexico, Poland, and Czech Republic), Turkey's FDI performance stands out poorly.

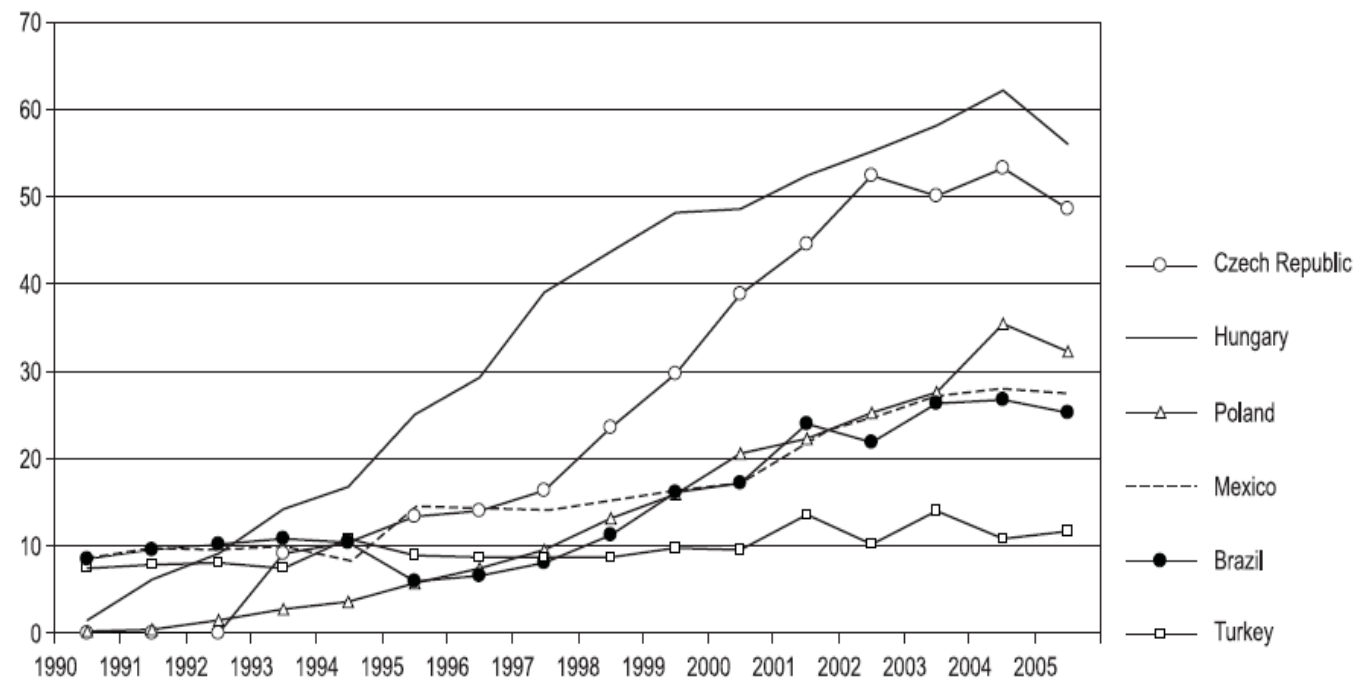

Figure 6: Percentage of FDI inflow in GDP for selected emerging market economies. Source: UNCTAD 2006, adopted from Dumludağ, Devrim, 2009

The relatively poor performance of Turkey could be explained by various factors. Possibly besides economic and political stability factors some other institutional factor are also playing a role. Intuitional factors are informal and formal rules and enforcement mechanism (Dumludağ, 2009).

\section{Conclusions}

In accordance with the literature and statistics reviewed, Turkey tried to attract FDIs from abroad. In early periods of the Turkish Republic protective import substitution and trade policies prevented Turkey to attract significant levels of FDIs. Trade liberalization policies implemented in 1980s was a turning point for igniting FDIs coming in Turkey. However, initially Turkey was not successful in stimulating inflow of FDIs due to lack of experience and deficiencies in its regulatory structure and fluctuating business cycles. Accelerated inflationary periods followed by couple of economic recessions during 1990s and worst crisis 2001 and lastly 2008 global financial crises negatively impacted FDI inflows. Fortunately prudent measures taken after 2001 economic crisis and political stability established after 2002, the passage of Foreign Direct Investment Law in 2003 opened opportunities for Turkey to attract FDIs. Additionally Turkish effort to modify various laws to align those European Union standards was helpful. Furthermore global expansion happening during 2000s was blessing for increased FDIs up until 2008 global crisis. Like many other countries the latest economic crises fractured FDI inflows coming into the country. Turkey slowly came out of this stagnation, but worsening balance of trade position and increased foreign debt levels, coupled with still stagnating Europe, particularly in periphery countries slowed economic growth and FDI inflows. Despite upon these negative factors Turkey's effort to attract FDIs deserve applause. However the road to make Turkey attractive for FDI heaven in the globe requires further actions. It is important to eliminate bureaucracy and informal sector. In Earnt \& Young survey bureaucracy came out to be the number one desired area for improvement. Reduction in informal sector will eliminate unfair competition for potential investors from abroad. Improvement in legal system and accelerated court processes should be considered. Increased productivity and flexibility in the labor market along with better labor regulations will help to stimulate FDIs. Addionally, transparent economic policy that would eliminate surprises and help to manage future expectations of businesses contribute to stable economic outlook. This outlook supported with political stability will further strengthen attractiveness for FDI inflows. 
Appendix:

\begin{tabular}{|l|l|}
\hline \multicolumn{1}{|c|}{ Year / Date } & \\
\hline 1954 & Foreign Capital Law passed \\
\hline 1963 & State Planning Organization Founded \\
\hline 1974 and 1999 & Economic Crisis \\
\hline 1995 & Custom Union Accession \\
\hline January 1980 & Declaration of Liberalization Policies for Free Trade \\
\hline 1980 & $\begin{array}{l}\text { Foreign Capital Directorate established. } \\
\text { Free Trade Zone Directorate founded. }\end{array}$ \\
\hline 1982 & $\begin{array}{l}\text { Incentives for tourism establishment declared. } \\
\text { Financial Leasing Rules written. }\end{array}$ \\
\hline 1985 & Restrictions to acquire real estate lifted. \\
\hline 1994 & Protection of Competition Law \\
\hline 1995 & $\begin{array}{l}\text { Protection of patent rights } \\
\text { Protection of Brands } \\
\text { Protection of Customers }\end{array}$ \\
\hline 2001 & Economic crisis \\
\hline 2001 & Turk Telecom privatization \\
\hline 2003 & Foreign Direct Investment Law passed \\
\hline
\end{tabular}

Table A1: Significant Events Related to Foreign Direct Investments

\section{References}

- Bloomberg (2014) : http://www.bloomberg.com/news/articles/2014-03-26/turkey-2014-fdi-seen-meetinglast-year-level-amid-graft-probe (viewed 07.06.2015)

- Cavusgil, S.T., Knight, G. , Riesenberger, J.R. (2012). International Business. New Jersey: Pearson. Second Edition

- Czinkota, M.R., Ronkainen, I.A., Moffett, M.H. (2005). International Business. USA: South-Western, Thompson. Seventh Edition.

- Dumludağ, Devrim (2009) “An Analysis of the Detarminants of Foreign Direct Investment in Turkey: The role of the Institutional Context”. Journal of Business and Management. 10:1, p 15-30.

- $\quad$ Ernst \& Young's Attentiveness Survey: Turkey 2013

- Erçakar, M. E. and Karagöl, E. T. (2011). Türkiye'de Doğrudan Yabancı Yatırımlar. Seta Analiz.

- Hill, C.W.L (2009). Global Business Today. New York: McGraw-Hill. Sixth Edition.

- Hürriyet Daily News (2014): http://www.hurriyetdailynews.com/fdi-inflow-to-turkey-rises-by-10-percentin-2014-----aspx?pageID $=238 \& n I D=73524 \& N e w s C a t I D=345$ (viewed 07.06.2015)

- Tezel, Y.S. (2002). Cumhuriyet Döneminin İktisadi Tarihi (1923-1950). İstanbul: Tarih Vakfi Yurt Yayınları.

- UNCTAD. (2006). United Nations Conference of Trade and Development. Handbook of Statistics UNCTAD: http://www.unctad.org/Templates/Page.asp?intItemID=1584\&lang=1 (viewed 07.06.2015)

- UNCTAD.(2013). United Nations Conference of Trade and Development. Handbook of Statistics UNCTAD: http://unctad.org/Sections/dite dir/docs/WIR2014/WIR14 tab28.xls (viewed 07.06.2015)

- $\quad$ Ünay, S.(2013). Modern Kalkınmacılık. İstanbul: Küre Yayınları. 


\title{
Economic Expectations for Turkey, Central Asia and Caucasus Beyond 2050
}

\author{
Dr. Ahmet Salih İkiz (Muğla University, Turkey)
}

\begin{abstract}
In this study main international strategic theories will be shortly discussed under the time and space dimension. Almost all of the Turkic republics do have common historical and cultural ties with Turkey compared to the other European countries. Even though common values have simply forgotten during the time frame under different regimes spatial history and ties had never disappeared. Thus, the citizens of those countries preserve common spatial memory so they shared same land in history. So it is expected that those people would reach the idea of economic and political integration if certain social grounds were initiated. This is basically the idea of economic integration between those republics and Turkey for better economic standards. So, in final part of the study, author will provide his humble opinions for future expectations for 2050 and beyond.
\end{abstract}

\section{Introduction}

"In politics or geopolitics, scenario analysis involves modeling the possible alternative paths of a social or political environment and possibly diplomatic and war risks. For example, in the recent Iraq War, the Pentagon certainly had to model alternative possibilities that might arise in the war situation and had to position material and troops accordingly." (Wikipedia).

The relation between economic power geographical locations of countries is the main research area of Geoeconomics science. Geo-economics reveals the impacts of countries technology, capital, and natural resources on political power in globe. Thus it can be classified as the sub section of both economics and political science. In today's world most of the international conflict rooted by international trade interests of host countries. That increases the importance of that particular science. The globalization wave accompanied by mercantilist economic policies forced European countries penetration in the rest of world. The political elite and military command draw special attention to govern and control the rest of the globe. Implementation of this strategy backed first by British Mackinder as heartland theorem and followed by American Spykman's Rim land strategy.

British geopolitical strategy born in 19th century for the security and economic purposes of Empire. In late 19th century American Admiral Alfred Mahan published his study called The Influence of Sea power upon History. Mahan geopolitics believes countries with sea borders are easy to defend. Countries surrounded by ocean reinforce their military powers for intervention to other countries. As long as they have strong sea power they easily control world strategic points easily. In following years US geo-economics policy surrounded main energy resources and trade corridors in world by its naval force.

British academic John MacKinder wrote his book Historical Pivot of the History and introduced Heartland theory. According to the theory world strategic center heartland situated in central Asia and Volga Basin. This region is like natural castle with its topographic and geographic location. His assumption based on the geographic location of land is important. So all world can be divided to 3 geographical locations:

- Heartland (Kalpagh) Eastern Europe and Siberia

- Inner Crescent Turkey, Germany, India and China

- Crescent United Kingdom, South Africa and Japan

Thus if any country or political power rules Eastern Europe dominates Hearth land. The geopolitical center of Eurasia lies on Hearthland. So the political master of Eurasia is the world leader in geoeconomics.

After WWI the German geopolitics reinforced Lebensraum strategy for German invasion till the end of WWII. This strategy based upon the idea of Darwin's survival of the fittest theory. Every country must be considered as living organism and in order to keep the country alive it has to create its own living area for enlargement. I.e. the occupation of other countries. Following the collapse of third Reich European impact on world order diminished since most of the countries such as Brittan and France faced with devastating economic ruins. German strategy ironically reincarnated in different forms when German economic power seized most of the Balkan countries in1990's under EU umbrella. First German mark and then Euro circulated as hard currency in those countries as economic hegemonic power of Germany after couple of decades of German tanks in those countries.

That was the beginning of US empowerment in foreign policy and world order. USA policy mainly leans on containment policy due to fear of USSR war capacity. Border and edge countries like Turkey had solid support from US as a bumper. Creation of US led opposition movement in USSR neighbor countries and Turkic republics was main aim to destabilize possible Moscow penetration on western world. In those times there was almost no international relation between Turkic States and Turkey because of strict Soviet control. During the cold war world has two power polar USSR and USA. Those countries were the main determinants of pivot and 
bumper countries foreign policies. The US strategy was to impose and improve soft Islamic power around USSR. Under the green zone approach Islamic groups in periphery countries re supported. The main aim was to create artificial enemy to Marxist, atheist communist world. Containment policy is theoretical reflection of Rimland theory of Spkysman. Contrary to Hearthland theory Rimland approach focuses on crescent of Eurasian regions. In order to diminish USSR power in Eurasia US must target to improve its penetration on those countries. The North Korean, Vietnam and Afghanistan wars were main power struggles and conflict zones during the cold war since they are vital countries under this policy.

Dramatic collapse of USSR due to economic inefficiencies ended cold war period. That is also limited the global political power of USSR. Fransis Fukuyama called that The End of History where the US led economic system will be the unique in world order. In same time frame Huntington announced the new paradigm as Clash of Civilizations. According to him there are five different civilizations in world Orthodox, Catholic, Islam, Indian and Japan. The borders of those civilizations are new breaking points between countries. Countries with different cultures would have problems in their countries such Former Yugoslav countries. This is what he called the clash of civilizations. The war in Bosnia was one of the examples of this geographical conflict. Russian Federation was hampered by those wars during the disintegration process of USSR.

Eurasia in geological terms can be classified in narrow definition is the borders of Central Turkic Republics. In broader sense Eurasia reaches China, Afghanistan Pakistan and Russia. Those geographical definitions also reflect the Turkish and other countries approach to region. Turkey for a period of time stick to narrow definition while Russian Federation and USA concentrated on broader sense especially after 9/11. Russian Eurasian policy considered Turkey as rival country. The theoretical background of Eurasian policy had changed as it turned to opposition to westernization in cultural and economic life.

Following Putin presidency the foreign policy of Russian Federation radically changed and shaped by Dugin's Neo Eurasian philosophy. In former USSR borders establishment of Commonwealth of Independent States improved the relations with former USSR countries. In foreign security China, Russian Federation, Kazakhstan, Kirghizstan, Tajikistan and Uzbekistan founded Shanghai Security Organization. This has similar functions of NATO for those countries. This new paradigm possibly aims to solve the integration problems multiethnic Russian society. The authoritarian, state controlled economic structure and governance will create modern society without Atlantic western democratic codes in country.

In modern geo-economics the variables of spatial location, identity and economics are the main determinants of strategic analyses. In today's global society the historical legacies of ancient societies become quite significant in identity formation. Preserved identities in former USSR countries are very essential leverage for the foundation and integration of Turkic Union in that part of the world. Hard power always must be accompanied with soft power in international relations. The historical heritage of Turkish culture in those countries will serve an eminent tool for that. All these theories became much more complex in today's cyber global society where small minor change in any part of the world would create a butterfly effect in some other country.

\section{Eurasia and Turkey}

Turkish inhabitance in Eurasia starts from BC 4th in region. There were hundreds of nomads in Central Asia. The integration of those tribes created Turkic empire in Central Asia and ruled relatively long period of time. That kept security and stability from China to Byzantium on Silk Road and created Pax Turcica (Findley 57). So that identity formation with same language, cultural habits, and religious ceremonies easily created within those tribes in spatial dimension. The Chinese threat, scarce natural resources for nutrition and internal conflicts forced them to move to west in AD 11th century. Migration of tribes was also the beginning of the establishment of new civilizations and states in Anatolia. In chronological order Seljuk, Ottoman empires and finally Turkish Republic founded in this land. During the Seljuk and Ottoman empires the Central Asia still have Turkic origin Mongols. When Ottomans were transformed to Islamic dominant global state Mongols were trying to sustain their persistence in Asia. In early 16th Century Turks in Central Asia lost their independence under Russian occupation. That dimension nevertheless created Russian dominance and oppression on language and culture. So that until early 20th Century Turks living in Central Asia, Anatolia and other parts of Ottoman empire do not need any other language for communication that maintain common identity in most of the daily life. For example Findley searched the similarities of Turkish rugs and carpets in different parts of Anatolia and Central Asia and find a lot of resemblance in history. Loss of momentum of development of Ottomans and Russian policies vanished the communication of Turks in west and east especially after the WWII.

After 1917 revolution Russian central government privileged the self determination of Turkic states in language and education in order to end the traumatic totalitarian chauvinist policies of old Char regime. Thus Muslim Turks in Central Asian Republics were quite convinced and supported USSR regime for a period of time. The general discourse was the reflexive division of Islamic conservatives and contemporary nationalists. The left wing nationalists cooperated with Bolsheviks and the domain governing mind till mid-1930s (Aydin, 38). The tone and intervention of USSR policies towards Turks changed after Stalin era. The education system 
centralized by Russian alphabet, international relations of republics with foreign world restricted and central planning changed economic distribution channels radically. This is the beginning of the isolation of Central Asia from other countries but mainly Turkey. Same time Turkey joined NATO and had limited ability towards his foreign policies towards USSR. For a long period of time the case of Central Asian Turkic Republics considered as internal affairs of USSR by Turkish Republic. The Cold war period could be classified as finite political game between two polar world powers. Each party has its own strategy and tactics in economics, military and trade areas in world system. There was few relations between two blocks. Both parties have its own strategy on Turkic Republics. USSR granted limited determination in internal policies and was ultimate decision maker in international policies. US strategy based on Rimland theory and aims to create instability in those states. The soviet economic system had been working inefficiently under central planning system and it was not sustainable for long term economic growth. Coming to 1990's Increasing defense expenditures became a real burden on state budget which started disintegration process of Soviet bloc. After the disintegration, Turkic world had its own policy formation in both interior and international affairs. So after 1991 the economic and cultural and educational corporations and bilateral policies increased between Turkey and those countries. The oversimplification of differences between Anatolian Turks and Asiatic Turks sometimes created artificial relations among partners (Aydin, 8). Turkish behavior towards the region sometimes like older brother of those states which in turn created negative impacts on Turkish presence. For decades Turkic Republics experienced the same treatment and policy by USSR and got negative experiences. In order to not engage the same parental treatment they do have limited support to the integration efforts of Turkey. Thus the both parties have lost their momentum in further cooperation in different aspects of relations. For example today the foreign trade between those countries and Turkey less than $\% 3$ in Turkish whole foreign trades. Those countries still do need Russian interference since most energy infrastructure belongs to Moscow. The poor human capital and lack of education needs Russian technological manpower and engineers. The strategic shift mainly affected by Russian dominant policy in region and energy security and corridors policy became the main concern in formation Turkish international policy to Central Asian countries.

Russian policy towards Central Asia has reshaped in 2000 and this geographical region became area of interest and power infusion for Russia. The increasing economic penetration of Russia melted the power infusion of USA to Turkic world. Turkey also lost its momentum with Turkic world due to declining volume of trade. Also Russia became main player in defining the energy transport routes of those energy rich countries. The economic power of Russia backed my some military interventions to Georgia and Ukraine by stretching the mussels. The spatial ties in history survived but overshadowed by Dugins strategy in Turkic world. The Blue Stream was total bypass of supplier countries and also Russia got advantage international chess board by starting to construct Turkish Stream.

\section{Year 2050 and Beyond}

Anatolia is the harmony of eastern and western cultures. It was also the nest of many different civilizations. That enables the cohesion in much aspect with neighbor countries. This is also improves spatial tolerance between Turkish speaking world. In following part of the study I will explore possible future expectations in world political order with special emphasis on Turkic world and Turkey.

Coming years there will be the changing power blocks in world. British and following USA dominance in world order will have new global players such as, Russia, China, Japan and Turkey. The Caucasus and Central Asia will be main interest of all those countries. The World has witnessed that the growing economies like China and India have become part of the global market and integrated to the global economy in the last 20 years with rapid globalization process. With high performance of emerging economies like China and India, developed countries' share of global GDP declined, while developing countries' share increased. These trends in the global economy negatively affected the role of US and Europe used to be a dominant before and emerging new powers increased room for maneuver (MGK, 8). Kazakhstan and Turkmenistan have strong economic path and attained high growth rates. With other Turkic Republics Turkey would increase the volume of international trade and economic cooperation in coming years. Southern Caucasus is the main location for energy and transport corridors to Eurasia. The Russian interest on Azerbaijan, Georgia and Armenia starts in 13 AD where Georgian Christian tribes demanded Russian support for Turkish and Ottoman presence in region (Aydın, 27). So this region had conflict of interest with those countries. Peace, security and welfare in this region plays important role for Turkey

China has close historical ties with eastern Turkistan. The hew Silk Road project of Shanghai Security Organization improved economic bridges between those countries and China. According to World Energy Institute resources since 2009 Chinese demand of energy resources higher than US. This indicator reveals the Chinese eagerness towards Central Asia. In order to secure its energy demand by close energy supply countries this country will cooperate with Russia. As long maintain financial stability and interior stability China will be one of the main powers in region (Erkin, 268). Even if Russia and China got some imperial balance on region their international power will decline due to interior problems. China although has very fast economic growth 
rates regional differences in economic growth and education is quite high in different geographical parts of the country. Unsustainable economic achievements will create social unrest in low income masses. Meantime country got economic and military threat from Japan and USA. So it concentrates rather on internal issues and got weak interest on Turkic world. Putin's dominant strategy in region must be backed by economic and financial power. Russia never has been competitive in industrial production in world wide. That created relatively weak economic structure which is depending on export revenues of raw materials, precious metals and energy resources. By the leverage of this policy it has moved to the penetration area towards Caucuses and Eastern Europe in former borders. But there are some backward trends in Russia. First the population is seriously declining which diminishes military power which is essential to stop any threat from western borders. During the Napoleon French attack and German invasion in WWII followed flat lines close to ST Petersburg. Loss of military power and declining economic growth due to the declining energy revenues limits the size of Moscow to any other attempts to Central Asian countries. The internal conflicts of both countries will increase the impoartence of Turkey, Japan and Poland İn those region. Turkey with its special spatial memory coming from historical ties has clear advantage in construction cultural bridges between Muslim and Turkish minorities in region. Then the expected political map for 2050 in the region will be as same as the Friedman's expectations in his book (Friedman, 267).

USA support to Turkey as counter balancing power for its policies to Central Asia and Middle East is essential part of its global strategy. In order to create a contra power to Russian strategic influence on petroleum and gas resources American support for Turkey is crucial. European policy towards Russia is quite reluctant since they are heavily depending on energy supply and transport of this country. Turkey with his nephew's Kazakhstan, Uzbekistan and Turkmenistan in Central Asia planning to construct TransHazar facility for EU and its leaving Iran and Russia out of the table. This has been confronted and bypassed by Russian Turk stream pipe line attack which is totally against it.

With new defense concept Russia founded an alternative security organization to NATO in Central Asia in 1997. Shanghai Security Organization member countries have clash of interest on their hegemonic power on rich energy resources in Central Asia (Özkan, 126). After the collapse of the Soviet Union, Russia and its orbit states economic, military and social relations have been changed with the orbit states political leaders (SDE, 124). Also Russia is not happy with US dominance in region. So in order to lessen US intervention they would prefer to have closer relations with Turkey which is heavily based on economic interest (SDE, 141). Turkey would enjoy the economic benefits of close relations with Russia and Muslim Turkish Republics even if with the expense of neglecting his western alliances such as EU and US (Ahmad, 264). So far it seems US lost against Russia but my expectation is it won't go long since after 2020 Russia has third disintegration process.

Our homeland Turkey in those times would reinforce its penetration and even move so far to Caucasus and Ukraine in order to create new crescent strategy around Russia. The ethno linguistic similarities and Ottoman Turkic past would also ease this policy. There is vast number of agencies and organizations playing an important role in development path of those countries. For example the success of cultural, economic and social projects of Turkish TIKA organization has positive impacts on Turkish presence after 1993 (Yesevi 262).

The spatial history in Central Asia has two main grounds in sociological claster analyses. The first one is religious identity which is dominated by Islam. The second one is ethnic identity which is dominated by Turkish ancestors. Those two elements in this region have living in daily social life and culture. Turkey would play important role in former USSR countries since they do share same religion (Fuller, 228). Those two sub identities had long live cultural heritage in Kazakhstan, Uzbekistan, Turkmenistan, Tataristan, Kirgizstan, Mongolia and Caucasus. Since first presence of different ethnic Turkish tribes nomad culture has grown in steppes and plains of Central Asia. Religious belief of those people was shamanism which is basically to adoration to naturel objects, mountains, sun and others. Shamanism is quite similar to old Roman pagan belief in a sense. From the very beginning till these days some daily habits and superstitious beliefs are very similar to old shamanic beliefs in Turkish culture such as water cult, nevroz and worship to sun and moon. There are also same daily routine in those geographic region, similar cousin, dressing and language. All these are embodied in the genetic code of cultural norms in all Turkish origin people. Following the islamisation of those tribes the second identity formation process began. The Sufi belief in this region reemerged and transmitted to western world by emigration of those tribes to Asia minor and Balkans in 11. Century. The colonization of Anatolia as old Roman country by those cultures created similar cultural origin from Central Asia.

The common spatial history and culture will build Turkish kalpahgh in Central Asia in 2030 and after. The Japan Turkish cooperation against Russia will also hamper Russian dominance on Turkic Republics (Passig, 223). Turkey will be new regional power between East and West with its considerable independent military and political power. The security of energy corridors in Hazar lake region will be the main priority of Turkish government. In order to maintain these aim military and other tools would be used in significant ways. This is the beginning of new big game (Özkan, 36). It is expected that competition among the USA.,EU, Turkey, Russia, China, Iran and other actors over the routes of oil and natural gas reserves of the region will be transported to the international markets will continue and Turkey will become one of the key countries of the east-west as well as 
the north-south energy corridor. As long as maintain sustainable economic growth and financial stability Turkey would also become energy market where almost $3 / 4$ of the entire world main energy supply in its neighbor countries. According to WEC estimations and some case studies this is one of the highest expectations in future (WEC, 59).

All these expectations are mainly based on strong performance of Turkish economy. It is the biggest economy among those countries and compared to neighbors it's the number one. There are some structural problems in Turkish economy such current account deficit and high unemployment rate. As long as solve cheap and sustainable energy supply and invest in competitive innovative new industries the possibility of successful economic model will be achieved in Turkey.

\section{Conclusion}

Spatial geoeconomic dimension one of the key elements in preserving common identity among Turkish speaking world. Most of jeoeconomic strategic theories put special emphasis on Turkic World in Central Asia. In this paper we briefly discussed Turkish presence in those Republics in historical context under the framework of cultural, spatial and economic dimensions. According to our expectations the new global players will be USA, Japan, Turkey and Poland. All these countries have common interest on Central Asia due to istrategic reasons. At the end of the paper we did some exploration for the future developments in Turkey regarding to those Republics in following decades. Turkish success for coming years in region is heavily depend upon its macroeconomic stability.

\section{References}

- Ahmet Yesevi Üniversitesi, Bağımsızlıklarının 20 Yılında Türki Cumhuriyetler, Uluslararası Sempozyumlar Dizisi Yayın No: 1 ISBN: 978-9944-237-13-0

- Ahmad Feroz, Modern Türkiye'nin Oluşumu, Kaynak yayınları, İstanbul,2009

- Aydın Mustafa, Üç Büyük Gücün Çatışma Alanı Kafkaslar, Gökkubbe yayınları, İstanbul, 2008

- Aydın Mustafa, Erhan Çağrı, Editörler, Beş Deniz Havzasında Türkiye, Siyasal Kitapevi, Ankara, 2006

- Dünya Enerji Konseyi Türkiye Milli Komitesi Enerji Senaryoları Çalışma Gurubu, Ankara,2007

- Ekrem Erkin, Çin'in Orta Asya Politikaları, Hoca Ahmet Yesevi Üniversitesi Araştırma Raporu, Ankara, 2011

- $\quad$ Findley Carter, Dünya Tarihinde Türkler, Kitap Yayıenevi, İstanbul,2006

- Friedman, Gelecek 100 Y11, Pegasus Yayınları, İstanbul 2011

- Fuller Graham, Lesser Ian, Balkanlardan Batı Çin’e Türkiyenin Yeni Jeopolitik Konumu, Alfa Yayınları, İstanbul,2000

- Özkan Gökhan, Türkiye'nin Orta Asya ve Kafkaslardaki Politikasında Enerji Güvenliği, Gazi Akademik Bakış, Cit 4 Sayı 7, Kış 2010

- Ö̈kan Gökhan, Soğuk Savaş Sonrasında Orta Asya ve Kafkasya Ekseninde Türkiye NATO Rusya İlişkileri ve Türk Dış Politikasına Yansımaları, Gazi Üniversitesi İktisadi ve İdari Bilimler Fakültesi Dergisi 12/1 (2010). 109-1322

- $\quad$ Passig David, 2050, Koton kitap, İstanbul,2011

- $\quad$ Stratejik Düşünce Enstitüsü, Rusya Raporu, Ankara,2010

- Strateji Yazıları, Milli Güvenlik Perspektifinden İç ve Dış Meseleler, ISBN: 978-975-19-6041-2, Milli Güvenlik Kurulu Genel Sekreterliği Yayınları, Ankara,2014

- Yılmaz, Sait, Güç ve Politika, Alfa Yayınları, İstanbul, 2008 


\title{
The European Union's Attitude towards Russia between Values and Interests
}

\author{
Asst. Prof. Dr. Armağan Gözkaman (Beykent University, Turkey)
}

\begin{abstract}
The study will focus on the European Union's attitude towards Russia by taking into consideration a dilemma: The European Union (EU) wants to uphold its values and principles while endeavoring to maximize its interests. In the post-Cold War period, Moscow's policy choices have often been problematic for the Europeans. In the period following the Ukrainian conflict, the analysis of the relations between the two "strategic partners" is more difficult than ever. At least three reasons underlie this difficulty. First, the EU is notoriously incapable of reaching a common position on how to deal with the Russian problem. Second, trade is an important factor for the relations between the EU and Russia where oil occupies a significant place. Third, Russia has also a signification position vis-à-vis the EU as a powerful actor of international relations.
\end{abstract}

\section{Introduction}

Russia is a very important partner for the European Union (EU). It is also a very difficult one. At present, the problem of Ukraine made the balance between Brussels and Moscow all the more delicate. Russia began a military operation after the Ukrainian president had fled his country. In mid-March 2014, a referendum was held in Crimea with the remit of secession from Ukraine. 97\% of the voters supported Russian sovereignty over the peninsula. The EU, together with the USA, reacted quickly by depicting the referendum as a sham. The annexation of Crimea and Sebastopol to Russian Federation and the latter's continuous involvement in the crisis have become problematic issues for the relations between the EU and Russia.

The EU needs to uphold its values and confront the latter whenever necessary. Because Russia is a crucial actor of international relations, the Union feels the necessity to carry on good relations with it. Nevertheless, that is easier said than done. There are at least three reasons that underlie the current stalemate. The existence of twolevel relations between the EU and Russia is one of them (1). The fact that the EU member states conduct differing policies towards Russia is another point that merits attention (2). In addition, the European Union's Common Foreign and Security Policy, established with the entry into force of the Treaty of Maastricht in 1993, has not been adequate for the EU members to build up a unified foreign policy towards Russia.

\section{Relations between the European Union and Russia: A Two-Level Game}

The EU has adopted some policy lines that form the basis of its relations with Russia after the collapse of the Soviet Union. It is important to remember that 1990 s were the time period when the European continent underwent profound political changes. Back then, the European Union's (EU) agenda was remarked by designing the post-communist transformation process with a western template (Timmins, 2004). In the first half of the decade, the Technical Assistance to the Commonwealth of Independent States (TACIS) preceded the Partnership and Co-operation Agreement (PCA). The latter's ratification, however, could only take place after Russia had put an end to its military action in Chechnya in 1997, three years after the beginning of its intervention in the region.

Chechnya was not the only source of discord in EU-Russia relations. The perspective of membership given to the countries in the Central and Eastern Europe was a further blow for Moscow because of economic and political reasons. The Balkan crisis had a negative effect on the relations between the two sides as well (Timmins, 2004). However, these issues have not run counter to the adoption of a Common Strategy on Russia in 1999. The strategy, despite its late adoption by the EU members, increased the coherence and efficiency of EU actions in Russia (Delcour, 2005). The fact that 19 agreements have been signed between Russia and the EU since 1998 -covering a wide range of political and economic matters- is also noteworthy (European Commission).

A study on the EU-Russia relations will be incomplete if the bilateral relations between Moscow and the European capitals are not taken into consideration. That the European capitals have differing attitudes -resulting in various policies- towards Moscow is a fact. Many EU member states have strong political and economic relations with Russia that are even depicted as "strategic" or "special" partnerships specified in legal frameworks (David et al., 2011). This held especially true for the big states. In the case of Germany, for instance, the prioritization of national interests over the European ones has been criticized on many occasions. If Germany has done much more than the other EU member states in order to promote the EU policies on Russia, she has also done much to undermine them (Timmins, 2011). With regard to the United Kingdom, although political relations with Russia have been "less than special" the economic relations have been strong (David, 2011). Over the years, Spain has developed good economic relations with Russia in accordance with her national interests. She may 
follow "further a path of strict national interest assessment" as the motivation for the European integration has been fading away (Simao, 2011).

Some smaller states have also very close relations with Russia. Greece is among the examples that can be cited. She enjoys excellent relations in accordance with the "traditional friendly relations of the two peoples" that endured for centuries (Christou, 2011). Despite the lack of leadership and credibility in the case of Benelux countries, Netherlands has important commercial relations with Russia especially in the field of energy. Belgium could "punch above its weight" thanks to her being home to NATO and to the EU on the one hand, and her hosting frequent high-level visits from third countries on the other (Casier, 2011). These states had frequent bilateral summits with Russia resulting in important agreements that touched upon the key sectors such as energy and trade and that did not exclude the fields of security and culture (David et al., 2011).

\section{Russia: An Unavoidable Trading Partner for the EU}

The importance of Russia for the EU member states originates from a number of factors. Economy is one of them. The Russian market, despite the weaknesses generated by the macroeconomic problems, is still attractive for the European companies. As shown by the Figure 1, the EU's export to Russia almost doubled over the last decade. From 2005 to 2008 , a steady growth rate can be observed. The recession that hit Russian economy and the subsequent measures taken by Moscow explain why the trade volume decreases in 2009 (European Commission, 2013b). Then again, the trade between the two sides gained momentum to reach the highest level in 2012 and tended to decline afterwards.

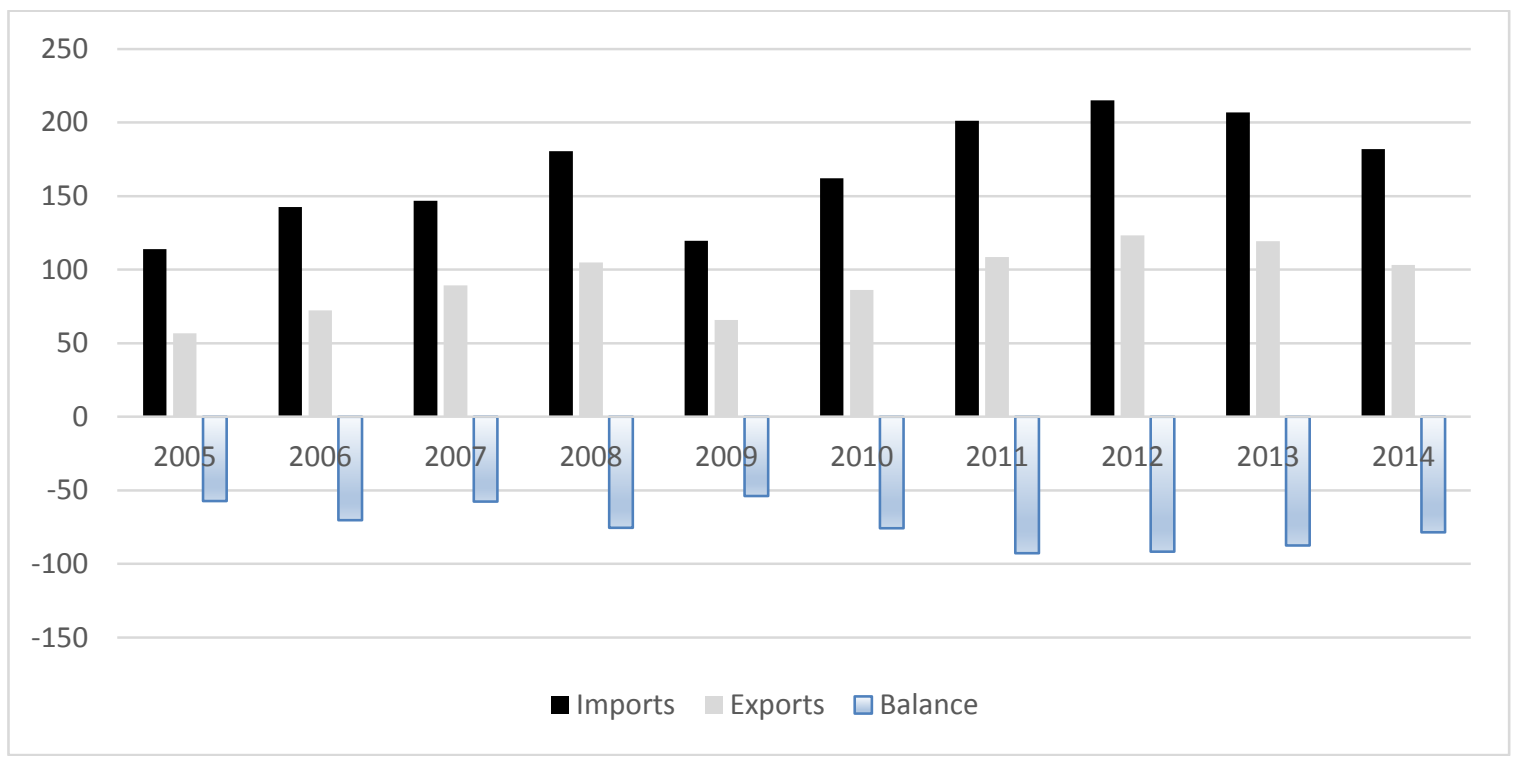

Figure 1: European Union, Trade with Russia, billion Euros (European Commission Directorate-General for Trade)

One can also highlight the place that Russia and the European Union hold in each other's trade: Russia has the third rank in the EU's trade with the outside world. The EU, for its part, holds the first position in Russia's foreign trade activities. Moreover, the EU is the biggest investor in Russia. Estimations suggest that around two thirds of foreign direct investment stocks in Russia originate from the EU member states (European Commission).

Indeed, fossil fuels are the decisive item in the relations between European capitals and Moscow. Russia is the main energy supplier of the European Union, and the EU provides a unified market to Russia. In this context, both sides have agreed to set up mechanisms to ensure security of supply and energy efficiency. The EU-Russia Energy Dialogue is one of them. Established in October 2000 with the objective of enabling progress for partnership, the initiative constituted the first example of an energy dialogue with a third party (European Commission, 2011). In February 2011, the European Commission and the Russian government went further by agreeing to build up a long-term perspective for their relations in the energy sector through the Common Understanding on the Preparation of the Roadmap of the EU-Russia Energy Cooperation until 2050 which stipulated the necessity to

"concentrate on an analysis of different scenarios and their impact on EU-Russia energy relations, look into their consequences for the energy sectors, elaborate long-term opportunities and risks of the overall energy supply and demand situation and investigate the potential for long-term cooperation in the field of energy." (European Commission, 2013a). 
Thanks to the statement above, there is no need to spill much ink to explain the reasons why the EU and Russia have signed the roadmap. The emphasis on the long-term cooperation reveals the concern to ensure the energy supply. At this point, one can legitimately maintain that the seller is in an advantageous position vis-à-vis the buyer -and that the mere possession of the energy resource bestows the owner with a power over the one that needs it. Thus, there is simultaneously an importer for whom the security is linked to the energy supply guaranteed by the market and an exporter for whom energy security is an integral part of a power strategy (Laïdi, 2008). That oil and natural gas constitute a significant factor in the EU-Russia relations is plain to see.

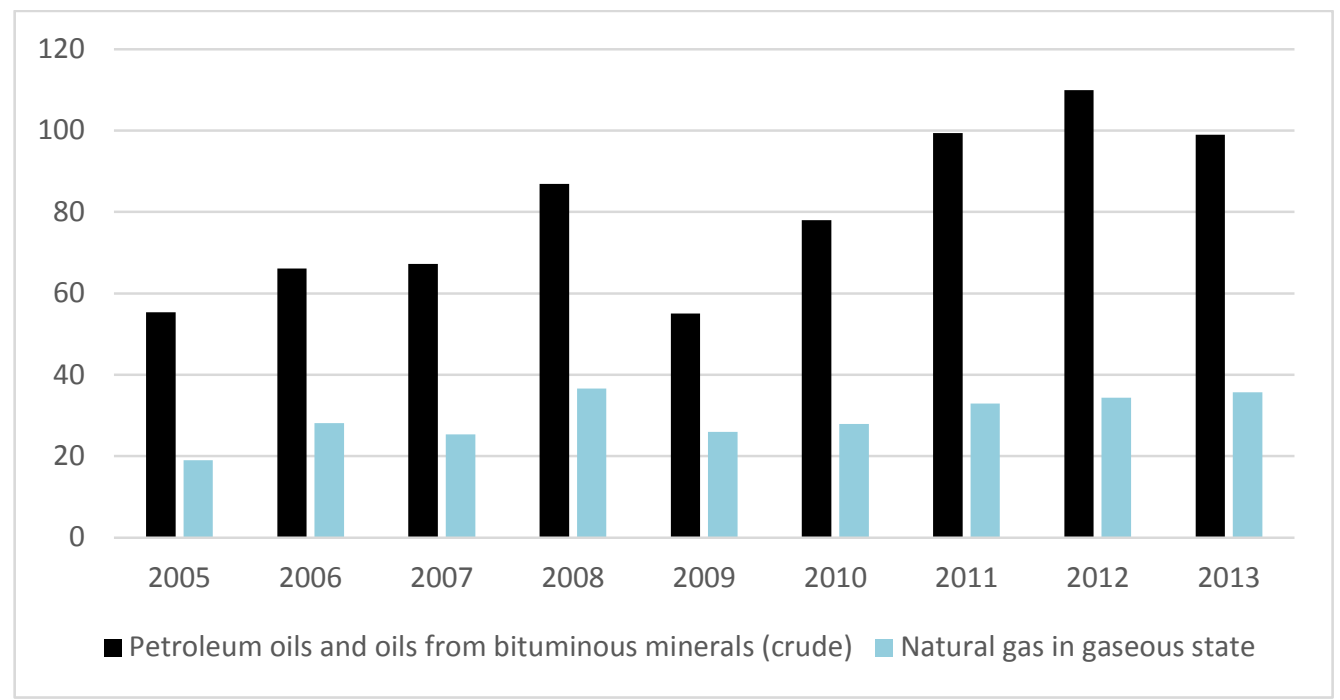

Figure 2: EU-28 Imports of Energy Products 2005-2013, billions of Euros Source: Eurostat

Figure 2 shows that the volume of fossil fuel trade between the two sides is also significant. The oil imported by the then-27 members of the EU and Croatia reached an approximate total of 110 billion Euros in 2012, to beat a record. The same year, they also paid 34,4 billion Euros for Russian natural gas. These amounts are all the more meaningful when they are evaluated together with the data represented by the Figure 3 below. Because the Russian currency lost 35\% of its value between 2008 and January 2009 (Maternovsky, 2009), the EU payments for Russian oil and natural gas in 2009 were limited to 55 and 26 billion Euros consecutively. Yet, the same year, the decrease of European demand to Russian natural gas is low (it falls from $37,6 \%$ in 2008 to $33 \%$ in 2009) whereas an increase of the Russian share in European crude oil purchase is observed.

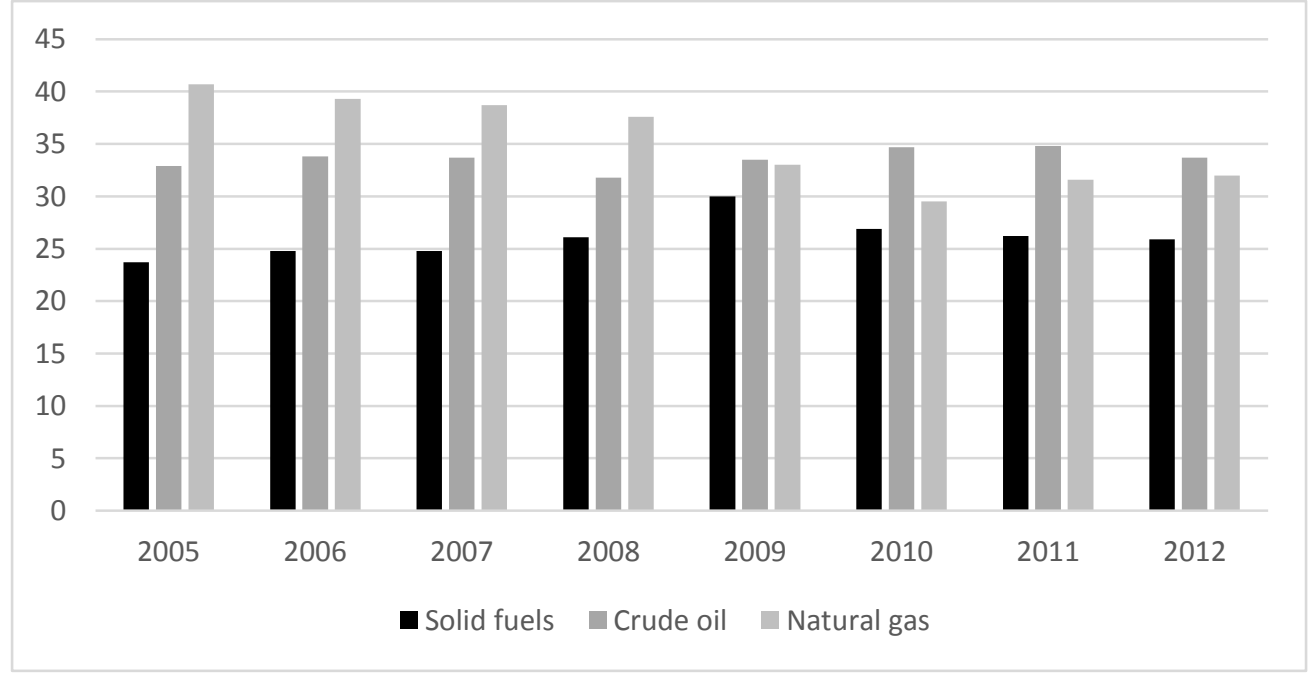

Figure 3: Russia's Share (\%) in the EU-28 Imports of Solid Fuels, Crude Oil and Natural Gas Source: Eurostat, 2014

\section{Russia: A Powerful International Actor with Its Own Agenda}

The EU endeavored to de-escalate the crisis in Ukraine by political and economic instruments. It has called on all sides to maintain dialogue for Ukraine's unity and territorial integrity. It also requested Russia to withdraw its troops back to the legal bases stipulated in the Agreement on the Status and Conditions of the Black Sea Fleet of 1997 (Council of the European Union, 2014). As a reaction to the illegal annexation of Crimea by Russia and the Russian involvement in the destabilization of Ukraine, the EU has agreed upon a variety of restrictive measures. 
Some of them are diplomatic, such as the cancellation of the EU-Russia summit and the support to the suspension of negotiations on Russia's OECD membership perspective. Some are of restrictive nature, including asset freezes and visa bans. The sanctions also include prohibitions on imports, investment, tourism services and exports (European Union Newsroom). Because the EU continues to condemn the above-mentioned illegal annexation, it "remains committed to fully implement its non-recognition policy" (Council of the European Union, 2015).

Yet, the question "How far the EU can go towards its objective to see the Ukrainian conflict resolved?" does not leave much room for optimism. As seen in the previous section, the member states are not able to establish and implement a common strategy towards Russia and the EU's dependency on this country is high. The Ukrainian case reveals the EU's capabilities and deficiencies, along with the time and determination that will be necessary for dealing with it (Suremain, 2014). In addition, Moscow is definitely a key actor in the international relations due to its membership of the United Nations Security Council and its potential to make a qualitative change in the international issues. Its cooperation in global issues is highly valued; and the Europeans cannot neglect this value while adopting policies towards Russia.

This strong position gives Russia some possibility to play by its own rules. Obviously, Kremlin does not have a serious concern to align itself with the European Union's principles or priorities. Vladimir Putin has been calling into question the decades-long European security system through revisionist politics (Grand, 2014), possibly in line with his earlier projects (Thom, 2014; Lefort, 2014). At this point, it is also important to remember that the compatibility between the EU's and Russia's interests is very low and that they share very little in their policies (Haukkala, 2015; Makarychev, 2014). This may be linked, among other factors, to the difference of both sides' conceptions of Europe. Against the wider Europe vision that reflects the idea of the continent centered on the European Union, Moscow upholds the vision of a greater Europe that postulates a multipolar continent with no single ideology (Sakwa, 2015).

In this dire context, one way out of the crisis can be to establish a dialogue between Russia and the EU on solid -and realistic- grounds by taking into consideration the Russian interests and sensibilities (Tchernega, 2014). Back in 2012, Pascal Boniface had affirmed that Russia was rather a partner than an ally. A similar argument can be brought up, by saying that Russia will never be on the same line with the European Union, but she can be suitable for working together. A process of 'give and take' seems more plausible to bring an end to Russia's support to the destabilization of Ukraine. After all, Russia will not benefit from the prolongation of the crisis which will lead to an environment of antagonism similar to the one witnessed in the post-Second World War period (Andréani, 2014).

\section{Concluding Remarks}

The recent crisis in Ukraine has been a hard blow for EU-Russia relations. The EU has reacted to Russia's move in Ukraine, with limited instruments indeed. So far, its retaliations have not had a tangible effect upon Kremlin's political choices. One cannot expect a change in the situation any time soon.

For the EU to make a progress in the resolution of the conflict, a two-level action is necessary. The unified and coordinated approach at the EU level must be echoed at the national levels as well. The alignment of national interests with the European ones can bear fruit, especially in the presence of a determination to combine economic and political components for dealing with Russia.

To recommend the diversification of energy suppliers seems also commonsensical. Indeed, such a project may not be realized quickly. Nevertheless, the high dependence on Russian fossil fuels weakens the European prospects to ease antagonism with Moscow. Thus, the diversification efforts must be conceived as a 'political investment' for the future.

There is room for optimism anyway. In fact, the resolution of the crisis will benefit both Russia and the West. In the long run, neither of them will benefit from a new context of Cold War. Hence, an active involvement of the EU (along with its member states) in accordance with a viable political project can facilitate the process of crisis resolution.

\section{References}

- Andréani, 2014. "Poutine et l’Ukraine”, Commentaire, 146, p. 291.

- Boniface, 2012. “La Russie n'Est pas Une Alliée, mais Elle Peut Etre Un Partenaire”, Le Monde, http://www.lemonde.fr/idees/article/2012/06/25/la-russie-n-est-pas-une-alliee-mais-elle-peut-etre-unepartenaire 1723976 3232.html\# ((Accessed 01.06.2015).

- Casier, 2011. "The Bilateral Relations of the Benelux Countries with Russia: Between Rhetorical EU Engagement and Competitive Business Interests", Journal of Contemporary European Studies, 19, p. 240.

- Christou, 2011. "Bilateral Relations with Russia and the Impact on EU Policy: The Cases of Cyprus and Greece”, Journal of Contemporary European Studies, 19, p. 229. 
- Council of the European Union, 2014. "Crimea: EU Extends Restrictions in Response to Illegal Annexation”, Press Release, 469/15, www.consilium.europa.eu/en/workarea/downloadasset.aspx?id=15519 (Accessed 13.06.2015).

- Council of the European Union, 2015. Press Release, $3505^{\text {th }}$ Council Meeting, Presse 114, PR CO 13, Brussels, http://www.consilium.europa.eu/en/press/press-releases/2015/06/19-crimea-eu-extendsrestrictions-illegal-annexation/ (Accessed 13.06.2015).

- David, 2011. “A Less than Special Relationship: The UK's Russia Experience”, Journal of Contemporary European Studies, 19, p. 209.

- David, Gower, Haukkala, 2011. "Introduction: The European Union and Russia”, Journal of Contemporary European Studies, 19, p. 183.

- Delcour, 2005. “L’Union Européenne et la Russie: Les Politiques Communautaires, Pierre Angulaire du Partenariat”, in Helly and Petiteville (Eds.), L'Union Européenne, Acteur International. L'Harmattan, Paris, p. 156.

- European Commission, Directorate-General for Trade. "European Union. Trade in Goods with Russia", http://rade.ec.europa.eu/doclib/docs/2006/september/tradoc_113440.pdf (Accessed 14.06. 2015).

- European Commission. "Treaties Office Database", http://ec.europa.eu/world/agreements/searchByCountryAndContinent.do? countryId=3853\&countryName=R ussia (Accessed 14.06. 2015).

- European Commission, 2011. "EU-Russia Energy Dialogue. The First Ten Years: 2000-2010", http://ec.europa.eu/energy/international/russia/dialogue/dialogue en.htm (Accessed 13.06. 2015).

- European Commission, 2013. "Roadmap. EU-Russia Energy Cooperation until 2050", http://ec.europa.eu/energy/en/topics/international-cooperation/russia (Accessed 13.06. 2015).

- $\quad$ European Commission, 2013. "Enhancing Business Ties with Russia through Regulatory, Business and Tourism Cooperation", http://ec.europa.eu/growth/toolsdatabases/newsroomYcf/itemdetail.cfm?item id=1028\&title=Enhancing-business-ties-with-Russia-trhoughregulatory\%2C-business-and-toursim-cooperation (Accessed 14.06. 2015).

- European Union Newsroom. "EU Sanctions against Russia over Ukraine Crisis", http://europa.eu/newsroom/highlights/special-coverage/eu sanctions/index en.htm\#5 (Accessed 13.06. 2015).

- Eurostat. "EU28 imports of energy products from Russia, 2005-2013", http://ec.europa.eu/eurostat/statisticsexplained/index.php/File:EU28_imports_of_energy_products_from_Russia,_20052013 \%28EUR billion\%29.png (Accessed 15.06. 2015).

- Eurostat, 2014). "Main Origin of Primary Energy Imports, EU-28, 2002-2012 (\% of Extra EU-28 imports)", http://ec.europa.eu/eurostat/statisticsexplained/index.php/File:Main_origin of primary energy imports, EU28,_2002\%E2\%80\%9312_\%28\%25_of_extra_EU-28_imports\%29_YB14.png (Accessed 15.06. 2015).

- Grand, 2014. "La Russie, l'Occident et la Paix Froide”, Commentaire, 146, p. 293.

- Haukkala, 2015. "From Cooperative to Contested Europe? The Conflict in Ukraine as a Culmination of a Long-Term Crisis in EU-Russia Relations”, Journal of Contemporary European Studies, 23, p. 31.

- Laïdi (2008). La Norme sans la Force. L'Enigme de la Puissance Européenne. Presses de Sciences Po, Paris.

- Lefort, 2014. “La Crise Ukrainienne ou le Malentendu Européen”, Politique Etrangère, 2, p. 120.

- Makarychev, 2014. "Russia and/versus the EU: From Post-Political Consensus to Political Contestations", L'Europe en Formation, 374, p. 36.

- Maternovsky, 2009. "Ruble Gains versus Dollar 'Inevitable', Zadornov Says (Update1)”, Bloomberg, http://www.bloomberg.com/apps/news?pid=newsarchive\&sid=aPzxsrEg7GUc (Accessed 15.06. 2015).

- Sakwa, 2015. "The Death of Europe? Continental Fates after Ukraine”, International Affairs, 91, pp. 558559.

- Simao, 2011. "Portuguese and Spanish Relations with Moscow: Contributions from the EU's Periphery to the CFSP", Journal of Contemporary European Studies, 19, p. 222.

- Suremain, 2014. “L’Ukraine en Crise, l’Europe Fracturée”, Commentaire, 148, p. 745.

- Tchernega, 2014. "Pourquoi Russie et Union Européenne Doivet Coopérer en Ukraine", Politique Etrangère, 2, p. 107.

- $\quad$ Thom, 2014. “Poutine. L'Heure de Vérité”, Commentaire, 147, p. 503. 
- Timmins, 2004. "Coping with the New Neighbours: The Evolution of European Union Policy towards Russia”, Perspectives on Politics and Society, 5, pp. 358-359.

- Timmins, 2011. "German-Russian Bilateral Relations and EU Policy on Russia: Between Normalisation and the 'Multilateral Reflex”, Journal of Contemporary European Studies, 19, p. 197. 


\title{
The Resource Potential of the Participating Countries of the Eurasian Economic Union
}

\author{
Prof. Dr. Saulesh Kalenova (Turan University, Kazakhstan) \\ Prof. Dr. Rahman Alshanov (Turan University, Kazakhstan) \\ Prof. Dr. Ali Abishev (Kazakh Economics University, Kazakhstan) \\ Prof. Dr. Valentina Gerasimenko (Moscow State Lomonosov University, Russia)
}

\begin{abstract}
Against the background of international openness and globalization of the world economy, it is very difficult to achieve higher competitiveness in the state without the support of friendly neighbors. In this age of competition of constructive ideas, high technologies, knowledge-intensive the problem of innovative development of the Republic of Kazakhstan in the context of the Eurasian Economic Union became central dominant of understanding the goals and methods of reforming the modern state economy.

The main ambitious goal is a breakthrough of Kazakhstan in the 30 most competitive countries of the world. This goal promotes the development of a coherent policy of modern developments management and the formation of a national innovation system with effective mechanisms of interaction between government, business and science in the context of the EEU. Kazakhstan tries to integrate experience of developed countries into this process. These countries began their journey to progress from the unification into regional economic alliances.

The article analyzes the integration processes and actions of economic activity of participating countries of the Eurasian Economic Union in the new environment. It also examines contemporary processes of globalization and the necessity of creating an economic union, particular features of the regional economic communities. The article includes materials of the Eurasian Economic Union historical background. There was conducted analysis of integration processes development in the economic environment on the example of post-Soviet states joined in the Eurasian Economic Union.
\end{abstract}

\section{Introduction}

There are certain challenges to achieve higher competitiveness for any government against the background of the international openness and globalization in world economy if there is no friendly support from the neighborcountries. Innovative development of Republic of Kazakhstan in the context of the Eurasian Economic Union (EEU) has become central dominant in understanding of the goals and methods to reform modern state economy in age of competition in constructive ideas, high technologies and science intensity.

The main ambitious goal is to breakthrough Kazakhstan to 30 most competitive countries in the world, which has set by the state leader. This goal supports in elaboration the coherent policy in managing the modern developments and formatting the national innovative system with effective mechanisms for interaction between government, business and science in context of the EEU.

Kazakhstan is trying to integrate the experience of many developed countries to this process. These countries began their journey to the progress from the joining them to the regional economic unions. Practically, separate state cannot exist apart from other countries, without joining to variety of economic relations, which nowadays are not limited by foreign trade and barter. These include an allocation of financial capital between countries, labor migration and of course scientific and technical exchange. While, none could forget own national interests.

Taking in account the time of being part of the Soviet Union from 1922 to 1991, when Superpower was located on the sixth part of the Earth, there were long-term history of political and economic community of the post-Soviet states. Union was considered as a common system in political, legislative and executive aspects. The short period of disunity by historical measures (since 1991) has shown the possibility of independent political development of world is largest state - the USSR, which has collapsed at one time. However, economic disunity could not enrich the post-Soviet independent countries and we have repeatedly returned to the different kinds of integration, such as Eurasian Economic Community (EurAsEC), Common Economic Space (CES), the Customs Union (CU), a free trade area (FTA).

Russia, Belarus and Kazakhstan are countries, which have been absolute partners in all these integration models despite arisen problems, improvement or deterioration of the political, economic, migration and other spheres. We understand and realize that even the most highly developed country cannot provide all their needs without friendly unions. At present stage of development of world economy, set of national economies, as well as their economic and political relations, acquire totally different quality. Considering that a process of globalization covers all countries of the planet in varying degrees, we are talking about important phenomena: 
internationalization of economy, development of a unified system of the world relations, change and easing the state functions, revitalization of transnational corporations.

The second half of the XX century was characterized by growing interdependence of national economies, contributing to formation of an integrated world economic system, which determined internationalization of production. During this period, many countries began to shift to a new type of international socialization of production called «integrational». The objective necessity of such a move was due to the whole course of world economic development, caused by the current problems and cannot be resolved by states neither without any help nor on the basis of old system of international division of labor. Dynamic changes occurring in the global economy refer to developed countries and developing countries, and also emerging new emerging markets.

Usually globalization of economy is understood as a rapid increase of flow of goods, investment, credit, information, human resources and exchanges of ideas, as well as expanding geography of their distribution. Speed, intensity and penetration depth of the flow increase to a point where national economies become interdependent. Elements of national economies (national producers, consumers, financial and other institutions) are directly integrated into the overall world economy. As a result, domestic producers are increasingly linked to foreign consumers. If earlier there was a quantitative increase in the interaction of individual national economies in the form of an increased flow of goods, capital and investments, today there is a qualitative change in their interaction.

\section{Advantages and Disadvantages of Globalization}

Let us consider the distinct features of the onset of a new stage in development of global economy, to which we refer:

1) openness as main principle of any country and the world community relations, expansion of world trade at the active liberalization of foreign economic activity;

2) formation of regional entities aimed at integration and interaction of separate states' economies, use of a sufficiently reliable and effective regulatory mechanisms of economic cooperation between countries;

3) growth and widespread usage of transnational companies, which increasingly play a decisive role in international investment and trade policies;

4) intensive development of high and advanced technology, computer science, etc., which leads to rising of productivity, closer connection of individual countries and regions markets;

5) establishing systems of international organizations ensuring stable and balanced economic development of world and national economies;

6) formation of international trading system based on internationally accepted rules and conditions of crosscountry migration of labor, capital and technology;

7) general functioning of financial sector, not directly related to foreign trade and international movement of factors of international production.

Based on active promotion of these processes from the $1980 \mathrm{~s}$, current period of globalization of the world economy has been originated. It subsequently resulted in the formation of a single coherent space thanks to further development of global market of transnational capital, new technologies, providing a qualitatively new level of economic ties.

The impact of globalization on world economy, as a rule, is tracked through traditional macroeconomic indicators. However, we may see more meaningful analysis of the impact through the most important characteristic manifestations of modern times, which include the following:

1. Informational and technological revolutions

2. Easing of movement of goods, services and capital

3. Development of the tertiary sector of the world economy

4. Qualitative breakthrough in the development of international capital market

5. Strengthening of the power and value of industrial and banking transnational corporations

The general result of all the mentioned factors is an increase of interdependence of national economies as one of determining features of the global community.

Globalization should be understood as a new stage of internationalization of economic life and growing economic cohesion of countries around the world as a result of increasing volume and diversity cross-border movement of goods, services, and international capital flows, as well as through more rapid and widespread diffusion of technology.

Costs and benefits of globalization are distributed among its participants extremely uneven. Increase of productivity, reduce of costs, increase of income and wealth at one pole is achieved at the cost of increasing 
uncertainty, risk, inequality, and poverty on the other. As these costs and benefits, unity and contradiction of interests simultaneously manifested not only in individual countries but also far beyond them, problems cannot be solved only through international cooperation.

With regard to benefits of globalization:

- Firstly, it has caused aggravation of international competition. Healthy competition and market expansion lead to greater specialization and international division of labor, stimulating, in its turn, increase of production not only at national but also at global level;

- Secondly, globalization leads to economies of production scale, which could potentially lead to reduced costs and lower prices, therefore, to sustainable economic growth. It can provide an increase of productivity as a result of streamlined work processes at the global level and distribution of advanced technologies, as well as competitive pressures for continuous innovation on a global scale;

- Thirdly, positive traits of globalization are also associated with gains from mutually beneficial trade satisfying all parties, who may be individuals, firms and other organizations, states, trade unions and even continents.

In general, globalization can improve position all partners receiving opportunity to raise wages and living standards by increasing production. Its end result should be general welfare of the planet.

At the same time, despite advantages of globalization, this process is in world economy, new hotbeds of conflict and controversy.

Firstly, there is a rapidly increasing gap between weak and strong countries, which is explained by an abrupt increase of unequal exchange. World Economic competition is reduced in a similar situation to the struggle between industrial states' rights and a possibility of supplying their products in industrialized countries.

Secondly, it is on the basis of deformation of globalization of financial and market mechanisms. This is manifested through generalized anti-liberal rebirth tools of competition: it degenerates, turning into its opposite. And it does not spur lagging, does not encourage them to build competitive advantage, and destroys many of those who in other circumstances would have had a chance to survive. Moreover, this applies not only to business entities, but also of entire countries.

Thirdly, serious threats to sustainable development of economy comes from excessive expansion international capital, especially speculative, sad consequences of one can observe in people's life. Now most of the capital under influence of new global benefits commensurate with ordinary profit, reoriented to speculative enrichment. Powerful waves that are born from Him Nakata destabilize economies of not only weak, but also strong states.

Fourthly, changing the very nature of the world's GNI (gross national income). It quickly increasing the share of high-tech products. Production information and related products becomes most important indicator of economic growth. Human, intellectual capital is increasingly acquiring the features of a direct productive force. Its quality is transformed into the main indicator of the level of development of countries and regions.

Fifthly, globalization is associated with potential regional or general instability, due interdependence of national economies in the world. Local economic fluctuations or crises in one country can have wide-ranging, even planetary consequences. This danger is not only theoretical, but it is quite realistic, which is confirmed by recent global financial crisis. Such disasters show great vulnerability of interconnected economies, and current prolonged sluggish global crisis confirms this.

Sixthly, it is suggested that the control of the economies of individual countries may go from their governments in other hands, including the strongest powers, transnational or global corporations and international organizations. Because of this, some look at globalization to as an attempt to undermine state sovereignty. Such sentiments can easily go to extreme nationalism with calls for protectionism, lead to the growth of extremist political movements that potentially lead to serious conflicts. Strengthening the same state and its institutions is a prerequisite not only of survival, but also the nation's development in the context of globalization. It does not die, moreover, can and should take strategic functions of participation in these processes.

\section{The Influences of Global Economy on Kazakhstan}

In general, recognizing globalization as an objective process should be perceived as a challenge to nationstates, as well as new opportunities for them. For the Republic of Kazakhstan following negative consequences on globalization can be applied:

- Consolidation of the Kazakhstan raw specialization in the global economy;

- Reducing a role of government in the context of globalization and increasing a role of international organizations;

- $\quad$ Threats to Kazakh national business, which cannot to compete with multinational corporations (TNCs); 
- Increase of the impact of external forces on political situation in the country.

- At the same time, globalization brings to Kazakhstan the following benefits:

- Attracting investments for development of economy;

- Ensuring a balance of foreign policy, using complex geopolitical environment of Kazakhstan;

- Development of international economic cooperation;

- $\quad$ Strengthening cooperation in the field of security;

- Bringing new technologies to the Republic of Kazakhstan to raise quality level of our economy;

- Assistance from international community to address social problems such as poverty, unemployment, and ecology.

To use the opportunities of globalization one needs to develop competitiveness economy, to develop regional integration, improve the system of governance, determine the country's development strategy in the context of globalization. However, it is obvious that the above factors that have a direct impact on it will develop in the future, therefore, the process of globalization, apparently will only accelerate.

Thus, the modern economy is becoming the norm, when medium and small company previously focused mainly on the domestic market; feel free to go to the markets of other countries steadily increasing their share of exports.

At the current stage of development of globalization, there is increasing interdependence of national states and regions, forming the world community, their gradual integration into a single system common to all rules and regulations of economic, political and cultural behavior. At the same time, globalization is a dual process developing in interstate and transnational forms. Hence the multiplicity of its carriers: country, their coalition, international organizations, non-governmental entities, transnational corporations and even some individuals (Bill Gates, George Soros and et al.). Sphere of special interest are the national economies developing their activities on background of globalization. Positive developments in the international economic relationships by globalization and integration of national economies were main prerequisites for emergence of the post-Soviet Eurasian cooperation in its various versions.

A model of strong economic mutual cooperation are:

EU (European Union)

NAFTA (North American Free Trade Agreement)

APEC (Asia-Pacific Economic Cooperation)

Mercosur (Economic Community of South American countries)

EFTA (European Free Trade Association)

SADC (Southern African Development Committee)

UEMOA (West African Economic and Monetary Union)

SAARC (South Asian Association for Regional Cooperation) and others.

All listed integrations represent different models of cooperation and exist in different economic conditions and as such no one of them may be the best example of integration for others, nevertheless it is difficult to imagine development without integration. All above-mentioned alliances between countries arise certain tensions, misunderstandings of economic nature, however without integration of the world community modern national economies can hardly survive at all.

So, summing up the foregoing, it can be noted that, firstly, the development of international trade has provided a deeper division of labor between countries and contributed to further integration of national economies into the world. Therefore, firms from different countries have become to seek more favorable conditions for their business in foreign markets, through development of which they would be able to increase the volume of production and deepen specialization.

From 1 January 2015 the economic relations between the participating countries of EAEC, namely Russia, Kazakhstan, Belarus, Armenia reached a qualitatively new level. In May 2015 Kyrgyzstan will join this union. Therefore, we consider it appropriate to conduct further analysis of the economic parameters of the five states with the Kyrgyz Republic.

Already today it is the first in the world economic community in surface area is more than 20 million sq. $\mathrm{m}$. $\mathrm{km}$, giving the GDP according to the IMF (5th place in the world community) on the amount of 4.0771 trillion US dollars.

As we noted above, economic integration and cooperation shall be construed as mutual adaptation of individual sovereign states, when we are talking about close mutual cooperation in the field of efficient division of labor, free movement of goods, services, capital and labor. It is not a secret that products are released for domestic market and as such always has a sufficiently high cost due to high production costs and low product 
sales opportunities within its own market, respectively the price higher than the average, and the product or service becomes noncompetitive. Also it is absolutely clear that no nation can develop and compete in all areas of the economy. Today it also became clear that Kazakhstan plays in such areas as production and sale of agricultural products, trade in petroleum products (gasoline and diesel) automobile, but its business is also not competitive. Therefore it is important to examine what the advantages, potential of our country are, where we can get a win in the development of our state.

The model of mutually advantageous integration and cooperation between the states is defined by unambiguously historical community of communications, a complex of geo-economic and geopolitical factors, a similar vector of economic development at the heart of which there is a resource potential. At the same time in the course of formation of integration communications there are complex methodological problems on which success of international integration considerably defining destinies not only of people of certain countries, but also the whole continents in many respects depends. The combination of complexity and high responsibility of the made strategic decisions does this area of research especially significant.

Russia and Kazakhstan play a huge backbone role in development of multilateral integration at the Eurasian space. Considering that domestic markets of majority of countries of the former Soviet Union in modern conditions are insufficient for development of even rather small part of productions, especially knowledgeintensive, they have to seek for association as it does a majority of industrialized countries.

Besides, for development of interstate cooperation of the former Soviet republics there is certain bases in the form of complementary productions and general technologies, structural development increasing competitiveness of national farms, and also traditional cultural and public relations.

Many representatives of member countries of EEU peculiar interpret our union. Opinions that it is not favorable to Russia to approach the weak states move forward. In the Kazakhstan press there were also many discussions on necessity of entering the union and development of our economy without participation of neighboring states. The example of 2014, when the Russian Federation was attacked by various sanctions from foreign states confronting in the political plan, which naturally painfully struck on economy, according to and on the social growth of our neighbor.

Kazakhstan in principle is economically the least vulnerable party as possesses considerable minerals. So, from 105 elements of the table of Mendeleyev in a subsoil of our republic 99 elements are revealed (stocks on 70 elements are reconnoitered and more than 60 elements are already involved in production). 493 fields containing 1225 types of mineral raw materials are reconnoitered. On the volume of reserves of minerals our Republic wins first place among the CIS countries on chrome ores and lead, the second - on reserves of oil, silver, copper, manganese, zinc, nickel and phosphoric raw materials, the third place - on gas, coal, gold and tin.

2014 for the Republic of Kazakhstan in the economic plan, without watching in general at world problems. So, GDP growth in 2014 to previous year made 104,3\%, while GDP growth in the Russian Federation made 100,6\%, in the Republic of Belarus - 101,6\%, in Kyrgyzstan - 103,6\%.

At the same time in absolute expression of GDP of the Russian Federation is much higher, than in the Republic of Kazakhstan and the Republic of Belarus. So, GDP of Russia in 2014 made 1869,3 bln. US dollars (including, at the expense of the industry of 1143,2 bln. US dollars, at the expense of agriculture of 109,8 bln. US dollars), in the Republic of Belarus - 75,9 bln. dollars of the USA (including, at the expense of the industry of 64,1 bln. dollars of the USA, at the expense of agriculture of 10,8 bln. dollars of the USA), in the Republic of Kazakhstan $-212,2$ bln. dollars of the USA (including at the expense of the industry of 99,9 bln. dollars of the USA, at the expense of agriculture of 14,0 bln. dollars of the USA). However one should not forget that population Kazakhstan (17,3 million people) is much smaller than that of Russia (146,3 million people).

In the directions of investments into fixed capital our republic advances this indicator across Russia (investments into fixed capital as a percentage to previous year made in Kazakhstan 103,9\%, in the Russian Federation $-97,5 \%$, to Belarus - 91,5\%).

GDP per capita in 2013 in dollar expression made 13612 US dollars that is not much lower than in the Russian Federation - 14618,8 US dollars in Kazakhstan, but is much higher, than in Belarus - 7498,7 US dollars (fig.1). 


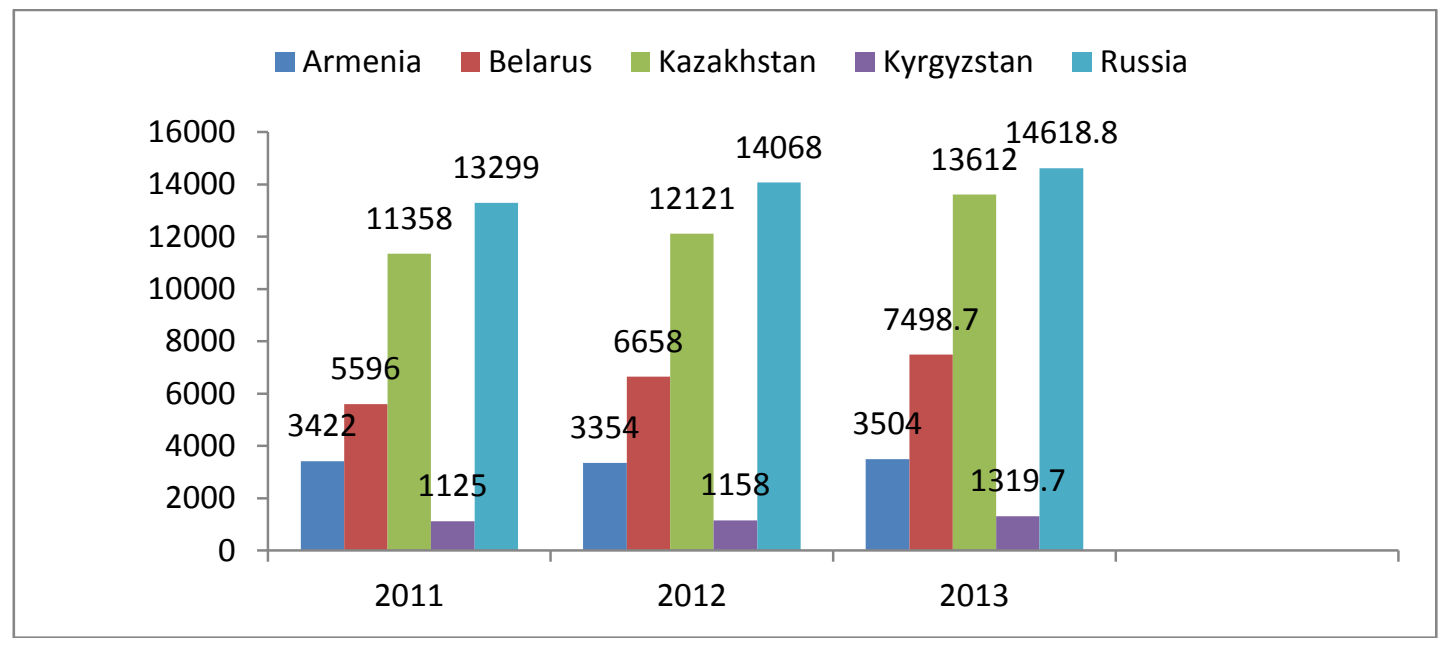

Figure 1. The GDP of the EEU per capita (US dollars)

It is necessary to be realist and to tell that, despite positive tendencies of economic development of the Republic of Kazakhstan, we much more lag behind on a standard of living of the population the Russian Federation (fig.2).

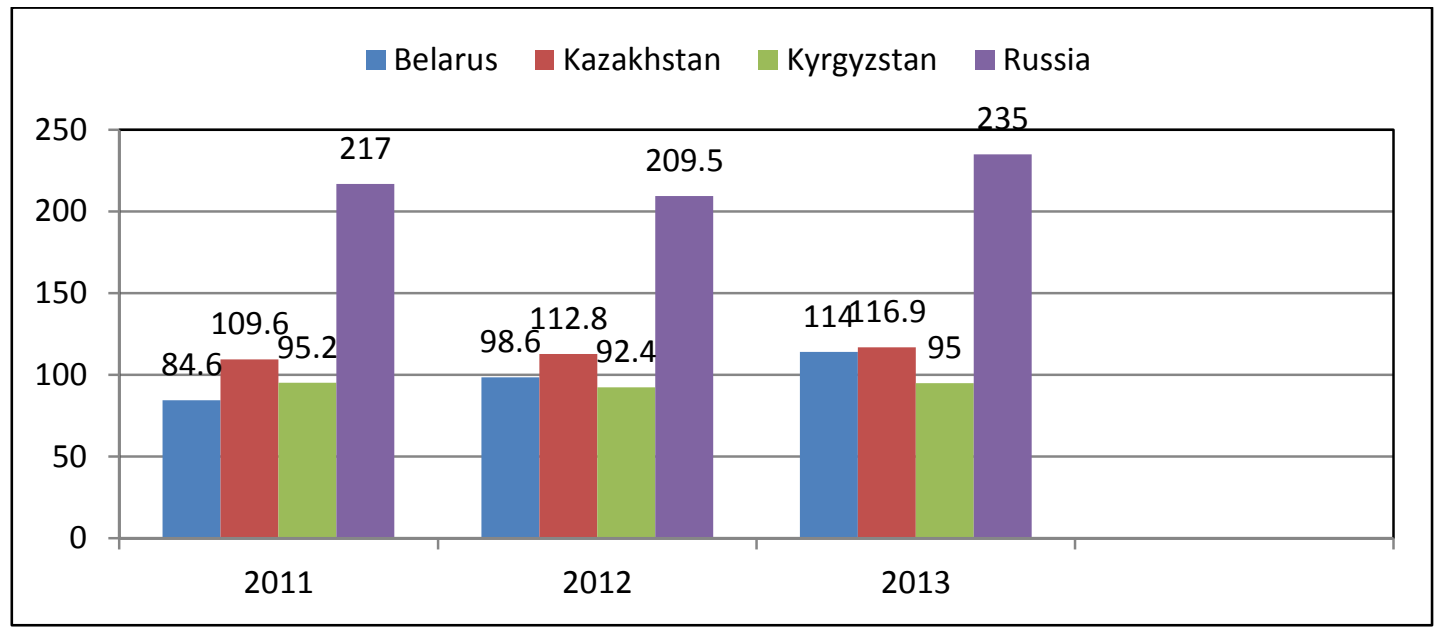

Figure 2. The minimum subsistence level of the EEU (US dollars)

So, in Russia the size of a living wage according to 2013 makes 235 US dollars, the average size of pension 315,5 US dollars, in Kazakhstan these figures much lower and make 116,9 US dollars and 206,3 US dollars respectively. It is remarkable that unemployment rate in Republic of Belarus is much lower, than in Kazakhstan and Russia (0,5\% against 5,2\% and 5,5\% respectively) (fig. 3 ).

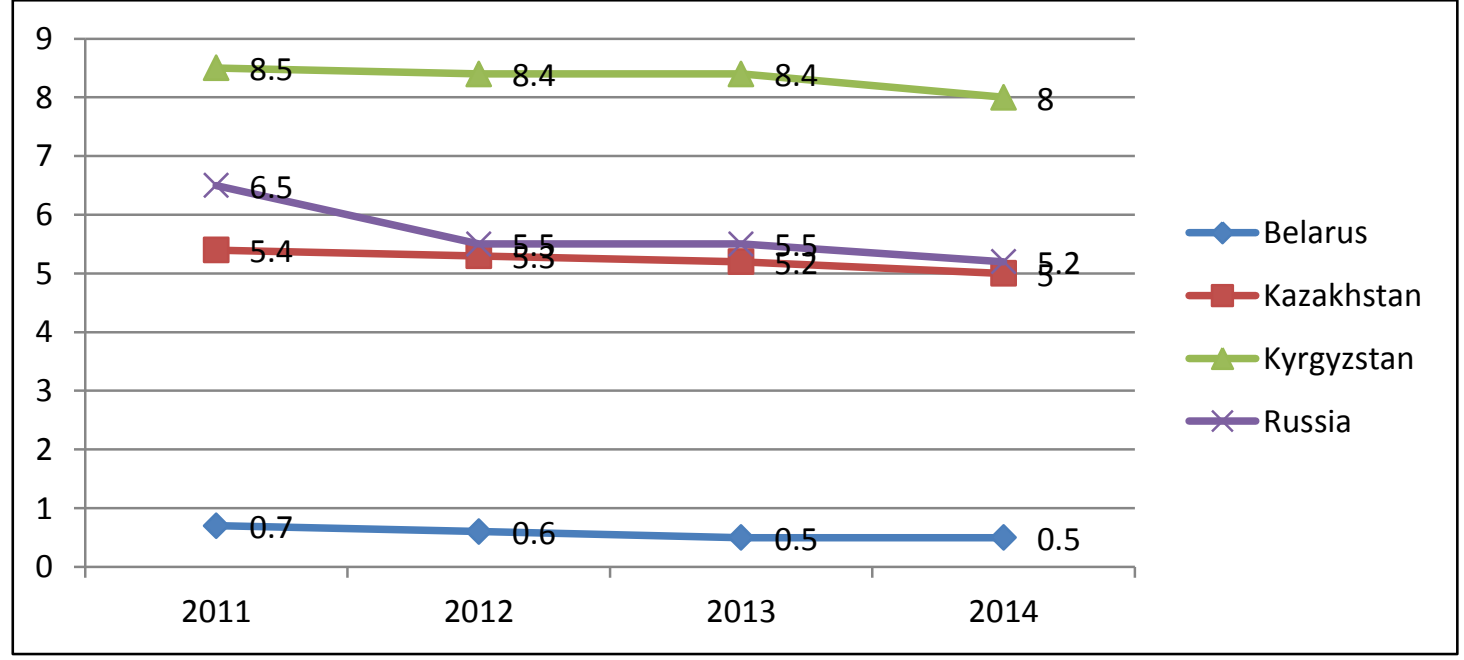

Figure 3. The unemployment rate of the EEU (in percent) 
The analysis of a foreign trade turnover shows that Russia much more advances other countries of EEU (fig.4) on these indicators.

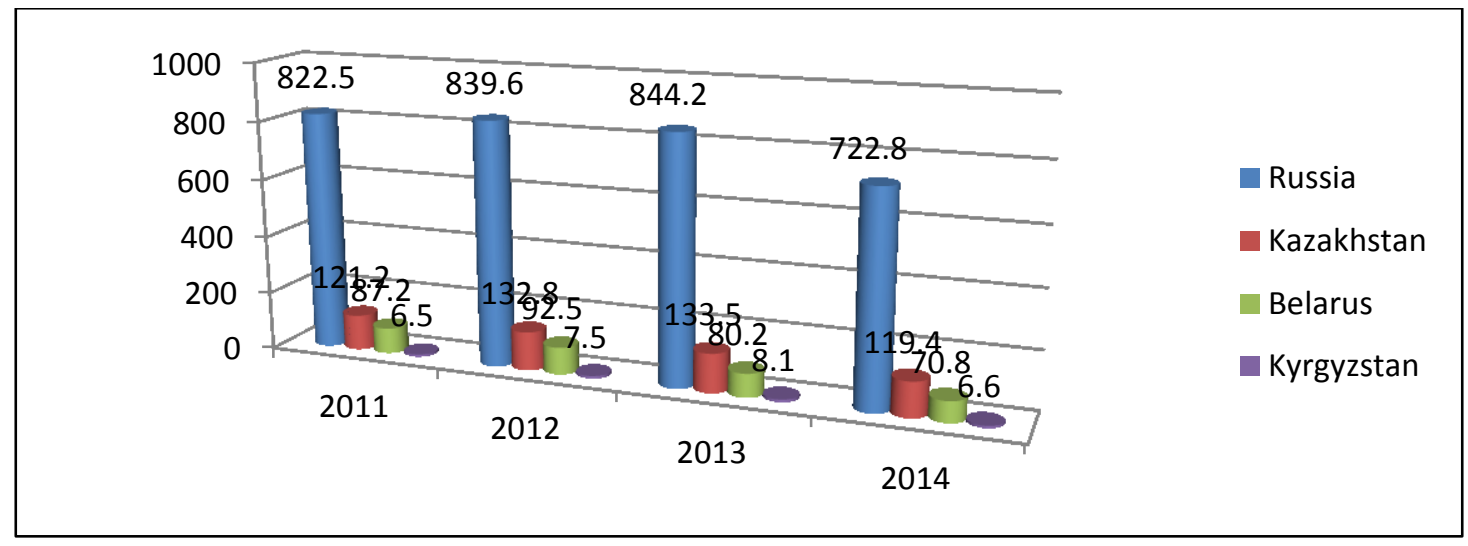

Figure 4. The foreign trade turnover of the EEU (billion US dollars)

It is a gap it is considerable as on export (fig.5)

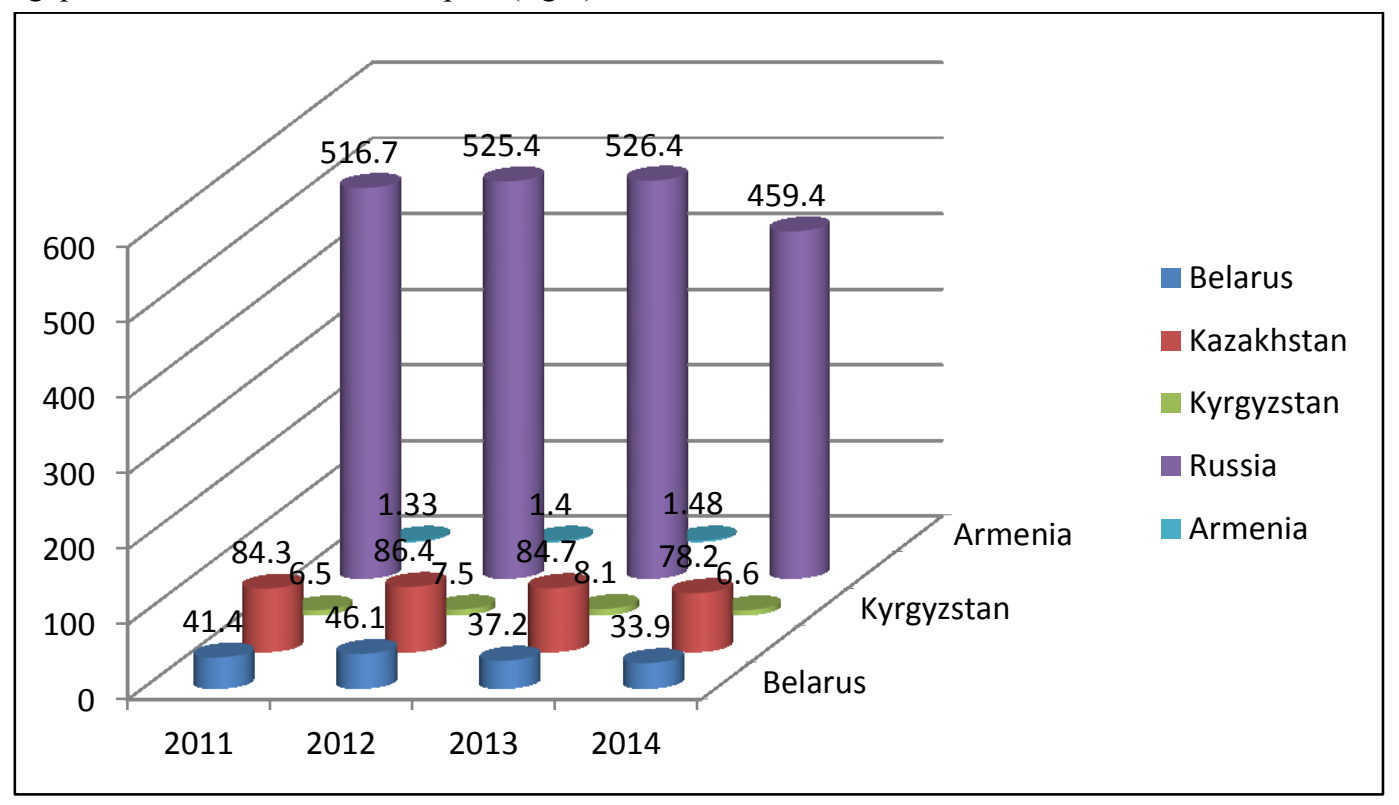

Figure 5. The volume of exports of the EEU (billion US dollars)

and on import (fig.6)

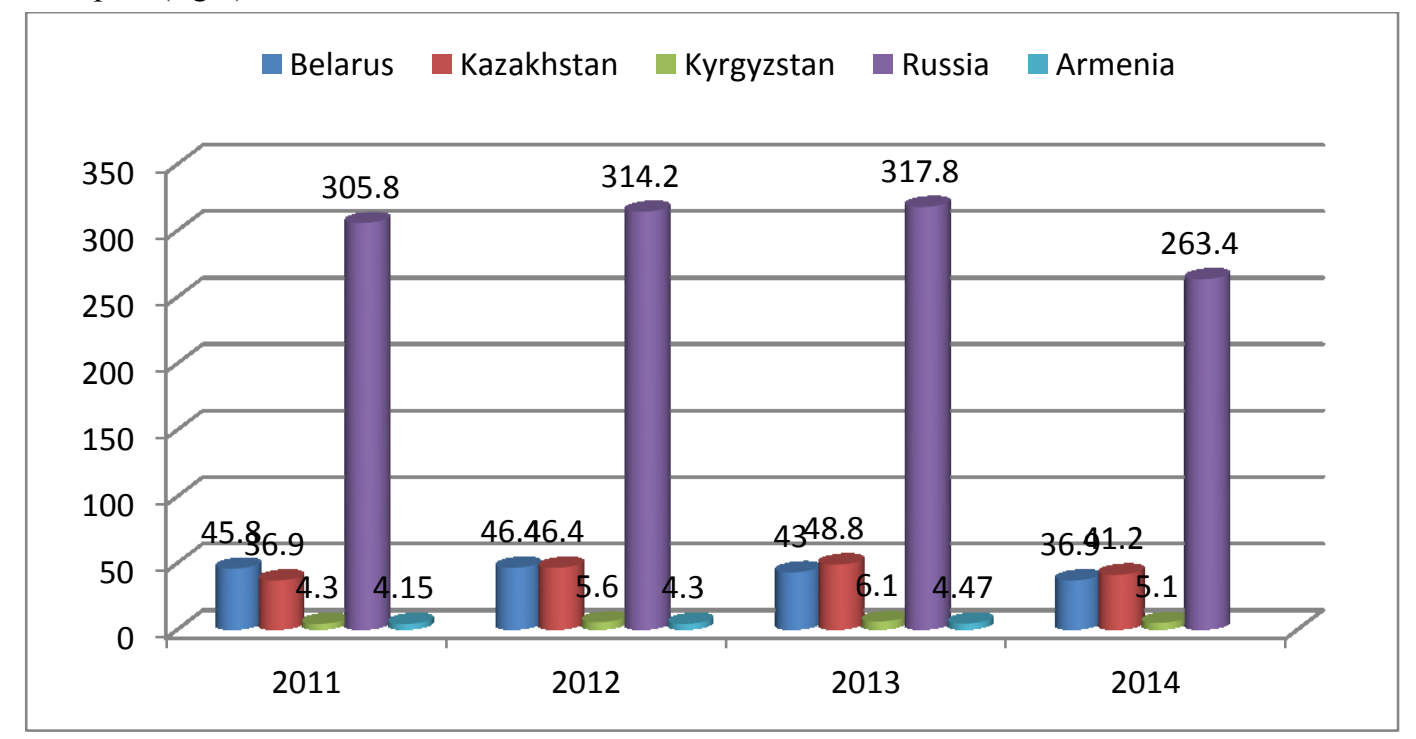

Figure 6. The volume of goods imports of the EEU (billion US dollars) 
We subjected to the detailed analysis data in one year, but in dynamics as show, the data presented in charts, special deviations in recent years since 2011 occur.

Unfortunately, as we noted above, the negative moments in Russian Federation economy, which might affect the commonwealth economic countries of EEU have occurred in 2014.

Therefore, in our opinion, identification of integration potential, current trends of development and possible consequences of formation of a common economic space, development of perspective directions of innovative development and modernization of economy of the countries are crucial. New forms of integration demand theoretical judgment and correction of developed paradigm of the analysis of the international economic integration. Besides, there are still certain fundamentals as a complementary industries and common technologies, structural development, which increase competitiveness of national economies as well as traditional cultural and public relations for former Soviet republics' intergovernmental cooperation development. This is important especially for Kazakhstan, which unfortunately has a small domestic consumer market.

Kazakhstan generally is associated with the fast-growing market. Despite significant influence of international financial crisis, which caused also the economic activity recession in Kazakhstan, our country quite quickly succeeded in restoring the economic growth rate.

In order to reach successful competition and corresponding increasing of national wealth fare there is a strong need for Republic of Kazakhstan in standing more actively against existing bureaucracy, corruption, and government administrative pressure on business processes and propagandizing more actively investment attraction of our state. There is also a need to take in account downward tendency in level of world prices on hydrocarbons and reduce budget dependence on oil income at the same time plan expansion of the transport corridors due to increasing of the capacity of "KTK" and "Kazakhstan-China" oil pipelines.

RK government should: 1) direct more efforts in modernization of agro-industrial complex, increasing of business activity in underdeveloped regions, provide an integrated approach in modernization of economy, i.e. finance programs, which give the greatest multiplicative effect on growth of economy and employment of the population; 2) provide a targeted public support to fight the price collusion and unfair competition through the containment of prices for socially valuable food products; 3) consider the world financial markets situation; 4) continuer further macro prudential regulation in financial system; 5) work on improvement of quality of credit portfolios; 6) institute flexible tax regime within EEU, that could allow to attract additional resources for further economic growth due to the absence of restrictions on capital allocation.

Must be evidently clear that despite significant progress there is still a need in further substantial improvement of regulatory environment in Kazakhstan. There is also necessity in increasing of the level of transport infrastructure, logistics and, definitely, in activisation of the innovative activities in the current technological century.

Kazakhstan has to use competitive advantages, including considerable reserves in minerals, geographical location between markets of China, Europe, Russia and Middle East, positive macroeconomic forecast, sustainable relationships with main business partner. Kazakhstan has to continue also focus on development the state social and economic infrastructure in order to realize fully its economic potential and increase its competitiveness.

\section{References}

- Brzezinski Z., 1998. The Grand Chessboard: American Primacy and Its Geostrategic Imperatives. Basic Books, New York.

- $\quad$ Porter M., 2008. Competitive Strategy: Techniques for Analyzing Industries and Competitors. Free Press, New York.

- Samuel P. Huntington, 2011. The Clash of Civilizations and the Remaking of World Order. Simon \& Schuster.

- Stiglitz, Joseph E.; Charlton, 2005. Andrew. Fair Trade for All. How Trade Can promote Development. Oxford University Press.

- $\quad$ www.stat.gov.kz, 2015 


\title{
Changes in the World Power: The United States within the New Balance of Power
}

\author{
Ph. D. Candidate Paulo Duarte (Université Catholique de Louvain, Portugal)
}

\begin{abstract}
This article aims to analyse the behaviour of the United States as a world power. The working hypothesis is that the only superpower has become, nowadays, impotent, affected by a relative decline. However, this should be understood as something natural, since it has never happened that any society would permanently remain ahead of the others. We assume here that the use of the qualitative method, through the hermeneutic analysis is, certainly, the basic methodology used for this investigation. We will try to conclude that notwithstanding their relative decline, the USA will tend to remain, in the short and medium term, the only world superpower. It is recommended that further investigation must assign a special attention to China's emergence and its consequences on the balance of world power, in particular with regard to the durability of American hegemony.
\end{abstract}

\section{Introduction}

The word decline scares. How to conceive that the United States, the winner of World War II, with the strongest currency in the world, is now in decline? This upsets the spirits, leads to debates, and causes strong reactions. The media also contribute to give the impression of a stronger America that it actually is.

It is a ridiculous word, the decline. How is the country, which fills with fast food all the stomachs from Beijing to Brazil, from Sydney to Tokyo and marvels the eyes of the whole world with magnificent Hollywood films, in decline? How will this country, which has already reached the Moon, manage to explore the surface of Mars if in reality it is losing its hegemony? Is the land of Coca-Cola, General Motors, Motorola, Ford, IBM or Microsoft going through a valley of tears? The country that has the largest armed forces in the world, which patrols the oceans, which controls the air or dominates on the ground, is it at the end of its glory days? This are complicated questions, whose answers are divided between the supporters of the uninterrupted supremacy and those who, instead, announce its end.

Between one and another critical approach, we believe that the right measure lies rather in the middle. That is, we will not defend here the radical theory of an absolute decline but we will opt for the demonstration of a relative decline, which is something natural in the history of the great powers. As Brzezinski also says "for all power, the decline is inevitable; [...] hegemony is a transitory historical phase [...]; in time, even if it is far away, the American global hegemony will erode" (2004: 283). Nevertheless, as Nye (1990) warns, decline is a tricky word as it bundles together two different concepts: a decrease in external power and internal deterioration or decay, however, a country may experience decline in one sense, but not in the other.

Convinced that the behaviour of the states, the power or influence are not likely to translate into tangible realities, mathematical formulas, or mere statistics, we assume, from this point, that the use of the qualitative method, through the hermeneutic analysis, is, certainly, the methodology supporting the present investigation. In this sense, it is imperative to penetrate the sphere of subjectivity, i.e. the understanding of causality inherent in the action of the various actors, that reaches us through the analysis of a whole panoply of scientific articles, monographs, theses, among other available sources regarding the subject of this study, in order to try to understand what drives the USA to act in this or that way.

It is important to consider, within the framework of the analysis that follows that, as Nye explains, "the word 'decline' mixes up two different dimensions: absolute decline, in the sense of decay, and relative decline, in which the power resources of other states grow or are used more effectively" (2010: para. 8). Starting from this fundamental distinction, we shall repeat once more that this article does not conceive the decline of the United States as absolute, but rather as relative regarding, in particular, the emergence of other actors in the international system, or better, several poles, which contribute to the fragmentation of power, as we will see, towards an uncertain and unstable system. It's not unreasonable to state that China is, eventually, one of these poles susceptible to reverse the balance of power against the American hegemon, given the extraordinary Chinese economic growth over the past few decades, along, at the same time, with a modernisation of the Chinese armed forces and of a gradual assertion of the soft power and pragmatism of Chinese foreign policy on the world stage. However, as we will conclude, the USA, although crossing a relative decline, will tend to remain the only superpower in the short and medium term.

\section{Upheavals in Power: Towards a New Order}

Today the power has changed. If once it was imposed by the simple force of the arms, demanding and eventually getting the respect of the enemy, today this one has become, more than ever, a protester against the power. In the past, the power was a balance element in the sense that it "was functional on the international 
scene, it regulated alliances, organised the protections [...]" (Badie, 2004: 277). Today, with the end of bipolarity, new actors are claiming a place in the world political arena. They now seek to impose their own points of view, rather than to accept the status quo.

In an increasingly globalised world, actors feel a sense of indignation and dissatisfaction regarding the United States hegemony. And then arose chaos and disorder which the power of the past was no longer able to control or suppress. This explains, according to Joseph Nye, that the United States will have more difficulty in achieving its goals in the 21st century (1990: 175). But this does not happen only with the United States because, in reality, any power which has great resources (economic, cultural and military) will find obstacles to its hegemony. Similarly, the author believes that power is disseminated primarily because of five factors. Namely, "economic interdependence, transnational actors, nationalism functioning in weak states, transfers of technology and the new political problems" (Nye, 1992: 166). In addition, the fact that actors are individual and multiple at the same time, almost anonymous and invisible, makes it even more difficult to contain their movements and requires negotiation and consensus often very difficult and slow.

Richard Haass also shares this point of view, speaking of the dangers caused by the existence of a "nonpolar" world. Similarly, Haass believes that nonpolarity will be the cause of a series of threats which have been caused by terrorists, the rogue states, among others. If the author claims that the emergence of this non-polarity is inevitable, he defends, however, the idea that actors may try to counter the negative effects so that the global order is the least unstable possible (Haass, 2008).

The former power is thus threatened. It is diluted while the political arena becomes fragmented. Moreover, we do not know very well how the new post-bipolar order will be structured. In fact, "we know what we lose; we guess wrong what we win" (Badie, 2004: 280). The problem of the instability of the power in the political sphere is also dear to James Rosenau. According to this author, hegemony is declining, borders are fading and the authority or the power (considered in general terms) is increasingly challenged. In short, the world is changing (as it has always been, in fact), but this change is marked by a trait of unpredictability in what concerns power. While global governance vacillates, social systems deteriorate, conflicts between groups increase and the traditional order is questioned. To conclude this part, let's say that the order and governance are interrelated insofar as this last one conditions and models the nature of the order of the political system. One exists only because the other is present and vice versa. Similarly, it is also possible to have governance without government (Rosenau, 1992: 1-29). But then some may think in this regard that the absence of a central authority - capable of imposing force if necessary - will maybe lead to anarchy. In this perspective, we would probably not be very far from chaos if the United States (which owns the largest army of the planet) renounced their "role of policemen of the world". The question, then, is what can happen if the Power wants to stay on the sidelines of the world (as, indeed, it was in the past) or if it is not powerful enough to manage everything and everyone and at the same time. The Americans have reason to be interested in possible threats to their hegemony in this new century. In other words, while the decline of America continues, other actors seem to emerge. In addition to the United States, the famous Palmerstonian pentarchy includes: "Russia, China, India and Japan". In this form of power for the 21st century, "Europe has disappeared [...]" while Asia focuses attention (Schmiegelow Partners, 2008: 21). Indeed, if one takes a look at the "recent growth rates of the two most populous nations of the world, China and India" as well as their enormous potential "labour, territory and capital", we see how important Asia is (Schmiegelow, 2006: 10). As Henrik Schmiegelow points out, the Asian integration and development model seems to practice "more consistently than America a philosophy which is (in fact) American: the philosophy of pragmatism" (2006: 18).

Declinist theses have been recurrent in American intellectual circles over the past few years. In fact, since the end of World War II, the theme of the decline has been present on the national discourse about the role of the United States worldwide. But would Paul Kennedy's work The Rise and Fall of the Great Powers, in 1987, be an important catalyst for the debate on whether the United States would, or not, be in the midst of decline or renewal? The supporters of the decline evoked three major arguments: "the economic performance of the United States was in relative decline compared to other powers; 2) economics is the central element of national strength; and 3) the relative decline of the United States was largely caused by excessive military spending that resulted from wide-reaching US political commitments around the globe" (Edelman, 2010: 24). Now, this resulted in a speculation on whether the United States would be, after all, in the same declinist trajectory as other great imperial powers that preceded them, like Spain, France, or England. In this regard, Joseph Nye (1990) argues that the situation for the United States at the end of the twentieth century is quite different from that of Britain at the century's beginning, which explain that loose historical analogies and falsely deterministic political theories are worse than merely academic, in the sense that, according to Nye, they may divert Americans from addressing the true nature of their situation.

The debate of U.S. decline is a debate about the relevance of history, i.e., "declinists contend that history tends to repeat itself and that the history of world politics can be characterized as a 'succession of hegemonies' [...], as an 'observable pattern of great power emergence', or as a series of 'long cycles"' (Beckley, 2012: 22). Authors such as Robert Gilpin share the realistic perspective of the American decline, defending, on the other hand, that 
the tendency toward breakdown or fragmentation of the system greatly increases with the relative decline of the hegemon. Gilpin (1987) tried to draw a general scenario of the relative economic decline of the United States, which has also its impact on the overall hegemony it wields in the political and military domains. Experts such as Michael Cox argue that "the question is not whether decline is going to happen - it already is - but how successfully the United States will adjust to the process" (2007: 653). However, Cox recognizes that "the U.S. still retains a great deal of hard power", and that "it will for some time to come, remain the most significant international actor to which others will tend to turn when in trouble" (2007: 653). Fareed Zakaria takes a similar position. Em The Post-American World, Zakaria (2008) prefers not to put the emphasis on the decline of America, but rather on 'the rise of everyone else'. Zakaria (2008) sustains that the U.S. relative power, in fact, is not declining significantly, believing that the American power can retain most of its international political dominance, since, after all, according to the author, its decline is economic - and not geopolitical - and relative, rather than absolute.

Declinists such as Arthur Stein argue that the United States is suffering from a classic case of the "hegemon's dilemma" (1984: 384). According to Ian Bremmer, "the greatest concern underlying the declinist mood at large [in the USA] today is not really whether the United States can afford to continue playing its role in the world, it is whether the Americans are capable of solving any of their most pressing economic and social problems" (2012: 9). The real question, in Bremmer's opinion is "can Americans do what needs to be done to compete effectively in the twenty-first-century world?" (2012: 9). It will be difficult, as predicted by Parag Khanna, another supporter of the declinist theses vis-à-vis American hegemony. Khanna (2008), who paints a stark picture of an America in decline, believes that the United States are nowadays faced with fierce competition for world hegemony, which they will hardly maintain. This is essentially due, according to the author, to imperial overstretch, domestic political malfunction, economic weakness, and diminishing soft power. To the question how long can American unipolarity last?, the supporters of the decline highlight the transformation of the policy and the international system (towards multipolarity), driven either by globalisation, or by geopolitical competition between the United States and emerging powers such as China. Power diffusion may pose a bigger danger than power transition in this new century. Nye (2010) sustains that the distribution of power today resembles a 'complex three-dimensional chess game'. What Nye is telling us is that it can be misleading and inaccurate describing power transition in this new century as a traditional case of hegemonic decline. In fact, Nye argues that "the United States is not in absolute decline, and in relative terms, there is a reasonable probability that it will remain more powerful than any single states in the coming decades" (2010: para. 42). Bringing a further contribution to the debate about the decline, the National Intelligence Council's Global Trends 2025 (published in 2008) warns that in addition to relative decline, the United States will confront other constraints on its international role; U.S. military supremacy will no longer be as dominant as it has been since the Cold War's end; The United States' soft power may diminish as its liberal model of political and economic development is challenged by authoritarian/statist alternatives. At home, economic and political constraints may undermine U.S. hegemony. Global Trends predicts that over the next two decades, the dollar's role as the international economy's preeminent reserve currency will erode. But while the National Intelligence Council, Zakaria and Khanna conceive China as the rising power with more potential to challenge the American hegemony, others, non-supporters of the declinist theses, such as Brooks and Wohlforth, devalue China's growth and rise, as well as its ability to supplant the United States hegemony (Layne, 2009).

In general, anti-declinists are divided into different branches. The economic revivalists, such as Aaron Friedberg, Edward Luttwak and Robert Lieber, sustain that the US economic decline is overstated and that declinists undervalue the economic resilience of America's open, free-market economy. Besides, there are those who highlight American soft power, such as Joseph Nye, or another school - the so-called structural positionists, like Joffe, Singh, Friedberg and Luttwak - which puts the emphasis on "the advantages of America's geopolitical location and the resulting demand by others for the United States to provide leadership in solving international problems" (Edelman, 2010: 28). Finally, Kristol and Kagan are perhaps the most important representatives of the benign hegemonists' school who profess "the attractiveness of American ideology, its global leadership role and the willingness of others to follow the US lead" (Edelman, 2010: 28). We share, in this article, Charles Krauthammer's thesis, when the author argues that "the question of whether America is in decline cannot be answered yes or no" (2009: para. 5). However, we do not fully agree with Krauthammer's unconditional belief in the capacity of a country (in this case the U.S.) to choose or not its own decline, given that there is no infallible certainty as to whether the mutation of power and transformation of international politics, can themselves prevail (or not) over the will of the Americans to avoid, delay or prevent the (relative) decline of their country.

\section{The (Relative) Decline of the United States}

According to Senator J. William Fulbright, “[...] America is now at that historical point at which a great nation is in danger of losing its perspective on what exactly is within the realm of its power and what is beyond it. Other great nations, reaching this critical juncture, have aspired to too much, and by overextension of effort have declined and then fallen" (1966: 3). It is interesting that the above sentence was referred to by an American 
about forty years ago and that it remains always contemporary. It is also curious the fact that this same American (who was not a common man, but a Senator) had established, even only implicitly, an analogy between the possible fate of the United States and that of other major nations. And finally, very timeless on the behaviour of America towards the rest of the world, was his book whose title is enough compromising: The Arrogance of Power. We notice that large nations such as the United States tend to understand their power as a "sign of God's favour" (Fulbright, 1966: 3). Thus, they believe to be different from other countries, with a 'worldwide' mission, with responsibility towards other nations (Hassner, 2003: 57). This means that their life patterns are considered the most correct and should therefore be extended to other peoples. It's almost a duty to bring these nations out of the 'darkness' and in addition it must be done because it is believed that God wishes so. It is, therefore, established a kind of dichotomy between good and evil, which governs the external policies of the great powers. For example, President Mckinley believed that God had entrusted to the Americans the duty to civilise and Christianise the inhabitants of the Philippines.

Moreover, President Bush "introduces himself as an instrument of the Lord", convinced that "providence has given the United States the task to correct the political, moral, spiritual and economic mistakes of the less fortunate nations of the planet" (Lapham, 2002, 41). But what is the arrogance of power and how can it carry the germ of a possible decline of the United States? The arrogance of power means "a psychological need nations seem to have to prove that they are bigger, better or stronger than other nations" (Fulbright, 1966: 5). According to this point of view, the basis of power and the best proof of a country's superiority lay in the force. Owning the largest army means, thus, having the most developed institutions, the best principles and the best civilisation. In addition, the signs of arrogance may be observed through the way Americans behave when they are abroad. Indeed, the awareness that they belong to the richest country in the world is, in itself, a factor which does not help to reduce national pride (Fulbright, 1966: 3-22).

\subsection{The Economic Decline of the Superpower}

According to declinists, one of the main causes of the (relative) decline of America is the economy. We touch here the strong point. The ratio of forces is reversed. The United States is no longer the economic giant that causes fear. On the contrary, declinists argue that it is the Americans today who are worried about the globalisation of the economy and the emergence of new actors. In addition, the debate on the economic decline of the United States is dense, controversial and steeped of ideology, of passion, of subjectivity... This is, maybe, because it is not about any country but about a great power. However, the phenomena in question have an objective nature; they are based on the figures and not on desires. We verify that the United States consumes more than it produces, it lives at the expense of the world (Umberto, 2003). The question "How to manage a superpower economically dependent but politically useless?" raised by Emmanuel Todd expresses the dilemma that now worries Washington leaders (2003: 26). The U.S. trade balance became unstable and the deficit is alarming. There is no balance between what the United States consumes and what it exports. Supporters of the declinist thesis argue that it is doubtful that the United States is still a hegemon. They recall, for instance, that "at the April 2009 Group of 20 meeting in London, President Barack Obama acknowledged that the United Sates no longer is able to play this role, and the world increasingly is looking to China (and India and other emerging market states) to be the locomotives of global recovery" (Layne, 2009: 170). This is curious if we take especially into account the fact that the United States had previously been the dominant economic power in the post-World War II. Let us recall the 'miracle' that the Marshall plan represented for a Europe that was in shortage and which was hungry. This is not the place to discuss the double intentions of such a plan regarding a red peril. What matters is rather to note the irony of history, because it is constantly changing. Today, Europe is no longer hungry. On the contrary, declinists sustain that it is the old continent (between other global economic actors) who must feed, with the most varied products, a gourmand America.

Besides, the U.S. trade deficit figures do not deceive. Let us mention those for the year 2001: "83 billion dollars deficit with China, 68 with Japan, 60 with the European Union, [...], 30 billion with Mexico, 13 with Korea, 4.5 billion with Israel; 3.5 with Russia and 0.5 with the Ukraine" (Todd, 2003: 80). Todd notes, as strange as it may seem, that "the majority of the U.S. deficit does not concern the first needs, on the contrary, they are instead other materials, among which mainly manufactured products, which constitute the largest deficit slice 366 billion dollars in 2001" (2003: 80). Agriculture has also become a field affected by this relative decline. The 'world flooded with food' is something that Paul Kennedy had already mentioned in his book Naissance et déclin des grandes puissances. How does this represent a threat to the U.S. economy? Kennedy explains that this affects US farmers as, in a world where food is abundant, there is now a rapid decline of "agricultural prices and of U.S. food exports" (1989: 583). Declinists find it curious to note that it is mainly due to the indirect help of western countries that the world has agricultural surpluses. In fact, these powers have paid money, by funding research to find out how to increase agricultural production in other countries. The consequence is that these countries have themselves eventually become major exporters of food products, and therefore potential competitors of America. This, in turn, generated a huge protest in the agricultural sector in the United States, culminating finally with protectionist measures. Nevertheless, one must be careful on the assessment, because the anti-declinist view argues that "the US food industry is the largest in the world, representing almost 13 per 
cent of GDP", adding that "America's farmers and producers have never been more efficient or productive than they are today" (Edelman, 2010: 69).

Coming back to the arguments shared by declinists, not only agriculture was affected. For example, Kennedy also mentions in his book the existence of a Japanese competition with regard to the 'Silicon chips'. The author explains that they entered the United States market at a lower cost than the cost price. Again discontent manifested itself, snapping once again protectionist feelings. Of course, all this had as a result the questioning of American supremacy in different areas of production. Furthermore, it must be said that this protectionism follows an era where American and English had devoted the primacy to a market where the state did not intervene (Kennedy, 1989: 583).

Compared to the industry, we can say that the Americans master the leading sectors, which does not, however, prevent them to remain deficient in low technology products, as Kennedy notes. The chemical, the textiles or the steel industry can be used as examples in this regard (Kennedy, 1989). However, according to Todd, the reality is surprising because the United States has attended, in recent years, even in the field of high technology, a situation which is more and more unfavourable to it. Todd shows here for example, the fact that in 2003, Airbus (European) and Boeing (American) had produced almost the same amount of aircraft. According to the author, "the surplus of the U.S. trade balance for advanced technology goods changed from 35 billion dollars in 1990 to 5 billion in 2001, and it was in deficit in January 2002" (Todd, 2003: 80-81).

So, all these sectors together threaten American finance, by converting the United States, "the world's largest creditor" so far, says Paul Kennedy, into 'the largest debtor" (1989: 584). Obviously, there are positive aspects in the American economy, despite declinist arguments. This explains, for exemple, that the American El Dorado continues, even today, to be coveted by millions of people who want to seek a better life in the United States. Furthermore, we should notice that the United States takes precedence in relation to the field of research on all other countries of the world. Needless to say, quoting Beckley, that "the United States increased its lead in terms of Research and Development spending over the last twenty years and still accounts for 50 percent of the world's most highly cited scientific articles" (2012: 73).

However, according to the partisans of declinism, reality is now more hostile to the goals of a power that wants to continue to maintain its supremacy in the world. Otherwise, let us think about it. How can the country, the greatest world debtor, which must now face a very violent competition at the international level, and that has also a trade balance, whose exchanges are uneven, continue to ensure its superpower status? The answer, according to declinists, is: it is very difficult. Beckley adds here that "because the United States allows the dollar to function as a global reserve and exchange unit, it must run persistent balance-of-payments deficits to supply the world with liquidity" (2012: 26). However, Beckley explains that "doing so undermines not only the competitiveness of U.S. exports but also the confidence of markets and central banks in the dollar, thereby increasing the risk of a dollar collapse" (2012: 26). More important, the author argues that "foreign governments that hold dollar reserves depend on U.S. prosperity for their continued economic growth and are thus 'entrapped', unable to disentangle their interests from those of the United States" (Beckley, 2012: 30). Others, like Fareed Zakaria, while admitting the existence of an economic decline (not geopolitical) of the United States, argue that "the problems besetting the U.S. economy - overconsumption, low savings, current account and budget deficits, and reliance on foreign creditors - could be fixed except that a dysfunctional U.S. political system is incapable of undertaking needed reforms" (in Layne, 2009: 155).

In turn, supporters of the anti-declinist theses, as Daniel Drezner, note that despite "prior to 2008, numerous foreign policy analysts had predicted a looming crisis in global economic governance", on the whole "the system has worked" (2012: 2). Among the various reasons which explain that the system has worked, Drezner points out that "the relative power of the United States was underestimated; the pre-existing institutional commitment to an open economic order made it easier to reinforce the status quo; the relative efficiency of prior eras of global economic governance has been overestimated, exaggerating the contrast between the past and the present" (2012: 4). Bremmer also believes that "the debt-ceiling debacle did not prove that U.S. politics is fractured for the long term" (2012: 2). In fact, Bremmer explains that it showed the opposite. Therefore, such facts lead us to mitigate the emphasis often placed by the supporters of the economic decline of the American superpower, since, as already mentioned, the system, with all its weaknesses and predictions of failure, has worked, after all.

Returning to the arguments raised by declinists, they argue that is not enough to have an armed power stronger than any country considered individually. It is necessary that other states recognise the American hegemony. A curious issue regarding the United States was raised by Paul Kennedy: "If ever a war breaks out in the world, how could the United States handle it as, once in the conflict, they would not have not a sufficiently effective industry able to meet all its needs?" (1989: 587). Kennedy argues that one can well see that "having the largest army in the world is certainly an important but insufficient factor, because this army could not feed the population" (1989: 587).

Once we are here discussing the economic aspects, what is the ratio between the expenses that the Americans spend on defence and their effects on the economy? It is a hot spot especially if one adopts a comparative 
perspective between the United States and the world's major economic powers. Declinists argue that as the world's only superpower wants to maintain a hegemonic force, it is likely that other sectors of the economy will be negatively affected.

While countries such as Germany or Japan channel much of their investment in the improvement and development of the commercial sector and research, Americans are rather concerned with defence, as declinists note. This results in the channelling of the attention of experts mainly in military research because they want to have the best technology in order to cope with any situation. Paul Kennedy confirms that we [USA] distract the attention of those technicians in favour of the military progress, with, as a result, a weakening of the attention given to the civilian sectors (1989: 589-590). Robert Kagan stresses that "American land and air forces are equipped with the most advanced weaponry, and are the most experienced in actual combat, [able to] defeat any competitor in a head-to-head battle; [...] American naval power remains predominant in every region of the world" (2012: para. 12). Beckley adds here that "militar superiority allows the United States to employ force without war, pressuring other countries into concessions by shifting militar units around or putting them on alert" (2012: 29).

In this (declinist) angle of analysis it is therefore not surprising to see a U.S. industry that weakens, and which must necessarily resort to imports to compensate for shortcomings. Besides, it is not surprising to see the American economy becoming strongly in deficit and dependent towards abroad. At the same time, other countries, which have fewer security concerns, take the advantage commercially. The choice between defence and the civil sector is increasingly becoming the crucial issue. Are Washington leaders willing to pay any price to ensure the supremacy of security? Are they able to reconcile the challenges of a highly competitive global economy with the maintenance of the largest war machine in the world? Whatever the answers, declinists warn that one has to take into account the fact that the reality and pace that manage the world do not stop to wait for the Americans. On the contrary, it is the Americans who must run against time to try to reverse the economic balance. In this regard, declinists see a causal relationship between the economic decline of the superpower and the desperate effort of its leaders to stop it. Indeed, Washington believed that a series of belligerent companies in the Middle East and Asia could be the solution to stop the weakening of the economy. But such a project, so ambitious, failed, and the Americans have not managed to control these vital regions from a strategic point of view, which if successful, would have enabled them to possess approximately $70 \%$ of the oil resources of the world. This could also, therefore, have led to a global financial supremacy, as it was the case in the good times when the dollar was the strongest currency.

The problem is that U.S. leaders had aimed too high and that today they lose more and more influence in Eurasia. In addition, and concluding on this point, why is Eurasia therefore so important to the United States? Because it is in Eurasia, where "75\% of the world's population" lives, that the global "bulk of the political and military destiny" is played (Brzezinski, 1997: 18). In this context, declinists stress the obsession of the United States in keeping its supremacy in this region so vital in energy and human resources, among others. The fact that Eurasia occupies a central position in the world, also explains the obstinacy of Brzezinski by saying that "whoever controls this continent, controls the planet", linking the sustainability of American hegemony to its policy in the region (1997: 24). In brief, any disruptions or conflict in this space is perceived as a threat to American interests, a threat which would legitimise in the eyes of Washington, the use of force.

\subsection{The Decline of the Dollar}

According to declinists, it is a long time since the United States has been emitting a currency whose future value is not certain. On the other hand, it receives goods and services provided by other powers. The U.S. economy is no longer what it was in the 50s, 60s or 70s (Ribeiro, 2007). Until the end of the World War II, American hegemony has as major symbols the dollar and the Pentagon. These two pillars experienced a peak between 1945 and 1971, the year when Washington decided to liquidate the conversion of the dollar into gold, because the reserves of dollars of other countries were threatening it. John Foster said in this regard that "the large export of dollars abroad, associated [...] to the growth of the Empire, had created a huge Eurodollar market" (2005: 39). This has weighed heavily in Nixon's decision to finish with the conversion of the dollar into gold. The year 1971 is, then, a key year because from this moment the dollar is no longer the currency of a strong power that continues its economic rise. Obviously the decline is a complex and historical process, having not started in 1971, but sometime during the post-World War II, and which manifested itself more or less clearly especially from the 1970s (Ribeiro, 2007). From now on, competitiveness and U.S. oil production plunge into decline. On the other hand, domestic consumption, and therefore imports, grew still more. In addition, Americans seem to be very good clients for Europeans and Asians.

According to declinists, there is not only a cause, but rather a set of causes, which are at the origin of the economic crisis that Americans are undergoing today. On one side, we have, for example, the increase in private and public spending which can be joined to military expansion and the typical consumption of a capitalist society. On the other hand, we should mention the existence of a certain delay at the level of productive innovation, as well as the weakening of industrial competitiveness. Furthermore, all these factors are in closely 
related to a context of growing discontent and apathy of the society towards politicians, the increase of crime, institutional and cultural deterioration (Beinstein, 2007).

Subsequently, declinists argue that the economic decadence results in the decrease in the balance between foreign investment in the United States and American investment abroad. It should be recalled that this balance, which partly offset trade deficits in the past, has however become negative for the first time in 2006. At a time when US production was falling, the other countries had opened the door of credit to the United States. Americans, far from saving, increasingly contributed, through unbridled consumption, to the growth of the external debt. If Bush's (son) Government appeared, in a first moment, to succeed in stemming the continuous economic decline and giving the impression of a return to prosperity, it was nevertheless only causing an increase of consumption, without having a sufficient internal productivity back. Therefore, the relative feeling of economic wellbeing that George W. Bush had induced in American society was, in fact, only an illusion. In fact, the economic weakening has never been stopped and the fact that the President had given the opposite impression served perfectly the Government's expansionist and military interests (Ribeiro, 2007). Moreover, pursuing the path of militarisation, with all the expenses that this led, George W. Bush caused a worsening of the American economic situation. For example, the imperialist invasion of the Iraq not only has not helped the improvement in the economy, but has also helped, according to Immanuel Wallerstein, "the diminution of the [U.S.] hegemon's power" (2006: 44).

Almost two years ago, Jaime Caruana feared that "a decline of the dollar strengthens itself and becomes disordered, increasing volatility on global financial markets and putting to the test the elasticity of the global financial system" (Mondialisation.ca, 2006: 4). As Director of the IMF's international capital markets Department, Caruana was well aware of "a potentially very expensive risk [...] threatening the global financial system" (Mondialisation.ca, 2006: 4). If we consider, moreover, the opinion of the historian and economist Oswaldo Coggiola, one realises that it is less 'modest' than the previous, as for Coggiola "it is the biggest global financial crisis since the 'thirties"' (in Filho, 2007: 2). For this author, the fact that the central banks have helped the affected areas by decreasing the interest rate is rather a panacea and not 'the solution' because such a decrease will only delay the emergence of economically even more difficult times.

According to declinists, the financial crisis has not really surprised because all knew well how the real estate market took a strange allure: people became more and more indebted and saw their properties mortgaged. As an example, Mike Whitney informs us that in Santa Barbara (California) parking lots were turned into dormitories so that families who had lost their homes in the mortgage scandals could sleep in their cars. The same thing happened in Los Angeles where people have lost their jobs and do not have anything to cover their expenses (Whitney, 2008).

It is the speculative system based on the sale of loans, to a sector of the population with low resources, which has been ruined. Furthermore, what was a real estate crisis at the beginning became a simultaneous crisis of the financial sector, banks and a foreign exchange market crisis. Similarly, according to Coggiola, we weren't expecting that the crisis assumed such a dimension, a situation which can still cause "a currency war, a tendency to the brutal devaluation of the dollar and a fall of world trade" (in Filho, 2007: 8).

Other problems are related to this situation, namely: the increase in unemployment (a consequence of the reduction of economic activity), the increase in the price of imported goods and, by extension, the cost of living. It will be mainly the working masses and the "peripheral countries" that will pay, according to Coggiola, the global financial crisis, this through "the reduction of the level of employment and real wages, by assigning at the very least the central nations" (in Filho, 2007: 9). Although this is a typical crisis of capitalism, the author believes that it is however different from the crises of the past given its impact, greater than ever, and the extreme interdependence of all financial systems. Furthermore, according to Garcia, "central banks lose their faith in the dollar and begin to put it back into the market in quantities that can be fabulous, thereby threatening to plunge the 'greenback' even more" (2006: 76).

Despite the arguments mentioned above by the supporters of the decline of the dollar, and in a broad sense, of the US economy, it is important to present the opposite vision, reflected, for example, in Barry Eichengreen's famous book Exorbitant Privilege (2012). In fact, this author tries to demystify and devalue certain declinist theses, unfounded according to him, intending for the purpose, to analyse the role of the dollar before, during and after the crisis of 2008, in order to indicate the possible consequences both for the American and world economy, in case of a weakening of the greenbacks. Barry Eichengreen (2012) concludes that, in spite of the periods of instability the dollar has been through, it still kept its exorbitant privilege. The author conceives the exorbitant privilege as the ability of the United States to generate successive deficits in current account, simply covering them with currency issuance, since the existence of debt denominated in its own currency is paid with 'paper and ink'. However, such privilege would only end if other currencies, like the euro or the yuan, for example, would replace the dollar as the reserve currency, a scenario that the author discards for now. This vision contributes, once more, to mitigate the pessimistic impact of the declinist theses in what concerns, in this case, the American economy. 


\section{Conclusion}

At this stage, we insist that, speaking of decline, we do precede this word with the adjective relative in parentheses. We did it on purpose because we don't want at any time that the reader thinks that the United States finds itself in a situation of absolute decline. We prefer, anyway, the conscious repetitions to the idea of unintended omission.

Then, why can't we talk of absolute decline for the United States? Just like the great empires of history, the United States, may also fall. When? Nobody knows. The author of Naissance et déclin des grandes puissances is clear on the question of whether the United States can maintain its current situation "[...] not because it was never given to any society to maintain on top permanently, because it would mean that it freezes differences in growth rate, in technological and military developments that have existed for a very long time" (Kennedy, 1989: 591). Various factors prevent us from stating that this decline will be absolute. Indeed, we need only to remember the geographic size, the number of inhabitants or the resources possessed by the United States. This set is quite significant and powerful to enable the United States to occupy a position of weight no matter the power upheavals in the political scene.

Similarly, the fact that the U.S. Army, culture and ideology are highly prevalent and implanted everywhere explains that we can't condemn the United States to the darkness (although this was the fate of some empires in the past). In fact, we do agree with Eric Edelman, when the author mentions that "the United States is the first leading state in modern international history with decisive preponderance in all the underlying components of power: economic, military, technological and geopolitical" (2010: 64). It is also worth mentioning Zakaria (2008), who argues that the United States can remain at the center of the international system for a long time to come because there is still a strong market for American power, for both geopolitical and economic reasons. However, according to Zakaria (2008), the way to preserve its pivotal status in international politics is by using its soft power, not its hard power. We also share Nye's view that the U.S. has the soft ideological and institutional resources to retain its leading place in the new domains of transnational interdependence, given that the country remains the largest and richest power with the greatest capacity to shape the future. But, as Nye (1990) warns, the critical question is whether the USA will have the political leadership and strategic vision to convert its power resources into real influence in a transitional period of world politics.

However, the decline, as a natural process, must be interpreted with realism and knowledge of the History since nationalistic passions and emotions are only complicating the way that Americans are currently following. The passion is inconsistent with the reason because it blurs the intelligence. On the other hand, realism tries to find the best way to delay the decline, which as we have seen, is inevitable in the life of a great nation. While the system is becoming multipolar, this does not mean that the United States will dilute in a complex game of actors, losing its singularities. Nevertheless, it will be less strong than today but more powerful than any other country considered individually. In this context, the question of whether the United States is in decline must now give way to the real question: who will replace it in this new century? Only future will tell but, for the moment, there are already a few 'candidates' to this place: China, Japan, India or Russia. Of course that the European Union must certainly not be overlooked, despite the fact that some, such as the American Palmerstonians, have not included it in the pentarchy of the 21 st century. It is certainly economically powerful (and, we must add, militarily weak), such as Japan, but it is China which seems to concentrate all the attention. When this huge country wakes up, it can then shake not only the Americans, heavily dependent on it, but the world.

As Zaki Laidi says, "considering China's potential, Russia and India's ambitions we will see [...] that it is not impossible that the world order of the 21 st century is marked by the return of the logic of power". If this is true, it is not surprising that the Americans see their hegemony threatened in a multipolar world. They will then try to do everything to "prevent challengers" to their power (Laidi, 2003: 22). It is thus legitimate to think that if China becomes more powerful (as indeed current indicators suggest), it will want to have a word to say on regional and even global affairs. This explains that the relationship between the two giants, the United States and China, can range from cooperation to conflict. Taiwan is also a focal point in the relationship between the two powers, but this does not mean that, despite the challenge, the two countries would be actually willing to use nuclear weapons. In such a way that China is well aware of the importance of maintaining such a special 'client' which allows it to develop its economy. Impregnated with a mixture of reciprocal passion and mutual distrust, SinoAmerican relations oscillate between cooperation and rivalry. In fact, although China proves to be an indispensable partner for the issues of nuclear proliferation and terrorism, it is still regarded, however, in certain American political circles as a 'strategic competitor'. Beijing, in turn, refutes the siege policy that Washington leads about it, in order to circumscribe the Chinese power. Ambiguous, the American attitude towards China is based on a mixture of tactical prudence and strategic indetermination. Certain authors have created, in addition, the term of 'endigagement', which explains a strategy designed to 'isolate Beijing politically', trying, however, to maintain at the same time an 'active partnership in what concerns economic and trade issues'. Acting in the 'same fields' (namely in Africa and Asia), both powers want to ensure their access to raw materials, as well as to control the 'other's gestures'. The future of their relationship, including the risk of a potential conflict, will be 
determined mainly by the way how Washington and Beijing will deal with their economic competition, with Taiwan's issue, with human rights and world governance. But, at this moment, the two countries are neither 'supreme enemies' nor 'long-lasting partners'.

Despite all these apprehensions, rivalries and distrust, 'the Chinese threat' towards American hegemony is, for now, reduced, due to the internal problems (social instability, high corruption and abyssal imbalances between the rich coastal areas and a poor inland, environmental negligence, a barrier that the nature of the Communist party paradoxical and interestingly puts to the growth and progress of the country). This does not mean, however, that the Chinese will not fight to rediscover the way of the 'imperial temptation', to become again the 'great nation' they were in the past. This amalgam of 'manifest destiny', of 'historical mission', nationalism, prestige and nostalgia for a glorious past may, one day, make China a superpower. As H. Christophe underlines, "apart from some major incident, unexpected event or a serious strategy error on the part of the Chinese Communist Party, Beijing seems to have every advantage in hand to achieve it" (2006:8). In fact, "today's weaknesses will be, perhaps, the strengths of tomorrow, being hardly conceivable that such a large state, territorial and demographically, will not play a more important role in the future" (Christophe, 2006: 8). At that time, still distant and uncertain, it cannot be excluded that China will become, one day, a 'threatening' actor. But this possibility should not be perceived as a strange phenomenon. On the contrary, it fits into the natural dynamics of the 'birth and decline of great powers', where either one or several states will dominate, or will decline.

However, for now, despite the relative decline of the United States, these will tend to remain the only superpower, i.e. the hegemon, in the short and medium term. In fact, it does not exist, in military and/ or economic terms, any power or group of powers that can still stand up to the American power, which spends more on defence than all the other countries together (according to Beckley, "the U.S. defense budget exceeds half a trillion dollars, i.e. eight times greater than China's and rising, even when supplemental funding for the wars in Afghanistan and Iraq is excluded") (2012: 83). Furthermore, as Barry Eichengreen concludes, in 'Exorbitant Privilege', there is still no currency that can replace the dollar as a means of global exchange. It should be noted that, after all, the American economy remains the largest in the world and, despite having produced a systemic crisis in 2008, it shows clear signs of regaining and recovery of production. The USA still have, for all purposes, the most profitable portion of production global chains (innovation, design, high technology), which, even under a Marxist or Dependency perspective, still means that they systematically control global production. There is not even any evidence or proof that the existence of systematic deficits necessarily generates the decline of a superpower. Unlike any other country, the U.S. may produce deficits because they are responsible for the system trading currency and they are also responsible for global liquidity (a fact highlighted by emerging powers when they complained about a 'currency war' and a 'monetary tsunami' in the years following the crisis of 2008).

On the whole, we do agree with Edelman's arguments, which sustain that America's enduring primacy and the length of the unipolar moment are clearly going to be a matter of intensified debate in the next few years. A "proper evaluation", as Edelman adds, will depend "on how we attempt to measure the power of those countries that might become additional poles in a multipolar world, and how we evaluate America's enduring strength and capacity for revival" (2010: 30). That said, it would be interesting if other researchers and studies devoted more attention to the Chinese phenomenon, that is, to the contours and consequences that China's emergence in the world arena can bring for the balance of power, in particular for the survival of the American hegemon as the only world superpower in the years to come.

\section{Bibliography}

- Badie, 2004. L'impuissance de la puissance: essai sur les nouvelles relations internationales, Paris : Fayard.

- Beckley, 2012. The Unipolar Era: Why American Power Persists and China's Rise is Limited. Submitted in partial fulfillment of the requirements for the degree of Doctor of Philosophy in the Graduate School of Arts and Sciences. Columbia University.

- Beinstein, 2002. Uma louca fuga para a frente. O declínio do dólar ... e dos Estados Unidos, 18/01/2007, http://resistir.info/eua/beinstein_17jan07.html

- Bremmer, 2012. "Five Myths About America’s Decline". Washington Post, May 3.

- Brzezinski, 1997. Le Grand Échiquier : L'Amérique et le reste du monde, Paris : Bayard Éditions.

- Brzezinski, 2004. Le vrai Choix : L’Amérique et le reste du monde, Paris: Odile Jacob.

- Christophe, 2006. "La Chine pourrait-elle devenir la prochaine superpuissance? Analyse de l'évolution d'un pays en plein essor selon les différents critères théoriques de "puissance", Mons: Faculté de Sciences Sociales et Politiques.

- Cox, 2007. Is the United States in decline - again? An essay. International Affairs, v.83, n. ${ }^{\circ} 4$, pp. 643-653.

- Drezner, 2012. The Irony of Global Economic Governance : The System Worked, The Fletcher School of Law and Diplomacy Tufts University, October, pp. 1-31. 
- Edelman, 2010. Understanding America’s Contested Primacy. Center for Strategic and Budgetary Assessments, pp. 1-80.

- Eichengreen, 2012. Exorbitant Privilege: The Rise and Fall of the Dollar and the Future of the International Monetary System. Paperback.

- $\quad$ Filho, 2007. A Crise no mercado financeiro pode deflagrar guerra de moedas, Controvérsia (Blog), 13-0907, http://blog.controversia.com.br/2007/09/13/a-crise-no-mercado-financeiro-pode-deflagrar-guerra-demoedas/

- Foster, 2005. "Naked Imperialism”, Monthly Review, v. 57, nº4, http://www.monthlyreview.org/0905jbf.html

- Fulbright, 1966. The Arrogance of power, New York: Vintage books.

- Garcia, 2006. A queda do dólar e a hegemonia global, 01-12-06, http://brigadasinternacionais.blogspot.com/2006/12/queda-do-dlar-e-economia-global_01.html

- Gilpin, 1987. The Political Economy of International Relations, Princeton, N.J: Princeton University Press.

- Haass, 2008. We must guard against the worst in a nonpolar world, The Daily Star, April 24, http://www.cfr.org/bios/3350/

- Hassner, 2003. Washington et le monde : Dilemmes d'une superpuissance, Editions Autrement.

- Kagan, 2012. The myth of American decline. The New Republic, January 11, http://www.newrepublic.com/article/politics/magazine/99521/america-world-power-declinism

- Kennan, 1969. American Diplomacy 1900-1950, The University of Chicago Press.

- Kennedy, 1989. Naissance et déclin des grandes puissances : transformations économiques et conflits militaires entre 1500 et 2000, Paris : Payot.

- Khanna, 2008. The Second World: Empires and Influence in the New Global Order, New York: Random House.

- Krauthammer, 2009. Decline Is a Choice: The New Liberalism and the end of American ascendancy. The Weekly Standard. October 19, V.15, N. ${ }^{\circ}$, published on http://www.weeklystandard.com/Content/Public/Articles/000/000/017/0561fnpr.asp?page=1

- $\quad$ Laidi, 2003. La question multipolaire, CERI/CNRS, published on septembre, http://www.cerisciencespo.com/archive/sept03/artzl.pdf

- $\quad$ Layne, 2009. "The Waning of U.S. Hegemony - Myth or Reality? A Review Essay". International Security, v. $34, \mathrm{n}^{\circ} 1$ (Summer), pp. 147-172

- Le Krach immobilier aux États-Unis et ses conséquences, 2006. Mondialisation.ca, 21-09-06, http://www.mondialisation.ca/index.php?context=va\&aid=3295

- $\quad$ National Intelligence Council, 2008. Global Trends 2025: A Transformed World, Washington, D.C.: U.S. Government Printing Office.

- Nye, 1990. Bound to lead: the changing nature of American power, New York (N.Y.): Basic books.

- Nye, 1992. Le leadership américain: quand les règles du jeu changent, Nancy : Presses Universitaires de Nancy.

- Nye, 2010. The Future of American Power: Dominance and Decline in Perspective. Foreign Affairs, November/December, http://www.foreignaffairs.com/articles/66796/joseph-s-nye-jr/the-future-of-americanpower

- Ribeiro, 2007. Declínio e queda do império norte-americano?: CMI Brasil, published 02/10/2007, http://www.midiaindependente.org/pt/green/2007/10/397103.shtml

- Rosenau, 1992. Governance without Government: Order and Change in World Politics, Cambridge University Press.

- Schmiegelow_Partners_2008. How should the Atlantic Community view the Asian Community, Policyanalysis, January, http://policyanalysis.wordpress.com/

- Schmiegelow, 2006. How 'Asian'will Asia be in the $21^{\text {st }}$ Century?, Policyanalysis, July, http://www.schmiegelowpartners.com/download/HSHowAsianAsien.pdf

- Todd, 2003. Après l'Empire: essai sur la décomposition du système américain, Paris: Gallimard.

- Umberto, 2003. Reflexões sobre o declínio da liderança económica dos EUA, published 01/10/2003, http://resistir.info/brasil/dolar_u_martins.html

- Wallerstein, 2006. Questions sur les États-Unis et le Monde: Les États-Unis face à leur déclin, Université de Montréal, 26/092006, http://resistir.info/brasil/dolar_u_martins.html 
- Wallerstein, 2002. Os Estados unidos em declínio?, maio, http://www.revan.com.br/catalogo/0267b.html

- Whitney, 2008. Depressão económica nos EUA, 02-06-08, $\mathrm{http}: / /$ resistir.info/crise/economic_depression_02jun08_p.html

- Zakaria, 2008. The Post-American World. New York: W. W. Norton \& Company. 


\title{
Gender Differences in Work Experiences and Work and Learning Outcomes among Employees in the Manufacturing Sector in Turkey: An Exploratory Study
}

\author{
Prof. Dr. Mustafa Koyuncu (Çanakkale Onsekiz Mart University, Turkey) \\ Asst. Prof. Dr. Fusun Tekin Acar (Erciyes University, Turkey) \\ Prof. Dr. Ronald J Burke (York University, Canada) \\ Kadife Koyuncu (Çanakkale Onsekiz Mart University, Turkey)
}

\begin{abstract}
This study examined gender differences in work experiences and work outcomes among 215 male and 46 female employees working in the textile and furniture sectors in Turkey. Data were collected from 261 employees, a 65 percent response rate, using anonymously completed questionnaires. Respondents were mostly male, worked full-time, had relatively short job and firm tenures, generally held jobs involving some supervisory responsibilities, and worked 41 to 50 hours per week in fairly large firms. All measures used here had been used and validated previously by other researchers. Work experiences included perceptions of supervisor empowering behaviors; outcomes included job satisfaction, affective commitment, work engagement, engaging in voice behaviors, and intent to quit. Learning related outcomes included learning opportunities and self-rated employability. There were small differences in departments in which men and women worked with a slightly higher percentage of men in production and a slightly lower percentage of men in accounting, human resource management and marketing. Consistent with earlier work, significant gender differences were found on several personal demographic and work situation characteristics. Women were younger, less likely to be married, were more highly educated, were at lower organizational levels, had less job and organizational tenure. Males and females had similar perceptions of their supervisor's empowering behaviors, their own levels of psychological empowerment, similar learning opportunities and levels of self-rated employability and on most work outcomes (e.g, job satisfaction, organizational commitment, intent to quit).
\end{abstract}

\section{Introduction}

This study examined potential gender differences in work experiences, important work outcomes typical of organizational research (e.g., job satisfaction, work engagement), as well as workplace learning-related opportunities and potential benefits of these to levels of worker employability. In addition, the study was undertaken in Turkey to address the relative lack of research undertaken there on women in management and the professions. The Turkish society and culture may also pose additional challenges to women in the workplace.

Supervisor empowering behaviors and psychological empowerment

Organizational cultures that empower employees are more likely to realize higher levels of employee and organizational performance (Bowen and Lawler, 1995, 1992; Menon, 2011; Quinn and Spreitzer, 1997, Zemke and Schaaf, 1989). Empowered employees have a more proactive view of their jobs bringing more energy, dedication and risk taking to their work.

Empowerment exists at two levels, macro or organizational and micro or individual (Spreitzer, 1997; Quinn and Spreitzer, 1997). Macro factors exist at the organization level and include organizational structure and hierarchy, policies, practices, and leader behaviors. Micro level empowerment considers individual perceptions and feelings of empowerment.

Work outcome benefits of empowerment

Empowered employees have been found to report more positive work outcomes. These would include higher levels of job satisfaction, work engagement, organizational commitment and lower levels of quit intentions (Seibert, et. al, 2011), which in turn get translated into higher levels of organizational success (Zemke and Schaaf,1989 ; Lawler, 1992; Lawler, et. al, 1995).

Workplace learning

Organizations that learn are likely to have competitive advantages given the increasing number of challenges they face in the form of heightened competition, the faster pace of change, increasing use of new technologies and processes, and the need for higher levels of innovation, among others (Salas and Von Glinow, 2008). Organizations however do not learn; individuals in organizations are the agents of all learning that takes place within organizations.

Organizations that exhibit high levels of individual learning have learning cultures, such cultures supporting learning at individual, team and organizational levels. Marsick and Watkins (2003) suggest seven dimensions of a learning culture, developed measures of these, and using a number of samples, showed a link between more supportive learning cultures and organizational performance. 
Individual learning in the workplace takes place formally through training initiatives dictated by the organization as well as informally through one's work experiences. Some writers have concluded that informal learning is more useful to individuals and their organizations than formal organization-sponsored learning events. We have come to better understand barriers, facilitators, and outcomes of informal workplace learning (Crouse, et. al, 2011; Lohman, 2009, 2006, 2005, 2000) and thus how to enhance it.

\section{Employability}

Another important outcome for both individuals and organizations from workplace learning is the concept of employability. Rothwell and Arnold (2007, p.75) define employability as "the individual ability to keep the job one has and of getting the job one desires". Individuals, through informal learning, acquire skills, behaviors, attitudes, values, relationships, information, and knowledge which helps them perform their present jobs at a high level and makes it more likely to advance their careers inside or outside their present organization. Employability has been found to predict objective early career success and the number of promotions for late career employees (vander Heijden, et. al, 2009). Interestingly, individuals having higher levels of self-rated employability were more rather than less likely to remain with their employers (DeCuyper and deWitte, 2011) appreciating what their employers did to contribute to their employability.

\section{Women in management and the professions in Turkey}

There are reasons for both optimism and pessimism as far as women's job prospects and career advancement in Turkey are concerned. Turkey has a significant number of women working as physicians, dentists, pharmacists, lawyers, and professors, but few of these women are at senior levels in these occupational groups. Women also have a presence in the public sector. (Kabasakal, et. al, 2011; Kabasakal, et. al, 2004; Boydak and Akpinar, 2002)

In addition, studies of gender differences in several occupations showed that although women and men differed considerably on personal demographic and work situation characteristics (e.g, women were younger, less likely to be married or have children, had lower salaries, were at lower organizational levels) gender differences on work outcomes such as job satisfaction, work engagement, intent to quit were few and small (Burke, et. al, 2009; Burke, et. al, 2011; Koyuncu, et. al, 2006).

There are some reasons for pessimism as well. The Republic of Turkey was created in 1923 with Mustafa Kemal Ataturk as president. He appeared to have very progressive attitudes towards the role of women, very much ahead of his time. However the current President of Turkey, Recep Tayyip Erdogan. Speaking in Istanbul at a meeting of an association advocating women's rights, said that gender equality goes against nature, pregnant women should not be in the same situation as working men, a woman breast feeding a child is not equal to a man, that Islam worships women ad mothers and that working women should instead stay at home with their children, and attacked feminists for not accepting the concept of motherhood. Women and men cannot be equal as they have different natures and bodies. Turkey is a secular Islamic country but Erdogan is trying to move the country in a more Islamic direction.

Here is some research evidence. Aycan (2004) found that Turkish men held stereotypes views of the managerial job and women in management. Guney, et. al, (2006), in a study of male and female teachers in Turkey and Pakistan reported that both men and women in Turkey had negative attitudes towards women managers, more so than did Pakistani male and female teachers. Besler and Oruc (2010) examined the portrayal of men and women in the media finding support for the "think manager, think male" viewpoint. Sanal (2008) noted the following factors as barriers to women's advancement: gender role stereotypes, conflict of work with roles of wife and other, men's negative attitudes to women in management (e.g., women less competent) and the "old boys" network. Women are always paid less than men holding the same jobs (Kabasakal, et. al, 2011). Ozbilgin and his colleagues (Ozbilgin 2000; Ozbilgin and Healy, 2004; Ozbilgin and Woodward, 2004a, Ozbilgin and Woodward, 2004b; Woodward and Ozbilgin, 1999) have highlighted the special challenges face in the financial, banking and university sectors in Turkey. Though women are entering educational offerings at all levels, more men than women receive the highest levels of education and men more than women tend to focus on the technological areas (Kabasakal, et. al, 2011).

Few private sector organizations make efforts to support the career advancement of their qualified female employees and though legislation supporting gender equality exists it is not clear the extent to which it is monitored or sanctions applied to organizations that fail to comply with it (Burke and Koyuncu, 2013).

Finally, a United Nations Development Programme (2008) report comparing the percentages of women among managers, legislators and union officials in 13 countries indicated that Turkey placed last having only $7 \%$ of these positions occupied by women as opposed to $52 \%$ in the United States, $37 \%$ in Germany and $36 \%$ in Canada.

\section{The present study}

In this study, we consider the relationship of employee perceptions of supervisor/leader empowerment behaviors, levels of felt psychological empowerment, important work outcomes (job satisfaction, affective organizational commitment, work engagement, engaging in voice behavior, intent to quit), and opportunities for 
learning and employability. Although the wider Turkish society and culture poses significant challenges to women in the workforce, women and men have been shown to have similar work experiences and outcomes.

We examine the following general hypotheses based on previous research findings.

1. Female employees with be significantly different from male employees on personal demographic and work situation characteristics.

2. Female and male employees will report similarly positive work experiences and work outcomes.

3. Female and male employees will report similar learning opportunities and self-rated employability.

\section{Method}

\subsection{Procedure}

The Employment Agency of the Kayseri Region of Turkey was approached in 2014 and indicated there were 58 furniture and 37 textile manufacturing organizations in their region. Fifty organizations, 30 from the furniture sector and 20 from the textile sector, were randomly selected to participate in the research. A total of 400 questionnaires were sent to these 50 organizations. Data were collected over a five month period, September 2014 to January 2015).Two hundred and sixty one individuals completed the survey, a $65 \%$ response rate.

\section{Respondents}

Table 1 presents the personal demographic and work characteristics of our sample $(\mathrm{n}=261)$. Most were male $(82 \%)$, worked full time (96\%), were between 31 and 40 years of age $(43 \%)$, were married $(71 \%)$, had children (87\%), had high school educations (38\%), worked in their present jobs between 1 and 5 years $(44 \%)$, worked for their present organization between 1 and 5 years (40\%), held non-management positions ( $35 \%$ ), earned between $\$ 5000-\$ 10,000$ US $(50 \%)$, worked between 41 and 50 hours per week $(82 \%)$, worked in a variety of departments but mostly in production (63\%), worked mostly in the furniture sector $(66 \%)$, and in organizations having 250 or more employees (44\%).

\subsection{Measures}

All measures used in the research were translated from English to Turkish and back by members of the research team fluent in both languages using the back translation method.

Personal and work situation demographics

Personal and work setting characteristics were assessed by a number of single items. The former included: gender, age, current work status, current marital and parental status, and level of education. The latter included hours worked per week, organizational level, job tenure, organizational tenure, and whether respondent had supervisory duties. These items served as control variables in some of our analyses.

Supervisory empowerment behaviors

Arnold, et. al, (2000) developed and validated a measure of empowering leader behaviors. They ended up with five factors: Coaching, Informing, Leading by example, Participative Decision Making, and Showing concern/Interacting with their team. In the present research, each of these five dimensions was measured by five items. Respondents indicated how frequently their supervisor exhibited each behavior on a five point Likert Scale $(1=$ Never, $3=$ Sometimes, $5=$ Always $)$. 


\begin{tabular}{|c|c|c|c|c|c|}
\hline Gender & $\underline{\mathrm{N}}$ & $\underline{\%}$ & $\underline{\text { Age }}$ & $\underline{\mathrm{N}}$ & $\underline{\%}$ \\
\hline Male & 215 & 82.4 & 20 or less & 8 & 3.1 \\
\hline \multirow[t]{2}{*}{ Female } & 46 & 17.6 & $21-30$ & 80 & 31.1 \\
\hline & & & $31-40$ & 112 & 43.6 \\
\hline Work Status & & & $41-50$ & 49 & 19.1 \\
\hline Full time & 251 & 96.2 & 51 or more & 8 & 3.1 \\
\hline \multirow[t]{2}{*}{ Part time } & 10 & 3.8 & & & \\
\hline & & & $\underline{\text { Parental Status }}$ & & \\
\hline Marital Status & & & Children & 171 & 87.7 \\
\hline$\overline{\text { Single }}$ & 76 & 29.3 & No children & 24 & 12.3 \\
\hline \multirow[t]{2}{*}{ Married } & 183 & 70.7 & & & \\
\hline & & & Hours worked & & \\
\hline Education & & & 39 or less & 6 & 2.3 \\
\hline Elementary & 58 & 22.2 & 40 to 50 & 212 & 82.5 \\
\hline High school & 99 & 37.9 & 50 or more & 39 & 15.2 \\
\hline Bachelors & 91 & 34.9 & & & \\
\hline \multirow[t]{2}{*}{ Master/PhD } & 13 & 5.0 & $\underline{\text { Supervisory duties }}$ & & \\
\hline & & & Yes & 184 & 70.5 \\
\hline Organizational level & & & No & 27 & 29.5 \\
\hline Non-supervisory & 91 & 34.9 & & & \\
\hline Supervisor & 87 & 33.3 & Organizational tenure & & \\
\hline Middle management & 69 & 26.4 & 5 years or less & 103 & 39.9 \\
\hline \multirow{2}{*}{ Senior management } & 16 & 5.4 & 6 to 10 years & 74 & 28.7 \\
\hline & & & 11 to 20 & 67 & 26.0 \\
\hline Income (US\$) & & & 21 or more & 14 & 5.4 \\
\hline$\overline{5000 \text { or less }}$ & 34 & 13.0 & & & \\
\hline 5001 to 10,000 & 130 & 49.8 & Organizational size & & \\
\hline 10,001 to 20,000 & 56 & 21.5 & 49 or less & 42 & 16.1 \\
\hline 20,001 to 30,000 & 28 & 10.7 & 50 to 249 & 104 & 39.8 \\
\hline 30,001 or more & 13 & 5.0 & 250 or more & 115 & 44.1 \\
\hline Job Tenure & & & $\underline{\text { Sector }}$ & & \\
\hline$\overline{\text { Less than } 1}$ year & 55 & 21.3 & $\overline{\text { Textile }}$ & 90 & 34.3 \\
\hline $1-5$ years & 114 & 44.2 & Furniture & 171 & 65.5 \\
\hline $6-10$ years & 52 & 24.0 & & & \\
\hline $11-20$ years & 25 & 9.7 & Department & & \\
\hline \multirow[t]{7}{*}{21 years or more } & 2 & .8 & Production & 163 & 62.9 \\
\hline & & & Marketing & 27 & 10.4 \\
\hline & & & Accounting & 41 & 15.8 \\
\hline & & & Finance & 3 & 1.2 \\
\hline & & & HR & 8 & 3.1 \\
\hline & & & $R \& D$ & 2 & .8 \\
\hline & & & Other & 15 & 5.8 \\
\hline
\end{tabular}

Table 1: Demographic Characteristics of the Sample

Leading by example $(\alpha=.89)$ An item was "Leads by example."

Participative decision making ( $\alpha=.94)$ One item was "Encourages work group members to express their ideas/suggestions".

Coaching $(\alpha=.93)$ An item was "Suggests ways to improve my work group's performance."

Informing $(\alpha=31)$ One item was "Explains h9ow my work group fits into the company."

Showing concern/Interacting with the team $(\alpha=91)$ An item was "Shows concern for work group members well-being." As these five dimensions were positively and highly correlated, a composite measure of total leader empowering behaviors was created.

Psychological empowerment

Psychological or personal feelings empowerment was measured by a twelve item scale developed and validated by Spreitzer $(1996,1995)$. This measure tapped four dimensions, each addressed by three items.

Respondents indicated their agreement with each item on a seven-point Likert scale ( $1=$ Very strongly disagree; $4=$ Neutral, $7=$ Very strongly agree).

Meaning $(\alpha=.92)$ "The work I do is meaningful to me."

Competence $(\alpha=.85)$ "I am confident about my ability to do my job."

Self-determination $(\alpha=.85)$ "I have significant autonomy in determining how I do my job." Impact $(\alpha=91$.$) "My impact on what happens in my department is large".$ 
And as these four dimensions were positively and significantly correlated, a composite measure of psychological empowerment was created.

Work and well-being outcomes

Eight work and well-being outcomes were included.

Job satisfaction was assessed by a seven item scale $(\alpha=83)$ developed and validated by Taylor and Bowers (1972). Respondents indicated their agreement with each item on a five-point Likert scale (1-Very dissatisfied, $3=$ Neither satisfied nor dissatisfied; $5=$ Very satisfied. One item was "all in all, how satisfied are you with the persons in your work group?"

Affective commitment was measured by a six item scale $(\alpha=.93)$ developed and validated by Meyer and Allen (1997). Respondents indicated their agreement with each item on a five-point Likert Scale (1=Strongly disagree, $3=$ Neither agree nor disagree; $5=$ Strongly agree). One item was "I am proud to tell others I work at my hotel".

Work engagement

Three aspects of work engagement were assessed using measures created by Schaufeli, et. al, (2002).

Respondents indicated their agreement with each item on a five point Likert scale (1=strongly disagree,

$3=$ neither agree nor disagree, $5=$ strongly agree)

Dedication was measured by five items $(\alpha=.87)$. One item was "I am proud of the work I do."

Vigor was assessed by six items $(\alpha=.87)$ An item was "At my work I feel bursting with energy."

Absorption was measured by six items $(\alpha=.77)$. One item was "I am immersed in my work."

Employee Voice

Employee voice behaviors were measured by a six item scale $(\alpha=.93)$ developed by Van Dyne and LePine (1998). Respondents reported how often they engaged in voice behaviors in their workplaces by indicating the frequency of each item on a five point Likert scale ( $1=$ Never, $3=$ sometime, and $5=$ Very frequently). One item was "I speak up in my workplace with ideas for new projects or changes in the way we do things."

Intent to quit was measured by two items $(\alpha=.91)$ used by Burke (1991). Respondents indicated "yes or no" for both items. One item was "Are you currently looking for a different job in a different organization?"

Employee health complaints was assessed by a 19 item scale $(\alpha=90)$ developed and validated by Quinn and Shepard (1974.) Respondents indicated how often they experienced each complaint on a four-point Likert scale (1=Never, 4=often).

Learning- related outcomes

Workplace learning potential

Workplace learning potential was assess by a twelve item scale developed and validated by Nikolova, Van Ruysseveldt, de Witte and Syroit (2014). It included four potential sources, each measured by three items. Respondents indicated how applicable each item was to their current work situation on a five point Likert scale $(1=$ Not applicable at all; $5=$ completely applicable). Learning potential sources included: Learning through reflection $(\alpha-.88)$ 'In my work I am given the opportunity to contemplate about different work methods; Learning through experimentation $(\alpha=.79)$ "In my job I can try different work methods even if that does not deliver any useful result,"; Learning from colleagues $(\alpha=.85)$ " My colleagues tell me if I make mistakes in my work"; and Learning from supervisors $(\alpha=.88)$ "My supervisor helps me see my mistakes as a learning experience."

Self-perceived employability

Self-perceived f employability was measured by nine items $(\alpha=.83)$ developed and validated by Wittekind, et. al, (2010). Respondents indicated their agreement with each item as they saw themselves at work in a five-point Likert scale (1-strongly agree, 3+Neither agree nor disagree; 5=Strongly agree). One item was "If my organization offered me a possibility to obtain more work experiences, I would take it."

\section{Results}

Personal and work situation characteristics

Table 2 shows the comparisons of males and females on personal and demographic characteristics. The following comments are offered in summary. Significant gender differences were present on eight of the twelve measures. Females were younger, less likely to be married, were more highly educated, had less organizational and job tenures, were at lower organizational levels, and were less likely to have supervisory duties. In addition, females tended to be in part-time positons, and a smaller percentage of females worked in production with more tending to be employed in accounting, marketing and human resources. 


Personal demographics
Age
Marital status
Parental status
Level of education
Work status

Work situation characteristics

Job tenure

Organizational tenure

Organizational level

Organization size

Hours worked

Income

Supervisory duties

\begin{tabular}{|c|c|c|c|c|c|c|}
\hline \multicolumn{3}{|c|}{ Males } & \multicolumn{4}{|c|}{ Females } \\
\hline$\underline{X}$ & $\underline{\mathrm{SD}}$ & $\underline{\mathrm{N}}$ & $\underline{X}$ & $\underline{\mathrm{SD}}$ & $\underline{N}$ & $\underline{P}$ \\
\hline 2.9 & .80 & 212 & 2.6 & 1.05 & 45 & .05 \\
\hline 1.8 & .42 & 214 & 1.4 & 49 & 45 & .00 \\
\hline 1.1 & .32 & 213 & 1.2 & .38 & 24 & NS \\
\hline 2.2 & .86 & 215 & 2.5 & .84 & 46 & .05 \\
\hline 1.0 & .16 & 215 & 1.1 & .28 & 46 & .10 \\
\hline
\end{tabular}

$\begin{array}{lllllll}2.3 & .94 & 212 & 2.0 & .78 & 46 & .05 \\ 2.1 & .94 & 212 & 1.5 & .78 & 46 & .001 \\ 2.1 & .90 & 215 & 1.8 & .95 & 46 & .05 \\ 2.3 & .72 & 215 & 2.0 & .73 & 46 & .05 \\ 2.2 & .42 & 213 & 2.0 & .26 & 44 & .10 \\ 2.5 & .98 & 215 & 2.4 & 1.15 & 46 & \text { NS } \\ 1.3 & .44 & 215 & 1.5 & .50 & 46 & .01\end{array}$

Table 2: Gender differences on Personal Demographic and Work situation Characteristics

Work experiences, work and learning- related outcomes

Table 3 shows the comparisons of males and females on their work experiences, work outcomes, and learningrelated outcomes. The following comments are offered in summary. First, males and females reported similar perceptions of their supervisor's level of empowering behaviors. Second males reported higher levels on one of the four dimensions of psychological empowerment, Impact. Which was then reflected in males having a higher total psychological empowerment score. Third, males and females reported similar levels of job satisfaction, the work engagement factor of Absorption, organizational commitment, quit intentions and psychological wellbeing. Females indicated significantly lower levels of vigor and dedication, two work engagement dimensions, and engaging in voice behaviors than did their male counterparts. Fourth, males and females reported similar levels of learning opportunities and self-assessed levels of employability.

Additional observations

It is possible that females lower levels of work engagement on vigor and dedication, and their engaging in less voice behaviors, reflected the facts that they had less organizational and job tenures and were in jobs at lower organizational levels. Not surprisingly, individuals at higher organizational levels reported both more supervisory/leader empowerment behaviors and higher levels of their own psychological empowerment. It is possible to instill characteristics of the experiences of these higher level respondents (more influence, more discretion) into lower level jobs as well- one approach to increasing levels of empowerment. 
Leader empowering behaviors

Example

Participation decisions

Informing

Coaching

Showing concern

Total empowering behaviors

$\underline{\text { Psychological Empowerment }}$

Meaning

Competence

Self-determination

Impact

Total Empowerment

Work Outcomes

Job satisfaction

Vigor

Dedication

Absorption

Organizational commitment

Voice behaviors

Intent to quit

Health complaints

Learning-related outcomes

Reflection
Experimentation
Co-workers
Supervisors
Self-related Employability

\begin{tabular}{|c|c|c|c|}
\hline Males & & & Females \\
\hline$\underline{X}$ & $\underline{\mathrm{SD}}$ & $\underline{N}$ & $\underline{X}$ \\
\hline$\overline{19} .2$ & $\overline{4.58}$ & $\overline{215}$ & $\overline{19} .2$ \\
\hline 18.8 & 5.43 & 215 & 19.5 \\
\hline 18.8 & 5.09 & 215 & 19.2 \\
\hline 18.5 & 5.27 & 215 & 19.3 \\
\hline 18.4 & 5.37 & 215 & 19.5 \\
\hline 93.6 & 23.62 & 215 & 96.6 \\
\hline
\end{tabular}

$\begin{array}{lll}\frac{\mathrm{SD}}{3.28} & \frac{\mathrm{N}}{46} & \underline{\mathrm{P}} \\ 4.43 & 46 & \mathrm{NS} \\ 4.37 & 46 & \mathrm{NS} \\ 4.70 & 46 & \mathrm{NS} \\ 4.77 & 46 & \mathrm{NS} \\ 19.43 & 46 & \mathrm{NS}\end{array}$

$\begin{array}{lllllll}13.4 & 2.35 & 215 & 12.9 & 2.92 & 46 & \text { NS } \\ 13.0 & 2.31 & 215 & 12.5 & 2.52 & 46 & \text { NS } \\ 11.7 & 2.70 & 215 & 11.3 & 2.57 & 46 & \text { NS } \\ 11.8 & 3.13 & 215 & 10.2 & 3.17 & 46 & .01 \\ 49.9 & 8.59 & 215 & 46.9 & 7.89 & 46 & .05\end{array}$

$\begin{array}{lllllll}25.4 & 5.08 & 215 & 26.4 & 5.25 & 46 & \text { NS } \\ 23.1 & 5.21 & 215 & 21.1 & 5.34 & 46 & .05 \\ 20.1 & 4.34 & 215 & 18.2 & 5.13 & 46 & .01 \\ 21.1 & 4.79 & 215 & 20.1 & 4.98 & 46 & \text { NS } \\ 24.3 & 6.01 & 215 & 24.1 & 5.45 & 46 & \text { NS } \\ 23.5 & 5.78 & 215 & 21.2 & 5.58 & 46 & .05 \\ 3.5 & .86 & 215 & 3.6 & .75 & 46 & \text { NS } \\ 34.7 & 10.87 & 215 & 35.0 & 10.36 & 46 & \text { NS }\end{array}$

$\begin{array}{lllllll}10.71 & 3.40 & 215 & 10.4 & 3.73 & 46 & \text { NS } \\ 0.9 & 3.32 & 215 & 9.9 & 3.27 & 46 & .10 \\ 11.6 & 3.30 & 215 & 11.3 & 3.87 & 46 & \text { NS } \\ 11.1 & 3.58 & 215 & 10.9 & 3.95 & 46 & \text { NS } \\ 27.8 & 5.64 & 215 & 27.7 & 4.68 & 46 & \text { NS }\end{array}$

Table 3: Gender differences on work and learning - related outcomes

\section{Discussion}

We found considerable support for our three hypotheses (see Tables 2 and 3), consistent with some previous gender research conclusions in studies of other occupations in Turkey. There were considerable gender differences on personal demographic and work situation characteristics but relatively few differences on perceptions of leadership behaviors, a range of work outcomes, and indicators of workplace learning opportunities associated with the concept of employability. Thus it may be possible for women to transcend obvious societal and cultural biases and obstacles in achieving work experiences and work outcomes similar to their male colleagues.

The few significant gender differences likely reflected the fact that men were at higher organizational levels and had longer organizational tenures. And although the differences were not statistically significant, a slightly higher percentage of men were working in production and a slightly lower percentage of men were working in marketing, accounting and human resources.

\subsection{Practical implications}

The absence of gender differences on important perceptions of work experiences, work outcomes, and learning-related opportunities and benefits, while not suggesting that women and men have identical work experiences, clearly supports the conclusion that women in the present study, and in others, have satisfying work experiences and responses. The responsibility then in workplaces is to continue to support the future career possibilities of their qualified male and female employees similarly (Hewlett \& Rashid, 201'1). This would involve equal access to both formal and informal learning and training opportunities, as well as considering women for advancement on the same basis as their male colleagues (Burke, Koyuncu \& Fiksenbaum, 2007a, 2006).

\subsection{Limitations of the research}

The present research has limitations which should be noted to better assess the results. First, all data were collected using self-report questionnaires with the possibility of response set tendencies and common method biases. Second, although the sample was relatively large, all respondents came from firms in the same industrial 
region of Turkey thus the extent to which our findings would apply to firms in other regions is indeterminate. Third, the females sample however was relatively small. Finally, the majority of our respondents had some level of supervisory responsibility and were generally satisfied with their work situations making it unclear the extent to which our findings would be replicated in a sample of non-supervisory employees.

\subsection{Future research directions}

It would be important to undertake a similar study focusing on women and men without supervisory responsibilities to assess the generalizability of the present findings. In addition, including measures that more directly address bias and discrimination would supplement what this and other earlier studies have shown. Finally, continuing this line of work hut examining gender in other occupations would be informative.

An important question that remains unexplored is the apparent gap or disconnect between the experiences of women working in the occupations under study and the wider societal context which embodies elements of bias and obstacles for women in the workplace.

\section{References}

- Arnold, Arad, Rhoades, and Drasgow, 2000. "The empowering leadership questionnaire: The construction and validation of a new scale for measuring leader behavior", Journal of Organizational Behavior, 21, p. 249-269.

- Aycan, 2004."Key success factors for women in management in Turkey", Applied Psychology: An International Review, 53, p.453-477.

- Besler, Oruc, 2010. "Women managers in the print media in Turkey", Anadolu University Journal of Social Sciences, 10, p. 17-38.

- Bowen and Lawler, 1995. "Empowering service workers”, Sloan Management Review, 36, p. 73-84.

- Bowen and Lawler, 1992. "The empowerment of service workers: What, why, how and when", Sloan Management Review, 33, p. 31-40.

- Boydak and Akpinar, 2002. "The success of women administrators in school administration", Firat University Journal of Social Science, 12, p. 219-234.

- Burke, 1991. "Early work experiences of female and male managers and professionals: Reasons for optimism?", Canadian Journal of Administrative Sciences, 8, p. 224-230.

- Burke and Koyuncu, 2013. "Women in management in Turkey: Opportunities and challenges" In M. Paludi (ed.) Women and management: global issues and promising solutions pp. 239-263, Praeger, Santa Barbara. CA.

- $\quad$ Burke, Koyuncu and Fiksenbaum, 2009. "Gender differences in work experiences, satisfactions and wellbeing among physicians in Turkey”, Gender in Management: An International Journal, 24, p. 70-91.

- $\quad$ Burke, Koyuncu and Fiksenbaum, 2007a. "Career priority patterns among managerial and professional women in Turkey: Benefits of putting career first?”, Women in Management Review, 22, p.405-417.

- $\quad$ Burke, Koyuncu and Fiksenbaum, 2006. “Organizational practices supporting women's career advancement and their satisfaction and well-being in Turkey", Women in Management Review, 21, p.610-624.

- $\quad$ Burke, Koyuncu, Singh, Alayoglu and Koyuncu, 2011. "Gender differences in work experiences and work outcomes among Turkish managers and professionals: Continuing signs of progress?", Gender in Management: An International Journal, 27(1), p. 23-35.

- Crouse, Doyle, and Young, 2011. "Workplace learning strategies, barriers, facilitators and outcomes: A qualitative study among human resource management professionals", Human Resource Development International, 14, p. 39-55.

- DeCuyper and DeWitte, 2011. "The management paradox: Self-rated employability and organizational commitment and performance", Personnel Review, 40, p. 152-172.

- Dewettnick and van Ameijde, 2011. "Linking leadership empowerment behavior to employee attitudes and behavioral intentions", Personnel Review, 40, p. 284-305.

- Guney, Gohar, Lailic and Akinci, 2006. "Attitudes toward women managers in Turkey and Pakistan", Journal of International Women's Studies, 8, p. 194-211.

- Hewlett and Rashid, 2011. Wining the war for talent in emerging markets: Why women are the solution. Harvard Business School Press, Boston, MA.

- Kabasakal, Aycan and Karakas, 2004. "Women in management in Turkey” In Davidson and Burke (eds) Women in management worldwide: Facts, figures and analysis. p. 223-253, Gower, Aldershot.

- Kabasakal, Aycan, Karakas and Maden, 2011. "Women in management in Turkey" In Davidson and Burke (eds.) Women in management worldwide: Progress and prospects p. 317-330, Gower, Aldershot. 
- Koyuncu, Burke and Fiksenbaum, 2006. "Work experiences and satisfaction of male and female professors in Turkey: signs of progress?", Equal Opportunities International, 25, p. 38-47.

- Lawler, 1992. The ultimate advantage: Creating the high involvement organization. Jossey-Bass, San Francisco.

- Lawler, Mohrman, and Ledford, 1995. Creating high performance organizations: Practices and results of employee involvement and total quality management in Fortune 1000 companies. Jossey-Bass, San Francisco.

- Lohman, 2009. "A survey of factors influencing the engagement of information technology professionals in informal learning activities”, Information Technology, Learning and Performance Journal, 25, p. 43-53.

- Lohman, 2006. "Factors influencing teachers' engagement in informal learning activities", Journal of Workplace Learning, 18, p. 1141-1156.

- Lohman, 2005. "A survey of factors influencing the engagement of two professional groups in informal workplace learning activities", Human Resources Development Quarterly, 16, p. 501-527.

- Lohman, 2000. "Environmental inhibitors to informal learning in the workplace: A case study of public school teachers", Adult Education Quarterly, 50, p. 83-1201.

- Marsick and Watkins, 2003. "Demonstrating the value of an organization's learning culture: The dimensions of the Learning Organization Questionnaire", Advances in Developing Human Resources, 5, p. 132-151.

- Menon, 2001. "Employee empowerment: An integrative psychological approach", Applied Psychology: An International Review, 50, p. 153-180.

- Meyer and Allen, 1997. Commitment in the workplace: Theory, research, and applications. Sage Publications, Thousand Oaks, CA:

- $\quad$ Nikolova, I., Van Ruysseveldt, J., De Witte, H., \& Syrioit, J. (2014) “Work-based learning: Development and validation of a scale measuring the learning potential of the workplace (LPW)" Journal of Vocational Behavior 84, p. 1-10.

- Ozbilgin, 2000. "The way forward for equal opportunities by sex in employment in Turkey and Britain", Management International Review, 7, p. 55-65.

- Ozbilgin and Healy, 2004. "The gendered nature of career development of university professors: The case of Turkey", Journal of Vocational Behavior, 64, p. 358-371.

- Ozbilgin and Woodward, 2004a. Banking and gender: Sex equality in the financial services in Britain and Turkey. L. B. Tauris, London.

- Ozbilgin and Woodward, 2004b. "Belonging" and "otherness": Sex equality in banking in Turkey and Britain”, Gender, Work and Organization, 11, p. 668-688.

- Quinn and Shepard, 1974. The 1972-73 Quality of Employment Survey. MI Institute for Social Research, University of Michigan, Ann Arbor.

- Quinn and Spreitzer, 1997. "The road to empowerment: seven questions every leader should consider", Organizational Dynamics, 26, p. 37-49.

- Rothwell and Arnold, 2007. "Self-perceived employability: Development and validation of a scale", Personnel Review, 37, p. 23-41.

- $\quad$ Salas and Von Glinow, 2008. "Fostering organizational learning: Creating and maintaining a learning culture" In Burke and Cooper (eds) Building more effective organizations. p. 207-227. Cambridge University Press. Cambridge.

- Sanal, 2008. "Factors preventing women's advancement in management in Turkey", Education, 128, p. 380391.

- Schaufeli, Salanova, Gonzalez-Roma and Bakker, 2002. "The measurement of engagement and burnout: A two sample confirmatory factor analysis approach", Journal of Happiness Studies, 3, p. 71-92.

- Seibert, Wang and Courtright, 2011. "Antecedents and consequences of psychological and team empowerment in organizations. A meta-analytic review”, Journal of Applied Psychology, 96, p. 981-1003.

- Spreitzer, 1997. "Toward a common ground in defining empowerment", Research in Organizational Change and Development, 10, p. 31-62.

- Spreitzer, 1996. "Social structural characteristics of psychological empowerment", Academy of Management Journal, 39, p. 483-504.

- Spreitzer, 1995. "Psychological empowerment in the workplace: Dimensions, measurement, and validation", Academy of Management Journal, 38, p. 1442-1465. 
- Taylor and Bowers, 1972. Survey of organizations: A machine-scored standardized questionnaire instrument, MI.: Institute for social Research, Ann Arbor.

- United Nations Development Programme, 2008. Human development report 2007-2008, Oxford University Press, New York.

- Van Dyne and LePine, 1998. "Helping and voice extra-role behaviors: Evidence of construct and predictive validity", Academy of Management Journal, 41, p. 108-119.

- Van der Heijden, de Lange, Demerouti and van der Heijde, 2009. "Age effects on the employability-career success relationship”, Journal of Vocational Behavior, 74(2), p. 156-164.

- Wittekind, Raeder and Grote, 2010. "A longitudinal study of determinants of perceived employability”, Journal of Organizational Behavior, 31, p. 566-586.

- Woodward and Ozbilgin, 1999. "Sex equality in the financial services sector in Turkey and the UK", Women in Management Review, 14, p. 325-332.

- Zemke and Schaaf, 1989. The service edge: 101 companies that profit from customer care. New American Library, New York. 


\title{
What are the New Functions of Agriculture Cooperatives in the Progress of Globalization? The Case of Agriculture Cooperatives of Kastamonu
}

\author{
Mustafa Yücel (Kastamonu University, Turkey) \\ Prof. Dr. Yaşar Aktaş (Kastamonu University, Turkey) \\ Neslişah Taner (Kastamonu University, Turkey)
}

\begin{abstract}
While production and markets have been becoming more integrated since barriers to the international trade reduced, capital movements and the speed of spreading of technology increased with the progress of globalization, issues regarding to agriculture, environment, women, employment, and education became more critical.

In this research, "by which functions and missions can agricultural cooperatives sustain their assets under globalized conditions" is the major research question. In the research, 19 cooperatives were chosen among 308 cooperatives, depending on their distance to Kastamonu, foundation year, and the amount of member. Subjects were determined by their traits and occupations. 164 subjects were interviewed via survey questions in 20142015. In research, "The situation-specific approach" model, developed by Hartmut Albrecht was applied.

Because of the progress of change in organizational values, agriculture cooperatives have to undertake new functions in addition to maintaining agricultural production. The functions can be classified into 4 categories as socio-economic (taking local goods to international markets, recording incomes in the agriculture sector, and creating new employment positions to reduce migration to urban), international relations (developing new projects toward internationalizing to collaborate with other cooperatives), planning (making long-term strategic plans), and education (training women in rural areas, and obtaining their collaboration in cooperative campaigns, and educating future's cooperative managers).
\end{abstract}

\section{The Scope and Aim of the Study}

This research is conducted in a Project, which financially supported by the Commission of Scientific Research Projects of Kastamonu University. Since the main research question of this study is "How can agricultural cooperatives sustain their assets under globalized conditions", the phenomenon of globalization is required to be described at first.

\subsection{What is Globalization?}

Globalization or "the new world order" is an economic - political - cultural result of the capitalist system. It is the production of central countries (USA and EU), in order to raise their profit rates which had been decreasing; and it is the world of capitalism which has been unrivaled after the collapse of Soviet Union (socialist block). Here, the term of globalization, and the supportive or opposing opinions of the globalization will be presented briefly.

The term of globalization doesn't reflect its real meaning by means of its economic, political, social content. Therefore, it is stated that the globalization hides the disorder of "the new world order", so it is a "tricky word" (Mattelart, 2001). Also, it is claimed that neo-liberalism is one of the ideological invasion tools as a fraud concept (Koray, 2008).

According to OECD, the globalization is a progress, which manufacturing and markets of different countries become more dependent to each other (İrmiş, 2010). This is a superficial definition, doesn't describe some crucial points such as which country, in which context and which depth, is dependent to other countries. In addition, the globalization is stated as an environment, which barriers on the international commerce become lesser, obstacles that preventing international powers are destroyed, and the movement speed of capital become faster (O’Rourke, 2013).

The two definition above were created by central countries, and don't state any information about the negative effects of the globalization on economic, political, social structures of underdeveloped periphery countries. Now, let's touch upon the opinions that criticize the globalization. The globalization is an effort to make the phenomenon called imperialism more respectful, and to create desperation against it (Boratav, 1997). Furthermore, the globalization is stated as "financial imperialism" and the maximum level of capitalism (Eğilmez, 2009). Another significant statement about the negativity of the globalization is the book called "Globalization and its Discontents", published in 2002 by George Stiglitz.

Based on the concepts above, the globalization is a "Trojan Horse" for the periphery countries since its external appearance is radically different than its inner contents. After describing the globalization, explaining 
the specifications of the relationship between the globalization and agriculture sector will help this research to be more comprehensible.

\subsection{The Globalization, Agreement on Agriculture, and the Consequences Regarding the Agriculture.}

After giving a brief about the fundamental consequences of the agreement on agriculture, also known as the Framework for Establishing Modalities in Agriculture or Uruguay round, the situation of Turkey will take place.

At the beginning of 1958, the agricultural production of the 6 countries, which formed "European Economic Community" wasn't enough to fulfill their own needs. In 1962, implementation of "common agricultural policy" was started. The 6 country first became self-sufficient in a short time and had surplus production after 1980. This became a financial burden for the EU. As a natural consequence, EU started to develop policies in order to sell its surplus to foreign market. In the meantime, the USA too had agricultural production surplus.

This means that these are the regulations that obligate periphery countries to decrease internal incentives on agriculture and export, also facilitate penetration to the foreign markets or direct foreign investments for the convenience of central countries.

As a result, the agriculture sector was adjusted to the globalization and gained specification as a fundamental element of international economic development. In other words, it absolutely liberated from the political, social, and natural factors and became an economic sector (Şahinöz, 2005). This means that countries will not be able to apply intervention price, supporting the purchase, export incentive and credit without confirmation of WTO.

It is claimed that this absolute adjustment of the agriculture sector to the market economy will be destruction for the underdeveloped countries especially for the ones which haven't overcome their structural problems yet, since it will decrease the production level by eliminating the exporting opportunities.

In this manner, agriculture became a tool in order to solve the problems of EU, USA, and their large international companies. In short, the problems of underdeveloped countries are taken into account with the perception of central countries. Subsequently, this means re-ordering the world.

EU and USA apply a double morale agriculture policy. While subsidizing their own agriculture, they have been demanding periphery countries to implement WTO regulations strictly since 1995.

For instance, the incentive provided on agriculture in OECD countries is six times more than the incentives for development. As a more precise example, EU uses 50\% of the GDP for agriculture issues. The annual incentive amount that the USA provided to 25000 cotton producers is approximately 3,9 billion dollars in 2002 (United Nations, 2015).

Whereas the market share of the EU and the USA in the world agriculture market is increasing, the market share of periphery countries is decreasing.

Periphery countries are threatened in two ways. Firstly, there is incentivized agriculture surplus of developed countries. Secondly, there are regulations of WTO and structural adjustment programs as a content of "stand by" agreements of IMF.

The surplus in agriculture production decreases international price levels artificially, so incentivized imports of central countries threats the existence of local producers in developing countries that are unable to subsidize exporting. In short, the regulations of WTO wipe out the periphery countries from the international market and start the dynamics that will eliminate the agricultural producers, which are the foundation of the economy.

\subsection{The Consequences of Agreement on Agriculture of WTO and Turkey}

The countries, which apply to IMF in order to relieve from a recession, are obliged to implement agriculture policies of WTO as an essential part of structural adjustment policies. In other words, the countries have to cut off their agricultural incentives and allow importing. Actually, Turkey made its political choice in this way on the 24th of January in 1980 by signing "economic stability program", and expressed its consistency on these policies with the "intention letter" on December, 1998.

In brief words, because of signing structural adjustment programs, Turkey had to implement agricultural policies, which exceed the liberal agricultural policies of WTO. As a result, the agricultural structure of Turkey turned into a shape, which starts to lose its self-sufficiency and becomes more dependent to foreign countries (Günaydın, 2005a). These movements intend the elimination of villagers and domination of capitalist production style in the agriculture sector of Turkey (Günaydın 2005b).

It can be claimed that Turkey jeopardized agricultural producers and nutrition of citizens by leaving agriculture to the market mechanism. It is known that one of the reasons of the downfall of the Soviet system was being unable to handle agricultural production issues.

The consequences of agriculture policies stated above, created by IMF, WTO, World Bank (WB) and EU become solid in 5 specifications:

a) Agricultural population and employment rate must be decreased to 5\%: Whereas 35\% of the general population lives in the rural areas in 2005 , only $21 \%$ of the population lives in the rural areas in 2013. 
b) Average of business size should be increased from 6 hectares to 13 hectares, which is the average size in EU; otherwise small businesses should be eliminated: The amount of cultivated area is decreasing every year with an increasing speed since the agricultural producers leave their lands empty under the conditions of the high input and low output prices. The total amount of cultivated land declined 1,9 million hectares. Furthermore, the reduction amount of livestock is 4 million (Özkaya, 2010).

c) All of the state-owned enterprises should be privatized: All government business enterprises, which contribute and support agricultural production, were either fractionally closed or sold to national and foreign investors. For instance, few companies took the market dominance in the milk processing sector after state-owned enterprises resign. This situation is described as demobilization of all government agricultural research institutes and government business enterprises, assuring limitless-lawless usage of agricultural lands, leaving the sector to the international companies, collapsing a country's agriculture by making it absolutely dependent with every input and output (Günaydın, 2005b).

d) The connection between agricultural incentives and production must be cut off: Incentives by government reduced fractionally. The application of giving a low-interest loan of Agriculture Bank of Turkish Republic was canceled. This was a kind of doom for the agricultural producers.

e) The share of agriculture in export: The share of agricultural products gradually reduced till $4 \%$. Turkey started to import agricultural products approximately 3 billion dollars per year.

It is stated that customs union agreement with EU, agreement on agriculture with WTO, and stand-by agreements with IMF provided a base for a decline in agriculture of Turkey (Oral, 2006). On the other hand, four years later, another statement was made that agreement on agriculture with WTO doesn't have direct destructive effects on the agricultural structure of Turkey; however, because of the impacts of stand-by agreements, it limits agriculture incentives significantly. Furthermore, Turkey is able to protect its internal market with the custom policies. It is obvious that the Customs Union, agreement of agriculture, and stand-by agreements became external determinants of Turkish agricultural policies (Özkaya, et. al, 2010).

\subsection{Research Objective, Question, and Hypothesis}

In the scope of this research, the contribution of KÖY-KOOP (agricultural cooperatives union of Kastamonu) in rural development, and evaluation of the members regarding the projects of the union are examined.

The objective of the research is studying the evaluation results of the union affiliates and developing recommendations in the context of globalization for the future.

The research question was defined as "by which functions and missions can agricultural cooperatives sustain their assets under globalized conditions".

Hypothesis: Since the affiliates are effective in building milk collection centers, marketing and increasing milk prices, and the annual income of the affiliates increased after joining the union, the administration of KÖYKOOP evaluated as successful.

\section{Theoretical Framework}

In the research, the adjusted version of an approach, developed by Albrecht (1974), based on the data obtained from the previous studies $(1976 ; 2000 ; 2005 a, b$.$) .$

The concept of assessment, the self-criticism of the action that will be researched, the result of applied program, and determination of effective variables are used in order to analyze cause and effect relation scientifically. In this research, assessment period was done basically in three stages. At the initial stage, data collected by making observations. Secondly, some measurements and assumptions were determined based on the observations. In the final stage, some propositions mentioned regarding the effect of KÖY-KOOP. This research is a post-hoc-evaluation since operations of KÖY-KOOP are still running. So it was possible to acquire the cause and effects, which occurred during the application directly. In this way, helping KÖY-KOOP to sustain and advance its accomplishments via the data acquired during this research will be possible.

\section{Methodology}

Kastamonu KÖY-KOOP is formed by 308 agricultural cooperatives, located in Bartın, Çankırı and Kastamonu cities. The cooperatives classified into 4 categories as milk production, milk production $\&$ forest products, forest products, and irrigation. In this paper, the survey results acquired from milk production cooperatives are presented. This research project is carried out the dates between March 2014 and December 2015. In this paper, the initial results of the project by the data obtained until May 2015 is presented. Apart from this, the researchers acquired information about the problems and projects of unit cooperatives by attending the plenary committees, and the training programs, both conducted in the daytime and at nights.

Furthermore, the contribution of KÖY-KOOP is examined by interviewing authorities from relevant government institutions such as financial office, regional directorate of forestry, provincial directorate of 
agriculture etc. Moreover, reasonable information related with the discussed subjects and the problems attained by attending plenary committees of KÖY-KOOP, and The National Cooperative Union of Turkey. Also, training programs of Republic of Turkey Ministry of Food, Agriculture and Livestock are observed.

\subsection{Selection of the Interviewees}

The number of participants is selected by stratified random sampling as following: the survey was conducted with minimum 5 members from each cooperative. According to the latest data of KÖY-KOOP, there exist 1116 female members of the union. Although surveying with female members was a high priority in research, it was rarely possible. As a research methodology, milk production cooperatives are selected initially. In this scope, 19 cooperatives were selected, depending on their distance to Kastamonu, foundation year, and the amount of the affiliates. The interviewees were selected by their traits and occupations. However, in case of being unable to find the determined interviewees or an interviewee doesn't want to survey, $10 \%$ more affiliates were selected, which means another 11 people were taken as back up. In short, survey was applied by face to face sessions with 164 participants. 6 of the surveys weren't taken into account since the information acquired was conflictive.

\begin{tabular}{|c|c|c|c|c|c|c|c|c|c|c|}
\hline \multirow{3}{*}{ Districts } & \multirow{2}{*}{\multicolumn{2}{|c|}{$\begin{array}{c}\text { Milk } \\
\text { Cooperatives }\end{array}$}} & \multirow{2}{*}{\multicolumn{2}{|c|}{$\begin{array}{c}\text { Selected } \\
\text { Cooperatives }\end{array}$}} & \multirow{2}{*}{\multicolumn{2}{|c|}{$\begin{array}{c}\text { Selected } \\
\text { Affiliates }\end{array}$}} & \multicolumn{4}{|c|}{$\begin{array}{c}\text { Foundation Years of Selected } \\
\text { Cooperatives }\end{array}$} \\
\hline & & & & & & & \multicolumn{2}{|c|}{ Before 1998} & \multicolumn{2}{|c|}{1998 \& Later } \\
\hline & $\mathbf{N}$ & $\%$ & $\mathbf{N}$ & $\%$ & $\mathbf{N}$ & $\%$ & $\mathbf{N}$ & $\%$ & $\mathbf{N}$ & $\%$ \\
\hline Central District & 28 & 33,73 & 8 & 42,1 & 63 & 38,4 & 3 & 37,5 & 5 & 45,45 \\
\hline Taşköprü & 43 & 51,81 & 9 & 47,4 & 82 & 50,0 & 4 & 50 & 5 & 45,45 \\
\hline Daday & 8 & 9,63 & 1 & 5,25 & 11 & 6,7 & 1 & 12,5 & 0 & 0,0 \\
\hline İhsangazi & 4 & 4,82 & 1 & 5,25 & 8 & 4,9 & 0 & 0,0 & 1 & 9,1 \\
\hline Total & 83 & 100,0 & 19 & 100,0 & 164 & 100,0 & 8 & 100,0 & 11 & 100,0 \\
\hline
\end{tabular}

Table 1. Measurement of Cooperative Selection

\begin{tabular}{|c|c|c|c|c|c|c|c|c|c|c|c|c|}
\hline \multirow{3}{*}{ Education Level } & \multicolumn{4}{|c|}{ Income } & \multicolumn{6}{|c|}{ Satisfaction } & \multicolumn{2}{|c|}{ Total } \\
\hline & \multicolumn{2}{|c|}{ Increased } & \multicolumn{2}{|c|}{ Otherwise } & \multicolumn{2}{|c|}{ Very Pleased } & \multicolumn{2}{|c|}{ Pleased } & \multicolumn{2}{|c|}{ Displeased } & & \\
\hline & $\mathrm{N}$ & $\%$ & $\mathrm{~N}$ & $\%$ & $\mathrm{~N}$ & $\%$ & $\mathrm{~N}$ & $\%$ & $\mathrm{~N}$ & $\%$ & $\mathrm{~N}$ & $\%$ \\
\hline Primary School & 100 & 92,6 & 8 & 7,4 & 52 & 48,1 & 56 & 51,9 & 0 & 0,0 & 108 & 100 \\
\hline $\begin{array}{l}\text { Secondary } \\
\text { School }\end{array}$ & 23 & 95,8 & 1 & 4,2 & 8 & 33,3 & 16 & 66,7 & 0 & 0,0 & 24 & 100 \\
\hline $\begin{array}{c}\text { High } \\
\text { School/Academy }\end{array}$ & 32 & 100 & 0 & 0,0 & 19 & 59,4 & 13 & 40,6 & 0 & 0,0 & 32 & 100 \\
\hline Total & 155 & 93,7 & 9 & 6,3 & 79 & 48,2 & 85 & 51,8 & 0 & 0,0 & 164 & 100 \\
\hline \multirow{2}{*}{ Business Size } & \multicolumn{2}{|c|}{ Increased } & \multicolumn{2}{|c|}{ Otherwise } & \multicolumn{2}{|c|}{ Very Pleased } & \multicolumn{2}{|c|}{ Pleased } & \multicolumn{2}{|c|}{ Displeased } & & \\
\hline & $\mathrm{N}$ & $\%$ & $\mathrm{~N}$ & $\%$ & $\mathrm{~N}$ & $\%$ & $\mathrm{~N}$ & $\%$ & $\mathrm{~N}$ & $\%$ & $\mathrm{~N}$ & $\%$ \\
\hline $0,1-3$ Hectares & 16 & 100 & 0 & 0,0 & 10 & 62,5 & 6 & 32,5 & 0 & 0,0 & 16 & 100 \\
\hline $3,1-5$ Hectares & 25 & 92,6 & 2 & 7,4 & 14 & 51,9 & 13 & 48,1 & 0 & 0,0 & 27 & 100 \\
\hline 5,1-10 Hectares & 77 & 97,5 & 2 & 2,5 & 38 & 48,1 & 41 & 51,9 & 0 & 0,0 & 79 & 100 \\
\hline $10,1+$ Hectares & 37 & 88,1 & 5 & 11,9 & 17 & 40,5 & 25 & 59,5 & 0 & 0,0 & 42 & 100 \\
\hline Total & 155 & 94,5 & 9 & 5,5 & 79 & 48,2 & 85 & 51,8 & 0 & 0,0 & 164 & 100 \\
\hline Number of & \multicolumn{2}{|c|}{ Increased } & \multicolumn{2}{|c|}{ Otherwise } & \multicolumn{2}{|c|}{ Very Pleased } & \multicolumn{2}{|c|}{ Pleased } & \multicolumn{2}{|c|}{ Displeased } & & \\
\hline Dairy Livestock & $\mathrm{N}$ & $\%$ & $\mathrm{~N}$ & $\%$ & $\mathrm{~N}$ & $\%$ & $\mathrm{~N}$ & $\%$ & $\mathrm{~N}$ & $\%$ & $\mathrm{~N}$ & $\%$ \\
\hline $1-10$ & 84 & 95,5 & 4 & 4,5 & 43 & 48,9 & 45 & 51,1 & 0 & 0,0 & 88 & 100 \\
\hline $11-20$ & 53 & 94,6 & 3 & 5,4 & 25 & 44,6 & 31 & 55,4 & 0 & 0,0 & 56 & 100 \\
\hline $21+$ & 18 & 90,0 & 2 & 10,0 & 11 & 55,0 & 9 & 45,0 & 0 & 0,0 & 20 & 100 \\
\hline Total & 155 & 94,5 & 9 & 5,5 & 79 & 48,2 & 85 & 51,8 & 0 & 0,0 & 164 & 100 \\
\hline District of & \multicolumn{2}{|c|}{ Increased } & \multicolumn{2}{|c|}{ Otherwise } & \multicolumn{2}{|c|}{ Very Pleased } & \multicolumn{2}{|c|}{ Pleased } & \multicolumn{2}{|c|}{ Displeased } & & \\
\hline Cooperative & $\mathrm{N}$ & $\%$ & $\mathrm{~N}$ & $\%$ & $\mathrm{~N}$ & $\%$ & $\mathrm{~N}$ & $\%$ & $\mathrm{~N}$ & $\%$ & $\mathrm{~N}$ & $\%$ \\
\hline Central District & 56 & 88,9 & 7 & 11,1 & 30 & 47,6 & 33 & 52,4 & 0 & 0,0 & 63 & 100 \\
\hline Taşköprü & 81 & 98,8 & 1 & 1,2 & 43 & 52,4 & 39 & 47,6 & 0 & 0,0 & 82 & 100 \\
\hline Daday & 10 & 90,9 & 1 & 9,1 & 3 & 27,3 & 8 & 72,7 & 0 & 0,0 & 11 & 100 \\
\hline İhsangazi & 8 & 100 & 0 & 0,0 & 3 & 37,5 & 5 & 62,5 & 0 & 0,0 & 8 & 100 \\
\hline Total & 155 & 94,5 & 9 & 5,5 & 79 & 48,2 & 85 & 51,8 & 0 & 0,0 & 164 & 100 \\
\hline
\end{tabular}

Table 2. Evaluation of $K O ̈ Y-K O O P$ 


\section{Results}

The results were evaluated in two sections. The first section consists of the foundation and development. The second one includes brief results of the survey study, conducted with cooperative members.

\subsection{The Foundation and Development of KÖY-KOOP}

Many unit cooperatives form the regional unions, and the unions from different regions form the central union, located in Ankara. There are 23 cooperative unions like KÖY-KOOP that form the central union.

Although KÖY-KOOP was founded in 1977, it only stayed active for 3 years. From 1980 to 1996, the union made no activity. The union is a multi-purpose organization, and it incorporates 308 units, related with different subjects, which are agriculture, livestock, forestry, irrigation, product processing, supplying input, and marketing. The union has 18592 members, which 1116 of them are female (Anonymus, 2015). There are 42 milk collection centers in 31 different locations, and 80 local cooperatives and 120 villages benefit from this. The first milk collection center started to work in 1997.

Whereas the income was 1.021.452 TL in 2008, it was 2 million TL in 2014 (Anonymus, 2015); which means it increased at a double rate. The capital receipt of the union is 1646 257, 97TL. While only 1,5 million liter milk is produced in 1997, 172 million liters was produced in 2013, which is an amount higher than a hundred times more.

KÖY-KOOP employs 1 senior agriculture engineer, 2 agriculture engineers, 2 agriculture technicians, 2 forest engineers. All the employees work at the office building located in the city center of Kastamonu. When it is needed, they visit towns and villages by using the vehicles of the union. In other words, there exist no agencies of the union in the towns or villages. The union possesses a two-storey building and 2 vehicles.

\subsection{Does KÖY-KOOP Have A Strategy Against The Globalization?}

Four dimensions take part in this context.

International relations of KÖY-KOOP: The international relations of KÖY-KOOP can be divided into two categories. The first one is directly collaborating with the other cooperative unions located in the EU countries; the second category is submitting projects to international organizations such as EU, UN, WB in order to obtain financial support.

Currently KÖY-KOOP is in collaboration with German Cooperative and Raiffeisen Confederation in various subjects such as livestock, milk quality control, ecotourism, forestry, empowering the performances of the unit cooperatives, under the KÖY-KOOP. Also, it financially supports the periodic training programs of KÖY-KOOP, carried out for administrators and volunteers of cooperative.

In addition, training programs and applications, financed by EU, were held regarding quality improvement for raw milk to reach EU standards. Also, programs implemented in order to train forestry workers. In the scope of the first project, a laboratory was founded, which is helpful to analyze ingredients and bacteria rate of the raw milk. In the second project, applied certification training was held in order to prevent casualties. Also, regulations were formed in this direction.

Furthermore, KÖY-KOOP is handling 2 projects, financed by United Nations (UNDP). In the first project protecting trees called şimşir (Buxus sempervirens), organizing training programs in spoon engraving, and establishing required workshops were aimed. In the second project, satisfying the local energy requirement was aimed. In this manner, biogas produced by using the disposal of 5 cows was able to cover gas needs in the kitchens of 2 houses.

By applying these kinds of projects, KÖY-KOOP aims to develop the cooperative system, by having more functions than simply marketing milk and forestry products in order to increase the income of local people.

Planning and strategic plan: Strategic planning describes the path between the points, which an organization stands and aims to reach. By strategic planning, adopting the potential harsh situations of globalization will be easier. In 2012, "Cooperation Strategy and Action Plan" was formed with the collaborative work of related ministries, and all cooperative unions. Within the scope of this strategic plan, a strategy team, consist of 13 experts was organized in KÖY-KOOP in order to form a unique strategic plan for the organization at the end of 2013. Based on the SWOT analysis, mission and vision were determined. Also, opinions of internal and external shareholders were considered while a strategy plan, covers the years from 2014 to 2017, was being prepared.

Within the frame of the strategic plan, four strategic aims, eleven objectives, and fifty action plans was determined as follows:

1. Improving the structures of unit-cooperatives.

2. Increasing the service quality.

3. Empowering the organizational structure.

4. Branding 
These aims were determined within the vision of "being a reference in the international standards". This strategic plan was printed as a book at the end of 2014 and published. Also, it was presented to shareholders and related institutions by word of mouth. In this paper, the details of objectives and action plans will not be mentioned. However, it must be stated the plan doesn't include anything about the environmental issues. By making strategic plan, while new functions will be added to Turkish cooperative system, the following contributions will take place:

The importance of agricultural cooperation will take attention of public. The current prejudice of public and universities against cooperatives will decline because the aims of the plan are eligible to contribute to economicpolitic lives of agricultural producers of Turkish society.

It possesses the characteristic of being the first step toward forming a unique cooperative model in Turkey since it provides a foundation for a transition to functional cooperation.

In addition to the 2 contributions above, KÖY-KOOP will have an extra contribution by becoming institutionalized, forming an organizational identity, helping unit cooperatives to realize their own capabilities, working more efficient, becoming well-disciplined, and planning their actions scientifically.

Situation in marketing of milk: Till 1996, milk collectors were dominated in the milk collection and marketing businesses. Price and payment period was uncertain. Because of this structure, milk producers were not able to get government incentives for milk production. The producers didn't have the power to negotiate to sell milk. There was also no milk cooling tank, and laboratory to analyze milk.

In Kastamonu, the problems of local factories and businesses, busy with milk processing were at reasonable levels. They weren't able to diversify their products, couldn't make a brand, and the quality of their products were low. This situation prevented the development of livestock and milk production.

KÖY-KOOP, by its activities, attained 2 consequences as follows:

It provided the environment for the producers to produce high-quality milk.

It helped producers to have more power to negotiate for the milk price.

Local milk processing factories and businesses in Kastamonu were dictating milk prices to producers. Their capacities for milk processing were limited. Under these conditions, KÖY-KOOP achieved to sell milk above the local prices by making an agreement with a large company, operating in national dimension. So, local factory owners had to make adjustments regarding the product processing quality and price.

Creating employment opportunities: As a consequence of the globalization and agreements on agriculture, the agricultural producers especially younger generations, started to leave rural areas. However, since there is insufficient industrial structure, migrating to city centers caused significant problems in the subjects of employment, economic, cultural, and social areas. In the context of finding a solution for this problem, KÖYKOOP provides job facilities to 85 people in milk collection centers.

Is income recorded?

Usually, informality is known as common in all economic sectors in Turkey. This can be considered as an obstacle to tax collection, so it can prevent investments by government. In the agricultural sector, informality is a bit higher when compared to other sectors, because of the agricultural policies. However, according to the financial office of government, whereas the total tax amount, paid by KÖY-KOOP in 2010 was 1.092.672,91 TL, it was 1.725.396,30 TL in 2013. In other words, KÖY-KOOP both increase income and record it. This is a reasonable contribution of KÖY-KOOP to the local economy.

Which Agricultural Extension and Training Program is Being Conducted?

The extension activity of KÖY-KOOP covers informing about the incentives of the ministry of food, agriculture and livestock, handling processes, providing inputs to cooperative members, marketing the products of cooperatives, direct extension and training activities. There are 2 ways of training activities, which are face to face communication and intensified training programs that continues for a week.

The intensified training programs are held two times per year, in Antalya city in Turkey and supported by German Cooperatives Federation (DGRV). 30-40 participants among cooperative administrators are chosen and trained by DGRV specialists, ministry of food, agriculture and livestock inspectors, and trainers by a consultant company.

The content of the training consist of the subjects such as introduction to cooperation, forming of entrepreneur cooperatives, personal competence, leadership, the accounting system of cooperatives in Turkey, authorization and responsibility of the board of inspectorate etc.

Are there training programs for female members of cooperatives?

Another kind of training program is held for female members of cooperatives. The sessions for women usually held in winter seasons, at the meeting room of milk collection centers. The subjects of the program can be categorized under three headlines. The first headline includes the situation of women in Turkey and in the World, 
women's rights, gender equality, sexual health, and hygiene. The second heading is cooperation and woman, incentives for rural development, entrepreneurship, leadership and woman. Finally, the third one is plant and animal diseases, milking techniques, hygiene of cowshed. Approximately 30 affiliates attend these training programs; certification is given to participants at the end of the program.

\subsection{Relationships with the Ministry of Food, Agriculture and Livestock:}

According to the law, the ministry of food, agriculture and livestock is the authority for agricultural cooperatives and cooperative unions. The ministry takes part at the plenary committee, reports about the committee, and takes the floor if it is necessary. The representative of the ministry is paid 75 TL per session, and his transportation handled by KÖY-KOOP. This makes collaboration become easier. The representative provides detailed information about incentives to the committee.

\subsection{What Is The Evaluation of Participants Regarding the Success of KÖY-KOOP?}

In table 2, education level, income, and satisfaction are examined. When interpreting by merging the participants, graduated from primary school, high school, and academy, the following results emerge: When the interviewees are asked if their income increased after joining the KÖY-KOOP, $92,2 \%$ of the participants, who graduated from primary school responded affirmatively, and only 7,8\% of them stated that their income hasn't increased. For the percentage of responding affirmatively among the interviewees, graduated from a high school or an academy is $96,65 \%$. In brief, the difference between the primary school, high school, and the academy is $4,45 \%$. In other words, there is no noticeable effect of education in evaluating KÖY-KOOP. Also, the number of participants, who claim that there is no increase in their income, is quite a few.

When satisfaction regarding activities of KÖY-KOOP was asked, 46,1\% of the interviewees, who graduated from primary school responded as very pleased, while it is $34,6 \%$ among high school graduates, $55,9 \%$ for the academy graduates.

The affiliates, whose business size is between 0,1 and 5 hectares, are considered together. Whereas the percentage of the interviewees, who stated that their income level increased is $93,95 \%$, this percentage increases $97,6 \%$ for the interviewees who possess between 0,51-10 hectares land. Also $86 \%$ of the interviewees who possess more than 10 hectares stated that their income increased.

It can be seen that percentage of being very pleased decreases as the business size grows. Being moderately pleased among small businesses is lower than the large businesses. Also, the number of interviewees who stated their less satisfaction is quite few. This shows that KÖY-KOOP is in a better communication with small business owners.

The results related with dairy cow number as following: The percentage of interviewees who do not have more than 20 dairy cows, and responded that their income increased is almost the same at around 95\%. However, this percentage declines to $85 \%$ for the interviewees, who possess more than 20 dairy cows. In satisfaction regarding the activities of KÖY-KOOP, $43,6 \%$ of the producers who have dairy cow between 1-10 stated that they are very pleased. The percentage for the interviewees who have dairy cows between $11-20$ is $43,3 \%$. For the producers who have more than 21 dairy cows, the percentage increases to $55 \%$. Furthermore, $52,6 \%$ of the interviewees whose dairy cow number is between $1-10,55 \%$ of the interviewees, possess dairy cows between $11-20,40 \%$ of the interviewees who have more than 20 dairy cows mentioned that they are moderately pleased.

When the rise in income level is considered depending on the towns, 98,9\% of the participants from Taşköprü, $87,7 \%$ from Central District, 90,9\% from Daday, and 88,9\% from İhsangazi mentioned that their income increased. It is clearly seen that all the percentages from different towns are very close to each other except Taşköprü with approximately $10 \%$ difference. This situation can be explained that the members of the cooperative in Taşköprü care about the quality of milk more than the members from other cities. Moreover, conditions for feeding are better in Taşköprü.

When satisfaction depending on the towns is considered, the percentage of very pleased members is $50 \%$ in Taşköprü, 46,2\% in Central District, 27,3\% in Daday, and 33,3\% in İhsangazi. The reason of this situation can be explained as follows: The milk collection centers of the cooperatives in the towns other than Taşköprü established recently. As the milk marketers had already been a member of a cooperative before milk collection centers established, the producers haven't noticed a reasonable difference yet. ANOVA test was applied; however significant situation couldn't be attained since the criteria and the consideration rates of the interviewees are very close to each other.

\section{Conclusions and Discussion}

Conclusions and recommendations can be related with the phenomenon of globalization, the perception of Turkish government to cooperatives, and KÖY-KOOP. The inferences are categorized in four groups below. 


\subsection{Conclusions}

Conclusions will be discussed in 2 dimensions. The first dimension is the globalization and agriculture, and the second one is related with KÖY-KOOP.

What are the conclusions regarding the ministries related with the globalization or cooperatives?

There is a very close relationship between the perception of globalization and Turkish governments to agricultural cooperatives since the governments of Turkey accepted the control of the globalization by the agreements they signed, as stated before. The following statements can be asserted regarding the globalization:

Obviously the globalization will keep its existence although the continuing effects of the crisis in 2008; however its former power will be diminished. It also seems that the trust in the globalization of its radical supporters is lesser than before.

There are 3 ministries, which are in charge of cooperatives. Initially, the perception of Ministry of Food, Agriculture and Livestock against cooperatives should be briefed. First, it takes cooperatives into account, only as a production instrument. Therefore, the ministry neglects the commercial function of cooperatives during the progress of globalization. Secondly, since the ministry regards the cooperatives as dissident communist institutions especially after the military coup in 1980, it hinders the activities of cooperatives, instead of supporting. For example, the ministry founded "producers union" as a rival to cooperatives. A part of the incentives to the agricultural producers are provided via the unions. Therefore, the producers have to join the "producers unions", which are less contributive than the cooperatives. So, the development of cooperatives is hindered. As a solution, the Ministry of Food, Agriculture and Livestock should provide incentives directly through the cooperatives, so the cooperatives become more efficient and effective to contribute rural development. In this way, surviving will get easier under the harsh conditions of the globalization. As a result, the capabilities of the unit cooperatives in collaborating with each other, and marketing the products can develop. Furthermore, as this will financially strengthen KÖY-KOOP, the implementation of projects to assist affiliates of KÖY-KOOP can take place sooner. In this context, the following two statements can be advised:

There is a need of coordination in the regulations of cooperatives in order to make efficient applications (TÜSİAD, 2014). For innovation government incentives, also business models, which bring collaboration between public, private sector and cooperatives, should be applied in the agriculture and livestock sector.

Conclusions regarding KÖY-KOOP: The conclusions regarding KÖY-KOOP can be categorized under 4 headings: Assessment by cooperative members, communication problems, management and inspection of cooperatives, and agricultural training-extension activities.

Evaluation on the activities of KÖY-KOOP by cooperative members: There is a steady increase in the income level of the affiliates of KÖY-KOOP. The usual satisfaction level is either pleased or very pleased. There were no "less pleased" or "unpleased" interviewees in the research. Also, KÖY-KOOP is effective in the milk market. In brief, the education level, business size, dairy cow number of the cooperative members, or the district they live doesn't affect the satisfaction level or increase in income significantly. The services that KÖY-KOOP provides gradually increased; so it affected the satisfaction of members positively. As the number of affiliates increases, both quantity and quality of the services of KÖY-KOOP will increase. It is possible that KÖY-KOOP becomes a power in national dimension in future. Subsequently, it can be claimed that KÖY-KOOP will be able to survive under the conditions of globalization without having much trouble.

Communication problems: Although face to face communication is common, there are relative communication problems both in the horizontal and vertical lines of the organization's structure. Especially the managers of the cooperatives, who join training seminars, have difficulties in sharing the information and experiences they obtained. According to their assertion, the reason is the disinterest of the affiliates. Even the attendance to the annual conference is low. The members highly interested in the financial incentives of the Ministry of Food, Agriculture and Livestock, but not in any other subject. In this manner, the managers of the cooperatives don't make much effort to share the information they acquired in the seminars. This disconnection causes failures in working.

The management and inspection of cooperatives, affiliated to KÖY-KOOP: There are certain problems related with inspecting the annual financial statement of the cooperatives. Firstly, most of the members of the board of inspectorate of the cooperatives have only graduation from primary school, and they do not have any information regarding the financial statements, which they are supposed to inspect. In this case, accountants are hired to handle the inspection. This expresses the existence of problems in general and financial management of cooperatives.

Furthermore, according to the law, Ministry of Food, Agriculture and Livestock has the authority and responsibility of inspecting cooperatives. Nonetheless, because of the insufficiency of inspector working in the ministry, not every cooperative can be inspected. In many cases, cooperatives are never inspected unless there is complain. Training the members of the board of inspectorate of the cooperatives could be a solution for the problem; however, since the members of board change every year, training cannot be efficient and permanent. 
Recommendation: Recommendations can be mentioned on 3 points regarding their efficiency.

Firstly, the people who participate in extension projects of Kastamonu KÖY-KOOP should be trained about communication systematically and permanently. So, the communication between the managers and the members can be more fluent, and the transmission of information through the vertical and horizontal lines of the organization will be fixed. This way may contribute KÖY-KOOP to become institutionalize as well. In future, the transmission of information may be conducted via the internet. Currently, the administration of KÖY-KOOP has completed its database; for efficient usage of it, face to face training should be handled well at first.

Secondly, a library, which includes relevant books, and which all technician personnel and affiliates of cooperatives can benefit, should be established. In this way, both gaining reading habit among members and acquiring direct information may be possible.

Finally, as a requirement of the "Transatlantic Trade and Investment Partnership" and "customs union" agreements, Turkey has to allow other relative countries to get into its market. Nevertheless, Turkey is not capable to enter the markets of the agreed countries (Turhan ve Yalçın, 2014). Moreover, it is clear that the absolute membership of EU will not come true in the sooner future. By including agricultural products in the agreements properly, which means allowing Turkey to sell agricultural products freely, Turkey will be able to enter the markets of other countries; so this will help Turkey to increase its efficiency.

\section{References}

- $\quad$ Aktaş, Yaşar, Öcal Kara, Fatma, Demirdöğen, Alper. 2010. Tarımsal Yayım’a Yeni Bir Yaklaşım: İnsancıl Tarımsal Yayım. Tarım Ekonomisi Dergisi 16(2):45-57, İzmir

- Aktaş, Yaşar. et.al. 2005. Beratung zum umweltschonenden Weizenanbau in Südostanatolien. Berichte über Landw. Bonn, Band. 83 (2) S. 294-317

- $\quad$ Aktaş, Yaşar. 1976. Organisation und Arbeitsweise der Projektbezogenen Landwirtschaftlichen Beratung (Ces) Im Bewaesserungsgebiet der Unteren Seyhan Ebene In der Südtürkei. Ein Versuch zur Ermittlung effizienzrelevanter Faktoren. Universitaet Hohenheim. 243S

- Albrecht, H. 1974. Systematik der Planung der Beratungsarbeit. Einführung und Begründung. Der Föredeungsdienst Sonderheft 2, Wien 22. Jg S.:41-44

- Anonymus, 2015. Kastamonu Köy Kalkınma ve Diğer Amaçlı Kooperatifler Birliği 2014 Yılı Olağan Genel Kurul Toplantis1. 13.Haziran 2015.

- Anonymus 2014. Kastamonu Köy Kalkınma ve Diğer Tarımsal Amaçlı Kooperatifler Birliği. Stratejik Plan. 2014-2017. Kastamonu

- Anonymus 2012. Makro Ekonomik Göstergeler. İTO yayın No: 2012-6/3

- Boratav, K. 1999. Ekonomi ve Küreselleşme. I. Kansu (Ed.) Emperyalizmin Yeni Masalı Küreselleşme, Ankara, 4. Basım S. 25-35

- Eğilmez, Mahfi. 2009. Küresel Finans Krizi Piyasa Sisteminin Eleştirisi. Remzi Kitabevi, İstanbulEngin, Gürol. 2002. TMMOB ZMO Küreselleşme ve Türkiye Tarımı Sempozyumu Açılış Konuşması. Ankara

- $\quad$ Frutchey, F. P. 1959. Evaluation -What it is. Bryn, D. (Editör): Evaluation in Extension. Prepared byDivision of Extension Researchand Training, S.: 1-5.

- Günaydın, Gökhan. 2005a. AB Hazırlık ve Müzakere Dönemleri ile Üyelik Koşullarında Türkiye Tarım Sempozyumu. 4-5 Mayıs 2005. Ankara, S. 65-96

- Günaydın, Gökhan. 2005b. Küreselleşme Sürecinde Tarım Politikalarında Değişim. TMMOB Toprak Reformu Kongresi. 11-13 Kasım 2005 Şanlıurfa, S. 118-123

- Günaydın, Gökhan. 2008a. Onurlu Üyelikten Akdeniz Ortaklığına: Bir Avrupa Birliği Öyküsü. MemleketSiyaset-Yönetim. Ankara, 2008/7 S. 29-60

- Günaydın, Gökhan. 2008b. Süt Sığırcılığının Ekonomi Politiği. Türkiye Süt Sığırcılığg Kurultayı, İzmir.

- İ̀miş, A. 2010. Küreselleşme Çarkı İçinde Fason Üretim ve Çin Dişlisi. Yayla, N. (Ed.) Prof. Dr. Ferhat Erarı’nın Anısına Ekonomi Yazıları. Pamukkale Üniversitesi Yayınları, Ankara, S.43-94

- Koray, Semih, 2008. Küreselleşmenin İçyüzü, Bilim ve Ütopya dergisi, 170, pp. 4-13

- Mattelart, Armand, 2001. İletişimin Dünyasallaşması, (Halime Yücel, Trans.). İstanbul: İletişim Yayınları.

- Oral, Necdet. 2006. Türkiye Tarımında Kapitalizm ve Sınıflar. TMMOB Ziraat Mühendisleri Odası Tarım Politikaları Yayın Dizisi No: 6, Ankara

- O'Rourke, Kevin, 2001. Globalization and Inequality: Historical Trends. NBER working paper series, WP8339, http://www.nber.org/papers/w8339 
- Özkaya, Tayfun, et. al, 2010. Tarım Politikaları ve Tarımsal Yapıdaki Değişimler. Türkiye Ziraat Mühendisleri VII. Teknik Kongresi, Ankara, S. 2-22

- Şahinöz, A. et. al, 2005. Küreselleşme Sürecinde Türkiye Tarımı. TMMOB Ziraat Mühendisleri Odası Teknik Kongresi 3-7 Ocak 2005. Ankara S.1-21

- $\quad$ TÜSİAD. 2014. Gıda, Tarım ve Hayvancılık Rekabet Gücü Temel Bulgular. Erişim 18.06.2015.

- Turhan, Ebru ve Yalçın, Erdal. Çok Vitesli Avrupa’ya Uyum Sürecinde Gümrük Birliği. Görüş, Aralık 2014, Say1:87 S. 58-61

- $\quad$ TÜİK (2003). İllerin Gelişmişlik Performansı, Ankara

- United Nations, 2015. Mounting opposition to Northern farm subsidies, http://www.un.org/en/africarenewal/vol17no1/171agri4.htm 


\title{
Pivotal Points in Utilizing Cloud Services in Turkey
}

\author{
Asst. Prof. Dr. Ediz Şaykol (Beykent University, Turkey) \\ Ayşe Seçil Avcı (Nişantaşı University, Turkey)
}

\begin{abstract}
The term of Cloud Computing has become a buzzword that almost every single person has heard. Although, it is defined at various platforms in various ways even with exactly different sentences, the most wide-reaching definition was made by NIST as a model for enabling convenient, on-demand network access to a shared pool of configurable computing resources with minimal management effort or service provider interaction. As Cloud Services entered daily lives, organizations and even ordinary people started to manage their business at any time anyplace in solid and reasonable costs with the help of considerably faster, at a high performance level, flexible clouds. The datas, softwares and platforms that stored in cloud has become accessible from where you are without a need of a server center. These lead to the problem of selecting and providing appropriate cloud services for customers and providers, respectively. The relation between these two depends on a win-win relationship, and hence the pivotal points that they raise becomes crucial from business perspective. In this study we present an analysis for the IT sector in Turkey to elaborate on a possible set of pivotal points from Cloud Customer and Cloud Service Provider perspectives depending on a survey-based study.
\end{abstract}

\section{Introduction}

Cloud Computing has become a buzzword that almost every single person has heard. It has been defined at various platforms in various ways even with exactly different sentences; however, the most widespread definition was made by United States National Institute of Standards and Technology (NIST). As NIST defines, "Cloud Computing is a model for enabling convenient, on-demand network access to a shared pool of configurable computing resources (e.g., networks, servers, storage, applications, and services) that can be rapidly provisioned and released with minimal management effort or service provider interaction" (NIST, 2014). Besides many utilities it provides, the fact that it helps out companies to reduce costs outshines all the others.

Whereas considering the datas and even some basic documents- those needed to be stored in computer-which a random person can have in his entire life it is predictable that a huge storage area is needed. Moreover, the need of being provided software, infrastructure, and platforms as a service is much bigger amongst companies. In older times, industries built up their own server\&data centers. These server centers have been an impediment for companies since because they were conceiving extra expenses and waste of time. On the other hand, lack of flexibility and not being at a desired performance level were handicaps for companies (Armbrust et al., 2009).

There has become such no more need for these server centers after Cloud Computing entered daily lives. Instead, organizations, companies or even ordinary people started to manage their business at any time anyplace in solid and reasonable costs with the help of considerably faster, at a high performance level, flexible clouds. The datas, softwares and platforms that stored in cloud has become accessible from where you are without a need of a server center. Deciding to move an existing service to the cloud depends various factors both economical and technological, such as the expected resource utilization, and various operational costs depending on the cloud environment being considered, as discussed deeply in (Saykol, 2014).

In the Cloud Computing story there are two leading roles: Cloud Customer and Cloud Service Provider. This connection between them depends on a win-win relationship. The key point advantage that it brings makes Cloud Computing preferable as well as the utilities that customers can have in a wide variety. From computer engineering point of view, there is also another role, namely Cloud Service Developers, however the details of this role is outside the scope of this paper (McCabe and Nachbar, 2010).

In this paper, some preliminary information is given in Section 2 for those who are unfamiliar to cloud computing terms at all. Section 3 and Section 4 are discussing the main purpose of the paper which is to let you take a look at to key points of Cloud Computing from both cloud Service Provider's and Cloud Customer's perspective in Turkey. Finally, Section 5 concludes the paper.

\section{Preliminaries on Cloud Computing}

Essentially, cloud computing is not a technology that has just entered into our lives. More than 10 years we have been using services such like Msn, Hotmail, etc. In fact, the main reason that made it this much developed and spreaded is the development of bandwidth technologies. Workload of the firms is already not just staying at work. Workers may need to reach their files from anywhere any second. In the circumstances you need to work at home, you have to be at office since because the files and folders are there. But if we take a look at Cloud Computing; the place where you are is not important, you are not connected to office, you can work from where 
ever you are. Not you, the files are going to work depending on you and you can see the benefits of this technology that yield to your company.

Cloud computing lets datas heap together in one center and widen work place area. It takes away the complexity of infrastructure. Decidedly, it reduces the cost. Cloud Computing is the technology that lets you reach the data in the fastest way it can without a setup need and with a low cost. Figure 1 provides an overview on cloud computing notion.

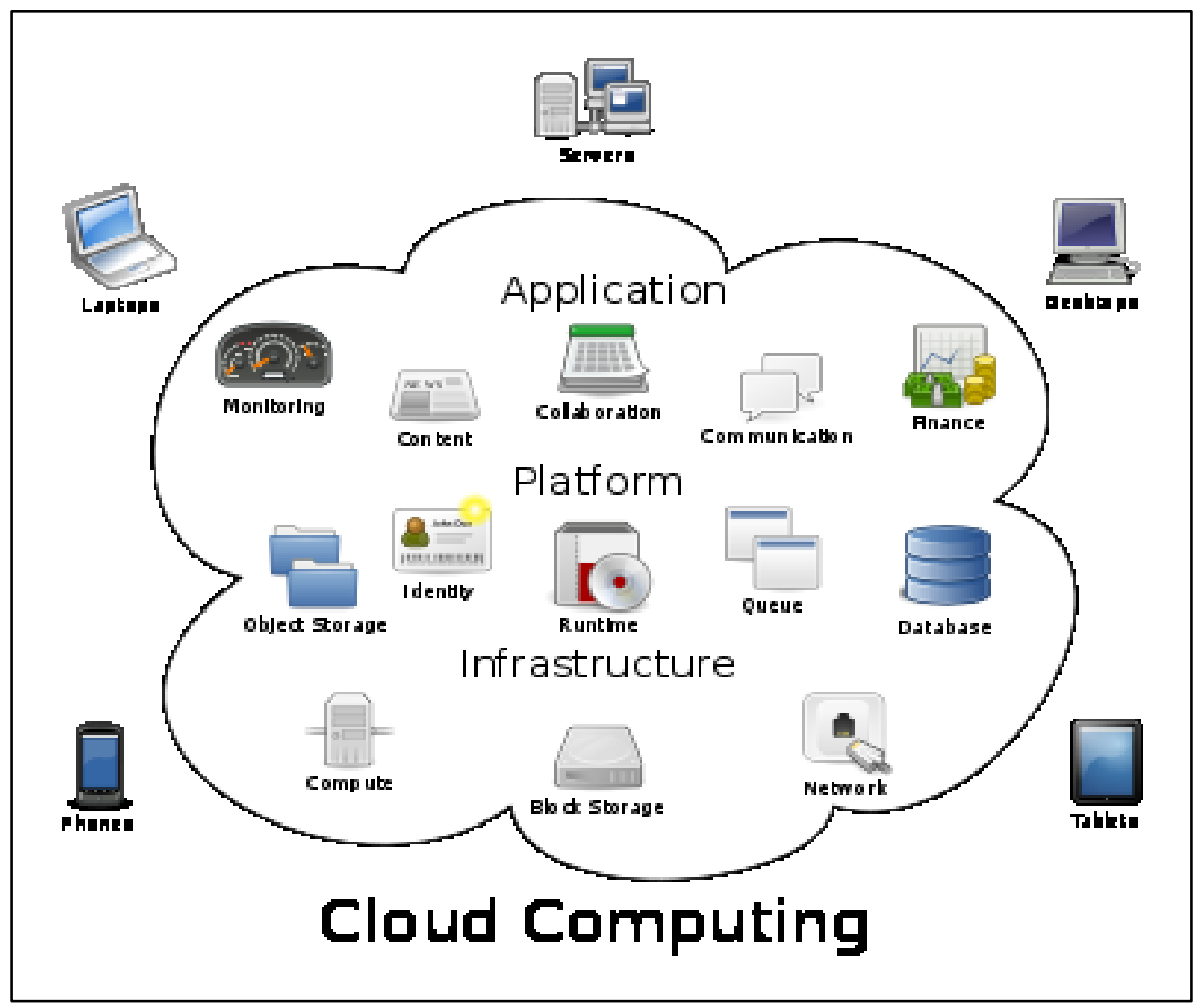

Figure 1. Cloud Computing overview. Source: (Infraworx, 2015)

Cloud Computing Service Models

A definition that is made in a shorten and coherent way about cloud computing would be that it is the remote control of the necessaries such like hard disk, software, hardware etc. Likewise, it helps getting access to pictures, documents, music and video files via other computers. In this manner, cloud computing is that using the necessary domain in every place that has internet connection and in an efficient way.

Cloud technology -in simplest- is the software applications that is accessible through internet, data storage services and operation capacity. In this technology, accessing to the informatique facilities that companies need at any time (or whenever it is needed) anyplace is grounded on (Papazoglou et al., 2007).

Cloud computing gives us solutions with 3 different service supplier models:

- Software as a Service (SaaS): Software service, yields programs such like CRM, ERP, Finance and Accounting software via Cloud. For the companies which have different office locations, SaaS doesn't have extra software costs and by this way SaaS provides a serious economic advantage.

- Platform as a Service (PaaS): Platform service, yields hardware and software layers to application developers to let them develop their projects. This service offers platforms such like system management, operating system, programming languages platform, database etc. Since the system management is carried out by service supplier, you only manage your applications and datas.

- Infrastructure as a Service (IaaS): Infrastructure service lets you take advantage of software, dataware house or network devices without any investing in and with fully help of an external source. 


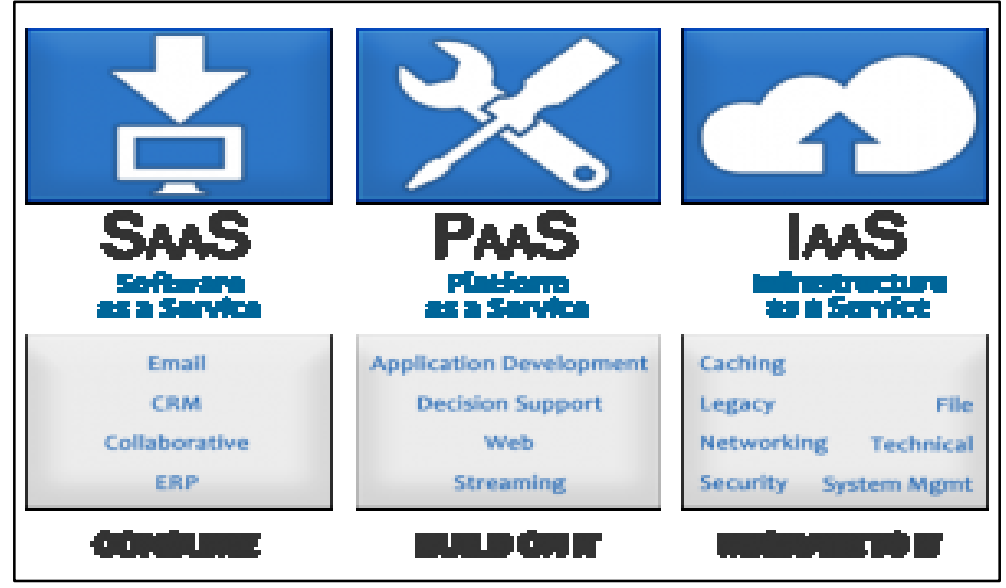

Figure 2. Cloud computing service models. Source: (Consultia, 2015)

As shown in Figure 2, these services determine the service level that we get and designate the ways for businesses to adopt cloud computing to their services. As a consumers, businesses generally find SaaS adequate, however, if the companies would like to develop services they prefer PaaS. Even further, business organize specialized teams and utilize cloud services as IaaS.

\section{Adopting to Business Models}

Just like the rest of the World, from every sector different sizes of corporations are using the cloud information services in Turkey as well. According to researches the number of the users who are using cloud services are same as the ones in Eastern Europe and Middle East, yet the number is still lower than the users in Western Europe and America. But the need and demand is rapidly increasing. There are quiet many local firms in Turkey who are in service for the cloud services (Y1ld1z, 2009).

Software application developers, small businesses and the students are using cloud services which do not have serious access and service agreements but simply agreeing a common terms and conditions text and they even can purchase these services with their credit cards. However middle sized businesses and corporate firms are preferring well written agreements for their special needs and respecting the data pricay for longer terms.

The service that is provided in Turkey is actually an all virtual data center. The firms can simply use a browser to access the cloud for doing anything that they can do on their local data center. This means that you do not need the space and the infrastructure like air-conditioning systems, ups, generators and the security for a data center anymore. Continuous and backup connection services are provided with this service as well.

One can create all of the servers, design the system, manage the firewall and make load balancing definitions virtually over the cloud. One can increase or decrease the sources on demand. Over all one can do all of these from a single screen and can see the real time cost of the services. One can even add different devices to cloud and manage them all from the same screen.

Figure 3 graphically list the top ways businesses adopt clod computing to their businesses. The results are based on a survey report, and provided in Forbes magazine. Not surprisingly, most businesses require cloud computing to reduce their cost, and provide efficient workforce, possibly via mobile devices. The businesses also assume that the time-to-market duration would be faster with the help of cloud computing.

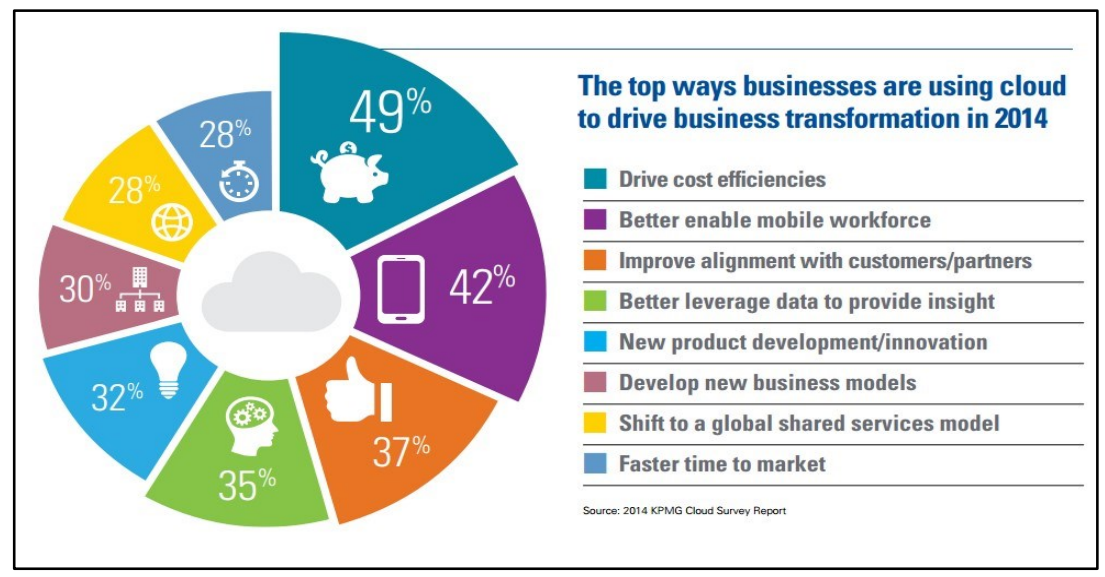

Figure 3. The top ways that businesses utilize cloud computing to your service. Source: (Forbes, 2015) Key Points in Selecting Cloud Computing 


\section{From Service Provider Point of View}

The budget for the infrastructures and technologies for the traditional IT models has its own problems like instead of monthly, annually or per user fees; firms has to deal with new technology or infrastructure costs. No such fees are needed for the use of cloud services. Instead of that you just have to pay for the apps per user every month which you can exclude from operational budgets.

Low cost and small budgets are the main reason for the demand on cloud services. The on-demand softwares are billed by per user and per use principles so the service cost becomes much cheaper than the on premise softwares. Besides that SaaS softwares does not need extra hardware or extra human resources. The classical licensed softwares updates are done annually with a need for an update fee where the SaaS softwares are always up to date and these updates are free of charge.

Worldwide access is another reason for the popularity of the use of the cloud services. Users can access the services from anywhere on the world from any computer without the need for an office or installation of a software. Lately, this need has shifted from the business use to personal use as well. Besides that the specification of the computer for using these services are not necessarily needs to be high end. A middle level simple computer can be adequate for these services.

These are numerous improvements for the cloud services on access levels. One of them is the minimization of the business risk factors. The Service providers' enormous data farms have a lot of infrastructures for the security of the data. Also the numerous numbers of the backups allows additional security in case of the data loss.

But when it comes to the use of the cloud services, besides the benefits of the higher mobility the constant access to the cloud has to be kept in mind. Mobile users can use the services outside the office constantly. The full integration of the windows phone for the cloud services makes the use of these services more effective.

Some other advantages for the use of this technology are: The compatibility between different operating systems, the openness for the group work, privacy, security, unlimited storage, etc. The SaaS softwares are generally provided with free test times. This allows the users to assess the benefits and comfort that the software provides for them.

\section{From Service Provider Point of View}

It is for sure that we must be careful and reasonable while taking advantages of cloud computing benefits. The most important issue that it has to be taken serious is security. There are 3 matters that you must be careful on:

- Work persistence

- Service persistence (that you get from supplier)

- Security of your datas

For the first two cases, the solution might be to work with a service supplier that improved it and has strong references. Means, you need to investigate the firm that you get cloud services from about how much capital it invest in and how dependable it is. You can decide from checking firm's background if it is a vision holder company or not.

From a cloud service supplier's perspective; it is also more reasonable to work for cloud services. Any computer stays free for a $99.9 \%$ part of its processing time or keeps doing $1 / 0$. Since there is this much of a processing power, it is precisely logical to sell it/share it to/with some other people.

In older times, many majority of companies were spending almost $100.000 \$$ for computers or $50.000 \$$ for server centers, many thousand dollars for hardware, another thousand dollars for each computing brand, etc. While paying this much of money, people were being directed to oneself, each time to different people. In this circumstances, serious moneys were spent and serious invests were made. As the result of this vicious cycle, OPEX (operational expenditure) was increasing from day to day. Here, cloud service suppliers sell cloud solutions to decrease this expenditure.

What companies do is to buy hardware and hire it, maintain it, if it is necessary expand the capacity. Those can hire the same virtual machine to different companies at different time periods. As an example, assume one of those virtual machines is hired by 5 people. Simply, that single machine will fulfill its cost.

Just to give an example to this 'hire' issue, we can show SaaS (Software as a Service) solutions. Many software products developed by software developers might be so expensive. Hence, there are not that many of companies and people who can buy software that costs $100.000 \$$. It requires being at a highly financial power level to spend that money. There might be only a few people who can effort this but with cloud services this software can meet with millions of people. By this way, cloud supplier can get a chance to service to wide range of communities. This is another reason to be a cloud service supplier; being preferable by millions. The main reason and gain of cloud service provider is to reduce total cost of ownership.

Many companies that serve cloud service solutions in Turkey give IaaS (Infrastructure as a Service) solutions to customers. That is to say, those build up a full automatic system by virtualizing hosts and give various 
solutions with 3rd party solution partners. Such system examples can be given among the uses in accounting systems (Seyrek, 2011).

\section{Evaluating the Situation in Turkey}

In this study it is intended to highlight the key point benefits of both when buying and selling cloud computing services. It is for sure that cloud computing brings many eases to daily and professional lives. There are even several more reasons to get it or provide it. The most common and guarantee reason to get is money austerities. The smart face of cloud computing's on-demand services brings many utilities on economical side.

The adaptation of cloud services and cloud usage status in Turkey is discussed in (Saykol, 2014). Moreover, in a joint work supported by TÜBITAK, the companies in Turkey are interested in the new technological trends, such as Cloud Computing (Silahtaroğlu et al., 2014).

The following are the key points that were determined as important by the companies, actually cloud service users, in Turkey.

- Dependency to the cloud service provider: This dependence reduces the freedom of the company to work with other solution providers, and other $3^{\text {rd }}$ party companies (Armbrust et al., 2009). Hence, the companies pay importance to this item.

- The capacity of the network bandwidth: The amount of cloud use necessitates high bandwidth for the companies (Saykol, 2014). If the size is not enough for the products/services of the company, this will lead to a business failure, which businesses surely do not accept.

- Network security, especially data confidentiality: The company-specific data and the customer data that the companies hide should not be accessed by other parties. Even though most cloud providers have enhanced security and confidentiality mechanisms (McCabe and Nachbar, 2010), the business are quite reluctant to use these cloud services.

- Compliancy with the standards and governmental regulations: Businesses generally prefer service-level agreements with the service providers, as other utility services, such as electricity. However, the companies would like their cloud to be adaptive and compliant with the governmental regulations (Yildiz, 2009). In Turkey, the laws and regulations change quite frequently depending on the technological needs and to care data privacy, the business do not want to pay more attention to these issues by themselves. In fact, they require the cloud service provides take care of these.

\section{Conclusion}

As the widespread of Cloud Services in our lives, organizations and even ordinary people started to manage their business at any time anyplace in solid and reasonable costs with the help of considerably faster, at a high performance level, flexible clouds. The datas, softwares and platforms that stored in cloud has become accessible from where you are without a need of a server center. These lead to the problem of selecting and providing appropriate cloud services for customers and providers, respectively.

Here, we present an analysis for the IT sector in Turkey to elaborate on a possible set of pivotal points from Cloud Customer and Cloud Service Provider perspectives depending on a survey-based study. We found that the key points that were determined as important by the companies, actually cloud service users, are dependency to the cloud service provider, the capacity of the network bandwidth, network security, especially data confidentiality, compliancy with the standards and governmental regulations.

In our future work, we would like to provide multi-criteria selection mechanisms for selecting appropriate service provides for the IT companies in Turkey based on the achievements in this work.

\section{References}

- $\quad$ Armbrust, Michael, Fox, Armando, Griffith, Rean, Joseph, Anthony D., Katz, Randy H., Konwinski, Andrew, Lee, Gunho, Patterson, David A., Rabkin, Ariel, Stoica, Ion and Zaharia, Matei, 2009, “Above the Clouds: A Berkeley View of Cloud Computing", UCB/EECS-2009-28, http://www.eecs.berkeley.edu/Pubs/TechRpts/2009/EECS-2009-28.html.

- $\quad$ Bayrak, Ergin, Conley, John Patrick and Wilkie, Simon, 2011, "The Economics of Cloud Computing", No 1118, Vanderbilt Uni. Dept of Economics, http://EconPapers.repec.org/RePEc:van:wpaper:1118.

- Consultia, 2015, “Cloud computing service models", http://www.consultia.co/choosing-your-right-cloud/.

- Forbes, 2015, “The top ways that businesses utilize cloud computing”, http://www.forbes.com.

- Hancock, Ian and Hutlay, Nikki, 2012, "Modelling the Economic Impact of Cloud Computing", KPMG Report, http://www.kpmg.com/au/en/issuesandinsights/articlespublications/pages/modelling-economicimpact-cloud-computing.aspx. 
- Infraworx, 2015, “Cloud Computing”, http://www.infraworx.com.

- $\quad$ Marston, Sean, Li, Zhi, Bandyopadhyay, Subhajyoti, Zhang, Juheng, Ghalsasi, Anand, 2011, “Cloud computing - The business perspective”, Decision Support Systems, 51, 176-189.

- $\quad$ McCabe, Karen, Nachbar, Robert, 2010, "Survey by IEEE and Cloud Security Alliance Details Importance and Urgency of Cloud Computing Security Standards", https://cloudsecurityalliance.org/media/news/surveyby-ieee-and-cloud- security-alliance-details-importance-and-urgency-of-cloud-computing-securitystandards/.

- National Institute of Standards and Technology (NIST), 2014, "Definition of Cloud Computing", http://www.nist.gov/itl/cloud/index.cfm.

- Papazoglou, Michael. P., Traverso, Paolo, Dustdar, Schahram, Leymann, Frank, 2007, "Service-Oriented Computing: State of the Art and Research Challenges", IEEE Computer, 64-71.

- Saykol, Ediz, 2014, "On the Economical Impacts of Cloud Computing in Information Technology Industry", Proceedings of 5th International Conference on Eurasian Economies (EECON'14), Skopje, Macedonia.

- Seyrek, İbrahim Halil, 2011, “Bulut Bilişim: İşletmeler için Fırsatlar ve Zorluklar”, Gaziantep Üniversitesi Sosyal Bilimler Dergisi 10(2), 701-713.

- Silahtaroğlu, Gökhan, Saykol, Ediz, Doğan, İdil, Kocamaz, Ahmet, 2014, "On the Use of Analytics in Turkey: A Data Mining Study”, Proceedings of 1st International Conference on Recent Trends and Applications in Computer Science and Information Technology (RTA-CSIT'14), Tirana, Albany.

- Yıldız, Özcan Rıza, 2009, "Bilişim Dünyasının Yeni Modeli: Bulut Bilişim (Cloud Computing) ve Denetim”, Sayıştay Dergisi, 5-23. 


\title{
The Impact of Microfinance on Entrepreneurship in Kyrgyzstan
}

\author{
Asst. Prof. Dr. Kamalbek Karymshakov (Kyrgyzstan-Turkey Manas University, Kyrgyzstan) \\ $\mathrm{Ph}$. D. Candidate Kadyrbek Sultakeev (Kyrgyzstan-Turkey Manas University, Kyrgyzstan) \\ $\mathrm{Ph}$. D. Candidate Burulcha Sulaimanova (Kyrgyzstan-Turkey Manas University, Kyrgyzstan)
}

\begin{abstract}
This paper aims to investigate the impact of microfinance on entrepreneurship in Kyrgyzstan. For estimation the nationally representative "Kyrgyz Integrated Household Survey" for 2013 is used, which covers around 5000 households from all regions in the country. The main variable of interest, the probability of being an entrepreneur of household members depends on individual, household level characteristics and on microfinance loan receiving status. Following the literature, due to the endogeneity issue in using microcredit loan in estimation, this research applies binary response model with instrumental variables. Estimation results show that participation in the micro loan raises the probability of individual to be entrepreneur.
\end{abstract}

\section{Introduction}

Lack of access to crediting in low-income countries is generally seen as one of the main impediments in developing entrepreneurial activities. Individuals with low income or limited wealth have no access to loans from the banking system, due to absence of collateral, while microfinance institutions (MFI) are solving this issue, enabling financial access to all. The importance of microfinance organizations, in facilitating the financial resources to borrowers, has risen rapidly in the last ten years in Kyrgyzstan. In spite of the fact that the financial services of microfinance institutions including microcredit, insurance, savings, money transfers and other financial products are targeted to support poor and low-income borrowers; in the case of Kyrgyz Republic it works mainly in giving microcredit only. In 2002 Kyrgyz Republic has adopted a law "On microfinance organizations", under which MFIs can determine their own sizes of loans and interest rates, as well as commission rates. This, in turn, enabled rapid start-ups in this sector, reaching MFIs loan portfolio share with respect to GDP of country up to 8\%. Thus, since 2002 the number of MFIs increased from 18 to 204, while the loan amount has grown more than 16 times (from $\$ 1$ billion KGS to 16.8 billion KGS) and number of borrowers increased from 80000 to 429000 people.

According to the National Bank of the Kyrgyz Republic, in 2014 the microfinance sector is represented by 5 microfinance companies, 145 microcredit companies and 54 microcredit agencies. Such statistics show widespread characteristics of MFIs in Kyrgyzstan, where total population is around 5.5 million people. Moreover, according to National Statistical Committee of Kyrgyz Republic (NSCKR) in 2014 the $72 \%$ percent of borrowers of MFIs are between 30 and 60 ages, while $20 \%$ are people younger than 30 years; this shows that the most of microfinance clients are in working age and can use credits in income generating activities. It is important to mention that, according to NSCKR, the share of women borrowers in all regions of Kyrgyzstan is bigger. In 2014 the $64 \%$ of borrowers were women, while only $36 \%$ were men. Another significant fact is that $65 \%$ of total population lives in rural areas and microcredit loans are widely used for agricultural purposes, which includes credits for cultivating crops and processing agricultural products by small firms or self-employed workers. Another purpose of microcredit loan is to use it in trading and catering, which are mainly presented by small enterprises or own-account workers in Kyrgyzstan. In average, the amount of loans value around 66,400 KGS (1 050 USD), shows that microfinance institutions are commonly facilitating credits to the poorer people in the country, which is $35 \%$ of total population (NSCKR).

Empirical evidence on the microfinance impact on the enterprises in general show that participation in microcredit program have positive effects, thus microcredit loan relaxes credit constraints, which in turn enables entrepreneurs to manage financial resources optimally and to increase the business revenue, profits and employment (see Karlan and Valdiva (2011); Field et al. (2013); Buera et al. (2012); Kholis (2009); Babajide (2012); Wang (2013)). However, few studies have been undertaken in investigating how microfinance influences entrepreneurial decision of beneficiaries'. One of recent studies on this belongs to Amin et al. (2012) who assessed the impact of microcredit loan on women entrepreneurship in Bangladesh. He found that the access to microcredit has a significant positive impact both on women and men entrepreneurs. Limited studies have been undertaken to analyze the microfinance impact in Kyrgyzstan case, and they mostly consist of qualitative evaluation and analysis of microfinance institutions in Kyrgyzstan. To our best knowledge there are only two empirical studies on microfinance impact in Kyrgyzstan case. Sultakeev (2012) investigates the effect of microcredit on microenterprises income in Kyrgyzstan. Angioloni et al. (2013), which empirically assesses the impact of microcredit loan on household welfare. However, the study of Sultakeev (2012), suffers from some limitations, such that sample size of the study is small and covers only two regions out of seven region of the country and not nationally representative. While the research of Angioloni et al. (2013) which estimates welfare effect of microfinance impact, do not correct the endogeneity issue, which is arising from microcredit program 
participation. For the given reasons and due to the importance of microfinance in facilitating access on financial resources among all regions of Kyrgyzstan and its availability to the low-income borrowers, this paper aims to empirically investigate how micro-credit impact the entrepreneurial decision of beneficiers in Kyrgyzstan.

The paper is organized as follows: in section two, the information of data used and its descriptive statistics are given; in third section the methodology with variable description are presented; in fourth and fifth sections empirical estimation results and conclusion are provided.

\section{Data and descriptive statistics}

To investigate the microfinance impact on entrepreneurship in Kyrgyzstan the Kyrgyz Integrated Household Survey (KIHS) data for 2013 is used. This survey was conducted by National Statistics Committee of Kyrgyzstan, and includes sample of 5000 households and representative at the national level, as well as for urban and rural areas of the country. Also, this survey includes wide range of data information on household characteristics (composition, education, child education, health etc.) and individual (education, health, labor market participation, movements etc.) characteristics.

The table 1 describes the main individual and household characteristics, such as age, gender, marital status, education level of individual, residential and compositional specification of the households, both for borrowers and non-borrowers from microfinance institutions. In general, there is no significant difference in ages between borrowers and non-borrowers, and most of the borrowers are married.

\begin{tabular}{|c|c|c|c|c|c|}
\hline & \multirow[t]{2}{*}{ Total } & \multicolumn{2}{|c|}{$\begin{array}{l}\text { Microcredit non- } \\
\text { borrowers }\end{array}$} & \multicolumn{2}{|c|}{ Microcredit borrowers } \\
\hline & & Amount & $\%$ & Amount & $\%$ \\
\hline \multicolumn{6}{|l|}{ Individual characteristics: } \\
\hline Age & 40.0634 & 40.04683 & - & 40.56458 & - \\
\hline \multicolumn{6}{|l|}{ Marital status } \\
\hline - $\quad$ Married & 11971 & 11597 & 75.22 & 374 & 77.92 \\
\hline - $\quad$ Single, divorced, widowed & 3926 & 3820 & 24.74 & 106 & 22.08 \\
\hline \multicolumn{6}{|l|}{ Occupational choice: } \\
\hline - $\quad$ Entrepreneurs & 3592 & 3438 & 22.30 & 154 & 32.08 \\
\hline - $\quad$ Employee & 9890 & 9592 & 62.22 & 298 & 62.08 \\
\hline - $\quad$ Family contributing worker & 2415 & 2387 & 15.48 & 28 & 5.83 \\
\hline \multicolumn{6}{|l|}{ Education level: } \\
\hline - $\quad$ Secondary, basic & 9132 & 8849 & 57.4 & 283 & 58.96 \\
\hline - $\quad$ Technical education & 2203 & 2155 & 13.98 & 48 & 10.00 \\
\hline $\begin{array}{ll}- & \text { Tertiary education } \\
\end{array}$ & 4563 & 4413 & 28.62 & 149 & 31.04 \\
\hline \multicolumn{6}{|l|}{ Household characteristics: } \\
\hline - Household size (mean) & 4.5199 & 4.5137 & - & 4.7208 & - \\
\hline - Child ratio, $0-5$ years & 0.1193 & 0.1192 & - & 0.1252 & - \\
\hline - Child ratio, 6-17 years & 0.2094 & 0.2091 & - & 0.2218 & - \\
\hline \multicolumn{6}{|l|}{ Residence } \\
\hline - Urban & 7118 & 6967 & 45.19 & 150 & 31.25 \\
\hline - Rural & 8780 & 8450 & 54.81 & 330 & 68.75 \\
\hline $\begin{array}{l}\text { Household total expenditure per } \\
\text { capita (mean, in soms) }\end{array}$ & 36067.72 & 35800.62 & - & 44646.41 & - \\
\hline $\begin{array}{l}\text { Household micro-credit loan } \\
\text { (mean, in soms) }\end{array}$ & - & - & - & 18135.63 & - \\
\hline
\end{tabular}

Table 1. Basic characteristics of microcredit borrowers and non-borrowers; Source: KIHS data, 2013

The occupational choice distribution of micro-credit borrowers shows that significant parts of borrowers are employees, almost $63 \%$. However, the share of entrepreneurs borrowing microcredits is high as well, reaching $33 \%$ of total micro-credit borrowers, showing that these loans may be used in facilitating income generating activities, which are related with works, such as enlarging business, employing more workers, increasing production etc.

More than half of individuals borrowing micro-credit have secondary and basic education, while $31.04 \%$ have tertiary education. The share of borrowers with technical education, is much more less, and counts around 10 percent.

Around $70 \%$ of borrowers are residing in rural areas, showing that the micro-credits are mostly demanded by rural population rather than urban. This could be explained with high concentration of banks and financial 
institutions in urban areas, which are enabling customers to choose credits among various types of organizations. While in rural areas it is mostly the micro finance institutions, which have micro loan to population.

Expenditure per capita in borrower-households is in average more for 8000 soms than in non-borrower households. The household size and its composition do not differ significantly among borrower and nonborrower households.

\section{Methodology}

The probability of individual to be an entrepreneur $\left(y_{1 i}\right)$ will be estimated with binary choice model, Probit model; which will be conditional on receiving micro credit loan $\left(y_{2 i}\right)$, individual, household characteristics $\left(x_{1 i}\right)$. Formally, model is given below (Newey, 1987):

$$
\begin{aligned}
& y_{1 i}=z_{i} \delta+u_{i} \\
& y_{2 i}=x_{i} \Pi+v_{i}
\end{aligned}
$$

where $z_{i}=\left(y_{2 i}, x_{1 i}\right), x_{i}=\left(x_{1 i}, x_{2 i}\right), \delta$ and $\Pi$ are the vectors of structural and reduced-form parameters, respectively (for detailed variable description see Table 2 ).

\begin{tabular}{ll}
\hline Dependent Variable & \\
\hline \hline Entrepreneurship & $1=$ individual owns enterprise, $0=$ otherwise. \\
\hline \hline Explanatory Variables & $1=$ household borrows microcredit, $0=$ otherwise. \\
\hline Micro credit loan & Age of individual (years). \\
\hline Age & $1=$ individual is male; $0=$ female. \\
\hline Gender & $1=$ individual is married; $0=$ otherwise. \\
\hline Marital status & $1=$ individual has basic and secondary education; $0=$ otherwise. \\
\hline Education category: & $1=$ individual has technical education; $0=$ otherwise. \\
\hline - Technical education & $1=$ individual has tertiary education; $0=$ otherwise. \\
\hline - Tertiary education & The total number of household members. \\
\hline Household size & The ratio of children in household, aged between $0-5$ years. \\
\hline Child ratio & The expenditure of household per capita in logarithm. \\
\hline Expenditure per capita & $1=$ household owns agricultural land, $0=$ otherwise. \\
\hline Land ownership & $1=$ household resides in rural area, $0=$ otherwise. \\
\hline Residence & $1=$ household resides Bishkek or Chui oblast, $0=$ otherwise. \\
\hline Regional dummies for household \\
\hline - Central region & $1=$ household resides Naryn, Talas, Issyk-Kul oblasts, $0=$ otherwise. \\
\hline - North region & $1=$ household resides Jalal-Abad, Osh, Batken oblasts, Osh city, $0=$ otherwise \\
\hline - South region & Share of households with microfinance loan in total household number in \\
\hline \hline
\end{tabular}

Table 2. Variable definitions

However, model estimation in microfinance related researches faces the endogeneity issue; due to correlation of micro-credit loan or participation status with some household's unobserved characteristics, which are not included in model, thus making credits endogenous. In other words, households that are borrowing micro-credit loan may have specific characteristics, which in turn may also have impact on entrepreneurial activities. As it mentioned in Coleman (1999) disregarding the selection bias or endogeneity issue in microcredit program placement may significantly overestimate the impact of program loans. To deal with this problem, we introduce equation (2), an instrumental variable approach, which is the standard method to manage endogeneity. This instrumental variable should obey exclusion restriction, meaning that a variable $x_{2 \mathrm{i}}$ should be related to credit loan $\left(y_{2 \mathrm{i}}\right)$ but not related to entrepreneurship $\left(y_{1 \mathrm{i}}\right)$. Following the literature, in this study the availability of funds at community level will used as the instrumental variable (Bui, 2014; Khandker 2003). For this the share of microcredit borrower households to the total amount of households in the community is calculated. The rationale behind using this type of variable as instrument for microcredit is that community with higher access to microfinance loan would have more households with microfinance loan.

Since our model consists of binary dependent variable and binary endogenous variable (microfinance participation status) the efficient estimation technique for this case is suggested by Roodman (2011) within the 
"conditional mixed process" or CMP. Precisely, it is not appropriate to use standard Instrumental Variable Probit (IV-Probit) command in STATA for discrete endogenous regressors, for this reason the IV-Probit model will be estimated within CMP modelling method.

\section{Estimation results}

Table 3 reports estimation results both in coefficient and marginal effect estimates from IV-Probit CMP. First stage results on using instrumental variable approach within IV-Probit CMP command show that instrumental variable is highly significant. Test of the exogeneity of instrumented variable to outcome variable for models estimated with CMP command is the correlation between the disturbance terms of the first stage and the main equation, which is provided as atanhrho output. The null hypothesis for this is that microcredit participation is uncorrelated with the error term in the occupational choice equation, in our case with entrepreneurship. Due to the rejection of null hypothesis, we can conclude that microcredit participation is endogenous variable, should be corrected for endogeneity in estimation, by using instrumental variable.

\begin{tabular}{|c|c|c|c|}
\hline & \multicolumn{2}{|c|}{ IV-Probit CMP } & \multirow{2}{*}{$\mathrm{dy} / \mathrm{dx}$} \\
\hline & Entrepreneurship & Micro credit loan & \\
\hline Micro credit loan ( $1=$ household borrows credit $)$ & $\begin{array}{c}0.8268 * * * \\
(0.1809) \\
\end{array}$ & & $0.2254 * * *$ \\
\hline \multicolumn{4}{|l|}{ Individual characteristics: } \\
\hline Age & $\begin{array}{c}0.0193 * * * \\
(0.0013)\end{array}$ & $\begin{array}{l}-0.0008 \\
(0.0023)\end{array}$ & $0.0035^{* * *}$ \\
\hline Gender $(1=$ male $)$ & $\begin{array}{c}1.1369 * * * \\
(0.0314) \\
\end{array}$ & $\begin{array}{l}0.1061 * \\
(0.0549)\end{array}$ & $0.1998 * * *$ \\
\hline Marital status $(1=$ married $)$ & $\begin{array}{c}0.1044 * * * \\
(0.0390) \\
\end{array}$ & $\begin{array}{l}-0.1063 \\
(0.0689) \\
\end{array}$ & $0.0184 * * *$ \\
\hline \multicolumn{4}{|c|}{ Educational category (reference: Secondary and basic education) } \\
\hline - $\quad$ Technical education & $\begin{array}{c}-0.6113 * * * \\
(0.0484)\end{array}$ & $\begin{array}{c}-0.2774 * * * \\
(0.0900)\end{array}$ & $-0.0838 * * *$ \\
\hline - $\quad$ Tertiary & $\begin{array}{c}-0.8081 * * * \\
(0.0405)\end{array}$ & $\begin{array}{l}-0.0610 \\
(0.0638) \\
\end{array}$ & $-0.1200 * * *$ \\
\hline \multicolumn{4}{|l|}{ Household characteristics: } \\
\hline Household size & $\begin{array}{c}-0.0256 * * * \\
(0.0098)\end{array}$ & $\begin{array}{c}0.0768 * * * \\
(0.0183) \\
\end{array}$ & $-0.0047 * * *$ \\
\hline Child ratio & $\begin{array}{c}0.2880^{* * *} \\
(0.1016) \\
\end{array}$ & $\begin{array}{l}-0.2786 \\
(0.2019) \\
\end{array}$ & $0.0525 * * *$ \\
\hline Expenditure per capita (log) & $\begin{array}{c}-0.1983 * * * \\
(0.0318)\end{array}$ & $\begin{array}{c}0.4310 * * * \\
(0.0528) \\
\end{array}$ & $-0.0361 * * *$ \\
\hline Land ownership ( $1=$ owns land $)$ & $\begin{array}{c}0.7296^{* * *} \\
(0.0802) \\
\end{array}$ & $\begin{array}{c}0.0717 \\
(0.0946) \\
\end{array}$ & $0.0966^{* * *}$ \\
\hline Residence $(1=$ rural $)$ & $\begin{array}{c}1.0554 * * * \\
(0.0352) \\
\end{array}$ & $\begin{array}{c}0.7369 * * * \\
(0.0727) \\
\end{array}$ & $0.1845^{* * *}$ \\
\hline \multicolumn{4}{|l|}{ Regional dummies (reference: Central region) } \\
\hline - North & $\begin{array}{c}0.7179 * * * \\
(0.0515) \\
\end{array}$ & $\begin{array}{c}0.9428 * * * \\
(0.1754) \\
\end{array}$ & $0.1430 * * *$ \\
\hline - South & $\begin{array}{c}0.5545 * * * \\
(0.0516) \\
\end{array}$ & $\begin{array}{c}0.4130 * * \\
(0.1839) \\
\end{array}$ & $0.1075^{* * *}$ \\
\hline \multicolumn{4}{|l|}{ Instrumental variable: } \\
\hline Microfinance availability & - & $\begin{array}{c}0.0239 * * * \\
(0.0011)\end{array}$ & - \\
\hline Constant & $\begin{array}{c}-2.0255^{* * *} \\
(0.3665)\end{array}$ & $\begin{array}{c}-8.3756 * * * \\
(0.6443)\end{array}$ & - \\
\hline Number of observations & 15897 & & \\
\hline LR chi2 & $7428.04 * * *$ & & \\
\hline Log likelihood & -6921.3912 & & \\
\hline atanhrho_12 & $\begin{array}{c}-0.5819 * * * \\
(0.1350) \\
\end{array}$ & & \\
\hline
\end{tabular}

Table 3. Estimation results (coefficient and marginal effect estimates) 
Findings for our main variable of interest, the dummy variable for microfinance participation show that there is statistically significant and positive relation exists between entrepreneurship and microfinance participation. Meaning that participation in the micro loan rises the probability of individual to be entrepreneur for $22.54 \%$.

The estimated coefficients of explanatory variables have the expected signs and significance levels. Results show that statistically significant gender differences exist among men and women on taking decision to be entrepreneur. Thus men are more likely to be entrepreneur with respect to women for $19.98 \%$. While with increase of age, the probability of being entrepreneurs is increasing little. In other words, entrepreneurial status of individual is positively related to its age, which may indicate that individual with age getting more experienced in labor market and makes decision on owning own enterprise. The same can be concluded for marital status of individual, though the probability is not high but married individual more likely to be entrepreneurs rather than unmarried ones.

More educated individual are less likely to be entrepreneurs. This could be explained with labor market specification in Kyrgyzstan, own-account workers or entrepreneurs mostly maintain, manage small trade markets, shops, which do not require particular educational or labor skills. Along with these characteristics in Kyrgyzstan, most of the individuals with land ownership are considered as own-account workers. It means that even if individuals are not employed at any other sectors, but just work as family unpaid agriculture worker with low productivity they are considered as own-account worker. The dummy variable showing ownership of land by household has positive and significant effect on entrepreneurship decision of individual. Showing that individuals in households with agricultural land, more likely to be entrepreneur than those, who are in households without agricultural land.

Residence of household has impact on entrepreneur decision of individual. Thus individuals residing in rural household for $18.45 \%$ are more likely to be entrepreneur than those residing in urban areas. Moreover, regional differences in entrepreneurship can be observed. The estimation results show that individuals from north and south regions are more likely to be entrepreneur with respect to those, who are residing in Bishkek city or Chui oblast for $14.30 \%$ and $10.75 \%$ respectively. Showing that individuals from central region more likely to be wage paid workers.

\section{Conclusion}

Using the Kyrgyz Integrated Household Survey data for 2013 the present study analyzed the impact of microfinance impact on entrepreneurship. For this binary dependent IV-Probit model is estimated. The entrepreneurship is observed in case if individual owns an enterprise. The probability of individual to be an entrepreneur is conditional on explanatory variables, such as micro-credit participation and other individual and household characteristics. Estimation results show that participation in the micro loan rises the probability of individual to be entrepreneur, showing that in general wide spread micro-credit loan in Kyrgyzstan has positive effect on entrepreneurial activity. Results on the individual and household level characteristics show that the decision of being entrepreneur is highly dependent not only individual characteristics, but also on households" characteristics, such as location, composition and wealth of households.

There is a significant gender difference among men and women on taking decision to be entrepreneur, thus men are more likely to be entrepreneur with respect to women. One of the interesting findings is that elderly, less educated and married individuals are more likely to be entrepreneur. This findings show that in Kyrgyzstan entrepreneurship mostly presented by unskilled workers, which may be conditional on the fact that owning enterprise in Kyrgyzstan, in most times presented in managing small trade markets, shops, owning land to generate income which do not require particular educational or labor skills.

Therefore, we can conclude that entrepreneurship in Kyrgyzstan mostly presented by micro-enterprises located mostly in rural areas, and that micro-credit currently plays role as one of important instrument in facilitating financial access in non-urban areas, where the financial institutions are not wide-spread.

\section{References}

- Angioloni, S., Kudabaev, Z., Ames, G. C., \&Wetzstein, M. E. (2013). Micro-credit impact in Kyrgyzstan: A study case. Southern Agricultural Economics Association, 23.

- Babajide, A. (2012). "Effects of Microfinance on Micro and Small Enterprises (MSEs) Growth in Nigeria" Asian Economic and Financial Review Vol.2, No. 3, pp. 463-477.

- Buera, F. J., Kaboski, J. P., \& Shin, Y. (2012). The macroeconomics of microfinance (No. w17905). National Bureau of Economic Research.

- Bui, L. T. V. (2014). Microfinance and Poverty Alleviation: Does Credit Access Contribute to Reduce Household Poverty in Vietnam?.

- Chowdhury, M. J. A., Amin, S., \&Farha, T. (2012). Access to Credit and Women Entrepreneurship: Evidence from Bangladesh. 
- Coleman, B. E. (1999). The impact of group lending in Northeast Thailand. Journal of Development Economics, 60(1), 105-141.

- $\quad$ Field, E., Pande, R., Papp, J., \&Rigol, N. (2013). Does the classic microfinance model discourage entrepreneurship among the poor? Experimental evidence from India. The American Economic Review, 103(6), 2196-2226.

- Karlan, D., \& Valdivia, M. (2011). Teaching entrepreneurship: Impact of business training on microfinance clients and institutions. Review of Economics and Statistics, 93(2), 510-527.

- $\quad$ Khandker, S. R. (2003). Micro-finance and poverty: evidence using panel data from Bangladesh. World Bank Policy Research Working Paper, (2945).

- $\quad$ Khandker, S. R. (2005). Microfinance and poverty: Evidence using panel data from Bangladesh. The World Bank Economic Review, 19(2), 263-286.

- Kholis, N., (2009). "The Contribution of Islamic Microfinance Institution in Increasing Social Welfare in Indonesia (A Case Study of Bmt's Role at Pakem Market Micro Traders Yogyakarta)”. In International Seminar on Islamic Financial Engineering. (2009):1-25

- Newey, W. K. (1987). Efficient estimation of limited dependent variable models with endogenous explanatory variables. Journal of Econometrics 36: 231-250.

- $\quad$ NSCKR, National Statistics Committee Of Kyrgyz Republic, http://stat.kg/index.php?option=com_content\&task=view\&id=37\&Itemid=101, accessed in May 2015

- $\quad$ Pitt, M. M., \&Khandker, S. R. (1998). The impact of group-based credit on poor households in Bangladesh: Does the gender of participants matter? Journal of Political Economy, 106, 958-996.

- Roodman, D. (2009). Estimating fully observed recursive mixed-process models with cmp. Available at SSRN 1392466.

- Roodman, D., \&Morduch, J. (2014). The impact of microcredit on the poor in Bangladesh: Revisiting the evidence. Journal of Development Studies, 50(4), 583-604.

- Sultakeev, Kadyrbek. (2012) “Kırgızistan'daYoksulluğuÖnlemedeMikrokrediUygulamaları” (Microcredit practice and poverty alleviation in Kyrgyzstan), Master Thesis, Kyrgyz-Turkish Manas University, 2012.

- The Kyrgyz Republic Law “About restriction of usurious activities in the Kyrgyz Republic”, Public Law 163, 24 July, 2013

- The Kyrgyz Republic Law “On Micro-finance organizations in the Kyrgyz Republic”, Public Law 124, (23 July, 2002) 3.

- Valdivia, M. (2011). Teaching entrepreneurship: Impact of business training on microfinance clients and institutions. Review of Economics and Statistics, 93(2), 510-527.

- Wang, X. (2013). The Impact of Microfinance on the Development of Small and Medium Enterprises: The Case of Taizhou, China. 


\title{
Workplace Learning Cultures, Learning Potential and Important Work Outcomes among Managerial Employees in Five-Star Turkish Hotels
}

\author{
Kadife Koyuncu (Çanakkale Onsekiz Mart University, Turkey) \\ Dr. Bekir Esitti (Çanakkale Onsekiz Mart University, Turkey) \\ Prof. Dr. Ronald J Burke (York University, Canada) \\ Prof. Dr. Mustafa Koyuncu (Çanakkale Onsekiz Mart University, Turkey)
}

\begin{abstract}
This research investigated the relationship of perceived workplace learning culture, workplace learning potential, perceived employability, feelings of psychological empowerment, important work outcomes, and selfreported assessments of service quality among supervisors and managers in five star hotels in Turkey. Data were collected from 205 managers, an eighty-nine percent response rate, from twelve hotels, using anonymously completed questionnaires. Work outcomes included job satisfaction, perceptions of service quality and intent to quit. Managerial Self-efficacy was significantly related to perceptions of workplace learning culture, opportunities for learning, employability and all other work outcomes. In addition, stronger workplace learning cultures and more opportunities for learning also had positive effects of several work outcomes.

The present research has limitations which should be noted to better assess the results. First, all data were collected using self-report questionnaires with the possibility of response set tendencies and common method biases. Second, all data were collected at one point in time making it challenging to address issues of causality. Third, although the sample was relatively large, all respondents came from high quality properties in only one large city in Turkey (Istanbul), thus the extent to which our findings would apply to hotels in other regions or hotels of lower quality is indeterminate.

Practical implications include training supervisors on ways to develop and support a workplace learning culture, training all employees on the benefits of personal efficacy and ways to increase it, and training employees on the benefits of their own learning and ways to enhance this.
\end{abstract}

\section{Introduction}

This study examined the relationship of workplace learning culture, opportunities and sources of workplace learning, self-perceptions of employability, important work outcomes such as job satisfaction, feelings of empowerment, quality of service provided, and intentions to quit among managers working in five- star hotels in Turkey. The motivation and performance of these employees are significant factors in hotel effectiveness and success (Kusluvan, 2003; Kusluvan, 2003; Kusluvan, et. al, 2012).

Interestingly, workplace learning cultures, staff empowerment and staff employability may even play a larger role in the performance of hospitality organizations given both the negative images and the negative realities of working in this sector such as low pay, routine jobs, long work hours, uncaring supervision, unpleasant working conditions, limited career advancement, and high levels of staff turnover (Baum, 2007; Kusluvan, et. al, 2012).

The hospitality and tourism sector in Turkey

The tourism and hospitality sector is a major and growing contributor to the Turkish economy (Duman and Tosun, 2010; Gokovali, 2011). The tourism and hospitality sector has been shown to be significant contributor to economic growth in Turkey as a whole (Gunduz and Haemi-J, 2005). Turkey ranks in the top ten countries in the world in both numbers of tourists and tourism revenues. Thus providing high quality service and experiences is important not only to continuing and increasing success in an increasingly competitive environment, but also as a significant contributor to the economic fortunes of Turkey as a whole.

Service quality

Service quality has been found to be is a major factor in the success of organizations in the hospitality and tourism sector (Zemke and Schaaf, 1989; Bowen and Lawler, 1995). Organizational cultures and climates that foster high levels of service quality include several features such as managerial leadership, giving high priority to human resource management policies and practices, providing staff training and development opportunities, and encouraging staff to help each other perform their jobs (Kusluvan, et. al, 2012).

Review of the literature

Organizational learning

Researchers and writers have discussed the role that organizational learning plays in organizational success (Salas and Von Glinow, 2008, Wilhelm, 2006). But organizations do not learn, individuals within organizations learn. All organizational learning then results from the learning of individuals (Argyris, 2003, 1997). As a consequence, organizations that support and encourage employee workplace learning will derive benefits 
(Denton, 1998; Teare, 19978; Teare and Rayner, 2002). Learning and knowledge creation become a competitive advantage (Nonaka 1991).

Learning in organizations takes place at all levels. Li, et. al, (2011) document ways that newly appointed hotel general managers lean how to manage their hotels, Magnini (2009) illustrates how expatriate hotel employees learn how to function in new countries and cultures, and Doyle, et. al, (2012) show how people in low level front lie service jobs engage in informal workplace learning.

\section{Workplace learning cultures}

Some organizations are learning organizations, possessing learning cultures. Human resource development policies and practices have a central role to play in the development and support of a workplace learning culture. Marsick and Watkins (2003) suggest that informal learning occurs across three levels: individual, work team, and organizational. They developed a measure of the learning organizational cultures having seven dimensions and by 2003 had collected data from over 200 organizations using their measures. They reported that these dimensions predicted organization outcomes such as knowledge and financial performance. We use a shortened version of their measures in our investigation.

Lopez, et. al, (2005), in a study of 195 Spanish firms employing 200 or more employees found that high performance human resource management practices (e.g., hiring, training, compensation, employee participation efforts) increased levels of organizational learning, which in turn had a positive effect on three indirect measures of business financial performance.

Law and Ngai (2008), in a study of 134 firms in manufacturing and wholesale retail operations in Hong Kong, reported higher levels of firm performance in firms indicating higher levels of knowledge sharing and learning behaviors.

Creating a workplace learning culture is particularly relevant for the hospitality and tourism sector on at least three fronts. First, the bulk of their workforces tends to be relatively young, new to their jobs, and having the potential for high levels of turnover. A workplace learning culture would help these relative newcomers master their jobs in a more timely fashion. A workplace learning culture might also interest these employees in other more responsible and higher level jobs cutting down turnover. Finally, development and support of a workplace learning culture could address some of the common negatives in the hospitality sector such as routine jobs, limited upward mobility, and poor supervision.

\section{Learning potential of workplaces}

Ideally, individuals can learn throughout their working and non-working lives. Such learning benefits individuals and organizations. Individuals remain productive and adaptable in their jobs, increase their prospects for both internal mobility and promotion and their employability with other organizations; organizations remain successful in an increasingly competitive international marketplace. There is also increasing pressure on individual and learning as new knowledge and fast changing technologies appear.

Much work-based learning occurs informally and takes place with workplaces. Individuals can learn by observing others, by taking with others, by reflecting on one's work experiences and results, and from advice from one's supervisors. Workplace learning has generally been unplanned.

Nikolova, et. al, (2014) propose and develop a measure of two types of potential work-based learning: interactional resources from others (from colleagues, from supervisors) and task-based learning (from reflection and from experimentation). We use their measures in this study.

Employability

One individual and organizational by-product of workplace learning is increased employability on the part of individual employees. Rothwell and Arnold (2007, p.25) define employability as

"The individual's ability to keep the job one has, and of getting job ones desires". One of the consequences of work-based learning by individuals is that they acquire attitudes, behaviors, skills and knowledge reflected in a high likelihood of their retaining their jobs and advancing their careers both inside and outside their current workplaces (van der Heijde and van der Heijden 2006). Employability helps individuals remain successful in their jobs and careers and contributes to organizational success (van der Heijden, et. al,, 2009). Highly employable individuals help their organizations respond to job changes and increasing demands for new products and services. Some workplaces are more supportive of worker employability than are others (Nauta, et. al, 2009). Employability has been found to be related to objective career success for early career employees and to number of promotions for late career employees (van der Heijden, et. al, 2009). In a study of 215 Dutch nonacademic university staff both informal and formal learning opportunities increase employability.

Van Dam (2004), in a study of 339 employees at various levels of a Dutch bank, found that employability orientation was positively related to openness, initiative, and a managerial career anchor and negatively related to tenure, continuance commitment, and technical competence and security career anchors. Employability orientation, not surprisingly was a strong predictor of employability activities (e.g., keeping informed of internal job openings, managing one's career, engaging in developmental activities). 
Wittekind, et. al, (2010), in a longitudinal study of 465 employees form four companies in Switzerland, reported that education, support for career and skill development, current level of job-related skills, and willingness to change jobs were significant predictors of perceived employability; however willingness to develop new competencies, opportunity awareness and self-presentation skills had no relationship with perceived employability.

But there may also be a downside to increasing managerial employability. De Cuyper and De Witte (2011) consider what they term "the management paradox"; high levels of employability will be associated with greater employee intentions to quit and seek employment elsewhere, so why increase employee employability? Interestingly, self-reported employability was found to be positively related to higher levels of organizational commitment and individual performance in a study of 551 workers in Belgium.

\section{Self-efficacy}

It has been suggested that some individuals are more likely to take advantage of possibilities associated with opoortunhi9ttes for learning and growth and interest in increasing their employability. One individual differences characteristic likely to be relevant here is the concept of self- efficacy. Maddux (2002, p.270) defines selfefficacy as "what I believe I can do with my skills under certain conditions". If people believe they can produce desired outcomes through their actions they will persevere despite obstacles. Stajkovic and Luthans (1998), in a meta-analysis of 114 studies having 157 samples, $(n=21,616)$ found a significant correlation between selfefficacy and a variety of work-related perforce outcomes. Others (Luszczynska, et. al, 2005; Luszczynska, et. al, 2005) have reported positive associations of self-efficacy and a variety of favorable well-being outcomes in a number of different countries as well.

\section{The present study}

In this study, we consider the relationship of employee perceptions of the presence of a workplace learning culture, potential sources of their learning, benefits of any such learning to their employability levels of felt psychological empowerment, important work outcomes (job satisfaction, intent to quit), and assessments of quality of service provided to guests and clients.

We examine the following general hypotheses.

1. Personal demographic characteristics, including self-efficacy, will be associated with perceptions of workplace learning culture, potential sources of workplace learning, and various work outcomes.

2. Workplace learning culture and potential sources of workplace learning will be positively associated selfreported employability, with psychological empowerment, job satisfaction, and assessments of service quality provided to clients and negatively associated with intention to quit.

\section{Method}

\subsection{Procedure}

Data were collected using anonymously completed questionnaires from full-time employees working in managerial positions in twelve five-star hotels in Istanbul Turkey. All hotels operated on a year round basis. A total of 230 questionnaires were distributed to executive managers or human resource managers of each hotel. Questionnaires were then administered to employees working in supervisory or managerial positions. Completed questionnaires were then placed in container in the human resource department. Two hundred and five questionnaires, an $89 \%$ response rate, were obtained. The questionnaire was translated from English to Turkish than back again to English using the back-translation procedure by individuals fluent in both languages. Hotels ranged in size from 134 to 270 total employees with numbers of managers ranging from 14 to 50 .

\subsection{Respondents}

Table 1 presents the personal demographic and work characteristics of our sample $(\mathrm{n}=205)$. All worked fulltime and all had supervisory responsibilities. Most were male (56\%), were between 31 and 40 years of age $(83 \%)$, were married (54\%), without children (26\%), had bachelor's level degree educations $(67 \%)$, worked in their present jobs 5 years or less $(50 \%)$, and worked for their present hotels between 6 to 10 years $(43 \%)$, most were in lower management positions ( $56 \%$ ), worked between 46 and 50 hours per week (39\%), and worked in a variety of departments, most being in food and beverage and housekeeping ( $25 \%$ and $22 \%$, respectively).

\subsection{Measures}

All measures used in the research were translated from English to Turkish and back by members of the research team fluent in both languages using the back translation method.

Personal and work situation demographics

Personal and work setting characteristics were assessed by a number of single items. The former included: gender, age, current work status, current marital and parental status, and level of education. The latter included hours worked per week, organizational level, job tenure, organizational tenure, and whether respondent had supervisory duties. These items served as control variables in some of our analyses. 


\section{Self-efficacy}

Self-efficacy was measured by a ten item scale $(\alpha=.85)$ developed and validated by

Schwarzer and Jerusalem (1995). Respondents indicated how true they felt each item was as a description of themselves on a five point Likert scale ( 1 =not at all true, $3=$ moderately true, $5=$ exactly true). One item was "I can always manage to solve difficult problems if I try hard enough."

Workplace learning culture

Workplace learning culture was assessed by a 21 item scale $(\alpha=.96)$ developed by Marsick and Watkins (2003) and Yang, et. al, (2004), items falling at three levels: individual, work team, and organizational. Respondents indicated their agreement with each item on a six point Likert scale (1=Almost never, 6=Always). Sample items included "In my organization people help each other learn." "In my organization, teams/workgroups revise their thinking as a result of group discussions or information collected." and "My organization supports employees who take calculated risks." Scores on the three levels of workplace learning culture were positively and significant inter-correlated (average inter-correlation $=.44, \mathrm{p}<.001$ ), thus a composite measure was developed.

\begin{tabular}{|c|c|c|c|c|c|}
\hline Gender & $\underline{N}$ & $\underline{\%}$ & $\underline{\text { Age }}$ & $\underline{N}$ & $\underline{\%}$ \\
\hline Male & $\overline{114}$ & $\overline{55.6}$ & $\overline{30}$ or less & $\overline{38}$ & $\overline{18.7}$ \\
\hline \multirow[t]{2}{*}{ Female } & 91 & 46.4 & $31-35$ & 64 & 31.1 \\
\hline & & & $36-40$ & 61 & 31.8 \\
\hline$\underline{\text { Parental Status }}$ & & & $41-45$ & 30 & 14.6 \\
\hline Children & 99 & 48.5 & 46 or more & 12 & 5.9 \\
\hline \multirow[t]{2}{*}{ No Children } & 105 & 51.5 & & & \\
\hline & & & Marital Status & & \\
\hline$\underline{\text { Department }}$ & & & Single & 94 & 45.9 \\
\hline Housekeeping & 11 & 5.4 & Married & 111 & 54.1 \\
\hline Food and beverage & 51 & 24.9 & & & \\
\hline Front office & 41 & 20.0 & Education & & \\
\hline Accounting & 26 & 12.7 & $\overline{\text { Elementary school }}$ & 2 & 1.0 \\
\hline Human resources & 44 & 21.5 & High school & 38 & 18.5 \\
\hline \multirow[t]{2}{*}{ Other } & 32 & 15.1 & Bachelor's degree & 137 & 66.8 \\
\hline & & & Master's & 27 & 13.2 \\
\hline Hours Worked & & & Doctorate & 1 & .5 \\
\hline 45 or less & 46 & 22.5 & & & \\
\hline $46-50$ & 80 & 39.0 & Organizational level & & \\
\hline $51-55$ & 56 & 27.4 & Lower management & 115 & 56.1 \\
\hline \multirow[t]{2}{*}{56 or more } & 23 & 11.3 & Middle management & 67 & 32.7 \\
\hline & & & Senior management & 23 & 11.2 \\
\hline \multicolumn{6}{|l|}{ Organizational tenure } \\
\hline 5 year or less & 80 & 38.9 & $\underline{\text { Job tenure }}$ & & \\
\hline $6-10$ years & 88 & 43.0 & $\overline{5 \text { year or less }}$ & 103 & 50.3 \\
\hline $11-15$ years & 32 & 15.7 & $6-10$ years & 88 & 42.9 \\
\hline 16 years or more & 5 & 2.5 & $11-15$ years & 13 & 6.4 \\
\hline
\end{tabular}

Table 1: Demographic Characteristics of Sample

\section{Workplace learning potential}

Workplace learning potential was measured by a twelve item scale $(\alpha=.89)$ developed and validated by Nilolova, et. al, (2014). Four dimensions were included, each measured by three items. Respondents indicated how applicable each item was to their current work situation on a five point Likert scale (1=not applicable at all; $5=$ completely applicable). Dimensions and a sample item of each included: learning through Reflection $(\alpha=.78)$ "In my work I am given the opportunity to contemplate about different work methods; Learning through Experimentation $(\alpha=.62)$. "In my job I can try different work methods even if that does not deliver any useful result." Learning from colleagues $(\alpha=.76)$ "My colleagues tell me if I make mistakes in my work" and Learning from Supervisor $(\alpha=.93)$ "My supervisor helps me see my mistakes as a learning experience." These four scales were positively and significantly inter-correlated (average inter-correlation $=.52, \mathrm{p}<.001$ ), so a composite measure was created.

\section{Perceived employability}

Perceived employability was assessed by nine items $(\alpha=.75)$ developed and validated by Wittekind, et. al, (2010). Respondents indicated their agreement with each item as they described themselves at work on a five point Likert scale ( $1=$ strongly disagree; $3=$ neither agree nor disagree, $5=$ strongly agree) One item was "If my organization offered me a possibility to obtain new work experiences, I would take it." Two aspects of employability were addressed: Employability orientation -5 items $(\alpha=.62)$ and employability activities -4 items 
( $\alpha=.72) \mathrm{S}$ Scores on the two scales were positively and significantly correlated $(r=.48, p<.001)$, thus a composite score was created.

Psychological empowerment

Psychological or personal feelings empowerment was measured by a twelve item scale $(\alpha=.87)$ developed and validated by Spreitzer (1996, 1995). This measure tapped four dimensions, each addressed by three items. Respondents indicated their agreement with each item on a seven-point Likert scale (1=very strongly disagree; $4=$ neutral, $7=$ very strongly agree). Meaning $(\alpha=.92$.) "The work I do is meaningful to me." Competence $(\alpha=.68)$ "I am confident about my ability to do my job." Self-determination $(\alpha=89)$ "I have significant autonomy in determining how I do my job." and Impact $(\alpha=.90)$ "My impact on what happens in my department is large". These four scales were positively and significantly inter-correlated (average inter-correlation $=.36, p<.001$ ), thus a composite measure was created.

Work outcomes

Three work outcomes were included.

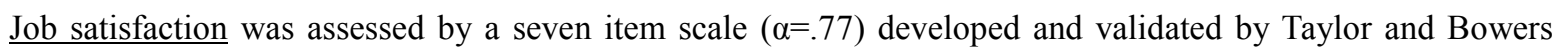
(1972). Respondents indicated their agreement with each item on a five-point Likert scale (1-very dissatisfied, $3=$ neither satisfied nor dissatisfied; $5=$ very satisfied. One item was "All in all, how satisfied are you with the persons in your work group?"

Service excellence

Quality of service provided by respondents to guests or clients was assessed by a six item scale $(\alpha=.81)$ developed and validated by Peccei and Rosenthal (2001) Respondents indicated their agreement with each item on a five-point Likert scale $1=$ strongly disagree; 3 -neither agree nor disagree, 5=strongly agree. An item was "I am strongly committed to service excellence".

Intent to quit was measured by two items $(\alpha=.61)$ used by Burke (1991). Respondents indicated "yes or no" for both items. One item was "Are you currently looking for a different job in a different organization?"

\section{Results}

Hierarchical regression analyses

Hierarchical regression analyses were undertaken in which predictor variables were entered in blocks in a specified order. In the first of two sets of hierarchical regression analyses, work outcome variables were separately regressed on three blocks of predictors. The first block of predictors, Personal demographics $(n=5)$ included gender, age, marital status, parental status and level of education. The second block of predictors Work situation characteristics $(n=4)$ included Job tenure, Organizational tenure, Organizational level, and Work hours. The third block of predictors included the measure of Self efficacy. When a block of predictors accounted for a significant amount or increment in explained variance on a given work outcome $(p<.05)$, individual measures within these blocks having independent and significant relationships with this work outcome $(\mathrm{p}<.05)$ were identified. In the second set of hierarchical regression analyses, two additional blocks were added. The fourth block included the measure of Workplace Learning Culture, and the fifth block included the measure of Workplace Learning Opportunities.

Personal and work situation characteristics and work outcomes

Table 2 presents the results of the first set of hierarchical regressions. The following comments are offered in summary. First, all three blocks of predictors accounted for a significant amount or increment in explained variance on Workplace Learning Culture. Managers who were single, at higher organizational levels, and indicating higher levels of self-efficacy reported higher levels of Workplace Learning Culture $(\mathrm{Bs}=-.17, .16$ and 41 , respectively)

Second, two blocks of predictors accounted for significant increments in explained variance on Workplace Learning Opportunities. Managers indicating higher levels of self-efficacy also reported more workplace learning Opportunities $(\mathrm{B}=.42)$.

Third, all three blocks of predictors accounted for a significant amount or increment in explained variance on Employability. Managers who were older, had lower levels of education, and indicated higher levels of selfefficacy also reported greater employability $(\mathrm{Bs}=.23,-.19$, and .44, respectively).

Fourth, all three blocks of predictors accounted for a significant amount or increment in explained variance on Job Satisfaction. Managers having longer organizational tenures and managers indicated higher levels of selfefficacy also reported greater Job Satisfaction ( $\mathrm{Bs}=.18$ an $\mathrm{d} .32$, respectively)

Fifth, all three blocks of predictors accounted for a significant amount or increment in explained variance on Psychological Empowerment. Managers indicated higher levels of self-efficacy also reported higher levels of Psychological Empowerment $(\mathrm{B}=.36)$ 
Sixth, two blocks of predicts accounted for significant increments in explained variance on perceptions of Quality of Service. Managers indicating higher levels of self-efficacy also reported higher levels of Quality of Service $(B=.51)$.

Finally, only one block of predictors accounted for a significant amount or increment in explained variance on Intent to quit. Managers indicating higher levels of self-efficacy also reported less intent to quit $(\mathrm{B}=.23$.)

Two more general observations are worth noting. First, most of the predictors accounted for significant amounts or increments in explained variance on these work outcomes. Second, levels of self-efficacy had significant relationships with all work outcomes included in the study.

Workplace learning culture, opportunities for workplace learning, and work outcomes

Table 3 presents the results of the second set of hierarchical regressions. The following comments are offered in summary. First, all five blocks of predictors accounted for significant amount or increment in explained variance on Employability. Older managers, managers having more education, manager indicating higher levels of self-efficacy, and managers describing higher levels of both workplace learning culture and workplace learning opportunities indicated higher levels of employability $(\mathrm{Bs}=.19, .19, .23, .30$ and 24, respectively).

Second, four of the five blocks of predictors accounted for a significant amount or increment in explained variance on job satisfaction. Managers having longer organizational tenures and managers describing higher levels of workplace learning culture also reported higher levels of Job Satisfaction (Bs=.17 and .58, respectively).

Third, four of the five blocks of predictors accounted for a significant amount or increment in explained variance on Psychological Empowerment. Managers having longer job tenures, those scoring higher on selfefficacy, and those describing a stronger workplace learning culture also indicated higher levels of psychological empowerment $(\mathrm{Bs}=.17, .28$ and 16 , respectively)

Fourth, three blocks of predictors accounted for significant increments in explained variance on perceptions of Quality of Service. Managers who were younger, and managers indicating higher levels of self-efficacy also reported more favorable perceptions of Quality of service ( $\mathrm{Bs}=-.21$ and .44, respectively).

Finally, three blocks of predictors accounted for significant increment $\mathrm{s}$ in explained variance on Intent to quit. Managers indicating stronger Workplace learning cultures and more opportunities for workplace learning indicated lower intentions to quit ( $\mathrm{Bs}=.20$ and .37 , respectively).

Four more general observations follow from these findings. First, predictor variables generally had significant relationships with these work outcomes. Second, managerial self-efficacy remained a significant predictor of Employability, Psychological Empowerment and Quality of Service perceptions. Third, Workplace Learning Culture had significant relationships with four of the five work outcomes. Fourth, Workplace Learning Opportunities had significant relationships with two work outcomes (Employability and Intent to quit).

\section{Additional observations}

Some broader observations can also be drawn from these findings. Self-efficacy emerged as an important individual difference characteristic associated with the empowerment measures. This suggested that individual attitudes, skills and feelings of personal confidence made employees more amenable and embracing of empowerment practices and were more likely to take advantage of the opportunity extended to them by higher levels of learning opportunities.

\section{Discussion}

The results of our research provide considerable support for the hypotheses underlying our work on several fronts. First, managerial self-efficacy emerged as a significant predictor of each work outcome. Second. Workplace learning culture, and associated workplace learning opportunities, also had significant relationships with some -but not all- of the work outcomes.

Our findings on the central role of personal efficacy (see Table 2) in being associated with both capitalizing on workplace learning processes and learning opportunities and sources, as well as being associated with valued work outcomes, was consistent with a growing body of research evidence (Luszcynska, et. al, 2005; Luszcynska, et. al, 2005; Maddox, 2002; Stajkovic and Luthans, 1998).

In addition, our findings on the benefits of creating workplace learning cultures and a greater number of learning sources and opportunities was also consistent with the work of others (Yang, et. al, 2004; Msarscik and Watkins, 2003; Nikolova, et. al,, 2014) 
Work outcomes

$\underline{\mathrm{R}}$

Workplace learning culture $(\mathrm{n}=199)$

Personal demographics

Marital status (-.17)

Education (-.17)

Work situation characteristics

Organizational level (.16)

Self-Efficacy (.41)

Learning opportunities ( $\mathrm{n}=203$ )

Personal demographics

Work Situation characteristics

Self-Efficacy (.42)

Employability ( $\mathrm{n}=201)$

Personal demographics

Age (.23)

Education (.19)

Work situation characteristics

Self-efficacy (.44)

Job satisfaction $(\mathrm{n}=202)$

Personal Demographics

Work situation characteristics

Organizational tenure (.18)

Self-efficacy (.32)

Psychological empowerment ( $\mathrm{n}=202$ )

Personal demographics

Work situation characteristics

Self-efficacy(.44)

Quality of service ( $\mathrm{n}=203$ )

Personal demographics

Work situation characteristics

Self-efficacy (. 51)

Intent to quit ( $\mathrm{n}=203$ )

Personal demographics

Work situation characteristics

$\underline{\text { Self-efficacy (.23) }}$

$\underline{\mathrm{R}^{2}}$

$\underline{\Delta \mathrm{R}^{2}}$

$\underline{P}$

.14

.14

.07

.13

.001

.34

.09

.12

.25

.09

.03

.13

.01

NS

.001

.41

.17

.001

.47

.60

.22

.05

.14

.001

.001

.32

.50

.10

.10

.07

.001

.01

.25

.08

.001

.38

.001

.06

.10

.01

.21

.26

.57

$$
.04
$$

.04

$$
.09
$$

NS

.00

$.19 \quad .001$

$\begin{array}{llll}.13 & .02 & .02 & \text { NS } \\ .22 & .05 & .03 & \text { NS } \\ .29 & .08 & .03 & .01\end{array}$

Table 2: Personal and Work Situation Characteristics and Work Outcomes

\subsection{Practical Implications}

We have come to better understand factors associated with increased levels of workplace learning (Crouse, et. al, 2011; Hicks, et. al, 2007; Lohman,2009, 2006, 2005) for example Crouse, et. al, (2011) review the literature on workplace learning strategies, barriers and facilitators. Workplace learning strategies refer to ways that employees acquire new knowledge, skills and attitudes. Crouse and her colleagues grouped learning strategies into nine categories: taking courses, and programs, doing new tasks at work, working with others, e-learning, watching others, by trial and error, reading and conducting research, reflecting on one's actions, and trying to repeat what was based on learning. Barriers to learning were things that prevented, interrupted, impeded and stopped learning for moving forward. They identified nine barriers to workplace learning: Learning lack of resources, limited access to training and equipment, technological constraints, personal factors (e.g., fear of failure, low motivation), interpersonal constraints (others unwilling to help), workplace culture constraints (culture does not support learning), too much and too rapid change, little power to make decisions), and limited value in formal training offerings (poor instructors, too much to learn). Facilitators were things that motivated, sustained and heightened learning. They identified six categories of facilitators: the role and help of others, training from others, job-related experiences and needs, increased resources, work cultures that support learning, and personal attributes (being able to ask for help, being open to new ideas). Organizations need to increase facilitating factors and reduce barriers to workplace learning. 
Work Outcomes

Employability $(\mathrm{n}=198)$

Personal demographics

Age (.19)

Education (.19)

Work situation characteristics

Self-efficacy(.23)

Workplace learning culture(.30)

Workplace learning opportunities (.24)

\section{$\underline{\mathrm{R}}$}

Job Satisfaction $(\mathrm{n}=197)$

Personal demographics

Work situation characteristics

Organizational tenure (.17)

Self-efficacy

Workplace learning culture (.58)

Workplace learning opportunities

Psychological empowerment ( $\mathrm{n}=198$ )

Personal demographics

Work situation characteristics

Job tenure (.17)

Self-efficacy (.28)

Workplace learning culture (.16)

Workplace learning opportunities

Quality of service ( $\mathrm{n}=199)$

Personal demographics

Work situation characteristics

Self-efficacy (.44)

Workplace learning culture

Workplace learning opportunities

Intent to quit ( $\mathrm{n}=199)$

Personal demographics

Work situation characteristics

Self-efficacy

Workplace learning culture (.30)

Workplace learning opportunities (.37)

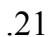

.35

.57

.58

.59

\section{3}

.21

.29

.43

.51
.42

.62

.71

.73

$\underline{\mathrm{R}^{2}}$

$\underline{\Delta \mathrm{R}^{2}}$

$\underline{P}$

.001

.05

.001

.001

.001

.001

.01

.001

$\begin{array}{lll}.51 & .27 & .001 \\ .52 & .01 & \text { NS }\end{array}$

$\begin{array}{lll}.51 & .27 & .00 \\ .52 & .01 & \text { NS }\end{array}$

.73

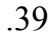

.15

.15

.001

.46

.21

.06

.01

.56

.32

34

.35

.001

.01

$\begin{array}{ll}.01 & .01 \\ .01\end{array}$

\section{.04}

.12

$$
.33
$$

$\begin{array}{ll}.04 & \text { NS } \\ .08 & .01 \\ .21 & .001 \\ .01 & .05 \\ .01 & \text { NS }\end{array}$

Table 3: Workplace Learning Culture, Workplace Learning Opportunities and Work Outcomes

Workplaces interested in increasing workplace learning need to first position this as an important part of their business strategy and then communicate this throughout their organizations. They then need to develop human resource management policies and practices, provide resources (e.g, technology, time, space to think and talk), to support this priority. Employees should receive training in the range of informal learning strategies that are possible.

Workplaces interested in developing and support a learning culture need to develop cultures of trust, learning and innovation, increase levels of managerial and supervisory support, increase individual confidence in sharing useful knowledge, and address cross cultural/international issues (Teare, 1998; Teasre and Rayner, 2002). The good news is that there are established and well validated measures of workplace learning culture (Marsick and Watkins, 2003) as well as of workplace learning opportunities and sources (Nikoloava, et. al, 2014) that could be used to diagnose where they currently stand in terms of workplace learning possibilities and initiate cultural change initiatives.

Organizations should also undertake efforts to increase employee self-efficacy. Maddox (2002) writes that selfefficacy beliefs develop through experience over time. Self-efficacy can be increased by having individuals evaluate their own performance experiences. By encouraging individuals to take small risks that could lead to small successes, by seeing one's successes as having a positive impact, and by creating situations where individuals experience success based on their own efforts. 


\subsection{Future Research Directions}

Our understanding of the benefits of workplace learning would be increased by including assessments of ways in which informal learning outcomes have been transferred to actual job performance. In addition, examining ways that formal training and informal workplace learning can augment each other would be useful.

\section{References}

- Argyris, 2003. “A life full of learning”, Organizational Studies, 24, p. 1178-1197.

- Argyris, 1997. "Double loop learning in organizations”, Harvard Business Review, 55, p. 115-124.

- Baum, 2007. "Human resources in tourism: Still waiting for change”, Tourism Management, 28, p. 13831399.

- Bowen and Lawler, 1995. "Empowering service employees", Sloan Management Review, 36, p. 73-84.

- Burke, 1991. "Early work experiences of female and male managers and professionals: Reasons for optimism?”, Canadian Journal of Administrative Sciences, 8, p. 224-230.

- Crouse, Doyle, and Young, 2010. "Workplace learning strategies, barriers, facilitators and outcomes: A qualitative study among human resource management professionals "Human Resource Development International,14,p.39-55

- DeCuyper and De Witte, 2011. "The management paradox: self-rated employability and organizational commitment and performance", Personnel Review, 40, p. 152-172.

- Denton, 1998. Organizational learning and effectiveness. Routledge, London.

- Duman and Tosun, 2010. "Current developments in Turkish tourism", Anatolia: An International Journal of Tourism and Hospitality Research, 21, p. 5-9.

- Gokovali, 2010. "Contribution of tourism to economic growth in Turkey", Anatolia: An International Journal of Tourism and Hospitality Research, 21, p. 139-153.

- Gunduz and Hatemi-J, 2005. "Is the tourism-led growth hypothesis valid for Turkey?" Applied Economics Letters, 12, p. 499-504.

- Hicks, Bagg, Doyle, and Young, 2007. “Canadian accountants: Examining workplace learning”, Journal of Workplace Learning, 19, p. 61-77.

- Kusluvan, 2003. Managing employee attitudes and behavior in the tourism and hospitality industry. Nova Science, New York.

- Kusluvan, Kusluvan, Ilhan, and Buyruk, 2012. "A review of human resources management issues in the tourism and hospitality industry”, Cornell Hospitality Quarterly, 51, p. 171-214.

- Law and Ngai, 2008. "An empirical study of the effects of knowledge sharing and learning behaviors on firm performance”, Expert Systems with Applications, 34, p. 2342-2349.

- Li, Gray, Lockwood, and Buhalis, 2011. "Learning about managing the business in the hospitality industry", Human Resource Development Quarterly, 24, p. 525-559.

- Lohman, 2009. "A survey of factors influencing the engagement of information technology professionals in informal learning activities”, Information Technology, Learning, and Performance Journal, 25, p. 43-53.

- Lohman, 2006. "Factors influencing teachers' engagement in informal learning activities", Journal of Workplace Learning, 18, p. 141-156.

- Lohman, 2005. "A survey of factors influencing the engagement of two professional groups in informal workplace learning activities", Human Resource Development Quarterly, 16, p. 512-527.

- Lopez, Montez Peon, and Vazquez Ordas, 2006. "Human resource management as a determining factor in organizational learning”, Management Learning, 37, p. 215-230.

- Luszczynska, Gutierrez-Dona, and Schwarzer, 2005. "General self-efficacy in various domains of human functioning: evidence from five countries”, International Journal of Psychology, 40, p. 80-89.

- Luszczynska, Schoklz, and Schwarzer, 2005. "The General Self-Efficacy Scale: Multicultural validation studies. Journal of Psychology, 139, p. 439-457.

- Maddux, 2002. Self-efficacy: The power of believing you can. In C. R. Snyder and s. J. Lopez (eds.) Handbook of Positive Psychology. Oxford University Press, New York. p. 27-287.

- Magnini, 2009. "An exploratory investigation of the real-time training modes used by hotel expatriates", International Journal of Hospitality Management, 28, p. 513-518.

- Marsick and Watkins, 2003. "Demonstrating the value of an organization's learning culture: The dimensions of the Learning Organization Questionnaire", Advances in Developing Human Resources, 5, p. 132-151. 
- Nauta, van Vianen, van der Heijden, van Dam, and Willemsen, 2009. "Understanding the factors that promote employability orientation: The impact of employability culture, career satisfaction, and role breadth self-efficacy", Journal of Occupational and Organizational Psychology, 82, p. 233-251.

- Nikolova, Van Ruysseveldt, De Witte, and Syroit, 2014. "Work-based learning: Development and validation of a scale measuring the learning potential of the workplace (LPW)", Journal of Vocational Behavior, 84, p. $1-10$.

- Nonaka, 1991. "The knowledge creating company", Harvard Business Review, 69, p. 96-104.

- Peccei and Rosenthal, 2001. "Delivering customer-oriented behavior through empowerment: An empirical test of HRM assumptions”, Journal of Management Studies, 38, p. 833-857.

- Rothwell and Arnold, 2007. "Self-perceived employability: Dimensions and validation of a scale" Personnel Review, 37, p. 23-41.

- Salas and Von Glinow, 2008. Fostering organizational learning: Creating and maintaining a learning culture. In R. J. Burke \& C.L. Cooper (eds), Building more effective organizations: HR management and performance and practice. Cambridge University Press, Cambridge. p. 207-227.

- Schwarzer and Jerusalem, 1995. Generalized self-efficacy scale. In J. Weinman, S. Wright \& M. Johnston (eds.) Measures in health psychology: A user's portfolio. Causal and control beliefs. Nelson Windsor, p.35-37.

- Spreitzer, 1996. "Social structural characteristics of psychological empowerment", Academy of Management Journal, 39, p. 483-504.

- Spreitzer, 1995. "Psychological empowerment in the workplace: dimensions, measurement, and validation", Academy of Management Journal, 38, p. 1442-1465.

- Stajkovic and Luthans, 1998. "Self-efficacy and work-related performance: A meta-analysis", Psychological Bulletin, 124, p. 240-261.

- Taylor and Bowers, 1972. Survey of organizations: A machine-scored standardized questionnaire instrument. MI.: Institute for Social Research, Ann Arbor.

- Teare, 1997. "Enabling organizational learning”, International Journal of Contemporary Hospitality Management, 9, p. 3125-324.

- Teare and Rayner, 2002. "Capturing organizational learning”, International Journal of Contemporary Hospitality Management, 14, p. 354-360.

- Tracey and Hinkin, 1994. "Transformational leaders in the hospitality industry", Cornell Hotel and Restaurant Administration Quarterly, 35, p. 18-24.

- Van Dam, 2004. “Antecedents of employability orientation”, European Journal of Work and Organizational Psychology, 13, p. 29-51.

- Van der Heijde and van der Heijden, 2006. "A competence-based and multidimensional operationalization and measurement of employability", Human Resource Management, 45, p. 449-476.

- Van der Heijden, Boon, van der Klink, and Meijs, 2009. "Employability enhancement through formal and informal learning: An empirical study among Dutch non-academic university staff members", International Journal of Training and Development, 13, p. 19-37.

- Van der Heijden, de Lange, Demeroutii, and van der Heijde, 2009. “Age effects on the employability-career success relationship", Journal of Vocational Behavior, 74, p. 156-164.

- Wilhelm, 2006. "Learning organizations", Leadership Excellence, 23, p. 17-30.

- Wittekind, Raeder, and Grote, 2010. "A longitudinal study of determinants of perceived employability", Journal of Organizational Behavior, 31, p. 566-586.

- Yang, 2007. "Knowledge sharing: Investigating appropriate leadership roles and collaborative culture", Tourism Management, 28, p. 530-543.

- Zemke and Schaaef, 1989. The service edge: 101 companies that profit from customer care. New American Library, New York. 


\title{
Comparative Analysis of Central Asian Tourism Product from Point of View of Turkish Travelers: A Case of Kyrgyzstan, Kazakhstan, Tajikistan, Uzbekistan and Turkmenistan
}

\author{
Prof. Dr. Kemal Kantarcı (Alanya Alaaddin Keykubat University, Turkey) \\ Assoc. Prof. Dr. Murat Alper Basaran (Alanya Alaaddin Keykubat University, Turkey) \\ Ph. D. Candidate Paşa Mustafa Özyurt (Akdeniz University, Turkey)
}

\begin{abstract}
Central Asia (CA) region consist of five countries, Kazakhstan, Kyrgyzstan, Tajikistan, Turkmenistan and Uzbekistan, which is the core of Asian continent. Ancient Silk Road has played the critical role of connecting the East and West through the history and today. CA has a rich history, culture and nature conditions as pull factors for world tourism market. This region as a new destination is becoming more important in the international travel and tourism market. All five countries have been experiencing transition period and have been facing some domestic and international issues with respect to tourism perspective.

In this study, Turkish travelers for different motivations ranging from business to vacation visiting Central Asia are asked to evaluate the region based on some personal and expectation attributes. The investigation includes some fundamental factors such as key desires to travel to Central Asia or some mind-set not visiting there. For this purpose, approximately 200 responses are gathered from persons traveling there for different motivations including business, travel and so on. Multi Dimensional Scaling is run in order to display graphically the attributes on two dimensional graphs. This research is a pioneer work that sheds light on the future studies that will be conducted by both academicians and practitioners. Also, it reflects the Turkish travelers' expectations to $\mathrm{CA}$ region as a tourism destination.
\end{abstract}

The main findings can be summarized as the key factors leading people either to travel CA or not to travel there by gender, country and some other personal attributes.

\section{Introduction}

The Central Asia (CA) region has been unjustly neglected by global tourism and is home a wide variety of medieval historical monuments, as well as great natural beauties (Horak, 2014). This region has been at the crossroads of the Silk Road Route through the centuries that is perhaps the greatest and well known trade route in the history, which connected Europe and Asia. This amazing trade route formed the first bridge between east and west and increased trade among the ancient Empires of China, India, Persia, and Rome. The route, dating back to 200 B.C. was a channel for contact between people and cultures, inspiring the exchange of dialog, art, religion, ideas, and technology. Nowadays, the Silk Road has a chance to get its popularity back again. WTO (World Tourism Organization) initiated a Silk Road program in 1991 when the newly independent Central Asian countries came into the political arena (Develioglu and Kantarci, 2014; The European Union and Central Asia, 2009).

These CA countries occupying a territory of nearly 4 million $\mathrm{km}^{2}$ and having a total population of nearly 66 million consists of Kazakhstan having 2,7 million $\mathrm{km}^{2}$ with a population of 16.4 million, Kyrgyzstan having $199,951 \mathrm{~km}^{2}$ with a population of 5.5 million people, Turkmenistan having $488,100 \mathrm{~km}^{2}$ with a population of 5.2 million, Uzbekistan having $447,400 \mathrm{~km}^{2}$ with a population of 28.3 million, and Tajikistan having $143,100 \mathrm{~km}^{2}$ with a population 8.2 million people, respectively (UNDP, 2013). The region stretches from the Caspian Sea in the west to China in the east, and from Central Siberia in the North to Afghanistan, Iran and Pakistan in the South (Buyers, 2003; Kantarci, 2014).

CA countries located in the core of the Asia and contain large and untapped tourism resources to serve world tourism market. Although its share has been increasing very slowly, the region as a new destination has been gaining importance. After the collapse of the USSR in 1991, the CA countries have sharply developed tourism infrastructures and superstructures. In this short period despite the hard conditions and insufficient fund, lack of law and human resources, these countries achieved significant developments. To strive with lack of tourism and travel regulatory framework, tourism and travel business environment and infrastructure and undeveloped tourism and travel human resources can lead CA countries to understand tourism system clearly so that they might be better and deeper integrated with the world tourism market.

The five CA countries as a tourism destination have some similarities and differentiations. These five countries form the whole CA region as a tourism product, yet they are rivals to each other as a single tourist destination. These countries offer their unique tourism products on the base of the common culture and history of the region. In this point, having a unique tourism product might be determinative factor in order to have a comparative advantage. Each country has its own history, culture, traditions, geographical location and locals' involvement 
and acceptance of tourism. That's why the selection of a proper development tool is crucial. It is argued that public support for tourism development, resources and attractions, level of government involvement and the size of market are determinative factors for appropriate method of development model (Gartner, 1996; Kapiki and Tarikulov, 2014). Besides, comfort levels of host country accommodations, conditions of host country transportation infrastructure, natural and scenic beauty, quality of historical and cultural attractions, and perceptions of safety and security are also important pull factors (Uysal et al., 2008). However, to take benefit of these potential needs a long, complicated and expensive process. The success of this process depends on the availability of domestic and foreign capital and acceptable image (Uysal and Kantarci, 2006).

Tourism offers a wide range of benefits to countries. International tourist numbers reached 1,133 million and receipts reached US\$ 1.245 billion worldwide in 2014. In addition, tourism generated 1 in 11 jobs and $9 \%$ of total GDP worldwide in 2014 (UNWTO, 2015). It is known that CA countries have a great tourism potential. In order to strength its position in the market, CA countries needs to develop competitive strategies. Competitiveness has become the most critical field for the countries and the organizations in all areas including tourism. Table 1 shows inbound tourist numbers and tourism receipts of CA countries.

\begin{tabular}{clcccc}
\hline $\begin{array}{c}\text { Central Asian } \\
\text { Countries }\end{array}$ & Variables & $\mathbf{2 0 1 0}$ & $\mathbf{2 0 1 1}$ & $\mathbf{2 0 1 2}$ & $\mathbf{2 0 1 3}$ \\
Kazakhstan & Tourist arrivals (000) & 3,196 & 4,434 & 4,807 & 4,926 \\
& Tourism receipts (US\$ million) & 1,236 & 1,524 & 1,572 & 1,717 \\
& Tourist arrivals (000) & 975 & - & - & 1,969 \\
Uzbekistan & Tourism receipts (US\$ million) & - & - & - & - \\
Kyrgyzstan & Tourist arrivals (000) & 855 & 2,278 & 2,406 & 3,076 \\
& Tourism receipts (US\$ million) & 212 & 405 & 486 & 585 \\
Tajikistan* & Tourist arrivals (000) & - & - & - & - \\
& Tourism receipts (US\$ million) & - & - & - & - \\
Turkmenistan* & Tourist arrivals (000) & - & - & - & - \\
& Tourism receipts (US\$ million) & - & - & - & - \\
\hline
\end{tabular}

Table 1. Central Asian Countries Inbound Tourist Numbers and Receipts of 2010-13 Source: UNDATA, 2015

*: No Available Data

Porter (2004) stated that "competitive strategy is the search for a favorable competitive position in an industry, the fundamental arena in which competition occurs. Competitive strategy aims to establish a profitable and sustainable position against the forces that determine industry competition". According to Ritchie and Crouch (2003) competitiveness in tourism helps to tourism destinations to increase tourism expenditure, to attract more visitors while providing them quality tourist experience, enhancing quality of life of locals and visitors and preserving the environment in a profitable way. Economic coordination with neighboring countries can significantly strength competitiveness. In this point, tourism can help countries to regulate balance of payments and create new jobs, stimulate economy and encourage co-operations and collaborations among countries (Develioglu and Kantarci, 2014).

\section{CA Countries}

Kazakhstan has showed considerable progress in tourism infrastructure, accommodation sector, accessibility and good relation with neighbor countries and some mega tourism projects, promoting its image as an attractive, tourism friendly and dynamic Eurasian destination compared to neighboring countries in the region. Kazakhstan's competitive advantage is to have exotic culture, more familiar image, natural environment, more developed business environment, and sport and adventure tourism. Four core attractions of the country are on the UNESCO World Heritage Lists which are Mausoleum of Khoja Ahmed Yasawi, Petroglyphs within the Archaeological Landscape of Tamgaly, Silk Roads: the Routes Network of Chang'an-Tianshan Corridor, and Saryarka- Steppe and Lakes of Northern Kazakhstan (UNESCO, 2015). Especially nomad culture of Kazakhstan is known by the American and European tourism markets (Yessenova, 2014). The government considers tourism as one of the priority sectors for the economy. The strong side of the country is to have good basic workforce skills, low electricity cost, modern airport infrastructure and attractiveness for foreign direct investment. Weaknesses are the insufficient physical infrastructure, shortage of managerial skills and entrepreneurship, lack of advanced technical skills, safety and security and environmental sustainability (Porter, 2005; Baisakalova and Garkevenko, 2014).

Uzbekistan, one of the key countries on Silk Road, has a very rich cultural and natural resources such as mountains, steppes, lakes and religious attraction. The country has four cultural attractions in the UNESCO World Heritage List which are, Historic Center of Bukhara, Historic Center of Shakhrisyabz, Itchan Kala and Samarkand Crossroad of Cultures (UNESCO, 2015). Uzbekistan is considered to be a country with competitive 
advantage in the tourism sector, comparing with neighboring countries. Despite of having a great tourism potential, due to lack of proper promotion, insufficient funds and perceived negative image, Uzbekistan is not an important tourism destination in the world tourism arena. Lack of a unified tourism policy and strategy are urgent issues that stand in front of tourism development. Uzbek National Tourism Board, which is a public tourism organization, is the main ruler of tourism sector in the country (UNDP, 2007; Kapiki and Tarikulov, 2014).

Kyrgyzstan is a mountainous country with undiscovered natural beauties and unpolluted environment. The country has numerous lakes, mountains, valleys and glaciers that are very valuable recourses for tourism. The Issyk-Kul is the second largest alpine lake at high altitude and the deepest on the earth. Kyrgyzstan has two monumental structures listed in UNESCO World Heritage List which are Silk Roads: the Routes Network of Chang'an-Tianshan Corridor and Sulaiman-Too Sacred Mountain (Özcan, 2010; UNESCO, 2015). Tourism has many reasons to become a major alternative economy for the country and has been developing rapidly. Yet, there are some main obstacles that slowing down tourism development such as the soviet legacy, economic problems, political problems and legal problems. Tourism infrastructure, accommodation facilities, safety and security and corruption in bureaucracy affects the demand of direct foreign investments and tour operators to the country (Akçalı, 2014).

Turkmenistan has very rich natural resources and its economy largely depends on exports of energy recourses. The country has unique cultural and natural heritages such as Kunya-Urgench, Parthian Fortresses of Nisa and State Historical and Cultural Park Ancient Merv that are listed in UNESCO World Heritage List (UNESCO, 2015). The Awaza Tourist Zone, the biggest project in the history of country, aimed to attract foreign tourists to the country. The Karakum Desert occupies $80 \%$ of the whole country. Turkmenistan faces lack of infrastructure, transportation, accessibility to destinations, information and data. Visa regime still takes a lot of time and effort from demand side. Tourism education is relatively undeveloped. The difficulties and the corruption in bureaucratic procedures still exist. Turkmenistan's labor force generally lacks knowledge of standard (Doing Business in Turkmenistan, 2012).

Tajikistan is the poorest country in the region. It has two sites in UNESCO World Heritage List which are Proto-urban Site of Sarazm and Tajik National Park (Mountains of the Pamirs) (UNESCO, 2015). The country's tourism potential based on natural and historical resources. Tourism in Tajikistan has low impact on the national economy. Yet, the government devotes special attention to tourism and aiming to attract foreign investors that might create new jobs and revenues. Main challenges are lack of tourism infrastructure such as number and quality of accommodation facilities, transportation and promotion, safety and security conditions and negative image (Asia Policy Research, 2006).

\section{Methodology and Findings}

Questionnaires (2012-13) were directed to a number of 200 Turkish travelers familiar with the region in order to evaluate their experience and perceptions regarding the CA countries. The first part of statistical analysis summarizes some descriptive statistics. Despite of the fact the number of participants are mentioned to be 200, missing observation are observed. The frequencies based on some variables such as age, sex, and marital statuses are denoted through Tables 2-4 below. In Table 5, the frequencies of what types of means used are tabulated

The age of the travelers are tabulated in Table 2.

\begin{tabular}{|ll|}
\hline Statistics & Values \\
\hline Mean & 39.03 \\
Std. dev. & 12.15 \\
Min & 22 \\
Max & 69 \\
Missing & 28 \\
The number of respondents & 172 \\
\hline
\end{tabular}

Table 2: The Age of Travelers

The gender of travelers is tabulated in Table 3.

\begin{tabular}{|lll|}
\hline Gender & N & \% \\
\hline Male & 152 & 76 \\
Female & 48 & 24 \\
The number of respondents & 200 & 100 \\
\hline
\end{tabular}

Table 3: The Gender of Travelers 
The marital status of travelers are Tabulated in Table 4.

\begin{tabular}{|lll|}
\hline Marital Status & $\mathbf{N}$ & $\mathbf{\%}$ \\
\hline Married with kids & 93 & 46.5 \\
Single & 77 & 38.5 \\
Married & 26 & 13.0 \\
Missing & 4 & -- \\
The number of respondents & 196 & -- \\
\hline
\end{tabular}

Table 4: The Marital Status of Respondents

When traveling to CA, what types of organizations are used by travelers are tabulated in Table 5

\begin{tabular}{|lll|}
\hline Organization Type & $\mathbf{N}$ & $\mathbf{\%}$ \\
\hline Individual & 100 & 57.8 \\
Others & 39 & 22.5 \\
All-inclusive package & 18 & 10.4 \\
Flight and Hotel & 16 & 9.2 \\
Missing & 27 & -- \\
The number of respondents & 173 & -- \\
\hline
\end{tabular}

Table 5: The Types of Organizations Used By Travelers

Which country is the most preferred destination among travelers is determined that is denoted in Table 6.

\begin{tabular}{|lll|}
\hline CA Destinations & $\mathbf{N}$ & $\mathbf{\%}$ \\
\hline Kazakhstan & 76 & 38.0 \\
Whole region & 51 & 25.5 \\
Uzbekistan & 32 & 16.0 \\
Kyrgyzstan & 21 & 10.5 \\
Turkmenistan & 8 & 4.0 \\
Different combinations & 7 & 3.5 \\
Missing & 5 & -- \\
Responses & 195 & -- \\
\hline
\end{tabular}

Table 6: The Most Preferred Destination among Travelers

Some questions directed to travelers in order to express their perceptions regarding the region. The first is asked to expressing three words that pops up in their minds, its results are denoted in Table 7.

\begin{tabular}{|llll|}
\hline Rank & Words & N & \% \\
\hline 1st & History & 64 & 32 \\
2nd & Nature & 31 & 15 \\
3rd & Cultural & 10 & 5 \\
& Attractions & & \\
\hline
\end{tabular}

Table 7: The First Three Words Popping Up In Travelers' Mind Regarding CA

The second is asked to articulating three words travelers expect and feel about denoted in Table 8.

\begin{tabular}{|llll|}
\hline Rank & Words & N & \% \\
\hline 1st & Happy & 54 & 27 \\
2nd & Thrill & 20 & 10 \\
3rd & Sincere & 8 & 4 \\
\hline
\end{tabular}

Table 8: The First Three Feelings Popping Up In Travelers'Mind Regarding CA

The third is asked to articulating three cities that pop up in their minds of travelers when considering CA as destination. The cities and their frequencies are denoted in Table 9. 


\begin{tabular}{|llll|}
\hline Rank & Cities & N & \% \\
\hline 1st & Alma-Ata & 33 & 17 \\
2nd & Samarkand & 25 & 13 \\
3rd & Tashkent & 25 & 13 \\
\hline
\end{tabular}

Table 9: The Three Cities Popping Up In Travelers' Minds

The fourth is asked to expressing how they have been informed about CA denoted in Table 10.

\begin{tabular}{|llll|}
\hline Rank & Means of information & N & \% \\
\hline 1st & Friends and family members & 43 & 22 \\
2nd & Books and Movies & 36 & 18 \\
3rd & TV programs & 27 & 14 \\
\hline
\end{tabular}

Table 10: The Means of Information Obtained By Travelers

The fifth is asked to articulating similarities and dissimilarities of countries denoted in Table 11.

\begin{tabular}{|llllll|}
\hline Similar Countries & $\mathbf{N}$ & $\mathbf{\%}$ & Dissimilar Countries & $\mathbf{N}$ & $\mathbf{\%}$ \\
\hline Russia & 87 & 44 & Japan & 80 & 40 \\
Iran & 22 & 11 & Thailand & 17 & 9 \\
China & 16 & 8 & Iran & 16 & 4 \\
\hline
\end{tabular}

Table 11: Similarities and Dissimilarities of CA Countries with Other Asian Countries

The sixth is asked to describe the "best" three countries in Asia in terms of some attributes denoted in Table 12.

\begin{tabular}{|llll|}
\hline Features & 1st & 2nd & 3rd \\
\hline Shopping & China & Japan & Kyrgyzstan \\
Cultural/Historical Places & Uzbekistan & China & India \\
Nature & Kyrgyzstan & China & Russia \\
Climate & Kyrgyzstan & Uzbekistan & China, Japan, India \\
Accommodation & Japan & Russia & China \\
Service quality & Japan & Russia & Kazakhstan \\
Organizational capacity & Japan & Kyrgyzstan & Uzbekistan \\
Friendly attitude & Japan & Kyrgyzstan & Uzbekistan \\
Cost & Kyrgyzstan & China & Uzbekistan \\
Transportation to destination & Russia & Kyrgyzstan & Iran \\
Transportation within country & Japan & Russia & Kyrgyzstan \\
Security & Japan & China & Kazakhstan \\
Entertainment & Russia & Thailand & Ukraine \\
Purchasing power & Kyrgyzstan & china & Uzbekistan \\
Tourism information & Japan & Russia & China \\
Cleanliness & Japan & Russia & Kazakhstan \\
Environmental quality & Japan & Russia & China \\
\hline
\end{tabular}

Table 12: The "Best” Three Countries in Asia In Terms Of Some Attributes

The seventh is asked to articulating the "best" destination among countries in terms of some attributes denoted in Table 13. 


\begin{tabular}{|llllll|}
\hline \multicolumn{1}{|c}{ Features } & $\mathbf{1}^{\text {st }}$ & $\mathbf{2}^{\text {nd }}$ & $\mathbf{3}^{\text {rd }}$ & $\mathbf{4}^{\text {th }}$ & $\mathbf{5}^{\text {th }}$ \\
\hline Shopping & Kazakhstan & Kyrgyzstan & Uzbekistan & Turkmenistan & Tajikistan \\
Cultural/Historical Places & Uzbekistan & Kyrgyzstan & Kazakhstan & Turkmenistan & Tajikistan \\
Nature & Kyrgyzstan & Kazakhstan & Uzbekistan & Turkmenistan & Tajikistan \\
Climate & Kyrgyzstan & Uzbekistan & Kazakhstan & Turkmenistan & Tajikistan \\
Accommodation & Kazakhstan & Uzbekistan & Kyrgyzstan & Turkmenistan & Tajikistan \\
Service quality & Kazakhstan & Uzbekistan & Kyrgyzstan & Turkmenistan & Tajikistan \\
Organizational capacity & Kazakhstan & Uzbekistan & Kyrgyzstan & Turkmenistan & Tajikistan \\
Friendly attitude & Kyrgyzstan & Turkmenistan & Turkmenistan & Kazakhstan & Tajikistan \\
Cost & Kyrgyzstan & Uzbekistan & Turkmenistan & Kazakhstan & Tajikistan \\
Transportation to & Kazakhstan & Kyrgyzstan & Turkmenistan & Uzbekistan & Tajikistan \\
destination & & & & Turkmenistan & Tajikistan \\
Transportation within & Kazakhstan & Kyrgyzstan & Uzbekistan & Tuan \\
country & & & & Tajikistan \\
Security & Kazakhstan & Uzbekistan & Kyrgyzstan & Turkmenistan & Tajikistan \\
Entertainment & Kazakhstan & Kyrgyzstan & Uzbekistan & Turkmenistan & Turkmenista \\
Purchasing power & Kyrgyzstan & Uzbekistan & Kazakhstan & Tajikistan & Tajikistan \\
& & & & & Tajikistan \\
Tourism information & Kazakhstan & Uzbekistan & Kyrgyzstan & Turkmenistan & Tajikistan \\
Cleanliness & Kazakhstan & Uzbekistan & Turkmenistan & Kyrgyzstan \\
Environmental quality & Kazakhstan & Uzbekistan & Kyrgyzstan & Turkmenistan & Tuan \\
\hline
\end{tabular}

Table 13: The “Best” Destination among CA Countries In Terms Of Some Attributes

The second part of analysis uses Multi-Dimensional Scaling (MDS) in order to graphically display attributes, countries, some reasons to visit CA countries and some reasons not to visit CA countries. In MDS, the distances between attributes based on the count numbers, namely, frequencies are employed using SPSS 20 version so that the location of attributes are determined on a two dimensional graph for easy interpretation. The main objective of this analysis is to put similar attributes together by MDS. MDS is a multivariate statistical technique aiming at display attributes or observations on a two or three dimensional graph based on using distances among them. Its interpretation is dependent upon the similarities and dissimilarities of the observations. The closer distance between them, the more related observations are. One of the main advantages of it is to observe whole observations or attributes just shrinking dimension.

Before proceeding to those analysis, the profile of Turkish travelers in general will be revealed based on the data collected in this research. The main objective is to determine which attributes Turkish citizens looking for when traveling abroad in general. The graphical result generated by MDS is denoted in Figure 1.

Of twenty different attributes is observed that just three separate groups of attributes, which are different than Factor Analysis, are extracted. Therefore, similar attributes as a group are located at a particular region of the two dimensional graph saying that they are closely related based on the distance criteria.

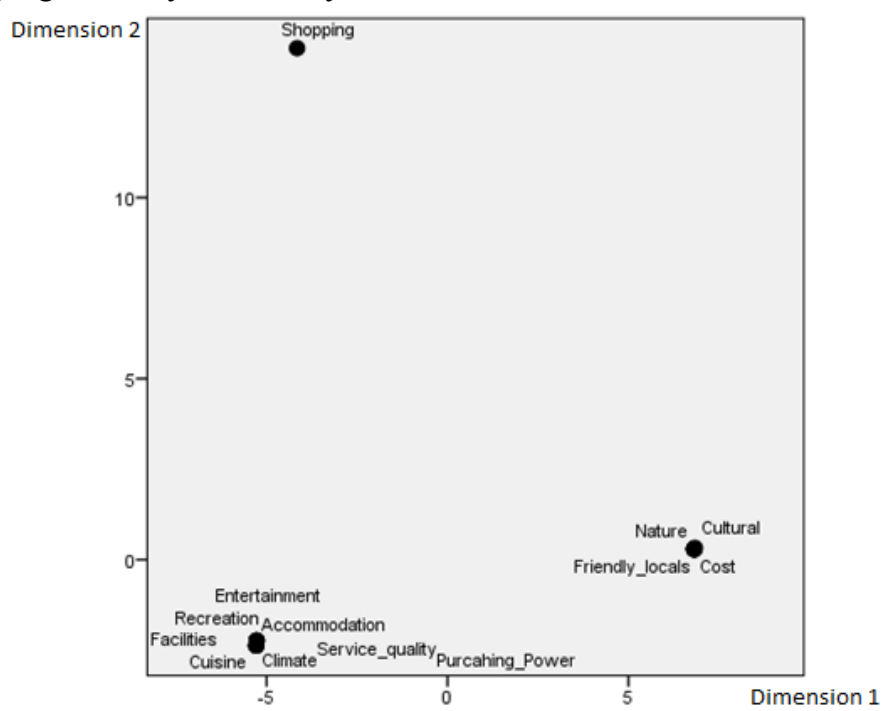

Figure 1. The Factors Determining Turkish Travelers Going Abroad 
When examining Figure 1, the first dissimilar attribute is shopping, the second group of attributes consisting of four features, namely, nature, cultural/historical, friendly locals and cost. The largest group of attributes consisting of several attributes, namely, entertainment, recreation, facilities, accommodation, cuisine, climate, purchasing power, and climate and service quality. It should be noted that not all attributes appear on the graph since the frequencies of some of responses are small. Whereas the second and third groups of attributes are equally likely important for travelers since both groups are located at bottom line on the two dimensional graph, the first factor, shopping, is seen differently than the others when Turkish travelers go abroad in general. Therefore, shopping is evaluated differently by Turkish travelers when going abroad. Its importance is relatively higher.

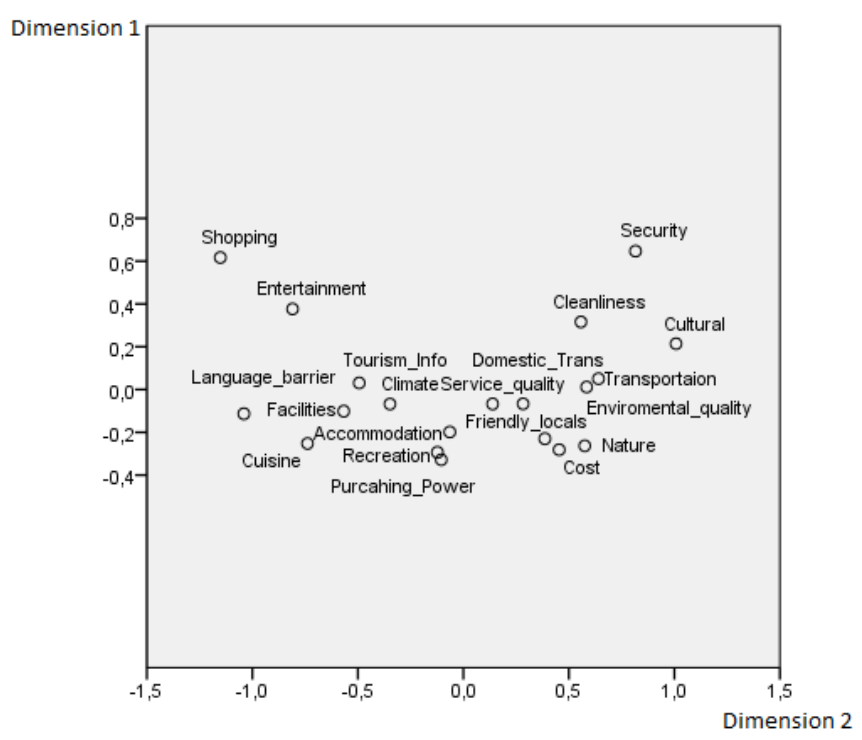

Figure 2. The Expectation of Turkish Travelers from CA Countries

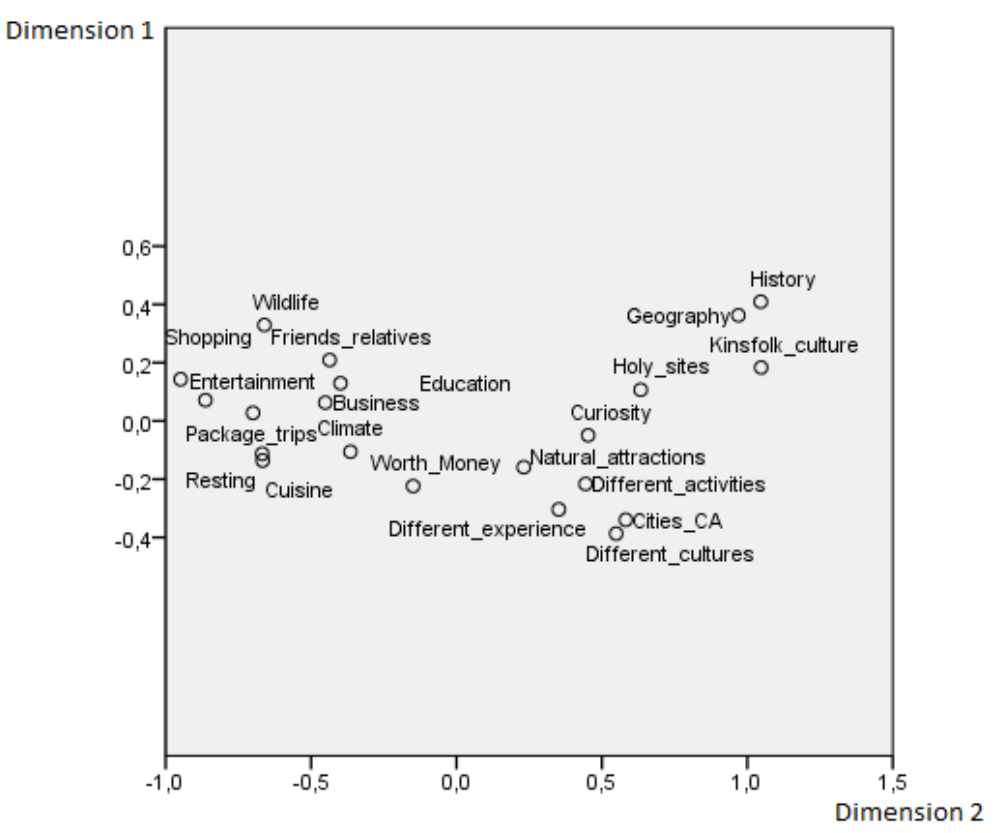

Figure 3. The Factors Affecting Your Trip to CA Countries

Figure 2 shows that when Turkish travelers visit CA countries, what types of tourism features they look for. The graph can be partitioned into two different sections including also an intersection area. The first section located at the left hand side of the graph tells that shopping, entertainment, tourism info, climates, accommodation, cuisine, recreation, facilities, purchasing power are a group of attributes. It is noted that while the shopping comes first, purchasing power comes last, which means that Turkish travelers again see shopping important when traveling to CA countries. On the other hand, purchasing power is seen the least significant attribute. The second section at the right hand side of the graph tells that security, cleanliness, cultural, transportation to destination, domestic transportation, environmental quality, nature and cost are group of attributes. It is noted that while security comes first, cost comes last, which means that Turkish travelers see 
security important when traveling CA countries. On the other hand, cost is seen the least significant attributes. The intersection area have quite few attributes such that climate, service quality and friendly locals saying that travelers are satisfied with those since they are significantly separated.

Figure 1 and Figure 2 providing us with comparison of the tourism features of Turkish travelers tells that shopping is very important for every type of destination. On the other hand, security, cleanliness and cultural attributes are seen important when traveling CA countries. Purchasing power and cost are two separate attributes believed to affecting different aspects of travelers. It is noted that while both are the least significant attributes for CA countries, they are not for other destinations, which means that Turkish travelers' purchasing power are strong and the cost of traveling those region is cheap.

When examining Figure 3 as the factors affecting travelers to visit CA countries, the two separate groups of attributes are seen. The first one located at the left hand side of the graph having attributes, namely, wild life, shopping, friends and relatives, entertainment, business, education, climate, package trips, resting, cuisine, worth money, and different experience. It should be noted that while wild life is seen as the most influential attribute, different experience is the least significant one. The second one located at the other side of the graph having attributes, namely, history, geography, kinsfolk's culture, holy cities, curiosity, natural attractions, different activities, cities in CA region and different culture. It should be noted that while history is seen the most influential attribute by Turkish travelers, the least one is the different culture.

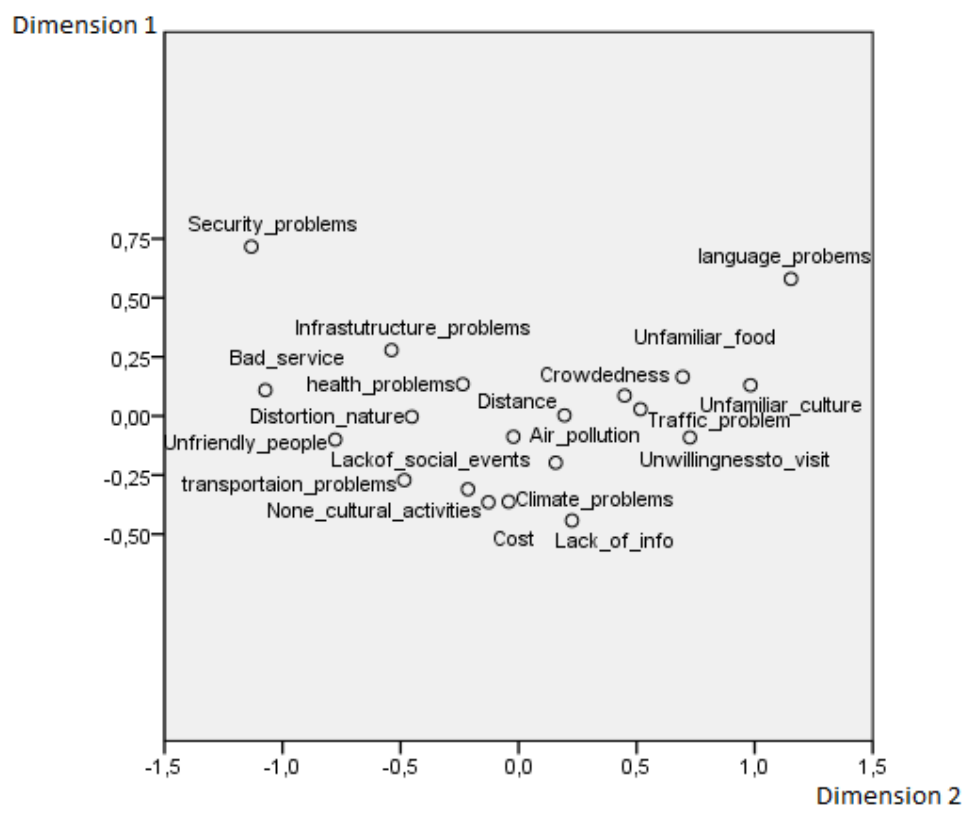

Figure 4. Factors Affecting Not to Visit CA Countries

When examining Figure 4 as the factors affecting travelers not to visit CA countries, the graph can be partitioned into two different sections including also an intersection area. The first section located at the left hand side of the graph has attributes, namely, security problems, infrastructure problems, bad service, health problems, and distortion of nature, unfriendly people, lack of social events, transportation problems, and lack of cultural events. It should be noted that while security problems and infrastructure problems are highly mentioned ones by travelers, lack of cultural events are the least mentioned ones. The right hand side of the graph has attributes, namely, language problems, unfamiliar foods, crowdedness, traffic problems, unwillingness to visit and lack of info. It should be noted that while language problems are mentioned most influential attribute as not to visit CA countries, the least influential attribute as not to visit CA region is lack of info. 


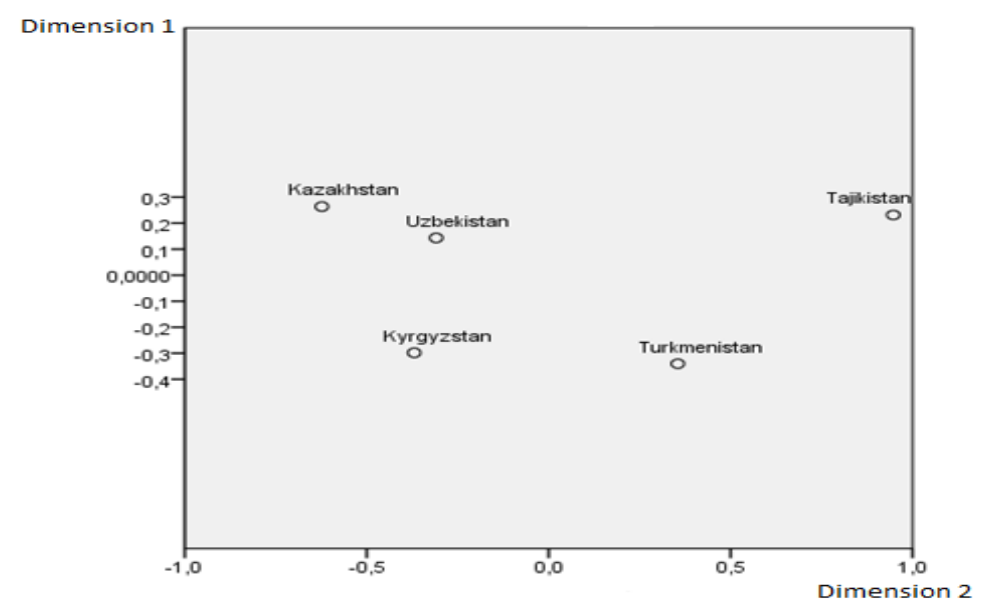

Figure 5. The Overall Evaluation of CA Countries in Terms of Tourism Destination

Examining Figure 5 in order to determine which country outperforms with respect to overall evaluation results in Kazakhstan. However, graphical display tells that Kazakhstan and Uzbekistan are similar countries. The second group of countries is Kyrgyzstan and Turkmenistan. Even though Kyrgyzstan and Turkmenistan are group of countries, Turkmenistan' position on the graph is between Kyrgyzstan and Tajikistan which means that similarities and dissimilarities of Turkmenistan are even. The most dissimilar one is Tajikistan which has the worst performance.

\section{Conclusion}

In this study, Turkish travelers' perceptions and expectations are mainly investigated when the tourism destination of CA region is chosen. Also, some comparison is provided based on the some tourism features Turkish travelers looking for when visiting abroad is partitioned into CA destination and others. Interesting findings are reached.

The way of organizing trip to CA is mainly conducted by travelers with almost 60 percent which means that either professional services such travel agencies and other package tours are poor or they are not preferred by traveler for some reasons. Kazakhstan is the most preferred destination among Turkish travelers. Interestingly, whole region as a destination comes after just Kazakhstan. History is the first word popping up in travelers' mind. Also, travelers believe to be happy and thrilled when thinking of CA a destination. The most attractive cities travelers want to visit are Alma-Ata, Saamrkand and Tashkent, respectively. The information sources used by travelers are friends and family members, books and movies and TV programs, respectively. While travelers find CA region very much similar to Russia, it is told that Japan is the most dissimilar county in Asia. When total of seventeen attributes are taken in to account, Kyrgyzstan (out of 4) and Uzbekistan (out of 1) are superior then other countries in Asia. The same comparison is made when CA is taken into account, Kazakhstan (out of 11), Kyrgyzstan (out of 5) and Uzbekistan (out of 1) are superior then other countries in CA region. According to Figure 5, Kazakhstan is the most competitive in terms of tourism country when it is compared to other countries in $\mathrm{CA}$ region.

On the other hand, the shopping attribute is the most influential one for both CA and other destinations. Turkish travelers have a special interest to CA region based on some very interesting attributes such as history, geography, kinsfolk's culture (root culture) and curiosity. Also, some issues needs to mentioned, which are security problems, lack of cleanliness, transportation problems and language barriers.

The region is vast and peoples of the region have common in history, culture and roots. Business, trade, education and other relations in the last few decades have increase travel density. However, it cannot be said that organized and mutual beneficial tourism has not been constructed. If doing so, both partners and region benefit from much.

Turkey has a potential market to CA region due to having common history, culture and root. CA region should reinvent their tourism products just targeted to Turkey's market. Hence, the number of visitors from Turkey should be increased which helps directly improve the economies of the region.

\section{References}

- Akçalı, P. 2014. Tourism in Kyrgyzstan, 259-286, in Tourism in Central Asia: Cultural Potential and Challenges, Kantarci, K., Uysal, M., and Magnini, V., (Eds), Apple Academic Press, Canada; Francis \& Taylor Group. 
- Asia Policy Research 2006. Tourism and Related Services Sector Background Brief October 2006, Retrieved June 23, 2015, from

- $\quad$ http://www.carecprogram.org/uploads/events/2006/CAREC-BDF/Tourism-Background-Brief.pdf

- Baisakalova, A., and Garkavenko, V. 2014. Competitiveness of Tourism Industry in Kazakhstan, 15-40, in Tourism in Central Asia: Cultural Potential and Challenges, Kantarci, K., Uysal, M., and Magnini, V., (Eds), Apple Academic Press, Canada; Francis \& Taylor Group.

- Buyers, L. M. 2003. Central Asia in Focus: Political and Economic Issues. Nova Publishers.

- Develioglu, K., \& Kantarci, K. 2014. Clustering Silk Road Countries Based On Competitiveness Factors In Tourism Industry, 201-232, in Tourism in Central Asia:Cultural Potential and Challenges, Kantarci, K., Uysal, M., and Magnini, V., (Eds), Apple Academic Press, Canada; Francis \& Taylor Group.

- Doing Business in Turkmenistan: 2012 Country Commercial Guide for U.S. Companies (2012). Retrieved May 14, 2015, from

http://photos.state.gov/libraries/turkmenistan/49351/pdf/Doing\%20Business\%20in\%20Turkmenistan\%2020 $12 \% 20$ CCG.pdf

- Gartner, W. C. 1996. Tourism Development: Principles, Processes, and Policies. Wiley.

- Horák, S. 2014. Visa Regimes And Regulatory Documents As An Obstacle For Tourism Development In Central Asia, 233-258, in Tourism in Central Asia:Cultural Potential and Challenges, Kantarci, K., Uysal, M., and Magnini, V., (Eds), Apple Academic Press, Canada; Francis \& Taylor Group.

- Kantarci, K., Uysal, M., \& Magnini, V. 2014. Exploring Tourism Potential in Central Asia, 1-14, in Tourism in Central Asia: Cultural Potential and Challenges, Kantarci, K., Uysal, M. \& Magnini, V. (Eds), Apple Academic Press, Canada; Francis \& Taylor Group.

- $\quad$ Kapiki, S. T., \& Tarikulov, M. 2014 . Development Prospects of Uzbekistan's Tourism and Hospitality Industry by Utilizing the EU Experience. In the Proceedings of the "International Conference on Tourism Milestones-Preparing forTomorrow", Sharjah, United Arab Emirates, DOI (Vol. 10, No. 2.1, pp. 4753 1845). Available at SSRN: http://ssrn.com/abstract=2546187

- Özcan, G. B. 2010. Building States and Markets: Enterprise Development in Central Asia. Palgrave Macmillan.

- $\quad$ Porter, M. E. 2004. Competitive Advantage. Free Press: New York

- Porter, M. E. 2005. Kazakhstan's Competitiveness: Roadmap Towards a Diversified Economy. Institute for Strategy and Competitiveness. Retrieved May 14, 2015, from

- $\quad$ http://www.hbs.edu/faculty/Publication\%20Files/Kazakhstan_Competitiveness 2005.01.26 35321255da68-4cb9-a97b-1cba5f2535f5.pdf.

- Ritchie, J. B., \& Crouch, G. I. 2003. The Competitive Destination: A Sustainable Tourism Perspective. Cabi.

- The European and Central Asia; The New Partnership in Action, 2009. Luxembourg.

- United Nation Data. 2015. Retrieved June 14, 2015, from

- http://data.un.org/Search.aspx?q=tourism

- United Nations Development Program. 2007. Policy Brief: Uzbekistan's Tourism Sector-an Unrealized Potential, No:2 (9), Tashkent 1-16.

- UNDP. (2013). World Population Prospects: The 2012 Revision. Retrieved from June 15, 2015, from

- $\quad$ http://esa.un.org/wpp/Documentation/pdf/WPP2012_\%20KEY\%20FINDINGS.pdf

- UNESCO. 2015. Retrieved June 20 2015, from http://whc.unesco.org/en

- UNWTO Tourism Highlights, Retrieved June 20 2015, from, http://dtxtq4w60xqpw.cloudfront.net/sites/all/files/pdf/unwto highlights14 en hr 0.pdf

- Uysal, M., Li, X., and Sirakaya Turk, E. 2008. Push-Pull Dynamics in Travel Decisions. Handbook of Hospitality Marketing Management, 412-439.

- Uysal, M., and Kantarci, K. 2006. An Integrative Approach to Image, Investment and Travel Conditions in Central Asia Countries (Kazakhstan, Kyrgyzstan, Uzbekistan, Turkmenistan). In Turk-Kazakh International Tourism Conference (pp. 138-146).

- Yessenova, S. 2014. Cinema as Branding, 173-200, in Tourism in Central Asia: Cultural Potential and Challenges, Kantarci, K., Uysal, M. and Magnini, V. (Eds), Apple Academic Press, Canada; Francis \& Taylor Group. 


\title{
Reverse Innovation Strategy: Local Technology Production Management Performance Booster Demand Trend Analysis
}

\author{
Prof. Dr. Ahmet Incekara (Istanbul University, Turkey) \\ Assoc. Prof. Dr. Elif Haykır Hobikoğlu (Istanbul University, Turkey)
}

\begin{abstract}
It was the most important condition of the competition in the information society to create high added value products. Additionally, the products with high added value are composed of the differentiated products that find the living area through the innovation leaded by the creativity. The innovation concept has been mostly perceived as developed country qualification. On the other hand, the reverse innovation provides opportunity for marketing the innovations belonged to the developing markets to entire world. The reverse innovation provides the extension of the market by reaching to the large population composed of people who cannot benefit from high developing countries. While the reverse innovation has been conveying the less qualified product and services that accomplish the same activity and provide cost advantage to the markets that have been developing but could not reach the product and services, it does not decrease the high quality product sales. It has reviewed the trend factors that define the telephone preferences providing local price advantage towards establishing the reverse innovation strategy by reviewing the demand structure of the mobile phone in the working telecommunication market.
\end{abstract}

\section{Introduction}

For Rastogi, the innovation appears by the implementation of new information for the production of goods and services. It should be targeted by the innovation to provide benefit for the economy towards increasing the difference between the values of goods and services and their costs. Innovation is to use the new technologic information and to provide development by using such resources as an additional vale to increase the difference between the cost values (Parag N. Rastogi, 1988).

According to Drucker, the innovation is based on the organized abandonment fact. Great changes occurred once in several centuries in the history affect the economic system. The most important miles stones are composed of finding printing houses, reform and renaissance period, invention of steam machine and current innovation age (Durucker, 1994).

It is the indicator of the success for the innovation to discover something that has not previously considered, to make something that has not been previously made and thanks to the innovations, by providing the profit increase to accelerate the development based on the competition power. By means of globalization, the pitch/demand for good has increased and homogenized accordingly. Under these circumstances, the price advantage is more than important for consumer. When the product and services are similar, the price pressure is increased, the prices are decreased and the profits are decreased. The unique solution is to present the innovations to the market by achieving profit increase through the innovations against the competition pressure. Innovation is established by a creativeness culture instead of research and development laboratory and advanced technology, the products including the low technology but active creativity could be a reason for the number of highest demands. The product should be designed in accordance with the requirements of the target mass as well as should be at the level where the price could be afforded by the target mass and the distribution channels should be selected to support the price structure (Kırıml1, 2006).

Overall innovations are available in the rich countries and flow into the developing countries however, in the reverse innovation, there was an innovation that goes opposite to the flow. We could say that the reverse innovation is each kind of innovation firstly applied in the developing countries.

The reverse innovation presents the product that provides price advantage by making concession from its performance and quality to the consumer group that does not buy the irrelevant product and services and it helps the low income group to come into market as a player.

In the study, the demand trend analysis was carried out under the direction of reverse innovation local telephone production. The road map in accordance with this strategy was established.

\section{Reverse Innovation Strategy}

Nowadays, approximately 7 billion people are living in the word. Only 1 billion is the consumer and the rest 6 billion could not consume anything. Most of 6 billion people have been living in the developing countries such as India, China and Turkey. It is a first number opportunity for the development to solve the problem for nonconsumers. When you solve the problem of people in need, it means that you have a product with reasonable price. For example; if you produce a product for a rich man, everyone could not purchase this product. However, 
if you produce a product for a poor man, at that time, everybody could purchase this product. Because, if a poor man can purchase this, the rich man could purchase as well. Hence, the product could be achieved by everyone. You could change entire world in this regard. According to the research, 85\% of people are living in the poor countries. In this sense, the companies that will make investment to the developing countries could not apply the methods in the rich countries. For example, if a person has 10 dollars in the rich countries, there are ten people who have 1 Dollars in the poor country. In a nutshell, it is not the reality to wait for the same condition between the rich and poor countries in terms of consumption behavior. For this reason, it could not be considered that the products and services of the rich countries will have a great effect on the poor countries (Govindaranjan, Chris, 2012). One of the most important reasons for decreasing the sales activities of the rich countries in the poor country markets is the income level of the societies and different requirements. There is no doubt that the parameters are not the same between the markets where a person could spend 100 Dollars but 100 people could spend 1 Dollar. For this reason, it is not right approach to wait for the product sustainability of rich countries in the poor country markets (Trimble \& Govindarajan, 2012).

Reverse innovation is every kind innovation applied in the developing countries. It could not be accepted in the developing markets so that product requirements of the rich countries are completely different. At this point, the reverse innovation gains acceleration. The reverse innovation presents a value that has been ignored for long years. It is more than important to realize the requirements and opportunities of the developing countries. Two third of the development around the world will come from the poor countries in ten and twenty years. There are many people who spend little money in the developing countries. At this point, the total expenditure is larger. The reverse innovation begins with forget but not innovation. It is really important to focus on the needs that have not been met in the developing country and to solve them accordingly. The developing countries do not request for the high performances that have been demanded in the developed countries. The developing countries are very keen on the technologies that provide sufficient performance with low costs. The developed countries have large infrastructural possibilities. The lack of infrastructure in the developing countries could be an opportunity for the reverse innovation developments. The developing countries could achieve environmental safe technologies for providing sustainable development. Due to the fact that the legal arrangements in the developing countries are less developed, the innovative solutions could be applied simply. By considering the interests and preferences of the countries, it will help to benefit from the advantages of new innovations for the reverse innovation. The developed countries provide important opportunities. The reverse innovation provides global effect. The reverse innovation provides a trend towards closing the differences among the regions. In order to cover the market needs, the reverse innovation that provides low cost and ease of use having similar performance with the expensive product and it provides a trend towards covering the requirement needs. The reverse innovation dynamics will be successful if it becomes a part of the strategy dialogue in the multinational companies. The reverse innovation is the best solution for the market customer under the development. It establishes new basic abilities, new consumers and it provides low price and high volume, it develops product for the solution of the consumers 'problems as well as it established new basic qualifications and it provides development processes for the developing markets .(Govindarajan and Trimble, 2012)

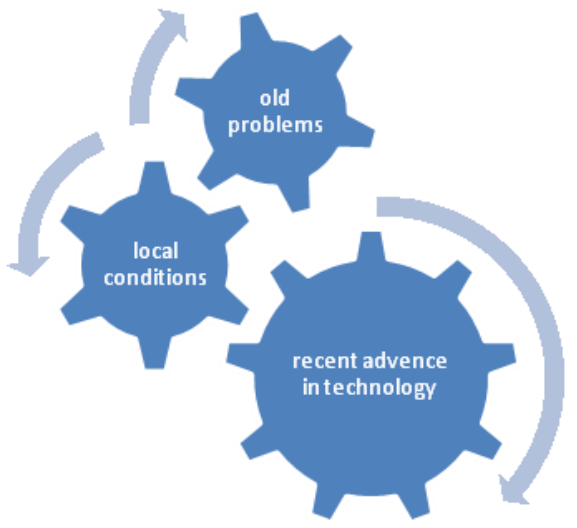

Figure 1. Creative Solution Gear

Reverse innovation is a market focused approach. It attempts to produce relevant solutions for the consumer needs of the countries respectively. Most of the reverse innovation is the business model innovation. New processes, partnership and re-created value chain are required. The strongest reverse innovation is the platform innovations that could decrease and increase the scales as if meeting the various price points. The reverse innovation requires the redesign the innovation and product accordingly.

In order to establish reverse innovation mind, the businesses should focus on the developing markets in the first step and they should develop their information and expertise about the developing markets and they should emphasize the changes that could be easily recognized by the symbolic personal movements. 
The reverse innovation is based on the weight shifting strategy. The most important decision makers are settled in low income countries. By establishing new senior management offices that will observe the developing markets, the performances as well as profit and losses should be assessed. In the developing markets, the research and development expenditures focused on the local needs should be increased. The information and expertise about the developing markets should be increased. It helps to understand the consumer problems in the countries with the low income level and it transfers information and skills to those countries. It increases the social ties between the developed countries and developing countries and it strengthens the strategy of the reverse innovation.

On the ground of the reverse innovation, it is focused on that the consumers will be more than happy by a product with the low cost without considering the quality.

Establishment of the local development teams is very important for reverse innovation: The persons and factors that will provide solution for the developing markets should be convened. The sales and marketing should be integrated with the research and development. It is also important to reach the relevant new abilities and skills about the issue.

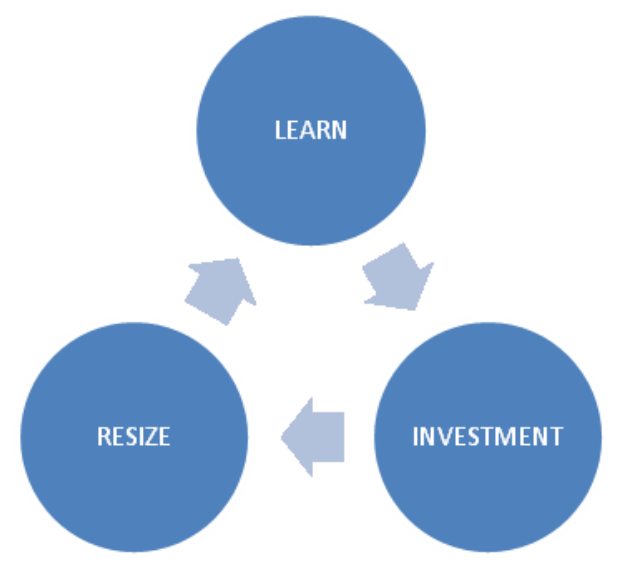

Figure 2. Local improvement team fast and low cost circle

Low priced products will provide the demand between the people who will never buy high priced costs. The reverse innovations provide the demand between the people who have never been served by the services. By emphasizing the reasons of the consumer dissatisfaction, the solution must be achieved in this regard.

On the other hand, it is important to have the information in the local level and to transfer them to the global level. The price, size, frequency of occurrence and consumer income combination should be well analyzed.

\section{Research Goal, Analyses and Results}

In our study where the telecommunication market has been reviewed, 820 surveys have been applied to people selected by unconfined sample. Our target is everybody who wants to have mobile phone and the survey was made in accordance with the random selection method. The research was made in the Anatolian side of Istanbul. The purpose of this research is to define the attitudes towards reverse innovation strategy about the preferences of the local mobile phones in accordance with their mobile phone requirements of people living in Anatolian Site of Istanbul. 1000 survey forms were distributed and 820 of them were approved by the analysis.

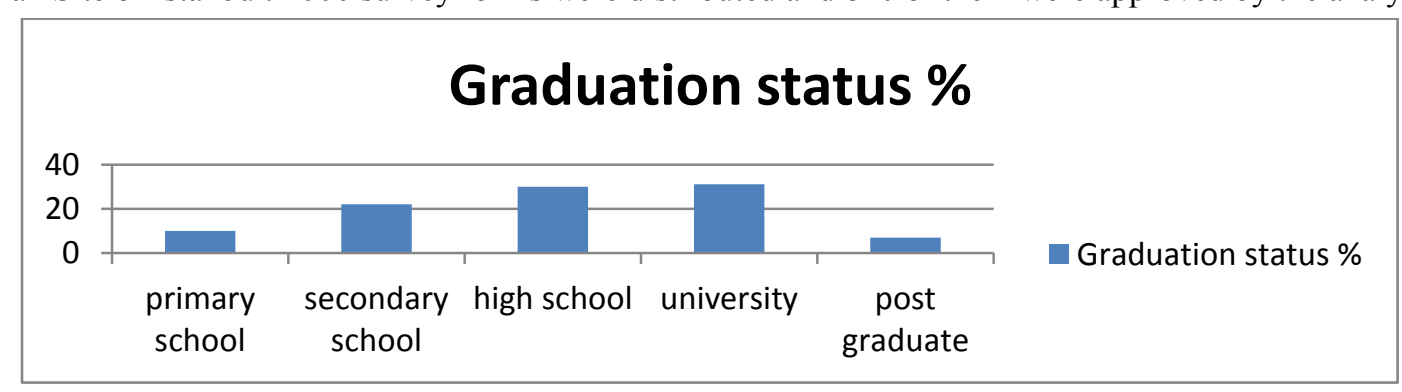

Figure 3. Educational Level

While $38 \%$ of people who participated in the study were graduated from the university and post graduate, $52 \%$ was graduated from high school and intermediary school, \%10 was graduated from primary school. The rate of non-university and master graduation is about $62 \%$. 


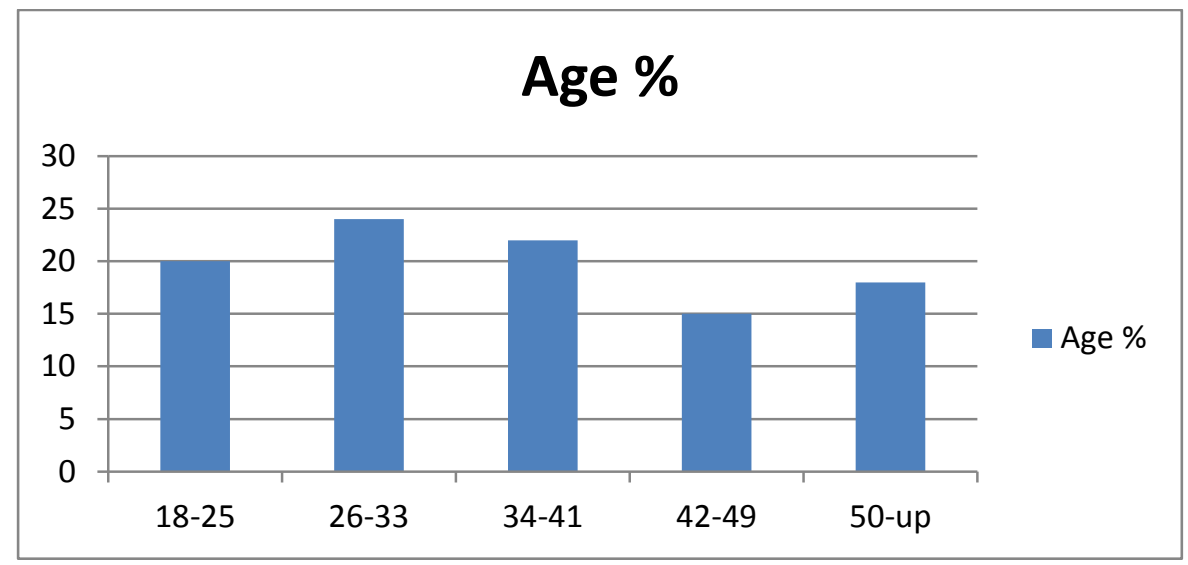

Figure 4. Age

$20 \%$ of people who participated in the study are between $18-25,24 \%$ is between $26-33,22 \%$ is between $34-41$, $15 \%$ is between $42-49,18 \%$ is more than 50 . The participation rate is about $61 \%$ between $26-49$.

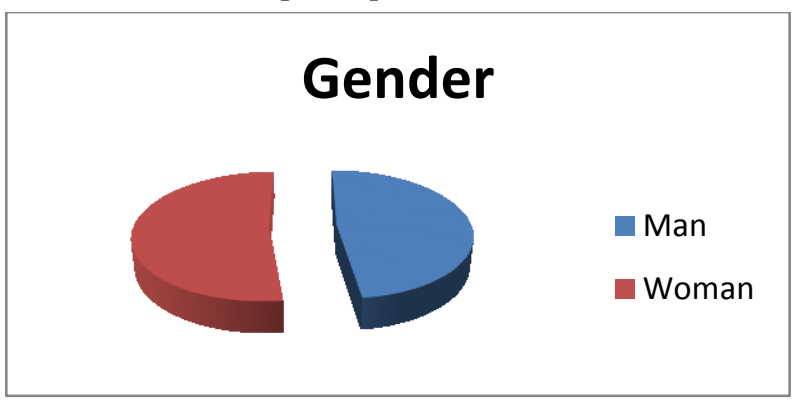

Figure 5. Gender

$48 \%$ of people who participated in the study is composed of men, $52 \%$ is composed of women population.

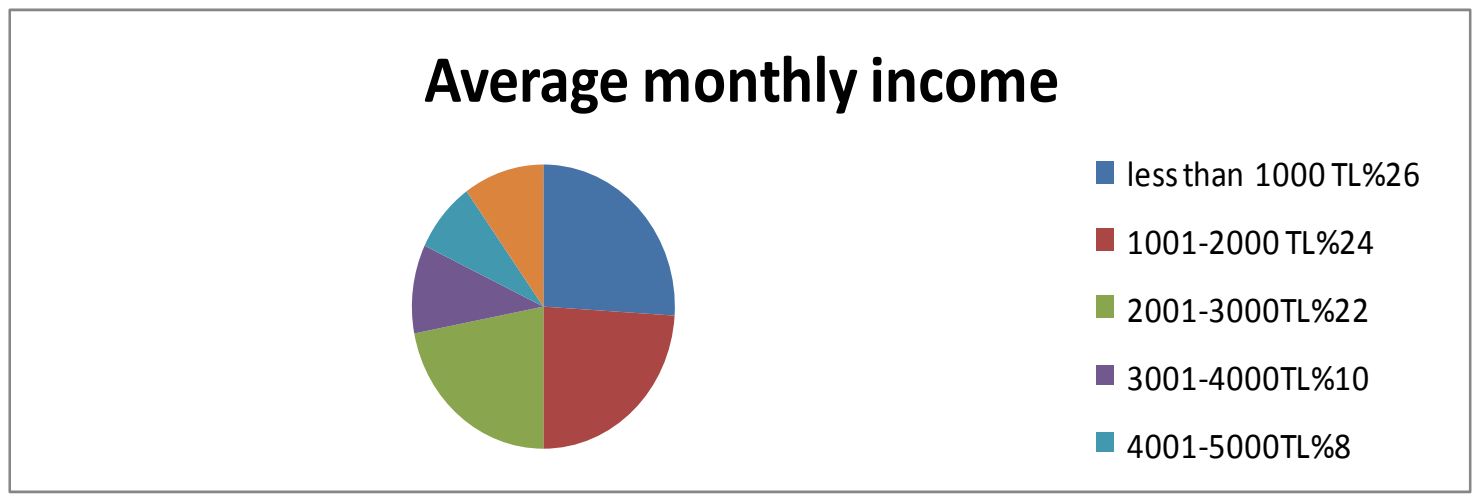

Figure 6. Monthly average income

While only $10 \%$ of people who participated in the study have been earning monthly average income more than 5000TL, per capita income in Turkey in 2014 is about 10.000 US Dollars. 50\% of people who participated in the study in Turkey where the per capita monthly income is $2.250 \mathrm{TL}, 50 \%$ of people participated in the study in Turkey has income lover than this income, $28 \%$ of people has $3.000 \mathrm{TL}$ and more accordingly. 


\begin{tabular}{|l|c|}
\hline \multicolumn{1}{|c|}{ Specification } & Importance rate \\
\hline Price advantage & $83 \%$ \\
\hline Charge time & $82 \%$ \\
\hline Ease of using & $81 \%$ \\
\hline Internet speed and ease of internet using & $76 \%$ \\
\hline Touchscreen & $74 \%$ \\
\hline Battery life & $71 \%$ \\
\hline Screen size (inch) & $52 \%$ \\
\hline Talking time (hour) & $48 \%$ \\
\hline Weight & $38 \%$ \\
\hline Trademark & $33 \%$ \\
\hline Camera specifications & $29 \%$ \\
\hline Image resolution & $28 \%$ \\
\hline Resolution & $\% 27$ \\
\hline Process rate & $\% 26$ \\
\hline Operating system & $\% 20$ \\
\hline Ram & $\% 12$ \\
\hline Core & $\% 10$ \\
\hline
\end{tabular}

Table 1. The most important specification orders that directs the preferences for buying mobile phone

The participants could mark more than one option. The most important specification in the smart phones is the price advantage by $82 \%$ and the charge time is in the second rank as well as the ease of using is in the third rank and internet speed and internet using on the phone is in the fourth rank accordingly. Comparing the smart phone imports with the local phones in terms of technology will develop the local production and exporting activities and it helps to produce local smart phones that cover the phone requirements in the developing countries and exporting activities as well in term of saving. In order to apply a reverse innovation in the smart telephone sector, the demand requirement should be effectively directed and should be researched.

The applications percent that has been mostly used in the smart mobile phones

\section{Demand side order of preference}

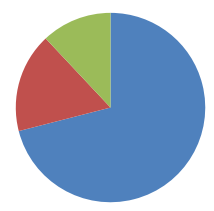

- Price advantage

Brand

Material quality

Figure 7. Preference order of Demanded Mobile Phone

$71 \%$ of the target mass that is adapted with the reverse innovation that participated in the study emphasizes the price importance. While $17 \%$ considers that the trademark of the mobile phone is important, only $12 \%$ is focused on the material quality of the mobile phone.

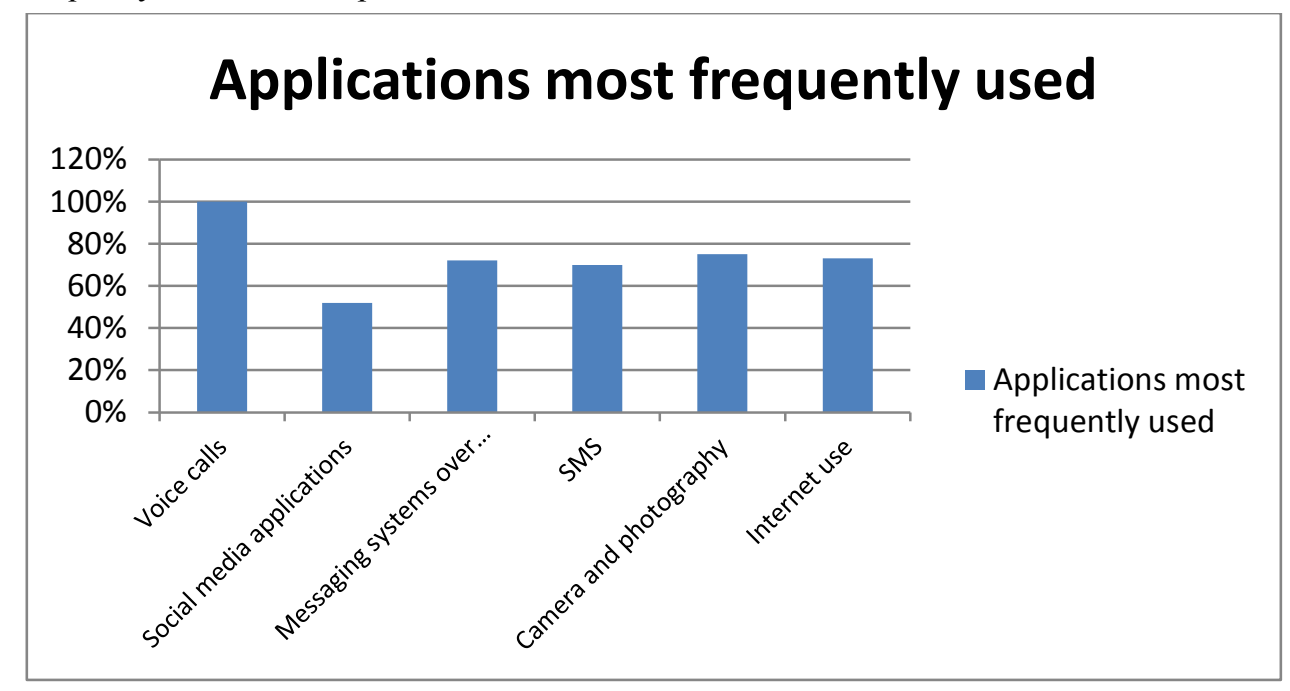

Figure 8. The most preferred mobile phone functions 
When considering the most preferred mobile phone function, $100 \%$ of people who participated in the study have been using the mobile phone as the voice communication tool and $75 \%$ is focused on the messaging systems and image applications on the internet. 52 percent of people who participated in the study consider that mobile phone is a social media tool. The most important specifications for the mobile phones are respectively voice talking, camera, taking photo, internet using, messaging system on the internet, SMS and social media.

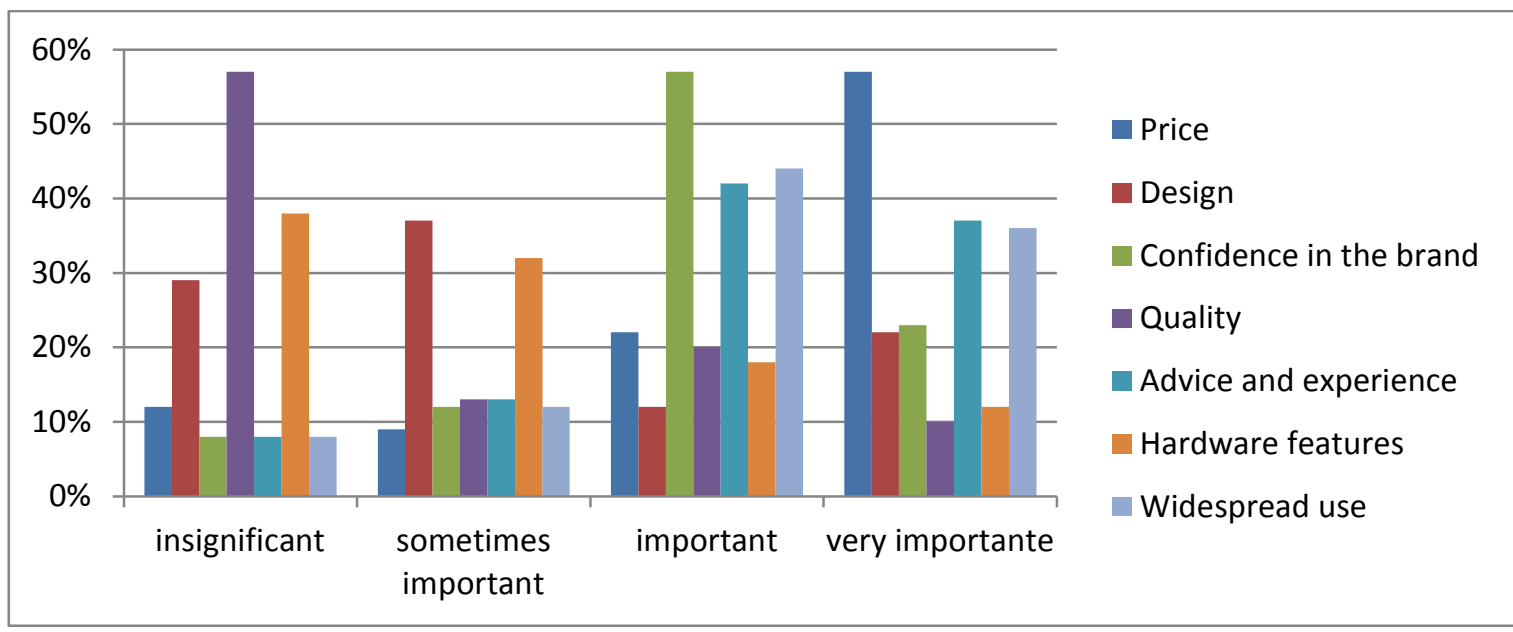

Figure 9. The factors that provide smart phone demand trends

While purchasing the mobile phone, the factors that have been considered effective on people are respectively sorted. The price having $57 \%$ rate is in the first and important rank, the quality is the least significant factor. Due to the fact that the mobile phone change rate is high and material quality is high and the number of mobile phone that is still active have not been used, the quality factor is seen as the least significant in the demand structure.

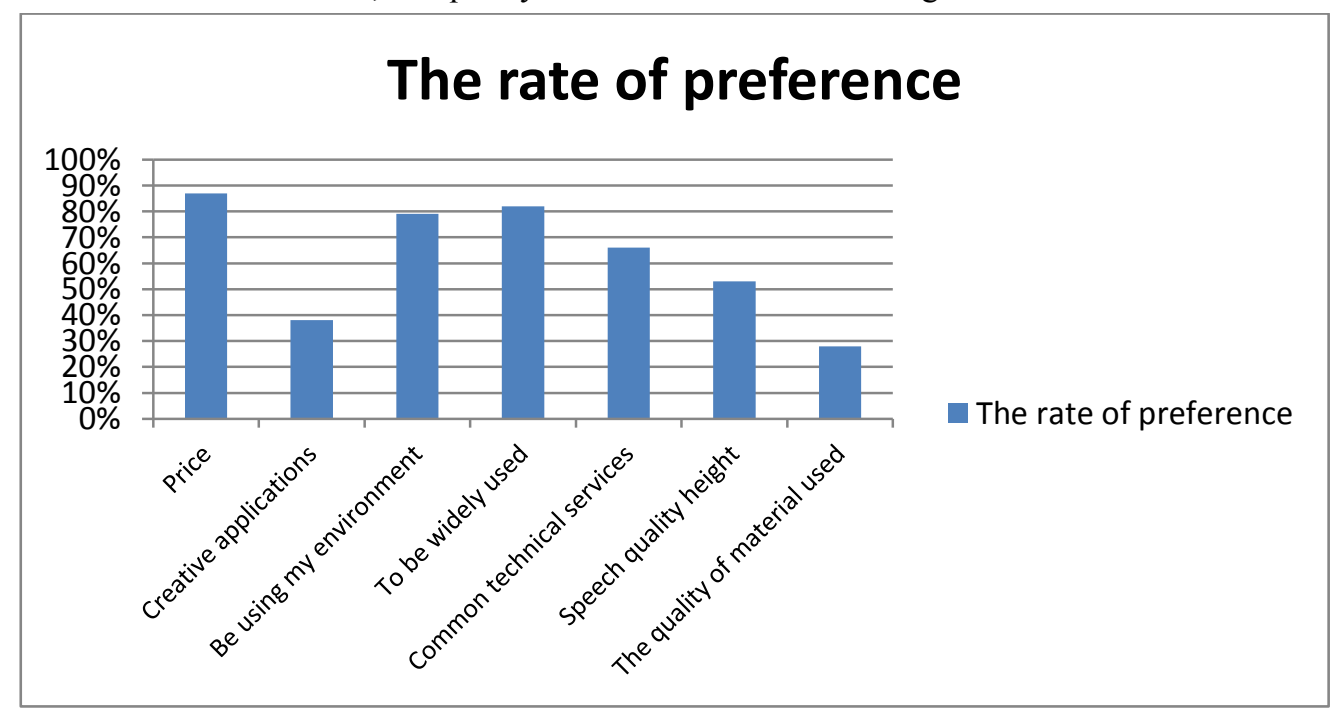

Figure 10. The elements that tiger the purchasing trend for local produced mobile phone

In the study where the limited function of the mobile phones are used and where consumer attended whose monthly income is under $5000 \mathrm{TL}$, there are three basic preference points that will affect positively the trend of local mobile phone procurement. $87 \%$ of people who participated in the study emphasized that they could prefer local production if there is any price opportunity, $82 \%$ said that they could buy local production if the local mobile phone has larger using area and $79 \%$ of people defined that they could prefer this production if people around they prefer such phones. While producing mobile phone, we could face with a factor that is ignored about the quality at the rate of $28 \%$.

\section{Conclusion}

We can define the reverse innovation as to make innovation for the consumers with low income in the developing countries then to market these products that could be purchased by everyone all around the world. The production of the goods and services that could cover the consumer requirements and that has best analyzed and that provides price advantage to be designed for the consumers with the low income have replaced with the unsalable products if the high price and utilization could not be paired. The innovation capacity for the 
developing capacity by means of the reverse innovation strategy has not affected the product sales in the high quality and high price and it opens a new market for itself.

$62 \%$ of people who participated in the study were not graduated from university, $72 \%$ has monthly income under 3000 TL. For approximately 80 percent of people who have above mentioned demographic specifications, the price advantage, charge time and ease of using are more than important for the preference of the mobile phone. $82 \%$ indicated that it is also important if the local produced mobile phone has common usage network. For people who have low income, the mobile phones that have been produced by the local resources could achieve to the global market.

Consequently, it was analyzed that in comparison with the high technologic mobile phones, the local production mobile phones that provide high rated price advantage, long battery life, ease of using, voice communication, messaging service on the internet such as whatsup etc. and that have camera specifications without taking into the consideration of resolution could be preferred by the consumers whose monthly incomes are under 3000TL. In the second step, when disseminating the above mentioned functions and the production that provide large area of use by means of advertisement and public relations, positive suggestions and sharing the experiences about the product, the promotional activities about the area of use, these will increase the preference rate of the local mobile phones. Due to the fact that people tend to use the popular telephone trademarks that have been used by their relatives and friends, the success could be achieved by means of the reverse innovation strategy by supporting the mobile phone procurements together with the social environment and by providing moral and material support. The reverse innovation strategy starting from the local could begin a global current towards the developing countries.

\section{References}

- Arman Kırımlı, 2006. Karlı Büyümenin Reçetesi İnnovasyon, Sistem Yayıncılık, İstanbul.

- Carlson C, Wilmont W, 2006. Innovation The Five Disciplines for Creating What Customers Want, Raymond, New York.

- Govindarajan V, Trimmple C. 2012. Reverse Innovation, Harward Business Review Press, Boston, Massachusetts

- Parag N. Rastogi, 1988. Productivity, Innovation, Management and Development, Sage Publication, California.

- Peter Durucker, 1994. Kapitalist Ötesi Toplum, Inkılap Kitapevi, İstanbul.

- Trimble C, Govindarajan V. 2012. Reverse Innovation: Create Far From Home, Win Everywhere. Harvard Business School Press Books, Boston, Massachusetts

- $\quad$ http://stratejikplanlama.net/gelir-ucurumunu-ters-inovasyon- (12.3.2015) 


\title{
Avrasya Ülkelerinde Zamanlararası Bütçe Kısıtının Göstergeleri Implications of Intertemporal External Budget Deficits in Euroasian Countries
}

\author{
Assoc. Prof. Dr. Sabri Azgün (Ataturk University, Turkey)
}

\begin{abstract}
Economies should pay attention to the deficits of the balance of payments in order to achieve a sustainable economic growth and development within the process of globalisation. A country having risks in terms of current account deficits can be evaluated as the current economic policy is having problems at present and will have in days to come in the point of sustainability. The sustainability of the current account deficits are defined by the intertemporal budget constraint. According to the budget constraints, the path of outlays to the external world with revenues obtained from abroad determines intertemporal solvency contidion. If there is no long-run equilibrium relationship between these two variables, intertemporal budget constaint will not be provided. The aim of this study is to determine whether it satisfies the intertemporal solvency condition of Euorasian economies for the period 2005Q1-2014Q4. In this study, by analyzing intertemporal externel budget consratint by unit root and cointegration methods, it is examined that carries potantieal risk in terms of the current account balance of Euroasian economies.
\end{abstract}

\section{Giriș}

Dışa açık bir ekonomide cari işlemler dengesini bir ülkenin toplam üretimi ile toplam harcamaları arsındaki fark olarak tanımlanır. Açık bir ekonomide, Eger bir ülkenin toplam üretimi harcamalarından az olursa, cari işlemler açık verecektir. Cari işlemler açığının sürdürülebilir düzeyde olması, ülke ekonomisinin dış şoklara karşı dayanıklılı̆g açısından son derece önemlidir. Ekonomik literatürde açık sonunu farklı bir bakış açısıyla incelenmektedir. İktisatçılar zamanın her hangi bir noktasındaki açığın büyüklüğü yerine, açık sorununu yükümlülüklerin hali hazır değerini ölçen zamanlararası geri ödeme yeteneği koşulu ile belirlemektedirler. Esasen geri ödeme yeteneği koşulu, cari ekonomi politikasının hali hazır değer borçlanma kısıtının dikkate alınarak yürütülmesi olayıdır.

Cari işlemler açığının sürdürülebilirliği zamanlararası bütçe kısıtı (veya zamanlararası geri ödeme yeteneği koşulu) tarafından belirlenmektedir. Söz konusu kısıta göre, hali hazır değer terimlerinde, ifade edilen cari ve beklenen faiz dışı dış aleme yapılan harcamaların toplamı, iskonto edilmiş dış alemden elde edilen gelirlerin toplamını aşmamalıdır. Bu bağlamda zamanlararası dış bütçe kısııııı (veya geri ödeme yeteneği koşulunu) faiz dışı dış âlemden elde edilen gelirlerle dış aleme yapılan harcamaların izleyeceği yol belirlemektedir. Bu iki değişken uzun dönem denge ilişkisi içerisinde değillerse, zamanlararası dış bütçe kısıtı sağlanmamış olacaktır.

Kamu sektörü zamanlararası bütçe kısıtı ve cari işlemler dış bütçe kısıtı ile ilgili geniş bir literatür mevcuttur. Zamanlararası borçlanma kısıtı olarak adlandırılabilecek söz konusu kısıt, hükümet açık bütçe politikası uyguladığında veya cari işlemler açık verdiğinde, uygulanan cari hükümet politikasının birikmiş kamu ve dış borç ve faizlerini ödemek için yeteri kadar bütçe fazlası veya dış fazla verip vermeyeceğinin teknik ölçütüdür. Söz konusu kısıta ilişkin temel çalışmalar Hamilton ve Flavin (1986), Wilcox (1988), Trehan and Walsh (1991), Hakkio ve Rush (1991) tarafindan yapılmıştır. Bu çalışmaların önermelerini esas alarak Baglini ve Cherubini (1993), Tanner (1994), Ahmet ve Rogers (1995), Caparole (1995), Bohn (1998), zamanlararası bütçe kısıtı kuramını muhtelif ülkelerin kamu açıklarına ve cari işlemler açıklarına uygulamışlardır. Azgun (2009) ve Binatli ve Sohraji (2012) zamanlararası borçlanma kısıtı koşulunu Türkiye için araştırmışlardır.

$\mathrm{Bu}$ çalışmada 1990'lı yıllarda Sovyetler Birliğinden ayrılarak bağımsızlığına kavuşan Avrasya ekonomilerinden Azerbaycan, Kazakistan, Kırgızistan, Türkmenistan, Özbekistan ve Türkiye ekonomilerinde zamanlararası bütçe kısıtının sağlanıp sağlanmadığı araştırılmaktadır. Zira Bu ekonomilerin bağımsızlıklarına kavuştuktan sonra, sürdürülebilir bir ekonomik yapı oluşturup, oluşturamadıklarının belirlenmesi açısından temel göstergelerinden birisi cari işlemler açıklarıdır. Zira cari işlemler hesabının sürekli olarak açık vermesi ülkenin üretim olanaklarının ötesinde bir yaşam sürdürmesi anlamına da gelecektir. Bu da ekonomik bağımsızlığın yitirilmesi sonucunu doğuracaktır.

\section{Zamanlararası Dış Borçlanma Kısıtı}

Bu kesimde, zamanlararası dış bütçe kısıtı her hangi bir ülke için tanımlanmakta ve cari işlemler açı̆̆ı için geri ödeme yeteneği koşulu matematiksel olarak tartışılmaktadır. Hükümet her dönem için bir dış bütçe kısıttı ile karşı karşıya kalmaktadır. Hükümetin karşılaştığı bütçe kısıtı aşağıdaki gibi ifade edilebilir.

$$
d e_{t}+(1+r) f_{t-1}=c r_{t}+f_{t}
$$


Yukarıdaki eşitlikte $f_{t}$ hükümetin ilgili dönemde dış piyasadan fon sağlamak için ihraç ettiği borç senetlerini tanımlamaktadır. $d e_{t}$ hükütmetin mal hizmet alımları için dış dünyaya yaptığı harcamalar ile dış dünyaya yapılan transferleri göstermektedir. $\mathrm{Cr}_{t}$ mal ve hizmet ihracı yoluyla dış dünyadan elde edilen gelirler ile dış aleme sağlanan transferleri göstermektedir.

$r_{t}$ ise $\mathrm{t}$ dönemindeki reel faiz oranını ifade eder. Eşitlik (1) ile verilen matematiksel eşitliğin sol tarafı hükümetin $t$ dönemi boyunca dış âleme yaptığı harcamaları ifade ederken, eşitliğin sağ tarafı hükümetin aynı dönemdeki dış alemden elde ettiği gelirini göstermektedir. Hükümetin her hangi bir t döneminde karşı karşıya olduğu zamanlararası dış bütçe kısıtını ifade eden (1) nolu eşitlikteki değişkenler nominal veya reel terimler cinsinden de ifade edilebilir. Eşitlik (1)'in sol tarafındaki ikinci terim dış dünyaya yapılan borç servisini gösterirken, söz konusu eşitliğin sağ tarafındaki ikinci terim borçlanmalar yoluyla dış dünyadan elde edilen gelirleri göstermektedir.

Eşitlik (1) de $\mathrm{t}$ dönemi için ifade edilen bütçe kısıtı bütün $\mathrm{t} i+(1,2,) \mathrm{i}=\mathrm{L}$ dönemleri için geçerlidir. Bu ifade $\mathrm{t}$ $+1, t+2, t+3 \ldots$ Dönemleri için ileriye doğru çözülürse, zamanlararası dış bütçe kısıtı elde edilir:

$$
f_{t}=\sum_{t=1}^{\infty} r_{t}\left(c r_{t}-d e_{t}\right)+\lim _{n \rightarrow \infty}\left(r_{n} f_{n}\right)
$$

Eşitlik (2)'de $r_{t}=\prod_{s-t}^{t} f_{s}$ ve $f_{s}=1 / 1+f_{s}$

zamanlararası dış bütçe kısıtındaki en önemli unsur eşitliğin săg tarafındaki $\lim _{n \rightarrow \infty}\left(r_{r} f_{n}\right)$

$$
\begin{aligned}
& \lim _{n \rightarrow \infty}( \\
& n=0
\end{aligned}
$$

$$
\lim _{n \rightarrow \infty}\left(r_{r} f_{n}\right)=0
$$

son terimdir. Bu terin sıfira yakınsadığında, bir başka ifadeyle $n \rightarrow \infty$ " $r$. borçlanma kısıtı tatmin edilmiş olur. Zamanlararası bütçe kısıtı; borç senetleri stokunun, cari işlemler fazlalarının hali hazır değerine eşit olduğunu ifade eder. Bu limitin sıfır olmaması hükümetin cari işlemler açığını yeni borç senedi ihraç ederek finanse ettiği anlamına gelmektedir. Hükümetin "Ponzi finansı" olarak adlandırılan bu durumu uzun süre devam ettirebilmesi mümkün değildir. Diğer bir ifade dış borçlar reel faiz oranından daha büyük bir oranda sonsuza kadar büyüyemez. Cari ekonomik politikanın sürdürülebilir olup olmadığı benzer politikanın uygulandığı dönemler esas alınarak, hali hazırda ve yakın gelecekte cari hükümet ekonomi politikasının sürdürülebilir yolda olup olmadığı belirlenmeye çalışılır. Böylece belirli bir ekonomi politikasının $\lim _{n \rightarrow \infty}\left(r_{r} f_{n}\right)=0$ uygulandığı dönemin verileri ile $n \rightarrow \infty \quad$ koşulunun sağlanıp sağlanmadı̆̆ araştırılır. ${ }_{t}{ }^{n e}$ ve $e_{t}$
değişkenlerinin stokastik süreçler oldukları varsayılırsa, sürdürülebilirlik için limit ifadesinin beklenen değerinin

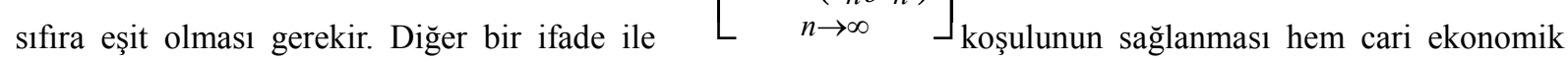
politikanın ve hem de cari işlemler açıklarının sürdürülebilir olduğunun bir göstergesidir.

Dış açıklar itibariyle zamanlararası geri ödeme yeteneği veya borçlanma koşulu, eşitlik (2)'deki gibi ifade edilmekle birlikte, bu ifade cari işlemler açıklarının ekonometrik analizi için kullanılamaz. Ancak, eşitlik (2) ile tanımlanan matematiksel ifadeyi ekonometrik olarak test edilebilir forma dönüştürmek mümkündür.). Eşitlik (1)'in her iki tarafından $r f_{t-1}$ ifadesi çıkarılırsa, Eşitlik (3) elde edilir.

$$
d b_{t}+(1+r) f_{t-1}=c r_{t}+f_{t}
$$

Burada, $d b_{t}=d e_{t}+\left(i_{t}-i\right) f_{t}$ bu ifade de faiz oranlarını durağan ve beklenen değerinin r'ye eşit olduğu varsayımı yapılmaktadır (Hamilton ve Flavin, 1986). Dolayısıyla, örtülü olarak $d e_{t}$ değişkeninin $d b_{t}$ değişkenine eşit olduğu varsayımı yapılmıştır. Eşitlik (3) bütün dönemler için geçerlidir. Eşitlik (3) birinci farklar cinsinden ifade edilirse, aşağıdaki eşitliğe ulaşılır.

$$
\Delta f_{t}=(1+r) f_{t-1}+\Delta d b_{t}-\Delta c r_{t}
$$

Eşitlik (4)'de $\Delta$ birinci farkları göstermektedir. Eşitlik (4), temel eşitlik olan Eşitlik (1)'ün içerisine konulur ve ileriye doğru çözülerse, aşağıdaki ifadeye ulaşılır. 


$$
d m_{t}=c r_{t}+\lim _{i \rightarrow \infty} \frac{\Delta f_{t+i}}{(1+r)^{i}}+\sum_{j=t+1}^{\infty} \frac{\Delta c r_{j}-d b_{j}}{(1+r)^{j-t}}
$$

Yapılan ampirik çalışmalar $c r_{t}$ ve $d b_{t}$ değişkenlerinin birikimli rassal yürüyüş süreci (random walks with dirft) izlediklerini göstermektedir:

$$
\begin{aligned}
& c r_{t}=a_{1}+c r_{t-1}+u_{1+t} \\
& d e_{t}=a_{2}+d e_{t-1}+u_{2+t}
\end{aligned}
$$

$\mathrm{Bu}$ durumda eşitlik (15) aşağıdaki gibi yeniden ifade edilir:

$$
d e_{t}=c r_{t}+\lim _{n \rightarrow \infty} \frac{\Delta f_{t-j}}{(1+r)^{j}}+\frac{a_{1}+a_{2}}{r}+\sum_{j=t+1}^{\infty} \frac{\left(u_{1 t}-u_{2 t}\right)}{(1+r)^{j-t}}
$$

Eşitlik (6) test edilecek hipotezin matematiksel ifadedir. Eğer cari işlemler açı̆̆ı için geri ödeme yeteneğinin sağlandığı durumda, eşitliğin sağ tarafındaki terim sıfıra yakınsadığı varsayılır. Çünkü. Böyle bir varsayımın yapılmaması durumunda sonsuza kadar borcun borçla çevrilebileceği şeklinde bir durum ortaya çıkar. Böyle bir durum, rasyonel davranan İktisadi birimlerin (borç verenler ve borç alanlar) çıkarları ile bağdaşmaz. Zamanlar arası dış borçlanma kısıtının sağlandığı Kabul edilirse, Eşitlik (6) aşağıdaki gibi yazılır:

$$
c r_{t}=a_{t}+b d m_{t}+u_{t}
$$

Eşitlik (7)'deki $c r_{t}$ ve $d b_{t}$ değişkenlerinin uzun dönemdeki denge ilişkisi, sürdürülebilirlik ilişkisini ifade etmektedir.

\section{Ekonometrik Yöntem}

Eşitllik (7) deki değişkenlerin eş bütünleşmesi, uzun dönemde, zamanlarası borçlanma kısıtının sağlandığı anlamına gelir. Diğer yandan, dm değişkenin modelde bağımsız değişken olarak yer alması merkezi hükümetlerde bütçeler hazırlanırken, harcamaların gelirlerden daha öncelikli olması şeklinde yorumlanmalıdır. Çalışmamızda ARDL Sınır testi yaklaşımı kullanılacaktır. Eşitlik (7) ile tanımlanan dış borçlanma fonksiyonundaki değişkenler arasında eş bütünleşme ilişkisini test etmek için, (Johansen, 1998) ve iki adımlı Engle-Granger (1987) gibi muhtelif eş-bütünleşme testleri kullanılabilir. Johansen yönteminin en büyük avantajı, eş-bütünleşme ilişsisinin mevcut olduğu çok sayıda vektörün tahmin edilmesine olanak sağlamasıdır. Bununla birlikte, Johansen uygulaması, açıklayıcı değişkenlerin tamamının birinci sıradan bütünleşik olduğunu baştan varsaymaktadır. Durağan ve birim kök içeren serilerin birlikte mevcut olduğu durumda, geleneksel olabilirlik oran testleri üzerine dayalı standart istatistiksel yorum artık geçerli değildir ve johansen yaklaşımı hatalı yorumlara yol açabilir (Pesaran ve Shin, 1999). (Pesaran ve Shin, 1999) analize konu olan serilerin I(0), I(1) olup olmadığına dikkat etmeksizin eş-bütünleşme ilişkisinin varlı̆̆ını test etmek için uygulanabilen bir ARDL sınır testi yaklaşımını geliştirmiş̧tir. Bu yaklaşım, bir tipik Johansen çatısında açıklayıcı değişkenlerin I(0) ve I(1) olması durumunda karşılaşılan sorunların üstesinden gelirken, ARDL çatısını iyileştirmektedir.

Bir ARDL yaklaşımı açıklayıcı değişkenlerin eş-anlı ve gecikmeli değerlerini ve açıklanan değişsenin gecikmeli değerlerini kullanan bir genel dinamik tahmindir. ARDL ile, kısa dönemli etkiler doğrudan ve uzun dönemli etkiler dolaylı olarak tahmin edilebilir. Pesaran and Shin (1999) ARDL tahmini kapsamında kullanılabilen eş- bütünleşme için sınır testini takdim etmektedir. Bu yöntem diğer eş-bütünleşme yöntemleri ile karşılaştırıldığında önemli avantajlara sahiptir. Çünkü ARDL tahmini değişkenlerin kesirli olarak eş- bütünleşik veya $\mathrm{I}(0)$ ve I(1) olup olmadığına bakılmaksızın kullanılabilir. Böylece, sınır testi bütünleşme sırasının ön-testi ile ilişkili belirsizliği ortadan kaldırmaktadır. İkinci olarak, ARDL tahmini küçük örnekler için kullanılabilir. Halbuki, Johansen ve Engle-Granger yöntemleri oldukça küçük örnekler için güvenilir değildir (Narayan, 2004).

ARDL yaklaşımı uzun dönem ilişkisini tahmin etmek için iki adım ihtiva eder. Birinci adım inceleme altındaki eşitlikteki bütün değişkenler arasında bir uzun dönem ilişkisinin varlığını incelemektir. Söz konusu değişkenler arasında eş-bütünleşme ilişkisi teyit edilirse, ikinci safhada, uzun dönem ve kısa dönem katsayıları ARDL ve ECM yaklaşımları kullanılarak tahmin edilebilir. Eş-bütünleşme ilişkisini test etmek için aşağıdaki şartlı kısıtsız hata düzeltme modeli (UECM) inşa edilir:

$$
\begin{aligned}
& \Delta d m_{t}=\alpha+\sum_{i=0}^{m} \beta_{i} \Delta c r_{t-i}+\sum_{i=0}^{k} \phi_{i} \Delta d m_{t-i}+ \\
& \eta_{1} \log c r_{t-1}+\eta_{2} d m_{t-1}+\varepsilon_{t}
\end{aligned}
$$


Burada, $\Delta$ birinci farkı göstermektedir. Eş-bütünleşme eşitliği aşağıdaki gibi tanımlanır.

$$
\eta_{1} c r_{t-1}+\eta_{2} d m_{t-1}=0
$$

Sınır testi metodolojisi, Wald veya F- istatistiğine dayalı $c r_{t-1}$, ve $d m_{t-1}$ gecikmeli değişkenlerinin müşterek testi yoluyla hiçbir eş-bütünleşme ilişkisinin olmadığı boş hipotezini incelemeyi ima etmektedir:

$$
\begin{aligned}
& H_{o}: \eta_{1}=\eta_{2}=0 \\
& H_{1}: \eta_{1} \neq \eta_{2} \neq 0
\end{aligned}
$$

Pesaran ve Shin (1999)'e göre değişkenlerin bütünleşme derecesine bakılmaksızın ve hiç bir eş-bütünleşmenin olmadığı boş hipotezi altında, elde edilen F- istatistiğinin asimptotik dağılımı standart değildir. Bu ARDL modelinde ihtiva edilen değişkenlerin $\mathrm{I}(0)$ veya $\mathrm{I}(1)$ olup olmadığına, bağımsız değişkenlerin sayısına, ARDL modelinin sabit ve/veya trend ve örneklem hacmine bağlıdır. Alt sınır ve üst sınırları gösteren Kritik Fdeğerlerinin iki seti, büyük örnekler için Pesaran ve Shin (1999) tarafından sağlanmaktadır. Narayan (2004) 3080 arasında değişen örnek hacmi için kritik F- değerleri takdim etmektedir. Eğer seçilen önem düzeyi için hesaplanan F-istatistiği kritik sınırların dışına düşerse, değişkenlerin eş-bütünleşmesi ile ilgili kesin bir karar verilebilir. Eğer istatistik üst sınırdan daha yüksek ise, hiçbir eş-bütünleşmenin olmadığı boş hipotez reddedilebilir.

\section{Analiz}

Çalışmada Azerbaycan, Kırgızistan Kazakistan ve Türkiye Ekonomileri cari işlemler açıkları açısından analiz edilmektedir. Analizde 2005Q1-2014Q4 dönemi çeyrek yıllık verilerle test edilmektedir. $\mathrm{cr}$ ve $d e_{\text {sırasıyla }}$ cari işlemler dengesinin gelir ve harcamalarını ifade etmektedir. Ülkelerin uluslararası plaka kodları ilgili değişkenlerin (cr ve de) başına eklenerek ilgili tanımlanmaktadır. Veriler IMF'den alınmıştır. Türkmenistan ve Özbekistan verileri bulunamadığından bu ülkelerin cari işlemler hesabı incelenememektedir.

Değişkenlerin birim test istatistik sonuçları Tablo 1'de analiz edilmiştir. Türkiye'nin cari işler gider değişkeni hariç diğer bütün ülkelerin cari işlemler gelir ve harcama değişkenleri düzey değerlerinde durağan değilken, birinci farklarında, durağan hale gelmektedir. Dolayısıyla Türkiye Hariç bu ülkeler için analiz de Johansen bütünleşme testi uygulanabilir. Johansen Eş bütünleşme test sonuçları, Tablo 2'de özetlenmiştir.

\begin{tabular}{|l|l|l|l|}
\hline Değişken & ADF Test İstatistiği & Kritik Değerler (\%5) & C,T,L (SIC) \\
\hline LCRAZ & -2.430778 & -3.533083 & $\mathrm{C}, \mathrm{T}, 1$ \\
\hline LDEAZ & -3.167469 & -3.529758 & $\mathrm{C}, \mathrm{T}, 0$ \\
\hline DCRAZ & -5.736448 & -3.536601 & $\mathrm{C}, \mathrm{T}, 1$ \\
\hline DDEAZ & -6.550621 & -3.533083 & $\mathrm{C}, \mathrm{T}, 0$ \\
\hline LCRKZ & -2.749032 & -3.452358 & $\mathrm{C}, \mathrm{T}, 0$ \\
\hline LDEKZ & -2.723183 & -3.454032 & $\mathrm{C}, \mathrm{T}, 3$ \\
\hline DCRKZ & -10.39548 & -3.452764 & $\mathrm{C}, \mathrm{T}, 0$ \\
\hline DDEKZ & -10.39690 & -3.452764 & $\mathrm{C}, \mathrm{T}, 0$ \\
\hline LCRKS & -2.450454 & -3.557759 & $\mathrm{C}, \mathrm{T}, 4$ \\
\hline LDEKS & -3.169725 & -3.557759 & $\mathrm{C}, \mathrm{T}, 4$ \\
\hline DCRKS & -9.949247 & -3.552973 & $\mathrm{C}, \mathrm{T}, 2$ \\
\hline DDEKS & -6.562851 & -3.557759 & $\mathrm{C}, \mathrm{T}, 2$ \\
\hline LCRTR & -3.378102 & -3.544284 & $\mathrm{C}, \mathrm{T}, 4$ \\
\hline LDETR & -3.965468 & -3.544284 & $\mathrm{C}, \mathrm{T}, 4$ \\
\hline DCRTR & -9.407459 & -3.536601 & $\mathrm{C}, \mathrm{T}, 1$ \\
\hline DDETR & -5.380098 & -3.533083 & $\mathrm{C}, \mathrm{T}, 2$ \\
\hline
\end{tabular}

Tablo 1: ADF Birim Kök Testleri

\begin{tabular}{|l|l|l|l|}
\hline Değişkenler & Trace Değeri & Kritik Değer (\%5) & Eş bütünleşme \\
\hline $\begin{array}{l}\text { LCRAZ - } \\
\text { LDEAZ }\end{array}$ & 12.59541 & 15.49471 & Yok \\
\hline $\begin{array}{l}\text { LCRKZ- } \\
\text { LCRKZ }\end{array}$ & 21.80274 & 15.49471 & Var \\
\hline $\begin{array}{l}\text { LCRKS- } \\
\text { LDEKS }\end{array}$ & 18.10720 & 15.49471 & Var \\
\hline
\end{tabular}

Tablo 2: Johansen Eşbütünleşme Test Sonuçları 
Elde edilen sonuçlara göre Azerbaycan için CR ve DE değişkenleri arasın uzun dönem denge ilişkisi bulunmazken, Kazakistan ve Kırgızistan için CR ve DE değişkenleri arasından uzun denge ilişkisi içerisindedir.

\begin{tabular}{|l|l|l|l|l|l|}
\hline Ülke & Trend & Hesaplanan F & \multicolumn{3}{|c|}{ Kritik Değerler } \\
\hline & & & $\% 10$ & $\% 5$ & $\% 1$ \\
\hline AZ & Yok & 5.72 & $4,04-4,78$ & $4,94-5,73$ & $6,84-7,84$ \\
\hline AZ & Var & 3.67 & $5,59-6,26$ & $6,56-7,30$ & $8,74-9,63$ \\
\hline KZ & Yok & 5,04 & $4,04-4,78$ & $4,94-5,73$ & $6,84-7,84$ \\
\hline KZ & Var & 5,25 & $5,59-6,26$ & $6,56-7,30$ & $8,74-9,63$ \\
\hline KS & Yok & 6.66 & $4,04-4,78$ & $4,94-5,73$ & $6,84-7,84$ \\
\hline KS & Var & 4.28 & $5,59-6,26$ & $6,56-7,30$ & $8,74-9,63$ \\
\hline TR & Yok & 5.15 & $4,04-4,78$ & $4,94-5,73$ & $6,84-7,84$ \\
\hline TR & Var & 4.92 & $5,59-6,26$ & $6,56-7,30$ & $8,74-9,63$ \\
\hline
\end{tabular}

Tablo 3: ARDL Sinır Testi Özet İstatistikleri

Söz konusu analiz ARDL Sınır testi yardımıyla yapılmıştır. Analiz sonuçları Tablo 3'de özetlenmiştir. Trend değişkeninin modele dahil edilemediği, sadece \%10 önem düzeyinde, Azerbaycan, Kazakistan, Kırgızistan ve Türkiye için cr ve de değişkenleri arasında eş bütünleşme ilişkisi bulunmaktadır. \%5 önem düzeyinde Azerbaycan için eş bütünleşme ilişkisi yok, Kazakistan kararsızlık bölgesinde, Kırgızistan için eş bütünleşme ilişkisi yok, Türkiye kararsızlık bölgesinde, Trend değişkeninin modele dahil edildiği durumda hiç bir ülke için eş bütünleşme ilişkisi bulunmamaktadır.

\section{Sonuç}

Azerbaycan, Türkmenistan, Özbekistan, Kırgızistan, Kazakistan ülkeleri 1990'lı yıllarda Sovyetler Birliği’nin dağılmasıyla birlikte bağımsızlığına kavuşmuşlardır. Söz konusu ülkeler ekonomik kurumlarını oluşturmaları ile birlikte uluslararası ekonomik kuruluşlara üye olmuşlardır. Bu çalışmada Avrasya Ülkelerinin cari işlemler açısından analiz edilmişlerdir. Özbekistan ve Türkmenistan ekonomileri için veri bulunamadığından bu ülkeler cari işlemler açısından değerlendirilememişlerdir. Cari işlemler açığı bir ülkenin yurt içi üretimi ile harcamalara bağlı olarak belirlenmektedir. Eğer bir ülkenin üretimi harcamalarından azsa cari işlemler hesabı açık verecektir. $\mathrm{Bu}$ noktada cari işlemler açığının sürdürülebilirliği önem kazanmaktadır. Cari işlemler hesabının sürdürülebilirliği, cari ekonomi politikasının da sürdürülebilirliğinin bir göstergesidir. Diğer yandan, bu ülkeler için açısından cari işlemlerinin sürdürülebilirliği ülkelerin kurumsal bir yönetim oluşturup oluşturamadıklarının bir göstergesi olarak değerlendirilebilir. Zamanlarası borçlanma kısıtı, söz konusu ülkeler için değerlendirildiğinde, her iki test itibariyle hiçbir ülke \%5 önem düzeyinde zamanlararası borçlanma kısıtı koşulunu sağlayamamaktadır. Kazakistan ve Kırgızistan \%5 önem düzeyinde Johansen Eş bütünleşme testine göre, zamanlararası geri ödeme yeteneği koşulunu sağlarken, Sınır testi yaklaşımında sadece trend değişkeninin dahil edilmediği durumda \%10 önem düzeyin cari işlemler disiplini açısından sorun ortaya çıkmadığ söylenebilir. Genel olarak değerlendirildiğinde, ülkelerin cari işlemler açılarının sürdürülemez boyutlarda olduğu söylenemez. Ancak, Bu ülkelerin genç ülkeler olması ihracat mallarının ağırlıklı olarak doğal gaz ve petrole dayalı olması ve ithalat olarak sermaye malları ve teknoloji ürünleri açısından dışa bağımlı olmaları nedeniyle dış ticaret politikasının cari işlemelerde sıkıntı yaratmayacak şekilde düzenlemesi son derece önemlidir.

\section{Kaynaklar}

- $\quad$ Ahmed, S. and J. H. Rogers (1995) “Government Budget Deficits and Trade Deficits Are Present Value Constraints Satisfied in Long-Term Data?,” Journal of Monetary Economics, 36(2), 351-374.

- Azgun, S. (2009) “Is Current Account Deficit 'Too Large': Some Further Evidence” Trakia Journal of Sciences, 7(3), 51-56.

- Baglioni, A. and Cherubini U. (1993) "Intertemporal Budget Constraints and Public Debt Sustainability: The case of Italy", Applied Econometrics, 25(2), 275-283.

Binatl, A.O., Sohrabji, N.(2012) “Intertemporal Solvency of Turkey’s Current Account”, Panoeconomicus, 59(1), 89-104.

- Bohn, H. (1998) "The Behavior of U.S. Deficits Public Debt and Deficits" Quarterly Journal of Economics, $113(3), 949-963$.

- Caparole, M. G. (1995) "Bubble Finance and Debt Sustainability: a Test of the Government's Intertemporal Budget Constraint", Applied Econometrics, 27(12), 1135-1143.

- Hakkio, C. S. and M. Rush. (1991) 'Is the Budget Deficit 'Too Large?”' Economic Inquiry, 29, (3), 429445 . 
- Hamilton, J. D. and M. A. Flavin. (1986) "On the Limitations of Government Borrowing: A Framework for Empirical Testing”. The American Economic Review, 76(4), 808-819.

- $\quad$ Pesaran, M. H., Shin, Y. Smith, R. J.(2001) "Bounds Testıng Approaches To The Analysis of Level Relatıonshıps”, Journal of Applied Econometrıcs, 16(3 ), 289-326.

- Quintos, Carmela E. (1995) "Sustainability of Deficit Process with Structural Shifts," Journal of Business \& Economic Statistics, 13, (4), 409- 417.

- Tanner, E. and Liu P. (1994) “The Budget Deficit 'Too Large’ Some Further Evidence,” Economic Inquiry, 32(3), 511-518.

- Trehan, B. and C. E. Walsh (1991) “Testing Intertemporal Budget Constraints: Theory and Applications to U.S. Federal Budget and Current Account Deficits," Journal of Money, Credit and Banking, 23(2), $206-223$.

- Wickens, M.R. and Uctum M. (1993) "The Sustainability of Current Account Deficits: A Test of The U.S. Intertemporal Budget Constraint.” Journal of Economic Dynamic and Control, 17(3), 423-441.

- Wilcox, D. W. (1989) "The Sustainability of Government Deficits: Implications of the Present-Value Borrowing Constraint, Journal of Money, Credit and Banking, 21(3), 291-306. 


\title{
Keynesgil Sistem, Keynesgil Politikalar ve Keynes'in Gözünden Günümüzün Bir Değerlendirmesi
}

\section{Keynesian System, Keynesian Policies and an Evaluation of What Keynes Might Have Advised Today}

\author{
Assoc. Prof. Dr. Özlen Hiç (Istanbul University, Turkey)
}

\begin{abstract}
We have surveyed in this article the development of the Keynesian macroeconomic system since 1936 up to the present. Our approach was, however, analytical rather than historical and descriptive. Keynesian System, hence Neo-Keynesians and modern Keynesian schools, such as New Keynesian Economics and Post-Keynesian Economics visualize that, if left by itself, the economy will give unemployment due to insufficiency of aggregate demand. In the article, the Keynesian policies are analysed with respect to their efficiency. Keynesian System was developed and modified in the face of criticisms by its opponents. We emphasize in our article that the Keynesian System was mainstream most of the time both in academic circles and in implementation. Presently again, basically Keynesian System has the upper hand, mostly New Keynesian Economics and also to some extent, Post-Keynesian Economics.The last section of the article covers an evaluation of what Keynes might have said for today's economic problems.
\end{abstract}

\section{Giriș}

Klasik Sistem'in aksi varsayımlarına karşın ekonomiler sistemli konjonktür dalgalanmaları göstermişler, özellikle konjonktürün depresyon dönemlerinde büyük ölçülere varan gayrı iradi işsizlikle karşılaşmışlardı. Klasik Sistem konjonktür dalgaları ve depresyonla mücadele edebilecek etkin bir politika reçetesi vermekten çok uzaktı. İşte Keynes meşhur eserini (The General Theory of Employment, Interest and Money) 1936'da ve 19291934 Büyük Dünya Buhranının hemen sonrasında yayınlamış ve yepyeni bir makro sistem meydana getirmiştir. Keynes bu sisteminde Fiyat Beklentileri ve bu beklentilerde yanılmalar, Likidite Tercihi Eğrisi, Yatırımların Marjinal Etkinliği, Marjinal Tasarruf ve Marjinal Tüketim Meyli gibi yeni kavram ve fonksiyonel ilişkiler geliş̧irdiği gibi, kurumsal bir varsayım olarak işçi sendikalarının varlığını ve kuvvetini, sendikaların nakit ücreti tayin edeceği varsayımını, kısaca nakit ücretlerin rijitliğini de kabul etmiş̧tir.

Keynesgil makro sisteme göre ekonomi kendi haline burakıldığında otomatik olarak tam istihdamı sağlayamayacaktır. Aksine, efektif talep noksanı dolayısıyla eksik istihdam dengesi verecek, efektif talep noksanından doğan açık veya gayrı iradi işsizlikle karşılaşılacaktır. Buna karşı, efektif talebin yükseltilmesini sağlamak üzere, devletin makro düzeyde ekonomiye müdahale ederek toplam talebi yükseltmesi gerekecektir. Bunu sağlayacak en etkili politika ise, Keynes'e göre, devlet harcamalarının yükseltilmesi ve/veya vergi meylinin düşürülmesi, kısaca maliye politikasıydı. Para politikası ve para arzının yükseltilmesi de yardımcı ya da tamamlayıcı bir politika olarak uygulanabilir. Keynes'in makro sistemi efektif talep eksiği, yani deflasyonist açık veya gayrı iradi işsizlik yanında toplam talebin tam istihdam reel gelir azami düzeyinin üstüne çıkması, yani enflasyonist açık ve talep enflasyonu durumunu da içermekteydi. Bu durumda ise, depresyon için önerilen maliye ve para politikalarının tam tersinin uygulanması gerekecekti.

Keynesgil Sistem çerçevesinde uygulanan maliye ve para politikaları sonucu 1929-34 Büyük Dünya Buhranı atlatıldığı gibi, 1939-1945 2. Dünya Savaşını izleyen yıllarda ABD ve Avrupa ülkeleri kayda değer bir yüksek hızla gelişmeyi nisbi bir istikrar içinde başarabilmişlerdir. Konjonktür dalgalanmaları geniş ölçüde törpülenmiş, bunun yanında fiyat istikrarı da sağlanabilmiştir. Bu arada iktisat literatürü konjonktür dalgaları, büyüme, tüketim ve tasarruf fonksiyonu, para talebi ve portföy analizi, dış ekonomik ilişkiler, makro planlama, ekonometri vb. tüm konularda büyük bir gelişme göstermiştir. Bu nedenle de Lawrence R.Klein'i izleyerek Keynes'in getirdiği yenilikler "Keynesgil Devrim" (Keynesian Revolution) olarak adlandırılmaktadır.

\section{2 İşsizlik, Eksik İstihdam Dengesi, Konjonktür Dalgaları ve Keynes}

İşsizlik sorununun cevabı 1929-1934 Büyük Dünya Buhranını izleyerek ve 1936'da J.M.Keynes tarafından verilmiştir (The General Theory of Employment, Interest and Money). Esas itibariyle gelişmiş ekonomilerin bünyesini depresyon dönemi şartları altında inceleyen Keynes bu ülkelerde devlet makro alanda müdahalede bulunmadı̆̆ zaman ekonominin efektif talep noksanı nedeniyle eksik istihdamda dengeye geleceğini ve gayrı iradi işsizliğin ortaya çıkacağını göstermiştir. Keynes böylece yepyeni bir makroekonomik sistem kurmuş, yani gelişmiş ekonomilerin Klasik iktisaţ̧ıların iddia ettiği tarzda değil, başka tarzda işlediğini ifade etmiş ve makro iktisat analizlerinde yeni ve büyük bir çığır açmıştır. Keynes'e göre ekonominin kendi haline bırakıldığında efektif talep noksanı nedeniyle eksik istihdamda dengeye gelmesi karşısında, tam istihdam dengesine ulaşmak üzere devletin makro düzeyde müdahalesi gerekecektir. Keynes'e göre tam istihdama ulaşılmasında en etkin yol 
maliye politikalarıdır (devlet harcamalarının arttırılması, vergi meylinin düşürülmesi). Para politikası (para arzının arttırılması) ise daha az etkindir ve ikincil bir politika aleti olarak kullanılabilir. Keynes'in maliye politikalarının etkinliği hakkındaki görüşü depresyon dönemi için doğrudur. Fakat, sonraki analizler göstermektedir ki, resesyon dönemlerinde para politikası bu kere maliye politikalarından daha etkin olmaktadır (Hiç, 1994).

Keynes'in makro sistemi çerçevesinde ekonomiye devlet tarafindan yapılan makro müdahaleler, uygulanan maliye ve para politikaları sonucu bugün konjonktür dalgaları geniş ölçüde önlenmiştir, diyebiliriz. Bu hususta 1929-34 Büyük Dünya Buhranından ve 2. Dünya Savaşını da izleyerek Avrupa ülkelerinin altın para sistemini terk etmeleri de yardımcı rolü olmuştur. Çünkü altın sisteminde bir ülkedeki buhran kolayca diğer ülkelere sıçramaktaydı. Nitekim 1929-34 Dünya Buhranı bu şekilde sıçramalarla yaygınlaşmış ve derinleşmişti.

Keynes'i izleyerek iktisatçılar başlıca iki kampa ayrılmışlardır: Keynes ve Keynesgil iktisatçılar, Neo Klasik İktisatçılar. Bu iki ekol arasında ekonominin kendiliğinden tam istihdamı sağlayıp sağlayamayacağı sorunu üzerindeki tartışmalar uzun süre devam etmiştir (Branson, 1979).

Keynes'in Sistemi'ni izleyerek ve Keynesgil çarpan ilkesine yatırımların da hızlandıran etkisinin (gecikmesiz olarak) ilavesiyle, Harrod (1939 ve 1954) ve Domar (1957) gibi Keynesgil büyüme modelleri geliştirilmiştir. Çarpan ve hızlandıranın gecikmeli olarak işlemesi ise çarpan-hızlandıran konjonktür modellerini vermiş ve bu modeller konjonktür dalgalarının açıklanmasında ilk önemli adımı oluşturmuştur (Samuelson, 1939). Bu modelleri daha sonra Hicks (1950) ve Duesenberry (1958) gibi, parasal faktörleri de içeren daha karmaşık konjonktür modelleri izlemiştir.

Diğer taraftan, Solow (1956), Meade (1961) gibi iktisatçılar ise, faize karşı çok elastik bir yatırım fonksiyonunun varlığ halinde hızlandıran etkisinin bertaraf edileceğinden hareketle, ekonominin devamlı tam istihdam dengesinde yürüdüğü, Neo-Klasik büyüme modelleri geliştirmişlerdir.

\section{Keynes'in Getirdiği Yeni Kavramlar ve Eksik İstihdam Sonucu}

J.M.Keynes meşhur eseri, "The General Theory of Employment, Interest and Money"i 1936'da, hemen 19291934 Büyük Dünya Buhranından sonra yayınlamıştır. Bu yıllar konjonktür dalgaları ve Büyük Dünya Buhranı karşısında Klasik Sistem'in aciz kaldığı, klasik açıklamalar ve reçetelerle buhranın çözülemeyeceğinin çok açık olarak ortaya çıktığı bir dönemdi. Daha önceleri Klasik Sistem ye Miktar Teorisi yanlısı olan Keynes (1930) bu durum karşısında yeni kavramlar ve yeni fonksiyonel ilişkiler içeren yepyeni bir makroekonomik sistem meydana getirmiş, gelişmiş ekonomilerin işleyişinin klasik sistemle değil, kendi ileri sürdüğü sistemle temsil edilebileceğini iddia etmiştir. Bu yeni makroekonomik sisteme göre devletin müdahalesi olmadığı ve ekonomi kendi haline bırakıldığında, -mal ve faktör piyasalarında TRŞ geçerli olsa dahi- tam istihdam dengesi otomatik olarak sağlanamayacaktır. Aksine, bu durumda ekonomi efektif talep noksanı nedeniyle eksik istihdamda denge bulacak, ortaya bir gayrı iradi yahut açık işsizlik çıkacaktır. Bunu önlemek üzere devletin makro politikalarla ekonomiye müdahale ederek efektif talebi yükseltmesi gerekir. Toplam talep düzeyini etkileyecek (demand management) başlıca iki makro politika söz konusudur:

i) maliye politikaları (devlet harcamalarının yükseltilmesi ve/veya vergi meylinin düşürülmesi)

ii) para politikası (faiz oranını düşürmek, bu yoldan yatırımları yükseltmek üzere para arzının arttırılması)

Keynes tam istihdamın sağlanmasında maliye politikalarının daha etkili olduğunu, para politikasının esas itibariyle maliye politikasına yardımcı olarak kullanılabileceğini ileri sürmüştür.

Devlet, sistemli bir biçimde maliye ve para politikaları yoluyla toplam talebi ayarlayarak depresyonları ve konjonktür dalgalarını önlemek imkanına sahip olacaktır.

Keynes efektif talep noksanından doğan eksik istihdam ve açık işsizlik dengesi sonucuna ulaşırken, makro analizlere yeni kavramlar, kurumsal şartlar ve fonksiyonel ilişkiler getirmiştir. Keynes'in getirdiği başlıca yenilikleri şu noktalarda toplayabiliriz (Ackley, 1961, Branson, a.g.e., Hiç, a.g.e.):

i) Fiyat beklentileri $(\mathrm{Pe})$ ve bu beklentilerde yanılmalar

ii) Paranın klasik muamelat saiki yanında ayni zamanda spekülasyon saikiyle de talep edilmesi ve faiz oranı ile ters orantılı bir likidite tercihi eğrisinin varlığı. Muamelat saikiyle yapılan para talebi makro iktisat literatüründe "aktif ankes", spekülasyon saikiyle yapılan para talebi "atıl ankes" olarak adlandırılmaktadır.

iii) Yatırımın reel bir sermaye artışı olarak değil, bir nakit akımı olarak ele alınması gereği ve bunu sağlayan "yatırımların marjinal etkinliği" (MEI: Marginal Efficiency of Investments) kavramı. Klasikler yatırımın getirişinin yatırım maliyetine eşitlendiği yatırım dengesinin reel bir kavram olan sermayenin marjinal verimliliğinin (MPK) faiz oranına eşit olduğu noktada oluşacağını ifade ediyorlardı. MPK kavramında fiyatlar sabit varsayılır. Hâlbuki belirli bir kısa dönemde yatırım talebi ve hacmi arttığında sermaye malları fiyatları artar, bu da yatırımların kârlılı̆ı̆ının düşmesinde en önemli rolü oynar. Bu nedenle Keynes, yatırım dengesi analizlerine bir nakit kavramı olan ve sermaye fiyatlarının yükselmesini içeren MEI kavramını getirmiştir. Sonuçta gerek Klasik gerek Keynesgil yatırım fonksiyonu faiz ile ters yönlü şekilde ilişkilidir. Ne var ki Klasiklere göre yatırım 
fonksiyonunun eksi faiz elastikliği yüksek iken Keynes'de bu elastiklik düşüktür. Bu özellik gerek ekonominin eksik istihdam dengesi göstermesinde gerek para ve maliye politikalarından hangisinin daha etkili olduğunun saptanmasinda belirleyici rol oynar.

iv) Tasarruf ve Tüketim Meyli: Klasiklerde tasarruf ile faiz oranı arasında doğru yönlü bir ilişki, tüketimde ise bunun aksi, faiz oranı ile ters bir ilişki kabul edilmektedir. Buna göre, Klasiklerde tasarruf ve tüketim fonksiyonunda kaymalar birbirini götürür ve yatırım ve tüketim harcamalarından oluşan toplam talep ayni düzeyde kalır. Benzer şekilde yatırımların artması da tüketimin aynı miktarda azalmasıyla bir arada görülecektir. Keynes'e göre ise gerek tasarruf gerek tüketim düzeyi faiz oranından ziyade reel gelir düzeyine bağlıdır. Yüksek gelir düzeylerine çıkıldıkça marjinal tasarruf meyli (MPS) yükselecek, marjinal tüketim meyli (MPC: Marginal Propensity of Consumption) düşecektir.

Yukarıda sayılan temel kavramlar, ilişkiler ve fonksiyonlar ekonominin makro dengesinin Klasiklerden ve otomatik istihdam dengesinden tamamen farklı olduğunu göstermeye yetmektedir.

Klasiklerde reel gelir emek piyasasında emek arz ve talebinin kesiştiği noktada (tam istihdam noktasında) dengeye gelmekteydi. Yatırım ve tüketim harcamaları ve toplam talep faiz oranı yoluyla bu dengeye göre ayarlanır. Para arz ve talebi ise sadece fiyatlar genel seviyesini ve nominal parametrelerin denge değerlerini belirler. Buna reel ve parasal sektörlerin ayrı olması, "dikotomi" (dichotomy) denmektedir.

Keynes'de ise dikotomi yoktur; ekonominin reel sektörleri ile parasal sektörlerinin dengeleri, atıl ankes talebinin mevcudiyeti ve faiz oranı yoluyla bir arada oluşur. Fakat daha önemlisi, denge faiz oranına göre oluşacak denge yatırım seviyesinin tam istihdam reel gelir seviyesinde oluşacak tasarrufa eşit olması mümkün değildir. Çünkü yatırım fonksiyonunun eksi faiz elastikliği düşüktür ve hatta faiz oranı sıfıra düşürülse dahi sıfır faiz oranında oluşacak yatırım seviyesi tam istihdam gelir düzeyindeki tasarrufun altındadır. O halde, ekonomide emek piyasasının verebileceği tam istihdam dengesi oluşamaz. Bu sonuçta iki etken bir arada rol oynamaktadır. Birincisi, yatırım fonksiyonunun (MEI'nin) eksi faiz elastikliğinin düşüklüğü, ikincisi marjinal tasarruf meylinin (MPS) yüksek oluşudur. Bu şartlar altında ekonomide denge gelir seviyesi yatırım ve tasarrufun eşit olduğu noktada yahut diğer yönüyle bakılacak olursa, yatırım ve tüketim harcamaları toplamını ifade eden "efektif talep" düzeyine göre oluşur ve efektif talep noksanı dolayısıyla, bu bir eksik istihdam dengesi olacaktır.

Bu durumu emek piyasası açısından şöyle izleyebiliriz: Firmalar toplam üretimlerini toplam talep düzeyine göre ayarlarlar. Üretim fonksiyonu ise bu üretim düzeyinin sağlanması için ne kadar emek istihdam edileceğini vermektedir. Bu da efektif talep noksanı nedeniyle tam istihdamın altında bir nokta olacaktır.

v) Keynes’in makro analizlere getirdiği bir başka değişiklik emek piyasasıyla ilgilidir. Keynes'e göre emek piyasasında TRŞ yoktur; işçi sendikaları mevcuttur ve işveren sendikalarına kıyasla daha güçlü durumda olan işçi sendikaları nakit ücreti belirler. İşçi sendikaları nakit ücreti fiyatlar genel seviyesine göre ve firmaların verebileceği azami reel ücreti hedefleyecek biçimde belirleyeceklerdir (Acley, a.g.e.). Buna göre, emek piyasasında reel gelir değil, reel ücret ve istihdam dengesi teşekkül etmiş olur. Reel ücret ise yüksek olduğuna ve bu reel ücret düzeyinde işçilerin emek arzı emek talebinin üstünde olduğuna göre, bu bir eksik istihdam dengesidir. Ortaya çıkan açık işsizlik ise aslında ücretlerin yüksek tutulmasından değil, efektif talep noksanından doğmaktadır. Efektif talep noksanı yatırımın eksi faiz elastikliğinin düşüklüğü ve marjinal tasarruf meylinin yüksekliğinden doğduğu için buna makro iktisat literatüründe "yatırım-tasarruf tutarsızlığı" denmektedir.

Ayni özellikler Keynesgil Sistem'de nakit ücretlerin ve fiyatların yükselmesine paralel olarak artan, yani doğru yönlü eğimli bir toplam arz eğrisi karşımıza çıkarmaktadır. Bu da toplam talebi etkileyecek maliye ve para politikaları uygulanması sonucunda reel gelir ve istihdam düzeyinin mutlaka artacağını göstermektedir.

Emek arzı özellikleri alternatif bir açıklama tarzı olarak işçilerin para aldanmasına sahip olmaları ve fiyat ve reel ücret beklentilerindeki yanılmaları ile de açıklanabilir. Buna göre işçiler fiyat artışlarını tam tahmin edemedikleri, fiyat beklentilerinde yanılgıya düştükleri için fiyat artışları karşısında emek arzını tam olarak kısmayacaklardır. Bu alternatif açıklama tarzı da karşımıza yine beklentilerdeki sürekli yanılmalardan doğan doğru yönlü eğimli bir toplam arz eğrisi çıkartacaktır (Branson, a.g.e.).

vi) Keynes ithalatın da fiyatlar ve döviz kuru yanında reel gelir düzeyine bağlı olduğunu, buna göre bizim ihracatımızın reel düzeyinin bizden ithalat yapan ülkelerin reel gelir düzeyine bağlı olduğunu ileri sürmüştür. Bu kavram ve analizler dış ekonomik ilişkiler alanında büyük adımlar atılmasına yol açmıştır. Ancak bu tezde basitlik açısından kapalı modellerle çalışılacaktır. Buna göre ve para ve maliye politikalarının etkinliğini araştırmak üzere kullandığımız modellere devlet (kamu harcamaları ve vergi meyli) dâhil edilecek fakat dış ilişkiler (ihracat ve ithalat) dışarıda bırakılacaktır.

\section{Keynesgil Devrim}

Keynes'in getirdiği yenilikler ve yeni makro ekonomi sistemi LR.Klein'ın da nitelendirdiği gibi, gerek literatürde ve özellikle makro ekonomi alanında gerek uygulama ve iktisat politikalarında bir "Keynesgil Devrim" (Keynesian Revolution) yaratmıştır (Klein, 1961). Her şeyden önce birçok tanınmış iktisatçı Keynesgil Sistem'i benimsemiş, bu sistemi geliştirmiş ve iktisat teorisine ve Keynesgil Sistem'e katkılarda bulunmuşlardır. 
Burada bu iktisatçılardan sadece bir kaçını sayabiliriz: Lawrence Klein, J.R.Hicks, Roy F.Harrod, N.Kaldor, M.Kaleski, A.W.Phillips, Alvin Hansen, Paul A.Samuelson, James Duesenberry, Ragnar Frisch, Evsey D.Domar, Charles Kindleberger, Oskar Lange, S.S.AIexander, Gardner Ackley, Walter Heller, James Tobin, Franco Modigliani ve daha yeni kuşaktan olan S.Blinder ve John B.Taylor, vb. (Klamer, 1985).

Keynesgil makro iktisat politikaları uygulamaya konmuş ve bu politikalarla ABD ve Avrupa ülkeleri 19291934 Dünya Buhranı ve onu izleyen 1939-1945 2. Dünya Savaşı'ndan sonra uzun bir süre ve 70’li yıllara kadar kayda değer bir ekonomik büyüme ve gelişmeyi yine kayda değer bir fiyat istikrarı içinde başarabilmişlerdir. Bu arada konjonktür dalgaları büyük ölçüde kontrol altına alınabilmiştir. Bu şiddetli dalgalanmalar Keynes'den sonra fiilen resesyonlara ve 1lımlı enflasyonist eğilimlere indirgenmiş, bunlar dahi önlenebilmiştir (Klamer, a.g.e.).

\section{Keynesgi Sistem'de Para ve Maliye Politikalarının Etkinliği}

\subsection{Buhran Döneminde Uygulanması Gereken Politikalar}

Keynes'e göre, başlangıç noktası olarak buhran dönemi ve eksik istihdam dengesinden hareket edecek olursak, efektif talebi yükselterek tam istihdama ulaşmak konusunda en etkili politika maliye politikalarıdır (Şekil 1'e yeniden bak1labilir).

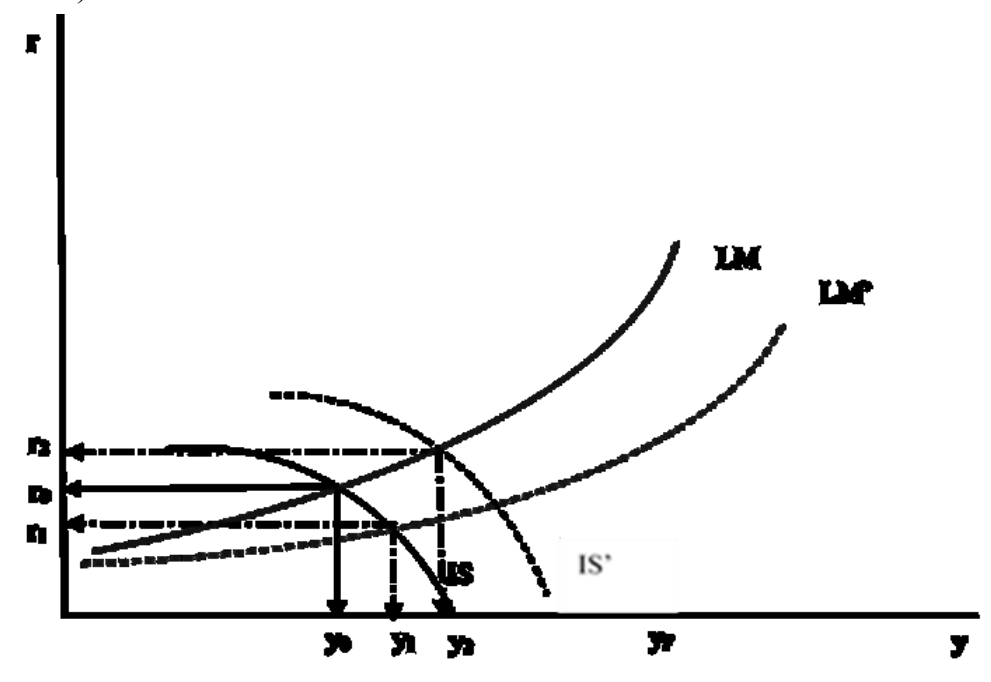

Şekil 1. IS-LM Ë̆rileri Yardımıyla Keynesgil Sistem 'in Temsili

Özellikle devlet reel harcamaları (g) düzeyinin yükseltilmesi aynen yatırım fonksiyonunun (diyelim ki, teknik ilerleme etkisiyle) yükselmesi şıkkında meydana geleceği gibi, efektif talebi, dolayısıyla üretim ve istihdamı bir çarpan etkisiyle arttırır (Branson, a.g.e., Dornbusch, vd, 1990, Musgrave, vd, 1989). Şüphesiz Genelleştirilmiş Keynes Sistemi'nde devlet harcamalarının toplam talep ve reel geliri arttırması ile birlikte, bu sistemin genel makro denge şartları çerçevesinde, faiz oranı de bir miktar yükseleceği için, özel yatırımlar, az da olsa, bir miktar düşer. Bu olay "dışlanma etkisi" (crowding-out effect) olarak adlandırılmaktadır. Özel yatırım düzeyindeki bu düşme devlet harcamalarını arttırmanın (veya yatırım fonksiyonunun teknik ilerleme dolayısıyla yükselmesinin) reel geliri ve istihdamı yükselten çarpan değerini biraz aşağıya çekecektir. Fakat yine de en etkili politika devlet harcamalarının yükseltilmesidir. Çünkü bu politika sonucunda reel gelir önemli ölçüde arttığı gibi, er geç tam istihdam noktasına ulaşmak da mümkün olabilecektir.

Diğer taraftan, vergi meylinin düşürülmesi de bu kere çarpan değerini yükselterek efektif talebi, reel gelir ve istihdamı arttırır. Çünkü vergi meylinin düşürülmesi halkın eline geçen "kullanılabilir gelir" (disposable income) düzeyini yükseltir. Bu ise kısmen tasarruf düzeyini ve fakat kısmen de tüketim harcamalarını arttırır. t(y)'nin düşürülmesinin gelir arttırıcı etkisinin g'nin yükseltilmesinin gelir arttırıcı etkisinden biraz daha düşük olduğu açıktır. Kaldı ki, g’nin yükseltilmesi bir hükümet kararıdır ve kesin biçimde gerçekleştirilir.

Buna karşın, t(y)'nin düşürülmesi kesin olarak halkın kullanılabilir gelirini yükseltir. Fakat buradan hareketle tüketim harcamalarının yükseltilmesi hane halklarının kararlarına bağlı bir konudur. Örneğin, hane halkları bu vergi düşürülmesini geçici kabul edebilirler yahut başka çeşitli nedenlerle kullanılabilir gelirleri arttığı halde tüketim harcamalarını arttırmayabilirler veya yeterince arttırmayabilirler. Dikkat edilirse g'nin yükseltilmesi ve/veya t(y)'nin düşürülmesi bütçe açığı yaratacaktır. Fakat bu buhran döneminden çıkmanın ve istihdam arttırmanın tek etkili yolu ve bedelidir.

Para politikasına gelince, yine diyelim ki buhran döneminde veya eksik istihdamın mevcut olduğu başlangıç noktamızda Merkez Bankası açık piyasa işlemleri (sermaye piyasasından esham tahvil satın almak ve bedelinin halkın banka mevduat hesaplarına ödenmesi) ve reeskont oranının düşürülmesi yoluyla para ve kredi hacmini 
genişletmeye çalışsın. Bu politika da faiz oranını düşürmek, böylece yatırımları arttırarak efektif talebi, reel gelir ve istihdam düzeyini yükseltebilir. Fakat genişleyici (expansionary) para politikasının etkisi sınırlıdır ve sırf para politikası yoluyla tam istihdam dengesine ulaşmak hiç bir zaman mümkün değildir. Çünkü birincisi para arzı artışı, atıl ankes talebinin eksi faiz elastikiyetinin yüksek olması nedeniyle faiz oranı fazla düşürülemez. İkincisi, bu faiz düşmesi karşısında, yatırım fonksiyonunun eksi faiz elastikliğinin küçük olması nedeniyle yatırımlar çok fazla yükselmez. Dolayısıyla da para politikasıyla efektif talep ve istihdam bir miktar arttırılabilse dahi, tam istihdam dengesine ulaşmak hiç bir zaman mümkün olmayacaktır. Kaldı ki, fiyat değişmelerinin yatırım ve tüketim üzerindeki dinamik etkileri yahut başka etkilerin ağır basması sonucu faiz oranının düşürülmesine rağmen yatırımlar yükselmeyebilir. Bu nedenlerle de Keynes’e göre buhran döneminde maliye politikası esastır; para politikasına maliye politikası yanında ancak yardımcı olarak başvurulabilir.

Keynesgil makro sistem sadece buhran dönemini aydınlatmakla kalmamaktadır; genel nitelikte bir teori yahut makro sistemdir. Nitekim bu kere enflasyona ve konjonktürün refah dönemlerindeki enflasyonist eğitimlere karş1 da etkili politika tavsiyeleri yapmamıza olanak vermektedir. Nitekim eğer efektif talep herhangi bir dönemde ekonomi için tam istihdam ile çizilmiş olan azami üretim ve reel gelir limitini aşmışsa, bu bir enflasyonist açık ve talep enflasyonu yaratacak, fiyatlar devamlı yükselecektir. Bu durumda Keynesgil Sistem çerçevesinde hükümet devlet harcamalarını azaltmak, vergi meylini yükseltmek ve gerekirse bütçe fazlası vermek, para arzı mutlak seviyesini veya en azından para arzı artış hızını düşürerek toplam talebi kısabilir. Böylece enflasyonist açık ve talep enflasyonu önleyebilir.

Benzer şekilde, devletin konjonktür dalgalarını önleyici uzun vadeli politikalar izlemesi de mümkündür. Nitekim konjonktürün buhran döneminde devlet harcamalarını arttırmak, vergileri düşürmek ve bütçe açıkları vermek bahasına toplam talep yükseltilir. Bunun yanında para arzı arttırılarak faiz oranı düşürülür. Yüksek konjonktür ve enflasyonist eğilimler döneminde bu kere aksine, devlet harcamaları azaltılır, vergi meyli yükseltilir ve bütçe fazlalıkları vererek toplam talep artışı dizginlenir. Aynı şekilde para arzı düşürülür ve faizler yükseltilir. Buhran dönemindeki bütçe açıkları konjonktürün yüksek dönemlerindeki bütçe fazlalıklarıyla kapanabilir ve uzun vadede bütçe dengesi muhafaza edilmiş olur (Hansen, a.g.e.).

Yine Keynes'e göre gelir dağılımını düzeltici yönde politikalar da toplam talebi ve dolayısıyla istihdam düzeyini arttırabilir. Örneğin, müterakki gelir vergisi yoluyla düşük gelirlilerin "kullanılabilir gelirleri" (vergi tenzil edildikten sonraki gelirleri) yükseltilsin; yüksek gelirlilerin kullanılabilir gelirleri ise düşürülsün. Düşük gelirlilerin marjinal tasarruf meyilleri düşük, yüksek gelirlilerinki ise yüksek olduğuna göre, kullanılabilir gelir farklarının müterakki yahut uygulanmakta olana kıyasla daha müterakki gelir vergisi yoluyla kullanılabilir gelir farklarının azaltılması makro marjinal tasarruf meylini düşürecek, makro marjinal tüketim meylini yükseltecektir. Böylece, yeni dengede toplam harcamalar ve istihdam seviyesi de yükselmiş olacaktır. Müterakki gelir vergisi düşük gelir düzeylerinde az vergi alarak kullanılabilir geliri fazla azaltmamak, yüksek gelir düzeylerinde yüksek vergi alarak kullanılabilir geliri ve bu yoldan tüketim harcamalarını biraz kısarak ekonomiye bir ölçüde otomatik istikrar getirici rol de oynamaktadır (built-in stabilizer) (Musgrave, vd, a.g.e.).

\subsection{Buhran Dönemi Dışında Uygulanması Gereken Politikalar}

Keynes, buhran dönemi şartlarının etkisi altında efektif talebi yükselterek istihdamı arttırmak, tam istihdam noktasına ulaşmak hususunda maliye politikasının etkin olduğunu, para politikasının daha az etkili olduğunu ve ancak yardımc1 politika olarak kullanabileceğini öne sürmüştü. Aynı sorunu Şekil 2'de görüldüğü gibi, LM-IS eğrileri yardımıyla ve geniş bir perspektif içinde inceleyebiliriz. Ve meseleyi çok farklı gelir düzeyleri açısından bir mukayeseye tabi tutabiliriz (Branson, a.g.e., Hiç, a.g.e.).

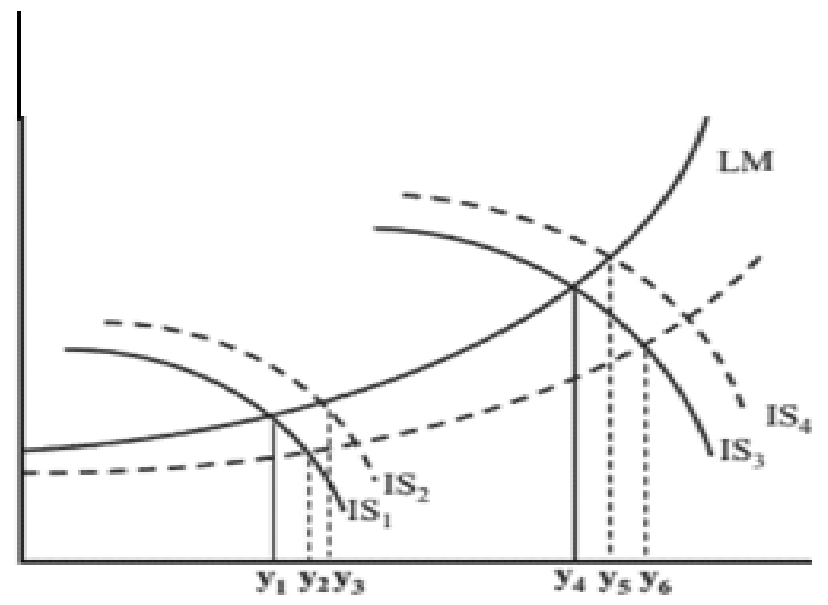

Şekil 2. IS-LM Ĕ̆rileri Yardımıyla Keynesgil Maliye ve Para Politikalarının Etkinliği

Şekil 2'de de görüldüğü gibi, ekonomi düşük gelir düzeylerinde bulunuyorsa (buhran dönemlerinde olduğu gibi) bu düşük gelir düzeylerinde LM eğrisinin yatık olması dolayısıyla para arzındaki yükselme (LM eğrisinin 
sağa kayarak LM' olması) durumunda reel gelir seviyesi $\mathrm{y}_{1}$ 'den ancak $\mathrm{y}_{2}$ 'e yükselebilecektir. Hâlbuki IS eğrisinin maliye politikası (devlet harcamalarının yükseltilmesi ve/veya vergi meylinin düşürülmesi) ile IS $_{1}$ 'den $I_{2}$ 'ye kaydırılması reel gelir seviyesini $y_{3}$ 'ye yükseltebilecektir. Kısaca düşük gelir düzeylerinde, Keynes'in de iddia ettiği gibi, maliye politikası etkili; para politikası ise fazla etkili değildir.

Buna karşın, daha yüksek gelir düzeylerinde, diyelim ki y4 düzeyinde isek, bu kere geliri ve istihdam daha da yükseltmek istiyorsak, LM eğrisinin dikleştiği bölgelerde olduğumuz için para politikası etkili olmakta ve reel gelir düzeyini $\mathrm{y}_{6}$ 'e yükseltmektedir. Maliye politikası (IS eğrisinin IS $_{3}$ 'den IS $_{4}$ 'ye kayması) ise fazla etkili değildir ve reel geliri ancak $y_{5}$ 'e yükseltebilmektedir.

Bunu, yüksek gelir ve resesyon dönemlerinde para politikası maliye politikasından daha etkilidir şeklinde özetleyebiliriz. Bu sonuç Keynes'in Sistemi'ne aykırı değil, tamamen bu sistemin özelliğinin tabii bir sonucu olarak karşımıza çıkmaktadır. Kısaca, buhran dönemleri yahut ciddi durgunluk ve düşük konjonktür dönemlerinde maliye politikalarına, yüksek konjonktür ve resesyon dönemlerinde para politikalarına öncelik verilmelidir. Keynesgil Sistem'in uygulanmasının tabii sonucu budur.

\section{Keynesgil Politikaların Fiili Uygulamaları ve Sonuçları}

\subsection{Konjonktür Dalgalanmaları, Buhranlar ve İşsizlik karşısında Keynesgil Politikalar}

Keynes'in makro sisteminden hareketle buhrana karşı Keynesgil politika reçetelerinin uygulanmasına paralel olarak ise konjonktür dalgalarının adeta ortadan kalktığını gözlemekteyiz. Keynes buhran döneminde esas olarak maliye politikası izlenmesini öneriyordu. Devlet harcamalarının arttırılması, vergi meylinin düşürülmesi ve bütçe açıklarının meydana getirilmesi bahasına efektif talebin etkin şekilde yükseltilmesi Keynes'in temel politika ilkesini oluşturmaktaydı. Para genişlemesi ancak yardımcı bir politika kabul edilebilirdi.

Keynes uygulanacak maliye politikaları sonucu meydana gelecek bütçe açığından fazla endişe edilmemesi gerektiğini savunuyordu. Çünkü her şeyden önce bu sayede reel gelir ve istihdam artacaktı. İkincisi, bu reel gelir artışı aslında vergi gelirlerini de arttıracak, sonuçta bütçe açığı bir ölçüde azalmış olacaktı. Kaldı ki, uzun vadede ve refah döneminde, enflasyonist eğilimleri önlemek üzere bu kere efektif talebi kısmak üzere devlet harcamaları kısılacak, vergi oranları yükseltilecek, bütçe fazlalıkları meydana getirerek efektif talep ve harcama düzeyi kısılacaktı. Bu bütçe fazlalıkları buhran dönemindeki bütçe açıklarından doğan borçların ödenmesinde kullanılır; böylece bütçe dengesi uzun vadeli olarak sağlanabilirdi.

Keynes para politikasının da yardımcı bir alet olarak etkili biçimde kullanılması ve para genişlemesinin gerekli ölçüde sağlanabilmesi için altın sisteminin terk edilmesini ve kâğıt para sisteminde kalınmasını önermiştir.19291934 Dünya Buhranı dolayısıyla Avrupa ülkeleri altın sistemini terk etmişler ve fiilen kâğıt para rejimine girmişlerdi. Ayni durum 1939-1945 2. Dünya Savaşında da görülmüş̧ü. Keynes 2. Dünya Savaşından sonra da kâğıt para rejimine devam edilmesi gereğini savunmuştur. Keynes bu vesile ile dış ödemeler dengesiyle ilgili otomatik altın standardı teoremini de eleştirmiştir. Klasik Sistem ve Miktar Teorisi çerçevesinde Klasikler altın sisteminde altın giriş ve çıkışları, para arzındaki bu değişmelerin yaratacağı fiyat değişmeleri yoluyla ödemeler dengesinin otomatik olarak sağlanacağını iddia ediyorlardı. Keynes'e göre para arzının değiştirilmesi ise sadece fiyatları değil, ayni zamanda reel gelir ve reel gelire bağlı olarak ithalatı değiştirecekti. Demek ki dış ödemeler bilançosundaki düzelme kısmen reel gelir düzeyinin azaltılması bahasına sağlanmış olacaktı.

ABD'de Franklin D.Roosevelt'in 1933'den itibaren uyguladığı New Deal politikası ile, Avrupa ülkeleri de Keynesgil reçetelerin uygulanması yardımıyla 1929-1934 Büyük Dünya Buhranını atlatabilmişler ve ileriki yıllar için de konjonktür dalgalanmalarını önleyebilecek bilgi ve aletlere sahip olmuşlardır. Nitekim, Büyük Dünya Buhranı ve 2. Dünya Savaşından sonra ABD ve Avrupa ülkelerinin konjonktür dalgalanmalarıyla karşılaştıkları söylenemez. Birçok ülkede zaman zaman ödemeler bilançosu devamlı açıklar nedeniyle meydana gelen ve devalüasyonla, devalüasyonla birlikte büyüme hızının kısılması, fiyat istikrarının sağlanmasını hedefleyen politikaların uygulanmasıyla çözümlenen sorunlar ayrıdır ve bu krizlerin konjonktür dalgalanmalarıyla ilgisi yoktur (Hiç, a.g.e.).

\section{2 İlerleyen Ekonomik Gelişmeler Karşısında Keynesgil Politikalar}

Globalizasyon'un ilk dönemlerinde konjonktür dalgaları yerini hafif resesyonlara veya 1 lımlı enflasyonist ortamın meydana çıkmasına bırakmıştır. Bu sorunlar ise genellikle maliye politikalarından ziyade para politikası yoluyla çözümlenebilmektedir. Fakat bu şartlar altında maliye politikalarından ziyade para politikası uygulanması Keynes'in makroekonomik sistemine aykırı değildir. Daha önce de belirtildiği gibi, Keynes'den sonra, Keynesgil Sistem'den hareketle yapılan analizler resesyon dönemlerinde, buhran döneminin aksine, para politikasının maliye politikasından daha etkili olacağına işaret etmektedir. Ilımlı enflasyonların önlenmesi de doğaldır ki, daha ziyade para politikası ve para arzı artışının kısıtlanması yoluyla başarılabilir.

Günümüzde ise yeniden resesyon dönemlerine dönülmüştür. Keynes Sistemi'nin ve Keynesgil reçetelerin konjonktür dalgalanmaların geniş ölçüde kontrol altına alması, buhranların önlenmesi en belirgin bir gözlem olarak karşımızdadır. 
Keynes'in makro sistemi ve politika tavsiyeleri sadece buhranların önlenmesinde değil, ayni zamanda enflasyonların önlenmesinde de etkili biçimde kullanılmıştır. Nitekim 1929-1934 Dünya buhranının aşılmasından hemen sonra savaş hazırlıkları ve 1939-1945 2. Dünya Savaşı çeşitli ekonomik, sosyal ve siyasi sorunlar yanında enflasyonist eğilimleri de kamçılamıştı. Bu enflasyonist eğilimlerin kontrol altına alınmasının sadece para politikası ve para arzının kısılmasıyla arzu edilir düzeyde kısıtlanamayacağı açıktı. Bu nedenle bu enflasyonist dönemde de Avrupa ülkeleri Keynesgil politikalar uygulamışlar, para arzı artışının kısılması yanında kamu harcamalarının da kısılmasına çalışmışlardır. En azından savaş masrafları dışındaki harcamaları kısmışlar, vergiler yükseltmişler, faizi yükselterek iç borçlanmaya gitmişler, böylece özel tüketim harcamalarını kısıtlamışlardır. Maliye politikaları yoluyla efektif artışının kısıtlanmaya çalışılması açık şekilde Keynesgil makro sistemden doğmaktadır, Klasik Sistem ile pek ilişkili değildir (Keynes, 1941).

\subsection{Günümüz Ekonomik Şartları ve Sorunları Karşısında Keynesgil Politikalar}

Keynes ile bir taraftan konjonktür dalgalanmaları başarılı bir şekilde önlendikten, en azından geniş ölçüde kontrol altına alındıktan sonraki zaman boyunca bu kere gelişmiş ülkelerde genellikle devlet müdahalesi giderek artmıştır. Bu arada, birçok ülkede bütçe açıkları baş gösterdiği halde etkili tedbir alınmamıştır. Enflasyon ve verimlilik farkları ayrıca dış ödemeler bilançosu açıklarına yol açmış, buna rağmen paranın dış değeri muhafaza edilmek istendiği için dış ödemeler bilançosu krizleri baş göstermiştir. Bu krizler er geç devalüasyon yapılarak önlenmiştir. 1971'den sonra ise ABD tahditli altın sistemini terk etmiş ve ABD dahil tüm gelişmiş ülkeler genellikle esnek, döviz kuru uygulamalarına geçmişlerdir. Döviz kurunun tespiti geniş ölçüde serbest piyasaya bırakılmıştır.

Bu ülkelerde sosyal baskılar sonucu sosyal yönde müdahaleler de yoğunlaşmış, sosyal haklar, maliyetler de ve sosyal gayeli kamu harcamaları önemli bir yer işgal eder duruma gelmiştir. Böylece Keynes'in buhran dönemi için önerdiği ve buhran döneminden çıkılması hususunda faydalı olabilecek politikaların bu kere bugünkü ekonomik şartlar altında uygulanmaya devam edilmesi sorunlar yaratmaya başlamıştır. Kaldı ki, aynı dönem boyunca ve zamanla ekonomiler dinamizm kazanmış özel sektör büsbütün gelişmiş, teknolojik ilerlemeler hızlanmıştır. Bazı gelişmiş ülkeler sınai ekonomi olmaktan çıkarak bilgisayarlı iletişim-haberleşme çağına girmiştir. Buna paralel olarak dış ticaret, -gerek mal gerek insan gücü alımı hızla artmış, dış ticaret daha serbest hale getirilmiştir. Malî piyasalar da birbiriyle irtibatlanmış, gerek sabit sermaye gerek portföy yatırımları yahut fon akımları büyük ölçülerde artmıştır (Kennedy, 1993, Naisbitt, vd, 1990).

Bu hızlı gelişme her şeyden önce bir konuyu açık olarak ortaya sermektedir. Keynes, gelişmiş ülkeler için uzun vade açısından da kötümserdi ve işsizliğin kronik hale geleceğini tahmin ediyordu. Buna neden olarak da başlıca üç etken öne sürmekteydi. Birincisi, Avrupa ülkelerinin yeni sürüm imkânları azalmıştı. İkincisi, teknolojik ilerleme hızı yavaşlamıştı ve teknik ilerleme sermayeden tasarruf sağlayan üretim metodlarının uygulanmasına yönelmişti. Üçüncüsü, tüketim harcamalarını kamçılayacak olan nüfus artış hızı düşmüştü. Gerek 2. Dünya Savaşı sonrası gerek bugünkü tecrübeler ve hızlı teknolojik gelişme ve büyüme Keynes'in uzun vadeli bu kötümser görüşlerinin ne kadar yanlış olduğunu belirgin biçimde ortaya koymuştur.

Fakat ileriye ait tahminler ve bu tahminlerde yanılma başka, Keynes'in kurduğu makro sistemin temellerinin doğru olup olmaması başka bir konudur.

Uzun zamandır gelişmiş ekonomilerin içinde bulunduğu şartlar altında Keynes'in buhran dönemi için önerdiği politikaların geçersiz olduğu açıktır. Çünkü en son yaşanan finansal krize kadarki dönemde ekonomilerdeki esas sorun ciddi ve derin buhran döneminden kurtulmak değildi. Fakat en son döneme kadar da uygulanması gerekli olan politikaları veya uygulanan ve olumlu sonuçlar veren politikaları Keynesgil makro sisteme dayanarak önermek mümkün değil miydi? Keynes’i sadece buhran dönemini ele alan bir iktisatçı kabul etmek ne derece doğruydu? Yoksa gelişmiş ülkelerin son dönemlerindeki şartlar altında Yeni Klasik Okul ve Yeni Klasik Okuldan doğan politika tavsiyeleri mi geçerli kabul edilmeliydi? Devlet müdahale ve politika uygulamalarından sakınılması konusunda "Rasyonel Beklentiler" modelinin yeri ve önemi neydi? Bu konuların tartışması Yeni Klasik Okul da gözden geçirilmesini izleyerek farklı bir araştırma olarak yapılmalıdır.

Nitekim günümüz ekonomik şartları Keynesgil Sistem'in geçerliliği ve Keynesgil politika tavsiyelerinin doğruluğunu bir kez daha kanıtlamıştır. 2008 finansal kriz ve bunu izleyen yıllarda Keynesgil politikalar yeniden uygulanmaya konmuştur.

\section{Keynes'in Günümüz İçin Ne Derdi?}

Günümüz ekonomik şartları Keynesgil Sistem'in geçerliliği ve Keynesgil politika tavsiyelerinin doğruluğunu bir kez daha kanıtlamıştır. 2008 finansal kriz ve bunu izleyen y1llarda Keynesgil politikalar yeniden uygulanmaya konmuştur. Bu konuyu daha detaylı belirtmek adına, günümüz ekonomistlerinin görüşleri aşağıda sunulmaktadir.

N. GREGORY MANKIW, The New York Times, ECONOMIC VIEW, “Keynes olsa ne yapard1?”, 28 Kasım 2008: 
"Ekonomide karşılaşılan problemleri anlamak için sadece tek bir iktisatçı arıyorsanız, bu kuşkusuz John Maynard Keynes olmall. Keynes neredeyse yarım yüzylldan fazla bir zaman önce ölmesine ră̆men, onun resesyon ve depresyon tahlilleri modern makroekonominin temelleri olarak kalmıştır. Bizim şimdi karşılaştığımız zorluları açılklamada onun iç görüsü uzun yol kat etmiştir.

Keynes'e göre, ekonomik gerileme döneminin temel sebebi toplam talep noksanıdır. Mal ve hizmetler için toplam talep düştügünde, ekonomideki firmaların satışları da düşüş yaşar. Daha düşük satışlar, firmaları üretimi kesmeye ve işçi çıkarmaya zorlar. Artan işsizlik, düşen kar, çok umutsuz bir sona giden talep düşüşüne de neden olur.

Keynesgil teori der ki, sadece ekonomideki bazı olaylar veya politikalar toplam talebi arttırdı̆̆ında bu durum tersine çevrilir. Şimdiki problem, bu talebin nereden gelebileceğini görme zorluğudur.

Ekonominin mal ve hizmet çıktısı, geleneksel olarak dört bileşene ayrllır: tüketim, yatırım, net ihracat ve hükümet alımları. Talepteki herhangi bir genişleme bu dördünden birinden gelmek zorundadır. Ancak her bir durumda, ekonomideki güçler harcamaları dü̧̈ük tutar.

TÜKETIM: Açılanan raporlarda tüketici güvenliğinin çok düşük olduğunu görüyoruz. Tüketicilerin neden böyle korktuğunu anlamak kolaydır. Evlerin değerleri düştü, 401(k) dengeleri sarsıldı ve işsizlik arttı. Pek çok insan için, ekonomik belirsizliğin boyutu önceden deneyimlediklerinden daha büyük. Yeni bir ev, araba ya da çamaşır makinesi gibi isteğe bă̆ll alımlara gelirsek, "bekle ve gör” taktiği en önemli gidişattır.

Biraz daha fazla birikim, tamamen beklenti dışıdır. Pek çok ekonomist, ulusal ve tarihi standartlara göre düşük olan ABD tasarruf oranı ile ilgili uzun zamandır yakınıyor.

Fakat, ekonominin bütünü için resesyon, hanelerin tasarrufa başlaması için en iyi zaman değildir. Keynesgil teori bir "tasarruf paradoksu"nu da öngörmektedir. Ĕ̆er tüm hane halkı daha fazla tasarruf etmeye çalışırsa, kisa dönemde toplam talep azaltacak ve böylece daha az ulusal gelir elde edilecektir. Azalan gelir de hane halkının yeni birikim hedeflerine ulaşmasını engeller.

YATIRIM: Normal zamanlarda, tüketimdeki bir düşüş, yatırımda bir artış ile karşılaşılabilir yani işyerleri tesis ve donanıma yatırım yapabilir, hane halkı da yeni ev alarak yatırım yapabilir. Ancak pek çok faktör, yatırım harcamalarını emniyette tutar.

En belirgin sebep, günümüz konut piyasasının durumudur. Son üç yılda, konut yatırımı yüzde 42 düştü. Ev fiyatlarındaki düşüşün devamı, yeni evlerin artan bina inşasına birkaç yıl içinde güçlü bir talep olması muhtemel değildir.

İş piyasalarındaki yatırım ise son zamanlarda konut yatırımından daha güçlü olmuştur, ancak yakın gelecekte boşluğu toparlamak pek mümkün değildir. Borsanın aşağl düşüşü, kurumsal bonolarda faiz oranlarındaki yükseliş ve kötü bir sonun eşiğinde olan bankacılık sistemi ile yeni iş projelerini finanse etmek kolay olmayacaktır.

NET IHRACAT: Çok uzun olmayan bir zaman önce, dünyanın geri kalanı Amerikan ekonomisini resesyonun derinleşmesinden kurtaracak gibi görünüyordu. Mart 2004'ten, Mart 2008'e kadar, dolar diğer majör dövizler karşısında ortalama yüzde 19 düşı̈̈. Amerika Birleşik Devletleri'ndeki yabancı malların fiyatını artırarak ve yurtdışındaki Amerikan mallarının fiyatını düşürerek, ithalat azaltıldı ve ihracat teşvik edildi. Son üç yılda, reel net ihracat yaklaşık 250 milyar dolar arttı.

Ancak, önümüzdeki aylarda, durum bir şekilde tersine dönebilir. Amerika'da başlayan finansal kriz dünyanın geri kalanına yayıldı̆̆ için, hızlı hareket eden uluslararası sermaye güvenli bir sı̆̆ınak aramaya başlamıştır. Ironik olarak, bu siğınak yine Amerika Birleşik Devletleridir. Mart ayından bu yana, dolar, yüzde 19 değer kazandı bu da ihracat patlamasina bir halka daha ekleyen bir harekettir.

DEVLET ALIMLARI: Bu talep hükümete bırakılır. Altyapı harcamalarını arttırmak suretiyle toplam talebi arttırmak Keynesgil politikaların bir parçasıdır. Prensip olarak, devlet tarafindan harcanan her dolar, eğer daha canlı bir ekonomiye öncülük eder ve tüketicileri ve şirketleri harcama yapmaya teşvik ederse milli gelirin bir dolardan fazla artmasını sağlayabilir. Tüm raporlara göre, bu, tam da gelen Obama yönetiminin aklında olan plandır. Küçük pürüzler-ya da belki daha büyük - olsa da uzun vadeli maliye politikası budur. Ama artan kamu harcamaları kısa dönemli bir düzelme yaratabilir, ama bütçe açı̆̆ını da arttırır. Íkinci Dünya Savaşı ve soğuk savaş arasında doğmuş olanlar şimdi emekli oluyor ve Sosyal Güvenlik ve tıbbi bakım faydalarl istiyorlar. Bütçe açı̆̆ındaki herhangi bir artış ise, önümüzdeki yıllarda bu finanse edilmemiş vaatleri yerine getirmede zorlanacaktır.

Ekonomide kısa vadeli problemler olduğunda Keynesgil iktisatçllar genellikle bu uzun vadeli endişeleri göz ardı ederler; Keynes 'in dediği gibi; "Uzun vadede hepimiz ölmüş olacağız."

Ancak şimdi yüz yüze geldiğimiz uzun vadeli sorun, Keynes'in öngörüsünden de daha ciddi olabilir. Bir sonraki nesillere şu andakinden daha büyük bir ulusal borç yüklemek çocuksuz olanlara cazip görünebilir. (Keynes kendisi de çocuksuzdu). Ama geri kalanımız, uzun dönemde, biz öldüğümüzde çocuklarımız ve torunlarımızın mali sıkıntı içinde olacă̆ını bilerek kendimizi rahat hissedemeyiz. 
Pekiyi yapılması gereken nedir? Birçok iktisatçı hala Federal Rezerv'in günü kurtaracă̆ını umuyor.

Normal zamanlarda, Fed faiz oranlarını düşürerek toplam talebi arttırabilir. Düşük faiz oranları, hane halkını ve firmaları borç alma ve harcama konusunda teşvik eder. Aynı zamanda öz sermaye değerini arttırır ve uluslararası sermayenin başka bir ülkelere kaymasını teşvik ederek, uluslararası döviz piyasalarında doların değerini düşürür. Böylece hem tüketim, hem yatırım hem de net ihracat harcamalarının tümü artar.

Ancak bu normal zamanlar değildir. Fed zaten federal fon oranlarını yüzde 1 azalttı ki bu da en düşük sınır olan sıfıra yakındı. Bazıları, Merkez Bankasının neredeyse mühimmat dışında olduğundan korkuyorlar.

Neyse ki, Fed'in elinde birkaç gizli silahı vardır: uzun vadeli faiz oranları için bir hedef faiz belirleyebilir; böylece sürdürülebilir bir süre için faiz oranların düşük tutmayı taahhüt edebilir. Ama en önemlisi, Fed uzun dönemli deflasyonu önlemek için ne gerekiyorsa yapacakları konusunda piyasalara teminat vererek beklentileri denetleyebilir. Mortgage borçlarını satın alınacă̆ı kararı, Fed'in yaratıcı bir şekilde hareket etmeye olan istekliliğini göstermektedir.

Para ve maliye politikasının resesyondan ve depresyondan kaçınmak için nasıl olması gerektiğini söylemek zordur. Ama olaylar ortaya çıktıkça Fed ve Hazine'de politikaya yön verenlerin olaylara Keynes'in merceğinden bakıyor olacă̆ına emin olabilirsiniz."

TOM SIGHTINGS, US News, "Keynes Ekonomimizi Nasıl Koruyacaktı? Bir yüzyıl önceki ekonomik fikirler bize şimdi nasıl yardımcı olur? Kararı sen ver.”, 17 Temmuz 2012:

“2008 ve 2009 yılında, biz Büyük Burhan'dan bu yana en kötü resesyonu yaşadık. Ve şimdi, modern tarihin en zayıf toparlanmasını yaşıyoruz. Burada bir ekonomik genişlemenin üçüncü yılındayız ve başladı̆̆ımız yere ancak geri döndük. Ama en önemli göstergelerden biri olan işsizlik konusunda henüz başladı̆̆ımı yere geri dönmekte başarısız kaldık.

Avrupa'daki kriz ve Çin ekonomisindeki yavaşlama ile işlerin daha da kötüye gitmesi bazı insanlarl gelecek sene yeni bir resesyonun baş gösterebileceğinden endişelendiriyor, çünkü özellikle artan vergilerin hâlihazırdaki mali uçurumları daha da tetikleyerek ekonominin tepetaklak olacağından ve hükümetin de artık ekonomiyi uyarıcı etkisinin son bulacă̆ından korkuyorlar.

O zaman, ana konuya geri dönelim. Keynes olsa ne yapardı?

John Maynard Keynes (1883-1946) 20. Yüzyllın en etkili iktisatçısı oldu. Onun fikirleri, Franklin D. Roosevelt tarafindan Büyük Buhran ile baş etmek için benimsendi. İktisatçıların çoğu, hatta pek çok Cumhuriyetçi bile, 1930larda Amerikalıları tekrar işgücüne katarak, ABD'ye ekonomik felaketten kurtulmaya çalışmalarına yardım ederek ve savaş sonrası ekonomik canlanmanın adımlarını oluşturma yolunda Roosevelt ve Keynesgil Sistem'e güvendi. 1971 itibariyle, Başkan Richard Nixon “Şimdi artık biz, hepimiz Keynesgiliz," itirafinda bulundu

Keynes 'in Sistemine göre, resesyon dönemlerinde ekonomideki karar birimleri korkarlar ve hane halkı daha az harcama yapar, bunun sonucunda firmalar daha fazla işten çıkarma kararı alır ve en sonunda harcamalar daha da düşer ve kısır döngüye girilir. Keynes'e göre, bu kısır döngüyü kırmanın tek yolu hükümeti, yollar ve köprüler gibi altyapı harcamalarını ve diğer kamu harcamalarını arttırmak için teşvik etmektir. Zamanında FDR bile ülkeler ve şehirler üzerinde kılavuz kitapları üretmek için ülkeye seyahat eden Federal Yazarlar Projesi için işsiz yazarları kiraladı.

Keynes piyasaların tam istihdamda dengeye geldiğini söyleyen Klasik Sistem'e karşı çıkt. Keynes toplam talebin, ekonomik aktivite düzeyini (reel gelir) belirlediğini savundu. Talep yeterli olmazsa bu, durgunluk ve yüksek işsizliğe yol açar. Keynesgil İktisat, Başkan Reagan döneminde gözünden düştü, ama George Bush, 2000'li yıllarda toplam talebi pompalamak için harcamayı arttırarak, Keynes'i geri getirdi ve Başkan Obama sınırlı başarı ile aynı davayı takip etmeye çalıştı.

O halde, Keynes 2012'de ne yapard ? Haydi, tahmin edelim:

1. Açıkçası, o, federal hükümete altyapı, yollar ve köprüler inşa etme, elektrikli ızgara geliştirme, uzay programın canl tutma ve alternatif enerji geliştirme, federal hükümet altyapısına yatırım yapma gibi konularda tavsiyelerde bulunacaktır. Unutmayın ki, Grand Coulee Barajı'ndan Tennessee Vadisi Yönetimine kadar, onun zamanının alternatif enerji altyapısını inşa eden FDR idi.

2. Keynes, işçilerin iş talebinin düşmesi karşısında kendi ücretlerinin düşürülmesine karşı direnç göstermeleri anlamına gelen "fiyat ve ücretlerin sertliği" kavramını getirdi. Keynes kesinlikle bir liberaldir, ama yine de, devlet çallşanlarının maliyeti ödenemeyecek yükseklikteki maaşlarıyla ilgili geçmiş vaatlerin yükü altındaki devletin mevcut mali sorunların kesinlikle görecektir. Muhtemelen, Wisconsin Valisi Scott Walker gibi görevlilerin, işçilerin haklarının elinden alınması için sert tedbirlerini desteklemeyecektir. Buna karşın, günümüz ekonomik koşullarında bütçelerini dengelemek üzere New York ve California gibi eyaletlerde uygulanan bazı bütçe kısıntılarını destekleyecektir.

3. Keynes, tasarruf edilen paranın yatırım yapılan para miktarını aşması durumunda, işsizliğin artacă̆ını söyledi. Kurumsal bilançolarda biriken tüm parayı düşünün. Google tek başına neredeyse 50 milyar dolarlık nakit bulunduruyor. Microsoft, neredeyse 60 milyar dolara sahiptir. Keynes, büyük ihtimalle Amerikan 
şirketlerinin yurtdışında tuttukları fonlar üzerindeki vergilerin düşürülmesini, böylelikle bu paraların yeniden yurda dönmesini desteklerdi. Ve Keynes kesinlikle, şirketleri yeni fabrikalar inşa etmek ve araştırma ve geliştirmeye yöneltmek için vergi muafiyeti ve diğer benzeri teşvikleri desteklerdi.

4. Keynes, ülkelerin ticaret fazlası veya açı̆̆ı vermemesi gerektiğini biliyordu. Dolayısıyla, Amerika’nın ihracatını artırmak, çok uluslu şirketlere rekabet avantajı sağlamak ve Amerika'nın ticaret açığını azaltmak için doların değerini düşürmeyi destekleyecekti.

5. Son olarak, Keynes, II. Dünya Savaşı'nın maliyetinin yüksek vergilendirme ile karşılanması gerektiğini savundu. Bir yere kadar yüksek vergi, talebi azaltmaz. Gelirleri 250.000 doların üzerindekilerden alınan yüksek vergilerin de, toplam talebi azaltacağı konusunda da çok az delil vardır, çünkü bu gelir grubundakiler "çok fazla" nakdi olan insanlardır. Keynes, vergilerin "ultra” zenginlerden ve "ultra” zengine yakın kişiler üzerinden artırma taraftarı olacaktır. Böylece artan vergi gelirleri ile askeri girişimler, finans altyapı yatırımları karşılanabilecek, bütçe açı̆̆ı da daraltıla bilinecektir."”

\section{Kaynakça}

- Ackley, 1961. Macroeconomic Theory. New York.

- Baumol, 1959. Economic Dynamics. New York.

- Branson, 1979. Macroeconomic Theory and Policy. New York.

- Domar, 1957. Essays in the Theory of Economic Growth. New York.

- Dornbusch ve Fischer, 1990. Macroeconomics. New York.

- Duesenberry, 1958. Business Cycles and Economic Growth. New York.

- Harrod, 1939. “An Essay in Dynamic Theory”, The Ecnomoic Journal, Vol. 49, No. 193, pp. 14-33.

- _ _ 1954. Towards a Dynamic Economics. London.

- Hicks, 1950. A Contribution to the Theory of the Trade Cycle. London.

- Hiç, 1994. Para Teorisi ve Politikası. İstanbul.

- Kennedy, 1993. Preparing for the Twenty-First Century, Toronto 1993.

- Keynes, 1930. A Treatise on Money. London.

- _ _ 1941. How to Pay for the War. London.

- Klamer, 1984. The New Classical Economics, Conversations with the New Classical Economists and their Opponents. Brighton.

- Klein, 1961. The Keynesian Revolution. New York.

- Meade, 1961. A Neo-Classical Theory of Economic Growth. London.

- Musgrave ve Musgrave, 1989. Public Finance Theory and Practice. New York.

- Naisbitt ve Aburdane, 1990. Mega-Trends 2000. New York.

- Samuelson, 1939. "Interaction between the Multiplier Analysis and the Principle of Acceleration", Review of Economics Statistics, Vol. 21, No. 2, pp. 75-78.

- Solow, 1956. "A Contribution to the Theory of Economic Growth”, Quarterly Journal of Economics, Vol. 70, No. 1, pp. 65-94.

- The New York Times, November 28, 2008: “What Would Keynes Have Done?” by N. Gregory Mankiw.

- $\quad$ US News, July 17, 2012: "How Would Keynes Save Our Economy? Could economic ideas from a century ago help us now? You be the judge." by Tom Sightings. 


\title{
Türki Cumhuriyeti Ülkelerinde Dış Borçların Sürdürülebilirliği The Sustainability of External Debts for Turkic Countries
}

\author{
Prof. Dr. Haluk Egeli (Dokuz Eylül University, Turkey) \\ Pınar Egeli (Dokuz Eylül University, Turkey)
}

\begin{abstract}
Resources provided from one country to another country fulfills the function of closing the gap for currency and savings for the country acquiring these resources. Regarding the current position of emerging countries, these two concepts take important place for their development efforts. In this paper, developments in Turkic Countries are analyzed to put forth their external debts' sustainability for the transition period. The model is constructed by using variables with inter temporal budgetary constraints approach. Inter temporal budgetary constraint approach take into consideration external debt as well as interest rates in international financial markets. Panel data techniques are used for empirical analysis and based on the empirical findings for above mentioned countries, comments are made for their liquidity constraints and the sustainability of their external debts.
\end{abstract}

\section{Giriş}

Gelişmekte olan ülkelerin kalkınma çabaları açısından dış kaynaklar, hem tasarruf hem de döviz açığını kapatma fonksiyonunu yerine getirir. Burada ele alındı̆̆ı biçimiyle tasarruflar; 'yabancı özel sermaye', 'dış borçlar' ve 'hibeler' olmak üzere üç ana grupta toplanabilecek olan tüm kaynakları kapsayan geniş bir anlama sahiptir. Bunlardan birincisi, ele alınan ülke ekonomisine yabancı ülke müteşebbisleri tarafından getirilen yatırım fonlarını; ikincisi, ülkedeki özel kesim veya kamu kesimi tarafından belli bir vade içinde anapara ve faiziyle birlikte geri ödenmek üzere dış kaynaklardan sağlanan kredileri; üçüncüsü de, geri ödeme zorunluluğu olmaksızın dış kaynaklardan sağlanan yardımları kapsar. Bu üç kaynak; bir dış kaynak olarak yukarıda belirtilen iki temel fonksiyonu yerine getirme açısından sahip oldukları benzerliklere karşılık, elde edilme ve kullanım koșulları ile ekonomik etkileri açısından önemli farklılıklar taşımaktadır.

\section{Türki Cumhuriyeti Ülkelerinde Dış Borçların Gelişimi}

Bir ülkenin belli bir süre sonunda anapara ve faiziyle birlikte geri ödemek koşuluyla dış kaynaklardan elde ettikleri borçlar olarak tanımlayabileceğimiz dış borçlar, çeşitli açılardan değişik şekillerde sınıflandırılabilir. Örneğin vade yapılarına göre 'kısa, orta ve uzun vadeli krediler' borçlulara göre 'kamu kesimi - özel kesim borçları', alacaklılara göre 'çok taraflı (uluslararası kuruluşlardan sağlanan) - iki taraflı krediler', koşullarına göre 'resmi (dış) - ticari (piyasa koşullarına göre) krediler', kullanım biçimlerine göre 'bağlı - serbest krediler' ve 'program - proje kredileri' gibi çeşitli sınıflandırmalardan da anlaşılacağı üzere, herhangi bir ülkenin elde edebileceği dış borçlar, gerek miktar gerekse taşıdığı özellikler itibariyle, pek çok iç ve dış ekonomik ve politik faktörün etkisi altında bulunmaktadır. Politik etmenler ve dış koşullar bir yana, bir ülkenin dış borç bulma kapasitesi (kredibilitesi, kredi değerliliği), ekonomisinin genel performansıyla ve bu arada mevcut dış borç yükü ve geri ödeme kapasitesiyle yakından ilişkilidir (Egeli ve Egeli, 2008).

Dış borçlarla ilgili başka bir durum bunların dış yardımlardan kesin olarak ayırımındaki zorluktur. Günümüzde her dış borcun bir dış yardım olduğu ve dış yardımların da büyük ölçüde dış krediler şeklinde olduğu söylenebilir. Dış yardım kavramı, dış finansman, dış borçlanma, dış kaynak temini terimleri ile uygulamada aynı anlamda kullanılmaktadır. Terimlerin tümü geri ödeme problemi oluşturmayan bağıș ve hibe gibi kaynaklardan belirli bir süre sonra belirli bir birlikte ödenmek zorunda olan, uluslararası borçlara kadar çeşitli derecelerdeki kaynakları içermektedir (Meriç, 2013).

Kaynakların dünya ölçeğinde dengesiz dağılımı iç kaynak sorununu ortaya çıkarmakta, özellikle gelişmekte olan ülkelerde sermaye, teknoloji ve nitelikli işgücü yetersizlikleri bu ülkeleri dış kaynak arayışına yöneltmektedir (Takım, 2012).

Türki Cumhuriyetlerin toplam dış borçlarındaki gelişmeler çeşitli yıllar itibariyle aşağıdaki tabloda yer almaktadır (Tablo:1). Ele alınan ülkelerden Türkmenistan hariç diğerlerinde toplam dış borç stoku yükselme eğilimi göstermiştir. Dış borçların vade yapılarında ise tüm ülkelerde toplam borçlar içinde uzun vadeli borçların payı ağırlıklı bir yer kaplamaktadır. 


\begin{tabular}{|l|r|r|r|r|r|r|}
\hline Ülkeler (milyon \$) & \multicolumn{1}{|c|}{$\mathbf{2 0 0 0}$} & \multicolumn{1}{|c|}{$\mathbf{2 0 0 5}$} & \multicolumn{1}{|c|}{$\mathbf{2 0 1 0}$} & \multicolumn{1}{|c|}{$\mathbf{2 0 1 1}$} & $\mathbf{2 0 1 2}$ & \multicolumn{2}{|c|}{$\mathbf{2 0 1 3}$} \\
\hline Azerbaycan & 1.524 .3 & 2.118 .8 & 7.093 .5 & 8.369 .6 & 9.712 .3 & 9.219 .0 \\
\hline Gürcistan & 1.825 .5 & 2.151 .3 & 9.519 .2 & 11.359 .2 & 13.426 .3 & 13.693 .7 \\
\hline Kazakistan & 12.890 .2 & 43.857 .0 & 119.144 .5 & 124.316 .7 & 137.013 .9 & 148.456 .0 \\
\hline Kirgizistan & 1.937 .8 & 2.256 .6 & 4.114 .5 & 5.485 .9 & 6.025 .9 & 6.804 .0 \\
\hline Özbekistan & 4.979 .9 & 4.655 .8 & 7.782 .4 & 8.417 .0 & 8.852 .7 & 10.605 .0 \\
\hline Tacikistan & 1.141 .1 & 1.121 .4 & 3.082 .3 & 3.323 .0 & 3.648 .3 & 3.537 .7 \\
\hline Türkmenistan & 2.609 .3 & 1.157 .8 & 529.1 & 454.3 & 492.4 & 501.9 \\
\hline
\end{tabular}

Tablo 1. Türki Cumhuriyetlerinin Toplam Dış Borç Miktarı Kaynak: Asian Development Bank, The Worldbank

Bir ülkenin dış borç yükünün önemli bir göstergesi toplam dış borçların GSYH'ya oranıdır. Bu oranın yüksekliği ülkenin önemli bir dış borç yükü altında bulunduğuna ve muhtemelen geri ödemede zorlanacağına işaret eder. $\mathrm{Bu}$ çerçevede ele alınan ülkeler içinde başta Kırgızistan olmak üzere, Gürcistan, Kazakistan ve Tacikistan \%50'nin üzerindeki oranlar ile çok borçlu ülke kategorisinde yer almaktadır (Tablo:2).

\begin{tabular}{|l|c|c|c|c|c|c|}
\hline Ülkeler (\%) & $\mathbf{2 0 0 0}$ & $\mathbf{2 0 0 5}$ & $\mathbf{2 0 1 0}$ & $\mathbf{2 0 1 1}$ & $\mathbf{2 0 1 2}$ & $\mathbf{2 0 1 3}$ \\
\hline Azerbaycan & 30.6 & 18.3 & 14.3 & 14.8 & 16.3 & 12.5 \\
\hline Gürcistan & 57.5 & 33.2 & 84.4 & 81.1 & 85.4 & 84.5 \\
\hline Kazakistan & 75.7 & 84.7 & 92.6 & 77.5 & 79.0 & 64.0 \\
\hline Kırgızistan & 150.5 & 95.1 & 92.5 & 96.8 & 99.1 & 94.2 \\
\hline Özbekistan & 36.8 & 32.6 & 19.2 & 17.9 & 16.6 & 17.8 \\
\hline Tacikistan & 138.4 & 50.2 & 55.3 & 51.6 & 52.7 & 52.2 \\
\hline Türkmenistan & 95.7 & 15.4 & 2.6 & 1.7 & 1.6 & 1.2 \\
\hline
\end{tabular}

Tablo 2. Türki Cumhuriyetlerinin Dış Borç/GSYH Oranları Kaynak: Asian Development Bank, The Worldbank

Dış borçların ödenmesinde en temel ve güvenilir kaynağı ihracat gelirleri oluşturmaktadır. Bu çerçevede, bir ülkenin dış borç geri ödeme kapasitesini ölçmede kullanılan göstergelerden biri de "dış borç servis oranı" olarak bilinen ve yıllık dış borç anapara ve faiz ödemeleri toplamının o yılın ihracat gelirlerine oranlanmasıyla elde edilen büyüklüktür. Bu oranın küçüklüğü, ülkenin dış borç ödeme kapasitesinin yüksek olduğuna işaret eder. D1ş borç servis oranı hesaplanırken, paydada, en sağlam ve güvenilir döviz kaynağı olması nedeniyle genellikle yalnızca ihracat gelirleri alınmakla birlikte, kuşkusuz, ülkenin ihracat dışındaki diğer döviz gelirleri de (turizm gelirleri, işçi dövizleri, diş müteahhitlik hizmeti gelirleri vb.) diş borç ödeme kapasitesini yükseltici etki yapacaktır. Ayrıca ülkenin sözü edilen bu döviz gelirlerinin yalnızca dış borç servisinde kullanılmayacağı, mal ve hizmet ithalinin de döviz kullanmayı gerektirdiği açıktır. Bunların yanı sıra ülkenin mevcut döviz rezervlerinin durumu ile yeni dış kaynak bulma kapasitesi de dış borç ödeme gücü açısından önem taşımaktadır (EGELİ, 1992). Borç servisinin ihracata oranı \%30'un üzerinde olan ülke çok borçlu olarak değerlendirilmekte ve olası tehlikeli bir durumu işaret etmektedir. Bu durum Türki Cumhuriyetleri içinde son dönemde Gürcistan, Tacikistan ve Kırgızistan için geçerliliğini sürdürmektedir (Tablo:3).

\begin{tabular}{|l|c|c|c|c|c|c|}
\hline Ülkeler (\%) & $\mathbf{2 0 0 0}$ & $\mathbf{2 0 0 5}$ & $\mathbf{2 0 1 0}$ & $\mathbf{2 0 1 1}$ & $\mathbf{2 0 1 2}$ & $\mathbf{2 0 1 3}$ \\
\hline Azerbaycan & 3.4 & 2.1 & 0.8 & 5.3 & 5.8 & 7.2 \\
\hline Gürcistan & 17.4 & 9.0 & 31.2 & 46.9 & 39.8 & 64.0 \\
\hline Kazakistan & 36.3 & 46.5 & 77.8 & 38.1 & 26.7 & 24.1 \\
\hline Kirgizistan & 31.2 & 15.5 & 30.1 & 17.0 & 16.7 & 45.9 \\
\hline Özbekistan & 24.9 & 14.1 & 4.7 & 4.1 & 4.9 & 10.5 \\
\hline Tacikistan & 6.1 & 4.9 & 148.9 & 97.6 & 51.9 & 54.7 \\
\hline Türkmenistan & 18.6 & 6.2 & 1.6 & 0.8 & 0.3 & 0.3 \\
\hline
\end{tabular}

Tablo 3. Türki Cumhuriyetlerinin Dış Borç Servisi/İhracat Oranlarl Kaynak: Asian Development Bank, The Worldbank

\section{Türki Cumhuriyetlerinde Dış Borçların Sürdürülebilirliğine Yönelik Bir Uygulama}

Bu kısımda, yukarıda yer alan açıklamaları desteklemek amacıyla ampirik bir uygulama yapılmıştır. Bununla ilgili açıklamalar aşağıda yer almaktadır.

\subsection{Veriler ve Değişkenlerin Tanımlanması}

Bu çalışmada kullanılan ülkelere ait veriler Asian Development Bank ve The Worldbank'dan alınmıştır. Ayrıca bu ülkeler içinde yer alan üç ülkeye (Gürcistan, Özbekistan, Tacikistan) ait olan veriler ise Quandle Data sayfasından alınmıştır. Uluslararası faiz oranlarını temsilen bir yıllık LIBOR oranları da Quandle Data sayfasından oluşturulmuştur. Uluslararası faiz oranları ile ülkelerin indirgenmiş cari açık değerleri hesaplanmıştır. Bu hesaplanmaya ilişkin yaklaşım aynı zamanda dış sürdürülebilirliğine dayalı modele dayalı olarak hesaplanmıştır. 


\section{2 İktisadi Model ve Ekonometrik Yöntem}

$\mathrm{Bu}$ çalışmanın ampirik uygulaması iktisadi açıdan açık veren bir ülkenin dış borç birikiminin artacağ yönündeki kabule dayalıdır. Bu çerçevede eğer bir ülkenin gelecekteki cari dengesinin bugünkü net değeri ile dış borç artış oranı aynı olması sürdürebilirlilik için yeterlidir. Burada ülkelerin cari gelecekteki değerlerinin bugünkü değerleri dikkate alındığından dolayı yaklaşım zamanlararası olarak ifade edilebilmektedir (Hakkio ve Rush, 1991). Burada zaman boyutu faiz oranları yoluyla kurulmaktadır. Bu açıdan değerlendirildiğinde bu çalışmada ödemeler bilançosuna zamanlararası bütçe kısıtı çerçevesinde zamanlararası sürdürebilirlilik koşuluna dayalı bir analiz yapılmıştır. Zamanlararası sürdürebilirlilik koşulu (Utkulu, 1997; Wilcox, 1989):

$$
D_{t}=E_{t} \sum_{j=t+1}^{\infty} \frac{S_{t}}{\prod\left(\begin{array}{c}
j-t \\
j=1
\end{array} r_{t+1}\right)}
$$

eşitliği şeklinde ifade edilebilir.

Bu eşitlikte D; reel dış borç stokunu, S; dış ticaret dengesini, r; uluslararası reel faiz oranlarını göstermektedir. $\mathrm{E}$ ise beklentileri temsil etmektedir. Bu eşitlikte dış borç stoku, gelecekteki cari açıkların bugünkü değerine eşit olmasına bağlı olmaktadır. Bu zaman içinde değişmiyorsa, borçlar sürdürülebilirdir. Bu eşitlikte; cari denge değişkeni yerine dış borç stoku konursa, dış borç stokunun net değerine (piyasa değerine) ulaşılmış olmaktadır. Söz konusu ifade şekli literatürde dış borçların sürdürebilirliği koşulu olarak ifade edilmektedir. Bu ifade ülkeler için ponzi tipinde olmayan bir borçlanma durumunu göstermektedir.

Dış borçların sürdürülebilirliği iki noktada önemlidir. Birincisi, borçların tekrar borçlanmayla ödenmesidir. İkincisi ise bu koşulun faiz oranlarına bağlı olmasıdır. Yani bir ülke borçlarını çevirirken her defasında daha yüksek faiz oranından borçlanıyorsa, bu sürdürülemezdir. $\mathrm{Bu}$ sürdürülemezdik durumu ponzi tipi finansman olarak tanımlanmaktadır.

Yukarıda tanımlanan durumun bir ülke için geçerli olup olmadığının testi, indirgenmiş borç stokunun ortalamasının zaman içinde değişip değişmediğine bağlıdır. Bu çerçevede dış borç stokunun sürdürebilirliği, cari dengenin iskonto edilmiş değeri ile dış borç stoku arasındaki uzun dönemli ilişki varlığına bağlı olarak araştırılmaktadır. Ancak ele alınan ülkelere ait verilerinin sayısının düşük olması ileri tekniklerin uygulanması konusunda önemli bir kısıt oluşturmaktadır. Bu ayrıca yapılacak ampirik analiz sonuçlarının tutarsız ve sapmalı olmasına yol açabilmektedir. İlk olarak analiz için ilgili değişkenlere ilişkin birim kök analizi yapılmıştır.

Çalışmanın bu kısmında yapılan ampirik sonuçlar STATA 14 yazılımı kullanılarak gerçekleştirilmiştir.. Bunun en önemli nedeni literatürdeki ampirik teorik yaklaşımların uygulamasının söz konusu yazılımda analizler yapılacak biçimde araştırmacılara sunulmasıdır. Bundan dolayı bu kısımda yapılan açıklamalarda bu çerçevede yazılmıştır.

$\mathrm{Bu}$ çalışmada ülkelere ait verilerin kısıtlı olması dikkate alınarak panel veri analiz ampirik teknik olarak kullanılmasına karar verilmiştir. Genel olarak her birime ait veri sayısının az olmasının ekonometrik olarak ortaya çıkardığı sorunlara karşı panel veri analizi kullanılabilecek en temel teknik olmaktadır. Ancak panel veri yönteminde her bir birime ait özelliklere bağlı olarak sorunlar ortaya çıkmaktadır. Bu sorunların başında bir yatay kesit veri sorunu olarak bilinen değişen varyans sorunudur. Bu değişen varyans sorunu zaman boyutu içeren panel veri analizlerinde bir heterojenlik problemine yol açmaktadır. Bundan dolayı Zaman serisi ve yatay kesit analizlerinde heterojenliğe bağlı olarak elde edilen bulguların sapmalı olma riski vardır. Genel olarak panel veri analizlerinde bu bireysel heterojenliğin varlığına yönelik yaklaşımlarla sapmasız ve etkin tahminciler geliştirilmesine yönelik çabalar vardır.(Baltagi, 2005). Bundan dolayı panel veri analizlerinde değişkenlerin, uygulanacak yöntemin seçilmesine yönelik olarak homojen veya heterojenlik özelliğine karar verilmelidir.

Çalışmada, delta testi (Pesaran ve Yamagata, 2008) yardımıyla değişkenlerin homojenliği araştırılmış, bulgular raporlanmıştır. Değişkenler düzeyde çalışılmıştır. Bunun ana nedeni veriler içinde negatif değerlerin olmasıdır. Yarı logaritmik model verilerdeki değerlerin büyüklüğü dikkate alındığında varyans üzerinde aşırı bir etki yaratmasinı engellemektir.

\section{Yatay Kesit Bağımlılığa Yönelik Analiz}

Bu çalışmada değişkenlere ait her birim için aralarında bir bağımlılığın olup olmadığının analizine yönelik (Peseran, 2004), ortalama korelasyon katsayılarına dayalı yatay kesit bağımlılığın varlığı CD testi ile araştırılmıştır. Elde edilen bulgulara bağlı olarak yatay kesit bağımlılığı dikkate alan birim kök testleri uygulanmıştır. Panel veri yaklaşımlarında değişkenleri temsil eden serilerin birimlerinin arasındaki ilişki başka bir ifadeyle yatay kesit bağımlılık tahmincilerin taşıması gereken özellikler açısından önelidir. Bu analiz yöntemiyle panel veri sistemi içinde şok olarak tanımlanacak bir etkiyi taşımadık taşımadıkları ortaya konmuş olmaktadır. Bu çalışmada bu özelliğin varlığının analizi için Peseran tarafından geliştirilen yaklaşım kullanılmıştır. Peseran analizi için aşağıdaki eşitlikten yararlanmıştır. Aşağıdaki eşitlikten elde edilen hata 
terimleri arasında yatay kesitte korelasyon olması durumunda yatay kesit bağımlılık ortaya çıkmaktadır (Pesaran, 2004, 4).

$$
\begin{aligned}
& \Delta \mathrm{Y}_{\mathrm{it}}=\alpha_{\mathrm{i}}+\mathrm{b}_{\mathrm{i}} \mathrm{y}_{\mathrm{i}, \mathrm{t}-1}+\sum_{\mathrm{j}=1}^{\mathrm{p}_{\mathrm{i}}} \mathrm{c}_{\mathrm{ij}} \Delta \mathrm{Y}_{\mathrm{i}, \mathrm{t}-\mathrm{j}}+\mathrm{d}_{\mathrm{i}} \mathrm{t}+\mathrm{h}_{\mathrm{i}} \overline{\mathrm{y}}_{\mathrm{t}-1}+ \\
& \sum_{\mathrm{j}=0}^{\mathrm{p}_{\mathrm{i}}} \eta_{\mathrm{u}} \Delta \overline{\mathrm{y}}_{\mathrm{i}, \mathrm{t}-\mathrm{j}}+\varepsilon_{\mathrm{i}, \mathrm{t}}
\end{aligned}
$$

Bu korelasyonların istatistiksel açıdan varlığına yönelik literatürde geliştirilen ilk test Breusch ve Pagan (1980) LM testidir. Bu testin önemli bir özelliği panel veri analizi için değişen varyans testi olmasıdır. Genel olarak Breusch ve Pagan ile Peseran testi zaman boyutunda verinin birimlerden fazla olması durumunda kullanılmaktadır. Ancak söz konusu testler grup ortalamasını sıfır ve birimlerin ortalamasını sıfırdan farklı olarak almadığından dolayı tahminciler sapmalı olabilmektedir. Bu durum Peseran ve diğerleri tarafından geliştirilen yaklaşım ile ortadan kaldırılmıştır. Breusch ve Pagan (1980) LM test istatistiği aşağıdaki gibidir.

$$
L M=T \sum_{i=1}^{N-1} \sum_{j=i+1}^{N}\left(\hat{\rho}_{i j}^{2}\right) \sim \frac{\chi_{N(N-1)}^{2}}{2}
$$

$\mathrm{Bu}$ eşitlik Pesaran, Ullah, A. ve Yamagata tarafından geliştirilmiş aşağıdaki LM istatistiği hesaplanmasını sağlayan eşitliğe ulaşılmıştır.

$$
L M_{a d j}=\left(\frac{2}{N(N-1)}\right)^{1 / 2} \sum_{i=1}^{N-1} \sum_{j=i+1}^{N}\left[\hat{\rho}_{i j}^{2}\left(\frac{(T-K-1) \hat{\rho}_{i j}-\hat{\mu}_{T i j}}{v_{T i j}}\right)\right] \sim N(0,1)
$$

$\mathrm{Bu}$ eşitlikte $\mu$ Tij ortalamayı vTij varyansı göstermektedir. Bu parametreye bağlı elde edilecek test istatistiği standart normal dağılma göstermesine bağlı olarak asimtotik açıdan da etkin olmaktadır. Bu test istatistiğinin boş hipotezi $\left(\mathrm{H}_{0}\right)$ yatay kesit bağımlılığının olmadığını göstermektedir. Bu hipotez red edilirse $\left(\mathrm{H}_{1}\right)$ yatay kesit bağımlılı̆̆ın olduğu ifade edilmektedir.

Uygulamada kullanılan verilere ilişkin olarak yatay kesit bağımlılığın tespit edilmesine bağlı olarak bu özelliği dikkate alan birim kök testlerinin uygulanması gereklidir. Bu amaçla bu çalışmada Pesaran (2007) tarafindan geliştirilen birim kök (CADF) testi kullanılmıştır.

\section{Yatay Kesit Varlığında Durağanlık Analizi}

Peseran ortalamasının sıfırdan farklı olması durumunda birimlerin (N) sonsuza gitmesine bağlı olarak bağımlı değişkenin farkının ortalamasının gecikmeli değerleri ile birlikte otokorelasyonu kaldırarak hata terimlerin homojenliği altında birim kök testi geliştirmiştir (Pesaran, 2007). Bu amaçla Perseran aşağıdaki eşitliğe ilişkin katsayıların tahmin edilmesini önermiştir. $\mathrm{Bu}$ eşitlikte $b_{i}$ katsayısı birim kök varlığına yönelik olarak bilgiyi veren katsayıdır. Bu katsayının " $t$ ” istatistiği Peseran tarafından geliştirilen tablo değerlere karşılaştırılarak birim kökün varlığı test edilir.

$$
\begin{aligned}
& \Delta \mathrm{Y}_{\mathrm{it}}=\alpha_{\mathrm{i}}+\mathrm{b}_{\mathrm{i}} \mathrm{y}_{\mathrm{i}, \mathrm{t}-1}+\sum_{\mathrm{j}=1}^{\mathrm{p}_{\mathrm{i}}} \mathrm{c}_{\mathrm{ij}} \Delta \mathrm{Y}_{\mathrm{i}, \mathrm{t}-\mathrm{j}}+\mathrm{d}_{\mathrm{i}} \mathrm{t}+\mathrm{h}_{\mathrm{i}} \overline{\mathrm{y}}_{\mathrm{t}-1}+ \\
& \sum_{\mathrm{j}=0}^{\mathrm{p}_{\mathrm{i}}} \eta_{\ddot{\mathrm{u}}} \Delta \overline{\mathrm{y}}_{\mathrm{i}, \mathrm{t}-\mathrm{j}}+\varepsilon_{\mathrm{i}, \mathrm{t}}
\end{aligned}
$$

Pesaran Monte Carlo simülasyonlarıyla ile birlikte geliştirmiş olduğu birim kök testi (CADF) hem N>T hem de $\mathrm{T}>\mathrm{N}$ için kullanılabilir olduğunu ortaya koymuştur(Pesaran, 2007). Serilere ait birim kök analizlerinden sonra yata kesit bağımlılığı dikkate alan panel eşbütünleşme testi uygulanmıştır.

\section{Yatay Kesit Bağımlılık Varlığında Durağanık Analizi}

$\mathrm{Bu}$ çalışmada ele alınan ülkelere ait değişkenleri temsil eden serilerin hem heterojen hem de yatay kesit bağımlık özelliklerine sahip olmasına bağlı olarak, Westerlund yaklaşımı ile dış borçların sürdürülebilirliği analiz edilmiştir.

Westerlund (2007,) panel hata düzeltme yaklaşımı dört teste dayalı olarak geliştirmiştir. Bu testlerin ikisi grup ortalama istatistiklerine, diğer ikisi ise panel istatistiklerine karşılık gelmektedir. Westerlun yaklaşımı sistemde yer alan serilerin aynı dereceden bütünleşme derecesine sahip olduğunu varsaymaktadır (Westerlun, 2007). Analiz için aşağıdaki eşitlik tahmin edilir.

$$
\Delta \mathrm{Y}_{\mathrm{it}}=\delta_{\mathrm{i}} \mathrm{d}_{\mathrm{t}}+\lambda_{\mathrm{i}} \mathrm{x}_{\mathrm{it}-1}+\sum_{\mathrm{j}=1}^{\rho_{\mathrm{i}}} \mathrm{a}_{\mathrm{ij}} \Delta \mathrm{Y}_{\mathrm{it}-1}+\sum_{\mathrm{j}=0}^{\rho_{\mathrm{i}}} \lambda_{\mathrm{i}} \Delta \mathrm{x}_{\mathrm{it}-\mathrm{j}}+\mathrm{e}_{\mathrm{t}}
$$

$\mathrm{Bu}$ eşitlik yoluyla eş bütünleşmenin varlığını gösteren hata düzeltme katsayısı ve bunun istatiksel anlamlılığının analizine yönelik olarak hesaplanacak $\mathrm{t}$ istatistiği için standart hatanın hesaplanmasını sağlayan eşitlikler görülmektedir. 


$$
\begin{aligned}
& \mathrm{a}_{\mathrm{i}}=\left[\sum_{\mathrm{i}=1}^{\mathrm{N}} \sum_{\mathrm{t}=2}^{\mathrm{T}}\left(\widetilde{\mathrm{Y}}_{\mathrm{it}-1}\right)^{2}\right]^{-1} \sum_{\mathrm{i}=1}^{\mathrm{N}} \sum_{\mathrm{t}=2}^{\mathrm{T}} \frac{1}{\mathrm{a}_{\mathrm{i}}(1)} \widetilde{\mathrm{Y}}_{\mathrm{it}-1} \Delta \widetilde{\mathrm{Y}}_{\mathrm{it}} \\
& \text { S. } \mathrm{E}\left(\mathrm{a}_{\mathrm{i}}\right)=\left[\left(\widetilde{\mathrm{S}}_{\mathrm{N}}\right)^{2} \sum_{\mathrm{i}=1}^{\mathrm{N}} \sum_{\mathrm{t}=2}^{\mathrm{T}} \widetilde{\mathrm{Y}}_{\mathrm{it}-1}{ }^{2}\right]^{-1 / 2}
\end{aligned}
$$

$\mathrm{Bu}$ eşitliklerde ai katsayısının sıfırdan farklı olup olmadığı eş bütünleşme ilişkisinin olup olmadığını göstermektedir. $\mathrm{H}_{0}$ hipotezi ai olmasın kapsamaktadır. Bu nedenle birim kökün varlığını göstermektedir.

\section{Dış Borçların Sürdürülebilirliğine Yönelik Analiz Sonuçları}

Çalışmanın bu kısmında uygulanan ampirik yöneteme ilişkin tahmin ve test sonuçları yer almaktadır. Sonuçlar ikinci kısımda verilen sıralamaya göre verilmiştir.

\subsection{Değişkenlerin Homojenlik Özelliğinin Analizi}

Peseran ve Yamagata tarafından geliştirilen test sonuçları ekte aşağıda görülmektedir. Literatürde delta testi olarak ifade edilen test sonucuna göre değişkenleri temsil eden serilerin homojen veya heterojen yapısı ortaya konabilmektedir.

\begin{tabular}{lll}
\hline Test & Test İstatistiğ & Olasılık Değeri \\
\hline$\Delta$ & 3.368 & 0.000 \\
$\Delta$ adj & 3.766 & 0.000 \\
\hline
\end{tabular}

Tablo:4 Değişkenlere Ait Homojenlik Test Sonuçları

Tablo 4 değişskenlere ait homojenlik test sonucuna göre, değişkenlerin heterojen olduğu görülmektedir. Test istatistiklerinin istatistiki olarak anlamlı olması (olasılık değerleri 0.01 den küçük) bu sonucu desteklemektedir. $\mathrm{Bu}$ açıdan bundan sonraki aşamalar bu özelliğe bağlı olarak devam etmiştir.

\subsection{Yatay Kesit Bağımlılık ve Birim Kök Test Sonuçları}

Tablo 5 de yatay kesit bağımlılığın analizine yönelik olarak elde edilen CD test sonuçları görülmektedir. Bu sonuçlara göre ülkelere ait Dış Borç stok verileri(ED) arasında yatay kesit bir bağımlılık olduğu görülmektedir. Bunun anlamı söz konusu ülkelerin dış borçları üzerinde etkili olan şokların ortak olduğu ifade edilebilir. Başka bir ifadeyle söz konusu dışsal şokun ülkeler üzerindeki etkisi aynıdır.

\begin{tabular}{ccc}
\hline Değişkenler & CD test Sonucu & Olasılık Değeri \\
\hline ED & 10.08 & 0.000 \\
DCA & -1.68 & 0.094 \\
\hline
\end{tabular}

Tablo:5 Yatay Kesit Bă̆ımlık Test Sonuçları

Cari dengenin bugünkü değerini ifade eden DCA değişkenin analiz sonucuna göre ancak \%10 anlamlılık düzeyinde bir yatay kesit bağımlılığa ulaşılmıştır. Bu iktisadi açıdan beklenen bir sonuç olup, ülkelerin ekonomik yapı ve politikaları tarafında belirlenen bir değişken olduğu anlaşılmaktadır. Bu açıdan bu değişkeni etkileyen şoklar aynı derecede ülkeler üzerinde bir etkisi olamamaktadır. DC serisinin \%10 anlamlılık düzeyinde yatay kesit bağımlılığı dikkate alınarak yatay kesit bağımlılığı durumda uygulanan birim kök testine tabi tutulmuştur.

Peseran tarafından geliştirilen ve bu çalışmada yatay kesit bağımlılığa altında değişkenlerin duranlığının araştırılmış ve Tablo 6 daki sonuçlar elde edilmiştir.

\begin{tabular}{ccc}
\hline Değişkenler & Test & Olasılık Değerleri \\
\hline ED & -1.601 & 0.630 \\
DCA & -0.560 & 0.999 \\
\hline
\end{tabular}

Tablo:6 Yatay Kesit Birim Kök Test Sonuçlarl

Tablo 6 daki sonuçlara göre seriler yatay kesit bağımlılık özelliğine sahipken aynı dereceden entegre oldukları görülmektedir. Serilerin yatay kesit bağımlıkla birlikte durağan olamadığı olasılık değerlerinin $\% 5$ anlamlılık düzeyinin üzerinde olmasından anlaşılmaktadır. Bununla birlikte söz konusu test istatistik değerleri Peseran tarafından rapor değerlerden küçüktür. Serilerin aynı dereceden durağan olduğuna karar verildikten sonra dış borçların sürdürülebilirliğine yönelik eş bütünleşme analizine geçilmiştir.

\section{Panel Eşbütünleşme Test Sonuçları}

Tablo 7 de Westernlund eş bütünleşme test sonuçları görülmektedir. Tablo değerlerine göre yatay kesit grup ortalamaları dikkate alındığında birimler arasında eş bütünleşme ilişkisi (Gt, Ga) olduğu görülmektedir. Bununla birlikte panelin bütünü için bu yorumu yapamıyoruz. Ancak genel olarak anlamlı bir sonucumuz olmasına karşın 
burada uzun dönemli bir ilişkinin olduğu görülmektedir. Bu ilişkinin ülkeler açısından hangisinde geçerli olup olmadığının görülmesine yönelik olarak havuzlanmış ortalama grup analiz yaklaşımından yararlanılmıştır.

\begin{tabular}{ccll}
\hline İstatistiki Parametreler & Değerler & Z değerleri & Olasılık değerleri \\
\hline $\mathrm{Gt}$ & -4.338 & -6.529 & 0.000 \\
$\mathrm{Ga}$ & -15.614 & -1.478 & 0.070 \\
$\mathrm{Pt}$ & 6.441 & 14.013 & 1.000 \\
$\mathrm{~Pa}$ & 3.551 & 5.538 & 1.000 \\
\hline
\end{tabular}

Tablo: 7 Westernlund Panel Eşbütünleşme Test Sonuçları

Westernlund analiz sonucuna göre ele alınan ülke grupları için dış borçların sürdürebilirliğinin geçerli olduğu ifade edilemez. Ancak bu ilişkinin ülkelerin bazıları için geçerli olduğu söylenebilir. Bu ülke gruplarını ifade etmek için bir sonraki analiz sonuçları elde edilmiştir.

Elde edilen tahmin sonuçları birimlerin her biri için bir eşbütünleşme ilişkisi konusunda bilgi sağlamaktadır. Bu amaçla çalışmanın bu kısmında Yatay kesit bağımlılığının varlığı durumunda eş bütünleşme katsayılarının tahminine yönelik Pesaran(2006) tarafindan geliştirilen CCE (Common Correlated Effects: Ortak ilişkili Etkiler) yaklaşımı kullanılmıştır. Bu yaklaşımın önemli özelliği birimlere ait eşbütünleşme katsayıları ile birlikte panelin bütünü için eşbütünleşme katsayılarını vermesidir. Panelin bütününe ait katsayıların elde edilmesini sağlayan söz konusu yaklaşım (Common Correlated Mean Group Effects: Ortalama Grup Etkisi) tanımlanmaktadır. Bu yöntem birimlere ait katsayıların ortalamasına dayalı tahminden ortalama grup etkisi olarak tanımlanmaktadır. $\mathrm{Bu}$ çalışmada grup etkilerini göstermek amacıyla yalnızca ortak etkiler ortalaması yaklaşımı kullanılmıştır. Tablo 8 de elde edilen tahmin sonuçları görülmektedir. Panel verinin tümünü kapsayan cari açığın bugünkü değerini temsil eden dca değişkenine ait katsayı 0.00412 bulunmuş olup istatistiki olarak anlamsız çıkmıştır. Bu Westernlund yaklaşımın sonucuyla benzerdir. Bununla birlikte grup etkileri dikkate alındığında her bir ülkeye ait etkiler açısından farklılık görülmektedir.

\begin{tabular}{cc}
\hline Değişkenler & Katsayılar \\
\hline dca & 0.041 \\
& 0.08 \\
ed_avg & 0.928 \\
& 1.28 \\
dca_avg & 1.209 \\
& 1.40 \\
Sabit & $5.10 \mathrm{e}^{+}$ \\
& 0.60 \\
\hline
\end{tabular}

Grup Etkileri

\begin{tabular}{|c|c|c|c|c|c|c|c|}
\hline \multirow[b]{2}{*}{ Değişkenler } & \multicolumn{7}{|c|}{ ÜLKELER } \\
\hline & $\mathrm{AZB}^{* *}$ & $\mathrm{KZK}^{* *}$ & KIR** & ÖZB** & $\mathrm{TMN}^{* *}$ & TAN** & GUR** \\
\hline \multirow[t]{2}{*}{ dca } & -0.168 & -1.725 & -0.763 & -0.645 & -.2895 & 1.787 & 2.096 \\
\hline & -1.40 & $-3.37 *$ & $-2.40 *$ & 0.12 & -0.32 & $1.95^{*}$ & $3.19^{*}$ \\
\hline \multirow[t]{2}{*}{ ed_avg } & 0.372 & 5.255 & 0.151 & 0.236 & -0.055 & 0.084 & 0.451 \\
\hline & 5.92 & 22.59 & 6.13 & 0.00 & -1.96 & 5.61 & 8.04 \\
\hline \multirow[t]{2}{*}{ dca_avg } & 0.621 & 6.311 & -0.010 & 0.185 & -0.055 & 0.263 & 1.153 \\
\hline & 1.54 & 2.75 & -0.08 & 0.66 & -0.28 & 2.39 & 2.85 \\
\hline \multirow[t]{2}{*}{ Sabit } & $-3.05 \mathrm{e}+$ & $-4.01 e^{+}$ & $9.48 \mathrm{e}+$ & $3.17 \mathrm{e}^{+}$ & $1.96 \mathrm{e}^{+}$ & $8.84 \mathrm{e}^{+}$ & $9.17 \mathrm{e}^{+}$ \\
\hline & -0.78 & -2.50 & 4.80 & 0.00 & 7.17 & 2.39 & 1.66 \\
\hline
\end{tabular}

Tablo:8 Ortak Illişkili Etkiler Tahmin Sonuçları

(**) ülke isimlerinin kısaltması olup; AZB (Azerbaycan), KZK (Kazakistan), KIR (Kırgızistan), OZB (Özbekistan), TMN (Türkmenistan), TAN (Tacikistan), GUR (Gürcistan)'1 ifade etmektedir. Grup etkileri dikkate alındığında dca değişkenine ait katsayılar Kazakistan, Kırgızistan, Tacikistan ve Gürcistan için anlamlı çıkmıştır. Anacak Kazakistan, Kırgızistan için dış borçların sürdürebilir olduğu bulunurken, Tacikistan ve Gürcistan için dış borçlar sürdürülemez bulunmuştur. Bunun nedeni her iki ülkeye ait dca katsayılarının pozitif çıkmış olmasıdır. Bununla birlikte dış borçların sürdürebilirliği açısından diğer ülkeler için kesin bir sonuca istatistiki olarak ulaşılmamış olmakla birlikte dış borçların sürdürebilir bir eğilimde olduğunu ifade edebiliriz. En azından bu ülkelere ait dca değişkenine ait katsayının negatif eğilimli olması bunu göstermektedir. Bununla birlikte Azerbaycan, Kazakistan, Türkmenistan'ın enerji ihracatçısı ülkeler olması Özbekistan'ın da altın ihracatının olması bu eğilimin en önemli nedeni olduğunu kanaatindeyiz. 


\section{Sonuç}

Yapılan analizler ve elde edilen bulgulara göre Kazakistan, Kırgızistan için dış borçların sürdürebilir olduğu bulunurken Tacikistan ve Gürcistan için bu durumun istatistiki anlamlılık düzeyi açısından geçerli olmadığı sonucuna ulaşılmıştır. Bununla birlikte enerji ve değerli maden ihracatına sahip diğer ülkelerin diş bor stokunda azalma eğiliminin olduğu anlaşılmakla birlikte bu durum istatistik açıdan güçlü bir sonuçla desteklenememiştir. Ancak ülkeler arasında yatay kesit bağımlılığın varlığı şokların birbiri üzerinde etkili olacağını göstermesi açısından, olumlu şokların da Tacikistan ve Gürcistan üzerinde pozitif etkileri olacağını göstermektedir.

Kullanılan değişkenlerden indirgenmiş cari denge değişkenin değerini belirleyen faktörlerden biri uluslararası faiz oranlarıdır. Bu açıdan bu sonuçların LIBOR faiz oranına bağlı olarak elde edildiği dikkate alınmalıdır. Bundan dolayı uluslararası faiz oranlarındaki değişime bağlı olarak bu sonuçların tekrar tahmin edilmesi politika önerilerinin gelişmesinde ilave katkı sağlayacaktır. Bununla birlikte enerji ürünleri ihraç eden ülkeler için dış borç sorunundan daha çok likidite sorununa yönelik politikaların geliştirilmesi daha önemli bir yönetim sorunu olarak öne çıkmaktadır. Bu sonuç, çalışmada ulaşılan en önemli bulgudur.

\section{Kaynakça}

- Asian Development Bank 2014. Key Indicators For Asia and The Pasific.

- $\quad$ Baltagi, B., 2005. Econometric Analysis of Panel Data. Third Edition, John Wiley \& Sons Press. 4-6.

- Bayraktutan, Y. ve Bayraktar, Y., 2008. “Orta Asya Ülkelerinde Dış Borçların Niteliği”, II. Uluslararası Sosyal Bilimler Kongresi, 22-24 Ekim, Bişkek, pp. 148-164.

- Breusch, T.S ve Pagan, A.R., 1980. "The Lagrange Multiplier Test and Its Applications to Model Specification Tests in Econometrics”, Review of Economic Studies, 47, pp. 239-53.

- $\quad$ Egeli, H. A., 1992. “Türkiye’nin Dış Borç Yapısının Analizi(1980-1990)”, A.Ü. Siyasal Bilgiler Fakültesi Dergisi, 47, (3-4), pp. 123 - 127.

- Egeli, H. A. ve Egeli H., 2008. "Bir Geçiş Ekonomisi Olarak Dış Borçlarının Sürdürülebilirliğii”, SosyoEkonomi, Ocak-Haziran, 1, 080101, pp.11-25.

- Hakkio, C. S. ve Rush, M., 1991. “Cointegration: How Short Is the Long Run?”, Journal of International and Finance, N.10, pp. 81-575.

- Meriç, M., 2013. Devlet Borçları, Ankara.

- Peseran, H. M., 2004. “General Diagnostic Tests for Cross Section Dependence in Panels”, Working Paper No:0435, University of Cambridge.

- Peseran, H. M. ve Yamagata, T., 2008. “Testing Slope Homogeneity in Large Panels”, Journal of Econometrics, 142, pp. 50-93.

- Takım, A., 2012. “D1ş Finansal Liberalleşme Sonrası Türkiye’nin Dış Borç Dinamiğindeki Değişmeler: Bir Literatür Araştırması”, Sosyo Ekonomi, 2, pp. 23-44.

- THE WORLD BANK 2014. Countries and Economies.

- UTKUlU, U., 1997. "Is The Turkish External Debt Sustainable? Evidence From Unit Root Testing”, DEÜ. IIBF. Dergisi, 12(1), pp. 231-238.

- Westerlund, J., 2007. "Testing for Error Correction in Panel Data", Oxford Bulletin of Economics and Statistics, 69(6), pp. 709-74.

- Wilcox, D. W., 1989. “The Sustainability Of Goverment Constain”, Journal of Money, Credit and Banking, 21(3), pp. 291-306.

- http://www.adb.org/sites/default/files/publication/43030/ki2014_o.pdf. Erişim tarihi:23.06.2014.

- http://www.data.worldbank.org/country/ Erişim tarihi: 23.06.2014. 


\title{
Türkiye Ekonomisinin Orta Gelir Tuzağına Düşüp Düşmediğine Dair Tartışma: Kur Değerlenmesi Çerçevesinde Bir Bakış
}

\section{A Discussion on Whether Turkish Economy is in Middle Income Trap or Not: A Perspective on Framework of the Exchange Rates Appreciation}

\author{
Prof. Dr. Murat Nişanc1 (Erzincan University, Turkey) \\ Prof. Dr. Mine Gerni (Marmara University, Turkey) \\ $\mathrm{Ph}$. D. Candidate Adem Türkmen (Erzincan University, Turkey) \\ Prof. Dr. Ömer Selçuk Emsen (Atatürk University, Turkey)
}

\begin{abstract}
Since 2007 long staying in the middle income group or especially unable to state a higher category, has begun to be considered as middle-income trap (MIT). According to World Bank (WB) classification, in 1955, Turkey reached to lower-middle income countries category from low-income category and staying there about 50 years. In 2004 Turkey has been reached constantly to upper-middle income countries category. However, last three years' low growth figures and reaching $20 \%$ of the US income per capita have created many discussions whether Turkey entered in MIT. Besides, in parallel the integration of Turkish Economy to the world economy and to be exposed financial flows because of the world expansionary policies may result to have excessive appreciation of the national currency and to seem overvalued than real level of GDP in dollars. In emerging artificial bloating in income per capita is a result of undervaluation on the exchange rate. Therefore, in this study; the correct exchange rate is calculated with using base year determined depending on current account deficit's minimum valued year or years which is assumed correct value of the exchange rate. By using calculated exchange rate, examined new GDP per capita series shows that Turkish economy could not reach the threshold 10000-12000 dollars despite being included in upper-middle income group in the WB classification. Furthermore, according to other classifications which are investigating MIT, it is also reached that Turkey has been placed in MIT long time period due to exchange rate pressures in terms of Turkey reached upper middle income position.
\end{abstract}

\section{Giriş}

Bireysel olarak ülke ekonomilerinin temel hedefi, sürekli ve yüksek büyüme skorları yakalayarak fert başına gelir seviyesinin en üst düzeye çıkarma ve böylece ihtiyaçlar hiyerarşisinde üst düzey ihtiyaçlar kategorisine sıçramayı sağlamaktır. Dolayısıyla daha fazla gelir ve buna bağlı olarak daha fazla tüketim yapılarak refah seviyesinin daha üst düzeye çıkarılması amaçlanmaktadır. Özellikle toplumsal kayıtsızlık paftasında daha üstte yer alan kayıtsızlık eğrisi üzerinde dengeye gelmekle ifade edilebilecek refah artışı, özelde gelişmekte olan ülkeler bağlamında kalkınma iktisadının ve genelde de büyüme iktisadının ilgi alanları arasındadır. Büyüme iktisadının Solow ve öncesi teorilerinde ise gelir açısından ileri ülkelerin büyümelerinin zamana bağlı olarak giderek durağanlaşma göstereceği ileri sürülür. Buna karşılık geri kalmış ülkelerin yüksek büyüme performansı sergilemeleriyle gelişmiş ülkeler ile aralarındaki açığı kapatacağına dair “yakınsama hipotezi”nin II. Dünya Savaşı sonrasında gerçekleşebilirlikten uzak kalması, teoride ve uygulamada hem yeni büyüme teorilerinin hem de kalkınma iktisadının doğuşuna zemin hazırlamıştır. Diğer bir ifadeyle iktisadi büyüme ve gelişme iktisadında yakınsama değil, aksine "Iraksama hipotezi”ne bağlı olarak ortaya çıkan literatüre ilaveten günümüzde karşı karşıya kalınan bir diğer sorun ise “orta gelir tuză̆ı" (OGT)'nın farkındalığıdır.

Kavramsal olarak henüz yeni yeni tanımlaması yapılmaya başlanan OGT, orta gelirli bir ülke ekonomisinin görece yüksek gelirli ülkelerin sergiledikleri büyüme performansından daha yüksek büyüme sergileme sürecinin sonlanması; büyüme trendinin yüksek gelirli ülkeler ile olan mesafesini kapatamayacak şekilde yerinde saymasıdır. Dolayısıyla OGT'ye giren ülkenin ekonomisi bir tür “mehter yürüyüşü̈” sergilemeye başlar. Ekonominin mehter yürüyüşünde ise düşük büyüme skorlarının yanı sıra istikrarsız büyümeler de etkili olur. Şöyle ki, istikrarsız büyüme skorlarında bir süre yüksek büyüme rakamları kaydedilirken, bunun sürdürülememesi ve daha da önemlisi, ekonomik krizlerle ekonomik gelişmişlik açısından kat edilen ileriye doğru mesafenin bir tür iadesi söz konusu olmakta; ekonomide önemli salınımlar kendini göstermektedir.

Türkiye ekonomisi özelinde OGT'yi ele alan tartışmalarda 2001 krizi sonrasında elde edilen yüksek büyüme skorları sonrasında 2005 yılında üst-orta gelir gurubuna geçiş ile sağlanan başarının sürdürülebilirliği ya da üst gelir gurubuna çıkıp çıkamayacağı tartışılır olmuştur. Üst-orta gelir sınıfına sıçramaya karşılık, büyümenin 2007'de ortalamanın altında kalması ve küresel krizin de etkisiyle 2008'de sıfırlanması, 2009'da da negatif skor olarak kendini göstermesi dikkati çeken en önemli unsur olmuştur. Küresel ekonomiye eklemlenmenin bir tür maliyeti olarak ifade edilebilecek bu yüksek oranlı küçülmeden sonra 2010 ve 2011'deki telafi edici yüksek 
büyüme ise sürdürülememiştir. Şöyle ki, 2012 ve sonrasındaki büyüme skorları Türkiye'nin ortalama büyümesinin altında, oldukça düşük seviyelerde gerçekleşmesi, Türkiye'nin OGT'ye düştüğüne dair tartışmaları gündeme taşımıştır. Literatürde OGT'nin fert başına gelir açısından 10 bin dolar ile 13 bin dolar arasında sıkışıp kalan ekonomilerin, orta gelirli ülke olarak adeta kalmaya mahkûm olması ile ifade edilen durumun, yani orta gelirli olarak kalmaya mahkûmiyetinin, daha çok düşük büyüme skorlarının bir yansıması olduğu açıktır. Burada Türkiye ekonomisinin 2002 yılındaki fert başına gelirinin 2-3 bin dolardan hâlihazırda 10 bin doları aşmış olmasına rağmen, son üç yıldaki düşük büyüme skorları ile OGT’ye düştüğü iddialarını destekleyen bulgu olarak görülmektedir.

Ancak, bu çalışmada Türkiye ekonomisinin iddia edildiği gibi OGT'ye düşmesinden de daha dramatik sonucu, OGT düzeyine ulaşmış olsa da, bu gelir düzeyinde uzun süre bulunacağı iddiası tarafimızdan dile getirilecektir. Şöyle ki, 2001 sonrasında Türkiye ekonomisinde yaşanan reel fert başına büyüme skorları dikkate alındığında, dolar bazında gözlenen 4 katlık artıştan ziyade 2 katına dahi varmayan bir artışın varlığı dikkat çekmektedir. Bu durumda dolar bazında milli gelirin olduğundan fazla bir gelir artışına sinyal teşkil eden bulguların varlığından söz edilebilir. Daha açık bir ifadeyle ABD dolarının piyasa fiyatının Türkiye'de olması gereken seviyenin altında belirlenmiş olması olasılığının varlığına işaret eden bulgudan bahsedilebilir. Zira kurun uzun dönem denge değerini ifade eden satınalma gücü paritesi (SGP)'den sapmalar bu duruma sebebiyet vermektedir. Kurun SGP'den sapmasına yol açan finansal hareketler durduğunda, kurun SGP ölçüsünde kendi kendini düzeltmesi söz konusu olabilmektedir. Özellikle senyoraj gelirleri elde eden yüksek konvertibl paralardaki genişlemeler kurda eksik değerlendirmeyi mümkün kılmaktadır. Bu durumda dolar bazlı ulusal gelir de olduğundan fazla hesaplanabilmektedir. Dolayısıyla bu çalışmada cari açığın görece en düşük olduğu ve böylece kurun olması gereken seviyeye yaklaşmış olduğu 1987, 1989, 1995 ve 2003 yılları baz alınarak kur hesaplaması ve buna bağlı olarak dolar bazlı milli gelir rakamları ortaya konularak, Türkiye'nin orta gelir tuzağına düşmekten ziyade; halihazırda bulunduğu gelir düzeyinin bile suni olup olmadığı tartışılacaktır.

\section{OGT Üzerine Teorik Tartışmalar}

Dünya ekonomisinde ülkeler; (i) düşük gelirli, (ii) orta gelirli ve (iii) yüksek gelirli ülkeler şeklinde sınıflandırılmaktadır. İlk etabı oluşturan düşük gelirli ülkelerin bu sınıf içerisinde uzun süre kalması ya da diğer bir ifadeyle yoksulluğu kader olarak kabullenmesi durumu "yoksulluk tuzağı”" olarak tanımlanmaktadır (Koçak ve Bulut, 2014). Yoksulluktan siyrılamamanın veya iktisat jargonuyla kalkın(a)mamışlı̆̆ın temel belirleyicilerinin varlığı konusunda tam bir konsensüsün olduğu söylenemez. Dolayısıyla zenginliğin ve yoksulluğun kökenleri sosyal bilimcilerin bakış açısına göre değişmekte ve bu da literatürde temel tartışma konularından birini oluşturur. İleri sürülen belli başlı hipotezler arasında yer alan (i) coğrafya hipotezi, (ii) kültür hipotezi ve (iii) cehalet hipotezinin ise münferit ülke örneklerini açıklamaktan uzak kaldığı iddiaları gündemdedir. Az gelişmişliğin onların geçmişten devraldıkları "sosyal-siyasal-kültürel-ekonomik kurumlar"dan ve özellikle "sömürücü siyasal ve ekonomik kurumlar"dan miras kaldığı ileri sürülmektedir (Acemoğlu ve Robinson, 2014). Az gelişmişliğe özgü özellikler olarak nitelendirilen mirasa benzer olgular, aynı zamanda orta gelirli ülkelerde de kendine özgü bir şekilde tezahür etmiş ve dolayısıyla bunlarda gözlenen izdüşümü ise "orta gelir tuză̆

Burada temel alınan yöntemlerden biri Dünya Bankası'nın sınıflandırması olan orta gelirli ülkelerin alt-orta ve üst-orta şeklinde yapılan sınıflandırmasıdır. OGT literatürüne göre bir ülkenin alt-orta gelir grubunda kalması gereken minimum süre 28 yıl ve ortalaması 33 yıl iken, üst orta gelir düzeyinde ise minimum süre 7 ve ortalaması 14 yıldır (Felipe v.d., 2012). Bu süreler aşılmasına rağmen bulundukları kategoriden üst kategoriye sıçrayamama sorunu yoksulluk tuzağı olarak değil, OGT olarak adlandırılmaktadır. Diğer bir ifadeyle OGT kavramı genel olarak ülkelerin bu sınıflandırma içerisinde bulundukları kategoriden bir üst kategoriye sıçrayamaması olarak adlandırılırken; tanımın belirttiği asıl özel husus ise alt-orta gelirli ülke gurubunda veya üst-orta gelir gurubunda çakılı olarak kalma söz konusudur. DB'nin belirlediği alt-orta ve üst-orta sınırlarını kabul etmeyen çalışmada (Felipe vd., 2012) 124 ülke yeniden sınıflandırılmış ve SGP'ye göre kişi başı gelir cinsinden alt-orta ülke grubunun geliri 2.000 dolar ila 7.250 dolar arasında; üst-orta gelir gurubunun ise 7.250 dolar ila 11.750 dolar arasında olduğu belirtilmiştir. Bu veriler şüphesiz dünya ekonomisindeki gelişmelere bağlı olarak güncellenebilir nitelikte olduğu da göz ardı edilmemelidir.

OGT'yi tanımlayan bir başka çalışmada OGT'nin yükselen ekonomilerde büyüme yavaşlaması olduğu belirtilmiştir (Eichengreen vd. 2013). Büyüme yavaşlamasının varlığı da üç koşula bağlıdır. İlki, 7 yıllık ortalama kişi başı büyüme rakamı (satınalma gücü paritesi ve 2005 sabit dolar fiyatları cinsinden) en az \%3,5 olmalıdır. İkincisi, birbiriyle örtüşmeyen iki 7 yıllık periyod arasında kişi başı gelir büyümesinde en az \%2'lik bir düşüş olmalıdır. Üçüncüsü ise, büyüme yavaşlaması (sabit fiyat ve SGP ye göre) kişi başı geliri en az 10.000 dolar seviyesinde olan olgun ekonomilerde görülebilir.

Diğer taraftan OGT'ye düşen ülkelerin sınırlarını ABD kişi başı geliri ile ilişkilendiren çalışmalardan birinde (Robertson ve Ye, 2013) orta gelir tuzağına düşen ülkelerin ABD kişi başı gelirinin \%8 ile \%36'sı arasında bulunduğunu, bir diğerinde ise (Woo, 2012) bu rakamın \%20 ile \%55 arasında olduğu belirtilmektedir. 
OGT öncesinde ülke ekonomisi az gelişmiş ya da durağan büyüme durumunda iken; ekonomiden siyasete, kültürden sosyal alanlara varıncaya kadar radikal değişimlere gidilerek adeta devrim niteliği taşıyacak adımlar atılması-yapısal değişimlere gidilmesiyle durağanlığın aşılması hedeflenir. Köklü değişimler ülke ekonomisinde bir tür altın çağı başlatır ve bunun getirdiği dinamizm ile birlikte yüksek büyüme skorlarının gelmeye başlaması, bir tür "büyüme devrimi" olarak kendini hissettirir. Uzun dönemli yıllık büyüme performansının üzerinde büyüme skorları elde edilmeye başlanarak gelişmiş ülkelerle olan mesafe kapanmaya başlar. Ekonomide ortaya çıkan bu "Iale devri" ortamı aynı zamanda dünya ekonomisinde de teyidini alarak yabancı çevrelerden olumlu tepki alır ve ülkenin büyümesi için gereksinim duyduğu yabancı sermaye ülkeye akmaya başlar. Ancak, bu olumlu iklimi sağlayan radikal değişimler bir süre sonra vazgeçilmez-kırılamaz paradigma halini alır. Ülkenin gereksinim duyduğu yenilikçi ortam kaybolmaya başlar. Ve bundan da ekonomi nasibini alarak bir süre sonra atalete düşmeye başlar. Eskide kalan önceki paradigma değişiminin sağlamış olduğu olumlu iklimin büyüsünde kalan siyaset ve bürokrasi, eskiye olan amentüsüne sıkı sıkıya bağlılı̆̆ı ve bunu değiştirme gereksiniminin farkındalı̆̆ını kaybeder.

Burada her reformist yapı ya da köklü yapısal değişimden bir süre sonra "cari reformlar kırılamaz birer paradigma haline dönüşürrse", toplumda ataletin-durağanlığın ortaya çıkması özellikle eski Sovyetler ya da benzeri deneyimlerden bilinmektedir. Bilindiği gibi Sovyetler Birliği, 1917 Bolşevik Devrimi ile başlayan bir süreç olup, ekonomiyi az gelişmiş bir ekonomiden modern bir yapıya dönüşümü sağlama ve bu çerçevede kat edilen yolda GSMH değeri itibarıyla ABD'den sonra dünyanın ikinci büyük ekonomisine dönüşümü ifade eder. 1960'larda vardığı nokta itibarıyla Sovyetler askeri açıdan da ABD ile boy ölçüşebilecek seviyeye ulaşmıştır. Burada Simon Kuznets'in ifadesiyle ekonomiden sosyo-kültürel alana varıncaya kadar ortaya çıkan devasa dönüşüm aynı zamanda diğer az gelişmiş ülkeler için de model olabileceği tartışmalarını beraberinde getirmiştir. Bu yönüyle hem Kuznets $(1966,1971)$ hem de Alexander Gerschenkron $(1962,1968)$ Sovyet dönüşümünü modern Batı literatürü ile karşılaştırmalı olarak almışlardır. Dolayısıyla otoriter ve sosyalist rejim 1920'lerin sonunda, yani ihtilalden sonraki 10 yılda tesis edilmiştir. 1950'lerin sonuna kadar devam eden bu başarı öyküsünün ise ABD’yi yakalayıp yakalamayacağı tartışmaları arasında sistemin en önemli zafiyetine başta Friedrich A. Hayek olmak üzere Ludwig von Mises ve Oscar Lange gibi düşünce adamları vurgu yapmıştır. Bu düşünce adamlarının öngörüsüyle, 1920'lerdeki heyecana paralel olarak özgürlükleri kısıtlayan yapılar ihmal edilmiş ve Birlik de özgürlüklerin ihmal edildiği-yenilenemediği yapıda durağanlığa girmiştir. Öngörüler gerçekleşerek 1960'lardan itibaren 20 yıllık süreçte sistem durağanlaşmıştır (Ofer, 1987); insan refahına mal edilemeyen büyümenin suni ya da teknolojiden yoksun rekabetçilik olarak adlandırılması söz konusu olmuştur. Sovyetler Birliği’ne özgü suni büyüme, merkezi komuta yapısı sayesinde tarımda (çok düşük verimlilikle) kullanılan kaynakların sanayiye aktarmasıyla zorlamalı sanayileşme gerçekleşirken, bu sanayileşme de daha çok insan refahına etkisi zayıf olan silah sanayinde gerçekleşmişti. Bu türden bir büyüme geri kalmış pek çok alanda arayı kapatabilmek için bir dereceye kadar genel geçerliliğe sahipti ve sistemin özünde yaratıcı yıkım olmadığından, sömürücü kurumlara dayalı büyüme daha kolay gerçekleşmiştir. Ancak, bir tür denizin bitmesi, yani tarımdan aktarılacak kaynakların kalmadığı yapıda Sovyet ekonomisinde çöküşün yaşanması kaçınılmaz hale gelmiştir. Servetin ve gücün dar bir zümrenin-elitin elinde toplanması ise diğer gurupların karşıt harekete geçmesini tetikleyen unsur olmuştur (Acemoğlu ve Robinson, 2014). Dolayısıyla başarılı büyüme oranları ile dikkat çeken Sovyetler, 1928-1984 döneminde ortalama \%4.3-\%4.8 arasında skorlar yakalamıştır. Bu orana 1874-1984 arası dönem için ancak \%4.5'lik bir ortalamayı tutturan Japonya yaklaşabilmiştir. Sosyalist planlamacılığın bu başarısının 1975'lerden itibaren düşüşe geçtiği ve 1980’lerde de durgunlaşmaya başladığı belirgin bir şekilde gözlenmiştir (Emsen vd., 2011).

Genel olarak dünya deneyimleri ve özelde de Sovyetler için gözlenen durağanlaşma kavramının yarattığ sosyo-ekonomik değişimler, durağanlığın hem tanımını hem de sebeplerini sorgulatmaya başlamıştır. Bu çerçevede OGT terimi literatürde ilk kez Dünya Bankası'nın (2007) yayınladığı “An East Asian Renaissance Ideas for Economic Growth" adlı raporda tanımlanmıştır. Kavramın bu ilk kullanımına paralel olarak OGT, literatürde hem genel kabul görmüş hem de yaygın bir şekilde kullanılmaya başlamıştır. Raporda orta gelir düzeyinde bulunan ülkelerin 21. yüzyılda ekonomik çeşitliliğe ayak uyduramadıkları ve dolayısıyla zengin ülkelere göre daha yavaş büyüyeceği ileri sürülmektedir. Dolayısıyla OGT'ye düşmeyen ekonomi, S. Kuznets'in ifadesiyle topluma her türlü mal sağlama becerisine sahip ekonomilerdir ve bu ekonomiler olgun ekonomiler olarak adlandırılmaktadır. Dolayısıyla olgun ekonomi düzeyine ulaşamayan, yani orta gelir tuzağına yakalanan ülkelerin kendisi ile mukayese edildiğinde, görece düşük ücretli-fakir ülkelere karşı standart imalat sanayi ürünlerinde rekabet gücü zayıflamakta ve buna ilaveten inovasyona dayalı olarak büyüme performansı sergileyen zengin ülkeleri yakalamakta zorlanmaktadırlar. OGT’ye düştüğ̈̈ kabul edilen ülkeler için (bkz. Eichengreen vd., 2011, 2013) kişi başına düşen gelirin 10.000-11.000 dolar ve 15.000-16.000 dolar düzeyine ulaştıktan sonra gelirlerini daha fazla yükseltememesi sonucu ortaya çıkan tıkanıklık olarak ifade edilmiştir. Bu eşiklerin aşılmasına paralel olarak ABD kişi başına gelir düzeyinin \%58'inin üzerine çıkılması ve imalat sanayinin ulusal gelir içerisindeki payının \%23'lerde olması da OGT'den çıkma yönündeki gücün hem sebebi hem de sonucu olarak kabul edilir (Bozkurt, 2014; Berber, 2011, Eichengreen vd., 2011). 


\section{Türkiye'de OGT Üzerine Yapılmış Çalışmalar}

Koçak ve Bulut (2014) tarafından yapılan çalışmada 1950-2010 dönemi için ABD ve Türkiye’ye ait SGP 2005 yılı fiyatları kullanılarak elde edilen GSYİH serilerinin doğal logaritmaları alınmış ve Türkiye'nin serisi ABD serisinden çıkarılmıştır. Çalışmada Roberson ve Ye (2013) tarafından kullanılan ve yapısal kırılmaları dikkate alan birim kök testleri kullanılmıştır. Yapısal kırılmaları inceleme konusu yapan birim kök sınama tekniklerinde Lee ve Strazicich (2003)'in iki yapısal kırılmalı ve Carrion-i Silvester vd. (2009)'in beş yapısal kırılmalı birim kök testleri kullanılmıştır. İlk testte kırılmalar 1978/1971 ve 1993/1992 iken, ikinci testte kırılmalar 1956, 1962, 1977, 1993 ve 2000’dir. Birim kök sınamalarında serinin düzey değerlerde durağan olmayıp birinci farklarda durağan olduğu belirlemesi yapılarak, buradan Türkiye ekonomisinin OGT'de bulunmadığı sonucuna varılmıştır (Koçak ve Bulut, 2014).

Bozkurt vd. (2014) tarafından yapılan çalışmada Türkiye'nin yüksek gelirli ülkelere yakınsayıp yakınsamadığı mutlak ve koşullu yakınsama (yükseköğretimde okullaşma, yurtiçi tasarruflar ve imalat sanayinin GSYİH içindeki payı) boyutuyla 1971-2012 yılları arası veri seti ile ülkelerin 2005 sabit fiyatlarıla SGP gelirleri alınarak araştırılmıştır. Lee ve Strazicich (2003)'in yapısal kırılmalı birim kök sınamalarında Türkiye ve yüksek gelirli ülkeler arasındaki kişi başına düşen gelir farkının seviye değerlerinde durağan olduğu tespit edilmiş ve bu da gelir açısından Türkiye’nin yüksek gelirli ülkelere yakınsadığına sinyal kabul edilmiştir. Koşullu yakınsama için kullanılan ARDL yaklaşımında kişi başına gelir düzeyi üzerine imalat sanayinin GSYİH içindeki payı dışındaki yükseköğretimde okullaşma ve yurtiçi tasarruflar değişkenlerindeki artışların olumlu etkilerinin olduğu belirlemesi yapılmıştır (Bozkurt vd., 2014).

Tuncel (2014) tarafından yapılan çalışmada 1953-2010 verileri kullanılarak Türkiye ile gelişmiş Asya ülkeleri (Japonya, G. Kore ve Tayvan), gelişmekte olan Asya ülkeleri (Tayland, Malezya ve Çin) ile Latin Amerika ülkelerinde (Brezilya, Arjantin ve Meksika) kişi başı gelir düzeyi ABD=100 endeksi baz alınarak betimleyici bir şekilde inceleme konusu yapılmıştır. Grafiksel gösterimlerde birinci gurup ülkelerden Japonya'nın Türkiye'den önde başladığı, ancak 1990'lardaki deflasyonist eğilimle düşüş göstermesine karşılık yine de ileride olduğu; G. Kore'nin 1970'lerin başında ve Tayvan'ın ise 1970'lerin sonunda Türkiye'yi geçtiği görülmüştür. İkinci gurupta ise Türkiye'nin önde gidişinin kapanmaya başladığı ve hatta 1995'de Malezya'nın Türkiye'yi geçtiği ve Çin ile Tayland'ın trendinin yükselme eğiliminin Türkiye'ye yakınsadığı şeklinde sinyallerin var olduğu dikkat çekmektedir. Latin Amerika ülkeleri kategorisi içerisinde endeksin dalgalı seyrinin adeta gelirde benzeşecek şekilde birbirine yakınsadığ 1 tespiti bulunmaktadır (Tuncel, 2014).

Yaşar ve Gezer (2014) tarafindan yapılan çalışmada 2005 sabit fiyatlarla Türkiye'de kişi başı gelirin ABD gelirine oranı ele alınırken, 1980-2012 arası dönemde bunun \%14.67 ila \%19.82 arasında dağılım gösterdiği belirlemesi yapılmıştır. OGT tanımlamasında bu oranın \%57'de sürekli kalması şeklindeki literatür bilgisi ışığında, Türkiye'nin henüz bu seviyeye ulaşamadığı ileri sürülmüştür. OGT'de takılı kalmanın göstergelerinden imalat sanayi istihdamının toplam istihdamdaki payının \%23'e ulaşan ülkenin büyüme performansının yavaşlayacağına dair kritere karşılık Türkiye'de bu oranın \%18.82 olması nedeniyle henüz takılı kalma potansiyelinin bulunmadığı belirtilmiştir. Türkiye'nin üst-orta gelir gurubuna 2005 'de geçtiği ve orta gelirde kalma süresinin ortalama 14 yıl olduğuna dair belirleme 1şı̆̆ında, giderek düşen büyüme performansı ile Türkiye'nin orta gelirde uzun süre kalma olasılığının yüksek olduğu ileri sürülmüştür (Yaşar ve Gezer, 2014).

Dalgıç vd. (2014), 1990-2013 dönemi için düşük-orta ve yüksek-orta gelirli 50 ülkede, OGT'den çıkışta bağımlı değişken olarak, ortalama büyümeden fazla olduğunda 1 ve az olduğunda ise 0 kukla değişken kullanarak, teknoloji ve beşeri sermaye ile kurumsal faktörlerin rolünü probit modellerle inceleme konusu yapılmıştır. Elde edilen bulgularda teknoloji değişkeninin (patent başvuruları, Ar-Ge'de çalışan araştırmacı sayısı, ileri teknoloji ihracatının payı, Ar-Ge harcamalarının gelir içindeki payı ile orta öğretime kayıt oranı) gelir artışını pozitif etkilediği belirlenmiştir. Makro değişkenlerin (fiyat istikrarı, doğrudan yabancı sermaye girişleri, yatırım ve tüketim harcamalarındaki artış ve dış ticaret hadlerindeki iyileşme) de OGT’den kurtulmada pozitif etkilerinin olduğu ve buna karşılık kamu harcamalarında ve dışa açıklıkta artışlar ile reel kur yükselişlerinin ise olumsuz etkilerinin olduğu gözlenmiştir. Kurumsal faktörlerden yolsuzluk ve bürokrasideki artışların gelirde olumsuz ve buna karşılık demokratik hesap verebilirlik, hükümet istikrarı ve yatırım profilindeki değişmelerin ise olumlu etkilerinin olduğu tespit edilmiştir (Dalgıç vd., 2014).

OGT ve bundan çıkabilme yeteneğinde arz (GSYİH) boyutundan ziyade talep (hane halkı, kamu ve özel yatırım harcamaları ya da gayrisafi sermaye birikimi) boyutunun önemine Türkiye özelinde vurgu yapan çalışma Mert (2014) tarafindan yapılmıştır. Toplam değerlerin nüfusa bölünmesi sonucu her bir değişkenin kişi baş1 değerleri oluşturularak elde edilen verilerde betimleyici analizlerle kişi başı gelir açısından Güney Doğu Asya ile Latin Amerika ülkeleri arasında birinci gurubun yükseliş ve ikinci gurubun ise düşüş seyrine karşılık Türkiye'nin durağan bir seyir takip ettiği belirlenmiştir. OGT'den kurtulabilme yeteneğini sergileyen ülkeler net yurtiçi talebin dış talepten yüksek olduğu ülkelerdir ve bu ülkelerde dinamik bir iç talebin varlığının büyümeye katkılarının yüksek olduğu ileri sürülürken; Türkiye özelinde buna ilaveten net yatırımlarda artış sağlanabilirliğin önemli olduğuna vurgu yapılmıştır (Mert, 2014). 
Oldukça yeni bir literatürün oluştuğu OGT üzerine tartışmalarda bir kısım çalışmalarda Türkiye ekonomisinin OGT'ye düşmediği ileri sürülürken, bir kısım çalışmalarda OGT'ye düştüğü iddia edilmektedir. Bu literatürde tam bir konsensüse varılamamış olmasına rağmen, OGT’ye karşı önlem olarak politik değişkenler ile yabancı sermaye çekebilirlik ve yatırım iklimindeki artışlardan oluşan ekonomik değişkenlerin önem arz ettiğine vurgu yapılmaktadır.

\section{Türkiye Üzerine Betimleyici İnceleme}

Düşük gelirli ülke tanımlamasından alt-ortaya, alt ortadan üst-ortaya ve üst-ortadan da yüksek gelirli ülkeler kategorisine geçişler için politik-ekonominin ihtiyaç duyduğu en temel unsurların başında esneklik ve yenilikçilik gelmektedir. Esneklik açısından kastedilen ise olması gereken kur $\left(\mathrm{e}_{\mathrm{i}}\right)$ ile fiili kur $\left(\mathrm{e}_{\mathrm{c}}\right)$ arasındaki bağın kopmasıdır. Kur bağının kopması siyasetçi için oldukça hoş karşılanabilir yansımalara sahiptir. Bunlardan birincisi, dolar bazlı ulusal gelirin olduğundan fazla-yüksek çıkmasıdır. (Düşük) kura bölünerek hesaplanan döviz bazlı milli hasılanın olduğundan fazla-yüksek çıkması aynı zamanda iç politikada başarının simgesi olarak kullanılır. Buna bağlı olarak ortaya çıkan ikinci unsur da, düşük kurdan dolayı ucuz ithalat ve böylece ithal girdiye bağlı düşük enflasyonun ortaya çıkmasıdır. Üçüncüsü, dolar bazında suni gelir artışı düşük kur ile birleşince daha fazla ithalat yapma imkanının doğmasıyla, tüketimde ve dolayısıyla refahta suni ilerlemeler sağlanabilmekte; ithalat artışları ekonomide arz ve talep uyumsuzluklarından doğacak talep enflasyonunu baskılamaya imkan sağlamaktadır. Dolayısıyla siyasal iktidarların özellikle seçimlerden önceki süreçte takip ettikleri yol, düşük kura dayalı bir yapıyı oluşturarak iktidarlarının sürdürülebilirliği açısından hayati önem taşımaktadır. Uygulamada döviz bolluğunun sağlanabilirliği ve dolayısıyla ülkelerin ithal mal cennetine dönüştürülerek suni refah artışının sağlanabilmesi için yüksek faiz uygulamasına gidilmesi de elzem gözükmektedir. Bunu besleyen dünya konjonktürünün varlığı ise görece daha düşük bir faiz maliyetiyle sağlanabilirliği ekonomiyi rahatlatıcı gözükmektedir. Düşük kur ve ucuz ithalatın yansımaları arasında yerli girdi kullanım eğilimini düşürerek, "ithalata dayalı ihracat" eğilimini, yani bir tür re-ekspotçu olmayı kamçılamaktadır. Genelde sorulan soru, "niçin ihracat yapılır, ülkede bulunmayan ya da yeterli olmayanları ithal yapmak içindir" cevabı bu kez tersine dönmekte; ihracat yapabilirlik ithalata dayalı hale gelmektedir. Diğer taraftan ucuz ithal malları tüketim iştahını kabartarak toplumda tasarruf yapma eğilimini zayıflatmakta; düşen tasarruflar, düşen yatırımlar ve buna bağlı düşük büyüme $(\mathrm{g}=\mathrm{s} / \mathrm{k})$ sarmalına düşülmektedir. İlaveten mevcut yatırımlar da üretken alanlardan ziyade spekülatif alanlara kaymaktadır.

Yukarıda belirtilen avantajlarından dolayı düşük kura dayalı bir yapılanmanın popülist eğilimlerin yüksek olduğu ülkelerde yaygın olduğu dikkat çekmektedir. Bu açıdan bakıldığında, kurun reel ekonomik faaliyetlerden koparak daha çok parasal ekonomi orijinli olarak belirlenir olması, uzun vadede reel ekonomik aktörlerle kurun kendi kendini düzeltmesi ise kriz olgusu olarak ortaya çıkmaktadır. Kurda ortaya çıkan düzeltmeler ise dolar bazlı milli gelirde "mehter yürüyüşüne benzer salınımlar"a sebebiyet vermektedir. Türkiye ekonomisinde 24 Ocak Kararları sonrasında kurdaki dalgalanmalara paralel olarak dolar bazlı milli gelir dalgalanmaları kendini göstermiş ve bu çerçevede gelir rakamlarında 1994, 2001 ve 2009 yıllarında ciddi düşüşler gözlenmiştir.

Kura bağlı salınımların belirgin bir şekilde gözlendiği Türkiye ekonomisinin alt-orta gelir gurubunda kalma süresi de uzun sürmüştür. Şöyle ki, Türkiye'nin düşük gelirli ülke sınıflandırmasında alt-orta gelirli ülke kategorisine geçiş yılı 1955 olarak kabul edilmekte ve ortalama fert başına gelir artışında \%2.6'lık bir skor yakalayarak ancak 50 yıl sonra, 2005 yılında üst-orta gelir sınıfına dahil olduğu gözlenmektedir (Felipe v.d., 2012). Atlas Metodu'na göre; 2013 yılı verileriyle kişi başına düşen geliri, 1.045 dolar ve altında olan ülkeler düşük gelirli ülkeler, 1.046 dolar ile 4.125 dolar arasında olan ülkeler alt-orta gelirli ülkeler, 4.126 dolar ile 12.745 dolar arasında olanlar ülkeler üst-orta gelirli ülkeler ve 12.745 dolardan daha yüksek olan ülkeler ise yüksek gelirli ülke grubundadırlar. Şekil 1'de Atlas metodunun 1987'den günümüze kadarki süreçte yapılacak sınıflandırma için kullandığı aralıklar gösterilmiştir. 


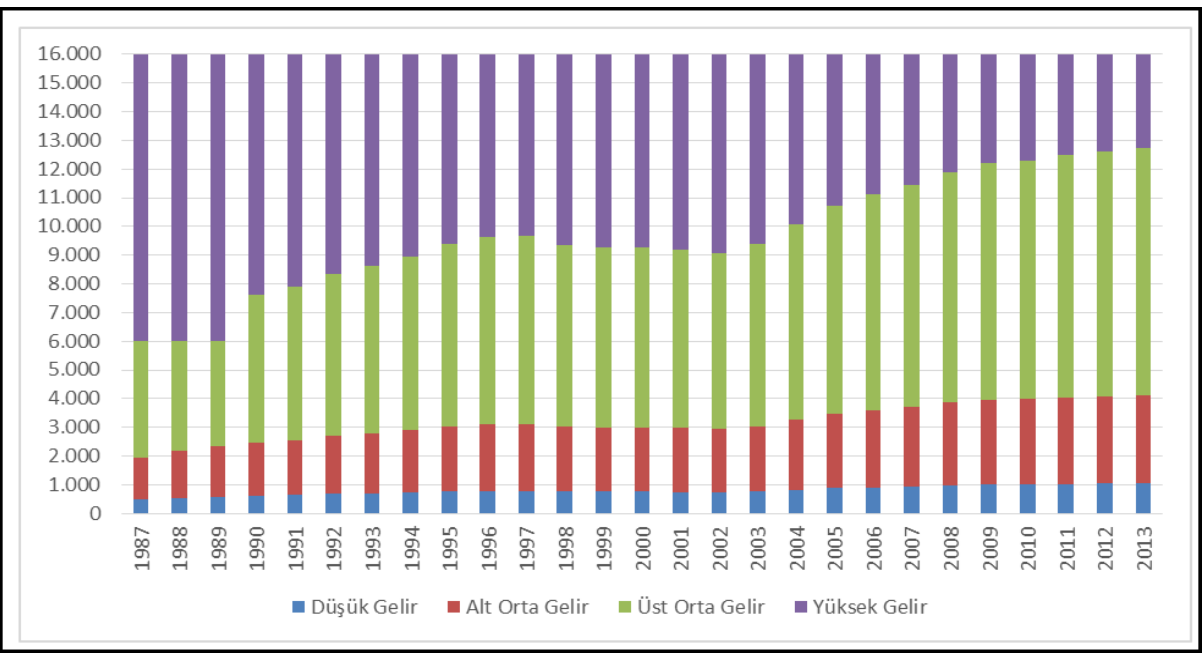

Şekil 1. Atlas Metoduna göre ülke sinıflandırması sinırları 1987-2013 Kaynak: Worldbank Atlas metodu Tarihçesi verileri kullanılarak hazırlanmıştır.

Dünyada finansal akımların yol açtığı kur dengesizlikleri zaman zaman yaşanan döviz krizleri ya da kırılmalarla düzeldiği kriz literatüründen bilinmektedir. Ancak, ülkeye özgü krizler ya da kırılmaların finansal sistemden kaynaklanan genişlemeleri ise ülkelerde döviz krizi şeklinde yansımalarda bulunmamakta; ülke parasının uzun süre değerli veya değersiz olmasına yol açabilmektedir. Değersiz kur da ulusal gelirin suni olarak şişmesine, yani olduğundan fazla gözükmesine yol açmaktadır. Dolayısıyla olması gereken kur tanımında, cari işlemler bilançosu (CIB) açığının ulusal gelire oranının minimal düzeyde kaldığı yıl veya yıllar baz yıl alınarak hesaplanan SGP orijinli döviz kuru daha gerçekçi bir kur olabilmektedir. Daha gerçekçi SGP orijinli kura göre hesaplanacak dolar bazlı ulusal gelirin de yine daha gerçekçi gelir olacağı ileri sürülebilir.

Yukarıdaki ifadelerden hareketle öncelikle Türkiye'de CİB açı̆̆ının GSYİH'ya oranı ile reel efektif kur değişkenini içeren ilişkiler görsel olarak sunulmaya çalışılmıştır (bkz. Şekil 2). Grafikte sol dikey eksen cari işlemler bilançosunun GSYİH içindeki payını ve sağ dikey eksen ise reel efektif kuru göstermektedir. Grafikteki dikkat çekici noktalardan birisi özellikle kriz yıllarında kur ile cari açık arasında ters yönlü ilişkilerin varlığıdır. 2008 küresel krizi hariç, genelde cari işlemler açı̆̆ı fazlaya dönüşürken, 2009'da açık azalmasına rağmen fazlaya dönüşmemiştir. Ancak, kur ve cari açık arasındaki bu ilişkilerin ise özellikle 2001 sonrasında önemli ölçüde koptuğu söylenebilir. Kriz yılları dışında, CİB/GSYİH değerinin iyileşme gösterdiği yıllar ise 1987, 1989, 1995 ve 2003 yılları olarak dikkat çekmekte ve çalışmada da bu yıllar baz yıl olarak seçilmiştir ki, bu yıllardan 1995 ve 2003 yılı aynı zamanda Türkiye Cumhuriyet Merkez Bankası tarafindan da reel kur belirlemede baz yıllar olarak alınmıştır.

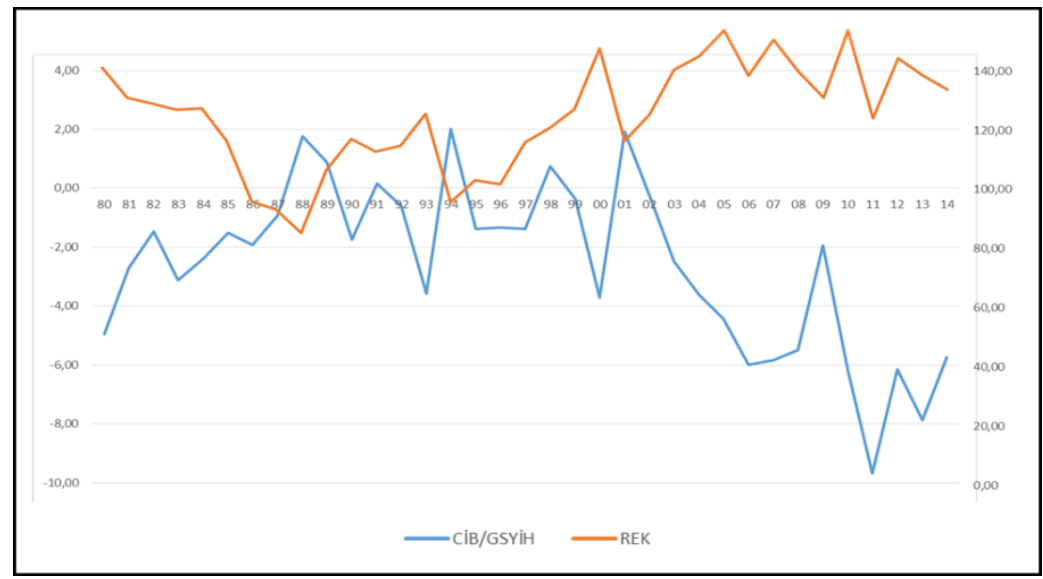

Şekil 2. Cari İşlemler Bilançosu Açı̆̆ının GSYİH İçindeki Payı ile Reel Efektif Kurun Eşanlı Seyri (1980-2014) Kaynak: Worldbank, World Development Indicators ve TCMB EVDS veri tabanı kullanılarak hazırlanmıştır.

Şekil 2 yardımıyla belirlenen yıllar baz yıl olarak alınırken, Türkiye ve ABD GSYİH deflatör verileri yardımıyla SGP'ye göre yeni kur hesaplamaları yapılmıştır. Buradaki temel amaç kurdaki aşırı değerlenme veya aşırı değer kaybının uzun dönemde doğru sonuçlar veren SGP kuru ile ortadan kaldırılarak, Türkiye'de kişi başı gelirin gerçekte literatürde bahsedilen OGT aralığında olup olmadığının tespit edilmesidir. Literatürde 2005 yılı olarak belirtilen reel kur bilgilerinin aksine, DB'nin kullandığı atlas metoduna göre Türkiye 1998'den itibaren üst-orta gelir gurubunda yer almaktadır. Fakat literatürde revizyon öncesi görünüm hakim olduğundan, 
Türkiye'nin sürekli olarak üst-orta gelir gurubuna geçtiği yıl 2004 yılı olarak alınmaktadır. (bkz. Şekil 3). Şekil 3, 4, 5, 6 ve 7'de üst-orta gelirin alt sınırı aynı zamanda alt-orta gelirin de üst sınırıdır (kırmızı eğri). Benzer şekilde üst-ortanın tavanı ise üst-orta gelir gurubundan yüksek gelirli guruba geçişin sınırını (yeşil eğri) göstermektedir.

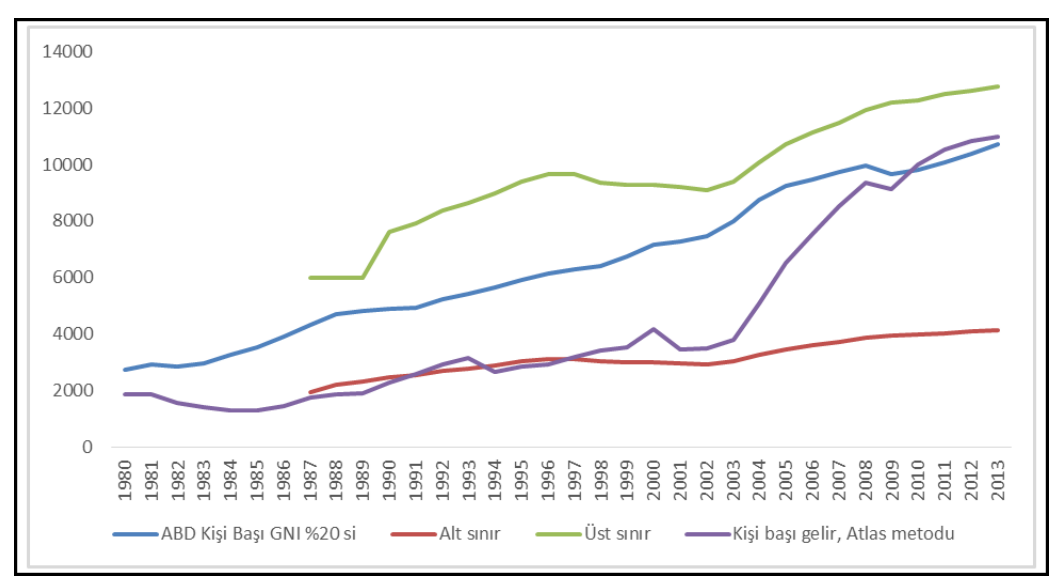

Şekil 3. Dünya Bankası Atlas Metodu Türkiye’de Kişi Başı Gelirin Seyri (1980-2013) Kaynak: Worldbank, World Development Indicators kullanılarak hazırlanmıştır.

Şekil 3'te Türkiye'nin hiçbir hesaplama yapılmadan var olan cari durumu gözlenmektedir. Eichengreen vd. (2013) ile Woo (2012) tarafından yapılan çalışmalar da dikkate alınarak OGT için bir diğer kriter olan ABD kişi başı gayrı safi milli hasıla (GNI)'sinin \%20 sini ifade eden doğru da grafiğe eklenmiştir. Bu bağlamda Türkiye'nin 1997'den beri sürekli bir şekilde üst-ortada yer aldığ görülmektedir. 1997'den bu yana üst gelir gurubuna çık(a)madığı (14 yılı geçmesine rağmen hala aynı gurupta kalması), ABD GNI'sinin \%20'sini 2009'da geçmesi ve kişi başı 10.000 dolar seviyesini aşmış olması da dikkate alındığında, Türkiye'nin OGT'ye düştüğü tartışmalarına dair argümanlara haklılık kazandırmaktadır.

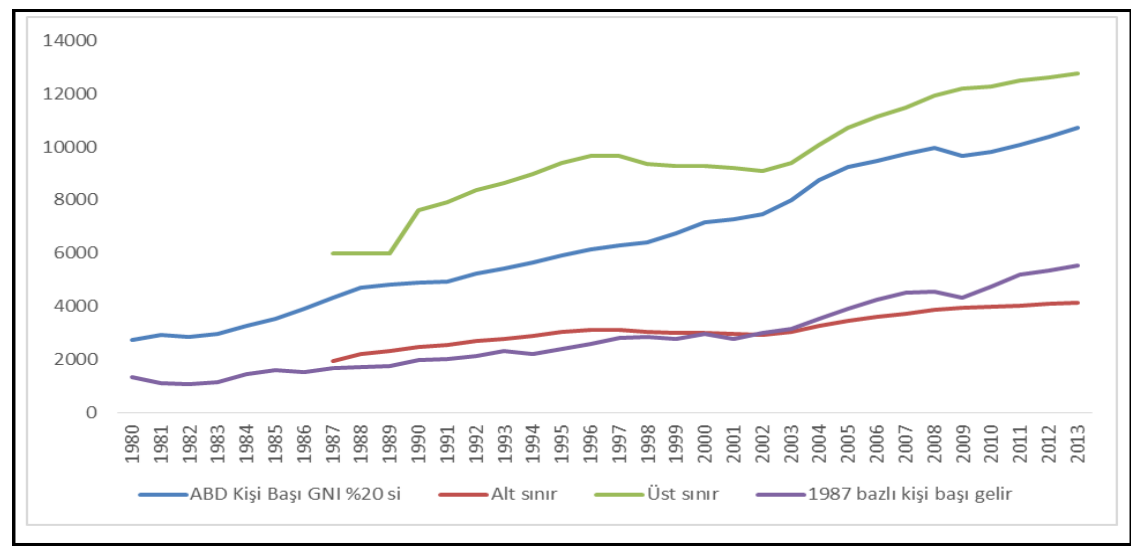

Şekil 4. 1987 Baz Yıl Alınarak Hesaplanan Atlas Metodu Türkiye’de Kişi Başı Gelirin Seyri (1980-2013)

Kaynak: Worldbank, World Development Indicators ve TCMB EVDS veri tabanı kullanılarak hazırlanmıştır.

Şekil 4'te 1987 baz yıl alınarak SGP'ye göre dolar kuru hesaplanmış ve Atlas metodu yerel kişi başı geliri bu kurdan dolara çevrilmiştir. Şekilden görüleceği üzere Türkiye 2004'den itibaren geçtiği üst-ortadan bir üst guruba geçememiş ve 2013 yılı itibariyle kişi başı geliri ancak 5.500 dolar seviyesine çıkabilmiştir. Bu bağlamda Türkiye hem 10.000 dolar seviyesini görememiş, hem ABD kişi başı gelirinin \%20'sine ulaşamamış hem de Felipe v.d., (2012) sınıflandırmasına (7.250 doları geçmelidir) göre üst-orta gelir gurubunun en alt düzeyinde bulunmaktadır. Dolayısıyla 1987 baz yıllı gelir hesaplamalarında Türkiye halen daha alt-orta gelirin hemen üzerinde, sınırda yer almaktadır. 


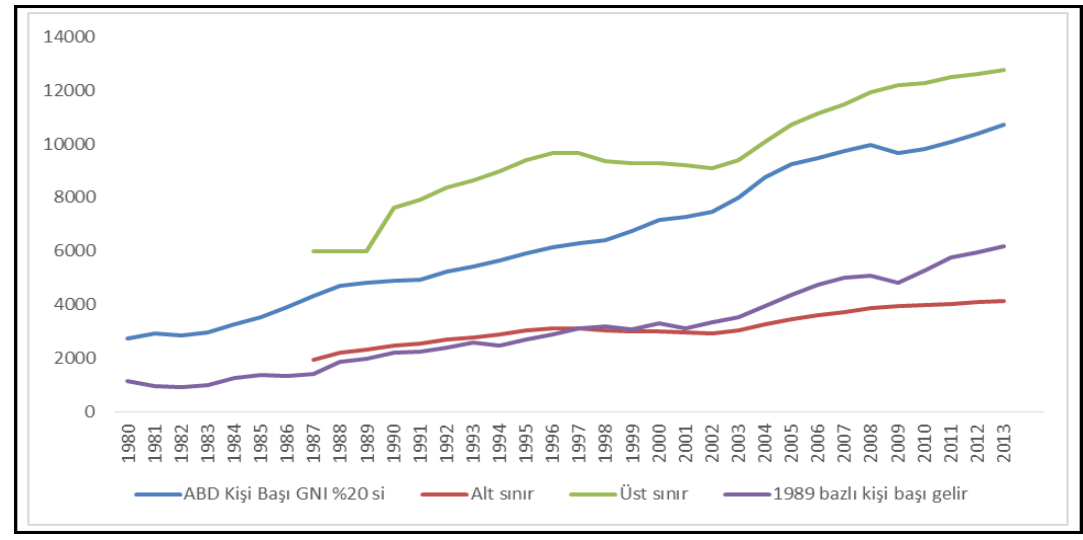

Şekil 5. 1989 Baz Yll Alınarak Hesaplanan Atlas Metodu Türkiye'de Kişi Başı Gelirin Seyri (1980-2013) Kaynak: Worldbank, World Development Indicators ve TCMB EVDS veri tabanı kullanılarak hazırlanmiştır.

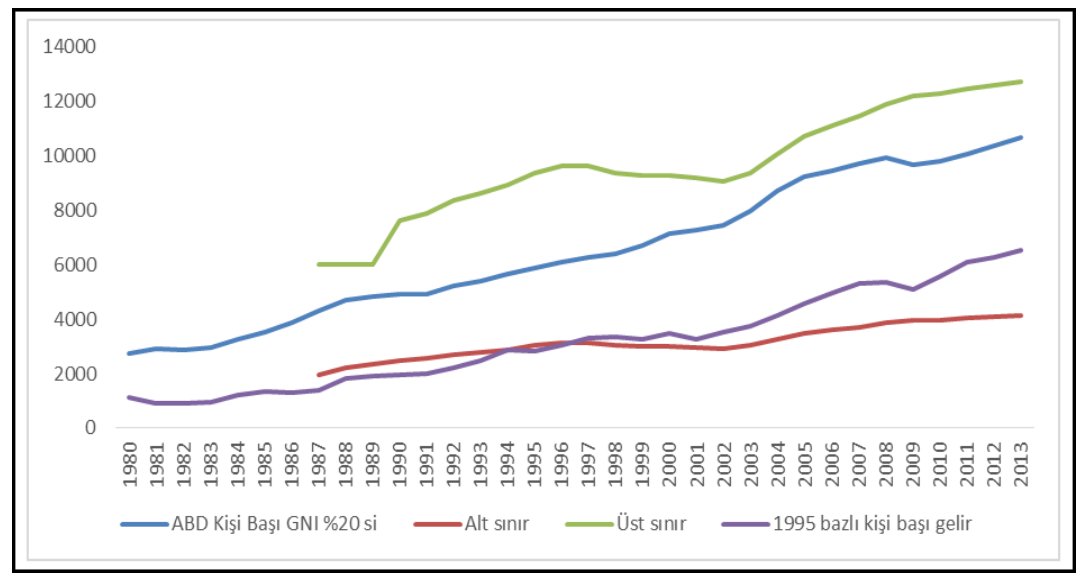

Şekil 6. 1995 Baz Yll Alınarak Hesaplanan Atlas Metodu Türkiye’de Kişi Başı Gelirin Seyri (1980-2013) Kaynak: Worldbank, World Development Indicators ve TCMB EVDS veri tabanı kullanılarak hazırlanmiştır.

Şekil 5 ve Şekil 6 için de Şekil 4’teki tespitlere benzer tespitlerde bulunmak mümkündür. 1989 ve 1995 baz yıl alınarak hesaplanan kişi başı gelirler açısından Türkiye 7 bin dolar seviyesine bile ulaşamadığı görülmektedir. Ancak, 1989 bazına göre 1999'da ve 1995 bazında göre ise 1997'de üst-orta gelir gurubuna geçtiği ve dolayısıyla 1987 baz yıla göre daha erken üst-orta gelir gurubuna geçmiş olduğu söylenebilir. Ancak, üst-orta gelir gurubuna geçilmiş olmasına rağmen, 1989 bazında göre 16 yıldır ve 1995 bazına göre de 18 yıldır üst-orta gelir gurubunda bulunmakta ve bu sınıfın da en alt sınırlarında dolaştığı dikkate alınırsa, OGT'ye düştüğü söylenebilir.

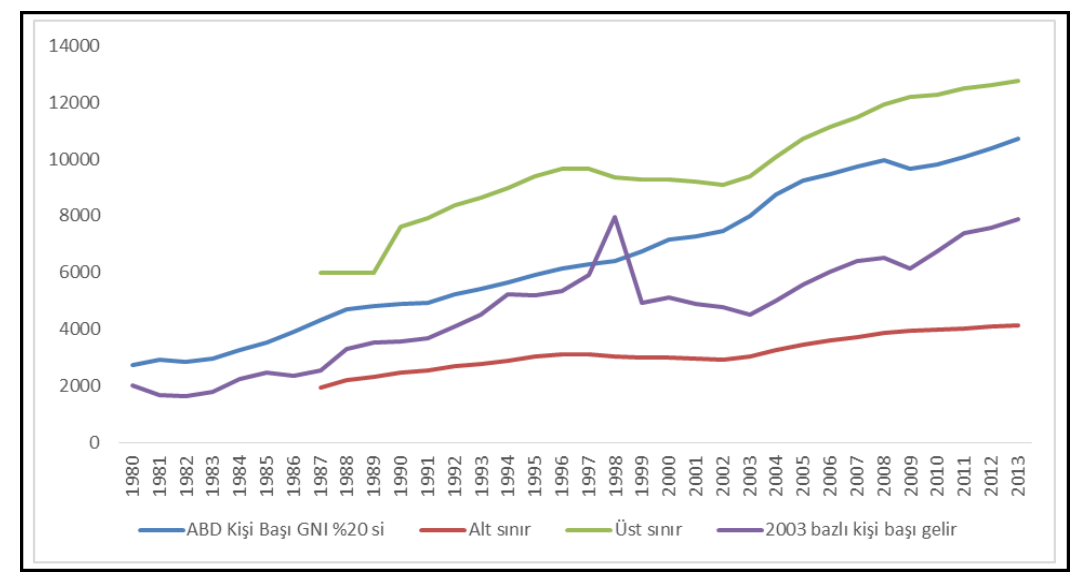

Şekil 7. 2003 Baz Yıl Alınarak Hesaplanan Atlas Metodu Türkiye’de Kişi Başı Gelirin Seyri (1980-2013)

Kaynak: Worldbank, World Development Indicators ve TCMB EVDS veri tabanı kullanılarak hazırlanmıştır.

Diğerlerinden farklı olarak 2003 baz yılı kullanıldığında, Türkiye'nin atlas metoduna göre 1987'den beri üstorta gelir gurubunda yer aldığı ve hatta 1998 yılındaki kurun kriz öncesi baskılanması nedeniyle muhtemelen ABD \%20 sini bir yıllığına geçtiği gözlenmektedir. Ayrıca 2011'den itibaren 7.250 doları da geçtiği fakat 10.000 
dolar eşiğine çıkamadığı görülmektedir. Bu bağlamda OGT’ye düştüğü bazı yazarların sınıflandırmasına göre kabul edilebilir niteliktedir.

\section{Literatürde OGT'ye Karşı Önlemler}

Büyümede sürdürülebilirliğin koşulunun kişi başına gelir ve işçi başına verimliliğin artırılmasıyla tanımlanabileceğini ileri süren Kuznets, bunun da yine sürekli yapısal değişimle mümkün olabileceğini iddia etmiştir (Ofer, 1987). Şöyle ki, büyüme kalıbının en temel belirleyicisinin sürekli devinimi içeren yapısal değişimlerle olacağı savı, ihtilal(ler) ile siyasal, ekonomik ve sosyal yapısı kırılmaz kalıplara büründürülen sistemin, belki ihtilal ile çağı yakalaması ve hatta öne geçmesine karşılık; devam ede gelen süreçte çağın gerisinde kalması en temel sorun olarak ortaya çıkmıştır. Dolayısıyla başlangıçta büyüme ve çağı yakalama adına çağın da ötesine geçen kurumsal yapılar, totaliter yapı gereği, ilerleyen zamanlarda çağın gerisinde kalmıştır. Bunlar sistem gereği birer "dogma" halini alırken; cari nesil için "ileri devrim” niteliği taşıyan yapı, gelecek nesil için "geri paradigma" haline dönüşmüştür. Dolayısıyla Rusya'ya özgü ortaya çıkan bu durumu "bünyesinde köklü çelişkiler barındıran Rusya mı?" (Şafak, 2010) sorusu ile adeta tek bir cümle ile özetlemek mümkün olabilmektedir. Kuznets orijinli bakış açısı dikkate alındığında, Türkiye’de emek verimlilik artış hızlarında gözlenen yavaşlamalar OGT sinyali olarak kabul edilmektedir (Koçak ve Bulut, 2014).

Diğer taraftan OGT boyutu Yeldan (2012)'a göre yapısal dönüşüm şeklinde reformist olamama ya da insanın üretkenliğini artırıcı eğitim ve Ar-Ge harcamalarında rakiplerinin gerisinde kalma şeklinde ifade edilmiştir. Buna ilaveten Yeldan vd. (2012)'ye göre tasarruf düzeylerinde gerilemeler ve kurumsal yönetim yetersizlikleri de OGT'ye yol açan unsurlardandır. Sak (2012) ise imalat sanayinde katma değeri yüksek üretim yapılmaması ve dolayısıyla imalat sanayinin büyümeye katkısının sınırlı kalması OGT'yi doğuran önemli bir öge olarak kabul edilmektedir. Bu açıdan değerlendirildiğinde, Türkiye'nin 2000-2010 arası dönemde imalat sanayinin büyümeye katkıs1 \%6.3 iken, üst-orta gelir gurubundaki ülkelerde bu oran \%18.5 ve tüm orta gelirli ülkelerde \%18 olarak tespit edilmiştir. Eichengreen vd. (2013) çalışmasında OGT'den çıkmanın yollarından biri olarak imalat sanayinin GSYİH'ya katkısının \%23'ü geçmesi gerektiği belirtilmiştir. Türkiye’nin bu konudaki durumu üst-orta gelirli ülke ortalamasından görece iyi olsa da \%23'lük payı geçerek burada sürekliliği yakalamayı henüz başaramadığ 1 ve 1998 'den itibaren ortaya çıkan düşüş trendini yeniden yükselişe çeviremediği dikkat çekmektedir (bkz. Şekil 8).

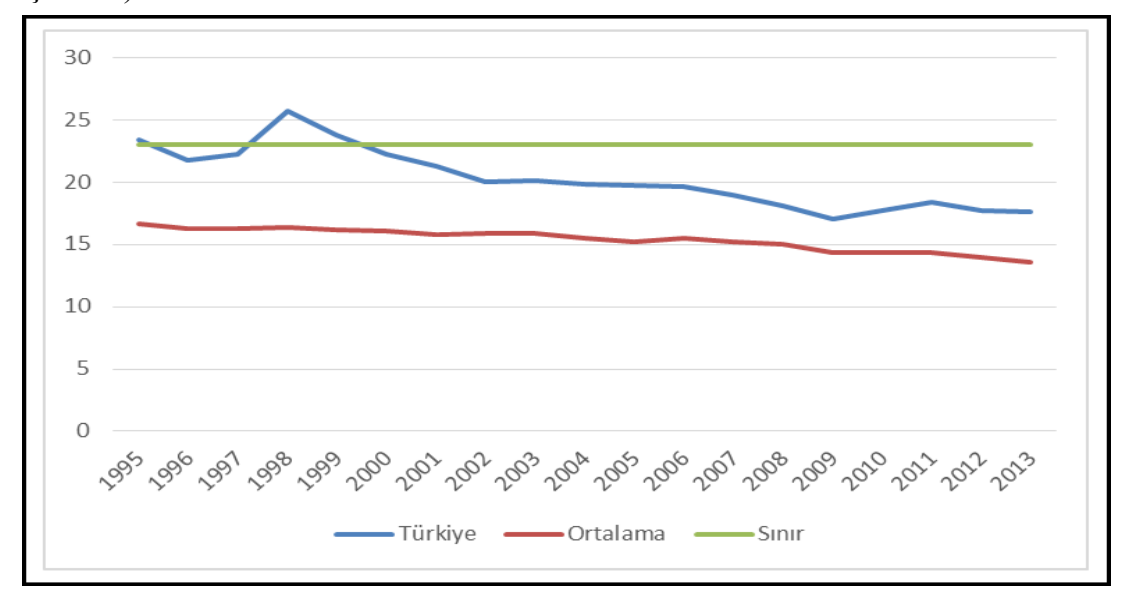

Şekil 8. Üst Orta Gelir Gurubunda Yer Alan 37 Ülke Imalat Sanayi Katma Değeri (GSYİH) Ortalaması ve Türkiye'nin Durumu (1995-2013) Kaynak: Worldbank, World Development Indicators kullanilarak hazırlanmıştır.

Toprak (2012)'da Türkiye'nin OGT’ye düşüşünde mülkiyet hakları endeksinin düşük olması, patent performanslarının yetersizliği, firmaların finansal kaynaklara erişimindeki kısıtlar, nitelikli işgücü yetersizliği ve eğitim kalitesinin düşüklüğünü sıralamıştır. Öz (2012) ise Türkiye'nin OGT'den çıkabilmesinin üretim ve istihdam yapısını çeşitlendirebilmesine, inovasyon faaliyetlerini artırması ve çalışanları yeni teknolojilere adapte edebilmesinin yanı sıra yeni ürün ve süreçler yaratılabilirliğine bağlı olduğuna vurgu yapmıştır (Koçak ve Bulut, 2014). OGT'den kurtuluşta arz boyutunun yanı sıra talep boyutuna değinen çalışmalarda da özellikle yurtiçi hanehalkı talep düzeyinin dinamik ve canlı olmasının yanı sıra özel yatırım harcamalarının yüksekliğine temas edilmiştir (Mert, 2014). Pamuk (2014) tarafından yapılan OGT belirlemesinde ise arz ve talep boyutunun özet bir şekilde sentezlendiği dikkat çeker. Buna göre düşük yatırım oranları, mamul mal üretim hızının düşüklüğü ve yeterince çeşitlendirilmeye gidilmemesi gibi faktörlerin ön planda olduğuna vurgulanmaktadır (Pamuk, 2014).

\section{Sonuç}

Döviz kurunun aşırı değerlenmesi şüphesiz dolar bazında hesaplanan ulusal gelirin de olduğundan daha yüksek çıkmasına yol açmaktadır. Diğer bir ifadeyle kurun değersizleşmesi ile dolar bazlı milli gelir arasında ters 
yönlü bir ilişki olduğu açıktır. Bu noktada kurun olması gereken seviyesinin altında kalmasında özellikle kurların uzun dönemde fiyatlamasını ifade eden SGP'den sapmalar, yani finansal akımlar etkili olmaktadır. SGP'den sapmalar da cari açıkta derinleşmenin sebeplerindendir. Dolayısıyla kurun olması gereken seviyeleri yakaladığı dönemlerde cari açığın minimum düzeylerde olduğu ve hatta cari fazla verildiği dikkate alınırsa, kurun uzun dönemde SGP ölçüsünde dengeyi bulacağına dair teorik kur literatürü önemli bir göstergedir. Bu çalışmada, Türkiye ekonomisinde OGT tartışmaları, cari kurlardan hareketle inceleme konusu yapan çalışmalardan farklı olarak SGP kuru ile ele alınması yoluna gidilmiştir. Cari açığın minimum olduğu yıllar baz alınarak, o yıl (veya yıllar) olması gereken kur değeri olarak tespit edilmiş ve bu yıllar baz alınarak hesaplanan kurlardan hareketle ulusal gelir rakamları teşkil ettirilmiştir.

OGT tartışmalarında cari dolar kurundan Türkiye'nin 1955 yılında alt-orta sınıfa girdiği ve burada 50 yıl kalarak 2005 yılında üst-orta gelir gurubuna geçtiği kabul edilmektedir. Veri bu bilgiye karşılık, kurun olması gereken seviyelerindeki tartışmalar da dikkate alınarak 1980-2013 yılları aralığında Türkiye'de 1987, 1989, 1997 ve 2003 yıllarında cari açığın minimum düzeylerde olduğu ve hatta fazla verdiği yıllar olarak gözlenmiştir. Bu yıllar baz alınarak hesaplanan kişi başı gelir rakamlarında Türkiye ekonomisinin literatürde belirtildiği gibi 2005 yılında üst-ortaya geçmediği; Dünya Bankasının Atlas Metodunda belirttiği gibi 1997 yılından ve hatta daha öncesinde üst-orta guruba girdiği belirlemesi yapılmıştır. Baz alınan yıllara göre Türkiye ekonomisinin üstortaya geçiş yılları ve kaç yıldır bu düzeyde kaldığına ilişkin bilgiler şu şekildedir:

1987 bazında 2004 yilında ve 9 yildır,

1989 bazında 1999 yılında ve 14 yıldır,

1995 bazında 1997 yılında ve 16 yıldır,

2003 bazında 1987 yılında ve 27 yıldır,

Yukarıdaki tespitler dikkate alındığında, baz yıl ne kadar geriye giderse, üst-orta gelir gurubunda bulunma süresi de o kadar şimdiki tarihe yaklaşmaktadır. Özellikle dünya ekonomisinde finansal genişlemenin/para bollaşmasının yaygınlaştığı 2000'li yıllardan itibaren SGP kur bağlantısının kopması ile birlikte yükselen ekonomilerde suni refah edinimleri yaşandığı bilinmektedir ki, baz yılın şimdiki tarihe yaklaşmasına paralel olarak Türkiye'nin üst-orta gelire daha önce geçtiği gibi bir sav ile de bu desteklenmektedir. Dolayısıyla Türkiye ekonomisinde suni olarak değersizleşen kurlardan dolayı orta gelire bile yaklaşamadığına dair uç iddialar bir tarafa, OGT'de ortalama kalma süresinin 14 yıl olduğu dikkate alınırsa, Türkiye'nin OGT'ye düştüğü açıkça gözükmektedir. Bu durum oluşturulan her veri seti için ekonometrik yöntemlerle test edilebilir.

OGT'de bulunan Türkiye'nin bu süreyi kısa tutabilmesi, üst gelire sıçraması ile aş anlamlıdır. Üst gelir gurubuna geçiş için de "sanayileşme eşittir kalkınma" terimini de dikkate alacak ve daha da ötesi yüksek katma değerli ürünler üretebilme yeteneğini geliştirecek uygulamalar içinde olması önem arz etmektedir. Yüksek katma değerin de ekonomik çeşitliliğe dayandırılması gerekliliği ihmal edilmemelidir. Ayrıca katma değerin yüksekliğinin de eğitim, bilgi ve teknolojiye dayalı politikalarla olacağı ve bunların da, "daha demokratözgürlükçü-şeffaf-hesap verebilir" bir yapının varlığıyla, yani rant yaratan ekonomi değil, üreten ekonomiyle mümkün olacağı açıktır.

\section{Kaynakça}

- Acemoğlu, D. ve J. A. Robinson, Ulusların Düşüşü: Güç, Zenginlik ve Yoksulluğun Kökenleri, (Çev. F. R. Velioğlu), Doğan Kitap, İstanbul, 2014.

- Başoğlu, U., N. Ölmezoğulları ve İ. Parasız, Dünya Ekonomisi: Küreselleşme, Finansal Kurumlar ve Küresel Makro Ekonomi, Ezgi Kitabevi, Bursa, 1999.

- Berber, M. İktisadi Büyüme ve Kalkınma: Büyüme Teorileri ve Kalkınma Ekonomisi, Derya Kitabevi, Trabzon, 2011.

- Bozkurt, E., Orta Gelir Tuzağı: Türkiye ve Seçilmiş Gelişmekte Olan Ülkeler Üzerine Bir Araştırma, Atatürk Üniversitesi SBE (Yayınlanmamış Doktora Tezi), Erzurum, 2014.

- Bozkurt, E., S. Bedir, D. Özdemir ve E. Çakmak (2014), “Orta Gelir Tuzağı ve Türkiye Örneği”, Maliye Dergisi, Say1: 167, ss: 22-39.

- Dalgıç, B., P. Varol İyidoğan ve E. Balıkçıoğlu (2014), “Orta Gelir Tuzağından Çıkışta Hangi Faktörler?”, Maliye Dergisi, Say1: 167, ss: 116-125.

- $\quad$ Eichengreen, B., D. Park and K. Shin, "Growth Slowdowns Redux: New Evidence on the Middle Income Trap”, (Working Paper No: 18673), National Bureau of Economic Research (NBER), Cambridge, January 2013, 2.

- $\quad$ Eichengreen, B., D. Park and K. Shin, "When Fast Growing Economies Slow Down: International Evidence and Implications for China", (Working Paper No: 16919), National Bureau of Economic Research (NBER), Cambridge, March 2011, 16. 
- $\quad$ Emsen, Ö. S., Ş. M. Ersungur ve D. Özdemir, Ekonomik Sistemler ve Geçiş Ekonomileri: Orta Asya ve Kafkasya Geçiş Ekonomilerine Bir Bakış, Siyasal Kitabevi, Ankara, 2011.

- Felipe, J., A. Abdon and U. Kumar, “Tracking the Middle-Income Trap: What Is It, Who Is in It, and Why?”, (Working Paper No:715), Levy Economics Institute of Bard College, New York, 2012.

- Gerni, C., Ö. S. Emsen ve M. K. Değer (2008), “İthalata Dayalı İhracat ve Ekonomik Büyüme: 1980-2006 Türkiye Deneyimi”, İzmir İktisat Kongresi Anısina 2. Ulusal İktisat Kongresi, Dokuz Eylül Üniversitesi, İzmir, 20-22 Şubat 2008, ss: 1-21.

- $\quad$ Koçak, E. ve Ü. Bulut (2014), “Orta Gelir Tuzağı: Teorik Çerçeve, Ampirik Yaklaşımlar ve Türkiye Üzerine Ekonometrik Bir Uygulama”, Maliye Dergisi, Sayı: 167, ss: 1-21.

- Kuşkay, S. Y., Sovyet-Tipi Ekonomilerin Merkezi Plandan Serbest Piyasaya Geçiş Deneyimi (19892000): Türkiye ve Diğer Gelişmekte Olan Ülkelere Dersler, Atatürk Üniversitesi SBE (Yayınlanmamış Doktora Tezi), Erzurum, 2001.

- Kutlu, E. ve R. Eşkinat, Dünya Ekonomisi, Anadolu Üniversitesi Eğitim, Sağlık ve Bilimsel Araştırma Çalışmaları Vakfı Yayın No: 150, Eskişehir, 2002.

- Mert, M. (2014), “Türkiye'de ve Dünyada Orta Gelir Tuzağının Talep Yönlü Boyutuna İlişkin Bir Tartışma”, Maliye Dergisi, Sayı: 167, ss: 93-115.

- Ofer, G. (1987), “Soviet Economic Growth: 1928-1985”, Journal of Economic Literature, 25 (4), pp: $1767-$ 1833.

- Pamuk, Ş., Türkiye'nin 200 Yıllık İktisadi Tarihi, Türkiye İş Bankası Kültür Yayınları, 2. Baskı, İstanbul, 2014.

- Robertson, P. E. and L. Ye (2013), “On the Existence of a Middle Income Trap", Available at SSRN: http://ssrn.com/abstract=2227776 or http://dx.doi.org/10.2139/ssrn.2227776.

- Sak, G. (2012), “Çok Alametler Belirdi: Türkiye Sanayisizleşiyor”, TEPAV, 26 Aralık, İstanbul, http://www.tepav.org.tr/upload/files/haber/1357213303-

8.Guven_Sak_Cok_Alametler_Belirdi_Turkiye_Sanayisizlesiyor.pdf (Erişim Tarihi: 26.04.2015)

- Şafak, E., Firarperest, Doğan Kitap, İstanbul, 2010.

- TCMB, 2014, Elektronik Veri Dağıtım Sistemi, http://evds.tcmb.gov.tr/

- Tuncel, C. O. (2014), “Orta Gelir Tuzağı ve İnovasyon Politikaları: Doğu Asya Deneyimi ve Türkiye İçin Dersler”, Maliye Dergisi, Sayı: 167, ss: 40-70.

- Woo, W. T. (2012), "China Meets the Middle-Income Trap: The Large Potholes in the Road to CatchingUp”, Journal of Chinese Economic and Business Studies, 10/4, pp: 313-336.

- Worldbank, 2014, Atlas Method, https://datahelpdesk.worldbank.org/knowledgebase/articles/378834-howdoes-the-world-bank-classify-countries

- Worldbank, 2014, World Development Indicators, http://data.worldbank.org/data-catalog/worlddevelopment-indicators.

- Yaşar, E. ve M. A. Gezer (2014), “Türkiye’nin Orta Gelir Tuzağına Yakalanma Riski ve Bu Riskten Kurtulma Önerileri”, Maliye Dergisi, Sayı: 167, ss: 126-148.

- Yeldan, E. (2012), “Türkiye Orta Gelir Tuzağına Yaklaşırken”, İktisat ve Toplum, Sayı 21-22, s. 26-30.

- Yeldan, E., Taşçı, K., Voyvoda, E. ve Özsan, M.E. (2012), “Orta Gelir Tuzağından Çıkış: Hangi Türkiye?”, Türkonfed Raporu. 


\title{
Türkiye'de Tahıl Üreticilerinin Tarımsal Amaçları ve Üretimlerini Sürdürme Eğilimleri
}

\section{Cereals Producers' Agricultural Aims and Their Tendencies to Sustain Agricultural Production in Turkey}

\author{
Dr. Gonca Gül Yavuz (Agricultural Economics and Policy Development Institute, Turkey) \\ Prof. Dr. Bülent Miran (Ege University, Turkey) \\ Dr. Tijen Özüdoğru (Agricultural Economic and Policy Development Institute, Turkey)
}

\begin{abstract}
The change in income level and urbanization bring a different dimension to the demand to agricultural products from the food habits to supply food, increase the attention to the cereals production and enhance the agricultural effect of cereals which are the main food source of people and are used as feed and in industry. Cereals have the biggest share in agricultural production in terms of both production volume and sowing area in Turkey which produces a lot of agricultural products thanks to the climate and soil characteristics. In this study, in Turkey which is globally an important actor in cereals production and trade, the aims of producers in agricultural production and the factors in the process of making decision toward sustaining production are studied by the best-worst analysis method. Also, the relationship between the sustainability of the agriculture and cereals production, and the individual characteristics and farm structures of producers are examined by bivariate probit analysis method. In this context, study is conducted by 961 producers with face-to-face surveys in 14 provinces. According to the results, while "to increase living standards" is the most important agricultural aim, "good crop price" is the most important factor for sustainability of the agriculture. Moreover, education, agricultural experiences, household size, cereals area and total farm land are determined as the effective factors on sustainability.
\end{abstract}

\section{Giris}

Tarım sektörü, nüfusun gıda maddeleri gereksinimini karşılaması, tarıma dayalı sanayinin hammadde kaynağını oluşturması, istihdam yaratması, dışa bağımlılığın azaltılması gibi nedenlerle ekonomi üzerinde stratejik bir öneme sahiptir. Türkiye 2014 yılı itibariyle gıda güvenliğini sağlamış az sayıda gelişmekte olan ülke arasında olup, kişi başına gelir artışı, gelir dağılımındaki dengesizliğin azalması, nüfus artışı, kentleşme, nüfusun yaş piramidindeki değişimi ve turist sayısındaki artış gibi faktörler gıda ürünlerine olan talebin büyümesini hızlandırmışıır. Bu durum, arz açığının önüne geçilebilmesi ve kendine yeterliliğin sağlanabilmesi açısından öncelikle tarımsal sürdürülebilirliği gerekli kılmaktadır.

Tahıllar tüm dünyada insan beslenmesinin en önemli kaynağı olmakla birlikte yemlik ve endüstriyel amaçlı geniş bir kullanım alanına sahiptir. Türkiye'de 3,5 milyon tarım işletmesinin hemen hemen tamamı bir ya da iki çeşit tahıl üretmekte olup toplam bitkisel üretimin yaklaşık \%55'ini tahıllar oluşturmaktadır.

2014 yılı verilerine göre Türkiye'de 11.7 milyon ha alanda tahıl ekimi yapılmış olup 32.7 milyon ton üretim gerçekleştirilmiştir. Buğday üretimi 19 milyon ton ile toplam tahıl üretiminden \%58 pay almakta olup bu oran ile buğdayın Türkiye'de gıda güvencesi açısından stratejik önemi de açık bir şekilde görülmektedir. Tahıllar arasında üretimden aldığı $\% 19$ pay ile arpa ikinci sırada yer alırken \%18 ile mısır üçüncü sırada yer almaktadır. Çeltik tahıl üretiminin \%3'ünü karşılamakta olup çavdar, yulaf, triticale, sorgum ve kuş yemi üretilen diğer tahıllardır (TÜIK, 2015). Yapılan araştırmada tahıllar kapsamında dünya tarım ürünleri piyasalarında hem üretim hem de ticareti ile oldukça önemli yere sahip olan buğday, mısır ve çeltik ele alınmıştır.

\section{Materyal ve Yöntem}

Araştırmanın ana materyalini, ele alınan buğday, mısır ve çeltiğin yoğun olarak yetiştirildiği illerdeki üreticilere uygulanan anketler oluşturmuş olup ulusal ve uluslararası yayınlar, araştırmalar, istatistikler ve raporlar gibi ikincil kaynaklardan da yararlanılmıştır. Örnek ana kitlesinin belirlenmesinde Türkiye'de en fazla buğday, mısır ve çeltik üretilen illerdeki üretici sayısı örnek popülasyonuna dahil edilmiştir. Bu kapsamda buğday için Ankara, Diyarbakır, Konya, Şanlıurfa ve Yozgat, mısır için Adana, Şanlıurfa, Osmaniye, Sakarya, Mardin, çeltik için ise Edirne, Samsun, Balıkesir, Çanakkale ve Çorum illeri olmak üzere toplam 14 il popülasyonunu oluşturmaktadır. Örnek hacmi ise ÇKS kayıtları dikkate alınarak her bir ürünün ekim alanına göre belirlenmiştir. Örnek hacminin belirlenmesinde tabakalı tesadüfî örnekleme yöntemi kullanılmıştır.

Tabakalı Tesadüfî Örnekleme Formülü (Miran, 2002):

$$
n=\frac{N z^{2} \sigma^{2}}{d^{2}(N-1)+z^{2} \sigma^{2}}
$$


$\mathrm{N}=$ Ana kitle büyüklüğünü, $\sigma^{2}=$ Anakitle varyansını, $d=$ Hata değerini, $\mathrm{z}=$ Seçilen olasıllk düzeyi için normal dağılış tablo değerini göstermektedir.

Hesaplamalarda güven aralığı \%95, hata payı ise \%10 olarak alınmıştır. Bu hesaplamalar sonucunda ürünlere göre örnek hacmi, buğday için 359, mısır için 349, çeltikte için ise 253 olarak hesaplanmış olup toplam örnek hacmi 961 'dir.

\begin{tabular}{|l|c|c|c|c|c|}
\hline \multirow{2}{*}{ Ürünler } & \multicolumn{4}{|l|}{ Tabakalara Düşen Örnek Sayıs } & \multirow{2}{*}{$\begin{array}{c}\text { Toplam } \\
\text { Örnek Saylsı }\end{array}$} \\
\cline { 2 - 5 } & $n<5$ & $5=n<30$ & $30=n<100$ & $n \geq 100$ & 359 \\
\hline Buğday & 101 & 61 & 46 & 151 & 349 \\
\hline Misır & 81 & 76 & 47 & 145 & 253 \\
\hline Çeltik & 29 & 33 & 23 & 168 & 961 \\
\hline Toplam & 211 & 170 & 116 & 464 & \\
\hline
\end{tabular}

Tablo 1. Tabakalara Göre Örnek Hacmi

Yapılan araştırmada üreticilerin tarımsal üretim yapma amaçları ve üretimlerini sürdürme eğilimleri BestWorst yöntemi ile incelenmiştir. Best Worst yöntemi ilk defa 1980'li yıllarda, Jordan Louviere tarafindan geliştirilen bir ayrık seçim modelidir. İlk makale ve yayınlar 1990'ların başlarında ortaya çıkmıştır. Bu yöntemde katılımcılara, bir dizi objeler (öğeler) gösterilir ve onlardan en önemli ve en önemsiz (en iyi/en kötü, en çok/en az vb.) olanlarını göstermeleri istenmektedir. Best Worst yöntemine yönelik anket soruları katılımcıların çoğu için anlaşılması oldukça kolay sorulardır. Ayrıca, bu yöntem ile insanların uçlardaki (extrem) objeler arasındaki farkları orta halli olanlardan daha iyi ayırması nedeniyle önyargılar için firsat yaratılmamış olmaktadır.

Araştırmada ayrıca üreticilerin tarımsal ve tahıl üretimlerinin sürdürülebilirliğini analiz etmek için "Bivariate Probit Model" kullanılmıştır. Bivariate probit model, bir değişkenden daha fazla değişkenin olduğu çok değişkenli probit modelin özel bir hali olup ayrı ayrı tahmin edilebilen bağımsız probit denklemlerinden oluşmaktadır. Bu modelde iki değerli kararları ifade etmek üzere bir sistem düzenlenmektedir. Böylece iki değerli iki bağımlı değişkenin eşanlı belirleyicileri ve aralarındaki nedensel ilişsi ortaya konulabilmektedir. Bivariate probit model, $\mathrm{P}_{11 \mathrm{i}}, \mathrm{P}_{10 \mathrm{i}}, \mathrm{P}_{01 \mathrm{i}}, \mathrm{P}_{00 \mathrm{i}}$ olasılıkları ile dört değer alan tek bir kesikli bağımlı değişken için multinominal modele eşdeğerdir. $\mathrm{Bu}$ modelde, $\mathrm{P}_{11 \mathrm{i}}, \mathrm{P}_{10 \mathrm{i}}$ ve $\mathrm{P}_{01 \mathrm{i}}$ bağımsız değişkenler ve bilinmeyen parametrelerin fonksiyonları olup $\mathrm{P}_{00 \mathrm{i}}$, bir eksi diğer üç olasılığın toplamı olarak belirlenmektedir (Greene, 2000; Sanzidur, 2001; Akın, 2002; Pazarlığlu, 2007; Thapa, 2008).

Araştırmada, "tarımsal sürdürülebilirlik" ve "tahıl üretiminin sürdürülebilirliği” bivariate probit modelin iki kukla değişkeni olarak alınmıştır. Üreticilerin yaşı, eğitimi, tarımsal deneyimi, hanehalkı büyüklüğü, tahıl arazisi ve toplam işletme arazisi ise modelde ele alınan bağımsız değişkenlerdir.

\section{Bulgular}

\section{1 Üretici ve İşletme Özellikleri}

İşletme yöneticilerinin bireysel özelliklerinin yanı sıra ekonomik ve sosyal şartları işletmelerin yönetim biçimi, organizasyonu, teknolojik yeniliklerin benimsenmesi ve uygulanması gibi bütün işletme faktörleri üzerinde etkilidir. Bu nedenle araştırmanın bu bölümünde üreticilerin yaşı, eğitim durumu, kendi adına tarımla uğraştığı süre, hanelerindeki kişi sayısı ve hanelerinde tarımda çalışan kişi sayısının yer aldığı genel bilgiler incelenmiştir.

Tarımsal faaliyette bulunan üreticilerin yaş durumu üretim sonuçlarını çeşitli şekillerde etkilemektedir. Buna bağlı olarak öncelikle üreticilerin yaşları dikkate alınmış olup, elde edilen veriler incelendiğinde; işletmelerde en genç üreticinin 18, en yaşlı üreticinin 97 yaşında olduğu belirlenmiştir. Üreticilerin ortalama yaşları ise 48.67 'dir.

Üreticilerin eğitim durumları incelendiğinde; okuma yazması olmayan üreticilerin yanı sıra üniversite mezunu üreticilerin de olduğu belirlenmiştir. Bununla birlikte tahıl üreticilerinin ortalama eğitim süresi 7.64 olarak hesaplanmıştır.

Üreticilerin tarımsal deneyimleri (yıl) ele alındığında dağılımın 2 ile 80 yıl arasında olduğu belirlenmiş olup, ortalama sürenin 24.44 yıl olduğu görülmektedir.

Tarımsal işletmelerde bulunan nüfus, işletmelerin idaresinden işgücü kaynağına kadar birçok görevi üstlenmektedir (Özüdoğru, 2010). Bu nedenle araştırmada üreticilerinin hanelerindeki kişi sayısı ile birlikte hanelerinde tarımda çalışan kişi sayısı da incelenmiştir. Buna göre; hane halkı büyüklügünün 5.67 kişi, hanede tarımda çalışan kişi sayısının ise 2.50 olduğu belirlenmiştir. Genel olarak değerlendirildiğinde ise buğday, mısır veya çeltik üreticilerinin genel bilgileri arasında farklılık görülmemiştir (Tablo 2). 


\begin{tabular}{|l|c|c|c|c|c|}
\hline Ürünler & Yaş & $\begin{array}{l}\text { Ĕ̈itim } \\
\text { Durumu (yıl) }\end{array}$ & $\begin{array}{l}\text { Tarımsal } \\
\text { Deneyim (yıl) }\end{array}$ & $\begin{array}{l}\text { Hanehalkı } \\
\text { Büyüklüğ̈̈ (kişi) }\end{array}$ & $\begin{array}{l}\text { Hanede Tarımda } \\
\text { Çalışan Kişi Sayısı }\end{array}$ \\
\hline Buğday & 49.01 & 6.94 & 24.44 & 5.69 & 2.51 \\
\hline Çeltik & 48.11 & 7.61 & 27.26 & 4.66 & 2.37 \\
\hline Misır & 48.84 & 7.68 & 27.07 & 6.14 & 2.63 \\
\hline Genel & 48.67 & 7.64 & 26.21 & 5.67 & 2.50 \\
\hline
\end{tabular}

Tablo 2. Tahıl Üreticilerine Ait Genel Bilgiler

Arazi, tarımsal faaliyette üretim araçları içerisinde en önemlisi ve vazgeçilmez olanıdır. İşletme arazisi, mülkiyet ilişkisi, arazinin nevi ve faydalanma şekilleri dikkate alınmaksızın çiftçi ailesinin işlettiği toplam alandır (Tatlıdil, 1992). Bununla birlikte yapılan birçok araştırmada işletme büyüklügünün üretici kararları üzerinde etkili bir faktör olduğu da belirtilmektedir (Rogers, 1983; Konyar and Osborn 1990; Boz, 1993; Thungwa, 2000; Yavuz, 2010). İncelenen işletmelerde işletme arazisi, üretim döneminde üretici tarafindan işletilen arazilerin tamamından oluşmaktadır. Buna göre işletme arazisi üreticilerin sahip olduğu mülk arazilerin yanı sıra kiraladığı veya ortakçılıkla işlediği arazileri de kapsamaktadır. Bununla birlikte üretici kararlarında toplam işletme arazisinin yanı sıra mülk arazi genişliğinin de etkili olabileceği varsayılarak üreticilerin sahip olduğu mülk arazi genişliği de incelenmiştir.

Elde edilen bulgulara göre ortalama işletme arazisi 243.29 da olarak hesaplanmış olup işletme arazisinin buğday üreten işletmelerde daha büyük (303.12 da) mısır üreten işletmelerde ise daha küçük (181.29 da) olduğu belirlenmiştir. Ortalama mülk arazi genişliği ise 150.72 da ile toplam işletme arazisinin \%62'sini oluşturmaktadır. Mülk arazi genişliği en fazla buğday üreten işletmelerde yer alırken, mülk arazinin toplam işletme arazisine oranın da en büyük pay \%72.6 ile mısır üreten işletmelere aittir.

İşletmelerin parsel sayısı kaynakların etkin kullanımı açısından tarımsal üretimde oldukça önemli bir konudur. $\mathrm{Bu}$ nedenle araştırmada işletmelerin parsel sayısı da dikkate alınmış ve ortalama parsel sayısının 13.2 olduğu belirlenmiştir. Ortalama parsel sayısının en düşük olduğu işletmeler 7.38 ile mısır, en yüksek olduğu işletmeler ise 19.16 ile çeltik üreten işletmelerdir.

İşletmelerde ortalama 150.73 da alanda tahıl üretimi yapılmakta olup tahıl üretim alanı toplam işletme genişliğinin \%62'sini oluşturmaktadır. Tahıl ekim alanlarının buğday ve çeltik üreten işletmelerde mülk arazi genişliğinden fazla olması, bu işletmelerin kira veya ortakçılık yoluyla da tahıl üretimi yaptıklarını göstermektedir (Tablo 3).

\begin{tabular}{|l|c|c|c|c|c|c|}
\hline \multirow{2}{*}{ Ürünler } & Toplam Işletme & \multicolumn{2}{l|}{ Toplam Mülk Arazi } & \multicolumn{2}{l|}{ Tahıl Ekim Alanı } & \multirow{2}{*}{ Parsel Sayısı } \\
\cline { 3 - 6 } & Arazisi (da) & $(d a)$ & $\%$ & $(d a)$ & $\%$ & \\
\hline Buğday & 303.12 & 156.44 & 51.6 & 174.11 & 57.4 & 13.36 \\
\hline Çeltik & 255.35 & 132.68 & 52.0 & 173.05 & 67.8 & 19.16 \\
\hline Mısır & 181.29 & 131.66 & 72.6 & 114.02 & 62.9 & 7.38 \\
\hline Genel & 243.29 & 150.72 & 62.0 & 150.73 & 62.0 & 13.20 \\
\hline
\end{tabular}

Tablo 3. Tahil Işletmelerine Ait Genel Bilgiler

\section{2 Üreticilerin Tarımsal Üretim Amaçları ve Üretimi Sürdürme Eğilimleri}

Araştırmanın bu bölümünde ilk olarak üreticilerin tarımsal üretim yapma amaçları ve üretimlerini sürdürme eğilimleri Best-Worst (B-W) yöntemi kullanılarak değerlendirilmiştir. Daha sonra ise üreticilerin tarımsal ve tahıl üretimlerinin sürdürülebilirliği Bivariate Probit model kullanılarak analiz edilmiştir.

Best-Worst yöntemi kullanılarak oluşturulan tablolarda (B) ilgili değişkeni en önemli bulan üretici sayısını gösterirken, (W) ilgili değişkeni en önemsiz bulan üretici sayısını göstermektedir. Değerlendirmeler ise Ortalama B-W (Ort) değeri üzerinden yapılmıştır. Buna göre; en büyük pozitif değere sahip değişken en önemli, en küçük negatif değere sahip değişken ise en önemsiz olarak yorumlanmaktadır. Ortalama B-W değeri sıfır ise, orta derecede önemli bir değişkenden bahsedilmektedir.

Tablo 4'de üreticilerin tarımsal üretim yapma amaçlarına ait önem dereceleri yer almaktadır. Buna göre, üreticilerin tarımsal üretim yapma amaçlarından en önemlisi "Hayat standardını yükseltmek" tir. Bu durum buğday, mısır ve çeltik üreticileri için ayrı ayrı geçerli olmakla birlikte, çeltik üreticilerinde önem derecesi 0.12 ile daha yüksektir. Önem derecesine göre ikinci sırada "mevcut araziye iyi bakmak" gelmektedir. Bununla birlikte genel değerlendirmede "Tarımı meslek olarak icra etmek" -0.04 önem derecesi ile buğday ve çeltik üreticileri için tarımsal üretim yapma amaçları arasında en önemsiz olanıdır. Mısır üreticileri için ise bu değerin 0.01 olduğu belirlenmiştir. Ayrıca mısır üreticilerinin çevre kirliliği (-0.02) ve tüketicileri korumak amacıyla sağlıklı ürünler üretmek (-0.02) konularına daha az önem verdiği görülmektedir. 


\begin{tabular}{|c|c|c|c|c|c|c|c|c|c|}
\hline \multicolumn{2}{|c|}{$\frac{\pi}{\mathbb{J}}$} & 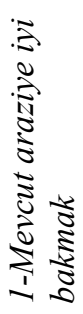 & 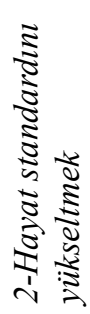 & 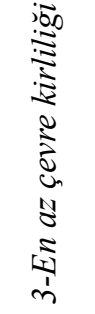 & 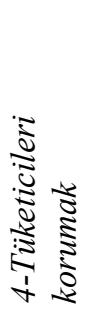 & 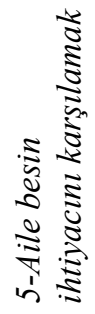 & 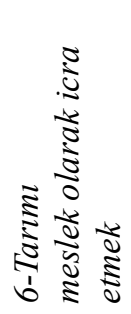 & 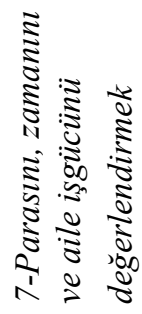 & 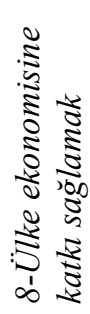 \\
\hline \multirow{3}{*}{$\begin{array}{l}\stackrel{\vec{J}}{D} \\
\vec{D} \\
\vec{D}\end{array}$} & $\mathrm{~B}$ & 53 & 144 & 22 & 4 & 48 & 19 & 15 & 11 \\
\hline & $\mathrm{W}$ & 19 & 8 & 43 & 40 & 41 & 99 & 25 & 41 \\
\hline & Ort & 0.02 & 0.07 & -0.01 & -0.02 & 0.00 & -0.04 & 0.00 & -0.01 \\
\hline \multirow{3}{*}{$\stackrel{\vec{\oplus}}{\sum}$} & B & 35 & 167 & 4 & 1 & 21 & 21 & 13 & 11 \\
\hline & $\mathrm{W}$ & 19 & 5 & 36 & 42 & 47 & 49 & 43 & 32 \\
\hline & Ort & 0.01 & 0.08 & -0.02 & -0.02 & -0.01 & -0.01 & -0.01 & -0.01 \\
\hline \multirow{3}{*}{$\frac{\underline{\Xi}}{0}$} & B & 48 & 242 & 2 & 2 & 12 & 24 & 34 & 21 \\
\hline & $\mathrm{W}$ & 29 & 4 & 57 & 57 & 71 & 106 & 23 & 38 \\
\hline & Ort & 0.01 & 0.12 & -0.03 & -0.03 & -0.03 & -0.04 & 0.01 & -0.01 \\
\hline
\end{tabular}

Tablo 4. Üreticilerin Tarımsal Üretim Yapma Amaçları

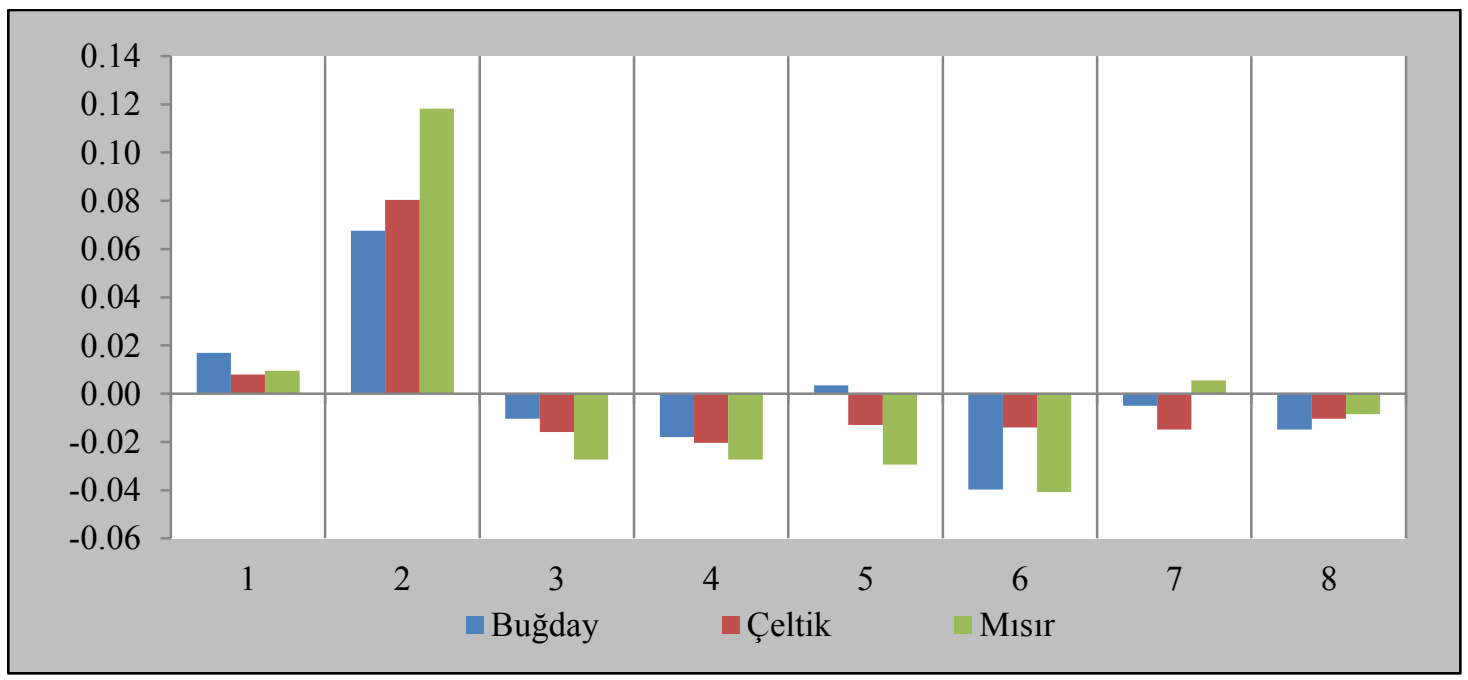

Şekil 1. Üreticilerin Tarımsal Üretim Yapma Amaçları

Araştırmada üreticilerin tarımsal üretimlerini sürdürebilmek için gerekli gördükleri koşullar belirlenmiştir. Elde edilen veriler üreticilerin tarımsal üretimlerini sürdürmek için en önemli koşulun "İyi fiyat" olduğunu göstermektedir. Hatta bu koşulun çeltik üreticileri için daha da önemli olduğu (0.16) belirlenmiştir. Burada iyi fiyat ile ürünün satış fiyatının üretim maliyetinin üzerinde ve üreticinin emeğinin karşılığını alabileceği/kar elde edebileceği bir fiyat kastedilmektedir. Bununla birlikte genel olarak değerlendirildiğinde fark ödemesi desteği adı altında üreticilere ödenen prim miktarı ve üretim girdilerinin (gübre-ilaç-tohum) istenen zamanda ve uygun fiyattan temin edilebilmesi 0.00 önem derecesi ile üreticiler için orta düzeyde öneme sahip koşullardır. "İstenen zamanda işçi temini" ve "Kolay kredi bulma" ise üreticiler için sürdürülebilirlik açısından en önemsiz koşullar olarak belirlenmiştir. 


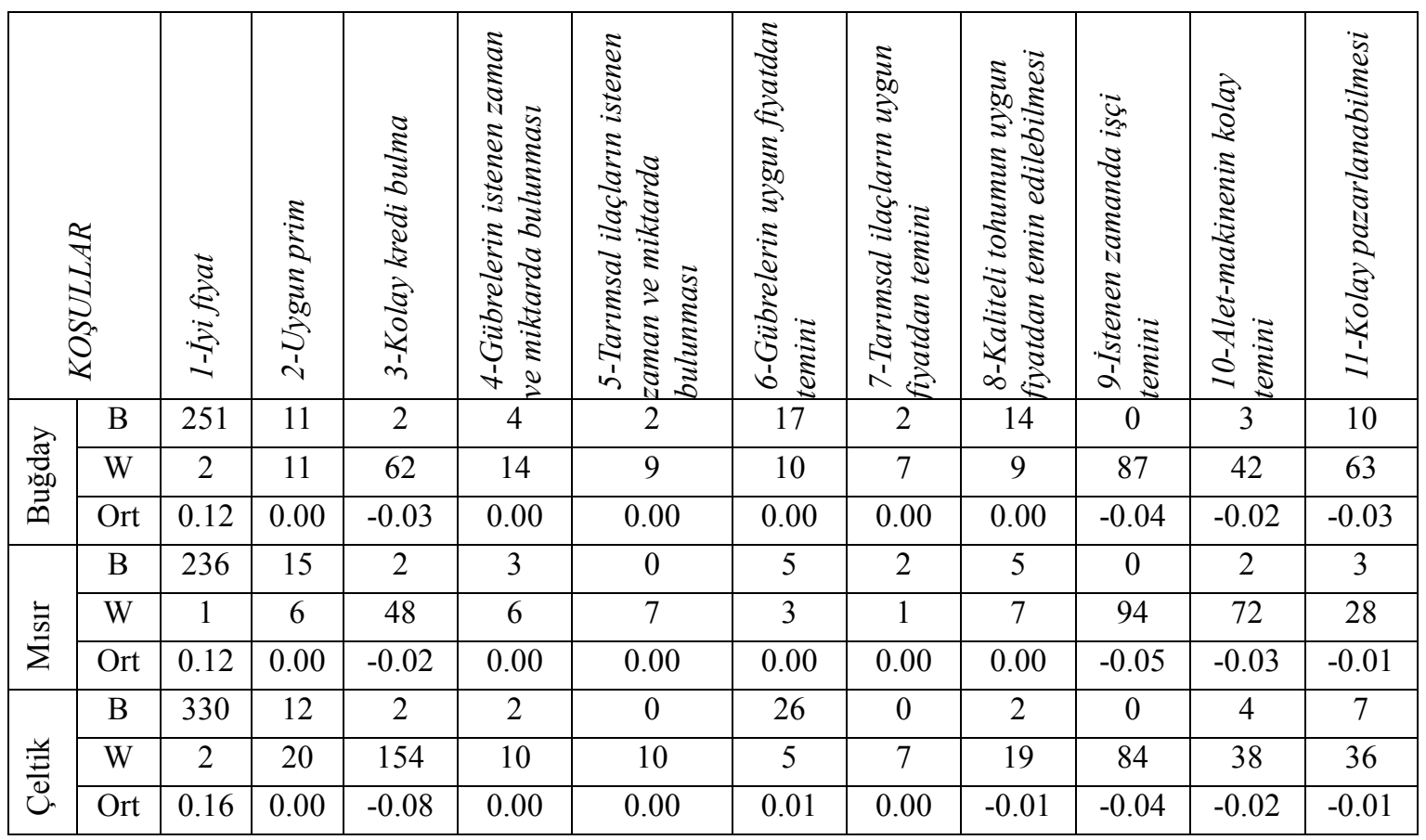

Tablo 5. Üreticilerin Tarımsal Üretimlerini Sürdürebilmek İ̧̧in Gerekli Gördükleri Koşullar

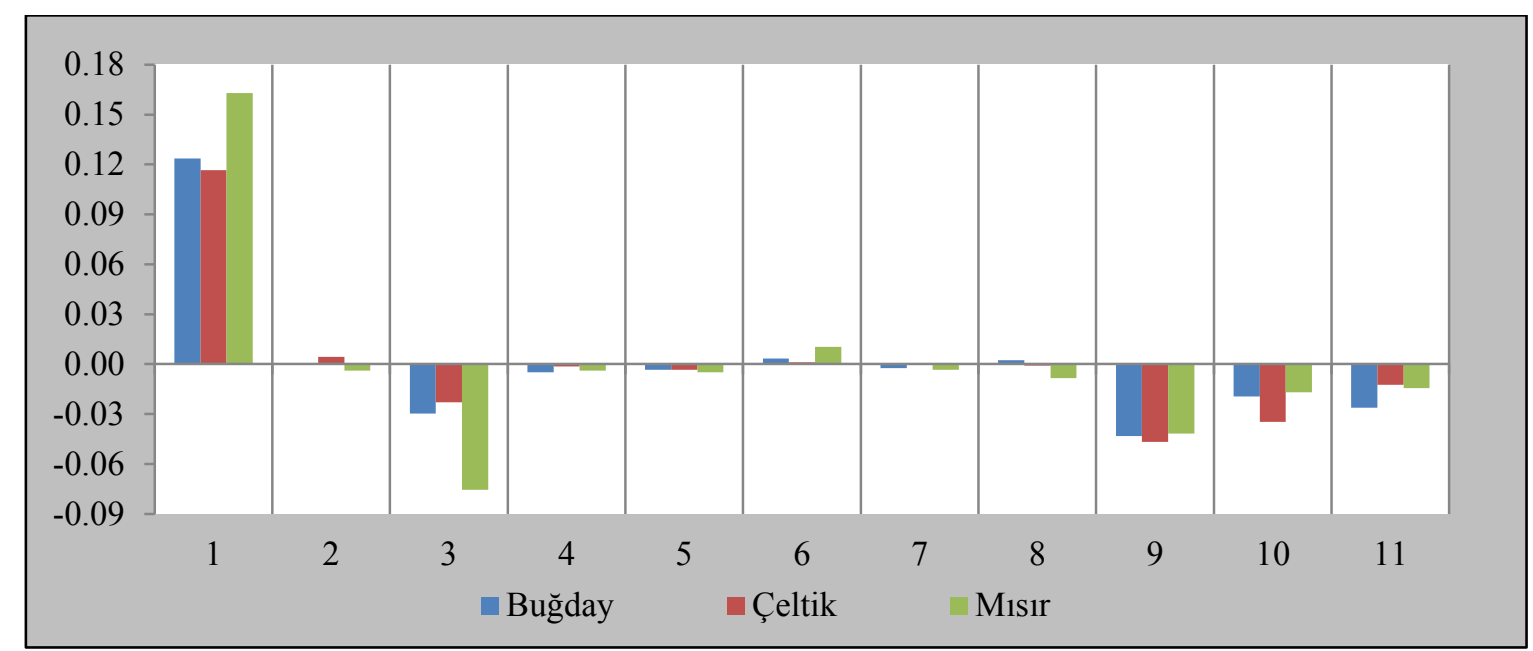

Şekil 2. Üreticilerin Tarımsal Üretimlerini Sürdürebilmek İ̧̧in Gerekli Gördükleri Koşullar

Araştırmada ayrıca üreticilerin tarımsal ve tahıl üretimlerinin sürdürülebilirliğini analiz etmek için Bivariate Probit model kullanılmıştır. Bu modelde, tarımsal sürdürülebilirlik ve tahıl üretiminin sürdürülebilirliği, bivariate probit modelin iki kukla değişkeni olarak alınmıştır. Bu iki kukla değişkenin birbirine bağımlı olarak gerçekleştiği hipotezini, tahmin edilen bivariate model doğrulamıştır. Yapılan bağımsızlık (independence) testi, üreticilerin bu iki kararı verirken birbirinden etkilendiğini göstermiştir (Tablo 6).

Elde edilen Bivariate probit tahmin sonuçları değerlendirildiğinde; toplam işletme arazisinin, tahıl arazisinin toplam işletme arazisi içerisindeki payının ve üreticilerin tarımsal deneyimlerinin tarımsal sürdürülebilirlik açısından etkili faktörler olduğu belirlenmiştir. Buna göre;

- Toplam işletme arazisi daha büyük olan üreticilerin tarımda kalma eğilimi daha fazladır. Küçük arazilerde faaliyet gösteren üreticilerin tarımı terketme isteği ise daha fazladır.

- Tahıl arazisinin toplam işletme arazisi içindeki payı (\%) arttıkça üreticilerin tarımda kalma eğilimi artmaktadır.

- Tarımsal deneyim arttıkça tarımda kalma eğilimi artmaktadır. Daha erken deneyim düzeyindeki üreticilerin tarımda kalma eğilimi daha azdır. 
Tahıl üretiminin sürdürülebilirliğinde ise tahıl arazisinin toplam işletme arazisi içerisindeki payı yine önemli bir faktör olarak belirlenmiştir. Ayrıca üreticilerin eğitim düzeyi ve hanehalkı büyüklüğü de tahıl üretiminin sürdürülebilirliğinde etkili olan diğer faktörlerdir. Buna göre;

- Tahıl arazisinin toplam arazi içindeki payı arttıkça, tahıl üretme eğilimi artmaktadır.

- Üreticilerin eğitim düzeyi arttıkça tahıl üretme eğilimi azalmaktadır.

- Üretici ailesindeki birey sayısı ne kadar fazla ise, tahıl üretme eğilimi daha azdır.

\begin{tabular}{|c|c|c|c|c|}
\hline & Katsayl & Standart Hata & $z$ & $p$ \\
\hline \multicolumn{5}{|l|}{ Tarımsal Sürdürülebilirlik } \\
\hline Sabit & -0.192267 & 0.29296 & -0.6563 & 0.5116 \\
\hline Yaş & 0.00439791 & 0.00563538 & 0.7804 & 0.4351 \\
\hline Eğitim & 0.00172106 & 0.0146114 & 0.1178 & 0.9062 \\
\hline Tarımsal deneyim & 0.00957966 & 0.00494669 & 1.9366 & $0.0528^{*}$ \\
\hline Hane halkı büyüklüğü & -0.0141859 & 0.0137701 & -1.0302 & 0.3029 \\
\hline Tahıl arazisi (\%) & 0.00419917 & 0.00130171 & 3.2259 & $0.0013^{* *}$ \\
\hline Toplam işletme arazisi & 0.000322141 & 0.000148708 & 2.1663 & $0.0303^{* *}$ \\
\hline \multicolumn{5}{|c|}{ Tahıl Üretiminin Sürdürülebilirliği } \\
\hline Sabit & 1.00814 & 0.295313 & 3.4138 & 0.0006 \\
\hline Yaş & -0.000451308 & 0.00570759 & -0.0791 & 0.9370 \\
\hline Eğitim & -0.035456 & 0.0147563 & -2.4028 & $0.0163^{* *}$ \\
\hline Tarımsal deneyim & 0.00272955 & 0.0049962 & 0.5463 & 0.5848 \\
\hline Hanehalkı büyüklüğü & -0.0482563 & 0.0128686 & -3.7499 & $0.0002^{* * *}$ \\
\hline Tahıl arazisi (\%) & 0.000309839 & 0.00014787 & 2.0953 & $0.0361^{* *}$ \\
\hline Toplam işletme arazisi & 0.000711029 & 0.00132041 & 0.5385 & 0.5902 \\
\hline Log-likelihood & -1095.131 & & & \\
\hline Bağımsızlık testi (rho) & 0.382644 & & & \\
\hline Ki-kare $\left(X^{2)}\right.$ & 47.2954 & & & \\
\hline
\end{tabular}

Tablo 6. Bivariate Probit Tahmin Sonuçları

() $\% 10,\left(^{* *}\right) \% 5$ ve ( $\left(^{* *}\right) \% 1$ önem düzeyinde anlaml

\section{Sonuç ve Öneriler}

Küresel iklim değişikliği ile birlikte, dünya genelinde kişi başına düşen tarım arazisi ve su kaynaklarındaki azalma, tarımsal üretimi önemli ölçüde etkilemektedir. Yaklaşık \%15'i uluslararası ticarete konu olan, yıllık üretimin \%20'sinden fazlası stoklanan, toplam üretimi 2 milyar tona yaklaşan hububat sektörü ise yaşanan bu değişikliklerden en çok etkilenen tarımsal üretim alanlarından biridir. Bu nedenle hububat sektörü için mevcut kaynakların etkin kullanımı yanında, olası riskleri yönetebilecek ve sürdürülebilir planlamalara ihtiyaç duyulmaktadır (Hasdemir, 2015).

Araştırmada üreticilerin tarımsal ve tahıl üretimlerinin sürdürülebilirliği analiz edilmiştir. Elde edilen bulgulara göre üreticilerin tarımsal üretimlerini sürdürebilmek için gerekli gördükleri en önemli koşulun "İyi fiyat" olduğu belirlenmiştir. Buna göre, üreticiler ürün fiyatının üretim maliyetlerinin üzerinde olması ve emeklerini karşılayacak düzeyde bir fiyat olması durumunda üretime devam edeceklerini bildirmişlerdir. Ancak serbest piyasa koşullarında fiyatlara müdahale edilememesi nedeniyle ürün fiyatları üzerine doğrudan bir müdahale yapılamamakta ve tarımsal faaliyetlerde fiyatlar sarkan etkisiyle ancak bir sonraki üretim dönemine etki etmektedir. Ayrıca, tahıl üreticilerinin bu beklentileri yanında, gıda fiyatları ve bu fiyatlar özelinde tahıl tüketicisi kitlenin satın alma gücü ile desteklenen talebin de dikkate alınması gerekmektedir. Nitekim fiyatların üretici aleyhine geliştiği yıllarda, maliyet ve fiyat arasında oluşan farkın tarımsal destekler ile telafi edilmesini sağlayacak politikalar sektörün sürdürülebilirliğine önemli katkılar sağlayacaktır. Buna karşılık, fiyatların aşırı yükselmesi, yurt içi fiyatlar ile dünya fiyatları arasındaki farkı artıracak, bu durum ithalat baskısı oluşturarak uzun dönemde tahıl üretiminin sürdürülebilirliğini olumsuz etkileyebilecektir.

Toplam işletme arazisi ve tahıl ekim alanlarının toplam işletme arazisi içindeki payı arttıkça tarımda kalma eğiliminin arttığı belirlenmiştir. Bununla birlikte hane halkı sayısı arttıkça tarımda kalma eğilimi azalmaktadır. Bu sonuç, tarımsal ve tahıl üretiminde sürdürülebilirliğin sağlanabilmesi için tarımsal işletmelerin büyümesini ama buna karşılık çiftçi ailelerinin küçülmesini öngörmekte olup, bu durum üretimde aile işgücünün yerini 
ücretli işgücünün almasını ve tarımsal işletmelerde ihtisaslaşmayı gerektirmektedir. Ancak 2014 yılının “Aile Çiftçiliği” yılı ilan edildiği ve aile çiftçiliğinin sürdürülebilirlik ve gıda güvenliği açısından önemine vurgu yapıldığı günümüzde, ihtisaslaşmış büyük ölçekli işletmelerin oluşturulması yanında küçük aile işletmelerini yerinde koruyabilecek tedbirler de göz ardı edilmemelidir.

Ayrıca araştırmada üreticilerin tarımsal üretim yapma amaçlarından en önemlisi "hayat standardını yükseltmek" olarak belirlenmiştir. Bununla birlikte üreticilerin çoğu tarafından tarımın meslek olarak görülmemesi ve tarımsal deneyim süresi azaldıkça üreticilerin tarımda kalma eğiliminin azalması, günümüzde gençlerin tarımsal faaliyetten uzaklaştıkları ve kırdan kente göç eğiliminin arttığı gerçeği ile örtüşmektedir. Ancak bu durum, gelecekte üretimin sürdürülebilirliği konusunda yaşanabilecek sorunlara işaret eden ve üzerinde önemle durulması gereken bir konudur. $\mathrm{Bu}$ nedenle, kırsal alanlarda yaşam koşullarının iyileştirilmesine ve bu alanların cazibe merkezleri haline getirilmesine yönelik kırsal kalkınma çalışmalara ağırlık verilmesi gerekli görülmektedir.

\section{Kaynakça}

- $\quad$ Akın, 2002. Kalitatif Tercih Modelleri Analizi, Ekin Kitabevi, Bursa.

- Boz, 1993. “Tarım Sigortasının Polatlı İlçesinde Yayılması ve Benimsenmesi Üzerine Bir Araştırma” Ankara Üniversitesi Fen Bilimleri Enstitüsü Yüksek Lisans Tezi, Ankara.

- Greene, 2000. Econometric Analysis, Macmillan Publishing Company, New York.

- Hasdemir, 2015. "Dünya'da Ve Türkiye'de Hububat Sektörü” Çiftçi ve Köy Dünyası Dergisi, TZOB, Ăgustos 2014, s.55.

- İnal, Topuz, Uçan, 2006. “Doğrusal Olasılık ve Logit Modelleri ile Parametre Tahmini”, Sosyo-Ekonomi Dergisi, 3/2006-1, Ankara.

- Konyar, Osborn, 1990. “A National Level Economic Analysis of Conservation Reserve Program Participation: A Discrete Choice Approach”, The Journal of Economics Research, 2, Washington.

- Louviere, Hensher, 1982. "On The Design and Analysis of Simulated or Allocation Experiments in Travel Choice Modelling”, Transportation Research Record, 890, p.11.

- Louviere, Woodworth, 1983.” Design And Analysis Of Simulated Choice or Allocation Experiments: An Approach Based on Aggregate Data", Journal of Marketing Research, 20, p. 350.

- $\quad$ Miran, 2002. Temel İstatistik, Ege Üniversitesi, İzmir.

- Özüdoğru, 2010. “Amasya Damızlık Sı̆̆ır Yetiştiricileri Birliğinin Yöre Çiftçilerine Ekonomik Etkilerinin Analizi”, Ankara Üniversitesi, Fen Bilimleri Enstitüsü Doktora Tezi, Ankara.

- Pazarlığlu, 2007. “İzmir Örneğinde İç Göçün Ekonometrik Analizi”, Celal Bayar Üniversitesi İIBF, Yönetim ve Ekonomi, 14(1), s:121.

- $\quad$ Rogers, 1983. Diffusion of Innovation. The Free Press, New York.

- Sanzidur, 2001. "Determinants of Crop Choices by Bangladeshi Farmers: A Bivariate Probit Analysis", Asian Journal of Agriculture and Development, Southeast Asian Regional Center for Graduate Study and Research in Agriculture, 5(1).

- Tatlıdil, 1992. “Konya İli Sulu ve Kuru Koşullardaki Tarım İşletmelerinde İşgücü, Döner Sermaye ve Traktör Güçlerine Göre Optimal İşletme Büyüklügünün Tespiti”, Ankara Üniversitesi Fen Bilimleri Enstitüsü Doktora Tezi, Ankara.

- Thapa, S. 2008. "Adoption of improved seeds and inorganic fertilizers in Nepal", http://web.unitn.it/files/download/11007/en full paper 17 07 2008.pdf

- Thungwa, 2000. The Decision Making on Mixed Farming Practices of Farmers in Sathing Phra, The National Research Council, Thailand.

- TÜİK, 2015. Bitkisel üretim istatistikleri, http://www.tuik.gov.tr/PreTablo.do?alt id=1001

- Yavuz, 2010. "Polatlı İlçesinde Üreticilerin Tarım Sigortası Yaptırmaya Karar Verme Sürecinde Etkili Olan Faktörlerin Analizi”, Ankara Üniversitesi Fen Bilimleri Enstitüsü Doktora Tezi, Ankara. 


\title{
Türkiye'de Baklagil Üretiminde Sürdürülebilirlik Açısından Etkili Faktörlerin Analizi
}

\section{Analysis of Effective Factors on Legumes Production in Terms of Sustainability in Turkey}

\author{
Dr. Mehmet Hasdemir (Republic of Turkey Ministry of Food, Agriculture and Livestock, \\ Turkey) \\ Prof. Dr. Bülent Miran (Ege University, Turkey) \\ Mine Hasdemir (Agricultural Economic and Policy Development Institute, Turkey) \\ Dr. Tijen Özüdoğru (Agricultural Economic and Policy Development Institute, Turkey, \\ Turkey)
}

\begin{abstract}
The changes in the economic, social and cultural life affect the agricultural and food sector from production to consumption. All these changes affect the protection of soil and water resources and the production and consumption of legumes which is the protein source of over 2 billion people. On the other hand, while cereal production has increased by $6.1 \%$, oil seed production has increased by $100.2 \%$, legumes production has decreased by $28.8 \%$ in Turkey. This situation is very important for sustainability in Turkey which is 3rd lentil producer, 4th chickpea producer and 23rd dry beans producer all over the world. The objective of the study is examined the effective factors on legumes production in terms of sustaining the production. For this purpose, the relationship between the legumes producers socio-economical characteristics and other factors (as price, marketing etc.), and sustainability of production is analysing by Logit analysis method. In this context, in 2014, a face to face survey is conducted by 835 producers in 14 provinces. According the results, total farm size and crop price are determined as effective factors for sustainability.
\end{abstract}

\section{Giriş}

Ekonomik, sosyal ve kültürel alanda yaşanan değişim, üretimden tüketime kadar tarım ve gıda sektörünü önemli ölçüde etkilemektedir. Küreselleşen tarım politikaları, başta yağlı tohumlar ve tahılların üretimine olan ilgiyi artırmakta ve tarımsal üretimde monokültürü öne çıkarmaktadır. Üretimde yaşanan değişim yanında, gelir seviyesindeki değişim ve hızlı kentleşme, beslenme alışkanlıklarından gıda teminine kadar tarımsal ürünlere olan talebe farklı bir boyut kazandırmaktadır. Tüm bu gelişmeler, toprak ve su kaynaklarının korunması yanında 2 milyardan fazla insanın ana protein kaynağı olan baklagillerin üretimini ve tüketimini önemli ölçüde etkilemektedir.

Dünyada 73 milyon hektar alanda yaklaşık 66 milyon ton olan baklagil üretimindeki artış, tahıllar veya yağlı tohumların oldukça gerisinde kalmaktadır. 2004-2014 yıllarını içeren son on yıllık dönemde tarım sektöründe önemli gelişmeler gösteren Türkiye tarımında da, tahıl üretimi \%6.1 oranında, yağlı tohumlar üretimi $\% 100.2$ oranında artarken, baklagil üretimi \%28.8 oranında gerilemiştir (TUIK, 2015). Bu durum, FAO 2013 y1lı verilerine göre dünya mercimek üretiminde 3'üncü, nohut üretiminde 4'üncü, kuru fasulye üretiminde 23'üncü sırada olan Türkiye tarımının sürdürülebilirliği açısından oldukça önemlidir.

\section{Materyal ve Yöntem}

Araştırmanın ana materyalini, ele alınan nohut, kuru fasulye ve kırmızı mercimeğin Türkiye'de yoğun olarak yetiştirildiği illerdeki üreticilere uygulanan anketler oluşturmuştur. Ayrıca ulusal ve uluslararası yayınlar, araştırmalar, istatistikler ve raporlar ikincil veri kaynağı olarak kullanılmıştır. Örnek ana kitlesinin belirlenmesinde Türkiye'de en fazla nohut, kuru fasulye ve kırmızı mercimek üretilen illerdeki üretici sayısı örnek popülasyonuna dahil edilmiş̧ir. Bu kapsamda nohut için Uşak Kırşehir, Antalya, Konya, Yozgat ve Kütahya, kuru fasulye için Konya, Karaman, Erzincan, Niğde, kırmızı mercimek için ise Şanlıurfa, Diyarbakır, Mardin, Kilis illeri olmak üzere toplam 14 il popülasyonu oluşturmaktadır. Örnek hacminin belirlenmesinde, Türkiye Gıda Tarım ve Hayvancılık Bakanlığı Çiftçi Kayıt Sistemi (ÇKS) dikkate alınarak her bir ürünün ekim alanına göre belirlenmiştir. Örnek hacmi, tabakalı tesadüfî örnekleme yöntemine göre belirlenmiş olup aşă̆ıda şekilde formüle edilmektedir (Miran, 2002):

$$
n=\frac{N z^{2} \sigma^{2}}{d^{2}(N-1)+z^{2} \sigma^{2}}
$$

$\mathrm{N}$ : Ana kitle büyüklüğ̈̈ 
$\sigma^{2}:$ Anakitle varyans1

d: Hata değeri

z: Seçilen olasılık düzeyi için normal dağılış tablo değeri

Hesaplamalarda güven aralığı \%95, hata payı ise \%10 olarak alınmıştır. Bu hesaplamalar sonucunda ürünlere göre örnek hacmi, nohutta 284, kuru fasulye 198, kırmızı mercimekte ise 353 olarak hesaplanmış olup toplam örnek hacmi 835'dir (Tablo 1).

\begin{tabular}{|l|l|l|l|l|l|}
\hline \multirow{2}{*}{ Ürünler } & \multicolumn{3}{|l|}{ Tabakalara Düsen Örnek Sayısı } & \multirow{2}{*}{ Toplam Örnek Sayısı } \\
\cline { 2 - 5 } & $n<5$ & $5=n<30$ & $30=n<100$ & $n \geq 100$ & \\
\hline Nohut & 105 & 84 & 44 & 51 & 284 \\
\hline Kuru Fasulye & 131 & 32 & 20 & 15 & 198 \\
\hline Kirmizı Mercimek & 55 & 83 & 45 & 170 & 353 \\
\hline Toplam & 291 & 199 & 109 & 236 & 835 \\
\hline
\end{tabular}

Tablo 1. Tabakalara Göre Örnek Hacmi

Yapılan araştırmada üreticilerin üretimlerini sürdürebilmeleri için gerekli koşullar Best-Worst yöntemi ile incelenmiştir. Best Worst yöntemi ilk defa 1980'li yılında, Jordan Louviere, Hensher ve Woodworth tarafından geliştirilen bir ayrık seçim modelidir. İlk makale ve yayınlar 1990'ların başlarında ortaya çıkmıştır. Bu yöntemde katılımcılara, bir dizi objeler (öğeler) gösterilir ve onlardan en önemli ve en önemsiz (en iyi/en kötü, en çok/en az vb.) olanlarını göstermeleri istenmektedir. Best Worst yöntemine yönelik anket soruları katılımcıların çoğu için anlaşılması oldukça kolay sorulardır. Ayrıca, bu yöntem ile insanların uçlardaki (extrem) objeler arasındaki farkları orta halli olanlardan daha iyi ayırması nedeniyle önyargılar için fırsat yaratılmamış olmaktadır.

Ayrıca üreticilerin baklagil üretimlerini sürdürebilmelerinde etkili olan faktörleri analiz etmek üzere Logit model kullanılmıştır. Logit modeller, genelleştirilmiş doğrusal modelin belirli koşullar altında oluşturulmuş özel durumlarıdır. Logit model, bağımlı değişkenin tahmini değerlerini olasılık olarak hesaplayarak olasılık kurallarına uygun sınıflama yapma imkânı veren, tablolaştırılmış ya da ham veri setlerini analiz eden bir istatistiksel yöntemdir (İnal vd. 2006). Ekonometrik çalışmalarda, bağımlı değişkenin nominal veya kategorik (sıralanmamış) olduğu durumunda, sınırlı bağımlı değişken regresyon modelleri kullanılmaktadır. İki durumu gösteren bağımlı değişken bir olayın olma ya da olmama durumunu ifade etmektedir. Olayın olma durumunda bağımlı değişken "1", olmama durumunda ise "0" değerini almaktadır. Elde edilen eğim katsayıları, bağımsız değişkenlerin değerindeki bir birimlik artışın, bir olayın gerçekleşme olasılığındaki değişmeyi göstermektedir (Gujarati, 2006). Bu nedenle logit model, kategorik bağımlı değişkenlerin çok değişkenli modellenmesi için bir analitik teknik seçenek haline gelmiştir.

Bağımlı değişkenin kategorik ve ordinal olduğu durumlarda ordered (sıralı) logit veya probit olasılık tahmin edicileri kullanılabilmektedir. Her iki yöntemde de en yüksek olabilirlik fonksiyonları kullanılmaktadır. Sıralı probit model, normal olasılık dağılımına dayanır iken, sıralı logit model standardize edilmiş lojistik olasılık dağılımından türetilmektedir. Sıralı logit model iki değerli logit modelin genişletilmiş halidir (Akın, vd, 2000; Kızılgöl, 2012). Sıralı logit ve probit modeller, ilk olarak Walker ve Duncan (1967) ile McKelvey ve Zavoina (1975) tarafından kullanılmıştır (Kızılgöl, 2012). Sıralı logit modelini sıralı probit modelinden ayıran özellik, hataların lojistik olarak dağılmasıdır (Chow, 1988). Sıralı logit model - $\infty$ ile $+\infty$ aralığında gözlenemeyen bir $y^{*}$ değişkeninin gözlenen y değişkeni ile ilişkilendirildiği bir modelden oluşturulabilir (Greene, 2003).

Bu çalışmada ikili logit model ile sıralı logit modelden yararlanılmıştır. İkili logit model, bağımlı değişkenin iki sınıfa ayrıldığı, sıralı logit model ise bağımlı değişkenin ikiden fazla değer ile sıralı bir biçimde sınıflandırıldığı modeller için kullanılmaktadır (Miran, 2003). Baklagil üretiminin sürdürülebilirliğini analiz etmek için baklagil üretimini sürdürme ve sürdürmeme kararına yönelik analizde logit model, baklagil fiyatının hangi derecede sorun olarak görüldüğünü analiz etmek üzere de ordered (sıralı) logit modeli kullanılmıştır.

\section{Bulgular}

\section{1 Üretici ve İșletme Özellikleri}

İşletme yöneticilerinin bireysel özellikleri yanında, ekonomik ve sosyal şartları, işletmelerin yönetim biçimi, organizasyonu, teknolojik yeniliklerin benimsenmesi ve uygulanması gibi bütün işletme faktörleri üzerinde etkilidir. Bu nedenle araştırmanın bu bölümünde üreticilerin yaşı, eğitim durumu, kendi adına tarımla uğraştığ1 süre, hanelerindeki kişi sayısı ve hanelerinde tarımda çalışan kişi sayısının yer aldığı genel bilgiler incelenmiştir.

Tarımsal faaliyette bulunan üreticilerin yaş durumu üretim sonuçlarını çeşitli şekillerde etkilemektedir. Buna bağlı olarak baklagil üreticilerin yaşları dikkate alınıp elde edilen veriler incelendiğinde; işletmelerde en genç üreticinin 19, en yaşlı üreticinin 90 yaşında olduğu belirlenmiştir. Üreticilerin ortalama yaşları ise 48.42'dir. 
Üreticilerin eğitim durumları incelendiğinde; okuma yazması olmayan üreticilerin yanı sıra üniversite mezunu üreticilerin de olduğu belirlenmiştir. Bununla birlikte baklagil üreticilerinin ortalama eğitim süresi 6.71 olarak hesaplanmıştır.

Üreticilerin kendi adına tarımla uğraştıkları süre (yıl) ele alındığında dağılımın 1 ile 70 yıl arasında olduğu ve ortalama sürenin 25.25 yıl olduğu görülmektedir.

Tarımsal işletmelerde bulunan nüfus, işletmelerin idaresinden işgücü kaynağına kadar birçok görevi üstlenmektedir (Özüdoğru, 2010). Bu nedenle araştırmada üreticilerinin hanelerindeki kişi sayısı ile birlikte hanelerinde tarımda çalışan kişi sayısı da incelenmiştir. Buna göre; hanedeki ortalama nüfusun 6.04, hanede tarımda çalışan ortalama nüfusun ise 2.87 olduğu belirlenmiştir (Tablo 2).

\begin{tabular}{|c|c|c|c|c|c|}
\hline Ürünler & Yaş & $\begin{array}{l}\text { Ë̆itim } \\
\text { Durumu }\end{array}$ & $\begin{array}{l}\text { Tarımla } \\
\text { Uğraştı̆̆ Süre }\end{array}$ & $\begin{array}{l}\text { Hanedeki } \\
\text { Kişi Sayısı }\end{array}$ & $\begin{array}{l}\text { Hanede Tarımda Çalışan } \\
\text { Kişi Sayısı }\end{array}$ \\
\hline Nohut & 50.27 & 6.74 & 25.80 & 4.76 & 2.55 \\
\hline K. Fasulye & 48.93 & 6.45 & 25.72 & 5.28 & 2.90 \\
\hline K. Mercimek & 46.73 & 6.76 & 24.60 & 7.39 & 3.09 \\
\hline Genel & 48.42 & 6.71 & 25.25 & 6.04 & 2.87 \\
\hline
\end{tabular}

Tablo 2. Baklagil Üreticilerine Ait Genel Bilgiler

Arazi, tarımsal faaliyette üretim araçları içerisinde en önemlisi ve vazgeçilmez olanıdır. İşletme arazisi, mülkiyet ilişkisi, arazinin nevi ve faydalanma şekilleri dikkate alınmaksızın çiftçi ailesinin işlettiği toplam alandır (Tatlıdil, 1992). Bununla birlikte yapılan birçok araştırmada işletme büyüklüğünün üretici kararları üzerinde etkili bir faktör olduğu da belirtilmektedir (Rogers, 1983; Konyar and Osborn 1990; Boz, 1993; Thungwa, 2000; Yavuz, 2010). İncelenen işletmelerde işletme arazisi, üretim döneminde üretici tarafından işletilen arazilerin tamamından oluşmaktadır. Buna göre işletme arazisi üreticilerin sahip olduğu mülk arazilerin yanı sıra kiraladığı veya ortakçılıkla işlediği arazileri de kapsamaktadır. Ancak üretici kararlarında toplam işletme arazisinin yanı sıra mülk arazi genişliğinin de etkili bir faktör olduğu ve bu nedenle üreticilerin sahip olduğu mülk arazi genişliğinin de incelenmesi gerektiği düşünülmüştür. Araştırma sonuçlarına göre baklagil üreten işletmelere ait özellikler Tablo 3'de verilmiştir.

Elde edilen bulgulara göre ortalama işletme arazisi 272.44 da olarak hesaplanmıştır. Baklagil üreten işletmelerden nohut ve kuru fasulye üreten işletmelerin işletme arazi büyüklükleri birbirine yakın olmakla birlikte kırmızı mercimek işletmelerin daha büyük (333.55 da) olduğu belirlenmiştir. Ortalama mülk arazi genişliği ise 169.05 da ile toplam işletmenin \%62.05'ini oluşturmaktadır. Mülk arazi genişliği en fazla kırmızı mercimek üreten işletmelerde olup mülk arazinin toplam işletme arazisine oranın da en büyük payı da \%74.93 ile kırmızı mercimek üreten işletmeler almaktadır.

Sulama, tarımsal arazilerde verim artışına yol açan en önemli etmenlerden biridir. Bu nedenle araştırmada işletme arazilerinin sulama durumu da incelenmiştir. Buna göre; toplam işletme arazilerinin \%45.28'ini sulanan araziler oluşturmaktadır. Kuru fasulye yetiştiriciliğinin genellikle sulu alanda yapılması nedeniyle, kuru fasulye işletmelerinin toplam işletme arazisi içerisindeki sulu alanların payı \%76.01 ile diğer işlemelere göre daha yüksektir.

İşletmelerin parsel sayısı kaynakların etkin kullanımı açısından tarımsal üretimde oldukça önemli bir konudur. $\mathrm{Bu}$ nedenle araştırmada işletmelerin parsel sayısı da dikkate alınmış ve ortalama parsel sayısının 14.62 olduğu belirlenmiştir. Ortalama parsel sayıları kuru fasulye (11.98) ve kırmızı mercimek (11.60) üreten işletmelerde birbirine çok yakın iken nohut üreten işletmelerde 20.21'dir. Nohut üreten işletmelerde, mülk arazi payının düşük buna karşılık ortak/kira arazi payının yüksek olmasının, parsel sayılarını artırdığı düşünülmektedir. Kira ve ortakçılıkla işlenen arazi miktarı arttıkça işletme arazileri dağılmakta ve parsel sayısı da buna bağlı olarak artış göstermektedir.

İşletmelerde ortalama 70.55 da alanda baklagil üretimi yapılmakta olup baklagil üretim alanı toplam işletme genişliğinin \%25.90'nını oluşturmaktadır. Baklagil ekim alanlarının toplam işletme arazisine oranı \%29.11 ile en yüksek kırmızı mercimekte iken nohutta bu oran \%25.34, kuru fasulyede ise \%16.88 olduğu görülmektedir. Kuru fasulye üreten işletmelerin toplam arazileri içerisinde sulanan alanın oransal olarak yüksekliği, bu işletmelerde sulu alanda yetiştirilebilen ürün seçeneğini artırmakta ve kuru fasulye üretimine ayrılan arazi payını oransal olarak azaltmaktadir.

\begin{tabular}{|c|c|c|c|c|c|c|c|c|}
\hline \multirow{2}{*}{ Ürünler } & \multirow{2}{*}{$\begin{array}{l}\text { Toplam İsletme } \\
\text { Arazisi (da) }\end{array}$} & \multicolumn{2}{|c|}{ Toplam Mülk Arazi } & \multicolumn{2}{|c|}{ Sulanan Arazi } & \multirow{2}{*}{$\begin{array}{l}\text { Parsel } \\
\text { Sayısı }\end{array}$} & \multicolumn{2}{|c|}{ Baklagil Ekim } \\
\hline & & $(d a)$ & $\%$ & $(d a)$ & $\%$ & & (da) & $\%$ \\
\hline Nohut & 225.42 & 115.22 & 51.11 & 28.32 & 12.56 & 20.21 & 57.13 & 25.34 \\
\hline K. Fasulye & 223.83 & 131.57 & 58.78 & 170.14 & 76.01 & 11.98 & 37.79 & 16.88 \\
\hline K.Mercimek & 333.55 & 249.92 & 74.93 & 182.36 & 54.67 & 11.60 & 97.09 & 29.11 \\
\hline Genel & 272.44 & 169.05 & 62.05 & 123.36 & 45.28 & 14.62 & 70.55 & 25.90 \\
\hline
\end{tabular}

Tablo 3. Baklagil Üreten İsletmelerine Ait Genel Bilgiler 


\section{2 Üreticilerin Baklagil Üretiminde Sürdürülebilirlik Açısından Etkili Faktörler}

Araştırmanın bu bölümünde üreticilerin baklagil üretimlerinin sürdürülebilirliğini belirleyebilmek için BestWorst (B-W) yöntemi kullanılarak değerlendirilmiştir. (B) ilgili değişkeni en önemli bulan üretici sayısını gösterirken, (W) ilgili değişkeni en önemsiz bulan üretici sayısını göstermektedir. Değerlendirmeler ise Ortalama B-W (Ort) değeri üzerinden yapılmıştır. Buna göre; en büyük pozitif değere sahip değişken en önemli, en küçük negatif değere sahip değişken ise en önemsiz olarak yorumlanmaktadır. Ortalama B-W değeri sıfır ise, orta derecede önemli bir değişkenden bahsedilmektedir.

Araştırmada üreticilerin baklagil üretimlerinin sürdürülebilirliğini belirleyebilmek amacıyla tarımsal üretimlerini sürdürebilmek için etkili olan faktörler belirlenmiştir. Elde edilen veriler doğrultusunda genel olarak baklagil üreticileri tarımsal üretimlerini sürdürmek için en önemli koşulun "İyi fiyat" (0.11) olduğunu belirtmiştir. Ayrıca kırmızı mercimek üreticileri için bu faktörün daha da önemli olduğu (0.16) belirlenmiştir. Burada iyi fiyat ile ürünün satış fiyatının üretim maliyetinin üzerinde ve üreticinin emeğinin karşılığını alabileceği/kar elde edebileceği bir fiyat kastedilmektedir. Bununla birlikte genel olarak değerlendirildiğinde fark ödemesi desteği adı altında üreticilere ödenen prim miktarı, gübrenin uygun fiyattan temin edilmesi, kaliteli tohumluğun uygun fiyatlardan temin edilebilmesi 0.00 önem derecesi ile üreticiler için orta düzeyde öneme sahip koşullardır. "İstenen zamanda işçi temini" ve "Kolay kredi bulma" (-0.03) ise üreticiler için sürdürülebilirlik açısından en önemsiz koşullar olarak belirlenmiştir.

\begin{tabular}{|c|c|c|c|c|c|c|c|c|c|c|c|c|}
\hline \multicolumn{2}{|l|}{ 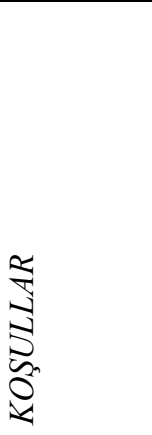 } & 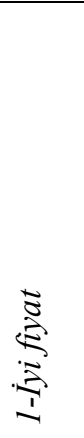 & 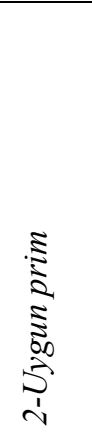 & 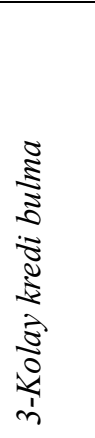 & 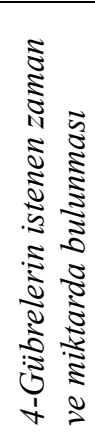 & 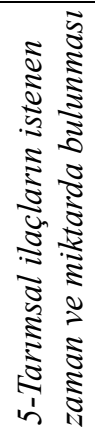 & 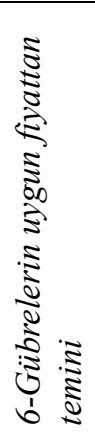 & 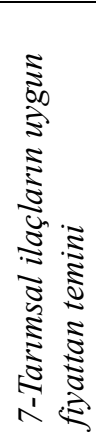 & 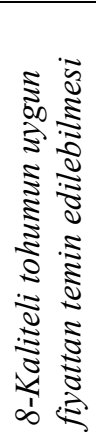 & 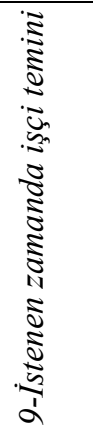 & 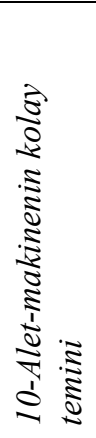 & 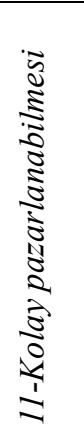 \\
\hline \multirow{3}{*}{ 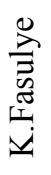 } & B & 135 & 15 & 6 & 2 & 0 & 2 & 0 & 14 & 3 & 2 & 6 \\
\hline & W & 0 & 17 & 54 & 4 & 11 & 12 & 9 & 3 & 35 & 22 & 18 \\
\hline & Ort & 0.07 & 0.00 & -0.02 & 0.00 & -0.01 & 0.00 & 0.00 & 0.01 & -0.02 & -0.01 & -0.01 \\
\hline \multirow{3}{*}{ 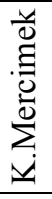 } & B & 322 & 19 & 3 & 4 & 1 & 11 & 3 & 5 & 0 & 2 & 5 \\
\hline & W & 0 & 31 & 61 & 17 & 19 & 11 & 25 & 20 & 95 & 38 & 58 \\
\hline & Ort & 0.16 & -0.01 & -0.03 & -0.01 & -0.01 & 0.00 & -0.01 & -0.01 & -0.05 & -0.02 & -0.03 \\
\hline \multirow{3}{*}{$\begin{array}{l}\text { 芳 } \\
\text { Z } \\
\text { Z }\end{array}$} & B & 234 & 11 & 2 & 0 & 2 & 5 & 0 & 10 & 5 & 1 & 20 \\
\hline & W & 0 & 8 & 83 & 17 & 18 & 14 & 9 & 7 & 52 & 65 & 17 \\
\hline & Ort & 0.12 & 0.00 & -0.04 & -0.01 & -0.01 & 0.00 & 0.00 & 0.00 & -0.02 & -0.03 & 0.00 \\
\hline
\end{tabular}

Tablo 4. Üreticilerin Baklagil Üretimlerini Sürdürebilmek İçin Gerekli Gördükleri Koşullar

Araştırmada sonuçlarına göre üreticilerin baklagil üretimlerinin sürdürülebilmek için gerekli gördükleri koşulları gösterir grafik Şekil 1'de verilmiştir. 


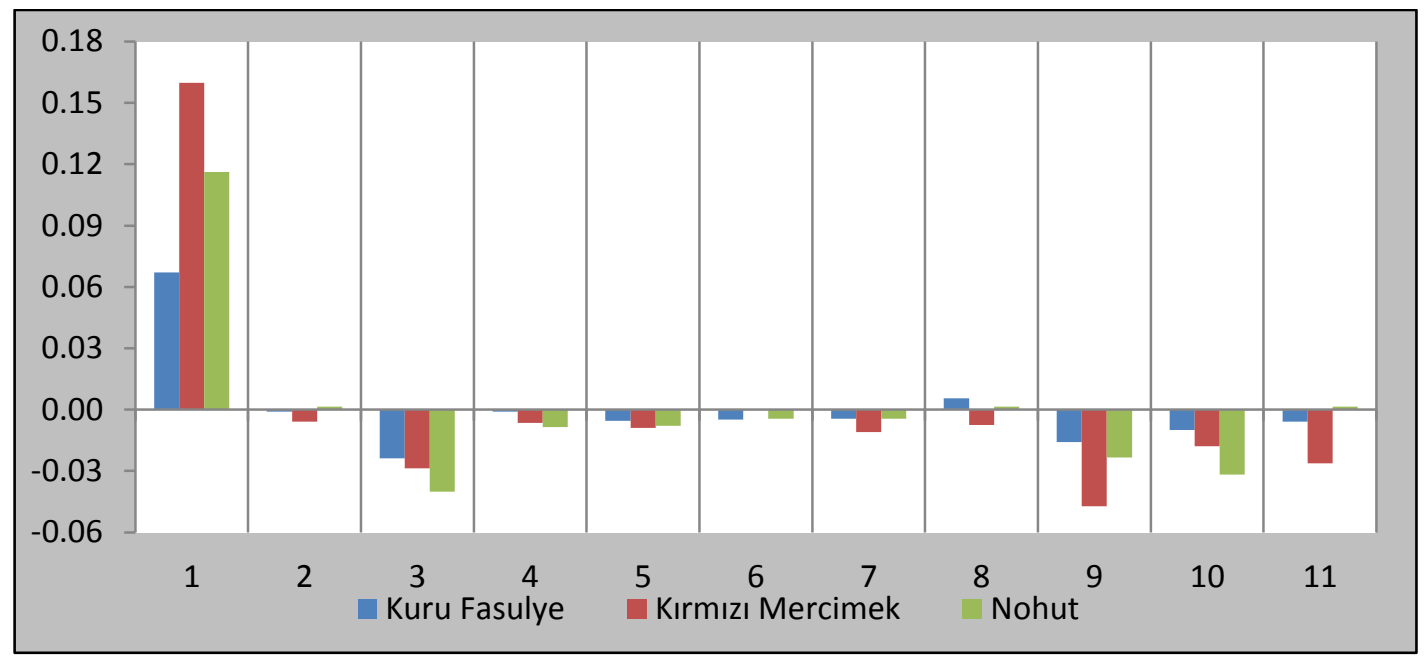

Şekil 1. Üreticilerin Tarımsal Üretimlerini Sürdürebilmek İ̧̧in Gerekli Gördükleri Koşullar

Araştırmada ayrıca üreticilerin baklagil üretimlerinin sürdürülebilirliğini analiz etmek için Logit model kullanılmıştır (Tablo 5). Buna göre;

- Hanesi kalabalık olanlar tarımda kalma eğiliminde değildir. Baklagil üretiminin geleceği çekirdek ailelerin elinde görünmektedir.

- İşletme arazisi daha büyük olan araziler baklagil üretmeye devam etmeyi istemektedir. Küçük işletmelerin baklagil üretimi açısından gelecek vadetmediği anlaşılmaktadır.

- Baklagilleri işletme arazisi içinde daha büyük oranda yetiştirenler, baklagil üretmeye devam etme arzusundadir.

- Baklagillerde iyi fiyat aldığını düşünenler baklagil üretmeye devam etme eğilimindedir. Baklagil üretiminin geleceği iyi fiyat veren politikalara bağlı görünmektedir.

- Pazarlama sorunu baklagil üretimi açısından önemli bir sorun olarak görünmemektedir.

\begin{tabular}{|l|r|r|r|}
\hline Dĕ̆işkenler & Katsayl & Std. Hata & Ĕ̈im \\
\hline Sabit & 0.4134 & 0.4958 & \\
\hline Eğitim & -0.0039 & 0.0258 & -0.0012 \\
\hline Tarımsal deneyim & 0.0024 & 0.0079 & 0.0004 \\
\hline Yaş & -0.0010 & 0.0086 & -0.0119 \\
\hline Hane halk1 büyüklüğ̈̈ & $-0.0490^{* *}$ & 0.0250 & 0.0002 \\
\hline Toplam ișletme büyüklüğü & $0.0008^{* *}$ & 0.0003 & 0.0001 \\
\hline Baklagile tahsis edilen alanı & 0.0003 & 0.0010 & -0.0303 \\
\hline Toplam alanda baklagilin pay1 & $0.0061 * *$ & 0.0028 & -0.0091 \\
\hline Fiyat sorunu (1: Kesinlikle kabul etmeme, 5: Kesinlikle kabul etme) & $-0.1200^{* *}$ & 0.0536 & 0.0015 \\
\hline Pazarlama sorunu (1: Kesinlikle kabul etmeme, 5: Kesinlikle kabul etme) & -0.0357 & 0.0487 & -0.0012 \\
\hline
\end{tabular}

\section{Tablo 5. Logit Model Sonuçlart}

Baklagil fiyatının baklagil üretiminin sürdürülebilirliğini önemli ölçüde etkilemesi nedeniyle, fiyatı hangi özellikteki çiftçilerin sorun olarak gördüğü ordered logit ile analiz edilmiştir (Tablo 6). Bu analizde, fiyatı sorununu kesinlikle kabul etmeyenler (1), kesinlikle kabul edenler (5) şeklinde kodlanmış olup ordered logit sonuçlarına göre;

- Eğitim düzeyi arttıkça fiyat konusundaki kaygılar artmaktadır. Eğitimi düşük çiftçiler düşük fiyatı kabullenirken, eğitimi yüksek olanlar daha fazla fiyat beklentisine sahiptir.

- Arazisi daha büyük olan çiftçiler, baklagil fiyatlarının beklediklerinin altında olduğu düşüncesine sahiptir. Küçük çiftçilerin fiyatın iyi olduğu düşüncesinde olduğu görülmektedir. 


\begin{tabular}{|c|c|c|c|c|}
\hline & Katsayl & Std. Hata & $Z$ & p-value \\
\hline Sabit & 0.0302707 & 0.0240366 & 1.2594 & 0.2079 \\
\hline Tarımsal deneyim & 0.0012133 & 0.00715907 & 0.1695 & 0.8654 \\
\hline Ĕgitim & 0.0673234 & 0.0232595 & 2.8944 & $0.0038 * * *$ \\
\hline Yaş & -0.00359585 & 0.00772199 & -0.4657 & 0.6415 \\
\hline Toplam işletme büyüklüğü & 0.000575609 & 0.000265122 & 2.1711 & $0.0299 * *$ \\
\hline Baklagile tahsis edilen alanı & -0.000506551 & 0.000790722 & -0.6406 & 0.5218 \\
\hline Toplam alanda baklagilin payı & 0.00253553 & 0.00254253 & 0.9972 & 0.3186 \\
\hline cut1 & -1.43266 & 0.430124 & -3.3308 & $0.0009 * * *$ \\
\hline cut2 & -0.722612 & 0.425463 & -1.6984 & $0.0894 *$ \\
\hline cut3 & 0.0841629 & 0.424341 & 0.1983 & 0.8428 \\
\hline cut4 & 0.708603 & 0.424894 & 1.6677 & $0.0954 *$ \\
\hline
\end{tabular}

Tablo 6. Ordered Logit Model Sonuçlarl

\section{Sonuç ve Öneriler}

Kurak ve yarı kurak alanlarda nohut ve mercimeğin, sulu alanlarda ise fasulyenin ekim nöbetine girmesi, gerek birim alandan elde edilen verimin artırılması, gerekse nadas alanlarının azaltılması açısından önem arz etmektedir. Besin değerleri bakımından zengin oldukları gibi yetiştirildikleri toprağa da olumlu etkilerde bulunmaları, havanın serbest azotunu toprağa bağlama özellikleri, çevrecilik ve sürdürülebilir tarımın popülaritesinin arttığı günümüzde bu bitkilerin önemini daha da artırmaktadır (GTHB, 2014). Ancak geleneksel olarak önemli bir baklagil üreticisi ve ihracatçısı olan Türkiye'de son yıllarda baklagil üretimi giderek azalmaktadır. Bu durum baklagil üretiminin sürdürülebilirliğini önemli ölçüde etkilemektir.

Araştırmada sonuçları, genel olarak baklagil üreticileri tarımsal üretimlerini sürdürmek için en önemli koşulun "iyi fiyat" olduğunu göstermektedir. Bu durum, sulu alanda yetiştirilen ve aynı alanda alternatifi fazla olan kuru fasulye üreticileri için daha da önemli hale gelmektedir. Genel itibariyle iyi fiyat aldığını düşünenler, baklagil üretmeye devam etme eğilimindedir. Analiz sonuçları, baklagil üretiminin geleceğinin iyi fiyat veren politikalara bağlı olduğunu göstermektedir. Ancak, baklagil üreticilerinin bu beklentileri yanında, gıda fiyatları ve bu fiyatlar özelinde baklagil tüketicisi kitlenin satın alma gücü ile desteklenen talebi de dikkate alınmak durumundadır. Fiyatların tüketici aleyhine geliştiğgi yıllarda, fiyat ile maliyet arasında oluşan farkı karşılayacak destekleme politikaları sektörün sürdürülebilirliğine önemli katkılar sağlayacaktır. Buna karşılık, fiyatların aşırı yükselmesi, yurt içi fiyatlar ile dünya fiyatları arasındaki farkı artıracak, bu durum ithalat baskısı oluşturarak uzun dönemde baklagil üretiminin sürdürülebilirliğini olumsuz etkileyebilecektir.

Genel olarak değerlendirildiğinde fark ödemesi desteği adı altında üreticilere ödenen prim miktarı, gübrenin ve kaliteli tohumluğun uygun fiyattan temin edilebilmesi üreticiler için orta düzeyde öneme sahip koşullardır. Bu nedenle, gübre ve mazot ile sertifikalı baklagil tohum destekleri konusunda mevcut politikalar geliştirilerek devam ettirilmelidir.

Tarım sektörünün en önemli yapısal sorunlarından biri olan işletme büyüklüğü, baklagil üretimi içinde geçerli olup büyük işletmeler baklagil üretmeye devam etmek istemektedir. Ayrıca baklagilleri işletme arazisi içinde daha büyük oranda yetiştirenler, baklagil üretmeye devam etme arzusundadır. Münavebe içerisinde baklagillere yer vermenin teşvik edilmesi yanında, ihtisaslaşmış işletmelerde baklagillerin üretildiği büyük ölçekli işletmelerin oluşturulması, küçük işletmelerin ise pazarlama ve yetiştiricilikte örgütlenerek faaliyette bulunmaları baklagillerin sürdürülebilirliğine katkı sağlayacaktır. Bununla birlikte, Birleşmiş Milletler Gıda ve Tarım Organizasyonun (FAO) Roma'da gerçekleştirilen 146. Konsey toplantısında, 2016 yılının "Uluslararası Bakliyat Yılı" olarak ilan edilmesi, baklagil üretimi ve tüketimini artırarak sektörün sürdürülebildiğine yönelik politikaların oluşturulması açısından önemli bir firsattır.

\section{Kaynakça}

- $\quad$ Akın, Deveci, ve Üçdoğruk, 2000. "İstanbul İli Hanehalkı Tüketim Harcamalarının Sıralı Probit Olasılık Modelleriyle İncelenmesi”, DİE Araştırma Sempozyumu,, Ankara, 27-29 Kasım 2000.

- Boz, 1993. "Tarım Sigortasının Polatlı İlçesinde Yayılması ve Benimsenmesi Üzerine Bir Araştırma”, Ankara Üniversitesi Fen Bilimleri Enstitüsü Yüksek Lisans Tezi, Ankara.

- Chow, 1988, Econometrics. McGraw-Hill Book Company, 4th Printing, Singapore.

- FAO, 2015. Bitkisel Üretim İstatistikleri. Birleşemiş Milletler Gıda ve Tarım Örgütü. http://faostat3.fao.org

- Greene, 2003, Econometric Analysis, Pearson Education Inc.,New Jersey.

- Gujarati, D.N. 2006. Basic Econometrics. Forth Edition, Mc Graw-Hill, USA. 
- GTHB, 2014. Yemeklik Baklagil Çalıştayı. Türkiye Cumhuriyeti Gıda Tarım ve Hayvancılık Bakanlığı, 5-6 Mart 2014 Konya. s.8.

- İnal, Topuz, Uçan, 2006. “Doğrusal Olasılık ve Logit Modelleri ile Parametre Tahmini”, Sosyo-Ekonomi Dergisi, 3/2006-1, Ankara.

- Kizilgöl, 2012. "Kişisel Kazançların Belirleyicileri: Türkiye Örneği”, Süleyman Demirel Üniversitesi İktisadi ve Ídari Bilimler Fakültesi Dergisi, 17, s.373-384.

- Konyar ve Osborn, 1990. “A National Level Economic Analysis of Conservation Reserve Program Participation: A Discrete Choice Approach”, The Journal of Economics Research, 2, Washington.

- Louviere ve Hensher, 1982. "On The Design And Analysis of Simulated or Allocation Experiments in Travel Choice Modelling”, Transportation Research Record, 890, p.11.

- Louviere ve Woodworth, 1983." Design And Analysis Of Simulated Choice or Allocation Experiments: An Approach Based on Aggregate Data”, Journal of Marketing Research, 20, p. 350.

- Mckelvey ve Zavoina, 1975. "A Statistical Model for the Analysis of Ordinal Level Dependent Variables", Journal of Mathematical Sociology, 4, s. 103-120.

- Miran, 2002. Temel İstatistik, Ege Üniversitesi, İzmir.

- Miran, 2003. Ekonometri Ders Notları, Ege Üniversitesi Ziraat Fakültesi Tarım Ekonomisi Bölümü. 12s.

- Ö̈züdoğru, 2010. “Amasya Damızlık Sığır Yetiştiricileri Birliğinin Yöre Çiftçilerine Ekonomik Etkilerinin Analizi”, Ankara Üniversitesi, Fen Bilimleri Enstitüsü Doktora Tezi, Ankara.

- $\quad$ Rogers, 1983. Diffusion of Innovation. The Free Press, New York.

- Tatlıdil, 1992. "Konya İli Sulu ve Kuru Koşullardaki Tarım İşletmelerinde İşgücü, Döner Sermaye ve Traktör Güçlerine Göre Optimal İşletme Büyüklüğünün Tespiti” Ankara Üniversitesi Fen Bilimleri Enstitüsü Doktora Tezi, Ankara.

- Thungwa, 2000. The Decision Making on Mixed Farming Practices of Farmers in Sathing Phra, The National Research Council, Thailand.

- $\quad$ TÜİK, 2015. Bitkisel Üretim Istatistikleri, Türkiye İstatistik Kurumu. http://www.tuik.gov.tr.

- Walker and Duncan, 1967. "Estimation of the Probability of an Event as a Function of Several Independent Variables", Biometrika, 54, s. 167-179.

- Yamane, 1967. Elementary Sampling Theory, Prentice-Hall Inc. Newyork.

- Yavuz, 2010. "Polatı İlçesinde Üreticilerin Tarım Sigortası Yaptırmaya Karar Verme Sürecinde Etkili Olan Faktörlerin Analizi”, Ankara Üniversitesi Fen Bilimleri Enstitüsü Doktora Tezi, Ankara. 


\title{
Öğrencilerin Beslenme Alışkanlıklarına Dair Kısıtlar Nelerdir? Yükseköğrenim Öğrencileri Üzerine Bir Araştırma What Constraints Do the Students have for Nutrition Habits? A Research on Higher Education Students
}

\author{
Prof. Dr. Orhan Batman (Sakarya University, Turkey) \\ Prof. Dr. Mehmet Sarışık (Sakarya University, Turkey) \\ Ph. D. Candidate Akif Gökçe (Sakarya University, Turkey)
}

\begin{abstract}
Heirs of future and potential tourists, students face with various difficulties during university period. The very primary step of physiological needs, eating habits and constraints, of such a wide audience who are supposed to be at the top of self-realization is an issue that is carefully be focused on. The aim of this study which tries to investigate Bartın Vocational School students' tendency and constraints on nutrition is to search and identify daily main meals and snacks of students; to determine body-mass index on age basis;; and to evaluate the arguments whether interdependent variables such as economic level, place of residence and gender which are allegedly affect nutritional care have influence on food choice. This study is considered important because it assesses dietary habits and tendencies of consumers with different levels of opportunity and limited incomes. In this context, secondary data have been given in theoretical framework. Primary data, on the other hand, have been obtained through a questionnaire that is compiled from various sources. Research problem and hypotheses have been tested by parametric test Independent-Samples $\mathrm{T}$ Test and frequency analysis. As results of the research, the findings that students do not have adequate nutrition awareness though their body-mass index is in normal range; that they consume fast food particularly during the day; and that this situation leads to the socalled morbid obesity health problems have been discussed. In addition, policy recommendations and suggestions have been made in this regard.
\end{abstract}

\section{Giriş}

İnsan ihtiyaçları önceliklerine göre psikolog Abraham H. Maslow tarafından gruplandırılmış ve ihtiyaçların bir hiyerarşi içinde olduğu ileri sürülmüştür. $\mathrm{Bu}$ hiyerarşiye göre ilk sırayı yeme, içme, uyku gibi fizyolojik ihtiyaçlar almaktadır. $\mathrm{Bu}$ görüşe göre kişilerin yaşamlarını sürdürmesi için gerekli fizyolojik ihtiyaçları karşılamadan güvenlik, sevgi, ün, estetik gibi üst basamak ihtiyaçları talep etmesi beklenemez. Bu durum göstermektedir ki tüketici araştırmalarında yardımcı olacak en önemli ve temel aşama beslenmenin içinde olduğu fizyolojik ihtiyacı anlamak olacaktır.

Beslenme, toplumların ekonomik, sosyal ve kültürel yapılarına bağlıdır. Bu nedenle beslenme alışkanlıkları zamanla değişiklikler gösterebilmektedir. Gelir artışına bağlı olarak kişilerin tüketim alışkanlıkları da değişebilmektedir. Düşük gelir düzeyinde olan kişiler fiyata karşı duyarlılıkları yüksek olduğu için besin değerinden çok doyuruculuğu yüksek ürünleri tercih etme eğilimindedir. Gelir düzeyi artışı ile birlikte geleneksel gıdaların yerini sağlık, çeşitlilik, kolaylık, kalite ölçütlerine sahip gıdalarla birlikte organik ürünler almaktadır. Sosyal ve kültürel değişimler de beslenme düzeyini önemli düzeyde etkilemektedir. Eğitim düzeyinin artması, annenin çalışma hayatından giderek artan oranda pay alması, ulusal pazar sınırlarının kalkması, iletişım olanaklarının artması, perakendeciliğin gelişmesi ve ulaşım olanaklarının artması toplumların gıda ürünleri tüketimini değiştirebilmektedir.

Yükseköğrenim öğrencileri, potansiyel turist olarak değerlendirildiğinde turizmin yakın gelecek eğilimlerini temsil ettiği söylenebilir. Esasen genellikle ikamet ettikleri yerin dışında öğrenim görmeleri, para kazanma amacı gütmemeleri, genellikle eğitimleri ardından yaşadıkları yerlere dönmeleri açısından turist olarak bile değerlendirilebilmelerine karşın bu sürecin öğrenim faaliyetlerinin kapsadığı 2-4 yıl arasında olduğu için, turistlerin kalış sürelerine dâhil olmamalarından ötürü potansiyel turist olarak değerlendirilmeleri daha anlamlı bulunmuştur. Potansiyel turist olsun ya da olmasın, geleceğin mirasçıları bu gençlerin en temel ihtiyaçlarından olan fizyolojik ihtiyaçların temelinde yer alan yeme-içme alışkanlıklarının belirlenmesi ve değerlendirilmesi, ekonomik boyutu da olan sosyal temel anlayışı güden her kesimin ilgisini cezbetmektedir.

\section{Kavramsal Çerçeve}

İnsan davranışı açısından yemek yemenin ya da seçim yapmanın, hatta yemek yeme zamanı konusunda karar vermenin insanın değişik gereksinimlerini karşıladığı söylenebilir. Bu gereksinimler arasında fiziki gereklerden sosyal gruplaşmadan kaynaklanan gereklere, duygusal gereklerden imaj kaynaklı gereklere kadar birçok faktör vardır (Sökmen, 2005). 
Yemek bireysel ve toplumsal yönleri ile birçok sair etkileyicisi olan bir kültürel unsurdur. İnsan, fizyolojik yapısı itibariyle yemekle doğrudan ilgisi olduğu gibi sosyal yönüyle de yaşadığı kültürün etkisi altında bir yemek anlayışına sahiptir. Yaşanan fiziki ve kültürel coğrafya yemek kültürünü etkilemekte ve yaşam şeklindeki değişim ve dönüşümler yemek kültürünün de değişmesine sebep olmaktadır (Beşirli, 2010). İnsan sağlığı; beslenme, kalıtım, iklim ve çevre koşulları gibi birçok etmenin etkisi altındadır. Bu etmenlerin en önemlisi ise beslenmedir (Saygin vd, 2011).

İnsan ihtiyaçlarının başında gelen beslenme, 'biyolojik olarak büyüme, gelişme, sağlıklı ve üretken olarak uzun süre yaşamak için gerekli olan öğelerin alınması ve vücutta kullanılması' olarak ifade edilebilir. T1bben beslenme kavramı ise "vücutta metabolik fonksiyonların devamı için gerekli enerjinin sağlanmasında önemli bir yeri olan fizyolojik olgu" olarak tanımlanmaktadır (Orak, vd, 2006). Öte yandan enerji ise vücut isısının sağlanması ve organik faaliyetlerin sürdürülebilmesi için temel koşuldur (Orak, vd, 2006). Ancak söz konusu enerjinin sağlanması için gerekli besinlerin temini, insan tüketimi için uygun hale getirilmesi ve tüketim davranışları süreci, beslenmeyi salt biyolojik bir eylem olmaktan çıkarmakta, kültürel bir olgu haline dönüştürmektedir (Beşirli, 2010). Besin gereksinmesindeki farkl1lıklar; yaş, cinsiyet, fiziksel aktivite, hastalık durumu ve genetik yapı gibi faktörlerden etkilenebilir (Saygın vd, 2011). Dahası her toplumda, vücudu beslemenin ötesinde sosyo-kültürel ve sembolik rollerin etki ettiği, bunun yanı sıra duygusal durumlardan da etkilenen beslenme alışkanlıkları vardır (Sayan, 1999).

Beslenme alışkanlıkları, ailelerin sosyo-ekonomik durumlarına göre farklılaşmaktadır. Bireylerin ekonomik durumları tüketim düzeylerini ve alışkanlıklarını etkilemektedir (Beşirli, 2010). Edinilen yemek alışkanlıkları, psikolojik çatışmalar ve kültürel değerler ile kalıpların etkileşimden kaynaklanan öteki sorunlar kadar karmaşıktır. Örneğin ergenlik çağındaki kızlar, önemli bir psikolojik çatı̧̧a ve gelişme döneminde yemek yeme ile fiziksel görünümün kalıpları arasındaki çeşitli baskılardan kaynaklanan sorunlara daha açıktır (Sayan, 1999). Ergen çağda, beden birimi başına gereken enerji ve besin öğelerinin miktarı erişkine göre daha yüksektir. Aynı zamanda beden yapısındaki farklılıktan dolayı erkeklerin enerji gereksinmesi kadınlardan daha fazladır. Bireyin fiziksel aktivitesi arttıkça besin tüketiminin de artması, azaldıkça azalması gerekir. Dengelenememesi durumunda sağlık sorunları ortaya çıkar. Genelde insanın sosyoekonomik statüsü yükseldikçe fiziksel aktivitesi azalmakta, buna karşın tükettiği besinlerin enerji ve besin öğeleri yoğunluğu artmaktadır (Saygın vd., 2011). Ayrıca cinsiyet farklılaşmasının yiyeceklere ve içeceklere de yansıdığı görülmektedir (Beşirli, 2010). Ayrıca bir hastalık olarak kabul edilen yemek yeme dürtüsü ile ilgili bozukluklar, 'vücut ağırlığı takıntısı, vücudun şekli ile ilgili olumsuz düşünceler ve beraberinde getirdiği duygulanım bozukluklarının olduğu özel bir hastalık grubu' olarak nitelendirilmektedir (Kundakc1, 2005).

Besin öğeleri, organizmanın gereksinim duyduğu miktarlarda alınmaz ise, bu durum yetersiz beslenme olarak tanımlanır (Yıldırım vd, 2011). Besin öğelerinden bir veya bir kaçının gereğinden az diğerlerinin ise gereğinden fazla tüketimi, dengesiz beslenme olarak tanımlanır (Arslan vd, 2001). Ülkemizde yetersiz ve dengesiz beslenme; büyük bir toplumsal sorundur. Besin tüketim dengesizliği, eğitim, sağlık ve diğer sosyal haklardan yararlanmadaki eşitsizliklere bağlı olarak ülkemizde hem gelişmiş, hem de gelişmekte olan ülkelerin sorunları bir arada yer almaktadır (Baysal, 2003). Beslenme sorunları açısından riskli grupların birini de üniversite öğrencileri oluşturmaktadır. Özellikle yurtta kalan öğrenciler için beslenme başlı başına bir sorundur. Öğrencilerdeki beslenme sorununun başlıca nedenleri; bilgisizlik ve ekonomik yetersizliktir. Bu dönemde; özellikle fiziksel büyüme ve gelişmenin belirgin şekilde hızlanması, yaşam şekli ve beslenme alışkanlıklarının değişmesi, devamlı diyet yapma, sigara kullanımı ve spor yapma gibi özel durumlar enerji ve besin gereksinimlerini etkilemektedir. Bu dönemde beslenme; bireyin sağlıklı olarak yaşamını devam ettirebilmesi, okul başarısı ve ileriki yaşlarda oluşabilecek şişmanlık, kalp damar hastalığı, diyabet, kanser gibi kronik hastalıkların önlenmesi açısından büyük önem taşır (Saygın vd., 2011). İleri yaşlarda ortaya çıkması beklenen kronik hastalıklarda rol aldığı düşünülen yanlış beslenme alışkanlıklarının tespit edilerek yanlışların düzeltilmesi, dengesiz ve düzensiz beslenmeye bağlı olarak ortaya çıkabilecek hastalıkların önlenmesini sağlayacaktır (Belmaker ve Cohen, 1985).

Tüm canlıların yaşamını sürdürebilmesi için hayatının her döneminde beslenmeye ihtiyacı vardır (Çalıştır, vd, 2005). Ne var ki, geleceğin önemli insan kaynaklarını oluşturacak bu topluluğun beslenme alışkanlıkları iyi bilinmemektedir. Yapılan günlük aktivitenin özelliğine göre besinlerden sağlanan kalorinin miktarı değişiktir. Bu değerler üniversite kız öğrencisi için 1250-1500 Kcal/gün iken, erkek öğrenci için ortalama 1750-2000 Kcal/gün gerekmektedir. Ekonomik yönden bağımlı olan öğrenciler bir aile ortamına veya normal ev koşullarına sahip olmadıkça yeterli ve dengeli beslenemeyip, çoğunlukla eksik öğün ve dengesiz beslendikleri kabul edilmektedir (Orak, vd, 2006). Sağlıklı beslenme "bireyin yaşı, cinsiyeti ve fizyolojik durumu göz önünde bulundurularak ihtiyacı olan tüm besin öğelerinin yeterli miktarda karşılanması" olarak tanımlanmaktadır (Saygın vd, 2011). Her şey yolunda olsa dahi bu dönemin hızlı büyüme dönemi olmasından ötürü genellikle 18-24 yaş arasında bulunan gençler, yetişkinlere göre daha çok enerji tüketmekte ve dolayısıyla daha fazla besin gereksinimine ihtiyaç duymaktadırlar. Çocukluk ve adölesan dönemdeki dengesiz ve düzensiz beslenme alışkanlıklarının, ileri yaşlarda bazı hastalıkların ortaya çıkmasında rol alan parametrelerden biri olduğu bilinmektedir (Benjelloun, 2000; Noor,2000). 
Beslenme sağlığını bozan sorunlar; yetersiz beslenme, dengesiz beslenme, aşırı beslenme ve isteğe bağlı olarak az beslenmeyi içermektedir. Yetersiz beslenme sorunu, sağlı̆̆ı önkoşulları kapsamında ele alındığı gibi, sosyal denge ve yeterli temel kaynaklara da bağlıdır. Dengesiz beslenme bilgisizlikten kaynaklanabileceği gibi gıda reklamları, ambalaj vs. ile sandviççi, kafeterya ve restoranlardaki menülerle de yakından ilgilidir. Kimi ülkelerde gıda işleme sanayii, alkol ve tütün sanayilerinin ötesinde en büyük imalat sanayisini oluşturmaktadır. Gıda işleme teknolojisi; tarımsal üretim ile gıda maddelerinin pazarlama, dağıtım ve tüketimini, herhangi bir bilinçli eğitim kampanyasının başarabileceğinden çok daha fazla bireyin beslenme alışkanlığını etkilemektedir (Sayan, 1999). 'Fert ve toplum olarak insan sağlığının korunması' anlamına gelen hijyen ve araç-gereç üzerindeki sağlığa zararlı mikroorganizmaları temizleme' anlamına gelen sanitasyon (Sökmen, 2001) kurallarına uygun olmayan gıda üretim kanallarının insan sağlığını tehlikeye atması beslenme açısından bir diğer sorundur. Çünkü 'temizlik, yiyeceğin ele alındığı her aşamada çok önemlidir' (Koçak, 2006).

Contento vd. (1998) tarafından yapılan bir çalışmada, genç tüketicilerin beş farklı gruba ayrıldığı görülmektedir. Bunlar, damak zevkini öne alanlar, sosyal/çevreciler, kişisel, kısmen destekli ve sağlık menşeili ebeveyn destekli gruplardır (Sezek, vd, 2008). Günümüz sosyo-ekonomik koşulları ve sağlık kuralları yiyecekiçecek gereksinimlerinin karşılanmasını rastgele bir şekilde değil bilinçli ve bilimsel temellere dayalı olarak yapılmasını zorunlu kılmaktadır (Türksoy, 2002).

\section{Yöntem}

YÖK tarafından en son istatistikleri verilen 2012-2013 öğretim yılı verilerine göre üniversitelerde öğrenim gören toplam öğrenci sayısı 2268 753’ü kız, 2 706 937'si erkek olmak üzere 4975 690'dır. Açık Öğretim hariç bu öğrencilerin 1257 828’i ön lisans (K: 615 072; E: 642 756), 2744 540’1 ise lisans (K: 1255 435; E: 1489 105) derecesinde ve üniversite kurumlarında eğitim almaktadır (ÖSYM, 2015).

$\mathrm{Bu}$ çalışmanın temel amacı Bartın Üniversitesi Bartın Meslek Yüksekokulu ölçeğinde yükseköğrenim öğrencilerinin beslenme alışkanlıkları tespit etmek ve Bartın ili düzeyinde gelişmişliği olan yerleşimlerdeki öğrencilerin beslenme kısıtlarını belirlemektir. Araştırma geleceğin sahibi olan ve turizm açısından da yakın geleceğin potansiyel turist kitlesini oluşturan öğrencilerin beslenme kısıtlarının neler olabileceğini belirleyip bunlara yönelik öneriler getirdiği için önemli görülmektedir. Ayrıca, araştırma bulguları sayesinde nüfus ve imkân açısından benzer gelişmişlik gösteren illerdeki öğrencilere yönelik beslenme kısıtların çözümüne yönelik bir örnek teşkil edebileceği için de önemli görülmektedir. Yeme-içme alışkanlıkları ve sıklıklarına dair yöneltilen tüm sorular, öğrencilerin yanıtlarına göre ayrı olarak ele alınacak ve görüş farklılıkları uygun testlerle (parametrik ya da parametrik olmayan) analiz edilecektir.

$\mathrm{Bu}$ amaçla konuya ilişkin önceki yazın taranarak bir anket formu geliştirilmiş ve Bartın Meslek Yüksekokulunda eğitimlerine devam eden öğrencilere uygulanmıştır. Anket formu, Orak, vd, (2006), Sezek, vd, (2008) ve Baysal (2003)'ün araştırmalarında başvurdukları anket formlarından uyarlanmıştır. Soru formu 3 bölümden oluşmaktadır: 'Beslenme Alışkanlıkları' başlığı altındaki ilk bölümde 10 adet kapalı uçlu, 1 adet çoktan seçmeli, toplam 17 adet kahvaltı besin ve içecekleri tercihine yönelik alt soruları olan 2 adet sıklık ve yemek seçiminde dikkat edilen özelliklere dair 6 alt kategorisi olan 1 adet derecelendirme sorusu; 'Yiyecek İ̧̧ecek Tüketimine Yönelik Sorular' başlığı altında ikinci bölümde 20 adet yiyecek ve 10 adet içecek tercihine yönelik alt soruları olan 2 adet sıklık sorusu yer almaktadır. 'Demografik Bilgiler' başlığı altında üçüncü ve son bölümde ise 2 adet açık uçlu boy ve kilo sorusu, 1 adet çoktan seçmeli ve 6 adet kapalı uçlu toplam 9 adet soru vardir.

Anket formu öğrencilere dağıtılmadan önce farklı sınıflardan 105 öğrenciye elektronik olarak bir ön uygulama yapılmıştır. Elde edilen dönütler ve akademik uzman değerlendirmesi doğrultusunda anketten işlemeyen sorular çıkartılmış ve soru formuna son hali verilmiştir. Pilot uygulamanın ardından anketler kolayda örneklem yöntemiyle ön uygulamada yer alan öğrenciler de dâhil edilerek toplam 547 kişiye Nisan-Mayıs 2015 tarihleri arasında araştırmacılar tarafından bizzat uygulanmıştır. Bartın Meslek Yükseokulunda 2014-2015 öğretim yılı itibariyle birinci öğretimde 1100 ve ikinci öğretimde 480 olmak üzere toplam 1580 öğrenci öğrenim görmektedir. Örneklem 'hedef çalışma evreni hakkında fikir sahibi olmak ve çalışma sonucunu tüm çalışma evrenine genelleme yapmak için o evrendeki öğelerden oluşan gruptur' (Böke, 2014). Bu çalışmanın örneklemi ana kitlenin \%34,62'isini oluşturmaktadır. Sekeran (1992) ölçeğine göre 1580 kişilik evren için kabul edilebilir örneklem sayısı 310 olarak ifade edilmiş (Altunışık, vd, 2010) olsa da araştırmanın güvenirliliğini artırmak amacıyla 547 kişiye ulaşılmıştır. Anketten elde edilen verilen istatistik paket programı kullanılarak analiz edilmiştir.

Ölçeğin güvenirlik düzeyi için, oldukça yaygın olarak kullanılan alfa katsayısı (Cronbach Alpha) hesaplanmış ve demografik sorular çıkarıldıktan sonra bu oran 0,804 olarak bulunmuştur. Bir araştırmanın güvenilir olarak kabul edilmesi için alfa değerinin 0 ile 1 arasında en az 0,7 olmasını (Altunışık, vd, 2010); 0,80 ile 1,00 arasında güvenirliğin ise yüksek olduğu (Kozak, 2014) görüşlerine göre araştırma soruları güvenilir bulunmuştur.

Çalışmada ayrıca normallik testlerine ve normallik grafiğine başvurularak her gruba ait veri dağılımlarının normal dağılım gösterip göstermediğine göre, parametrik ya da parametrik olmayan test tekniklerinin 
kullanılması planlanmıştır. Verilerin normal dağılım göstermesi ile birlikte, diğer varsayımları (verilerin nicel olması, incelenen grupların bağımsız bireylerden oluşması, örneklemin büyüklüğü) yerine getirip getirememe durumları dikkate alınarak parametrik ya da parametrik olmayan analiz yöntemlerine başvurulması ve böylece iki ya da daha fazla bağımsız değişkene göre gerekçeler arasında -varsa- anlamlı farklılıkların belirlenmesine çalışılmıştır.

Araştırma 2014-2015 eğitim öğretim yılında Bartın Meslek Yüksekokulunda öğrenim gören ve anketi cevaplamaya gönüllü olan öğrencilerle sınırlıdır. Ayrıca anketlere verilen cevapların içten ve doğruyu yansıtıcı düşünce ve alışkanlıklarından oluştuğu var sayılmaktadır.

\section{Bulgular}

\subsection{Demografik Özelliklere İlişkin Bulgular}

Tablo 1'de öğrencilere ilişkin demografik özellikler sunulmuştur. Bu bilgilere göre ankete katılan öğrencilerin çoğunluğu kadın, büyük oranda 21-22 yaş aralığında ve birinci sınıf öğrencisidir. Öğrenciler ağırlıklı olarak evde ikamet etmekte ve 400 " ve altı gelire sahiptir.

\begin{tabular}{|c|c|c|c|}
\hline & & $N$ & $\%$ \\
\hline \multirow[t]{2}{*}{ Cinsiyet } & Kadın & 308 & 56,3 \\
\hline & Erkek & 239 & 43,7 \\
\hline \multirow[t]{6}{*}{ Yaş } & $<17$ & 3 &, 5 \\
\hline & $18-20$ & 7 & 1,3 \\
\hline & $21-22$ & 487 & 89,0 \\
\hline & $23-24$ & 28 & 5,1 \\
\hline & $25-26$ & 6 & 1,1 \\
\hline & $27+$ & 16 & 2,9 \\
\hline \multirow[t]{3}{*}{ Sinif } & 1 & 445 & 81,4 \\
\hline & 2 & 92 & 16,8 \\
\hline & Uzatmalı & 10 & 1,8 \\
\hline \multirow[t]{2}{*}{ Öğretim türü } & Normal öğretim & 331 & 60,5 \\
\hline & İkinci öğretim & 216 & 39,5 \\
\hline \multirow[t]{5}{*}{ İkamet } & $\mathrm{Ev}$ & 246 & 45,0 \\
\hline & Devlet yurdu & 119 & 21,8 \\
\hline & Özel yurt & 117 & 21,4 \\
\hline & Pansiyon/otel & 37 & 6,8 \\
\hline & Aile ve akraba yanı & 28 & 5,1 \\
\hline \multirow[t]{4}{*}{ Aylık gelir } & $400 "$ ve alt1 & 248 & 45,3 \\
\hline & $401-700^{*}$ & 182 & 33,3 \\
\hline & $701-1000 *$ & 63 & 11,5 \\
\hline & $1001{ }^{*}$ ve üzeri & 54 & 9,9 \\
\hline
\end{tabular}

Tablo 1. Katılımcılara ilişkin demografik özellikler

Öğrencilerin kilolarını öğrenmek amacıyla yöneltilen ucu açık soruya verdikleri cevaba göre kadınlar için ortalamanın $56,27 \mathrm{~kg}$ olduğu, erkeklerin ise $70,69 \mathrm{~kg}$ olduğu tespit edilmiştir (Şekil 1).
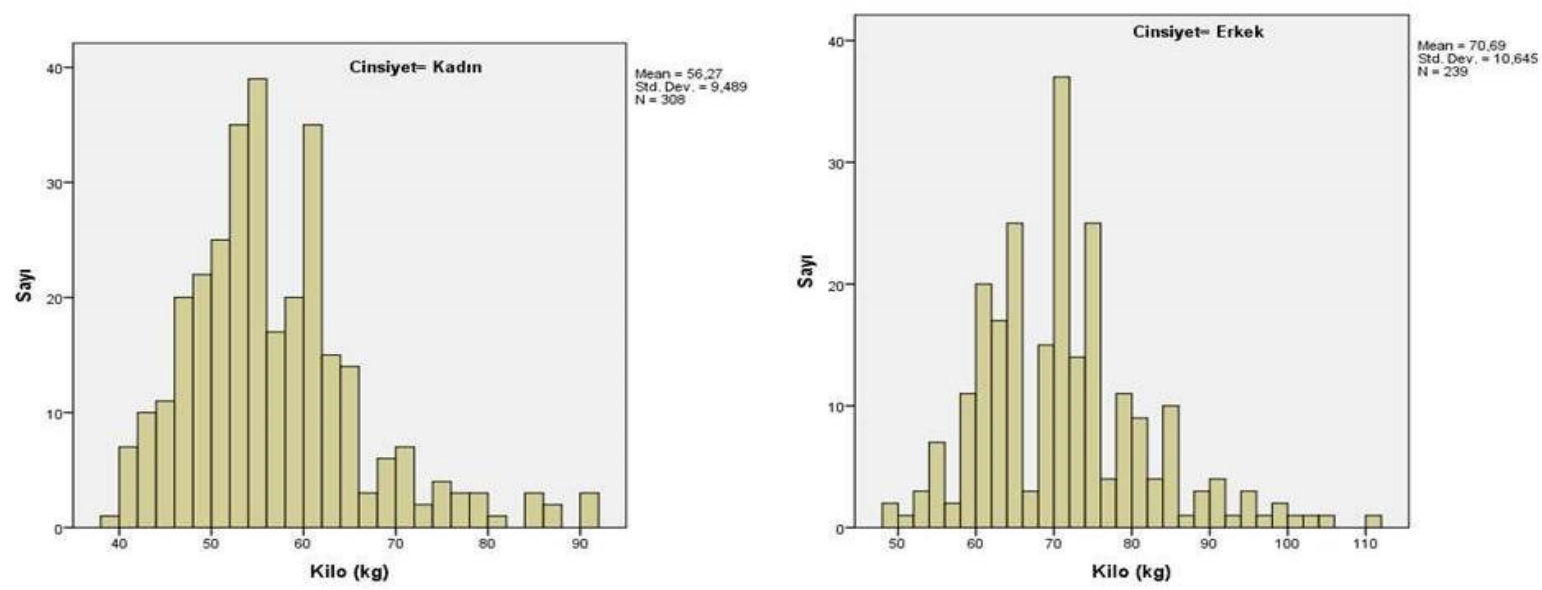

Şekil 1. Öğrencilerin kilo durumu 
Öğrencilerin boylarını öğrenmek amacıyla yöneltilen ucu açık soruya verdikleri yanıta göre kadınların 162,75 $\mathrm{cm}$ boy ortalamasına, erkeklerin ise $174,48 \mathrm{~cm}$ ortalamaya sahip oldukları görünmektedir (Şekil 2).
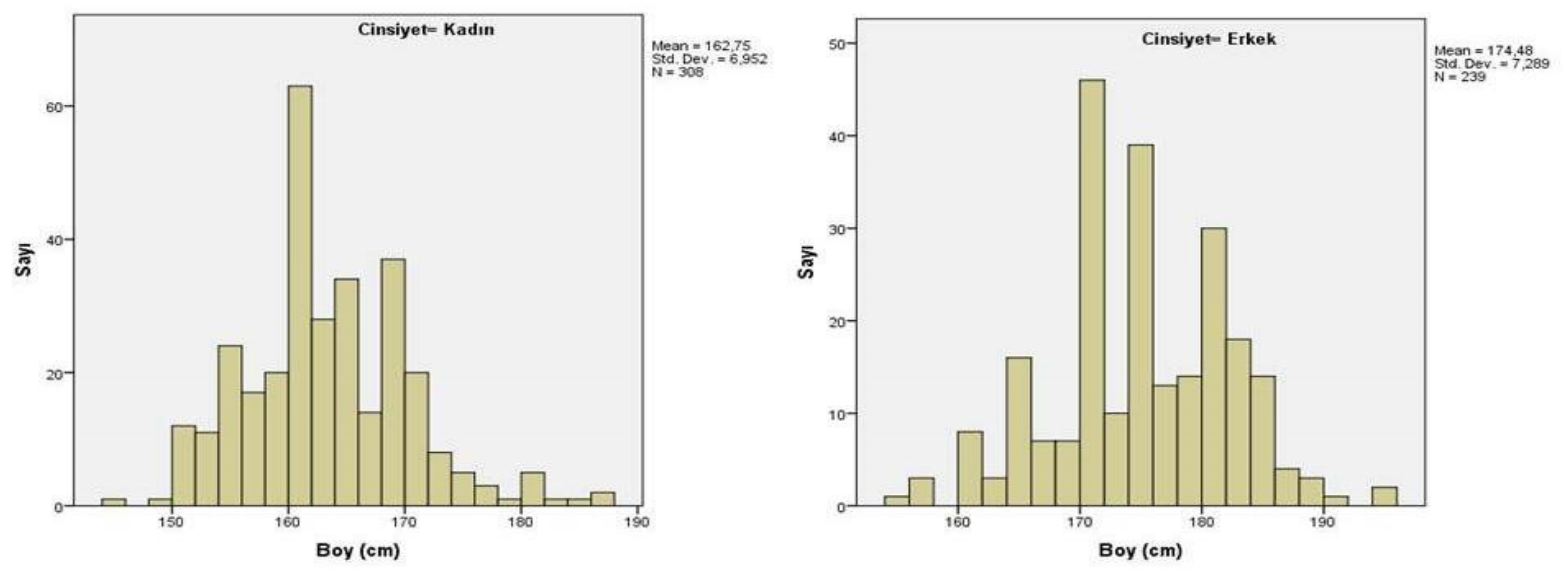

Şekil 2. Öğrencilerin boy durumu

Cinsiyetlere göre boy ve kilo bilgilerini kullanarak Vücut Kitle İndeksi hesaplamalarına göre ise kadınların

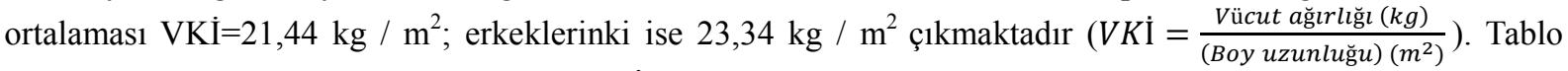
2'de görüldüğü üzere her iki grup için de VKİ değerlerinin "Sağllkll" aralığında olduğu, dolayısıyla öğrencilerin ortalamalarının "boylarına göre uygun ağırlıkta olduğunu" ve "yeterli ve dengeli beslenerek ve düzenli fiziksel aktivite yaparak bu ağırlıklarını korumaya özen göstermelerinin gerektiği”’ söylenebilir (Hesaplama, 2015).

Kilo $\quad 45.547 .750 .052 .354 .556 .859 .161 .463 .665 .968 .270 .572 .775 .077 .379 .581 .884 .186 .488 .690 .993 .295 .5$ !

\begin{tabular}{|c|c|c|c|c|c|c|c|c|c|c|c|c|c|c|c|c|c|c|c|c|c|c|c|c|}
\hline Boy & & Do & su & KI & & & 5 & al|k\| & & & & $\mathrm{Fa}$ & $\mathbf{Z} \mid$ & ilolu & & & 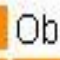 & & & & & D & & \\
\hline 52.4 & 19 & 20 & 21 & 22 & 23 & 24 & 25 & 26 & 27 & 28 & 29 & 30 & 31 & 32 & 33 & 34 & 35 & 36 & 37 & 38 & 39 & 40 & 41 & 42 \\
\hline 4.9 & 18 & 19 & 20 & 21 & 22 & 23 & 24 & 25 & 26 & 27 & 28 & 29 & 30 & 31 & 32 & 33 & 34 & 35 & 36 & 36 & 37 & 38 & 39 & 40 \\
\hline 7.4 & 18 & 19 & 20 & 21 & 22 & 22 & 23 & 24 & 25 & 26 & 27 & 28 & 29 & 30 & 31 & 32 & 33 & 33 & 34 & 35 & 36 & 37 & 38 & 39 \\
\hline 60.0 & 17 & 18 & 19 & 20 & 21 & 22 & 23 & 24 & 24 & 25 & 26 & 27 & 28 & 29 & 30 & 31 & 32 & 32 & 33 & 34 & 35 & 36 & 37 & 38 \\
\hline 32.5 & 17 & 18 & 18 & 19 & 20 & 21 & 22 & 23 & 24 & 24 & 25 & 26 & 27 & 28 & 29 & 30 & 31 & 31 & 32 & 33 & 34. & 35 & 36 & 37 \\
\hline 65.1 & 16 & 17 & 18 & 18 & 20 & 20 & 21 & 22 & 23 & 24 & 25 & 25 & 26 & 27 & 28 & 29 & 30 & 30 & 31 & 32 & 33 & 34 & 35 & 35 \\
\hline 7.6 & 16 & 17 & 17 & 18 & 19 & 20 & 21 & 21 & 22 & 23 & 24 & 25 & 25 & 26 & 27 & 28 & 29 & 29 & 30 & 31 & 32 & 33 & 34 & 34 \\
\hline 70.1 & 15 & 16 & 17 & 18 & 18 & 19 & 20 & 21 & 22 & 22 & 23 & 24 & 25 & 25 & 26 & 27 & 28 & 29 & 29 & 30 & 31 & 32 & 33 & 33 \\
\hline 2.7 & 15 & 16 & 16 & 17 & 18 & 19 & 19 & 20 & 21 & 22 & 22 & 23 & 24 & 25 & 25 & 26 & 27 & 28 & 28 & 29 & 30 & 31 & 32 & 32 \\
\hline 75.2 & 14 & 15 & 16 & 17 & 17 & 18 & 19 & 20 & 20 & 21 & 22 & 22 & 23 & 24 & 25 & 25 & 26 & 27 & 28 & 28 & 29 & 30 & 31 & 31 \\
\hline 77.8 & 14 & 15 & 15 & 16 & 17 & 18 & 18 & 19 & 20 & 20 & 21 & 22 & 23 & 23 & 24 & 25 & 25 & 26 & 27 & 28 & 28 & 29 & 30 & 30 \\
\hline 180.3 & 14 & 14 & 15 & 18 & 18 & 17 & 18 & 18 & 19 & 20 & 21 & 21 & 22 & 23 & 23 & 24 & 25 & 25 & 26 & 27 & 28 & 28 & 29 & 30 \\
\hline 82.8 & 13 & 14 & 14 & 15 & 16 & 17 & 17 & 18 & 19 & 19 & 20 & 21 & 21 & 22 & 23 & 23 & 24 & 25 & 25 & 26 & 27 & 27 & 28 & 29 \\
\hline 85.4 & 13 & 13 & 14 & 15 & 15 & 16 & 17 & 17 & 18 & 19 & 19 & 20 & 21 & 21 & 22 & 23 & 23 & 24 & 25 & 25 & 26 & 27 & 27 & 28 \\
\hline 87.9 & 12 & 13 & 14 & 14 & 15 & 16 & 16 & 17 & 18 & 18 & 19 & 19 & 20 & 21 & 21 & 22 & 23 & 23 & 24 & 25 & 25 & 26 & 27 & 27 \\
\hline 0.5 & 12 & 13 & 13 & 14 & 15 & 15 & 16 & 16 & 17 & 18 & 18 & 19 & 20 & 20 & 21 & 21 & 22 & 23 & 23 & 24 & 25 & 25 & 26 & 26 \\
\hline 93.0 & 12 & 12 & 13 & 14 & 14 & 15 & 15 & 16 & 17 & 17 & 18 & 18 & 19 & 20 & 20 & 21 & 22 & 22 & 23 & 23 & 24 & 25 & 25 & 26 \\
\hline
\end{tabular}

\section{Tablo 2. Vücut Kitle İndeksi (VKI) Kaynak: ozeldiyet.net}

\subsection{Beslenme Alıșkanlıklarına İlișkin Bulgular}

Öğrencilerin ana öğünlerini sıklıkla nere yaptıkları ve ne yediklerine ilişkin frekans analizi sonuçları Tablo 3'de verilmiştir. Buna göre öğrencilerin yarıdan fazlası kahvaltılarını evde yapmakta; öğle yemeklerini en yüksek oranda okulun yemekhanesinde ve evde; akşam yemeklerini ise evde yemektedirler. Okul yemekhanesinde özel bir kahvaltı sunumunun olmaması göz önünde bulundurulacak olursa, başlangıç ve en temel öğün olan kahvaltının genellikle evde yapılıyor olması (bilinçli bir tercih sonucu olsun ya da olmasın) sağlıklı bir beslenme alışkanlığı olarak değerlendirilebilir. Kahvaltının içeriğine dair yapılan tanımlayıcı istatistiksel veriye bakıldığında öğrencilerin en sık tükettikleri besin sıralaması en sıktan en aza, (sıklık değeri 
ortalaması $\overline{\boldsymbol{X}} \geq \mathbf{3}$ olarak ele alındığında) zeytin, peynir, domates ve yumurta olarak belirlenmiştir. Besinlerden en az tüketilenler ise (ortalaması $\bar{X} \leq \mathbf{2}$ olarak ele alındığında) en az sıktan en sıka çorba, tahıl gevreği, meyve, tereyağ-margarin, salam, tost, poğaça ve bal olarak ifade edilmiştir. Kahvaltıda tercih edilen içecek olarak ise çay ön plana çıkarken kahve ve süt en az tercih edildiği tespit edilmiştir. 'iyi bir kahvaltı güne başarı ile girme şansını artırır' (Yörükoğlu ve Yörükoğlu, 1998)

Gün ortası öğünün çoğunlukla okul yemekhanesinde yeniliyor olmasının yemek çeşitlendirilmesi ve kalori denetimlerinin yapıldığı düzende olmasından ötürü yemekhane fiyatlarının öğrenci bütçesince karşılanabilir makul seviyelerde olmasının sağlık açısından bir avantaj olduğu iddia edilebilir.

Gün ortası ve gün sonu öğünlerinde neler yediklerine dair bir sorgulama yapıldığında ise öğrenciler, öğle ve akşam yemeklerinin her ikisinde de sebze ağırlıklı sulu yemek yediklerini belirtmektedirler. Ne var ki her iki ana öğünde de hamburger, patates kızartması, ekmek arası döner-köfte, sandviç, simit, tost gibi hızlı yiyeceklerin ikincil olarak tüketiliyor olması imkân ve sağlık açısından bir riskin kapıda olduğuna işaret ediyor olabilir.

\begin{tabular}{|c|c|c|}
\hline Kahvaltınızı sıklıkla nerede yaparsınız? & $\mathrm{N}$ & $\%$ \\
\hline Evde & 355 & 64,9 \\
\hline \multirow[t]{2}{*}{ Okulda } & 192 & 35,1 \\
\hline & 547 & 100,0 \\
\hline \multicolumn{3}{|l|}{ Öğle yemeklerinizi sıklıkla nerede yersiniz? } \\
\hline Evde & 161 & 29,4 \\
\hline Okul yemekhanesinde & 215 & 39,3 \\
\hline Restoranda & 43 & 7,9 \\
\hline Hizlı yiyecek içecek işletmesinde & 68 & 12,4 \\
\hline Kafe-kantin-pastanede & 58 & 10,6 \\
\hline \multirow[t]{2}{*}{ Kendim hazırlayıp götürüyorum } & 2 & ,4 \\
\hline & 547 & 29,4 \\
\hline \multicolumn{3}{|l|}{ Öğle yemeklerinde genellikle ne tür besinler tercih ediyorsunuz? } \\
\hline Sebze ağırlıklı (sulu yemekler) & 223 & 40,8 \\
\hline Et ağırlıklı yemekler & 110 & 20,1 \\
\hline $\begin{array}{l}\text { Fast-food (hamburger, patates kızartması, ekmek arası döner-köfte, sandviç, simit, } \\
\text { tost) }\end{array}$ & 212 & 38,8 \\
\hline $\begin{array}{lll}20 p l a m & \text { Topla }\end{array}$ & 545 & 99,6 \\
\hline Eksik veri & 2 & ,4 \\
\hline \multicolumn{3}{|l|}{ Akşam yemeklerinizi sıklıkla nerede yersiniz? } \\
\hline Evde & 400 & 73,1 \\
\hline Okul yemekhanesinde & 65 & 11,9 \\
\hline Restoranda & 36 & 6,6 \\
\hline Hızlı yiyecek içecek işletmesinde & 29 & 5,3 \\
\hline Kafe-kantin-pastanede & 16 & 2,9 \\
\hline \multirow[t]{2}{*}{ Kendim hazırlayıp götürüyorum } & 1 & ,2 \\
\hline & 547 & 100,0 \\
\hline \multicolumn{3}{|l|}{ Akşam yemeklerinde ne tür besinler tercih edersiniz? } \\
\hline Sebze ağırlıklı (sulu yemekler) & 260 & 47,5 \\
\hline Et ağırlıklı yemekler & 99 & 18,1 \\
\hline $\begin{array}{l}\text { Fast-food (hamburger, patates kızartması, ekmek arası döner-köfte, sandviç, simit, } \\
\text { tost) }\end{array}$ & 185 & 33,8 \\
\hline Toplam & 544 & 99,4 \\
\hline Eksik veri & 3 & 6 \\
\hline
\end{tabular}

Tablo 3. Öğrencilerin Ana Öğ̈̈nlerini Nerede Yaptıkları ve Sıklıkla Ne Yediklerine İlişkin Frekans Analizi

Beslenme alışkanlıklarının cinsiyete göre karşılaştırılması amacıyla yapılan bağımsız t-testine sonuçları Tablo 4'te verilmiştir. Tabloda da görüldüğü gibi öğrencilerin günde kaç adet ana ve ara ögün yeme düzeyleri istatistiki açıdan $\mathrm{p}<0,05$ anlamlılık düzeyinde bir farklılık yoktur. Ne var ki ana öğüt atlama durumu iki yönlü anlamlılık derecesi olarak, $025<0,05$ olduğundan cinsiyetler arasında istatistiksel olarak anlamlı bir fark söz konusudur. 


\begin{tabular}{|c|c|c|c|c|c|c|}
\hline İfadeler & Cinsiyet & $\mathbf{N}$ & $\bar{X}$ & S.S. & $\mathbf{t}$ & $\begin{array}{c}\text { Sig. } \\
\text { (2-tailed) }\end{array}$ \\
\hline Ana öğün atlar mısınız? & $\begin{array}{l}\text { Kadın } \\
\text { Erkek }\end{array}$ & $\begin{array}{l}308 \\
239\end{array}$ & $\begin{array}{l}1,3019 \\
1,4310\end{array}$ & $\begin{array}{l}, 45985 \\
, 79020\end{array}$ & $-2,246$ &, $025^{*}$ \\
\hline $\begin{array}{l}\text { Günde kaç ana öğün yemek yersiniz? } \\
\text { (Sabah-öğle-akşam) }\end{array}$ & $\begin{array}{l}\text { Kadın } \\
\text { Erkek }\end{array}$ & $\begin{array}{l}308 \\
239\end{array}$ & $\begin{array}{l}2,3442 \\
2,3849\end{array}$ & $\begin{array}{l}56936 \\
, 64360 \\
\end{array}$ &,- 773 & ,440 \\
\hline $\begin{array}{l}\text { Günde kaç ara öğün yemek yersiniz? } \\
\text { (Kuşluk-ikindi-gece) }\end{array}$ & $\begin{array}{l}\text { Kadın } \\
\text { Erkek }\end{array}$ & $\begin{array}{l}308 \\
239\end{array}$ & $\begin{array}{l}1,9513 \\
1,8787\end{array}$ & $\begin{array}{l}1,00207 \\
1,00311\end{array}$ &, 841 & ,401 \\
\hline
\end{tabular}

Tablo 4. Beslenme Alışkanlıklarının Cinsiyete Göre Karşılaştırılması

\section{Sonuç ve Öneriler}

Bartın, TUİK adrese dayalı nüfus kayıt sistemine göre 72995 şehir merkezi nüfuslu Batı Karadeniz Bölgesinde yer alan ve 28.08.1991 tarih ve 3760 sayılı kanunla Türkiye'nin 74. ili hüviyetine kavuşmuş bir yerleşim yeridir (Bartın Valiliğii, 2015; Bartın Belediyesi, 2015).

Bartın Üniversitesi ise 5765 sayılı ve 22.05.2008 tarihinde kurulmuş bir devlet üniversitesidir. Bünyesinde; 7 Fakülte, 3 Enstitü, 1 Yüksekokul, 2 Meslek Yüksekokulu bulunmaktadır. 2013-2014 öğretim döneminde personel sayısı 424'ü akademik ve 236 'sı idari olmak üzere toplam 660 'tır. Öğrenci sayısı ise 3.168'i k1z, 4.517'si erkek ve 121'i uzaktan eğitim olmak üzere toplam 7.865'tir. Bu öğrencilerin 1592'si Bartın Meslek Yüksekokulunda kayıtlıdır (Bartın Üniversitesi, 2015; Bartın Meslek Yüksekokulu, 2015).

Ülkemizin küçük-orta büyüklükteki illeri gibi Bartın, gerek yerel bir idari birim olarak gerekse bünyesindeki üniversite olarak gelişmekte olan özellikler göstermektedir. Bu durum geleceğin sahipleri olan öğrencilerin gelişme aşamasındaki bireysel gelişimlerinde önemli bir taraf olan beslenme eğilimlerinin ve bu konudaki kısıtların araştırılmasını gerekli kılmaktadır.

Öğrenciler verdikleri bilgiler doğrultusunda yeterli ve dengeli beslenerek ve düzenli fiziksel aktivite yaparak bünyelerini korumaya özen göstermelerinin gerekli olduğu normal aralıkta vücut kitle indeksi değerine sahip bulunmuştur. Ne var ki temel beslenme alışkanlığının göstergesi olan ara öğünlerin edinildiği yerler ve bu ögünlerde alınan besinler sorgulamasında okul bünyesinde faaliyet gösteren yemekhane ve kantin/kafeterya birimlerinin başı çektiği ancak özellikle gün başı ve orta öğünlerde yenilen besinlerin hızlı yiyeceklerden oluştuğu gözlenmektedir. Özellikle morbid obezite olarak adlandırılan ve Avrupa ve Amerika'da gençlerin gelişiminde önemli bir sağlık sorunu olan aşırı kilo alımının bu tür yiyeceklerden kaynaklandığı ise bilimsel pek çok araştırma sayesinde ifade edilmektedir. Hal böyleyken günlük beslenimlerine dikkat etmesi gerek öğrencilerin daha beslenme konusunda daha bilinçli olmaları için seminer ve eğitimler düzenlenip onların yemek yiyeceği işletmelerin çeşitlenmesi ve denetlenmesi gerektiği söylenebilir.

Öğrencilerin tükettikleri besinlere bakıldığında ise en üst sıraları karbonhidrat ağırlıklı besinlerin olduğu; protein içeren et ürünleri ve sebzelerin ise aşağı sıralarda tüketildiği anlaşılmaktadır. Günlük tüketilen içecekler sıralamasında da durum pek farklı değildir. Öğrenciler en çok çay, kahve ve hazır meyve sularını tükettiklerini ifade etmekte bitki çayı, taze sıkılmış meyve suyu gibi içecekler ise geri sıralarda yer almaktadır. Bu durum bilinçsizlik eğilimini gösteriyor olduğu kadar ekonomik ve yiyecek-içecek işletmelerinde bulamamakla da ilgili olabilir. Her iki durumda öğrencilerin sağlıklı besinler tüketme eğilimlerinde kısıtların olduğu ve bu konuda gerekli önlemlerin alınması gerektiği sonucu çıkartılabilir.

Öğrencilerin beslenme alışkanlıkla ne cinsiyete göre ne de beslenme bilincine göre farklılık göstermektedir. Aralarındaki fark sadece kötü beslenme alışkanlığı olarak da ifade edilebilecek olan ara öğün tüketim sıklığında ve en alt düzey gelirin olduğu gruplar arasında görülmektedir. Bunun nedenlerinin en başında beslenme kısıtlarının ekonomik nedenlere bağlı olması ve yazında yer alan 'ekonomik düzey düştükçe besinlerin sağlılı oluşundan çok doyurucu olmasına bakıldığı’ bulgusuyla örtüştüğü söylenebilir (Saygın vd., 2011; Beşirli, 2010; Orak, vd, 2006).

Öğrencilerin beslenme alışkanlıklarına yönelik kısıtları verdikleri cevaplara göre genellikle şu unsurlardan oluşmaktadır:

- Ekonomik olanaklarım yetersizliği

- Yemek yiyecek yer bulamamaları

- Zamanın kısıtlı oluşu

- Evde hazırlayanın olmayışı (özellikle bekâr evinde kalanlar için)

- Okula, kursa, spor faaliyetlerine vb. etkinliklere geç kalma

- Kökten alışkanlığın olmaması ve dolayısıyla iştah yoksunluğu

- Yalnız olmaları

- Rejim yapmaları 
Tüm bu kısıtlar esasen yerleşmemiş üniversite kültürünün ve aileden bağımsız öğrencilik olan üniversite öğrencilere yönelik kuruluşların yeterli olmayışına bağlanabilir. Beslenme kısıtlarının giderilmesi ve sağlıklı beslenmeye yönelik öneriler ise şu şekilde özetlenebilir:

1. Gelir dağılımı dengesizliğinin kabul edilebilir düzeye indirilerek temel besinlerden vergi alınmamalıdır.

2. Beslenme sağlığımız için en ideal olanı değişik besinlerden alınmasıdır. Örneğin protein ihtiyacı sadece hayvansal besinlerden değil yaklaşık değerlere sahip baklagillerden sağlanabilir.

3. Haftada birkaç kez beyaz et (tavuk, balık), yumurta, her gün kuru baklagiller, tahıllar, sebze ve meyveler ile süt ve süt ürünleri tüketilmeli ve bunların tüketimi teşvik edilmelidir.

4. Yeterli nişasta ve lifi bulunduran rafine edilmemiş tahıldan yapılan ürünler(kepekli ekmek), baklagiller, sebze ve meyveler tüketilmelidir.

5. Kızartılmış yiyecekler, sebzeler yerine haşlanmış ya da suda pişirilmiş olanı tercih edilmelidir. Bitkisel sıvı yağlar kullanılmalıdır. Yemeklere konan yağlar kızartılmadan doğrudan konmalıdır.

6. Kola, gazoz, hazır meyve suları gibi içecekler yerine ayran, süt, taze sıkılmış meyve suları içilmesi tercih edilmeli; mayalı ya da mayasız alkollü içeceklerin tüketilmesi için ise yaş sınırı üniversite eğitimi ortalaması olan 21-22'nin üzerine çıkartılmalıdır.

7. Nitrat ve nitrit içeren salam, sosis gibi yiyecekler sık tüketilmemeli ve bunları içeren tost, pide gibi yiyecekler kısitlanmalıdır.

8. Sağlık hizmetlerini parayla alınıp-satılır ve sadece tedaviye yönelik durumundan kurtararak koruyucu sağlık sistemine yönlendirilmeli ve bu hizmetlerde beslenme eğitiminin etkin bir şekilde dâhil edilmelidir.

9. Eğitim-öğretim ve sağlık hizmetlerinin her kademesinde beslenme eğitimine yer verilmelidir. Bunun için temel eğitim ve yükseköğretim kurumlarında beslenme faaliyetleri, beslenme öğretmeninin denetiminde yürütülmeli, eğitim-öğretim programlarında beslenme konuları yer almalıdır.

\section{Kaynakça}

- Altunışık, Coşkun, Bayraktaroğlu, ve Yıldırım, 2010. Sosyal Bilimlerle Araştırma Yöntemleri SPSS Uygulamalı. Sakarya Yayıncılık, Sakarya

- Arslan, Bozkurt, Karaağaoğlu, Mercanlıgil ve Erge 2001. Yeterli- Dengeli Beslenme ve Sağlıklı Zayıflama Rehberi. Özgür Yayınları, İstanbul.

- Balmaker ve Cohen 1985. "The advisability of the prudent diet in adolescence", J Adolesc Health Care, 6, 224-232.

- Bartın Belediyesi, 2015. http://www.bartinbelediyesi.com

- Bartın Meslek Yüksekokulu, 2015. http://myo.bartin.edu.tr/

- Bartın Üniversitesi, 2015. www.bartin.edu.tr

- Bartın Valiliği, 2015. www.bartin.gov.tr

- Baysal, 2003. “Sosyal Eşitsizliklerin Beslenmeye Etkisi”, C. Ü. Tip Fakültesi Dergisi, XXV (4), 66-72.

- Benjelloun, 2002. "Nutrition transition in Morocco", Public Health Nutr, 5 (1A), 135-140.

- Beşirli, 2010. "Yemek, kültür ve kimlik”,. Milli Folklor (87), 159-169.

- Böke, 2014. “Örnekleme”, içinde Sosyal Bilimlerde Araştırma Yöntemleri (Ed: Kaan Böke), Alfa Yayınları, İstanbul

- C Çalıştır, Dereli, Eksen ve Aktaş 2005. "Muğla Üniversitesi öğrencilerinin beslenme konusunda bilgi düzeylerinin belirlenmesi", Uluslararası Ínsan Bilimleri Dergisi, 2 (2), 1-8.

- Hesaplama, 2015. http://vucut-kitle-endeksi.hesaplama.net

- Koçak, 2006. Yiyecek İçecek Hizmetleri Yönetimi. Detay Yayıncılık, Ankara.

- Kozak, 2014. Bilimsel Araştırma: Tasarım, Yazım ve Yayım Teknikleri. Detay Yayıncılık, Ankara.

- Kundakcı, 2005. Üniversite Öğrencilerinin Yeme Tutumları, Benlik Algısı, Vücut Algısı ve Stres Belirtileri Açısından Karşılaştırılması, Yayınlanmamış Yüksek Lisans Tezi. Ankara: Ankara Üniversitesi, SBE

- Noor 2000. "The nutritition and health transition in Malaysia", Public Health Nutr, 5 (1A), 191-195.

- Orak, Akgün, ve Orhan 2006. "Süleyman Demirel Üniversitesi öğrencilerinin beslenme alışkanlıklarının araştırılması", S.D. Ü. Tıp Fakültesi Dergisi, XIII (2), 5-11.

- ÖSYM, 2015. www.osym.gov.tr/belge/1-19213/2012-2013-ogretim-yili-yuksekogretim-istatistikleri.html

- $\quad$ Özel Diyet, 2015. www.ozeldiyet.net 
- Sayan, 1999. "Beslenme alışkanlıkları ve temel besin gereksinimleri”, Atatürk Üniversitesi Hemşirelik Yüksekokulu Dergisi, II (2), 53-65.

- Saygın, Öngel, Çalışkan, Yağlı, Has, Gonca, ve Kurt 2011. "Süleyman Demirel Üniversitesi öğrencilerinin beslenme alışkanlıkları”, S.D.Ü. Tıp Fakültesi Dergisi, XVIII (2), 43-47.

- Sezek, Kaya, ve Doğan 2008. "Üniversite öğrencilerinin genel beslenme alışkanlıkları, katkılı besinler hakkındaki bilgi, görüş ve tutumları", Çankaya Üniversitesi Fen-Edebiyat Fakültesi, Journal of Arts and Sciences (10), 117-134.

- Sökmen, 2001. Konaklama ve Yiyecek İçecek İşletmelerinde Servis Tekniği ve Uygulamaları. Detay Yayıncilık, Ankara.

- Sökmen, 2005. Yiyecek İçecek Hizmetleri Yönetimi ve İşletmeciliği. Detay Yayıncılık, Ankara.

- Türksoy, 2002. Yiyecek ve İçecek Hizmetleri Yönetimi. Turhan Kitabevi, Ankara.

- Yıldırım, Yıldırım, Tortop ve Poyraz, 2011. “Afyon Kocatepe Üniversitesi Beden Eğitimi ve Spor Yüksekokulu öğrencilerinin beslenme alışkanlıkları ve bunları etkileyen faktörler”, Uluslararası İnsan Bilimleri Dergisi, 8 (1), 1375-1390.

- Yörükoğlu ve Yörükoğlu, 1998. Konaklama-Ağırlama İşletmelerinde Servis Yönetimi. Detay Yayıncılık, Ankara.

- Yüksel ve Yüksel, 2004. Turizmde Bilimsel Araştırma Yöntemleri. Turhan Kitabevi Yayınları, Ankara. 


\title{
Türkiye'de Tarımsal Destekleme Politikaları Agricultural Support Policies in Turkey
}

\author{
Assoc. Prof. Dr. Sibel Tan (Çanakkale Onsekiz Mart University, Turkey) \\ Dr. Mehmet Hasdemir (Republic of Turkey Ministry of Food, Agriculture and Livestock, \\ Turkey) \\ Dr. Bengü Everest (Çanakkale Onsekiz Mart University, Turkey)
}

\begin{abstract}
Agriculture is the leading strategic sector of Turkey as it was in entire world. Despite this strategic significance, risks and uncertainties because of the dependency on natural conditions turn agriculture into a disadvantaged sector. Just because of those disadvantages, agriculture is protected with various support policies throughout the world. Agricultural policies of Turkey have initiated with institutionalization policies of the Republican period and progressed through product supports, input supports and low-interest credit implementations of the planned period. These policies experienced serious reforms at the beginning of $2000 \mathrm{~s}$. Within the scope of Agricultural Reforms Implementation Project (ARIP), agricultural supports were tried to be gathered under a single roof and Direct Income Support (DIS) implementations have started. The DIS implementations lasted for 8 years and terminated in 2008. Current agricultural policy tools are implemented as area-based supports, subsidiary payments, rural development and agricultural insurance supports. The budget allocated to agriculture and the share of agricultural supports in Gross Domestic Product (GDP) of Turkey did not exhibit much change in years. Considering the policies and supports provided in developed countries and especially in European Union (EU) countries, it is recommended for Turkey that share of agricultural supports in total budget should be increased to levels in those countries.
\end{abstract}

\section{Giriş}

Tüm dünya ülkelerinde olduğu gibi tarım Türkiye'de de öncelikle halkın beslenmesi açısından hem ülke içinde hem de uluslararası düzeyde stratejik bir sektördür. Milli gelirdeki, istihdamdaki ve dış ticaretteki payı incelendiğinde Türkiye'de ekonomik sektörler içerisindeki önemini sürekli korumaktadır. Nitekim Türkiye İstatistik Kurumu (TUİK) 2014 rakamlarına göre tarımın Gayri Safi Yurtiçi Hasıla (GSYİH) içerisindeki payı $\% 8.8$, toplam istihdam içerisindeki payı $\% 21.10$, ihracattaki payı $\% 3.82$, ithalattaki payı ise $\% .3 .54$ dür.

Diğer taraftan tarım ülke ekonomisindeki önemine rağmen doğal şartlara bağımlılığı dolayısıyla risk ve belirsizliklerin fazla olduğu dezavantajlı bir sektördür. Tarım, sahip olduğu dezavantajlı özellikler dolayısıyla gelişmiş ülkeler başta olmak üzere tüm ülkelerde destekleyici politikalarla korunan sektörlerin başında gelmektedir. Tüm ülkelerde olduğu gibi ülkemizde de, uygulanan tarım politikalarının üreticinin gelir ve refah seviyesini artırma, fiyat istikrarı sağlama, kırsal kalkınma ve döviz tasarrufu sağlama gibi çeşitli amaçları vardır (Tan, 2011).

Dolayısıyla tarım tüm dünya genelinde kırsal kesimin başlıca geçim kaynağı olup tarımsal desteklerin kırsal gelirde yoksulluğu azaltmasında etkili olduğu bir gerçektir. Ancak unutulmamalıdır ki tarımsal destekler, tek başına çiftçi refahını ve kırsal yoksulluğu açıklamada yetersiz kalır. Tarımsal ve kırsal refah üzerinde etkili doğal, ekonomik, sosyal, kültürel hatta politik pek çok faktör vardır (Demirdöğen, vd, 2012).

Türkiye'de Cumhuriyetin ilanından itibaren özellikle de Planlı Dönemin başlangıcı olan 1963 yılından itibaren çok farklı tarım politikası uygulamaları ve tarım politikası araçları kullanılmıştır. Planlı Dönemin 1963 yılında başlamasıyla birlikte Türkiye'de tarımı destekleme politikaları beş yıllık planlar ve yıllık programlar kapsamında düzenlemeye alınmış, uzun yıllar tarım destekleme alımları ile korunmuştur. Fakat 1980 sonrasının ekonomi politikaları uygulamasında destekleme alımları büyük ölçüde ikincil duruma getirilmiştir. Desteklenen ürün sayısı hızla azaltılarak 1980'de 29'dan 22'ye, 1985 yılında 13'e, 1990 yılında da 10'a inmiştir. Desteklenen ürün sayısı 1991 ve 1992 yıllarında yeniden yükseltilerek sırasıyla 24 ve 26 olmuştur. 5 Nisan 1994 ekonomik istikrar tedbirleriyle, fiyat garantisiyle destekleme alımları, tahıllar, tütün ve şekerpancarı ile sınırlandırılmıştır (Abay, $\mathrm{vd}, 2001)$.

Türkiye'deki tarımsal destekleme politikalarında en büyük değişiklik 2000'li yılların başında uygulanan Doğrudan Gelir Desteği (DGD)'ni kapsayan Tarım Reformu Uygulama Projesi (ARIP) ile gerçekleşmiştir. DGD, uygulanan tarımsal destekleme politikalarına alternatif olarak sunulmuştur. DGD, diğer bazı desteklemelerin sonlandırılmasına sebep olmuş ve doğrudan desteklemelerin tüm destekler içerisindeki payı 2002 yılında \%78 seviyesine ulaşmıştır. Ancak 2006-2010 Tarım Kanunu ve Strateji Belgesinde DGD için ayrılan \%78'lik bütçe payının aşamalı olarak \%45'e indirilmesi kararı alınmıştır (Karaman ve Yavuz, 2012). DGD uygulaması 2008 yılında sona ermiştir. 
Türkiye'de günümüzde uygulanan tarımsal desteklemeleri bitkisel üretim, hayvansal üretim, tarımda yapısal iyileştirmeler sağlama amaçlı destekler, kırsal kalkınma ve çevre amaçlı desteklemeler olarak sınıflandırabiliriz. Çeşitli biyolojik mücadele destekleri, mazot, gübre toprak analiz destekleri, tarımsal danışmanlık, çiftlik muhasebe veri ağı sitemi kayıt destekleri tarımsal alt yapıyı güçlendirecek desteklemeler kapsamındadır. Ayrıca kırsal kalkınma yatırımlarının desteklenmesi programı (KKYDP) ve çevresel amaçlı tarım arazilerinin korunması (ÇATAK) projesi de bakanlığın kırsal kalkınma ve çevre kapsamında uyguladıkları politikalarıdır. İlave olarak \%50 devlet destekli olarak uygulanan tarım sigortası (TARSIM) uygulaması da tarımda risk yönetimi ve üretici gelirinde istikrar sağlamaya dönük önemli bir politika aracı olarak karşımıza çıkmaktadır.

Uygulanan tarım politikaları kapsamında, tarımdaki yapısal ve teknolojik gelişmeler de dikkate alındığında Türkiye tarımında son on yılda önemli değişimler meydana gelmiştir. Toplam tarım alanları ve ekim alanlarındaki azalmaya rağmen buğday, arpa, ayçiçeği, mısır, pamuk gibi ürünlerin üretim miktarında artışlar meydana gelmiştir. Yine aynı şekilde hayvansal üretimde kültür ve melez ırklardaki artışa bağlı olarak üretim sürekli artmıştır. Tarımın GSYİH daki ve istihdamdaki payının azalmasına rağmen 2007 yılında yaşanan küresel iklim krizi dışındaki bütün yıllarda tarımsal büyüme oranı pozitif yönde gerçekleşmiştir. Uygulanan kırsal kalkınma politikaları ile tarıma dayalı sanayi ve tarımsal yatırımlar gelişmiştir. \%50 devlet destekli tarım sigortası uygulamaları ile üretici gelirini garanti altına alma konusunda önemli adımlar atılmıştır (Tan, vd, 2015).

$\mathrm{Bu}$ çalışmada Türkiye'de uygulanan tarım politikaları kapsamında üreticiye verilen desteklerin değişimi incelenmiştir. Ayrıca bu desteklerin bütçedeki payları yıllar itibariyle incelenmiştir.

\section{Türkiye'de Tarımsal Desteklemelerin ve Bütçe İçerisindeki Payı}

Bütçeler, devletin üstlenmiş olduğu görevleri yerine getirmede kamu maliyesinin temel araçlarından birisidir. Bütçe ile yapılan harcamaların nitelikleri ve boyutu ile devletlerin toplumsal ihtiyaçları karşılamada ne kadar başarılı olduğu ortaya konulabilmektedir (Buhur, 2012). Dolayısıyla yasama, güvenlik, adalet, eğitim ve sağlık alanlarında olduğu gibi yaşamsal öneme sahip tarım sektöründe bütçe büyüklükleri ve payları son derece önemlidir.

Türkiye'de son on yıl içerisinde tarımın bütçedeki payı Tablo 1.'de gösterilmiştir. Tarımın merkezi yönetim bütçe büyüklüğü 2004 yılında 3.084 milyon TL iken yaklaşık üç katı bir artışla 2014 yılında 9.470 milyon TL. olmuştur. Tarım sektöründe merkezi bütçe büyüklüğünün GSYH’ladaki payı yıllar itibariyle çok fazla değişiklik göstermemiş $\% 0.5$ ile \%0.6 arasında bir oranda kalmıştır. Tarım sektörüne ayrılan merkezi bütçe büyüklüğünün toplam bütçe içerisindeki payı 2004 yılında \%2,0 oranında iken $2006 \% 2.7$ 'ye yükselmiş, 2007 yılında ise \%2,6 olmuştur. Daha sonraki yıllarda bu oran düşüş göstererek \%2,0 ile \%2,2 arasında bir orana sahip olmuştur. Yine aynı şekilde tarımsal desteklerin faiz hariç yönetim giderlerindeki payı 2004 yılında \%3,2 iken 2006 yılında \%3.6'ya yükselmiş 2014 yılında ise \%2.5'e düşmüştür. Önemli bir gösterge olarak tarımda merkezi yönetim bütçelerinin önceki yıllara göre artışları incelendiğinde 2004 yılında bir önceki yıla göre \%20,2 oranında 2006 yılında ise bir önceki yıla göre \%17,0 oranında arttı̆̆ görülmektedir. Bu oran 2007 yılında önceki yıla göre \%4,6 oranında artmış, 2008 yılında ise \%22,6 oranında azalmıştır. Bu düşüşün temel sebebi 2007 yılında yaşanan küresel iklim krizi ve hemen devamında yaşanan küresel ekonomik krizdir. Devam eden yıllarda 2010 yılında tarımsal desteklerin bütçe içerisindeki artış oranı 2010 yılında \%19,7, 2012 yılında \%15,0 ve 2014 yılında ise $\% 9,0$ oranında olmuştur.

Bu konuda genel bir değerlendirme yapılacak olursa ülke nüfusunun \%20'den fazlası tarım sektöründen geçimini sağlarken son 10 yıllık süreçte tarıma ve tarımsal desteklemelere ayrılan payların diğer bütçe kalemlerine nazaran daha oldukça düşük seviyede kaldığı görülmektedir. Gelişmiş ülkelerin özellikle de Avrupa Birliği’nin genel bütçelerinde tarımın payını giderek artırdığını düşünürsek bu durum üzerinde durulması gereken bir konudur.

\begin{tabular}{|l|l|l|l|l|l|l|l|}
\hline & $\mathbf{2 0 0 4}$ & $\mathbf{2 0 0 6}$ & $\mathbf{2 0 0 7}$ & $\mathbf{2 0 0 8}$ & $\mathbf{2 0 1 0}$ & $\mathbf{2 0 1 2}$ & $\mathbf{2 0 1 4}$ \\
\hline $\begin{array}{l}\text { Tarımda Merkezi Yönetim Bütçe Büyüklükleri } \\
\text { (Milyon TL) }\end{array}$ & 3.084 & 4.747 & $\mathbf{5 . 5 5 5}$ & 5.809 & 6.961 & 8.684 & 9.470 \\
\hline $\begin{array}{l}\text { Tarımda Merkezi bütçe büyüklüklerinin GSYH } \\
\text { daki payları (\%) }\end{array}$ & 0,6 & 0,6 & $\mathbf{0 , 7}$ & 0,6 & 0,5 & 0,5 & 0,6 \\
\hline $\begin{array}{l}\text { Tarımda Merkezi bütçe büyüklüklerinin bütçe } \\
\text { içindeki payları (\%) }\end{array}$ & 2,0 & 2,7 & $\mathbf{2 , 7}$ & 2,6 & 2,0 & 2,1 & 2,2 \\
\hline $\begin{array}{l}\text { Tarımda Merkezi yönetim giderlerinin faiz hariç } \\
\text { yönetim giderlerindeki payları (\%) }\end{array}$ & 3,2 & 3,6 & $\mathbf{3 , 6}$ & 3,3 & 2,4 & 2,4 & 2,5 \\
\hline $\begin{array}{l}\text { Tarımda Merkezi yönetim Bütçelerinin bir önceki } \\
\text { yıla göre değişimleri (\%) }\end{array}$ & 20,2 & 17,0 & $\mathbf{4 , 6}$ & $-22,6$ & 19,7 & 15,0 & 9,0 \\
\hline
\end{tabular}

Tablo 1. Tarımsal Destekleme Ödemelerinin Bütçedeki Payları Kaynak: T.C. Maliye Bakanlı̆̆ı 2015 Yılı Bütçe Gerekçesi 


\section{Tarımsal Desteklerin Destekleme Konusuna ve Yıllara Göre Dağılımı}

Planlı dönemin başlangıcından 2000'li yılların başına kadar Türkiye'de uygulanan tarım politikaları genellikle ürün destekleri, girdi destekleri ve düşük faizli krediler şeklinde olurken 2000 yılından itibaren Tarım Reformu Uygulama Projesi (ARIP) ile birlikte ciddi reformlar geçirmiş bu dönemden itibaren alan bazlı destekler ve kırsal kalkınma politikaları gündeme gelmiştir. Günümüzde uygulanan politika araçları ise bitkisel üretimde mazot, gübre, toprak analiz destekleri, biyolojik mücadele destekleri, tarımsal danışmanlık, çiftlik muhasebe veri ağ sitemi kayıt destekleridir. Hayvancılıkta verimliliği artırmak, gen kaynaklarını korumak ve alternatif gelir kaynağı elde etmeye dayalı politikalar uygulanmaktadır. Tarım sanayi entegrasyonunu sağlamak amacıyla $\% 50$ hibe destekli projelere dayalı kırsal kalkınma politikalarıdır. Tarımsal alt yapının güçlendirilmesi ve üretici gelirinin korunması amacıyla arazi toplulaştırma ve tarım sigortası destekleri de diğer önemli tarım politikası uygulamalarıdır.

Destek konusuna göre tarıma yapılan ödemeler tablo 2'de gösterilmiştir. Son on yıllık süreçte içinde destekleme miktarları 2004 yılında 3.049 milyon TL'den yaklaşık üç kat bir artışla 2014 yılında 9.056 milyon TL'ye yükselmiştir. Desteklerin konularına göre dağılım incelendiğinde DGD uygulamasının önce azalan oranlarda uygulanması ve daha sonar 2008 yılında tamamen kaldırılmasına bağlı olarak alan bazlı ödemeler giderek azalmıştır. Diğer taraftan fark ödemesi destekleri, hayvancılık destekleri, telafi edici ödemeler giderek artış göstermiştir. Kırsal kalkınma destekleri Tarım Reformu Uygulama Projesi (ARIP)'in bir parçası olarak 2006 yılından itibaren artış göstermiştir. Tarım sigortası için ayrılan destekler ise TARSİM yasasının 2006 da çıkmasıyla birlikte uygulanmaya başlamıştır. Bir defaya mahsus olmak üzere küresel iklim krizinin yaşandığ 1 2007 yılını takiben kuraklık desteği 2010 yılında ise don desteği uygulanmıştır.

\begin{tabular}{|l|c|c|c|c|c|c|}
\hline Destek Konusu (Milyon TL) & $\mathbf{2 0 0 4}$ & $\mathbf{2 0 0 6}$ & $\mathbf{2 0 0 8}$ & $\mathbf{2 0 1 0}$ & $\mathbf{2 0 1 2}$ & $\mathbf{2 0 1 4}$ \\
\hline Alan bazlı destekler ve DGD & 2.444 & 2.661 & 1.953 & 1.859 & 2.167 & 2.406 \\
\hline Fark Ödemesi & 350 & 1.290 & 1.647 & 2.071 & 2.379 & 2.691 \\
\hline Hayvancılık destekleri & 250 & 679 & 1.330 & 1.193 & 2.216 & 2.589 \\
\hline Tarım Reformu Projesi ile ilgili Destekler & 1 & 2 & 34 & 0 & 0 & 0 \\
\hline Tarım sigortası & 0 & 2 & 55 & 81 & 263 & 357 \\
\hline Telafi edici ödemeler & 4 & 73 & 80 & 77 & 99 & 123 \\
\hline Diğer tarımsal amaçlı destekler & 0 & 37 & 93 & 124 & 194 & 274 \\
\hline Kırsal kalkınma amaçlı & 0 & 0 & 109 & 284 & 196 & 313 \\
\hline Kirsal Kalkınma Kurumu (IPARD & 0 & 0 & 0 & 0 & 39 & 303 \\
\hline Kuraklık Desteği & 0 & 0 & 549 & 0 & 0 & 0 \\
\hline Don Afeti & 0 & 0 & 0 & 128 & 0 & 0 \\
\hline GENEL TOPLAM & $\mathbf{3 . 0 4 9}$ & $\mathbf{4 . 7 4 4}$ & $\mathbf{5 . 8 5 1}$ & $\mathbf{5 . 8 8 1}$ & $\mathbf{7 . 6 3 5}$ & $\mathbf{9 . 0 5 6}$ \\
\hline
\end{tabular}

Tablo 2. Tarımsal desteklerin Destekleme Konusuna ve Yıllara Göre Dağılımı Kaynak: T.C. Gıda Tarım ve Hayvancılık Bakanlı̆̆l, Tarım Reformu Genel Müdürlüğ̈̈ Verileri (2014-2015).

Tarımsal desteklerin oransal dağılımı tablo 3'de gösterilmiştir. Toplam destekler içerisinde 2004 y1lında en yüksek payı DGD ödemelerine bağlı olarak \%80,1 ile alan bazlı destekler alırken bu uygulamanın 2008 yılında son bulması ile giderek düşmüştür. 2014 yılında ise alan bazlı olarak uygulanan mazot, gübre ve toprak analizi destekleri için yapılan ödemelerin toplam içindeki payı \%26,6 olarak gerçekleşmiştir. Fark ödemesi destekleri 2004 yılında \%11,5 iken 2014 yılında \%28.6'ya ulaşmıştır. Son on yılda uygulanan tarım politikaları ve yapılan destekleme ödemelerinden en dikkati çekenlerinden biri de hayvancılık uygulamalarıdır. Nitekim 2004 yılında \%8,2 olan hayvancılık destekleri 2014 yılında \%29.7 oranına ulaşmıştır. Tarım sigortası desteği \%50 devlet destekli bir uygulama olup 2006 yılından itibaren uygulanmaya başlamış ve bugün toplam destekler içindeki oranı \%3,9 dur. Diğer taraftan Gıda Tarım ve Hayvancılığı bünyesinde uygulanan projeler kapsamında verilen kırsal kalkınma desteklerinin toplam destekler içerisindeki payı 3,5 IPARD aracılığı ile verilen kırsal kalkınma desteklerinin toplam içindeki payı ise 2014 yılı itibariyle \%3,3'dür. Ayrıca telefi edici ödemelerin toplam desteklemeler içerisindeki payı \%4.1 civarındadır. 


\begin{tabular}{|l|l|l|l|l|l|l|}
\hline Destek Konusu (\%) & $\mathbf{2 0 0 4}$ & $\mathbf{2 0 0 6}$ & $\mathbf{2 0 0 8}$ & $\mathbf{2 0 1 0}$ & $\mathbf{2 0 1 2}$ & $\mathbf{2 0 1 4}$ \\
\hline Alan bazlı destekler ve DGD & 80,1 & 56,1 & 33,4 & 31,6 & 28,4 & 26,6 \\
\hline Fark Ödemesi & 11,5 & 27,2 & 28,1 & 35,2 & 31,2 & 29,7 \\
\hline Hayvancılık destekleri & 8,2 & 14,3 & 22,7 & 20,3 & 29,0 & 28,6 \\
\hline Tarım Reformu Projesi ile ilgili & 0,0 & 0,0 & 0,6 & 0,0 & 0,0 & 0,0 \\
\hline Tarım sigortası & & 0,0 & 0,9 & 1,4 & 3,4 & 3,9 \\
\hline Telafi edici ödemeler & 0,1 & 1,5 & 1,4 & 1,3 & 1,3 & 1,4 \\
\hline Diğer tarımsal amaçlı destekler & & 0,8 & 1,6 & 2,1 & 2,5 & 3,0 \\
\hline Kırsal kalkınma amaçlı & & 0,0 & 1,9 & 4,8 & 2,6 & 3,5 \\
\hline Kırsal Kalkınma Kurumu (IPARD) & & 0,0 & 0,0 & 0,0 & 0,5 & 3,3 \\
\hline Kuraklık Desteği & & 0,0 & 9,4 & 0,0 & 0,0 & 0,0 \\
\hline Don Afeti & & 0,0 & 0,0 & 2,2 & 0,0 & 0,0 \\
\hline GENEL TOPLAM & 100,0 & 100,0 & 100,0 & 100,0 & 100,0 & 100,0 \\
\hline
\end{tabular}

Tablo 3. Tarımsal Desteklerin Destekleme Konusuna ve Yıllara Göre Oransal Dă̆ılımı Kaynak: T.C. Gıda Tarım ve Hayvancılık Bakanlı̆̆ı, Tarım Reformu Genel Müdürlüğ̈̈ Verileri (2014-2015).

\section{Sonuç ve Öneriler}

Bu çalışmada son on yıllık süreçte Türkiye'de tarımsal desteklerin bütçe içerisindeki payı ve desteklerin konularına göre dağılımları ve değişimleri incelenmiştir. Tarım sektöründe merkezi bütçe büyüklüğünün GSYH'daki payı yıllar itibariyle çok fazla değişiklik göstermemiş $\% 0.5$ ile $\% 0.6$ arasında bir oranda kalmıştır. Tarım sektörüne ayrılan merkezi bütçe büyüklüğünün toplam bütçe içerisindeki payı ise 2004 yılında \%2,0 oranında iken $2006 \% 2.7$ 'ye yükselmiş, 2007 y1lında ise \%2,6 olmuştur. Daha sonraki yıllarda bu oran düşüş göstererek \%2,0 ile \%2,2 arasında bir orana sahip olmuştur.

Tarımsal desteklerin konularına göre dağılımı incelendiğinde 2004 yılında desteklerin \%80’i DGD şeklinde üreticiye aktarılırken günümüzde uygulanan desteklemelerin oranı sırasıyla fark ödemesi \%29,7, hayvancılık destekleri \%28,6, alan bazlı destekler \%26,6 tarım sigortası \%3,9, kırsal kalkınma amaçlı destekler \%3,5, IPARD aracılığı ile verilen destekler $\% 3,3$ ve telafi edici ödemeler $\% 1,4$ oranındadır. Son on yıllık değişim incelendiğinde fark ödeme destekleri, hayvancılık destekleri, kırsal kalkınma ve tarım sigortası desteklerinde artış olurken alan bazlı desteklerde DGD’nin son bulmasına bağlı olarak azalış görülmektedir.

Çalışmadan elde edilen bulgular 1şı̆̆ında tarımın toplam bütçe içerisindeki payının diğer sektörlere göre çok düşük olduğu, tarım ve destekleme politikalarındaki sürekli değişime rağmen bütçenin değişmediği görülmüştür. Diğer taraftan konularına göre desteklemelerin dağılımı incelendiğinde hayvancılık desteklerinin ve özellikle arz açığı olan ürünlerde uygulanan fark ödeme desteklerindeki artış olumlu bir bulgu olarak karşımıza çıkmaktadır.

$\mathrm{Bu}$ bulgulardan yola çıkarak tarıma ayrılan bütçenin gelişmiş ülkeler seviyesine çıkarılması başta gelen öneriler arasındadır. Diğer taraftan özellikle bölgesel üretim potansiyelinin değerlendirilmesi açısından çok önemli olan Havza Bazlı Destekleme Modelinin geliştirilmesi önemlidir. Ayrıca tarıma dayalı sanayinin geliştirilmesi için hibe destekli projelerden faydalanma konusunda proje hazırlama ve uygulama potansiyelinin geliştirilmesi, özellikle üretici örgütlerinin bu konuda teşvik edilmesi gerekir. Üreticilerin tarım politikaları konusunda bilinç düzeyinin geliştirilmesi, desteklerin kullanımındaki bürokratik engellerin azaltılması ve çiftçi eğitiminin geliştirilmesi uygulanan politikaların etkinliğini artırmak için zorunludur.

\section{Kaynakça}

- Abay, C., Sayan, S., Miran, B., Bayaner, A., 2001. Türkiye'deki Tarımsal Destek Harcamalarının Enflasyonist, Etkilerinin Ekonometrik Analizi, TEAE Yayınları, Ankara.

- Buhur, S., “Tarımsal Destekleme Ödemelerinin Bütçe İçerisindeki Payının Analizi” Vergi Sorunları Dergisi.

- Demirdöğen, A., Ören, M.N., Alemdar, T., 2012 "Türkiye’de Tarım Politikaları Kapsamında Sağlanan Destekler ve Kırsal Yoksulluk” 10. Ulusal Tarım Ekonomisi Kongresi, p.85.

- Karaman, C., Yavuz, F., 2012 "Dünyadaki Eğilimler Işığında Türkiye Tarımsal Destekleme politikalarının Değerlendirilmesi” 10. Ulusal Tarım Ekonomisi Kongresi, p.166.

- Tan, S., 2011. “Türkiye'de Uygulanan Tarım Politikaları Kapsamında Çanakkale'nin Mevcut Durumu”, Çanakkale Tarımı Sempozyumu, p.3.

- Tan, S., Atak, Ş., Ümran, Ş., Tan, S. S., 2015. "The Evaluation of the Changes in the Agricultural Sector with Common Economic Indicators in Turkey during the Last Decade" Mediterranean Journal of Social Sciences, Vol 6 No:2 p.588. 
- T.C. Gıda Tarım ve Hayvancılık Bakanlığı, 2014. Tarım Reformu Genel Müdürlüğü Verileri.

- T.C. Maliye Bakanlığı, 2015.Bütçe Gerekçesi, https://pbk.tbmm.gov.tr/dokumanlar/2015 merkezi yonetim_butce tasarisi.pdf (Erişim Tarihi: 01.07.2015)

- TUIK, 2015. İstihdam, işsizlik ve Ücret İstatistikleri, http://www.tuik.gov.tr/UstMenu.do?metod=temelist (Erişim Tarihi: 01.07.2015)

- TUIKK, 2015, Dış Ticaret İstatistikleri http://www.tuik.gov.tr/PreTablo.do?alt_id=1046, (Erişim Tarihi: 07.07.2015) 


\title{
Kırgızistan Ekonomisi İçin İkiz Açık Hipotezinin Test Edilmesi Testing the Twin Deficit Hypothesis for Kyrgyzstan Economy
}

\author{
Dr. Damira Baigonushova (Kyrgyzstan-Turkey Manas University, Kyrgyzstan)
}

\begin{abstract}
Twin deficits hypothesis suggests that there is a positive relationship between budget and current account deficits. The present study examines Twin Deficits Hypothesis over the period of 2005:01-20013:12 in Kyrgyzstan by using Vector Autoregressive Model technique. The results show that there are relationships between government expenditure, export and import. The causalities are from government expenditure to export and import. These results confirm the Keynesian view, which asserts the existence of twin deficits, meaning that the state budget deficit at weak real economy, in an open economy, increase imports, which is the cause of twin deficits in the economy of Kyrgyzstan. To solve the problem of twin deficits, the state must pursue an active foreign trade policy in addition to fiscal policy, as it is proven empirically the state budget deficit has a big impact on trade deficit, but not the main factor of trade deficit.
\end{abstract}

\section{Giriş}

Bir ülkenin bütçe dengesi ve cari işlemler dengesi o ülkenin makroekonomik istikrarının önemli göstergeleri arasında yer almaktadır. Bu çerçevede maliye politikası neticesinde ortaya çıkan bütçe dengesizliklerinin ekonomi üzerindeki etkileri konusunda 4 ayrı bakış açısı mevcuttur. Onlardan ilki Neo-klasik yaklaşımın üç önemli öğesi bulunmaktadır. Bunlardan ilkine göre her birey tüketim miktarını zamanlararası tüketim optimizasyonu yaparak belirlemektedir. İkincisine göre bireylerin sınırlı (beklenen) yaşam süreleri vardır. Üçüncüsüne göre de her süreçte piyasa temizlenmesi (market clearing) sağlanmaktadır. Neo-klasikler'e göre tüketim yaşam boyu gelirin bir fonksiyonu olduğundan yaşam boyu gelirin artması tüketimin de artmasını sağlayacaktır. Eğer ekonomi tam istihdamdaysa (üçüncü varsayım gereği) artan tüketim tasarrufların azalmasına yol açacak, bu durum da faizlerin artmasına, böylece de özel sermaye birikimi üzerinde dışlama etkisi (crowding out) yaratılmasına sebep olacaktır. Birçok iktisatçı böyle bir sonucun ekonominin geneli için oldukça zararlı olduğu noktasında hem fikirdir. Böylece Neo-klasik görüş özellikle geçici bütçe açıklarının, (tüketim düzleştirmesi nedeniyle) ekonomiye oldukça küçük ve ihmal edilebilir etkileri olduğunu, sürekli bütçe açıklarının ise sermaye birikimini engelleyerek ekonomi üzerinde olumsuz etkilere yol açtığını belirtmektedir (Bernheim, 1989: 57-59).

Ikkincisi Geleneksel Keynesyen görüş, Neo-klasik yaklaşımdan iki temel noktada ayrılmaktadır. I) Miyopluk hipotezi (myopia hypothesis) basitçe uzağı görememe olarak tanımlanabilir (Dornbusch ve Fischer, 2004: 314). Buna göre bireyler, örneğin bugünkü bir vergi indiriminin gelecekteki etkilerini yeterince değerlendirememekte ve anlayamamaktadırlar. II) Likidite sınırlılığl tüketicilerin bugün daha çok tüketebilmek için borçlanma olanaklarının olmadığını ifade eder (Mankiw, 2002: 417). Keynesyen görüşe göre bireyler harcanabilir gelirlerinden tüketime oldukça yüksek miktarda pay ayırabilmektedirler. Dolayısıyla vergilerdeki geçici bir düşüş toplam talebi hemen artırıcı ve önemli bir etki yaratmaktadır. Ekonomi eksik istihdamda ise toplam talep artışı milli geliri çarpan etkisiyle artıracak ve böylece bütçe açığı hem tüketimi hem de milli geliri uyardığından tasarruflarda ve sermaye stokunda ters yönde bir değişimi gerektirmeyecektir. Neoklasikler'in aksine, birçok Keynesyen, bütçe açıklarının özel yatırımları dışlama etkisinden ziyade bunları artırıcı (crowding in) etkisinin olduğunu belirtir (Eisner, 1989: 83). Keynesyenler bu durumu devlet yatırımlarının özel yatırımların marjinal verimliliğini artırmasına bağlarlar. Çünkü devlet yol, köprü ve havaalanı gibi altyapı yatırımları yaparak özel yatırımların etkinliğini ve verimliliğini artırır. Sonuçta, doğru zamanlanmış açıklar faydalı sonuçlar sağlayabilecektir.

Üçüncüsü de Parasalcı (Monetarist) Yaklaşım. Bu yaklaşıma göre bütçe açıklarının ekonomi üzerindeki en önemli etkisi toplam harcamaların artması ve ekonominin tam istihdamda olmasından dolayı bu talep artışının enflasyonist baskı yaratmasıdır. Bütçe açıklarının hangi yoldan finanse edildiği hiçbir şeyi değiştirmez.

Dördüncüsü de Ricardocu Yaklaşım. Bu yaklaşıma göre birbirini takip eden nesiller kaynak transferi anlamında birbirlerine bağlıdırlar. Bu durumda tüketim, şu an itibariyle vergi mükellefi olan bireyin ve onun tüm torunlarının kaynaklarının toplamının bir fonksiyonu haline gelir. Böylece analizde sadece bugünkü tüketiciler değil onların çocukları ve torunlarını da kapsayan tüm aile kaynakları (gelirleri) işin içine katılır. Bütçe açıkları geleceğe ertelenmiş vergi ödemelerinden ibaret olduğundan ailenin kaynaklarında bir değişme olmaz ve bu yüzden de açıklar makroekonomik bir etki yaratmaz (Bernheim, 1989: 56). Özellikle devlet harcamasının borç ya da vergiyle finansmanının faiz oranı, yatırım, milli gelir, tasarruf vb. üzerinde herhangi bir etkisi bulunmamaktadır (Barro, 1979: 940).

Ricardocu Yaklaşım hariç diğer teoriler bağlamında, özellikle Keynesyen teori açısından ele alındığında bütçe açıklarının cari işlemler üzerinde önemli etkileri bulunmaktadır. Dışa açık bir ekonomide genişletici maliye 
politikası sonucunda ortaya çıkan bütçe açıkları reel gelir, faiz ve döviz kuru mekanizmaları aracılığıyla cari işlemler açığı da doğurabilmektedir ya da mevcut cari işlemler açığının artmasına neden olabilmektedir. Diğer yandan ülkenin yüksek enflasyona yol açmamak kaydıyla uyguladığı sıkı para politikasının faiz yoluyla etkisi ve dış ticarette önemli partner ülkelerin uyguladığı daraltıcı makro politikaları da dış açığı daha da artırmaktadır.

Dolayısıyla bir ekonomide aynı anda hem bütçe açığı, hem de cari işlemler açı̆̆ı görülmekte ve bu iki açık arasında yukarıdaki gibi bir bağlantı söz konusu ise o ülkede ikiz açık var demektir. İki açık arasında bağlantının olmadığı durumda da ikili açık olarak adlandırılmaktadır ve bu durum teoride Ricardocu Eşdeğerlik Hipotezi olarak geçiyor.

Ricardocu Eşdeğerlik Hipotezinin bazı varsayımları şöyledir: sermaye piyasasında tam rekabet şartları vardır, tüketicilerin likidite kısıtı yoktur, herkesten götürü usulü vergi alınmaktadır; vergilerin bozucu etkisi yoktur; nesiller arası transferler söz konusudur, devletin geleceğe yönelik maliye politikası tam olarak belirgindir ve bireyler rasyoneldir (Karatay, 2008). Diğer yandan Ricardocu Eşdeğerlik Hipotezi, Keynesyen görüşün tam tersine ekonomik ajanların rasyonel olduğunu ve dolayısıyla ileriye yönelik doğru öngörülerde bulunabildiklerini varsayar. Bu nedenle de sözgelimi hükümetin bir vergi indirimi, ileride bunun borçlanma ile geri döneceğini gören bireylerin tasarruflarında düşüşe ya da tüketimlerinde artışa yol açmaz; böylece cari işlemler dengesi de tetiklenmez.

Cari işlemler açığının ekonomi üzerindeki etkilerini de kısaca açıklamak gerekirse, cari işlemler dengesizliklerinin reel döviz kuru ve faiz oranını artırdığı ve reel sektör üzerinde olumsuz etkiler yarattığı göz önünde bulundurulduğunda, açıkların dış borçlanmayla finansmanının sürdürülemez boyuta ulaştı̆̆ ekonomilerde kriz sürecine girilmesi kaçınılmaz olmaktadır. Bu kapsamda ekonomik yapı üzerinde önemli etkilere sahip olan ilgili iki değişken arasındaki ilişkinin ortaya konulması, iç ve dış dengesizlikler çerçevesinde makro ekonomi politikalarının şekillendirilmesi açısından gereklidir (İyidoğan, 2013:83).

İkiz Açık konusu üzerindeki araştırmalar hipotezin ilk önce ABD'de ortaya atılmış olmasına bağlı olarak ABD'de başlamış, sonra da dünya ülkelerine yayılmıştır. Her ülke için faklı sonuçlar elde edildiği gibi, bazen aynı ülke üzerinde farklı yöntemler, dönemler ve değişkenler ile araştırmalar yapılmış ve farklı sonuçlar elde edilmiştir (Tablo 1-2). Ayrıca Keynesyen ve Ricardocu yaklaşıma uygun olmayan, nedensellik yönünün cari işlemlerden bütçe açıklarına doğru olduğunu tespit eden sonuçlar (Alkswani, 2001) da vardır.

\begin{tabular}{|l|l|l|l|l|}
\hline $\begin{array}{l}\text { Çalışmanın Yazar(lar)ı ve yayın } \\
\text { yılı }\end{array}$ & $\begin{array}{l}\text { Araştırmaya alınan } \\
\text { dönem ve frekansı }\end{array}$ & Kullanılan analiz yöntemi & $\begin{array}{l}\text { Araştırılan } \\
\text { ülke }\end{array}$ & \multicolumn{2}{|l|}{ Sonuç } \\
\hline Paul Evans, 1988 & Yatay kesit verileri & Mikroekinimiye dayalı model & ABD \\
\hline Dewald ve Ulan 1990 & $1954-1987$, yıllık veriler & Nedensellik testi & ABD \\
\hline Haug 1990 & $\begin{array}{l}1929-1985 \text { yıllık veriler } \\
\text { Koentegrasyon ve Granger } \\
\text { nedensellik }\end{array}$ & ABD \\
\hline Faik Bilgili ve Emine Bilgili, 1998 & $1975-1993$ yıllık veriler & Regresyon & $\begin{array}{l}\text { ABD, Singapur } \\
\text { ve Türkiye }\end{array}$ \\
\hline $\begin{array}{l}\text { Bedriye Tunçsiper ve Dilek Sürekçi } \\
\mathbf{2 0 1 1}\end{array}$ & $\begin{array}{l}1987: 01-2007: 03 \text { çeyrek } \\
\text { veriler }\end{array}$ & VAR & Türkiye \\
\hline
\end{tabular}

Tablo 1. Rikardocu Yaklaşıma Uygun Sonuçlar Elde Etmiş Olan Çalışmalar 


\begin{tabular}{|c|c|c|c|c|}
\hline $\begin{array}{l}\text { Çalışmanın Yazar(lar)ı ve } \\
\text { yayın yılı }\end{array}$ & $\begin{array}{l}\text { Araştırmaya alınan } \\
\text { dönem ve frekansı }\end{array}$ & $\begin{array}{l}\text { Kullanılan analiz } \\
\text { yöntemi }\end{array}$ & $\begin{array}{l}\text { Araştırılan } \\
\text { ülke }\end{array}$ & Sonuç \\
\hline $\begin{array}{l}\text { Alper Yilmaz } \\
1993\end{array}$ & 1987-1992, aylık veriler & $\begin{array}{c}\text { Granger nedensellik ve } \\
\text { regresyon. }\end{array}$ & Türkiye & $\begin{array}{l}\mathrm{BD} \rightarrow \mathrm{TD} \text { (dolaylı yoldan); } \\
\mathrm{TD} \rightarrow \mathrm{BD} \text { (doğrudan etki) }\end{array}$ \\
\hline $\begin{array}{l}\text { Ahmet Zengin } \\
1999\end{array}$ & $\begin{array}{l}\text { 1987-1998, çeyrek } \\
\text { veriler }\end{array}$ & Yapisal olmayan VAR & Türkiye & $\begin{array}{l}\mathrm{BD} \rightarrow \mathrm{TD} \text { (doğrudan ve } \\
\text { dolaylı); TD } \rightarrow \text { BD (dolaylı } \\
\text { etki) }\end{array}$ \\
\hline Öznur Ümit 2007 & 1987:01-2005:04 çeyrek & Granger nedensellik, VAR & Türkiye & $\mathrm{BD} \rightarrow \mathrm{TD}$ \\
\hline $\begin{array}{l}\text { Görkem Bahtiyar, Hasan } \\
\text { Bakir 2011 }\end{array}$ & $\begin{array}{l}1980-2010 \\
\text { y1llık veriler }\end{array}$ & Regresyon & Türkiye & $\mathrm{BD} \rightarrow \mathrm{TD}$ \\
\hline $\begin{array}{l}\text { Binhan Elif Yılmaz } \\
2002\end{array}$ & $\begin{array}{l}1980-2001 \\
\text { y1llık veriler }\end{array}$ & Granger nedensellik, VAR & Türkiye & $\mathrm{TD} \leftrightarrow \mathrm{BD}$ \\
\hline $\begin{array}{l}\text { Elif Akbostancı ve Gül Ipek } \\
\text { Tunç } 2002\end{array}$ & $\begin{array}{l}\text { 1987-2001, } \\
\text { y1llik veriler }\end{array}$ & $\begin{array}{r}\text { Koentegrasyon ve hata } \\
\text { düzeltme modeli }\end{array}$ & Türkiye & $\begin{array}{l}\text { Kısa dönemde } \mathrm{BD} \rightarrow \mathrm{TD} ; \\
\text { Uzun dönemde } \mathrm{BD} \leftrightarrow \mathrm{TD} ;\end{array}$ \\
\hline $\begin{array}{l}\text { Emine Kılavuz, Yasemin } \\
\text { Dumrul } 2012\end{array}$ & $\begin{array}{l}\text { 2006:01-2010:12 } \\
\text { aylik veriler }\end{array}$ & Granger nedensellik, VAR & Türkiye & $\begin{array}{l}\text { Kısa dönemde TD } \leftrightarrow \mathrm{BD} ; \\
\text { Uzun dönemde } \mathrm{BD} \leftrightarrow \mathrm{TD}\end{array}$ \\
\hline $\begin{array}{l}\text { Süleyman Bolat, Murat } \\
\text { Belke, Ozan Aras, } 2011\end{array}$ & $\begin{array}{l}\text { 1998:1-2010:4 } \\
\text { çeyrek veriler }\end{array}$ & ARDL & Türkiye & $\begin{array}{l}\text { Kisa dönemde } \mathrm{BD} \rightarrow \mathrm{TD} \\
\text { Uzun dönemde } \mathrm{BD} \leftrightarrow \mathrm{TD}\end{array}$ \\
\hline Fatih Mangır, 2012 & $1980-2011$ yillık & Johansen Koentegrasyon & Türkiye & $\mathrm{BD} \rightarrow \mathrm{TD}$ \\
\hline Burhan Doğan, 2010. & $1980-2003$ & İstatistiki analiz & Türkiye & $\mathrm{BD} \rightarrow \mathrm{TD}$ \\
\hline $\begin{array}{l}\text { Hayati Aksu ve Selim Başar } \\
2009\end{array}$ & 1994: 09-2008: 09 & \begin{tabular}{|c} 
Sinir testi (Pesaran vd. \\
$(2001))$
\end{tabular} & Türkiye & $\mathrm{BD} \rightarrow \mathrm{TD}$ \\
\hline $\begin{array}{l}\text { Fatih Yücel, Ahmet Yılmaz } \\
\text { Ata } \\
2003\end{array}$ & 1975-2002, y1llık & $\begin{array}{l}\text { Engle-Granger iki aşamalı } \\
\text { koentegrasyon testi ve } \\
\text { Granger nedensellik }\end{array}$ & Türkiye & $\begin{array}{l}\text { 1-4-gecikmede } \mathrm{BD} \rightarrow \mathrm{TD} \\
\text { 4-7-gecikmede } \mathrm{TD} \rightarrow \mathrm{BD}\end{array}$ \\
\hline $\begin{array}{l}\text { Ahmet Ay, Zeynep Karaçor, } \\
\text { Mehmet Mucuk, Savas } \\
\text { Erdoğan'ın } 2004\end{array}$ & 1992-2003 aylık & $\begin{array}{l}\text { Granger nedensellik ve } \\
\text { regresyon. }\end{array}$ & Türkiye & $\begin{array}{l}\mathrm{BD} \leftrightarrow \mathrm{TD} ; \\
\mathrm{BD} \rightarrow \mathrm{TD} \text { daha güçlü; } \\
\mathrm{TD} \rightarrow \mathrm{BD} \text { etki zayıf }\end{array}$ \\
\hline Elmas Yaldız, 2006 & 1994:1 - 2005:3, çeyrek & Koentegrasyon & Türkiye & $\mathrm{BD} \rightarrow \mathrm{TD}$ \\
\hline Utku Utkulu, 2003 & 1950-2000, y1llık & VAR & Türkiye & $\begin{array}{l}\text { Kısa dönemde } \mathrm{BD} \rightarrow \mathrm{TD} ; \\
\text { Uzun dönemde } \mathrm{BD} \leftrightarrow \mathrm{TD}\end{array}$ \\
\hline Binhan Elif Yılmaz 2002 & 1980-2001, y1llik & Granger nedensellik & Türkiye & $\mathrm{TD} \leftrightarrow \mathrm{BD}$ \\
\hline Sever ve Demir, 2007 & $1987-2006$ & Granger nedensellik, VAR & & \\
\hline Paul A. Volcker, 1984 & & $\begin{array}{ccc}\begin{array}{c}\text { Teori } \\
\text { araştırması }\end{array} & \text { ve istatistik } \\
\end{array}$ & $\mathrm{ABD}$ & $\mathrm{BD} \rightarrow \mathrm{TD}$ \\
\hline Ali F. Darrat, 1988 & 1960-1984, çeyrek & Granger nedensellik & $\mathrm{ABD}$ & $\mathrm{TD} \leftrightarrow \mathrm{BD}$ \\
\hline Rosenweig ve Tallman 1991 & 1971-1989 çeyrek & VAR & $\mathrm{ABD}$ & $\mathrm{BD} \rightarrow \mathrm{TD}$ \\
\hline Zietz ve Pemberton 1989 & 1972:4 - 1987:2 çeyrek & İki aşamalı EKK & $\mathrm{ABD}$ & $\mathrm{BD} \rightarrow \mathrm{TD}$ \\
\hline \begin{tabular}{ll|} 
Mohsen & Bahmani-Oskooee \\
1989
\end{tabular} & 1973-1985, çeyrek & \begin{tabular}{|l} 
İki aşamalı EKK ve \\
doğrusal regresyon
\end{tabular} & $\mathrm{ABD}$ & $\mathrm{BD} \rightarrow \mathrm{TD}$ \\
\hline John D. Abell, 1990 & 1979-1985, aylik & VAR & $\mathrm{ABD}$ & $\mathrm{BD} \rightarrow \mathrm{TD}$ \\
\hline D. David Banchman 1992 & 1974-1988 çeyrek & VAR & $\mathrm{ABD}$ & $\mathrm{BD} \rightarrow \mathrm{TD}$ \\
\hline Selahattin Diboglu 1994 & 1957-1992, çeyrek & En çok benzerlik & $\mathrm{ABD}$ & $\mathrm{BD} \rightarrow \mathrm{TD}$ \\
\hline Chowdhury and Saleh 2007 & $1970-2005$ & ARDL & Sri Lanka & $\mathrm{BD} \leftrightarrow \mathrm{TD}$ \\
\hline Kim and Kim, 2006 & $1970-2003$ & Granger "non-causality" & Kore & $\mathrm{TD} \leftrightarrow \mathrm{BD}$ \\
\hline George A. Vamvoukas, 1999 & 1948-1994 yıllık veriler & \begin{tabular}{|lrr}
\multicolumn{2}{|c}{ Koentegrasyon, } & hata \\
düzeltme ve & Granger \\
nedensellik & \\
\end{tabular} & Yunanistan & $\begin{array}{l}\text { Hem kisa hem uzun } \\
\text { dönemde BD } \rightarrow \text { TD }\end{array}$ \\
\hline $\begin{array}{l}\text { Olugbenga A., Onafowora } \\
\text { and Oluwole Owoye, } 2006\end{array}$ & $1980-2001$ & $\begin{array}{l}\text { Koentegrasyon, } \\
\text { düzeltme }\end{array}$ & Nijerya & $\mathrm{TD} \rightarrow \mathrm{BD}$ \\
\hline $\begin{array}{l}\text { Chin-Hong Puah, Evan Lau } \\
\text { and Kim-Lee Tan }\end{array}$ & 1970-2005 yıllık veriler & $\begin{array}{l}\text { Johansen-Juselius (1990) } \\
\text { koentegrasyon, Toda- } \\
\text { Yamamoto (1995) } \\
\text { nedensellik } \\
\end{array}$ & Malezya & $\mathrm{TD} \rightarrow \mathrm{BD}$ \\
\hline M. Faizul Islam, 1998 & 1973:1 - 1991:4,çeyrek & Granger nedensellik & Brezilya & $\mathrm{TD} \leftrightarrow \mathrm{BD}$ \\
\hline $\begin{array}{l}\text { Leonardo Bartolini and } \\
\text { Amartya Lahiri, 2006 }\end{array}$ & $1972-2003$ & $\begin{array}{l}\text { Sabit etkili OLS (panel veri } \\
\text { analizi) }\end{array}$ & $\begin{array}{l}\text { OECD’nin } 18 \\
\text { üye ülkesi }\end{array}$ & \\
\hline $\begin{array}{l}\text { Giancarlo Corsetti and } \\
\text { Gernot Muller } \\
2006\end{array}$ & $\begin{array}{l}\text { 1979:1 - 2005:3 } \\
\text { çeyrek veriler }\end{array}$ & VAR & $\begin{array}{l}\text { Avustralya } \\
\text { Kanada } \\
\text { İngiltere } \\
\text { ABD } \\
\end{array}$ & $\begin{array}{l}\mathrm{BD} \rightarrow \mathrm{TD} \\
\text { *ülkelerin dişa açıklık } \\
\text { derecesi ne kadar yüksek } \\
\text { ise etki o kadar güçlü. }\end{array}$ \\
\hline $\begin{array}{l}\text { Ahmad Zubaidi } \\
\text { Baharumshah, Evan Lau Ve } \\
\text { Ahmed M. Khalid } \\
2006\end{array}$ & 1976-2000 çeyrek & Koentegrasyon & $\begin{array}{l}\text { Malezya, } \\
\text { Endonezya, } \\
\text { Filipinler, } \\
\text { Tayland } \\
\end{array}$ & $\begin{array}{l}\text { Tayland BD } \rightarrow \text { TD; } \\
\text { Malezya, } \quad \text { Endonezya, } \\
\text { Filipinler TD } \rightarrow \text { BD }\end{array}$ \\
\hline
\end{tabular}

Tablo 2. Keynesyen Yaklaşıma Uygun Sonuçlar Elde Etmiş Olan Çalışmalar

\section{Kırgızistan'da Egemenlik Sonrası Kamu Açıkları ve Cari İşlemler Dengesi}

Bütçe dengesi ve cari işlemler dengesi arasındaki ilişkinin analizi ABD ekonomisi gibi gelişmiş, Türkiye gibi hızla gelişmekte olan ekonomilerin yanısıra piyasa ekonomisine geçiş sürecini yakın zamanda tecrübe eden ekonomiler için de önem taşımaktadır. Söz konusu bu ekonomiler içerisinde yer alan Orta Asya ülkelerinde 
planlı bir ekonomiden piyasa ekonomisine geçiş süreci ile birlikte bütçe açıkları artmıştır. Mali dengedeki bu bozulma, bir taraftan piyasa ekonomisi için gerekli sosyal, kurumsal ve ekonomik alt yapının oluşturulması için artan kamu harcamaları ve vergi düzenlemelerine; diğer taraftan da özellikle geçiş sürecinin ilk dönemlerinde reel GSYİH'deki azalış sonucu ortaya çıkan vergi gelirlerindeki düşüşe bağlanabilir (Aristovnik, 2005; Aristovnik, 2006). Bu ülkelerde mali dengedeki bozulma yanında geçiş süreci ile birlikte dış ticaretin ve sermaye hareketlerinin serbestleşmesi cari işlemler açıklarını artırmıştır.

$\mathrm{Bu}$ çerçevede çalışmada, bütçe dengesi ve cari işlemler dengesi arasındaki ilişkinin piyasa ekonomisine geçiş ve serbestleşme süreci ile birlikte yüksek bütçe ve cari işlemler açıkları kaydeden Kırgızistan için ampirik olarak incelenmesi amaçlanmaktadır. Bu konuda Kırgızistan ekonomisi üzerinde Güven (2014) tarafından Yüksek Lisans tezi hazırlanmıştır, onun dışında herhangi bir çalışma yapılmamıştır. Adı geçen çalışmada Kırgızistan'ın 2000:1-2013:3 dönemleri arası çeyrek verileri kullanılarak regresyon analizi yöntemiyle ikiz açık hipotezi test edilmiştir ve Kırgızistan'da ikiz açıklar hipotezinin geçerli olmadığı, Ricardocu yaklaşımın geçerli olduğu sonucuna ulaşılmıştır. Ancak çalışmada cari işlemler dengesinin kullanılmasından dolayı bu sonucun yanıltıcı olabileceğini söylemek gerekir. Çünkü yukarıda saydığımız Ricardocu varsayımların hiçbiri Kırgızistan ekonomisi için geçerli değildir, hem de teoride açıkların bütçe açıkları ve cari işlemler açığı olarak geçmesine rağmen, dikkat edilecek olursa aslında dış ticaret açığı kastedilmektedir. Cari işlemler hesabının alt kalemleri arasında dış ticaret dengesi çok önemli yere sahip olan ülkeler açısından analize dış ticaret açığı veya cari işlemler açığının alınmasının bir sakıncası yoktur, çünkü bu sonuçların değişmesine yol açmaz. Fakat Kırgızistan gibi cari işlemler hesabının alt hesapları olan net transfer ve gelirler de cari işlemler dengesini büyük ölçüde etkileyen ülkelerde yanıltıcı sonuçlara neden olabilmektedir (Şekil 3). Dolayısıyla bu çalışmada dış ticaret dengesi verileri kullanılmıştır.

Ülke bütçesinde1990'dan günümüze kadar sadece 2001, 2005, 2007 ve 2008'de bütçe fazlaları kaydedilmiştir. Bunların ilki bütçede vergi dışı gelirlerin beklendiğinden daha fazla olmasından, ikincisi ülkedeki siyasi devrim sonucu planlanmış harcamaların yapılmamasından, son ikisi de ekonomide inşaat ve iletişim sektörlerinin çok hızlı büyümesi nedeniyle bütçe gelirlerinin hızla artmasından kaynaklanmıştır. Ancak Şekil 1'den de görüldüğü gibi 2008 senesi dışındaki bütçe fazlaları çok düşüktür.

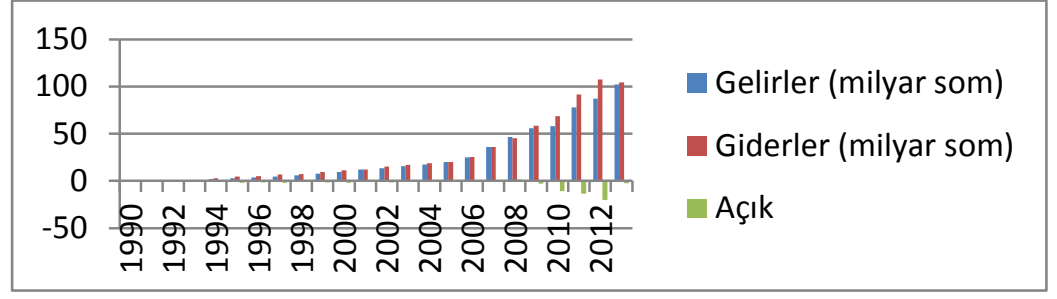

Şekil 1. Kırgızistan'ın Devlet Bütçesi (1990-2013 dönemi) Kaynak: Kırgızistan İstatistik Komitesi verilerinden yararlanarak oluşturulmuştur (www.stat.kg)

2009 sonrası dönemde ise ülke bütçesi çok büyük açıklar vermektedir. Bu açıkların finansman kaynaklarına baktığımızda da ülkenin genel olarak dış finansmana önem verdiğini görmek mümkündür (Şekil 2).

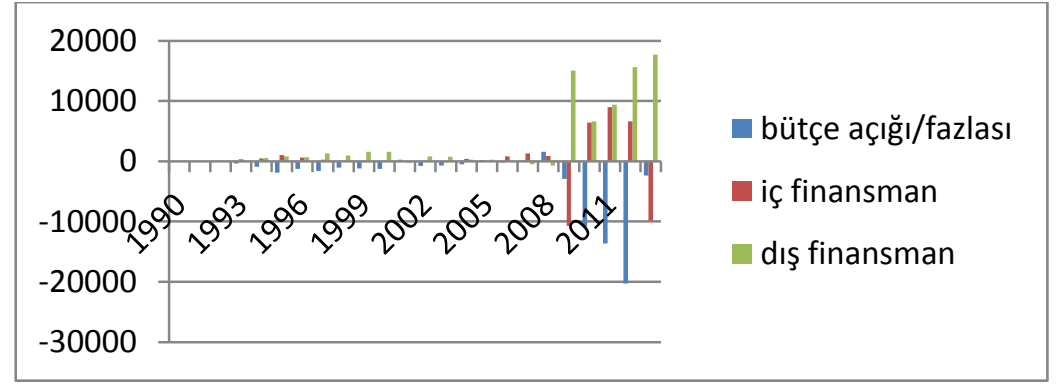

Şekil 2. Bütçe Açıklarının Finansmanı (mln. som) Kaynak: Kırgızistan İstatistik Komitesi verilerinden yararlanarak oluşturulmuştur (www.stat.kg)

Bunun bir nedeni de devletin iç kaynaklardan borçlanmada faizleri yükseltmek zorunda kalmasıdır. Bazen de devlet bütçe gelirlerinin bir kısmıyla iç piyasaya finansman sağlamaktadır. Örneğin, 2013'de tarım üreticilerine düşük faizli kredi sağlamak amacıyla dış fonlardan yararlanılmıştır. Ülke iç finansman kaynağı olarak devlet hazine bonolarını 2009'dan itibaren kullanmaya başlamış, fakat ilk sene faiz oranı düşük olduğu için bütçeye önemli ölçüde gelir sağlanamamıştır. Ancak, 2010 devrimi sonrası bir yandan ülkenin dış kaynaklardan yeteri kadar finansman sağlayamaması, diğer yandan da devlet harcamalarını artırma ihtiyacı Hükümeti son yıllarda yüksek faizli devlet hazine bonoları ve tahviller aracılığıyla iç borçlanmaya daha fazla başvurmaya zorlamıştır (Tablo 3). 
Özetlemek gerekirse, Kırgızistan bağımsızlığına kavuştuğu 1991'den bu yana yeniden yapılanma, 1998 Asya ve Rusya krizi, 2002 Kumtör'deki kaza ve 2005/2010 devrimleri gibi birçok ekonomik ve siyasi krizlere maruz kalmış ve bunların devlet bütçesi üzerinde de büyük etkileri olmuştur. Devletin uzun dönemde izleyeceği maliye politikası hala net değildir. Bu da Ricardocu yaklaşımın "devletin geleceğe yönelik maliye politikası tam olarak belirgindir" hipotezine ters düşmektedir. Fakat diğer yandan Kırgızistan gibi küçük ülkeler açısından "devlet bütçe açıklarının sürekli artması iç borç faiz oranlarını artırır, faizin artması bono ve tahvil talebini artırır, yabancıların bono ve tahvil talebinin artması yerli para talebinin artmasına neden olur, sonuç olarak da ülke parası değer kazanır ve dış ticaret bundan negatif etkilenir" şeklinde ifade gören Keynesyen teorinin de geçerliliği şüphe doğurmaktadır. Çünkü bu tür ülkeler iç faiz oranlarını sabit tutarak, bütçe açıklarını dış kaynaklardan finanse edebilmektedirler.

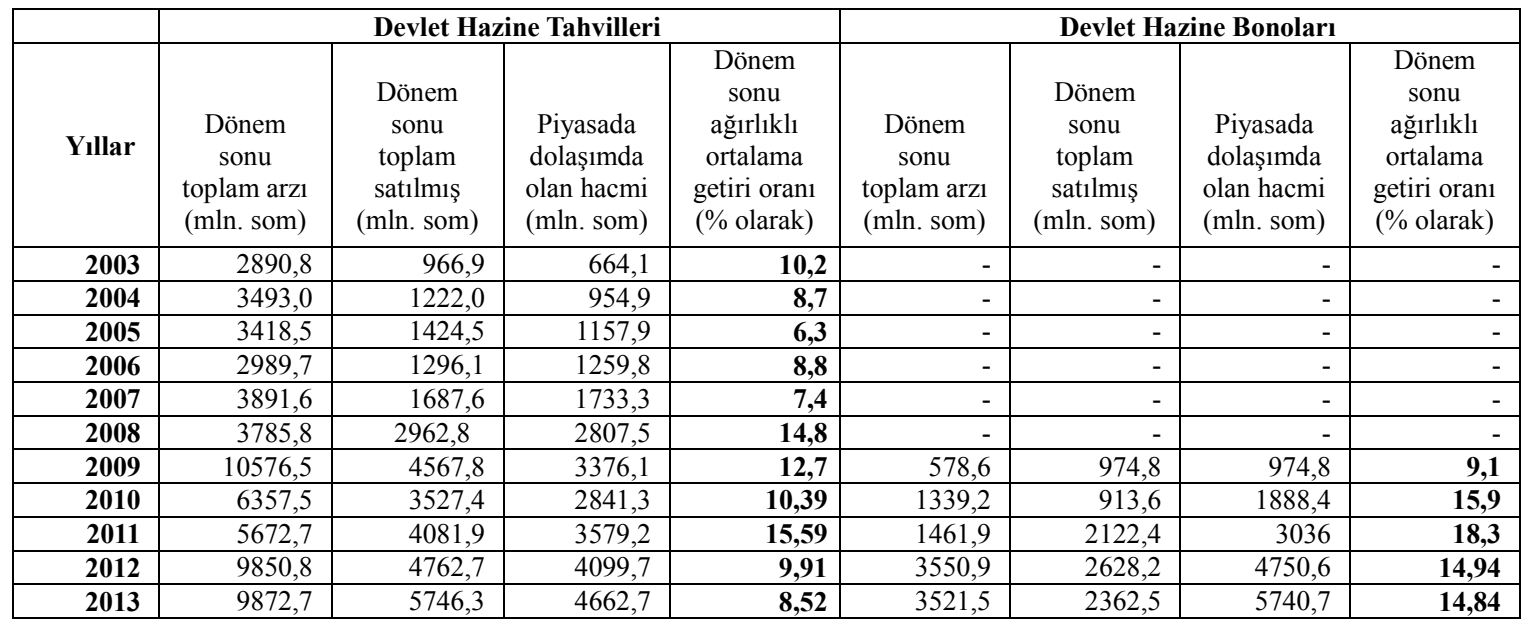

Tablo 3. Devlet Hazine Tahvil ve Bonolarının Ağırlıklı Ortalama Getiri Oranları Kaynak: Kırgızistan Milli Bankası verilerinden yararlanılarak oluşturulmuştur (www.nbkr.kg).

Kırgızistan bağımsızlık döneminde bir yandan hızlı bir şekilde liberal piyasa sistemine geçiş reformlarını gerçekleştirdi, özelleştirme yaparak özel mülkiyeti geliştirdi, diğer taraftan da liberal dış ticaret politikası izledi. 1998'de ülkenin DTÖ’ye üye olması bunun en önemli göstergesidir. Günümüzde bunun ülke ekonomisine olan etkisinin pozitif veya negatif olduğu konusunda net bir görüş birliği yoktur. Serbest ticaret politikası sonucunda özellikle Çin'in de 2002'de DTÖ'ye üye olması sonucu Çin'den gelen ucuz ithalat pek çok sektörlerde iç üretimin gelişememesine neden olmuştur ve bunun sonucunda da Kırgızistan'da ithalata bağımlılık artarak dış ticaret açı̆̆1 kronik hale gelmiştir (Şekil 3).

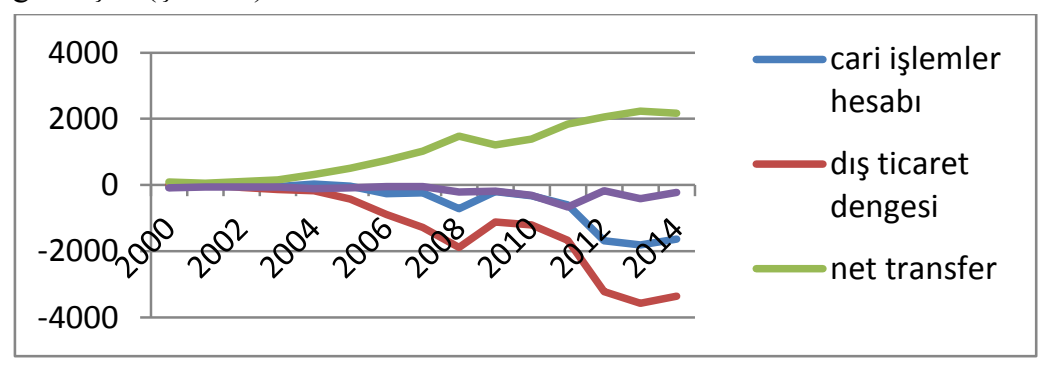

Şekil 3. Kırgızistan'da Cari Iş̧lemler Hesabı ve Alt Hesaplarının Dengeleri (2000-2014 dönemi), milyon ABD doları Kaynak: Kırgızistan Milli Bankası verilerinden yararlanarak oluşturulmuştur (www.nbkr.kg)

Ülke halkının kısmen Veblen etkisi nedeniyle tüketim toplumuna dönüşmesi dış açık sorununu daha da güçlendirmiştir. Bilindiği gibi, dış açık bir taraftan iç üretimi negatif etkilerken, diğer taraftan dış borçları artırır. Fakat gümrük vergilerinin düşük olması ülkenin re-eksport imkanını artırarak "Dordoy”, "Karasuu” gibi Orta Asya'daki büyük pazarların oluşmasına yol açmıştır ve ülkede önemli istihdam imkanları yaratmıştır. Ayrıca, ucuz malların tüketicilerin genel refahını artırdığını söylemek mümkündür. Serbest ticaretin bunun gibi negatif ve pozitif etkilerinin net olarak ülke ekonomisine faydalı veya zararlı olduğunu söylemek güçtür.

Tablo 4'den ülkede ithalatın giderek arttı̆̆ını, ihracatın GSYİH'ya oranının ise fazla değişmediğini görmek mümkündür. Bu da ülkenin dışa bağımlılığının giderek arttığının bir göstergesidir.

\begin{tabular}{|l|c|c|c|c|c|}
\hline & $\mathbf{2 0 0 9}$ & $\mathbf{2 0 1 0}$ & $\mathbf{2 0 1 1}$ & $\mathbf{2 0 1 2}$ & $\mathbf{2 0 1 3}$ \\
\hline Mal ve hizmet ihracat1/GSYIH & 50,8 & 49,8 & 52,6 & 45,2 & 46,2 \\
\hline Mal ve hizmet ithalatı/GSYIH & 76,8 & 79,2 & 83,2 & $\mathbf{1 0 0 , 3}$ & 96,0 \\
\hline
\end{tabular}

Tablo 4. Dış Ticaretin GSYİH'ya Oranları Kaynak: Kırgızistan Istatistik Komitesi verilerinden yararlanılarak hazırlanmıştır (www.stat.kg) 
Dış ticarette Kırgızistan'ın durumunun kötüleşmesine neden olan faktörleri kısaca aşağıdaki gibi sıralamak mümkündür:

> Öncelikle SSCB döneminde başka komşu ülkeler ile ortaklaşa faaliyet gösteren büyük üretim fabrikalarının sistemin çöküşü ile faaliyetlerinin durdurulması. Ardından da "özelleştirme” bahanesiyle parçalanarak yok edilmesi;

> Yolsuzluk ve kayıt dışı ekonomi dolayısıyla ülkede adaletsiz rekabetin yer alması ve sonuç olarak da ülkenin yabancı piyasalarda rekabet edememesi, üretimin düşük olması;

$>$ Reeksport olanaklarının artmasi;

$>$ İşçi gelirlerinin artması;

> Ülkede inşaat ve iletişim sektörlerinin gelişmesi ve gerekli her türlü yatırım, ara, tüketim mallarının ithalatının artması;

$>$ Halkın Veblen Etkisi nedeniyle tüketim toplumuna dönüşmesi;

> Ülkenin DTÖ’ne üye olması nedeniyle dış ticareti kontrol altına alabilecek tarife ve kotalar gibi dış koruma araçlarından fazla yararlanamaması vs.

Ülkenin cari işlemler hesabında net transferlerin önemli miktarlara ulaşarak cari işlemler hesabındaki açığın büyük bir kısmını kapatmakta olduğunu görmek mümkündür (Şekil 3). Net transfer hesabının büyük kısmı yurtdışında çalışan işçilerin ülkede bulunan akraba ve ailelerine para transferi sistemleri kanalıyla havale ettikleri paralardan, yani işçi gelirlerinden oluşmaktadır. Ancak bu paraların aslında bir kısmının ihracat ve reeksport gelirleri olduğunu, fakat resmi istatistiklerde bu ikisini ayrı ayrı kayıt altına alma imkanı olmadığından dolayı istatistiklerde aynı hesapta yer aldığını belirtmekte yarar vardır. Dolayısıyla bir kısmı ihracat gelirlerinden oluşan net transfer rakamlarının cari işlem hesabını çok değiştirmekte ve ampirik çalışmaların ikiz açı̆̆ı reddeden sonuçlara ulaşmasına neden olabilmektedir.

\section{Ekonometrik Yöntem ve Sonuçları}

Kırgızistan ekonomisinde ikiz açık hipotezinin test edilmesi için 2005-2013 dönemi kapsayan TÜFE (CPI), devlet bütçesi harcamaları (G), döviz (ABD doları) kuru (ER), para arzı (M2), ithalat (M), ihracat (X), yabancı ülkelerden transferler (REM) ve GSYİH (GDP) verileri aylık frekansta verileri kullanılarak VAR (Vector autoregression) analizi yapılmıştır. Transferlerin de analize alınmasının nedeni ülkede son zamanlarda dış ticaret açıklarının artmasına en çok işçi gelirlerinin neden olduğu (Akmoldoev ve Budachieva, 2012:6-13) sonucunun doğruluğunu araştırmaktır.

Veriler Kırgız Cumhuriyeti Milli Bankası ve Devlet İstatistik Komitesi verilerinden, ayrıca GSYİH'nın son iki senelik verileri de ülke birimlerinin aylık frekanstaki verilerin dağıtımını durdurması nedeniyle BDT'nın elektronik veri tabanından (www.cisstat.org) temin edilmiştir. CPI ve ER verileri dışında tüm veriler ABD dolarına çevrilmiş ve bütün seriler logaritmik hale dönüştürülmüş, mevsimsellikten arındırılmıştır (Census X12 yardımıyla). VAR analizi için ilk olarak zaman serilerinin durağanlık özelliklerine bakılması gerekir. Bu amaçla çalışmada Genişletilmiş Dickey-Fuller (ADF) testi ile Phillips-Perron (PP) durağanlık testleri kullanılmıştır (Tablo 5). Tablodan görüldüğü gibi CPI hariç tüm seriler birinci farkında durağandır.

\begin{tabular}{|l|c|c|c|c|}
\hline & \multicolumn{2}{|c|}{ ADF test sonuçları } & \multicolumn{2}{c|}{ PP test sonuçları } \\
\hline Değişkenler & Düzey değerler & Birinci fark1 & Düzey değerler & Birinci fark1 \\
\hline GDP & $-1,08(1)$ & $-12,85^{*}(0)$ & $-1,02(2)$ & $-12,68^{*}(3)$ \\
\hline CPI & $-6,69(0)^{*}$ & $-9,38^{*}(2)$ & $-6,76^{*}(4)$ & $-43.63^{*}(56)$ \\
\hline ER & $-0,71(1)$ & $-5,64 *(0)$ & $-0,40(5)$ & $-5,50 *(6)$ \\
\hline X & $-2,47(1)$ & $-14,65^{*}(0)$ & $-3,36^{* *}(2)$ & $-24,95^{*}(17)$ \\
\hline M & $-1,46(1)$ & $-14,80^{*}(0)$ & $-1,12(5)$ & $-15,00^{*}(2)$ \\
\hline M2 & $-1,40(2)$ & $-4,15^{*}(1)$ & $-1,32(6)$ & $-7,09^{*}(5)$ \\
\hline G & $-1,69(4)$ & $-8,66^{*}(3)$ & $-2,13(2)$ & $-58,47^{*}(97)$ \\
\hline REM & $-2,59 * * *(2)$ & $-11,51^{*}(1)$ & $-2,41(12)$ & $-17,25^{*}(3)$ \\
\hline \multirow{2}{*}{ \%1, ** \%5 ve *** \%10 önem düzeyinde durağan olduğunu göstermektedir. } & \\
MacKinnon kritik değerleri Eviews 8 ekonometrik paket programı tarafindan otomatik olarak verilmektedir. \\
Parantez içindeki değerler optimal gecikme uzunlukları̈ı vermektedir. \\
Optimal gecikme uzunlukları Akaike Bilgi Kriterine göre belirlenmiş ve maksimum gecikme 12 olarak alınmıştır. \\
\hline
\end{tabular}

\section{Tablo 5. Serilerin Dură̆anlık Testleri}

VAR modelini belirlemede, uygun gecikme uzunluğunun seçimi önemlidir. Çalışmadaki modelde otokorelasyonu önleyen minimum gecikme uzunluğu sıralı değiştirilmiş LR test istatistiğine göre 6 gecikme olarak belirlenmiştir.

VAR analizinin üç aracı vardır: a) Granger nedensellik testi; b) etki tepki analizi; c) varyans ayrıştırması. Granger nedensellik testleri yapılarak, diğer iki analiz aracılığı ile bulunan sonuçlar desteklenmeye 
çalışılmaktadır. Modelin nedensellik sonuçları tablo7'de özetlenmiştir. Varyans ayrıştırması ve etki-tepki analizleri, modelin dinamik yapısının belirlenmesinde kullanılır (Enders, 1995:305-311).

\begin{tabular}{|c|c|c|c|c|c|}
\hline Nedenselliğin yönü & Ki kare değeri & Olasılık & Nedenselliğin yönü & Ki kare değeri & Olasılık \\
\hline $\mathrm{M} \rightarrow \mathrm{ER}$ & 14,53 & 0,024 & $\mathrm{CPI} \rightarrow \mathrm{REM}$ & 28,001 & 0,000 \\
\hline $\mathrm{ER} \rightarrow \mathrm{G}$ & 18,919 & 0,004 & $\mathrm{ER} \rightarrow \mathrm{REM}$ & 13,177 & 0,040 \\
\hline $\mathrm{CPI} \rightarrow \mathrm{M} 2$ & 12,627 & 0,049 & $\mathrm{M} 2 \rightarrow \mathrm{REM}$ & 23,341 & 0,001 \\
\hline $\mathrm{G} \rightarrow \mathrm{GDP}$ & 13,639 & 0,034 & $\mathrm{G} \rightarrow \mathrm{M}$ & 13,185 & 0,040 \\
\hline $\mathrm{M} \rightarrow \mathrm{GDP}$ & 12,626 & 0,049 & $\mathrm{GDP} \rightarrow \mathrm{M}$ & 14,977 & 0,020 \\
\hline $\mathrm{G} \rightarrow \mathrm{X}$ & 13,373 & 0,037 & $\mathrm{X} \rightarrow \mathrm{M}$ & 18,152 & 0,006 \\
\hline $\mathrm{GDP} \rightarrow \mathrm{X}$ & 14,501 & 0,024 & $\mathrm{REM} \rightarrow \mathrm{M}$ & 16,636 & 0,010 \\
\hline
\end{tabular}

Tablo 6. Granger Nedenselliği /Wald testi

İkiz Açık hipotezi açısından bakıldığında sonuçlar devlet harcamalarından ihracat ve ithalata doğru bir nedenselliğin olduğunu, tersine bir ilişkinin sözkonusu olmadığını göstermektedir.

Etki-tepki analizi, değişkenlerden birine bir standart sapmalık şok uygulandığında hem kendisinin hem de diğer değişkenlerin bu değişime vermiş olduğu tepkileri gözlemlemektedir. Bu şekilde, değişkenler arasındaki dinamik ilişkiler ortaya konularak, etkili bulunan değişkenin politika aracı olarak kullanılabileceği belirlenmektedir (Warne, 2004:5). VAR modelinde etki-tepki fonksiyonunun katsayılarını elde etmede yaygın olarak, hataların Cholesky ayrıştırması kullanılmaktadır. Şekil 4'de Granger nedensellik sonuçlarına uygun olarak devlet harcamalarında meydana gelen bir standart sapmalık şoka ihracat, ithalat ve GSYİH'nın nasıl tepki gösterdiği grafik olarak sunulmuştur.

Etki-Tepki sonuçları devlet harcamasındaki değişmenin ihracata daha çok kısa dönemde, ithalata 5. ve 6.dönemlerde, GSYIH'ya ise hem kısa hem orta dönemde anlamlı etki verdiğini ortaya koymaktadır. Ancak şok karşllığında ithalat 5.dönemde $-0,035$ birim azalma, hemen sonraki dönemde 0,042 birim artma göstererek genel durum değişmemektedir. İhracat ise ilk 2 dönem sirasılyla $-0,005$ ve $-0,08$ birim azalma yönünde etkilenmektedir. GSYİH ilk dönem $-0,006$ birim ve 8 .dönem $-0,017$ birim negatif etkilenmektedir. Demek ki, devlet bütçe harcamalarındaki negatif değişme ihracat ve GSYIH üzerinde negatif tepki meydana getirmektedir. Dolayısıyla ikiz açığa karşı, devlet harcamalarının azaltılarak bütçe açı̆ı̆ını kapatma yoluna gidilmesi ülke ekonomisini negatif etkileyebilecektir.

Response to Cholesky One S.D. Innovations \pm 2 S.E.

Response of $M$ to $G$
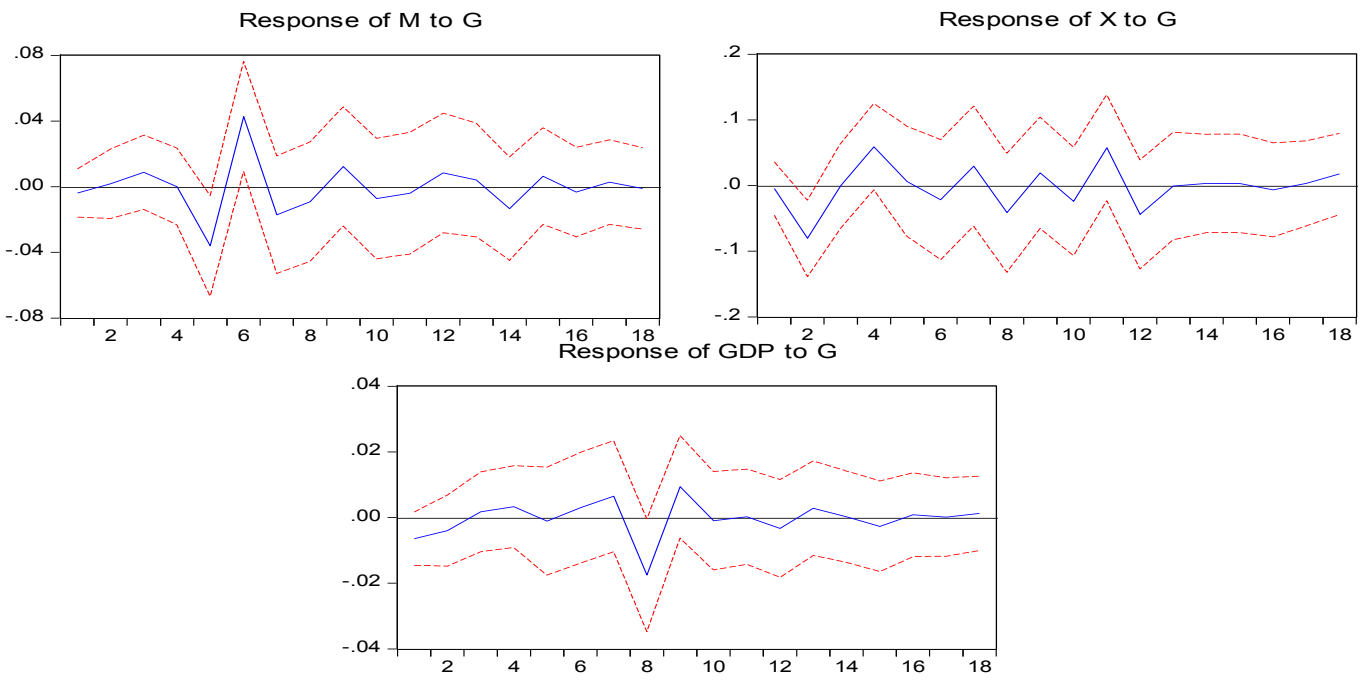

Şekil 4. Etki-Tepki Analizi Sonuçları

Şekil 5'de devlet harcamasını etkileyen faktördeki bir standart sapmalık şoka karşı kamu harcamalarının gösterdiği tepki yansıtılmıştır. Şekilden görüldüğü gibi döviz kurundaki bir standart sapmalık şok kamu harcamalarını ikinci dönem -0,043 birim azaltmakta, 4.dönem de 0,12 birim artırmakta ve 5 .dönem tekrar -0,052 birim azaltmaktadır. Genel olarak bakıldığında kamu harcamalarında ne tam olarak azaltıcı ne de tam olarak artırıcı yönde değişmelere neden olmaktadır. 


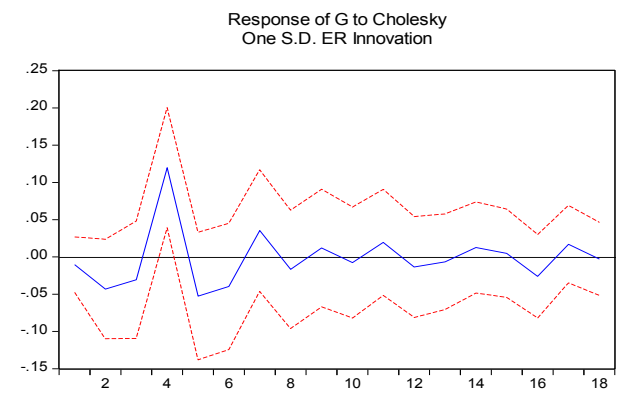

Şekil 5. Döviz Kurundaki Şoka Karşı Devlet Harcamalarının Tepkisi

Varyans ayrıştırması da değişkenlerin her birinin varyansında meydana gelen değişmenin yüzde kaçının kendi gecikmesinden, yüzde kaçının ise diğer değişkenlerden kaynaklandığını gösterir. Bu analiz, bir makroekonomik büyüklüğün üzerinde en etkili değişkenin hangisi olduğunu göstermektedir. Burada ayrıca nedenselliğin derecesi konusunda bilgi almak mümkündür. Modeldeki $G, M$ ve $X$ değişkenlerinin varyans ayrıştırma (variance decomposition) sonuçları sırasıyla Tablo 7; 8 ve 9'da verilmektedir.

\begin{tabular}{|c|c|c|c|c|c|c|c|c|c|}
\hline Per & S.E. & CPI & ER & G & M2 & GDP & X & REM & M \\
\hline 1 & 0.196 & $\mathbf{9 . 8 1 8}$ & 0.279 & 89.90 & 0.000 & 0.000 & 0.000 & 0.000 & 0.000 \\
\hline 2 & 0.289 & $\mathbf{6 . 1 9 5}$ & 2.341 & 88.81 & 1.420 & 0.173 & 0.060 & 0.003 & 0.986 \\
\hline 3 & 0.308 & $\mathbf{7 . 3 8 5}$ & 3.057 & 80.03 & 4.844 & 0.219 & 0.744 & 0.201 & 3.515 \\
\hline 4 & 0.339 & $\mathbf{8 . 9 6 7}$ & $\mathbf{1 4 . 9 8}$ & 66.02 & 4.083 & 1.867 & 0.615 & 0.410 & 3.040 \\
\hline 5 & 0.351 & $\mathbf{9 . 0 4 0}$ & $\mathbf{1 6 . 1 6}$ & 61.43 & 4.036 & 3.664 & 1.042 & 0.620 & 4.002 \\
\hline 6 & 0.358 & $\mathbf{8 . 9 0 4}$ & $\mathbf{1 6 . 8 3}$ & 59.34 & 3.904 & 3.576 & 1.132 & 0.784 & $\mathbf{5 . 5 1 6}$ \\
\hline 7 & 0.363 & $\mathbf{8 . 8 2 2}$ & $\mathbf{1 7 . 2 3}$ & 58.66 & 3.841 & 3.840 & 1.211 & 1.027 & $\mathbf{5 . 3 5 5}$ \\
\hline 8 & 0.376 & $\mathbf{8 . 4 3 9}$ & $\mathbf{1 6 . 3 0}$ & 56.44 & 3.932 & 3.592 & 3.607 & 1.212 & $\mathbf{6 . 4 6 0}$ \\
\hline 9 & 0.380 & $\mathbf{8 . 3 2 1}$ & $\mathbf{1 6 . 0 5}$ & 55.25 & 3.864 & 3.852 & 4.240 & 1.272 & $\mathbf{7 . 1 3 5}$ \\
\hline 10 & 0.382 & $\mathbf{8 . 2 4 4}$ & $\mathbf{1 5 . 9 4}$ & 54.73 & 3.894 & 3.906 & 4.233 & 1.946 & $\mathbf{7 . 0 9 6}$ \\
\hline
\end{tabular}

Tablo 7. G'nin Varyans Ayrıştırma (Variance Decomposition) Sonuçları

Sonuçlar devlet harcamasındaki değişmelerin en çok kendi geçmiş değerlerinden etkilendiğini, yani serinin dışsal olduğunu göstermektedir. Onun dişında en çok döviz kurundan, sonra da enflasyondaki ve ithalattaki değişmelerden, fakat kısa dönemde daha çok enflasyondan etkilendiği görülmektedir.

\begin{tabular}{|c|c|c|c|c|c|c|c|c|c|}
\hline Per & S.E. & CPI & ER & G & M & GDP & X & REM & M \\
\hline 1 & 0.076 & $\mathbf{6 . 6 2 4}$ & 4.988 & 0.448 & 1.581 & 4.105 & 3.761 & $\mathbf{1 6 . 7 8}$ & 61.70 \\
\hline 2 & 0.089 & $\mathbf{5 . 0 5 3}$ & 4.908 & 0.393 & 1.146 & $\mathbf{1 3 . 0 5}$ & 4.236 & $\mathbf{1 2 . 3 7}$ & 58.83 \\
\hline 3 & 0.095 & $\mathbf{4 . 5 6 4}$ & 4.369 & 1.166 & $\mathbf{8 . 2 2 6}$ & $\mathbf{1 4 . 5 2}$ & 4.156 & $\mathbf{1 0 . 9 9}$ & 51.99 \\
\hline 4 & 0.099 & $\mathbf{4 . 2 0 5}$ & 4.117 & 1.070 & $\mathbf{7 . 9 3 5}$ & $\mathbf{1 6 . 3 7}$ & 5.879 & $\mathbf{1 2 . 2 1}$ & 48.20 \\
\hline 5 & 0.109 & $\mathbf{3 . 8 3 0}$ & 4.624 & $\mathbf{1 2 . 1 5}$ & 9.171 & $\mathbf{1 3 . 6 8}$ & 4.909 & $\mathbf{1 0 . 7 8}$ & 40.83 \\
\hline 6 & 0.123 & $\mathbf{9 . 1 9 8}$ & 4.694 & $\mathbf{2 1 . 4 1}$ & 7.751 & $\mathbf{1 1 . 3 2}$ & 4.134 & $\mathbf{8 . 7 1 1}$ & 32.77 \\
\hline 7 & 0.130 & $\mathbf{9 . 4 9 3}$ & $\mathbf{1 2 . 4 4}$ & $\mathbf{2 0 . 2 9}$ & 7.177 & $\mathbf{1 0 . 1 9}$ & 3.662 & 7.725 & 29.01 \\
\hline 8 & 0.135 & $\mathbf{9 . 4 9 5}$ & $\mathbf{1 3 . 5 3}$ & $\mathbf{1 9 . 6 2}$ & 7.001 & $\mathbf{1 0 . 4 4}$ & 3.642 & 8.628 & 27.62 \\
\hline 9 & 0.138 & $\mathbf{9 . 0 8 1}$ & $\mathbf{1 4 . 1 7}$ & $\mathbf{1 9 . 6 7}$ & 7.402 & $\mathbf{1 0 . 1 1}$ & 3.615 & 8.609 & 27.33 \\
\hline 10 & 0.139 & $\mathbf{8 . 8 4 9}$ & $\mathbf{1 4 . 1 3}$ & $\mathbf{1 9 . 3 8}$ & 7.282 & 9.936 & 3.545 & 8.593 & 28.26 \\
\hline
\end{tabular}

Tablo 8. M'nin Varyans Ayrıştırma (Variance Decomposition) Sonuçları

İthalat da uzun dönemde en çok devlet harcamalarından, döviz kurundan, enflasyon ve GSYİH'dan etkilenmektedir. Fakat 2 ile 5. dönemler arasında daha çok işçi gelirleri, GSYİH ve para arzından etkilenmektedir (Tablo 11). Kendi gecikmesinden de ilk dönem \%61 kadar etkilenirken 8 dönem boyunca bu oran hızla düşmekte ve \%27-28'de sabitlenmektedir. GSYİH'dan kısa dönemde etkilenmesi ülkede tekstil gibi hafif sanayinin ekonomik etkilerinden kaynaklanabilir. İşçi gelirlerinin etkisi de \%16’yı aşmaktadır. İşçi gelirleri ile kamu harcamalarının ithalata etkileri karşılaştırıldığında işçi gelirlerinin kısa dönemde etkisinin daha fazla olduğunu, kamu harcamalarının etkisi de daha çok uzun dönemde görüldügüün̈ söylemek mümkündür.

\begin{tabular}{|r|c|c|c|c|c|c|c|c|c|}
\hline Per & S.E. & CPI & ER & G & M2 & GDP & X & REM & M \\
\hline 1 & 0.204 & 1.091 & 0.141 & 0.054 & 0.584 & $\mathbf{2 9 . 8 0}$ & 68.32 & 0.000 & 0.000 \\
\hline 2 & 0.257 & 3.772 & 1.554 & $\mathbf{9 . 5 3 7}$ & 0.373 & $\mathbf{1 9 . 0 1}$ & 65.68 & 0.026 & 0.034 \\
\hline 3 & 0.268 & 3.566 & 4.934 & $\mathbf{8 . 7 8 4}$ & 2.516 & $\mathbf{1 7 . 7 8}$ & 60.69 & 1.348 & 0.364 \\
\hline 4 & 0.281 & 4.060 & 4.549 & $\mathbf{1 2 . 3 8}$ & 2.365 & $\mathbf{1 7 . 0 4}$ & 55.73 & 1.275 & 2.588 \\
\hline 5 & 0.287 & 4.781 & 6.224 & $\mathbf{1 1 . 8 9}$ & 2.982 & $\mathbf{1 6 . 3 7}$ & 53.76 & 1.496 & 2.483 \\
\hline 6 & 0.302 & $\mathbf{6 . 0 1 3}$ & $\mathbf{8 . 1 7 2}$ & $\mathbf{1 1 . 1 4}$ & 4.745 & $\mathbf{1 6 . 9 4}$ & 48.67 & 1.618 & 2.681 \\
\hline 7 & 0.306 & $\mathbf{6 . 1 1 0}$ & $\mathbf{7 . 9 7 8}$ & $\mathbf{1 1 . 7 5}$ & 4.956 & $\mathbf{1 7 . 4 7}$ & 47.26 & 1.629 & 2.837 \\
\hline 8 & 0.320 & $\mathbf{9 . 1 8 5}$ & $\mathbf{8 . 6 1 8}$ & $\mathbf{1 2 . 2 4}$ & 5.729 & $\mathbf{1 6 . 1 5}$ & 43.49 & 1.876 & 2.692 \\
\hline 9 & 0.329 & $\mathbf{8 . 8 8 3}$ & $\mathbf{1 0 . 5 3}$ & $\mathbf{1 1 . 8 5}$ & 5.427 & $\mathbf{1 5 . 4 6}$ & 43.44 & 1.827 & 2.554 \\
\hline 10 & 0.333 & $\mathbf{8 . 6 9 3}$ & $\mathbf{1 0 . 3 2}$ & $\mathbf{1 2 . 1 0}$ & 5.381 & $\mathbf{1 5 . 8 8}$ & 42.60 & 1.835 & 3.178 \\
\hline
\end{tabular}

Tablo 9. X'in Varyans Ayrıştırma (Variance Decomposition) Sonuçları

İhracat'ın varyans ayrıştırma sonuçlarına göre ihracat hem uzun hem kısa dönemde en çok GSYİH ve devlet harcamalarından, uzun dönemde döviz kuru ve enflasyondan etkilenmektedir. Bu durumu ülkede ihracat malları içerisinde ülke altınının önemli paya sahip olması ile açıklamak mümkündür. 


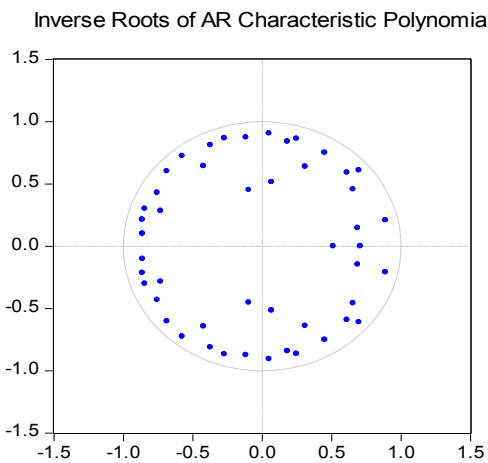

Şekil 6. Modelin Kararlllı̆̆

Şekil 6'ya göre modelin bütün olarak anlamlı ve güvenilir olduğu söylenebilir.

\section{Sonuç ve Değerlendirme}

Yapılan tüm analizlerden genel bir sonuç çıkartılacak olursa, Kırgızistan ekonomisinde İkiz Açık hipotezinin temelinde yer alan, bütçe açıkları ile cari işlemler açıkları arasında ilişkinin olduğunu ve genel olarak nedensellik yönünün bütçe açıklarından cari işlemler açıklarına doğru olduğunu savunan Keynesyen teorinin geçerli olduğunu söylemek mümkündür. Ülkede bütçe açıkları devlet harcamalarının sürekli artırılmasından kaynaklanmaktadır. VAR analizi bütçe harcamalarını kısma yoluyla dış ticaret açığını azaltmanın mümkün olmayacağını, bu tür yöntemin ekonomiyi negatif etkileyebileceğini göstermektedir. Diğer yandan Etki-Tepki ve Varyans Ayrıştırma analizi sonuçlarına göre ülkede enflasyon ile döviz kuru yaklaşık tüm değişkenler üzerinde çok büyük etkilere sahip olmaktadır. Bilindiği gibi Kırgızistan yönetimli dalgalanan döviz kuru sistemini benimsemiştir. Ancak küreselleşmenin artması sonucu ekonomik, finansal, siyasi ve diğer her türlü krizler özellikle döviz kurları kanalıyla diğer ekonomileri çok hızla etkileyebilmektedir. Kırgızistan hem çok büyük ölçüde dışa açık olması, hem de döviz rezervlerinin çok az olmasından dolayı döviz kurlarındaki şoklara karşı uyum sağlayamamakta ve dolayısıyla iç politikalarından ziyade dış alemdeki değişmelerden daha çok etkilenmektedir.

Bu sonuçların ışı̆̆ında Kırgızistan ekonomisindeki ikiz açık sorununu çözmek için devlet tarafından devlet harcamalarını kısmak yerine gelir kaynaklarını artııcı mali politikalar yanında aktif dış ticaret politikasının da uygulanması önerilmektedir. Bütçe gelirlerini artırabilmek için vergi düzenlemelerinin bir daha gözden geçirilerek Avrasya Ekonomi Birliği içerisinde reel ekonomiyi teşvik edebilecek şekilde uyumlaştırılması gerekir.

Bilindiği gibi ülkenin GSYİH'sında hizmet sektörü büyük paya sahiptir, ancak bütçeye en çok gelir sağlayacak olan reel sektördür. Ülke ekonomisinin yeni bölgeselleşme şartlarına ayak uydurabilmesi için de reel sektöre önem verilmesi, gerekirse hizmet sektöründeki kaynakların reel sektöre kaydırılması gerekir. Bu amaçla Tacikistan'da olduğu gibi üretim ve hizmet sektörleri için farklı vergi oranları uygulanabilir. Örneğin Tacikistan'da hizmet sektöründe kurumlar vergisi reel sektöre göre $\% 10$ daha yüksektir, 2015 'de sirasıyla $\% 24$ ve \%14 olarak belirlenmiştir (Налоговый кодекс Республики Таджикистан, 2013: 95-99). Fakat burada turizm gibi ülke ekonomisinin gelişmesine önemli katkı sağlayan sektörlere zarar gelmemesine özen gösterilmesi lazım.

Bütçe gelirlerini artırmanın diğer bir yöntemi de kayıt dışı ekonominin kayıt altına alınması ve yolsuzluğa karşı önlemlerin daha da sertleştirilmesidir. Sebebi de belli olduğu gibi Kırgızistan hem kayıt dışı ekonomi bakımından hem de yolsuzluk göstergeleri açısından dünyanın en kötü durumdaki ülkeleri arasında yer almaktadır. Bu iki öğe uzun zamandır ülkede haksız rekabete neden olarak reel sektörün gelişmesine engel olmuştur. Son senelerde bu konu üzerinde ülke çapında yoğun çalışmalar yapılmaktadır ve son yılın sonuçlarına göre de 2013'te 177 ülke arasında 150. siradayken 2014'de 175 ülke arasında 136. siraya yükselmiştir (www.knews.kg, 2015). Bu çalışmaların daha da yoğun olarak devam etmesi önemlidir, çünkü eğer ülke kısa sürede bu durumu ne kadar iyileştirebilirse entegrasyonun negatif etkileri de o kadar az olacaktır.

Dış ticaret açısından Kırgızistan'ın Avrasya Ekonomik Birliği'ne üye olması ile birlik dışındaki ülkeler ile olan ticaretinde gümrük tarifelerinin yükseltilmesi ile dış ticaret açığının otomatik olarak azalması, diğer yandan iç fiyatların yükselmesi ile iç rekabetin ve üretiminin artması beklenmektedir. Ancak daha önce belirtildiği gibi Kırgızistan'da gösteriş amaçlı tüketim de çok yüksektir ve bilindiği gibi fiyatların artması bu tür tüketimi azaltmayabilir. Dolayısıyla lüks mallara katma değer vergisini artırmak lüks tüketimi azaltarak dış ticaret açığının azalmasına imkan sağlayabilir, lüks tüketiminden vazgeçmeyen zengin sınıftan da daha çok vergi alınarak bütçe geliri artırılabilir.

Diğer yandan Avrasya Ekonomik Birliği dışındaki ülkelerden mal ithalatında tarifelerin yükselmesi ile ithalatın azalacağı, diğer taraftan gümrük vergilerinden bütçeye gelecek gelirin öncekine göre daha yüksek olacağı 
beklenmektedir. Bu bakımdan Kırgızistan ekonomisindeki İkiz Açık sorununun çözümünde bu birliğe girmenin avantajlı olacağı belirtilebilir.

Döviz kurundaki ve petrol fiyatlarındaki şoklar şeklinde yansımakta olan dış ekonomilerdeki krizlerin etkisi de parasal birliğe gidilerek ve Kazakistan ve Rusya gibi petrol ihracatçısı ülkeler ile birlik içerisinde olarak azaltılabilir.

\section{Kaynakça}

- Abell, John. (1990). Twin Deficits During The 1980's: En Emprical Investigation. Journal of Macroeconomics. Vol:12(1): 81-96.

- Akbostanc1, Elif ve Gül Ipek Tunç. (2002). Turkish Twin Deficits: An Error Correction Model Of Trade Balance. Erc Working Papers In Economics 01/06, May 2002 (Open Access Ideas.Repec.Org/P/Met/Wpaper/0106.Html, 16.03.1015)

- Akmoldoev, K. and Budaichieva, A. (2012). The Impact Of Remittances In Kyrgyzstan Economy. International Conference On Eurasian Economies, pp. 6-13.

- Aksu, Hayati Ve Başar, Selim. (2009). Türkiye Için İkiz Açiklar Hipotezi'nin Tahmini: Bir Sınır Testi Yaklaşımı. Ankara Üniversitesi Sbf Dergisi, 64(4):1-14.

- Alkswani, Mamdouh Alkhatib. The Twin Deficits Phenomenon In Petroleum Economy: Evidence From Saudi Arabia, (http://www.erf.org.eg/html/finance1.pdf, 25.04.2014).

- Aristovnik, A. (2005). Public Sector Stability and Balance of Payments Crises in Selected Transition Economies. Democratic Governance for the XXI Century: Challenges and Responses in CEE Countries, May 2005.

- Aristovnik, A. (2006). The Determinants and Excessiveness of Current Account Deficits in Eastern Europe and the Former Soviet Union. William Davidson Institute Working Paper, 827.

- Ay, Ahmet., Zeynep Karaçor, Mehmet Mucuk ve Savas Erdogan. (2004). Bütçe Açıgı-Cari İslemler Açıgı Arasındaki İlişki: Türkiye Örnegi (1992-2003)", http//www.sosyalbil.selcuk.edu.tr/sos_mak/makaleler, (erisim tarihi 11 Nisan 2014).

- Baharumshah, Ahmad Zubaidi, Evan Lau, Ahmed M. Khalid. (2006). Testing Twin Deficits Hypothesis: Using Vars And Variance Decompositon. Journal Of The Asia Pacific Economy, Volume 11(3): 331-354.

- Bahmani-Oskooee, M. (1989). Effects Of The U.S. Government Budget Deficits On Its Current Account: An Empirical Inquiry. Quarterly Review Of Economics And Finance, Vol. 29/4: 76-91.

- Bahtiyar, Görkem ve Hasan Bakir. (2011). Türkiye'de İkiz Açik Hipotezi. Ekonomi Bilimleri Dergisi Cilt 3(2), Issn: 1309-8020 (Online): 79-88.

- Banchman, Daniel David. (1992). Why Is The U.S. Current Account Deficit So Large? Evidence From Vector Autoregressions. Southern Economic Journal, Vol.59(2):232-240.

- Barro, J. Robert. (1979). On The Determination Of The Public Debt. Journal Of Political Economy, Volume: 87: 940-971.

- Bartolini, Leonardo and Amartya Lahiri. (2006). Twin Deficits, Twenty Years Later. Federal Reserve Bank Of New York Volume 12(7): 1-7.

- Bernheim, B. Douglas. (1989). A Neoclassical Perspective On Budget Deficits. Journal Of Economic Perspectives, Volume: 3(2): 55-72.

- Bernheim, B.Douglas and Kyle Bagwell. (1986). Is Everythıng Neutral? Nber Workıng Paper, No: 2086.

- Bilgili, E. ve Bilgili, F. (1998). Bütçe Açıklarının Cari Islem Dengesi Üzerindeki Etkileri: Teori ve Uygulama. İktisat, İletme ve Finans Dergisi, Y1l: 13(146): 4-16.

- Bolat, Süleyman, Murat Belke ve Ozan Aras. (2011). Türkiye'de İkiz Açık Hipotezinin Geçerliliği: Sınır Testi Yaklaşımı. Maliye Dergisi, Sayı 161: 347-364.

- Chowdhury, K. ve Saleh, A.S. (2007). Testing The Keynesian Proposition Of Twin Deficits In The Presence Of Trade Liberalisation: Evidence From Sri Lanka. University Of Wollongong Economics Working Paper Series, Wp 07-09.

- Corsetti, Giancarlo and Muller, Gernot. (2006). Twin Deficits: Squaring Theory, Evidence and Common Sense. Economic Policy, Vol. 21(48): 599-638.

- Darrat, D. A. (1988). Have Large Budget Deficits Caused Rising Trade Deficits? Southern Economic Journal, Vol: 54:879-887.

- Dewald, G. William. ve Michael Ulan. (1990).The Twin Deficit Illusion. Cato Journal, Vol.9(3): 689-707.

- Diboğlu, Selahattin. (1994). Accounting For U.S. Current Account Deficits: An Emprical Investigation. International Finance 9502003, Econwpa.

- Doğan, Burhan. (2010). Türkiye Ekonomisinde Kriz Öncü Göstergeleri Ve İkiz Açik. Journal Of Azerbaijani Studies (Açık Erişim: Http://Jhss-Khazar.Org/Wp-Content/Uploads/2010/06/TurkiyeEkonomisinde-Kriz-Oncu.Pdf, 08.02.1014) ss. 500-521. 
- Dornbusch, Rudiger, Stanley Fisher, ve Richard Statz. (2004). Macroeconomics. 9 Th Edition, Boston: Mcgraw Hill.

- Eisner, Robert. (1989). Budget Deficits: Rhetoric And Reality. The Journal Of Economic Perspectives, Volume:3(2): 73-93.

- $\quad$ Enders, W. (1995). Applied Econometric Time Series. John Wiley \& Sons, Inc, pp. 305-311.

- Evans, Paul. (1988). Are Consumers Ricardian? Evidence For The United States. The Journal of Political Economy, Vol. 96(5):983-1004.

- Güven, Hakan. (2014). İkiz Açıklar Hipotezi: Kırgızistan Örneği. Yayınlanmamış Yüksek Lisans Tezi, SBE Kırgızistan-Türkiye Manas Üniversitesi.

- Islam, M. Faizul. (1998). Brazil's Twin Deficits: An Empirical Examination Aej: June 1998, Vol. 26(2):121 -128 .

- İyidoğan, Pelin Varol. (2013). Merkez Ve Doğu Avrupa Ülkelerinde Bütçe Dengesi Ve Cari İşlemler Dengesi İlişkisi: Ekonometrik Bir İnceleme. Maliye Dergisi, 164:82-98.

- Karatay, Pelin. (2008). İkiz Açıklar Hipotezi Ve Türkiye Uygulaması. Gaziantep Üniversitesi Lisansüstü Tezi. (http://www.yok.gov.tr)

- Kilavuz, Emine ve Yasemin Dumrul. (2012). İkiz Açiklar Hipotezinin Geçerliliği: Teori Ve Uygulama. Atatürk Üniversitesi İktisadi Ve İdari Bilimler Dergisi, Cilt: 26(3-4): 239-528.

- Kim, C. H. and Kim, D. (2006). Does Korea Have Twin Deficits? Applied Economics Letters, vol 13: 675680 .

- Mangır, Fatih. (2012). Türkiye İçin İkiz Açiklar Hipotezi Testi (1980-2011). Niğde Üniversitesi İİİBF Dergisi Cilt: 5(2): 136-149

- Mankiw, N. Gregory.(2002). Macroeconomics, 5th Eddition, New York: Worth Publishers.

- Olugbenga, A. Onafowora and Oluwole Owoye. (2006). An Empirical Investigation Of Budget And Trade Deficits: The Case Of Nigeria. The Journal Of Developing Areas Volume 39 (2): 153-174.

- Puah, Chin-Hong, Evan Lau and Kim-Lee Tan. (2006). Budget-Current Account Deficits Nexus In Malaysia. (Online At Http://Mpra.Ub.Uni-Muenchen.De/37677/ Mpra Paper No. 37677, Posted 27. March 2012 12:54 Utc, 16. 03. 2015).

- $\quad$ Rosenweig, J. A. And Tallman, E. W. (1993).Fiscal Policy And Trade Adjustment: Are The Deficits Really Twins? Economic Inquiry, Vol.31:580-594.

- Sever, E. ve Demir, M. (2007). Türkiye'de Bütce Açığı Ile Cari Açık Arasındaki İlişkilerin Var Analizi Ile İncelenmesi. Eskişehir Osmangazi Üniversitesi IIBF Dergisi, 2(1):47-63.

- Tunçsiper, Bedriye ve Dilek Sürekçi. (2011). Türkiye'de İkiz Açiklar Hipotezinin Geçerliliğinin Zaman Serisi Analizi. Anadolu Üniversitesi Sosyal Bilimler Dergisi Cilt: 11(3): 103-120.

- Utkulu, Utku. (2003). Türkiye'de Bütçe Açiklari Ve Diş Ticaret Açiklari Gerçekten İkiz Mi? D.E.Ü.İ.İ.B.F.Dergisi Cilt:18(1):45-61.

- $\quad$ Ümit, Öznur. (2007). Türkiye'de Bütçe Açigi İle Cari İslemler Arasindaki İlişkilerin Zaman Serisi Analizi. (Doktora Tezi) Eskisehir, Anadolu Üniversitesi Sosyal Bilimler Enstitüsü, 211 sayfa.

- Vamvoukas, G. A. (1999). The Twin Deficits Phenomenon: Evidence From Greece. Applied Economics, 31 : 1093-1100

- Volcker, Paul A.(1984). Facing up to The Twin Deficits. Challenge, Vol. 27(1): 4-9.

- Yaldız, Elmas.(2006). İkiz Açıklar Hipotezi Ve Türkiye. İzmir İktisat Kongresi Arastırma Merkezi, Bilimsel Çalısma Raporları Serisi, Bçr No: 2006/01. Yıl 19: 5-17.

- Yılmaz, Alper. (1993). İkiz Açıklar Hipotezi’nin Türkiye Örnegine Uygulanması. Yayınlanmamıs Yüksek Lisans Tezi, Bilkent Üniversitesi SBE, Ankara.

- Yılmaz, Binhan Elif. (2002). “İkiz Açık” Teorisi: Türkiye’nin 1980-2001 Dönemi Bütçe Açıkları Ve Dış Ticaret Açıkları Üzerine Bie Nedensellik Araştırması. İ.Ü. İktsat Fakültesi Maliye Araştırma Merkezi Konferanslar1 14.Seri, ss. 139-152.

- Yücel, Fatih Ve Ahmet Yılmaz Ata. (2003). Es-Bütünlesme ve Nedensellik Testleri Altında İkiz Açıklar Hipotezi: Türkiye Uygulaması. Çukurova Üniversitesi Sosyal Bilimler Enstitüsü, Sosyal Bilimler Dergisi, Cilt:12(12):1-13.

- Warne, A. (2004). Lecture Notes on Stuructural Vector Autoregression. (10 Mart 2008) (http://texlips.hypermart.net/download/lecture_notes.pdf)

- Zengin, Ahmet. (1999).İkiz Açıklar Hipotezi (Türkiye Uygulaması). Yayınlanmamıs Doktora Tezi, Karadeniz Teknik Üniversitesi S.B.E., Trabzon.

- Zietz, J.,and Pemberton, D. K. (1990). The Us Budget And Ttrade Deficits: A Simultaneous Equation Model. Southern Economic Journal, 57: 23-34.

- Налоговый Кодекс Республики Таджикистан. (2013). В редакции законов РТ от 28.12.2013г. №1046. (http://base.spinform.ru/show_doc.fwx?rgn=7913, 24.03.2015) стр.95-99.

- http://www.knews.kg/econom/57773/ 


\title{
Türki Cumhuriyetlerin İş Yapılabilirlik Potansiyeli Açısından Değerlendirilmesi
}

\section{Evaluation of Turkic Republics In Terms of Business Feasibility Potential}

\author{
Assoc. Prof. Dr. Serkan Dilek (Kastamonu University, Turkey) \\ Asst. Prof. Dr. Ali Konak (Karabük University, Turkey)
}

\begin{abstract}
Today, level of countries' business feasibility in terms of global competition has a great importance. For businessmen, determination of the level of countries' business feasibility provides important information about the level of overall business feasibility of the examined countries and plays an important role on understanding the levels of the investment feasibility of countries. In this context, in our search, the levels of business feasibility of countries Azerbaijan, Kazakhstan, and Kyrgzstan presenting available business feasibility index and Global Competitiveness Index between 2004-2014 has been examinated with the help of the business feasibility index prepared by World Economic Forum (WEF), thus it has been trying to put forward strengths and weaknesses in terms of getting feasibility business in these countries. As a result of studies, with together change from country to country and from year to year, the most important barriers in front of the feasibility business in the examined Turkic Republics in recent years, has been determined that they are based on inability to access enough to an electrical source, the lack of protection of investors and inability to perform remarkable progress in the matter of tax paid. After all, in Turkish Republics, it was that there are positive developments in the process of starting work, also significantly reduced in bankruptcy, besides, the realization of significant progress about formalization of property and reaching credit resources and in line with these developments, it has been concluded that Turkic Republics -except Tajikistan- has slightly developments in being business feasible country.
\end{abstract}

\section{Giriş}

Küreselleşmenin hızlı bir şekilde yaşandığı günümüzde ülkeler arasındaki uluslararası rekabet de hızlı bir artış eğilimi içerisindedir. Bu rekabet sürecinde ülkeler birbirlerine karşı bir takım üstünlükler sağlamaya çalışmakta ve bu üstünlükler sayesinde diğer ülkelerin önüne geçme gayreti içerisinde olmaktadır. Özellikle teknoloji, iletişim ve ulaşım alanlarındaki hızlı gelişmeler, ülkeleri ekonomik gelişmişlik açısından çetin bir rekabet sürecinin içine sokmuştur. Bu süreçte başarılı olmak ise önemli ölçüde diğer ülkeler karşısında çeşitli açılardan elde edilebilecek üstünlüklere bağlıdır. Diğer ülkeler karşısında rekabet üstünlüğü elde etmek ise sermaye birikimi yetersiz olan ülkelerin özellikle de gelişmekte olan ülkelerin yabancı sermayeyi ülkelerine çekebilme kabiliyetlerine bağlıdır. Rekabet üstünlüğü elde etmeyi başaran ülkeler; yatırımlarını, üretimlerini, ihracatını ve bütün bu gelişmelerin doğal bir sonucu olarak GSMH'larını artıracaklardır. Bu çalışmada Türki Cumhuriyetler (Kazakistan, Kırgızistan, Azerbaycan, Özbekistan ve Türkmenistan) iş yapılabilirlik potansiyeli açısından değerlendirilmiştir. İnceleme kapsamındaki her bir Türki Cumhuriyet açısından iş hayatına yönelik olarak yabancı yatırımların ülkeye çekilmesinde en çok sorun teşkil eden 10 faktör ortaya konulmuş, 2013-2014 raporu doğrultusunda Türki Cumhuriyetlerinin iş hayatındaki mevcut sorunları üzerinde durulmuştur.

\section{Türki Cumhuriyetlerde İş Dünyasina Yönelik Problemler}

İnceleme kapsamımızda bulunan Türki Cumhuriyetlerinin iş hayatına ilişkin önemli sorunlarının bulunduğunu belirtmekte ve bu sorunların genel bir değerlendirmesini yapmakta fayda vardır. Böyle bir değerlendirme yapmaktaki temel amaç, Türki Cumhuriyetlerde, iş hayatına yönelik sorunların tespit edilerek bir farkındalık oluşturmak ve yabancı yatırımların ülkeye çekilebilmesi için ne gibi düzenlemelerin yapılması gerektiğinin tespitine yardımcı olmaktır. Tablo 1. Türki Cumhuriyetlerinde iş dünyasına yönelik problemleri ortaya koymaktadır. İş dünyasına yönelik problemler Tablo 1'deki yüzde değerlerden ve endeks sıralamasından yararlanarak her ülke için ayrı ayrı değerlendirmeye tabi tutulmuştur. 


\begin{tabular}{|c|c|c|c|c|c|c|c|c|}
\hline & & \multicolumn{7}{|c|}{ DÖNEMLER } \\
\hline & $\begin{array}{l}\text { Iş Dünyasına } \\
\text { Yönelik } \\
\text { Problemler }\end{array}$ & $\begin{array}{c}2008-2009 \\
(\%)\end{array}$ & $\begin{array}{c}2009-2010 \\
(\%)\end{array}$ & $\begin{array}{c}2010-2011 \\
\text { (\%) }\end{array}$ & $\begin{array}{c}2011-2012 \\
(\%)\end{array}$ & $\begin{array}{c}2012-2013 \\
(\%)\end{array}$ & $\begin{array}{c}2013-2014 \\
(\%)\end{array}$ & $\begin{array}{c}2014-2015 \\
\text { (\%) }\end{array}$ \\
\hline \multirow{10}{*}{ 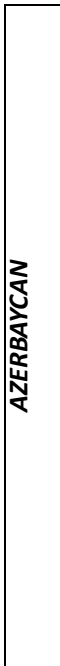 } & Rüşvet & 20.4 & 19.6 & 21.6 & 19.6 & 23.4 & 23.6 & 19.9 \\
\hline & $\begin{array}{c}\text { Finansmana } \\
\text { Erişim Zorlukları }\end{array}$ & 10.7 & 8.2 & 14.3 & 13.6 & 14.2 & 10.6 & 14.6 \\
\hline & Vergi Oranları & 11.4 & 9.8 & 7.9 & 10.4 & 9.8 & 13.2 & 11.8 \\
\hline & $\begin{array}{c}\text { Yetersiz } \\
\text { Eğitilmiş İşgücü }\end{array}$ & 7.0 & 10.2 & 10.0 & 9.1 & 8.9 & 11.2 & 11.3 \\
\hline & $\begin{array}{c}\text { Alt Yapı } \\
\text { Yetersizlikleri }\end{array}$ & 5.5 & 8.1 & 7.9 & 10.5 & 10.0 & 4.5 & 10.1 \\
\hline & $\begin{array}{c}\text { Yenilikler İçin } \\
\text { Yetersiz Kapasite }\end{array}$ & - & - & - & - & 3.3 & 3.9 & 7.2 \\
\hline & $\begin{array}{c}\text { Ulusal işs } \\
\text { gücünün Isş } \\
\text { Ahlakı Zayıflığı }\end{array}$ & 3.8 & 7.8 & 5.9 & 5.9 & 6.8 & 4.9 & 6.6 \\
\hline & $\begin{array}{c}\text { Verimsiz Kamu } \\
\text { Bürokrasisi }\end{array}$ & 10.2 & 8.5 & 10.8 & 6.0 & 7.4 & 7.0 & 4.8 \\
\hline & $\begin{array}{c}\text { Vergi } \\
\text { Düzenlemeleri }\end{array}$ & 7.1 & 9.5 & 11.9 & 11.2 & 8.3 & 10.6 & 4.6 \\
\hline & $\begin{array}{l}\text { Kısıtlayıcı İşgücü } \\
\text { Düzenlemeleri }\end{array}$ & 2.7 & 3.0 & 3.4 & 3.7 & 2.7 & 1.3 & 2.2 \\
\hline \multirow{10}{*}{$\begin{array}{l}3 \\
\frac{3}{5} \\
\frac{2}{2} \\
\frac{1}{2} \\
\frac{1}{2}\end{array}$} & Rüşvet & 15.7 & 19.2 & 17.3 & 17.3 & 15.7 & 18.9 & 16.7 \\
\hline & $\begin{array}{c}\text { Finansmana } \\
\text { Erişim Zorlukları }\end{array}$ & 10.3 & 11.9 & 12.1 & 12.1 & 9.5 & 8.5 & 14.6 \\
\hline & $\begin{array}{c}\text { Verimsiz Kamu } \\
\text { Bürokrasisi }\end{array}$ & 6.0 & 7.5 & 10.8 & 10.8 & 9.0 & 8.8 & 8.0 \\
\hline & $\begin{array}{c}\text { Vergi } \\
\text { Düzenlemeleri }\end{array}$ & 12.9 & 11.0 & 8.9 & 8.9 & 9.6 & 7.4 & 7.8 \\
\hline & $\begin{array}{c}\text { Alt Yapı } \\
\text { Yetersizlikleri }\end{array}$ & 6.1 & 1.7 & 5.3 & 5.3 & 4.7 & 5.3 & 7.4 \\
\hline & Enflasyon & 12.4 & 14.4 & 7.6 & 7.6 & 4.6 & 5.2 & 6.9 \\
\hline & $\begin{array}{c}\text { Yetersiz Eğitilmiş } \\
\text { Işsücü }\end{array}$ & 8.1 & 4.8 & 12.3 & 12.3 & 17.2 & 13.3 & 6.8 \\
\hline & $\begin{array}{c}\text { Yenilikler İçin } \\
\text { Yetersiz Kapasite }\end{array}$ & - & - & - & - & 7.5 & 5.0 & 6.1 \\
\hline & Vergi Oranları & 11.8 & 11.1 & 7.3 & 7.3 & 6.1 & 7.1 & 5.9 \\
\hline & $\begin{array}{c}\text { Yabancl } \\
\text { Paralara İlişkin } \\
\text { Düzenleme }\end{array}$ & 1.6 & 2.8 & 3.0 & 3.0 & 1.2 & 2.1 & 4.7 \\
\hline \multirow{10}{*}{ 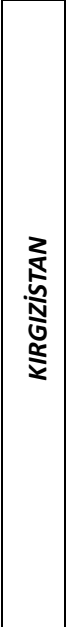 } & $\begin{array}{c}\text { Devlet } \\
\text { istikrarsızlıları / } \\
\text { darbeler }\end{array}$ & 7.4 & 9.9 & 12.9 & 22.8 & 11.3 & 18.7 & 20.2 \\
\hline & Rüşvet & 20.8 & 13.6 & 17.3 & 20.4 & 17.3 & 21.5 & 17.4 \\
\hline & $\begin{array}{c}\text { Politik } \\
\text { Istikrarsızlık }\end{array}$ & 10.0 & 13.1 & 16.1 & 20.0 & 17.7 & 18.6 & 13.1 \\
\hline & $\begin{array}{l}\text { Verimsiz Kamu } \\
\text { Bürokrasisi }\end{array}$ & 6.9 & 7.9 & 6.2 & 8.4 & 9.3 & 6.6 & 8.9 \\
\hline & $\begin{array}{c}\text { Yetersiz Eğitilmiş } \\
\text { işsücü }\end{array}$ & 7.0 & 3.5 & 4.3 & 1.6 & 5.8 & 1.9 & 6.2 \\
\hline & $\begin{array}{c}\text { Finansmana } \\
\text { Erişim Zorlukları }\end{array}$ & 5.3 & 12.2 & 7.7 & 7.7 & 8.1 & 3.7 & 5.9 \\
\hline & Suç ve Hırsızlık & 2.2 & 3.2 & 3.6 & 5.9 & 4.5 & 7.0 & 5.6 \\
\hline & $\begin{array}{c}\text { Ulusal } \\
\text { İşgücünün Iss } \\
\text { Ahlakı Zayıflığı }\end{array}$ & 1,6 & 2.6 & 2.8 & 0.8 & 2.8 & 2.4 & 4.6 \\
\hline & Vergi Oranları & 8.1 & 7.1 & 7.2 & 3.9 & 5.4 & 4.8 & 4.6 \\
\hline & Enflasyon & 6.1 & 5.6 & 6.0 & 2.5 & 4.4 & 2.5 & 4.3 \\
\hline
\end{tabular}

Tablo 1.Türki Cumhuriyetlerde İş Dünyasına Yönelik Problemler ve Bu Problemlerin Yillara Göre Yüzde Dağılımı Kaynak: World Economic Forum (WEF) Tarafından 2008-2014 Dönemi için Yıllar İtibariyle Hazırlanan Küresel Rekabet Endekslerinden Yararlanılarak Tarafımızca Hazırlanmıştır. 


\section{AZERBAYCAN}

Türki Cumhuriyetlerin iş dünyasına yönelik sorunlarının yer aldığı Tablo 1'i incelediğimizde, Azerbaycan iş dünyasında en çok karşılaşılan sorunların başında rüşvetin geldiği görülmektedir. Rüşvet gerçekten ülkenin önemli sorunlarından biri teşkil emektedir. Asker'in (2011:8) de ifade ettiği üzere ülkede çok yaygın olan rüşvet ve yolsuzluk, halkın üzerinde olumsuz psikolojik hava oluşturmaktadır. Ülkedeki rüşvet uygulamalarının neden olduğu bu olumsuz hava doğal olarak yabancı yatırımcılara da yansımakta ve yabancı yatırımcıların ülkeden uzak durmasına neden olan en önemli faktör olarak karşımıza çıkmaktadır. Önceki yıllarda çok daha yüksek seviyelerde ortaya çıkan rüşvet uygulamasının ülke ekonomisine neden olduğu zararlar görülmüş olacak ki alınan bazı önlemler nedeniyle rüşvet uygulamasının dünya ekonomik forumu tarafından hazırlanan 2014-2015 dönemine ait küresel rekabet endeksinde önceki yıllara kıyasla bir miktar azaldığı görülmektedir. Ama yine de rüşvet ülkenin iş dünyasındaki en önemli sorunu olmaya devam etmektedir. Azerbaycan iş dünyasında karşılaşılan ikinci önemli sorun ise finansmana ulaşımdaki zorluklardır. Finansmana ulaşılmada karşılaşılan zorlukların aşılması aşamasında, petrol gelirleri önemli rol oynamaktadır. $\mathrm{Bu}$ süreçte bütçeden yapılan cari harcamaların petrol dışında kalan sektörlerden elde edilen vergi gelirleriyle karşılanması, buna karşın kamusal yatırımları gerçekleştirmek amacıyla yapılan kamu harcamalarının finansmanının ise Devlet Petrol Fonu'ndan yapılan transferlerle karşılanması hedeflenmiştir. $\mathrm{Bu}$ doğrultuda Azerbaycan hükümeti petrole bağımlılığ azaltmak için çok bileşenli ve sistemli bir politika izlemektedir (Ahmet Yesevi Üniversitesi, 2015:39-41). Böyle bir planlama ile ülkede söz konusu olan finansmana erişim probleminin önüne geçilmeye çalışılmaktadır. Yine ülkede iş dünyası açısından karşılaşılan bir diğer önemli sorun da vergi oranlarının yüksek olmasıdır. Gelişmekte olan her ülke için olduğu gibi Azerbaycan için de vergi gelirleri çok önemli bir gelir kalemini teşkil etmektedir. Ancak vergi oranlarının yüksekliği hem iç piyasada piyasanın işleyişinin aksamasına neden olabilir hem de yabancı yatırımcıların ülkeye yapacağı reel yatırımların önünde önemli bir engel teşkil edebilir. Bu nedenle arz yetersizliğinin önemli bir faktör olarak ortaya çıktığı Azerbaycan ekonomisinde ekonomik durağanlığın ortadan kaldırılabilmesi için vergi indirimlerine gidilmesi ve vergideki bu indirimler neticesinde üretim faktörlerinin üretimi artıracak şekilde harekete geçirilmesi büyük önem arz etmektedir (Süleymanov ve Hasanov, 2013:90). Yabancı yatırımların ülkeye gelmesinin önündeki en önemli engellerden bir diğeri olan altyapı eksiklikleri, yabancı yatırımcıların bu ülkeye yatırım yapma noktasında isteksiz olmalarına neden olmaktadır. Yabancı yatırımcılar açısından böyle isteksiz bir tablonun ortaya çıkmasında, alt yapı eksikliklerinden kaynaklı üretim kalitesindeki düşüşler yanında üretim sürecinin zorlaşması ve üreticilerin ekstra maliyetlere katlanmak zorunda kalacak olmaları önemli rol oynamaktadır. Azerbaycan'da karşılaşılan bu önemli sorunlar dışında ülkedeki iş gücünün yeterince eğitilememiş olması ve teknik konulardaki eğitim eksikliği, üretim sürecindeki yeniliklere yeterince açık olunmaması ve yeterli üretim kapasitesine sahip olunmaması, verimliliği olumsuz yönde etkileyen yaygın bürokratik uygulamalar, etkinsiz vergi düzenlemeleri ve işgücünü faaliyetlerini kısıtlayıcı uygulamalar diğer önemli sorunları teşkil etmektedir.

\section{KAZAKISTAN}

İş dünyasına ilişkin sorunları Tablo 1'deki değerlerden yararlanarak Kazakistan açısından yaptığımızda, Azerbaycan ile paralellik gösterdiği gözlenmektedir. Azerbaycan da olduğu gibi rüşvet ve finansmana erişim zorlukları ülkedeki iş dünyasına yönelik en önemli iki sorunu teşkil etmektedir. Rüşvet, bağımsızlığını yeni kazanmış pek çok Türki Cumhuriyette olduğu üzere Kazakistan'da da ülkenin üstesinden gelmesi gereken bir sorun olarak ortaya çıkmış durumdadır. Özellikle bağımsızlıklarının ilk yıllarında bu ülkelerde söz konusu olan otorite boşluğu rüşvetin yaygınlaşmasına neden olmuştur. Bağımsızlığın ilk yıllarında otorite boşluğuna bağlı olarak ortaya çıkan rüşvet sorunu günümüzde de Kazakistan'ın iş dünyasına yönelik en önemli sorununu teşkil etmektedir. Rüşvet dışında finansmana erişim konusu da Kazakistan'ın iş dünyasına yönelik bir diğer sorunudur. Kazakistan finansmana erişim noktasında karşılaştığı sorunların üstesinden gelebilmek için Uluslararası Para Fonu (IMF) desteği ile 2000-2002 yılında ekonomik program uygulamaya koymuştur. Bu program ile serbest döviz kuru ortamında hassas bir para politikası izlenerek kamu finansmanını vadesi uzatılmaya ve yapısal reformların devamlılığı sağlanmaya çalışılmıştır. Ayrıca finansmana erişimde kolaylıklar sağlayan bu program ülkede uygulandığı süre boyunca ekonomik istikrarda devamlılığın sağlanmasına ve makroekonomik hedeflere ulaşılmasına katkı sağlamıştır (Alagöz, 2012: 480). İş dünyasında karşılaşılan bu önemli sorunlara ilaveten bürokrasinin neden olduğu olumsuzluklar, etkinsiz vergi düzenlemeleri ve vergi oranlarının yüksekliği, enflasyon, alt yapı yetersizlikleri ve iş gücü piyasasında kalifiye eleman eksikliği Kazakistan'ın mücadele etmesi gereken diğer sorunları teşkil etmektedir.

\section{KIRGIZISTAN}

Kırgızistan da iş dünyasına yönelik olarak karşılaşılan sorunların başında ise daha önce incelenen iki ülkeden farklı olarak devlet istikrarsızlıkları ve darbelerin ön plana çıktığı görülmektedir. Ülkede istikrarsız bir tablonun ortaya çıkmasının pek çok önemli nedeni bulunmaktadır. Bu nedenlerin başında ülkedeki siyasi iktidarın kırılgan yapıya sahip olması, günümüzde bile devlet otoritesinin oldukça zayıf oluşu ve toplumun farklı kesimler arasında sosyal barışın henüz oluşturulamamış olması gelmektedir. Bu süreç, taraflar arasında çatışma riskine ve yeni yeni istikrarsızlıkların ortaya çıkmasına zemin hazırlamaktadır (Özkan, 2011). Buna ilaveten idari krizlerin yaşandığı süreçlerde, iktidar boşluğundan yararlanan çeşitli çıkar gruplarının varlığg, ülkedeki siyasetin bölgeler 
ve çıkar grupları üzerinden yapılması, ülkenin farklı bölgeleri arasındaki büyük kalkınmışlık farklılıkları, bireyler arasındaki sosyo-ekonomik uçurumlar ve etnik farklılıklar, ülkedeki önemli istikrarsızlık kaynakları olarak ortaya çıkmıştır (Sarı, 2010:29). Ayrıca ülkedeki alt yapı eksiklikleri de istikrarsızlı̆̆a neden olan bir diğer önemli unsuru teşkil etmektedir. Alkan (2011:3) Kırgızistan da güçlü bir devlet partisinin ortaya çıkmasına olanak sağlayacak bir alt yapının bulunmayışının ülkedeki siyasi ve ekonomik istikrarsızı besleyen bir unsur olduğunu ifade etmiştir. Özellikle ülkede hakim olan kırılgan siyasi yapı nedeniyle diğer Türki Cumhuriyetlerden farklı olarak 24 Mart 2005 tarihinde bir halk ayaklanması yaşanmış ve bu halk ayaklanması iktidar değişikliği ile sonuçlanmıştır. Ancak yaşanan iktidar değişikliği beklentileri karşılamamış, iktidar değişikliği sonrasında rüşvet ve adam kayırmacılık olayları artmıştır (Ahmet Yesevi Üniversitesi, 2013:130-131). Doğal olarak siyasi istikrarsızlık enflasyon, vergi oranlarının yükselmesi, suç ve hırsızlık oranlarının artış göstermesi ve finansmana erişimin zorlaşması gibi bir takım ekonomik ve sosyal sorunu da beraberinde getirmiştir.

\section{ÖZBEKISTAN}

Türki Cumhuriyetler içinde çeşitli açılardan önem arz eden bir diğer ülke de Özbekistan'dır. İş dünyasında sıklıkla karşılaşılan sorunlara değinmeden önce Özbekistan’ın, inceleme kapsamımızda yer alan diğer ülkelerden farklı olarak kendine has bir takım özelliklere sahip olduğunu söylemek gerekir. Bu özelliklerin başında da ekonomik yapıya ilişkin unsurlar ön plana çıkmış durumdadır. 1 Eylül 1991'de bağımsızlığını ilan eden Özbekistan, dışa kapalı bir ekonomiye sahiptir ve böyle bir ekonomik yapıya sahip olması nedeniyle de dünyadaki ekonomik gelişmelerden nispeten daha geç ve dolaylı yönden etkilenmektedir (Taşkent Büyükelçiliği Ticaret Müşavirliği, 2015:37). Bağımsızlığın kazanmasının hemen ardından ülkede beklenilenin aksine serbest piyasa ekonomisinden biraz uzak bir iktisat politikası uygulanmıştır. Tüketiciler, çeşitli devlet destekleriyle devlet tarafından gerçekleştirilen sıkı fiyat kontrolleriyle ve ücret artışlarını engellemeye yönelik çeşitli düzenlemelerle enflasyona karşı korunmuşlardır. Ancak bütün bu düzenlemelere rağmen ekonomide ortaya çıkan ve etkisini artıran iktisadi sorunlar, 1994 yılında, ülkede bir ekonomik reform programının hazırlanmasını zorunlu kılmıştır. Bu reform programı kapsamında ülkede, sıkı mali politikaları uygulamaya konularak kamusal harcamalara bir takım sınırlamalar getirilmiş, devletin fiyatlar üzerindeki kontrolleri azaltılmış, ekonomik nitelikte faaliyetlerde bulunan uluslararası kuruluşlarla yakın işbirliğine gidilmiş, ülkenin para birimi belirlenmiş ve kamuya ait işletmelerin özelleştirilmesi yoluna gidilmiştir (DEİK, 2012:5). Ekonomiyi geliştirme adına gerçekleştirilen bütün bu düzenlemelere rağmen 2008 yılında ABD'de başlayan küresel nitelikli kriz, ülke ekonomisini son yıllarda etkileyen en önemli olay olarak ön plana çıkmıştır (Okan Üniversitesi Avrasya Merkezi, 2013:2). ABD kaynaklı küresel kriz, Özbekistan'ın ihracatında önemli bir paya sahip olan Rusya'nın krizden önemli ölçüde etkilenmesine bağlı olarak ve dolaylı yoldan Özbekistan'ı etkilemiş ve 2008 yılında Özbekistan'ın ihracatının düşmesine neden olmuştur (Taşkent Büyükelçiliği Ticaret Müşavirliği, 2015:37). Ancak 2008 yılındaki bu krizden Özbekistan'ın, dışa kapalı bir ekonomiye sahip olması nedeniyle diğer ülkelere kıyasla daha az etkilendiğini ve krizden daha kolay çıktığını söylemek mümkündür. Sonraki yıllarda da Özbekistan da ekonomik gelişimi sağlamak amacıyla pek çok düzenlemeye gidildiği gözlenmektedir. Bu düzenlemeler, Özbekistan'da iş yapmayı düşünen yerli ve yabancı yatırımcıları da yakından ilgilendirmektedir.

Özbekistan ekonomisi ile ilgili olarak verilen bu genel bilgilerden sonra, Özbekistan da iş dünyasına yönelik olarak karşılaşılan en önemli sorunları ortaya koyabilir ve bu sorunların giderilmesi için ülkede ne gibi düzenlemelerin yapıldığını açıklamaya çalışabiliriz. Özbekistan da iş dünyasına yönelik olarak karşılaşılan en önemli sorunları, üretim gerçekleştirilir iken kaynakların verimsiz bir şeklide kaynak kullanılması, döviz darboğazı, ithalata bağımlı ticari yapı, enflasyon, tekelcilik ve bürokrasi şeklinde sıralamak mümkündür. Ayrıca döviz transferinde yaşanan problemler de iş dünyasına yönelik önemli sorunlardan bir diğerini teşkil etmektedir (Okan Üniversitesi Avrasya Merkezi, 2013:2). Bu sorunlara ilaveten başlangıçta uygulanan ithal ikameci sanayileşme modeli, ülkede ihracat kapasitesi düşük ve yerel talebin de az olduğu malların üretildiği, düşük katma değerli bir sanayi yapısının ortaya çıkmasına neden olmuştur (DEIK, 2012:8). Bunun dışında Özbekistan, petrol üretimi gerçekleştirilen bir ülke olmasına karşın, sektör, petrol üretimi sürecinde bir takım sorunlarla mücadele etmek durumundadır. Bu sorunların başında ise üretilen petrolün dünya pazarlarına taşınabilmesi için gerekli olan petrol boru hattının yetersiz olması, yeni alanlardan petrol çıkarılabilmesi için ihtiyaç duyulan finansman eksikliği ve petrol arama-çıkarma çalışmaları için gerekli olan teknolojik yetersizlikler gelmektedir (KTO, 2008:14). Bu sorunların dışında finansal düzenlemeler açısından bir takım ilerlemeler sağlanmış olmasına karşın ülkede halen liberal bir bankacılık sisteminin ve etkin bir sermaye piyasasının varlığından söz edilemez (DEİK, 2012:12). Bu eksikliklerin giderilmesi için geçmişte bazı uluslararası kuruluşlardan bir takım finansal destekler alınmıştır ve bu finansal destekler günümüzde de alınmaktadır (KTO, 2008:14). Ancak bahsedilen eksikliklerin giderilebilmesi için uluslararası kuruluşlardan temin edilen kaynaklar sınırlı seviyelerde kalmaktadır. Bu nedenle söz konusu eksikliklerin giderilebilmesi için yabancı yatırımcıların ülkeye çekilmesi büyük önem arz etmektedir. Yabancı yatırımcıları ülkeye çekmeye yönelik düzenlemelere bağlı olara ülkeye yapılacak olan yabancı sermayeli yatırımlardaki artışlar, iş dünyasına yönelik sorunların hafifletilmesinde ya da ortadan kaldırmasında büyük kolaylıklar sağlayacaktır. 
Bu kapsamda 11.04.2005 tarihinde yürürlüğe giren "Doğrudan Özel Yabancı Yatırımlarının Teşvik Edilmesine İlişkin Ek Tedbirler" ile yabancı yatırımcılar açısından güvenli hukuksal bir ortam oluşturularak yabancı yatırımların ülkeye çekilmesine çalışılmıştır. Bu sayede ülkedeki yatırım ortamının daha da geliştirilmesi, özelleştirmelerin hızlandırılması, üretim sürecinde kullanılan araç ve gereçlerin teknik açıdan geliştirilmesi ve son olarak da işsizliğin fazla olduğu bölgelerde yeni istihdam alanlarının oluşturulması amaçlanmıştır. Yabancı yatırımcıları ülkeye çekerek ekonomik kalkınmanın gerçekleştirilebilmesi amacıyla 1994 yılından sonra ülkede uygulamaya konulan ekonomik reform programları kapsamında 1996 yılında uygulamaya konulan kurumsal piyasa reformları, ulusal ekonominin gelişmesinde etkin bir rol oynamaya başlamıştır. Uygulanan bu reformlar, küçük ve orta ölçekli firmaların gelişimine ortam hazırlamış, büyük ölçekli şirketlerin ise özelleştirilmesinin yolu açılmıştır. 1998 yılında Özbek Hükümeti tarafından kabul edilen ve uygulamaya konulan "Yabancı Yatırımlar Kanunu" ile çekilen yabancı sermaye artırılmaya çalışılmıştır. Uygulamaya konulan bu kanun ile yabancı sermayeli işletmelere bir takım vergi istisnaları getirilmiş ve gümrük vergisinden muafiyetler tanınmıştır. Ayrıca söz konusu kanunda 2013 yılında yapılan revizyon ile de yabancı yatırımcıların Özbekistan da yaptıkları yatırımlardan elde edecekleri gelirlerden vergi ve diğer zorunlu ödemeleri yaptıktan sonra kalan gelirleri diledikleri gibi kullanabilecekleri karara bağlanmıştır. Yabancı yatırımcıları ülkeye çekmek için yapılan düzenlemelerden bir diğeri bürokratik uygulamaları en aza indirerek yatırım sürecini hızlandırmak olmuştur. Bu bağlamda yine 1998 yapılan düzenlemelerle kuruluş sermayesinin sınırı düşürülerek ve iş yeri açma prosedürleri kolaylaştırılarak küçük ve orta ölçekli işletmeleri güçlendirmesi amaçlanmıştır. Ayrıca doğrudan yabancı sermayeli işletmelerin ticari faaliyete başlayabilmesi için de gereken evrakların toplama sürecini kısaltmak için "tek gişe" uygulamasına gidilmiş, böylece yabancı yatırımların ülkeye yönelmesine önemli katkılar sağlanmıştır (Taşkent Büyükelçiliği Ticaret Müşavirliği, 2015:35-36). Bürokratik engellerin en aza indirilmesi ülkeye yapılacak yatırımların artışında çok önemli olmaktadır. Bunun dışında Hükümet, son yıllarda Telekomünikasyon ve bilişim teknolojilerinin gelişimini sağlamak amaçla haberleşme altyapısını geliştirmeye yönelik yatırımlara ağırlık vermiştir (DEİK, 2012:9). İletişim ve haberleşme ağını geliştirmeye yönelik düzenlemeler yabancı sermayenin ülkeye çekilebilmesi açısından önem arz eden düzenlemeler olarak dikkat çekmektedir.

Bu resmi düzenlemeler dışında Özbekistan, yabancı sermayeyi ülkeye çekebilecek bir takım doğal avantajlara da sahiptir. Ülke, yatırımların etkin bir şekilde gerçekleştirilebilmesi için ihtiyaç duyulan enerji kaynakları açısından kendi kendine yetebilen nadir ülkelerden biridir. Ülkenin önemli miktarda enerji kaynağına sahip olması ve enerjinin ucuza elde edilebilir olması, yabancı yatırımcılar için maliyetleri azaltan bir unsur olmakta ve ülkeye yabancı yatırımların yönelmesi açısından önemli avantajlar sağlamaktadır. Herhangi bir enerji problemi olmayan Özbekistan, doğal gaz üretimi açısından Türki Cumhuriyetler içerisinde önemli bir paya sahiptir. Ülkede bulunan enerji kaynakları olarak doğalgaz, petrol ve kömür gelmektedir (KTO, 2008:12). Bu enerji kaynaklarına sahip olmak Özbekistan'a yatırım yapacak olan yabancı yatırımcılar için önemli bir avantajı teşkil etmektedir. Bütün bu düzenlemeler neticesinde Özbekistan ekonomisinde belirgin bir iyileşmenin yaşandığını söylemek mümkündür. Bu düzenlemeler haricinde son yıllarda da ekonomiyi geliştirmeye yönelik düzenlemeler yapılmaya devam edilmektedir. Tablo 2'de yapılan bu düzenlemelerin etkileri net bir şekilde gözlenebilmektedir.

\begin{tabular}{|c|r|r|r|r|c|}
\hline \multirow{2}{*}{ YILLAR } & \multicolumn{4}{|c|}{ TOPLAM YABANCI YATIRIMLAR } & \multicolumn{2}{|c|}{$\begin{array}{c}\text { DOĞRUDAN YABANCI } \\
\text { YATIRIMLAR }\end{array}$} & $\begin{array}{c}\text { DYY'IN GSYIH } \\
\text { içiNDEKI PAYI \% }\end{array}$ \\
\hline & Milyar Sum & Milyon USD & Milyar Sum & \multicolumn{1}{c|}{ Milyon USD } & \multicolumn{1}{c|}{ Milyon USD } \\
\hline 2001 & 349,7 & 827,4 & 31,4 & 74,3 & 0,4 \\
\hline 2002 & 294,9 & 382,4 & 73,0 & 94,6 & 0,9 \\
\hline 2003 & 492,1 & 506,8 & - & - & - \\
\hline 2004 & 605,8 & 594,2 & 155,1 & 152,2 & 1,2 \\
\hline 2005 & 577,0 & 520,0 & 250,8 & 226,1 & 1,6 \\
\hline 2006 & 730,4 & 599,1 & 499,0 & 409,3 & 2,4 \\
\hline 2007 & 1247,7 & 981,9 & 946,3 & 744,7 & 3,4 \\
\hline 2008 & 2193,7 & 1574,8 & 1591,8 & 1142,7 & 4,3 \\
\hline 2009 & 4058,1 & 2685,7 & 1465,5 & 969,9 & 3,1 \\
\hline 2010 & 4437,8 & 2.808 .7 & $2.744,5$ & 1.737 .2 & 2.2 \\
\hline 2011 & 4592,5 & 2.685 .7 & $2.348,8$ & 1.373 .5 & 5.9 \\
\hline 2012 & $4.788,5$ & $2.253,5$ & $4.190,3$ & $2.208,3$ & 4.9 \\
\hline 2013 & $5.595,6$ & $2.670,6$ & $2.700,1$ & $1.293,4$ & 2.3 \\
\hline 2014 & $6.810,5$ & $2.944,7$ & $5.809,4$ & $2.511,8$ & 4,0 \\
\hline
\end{tabular}

Tablo 2. Yabancı Yatırımlar Ve Dış Krediler (2001-2014) Kaynak: Özbekistan Devlet İstatistik Komitesi.

Tablo 2. de görüldüğü üzere toplam yabancı yatırımlar 2006 yılına kadar inişli çıkışlı bir grafik sergilemiştir. iş dünyasında karşılaşılan sorunların çözümüne yönelik olarak yapılan düzenlemeler neticesinde toplam yabancı yatırımların 2006 yılından itibaren düzenli bir şekilde artış eğiliminde olduğu ve özellikle 2009 yılında toplam yabancı yatırımların bir önceki yıla kıyasla neredeyse yüzde 80 oranında arttığı görülmektedir. Sonraki yıllarda 
da toplam yabancı sermayeli yatırımlarındaki artış devam etmiş ve 2014 yılında yaklaşık 3 milyar dolar seviyesine ulaşmıştır. Benzer şekilde doğrudan yabancı yatırımlarında 2014 yılı itibariyle 2,5 milyar dolar ile en yüksek seviyesine ulaştığı görülmektedir. Her ne kadar doğrudan yabancı yatırımlar 2014 yılında en yüksek seviyesine ulaşmış olsa da 2001 yılından 2014 yılana kadar geçen süreçte dalgalı bir eğilime sahip olmuş ve istikrarsız bir görünüm sergilemiştir.

\section{TÜRKMENISTAN}

Türki Cumhuriyetler içerisinde yer alan önemli ülkelerden bir diğeri de Türkmenistan'dır. Türkmenistan'ın siyasi yapısındaki farklılık ekonomisine de doğrudan yansımıştır. Türkmenistan'da devlet, ekonominin düzenlenmesinde etkin rol oynamaktadır. Türkmenistan'da faaliyette bulunan firmaların önemli bir kısmı devlet kontrolü altındadır ve devlet ekonomiye yoğun bir şekilde müdahale etmektedir. Ayrıca kur ve fiyat kontrolleri de devlet tarafından yapılmaktadır. Buna bağlı olarak da ülkede serbest piyasa uygulamaları gerçekleştirilememiş, yabancı yatırımlar için uygun olmayan bir ekonomik ortam söz konusu olmuş ve devlete ait işletmelerin ekonomide önemli bir paya sahip olması özel sektörün gelişmesini olumsuz yönde etkilemiştir (BMD, 2012:10). Bağımsızlığın kazanılmasının ardından Bağımsız Devletler Topluluğu ile Gümrük Birliği’ne girmeyen ve hiç bir ülke ile serbest ticaret anlaşması yapmayan Türkmenistan, ağırlıklı olarak ikili ticaret anlaşmaları ile dış ticaretini şekillendirmektedir. Ülkede, hükümet tarafından uygulanan yüksek oranlı gümrük vergileri de dış ticaretin önünde önemli bir engel teşkil etmektedir (EBSO, 2013:7). Bağımsızlığın kazanılmasının ardından Türkmenistan, IMF tarafından hazırlanan ve önerilen programları uygulamayı reddetmiş ve iktisadi olarak dişa kapalı bir iktisat politikası izlemeyi tercih etmiştir. Bu tercih neticesinde küresel mali piyasalardan izole bir ülke haline gelmiştir (BMD, 2012:10). Türkmenistan'ın uluslararası para piyasalarından izole olması ise ülkeye birtakım avantajlar sağlamış, ülke ekonomisinin, 2008 yılı sonlarında ortaya çıkan ve 2009 yılında ülkeler arasında yayılarak genişleyen küresel mali krizden minimum seviyede etkilenmesine imkân vermiştir (KASİAD, 2012:6).

Türkmenistan, doğal kaynaklar ve özellikle de yer altı zenginlikleri açısından da önemli potansiyele sahip olan ülkelerden biridir. Türkmenistan'da ekonomik yapı doğrudan enerji piyasasının güncel durumuna göre şekillenmektedir. Doğalgaz ve petrol ürünleri açısından çok büyük bir rezerve sahip olan ülkede, Hükümet enerji sektörünün gelişimini önemsemekte ve bu nedenle de sektörün sahip olduğu potansiyelin ortaya çıkarılarak kullanılabilir hale getirilmesi için bazı projeler yapılmaktadır. Doğal gaz ve petrol ürünleri ihracat gelirlerinin yaklaşık \% 85'ini teşkil etmektedir. Enerji sektörü içerisinde hidrokarbon endüstrisi ihracat gelirinin önemli bir kısmını oluşturmaktadır (KASİAD, 2012:7). Bunun yanında ülke, önemli bir pamuk üreticisi konumundadır. Tarım yapılabilen arazilerin neredeyse yarısında pamuk yetiştirilmektedir (BMD, 2012:23). İhraç ürünü niteliğindeki pamuk ipliği ve tekstil ürünlerinin ihracatı mutlak değer olarak artmış olmakla birlikte, bu ürünlerin toplam ihracat içindeki payları azalış göstermekte dolayısıyla da pamuklu ürünlerin ihraç edilmesi sonucu elde edilen gelirler son yıllarda sürekli olarak azalmaktadır. Böyle bir sonucun ortaya çıkmasında uluslararası piyasalarda pamuklu malların fiyatlarının düşük olması önemli olmuştur. Ayrıca elektrik de Türkmenistan`ın ihraç gelirleri içinde yer alan bir diğeri unsurdur (KTO, 2008:16).

Türkmen hükümeti, daha önce de ifade edildiği üzere son y1llarda enerji sektörünün geliştirilmesine çalışmakta, sektör potansiyelinin ortaya çıkartılması amacıyla çeşitli projeler yürütmektedir. Söz konusu projelerin başarılı olabilmesi için önemli ölçüde yabancı yatırımın ülkeye girmesi gereklidir. Önemli petrol ve doğalgaz rezervlerine sahip olan Türkmenistan, bu yönüyle pek çok ülkenin dikkatini cezbetmektedir. Ancak yabancı sermeyenin de ülkeye gelmesi için iş dünyasına yönelik sorunların minimuma indirilmesi gereklilik arz etmektedir. Bununla birlikte yabancı yatırımların ülkeye çekilebilmesi önünde çok ciddi engeller, sorunlar bulunmaktadır. Bu sorunların başında da ülkenin en önemli ihracat gelirini oluşturan doğalgaz ve petrol ürünlerinin uluslararası piyasalara nasıl taşınacağı gelmektedir. SSCB'nin dağılmasının ardından Türkmenistan gibi devletlerin açık denizlere nasıl çıkacakları konusu önemli bir sorun haline gelmiştir (Uibopuu, 1995:119). Açık denizlere kıyısının bulunmayışı Türkmenistan'ın ürettiği petrol ve doğal gazı deniz yolu ile yurt dışındaki piyasalara satamamasına neden olmaktadır (Baycaun, 2001:25). Bu durum ise ucuz doğal gaz ve petrol kaynaklarının, daha genel bir ifadeyle ucuz enerji kaynaklarından yararlanmak isteyen yabancı yatırımcıları etkilememektedir. Ucuz iş gücünden faydalanmak isteyen ve bu enerji kaynaklarının yurt dışına taşınmasına yönelik olarak yatırımlar yapacak olan yabancı yatırımcıların ise bu ülkeye yönelik yatırım yapma hevesleri kırılmaktadır. Bu sorunun çözmek amacıyla 1997 yılında düşük kapasiteli bir doğal gaz boru hattı inşa edilmiştir (Aydal, 2009:51).

Doğalgaz ve petrolün taşınması konusunda önemli sorunlarla karşılaşan Türkmenistan'da enerji sektörü, yabancı yatırımcılar için yine de önemli bir potansiyel sunmakta ve birtakım olanaklar sağlamaktadır. Sektördeki bu olanaklara rağmen Türkmenistan`a yapılan yabancı sermayeli yatırımlar yine de düşük seviyelerde gerçekleşmektedir. Bu durumun başlıca sebeplerini, yatırım olanaklarının yetersizliği, yasal düzenlemelerin ve altyapının zayıflığı ile Türkmenistan'a komşu olan ülkelerin yabancı yatımları ülkelerine çekebilmek için daha cazip olanaklar sunmaları şeklinde sıralamak mümkündür (EBSO, 2013:6). Bu eksikliklerin dişında ülkedeki döviz kurunda yaşanan belirsizlikler, yatırımlar için finansman yetersizlikleri ve bankacılık sektörünün eksiklikleri, vergi oranlarının yüksekliği, sosyal olanakların yetersizliği, yetişmiş eleman ve teknolojik 
eksiklikler ve bürokratik engellerde yabancı yatırımcıları olumsuz yönde etkileyen diğer sorunlar olarak ortaya çıkmaktadır.

Türkmenistan`a yatırım yapacak olan yabancı yatırımcıların öncelikle Yabancı Yatırımlar Devlet Ajansı`na başvurması gerekmektedir ki bu başvuru çok zaman alan bürokratik bir süreçtir (KTO, 2008:18). Ülkedeki aşırı bürokrasi, yabancı yatırımlar ile ilgili son kararların devlet başkanı tarafından alınması ve yatırımların gerçekleşebilmesi için bir miktar rüşvet ödenmek zorunda kalınması, yabancı yatırımların gerçekleşmesi önündeki önemli engelleri teşkil etmektedir (Baycaun, 2001:21). Türkmen Hükümetinin, ülkeye yabanc1 yatırımları çekmek istemesine karşın ülkede var olan bürokratik engeller, ülkeye yeterli miktarda yabancı sermaye girişine engel olmaktadır (KASİAD, 2012:5). Ayrıca, Sovyet döneminde hazırlanmış olan rüşveti önlemeye yönelik yasalar, zaman içinde güncelleştirilmek ve etkinleştirilmek amacıyla bir takım düzenleme ve değişiklilere tabi tutuldu ise de rüşveti önlemek için yine de yeterli değildir. Bu kapsamda ülkeye reel yatırım yapmak isteyen yabancı yatırımcılar rüşveti ciddi bir sorun olarak görmektedir (Baycaun, 2001:31). Yabanc1 yatırımcılar açısından pek çok sıkıntı ve şüpheyi barındıran ülkede bir de rüşvet sorunuyla karşı karşıya kalınması yabancı yatırımcıların yatırım şevkinin kırılmasına neden olmaktadır.

Ayrıca, genel olarak bakıldığında ülkede yetişmiş elemen sayısının sınırlı olması ve teknolojik açıdan geri kalmışlık da yabancı yatırımcıların gelişmekte olan ülkelerde karşı karşıya kaldıkları bir diğer sorundur. Benzer sorunlar Türkmenistan içinde geçerli olmuştur. Ülkenin imalat sanayine yönelik faaliyetleri, SSCB döneminden kalma eski fabrikalarda ve eskimiş araç gereçler ile yürütülmeye çalışıldığından verimsizdir. Doğalgaz sektörü dışındaki sektörlerin katma değeri azdır (Baycaun, 2001:29). Türkmenistan'da üretim faaliyetleri daha çok petrol, doğalgaz, pamuk ve gıda işleme alanlarında gerçekleştirilmiş, fakat ülke sanayisi bu sektörler ile kısıtlı kalmıştır (KASİAD, 2012:7). İmalat sanayinde söz konu olan altyapı eksiklikleri yabancı yatırımcıların Türkmenistan'da yatırım yapma isteklerini olmuşuz yönde etkilemektedir.

Ülkede yaşanan ve yabancı sermayeyi olumsuz yönde etkileyen konulardan biri de bankaların yapısı ve finansman sorunlarıdır. Türkmenistan'da bankacılık sektörü ağırlıklı olarak devlet kontrolündedir ve sadece 1997 yılında yapılan düzenleme ile Merkez Bankasına sınırlı bir özerklik tanınmıștır. Banka kredilerinin \%95'i kamu sektörüne verilmekte ve kamu açıklarının finansmanı için kullanılmaktadır. Bu doğrultuda ülkede bağımsız bir Merkez Bankasının olmaması, Merkez Bankasının hükümet harcamalarının finansmanında kullanılması ve ülkede para ve sermaye piyasalarının oluşmaması bankacılık ve finans sektörünün önemli eksikliklerini teşkil etmektedir (BMD, 2012:24). Ülkede ticari bankacılığın gelişimi, ülkede ticari faaliyette bulunan özel sektörün az gelişmişliği ve devletin ekonomiye fazlası ile müdahale etmesi nedeniyle sınırlı bir seviyede gerçekleşmiştir (KASİAD, 2012:9). Bunun yanında döviz rezervleri oldukça düşük olan Türkmenistan'da yabancı sermayeli işletmeler, döviz işlemi yaptırırken bazı problemlerle karşı karşıya kalabilmektedirler. Bu bağlamda Türkmen bankaları gerek Manat, gerekse Dolar cinsinden likidite sıkıntısı çekmekte, yerel paranın dövize ya da dövizin yerel paraya çevrilmesi konusunda yetersizlikler söz konusu olmaktadır (Baycaun, 2001:31). Ayrıca hükümet tarafından döviz kuruna sık sık yapılan müdahaleler, mevcut fiyatların gerçek gösterge olma özelliğini ortadan kaldırmaktadır. Ülke ekonomisinde fiyat kontrolleri oldukça yaygın bir uygulamadır. Hükümet tarafindan yoğun şekilde verilen sübvansiyonlar ise genellikle ihraç gelirleri ile karşılanmaktadır. Türkmenistan ekonomik yapısı piyasa mekanizmasının sorunlu olduğunu göstermektedir (BMD, 2012:24). Bankacılık sektöründe var olan bu eksiklikler ve sınırlamalar ile piyasa mekanizmasında ortaya çıkan sorunlar zaman zaman ülkede ihtiyaç duyulan finansman ihtiyacının karşılanamamasına ve önemli finansman sorunlarının ortaya çıkmasına neden olmaktadır. Bankacılık sektöründen kaynaklanan ve finansman eksikliği şeklinde oraya çıkabilen sorunlar yabancı yatırımcıların olumsuz etkilenmesine ve ülkeye yatırım yapma noktasında isteksiz davranmasına neden olmaktadir.

$\mathrm{Bu}$ olumsuzluklar dışında ülkede, petrol ürünleri ya da doğalgaz üretimi dışında başka bir alanda üretim faaliyetinde bulunmak isteyen yabancı yatırımcıların yapacağı yatırımları hukuken koruyan bir sistem de bulunmamaktadır (KASİAD, 2012:10). Ayrıca yerli ve yabancı sermayeli firmalara farklı oranlarda gelir ve kurumlar vergilerinin uygulanmaktadır ve bu durum yabancı yatırımları engellemektedir. Bu kapsamda yerli firmaların yıllık hasılalarının \%2,3 ünü vergi olarak ödemeleri istenir iken yabancı şirketlerden \% 15 oranında KDV ve \% 20 oranında da Kurumlar Vergisi ödemesinin istenmesi, yabanc1 yatırımc1ları olumsuz etkilemektedir (KASİAD, 2012:10). Bu uygulamalar yabancı yatırımcıların Türkmenistan'da gerçekleştirmeyi düşündükleri reel yatırımları yapmaktan vazgeçmelerine neden olmaktadır. Son olarak Türkmenistan'da, işgücü, sağlık ve sosyal güvenliğe ilişkin yasal düzenlemelerde de önemli eksiklikler bulunmaktadır. Ekonomik reformların hayata geçirilmesi noktasında Türkmenistan, diğer Bağımsız Devletler Topluluğu ülkeleri ile kıyaslandığında bir hayli geride kalmıştır. Bunun en önemli nedeni ise ülkedeki finansal kaynak sıkıntısıdır (Baycaun, 2001:21). Üzerinde durulan bu sorunların çözüme kavuşturularak kalkınma için çok önemli olan yabancı sermeyenin ülkeye çekilebilmesi için bir takım siyasi ve iktisadi düzenlemelerin yapılması büyük önem arz etmektedir.

Bu kapsamda ülkedeki mevcut olumsuz ekonomik durumun ortadan kaldırılabilmesi için yabancı yatırımların öneminin ve gerekliliğinin anlaşılmasının ardından Türkmen hükümeti, yabancı sermayeyi ülkeye çekebilmek için bir takım önemli düzenlemeleri hayata geçirmeye çalışmaktadır. Bu kapsamda yabancı yatırımların korunmasını sağlayan hukuki düzenlemelere ve iktisadi alt yapı yatırımlarına ağırlık verilmekte, yabancı ülkeler 
ile ticarî ve iktisadî işbirliğine girişilmektedir. Bunun dışında, yapılan düzenlemeler ile yabancı yatırımcılara, Türkmenistan'da gerçekleştirdikleri ticari faaliyetten elde ettikleri kârları serbestçe ülkelerine transfer edebilmeleri ve Merkez Bankası tarafından düzenli olarak belirlenen kurdan döviz satın alabilmeleri imkanı tanınmıştır (Baycaun, 2001:31). Yabancı sermayeyi ülkeye çekmeye yönelik bu uygulamalar dışında hükümet tarafından, serbest piyasa ekonomisine geçiş için bir takım adımlar atılmış, bazı mallar üzerindeki fiyat kontrollerini kaldırılmış ve mali sistemin yeniden yapılandırılması yönünde düzenlemeler yapılmıştır. Ayrıca ekonomik istikrarı sağlayarak ve iktisadi güven ortamını oluşturarak yabancı sermaye ülkeye çekebilmek için vergi gelirlerinin arttırılması ve kamu harcamalarının azaltılması suretiyle bütçe açığını en aza indirmeye yönelik düzenlemelere ağırlık verilmiştir (Baycaun, 2001:20-21). Bunun dışında ülkede ekonominin petrol ve doğalgaza olan bağlılı̆̆ını ortadan kaldırmak amacıyla yeni yeni sektörlerin ortaya çıkabilmesi için özel girişimcilere devlet eliyle düşük faizli kredilerin verilmesi yoluna da gidilmektedir (BMD, 2012:10). Hükümet tarafından yapılan bu düzenlemelerin ciddiyetle ve etkili bir şekilde uygulanması yabancı yatırımcıların ülkeye gelmesi açısından son derece önemlidir.

Türkmenistan'da hükümet yetkililerince yabancı sermayenin ülkede yatırım yapmaya teşvik edildiği sıklıkla ifade edilmiş olsa da yabancı sermayenin ülkeye çekilebilmesi için gerekli olan siyasi ve makroekonomik düzenlemeler henüz hayata geçirilmiş değildir (KTO, 2008:18). Ülkede kesimin gelişebilmesi için küçük ve orta ölçekli işletmelerin desteklenmesi amacıyla kanunlar çıkarılmış olmasına karşın özel sektörün gelişimi yavaş bir şekilde gerçekleşmektedir. Özel sektörün bu şekilde yavaş bir gelişim göstermesi doğal olarak yabancı yatırımların olumsuz etkilenmesine ve yavaş gelişimine neden olmaktadır. Ayrıca yabancı sermayenin çekilebilmesi için gerçekleştirilmesi gereken özelleştirme faaliyetleri çok yavaş ilerleme göstermiş, enerji, telekomünikasyon ve ulaştırma sektörleri gibi önemli sektörler özelleştirme kapsamı dışında bırakılmıştır (KASİAD, 2012:5-6). Bütün sayılan bu nedenlerden dolayı her ne kadar ülke yabancı sermayeye açılmak istense de ekonomik açıdan ihtiyaç duyulan reformların gerektiği gibi yapılamaması, ülkede ekonomik yapıya yoğun bir devlet müdahalesinin bulunması ve bürokratik uygulamalar ile rüşvetin hala etkin bir şekilde varlığını sürdürmesi yabancı yatırımların ülkeye yeterince çekilebilmesine olanak sağlamamıştır.

\section{SONUÇ}

Türki Cumhuriyetlerdeki iş dünyasına yönelik bu inceleme ve değerlendirmeler neticesinde ülkelerin ekonomik yapılarındaki ortaya çıkan aksaklıklar ortaya koyulmaya ve söz konusu sorunlara yönelik olarak bir farkındalık oluşturulmaya çalışılmıştır. Özellikle bağımsızlıklarını yeni yeni elde etmeye başlayan Türki Cumhuriyetlerinde, sermaye yetersizliği nedeniyle gerçekleştirilemeyen yatırımlar ve kalkınma hamlelerinin yapılabilmesi için yabancı sermayenin bu ülkelere yönelmesi büyük önem arz etmektedir. Bu yönelim hem bu ülkelerin kalkınmasına hem de uluslararası arena da rekabetçi bir güce sahip olmasına katkıda bulunacaktır. Ancak Türki Cumhuriyetlerinin gelişimi için bu denli önemli olan yabancı sermayenin ve yabancı yatırımcıların ülkeye çekilebilmesi için de yatırım ortamının cazip hale getirilmesi gerekmektedir ve Türki Cumhuriyetlerdeki yönetimlere büyük iş düşmektedir. Dünya ekonomik forumu tarafından hazırlanan küresel rekabet endeksleri incelendiğinde önem sıralaması ülkeden ülkeye değişiklik göstermekle birlikte incelenen Türki Cumhuriyetlerinde iş dünyası açısından en çok karşılaşılan sorunların ağırlıklı olarak, rüşvet, finansmana erişim zorlukları, verimsiz bürokratik uygulamalar ve bürokratik engeller, enflasyon ve vergi oranlarının yüksekliği şeklinde ortaya çıktığı görülmektedir. Ayrıca kısıtlayıcı iş gücü düzenlemeleri ve yetersiz eğitilmiş iş gücü şeklindeki iş hayatına ilişkin eksiklikler, ekonomide söz konusu olan eksiklikleri tamamlayıcı niteliktedir. Son olarak söz konusu bu ülkelerin bağımsızlıklarını yeni elde etmiş olmaları nedeniyle söz konusu olan politik istikrarsızlıklar ve alt yapı eksiklikleri de bu ülkelerin iş hayatı açısından diğer önemli sorunlarını teşkil etmektedir.

Özellikle gelişme yolunda bir takım adımlar atmış olan Azerbaycan ve Kazakistan'da iş dünyasına yönelik sorunlar paralellik arz ederken Kırgızistan'ın gelişim sürecinde geride kalmasına neden olan iş dünyasına yönelik sorunlar diğer iki ülkeden farklılık arz etmektedir. Özellikle Kırgızistan'daki kırılgan siyasi yapı, siyasi otorite boşluğu ve iktidarın seçimle değil de halk ayaklanması ile el değiştirmesi, Kırgızistan özelinde yukarıda ifade ettiğimiz sorunların neredeyse tamamının ortaya çıkmasında tetikleyici bir faktör olmuştur.

Türki Cumhuriyetlerinde iş dünyasına yönelik sorunların tespiti önemli olmakla birlikte bu sorunların çözümüne yönelik olarak ülkelerin uygulayacağı düzenlemeler çok daha fazla önem arz etmektedir. Özellikle yeterli sermaye birikimine sahip olmayan ve yaygın bir rüşvet uygulamasının söz konusu olduğu Türki Cumhuriyetlerinde hem yabancı sermayenin ülkeye çekilmesi hem de yerli sermayenin elindeki kaynakları yatırıma yöneltmeye teşvik edilmesi, üzerinde durulan sorunların hızlı bir şekilde çözülmesine ve yabancı sermayeyi ülkeye çekecek düzenlemelerin yapılması bağlıdır. Eğer ülkesel ve bölgesel bir kalkınma hedefleniyorsa bu sorunların süratle çözümlenmesi, küresel rekabet gücü bağlamında biraz gerilerde kalmış olan Türki Cumhuriyetlerinde açısından büyük önem arz etmektedir. Mevcut sorunların çözümüne bağlı olarak ülkedeki yerli ve yabancı yatırımlardaki artışlara bağlı olarak üretim artışları, gelir artışları ve bütün bu olumlu gelişmeler neticesinde de hem ülkenin rekabetçilik gücünde artışlar hem de ülke vatandaşlarının refahında artışlarının gerçekleşmesi mümkün olabilecektir. 


\section{Kaynakça}

- $\quad$ ALAGÖZ Mehmet, 2012, "Bağımsızlığının 20. Yılında Kazakistan Cumhuriyeti’nin Makro Ekonomik Performansı: 1992-2011”, M. Savaş Kafkasyalı (Der.), Bölgesel ve Küresel Politikalarda Orta Asya, (Ankara-Türkistan: Hoca Ahmet Yesevi Uluslararası Türk-Kazak Üniversitesi).

- ALKAN Haluk, 2011, "Türk Cumhuriyetlerinde Siyasal Sistemler: 20 Yıllık Bilanço" Erciyes Üniversitesi Stratejik Araştırmalar Merkezi (ERUSAM) Yayını, http://www.erusam.com/images/dosya/Haluk_Alkan_konf_metin.pdf

- ASKER Ali, 2011, "Bağımsızlığının 20. Y1lında Azerbaycan”, 21. YÜZYIL, Sayı: 35, Sf. 2-9

- AYDAL Doğan, 2009, “Enerji Kan Kokuyor: Biyokimyasal Savaş ve Enerji Kartelleri”, İstanbul: Timaş Yayınları, 219 sf.

- BAYCAUN Saule, 2001, "10 Yıllık Bağımsızlık Sürecinde Türkmenistan Ekonomisine Genel Bir Bakış”Avrasya Dosyası, Türkmenistan Özel Sayısı, Cilt: 7, Sayı:2, sf. 17-38

- BMD (Birleşmiş Markalar Derneği), 2012, “Türkmenistan Ülke Raporu”, sf.2-50,

- http://birlesmismarkalar.org.tr/file/hedefulkeraporlari/Turkmenistan.pdf,

- Erişim:(23.06.2015)

- DEIK (Dış Ekonomik İliş̧kiler Kurulu), 2012, “Özbekistan Ülke Bülteni”, DEIK /Türk-Özbekİş Konseyi, Sf. 2-20, https://www.deik.org.tr/Contents/FileAction/2717 Erişim : (24.06.2015)

- EBSO (Ege Bölgesi Sanayi Odası), 2013, 'Türkmenistan”, EBSO Uluslararası İlişkiler Şefliği, Sf. 1-10, www.ebso.org.tr/ebsomedia/.../turkmenistan-ulkeraporu_48344756.doc, Erişim : (22.06.2015)

- KASİAD (Kocaeli Aktif Sanayici ve İşadamları Derneği), 2012, "Türkmenistan Ülke Raporu”, Sf. 3-20

- https://www.academia.edu/3814285/T\%C3\%9CRKMEN\%C4\%B0STAN \%C3\%9CLKE_RAPORU Erişim: (22.06.2015)

- KTO (Konya Ticaret Odası), 2008, “Türkmenistan Ülke Raporu”, Etüd-Araştırma Servisi, Sf. 3-35, www.kto.org.tr/d/file/turkmenistn-ulke-raporu.doc Erişim : ( 23.06.2015)

- KTO (Konya Ticaret Odası), 2008, “Özbekistan Cumhuriyeti Ülke Raporu”, Etüd-Araştırma Servisi, Sf 2-29

- $\quad$ www.kto.org.tr/d/file/ozbekistan--ulke-raporu.doc Erişim : (23.06.2015)

- OKAN ÜNIVERSITESİ AVRASYA MERKEZİ, 2013, "Özbekistan Ülke Raporu”, http://avrasyamerkezi.okan.edu.tr/sayfa/ozbekistan Erişim: (23.06.2015)

- ÖZKAN Güner, 2011, “Kırgızistan'da Koalisyon Hükümetini Bekleyen Acil Sorunlar”,USAK Raporları, Uluslararası Stratejik Araştırmalar Kurumu (USAK) Yayını www.usak.org.tr/analiz_det.php?id=5\&cat=1107

- Erişim: 34.06 .2015

- SARI Yaşar, 2010, “Kırgızistan'da İktidarın El Değiştirmesi: Akayev ve Bakiyev'in Düşüşü”, Orta Asya ve Kafkasya Araştırmaları (OAKA), Cilt:5, Sayı: 9, ss. 27-47

- SÜLEYMANOV Elçin ve Fahri HASANOV, 2013, “Azerbaycan'ın Türkiye'nin Enerji Sektörüne Yatırımlarının Azerbaycan-Türkiye Ekonomik İlişkilerindeki Rolü”, Çankırı Karatekin Üniversitesi Uluslararası Avrasya Strateji Dergisi, Cilt. 2, Sayı.2, Sf. 73-100

- T.C.TAŞKENT BÜYÜKELÇİLIĞİ TİCARET MÜŞAVİRLİĞİ, 2015, “2014 Y1lı Özbekistan'ın Genel Ekonomik Durumu ve Türkiye ile Ekonomik-Ticari İlişkileri”, sf 1-89

- TÜRK CUMHURIYETLERİ VE TOPLULUKLARI YILLIĞI 2013, 2015, Ahmet Yesevi Üniversitesi, Hoca Ahmet Yesevi Uluslararası Türk-Kazak Üniversitesi İnceleme-Araştırma Dizisi; Yayın No: 18, 648 sf. Edit. Turgut DEMIRTEPE ve Murat YILMAZ), Ankara http://ayu.edu.tr/duyurular/yayinlar/turk_topluluk_almanak.pdf

- UIBPUU Henn-Juori, 1995, "The Caspian Sea: A Tangle of Lega1 Problems", The World Today, Vol:51, No:6, pp. 119-123 


\title{
Orta Asya Türk Devletleri ile Türkiye Arasındaki Turizm Potansiyeli ve Ekonomi Açısından İncelenmesi
}

\section{Tourism Potential between Central Asia Turkish Government and Turkey and examining it in Terms of Economy}

\author{
Muhammet Fatih Sancar (Siirt University, Turkey) \\ Prof. Dr. Said Kıngır (Bartın University, Turkey) \\ Mesut Soyalın (Siirt University, Turkey)
}

\begin{abstract}
Turkey is leading of countries which showing continuous and rapid development in terms of tourism but tourism potential between Turkey and Central Asia Turkish Governments is not sufficient. The origin of most of the people living in Turkey is basing on the Central Asian Turks and Turkey should improve of the tourism activity between the Turkish government in this study has attempted to reveal tourism potential between Central Asia Turkish government and Turkey. In addition, has been mentioned economic impacts of the potential of tourism between the countries. The data were obtained by applying surveys intended for tourism businesses which have activities towards Turkey, Kazakhstan, Kyrgyzstan, Turkmenistan, Tajikistan and Uzbekistan (Accommodation and Travel Business) and various tourism businesses in these countries in relation to increasing the inadequate tourism potential of among the countries, the causes of problems between the countries and the impact on the economy, tourism businesses. By analyzing the obtained datas, several conclusions are revealed and recommendations were presented. Also it is planned to conduct interviews with Central Asia Turkish Governments consulates and Turkey's consulates in located in Turkey. In this study, legal and political barriers, it has emerged as a major challenge in the development of tourism between countries. The study consists of two parts. In the first section, information about the countries and literature survey subject to was conducted. In the second part, it is interpreted by analysis with the obtained data and information.
\end{abstract}

\section{Giriș}

Türkiye ile Orta Asya Türk Devletleri ortak kökene sahip olmaları nedeniyle, turizm açısından daha iyi ilişkilere sahip olmalıdırlar. Özellikle etnik ve kültür turizmi açısından bu ülkeler arasında turizm potansiyelinin arttırılması, ülkelerin ekonomileri açısından da büyük önem arz etmektedir. Türkiye, Orta Asya Türk devletlerine göre çok daha iyi turizm geliri ve turist sayısına ulaşmış durumdadır. Özellikle Türkiye'de yaşayan halkta, kendi kökenine ait toprakları ziyaret etme isteğinin ortaya çıkarılması, Kazakistan, Özbekistan, Kırgızistan, Türkmenistan ve Tacikistan gibi ülkelerin turizm gelirlerini ve ülkeler arasındaki işbirliğini olumlu etkileyecektir.

$\mathrm{Bu}$ çalışmada Türkiye ile Orta Asya Türk devletleri arasındaki turizm potansiyeli ortaya çıkarılmaya çalışılacak ve turizmin ekonomiye etkisi incelenecektir. Ayrıca ülkelerde turizm konusunda yaşanan sorunlar da ele alınmaya çalışılacaktır.

Çalışma temel olarak iki bölümden oluşacaktır. İlk bölümde çalışma ile ilgili literatür yer alacak ve ülkelerin turizm konusundaki durumları ve istatistiki bilgilerine yer verilecektir. İkinci bölümde ise konu ile ilgili seyahat acentaları ve otel işletmelerinden elde edilen bilgiler doğrultusunda çeşitli sonuçların ortaya çıkarılması amaçlanmıştır.

\section{Literatür}

\subsection{Genel Olarak Turizm-Ekonomi İlişkisi ve Etnik Turizm}

Günümüzde turizm, gelir yaratıcı etkisi, sağladığı döviz girdisi ve istihdam yaratıcı özelliği ile dünya ekonomilerinin önemli sektörlerinden biri olarak kabul edilmektedir. Ekonomik öneminin ön plana çıkması ile birlikte turizm, 21. yüzyılda küresel ekonomide telekomünikasyon ve bilgi teknolojileri ile birlikte en hızlı gelişen sektörlerden bir tanesi olmuştur (Oktayer, vd, 2007). Turizm sektörü diğer ekonomik alanların gelişmesine katkısının yanı sıra, dünya refahının toplumlara dağılımını sağlaması yönüyle de küreselleşmenin önemli ölçüde yer aldığı sektörlerden biridir. Ekonomik göstergeler turizmin dünyadaki GSYH'nın \%11,7'sini teşkil ettiğini ve dünyadaki her 12 işten birini sağlayan en büyük sektör olduğunu göstermektedir (Alvarez,vd, 2007). Turizmin ekonomi üzerinde çeşitli olumlu ve olumsuz etkileri bulunmaktadır. Ödemeler dengesi üzerine etkisi, gelir yaratıcı etkisi, altyapı ve üstyapının geliştirilmesi etkisi, istihdam yaratıcı etkisi ve bölgelerarası ekonomik dengesizliğin ortadan kaldırılması etkisi olumlu etkiler arasındadır. Fırsat maliyeti etkisi, dış ülkelere bağımlılık, bölgesel enflasyon, mevsimlik dalgalanma ve yabancı işgücü etkisi ise olumsuz ekonomik etkileri arasindadır (ogu, 2015). 
WTO'ya göre günümüzde 1.3 milyar olan dünyadaki turist sayısı, 2020 yılında 1,6 milyara ulaşacak olup, toplam turizm gelirinin ise 2 trilyon ABD doları olacağı öngörülmüştür. en fazla büyümenin ise Asya ve pasifik ülkelerinde yaşanacağı öngörülmektedir (Unwto, 2015). Ayrıca toplam turist sayısının \%30'u Asya-Pasifik ülkelerine giden ziyaretçilerden oluşmaktadır (Unwto, 2015).

Nostaljik veya etnik turizm bir egzotik turizm türüdür. Bu seyahatler sırasında turistler belirli bir etnik grubun hayatını, yaşam tarzını, kültürünü, yemek kültürünü vs. öğrenmeye çalışmaktadırlar. Bu, kendi kökenini ya da belli bir milletin tarihini öğrenmek için çok iyi bir firsattır. Bu turlar sayesinde insanlar diğer ülkelerden kendi akrabalarını bulmaktadırlar. Bazen insanlar atalarının, dedelerinin ya da küçükken kendilerinin oturduğu topraklara gitmektedirler. Farklı halkların göç aşamalarını sonsuza kadar anlatmak mümkündür. Ama bu göç aşamaları etnik turların oluşmasına neden olmaktadır. Etnik turlar bazı insanların atalarının, babalarının ve belki de küçükken kendilerinin yaşadığı yerleri gezme gibi firsatları yaratmaktadır (Akimov, 2010).

\subsection{Orta Asya Türk Devletleri Turizmine Genel Bakış}

Orta Asya Türk Devletleri'nin turizm ile ilgili mevcut durumları ve genel turizm bilgileri literatür taraması yapılarak ve yetkili kişilerle görüşülerek elde edilmeye çalışılmıştır. Orta Asya Türk Devletleri'nden Kazakistan ve Kırgızistan'ın turizm açısından diğer ülkelere göre daha iyi durumda olup, bu ülkeleri Özbekistan izlemektedir. Türkmenistan ve Tacikistan'da ise turizm yeterli seviyede gelişememiştir. Türkiye ise bu ülkelere göre çok daha iyi bir turizm yapısına sahiptir.

Genel olarak bu ülkelerin hepsinde önemli bir turizm potansiyeli söz konusudur. Özbekistan Semerkant, Buhara, Hiva, Termez, Andijan, Taşkent vb. pek çok tarihi ve turistik kente sahipken, Kazakistan Almata, Türk Dünyasının manevi başkenti Türkistan, kuzeyde Kökçetav, Aktöbe gibi güzel yerlere sahipken, Kırgızistan, muhteşem Tanrı Dağları(Tiyenşan), Narin Nehri kıyısındaki cennet misali vadileri, Issık Göl ve Sarı Çelenk gibi cennet misali gölleri, Oş ve Özgen gibi tarihi kentlere sahipken, Tacikistan gökyüzüne uzanmış muhteşem dağlara ulaşan yolları, vadileri, tarihsel kentleri, Türkmenistan ise Karakum Çölünün kendine özel güzelliği, yine tarihi kentleriyle önemli bir turizm potansiyeline sahip bulunmaktadır (Karaağaçlı, 2012).

Kazakistan, turizm açısından önemli gelişme göstermekte ve turizm konusunda çeşitli hedefler ortaya koymaktadır. Ülkeye 2010 yılında 3.196.000 turist gelmiş olup, bu rakam 2013 yılında 4.926.000'e yükselmiştir (Worldbank, 2015). Turizmden elde ettiği gelir ise 2013 yılında 1.5 milyar dolar civarında olmuştur. Kazakistan'da turizm gelirlerinin gayri safi yurt içi hasılası içerisindeki payı \%0,4'tür. Kazak tarihine paralel olarak Kazak halkının göçebe yaşam tarzını gösteren tarihi yerler, eski şehirler ve antik binalar minimal sayıda bulunmaktadır. Kazakistan'ın turizm faaliyet içerisinde dört temel alan bulunmaktadır. Bunlar iş/ticaret turizmi, eko ve doğa turizmi, kış turizmi ve sağlı turizmidir (Ekoavrasya, 2015). 2013 yılı verilerine göre Kazakistan'da 700 turistik tesis hizmet vermektedir. Bunun içinde 385 otel, 13 kamping, 40 sanatoryum, 17 tedavi amaçlı sanatoryum, 14 sağlık pansiyonu, 7 sağlık-tedavi merkezi, 8 pansiyon, 29 dinlenme merkezi, 31 dinlenme evi, 24 turistik bazı, 35 tedavi kampı, 5 dağ-kayak bazı, 66 konaklama evi, 9 avcılar evi, 2 çocuk-yetişkin turizm merkezi, 7 sağlık tedavi kompleksi bulunmaktadır. Kazakistan'da bulunan 385 otelin $340^{\text {ee }} 1$ özel sektöre aittir. (Kobeshova, 2013). Kazakistan'da Turizm Sektörü Geliştirme Programı ile turizm sektörünün gelişmesi amaçlanmış ve bu program çerçevesinde turizm uygulamaları gerçekleştirilmiştir. Kazakistan'ın turist sayısı 2013 yılında, 2010 yılına göre \%50'nin üzerinde artmıştır. Turizm Sektörü Geliştirme Programı'nın uygulanması ve ülkedeki ekonomik büyüme ile birlikte Kazakistan'da turizmin hızlı bir şekilde gelişmesi beklenmektedir.

Kırgızistan'da Orta Asya Türk Devletleri arasında önemli potansiyele sahip devletler arasında yer almaktadır. Kırgızistan'1 2011 yılında 2.278.000 turist ziyaret etmiş olup, 2013 yılında 3.076.000 kişi ziyaret etmiştir (Worldbank, 2015). Kırgızistan'ın turizmden elde ettiği gelir ise 1 milyar dolara yakın olmuştur. Kırgızistan bağımsızlığını kazandıktan sonra turizm hareketinde büyük değişmeler gözlenmiştir. En önemlisi, Eski Sovyetler Birliği ülkelerinden yaz tatili amacıyla gençlik ve izci kamplarına gelen turist sayısında büyük azalmalar görülmüş̧; buna karşın iş amacıyla Batılı ve komşu ülkelerden daha fazla yabancı turist gelmeye başlamıştır (isgucdergi, 2015). Günümüzde Kırgızistan'ın dağ turizmi, av turizmi, sağlık turizmi, iş turizmi, ekoturizm ve macera turizmi konusunda önemli potansiyele sahip olduğu düşünülmektedir. Kırgızistan çok sayıda ve çeşitli av hayvanlarını barındırmakta olup, özellikle av turizmi için dünyanın birçok yerinden insanın Kırgızistan'a gittiği bilinmektedir. Kırgızistan'da turist sayısı 2013 yılında, 2011 yılına göre \%50'ye yakın oranda artmıştır. Kırgızistan'da özellikle son dönemlerde av turizmi, dağcılık ve sağlık turizmi konusunda uluslararası bilinirliği artmıştır. Bundan dolayı Kırgızistan'da turizmin, devletin turizm planlamalarının da etkisiyle çeşitli turizm türleri etrafında hızla büyümesi beklenmektedir.

Özbekistan, tarihiyle ve eski çağlardan kalan tarihi yapılarıyla pek çok insanın dikkatini çekmektedir. Büyük İpek yolu Avrupa ile Asya'yı birbirine bağlarken Orta Asya bölgesinin özellikle; İslam mimarisinin kervansaraylarıyla ve ortaçağa ait eserleriyle doğu şehirlerinin eşsiz görüntüsünü bugün de koruyan Semerkant, Buhara, Hive ve bugünkü Taşkent'in gelişmesine ve esenliğine yardımcı olmuştur. Asya'nın turistik merkezlerinden birine yavaş dönüştürülen Özbekistan'ın bu şehirlerine dünya çapında ilgi artmaya başlamıştır (Uzembassy, 2015). Özbekistan, 2010 yılında 975.000 turist ağırlarken, bu rakam 2013 y1lında 1.969.000 olmuştur (Worldbank, 2015). Özbekistan'ın turizm geliri tam olarak bilinmemekte olup, 2013 y1lı için 500 
milyon dolara yakın olduğu tahmin edilmektedir. Özbekistan'da özellikle turizm konusundaki aşırı bürokrasi, turizmin gelişimini olumsuz etkileyen etmenlerin başında yer almaktadır.

Tacikistan'ı ziyaret eden turist sayısı, yukarıda ele aldığımız ülkelere göre çok azdır. 2010 yılında 160.000 turist ziyaret ederken, bu sayı 2013 yılında 208.000 olmuştur (Worldbank, 2015). Turizmden elde edilen gelir konusunda ise herhangi bir veriye ulaşılamamıştır. Pamir Dağları dünyada alpinizm alanında çok ayrı bir yere sahiptir. Zirvelere çeşitli zorluklarda tırmanış yolları mevcut olup turistlerin sıkça uğradıkları yerlerden biridir. Genellikle Kırgızistan'daki tırmanış turları ile birleştirilerek arz edilmektedir. Ülkede turizm potansiyelinin olduğu bilinmekle birlikte, ülke içindeki durum ile üst ve alt yapı yetersizliğinden dolayı turist gelişleri azalmaktadır (Kulnazarova, 2010).

Türkmenistan'ın coğrafi yapısının büyük bölümünü çöller oluşturduğundan bitki örtüsü genellikle endemik sınıfındandır. Petrol ve doğal gaz üretimi ağırlıkta olan ülkede, yetersiz su kaynakları ve çevre kirliliği gibi etkenlerden koruma amacıyla doğal çekicilikler hükümet tarafından koruma altına alınmıştır. Milli Parklardan Repetek Biyosfer Rezervi Karakum çölünde yer almaktadır ve 1979 yılında UNESCO'nun dünya doğa ekosistemleri listesine alınmıştır (Kulnazarova, 2010). Ayrıca son dönemlerde Avaza, turizm bölgesi ilan edilerek turizmde gelişme sağlanması hedeflenmiştir. Ancak Türkmenistan'ın siyasi olarak içe kapalı bir politika yürütmesi, turizmin gelişimi konusunda en büyük engeldir. Türkmenistan'ın izlediği politika nedeniyle turizm verilerine de ulaşılamamaktadır.

Özbekistan, Türkmenistan ve Tacikistan ülkeleri turizm konusunda gelişme göstermeyi amaçlasalar da bu ülkelerde izlenen içe kapalı politika nedeniyle, turizm konusunda büyümenin yavaş olması beklenmektedir.

\subsection{Türkiye'de Turizme Genel Bakış}

Türkiye, turist sayısı ve turizm geliri açısından Orta Asya Türk Devletleri'ne göre çok daha iyi bir seviyededir. Türkiye'de deniz-kum-güneş turizmi açısından büyük bir potansiyel bulunmasının yanı sıra özel ilgi turizmi türleri açısından da önemli turizm kaynaklarına sahiptir. Türkiye'yi 2011 yılında 31.456 .000 turist ziyaret ederken, bu rakam 2014 yılında 36.837.900 olmuştur. Türkiye'nin 2014 yılında elde ettiği geliri ise 34 milyar doların üzerinde olmuştur (tursab, 2015). Özellikle deniz turizmine uygun alanların çokluğu ve Anadolu'nun çok eski bir geçmişe sahip olması, Türkiye'nin turizmde önemli bir ülke olmasını sağlayan etkenler olmuştur. Türkiye Turizm Stratejisi-2023 Belgesi'nde belirlenen stratejik yaklaşımlar çerçevesinde yapılacak çalışmalar tamamlanması, geliştirilmesi öngörülen bölgelerdeki altyap1 ve konaklama ihtiyaçlarının karşılanması durumunda, 2023 yılında, 63 milyon turist, 86 milyar \$ diş turizm geliri ve turist başına yaklaşı 1350 \$ harcamaya ulaşılması öngörülmektedir. Bu hedeflere ulaşma konusunda, turizmin çeşitlendirilmesinin büyük önem taşıdığı da ön plana çıkarılmıştır (İzka, 2015).

\subsection{Türkiye ile Orta Asya Türk Devletleri Arasındaki Turizm İlişkisi ve İstatistikler}

Türkiye ile Orta Asya Türk Devletleri ortak kökene sahip olmalarına rağmen, ülkelerin birbirleriyle olan turizm potansiyeli çok yetersiz seviyede kalmıştır. Özellikle etnik turizm ve kültür turizm konusunda ülkeler arasında turist alışverişi için çok uygun bir ortam bulunmaktadır.

Türkiye ile Orta Asya Türk Devletleri arasındaki turizm ilişkisinin ortaya çıkarılmasında, öncelikle ülkeler arasındaki ziyaretçi rakamlarının bilinmesi gerekmektedir. Bu rakamlar aşağıdaki tabloda verilmiştir.

\begin{tabular}{|l|l|l|l|}
\hline Milliyet & 2012 & 2013 & 2014 \\
\hline Kazakistan & 380.046 & 427.773 & 437.971 \\
\hline Türkmenistan & 135.168 & 148.709 & 180.395 \\
\hline Özbekistan & 105.976 & 129.292 & 143.354 \\
\hline Kırgizistan & 42.866 & 64.905 & 81.941 \\
\hline Tacikistan & 22.823 & 27.174 & 34.678 \\
\hline Toplam & 686.879 & 795.853 & 878.339 \\
\hline
\end{tabular}

Tablo 1.Türkiye'ye Gelen Turistlerin Orta Asya Türk Devletleri'ne Göre Dağılımı Kaynak: Tursab

Tablo1. de yer alan turist sayılarına göre, Türkiye'ye en fazla turist gönderen ülke Kazakistan olmuştur. Özellikle Türkmenistan ve Özbekistan'da yıllar itibariyle meydana gelen artış dikkat çekicidir. Tablo1. de yer alan ülke vatandaşları, Türkiye'ye vizesiz olarak giriş hakkına sahiptirler. Vizesiz giriş kolaylığının sağlanması, bu ülkelerden gelen turist sayısının artmasında büyük önem taşımaktadır.

\begin{tabular}{|l|l|l|l|}
\hline Milliyet & 2012 & 2013 & 2014 \\
\hline Kazakistan & 54.229 & 50.279 & 74.766 \\
\hline Türkmenistan & 38.281 & 33.780 & 50.904 \\
\hline Özbekistan & 15.283 & 15.420 & 13.293 \\
\hline Kirgizistan & 12.777 & 9.998 & 37.017 \\
\hline Tacikistan & 3.587 & 1.067 & 14.173 \\
\hline Toplam & 124.158 & 110.544 & 190.153 \\
\hline
\end{tabular}

Tablo 2. Orta Asya Türk Devletlerine Giden Türkiye Vatandaşları'nın Ülkelere Göre Dăğlımı Kaynak: TUİK 
Tablo 2. yurt dışına çıkan Türkiye vatandaşlarının Orta Asya Türk Devletleri arasındaki dağılımını göstermektedir. Türkiye vatandaşları en çok Kazakistan'ı tercih etmişlerdir. Üç yıllık süreçte en az tercih edilen ülke ise Tacikistan olmuştur. Kırgızistan'a gidişler 2013 yılından 2014 yılına göre önemli bir artış göstermiştir. Türkiye Cumhuriyeti vatandaşları vizesiz olarak Kazakistan ve Kırgızistan'a girebilmektedirler. Türkmenistan, Özbekistan ve Tacikistan ülkelerine girişte vize talep edilmektedir.

Orta Asya Türk Devletleri'nden Türkiye'ye gelen ziyaretçi sayısı sürekli artış göstermiştir. Ülke halkaları arasındaki yakın kültür, Türkiye'de turizmin, turizm açısından benzer yapıdaki ülkelere göre daha ucuz olması nedeniyle, ülkeler arasındaki ekonomik faaliyetlerin artması ve Türkiye'nin bu ülke halklarına yönelik gösterdiği kolaylıklar nedeniyle, Orta Asya Türk Devletleri'nden Türkiye'ye gelen ziyaretçi sayısının 2-3 yıl içerisinde 2 milyona ulaşması beklenmektedir. Tablo 1. deki artış oranları dikkate alındığında, bu beklentinin olabilirliği yüksektir.

Türkiye'den bu ülkelere giden ziyaretçi sayısındaki artışın hızlı olduğunu söylemek pek mümkün değildir. Hatta ziyaretçi sayısında düşüş yaşanan yıllar olmuştur. Bölgenin Türkiye vatandaşları tarafindan pek tanınmaması ve Türkmenistan, Özbekistan ve Tacikistan ülkelerinin vize uygulamaları nedeniyle ziyaretçi sayısının gelecekte hızlı bir artış göstermesi beklenmemektedir.

\section{Orta Asya Türk Devletleri ile Türkiye Arasındaki Turizm Potansiyelinin Belirlenmesine Yönelik Uygulama Çalışması}

\subsection{Araștırmanın Amacı ve Yöntemi}

Araştırmanın amacı, Türkiye ile Orta Asya Türk Devletleri arasındaki turizm potansiyeli ve turizm sorunlarını ortaya çıkarılmasını, ülkeler arasında turizmin gelişmesi ve mevcut durumun ekonomiye etkisini ve turizmin geliştirilmesi amacıyla yapılması gerekenlerin belirlenmesini amaçlamaktadır.

Araştırma kapsamında anket yöntemi uygulanmak istenmişse de, anket uygulanacak evrenin sayı olarak azlığı nedeniyle bu yöntemden vazgeçilmiştir. Türkiye ile Orta Asya Türk Devletleri arasında turizm faaliyetinde bulunan sadece 17 seyahat işletmesi tespit edilmiştir. Ülkelerde ortak konaklama işletmeleri bulunan 2 firma da tespit edilmiştir. Tespit edilen toplam 19 işletme ile iletişime geçilmeye çalışılmış, bunlardan 16 işletmenin yöneticisi ile görüşme imkanı bulunmuştur. Ayrıca Türkiye'nin Orta Asya Türk Devletleri'ndeki 4 konsolosluk yetkilisiyle görüşme imkanı sağlanmıştır. Yapılan görüşmeler, telefon aracılığıyla, mail yoluyla sorular sorularak ve bir kısmı da yüz yüze olmuştur. Sorular, ön çalışma yapılarak belirlenmiştir.

Tüm yöneticilere yönelik benzer sorular sorulmuş ve elde edilen cevaplar kayıt altına alınmıştır. Elde edilen veriler doğrultusunda, genel sonuçlar ortaya çıkarılmaya çalışılmış ve sonuçlar doğrultusunda yorumlar yapılmıştır. Elde edilen veriler her ne kadar anket yönteminden elde edilen verilerin analizi kadar kesin sonuçlar çıkarmasa da, ülkeler arasındaki turizm ilişkisi konusunda genel sonuçlar ortaya çıkarmasını sağlaması hedeflenmektedir.

\subsection{Araştırma Kapsamında Elde Edilen Veriler ve Verilerin Yorumlanması}

- Illk olarak Orta Asya Türk Devletleri'nin turizm potansiyeli sorulmuş, potansiyel var ise turizmin hangi türleri için olduğu ögrenilmeye çalışılmıştır. Kazakistan'ın ekoturizm, kültür turizmi, iş turizmi ve macera turizmi konusunda önemli potansiyele sahip olduğu görüşü hakimdir. Özbekistan için özellikle Buhara ve Taşkent gibi tarihi kentlerin varlığı önemli görülmüştür. Ayrıca dağcılık içinde turizm potansiyeli olduğu ortak görüşler arasındadır. Türkmenistan'da çok sayıda milli parkın olması, yerel kültürü ve termal tesisleri önemli turizm çekicilikleridir. Ayrıca Avaz turizm bölgesinin son yıllarda ülke turizmi için önemli olduğu görüşü çoğunluktadır. Kırgızistan için av turizmi, doğa yürüyüşü ve dağcılık temel turizm unsurları olarak görülmektedir. Tacikistan turizmi için sadece dağ tırmanışı ön plana çıkmıştır. Ayrıca ülkelerin kendine has yaşam tarzları ve yemek kültürlerinin de bulunmasının önemli bir ayrıcalık olduğu belirtilmiştir.

- Orta Asya Türk Devletleri'nde turizm potansiyelinin dĕgerlendirilip dĕgerlendirilemediği sorulmuştur. Değerlendirilemiyorsa nedenlerinin neler olduğu ögrenilmeye çalışılmıştır. Soruları cevaplayan yöneticilerin genel görüşü tüm ülkelerde turizm potansiyelinin çok az seviyede değerlendirilebildiğidir. Bunun nedeni olarak bu ülkelerde yetersiz tanıtımın olması ve turistik alanların turizm dışı alanlarda değerlendirilmesi görüşü hakimdir. Ayrıca özellikle Türkmenistan ve Tacikistan' da devlet yönetiminin içe kapalı uygulamalarının etkili olduğu düşünülmektedir. Ayrıca turizm alanlarına ulaşımın zorluğu da etken olarak görülmektedir.

- Orta Asya Türk Devletleri'nde hangi turizm türleri üzerine yoğunlaşılması gerektiği ve ekonomi açısından en faydalı turizm türünün ne olabileceği sorulmuştur. Yöneticiler, Kazakistan'da iş turizmi ve etnik turizmi ön plana çıkarmışlardır. Kırgızistan'da av turizmi, Türkmenistan'da Avaza bölgesinde deniz turizmi, Özbekistan kültür ve tarih turizmi, Tacikistan'da ise dağcılık turizmi ön plana çıkmıştır. Tercih edilen turizm türlerinin genelde özel ilgi turizmi türlerine dayanması ve turist başına harcamanın yüksek olduğu türler olması nedeniyle ekonomik getirisinin de yüksek olacağı düşüncesi hakimdir. 
- Türkiye Cumhuriyeti vatandaşlarının Orta Asya Türk Devletleri'ni ziyaret etmelerinin temel sebeplerinin neler olabileceği hakkında yöneticilerin görüşleri alınmıştır. Kazakistan başta olmak üzere tüm ülkelere giden Türkiye vatandaşlarının büyük kısmının iş amaçlı gittikleri kanaati hakim olmuştur. Ayrıca kültürel amaçlı ve av turizmi amaçlı olarak da gittikleri görüşü ortaya çıkmıştır. Türkiye İstatistik Kurumu'nun verilerine göre de, Türkiye Cumhuriyeti Vatandaşları iş amaçlı olarak en fazla Orta Asya Türk Cumhuriyetleri'ni ziyaret etmişlerdir. 2013 yılında 90.000 T.C vatandaşı iş amaçlı olarak Orta Asya Türk Devletleri'ni ziyaret etmiştir. Türkiye'den bu ülkelere iş amaçlı olarak yapılan ziyaretlerin fazla olması, ülkeler arasındaki ekonomik ilişkiyi de geliştirmektedir.

- Türkiye'den Orta Asya Türk Devletleri'ne giden turist sayısının az olmasının nedenlerinin neler olabileceğiyle ilgili yöneticilerin görüşleri alınmıştır. Orta Asya Türk Devletleri'nin Türkiye'de yeterince tanıtılamaması, Türkiye'den ulaşımın yorucu ve pahalı olması, ülkelerde turizm endüstrisinin düşük standartta olması, bölgeye yönelik tur düzenleyen çok az seyahat işletmesinin bulunması ve Türkmenistan, Özbekistan ve Tacikistan'ın vize talebi nedenleriyle turist sayısının az olduğu yöneticilerin genel görüşü olmuştur. Ayrıca güvenlik konusuyla ilgili tereddütler olduğu ve bunun da ziyaretçi sayısını olumsuz etkilediği görüşünü belirten yöneticiler de olmuştur.

- Orta Asya Türk Devletleri'nden Türkiye'ye gelen ziyaretçilerin temel geliş nedenlerinin neler olduğu, ziyaretçi sayısının yeterli olup olmadı̆̆ ve ekonomik getirileri konusunda sorular yöneltilmiştir. Orta Asya Türk Devletleri'nden Türkiye'ye gelen ziyaretçi sayısının yetersiz olduğu konusunda yöneticiler hemfikir olmuştur. Kazakistan'dan gelen ziyaretçi sayısının ise diğerlerine göre daha tatmin edici olduğu görüşü hakimdir. Türkiye'ye temel geliş nedenlerinin ülkelere göre değişiklik gösterdiği görülmüştür. Kazakistan'dan gelen ziyaretçilerin genellikle deniz turizmi, kültür turizmi ve eğlenme amaçlı olarak geldikleri kanaati yaygındır. Türkmenistan, Kırgızistan ve Özbekistan'dan gelen ziyaretçilerin genellikle iş amaçlı ve eğitim amaçlı geldikleri belirtilmiştir. Kazakistan'dan gelen turistlerin, ekonomik anlamda getirilerinin yüksek olduğu ancak diğer ülkelerden gelen ziyaretçilerin Türkiye'ye olan ekonomik katkısının çok az olduğu görüşü yaygındır.

- Orta Asya Türk Devletleri'nden Türkiye'ye gelen ziyaretçilerin sayısının nasıl arttırılabileceği ve Türkiye'yi ziyaret etmelerinin önündeki temel engellerin neler olduğu konusu hakkında bilgi elde edilmeye çalışılmıştır. Orta Asya Türk Devletleri'nde kişi başına düşen yıllık gelirin düşük olması ülke dışına yapılacak seyahatler için en önemli engel olarak görülmüştür. Ayrıca ulaşımın yorucu ve pahalı olası da olumsuz bir etken olarak görülmüştür. Ayrıca bu ülkelerde Türkiye'ye tur düzenleyen seyahat işletmelerinin çok az sayıda olması da önemli bir engel olarak görülmektedir. Ülkelerin kişi başı yıllık gelirine değinilmesi yukarıdaki açıklamaya destek verecek niteliktedir. IMF'nin 2014 yılı verilerine göre kişi başına düşen yılık gelir Kazakistan'da 12.500 dolar, Türkmenistan'da 6.500 dolar, Özbekistan'da 3.500 dolar, Kırgızistan'da 2.500 dolar ve Tacikistan'da 2.000 dolardır. Türkiye ve Orta Asya Türk Devletleri arasında ekonomik göstergeler arasında büyük fark olması, Orta Asya Türk Devletleri vatandaşlarının Türkiye'ye yapacakları ziyaretlerde önemli bir engeldir. Ziyaretçi sayısının arttırılması için, tüm ülkelerde yeterli turizm tanıtımının yapılması gerekliliği ön plana çıkmıştır. Deniz turizmi üzerine yoğunlaşılması ve uygun fiyatlı turların sunulmasının Türkiye'ye bu bölgeden yapılacak ziyaretleri arttıracağı görüşü hakim olmuştur.

- Yöneticilere, Orta Asya Türk Devletleri'nde etnik turizm potansiyeli ve bu potansiyelin Türkiye Cumhuriyeti vatandaşları için bir çekim unsuru oluşturup oluşturmadığ sorulmuştur. Kazakistan'da Kızılorda ve Türkistan çevresi, Özbekistan'da Semerkant, Buhara ve Taşkent şehirleri, Türkmenistan'da Merv nehri çevresi başta olmak üzere, etnik turizm için 5 ülkede de çok sayıda önemli tarihi yapılar, eserler ve Türk kültürüne ait değerlerin bulunduğu görüşü hakim olmuştur. Bu potansiyel Türkiye Cumhuriyeti vatandaşları için aslında önemli bir çekim unsuru olduğu ancak tanıtım yetersizliği ve seyahat işletmesi azlığı nedeniyle bu potansiyelin yeteri seviyede değerlendirilemediği genel yargi olmuştur.

- Yöneticilerden, Orta Asya Türk Devletlerinde turizmin gelişmesi açısından en büyük problemlerin neler olduğunun önem düzeyine göre sıralanması istenmiştir. Yöneticiler, tanıtım yetersizliğini ilk sıraya yerleştirmişlerdir. Turist gönderen ülkelerle ulaşımın zorluğu ikinci sırada yer alırken, üçüncü sırayı ülkelerin izlediği içe kapalı politika almıştır. Turizm endüstrisinin dünya standartlarında olmaması ve turizm işletmelerinde kalite yetersizliği dördüncü sırada yer almıştır. Beşinci sırada, ülke yönetiminin turizm alanlarına gerekli yatırımı yapmaması gelmektedir. Son olarak güvenlik problemi de turizmin gelişmesinde engel olarak görülmüştür.

- Yöneticiler ülkelerdeki turizm işletmelerinin yeteri sayıda ve kalitede olup olmadıkları sorulmuştur. Ortak görüş, otel işletmeleri, seyahat işletmeleri, yitecek-içecek işletmeleri ve eğlence işletmelerinin Orta Asya Türk Devletleri'nde hem sayı hem de kalite olarak çok yetersiz olduğudur. Ancak Kazakistan'ın diğer ülkelere oranla daha iyi durumda olduğu belirtilmiştir. Türkmenistan'da ise son dönemlerde turizm işletmeleri konusunda kalite ve sayı yönünden olumlu gelişmeler yaşanmaya başlandığı görüşü dile getirilmiştir. 
- Yöneticilere, Orta Asya Türk Devletleri'nin turizm açısından geliştirilmesinde neler yapılabileceği ve Türkiye'nin ne tür katkısı olabileceği sorusu yöneltilmiştir. Çok iyi tanıtım yapılması, ulaşımın kolaylaştırılması ve iyileştirilmesi, turistik çekim merkezlerine gerekli önemin verilmesi, yasaların turistlerin lehinde değiştirilmesi, turizm sektöründe yatırımların teşvik edilmesi, kamunun altyapı ve üstyapıyı geliştirmesi, turistik tesis sayısı ve kalitesinin arttırılması, uluslararası tur operatörlerinin bölgeye yönelik turlar konusunda teşvik edilmesi ve yönlendirilmesi, yerel halkın turizme katılımının ve katkı alınmasının sağlanması ile turizmin geliştirilebileceği görüşü hakimdir. Türkiye'nin halkını bölgeye gidiş konusunda teşvik ederek, turizm işletmelerine yönelik yatırımlar yaparak, turizmde kalifiye eleman yetiştirilmesi konusunda eğitim vererek ve turizm konusunda işbirliği yaparak katkı sunmasının mümkün olduğu belirtilmiştir.

\section{Sonuç ve Öneriler}

Yapılan literatür taraması, elde edilen istatistiki bilgiler ve turizm işletmeleri ve konsolosluk yöneticileriyle yapılan görüşmelerden, Orta Asya Türk Devletleri'nin önemli bir turizm potansiyeline sahip olduğu ancak birçok sorun ve engelden dolayı turizmin istenilen seviyeye gelemediği belirlenmiştir. Kazakistan'ın diğer devletlere göre turizm için daha iyi bir seviyede olduğu söylenebilir. Turizm bakımından en geride olan ülke ise Tacikistan'dır. Orta Asya Türk Devletleri'nde genel olarak iş turizmi, dağcılık, kültür turizmi, av turizmi, sağlık turizmi ve doğa yürüyüşü gibi turizm türlerinde önemli bir potansiyeli olduğu görüşü hakim olmuştur. Turist sayısının çok yetersiz olduğu bu ülkelerde, turizm geliri de aynı şekilde çok düşüktür. Orta Asya Türk Devletleri'nde turizmin gelişmesi konusundaki en büyük sorunlar ve engeller, tanıtımın çok yetersiz olması, ülkelerin içe kapalı politikaları ve turistin gelişini zorlaştıran mevzuatlar, ulaşım olanaklarının yetersiz ve zor olması, turizm işletmelerinin kalite ve sayı olarak yetersiz olması ve güvenlik problemleridir. Araştırmaya göre bu sorunların en az yaşandığı ülkenin Kazakistan olduğu da ortaya çıkmıştır.

Türkiye ile Orta Asya Türk Devletleri arasındaki turizm ilişkisinin de çok yetersiz olduğu, özellikle aynı kökene sahip olmaları ve atalarının Orta Asya'dan göç etmesine rağmen bölgeye giden Türkiye Cumhuriyeti vatandaşlarının sayısının çok yetersiz seviyede olduğu kanaatine varılmıştır. Türkiye'den bölgeye genellikle iş turizmi amacıyla gidildiği sonucu ortaya çıkmıştır. Orta Asya Türk Devletleri arasından Türkiye'ye en fazla turist gönderen ülke Kazakistan olmuştur. Bunun nedeni olarak Kazakistan'da kişi başı gelirin diğer ülkeler göre çok daha iyi seviyede olması görülebilir.

Orta Asya Türk Devletleri'nde turizmin geliştirilmesi ve Türkiye ile turizm ilişkilerinin arttırılabilmesi amaciyla şu öneriler getirilebilir;

- Turist gönderen ülkeler yönelik yoğun tanıtım yapılması,

- Ülkeler ulaşımın kolaylaştırılması, bu amaçla turist gönderen ülkelerden bölgeye direk uçak seferlerinin sağlanması ve ülke içinde turizm alanlarına ulaşımın iyileştirilmesi,

- İçe kapalı ülke politikalarının değiştirilmesi ve turistlerin gelişine engel olan mevzuatları değiştirilmesi,

- Turizm işletmelerinin sayı ve kalite olarak iyi bir seviyeye getirilmesi ve bu amaçla devletin teşvik sağlamas1,

- Uluslararası tur operatörlerinin ülkelere turist çekmeye yönlendirilmesi ve teşvik edilmesi,

- Ülkelerin, sahip oldukları turizm çekiciliklerini sürdürülebilir turizm kapsamında iyileştirmesi,

- Ülkelerin her birinin, ülkelerine uygun bir turizm destinasyon imajı oluşturması,

- Türkiye'den ziyaretçi sayısının arttırılması amacıyla etnik turizm üzerine yoğunlaşılması.

$\mathrm{Bu}$ çalışma ile Türkiye ile Orta Asya Türk Devletleri arasındaki turizm potansiyelinin ortaya çıkarılması konusunda çeşitli bulgular elde edilmiştir. İleride bu konuda yapılacak çalışmaların özellikle ziyaretçilere yönelik yapılmasının önemli katkılar sunacağı tahmin edilmektedir. Ziyaretçilerin memnuniyet düzeyleri, yaşanan sorunlar ve beklentilerinin araştırılması gerekmektedir. $\mathrm{Bu}$ devletler arasından iki ülkenin turizm ilişkilerinin ele alınacağı çalışmaların yapılması da daha ayrıntılı sonuçların ortaya çıkmasını sağlayacaktır. Bu çalışmada özellikle bazı istatistiki verilere tam olarak ulaşılamamıştır. Bundan dolayı ülkelerde yer alan üniversitelerin turizm bölümü araştırmacılarının kendi ülkeleriyle ilgili turizm konusunda tüm bilgilere ulaşıp, çalışmalar hazırlamaları büyük önem taşımaktadır.

\section{Kaynakça}

- Akimov, 2010, Etnik Turizm ve Kazakistan'da Bir Butik Otel Projesi Değerlendirilmesi, İstanbul Üniversitesi Turizm İşletmeciliği Anabilim Dalı Yüksek Lisans Tezi, s. 37

- Alvarez, Diaz and Casiellers, (2007), Relationship Marketing and Information and Communication Technologies: Analysis of Retail Travel Agencies, Journal of Travel Research, vol. 45 no. 4, s.453 
- Karaağaçlı, 2012, Orta Asya Devletleri’nde Siyasal İstikrar ve Ekonomik Gelişmenin Karşılıklı Etkileşimi. Dergi Karadeniz, Mart. 2012, s.1

- Kobeshova, 2013, Kazakistan eeda Turizm Potansiyelini Geliștirmeye Yönelik Politikalar, İstanbul Üniversitesi Sosyal Bilimler Enstitüsü Turizm İşletmeciliği Anabilim Dalı Yüksek Lisans Tezi s.60

- Kulnazarova, 2010, Orta Asya Geçiş Ekonomilerinde Turizm Sektörünün Mevcut Durumu ve Gelişme Olanakları: Kırgızistan Örneği, Balıkesir Üniversitesi Sosyal Bilimler Enstitüsü Turizm İşletmeciliği ve Otelcilik Anabilim Dalı Doktora Tezi, s. 71-72

- Oktayer, Susam ve Çak, 2007, Türkiye'de Turizm Ekonomisi, İstanbul Ticaret Odası Yayınları, No: 200769, İstanbul

- Ekoavrasya, 2015, http://ekoavrasya.net/duyuru.aspx?did=65\&Pid=10\&Lang=TR

- İsgucdergi, 2015, http://www.isgucdergi.org/?p=makale\&id=199\&cilt=6\&sayi=1\&yil=2004

- $\quad$ İzka, 2015, http://www.izka.org.tr/files/planlama/1_Ust_Olcekli_Plan_Programlar/Turkiye_Turizm_Strateji.pdf

- Ogu, 2015, http://csecilmis.ogu.edu.tr/turizmtalebive.pdf

- Tursab, 2015, http://www.tursab.org.tr/tr/istatistikler/milliyetlerine-gore-gelen-yabanci-ziyaretciler

- Tursab, 2015, http://www.tursab.org.tr/tr/istatistikler/turist-sayisi-ve-turizm-geliri

- Unwto, 2015, http://www.unwto.org/facts/eng/vision.htm

- Unwto, 2015, http://media.unwto.org/press-release/2015-04-15/exports-international-tourism-rise-us-15trillion-2014

- Uzembassy, 2015, www.uzembassy.org.tr/files/.../tr/UZBEKISTAN_Turk_30082010.doc

- Worldbank, 2015, http://data.worldbank.org/indicator/ST.INT.ARVL 


\title{
Petrol Fiyatlarındaki Oynaklığın Dıș Ticaret ve Milli Gelir Üzerindeki Etkisi: Seçilmiş Bazı Avrasya Ekonomileri Üzerine Bir İnceleme
}

\section{The Effects of Oil Price Volatility on Foreign Trade Revenue and National Income: A Comparative Analysis on Selected Eurasian Economies}

\author{
Dr. Müjgan Hacığlu Deniz (Istanbul University, Turkey) \\ Assoc. Prof. Dr. Kutluk Kağan Sümer (Istanbul University, Turkey)
}

\begin{abstract}
The aim of this study is to identify the effects of the volatility of oil prices and exchange rates on foreign trade revenue of a few selected Eurasian Economies. These countries are oil and natural gas exporting countries and getting most of their trade revenue from exporting these commodities. The effects of sharply falling oil prices since June 2014 and depreciating exchange rates on these countries' external trade were analyzed by using alternative econometric models. The sample of this analysis covered the period from June 2014 when oil prices has started falling sharply - till June 2015 in which still world oil price is lower than the price of 140-150 dollars for per gallon in the previous years. Decreasing prices basically destabilize the revenues of these states since approximately two third (2/3) of their export revenue and substantial part of their budget revenue that comes from oil and natural gas. In Russian economy falling prices of oil depreciates both public revenue and economic activity. This means predominantly depending on one commodity for export and foreign trade makes these countries' economies in dependence of that commodity's price and makes these economies so vulnerable to global crisis and price volatilities. In order to avoid from this situation, these countries should divert their production and increase in variety for exporting goods.
\end{abstract}

\section{Giriș}

Enerji kaynakları özellikle petrol, gelişmiş ve gelişmekte olan tüm ekonomiler açısından önemli hammaddelerden biridir. Petrol ve petrol türevleri yani ondan elde edilen çeşitli ürünler ulaştırma ve taşımacılık sektöründen ağır sanayiye, savunma sanayinden tekstile, birçok sektörde girdi ve hammadde olarak kullanılmaktadır. Bu nedenle, petrol fiyatları uluslararası ekonomide ve küresel ticarette anahtar fiyatlardan biridir; ayrıca diğer enerji kaynakları için örneğin doğalgaz gibi yaygın bir şekilde referans değer olarak kullanılmakta ve onların fiyatlarını da etkilemektedir.

Son yıllarda enerji konusunda ilginin, Orta Doğu'dan Avrasya Bölgesi'ne kaymış, olması da dikkate değer bir gelişmedir. Bölgenin ekonomik yapısı ağırlıklı olarak enerji sektöründe yoğunlaşmıştır. Bu bölgenin öneminin giderek artmasının ardında, başka nedenler olmakla birlikte, iki önemli olayın belirgin bir biçimde etkisinin bulunduğunu belirtilmektedir. Bunlardan birincisi bölge kaynakları üzerindeki Sovyet egemenliğinin sona ermesine yol açan Sovyetler Birliği'nin dağılmasıdır. Diğeri ise, enerji aktarımında güvenlik sorununun öneminin giderek artmış olmasıdır. Öyle ki, gittikçe istikrarsızlaşan Orta Doğu'ya alternatif enerji kaynakları arayışı daha da ön plana çıkmıştır. Dolayısıyla, Avrasya bölgesindeki yeni kaynaklara uluslararası yatırımların hızlanmasına da yol açmıştır. Belirtilen iki olayın yanı sıra yakın gelecekte rezervlerinin biteceği tahmin edilen petrol ve doğal gazın yenilenemeyen enerji kaynaklarından olması nedeniyle, dünya nüfusunun ve buna bağlı olarak giderek artan enerji talebinin karşılanması için yeni enerji rezervleri arayışı bir zorunluluk haline dönüşmüştür (Narin, 2006: 154).

Uluslararası piyasalarda petrol fiyatları 2003 yılından itibaren 2008 yılına kadar hızlı bir artış göstermiștir. Bu durum daha çok dünya ekonomisindeki hızlı büyümeye paralel olarak artan petrol talebi ve spekülatif faktörlerin ortak bir sonucu olarak kabul edilebilir. Ancak beklenmedik bir küresel finansal kriz tüm bu artan petrol ve emtia fiyatlarını aşağı yönde revize etti. 2009 yılında petrol fiyatları hızlı bir düşüş süreci yaşamıştır. 2008 yılında ABD'de başlayıp küresel finansal bir krize dönüşen mortgage krizi sonrasında, 60 dolar seviyelerine kadar gerileyen petrol fiyatı, takip eden yıllarda gelişmekte olan ülkelerdeki hızlı büyüme trendi ve Arap Baharı ile petrol arzında muhtemel bir azalma beklentisi nedenleri ile yeniden yükselişe geçmiştir. Nitekim, Dünya petrol piyasalarında 160 dolara kadar yükselen fiyatlar, 2010 yılından itibaren -son dört yıldır- 100 doların üzerinde seyreden bir trend oluşturdu. (OPEC, 2014) Bu yükseliş trendi de 2014 Haziranından itibaren tekrardan keskin ve sürekli bir düşüş trendine girdi. Öyle ki, 2015 yılının ilk aylarında 50 dolar seviyelerine kadar gerileyen petrol fiyatları, halen 2015 yılı için öngörülen yüksek fiyat seviyelerine ulaşamamış, hatta İran ile Batılı devletler arasında nükleer müzakereler konusunda bir anlaşmaya varılması sonucu petrol fiyatları Nisan 2015'ten sonra tekrardan rekor düşük seviyeye inerek 56.32 dolara kadar gerilemiştir. 
Petrol fiyatlarında son dönemde yaşanan sürekli düşüş öncelikle ekonomisi petrole dayanan devletlerin gelirlerini vurmuş ve büyük oranda petrol ve doğalgaz gibi enerji ihracatından elde ettiği gelirlerle kamu harcamalarını finanse eden devletler bu durumdan ekonomisi en çok zarar gören taraf olmuştur. Bunların içinde Azerbaycan, İran, Kazakistan ve Rusya gibi Avrasya bölgesi ülkeleri de bulunmaktadır.

\section{Petrol Fiyatlarının Ekonomik Faaliyetler Üzerindeki Olası Etkileri}

Altıntaş (2013: 5) teorik açıdan petrol fiyatı şoklarının döviz kuru ve diğer değişkenler üzerindeki aktarım mekanizmasının işleyişini şu şekilde ifade etmiştir: Başlangıçta artan petrol fiyatları enflasyonist baskıları artırmakta ve hane halkının reel gelirlerini azaltmaktadır; sonuçta tüketim harcamaları baskı altına alınmaktadır. Dolayısıyla, ekonomideki toplam üretim, yurtiçi talebin gittikçe zayıflaması ve şirket karlarının azalması sonucunda olumsuz etkilenebilmektedir. Nitekim, petrol ithal eden ülkeler açısından petrol fiyatlarındaki artış üretim maliyetlerini arttırırken, yurtiçi fiyat düzeyini de negatif etkilemektedir. Diğer taraftan petrol fiyatlarındaki artışın petrol ithal eden bir ülkeden petrol ihraç eden bir ülkeye gelir transferine yol açmakta olduğu bulgusuna varılmıştır. (Altıntaş, 2013: 6)

Son dönemde yaşanan petrol fiyatlarındaki gerilemenin oluşturacağı ekonomik etkiler Ortadoğu ve Kuzey Afrika ülkeleri özelinde değerlendirildiğinde, petrol ihraç eden ülkeler ve ithal eden ülkeler açısından farklılıklar arz etmektedir. ORSAM'ın 2014 yılı raporuna göre petrol ithal eden ülkeler, petrol fiyatlarındaki düşmeden cari işlemler dengesi ve enflasyon açısından olumlu yönde etkileneceği beklenebilir. Fakat aynı zamanda yapılan çalışmalarda, bölgede petrol ihracatçısı olmayan ülkelerin de fiyat stoklarından etkilendiği ortaya konulmuştur (Berument vd., 2010). Fiyatlardaki düşüss, petrol ihracatçısı ülkelerde gelir azalmasından dolayı talep daralmasını da beraberinde getireceğinden, bu ülkelere yönelik ihracat yapan ekonomilerin de olumsuz yönde etkilenebileceği beklenmektedir.

Fiyatlardaki düşüş öncelikle ekonomisi petrole dayanan devletlerin gelirlerini vuruyor. Avrasya coğrafyasında gelirlerinin önemli bir bölümünü enerji ihracatından alan ülkeler arasında Rusya, Azerbaycan, İran ve Kazakistan gelmektedir. Petrol ihraç eden bu gibi ülkelerde ekonomi, petrol fiyatları ile ivmelenen kamu harcamalarına yüksek oranda bağımlıdır. Bu nedenle, petrol fiyatlarının artıyor olması bu ülkelerde kamu harcamalarının artmasına yol açmaktadır ve bu durumda da istihdam ve kişi basına düsen milli gelir artmaktadır. Ancak, son yıllarda olduğu gibi enerji fiyatlarındaki gerileme durumunda ise ters yönlü bir etki oluşmaktadır. Diğer bir ifadeyle, petrol fiyatlarının düşüyor olması bu ülkelerde bütçe gelirleri ve dolayısıyla kamu harcamalarının azalmasına yol açmaktadır.

Petrol ihraç eden ülkeler açısından, fiyatlardaki gerileme sıkıntılı günlerin habercisidir. Düşük fiyatların sürekliliği OPEC ülkelerinin yansıra, petrol gelirlerine bağımlılığı yüksek düzeydeki Avrasya ekonomileri açısından (Rusya, Kazakistan, Azerbaycan, Türkmenistan ve İran) da büyük riskler taşımaktadır. Nitekim ihracat gelirlerinin yaklaşı üçte ikisini (2/3'ünü), bütçe gelirlerinin önemli bir bölümünü petrol ve doğal gazdan elde eden Rusya'da düşük petrol fiyatları hem kamu gelirlerini, hem de ekonomik aktiviteyi zayıflatırken, iç talebi olumsuz etkilemektedir.

Son yıllarda sadece petrol şoklarının ekonomik resesyonu açıklamada yeterli olmadı̆̆ı daha da belirginleşmiştir. Nitekim, son iki yıldır petrol fiyatlarındaki düşüşe ve enerji fiyatlarının beklentilerin altında kalmasına rağmen gelişmiş ve gelişmekte olan ekonomilerde büyüme oranları istenilen düzeye çıkarılamamakta ve hatta Japonya gibi ekonomisi ithal enerji kaynaklarına bağımlı olan gelişmiş bir ülke resesyona girebilmektedir. Diğer bir ifadeyle, petrol fiyatındaki bir artış reel büyümeyi azaltıcı etkiye yol açabilse de, aksine petrol fiyatındaki bir azalma ekonomik faaliyetleri canlandıramamaktadır.

Ekonomik faaliyetleri çoğunlukla bir sektöre ve belli başlı birkaç ürüne dayanmaktadır. Benzer şekilde bu ülkelerin dış ticaretine konu olan malların sayısı da oldukça sınırlıdır. Genelde petrol ve doğalgaz rezervleri bakımından zengin yer altı kaynakları olan bu ülkeler büyük oranda işlenmemiş hammadde (petrol, doğal gaz vb.) ihraç ederken, işlenmiş ve katma değeri olan birçok ürünü ve teknolojik ürünlerin çoğunu da dişardan ihraç etmekteler. Dolayısıyla, ihraç ettikleri bu bir kaç ürüne bağımlı birer ekonomi olmaları ve ticaretlerinde ürün çeşitlendirmesine gidememelerinden ötürü ihraç ettikleri hammaddelerin fiyatlarındaki değişimlerden de fazlasıyla etkilenmektedirler. Kısacası, enerji zengini ekonomiler olmalarına rağmen sanayileşmemiş ülkeler olarak dış ticarette aslında kendilerinin dışında gelişen dünya fiyatlarına bağımlı ve alternatifsiz birer ekonomidirler.

\section{Petrol Fiyatlarının Gelişimi ve Fiyatlardaki Değişimlerin Ekonomiye Geçiş Etkisi}

Petrol fiyatlarının reel ekonomik faaliyetleri etkilemesi mekanizması, hem arz hem de talep kanallarının dahil edilmesiyle ortaya çıkmaktadır. Bazı araştırmalar artan petrol fiyatlarının etkilerinin temel kanal olarak aktarımının arz yönlü olmasından dolayı resesyona yol açacağını açıklamaktadırlar. Bu durumda petrol fiyatındaki artışlar ekonomilerde potansiyel üretimi etkilemektedir. 
2010 y1lında başlayan son yükseliş trendi, ki bundan önce daralan küresel ekonominin etkisiyle 100 dolar seviyelerine kadar yükselen fiyatlar, 2009 yılında 61 dolar seviyesine kadar gerilemişti, gelişmekte olan ülkelerin büyüme performansındaki hızlı toparlanmadan kaynaklanmıştır. 2010 yllında tekrardan 80 dolar civarına gelen petrol fiyatı 2011 yllında ise 111 dolar seviyesine çıkmış ve 2012 yllında da bu seviyeyi korumuş, 2013 yılı başında 113 dolar civarındayken haziran ayında 102 dolar seviyesine gerilemiştir. Haziran 2014 tarihinde ise brent petrolün varil fiyatları 115 dolardı. (OECDilibrary, 2014) Ancak, 2014 Kasım ayı sonu itibarıyla varil fiyatı 70 dolar seviyelerine hızla inmiş ve Aralık ayında 63 dolar seviyesine kadar gerilemiş̧tir. Avrupa Birliği ülkeleri ve Birleşik Devletler'de yaşanan durgunluğun gelişmekte olan piyasalara yayılması ve arz yönlü etkiler - kaya gazı (shale gas) üretimi $\mathrm{ABD}$ ve Kanada'da büyük artış göstermiş ve günümüzde kaya gazı teknolojisi LNG çevrilebilir hale gelmiş (Sevim, 2014; 49)- nedeni ile petrol fiyatlarında Haziran 2014'ten beri hızlı bir düşüş yaşanmış ve halen 2015 yılı itibariyle petrol fiyatları - 60 ila 70 dolar civarında- daha önceki yıllara göre düşük seyrini sürdürmektedir.

Petrol fiyatlarında 2014 yılı haziran ayında başlayan düşüş, trendine neden olan faktörleri arz ve talebe bağlı faktörler olarak ikiye ayırmak gerekir. Talep yönünden bakıldığında küresel ekonomide büyüme oranının beklentilerden düşük gelmesi, Avrupa Birliği ekonomilerindeki toparlanmanın yavaş oluşu ve geleceğe dönük beklentilerin aşağı yönlü revize edilmesi en önemli nedenler olarak gösterilmektedir. Gelişmiş ülkeler ve Avrupa ekonomilerinin son dört yılda gösterdiği düşük performansın küresel petrol talebi ve fiyatlarını aşağı yönlü etkilediği bilinmektedir. Yine OECD ülkelerinin üretimi kısmayarak arzı azaltmaması da dünya ham petrol fiyatlarının artmasına engel olmaktadır. Bunun sonucunda fiyatın düşmesine bağlı olarak, kamu gelirlerindeki azalma ve iç talepteki kötüleştirici etki petrol üreticisi ülkeleri zor durumda bırakmaktadır.

Petrol fiyatlarındaki değişmeler, petrol ithal eden ülkelerle ihracatçı ülkeler arasında bir refah transferine yol açar. Petrol fiyatlarındaki artışlar ihracat yapan ülkelerde cari işlem fazlasını arttırırken, fiyatların düşmesi Cari işlemler üzerinde olumsuz etkilerde bulunur. (ORSAM, 2014: 10) Petrol ihracatçısı ülkeler açısından düşen petrol fiyatları değerlendirildiğinde, petrol fiyatlarındaki gerilemenin sürekli olması halinde bu ülkelerde ekonomik durgunluk kaçınılmaz gibi görünmektedir. Nitekim, bu ülkelerde 2012 sonrası büyüme hızında bir yavaşlama trendi görülmektedir. Diğer bir ifadeyle, petrol ve enerji fiyatlarındaki düşüsün sürekli olması ciddi bir ekonomik daralmayı beraberinde getirebilir. Büyümenin yavaşlaması ve petrol gelirlerindeki azalma kamu gelirlerinin de azalmasına yol açacağından kamu bütçe dengesi üzerindeki baskıları artıracaktır.

Petrol fiyatlarının ekonomik etkileri, Cari İşlemler, Kamu Harcamaları ve Döviz Kurları olmak üzere üç mekanizma aracılığı ile gerçekleşmektedir. (Berument vd., 2010: 150-76). Örneğin, petrol fiyatlarındaki değişimler petrole bağımlılığı yüksek düzeyde olan Ortadoğu ülkelerinde ekonomik performansı doğrudan etkilemektedir. Nitekim, bölge ülkelerinde petrol fiyatları ile ekonomik performans arasında ilişkiyi test eden çok sayıda araştırma yapılmıştır. Sonuç olarak, bu çalışmaların hemen hepsinde petrol ihraç eden ülkelerde petrol fiyatlarında meydana gelen artısın ekonomik büyümeyi arttırdığ sonucuna ulaşılmıştır.

\section{Ekonometrik Uygulama}

Avrasya bölgesindeki birincil enerji kaynakları, 2005 yılında dünya toplam birincil enerji kaynaklarının \% 15'i, bölgede yer alan Türk Cumhuriyetlerindeki enerji kaynakları ise \% 2.5'ini, Türk Cumhuriyetlerinin petrol rezervleri, dünya rezervlerinin \% 4'ünü, doğal gaz ise \% 5.1'ini oluşturmaktadır (Narin, 2006: 155). Bu paylar ve bölgedeki Türk Cumhuriyetlerinin petrol ve doğal gaz rezervleri ve bu rezervlerin aranma ve üretim maliyeti dikkate alındığında, Orta Doğu rezervleri ile karşılaştırılacak büyüklükte olmadığı görülmektedir. Ancak, arz güvenliği, kaynak çeşitliliği ve yeni rezervlerin keşfediliyor olması açısından, bu kaynakların önemi hızla artmaktır ve yeni yapılmakta olan yatırımlar ve planlanan enerji projeleriyle bölge rezervleri önem arz etmektedir.

Azerbaycan, Çin, Ermenistan, Gürcistan, Kazakistan, Kırgızistan, Özbekistan, Rusya Federasyonu, Türkiye, Türkmenistan, Ukrayna'ya ait 1990-2013 yılları arasındaki Gayrisafi Yurt İçi Hasıla ve İhracat rakamlarıyla Petrol fiyatları arasında modeller kurulmuştur. Yukarda sözü edilen on bir ülkenin ihracatları ve Gayrisafi Yurt İçi Hasılalarıyla kurulan modeller aşağıda verilmiştir.

\subsection{GSYIH Modelleri}

Ülkelere ait GSYIH'lar Dünya Bankası veri tabanından alınmıştır. Petrol fiyatları ise BP'nin internet sitesinden temin edilmiştir. Modeller 1990-2013 arası 24 gözlemden oluşmuştur. Modellerin matematiksel formu:

$$
\begin{aligned}
& \text { GSYIH }=\alpha{\text { Petrol Fiyat }{ }^{\beta}}^{\beta} \\
& \ln (G S Y I H)=\ln (\alpha)+\beta \ln (\text { Petrol Fiyat })
\end{aligned}
$$

şeklindedir. 24 yıla ait dalgalanmaları grafik üzerinde gösterecek olursak: 


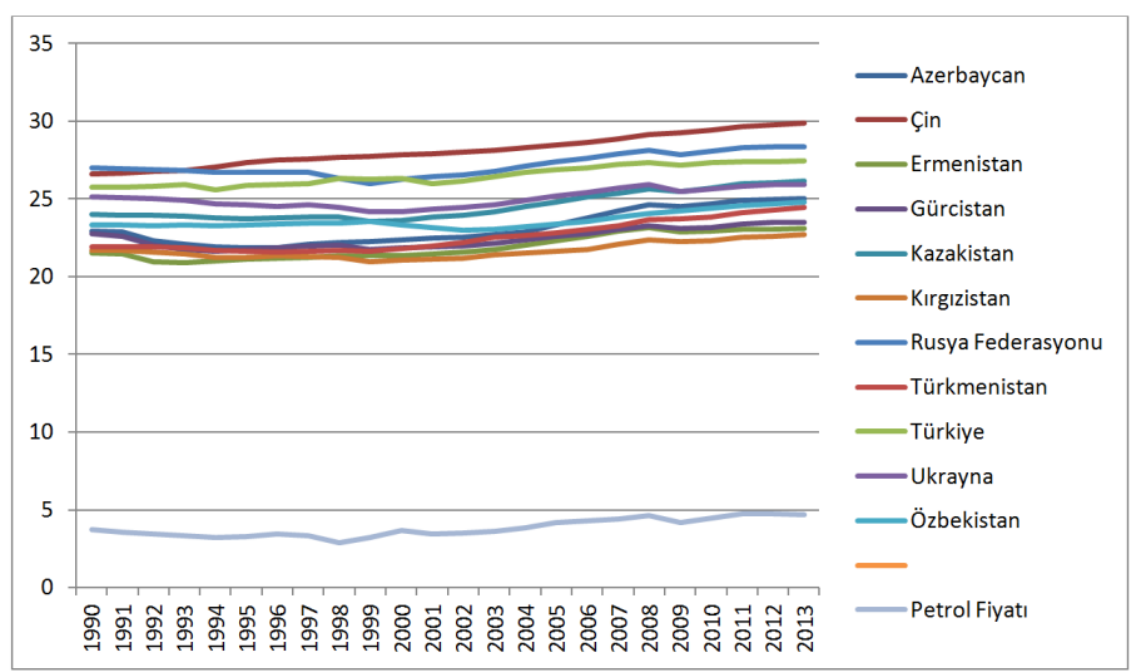

Şekil-1: Seçilmiş Avrasya Ülkelerine ait GSYIH'lar ve Petrol Fiyatlarında Dalgalanmalar

Kurulan modelleri inceleyecek olursak:

\begin{tabular}{|l|r|r|r|r|r|}
\hline & \multicolumn{1}{|c|}{$\alpha$} & t-testi $_{\alpha}$ & $\boldsymbol{\beta}$ & t-testi $_{\beta}$ & \multicolumn{1}{c|}{$\mathrm{R}^{2}$} \\
\hline Azerbaycan & $\mathbf{1 5 . 9 3 3 3}$ & 33.6213 & $\mathbf{1 . 8 8 4 7}$ & $\mathbf{1 5 . 3 7 4 5}$ & 0.9149 \\
\hline Çin & $\mathbf{2 2 . 2 6 5 6}$ & 29.2384 & $\mathbf{1 . 5 2 8 8}$ & $\mathbf{7 . 7 6 0 9}$ & 0.7325 \\
\hline Ermenistan & $\mathbf{1 6 . 7 5 4 7}$ & 45.6654 & $\mathbf{1 . 0 5 1 9}$ & $\mathbf{1 4 . 2 4 4 2}$ & 0.9022 \\
\hline Gürcistan & $\mathbf{1 8 . 4 0 3 1}$ & 55.4872 & $\mathbf{1 . 0 5 4 8}$ & $\mathbf{1 2 . 2 9 4 7}$ & 0.8730 \\
\hline Kazakistan & $\mathbf{1 8 . 7 6 5 9}$ & 48.2836 & $\mathbf{1 . 5 0 4 4}$ & $\mathbf{1 4 . 9 6 4 3}$ & 0.9105 \\
\hline Kirg1zistan & $\mathbf{1 8 . 4 1 4 7}$ & 57.4614 & $\mathbf{0 . 8 5 1 5}$ & $\mathbf{1 0 . 2 7 1 4}$ & 0.8275 \\
\hline Özbekistan & $\mathbf{2 0 . 7 5 4 6}$ & 46.1054 & $\mathbf{0 . 7 4 7 5}$ & $\mathbf{6 . 4 1 9 7}$ & 0.6520 \\
\hline Rusya Federasyonu & $\mathbf{2 2 . 5 7 3 7}$ & 65.8729 & $\mathbf{1 . 1 9 8 5}$ & $\mathbf{1 3 . 5 2 0 6}$ & 0.8926 \\
\hline Türkiye & $\mathbf{2 2 . 6 2 1 0}$ & 55.6926 & $\mathbf{1 . 0 1 1 8}$ & $\mathbf{9 . 6 2 9 7}$ & 0.8082 \\
\hline Türkmenistan & $\mathbf{1 6 . 3 5 5 9}$ & 36.1543 & $\mathbf{1 . 6 2 4 7}$ & $\mathbf{1 3 . 8 8 3 9}$ & 0.8976 \\
\hline Ukrayna & $\mathbf{2 1 . 5 5 7 6}$ & 59.8452 & $\mathbf{0 . 9 0 7 1}$ & $\mathbf{9 . 7 3 5 2}$ & 0.8116 \\
\hline
\end{tabular}

Tablo-1: GSYIH'nın bă̆ımlı Petrol Fiyatlarının Bă̆ımsız Değişken Olduğu Modeller

Rakamlar dikkatli incelendiğinde petrol ihraç eden ve büyümesini petrole dayalı olarak yürüten ülkelerin tamamında $\beta$ parametresinin yüksek diğer ülkelerde bu değerin düşük olduğu Tablo-1 den açıkça görülmektedir. $\mathrm{Bu}$ parametrenin direk elastikiyeti verdiği düşünülecek olursa petrol fiyatlarındaki \%1 lik bir artış Rusya Federasyonu, Azerbaycan, Çin, Kazakistan ve Türkmenistan'ın GSYIH sı üzerinde çok etkilidir. Petrol üretimi olmadığı halde Türkiye ve Ermenistan'da bu değerin 1 civarında çıkması ilginçtir.

Bu modeller Rusya Federasyonu, Azerbaycan, Çin, Kazakistan ve Türkmenistan gibi kalkınmasını petrol ile sağlayan ülkelerin petrol fiyatlarına duyarlılıklarını açıkça göstermektedir. Buradan da anlaşılmaktadır ki, petrol fiyatlarındaki düşüşler bu ülkelerde ciddi refah kaybına sebep olmaktadır.

\section{2 İhracat Modelleri}

Ülkelere ait ihracatları Dünya Bankası veri tabanından alınmıştır. Petrol fiyatları ise daha öncede belirtildiği gibi BP'nin internet sitesinden temin edilmiştir. Modeller 1990-2013 arası 24 gözlemden oluşmuştur. Modellerin matematiksel formu:

$$
\begin{gathered}
\dot{\mathrm{I} h r a c a t}=\alpha \text { Petrol Fiyatl }^{\beta} \\
\ln (\dot{\text { Ih }} \text { racat })=\ln (\alpha)+\beta \ln (\text { Petrol Fiyat })
\end{gathered}
$$

şeklindedir. 24 yıla ait dalgalanmaları grafik üzerinde gösterecek olursak: 


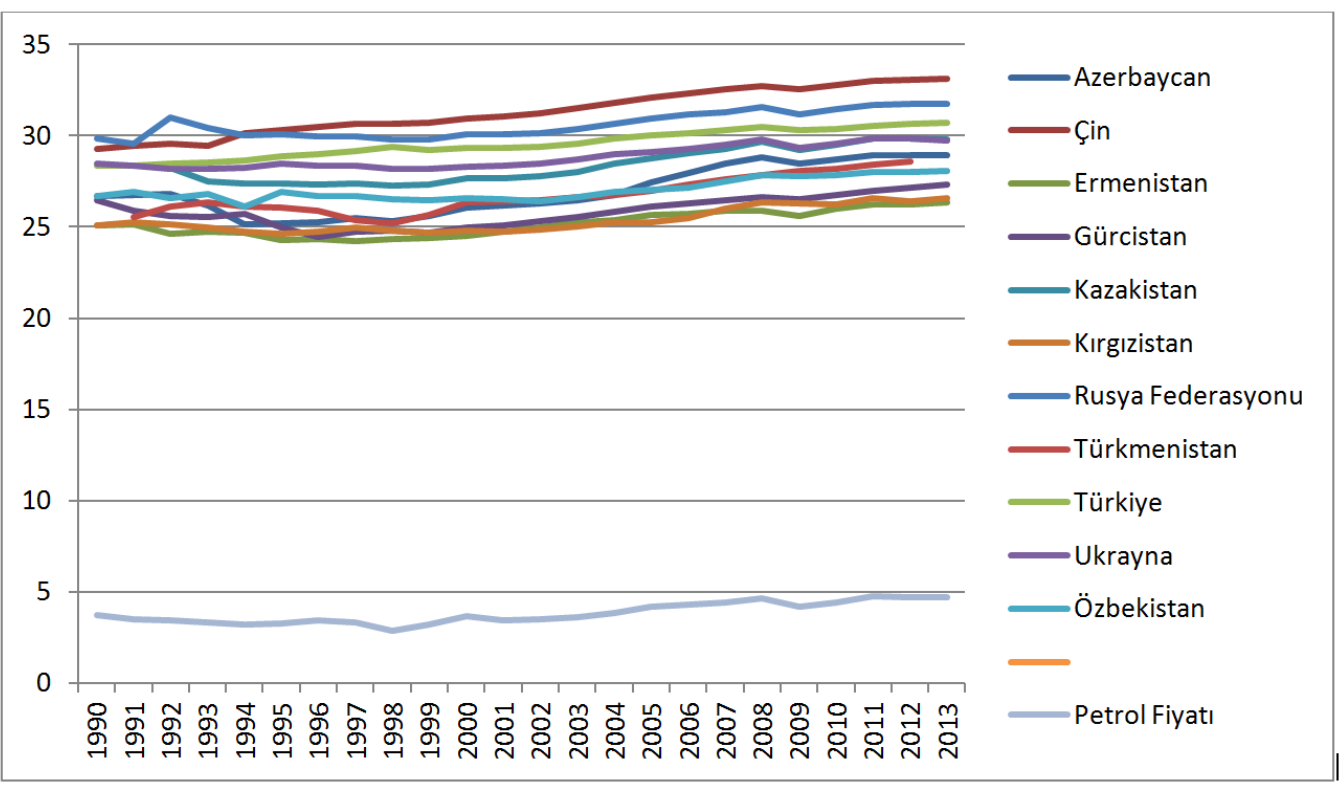

Şekil-2: Seçilmiş Avrasya Ülkelerine ait İhracatlar ve Petrol Fiyatlarındaki Dalgalanmalar

Kurulan modelleri Tablo-2 de inceleyecek olursak direk elastikiyetlerden hareket ettiğimiz de düşünülecek olursa açıkça Azerbaycan'ın ihracatı üzerinde Petrol Fiyatlarında \%1 lik bir artışın \%2.3 lük bir artışa sebep olduğu yani ihracatının parasal değer olarak 2,3 kat arttığı söylenebilir. Bu rakamlar Çin, Kazakistan, Türkmenistan içinde çok büyük önem arz etmektedir. Rusya Federasyonunda bu rakam diğer ihraç mamullerin içinde yine de Petrol'ün büyük önem arz ettiğini göstermektedir. Türkiye gibi petrol üretmeyen ülkelerde bu değerin 1 den büyük olması petrol girdisiyle yapılan üretimin maliyetleri ve fiyatları arttırdığın düşündürmektedir.

\begin{tabular}{|l|r|r|r|r|r|}
\hline & \multicolumn{1}{|c|}{$\alpha$} & \multicolumn{1}{|c|}{ t-testi $_{\alpha}$} & \multicolumn{1}{c|}{$\boldsymbol{\beta}$} & \multicolumn{1}{|c|}{ t-testi $_{\beta}$} & $\mathrm{R}^{2}$ \\
\hline Azerbaycan & $\mathbf{1 8 . 1 1 9 6}$ & 33.8346 & $\mathbf{2 . 3 0 6 5}$ & 16.6500 & 0.9265 \\
\hline Çin & $\mathbf{2 4 . 1 2 8 1}$ & 24.8839 & $\mathbf{1 . 8 7 5 8}$ & 7.4787 & 0.7177 \\
\hline Ermenistan & $\mathbf{2 0 . 7 0 6 8}$ & 66.4294 & $\mathbf{1 . 1 6 8 7}$ & 14.4938 & 0.9052 \\
\hline Gürcistan & $\mathbf{2 0 . 8 1 6 2}$ & 37.7054 & $\mathbf{1 . 3 0 8 6}$ & 9.1633 & 0.7924 \\
\hline Kazakistan & $\mathbf{2 2 . 1 6 4 5}$ & 74.9760 & $\mathbf{1 . 6 1 6 7}$ & 21.2505 & 0.9576 \\
\hline Kırgizistan & $\mathbf{2 1 . 1 3 9 2}$ & 58.6166 & $\mathbf{1 . 1 0 5 1}$ & 11.8462 & 0.8645 \\
\hline Özbekistan & $\mathbf{2 3 . 3 8 1 4}$ & 64.1353 & $\mathbf{0 . 9 5 3 3}$ & 10.1094 & 0.8229 \\
\hline Rusya Federasyonu & $\mathbf{2 6 . 1 7 4 1}$ & 59.9417 & $\mathbf{1 . 1 5 5 6}$ & 10.2310 & 0.8263 \\
\hline Türkiye & $\mathbf{2 5 . 1 2 8 8}$ & 41.5502 & $\mathbf{1 . 1 5 2 1}$ & 7.3643 & 0.7114 \\
\hline Türkmenistan & $\mathbf{2 0 . 2 7 1 7}$ & 39.2963 & $\mathbf{1 . 7 0 0 7}$ & 12.6262 & 0.8885 \\
\hline Ukrayna & $\mathbf{2 4 . 7 8 8 4}$ & 108.1255 & $\mathbf{1 . 0 5 3 5}$ & 17.7644 & 0.9348 \\
\hline
\end{tabular}

Tablo-2: Ihracatın Bă̆ımlı Petrol Fiyatlarının Bağımsız Değişken Olduğu Modeller

\section{Sonuç}

Geçtiğimiz son çeyrek yüzyılı ele aldığımızda, küresel petrol fiyatları genel itibariyle 1990’lı yıllarda sürekli bir düşüş, trendi göstermiştir. 1997 Asya krizi sonrasında 12 dolar seviyesine gerileyen petrol fiyatları Rusya ve OPEC ülkelerinin petrol arzını azaltması ile tekrar yükselişe geçmiştir. 2002'de düşen petrol fiyatlarına karsı tekrar üretimi azaltma politikası uygulanmıştır. 2002 sonrasında küresel ekonomideki büyümeye bağlı talep artışı petrol fiyatlarının hızlı bir şekilde artmasına yol açmıştır. Bu yükseliş, süreci 2008 krizine kadar sürmüştür. Ancak küresel kriz ile fiyatlar gerilemiş daha sonra 2010'da tekrar bir yükseliş trendine girmiştir. 2014 y1lı ortalarından itibaren de çok hızlı bir düşüş yaşayan petrol fiyatları, küresel ekonomik durgunluk ve arz fazlası olmasının da etkisiyle bir türlü beklenen yükselişi gerçekleştirememiş ve ihracatçı ülkeleri ekonomik açıdan zor bir duruma sokmuştur.

Petrol fiyatları Avrasya Ekonomileri açısından özellikle 2000'li yıllardan itibaren oldukça önemli bir parametre olmuştur. Petrol fiyatlarındaki artış, ülke ekonomilerinin hızlı büyümesine yol açarken, fiyatlardaki 
düşüş, ekonomik daralmaya yol açmıştır. Bu sadece bölgedeki petrol ihraç eden ülkeler açısından değil, diğer ülkelerin de ekonomik performansını etkileyen önemli bir faktördür. Son aylarda yaşanan fiyatlardaki gerilemeye karşılık OPEC ülkelerinin 27 Kasım 2014'te Viyana'da yapılan toplantıda petrol arzını azaltmama kararı alması bu sürecin devam edeceğini göstermektedir. Dünya petrol talebinde 2015 yılında büyük bir artış, olmadığı düşünüldüğünde düşük petrol fiyatlarının önümüzdeki günlerde de devam edeceğini söyleyebiliriz. (Orsam Rapor, Aralık 2014: 16)

Hali hazırda dünya enerji piyasalarındaki istikrarsızlık ve küresel talepteki azalma ile arz fazlalığının sebep olduğu petrol fiyatlarındaki düşük seyir, petrol ihracatçısı Avrasya ekonomilerinde büyüme ve bütçe açıkları üzerindeki baskıları da arttıracaktır. Bu ülkeler açısından negatif petrol şokları karsısında en etkili mücadele ekonomik çeşitliliğin arttırılması ve ekonomin tek ürüne bağlı olmaktan çıkartılmasıdır. Ancak bu ülkelerde hala yüksek düzeyli petrol ve doğalgaza bağımlılık devam etmektedir. Bu nedenle bu ülkelerdeki etkilerin daha uzun sürede ortaya çıkacağı söylenebilir. Göz ardı edilmemesi gereken bir diğer gerçek, iktisat literatüründe "kaynakların laneti” (Uzunoğlu vd.: 1-27) olarak bilinen yani doğal kaynak zengini ülkelerin bu zengin oldukları doğal kaynakların ticaretine bağımlı olmaları durumunun aşılması ve bölgede yalnızca tek ürüne bağımlılığın ortadan kaldırılması olmalıdır.

\section{Kaynakça}

- Altıntaş, H. (2013). Türkiye'de Petrol Fiyatları, İhracat ve Reel Döviz Kuru İlişkisi: ARDL Sınır Testi Yaklaşımı ve Dinamik Nedensellik Analizi, Uluslararası Yönetim İktisat ve İşletme Dergisi, Vol. 9, No.19, s.1-30, http://www.ijmeb.org/index.phb/zkesbe/article/view/459.

- Berument H. , N.Ceylan \& N. Dogan (2010), “The Impact of Oil Price Shocks on the Economic Growth of Selected MENA Countries" The Energy Journal, Vol. 31, No. 1, 150-176,

- BP. (June 2015), Statistical Review of World Energy: 2014 in Review, http://www.bp.com/content/dam/bp/pdf/Energy-economics/statistical-revies-2015/.

- $\quad$ www.brentpetrol.com, Brent Petrol ve Ham Petrol Fiyatalrı

- Enerji Enstitüsü (2015), Petrolün Varil Fiyatı 3 ayın En Düşük Seviyesinde, Enerji Piyasası, www.enerjienstitusu.com

- $\quad$ EIA. (2015), International -U.S. Energy Information Administration, Short Term Energy Outlook (STEO) July 2015, http://www.eia.gov/forecast/steo/pdf/

- $\quad$ EIA. (2015), Energy Information Administration, Country Report: Iran http://www.eia.gov/beta/international/analysis_includes/countries_long/Iran/Iranpdf. (June 2015).

- EIA. (2015), Energy Information Administration, Kazakhstan Country Analysis Brief, Jan 2015, http://www.eia.doe.gov/emeuleabs/kazak.html.

- $\quad$ EIA. (2013), Energy Information Administration, Overview of oil and natural gas in the Caspian Sea Region, http://www.eia.gov/beta/international/analysis_includes/countries/countries/regions_of_interest/ Caspian_Sea/Caspian_seapdf, August 2013.

- Hamdi H. \& R. Sbia (2013)," Dynamic Relationships Between Oil Revenues, Government Spending and Economic Growth in an oil-dependent Economy", Economic Modelling, http://www.sciencedirect.com/science/article/pii/S0264999313002617, Volume 35, September 2013, pp. 118-125.

- $\quad$ IMF (2014), Regional Economic Outlook, Middle East and Central Asia, October 2014, https://www.imf.org/external/pubs/ft/reo/2014/mcd/eng/.../mreo1014.pdf.

- Karg1, B. (2014): The Effects of Oil Prices On Inflation and Growth: Time Series Analysis In Turkish Economy For 1988:01-2013:04 Period. Published in: International Journal of Economics and Research, Vol. 2, No. 5 (March 2014): pp. 29-36

- $\quad$ Mussa, M., (2000), The Impact of Higher Oil Prices on the Global Economy, International Monetary Fund Research Department, Erişim Tarihi: 19.06.2015, http://www.imf.org/external/pubs/ft/oil/2000/oilrep.PDF

- Narin, M. (2006), Avrasya Bölgesindeki Türk Cumhuriyetlerinin Enerji Kaynakları ve İletim Hatlarının Türkiye'ye Katkıları, Türk Dünyası İncelemeleri Dergisi/ Journal of Turkish World Studies, Cilt: VI, Sayıl, Sayfa: 151-167.

- $\quad$ ORSAM, Rapor No:194 Aralık 2014., s.18.

- $\quad$ OPEC. (2014), Annual Statistical Bulletin (ASB) 2014, http://www.opec.org/library/Annual\%20Statistical\%20Bulletin/interactive/current/FileZ/Main.htm.

- OECDiLibrary, www.oecd-ilibrary.org/energy-prices-and-taxes-volue-2014pdf.

- Pamir, N. (2015), www.tvarsivi.com/enerji-uzmani-necdet-pamirbolgede-enerji-politikalari, 29 haziran 2015. 
- Sevim, C. (2014), Kaya (Şeyl) Gazının Uluslararası Enerji Politikalarına Etkileri, Ege Stratejik Araştırmalar Dergisi, Cilt 5, Sayı 1, 2014 (49-64).

- Uzunoğlu, S., Ekizceleroğlu C., Özkan, L., Yürük, M. S. , Avrasya Bölgesine Yönelik Gelişme Stratejileri ve Potansiyetl Sektör Araştırması, 8-2pdf, s(1-27),

https://www.academia.edu/9918733/AVRASYA_BÖLGESINE_YÖNELİK_GELİSME_STRATEJILERİ_V E_POTANSIYEL_SEKTÖR_ARAŞTIRMASIpdf. 


\title{
Türk Cumhuriyetlerinin Bulanık Kümeleme Analizi ile Belirlenen Ekonomik Göstergelerle Sınıflandırılması
}

\section{Classification of Turkish Republics with Specific Economic Indicators in Fuzzy Clustering Analysis}

\author{
Asst. Prof. Dr. Necati Alp Erilli (Cumhuriyet University, Turkey) \\ Asst. Prof. Dr. Çağatay Karaköy (Cumhuriyet University, Turkey)
}

\begin{abstract}
Economic indicators in economic policies have an important place in determining the levels of development. Determining and classifying the existing social and economic structures of countries is very important for examining the development states and possible development tendencies of countries and forming regional development policies in line with these. The aim in cluster analysis, is to classify datas in to similarity and perform useful knowledge for the researcher. Cluster analysis, which became more popular among the subjects of statistical classification in recent years, can give more reliable results when there is apriori knowledge about number of clusters. Fuzzy models interested in fuzzy model structures and try to estimate system behaviours that has no knowledge about their structure. Fuzzy Cluster Analysis is try to decompose the groups which membership degrees cannot be determined. When the number of datas and variables increased or cluster structures came to closer for all, Cluster analysis has given more successful results then the other cluster analysis methods. In this study, Turkish Republics were classified in terms of the indicators determined by using Fuzzy C-Means (FCM) and Gath Geva methods which are frequently used in fuzzy clustering analysis. The objective was to find out the common class structures of Turkish Republics which came out with the disintegration of the Soviet Union in 1991 and which experienced economic similar problems and thus to help countries in the same clusters in similar economic planning. Results are also compared between fuzzy and crisp clustering analysis methods.
\end{abstract}

\section{Giriș}

Dünya ekonomisi 80'lerden sonra önemli değişmelerle karşı karşıya kalmıştır. Merkezi otoritelerin hakim olduğu birçok sosyalist ülke ekonomisi, serbest piyasa ekonomisinin içinde kendilerine yer bulmuş ve dönüşüm geçirmek zorunda kalmışlardır. Bu dönüşüm; iktisat politikaları, kurumlar ve uygulamalardaki değişimi de kaçınılmaz olarak beraberinde getirmiştir (Emsen, Karaköy. 2009). Geçiş ekonomisi olarak da adlandırılan bu dönüşüm, otoriter ya da merkezden planlama ile yönetilen ülkelerin günümüz serbest piyasa ekonomilerine uyma süreçleri olarak da tanımlanabilir. Fakat bu ekonomilerin serbest piyasa ekonomilerine geçme çabaları sıkıntılı bir süreci de beraberinde getirmiştir. Bunların başında alt yapı yatırımlarının eksikliği gelmektedir. Diğer sorunlar ise kendi istekleri dışında oluşan bu geçiş sürecidir. Geçiş süreci ile ülkeler iki gruba ayrılmıştır. Birinci grupta; Avrupa'ya daha yakın ve süreci daha kolay atlatabilen, ikinci grupta ise sürece hazırlıksı yakalanan ve kriz ortamıyla karşılaşan ülkeler yer almaktadır. Çalışmada, söz konusu ülkeler gurubundan ikinci kısma giren ve daha önce ekonomik anlamda sıkıntı içerisinde olmayan fakat geçiş süreci ilerledikçe ekonomik anlamda dar boğaz içerisinde olan ülkeler inceleme konusu yapılmıştır. Bu ülkeler ise sırasıyla Kazakistan, Azerbaycan, Özbekistan, Kırgızistan, Türkmenistan, Tacikistan’dır. Ülkelerin genel anlamda birbirlerine benzerlik içinde olması da çalışmaya ayrı bir değer katmaktadır. Ekonomilerin ortak özellikleri ise düşük gelirli olmaları ve borç kısır döngüsü içinde olmalarıdır. İkinci grupta yer alan ülkeler, ekonomik anlamdaki benzerliklerinin yanı sıra sosyal ve kültürel anlamda da birbirlerine yakınlık göstermektedirler. Kazakistan, Azerbaycan, Özbekistan, Kırgızistan, Türkmenistan, Tacikistan'ın 1990'lı yıllardan daha önceki konumlarında oldukları gibi birbirlerine bağımlı olmalarda dikkati çeken özellikleridir.

\section{Literatür Araștırması}

Merkezi Asya ülkelerinin birçoğunda özellikle Sovyetler Birliği'nin çöküşünden sonraki dönem olan geçiş sürecinde neoklasik uygulamalar görülmektedir. Özellikle bu modelin seçilmesinin sebebi ise merkezi planlı ekonomilerden sonra serbest piyasa ekonomisine geçişteki farklılıkların anlaşılmasına cevap vermekte etkin olmasıdır. Neoklasik geçiş modeli, ivedi ve radikal bir geçişi simgeleyen, aşamalı geçiş stratejileri şeklinde uygulanmaktadır. Bu bağlamda, merkezi planlı bir sistemden serbest piyasa ekonomisine geçişte esas alınan neoklasik model, neoklasik analiz metoduna dayalı liberalizasyon, istikrar ve özelleştirme politikaları seti sunmakta fakat belirlenen stratejiye göre bu modelin uygulama hızı ve şekli değişmektedir (Güler;2012.s. 96). Merkezi Asya ülkeleri ile ilgili yapılan çalışmalarda bu ülkelerin aynı geçiş sürecine farklı yaklaşmaları üzerinde durulmuştur. Geçiş süreci başlaması ile birlikte bu ülkelerin ne durumda oldukları süreci nasıl geçirecekleri konusunda çalışmalara 1 şık tutmuştur. Neoklasik model çerçevesinde geçiş süreci başlangıcında yaşanan 
sıkıntılara çözüm üretebilmek için radikal önlemler almanın gerekliliği görülmüş ve bu yönde reformlar yapılmıştır.

Etkileyici önlemlerin alınmasının altında yatan neden ise ekonomik anlamdaki ve finansal alandaki dengesizliklerdir. Dolaysıyla bu dengesizliklerin radikal yaklaşımlarla çözülmesi gerekmektedir. Kademeli olarak uygulanan politikalar daha çok istikrar sorunu olmayan ülkelerde uygulama alanı bulmuştur (Güler;2012.s. 96). Eski Sovyetler Birliği ekonomisi ile iç içe olan Merkezi Asya ülkeleri Kazakistan, Azerbaycan, Özbekistan, Kırgızistan, Türkmenistan ve Tacikistan; yapısal kültürel açıdan da birbirlerine benzerlik göstermektedirler. Bu ülkelerin aynı zamanda tarihsel açıdan da ortak noktaları bulunmaktadır. Kendilerine kalan bu ortak miras geçiş sürecinin sıkıntılar içerisinde devam etmesine sebep olmuştur. İlk grup olan geçiş ekonomilerinden farklı bir yapıya sahip olmaları da (örneğin bu ülkelerin ilk gruba göre bağımsız bir devlet ya da ulus devlet olma tecrübelerinin olmayışı) dönüşümdeki engellerin başında gelmektedir. Çalışmaya konu olan ülkelerin ekonomik göstergelerini kısaca incelediğimizde, geçiş sürecine başlangıç aşamasındaki refah düzeylerine ulaşabildikleri ve dünya ekonomisindeki yerlerine belirgin hale getirdiklerini söyleyebiliriz. Bundan dolayı, söz konusu ülkelerin ortak özellikleri dikkate alınarak son yıllarda Türkiye'de sıkça kullanılan bulanık kümeleme analizi ile sınıflama yöntemini Türk Cumhuriyetlerine uygulamanın uygun olacağı düşünülmüştür. Literatürde bulanık kümeleme analizi ile sınıflama çalışmaları son yıllarda sıkça kullanılmıştır. Erilli v.d. (2009) ve Yılancı (2010), Türkiye'deki illeri sosyo gelişmişlik düzeylerine göre; Erilli (2014), TR72 Bölgesi ilçelerinin sosyo-ekonomik verilere göre; Atalay ve Tortum (2010), Türkiye'deki illerin 1996-2006 yılları arası trafik kazalarına göre; Kılıç v.d. (2011), ülkelerin turizm istatistiklerine göre bulanık kümeleme analizi ile sınıflama çalışmaları yapmışlardır.

\section{Kümeleme Analizi}

Kümeleme analizi, en çok kullanılan ve en önemli çok değişkenli veri analiz yöntemlerinden biridir. Son yıllarda özellikle iş ve fen alanlarında sıkça kullanılan Kümeleme Analizi; bireylerin ya da nesnelerin sınıflandırılmasını ayrıntılı bir şekilde açıklamak amacıyla geliştirilen istatistiksel bir yöntemdir. Kümeleme Analizi, bir araştırmada incelenen birimleri aralarındaki benzerliklerine göre belirli gruplar içinde toplayarak sınıflandırma yapmayı, birimlerin ortak özelliklerini ortaya koymayı ve bu sinıflar ile ilgili genel tanımlamalar yapmayı sağlayan bir yöntemdir. Burada amaç; gruplanmamış verileri benzerliklerine göre sınıflandırmak ve araştırmacıya uygun, işe yarar özetleyici bilgiler elde etmede yardımcı olmaktır (Tatlıdil, 2002). Başka bir ifade ile veriler arasındaki benzerlikler dikkate alınarak benzer verileri aynı grupta veya kümede toplanmasını sağlamaktır. Kümeleme Analizi, önceden belirlenen seçme kriterine göre birbirine çok benzeyen birey ya da nesneleri aynı küme içinde sınıflandırır. Analizin sonucunda oluşan kümelerin kendi içindeki homojenliği yüksek ve kümeler arası heterojenliği düşük olacaktır (Kalaycı, 2005). Kümeleme Analizi, araştırmada gözlenen bireylerin ya da nesnelerin ölçülen tüm değişkenler üzerindeki değerlerini hesaplayarak, ortaya çıkacak kümelere veya gruplara odaklanmaktadır. Bireyler veya nesneler arasındaki benzerlikleri saptamak amacıyla uzaklık ölçüleri, korelasyon ölçüleri veya katsayıları karşılaştırma ölçütlerini kullanmaktadır. Veriler metrik ise uzaklık veya korelasyon, metrik değilse Karşılaştırma (Ortaklık) ölçütleri kullanılır (Erilli, 2009).

\section{Bulanık Kümeleme Analizi}

Bulanık kümelerin kümelemede kullanımı ilk kez 1964'de önerilmiştir (Bellman vd., 1964). Bulanık Kümeleme; verileri kümelemek için bulanık teknikler kullanırlar ve bu tekniklerde bir nesne birden fazla kümeye sınıflandırılabilir. Bu tip algoritmalar gerçek sayıların belirsizliğini ele aldığından, günlük yaşamın tecrübelerine uygun kümeleme şekillerinin ortaya çımasına yardımcı olur (Erilli, 2009).

Bu yaklaşımda, kümeler birbirinden belirgin bir şekilde ayrılmıyorsa ya da üyeliklerinde bazı birimler küme üyeliğinde karasızsa uygun bir yöntem olarak ortaya çıkmaktadır. Bulanık Kümeler kümedeki birimin üyeliği olarak tanımlanan 0 ile 1 arasındaki her birimi belirleyen fonksiyonlardır. Birbirine çok benzeyen birimler aynı kümede yüksek üyelik derecesine göre yer alırlar (Şahinli, 1999; Erilli,2009).

Diğer kümeleme yöntemlerine benzer olarak Bulanık Kümeleme de uzaklık ölçümlerine dayanır. Bu uzaklık yöntemlerinden hangisinin seçileceği küme yapısına ve kullanılan algoritmaya bağlıdır. Bulanık Kümelemenin kullanışlı bazı özelliklerini şu şekilde sıralayabiliriz (Naes vd, 1999):

i Yorum açısından kullanışlı olan üyelik değerleri sağlar.

ii Uzaklık kullanımı konusunda esnektir.

iii Üyelik değerlerinin bazıları bilindiğinde sayısal optimizasyonla birleştirilebilir.

Bulanık Kümelemenin klasik kümeleme yöntemlerine göre avantajı, veri hakkında daha detaylı bilgi vermesidir. Diğer taraftan dezavantajları da vardır. Çok sayıdaki birey ve küme durumunda çok fazla çıktı olacağından, özetlemek ve bilgiyi tasnif etmek zordur. Ayrıca bulanık kümeleme algoritmaları genellikle karmaşık yapıdadırlar ve daha çok belirsizlik söz konusu olduğunda kullanılır (Şahinli, 1999; Erilli, 2009).

Bulanık Kümeleme Algoritmalarını iki kategoriye ayırabiliriz. Bir tanesi bulanık kümeleme içi bulanık ilişkileri, diğeri ise amaç fonksiyonunu kullanır. Bulanık ilişkilere dayalı kümeleme, orijinal bireyler arasındaki 
ilişkisel yapıyla ilgilenirken; amaç fonksiyonuna dayalı algoritmalar ise kümeleme problemini optimizasyon problemi haline dönüştürerek çözümlemeyi amaçlar. Bu yöntemde küme içindeki benzersizliği ölçmek için amaç fonksiyonu kullanılır ve bu amaç fonksiyonu minimize edilerek en iyi bölünme elde edilmeye çalışılır (Güler, 2006; Erilli, 2009).

Bulanık Kümeleme Yöntemleri, diğer kümeleme yöntemlerinin aksine veri uzayındaki her bir bireyin elde bulunan bütün kümelere belirli ölçüde girmesine izin veren üyelik fonksiyonları kullanırlar (Erilli, 2009). Bu üyelik değerleri, veri setinin ve kümelerin yapısını anlama açısından kullanışlıdırlar. Hiyerarşik kümeleme gibi diğer kümeleme yöntemleri sonuç olarak kesin küme sonuçları vermektedir. Değişkenlerin veya bireylerin bu kümelere üyelik dereceleri bu yüzden ya 0 ya da 1 olmaktadır. Bulanık kümelemede ise bireylerin üyelik dereceleri 0 ile 1 arasında yer alırlar. Tüm değişken veya bireylerin bütün kümelere üyelik dereceleri toplamı ise 1 olmaktadır. Burada üyelik dereceleri $u_{i j} i=1,2, \ldots, n J=1,2, \ldots, c$ ise

$$
\forall i \text { ve } \forall j \text { için } u_{i j}>0 \text { ve } \sum_{j=1}^{c} u_{i j}=1
$$

şeklinde gösterilebilir (Bellman vd., 1964). Burada küme sayısı olan $c$, kümeleme işlemi boyunca sabittir. Ancak c'nin farklı değerleri denenip, en iyi sonucu veren küme sayılarından biri seçilebilir (Erilli, 2009).

\section{Bulanık C-Ortalamalar Yöntemi}

Bulanık c-Ortalamalar algoritması, amaç fonksiyonuna dayanan bütün kümeleme tekniklerinin temelini oluşturmaktadır. İlk olarak Bezdek (1974) çalışmasında tanıtılmıştır. BCO algoritması sonuçlandığında, p boyutlu uzaydaki noktalar küresel bir şekil halini alır. Bu kümelerin yaklaşık olarak aynı boyutta olduğu varsayılır. Her bir kümeyi, küme merkezleri temsil etmektedir ve bunlara prototip adı verilmektedir. Uzaklık ölçüsü olarak, veriler ile küme merkezi arasındaki Öklid uzaklığını kullanılır (Bezdek, 1974):

$$
d_{i k}=\left(x_{k}-v_{i}\right)=\left\|x_{k}-v_{i}\right\|=\left[\sum_{v=1}^{p}\left(x_{k j}-v_{i j}\right)^{2}\right]^{1 / 2}
$$

Bu tekniğin uygulanabilmesi için, küme sayısının ve bireylerin kümeye üyelik derecelerinin önceden bilinmesi gerekmektedir. Bu tür parametreler önceden bilinmesi zor olduğundan, bu değerler deneme yanılma yoluyla ya da geliştirilen bazı tekniklerle bulunabilir.

Bu kümeleme yöntemi için kullanılan amaç fonksiyonu şu şekildedir (Bezdek, 1974):

$$
J(u, v)=\sum_{j=1}^{n} \sum_{t=1}^{c} u_{t j}^{m}\left\|x_{k}-v_{t}\right\|^{2}
$$

Bu fonksiyon en küçük kareler fonksiyonudur. $n$ parametresi gözlem sayısını, $c$ ise küme sayısını gösterir. $u_{i j}^{m}$ ise $t$. Kümedeki $x_{j}$ 'nin üyeliği, $J(u, v)$ değeri ise tüm ağırlıklandırılmış kare hatalarının toplamının bir ölçüsüdür (Şahinli,1999).

Eğer $J(u, v)$ fonksiyonu $c$ 'nin her değeri için minimize edilecek olursa, diğer bir deyişle $v_{i}^{\prime}$ 'lere göre 1 . Dereceden türevi alınıp 0’a eşitlenirse BCO Algoritmasının prototipi şu şekilde olacaktır (Bezdek, 1974):

$$
v_{i j}=\frac{\sum_{j=1}^{n} u_{i j}^{m} x_{j}}{\sum_{j=1}^{n} u_{i j}^{m}}
$$

BCO Algoritması uygulandıktan sonra hangi bireyin hangi kümeye gireceğine karar vermek için üyelik dereceleri kullanılır. Her bir bireyin hangi kümeye olan üyeliğinin en büyük olduğuna bakılır ve bu bireyler o kümeye dâhil edilir. Ancak her bir birey diğer kümelere de belli bir üyelik dereceleri ile girebilir (Erilli, 2014).

BCO Algoritmasının sonucu başlangıçta rasgele üretilen değerlere oldukça bağlıdır. Bu yüzden rastgelelikten kaynaklanan problemleri ortadan kaldırmak için çeşitli algoritmalar geliştirilmiştir ve geliştirilmeye devam edilmektedir. BCO, küme merkezlerini ve her veri noktası için üyelik derecelerini iterasyon yöntemi ile günceller ve küme merkezlerini veri seti içinde olması gereken yere taşır. Küme merkezlerinin ilk yerleri, başlangıçta değeri rasgele atanan U matrisi kullanılarak oluşturulduğu için, BCO optimal sonuca yaklaşmayı garanti etmeyecektir (Sintas, 1999; Erilli v.d., 2009; Erilli, 2014). 


\section{Küme Geçerlilik İndeksi}

Kümeleme Analizi, benzer nesneleri aynı gruplara yerleştirmeyi amaçlamaktadır. Birçok kümeleme analizi yöntemi, küme sayısının önceden bilinmesini gerektirir. Gerçek hayat verilerinde; araştırmacının küme sayısı hakkında ön bilgisinin olmamasından dolayı, bulunan küme sayısının gerçek küme sayısından az ya da çok olup olmadığının bilinmemesi sorununa yol açmaktadır. Optimal küme sayısının belirlenme işlemlerine genel olarak Küme Geçerliliği (Cluster Validity) adı verilmektedir. Böylece kümeleme işlemleri yapıldıktan sonra bulunan küme sayısının doğruluğu tespit edilebilmektedir (Erilli, 2009).

\section{Yapay Sinir Ağlarına Dayalı Küme Geçerlilik İndeksi}

Bu yöntem Erilli v.d. (2011) tarafından önerilmiştir. Yöntem, en uygun küme sayısını bulabilmek için yapay sinir ağlarını kullanmaktadır. Bu yöntemde ilk olarak, veriye uygun olabilecek en düşük ve en yüksek küme sayısına karar verilir. Belirleyeceğimiz en uygun küme sayısı bu aralıkta olacaktır. En uygun küme sayısı $c_{o p t}$ en düşük küme sayısı $c_{\text {min }}$ ve en yüksek küme sayısı $c_{\text {maks }}$ olmak üzere; $c_{\text {min }} \leq c_{\text {opt }} \leq c_{\text {maks }}$ siralamas1 olacaktır. Daha sonra, girdisi veri matrisi ve hedef değeri bulanık kümeleme sonucunda her bir verinin atandığ küme numarası olacak şekilde ileri beslemeli yapay sinir ağları mümkün küme sayılarının her biri için uygulanır (Erilli v.d., 2011). Her bir küme sayısı için, çeşitli gizli tabaka birim sayılarına göre yapay sinir ağlarından elde edilen HKOK (Hata kareler ortalaması karekök değeri) değerlerinin medyanı hesaplanır. Her bir küme sayısı için elde edilen medyan değerlerinin veya sınıflama hatası grafiği çizilerek, ilk sıçramanın olduğu (HKOK medyan değerinin ilk aşırı büyüdüğü) küme sayısından bir önceki değer en uygun küme sayısı olarak belirlenir (Erilli v.d., 2011).

\section{Uygulama}

Uygulamada altı Türk Cumhuriyeti, belirlenen bazı ekonomik göstergeler yardımıyla sınıflandırılmıştır. Türk Cumhuriyetleri sırasıyla Azerbaycan, Kazakistan, Özbekistan, Tacikistan, Kırgızistan ve Türkmenistan'dır. Bu ülkelere ait 1995-2013 yıllarına ait Enflasyon, İşsizlik, Düzeltilmiş Net Milli Gelir, Mal İhracatı, Mal İhracatı, Mal ve Hizmet İthalatı, Mal ve Hizmet İhracatı, GSYİH, Düzeltilmiş Tasarruflar, Yurt Dışından Net Gelir ve Net Gelir değişkenleri (12 Adet) kullanılmıştır. Ayrıca ekonomiyi doğrudan etkilediği düşünülen Nüfus, Nüfus Artışı ve Net Göç değişkenleri de (3 Adet) analizde kullanılmıştır. Veriler Dünya Veri Bankası'nın web sitesinden alınmıştır (World Data Bank, 2015). Sınıflandırmada bulanık kümeleme analizinde en çok kullanılan Bulanık cOrtalamalar yöntemi ve küme sayılarının belirlenmesinde YSA'na dayalı küme geçerlilik indeksi kullanılmıştır. 1995-2013 yılları arasında yapılan bulanık kümeleme analizi sonucu, bu altı ülkenin 3 kümeye ayrıldığ belirlenmiştir. Her yıl için ayrı ayrı bulanık kümeleme analizi uygulanmış ve analiz sonuçları yıllara göre tabloda verilmiştir.

\begin{tabular}{|c|c|c|c|c|c|c|c|c|}
\hline \multicolumn{3}{|c|}{1995} & \multicolumn{3}{|c|}{1996} & \multicolumn{3}{|c|}{1997} \\
\hline 1.Küme & 2.Küme & 3.Küme & 1.Küme & 2.Küme & 3.Küme & 1.Küme & 2.Küme & 3.Küme \\
\hline Kazakistan & Azerbaycan & Türkmenistan & Kazakistan & Azerbaycan & Tacikistan & Azerbaycan & Kazakistan & Tacikistan \\
\hline \multirow[t]{2}{*}{ Özbekistan } & Kurgizistan & & Özbekistan & Kirgizistan & Türkmenistan & Kırgızistan & Özbekistan & \\
\hline & Tacikistan & & & & & Türkmenistan & & \\
\hline \multicolumn{3}{|c|}{1998} & \multicolumn{3}{|c|}{1999} & \multicolumn{3}{|c|}{2000} \\
\hline 1.Küme & 2.Küme & 3.Küme & 1.Küme & 2.Küme & 3.Küme & 1.Küme & 2.Küme & 3.Küme \\
\hline Azerbaycan & Kazakistan & Kurgizistan & Azerbaycan & Kurgizistan & Türkmenistan & Azerbaycan & Kirg1zistan & Türkmenistan \\
\hline \multirow[t]{2}{*}{ Türkmenistan } & Özbekistan & Tacikistan & Kazakistan & Tacikistan & & Kazakistan & Tacikistan & \\
\hline & & & Özbekistan & & & Özbekistan & & \\
\hline \multicolumn{3}{|c|}{2001} & \multicolumn{3}{|c|}{2002} & \multicolumn{3}{|c|}{2003} \\
\hline 1.Küme & 2.Küme & 3.Küme & 1.Küme & 2.Küme & 3.Küme & 1.Küme & 2.Küime & 3.Küme \\
\hline Azerbaycan & Kazakistan & Türkmenistan & Azerbaycan & Kazakistan & Tacikistan & Azerbaycan & Tacikistan & Kazakistan \\
\hline Kirgizistan & Özbekistan & & Kırgızistan & & Türkmenistan & Kırgızistan & & Türkmenistan \\
\hline Tacikistan & & & Özbekistan & & & Özbekistan & & \\
\hline \multicolumn{3}{|c|}{2004} & \multicolumn{3}{|c|}{2005} & \multicolumn{3}{|c|}{2006} \\
\hline 1.Küme & 2.Küme & 3.Küme & 1.Küme & 2.Küme & 3.Küme & 1.Küme & 2.Küme & 3.Küme \\
\hline Azerbaycan & Tacikistan & Kazakistan & Azerbaycan & Kazakistan & Kırgızistan & Azerbaycan & Kazakistan & Kırgızistan \\
\hline Kırgızistan & & Türkmenistan & Türkmenistan & Özbekistan & Tacikistan & Türkmenistan & & Tacikistan \\
\hline Özbekistan & & & & & & & & Özbekistan \\
\hline
\end{tabular}




\begin{tabular}{|c|c|c|c|c|c|c|c|c|}
\hline \multicolumn{3}{|c|}{2007} & \multicolumn{3}{|c|}{2008} & \multicolumn{3}{|c|}{2009} \\
\hline 1.Küme & 2.Küme & 3.Küme & 1.Küme & 2.Küme & 3.Küme & 1.Küme & 2.Küme & 3.Küme \\
\hline Azerbaycan & Kazakistan & Kurgizistan & Azerbaycan & Kazakistan & Tacikistan & Azerbaycan & Tacikistan & Kurgizistan \\
\hline \multirow[t]{13}{*}{ Türkmenistan } & & Tacikistan & Kırgızistan & & & Kazakistan & Özbekistan & Türkmenistan \\
\hline & & Özbekistan & Türkmenistan & & & & & \\
\hline & & & Özbekistan & & & & & \\
\hline & \multicolumn{3}{|c|}{2010} & \multicolumn{3}{|c|}{2011} & & \\
\hline & 1.Küme & 2.Küme & 3.Küme & 1.Küme & 2.Küme & 3.Küme & & \\
\hline & Azerbaycan & Tacikistan & Kırgizistan & Azerbaycan & Tacikistan & Kırgizistan & & \\
\hline & Kazakistan & Özbekistan & Türkmenistan & Kazakistan & Özbekistan & Türkmenistan & & \\
\hline & \multicolumn{3}{|c|}{2012} & \multicolumn{3}{|c|}{2013} & & \\
\hline & 1.Küme & 2.Küme & 3.Küme & 1.Küme & 2.Küme & 3.Küme & & \\
\hline & Azerbaycan & Tacikistan & Özbekistan & Azerbaycan & Kazakistan & Tacikistan & & \\
\hline & Kazakistan & & & Kurgizistan & & Özbekistan & & \\
\hline & Kirgizistan & & & Türkmenistan & & & & \\
\hline & Türkmenistan & & & & & & & \\
\hline
\end{tabular}

Tablo 1. Bulanık Kümeleme Analizi Sonuçları

Yukarıda verilen 19 yıla ait bulanık kümeleme analizi sonucundan elde edilen küme üyelik matrisi Tablo 2.'de verilmiştir.

\begin{tabular}{|l|c|c|c|c|c|c|}
\cline { 2 - 7 } \multicolumn{1}{c|}{} & Azerbaycan & Kazakistan & Özbekistan & Tacikistan & Türkmenistan & Kırgızistan \\
\hline Azerbaycan & --- & 6 & 6 & 2 & 7 & 10 \\
\hline Kazakistan & 6 & --- & 8 & 0 & 3 & 1 \\
\hline Özbekistan & 6 & 8 & --- & 6 & 1 & 6 \\
\hline Tacikistan & 2 & 0 & 6 & --- & 2 & 8 \\
\hline Türkmenistan & 7 & 3 & 1 & 2 & --- & 7 \\
\hline Kırgızistan & 10 & 1 & 6 & 8 & 7 & --- \\
\hline
\end{tabular}

\section{Tablo 2. Üyelik Matrisi}

Üyelik matrisi tablosuna baktığımızda, 19 yıllık kümeleme sonucunda Azerbaycan ve Kırgızistan'ın 10 defa aynı kümede yer aldıklarını görmekteyiz. Bu iki ülkeyi Kazakistan ve Özbekistan 8 defa aynı kümede yer alarak takip etmektedirler. Buna karşılık Tacikistan ve Kazakistan aynı kümede hiç yer almamışlardır. Türkmenistan; Özbekistan ile 1, Tacikistan ile de 2 defa aynı kümede yer almıştır. Üyelik matrisi yardımıyla hesaplanan korelasyon matrisi Tablo 3.’de verildiği gibidir.

\begin{tabular}{|l|c|c|c|c|c|c|}
\hline & Azerbaycan & Kazakistan & Özbekistan & Tacikistan & Türkmenistan & Kırgızistan \\
\hline Azerbaycan & --- & 0,38 & 0,38 & 0,12 & 0,44 & 0,64 \\
\hline Kazakistan & 0,38 & --- & 0,88 & 0 & 0,33 & 0,11 \\
\hline Özbekistan & 0,38 & 0,88 & --- & 0,5 & 0,09 & 0,5 \\
\hline Tacikistan & 0,12 & 0 & 0,5 & --- & 0,22 & 0,88 \\
\hline Türkmenistan & 0,44 & 0,33 & 0,22 & 0,22 & --- & 0,7 \\
\hline Kırgızistan & 0,64 & 0,11 & 0,88 & 0,88 & 0,7 & -- \\
\hline
\end{tabular}

Tablo 3. Korelasyon Matrisi

Buna göre 19 yıllık veri ve 15 değişken yardımıyla Türk Cumhuriyetleri’nin bulanık kümeleme sonucu şu şekilde oluşmuştur:

\begin{tabular}{|c|c|c|}
\hline 1.Küme & 2.Küme & 3.Küme \\
\hline Azerbaycan & Kazakistan & Tacikistan \\
\hline Kırgızistan & Özbekistan & \\
\hline Türkmenistan & & \\
\hline
\end{tabular}

Tablo 4. Bulanık Kümeleme Sonucu

Tablo 4.'de verilen sonuçlara göre; Azerbaycan, Kırgızistan ve Türkmenistan birinci kümeyi oluştururken; Kazakistan ve Özbekistan ikinci kümeyi ve Tacikistan tek başına üçüncü kümeyi oluşturmaktadır. 


\section{Sonuç}

Üyelik matrisi tablosuna baktığımızda, 19 yıllık kümeleme sonucunda Azerbaycan ve Kırgızistan'ın 10 defa aynı kümede yer aldıklarını görmekteyiz. Bu iki ülkeyi Kazakistan ve Özbekistan 8 defa aynı kümede yer alarak takip etmektedirler. Buna karşılık Tacikistan ve Kazakistan aynı kümede hiç yer almamışlardır. Türkmenistan; Özbekistan ile 1, Tacikistan ile de 2 defa aynı kümede yer almıştır.

Geçiş dönemi içerisinde farklı uyruğa sahip insanları bünyesinde barındıran bu ülkelerin, geçişin ilk yıllarındaki kültürel ve sosyal özelliklerinin artık homojenleştiğini söyleyebiliriz. Bunun sebepleri arasında; ülkelerin göç vermesi, ülke dişına iş gücünün çıkması ve üretimde kullanılan girdilerin içerisinde olan iş yapabilen nüfusun azalmasını gösterebiliriz. Bu sebepler; geçiş sürecinin daha da derinleşmesine ve uzun sürmesine sebep olmuştur. Ekonomik anlamda geçişin başlangıcındaki durumlarına ulaşabilmeleri ise yeni yeni mümkün olabilmektedir.

Merkezi Asya geçiş ekonomileri, hem kültürel anlamda hem de sosyal ve coğrafi anlamda birbirlerine oldukça yakın ve benzer konumdadırlar. Bu ülkelerin birbirlerine benzemeleri, ülkelerin bağımlılık yapılarını arttırdığı gibi birlikte hareket etmelerini de teşvik etmektedir. Çalışmada vurgulandığı gibi birbirine daha çok benzeyen ülkelerin, kendi aralarında gruplanarak işbirliği içinde olmaları, ilgili kurum ve kuruluşlarla daha demokratik ve daha üst düzeyde refah dağılımı yaratacağı düşünülmektedir. Oluşturulan kümeler ile elde edilen bilgiler; Türk cumhuriyetleri ile işbirliği ve ticaret yapmak isteyen ülkeler için de başvuru kaynağı niteliğinde olacaktır.

\section{Kaynakça}

- $\quad$ Atalay A. ve Tortum A., 2010. Türkiye’deki İllerin 1997-2006 Yılları Arası Trafik Kazalarına Göre Kümeleme Analizi. Pamukkale Üniversitesi Mühendislik Bilimleri Dergisi, Cilt 16, Sayı 3, 2010, Sayfa 335 343.

- Bellman R., Kalaba R., Zadeh L. A., 1964. Abstraction and Pattern Classification. The Rand Corporation, Santa Monica, California, ABD.

- Bezdek J.C., 1974. Cluster Validity with Fuzzy Sets. Journal of Cybernetics,3:58-73.

- $\quad$ Emsen S., Çağatay K., 2009. Merkezi Asya Ve Kafkas Ekonomilerinde Entegrasyonun Olabilirliği: AB'deki Kömür-Çelik Topluluğu Benzeri Su ve Enerjide İşbirliği Arayışı, Ç.Ü. Sosyal Bilimler Enstitüsü Dergisi. Cilt 18 sayı.1,s.181-202.

- $\quad$ Erilli N.A., 2014. TR72 Bölgesi İlçelerinin Sosyo-Ekonomik Verilere Göre Bulanık Kümeleme Analizi ile Sınıflandırılması. Ekonomik ve Sosyal Araştırmalar Dergisi, Cilt: 10, Y11:10, Sayı:2, s. 33-45.

- $\quad$ Erilli N.A., Tunç T., Öner Y., Yolcu U, 2009. İllerin Sosyo-Ekonomik Verilere Dayanarak Bulanık Kümeleme Analizi ile Sinıflandırılması. E-Journal of New World Sciences Academy, v.4, n.1.

- $\quad$ Erilli N.A., Yolcu U., Eğrioğlu E., Aladağ Ç.H., Öner Y., 2011. Determining the Most Proper Number of Cluster in Fuzzy Clustering by Artificial Neural Networks. Expert Systems with Applications, 38, 22482252.

- $\quad$ Erilli, N.A., 2009. Kümeleme Analizine Bulanık Yaklaşım Algoritmaları ve Uygulamaları, 19 Mayıs Üniv., Fen Bilimleri Enst., Yayınlanmamış Yüksek Lisans Tezi, Samsun. Bilimleri Enst., Samsun.

- Güler E., 2012. Sosyalizmden Kapitalizme Geçiş Sürecinde Rusya: Nasıl Bir Kapitalizm, Business and Economics Research Journal, Volume 3, pp. 93-120,ISSN: 1309-2448, www.berjoumal.com

- Kalaycı Ş., 2005. SPSS Uygulamalı Çok Değişkenli İstatistik Teknikleri, Asil Yayıncılık, Ankara.

- Kılıç İ., Emir O., Kılıç G., 2011. Bulanık kümeleme analizi ile ülkelerin turizm istatistikleri bakımından sınıflandırılması. Ístatistikçiler Dergisi, sayı:4, sayfa:31-38.

- $\quad$ Naes T., Mevik T.H., 1999. The Flexibility of Fuzzy Clustering Illustred By Examples, Journal Of Chemo Metrics.

- $\quad$ Sintas A.F., Cadenas J.M., Martin F., 1999. Membership functions in the Fuzzy c-Means Algorithm, Fuzzy Sets and Systems, 101.

- Şahinli F., 1999. Kümeleme Analizine Fuzzy Set Teorisi Yaklaşımı, Gazi Üniversitesi, Yayınlanmamış Yüksek Lisans Tezi, Ankara.

- Turan Erol; Geçiş Ekonomilerinde Yerelleşme Reformları: Azerbaycan Örneği (Selçuk Üniversitesi, Türkiye). Journal of Azerbaijani Studies. s.579

- Tatlıdil H., 2002. Uygulamalı Çok Değişkenli İstatistiksel Analiz, Akademi Matbaası, Ankara.

- World Data Bank, 2015. http://databank.worldbank.org

- Yılancı V., 2010. Bulanık kümeleme analizi ile Türkiye'deki illerin sosyoekonomik açıdan sınıflandırılması. Süleyman Demirel Üniversitesi İktisadi ve İdari Bilimler Fakültesi Dergisi, C.15, S.3 s.453-470. 


\title{
Bölgesel Dengesizliklerin Giderilmesinde Yatırım Teşviklerinin Rolü ve Başarı Kriteri Olarak Yakınsama Analizleri: Türkiye Örneği
}

\section{Role of Investment Incentives in Removal of Regional Imbalances and Convergence Analysis as Success Criteria: The Turkish Case}

\author{
Prof. Dr. Cevat Gerni (Doğuş University, Turkey) \\ Prof. Dr. Selahattin Sarı (Beykent University, Turkey) \\ Asst. Prof. Dr. Haktan Sevinç (Ağrı İbrahim Çeçen University, Turkey) \\ Prof. Dr. Ömer Selçuk Emsen (Atatürk University, Turkey)
}

\begin{abstract}
Together with starting to observe the situations like the development differences seen between the countries after industrial revolution between the cities and regions of the countries. This situation leads some of the cities to emigrate and some other cities to become more crowded. The negative externalities emerging in migrationreceiving cities make the life in those cities intolerable, whilst the decreasing population of emigrant cities triggers the decrease in both of demand and supply that is a production factor. The reflection of this situation shows itself as the cycle of "migration-revenue decrease-migration". Through the investment incentives given to underdeveloped regions in order to prevent the migration that is a reflection of regional imbalances, it is aimed to decrease the imbalances by increasing the employment and revenue. The incentives applied in the year after statistical region classification in Turkey consist of incentives in periods of 2004-2008 and 2009-2012. In this study, it has been examined if there is any convergence between the income per capita in city and region axes, and if the incentives have any influence on this convergence. The investment incentives prepared in accordance with the realities of the cities eliminate the development differences by creating more efficient results. As a policy argument, it can be asserted that the incentive implementations considering the comparative superiorities of the cities will play more important roles in both of ensuring the efficient use of the resources and closing the development differences.
\end{abstract}

\section{Giriş}

Ekonomik büyüme ve kalkınma dünyadaki tüm ülkelerin istisnasız bir şekilde arzuladığı ekonomik boyutunun yanı sıra sosyal yönlerinin de olduğu bir olgudur. Bu eksenden hareketle ekonomik büyüme, ülkelerin ellerindeki mevcut kaynaklarla daha fazla çıktı düzeyine ulaşmak ve/veya kaynakları ve yatırım düzeyini arttırarak çıktı düzeyini arttırmaktır. Birinci durumdaki mesele olan mevcut kaynaklarla üretim seviyesinin arttırılması, yani üretimde etkinlik artışı oluşturmak, her ülke için gerçekçi bir hedef olamayabilecekken; ikinci durumdaki kaynakların veya yatırım düzeylerinin arttırılması yoluyla ekonomik büyümenin sağlanması birçok ülke için daha gerçekçi ve daha çok arzulanan bir ekonomik hedeftir. Ayrıca ekonomik büyüme olgusunun en büyük dezavantajı, kaynak yetersizliğine ve konjonktürel ekonomik dalgalanmalara dayalı olarak istikrarsız bir seyir gösteren ekonomik faaliyetlerdir. Bu sebeple ekonomik faaliyetlerin daha istikrarlı bir hal almalarını sağlamak amacıyla yönetimler tarafından yürütülen ekonomi politikalarıyla uyumlu çeşitli müdahale araçları bulunmakta ve kullanılmaktadır. Müdahale araçları içerisinde önemli bir yeri olan teşvik politikalarına gelişmiş, gelişmekte olan ve azgelişmiş birçok ülke tarafından sıklıkla başvurulmaktadır. Teşvik politikalarının ekonomik büyüme ve kalkınma için birçok ülkede yaygın olarak kullanılan bir ekonomi politikası aracı olmasına rağmen, ülkelerin gelişmişlik seviyelerine bağlı olarak farklı amaçlar ve mekanizmalar içerebilmektedir. Dünya ölçeğinde gelişmiş veya gelişmekte olan ülkelerdeki teşvik uygulamalarına benzer biçimde bu kez ulusal ölçekte bölgesel dengesizlikleri telafi etmek amacıyla kullanıldığı gözlenmektedir. Teşviklerin gelişmiş ülkelerde stratejik öneme sahip öncelikleri daha fazla ön plana çıkarmayı hedeflediği, buna karşılık azgelişmiş ülkelerde ise piyasa ekonomisinin yaygınlaşmasına ve özel sektör yatırımlarının cesaretlendirilmesi amacı taşıdıkları dikkat çekmektedir.

Bu çalışmada bölgesel dengesizliklerin farkındalığına paralel olarak 2003 yılında oluşturulan İstatistiki Bölge Birimleri Sınıflandırması bağlamında bölgesel dengesizlikler ele alınırken; bölgesel dengesizliklerin elimine edilmesi amacıyla 2004-2008 ve 2009-2012 arası dönemde uygulanan teşvik politikalarının başarılı olup olmadığı araştırma konusu yapılması hedeflenmiştir. Literatürde ülkeler arasında olduğu gibi bir ülkenin illeri ve/veya bölgeleri arasında "yakınsama"nın zamana bağlı olarak ortaya çıkması, il veya bölge bazında "gelir

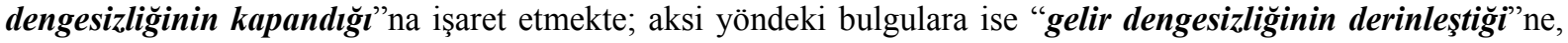
yani "Iraksama"nın varlığına sinyal teşkil etmektedir. Çalışmanın bundan hemen sonraki kısmında bölgesel dengesizlik ve yakınsama teorisinden oluşan teorik yap1 ele alınmış; literatür özetinde de il ve bölge bazlı 
ülkelere özgü uygulamalı literatür özeti verilmiştir. Çalışmanın uygulama kısmında ise Barro ve Sala-i Martin (1992)'nin kullanmış oldukları $\beta$ yakınsaması analizleri Türkiye özelinde il ve bölge bazlı olarak araştırılmıştır.

\section{Bölge Kavramı ve Bölgesel Yatırım Teşvik Türleri}

Temelde büyüklük esasına dayalı olarak tanımlan bölge kavramı, genellikle şehirlerden (kent) daha büyük fakat ülkelerden daha küçük büyüklükleri vurgulamak için kullanılırken, belirli bir bölge tanımlamasında bulunabilmek için de bir takım ölçütlere ihtiyaç duyulmaktadır. Bu ölçütlerin en yaygın olanları; coğrafi, sosyoekonomik, kültürel, fiziki veya kentsel ölçütlerdir (Roy ve Bezbaruah, 2002: 7). Sadece ekonomik eksende bir tanımlama yapıldığında, bölge kavramının analizinde ikili bir ayrıma gidildiği görülmektedir. Birinci ayrım, "bölgelerin ekonomik yapılarına veya durumlarına göre yapılan analize dayanmaktadır. "Ekonomik yapılarına veya durumlarına göre tanımlaması yapılan bölge" tasnifi daha çok Fransız ekolüne ait bir yaklaşımdır. Bu ayırıma göre bölgeler; homojen (türdeş), polarize (kutup-nodal) ve plan bölge şeklinde sinıflandırılmakta olup yapılan ayırım bölgesel planlama literatüründe ve bölgesel tahlillerde çok daha fazla yer almaktadır. İkinci ayrımsa; bölgelerin ekonomik gelişme düzeylerine göre yapılan analize dayanmaktadır. "Bölgelerin yapmış oldukları ekonomik faaliyetlerin derecesine ya da ekonomik gelişme düzeylerine göre bölgeler"se; gelişmiş, gelişmekte olan ve azgelişmiş bölge olarak gruplandırılmaktadır (Ersungur, 2005: 27; Roy ve Bezbaruah, 2002: 7).

Genel anlamıyla bölgeler arasında ekonomik ve sosyal firsat eşitsizliği şeklinde tanımlaması yapılan bölgesel dengesizlik ise gerek bölgelerin sahip olduğu özellikler, gerekse gelişme sürecine yön veren iktisadi ve sosyal faktörlerin ülke içinde dengesiz dağılımı şeklinde meydana gelen bir olgu olarak bölgesel/kentsel kalkınma literatüründe yer almaya başlamıştır. Şöyle ki, zaman içerisinde ülkelerin ve bölgelerin gelişme safhalarında ve hızlarında çeşitli nedenlerden dolayı farklılıklar meydana gelmiş ve bölgesel dengesizlikler ortaya çıkmıştır. Bu farklılıkların en önemli nedenleri arasında; (i) doğal faktörler (çeşitli doğal kaynaklar yönünden yoksunluk veya bolluk), (ii) tarihsel süreç içerisinde uygulanan liberal veya korumacı ekonomik politikalar ve (iii) uygulanmakta olan demokratik ve sosyo-politik nedenler yer almaktadır (Chaudhuri, 2001: 324-325; UN, 2001: 8). Dolayısıyla bölgesel dengesizlikler gelişmiş, gelişmekte olan ya da azgelişmiş her ülkede karşılaşılabilen önemli bir problem konumunda iken, bu olgu azgelişmiş ülkelerde daha belirgin olarak ortaya çıkmaktadır (Chaudhuri, 2001: 324). Çünkü bölgesel dengesizliklerin nedenleri arasında sayılan endüstriyel faaliyetlerden yoksunluk, altyapı yatırımlarının eksikliği ve yüksek işsizlik gibi faktörlerin birçoğu azgelişmiş ülkelerde daha belirgin ve kronik niteliktedir. Gelişmiş ülkelerdeki bölgesel dengesizlikler ise daha çok ülke geneline göre endüstriyel faaliyetlerin henüz başlamadığı veya ilerleyemediği, ekonomisi daha çok tarıma dayalı veya gerileyen sanayileri nedeniyle ekonomik etkinliğini giderek kaybeden bölgelerde rastlanmaktadır (Doğan ve Yıldız, 2007: 151).

Hangi sebepten kaynaklanırsa kaynaklansın, ortaya çıkan bölgesel dengesizlikleri giderecek veya en aza indirecek bazı politika uygulamaları ve araçları mevcuttur. $\mathrm{Bu}$ politika araçları arasında kamu yatırım ve harcamalarının arttırılmasına yönelik çalışmalardan, özel sektör yatırımlarının arttırılmasına dayalı çalışmalara, sanayi faaliyetlerine yönelik organize sanayi bölgelerinin oluşturulmasından, kalkınma ajanslarının oluşturulmasına yönelik olanlara olmak üzere sıklıkla kullanılan ve tercih edilen araçların varlığı dikkat çekmektedir. Bölgesel kalkınmayı sağlamaya yönelik bu araçlardan farklı olarak ve diğer birçok aracı etkilemesi ve birçoğuyla da ilişkili olması açısından bir diğer önemli araç da teşvik uygulamalarıdır.

Ekonomi literatüründe "teşvik" kavramı ise; özendirme, sübvanse etme, destekleme ve devlet yardımı gibi kavramları kapsamakta veya bu kavramlarla eş tutulmaktadır. Dolayısıyla teşvik kavramı; belirli düzeydeki ekonomik faaliyetlerin diğerlerine oranla daha fazla ve hızlı gelişmesini sağlamak amacıyla, kamu tarafindan doğrudan veya dolaylı yöntemlerle sağlanan tüm maddi veya gayri maddi destek, özendirme ve yönlendirmeleri tanımlamak için kullanılmaktadır (Ginevicius, 2011: 437).

Devlet yardımları ile belli bir işletmeyi veya üretimi, üretim yöntemini, üretim ya da faaliyet konusunu etkilemek, üreticileri teşvik veya himaye etmek veya firmaların rekabet gücünün arttırılmasına katkıda bulunmak amacı güdülür. Belirtilen amaçlar doğrultusunda teşvik politikaları; firma veya endüstrilerin kuruluş ve işleyiş yerlerini etkilemek suretiyle belirli bir bölgenin gelişmesini sağlamak, herhangi bir karşılık beklemeden veya bazı yatırımların kârlarını yatırıma çevirme gibi cebri uygulamaları olabilen uygulamaları da kapsarlar. Ayrıca kamu harcamaları politikası içinde teşviklerin payı ve rolü oldukça büyük olduğundan, teşvik politika araçlarının neden ve nasıl kullanıldığı önem taşımaktadır. Bu sebeple teşvikler; (i) ülke içindeki kaynak tahsisi kararlarını, (ii) gelir dağılımını ve (iii) harcamaların verimliliğini etkilemektedir. Teşvik veya sübvansiyonlar ise ister yatırım ve üretim aşamasında, isterse ihracat aşamasında yapılsın, kaynak dağılımını değiştiren, maliyetleri azaltan ve bir ekonomik faaliyeti diğerlerine oranla daha kârlı ya da avantajlı kılan dolaylı veya dolaysız kamu müdahaleleridir (İTO, 1995: 18; OKA, 2011: 11).

Diğer taraftan uluslararası alanda hızlı ve güçlü bir şekilde yaşanan rekabet, teşvik uygulamalarının ülkelere ve hatta ülke içerisinde yer alan bölgelere göre çeşitlenmesine yol açmıştır. Özellikle küreselleşme hareketlerinin ülkeleri adeta tek kutuplu bir dünya haline getirmesinden dolayı ortaya çıkan küresel sermaye hareketleri ve bu hareketlerden pay alma arzu ve isteği de yeni ve değişik teşvik uygulamalarının ortaya çıkmasına neden 
olmuştur. Ayrıca ülkelerin ekonomik ve sosyal yapılarındaki değişiklikler ile bazı teşvik uygulamaları da değişmekte veya yeniden belirlenmekte, daha önce uygulanan indirim veya istisnalar belli bir süre sonra kaldırılmakta, yeni indirim veya istisnalar uygulamaya konulmaktadır. Tarihsel seyri incelendiğinde, "teşvik uygulamalarının bir tür evrim geçirdiği, çağının gereklerine ve değişen düzene adapte edilebilirliği" dikkat çekmektedir.

Bu bağlamda birçok ülke tarafından yürütülen teşvik uygulamaları genel olarak üç kategoride ele alınmaktadır:

(i) Nakdi (Finansal) Teșvikler: Ya direkt olarak ülkeler ya da ülkelerce desteklenen bazı kuruluşlar tarafından firmaların doğrudan parasal (nakit ödemeler, hibeler, krediler, sermaye yatırımları, kredi sigortası ve kredi garantileri) olarak desteklenmesi şeklinde, iktisadi yardım amaçlı olan teşvik tedbirlerini içerir. Nakdi hibeler şeklindeki teşvikler, firmalara esneklik sağlaması ve sermaye harcamalarını azaltarak avantajlar doğurması nedeniyle firmalarca en çok tercih edilen teşvik uygulamalarıdır (Boadway ve Shah, 1992: 6; Poole vd., 1999: 12).

Nakdi teşvikler daha çok gelişmiş ülkeler tarafından başvurulan teşvik tedbiri türlerindendir. Nakit şeklinde yapılan ödeme türü olduklarından ödemenin yapılacağı kaynağın mevcut olması gerekmekte ve bu sebeple özellikle kamu bütçelerine ek bir maliyet getirmektedirler. Ayrıca nakit olarak bazen çok büyük ödemeler veya bazen de anında ödemeler şeklinde olması nedeniyle bazı nakdi teşvik uygulamaları yönetimleri zor durumlara düşürebilmektedir.

(ii) Vergisel (Mali) Teșvikler: Nakdi teşviklerde karşılaşılan çeşitli zorluklardan dolayı nakdi teşvik uygulamalarının özellikle bazı türlerinin ülkeler tarafından daha az tercih edilmesi sonucunu doğurmuştur. Vergisel teşvikler; belirli makroekonomik hedeflere ulaşabilmek için vergi kanunlarında değişiklik yapmak suretiyle çeşitli ekonomik faaliyetlerde vergisel kolaylıklar ve ayrıcalıklar sağlanmasını ifade eder (Benk, 2004; Giray, 2005: 95). Dolayısıyla vergisel teşvikler genel vergi sistemi içerisinde bir istisna durumu oluşturup, yatırımların maliyetini etkileyerek teşvikini amaçlamaktadır. Bu bağlamda vergisel teşvikler; ülkelerdeki genel vergi rejimi içerisinde bir istisna teşkil ederek ülkelerin kasasından doğrudan bir para çıkışı yerine, bir kısım gelirlerin terki gibi görüldüklerinden, birçok ülke için en fazla tercih edilen teşvik türüdür. Ayrıca birçok ülkede çok fazla tercih edilen teşvik türü olmasına ek olarak ekonomideki belli sektör veya alanlardaki vergi yükünü azaltması, ertelemesi veya tamamen bitirmesi nedeniyle de birçok firmayı cezp etmektedir (Küçükoğlu, 2005: 175; Uluatam, 1971: 41).

(iii) Diğer Teşvikler: Bu sınıflandırmalara tabi olan teşvik uygulamaları yukarıda da açıklandığı üzere daha çok nakdi ve vergisel teşvikler adı altında gruplandırılmaktadır. Ancak, gerek bu gruplandırmaların içerisine girmeyen teşvik uygulamalarının varlığı, gerekse değişen koşullara uygun yeni teşvik türlerinin de uygulanması farklı bir gruplandırılmaya gidilmesini gerekli kılmakta ve bu da diğer teşvikler adı altında toplanan teşvikleri oluşturmaktadır. Bu teşviklerse hem nakdi hem de vergisel türde olabilen ve daha çok ayni olarak nitelendirilebilen çeşitli indirim, muafiyet ve düzenlemelere dayalı teşvikleri ve belirli sektör ve bölgelere has bir şekilde uygulanan teşvikleri ifade eder (Barbour, 2005: 2; Poole vd., 1999: 1; UNCTAD, 2004: 6-7).

\section{Bölgesel Teşvikler Üzerine Literatür Özeti}

Ulusal bağlamda uygulanan teşvik politikaları ekonomik büyümeye olumlu katkılar sunan önemli bir politika aracı olarak birçok politikacı ve ekonomist tarafından büyük bir ilgiyle kullanılmakta ve araştırılmaktadır. Diğer taraftan görece daha mikro ölçekte bölgesel veya kent ekonomileri özelinde dengesizliklerin giderilmesi amacını da gütmektedir. Ancak, teşvik uygulamalarının özellikle ekonomiye çok büyük ve kestirilemeyen-net maliyetler yüklememesi nedeniyle politikacılar tarafından sık sık başvurulan bir ekonomi politikası bileşeni veya tamamlayıcısıdır. Ekonomi politikasına yön verenler kadar, akademik çevrelerde de teorik ve ampirik düzeyde birçok araştırmacı konuyu ilgiye değer görmektedir. Literatürdeki çalışmalar genellikle teşviklerin ekonomik büyümeye ve bölgesel kalkınmaya olan etkilerinin araştırıldığı düzeyde olan çalışmalardan oluşmakta ve bireysel ülke veya ülke gruplarını kapsamaktadırlar.

Teşviklerin bölgesel kalkınma üzerindeki etkilerini inceleyen Schalk ve Untiedt (2000), Chalk (2001), Tung ve Cho (2001), Gabe ve Kraybil (2002), Bondonio ve Greenbaum (2006), Porsse vd. (2007), Van Parys ve James (2010) gibi bazı yazarların çalışmaları, teşviklerin bölgesel dengesizliklerin giderilmesi ile bölgesel istihdam artışları ve kalkınmanın sağlanmasında olumlu yönde etkilerde bulunduğunu açık bir şekilde ortaya koymaktadır.

Buna karşılık Devereux (1991) vergisel temelli uygulanan teşviklerin asimetrik ve süreklilik arz etmeyen bir etki oluşturduğu kanaatine dayanarak, vergisel teşviklerin yatırım kararında olumlu yönde etkiler oluşturmadığ 1 bulgusuna ulaşmıştır. Buna benzer şekilde Van Parys ve James (2010) tarafindan yapılan çalışmada yabancı yatırımları teşvik etmede GSYİH ve dış ticaret hadleri üzerinde önemli ve pozitif; buna karşılık ihracata dayalı vergi tatilleri ve enflasyon oranlarının ise pozitif fakat önemsiz düzeyde etkili olduğunu ortaya koymuştur. 


\begin{tabular}{|c|c|c|c|}
\hline $\begin{array}{c}\text { Yazarı ve } \\
\text { Yılı }\end{array}$ & $\begin{array}{l}\text { Ülkesi ve } \\
\text { Dönemi }\end{array}$ & Yöntemi & Elde Edilen Bulgu \\
\hline \multicolumn{4}{|c|}{ Gelişmiş Ülke veya Ülke Grupları Niteliğinde Olanlar } \\
\hline $\begin{array}{l}\text { Devereux } \\
(1991)\end{array}$ & $\begin{array}{c}\text { İngiltere } \\
(1973-1986)\end{array}$ & $\begin{array}{l}\text { Panel Veri } \\
\text { Analizi }\end{array}$ & $\begin{array}{l}\text { Vergisel temelli uygulanan teşviklerin asimetrik ve } \\
\text { süreklilik arz etmeyen bir etki oluşturduğu kanaatine } \\
\text { dayanarak, vergisel teşviklerin yatırım kararında olumlu } \\
\text { yönde etkiler oluşturmadığı bulgusuna ulaşmıştır. }\end{array}$ \\
\hline $\begin{array}{c}\text { Schalk ve } \\
\text { Untiedt }(2000)\end{array}$ & $\begin{array}{c}\text { Almanya } \\
(1978-1989)\end{array}$ & $\begin{array}{l}\text { Panel Veri } \\
\text { Analizi }\end{array}$ & $\begin{array}{l}\text { Teşvik politikalarındaki arz ve talep yönlü unsurların } \\
\text { belirlenmesiyle oluşturulan modele yönelik analiz } \\
\text { sonucunda, hem yatırım hem de istihdam temelli olarak } \\
\text { yürütülen bölgesel teşvik politikalarının başarılı olduğu } \\
\text { yönünde sonuçlara ulaşmışlardır. }\end{array}$ \\
\hline $\begin{array}{c}\text { Gabe ve } \\
\text { Kraybil (2002) }\end{array}$ & $\begin{array}{c}\text { ABD } \\
(1993-1995)\end{array}$ & $\begin{array}{l}\text { Regresyon } \\
\text { Analizi }\end{array}$ & $\begin{array}{l}\text { Teşviklerin firmaların hedeflenen istihdam artışında } \\
\text { pozitif yönde etkiler çıkardığını ortaya koymuş, böylece } \\
\text { artan istihdam ile ekonomik büyümenin olumlu yönde } \\
\text { etkileneceğini belirtmiştir. }\end{array}$ \\
\hline $\begin{array}{l}\text { Bondonio } \\
\text { ve Greenbaum } \\
(2006)\end{array}$ & $\begin{array}{l}\text { Bazı AB } \\
\text { Ülkeleri ve } \\
\text { İtalya } \\
(1995-1998)\end{array}$ & $\begin{array}{l}\text { Farklardaki } \\
\text { Fark Analizi }\end{array}$ & $\begin{array}{l}\text { Çalışma sonucunda gerek AB'de gerekse İtalya'da } \\
\text { teşviklerin bölgesel istihdam oluşturma üzerinde pozitif } \\
\text { ve anlamlı etkiler çıkardığı sonucuna varmışlardır. }\end{array}$ \\
\hline \multicolumn{4}{|c|}{ Azgelişmiş veya Gelişmekte Olan Ülke veya Ülke Grupları Niteliğinde Olanlar } \\
\hline Chalk & $\begin{array}{l}\text { Filipinler ve } \\
\text { Bazı ASEAN } \\
\quad \text { Ülkeleri }\end{array}$ & $\begin{array}{c}\text { Betimleyici } \\
\text { Analiz }\end{array}$ & $\begin{array}{l}\text { Sonuç olarak hukuki altyapısı uygun, daha gerçekçi ve } \\
\text { uygulanabilir teşvik yasalarının yatırım düzeyini } \\
\text { arttırmada Filipinleri diğer ASEAN ülkelerinden çok } \\
\text { daha fazla ön plana çıkardığı kanaatine varmıştır. }\end{array}$ \\
\hline $\begin{array}{c}\text { Tung ve Cho } \\
(2001)\end{array}$ & $\begin{array}{c}\text { Çin } \\
(1988-1994)\end{array}$ & $\begin{array}{c}\text { Regresyon } \\
\text { Analizi }\end{array}$ & $\begin{array}{l}\text { Özellikle düşük vergi oranlarına dayalı vergisel } \\
\text { teşviklerin ve altyapı yatırımlarının yabancı sermayeyi } \\
\text { teşvik etmede ve ülkedeki bölgesel dağılımında çok } \\
\text { önemli değişkenler olduğunu ortaya koymuşlardır. }\end{array}$ \\
\hline $\begin{array}{l}\text { Porsse vd. } \\
\text { (2007) }\end{array}$ & Brezilya & $\begin{array}{c}\text { Genel Denge } \\
\text { Yaklaşımı }\end{array}$ & $\begin{array}{l}\text { Vergisel teşvik uygulamalarının yeni istihdam olanakları } \\
\text { oluşturmada pozitif etkiler oluşturarak, hane halkı } \\
\text { refahında ve ekonomik kalkınma üzerinde olumlu etkiler } \\
\text { oluşturduğunu tespit etmişlerdir. }\end{array}$ \\
\hline $\begin{array}{l}\text { Van Parys ve } \\
\text { James } \\
(2010)\end{array}$ & $\begin{array}{l}\text { Frank Kullanan } \\
12 \text { Merkezi } \\
\text { Afrika Ülkesi } \\
\quad(1994-2006)\end{array}$ & $\begin{array}{l}\text { Panel Veri } \\
\text { Analizi }\end{array}$ & $\begin{array}{l}\text { Frank kullanan } 12 \text { merkezi Afrika ülkesinde yabancı } \\
\text { yatırımları teşvik etmede GSYİH ve dış ticaret hadlerinin } \\
\text { önemli ve pozitif etkili olduğu, ihracata dayalı vergi } \\
\text { tatilleri ve enflasyon oranlarının ise pozitif fakat önemsiz } \\
\text { düzeyde etkili olduğunu ortaya koymuşlardır. }\end{array}$ \\
\hline
\end{tabular}

Tablo 1. Teşviklerin Bölgesel Kalkınmaya Etkisi Üzerine Dayalı Çalışmalar

Literatürde gerek ülkeler, gerekse bölgeler arasında yakınsama ve ıraksama analizlerine dayalı olarak yapılmış çok sayıda çalışma bulunmasına rağmen, analizlere kontrol değişkeni olarak teşvik ve özendirmelere dayalı değişkenlerin direkt olarak katılmasıyla yakınsama analizlerinin yapıldığı sadece bir çalışmaya rastlanılmıştır. Bu çalışma Martin (1998) tarafından bazı AB ülkeleri için 1989 ve 1993 yılları arası verilere dayalı olarak yapılmıştır. AB ülkeleri arasında gelir yakınsamasının araştırılmasıyla başlayan çalışma, ortaya çıkan bulgular sonrası bir gelir yakınsaması varsa, bu yakınsamaya $\mathrm{AB}$ tarafından yürütülen devlet desteklemelerinin herhangi bir etkisinin olup-olmadığının ortaya konulması ekseninde yürütülmüştür. Çalışmadan elde edilen bulgulara göre AB tarafından bölgesel gelişmişlik seviyelerinin azaltılması amacıyla uygulanan politikaların ülkeler arasındaki gelir farklılıklarını gidermede, düşük derecede önemli olmakla birlikte, herhangi bir yakınsamaya yol açmadığı sonucuna ulaşmıştır. Bununla birlikte düşük derecede de olsa ortaya çıkan ülkeler arası gelirlerdeki benzeşmelere $\mathrm{AB}$ tarafından yürütülen destekleme politikalarının olumlu yönde etkilerde bulunduğunu ve ülkelerin birbirlerine yakınlaşmalarını destekleyici nitelikte olduklarını ortaya koymuştur. Diğer taraftan devlet desteklemelerinin olumlu etkilerinin politik sebepler nedeniyle giderek azaldığını da vurgulayan çalışma, bölgesel teşviklerin bölgesel yakınsama üzerindeki önemini net bir şekilde tahmin edememiştir.

\section{Ekonometrik Yöntem ve Değiş̧kenler}

Ekonomik büyümenin kalkınma şeklinde tüm ülkelere veya bölgelere yayılması veya ülkeler veya bölgeleri birbirleriyle aynı seviyelere getirmesi durumu literatürde "yakınsama" olarak adlandırılmaktadır. Daha açık bir ifade ile yakınsama, ekonomik büyümenin bölgeler arası gelir adaletsizliğini ve dengesizliğini mutlak anlamda azaltması şeklinde ortaya çıkan ekonomik bir olgudur. Ayrıca ekonomik büyüme bölgelerde olumlu etkiler 
oluşturarak yakınsama oluşturacağı gibi, tam tersine bölgelerin gelir dengesizliğini daha da bozucu etkiler ortaya koyabilmektedir. Böylece büyümenin bölgeler arası gelir dengesizliklerini azaltıcı veya giderici etkiler ortaya koyması durumu yakınsama (convergence) olarak ifade edilirken, bölgeler arası gelir adaletini ve dengesizliklerini artırıcı yönde olumsuz etkiler koyması durumu ise rraksama (divergence) olarak tanımlanmaktadır.

Yakınsama analizleri, son yirmi yıllık zaman periyodu içerisinde önemli derecede bir atılım gerçekleştirerek birçok büyüme teori ve modelinde büyümenin yayılma etkilerinin araştırılması anlamında yer almaya başlamıştır. Bu süreç içerisinde ilk olarak yakınsama analizlerinin öncüsü Barro ve Sala-i Martin tarafından yapılan "Converenge" (1991) ve "Convergence across States and Regions" (1992) adlı çalışmalar kabul edilmektedir. İlgili çalışmalarda öncelikle bölgeler arasındaki gelir dengesizliklerinin giderilip giderilmediğini test etmek amacıyla kullanılacak yakınsama yöntemi, $\beta$ yakınsama analizine dayalı yöntemdir. $\beta$ yakınsaması Barro ve Sala-i Martin (1992)'in kullanmış olduğu eşitlik yardımıyla tahmin edilmekte ve bu çalışmada da yazarların yöntemi baz alınacaktır. Buna göre eğer göreceli olarak yoksul ülkeler veya bölgeler gelişmiş ülkeler veya bölgelerden daha hızlı büyüyorlarsa, bu süreç "Mutlak $\beta$ Yakınsaması” olarak adlandırılmaktadır.

Aşağıdaki (1) nolu eşitlik "Mutlak-Koşulsuz Yakınsama" olarak adlandırılan ve sadece gelire bağlı değişimlerin denkleme katılmasıyla oluşturulmuş modeli ifade etmektedir. $\mathrm{Bu}$ denklemde cari gelir üzerine başlangıçtaki gelir düzeyinin etkili olup olmadığ ölçülmekte; başlangıç gelirinin cari gelir üzerindeki etkilerinin sıfırdan küçük parametre değerini alması halinde yakınsamanın varlığından bahsedilmektedir.

$$
\left(\frac{1}{T}\right) \log \left(\frac{y_{i, t_{0}+T}}{y_{i, t_{0}}}\right)=B-\log \left(\frac{1-e^{-\beta T}}{T}\right) \log \left(y_{i, t_{0}}\right)+\varepsilon_{i}
$$

Modelde $\mathrm{T}$ zaman aralığını gösterir. $y_{i, t_{0}+T} \mathrm{i}$ ülkesinde $\mathrm{t}$ yılındaki kişi başına geliri, $y_{i, t_{0}} \mathrm{i}$ ülkesindeki başlangıç yılındaki kişi başına geliri, ve $\varepsilon_{i}$ hata terimini gösterir. $\beta$ ise koşulsuz yakınsama katsayısı olup istatistiki olarak anlamlı olmak şartıyla, $\beta<0$ olduğu durumlarda, mutlak yakınsamanın varlığını gösterir. Aksine $\beta>0$ veya $\beta=0$ olduğu hallerde, mutlak yakınsamanın gerçekleşmediği sonucuna varılır.

(2) nolu denklem ise mutlak yakınsamadan farklı olarak, yakınsama analizine potansiyel olarak etki edebilecek spesifik değişkenlerin eklenmesiyle oluşturulan "Şartl-Koşullu Yakınsama" denklemini ifade etmektedir.

$$
\left(\frac{1}{T}\right) \log \left(\frac{y_{i, t_{0}+T}}{y_{i, t_{0}}}\right)=\beta_{0}-\left[\log \left(y_{i, t_{0}-T}\right)\right]\left(\frac{1-e^{-\beta T}}{T}\right)+\beta_{1} X_{i}+\varepsilon_{i}
$$

İkinci denklemdeki $\beta_{l}$ koşullu yakınsama katsayısı iken, $X_{i}$ ise kontrol değişkenleri ifade etmektedir. Koşullu analizin verildiği ikinci denklemde, koşullu yakınsama katsayısı pozitif değer alan değişkenler yakınsamayı hızlandırmaktayken, ortaya çıkan negatif değerler ise yakınsamayı azaltarak ülkeleri veya bölgeleri birbirinden uzaklaştırmaktadır.

Çalışmanın değişkenleri mutlak yakınsamayı ortaya koymaya yönelik olarak bölgesel gelir değişkeni ile koşullu yakınsama sonuçlarını ortaya koymaya yönelik olarak yatırım teşvik tutarları değişkeninden oluşmaktadır. Bölgesel kişi başı gelir ülkelerin ekonomik büyüme ve gelişme seviyesinin açık bir göstergesi olduğu gibi, bölgelerin de ekonomik büyüme ve gelişme seviyesinin en önemli göstergesidir.

Türkiye'de bölgesel kişi başı gelir 2001 yılına kadar bölgesel GSYİH olarak hesaplanmaktayken, 2001 yılından sonra ise bölgesel GSYH hesaplamaları yapılmamaktadır. Bu sebeple bölgesel GSYİH değişkenini temsilen bölgesel toplam vergi gelirleri (illere göre tahakkuk eden gelir ve kurumlar vergisi toplamı) kullanılmaktadır. Literatürde gelir değişkeni olarak bölgesel GSYİH verilerinin olmaması ya da mevcut verilerin zaman açısından yeterli uzunluğa sahip olmaması gibi sebeplerden dolayı bir takım tartışmalar olsa bile, GSYİH değerini temsilen vergi gelirlerine başvuran çalışmaların varlığı da dikkat çekmektedir (bkz. Ottaviano ve Pinelli: 2006; Karahasan: 2010; Ekinci: 2013). Ayrıca Cornia ve Nelson (2010) tarafından yapılan çalışmada da vergi gelirlerindeki artışın ekonomik büyümeyi temsil edebileceği yönünde bulgulara rastlanılmıştır. Dolayısıyla çalışmada geliri temsilen vergi gelirlerinin alınması yoluna gidilmiş ve fert başına geliri temsil için vergi gelirleri nüfusa bölünerek temsili fert başına gelir rakamlarına ulaşılmıştır. Çalışmanın zaman boyutu 2004-2012 yılları arasını kapsamaktayken, mekan boyutu ise bölgeler arası farklılığı yansıtmak amacıyla Türkiye'nin 2003 yılında uygulamaya geçtiği 26 alt bölgesi, yani Düzey-2 alt bölge sınıflandırması ile 81 ili kapsayan sinıflandırma oluşturmaktadır.

Bölgesel teşvik uygulamalarında görece daha derli-toplu bir düzenlemeler bütünlüğünü içermesi nedeniyle 2004 ve 2009 teşvik uygulamalarının yansımaları inceleme konusu yapılmıştır. 2009'daki teşvik uygulamaları da 2012 yılında revize edildiğinden, çalışmanın uygulama dönemi 2004-2012 yılları aralığını kapsamıştır. 2012'deki düzenleme de 2015 'de revize edilmiştir. 


\begin{tabular}{|c|c|c|}
\hline & & \\
\hline 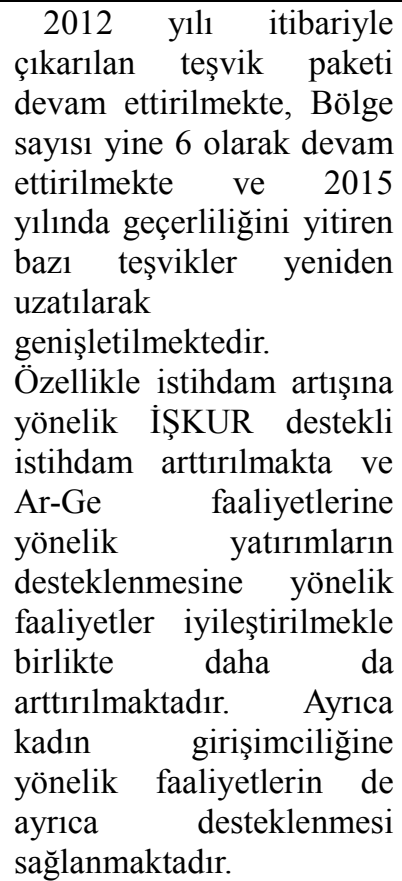 & 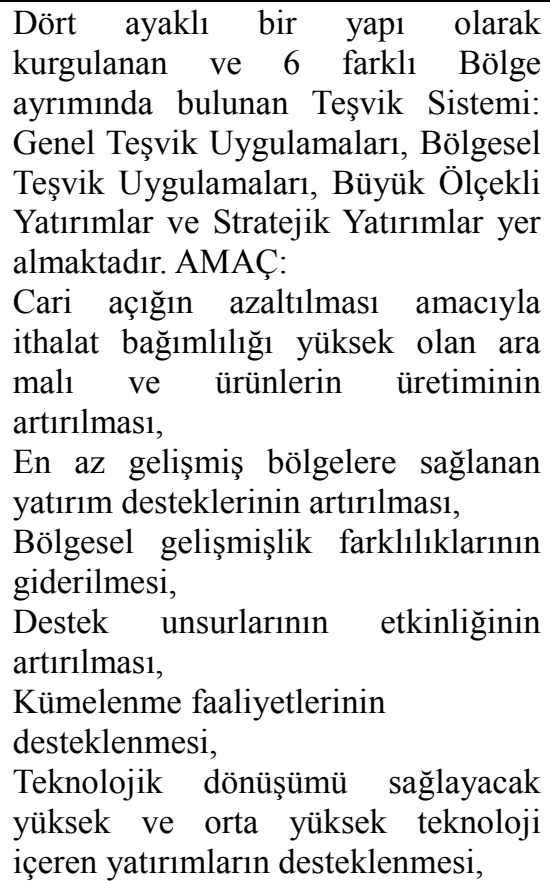 & $\begin{array}{l}\text { 1- Bölgesel gelişmişlik farklılıklarını } \\
\text { gidermek, } \\
\text { 2- Desteklenecek sektörleri, } \\
\text { bölgelerin koşullarına ve rekabet } \\
\text { avantajlarına uygun biçimde } \\
\text { belirleyerek kümelenme yaklaşımının } \\
\text { gelişmesine katkı sağlamak, } \\
\text { 3- Uluslararası rekabet gücünü } \\
\text { artıracak ve teknoloji ile araştırma- } \\
\text { geliştirme içeriği yüksek büyük ölçekli }\end{array}$ \\
\hline
\end{tabular}

Tablo 2. Türkiye'de Bölgesel Teşvik Uygulamaları

\section{Uygulama ve Bulgular}

Çalışmanın uygulaması olarak yakınsama analizinin yapılmasındaki temel faktör bölgesel dengesizlikleri gidermek amacıyla kullanılan teşvik politikalarının dengesizlikleri giderme amacına ulaşmadaki rolünü ve etkinliğini ortaya koymaktır. Bu bağlamda yakınsama analizi öncelikle bölgeler ve iller arasında bir gelir yakınsamasının olup-olmadığını ortaya koymaya yönelik olarak (1) nolu eşitlik yardımıyla ve en küçük kareler tahmin yöntemiyle bulunan mutlak $\beta$ yakınsaması olarak ifade edilmektedir. Daha sonra ise bölgeler veya iller arasında gelire dayalı bir yakınsamanın bulunmasıyla analiz bir adım daha öteye götürülmekte ve (2) nolu eşitlikteki koşullu yakınsama denkleminden yararlanılarak bölgeler veya iller arasında mutlak yakınsamaya yol açan değişkenlerin kontrol değişken olarak analize dâhil edilmesi ile koşullu yakınsama aşamasına geçilmektedir. Tablo 3 bölgeler ve illere yönelik Mutlak $\beta$ yakınsamasına ait analiz sonuçlarını göstermektedir.

\begin{tabular}{|c|c|c|c|c|}
\hline \multicolumn{5}{|c|}{ Bölgelere Dayalı Mutlak $\boldsymbol{\beta}$ Yakınsaması } \\
\hline Değişken & Katsayısı & Standart Hata & t-İstatistiki & p-Değeri \\
\hline $\mathrm{X}$ & $-0.023955^{(*)}$ & 0.004948 & -4.841722 & 0.0001 \\
$\mathrm{C}$ & $0.213918^{(*)}$ & 0.020474 & 10.44812 & 0.0000 \\
\hline $\mathbf{R}^{\mathbf{2}} 0.49$ & Düzeltilmiş $\mathbf{R}^{\mathbf{2}} 0.47$ & F-değeri: $23.44^{(* *)}$ & Prob (F):0.000062 & DW: 1.53 \\
\hline \multicolumn{5}{|c|}{ İllere Dayalı Mutlak $\boldsymbol{\beta}$ Yakınsaması } \\
\hline Değişken & Katsayısı & Standart Hata & t-İstatistiki & p-Değeri \\
\hline $\mathrm{X}$ & -0.000168 & 0.003187 & -0.052794 & 0.9580 \\
$\mathrm{C}$ & $0.125360^{(*)}$ & 0.053628 & 2.337571 & 0.0219 \\
\hline $\mathbf{R}^{2:} 0.04$ & Düzeltilmiş $\mathbf{R}^{\mathbf{2}:} 0.01$ & F-değeri: 0.01 & Prob (F):0.9580 & DW: 2.14 \\
\hline
\end{tabular}

Not: Tablodaki (*) ve (**) işaretleri değişkenlerin \%1 ve \%5 önem düzeylerinde anlamll olduğunu göstermektedir.

\section{Tablo 3. Bölgelere ve İllere Dayalı Mutlak $\beta$ Yakınsaması Tahmini Sonuçları}

Tablo 3'den görüleceği üzere mutlak yakınsamayı ifade eden $\beta$ katsayısı bölgesel düzeyli olarak -0.023955 olarak gözlemlenmiştir. $\beta$ katsayısı $(-0.023955<0)$ sıfirdan küçük ve olasılık değeri anlamlı olduğu için mutlak anlamda yakınsamanın varlığından söz edilebilir. Diğer taraftan illere dayalı mutlak yakınsamayı ifade eden $\beta$ katsayısı da -0.000168 olarak bulunmuş, fakat olasılık değeri anlamsız çıkmıştır. Böylece analizde ifade edilen Türkiye'deki 26 alt bölgenin bölgesel gelirlerinde bir yakınsamanın ortaya çıktığı, bölgesel gelirin giderek birbirine yaklaştığı (yakınsadığı) ve bölgesel dengesizliklerin giderek azaldığı sonucuna ulaşılabilmektedir. Ortaya çıkan bu sonuçlar daha önceden Türkiye ekonomisi için uygulanmış Sağbaş (2002), Ersungur ve Polat (2006) ile Zeren ve Yılancı (2011) gibi yazarlar tarafından yapılan çalışmaların sonuçlarıyla örtüşmekteyken, Borluk (2014) tarafından yapılan çalışma sonuçlarıyla ters düşmektedir. Bölgesel düzeyde yakınsama 
yakalanmasına karşılık, analizlerde iller bazında ortaya çıkan sonuçlar ise Türkiye'deki 81 ilin gelirlerinde mutlak anlamda yakınsamanın ortaya çıkmadığını göstermektedir.

Ayrıca bölgesel gelir anlamında mutlak yakınsamanın ortaya çıkmış olması, yakınsamaya etki eden faktörler arasında uygulanan teşvik politikalarının olup-olmadığının araştırılmasına yönelik koşullu yakınsama analizinin yapılmasını da gerekli kılmaktadır.

Koşullu beta yakınsama hipotezi ise ekonomilerdeki hükümet politikası, beşeri sermaye, yatırım düzeyi gibi bazı yapısal karakteristiklerin benzer olması ile negatif ilişkinin gerçekleşeceğini varsaymaktadır. Ayrıca koşullu yakınsama analizinde ekonomilerdeki teknoloji, tasarruf eğilimi, üretim biçimleri ve tercihi gibi yapısal faktörler arasında bazı farklılıklar olduğunu varsayarken, mutlak yakınsamada ise bu faktörlerin aynı-sabit olduğu kabul edilmektedir. Bu nedenle koşullu beta yakınsamasını sınamak için beta yakınsamasında kullanılan modele ilave kontrol değişkenleri eklenmektedir (Zeren ve Yılanc1, 2011: 145). Tablo 4 bölgeler ve illere yönelik koşullu yakınsama analizine ilişkin analiz sonuçlarını ortaya koymaktadır.

Koşullu yakınsama analizine ilişkin bulguların verildiği Tablo 4'den görüleceği üzere mutlak yakınsamaya etki edebilecek faktörlerden biri olarak varsayılan teşvik uygulamalarında çalışmanın dönemi olan 2004-2012 yılları arasında bazı yeni düzenlemelere gidilmiştir. Bu sebeple yeni düzenlemelerin ortaya çıkardığı değişimlerin izlenebilmesi için yatırım teşvik tutarları 2004-2008 ve 2009-2012 yıllarına göre gruplandırılmış ve analiz bu gruplandırmaya göre yapılmıştır.

Tablo 4'deki analiz sonuçlarına göre yatırım teşviklerinin 2004-2008 yılları arasında bölgesel düzeyde koşullu yakınsama şartını sağladığını, 2009-2012 yılları arasında ise il düzeyinde koşullu yakınsama şartını sağladığını göstermektedir. Böylece ilk dönem olan 2004-2008 yılları arasında bölgeler düzeyinde hem mutlak hem de koşullu yakınsamanın gerçekleşmiş olduğu sonucuna ulaşılmaktadır. Çünkü her iki durumda da yakınsama katsayısının anlamlı olduğu görülmektedir. Fakat koşullu yakınsamadaki kontrol değişken olan yatırım teşvik tutarlarının katsayısı negatif çıkmıştır. Bu bağlamda Türkiye'deki 26 alt bölge arasında yakınsamanın ortaya çıkmış olması, teoride beklendiği üzere yatırım teşvik uygulamalarının kişi başı milli gelirde ortaya çıkan büyümeyi pozitif yönde etkileyeceği yönündeki sonuca kontrol değişkenin negatif katsayısı dolayısıyla ulaşılamamaktadır. Bu durum 2004-2008 dönemi arasındaki yatırım teşviklerinin, bölgeler arasında meydana gelen gelir yakınsamasında pozitif yönlü bir etki oluşturmadığını göstermektedir. Ayrıca ikinci dönem olan 20092012 yılları arasındaki olasılık değerlerinden koşullu yakınsamanın gerçekleşmediği, fakat yatırım teşvik tutarlarının katsayısının pozitif olduğu anlaşılmaktadır.

\begin{tabular}{|c|c|c|c|c|}
\hline \multicolumn{5}{|c|}{ Bölgelere Dayalı Koşullu $\beta$ Yakınsaması } \\
\hline Değişken & Katsayısı & Standart Hata & t-İstatistiki & p-Değeri \\
\hline X2004-2008 & -0.000108 & 7.171700 & -1.522919 & 0.1442 \\
\hline YATTES2004-2008 & $-0.034057^{(*)}$ & 0.009983 & -3.414170 & 0.0024 \\
\hline $\mathrm{C}$ & $0.275791^{(*)}$ & 0.035129 & 7.850755 & 0.0000 \\
\hline $\mathbf{R}^{2:} 0.56$ & Düzeltilmiş $\mathbf{R}^{2:} 0.52$ & F-değeri: $14.8735^{\left({ }^{*}\right)}$ & \multicolumn{2}{|c|}{ Prob (F):0.00071 DW: 2.04} \\
\hline X2009-2012 & -0.011636 & 0.009782 & -1.189494 & 0.2464 \\
\hline YATTES2009-2012 & 1.828205 & 2.797905 & 0.652458 & 0.5206 \\
\hline $\mathrm{C}$ & $0.143342^{(*)}$ & 0.045370 & 3.159374 & 0.0044 \\
\hline $\mathbf{R}^{2: 0.06}$ & Düzeltilmiş $\mathbf{R}^{2:} 0.02$ & F-değeri: 0.7855 & \multicolumn{2}{|c|}{ Prob (F):0.4677 DW: 1.60} \\
\hline \multicolumn{5}{|c|}{ İllere Dayalı Koşullu $\beta$ Yakınsaması } \\
\hline Değişken & Katsayısı & Standart Hata & t-İstatistiki & p-Değeri \\
\hline X2004-2008 & -0.008273 & 0.008017 & -1.031913 & 0.3053 \\
\hline YATTES2004-2008 & -0.005060 & 0.006793 & -0.744920 & 0.4586 \\
\hline $\mathrm{C}$ & $0.281965^{(* *)}$ & 0.116175 & 2.427070 & 0.0175 \\
\hline $\mathbf{R}^{2: 0.09}$ & Düzeltilmiş $\mathbf{R}^{2:} 0.06$ & F-değeri: $3.6846^{(* *}$ & \multicolumn{2}{|c|}{ Prob (F):0.0295 $\quad$ DW: 2.21} \\
\hline X2009-2012 & $\begin{array}{c}- \\
0.012204^{(* * *)}\end{array}$ & \begin{tabular}{l|l}
0.006449 \\
\end{tabular} & -1.892417 & 0.0621 \\
\hline YATTES2009-2012 & $0.013866^{(* *)}$ & 0.006266 & 2.213046 & 0.0298 \\
\hline $\mathrm{C}$ & $0.246618^{(*)}$ & 0.092308 & 2.671673 & 0.0092 \\
\hline $\mathbf{R}^{2: 0.06}$ & Düzeltilmiş $\mathbf{R}^{2:} 0.04$ & F-değeri: $2.4910^{(* * *}$ & \multicolumn{2}{|c|}{ Prob (F):0.0893 DW: 2.17} \\
\hline
\end{tabular}

Not: Tablodaki (*), (**) ve (***) işaretleri değişkenlerin \%1, \%5 ve \%10 önem düzeyinde anlamll olduğunu göstermektedir.

Tablo 4. Bölgelere ve İllere Dayalı Koşullu Yakınsama Tahmini Sonuçları

Genel olarak hem mutlak hem de koşullu yakınsama analizlerinden elde edilen sonuçlarda Türkiye'de gelir ayrışmasının belirginleştiği yönünde sinyaller tespit edilmiştir. Özellikle yatırım teşviklerinin yakınsamada anlamsız sinyaller vermesi uygulanan teşvik politikalarının esastan eleştirilmesi gerekliliğini ortaya çıkarmaktadır. Özellikle Türkiye'nin uyguladığı teşvik sistemini inceleme konusu yapan Koreli uzmanların yönelttiği temel eleştiri, “teşvik sisteminin oldukça 'eşitlikçi' olarak nitelendirmeleri”’ olmuştur (Berkan, 2015). Dolayısıyla bölge, il ve hatta daha mikro bazda rekabet gücü belirlemesi yapılmadan, genel olarak uygulanan 
teşvik sisteminin avantajlar yaratmadığı, yani ayırımcılık doğurmadığı gibi bir durumun varlı̆̆ından söz edilebilir.

Diğer taraftan 2009-2012 yılları arasında il bazlı olarak mutlak anlamda yakınsamanın ortaya çıkmamasına rağmen, koşullu yakınsama şartının gerçekleştiği ve kontrol değişken olan yatırım teşvik tutarlarının katsayısının pozitif olduğu gözlemlenmiştir. Böylece Türkiye'deki 81 il arasında koşullu yakınsamanın ortaya çıkması teoride beklendiği üzere yatırım teşvik uygulamalarının kişi başı milli gelirde ortaya çıkan büyümeyi pozitif yönde etkileyeceği yönündeki önsel hipotezle paralellik göstermektedir. Ayrıca ilk dönem olan 2004-2008 yılları arasındaki il bazlı koşullu yakınsama sonuçlarının hem olasılık değerinin anlamsız hem de yatırım teşvik tutarlarının katsayısının negatif olmasından dolayı koşullu yakınsama şartının sağlanmadığı söylenebilir.

Elde edilen sonuçlar 2004-2008 ile 2009-2012 yılları arasında yürütülen, 2004 ve 2009 yıllarındaki teşvik uygulamalarından 2004 yılı teşvik uygulamasının bölgesel bazda, 2009 yılı teşvik uygulamasının ise iller bazında etkin ve nispeten daha başarılı olduğunu ortaya koymaktadır. Böyle bir sonucun ortaya çıkmış olmasında 2009 yılına kadar uzunca bir dönem devam eden bölgelere dayalı teşvik uygulamalarından vazgeçilerek kısmen de olsa illere dayalı bir teşvik uygulamasına gidilmek istenmesinin büyük bir rol oynadığı söylenebilir. Ayrıca bu dönem öncesinde Türkiye'de meydana gelen büyük ekonomik krizlerden dolayı önemli bir daralma yaşayan ülke ekonomisinin, uygulamaya konan ekonomi politikalarına hızlı bir şekilde yanıt vermesinin ve krizlerden çıkış yıllarının bu yıllara denk gelmesinin bir sonucu olarak da görülebilir. Aynı şekilde 2000 yılından sonra daha çok sektörel teşvikler bölge temelli olarak uygulanmaktayken, 2009 yılı yatırım teşvik uygulamasıyla bölgelerle birlikte illere has teşvik uygulamalarına daha fazla ağırlık verilmiştir. Son olarak bu dönemde yürütülen teşvik uygulamalarının 2009 yılındaki yeni teşvik düzenlemesine kadar özel sektörden gelen çeşitli talepler doğrultusunda sürekli olarak bazı revizyonlara tabi tutulmasının da, bu dönemdeki teşvik uygulamalarının işlerliğini ve etkinliğini arttırarak daha iyi sonuçlar vermesinde etkili olduğu sonucunu çıkarabilmektedir.

Diğer taraftan 2009 yılı uygulamasıyla ilk kez İBBS Düzey-2 kapsamındaki bölgelere yönelik teşvik uygulamalarına gidilmesi, 2009 teşvik uygulamasının bölgesel bazdaki önemini ortaya koymaktadır. Fakat bu dönemin hemen öncesindeki 2008 yılı küresel çaptaki büyük resesyon ve dolayısıyla Türkiye'de özellikle yabancı yatırımlara dayalı yatırım düzeyenin düşmesi yönünden önemli derecede etkilenmiştir. Bu bağlamda yurtiçi yatırım düzeyinin azalması nedeniyle yatırım teşvikleri de düşüş eğilimine girmiş ve 2009 yılı düzenlemesinden arzu edilen sonuçlar alınamamıştır.

Ayrıca 2009 yılı teşvik uygulamasının illere yönelik olarak bazı uygulamalar da içermesi ve 2009-2012 yılları arasındaki il bazlı koşullu yakınsama analiz sonuçlarının olumlu çıkması, Türkiye'de bölgesel ölçeğe dayalı teşviklerden ziyade illere dayalı teşvik uygulamalarının gerekliliğini ispatlar niteliktedir. Çünkü illerin kendi güçlü yönlerine ve rekabetçi yapıdaki üstünlüklerine göre sunulacak teşvik politikalarının illerin, dolayısıyla bağlı bulundukları bölgelerin kalkınmasına olumlu yönde katkılar ve dışsallıklar sunacağı aşikârdır. Nitekim 2012 yılında çıkarılan yeni teşvik düzenlemesinin tam bir şekilde olmasa da illere dayalı teşvik politikalarını da uygulamaya koyması bu sorunu bertaraf etmeye yönelik bir çabanın yansıması konumundadır.

\section{Sonuc}

Bu çalışmada Türkiye'de uzun yıllardır yürütülen yatırım teşvik politikalarının daha çok son dönemlerde amaç edindiği bölgesel kalkınma temelli hedeflerine ulaşılıp ulaşılmadığı Yakınsama Analizi doğrultusunda araştırılmıştır. Bu amaçla çalışma İBBS'ye göre ayrımı yapılan ve Düzey-2 kapsamında olan 26 alt bölgeyi ve 81 ili ve zaman boyutu da İBBS'nin başlangıç yılı olan 2003 yılındaki bazı verilerin eksikliği ve bulunamamasından dolayı 2004-2012 yılları arasını kapsamıştır. Çalışmada ilk olarak söz konusu dönemde bölgelerin gelirleri arasında bir yakınsamanın olup-olmadığını ortaya koymak amacıyla mutlak $\beta$ yakınsaması analizi yapılmıştır. Yakınsama analizini müteakip bölgelere verilen yatırım teşviklerinin bölgesel kalkınmaya olan muhtemel etkileri, yine yakınsama analizi ekseninde, koşullu yakınsama analiziyle değerlendirilmiştir.

Çalışmaya ait analiz bulguları çalışma dönemi içerisinde ortaya çıkan kişi başı gelir artışlarının bölgeler arasında mutlak anlamda bir yakınsamaya neden olduğunu göstermiştir. Böylece analizde ifade edilen Türkiye'deki 26 alt bölgenin bölgesel gelirlerinde bir yakınsamanın ortaya çıktığı, bölgesel gelirlerin giderek birbirine yaklaştığı (yakınsadığı) ve bölgesel dengesizliklerin giderek azaldığı sonucuna ulaşılmıştır. Diğer taraftan yatırım teşviklerinin kontrol değişken olarak yakınsama analizine katılmasıyla oluşturulan koşullu yakınsama analizinde ise yatırım teşviklerinin, bölgeler arasında meydana gelen gelir yakınsamasında pozitif yönlü bir etki oluşturmadığını ortaya koymuştur. Koşulsuz yakınsamanın gerçekleşmesinde de az gelişmiş il ve bölgelerde yaşanan göç ve buna dayalı olarak kişi başı gelir artışlarının ortaya çıkması ihtimal dahilindedir. Dolayısıyla yakınsamanın göç ve suni gelir artışı bağlamında ortaya çıkma olasılığı vardır ki, net göç hızlarının yakınsamada modellenmesi ile bu durum da test edilebilir. Şayet göçe dayalı bir yakınsamanın varlığı tespit edilmişse, dengesizliğin daha da derinleştiği gibi bir sonuçtan bahsedilebilir.

Sonuç olarak 2004-2012 yılları arasında bölgeler arasında ortaya çıkan mutlak anlamdaki gelir yakınsamasına koşullu yakınsama sonuçlarının da ilave edilmesiyle, bölgesel ölçekte yürütülen yatırım teşvik uygulamalarının bölgesel ölçekteki gelir yakınsamasındaki rolünün pozitif yönde olmadığı ortaya çıkmıştır. Bu durum, bölge 
kapsamındaki illerde homojenitenin sağlanamaması sonucunu ortaya koymaktadır. İl bazında yapılan analizlerde ise 2004-2008 teşvik düzenlemelerinden ziyade 2009-2012 düzenlemelerinin daha etkin sonuçlar sunduğu gözlenmiştir. Böylece son teşvik uygulamasının görece illerin rekabet gücünü dikkate almasının, iller arasında bir yakınsama oluşturduğu ve dolayısıyla iller arasındaki gelişmişlik farkını elimine edici sonuçlar doğurduğunu ortaya koymuştur. Bu yönüyle genel teşvik uygulamalarından ziyade daha özle, yani mikro ölçekli ve yöreye özgü teşvik uygulamalarının daha etkin sonuçlar doğuracağı ileri sürülebilir. Ayrıca yöreye özgü rekabetçi yapıya ve yenilikçi uygulamalara has teşvik ve özendirme uygulamalarıyla da teşvik politikaları yerel ölçeğe indirgenerek uygulama sonuçları daha başarılı seviyelere çıkartılabileceği gibi teşviklerin daha ayırımcı ve şeffaf olmasının önem arz edeceği söylenebilir.

\section{Kaynakça}

- Barbour, P. (2005). “An Assessment of South Africa's Investment Incentive Regime with a Focus on the Manufacturing Sector”. ESAU Working Paper 14, London: Overseas Development Institute.

- Barro, R. J. and Sala-i-Martin, X. (1991). "Convergence across States and Regions". Brookings Papers on Economic Activity, 1.

- Barro, R. J. and Sala-i-Martin, X. (1992). “Convergence”. Journal of Political Economy, 100(2), $223-251$.

- Benk, S. (2004). “Doğrudan Yabancı Sermaye Yatırımları ve Vergisel Teşvikler”. İş-Güç, Endüstri İlişkileri ve Insan Kaynaklart Dergisi, 6(1). http://www.isguc.org/?p=article\&id=195\&cilt=6\&sayi=1\&yil=2004.

- Berkan, İ (2015). “Orta Teknoloji ve Orta Gelir Tuzağı”, Hürriyet Gazetesi, 9 Mayıs 2015.

- Boadway, R. and Shah, A. (1992). "How Tax Incentives Affect Decisions to Invest in Development Countries". Country Economics Department The World Bank, November 1992, WPS 1011.

- Bondonio, D. and Greenbaum, R.T. (2006). "Do Business Investment Incentives Promote Employment in Declining Areas? Evidence from EU Objective 2 Regions”. European Urban and Regional Studies, 13(3), 225-244.

- Borluk, S. (2014). “Türkiye’de Bölgesel Gelir Dağılımı Iraksaması, Verimlilik ve Diğer Dinamiklerle İlişkisi”. Verimlilik Dergisi, T.C. Bilim, Sanayi ve Teknoloji Bakanlığı Verimlilik Genel Müdürlüğü, Sayı: 2014/4, 19-44.

- Chalk, N. A. (2001). "Tax Incentives in The Philippines: A Regional Perspective". IMF Working Paper, No:01/181, http://www.imf.org/external/pubs/ft/wp/2001/wp01181.pdf.

- Chaudhuri, R. H. (2001). An Introduction to Development and Regional Planning. India: Orient Longman Limited, Hyderabad.

- Cornia, G. C. and Nelson, R. D. (2010). "State Tax Revenue Growth and Volatility". Federal Reserve Bank of St. Louls Regional Economic Development, 6(1).

- Devereux, M. (1991). "Corporation Tax Asymmetries and Investment: Evidence from UK Panel Data". Queen's Economics Department Working Paper No. 820.

- Doğan, S. ve Yıldız, Z. (2007). "Bölgesel Kalkınma, Turizmin İlişkisi ve Göller Bölgesi Kalkınmasında Alternatif Turizm Potansiyelinin Kullanılabilirliğine Yönelik Bir Araştırma”. Journal of Suleyman Demirel University Institue of Social Sciences, Year: 2007/2, Number: 6.

- Ekinci, D. (2013). Yığılma Ekonomilerinin Nedenleri ve Etkileri: Türkiye Alt Bölgeler Bazında Bir Uygulama (1990-2009). (Yayımlanmamış Doktora Tezi), Erzurum: Atatürk Üniversitesi, Sosyal Bilimler Enstitüsü.

- $\quad$ Ersungur, Ş. M. (2005). Bölgesel İktisat. Erzurum: Atatürk Üniversitesi İktisadi ve İdari Bilimler Fakültesi Z. F. Fındıkoğlu Araştırma Merkezi Yayın No: 219.

- Ersungur, Ş. M. ve Polat, Ö. (2006). “Türkiye'de Bölgeler Arasında Yakınsama Analizi”. Atatürk Üniversitesi Sosyal Bilimler Enstitüsü Dergisi, 8(2), 335-343.

- Gabe, T. M. and Kraybill, D. S. (2002). "The Effect of State Economic Development Incentives on Employment Growth of Establishments”. Journal of Regional Science, 42(4), 703-730.

- Ginevicius, R. and Simelyte, A. (2011). "Government Incentives Directed Towards Foreign Direct Investment: A Case of Central and Eastern Europe”. Journal of Business Economics and Management, ISSN 1611-1699, 12(3), 435-450.

- Giray, F. (2005). "Küreselleşme Sürecinde Vergi Rekabeti ve Boyutları”. Akdeniz İ.̇.B.F. Dergisi, Say1 9, 2005.

- İ́stanbul Ticaret Odası (İTO) (1995). Türkiye'de Teşvik Sistemi, Genel Değerlendirme. Yayın No: 1995-10.

- Karahasan, B. C. (2010). Dynamics and Variation of Regional Firm Formation: Case of Turkey. (Yayınlanmamış Doktora Tezi). İstanbul: Marmara Üniversitesi, Sosyal Bilimler Enstitüsü. 
- Küçükoğlu, M. (2005). Vergisel Teşviklerin Bölgesel Kalkınmadaki Rolü: Güneydoğu Anadolu Bölgesi Üzerine Bir Uygulama. (Yayımlanmamış Doktora Tezi). Bursa: Uludağ Üniversitesi Sosyal Bilimler Enstitüsü.

- Martin, R. (1998). "Regional Incentive Spending for European Regions”. Regional Studies, 32(6), 527-536.

- Orta Karadeniz Kalkınma Ajansı (OKA) (2011). “Türkiye'de Sağlanan Teşvik ve Destekler”. http://www.oka.org.tr/Documents/okatesvikvedesteklerekitap180820111.pdf.

- Ottaviano, G. I. P. and Pinelli, D. (2006). "Market Potential and Productivity: Evidence from Finnish Regions". Regional Science and Urban Economics, 36, 636-657.

- Poole K. E., Erickcek, G. G., Iannone, D.T., Mccrea, N. and Salem P. (1999). "Evaluating Business Development Incentives". National Association of State Development Agencies, ACCRA, Washington, D.C., http://www.eda.gov/PDF/1g3_ebdi_report.pdf.

- $\quad$ Porsse, A., Haddad, E. and Ribeiro, E. P. (2007). "Economic Effects of Regional Tax Incentives: A General Equilibrium Approach". Latin American Business Review, 7(3-4), 195-216.

- $\quad$ Roy, N. and Bezbaruah, M. P. (2002). Agricultural Growth and Regional Economic Development. New Delhi: India.

- Sağbaş, İ. (2002). “Türkiye'de Kamu Harcamalarının Yakınsama Üzerindeki Etkisi”. Afyon Kocatepe Üniversitesi, ïBBF Dergisi, IV(2).

- Schalk, H. J. and Untiedt, G. (2000). "Regional Investment Incentives in Germany: Impact on Factor Demand and Growth". Annals of Regional Science, 34, 173-195.

- Tung, S. and Cho, S. (2001). "Determinants of Regional Investment Decisions in China: An Econometric Model of Tax Incentive Policy". Review of Quantitative Finance and Accounting, 17, 167-185.

- Uluatam, Ö. (1971). Yatırımları Teşvik Edici Vergi Politikası. Ankara Üniversitesi Siyasal Bilgiler Fakültesi Yayınlar1, No: 311.

- United Nation (2001). Reducing Disparities: Balanced Development of Urban and Rural Areas and Regions within the Countries of Asia and the Pacific. Economic and Social Commission for Asia and the Pacific, ISBN: 92-1-120037-7.

- United Nations Conference on Trade and Development (UNCTAD) (2004). Incentıves. United Nations New York and Geneva.

- Van Parys, S. and James, S. (2010). “The Effectiveness of Tax İncentives in Attracting İnvestment: Panel Data Evidence from the CFA Franc Zone”. International Tax Public Finance, 17, 400-429.

- Zeren, F. ve Yılancı, V. (2011). “Türkiye'de Bölgeler Arası Gelir Yakınsaması: Rassal Katsayılı Panel Veri Analizi Uygulaması”. Business and Economics Research Journal, 2(1), 143-151.

- $\quad$ http://www.tuik.gov.tr

- http://www.ekonomi.gov.tr

- http://www.gib.gov.tr. 


\title{
Orta Asya Türk Cumhuriyetlerinin Ekonomik Performanslarının TOPSIS Metodu ile Karşılaștırılması
}

\section{Comparison of the Economic Performance of Turkish Republics in Central Asia with TOPSIS Method}

\author{
Prof. Dr. Ziya Gökalp Göktolga (Cumhuriyet University, Turkey) \\ $\mathrm{Ph}$. D. Candidate Engin Karakış (Cumhuriyet University, Turkey) \\ Asst. Prof. Dr. Hakan Türkay (Cumhuriyet University, Turkey)
}

\begin{abstract}
The aim of this study is to compare the economic performance of Turkish Republics in Central Asia with Multi Criteria Decision Making (MCDM) methods. Turkish Republics have been experiencing a transition from a centrally planned economy towards a market economy since their independence. In this study important macroeconomic indicators are used to determine economic performance. Economic performance evaluation of the country is an important issue for economic management, investors, creditors and stock investors. Technique for Order Preference by Similarity to Ideal Solution (TOPSIS) method outranks the countries according to the proximity of the positive ideal solution and distance of the negative ideal solution. Economic Performance of Turkish Republics in Central Asia (Azerbaijan, Turkmenistan, Kazakhstan, Kyrgyzstan, and Uzbekistan) are compared with TOPSIS method. Investigated with TOPSIS method countries best and worst economic performance years are detected during mentioned period and results are analyzed.
\end{abstract}

\section{Giris}

Uzun yıllar merkezi planlama anlayışına sahip bir ekonomi içinde yer alan Orta Asya Türk Cumhuriyetleri 1990’lı yılların başında bağımsızlıklarını kazanarak ekonomilerini piyasa ekonomisi kuralları içinde yönetmeye başlamışlardır. Planlamacı Sovyet ekonomisi içinde genellikle tedarikçi ya da hammadde üreticisi olarak, bir iş bölümü içerisinde kendilerine verilen görevleri yerine getiren Türk Cumhuriyetleri, bağımsızlıklarını kazandıktan sonra ekonomilerini kendileri yönetme imkanına kavuşmuşlardır. Bağımsızlıklarını kazandıktan sonra serbest piyasa ekonomisine uyum sağlayarak başarı göstermek için çaba harcamışlardır. Bağımsızlığını kazanan Orta Asya Türk Cumhuriyetleri için piyasa ekonomisinin kurum ve kurallarını yerleştirerek, işlerliğini sağlamak önemli bir değişim süreci olmuştur. Sovyetler Birliği üyesi olan ülkelerin yürüttükleri ekonomik faaliyetler, o dönemde birlik ekonomisi için bir uyum ve iş bölümünün gereği iken bu işlevsel görev dağılımı Türk Cumhuriyetlerinin bağımsızlıklarını kazanmalarından sonra kendileri için dezavantaja dönüşmüştür. Örneğin, enerji bakımından oldukça zengin kaynaklara sahip olan Orta Asya Türk Cumhuriyetleri ham maddde üreticisi veya bir tedarikçi gibi Sovyetler Birliği içinde yer alırken bağımsızlıklarını kazandıktan sonra üretim tesisilerinden ve teknolojik araç ve gereçten mahrum kalmıştır (Erol ve Şahin, 2013). Bu şartlar altındaki Türk Cumhuriyetleri sanayileşme ve dünya ekonomisi ile bütünleşme çabası içerisine girmişlerdir. Dünya ekonomisi ile piyasa ekonomisi kuralları içerisinde entegresyon sağlayarak bağımsız ekonomiler kurma yolundaki Türk Cumhuriyetlerinin, sahip oldukları kaynaklarını sanayileşmek ve kendi sanayi üretimleri için kullanma zorunluluğu ortaya çıkmıştır. Sovyetler Birliğinin dağılması ile birlikte, sayılan yapısal nedenlerle bağımsız Türk Cumhuriyetlerinin ekonomileri 2000'li yılların başlarına kadar üretememiş hatta gerileme göstermiştir. 2000'li yılların başlarından itibaren serbest piyasa ekonomisine geçiş ve dünya ekonomisi ile bütünleşmenin sağlanmasına yönelik olarak yapılan yapısal dönüşümlerin sağlanması ile ekonomik iyileşmeler görülmeye başlanmıştır. Türk Cumhuriyetleri bağımsızlık öncesi etkin ve verimli kullanamadığı ham madde zenginliğini, bağımsızlık sonrası ülkenin sanayileşmesine katkı yapacak şekilde kullanmaya başlamaları ile ekonomik iyileşmeler göstermeye başlamışlardır (Alagöz vd.,2011).

Çalışmanın amacı Orta Asya Türk Cumhuriyetlerinin bağımsızlıklarını kazanmalarından sonra dünya ekonomisi ile bütünleşmelerindeki gelişimi ve geldikleri ekonomik gelişim seviyelerini temel ekonomik göstergelerden faydalanarak ortaya koymaktır. Günümüzde ülkeler ekonomik ve sosyal göstergelere göre çeşitli yöntemler ile karşılaştırılır ve elde edilen sonuçlar ülkelerin belirli dönemleri kapsayan performansları olarak kabul edilebilir. Ülkelerin ekonomik performansları, sahip oldukları kaynaklarını amaçlarına ulaşmak için ne derece etkin kullandıklarını ifade eder. Çok Kriterli Karar Verme (ÇKKV) yöntemleri ülkelerin, kurum ve kuruluşların karşılaştırılmasında kullanılan ve elde edilen sonuçlar ile alternatifleri sıralama, seçme ve sınıflandırma yapabilen yöntemler olarak araştırmalarda kullanılmaktadır (Urfalıoğlu ve Genç, 2013; Ishizaka ve Nemery, 2013).

Gerek ülkeler ve işletmeler arasında ekonomik karşılaştırmalar yapmak gerekse birden çok alternatif ve birden çok kriterin değerlendirildiği karar problemlerinde ÇKKV verme yöntemleri uygun yöntemler olarak görülmektedir. Ekonomik karşılaştırmalar yapabilmek için birbiri ile çelişebilen birden çok ölçütü birlikte 
değerlendirmek gerektiğinden ÇKKV yöntemleri kullanılmaktadır. Ekonomik performanslarına göre ülkelerin sıralanması ve kıyaslanması çok sayıda kriteri birlikte değerlendiren matematiksel yöntemler ile yapılabilir. Çok kriterli karar verme yöntemleri alternatifler arasında seçim, sıralama, sınıflandırma ve değerlendirme yapmak amacıyla çeşitli yöntemler kullanılmaktadır. Analitik Hiyerarşi Prosesi (AHP), Analitik Network Prosesi(ANP), Multiple Attribute Utility Theory(MAUT), The Preference Ranking Organization Methods for Enrichment Evaluation(PROMETHEE), Technique for Order Preference by Similarity to İdeal Solution(TOPSIS), Data Envolepment Analysis (DEA), Elimanation and Choice Translating Reality (ELECTRE), kullanılan karar yöntemlerinden bazılarıdır. Bu çalışmada Orta Asya Türk Cumhuriyetlerinin Ekonomik Performanslarının çok kriterli karar verme tekniklerinden TOPSIS Metodu ile karşılaştırılması amaçlanmıştır. Bu yöntem ile ülkelerin ekonomik verileri tek bir puanla matematiksel olarak ifade edilebilmekte ve ülkeler kendi aralarında ekonomik performanslarına gore sıralanabilmektedir (Yurdakul ve İç, 2003).

Çalışmada öncelikle TOPSIS yöntemi açıklanmış, daha sonra ekonomik performans karşılaştırmasında kullanılan kriterlerle ilgili bilgi verilerek ülkelerin 2003 ve 2013 yılları arasındaki ekonomik performans analizi yapılmıştır.

\section{TOPSIS yöntemi}

TOPSIS (Technique for Order Preference by Similarity to İdeal Solution) yöntemi Hwang ve Yoon (1981) tarafından ortaya atılmıştır. TOPSIS yöntemi ELECTRE yöntemine alternatif olarak geliştirilmiş ve en çok kullanılan çok kriterli karar verme yöntemlerinden olmuştur. Çok kriterli karar verme tekniklerinden olan TOPSIS yöntemi karar alternatiflerinin İdeal pozitif çözüme ve negatif ideal çözüme olan uzaklıklarına göre karar verilmesini sağlamaktadır(Tzeng ve Huang, 2011) Pozitif ideal çözüm noktası faydanın en yüksek, maliyetin en düşük olduğu çözümü verirken negatif ideal çözüm faydanın en düşük, maliyetin en yüksek olduğu çözümü verir. TOPSIS yaklaşımının temelinde pozitif ideal çözüme en yakın mesafedeki çözüm noktasının bulunması yanında negatif ideal çözüme en uzak mesafede olan çözüm noktasının bulunması vardır (Ergül, 2010).

\section{Kriter 2}

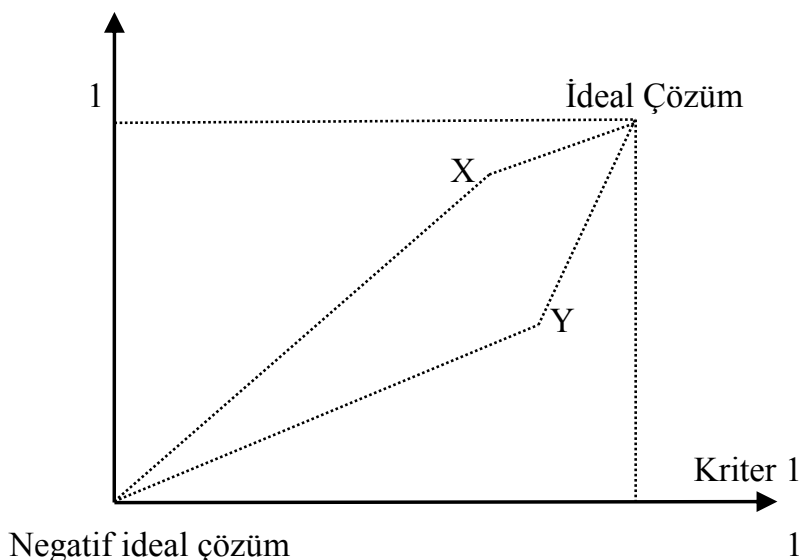

Şekil 1. TOPSIS Yönteminin Geometrik Gösterimi. Kaynak: Alessio Ishizaka and Philippe Nemery, 2013. MultiCriteria Decision Analysis: Methods and Software, First Edition. John Wiley \& Sons, Ltd.

Şekilde X ve Y noktaları alternatifleri göstermek üzere X noktası ideal çözüme en yakın olması ve negatif ideal çözüme uzak olması nedeniyle $Y$ 'ye göre $X$ tercih edilir. Y alternatifi ise $X$ 'e göre ideal çözüm noktasından uzak ve negatif ideal çözüm noktasına yakınlığ nedeniyle tercih edilmemiştir.

ÇKKV yöntemlerinden olan TOPSIS çok kullanılan bir karar verme yöntemidir. TOPSIS basit ve kolay anlaşılabilir olması nedeniyle sıkça uygulanan bir ÇKKV yöntemidir. Alternatiflerin nicel veriler olması durumunda TOPSIS yönteminde kriter ağırlıklarının belirlenmesi yöntemin sübjektif yönünü oluşturmaktadır (Ishizaka ve Nemery, 2013; Dumanoğlu, Ergül 2010). Yöntemde kriter ağırlıklarının belirlenmesi için AHP gibi çeşitli karar verme yöntemlerinin TOPSIS yöntemine entegre edilerek uygulanabildiği görülmektedir. Kriter ağırlıklarının belirlenmesi sırasında seçim ve değerlendirilmesi yapılan konudaki uzmanların değerlendirme ve düşüncelerine başvurmak yöntemin başarısını artırmaktadır.

TOPSIS yöntemi ile alternatiflerin seçimi, sıralanması ve değerlendirilmesi yapılmaktadır. Yöntemin ilk aşaması karar matrisinin oluşturulmasıdır. Karar matrisinin elde edilmesinden sonra normalize edilmiş karar matrisi elde edilerek elde edilen bu matriste kriterler ağırlıklandırılır. Ağırlıklar ile normalize edilmiş karar matrisinden hareketle ağırlıklandırılmış karar matrisi elde edilir. Daha sonra pozitif ve negatif çözüm noktaları tespit edilerek alternatif noktalarının pozitif ideal çözüme ve negatif ideal çözüme olan uzaklıkları hesaplanır. 
TOPSIS yönteminde alternatiflerin pozitif ve negative ideal çözümden uzaklıkları Euclid uzaklığı ile hesaplanır. Yöntem pozitif ideal çözüme en yakın olan alternatifi en iyi alternatif olarak Kabul ettiği için Euclid yardımı ile bulunan uzaklıkların ikili karşılaştırması yapılarak alternatifler sıralanmaktadır (Chen vd, 2002). Yöntemin çözüm aşamaları sırası ile aşağıdaki şekilde gösterilebilir;

1. Adım: Karar matrisinin (A) oluşturulması.

Yöntemin uygulanması sırasında öncelikle karar matrisi (A) oluşturulur. Karar matrisinin satırları alternatifleri, sütunları ise sıralamaya esas oluşturan kriterleri göstermektedir. Karar matrisi karar verici tarafindan oluşturulan başlangıç matrisi olup aşağıdaki şekilde gösterilebilir:

$$
A_{i j}=\left[\begin{array}{cccc}
a_{11} & a_{12} & \cdot & a_{1 n} \\
a_{21} & a_{22} & \cdot & a_{2 n} \\
\cdot & \cdot & \cdot & \cdot \\
\cdot & \cdot & \cdot & \cdot \\
a_{m 1} & a_{m 2} & \cdot & a_{m n}
\end{array}\right]
$$

$A_{i j}$ matrisinde n kriter, m alternatiflerin sayısını göstermektedir.

2. Adım: Normalize karar matrisinin oluşturulması.

Karar matrisinin normalleştirilmesi için farklı yöntemler kullanılabilmektedir. Burada vektör normalizasyonu yöntemi kullanılmıştır. Bu yöntemde normalize karar matrisi karar matrisindeki her bir değer bulunduğu sütunun değerlerinin kareleri toplamının kareköküne bölünerek oluşturulur.

Fayda kriteri aşağıdaki formül yardımı ile normalize edilmektedir:

$$
r_{i j}=\frac{a_{i j}}{\sqrt{\sum_{i=1}^{m} a_{i j}^{2}}} \quad \mathrm{i}=1,2, \ldots \ldots \mathrm{m} \quad \mathrm{j}=1,2, \ldots . \mathrm{n}
$$

Normalize karar matrisinin oluşturulması için yapılan hesaplamalar sonucunda R matrisi aşağıda görüldüğü gibi ifade edilir:

$$
R_{i j}=\left[\begin{array}{cccc}
r_{11} & r_{12} & \cdot & r_{1 n} \\
r_{21} & r_{22} & \cdot & r_{2 n} \\
\cdot & \cdot & \cdot & \cdot \\
\cdot & \cdot & \cdot & \cdot \\
r_{m 1} & r_{m 2} & \cdot & r_{m n}
\end{array}\right]
$$

3. Adım: Ağırlıklı normalize edilmiş karar matrisinin (v) oluşturulması.

Normalize edilmiş ağırlıklı karar matrisinin elde edilmesi için öncelikle kriterlerin ağırlıklarının $\left(w_{j}\right)$ karar verici tarafından belirlenmesi gereklidir. Daha sonra normalize edilmiş karar matrisi kriter ağırlıklarıyla çarpılarak ağırlıklandırılmış normalize matris $\left(V_{i j}\right)$ elde edilmektedir.

$$
\sum_{i=1}^{n} W_{j}=1 \quad V_{i j}=W_{j} \cdot X_{i j}, \quad \mathrm{i}=1,2, \ldots \ldots \mathrm{m} \quad \mathrm{J}=1,2, \ldots \ldots . \mathrm{n}
$$

Burada $W_{j}$, j’inci kriterin ağırlığıdır

$\mathrm{V}$ matrisi aşağıdaki gibi gösterilebilir:

$$
V_{i j}=\left[\begin{array}{cccc}
w_{1} x_{11} & w_{2} x_{12} & \cdot & w_{n} x_{1 n} \\
w_{1} x_{21} & w_{2} x_{22} & \cdot & w_{n} x_{2 n} \\
\cdot & \cdot & \cdot & \cdot \\
\cdot & \cdot & \cdot & \cdot \\
w_{1} x_{m 1} & w_{2} x_{m 2} & \cdot & w_{n} x_{m n}
\end{array}\right]=\left[\begin{array}{cccc}
v_{11} & v_{12} & \cdot & v_{1 n} \\
v_{21} & v_{22} & \cdot & v_{2 n} \\
\cdot & \cdot & \cdot & \cdot \\
\cdot & \cdot & \cdot & \cdot \\
v_{m 1} & v_{m 2} & \cdot & v_{m n}
\end{array}\right]
$$

4. Adım: İdeal ve negatif ideal çözüm değerlerinin elde edilmesi.

Ağırlıklandırılmış normalize matris (V) elde edildikten sonra problemin yapısına bağlı olarak amacımız maksimizasyon ise her bir sütuna ait maksimum değerler belirlenir. Bu değerler ideal çözüm ya da pozitif ideal çözüm değerleridir. Daha sonra her bir sütuna ait minimum değerler tespit edilir. Bu değerler ise negatif ideal çözüm değerleridir (Yıldırım, Önder, 2014).

İdeal çözüm ve negatif ideal çözüm değerlerinin elde edilmesi aşağıdaki formül ile gösterilebilir;

Pozitif ideal çözüm değerleri:

$$
\begin{aligned}
& A^{+}=\left\{\max v_{i j} \mid j=1,2, \ldots \ldots, p ; i=1,2, \ldots \ldots . m\right\} \\
& A^{+}=\left\{v_{1}^{+}, v_{2}^{+}, \ldots \ldots . v_{n}^{+}\right\}, \text {her bir sütuna ait maksimum değerler, }
\end{aligned}
$$


Negatif ideal çözüm değerleri:

$$
\begin{aligned}
& A^{-}=\left\{\min v_{i j} \text { olmak üzere }\right\} \\
& A^{-}=\left\{v_{1}^{-}, v_{2}^{-}, \ldots \ldots . v_{n}^{-}\right\}, \text {her bir sütuna ait minimum değerlerdir. }
\end{aligned}
$$

5. Adım: İdeal ve negatif ideal çözüm noktalara olan uzaklık değerlerinin elde edilmesi.

İdeal ve negatif ideal çözüm noktalarının uzaklık değerleri hesaplanırken öklidyen uzaklık kullanılmaktadır. Koordinat düzleminde $\mathrm{x}$ ve y gibi koordinatları bilinen iki noktanın birbirine olan uzaklığı aşağıdaki formül ile hesaplanir:

$$
\begin{aligned}
& d_{i j}=\sqrt{\sum_{k=1}^{p}\left(x_{i k}-y_{j k}\right)^{2}} \\
& x_{i k}: \text { Gözlemin k. Değişken değeri } \\
& y_{j k}=\text { Gözlemin k. Değişken değeri } \\
& \text { P: Değişken sayısını göstermektedir. }
\end{aligned}
$$

İdeal çözüme olan uzaklıkların negatif ve ideal çözüm noktalarının uzaklıklarının bulunması için formül aşağıdaki gibi olacaktır:

$$
\begin{aligned}
& \text { İdeal uzaklık: } S_{i}^{+}=\sqrt{\sum_{j=1}^{n}\left(v_{i j}-v_{j}^{+}\right)^{2}} \\
& \text { Negatif İdeal uzaklık: } S_{i}^{-}=\sqrt{\sum_{j=1}^{n}\left(v_{i j}-v_{j}^{-}\right)^{2}} \\
& \text { Burada kriter sayısı kadar } S_{i}^{+} \text {ve } S_{i}^{-} \text {bulunacaktır. }
\end{aligned}
$$

6. Adım: İdeal çözüme göreli yakınlığın hesaplanması.

Her bir alternatifin ideal çözüme göreli yakınlığının hesaplanması için ideal ve ideal olmayan noktalara uzaklıklardan faydalanılır. İdeal çözüme göreli yakınlık $C_{i}^{*}$ ile sembolize edilmektedir. $C_{i}^{*}$ değeri $0<C_{i}^{*}<1$ aralığında değer almaktadır. $C_{i}^{*}=1$ karar noktasının ideal çözüme mutlak yakınlığını ifade ederken $C_{i}^{*}=0$ olması karar noktasının negatif ideal çözüme eşit olduğunu ifade etmektedir (Yıldırım, Önder, 2014).

$$
C_{i}^{*}=\frac{s_{i}}{s_{i}^{-}+s_{i}^{+}}
$$

7. Adım: Her bir alternatifin göreli sıralamasının bulunması.

TOPSIS yönteminde çözüm için yukarıdaki adımlar sırayla gerçekleştirildikten sonra alternatifler altıncı adımda bulunan göreli yakınlıklar büyükten küçüğe doğru sıralama yapılarak değerlendirilir.

\section{Orta Asya Türk Cumhuriyetlerinin Ekonomik Performanslarının Karşılaştırılması}

Çalışmada Orta Asya Türk Cumhuriyetlerinden Azerbaycan, Kazakistan, Kırgızistan, Türkmenistan ve Özbekistan'ın 2003-2013 yılları arasındaki ekonomik performansları ÇKKV yöntemlerinden TOPSIS yöntemi ile incelenerek sıralanmıştır. Ülkelerin ekonomik performansları 2003 ve 2013 yılları arasında her yıl için ayrı ayrı derecelendirilerek yapılmıştır. Çalışmada ekonomik performansların belirlenmesinde kriter olarak Büyüme Hızı, Kişi Başına Gayri Safi Yurtiçi Hasılaları, İşsizlik Oranları, İhracat, İthalat ve Enflasyon Oranı kullanılmıştır. Çalışmada ekonomik başarıda en çok üzerinde durulan kriterler kullanılmıştır. Kullanılan kriterler iktisadi başarı kriteri olarak algılanan kriterler arasında da yer almaktadır (Eleren ve Karagül, 2008). Çalışmada kullanılan kriterlere ilişkin veriler Dünya Bankası, Özbekistan Devlet İstatistik Kurumu, Türkmenistan Devlet İstatistik Kurumu ve IMF 'nin web sitesinden temin edilmiştir. Belirlenen kriterler ve bu kriterlerin ekonomik performansa olan etkileri Tablo 1.'de gösterilmiştir.

\begin{tabular}{ll}
\hline Kriterler & Performansa Olan Etki \\
\hline Büyüme Hızı & Pozitif Etki \\
Kişi Başına Gayri Safi Yurt İçi Hasıla & Pozitif Etki \\
Enflasyon & Negatif Etki \\
İhracat & Pozitif Etki \\
İthalat & Negatif Etki \\
İşsizlik Oranı & Negatif Etki \\
\hline
\end{tabular}




\section{Tablo 1.Kriter Olarak Kullanılan Ekonomik Göstergeler}

Çalışmada performansa negatif etkisi olan kriterlere ilişkin veriler dönüştürülmüş ve pozitif etki eden kriterler gibi değerlendirilmiştir. Dönüştürme işlemi iki yaklaşım ile yapılmaktadır. Birincisi j. kriterin yüksek olması negatif etki veya olumsuzluğu ifade ediyor ise bu kriterin değerinin yükselmesi durumunda olumsuzluk artacaktır. Dolayısıyla bu kriterin küçük olması istenecektir. Kriterin küçük bir değer alması durumunda pozitif

etki eden kriter gibi değerlendirilecektir. Bu kritere ilişkin dönüştürülmüş değer $x_{i j=1}^{i} x_{i j}$ olarak elde edilir. İkinci yaklaşım ise; j. kriterin alternatiflere ilişkin maksimum değerinden diğer değerler çıkarılarak dönüştürme

sağlanır. Dönüştürme işlemi $x_{i j=\text { maks }}^{i} x_{i j-} x_{i j}$ formula ile yapılarak $x_{i j}^{i}$ değeri analizde pozitif etkiye sahip bir kriter gibi değerlendirilir (Özden,2011). Bu çalışmada Tablo 1 'de gösterilen negatif etkiye sahip kriterlerin dönüştürülmesinde ikinci yaklaşım kullanılmıştır.

Çalışmada ülkelerin ekonomik performanslarını incelemede kullanılan temel ekonomik göstergelerin kriter ağırlıkları eşit olarak ağırlıklandırılmıştır. Ağırlık toplam puanı olan 1 değeri kriter sayısına bölünerek her bir kriter için ağırlık puanları elde edilmiştir. Buna göre her bir kriterin ağırlık değeri 0,1667 olarak hesaplanmıştır. Çalışmanın geliştirilerek yapılabilmesi amacıyla Thomas L. Saaty tarafından geliştirilen ANP, AHP gibi ikili karşılaştırmalara dayalı yöntemler kullanılarak da ağırlıklandırma yapılabilir.

\subsection{Bulgular}

Çalışmada belirlenen kriterlere göre ülkelerin ekonomik performanslarının incelenerek sıralanmasında MS Excel eklentisi olarak çalışan SANNA programı kullanılmıştır. Yöntemin uygulanmasında, yapılan işlemlere çalışmanın uzun yılları kapsaması ve çok yer tutması nedeniyle yer verilmeyerek sadece 2013 yılı verilerine ve bütün yıllara ait sonuçlara yer verilmiştir.

\begin{tabular}{|l|r|r|r|r|r|r|}
\hline & \multicolumn{1}{|c|}{$\begin{array}{c}\text { Büyüme } \\
\text { Hizı (\%) }\end{array}$} & $\begin{array}{c}\text { KBGSYİH } \\
\text { (US\$) }\end{array}$ & İthalat (US\$) & İhracat (US\$) & $\begin{array}{c}\text { Enflasyon } \\
(\%)\end{array}$ & $\begin{array}{c}\text { İsizlik } \\
(\%)\end{array}$ \\
\hline Azerbaycan & 5,79 & 7.811 & 19.765 .583 .174 & 35.841 .555 .131 & 2,42 & 5,5 \\
\hline Kazakistan & 6 & 13.611 & 61.901 .643 .471 & 88.691 .662 .087 & 5,83 & 5,19 \\
\hline Kirgızistan & 10,53 & 1.263 & 6.931 .291 .690 & 3.408 .490 .424 & 6,60 & 8 \\
\hline Türkmenistan & 10,19 & 7.986 & 16.090 .000 .000 & 18.854 .200 .000 & 4,02 & 10,60 \\
\hline Özbekistan & 7,99 & 1.877 & 17.954 .600 .000 & 15.710 .800 .000 & 6,80 & 10,69 \\
\hline
\end{tabular}

Tablo 2.Ülkelerin 2013 Yll Verileri

Ülkelerin seçilen kriterlere göre yapılan ekonomik performans sıralamasında bazı yıllardaki değişiklikler hariç genellikle aynı sıralamanın olduğu görülmektedir. Tablo 2.'de ülkelerin yıllar itibariyle belirlenen kriterlere göre ekonomik performansları görülmektedir. Analizin 2013 yılı değerlendirildiğinde Büyüme Hızı kriterine göre en yüksek olan ülke Kırgızistan $(0,09404)$ ve bu ülkenin ardından Türkmenistan $(0,09104)$ gelirken bu kritere göre en düşük performansı Azerbaycan $(0,05175)$ göstermiştir. Kişi başına Gayri Safi Yurt İçi Hasıla kriterine göre en yüksek performansa Kazakistan, Türkmenistan ve onun ardından Azerbaycan'ın sahip olduğu görülmektedir. Bu kritere göre 2013 yılında sırasıyla Özbekistan ve Kırgızistan sonda yer alarak daha düşük performans sergilemişlerdir. 2013 yılı analizine bakıldığında ithalat kriterine göre en yüksek performansa Kırgızistan sahip iken bu kritere göre Kazakistan ekonomisi ülkeler arasında en sonda yer alarak düşük bir performansa sahip olduğu görülmektedir. İhracat kriterine bakıldığında en yüksek performansa sahip ülke Kazakistan olurken, onu sırasıyla Azerbaycan, Türkmenistan, Özbekistan ve Kırgızistan takip etmiştir. Enflasyon oranı kriterine göre en yüksek performansa sahip ülke Azerbaycan olurken bu ülkeyi sırasıyla Türkmenistan, Kazakistan, Kırgızistan ve Özbekistan takip etmiştir. Enflasyon kriterine göre en düşük performansa sahip ülkenin Özbekistan olduğu görülmektedir. İşsizlik Oranı kriterine göre bakıldığında en yüksek performansı Kazakistan ekonomisi gösterirken bu ülkeyi Azerbaycan takip etmiştir. Bu kritere göre en düşük performansı Özbekistan ekonomisi göstermiştir. Bütün kriterler birlikte dikkate alındığında 2013 yılında en yüksek performansı Azerbaycan ekonomisi göstermiştir. Azerbaycan ekonomisini sırasıyla Kazakistan ekonomisi, Türkmenistan ekonomisi, Kırgızistan Ekonomisi izlerken en düşük performansı Özbekistan ekonomisi göstermiştir.

Kriterler bazında yapılan değerlendirmeler ülkelerin toplam performansı hakkında bilgi sunmamaktadır. Bütün kriterler dikkate alınarak hesaplanan yakınlık katsayısı ile ülkelerin yıllar itibari ile ekonomik performansları değerlendirilmektedir. Bütün kriterler dikkate alınarak yapılan analizde 2013 yılı itibariyle Azerbaycan'ın 0,64324 yakınlık katsayısı ve Kazakistan'ın 0,59324 yakınlık katsayısı ile birbirine yakın en yüksek ekonomik performans gösterdikleri görülmektedir. Bu ülkeleri 0,44465 yakınlık katsayısı ile Türkmenistan, 0,33912 yakınlık katsayısı ile Kırgızistan ve 0,25317 yakınlık katsayısı ile Özbekistan ekonomileri takip etmektedir. Bütün kriterler dikkate alınarak bakıldığında en düşük performansı Özbekistan’ın gösterdiği görülmektedir.

Çok Kriterli Karar Verme yöntemlerinde TOPSIS yöntemi ile Türk Cumhuriyetlerinin ekonomik performanslarının sıralaması ülkelerin performansları ile ilgili bir sonuç ve tespit olup sıralamanın ekonomik 
nedenleri incelenerek tespit edilmelidir. Aşağıda Tablo 2'de Orta Asya Türk Cumhuriyetlerinin 2003-2013 yılları arasındaki ekonomik performansı her bir kriter bazında ve bütün kriterler bazında gösterilmiştir. Tablonun en son iki sütunu bütün kriterler bazında hesaplanan ve ülkelerin ekonomik performansını ifade eden yakınlık katsayıları ile performans sıralamasını göstermektedir. TOPSIS yöntemine göre yakınlık katsayıları pozitif ideal çözüm ve negatif ideal çözüm noktaları ile alternatiflerin ideal çözüme olan uzaklıklarına göre performans sıralamasını vermektedir.

\begin{tabular}{|c|c|c|c|c|c|c|c|c|c|c|c|}
\hline & Ülkeler & $\begin{array}{l}\text { Büyüme } \\
\text { Hızı \% }\end{array}$ & $\begin{array}{l}\text { KBGSYiH } \\
\text { (US\$) }\end{array}$ & $\begin{array}{l}\text { ithalat } \\
\text { (US\$) }\end{array}$ & $\begin{array}{l}\text { ihracat } \\
\text { (US\$) }\end{array}$ & $\begin{array}{l}\text { Enflasyon } \\
\%\end{array}$ & İşsizlik \% & $S_{i}^{+}$ & $s_{i}^{-}$ & $C_{i}^{*}$ & $\begin{array}{l}\text { Per. } \\
\text { Sira }\end{array}$ \\
\hline \multirow{8}{*}{2003} & Azerbaycan & 0,10967 & 0,05561 & 0,06854 & 0,03154 & 0,10468 & 0,09843 & 0,1484 & 0,1815 & 0,55014 & 2 \\
\hline & Kazakistan & 0,09107 & 0,13015 & 0,00000 & 0,15405 & 0,02543 & 0,12030 & 0,1289 & 0,2265 & 0,63727 & 1 \\
\hline & Kırgızistan & 0,06884 & 0,02395 & 0,09999 & 0,00766 & 0,09072 & 0,06015 & 0,1954 & 0,1523 & 0,43803 & 3 \\
\hline & Türkmenistan & 0,03201 & 0,08093 & 0,07971 & 0,03843 & 0,08913 & 0,00000 & 0,1922 & 0,1359 & 0,41434 & 4 \\
\hline & Özbekistan & 0,04113 & 0,02493 & 0,08202 & 0,03895 & 0,00000 & 0,00000 & 0,2340 & 0,0882 & 0,27387 & 5 \\
\hline & Ağırlık & 0,1667 & 0,1667 & 0,1667 & 0,1667 & 0,1667 & 0,1667 & & & & \\
\hline & $\mathrm{A}^{+}$ & 0,10967 & 0,13015 & 0,09999 & 0,15405 & 0,10468 & 0,12030 & & & & \\
\hline & $A^{-}$ & 0,03201 & 0,02395 & 0,00000 & 0,00766 & 0,00000 & 0,00000 & & & & \\
\hline \multirow{8}{*}{2004} & Azerbaycan & 0,09360 & 0,05054 & 0,06928 & 0,02948 & 0,06675 & 0,010658 & 0,1742 & 0,1558 & 0,47208 & 3 \\
\hline & Kazakistan & 0,08809 & 0,13900 & 0,00000 & 0,15770 & 0,06190 & 0,09237 & 0,1257 & 0,2256 & 0,64220 & 1 \\
\hline & Kırgızistan & 0,06448 & 0,02095 & 0,09768 & 0,00655 & 0,13959 & 0,08881 & 0,1948 & 0,1930 & 0,49772 & 2 \\
\hline & Türkmenistan & 0,04589 & 0,07041 & 0,08157 & 0,02935 & 0,00252 & 0,00000 & 0,2320 & 0,0981 & 0,29714 & 4 \\
\hline & Özbekistan & 0,07066 & 0,02249 & 0,08236 & 0,03367 & 0,00000 & 0,00000 & 0,2460 & 0,0901 & 0,26819 & 5 \\
\hline & Ağırlık & 0,1667 & 0,1667 & 0,1667 & 0,1667 & 0,1667 & 0,1667 & & & & \\
\hline & $A^{+}$ & 0,09360 & 0,13900 & 0,09768 & 0,15770 & 0,13959 & 0,010658 & & & & \\
\hline & $\mathrm{A}^{-}$ & 0,04589 & 0,02095 & 0,00000 & 0,00655 & 0,00000 & 0,00000 & & & & \\
\hline \multirow{8}{*}{2005} & Azerbaycan & 0,13801 & 0,05860 & 0,07166 & 0,04286 & 0,04488 & 0,11164 & 0,1674 & 0,2044 & 0,54963 & 2 \\
\hline & Kazakistan & 0,05129 & 0,14001 & 0,00000 & 0,15623 & 0,08035 & 0,08750 & 0,1407 & 0,2337 & 0,62415 & 1 \\
\hline & Kırgızistan & 0,00000 & 0,01769 & 0,09345 & 0,00484 & 0,13486 & 0,08750 & 0,2398 & 0,1859 & 0,43674 & 3 \\
\hline & Türkmenistan & 0,06863 & 0,06337 & 0,08384 & 0,02710 & 0,03348 & 0,00000 & 0,2240 & 0,1242 & 0,35676 & 4 \\
\hline & Özbekistan & 0,03726 & 0,02030 & 0,08295 & 0,02785 & 0,00000 & 0,00000 & 0,2648 & 0,0938 & 0,25946 & 5 \\
\hline & Ağırlık & 0,1667 & 0,1667 & 0,1667 & 0,1667 & 0,1667 & 0,1667 & & & & \\
\hline & $\mathrm{A}^{+}$ & 0,13801 & 0,14001 & 0,09345 & 0,15623 & 0,13486 & 0,11164 & & & & \\
\hline & $\mathrm{A}^{-}$ & 0,00000 & 0,01769 & 0,00000 & 0,00484 & 0,00000 & 0,00000 & & & & \\
\hline \multirow{8}{*}{2006} & Azerbaycan & 0,14907 & 0,06566 & 0,07327 & 0,05204 & 0,06061 & 0,12074 & 0,1393 & 0,2166 & 0,60855 & 1 \\
\hline & Kazakistan & 0,04623 & 0,14049 & 0,00000 & 0,15398 & 0,05631 & 0,08781 & 0,1533 & 0,2241 & 0,59375 & 2 \\
\hline & Kırgızistan & 0,01341 & 0,01442 & 0,09078 & 0,00441 & 0,11641 & 0,07409 & 0,2425 & 0,1651 & 0,40508 & 3 \\
\hline & Türkmenistan & 0,04739 & 0,05683 & 0,08677 & 0,02801 & 0,08592 & 0,00000 & 0,2207 & 0,1357 & 0,38075 & 4 \\
\hline & Özbekistan & 0,03154 & 0,01707 & 0,08149 & 0,02359 & 0,00000 & 0,00000 & 0,2725 & 0,0857 & 0,23925 & 5 \\
\hline & Ağırlık & 0,1667 & 0,1667 & 0,1667 & 0,1667 & 0,1667 & 0,1667 & & & & \\
\hline & $\mathrm{A}^{+}$ & 0,14907 & 0,14049 & 0,09078 & 0,15398 & 0,11641 & 0,12074 & & & & \\
\hline & $A^{-}$ & 0,01341 & 0,01442 & 0,00000 & 0,00441 & 0,00000 & 0,00000 & & & & \\
\hline \multirow{8}{*}{2007} & Azerbaycan & 0,13254 & 0,07745 & 0,07667 & 0,06480 & 0,00000 & 0,11808 & 0,1470 & 0,1868 & 0,55947 & 2 \\
\hline & Kazakistan & 0,04709 & 0,13617 & 0,00000 & 0,14880 & 0,07672 & 0,09348 & 0,1296 & 0,2233 & 0,63273 & 1 \\
\hline & Kırgızistan & 0,04520 & 0,01451 & 0,09011 & 0,00579 & 0,08454 & 0,07134 & 0,2132 & 0,1426 & 0,40088 & 4 \\
\hline & Türkmenistan & 0,05852 & 0,05242 & 0,08644 & 0,02748 & 0,10465 & 0,00246 & 0,2014 & 0,1432 & 0,41550 & 3 \\
\hline & Özbekistan & 0,05027 & 0,01670 & 0,07942 & 0,02547 & 0,06160 & 0,00000 & 0,2283 & 0,1025 & 0,30991 & 5 \\
\hline & Ağırlık & 0,1667 & 0,1667 & 0,1667 & 0,1667 & 0,1667 & 0,1667 & & & & \\
\hline & $\mathrm{A}^{+}$ & 0,13254 & 0,13617 & 0,09011 & 0,14880 & 0,10465 & 0,11808 & & & & \\
\hline & $A^{-}$ & 0,04520 & 0,01451 & 0,00000 & 0,00579 & 0,00000 & 0,00000 & & & & \\
\hline
\end{tabular}

Tablo 3. 2003-2007 Yılları Arasında Pozitif İdeal Çözüm ve Negatif İdeal Çözüm Noktaları ile Ülkelerin İdeal Çözüm Noktasına Uzaklkklarına Göre Ekonomik Performans Siralaması 


\begin{tabular}{|c|c|c|c|c|c|c|c|c|c|c|c|}
\hline & Ülkeler & $\begin{array}{l}\text { Büyüme } \\
\text { Hızı \% }\end{array}$ & $\begin{array}{l}\text { KBGSYiH } \\
\text { (US\$) }\end{array}$ & $\begin{array}{l}\text { İthalat } \\
\text { (US\$) }\end{array}$ & $\begin{array}{l}\text { ihracat } \\
\text { (US\$) }\end{array}$ & $\begin{array}{l}\text { Enflasyon } \\
\%\end{array}$ & $\begin{array}{l}\text { İşsizlik } \\
\%\end{array}$ & $S_{i}^{+}$ & $s_{i}^{-}$ & $C_{i}^{*}$ & $\begin{array}{l}\text { Per. } \\
\text { Sira }\end{array}$ \\
\hline \multirow{5}{*}{2008} & Azerbaycan & 0,08074 & 0,08450 & 0,07780 & 0,06331 & 0,03062 & 0,11611 & 0,1416 & 0,1784 & 0,55753 & 2 \\
\hline & Kazakistan & 0,02473 & 0,12905 & 0,00000 & 0,15025 & 0,06048 & 0,10048 & 0,1430 & 0,2186 & 0,60459 & 1 \\
\hline & Türkmenistan & 0,11015 & 0,05940 & 0,08532 & 0,02432 & 0,12787 & 0,00223 & 0,1836 & 0,1824 & 0,49842 & 3 \\
\hline & Özbekistan & 0,06745 & 0,01551 & 0,07794 & 0,02395 & 0,08265 & 0,0000 & 0,2153 & 0,1227 & 0,36312 & 4 \\
\hline & $A^{-}$ & 0,02473 & 0,01465 & 0,00000 & 0,00542 & 0,00000 & 0,00000 & & & & \\
\hline \multirow{5}{*}{2009} & Azerbaycan & 0,01158 & 0,08488 & 0,07872 & 0,06716 & 0,10373 & 0,11996 & 0,0866 & 0,2215 & 0,71884 & 1 \\
\hline & Kazakistan & 0,01410 & 0,12286 & 0,00000 & 0,14168 & 0,03717 & 0,09959 & 0,1598 & 0,2023 & 0,55864 & 2 \\
\hline & Kırgızistan & 0,03391 & 0,01494 & 0,09655 & 0,00753 & 0,04177 & 0,05885 & 0,2122 & 0,1221 & 0,36532 & 4 \\
\hline & Türkmenistan & 0,07172 & 0,06961 & 0,08169 & 0,04428 & 0,11786 & 0,00226 & 0,1670 & 0,1680 & 0,50144 & 3 \\
\hline & $\mathrm{A}^{-}$ & 0,01410 & 0,01494 & 0,00000 & 0,00753 & 0,00000 & 0,00000 & & & & \\
\hline \multirow{8}{*}{2010} & Azerbaycan & 0,05476 & 0,08278 & 0,07853 & 0,06413 & 0,09180 & 0,11433 & 0,1060 & 0,1975 & 0,65067 & 2 \\
\hline & Kazakistan & 0,07991 & 0,12851 & 0,00000 & 0,14622 & 0,07099 & 0,11009 & 0,1026 & 0,2383 & 0,69889 & 1 \\
\hline & Kırgızistan & 0,00000 & 0,01247 & 0,09509 & 0,00552 & 0,05874 & 0,05081 & 0,2219 & 0,1227 & 0,35618 & 4 \\
\hline & Türkmenistan & 0,09942 & 0,06224 & 0,08064 & 0,03847 & 0,10422 & 0,00212 & 0,1697 & 0,1755 & 0,50845 & 3 \\
\hline & Özbekistan & 0,09225 & 001951 & 0,07788 & 0,02780 & 0,00000 & 0,00000 & 0,2240 & 0,1229 & 0,35439 & 5 \\
\hline & Ağırlık & 0,1667 & 0,1667 & 0,1667 & 0,1667 & 0,1667 & 0,1667 & & & & \\
\hline & $\mathrm{A}^{+}$ & 0,09942 & 0,12851 & 0,09509 & 0,14622 & 0,10422 & 0,11433 & & & & \\
\hline & $\mathrm{A}^{-}$ & 0,00000 & 0,01247 & 0,00000 & 0,00552 & 0,00000 & 0,00000 & & & & \\
\hline 2011 & Azerbaycan & 0,00057 & 0,08132 & 0,07462 & 0,06169 & 0,08756 & 0,11238 & 0,1630 & 0,1836 & 0,52970 & 2 \\
\hline \multirow{8}{*}{2012} & Azerbaycan & 0,02542 & 0,07761 & 0,07684 & 0,05961 & 0,11590 & 0,11346 & 0,1430 & 0,2003 & 0,58336 & 2 \\
\hline & Kazakistan & 0,05653 & 0,12722 & 0,00000 & 0,14815 & 0,06516 & 0,11147 & 0,1283 & 0,2315 & 0,64336 & 1 \\
\hline & Kırgızistan & 0,00000 & 0,01236 & 0,09646 & 0,00474 & 0,09520 & 0,04976 & 0,2317 & 0,1443 & 0,38385 & 4 \\
\hline & Türkmenistan & 0,12432 & 0,07135 & 0,08033 & 0,04160 & 0,03218 & 0,00199 & 0,1848 & 0,1666 & 0,47418 & 3 \\
\hline & Özbekistan & 0,09208 & 0,01804 & 0,07821 & 0,02287 & 0,00000 & 0,00000 & 0,2351 & 0,1223 & 0,34215 & 5 \\
\hline & Ağırlık & 0,1667 & 0,1667 & 0,1667 & 0,1667 & 0,1667 & 0,1667 & & & & \\
\hline & $\mathrm{A}^{+}$ & 0,12432 & 0,12722 & 0,09646 & 0,14815 & 0,11590 & 0,11346 & & & & \\
\hline & $A^{-}$ & 0,00000 & 0,01236 & 0,00000 & 0,00474 & 0,00000 & 0,00000 & & & & \\
\hline \multirow{8}{*}{2013} & Azerbaycan & 0,05175 & 0,0733 & 0,07475 & 0,06045 & 0,13822 & 0,10784 & 0,1151 & 0,2075 & 0,64324 & 1 \\
\hline & Kazakistan & 0,05356 & 0,12778 & 0,00000 & 0,14959 & 0,03043 & 0,11406 & 0,1508 & 0,2192 & 0,59234 & 2 \\
\hline & Kırgızistan & 0,09404 & 0,01186 & 0,09751 & 0,00575 & 0,00611 & 0,05599 & 0,2344 & 0,1202 & 0,33912 & 4 \\
\hline & Türkmenistan & 0,09104 & 0,07498 & 0,08127 & 0,03180 & 0,08781 & 0,00207 & 0,1789 & 0,1432 & 0,44465 & 3 \\
\hline & Özbekistan & 0,07141 & 0,01763 & 0,07796 & 0,02650 & 0,00000 & 0,00000 & 0,2455 & 0,0832 & 0,25317 & 5 \\
\hline & Ağırlık & 0,1667 & 0,1667 & 0,1667 & 0,1667 & 0,1667 & 0,1667 & & & & \\
\hline & $A^{+}$ & 0,09404 & 0,12778 & 0,09751 & 0,14959 & 0,13822 & 0,11406 & & & & \\
\hline & $\mathrm{A}^{-}$ & 0,05175 & 0,01186 & 0,00000 & 0,00575 & 0,00000 & 0,00000 & & & & \\
\hline
\end{tabular}

Tablo 4. 2008-2013 yılları arasında Pozitif İdeal Çözüm ve Negatif İdeal Çözüm Noktaları ile Ülkelerin İdeal Çözüm Noktasına Uzaklıklarına Göre Ekonomik Performans Stralaması

Ülkelerin ekonomik performansına ilişkin TOPSIS yöntemi ile yapılan sayısal analizin yıllar itibariyle grafikle gösterimi aşağıdaki şekildedir. Bütün kriterler dikkate alınarak yapılan değerlendirmede Kazakistan ve Azerbaycan'ın genel ekonomik performanslarının diğer ülkelere göre daha yüksek ve birbirine yakın olduğu görülmektedir. Kırgızistan, Türkmenistan ve Özbekistan'ın ekonomik performanslarının ise Kazakistan ve Azerbaycan'a göre daha düşük gerçekleştiği görülmektedir. Bütün kriterler dikkate alınarak bakıldığında en düşük performansı 2008 yılı dışındaki yıllarda Özbekistan ekonomisinin gösterdiği görülmektedir. Özbekistan ekonomisi yıllar itibariyle en düşük performansa sahip olurken 2008 yılında bir iyileşme gösterdiği Şekil 2'deki grafikte de görülmektedir. 


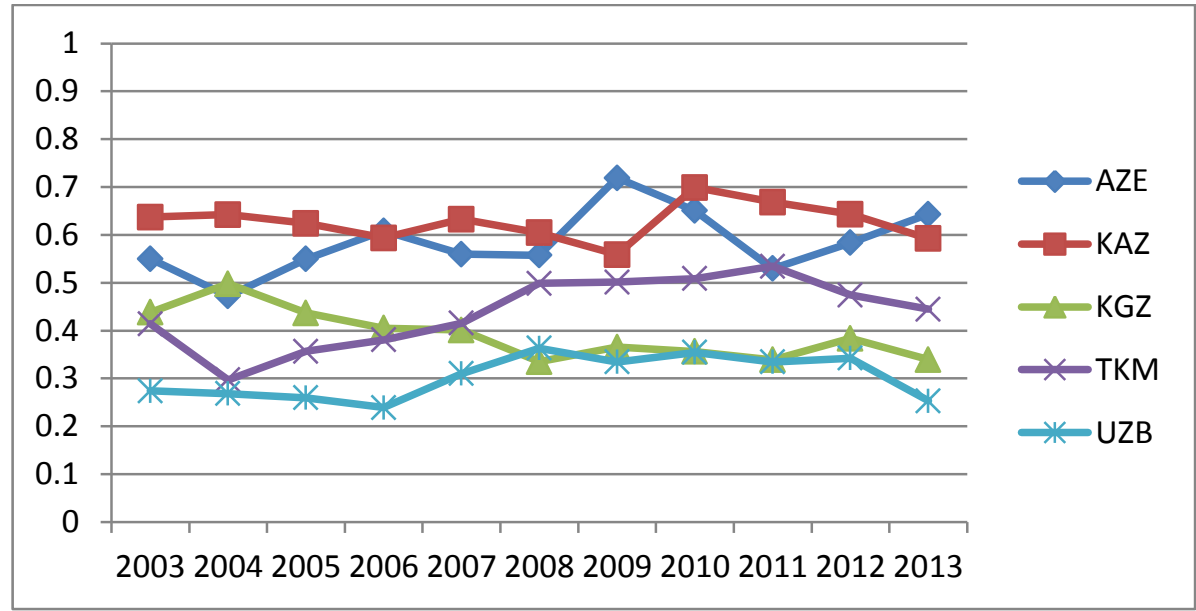

Şekil 2.Ülkelerin 2003-2013 Yılları Arasındaki Ekonomik Performanslarının Grafikle Gösterimi

\section{Sonuç}

Alternatiflerin değerlendirilmesi, sıralanması ve analiz edilmesi çelişen kriterleri de içinde bulunduran çok kriterli bir karar analizidir. Bu nedenle çok kritere sahip pek çok karar durumunda sıralama, değerlendirme ve analizler yapmak zorlaşmaktadır. Ülkelerin ekonomik performanslarının ölçümü de çok kriter ile yapılan ve kriterlerin çelişebildiği zorlanılan bir karar analizidir. Bu çalışmada çok kriterli karar verme yöntemlerinden TOPSIS yöntemi ile Orta Asya Türk Cumhuriyetlerinin ekonomik performansları seçilen kriterler doğrultusunda ölçülerek sıralamaları yapılmıştır. Çalışma 2003 ile 2013 yıllarını kapsamaktadır. TOPSIS yöntemi ile yapılan analiz sonuçlarına göre 2006, 2009 ve 2013 yılı dışındaki bütün yıllarda Kazakistan ekonomik performansı birinci sırada yer alırken bu ülkeyi Azerbaycan ekonomisi izlemiştir. Azerbaycan ekonomisi 2006, 2009 ve 2013 yıllarında ilk sırada yer almıştır. Bu ülkeleri Türkmenistan ve Kırgızistan ekonomilerinin ekonomik performansı izlemiştir. Özbekistan’ın ekonomik performansı 2008 yılı hariç bütün yıllarda en son sırada yer almıştır.

Araştırmada kullanılan kriterlere yeni kriterler eklendiğinde veya bazı kriterler çıkarıldığında araştırma sonuçları da değişecektir. Buna ilaveten kullanılan kriterler yanında kriterlerin önem ağırlıkları da sıralama ve analizi etkileyen önemli bir faktördür. Belirlenen kriterler için farklı ağırlıklar kullanıldığında alternatifler arasındaki sıralama değişecektir. Yöntemdeki bu durum ülkelerin ya da ekonomik kurum ve kuruluşların ekonomik performans değerlendirilmesinde karar vericiye farklı bakış açıları ile değerlendirme esnekliği imkanı sunmaktadır. Örneğin bir tedarikçi seçim probleminde karar verici açısından öne çıkan önem ağırlığı ya da kriterler karar analizine yansitılabilmektedir.

Ülkelerin ekonomik performanslarının çeşitli kriterlere göre ve farklı yöntemler ile incelenmesi ekonomik karar birimleri açısından yararlı bilgiler sunacaktır. Ülkelerin ekonomik performansları ile ilgili matematiksel analizler, başta ekonomi yönetimi olmak üzere yatırımcıların, konuyla ilgili tarafların karar almaları ve politika oluşturmalarında son derece önemlidir. Yapılacak çalışmalarda kullanılan çok kriterli karar verme yöntemi, analiz periyodu, analizde kullanılan kriterler ve kriter ağırlıkları değiştirilerek ekonomik performans ölçümü yapılması karar analizi ve teknikleri literatürüne katkılar sağlayacaktır.

\section{Kaynakça}

- $\quad$ Akbulut ve Rençber, 2015. “BİST’te İmalat Sektöründeki İşletmelerin Finansal Performansları Üzerine Bir Araştırma”, Muhasebe ve Finansman Dergisi, Sayı: 65, 117-136.

- $\quad$ Alagöz, Erdoğan ve Saçık, 2011. “Kazakistan Cumhuriyeti’nin Ekonomik Performansının Ölçümü: 19922008" Avrasya Etüdleri, 38, 1, 49-75.

- Alagöz, Yapar ve Uçtu, 2004. "Türk Cumhuriyetleri ile İlişkilerimize Ekonomik Açıdan Bir Yaklaşım” Selçuk Üni. Sosyal Bilimler Dergisi, Sayı:12, s.59-74.

- Ardor, 2006. “Türk Cumhuriyetlerinin Dünya ile Bütünleşmesi” Gazi Üniversitesi, İktisadi ve İdari Bilimler Dergisi, 8/2, s.35-52.

- Chen, 2000. "Extensions of The TOPSIS for Group Decision-Making Under Fuzzy Environment", Fuzzy Sets and Systems. 114, p.1-9.

- Chen, Chan and Huang, 2002. "Using Multiple Criteria Decision Analysis For Supporting Decisions of Solid Waste Management”, Journal of Environment Science Health, Vol:37, No:6, p.975-990. 
- Çınar Tırmıkçıŏlu, 2011. "Grup Kararı Vermede Kullanılan Bulanık Topsıs Yöntemleri ve Bir Uygulama: Banka Şube Yeri Seçimi”, Sigma Mühendislik ve Fen Bilimleri Dergisi, Sayı: 29, 11-24.

- Dumanoğlu, 2010. "İMKB’de İşlem Gören Çimento Şirketlerinin Mali Performansının Topsıs Yöntemi ile Değerlendirilmesi”, Marmara Üniversitesi, İ.̇̇.B.F. Dergisi, 29, 2, 323-339.

- Dumanoğlu ve Ergül 2010. "İMKB'de İşlem Gören Teknoloji Şirketlerinin Mali Performans Ölçümü” Muhasebe ve Finansman Dergisi, 48, 101-111.

- Eleren ve Karagül, 2008. "1986-2006 Türkiye Ekonomisinin Performans Degerlendirmesi” Celal Bayar Üniv. İ.İ.B.F. Yönetim ve Ekonomi Dergisi, Cilt: 15, Sayı:1, 1-14.

- $\quad$ Ergül, 2010. İMKB'de İşlem Gören Enerji Şirketlerinin Mali Performanslarının TOPSIS Yöntemi ile Analizi, Beta Basım Yayım, İstanbul.

- $\quad$ Erol ve Şahin, 2013. "Bağımsızlıklarının 20. Yilinda Orta Asya ve Kafkasya'daki Türk Cumhuriyetlerinin Entegrasyon Süreci (1991 - 2011)” Karadeniz Araştırmaları, Sayı: 37, s.111-136.

- Gömeç, 2007. "Türkiye-Türk Cumhuriyetleri İlişkileri Üzerine Bir Değerlendirme” Uluslararası Sosyal Araştırmalar Dergisi, Cilt: 1, Sayı: 1, 114-131.

- IMF,2015.http//imf.org/external/pubs/ft/weo/2014/02/weodata/weorept.aspx?sy=2003\&ey=2013\&scsm=1 $\&$ ssd $=1 \&$ sort $=$ country\&ds $=. \& b r=1 \& p r 1 . \mathrm{x}=83 \& \mathrm{pr} 1 . \mathrm{y}=15 \& \mathrm{c}=912 \% 2 \mathrm{C} 925 \% 2 \mathrm{C} 916 \% 2 \mathrm{C} 927 \% 2 \mathrm{C} 917 \& \mathrm{~s}=\mathrm{P}$ $\mathrm{CPIPCH} \% 2 \mathrm{CPCPIEPCH \& grp}=0 \& \mathrm{a}=$

- Ishizaka and Nemery, 2013. Multi-Criteria Decision Analysis, Methods and Software. John Wiley\&Sons, Ltd. London.

- $\quad$ Özden, 2011. "Topsis Yöntemi ie Avrupa Birliğine Üye ve Aday Ülkelerin Ekonomik Göstergelere Göre Sıralanması” Trakya Üniversitesi Sosyal Bilimler Dergisi, Aralık, Cilt:13, Sayı:2, 215-236.

- $\quad$ Ömürcek ve Mercan, 2014. "İmalat Alt Sektörlerinin Finansal Performanslarının TOPSIS ve ELECTRE Yöntemleri İle Değerlendirilmesi” Çankırı Karatekin Üniversitesi, İktisadi ve İdari Bilimler Fakültesi Dergisi, Cilt: 4, Say1: 1, 237-266.

- $\quad$ Öztürk, Ertuğrul ve Karakaşoğlu 2008. "Nakliye Firması Seçiminde Bulanık AHP ve Bulanık TOPSIS Yöntemlerinin Karşılaştırılması” Marmara Üniversitesi İ.İ.B.F. Dergisi Cilt: 25, Sayı:2, 785-824.

- Özbekistan Devlet İstatistik Kurumu, http://www.stat.uz/en/index.php/dinamicheskie-ryady

- Perçin ve Karakaya, 2012. "Bulanık Karar Verme Yöntemleriyle Türkiye’de Bilişim Teknolojisi Firmalarının Finansal Performanslarının Değerlendirilmesi” Marmara Üniversitesi, İ.İ.B.F. Dergisi, Cilt: XXXIII, Say1: II, 241-266.

- Solak ve Sarıdoğan, 2011. "Küresel İktisadi Krizin Türk Cumhuriyetleri’ne Etkileri” Marmara Üniversitesi, İ.̇̇.B.F. Dergisi, Cilt: XXX, Sayı: I, s.93-115.

- Türkmen ve Çağıl, 2012. “IMKB’ye Kote Bilişim Sektörü Şirketlerinin Finansal Performanslarının TOPSIS Yöntemi ile Değerlendirilmesi” Maliye ve Finans Yzıları, Sayı: 95, 59-78.

- Türkmenistan Devleti istatistik Kurumu, 2015. http//stat.gov.tm/assets/social/makro 20072014 t.pdf

- Tzeng and Huang, 2011. Multiple Attribute Decision Making Methods and Applications. CRC Press, Taylor \& Francis Group, Newyork.

- Urfalığlu ve Genç, 2013. “Çok Kriterli Karar Verme Teknikleri ile Türkiye’nin Ekonomik Performansının Avrupa Birliği Üye Ülkeleri ile Karşılaştırılması” Marmara Üniversitesi; İ.İ.B.F. Dergisi, Cilt: XXXV, Say1: II, 329-360.

- Uygurtürk ve Korkmaz, 2012. "Finansal Performansın TOPSIS Çok Kriterli Karar Verme Yöntemi ile Belirlenmesi: Ana Metal Sanayi İşletmeleri Üzerine Bir Uygulama” Eskişehir Osmangazi Üniv. İ.İ.B.F. Dergisi, 7, 2, 95-115.

- Wang, 2014. "The evaluation of financial performance for Taiwan containershipping companies by fuzzy TOPSIS”, Applied Soft Computing, 22, p.28-35.

- World Bank, 2015. http// databank.worldbank.org/data/views/reports/tableview.aspx

- Yıldırım ve Önder (Ed.), 2014. Operasyonel, Yönetsel, ve Stratejik Problemlerin Çözümünde Çok Kriterli karar verme Yöntemleri. Dora basım-Yayın Dağıtım, İstanbul.

- Yurdakul ve İç, 2003. "Türk Otomotiv Firmalarinin Performans Ölçümü Ve Analizine Yönelik Topsis Yöntemini Kullanan Bir Örnek Çalişma” Gazi Üniv. Mühendislik Mimarlık fakültesi Dergisi, Cilt: 18, No:1, 1-18. 


\title{
Türkiye Kazakistan İlişkilerinin Dış Ticaret Verileri ve Kurumlar Perspektifinden İncelenmesi
}

\section{Examination Relations of Turkey and Kazakhstan from the Perspective of Foreign Trade Datas and Organizations}

\author{
İlker Salih Ebrem (Siirt University, Turkey)
}

\begin{abstract}
Established after the disintegration of the Soviet Union and Turkic Republics has tried to improve its relations with Turkey but relations have not developed to the required level. Existing relations between Turkey and Kazakhstan which from one of these countries, is assessed, have been mentioned economic and political contributions of organizations such as Turkish Exim Bank, Turkish International Cooperation and Coordination Agency (TIKA) and Hoca Ahmet Yasawi University, which are effective in the development of bilateral relations. Turkey and Kazakhstan relations has reached a momentum in recent years. The development of bilateral relations have also reflected the economic figures but this level of development is not enough.

Finally, by examining the trade volume between the two countries, import and export rates and which product mainly taken place in the foreign trade volume are examined and interpreted.
\end{abstract}

\section{Giriș}

Berlin Duvarının 9 Kasım 1989 yılında yıkılmasıyla ile birlikte SSCB'den ayrılan ve genellikle "Türk Cumhuriyetler" adı verilen devletlere, o dönemde bölgenin parlayan yıldızı olan ve çok kilit bir konumda bulunan Türkiye Cumhuriyeti destek olmaya çalışmıştır bu destekte etnik, dini ve kültürel nedenlerde etkilidir. Türkiye'nin bölgede meydana gelen yeni oluşum içinde liderlik rolüne yönelmesi sadece Türkiye'nin arzusu değil, dönemin koşulları içerisinde başta $\mathrm{ABD}$ olmak üzere batılı devletlerin uygun gördüğü bir modeldi. Zira batıdan bakıldığında Türkiye, batı ile barışık demokratik ve piyasa ekonomisine açık, dönemin uluslararası koşulları dikkate alındığında ise radikal İslam'a izin vermeyecek bir modeldi. Bu modelin uygulanması için Türkiye'nin soydaş gördüğü yeni bağımsızlıklarını kazanan ülkeler ile ilişkilerini geliştirmesini sağlayacak adımlar atmıştır (Erdoğan ve Bağcı, 2013). Türkiye, Joseph Nye'ın yumuşak güç tanımlamasına uygun olarak bölge ülkeleri ile ilişkilerini geliştirecek kurumlar oluşturmuş, ortak projelere imza atmıştır ancak Türkiye'nin bölgedeki Türk cumhuriyetlerinin üzerinde etkinlik kurma istediği dönemin konjonktürünün değişmesi Rusya'nın bocalama dönemini çabuk atlatıp tekrar bölgede hâkimiyet kurması ve ABD'nin Türkiye'ye verdiği desteği 1993 sonrasında Rusya ile dengeleme çabası, Türkiye'nin kaynaklarının yetersiz olması ve ülke içindeki yaşanan ciddi siyasal krizler istikrarlı bir Orta Asya-Kafkasya politikasını zorlaştırmıştır. Türkiye'nin bağımsızlıklarını kazanan Türk Cumhuriyetleri üzerindeki "ağabey” rolü üstlenme söylemi zaman zaman bölge ülkeleri içinde tepki ile karşılanmıştır (Erdoğan ve Bağc1, 2013). Bu söylemin yanı sıra bölge ülkelerinin Sovyetler Birliği altında uzun seneler geçirmiş olmaları, ortak sosyalist geçmişi, Rusçanın ortak bir dil olarak aralarında kullanılmasını, bölge içindeki ekonomik bağların kuvvetli olması gibi unsurlar dikkate alındığında Türkiye hem kültürel hem siyasal bakımdan Avrasya dışı bir ülke olarak görülme eğilimindedir (Denizhan,2010). Özellikle 2002 sonrası Türk dış politikası Avrasya bölgesine yönelik yeni arayışlara girmiş bölge ile kültürel bağlara vurgu yapmıştır. Yumuşak gücün unsurlarını bölgede kullanmak üzere, kurumlarının kuruluş amaçlarına göre hareket etmelerini sağlamıştır. Türkiye'nin son yıllarda gerçekleştirdiği pro-aktif dış politika söylemi bölge ülkelerine de yansımış, bu gelişmeler ile birlikte bölge ile olan ilişkiler geliştirilmiştir.

Bölge ülkeleri ile birlikte bağımsızlığını kazanan Kazakistan için Türkiye ile ilișkiler dengeli olmuștur zira bölgedeki Rusya faktörü, Türkiye ile olan ilişkileri etkilemiştir. Kazakistan ile ilişkiler Türkiye'nin ortak soy ve kültürel özellikleri üzerinden yürütülmüş bu amaç ile kurulan kurumlar etkin rol oynamıştır. Avrasya bölgesinde Kazakistan, Türkiye'nin en önemli ticaret partnerlerinden birisidir. Bu ülke ile yapılan ticaret hacmi ve ikili ilişkilerdeki gelişme azımsanmayacak noktaya ulaşmıștır. 2007 yılından bu yana ise ilişsiler yeniden belirli bir ivme yakalamıştır. 2009 yılında imzalanan Stratejik Ortaklık Anlaşması ile yakın ilişkiler pekiştirilmiştir. Bir zamanlar "ağabeylik" yakıştırması ile yönlendirilen Türk dünyası ideali, geldiğimiz noktada "eşitler arası ilişkilerde en yüksek entegrasyon" amacına yönelmiştir ancak iki ülkenin ekonomik kapasitelerine bakıldığında mevcut durumun iki ülke arasındaki potansiyeli yansıtmadığı görülmektedir (Aljazeera, 2015).

\section{Yumuşak Güç Kavramı ve Kurumların İşlevleri}

Uluslararası ilişkilerde güç kavramı dış politikanın en belirleyici faktörlerindendir. Joseph Nye'ın güç tanımlamaları son yıllarda dış politikada önemli yer tutmuştur. Nye göre güç başkalarının davranışlarını, istenilen sonuçlara ulaşıncaya kadar etkileyebilme kapasitesidir. Nye, yumuşak gücü ise işbirliği ve çekiciliği sağlayarak istenileni yaptırma gücü olarak tanımlamaktadır. Örneğin yumuşak güç ile ülkeler başka ülkelerin 
kendi kültürel, ahlaki değer ve refah seviyelerini özendirmekte ve diğer ülkelerin onlar gibi olmak istemelerini sağlamaktadır (Çavuş, 2012). Devletlerin sert güç (hard power) olarak nitelendirilen, devletlerin askeri ve ekonomik yöntemler kullanarak, karşıdaki devleti zor durumda bıraktığı ve istediği politikayı uygulatmayı amaçladığı diplomasi yapma yönteminin yanı sıra yumuşak güç (soft power)olarak nitelendirilen, devletin daha çok kültürel ve diplomatik yöntemleri kullanarak karşıdaki devletin rızası ile gönüllü bir şekilde istenilen politikaya razı gelmesini sağlamaya çalışmak veya devletlerin yürüttükleri ortak politikalarda birbirlerine olan güvensizliklerini ortadan kaldırmalarını sağlamaktadır (Karagül, 2013). Soğuk savaşın sona ermesi ile birlikte iki bloklu dünya sistemi tek kutuplu bir hal almış, dolayısıyla yeni sistem devletlerin dış politika yapımını, tehdit algılamalarını ve güç dengelerinde köklü değişikliklere yol açmıştır. Dış politikada devletlerarası diyalog artmış sosyal ve kültürel etkileşim önemli rol almaya başlamıştır (Kardaş ve Erdağ, 2012).

Yeni dönem dış politika yapıcıları Türkiye'nin bölgesinde daha aktif bir dış politika yöntemi geliştirmesi yönünde adımlar atmıştır. Bu politikaların uygulanması en uygun alanlarından biri ise Sovyetler Birliğinin dağılmasının ardından bağımsızlıklarını kazanan Türk cumhuriyetler olmuştur zira Nye'e göre, ülkelerin yumuşak gücü kullanarak kültürel açıdan elverişli bir zemin bulduklarında, uluslararası düzeyde daha saygın bir konuma yükseleceklerini vurgulamaktadır. Nye’a göre yumuşak gücü elde etmenin başlıca yolu cazip kimlikli kültür, siyasal değerler ve kurumsal yapılarla birlikte meşruiyete dayanan politikalar üzerinden bir cazip çekim merkezi yaratmaktır (Karagül, 2013).

Türkiye'nin Yumuşak güç kullanım stratejilerinde üç başlık ön plana çıkmaktadır. Bunlardan ilki Kültürel etkileşim faaliyetleridir. Yumuşak gücün kaynaklarından olan kültür bir meşruiyet aracıdır. Avrasya coğrafyasında bu faaliyetlerin yürütülmesinde TİKA büyük rol oynamaktadır. Anlaşmalı üniversiteler ile yapılan akademisyen değiştirme anlaşmaları ve öğrenci değişim programları, bu başlık altında önemli yer tutmaktadır. İkincisi dış politikada düzen kurucu rol'dür. Türkiye bu kapsamda bölgesinde düzen kurucu bir ülke olabilmek için çeşitli politikalar geliştirmiştir. Örneğin komşular ile sıfır sorun ve medeniyetler ittifakı gibi projeler bu kapsamada değerlendirilebilir. Son başlık ise Ekonomik kalkınmayla işbirliği ve insanı yardımlarda bulunmaktır. Türkiye bu başlığı TİKA üzerinden yürütmektedir (Çavuş, 2012).

Türkiye'nin yumuşak gücünü öne çıkarmada değerler ve kültür öğelerini kullanmış ve Türk cumhuriyetleri ile olan ilişkilerin geliştirilmesi için başlıca yumuşak güç kavramı ile uyumlu kurumlar oluşturulmuş ve yeni stratejiler geliştirilmiştir. Bu stratejilerden bazıları, Türk İşbirliği ve Koordinasyon Ajansı Başkanlığının (TİKA) kurulması, Türk Kültür ve Sanatları Ortak Yönetiminin (TÜRKSOY) kurulması, Türk Eximbank'1n kurulması, TRT'nin bölgeye yönelik yayınlara başlaması ve Türk Hava Yollarının bölgeye sefer sayılarının arttırılmasıdır (Erdoğan, Bağc1,2013).

Türk dış politikasında pro-aktif dış politika söylemi beraberinde yumuşak güç ve yumuşak güç kullanımı için gerekli olan kurumlara tekrardan önem verilmiş ve geçmişte yapılan hataların farkına varılarak kurumların yeni döneme adapte edilmesi sağlanmıştır. Türkiye’nin yardım yapan bir ülke olarak öne çıkması ile dış politikada pro-aktif bir tutum sergilemesi aynı döneme rastlamaktadır (Akçay, 2012). Bu iki kavram birbiri ile son derece yakındır zira pro-aktif bir dış politika söylemi bölgede ve dış politika yapıcılarının uygulamalarında yumuşak güç argümanlarını ön plana çıkararak, kurumlar aracılığı ile yardım yapan ve teknik danışmanlık hizmetleri sağlamayı gerektirir.

Bu perspektif kapsamında Avrasya coğrafyası ile bağların güçlenmesini sağlayan kurumların başında Türk Eximbank, Türkiye İşbirliği ve Koordinasyon Ajansı Başkanlığı ve Ortak kurulan Üniversiteler gelmektedir.

\subsection{Türk Eximbank’ın Amaçları ve Kazakistan Faaliyetleri}

Eximbank'ların kuruluş amaçlarına bakıldığında şu gerçek ile karşılaşılmaktadır. Genellikle gelişmekte olan ülkelere ait firmaların öz sermayeleri İhracat yapabilecek birikimden uzaktır. Böyle bir ortamda dış ticaretin beraberinde getirdiği riskler dolayısı ile bankalar kredi vermekte daha tutucu davranmaktadır. Buda firmaların ya daha yüksek faiz oranlarını kabul etmelerini gerektirmekte ya da firmaların ipotek vermeye zorunlu bırakmaktadır. Böyle bir ortamda ülke içindeki ihracatçıların gereksinimlerini karşılamak amacı ile devlet destekli kredi kuruluşları ile birlikte ticari bankaların ortaklığı bir araya gelerek Eximbank'ları devreye sokmaktadır (Konak, 2006).

Türk Eximbank'ın kuruluş amacı; ülke ekonomisine doğrudan etki eden ihracatın geliştirilmesi, ihraç edilen mal ve hizmetlerin çeşitlendirilmesinin sağlanması, ihraç edilecek mallara yeni pazar alanlarının kazandırılması, ihracat yapan firmaların uluslararası ticarette paylarının artırılmasının teşvik edilmesi ve bu firmaların girişimlerinde gerekli desteğin sağlanmasıdır (Eximbank, 2015). İhracatçılar ile yurt dışında faaliyet gösteren müteahhitler ve yatırımcılara uluslararası piyasalarda rekabet gücünü arttıracak ve güvence kazandırabilecek desteklerin verilmesi, yurt dışında yapılacak yatırımlar ile ihracat maksadına yönelik yatırım malları üretim ve satışının desteklenerek teşvik edilmesi Türk Eximbank'ın diğer amaçlarındandır (Eximbank, 2015). Böylece banka aracılığı ile ihracat teşvik edilmekte, gelişmekte olan ülkeler ise yapılan yatırımlar aracılığı ile ekonomik kazanımlar elde etmektedir. Böyle bir ortamda Kazakistan'a yapılacak ihracat ve geliştirilecek projeler aracılığı ile iki devletin ekonomik ve siyasi ilişskileri gelişmektedir. 
Kazakistan ile Türkiye'nin ekonomik ilişkilerinin gelişmesinde şüphesiz Türk Eximbank önemli bir yer tutmaktadır. Türk Eximbank Kazakistan'da yerleşik Tsesna Bank’a ticaretin finansmanı ve Türk müteahhitlerin Kazakistan'da gerçekleştirecekleri projelere finansman sağlamak amacıyla 32 milyon ABD Doları tutarında kredi limiti tahsis etmiştir. Kredi ile Kazakistan'daki Türk sermayeli yatırımlar gelişme göstermiştir (Eximbank Faaliyet Raporu, 2013).

2013 yılına kadar olan Türk Eximbank ülke kredi/garanti programları incelendiğinde Kazakistan'a 240 milyon ABD doları kredi limiti açmış kümülatif kullandırımı ise 213,1 ABD doları olmuştur. (Eximbank Faaliyet Raporu, 2013)

\begin{tabular}{|l|c|c|}
\hline Ülke & Kredi Limiti & Kümülatif Kullandırım \\
\hline KAZAKİSTAN & 240 & 213,1 \\
\hline a) Mal Kredisi & 55,7 & 40 \\
\hline b) Proje Kredisi & 184,3 & 173,1 \\
\hline
\end{tabular}

Tablo 1. Türk Eximbank Kazakistan Kredi Limiti ve Kümülatif Kullandırım miktarları Kaynak: Türk Eximbank, Faaliyet Raporu

Türk Eximbank’ın Kazakistan'da Ülke Kredi ve Garanti Programı çerçevesinde finanse edilen projelerden bazıları şunlardır (Eximbank, 2015).

- Kazakistan Alatau Oteli

- Kazakistan Ankara Oteli

- Kazakistan Astana Oteli

- Kazakistan Makarna Fabrikası

- Kazakistan Medeo Oteli

\subsection{Türk İşbirliği ve Koordinasyon Ajansı Başkanlığı'nın Amaçları ve Kazakistan Faaliyetleri}

Kalkınma gösteren ve gelişmemiş veya gelişmekte olan ülkelere yapılacak olan dış yardımlar önemli bir dış politika unsurudur. Güçlü ve ekonomileri gelişmiş ülkelerin gelişmekte olan ülkelere yaptıkları dış yardımlar ile birlikte ikili ilişkilerini geliştirdikleri ve bölgede önemli bir güç oluşturdukları bilinmektedir (Kardaş ve Erdağ, 2012). Bu politika temelinde, Sovyetler birliğinin dağılması ile birlikte Asya ve Kafkasya'da birçok devlet kurulmuştur bunlardan bazıları da Türkî cumhuriyetlerdir. Türkiye bağımsızlığına kavuşan Kazakistan, Tacikistan, Özbekistan, Azerbaycan ve Kırgızistan'ı tanıyan ilk ülke olmuştur. Türkiye’nin yumuşak güç stratejilerinin başında gelen ekonomik kalkınma ile işbirliği ve insani yardımlar stratejisinin (Çavuş, 2012) ana uygulayıcılarından biri TİKA'dır. Türkiye yeni kurulan devletlerinin güçlenmesi için dış yardımlar ile sosyal, ekonomik ve kültürel alanda birçok çalışma yapmıştır. Bölgede yapılan çalışmalar uzun soluklu olunca bu projeleri koordine edecek organizasyon ihtiyacı doğmuştur. Bu kapsamda Türk İşbirliği koordinasyon Ajans1 Başkanlığı (TİKA) 1992 yılında kurulmuştur (TİKA, 2015).

TİKA bir dış politika yapıcı veya dış politikada belirleyici rol oynayan bir kurum değildir. Türkiye'nin dış politikası kurum ve kuruluşlarca bir bütün halinde Dışişleri Bakanlığı tarafından belirlenmektedir. TİKA ise hedeflenen dış politikanın uygulayıcısı konumunda olan bir kurumdur (Kardaş ve Erdağ, 2012). Dışişleri Bakanlığının belirlediği dış politika ile uyumlu olarak TİKA’nın amacının Türk Cumhuriyetlerinin kendi sosyal yapısını üretmesi, kendi kimliğini sağlıklı bir şekilde inşa etmesi, kültürel ve siyasi hakların gelişmesi, teknik alt yap1 konusunda eksiklerin giderilmesi olarak özetleyebiliriz. Eğitim, sağlık, restorasyon, tarımsal kalkınma, maliye, turizm, sanayi alanında birçok proje ve faaliyet TİKA tarafından gerçekleştirilmiş (TIKKA, 2015).

TİKA yukarıda belirtilen amaçlar kapsamında ve Türkiye'nin bölgede etkin güç olma yönündeki politikaları ile birlikte Kazakistan'da faaliyet göstermektedir. Bu faaliyetler kapsamında 1992'den beri Türk İşbirliği ve Koordinasyon Ajansı (TİKA) tarafından Kazakistan'da gerçekleştirilen projelerin maliyeti yaklaşık 57 milyon doları bulmuştur (Aljazeera, 2015).

2013 yılında Kazakistan'ın TİKA bütçesinden 39,30 milyon ABD doları yararlanmıştır. 2013 yılı için Kazakistan TİKA bütçesinden en çok pay alan sekizinci ülkedir (Türkiye Kalkınma Yardımları Raporu,2013). TİKA'nın Kazakistan'daki faaliyetleri incelendiğinde, 2013 yılındaki Kazakistan'da yapılan harcamaların \%82,01 Eğitim, \%9,57 İdari ve Sivil Altyapılar, \%3,66 Sağlık, \% 3,45 Diğer Sosyal Altyap1 ve Hizmetler, \%1,31'ini ise Üretim sektörünün oluşturduğunu görmekteyiz (TİKA Faaliyet Raporu,2013). Kazakistan'ın yıllara göre TİKA bütçesinden aldığı pay(\%) tablodaki gibi olmuştur.

\begin{tabular}{|c|c|c|c|c|c|}
\hline $\mathbf{2 0 0 8}$ & $\mathbf{2 0 0 9}$ & $\mathbf{2 0 1 0}$ & $\mathbf{2 0 1 1}$ & $\mathbf{2 0 1 2}$ & $\mathbf{2 0 1 3}$ \\
\hline 0,73 & 0,90 & 3,18 & 9,28 & 1,96 & 1,86 \\
\hline
\end{tabular}

Tablo 2. TIKKA'nın Yıllara Göre Kazakistan'a Bütçesinden Ayırdı̆̆ı Pay Kaynak: TIKA Faaliyet Raporu

\section{3 Öğrenci Değişimleri ve Hoca Ahmet Yesevi Uluslararası Türk-Kazak Üniversitesi}

Türkiye'nin Avrasya bölgesine yönelik yumuşak güç enstrümanların da öne çıkan uygulamalardan olan kültürel etkileşim faaliyetleri kapsamında Hoca Ahmet Yesevi Üniversitesi Türk-Kazak eğitim işbirliğinin 
önemli adımlarından biridir. Türkiye ve Kazakistan Cumhuriyetlerinin uluslararası, özerk statüye sahip, ortak devlet üniversitesidir. Üniversitenin temelleri Kazakistan tarafından Türkistan Devlet Üniversitesi olarak atılmış ancak 29 Nisan-1Mayıs 1992 tarihinde gerçekleşen Almatı Zirvesinde Nursultan NAZARBAYEV ve Süleyman DEMIREL'in görüşleri sonucu zirvenin ortak bildirisine göre Türkistan devlet Üniversitesi iki ülkenin ortak üniversitesi haline getirilmesi kararlaştırılmıştır. İki ülke Hükümetleri arasında, "Türkistan Şehrinde Uluslararası Hoca Ahmet Yesevi Türk-Kazak Üniversitesi Kurulmasına Dair Anlaşma” ise, 31 Ekim 1992'de Türk Dili Konuşan Ülkeler Devlet Başkanları Zirvesi'nde Ankara'da imzalanmıştır. Tüzük gereği Üniversite Rektörü Kazakistan Cumhuriyeti, Rektör Birinci Yardımcısı ise Türkiye Cumhuriyeti Yüksek Öğretim Kurulu tarafından atanmaktadır (Yesevi, 2015).

Kurulan ortak üniversite iki ülke arasındaki ilişkileri geliştirmiş ve karşılıklı öğrenci alışverişini arttırdığı gibi Kazakistan'ın eğitiminin gelişmesine katkı sağlamıştır. Ahmet Yesevi Üniversitesinde, 11 fakülte ve 1 yüksekokulda, 4000'i Türkiye'den, 750'si Kazakistan dışındaki Türk Devletleri ve Topluklarından olmak üzere yaklaşık 16 bin öğrenci öğrenim görmekte ve 1100'ü aşkın akademik personel görev yapmaktadır (Yesevi, 2015).

Akademisyen değişimleri ve öğrenci değişim programları Avrasya coğrafyasında bulunan Türk cumhuriyetleri ile kültürel etkileşim bakımından önemlidir zira bu projeler, kültürel etkileşimi gerçekleştirmekte buda kültürümüzün ve dilimizin yayılmasını sağlamaktadır. Türkiye'den Kazakistan'a gelen öğrenci sayıs1 azımsanmayacak ölçüdedir. Yüksek Öğrenim Kurumu’nun başlattığı Mevlana Değişim Programı'na Kazakistan'dan 9 Üniversite dahil olmuştur. Bu rakam ile Kazakistan, Mevlana Değişim Programına üniversite sayısı bakımından en çok katkı veren üçüncü ülkedir (YÖK Mevlana Programı, 2014). Ancak kazak öğrencilerin Türkiye'deki sayılarının düşük olduğunu belirtmek gerekir. Aşağıdaki tabloda Kazak öğrencilerin öğrenim düzeylerine göre sayısı verilmiştir.

\begin{tabular}{|l|c|}
\hline Ë̆itim Düzeyi & Sayı \\
\hline Ön Lisans & 11 \\
\hline Lisans & 269 \\
\hline Yüksek Lisans & 111 \\
\hline Doktora & 77 \\
\hline Tıpta Uzmanlık & 7 \\
\hline Toplam & $\mathbf{4 7 5}$ \\
\hline
\end{tabular}

Tablo 3. 2014 Yılında Türkiye’de Bulunan Kazak Öğrenci Sayıları Kaynak: T.C Milli Ĕ̈itim İstatistikleri

Tabloda görüldüğü üzere Kazak öğrenci sayısının gelecek yıllar içerisinde arttırılması için eğitim alanında işbirliklerinin geliştirilmesi gerekmektedir. Mevlana Değişim Programı özendirilmeli ve öğrencilere verilen destekler artırılmalıdır. Zira öğrenci değişimi ülke ekonomisine katkı sağladığı gibi Turistik açıdan da tanıtım elçiliği yapılmaktadır. Öğrenci değişim Programları ile ya da çeşitli kademelerde eğitim almaya giden öğrencilerin, gittikleri ülkenin güzelliklerini kendi ülkelerinde anlatarak, öğrenci oldukları ülkenin turizm açısından çekiciliğini arttırmaktadırlar bu gerçeklik dolaylıda olsa ülkelerin turizm çekiciliklerini artırmaktadır.

\section{Kazakistan-Türkiye Ekonomik İlişkileri}

Ülkelerin kalkınmasında ekonomik, sosyal ve kurumsal yapının büyük önemi vardır ancak bu yapıyı oluşturan etmenler uluslararası ticaret ilişkileri ile beraber bir anlam ifade etmektedir. Uluslararası ticaret olmadan kalkınma stratejilerinin tek başlarına az gelişmiş bir ülkeyi kalkındırması mümkün değildir. Günümüz dünya ekonomisinde küreselleşme ile birlikte uluslararası ticaretin önemi hayati boyutlara ulaşmıştır (Batmaz, 2004).

Kazakistan'da bağımsızlık sonrası bazı ekonomik sorunlar ile karşılaşmış ve bu sorunları kısa sürede atlatıp 1998'den sonra ise hızlı bir büyüme sürecine girmiştir. Özelikle ülkede bulunan petrol ve doğalgaz kaynakları başta Avrupa Birliği olmak üzere birçok ülkeyi cezp etmektedir. Petrol fiyatlarının artmasıyla beraber ülkenin gelir düzeyi de artmıştır (Ersungur, vd, 2007). Türkiye ise Kazakistan'ın bağımsızlığının hemen ardından ekonomik ilişkilere başlamış ve ortak kültürü fursata çevirmenin yollarını aramıştır.

Kazakistan'da bulunan Türk firmalarının başlıca faaliyet alanları incelendiğinde müteahhitlik hizmetleri ön plana çıkmaktadır. Bu hizmeti gıda, süt ürünleri, tuğla, bakır, demir-çelik, tekstil, dericilik gibi sektörler izlemektedir (Uzun Kocamış, vd, 2012).

\subsection{Dış Ticaret Göstergeleri}

Yıllara göre dış ticaret hacmi Türkiye'nin Kazakistan'dan petrol ürünleri ithalatının arttırması ve Türkiye'nin ihracat miktarının artması sonucunda dış ticaret hacminde büyüme meydana gelmiştir. Yıllara göre TürkiyeKazakistan Dış Ticaret Göstergeleri aşağıdaki tabloda verildiği gibi gelişmiştir. 


\begin{tabular}{|c|c|c|c|c|}
\hline YIL & IHRACAT & ITHALAT & HACIM & DENGE \\
\hline $\mathbf{2 0 0 3}$ & 234 & 266,6 & 500,6 & $-32,6$ \\
\hline $\mathbf{2 0 0 4}$ & 355,6 & 442,2 & 797,8 & $-86,6$ \\
\hline $\mathbf{2 0 0 5}$ & 459,9 & 558,9 & 1018,8 & -99 \\
\hline $\mathbf{2 0 0 6}$ & 696,8 & 993,7 & 1690,6 & $-296,9$ \\
\hline $\mathbf{2 0 0 7}$ & 1079,9 & 1284 & 2363,9 & $-204,2$ \\
\hline $\mathbf{2 0 0 8}$ & 890,6 & 2332 & 3222,6 & $-1441,4$ \\
\hline $\mathbf{2 0 0 9}$ & 633,4 & 1348,9 & 1982,3 & $-715,5$ \\
\hline $\mathbf{2 0 1 0}$ & 818,9 & 2471 & 3289,9 & $-1652,1$ \\
\hline $\mathbf{2 0 1 1}$ & 947,8 & 3020 & 3967,8 & $-2072,2$ \\
\hline $\mathbf{2 0 1 2}$ & 1068,6 & 3371 & 4439,6 & $-2302,4$ \\
\hline $\mathbf{2 0 1 3}$ & 1039,4 & 3106,1 & 4145,5 & $-2066,8$ \\
\hline $\mathbf{2 0 1 4}$ & 977,8 & 2453,4 & 3431,3 & $-1475,6$ \\
\hline
\end{tabular}

Tablo 4. Dış Ticaret Göstergeleri (Milyon Dolar) Kaynak: T.C. Ekonomi Bakanlı̆̆

Tabloda da görüldüğü üzere Kazakistan ile yükselme trendinde olan diş ticaret hacminden bahsedilebilir. 2014 yılı dış ticaret hacminde bir önceki yıla oranla 714,2 milyon dolarlık bir düşüş gözlenmekte. İki ülke arasındaki dış ticaret dengesine bakıldığında ise Türkiye'nin her zaman eksi değerde olduğu görülmektedir. Bunun başlıca sebebi Türkiye'nin petrol tüketen bir ülke olması ve petrol kaynaklarının gereksinimlerinin çok az bir miktarını karşılaması sonucunda petrol ithalatı yapmasıdır. Kazakistan'dan yapılan ithalatın büyük miktarını da petrol ve türevleri oluşturmaktadır. İki ülke arasındaki ihracat ve ithalat ürünlerine bakılınca olay daha net anlaşılacaktır. Aşağıdaki tabloda Türkiye'nin Kazakistan'a ihracatında başlıca ürünlerin ilk beşi verilmiştir.

\begin{tabular}{|c|c|c|c|}
\hline ÜRÜN ADI & 2012 & 2013 & 2014 \\
\hline $\begin{array}{l}\text { Mücevherci eşyası ve aksamı (kıymetli metallerden veya kıymetli } \\
\text { metallerle kaplama metallerden) }\end{array}$ & 129,2 & 114,6 & 74,7 \\
\hline $\begin{array}{l}\text { Plastikten monofiller, ince ve kalın çubuklar ve profiller (enine kesitinin } \\
\text { en geniş yeri }>1 \mathrm{~mm} \text { ) }\end{array}$ & 37 & 35 & 28,2 \\
\hline $\begin{array}{l}\text { Demir veya çelikten inşaat ve inşaat aksamı, inşaatta kullanılmak üzere } \\
\text { hazırlanmış demir veya çelik }\end{array}$ & 16,8 & 23 & 23,1 \\
\hline $\begin{array}{l}\text { Dokunmuş halılar ve dokumaya elverişli maddelerden diğer yer } \\
\text { kaplamaları }\end{array}$ & 26,5 & 24 & 22,8 \\
\hline $\begin{array}{l}\text { Plastikten hortumlar, borular ve bağlantı elemanları (manşon, nipel, } \\
\text { dirsek, flanşlar, vb.) }\end{array}$ & 19,6 & 21,8 & 22,3 \\
\hline
\end{tabular}

Tablo 5. Türkiye'nin Kazakistan'a İhracatında Başlıca Ürünler (Milyon Dolar) Kaynak: T.C. Ekonomi Bakanlı̆̆

Görüldüğü üzere Kazakistan'a yapılan ihracat'ın genelini değerli ve işlenmiş maden ürünleri ve inşaat malzemeleri oluşturmaktadır. İnşaat malzemelerinin ihracatta büyük paya sahip olmasını da Kazakistan'ın gelişmekte olan ve büyüyen bir ülke olması dolayısıyla büyük miktarda konut ve yapılaşma içerisinde olmasının etkisi vardır. Bu sektörde Türk müteahhitlik hizmetleri de Kazakistan'da büyük yatırımlar gerçekleştirmiştir. Türk müteahhitlerince bugüne kadar Kazakistan'da üstlenilen projelerin toplam değeri ise 20 milyar Dolar'a yaklaşmıştır (T.C Dış İşleri, 2015). Astana'nın Kazakistan'ın başkenti olduğu günden bu yana Astana'da ki inşaat projelerinin yaklaşık yüzde 70'i Türk müteahhitler tarafından yapılmıştır (Dış Ekonomik İlişkiler Kurulu, 2011).

Başta petrol, telekomünikasyon, otelcilik ve bankacılık alanlarında olmak üzere Kazakistan'daki toplam Türk yatırımı 2,05 milyar Dolar tutarındadır (T.C Dış İşleri, 2015). Kazakistan İstatistik Ajansı verilerine göre, Kazakistan'daki yabancı sermayeli şirket sayıları dikkate alındığında Türkiye, Rusya ve Çin'den sonra Kazakistan'da en fazla yabancı hisseli şirkete sahip olan üçüncü ülkedir (Dış Ekonomik İlişkiler Kurulu, 2011). Öte yandan Türkiye'nin Kazakistan'dan ithalatında ilk beş ürüne bakıldığında şu tablo ile karşılaşmaktayız.

\begin{tabular}{|c|c|c|c|}
\hline ÜRÜN ADI & 2012 & 2013 & 2014 \\
\hline Ham petrol (petrol yağlar1 ve bitümenli minerallerden elde edilen yağlar) & 1314,9 & 1346 & 1217,2 \\
\hline Petrol gazları ve diğer gazlı hidrokarbonlar & 560,9 & 509,2 & 448,8 \\
\hline Rafine edilmiş bakır ve bakır alaşımları (ham) & 838,5 & 789,1 & 331,7 \\
\hline İşlenmemiş çinko & 168 & 179,5 & 172,7 \\
\hline İşlenmemiş alüminyum & 95,7 & 120,1 & 98,1 \\
\hline
\end{tabular}

Tablo 6. Türkiye'nin Kazakistan'dan İthalatında Başlıca Ürünler (Milyon Dolar) Kaynak: T.C. Ekonomi Bakanlığ 
Türkiye'nin Kazakistan'dan ithal ettiği başlıca ürünlerin yoğun olduğu sektör genelde işlenmemiş petrol ve maden ürünleridir. Veriler üzerinden bakıldığında Kazakistan'dan yapılan ithalatın hammadde üzerine yoğunlaştığı açıktır. Türkiye'nin petrol rezervlerinin azlığı ve Türkiye'de çıkarılan petrolün ihtiyaç duyulan petrolü karşılama oranı \%7 olmasından dolayı (Thelira, 2015) Türkiye'nin dış ticaret açığının ciddi bir bölümü petrol ve türevlerinden oluşmaktadır. Bu kapsamda Kazakistan ile yapılan ithalatın büyük bir kısmını petrol ürünleri oluşturmaktadır. Zira Kazakistan, Türkiye'nin ham petrol ithalatında dördüncü sırada yer almaktadır (Bugün, 2015).

Türkiye'nin Kazakistan'dan ithalatındaki başlıca ürünlerin yıllara göre miktarlarına bakıldığında ham petrol ve türevleri ile işlenmemiş çinko, işlenmemiş alüminyum ithalatında 2012 ile 2014 yılları arasında çok bariz değişimlerin olmadığ 1 görülmektedir. Rafineri edilmiş bakır ve bakır alaşımlarının ithalat oranında ise 2013 yılı sonrasında çok ciddi düşüş gözlemlenmektedir. İthal edilen bakır ve bakır alaşımı miktarının ciddi derecede düşmesinde 2013 yılında Türkiye'nin Siirt ilinde bulunan 23 milyon ton bakır rezervinin bulunması etkili olduğu düşünülmektedir. Bulunan madenden yıllık 1,5 milyon ton bakır,125 bin ton bakır konsantresi çıkarılması hedeflenmiştir (İnternethaber, 2015). Bu miktar Türkiye'nin bakır ve bakır alaşımının ithalatını etkilediği düşünülmektedir.

Türkiye ve Kazakistan arasındaki işbirliğinin büyük bölümü enerji politikalarından oluşmaktadır ancak Türkiye ikili ilişkilerini sadece enerji üzerinden sınırlandırmamalı, dış ticaret ve doğrudan yatırımlar alanlarındaki firsatları değerlendirmelidir. Kazakistan'ın cari işlemler fazlasından doğan ekonomik girdiler yurt dışı yatırımı için kaynak oluşturmaktadır. Bu kaynağı çekebilecek potansiyele sahip olan ülkelerin başında Türkiye gelmektedir zira Türkiye, genç nüfusu, bölgesel konumu ve ekonomik yapısı ile ön plana çıkmaktadır. Dolayısıyla Türkiye sadece Kazakistan ile olan ilişkilerini geliştirmekle kalmamalı bölge ülkeleri ile olan siyasi ve ekonomik iliş̧ilerini geliştirecek ve işbirliği alanlarını arttıracak fırsatları değerlendirmelidir (Macit, 2013).

\section{Sonuç ve Öneriler}

Sovyetler Birliği’nin dağılması ile birlikte bağımsızlığını kazanan Türk Cumhuriyetler ile Türkiye ilişkilerini geliştirmeye çalışmıştır. Türkiye, Türki Cumhuriyetler ile olan ortak kültür ve değerlerini firsata çevirmenin yollarını aramıştır. Yumuşak gücün bu unsurlarının kullanımında kimi zaman başarısız olunsa da, Türk cumhuriyetler, Türk diş politikasında önemli yer tutmuştur.

Kazakistan’ın bağımsızlığını kazanması ile başlayan samimi ve yoğun ikili ilişkiler bölgesel faktörler ve özelliklede Rusya faktörü nedeni ile siyasal anlamda çok derinleşememiş ancak ekonomik açıdan iki ülkede her geçen gün daha iyi bir noktaya ulaşmıştır. Gelinen noktada ikili ilişkilerin yeterli düzeyde olmadığı soy ve kültürel ortaklığın avantajlarının yeterince kullanılmadığı açıktır. TİKA bütçesinden Kazakistan'a yapılan yatırım miktarları düşük kalmaktadır. TİKA bütçesinden ayrılan pay arttırılmalıdır. Eğitim alanındaki işbirliği incelendiğinde Kazak öğrenicilerin Türkiye'de eğitim alma oranları son derece düşük olduğu görülmektedir. Eğitim alanının daha cazip hale getirilip öğrenci değişim oranlarının arttırılması gereklidir. Öğrenci değişimi sadece eğitim alanında işbirliğini sağlamayacak, kültürlerin tanınmasını ve turizmin gelişmesini de sağlayacaktır.

Kazakistan yatırım için cazip bir ülkedir ancak ülkedeki yapısal sorunların kısa vadede çözülmesi gerekmektedir. Ekonominin doğal kaynakların ihracatına bağlı olması Kazakistan için olumsuz bir durumdur. Kazakistan ekonomisindeki Rus etkisinden kurtulmalı, ticaret partnerlerini çeşitlendirmelidir.

Türkiye'nin Kazakistan'da inşaat sektöründe etkin olması olumlu ancak tek sektöre yoğunlaşması olumsuz bir durumdur. Türkiye Kazakistan diş ticaret göstergelerine bakıldığında Türkiye'nin petrol ürünleri ithalatı nedeni ihracat-ithalat dengesinde yaklaşık iki kat açık vermektedir bundan ötürü Türkiye Kazakistan'a yapacağı ihracatı arttıracak politikalar geliştirilmelidir. İki ülke arasında turizm potansiyeli istenilen düzeyde değildir. Turizmin geliştirilmesi için ülkeler arasında tanıtımın arttırılması gerekmektedir. Sigorta sistemi ile bölgedeki yatırımlar güvence altına alınmalıdır.

\section{Kaynakça}

- $\quad$ Ahmet Yesevi Üniversitesi, 2015. Hakkında, www.yesevi.edu.tr

- Akçay, 2012.’Bir Dış Politika Enstrümanı Olarak Türk Dış Yardımları”, Turgut Özal Üniversitesi Yayınları, No:5, syf.2

- Aljazeera Türk, 2015. Erdoğan'ın Ziyareti Kazakistan İle Stratejik Ortaklığ1 Pekiştirecek, http://www.aljazeera.com.tr/gorus/erdoganin-ziyareti-kazakistan-ile-stratejik-ortakligi-pekistirecek

- Bugün Gazetesi, 2015. Türkiye En Pahalı Petrolü Kazakistan'dan Alıyor, http://www.bugun.com.tr/sondakika/-turkiye-en-pahali-petrolu--haberi/1142051

- $\quad$ Batmaz, 2004.’Türkiye-Kazakistan Arasındaki Ticari-Ekonomik İlişkiler, Türk Müteşebbislerinin Bu Ülkede Yaptıkları Yatırımların Boyutu ve Karşılaştıkları Sorunlar”, Bilig Dergisi, Sayı: 29, syf.86. 
- Çavuş, 2012.’Dış Politikada Yumuşak Güç Kavramı ve Türkiye’nin Yumuşak Güç Kullanımı”, Kahramanmaraş Sütçü İmam Üniversitesi İktisadi ve İdari Bilimler Fakültesi Dergisi, Cilt: 2, syf.25, 31, 32, 33.

- Denizhan, 2010.’Türkiye'nin Kafkasya ve Orta Asya Politikası ve TİKA”, Sosyal ve Beşeri Bilimler Dergisi, Cilt 2, syf.21.

- D1ş Ekonomik İlişkiler Kurulu,2011. "Kazakistan Ülke Bülteni”, syf.9

- Erdoğan, Bağcı,2013. Türk Dış Politikası II, T.C Anadolu Üniversitesi Yayını, 2984, syf. 41-42,77-78.

- Ersungur, Kızıltan, Karabulut,2007.’Türkiye ile Diğer Türk Cumhuriyetlerinin Ekonomik İlişkilerinin Analizi”, A.Ü Türkiyat Araştırmaları Enstitüsü Dergisi, Sayı:35, syf.294-295

- İnternethaber, 2015. Ciner Siirt'te Dev Maden Rezervine Ulaşt1, http://www.internethaber.com/ciner,-siirttedev-maden-rezervine-ulasti-564442h.htm

- Karagül,2013.’Türkiye'nin Balkanlardaki "Yumuşak Güç” Perspektifi: Türk İşbirliği ve Koordinasyon Ajansı", Girişimcilik ve Kalkınma Dergisi,8:1,syf.80-83

- Kardaş ve Erdağ, 2012.'Bir Diş Politika Aracı Olarak TİKA”, Akademik Incelemeler Dergisi, Cild 7, syf.170-187.

- Konak,2006.’’ihracatın finansmanında Eximbank Kredileri: Türkiye Örneği”, Uludağ Üniversitesi Sosyal Bilimler Enstitüsü İktisat Anabilim Dalı, Yüksek Lisans Tezi, syf.90.

- Macit," Türk Konseyi Ekonomik İlişkileri Yeterli mi? ”Hazar Raporu Bahar 2013, syf.86, http://www.hazar.org/UserFiles/yayinlar/Blog/FatihMacit.pdf

- $\quad$ T.C. Başbakanlık TİKA, 2013. "Faaliyet Raporu”, syf. 97

- Thelira, 2015. Türkiye'de Petrol Var mı?, http://www.thelira.com/yazar/2/yavuz-semerci/1840/turkiyedepetrol-var-mi?

- Türk Eximbank, 2015. Turk Eximbank hakkında bilgi, http://www.eximbank.gov.tr/TR,5/hakkimizda.html

- Türk Eximbank, 2015. Turk Eximbank hakkında genel bilgi, http://www.eximbank.gov.tr/TR,472/genelbilgi.html

- Türk Eximbank, 2013. "Faaliyet Raporu”, syf. 37

- Türk Eximbank, 2015. Destek Verilen Projeler, https://www.eximbank.gov.tr/TR,860/destek-verilenprojeler.html

- Türk İşbirliği ve Koordinasyon Ajansı Başkanlığı, 2013. “Türkiye Kalkınma Yardımları Raporu”. Syf.11

- Uzun Kocamış, Kuzu, Aksu, 2012.”Orta Asya'daki Ekonomik Gelişmeleri Bağlamında Türkiye’nin Kazakistan ile İlişkilerine Genel Bir Bakış”, International Conference on Eurasıan Economies, syf.267.

- Yükseköğretim Kurulu Başkanlığı, 2014. “Mevlana Değişim Programı Kitapçı̆̆ı.” Syf.17 


\title{
Avrasya Gümrük Birliği ve Türkiye'nin Üyeliği Eurasian Customs Union and Turkey's Membership
}

\author{
Prof. Dr. S. Rıdvan Karluk (Turgut Özal University, Turkey)
}

\begin{abstract}
Leaders of Russia, Belarus, and Kazakhstan which are the countries of disintegrated Soviet Union signed an agreement in order to establish a Union named Eurasian Economic Union on the date of 29 May 2014. With this attempt Russia wants to protect its former penetration on former Soviet geography by providing economic integration. Positive messages upon the membership of Turkey to Eurasia Economic Union were given at Eurasia Economic Union meeting which was held in Ankara in January mid-2015 and hosted by Andrey Karlov, Ambassador of Russia. Nursultan Nazarbayev, who is the pioneer of this idea, has stressed that Turkey should be a member of the Community several times before now. The idea of Sergey Markov, who is the point man of Putin as "Turkey should enter Eurasia Union not European Union, it can gain strength in this way", is void within the scope of international agreements which Turkey signed with European Union and of the rules of WTO. Erdoğan, Prime Minister of the relevant term said Putin that "Take Turkey into Shanghai Cooperation Organization and ease our difficulty"; in Russian- Turkey peak held on 23 November 2013 in St. Petersburg province of Russia. This explanation is not possible in terms of international law. Explanation of Zeybekçi, Minister of Economy as "Eurasia Customs Union is a must for Turkey. We have to be there" is not realistic. In our paper we will deal and explain why Turkey cannot enter Eurasia Customs Union and why an axial dislocation cannot occur in Turkey.
\end{abstract}

\section{Giriș}

Türkiye'nin gelecek yıllarda gerek küresel, gerek bölgesel imkanları nasıl değerlendirebileceği, ne türden stratejiler belirleyeceği çok önemlidir. Bu sorulara cevaplar aranırken dünyada mevcut ve muhtemel, geniş ve dar kapsamlı ekonomik birleşme hareketlerini iyi izlemek gerekir. Türkiye'nin küreselleşen dünyadaki yerini sağlıklı bir şekilde belirlemek, kısa ve uzun vadeli durum değerlendirmelerinde bulunmak, 21'nci yüzyılda çağdaş bir ülke olmak için büyük önem taşımaktadır. Türkiye, ekonomisini liberalleştiren ve dünya ekonomisi ile bütünleşme çabası içinde olan gelişme yolundaki ülkelerden biridir. Avrupa kıtasında olmayan ülkelerden temel farkı, Avrupa'nın politik ve ekonomik kuruluşlarının tamamına yakınına üye olmasıdır.

Türkiye bulunduğu bölgede Karadeniz Ekonomik İşbirliğii, Ekonomik İşbirliği Kuruluşu ve İslam Konferans1 Kuruluşu çerçevesinde işbirliği çabalarını sürdürmektedir. Türkiye'nin değişen dünya şartlarına uyum sağlaması ve dünya ekonomisiyle istenilen şekilde bütünleşebilmesi için, orta ve uzun vadeli stratejilere ihtiyacı vardır. Bu stratejiler içinde Avrasya Ekonomik (Gümrük Birliği) Birliği, Şanghay İşbirliği Kuruluşu ya da bazı akademisyenleri tanımlamasıyla Altay Birliği yoktur. Bildirimizde bu alternatifler değerlendirilecek ve Türkiye’nin Avrasya Ekonomik Birliği’ne neden üye olamayacağı açıklanacaktır.

\section{Uluslararası Ekonomik Birleşmeler Kapsamında Gümrük Birlikleri}

Ekonomik birleşme; ulusal, uluslararası ve dünya birleşmesi olarak başlıca üç şekilde incelenebilir. Her ekonomik birleşme işbölümüne dayanır, ileri derecesinde malların ve üretim faktörlerinin serbest dolaşımını, bunların kaynağa ve yöneldiği bölgeye göre ayrıcalıklı olmayan bir uygulama görmesini öngörür. Genel tanımıyla uluslararası ekonomik birleşme, birleşmeye giden ekonomilerde mal ve hizmetler akımlarına serbesti sağlayıp ticarete engel olan kısıtlamaları ortadan kaldırarak bir ortak pazar yaratmaktır. Böylece ekonomik birleşme ile daha geniş bir pazara üretim yapmak ve büyük çapta üretimin sağladığı imkanlardan yararlanmak mümkün olmaktadır (Karluk,2013).

Uluslararası ekonomik birleşmeler literatürde çeşitli ekonomik bütünleşme türlerini kapsayan genel bir terim olarak kabul edilmektedir (Balassa, 1961). Latince "integratio" kelimesinden türetilen "integration" kelimesinin anlamı "bütünleşme" olmakla birlikte, Türkçe literatürde daha çok "birleşme" şeklinde kullanıldığı için bildirimizde bu ifade tercih edilmiştir. Ekonomik birleşme terimi ilk defa 31 Ekim 1949 tarihinde OEEC Konseyi'nde Paul G. Hoffman tarafından verilen bir bildiride yer almıştır (Machlup, 1977).

Uluslararası ekonomik birleşmelerin başarılı olabilmesi için bazı temel şartlar gereklidir. Bunlar; taşıma giderleri sebebiyle aynı coğrafyada bulunmak, ekonomik ve politik sistemlerde benzerlik, aynı askeri ittifaklara dahil olmak, ekonomik gelişme seviyesi bakımından üyeler arasında yakınlık ile tarihi, sosyal, kültürel ve dini açılardan aynı değerleri paylaşmaktır. Bu faktörler uluslararası ekonomik birleşmelerin başarıya ulaşmasında çok önemlidir (Tinbergen, 1965).

Uygulamada başlıca 5 çeşit ekonomik birleşme vardır (Frankel, 1997). Tercihli ticaret düzenlemeleri, iki ve daha fazla ülke arasında ticareti etkileyen tarife ve tarife dışı engellerin bazı seçilmiş ürünlerde kaldırılarak 
taraflar arasında bir serbest ticaret alanı (bölgesi) oluşturulmasını sağlar. 2015 yılında Dünya Ticaret Kuruluşu çerçevesinde 27 düzenleme yapılmıştır. Taraf ülkeler bazı seçilmiş ürünlerde tarife indirimlerinde bulunurken, yüksek tarifeleri diğer ürünlerde uygulamaya devam ederler. Açıkçası, ticaret blokuna dahil olan ülkeler bazı ürünlerde diğer bazı ülkelere tarife indirimlerinde bulunur, fakat tarifeleri tamamen kaldırmazlar.

Serbest ticaret bölgesi bölge ülkeleri arasında ticareti kısıtlayan veya engelleyen tarife ve kota gibi sınırlamaların ortadan kaldırıldığ 1 ve üye ülkelerin birlik dışında kalanlara karşı ortak bir tarife uygulama yükümlülügü altında bulunmadıkları ekonomik birleşme türüdür. Gümrük birliği, serbest ticaret bölgelerine göre daha geniş kapsamlı bir ekonomik birleşme türüdür. Burada serbest ticaret bölgesindeki şartlara ek olarak birliğe üye ülkelerin serbest dış ticaret politikası izleme imkanları sınırlandırılmış olduğundan, gümrük birliği serbest ticaret bölgesine göre ileri bir ekonomik birleşmedir (El-Agraa, 1982).

Ekonomik birleşmenin dördüncü aşaması ortak pazardır. Gümrük birliğinin doğal sonucu olarak birliğe üye ülkeler arasındaki emek, sermaye ve müteşebbis gibi üretim faktörlerinin birlik içinde serbestçe hareket edebilmeleri sağlanmış ise, gümrük birliği için gerekli şartların varlığının devam etmesi durumunda, üye ülkeler arasında bir ortak pazar kurulmuş demektir. Uygulamada ortak pazar terimi, ilk defa 1956 tarihli Spaak Raporu'nda yer almış ve Roma Anlaşması'nın yürürlüğe girmesiyle sıkça kullanılmaya başlanmıştır. Türkçe literatürde geçmişte Avrupa Ekonomik Topluluğu'na Ortak Pazar da denilmektedir. Ortak pazar bazı iktisatçılar tarafindan "derin entegrasyon" olarak tanımlanmaktadır (Lawrence, 1995). Çünkü ortak pazar, ekonomik birleşmelerin sondan bir önceki aşamasıdır. Ekonomik ve parasal birlik ekonomik birleşmenin son aşamasıdır. Ekonomik birlik, birliğe üye ülke ekonomilerinin birleştirilmesidir (Tinbergen, 1965). Yukarıda belirtilen ekonomik birleşmelerdeki şartlara ek olarak, ekonomi, para ve sosyal politikalar ile kurumların da birleştirilmesini öngörür.

\section{Asya'da Yeni Ekonomik Yapılanma ve Türkiye}

Sovyetler Birliği'nin dağılmasından sonra Sovyet ardılı ülkeler arasında 5 yeni ekonomik yapılanma oluşmuştur. Bağımsız Devletler Topluluğu (CIS) 8 Aralık 1991 tarihinde Beyaz Rusya, Rusya Federasyonu ve Ukrayna arasında Bleovejskaya Puşsa'da imzalanan Minsk Anlaşması ile kurulmuş, böylece Sovyetler Birliği'ne son verilmiştir (Scollay ve Gilbert, 2001). Baltık devletleri ve Gürcistan dışında tüm eski Sovyetler Birliği Cumhuriyetleri Anlaşma'ya taraf olmuştur. Azerbaycan ve Gürcistan 1993 yılına kadar anlaşmay1 onaylamamıştır. BDT kurucu üyeleri; Beyaz Rusya, Ermenistan, Kazakistan, Kırgızistan, Moldova, Özbekistan, Ukrayna, Türkmenistan, Tacikistan ve Rusya Federasyonu'dur. Türkmenistan 26 Ağustos 2005 tarihinde ortak üye statüsüne geçmiş̧ir. Gürcistan Topluluk'tan 17 Ağustos 2009 tarihinde ayrılmıştır. Ukrayna 2014 Mart ayında Rusya'nın Kırım'ı ilhak etmesinden sonra üyelikten çıkmıştır. BDT pazarı 240 milyonluk nüfusu ile dünyanın önde gelen en büyük pazarları arasındadır (Karluk, 2014a).

Ortak Ekonomik Alan'ın (CES) oluşumu amacıyla Rusya, Ukrayna, Belarus ve Kazakistan, Moskova'nın dışında Novo-Oganevo'da 23 Şubat 2003 tarihinde bir toplantı yapmışlardır. Beyaz Rusya, Kazakistan, Rusya ve Ukrayna arasında Ortak Ekonomik Alan Kurulmasına İlişkin Serbest Ticaret Anlaşması anılan ülkelerin devlet başkanları tarafından 19 Eylül 2003 tarihinde Yalta'da imzalanmış, 20 Eylül 2004 tarihinde onaylanmıştır.

22 Mayıs 2003 tarihinde Ukrayna Parlamentosu CES'e katılmayı anayasasına uygunluk şartıyla kabul etmiştir. Anlaşma üye ülkeler arasında serbest ticaret bölgesi kurulmasını, mal ve hizmetler ticaretinde sınırlamaların kaldırılarak ortak gümrük ve ticaret politikaları uygulanmasını amaçlamışıı. Avrasya bölgesinde Türkiye ve Orta Asya Türk Cumhuriyetlerinin bir arada bulunduğu bir diğer önemli kuruluş 1985 yilında Türkiye, İran ve Pakistan tarafindan oluşturulan Ekonomik İşbirliği Kuruluşu'dur (ECO). Türkiye, İran ve Pakistan Devlet ve Hükümet Başkanları, bölgesel ekonomik işbirliğini geliştirmek amacıyla 1964 yılında İstanbul'da bir bildiri yayınlayarak Kalkınma İçin Bölgesel İşbirliği Kuruluşu'nu kurmuşlardır.

1977 tarihli İzmir Anlaşması ile yasal statüsü oluşturulmuş, 1985 yılında Ekonomik İşbirliği Kuruluşu'na dönüşmüştür. Sovyetler Birliği'nin dağılması sonrasında 1992 yılında bağımsızlıklarını kazanan Azerbaycan, Kazakistan, Kırgızistan, Özbekistan, Türkmenistan, Tacikistan ile Afganistan'ın da katılmasıyla toplam 7 milyon km2 alan üzerinde yaklaşık 400 milyon nüfusa hitap eden ekonomik ağırlıklı bir bölgesel kuruluş olmuştur.

Şanghay İşbirliği Kuruluşu (SCO) adını Kuruluş'un ilk toplandığı yer olan Çin'in Şanghay kentinden almıştır. Çin Halk Cumhuriyeti, Rusya, Kazakistan, Kırgızistan ve Tacikistan'ın 1996 yılında başlattıkları girişime Şanghay Beşlisi denmiştir. Oluşumunda Çin Halk Cumhuriyeti önemli rol oynamıştır. Sınır güvenliği, Batı ve Orta Asya bölgelerinin gelişimi, büyüyen enerji ihtiyacı ve Soğuk Savaş sonrası stratejik ortam, Kuruluş'un oluşmasındaki önemli faktörlerdir. 15 Haziran 2001 tarihinde Özbekistan'ın katılımıyla üye sayısı altıya çıkmıştır. 7 Haziran 2002 tarihli Saint Petersburg'taki Zirve'de Rusya, Çin, Kazakistan, Özbekistan, Kırgızistan ve Tacikistan'ı birleştiren SCO'nun kurulmasına ilişkin belgeler kabul edilmiştir.

Kuruluş, üyeleri arasında ekonomik, güvenlik ve kültürel işbirliği öngörmektedir. Dönemin Rusya Devlet Başkanı Putin Ağustos 2007'deki Bişkek Zirvesi'nde "Tek kutuplu dünya kabul edilemez" diyerek Kuruluş'un misyonu hakkında ipucu vermiştir. Şanghay İşbirliği Kuruluşu'na Afganistan, Hindistan, İran, Moğolistan ve 
Pakistan "gözlemci ülke" (observer) statüsüyle katılmaktadır. Beyaz Rusya (Belarus), Sri Lanka ve Türkiye diyalog ortağ (dialogue partner) ülkelerdir.

Avrasya Ekonomik Birliği'nin (EurAsEC) kurulma süreci 6 Ocak 1995'te Rusya ile Belarus arasında imzalanan Gümrük Birliği Anlaşması ile başlamıştır. Kuruluş Anlaşması 10 Ekim 2000 tarihinde Astana'da Rusya, Beyaz Rusya, Kazakistan, Kırgızistan ve Tacikistan Cumhurbaşkanlarınca imzalanmıştır. 2002 yılında Moldova ve Ukrayna, 2003 yılında da Ermenistan gözlemci olarak, 7 Ekim 2005 tarihinde Özbekistan Birliğe katılmış, böylece üye sayısı 6'ya çıkmıştır. Özbekistan üyeliğini 2008 yılında dondurmuştur (Park, 2006). Ağustos 2006 Zirve'nde gümrük birliğinin gerçekleştirilmesi kararlaştırılmıştır.

$\mathrm{Bu}$ temel üzerinde üye devletleri ekonomik yönden birleştirmek ve uzun vadede diğer CIS devletlerini aynı çatı altında toplamak amaçlanmıştır. Bu doğrultuda Rusya, Beyaz Rusya ve Kazakistan 29 Mayıs 2015 tarihinde Astana'da Avrasya Ekonomik Birliği Anlaşması'nı imzalamışlardır. Birliğe Ermenistan’ı dahil eden Anlaşma 9 Ekim 2014'de onaylanmış, Rusya Devlet Duması Anlaşma'y1 26 Eylül 2015'de uygun bulmuştur. Anlaşma 1 Ocak 2015 tarihinde yürürlüğe girmiştir. Birlik, Rusya'nın Orta Asya'daki ekonomik ayağı olarak değerlendirilebilir. Ekonomik birleşmedeki sorunlar göz önünde bulundurulduğunda, Birliğin siyasi yönü daha ağır basmaktadır.

\section{Türkiye'nin Avrasya Ekonomik Birliği’nin Çatı Kuruluşu Olan Şanghay İşbirliği Kuruluşu'na Katılım Girişimleri}

Rusya Devlet Başkanı Vladimir Putin, Asya'da oluşan ve giderek güçlenen bir organizasyon haline gelmeye başlayan Şanghay İşbirliği Kuruluşu'na Türkiye’nin ilgisini 2005 yılı başında Kazakistan'a yaptığı ziyaret sırasında açıklamıştır. Dönemin Başbakanı Recep Tayyip Erdoğan, 6 Aralık 2004'de tarihinde Rusya Devlet Başkanı Vladimir Putin'in Türkiye ziyaretinden sonra 9-11 Ocak 2005 tarihlerinde Moskova'ya resmi bir ziyaret gerçekleştirmiştir.

Putin, Başbakan Erdoğan ile görüştükten kısa bir süre sonra Kazakistan’a gitmiş ve Türkiye ile ilgili sürpriz bir açıklama yaparak Ankara'nın Şanghay İşbirliği Kuruluşu'na üye olmak istediğini Kazakistan Devlet Başkanı Nursultan Nazarbayev’e şöyle açıklamıştır: “Dün Türkiye Başbakanı Sayın Tayyip Erdoğan’ ı Moskova'da misafir etme, onunla detaylı görüşme imkanım oldu. Temaslarımız sırasında Erdoğan'dan, ülkesinin Şanghay Işbirliği Örgütü'ne büyük ilgi duymaya başladı̆̆ını memnuniyetle ögrendim. Türkiye'nin dile getirdiği bu ilgi bence önemli bir pozitif sinyal olarak algllanmall." (Özsöz, 2013).

Nazarbayev, Putin'in bu sözleri üzerine Türkiye'yi her zaman aralarında görmekten mutluluk duyacaklarını belirtmiştir. Başbakan Erdoğan, 18 Temmuz 2012 tarihinde gerçekleştirdiği Rusya ziyaretinde Putin'e "Zaman zaman bize takllyorsun. AB'de ne işin var diyorsun. $O$ zaman ben de şimdi size takılayım. Hadi gelin bizi Şanghay Beşlisi'ne dâhil edin, biz de AB'yi gözden geçirelim şeklinde bir latife yaptım” demiştir.

Türkiye, 23 Mart 2011 tarihinde Kuruluş'a diyalog ortağ1 statüsü kazanmak üzere başvuruda bulunmuştur. Başvuru, 14-15 Haziran 2011 tarihlerinde yapılan Devlet Başkanları Astana Zirve'sinde ele alınmış, fakat usul sorunları sebebiyle sonuçlandırılamamıştır. Kasım 2011'de Rusya'nın Saint Petersburg kentinde yapılan Zirve öncesinde Rusya Dışişleri Bakanlığı, SCO üye ülkelerinin Türkiye'ye diyalog ortağı statüsünün verilmesinden yana olduğunu açıklamıştır. Türkiye'nin başvurusu 6-7 Haziran 2012 tarihlerinde Pekin'de düzenlenen Devlet Başkanları Zirvesi'nde onaylanmıştır.

\section{Türkiye’nin AB ile Olan Gümrük Birliği Kapsamında Avrasya Gümrük Birliği’ne Üyeliği}

Türkiye'nin, o zamanki ismiyle Avrupa Ekonomik Topluluğu'na “ortak üyelik” için 1959 yılında başvuruda bulunmasının üzerinden 56 yıl, 1987 yılındaki "üyelik" başvurusu üzerinden de 28 yıl geçmiştir. Türkiye, Turgut Özal'ın ifadesiyle bu ince uzun yolda, (Karluk, 2015) günün birinde AB üyesi olma ümidiyle AB'nin tüm çifte standartlarını görmezden gelerek yükümlülüklerini yerine getirmeye çaba harcamıştır. Katılım müzakerelerinin, dönemin Dışişleri Bakanı Davutoğlu'nun ifadesiyle 2023 yılına kadar tamamlanıp, Türkiye Cumhuriyeti'nin 100'ncü kuruluş yılında $\mathrm{AB}$ üyesi olmasının mümkün olmadığı gerçeğini artık herkes bilmektedir. AB'nin Kıbrıs konusunda Türkiye'ye yaptığı baskılar, Türkiye'ye 1srarla önerdiği imtiyazlı ortaklık ve Türkiye'ye karşı uyguladığı Bobon kriterleri (BO: Bizden Olanlar, BON: Bizden OlmayaNlar) sebebiyle Türk kamuoyunda AB'ye karşı doğan tepki artmakta ve AB'ye yönelik sempati giderek azalmaktadır.

Türkiye AB ilişkilerinde son zamanlarda yaşanan sorunlar ve AB ile olan gümrük birliğinin gözden geçirilmesi gündemde iken Ekonomi Bakanı Nihat Zeybekçi'nin Pamukkale'de Aralık 2014'de düzenlenen Serbest Bölgeler Çalıştay'ında yaptığı konuşmada, Türkiye'nin AB sürecinden asla ayrılmaması ancak Avrasya'yı da unutmaması gerektiğini belirtmesi ve “...Avrasya, Gümrük Birliği’ni göz ardl ederse çok büyük hata yapar ...Avrasya Gümrük Birliği, Türkiye için vazgeçilmezdir. Biz orada olmak zorundayız. Körfez İşbirliği Teşkilatı içinde olmak zorundayız. Orta Afrika Birliği denen... birliğin içinde yer almak zorundayız” açıklaması gerçekçi değildir. 
Yürürlükte bulunan Ankara Anlaşması ve Katma Protokol değiş̧mediği sürece GATT/WTO kuralları gereğince Türkiye aynı anda iki farklı gümrük birliği içinde olamaz.

Prof. Dr. Emine Nur Günay 2011 yılında Barış Can ile yaptıkları "Orta Asya, Güney Kore ve Türkiye Arasında Olası Bir Gümrük Birliği: Türkiye'nin Potansiyel İhracat Kazanımları" başlıklı çalışmada (Günay, 2011) Altay Birliği önermiştir: "Avrupa'daki sorun ve Çin'in önlenemez yükselişi, Türkiye'nin bölgedeki potansiyel kazanımlarının araştırllmasının önemini vurgulamaktadır. Altay Birliği isimli Türkiye, Azerbaycan, Kazakistan, Kirglzistan, Güney Kore, Türkmenistan ve Özbekistan arasinda kurulacak tarihi, sosyal ve kültürel bağlarla desteklenen, küresel ekonomiye uyarlanmış, modern bir birlik önerilmektedir.” Öncelikle bilinmesi gerekir ki, sadece "tarihi, sosyal ve kültürel bağlarla" bir yere varılamaz. Ülkeler arasındaki esas bağ dokusu ekonomik ilişkilerdir.

Nitekim Tasam Başkanı Süleyman Şensoy 11 Nisan 2013 tarihinde şu doğru tespiti yapmıştır: "Sadece din, dil, tarih, coğrafya gibi etmenlerin bizi kurtaracağını, bizi bu çok boyutlu rekabette başarıll kılacağını zannedersek yanılırız diye düşünüyorum." (Şensoy, 2013) Prof. Günay, Türkiye'nin Orta Asya ülkeleri ile bir "ekonomik birlik" kurmasını önermektedir. Bu birlik şüphesiz gümrük birliğine dayanacaktır. Altay Birliği’nde Türkiye'nin Orta Asya ülkeleri ile gümrük birliği gerçekleştirmesi WTO kurallarına aykırıdır. Bunun için Türkiye'nin öncelikle AB ile imzaladığı Ankara Anlaşması ve Katma Protokol'ü karşılıklı olarak feshetmesi gerekmektedir. Şimdilik böyle bir girişim yoktur. Türkiye'nin Avrasya Ekonomik Birliğine üyeliğini destekleyenler, GATT/WTO ilkelerini bilmemektedirler.

Türkiye'nin Şanghay İşbirliği Kuruluşu ile ekonomik ilişkilerini geliştirme ve de Avrasya Birliğine girme konusundaki 1srarı karşısında Rusya'nın Ankara Büyükelçisi Andrey Karlov'un ev sahipliğinde Ocak 2015 ortasında Ankara'da gerçekleşen Avrasya Ekonomik Birliği toplantısına Kazakistan, Belarus ve Kırgızistan'ın Ankara Büyükelçileri katılmıştır. Toplantıda Türkiye'nin Birliğe üyeliğine ilişkin olumlu mesajlar verilmiştir. Avrasya Ekonomik Birliği fikrinin öncülerinden olan Kazakistan Cumhurbaşkanı Nursultan Nazarbayev Türkiye'nin bu Birlikte yer alması gerektiğini birçok defa vurgulamıştır. Ankara'daki toplantıda Belarus Büyükelçisinin Türkiye'nin üyeliğiyle ilgili olumlu yaklaşım belirtmesi önemlidir.

Rusya Devlet Başkanı Putin'in sözcüsü, Birleşik Rusya Partisi milletvekili, siyaset bilimci Sergey Markov ise global arenada kendine yer arayan bu iki güçlü ülkenin yeni bir modelde birleşmesi gerektiğini söyleyerek Türkiye'nin AB'ye değil, Avrasya Birliği'ne katılarak güçlenebileceğini vurgulamıştır. Gürcistan, Azerbaycan dahil Kafkasya ülkelerinin de içinde olacağı Avrasya Birliği'nin Avrupa Birliği ile çatışan ona karşı duran bir yapıda olmayacağına dikkat çeken Markov, bu yapının küçük Avrupa olarak görülmemesi gerektiğini özellikle belirtmiştir (Markov, 2011).

Ocak 2015'de Uluslararası Antalya Üniversitesi tarafından Uluslararası Bilimsel Gelişim ve İşbirliği Enstitüsü ve Rusya Bilimler Akademisi Şarkiyat Enstitüsü işbirliği ile düzenlenen 3'ncü Türk-Rus Entelektüeller Buluşması'nda Markov, "Rusya'da AB üyeliğini isteyen kesimin oranı yüzde 4. Rusya davet edilmediği bu oluşumun yerine kendi modelini sahipleneceği bir birliği kurmak istiyor. Bu noktada birbirini çok iyi tamamlayan Türk ve Rus ekonomisinin bu birlik içinde önemli atılımlara imza atacağını düşünüyorum. Zira Türkiye'deki işsizliğin de Rusya'daki iş gücü ihtiyact ile çözülebileceğine inaniyorum. Bu noktada tüm şartlar Kafkaslarda bir Avrasya Birliğg'nin kurulmasina uygun görünüyor. Bu birliktelik bölgedeki bütün ülkelerin gerek bilim ve teknoloji gerekse de ekonomik anlamda kalkınmalarını sağlayacak çok önemli bir yapılanma olacaktır" demiştir.

23 Aralık 2014 tarihinde Kırgızistan ve Ermenistan; Rusya, Belarus ve Kazakistan'ın oluşturduğu ve 1 Ocak 2015 tarihinde hayata geçen Avrasya Ekonomik Birliği'ne kabul edilmiştir. Rusya Devlet Başkanı Vladimir Putin Moskova'da düzenlenen Avrasya Ekonomik Yüksek Konseyi toplantısında yaptı̆̆ı konuşmada şu görüşü özellikle vurgulamıştır: "Kırgızistan ve Ermenistan'ın Birliğe katılmalarının bu ülkelerin temel ulusal çıkarlarına cevap verdiğine ve sosyo-ekonomik kalkinmaları için geniş ufuklar açtı̆̆ına eminiz."

Kazakistan, Rusya ve Kırgızistan aynı zamanda üst çatı kuruluşu olan SCO üyesidir. Belarus ise diyalog ortağıdır. Ermenistan'ın içinde bulunduğu gümrük birliğine Türkiye'nin girmesi, Ermenistan'a uygulanan ambargoların kalkması ve Ermenistan'ın Türkiye aleyhine tüm dünyada yürüttüğü sözde Ermeni soykırım iddialarının kabul edilmesi anlamına gelir. Türkiye $A B$ ilişkilerinin donmasına ve 8 müzakere başlığının Güney Kıbrıs Rum Yönetimi'nin talebiyle 2006 yılında dondurulmasının sebebinin Türkiye'nin Güney Kıbrıs Rum Yönetimi ile gümrük birliğini gerçekleştirmemesi olduğu unutulmamalıdır. Böyle bir birlikte yer almak bir akıl tutulmasidir (Karluk, 2014a).

AEB'ye Türkiye'nin de girmesini isteyen Kazakistan Cumhurbaşkanı Nursultan Nazarbayev'dir (Nazarbayev, 2000). Nazarbayev 24 Ekim 2013 tarihinde Misk’te gerçekleşen Yüksek Ekonomik Konsey toplantısında Türkiye'nin Avrasya Birliğine katılması yönünde tavsiyede bulunmuştur. Kazakistan için bir müttefik olarak görülen Türkiye, Rusya için siyasi, jeopolitik ve de jeokonjonktürel bir rakiptir. Rusya'nın Avrasyasında Türkiye kapının dışında önemli bir ortak olup, Avrasya kapısından içeri kalıcı olarak girmesi Rusya için bir tehdittir. Rusya için Avrasya Birliği bir ekonomik birleşme projesi değil, Avrasya projesi kapsamında eski Sovyetler 
Birliğini yeniden hayata geçirme projesidir. Projede Orta Asya'daki Türk Cumhuriyetleri vardır ama Türkiye yoktur (Dugin, 2010).

Bu durum, Esengül Kafkızı'nın Prof. Dr. Abdülvahap Kara tarafindan çevrilen ve Türkistan gazetesinde 14 Kasım 2013 tarihinde yayınlanan “Ankara Gümrük Birliği’ne Katılmayı Gerçekten İstiyor mu? Kazakistan Cumhurbaşkanın Teklifi Üçlü Gümrük Birliği’nde Görüşlerin Farklı Olduğunu Ortaya Çıkarmış Gibidir” başlıklı makalesinde açık bir şekilde ortaya konmuştur. Cumhurbaşkanı Erdoğan'ın “AB bizi oyalarsa biz de alternatif ararız, Şanghay 5’lisi bizi kabul etsin, AB'ye hoşça kal deriz” demecinin de perde arkasını açıklamaktadır. Makale şöyledir:

“Beyaz Rusya'nın başkenti Minsk'te gerçekleşen Avrasya Ekonomik Yüksek Kengeşi’nin (Konseyi) olağan toplantısında Kazakistan Cumhurbaşkanı Nursultan Nazarbayev Türkiye’nin Birliğe alınması konusunda teklif yaptı. Nazarbayev 'Dış seyahatlerimde bana sizler Gümrük Birliği ile eski Sovyetler Birliği'ni tekrar kurmayı mi, yoksa Rusya'nın himayesine girmeyi mi istiyorsunuz? diye çok sık soruyorlar. Belki, Türkiye gibi büyük ülkeyi birliğe alırsak böyle soruların sorulmasını önlemiş oluruz'şeklinde konuştu. Nazarbayev'in bu sözlerinin Gümrük Birliği'ndeki meslektaşları üstünde şok etkisi yarattığında şüphe yoktur. Ancak, Rusya Devlet Başkanı Putin bu konuda doğrudan bir fikir serdetmedi, sadece Gümrük Birliği ile bir serbest ticaret anlaşması yapmaya Hindistan'ın istekli olduğunu belirtmekle yetindi.

Bu ifadelerin altında çeşitli sebepler arayan Rusya'nın basın organları da Türkiye’nin esas amacının Gümrük Birliği'ne girmek değil, Avrupa Birliği'ne üye olmak olduğuna vurgu yaptıktan sonra Nazarbayev'in bu teklifinin Türk dünyasının en büyük ülkesinin yöneticileri için beklenmedik bir jest olduğu yorumunda bulundular. Kommersant gazetesi Türkiye Dışişleri Bakanlığındaki güvenilir kaynaklara dayanarak verdiği bilgi de 'Ankara'daki resmi görevliler için bu ifade beklenmedik bir gelişme oldu' demektedir.

Avrasya Ekonomi Komisyonu Başkanı Viktor Hristenko Türkiye’nin Gümrük Birliği’ne üye olma konusunda bir başvuruda bulunmadığını söyledi. Siyasi gözlemcilere göre, Nazarbayev'in bu teklifinin altında yatan iki sebep olabilir. Birincisi Suriye konusunda Rusya ile taban tabana zıt bir politika takip eden Türkiye'yi Gümrük Birliğine üyeliğe sunmak ve böylece yakın zamanlarda Rusya'nın 'Suriye'nin birliğe üye olması mümkündür' şeklindeki ifadesine karşılık yapılmış bir hamledir. Ayrıca üye devletler gelecek yıl kurulması beklenen Avrasya Ekonomik Birliği'ne sicak bakmamaktadır.

Nazarbayev toplantıda ayrıca gümrük tarifeleri ile ilgili olarak da Rus meslektaşlarını eleştirdi. Gümrük Birliği'nden fayda yerine zarar gördüklerini söyleyen Nazarbayev, Kazakistan ürünlerinin Rusya pazarına girmekte engellerle karşılaştı̆̆ını ve gümrük tarifeleri ile ilgili olmayan zorlukların var olduğunu, ürünlerinin kalite, temizlik ve diğer kontrolleriyle ilgili taleplerin arttırıldı ̆̆ını, karşılıklı ticaretin gittikçe karmaşılklaştı̆̆ını ifade etti. Nazarbayev, Avrasya Ekonomi Komisyonu'nun Rus üyelerini de eleştirdi. Kazakistan Cumhurbaşkanı 'Kanuna göre Komisyon üyeleri hiçbir hükümete karşı sorumlu değildir. Ancak Avrasya Ekonomik Komisyon'unun Rus üyeleri Rusya Hükümeti'nin toplantılarına katılmakta ve özel talimatlar almaktadır' dedi. Bu sözlerden Kazakistan Cumhurbaşkanı'nın Rusya'nın siyasi nüfuzuna kolay kolay boyun eğmeyeceğini anlaşılmaktadır. Nazarbayev bir amacl da Türkiye'nin Gümrük Birliği’ne üye olmasını teklif ederek, Ermenistan 'ın Gümrük Birliği'ne üye olmak yolundaki istemine karşı tepkisini ortaya koymak olabilir.

Avrupa Birliği yıllardır Türkiye’ye üyelik şartı olarak Ermenilere karşı yaptı̆̆ı soykırımı kabul etmesini talep etmektedir. Ancak, Ermenistan bölgesel birlik için Avrupa yerine Rusya'yı tercih etme yolunu seçmektedir. Belki de bundan dolayı birkaç yıldan beri yerinde sayan Türkiye ile Avrupa Birliği arasındaki müzakereler yeniden başlayacaktır. Gümrük Birliği konusunda beklenmedik bir çıkış yapan Kazak meslektaşının tavrına Rusya Devlet Başkanı Putin hiçbir tepki göstermedi. Ancak Rus siyasi gözlemcilerinin şimdiye kadar ortaya koydukları yorumlardan anladı̆̆ımıza göre, Rusya Türk dünyasının en güçlü ülkesinin Moskova'nın siyasi projelerine dahil olmasını kesin olarak karşıdır.

Rusya gazetelerin birinde 'Gümrük Birliği Moskova'nın bir projesidir. Gelecekte o Avrasya Birliği'nin temeli olacaktır. Avrasya Birliği’nin kurulması fikrinin sahibi Rusya'nın bugünkü lideri Putin'dir. Birçok uzmanlar Kremlin'in bu planını eski Sovyet ülkelerinin önce ekonomik, daha sonra siyasi egemenliğini yok etmeye yönelik bir proje olarak görmektedirler' diye yazıldı. Aynı gazetede 'Özbekistan'ın bu birlikten kendisini uzak tutmasının bir sebebi de budur' şeklinde görüş belirtildi. 2011'de Özbekistan Cumhurbaşkanı İslam Kerimov Taşkent'in Gümrük Birliği'ne katılmamasının temel sebebi olarak, bu Birliğin gizli gündeminde ekonomik menfaatlerden çok siyasi amaçların bulunduğunu söylemişti. Beyaz Rusya Cumhurbaşkanı Lukaşenko ise Gümrük Birliği'ne Ermenistan ve Türkiye 'nin üye olmasının mümkün olmadı̆̆ını fikrindedir.

Ĕ̆er Türkiye Gümrük Birliği'nin kapısını çalacak olursa, bu durum Putin'in Rusya'nın eski nüfuzunu koruma ve onu tekrar eski dönemlerdeki gücüne kavuşturma gibi amaçlarını gerçekleşmesine engel olacaktır. Bunun sebeplerine bakacak olursak, öncelikle Türkiye'nin ekonomisi Rusya ekonomisinden daha ileridir. Hafif endüstrisi gelişmiştir, ayrıca Tayyip Erdoğan'ın başbakanlı̆̆ döneminde dünya krizini yara almadan atlatmıştır. Ayrıca Türkiye’nin birliğe katılması durumunda dil - kültür dengeleri değişecektir. Asırlar öncesinden günümüze değin bölgede etkili olan Rusya ve diğer Slav ülkelerin dil ve kültürleri üstünlüğ̈̈nü 
kaybedecek ve Türkiye Birlik içinde kendi kurallarını koymaya başlayacaktır. Birlik içinde uluslararası belgelerin sadece Rusça değil, ikinci bir dilde daha hazırlama zorunluluğu ortaya çıkacaktır.

Bunlara ek olarak Kazakistan'ın Türkiye ile birlikte Türk Kengeşi'ne üye olduğu da göz ardl edilmemelidir. Kazakistan Cumhurbaşkanı Nursultan Nazarbayev'in geçen yıl İstanbul'da yaptı̆̆ konuşmayı da hatırlamak gerekir. Nazarbayev konuşmasında; Rus sömürgeciliği üzerinde durmuş, Ankara'dan Altaylar kadar olan coğrafyada yaşayan 200 milyon Türk'ün birlik olması durumunda dünyada büyük bir güce dönüşebileceklerine, Rus hegemonyası dolayısıyla milli kültür ve dilleri kaybetme tehlikesiyle karşı karşıya kaldıklarına değinmişti. Demek ki, Rusya için Türkiye'nin Gümrük Birliği’nde girmesi hiç te istenen bir durum değildir. Çünkü Gümrük Birliği'nin amacı Rusya'nın eski Sovyet ülkelerindeki nüfuzunu güçlendirmektir. Bunu, Rusya'nın siyasi gözlemcileri de kabul etmektedir. Rusya'da yayınlanan bir makalede 'Rusya, ekonomisi küçük ülkeler de kendi hegemonyasını sürdürmeyi amaçlar, bundan dolayı kendisinden büyük ekonomilere Birliğin kapısını açmak istemez' ifadelerine rastllyoruz. Çünkü bu birlikte eşitler arasındaki ortaklık şeklinde bir anlayış henüz oluşmamıştır.

Nazarbayev'in bu toplantıdaki konuşması, Kazakistan'ın Rusya'nın kolaylıkla avucuna düşmeyeceğini, hatta aksine Rusya'dan başka da destek göreceği ülkelerin var olduğunu gösterdi. Plana göre, Mayls 2014'de Avrasya Ekonomik Birliği'nin kurulması gerekiyor. Birkaç ay içinde böyle bir adımın atılmasına ne Kazakistan, ne de Beyaz Rusya hazır görünmüyor.”

2000'li yılların başında Rusya'da Putin'in iktidara gelmesinin ardından çeşitli bölgesel kuruluşlar aracılığıyla Sovyet ardılı ülkeler arasında eski Sovyetler Birliği’ne benzeyen bir birliğin sağlanması amaçlanmıştır. Putin'in amaç ve söylemlerinde büyük bir değişimin olduğunu söylemek mümkün değildir. $O$ halde neden Avrasya Ekonomik Birliği Türkiye için yeni firsat olarak gösterilmektedir? Böyle bir oluşum içerisinde, Rusya'nın Türkiye'yi gerçekten görmek isteyip istemeyeceği de ayrı bir konudur.

\section{Sonuç}

Türkiye, 1856 Paris Anlaşması'ndan bu yana yüzünü Batı'ya çevirmiş, Tanzimat'tan bu yana Batı'ya yönelmiş dünyadaki tek Müslüman ülkedir. Türkiye, laik ve demokratik ilkeleri benimsemiş, Batı dünyası ile ortak sınıra sahip ve ona komşu, AB ülkeleri ile tarihi ilişkileri bulunan, dünya üzerinde mevcut 57 İslam ülkesi arasında ekonomik, politik, sosyal, kültürel ve sportif alanlarda en gelişmişler arasında yer alan, hayat tarzı olarak kendi kültürel değerlerini koruyarak Batı’yı seçmiş bir ülkedir.

Türkiye için zaman zaman "Batıya giden gemide doğuya koşan ülke” benzetmesi yapılmıştır ama bunun doğru olmadığı Türkiye'nin üye olduğu Avrupalı ekonomik, askeri ve siyasi kuruluşlar tarafından ispatlanmıştır. Türkiye'nin dışında hiçbir Müslüman ülke AB dışındaki tüm Avrupalı kuruluşlara üye değildir. Uluslararası ekonomik ve siyasi ilişkilerde ülkelerin birbirlerini nasıl algıladıkları çok önemlidir. Bu algı, tarafların birbirlerine karşı tarihsel imaj ve kültürel birikimlerin etkisinden geçerek oluşur. Algılar bazen peşin yargılardan etkilenir ama algıların varlığg maddi gerçekliğin küçümsenmesi anlamına gelmez. Maddi gerçekliğe anlam kazandıran, o gerçekliğe taraflarca atfedilen önemdir. Günümüzün küresel dünyasında algılar statik olmayıp hızla değişebilmektedir. Tarafların eylemleri algıları doğurur. Bu sebeple eylem değişince algı da değişebilir.

Türkiye'nin gösterdiği ekonomik performans ve izlediği aktif dış politika, ülkemizin Batı dünyasındaki algısının değişmesini sağlamıştır. Türkiye değişirken Batı'nın Türk dış politikası algısı da değişmektedir. NATO üyeliğinden sonra Türkiye, Batı Dünyası'nın sadık bir müttefiki olarak algılanmıştır. Türkiye'nin dış politikada belli değer ve ilkeler belirleyerek bunları uygulamaya koyması, son yıllarda ABD ve Avrupa Birliği'nde endişe doğurmuştur ama bu bir eksen kayması anlamına gelmemektedir.

Türkiye'nin Batı'nın çifte standartlarına yönelik Ortadoğu, Balkanlar ve Kafkaslar gibi Batılı olmayan bölgelerde seslendirdiği eleştiriler zaman zaman Türkiye'nin bir ortak değil, "rakip güç" olarak algılanmasına yol açmakta, Ortadoğu'daki Batı karşıtı aktörler ve gruplarla sıkı ilişkileri ise Türkiye'nin Avrupa'da ne tür bir ortak olacağı konusunun sorgulanmasına sebep olmaktadır. Türkiye'de eksen tartışmalarının doğmasına zemin hazırlayan gelişme, Türkiye - AB ilişkilerinin bir çıkmaz sokağa girmesidir (Karluk, 2014b). Türk kamuoyu artık Türkiye'nin bir gün AB üyesi olacağına inanmamaktadır. 1999-2005 yıllarında kamuoyunun yaklaşık yüzde 80'i tam üyeliğe destek verirken, bu oran son yıllarda yüzde 40'lar seviyesine gerilemiştir.

AB, Kıbrıslı Türklere verdiği sözleri yerine getirmeyeceğine ve de Türkiye’ye karşı uyguladı̆̆ı Bobon kriterleri sebebiyle Türk kamuoyunda AB'ye verilen destek daha da düşeceğine göre, ileride bazı alternatifler gündeme gelebilecektir. Çünkü kamuoyu desteği olmadan Türkiye Cumhuriyeti'nde hiçbir hükümet AB'ye üyelik konusunda istekli olmayacak, bu durumda Türkiye ile Batı dünyası arasındaki ilişkiler zayıflayacak ve Türkiye'de bir eksen kayması belki bu durumda olabilecektir. Bu sebeple AB, ilişkileri koparmamak ve Türkiye'nin başka denizlere yelken açmasını önlemek amacıyla "Pozitif Gündem” adıyla bir girişim başlatmıştır. $\mathrm{Bu}$ yeni yaklaşım katılım sürecinin yerine geçmeyi değil onu tamamlamayı, ayrıca AB-Türkiye arasında daha yapıcı ve olumlu bir ilişkinin geliştirilmesini hedeflemektedir. 
Başbakan Erdoğan 12 Ağustos 2010 tarihinde Ankara'daki büyükelçilere vermiş olduğu iftar yemeğinde "Türkiye'nin dlş politika ekseni değişmemiştir" dese de önümüzdeki 50 yıl içinde dünyada, bölgemizde ve Avrupa'da büyük değişikler olacaktır. Bu gerçeği görerek Türkiye yeni bir strateji belirlemek zorundadır. 63 yıl önce NATO kurulduğunda hiç kimse 1989 yılında Sovyetler Birliği’nin çökeceğini, Avrupa'nın iki bloklu yapısının ortadan kalkacağını, Varşova Paktı'nın 1 Temmuz 1991'de dağılacağını ve böylece Savaş sonrası Avrupa'sının iki kutuplu yapısının askeri bakımdan tarihe karışacağını, Polonya, Çek ve Slovak Cumhuriyetleri, Slovenya, Macaristan, Estonya, Letonya, Litvanya, Romanya ve Bulgaristan gibi eski sosyalist ülkelerin bir gün Türkiye'den önce Avrupa Birliği üyesi olacaklarını tahmin etmiyordu.

2001, 2003 ve 2008 yıllarında güncellenerek Bakanlar Kurulu kararıyla Resmi Gazete'de yayınlanan AB üyeliği hedefine yönelik Türkiye Ulusal Programı'nın giriş bölümündeki hedefte şimdilik bir değişiklik olmamıştır. Dokuzuncu Cumhurbaşkanı merhum Süleyman Demirel'in Aydın Doğan'a 7 Şubat 2015 tarihinde yazmış olduğu mektupta önemle üzerinde durduğu husus, "Türkiye, ne olursa olsun, Avrupa Birliği çıpasına sarılmalıdır. Bundan vazgeçmek olmaz”dır.

Avrasya Ekonomik Birliği ülkelerinin şu anki toplam nüfusu 170 milyondur. 76 milyonluk bir Türkiye'nin Birliğe katılması Birlik içindeki nüfus ağırlığını değiştireceği ve Türkiye'nin etkinliğini arttıracağı için Rusya bu üyeliğe sıcak bakmaz (Andican, 2015). Orta Asya Türk Cumhuriyetlerinin nüfusu, nüfusunun büyük bölümü Özbek ve Kırgızlardan oluşan Tacikistan da dahil toplam 65 milyondur. Türkiye'nin nüfusuna bu nüfus da eklenirse 141 milyonluk Türk nüfus 170 milyonun etkinliğini büyük ölçüde önler. Aslında Rusya istese bile Türkiye'nin bu Bilik’te yer alması AB ile olan yükümlülükleri kapsamında mümkün değildir. Çünkü yürürlükte bulunan Ankara Anlaşması ve Katma Protokol değişmediği sürece, GATT/WTO kuralları gereğince Türkiye aynı anda iki farklı gümrük birliği içinde yer alamaz.

Buna rağmen Türkiye'nin Avrasya Ekonomik Birliği'ne üyeliğinin gündeme getirilmesi, GATT/WTO kurallarının yeterince bilinmemesinden kaynaklanmaktadır. Ayrıca Putin'in, Türkiye'nin Avrupa Birliği'ne üyelik sürecini espri konusu yaptığını da unutmamak gerekir. Rusya'da yabancı uzmanların oluşturduğu Valday Kulübü toplantısında Kommersant gazetesine göre konuk uzmanlardan biri Putin'e Türkiye'nin AB üyeliğine nasıl baktığını sorunca gülerek şu cevabı vermiştir: “Türkiye'nin AB'ye giriş kağıtlarını verin imzalayayım. Bana ne zararl var?"

Türkler Batı’ya yönelmiş bir millettir. Atatürk’ün 29 Ekim 1923 tarihinde açıkladığı hedeften şaşmamak gerekir: "Memleketimizi asrileştirmek istiyoruz. Bütün çalışmamız Türkiye'de asri binaenaleyh batılı bir hükümet vücuda getirmektir. Medeniyete girmek arzu edipte Batı'ya yönelmemiş millet hangisidir?" Lucius Annaeus Seneca "Hangi kapıya yöneldiğini bilmeyen hiçbir zaman uygun esen rüzgarı bulamaz" (Ignoranti quem portus petat nullus ventus suus est) derken çok haklı idi. Yöneldiğiniz kapıyı bilmezseniz, hiçbir zaman uygun esen rüzgarı yakalayamazsınız. Ama bazen kapıyı bulmanız yeterli olmayabilir. Çünkü rüzgar eğer tersten eserse, sizi uygun olan kapıya değil istemediğiniz bir kapıya yönlendirebilir. Türkiye, Batı Dünyası ile ilişkilerini kesmeden aşağıdaki fotoğraf karesinde yer alamaz.

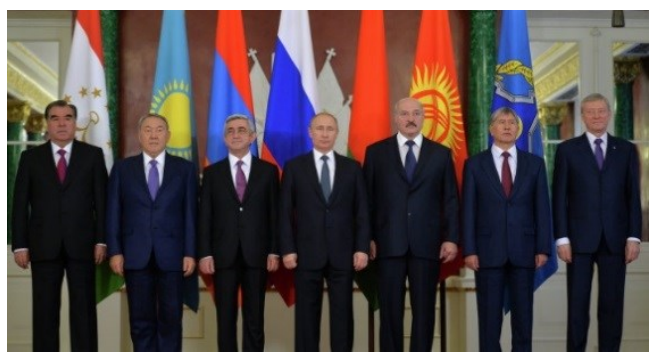

Kaynakça

- Andican, 2015. “Orta Asya Türk Cumhuriyetleri 2023 Yılında Nerede Olacaklar?” Türk Diasporası ve Türk Dünyasi. Tasam Yayınları, İstanbul.

- Balassa, 1961. Economic Integration. Richard D. Irwin, Illionois.

- Dugin, 2010. Rus Jeopolitiği. Küre Yayınları, İstanbul.

- El-Agraa, 1982. International Economic Integration. Macmillan, London.

- Frankel, 1997. Regional Trading Blocks in the World Economic System, Institute for International Economics. Institute for International Economics, Washington D.C.

- Günay 2011, “Orta Asya, G. Kore ve Türkiye Arasında Olası Bir Gümrük Birliği: Türkiye’nin Potansiyel İhracat Kazanımları” Maliye Finans Yazıları, Maliye Finans Yazıları Yayımcılık Ltd., İstanbul.

- Karluk, 2013. Uluslararası Ekonomi. Beta Basım A.Ş., İstanbul.

- Karluk, 2014a. Uluslararası Kuruluşlar. Beta Basım A. Ş., İstanbul.

- Karluk, 2014b. Avrupa Birliği Türkiye İlişkileri: Bir Çıkmaz Sokak. Beta Basım Yayın A.Ş., İstanbul. 
- Karluk, 2015. "Turgut Özal ve Avrupa Birliği: Uzun ve Meşakkatli Bir Yol”, Turgut Özal: Değişim, Dönüşüm, Turgut Özal Üniversitesi Yayınları, Ankara.

- Lawrence, 1995. Regionalism, Multilateralism and Deeper Integration, Integrating National Economies. Brookings Institution.

- Machlup, 1977. A History of Thought on Economic Integration. Columbia University Press, New York.

- Markov, 2011.Türkiye'yi Avrasya Birliği'ne davet etti, http://www.samanyoluhaber.com/dunya/Turkiyeyi-Avrasya-Birligine-davet-etti/716995/

- Nazarbayev, 2000. Tarihin Akışında. Om Yayınevi, İstanbul.

- Özsöz, 2014. Unutulan AB Gündemine Can Suyu: AB Aday Ülkesi Türkiye'nin Şanghay Beşlisi Tartışması. İKV Yayınları, İstanbul.

- Park, 2006. Economic Liberalisation and Integration in East Asia: A Post-Crisis Paradigm. Oxford University Press, London.

- Scollay and Gilbert, 2001. New Regional Trading Arrangements in the Asia Pacific? Institute for International Economics.

- Şensoy, 2014. “2. Dünya Türk Forumu Açılış Konuşması: Din, Dil, Tarih ve Coğrafya Yetmez,” Tasam Yayınları, İstanbul.

- Tinbergen, 1965. International Economic Integration. Elsevier Publishing Company, Amsterdam. 


\title{
Ortak Para Otoritesine Giden Yol: Ekonomik Entegrasyon Sürecinde Avrasya Ekonomik Birliği Ülkelerinin Bankacılık Sektörleri Üzerine Bir Değerlendirme
}

\section{Path to the Common Monetary Authority: An Assessment on Banking Sector of the Eurasian Economic Union Countries during the Economic Integration Process}

\author{
Asst. Prof. Dr. Fatma Gündoğdu Odabaşığlu (Atatürk University, Turkey)
}

\begin{abstract}
Monetary union is one of the advanced stages of international economic integration and involves shared monetary and exchange rate policies that are executed collectively across union members. This common policy warrants price stability and requires a common supranational monetary authority. Existence of an established banking sector is crucial for effective execution of policy decisions taken by said monetary authorities. Eurasian Economic Union (EAEU) is officially established on January 1st of 2015 and is an example for a regional economic integration. Aim of the Union, which is comprised of Russia, Kazakhstan, Belarus and Republic of Armenia; is to increase collaboration among economies, to improve the living standards of the participating nations and to promote stable development.

This study is based on assessment banking industries of member countries, working towards common monetary authority during the transition to EAEU economic integration between years 1995 and 2014. Data acquired from World Bank and member countries' central banks is used to determine the capabilities and limitations of partaking economies based on generally accepted financial strength indicators.

In conclusion; Russian Federation and the Republic of Kazakhstan are observed to be the principal EAEU members due to their advanced and strong banking industries. Increasing fragilities over the years, amplified also by developments in global markets, are evident in member countries; especially in Belarus and Armenia. Significance of achieving price stability in founding country Russian Federation is emphasized for successfully establishing a common monetary authority.
\end{abstract}

\section{Giriş}

Uluslararası ekonomik entegrasyon farklı ülkeler arasında mal ve hizmet akımlarını serbestleştirmek ve ticaretteki tarifeleri ve diğer kısıtlamaları ortadan kaldırmaya yönelik önlemler alınması süreci olarak tanımlanabilmektedir. Bölgesel bir ekonomik entegrasyon örneği olan Avrasya Ekonomik Birliği (AEB), fikir olarak ilk kez Kazakistan Cumhurbaşkanı N. Nazarbayev tarafından 1994 yılında Moskova Üniversitesi'nde dile getirilmiştir. 29 Mayıs 2014'te Gümrük Birliği ve Tek Ekonomik Alan üye ülkeleri Rusya Federasyonu, Kazakistan ve Belarus Cumhuriyetlerinin liderleri tarafından imzalanan bir antlaşma ile temelleri atılmış, 10 Ekim 2014'de Ermenistan Cumhuriyetinin katıldığı ve 23 Aralık 2014'te Kırgız Cumhuriyeti Cumhurbaşkanı'nca Kırgız katılım anlaşmasının imzalanmış olduğu Birlik, resmen 1 Ocak 2015 'te kurulmuştur. Birlik, üye ülke ekonomileri arasındaki rekabet gücünü ve işbirliğini artırmak ve üye ulusların yaşam standartlarını yükseltmek amacıyla istikrarlı kalkınmayı teşvik etmeyi amaçlamaktadır.

Uluslararası ekonomik entegrasyon sürecinin ileri aşamalarından biri, parasal birlik olup, para ve döviz kuru politikasının birlik düzeyinde birleştirilmesini ve ortak yürütülmesini kapsamaktadır. Bu ortak politika, fiyat istikrarı için önemli bir güvence olmakta ve uluslarüstü ortak para otoritesini gerektirmektedir. Ortak para birimi, uzun zamandır Avrasya bölgesel entegrasyonun merkezinde yer alan tartışmadır. Nisan 2003'de ilk defa Kazakistan Başkanı Nursultan Nazarbayev, Tek Ekonomik Alanda "Altın” adını taşıyan yeni bir bölgesel para birimi teklifini yapmıştır. Nazarbayev için, Altın, bölgeler arası ticaret ve ekonomik işbirliğini teşvik edecek bir araç olarak görülmekteydi. Rus "Rossiiskaya Gazeta" gazetesinde yayımlanan "Krizin anahtarları" başlıklı makalede, Nazarbayev açıç̧a, var olan dünya para biriminin yasal olup olmadığını sorgulamış, Yeni Dünya para biriminin evrensel hukuk kurallarına dayanarak, çoğu ülke parlamentoları tarafindan onaylanması gerektiğini belirtmiştir (Назарбаев, 2009). Böylece, AEB'nin sürdürülebilirliğine bağlı olarak, ortak para birimine geçiş ve ortak para alanında fiyat istikrarını sağlamakla görevli bir ortak para otoritesinin kurulması, ekonomik entegrasyonun nihai aşamasına ulaşmak yolunda, Birlik üyesi ülkelerce atılması öngörülen adımlar arasında yer almaktadır.

Bu bağlamda, çalışmanın amacı 1995-2014 dönemi itibariyle, AEB ekonomik entegrasyonuna geçiş süreci ve ortak para otoritesi hedefi doğrultusunda üye ülkelerin bankacılık sektörlerinin değerlendirilmesidir. Çalışmada, öncelikle ülke yetkililerinin ortak para birimine geçilmesine yönelik bakış açılarına yer verilmekte, belirli finansal derinlik ve sağlamlık ölçütleriyle, ekonomilerin entegrasyon süreci açısından imkan ve sınırları 
belirlenmektedir. Verilerde standart sağlamak amacıyla, Uluslararası Para Fonu (IMF) ve Dünya Bankası kaynaklarından faydalanılmaktadır. Finansal sağlamlık göstergelerine ilişkin verilere tüm ülkeler için ulaşılamamış olması çalışmanın kısıtını oluşturmaktadır.

\section{AEB ve Ortak Para Otoritesine Giden Yol}

20 Mart 2015'de Kazakistan'ın başkenti Astana'da yapılan zirvede üye ülke liderlerince ortak para birimi için imkânların belirlenmesinin, ortak plan ile çalışarak, dişardan gelen ekonomik ve mali tehditlere daha kolay tepki gösterebileceğinin önemi vurgulanmış, bunu takip eden süreçte, Rusya devlet başkanı Putin, hükümet ve merkez bankasına talimat vererek 1 Eylül 2015 tarihine kadar; "gelecekte para birliğini tesis etmenin fizibilitesi" çalışması ile AEB içindeki parasal ve finansal entegrasyonun gelecekteki ana hatlarının belirlenmesini istemiştir (Дружинин, 2015). Bununla beraber; Dolar ve Euro'nun bölgesel ticaret ve ekonomik etkileşimlerine meydan okuyabilecek yeni bir bölgesel para birimi konusunun, Rusya ve Batı arasında sürmekte olan anlaşmazlıklar kapsamında, giderek Jeopolitik nitelik de taşımaya başladığı, bu konunun karşılıklı ticarette kötüleşen Rusya'da ekonomik krizi ve rublenin devalüasyonu sonucunda gündeme gelmiş olduğu dikkat çekmektedir. Yeni bir ortak para birimine geçme konusunda Rusya’nın Birlik partnerlerinin kısmen de olsa isteklerinin azaldığ gözlenmektedir. Öncelikle, Birlik yetkililerinin çoğunluğu, üye ülke finansal piyasalarının 2020 den önce uyum sağlayamayacağını dolayısıyla ortak para tanımlanmasının bu tarihten sonrasına kalacağını düşünmektedirler (Kim, 2015). Daha da ötesi, Belarus ve Kazakistan başkanları, ortak paraya geçiş konusundaki görüşlerini açıkça değiştirmişlerdir.

Belarus başkanı Alyaksandr Lukashenko ve Nursultan Nazarbayev'in tahminleri, ortak para girişiminin her ikisinin de karşı oldukları politik entegrasyonun parçası olduğu yönündedir. Lukashenko, 2000'li yılların başlarında ülkesi ile Rusya'nın Ruble bölgesi arasındaki entegrasyonu çok istemekte iken son dönemde, başkanlığı esnasında ortak para birimine geçilmeyeceğini belirtmektedir (Букчин, 2015).

Kazakistan'daki genel görüş, ortak para birimi fikrine ciddi anlamda karşıdır. Bu bakış açısı, en iyi, Kazakistan'da iş dünyasıyla ilgili muhafazakar görüşleriyle tanınan ve kısa zaman önce Avrasya entegrasyonunun kaçınılmazlığı hakkında konuşan Ulusal Girişimciler Odası Başkan Yardımcısı Rahim Oshakbaeva'in sözleri ile özetlenebilir: Oshakbaeva bu konuda düşüncelerini: "Yakın gelecekte umarım asla ortak para birimine geçmeyiz. Kazakistan bağımsız bir ülke ve biz kendi ulusal para birimimize sahip olacağız Tenge" şeklindeki cümle ile özetlemiştir. (Севостьянова, 2014). 2012 yılında Bağımsız Devletler Topluluğu (CIS) ekonomik forumunun, ortak para birimi konulu özel oturumunda konuşma yapan Kazakistan'ın Avrasya Ekonomik Komisyon temsilcisi Timur Suleimenov'a göre ise; ekonomik bakış açısıyla Birlik içi ticaret ortak para birimine geçilmeden önce gerekli olan eşiğin altındadır. Suleimenov, Avrupa Birliği’nde, mal ve hizmet ticareti ve karşılıklı yatırım oranı, Euro'ya geçildiğinde \% 60 civarında iken, AEB'de mevcut oranın \%11 seviyesinde bulunduğunu, \% 60 seviyesine ulaşmanın neredeyse imkânsız olacağını ve Birlik üyesi ekonomiler arasında çok büyük farklar bulunduğunu ve bu nedenle asla AB'ye benzeyemeyeceklerini vurgulamıştır.

Özetle, Birliğin devamlılığını sağlama yollarını arama anlamında ve bir parasal entegrasyon konusunda, üye ülke yetkilileri arasında başlamış olan tartışmaların daha da büyüyebileceği ve çok uzun zamana yayılacağı düşünülmektedir.

\section{AEB Ülkelerinin Bankacılık Sektörleri Üzerine Bir Değerlendirme}

Bir ekonomide, bankacılık sektörünün en önemli işlevlerinden biri, fon arz edenlerle talep edenler arasında aracılık yapmaktır. Fonların getirisi yüksek alanlara yönlendirilmesi, kaynak dağılımda etkinlik sağlamaktadır. Finansal gelişmeye bağlı olarak finansal sistemin aracılık yapma fonksiyonu da gelişmekte, bankalar dışında yeni finansal aracılar ortaya çıkmakta ve finansal araç çeşitliliği artmaktadır. Bankalar ve diğer finansal aracılar kanalıyla sermaye dağılımında etkinlik sağlandığı ölçüde ekonomik büyüme de artmaktadır (Öztürk, Barışık ve Darıc1, 2010). Ekonomilerde tasarrufları yatırıma dönüştüren kanalların yaygınlaşması finansal derinlik kavramı ile ifade edilebilmekte ve farklı yöntemlerle ölçülebilmektedir. En sık kullanılan finansal derinleşme göstergelerinden biri, geniş tanımlı para arzı (M2) nın gayrisafi yurt içi hasıla (GSYİH) ya oranıdır (Mathieu, 1998). Bu oran, ekonominin parasallaşma derecesini ve hane halklarının bankacılık sistemini kullanma düzeyini de yansıtmaktadır. AEB üyesi ülkelerde 1995-2014 dönemi itibariyle M2/GSYİH oranları Tablo 1'de verilmektedir. Buna göre; incelenen ülkeler genelinde M2/GSYİH oranları yıllar içerisinde artış göstermekle beraber, bu artışların Birlik üyesi ülkelerin finansal alanlarında önemli finansal gelişmeleri yansıtmadığı ve finansal derinliğin düşük seviyelerde kaldığ1 gözlenebilmektedir. Yıllar itibariyle, M2/GSYİH oranlarının en yüksek olduğu ülke Rusya'da bile 2013 yılında \% 55,8 seviyesine ulaşılabilmiş ve bu oran \% 100’leri aşan seviyelere yıllar öncesinde ulaşmış olan önemli entegrasyon örneği Avrupa Birliği ülkelerinin seviyesinden çok düşük kalmaktadır. Rusya’yı sırasıyla Kazakistan, Ermenistan, Belarus ve Kırgızistan ülkeleri izlemektedir. 


\begin{tabular}{|c|c|c|c|c|c|}
\hline & Belarus & Ermenistan & Kazakistan & Kirgıistan & Rusya \\
\hline 1995 & 14,77 & 7,71 & 11,38 & 17,20 & 19,31 \\
\hline 1996 & 14,25 & 8,22 & 9,85 & 13,63 & 17,80 \\
\hline 1997 & 15,75 & 8,73 & 10,35 & 13,73 & 19,65 \\
\hline 1998 & 30,94 & 10,05 & 8,57 & 14,49 & 24,10 \\
\hline 1999 & 16,70 & 11,08 & 13,58 & 13,58 & 20,59 \\
\hline 2000 & 17,67 & 14,70 & 15,27 & 11,32 & 21,54 \\
\hline 2001 & 14,92 & 13,45 & 17,72 & 11,14 & 23,90 \\
\hline 2002 & 14,61 & 15,55 & 21,07 & 14,63 & 26,42 \\
\hline 2003 & 16,12 & 14,39 & 21,07 & 17,53 & 29,94 \\
\hline 2004 & 17,68 & 14,99 & 28,11 & 20,58 & 31,06 \\
\hline 2005 & 19,32 & 16,30 & 27,21 & 21,17 & 33,38 \\
\hline 2006 & 22,08 & 18,29 & 36,01 & 28,44 & 37,62 \\
\hline 2007 & 25,22 & 21,95 & 36,03 & 30,39 & 42,82 \\
\hline 2008 & 23,85 & 19,84 & 39,04 & 17,20 & 39,43 \\
\hline 2009 & 27,73 & 25,94 & 44,02 & 13,63 & 49,21 \\
\hline 2010 & 30,56 & 26,34 & 38,88 & 13,73 & 51,38 \\
\hline 2011 & 37,42 & 29,83 & 35,37 & 14,49 & 51,38 \\
\hline 2012 & 30,41 & 33,65 & 34,67 & 13,58 & 51,80 \\
\hline 2013 & 30,36 & 36,17 & 32,88 & 11,32 & 55,83 \\
\hline
\end{tabular}

Tablo 1. AEB Üyesi Ülkelerde M2/GSYIHH Oranlarl (Yüzde) Kaynak: IMF

Bir diğer derinlik göstergesi, borsa kapitalizasyon oranı olup, menkul kıymetler borsası reel işlem hacminin GSYİH'ye oranı ile ifade edilmektedir (Bayraktar, 2014). Bu oranın yüksekliği, firmaların doğrudan finansman sağlayabildikleri menkul kıymetler borsasının gelişmişlik seviyesine yönelik bilgi vermektedir. AEB ülkelerinde borsa kapitalizasyon oranlarına Tablo 2'de verilmektedir. Tablodan, üye ülkelerden Rusya ve Kazakistan'da 1997-2012 dönemi itibariyle kapitalizasyon oranlarında dikkat çeken ölçüde artışlar gerçekleştiği gözlenebilmektedir.

\begin{tabular}{|c|c|c|c|c|}
\hline & Ermenistan & Kazakistan & Kirgizistan & Rusya \\
\hline 1997 & & 6,05 & & 31,66 \\
\hline 1998 & & 8,27 & & 7,6 \\
\hline 1999 & & 13,43 & 0,32 & 36,86 \\
\hline 2000 & & 7,34 & 0,28 & 14,99 \\
\hline 2001 & 0,1 & 5,44 & 0,25 & 24,85 \\
\hline 2002 & 0,43 & 5,44 & 0,46 & 35,99 \\
\hline 2003 & 0,97 & 7,86 & 1,6 & 53,63 \\
\hline 2004 & 0,51 & 9,13 & 1,54 & 45,34 \\
\hline 2005 & 0,87 & 18,42 & 1,71 & 71,8 \\
\hline 2006 & 0,94 & 53,93 & 3,27 & 106,79 \\
\hline 2007 & 1,14 & 39,46 & 3,18 & 115,64 \\
\hline 2008 & 1,51 & 23,29 & 1,82 & 23,91 \\
\hline 2009 & 1,62 & 50 & 1,53 & 70,46 \\
\hline 2010 & 1,56 & 41,03 & 1,65 & 65,87 \\
\hline 2011 & 1,38 & 23,03 & 2,66 & 41,81 \\
\hline 2012 & 1,33 & 11,54 & 2,5 & 43,35 \\
\hline
\end{tabular}

Tablo 2. AEB Üyesi Ülkelerde Borsa Kapitalizasyon Oranlarl (Yüzde) Kaynak: IMF

Rusya için 1998 y1lında bir önceki yıla göre gerçekleşen ciddi düşme, büyük ölçüde 1997 yılında patlak veren Doğu Asya Mali Krizi'nin Rusya'yı da etkilemiş olmasından kaynaklanmıştır. Petrolün kamu ve ihracat gelirlerinin büyük kısmını oluşturduğu Rusya'da, petrol fiyatlarındaki düşme, aşırı değerlenmiş Ruble, bankacılık sektöründeki zayıf düzenleme ve denetim faktörleri, özellikle de kısa vadeli ve büyük bir oranı yabancı yatırımcıların elinde bulunan iç borçlanma araçları, krizin etkilerinin daha güçlü hissedilmesine zemin hazırlayarak, ekonominin kırılganlığını artırmış ve Rusya 17 Ağustos 1998'de moratoryum ilan etmiştir (Değertekin, 2008).

Tabloda 2006 ortalarından itibaren uluslararası piyasalarda risk azalmasının Rusya'yı da olumlu yönde etkilediği ve borsa kapitalizasyon oranının 2007 yılında en yüksek seviyeye ulaştığı görülebilmektedir. Bu yükselişin ardından 2008'de dibe vuruş, Amerika Birleşik Devletleri kaynaklı 2008 küresel kriz ve varlık fiyatları balonu patlamasının Rus ekonomisini de etkilemesi ile gerçekleşmiştir. Rusya'da kriz, tıpkı diğer dünya ülkeleri gibi, sadece borsa ve bankacılık alanlarında yaşanmamış, ek olarak petrol fiyatlarının düşmesi, krizin etkisini katlamıştır. Putin, devlet başkanlığı görevine başladığı dönemde, gerek işadamları gerekse yetkililerle yaptığı toplantılarda, sürekli olarak, Rusya'nın petrol ve doğal gaza bağımlı olarak yaşamaktan kurtulmasının, 
üretim yelpazesinin çeşitlendirilmesinin ve özellikle yüksek teknolojili üretim sektörlerine yönelinmesinin gerekliliğini vurgulamıştır (Gaddy ve Ickes, 2010).

Petrol fiyatlarındaki düşüşle, zenginliği daha çok petrol ve doğal gaz rezervlerine dayanan Orta Asya'nın en büyük ve umut vadeden Kazakistan borsası da krizden olumsuz etkilenmiştir. Bu etkilenmede, ekonomik ilişkilerinin güçlülüğü nedeniyle, Rusya'daki gelişmelerin yansıması da rol oynamıştır. Rusya ile ilişkileri güçlü ve ekonomisi daha çok tarım ve hayvancılık ağırlıklı bir yapıya sahip olan Kırgızistan menkul kıymetler borsasının da küresel krizden etkilendiği ve borsa kapitalizasyon oranının bir önceki yıla göre düştüğü yine tablodan izlenebilmektedir.

Ermenistan ve Kırgızistan menkul kıymetler borsalarının incelenen dönem içerisinde henüz gelişemediği gözlenebilmektedir. Belarus için ise veri bulunamamıştır.

Finansal istikrarın tanımına ilişkin bir görüş birliği bulunmamakla beraber, genel olarak kabul edilen bir tanım, finansal kuruluşlar, piyasalar, ödemeleri kapsayan finansal sistemin düzgün şekilde işlemesi şeklinde yapılmaktadır (Čihák, 2006). Finansal istikrar, finansal sağlamlık göstergeleri ve makro göstergeler yardımıyla değerlendirilebilmektedir. Finansal sistemin güçlü ve zayıf yanlarını belirlemek amacıyla, üye ülkelerce yapılan anket sonrasında, IMF İcra Direktörleri Kurulu'nca bir Finansal Sağlamlık Göstergeleri listesi onaylanmıştır (Ayrıntılı bilgi için bkz. IMF, 2011). 2008 sonrası dönemi kapsayan bu göstergeler itibariyle, AEB üye ülkelerinden yalnızca başat rolünü üstlenen Rusya ve son dönem gelişmelerini yansıtmasa da sadece 2008 yılında Ermenistan bankacılık sektörleri için elde edilebilen belirli finansal sağlamlık rasyolarına sırasıyla Tablo 3 ve Tablo 4'de yer verilmektedir. Buna göre Rusya bankacilık sektöründe;

Sermaye yeterlilik rasyoları açısından, Rus bankacılık sektöründe ana sermaye/risk ağırlıklı varlıklar ve Tier 1 sermaye/risk ağılıklı varlıklar oranlarının yıllar içinde azalmakla birlikte genel olarak yeterli seviyelerde olduğu gözlenmektedir. Basel II ve ek düzenlemeler seti niteliği taşıyan Basel III düzenlemeleri, bankaların, bilançolarında yer alan varlıkları nedeniyle taşıdıkları finansal riskleri (kredi riski ile faiz, kur ve likidite risklerini içeren piyasa riski) ve operasyonel riski kompanse etmeye yetecek kadar bir sermayeye sahip olmalarını gerektirmektedir. Dünyadaki tüm bankalar tarafından aynı yöntemle hesaplanması istenen ana sermaye/risk ağırlıklı varlıklar oranının minimum $\% 8$ ve Tier 1 sermaye/risk ağılıklı varlıklar oranının minimum \% 4 olması tavsiye edilmektedir (Cangürel ve diğerleri, 2010).

Likidite durumu, banka performansının önemli içsel belirleyicilerinden biridir ve likidite riski finansal başarısızlık ölçüsü olarak değerlendirilebilmektedir (Çelik ve Akarım, 2012). Rus bankacılık sektöründe likidite rasyoları açısından, likit varlıklar/toplam varlıklar oranı, genel olarak yıllar içinde azalmakla beraber, likit varlıklar/kısa vadeli yükümlülükler oranı, beklenmedik durumlarda ani mevduat çekilişlerini karşılayabilmek açısından yüksek seviyelerde olup, bankacılık sektöründe likidite yönetiminin başarılı olduğu izlenimini doğurmaktadır.

Kur riski rasyoları açısından, Rusya bankacılık sektöründe, yabancı para net açık pozisyon/sermaye yabancı para cinsinden krediler/toplam krediler, yabancı para cinsinden yükümlülükler/toplam yükümlülükler oranlarının yıllar itibariyle çok riskli seviyelere ulaşmadığı gözlenmektedir.

Bununla beraber, uluslararası kredi derecelendirme kuruluşlarının 2014 yılı itibariyle, Rus ekonomisine yönelik değerlendirmeleri özetle şöyledir: Fitch, Ukrayna'daki krizin, düşen kur ve artan sermaye kaçışları nedeniyle, zayıflayan Rus ekonomisinin üzerindeki riskleri artırdığını, ancak, Rusya'nın kredi profili sağlamlığının ülkenin BBB notunu etkilemeyeceğini vurgulamıştır. Öte yandan Moody's, Ukrayna ve Rusya belirsizliğinin Rusya'nın kredi notu üzerindeki etkisinin olumsuz olduğuna işaret ederek, Rus bankalarının kısa vadeli bir krizi kaldırabilecek güçte olduklarına, krizin uzaması halinde ise, zayıflayacaklarına dikkat çekmiştir (Türkiye Cumhuriyeti Kalkınma Bakanlı̆̆ı, 2014). Standard and Poor's da yayınladığı raporda yükselen piyasa ekonomilerinin bankacılık sektörleri arasında en kırılganının Rus bankacılık sektörü olduğuna ve Ukrayna krizi nedeniyle, Batı yaptırımlarının bankacılık sektörü varlıklarının yüzde 50' den fazlasını doğrudan etkilediğine işaret etmiş̧tir (Demianchuk, 2014). 2015'e gelindiğinde ise; 3 Temmuz'da Fitch, Rusya'nın yerel ve yabancı para cinsinden temerrüt derecelendirme puanlarını uzun vadeli "BBB-" ve kısa vadeli "F3" (yatırım yapılabilir) olarak teyit etmiştir (Reuters, 2015). Diğer taraftan, Putin, Batı'ya yaptırım resti çekerek dış politika stratejilerinin değişmeyeceğine yönelik mesajlarını sürdürmektedir (Isachenkov, 2015). 


\begin{tabular}{|c|c|c|c|c|c|c|c|c|}
\hline Başlıklar & Göstergeler & 2008 & 2009 & 2010 & 2011 & 2012 & 2013 & 2014 \\
\hline \multirow{2}{*}{$\begin{array}{l}\text { Sermaye } \\
\text { Yeterliliği }\end{array}$} & $\begin{array}{l}\text { Ana sermaye/risk } \\
\text { ağırlıklı varlıklar }\end{array}$ & 16,8 & 20,9 & 18,1 & 14,7 & 13,7 & 13,5 & 12,5 \\
\hline & $\begin{array}{l}\text { Tier } 1 \text { sermaye*/risk } \\
\text { ağırlıklı varlıklar }\end{array}$ & 11,6 & 14,7 & 13,2 & 11,1 & 10,6 & 10,9 & 9,0 \\
\hline \multirow{2}{*}{$\begin{array}{l}\text { Likidite } \\
\text { Riski }\end{array}$} & $\begin{array}{l}\text { Likit varlıklar/toplam } \\
\text { varlıklar }\end{array}$ & 27,1 & 30,4 & 29,0 & 25,5 & 24,7 & 21,7 & 23,4 \\
\hline & $\begin{array}{l}\text { Likit varlıklar/kısa } \\
\text { vadeli yükümlülükler }\end{array}$ & 92,1 & 102,4 & 94,3 & 81,6 & 82,9 & 78,7 & 80,4 \\
\hline \multirow{3}{*}{ Kur Riski } & $\begin{array}{l}\text { Yabancı para net açık } \\
\text { pozisyon/sermaye }\end{array}$ & 0,8 & 0,9 & 0,6 & 0,6 & 2,5 & 1,7 & 0,5 \\
\hline & $\begin{array}{l}\text { Yabancı para } \\
\text { cinsinden krediler/ } \\
\text { toplam krediler }\end{array}$ & 30,2 & 29,9 & 27,0 & 25,4 & 21,3 & 22,7 & 29,4 \\
\hline & $\begin{array}{l}\text { Yabanc1 para } \\
\text { cinsinden } \\
\text { yükümlülükler/toplam } \\
\text { yükümlülükler } \\
\end{array}$ & 33,3 & 31,5 & 28,2 & 26,1 & 25,2 & 25,4 & 34,7 \\
\hline
\end{tabular}

Tablo 3. Rusya Finansal Să̆lamlık Göstergeleri (Yüzde) Kaynak: IMF

* Tier 1 (Ana Sermaye): Ödenmişsermaye, dağıtılmamış kar ve yedek akçelerden oluşmaktadır (Bank for International Settlements, 2015).

Tablo 4'de sermaye yeterlilik rasyoları açısından, 2008 yılında Ermenistan bankacılık sektöründe ana sermaye/risk ağırlıklı varlıklar ve Tier 1 sermaye/risk ağırlıklı varlıklar oranının yüksek seviyelerde olduğu gözlenmektedir.

Ermenistan bankacılık sektöründe likidite rasyoları açısından, 2008 yılı itibariyle, likit varlıklar/toplam varlıklar oranı ve likit varlıklar/ kısa vadeli yükümlülükler oranlarının ani mevduat çekilişlerini karşılayabilmek açısından yeterli seviyede oldukları görülmektedir.

\begin{tabular}{|l|l|c|}
\hline Başlıklar & Göstergeler & 2008 \\
\hline \multirow{5}{*}{ Sermaye Yeterliliği } & Ana sermaye/risk ağırlıklı varlıklar & 27,5 \\
\cline { 2 - 3 } & $\begin{array}{l}\text { Tier 1 sermaye/risk ağırlıklı } \\
\text { varlıklar }\end{array}$ & 26,9 \\
\hline \multirow{5}{*}{ Likidite } & Likit varlıklar/toplam varlıklar & 21,8 \\
\cline { 2 - 3 } & $\begin{array}{l}\text { Likit varlıklar/kısa vadeli } \\
\text { yükümlülükler }\end{array}$ & 60,3 \\
\hline & $\begin{array}{l}\text { Yabancı para net açık } \\
\text { pozisyon/sermaye }\end{array}$ & $-8,8$ \\
\cline { 2 - 3 } & $\begin{array}{l}\text { Yabancı para cinsinden } \\
\text { krediler/toplam krediler }\end{array}$ & 37,3 \\
\cline { 2 - 3 } & $\begin{array}{l}\text { Yabancı para cinsinden } \\
\text { yükümlülükler/toplam } \\
\text { yükümlülükler }\end{array}$ & 55,1 \\
\hline
\end{tabular}

Tablo 4. Ermenistan Finansal Să̆lamlık Göstergeleri (Yüzde) Kaynak: IMF

Kur riski rasyoları açısından, Ermenistan bankacılık sektöründe, yabancı para net açık pozisyon/sermaye oranının negatif değer alması, bankaların yabancı para cinsinden varlıklarının, yabancı para cinsinden yükümlülüklerini karşılayamadığı anlamına gelmektedir. Yabancı para cinsinden krediler/toplam krediler, yabancı para cinsinden yükümlülükler/toplam yükümlülükler oranlarının 2008 itibariyle riskli seviyede olduğu gözlenmektedir.

Birlik üyesi ülkelerin bankacılık sektörlerinde aktif kalitesi itibariyle finansal sağlamlık göstergelerinden biri olan takipteki alacaklar/toplam brüt krediler oranlarına Tablo 5'de yer verilmektedir. Oranların, Rusya ve Ermenistan için düzenlenmiş olan genel finansal sağlamlık göstergeleri tablolarında yer almamalarının nedeni, sadece bu orana ilişkin olarak AEB üye ülkelerinin tümü için 2000-2013 yıllarını kapsayacak verilere ulaşılabilmesidir. Kredi riskini yansıtan oranın en yüksek seyrettiği ülkelerin sırasıyla Kazakistan ve Kırgızistan olduğu görülmektedir. Belarus ve Ermenistan için yıllar içinde belirgin düşmeler gerçekleştiği, Rusya için ise, yıllara göre çok dengeli bir seyir takip etmediği dikkat çekmektedir. Kredi riski bankaların verdiği kredilerin geri dönmeme riski olarak tanımlanmaktadır. Etkin bir kredi riski yönetiminin olmaması sorunlu kredilerin artmasına neden olmakta ve bankaların bilançolarını, aktif kalitelerini, karlılıklarını ve sermaye yeterliliği rasyolarını 
olumsuz yönde etkilemektedir. Bankalar tarafından kredi riski yönetimine gereken önemin verilmemesi bankacılık krizlerine neden olan önemli faktörlerden biri olarak görülmektedir (Şahbaz ve İnkaya 2014).

\begin{tabular}{|c|c|c|c|c|c|}
\hline & Belarus & Armenia & Kazakistan & Kirgizistan & $\begin{array}{c}\text { Rusya } \\
\text { Federasyonu }\end{array}$ \\
\hline 2000 & 10,8 & 17,5 & & & 7,7 \\
\hline 2001 & 14,9 & 24,4 & & & 6,2 \\
\hline 2002 & 9 & 9,9 & & & 5,6 \\
\hline 2003 & 3,7 & 5,4 & & & 5 \\
\hline 2004 & 2,8 & 2,1 & & & 3,8 \\
\hline 2005 & 3,1 & 2 & & & 2,6 \\
\hline 2006 & 2,8 & 2,4 & & & 2,4 \\
\hline 2007 & 1,9 & 2,4 & & 3,6 & 2,5 \\
\hline 2008 & 1,7 & 4,3 & 7,1 & 5,3 & 3,8 \\
\hline 2009 & 4,2 & 4,9 & 18,9 & 8,2 & 9,5 \\
\hline 2010 & 3,5 & 3 & 20,9 & 15,8 & 8,2 \\
\hline 2011 & 4,2 & 3,4 & 20,7 & 10,2 & 6,6 \\
\hline 2012 & 5,5 & 3,7 & 19,4 & 7,2 & 6 \\
\hline 2013 & 4,6 & 5,6 & 19,5 & 5,5 & 6 \\
\hline
\end{tabular}

Tablo 5. AEB Üyesi Ülkelerde Aktif Kalitesi (Yüzde) Kaynak: World Bank

\section{Sonuç}

1995-2014 dönemi itibariyle, AEB ekonomik entegrasyonuna geçiş süreci ve ortak para otoritesi hedefi doğrultusunda üye ülkelerin bankacılık sektörlerinin değerlendirildiği bu çalışmada ulaşılan sonuçlar özetle şöyledir:

İncelenen ülkeler genelinde M2/GSYİH oranları yıllar içerisinde artış göstermekle beraber, bu artışların ülkelerin finansal alanlarında önemli finansal gelişmeleri yansıtmadığı ve finansal derinliğin düşük seviyelerde kaldığı gözlenebilmektedir. Rusya'yı sırasıyla Kazakistan, Ermenistan, Belarus ve Kırgızistan ülkeleri izlemektedir.

AEB ülkelerinde menkul kıymetler borsasının gelişmişlik seviyeleri açısından, üye ülkelerden Rusya ve Kazakistan'da 1995-2013 itibariyle dikkat çeken ölçüde artışlar gerçekleştiği, Ermenistan ve Kırgizistan menkul kıymetler borsalarının henüz gelişemediği gözlenebilmektedir. Belarus için ise veri bulunamamıştır.

Sermaye yeterlilik rasyoları açısından, Rus ve Ermenistan bankacılık sektörlerinde ana sermaye/risk ağırlıklı varlıklar oranının genel olarak yeterli seviyelerde olduğu, Tier 1 sermaye/risk ağırlıklı varlıklar oranının ise, yüksek seviyelerde olduğu gözlenmektedir.

Rus bankacılık sektöründe likidite rasyoları açısından, likit varlıklar/toplam varlıklar oranı, genel olarak yıllar içinde azalmakla beraber, likit varlıklar/kısa vadeli yükümlülükler oranı, beklenmedik durumlarda ani mevduat çekilişlerini karşılayabilmek açısından yüksek seviyelerde olup, bankacılık sektöründe likidite yönetiminin başarılı olduğu izlenimini doğurmaktadır. Ermenistan bankacılık sektöründe ise, likidite rasyoları açısından, 2008 yılı itibariyle, likit varlıklar/toplam varlıklar oranı ve likit varlıklar/kısa vadeli yükümlülükler oranlarının ani mevduat çekilişlerini karşılayabilmek açısından yeterli seviyede olduğu görülmektedir.

Kur riski rasyoları açısından, Rusya bankacılık sektöründe, yabancı para net açık pozisyon/sermaye, yabancı para cinsinden krediler/toplam krediler, yabancı para cinsinden yükümlülükler/toplam yükümlülükler oranlarının yıllar itibariyle çok riskli seviyelere ulaşmadığı gözlenmektedir. Ermenistan bankacılık sektöründe ise, yabancı para net açık pozisyon/sermaye oranının negatif değer alması, bankaların yabancı para cinsinden varlıklarının, yabancı para cinsinden yükümlülüklerini karşılayamadığı anlamına gelmektedir. Yabancı para cinsinden krediler/toplam krediler ve yabancı para cinsinden yükümlülükler/toplam yükümlülükler oranlarının 2008 itibariyle riskli seviyede olduğu gözlenmektedir

Birlik üyesi ülkelerin bankacılık sektörlerinde aktif kalitesi itibariyle, kredi riskini yansıtan takipteki alacaklar/toplam brüt krediler oranının en yüksek seyrettiği ülkelerin sırasıyla Kazakistan ve Kırgızistan olduğu görülmektedir. Belarus ve Ermenistan için yıllar içinde belirgin düşmeler gerçekleştiği, Rusya için ise, yıllara göre çok dengeli bir seyir takip etmediği dikkat çekmektedir.

Sonuç olarak, çoğu verilerine dahi ulaşmanın mümkün olmadığı Birlik üyesi ülkelerin finansal sistem ve bankacılık sektörleri geniş ölçüde birbirlerine benzememesi, entegrasyonun sürdürülebilirliğine bağlı olarak, ortak para otoritesinin kurulabilmesi ve ortak para birimine geçilebilmesinin, kaçınılmaz olarak çok aşamalı bir süreç olacağı düşüncesini ortaya koymaktadır. Entegrasyonun devamı ve diğer üye ülkelere destekte başrolü Rusya oynamaktadir. 


\section{Kaynakça}

- $\quad$ Bank for International Settlements, 2015. Monetary \& financial stability, Basel Committee on Banking Supervision, http://www.bis.org/publ/bcbs204.htm

- Bayraktar, N., 2014. "Measuring relative development level of stock markets: Capacity and effort of countries”, Borsa İstanbul Review, 14, p. 76.

- Cangürel, O. ve diğerleri, 2010. Bankacılık Düzenleme ve Denetleme Kurumu, Sorularla Basel III, ss. 1-2.

- C Čihák, M., 2006. "How Do Central Banks Write on Financial Stability?", IMF Working Paper, 06/163, p. 7.

- Çelik, S., Akarım, Y. D., 2012. "Likidite Riski Yönetimi: Panel Veri Analizi ile İMKB Bankacılık Sektörü Üzerine Ampirik Bir Uygulama”, Eskişehir Osmangazi Üniversitesi Sosyal Bilimler Dergisi, 13, s. 2.

- Değertekin, E. A., 2008. "Rusya Sermaye Piyasası”, Sermaye piyasasında Gündem, Türkiye Sermaye Piyasası Aracı Kuruluşları Birliği, İstanbul, ss. 7-8.

- Demianchuk, A., 2014. "Sanctions Affect Half Of Russia's Banking Sector, Report Says”, The Moscow Times, http://www.themoscowtimes.com/article.php?id=511423

- Gaddy C. G. and Ickes B. W., 2010. "Russia after the Global Financial Crisis", Eurasian Geography and Economics, 51, p. 307

- IMF, 2011. Data, Financial Soundness Indicators (FSIs) and the IMF, http://www.imf.org/external/np/sta/fsi/eng/fsi.htm

- IMF, 2015. Data, elibrary-Data, http://elibrary-data.imf.org/QueryBuilder.aspx?s=323\&key=1445284

- Isachenkov, V., 2015. "Russia Mulls New Selective Sanctions Against Western Nations", http://abcnews.go.com/International/wireStory/putin-western-sanctions-fail-split-russian-society-32210169

- Kim, A., 2015. The Jamestown Foundation, programs, Eurasia Daily Monitor, 12, http://www.jamestown.org/programs/edm/single/?tx_ttnews\%5Btt_news\%5D=43712\&cHash=965d3d424fe 9325ed36b197d121ccf66\#.VYXv4bvvrIU

- Mathieu, N., 1998. Financial Sector Reform: A Review of World Bank Assistance, The World Bank, Washington, D.C. p. 72

- $\quad$ Öztürk, N., Barışık, S. ve Darıcı, H. K., 2010. “Gelişmekte Olan Piyasalarda Finansal Derinleşme ve Büyüme İlişkisi: Panel Veri Analizi”, ZKÜ Sosyal Bilimler Dergisi, 6, ss. 97-98.

- Reuters, 2015. 'Fitch Affirms Russia at 'BBB-'; Outlook Negative”, Markets, Bonds, http://www.reuters.com/article/2015/07/03/idUSFit92754120150703

- Şahbaz, N. ve İnkaya, A. 2014 “Türk Bankacılık Sektöründe Sorunlu Krediler ve Makro Ekonomik Etkileri”, Optimum Ekonomi ve Yönetim Bilimleri Dergisi, 1, s. 70.

- World Bank, 2015. Data, Indicators, http://data.worldbank.org/indicator/FB.AST.NPER.ZS

- Букчин, А.,2015. RIA Novosti, http://ria.ru/world/20150129/1044895417.html

- Дружинин, А., 2015. “Дедолларизация на троих, Путин”, Назарбаев и Лукашенко стремятся к валютному союзу, Lenta, http://lenta.ru/articles/2015/03/20/astana/

- Назарбаев, Н. 2009. “Ключи от кризиса”, Российская газета, http://www.rg.ru/2009/02/02/autoritetno.html

- Севостьянова, И., 2014. “Эксперты спорят о введении единой валюты в рамках ЕАЭС”, Vlast, http://vlast.kz/jekonomika/jeksperty_sporjat_o_vvedenii_edinoj_valjuty_v_ramkah_eajes-8505.html

- Türkiye Cumhuriyeti Kalkınma Bakanlığı, 2014. Dünya Ekonomisindeki Son Gelişmeler Bülteni, s. 9. 


\title{
Ukrayna Krizi'nin Türkiye ve Ukrayna Ekonomik İlişkilerine Etkileri
}

\section{The Impact of Ukraine Crisis's on Turkey and Ukraine's Economic Relationship}

\author{
Prof. Dr. Sudi Apak (Beykent University, Turkey) \\ $\mathrm{Ph}$. D. Candidate Selin Kozan (Doğuş University, Turkey)
}

\begin{abstract}
After the breakup of the Soviet Union and independence declaration of Ukraine in 1991, as in the other Soviet countries, Ukraine has left a heavy industrial based economy with an insufficient technology. Trade relations with Turkey gained momentum in 2004 and has continued its growing until today. This trade relationship has a complementary role and mostly based on intermediate good export. Turkey is the second largest export volume partner of Ukraine and providing the largest trade surplus for Ukraine. Ukraine economy is very sensitive to foreign trade fluctuations, therefore in the 2009 global crisis, Turkey's trade volume with Ukraine declined more than two times. In 2014, military conflict in the East, Russian trade restrictions, the Hryvnia depreciation and tight fiscal austerity measures have exacerbated the existing macroeconomic challenges of Ukraine and pushed the country into its deepest recession since 2009.

This study analyses the Ukraine crisis effects on its economic situation and effects on the Turkey and Ukraine's economic relationship by using statistical methods. Data sources are: National Bank of Ukraine, State Statistics Service of Ukraine, Ministry of Finance of Ukraine, Trade Statistics for International Business Development, National Bank of Turkey, Turkish Exporters Assembly, Turkish Statistical Institute.

Turkey, as a country has earned trusts of both Ukraine and Russia, is able to lead a peacekeeping force in Ukraine. Furthermore, Turkey should evaluate the possibilities to provide a credit line to Ukraine and it would be useful for Turkey to search the other markets and trade conditions as well.
\end{abstract}

\section{Giriş}

Soyvetler Birliğinin dağılmasından sonra 1991 yılında bağımsızlığını ilan eden, coğrafi konumu ile sınır komşumuz olan Ukrayna, yaklaşık kırkbeş milyonluk nüfusu, yetişmiş iş gücü, hammadde kaynaklarının zenginliği, yeni yatırım ve modernizasyon ihtiyacı ile ülkemiz açısından çok önemli bir potansiyele sahiptir.

İki ülke arasında 1992 yılında başlayan ticaret 2000'li yıllarda 1.2 milyar dolar seviyesine ulaşmış, 2004 yılında önceki yıla göre en yüksek artışı göstererek 3 milyar seviyesine gelmiştir. 2008 yılında 8.3 milyar doları seviyesindeyken 2009 yılında yaşanan global krizden her iki ülkeyi de etkilemesiyle 4.2 milyar dolar seviyesine gerilemiştir. Bu dönemde Türkiye'den Ukrayna'ya yapılan ihracat oranı önceki yıla göre \%54 oranında düşüş gösterirken, Ukrayna'ya olan ithalat önceki yıla göre \%48 oranında düşüş göstermiştir. Bu gerilemedeki önemli etken Ukrayna ekonomisinin zarar görmesi ve siyasi krizle derinleşen istikrarsız ortamın oluşmasıdır. Siyasi durumun 2010'da yapılan başkanlık seçimleri ile düzeleceği öngörülse de bu durum ekonomide düzelmeyi sağlayamamış, Ukrayna iş yapma acısından zor bir ülke haline gelmiştir. 2011 yılında önceki yıla göre \%28 artıŞ göstererek 6.5 milyar dolara ulaşan ticare hacmi 2012 yılında \%5 düşüş göstermiş ve 6.2 milyar dolar seviyesine düşmüştür. Bunun sebebi 2012 yılında Ukrayna'dan ülkemize olan ithalatın \%8.7 oranında azalması ile birlikte Türkiye'den Ukrayna'ya ihracatın önceki yıla göre \%5.8 oranında artmasıdır. İki ülke arasındaki ticaret hacmi 2013 yılında önceki yıla göre \%7.7 artış göstererek 6.7 milyar dolara ulaşmıştır. Bu dönemde Ukrayna'ya olan ihracatımız \%20 oranda artmıştır. 2014 yılında ise hacim geçen yıla göre \%11 ile 5.9 milyar dolar seviyesine gerilemiştir. Bu yılda Türkiye'den Ukrayna’ya yapılan ihracat \%21 düşüş gösterirken, ithalat \%6 düşüş göstermiştir. 


\begin{tabular}{|c|c|c|c|c|c|}
\hline Yillar & İhracat & İthalat & $\begin{array}{c}\text { İkili Ticaret } \\
\text { Hacmi }\end{array}$ & $\begin{array}{c}\text { İkili Ticaret } \\
\text { Dengesi }\end{array}$ & $\begin{array}{l}\text { İhracatın İthalatı } \\
\text { Karşılama Oranı } \\
(\%)\end{array}$ \\
\hline 1992 & 36 & 90 & 126 & -54 & 40 \\
\hline 1993 & 37 & 473 & 510 & -436 & 8 \\
\hline 1994 & 76 & 535 & 611 & -459 & 14 \\
\hline 1995 & 199 & 856 & 1,055 & -657 & 23 \\
\hline 1996 & 268 & 762 & 1,030 & -494 & 35 \\
\hline 1997 & 337 & 918 & 1,255 & -581 & 37 \\
\hline 1998 & 274 & 989 & 1,263 & -715 & 28 \\
\hline 1999 & 226 & 774 & 1,000 & -548 & 29 \\
\hline 2000 & 258 & 982 & 1,240 & -724 & 26 \\
\hline 2001 & 289 & 758 & 1,047 & -469 & 38 \\
\hline 2002 & 313 & 991 & 1,304 & -678 & 32 \\
\hline 2003 & 445 & 1,332 & 1,777 & -887 & 33 \\
\hline 2004 & 576 & 2,509 & 3,085 & $-1,933$ & 23 \\
\hline 2005 & 821 & 2,651 & 3,472 & $-1,830$ & 31 \\
\hline 2006 & 1,121 & 3,059 & 4,180 & $-1,938$ & 37 \\
\hline 2007 & 1,481 & 4,519 & 6,000 & $-3,038$ & 33 \\
\hline 2008 & 2,188 & 6,106 & 8,294 & $-3,918$ & 36 \\
\hline 2009 & 1,005 & 3,157 & 4,162 & $-2,152$ & 32 \\
\hline 2010 & 1,261 & 3,833 & 5,094 & $-2,572$ & 33 \\
\hline 2011 & 1,730 & 4,812 & 6,542 & $-3,082$ & 36 \\
\hline 2012 & 1,830 & 4,394 & 6,224 & $-2,564$ & 42 \\
\hline 2013 & 2,190 & 4,516 & 6,706 & $-2,326$ & 48 \\
\hline 2014 & 1,729 & 4,242 & 5,971 & $-2,513$ & 41 \\
\hline
\end{tabular}

Tablo 1. Türkiye-Ukrayna Dış Ticaret Dengeler (000 \$) Kaynak: TUIK.

İki ülke arasındaki ticarette sıralamaya bakıldığında, 2014 yılında Ukrayna Türkiye'nin ithalat yaptı̆̆ı 13. ülke konumundadır ve Türkiye'nin toplam ithalatı içerisinde 1.8'lik paya sahiptir. Ukrayna tarafinda ise, 2013 yılında Türkiye Ukrayna'nın ihracatında 2. ülke (\%6'lık payla) ve ihracatında 8. ülke konumundadır. Bu iki ülkenin ticaret ilişkisi tamamlayıcı bir yapıdadır. Ukrayna'dan yapılan ithalatta hammadde ve yarı mamul maddeleri ağırlık taşımaktadır. Türkiye'den Ukrayna'ya yapılan ihracat ise esas olarak mamul maddelerinden oluşmaktadır. Ancak iki ülke arasındaki ekonomik ilişkiler olması gereken potansiyeli yakalayamamıştır, bunun başlıca nedenleri Ukrayna'nın ekonomik ve hukuki sistemlerinin şeffaf olmaması, yatırım ortamlarının gelişmiş olmamasidir.

Ukrayna müteahhitlik ve turizm açısından da Türkiye açısından önemli bir yere sahiptir. 1980'lerin sonunda Sovyetler Birliği'nde yaşanan gelişmelerle SSCB'nin geçirdiği değişim ve oluşan yeni devletler Türk müteahhitlerine yeni kapılar açmıştır. O zamandan bu yana Türk müteahhitleri Ukrayna'da önemli projeler almışlardır. Ülkede yenileme ihtiyacı olması yönünden inşaat konusunda önemli bir potansiyeli vardır.

Turizm tarafında Ukrayna Türkiye için çok önemli bir pazara sahiptir. Türkiye Ukrayna seyahat turizminde tercih ettikleri ilk ülke konumundadır. 2012 yılında ülkemize gelen Ukraynalı turist sayıs 635 bin seviyesindeyken, 2013 yılında 756 bine yükselmiş 2014 yılında ise \%13 gerileme ile 657 bin seviyesinde gerçekleşmiştir.

\section{Ekonomik Görünüm}

2000’li yıllarda Rusya ve Asya pazarındaki güçlü talebe bağlı olarak metaller ve kimyasallar sektöründe olan üretim artışları ile beraber ekonomide düzelmeler olmuş ülke ekonomisi 2008 yılına kadar büyüme trendi göstermiştir.

2009’da Rusya ile Ukrayna arasında çıkan doğalgaz krizi ve ekonomik kriz eşzamanlı olarak diş ticaret hacminde daralmaya sebep olmuştur. Ülkede reel ücretlerin düşüşü, işsizliğin artması, kredi hacminin daralması ve ülkenin para birimi olan Grivna'nın değer kaybetmesi sonucunda ithal malların maliyetinin artması gibi sebeplerden ötürü özel tüketim harcamaları azalmıştır.

Ekonomisi çelik gibi emtia fiyatlarına ve dış finansmana bağımlı olduğundan mali krizden en çok etkilenen ülkelerden biri olmuştur. Ayrıca demir çelik sektörü doğalgaz kullanarak çalıştığından, sektör doğalgaz fiyat artışlarından etkilenmektedir.

2009'da krizden etkilenen ülke ekonomisi \%14.8 küçülme yaşarken, 2010 yılında \%4.2 büyüyerek toparlanma yaşamıştır. 2011 yılına gelindiğinde sanayi üretimindeki artış ihracat rakamlarına yansımış büyüme 5.2 olarak 
gerçekleşmiştir. 2011 büyümesindeki ana etkenlerden birisi de özel tüketim harcamalarının yıllık reel büyümesinin \%15 oranına ulaşması olmuştur.

2012 yılında sanayi üretimindeki düşüşün etkisiyle büyüme oranı 0.2\%'ye gerilemiştir. Euro 2012 Avrupa Futbol Şampiyonası gibi yatırım olanakları ve ziyaretçi gelirlerine rağmen, ikinci yarıda görülen dış performansta görülen zayıflama büyüme rakamlarına yansımıştır. Dış performansta görülen zayıflama büyüme rakamlarına yansımasıyla yüksek faiz oranları ile özel yatırımlarda düşüşe neden olmuştur. Tarım, sanayi ve inşaat sektörleri sırayla \%4.5, \%1.8 ve \%13.8 daralma yaşamışlardır. Euro bölgesindeki gelişmeler, global ekonominin durumu ve ülkede politik krizin sonucu olarak da ülkede devlete ve devletin kurumlarına olan güven zayıflamıştır.

2013'ün öncesindeki 5 çeyrekteki yavaşlamadan sonra son çeyreğinde \%3.7 büyüme, 2013 genelinde büyümeyi \%0'a çekmiştir. 2013'de hem bütçe açığı hem cari açık GSYİH'nın sırasıyla \%8 ve \%9 açık vermiştir. Resmi rezervler tükenmiştir. 2010'da 34.6 milyar dolar civarında olan rezervler 2013 yılında 20.4 civarına gerilemiştir. Uluslararası finansal pazarlara erişim sağlanamamıştır. Devlet borcunun GSYİH'ya oranı 2013'te \%40'lara ulaşmıştır. Tarım sektöründe yaşanan önceki yıla göre \%13 büyüme, önemli derecede büyük olmasına rağmen sanayi (önceki yıla göre \%36.6 daralma) ve inşaat (önceki y1la göre \%21.3 daralma) sektörlerinde yaşanan önemli düşüşler GSYİH büyümesini negatif etkilemişlerdir. Ekonomik büyümenin gerçekleşememesi ile ülke sürdürülemez ekonomik duruma gelmiştir.

2010-2013 dönemi makroekonomik politikalara bakıldığında üç durum göze çarpmaktadır. Dolar karşısında değişmeyen sabit kur, ağır sübvansiyonlu enerji fiyatları, genişletici mali politikalar. 2013 yılında GSYİH cari fiyatlarla yaklaşık olarak 182 milyar dolar gerçekleşmiştir. Kişi başına düşen gelir de yaklaşık 4.003 dolar olarak gerçekleşmiştir.

2014'e gelindiğinde kemer sıkma politikalarının talebi negatif etkilemesi, Rusya ticareti ile olan kısıtlamalar ve daha yüksek enerji ithalatı fiyatları, doğudaki Rus bölücüler ile asgari çatışmalar makroekonomik dengeleri kötü etkilemiştir. Süregelen yönetimin de yetersizliği ile ülke 2009'dan bu yana en derin resesyon içine girmiştir. Ekonomik ilişkilerin bozulması, Donbas’taki çatışmaların sonucu altyapının bozulması, iç tüketimin zayıflaması, sermaye yatırımlarının ve ihracatın azalması ile ülke ekonomisi 2014 yılında \%7 daralma yaşamıştır.

2013'den 2014'e gelindiğinde düşüşün başlıca sebepleri söyle özetlenebilir. 2013'de toplam 85.3 milyar dolar olan mal ve hizmetler ithalatının \%26'sı Rusya'ya aitti. 2014'e gelindiğinde Rusya alımlarını \%50 civarında azaltarak kendi ekonomisini tehdit etmeyecek tüm alımları durdurdu. Bu durum Ukrayna'nın metalürji, makina ve gıda işleme gibi sektörlerini vurdu. Uygulanan devlet politikaları ile yüksek vergi oranları, gaz ve 1sıtma tarifelerinin yükselmesi, devlet istihdamının durması yerel tüketimi azalttı. Yine düşük banka likiditesi ve kredi darlığı tüketimi olumsuz etkiledi. Ayrıca Grivna'nın da değer kaybı refahı azaltarak tüketimi negatif etkiledi. 2014 'de özel ve devlet yatırımları ve harcamaları düştü. Politik ve ekonomik risklere bağlı olarak yerel ve yurtdışı özel yatırımlar büyük ölçüde azadı. Ayrıca Rusya Gazprom şirketinin 2014 ikinci çeyrekte doğalgaz fiyatlarını arttırması ülkeyi ödeme güçlüğüne sokmuştur.

2014'ün son çeyreğin reel GSYİH'sında \%15.2 daralma gerçekleşmiştir. Reel sektör performansının son çeyrekte bozulmasının (3. Çeyrek performansı \%5.3'e göre) başlıca sebebi Donbas'taki askeri çatışmaların Donbas'ın sanayisinde yarattığı zararlardır. Çünkü bölgede işgalcilerin el koydukları geniş topraklarda bulunan metalurji, makina, kimya ve maden gibi sanayi şirketleri muhabereden direkt etkilenmişlerdir. Üretimdeki aksamalar ve bölgelerdeki ulaşımın engellenmesi de sanayi üretimini dolaylı olarak etkilemiştir. Ayrıca mali konsolidasyonun sağlanamaması, Grivna'nin sert değer düşüklüğü, yükselen enflasyonu ve kredi darlığından hane halkının ve özel sektörün kredi bulamaması son çeyrekteki sert düşüşün sebeplerindendir.

2014 toplamında GSYİH \%6.8 küçülmüştür. Harcamalardaki en büyük düşüş özel yatırımlarda \%29.2 olarak gerçekleşmiştir. Bunu takip eden $14.5 \%$ düşüşle ithalat ve \%9.6 düşüşle özel harcamalarda gerçekleşmiştir. Devlet harcamaları ise sadece $\% 0.6$ düşmüştür.

2015'e gelindiğinde GSYİH'daki yavaşlamanın nedeni üç sebebe bağlıdır. Doğudaki çatışmaların devam etmesi, Grivna'daki belirsizlik ve artan enflasyon. (Şubat ayında yıllık \%35'e ulaşmıştır.) Çatışmalar sebebiyle çatışma bölgelerinde üretim rakamlarının değerlendirilmesi zorlaşmaktadır. Bunun yanı sıra Rusya ile olan ticaret ilişkisinin bozulması Ukrayna ekonomisi üzerinde baskı yaratmaktadır. Pozitif tarafta ise IMF'nin Ukrayna'ya sağlayacağı 17,5 milyar dolarlık kredinin 5 milyar dolarlık ilk kısmının 13 Mart 2015 kullanılması güvenin artmasını sağlamıştır ve makroekonomik dengeleri düzeltmesi için firsat yaratmıştır. Ayrıca, bu dönemde diğer finansal kuruluş ve devletlerden 8 milyon dolar alması için izin çıkmıştır. 


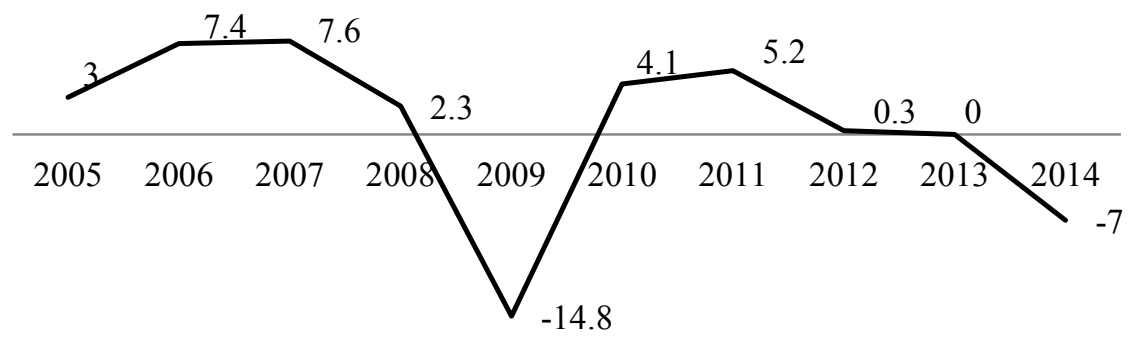

Şekil 1. Ekonomik Büyüme, yıllık yüzdesel Kaynak: Ukrayna Devlet Istatistik Kurumu

\begin{tabular}{|c|c|c|c|c|}
\hline & 2011 & 2012 & 2013 & 2014 \\
\hline GSYİH, milyar dolar & 163.4 & 176.6 & 182 & 127.4 \\
\hline Reel GSYH büyümesi, y1llık yüzdesel & 5.20 & 0.20 & 0.00 & -6.8 \\
\hline Özel tüketim, reel büyüme, yıllık yüzdesel & 15.00 & 11.70 & 7.80 & -9.6 \\
\hline $\begin{array}{l}\text { Mali denge, Naftogaz ve Emeklilik fonları dahil /GSYİH, } \\
\text { y1llk yüzdesel }\end{array}$ & -4.30 & -6.00 & -6.50 & -11.7 \\
\hline Kamu borcu/GSYİH, yıllık yüzdesel & 36.3 & 36.6 & 40.5 & 72.0 \\
\hline Tüketici enflasyonu, yılsonu yüzdesel & 4.6 & -0.2 & 0.5 & 24.9 \\
\hline Grivna/Dolar kuru, yılsonu & 8.0 & 8.0 & 8.0 & 15.8 \\
\hline Cari işlemler dengesi/GSYİH & -6.3 & -8.1 & -9.0 & -4.1 \\
\hline Doğrudan yabancı yatırım (milyar dolar) & 7.0 & 6.6 & 3.3 & 0.2 \\
\hline Uluslararası rezervler (milyar dolar) & 31.8 & 24.5 & 20.4 & 7.5 \\
\hline Diş borç (milyar dolar) & 126.2 & 135.1 & 142.5 & 135.0 \\
\hline
\end{tabular}

Tablo 2. Makroekonomik Göstergeler Kaynak: Ukrayna Devlet İstatistik Kurumu

\section{Sektörel Gelişmeler}

Ülkenin para birimi Grivna'nın da değer kaybetmesi, uygulanan kemer sıkma politikası, artan enflasyon ve kredi darlığı gibi faktörler iç tüketimi negatif etkilemiştir. Diğer yandan, ihracatın azalması ile reel sektör performansının düşmesi ve Rusya'nın ticaret kısıtlamalarına karşın, ülke Avrupa Birliği ile olan etkinliğini artırmış ve tarım sektöründe olumlu gelişmelere neden olmuştur. Ukrayna 2014 yılında, geçen yıl rekorunu $2.4 \%$ büyüterek 63.8 milyon ton ile tarihinin en yüksek hububat hasadına ulaşmıştır. 2014 yılında krizden en az etkilenen ve $\% 2.8$ oranı ile büyüme yakalayan tek sektör olmuştur.

Diğer sektörlerin durumuna bakıldığında önemli ölçüde azalışlar yaşanmıştır. Ukrayna ekonomisi açık şekilde küçülmüştür. İç tüketimin azalması, dış ticaretin bozulması, toptan satış ticareti hacminde \%9.6 ve perakende ticaretinde \%15 azalmaya neden olmuştur. Borçlanma koşullarının sıkılaşması yatırımlardaki hassasiyetin artmasına neden olmuş, bu da inşaat sektörüne \%22 oranında küçülme olarak yansımıştır. Hane halkı gelirinin \%13.5 düşmesi, taşımacılık sektörüne zarar vermiş, 2014 yılında kargo taşımacılığını \%11.7, yolcu taşımacılığını $\% 10.8$ azaltmıştır.

Doğudaki savaşın belirsizliği, döviz krizi, mali kemer sıkma politikası ve Rusya ile kötüye giden ticaret ilişkileri Ukrayna'nın reel sektör performansını doğrudan etkilemiştir. Sanayi, ekonomide en çok zarar gören sektörlerden olmuştur. Çoğu kömür ocağı çatışmaların olduğu bölgelerde olduğundan üretim düşmüş madencilik sektörü zarar gömüştür. Yine kömür arzına bağlı olarak, ulaşım altyapısının da zarar görmesiyle, metalurji ve elektrik üretimi sektörleri zarar görmüşlerdir. Makina yapımı sektörü de Rusya ticaret kısıtlamalarına takılan ve zarar gören sektörlerden olmuştur. 2014 yılında metalurji, makine, kimya ve madencilik sektörleri sırasıyla \%15, $\% 21, \% 15$ ve \%14 oranlarında sert düşüşler yaşamışlardır. Dünyada emtia fiyatlarının düşmesi ve Rusya'nın ticaret kısıtlamaları sektörlerdeki aşağı yönde düşüşleri desteklemiştir. Ukrayna'nın bölgeleri arasındaki ekonomik ayrılma ve üretimin durması diğer sektörleri de etkilemiştir. Taşkömürü ve elektrik ve kok kömürü arıtma oranları da sırasıyla \%6.5 ve \%22 düşüş yaşamışlardır. Öte yandan, 2014 yılında tarımda yaşanan artış ve AB pazarına erişimin gelişmesi Ukrayna'nın gıda sektörünün \%4 artmasını desteklemiştir. Grivna'nın değer kaybetmesi ise yerel tekstil ve ilaç sanayisindeki rekabeti artırmıştır. Toplamda, sanayi üretimi 2014 y1lında \%10.7 küçülme yaşamıştır. 


\begin{tabular}{|l|r|r|r|r|r|}
\hline & 2010 & 2011 & 2012 & 2013 & 2014 \\
\hline Tarım & -1.5 & 17.5 & -4.5 & 13.3 & 2.8 \\
\hline Sanayi & 11.2 & 7.6 & -1.8 & -4.3 & -10.7 \\
\hline İnşaat & -5.4 & 11.1 & -14 & -11.1 & -21.7 \\
\hline İç ticaret & \multicolumn{7}{|c|}{} \\
\hline Toptan satış & 0.4 & 0.6 & -4.4 & -2.0 & -15 \\
\hline Perakende & 9.8 & 14.7 & 15.9 & 9.5 & -8.6 \\
\hline Taşımac1lik & 6.4 & 5.7 & -7.6 & -3.9 & -10.8 \\
\hline Kargo & -0.2 & 3.3 & -1.2 & -2.9 & -11.7 \\
\hline Yolcu & \multicolumn{7}{|l|}{}
\end{tabular}

Tablo 3. Reel Sektör Göstergeleri (yıllık yüzdesel) Kaynak: Ukrayna Devlet İstatistik Kurumu

\section{Dıș Ticaret}

Ukrayna'nın dış ticaret hacmi son iki yılda küçülme yaşamıştır. 2012 yılında 153 milyar dolar seviyesinde olan toplam hacim, 2013 yılında 140 milyar dolar seviyesine, 2014 yılında ise 108 milyar dolar seviyesine düşmüştür. İhracat rakamı 2012 yılında 68.8 milyar dolar seviyesinden 2013'de (önceki yıla göre \%8 daralarak) 63.3 milyar dolar ve 2014 'de (önceki yıla göre \%15 daralarak) 53.9 milyar dolar seviyesine gerilemiştir. İthalat tarafındaki gerileme daha büyük olmuştur. 2012 yılında 84.7 milyar dolar ile en yüksek seviyesinde olan ihracat, 2013 yılında (önceki yıla göre \%9 daralarak) 77 milyar dolara, 2014 yılında ise (önceki yıla göre \%29 daralarak) 54.4 milyar dolara gerilemiştir.

Dış ticaret dengesi 2012 yılında 15.8 milyar dolar açık verirken 2013 yılında 13.7 milyar dolar ve ihracattaki düşüşten ötürü 2014 yılında 0.5 milyar dolar açık vermiştir. 2013 yılında ihracatın ithalatı karşıma oranı \%82 iken 2014 yılında \%99 seviyesine yükselmiştir.

\begin{tabular}{|l|c|c|c|c|c|c|c|c|c|}
\hline & 2006 & 2007 & 2008 & 2009 & 2010 & 2011 & 2012 & 2013 & 2014 \\
\hline Toplam İhracat & 38.9 & 49.8 & 67.7 & 40.4 & 51.4 & 68.4 & 68.8 & 63.3 & 53.9 \\
\hline Toplam İthalat & 44.1 & 60.4 & 83.8 & 45 & 60.7 & 82.6 & 84.7 & 77.0 & 54.4 \\
\hline Hacim & 83 & 110.2 & 151.5 & 85.4 & 112.1 & 151 & 153.5 & 140.3 & 108.3 \\
\hline Denge & -5.2 & -10.6 & -16.1 & -4.6 & -9.3 & -14.2 & -15.8 & -13.7 & -0.5 \\
\hline
\end{tabular}

Tablo 4. Ukrayna Yıllık Ticaret Rakamları (milyar \$) Kaynak: Ukrayna Devlet İstatistik Kurumu

2013'de toplam ticaretin \%25'ini oluşturan Ukrayna'nın sanayi bölgesi Donbas ithalatı, ülkedeki çatışmalar etkisiyle, Rusya'nın ticaret sınırlamalarıyla ve dünya emtia fiyatlarının aşağı doğru hareketi ile zayıflamıştır. Pozitif tarafta ise, 2013 yılında Avrupa Birliği pazarına girilmiştir ve yüksek tarım hasadı ithalatı desteklemiştir. İhracat tarafında ise, sıkı mali politikalarla oluşan zayıf iç talep, kurun değer kaybının fiyatlara etkisi ve düşük enerji arzı ihracatta daralmaya neden olmuştur.

Rusya'nın ithalatına uyguladığı kısıtlamalarla ve Rusya'yla genel ilişkilerin bozulmasıyla ihracat verileri 2014 yılında önceki yıla göre \%29 daralarak derin düşüş yaşamıştır.

Ukrayna'nın son iki yılda ihracat yaptı̆̆ı ülke dağılımına bakıldığında 2012'de toplam ihracatın \%32'sinin gerçekleştiği Rusya, Belarus ve Kazakistan'ın toplam payı 2014'de \%23'e 2015 Ocak ayında ise \%13'e gerilemiştir. İhracatında önemli pay alan bu ülkelerdeki payın \%50 civarında azalması toplam ihracatı etkilemiştir.

Son iki yılda Avrupa Birliği'ne olan ihracat 17 milyon dolar civarlarında sabit kalmıştır, ama ihracattaki küçülmeden dolayı toplam ihracattaki payı artarak 31\%’e çıkmıştır.

Geri kalan ülkelere yapılan ihracat büyüklüğü \%46 seviyelerindedir. Bu ülkelerle 2012 y1lında gerçekleşen ithalat rakamı 29 milyar dolardan 2014'de 24 milyar dolara düşüş yaşamıştır. Bunun ana sebebi de yine asgari çatışmalardan ötürü Ukrayna'nın sanayi üretim kapasitesinin ve altyapısının önemli oranda zarar görmüş olmasidir.

Ukrayna hızla yükselen talebi ile 2013 yılında Türkiye ihracatında geçen seneye göre \%19.6 ihracat artışı ile toplam 2 milyon dolar ihracat gerçekleştirmiştir. Türkiye'nin toplam ihracatındaki payı \% 1.4 seviyesindedir. Ukrayna Türkiye'den çok çeşitli mallar ithal etmektedir. Bunların başında \%9.5 pay ile yenilenebilir meyve ve \%9.2 pay ile örme giyim eşyaları gelmektedir. Böylece Ukrayna'ya yapılan ihracatta Türkiye'nin tarım ve tekstil sektörleri önemli pay almaktadır. Onları takip eden motorlu kara taşıtları \%6.6 ve makineler de \%5.8 pay almışlardır.

2013 Türkiye ithalat sıralamasında ise Ukrayna 4.5 milyon dolarla \%1.8'lik pay almıştır. Ukrayna'dan yapılan ithalatın başında \%51'lik payla demir-çelik sektörü gelmektedir. Türkiye demir çelik pazarının yarısından fazlasını Ukrayna'dan yapılan ithalat oluşturmaktadır. İthalat sıralamasında demir çelikten sonra yağlar \%8 pay, 
gübreler \%7.6 pay almışlardır. İthalat artışlarında ise hububat $(\% 196,3)$ ve cevherlerdeki (\%151.7) pazar büyümeleri dikkat çekicidir.

\section{Doğrudan Yabancı Sermaye Yatırımları}

Ukrayna’ya yapılan yabancı yatırımlar incelendiğinde kümülatif olarak 2013 yılsonu 58.1 milyar dolar ile en yüksek seviyeye çıkmış ancak 2014 yılında ise \%21 oranında düşüş göstererek 46 milyar dolar seviyesinde düşmüştür. Başlıca yatırım yapılan sektörler arasında metalurji, finans, araç ve araç yan sanayi ticareti ve imalatı, inşaat, gıda, ticari kiralama, emlak hizmetleri yer almaktadır.

2014 yılında yatırımcı ülkeler (off shore hesaplama yoluyla) sıralamasında \%30'luk 13.7 milyar dolarla Güney Kıbrıs ilk sırada yer almaktadır. Güney Kıbrıs'1, Almanya \%12.5 pay alarak (5.7 milyar dolar), Hollanda \%11'lik pay alarak (5.1 milyar dolar), Rusya Federasyonu \%5.9 payla (2.7 milyar dolar), Avusturya \%5.5'lik payla (2.5 milyar dolar) ve İngiltere \%4.7'lik payla (2.1 milyar dolar) takip etmektedir.

Rusya Federasyonu'nun 2013'de 4.3 milyar dolar seviyesinde yatırımı 2014'e gelindiğinde 2.7 milyar dolara düşmüştür. Yatırım yaptığı alanlara bakıldığında özellikle enerji dağıtımı, petrol, bankacılık, iletişim gibi stratejik sektörlere yatırım yaptığı gözlenmektedir. Hollanda tarafından yapılan yatırımların önemli bir kısmı ise Hollanda üzerinden başka ülke şirketlerince yapılan yatırımlardır.

2013 sonu itibarı ile Türkiye'nin Ukrayna'daki yatırımları 215,2 milyon dolar düzeyine ulaşmıştır. Ancak, Türk sermayesinin başka ülkeler yoluyla Ukrayna'ya girmesi nedeniyle fiiliyatta gerçekleşen yatırım miktarının kayıtların oldukça üzerinde olduğu söylenebilir.

Ukrayna'nın diğer ülkelere yaptığı doğrudan yabancı yatırımlar toplamı yıllar itibarı ile çok fazla değişiklik göstermemiştir. 2013 yılında 6.5 milyar dolar seviyesinde olan doğrudan yatırımlar, 2014 yılında 6.4 milyar dolar seviyesinde gerçekleşmiştir. Yatırım yapılan ülkeler sıralamasında \%91.6’lık payı Güney Kıbrıs almaktadır. İki ülke arasındaki sermaye akışı vergi kaçırma ve kara para aklama faaliyetlerinden kaynaklanmaktadır. Rusya Federasyonu, Letonya, Polonya, Gürcistan, Virgin Adaları ve Kazakistan yatırım yaptığı diğer ülkelerdir.

\section{Mali Politika}

2013 yılında kamu borcu önceki yıla göre \%13.3 artış göstererek 73 milyar dolar olmuştur. Bu dönemde kamu borcunun GSYİH'a oranı \%40 olarak gerçekleşmiştir. İç borçlar önceki yıla oranla \%35 artarak 32.1 milyar dolar, dış borçlar ise \%6.8 artarak 27.8 milyar dolar seviyesine ulaşmıştır. 2014'e bakıldığında toplam kamu borcu 93 milyar dolara ulaşmış, kamu borcu/GSYİH oranı \%70'e yükselmiştir.

2013 yılsonu toplam 142.5 milyar dış borcun sadece 31.7 milyar doları kamu sektörlerinin borcu, 22.5 milyar doları bankaların, 88.3 milyar doları özel sektörün borcudur.

2014'de yaşanan gerilemeler ile Ukrayna'nın konsolide kamu sektörü bütçe açı̆̆ı/GSYİH oranı (devlet bütçesi ve reel yönetim bütçesi, Naftogaz ve emeklilik fonu içeren) 2013 de 6-7\%'lerden, \%12'ye artmıştır.

2008'deki global kriz sonrası 2009'da \%9.6 seviyesine yükselen işsizlik oranı, 2013 yılında \%7.2 gerçekleşmiş, 2014'de işsizlik oranı \%9.7'ye yükselmiştir.

Ukrayna'nın zor durumda olan ekonomisi (ekonomik gerileme, asgari sorunlar, bankacılık sektörünün zayıflaması gibi) mali süreci yavaşlamaktadır. Mali iyileştirmeler için 2014 yıl boyunca IMF ile görüşmeler sonucu, 11 Mart 2015'de IMF Ukrayna için EFF (External Fund Facility) programı onaylanmıştır ve EFF programı, 2010 yılında IMF ile imzalanan 16.4 milyar dolarlık Stand-By anlaşmasının yerine geçmiştir. Bu programa göre Mart başından itibaren 4 yıllık 17.5 milyar dolarlık yeni bir kredi limiti açılacaktır. Bu limitin 10 milyar dolarının 2015'de kullanılabileceği öngörülmektedir. Kredinin birinci dilimi olan 5 milyar dolar Merkez Bankası'na transferi gerçekleşmiştir. Bu kaynağın yarısını devlet bütçe açı̆̆ının finansmanında kullanacak geri kalanı da rezervlere aktarılacaktır. Diğer finansman kaynaklarından 8 milyar dolarda 2015 'te kullanılmak üzere bekletilmektedir.

IMF programına göre devletin 2014 bütçe açığı hedefinde vergileri sadeleştirmek, çalışanların vergi yükünü azaltmak gibi önemli vergi reformları yapılması beklenmektedir. Program aynı zamanda bazı mali reformları da içermektedir. Mali kurumların gelirden tahsilatlarının ve harcamalarının açık ve kontrol edilebilir olması, vergi yönetimi ve usulünün güçlendirilmesi, devletin finansal yönetiminde bütçeleme ve nakit yönetiminin güçlendirilmesi gibi unsurlar bulunmaktadır.

\section{Para Politikası}

Grivna'nın hızlı değer kaybı, yakıt gibi ihraç edilen tüketici malları, tekstil, ilaç ve elektrikli aletlerin fiyatlarını direkt etkilemiştir. Ulaşım ve ihraç malları hammaddeleri de ulusal paranın değer kaybından dolaylı etkilenmiştir. Regüle uygulanan hizmet tarifeleri, demiryolu ücret tarifeleri, ekmek ve alkol fiyatları ve bazı tüketici vergi artışlarına (alkol ve tütündeki ve tıbbı ürünlerdeki KDV ayrıcalıklarının kaldırılması gibi) da etkili olmuştur. Bütçe açı̆̆ının büyüklüğü de enflasyon baskılarını artırmıştır. Rusya’nın Ukrayna ihraç malları 
üzerindeki kısıtlamaları, yüksek tarım hasadı, yerel tüketimin zayıflaması, dünyada enerji fiyatlarının düşüşü ve daraltıcı para politikaları da enflasyon üzerindeki bu baskının bir kısmını dengelemiştir.

TÜFE rakamlarına bakıldığında, 2014'de yiyecek enflasyonu yıllık \%24.8 artmıştır. Bu artışa yıllık meyve fiyatlarının dalgalanması (\% 56 civarında), balık ve balık ürünleri fiyatlarındaki artış (\%37.2 civarı), yumurta fiyatı artışı (\%35.3 civarı) etkili olmuştur. Bu yükselişin nedeni Grivna'nın değer kaybetmesi ve bu ürünlerin veya üretimindeki ara maddelerin tüketimlerinde ihracat payının yüksek olmasıdır. Benzer nedenden araba alımları, ev aletleri, giyim ve ayakkabı ve ilaç fiyatları 2014 yılında, sırasıyla yıllık $\% 73.5, \% 28, \% 14.5$ ve $\% 45$ artış göstermiştir. Dolaylı vergilerin ve idari fiyatların artışı ile alkollü içecekler yıllık \%26, ulaştırma servisleri $\% 20.5$ artış göstermiştir. Bununla birlikte ekmek fiyatları yıllık \%35 ve hizmet tarifeleri de $\% 34$ artış göstermiştir. Ukrayna ekonomisi büyük ölçüde fosil yakıtların ihracatına dayandığından, 2014'de petrol fiyatları artış göstermiştir. Yılın ikinci yarısında dünyada ham petrolde yaşanan gelişmelere rağmen Grivna değer kaybının ve hızlı artan tüketim vergilerinin sadece bir kısmı telafi edilebilinmiş̧ir. Bunun sonucu olarak da araç yakıt fiyatları yıllık \%61 artışa ulaşmışır. Reel gelirlerin azalmasıyla da, hizmetler enflasyondan daha düşük büyüme kaydetmiştir. Sağlık, eğitim, eğlence ve kültür sırasılyla yıllık $\% 17.4, \% 5$ ve $\% 9.5$ oranlarında büyüme yakalamışlardır. Durgun yerel talep ile bereketli tarım hasadı ve Rusya'nın ticari kısıtlamaları ile süt ve süt ürünleri, peynir, sebze ve şeker ve restaurant ve otel hizmetlerinde fiyat baskısı yaratmıştır.

2014'de devalüasyon etkileri, devam eden hizmet tarifesi ayarlamaları ve diğer idari fiyat düzenlemeleri ve dolaylı vergilerin durumu tüketici fiyat büyümesini belirleyen unsurlar olmuştur. 2015 için belirlenen 2014 sonunda onaylanan bütçe yasasına göre, devlet bütçe açığı için para sürmeye devam edecektir. Buradaki parasal genişleme riski, orta vadede enflasyon baskıları yaratmaktadır. Çünkü paraya olan talebin azalması, merkez bankasının enflasyon sürecinde olan kontrol gücünü kaybetmesine neden olacaktır. Bu nedenden devletin fiyat ayarlamalarının devamıyla, orta vadede tüketici fiyatları iki haneli büyümelere devam edecektir.

2015 tüketici fiyatları büyümesine baktığımızda etkisini destekleyecek iki önemli baskı görülmektedir. İlki Grivna'daki değer kaybının sürmesi, diğeri de tarifeler ve regüle edilmiş fiyatlardaki düzenlemelerdir. Grivna'nın dolar karşısında değer kaybı devletin tarifeleri yükseltmesini hızlandırmıştır. Devlet 1 Nisan 2015'de doğalgaz ve ısıtma tarifelerinin sırasıyla $\% 280$ ve $\% 66$ artacağını açıklamıştır. Hane halkı için elektrik fiyatları maliyeti karşılayacak şekilde artmıştır. 2015 Nisan'da elektrik tarifeleri ortalama fiyatın \%36 oranda, Eylül'de de $\% 25$ oranda artırılacaktır. Yakıt fiyatlarındaki ve ulaşım maliyetlerindeki artışla, devlet ulaşım tariflerinde de düzenlemeye gitmiştir. Kyiv'de 2015 Şubat’tan beri ulaşım tarifeleri iki katına çıkmıştır.

\section{Bankacılık Sektörü}

Bütçe açığından kaynaklanan parasallaşma ve Ukrayna Merkez Bankası'nın ticari bankalardan likidite tedarik etmesine karşın, tüketici enflasyonuna olan parasal etki sınılıdır. Bunun nedeni, Ukrayna Merkez Bankası'nın uluslararası rezervlerini satması ve iskonto oranlarını artırmasıyla olan sterilizasyon etkisi ile dengelenmesidir.

2014'de Ukrayna Merkez Bankası, devlet bütçesine kar transferi (22.8 milyar UAH-yaklaşık 1.4 milyar dolar) ve yerel devlet menkul kıymet alımı olarak toplamda piyasaya 175 milyar UAH ( yaklaşık 11 milyar dolar) para sürmüştür. 2014'ün sonunda Merkez Bankası'nın devlet tahvilleri 2 katından daha fazla artarak 318 milyar UAH (yaklaşık 20.1 milyar dolar)'a ulaşmıştır. Bunun sonucu olarak Merkez Bankası'nı üstlendiği Ukrayna'nın kamu borcu 2014 'de $\% 70$ 'lere yükseldi. Bu da parasal kaynak olarak Ukrayna devlet otoritelerine olan bağımlılığın artığını göstermektedir.

Ukrayna Merkez Bankası borçların refinansmanı için ticari bankalara 222.3 milyar UAH (yaklaşık 14 milyar dolar) kaynak sağlamıştır ve yüklü mevduat çıkışlarını dengeleyebilmek için uzun vadeli kredi sağlamıştır. Ticari bankalar önceki 2014'deki refinansman kredisi olan 189.4 milyar UAH (yaklaşı 12 milyar dolar)'1 öderken, Merkez Bankası iskonto kredilerindeki artış 33 milyar UAH (yaklaşık 2 milyar dolar) seviyesindeydi.

Uluslararası rezervler 2014 yıl başında 20.4 milyar dolardan, yılsonunda 7.5 milyar dolara gerilemiş ve Merkez Bankası faiz oranları da \%6.5 dan, \%14 oranında artmıştır. Para arzının yavaş büyümesi, 2014'de yıllık $\% 5$ den az artması kredi darlığına neden olmuştur.

Merkez bankası likidite desteği ticari bankaların kısa vadeli zayıflamasına engel olmuştur. Yüklü mevduat çıkışları ve ticari bankaların kredi portföylerinin niteliğini kaybetmesiyle yaşanan hızlı gerileme Merkez Bankası'nın likidite desteği ile giderilmeye çalışılmışıtır.

2015'e gelindiğinde Ukrayna bankacılık sektörü stres altındadır. Enflasyonun yükselmesi, Grivna'nın değer kaybı, mevduat geri çekimlerinde ve döviz işlemlerindeki kısıtlamalar, bankacılık mevduatını yönlendiren bankaların iflas açıklamaları durumun şiddetini ortaya koymaktadır. Mevduat çıkışlarıyla da bankacılık sistemi zorluk içine girmiştir, ticari bankaların kredi portföylerindeki sıkılaşma ile de dış finansman ihtiyacı artmıştır.

Derin ekonomik kriz, Doğu'daki çatışmalar ve Grivna değer kaybı ticari bankaların temerrüde düşen kredilerini arttırmıştır. Temerrüde düşen krediler 2013 4.çeyreğinde \%13 civarındayken 2014'ün dördüncü çeyreğinde $\% 19$ oranına yükselmiştir. 
2005-2008 arası kredi krizi yurt dışı finansal piyasalardan alınan borçlarla finanse edilmişti. Bu yıllarda

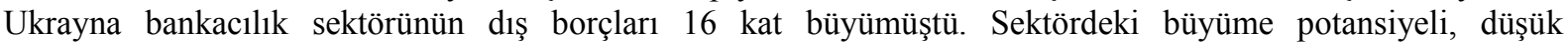
penetrasyon ve 2000'den sonraki etkileyici büyüme ile yabancı bankaların Ukrayna'nın bankacılık sektörüne katılımları artmıştır. Ancak 2008-2009'daki finansal kriz ve yapısal reformun uygulamaya koyulamaması ile yabancı bankalar ve yatırımcılar stratejilerini değiştirip Ukrayna pazarından çıkmışlardır.

2013 yıl sonu brüt dış borç 142 milyar dolar seviyesindeyken, 2015 yılsonu brüt borç 126 milyar dolar olarak hesaplanmıştır. Bu azalmaya rağmen sektörün dış borç finansmanı bu borçların yarısından fazlasını bir yıl içinde ödemek zorundadır. Grivna'nın değer kaybı ve neredeyse kapalı olan yurtdışı sermaye piyasaları, yüksek kısa dönem diş borçlar Ukrayna bankacılık sektörünü zorluk içine sokmuştur.

\section{Sonuç}

11 Şubat 2015'te bir araya gelen Ukrayna, Rusya, Almanya ve Fransa liderleri Minsk'te yaptığı uzun müzakerelerden sonra, 15 Şubat 2015'den itibaren ateşkesin sağlandığını duyurarak, krizin çözümüne yönelik Minsk 2 Mutabakatı'nı açıkladılar. Ancak, 17 Mart 2015'de Donbass bölgesinde bulunan Lugansk ve Donesk vilayetlerinde bazı bölgelerine ilişkin kabul edilen yasa, Minsk Mutabakatı'nı bitirecek maddeler içermiş ve çatışmaların tekrar başlaması riskini doğurmuştur. Kiev'in Donbas bölgesine yönelik tek taraflı politikası, çatışmaların tekrar alevlenmesine ve ülkede daha büyük ekonomik kayıplara neden olabilir.

Rusya'nın Doğu Ukrayna'da olan çatışmaların olduğu bölge coğrafi olarak Ukrayna'nın sadece \%4'lük alanını oluşturmasına rağmen ekonomik anlamda büyük ölçek kaplamaktadır. Bu bölge ihracatın \%14'ünü, sanayinin \%12'sini ve GSYİH'nın \%9'unu oluşturmaktadır. Çatışmalar yüzünden ithalat 2012'den 2014'e \%22 gerilemiştir. 2012'de ihracat GSYİH'ın \%45'ini oluştururken, 2014'de sadece \%6.8'ini oluşturabilmiştir. Grivna dolar karşısında 2014'de 8 UAH/\$'dan 2015'de 24 UAH/\$'a çıkmıştır, enflasyon 2014 sonu \%25'e yükselmiştir ve işsizlik oranı \%9'a çıkmıştır. Ülkeye olan güvenin azalmasıyla yaşanan mevduat çıkışları ülkenin finansal sektöründe problemlere yol açmıştır. Tüm bu faktörler özel yatırımları ve özel harcamaları düşürmüştür.

Krize yönelik iyileştirmeler adına Ukrayna devleti Eurobond yapılandırılması konusunda yabancı yatırımcılarla görüşmelerini sürdürmektedir. IMF’nin Ukrayna Merkez Bankası'na sağladığı kredi sayesinde Grivna'nın stabilize olunması sağlanacaktır ve mali yönetimin denetimi sağlanacaktır. Düşük cari açık ve finansman yardımı sayesinde Merkez Bankası rezervleri artacaktır.

Çatışmaların yaşandığı bölgelerde sosyal istikrarın sağlanması için diğer ülkelerden sağlanan yardım finansmana ihtiyaç duyulacaktır. Bu aşamada Türkiye yardım koşullarını değerlendirmelidir.

Ukrayna'nın yabancı yatırımlara çok ihtiyaç duyduğu bu ortamda Türkiye'nin sadece dış ticaret ile değil de ekonomik ve ticari gelişmeleri güçlendirecek yatırımlara yönelmeleri faydalı olacaktır. Bu aşamada büyük firmaların pazara girmesi küçük firmaları da beraberinde getireceği düşünülmektedir.

Rusya ile Ukrayna arasındaki sıkıntılar dolayısıyla ve Rusya'nın Ukrayna'ya uyguladığı bazı yaptırımlar ve ticari kısıtlar dikkate alındığında, Rusya Federasyonu'na yapılacak ihracat sevkiyatlarının transit olarak yapılmaması, direkt olarak Rusya Federasyonu'na gönderilmesi faydalı olacaktır. Ayrıca Ukrayna'dan alınan ithal malları için olası durumlara karşı alternatif pazar araştırmasının yapılması faydalı olacaktır.

Ukrayna ve Türkiye arasında devam eden serbest ticaret müzakerelerinin imzalanarak yürürlüğe girmesi iki ülkenin ticaret ve yatırımlar açısından önemli gelişme kaydedeceği düşünülmektedir.

Hem Ukrayna ile tarihi dost olan, hem de Rusya ile son dönemde özellikle enerji ilişsileri ve ticaret ilişkileri bakımından ilişkileri iyi giden Türkiye iki ülkenin de güvenini kazanmış bir ülke olarak barış gücüne katkı konusunda etkili rol oynayabilir ve hatta liderlik edebilir.

\section{Kaynakça}

- Sigma Bleyzer, "Ukraine Monthly Reports”, http://www.sigmableyzer.com/macroeconomicupdates/archive/

- T.C Kiev Büyükelçilği Ticaret Müşavirliği, Mayıs 2014, "Ukrayna’nın Ekonomik Durumu ve Türkiye ile Ekonomik Ticari İlişkileri"

- Trade Statistics for International Business Development, 2015. http://www.trademap.org/

- Türkiye İhracatçılar Meclisi, 2014 “Ekonomi ve Dış Ticaret Raporu”

- TUSİB, 2013 "Ukrayna Ülke Raporu”

- Türkiye Merkez Bankası, Türkiye İhracatçılar Meclisi, http://www.tim.org.tr/tr/

- Türkiye İstatistik Kurumu, http://www.tuik.gov.tr/

- Ukrayna Merkez Bankası, http://www.bank.gov.ua/control/en/

- Ukrayna Devlet İstatistik Servisi, http://ukrstat.gov.ua/

- Ukrayna Ekonomi Bakanlığ1, http://www.minfin.gov.ua/minfin/control/en/publish/category 


\title{
Geçişin 25. Yılında Orta Asya Türk Cumhuriyetlerinde Dönüşüm Sürecini Özelleştirme ve İktisadi Özgürlükler Açısından Değerlendirme
}

\section{Evaluating Transformation Process in Central Asian Turkic Republics in terms of Privatization and Economic Freedom on 25th Anniversary of the Transition}

\author{
Asst. Prof. Dr. Volkan Yurdadoğ (Çukurova University, Turkey) \\ Assoc. Prof. Dr. Haşim Akça (Çukurova University, Turkey) \\ Assoc. Prof. Dr. İlter Ünlükaplan (Çukurova University, Turkey)
}

\begin{abstract}
The phrase of "Transition economies", covering various countries as well as Caucasus and Central Asian Turkic Republics, was found its place in the literature by the 1980's and this transformation process from the centrally planned economy to market economy was analyzed with economic and fiscal dimension. Undoubtedly, the transition process of these countries wouldn't be easy and exhibits differences, especially for the Central Asian Turkic Republics, as they were governed under the command economy over many years. Related studies is put forward the increasing importance and future predictions within this scope.

Two of the most economical and fiscal prosperity indicators of the transition economies are reconstruction of government and privatization implementations. In this context, after literature review analyzing the privatization implementations and the level of economic freedom indexes related to reconstruction of government by many dimensions under seminal international databases are crucial for that countries.

In this study, after the 25 years of transition of Caucasus and Central Asian Turkic Republics, in 2016, reconstruction of government and privatization implementations are examined both in fiscal and economically. Kazakhstan and Azerbaijan are not only the prosperous countries in this respect but also have outstanding mining and underground resources. We also reach that the reform process of transition and the prosperity of economic indicators have not been strongly correlated.
\end{abstract}

\section{Giriş}

20. Yüzyıl gerek başlangıç dönemi gerekse bitiş dönemi itibarıyla bakıldığında ekonomik, sosyolojik ve siyasal yönlerden önemli olayların olduğu bir yüzyıl olarak tarih sürecinde yerini almıştır. Temelini "Ulusların Zenginliği”' isimli eseriyle 1776'da Adam Smith'den alan klasik iktisadi anlayış çerçevesinde liberal ekonominin egemen olması ve devletin ekonomik hayatta rolünün ve müdahalesinin minimal ölçüde öngörüldüğü piyasa ekonomisi anlayışı 1930'lara kadar devam etmiştir. Aslında devletin ekonomik hayatta gerek işletmeci olarak yer almasının gerekse ağır vergilerle özel sektörü vergilendirmesinin özel sektör üzerindeki olumsuz etkileri gibi kamu maliyesi ve devletle ilgili piyasa ekonomisinin temel fikirleri yüzyıllar önce İbn-i Haldun'un "Mukaddime" isimli eseri de incelendiğinde görülebilir.

1930'larda büyük bunalım yılları sürecinde Keynes'le birlikte devletin ekonomiye müdahalesinin öngörülmesiyle birlikte devletin ekonomideki varlığı ve rolü konusunda piyasa başarısızlıkları, devletin başarısızlıkları gibi teoriler ve ilerleyen süreçteki gelişmeler çerçevesinde devam eden ve edecek olan bir tartışmadır. Bunun her iki fikir yönünden de en son örneklerini 1980'ler sonrasında ve 2008 krizi süreciyle birlikte tekrar canlanan bir biçimde görebilmemiz mümkündür.

Yüzyılın başları 1917'deki Şubat Devrimiyle birlikte Çarlık Rusya'sının yıkılması ve Ekim Devrimiyle Bolşeviklerin Sovyet Sosyalist Cumhuriyetler Birliği'ni kurmalarıyla piyasa ekonomisi anlayışının tam tersi olan merkezi planlı ekonomi anlayışının ve komünist sistemin ilgili cumhuriyetlerde egemen olduğu bir dönemin başlamasıdır. Keza Çin gibi başka ülkelerde de aynı merkezi planlı ekonomik anlayışın hüküm sürmesini görmek mümkündür. 1991'de Sovyet Sosyalist Cumhuriyetler Birliği’nin dağılmasıyla cumhuriyetlerin bağımsızlıklarını ilan edip bağımsız birer devlet haline gelmeleriyle başlayan bir merkezi planlı ekonomik anlayışı yerine piyasa ekonomisi anlayışına dönüşüm süreci de yüzyılın sonuna damga vuran bir olaydır.

İçinde Kafkas ve Orta Asya Türk Cumhuriyetleri'nin de yer aldığı birçok ülkeyi kapsayan biçimde kullanılan Geçiş Ekonomileri terimi 1980'li yıllarla birlikte literatürdeki yerini almış ve iktisadi mali olmak üzere birçok açılardan merkezi planlı ekonomiden piyasa ekonomisine dönüşüm süreci inceleme altına alınmıştır. Hiç şüphesiz ki uzun yıllar merkezi planlı ekonomik sistemle yönetilen bu ülkelerin ve özellikle diğerlerine göre daha uzun süre bu sistem anlayışıyla yönetilen Türk Cumhuriyetleri'nin dönüşüm süreci kolay olmamakta ve 
farklılıklar göstermektedir. Bu konuda yapılan çalışmaların azalmakta değil artan önemini koruyan biçimde gelecek öngörülerini içeren çalışmalar göze çarpmaktadır.

Yapılacak olan bu çalışma ile devletin yeniden yapılanma sürecinde dönüşümün 25. yılında Kafkas ve Orta Asya Türk Cumhuriyetleri piyasa ekonomisine geçişin temel saç ayağı olan özelleştirme gibi geçiş göstergeleri ve devletin ekonomideki varlığı açısından mali özgürlük, hükümet harcamaları gibi ekonomik özgürlük endeksleriyle incelenerek sonuçları değerlendirilecektir. Literatür incelemesi yapılarak dönüşüm ve özelleştirme süreci, geçiş göstergeleri ve ekonomik özgürlükler endeksleri gerekli yönleriyle ele alınarak incelenecek, ilgili ulusal uluslararası veriler ışığında analiz edilerek ve kamu kesimi dengesi, büyüme gibi ekonomik ve mali açılardan durum değerlendirilecektir.

\section{Geçiş Ekonomileri}

Geçiş ekonomileri terimi 80’li yıllar sonrasında özellikle yıllarca merkezi planlama sisteminde yönetilen ülkelerin piyasa ekonomisine geçmesiyle yaygın olarak kullanılmaya başlanmış olup, bu ülke ekonomileri serbest piyasa ekonomisine dönüşümü tamamlayamadığı için geçiş ekonomileri olarak adlandırılmaktadırlar (Güler, 2012; Yıldız, 2004).

Bu ülkelerin başlangıç koşullarındaki farklılıklar ve bu ayrıma neden olan temel değişkenler Tablo 1'de de görülebilir (Sachs, vd, 2000; Sakınç; 2005).

\begin{tabular}{|l|l|}
\hline Başlangıç Koşulları Kategorisi & Temel Değişkenler \\
\hline Fiziksel coğrafya & $\begin{array}{l}\text { Limanlara uzaklık, karaya hapsolmuş nüfus ve ülke, gelişen } \\
\text { ekonomilere yakınlık, doğal kaynakların bolluğu gibi }\end{array}$ \\
\hline Makroekonomik değişkenler & $\begin{array}{l}\text { Gayri safi iç tüketim ve tasarruf, 85-89 GSYİH büyümesi, enflasyon, } \\
\text { kamu gelirleri ve harcamaları, kayıtdışı gelir, 1987-90 bastırılmış } \\
\text { enflasyon }\end{array}$ \\
\hline Demografi / Sağlık & $\begin{array}{l}\text { Çalışan işgücü nüfusu, doğum oranı, nüfus artış hızı, yaşam süresi, } \\
\text { bebek ölüm oranı, yaşam süresi, kamu sağlık harcamaları, kent ve } \\
\text { kırsal nüfus oranı }\end{array}$ \\
\hline Ticaret ve ticaret yönelimi & Diş ticaretin GSYİH'ya oranı, CMEA(COMECON) ülkelerine ihracat \\
\hline Altyapı & Kaldırımlı yollar, telefon, elektrik tüketimi, hastane yatak sayısı \\
\hline Refah & Kişi başı milli gelir, kişi başı televizyon, otomobil, özel tüketim \\
\hline Beşeri sermaye & Okullaşma oranı, eğitim endeksi, UNDP insani kalkınma endeksi \\
\hline Piyasa ekonomisi geçmişi & $\begin{array}{l}\text { Merkezi planlama altında geçen yıllar, ekonomik özgürlük endeksi, } \\
\text { politik haklar endeksi }\end{array}$ \\
\hline Fiziksel sermaye & Yerli sabit sermaye yatırımları gibi \\
\hline Kültür & Müslüman, Hıristiyan ve Ortodoks nüfusun oranı \\
\hline Politik durum & Savaş durumu, Bölgesel ve etnik çatışmalar gibi \\
\hline
\end{tabular}

Tablo 1 Başlangıç Koşulları Kategorisi ve Temel Değişkenleri Kaynak: Sachs, vd, 2000 ve Sakınç, 2005

Başlangıç koşulları yaklaşımı tipolojisi temelinde en yaygın kullanılan ayrım Sachs vd (2000)'ne göre “Doğu Avrupa" ve Eski Sovyetler Birliği” ülkeleri biçiminde olmakla birlikte geçiş ekonomilerinde yer alan ülkeler Havrylyshyn vd.'nin 1998, De Melo, Denizer ve Gelb'in 1996,, Szyrmer'in 1998, Dabrowski'nin 1996 ve Sachs, Zinnes ve Eilat'ın 2000'deki yaptıkları çalışmalarda coğrafi yakınlık, liberalizasyon aşaması, geçişin hızı ve kapsamı, geçiş performansı ve küme analizi çerçevesinde gruplandırılabilmeleri söz konusu olabilmektedir (Gupta, vd, 2001; Sachs, vd, 2000 - Ayrıntılı açıklama için bu iki çalışmaya bakılabilir). Geçiş Ekonomilerinin Politik Olarak Tasnifi (IMF Yaklaşımı) çerçevesinde de dört grupta şu ülkeler yer alır (Arıkan, 2002; Yıldız, 2004;Güler, 2012; Fırat, 2013; Ağcakaya, 2009; Yaman, 2002) :

\section{Avrupa ve Eski Sovyetler Birliği Geçiş Ekonomileri}

A) Merkezi Doğu Avrupa Ülkeleri-MDA: Arnavutluk, Bulgaristan, Hırvatistan, Çek Cumhuriyeti, FYR Makedonya, Macaristan, Romanya, Slovak Cumhuriyeti ve Slovenya

B) Baltık Cumhuriyetleri-BC: Estonya, Letonya ve Litvanya

C) Türk Cumhuriyetleri ve Bağımsız Devletler Topluluğu- BDT: Azerbaycan, Beyaz Rusya, Ermenistan, Gürcistan, Kazakistan, Kırgızistan, Moldova, Özbekistan, Tacikistan, Türkmenistan ve Ukrayna

D) Asya'daki Geçiş Ekonomileri-AGE: Çin, Kamboçya, Laos ve Vietnam

$\mathrm{Bu}$ çalışmada yer alan Türk Cumhuriyetleri olarak Azerbaycan, Kazakistan, Kırgızistan, Tacikistan, Türkmenistan ve Özbekistan IMF Yaklaşımına göre C grubunda, başlangıç koşulları tipolojisine göre Kafkas ve Orta Asya kümesi içinde yer almaktadır. Azerbaycan her ne kadar Kafkas kümesi içinde yer almakla birlikte birçok yönden benzerlikleri çerçevesinde çalışmamız içerisinde Orta Asya kümesi içinde değerlendirilecektir (Sachs vd, 2000).

Geçiş sürecinde kavranan gerçeklerden birisi, ülkeler arasındaki başlangıçtaki kurumsal, jeopolitik ve kültürel benzerliklere rağmen, geçişin başlamasından günümüze çok farklı yönlerde ilerlemiş olduklarıdır. Bu farklılıklar 
her şeyden önce uygulanan politikaların bir sonucudur. Bazılarında sürecin kısa, diğer bazılarında ise uzun ve sıkıntılı sürmesinin en önemli nedenlerinden birisi izlenen geçiş stratejisi kaynaklıdır (Bal, 2004)

Ülkeler arasında farklılıklar görülmekle birlikte, geçiş ekonomileri bazı temel sorunlarla karşı karşıya kalmışlardır:

1. Ekonominin tamamına yakını kamulaştırılmış, özel mülkiyete çok sınırlı yer verilmiştir.

2. Üretim yapan kamu kuruluşlarının büyük bir kısmı tekelleşmiş, fiyatlar ve yatırım kararları devlet tarafından kontrol edilir hale gelmiş, dişa kapalı, COMECON içi uzmanlaşmaya yönelik ekonomik politikalar izlenmiş, bu da ekonomileri rekabete kapalı yapılar haline getirmiştir.

3. Sosyal güvenlik harcamaları ekonomik faaliyetlerin hacmine göre büyük ölçüde artmış, harcamalar toplumda ortaya çıkabilecek rahatsılıkları gidermek amacıyla siyasi bir araç olarak kullanılır duruma gelmiştir.

4. Bu sorunların da etkisiyle makroekonomik dengeler bozulmuş, yüksek bütçe açıkları, kontrol edilemez hale gelen ücretler, para arzının sınırsız artışı ve yüksek enflasyon gibi önemli sorunlarla karşılaşılmıştır (Bastırmacı, 1998; Tandırcıŏlu, 2002).

Günümüzde özelleştirmeler, merkezi planlı ekonomiden piyasa ekonomisine geçiş sürecinin temeli olarak kabul edilmektedir. Bu ülkelerde siyasi yapıdaki dönüşümün ekonomik yapıya yansımasının ilk adımı serbest piyasa ekonomisine geçiş ve bu amaçla özelleştirme uygulamalarına başvurularak devlet mülkiyetinde olan işletmelerin özelleştirilmesidir. Bu süreçte tartışma konusu özelleştirmenin biçimi, temposu ve süresidir. Özelleştirmenin başarısı için öncesinde yeniden yapılanma ve kurumsal çerçevenin iyi hazırlanması gerekli koşuldur (Sağlam ve Ocak, 2014; Tandırcıŏlu, 2002).

\section{Literatür İncelemesi}

Çalışmamızın konusu kapsamında piyasa ekonomine geçişin temellerinden biri olan özelleştirme ve ekonomik özgürlük endeksleriyle ilgili gerek geçiş ekonomileri gerekse diğer ülkelerle karşılaştırma içerisinde farklı bağımlı değişkenler çerçevesinde etkileriyle ilgili birçok ampirik çalışmanın yapıldığı görülmektedir. Yapılan çalışmaların büyük çoğunluğu özellikle ekonomik büyüme konusunda yoğunlaştığı görülmekte, özelleştirmenin mali etkilerini veya mali özgürlükler bağlamında ilişkilerin incelendiği ampirik çalışmalar çok fazla değildir.

Özelleştirme ile ilgili geçmişten günümüze yapılan çok sayıda ampirik çalışmanın kullandıkları metodolojiler, ele aldıkları ülkeler, inceledikleri ve ulaştıkları sonuçlarla ilgili bunların gruplandırılarak açıklamaları ve karşılaştırmalı analizleri Kikeri ve Nellis (2002), Megginson ve Netter (2001), Djankow ve Murrel (2002), Havrylyshyn ve McGettigan (1999), Estrin vd.(2009)'ne ait çalışmalarda ayrıntılı bir biçimde görülebilir.

Bazı çalışma sonuçlarına göre de fiyat istikrarının sağlanması ve bütçe açıklarının azaltılması büyümeyi pozitif yönde etkilemektedir. Aslund ve Jenish (2005)'in çalışma sonuçlarına göre kamu harcamaları ve petrol ihracatı geçiş ekonomilerinde büyüme farklılıklarını açıklayan en önemli değişkenlerdir (Agayev ve Yamak, 2009).

Yapılan çalışmaların büyük çoğunluğunda özelleştirme ile ekonomik büyüme arasında olumlu ilişki bulunduğu görülmektedir. Erden ve Bolağatoğlu (2015) özelleştirmenin mali etkileri konusunda Barnett(2000)'in özelleştirme gelirleri bütçeye transfer edilmesiyle borç servisin veya borçlanmaya ikame olduğu ve kamu harcamaları ve vergi gelirleri üzerinde anlamlı etkinin olmadığını, Jeronimo vd(2000)'nin özelleştirme gelirlerinin bütçe açıklarını düşürdüğü, Katsoulos ve Likoyanni (2002)'nin ise bütçe açıklarıyla ilişkinin olmadığını ama kamu borcuyla negatif ilişkisi olduğu sonucuna ulaştıklarını, kendilerinin ise özelleştirme gelirlerinin borç servisi ve ödünç almada etkisinin olmadığını, harcamalarla pozitif ve gelirlerle negatif ilişkinin olduğunu bulduklarını belirtmektedirler.

Crivelli (2013)' göre Davis vd.(2000) yaptıkları çalışmada özelleştirmenin bütçe dengesi ve gelirlerinin iyileşmesiyle ilgili ampirik destek bulurken aksine Tanzi ve Tsibouris (2000) ve Matinez-Vazquez ve $\mathrm{McNab}$ (2000) gibi önde gelenlerin örnek olarak görülebileceği geçiş ekonomilerinde vergi sistemleriyle ilgili yazın özelleştirmenin vergi gelirleri üzerindeki negatif etkisini onayladı. Kendi çalışmasında özelleştirmenin değişik vergi kaynakları üzerinde negatif etkisinin olduğu ve özelleştirme bütçe dengesinin bozulmasıyla ilgili sonuç buldu (Crivelli, 2013).

Çatalbaş ve Yıldırım (2008) çalışmalarında Aghion ve Blanchard (1995)'ın şok terapinin esas unsurlarından olan hılı özelleştirmelerin işsizliği arttıracağını belirttiklerini, Dewatripont ve Roland(1995)'ın hızlı özelleştirmelerin siyasi olarak önemli maliyetleri olacağına değindiklerini, Fischer ve Sahay(2000) ile Pirtillä (2001)'nın yeniden yapılanmada daha hızlı olan geçiş ekonomilerinin mali gücünün zayıfladığını tespit ettiklerini belirtmektedir. Pirttilä(2001) tarafından yapılan ampirik analizde, büyüme oranının geçiş ekonomilerinin mali dengesi üzerinde olumlu etki yaptığı bulunmuştur. Özelleştirme ve yeniden yapılanma politikaları gibi geçiş reformlarının hızı ile mali açıklar arasında negatif bir değişim ilişkisi bulunmuştur. Özelleştirmenin işsizlik ve mali denge üzerindeki etkisi olumsuz bulunmuştur. Fiyat liberalizasyonunun ise bütçe dengesi üzerindeki etkisi olumlu bulunmuştur (Sakınç, 2005). 
Geçtiğimiz 15-20 yıl boyunca, çok sayıda çalışma özellikle ekonomik büyüme ve ekonomik özgürlük arasındaki olası bağlantıyı araştırdı. Bu çalışmaların çoğu, ekonomik büyüme oranına bilhassa toplam ekonomik özgürlük oranı biçiminde ekonomik özgürlüğün güçlü pozitif bir etkisi olduğu sonucunu çıkardı (Cebula ve Mixon Jr, 2012).

Ekonomik özgürlüklerle büyüme arasındaki ilişki ve etkiler üzerine yapılan çok sayıda ampirik çalışma ve karşılaştırmalı analizleri Haan (2003), Berggren (2003), Doucaliagos ve Ulubasoğlu (2006) ve Keseljevic (2007) 'e ait çalışmalarda ayrıntılı bir biçimde görülebilir. Yaptıkları bu incelemelerde genellikle ekonomik özgürlük ve büyümenin arasında pozitif bir ilişkinin olduğu bu çalışmalarda görülebilir.

Cebula ve Mixon Jr (2012) çalışmalarında hem vergilendirme hem de harcama yönüyle etkileri araştırmışlar ve azalan mali özgürlüğün ekonomik büyüme oranında azalmaya neden olduğu; ayrıca, aşırı hükümet büyüklüğünden sonuçlanan azalan özgürlüğün de ekonomik büyüme oranında azalmaya neden olduğu sonucunu bulmuşlardır.

McGee (2007) ise geçiş ekonomilerinin mali özgürlük endekslerini kullanarak karşılaştırmalı bir analiz yapmış ve ülkeleri değerlendirmiştir ( Türker, 2012).

\section{Orta Asya Türk Cumhuriyetlerinde Özelleştirme Geçiş Göstergeleri ve Ekonomik Özgürlük Endeksleri Yönüyle Mali ve Ekonomik Performans}

\subsection{Araştırmada Kullanılan Yöntem}

Geçiş ekonomilerinde dönüşüm sürecinin hangi aşamalarda olduğu ve değişik alanlarda yıllar içerisinde özelleştirme ve devletin yeniden yapılanmasında reformların durumunu görebilmek açısından bu çalışmada kullanacağımız ölçüt EBRD (Avrupa Yatırım ve Kalkınma Bankası) tarafından 1994 yılında geliştirilen geçiş göstergeleridir. Bu göstergeler büyük ölçekli özelleştirme, küçük ölçekli özelleştirme, fiyat liberalizasyonu, ticaret ve döviz sistemi, rekabet politikası bankacılık reform ve faiz oranı serbestliği, hisse senedi piyasası, borsa ve bankacılık dışı kurumlar ve tüm altyapı yatırımları biçiminde olmak üzere işletmeler, piyasalar ve ticaret, finansal piyasalar ve altyapı ana başlıklarında yapılan reformları ve performansı görmek üzere geliştirilmiş̧tir. Çalışmamız kapsamında hiç şüphesiz özelleştirme piyasa ekonomisine dönüşümü tek başına sağlamayacak olmakla birlikte sadece devletin ekonomideki varlığı açısından temel taşlardan biri olduğundan EBRD geçiş göstergelerinden büyük ölçekli özelleştirme ve küçük ölçekli özelleştirme göstergeleri çerçevesinde diğer makro ekonomik göstergelerle birlikte inceleme gerçekleştirilecektir. Kullanılan puanlama sistemi 1 ve 4 arasında temel olarak 1 e yaklaştıkça merkezi planlamadan uzaklaşılamadığı 4 e yaklaştıkça gelişmiş piyasa ekonomisi standartları ve performansının ulaşıldığı bir durumu göstermek üzere oluşturulmuştur. Bu kapsamda bakıldığında aslında EBRD geçiş göstergelerini piyasa ekonomisine doğru giden bir süreçteki serbestleşmeyi gösteren bir nevi ekonomik özgürlük endeksi gibi düşünebiliriz.

Çalışmada kullanacağımız ikinci ölçüt de Heritage vakfı tarafından hazırlanarak Wall Steet Journal ile birlikte her yıl yayınlanan Ekonomik Özgürlük Endeksi içindeki 10 özgürlük arasında yer alan ve yine devletin ekonomideki durumunu ve müdahalesini gelirler ve harcamalar yönüyle görebilme açısından mali özgürlük ve kamu harcaması özgürlük endeksleridir. $\mathrm{Bu}$ iki özgürlük endeksi bir bütün olarak bakıldığında kamu büyüklüğünü göstermektedir. Burada yapılan puanlama da 0 a 100 arasındaki puanlama olup, yüksek puan değerleri ilgili özgürlüklerde artışı göstermektedir. Ekonomik özgürlüğü ölçmek üzere Freedom House ve Fraser Enstitüsü tarafından yayınlanan genel kabul gören diğer endeksler de olmakla birlikte Orta Asya Türk Cumhuriyetlerine ilişkin bilgileri daha geniş bir zaman açısından alabildiğimiz 1995 yılından beri yayınlanan Heritage Vakfı Ekonomik Özgürlük Endeksi verileri kullanılacaktır. İlgili ülkelere ilişkin veriler Azerbaycan dışında 1998 yılından başladığı için 1998den günümüze olan bir zaman dilinde inceleme gerçekleştirilecektir (Sarıül, vd, 2013; Heritage Foundation Index of Economic Freedom).

Ayrıca mali ve ekonomik performansı görebilmek için GSYİH büyüme oranları, enflasyon oranları, GSYİH'nın \%'si olarak Kamu Kesimi Dengesi, GSYİH'nın \%'si olarak Kamu Harcamaları ele alınan diğer veriler olmuştur.

Mali özgürlük, bireylerin ve işletmelerin, gelirlerini ve servetlerini kendi yarar ve faydaları için muhafaza ve kontrol etmelerine devletin izin vermesi ölçüsünde dolaysız bir ölçümdür. Hükümet ekonomik faaliyet üzerine vergileme yoluyla mali yükler yükleyebilir. Hükümetlerin vergileme yoluyla ekonomik faaliyetlere müdahalesi mali özgürlüğ̈̈ azaltmaktadır. Aslında vergi yükünün bir ölçüsüdür. Mali özgürlüğün ölçümünde hem kişilerin üzerindeki dolaylı ve doğrudan vergi yükü hem de toplam vergi gelirlerinin gayrisafi yurtiçi hasılaya oranını dikkate almaktadır. Hesaplamada gerçek kişilerin tabi olduğu en yüksek vergi oranı, kurumların tabi olduğu en yüksek vergi oranı ve toplam vergi gelirlerinin gayrisafi yurtiçi hasılaya oranı da kullanılmaktadır (Sarıgül, vd, 2013).

Hükümetlerin uygulamış oldukları politikalar ve bununla beraber gelen aşırı yükümlülükler ekonomi üzerinde, kamu harcamaları ve kamu gelirleri yaratılması açısından önemli bir husustur. Kamu ağırlıklı bir ekonomi yüksek harcama potansiyeliyle kısa dönemde hızlı büyümeyi sağlayabilir. Ancak bu durum, kamu özgürlüğünün 
azalması ve dışlama etkisiyle ülkenin büyüme potansiyeli üzerinde uzun dönemde olumsuzluk oluşturabilir. Bir ülkede kamunun ekonomi içindeki payı ne kadar az ise ekonomik özgürlük o kadar fazla demektir (Erdem ve Türker, 2012).

\subsection{Dönüşüm Sürecinde Orta Asya Türk Cumhuriyetlerinin Değerlendirilmesi}

Şekil 1 ile Şekil 6 arası sırasıyla Orta Asya Türk Cumhuriyetleri için Özelleştirme Geçiş Göstergeleri-Kamu Dengesi -Büyüme İlişkisi; Şekil 7 ile Şekil 12 arası ise ekonomik özgürlükler ve büyüme ilişkisi görülmektedir. Şekil 13'de ise geçiş başlangıcındaki hiperenflasyon dönemleri hariç 1998 sonrası enflasyon oranları görülmektedir.

Bağımsızlıklarını kazanmaları ve Bağımsız Devletler Topluğu bünyesine dahil oldukları başlangıç yıllarında ortaya çıkan olumsuz ve mali tablo 6 ülke için de aynıdır. Bu yıllarda 2000'li seviyelere çıkan hiperenflasyon dönemi yaşanmış olup negatif yüksek büyüme oranları ve kamu kesimi dengesi açısından özellikle ciddi kamu geliri azalışıyla birlikte yüksek açıkların olduğu bir süreç göze çarpmakta. Geçiş ekonomilerinde vergi geliri, liberalizasyon (serbestleştirme), özelleştirme ve istikrar reformlarının uygulanmasının erken aşamalarında özellikle etkilenmiştir. Geçiş dönemi öncesi vergi sisteminin yapısının bir sonucu olarak, özelleştirme üç temel nedene dayanarak vergi tahsilatı gelirlerinde önemli bir düşüşle sonuçlandı: (i) geleneksel vergi matrahlarında düşüş, (ii) vergi idaresinin kapasitesinde kötüleşme ve (iii) vergi muafiyetleri ve yatırımları çekmek için diğer vergi teşviklerinin geniş ölçüde yaygınlaşması. Vergi idaresinin kapasite olarak yetersizliğiyle yeni döneme hazır olamaması vergi kaçırma ihtimallerini artırdığı açıktır (Crivelli, 2013). Sudan çıkan balık misali Sovyetlerin gerek mali gerekse her yönden tamamen birbiriyle bağlantılı ve tek başlarına bir şey yapamayacakları bir merkezi planlama anlayışı çerçevesinde bu durum ortaya çıkmıştır. Sovyetlerden gelen mali yardımların kesilmesi ve önceden KİT'lerin verdiği sosyal güvenlik harcamalarının bütçeden karşılanması da özellikle bütçe açı̆̆ı yönünde ciddi sıkıntı doğurmuştur.

75 yıl gibi diğer ülkelere göre çok daha uzun sure merkezi planlamada olup piyasa ekonomisiyle tanışmayan bu ülkeler reform programlarını ve özellikle özelleştirmeyi uygulamaya başlamışlardır. Özelleştirme göstergelerinde de artışlarla bu durum görülebilir. Ayrıca burada başlangıçta özellikle doğal kaynak zenginliği dışında benzer koşullara sahip bu ülkelerin birbirlerinden farklı biçimde ve hızda uygulamaları da görülmektedir. Mali istikrar ve açıklar geçişin başlangıç yıllarındaki durgunluk dışında, finansal krizler, bölgesel silahlı mücadele ve karışıklıklar ve kamu harcamalarının kısa zamanda azaltılamaması ya da politik gerekçelerden dolayı artması ile bağlantılıdır. Mali sürdürülebilirlikteki bu gelişme ve kamu açıklarındaki azalma özellikle 1990'ların sonunda başlayan harcama indirim programları ve vergi gelirlerindeki iyileştirmelerle bağlantılıdır. Özellikle hızlı büyüme yaşanan ülkelerde (Azerbaycan, Kazakistan) milli gelirler bağlantılı gelir artışlarının yanı sıra, fiyat düzeylerinde yükselmelerin neden olduğu artışlar da vergi gelirlerinin gelişmesine yardımcı olmuştur (Çevik, 2010).

Dönüşüm sürecinde Türk Cumhuriyetlerinde beliren ortak sorunlar olarak; a) başlangıç aşamasında GSYİH'daki ciddi düşüşler, b) nitelikli fakat verimlilik artışına yönlendirilmemiş işgücü stoku, c) aşırı fiziksel sermaye yatırımları, d) mali ve ticari faaliyetlerde ve tüketiciye yönelik hizmetlerde gerileme olması, e) ülkelerin ticari ilişkilerindeki birbirlerine bağımlılığın yüksek olması, f) karaborsanın yaygın olması ve döviz kurunda ikili fiyat uygulaması, g) hiyerarşik yapıdaki merkezi devlet sisteminin çöküşü sonrasında ortaya çıkan cılız ve iyi örgütlenmemiş ulus devletler, h) piyasa ekonomisi deneyimine ve kültürüne sahip olan bir neslin yetişmemiş olması sayılabilir (Sakınç, 2005).

Reform süreci bakımından geçiş ekonomileri için bir gruplandırmaya gidilirse, Orta Asya Türk Cumhuriyetleri'nin reform sürecini henüz tamamlamadığı görülmektedir. Özelleştirme ve ekonomik özgürlüklerle ilgili şekiller de incelendiğinde, Türk Cumhuriyetleri'nden özellikle Kazakistan ve Kırgızistan'ın özelleştirme ve ekonomik özgürlükler gibi ekonomik reformlarda diğer cumhuriyetlerden daha önde olduğu, Azerbaycan'ın da bu cumhuriyetlerle aynı kategoride yer almakla birlikte, Özbekistan ve Türkmenistan'ın çok istekli bir reform programı takip etmedikleri göze çarpmaktadır. Ancak başlangıç koşulları açısında diğer Türk Cumhuriyetleri arasında avantajlı bir durumda olan, reformlarını aşamalı olarak ve geciktirerek uygulayan Özbekistan şaşırtıcı bir biçimde olumlu bir ekonomik performans ve sürdürülebilir bir büyüme gerçekleştirmiştir. Piyasa ekonomisine geçişte başarısızlıklarının nedenleri olarak; a) üzerinde anlaşmaya varılmış ve benimsenmiş bir ekonomik reform stratejisine sahip olmamaları; b) reform amaçlarının kesin olarak tanımlanmaması; c) yapısal uyum politikaları ile diğer mali ve parasal politikalar arasında uyumluluğun olmaması; gösterilebilir (Sakınç, 2005; Yaman, 2002).

Geçiş ekonomilerinin geneli açısından özelleştirme adeta yeniden dağıtım işlevi görmüş, gelir dağılımının amaçlananın dışında şekillenmesinde belirleyici bir rol üstlenmiştir. Özelleştirmeyle beklenen en önemli amaçlardan biri servetin tabana yayılması iken, özellikle Türk Cumhuriyetlerinde seçilen özelleştirme yöntemleri ve çeşitli yolsuzluklar bu ülkelerde servetin belirli kişilerde toplanmasına ve gelir dağılımının bozulmasına neden olmuştur. Özellikle 1992 yılında IMF'in önerdiği şok terapi özelleştirme programı özelleştirilen kurumların büyük ölçüde eski yöneticilerine devredilmesi biçiminde olmuştur. Bu biçimde alelacele yapılan özelleştirme uygulamaları amaç yönünden başarısızlığa uğramış ve yolsuzluklar fazlasıyla artış göstermiştir. 
Ekonomide kamunun ağırlıklı rolünü azalmak ve piyasa ekonomisini işletmek için özelleştirme uygulamalarına devem edilmesi gerekmektedir. Ancak bununla birlikte özelleştirme uygulamalarının özelleştirmeden beklenen amaçlara hizmet edecek biçimde gerçekleştirilmesi gerekir. Bunun için de bir taraftan özelleştirme için ülke koşullarına en uygun yöntem ve zaman seçilirken, diğer taraftan destekleyici reform politikalarıyla özelleştirmenin başarılı olması sağlanmalıdır. Bunlar sağlanmadığı takdirde yaşanan sorunlar artarak devam edecektir (Yıldiz, 2004).

Şekillerde kamunun büyüklüğü alt başlıkları olarak mali özgürlükler ve kamu harcamaları özgürlüğü açısından bakıldığında 2000'li yıllarda Azerbaycan'a göre Tacikistan, Türkmenistan ve Özbekistan'da artışlar olduğu özellikle bu iki göstergede Türkmenistan açısından artışlar dikkat çekici olmakla birlikte, 2010 larda Özbekistan \%45ler, Türkmenistan \% 25ler,Tacikistan \% 50ler, Kırgızistan \%75ler, Kazakistan \%65ler Azerbaycan \% 75ler düzeyinde GSYİH da özel sektör payını belirtmek gerekir. Genel ekonomik özgürlük açısından da bakıldı̆̆ında Türkmenistan ve Özbekistan'la ilgili biraz öncekinin aksi bir durum karşımıza çıkmaktadır.

Şekiller incelendiğinde ilgili ülkelerde özelleştirme göstergelerinde, mali özgürlüklerde, ekonomik özgürlüklerde ve ekonomik büyüme oranlarında bir artış ve kamu kesimi dengesinde iyileşmeler olduğu görülmektedir. Sistemin şokları atlatılmaya başlanmıştır. Değerlendirmeleri yaparken bu ülkelere ilişki dış olumsuz şokları da unutmamak gerekir. Ancak gösterge ve endeksler incelemesinde mali ve ekonomik durumlar bakıldığında gerek büyüme açısından gerekse kamu kesimi açıkları açısından Erdem ve Türker(2012)'in de çalışmalarında belirttiği gibi uzun dönemli çok anlamlı bir ilişkinin olduğunu da söylemek mümkün değildir.

Mali özgürlük ile enflasyon artışı arasında güçlü bir korelasyon bulunmuştur. Özelleştirme ve dış ticaretin liberalizasyonu sonucunda kısa dönemde fiyat istikrarı bozulmuş; uzun dönemde ise liberalizasyon ile enflasyon arasında negatif bir ilişki ortaya çıkmıştır. Liberalizasyon sürecinin başında etkin piyasa kurumlarının ve serbest girişimin yokluğu, piyasalarda fiyatların artışına neden olmuştur. Reform sürecinde başarılı olan ülkelerde fiyat artışları orta ve uzun dönemde kontrol altına alınabilmiştir. Piyasa ekonomisine dönüşüm sürecinde reformların en ciddi olumsuz etkileri mali alanda ortaya çıkmıştır. Mali alandaki dengesizliklerin başında bütçe açıkları gelmektedir (Sakınç, 2005).

Tacikistan ve Kırgızistan gibi düşük gelir düzeylerindeki ülkelerde gelir artışlarına ve harcama indirim programlarına rağmen kamu harcamalarında kısmi artışlar nedeniyle kamu kesimi dengesinde kısmi iyileşmeler yaşanmıştır. Bu ülkeler 1990'ların ortalarında oldukça yüksek oranda bütçe açıkları yaşayan ülkeler olup, vergi gelirlerinde sağlanan artış büyük ölçüde mallar ve hizmetlerden alınan dolaylı vergi gelirlerinde artış dolayısıyla gerçekleşmiştir. Özellikle 1990'ların ikinci yarısından itibaren KDV'nin geçiş ekonomilerinde uygulanmaya başlaması bu ülkelerde meydana gelen genel vergi artışının önemli dayanaklarından biri olmuştur. Mali uyumlaştırma birçok ülkede kamu harcamalarının daraltılması ile sağlanmışsa da Azerbaycan, Kazakistan gibi hızlı büyüyen bazı ülkelerde 2000’lerin ortalarından itibaren kamu harcamalarında belirli ölçülerde artış görülür. Tacikistan ve Kırgızistan gibi düşük gelir düzeylerindeki ülkeler, doğal kaynaklar ve ihracat açısından da dezavantajlı olduklarından kamu kesimi açıkları ve borçların sürdürülebilirliği açısından hala sorunludurlar. Ayrıca Orta Asya Türk Cumhuriyetleri için bir başka sorun vergi sisteminin kurumsallaşmasındaki problemler ve kamu gelirlerinin yetersizliği olarak gözükmektedir (Çevik, 2010).

\section{Sonuç}

$\mathrm{Bu}$ ülkeler açısından genel bir değerlendirme yapılacak olursa ekonomik özgürlükler ve ekonomik mali performans bakımından her ne kadar ülkeler bakımından örneğin Özbekistan ve Türkmenistan bakımından özelleştirme ve devletin büyüklügü bakımından ve benimsenen reform stratejileri açısından farklılıklar olsa ve uzun dönemli anlamlı ilişkiler olmasa da 2010 larda Özbekistan \%45ler, Türkmenistan \% 25ler,Tacikistan \% 50ler, Kırgızistan \%75ler, Kazakistan \%65ler Azerbaycan \% 75ler düzeyinde GSYİH da özel sektör payını belirtmek gerekir. İncelemeye başlarken gruplandırmanın başlangıç koşulları çerçevesinde yapıldığı belirtilmiştir. Değerlendirme aşamasına geldiğimizde bu ülkelerin gerek kendi aralarındaki gerekse diğer ülkelerle olan başlangıç farklılıklarının uygulanan aşamaların ekonomik ve mali performans üzerinde etkili olduğunu göz önünde tutmak gerek. Başlangıç koşulları, endeksler, ekonomik ve mali yapı çerçevesinde de özellikle2000'li yıllarda doğal kaynak zenginliği enerjiyle bağlantılı olarak Kazakistan ve Azerbaycan ile şaşırtıcı biçimde 90'larda Özbekistan dikkat çekmekle birlikte özellikle sosyal yapıdaki bozulmalara dikkat edilmesini ve bundan sonraki süreçte dengesizliklerin olmaması ve iyi yönetim çerçevesinde hareket edilmesi gerekmektedir. 


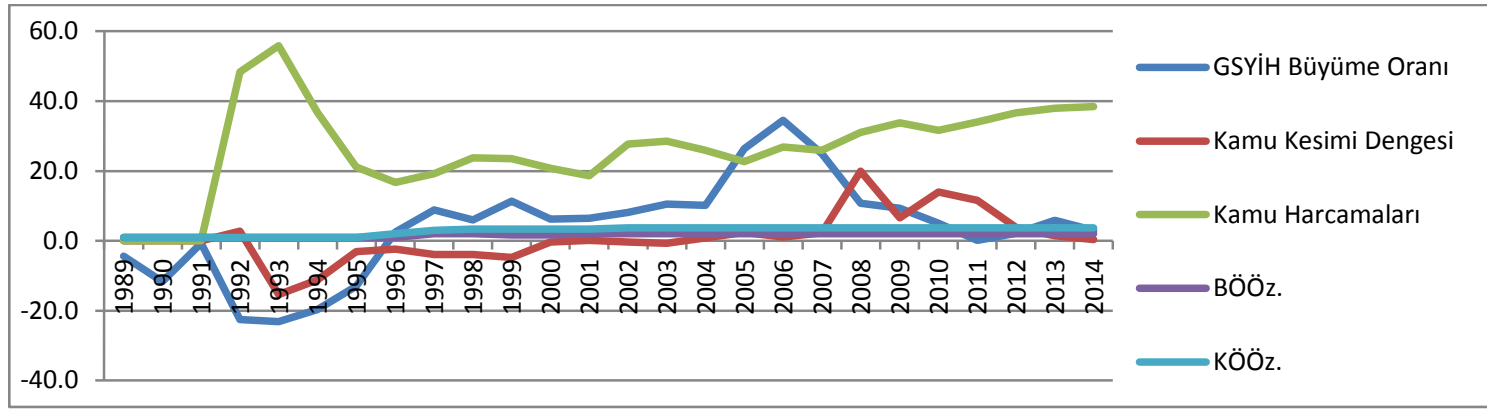

Şekil 1 Azerbaycan EBRD Özelleştirme Geçiş Göstergeleri-Kamu Dengesi-Büyüme İlişkisi Kaynak: EBRD Transition Reports, IMF World Economic Outlook Database

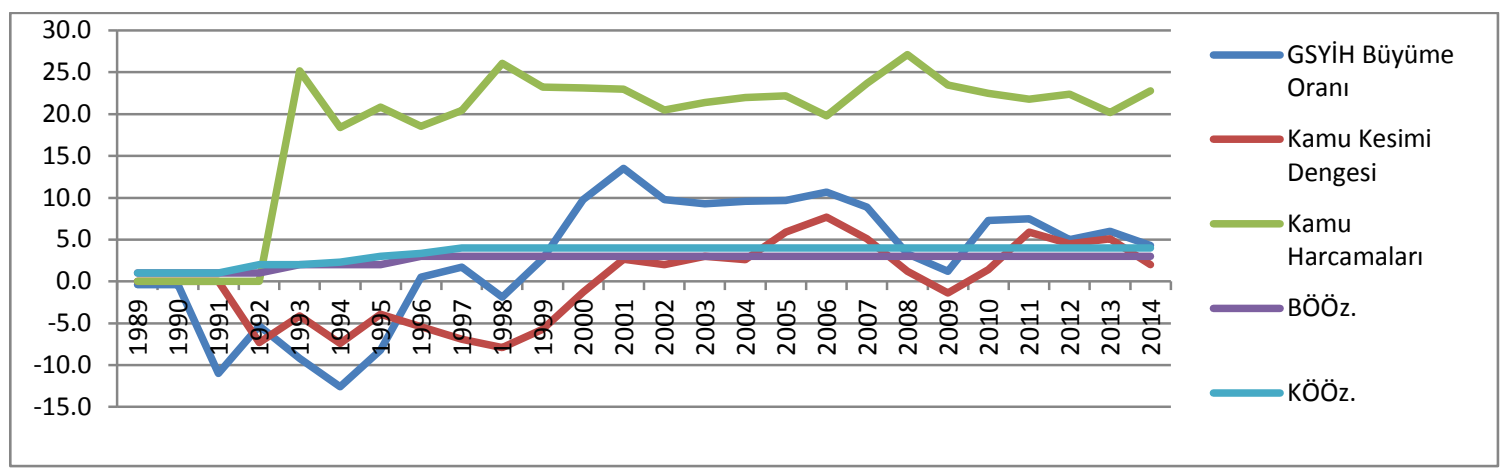

Şekil 2 Kazakistan EBRD Özelleştirme Geçiş Göstergeleri-Kamu Dengesi-Büyüme İlişkisi Kaynak: EBRD Transition Reports, IMF World Economic Outlook Database

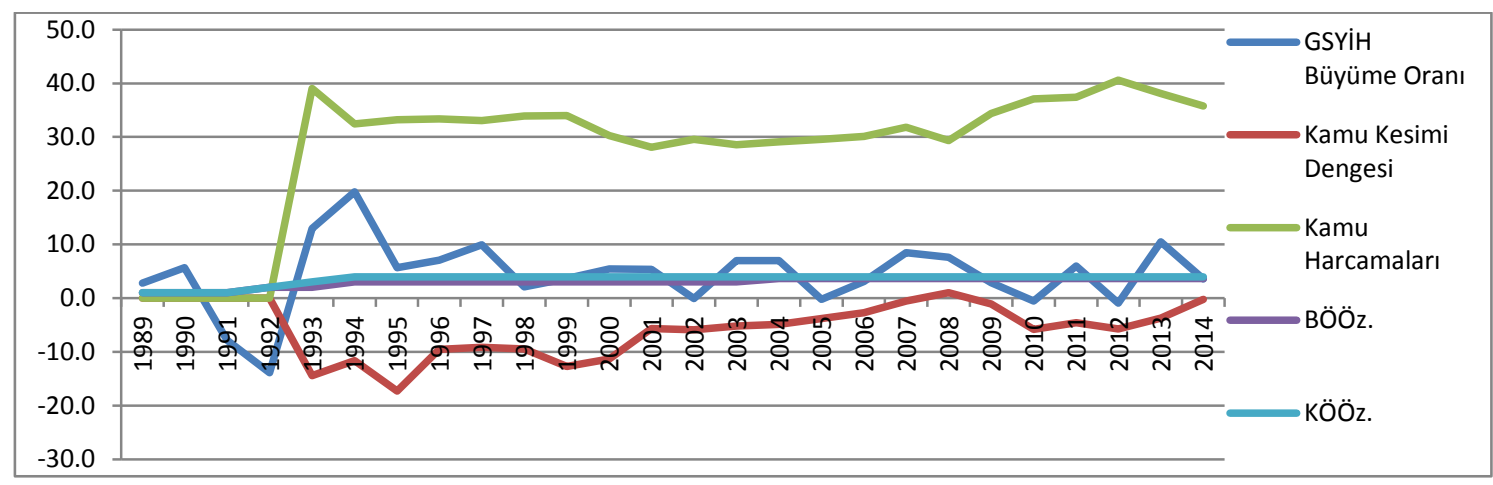

Şekil 3 Kırgızistan EBRD Özelleştirme Geçiş Göstergeleri-Kamu Dengesi-Büyüme İlişkisi Kaynak: EBRD Transition Reports, IMF World Economic Outlook Database

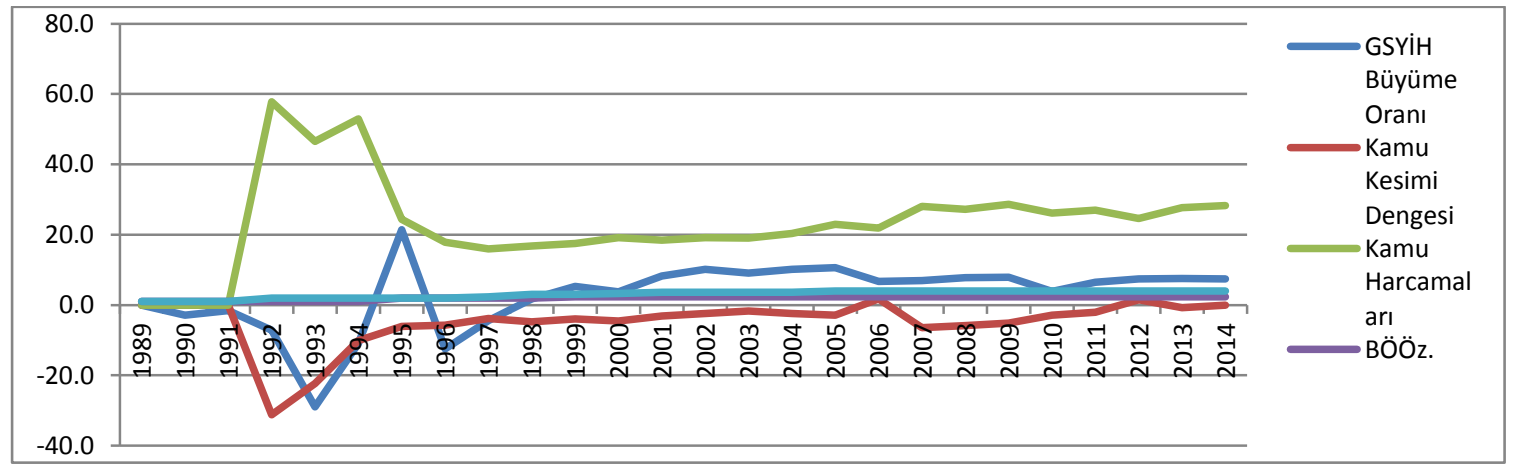

Şekil 4 Tacikistan EBRD Özelleştirme Geçiş Göstergeleri-Kamu Dengesi -Büyüme İlişkisi Kaynak: EBRD Transition Reports, IMF World Economic Outlook Database 


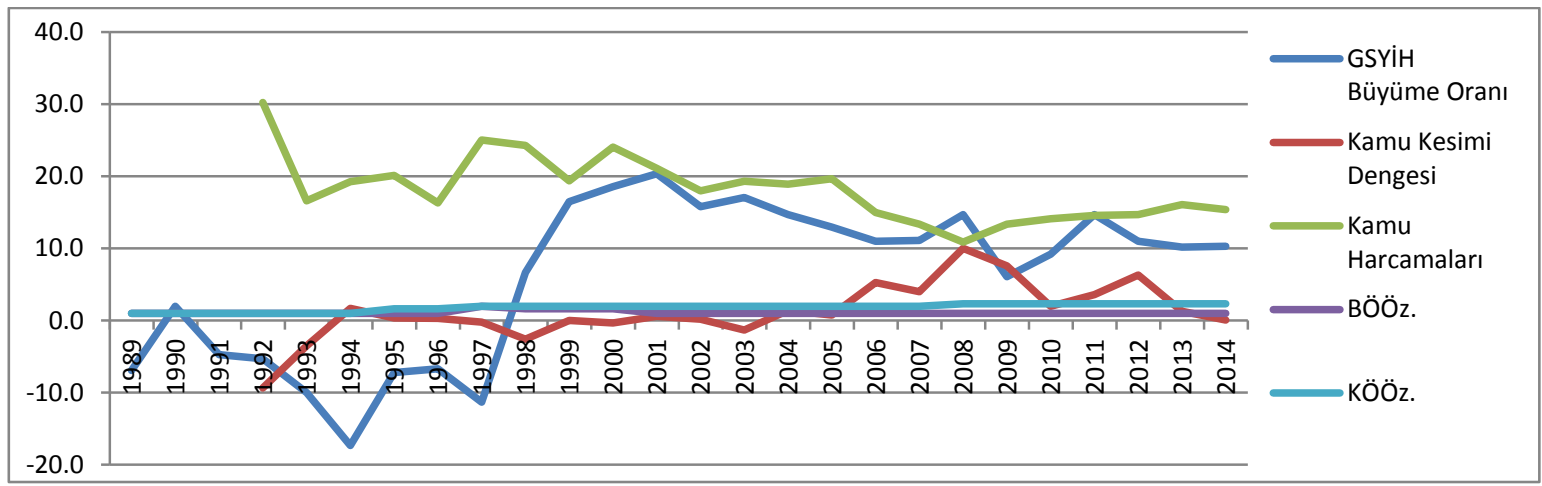

Şekil 5 Türkmenistan EBRD Özelleştirme Geçiş Göstergeleri-Kamu Dengesi -Büyüme İlişkisi Kaynak: EBRD Transition Reports, IMF World Economic Outlook Database

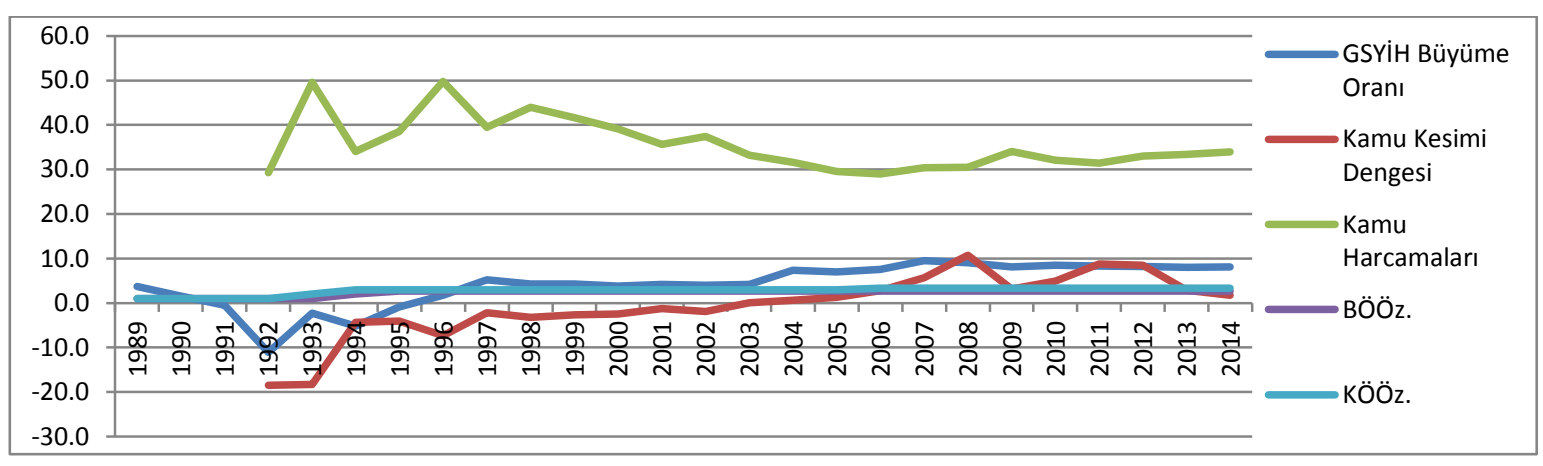

Şekil 6 Özbekistan EBRD Özelleştirme Geçiş Göstergeleri-Kamu Dengesi-Büyüme İlişkisi Kaynak: EBRD Transition Reports, IMF World Economic Outlook Database

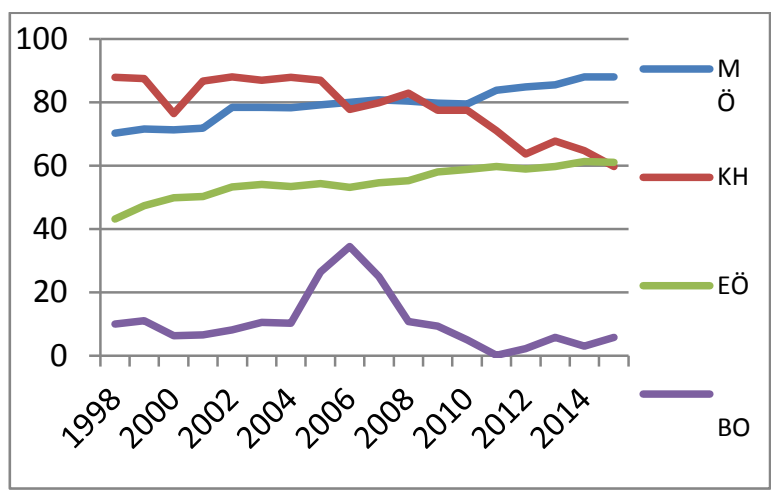

Şekil 7 Azerbaycan Ekonomik Özgürlükler Endeksleri

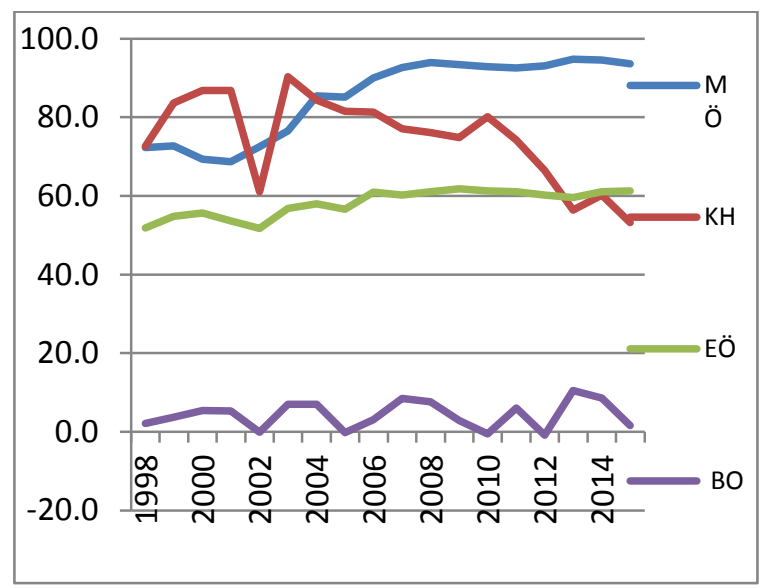

Şekil 9 Kırgızistan Ekonomik Özgürlükler Endeksleri

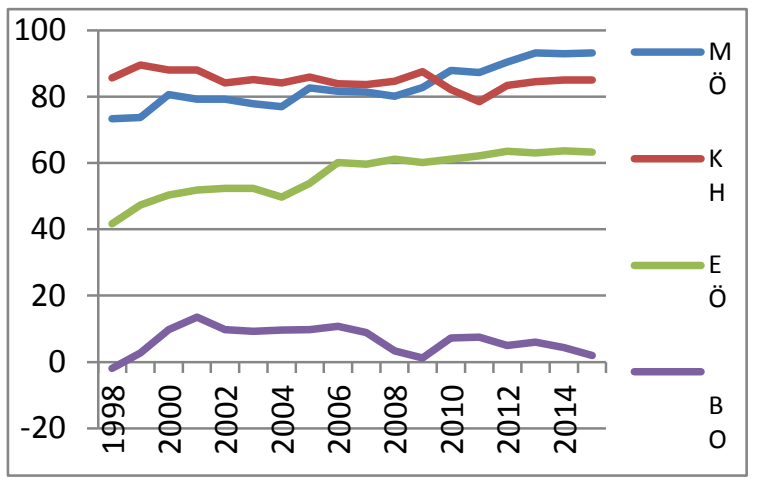

Şekil 8 Kazakistan Ekonomik Özgürlükler Endeksleri

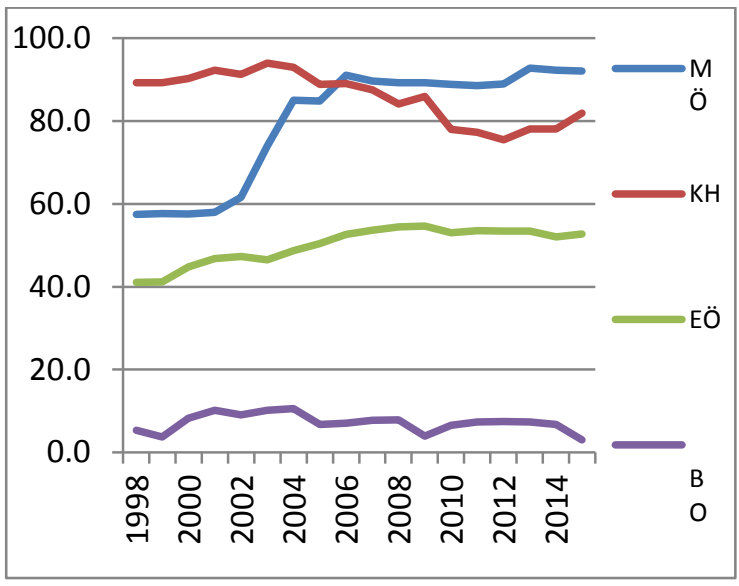

Şekil 10 Tacikistan Ekonomik Özgürlükler Endeksleri 

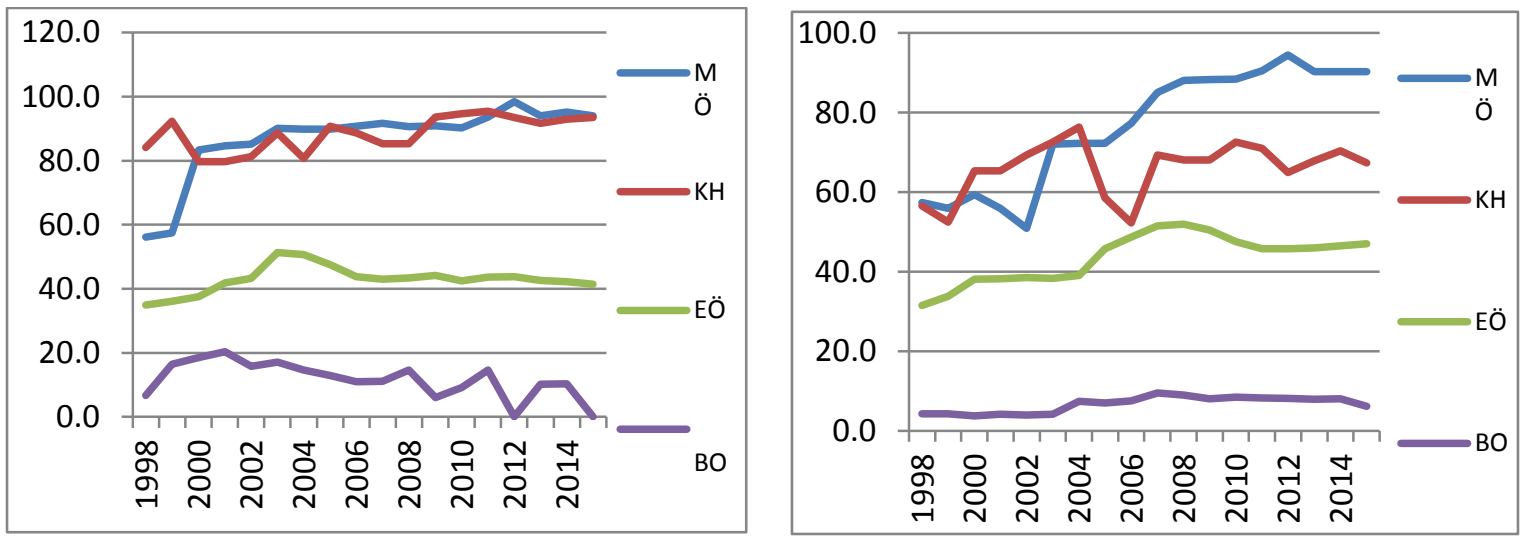

Şekil 11 Türkmenistan Ekonomik Özgürlükler Endeksleri Endeksleri Kaynak: Heritage Foundation

Şekil 12 Özbekistan Ekonomik Özgürlükler

(Şekil 7-12 için MÖ: Mali Özgürlük KH: Kamu Harcamalarl Özgürlüğ̈̈ EÖ: Ekonomik Özgürlük BO: GSYiH Büyüme Oranı \%)

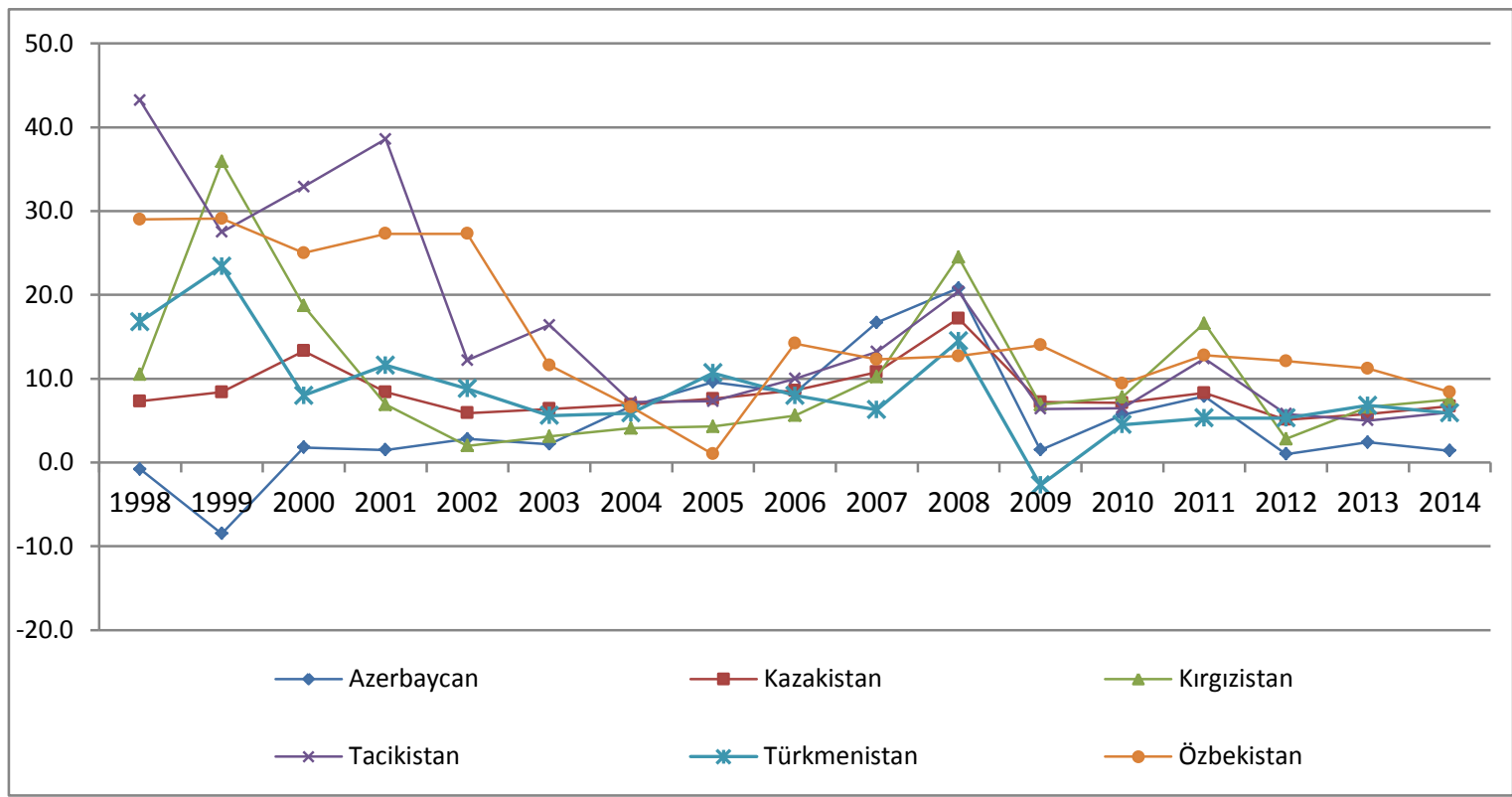

Şekil 13 Enflasyon (\%) Kaynak: EBRD Transition Reports, IMF World Economic Outlook Database

\begin{tabular}{|l|r|r|r|r|r|}
\hline & 1993 & 1994 & 1995 & 1996 & 1997 \\
\hline Azerbaycan & 1129,0 & 1664,0 & 489,0 & 19,7 & 3,5 \\
\hline Kazakistan & 1662,3 & 1892,0 & 176,3 & 39,1 & 17,4 \\
\hline Kirgizistan & 772,4 & 180,7 & 43,5 & 31,9 & 23,4 \\
\hline Tacikistan & 2195,0 & 350,0 & 612,5 & 418,4 & 88,0 \\
\hline Türkmenistan & 3102 & 1748,0 & 1005,3 & 992,4 & 83,7 \\
\hline Özbekistan & 534,2 & 1568,3 & 304,6 & 43,1 & 70,9 \\
\hline
\end{tabular}

Tablo 2 Hiperenflasyon (\%) Kaynak: EBRD Transition Reports, IMF World Economic Outlook Database

Bu çalı̧̧ma Çukurova Üniversitesi Bilimsel Araştırma Projeleri Koordinasyon Birimi tarafindan desteklenmiştir. Proje No: 4918

\section{Kaynakça}

- $\quad$ Ağayev, S., \& Yamak, N. (2009). "Bağımsız Devletler Topluluğu Ülkelerinde Ekonomik Büyümenin Belirleyicileri”. Atatürk Üniversitesi İktisadi ve İdari Bilimler Dergisi, 23(4), p.179-204

- $\quad$ Ağcakaya, S., 2009. “Geçiş Ekonomilerinden Orta Asya Türk Cumhuriyetleri'nde Bütçe Yönetimi ve Mali Disiplin Sorunu”, Akademik Baklş Dergisi, Sayı 16, Nisan.

- $\quad$ Arıkan, Z., 2002. “Geçiş Ekonomilerinde Mali Disiplin, Küreselleşme ve Geçiş Ekonomileri Uluslararası Sempozyumu”, Kırgızistan- Türkiye Manas Üniversitesi Yayınları:29, Kongre Dizisi:3, 02-04 Mayıs 2002, Bişkek- Kırgızistan 
- $\quad$ Atilla Bastırmacı, "Doğu Avrupa Ülkelerinde Özelleştirme Süreci”, www.foreigntrade.gov.tr/ead/dtdergi/1 ekim98/dogu.htm

- $\quad$ Bal H.,2004. "Geçiş Ekonomilerinde Ekonomik Büyüme Ve Dış Finansman", Türkiye Manas Üniversitesi Sosyal Bilimler Dergisi, p.155-172, 2004

- Çatalbas, N.ve Zubeyr Yıldırım, 2008. "Geçiş Ekonomilerinde Bütçe Açıklarının Nedenleri: Polonya ve Kırgızistan Örneği." Sosyoekonomi .7, p.133-156.

- Cebula, R.J. ve F.G.Mixon Jr, 2012. "The Impact of Fiscal and Other Economic Freedoms on Economic Growth An Empirical Analysis”, Journal of International Development, 27, p. 133-143

- Crivelli, Ernesto, 2013. "Fiscal Impact of Privatization Revisited: The Role of Tax Revenues in Transition Economies.”, Economic Systems, 37(2), 217-32.

- CÇevik, S., 2010. “Geçiş Ekonomilerinde Kamu Maliyesi ve Mali Sistem Reformları”, Avrasya Etüdleri, TİKA, Sayı: 37, Ankara, p. 90

- $\quad$ Doucouliagos, C., M.A. Ulubasoglu, 2006. "Economic Freedom and Economic Growth: Does Specification Make A Difference?", European Journal of Political Economy, 22(1), p. 60-81

- Erdem, E.,Türker, O. 2012. "Orta Asya Cumhuriyetlerinde Ekonomik Serbestlik ve Büyüme İlişkisi ”, International Conference On Eraslan Economies, 2012, Beykent University, Kyrgyzstan -Turkey Manas University Turan University, Almaty- Kazakistan , 11-13 October 2012, 175-182.

- $\quad$ Erden,L. ve N. Bolahatoğlu, 2015. "Fiscal Responses to Privatisation in Transition Economies an Empirical Assessment”, Journal of International Development, 27, p.133-143

- Frrat, E., 2013. “Geçiş Ekonomilerinde Liberalleşme Çabaları ve Kobilerin Önemi”, International Economic and Law Symposium (UEHSJUNE 2013), p.252-263.

- Güler, E., 2012. “Geçiş ekonomileri ve yeni kurumsal iktisat'1n yeniden yükselişi”, Doğuş Üniversitesi Dergisi, 13(1), p.52-68.

- Gupta, S., Leruth, L., de Mello, L., \& Chakravarti, S.,2001., “ Transition Economies: How Appropriate is the Size and Scope of Government\&quest”. IMF Working Paper, wp 1/55, p.1-44.

- Oleh Harvlyshyn and Donal McGettigan, "Privatization in Transition Countries: A Sampling of the Literature”, International Monetary Found European II Department, Working Paper:99/ 6.

- Sachs Jeffrey, Clifford Zinnes and Yair Eilat, 2000. "Patterns and Determinants of Economic Reform in Transition Economies: 1990-1998”, CAER II - Discussion Paper, 61, Vol.I, February

- Sağlam, N. ve M. Ocak, 2014. “Geçiş Ekonomilerinde Özelleştirme”, 14. International Conference On Eurasian Economies

- Sakınç, S., 2005. “Geçiş Ekonomileri ve Orta Asya Türk Cumhuriyetlerinde Ekonomik Reformlar”, Emek Matbaacilık, Manisa.

- $\quad$ Sarı̈̈l,H.;Özer,A ve H.Akbaş, 2013. "Ekonomik Serbestliklerin Bağımsız Devletler Topluluğu Ülkelerindeki Yabancı Banka Yatırımlarına Etkisi, International Economic and Law Symposium (UEHSJUNE 2013), p.212-217.

- Tandırcioğlu, H., 2002. “Geçiş Ekonomilerinde Özelleştirme”. Dokuz Eylül Üniversitesi Sosyal Bilimler Enstitüsü Dergisi, 4(3), p.198-226.

- $\quad$ http://www.sbe.deu.edu.tr/Yayınlar/dergi/2002sayi 3PDF/tandircioglu.pdf.

- Yaman, Ş., 2002.”Türk Cumhuriyetleri’nde Ekonomik Reformların On Yılı”, Dış Ticaret Dergisi,

- Ocak, Ankara. http://www.dtm.gov.tr/ead/dtdergl/ocakozel2002/reform.htm.

- Y Yıldız, H. "Geçiş Ekonomilerinde Dönüşüm Süreci ve Mali Reformlar”, Proceeding of the First International Manas University Conference in Economics on the "Recent Economic Development and Problem in the Transition Economics"“, Kyrgyz-Turkish Manas University Deparment of Public Finance, 23-24 Eylül,2004,Bishkek-Kryryzstan, p. 537-553

- EBRD, Transition Reports

- Heritage Foundation Index of Economic Freedom

- $\quad$ IMF World Economic Outlook Database 


\title{
Küresel Finans Krizi Sonrasında Sermaye Piyasalarında Şeffaflığın Arttırılması: Türkiye Örneği
}

\section{Increasing Transparency in Capital Markets after the Global Financial Crisis: The Case of Turkey}

\author{
Ph. D. Candidate Cüneyd Ebrar Levent (İstanbul Aydın University, Turkey)
}

\begin{abstract}
The need for financial transparency is way beyond reducing fluctuations on financial markets, the protection of small investors or fighting against money laundering. Asian crisis in 1997, Dot-com bubble in 2000, company crises such as Enron and the global financial crisis in 2008 have shown that a crisis caused by the lack of transparency in companies might not only affect the company and its stakeholders in a negative way but also the country and the region the company is in. After the financial crisis of 2008 many countries made various arrangements in capital accounts about increasing transparency and accountability which was seen as one of the reason of the crisis in addition the short and long term precautions. Dodd-Frank Wall Street Reform and Consumer Protection Act which came into force in the United States in July 2010 is one of the most significant arrangements. In this study, practices of increasing transparency in capital markets after global financial crisis have been discussed. In this context, in light of the new regulations and the Corporate Governance Principles, transparency and disclosure practices in Turkey have been examined. The results of these practices have been analyzed in the short term and its possible effects on capital markets, companies and shareholders have been discussed in the long term. Increasing transparency has been expected to help financial markets process more effectively and to provide benefits to all stakeholders.
\end{abstract}

\section{Giriș}

Küreselleşme ve sermaye piyasalarının iç içe geçmiş yapısı, bir şirkette, bir sektörde veya bir ülkede yaşanan bir gelişmenin, hızla diğer şirketlere ve ülkelere yansıyabilmesine neden olmaktadır. Gelişmekte olan ülkelerin birinde borsa endeksinin hızla düşmesi, aynı kategoride değerlendirilen başka bir ülkenin endeksinde de düşüşe yol açmaktadır. Üstelik bu iki ülke arasında coğrafi bir sınır olmasına, ciddi bir finansal ilişkisinin olmasına da gerek yoktur. Bu yüzden, sermaye piyasalarının bu yapısı, doğru, güvenilir ve doğru zamanlı bilgiye olan ihtiyacı daha da arttırmaktır.

Yatırımcılar normal olarak neye yatırım yaptıklarını, ne düzeyde bir risk aldıklarını bilmek isterler. Kurumsal yönetim anlayışına sahip olmayan veya yasal düzenlemelerin yeterli olmadığı bir ortamda faaliyet gösteren şirketler ise gerçek durumu yatırımcılardan gizleme eğilimindedir. Taraflardan birinin, diğer tarafa göre daha az bilgiye sahip olması asimetrik bilgi durumunu ifade eder (Akerlof, 1970). Bu, taraflar arasında eşitsizliğe neden olarak piyasalarının etkinliğini azaltır. Asimetrik bilgi yaklaşımına göre finansal kriz, finansal piyasaların fonksiyonun tam olarak yerine getiremediği bir durumdur (Miskhin, 1999). 2008 küresel finans krizinde dünya asimetrik bilginin neden olduğu problemlerle karşı karşıya gelmiş, birçok banka ya iflas etmiş ya da devletleştirilmiş, batmayacak kadar büyük denilen şirketler batmış, devletler sorgulanır hale gelmiştir.

Sermaye piyasalarında mevcut şeffaflık düzeyinin arttırılması için kamuyu bilgilendirme sistemlerin kurulması ve bunların sürekli geliştirilmesine ihtiyaç vardır. Açıklanan bilgilerin kaliteli standartlara uygun olarak hazırlanması, bu bilgilerin doğruluğuna bağımsız, uzman denetçiler tarafindan güvence verilmesi gerekmektedir. Sadece şirketin değil, o şirketin denetimini yapan kurumun da şeffaf ve hesap verebilir yani denetlenebilir olması şarttır. Gerçek durumun yatırımcılardan gizlendiği veya durumun olduğundan farklı gösterilmesi için hileye başvurulduğu ve bunun şirketi denetleyen kurumların bilgisi dahilinde yapıldığı durumlarda 2001'de Enron, 2003'de Parmalat, 2008'de Lehman gibi şirket krizleri ile karşı karşıya gelinmektedir.

Şeffaf bir piyasa ortamı için belki en önemli görev hükümetlere düşmektedir. Hükümetlerin, piyasaların etkin biçimde çalışmasına izin verecek şekilde gerekli esnekliği sağlayan bir düzenleyici çerçeveyi oluşturma sorumluluğu vardır (OECD, 2004). Düzenleyici çerçeve ile kamuya sunulan bilginin standartlarını, bilgilendirmenin nasıl, ne zaman, hangi sıklıkla, hangi araçlarla yapılacağına ilişkin kuralları belirlenmiş, hem hissedarların hem de paydaşların beklentileri karşılanmış olur.

$\mathrm{Bu}$ çalışmada küresel finans krizi sonrasında sermaye piyasalarında şeffaflığın arttırılması konusu incelenmiştir. Çalışmanın giriş bölümünü takip eden ikinci bölümünde kurumsal yönetim perspektifinde şeffaflık kavramının çerçevesi çizilmiş, kamuyu aydınlatma ve şeffaflık ilişkisi üzerinde durulmuş, kamuya açıklanacak bilginin taşıması gereken özellikler tartışılmıştır. Üçüncü bölümde sermaye piyasalarında şeffaflık konusu ele alınmış, sermaye piyasalarında çeşitli sınırlayıcı faktörler altında şeffaflı̆̆ın arttırılması mümkün müdür sorusuna cevap aranmıştır. Bu çerçevede küresel finans krizi sonrasında sermaye piyasalarında şeffaflık eksikliği ve bunun sonuçlarına yer verilmiştir. ABD'de finansal krizin tekrarlanmaması için çıkarılan Dodd-Frank 
Yasası'na değinilmiş, yasanın öne çıkan noktaları ortaya konulmuştur. Dördüncü bölümde ise Türkiye'de küresel finans krizi sonrası sermaye piyasalarında şeffaflığı arttırmaya yönelik uygulamalar ve yasal düzenlemeler ayrıntılı olarak incelenmiştir. Yeni Türk Ticaret Kanunu ve Sermaye Piyasası Kanunu sadece yasa maddeleriyle değil gerekçeleri ile de ele alınmış, kamuyu aydınlatma ve şeffaflık doğrultusunda getirilen düzenlemeler ortaya konulmuştur. Son olarak Türkiye'de hissedarların şirketlerin genel kurullara internet aracılığı ile katılabilmelerini sağlayan Elektronik Genel Kurul Sistemi (E-GKS) incelenmiş, şirketlere ve hissedarlara faydaları üzerinde durularak, bu sistemin kısa vadedeki sonuçları ortaya konulmuştur.

\section{2 Şeffaflık ve Kurumsal Yönetim}

Şeffaflık, adillik, hesap verebilirlik ve sorumluluk ile birlikte kurumsal yönetimin dört temel ilkesinden biri olarak kabul edilir (OECD, 1999; West, 2009). Şeffaflık kavramı, farklı disiplinlerde farklı şekillerde tanımlanmasına karşın bu tanımların çoğunda "bilgi verme" ve "bilgiye erişim" ön plana çıkmaktadır. Bilgi verenlere odaklanan bir tanıma göre şeffaflık, kurumlar tarafından kendilerini değerlendirmeye imkan veren bilgilerin açıklanmasıdır (Florini, 1999). Bilgiyi alacak kişiler açısından bakıldığında ise şeffaflık, doğru, güvenilir ve zamanında bilgiye erişebilmektir.

Şeffaflık kavramını kurumsal yönetim ve finans açısından inceleyen Vishwanath ve Kaufmann (1999), şeffaflığı, "ekonomik, sosyal ve politik bilgilerin zamanında ve güvenilir olarak akışının artırılması" olarak tanımlamıştır. OECD (Organisation for Economic Co-operation and Development) tarafından ulusal hükümetler, ilgili uluslararası kuruluşlar ve özel sektör ile birlikte 1999'da hazırlanan, 2004 yılında revize edilen Kurumsal Yönetim İlkeleri'nde ise şeffaflık, kamuya açıklama (disclosure) kavramı ile beraber ele alınmıştır. Dünya genelinde karar alıcılar, yatırımcılar ve diğer paydaşlar tarafından uluslararası bir referans kaynağı haline gelen bu ilkelere göre şeffaflık, kurumsal yönetim çerçevesinin içinde yer almaktadır, bu çerçeve şirketin mali durumu, performansı, mülkiyeti ve idaresi dahil olmak üzere şirketle ilgili bütün maddi konularda doğru ve zamanında açıklama yapılmasını sağlamalıdır (OECD, 2004).

Bütün bu tanımlardan ve açıklamalardan şeffaflığı, bilgi üretenler açısından bilgiyi duyurma, bilgiye ihtiyacı olanlar açısından ise bilgiye ulaşma olarak yorumlamak da mümkündür. Şeffaflığın temelinde bilgi olduğuna göre bu bilginin bazı özellikleri taşıması gerekmektedir.

İlk olarak açıklanacak bilgi doğru ve güvenilir olmalıdır. Hatalı bir bilgi, karar vericilerin yanlış kararlar almasına neden olabilecektir. Bilginin güvenilir olması için, bilgiler mevcut veya oluşturulacak temel standartlara uygun olarak hazırlanmalı, doğruluğu iç ve dış denetçiler tarafindan denetlenmelidir. Standartlara uygun olarak hazırlanan bilgiler, bilgi kullanıcılarına karşılaştırma imkanı vermektedir.

Kamuya açıklanacak bilgi, tam ve eksiksiz olmalıdır. Sunulan bilgi, doğru ve güvenilir olmasına karşın eksikler içeriyorsa burada şeffaflıktan bahsetmek mümkün değildir. Bir şirketi faaliyet raporunda öngörülebilir risklerden bazılarına yer verilmiyorsa burada eksik bilgi var demektir.

Sunulacak bilginin bir diğer özelliği de anlaşılabilirlikdir. Bilgi kullanıcılarının, bilgiyi doğru karar vermede kullanabilmeleri için, bilginin karmaşık ve anlaşılması zor yöntemler yerine basit ve anlaşılır yöntemlerle, user friendly bir formatta sunulmuş olması gerekmektedir. Bilgi açık ve net olmalı, bilginin ne anlam ifade ettiğinin kavranabilmesine olanak sağlamalı, bilgi gereksiz detaylardan arındırılmış olmalıdır. Anlaşılabilir uygun sembol, açıklama ve dipnotlarla desteklenen bir bilgi, kullanıcıların bilgiyi doğru şekilde yorumlamalarına yardımcı olur.

Kamuya açıklanacak bilgi zamanında sunulmalıdır. Bir bilgi ne kadar doğru ve güvenilir olursa olsun, eğer zamanında sunulmamışsa, bilgi kullanıcıları açısından çoğu zaman bir anlam ifade etmeyecektir. Bilgi, bilgi kullanıcıların alacakları ekonomik kararları etkileme gücünü kaybetmeden önce, karar alma sürecine dahil edilmelidir. Bilgiyi zamanında açıklama şeffaflığın bir ölçüsü olarak kabul edilmektedir. Sermaye piyasalarının mevcut olduğu bütün ülkelerde halka açık şirketlerde zamanında ve sürekli açıklama yapma gönüllülüğün ötesinde zorunluluktur.

\section{Sermaye Piyasalarında Şeffaflık}

Sermaye piyasaları güven ve şeffaflık temeline dayanmaktadır. Güvenin olmadı̆̆ bir ortamda sermaye piyasaları gelişemez. $\mathrm{Bu}$ yüzden dünyadaki düzenleme ve yürütme erkleri sermaye piyasalarında güveni sağlamaya ve pekiştirmeye yönelik olarak tedbirler almaktadır. Güveni sağlamanın en önemli yollarından birisi yatırımcıların doğru ve zamanında bilgi edinebilmesini sağlamaktır. Yatırımcılar şeffaf bir sermaye piyasası isterler, yatırım yaptıkları finansal araçların taşıdıkları risklerini bilmek, bu bilginin de herkese aynı zamanda ve eşit bir şekilde dağılmasını talep ederler. Şeffaf bir sermaye piyasası için yatırımcılar arasında bilgi asimetrisi oluşturulmaması gerekir.

Sermaye piyasalarında şeffaflı̆̆ın arttırılması bir yandan paydaşların çıkarlarına hizmet etmekte, diğer yandan piyasaların etkin işlemesine yardımcı olmaktadır. Şeffaf bir şirketin verimliliğinin artması, rasyonel karar vermesi ve hesap verebilirliğinin artması beklenmektedir. Burada iki soru karşımıza çıkmaktadır: Birincisi çeşitli 
sınırlamalara karşın şeffaflığın gerçekten arttırılması mümkün müdür? İkincisi ise şeffaflığın artması hem piyasaların hem de şirketlerin yararına olacak mıdır?

İlk soruya şöyle cevap verilebilir: Evet, şeffaflık soyut değil ölçülebilir bir kavramdır ve şeffaflık düzeyinin arttırılması mümkündür. Ancak şirket ölçeğinde istenen düzeyde bilginin sağlanmasında bir isteksizlik mevcuttur. Bunun birinci nedeni, bilginin toplanması, duyurulması şirketlere ek maliyetler getirmektedir. Paydaşlar doğal olarak bilgiye düşük maliyetle ulaşmak istemektedir. Bilgiyi sağlayanlar ise kamuyu bilgilendirmeden sağlayacakları marjinal yararla bunun marjinal maliyeti arasında bir denge kurmaya çalışacaklardır ki, bu da tamamen şeffaf olmak yerine daha az şeffaf olunmasının tercih edilmesine yol açabilmektedir. Şirketlerin bilgiyi açıklamaktan kaçınmalarına sebep olan bir başka neden de stratejik faktörlerdir. Bir sektörde rekabet yoğunsa, şirketler birbirlerine bağlantılı ise, bu durumda yöneticiler daha fazla bilginin açıklanması ile şirketin stratejik rekabet avantajının kaybolmasına neden olabileceğini düşünebilirler.

Şeffaflık ile ilgili ikinci önemli konu şeffaflığın arttırılmasının yararlı olup olmadığıdır. Literatürde şeffaflığın arttırılmasının yararları ile ilgili çok sayıda çalışma bulunmaktadır. Paydaşlara güvenilir, zamanında ve doğru bilgi sunulmasının şirketlere çeşitli yararlar sağladığı, şeffaf ve iyi kurumsal yönetim uygulamalarına sahip şirketlerin finansal performanslarının da iyi olduğu yönünde çok sayıda çalışma ile ortaya konulmuştur. Buna göre finansal piyasalarla ilgili bilginin kamuya açıklanması sermayenin daha verimli yatırımlara yönelmesine ve böylece hem verimliliğin hem de üretimin artmasını sağlamaktadır. Florini'ye göre şeffaflığın arttırılması ekonomik entegrasyonun gelecekteki başarısı için en temel anahtar olarak görülmektedir (Florini, 1999).

Buna karşın finansal krizlerinin tek nedenini şeffaflık eksikliği olarak değerlendirmek de yanlıştır. Şeffaf piyasalar olarak bilinen birçok gelişmiş ülke, Küresel Finans Krizi'nden ciddi şekilde etkilenmiş, şeffaflık bu ülkeleri krizden korumaya yetmemiştir. Bu yüzden, bazı durumlarda şeffaflığın zararları bile olabileceğini, örneğin zamanla kendini düzeltme imkanı bulabilecek bazı zayıf finansal kuruluşların kapatılmasına yol açabileceği öne sürülmektedir (Furman ve Stiglitz, 1998).

Sermaye piyasalarında şeffaflığa davranışsal finans açısından bakıldığında ise, karşımıza bambaşka bir fotoğraf çıkmaktadır. Şeffaflığa yatııımcı tepkileri farklı olmaktadır. Yatırımcılar, kötü haberlere iyi haberlerden daha şiddetli tepki verdiği tepki görülmektedir. Kriz durumlarında ise birçok yatırımcının aşırı hassasiyeti, şirketlerden gelen haberleri yanlış değerlendirmeye itebilmektedir. Örneğin bir şirketten gelen olumsuz haber, aynı sektörde yer alan ancak olumsuzluk yaşamayan diğer şirketleri de negatif yönde etkileyebilmektedir. Bu durum şeffaflığ 1 etkilemekte, kötü haberlerin yaygın olduğu kriz dönemlerinde şirketlerin genellikle daha az şeffaf hale geldikleri, daha az açıklama yapmayı tercih ettikleri görülmektedir (Andrews, 2012).

\subsection{Küresel Kriz Sonrası Sermaye Piyasalarında Şeffaflı̆̆ın Arttırılması}

Şeffaf olmayan finansal işlemler ve ürünler, mali kurumlarda risk yönetiminin göz ardı edilmesi gibi sebepler Küresel Ekonomik Krizin oluşmasında ana nedenleri oluşturmaktadır. 2007 yılında ABD'deki konut fiyatlarında gerileme ve konut kredilerinin geri ödemelerindeki sorunlarla başlayan süreç, konuta dayalı menkul kıymetlerin fiyatına hızla yansımıştır. Riski dağıtılmasında bir araç olarak kullanılan menkul kıymetleştirme (securitization), temel işlevini yerine getirememiş ve riskin yayılmasına neden olmuştur. Sonuç olarak, finans kuruluşlarının ardı ardına açıkladıkları iflas kararları ve sektördeki kamulaştırmalar neticesinde kriz, gelişmiş ve gelişmekte olan piyasaları da içine alarak küresel bir boyuta ulaşmıştır.

Sermaye piyasaları da bu krizden çok ciddi şekilde etkilenmiş, tüm dünyada özellikle hisse senedi piyasaları endeksleri ciddi şekilde gerilemiştir. Kriz sonrası, kısa vadede yüksek getiriyi teşvik eden finansal inovasyon, bilanço dışı bırakılan riskleri tahlil edemeyen muhasebe standartları, yüksek riskli ürünlere yüksek kredi veren kredi derecelendirme kuruluşları, finansal piyasalarda oluşan riski önemsemeyen düzenleyici ve denetleyici otoriteler, kısacası tüm finansal sistemin işlerliliği sorgulanmaya başlanmıştır. Krizden çıkarılan dersler doğrultusunda başlatılan reform çalışmaları halen sürmektedir.

\subsection{Dodd-Frank Yasası}

ABD'de finansal krizin sebep olduğu yapısal ve diğer sorunları gidermek için çıkarılan Dodd-Frank Wall Street Reformu ve Tüketiciyi Koruma Yasası, ABD Kongresinde kabul edilerek Temmuz 2010'da Başkan Obama tarafından imzalanmıştır. Bu yasanın amacı giriş bölümünde "finansal sistemde hesap verilebilirlik ve şeffaflğ̆ın geliş̧tirilerek Amerika Birleşik Devletlerinde finansal săğlamlı̆̆ının artırılması, "batmayacak kadar büyük" anlaylşına son verilmesi, ekonomik durumu kötüye giden finansal şirketlerin kurtarllmasina son verilerek vergi ödeyen vatandaşların korunması ve tüketicilerin kötüye kullanılan finansal hizmetlerden korunması" olarak belirtilmiştir (SEC, 2015).

Dodd-Frank yasası, var olan düzenleme yapısında şeffaflığı teşvik edici hükümler içermektedir. Yasa, finansal alanda yeni gözetim otoriteleri oluşturmuş, ülkedeki finansal kuruluşların denetimine ve finansal sistemin işleyişine yönelik önemli değişiklikler getirmiştir. Bazı düzenleyici kurumlar birleştirilmiş veya kaldırılmış, sistemin bütününü etkileyen riske sahip kurumların gözetimini arttıracak yeni düzenleyici kurumlar oluşturulmuş̧ur. 
Yasa 16 başlıktan oluşmaktadır. Bu başlıkların çoğunda kurumsal yönetime ve şeffaflığa atıflar bulunmaktadır. Dodd-Frank yasasının şeffaflığı arttırmaya yönelik öne çıkan noktaları özetle şu şekildedir:

- Şeffaflık ve karmaşık türev enstrümanlarının hesap verebilirliği

- $\quad$ Otorite ve bağımsızlıkla tüketicinin korunması

- İleri seviye uyarı sistemi

- Yönetici ücretleri

- Kurumsal yönetim

- Yatırımciların korunmasi

- Hesap ve kayitlardaki düzenlemelerin güçlendirilmesi

- Finansal okuryazarlığın güçlendirilmesi

\section{Türkiye'de Kriz Sonrası Sermaye Piyasalarında Şeffaflığın Arttırılması}

Türkiye, 2002-2007 yılları arasında oldukça yüksek bir büyüme performansı sergilemesine karşın, 2008 yılında dünyada baş gösteren küresel krizden olumsuz etkilenmiş, Türkiye'deki birçok ekonomik gösterge bozulmuştur. Küresel krizin etkilerinin Türkiye'ye yansıması farklı fakat birbiriyle ilişkili ekonomik olaylarla gerçekleşmiştir. 2008 yılında ülke ekonomisi büyüyememiş, enflasyon oranı iki haneli rakamlara ulaşmıştır. Türkiye'de krizin daha şiddetli hissedildiği 2009 senesinde ise GDP 4.8 \% küçülmüştür. Krizin etkisiyle bütçe açığı hızlı bir şekilde artmış, işsizlik \%14'e yükselmiştir.

Küresel kriz Türk sermaye piyasalarını da olumsuz etkilemiş, 2 Ocak 2008'de 54,708 olan Borsa Istanbul 100 endeksi (BIST 100), 20 Kasım 2008'de 21,228 seviyesine inmiştir. Bu iki dönem arasında değer kayb1 \% 61.12 olarak gerçekleşmiştir. Krizin yıkıcı etkisinin azalmaya başladığı 2009 yılı ilk çeyreğinin sonunda yükselişe geçen BIST 100 endeksi 2010 yılı başında kriz öncesi seviyesini yakalamayı başarmıştır (6 Ocak 2010'da BIST 100 endeks değeri 54,547).

Türkiye'de krizin, özellikle hisse senedi piyasalarında neden olduğu kısa süreli ama yıkıcı etki, ABD ve AB ülkelerinde yaşanan banka ve şirket iflasları, finansal sistemin az düzenlenmiş ya da hiç düzenlenmemiş alanlarının bulunduğunun farkına varılmasına sebep olmuştur. Mevcut düzenleme ve uygulamalar sorgulanmış, Türk Ticaret Kanunu, Sermaye Piyasası Kanunu gibi temel kanunlar revize edilmek yerine yeniden yazılmıştır. Böylece kriz sonrası şeffaflığın arttırılması, piyasaların daha etkin işlemesi amaçlanmıştır. Aşağıda Türk sermaye piyasalarında şeffaflığı arttırmaya yönelik bazı önemli düzenlemeler açıklanmaktadır. Bunlardan Türk Ticaret Kanunu 1956'dan beri, Türk Sermaye Piyasası Kanunu ise 1981 'den beri çeşitli değişikliklere rağmen yürürlükte idi. Kanunların yeniden yazılmasının Türk ticaret ortamına ve sermaye piyasalarına olumlu etkileri olmuştur. Gerek yeni kanunlar gerekse ikincil düzenlemelerle özellikle sermaye piyasalarının hukuki alt yapısı büyük ölçüde yenilenmiş, uluslararası normlara uyum sağlanmıştır.

\subsection{Yeni Türk Ticaret Kanunu}

1 Temmuz 2012'de yürürlüğe giren Yeni Türk Ticaret Kanunu ile kurumsal yönetimin çerçevesi belirlenmiş olmaktadır. Kanun gerekçesinde kurumsal yönetim dört taşıyıcı kolon üzerine oturan bir anlayış olarak belirtilmiştir. Bunlar şeffaflık, adillik, sorumluluk ve hesap verebilirliktir.

ABD'de Enron ve Worldcom skandallarından sonra çıkarılan, hesap verebilirliği, karşılaştırılabilirliği ve şeffaflığı daha ileri noktalara taşımayı hedefleyen Sarbanes-Oxley Act'ın yeni Türk Ticaret Kanunu için ilham kaynağı olduğu, kanunun gerekçelerinde açıkça görülmektedir. Yeni Türk Ticaret Kanununun gerekçelerinde şeffaflıkla ilgili öne çıkan hususlar şöyle özetlenebilir:

Şeffaflık, şirketin bütün kurumlarını kavrar ve bilgi toplumu ile beraber tanımlanır. Kamuyu aydınlatmanın ise daha çok anonim şirketlerle beraber anılan bir kavram olduğu, şeffaflığın kapsamının ise daha geniş olduğu vurgulanmıştır. Şeffaflık halka açık şirketleri merkez alan bir anlayışın değil, bilgi toplumu yaklaşımının bir ürünüdür.

Şeffaflık, pay sahiplerine ve sermaye piyasasında rol sahibi herkesin tam bilgilendirilmesini ve aydınlatılmasını hedefler. Burada önceki kanunlarda yer almayan paydaş kavramına vurgu yapılmıştır. Kanuna göre şeffaflığın yeni aracı, internet ve elektronik bilgi aktarımıdır. Şirket web sitesi, şeffaflı̆̆ sağlayan bir mekanizma olarak ifade edilmektedir.

Bütün bunlar yeni Türk Ticaret Kanununun ana felsefelerinden birisinin şeffaflığın sağlanması olduğunu göstermektedir. Sadece kanun gerekçeleri değil, kanunun kendisi de incelendiğinde kurumsal yönetim ilkelerinin ön planda tutulduğu ve kanunda özellikle kamuyu aydınlatma ve şeffaflık doğrultusunda düzenlemeler getirildiği görülmektedir:

1-Halka açık şirketlere şeffaflık ve kamuyu aydınlatma başlığını da içeren kurumsal yönetim ilkeleri çerçevesinde açıklama yapma zorunluluğu getirilmiştir. 
2-Halka açık şirketlerde, Riskin Erken Teşhisi komitesi kurma zorunluğu getirilmiştir (Madde 378).

3-İmtiyazlı paylar kaldırılmamakla birlikte sınırlandırılmıştır.

4-Açıklanacak finansal tablolar, Türkiye Muhasebe Standartlarına göre hazırlanmalıdır.

5-Tüm şirketlere bağımsız denetim yükümlülüğü getirilmiş̧ir.

6-Bağımsız yönetim kurulu üyeliği kavramı getirilmiştir. Bu konu, ikinci düzenlemelerle açıklı̆̆a kavuşturulmuş, kimlerin bağımsız yönetim kurulu olabileceği konusunda sınırlar çizilmiştir.

7-Azlık hakları güçlendirilmiştir (Madde 411).

8-Finansal tablolarda, yönetim kurulunda, bağımsız denetimde, iç denetimde tam şeffaflık aranmaktadır.

9-Şirketlerde genel kurulun (Madde 408 ve 616) ve yönetim kurulunun (Madde 375) devredilemez yetkileri kanunla net olarak tanımlanmıştır. Burada şirketlerin kurumsallaşmaları hedeflenmiş, şirketlerden şeffaf olmayan uygulamalardan kaçınmaları istenmiştir.

\subsection{Yeni Sermaye Piyasası Kanunu}

Türkiye'de Sermaye Piyasası Kanunu 30 Aralık 2012'de yürürlüğe girmiştir. Kanunun genel gerekçesinde, bu kanunun hazırlanma nedenlerinin başında 2008 Küresel Finans Krizi olduğu açıkça belirtilmiş, krizin nedenleri, sonuçları ve Türk sermaye piyasalarına etkisi üzerinde durulmuştur.

Yeni Türk Ticaret Kanunu gibi Yeni Sermaye Piyasası Kanunu'nda da kurumsal yönetim anlayışı hakimdir. Yasa incelendiğinde daha ilk maddede şeffaflığa vurgu yapıldığı görülmekte, yasanın amacının "sermaye piyasasının şeffaf, etkini istikrarl, adil ve rekabetçi bir ortamda işleyişinin sağlanması, yatırımcıların hak ve menfaatlerinin korunması için sermaye piyasasının düzenlenmesi ve denetlenmesi" olduğu belirtilmiştir.

Yasada sermaye piyasalarında şeffaflığın arttırılması ile ilgili önemli bazı hususlar şöyle özetlenebilir:

1-Kanunla sermaye piyasası araçlarının ihraç prosedürleri kolaylaştırılmakta, şirketlerin alternatif arayışlara girmeden sermaye piyasası sisteminde ve denetiminde kalmaları hedeflenmektedir.

2-Kanun, şeffaf olmayan, karmaşık ortaklık yapılarının önüne geçmek için şirketlerin kendi paylarını satın alabilmelerinin önünü açmıştır. Geçmişte bu, yasak olduğu için paravan şirketler yardımıyla yapılmaktaydı.

3-Finansal tablo ve raporlar şekil ve içerik olarak (IFRS'e uyumlu) Türkiye Muhasebe Standartları çerçevesinde, belirlenen düzenlemelere uygun olarak yapılmalıdır. Yeni Türk Ticaret Kanununda da buna benzer bir madde bulunmaktadır.

4-Madde 14 ve 15 'de kamuya açıklamanın çerçevesi çizilmiştir. Sermaye piyasası araçlarının değerini, piyasa fiyatını veya yatırımcıların kararlarını etkileyebilecek tüm bilgi, olay ve gelişmeler kamuya açıklanmalıdır. İkincil düzenlemelerle özel durum açıklamasına konu hususların kapsamı genişletilmiş̧ir.

5-Yeni Sermaye Piyasası Kanunu ile kamuyu aydınlatma ve şeffaflık bölümleri de dahil olmak üzere kurumsal yönetim ilkelerini belirleme, bir kısmını veya tamamını zorunlu tutma yetkisi Sermaye Piyasası Kurulu'na verilmiştir.

6-Önemli nitelikteki işlemlere ilişkin alınan genel kurul kararlarına muhalefet eden ortaklara, paylarını ortaklığa satarak ayrılma hakkı tanınmaktadır.

7-Genel kurullara çağrı, katılım ve oy kullanmaya ilişkin ayrıntılı düzenlemeler yapılmıştır.

8-Hissedarların korunması, şeffaflığın sağlanması, firmaların karlarını gerçek olmayan yollarla azaltma veya arttırmalarına neden olan örtülü kazanç arttırımı yasağı ayrı bir madde olarak kanuna eklenmiştir.

9-28. madde ile sermaye piyasası araçlarının mevcut tüm imtiyazlarının şeffaf ve anlaşılır detayda kamuya duyurulması zorunludur. Üst üste beş yıl zarar eden şirketlerde imtiyazların kaldırılacağı belirtilmiştir. Böylece imtiyaza sahip grupların diğer ortakların menfaatine uygun davranmasının ve verimsiz yönetimlerin değiştirilerek şirketi daha iyi yönetecek kişilerin göreve gelmesinin sağlanması amaçlanmıştır.

10- Kanun ile yatırımcıyı zarara uğratacak, kompleks, şeffaf olmayan şirket yapılarına müsaade edilmemekte, ortak sayısı 500'ü aşan şirketler halka açık şirket sayılmakta, Sermaye Piyasası Kurulu'nun denetimi ve gözetimine tabi olmaktadır.

11-Yatırımcı Koruma Fonu'nun yerine oluşturulan Yatırımcı Tazmin Merkezi ile sağlanan teminatın kapsamı tüm menkul kıymetleri içerecek şekilde genişletilmiştir.

12-Küresel Finans Krizi sonrasında en çok tartışılan konulardan biri de derecelendirme kuruluşlarının batmış şirketlere verdiği adil olmayan notlar ve bu kurumların denetimsizliği idi. Kanunla Sermaye piyasasında derecelendirme ve değerleme alanlarında düzenleme yapma yetkisi Sermaye Piyasası Kurulu'na verilmiş, bu kurumların sorumluluk esasları açıkça belirlenmiştir.

13-Bilgi suistimali (içeriden öğrenenlerin ticareti) yeniden tanımlanmış, cezaların caydıııc1lığı arttırılmıştır.

14-Sermaye piyasası araçlarının fiyatlarını, değerlerini ve yatırım kararlarını, arz ve taleplerine ilişkin yanlış ve yanıltıı izlenim uyandırmak amacıyla alım satım yapmak, piyasa dolandırıcılığı olarak tanımlanmış, cezalar 
artııılmıştır. Yatırım kararlarını etkileyebilecek yalan, yanlış, yanıltııı bilgi vermek, haber çıkarmak, söylenti yaymak, rapor hazırlamak ve yaymak da suç sayılmıştır.

\subsection{Kurumsal Yönetim İlkeleri'nde Yapılan Değişiklikler}

İyi kurumsal yönetim uygulamalarının sermaye piyasası için önemi de dikkate alınarak Sermaye Piyasası Kurulu tarafından ilk olarak 2003 yılında "Uygula, Uygulamıyorsan Açıkla" yaklaşımı altında kurumsal yönetim ilkeleri yayımlanmıştır. Bu suretle şeffaflık, paydaş haklarının korunması gibi hususlarda atılan adımlar Türkiye'de kurumsal yönetim uygulamalarının yaygınlaşmasına katkı sağlamıştır. Kurumsal yönetim ilkeleri bankalar dışında şirketlerin uymalarının zorunlu olmadığı, 2011 yılına kadar herhangi bir kanun, yönetmelik gibi düzenlemelerin içinde yer almayan ilkelerdi (Bankaların kurumsal yönetim ilkeleri ise Bankacılık Kanunu'na dayanılarak 2006'da çıkarılan yönetmelikle zorunlu hale gelmişsi. Bunda 2001 yllında Türkiye'de yaşanan Bankacılık Krizi'nin etkisi olduğu söylenebilir). Küresel finans krizi sonrasında (2011 yılında) ise bazı kurumsal yönetim ilkeleri banka dışındaki şirketlere de zorunlu hale getirilmişti. Aynı yıl içinde Sermaye Piyasası Kurulu'na şeffaflık ve kamuyu aydınlatma dahil kurumsal yönetim ilkelerini belirleme, gerekli gördüğü halka açık şirketlere kısmen veya tamamen uyma zorunluluğu getirme ve uymayanlara da gerekli müeyyide uygulama yetkisini vermiştir. Daha sonraki yıllarda ise kurumsal yönetim ilkelerine uyma zorunluluğu getirilen şirketlerin kapsamı genişletilmiş, şeffaflığın artıııımasına yönelik çeşitli revizyonlar yapılmıştır.

Yürürlükte olan, en son haliyle "Kurumsal Yönetim Tebliği"'nde şirketlerin uymakla yükümlü oldukları ilkelerin neredeyse tamamı şeffaflık ve kamuya açıklama ile bağlantılıdır. Bunlardan bazıları şunlardır:

1-Şirket ortaklık yapısı, imtiyazlı payları ve imtiyazların özelliklerinin şeffaf bir şekilde kamuya duyurulması,

2-Şirket faaliyetlerini önemli ölçüde etkileyecek yönetim ve faaliyet değişikliklerinin duyurulması,

3-Yönetim Kurulu üyeleri ile ilgili bilgilerin şeffaf bir şekilde duyurulması (özgeçmişleri, son on yılda yürüttükleri işler, atanmaları, azil gerekçeleri),

4-Esas sözleşme değişikliklerinin duyurulması,

5-Genel kurul toplantılarında şeffaflığın sağlanması. Bunun için genel kurul toplantısında soru sorulmasına imkan verilmesi, ticari sır olmayan her sorunun cevaplandırılması ve bunun şirketin internet sitesinde duyurulmasi,

6-Önemli ölçüde varlık/hizmet alımı ve satımı işlemlerinde yönetim kurulunda bağımsız üyelerin çoğunluğunun onayının bulunması ve bu durumun Kamuyu Aydınlatma Platformu'nda duyurulması. Tebliğde "önemli işler" kavramı ile ilgili çok detaylı sayısal kriterler belirtilmektedir.

7-Tebliğde yönetim kurulu üyeleri ve bağımsız yönetim kurulu üyelerinin yapısı, seçimi ve duyurulması ile ilgili zorunlu maddeler bulunmaktadır.

8-Kurumsal Yönetim Tebliği ile halka açık şirketlerin aşağıdaki komiteleri kurmaları zorunludur:

a. Denetimden Sorumlu Komite

b. Riskin Erken Saptanması Komitesi

c. Kurumsal Yönetim Komitesi

d. Aday Gösterme Komitesi (Yönetim kurulu ve idari sorumluluğu bulunan yöneticilik pozisyonları için uygun adayların saptanması, değerlendirilmesi konularında şeffaf bir sistemin oluşturulmasından sorumludur)

e. Ücret Komitesi (Yönetim kurulu ve idari sorumluluğu bulunan yöneticilerin ücretlendirilmesinde kullanılan ilke ve kriterleri belirler, verilecek ücretlere ilişkin önerilerini yönetim kurula sunar.)

Bu komitelerinin başkanlarının bağımsız yönetim kurulu üyesi olması ve komite üyelerinin çoğunluğunun icrada görevli olmayan yönetim kurulu üyelerinden seçilmesi zorunludur.

Yeni Türk Ticaret Kanunu'nda olduğu gibi, Kurumsal Yönetim Tebliği'nde de kurumsal internet sitesi ve faaliyet raporları şeffaflı̆ın önemli araçları olarak görülmüş, ayrı başlıklar halinde incelenmiştir. Bu iki konuya aşağıda bölümlerde değinilecektir.

\subsection{Kurumsal İnternet Siteleri ve Kamuyu Aydınlatma Platformu}

Türkiye'de sermaye piyasalarında faaliyet gösteren şirketlerin büyük bir kısmının küresel finans krizi öncesinde kurumsal web sitesi bulunmaktaydı. Ancak 2012'de yürürlüğe giren Yeni Türk Ticaret Kanunu'nda kurumsal web sitesi bir zorunluluk haline getirilmiş, ikincil düzenlemelerle birlikte web sitelerinde bulunması gereken asgari unsurlar tanımlanmıştır. Bu sayede şirketlerin kurumsallaşması, yerli ve yabancı yatırımcıların şirket hakkında doğru bilgilere sahip olması amaçlanmıştır. Yeni Türk Ticaret Kanunu'nun 1524. Maddesinin gerekçesinde, şirketlere internet sitesi açma zorunluluğu ile hedeflenenin en üst düzeyde şeffaflığın sağlanması olduğu belirtilmiş̧tir. Yeni Sermaye Piyasası Kanununda ve bu kanuna dayanılarak hazırlanan Kurumsal Yönetim Tebliği'nde de şirketlerin hazırlamakla yükümlü oldukları kurumsal web sitesi ve içeriği ile ilgili konular bulunmaktadır. Ancak bu konuda en kapsamlı düzenleme Gümrük ve Ticaret Bakanlığı tarafından Yeni Türk Ticaret Kanunu'na dayanılarak 31 Mayıs 2013'de yayımlanan "Sermaye Şirketlerinin Açacakları İnternet 
Sitelerine Dair Yönetmelik’te yapılmış, sermaye şirketleri tarafindan açılacak internet siteleri, erişime açık tutulacak asgari içerik yükümlülüklerine ilişkin usul ve kapsamlar açıkça belirtilmiştir. Bu yönetmeliğe göre şirketlerin internet sitelerinde yayımlanması gereken zorunlu içeriklerden bazıları şunlardır:

1-Şirketle ilgili temel bilgiler (Ünvanı, yönetim kurulu üyeleri, merkezi, sermaye miktarı vs),

2-Birleşme durumunda birleşme raporu, son üç y1llık finansal tablolar,

3-Bölünme durumunda birleşme raporu, son üç ylllık finansal tablolar,

4-Şirkete açılan fesih davaları ile ilgili hususlar,

5-Genel kurul toplantısı ile ilgili bilgiler (Toplantıya çağırma, genel kurul tutană̆ı, toplantının ertelenmesi, genel kurul kararlarının iptaline dair kararlar),

6-Şirket ana sözleşmesinin değiştirilmesi,

7-Sermaye azaltılmasının sebepleri, azaltmanın amacı, azaltmanın ne şekilde yapılacağının belirtilmesi, bu konuda hazırlanan rapor.

Görüldüğü gibi birleşme ve bölünme durumları haricinde halka açık olmayan şirketler için finansal tabloların internet sitesinde yayınlanması zorunlu değildir. Ancak halka açık şirketler başta finansal tablolar olmak üzere özel durum açıklamalarını internet üzerinde yayınlamak zorundadırlar. Bu durum ikincil düzenlemelerle düzenlenmiş durumdadır. Halka açık şirketler kendi internet sitelerini etkin olarak kullanılmakla birlikte, düzenlemelerde, duyurularda kullanılması gereken esas yer olarak Kamuyu Aydınlatma Platformu belirtilmiştir.

Kamuyu Aydınlatma Platformu (KAP), sermaye piyasası ve Borsa mevzuatı uyarınca kamuya açıklanması gerekli bildirimlerin elektronik imzalı olarak iletildiği ve kamuya duyurulduğu elektronik sistemdir. Sermaye Piyasası Kurulu'nun (SPK) 'Kamuyu Aydınlatma Platformu Tebliğ'i kapsamında, kamuya açıklanacak her türlü bilgi ve belgenin Kamuyu Aydınlatma Platformu'na (KAP) gönderilmesi gerekmektedir. "Sistem, tüm kesimlerin doğru, anlaşlllr, tam bilgiye, internet üzerinden eş anlı ve düşük maliyetle erişsebilmelerine imkan taniyacak şekilde tasarlanmıştır. Ayrıca, geçmişe dönük bilgilere de kolay ve düşük maliyetle erişim imkanı sağlayan elektronik bir arşiv niteliğindedir." (KAP, 2015).

Kamuyu Aydınlatma Platformu tam şeffaflığa giden yolda önemli bir adım olarak değerlendirilebilir. Bilgilerin elektronik imza ile gönderilmesi suretiyle verilerin güvenilirliği sağlanmaktadır. Bunun yanında yapılan açıklamaların bekletilmeksizin, sisteme gönderildiği anda kamuya açıklanması, kullanıcılara eş zamanlı, güvenli ve hızlı bir şekilde bilgiye ulaşabilme imkanını vermektedir. Kullanıcılar bilgiye daha hızlı ulaşmalarının yanında, finansal tablo kalemlerinin karşıllaştırılması imkanına sahiptirler. Kullanıcıların bilgi almak için herhangi bir üyeliğe veya ücret ödemelerine de gerek yoktur. Bildirimlerin elektronik ortamda sisteme gönderilmesiyle zaman, kağıt ve işgücü tasarrufu sağlanmaktadır.

\subsection{Faaliyet Raporları ile ilgili Yapılan Düzenlemeler}

Kapsadığı hesap dönemine ilişkin finansal bilgileri, şirketin gelecek dönemdeki hedeflerini ve bu hedeflere nasıl ulaşacağını anlatan faaliyet raporu şeffaflı̆̆ın önemi araçlarından biridir. Paydaşlar için her zaman önemli bir bilgi kaynağı olan faaliyet raporları, özellikle küresel finans krizi sonrasında yatırımcılar ve diğer paydaşların daha fazla şeffaflık ve daha çok bilgi ihtiyacını karşılayamaz hale gelmiştir. Bu yüzden şirketlerin hazırlamaları gereken faaliyet raporlarının içeriği ile ilgili yasalarda çeşitli değişiklikler yapılmıştır.

Yeni Türk Ticaret Kanunu'nun 516.maddesinde faaliyet raporunu çerçevesi şöyle çizilmiştir. "Yönetim kurulunun ylllk faaliyet raporu, şirketin, o ylla ait faaliyetlerinin aklşı ile her yönüyle finansal durumunu, doğru, eksiksiz, dolambaçsız, gerçeğe uygun ve dürüst bir şekilde yansittr. Bu raporda finansal durum, finansal tablolara göre değerlendirilir. Raporda ayrıca, şirketin gelişmesine ve karşılaşması muhtemel risklere de açıkça işaret olunur. Bu konulara ilişkin yönetim kurulunun değerlendirmesi de raporda yer alır."

Kurumsal yönetim ilkelerinden hesap verebilirlik ve sorumluluk, kaliteli bilgiye dayanılarak nelerin başarılmış olduğunu, ulaşılan performansı ve bu kapsamdaki gerekli açıklamaları içeren uygun zamanlı raporlamayı gerektirmektedir. Ancak 2000 yılından sonra yaşanan krizler sonrasında faaliyet raporlarının yönünün geçmişten geleceğe doğru çevrildiği görülmektedir. Türkiye'de bu bakış açısıyla hazırlanan kanun ve yönetmelikler, faaliyet raporlarının sadece geçmiş yılın finansal tablolarını sunan, şirketin yatırımcı ve hissedarlarına tanıımı yaptığı bir reklam broşürü olmaktan kurtulmasını amaçlamaktadır. Faaliyet raporları, şirketin araştırma geliştirme çalışmalarının, gelecekteki tehdit ve firsatlarının da anlatıldığı bir iletişim aracı olmak zorundadır.

Faaliyet raporlarında yer alması zorunlu hususlar daha detaylı olarak 28 Temmuz 2012'de yayımlanan yönetmelikle daha belirgin hale getirilmiştir. Bunlardan bazıları aşağıda özetlenmiştir:

1-Şirket ile ilgili genel bilgiler (Ünvanı, iletişim bilgileri, merkezi, şubeleri, yönetim kurulu, üst düzey yöneticileri, personel sayısı, şirketin organizasyon yapısındaki değişiklikler),

2-Yönetim Kurulu üyeleri ve üst düzey yöneticilere sağlanan mali haklar: Küresel finans krizinin ardından CEO'ların daha fazla kar etmek için şirketi aşırı riskleri sokmaları, bunun karşlığında yüksek prim almaları konusu özellikle ABD'de çok tartı̧ılmıştı. Türkiye'de bu konu fazla gündeme gelmese de bir önlem olarak hem Yeni Türk Ticaret Kanununa hem de bu yönetmeliğe girmiştir. 
3-Şirketin araştırma ve geliştirme çalışmaları,

4-Şirketin faaliyetleri ve faaliyetlerine ilişkin önemli gelişmeler (Yatırımlar, iç denetim sistemi, iç kontrol sistemi, şirketin doğrudan ve dolaylı iştirakleri, şirket aleyhine açılan davalar ve bu davaların olası sonuçları, geçmiş dönemde belirtilen hedeflere ulaşılıp, ulaşılmadığı, genel kurul kararlarının yerine getirilip getirilmediği, yıl içinde yapılan olağanüstü genel kurul toplantıları hakkında bilgiler, şirketin yaptığı bağış ve yardımlar, sosyal sorumluluk projeleri),

5-Finansal durum (Finansal duruma ilişkin analiz ve değerlendirme, planlanan faaliyetlerin gerçekleşme derecesi, stratejik hedefler, geçmiş yılların karşılaştırmalı analizi, geleceğe yönelik finansal beklentiler, şirket sermayesinin analizi, finansal yapıyı iyileştirmek için alınması düşünülen önlemler, kar dağıtım politikası),

6-Riskler (Şirketin öngörülen risklere karşı uygulayacağı risk yönetim politikası, riskin erken saptanması komitesinin çalışmaları, satışlar, verimlilik, gelir oluşturma kapasitesi, karlılık ile ilgili ileriye dönük riskler).

\subsection{Elektronik Genel Kurul Sistemi (E-GKS)}

1 Temmuz 2012'de yürürlüğe giren Yeni Türk Ticaret Kanunu, birçok yenilikçi ve şeffaflı̆̆ı arttırıcı uygulamayı da beraberinde getirmiştir. Özellikle anonim şirketler açısından getirilen en önemli yeniliklerden birisi de, hissedarların genel kurullara internet aracılı̆ğ katılabilme imkanı sağlanmasıdır. Merkezi Kayıt Kuruluşu (MKK) tarafindan gözetimde olan bu uygulama Elektronik Genel Kurul Sistemi (E-GKS) üzerinden gerçekleştirilmektedir.

Yeni Türk Ticaret Kanunu'na göre, payları borsaya kote olan şirketlerin genel kurullarını elektronik ortamda yapmaları zorunludur. Diğer anonim şirketler ise isterlerse genel kurullarını E-GKS üzerinden gerçekleştirebilmektedir.

Dünyada elektronik ortamda şirket genel kurul uygulamalarına bakıldığında, "virtual-only shareholder meeting" ve "hybrid shareholder meeting" olarak iki uygulama karşımıza çıkmaktadır. "Virtual-only" genel kurullar, toplantının yüz yüze yapılmadığı, hissedarların online teknoloji kullanarak sanal ortamda bir araya geldikleri kurulları ifade eder. "Hybrid" genel kurullarda ise hissedarlar toplantısı fiziksel bir yerde yapilır ancak dileyen hissedarların toplantıya online olarak katılmalarına, haklarını kullanmalarına izin verilir (Best Practices Working Group, 2012). Türkiye'de uygulanan E-GKS hybrid sistemlere bir örnektir.

E-GKS, genel kurullara hissedarların katılımını kolaylaştırarak, sermaye piyasalarında şeffaflığı arttırıcı en önemli araçlardan biri olarak görülmektedir. E-GKS, büyük veya küçük olduklarına bakılmaksızın hissedarlara şu imkanları sağlamaktadır:

1-Genel kurul, görüntü ve ses aktarımı sayesinde fiziken genel kurala katılmaksızın internet erişimi olan her yerden canlı olarak izlenebilmektedir.

2-Hissedarlar genel kurulda, toplantıya fiziken katılanlarla birlikte eş zamanlı olarak oy kullanabilmektedir.

3-Hissedarlar, görüşülen gündeme ilişkin görüş ve önerilerini eş zamanlı olarak iletebilmektedir.

4-Elektronik genel kurula katılmak için payların bloke edilmesine gerek yoktur.

5-Hissedarlar, yukarıda sayılan bu işleri vekil (temsilci) aracıllğı ile de yapabilir.

6-Hissedarlar genel kurul gündem maddelere online olarak muhalefet şerhi düşebilir.

7-Toplantı öncesi ve sonrası tüm dökümanlara, e-GKS ortamından ulaşılabilmektedir.

E-GKS, şirketlere de büyük kolaylık sağlamaktadır. Şirketin bütün hissedarlarına ulaşımı mümkün olmaktadır. Toplantıya uzaktan erişimin mümkün olması sebebiyle fiziken katılımcı sayısı uzun vadede azalmakta, toplantı organizasyon giderleri, toplantı salonu kiralama giderleri (daha küçük salon kiralama), yönetim kurulu üyeleri ve üst düzey yöneticilerin toplantı için seyahat ve konaklama giderleri azalmaktadır. Online genel kurul sistemlerinin karbon ayak izini azalttığı belirtilmektedir (Noked, 2012). (Örneğin daha az faaliyet raporu, toplantı dökümanı basılması, daha az seyahat edilmesinden dolayı daha düşük karbon salınımı gibi). Türkiye'de kullanılan hybrid sistem, fiziksel katılımla da entegre çalıştığı için şirketlere oylamalarda oy depolanması ve eş zamanlı olarak hissedarlara oy dağılımını sunma açısından da büyük kolaylık sağlamaktadır.

Online genel kurul sistemi ve elektronik oylama sistemi dünyada birçok ülkede uygulanmaktadır. Türkiye dünyada bu sistemi uygulayanlar içinde, bunu halka açık şirketler için zorunlu kılan ilk ülkedir. E-GKS'nin tam anlamıyla uygulanmaya başlandığı 30.10.2012 tarihinden yıl sonuna kadar 10 genel kurul toplantısı yapılmıştır. Bu toplantılara toplam 94 kişi EGKS'den katılmış ve haklarını kullanmıştır (MKK, 2012). 2013 ve 2014 yıllarında ise sistem her şirketler ve hem de hissedarlar tarafından tanınıp benimsenmiş, elektronik olarak katılan hissedar sayısı katlanmıştır. E-GKS ile ilgili istatistikler Tablo 1'de verilmektedir. 


\begin{tabular}{|l|c|c|c|c|}
\hline & $\mathbf{2 0 1 1}$ & $\mathbf{2 0 1 2}$ & $\mathbf{2 0 1 3}$ & $\mathbf{2 0 1 4}$ \\
\hline Fiziksel katılım & 9.093 & 8.394 & 6.339 & 5.236 \\
\hline Elektronik Kat1lım & --------- & 94 & 13.464 & 16.625 \\
\hline Elektronik Toplantı Sayısı & ---------- & 10 & 406 & 358 \\
\hline $\begin{array}{l}\text { Aynı gün içinde yapılan en } \\
\text { yüksek E-Genel Kurul sayısı }\end{array}$ & ---------- & NA & 32 & 33 \\
\hline Katılım yapılan ülke sayısı & --------- & $\begin{array}{c}\text { 8 farklı ülkeden } \\
\text { katılım }\end{array}$ & $\begin{array}{c}32 \text { farklı ülkeden } \\
\text { katılım }\end{array}$ & $\begin{array}{c}49 \text { farklı ülkeden } \\
\text { katılım }\end{array}$ \\
\hline
\end{tabular}

Tablo 1. E-GKS istatistikleri Kaynak: Merkezi Kayıt Kuruluşu (MKK)

Sisteme geçilmeden önce, fiziksel ve elektronik oylamaların eş zamanlı yapılacak olması sebebiyle oylama sürelerinin ve toplantı sürelerinin çok uzun sürmesi bekleniyordu. Ancak E-GKS fiziksel olarak toplantıya katılanların verilerini de bünyesinde topladığı için oy sayımını kolaylaştırmış, hem toplantı süreleri hem de oylama sürelerinde artma yerine tam tersine azalma olmuştur. 30 Ekim 2012 - 30 Eylül 2014 arasında E-GKS'de ortalama toplantı süresi 47 dakika, bir genel kurul maddesi için ortalama oylama süresi 11 saniye olarak gerçekleşmiştir (MKK, 2015).

Kısa vadede alınan olumlu sonuçlar, Türkiye örneğinin dünya için bir en iyi uygulama (best practice) olabileceğini göstermektedir. Türkiye'de bu sistemin başarıyla uygulaması birçok habere ve uluslararası çalışmaya konu olmuş olup, E-GKS 2013 yılında "Financial Sector Technology Awards" yarışmasında birincilik ödülü kazanmıştır (FSTech, 2013).

\section{Sonuç}

Küresel finans krizinden dünya ekonomisi ve sermaye piyasalarının olumsuz etkilenmesi, dünyada yeni bir yaklaşımın benimsenmesini zorunlu kılmıştır. Birçok ülkede düzenlemeler ve denetim yapıları yeniden ele alınmış, sistemin istikrarına yönelik tehdit olabilecek riskleri önceden tespite çalışan, daha güvenli ve daha şeffaf bir sermaye piyasası ortamının oluşturulması hedeflenmiştir.

Türkiye de sermaye piyasalarında şeffaflığı arttırmaya çalışan, düzenlemelerini gözden geçiren, yatırımcıları bilgilendirme mekanizmalarını geliştiren ülkeler arasında yer almıştır. Küresel kriz sonrasında, Türkiye'de sermaye piyasalarını ilgilendiren iki önemli kanun olan, Türk Ticaret Kanunu ve Sermaye Piyasası Kanunu, küresel krizden sonra değiştirilmek yerine yeniden yazılmış ve 2012 'de yürürlüğe girmiştir. Kamuyu aydınlatma, türev araçlar, derecelendirme kuruluşları, bağımsız denetim ve finansal raporlama gibi ikinci düzenlemelerin de tamamlanması ile paydaşların ihtiyaçlarını dikkate alan, daha etkin ve şeffaf bir sermaye piyasasının oluşması için önemli adımlar atılmıştır. Geçmişte uyulması zorunlu olmayan kurumsal yönetim ilkeleri küresel kriz sonrasında kanunlara girmiş, ilkelerin bir kısmı zorunlu hale getirilmiştir. Şeffaflığı sağlayan iki araç olan internet sitesi ve faaliyet raporları ile ilgili de şirketlere çeşitli yükümlülükler getirilmiştir.

Sermaye piyasalarında şeffaflığın artmasına yardımcı olan bir uygulama da elektronik genel kurullardır. Ancak sadece online genel kurul yaparak etkinliğin artacağını, hissedarların şeffaflık ihtiyaçlarının karşılanacağını düşünmek yanlış olur. Sanal genel kurulların yoğun olarak yapıldığı ABD'de virtual-only genel kurullara şirket yönetimini hissedarlardan uzaklaştırdığı gerekçesiyle karşı çıkıldığı görülmektedir. Bu çalışmada incelenen Türkiye örneğinde ise, virtual-only genel kurullara izin verilmemekte, bunun yerine hissedarların fiziken ve online olarak eş zamanlı olarak katılabildiği, daha dengeli bir sistem olan hibrit sistem tercih edilmektedir.

Bütün bu düzenlemeler ve uygulamalar ile Türkiye'nin Avrupa Birliği ve uluslararası standartları referans alan daha şeffaf bir hukuki altyapıya kavuştuğu söylenebilir. Düzenlemelerin de zorlamasıyla bazı şirketlerin yönetim ve yönetim kurulu yapılarını değiştirmeye çalıştıkları, daha kurumsal bir yapıya doğru yöneldikleri görülmektedir. Kanunlar ve ikincil düzenlemelerin hayata geçmesiyle birlikte zorunlu olmamasına rağmen kurumsal yönetim derecelendirme raporu alan şirket sayısında artış gözlenmiştir. Rapor alan şirketlerin büyük bir çoğunluğunda hem kamuyu aydınlatma ve şeffaflık hem de toplam kurumsal yönetim notlarında, düzenlemeler öncesine göre artma gerçekleşmiştir (TKYD, 2015). Uzun vadede daha fazla şirketin kurumsal yönetim derecelendirme raporunu alması beklenmektedir.

Şeffaflı̆̆ın bir diğer boyutu bütün bu düzenlemelerin, standartların uygulanması, yükümlülüklerin yerine getirilip getirilmediğinin takibidir. Şirket tarafında, kurumsal yönetim anlayışını benimsemeyen şirketlerin bir kısmı yasal düzenlemelere uymaktan, hissedarlarına olan sorumluluklarını yerine getirmekten kaçınmakta, şirketle ilgili mümkün olan en az bilgiyi paylaşmaya çaba gösterdiği görülmektedir. Özellikle birçok aile şirketinde komiteler etkin çalışmamakta, bağımsız üyeler, kanunlardaki bağımsızlık kriterlerini sağlamalarına karşın aslında aileye yakın olan kişilerden seçilmektedir. Enron ve Lehman gibi büyük boyutlu ve organize olmasa da, Türkiye'de de durumlarını olduğundan farklı göstermeye çalışan çok sayıda şirket bulunmaktadır. SPK tarafından suç işleyenlere verilen idari cezalar ve yaptırımlar şeffaf bir şekilde ilan edilmektir (SPK, 2015). Buna karşın, insider trading, piyasa dolandırıcılığı, piyasa bozucu işlemler, halka arz, birleşme ve satın alma 
yoluyla yatımcıların zarara uğratılması ile ilgili suçların ciddi oranda azaltılamaması, hatta bazı suçlarda artış olması yatırımcılarda yasal düzenlemelere rağmen bir şeyin değişmediği algısını oluşturmaktadır.

Şeffaflı̆̆ın artması için sadece yasal düzenlemeler tek başına yeterli değildir. Sermaye piyasalarının diğer tarafını oluşturan yatırımcıların da doğru ve güvenilir bilgiyi talep etmeleri gerekmektedir. Özellikle küçük yatırımcıları yatırım yaptıkları araçları bilmeleri, üstlendikleri risklerin farkında olmaları, ortak oldukları şirketi ve şirketin karar süreçlerini tanımaları hususu çok önemlidir. Bu çalışmada incelenen elektronik genel kurul sistemine kurumsal ve yabancı yatırımcılar hızla uyum sağlamış olmalarına rağmen, bireysel ve küçük yatırımcıların genel kurullara yeteri kadar ilgi göstermedikleri görülmektedir. Bundaki asıl nedenin E-GKS'nin karmaşıklığı değil, yerli yatırımcıların hisse senedi yatırımlarına bakış açıları olduğu söylenebilir. Rakamlar, 2014 yılında yabancı yatırımcıların hisse senetlerini ortalama elde tutma süresinin 290 gün, yerli yatırımcıların ise 41 gün olduğunu ortaya koymaktadır (TSPB, 2015). Finansal farkındalığın ve okur yazarlığın artması, bilinçli yatırım kararlarının alınmasına neden olacaktır. Bunun da, kişilerin finansal kuruluşlardan talep edecekleri bilgi düzeyinin ve çeşitliğinin yükselmesine, finansal piyasaların daha şeffaf olmasına yardımcı olacağı düşünülmektedir.

\section{Kaynakça}

- Akerlof, 1970. "The Market for "Lemons": Quality Uncertainty and the Market Mechanism", The Quarterly Journal of Economics, Vol.84, No.3, p. 488-500.

- Andrews, 2012. "Ilan Guttman: How Does Transparency Affect Financial Crises?", Stanford Business, https://www.gsb.stanford.edu/insights/ilan-guttman-how-does-transparency-affect-financial-crises

- Best Practices Working Group for Online Shareholder Participation in Annual Meetings, 2012. "Guidelines for Protecting and Enhancing Online Shareholder Participation in Annual Meetings", http://www.calstrs.com/sites/main/files/file-attachments/shareholder_participation_annual_meetings.pdf

- FSTech, 2013, http://www.fstech.co.uk/fst/2013_FStech_Awards_Winners.php

- Florini, 1999. "Does the invisible hand need a transparent glove? The politics of transparency.", World Banks Annual Conference on Development Economics, p. 163-184.

- Furman ve Stiglitz, 1998. "Economic Crises: Evidence and Insights From East Asia." Brookings Panel on Economic Activity, p. 1-135

- KAP (Kamuyu Aydınlatma Platformu), 2015. https://www.kap.gov.tr

- Mishkin, 1999. "Lessons from The Tequila Crisis", Journal of Banking and Finance, 23, p. 1521-1533

- MKK (Merkezi Kayıt Kuruluşu), 2011 Faaliyet Raporu

- MKK (Merkezi Kayıt Kuruluşu), 2012 Faaliyet Raporu

- MKK (Merkezi Kayıt Kuruluşu), 2013 Faaliyet Raporu

- MKK (Merkezi Kayit Kuruluşu), 2014 Faaliyet Raporu

- MKK (Merkezi Kayıt Kuruluşu), 2015. Elektronik Genel Kurul Sistemi: E-GKS, https://egk.mkk.com.tr/egkweb

- Noked, 2012. Online Shareholder Participation in Annual Meetings, http://corpgov.law.harvard.edu/2012/07/19/online-shareholder-participation-in-annual-meetings/

- OECD, 1999. "Corporate Governance - Improving Competitiveness and Access to Global Capital Markets", Corporate Governance: An International Review, Vol.7, No.2, p. 198-206.

- OECD, 2004. OECD Principles of Corporate Governance, http://www.oecd.org/corporate/ca/corporategovernanceprinciples/31557724.pdf

- Resmi Gazete, 28.08.2012, Şirketlerin Yıllık Faaliyet Raporunun Asgari İçeriğinin Belirlenmesi Hakkında Yönetmelik, Sayı: 28395

- Resmi Gazete, 31.05.2013, Sermaye Şirketlerinin Açacakları İnternet Sitelerine Dair Yönetmelik, Sayı: 28663

- Resmi Gazete, 03.01.2014, Kurumsal Yönetim Tebliği (II-17.1), Sayı: 28871

- $\quad$ SEC (U.S. Securities and Exchange Commission), The Dodd-Frank Wall Street Reform and Consumer Protection Act, https://www.sec.gov/about/laws/wallstreetreform-cpa.pdf

- Sermaye Piyasası Kanunu, 2012, http://www.mevzuat.gov.tr/MevzuatMetin/1.5.6362.pdf

- SPK, 2015, İdari Para Cezalar1, http://www.spk.gov.tr/apps/DavalarYasaklilar/idariparacezalari.aspx?submenuheader=-1

- TBMM (Türkiye Büyük Millet Meclisi), 2005. Türk Ticaret Kanunu Tasarı Gerekçesi, http://www2.tbmm.gov.tr/d22/1/1-1138.pdf 
- TBMM (Türkiye Büyük Millet Meclisi), 2012. Sermaye Piyasası Kanunu Tasarı Gerekçesi, https://www2.tbmm.gov.tr/d24/1/1-0638.pdf

- TKYD (Türkiye Kurumsal Yönetim Derneği), 2015. http://www.tkyd.org/tr/default.html

- $\quad$ TSPB (Türkiye Sermaye Piyasaları Birliği), 2015. Türkiye Sermaye Piyasası 2014, İstanbul.

- Vishwanath ve Kaufmann, 1999. "Towards Transparency in Finance and Governance", The World Bank, (http: //ssrn. com/abstract=258978).

- West, 2009. "Corporate Governance Convergence and Moral Relativism", Corporate Governance: An International Review, Vol.17, No:1, p. 107-119

- Türk Ticaret Kanunu, 2011. http://www.mevzuat.gov.tr/MevzuatMetin/1.5.6102.pdf 


\title{
2000-2014 Yılları Arasında Türkiye ve Rusya'da Finansal Risklerin Temel Ekonomik Veriler Üzerine Etkilerinin Analizi The Analysis of the Effects of Financial Risks in Turkey and
Russia on Basic Economical Data between 2000-2014
}

\author{
Dr. Yusuf Tengiz (Kadir Has University, Turkey) \\ Assoc. Prof. Dr. Emine Şule Aydeniz (Yeditepe University, Turkey)
}

\begin{abstract}
Financial risks affect the basic economic indicators in a negative way and cause structural deformation of the countries' economy. In this study, the most effected economic indicators due to financial risks in Turkey and Russia and to activate their economical future plans are determined. Thereby Turkey and Russia can execute economical collaboration due to their powerful economies. The basic reason for choosing Russia among the Eurasian countries is that Russia economic aspect is the most patronized among these countries. Linear regression analyze method is applied. Financial risks like exchange rates, interest rates and inflation are determined as independence variants and each economic indicator as dependent variant.

Gross domestic product (GDP) is mostly affected by annual deposit interest rate (ADIR) and annual loan rate (ALR) in Turkey and by annual loan rate and inflation in Russia. GDP growth rate is not affected by financial risks in Turkey and Russia. Public gross import stock is affected by ADIR and ALR in Turkey and ALR in Russia. Public gross export stock is affected by US-dollar rate of exchange (RoE) in Turkey and Euro (RoE) in Russia. Import is affected by ADIR and ALR in Turkey and by ALR and Euro - Rouble rate (ERR) in Russia. Both countries export are affected by the same parameters. Current account balance is affected by ADIR and ALR in Turkey and ADIR and ERR in Russia. Composite index is not affected by financial risks in both countries. Same result is valid in foreign direct investment and GDP growth rate.
\end{abstract}

\section{Giriş}

Küresel finansal krizler, ülkelerin döviz, faiz ve enflasyon dengelerini alt üst etmektedir. Özellikle gelişmekte olan ülkelerde ekonomik kırılganlığı arttırmaktadır. Bu durumda finans piyasaları, temel işlevini ve istikrarını kaybetmektedir. Finans piyasalarındaki yüksek dalgalanmalar da finans ve reel sektörü olumsuz etkilemektedir. Örneğin özel sektör firmaları ve bankalar, döviz üzerinden borçlandıkları için yerel para birimlerinde hızla borçları artmaktadır. Bunun yanında üretim yapan firmaların hammadde fiyat artışları sebebiyle maliyetleri de artmaktadır. Tüm bu değişimler, hem ülke ekonomisini, hem de faaliyet gösteren kurumları olumsuz etkilemekte ve ülke ve kurumların rekabet avantajını kaybetmelerine sebep olmaktadır.

2008 yılında yaşanmış olan finansal krizin temelinde finansal riskler yatmaktadır. Finansal risklerin yüksek olması sebebiyle ekonomiler, dışsal şoklardan dolayı büyük zararlara uğramaktadır. Finansal risklerin belirlenmesi ile birlikte gerekli tedbirler alındığı takdirde reel ekonomik büyüme sağlanabilmekte ve borçlanma istikrarlı hale gelebilmektedir. Ayrıca cari açık azalmakta, refah artmakta ve borçlanma azalmaktadır. Bunun sonucunda gelen finansal istikrar, Türkiye’nin ve Rusya'nın ekonomik yapısını güçlü hale getirecektir.

Çalışmanın amacı, Türkiye ve Rusya'da finansal risklerden en çok etkilenen ekonomik göstergeleri belirleyip ekonomi planlamalarını etkin yapmaktır. Böylece Türkiye ve Rusya, güçlü ekonomileri sayesinde güçlü ekonomik işbirliklerini gerçekleştirebilirler. Avrasya ülkeleri içerisinde Rusya'nın seçilmesinin temel sebebi, bu ülkeler arasında ekonomik haminin çok daha yüksek olmasıdır.

Finansal risklerin, Türkiye'nin ve Rusya'nın temel ekonomik verilerine etkilerini belirlemek için doğrusal regresyon analizi kullanılmıştır. Modelde, temel ekonomik veriler bağımsız değişkenler, finansal riskler de bağımlı değişkenler olarak belirlenmiştir. Finansal riskler olarak fiyat riski, döviz kur riski ve faiz riski dikkate alınmıştır.

\section{Türkiye ve Rusya Ekonomilerine Genel Bakış: 2000-2014}

\subsection{Türkiye'de Durum}

Tablo 1'de 2000-2014 yılları arasında Türkiye'nin temel ekonomik verileri gösterilmiştir. 


\begin{tabular}{|c|c|c|c|c|c|c|c|c|c|}
\hline & 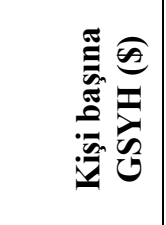 & 武离 & 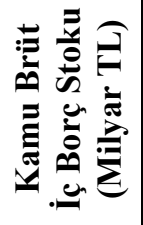 & 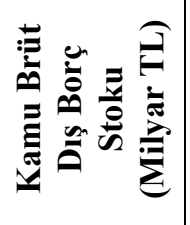 & 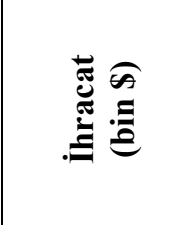 & \multicolumn{2}{|l|}{ 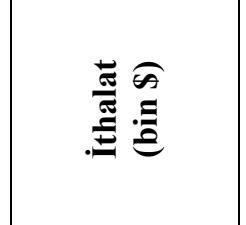 } & 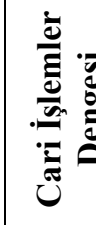 & 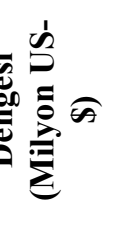 \\
\hline 2000 & 4.150 & 6,1 & 54,5 & 31,3 & 27.774 .906 & \multicolumn{2}{|c|}{54.502 .821} & & -9.920 \\
\hline 2001 & 3.010 & $-9,4$ & 95,5 & 59,3 & 31.334 .216 & \multicolumn{2}{|c|}{41.399 .083} & & 3.760 \\
\hline 2002 & 3.522 & 7,9 & 138,5 & 91,7 & 36.059 .089 & \multicolumn{2}{|c|}{51.553 .797} & & -626 \\
\hline 2003 & 4.533 & 5,9 & 183,8 & 96,8 & 47.252 .836 & \multicolumn{2}{|c|}{69.339 .692} & & -7.515 \\
\hline 2004 & 5.792 & 9,9 & 222,0 & 98,4 & 63.167 .153 & \multicolumn{2}{|c|}{97.539 .766} & & -14.431 \\
\hline 2005 & 7.040 & 7,6 & 250,7 & 94,5 & 73.476 .408 & \multicolumn{2}{|c|}{116.774 .151} & & -22.198 \\
\hline 2006 & 7.627 & 6 & 263,6 & 99,8 & 85.534 .676 & \multicolumn{2}{|c|}{139.576 .174} & & -32.193 \\
\hline 2007 & 9.206 & 4,5 & 273,2 & 89,5 & 107.271 .750 & \multicolumn{2}{|c|}{170.062 .715} & & -38.311 \\
\hline 2008 & 10.277 & 0,9 & 286,8 & 97,1 & 132.027 .196 & \multicolumn{2}{|c|}{201.963 .574} & & -41.946 \\
\hline 2009 & 8.527 & $-4,8$ & 330,2 & 118,1 & 102.142 .613 & \multicolumn{2}{|c|}{140.928 .421} & & -14.297 \\
\hline 2010 & 10.021 & 9,2 & 360,8 & 122,7 & 113.883.219 & \multicolumn{2}{|c|}{185.544 .332} & & -46.643 \\
\hline 2011 & 10.476 & 8,5 & 381,0 & 148,1 & 134.906 .869 & \multicolumn{2}{|c|}{240.841 .676} & & -77.089 \\
\hline 2012 & 10.531 & 2,2 & 401,3 & 154,3 & 152.461 .737 & \multicolumn{2}{|c|}{236.545 .141} & & -48.867 \\
\hline 2013 & 10.721 & 4 & 424,8 & 172,8 & 151.802 .637 & \multicolumn{2}{|c|}{251.661 .250} & & -65.400 \\
\hline \multirow[t]{2}{*}{2014} & 9.710 & 3,03 & 438,0 & 201,7 & 166.500 .000 & \multicolumn{2}{|c|}{262.000 .000} & & -55.000 \\
\hline & 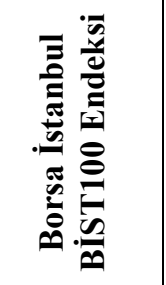 & 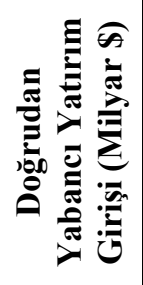 & 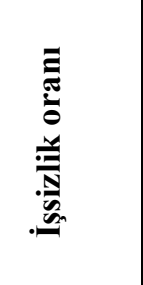 & 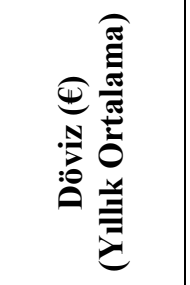 & 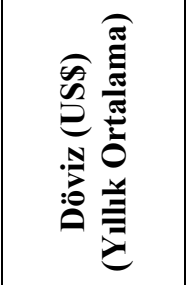 & 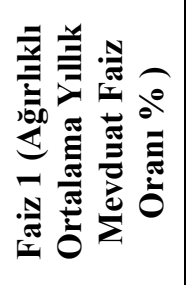 & & 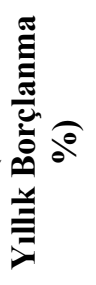 & 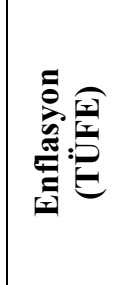 \\
\hline 2000 & $14.044,21$ & 3,6 & 6,5 & 0,5826 & 0,6237 & 45,60 & & 51,2 & 54,9 \\
\hline 2001 & $10.386,31$ & 2,7 & 8,4 & 1,0943 & 1,2229 & 62,50 & & 72,8 & 54,4 \\
\hline 2002 & $10.814,20$ & 2,2 & 10,3 & 1,4291 & 1,5046 & 48,19 & & 60,4 & 45 \\
\hline 2003 & $12.507,71$ & 1,7 & 10,5 & 1,6855 & 1,4871 & 28,59 & & 46,5 & 25,3 \\
\hline 2004 & $20.110,11$ & 2,8 & 10,8 & 1,7678 & 1,4223 & 22,10 & & 25,5 & 10,6 \\
\hline 2005 & $30.063,05$ & 10 & 10,6 & 1,6698 & 1,3474 & 18,47 & & 19,3 & 8,2 \\
\hline 2006 & $40.010,89$ & 20,2 & 10,2 & 1,7978 & 1,4365 & 16,39 & & 19,1 & 9,6 \\
\hline 2007 & $49.155,80$ & 20 & 10,3 & 1,7774 & 1,3066 & 17,98 & & 20,8 & 8,78 \\
\hline 2008 & $36.960,47$ & 18,1 & 11 & 1,3057 & 1,3056 & 17,59 & & 20,5 & 10,43 \\
\hline 2009 & $38.442,62$ & 7,6 & 14 & 1,554 & 1,554 & 14,30 & & 18,3 & 6,28 \\
\hline 2010 & $59.567,29$ & 9 & 11,9 & 1,5058 & 1,5058 & 9,27 & & 12,9 & 8,58 \\
\hline 2011 & $60.195,26$ & 16,1 & 9,8 & 1,6805 & 1,6805 & 9,22 & & 13,5 & 6,45 \\
\hline 2012 & $64.982,41$ & 13,2 & 9,2 & 1,8004 & 1,8004 & 10,05 & & 16 & 8,94 \\
\hline 2013 & $77.314,62$ & 12,4 & 9,7 & 1,9077 & 1,9077 & 8,07 & & 12,1 & 7,49 \\
\hline 2014 & $76.306,27$ & 12,5 & 9,4 & 2,1914 & 2,1875 & 9,86 & & 12 & 11,2 \\
\hline
\end{tabular}

Tablo 1. 2000-2014 Yılları Arasında Türkiye’nin Temel Ekonomik Veriler Kaynaklar: TUIK; TCMB; T.C. Başbakanlık Hazine Müsteşarlı̆̆ı, Kamu Finansmanı Genel Müdürlüğ̈̈; Borsa İstanbul, YASED

2000-2014 yılları arasında Türkiye ekonomisi 2 kriz atlatmıştır: 2000-2001 ve 2008 uluslararası finans krizi. 2008 finans krizinin etkileri, 2009'den itibaren hissedilmeye başlanmıştır. Temel ekonomik veriler, tablo 1'de görüldüğü gibi bu yıllarda hızla değer kaybetmiştir. 


\subsection{Rusya'da Durum}

Tablo 2'de 2000-2014 yılları arasında Rusya'nın temel ekonomik veriler gösterilmiştir.

\begin{tabular}{|c|c|c|c|c|c|c|c|c|c|}
\hline & 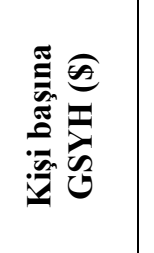 & 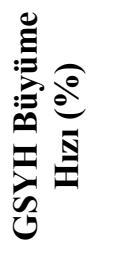 & 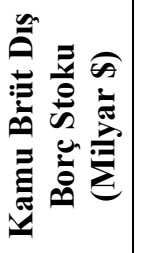 & 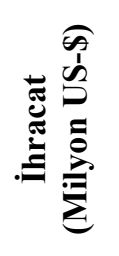 & . & & 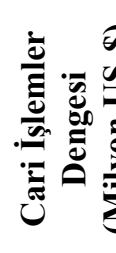 & \multicolumn{2}{|c|}{ 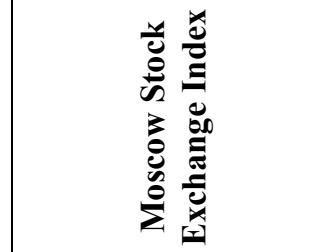 } \\
\hline 2000 & 1.775 & 10,0 & \begin{tabular}{l|l}
90,1 & 1 \\
\end{tabular} & 105.036 & \multicolumn{2}{|c|}{44.862} & 46.839 & \multicolumn{2}{|r|}{194,8} \\
\hline 2001 & 2.111 & 5,1 & $85,3 \quad 1$ & 101.886 & \multicolumn{2}{|c|}{53.765} & 33.935 & \multicolumn{2}{|r|}{169,0} \\
\hline 2002 & 2.380 & 4,7 & \begin{tabular}{l|l}
79,4 & 1 \\
\end{tabular} & 107.302 & \multicolumn{2}{|c|}{60.967} & 29.116 & \multicolumn{2}{|r|}{302,1} \\
\hline 2003 & 2.982 & 7,3 & \begin{tabular}{l|l}
84,9 & 1 \\
\end{tabular} & 135.930 & \multicolumn{2}{|c|}{76.070} & 35.410 & \multicolumn{2}{|r|}{426,0} \\
\hline 2004 & 4.111 & 7,2 & \begin{tabular}{l|l}
102,1 & 1 \\
\end{tabular} & 183.209 & \multicolumn{2}{|c|}{97.382} & 59.513 & \multicolumn{2}{|r|}{538,3} \\
\hline 2005 & 5.333 & 6,4 & \begin{tabular}{l|l}
95,2 & 2 \\
\end{tabular} & 240.025 & \multicolumn{2}{|c|}{123.840} & 84.389 & \multicolumn{2}{|r|}{777,3} \\
\hline 2006 & 6.932 & 8,2 & \begin{tabular}{l|l}
130,0 & 2 \\
\end{tabular} & 297.483 & \multicolumn{2}{|c|}{163.188} & 92.316 & \multicolumn{2}{|r|}{$1.456,0$} \\
\hline 2007 & 9.102 & 8,5 & \begin{tabular}{l|l}
151,1 & 3 \\
\end{tabular} & 346.530 & \multicolumn{2}{|c|}{223.083} & 72.193 & \multicolumn{2}{|r|}{$1.805,0$} \\
\hline 2008 & 11.639 & 5,3 & $151,0 \quad 4$ & 466.299 & \multicolumn{2}{|c|}{288.672} & 103.935 & \multicolumn{2}{|r|}{$1.197,5$} \\
\hline 2009 & 8.562 & $-7,8$ & $197,4 \quad 2$ & 297.155 & 183 & & 50.38 & & 999,0 \\
\hline 2010 & 10.671 & 4,3 & $183,2 \quad 3$ & 392.674 & 245 & & 67.4 & & $1.369,5$ \\
\hline 2011 & 13.320 & 4,3 & $192,2 \quad 5$ & 515.408 & 318 & & $97.2^{\prime}$ & & $1.658,7$ \\
\hline 2012 & 14.079 & 3,6 & $298,9 \quad 5$ & 527.433 & 335 & & 71.28 & & $1.409,0$ \\
\hline 2013 & 14.591 & 3,7 & \begin{tabular}{l|l}
375,9 & 5 \\
\end{tabular} & 523.276 & 341 & & 34.1 & & $1.452,7$ \\
\hline 2014 & 14.317 & 0,2 & \begin{tabular}{l|l}
351,2 & 4 \\
\end{tabular} & 496.661 & 308 & & 55.0 & & $1.456,0$ \\
\hline & 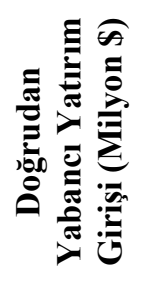 & 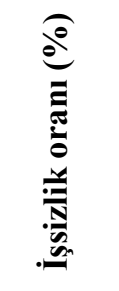 & 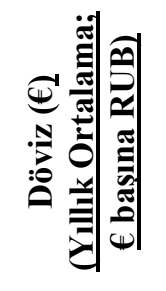 & 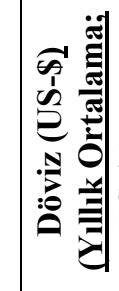 & 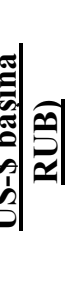 & 気 & 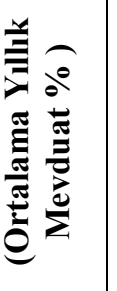 & 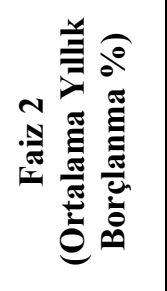 & 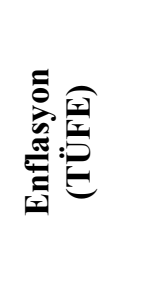 \\
\hline 2000 & 2.714 & 10,5 & 26,40 & & 8,57 & & 16,4 & 22,9 & 20,8 \\
\hline 2001 & 2.748 & 9,0 & 26,19 & & 9,24 & & 17,16 & 24,0 & 21,5 \\
\hline 2002 & 3.461 & 8,9 & 29,64 & & 1,33 & & 15,9 & 20,2 & 15,8 \\
\hline 2003 & 7.958 & 8,9 & 34,75 & & 0,76 & & 11,2 & 14,6 & 12,0 \\
\hline 2004 & 15.444 & 8,2 & 35,80 & & 8,79 & & 7,4 & 9,3 & 11,7 \\
\hline 2005 & 15.508 & 7,6 & 35,09 & & 8,22 & & 6,1 & 8,8 & 10,9 \\
\hline 2006 & 37.595 & 7,2 & 34,11 & & 7,19 & & 6,2 & 8,3 & 9,0 \\
\hline 2007 & 55.874 & 6,1 & 35,02 & & 5,58 & & 6,2 & 8,1 & 11,9 \\
\hline 2008 & 74.783 & 6,3 & 36,42 & & 4,87 & & 10,9 & 15,3 & 13,3 \\
\hline 2009 & 36.583 & 8,4 & 44,14 & & 1,74 & & 16,1 & 19,0 & 8,8 \\
\hline 2010 & 43.168 & 7,3 & 40,26 & & 0,39 & & 7,1 & 8,8 & 8,8 \\
\hline 2011 & 55.084 & 6,5 & 40,88 & & 9,41 & & 6,3 & 7,6 & 8,4 \\
\hline 2012 & 50.588 & 5,5 & 39,93 & & 1,10 & & 7,2 & 8,5 & 5,1 \\
\hline 2013 & 69.219 & 5,5 & 42,34 & & 1,87 & & 7,3 & 8,2 & 6,8 \\
\hline 2014 & 20.958 & 6,2 & 50,95 & & 8,57 & & 9,5 & 15,6 & 7,4 \\
\hline
\end{tabular}

Tablo 2. 2000-2014 Yillarl Arasında Rusya'nın Temel Ekonomik Verileri Kaynaklar: CIA World Factbook, Moskova Menkul Klymetler Borsası, Russian Federal Bank, Dünya Bankası Raporları 
Rusya ekonomisi, 2008 uluslararası finans krizini, Türkiye'de olduğu gibi, 2009'da olumsuz etkilerini görmüştür. Tablo 2'de görüldüğü gibi 2009'da temel ekonomik veriler hızla olumsuz yönde değişmiştir. 2014'de Ukrayna krizi ve Avrupa ülkelerinin uyguladıkları ambargo sebebiyle tablo 2'de gösterildiği gibi temel ekonomik veriler olumsuz yönde değişmiştir.

\section{Finansal Riskler}

Gelişen ve değişen ticaret ilişkileri içerisinde, risk de çeşitli boyutlarda kendisini göstermiştir. Genel anlamda risk, nesnel olarak belirlenebilen kaybetme olasılığı olarak tanımlanmaktadır. Teorik olarak risk, beklenilen değer ile gerçekleşen değer arasındaki hem olumlu hem de olumsuz sapmaları içermesine rağmen; genellikle risk kavramı olumsuz (aleyhte) sapmalar olarak algılanmaktadır. Günlük yaşamın hemen her alanında kullanılan risk kavramı, çalışmada beklenilen değer ile gerçekleşen değer arasındaki fark olarak (Gormann, 2009) değerlendirilecektir.

Çalışmada finansal riskler kapsamında ülke ekonomilerini etkileyen 3 ana risk unsuru analiz edilecektir (Christoffersen, 2012):

1) Döviz Kur Riski

2) Faiz Oranı Riski

3) Fiyat Riski (Enflasyon Riski)

\section{Türkiye ve Rusya'da Finansal Risklerin, Temel Ekonomik Veriler Üzerine Etkilerinin Analizi: 2000-2014}

\section{1 Çalışmanın Amaç ve Hedefleri}

Çalışmanın amacı, Türkiye ve Rusya'da finansal risklerden en çok etkilenen ekonomik göstergeleri belirleyip ekonomi planlamalarını etkin yapmaktır. Böylece Türkiye ve Rusya, güçlü ekonomileri sayesinde güçlü ekonomik işbirliklerini gerçekleştirebilirler. Avrasya ülkeleri içerisinde Rusya'nın seçilmesinin temel sebebi, bu ülkeler arasında ekonomik haminin çok daha yüksek olmasıdır.

\subsection{Araştırma Yöntemi ve Veri Toplanması}

Çalışmanın amacına ulaşmak için araştırma yöntemi olarak doğrusal regresyon analizi kullanılmıştır. Bağımlı değişkenler olarak finansal riskler kullanılmıştır:

1) Rusya analizinde $€$-Rouble kuru; Türkiye analizinde $€$-TL kuru

2) Rusya analizinde US-\$-Rouble kuru; Türkiye analizinde US-\$-TL kuru

3) Yıllık mevduat faiz oranı

4) Yıllık borçlanma faiz oranı

5) Enflasyon (TÜFE)

Her bir ekonomik gösterge de bağımlı değişken olarak regresyon modelinde kullanılmıştır. Ekonomik göstergeler olarak aşağıdaki veriler kullanılmıştır:

1) Kişi başına GSYH

2) GSHY Büyüme Hızı

3) Kamu brüt diş borç stoku

4) İhracat

5) İthalat

6) Cari işlemler dengesi

7) Borsa İstanbul Endeksi; Moskova Menkul Kıymetler Borsası Endeksi

8) Doğrudan Yabancı Sermaye Girişleri

9) İşsizlik Oranı

R-Kare 0-0,5 arasında ise bağımsız değişken ile bağımlı değişken arasında anlamlı bir ilişki bulunmamaktadır. R-Kare 0,5-0,7 arasında ise bağımsız değişken ile bağımlı değişken arasında anlamlı, ama orta derecede bir ilişki bulunmaktadır. R-Kare 0,7'nin üzerinde ise bağımsız değişken ile bağımlı değişken arasında anlamlı güçlü bir ilişki bulunmaktadır. Regresyon denkleminde x'in katsayısı + ise bağımlı ile bağımsız değişken arasında ilişki aynı yöndedir. Regresyon denkleminde x'in katsayısı - ise bağımlı ile bağımsız değişken arasında ilişki ters yöndedir.

Rusya ve Türkiye için eri toplama, çeşitli kaynaklardan gerçekleşmiştir

4.3 Türkiye'de Finansal Risklerin, Temel Ekonomik Veriler Üzerine Etkilerinin Analizi: 2000-2014 Tablo 3'de R-Kare gösterilmiştir. 


\begin{tabular}{|c|c|c|c|c|c|c|c|c|c|}
\hline R-Kare & 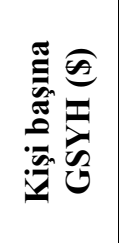 & 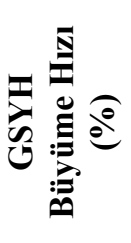 & 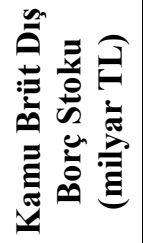 & 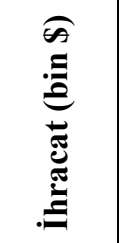 & 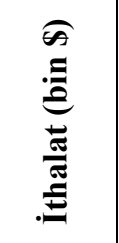 & 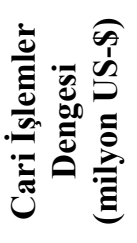 & 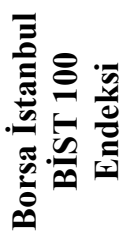 & 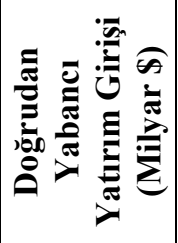 & 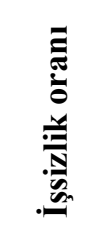 \\
\hline $\begin{array}{c}\text { Döviz }(€) \\
\text { (Y1llık Ortalama, } \\
€ \text { başına TL) }\end{array}$ & 0,3033 & 0,0476 & 0,06614 & 0,4169 & 0,388 & 0,2786 & 0,4067 & 0,1733 & 0,152 \\
\hline $\begin{array}{c}\text { Döviz (US-\$) } \\
\text { (Y1llık Ortalama; } \\
\text { US-\$ başına TL) }\end{array}$ & 0,3317 & 0,0003 & 0,9157 & 0,5488 & 0,5085 & 0,3484 & 0,5277 & 0,0732 & 0,1 \\
\hline $\begin{array}{c}\text { Faiz 1 } \\
\text { (Ağırlıklı Ortalama } \\
\text { Yıllık Mevduat } \\
\text { Faiz Oranı \% ) }\end{array}$ & 0,8185 & 0,1124 & 0,5485 & 0,7136 & 0,7151 & 0,6404 & 0,6652 & 0,4137 & 0,2175 \\
\hline $\begin{array}{c}\text { Faiz } 2 \\
\text { (Ortalama Y1llık } \\
\text { Borçlanma \%) }\end{array}$ & 0,8329 & 0,098 & 0,4812 & 0,7082 & 0,714 & 0,6409 & 0,6711 & 0,4771 & 0,1846 \\
\hline $\begin{array}{c}\text { Enflasyon } \\
\text { (TÜFE) }\end{array}$ & 0,7009 & 0,0678 & 0,4308 & 0,5801 & 0,5563 & 0,4662 & 0,4836 & 0,4181 & 0,3712 \\
\hline
\end{tabular}

Tablo 3. Türkiye Regresyonda R-Kare Sonuçları

Kişi başına GSYH ile sırasıyla yıllık borçlanma faiz oranı ile ters yönlü, yıllık mevduat faiz oranı ile ters yönlü ve TÜFE ile aynı yönde güçlü ilişki mevcuttur. Kişi başına GSYH 1 birim arttığı zaman yıllık borçlanma faiz oranı 130,37 birim ve yıllık mevduat faiz oranı 152,54 birim azalmakta ve TÜFE 131,96 birim artmaktadır.

GSYH büyüme hızının bağımsız değişkenlerle hiçbir anlamlı ilişkisi bulunmamaktadır. Kamu brüt dış borç stokunun US-\$-TL kuru ile güçlü ilişkisi bulunmaktadır. Kamu brüt dış borç stoku 1 birim arttı̆ğ zaman US-\$TL kuru 118,42 birim artmaktadır. Kamu brüt dış borç stokunun orta dereceli yıllık mevduat faiz oranı ile iliş̧kisi mevcuttur. Kamu brüt dış borç stoku 1 birim arttı̆̆ı zaman yıllık mevduat faiz oranı 1,9295 birim azalmaktadır.

İhracatın yıllık borçlanma ve mevduat faiz oranları ile güçlü ilişkisi; US-\$-TL kuru ve TÜFE ile orta dereceli ilişkisi mevcuttur. Aynı ilişki durumu ithalat için de geçerlidir. Cari işlemler dengesi ile yıllık mevduat ve borçlanma faiz oranları ile orta dereceli ilişkisi vardır. Cari işlemler dengesi 1 birim arttığı zaman yıllık mevduat faiz oranı 1.177,4 birim ve yıllık borçlanma faiz oranı 997,92 birim artmaktadır. BİST 100 endeksinin yıllık borçlanma oranı, yıllık mevduat oranı ve US-\$-TL kuru ile orta dereceli ilişkisi mevcuttur. BİST 100 endeksi 1 birim arttı̆̆ zaman yıllık borçlanma faiz oranı 989,94 ve yıllık mevduat faiz oranı 1.163,3 birim azalmakta; US\$-TL kuru ise 49.217 birim artmaktadır.

Doğrudan yabancı sermaye girişinin ve işsizlik oranının, finansal risklerle anlamlı bir ilişkisi bulunmamaktadır.

\subsection{Rusya'da Finansal Risklerin, Temel Ekonomik Veriler Üzerine Etkilerinin Analizi: 2000-2014}

Tablo 4'de Rusya verileri için R-Kare gösterilmiştir. 


\begin{tabular}{|c|c|c|c|c|c|c|c|c|c|}
\hline R-Kare & 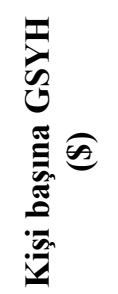 & 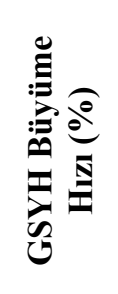 & 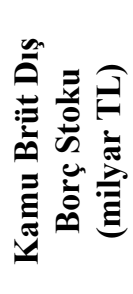 & 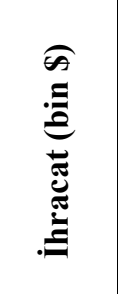 & 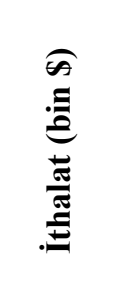 & 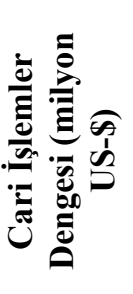 & 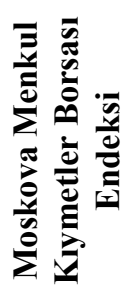 & 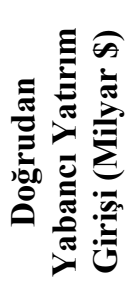 & 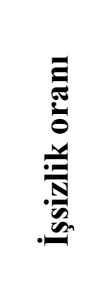 \\
\hline $\begin{array}{c}\text { Döviz }(€) \\
\text { (Yıllık Ortalama; } € \\
\text { başına TL) }\end{array}$ & 0,6728 & 0,4185 & 0,6517 & 0,6008 & 0,5975 & 0,0388 & 0,4647 & 0,235 & 0,4399 \\
\hline $\begin{array}{c}\text { Döviz (US-\$) } \\
\text { (Yıllık Ortalama; } \\
\text { US- } \$ \text { başına TL) }\end{array}$ & 0,0856 & 0,3025 & 0,3533 & 0,0431 & 0,0486 & 0,2423 & 0,0004 & 0,0664 & 0,0065 \\
\hline $\begin{array}{c}\text { Faiz 1 } \\
\text { (Ağırlıklı Ortalama } \\
\text { Yıllık Mevduat Faiz } \\
\text { Oranı \% ) } \\
\end{array}$ & 0,3076 & 0,0687 & 0,1204 & 0,3603 & 0,3275 & 0,3656 & 0,5306 & 0,2903 & 0,532 \\
\hline $\begin{array}{c}\text { Faiz 2 } \\
\text { (Ortalama Yıllık } \\
\text { Borçlanma \%) } \\
\end{array}$ & 0,31 & 0,0316 & 0,1218 & 0,3573 & 0,3339 & 0,3105 & 0,5335 & 0,3477 & 0,5182 \\
\hline $\begin{array}{c}\text { Enflasyon } \\
\text { (TÜFE) }\end{array}$ & 0,6236 & 0,163 & 0,5016 & 0,6075 & 0,5944 & 0,1248 & 0,5967 & 0,3516 & 0,5967 \\
\hline
\end{tabular}

Tablo 4. Rusya Regresyonda R-Kare Sonuçları

Kişi başına GSYH, orta derecede €-Ruble kuru ve TÜFE'den etkilenmektedir. Kiși başına GSYH 1 birim arttığı zaman €-Ruble kuru 0,0011 birim artmakta ve TÜFE 0,0008 birim azalmaktadır. GSYH büyüme hızının finansal risklerle ilişkisi zayıftır. Kamu Brüt Dış Borç Stokunun €-Ruble ve TÜFE ile orta dereceli ilişkisi vardır. Kamu Brüt Dış Borç Stoku 1 birim arttığı zaman €-Ruble 0,0545 birim artmakta ve TÜFE 0,0345 birim azalmaktadır.

İhracatın orta dereceli €-Ruble ve TÜFE ile orta derecede ilişkisi mevcuttur. Aynı durum ithalat için de geçerlidir. Cari işlemler dengesinin finansal risklerle ilişkisi zayıftır. Moskova Borsa Endeksinin yıllık mevduat faiz oranı, yıllık borçlanma faiz oranı ve TÜFE ile orta dereceli ilişkisi vardır. Moskova Borsa Endeksi birim arttığı zaman yıllık mevduat faiz oranı 0,0055 birim; yıllık borçlanma faiz oranı 0,0076 birim ve TÜFE 0,0065 birim azalmaktadır.

Doğrudan yabancı sermaye girişlerinin finansal risklerle ilişkisi zayıftır. İşsizlik oranının yıllık mevduat faiz oranı, yıllık borçlanma faiz oranı ve TÜFE ile orta dereceli ilişkisi vardır. İşsizlik oranı 1 birim arttı̆̆ zaman yıllık mevduat faiz oranı 2,108 birim; yıllık borçlanma faiz oranı 2,8749 birim ve TÜFE 2,4965 birim artmaktadir.

\subsection{Finansal Risklerin Temel Ekonomik Verileri Etkileme Derecesinde Türkiye ve Rusya'nın Karşılaştırmalı Değerlendirilmesi}

Finansal riskler, Türkiye ve Rusya'da ekonomik verileri genellikle farklı etkilemektedir. Türkiye'de Kişi başına GSYH ile sırasıyla yıllık borçlanma faiz oranı ile ters yönlü, yıllık mevduat faiz oranı ile ters yönlü ve TÜFE ile aynı yönde güçlü ilişki mevcut iken Rusya'da bu veriyi orta derecede €-Ruble kuru ve TÜFE'den etkilemektedir. Türkiye'de ve Rusya'da GSYH büyüme hızının bağımsız değişkenlerle hiçbir anlamlı ilişkisi bulunmamaktadır. Bu veride her iki ülkede finansal risklerin etkisi aynı sonuç doğurmuştur.

Türkiye'de Kamu brüt dış borç stokunun US-\$-TL kuru ile güçlü ilişkisi bulunmakta iken Rusya'da bu verinin $€$-Ruble ve TÜFE ile orta dereceli ilişkisi olduğu tespit edilmiştir. Türkiye'de İhracatın yıllık borçlanma ve mevduat faiz oranları ile güçlü ilişkisi; US-\$-TL kuru ve TÜFE ile orta dereceli ilişkisi mevcut iken Rusya'da bu verinin €-Ruble ve TÜFE ile orta derecede ilişkisi mevcuttur. İthalat için de her ülke de aynı sonuç ortaya çıkmıştır.

Türkiye'de Cari işlemler dengesi ile yıllık mevduat ve borçlanma faiz oranları ile orta dereceli ilişkisi var iken Rusya'da bu verinin finansal risklerle ilişkisi zayıftır. Türkiye'de BİST 100 endeksinin yıllık borçlanma oranı, yıllık mevduat oranı ve US-\$-TL kuru ile orta dereceli ilişkisi mevcut iken Rusya'da da bu veriyi aynı finansal riskler etkilemektedir. Türkiye'de Doğrudan yabancı sermaye girişinin ve işsizlik oranının, finansal risklerle anlamlı bir ilişkisi bulunmamakta iken Rusya'da da Doğrudan yabancı sermaye girişlerinin finansal risklerle ilişkisi zayıf, ancak İşsizlik oranının yıllık mevduat faiz oranı, yıllık borçlanma faiz oranı ve TÜFE ile orta dereceli ilişkisi vardır 


\section{Sonuç}

Küresel finansal krizler, ülkelerin döviz, faiz ve enflasyon dengelerini alt üst etmektedir. Özellikle gelişmekte olan ülkelerde ekonomik kırılganlığı arttırmaktadır. Bu durumda finans piyasaları, temel işlevini ve istikrarını kaybetmektedir. Finans piyasalarındaki yüksek dalgalanmalar da finans ve reel sektörü olumsuz etkilemektedir. Örneğin özel sektör firmaları ve bankalar, döviz üzerinden borçlandıkları için yerel para birimlerinde hızla borçları artmaktadır. Bunun yanında üretim yapan firmaların hammadde fiyat artışları sebebiyle maliyetleri de artmaktadır. Tüm bu değişimler, hem ülke ekonomisini, hem de faaliyet gösteren kurumları olumsuz etkilemekte ve ülke ve kurumların rekabet avantajını kaybetmelerine sebep olmaktadır

2008 yılında yaşanmış olan finansal krizin temelinde finansal riskler yatmaktadır. Finansal risklerin yüksek olması sebebiyle ekonomiler, dışsal şoklardan dolayı büyük zararlara uğramaktadır. Bu sebepten dolayı finansal risklerin temel ekonomik verileri nasıl ve ne yönde etkilediğini belirlemekle Türkiye ve Rusya, ekonomik planlamalarında bu sonuçları dikkate alarak finansal risk şoklarına karşı da belirsizliklerini ortadan kaldırmış olacaklardır.

Finansal riskler, Türkiye ve Rusya'da ekonomik verileri genelde farklı etkilemektedir. Türkiye'de Kişi başına GSYH ile sırasıyla yıllık borçlanma faiz oranı ile ters yönlü, yıllık mevduat faiz oranı ile ters yönlü ve TÜFE ile aynı yönde güçlü ilişki mevcut iken Rusya'da bu veriyi orta derecede €-Ruble kuru ve TÜFE'den etkilemektedir. Türkiye'de ve Rusya'da GSYH büyüme hızının bağımsız değişkenlerle hiçbir anlamlı ilişkisi bulunmamaktadır. $\mathrm{Bu}$ veride her iki ülkede finansal risklerin etkisi aynı sonuç doğurmuştur.

Türkiye'de Kamu brüt dış borç stokunun US-\$-TL kuru ile güçlü ilişkisi bulunmakta iken Rusya'da bu verinin $€$-Ruble ve TÜFE ile orta dereceli ilişkisi olduğu tespit edilmiştir. Türkiye'de İhracatın yıllık borçlanma ve mevduat faiz oranları ile güçlü ilişkisi; US-\$-TL kuru ve TÜFE ile orta dereceli ilişkisi mevcut iken Rusya'da bu verinin $€$-Ruble ve TÜFE ile orta derecede ilişkisi mevcuttur. İthalat için de her ülke de aynı sonuç ortaya çıkmıştır.

Türkiye'de Cari işlemler dengesi ile yıllık mevduat ve borçlanma faiz oranları ile orta dereceli ilişkisi var iken Rusya'da bu verinin finansal risklerle ilişkisi zayıftır. Türkiye'de BİST 100 endeksinin yıllık borçlanma oranı, yıllık mevduat oranı ve US-\$-TL kuru ile orta dereceli ilişkisi mevcut iken Rusya'da da bu veriyi aynı finansal riskler etkilemektedir. Türkiye'de Doğrudan yabancı sermaye girişinin ve işsizlik oranının, finansal risklerle anlamlı bir ilişkisi bulunmamakta iken Rusya'da da Doğrudan yabancı sermaye girişlerinin finansal risklerle ilişkisi zayıf, ancak İşsizlik oranının yıllık mevduat faiz oranı, yıllık borçlanma faiz oranı ve TÜFE ile orta dereceli ilişkisi vardır.

Finansal risklerin belirlenmesi ile birlikte gerekli tedbirler alındığı takdirde reel ekonomik büyüme sağlanabilmekte ve borçlanma istikrarlı hale gelebilmektedir. Ayrıca cari açık azalmakta, refah artmakta ve borçlanma azalmaktadır. Bunun sonucunda gelen finansal istikrar, Türkiye'nin ve Rusya'nın ekonomik yapısını güçlü hale getirecektir.

\section{Kaynakça}

- Borsa İstanbul, 2015. http://www.borsaistanbul.com/

- CIA World Factbook, 2015. https://www.cia.gov/library/publications/the-world-factbook/

- Christoffersen, 2012. Elements of Financial Risk Management. Elsevier, Oxford.

- Gormann, 2009. Hedging von Rohstoffpreisrisiken im Rahmen des Finanzrisikomanagements. GRIN Verlag $\mathrm{GmbH}$, Norderstedt.

- Moskova Menkul Kiymet Borsas1, 2015. Data Archice, http://www.micex.com/marketdata/indices/data/archive

- Russian Federal Bank, 2015. http://www.cbr.ru/eng/hd_base/Default.aspx?Prtid=mkr_base

- Russian Federation Federal State Statistics Service, 2015.

- http://www.gks.ru/wps/wcm/connect/rosstat_main/rosstat/en/main/

- Türkiye Cumhuriyeti Merkez Bankası, 2015. www.tcmb.gov.tr

- $\quad$ T.C. Başbakanlık Hazine Müsteşarlığı, Kamu Finansmanı Genel Müdürlüğü, 2015. https://www.hazine.gov.tr/tr-TR/Sayfalar/Hakkimizda-Kamu-Finansmani

- Türkiye İstatistik Kurumu, 2015. www.tuik.gov.tr

- World Bank, 2015. Statistical Data, http://data.worldbank.org/indicator/BN.CAB.XOKA.CD/countries?page=2

- YASED Uluslararası Yatırımcılar Derneği, 2015. http://www.yased.org.tr/webportal/Turkish/Pages/AnaSayfa.aspx 


\title{
Avrupa Borç Krizinin Makroekonomik Etkileri ve Türkiye The Macroeconomic Effects of European Debt Crisis and Turkey
}

\author{
Prof. Dr. Ahmet Ulusoy (Karadeniz Technical University, Turkey) \\ $\mathrm{Ph}$. D. Candidate Mehmet Ela (Karadeniz Technical University, Turkey)
}

\begin{abstract}
European sovereign debt crisis is the period that because of low interest rates, government and private debt increased substantially and also financial crisis transform private debt to high sovereign debt. In this period, low interest rates made government borrowing cost cheap and so sovereign debt increased considerably. In same period, private sector consumption and debt rose and this induced the housing bubbles. The expansionary fiscal policy against the effects of global financial crisis and bail-outs given to banks which are problematic made the sovereign debt highest and debt burden unsustainable for some countries. European sovereign debt crisis affect the world globally with the financial and economic links. Countries implemented fiscal and monetary policies against the recession and unemployment. In this respect, it is worthwhile researching the European sovereign debt crisis which is multifaceted and complex and offering suggestions for Turkey. Turkey must maintain the strong fiscal position and increased country resilience against crisis. And Turkey must also maintain banking regulation and supervision which are intended to steady financial sector.
\end{abstract}

The aim of this paper is analyzing the development of European sovereign debt crisis and its effects; and also emphasizing the actions Turkey can take and offering suggestions for Turkey.

\section{Giriş}

Avrupa Borç Krizi, kriz öncesi yıllarda görülen düşük faizler ve iyimser ekonomik beklentiler sonucu artan kamu sektörü borcu ile bu süreçte artan özel sektör borcunun bir sonucudur. Nitekim krizden önce düşük faizle borçlanabilen ülkeler, yapısal reformları ertelemiş, mali kuralları önemsememiş ve savurganca bir tutum takınmıştır. Bu suretle kamu borçları önemli derecede artmıştır. Diğer yandan ABD mortgage piyasası toksik varlıklarında bilançolarında bol miktarda bulunduran Avro Alanı bankaları bu durumdan olumsuz etkilenmiş ve yaşanan kredi daralması sonucu batma noktasına gelmişlerdir. Bu bankalara verilen yardım paketlerinden dolayı artan kamu borçları, Yunanistan'ın bütçe açığına ilişkin açıklamasıyla gün yüzüne çıkmıştır. Bu olayın sonucunda global olarak riskten kaçış başlamış, kredi derecelendirme kuruluşlarının da not kırmasıyla Avro Alanı çevre ülkeleri borçlanma maliyetleri hızla artmıştır. Böylece başlayan Avrupa Borç Krizi global olarak ekonomik görünümü etkilemiştir. Avro Alanını genel olarak finansal yolla etkileyen kriz Avro Alanı dışında etkilerini ekonomik yollarla (özelde ise ticari akımla) göstermiştir. Avrupa Borç Krizi sonucunda büyüme oranları düşmüş -Avro Alanında resesyon yaşanmış-, istihdam, enflasyon, global ticaret ve finansal akımlar azalmıştır. Avrupa Borç Krizinin etkilerinden Türkiye de nasibini almış ve Türkiye'de de global etkiler paralelinde negatif etkiler görülmüştür.

Türkiye, finansal yönden Avrupa ülkeleri ile yoğun biçimde ilişkili olmadığından Avrupa borç krizi ülkeyi finansal yönden önemli derecede olumsuz etkilememiştir. Ancak Türkiye ekonomik açıdan Avrupa ile entegre bir ülkedir. Bu açıdan Türkiye'nin Avrupa ülkelerine olan ihracatı ve bu ülkelerden olan sermaye akımları azalmıştır. Ayrıca ülkedeki makroekonomik göstergelerde olumlu görünüm ülkenin krizlere karşı daha dirençli hale gelmesini sağlamıştır.

Bu çalışmada Avrupa Borç Krizinin gelişimi ele alınmış ve krize giden yolda yapılan hatalar tespit edilmeye çalışılmıştır. Ardından Avrupa Borç Krizinin yayılma yolları ve bu yollarla global ekonomiye ve Türkiye'ye etkileri ele alınmıştır. Çalışmanın son bölümünde ise Avrupa Borç Krizinden Türkiye için bazı dersler çıkarıltılmış ve öneriler yapılmıştır.

\section{Avrupa Borç Krizinin Gelişimi}

Avro Alanı'nın inşa edilmesi ve Avro'nun ortak para birimi olarak kullanılmaya başlanmasıyla bir yandan yüksek ekonomik moral yaşanırken, diğer yandan faiz oranları oldukça düşük seviyelerde seyretmiştir. Bu süreç tüketimi ve savurganlı̆̆ artırmış, Avrupa borç krizine kapı aralamıştır (Tichy, 2012: 98). Krizin fitilini ateşleyen asıl olay ise Küresel Finansal Krizin ortaya çıkmasıdır.

Avro Alanı'na olan piyasa güveninin istikrarlı olması Avro Alanı çevre ülkelerin diğer ülkelerle aynı maliyetlerle borçlanabilmeleri gerekli yapısal reformları erteletmiş, kamu ve özel sektör harcamalarını artırmış ve rekabet güçlerini sınırlamıştır. Bu nedenle de bütçe açıkları ve borçlarında artışlar meydana gelmiştir (De Grauwe, 2010:8).

Küresel Finansal Kriz öncesinde yapısal reformları geciktiren, verimlilik ve rekabetçilikte geride kalan, Maastritch kriterlerine uymakta zorluk çeken Avro Alanı ülkelerinde borç krizi belirtisi görülmemiştir. Ancak, ABD ile finansal ve ekonomik yönden entegre olan Avro Alanı, Küresel Finansal Krizden olumsuz etkilenmiştir. 
Global finansal krizle birlikte güven ortamı sarsılmış (Tichy, 2012: 96,102) ve para piyasalarında bozulmalar ve kredi daralması görülmeye başlanmıştır. Ayrıca yatırımcılar riskten kaçmaya başlamış, bu nedenle Avrupa çevre ülkelerine olan yüksek miktarda sermaye akımı durmuştur.

Diğer yandan bankaların borç verme koşullarını sıkılaştırmaları ve bankalar arası piyasaların fonksiyonlarını azaltmaları gibi bir takım gelişmeler sonucunda ortaya çıkan kredi daralması, Avrupa ülkelerinin makroekonomik ve finansal yapılarındaki dengesizliklerin açığa çıkmasına neden olmuştur ( Lane, 2012: 54-55).

Avro Alanı bankalarının ABD piyasası toksik (zehirli) varlıklarına yatırımları nedeniyle likidite sıkıntısı çekmesi bankaların büyük kayıplar yaşamasına neden olmuştur. Finansal Krizle birlikte ortaya çıkan belirsizlik ortamı, bankaların borçlanmalarını da zorlaştırmıştır (Lane, 2012: 55). Batma noktasına gelen bankaları kurtarmak adına yardım paketleri hazırlanmıştır. Verilen yardım paketleri sonucu özel sektör borçları kamu borcuna dönüşmüş (Prinz ve Beck, 2012:186), ülke borçları daha da artmıştır.

Diğer yandan borç düzeyi yüksek olmayan İrlanda ve İspanya'da konut sektörüne verilen kredilerin geri ödenmesinde yaşanan sorunlar özellikle İrlanda bankalarını zor duruma sokmuştur. Kriz öncesi kamu maliyesi güçlü olan İrlanda, bankalara verdiği yardımlar nedeniyle borç krizi yaşayan ülkelere dahil olmuştur.

Avro Alanı çevre ülkelerinde krize karşı alınan genişletici politikalar, ülkelerin ekonomik durumlarının iyileşmesine yol açmış ve yaşanan küçük çaplı krizler önlenmiştir. Ancak alınan önlemlerin bütçeye getirdiği ağır yük ve büyümede yaşanan yavaşlamadan dolayı vergi gelirlerinin azalması nedeniyle devlet borçlarının artış eğilimi sürmüştür (2012:5). Fakat Yunanistan'ın Ekim 2009'da bütçe açıklarının daha önce açılanandan daha fazla olduğu beyanı ve bütçe açığını yukarı yönde revize etmesi piyasada çevre ülkelere olan güvenin azalmasına yol açmıştır. Bu gelişme Yunanistan'ın borçlanma maliyetlerini artırmış ve bu artışın çevre ülkelere sıçramasına neden olmuştur. Böylece özellikle PIIGS(*) ülkeleri borç sürdürülebilirliğine ilişkin şüpheler artmış, kredi derecelendirme kuruluşlarının not kırmasının da etkisiyle kamu tahvil faizleri hızla artarak Avrupa Borç Krizini başlatmıştır (Neri ve Ropele, 2015:9).

Kredi derecelendirme kuruluşlarının not azaltmaları ile borçlanmada büyük zorluk yaşamaya başlayan PIIGS ülkeleri kendilerini ciddi bir borç sorununun içerisinde bulmuştur (El-Erian, 2012:30). Bu durum ise ekonomik koşulları ve işsizlik sorununu daha da ağırlaştırmıştır. Avro Alanı çekirdek ülkeleri de krizden finansal yollar yanında piyasa güveni ve ticaret yolları ile olumsuz etkilenmişlerdir (Neri ve Ropele, 2015:26).

Krizden sonra Avrupa Birliği, Uluslararası Para Fonu (IMF) ve Avrupa Birliği Merkez Bankası (ECB)'ndan oluşan Troyka'nın yardım programlarından yararlanan İrlanda, Yunanistan ve İspanya'da kemer sıkma politikaları uygulanması koşulu getirilmiştir Bunun sonucunda çevre ülkelerde kemer sıkma programları uygulanmaya başlanırken diğer yandan ülkeler ücret ve fiyatlarda düşüşe (iç devalüasyon) zorlanmıştır (De Grauwe, 2014:6). Bu durum ise söz konusu ülkelerin büyümelerinde yavaşlamaya ve resesyona yol açmıştır (De Grauwe ve Ji, 2013). Ancak, mali konsolidasyonun (daralmanın) yoğunluğu 2014'te azalmaya devam etmiş ve 2015 'te söz konusu ülkelerde mali konsolidasyonun (kemer sıkma-daraltıcı politikalar) planlanmadığ belirtilmiştir (EC, 2015:14).

ECB'nin faiz indirimleri (birkaç kez) yanında uzun dönem refinansman operasyonları ve varlığa dayalı menkul kıymet alımı programları da açıklanmıştır (IMF; 2013:6). Bu doğrultuda 2015 yılında tahvil alımına (parasal genişleme) başlanmıştır. ECB'nin söz konusu müdahaleleri ise risk primlerinin düşmesine, varlık ve Avronun değerinin artmasına katkı yapmıştır (IMF, 2015).

Avrupa'nın borç krizine giren ekonomilerinde son dönemde iyileşmeler yaşandığı söylenebilir. İş alemi ve tüketici güveniyle yaşanan ihracat artışı ekonomik canlanmayı başlatmıştır. Diğer yandan azalan mali konsolidasyon önlemleri de talebi artırmıştır (IMF, 2014:1-10;European Comission, 2014:8-12; World Bank, 2014:12). Bununla birlikte tüketim, yatırım ve GSYH halen kriz öncesi döneme göre oldukça düşük düzeydedir. Kredi akışının normal seyrine dönmesi ve düşük petrol fiyatları da ekonomik canlanmayı desteklemektedir.

\section{Avrupa Borç Krizinin Makroekonomik Sonuçları}

Avrupa borç krizi Avro Alanı ülkeleri ve diğer dünya ülkelerini finansal ve ekonomik açıdan olumsuz etkilemiştir. Avrupa ülkelerinin birbirleriyle sıkı finansal entegrasyon içinde olmaları Avrupa borç krizinden hem finansal hem de ekonomik olarak etkilenmelerine neden olmuştur. Avro Alanı dışındaki ülkeler ise daha çok ekonomik yollarla ve ticaretle etkilenmiştir (Stracca, 2013:3). Avro Alanı, ekonomik kanallar yanında finansal kanallarla da olumsuz etkilenmiştir (Allegret, 2014:1).

Avrupa borç krizi, global üretimde düşüşe ve resesyondan dolayı işsizlikte artışa neden olmuştur. İşsiz düzeyindeki artış ve kredilerde azalma (bunun yanında özel sektörün borçlarını azaltma girişimi-leverage) toplam talebi azaltmıştır. Bu gelişmelerin sonucu olarak global ticaret daralmıştır(Na vd., 2013). Aşağıda Avrupa borç krizinin makroekonomik etkileri ayrıntılı olarak açıklanmaya çalışılacaktır.

\subsection{Büyümeye Etkisi}

Avrupa Borç Krizinin global olarak en önemli etkisi ülkelerin ekonomik büyümeleri üzerinde görülmüştür. Avrupa borç krizi, Avro Alanı kriz ülkeleri kadar alan dışındaki ülkeleri de olumsuz etkilemiştir. Dolayısıyla 
Avrupa Borç Krizi büyümeyi sadece yerelde değil global olarak da olumsuz yansımıştır (Na vd., 2013; STLOUSFIELD, 2012). Global olarak, gerek finansal gerekse de ekonomik yapıyı (özelde ise ticari akımları) etkileyen Avrupa Borç Krizi, ekonomik büyümenin yavaşlamasına neden olmuştur. Ancak krizin Avro Alanı dışındaki bölge ve ülkelerde büyümeye etkisi daha çok ticari bağlar ile ilişkilidir. Nitekim Avro Alanı'nın diğer bölge ve ülkelerle finansal enetegrasyonu bulunsa da, entegrasyon Avro Alanı ülkeleri arasında çok daha fazladır. Dolayısıyla krizin finansal sisteme sıçraması daha çok Avro Alanı için geçerlidir (Allegret, 2014:1). Grafik 3'te bazı ülke grupları ve Türkiye'nin ekonomik büyüme gerçekleşmeleri yer almaktadır.

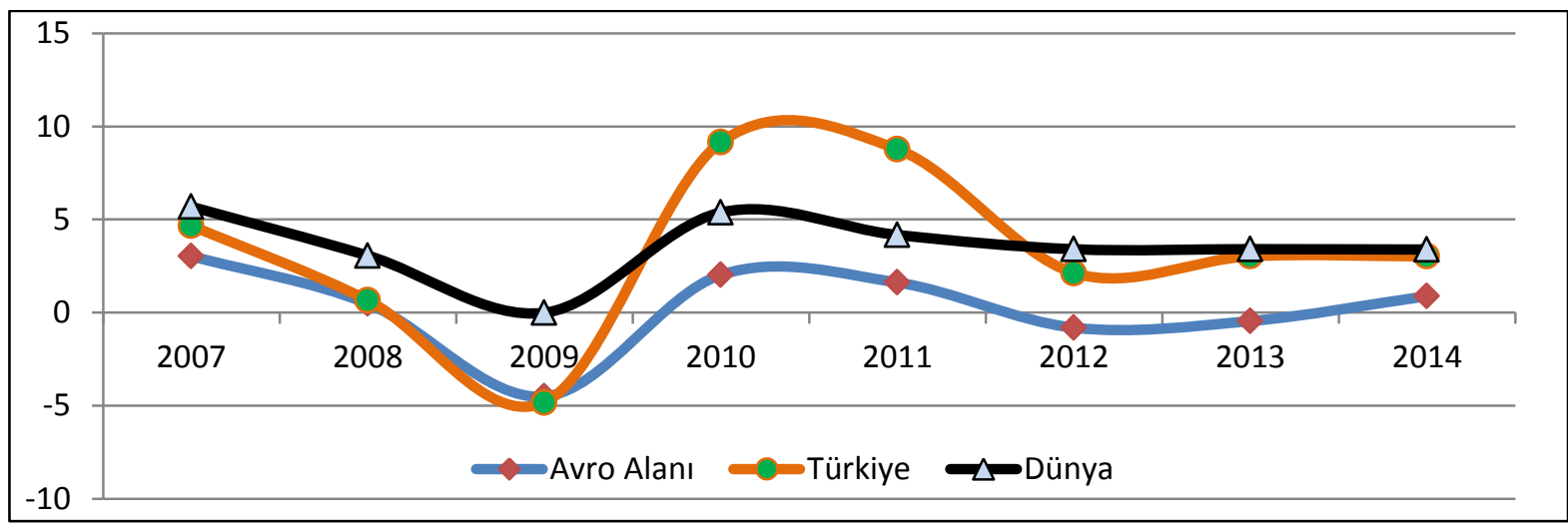

Grafik 1: Ekonomik Büyüme Oranları (GSYH Artışı) (\%) Kaynak: IMF, 2015 b.

Grafik 1'e göre, Avrupa Borç Krizi özellikle 2010 yılından itibaren global büyüme oranlarını etkilemiştir. Gelişmiş ülkeler kaynaklı olan Avrupa Borç Krizi, dünya GSYH'sının büyük bölümünün gelişmiş ülkelerce üretilmesinden dolayı global olarak ekonomik büyümeyi önemli ölçüde etkilemiştir. Avrupa Borç Krizi ile birlikte düşen ihracat rakamları, sabit yatırımlar ve kamu harcamaları global olarak azalmış, bu durum ise ülkelerin büyüme oranlarında bir düşüşü beraberinde getirmiştir. 2013 yılına kadar büyüme oranı Avro Alanı dışındaki ülkelerde pozitif kalırken Avro Alanı negatif büyümüştür (deflasyon yaşamıştır). Bu durum gelişmiş ülkelerin ekonomik büyümesinin artmasını engellemişlerdir (ILO, 2015:15,33).

Türkiye de Avrupa ile olan sıkı ekonomik ilişkilerden dolayı krizden önemli derecede etkilenmiştir. Nitekim Global Finansal Krizin etkilerini hızla atlatan Türkiye'de yeni bir kriz dalgası olan Avrupa Borç Krizi nedeniyle 2010 yılından itibaren büyüme hızları düşük oranlarda kalmaya devam etmiştir.

\section{2 İhracata Etkisi}

Borç krizleri doğrudan ihracatı etkilemektedir. Nitekim, borç krizleri krizden etkilenen ülkelerin ithalatlarının ve dış ticaret yaptığı diğer ülkelerin ihracatının azalmasına neden olmaktadır (Abiad vd., 2011:6; Kiendrebeogo, 2012). Bu anlamda, Avrupa Borç Krizi, Avro Alanı talebinde ve ekonomik büyümesinde azalışa (Ebrahimi vd., 2014:77) yol açarak hem global hem de Avro alanına yapılan ihracatı azaltıışır(Na vd., 2013). Azalan ihracatın bir diğer nedeni de düssen emtia fiyatlarıdır. Azalan global talep bir yandan ihracatı azaltırken diğer yandan da yapılan ihracatın getirisini azaltmıştır. Bu durum Grafik 2'den görülebilmektedir.

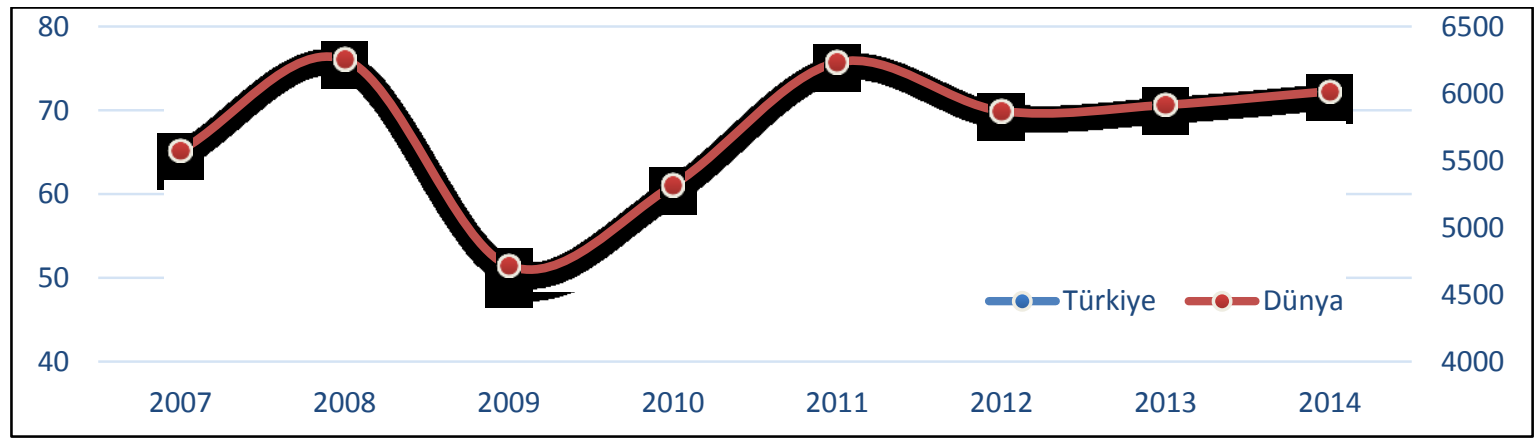

Grafik 2: Türkiye ve Dünya Ülkelerinin AB'ne İhracatı (Milyar Dolar) Kaynak: IMF, 2015 c.

Grafik 2'den görüldüğü üzere, Avrupa Borç Krizi global olarak Avro Alanı'na yapılan ihracatı azaltmıştır. 2011 yılı itibariyle dünya ülkelerinden Avro Alanı'na yapılan ihracat azalışa geçmiş ve 2014 yılı itibariyle 6019 milyar dolara ulaşmıştır. Diğer ülke grupları ve bölgelerde de benzer bir durum söz konusudur. Türkiye'nin Avro alanına ihracatı 2012 yılından sonra belirgin olarak farklılaşmakta ve artış eğilimine girmektedir.

\section{3. İşsizliğe Etkisi}

Avrupa borç krizi, Avro Alanı'nda olduğu kadar dünyada da işsizliğin artışında etkili olmuştur. Bunun nedeni azalan yatırımlar ve talep sonucu yaşanan resesyonun yayılma etkisiyle Avrupa ülkeleriyle ekonomik ilişkileri yoğun olan ülkelere sirayet etmesidir ( $\mathrm{Na}$ vd., 2013). İşü̈cü arzındaki artışın devam etmesine rağmen buna 
cevap verecek yeni istihdam imkanlarının yetersizliği işsizliğin önümüzdeki dönemde bir problem olarak devam edeceği anlamına gelmektedir. Şöyle ki, 2007-2014 arasında istihdam artış1 \%1.2 gibi düşük düzeylerde gerçekleşmiştir (ILO, 2015:16). Bu durum ise yaşanan krizlerin izlerini taşımaktadır.

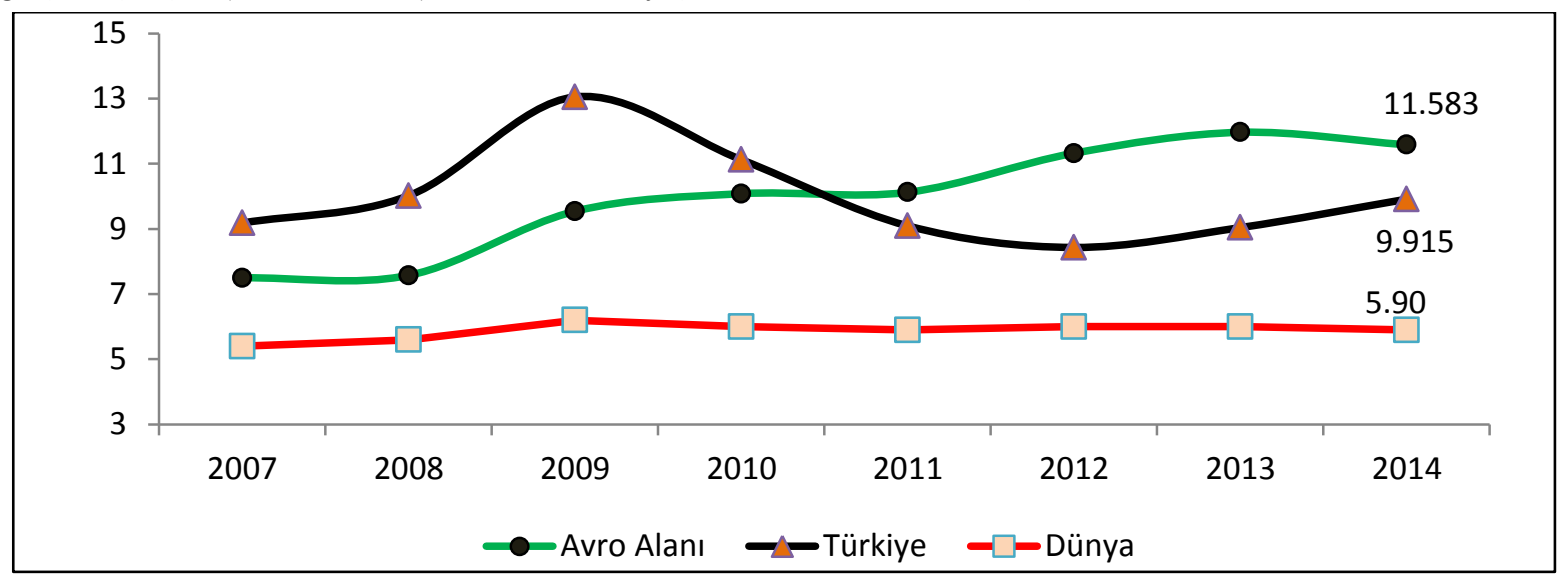

Grafik 3: İşsizlik Oranı (Toplam İşü̈cüne Oran \%) Kaynak: ILO, 2015b; IMF, $2015 b$.

Grafik 3'e bakıldığında işsizliğin global olarak istikrarlı olduğu göze çarpmaktadır. Avrupa Borç Krizinin global olarak işsizliğe etkisi 1lımlı derecede kalmıştır. Ancak yine de dünya işgücünün \%5,9'u hala işsizdir. Krizi yaşayan Avro Alanı güney ülkelerinde, son zamanlarda ılımlı istihdam artışına rağmen işsizlik azalmıştır. Ayrıca, Avro Alanı'nda yüksek genç işsizlikten bahsetmek mümkündür (Guerrieri, 2013:51).

Türkiye'de ise 2012 yılından itibaren işsizlik artmaya başlamış ve Avro alanı ortalamalarına yaklaşmıştır. Burada, Türkiye ekonomisindeki büyüme hızlarının Avro Alanından daha yüksek olmasına rağmen işsizlik daha hızlı artmıştır. Bunun nedeni, ekonomik büyümeyle yaratılan iş imkânlarının iş gücüne yeni katılan genç nüfusun istihdamını sağlamanın uzağında olmasıdır.

\subsection{Enflasyona Etkisi}

Avrupa borç krizinden dolayı, büyüme global olarak yavaşlamıştır. Bu durum, global olarak emtia (commodity) fiyatlarını düşürmüştür (STLOISFED, 2012:1). Diğer yandan petrol fiyatlarındaki düşüş de enflasyonun global olarak düşmesinde rol oynamaktadır (IMF, 2015b:2).

Avrupa Borç Krizi nedeniyle yaşanan resesyon, talebi azaltmış, bu nedenle dış ticaret ve emtia fiyatları düşmüştür. Avro Alanı çevre ülkelerinde ve Japonya gibi gelişmiş ülkelerde yaşanan deflasyon global olarak düşük fiyat artışının sürmesine katkı yapmaktadır. Benzer şekilde Avro Alanı'nda uygulanan mali konsolidasyon politikaları yanında, yatırımlarda ve tüketimde yaşanan azalma deflasyonun sürmesine yol açmaktadır. Diğer yandan petrol fiyatlarının azalması da gelişmiş ülkelerde enflasyonu aşağı çekmiştir (IMF, 2015b:3). Bu durum Grafik 4'de görülebilmektedir.

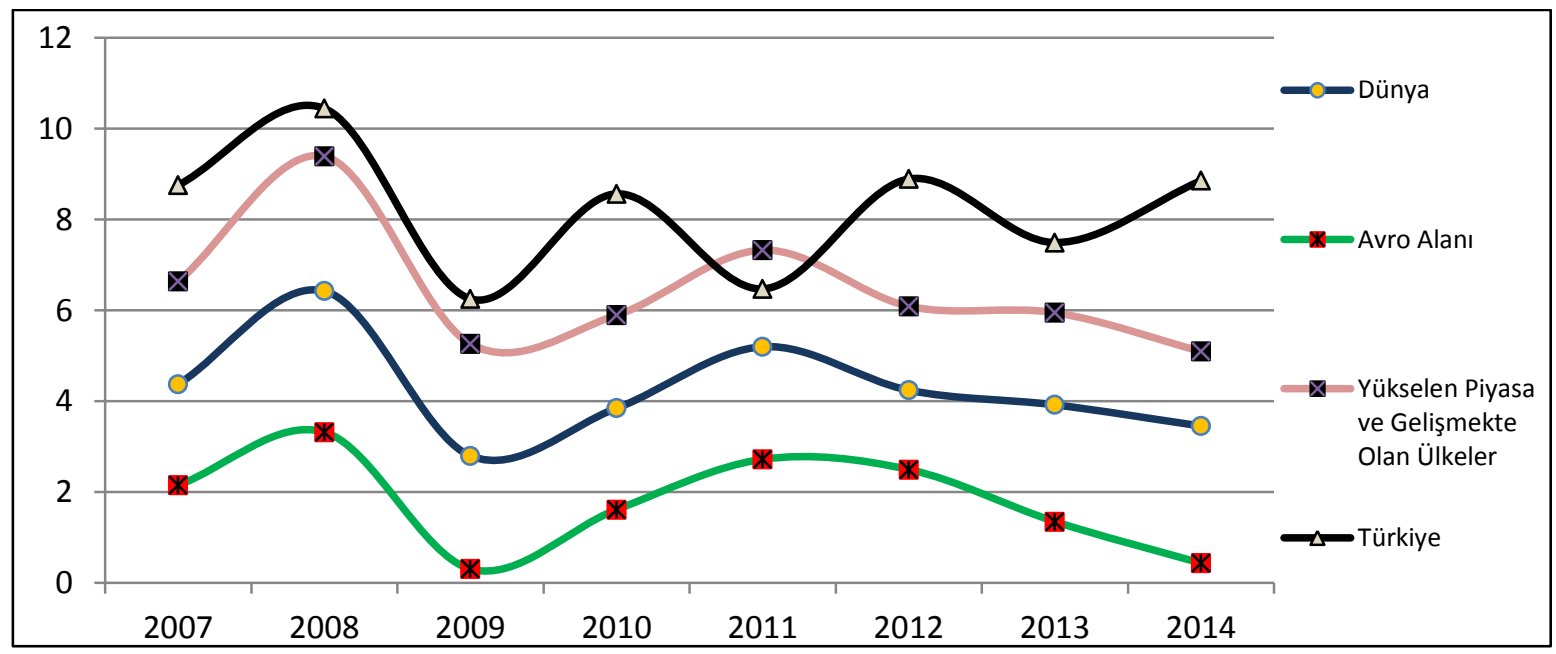

Grafik 4: Enflasyon Oranı (Ortalama Tüketici Fiyatları, \% Değişim) Kaynak: IMF, 2015 b.

Yükselen piyasa ekonomileri ve gelişmekte olan ülkelerde ise yine petrol ve emtia fiyatlarının enflasyon üzerindeki azaltıcı etkisini görmek mümkündür. Ayrıca bu ülkelerde yavaşlayan büyüme enflasyonun düşmesine neden olmaktadır. Ancak krizden dolayı iç tüketimi teşvik eden birçok ülke hedefin üzerinde enflasyon ile karşı karşıya kalmışlardır (IMF, 2015b:25). 
Türkiye'de enflasyon Avrupa Borç Krizi'nden etkilenmekle birlikte inişli çıkışlı bir görünüm arz etmiştir. Genel eğilimin aksine 2011 yılında düşen enflasyon oranı 2012'de artmış ve 2013'te tekrar azalışa geçmiştir. 2014 yılında yine artan enflasyon oranının temel nedenleri arasında döviz kurunda artış, parasal genişleme ve gıda fiyatlarında artış sayılabilmektedir (IMF, 2015b: 52). Burada, Türkiye'deki enflasyon oranlarının bütün ülke grupları ortalamalarının üzerinde seyrettiğini de belirtmek gerekir.

\subsection{Finansal Akımlara Etkisi}

Avrupa Borç Krizi, uluslararası risk algısını arttırmış ve finansal akımların seyrini değiştirmiştir. Bu açıdan sermaye akışı ile kamu ve özel sektör borçlanmaları Avrupa Borç Krizinden etkilenmiş, net sermaye akışı 2009 yılı itibariyle düşüş eğilimi gösterirken, Avro Alanı dışında borç akışı seyri önemli bir değişikliğe uğramamıştır.

Avrupa Borç Krizi ile yükselen risk algısı global olarak yatırımcıların riskten kaçınmaları nedeniyle net sermaye akımlarını da azalmıştır. Krizin sermaye akımlarına etkisi 2010 yılından itibaren görülmeye başlanmış, net sermaye akımları hızla azalmıştır.

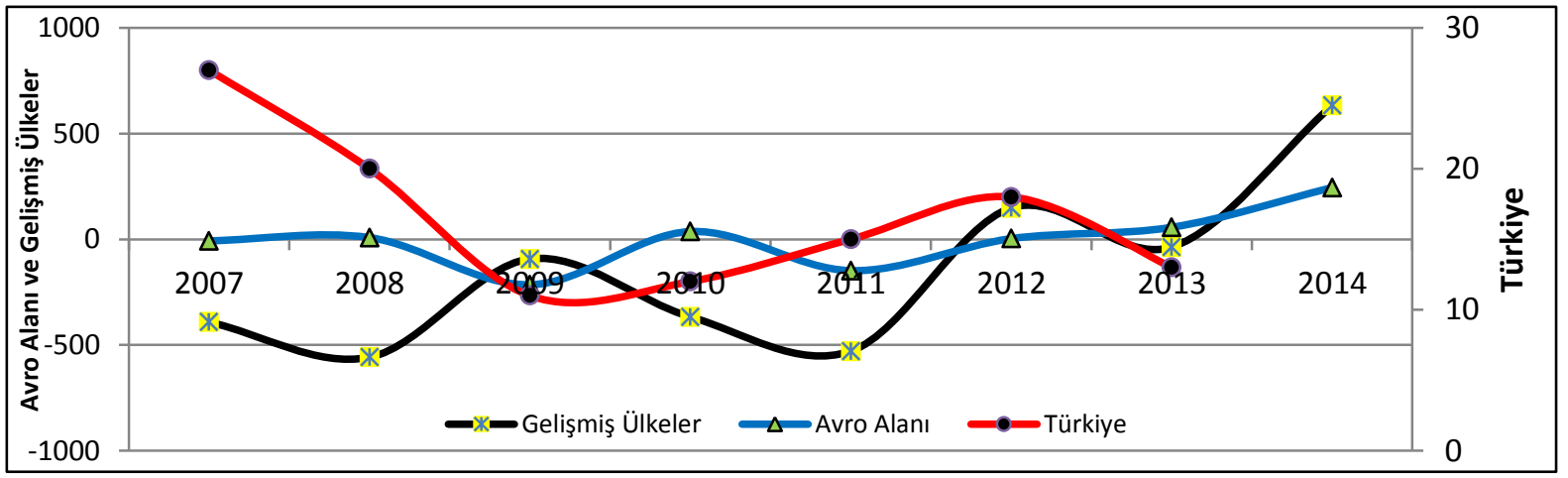

Grafik 5: Net Sermaye Akımları (Portföy+DYY) (Milyar Dolar) Kaynak: World Bank, 2015a; IMF, 2015 b.

Grafik 5'den görüldüğü üzere net sermaye akımları, gelişmiş ülkelerde 2009 yılından itibaren sert biçimde düşmüştür. 2011 yılından itibaren toparlanan net sermaye akımı 2012'den itibaren inişli çıkışlı bir grafik çizmiştir. Avro Alanı'nda net sermaye akımlarında istikrarsız bir yapı göze çarpmaktadır. 2010'da potföy yatırımlarında net çıkışın azalmasıyla dengelenen net sermaye akımı bu tarihten sonra portföy yatırımlarında net çıkışın azalması ve net girişin başlamasıyla toparlamıştır. Türkiye'de ise 2009'dan itibaren ılımlı biçimde azalan net sermaye akımı pozitif kalmayı sürdürmüş ve 2011 yılından itibaren toparlanma sürecine girmiştir. Bu süreçte Türkiye net sermaye girişine sahne olmuştur.

Avrupa Borç Krizi, finansal sistemi de etkileyerek borç akımının azalmasına yol açmıştır. Avro Alanı'nda kriz süresince azalan krediler, özellikle PIIGS'te kendisini hissettirmiştir. Söz konusu ülkelerde bankalar, daha az borç vermeye başlamış ve kredi faizini yükseltmişlerdir (Acharya vd., 2014:3). Kamu kağıtlarını bilançolarında bulunduran bankaların bu durumdan olumsuz etkilenmesi ve sonuçta ortaya çıkan kredi daralması, Avro Alanı için güçlü şekilde kendini hissettirmiştir (Allegret vd., 2014:1). Diğer ülkelerde de yukarıda bahsedilen kamu kağıtları-banka ilişkisi söz konusu olsa da (Stracca, 2013:3) Avro Alanı asıl kredi problemini yaşayan bölgedir.

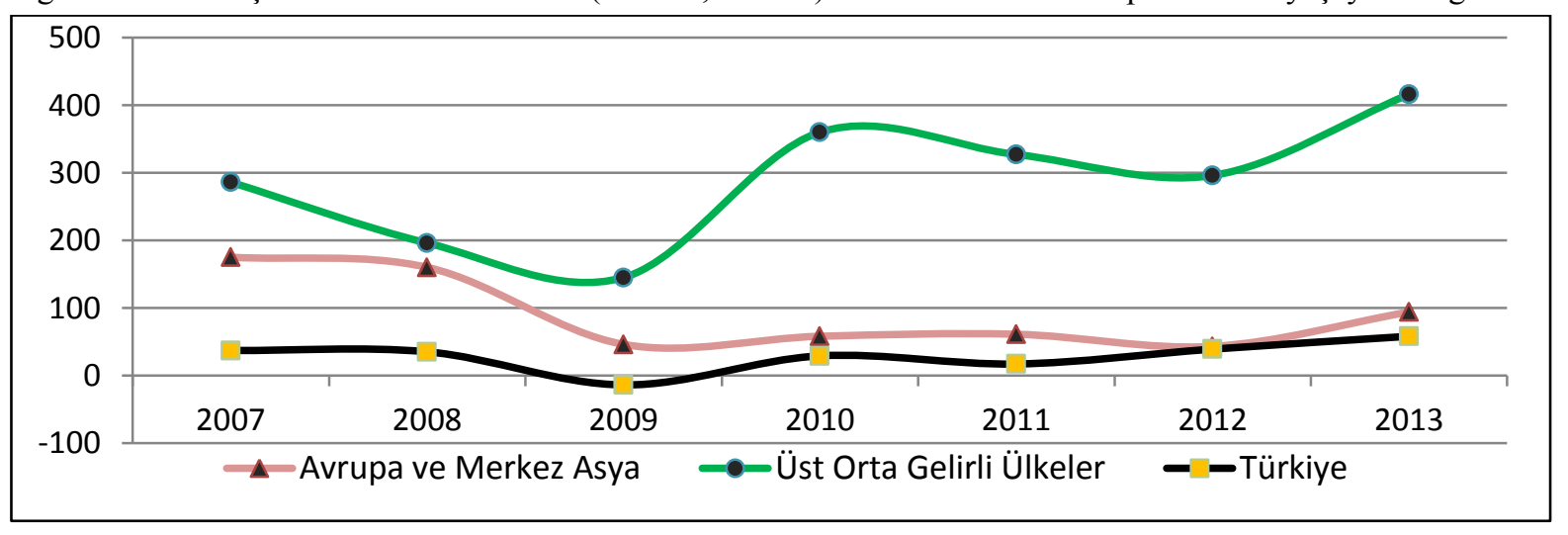

Grafik 6: Net Dış Borç Akımı (Milyar \$) Kaynak: World Bank, 2015 b.

Grafik 6'dan görüldüğü gibi, Avrupa Borç Krizi sonucunda net dış borç akımı azalmıştır. Diğer bir ifade ile alınan dış borçlarda azalma (veya geri ödemelerde artış) yaşanmıştır. Net dış borç akımında azalışı miktar olarak en çok yaşayan kesimler üst orta gelirli ülkeler ile düşük ve orta gelirli ülkeler olurken alt orta gelirli ülkelerde önemli bir azalma yaşanmamıştır. Avrupa ve Merkez Asya'da net dış borç akımı 2011 sonrası azalırken 2012'den itibaren artışa geçmiştir. Türkiye'de ise 2011'de azalan net dış borç akımı 2012 itibariyle artarak kriz öncesi seviyesini aşmıştır. 


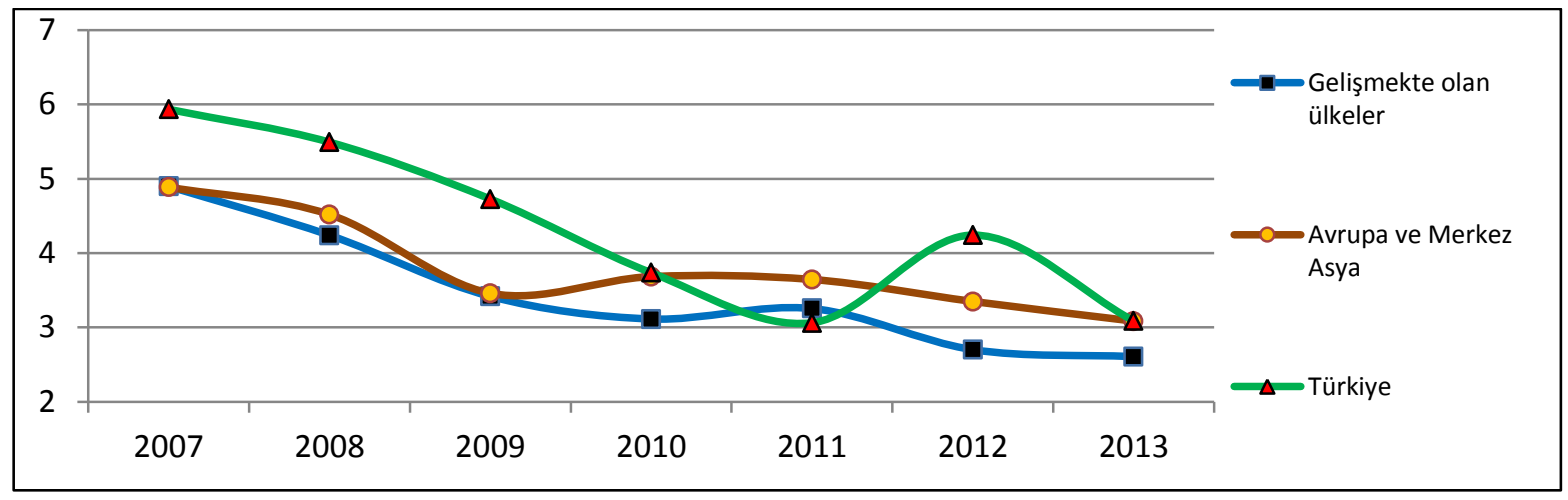

Grafik 7: Bazı Ülke Grubu ve Türkiye’de Kamu ve Kamu Garantili Dış Borçlanma Kaynak: World Bank, 2015 b.

Avrupa Borç Krizi kamu borçlanma maliyetlerini olumlu yönde etkilemiştir. Orta gelirli ülkeler ile gelişmekte olan ülkelerde yıl içinde yapılan kamu ve kamu garantili borçlanma faizleri dönem boyunca azalırken, orta üst gelirli ülkelerde sadece 2011 y1lında artış söz konusudur. Avrupa ve Merkez Asya'da 2009'dan itibaren artan faizler 2011 yılından itibaren düşüş eğilimine girmiştir. Orta Doğu ve Kuzey Afrika'da ise 2009 y1lından itibaren artan faizler 2012'den itibaren düşmüştür. Türkiye'de ise söz konusu faiz, 2011 y1lına kadar düşüş göstermiş ve 2012'de yükseldikten sonra tekrar düşüş trendine girmiştir. Kamu borçlanma faizinin düşmesinde özellikle gelişmiş ülkeler için son yıllarda düşen enflasyon ve enflasyon beklentisinin etkisi söz konusudur (IMF, 2015b:8).

\section{Avrupa Borç Krizinden Çıkarılacak Dersler}

Avrupa Borç Krizi, kamu sektöründe aşırı borçlanmanın ve yapısal reformların görmezden gelinmesinin sonucudur. Bu anlamda artan bütçe açıkları, mali kurallara uyulmaması, ertelenen reformlar ve rekabetçiliğin kaybedilmesi sonucunda Avro Alanı bir borç sarmalı içerisine girmiştir (Ulusoy ve Ela, 2014:102). Avrupa Borç Krizine girilmeden hemen önce uygulanan genişletici politikalar, krizin başlamasıyla yerini daraltıcı politikalara bırakmıştır. Dolayısıyla kriz sürecinde aşırı artan bütçe açıkları ve borç göstergeleri, Avro Alanı ülkelerinin politika alanında daralmaya neden olmuştur. Bu bağlamda borç krizine girmemek ve krizden etkilenmemek (direnci arttırmak) için, Avrupa borç krizi tecrübesi de dikkate alınarak, aşağıdaki öneriler sunulmuştur.

\subsection{Güçlü Mali Yapı}

Güçlü mali yapı, bir yandan krize girme olasılığını azaltırken diğer yandan krizlere karşı politika alanını genişletmektedir. Bu kapsamda Avrupa Borç Krizi tecrübelerinden yararlanmak adına Türkiye'nin ekonomik göstergelerindeki gelişmelerin Avro Alanı kriz ülkeleri ile karşılaştırması yapılmış ve Türkiye için dersler çıkartılmaya çalışılmıştır. Bu düşünceden hareketle Tablo 1 oluşturulmuştur.

\begin{tabular}{|c|c|c|c|c|c|c|c|c|c|c|c|}
\hline & 气ิં & 䒿 & ฮั่ & 气ั่ & 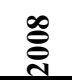 & ஓे & $\stackrel{8}{\overline{9}}$ & $\overline{\overline{4}}$ & $\stackrel{\frac{4}{9}}{\mathfrak{1}}$ & $\stackrel{m}{\bar{N}}$ & $\frac{\mathbb{\pi}^{2}}{\pi}$ \\
\hline $\begin{array}{l}\text { Türkiye M.Y. Bütçe } \\
\text { Açığı /GSYH }\end{array}$ & $-9,0$ & $-4,4$ & 0,8 & $-1,5$ & $-2,8$ & $-7,0$ & $-2,6$ & $-1,4$ & $-2,1$ & $-1,2$ & $-1,3$ \\
\hline $\begin{array}{l}\text { Türkiye Borç } \\
\text { Stoku/GSYH }\end{array}$ & 67,7 & 59,6 & 46,5 & 39,9 & 40,0 & 46,0 & 42,3 & 39,1 & 36,2 & 36,3 & 33,5 \\
\hline $\begin{array}{l}\text { AB } 27 \text { Bütçe } \\
\text { Açığı/GSYH }\end{array}$ & $-3,2$ & $-2,9$ & $-1,5$ & $-0,9$ & $-2,4$ & $-6,9$ & $-6,5$ & $-4,4$ & $-3,9$ & $-3,3$ & $-2,9$ \\
\hline $\begin{array}{l}\text { Yunanistan Bütçe } \\
\text { Açığı /GSYH }\end{array}$ & $-5,6$ & $-7,5$ & $-5,7$ & $-6,5$ & $-9,8$ & $-15,6$ & $-10,3$ & $-9,1$ & $-8,9$ & $-12,7$ & $-3,5$ \\
\hline $\begin{array}{l}\text { Portekiz } \\
\text { Bütçe Açığı/GSYH }\end{array}$ & $-3,7$ & $-4,0$ & $-4,6$ & $-3,1$ & $-3,6$ & $-10,2$ & $-9,8$ & $-4,3$ & $-6,4$ & $-4,9$ & $-4,5$ \\
\hline $\begin{array}{l}\text { AB } 27 \text { Borc } \\
\text { Stoku/GSYH }\end{array}$ & 61,9 & 62,2 & 61,5 & 58,9 & 62,2 & 74,5 & 80,2 & 82,7 & 85,5 & 87,4 & 86,9 \\
\hline $\begin{array}{l}\text { AB } 17 \text { Avro Alanı } \\
\text { Borç Stoku/GSYH }\end{array}$ & 69,2 & 69,6 & 68,6 & 66,4 & 70,2 & 80,1 & 85,6 & 87,5 & 90,8 & 92,7 & 92,2 \\
\hline $\begin{array}{l}\text { PIIGS Ülkeleri Borç } \\
\text { Stoku/GSYH }\end{array}$ & 68,4 & 67,9 & 68,0 & 68,0 & 75,0 & 89,6 & 102 & 114 & 122 & 130 & 129, \\
\hline
\end{tabular}

Tablo 1: AB Tanımlı Bütçe Açı̆̆ı ve Borç Stokunun GSYH’ya Oranı Kaynak: Eurostat, 2015; HM, 2015.

Avrupa Borç Krizi'nin temelleri Tablo 1'e bakıldığında daha iyi anlaşılabilir. Tabloya göre, küresel kriz öncesi bile Yunanistan ve Portekiz bütçe açı̆̆ı/GSYH oranı Maastricht kriterlerinin üzerindedir. Global Finansal Krizin etkisiyle uygulanan genişletici politikalar ve banka kurtarma paketleri sonucunda bütçe açığı ve borç yükü artmıştır. Daha sonra uygulanan daraltıcı politikalar (mali konsolidasyon) sonucunda bütçe açı̆̆ı azalırken borç 
stoku/GSYH oranında artı̧ gerek AB 27 ve AB 17 gerekse de PIIGS ülkelerinde devam etmiştir. Bunun temel nedeni GSYH'nin azalması yanında kamu gelirlerinin de düşmesidir (De Grauwe, 2014:9).

Türkiye, 2001 ekonomik krizinin etkilerine karşı aldığı ekonomik istikrar politikalarıyla başarılı sonuçlar elde etmiştir. Bu durum Tablo 1'de yer alan bütçe ve borç oranlarına da yansımıştır. Nitekim 2004 yılından itibaren hem borç/GSYH hem de bütçe açı̆̆ı/GSYH oranını Maastricht kriterlerine uydurmayı başarmıştır. 2009 yılında verilen yüksek bütçe açığı ise Global Finansal Krize karşı alınan önlemlerin bir sonucudur. Açıkça Türkiye son yıllarda mali disiplini sağlamış ve güçlü mali yapı ile ekonomik motivasyondan/güvenden üst düzeyde yararlanmıştır.

Global Finansal Krizden etkilenen Avro Alanı ülkeleri bu etkileri bertaraf etmek adına genişletici politikalar uygulamış, ancak bozulan mali dengeyi sağlamaları mümkün olmamıştır. Buna karşllık geliş̧ekte olan ülkelerin birçoğu, krize karşı genişletici önlemler alıp başarılı olmuşlardır. Avro Alanında yüksek bütçe açığı ve borçlanma bir yandan ülke riskini arttırarak ülkelerin borçlanma maliyetlerini arttırmış, diğer yandan da politika alanını kısıtlayarak krize müdahale etme kabiliyetini azaltmıştır. Ayrıca, kısa vadeli, yabancı para cinsinden ve değişken oranlı borca sahip ülkelerin dış şoklara karşı daha kırılgan olduğu göz önüne alındığında (IMF, 1998:80,83), Türkiye'nin kamu sektörü borcunun genelde uzun vadeli ve GSYH'ya oranla makul seviyede olmasının önemi bir kez daha ortaya çıkmıştır.

Bu bakımdan Türkiye, güçlü mali yapısı ile söz konusu krizi atlatııştır. Buna ilaveten Global Kriz Türkiye ekonomisinde negatif etki yapmasına karşın, Türkiye bir kriz ülkesi olmaktan kısa sürede kurtulmuştur, denebilir. Önümüzdeki dönemlerde de Türkiye daha ucuza borçlanabilmek ve borç krizine girmemek adına güçlü mali yapısını korumalıdır. Güçlü mali yapı iç ve dış şoklara karşı ülkenin kırılganlığını da azaltacaktır. Nitekim önemli kredi derecelendirme kuruluşlarından birininin değerlendirmesinde "Türkiye'nin güçlü mali yapısının krizlere karşı kırılganlığı azalttığı" vurgulanmıştır (Moody’s, 2014:45).

\subsection{Küresel Rekabet Gücü}

Küreselleşme ve dışa açılma ile global pazardan pay alabilmek için rekabetçi yapıyı güçlendirmek gerekiyor. Küreselleşme ile birlikte artan uluslararası ticaret akımları, rekabetçiliği global piyasada var olabilmenin anahtarı haline getirmiştir. $\mathrm{Bu}$ açıdan bakıldığında rekabet gücünü arttırmak; verimliliği ve üretilen mal ve hizmetlerin katma değerini yükseltmek, refah düzeyini arttırabilmek ve vatandaşların yaşam standartlarını iyileştirebilmektir (Ulusoy ve Ela, 2014:102).

Avrupa borç krizinin temelinde yer alan en önemli faktörlerden birisi rekabetçiliğin Avro Alanı çevre ülkelerinde gerilemesidir. Bu açıdan Tablo 2'ye bakıldığında Avro Alanı çevre ülkeleri olan İrlanda, İspanya, İtalya, Portekiz ve Yunanistan rekabetçilikte oldukça geri kalmışlardır. Krizle birlikte işgücü ücretlerinde düşüşe zorlanan söz konusu ülkeler, yapısal reformlarla da rekabetçiliği desteklemeye çalışmaktadırlar. Bu durum Tablo 2'ye de yansımıştır.

\begin{tabular}{|l|c|c|c|c|c|c|c|}
\hline $\begin{array}{l}\text { Yıllar } \\
\text { Ülkeler }\end{array}$ & $\begin{array}{l}\mathbf{2 0 0 6 - 2 0 0 7} \\
\text { Sira/Puan }\end{array}$ & $\begin{array}{l}\mathbf{2 0 0 8 - 2 0 0 9} \\
\text { Sira/Puan }\end{array}$ & $\begin{array}{l}\mathbf{2 0 0 9 - 2 0 1 0} \\
\text { Sira/Puan }\end{array}$ & $\begin{array}{l}\mathbf{2 0 1 0 - 2 0 1 1} \\
\text { Sira/Puan }\end{array}$ & $\begin{array}{l}\mathbf{2 0 1 1 - 2 0 1 2} \\
\text { Sira/Puan }\end{array}$ & $\begin{array}{l}\mathbf{2 0 1 3 - 2 0 1 4} \\
\text { Sira/Puan }\end{array}$ & $\begin{array}{l}\mathbf{2 0 1 4 - 2 0 1 5} \\
\text { Sira/Puan }\end{array}$ \\
\hline Almanya & $9 / 5,75$ & $7 / 5,46$ & $7 / 5,37$ & $5 / 5,39$ & $6 / 5,41$ & $4 / 5,51$ & $5 / 5,49$ \\
\hline Fransa & $15 / 5,66$ & $16 / 5,22$ & $16 / 5,13$ & $15 / 5,13$ & $18 / 5,14$ & $23 / 5,05$ & $23 / 5,08$ \\
\hline İrlanda & $23 / 5,46$ & $22 / 4,99$ & $25 / 4,84$ & $29 / 4,74$ & $29 / 4,77$ & $28 / 4,92$ & $25 / 4,98$ \\
\hline İspanya & $25 / 5,42$ & $29 / 4,72$ & $33 / 4,59$ & $42 / 4,49$ & $36 / 4,54$ & $35 / 4,57$ & $35 / 4,55$ \\
\hline İtalya & $48 / 4,70$ & $49 / 4,35$ & $48 / 4,31$ & $48 / 4,37$ & $43 / 4,43$ & $49 / 4,41$ & $49 / 4,42$ \\
\hline Portekiz & $34 / 5,22$ & $43 / 4,47$ & $43 / 4,40$ & $46 / 4,38$ & $45 / 4,40$ & $51 / 4,40$ & $36 / 4,54$ \\
\hline Yunanistan & $40 / 4,96$ & $67 / 4,11$ & $71 / 4,04$ & $83 / 3,99$ & $90 / 3,92$ & $91 / 3,93$ & $81 / 4,04$ \\
\hline Türkiye & $59 / 4,14$ & $63 / 4,15$ & $61 / 4,16$ & $68 / 4,49$ & $58 / 3,62$ & $56 / 4,75$ & $45 / 4,46$ \\
\hline
\end{tabular}

Tablo 2: Seçilmiş Avro Alanı Ülkelerinin Küresel Rekabet Endeksleri Kaynak: WEF (2006:19; 2008:10; 2009:13; 2010:15; 2011:15; 2013:15; 2014:13).

Tablo 2'ye göre Avro Alanı çevre ülkeleri, borç krizinden hemen önce rekabetçiliklerini kaybetmişlerdir.. Artan iç taleple birlikte düşen rekabetçilik gücü ülkelerin cari açıklarının artmasına yol açmıştır (Comujnale ve Hessel, 2014:1). Cari açıklar ise çevre ülkelerin borçlarını artıırmıştır (ECB, 2012:10). Son dönemlerde ise yapılan reformlar ve ulusal paranın değer kaybetmesiyle birlikte rekabetçiliğin arttığı göze çarpmaktadır.

Türkiye, kriz öncesinde ve kriz süresince rekabetçilik sıralamasında gerilemesine karşın, puan olarak 2013 dönemi hariç, artış yaşamışıır. Diğer yandan PIIGS ülkeleri ile karşılaştıııldığında, PIIGS ülkelerinde rekabetçilik azalırken Türkiye'nin rekabetçiliğinin son zamanlarda arttığı görülmektedir. Bu bakımdan Türkiye, rekabetçiliğini arttıracak politikalara önem vermelidir. Böylece bir yandan cari açıkta düzelme sağlanarak kırılganlık azaltılabilecek, diğer yandan da borçlanma düzeyini kontrol altında tutarak politika alanı genişletebilecektir. 


\subsection{Güçlü Finansal Sistem}

Avrupa Borç Krizinin temel nedenlerinden birisi olan denetim yetersizliği güçlü finansal sistemin borç krizini önlemek için önemini ortaya çıkarmıştır. Nitekim Avro Alanı bankalarının konut sektörüne verdikleri aşırı kredilerin geri dönmemesi ve bilançolarındaki toksik varlıklardan dolayı uğradıkları kayıplar sonucu birçok banka batma noktasına gelmiş ve söz konusu bankalara devletlerce kurtarma paketleri verilmiştir. Bu durum sonucunda özel borçlar kamu borcuna dönüşmüş (Brok ve Langen, 2012:191) ve kamu borçları aşırı derecede artmıştır. Bu açıdan bakıldığındaTürkiye'de bankacılık sektörünün krizlere karşı direncinin arttırılması Avrupa Borç Krizi benzeri bir krizi önlemek için önemlidir. Finansal sistemin ne ölçüde sorun yaşadığını anlayabilmek için takipteki alacaklara bakmak gerekir. Türkiye'de bankacılık sisteminde takipteki alacaklar Tablo 3'de verilmiştir.

\begin{tabular}{|l|c|c|c|c|c|}
\hline & Ara.2010 & Ara.2011 & Ara.2012 & Ara.2013 & Ara.2014 \\
\hline Takipteki alacaklar (milyar TL) (Türkiye) & 19,9 & 18,9 & 23,4 & 29,6 & 36 \\
\hline Takipteki alacaklar/Toplam kredi (Türkiye) & 3,5 & 2,6 & 2,7 & 2,6 & - \\
\hline Takipteki alacaklar/Toplam kredi (AB 27 ortalaması) & 6,7 & 7,5 & 8,9 & 10,5 & - \\
\hline $\begin{array}{l}\text { Takipteki alacaklar/Toplam kredi (PIIGS Ülkeleri } \\
\text { ortalama) }\end{array}$ & 8,3 & 11,4 & 15,7 & 18,4 & 18 \\
\hline
\end{tabular}

Tablo 3: Takipteki Alacaklar Kaynak: BDDK (2014b:2; 2014a:6,20; 2013:13,35; 2012:6,35; 2011a:12,27; 2010:2,20). World Bank, $2015 b$.

Tablo 3'e göre, takipteki alacaklar miktar olarak son yıllarda artış göstermiştir. Takipteki alacakların artması, verilen kredilerin sorgulanması gerekliliğini ortaya koymaktadır. Çünkü Avrupa Borç Krizinin temelinde ABD konut piyasasından doğan krizle birlikte İspanya ve İrlanda'da konut piyasasında verilen kredilerin geri dönmemesi yatmaktadır. Ancak konut fiyatlarında yıllık \%18 düzeylerine ulaşan artış oranı (TCMB, 2015) İspanya'da krizden önce yaşanan konut balonu (konut fiyatı artışı)'ndan daha fazladır (Ulusoy ve Ela, 2014:106). Son yıllarda Türkiye'de verilen konut kredisi artmakla birlikte temerrüt riskini ortaya koyan takibe dönüşme oranının konut kredileri için düşük kalması (BDDK, 2014b:15), konut balonunu Türkiye için önemli bir problem olmaktan çıkarmaktadır. Ancak bu durum Türkiye'de inşaat sektörü bazlı büyümenin sorgulanmasının ve konut fiyatlarının kontrol edilmesinin gerekliliğini gözardı etmek anlamına gelmemektedir.

\section{4 İhracat Çeşitlendirmesi}

Dışa açıklığın, dış şoklara karşı kırılganlığı arttırıp arttırmadığı literatürde tartışmalı (bkz. Calderon vd., 2008; Cavallo ve Frankel, 2008) olsa da dış şoklara karşı kırılganlığa etkisi ihracatın yapısına (çeşitliliğine) bağlıdır (Haddad vd., 2012). Bu anlamda ihracat fiyatları, gümrük tarifeleri ve uluslararası taşıma maliyetlerinde azalma, ihracat potansiyelini arttırmaktadır. Ayrıca, firmalara ihracat kolaylı̆̆ı (trade facilitation) sağlanması, ihracatta pazara erişimi kolaylaştırmaktadır (Shepherd, 2010). Diğer yandan ihracatta coğrafi çeşitlilik (ihracat yapılan ülke çeşitliliği) yanında ürün çeşitliliği de ihracatı artıran ve dış şoklara karşı kırılganlığı azaltan diğer bir faktördür (Haddad vd., 2012).

Bu bağlamda, Avrupa Borç Krizi sonucunda Türkiye'nin Avro Alanı'na ihracatının azalması (Tablo 1) bir yandan ihracatın büyümeye katkısını azaltırken diğer yandan Avro Alanı'na ihracat yapan sektörlerde istihdamı olumsuz etkilemektedir. Bu etkileri bertaraf etmek adına Türkiye ihracatta coğrafi çeşitlendirmeye giderek Kuzey Afrika, Yakın ve Orta Doğu ülkelerine ihracatı arttırmıştır. Ancak coğrafi çeşitlendirme tek başına yeterli değildir. Nitekim Kuzey Afrika ve Orta Doğu ülkeleri ile Avrupa Birliği ülkeleri tüketicilerinin talep ettikleri ürünler farklılaşabilmektedir (Vural, 2012:52). Bu açıdan Türkiye'de yapılan ihracatta coğrafi çeşitlendirme yanında ürün çeşitlendirmesine de önem vermek ülkenin Avrupa Borç Krizi gibi dış şoklara karşı direncini arttıracak (ya da kırılganlığını azaltacak) ve bu açıdan ülkenin büyüme oranları krizlerden daha az etkilenecektir.

\section{Sonuç}

Avrupa Borç Krizi, Avro Alanı ülkelerinde gerek kamu sektörü ve gerekse de özel sektörün aşırı borçlanmasının bir soncudur. Borçlanma sürecinde özel sektöre aşırı kredi verilirken, kamu sektörü de düşük faizler dolayısıyla yapısal reformları ertelemiş ve bu nedenle rekabetçiliği azaltmış, cari açığı ve borçları arttırmıştır.

Ayrıca, ABD mortgage piyasası toksik kağıtlarından bilançolarında bulunduran Avro Alanı bankaları Global Finansal Krizden olumsuz etkilenmiş ve devletlerce bu bankalara kurtarma paketleri verilmiştir. Bu yolla daha da artan kamu borçları artık sürdürülemez olmuş, Yunanistan'ın açıklamasıyla artan risk algısı sonucunda sermaye özellikle PIIGS ülkelerinden kaçmış ve bu ülkelerin borçlanma maliyetleri artmıştır. Böylece Avro Alanı krize girerek ekonomileri global olarak etkilemiştir. 
Avrupa Borç Krizi, global ekonomiyi genel olarak finansal ve ekonomik (özellikle ticari akımlar) yolla etkilemişken, Avro Alanı daha çok finansal yolla krizden etkilenmiştir. Avro Alanı dışındaki ülkeler ise çoğunlukla ticaret kanalıyla krizden etkilenmişlerdir. Bu etkileşim sonucunda global olarak ekonomik büyüme, ihracat, istihdam, enflasyon ve finansal akımlar azalmıştır. Tüm dünyayı etkileyen Avrupa Borç Krizinin Türkiye'ye etkisi ise genel eğilime yakındır. Nitekim Türkiye'nin ihracatı ve büyümesi Avrupa Borç Krizinden etkilenerek azalmış, işsizlik artmış, enflasyon belli dönemlerde azalmıştır. Belirtmekte yarar var ki, Türkiye Avrupa Borç Krizinden etkilenmesine rağmen içsel bazı dinamikler (gıda fiyatları artışı, hızla artan işgücü, iç talebe yönelik büyüme gibi) krizin etkisinin netleşmesini önlemiştir.

Diğer yandan düşen enflasyon global olarak devletlerin uzun dönem borçlanma faizinin azalmasına zemin hazırlamıştır. Özel sektöre verilen yurtiçi kredilerde ise Avro Alanı'nın aksine bir azalma olmamış, birçok ülkede artış yaşanmıştır. Dolayısıyla Avrupa Borç Krizi, daha çok gelişmiş ülkeleri (özelde ise Avro Alanını) finansal yolla, Avro dışındaki ülkeleri ekonomik yolla olumsuz etkilemiştir.

Türkiye, Avrupa Borç Krizinden negatif etkilenmiş ve krize karşı birtakım önlemler almıştır. Türkiye'nin güçlü mali yapısı ve jeopolitik konumunun yardımıyla alınan önlemlerin önümüzdeki dönemlerde de sürdürülebilmesi, Türkiye'de bir borç krizinin yaşanma ihtimalinin azaltılması ve krizlere karşı direncinin artırılması için bazi öneriler sunulabilir.

Bunlar; güçlü mali yapının sürdürülerek krizlere karşı politika alanını genişletilmesi ve krize girme ihtimalinin azaltılması; rekabetçiliğin arttırılarak cari açık ve borçlanmanın azaltılması, bu yolla güçlü mali yapının korunması ve makroekonomik kırılganlığın azaltılması; güçlü ve iyi denetlenen finansal sektör ile özel sektörden kamuya sıçrayabilecek olası bir -Avro Alanı benzeri- krizin önlenmesi; ihracatta çeşitlendirmeye gidilerek olası bir dış şokun (krizin) ticari yolla ülkeye vereceği zararı azaltmaktır.

(*)PIIGS, ekonomik kriz içindeki ülkeler Portekiz, Irlanda, İtalya, Yunanistan ve İspanya'yı belirtmek için son dönemde kullanılan klsaltmadır.

\section{Kaynakça}

- Abiad, Mishra ve Topalova, 2011. "How Does Trade Evolve in the Aftermath of Financial Crises?", IMF Working Paper. WP/11/3.

- Acharya, Elsert, Eufinger ve Hirsch, 2014. "Real Effects of the Sovereign Debt Crisis in Europe: Evidence from Syndicated Loans", http://www.cepr.org.

- Allegret, Raymond ve Houda, (2014). "The Impact of the Global and Eurozone Crises on European Banks Stocks Some evidence of Shift Contagion", Economix Working Paper, No. 2014-24.

- Arısoy, 2012. “Türkiye Ekonomisinde İktisadi Güven Endeksleri ve Seçilmiş Makro Değişkenler Arasındaki İlişkilerin Var Analizi”, Maliye Dergisi, 162, p. 304-315.

- $\quad$ BDDK, 2014b. Türk Bankac1lık Sektörü Temel Göstergeleri Sayı2014/2. www.bddk.org.tr (10.06.2015).

- $\quad$ BDDK, 2014a,2013, 2012, 2011a, 2010. Türk Bankacılık Sektörü Genel Görünümü. www.bddk.org (01.012015).

- $\quad$ BDDK, 2011b.. Finansal Piyasalar Raporu. Sayı 21, http://www.bddk.org.tr (12.06.2014).

- BDDK, 2004. Bankacılık Sektörü Temel Değerlendirme Raporu Haziran 2004. https://www.bddk.org.tr (10.06.2015).

- Brok ve Langen, 2012. "Sustainable Growth for Europe: The Four Crisis and a Call For Reform", Europan Wiew, 11, p.189-199.

- Candelon. ve Palm 2010. "Banking and Debt Crises in Europe: The Dangerous Liaisons”, De Economist, 158(1), p. 81-99.

- Caruana ve Andjiev, 2012. Sovereign Credithworthiness and Financial Stability: An International Perspective. Financial Stability Review, 16, 71-85.

- Comunale, ve Hessel, 2014. "Current Account Imbalances in the Euro Area: Competitiveness or Financial cycle?" DNB Working Paper, No. 443.

- Calderón, Loayza, Norman ve Schmidt-Hebbel, 2008. "Does Openness Imply Greater Vulnerability? Sudden Stops, or Less? Using Gravity to Establish Causality”, Journal of International Money and Finance, 27, p. 1430-1452.

- Cavallo ve Frankel,.2008. "Does Openness to Trade Make Countries More Vulnerable to Sudden Stops, or Less? Using Gravity to Establish Causality", Journal of International Money and Finance, 27, p. 1430-1452.

- De Grauwe 2010. "The Financial Crisis and the Future of Eurozone”. Bruges European Economic Policy Briefing, No. 21, pp. 1-12.

- De Grauwe, 2014. "Macroeconomic Policies in the Eurozone since the Sovereign Debt Crisis", Euroforum KU Leuven.

- De Grauwe ve Ji, 2013. "Panic-Driven Austerity in the Eurozone and Its Implications", http://www.voxeu.org (10.09.2014).

- European Commission, 2014. "European Economic Forecast” European Economy, 3/2014. http://ec.europa.eu (08.08.2014). 
- European Commission, 2015. "Commission Staff Working Document”, Report on the Euro Area.

- European Commission, 2010. Regional Economic Outlook. October. http://ec.europa.eu

- Everett, 2015. "International Liquidity and the European Sovereign Debt Crisis: Was Euro Area Unconventional Monetary Policy Successful?”, Grant-in-Aid for Scientific research Working Paper, No. 23.

- $\quad$ Ebrahimi, Zamani ve Tayebi, 2014. "Effects of European Sovereign Debt (Leverage) Crisis on Bilateral Trade Flows", International Journal of Business and Development Studies, 6(2), p. 59-80.

- $\quad$ Eurostat, 2015. http://epp.eurostat.ec.europa.eu/portal/page/portal/government_finance_statistics

- El-Erian, 2012. "When Western Sovereign Risk is in Play" Financial Stability Review, 16, 29-36.

- European Comission, 2012. "Current Account Surpluses in the EU”, European Economy 9|2012.

- Guerrieri, 2013. "The Rise of Unemployment in the Eurozone: The Worst of the Crisis is Not Over" in Think Tank 20: The G-20 and Central Banks in the New World of Unconvetional Policy, p.51-54.

- Haddad, Lim, Pancaro, ve Saborowski, 2012. "Trade Openness Reduces Growth Volatility When Countries AreWell Diversified”, ECB Working Paper Series No. 1491.

- Hazine Müsteşarlığı, 2015. http://www.hazine.gov.tr/default.aspx?.

- IMF, 2015c. Direction of Trade Statistics, http://elibrary-data.imf.org/DataReport.aspx?c=1449304\&d=

- $\quad 33061 \& \mathrm{e}=170921$ (Erişim: 30.06.2015).

- IMF, 2015b. World Economic Outlook. April 2015, IMF, Washington.

- IMF, 2010. Regional Economic Outlook. http://www.imf.org.

- ILO, 2015a.World Employment and Social Outlook. ILO Publishing, Washington.

- IMF 1998. "Financial Crises: Characteristics and Indicators of Vulnerability" in World Economic Outlook Financial Crises: Causes and Indicators, p. 74-79.

- Kiendrebeogo, 2012. "How do Financial Crises affect Trade Flows". University of Auvergne Working Paper

- Lane, (2012). “The European Sovereign DebtCrisis ”, The Journal of Economic Perspectives, 26(3), p. 4967.

- Moody’s, 2014. External Vulnerabilities, Exposures, Mitigates and Credit Supports, Moody’s Investors Service Special Com-ment, https://www.moodys.com (06.04.2014).

- NIELSEN, 2015. Consumer Confidence Report Quarter 4 2014. http://www.nielsen.com.

- Neri ve Ropele, 2015. "The Macroeconomic Effects of the Sovereign Debt Crisis in the Euro Area", Banca D'Italia Working Papers, Number 1007.

- Na Minjun ve Wen, 2013. "Impacts of the Euro Sovereign Debt Crisis on Global Trade and Economic Growth: A General Equilibrium Analysis Based on GTAP Model”, Chinese Economy of Sciences Working Paper.

- Prinz ve Beck, 2012. "Fighting Debt Explosion in the European Sovereign Debt Crisis", Intereconomics, 3, p. 185189.

- Schmidt ve Weigert, 2013. "Weathering the Crisis and Beyond: Perspectives for the EuroArea”. International Tax Public Finance, 20, 564-595.

- $\quad$ STLOISFED, 2012. The Global Economy and the European Sovereign Debt Crisis. OMFIF Golden Series Lecture. London.

- Stracca, 2013. "The Global Effects of the Euro Debt Crisis", ECB Working Paper Series. No 1573.

- Shepherd, 2010. "Geographical Diversification of Developing Country Exports", World Development 38( 9), p. $1217-1228$.

- Tichy, 2012. "The Sovereign Debt Crisis: Causes and Consequences”, Austrian Economic Quarterly, 2, 95-107.

- Ulusoy ve Ela, 2014. “Avrupa Borç Krizi ve Türkiye İçin Öneriler”, Emek ve Toplum. 3(3), p. 77-114.

- Volz, 2012. "Lessons of the European Crisis for Regional Monetary and Financial Integration in East Asia", $A D B I$ Working Papers, No. 347.

- WEF, (2006, 2008, 2009, 2010, 201, 2013, 2014). The Global Competitiveness Report, Genova.

- World Bank, 2014. Turkey Regular Economic Note, December 2014.

- World Bank, 2015a. International Debt Statistics. The World Bank Publishing, Washington.

- World Bank 2015b. http://data.worldbank.org/indicator/global.

- Vural (2012). “Krizin Türkiye’ye Yansıması”, in AB Krizi ve Türkiye’ye Olası Yansımaları, p. 51-56.

- TCMB,2015. Konut Fiyat Endeksi, http://www.tcmb.gov.tr/yeni/evds/yayin/kfe/KFE.pdf (04.07.2014). 


\title{
Regülasyon Teorilerinin Finansal Krizler Üzerindeki Etkileri Effects of the Theory of Regulation on Financial Crisis
}

\author{
Assoc. Prof. Dr. Kamil Uslu (Marmara University, Turkey) \\ Ph. D. Candidate Mustafa Batuhan Tufaner (Marmara University, Turkey)
}

\begin{abstract}
The role of the financial sector in the financial crisis occurring in the world economy and market failures throughout history, has brought the debate over financial regulation. Systemic risk cases, which plays a major role in the occurrence of the financial crisis, to ensure efficiency and stability of financial markets has revealed the need for regulations. The aim of this study is to evaluate how the impact of the financial crisis on the regulation theory. Financial crisis, leading to market failures, moral hazard problems and rent-seeking activities, economic and social structure has created negative. In this context, the pre-crisis and post-crisis regulatory measures can be taken, it is possible to say that the country would have a positive effect on macroeconomic fundamentals.
\end{abstract}

\section{Giriș}

Dünya ekonomilerinin 1980'den sonraki küresel gelişmelere bağlı olarak, ülkelerde rekabeti esas alan bir ekonomi politikası geliştirdiği ifade edilebilir. Gelişmiş sanayi ülkeleri tam rekabet piyasasının koşullarına göre hareket edebilmektedir. Tam rekabetin sağlanamadığ durumlardaki ülkeler ise, piyasa etkinliğinin sağlanmasında yetersiz kalmakta ve toplum refahını yerine getirememektedir. Ülkelerde yaşanan piyasa başarısızlıkları, çeşitli regülasyon teorilerinin öne sürdüğü hipotezlerle giderilmeye çalışılmıştır. Özellikle, ülke ekonomilerinde mevcut olan, asimetrik bilgi ve dışsallıklar gibi nedenler, piyasa başarısızlıklarını ortaya çıkaran temel faktörler olarak görülebilmektedir. Bunun için devlet, finansal krizlerle sonuçlanan piyasa başarısılıklarının ortadan kaldırılması amacıyla çeşitli regülasyon politikaları uygulayabilmektedir.

Literatürde konuyla ilgili birçok araştırma yayınlanmıştır. Bu araştırmaların büyük bir kısmı batı kaynaklarında görülmektedir. Bunların içerisinde; Johan den Hertog, Paul L. Joskow ve George J. Stigler'in çalışmaları önemli yer tutmaktadır. Türkiye'deki literatüre bakıldığında ise, yeteri kadar akademik çalışma bulunmadığından, yapılan çalışma bu yönüyle önem arz etmektedir. Yapılan saptamalar neticesinde, çalışmanın amacı, regülasyon teorilerinin finansal krizler üzerindeki etkilerinin araştırılmasıdır.

Çalışma üç ana başlık altında toplanmıştır. Buna göre; regülasyon teorilerinin gelişimi ve ekonomideki etkileriyle ilgili teorik bilgiler verilmiştir. Finansal regülasyonun nedenleri ve özellikleriyle finansal krizler ve regülasyonların önemi üzerinde durulmuştur.

\section{Regülasyon Teorilerinin Gelişimi ve Ekonomideki Etkileri}

Piyasaların regülasyonu konusu, 1970'li y1llardan itibaren iktisat literatüründe önemli bir yer tutmaya başlamıştır. Planlama döneminin terkedilmesiyle beraber, en önemli piyasa aktörü olan devletin ekonomiye müdahale biçimi, regülasyonlar çerçevesinde ele alınır hale gelmiştir. Diğer taraftan, piyasaların sürekli bir gelişim ve değişim içerisinde olması, devlet-piyasa ilişkilerine farklı boyutlar kazandırmıştır. Regülasyon ekonomisinde meydana gelen söz konusu gelişmeler, regülasyonu, günümüzde siyaset, bürokrasi ve piyasayı temel alan teorik araştırmalara yönlendirmiştir. Ortaya konulan regülasyon teorileriyle birlikte, regülasyonların piyasaları etkileme kanalları ve bu süreçte rol oynayan ekonomik aktörlerin rolü belirlenmeye çalışılmıştır.

\subsection{Regülasyonun Tanımı, Amacı ve Özellikleri}

Regülasyon kavramı, en yalın haliyle düzenleme anlamında kullanılmaktadır. Ancak, regülasyonun interdisipliner bir kavram olması, farklı ve daha geniş tanımlamalar yapılmasını gerekli kılmaktadır. Regülasyon, sosyal bilimcilere göre, toplum tarafından değer atfedilen faaliyetlerin bir kamu kurumu tarafindan, dişarıdan ve sürekli olarak kontrol edilmesi şeklinde ifade edilmektedir. Hukukçulara göre regülasyon; devlet ve piyasalar arasındaki sınır, siyaset bilimcilere göre; ülkeler için yaygın ve genel kabul gören bir olgu, ekonomistlere göre; devletin ya da hükümetlerin neye, nasıl ve ne ölçüde müdahalede bulunacağının bir ölçüsü olarak tanımlanabilmektedir (Taşar, 2009). Regülasyon faaliyetlerinin geniş alanlara yayılması ve birden çok işleve sahip olması, regülasyonların çeşitli kısımlara ayrılmasına neden olmuştur. Türleri açısından bakıldığında regülasyonlar; iktisadi, sosyal ve idari regülasyon olmak üzere üç grupta incelenmektedir.

İktisadi regülasyon; fiyatlar, piyasaya giriş-çıkışlar ve diğer iktisadi faaliyetler üzerine konulmuş yasal ve idari kontroller olarak ifade edilmektedir (Posner, 1974). Faiz oranı kontrolü, döviz kurunun kontrolü, kira kontrolleri, vergi ve sübvansiyon uygulamaları gibi konular iktisadi regülasyon çerçevesinde değerlendirilmektedir. İktisadi regülasyonlar da, yapısal ve davranışsal regülasyonlar olmak üzere iki kısma ayrılmaktadır. Yapısal regülasyonlar; eksik rekabetin önlenmesi ve rekabetin işlerlik kazanması amacıyla gerçekleştirilen yapısal 
düzenlemeleri kapsarken, davranışsal regülasyonlar ise; piyasa aktörlerinin ve toplumdaki diğer tüm bireylerin davranışlarının düzenlenmesini içermektedir (Ağcakaya ve Halıcı, 2005). Sosyal regülasyon, bireylerin toplum içerisindeki haklarının korunmasını ve sosyal refahın yükseltilmesini esas alan düzenlemelerden oluşmaktadır. Sosyal regülasyon olgusu, firmaların, yaratmış oldukları sosyal maliyetleri dikkate almayacakları düşüncesinden hareketle ortaya çıkmıştır. Çevrenin korunması, çalışanların sosyal haklarının çalışanlar lehine düzenlenmesi, tüketici ve çalışanların firsat eşitliğinin sağlanmasına yönelik düzenlemeler, sosyal regülasyon kapsamı içerisinde değerlendirilmektedir (Hertog, 1999). İdari regülasyon ise; toplumsal gelişmelere bağlı olarak, kamu yönetiminin düzenlenmesi, kamunun alacağı kararlar ve bu kararların idari yönden denetlenmesi gibi konularını içermektedir.

Regülasyonun amacı, bulunduğu sosyal, ekonomik ve idari yapıya göre şekillenmektedir. Temel amac1, toplumda yaşayan bireylerin refah düzeylerini yükseltmek olan regülasyonlar, bu hedefe, piyasalarda etkinlik ve verimliliği arttırmak suretiyle ulaşmaya çalışmaktadır. Ancak, regülasyon amaçları birbiriyle çelişebileceği için, regülasyonların tasarımında bazı dengelerin gözetilmesi zorunlu hale gelmektedir. Dolayısıyla, regülasyon kurallarının ve kararlarının çoğu kez "en mükemmel”den uzaklaşması kaçınılmaz olmaktadır. Pareto optimumunun sağlanamadığı böyle durumlarda, "ikinci hatta üçüncü en iyi” mantığı hakim olmakta ve optimal çözümler şartlara bağlı olarak gerçekleşebilmektedir (Atiyas, 2000).

Piyasa başarısızlıkları ekonomide aksak rekabet, kamusal mallar, doğal tekeller, asimetrik enformasyon ve dışsallıklar gibi etkinliğin sağlanamadığı durumlarda meydana gelebilmektedir. Devletler, süreklilik arz eden bu piyasa başarısızlıklarının giderilmesi için regülasyonlara başvurma ihtiyacı duymaktadır. Regülasyonlar ise, piyasa başarısızlıklarını önlemek için piyasalara; yapı boyutu, liberalizasyon ve davranış regülasyonu olarak üç şekilde tesir etmektedir (Vickers, 1997). Regülasyonun yap1 boyutu, özelleştirilmesi düşünülen şirketlerin bölünmesi, birleşmesi veya devralınması ile ilgili kararları içermektedir. Regülasyonların bir diğer tesir şekli liberalizasyon, ürün ve faktör fiyatlarının piyasa koşulları tarafından belirlendiği, kamusal otoritenin ekonomiye müdahalesinin en aza indirildiği ve ekonomide yer alan kesimlerin piyasa güçlerine açıldığı faaliyetler bütünü olarak tanımlanmaktadır. Davranış regülasyonu ise, piyasada hakim konumda bulunan firmalara yönelik olarak getirilen fiyat kısıtlamaları ve açık tekel kontrolleri gibi rekabet politikası önlemlerinden oluşmaktadır.

\subsection{Regülasyonların Tarihi Seyri}

Regülasyonların tarihi seyrine bakıldığında, adı konulmamakla beraber, modern devletlerin kurulmasından çok daha önce ortaya çıktığını ifade etmek mümkündür. Eski Yunan'da getirilen düzenlemeler göz önüne alındığında, regülasyonun insanlık tarihinin tüm dönemlerinde var olduğu anlaşılmaktadır. Bununla birlikte, modern regülasyonun 1800'lerin sonunda ABD'de başladığı görülmektedir. Modern anlamdaki ilk regülasyonla, tahıl depolarının kira bedelleri belirlenmiş ve böylece tüketicilerin, monopol sahiplerine karşı korunması amaçlanmıştır (Akça, 2007). Söz konusu düzenlemenin ardından, regülasyon faaliyetleri ABD’de hız kazanmaya başlamıştır. ABD’nin ardından öncelikli olarak Avrupa ülkelerinde benimsenen regülasyon faaliyetleri, daha sonra tüm dünya ülkelerini etkisi altına almıştır.

İkinci Dünya Savaşı sonrası dönemde, devlet tarafından uygulanan regülasyonlar artış göstermiş ve 1945-1970 arası dönem "regülasyon çağı" olarak nitelendirilmiştir. Söz konusu dönemde, birçok ülke, daha aktivist makroekonomik politikalara yönelmiştir. Mevcut işletmeler kamulaştırılmış, yeni kamusal girişimler kurulmuş ve regülasyon faaliyetlerinin derinliği artmıştır. Diğer taraftan, gelişmiş ülkelerin çoğunda düzenleyici rejimler arasında önemli farklar göze çarpmıştır. ABD, regülasyonlara daha çok önem verirken, İngiltere ve diğer ülkeler, regülasyonlara daha az ölçüde önem vermiştir.

1970'li yıllarda meydana gelen petrol krizleri ve borç krizleri, regülasyonlar açısından yeni bir dönem başlatmıştır. "Geçiş dönemi” olarak değerlendirilen 1970-1980 dönemiyle, devlet müdahalesi terkedilmeye başlanmış ve serbest piyasa ekonomisi geniş bir uygulama alanı bulmuştur. Bu dönemde, meydana gelen krizlerin önlenememesi, piyasa yanlısı teorilerin ağırlık kazanmasına neden olmuş ve düzenlenmiş kapitalizme olan inanç sarsılmıştır (Chang, 1997). Diğer taraftan, Doğu Asya ülkelerinin pazar paylarını genişletmesi, gelişmiş ülkelerin çoğunun endüstriyel kriz dönemine girmesine yol açmıştır. Yaşanan gelişmeler bağlamında, gelişmekte olan ülkelerde de düzenleyici uygulamalar eleştirilmeye başlanmış ve fiyatlara olan inanç yerini almaya başlamıştır.

1970’li yıllarda hükümet müdahalesine karşı başlayan akım, 1980'li yıllarda liberalizasyon sürecinin başlamasıyla birlikte daha belirgin hale gelmiştir. Bu dönemde ortaya çıkan çeşitli iç ve dış baskılar neticesinde, devlet ve piyasa arasındaki ilişkilerde yeniden yapılandırılma yoluna gidilmiştir. ABD ve İngiltere, deregülasyon sürecinin ilk temsilcileri olmuş ve dünya genelinde özelleştirme faaliyetleri yaygınlaşmaya başlamıştır. Bununla birlikte, dişsallık problemleriyle ilgili önemli bir teori ortaya konulmuştur. Deregülasyon süreci, bu dönemde, ekonomiler açısından bir takım yararlar sağlasa da, beklentileri tam olarak karşılayamamıştır (Chang, 1997).

\subsection{Regülasyon Teorileri}

İktisadi regülasyon teorilerinin odak noktasını, regülasyonun fayda ve maliyetlerini kimin üstleneceği ve ne tür regülasyon politikalarının uygulanacağı oluşturmaktadır. İktisadi regülasyon teorileri genel olarak; pozitif ve normatif teoriler olarak sınıflandırılmaktadır. Pozitif teori; regülasyonu oluşturan ekonomik, siyasi ve bürokratik 
güçler ile bu güçlerin düzenleyici kurumlar üzerindeki etkilerine yoğunlaşmaktadır. Normatif teori ise, piyasa başarısızlıklarının giderilmesi için hangi regülasyon türünün daha etkin veya optimal olduğuyla ilgilenmektedir. İktisadi regülasyon teorileri temelde, Kamu Yararı Teorisi, Özel Çıkar Grupları Teorisi, Kamu Tercihi Teorisi ve Piyasa Süreci Teorisi'nden oluşmaktadır.

A. C. Pigou tarafından iktisat literatürüne kazandırılan Kamu Yararı Teorisi (Public Interest Theory), kıt kaynakların bireysel ve toplumsal tüketim açısından en etkin şekilde tahsisi çerçevesinde oluşturulmuştur. Pozitif bir teori olarak normatif bir analiz şeklinde de adlandırılabilen Kamu Yararı Teorisi'nin temelde iki varsayım altında şekillendiğini söylemek mümkündür. $\mathrm{Bu}$ varsayımlardan ilki, ekonomik piyasaların kendi haline bırakıldığında oldukça kırılgan ve etkinlikten uzak bir çalışma eğiliminde olduğu ikincisi ise, devlet tarafindan uygulanan regülasyonların neredeyse hiç maliyet gerektirmediğidir (Posner, 1974). Kamu Yararı Teorisi’nin dayandığı üç temel argüman; doğal tekel piyasaları, dışsallıklar ve kamusal mallardır.

Kamu Yararı Teorisi'ne göre, piyasada taraflar arasında asimetrik bilginin bulunması durumunda, piyasaya devletin müdahale etmesi gerekmektedir. Bilgiyi elde etmenin maliyetli olması, mallar hakkında etkin bir bilgi seviyesi elde etmenin mümkün olmadığı anlamına gelir ve piyasa başarısızlığı olarak değerlendirilebilir. Bilginin taraflar arasında simetrik dağılımının söz konusu olmadığı durumlarda ters seçim ve ahlaki zafiyet gibi sorunlar meydana gelebilmektedir. Ters seçim ve ahlaki zafiyet problemleri ise, piyasada pareto optimumunun gerçekleşmesini engellemektedir. Böyle bir piyasaya devletin müdahale etmesi, bilgi arzını arttırarak taraflar arasında daha etkin bir mübadele yapılmasını ve limon piyasalarda asgari standartlar koyarak tüketicilerin korunmasını sağlayabilir (Çetin, 2005).

Özel Çıkar Grupları Teorisi, regülasyonların, endüstriler tarafından ele geçirilebileceği ve öncelikli olarak o endüstrilerin çıkarları doğrultusunda uygulanabileceği hipotezine dayanmaktadır. Düzenlemeler aracıllğıyla endüstrideki firmalara verilen doğrudan sübvansiyonlar, firmaların hakim konumlarını güçlendirebilmekte ve yüksek kârlar elde etmesini sağlayabilmektedir. Özel Çıkar Grupları Teorisi'ne göre regülasyonlar, çıkar grupları tarafindan servet transferi amaciyla talep edilirken, toplumun diğer kesimleri de bu servetin arz edicileri konumunda bulunmaktadır.

Çıkar grupları tarafından idrak edilen regülasyonun fayda ve maliyetleri ile çıkar gruplarının siyasi güçlerini kullanabilme yeteneği, bu transfer sürecinin kimin lehine sonuçlanacağı konusunda önemli rol oynamaktadır (Joskow ve Noll, 1981). Bununla beraber, bazı tüketici grupları, üretici gruplarına nazaran daha etkin organize olabilmektedir. Tüketici grupları daha düşük fiyatlarla kendi çıkarlarını maksimize etmek isterken, endüstriler veya üretici grupları daha yüksek fiyatlarla kendi çıkarlarını maksimize etmek istemektedir. Tekrar seçilme kaygısı güden siyasi mekanizma, üretici gruplarının yanı sıra, tüketici gruplarının da oylarını kazanmayı amaçlayacağı için devlet, arz ve talep ilkelerine göre işleyen bu transfer sürecinde, kamu yararı yerine çıkar gruplarının menfaatlerini gütmektedir.

Kamu Tercihi Teorisi veya diğer adıyla Rant Kollama Teorisi; James M. Buchanan ve Gordon Tullock gibi Virjinya Okulu iktisatçıları tarafından iktisadi regülasyon literatürüne kazandırılmıştır. Teoriye göre; politikacıların ve bürokratların ekonomi politikalarını oluşturma ve yönlendirme aşamasındaki davranışları da regülasyon süreçlerini etkileyebilmektedir. Kamu Tercihi Teorisi, bu noktadan hareketle, rant arama maliyetlerini de analize dahil etmiş ve rantları; doğal ve suni rantlar olarak ikiye ayırmıştır. Doğal rantlar rekabetçi piyasa sisteminde etkinliği arttırıcı kâr arama faaliyetlerini teşvik ederken, suni rantlar hiçbir olumlu sonuç doğurmamakla beraber genelde tekel piyasalarında görülmektedir.

Rant arama yaklaşımına göre, regülasyonlar vasıtasıyla tekel gücü elde etme çabaları, kaynakların israf edilmesine yol açmaktadır. Suni rantların oluşturulmasına yönelik olan bu çabalar, rant elde etmek isteyenlerin yanı sıra, bu transferleri önlemek isteyenler açısından da ek maliyetler doğurmaktadır. Rantlar için gerçekleştirilen politik rekabet, kaynakların etkin olmayan kullanımı dahil pek çok alanda israfa yol açmakta ve ekonomi, üretim imkanları eğrisi üzerinde işleyişini sürdürememektedir (Krueger, 1974).

Avusturya Okulu iktisatçılarının görüşleri etrafında şekillenen Piyasa Süreci Teorisi, diğer teorilerin aksine, devletin piyasaya müdahale etmemesi gerektiği görüşünü savunmaktadır. Bireylerin ekonomik davranışlarını, neo-klasik sentez çerçevesinde değerlendirmeyen bu analizin merkezinde asimetrik enformasyon, girişimcilik ve rekabet kavramları yer almaktadır (Benson, 2002). Teoriye göre, bireylerin piyasadaki davranışları, sürekli değişen zaman ve asimetrik enformasyon koşulları altında gerçekleştiğinden bilgi birikimi, piyasadaki tecrübeler yoluyla elde edilmektedir. Dolayısıyla bireyler, bilgi birikimindeki değişimler nedeniyle benzer durumlar karşısında farklı davranışlar sergileyebilmektedir. Böyle bir ortamda, hangi regülasyonun bireylerin tercihlerine cevap vereceği belirlenemeyeceğinden, oluşturulan düzenlemelerin etkinsizliklere neden olacağ düşüncesi ileri sürülmektedir.

Piyasa Süreci Teorisi, regülatörleri, birer bütçe maksimizasyoncusundan ziyade birer girişimci olarak görmektedir. Regülatör konumunda bulunan bürokratlar, yapılan düzenlemelerden çeşitli çıkarlar elde edebileceğinden, her türlü girişimsel faaliyetin peşinden koşmakta ve kendi çıkarını maksimize edecek firsatları aramaktadır (Bootke ve Lopez, 2002). Bürokrat, düzenlemenin kendine sağladığı fayda ölçüsünde daha fazla 
bürokrasiye neden olan bir hak oluşturma süreci tasarlayabileceğinden, regülatör, regülasyon uygulayıcıs1 olmaktan çok regülasyon savunucusu durumuna gelebilmektedir.

\section{Finansal Regülasyonun Nedenleri ve Özellikleri}

Finansal regülasyon, düzenleyici otoritenin, finansal ajanların kararlarına ve davranışlarına kendi sosyal amaç fonksiyonunu maksimize etmek için getirdiği kurallar ve kisitlamalar olarak ifade edilmektedir. Ekonomi sektöründeki diğer regülasyonların aksine, finansal regülasyon, finansal piyasalarda faaliyet gösteren kurumların güvenliğini, bütünlüğünü ve şeffaflığını korumak amacıyla bu kurumların davranışlarını izleme, disipline etme veya koordine etme çabalarından oluşmaktadır. Sistemik risk ile yakından ilişkili olan finansal regülasyonlar, finansal piyasaların yanı sıra, ekonominin geneli açısından da önemli bir rol oynamaktadır.

\subsection{Finansal Regülasyonun Nedenleri}

Finansal regülasyonun iki temel amacı bulunmaktadır. Bunlardan ilki; finansal sistemin güvenliğini ve istikrarını sağlamak, ikincisi ise; finansal piyasaların büyümesini ve gelişmesini teşvik etmektir. Bu iki amacın gerçekleştirilebilmesi için optimal bir regülasyon sisteminin; etkinlik, hesap verilebilirlik, yetki ve yasallık olmak üzere dört temel karakteristik altında tasarlanması gerekmektedir (Pan, 2011). Ekonomik ve ihtiyati regülasyon olmak üzere ikiye ayrılan finansal regülasyonlar, düzenleme alanları ve etki kanalları açısından birbirinden ayrılmaktadır. Ekonomik regülasyon; kaynakların dağılımındaki piyasa başarısızlıklarını azaltmayı amaçlarken, ihtiyat regülasyonu ise; finansal sistemin istikrarını ve yatırımcıları korumayı amaçlamaktadır.

Finansal piyasaların düzenlenmesi ihtiyacının nedeni, hile ve ahlaki olmayan uygulamaların engellenmesi yoluyla rekabeti sağlamaktır. Finansal regülasyon, finansal piyasalarda yer alan taraflara gerekli bilgilerin doğru bir şekilde ve doğru bir zamanda iletilmesini sağlayarak güvenilir bir ortamın kurulmasına da yardımcı olmaktadır. Uygulanan regülasyon politikaları, tüketiciyi sadece firmaların tekelci fiyatlandırmalarından korumakla kalmamakta, bunun yanı sıra finans sektörü ve ekonomin diğer sektörleri için kaynak tahsislerinin verimliliğini de arttırmaktadır. Finansal regülasyonların nedenleri genel olarak; piyasa başarısızlıkları ve parasal kontrol şeklinde sıralanmaktadır.

Piyasa başarısızlığı, piyasaların kendi hallerine bırakıldıklarında etkin koşullarda işlememesi durumudur. Ekonominin diğer sektörleriyle karşılaştırıldığında finansal piyasalarda ortaya çıkan başarısızlıkların yarattığı olumsuzluklar ekonominin geneli için yıkıcı sonuçlar doğurabileceğinden, kamu otoriteleri bu aksaklıkların üzerinde önemle durmaktadır. Finansal piyasalarda ortaya çıkabilecek piyasa başarısızlıklarının genel olarak üç sebepten kaynaklanmaktadır. Bunlar; asimetrik enformasyon, dışsallıklar ve piyasa gücüdür.

Finansal regülasyona gerekçe oluşturan en önemli piyasa başarısızlığı olarak gösterilen asimetrik enformasyon, piyasada yeterli düzeyde bilginin bulunmamasını veya piyasada mevcut olan bilginin taraflar arasında eşit dağılmamasını ifade etmektedir. Asimetrik enformasyon, ekonominin diğer sektörleri için mikro ölçekte bir sorun teşkil ederken, finansal piyasalar açısından makro sorunlar teşkil edebilmektedir. Bunun nedeni ise, finansal piyasalarda meydana gelen bilgi probleminin, diğer piyasa başarısızlıklarının nedeni veya tetikleyicisi olarak görülmesidir.

Finansal piyasalarda yaşanan asimetrik enformasyon problemi, finansal işlemlerin gerçekleşmesinden önce veya sonra meydana gelerek, ters seçim ve ahlaki tehlike sorunlarına yol açmaktadır. Bir finansal işlemin gerçekleşmesinden önce meydana gelen bilgi problemine ters seçim (adverse selection) denilmektedir. Kredi riski yüksek olan bireyler, kredi talebinde bulunurken kendi risk durumuna ait bilgileri, kredi verenden saklayabilmektedir. Bu durum neticesinde, kredi verenler, verdikleri kredinin büyük olasılıkla yüksek kredi riskine sahip bireyler tarafindan talep edileceğini düşünerek kredi açmamaya karar verebilirler ve bu da ters seçim problemine neden olabilir. Ahlaki tehlike problemi ise; krediyi alan kişinin, aldığı krediyi sözleşmede belirtilen amacın dışında kullanmasını veya kredi verenin yararına olmayan faaliyetlere girişme riskini ifade etmektedir. Ahlaki tehlikenin söz konusu olduğu durumlarda, kredi alan yüksek riskli projelere yatırım yapmakta, yüksek getiri elde ettiği takdirde kazançlı çıkmakta, zarar ederse kaybın önemli bir kısmını kredi verene yükleyebilmektedir (Er, 2011). Ahlaki tehlike, kredinin geri dönme riskini azalttığından tasarruf sahipleri, piyasada kredi talebinde bulunan bireylere borç vermeyi reddedebilmekte ve böylelikle tasarrufların, kârlı yatırım alanlarında kullanılması engellenmiş olabilmektedir.

Ters seçim ve ahlaki tehlike gibi finansal piyasalarda meydana gelen asimetrik enformasyon problemlerinin çözümü, piyasada yeterli miktarda bilgi üreterek mümkün hale gelmektedir. Ancak bilgi, rakipsizlik ve dışlanmazlık özelliği olan kamusal bir mal olduğundan piyasadaki herkes bu bilgiden yararlanabilmekte ve dolayısıyla bedavacılık sorunu ortaya çıkmaktadır. Piyasada bulunan bilgi arzı yetersizliği, devlet müdahalesi yoluyla çözülmesi gerekmektedir (Heremans, 2000).

Dışsallıklar, finansal piyasalarda faaliyet gösteren kişi veya kurumların, piyasadaki diğer birimlerin ekonomik durumlarına olumlu veya olumsuz etki etmesi olarak ifade edilmektedir. Finansal piyasalarda birçok dişsallık sorununa rastlansa da, düzenleyici otoritenin, üzerinde önemle durduğu konu, bankacılık sektöründe meydana gelen dışsallıklardır. Finansal piyasalarda rol oynayan katılımcılar, piyasada hakim olan yüksek volatilite 
nedeniyle, aktiflerin gerçek değerlerine göre karar vermek yerine ortalama düşünce ve inanışlara göre hareket edebilmektedir. Bunun yanı sıra, finansal sektörün ekonomideki diğer sektörlere nazaran daha bağımlı olması, finansal sistemde bulunan aktörlerin, dişsallıklardan daha fazla etkilenmesine neden olmaktadır. Piyasada meydana gelen bir başarısızlık durumunda, piyasaya hakim olan sürü psikolojisi nedeniyle finansal panikler (bank runs) ortaya çıkmaktadır.

Bankalarla ilgili bir diğer sorunun yayılma etkisi (contagion effect) olduğu söylenebilir. Bir bankanın iflas etmesi durumunda diğer bankalar, ödeme gücü üzerinde bir işaret almaktadırlar. Bu bankalar finansal açıdan sağlam olsa bile, iflas eden bankanın tetiklediği güven kaybı, mudilerin de güvenini kaybetmesine sebep olmakta ve kendi paralarını bankalardan çekmesine yol açabilmektedir. Dolayısıyla, bir bankanın iflasıyla başlayan bu süreç, bankanın ilişkide bulunduğu finansal kurumları ve piyasaları likidite riskiyle karşı karşıya bırakabilmekte ve bir bankanın bireysel riski aniden sistemik riske dönüşebilmektedir (Llewellyn, 1999). Finansal sistemde meydana gelen panik ve banka başarısızlıkları gibi negatif dışsallıkların meydana geldiği bu gibi durumlarda, kamu otoritelerinin sisteme müdahalesinin kaçınılmaz olduğu söylenebilmektedir.

Piyasa gücü, bir mal veya hizmeti arz edenlerin veya talep edenlerin satın almak istedikleri mal veya hizmetin piyasa fiyatını ve/veya miktarını etkilemesi olarak tanımlanabilir. Reel ekonomide olduğu gibi, finansal piyasalarda da piyasa gücünün belirli firmaların kontrolünde bulunması, regülasyona gerekçe oluşturan bir başka piyasa başarısızlığıdır. Finansal piyasaların düzenlenmesinde etkinlik-istikrar ikileminde (trade-off) istikrara daha fazla önem verildiğinden, reel sektör düzenlemelerine göre farklı bir boyut kazandığı söylenebilir.

Finansal piyasalardaki firmalar, ölçek ekonomisi avantajlarından yararlanarak piyasada yüksek fiyatlar uygulayıp aşırı kâr elde edebileceğinden, üretici artığı ortaya çıkarak, etkinsizliğe ve kaynak transferine neden olmaktadır. Giriş ve fiyat sınırlamaları yoluyla piyasayı rekabetçi bir seviyeye yaklaştıracak olan bir regülasyon, firmanın elde ettiği aşırı kârların düşmesine yol açabilir. Bu durumda, kârları düşen firma, kazancını arttırmak amaciyla daha fazla risk almak isteyecektir.

Parasal kontrol, finansal piyasalarda üretim ve fiyat istikrarını sağlamayı amaçlayan makroekonomik bir istikrar politikası aracı olarak işlev görmektedir. Para arzında meydana gelen sert düşüş ve artışlar, makro değişkenleri etkileyerek ekonomide çeşitli olumsuzluklar yaratabilmektedir. Para arzında meydana gelen bu değişmeler, merkez bankası tarafindan kontrol edilen parasal taban veya finansal sistem tarafindan üretilen toplam kredi miktarı yoluyla etkilenebilmektedir. Merkez bankası, para arzını kontrol altına almak amacıyla zorunlu karşılık oranı, disponibilite oranı ve açık piyasa işlemleri gibi regülasyon araçları kullanmaktadır.

\subsection{Finansal Regülasyon-Sistemik Risk İlişkisi}

Sistemik risk, finansal sistemin tamamını veya büyük bir kısmını etkileme gücüne sahip olan başarısızlıkların gerçekleşme olasılığını ifade etmektedir. Sistemik risk kavramı, finansal istikrar konusuyla yakından ilgili olarak bankacılık krizleri meydana geldiğinde daha çok dikkat çekmektedir. Bir bankacılık krizi durumunda çoğu finansal kurumun yükümlülüklerini yerine getirememesi, yayılma ve domino etkisi sebebiyle, ekonominin diğer alanlarının da olumsuz yönde etkilenmesine neden olabilmektedir (Tiryaki, 2012). Düzenleyici otoriteler, finansal piyasaların ve kurumların, sistemik risk oluşturabilecek şoklardan korunması için finansal regülasyon araçlarını kullanabilmektedir.

\section{Finansal Krizler ve Finansal Regülasyonların Önemi}

Tam rekabet koşulları altında şekillenen serbest piyasa süreci, 1929-1930 iktisadi krizine kadar devam etmiştir. 1929-1930 iktisadi krizinin getirdiği olumsuzluklar, tüm ekonomik verileri ve özellikle finansal piyasaları önemli ölçüde etkilemiştir. Tarihsel süreç içerisinde meydana gelen bu ve benzeri birçok finansal kriz nedeniyle günümüze kadar çeşitli şekillerde düzenleyici önlemlerin alındığı görülmüştür. Alınan bu düzenleyici tedbirler, ülkelerin finansal krizden kurtulmalarına vesile olmuş ve finansal istikrarın sağlanmasında önemli bir rol oynamıştır.

\subsection{Finansal Krizlerin Tanımı ve Ortaya Çıkışları}

Finansal kriz genel olarak, herhangi bir mal, hizmet veya finans piyasasında meydana gelen ve kabul edilebilir bir değişim sınırının ötesinde gerçekleşen şiddetli fiyat ve miktar dalgalanmaları olarak tanımlanmaktadır. Finansal krizler, finansal piyasaların etkin bir şekilde işlevlerini yerine getirmesini engelleyerek, ekonomik faaliyetlerde daralmaya yol açmaktadır. Ülke ekonomisinin kötüleşmesi ve bankaların durumlarındaki belirsizlik, banka paniklerine neden olarak, ters seçim ve ahlaki tehlike problemlerini ortaya çıarabilmektedir. Diğer taraftan, borç-deflasyon ortamında meydana gelen bir finansal kriz durumunda fiyat düzeylerinde önemli düşüşlerin yaşanması, firmaların borçlanma yükünü arttırmakta ve net değerlerinin daha da bozulmasına yol açmaktadır. Dolayısıyla, iyi işleyen bir finansal piyasa, ekonominin toparlanma sürecini belirleyen en önemli faktörlerden biri olarak görülmektedir (Mishkin, 1991).

\subsection{Finansal Kriz Modelleri}

Finansal krizlerin farklı boyutlarda ve değişik şekillerde ortaya çıkması, krizlerin farklı modeller yardımıyla açıklanma gerekliliğini ortaya koymuştur. Kriz sonrası oluşturulan teorik modellerin, ardından gelen krizleri 
açıklamakta yetersiz kalması ve eksik yönlerinin görülmesi, yeni kriz modellerinin ortaya konulmasına ortam hazırlamıştır. Genel itibariyle finansal kriz modelleri; birinci, ikinci ve üçüncü nesil kriz modelleri olarak sinıflandırılmaktadır.

Birinci nesil modeller, finansal krizlerin, bütçe açıklarının artmasına bağlı olarak ortaya çıktığı görüşünü savunmaktadır. Sabit döviz kuru rejiminin uygulandığı bir ekonomide, bütçe açıklarının senyoraj yoluyla finanse edilmesi, merkez bankasının piyasayı dengelemek için kullandığı döviz rezervlerini kaçınılmaz olarak azaltmaktadır. Dolayısıyla, merkez bankasının sahip olduğu sınırlı sayıdaki rezervlerin eriyerek minimum noktaya geldiği durumda ekonomik birimler, yerli paraya karşı spekülatif ataklar gerçekleştirmektedir (Tularam ve Subramanian, 2013).

İkinci nesil modellerin temelinde, iktisadi ajanların beklentileri ile uygulanan politikalar arasındaki karşılıklı etkileşim yer almaktadır. İkinci nesil modellere göre; para ve maliye politikaları arasında tutarlılık bulunsa bile döviz kuru, yine de spekülatif ataklara maruz kalmaktadır. Ancak, bu modele göre; spekülatif atakların kaynağı, birinci nesil modellerde olduğu gibi ekonomik temellerdeki bozulmalar değil, kendi kendini besleyen bekleyişlerdir (Özatay, 2013). İkinci nesil modellerin iki önemli karakteristiği bulunmaktadır. Bunlar; hükümetlerin, spekülatif ataklara karşı döviz kuru oranlarını değiştirerek net fayda maksimizasyonunu amaçlaması ve ekonomide çoklu dengelerin mümkün olduğu varsayımıdır.

Üçüncü nesil modellere göre, para ve bankacılık krizlerini ortaya çıkaran faktörlerin ortak olduğu ve ekonomi açısından kısır bir döngü oluşturduğu ifade edilmektedir. Bu modelde, finansal krizlerin, banka paniklerinin bir sonucu olarak ortaya çıktığı görüşü kabul edilmektedir. Bu görüşe göre; banka yükümlülüklerinin vadesinin, banka varlıklarının vadesinden kısa olması, bankaların vade uyuşmazlığı (maturity mismatch) ve likidite uyuşmazlığı (currency mismatch) sorunu yaşamalarına sebep olmaktadır (Chang ve Velasco, 1998).

\subsection{Belli Başlı Finansal Krizler}

Finans piyasalarında yaşanan krizler kendini, geçmişten günümüze kadar farklı şekillerde göstermiştir. Çıkış nedenleri ve etkileme biçimleri farklı olmasına rağmen finansal krizler, ekonomik ve sosyal hayatın her alanında etkilerini derinden hissettirmiştir. Tarihsel süreç içerisinde yaşanan finansal krizler, regülasyon teorilerinde öne sürülen hipotezler vasıtasıyla açıklanabilmektedir.

Kapitalizmin gelişme sürecinde yaşanan en büyük kriz olma özelliğini sürdüren 1929 Krizi, finansal piyasalardaki bozulmalar, altın sterilizasyonu, korumacılık ve aşırı üretim ile yayılmacı süreçten sonra uygulanan deflasyonist para politikası kombinasyonu sonucu meydana gelen bir krizdir (Rothermund, 1996, 48). Hisse senedi piyasasında meydana gelen ani bir çöküş, dünya kredi sistemini zayıflatmış ve yaşanan krizde rol oynayan temel faktör olmuştur. Bunun yanı sıra, spekülatörlerin piyasada hakimiyetinin artmasıyla birlikte ortaya çıkan panik havası, krizin meydana gelmesine yol açan bir diğer unsur olmuştur.

1920’li yıllarda büyük şirketlerin, rekabeti önlemek ve tekel gücüne sahip olmak amacıyla küçük şirketleri bünyelerine katmaları, piyasadaki hareketliliği arttırmıştır. Farklı şehirlerde aynı iş kolunda bulunan firmaların birleşmesi holdinglere, diğer şirketleri kontrol etme gücü sağlamıştır. Diğer taraftan yatırım şirketlerinin, sahip oldukları mal varlıklarının iki hatta üç katı kadar hisse senedi alabilmesi, hisse senedi hacminde genişleme yaşanmasının bir diğer nedeni olmuştur (Duman, 2011).Borsada gerçekleştirilen bilinçli alım satımlar neticesinde hisse senedi fiyatları yükselmiş ve halk ile kurumlar, ahlaki olmayan yöntemlerle aldatılmıştır. Kamu Tercihi Teorisi'nde öne sürülen suni rant kavramı, 1929 Krizi’ni besleyen süreci destekler nitelikte gelişmiştir.

1994 yılında ortaya çıkan Meksika Krizi’nin, sağlam yasal düzenlemelerin olmadığı bir zeminde gerçekleştirilen finansal liberalizasyon süreci ve sabit döviz kuru uygulaması sonucu meydana geldiği söylenebilmektedir. Yaşanan finansal kırılganlıklar ve zayıf bankacılık sistemi, Meksika krizinin ortaya çıkmasında rol oynayan temel etken olmuştur. 1980'li yıllarda başlayan liberalizasyon hareketiyle birlikte, Meksika ekonomisinde yapısal ve makroekonomik stabilizasyon değişim süreci başlamıştır. Liberalizasyon süreci, ülkeye giren net sermaye girişlerini arttırmış ve cari işlemler açığı, bu yatırımlar yoluyla finanse edilmeye çalışılmıştır.

Meksika Krizi'nde, özelleştirme sürecinin çıkar grupları ekseninde gerçekleştirilmesi, finansal sistemin istikrarını tehdit eden önemli bir unsur olmuştur. Bununla birlikte, uygulanan finansal regülasyonlar, etkinlik amacından ziyade sektörün çıkarları doğrultusunda oluşturulmuştur. Özellikle, regülasyonların oluşturulması aşamasındaki yaşanan problemler, Meksika Krizi’nin Kamu Tercihi (Rant Kollama) Teorisi’yle örtüştüğünü göstermiştir.

1997 yılında meydana gelen Güneydoğu Asya krizi; etkileme kanalları, yayılma süreçleri ve sonuçları açısından diğer krizlerden farklı bir karakteristiğe sahiptir. Büyük Bunalım ve Meksika krizlerinde, başarısız politikalara bağlı olarak ortaya çıkan ciddi makroekonomik bozulmalar krizin temel nedeni olarak görülebilirken, Güneydoğu Asya krizinde rol oynayan temel faktörün finansal piyasalarda artan kırılganlıklar olduğu söylenebilmektedir. Güneydoğu Asya krizi, bölgenin tümü üzerinde etkili olsa da, en çok Beş Güneydoğu Asya ülkelerini etkilemiştir. Bunlar; Tayland, Kore, Endonezya, Malezya ve Filipinler'dir. 
1997 Güneydoğu Asya Krizi’nin ortaya çıkmasındaki temel faktör, kurumsal altyapının sağlam olmaması ve düzenlemelerin başarıyla uygulanamamasıdır. Yetersiz düzenlemeler, finansal kurumların yüksek kaldıraç oranlarıyla faaliyet göstermelerine imkân vermiş ve finansal piyasaları, sistemik şoklara karşı savunmasız hale getirmiştir. Bunula birlikte, Asya ülkelerinde uygulanan regülasyonlar, politik baskılar sonucu oluşturulmuştur. Dolayısıyla, Güneydoğu Asya Krizi'nde uygulanan regülasyonlar başarısızlıkla neticelenmiş ve Özel Çıkar Grupları Teorisi’nin öne sürdüğü hipotez doğrultusunda şekillenmiştir.

1998 Rusya krizi, yanlış yönetim sonucu ortaya çıkan bir finansal kriz olarak nitelendirilebilmektedir. Ekonomik sistemin, bazı grupların çıkarlarına uygun olarak şekillendirilmesiyle, kamu kesiminin finansal açıklarının artması, krizin en önemli nedeni olarak görülebilmektedir. Bunun yanı sıra, Rusya'nın da üretiminde bulunduğu emtiaların dünya fiyatında düşüşlerin yaşanması ve Güneydoğu Asya krizi gibi dışsal faktörlerin de, Rusya krizin ortaya çıkmasında rol oynadığı söylenebilmektedir

Güneydoğu Asya Krizi’nden bir yıl sonra patlak veren Rusya Krizi, dış borç yükümlülüklerinin artması sonucu finansal olmayan sektörün bilançolarındaki bozulmalar nedeniyle patlak vermiştir. Kriz öncesi göstergeler ve mali yapı sağlam olmasına rağmen, regülasyonların bazı çıkar grupları etrafinda şekillenmesi, finansal sistemin istikrarını olumsuz yönde etkilemiştir. Rusya Krizi de, Güneydoğu Asya Krizi’nde olduğu gibi Özel Çıkar Grupları Teorisi'nin öngörüleri doğrultusunda gerçekleşmiştir.

2007 yılının sonlarına doğru ABD’de patlak veren krizin, aşırı borçlanma yoluyla şişirilen varlık ve kredi balonu nedeniyle ortaya çıktığı ifade edilebilir. Konut piyasasında verilen ipotekli kredilerle başlayan çöküş süreci, finansal piyasalarda büyük bir istikrarsızlığa yol açmış ve daha sonra bir likidite krizine dönüşmüştür. Finansal piyasalar aracılığıyla etkisini genişleten kriz, tüm dünya ülkelerine yayılarak, küresel krizin zeminini oluşturmuştur.

2007-08 Küresel Finansal Krizi, reel sektörün yanı sıra, siyasal ve toplumsal açıdan da büyük sıkıntıların baş göstermesine yol açmıştır. 2008 yılında ABD menşeli olarak ortaya çıkan Küresel Kriz'in temel nedeni, ipotekli konut piyasasında geri dönmeyen kredilerin, türev ürünler aracılığıyla tüm finansal sektörü etkisi altına alması olmuştur. Devlet destekli mortgage şirketlerine ilişkin düzenlemelerde, Özel Çıkar Grupları Teorisi'nde olduğu gibi kamu yararından ziyade, baskı gruplarının çıkarlarının gözetilmesi, regülasyon başarısızlığının arkasındaki en önemli sebep olmuştur.

\subsection{Krizlerin Çözümlenmesinde Finansal Regülasyonların Önemi}

Dünya ekonomileri, tarihsel süreç içerisinde oldukça yıkıcı finansal krizlerle karşı karşıya kalmıştır. Farklı nedenler neticesinde ortaya çıkan finansal krizlerde, çeşitli regülasyon politikaları uygulansa da, tüm regülasyonların ortak amacı, toplumsal refahın arttırılmasıdır. Bu amaca yönelik olarak, ekonomik regülasyonlar, ihtiyati regülasyonlarla eşanlı olarak uygulanmaktadır. Özellikle finansal sektörün düzenlenmesi ve finansal krizlerin önüne geçilmesi amacıyla, ihtiyati regülasyon uygulamalarına ağırlık verilmektedir. Regülasyonlar, ülkelerin içinde bulunduğu koşullara ve etkinlik amacına paralel olarak uygulandığında, krizlerden çıkışta çok önemli bir rol oynamaktadır. Bununla birlikte, düzenleyici otorite bu amaca ulaşmaya çalışırken, regülasyon başarısızlıklarını ve bunların ekonomiye yükleyeceği maliyeti hesaplamalıdır. Ancak, regülasyondan sağlanan faydanın ölçülmesi güç olabileceğinden, temel amaç, regülasyonun varsayılan faydalarına ulaşmak için maliyetleri minimize etmek olmalıdır.

\section{Sonuç}

1929’dan itibaren dünya ekonomilerinde meydana gelen finansal krizlerde bankacılık ve finansa sektörü büyük bir rol oynamıştır. Finansal sektörün bu önemi, regülasyon teorilerinin finansal krizler üzerindeki etkilerini tartışma konusu haline getirmiştir. Tartışmaların odak noktasını, finansal piyasalarda ortaya çıkan asimetrik bilgi, dışsallıklar ve piyasaların gücü problemlerinin önlenmesine yönelik konular oluşturmuştur. Bu çerçevede, finansal liberalizasyon sürecinden kaynaklanan sistemik risk sorununun bertaraf edilmesi amaçlanmıştır. $\mathrm{Bu}$ amaçlar ekseninde, finansal istikrarı sağlamaya yönelik olarak regülasyon politikalarına ağırlık verilmiştir.

Yapılan açıklamalara ilişskin olarak, regülasyon başarısızlıklarının, bilgi ve tecrübe eksikliği ile ekonomik aktörlerin karşılıklı çıkar ilişkilerine bağlı olarak ortaya çıktığı görülmüştür. Çeşitli ülke deneyimlerinden hareketle, regülasyon başarısızlıklarının, rant kollama faaliyetlerine ortam hazırlayarak, finansal krizlere neden olduğu sonucuna ulaşılmıştır. Bununla birlikte, ekonomik aktörlerin düzenleyici süreci etkilemeye yönelik davranışlarının, regülasyon teorilerini destekler nitelikte gerçekleştiği gözlemlenmiştir.

Finansal piyasalarda oluşturulmaya çalışılan düzenleyici yapının, ülkelerin kendine özgü koşulları doğrultusunda şekillendiğini ifade etmek mümkündür. Nitekim ABD’nin regülasyonlara büyük önem atfeden bir ülke olması, 2007-08 Küresel Krizi'nin yaşanmasına engel olamamıştır. Dolayısıyla, modern yenilikçi fỉnans ile eşgüdüm içerisinde olmayan regülasyonlar, başarısızlıklarla neticelenmektedir. Bu açıdan, regülasyonlar, etkinlik ve istikrar dengesi gözetilerek gerçekleştirilmeli ve sistemik risk olgusu üzerine inşa edilmelidir. 


\section{Kaynakça}

- Ağcakaya Serpil ve Nadide Sevil Halıcı, 2005. "Bir İktisat Politikası Aracı Olarak Regülasyon Politikası", Telekomünikasyon ve Regülasyon Dergisi, 2, ss. 96-105.

- Akça Haşim, 2007. Regülasyon Ekonomisi. Nobel Kitabevi, Adana.

- Atiyas İzak, 2000. "Ne için ve Nasıl Regülasyon”, Devletin Düzenleyici Rolü, 19, ss. 19-33.

- Benson Bruce L., 2002. "Regulatory Disequilibrium and Inefficiency: The Case of Interstate Trucking”, The Review of Austrian Economics, 2, ss. 229-255.

- Bootke Peter J. ve Edward J. Lopez, 2002. "Austrian Economics and Public Choice”, The Review of Austrian Economics, 2, ss. 111-119.

- Chang Ha-Joon, 1997. "The Economics and Politics of Regulation”, Cambridge Journal of Economics, 6, ss. 703-728.

- Chang Roberto ve Andres Velasco, 1998. "Financial Crises in Emerging Markets: A Canonical Model “, NBER Working Paper Series, 6606, ss. 1-45.

- Çetin Tamer, 2005. "Regülasyon İktisadı Üzerine Farklı Yaklaşımlar”, Telekomünikasyon ve Regülasyon Dergisi, 2, ss. 106-123.

- Duman Erhan, 2011. “Krizlerin Anatomisi: 1929 Ekonomik Buhranı ve 2008 Küresel Krizi’nin Karşılaştııılması", Karamanoğlu Mehmetbey Üniversitesi Sosyal Bilimler Enstitüsü, Yayımlanmamış Yüksek Lisans Tezi, Karaman.

- Er Selami, 2011. "Finansal Krizleri Önleme Aracı Olarak Finansal Sektörün Regülasyonu, Mortgage Krizi ve Türkiye", Maliye Dergisi,160, ss. 307-327.

- Heremans Dirk, 2000. "Regulation of Banking and Financial Markets", Encyclopedia of Law and Economics, 5850, ss. 950-986.

- Hertog Johan den, 1999. "General Theories of Regulation”, Encyclopedia of Law and Economics, 5000, ss. 223-247.

- Joskow Paul L. ve Roger C. Noll, 1981. "Regulation in Theory and Practice: An Overview", Studies in Public Regulation, ss. 1-65.

- Krueger Anne O., 1974. "The Political Economy of the Rent-Seeking Society", The American Economic Review, 3, ss. 291-303.

- Llwellyn David, 1999. “The Economic Rationale for Financial Regulation”, Financial Services Authority Occasional Papers in Financial Regulation, ss. 5-54.

- Mishkin, Frederic S, 1991. "Anatomy of A Financial Crisis", NBER Working Paper Series, 3934, ss. 1-24.

- Özatay Fatih, 2013. Finansal Krizler ve Türkiye. Doğan Kitap, İstanbul.

- Pan Eric J., 2011. "Structural Reform of Financial Regulation", Transnational Law \& Contemporary Problems, 796, ss. 797-853.

- Posner Richard, 1974. "Theories of Economic Regulation”, The Bell Journal of Economics and Management Science, 2, ss. 335-358.

- Rothermund Dietmar, 1996. The Global Impact of the Great Depression 1929-1939.Routledge Publishing, Londra.

- Taşar M. Okan, 2009. "Finansal Regülasyonlar ve Küresel Kriz Sürecinde Türk Dünyası Bankacıllk Sistemlerinin Yeniden Yapılandırılması", Journal of Azerbaijani Studies, ss. 147-186.

- Tiryaki Göksel, 2012. . Finansal İstikrar ve Bankacılık Düzenlemeleri- (1990-2010 Türkiye Tecrübesi Iş̧ı̆ıında). TBB Yayınları, İstanbul.

- Tularam Gurudeo A. ve Bhuvaneswari Subramanian, 2013. "Modeling of Financial Crises: A Critical Analysis of Models Leading to the Global Financial Crisis", Global Journal of Business Research, 3, ss. 101-124.

- Vickers John, 1997. "Regulation, Competition, and the Structure of Prices", Oxford Review of Economic Policy, 1, ss. 15-26. 


\title{
Türkiye ile Rusya Federasyonu Serbest Ticaret Anlaşmasının İki Ülke Ticaretine Olası Etkileri ve Vergisel Yansımaları
}

\section{Free Trade Agreement between Turkey and Russian Federation and its Possible Effects to these Countries' Trade and Taxational Reflections}

\author{
Raşit Gültekin (Trakya University, Turkey) \\ Assoc. Prof. Dr. Mustafa Erkan Üyümez (Anadolu University, Turkey)
}

\begin{abstract}
The last period of international trade in goods covers a process carried out with globalization and regionalization efforts. Many countries, on the one hand, take part in arrangements that are executed under the leadership by global actors and aim at removing or reducing conventional obstacles to international trade, on the other hand, participate in various and regional economic integrations to provide a more deep and comprehensive economic cooperation and to cope with the competition and trade restrictions which continually increasing due to political, commercial and economical motives. Trade relations between Turkey and Russian Federation is an important element of the two countries' multidimensional cooperation. The most effective attempt to raise the top level of the volume and quality of existing commercial relationships will be the signing and putting into practice of a comprehensive free trade agreements between the two countries that have not been done previously. The purpose of this study is to determine the potential effects of such a free trade agreements between Turkey and Russian Federation in terms of trade in goods between two countries. To this end, in this study, theoretical aspects of free trade agreements' effects and place within regional integration types will be considered the impact of the possible Turkey-Russia free trade agreement will be examined in a framework of basic provisions with customs duties that set out in free trade agreements, recent trade data and key issues related to these countries.
\end{abstract}

\section{Giriș}

Uluslararası ticaretin önemli bir bölümünü, ülkeler arasında yapılan anlaşmalarla kurala bağlanmış eşya hareketleri oluşturmaktadır. Tarafları, konusu, amacı ve kapsamı bakımından farklı türlere ayrılan bu anlaşmalar, özellikle İkinci Dünya Savaşı sonrasında artış göstermiş ve iki kutuplu dünya siyasal sisteminin sona erdiği 1990 sonrası dönemde gelişmekte olan ülkelerin diş ticaret politikalarına yön veren bir etken halini almıştır. Bunda, uluslararası ticaretin serbestleştirilmesi, maliyet unsurlarından arındıılması ve prosedürel bakımdan basitleştirilmesi çabaları yanında, ülkelerin küresel refahtan olabildiğince fazla pay almak istemesi etkili olmuştur.

Uluslararası eşya ticaretinin tam anlamıyla serbest olduğu ve tüm ülkelerin yararına gerçekleştiği söylenemez. Ülkeler ekonomik, siyasi, sosyal ve kültürel nedenlerle ticaretin işleyişine müdahale edebilmektedirler. Örneğin ithalatın yerel üreticilere zarar vermemesi, sanayileşme hızının artııılması, cari açı̆̆ın dengelenmesi, belirli sektörlerin özendirilerek rekabet gücünün artırılması, kamu sağlığının korunması, bitki ve canlı türlerinin korunması ya da uluslararası terörizmle mücadele amacıyla gümrük tarifeleri, kota, antidamping ve sübvansiyona karşı önlemler, kambiyo ve ihracat kontrolleri ile ambargo gibi çeşitli tarife ve tarife dışı önlemlere başvurulabilmektedir. Sayılan bu önlemlerden gümrük vergileri günümüzde görece önemini kaybetmiş, buna karşın ürün güvenliğine ve çevreye ilişkin idari düzenlemeler ve standartlar önem kazanmış durumdadır.

Uluslararası eşya ticaretinin bugün geldiği noktada, birbirine zit ve aynı zamanda birbirini tamamlayan iki akımın etkisi olmuştur. Bunlardan ilki ticaretin serbestleşmesinin itici gücü olan küreselleşmedir. Ticaretin küreselleşmesi, tarihi çok eskilere gitmekle birlikte, esas olarak, 1947'de Gümrük Tarifeleri ve Ticaret Genel Anlaşması'nın (GATT) imzalanmasıyla başlamaktadır. GATT'ın yerini, kurumsal bir yapı olarak, 1994'te Dünya Ticaret Örgütü (DTÖ) almış ve ticaretin serbestleştirilmesi amacıyla çok taraflı ve GATT’a göre daha kapsamlı düzenlemelere gidilmiştir. İkinci akım ise bölgeselleşme olup, bu akım, ticaret blokları oluşturmak suretiyle küresel ticarette rekabet avantajı kazanmak ve GATT/DTÖ sisteminin açmazlarını aşmak amacıyla çeşitli düzeylerde ekonomik entegrasyonlar şeklinde kendini göstermiş, özellikle de 1990 sonrası dönemde etkisini artırmıştır. Serbest ticaret alanı, gümrük birliği, tek pazar, ekonomik ve parasal birlik şeklindeki bölgesel ekonomik entegrasyonlara, belirli şartlar altında, GATT/DTÖ sistemi çerçevesinde de izin verilmektedir.

Uluslararası eşya ticaretinin geçirdiği kapsamlı gelişim süreci Türkiye ve Rusya Federasyonu arasındaki ticari ilişkiler açısından da belirleyici olmuştur. Nitekim 2008 yılında yaşanan kriz ve iki ülke arasında gümrük işlemlerinden kaynaklanan sıkıntılar sonrasında güçlendirilmiş çok boyutlu ticari ilişkiler kurulması yoluyla 100 Milyar Dolarlık dış ticaret hacmi hedefinin belirlenmesi, bu amaçla gümrük ve taşımacılık işlemlerinin hızlandırılmasına yönelik düzenlemelere gidilmesi ve nihayetinde bir serbest ticaret anlaşmasının yapılması 
iradesinin ortaya konulması, esasında küresel ve bölgesel akımların etkisiyle gerçekleşmiştir. Türkiye ve Rusya Federasyonu'nun gerek üyesi bulundukları ülkeler arası oluşumlar, gerekse diğer ülkelerle ticari ilişkileri ve dış ticaretlerine konu ettikleri eşya türleri, iki ülke arasında olası bir serbest ticaret anlaşmasının gerekliliğinin, kapsamının ve etkilerinin incelenmesi ihtiyacını doğurmaktadır. Bu bağlamda çalışmamızın birinci bölümünde, eşya ticaretinde küreselleşme ve bölgeselleşme akımlarına ve bu akımların kurala bağlanması açısından hukuki zemin oluşturan uluslararası anlaşmalara terminoloji ve kapsam açısından kısaca değinilecektir. İkinci bölümde, Türkiye ile Rusya Federasyonu arasında gerçekleşen eşya ticareti hacim ve içerik bakımından incelenerek ağırlıklı olarak ticarete konu eşya gruplarına ilişkin gümrük vergileri ile bağlantılı konular ele alınacaktır. Son bölümde de Türkiye ve Rusya Federasyonu arasında yürürlüğe girecek bir serbest ticaret anlaşmasının teori ve uygulama açısından iki ülke ticaretine etkileri değerlendirilecektir.

\section{Küreselleşme-Bölgeselleşme Akımları ve Uluslararası Ticaret Anlaşmaları}

Ülkeler arası eşya ticareti bir birine zıt ve aynı zamanda birbirinin tamamlayıcısı sayılabilecek iki akımın etkisi altında geliş̧mektedir. Her iki akımın da hukuki zeminini uluslararası anlaşmalar oluşturmaktadır. Aşağıda küreselleşme ve bölgeselleşme akımları ile eşya ticaretini kurala bağlayan anlaşmalara değinilecektir.

\subsection{Küreselleşme ve Bölgeselleşme Akımları}

Ülkeler ilk çağlardan itibaren, bir yandan üretim fazlasına pazar bulmak, diğer yandan da kendi kaynaklarıyla karşılayamadıkları ihtiyaçlarını karşılamak amacıyla birbirleriyle eşya ticareti yapmaktadırlar. Konusunu oluşturan eşyanın türüne bağlı olarak ihracatçı için yüksek gelirli, ithalatçı için düşük giderli olması hedeflenen bu ticaretin sürekliliğinin ve düzeninin korunması amacıyla küresel veya bölgesel girişimler söz konusu olabilmektedir. $\mathrm{Bu}$ girişimler, siyasi nedenler bir tarafa bırakıldığında, korumacılığın ve serbest ticaretin sağlanması şeklinde birbirine zıt (Ertürk, 2006) ya da tam tersine, birbirinin tamamlayıcısı (Şanlı 2004) sayılabilen iki akımın etkisi altında kalmıştır. Bu akımlardan ilkini, GATT/DTÖ çatısı altında çok taraflı anlaşmalar yoluyla gerçekleştirilmek istenen serbestleşmeyi esas alan küreselleşme; ikincisini de tercihli ticarete dayalı ekonomik entegrasyon türlerini esas alan bölgeselleşme oluşturmaktadır.

Ekonomik küreselleşme kavramı, gümrük duvarları, tarifeler, kotalar ve sermaye kısıtlamaları gibi engellerin kaldırılması veya azaltılması yoluyla eşya, hizmet, işgücü ve sermayenin ülkeler arasında hızlı ve kolay dolaşabilir hale gelerek dünyanın ekonomik olarak bütünleşmesidir (Adıgüzel, 2013). Küreselleşmenin ekonomik boyutu esasında ticari küreselleşme, mali küreselleşme ve üretimin küreselleşmesi olmak üzere üç saç ayağına dayanmaktadır. Bunlardan ticari küreselleşme, ticaretin önündeki gümrük tarifeleri ve kotaların kaldırılması yoluyla uluslararası ticaretin serbestleştirilmesini ifade etmektedir (Seyitoğlu, 1999; Karluk, 2009). Bu bağlamda DTÖ, Birleşmiş Milletler (BM), Dünya Gümrük Örgütü (DGÖ), Uluslararası Ticaret Odası (UTO) ve benzeri ekonomik ve mesleki kuruluşların faaliyetlerinin amacı işlemlerin azaltılması ve maliyetin düşürülmesi yoluyla gümrük sınırlarından olabildiğince kolay geçişinin sağlanması ve küresel ticaret ve refahın artırılmasidır.

Küreselleşme akımı, küresel çapta gelişen ekonomik krizlerin etkisi altında kalmıştır. Özellikle 1929 Krizi ile birlikte çoğu ülke yüksek gümrük tarifeleri, ithalat kısıtlamaları ve yasakları ile ihracat teşvikleri yoluyla ulusal ekonomilerine müdahale etmiş ve bu durum krizin tüm dünyaya yayılmasıyla ve dünya ticaretinin daralmasıyla sonuçlanmıştır (İncekara, 1995). Krizin atlatılması amacıyla Bretton Woods sistemi çerçevesinde Uluslararası Para Fonu, Uluslararası İmar ve Kalkınma Bankası (Dünya Bankası) ve Uluslararası Ticaret Organizasyonu'nun kurulması öngörülmüş (Seyidoğlu, 1999; Krueger, 1999) ve ayrıca 1947 tarihli GATT çerçevesinde kabul edilen en çok kayrılan ülke, ulusal işlem, tarifeler yoluyla koruma ve gümrük vergilerinin indirilerek konsolide edilmesi kurallarıyla uluslararası ticaretin serbestleşmesi yolunda adım atılmışır. 1947 tarihli GATT'ın yerine geçmek üzere 1994 tarihinde imzalanan ve ekleriyle birlikte 29 adet metinden oluşan DTÖ Anlaşmaları da ticarete ilişkin evrensel kuralların genişletilmesine ve derinleştirilmesine katkı sağlamıştır.

Bölgeselleşme akımı ise coğrafi olarak birbirine yakın ve aralarında ekonomik ilişki bulunan ülkelerin mal, hizmet ve sermaye akımlarını serbest hale getirerek, verimlilik ve rekabet güçlerini arttırma ve bir arada barış içinde yaşama amacına dayanmaktadır (Şanl1, 2004). Özellikle gelişmekte olan ülkeler tarafından uluslararası rekabet şartlarına birlikte karşı koyma ve dış pazar olanaklarını yükseltmede bölgeselleşme bir araç olarak görülmektedir. 1994 tarihli DTÖ'nün XXIV. maddesine göre, bildirimde bulunulması, üyeler arasındaki engellerin önemli ölçüde kaldırılması, üçüncü ülkelere yönelik ticari engellerin artırılmaması ile on yıllık sürenin gözetilmesi şartlarıyla, gümrük birlikleri ve serbest ticaret bölgelerinin oluşumların kurulması mümkündür.

Literatürde bölgeselleşme süreci, 1950-1990 arası dönemi için eski bölgeselleşme, 1990 sonrası dönemi için de yeni bölgeselleşme olmak üzere ikiye ayrılmaktadır. Latin Amerika ve Afrika'da bulunan gelişme yolundaki ülkeler arasında geniş kabul gören eski bölgeselleşme, Uzakdoğu ülkeleri ve Amerika Birleşik Devletleri’nin (ABD) çok taraflı serbestleşme eğilimini savunmaları nedeniyle akımdan uzak durduğu 1950-1990 arası iki kutuplu dünya siyasal sisteminde, yeni bir güç merkezi olabilmek amacıyla Avrupa bölgesindeki gelişmiş ülkeler arasında, diğer bölgelerde ise gelişme yolundaki ülkeler arasında gerçekleşmiştir (Çalışkan, 2011). Bu dönemin temel özelliği, dış ticarette ağırlıklı olarak ithal ikameci/korumacı politikaların takip edilmesidir. Yeni 
bölgeselleşme ise, 1990 sonrası oluşan tek kutuplu dünya siyasal sisteminde ABD’nin bölgeselleşme lehine tutum değiştirdiği ve bilgi ve ulaşım ağında yaşanan gelişmeler ile birlikte uluslararası ticaretin ağırlıklı olarak serbest ticaret anlaşmalarıyla yürütüldüğü dönemdir. Esasında yeni bölgeselleşme çok taraflı ticaret görüşmelerinin başarısızlı̆̆ına karşı alternatif bir yol ve baskı aracı olarak ortaya çıkmıştır (Genç ve Berber, 2011). Nitekim Doha Kalkınma Turu sonrasında çok taraflı ticaret müzakerelerinin açmaza girmesi, başta $A B$ ve ABD olmak üzere çok sayıda ülkeyi özellikle serbest ticaret anlaşmaları yoluyla bölgesel ticari düzenlemeler yapmaya yöneltmiştir (Akman, 2014). Coğrafi yakınlık, ticari ilişkilerin yoğunluğu, ekonomik, siyasi ve askeri konularda yakın işbirliği, yakın ekonomik gelişme düzeyi ve tarihi, sosyal ve kültürel bağların etkili olduğu bölgesel oluşumlar (Seyidoğlu,1999), küresel çapta ekonomik krizlerin yaşandığı dönemlerde artan korumacılık eğilimine paralel olarak, serbest ticaret bölgeleri ve birliklerine üyelik şeklinde daha da yaygınlaşmıştır (Günay ve Can, 2011).

Günümüz ticari ilişkilerinde küreselleşme ve bölgeselleşme akımı birlikte görülmektedir. Nitekim ülkelerin çok taraflı ticaret görüşmeleri yoluyla serbest ticaret sistemine katılması ve aynı zamanda artan rekabete ayak uydurma ve uluslararası ticaretten daha fazla pay almak için bölgeselleşme hareketlerine katılma eğilimi artarak devam etmektedir. Ancak ülkelerin bir yandan küreselleşme süreci içinde çok taraflı ticaret görüşmelerinde, diğer yandan da ikili ve bölgesel ticaret anlaşmalarında görülen artış, uluslararası ticaret açısından karmaşık bir yapı da ortaya çıkmıştır. Literatürde spagetti kasesi (spaghetti/noodle bowl) olarak adlandırılan (Bhagwati, 1995) bu durum Amerika, Avrupa, Afrika ve Asya olmak üzere dört merkezli ve karmaşık ticari ilişkiler ağ oluşturmuştur (Genç ve Berber, 2011; Baccini vd., 2011).

Küreselleşme ve bölgeselleşme süreci karşısında Türkiye ve Rusya Federasyonu'nun durumu ne olmuştur? Türkiye BM, DTÖ, DGÖ gibi kurumsal oluşumlar zemininde yürütülen çalışmalara katılarak küreselleşme akımına uyum sağlarken, bölgeselleşme bağlamında $\mathrm{AB}$ ile kurulan gümrük birliği çerçevesinde Birliğin üçüncü ülkelere dönük tercihli gümrük rejimlerini uygulamaktadır. Çok taraflı ticari ilişkiler ve ticaretin serbestleştirilmesi konusunda aktif üyesi olduğu DTÖ içinde ülkemiz, hem gelişme yolundaki ülkeler grubunda yer alarak karşılıksız tavizlerden yararlanan, hem de ekonomik gelişmişliği bakımından tavizden yararlandıran ülke konumundadır. Rusya Federasyonu ise 22 Ağustos 2012’de DTÖ’ye katılarak 156. üyesi olmuştur. Dünya ticaretinde yaşanan en geniş kapsamlı serbestleşme adımlarından biri sayılan bu üyelik sayesinde DTÖ'nün dünya ticaretindeki etki alanı \% 2 artarak \% 97'ye ulaşmıştır. DTÖ üyeliği ile küresel ekonomi ile bütünleşme yolunda Rusya Federasyonu, gümrük vergilerinin konsolide edilerek düşürülmesi, ayrımcı ticaret yasağına uyulması, izin ve belgelendirmede idari engellerin ve tarife dışı uygulamaların kaldırılması, sübvansiyon uygulamalarında DTÖ kurallarına uyulması gibi DTÖ kurallarına ve ilgili anlaşmalarına uymayı taahhüt etmiştir. Diğer taraftan Rusya Federasyonu, Belarus, Kazakistan, Kırgızistan ve Ermenistan ile birlikte Avrasya Gümrük Birliği'nin (AGB) üyesidir. AB'ye paralel şekilde, Rusya Federasyonu da AGB'nin etki alanını serbest ticaret anlaşmaları yoluyla genişletmek istemektedir.

\subsection{Eşya Ticaretine İlişkin Uluslararası Anlaşmalar}

Ülkeler, yabancılık unsuru içermesi nedeniyle dış ticaret alanını anlaşmalar yoluyla düzenlemektedirler. Ancak bu anlaşmalar, ülkelerin farklı ekonomik yapıları, hukuk sistemleri ve toplumsal düzenleriyle ilişkili olması nedeniyle katılım, taviz ve konu unsurları bakımından değişiklik gösterebilmektedir. Aralarındaki ayrımın net olarak ortaya konulması güç olmakla birlikte eşya ticaretine ilişkin uluslararası anlaşmalar, katılım bakımından; çok taraflı (multilateral/plurilateral), bölgesel (regional) ve iki taraflı (bilateral) anlaşmalar olarak üç, vergisel taviz unsuru bakımından; karşılıklı (reciprocal) ve karşılıksız/tek taraflı (non-reciprocal/unilateral) tercihli (preferential) ticaret anlaşmaları olmak üzere iki şekilde dizayn edilebilmektedir. Tercihli ticaret anlaşmaları çok taraflı veya iki taraflı yapılabilmektedir. Konusu bakımından anlaşmalar ise sadece eşya ticaretini veya eşya ticareti ile birlikte hizmet ticaretini kapsayan anlaşmalar şeklinde ikiye ayrılmaktadır. Bölgesel ekonomik entegrasyon kuran anlaşmalar ise serbest ticaret alanı (free trade area/FTA), gümrük birliği (customs union/CU), ortak pazar (common market/CM) ile ekonomik ve parasal birlik (economic and monetary union/EMU) kuran anlaşmalardır.

Yukarıda belirtildiği üzere eşya ticaretine yönelik çok taraflı girişimlerin en önemli örneğini, bu ticareti küresel düzeyde kurallara bağlayarak serbestleştirilmesini amaçlayan, 1947 tarihli GATT oluşturmaktadır. Kurumsal yapısının oluşmaması, kapsamın sadece eşya ticaretiyle sınırlı kalması ve anlaşmazlıkların çözümünde varlık gösterememesi gibi nedenlerle GATT yerini, 1 Ocak 1995'te, tarım ürünleri, hizmetler, fikri mülkiyet hakları ve ticaretle bağlantılı yatırımlar, antidamping ve telafi edici vergiler, menşe ve gümrük kıymetinin belirlenmesi gibi çok daha fazla konuyu kurumsal yapısı içinde ve bağlayıcı önlemlerle takip eden DTÖ’ye bırakmıştır. DTÖ ile birlikte uluslararası ticaret sistemi üç bölümden oluşan bir piramit gibi düşünülmüş ve bu piramidin zirvesinde çok taraflılığa, ortasında bölgeselliğe/iki taraflılığa ve zemininde de üye ülkelerin yerel ticaretine ve ekonomi politikalarına yer verilmiştir (Leal-Arcas, 2011). Esasında piramidin orta kısmında yer verilen bölgesel/ikili düzeydeki bölgesel ticari ilişkiler, DTÖ temelinde yürütülen çok taraflı ticari ilişkiler açısından bir tehdit olarak algılansa da, bu düzeydeki ilişkilerin uluslararası ticaretin gelişmesine önemli katkısı da olmuştur (U. Candaş, 2010; Cottier, 2005). İki taraflı ticaret anlaşmaları iki ülke arasında ya da bir ülke ile bir grup ülke arasında, bölgesel ticaret anlaşmaları ise bir bölgeye özgü belirli sayıda ülke arasında gerçekleşmektedir. İki taraflı veya 
bölgesel ticaret anlaşmaları tarife, kota veya diğer engellerin kaldırılması veya azaltılması amacıyla yürürlüğe girmektedir. Eşya ticareti yanında hizmetler, fikri mülkiyet haklarının korunması, yabancı yatırımlar, kamu alımları gibi konuları da kapsayan iki taraflı ve bölgesel ticaret anlaşmaları, anlaşma hükümlerinden sadece tarafların yararlanabilmesi bakımından tercihli ticaret anlaşması sayılmaktadır (Brownsell, 2012).

Eşya ticaretine ilişkin anlaşmalar, tercihli olma durumuna göre ayrıma da tabi tutulabilmektedir. DTÖ tarafından yapılan bir ayrıma göre tercihli ticaret anlaşmaları (preferential trade arrangements-PTAs); gelişmişlik düzeyi (taraf ülkelerin sadece gelişmiş ya da gelişmekte olan ülke olmaları ya da her ikisinin birlikte olması), coğrafi kapsamı (bir bölge içi veya bölgeler arası olması- örneğin Avrupa, Orta Doğu, Afrika, Bağımsız Devletler Topluluğu, Amerika -Avrupa), tipi (iki taraflı, çok taraflı, bölge blokları arası), piyasa entegrasyonu derecesi (örneğin serbest ticaret anlaşması, gümrük birlikleri) ve konusu (eşya, hizmet ve düzenleyici konular) olmak üzere beş gruba ayrılmaktadır (WTO, 2011). Diğer bir ayrıma göre tercihli ticaret anlaşmaları karş1lıklı (reciprocal) ya da karşı1ıksız (non-reciprocal) olabilmektedir. DTÖ düzenlemeleri uyarınca yapılan karşılıksız tercihli ticaret anlaşmaları, tek taraflı olarak en az gelişmiş ülkelere, gelişme yolundaki ülkelere ve özel teşvik uygulamaları kapsamındaki ülkelere uygulanan karşılıksız tavizli gümrük vergilerini içermektedir. Genelleştirilmiş Tercihler Sistemi (GTS) (Generalized System of Preferences-GSP) olarak adlandırılan bu uygulamada, anlaşmaya taraf ülkeler eşya grubuna göre taviz veren ya da tavizden yararlanan ülke statüsünde olabilmektedir. Tercihli ticaret anlaşmalarının karşılıklı tavizli tarife hükümleri içermesi de mümkündür. Bu durumda tek taraflı tavizli tarife tanıyan anlaşmalar için tercihli ticaret düzenlemesi (preferential trade arrangement) karşılıklı taviz hükmü içerenler ise tercihli ticaret bölgesi (preferential trade area) olarak adlandırmaktadır (Karluk, 2009).

Bölgesel ekonomik entegrasyonlar bağlamında yapılan ayrımda gümrük birliği kuran anlaşmalar, üyeleri arasında serbest ticaret alanı oluşturmakla birlikte, iç gümrüklerin kaldırılarak gümrük bölgesinde eşyanın serbest dolaşımına olanak tanınması ve üçüncü ülkeler için de ortak gümrük tarifesinin ve ortak ticaret politikalarının uygulanılması bakımından serbest ticaret anlaşmalarından ayrılmaktadır. Ortak pazar kuran anlaşmalar, eşya yanında, emek ve sermaye gibi üretim faktörlerinin de anlaşmaya taraf ülkeler arasında serbest dolaşımını sağlamaktadır. Ekonomik ve parasal birlik kuran anlaşmalar ise en ileri ekonomik entegrasyon sürecini başlatarak, üye ülkeler arasında para ve maliye politikalarının koordinasyonunu ve uyumlaştırılmasını sağlamaktadır.

Serbest ticaret anlaşmaları (Free Trade Agreements-FTAs), taraf ülkeler arasında bir serbest ticaret alanı (Free Trade Area-FTA) kuran ve bu ülkeler arasındaki ticaretteki engellerin ve ayrımcı tarifelerin, miktar kısıtlaması gibi diğer ticaret politikası önlemlerinin kaldırıldığı veya azaltıldı tercihli ticaret anlaşmalarıdır. Ekonomik birleşmelerin en zayıf türünü oluşturan (Karluk, 2009) serbest ticaret anlaşmasına taraf ülkeler, üçüncü ülkelere karşı ortak gümrük tarifesi uygulanması konusunda serbesttirler. Başlangıçta sadece gümrük vergilerini ve tarife dışı önlemleri kapsayan serbest ticaret anlaşmaları günümüzde, sanayi, tarım ve balıkçılık ürünleri, ticarete ilişkin ödemeler, devlet yardımları, damping, fikri ve sınai mülkiyet hakları, bitki sağlığı önlemleri, doğrudan yabancı sermaye akımları ile kamu alımları gibi pek çok konuyu kapsar hale gelmiştir (Kayıhan ve Eski, 2010). Nitekim literatürde ve uygulamada kapsamı genişleyen serbest ticaret anlaşmaları için artık ekonomik ortaklık anlaşması (Economic Partnership Agreement-EPA) ifadesi kullanılmaya başlanmıştır. Bölgesel ticaret anlaşmaları \% 82,6 oranında serbest ticaret anlaşması şeklinde gerçekleşmektedir. Kalan anlaşmalarının \% 10,5'i gümrük birliği, \% 6,9'u da diğer tercihli ticaret anlaşmalarından oluşmaktadır (Genç ve Berber, 2011).

Yukarıda açıklanan anlaşmalar arasında Türkiye ve Rusya Federasyonu için en uygun olanının serbest ticaret anlaşması olduğu görülmektedir. Nitekim siyasi, coğrafi ve kültürel nedenlerden dolayı Türkiye ile Rusya Federasyonu arasında bir gümrük birliğinin kurulması veya mevcut bir gümrük birliğine Türkiye'nin katılması olası değildir. Buna karşın $\mathrm{AB}$ ile Rusya Federasyonu arasında yürütülen müzakerelerin bir serbest ticaret anlaşmasının imzalanmasıyla sonuçlanması da kuvvetle muhtemeldir. Bu durumda gümrük birliği müktesebatı uyarınca Birliğin tercihli rejimlerini uyarlama yükümlülüğ̈̈ altına olan Türkiye'nin zorunlu olarak Rusya Federasyonu ile serbest ticaret anlaşması yapması gerekecektir. Ancak bu anlaşma, iki ülke ekonomik ve ticari ilişkilerinin yoğunluğu göz önüne alındığında kapsamlı ekonomik ortaklık anlaşması niteliğinde olacaktır.

\section{Türkiye ile Rusya Federasyonu Dış Ticaret Hacmi ve Ticaretle Bağlantılı Konular}

Türkiye ve Rusya Federasyonu enerji, tekstil, bitkisel ve hayvansal ürünler, otomotiv ve makine başta olmak üzere çok çeşitli eşyayı dış ticaretlerine konu etmektedir. Ticarete konu eşya ve bu eşyanın taşınması dönem dönem iki ülke arasında sorun oluştursa da, 2009 yılında iki ülke dış ticaretinin 100 Milyar \$ olması hedefi ortaya konulmuştur. Aşağıda iki ülke dış ticaret hacmi ve bu ticaretle bağlantılı konular incelenecektir.

\subsection{Dış Ticaret Hacmi}

Türkiye ile Rusya Federasyonu arasındaki ticari ilişkiler, Cumhuriyetin ilk yıllarına kadar girmekle birlikte 1987 yılında yürürlüğe giren doğal gaz anlaşmasıyla canlılık kazanmıştır. Merkezi planlamadan serbest piyasa ekonomisine sancılı bir şekilde geçen Rusya Federasyonu, 1997 ve 2008 yılında yaşanan krizlerden olumsuz etkilenmiştir. Aynı dönemde Türk ekonomisi de 1994, 1999 ve 2001 yıllarında ekonomik krizlerle mücadele 
etmiştir. Yerel ve küresel nitelikteki bu ekonomik krizler iki ülke arasındaki dış ticarete olumsuz yansımıştır. 2009 sonrasında ise küresel yükselişe paralel şekilde iki ülke ticaret hacmi, Türkiye aleyhine olmakla birlikte, artışa geçmiştir. İki ülke arasındaki ticarette Türkiye ithalat fazlası, Rusya Federasyonu ise ihracat fazlası vermektedir. Bunda 2002 yılı sonrasında petrol ve doğal gaz fiyatlarının artması, 2005 yılından itibaren Mavi Akım hattıyla Rusya'dan ithal edilen doğal gaz miktarının artması ve ekonominin liberalleşmesine paralel olarak Rusya pazarının rekabetçi özelliğinin artması etkili olmuştur (Özdal vd, 2013). Türkiye, iki ülke ticaretinde ülkemiz aleyhine olan ticaret açığını bütün görüşmelerde gündeme getirmesine rağmen, Rusya'daki inşaat sektörü yatırımları, bavul ticareti ve turizm sayesinde bu açığının kapandığı düşünülmektedir (Tepav, ?).

\begin{tabular}{|l|r|r|r|r|}
\hline & Dünya & $\begin{array}{c}\text { Türkiye ve } \\
\text { Rusya Federasyonu }\end{array}$ & Rusya Federasyonu & \multicolumn{1}{c|}{ Türkiye } \\
\hline İhracat & 18.682 .444 .395 & 649.859 .826 & 492.144 .880 & 157.714 .946 \\
\hline Payı & & 3,48 & 2,63 & 0,84 \\
\hline İthalat & 18.790 .832 .345 & 524.826 .326 & 282.602 .367 & 242.223 .959 \\
\hline Payı & & 2,79 & 1,50 & 1,29 \\
\hline Toplam & 37.473 .276 .740 & 1.174 .686 .152 & 774.747 .247 & 399.938 .905 \\
\hline Payı & & 3,13 & 2,07 & 1,07 \\
\hline
\end{tabular}

Tablo 1: 2014 yılı Türkiye ve Rusya Federasyonu Ticaret Hacmi (Bin \$) ve Dünya Ticaret Içindeki Payı (\%) Kaynak: ITC

Tablo 1'de yer alan 2014 yılı verilerine göre dünya ticaret hacmi içinde, iki ülkenin toplam ihracatı \% 3,48, toplam ithalatı \% 2,79 ve toplam dış ticaret hacmi \% 3,13 oranında paya sahiptir. Dış ticarette Türkiye ithalatçı, Rusya Federasyonu ise ihracatçı ülke konumundadır.

\begin{tabular}{|c|c|c|c|}
\hline \multirow{5}{*}{ 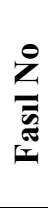 } & \multicolumn{2}{|c|}{ Yll } & 2014 \\
\hline & \multicolumn{2}{|c|}{ Toplam İhracat } & 157.714 .946 \\
\hline & \multirow{3}{*}{$\begin{array}{c}\text { Rusya } \\
\text { Federasyonu }\end{array}$} & Tutar1 & 5.945 .713 \\
\hline & & Pay1 (\%) & 3,77 \\
\hline & & Siralamas1 & 7 \\
\hline 87 & \multicolumn{2}{|c|}{ Nakil Vasitalar1 } & 646.807 \\
\hline 8 & \multicolumn{2}{|l|}{ Meyveler } & 622.918 \\
\hline 84 & \multicolumn{2}{|l|}{ Makineler } & 577.907 \\
\hline 7 & \multicolumn{2}{|l|}{ Sebzeler } & 385.002 \\
\hline 85 & \multicolumn{2}{|c|}{ Elektrikli Makineler } & 329.665 \\
\hline 39 & \multicolumn{2}{|c|}{ Plastikler ve mamulleri } & 307.423 \\
\hline 60 & \multicolumn{2}{|l|}{ Örme eşya } & 230.558 \\
\hline 54 & \multicolumn{2}{|c|}{ Sentetik ve suni filamentler } & 177.708 \\
\hline 61 & \multicolumn{2}{|c|}{ Örme giyim eşyası } & 147.680 \\
\hline 73 & \multicolumn{2}{|c|}{ Demir ve çelikten eşya } & 136.931 \\
\hline
\end{tabular}

\begin{tabular}{|c|c|c|c|}
\hline \multirow{5}{*}{$\frac{i}{z}$} & \multicolumn{2}{|c|}{ Yll } & 2014 \\
\hline & \multicolumn{2}{|l|}{ Toplam Ithalat } & 242.223 .959 \\
\hline & \multirow{3}{*}{$\begin{array}{c}\text { Rusya } \\
\text { Federasyonu }\end{array}$} & Tutar1 & 25.293 .392 \\
\hline & & Pay1 (\%) & 10,44 \\
\hline & & Siralaması & 1 \\
\hline 27 & \multicolumn{2}{|c|}{ Mineral Yakıtlar } & 16.498 .387 \\
\hline 72 & \multicolumn{2}{|l|}{ Demir ve çelik } & 2.689 .166 \\
\hline 10 & \multicolumn{2}{|l|}{ Hububat } & 1.451 .392 \\
\hline 76 & \multicolumn{2}{|c|}{ Alüminyum/alüminyum eşya } & 1.108 .816 \\
\hline 15 & \multicolumn{2}{|c|}{ Hayvansal/bitkisel yağlar } & 875.510 \\
\hline 31 & \multicolumn{2}{|l|}{ Gübreler } & 363.276 \\
\hline 74 & \multicolumn{2}{|c|}{ Bakır/bakırdan eşya } & 301.052 \\
\hline 23 & \multicolumn{2}{|c|}{ Gıda sanayii döküntüleri } & 288.149 \\
\hline 29 & \multicolumn{2}{|c|}{ Organik kimyasal eşya } & 248.483 \\
\hline 26 & \multicolumn{2}{|l|}{ Metal cevheri } & 219.189 \\
\hline
\end{tabular}

Tablo 2: 2014 yılı Türkiye ile Rusya Federasyonu Dış Ticaret Hacmi ve İlk On Fasıl (Bin \$) Kaynak: ITC

Tablo 2'de yer alan 2014 yılı verilere göre Rusya Federasyonu, Türkiye'nin ihracat yaptığı ülkeler arasında Almanya, Irak, İngiltere, İtalya, Fransa ve ABD’nin ardından \% 3,8 oranı ile 7. sırada, en çok ithalat yapılan ülkeler arasında \%10,44 oranı ile 1. sırada yer almaktadır. Rusya Federasyonu bakımından Türkiye, ihracatta \% 3,2 oranı ile 10 . siradayken ithalatta $\% 2,1$ oranı ile 14 . siradadır.

\begin{tabular}{|c|l|r|r|r|c|}
\hline \multirow{2}{*}{$\begin{array}{c}\text { Fasıl } \\
\text { No }\end{array}$} & \multicolumn{1}{|c|}{ Eşya Grubu } & $\mathbf{( 1 )}$ & $\mathbf{( 2 )}$ & $\mathbf{( 3 )}$ & $\mathbf{( 4 )}$ \\
\cline { 2 - 6 } & & 157.714 .946 & 5.945 .713 & 3,77 & \\
\hline $\mathbf{8 7}$ & Nakil vasıtaları & 18.065 .263 & 646.807 & 3,58 & 10,88 \\
\hline $\mathbf{8}$ & Meyveler & 4.330 .880 & 622.918 & 14,38 & 10,48 \\
\hline $\mathbf{8 4}$ & Makineler & 13.599 .014 & 577.907 & 4,25 & 9,72 \\
\hline $\mathbf{7}$ & Sebzeler & 1.083 .292 & 385.002 & 35,54 & 6,48 \\
\hline $\mathbf{8 5}$ & Elektrikli makineler & 9.698 .275 & 329.665 & 3,40 & 5,54 \\
\hline $\mathbf{3 9}$ & Plastik ve mamulleri & 6.099 .728 & 307.423 & 5,04 & 5,17 \\
\hline $\mathbf{6 0}$ & Örme eşya & 1.694 .296 & 230.558 & 13,61 & 3,88 \\
\hline $\mathbf{5 4}$ & Sentetik ve suni filamentler & 1.773 .377 & 177.708 & 10,02 & 2,99 \\
\hline $\mathbf{6 1}$ & Örme giyim eşyası & 10.034 .391 & 147.680 & 1,47 & 2,48 \\
\hline $\mathbf{7 3}$ & Demir ve çelikten eşya & 6.363 .861 & 136.931 & 2,15 & 2,30 \\
\hline
\end{tabular}

Tablo 3: 2014 yılında İlk On Fasılda Türkiye 'nin Rusya Federasyonu'na İhracatı (Bin \$) ve Dăgllımı (\%) Kaynak: ITC Açıklamalar: (1) Türkiye'nin Toplam İhracatı (2) Türkiye'nin Rusya Federasyonu'na İhracatı (3) Türkiye'nin İhracatı Iç̧inde Rusya Federasyonu'nun Payı (4) Fasılların Payı 
Tablo 3'te yer alan 2014 yılı verilere göre Türkiye'nin toplam ihracatı içinde Rusya Federasyonu'na yaptığı ihracatı oluşturan ilk on fasıl içinde, sırasıyla sebze, meyve, ayakkabı ve örme eşya yüksek paya sahiptir. Diğer taraftan Rusya Federasyonu'na yapılan ihracat nakil vasıtaları, meyve ve sebzeler ile makineler yer almaktadır.

\begin{tabular}{|c|l|r|r|r|r|c|c|}
\hline \multirow{2}{*}{$\begin{array}{c}\text { Fasıl } \\
\text { No }\end{array}$} & \multicolumn{1}{|c|}{ Eşya Grubu } & $\mathbf{( 1 )}$ & $\mathbf{( 2 )}$ & $\mathbf{( 3 )}$ & $\mathbf{( 4 )}$ & $\mathbf{( 5 )}$ & $\mathbf{( 6 )}$ \\
\cline { 2 - 8 } & & 242.223 .959 & 25.293 .392 & 492.144 .880 & 10,44 & 4,55 & \\
\hline $\mathbf{2 7}$ & Mineral yakıtlar & 54.906 .087 & 16.498 .387 & 288.361 .702 & 30,05 & 5,06 & 65,23 \\
\hline $\mathbf{7 2}$ & Demir ve çelik & 17.606 .032 & 2.689 .166 & 20.202 .919 & 15,27 & 11,78 & 10,63 \\
\hline $\mathbf{2 9}$ & Organik kimyasal eşya & 5.832 .864 & 248.483 & 4.438 .176 & 4,26 & 4,95 & 0,98 \\
\hline $\mathbf{7 4}$ & Bakır/bakırdan eşya & 3.570 .523 & 301.052 & 4.873 .518 & 8,43 & 5,47 & 1,19 \\
\hline $\mathbf{7 6}$ & Alüminyum eşya & 3.499 .977 & 1.108 .816 & 6.298 .128 & 31,68 & 15,58 & 4,38 \\
\hline $\mathbf{1 0}$ & Hububat & 2.338 .407 & 1.451 .392 & 6.972 .489 & 62,07 & 18,42 & 5,74 \\
\hline $\mathbf{1 5}$ & Hayvansal/bitkisel yağlar & 2.133 .548 & 875.510 & 2.216 .494 & 41,04 & 34,96 & 3,46 \\
\hline $\mathbf{3 1}$ & Gübreler & 1.470 .997 & 363.276 & 8.909 .523 & 24,70 & 3,61 & 1,44 \\
\hline $\mathbf{2 3}$ & Gida sanayii döküntüleri & 1.329 .366 & 288.149 & 1.204 .475 & 21,68 & 21,17 & 1,14 \\
\hline $\mathbf{2 6}$ & Metal cevheri & 1.151 .884 & 219.189 & 3.243 .414 & 19,03 & 5,98 & 0,87 \\
\hline
\end{tabular}

Tablo 4: 2014 yılında İlk On Fasılda Türkiye'nin Rusya Federasyonu'ndan İthalatı (Bin \$) ve Dağılımı (\%) Kaynak: ITC Açıklamalar: (1) Türkiye'nin Toplam İthalatı (2) Türkiye'nin Rusya Federasyonu'ndan İthalatı (3) Rusya Federasyonu'nun Toplam İhracatı (4) Türkiye'nin İthalatı İçinde Rusya Federasyonu'nun Payı (\%) (5) Rusya Federasyonu'nun Toplam Ihracatı (CIF) Iç̧inde Türkiye’nin Payı (6) Fasılların Payı

Tablo 4'te yer alan 2014 yılı verilere göre Türkiye'nin Rusya Federasyonu'ndan yaptı̆̆ı ithalat, toplam ithalatının \% 10,44'ünü oluşturmaktadır. Bu ithalat içinde petrol ve doğalgaz, demir ve çelik, buğday ve malut, alüminyum ve alüminyumdan eşya ağırlıklı paya sahiptir. Ayrıca Türkiye'nin ithal ettiği toplam hububatın \% 62,07'si, hayvansal ve bitkisel yağların \% 41,04'ü, alüminyum ve alüminyumdan eşyanın \% 31,68'i ve mineral yakıtların \% 30,05'i Rusya Federasyonu'ndan ithal edilmektedir.

\begin{tabular}{|c|l|r|r|r|r|c|c|}
\hline \multirow{2}{*}{$\begin{array}{c}\text { Fasıl } \\
\text { No }\end{array}$} & \multirow{2}{*}{ Eşya Grubu } & $\mathbf{( 1 )}$ & $\mathbf{( 2 )}$ & $\mathbf{( 3 )}$ & $\mathbf{( 4 )}$ & $\mathbf{( 5 )}$ & $\mathbf{( 6 )}$ \\
\cline { 2 - 7 } & & 282.602 .367 & 6.571 .952 & 157.714 .946 & 2,33 & 3,69 & \\
\hline $\mathbf{8 7}$ & Nakil vasıltaları & 30.977 .793 & 745.063 & 18.065 .263 & 2,41 & 3,65 & 2,41 \\
\hline $\mathbf{8}$ & Meyveler & 5.407 .336 & 813.024 & 4.330 .880 & 15,04 & 16,61 & 15,04 \\
\hline $\mathbf{8 4}$ & Makineler & 51.321 .293 & 742.775 & 13.599 .014 & 1,45 & 4,83 & 1,45 \\
\hline $\mathbf{7}$ & Sebzeler & 2.928 .943 & 598.416 & 1.083 .292 & 20,43 & 48,89 & 20,43 \\
\hline $\mathbf{8 5}$ & Elektrikli makineler & 33.361 .987 & 372.517 & 9.698 .275 & 1,12 & 3,40 & 1,12 \\
\hline $\mathbf{3 9}$ & Plastik ve mamulleri & 10.873 .316 & 311.326 & 6.099 .728 & 2,86 & 4,52 & 2,86 \\
\hline $\mathbf{6 0}$ & Örme eşya & 495.232 & 268.023 & 1.694 .296 & 54,12 & 14,00 & 54,12 \\
\hline $\mathbf{5 4}$ & Sentetik ve suni filamentler & 552.714 & 232.133 & 1.773 .377 & 42,00 & 11,58 & 42,00 \\
\hline $\mathbf{6 1}$ & Örme giyim eşyası & 3.675 .564 & 191.357 & 10.034 .391 & 5,21 & 1,69 & 5,21 \\
\hline $\mathbf{7 3}$ & Demir ve çelikten eşya & 6.822 .902 & 171.455 & 6.363 .861 & 2,51 & 2,38 & 2,51 \\
\hline
\end{tabular}

Tablo 5: 2014 yılında İlk On Fasılda Rusya Federasyonu'nun Türkiye'den İthalatı (Bin \$) ve Dağllımı (\%)

Kaynak: ITC Açılamalar: (1) Rusya Federasyonu'nun Toplam Itthalatı (2) Rusya Federasyonu'nun Türkiye'den İthalatı (3) Türkiye'nin Toplam İhracatı (4) Rusya Federasyonu'nun İthalatı İçinde Türkiye'nin Payı (\%) (5)

Türkiye'nin Toplam İhracatı (CIF) İçinde Rusya Federasyonu'nun Payı (6) Fasilların Payı

Tablo 5'te yer alan 2014 yılı verilerine göre Türkiye'nin ihracatı içinde Rusya Federasyonuna yaptı̆̆ı ihracatta sebze ve meyveler, örme eşya ve sentetik ve suni filamentler ağırlıklı bir paya sahiptir.

\subsection{Gümrük Vergileri}

Serbest ticaret anlaşmaları açısından en önemli düzenleme alanını tarife, yani gümrük vergileri oluşturmaktadır. Serbest ticaret anlaşmalarıyla anlaşma kapsamına giren eşya üzerinden alınan gümrük vergileri azaltılmakta veya kaldırılmakta ve gümrük işlemleri daha da basitleştirilmektedir. Eşyanın yararlanacağı tavizli rejim ise anlaşmaya ekli menşe protokolleri çerçevesinde belirlenmektedir. Menşe protokollerinde yer alan kurallar, eşyanın o ülke menşeli sayılması ve tavizli vergi uygulaması için gerekli görülen, doğrudan o ülkede üretilmiş ya da elde edilmiş olma veya birden fazla ülkede üretim sürecine konu eşyanın esaslı işçilik görmesi/esaslı dönüşüm geçirmesi ya da ağırlıklı katma değerin yaratılmış olması gibi temel kriterleri içermektedir.

Ülkemizde gümrük vergileri, Bakanlar Kurulunca kabul edilen Türk Gümrük Tarife Cetveline ve eşya ticaretine ilişkin tarife önlemlerini içeren diğer cetvellere göre hesaplanmaktadır. Gümrük tarifesi; gümrük vergi oranlarını, tarım politikası veya tarım ürünlerinin işlenmesi sonucu elde edilen bazı ürünlere uygulanan özel düzenlemeler çerçevesinde alınan ithalat vergilerini, bazı ülkeler veya ülke grupları ile yaptı̆̆ı tercihli bir tarife uygulaması gerektiren anlaşmalarda yer alan tercihli tarife uygulamalarını, ülkemiz tarafından tek taraflı olarak 
bazı ülke, ülke grupları veya toprak parçaları için tanınan tercihli tarife uygulamalarını ve şartlı muafiyet veya indirim uygulamalarını kapsamaktadır. Cari gümrük vergisi oranları yıl sonunda ya da ihtiyaç duyulması halinde cari yıl içinde güncellenen İthalat Rejimi Kararına ek Kararlar şeklinde yürürlüğe konulmaktadır.

\begin{tabular}{|c|c|c|c|c|c|c|c|c|c|}
\hline \multirow{3}{*}{$\frac{0}{\bar{z}}$} & \multirow[b]{3}{*}{ Eşya grubu } & \multirow{2}{*}{\multicolumn{2}{|c|}{ Kanuni }} & \multicolumn{4}{|c|}{ Tavizli } & \multirow{2}{*}{\multicolumn{2}{|c|}{ Üçüncü Ülkeler }} \\
\hline & & & & \multicolumn{2}{|c|}{ Karşılıklı } & \multicolumn{2}{|c|}{ Karşıllıksız } & & \\
\hline & & $\begin{array}{c}\text { En } \\
\text { Düşük }\end{array}$ & $\begin{array}{c}\text { En } \\
\text { Yüksek }\end{array}$ & $\begin{array}{c}\text { En } \\
\text { Düşük }\end{array}$ & $\begin{array}{c}\text { En } \\
\text { Yüksek }\end{array}$ & $\begin{array}{c}\text { En } \\
\text { Düşük }\end{array}$ & $\begin{array}{c}\text { En } \\
\text { Yüksek }\end{array}$ & $\begin{array}{c}\text { En } \\
\text { Düşük }\end{array}$ & $\begin{array}{c}\text { En } \\
\text { Yüksek }\end{array}$ \\
\hline 27 & Mineral yakitlar & 5 & 60 & $\mathrm{M} / 0$ & 0 & $\mathrm{M} / 0$ & 0 & $\mathrm{M} / 0,7$ & 8 \\
\hline 72 & Demir ve çelik & 5 & 30 & $\mathrm{M} / 0$ & 14 & $\mathrm{M} / 0$ & 40 & $\mathrm{M} / 0$ & 40 \\
\hline 10 & Hububat & 50 & 200 & 0 & 13 & - & - & 0 & 130 \\
\hline 76 & Alüminyum ve mamulü eşya & 10 & 60 & $\mathrm{M} / 0$ & 4,6 & $\mathrm{M} / 0$ & 6,5 & $\mathrm{M} / 0$ & 10 \\
\hline 15 & Hayvansal/bitkisel yağlar & 20 & 75 & $\mathrm{M} / 0$ & 46,8 & - & - & $\mathrm{M} / 0$ & 46,8 \\
\hline 31 & Gübreler & $\mathrm{M} / 10$ & 30 & $\mathrm{M} / 0$ & 0 & $\mathrm{M} / 0$ & 6,5 & $\mathrm{M} / 0$ & 6,5 \\
\hline 74 & Bakır/bakırdan eşya & 10 & 50 & $\mathrm{M} / 0$ & 3 & $\mathrm{M} / 0$ & 1,7 & $\mathrm{M} / 0$ & 5,2 \\
\hline 23 & Gıda sanayii döküntüleri & 5 & 15 & 0 & 13 & - & - & 0 & 13,5 \\
\hline 29 & Organik kimyasal eşya & $\mathrm{M} / 5$ & 60 & $\mathrm{M} / 0$ & 9,6 & $\mathrm{M} / 0$ & 9,6 & $\mathrm{M} / 0$ & 9,6 \\
\hline 26 & Metal cevheri & 5 & 10 & $\mathrm{M} / 0$ & 0 & $\mathrm{M} / 0$ & 12,5 & $\mathrm{M} / 0$ & 12,5 \\
\hline
\end{tabular}

Tablo 6: 2015 yılı için İlk On Fasıla Uygulanan Gümrük Vergisi Oranları Kaynak: 2015 Yılı Gümrük Giriş Tarife Cetveli ve 2015 yılı İthalat Rejimi Kararı Açıklama: M: Muaf

Tablo 6'te yer alan verilere göre, 2015 yılı için, Rusya Federasyonu'ndan yapılan ithalatta ağırlıklı paya sahip eşyaya, üçüncü ülkeler için hububat, hayvansal ve bitkisel yağlar ve gıda sanayi döküntüleri, gümrük vergisinin en yüksek uygulandığı eşya gruplarını oluşturmaktadır.

\begin{tabular}{|c|c|c|c|c|}
\hline Fasıl No & Eşya grubu & En Düşük & En Yüksek & Karşılıksız Tavizli \\
\hline 87 & Nakil vasıtaları & $\mathrm{M} / 5$ & 25 & \multirow{10}{*}{$\begin{array}{l}\text { Mevcut vergi oranında } \\
\% 25 \text { indirim şeklinde } \\
\text { uygulanmaktadır. }\end{array}$} \\
\hline 8 & Meyveler & 5 & 10 & \\
\hline 84 & Makineler & 5 & 20 & \\
\hline 7 & Sebzeler & 5 & 10 & \\
\hline 85 & Elektrikli makineler & 0 & 20 & \\
\hline 39 & Plastik ve mamulleri & 0 & 20 & \\
\hline 60 & Örme eşya & 3 & 10 & \\
\hline 54 & Sentetik ve suni filamentler & 0 & 20 & \\
\hline 61 & Örme giyim eşyası & 5 & 20 & \\
\hline 73 & Demir ve çelikten eşya & 0 & 15 & \\
\hline
\end{tabular}

Tablo 7: 2015 yılı için ilk On Fasılda Rusya Federasyonu Tarafindan Uygulanan Gümrük Vergisi Oranları (\%) Kaynak: Ortak Gümrük Tarifesi Hakkında 54 Nolu Karar Açıklama: M: Muaf

Rusya Federasyonu açısından bakıldığında, ülkemize benzer şekilde, gümrük vergileri bakımından DTÖ ve AGB üyeliği belirleyici bir etkiye sahiptir. Ortak gümrük tarifesi ve ticaret politikası önlemlerinin uygulanması yükümlülüğü doğuran AGB bir tarafa bırakılırsa, Rusya Federasyonu'nun DTÖ’ye üyeliği, gümrük vergilerinin kademeli olarak düşürülmesi yükümlülügü getirmiştir. Yine, GTS kapsamında karşılıksız tavizli tarife uygulayan Rusya Federasyonu, gelişme yolundaki ülke sayılan ülkemize cari gümrük vergisi oranlarını \% 25 indirimli uygulamaktadır. Bununla birlikte olası bir serbest ticaret anlaşması halinde Tablo 7'de belirtilen yürürlükteki gümrük vergisi oranları tavizli hale gelerek indirimli ya da sıfır olarak uygulanacaktır. İhracat vergileri bakımından Rusya Federasyonu üzerinde ayrıca durulmalıdır. Nitekim sadece doğalgaz üzerine konulan ve oranı \% 5 ila \% 30 arasında değişen ihracat vergileri, zamanla, gübre, kağıt, odun, demir-çelik gibi eşyayı da kapsamına almıştır.

\subsection{Gümrük İşlemleri ve Basitleştirilmiş Gümrük Hattı}

Ülkeler arasındaki eşya ticaretinin maliyet unsurlarından arındırılması ve olabildiğince basitleştirilmesi arzu edilen bir durum olmakla birlikte günümüzde halen başarılmış değildir. OECD tarafından yapılan bir analize göre dünya ticaretinde maliyetlerin \% 15'ini oluşturan gümrük işlemlerinin maliyetinde \% 1 oranında bir azalma, dünya gelirinde 40 Milyar \$ artış sağlayacaktır (OECD, 2013). Yine 189 ülkeyi kapsayan Doing Business Raporuna göre diş ticaret işlemlerinin yürütülmesindeki prosedürler ve maliyet unsurları bakımından 90. sırada olan Türkiye'de 9 belge kullanılarak yürütülen ihracat işlemleri için 13 gün ve konteyner başına 990 \$ ve 8 belge kullanılarak yürütülen ithalat işlemleri için 14 gün ve konteyner başına 1.235 \$ harcanmaktadır. Aynı rapora göre 155. sırada olan Rusya Federasyonu'nda 9 belge kullanılarak yürütülen ihracat işlemleri için 21,1 gün ve konteyner başına 2.401 \$ ve 10 belge kullanılarak yürütülen ithalat işlemleri için 19,4 gün ve konteyner başına 2.595 \$ harcanmaktadir (WB Group, 2014). 
Gümrük işlemleri açısından Türkiye ve Rusya Federasyonu için 2008 yılı dönüm noktası oluşturmaktadır. Nitekim bu tarihte başlayan ve yaklaşık bir yıl süren gümrük işlemleriyle ilgili krizin aşılması amacıyla gümrük işlemlerine konu eşyaya ve taşıma araçlarına ilişkin bilgilerin iki ülke gümrük idareleri arasında elektronik yolla önceden değişimine dayanan sistemden yararlanılması gündeme geliştirilmiştir. Basitleştirilmiş Gümrük Hattı (BGH) ya da yeşil koridor adlı bu sistem ile eşyaya ilişkin bilgileri gümrük idaresine gönüllü olarak önceden sunan firmalara, dış ticaret işlemleri sırasında, referans kıymet uygulamasından muafiyet, gümrük işlemlerinde öncelik, gümrükleme zamanını kısaltacak ve kolaylaştıracak ayrı bir gümrük hatlarının kullanımını, kaçakçılıkla ve gümrük suçlarıyla mücadele dışında gümrük kontrolünden muafiyet, dış ticaret işlemlerinde banka garantisini kullanımı ve eksik belge sunulması, TIR Karnesi, Taşıma Belgesi, Hava Konşimentosu, CMR gibi sadece taşıma belgelerinde yer alan bilgileri sunan ihracatçıların sundukları belgelerin uygun bulunması halinde fiziki kontrole tabi tutulmaması veya gümrük işlemlerinin en kısa sürede tamamlanması kolaylıklarından yararlanmaktadırlar. Böylece sisteme dahil olan firmalar geri gönderilme ya da bekleme riskinden kurtulmaktadır. BGH sistemine dahil olmayan firmaların bu türden herhangi bir kolaylıktan ya da basitleştirmeden yararlanması mümkün değildir.

BGH, ilk olarak, 18 Şubat 2010 tarihinde Moskova Vnukova Havalimanı ile İstanbul Sabiha Gökçen Havalimanı arasında başlamış, daha sonra iki ülke arasında yapılan Veri Değişimi Anlaşması kapsamında tekrar ele alınarak teknik alt yapısının geliştirilmesi ve farklı taşıma modlarını kapsayacak şekilde yaygınlaştırılması çalışmaları çerçevesinde, Rusya'ya kara yolu ile gelen eşya için Ukrayna sınırındaki Triyebortniye Sınır Kapısı'nı, Gürcistan sınırındaki Yukarı Lars Kara Sınır Kapısı'nı ve denizyolu ile gelen eşya için Karadeniz kıyısında bulunan Tuapse Limanı Gümrük İdaresini kapsamına almıştır. Ayrıca Novorossisk Limanı, Bryansk Gümrüğüne bağlı Noviye Yourkovichi ve Smolensk Gümrügüne bağlı Stabinski sınır kapıları da BGH kapsamında işlem terminali olarak kullanılabilmektedir. İstatistiksel açıdan bakıldığında BGH sistemi üzerinden Rusya Federasyonu'na 2010 yılında 8 Milyon dolar, 2011 yılında 33,6 Milyon Dolar, 2012 y1lında 133 Milyon Dolar ve 2013 yılı Ocak-Temmuz dönemi içinde 53,5 Milyon Dolar ihracat gerçekleştirilmiş olup toplam ihracat hacmi içinde BGH'nin payı henüz \% 2'yi bulmamıştır. Rusya'ya olan ihracatın en az \% 10'unun BGH kapsamında gerçekleşmesi ve sonraki dönemlerde bu hacmin daha da artırılması hedeflenmektedir (GTB, 2013).

\subsection{Teknik Düzenlemeler}

Gümrük vergileri ve gümrük işlemlerinin kolaylaştırılması çalışmalarında yaşanan gelişmeler iki ülke arasındaki ticaretin bütünüyle serbestleştiği anlamına gelmemektedir. Nitekim Rusya Federasyonu tarafından tarım ürünleri ithalatında uygulanan zirai karantina önlemleri ülkemiz ihracatçıları açısından halen ciddi bir endişe kaynağı oluşturmaktadır. DTÖ üyeliğiyle birlikte Rusya Federasyonu, belgelendirme ve ruhsat verme şeklindeki tarife dışı ticaret uygulamalarını DTÖ kurallarıyla uyumlu hale getireceğini ve bu türden uygulamaların şeffaflık düzeyini artıracağını taahhüt etse de, DTÖ Hayvan ve Bitki Sağlığı Anlaşması hükümlerine göre ülkeler kendi standartlarını uygulayabildiğinden Rusya Federasyonu açısından hareket serbestisi söz konusudur. Teknik düzenlemeler açısından beklenen, Türkiye ya da Rusya Federasyonu'ndan her hangi birinde düzenlenen uygunluk belgesinin iki tarafça da kabul edilmesidir. Nitekim Türk Standartları Enstitüsü ile Rusya'ya eşya ithalinde aranan uygunluk/standart belgelerini vermeye yetkili kurum olan GOSSTANDART arasında yapılan bir anlaşma çerçevesinde iki ülke laboratuarların ortak kullanımı ve Türk laboratuarlarınca verilecek uygunluk sertifikasının Rus gümrük idarelerince de kabul edilmesi yönünde çalışmalar yürütülmektedir.

\subsection{Fikri Mülkiyet Haklarının Korunması}

Türkiye ile Rusya Federasyonu arasındaki ticarette çoğu alanın aksine, Türkiye’ye yükümlülük düşen en önemli alan fikri mülkiyet haklarının korunmasıyla ilgilidir. Özellikle bavul ticareti kapsamında herhangi bir kayda girmeden Türkiye'den Rusya Federasyonu'na taklit ve korsan nitelikte eşyanın çıkış yaptığı bilinmektedir. BGH sistemi eşyanın gümrük kontrolünden geçmesini sağladığından, fikri mülkiyet haklarının gümrük işlemleri çerçevesinde korunması için önemli bir aşama teşkil etse de, bu sistem etkin bir uygulama değildir. Fikri mülkiyet haklarının korunması konusunda Rusya Federasyonu için de bir takım eksiklikler söz konusudur. Ülkenin DTÖ üyeliği fikri mülkiyet haklarının korunma düzeyinin artırılması açısından önemli bir gelişme kabul edilmektedir. Nitekim Rusya Federasyonu'nun DTÖ’ye yaptığı taahhütler arasında, fikri mülkiyet haklarının korunmasına karşı sınır uygulamalarının güçlendirilmesi ve geçiş dönemi olmaksızın Ticaretle Bağlantılı Fikri Mülkiyet Hakları Anlaşması hükümlerinin tamamının yerine getirilmesi bulunmaktadır.

\section{Türkiye ile Rusya Federasyonu Serbest Ticaret Anlaşmasının Olası Etkileri}

Türkiye ile Rusya Federasyonu arasındaki ticari ve ekonomik ilişkilerin hukuki dayanağını oluşturan anlaşmalar arasında Ticari ve Ekonomik İşbirliğine Dair Anlaşma, Karma Ekonomik Komisyonu Mekanizmasını Kuran Anlaşma, Turizm Alanında İşbirliği Anlaşması, Yatırımların Karşılıklı Teşviki ve Korunması Anlaşması, Gümrük Konularında Karşılıklı Yardım ve İşbirliği Anlaşması, Uluslararası Karayolu Taşımaları Hakkında Protokol ve Gümrük İşlemlerinin Basitleştirilmesine İlişkin Protokol bulunmaktadır. Halihazırda iki ülke arasında bir serbest ticaret anlaşması imzalanmış olmasa da, ekonomik ve ticari ilişkilerin yoğunluğu nedeniyle 
kapsamlı bir serbest ticaret anlaşması yapılması konusunda görüşmeler sürmektedir. Olası bir serbest ticaret anlaşmasının imzalanması halinde iki ülke dış ticaret hacminin artması, gümrük işlemlerinin basitleşmesi, teknik düzenlemelerinin ticareti zorlaştırıcı ve daraltıcı etkisinin azalması, taşımacılıkla ilgili işlemlerin kolaylaşması ve fikri mülkiyet halklarının korunmasıyla ilgili önlemlerin tekdüze hale getirilmesi gibi teknik ve mevzuat yoğun konularda olumlu gelişme yaşanacaktır. Çok taraflı ve bölgesel ticaret sistemlerinin parçası olan ve ticari ilişkilerini bu sistemlerin ilke ve kuralları çerçevesinde şekillendiren Türkiye ve Rusya Federasyonu'nun bölgeselleşme sürecini bir adım öteye taşıması anlamına gelecek olan serbest ticaret anlaşması, iki ülke ticaretini olumlu yönde etkileyecektir.

Teorik açıdan bakıldığında serbest ticaret anlaşmaları ihracat bakımından iki tür etkiye sahiptir. İlk olarak, gümrük vergileri kaldırıldığında taraf ülkelerin ihracatçılarının piyasaya ulaşma kapasitesi artmaktadır. İkincisi, bu ihracatçılar aynı zamanda tercihli tarife nedeniyle ithalatın azalmasından faydalanmaktadır. İthalat açısından bakıldığında tercihli ticaret anlaşmalarının etkisi belirsiz olsa da fiyat avantajı nedeniyle artan ithalat yüksek fiyatlı yerel üretim yerine daha verimli olan ithal eşyasından yararlanılması sonucunu doğurmaktadır. Bununla birlikte, tercihli ticaret anlaşması, taraflarının bu anlaşmadan kazanç sağlaması ya da kayba uğraması başlangıçtaki vergi oranlarına ve arz-talep elastikiyetine bağlıdır. Tercihli ticaret anlaşmaları üçüncü ülkeler bakımından olumsuz dışsallık etkisine sahip olup (WTO, 2011), olası bir serbest ticaret anlaşması halinde iki ülkenin ticari ortakları bundan olumsuz etkilenecektir.

Hemen hemen bütün ticaret anlaşmaları tercihli tarifeye ilişkin hüküm içermekle birlikte günümüzde çoğu tercihli ticaret anlaşması tercihli tarife uygulamaları yanında hizmetler, yatırım, fikri mülkiyet haklarının korunması ve rekabet politikaları konusunu da düzenlemektedir. Belirtilen bu konular niteliği itibariyle iç hukuka bağlı olarak düzenlenmekte olup anlaşmaların bu türden hükümler içermesi ya piyasa entegrasyonunu daha ileri bir düzeyde derinleştirmekte ya da bu alanlarda bölgesel standartların oluşumuna araçlık etmektedir. İlk olarak, ticari açıklık politika bağımlılığını artırmaktadır ki bu durum tek taraflı karar alma mekanizmalarını etkisiz hale getirerek kararların ortak şekilde alınması zorunluluğunu ortaya çıkarmaktadır (spillovers effect). İkinci olarak, belirli sektörler ve ekonomik birleşmeler daha derin bir entegrasyonu gerektirebilir. Nitekim uluslararası üretim ağları, düşük gümrük tarifeleri yanında, belirli alanlarda daha iyi bir yönetişim yapısına ihtiyaç duyar. Eğer bu anlaşmalar iç hukuk düzenlemeleri bakımından değişiklik yapılması şeklinde sonuçlanırsa ticaret yaratma ve ticareti kısma etkisinin sadece belirli ticaret ortakları için uyarlanması zor olacaktır (WTO, 2011).

Türkiye'nin Rusya Federasyonu'na ihracatında kayıt dışılığın önemli bir sorun oluşturması nedeniyle, BGH sistemi üzerinden yapılan ticaretin artış göstermesi Türkiye'nin ihracat rakamlarını, yeterli olmasa da olumlu yönde, etkilemektedir. Netice itibariyle BGH, gerek kapsamı gerekse yararlanma koşulları bakımından sınırlı bir uygulama görünümündedir. Olası bir serbest ticaret anlaşması hükümleriyle, BGH'nin kapsamının genişletilmesi ve tüm ihracatçıları kapsar hale getirilmesi Türkiye'nin lehine olacaktır. Benzer şekilde BGH sistemi, eşyanın gümrük kontrolünden geçmesini sağlayarak fikri mülkiyet haklarının gümrük işlemleri çerçevesinde korunması açısından önemli bir aşama teşkil etse de, alana ilişkin evrensel kuralları içeren bir serbest ticaret anlaşmasının varlığı koruma düzeyini ve ciddiyetini artıracaktır.

Rusya Federasyonu'nun istihdam sağlayan tarım sektörünü korumak amacıyla uyguladığı yüksek gümrük vergisi ile bitki ve hayvan sağlığı önlemleri ülkenin ithalatını sınırlayıcı bir etkiye sahiptir. Rusya Federasyonu DTÖ üyeliğiyle birlikte tarım ürünleri ithalatında DTÖ Hayvan ve Bitki ve Sağlı̆̆ı Anlaşmasına uyacağını ve böylece bu alanı örtülü bir korumacılık uygulaması olarak kullanmayacağını, tarım ürünleri ihracatında sübvansiyonlarını tamamen kaldıracağını taahhüt etmiş̧tir. Olası serbest ticaret anlaşmasıyla zirai karantinaya ilişkin uygulamaların bilimsel ve amacıyla sınırlı kalması sağlanabilecek ve ayrımcı uygulama yasağı kapsamında olan bu uygulamaların ticaret sapması yaratmayacak şekilde düzenlemeye konu edilmesi mümkün hale gelecektir. Ayrıca anlaşma yoluyla iki tarafça kabul edilmiş sertifikasyon sisteminin kurulması, iki ülke ticaretinin kolaylaştırılması ve maliyetinin azaltılması bakımından olumlu etki sağlayacaktır.

\section{Sonuç}

Türkiye ile Rusya Federasyonu arasındaki siyasi, ticari ve ekonomik ilişkilerin yoğunluğu dikkate alındığında iki ülke arasında olası bir serbest ticaret anlaşmasının, kapsamlı ekonomik ortaklık anlaşması niteliğinde olması beklenmektedir. Böyle bir anlaşma sayesinde iki ülke tarafından arzulanan diş ticaret hacmine ulaşılabileceği gibi karşılıklı ve eşitlik ilkesine dayalı olarak ticaretin serbestleştirilmesi ve hızlandırılması, adil rekabet ortamının kurulması, iş ve yatırım koşullarının iyileştirilmesi ve ticari ilişkilerin kurumsallaştırılması yoluyla ticarete ilişkin bölgesel ve küresel yükümlülüklere de cevap verilmiş olunacaktır.

İki ülke arasında gümrük alanında yapılan protokollerle bilgi değişimi, gümrük işlemlerinin basitleştirilmesi ve uyumlaştırılması, karşılıklı eğitim programlarının gerçekleştirilesi gibi konulara ilişkin çeşitli düzenlemelere gidilmiş olsa da serbest ticaret anlaşması yoluyla bu alandaki işbirliğinin derinleştirilmesi ve daha kapsamlı bir aşamaya götürülmesi mümkündür. Ayrıca serbest ticaret anlaşmasına konulacak çerçeve hükümlerle taşımacılık sistemlerinin yapılandırılması ve çoklu modlu taşımacılığın desteklenmesi ile sınır geçişlerinin basitleştirilmesi 
ve hızlandırılması gerçekleşebilir. Anlaşma ile, gerek Türkiye ile Rusya Federasyonu pazarına, gerekse üçüncü ülkelerin rekabet yapısına, piyasa giriş koşullarına ve istihdamına olumlu etkinin artacağı öngörülebilir.

\section{Kaynakça}

- Adıgüzel, 2013. "Ekonomik Küreselleşmenin Türkiye Ekonomisine Etkileri”, Akademik Bakış Dergisi, 35, pp. 1-20, http://akademikbakis.org/eskisite/35/30.pdf (Erişim Tarihi: 13.5.2015)

- Akman, 2014. "AB-ABD Transatlantik Ticaret ve Yatırım Ortaklığı: Türkiye Açısından Bir Değerlendirme", Ankara Avrupa Çalı̧̧aları Dergisi, 13, pp. 1-29.

- Baccini, Dür, Elsig, Milewicz, 2011. The Design of Preferential Trade Agreements: A New Dataset in the Making. Staff Working Paper, World Trade Organization Economic Research and Statistics Division, Geneva., https://www.wto.org/english/res_e/reser_e/ersd201110_e.pdf (Erişim Tarihi: 16.5.2015)

- Bhagwati, 1995. "US Trade Policy: The Infatuation with FTAs", Columbia University Discussion Paper, Series No: 726. http://storage.globalcitizen.net/data/topic/knowledge/uploads/20090222131937814.pdf (Erişim Tarihi: 16.5.2015)

- Brownsell, 2012. "Bilateral and Regional Trade Agreements", Advocates for International Development, http://a4id.org/sites/default/files/user/Bilateral\%20and\%20Regional\%20Trade\%20Agreements.pdf (Erişim Tarihi: 16.5.2015)

- Candaş, 2010. "Çok Taraflılık mı Tek Taraflılık mı? Tercihli Ticaret Anlaşmalarının Uluslararası Ticaret Sistemiyle İlişkisine Dair Bir Değerlendirme”, Uluslararası Hukuk ve Politika, 6, pp.55-76

- Cottier, 2005. "The Erosion of Non-Discrimination: Stern Warning Without True Remedies", Journal of International Economic Law, 8, pp. 595-601.

- CCalışkan, 2011. "Eski ve Yeni Bölgeselleşme Olguları: Karşılaştırmalı Bir Analiz”, Sunum, Ankara Üniversitesi, http://mpra.ub.uni-muenchen.de/56611/3/MPRA_paper_56611.pdf (Erişim Tarihi: 15.5.2015)

- Ertürk, 2006. Uluslararası İktisadi Birleşmeler. 4. Baskı, Alfa Aktüel, Bursa.

- Genç, Berber, 2011. "Bölgeselleşme ve Ticaret Akımları: Literatür İncelemesi”, Kocaeli Üniversitesi Sosyal Bilimler Enstitüsü Dergisi, 22, pp. 84-110.

- Gümrük ve Ticaret Bakanlığı (GTB), 2013. "Bakan Yazıc1: Rusya ile Ticarette Yeni Dönem Başlıyor", http://www.gtb.gov.tr/haberler/bakan-yazici-rusya-ile-ticarette-yeni-donem-basliyor (Erişim Tarihi: 16.5.2015)

- Günay, Can, 2011. “Orta Asya, G. Kore ve Türkiye Arasında Olası Bir Gümrük Birliği: Türkiye’nin Potansiyel İhracat Kazanımları", Maliye ve Finans Yazıları Dergisi, 93, pp. 9-58

- http://www.rusyaofisi.com/pratik.htm (Erişim Tarihi: 16.5.2015)

- International Trade Centre (ITC), Trade Map, Trade statistics for international business development, http://www.trademap.org/ (Erişim Tarihi: 16.5.2015)

- İncekara, 1995. Globalleşme ve Bölgeselleşme Sürecinde NAFTA ve Etkileri. İstanbul Ticaret Odası Yayın No: 1995-14, İstanbul.

- Karluk, 2009. Uluslararası Ekonomi. 9. Baskı, Beta, İstanbul.

- Kayıhan, Eski, 2010. Uluslararası Ekonomi Hukuku. Seçkin, Ankara.

- Krueger, 1999. “Are Preferential Arrangements Trade-Liberalizing or Protectionist?”, Journal of Economic Perspectives, 13, pp. 105-124.

- Leal-Arcas, 2011. "Proliferation of Regional Trade Agreements: Complementing or Supplanting Multilateralism?" Chicago Journal of International Law, 11, pp. 597-629.

- Moïse, Bris, "2013. Trade Costs: What Have We Learned? A Synthesis Report”, OECD Trade Policy Paper, No: 150, pp.1-44

- Özdal, Özertem, Has, Demirtepe, 2013. Türkiye-Rusya İlişkileri: Rekabetten Çok Yönlü İşbirliğine. Uluslararası Stratejik Araştirmalar Kurumu Avrasya Araştırmaları Merkezi, Rapor No: 13-06, Ankara.

- Resolution No. 54, July 16, 2012, Common Customs Tariff of the Customs Union, http://www.eurasiancommission.org/en/act/trade/catr/ett/Pages/default.aspx (Erişim Tarihi: 17.5.2015)

- Seyidoğlu, 1999. Uluslararası İktisat. 13. Baskı, Kurtiş Matbaası, İstanbul.

- Şanl1, 2004. "Küreselleşme ve Ekonomik Entegrasyonlar”, Fırat Üniversitesi Doğu Anadolu Bölgesi Araştırmaları Dergisi, 3, pp. 160-165.

- TEPAV, (?). "Rusya Federasyonu'nun Dünya Ticaret Örgütüne Katılımına İlişskin Değerlendirme”, Türkiye Ekonomi Politikaları Araştımaları Vakfı Ticaret Araştırmaları Merkezi, pp.1-23, http://gebzeto.org.tr/upload/duyuruekler/3400_1a67777be655d635937daa712bf07ad6.pdf (Erişim Tarihi: 16.5.2015).

- The Worldbank Group, 2014. Duing Business 2015 Going Beyond Efficiency. 12th Edition, World Bank: Washington.

- World Trade Organisation (WTO), 2011. The WTO and preferential trade agreements: From coexistence to coherence, WTO, Switzerland. 


\title{
İhracat Ve Ekonomik Büyüme Arasındaki Nedensellik İlişkisi: Rusya Örneği \\ Causality Relationship between Export and Economic Growth: The Case of Russia
}

\author{
Asst. Prof. Dr. Özgür Uysal (Alanya Alaaddin Keykubat University, Turkey) \\ Mrs. Sultan Sat (Alanya Alaaddin Keykubat University, Turkey)
}

\begin{abstract}
Nowadays, together with the process of globalization, the relation between export and economic growth has begun to gain importance when decisions regarding economic situation of a country are taken, and when estimations concerning economy are made. The relation between economic growth and export has become one of the most disputable issues of the economic literature. The main objective of this study is to find out the direction of the relation between export and economic growth in Russia. Analysis was performed by using quarterly export and economic growth data of belonging from 1997:01 to 2014:04. The stability of the variables was initially determined by using Augmented Dickey - Fuller (ADF) unit root test. Subsequently, the existence of co-integration between variables was investigated by using Johansen Co-integration Test. In the last stage, the direction of the relationship between variables was determined by using Granger Causality Test. As a result of the analyses carried out, it was determined that bi-directional causality exists between export and economic growth in Russia between the years 1997-2014.
\end{abstract}

\section{Giriș}

Globalleşen dünyada, dünyanın tek bir pazar haline geldiği bugünlerde ihracatın hem reel ekonomi hem de finansal ekonomi üzerinde büyük bir etkisi bulunmaktadır. İhracat; enerji, yatırım malları ve ara malları ithalatının finansmanı için gerekli olan döviz girdisini sağlamada ve ülkenin oluşan döviz rezervleri ile büyüme sürecinde büyük bir öneme sahiptir (Aktaş, 2009). Literatürde ekonomik büyümenin değişik tanımları yapılsa da, en genel ifade ile ekonomik büyüme, 'ülkelerin üretim seviyelerinin artması; kişi başı düşen milli hâsılanın yükselmesidir' (Sandalcılar, 2012).Ekonomi literatürünün en kapsamlı konulardan biri istikrarlı ekonomik büyüme sürecinin nasıl gerçekleştirilebileceği olup, ekonomik büyümenin kaynaklarından birinin de ihracat olduğu bilinmektedir. Ekonomik büyüme ve ihracat arasındaki ilişki dinamik nitelikte olup,bu ilişki literatürde ‘ihracat büyümenin motoru mu, yoksa yardımcı bir öğesi midir?' sorusu etrafında tartışılmaktadır (Yiğidim ve Köse, 1997). Bu ilişkinin gerek küreselleşme eğilimindeki dünya ekonomisi, gerekse özelde dünyanın en büyük enerji ihracatçısı olan Rusya ekonomisi için araştırılması önem kazanmaktadır. Rusya Federasyonu, büyük bir ekonomik gücün temeli olan doğal kaynaklara ve insan gücüne sahip dünyadaki belli başlı ülkelerden biri konumundadır. Bu özelliği ile Rusya, BRICS (Brezilya, Rusya, Hindistan, Çin, Güney Afrika) olarak adlandırılan ve dünya ekonomisinde en hızlı gelişen 'yükselen piyasalar' veya 'yükselen ekonomiler' olarak kabul edilen ekonomiler ve ülkelerden birisidir.

Bu çalışmanın temel amacı, Rusya'da ihracat ile ekonomik büyüme arasındaki nedensellik ilişkisinin araştırılmasıdır. Çalışmada ilk olarak ihracat ve ekonomik büyüme konusu ile ilgili teorik bir çerçeve çizilmiş ve literatür taraması yapılmıştır. Daha sonra 1997:01 - 2014:04 dönemlerine ait çeyrek yıllık veriler kullanılarak, Granger nedensellik testi ile değişkenler arasındaki ilişkinin yönü tespit edilmeye çalışılmış ve sonuçlar değerlendirilmiştir.

\section{Teorik Çerçeve}

Ticaretin ortaya çıkışı oldukça eskiye dayanmakta olup, ihracat ve ekonomik büyüme arasındaki ilişki uzun yıllardan beri iktisatçıların üzerinde çalıştığı önemli konulardandır.

Acar (2004)'a göre dış ticaret ile büyüme arasındaki ilişkiyi teorik çerçevede ilk olarak John StuartMill ele almıştır. Mill, teknolojik gelişme, büyüme ve dış ticaret hakkındaki Klasik görüşleri birlikte ele almıştır. Fakat Mill, bu konuda bir teori kurmamış, yalnızca teknolojinin gelişmesi ile zorunlu ve lüks malların ticaretinin bu durumdan etkilenişine ve özellikle ithalatı artırıcı etkisine değinmiştir.

F. Y. Edgeworth büyüme ve dış ticaret konusunu daha net olarak ele almıştır. Büyüme ve dış ticaret konusunu karamsar bir açıdan ele alarak “zararlı büyüme”den söz etmiştir. Edgeworth'a göre, ekonomik büyüme dış ticaret hadlerini ülke aleyhine bozduğu için ülke ekonomik anlamda refah kaybına uğramaktadır (Krugman ve Obsfeld, 1991).

Büyüme ve ticaret arasındaki daha açıklayıcı çalışma Sir John Hicks tarafından yapılmıştır. Aynı konu daha sonra 1955 yılında T. N. Rybczynski, 1957' de H. G. Johnson ve 1958 de Bhagwati tarafından ele alınmıştır. 
Seyidoğlu (2009)'na göre Sir John Hicks büyüme ve ticaret hadleri gibi reel konuları verimlilik artışı gibi başka bir reel olaya dayandırmıştır. Hicks, İngiltere ve Amerika arasındaki dış ticaret sonrası ticaret hadlerinin İngiltere aleyhine gelişmesinin nedenleri üzerine bir çalışma yapmış ve standart dış ticaret modelinde bir ülkenin ihracat sektöründe verimliliğin artması halinde dış ticaret hadlerinin ülke aleyhine geliştiğini tespit etmiştir. Dolayısıyla ithalata yönelik büyüme dış ticaret hadlerini olumlu etkilerken ihracata yönelik büyüme dış ticaret hadlerini olumsuz etkilemekte ve ülke dış ticaretten zararlı çıkmaktadır.

T. N. Rybczynski'ye göre, iki-mallı ve iki-faktörlü bir modelde ve tam istihdam şartları geçerliyken, üretim faktörlerinden birisinin arzı arttığında bu faktörü yoğun olarak kullanan malın üretimi artarken, diğer faktörü yoğun olarak kullanan malın üretimi ise azalır. Sadece ihraç malında yoğun olarak kullanılan faktörde artış olduğunda, dış ticareti artırıcı bir büyüme ortaya çıkar. Bu durumda ihraç malı üretimindeki artış ihracatı ve dış ticaret hacmini artıracaktır. Fakat sadece ithal ikamesi malının üretiminde yoğun olarak kullanılan üretim faktöründeki bir artış ithalatı azaltacağı için dış ticareti azaltıcı yönlü (dış ticarete karşıt) bir büyüme oluşturacaktır. Diğer yandan ihraç malı üretimi azalacaktır. Yani hem ihraç malı üretiminin azalması hem de ithal ikamesi mallarının üretimi artmasından kaynaklanan ithalat azalışı sonucu dış ticaret hacmi azalacaktır (Çelik, 2013).

H. G. Johnson 1957 yılında yaptığı çalışmada, dış ticaret hadlerindeki artışın ekonomik büyüme üzerinde olumsuz etki yaptığını göstermiştir. Büyümenin gelir ve dolayısıyla ithal malları talebi üzerindeki etkilerini dış ticaret hadlerindeki değişikliklere bakarak açıklamıştır. 'Nötr (yansız) büyüme', 'ticarete yönelik büyüme', 'ticarete aşırı yönelik büyüme', 'ticarete karşıt büyüme', 'ticarete aşırı karşıt büyüme' gibi 5 farklı kavram ile bu etkileri ortaya koymuştur (Acar, 2004).

Ticaret ve büyüme ilişkisini inceleyen diğer bir iktisatçı Bhagwati'dir. Bhagwati, büyümenin refah üzerindeki olumsuz etkisini ele alarak "yoksullaştıran büyüme" kavramını ortaya çıkarmıştır. Bu hipoteze göre, ekonomik büyüme sonrasında ortaya çıkan ticaret hadlerindeki bozulmalar ülke refahında oluşan olumlu etkileri bertaraf etmekte, tüketim üzerinde olumsuz etkide bulunmakta ve genel refah düzeyini azaltmaktadır (Jayme, 2001).

\section{Literatür İncelemesi}

Günümüze kadar ihracat ile ekonomik büyüme arasındaki ilişki birçok çalışmaya konu olmasına rağmen, her çalışmada farklı sonuçlara ulaşılmıştır. Birçok çalışmada ihracatın büyümeyi artırdığını öngören ihracata dayalı büyüme modelleri görülürken, bazı çalışmalarda ise ithalatın büyümeyi artırdığı görülmektedir. Literatürde "İhracata Dayalı Büyüme Hipotezi” olarak isimlendirilen modele göre, ihracattaki artış, rekabet ve kaliteli ürün uygulaması, ölçek ekonomisine geçiş ve dolayısıyla istihdam ve işgücü verimliliği artışı; dış piyasalardaki teknolojik yenilik, ekonomik büyümeyi tetikleyecektir (İspir vd., 2009: 60). Tüm bu konularda gerçekleştirilmiş çalışmaların seçilmiş özeti, tarih sırasına göre aşağıda verilmiştir.

J. Thornton 1997 yılında Almanya, Danimarka, İngiltere, İsveç, İtalya ve Norveç’i kapsayan altı ülkede 19.yy'ın ikinci yarısından birinci dünya savaşına kadar olan dönemde ekonomik büyüme ile ihracat arasındaki ilişkiyi incelemiştir. Granger nedensellik testinin uygulandığı çalışmada ülkeler için farklı sonuçlara ulaşılmıştır. İtalya, İsveç ve Norveç’te ihracattan ekonomik büyümeye doğru bir nedenselliğin olduğu, İngiltere'de ekonomik büyümeden ihracata doğru bir nedenselliğin olduğu, Almanya ve Danimarka'da ihracat ve ekonomik büyüme arasında çift yönlü nedensellik ilişkisinin var olduğu, yani ihracatın ekonomik büyümeyi etkilediği gibi ekonomik büyümenin de ihracatı etkilediği sonucuna ulaşılmıştır (Hüseyni, 2012).

Afxentiou ve Serletis 2000 yılında gelişmekte olan 50 ülkenin 1970-1993 yılları arasındaki GSYIH, ithalat ve ihracat verilerini kullanarak aralarındaki ilişkiyi incelemiştir. Birim kök testinin, Engle Granger eş bütünleşme testinin ve Granger Nedensellik testinin uygulandığı çalışmada sadece Güneydoğu Asya ülkeleri için ihracatın ekonomik büyümenin motoru olduğu tezinin geçerli olduğunu ve diğer ülkeler için böyle bir şey söylenemeyeceğini ortaya koymuşlardır (Hüseyni, 2012).

Özer (2006)1987-2006 yılları arasında Türkiye'de reel ekonomik büyüme-ihracat arasındaki ilişkiyi Granger nedensellik testi ile incelemiştir. Çalışmanın sonucunda, değişkenler arasında tek yönlü bir nedensellik olduğu, yani ihracattan ekonomik büyüme ile ithalata ve ithalattan ekonomik büyümeye doğru bir nedensellik ilişkisi olduğu tespit edilerek, Türkiye'de ihracat öncelikli büyüme hipotezinin geçerli olduğu sonucuna varılmıştır.

Konya (2006), 1960-1997 döneminde yirmi dört OECD ülkesinde reel GSYİH ile reel ihracat arasında Granger nedensellik olasılığını araştırmıştır. Bu araştırmada iki farklı model kullanılmıştır. Bunlar iki değişkenli (GSYIH-ihracat) model ve üç değişkenli (GSYIH- ihracat-dışa açıklık) modeldir. Hollanda, Finlandiya ve Kanada'da ihracatla büyüme arasında çift taraflı bir ilişki tespit edilirken; İsveç, İspanya, Yeni Zelanda, İtalya, İrlanda, İzlanda, Danimarka ve Belçika'da ihracattan GSYİH'ya doğru tek taraflı bir nedensellik; Portekiz, Norveç, Meksika, Japonya, Yunanistan, Fransa ve Avusturya'da GSYIH'dan ihracata doğru tek taraflı ilişki tespit edilmiş̧tir. Avustralya, Kore, Lüksemburg, İsviçre, İngiltere ve ABD'de değişkenler arasında herhangi bir nedensellik ilişkisi tespit edilememiş̧ir. 
Aktaş (2009) Türkiye'de 1996-2006 dönemindeki verilerle ihracat, ithalat ve ekonomik büyüme arasındaki nedensellik ilişkisini Johansen Eş-bütünleşme testi kullanarak incelemiştir. Çalışma sonucuna göre, kısa dönemde ihracat, ithalat ve ekonomik büyüme arasında iki yönlü bir nedensellik ilişkisi tespit edilmiştir. Uzun dönemde ise; ihracattan ithalata, ithalattan ihracata, büyümeden ihracata ve büyümeden ithalata doğru tek yönlü bir nedensellik ilişkisi olduğu görülmüştür.

Alagöz (2009) Türkiye'de 1980-2006 yılları arasında büyüme ve dış ticaret ilişkisini Granger nedensellik analizi ile içsel büyüme değişkenleri çerçevesinde incelemiştir. Çalışmanın sonucunda, dış ticaretten GSYİH'ya doğru tek taraflı bir nedensellik ilişkisinin olduğu görülmüştür.

Taştan (2010) 1985:01-2009:05 dönemi Türkiye ekonomisinde, ihracat, sanayi üretimi ve ithalat değişkenleri arasındaki karşılıklı etkileşim ve nedensellik ilişkilerini frekans alanı yöntemleri kullanarak incelemiştir. Çalışma sonucunda, uzun dönemde nedenselliğin yönünün, sanayi üretimi büyüme oranından ihracat büyüme oranına doğru olduğu görülmüştür. Bu bulgular "ithalata dayalı büyüme" ve "büyüme çekişli ihracat" hipotezlerini desteklemektedir.

Takım (2010) 1975-2008 Türkiye verilerini kullanarak ihracat ile büyüme arasındaki ilişkiyi Granger Nedensellik analiziyle test etmiş ve ihracat artışının büyümedeki artışı desteklemediği sonucuna ulaşmıştır.

Sandalcılar (2012) 1975-2010 tarihli veriler ile BRIC ülkelerinde ihracat ve ekonomik büyüme arasındaki ilişkiyi analiz etmiştir. Analizde, panel birim kök, panel eş bütünleşme ve panel nedensellik testleri kullanılmıştır. $\mathrm{Bu}$ çalışmada, kısa ve uzun dönemli nedensellik analizlerinde ilişki ihracattan ekonomik büyümeye doğru olduğu; tersi durumun anlamlı olmadığı tespit edilmiştir.

Göçer (2013) Asya ülkeleri için, 1980-2012 dönemi verilerini kullanarak, ihracatın, ekonomik büyüme üzerindeki etkilerini panel veri analizi yöntemleriyle incelemiştir. Yapılan analiz sonucunda; bu ülkelerde ihracatın ekonomik büyümeyi pozitif ve anlamlı düzeyde etkilediği, ihracatta meydana gelen yüzde 10 oranındaki artışın, ekonomik büyümeyi yüzde 1 oranında arttırdığı tespit edilmiştir.

Korkmaz (2014) Türkiye'de 1998:01-2013:03 dönemlerine ait çeyrek yıllık veriler kullanarak, ihracat ve ekonomik büyüme değişkenleri arasında bir nedensellik ilişkisi olup olmadığını araştırmıştır. Araştırma sonucunda, ihracattan büyümeye doğru tek yönlü nedenselliğe rastlanılmıştır.

\section{Veri Seti, Ekonometrik Yöntem Ve Bulgular}

\subsection{Veri Seti}

Rusya'da1997:01- 2014:04 dönemlerinde ihracat ve ekonomik büyüme arasındaki ilişkiyi ölçmek üzere, veriler ITC-Trademap ve OECD veri tabanlarından temin edilmiştir. Analizlerin gerçekleştirilmesinde Eviews 5.0 programı kullanılmıştır.

\subsection{Ekonometrik Yöntem}

Bu çalışmada, ekonometrik yöntem olarak zaman serisi yaklaşımı kullanılmıştır. Bu çerçevede, seriler Eviews programında hareketli ortalamalar yöntemi ile mevsimsel düzeltmeye tabi tutulmuştur. Bu işlemden sonra ilk olarak, AugmentedDickey-Fuller (ADF) birim kök testi kullanılarak değişkenlerin durağanlığı test edilmiştir. İkinci olarak, JohansenKoentegrasyon Testi kullanılarak değişkenler arasında eş-bütünleşmenin varlığ araştırılmıştır. Son aşama olarak da, Granger nedensellik testi kullanılarak değişkenler arasındaki ilişkinin yönü tespit edilmeye çalışılmıştır.

Zaman serileri arasındaki regresyon hesaplanırken, değişkenler arasında anlamlı bir ilişki olmasa bile genellikle yüksek bir $R^{2}$ değeri ortaya çıkmaktadır. Bu duruma düzmece regresyon denilmektedir. Gözlenen yüksek $R^{2}$ değeri gerçek bir ilişkiden ziyade trend eğilimindeki benzerliğin bir sonucu olarak ortaya çıkmaktadır. $\mathrm{Bu}$ sorunu gidermek için serilerin durağan olup olmadığına bakmak gerekir (Gujarati, 2009). Serilerde durağanlığı tespit etmek için birim kök testlerine başvurulmaktadır. Eğer seri birim kök içeriyorsa durağan değildir ve serileri durağan hale getirmek gerekmektedir. Bir zaman serisinin birim köke sahip olup olmadığını belirlemede yaygın olarak kullanılan testlerden en önemlileri, AugmentedDickey-Fuller (ADF) ve PhillipsPerron (PP) testleridir (Özer ve Erdoğan, 2006).

Dickey-Fuller testleri seri birim köke sahipse ve bu durum fark alma yöntemiyle ortadan kaldırılabiliyorsa kullanılması uygun olur. Tarı (2011)'ya göre serilerin durağanlığının sınanması için $Y t=P Y t-1+u t$ gibi bir model oluşturulduğunda $u t$ skolastik bir hata terimidir. $\mathrm{P}$ katsayısı için $\mathrm{P}=1$ bulunursa birim kök sorunu ortaya çıkar ve ilişki, $Y t=Y t-1+u t$ biçimini alır. Denklemin sağ ve sol tarafından $Y t$-1çıkarıldığında, $\Delta Y t=$ $(P-1) Y t-1+u t$ denklemi elde edilir. $\Delta Y t=(Y-Y t-1)$ birinci farktır. (P-1) de $\delta$ olarak ifade edilirse ilişki, $\Delta Y t=$ $\delta Y t-1+u t$ olarak yazılabilir. $\mathrm{P}=1$ olduğunda $\delta=0$ olur. Bu durumda, $\Delta Y t=(Y-Y t-1)=u t$ olacak ve birinci fark durağan olacaktır.

Seriler arasındaki eşbütünleşme ilişkisini belirlemede, yaygın olarak Engle ve Granger ileJohansen ve Juselius tarafından önerilen yöntemler kullanılmaktadır. Maksimum özdeğer ( $\lambda$ Max) ve iz istatistiği ( $\lambda$ Trace) şeklinde iki olabilirlik test istatistiği kullanılarak seriler arasındaki uzun dönemli ilişki Johansen-Juselius yöntemi ile belirlenebilir (Arısoy ve Ünlükaplan, 2010). 
Bir sistemde kullanılan serilerin durağan olmamasına karşın bu serilerin lineer kombinasyonları durağan olabilir ve bu durum eşbütünleşme kavramı ile açıklanabilir. Eşbütünleşme analizi sayesinde birbirleriyle ilişkili olduğu düşünülen ekonomik değişkenlerin uzun dönemde birlikte hareket edip etmediği ortaya çıkarılabilir (Bayraktutan ve Arslan, 2008).

Granger (1969)'e göre nedenselliğin tanımı şu şekildedir: “Y'nin öngörüsü, X'in geçmiş değerleri kullanıldı̆̆ında X'in geçmiş değerleri kullanılmadı̆̆ duruma göre daha başarılı ise X, Y’nin Granger nedenidir”. $\mathrm{Bu}$ tanım doğrulanırsa ilişki $\mathrm{X} \rightarrow \mathrm{Y}$ şeklinde gösterilir. Bu test yapılmadan önce değişkenlerin önceden durağanlaştırılması gerekir. Seriler durağan değilse regresyon analizi ile elde edilen sonuçlar gerçek ilişkiyi yansıtmada yanıltıcı olmaktadır (Granger, 1974).

Değişkenler arasında nedensellik ilişkisi tespit edildikten sonra, iki değiş̧kenin birlikte değişimini göstermek için korelasyon analizi gerçekleştirilmiştir. Korelâsyon analizinde amaç, bağımsız değişken değiştiğinde, bağımlı değişkenin ne yönde değiştiğini tespit etmektir. Korelâsyon katsayısı $(r)$ ile gösterilmekte ve alabileceği değerler -1 ile +1 arasında değişmektedir. Ortaya çıkan değerlerin yorumlanması şu şekildedir (Kalaycı, 2005):

- $\quad 0,00-0,25$ Çok zayıf düzeyde ilişki

- $\quad 0,26-0,49$ Zayıf düzeyde ilişki

- $\quad$ 0,50-0,69 Orta düzeyde ilişki

- $\quad 0,70-0,89$ Yüksek düzeyde ilişki

- $\quad$ 0,90-1,00 Çok yüksek düzeyde ilişki.

\subsection{Ekonometrik Bulgular}

İhracat ve ekonomik büyüme arasındaki ilişkinin istatistiksel açıdan anlamlı sonuçlar vermesi için, verilere ilk olarak ADF (AugmentedDickey-Fuller) birim kök testi yardımıyla durağanlık sınaması yapılmış ve sonuçlar Tablo 1'de sunulmuştur:

\begin{tabular}{|c|c|c|c|c|c|}
\hline & \multicolumn{2}{|l|}{ İHRACAT } & \multicolumn{2}{|c|}{ EKONOMİK BÜYÜME } \\
\hline & & t-istatistiği & Olasılık & t-istatistiği & Olasılık \\
\hline $\begin{array}{l}\text { ADF test } \\
\text { istatistiği }\end{array}$ & & -1.015010 & 0.7436 & -0.686615 & 0.8428 \\
\hline \multirow{3}{*}{$\begin{array}{l}\text { Test } \\
\text { KritikDeğerleri }\end{array}$} & $\% 1$ & -3.528515 & & -3.528515 & \\
\hline & $\% 5$ & -2.904198 & & -2.904198 & \\
\hline & $\% 10$ & -2.589562 & & -2.589562 & \\
\hline
\end{tabular}

Tablo 1. Serilerin Düzey Değerleri

Seride birim kök değişkenlerin, düzeylerine ilişkin Dikey-Fuller birim kök testi sonucu yüzde bir, yüzde beş ve yüzde on hata payı ile (H0: Seri durağan değildir, H1: Seri durağandır) sıfır hipotezinin reddedilemediği görülmektedir $(p=0,7436 \geq 0,05, \mathrm{p}=0,8428 \geq 0,05)$. Ayrıca $t$ istatistik değeri ihracat serisi için $|-1.015010|<$ Test kritik değerleri $|-3.528515|,|-2.904198|,|-2.589562|$. $T$ istatistik değeri büyüme serisi için, $|-0.686615|<$ Test kritik değerleri |-3.528515|, |-2.904198|, |-2.589562|. Genel olarak, ihracat vebüyüme serisi için, $t$ istatistik değerlerinin tüm anlamlılık seviyesinde test kritik değerlerinden mutlak değer olarak küçük olmasi, ihracat ve büyüme serilerinin durağan olmadığını göstermektedir. Bu nedenle serilerin birinci derece farkı alınarak test işlemi tekrar yapılmış ve sonuçlar Tablo 2'de sunulmuştur:

\begin{tabular}{|l|l|l|l|l|l|}
\hline \multicolumn{2}{|c|}{} & \multicolumn{2}{|l|}{ İHRACAT } & \multicolumn{2}{l|}{ EKONOMİK BÜYÜME } \\
\cline { 3 - 6 } \multicolumn{2}{|c|}{} & t-istatistiği & Olas1lık Değeri & t-istatistiği & Olas1lık Değeri \\
\hline \multirow{2}{*}{$\begin{array}{l}\text { ADF test } \\
\text { istatistiği }\end{array}$} & & -5.881650 & 0.0000 & -3.166309 & 0.0019 \\
\hline $\begin{array}{l}\text { Test Kritik } \\
\text { Değerleri }\end{array}$ & $\% 1$ & -2.598907 & & & \\
\cline { 2 - 6 } & $\% 5$ & -1.945596 & & -2.598907 & \\
\cline { 2 - 6 } & $\% 10$ & -1.613719 & & -1.945596 & \\
\hline
\end{tabular}

Tablo 2. Serilerin Birinci Farkları Alınmış Değerleri

Tablo 2'de, 1997:01- 2014:04 dönemleri için, çalışmada kullanılan iki değişkenin birinci farklarda durağan oldukları görülmektedir $(\mathrm{p} \leq 0,05)$. Ayrıca $t$ istatistik değeri ihracat serisi için $|-5.881650|>$ Test kritik değerleri $\mid-$ 2.598907|, |-1.945596|, |-1.613719|. T istatistik değeri büyüme serisi için, |-3.169817|> Test kritik değerleri |2.598907|, |-1.945596|,|-1.613719|. $T$ istatistik değerinin her iki anlamlılık seviyesinde de test kritik değerlerinden mutlak değer olarak büyük olması, ihracat ve büyüme serilerinin durağan olduğunu göstermektedir. Tablolarda ele alınan verilerin tamamının, birinci farkları [I(1)] ile durağan hale geldikleri veya birim kök içermedikleri gözlenmektedir. Verilerin hepsinin birinci farkının durağan olması sebebiyle eşbütünleşme testine geçilmiştir. Öncelikli olarak değişkenlerin eş-bütünleşme testi yapılacağı için değişkenlerin düzey değerleri kullanılarak VAR modeli kurulmuş ve Akaike (AIC), LL, LR, FBE, SC ve HQ bilgi 
kriterleriyardımıyla uygun gecikme sayısı iki olarak belirlenmiştir. Uygun gecikme uzunluğunun belirlenmesine ilişkin analiz sonuçları Tablo 3 'te sunulmuştur:

\begin{tabular}{|c|l|l|l|l|l|l|}
\hline Gecikme Say1S1 & \multicolumn{1}{c|}{ LL } & \multicolumn{1}{c|}{ LR } & \multicolumn{1}{c|}{ FPE } & \multicolumn{1}{c|}{ AIC } & \multicolumn{1}{c|}{ SC } & \multicolumn{1}{c|}{ HQ } \\
\hline 0 & -1704.528 & NA & $2.15 \mathrm{e}+19$ & 50.19199 & 50.25727 & 50.21786 \\
\hline 1 & -1476.913 & 435.1451 & $3.00 \mathrm{e}+16$ & 43.61510 & 43.81094 & 43.69270 \\
\hline 2 & -1449.007 & $51.70811^{*}$ & $1.48 \mathrm{e}+16$ & 42.91198 & $43.23838^{*}$ & $43.04131^{*}$ \\
\hline 3 & -1444.870 & 7.422682 & $1.48 \mathrm{e}+16^{*}$ & $42.90795^{*}$ & 43.36490 & 43.08901 \\
\hline 4 & -1443.428 & 2.503492 & $1.60 \mathrm{e}+16$ & 42.98316 & 43.57068 & 43.21595 \\
\hline
\end{tabular}

Tablo 3. Uygun Gecikme Saylst

Notlar: LR=Logaritmik Olasılı Oranl/'IheLikelihoodRatio, FBE=Son Tahmin Hatast/Final PredictionError, AIC=Akaike Bilgi Kriteri/Akaike Information Criterion, SC: Schwartz Kriteri, HQ= Hannan-Quinn Kriteri.

* ilgili test için uygun gecikme uzunluğunu göstermektedir.

Uygun gecikme uzunluğunun belirlenmesinin ardından JohansenEşbütünleşme testine geçilmiştir. Bu teste ilişkin sonuçlar aşağıda yer alan Tablo 4’te gösterilmiştir:

\begin{tabular}{|c|c|c|c|c|c|c|c|c|c|}
\hline \multicolumn{2}{|c|}{ Maximum Özdeğer Testi (Max. Eigenvalue Testi) } & \multicolumn{1}{|l|}{ İz Testi (Trace Test) } \\
\hline Ho Hipotez & $\begin{array}{c}\text { Alternatif } \\
\text { Hipotez }\end{array}$ & $\begin{array}{c}\text { Test } \\
\text { İstatistiğ }\end{array}$ & $\begin{array}{c}\text { \%5 Kritik } \\
\text { Değeri }\end{array}$ & Olasılık & $\begin{array}{c}H 0 \\
\text { Hipotez }\end{array}$ & $\begin{array}{c}\text { Alternatif } \\
\text { Hipotez }\end{array}$ & $\begin{array}{c}\text { Test } \\
\text { İstatistiği }\end{array}$ & $\begin{array}{c}\text { \%5 Kritik } \\
\text { Değeri }\end{array}$ & Olasıllk \\
\hline$r=0$ & $r=1$ & 11.29880 & 19.38704 & 0.4830 & $r=0$ & $r=1$ & 15.07893 & 25.87211 & 0.5680 \\
\hline$r=1$ & $r=2$ & 3.780135 & 12.51798 & 0.7737 & $r=1$ & $r=2$ & 3.780135 & 12.51798 & 0.7737 \\
\hline
\end{tabular}

Tablo 4.Johansen Eş-bütünleşme Test Sonuçları

Tablodaki sonuçlar incelendiğinde hem maksimum öz değer testi hem de iz testi açısından ele alınan seriler arasında uzun dönemli bir ilişkinin olmadığı görülmektedir.Herhangi bir eş-bütünleşik vektörün bulunmadığ ifade edilen $H 0$ hipotez için, maksimum öz değer 11.29880 olup, \%5 anlamlılık düzeyindeki kritik değer olan 19.38704' den küçüktür.İz testi açısından da değerler sırasıyla 15.07893ve 25.87211olduğundan $H o$ hipotezi kabul edilmektedir ( $p \geq 0.05$ ). Seriler arasında birden fazla eş-bütünleşik vektör olduğuna dair test edilen hipotez için hesaplanan değerler kritik değerlerin altında kalmaktadır. Bütün bu veriler ışığında seriler arasında bir eşbütünleşik vektör bulunmadığı sonucuna ulaşılmaktadır.

İhracat ve ekonomik büyüme arasındaki nedensellik ilişkisini belirlemek amacıyla Granger nedensellik testi kullanılmış olup, teste ilişkin sonuçlar Tablo 5'te sunulmuştur:

\begin{tabular}{|l|l|c|c|}
\hline Sifır Hipotez & F-Değeri & Olasılık Değeri (p) & \%5 Önem Düzeyinde Karar \\
\hline Büyüme İhracatın Granger nedeni değildir & 17.93921 & 0.0005 & Reddedilir \\
\hline İhracat Büyümenin Granger nedeni değildir & 8.132937 & 0.0433 & Reddedilir \\
\hline
\end{tabular}

Tablo 5. İhracat ile Ekonomik Büyüme Arasındaki Nedensellik İlişkisi

Tablo 3 'te nedensellik testinin gecikme uzunluğu iki olarak hesaplanmıştır. Tablo 5'e göre, Büyüme ihracatın granger nedenidir, İhracat Büyümeningranger nedenidir. Hohipotezleri yüzde 5 anlamlılık düzeyinde red edilmektedir $(p \leq 0,05)$. Gecikme uzunluğu iki alındığında, ihracattan büyümeye ve büyümeden ihracata doğru çift yönlü bir nedensellik ilişkisi bulunmuştur.

Ekonomik Büyüme ve İhracat arasında tespit edilen çift yönlü nedensellik ilişkinden sonra, bir değişken değiştiğinde diğer değişkenin ne yönde ve hangi oranda değiştiğini görmek amaciyla korelasyon analizi gerçekleştirilmiş ve sonuçlar Tabla 6'da sunulmuştur:

\begin{tabular}{|l|c|c|}
\hline & İhracat & Ek. Büyüme \\
\hline İhracat & 1 & 0.963 \\
\hline Büyüme & 0.963 & 1 \\
\hline
\end{tabular}

Tablo 6. Ihracat ve Ekonomik Büyüme Korelasyon Analizi

Tablo 6'da yapılan korelasyon analizi sonucunda, değişkenler arasında yani ihracat ve büyüme arasında pozitif yönlü çok güçlü bir korelasyon bulunduğu görülmektedir. İhracat arttıkça büyüme artmakta, büyüme artıkça ihracat artmaktadır.

\section{Sonuç}

Küreselleşmenin etkisiyle ülkeler mal, hizmet ticareti ve finansal sektörler açısındanbirbirleriyle yakın ilişki içerisinde olmuşlardır. Özellikle yükselen ekonomiler olarak kabul edilen ülkeler, bu ticaret ağının içerisinde 
daha fazla yer almaktadır. Bu ticaret ağının gelişmesi bir ülkenin verimliliği artmakta, teknolojisi ilerlemekte ve ülkeye döviz girdisi sağlanarak ülke ekonomisi büyüyebilmektedir.

İhracat artışının büyümeye yol açmasının yanında, büyümenin de ihracat artışına yol açması söz konusu olabilmektedir. $\mathrm{Bu}$ durum büyümenin kaynağına göre, farklılık göstermektedir. Büyümenin kaynağı üretim faktörleri stokundaki artış ise, ekonomik büyüme ihracatı artırmaktadır. Bunun yanında ihracattaki artış, ülkelerdeki teknolojik yenilikler sonucu da ortaya çıkabilmektedir. Fakat bu teknolojik yeniliklerin ülkelerdeki ihracatı artırması, bu teknolojik yeniliklerin ihracat kesiminde ortaya çıkması ile gerçekleşmektedir. Ancak bu teknolojik yeniliklerin ihracat kesiminde değil de, farklı bir kesimde ortaya çıkması halinde ihracat azalacaktır. Büyümenin ihracat artışına neden olması, yükselen ekonomilerde yurtiçi talebin üretim artışı karşısında yetersiz olmasından da kaynaklanabilmektedir.

Bu çalışmada Rusya'da 1997:01-2014:04 dönemi arasında ihracat ve ekonomik büyüme arasındaki nedensellik ilişkisi incelenmiştir. Çalışmada öncelikle değişkenlerin birim kök taşıyıp taşımadıkları araştırılmıştır. Durağanlık testi sonucunda bütün değişkenlerin birinci faklarında durağan oldukları tespit edilmiştir. Serilerin durağanlığının sağlanması ile birlikte uzun dönemli ilişkinin araştırılması için koentegrasyon testi yapılmıştır. Koentegrasyon testi neticesinde değişkenler arasında uzun dönemli bir ilişkinin bulunmadığı sonucuna varılmıştır.

Tahmin sonuçlarına göre, Rusya ekonomisinde ihracat ile ekonomik büyüme arasında hem ihracattan ekonomik büyümeye hem de ekonomik büyümeden ihracata doğru çift yönlü nedensellik ilişkisi bulunmuştur. Araştırma sonuçlarına göre, Rusya'da ihracat ile ekonomik büyümenin birbirini etkilediğini söylemek mümkündür.

Rusya ekonomisi ağırlıklı olarak hammadde ihracatına dayanmaktadır. Özellikle ekonomik kriz dönemlerinde (1998 ve 2008 ekonomik krizlerinde), petrol ve diğer hammadde fiyatlarında düşüş gerçekleşmesi Rusya GSYİH'nda daralmaya neden olmuştur. Bunun yanında çeşitli kaynaklara dayanan büyüme ihracatta artışa yol açabilmektedir. Bu çalışma ile Rusya ekonomisinde ihracat ve ekonomik büyüme arasında çift yönlü nedensellik ilişkisi bulunduğu sonucuna varılmıştır. Ayrıca ihracat ve ekonomik büyüme arasında pozitif yönlü çok güçlü bir korelasyon olduğu tespit edilmiştir.

\section{Kaynakça}

- Acar, 2004. Uluslararası Reel Ticaret: Teori, Politika, Dokuz Eylül Yayınları, İzmir.

- Aktaş, 2009. “Türkiye'nin İhracat, İthalat ve Ekonomik Büyüme Arasındaki Nedensellik Analizi”, Kocaeli Üniversitesi Sosyal Bilimler Enstitüsü Dergisi, 18, s. 35.

- $\quad$ Alagöz, 2009. "İçsel Büyüme Teorisi Çerçevesinde Türkiye'de Dış Ticaret ve Büyüme İlişkisi Üzerine Bir Nedensellik Analizi (1980-2006)”, Finans Politik\& Ekonomik Yorumlar, 46, s. 529.

- Arısoy, Ünlükaplan, 2010. “Türkiye'de Mali Açıkların Sürdürülebilirliği ile Kamu Gelirleri ve Harcamaları İlişkisinin Analizi”, Maliye Dergisi, 159, s. 444-462.

- $\quad$ Bayraktutan, Arslan, 2008. "Türkiye'de Sabit Sermaye Yatırımlarının Ekonomik Büyüme Üzerindeki Etkisi: Ko-Entegrasyon Analizi (1980-2006)", KMU IIIBF Dergisi, 10, s. 14.

- Çelik, 2013.Hecksher-Ohlin (Faktör Donatımı) Teorisi, İlkay Öner Bodurlar (Ed.), Uluslararası İktisat, Anadolu Üniversitesi, Eskişehir.

- Göçer, 2013. "Ekonomik Büyümenin Belirleyicisi Olarak İhracat: Gelişmekte Olan Asya Ülkeleri İçin Yatay Kesit Bağımlılı̆̆ı Altında Çoklu Yapısal Kırılmalı Panel EşbütünleşmeAnalizi”, Bankacılar Dergisi,27, s. 86.

- Granger 1974. "Spurious Regressions in Econometrics”, Journal of Econometrics, 2, s. 111-120.

- Gujarati, 2009. Temel Ekonometri (Cev. Şenesen, U. ve Şenesen, G.G.), Literatür Yayıncılık, İstanbul.

- Hüseyni, 2012. Dış Ticaret Ve Ekonomik Büyüme Analizi, Atatürk Üniversitesi Sosyal Bilimler Enstitüsü İktisat Anabilim Dalı, Yüksek Lisans Tezi İktisat Anabilim Dalı, s.35.

- İspir, 2009. “Türkiye'nin Büyüme Dinamiğinde İhracat mı İthalat mı Daha Etkin?”, Dokuz Eylül Üniversitesi, İktisadi ve İdari Bilimler Fakültesi Dergisi, 24, s. 59-72.

- Jayme, 2001. Notes on TradeandGrowth, http://www.cedeplar.ufmg.br/pesquisas/td/TD\%20166.pdf, 02.05.2015.

- Kalaycı, 2005. SPSS Uygulamalı Çok Değişkenli İstatistik Teknikleri, Asil Yayın Dağıtım, Ankara.

- Konya, 2006. "ExportsandGrowth: Granger Causality Analysis on OECD Countrieswith a Panel Data Approach”, EconomicModeling, 23, s. 978-992.

- Korkmaz, 2014. "Türkiye Ekonomisinde İhracat ve Ekonomik Büyüme Arasındaki Nedensellik İlişkisi”, Business and Economics Research Journal, 5, p. 119. 
- Krugman, 1991.International Economics. TheoryandPolicy, HarperCollinsPublishers, New York.

- OECD, 2015. Country statistics, https://data.oecd.org

- Özer, Erdoğan, 2006. "Türkiye'de İhracat, İthalat ve Ekonomik Büyüme Arasındaki İlişkilerin Zaman Serisi Analizi”, Gazi Üniversitesi Ekonomik Yaklaşım, 17, s. 93.

- Sandalcılar, 2012. "BRIC Ülkelerinde Ekonomik Büyüme ve İhracat Arasındaki İlişki: Panel Eşbütünleşme ve Panel Nedensellik", Süleyman Demirel Üniversitesi İktisadi ve İdari Bilimler Fakültesi Dergisi, 17, s. 161-17.

- Seyidoğlu, 2009. Uluslararası İktisat Teori Politika ve Uygulama, Güzem Can Yayınları, İstanbul.

- Takım, 2010. “Türkiye'de GSYİH ile İhracat Arasındaki İlişki: Granger Nedensellik Testi”, Atatürk Üniversitesi Sosyal Bilimler Enstitüsü Dergisi, 14, s. 1-16.

- Tar1, 2011. Ekonometri, Umuttepe Kitapevi, İstanbul.

- Taştan, 2010. “Türkiye'de İhracat, İthalat ve Ekonomik Büyüme Arasındaki Nedensellik İlişkilerinin Spektral Analizi”, Ekonomi Bilimler Dergisi, 2, s.87-98.

- TradeMap, 2015. Tradestatisticsforinternationalbusinessdevelopment, http://www.trademap.org

- Yiğidim, Köse, 1997. "İhracat ve Ekonomik Büyüme Arasındaki İlişki, İthalatın Rolü: Türkiye Örneği (1980-1996)", Ekonomik Yaklaşım, 8,s.71-85. 


\title{
Türkiye'nin Avrupa Birliği Ülkeleri ile Endüstri-içi Ticaretinin Belirleyicileri: Çekim Modeli Sonuçları (1996-2013) The Determinants of Turkey's Intra-Industry Trade with
European Union Countries: The Gravity Model Results
$(\mathbf{1 9 9 6 - 2 0 1 3 )}$
}

\author{
Prof. Dr. Mustafa Kemal Değer (Karadeniz Technical University, Turkey) \\ Muharrem Akın Doğanay (Karadeniz Technical University, Turkey) \\ Asst. Prof. Dr. Osman Murat Telatar (Karadeniz Technical University, Turkey)
}

\begin{abstract}
In recent years, structure of world trade is transformed to intra-industry trade (IIT) that is defined as the import and export of similar commodities. The transformation of foreign trade structure has led to increase either theoretical or empirical studies on IIT. A large part of the empirical studies on international trade deals with gravity model for explaining the determinants of foreign trade. According to gravity model, trade between countries, is affected negatively to the distance between them and positively to the size of the country. Similar statements can be used in terms of the determinants of IIT. Therefore, this study will be carried out determinants of IIT with using the gravity model.

In this paper, determinants of intra-industry trade in manufacturing sectors between Turkey and European Union (EU) 15 countries will be estimated by panel data regression analysis in 1996-2013 periods. The results of this study indicate that market size and foreign direct investments have positive effects and distance between countries and real effective exchange rate have negative effects on Turkey's manufacturing sector IIT with EU 15.
\end{abstract}

\section{Giriş}

Ticari küreselleşme ile ilgili olarak iki büyük dalga söz konusudur. Ticari küreselleşmenin birinci büyük dalgası, Sanayi Devrimi sonrası İngiltere'nin öncülüğünde ortaya çıkmış ve I. Dünya Savaşı’nın başladığg 1914 yılına kadar sürmüştür. Savaş sonrası dönemde ticareti serbestleştirmeye yönelik çabalar olsa da 1929 Büyük buhran nedeniyle ülkeler dış ticareti yoğun korumacı politikalarla baskı altına almışlardır. Bu gelişmelere paralel olarak dünya ekonomisi de durma noktasına gelmiştir. Bu durumdan rahatsız olan sanayileşmiş ülkeler, dünya ticaretinin serbestleştirilmesine yönelik anlaşma ve çabalara hız vermişler ve böylelikle II. Dünya Savaşı sonrası ticari küreselleşmenin ikinci büyük dalgası yaşanmaya başlamıştır. Dünya ticareti önündeki engellerin kaldırılmasıyla beraber dünya ticaret hacmi giderek artmaya başlamıştır. Dünya ticaret hacminde yaşanan bu artışın yanında dünya ticaret yapısında da önemli değişmeler yaşanmaya başlanmıştır. Şöyle ki son ticari küreselleşme dalgası ile farklı ürünlerin ticaretini ifade eden endüstriler-arası ticaret ağırlıklı dünya ticaret yapısı, aynı türden ürünlerin ticareti olarak bilinen endüstri-içi ticaret ağırlıklı bir yapıya doğru dönüşmeye başlamıştır.

Endüstri-içi ticaretin geleneksel teoriler ile açıklanamaması, son yıllarda ölçek ekonomileri ve piyasa yapıları ile endüstri-içi ticareti açıklamaya yönelik yeni teorilerin de ortaya çıkmasına neden olmuştur. Konu ile ilgili teorik literatürde yaşanan bu gelişmeler, ampirik çalışmaların da ortaya çıkmasına yol açmıştır. Bu bağlamda son yıllarda endüstri-içi ticaretin belirleyicilerini ampirik olarak test eden önemli miktarda bir literatür belirginleşmeye başlamıştır.

Bu çalışmanın amacı Türkiye'nin en büyük ticari partneri olan Avrupa Birliği (AB) ile endüstri-içi ticaretinin belirleyicilerini panel veri regresyon analizleri ile ortaya koymaktır. Bu amaç doğrultusunda çalışmanın takip eden ilk kısmında endüstri içi ticaretin ölçülmesi ve genel olarak ticaretin açıklanmasında kullanılan çekim modeli hakkında bilgiler yer alacaktır. Ayrıca çalışmanın ilk kısmında son yıllarda belirginleşmeye başlayan endüstri-içi ticaretin belirleyicileri üzerine yoğunlaşan ampirik çalışmalara ait bulgulara yer verilecektir. Çalışmanın takip eden kısımlarında ise analizlerde dikkate alınacak veri ve metodoloji hakkında bilgi verilerek panel veri regresyon analizi sonuçları aktarılacaktır. Çalışmanın sonuç ve değerlendirme kısmında ise elde edilen ampirik bulgular değerlendirilecek ve Türkiye için politika önerisinde bulunulacaktır.

\section{Endüstri-içi Ticaretin Ölçülmesi ve Belirleyicileri Üzerine Literatür Özeti}

Endüstri-içi ticaret (intra-industry trade), belirli bir endüstri kapsamında, birbirinden farklılaştırılmış yapıdaki ürünlerin eşzamanlı olarak ihraç ve ithal edilmesidir. Daha açık bir ifade ile ürün ve fiyat farklılığı nedeniyle bir ülkenin aynı türden malların hem ihracatını hem de ithalatını yapması durumuna endüstri-içi ticaret adı verilir. Örneğin otomobil ihracatçısı bir ülkenin fiyat ve ürün farklılığı nedeniyle otomobil ithalatçısı olması, endüstri-içi 
ticarete işaret etmektedir. Bu durum sadece nihai mallar için değil; aynı sektördeki ürün ve mallar için de geçerlidir. Yani otomobil ihracatçısı bir ülkenin otomobil üretimi için gerekli ara malları ve girdileri dışardan ithal etmesi de endüstri-içi ticaret anlamına gelmektedir.

Endüstri-içi ticaretin ölçülmesine yönelik ilk çaba, Grubel ve Lloyd (1975) tarafindan gerçekleştirilmiştir. Endüstri-içi ticareti (IIT) ölçmede yaygın olarak kullanılan Grubel-Lloyd indeksi aşağıdaki gibi tanımlanmaktadır:

$$
I I T_{i}=\left[1-\frac{\left|X_{i}-M_{i}\right|}{X_{i}+M_{i}}\right]
$$

Eşitlik (1)'de IIT $_{i}$, i sektörü için endüstri-içi ticareti, $X_{i}$, i sektöründeki ülkenin ihracatı ve $M_{i}$ ise $i$ sektöründeki ülkenin ithalatını göstermektedir. Eğer IIT'nin değeri, 1'e yaklaşırsa, endüstri-içi ticarete; IIT'nin değeri 0 yaklaşır ise endüstriler-arası ticarete işaret eder.

Son yıllarda dünya ticaret yapısında endüstri-içi ticaret ağılıklı bir dönüşüm yaşanmaktadır. Dolayısıyla literatürde dış ticaretin belirleyicileri üzerine oldukça fazla yapılmış çalışmalar (bkz: Tatlıcı ve Kızıltan (2011), Genç ve Berber (2011)) yanında son zamanlarda endüstri-içi ticaretin belirleyicilerine yönelik bir ampirik literatür de ortaya çıkmaya başlamıştır. Ticaretin belirleyicileri üzerine yapılan ampirik çalışmaların büyük bir kısmı, Newton'un "Çekim Yasası"nı ticarete uyarlayan bir model kullanmaktadırlar. Çekim Yasası'na göre kütlelerin çekim kuvveti, kütlelerin büyüklüğü ile doğru orantılı ve kütleler arası mesafe ile ters orantılıdır. Ticaret açısından çekim modeline göre ise ülkeler arasındaki ticaret hacmi, ülkelerin büyüklüğü (örneğin Gayri Safi Yurtiçi Hâsıla (GSYIH) ve nüfus gibi) ile doğru orantılı iken, ülkeler arası mesafe ile ters orantılıdır. Daha açık bir ifadeyle iki ülke arasındaki ticaretin, ülkelerin ekonomik ve nüfus büyüklüğünden olumlu, taşıma maliyetleri nedeniyle ülkeler arasındaki mesafeden ise olumsuz etkilenmesi beklenmektedir. En basit haliyle çekim modeli, Eşitlik (2)'de sunulduğu şekildedir (Tinbergen, 1962):

$$
X_{i j}=A \frac{Y_{i} Y_{j}}{D_{i j}}
$$

Eşitlik (2)'de $X_{i j}$, i ülkesinin $j$ ülkesine yapmış olduğu ihracatı, $Y_{i}$ ve $Y_{j}$ sırasıyla $i$ ve $j$ ülkelerinin GSYIH'larını, $D_{\mathrm{ij}}$, $i$ ve $\mathrm{j}$ ülkesi arasındaki fiziki mesafe uzunluğunu ve $\mathrm{A}$ ise sabiti göstermektedir.

Ülkelerin ihracatının açıklanmasında kullanılan çekim modeli, son yıllarda ticaret yapısındaki değişime paralel olarak endüstri-içi ticaretin belirleyicilerinin test edilmesinde de kullanılmaya başlanmıştır. Çekim modelini kullanarak endüstri-içi ticaretin belirleyicilerini araştıran ampirik çalışmaların literatür özeti Tablo 1'de sunulmuştur.

Tablo 1'de verilen endüstri-içi ticaretin belirleyicilerini ampirik olarak test eden çalışmaların bulguları genel olarak değerlendirildiğinde, elde edilen sonuçlar temel çekim modelini doğrular niteliktedir. Daha açık bir ifadeyle endüstri-içi ticaret üzerinde ülkelerin ekonomik büyüklükleri pozitif etkilere sahipken, ülkeler arası mesafe ise negatif etkilere yol açmaktadır. Bu genel değerlendirmenin yanında ampirik literatürde diğer açıklayıcı değişkenlerin işareti açısından büyük ölçüde benzerlikler bulunmakla birlikte bazı çalışmalar açısından farklılaşan durumlar da söz konusudur. 


\begin{tabular}{|c|c|c|c|}
\hline Yazarın Adı & Ülke ve Dönemi & $\begin{array}{l}\text { Kullanılan } \\
\text { Yöntem }\end{array}$ & Bulgular \\
\hline $\begin{array}{l}\text { Clark ve Stanley } \\
(1999)\end{array}$ & $\begin{array}{l}\text { ABD ve Gelişmekte Olan } \\
\text { Ülkeler (1992) }\end{array}$ & Panel Veri Analizi & $\begin{array}{l}\text { Ekonomik Büyüklük (+), Ticari Oryantasyon (+), } \\
\text { Mesafe (-), Faktör Donatımındaki Farklılık (-) }\end{array}$ \\
\hline Sharma (1999) & $\begin{array}{l}\text { Avustralya (1979-1980 ve } \\
\text { 1992-1993) }\end{array}$ & $\begin{array}{l}\text { Logit Regresyon } \\
\text { Modeli }\end{array}$ & $\begin{array}{l}\text { Ürün Farklılığ }(+) \text {, Ekonomik Büyüklük (+), AR- } \\
\text { GE Yatırımları (0), } \\
\text { Doğrudan Yabancı Yatırımlar (DYY) (-), } \\
\text { Ekonomik Entegrasyon (0), Ticari Engeller (0) }\end{array}$ \\
\hline $\begin{array}{l}\text { Brülhart ve } \\
\text { Thorpe }(2000)\end{array}$ & Malezya (1970-1994) & Panel Veri Analizi & Tüketimdeki Değişim (+), Ticari Açıklık (-) \\
\hline $\begin{array}{l}\text { Clark ve Stanley } \\
(2003)\end{array}$ & $\begin{array}{l}\text { ABD ve } 22 \text { Sanayileşmiş } \\
\text { Ülke (1992) }\end{array}$ & Panel Veri Analizi & $\begin{array}{l}\text { GSYİH (+), Mesafe (-), Sermaye/İşgücü Oranı } \\
\text { Farkl11ıkları (+), Nitelikli İşgücü Farklılıkları (-), } \\
\text { Toprak/İşgücü Oranı Farklılıkları (-) }\end{array}$ \\
\hline Emirhan (2005) & $\begin{array}{l}\text { Türkiye - } 9 \text { Büyük Ticari } \\
\text { Ortak (1989-2002) }\end{array}$ & Panel Veri Analizi & GSYİH Seviyesi (+), Mesafe (-) \\
\hline $\begin{array}{l}\text { Zhang vd. } \\
(2005)\end{array}$ & $\begin{array}{l}\text { Çin ve } 50 \text { Ticari Partner } \\
\text { Ülke }(1992-2001)\end{array}$ & Panel Veri Analizi & $\begin{array}{l}\text { Ekonomik Büyüklük (+) DYY (+), Sınır Ülke (+), } \\
\text { Ticari Engeller (-) }\end{array}$ \\
\hline Gabrish (2006) & $\begin{array}{l}\text { AB ve Sinır Ülkeleri } \\
(1993,2000 \text { ve } 2004)\end{array}$ & Panel Veri Analizi & Kişisel Gelir Eşitsizliği (+), Teknoloji Farklılığı $(+)$ \\
\hline $\begin{array}{l}\text { Caetano ve } \\
\text { Galego (2007) }\end{array}$ & $\begin{array}{l}\text { Avrupa Birliği } \\
(1993-2001)\end{array}$ & Panel Veri Analizi & Ülke Büyüklüğü (-), Mesafe (-), DYY (+) \\
\hline $\begin{array}{l}\text { Vogiatzoglou } \\
(2007)\end{array}$ & $\begin{array}{l}\text { Yunanistan ve AB } \\
(1981-2002)\end{array}$ & Panel Veri Analizi & $\begin{array}{l}\text { Ekonomik Büyüklük Farklılığı (-), Gelişmişlik } \\
\text { Farklılığı (-), Mesafe (-), Ortak Pazar (+), Ticari } \\
\text { Akım (+) }\end{array}$ \\
\hline $\begin{array}{l}\text { Faustino ve } \\
\text { Leitão (2007) }\end{array}$ & $\begin{array}{l}\text { Portekiz ve AB Ülkeleri } \\
(1996-2002)\end{array}$ & Panel Veri Analizi & Endüstriyel Yoğunlaşma (+), Verimlilik (-) \\
\hline $\begin{array}{l}\text { Ekanayake vd. } \\
\text { (2007) }\end{array}$ & $\begin{array}{l}\text { ABD ve } 20 \text { Latin Amerika } \\
\text { Ülkesi } \\
(1990-2005)\end{array}$ & Panel Veri Analizi & $\begin{array}{l}\text { GSYİH Farklılıkları (-), Ürün Farklılaştırması (+), } \\
\text { Endüstriyel Yoğunlaşma (-), Endüstri Büyüklüğü } \\
(+), \text { Ürün Kalite Farklılıkları (+) }\end{array}$ \\
\hline $\begin{array}{l}\text { Lefillear ve } \\
\text { Maure }(2010)\end{array}$ & $\begin{array}{l}\text { Merkez ve Doğu Avrupa } \\
\text { Ülkeleri (1993-2005) }\end{array}$ & Panel Veri Analizi & DYY (+), İşçi Maliyetleri (-) \\
\hline $\begin{array}{l}\text { Türkcan ve Ateş } \\
\text { (2010) }\end{array}$ & $\begin{array}{l}\text { ABD ve } 37 \text { Ticari Partner } \\
\text { Ülke } \\
(1989-2006)\end{array}$ & Panel Veri Analizi & $\begin{array}{l}\text { Ortalama GSYİH (+), GSYİH Farkları (+), } \\
\text { Kişi Başına Gelir Farkları (+), Mesafe (-), DYY } \\
(+) \text {, Döviz Kuru (+) }\end{array}$ \\
\hline Kang (2010) & $\begin{array}{l}\text { Merkez ve Doğu Avrupa } \\
\text { Ülkeleri }(1998-2006)\end{array}$ & Panel Veri Analizi & $\mathrm{DYY}(+)$ \\
\hline $\begin{array}{l}\text { Sawyer vd. } \\
(2010)\end{array}$ & $\begin{array}{l}\text { Seçilmiş } 22 \text { Asya Ülkesi } \\
\text { (2003) }\end{array}$ & $\begin{array}{l}\text { Tobit Regresyon } \\
\text { Modeli }\end{array}$ & $\begin{array}{l}\text { AR-GE Harcamaları (+), Açıklık (+), İmalat } \\
\text { Sanayi İhracat Payı (+), Mesafe (-), } \\
\text { Ekonomik Büyüklük Farkı (-) }\end{array}$ \\
\hline $\begin{array}{l}\text { Fainstein ve } \\
\text { Netsunajev } \\
(2011)\end{array}$ & $\begin{array}{l}\text { Estonya, Letonya ve } \\
\text { Litvanya (1999-2007) }\end{array}$ & Panel Veri Analizi & $\begin{array}{l}\text { Pazar Büyüklüğü (+), Beşeri Sermaye (+), } \\
\text { Mesafe (-) }\end{array}$ \\
\hline $\begin{array}{l}\text { Rasekhi ve } \\
\text { Shojaee (2012) }\end{array}$ & $\begin{array}{l}\text { İran ve } 24 \text { Ticari Partner } \\
\text { Ülke (2001-2007) }\end{array}$ & Panel Veri Analizi & $\begin{array}{l}\text { Kişi Başına Gelir (+), İnsani Gelişim Göstergesi } \\
(+), \text { Tarımsal Alanlar (+), Pazar Büyüklüğ̈̈ } \\
\text { Farklılıkları (-) }\end{array}$ \\
\hline $\begin{array}{l}\text { Akram ve } \\
\text { Mahmood } \\
(2012)\end{array}$ & $\begin{array}{l}\text { Pakistan ve SAARC } \\
\text { Ülkeleri (1990-1991, } \\
\text { 1995-1996 ve 2000-2001) }\end{array}$ & Panel Veri Analizi & $\begin{array}{l}\text { Ortalama Gelir Seviyesi (+), İnsani Gelişmişlik } \\
\text { Farkı (+), Kişi Başına Gelir Farklılığı(-), Mesafe (- } \\
\text { ) }\end{array}$ \\
\hline Botric (2013) & $\begin{array}{l}\text { Batı Balkan Ülkeleri ve } \\
\text { AB }(2005-2010)\end{array}$ & Panel GLS Modeli & $\begin{array}{l}\text { Gelir Seviyesi (+), Mesafe (-), Faktör Donatımları } \\
(+) \text {, Ticari maliyetler }(-)\end{array}$ \\
\hline Leitao (2013) & $\begin{array}{l}\text { Portekiz ve AB } 27 \\
(2000-2010)\end{array}$ & Panel Veri Analizi & Göç (+) \\
\hline $\begin{array}{l}\text { Thorpe ve } \\
\text { Leitao (2013) }\end{array}$ & $\begin{array}{l}\text { ABD ve } 16 \text { Ticari Ortağ } 1 \\
\text { Ülke (1995-2008) }\end{array}$ & Panel Veri Analizi & $\begin{array}{l}\text { Göreceli Benzerlikler (+), Mesafe (-), DYY (+), } \\
\text { Toplam Pazar Büyüklüğü }(+)\end{array}$ \\
\hline $\begin{array}{l}\text { Şentürk ve } \\
\text { Kösekahyaoğlu } \\
(2014)\end{array}$ & $\begin{array}{l}\text { Türkiye ve } 20 \text { Ticari } \\
\text { Ortağı Ülke (1995-2012) }\end{array}$ & Panel Veri Analizi & $\begin{array}{l}\text { Ortalama Piyasa Büyüklüğü (+), Gelişmişlik Farkı } \\
(-), \text { Dışa Açıklık(+), Mesafe }(-), \\
\text { Ekonomik Entegrasyonun Varlığ }(+)\end{array}$ \\
\hline $\begin{array}{l}\text { Phan ve Jeong } \\
(2014)\end{array}$ & $\begin{array}{l}\text { Kore ve Asya Ülkeleri } \\
(1997-2011)\end{array}$ & Panel Veri Analizi & $\begin{array}{l}\text { Ortalama Gelir Seviyesi (+), DYY Akımı (+), } \\
\text { Faktör Donatımında Farklılık (-) }\end{array}$ \\
\hline Lapinska (2015) & $\begin{array}{l}\text { Polonya ve AB Ülkeleri } \\
(2002-2011)\end{array}$ & Panel Veri Analizi & $\begin{array}{l}\text { Entegrasyon (+), Ticari Engeller (-), Aynı Dil (+), } \\
\text { Ticari Dengesizlik (-) }\end{array}$ \\
\hline
\end{tabular}

Tablo 1: Endüstri-içi Ticaretin Belirleyicileri Üzerine Ampirik Literatür 


\section{Veri ve Metodoloji}

$\mathrm{Bu}$ çalışmada, Türkiye ekonomisinin $\mathrm{AB} 15$ ülkeleri ile yaptığı imalat sanayi ürünlerindeki endüstri-içi ticaretin belirleyicileri çekim modeli kullanılarak tespit edilmeye çalışılmıştır. Çalışmada dikkate alınan AB 15 Ülkeleri, birliğe katılım tarihine göre şunlardır: Almanya, Fransa, İtalya, Hollanda, Belçika, Lüksemburg (Kurucu Altılar), İngiltere, İrlanda, Danimarka, Yunanistan, İspanya, Portekiz, Avusturya, İsveç ve Finlandiya. Çalışmada Türkiye ile AB 15 ülkeleri arasında 1996-2013 dönemi yıllık verilerine dayanan panel veri regresyon analizlerine yer verilmiştir. Çalışma döneminin 1996 yılından başlatılmasının temel nedeni, Türkiye'nin 1/95 sayılı Ortaklık Konseyi kararı ile sanayi malları üzerinde AB ülkeleriyle bir gümrük birliği entegrasyonuna katılmış olmasıdır.

Bu çalışmada IIT ölçülmesinde dikkate alınan Grubel-Lloyd indeksinin hesaplanmasında Revizyon 3 göre ihracat ve ithalat verileri, imalat sanayi alt sektörleri (kimyasallar ve ilgili ürünler, hammaddesine göre sınıflandırılmış imalat sanayi ürünleri, makine ve taşıma araçları ve diğer imalat sanayi ürünleri) için UN Comtrade 'den elde edilmiştir. Bireysel imalat sanayi alt sektörleri ticaret verilerinden hareketle imalat sanayi toplamı için Grubel-Lloyd indeksi aşağıdaki eşitlik dikkate alınarak hesaplanmıştır.

$$
I I T_{i}=\left[1-\frac{\sum_{i=1}^{4}\left|X_{i}-M_{i}\right|}{\sum_{i=1}^{4}\left(X_{i}+M_{i}\right)}\right]
$$

Çalışmada çekim modeline dayanan aşağıdaki eşitlik regresyon analizlerinde kullanılmıştır.

$$
\begin{aligned}
\log \left(\frac{I I T_{i j}}{1-I I T_{i j}}\right)= & \alpha_{0}+\alpha_{1} \log \left(A G D P_{i j}\right)+\alpha_{2} \log \left(D R G D P_{i j}\right)+\alpha_{3} \log \left(D R K B G D P_{i j}\right)+\alpha_{4} W D I S T_{i j}+ \\
& \alpha_{5} E X C_{j}+\alpha_{6} F D I_{i}+\varepsilon_{t}
\end{aligned}
$$

Eşitlik (4)'de, i, Türkiye'yi ve $\mathrm{j}$ ise ilgili AB 15 ülkesini temsil ederken, IIT $_{\mathrm{ij}}$, Grubel-Lloyd indeksi dikkate alınarak hesaplanan toplam imalat sanayi sektörlerindeki endüstri-içi ticareti, AGDP $_{\mathrm{ij}}$, i ve $\mathrm{j}$ ülkelerinin reel GSYİH'larının ortalama değerlerini, DRGDP ${ }_{\mathrm{ij}}$, i ve j ülkelerinin reel GSYİH'ları arası farkı, DRKBGDP $\mathrm{ij}_{\mathrm{j}}, \mathrm{i}$ ve $\mathrm{j}$ ülkelerinin reel kişi başı GSYİH farklılıkları, WDIST $\mathrm{ij}_{\mathrm{j}}$, $\mathrm{i}$ ve j ülkeler arasındaki ağırlıklandırılmış mesafeyi, $\mathrm{EXC}_{\mathrm{j}}, \mathrm{AB} 15$ ülkelerinin reel efektif döviz kuru indeksini $(2010=100), \mathrm{FDI}_{\mathrm{i}}$, Türkiye'de yapılan doğrudan yabancı yatırımların GSYİH'içindeki payını ve $\varepsilon_{\mathrm{t}}$ ise hata terimini göstermektedir. Analizde kullanılan ticaret verisi dışındaki değişkenlere ait veriler, Dünya Bankası'nın “World Development Indicators" isimli veri tabanından, ülkeler arası mesafe uzunlukları ise çeşitli internet sitelerinden derlenmiştir. Ülkeler arası mesafe zamanla değişmeyen sabit bir değişken olduğu için çalışmada yapılacak olan panel veri analizleri açısından sabit etkiler modelinin kullanılmasını imkansız hale getirmektedir. Bu nedenle çalışmada ticari partner ülkenin GSYİH'na göre ağırlıklandırmaya gidilmiş ve ağırlıklandırılmış mesafe göstergesi (WDIST) şu şekilde hesaplanmıştır (Balassa ve Bauwens, 1987):

$$
W D I S T_{i j}=\frac{D I S T_{i j} * G D P_{j}}{\sum_{j=1}^{15} G D P_{j}}
$$

Eşitlik (5)’te DIST $\mathrm{ij}_{\mathrm{j}}$, Türkiye'nin en büyük üretim ve ticaret merkezi olan İstanbul ile her bir AB15 ülkesinin başkenti arasındaki karayolu uzunluğunu, GDP ${ }_{\mathrm{j}}$, her bir AB15 ülkesinin reel GSYİH'sını göstermektedir. Çalışmada yapılan regresyon analizleri ile diğer testler, STATA 12 isimli paket programı kullanılarak gerçekleştirilmiştir.

\section{Ampirik Bulgular}

Çalışmada panel veri regresyon analizlerinde kullanılan değişkenler, öncelikle birim-kök testleri ile durağanlık sınamalarına tabi tutulmuş ve durağanlık sınama testi sonuçları Tablo 2'de verilmiştir.

\begin{tabular}{|l|l|l|l|l|l|l|l|}
\hline Yöntem & IIT & LARGDP & LDRGDP & LDRKBGDP & WDIST & EXC & FDI \\
\hline Levin, Lin \& Chu t* & $-2.353^{\mathrm{a}}$ & -0.734 & 1.282 & -1.068 & 1.073 & 0.015 & 2.737 \\
\hline Breitung t-stat & -0.212 & -0.794 & 6.102 & 8.014 & 4.788 & $-3.628^{\mathrm{a}}$ & $-3.492^{\mathrm{a}}$ \\
\hline Im, Pesaran and Shin W-stat & 0.061 & 0.696 & 1.499 & 4.147 & 2.060 & $-1.410^{\mathrm{c}}$ & 1.470 \\
\hline ADF - Fisher Chi-square & 32.257 & 23.380 & 30.228 & 12.304 & 24.234 & 34.329 & 12.972 \\
\hline PP - Fisher Chi-square & 27.093 & 23.743 & 11.081 & 5.511 & 13.544 & 36.832 & 12.972 \\
\hline Not: a, ve c sirastyla istatistiki olarak\%1 ve\%10 önem seviyesinde anlamli olduklarinu ifade etmektedir. \\
\hline
\end{tabular}

Tablo 2. Birim-Kök Sınama Sonuçları (Trendli ve Sabitli)

Tablo 2'de verilen durağanlık sınama sonuçlarına göre bütün değişkenlerin seviyesinde durağan olmadıkları tespit edilmiştir. Dolayısıyla serilerin I(1) olduğuna karar verilmiştir.

\subsection{Tanımlayıcı İstatistikler ve Korelasyon Analizi Sonuçları}

Eşitlik (4)'de verilen değişkenlere ait tanımlayıcı istatistikler Tablo 3'de verilmiştir. 


\begin{tabular}{|l|l|l|l|l|l|l|l|}
\hline Değişkenler & ITT & $\begin{array}{l}\text { ARGDP } \\
\text { (Milyar\$) }\end{array}$ & $\begin{array}{l}\text { DRGDP } \\
\text { (Milyar\$) }\end{array}$ & DRKBGDP & WDIST & EXC & FDI (\%) \\
\hline Ortalama & 0.504 & 685 & 690 & 29908 & 182.720 & 99.716 & 1.434 \\
\hline Medyan & 0.510 & 441 & 305 & 29426 & 77.607 & 100.000 & 1.397 \\
\hline Maksimum & 0.827 & 1910 & 2550 & 78352 & 559.964 & 125.727 & 3.802 \\
\hline Minimum & 0.116 & 198 & 6 & 9492 & 5.496 & 80.928 & 0.314 \\
\hline Standart Sapma & 0.139 & 464 & 737 & 12671 & 181.722 & 6.768 & 1.060 \\
\hline Gözlem Sayısı & 261 & 261 & 261 & 261 & 261 & 261 & 261 \\
\hline Not: $a$, ve c sirastyla istatistiki olarak\%1 ve\%10 önem seviyesinde anlamli olduklartnı ifade etmektedir. \\
\hline
\end{tabular}

Tablo 3. Değişkenlere Ait Tanımlayıcı Ístatistikler

1996-2013 döneminde Türkiye'nin AB 15 ülkeleri ile yaptığı imalat sanayindeki Grubel-Lloyd indeksi ortalama olarak 0.504 değerini almıştır. Grubel-Lloyd indeksinin bu dönemdeki en yüksek değeri 0.827 ile 2009 yılında Türkiye'nin İtalya ile yaptığı ticarette ortaya çıkmıştır. Bu indeksin en küçük değeri ise 0.116 olup, 1999 yılında Türkiye'nin İsveç ile yaptığı ticarette ortaya çıkmıştır. Türkiye'nin reel GSYİH ile AB 15 ülkelerinin reel GSYİH'nın ortalama değeri 1996-2013 dönemi için 685 Milyar \$ olarak gerçekleşmiştir. Ortalama reel GSYİH değişkeni en yüksek değere 1910 Milyar \$ ile 2013 yılında Almanya ile gerçekleşmiş iken, 198 Milyar \$ ile en düşük düzeyde 1996 yılında Lüksemburg ile gerçekleşmiştir. 1996-2013 döneminde Türkiye'nin Kişi başına reel GSYİH ile AB 15 ülkelerinin kişi başına reel GSYİH arasındaki farkın mutlak değeri ortalama 29908 \$ olarak gerçekleşmiştir. Kişi başına gelir farklılıklarındaki en yüksek değer, 78352 \$ ile 2007 yılında Lüksemburg ile Türkiye arasında ortaya çıkmış iken, en küçük değer 9492 \$ ile 2013 yılında Portekiz ve Türkiye arasında ortaya çıkmıştır. Aynı dönemde ağırlıklandırılmış mesafe göstergesi ortalama olarak 182.7 olmuştur. En yüksek ağırlıklandırlımış mesafe göstergesi 2013 yılında İngiltere ve Türkiye arasında 559.9 olarak gerçekleşmiş iken, en düşük mesafe değeri ise 5.5 ile 1996 yılında Lüksemburg ve Türkiye arasında gözlemlenmiştir. Reel efektif döviz kurunun 1996-2013 döneminde ortalama değeri 99.72 iken, parası en fazla değerlenmiş olan ülke 2007 yılında İngiltere; parası en fazla değer kaybeden ülke ise 2000 yılında İrlanda'dır. 1996-2013 döneminde Türkiye'de yapılan DYY'lerin GSYİH içindeki payı ortalama \% 1.4 olarak gerçekleşmiştir. 2009 yılında \% 3.8 ile Türkiye'de yapılan DYY'ların GSYİH içindeki payı en yüksek değere ulaşmış iken, 1999 yılında ise \% 0.3 ile DYY'ların payı en düşük seviyede gerçekleşmiştir.

Çalışma kapsamına alınan değişkenler arasındaki ilişkiyi belirlemeye yönelik olarak öncelikle korelasyon analizine yer verilmiş ve sonuçlar Tablo 4'de sunulmuştur.

\begin{tabular}{|l|l|l|l|l|l|l|l|}
\hline Değişkenler & IIT & LARGDP & LDRGDP & LDRKBGDP & WDIST & EXC & FDI \\
\hline IIT & 1.000 & & & & & & \\
\hline LARGDP & $0.482^{\mathrm{a}}$ & 1.000 & & & & & \\
\hline LDRGDP & $0.389^{\mathrm{a}}$ & 0.810 & 1.000 & & & & \\
\hline LDRKBGDP & $-0.123^{\mathrm{b}}$ & -0.038 & -0.045 & 1.000 & & & \\
\hline WDIST & $0.363^{\mathrm{a}}$ & 0.947 & 0.812 & -0.053 & 1.000 & & \\
\hline EXC & -0.017 & 0.307 & 0.202 & 0.224 & 0.317 & 1.000 & \\
\hline FDI & $0.349^{\mathrm{a}}$ & 0.132 & 0.112 & 0.147 & -0.021 & 0.196 & 1.000 \\
\hline Not: $a$, ve b sirastyla istatistiki olarak\%1 ve\%5 önem seviyesinde anlamli olduklarinu ifade etmektedir. \\
\hline
\end{tabular}

Tablo 4. Korelasyon Katsayılarl

Tablo 4'deki korelasyon katsayılarına göre Türkiye'nin AB 15 ülkeleri ile yaptı̆̆ı imalat sanayindeki endüstri içi ticaretin varlığı ile ülkelerin ortalama GSYİH, ülkelerin GSYİH farkları, ağırlıklandırılmış mesafe göstergesi ve Türkiye'de yapılan doğrudan yabancı yatırımlar arasında pozitif; Türkiye ile AB 15 ülkelerindeki kişi başına reel gelir farklılıkları ile reel efektif döviz kuru arasında ise negatif bir korelasyon söz konusudur. Mesafe göstergesinin pozitif işaret alması, teorik olarak çekim modeli açısından beklentilerle örtüşmemektedir. Diğer taraftan döviz kurunun endüstri-içi ticaret üzerindeki etkileri, Grubel-Lloyd indeksinin hem ithalat hem de ihracat değişkenlerini içermesi nedeniyle belirsizdir. Ancak buradaki bulgular, korelasyon katsayılarına dayandığı için bu sonuçlara göre kesin yorum yapmak yanlış olacaktır.

\subsection{Panel Veri Regresyon Analizi Sonuçları}

Çalışmada, endüstri-içi ticaretin belirleyicilerini analiz etmek için havuzlanmış, sabit etkili ve tesadüfi etkili panel veri regresyon analizlerine yer verilmiştir. Eşitlik (4)'ün panel veri regresyon analizi sonuçları Tablo 5'de verilmiştir. 


\begin{tabular}{|c|c|c|c|c|c|c|}
\hline \multirow{2}{*}{ Değişkenler } & \multicolumn{2}{|c|}{ Havuzlanmış EKK } & \multicolumn{2}{|c|}{ Sabit Etkili Model } & \multicolumn{2}{|c|}{ Tesadüfi Etkili Model } \\
\hline & Katsayılar & Olasılık & Katsayılar & Olasılık & Katsayılar & Olasılık \\
\hline LARGDP & 0.978 & 0.000 & 1.383 & 0.000 & 1.279 & 0.000 \\
\hline LDRGDP & 0.017 & 0.707 & 0.073 & 0.408 & 0.069 & 0.333 \\
\hline LDRKBGDP & -0.158 & 0.032 & -0.250 & 0.506 & -0.173 & 0.299 \\
\hline FDI & 0.149 & 0.000 & 0.110 & 0.001 & 0.115 & 0.000 \\
\hline WDIST & -0.002 & 0.003 & -0.007 & 0.054 & -0.003 & 0.000 \\
\hline RKURAB & -0.016 & 0.001 & -0.021 & 0.000 & -0.020 & 0.000 \\
\hline Sabit & -23.527 & 0.000 & -33.657 & 0.000 & -32.295 & 0.000 \\
\hline $\mathrm{R}^{2}$ & \multicolumn{2}{|l|}{0.398} & \multicolumn{2}{|l|}{0.339} & \multicolumn{2}{|l|}{0.335} \\
\hline $\mathrm{F}(6,254)$ & \multicolumn{2}{|l|}{$27.97^{\mathrm{a}}$} & \multicolumn{2}{|l|}{$20.52^{\mathrm{a}}$} & \multicolumn{2}{|l|}{$133.61^{\mathrm{a}}$} \\
\hline \multicolumn{7}{|l|}{ Bireysel Etkiler İçin Testler } \\
\hline F Testi & & & \multicolumn{2}{|l|}{$7.68^{\mathrm{a}}$} & & \\
\hline LR Testi & & & \multicolumn{2}{|l|}{$49.01^{\mathrm{a}}$} & & \\
\hline Breusch-Pagan LM ve ALM & & & & & $134.95^{\mathrm{a}}$ & $56.53^{\mathrm{a}}$ \\
\hline \multicolumn{7}{|l|}{ Sabit ve Tesadüfi Etkiler Testi } \\
\hline Hausman Testi & & & & & \multicolumn{2}{|l|}{3.22} \\
\hline \multicolumn{7}{|l|}{$\begin{array}{l}\text { Levene, Brown ve Forsythe } \\
\text { Heteroskedasite Testi }\end{array}$} \\
\hline W0 $(14,246)$ & & & & & \multicolumn{2}{|l|}{$5.199^{\mathrm{a}}$} \\
\hline W50 $(14,246)$ & & & & & \multicolumn{2}{|l|}{$3.530^{\mathrm{a}}$} \\
\hline $\mathrm{W} 10(14,246)$ & & & & & \multicolumn{2}{|l|}{$4.784^{\mathrm{a}}$} \\
\hline Otokeralasyon LM ve ALM Testi & & & & & $180.92^{\mathrm{a}}$ & $102.500^{\mathrm{a}}$ \\
\hline
\end{tabular}

Tablo 5. Panel Veri Regresyon Analizi Sonuçları

Yapılan üç farklı panel veri regresyon analizleri arasında öncelikle bireysel etkilerin varlığı, F, LR ve BreuschPagan LM ve ALM testleri ile belirlenmeye çalışılmıştır. Yapılan testlerin tamamı modelde bireysel etkilerin varlığına işaret etmektedir. Daha sonra bireysel etkili modellerden hangisinin daha tutarlı ve sapmasız sonuçlar verdiği Hausman testi ile araştırılmış ve tesadüfi etkili model sonuçlarının daha güvenilir olduğu bulgusuna ulaşılmıştır.

Tesadüfi etkili model sonuçlarına göre ülkelerin ortalama GSYIH'sı ile Türkiye'de yapılan doğrudan yabancı yatırımların imalat sanayi endüstri-içi ticaretini istatistiki açıdan anlamlı ve olumlu bir şekilde etkilerken, ülkeler arası mesafe ve reel efektif döviz kuru ise imalat sanayindeki endüstri-içi ticareti istatistiki açıdan anlamlı fakat negatif bir şekilde etkilemektedir. Çalışmadan elde edilen bulgular, endüstri-içi ticaretin belirleyicilerini ele alan ampirik literatür ile özelde de çekim modeli ile tutarlılık arz etmektedir. Bununla birlikte tesadüfi etkili model sonuçları için yapılan otokorelasyon ve değişen varyans testleri, elde edilen bu bulgularda problemler bulunduğuna işaret etmektedir. Dolayısıyla değişen varyans ve otokorelasyon varlı̆̆ında Arellano (1987), Froot (1989) ve Rogers (1993)'ün çalışmaları ile şekillenen kümelenmiş standart hatlarla tesadüfi etkiler modeli tahmin edilmiş ve yeni sonuçlar Tablo 6'da sunulmuştur.

\begin{tabular}{|l|l|l|l|l|}
\hline Değişkenler & Katsayılar & Tutarlı Standart Hata & z Değeri & Olasılık \\
\hline LARGDP & 1.279 & 0.395 & 3.240 & 0.001 \\
\hline LDRGDP & 0.069 & 0.070 & 1.000 & 0.319 \\
\hline LDRKBGDP & -0.173 & 0.257 & -0.670 & 0.503 \\
\hline FDI & 0.115 & 0.023 & 4.960 & 0.000 \\
\hline WDIST & -0.003 & 0.001 & -2.310 & 0.021 \\
\hline RKURAB & -0.020 & 0.010 & -1.920 & 0.055 \\
\hline Sabit & -32.295 & 9.926 & -3.250 & 0.001 \\
\hline R2 & 0.3351 & \multicolumn{5}{|l|}{} \\
\hline Wald X2 & $110.03^{\mathrm{a}}$ \\
\hline Not: a istatistiki olarak\%1 onem seviyesinde anlaml olduklarln ifade etmektedir. \\
\hline
\end{tabular}

Tablo 6. Dirençli Standart Hatalarla Tesadüfi Etkiler Modeli Tahminleri 
Tablo 6'da verilen tutarlı standart hatalı sonuçlar, Tablo 5'deki tesadüfi etkili model sonuçları ile karşılaştırıldığında parametre katsayılarında bir değişmenin olmadığı, sadece standart hatalar ve buna bağlı olarak olasılık değerlerinde değişmeler yaşandığı tespit edilmiştir. Elde edilen bu yeni sonuçlar anlamlılık açısından daha önceki sonuçlarla tamamen örtüşmektedir.

\section{Sonuç ve Değerlendirme}

Ekonomik kalkınma çabası içerisinde olan az gelişmiş ve gelişmekte olan ülkeler, sanayileşmeyi gerçekleştirmek durumundadırlar. Örneğin birinci, ikinci ve üçüncü nesil Asya kaplanları olarak adlandırılan ülkeler, sanayileşmelerine paralel olarak dünya ticaret paylarını artırırken, ihracat yapılarında da önemli değişimler yaşamışlardır. Bu ülkeler, tarımsal ürün ve emek yoğun sanayi ürün ihracatından sermaye yoğun hatta ileri teknoloji ürün ihracatına yönelik önemli mesafeler kat etmişlerdir. Sonradan sanayileşen ülkelerden gelen fiyat rekabeti ve ürün çeşitliliği, dünya ticaretinin de giderek endüstri-içi nitelik kazanmasına yol açmıştır.

Endüstri-içi ticaretin artan önemine binaen son yıllarda konuyu hem teorik hem ampirik olarak ele alan çalışmalarda artış yaşanmaya başlanmıştır. Endüstri-içi ticaretin belirleyicilerini ele alan ampirik çalışmalar, çoğunlukla çekim modelini kullanmışlardır. Çekim modelinin temel iki değişkeni vardır. Bunlardan birincisi ülkelerin ekonomik büyüklükleri iken, ikincisi ülkeler arası mesafedir. Ampirik çalışmalar bu iki ana değişkene sadık kalarak bazı yeni ilave değişkenlerle modeli genişletme yoluna gitmişlerdir.

Bu çalışma, Türkiye'nin AB 15 ülkeleri ile 1996-2013 döneminde gerçekleştirdiği imalat sanayindeki endüstriiçi ticaretinin belirleyicilerini ortaya koymayı amaçlamıştır. Bu amaç doğrultusunda çalışmada panel veri regresyon analizlerine yer verilmiş ve bu analizler içerisinde en güvenilir ve tutarlı sonuçları vermesi nedeniyle tesadüfi etkili model bulguları değerlendirmeye alınmıştır. Tesadüfi etkiler modeli sonuçlarına göre Türkiye'nin AB 15 ülkeleri ile yaptığı imalat sanayindeki endüstri-içi ticareti üzerinde ülkelerin pazar büyüklükleri ile doğrudan yabancı yatırımların pozitif ve istatistiki açıdan anlamlı; ülkeler arasındaki mesafe ile reel efektif döviz kurunun ise negatif ve istatistiki açıdan anlamlı etkilere sahip olduğu tespit edilmiştir.

Çalışmadan elde edilen bu bulgulardan hareketle, Türkiye'nin AB 15 ülkeleri ile yaptığı ticaretinin endüstri-içi nitelik kazanması için, AB 15 ülkelerinden GSYİH yüksek ve Türkiye'ye coğrafi olarak yakın ülkelerle ticaretine ağırlık vermesi gerekmektedir. Ayrıca Türkiye'nin sanayi sektörlerini önceleyen ekonomik politikalarla yüksek büyüme hızlarına yakalaması ve ülkenin ulaşım altyapısının iyileştirilmesi ve buna bağlı olarak da lojistik hizmetlerinin artırılmasına ihtiyaç duyulmaktadır.

Öte yanda DYY'ların endüstri-içi ticareti uyardığı bulgusu ve Türkiye'deki DYY'ların büyük bir kısmının AB ülkelerinden geldiği gerçeği dikkate alındığında yabancı yatırımları artıracak ekonomik teşvikler yanında ekonomik ve siyasal istikrarın sağlanması da önem arz etmektedir. Yabancı yatırımları çekebilecek yatırım ortamının sağlanması için ek olarak yabancı yatırımcıları tedirgin edecek söylem ve eylemlerden de uzak durulması faydalı olacaktır.

\section{Kaynakça}

- Akram ve Mahmood, 2012. "Determinants of Intra-Industry Trade between Pakistan and Selected SAARC Countries”, The Pakistan Developments Review, 51(1), pp. 47-59.

- Arellano, 1987. "Computing Robust Standard Errors for Within-Groups Estimators”, Oxford Bulletin of Economics and Statistics, 49(4), pp 431-434.

- Balassa ve Bauwens, 1987. "Intra-Industry Specialization in the United State Trade", The Economic Journal, 97(388), pp.923-939.

- Botric, 2013. "Determinants of Intra-Industry Trade between Western Balkans and EU-15: Evidence from Bilateral Data”, International Journal of Economic Sciences and Applied Research, 6(2), pp. 7-23.

- Brülhart ve Thorpe, 2000. "Intra-Industry Trade and Adjustment in Malaysia: Puzzling Evidence", Applied Economics Letters, 7, pp. 729-733.

- Caetano ve Galego, 2007. "In Search for the Determinants of Intra-Industry Trade Within an Enlarged Europe”, South-Eastern Europe Journal of Economics, 2, pp. 163-183.

- Clark ve Stanley, 1999. "Determinants of Intra-Industry Trade between Developing Countries and United States”, Journal of Economic Development, 24(2), pp. 79-95.

- Clark ve Stanley, 2003. "Determinants of Intra-Industry Trade between the United States and Industrial Nations", International Economic Journal, 17(3), pp. 1-18.

- Ekanayake vd., 2007. "Intra-Industry Trade Between the United States and Latin American Countries", The International Journal of Business and Finance Research, 1(2), p. 109-124.

- Emirhan, 2005. "Determinants of Vertical Intra-Industry Trade of Turkey: Panel Data Approch", Dokuz Eylül University Faculty of Business Department of Economics Discussion Paper, 05/05, pp. 1-12. 
- Fainstein ve Netsunajev, 2011. "Intra-Industry Trade Development in the Baltic States", Emerging Markets Finance \& Trade, 47(3), pp. 95-110.

- Faustino ve Leitão, 2007. "Intra-Industry Trade: A Static and Dynamic Panel Data Analysis", International Advanced Economic Research, 13, pp. 313-333.

- Kenneth, 1989. "Consistent Covariance Matrix Estimation with Cross-Sectional Dependence and Heteroskedasticity in Financial Data” Journal of Financial and Quantitative Analysis, 24, pp 333-355.

- Gabrish, 2006. "Vertical Intra-Industry Trade between EU and Accession Countries", IWH Discussion Papers, 12, pp. 1-25.

- Genç ve Berber, 2011, "Bölgeselleşme ve Ticaret Akımları:Literatür İncelemesi”, Kocaeli Üniversitesi Sosyal Bilimler Enstitüsü Dergisi, 22, ss. 84-110

- Grubel ve Lloyd, 1971. “The Empirical Measurement of Intra- industry Trade”, Economic Record, V 470, pp. 494-517.

- Kang, 2010. "Intra-Industry Trade in an Enlarged Europe: Trend of Intra-Industry Trade in the European Union and its Determinants", KIEP Working Paper, 10-02, pp. 1-65.

- Lapinska, 2015. "The Economic Integration as a Determinant of Intra-Industry Trade: The Case of Poland”, Vol. 22, pp 77-87,

- Lefillear ve Maure, 2010. "Inter- and Intra-Industry Linkages as a Determinant of FDI in Central and Eastern Europe", Economic Systems, 34, p. 309-330.

- Leitao, 2013. "The Impact of Immigration on Portuguese Intra-Industry Trade”, Nota di Lavoro, 20, pp. 120.

- $\quad$ Phan ve Jeong, 2014. “An Empirical Analysis of Intra Industry Trade in Manufactures Between Korea and ASEAN", Journal of Economic Studies, Vol. 41, pp. 833 - 848

- Rasekhi ve Shojaee, 2012. "Determinant Factors of the Vertical Intra-Industry Trade in Agricultural Sector: A Study of Iran and its Main Trading Partners", Agriculture Economics-Czech, 58(4), pp. 180-190.

- Rogers, 1993. "Regression Standard Errors in Clustered Samples”, Stata Technical Bulletin 13, 19-23, pp. 295.

- Sawyer vd., 2010. "Patterns and Determinants of Intra-Industry Trade in Asia", Journal of Asian Economics, 21, pp. 485-493.

- SSentürk ve Kösekahyaoğlu, 2014. “Türkiye’nin Endüstri İçi Ticaretinin Ülke ve Politika Temelli Belirleyicilerine Yönelik Bir Uygulama”, Marmara Üniversitesi İI.B. Dergisi, 36(2), ss. 299-325.

- Sharma, 1999. "Pattern and Determinants of Intra-Industry Trade in Australian Manufacturing", Yale University Economic Growth Center Discussion Paper, 813, pp. 1-21.

- Tinbergen, 1962. "Shaping The World Economy Suggestions for An International Economic Policy", Twentieth Century Fund, New York.

- Tatlıcı ve Kızıltan, 2011. "Çekim Modeli: Türkiye’nin İhracatı Üzerine Bir Uygulama” Atatürk Ü. İIBF Dergisi, 10. Ekonometri ve İstatistik Sempozyumu Özel Sayısı, ss. 28-299.

- Thorpe ve Leitao, 2013. "Determinants of United States' Vertical and Horizontal Intra-Industry Trade", Global Economy Journal, 13(2), pp. 233-250.

- Turkcan ve Ateş, 2010. "Structure and Determinants of Intra-Industry Trade in the U.S. Auto-Industry", Journal of International and Global Economic Studies, 2(2), pp.15-46

- Vogiatzoglou, 2007. "Inrta and Exra-EU Intra-Industry Trade in Greece: Trends, Determinants, and Structural Adjustment”, Journal of Economic and Social Research, 9(1), pp. 19-54.

- Zhang, Witteloostuijn ve Zhou, 2005. "Chinese Bilateral Intra-Industry Trade: A Panel Data Study for 50 Countries in the 1992-2001 Period”, Review of World Economics, 141(3), pp. 510-540. 


\title{
Türkiye-Rusya Dış Ticaretinin Sektörel Düzeyde Analizi
}

\section{The Analysis of Turkey-Russia External Trade at the Sectoral Level}

\author{
Ph. D. Candidate Gizem Akbulut (Gümüşhane University, Turkey) \\ Candan Y1lmaz (Gümüşhane University, Turkey)
}

\begin{abstract}
Generally the growth of country and the development of countries'regional level depend upon the competitive power of other countries and their regions as well. In this context with globalization, the concept of competition in terms of individuals or firms have been not only limited to the local level, but also moved into the international order. Turkey has started to implement export-oriented industrialization policy taken decision on 24 April 1980 and thereby the capacity of its foreign trade has gradually increased in the current process.

Starting from this direction, the aim of the study is to determine the sectoral analysis of the 2001-2014 periods in terms of the foreign trade relationship between Turkey and Russia. The main purpose of this study is to analyze the Turkey-Russia's foreign trade on the basis of commodity groups. In this study, commodity group data located in Standard International Trade Classification obtained from the Turkey Statistical Institute database was used. In the analysis of study the Revealed Comparative Advantage index was calculated to measure the strength of competition between Turkey and Russia. Since the 2000s, considering Russia's trade profile as one of the Turkey's most important trade partner, energy and natural resources in exports and consumer goods in import have a siginificant share in trade between these contries. In conclusion, despite the increasing trade between the two countries, in terms of assestment of the competitive power and the commodity group, it has been found that leading countries has not been changed.
\end{abstract}

\section{Giriş}

24 Ocak 1980 kararı sonrası Türkiye dış ticarette liberalleşme dönemine girmiş olup ithal ikamesine dayalı ticaret yerine ihracata yönelik sanayileşme politikası izleyerek bir taraftan dünya ülkeleri ile ilişkilerini geliştirirken diğer taraftan da dış ticaret hacmini arttırmıştır. Bu dönemden itibaren Türkiye'nin hem ihracatı hem de ithalatı artarken 2000' li yıllara gelindiğinde önemli ölçüde dış ticaret açığı verdiği bilinmektedir. Bu açıdan Türkiye'nin dış ticaret açığının oldukça yüksek olmasının en önemli sebeplerinden biri enerjide dışa bağımlı olmasıdır. Bu noktada Türkiye'nin 2000 dönemi sonrası en fazla ithalat yaptığı ülkeler sıralamasına bakıldığında Rusya'nın ilk sırada yer aldığı görülmektedir. Bunun sebebi Türkiye'nin Rusya'dan yüksek oranda petrol ve doğalgaz ithal ediyor olmasıdır. Dolayısıyla Türkiye açısından Rusya ile olan ikili ticari ilişkilerini karşılaştırmak önem arz etmektedir.

\begin{tabular}{|c|c|c|c|c|}
\hline Yllar & İhracat & İthalat & $\begin{array}{c}\text { Diş Ticaret } \\
\text { Hacmi }\end{array}$ & $\begin{array}{c}\text { İhracatın İthalatı } \\
\text { Karşıma Oranı } \\
\mathbf{( \% )}\end{array}$ \\
\hline $\mathbf{2 0 0 1}$ & 924107 & 3435673 & 72733299 & 75,7 \\
\hline $\mathbf{2 0 0 2}$ & 1172039 & 3891721 & 87612886 & 69,9 \\
\hline $\mathbf{2 0 0 3}$ & 1367591 & 5451315 & 116592528 & 68,1 \\
\hline $\mathbf{2 0 0 4}$ & 1859187 & 9033138 & 160706919 & 64,8 \\
\hline $\mathbf{2 0 0 5}$ & 2377050 & 12905620 & 190250559 & 62,9 \\
\hline $\mathbf{2 0 0 6}$ & 3237611 & 17806239 & 225110850 & 61,3 \\
\hline $\mathbf{2 0 0 7}$ & 4726853 & 23508494 & 277334464 & 63,1 \\
\hline $\mathbf{2 0 0 8}$ & 6483004 & 31364477 & 333990770 & 65,4 \\
\hline $\mathbf{2 0 0 9}$ & 3189607 & 19450086 & 243071034 & 72,5 \\
\hline $\mathbf{2 0 1 0}$ & 4628153 & 21600641 & 299427551 & 61,4 \\
\hline $\mathbf{2 0 1 1}$ & 5992633 & 23952914 & 375748545 & 56,0 \\
\hline $\mathbf{2 0 1 2}$ & 6680777 & 26625286 & 389006877 & 64,5 \\
\hline $\mathbf{2 0 1 3}$ & 6964209 & 25064214 & 403463887 & 60,3 \\
\hline $\mathbf{2 0 1 4}$ & 5943189 & 25288597 & 399793888 & 65,1 \\
\hline
\end{tabular}

Tablo 1. 2001 - 2014 Yıllarında Türkiye - Rusya Dış Ticaretinin Gelişimi (Bin \$) Kaynak: TÜIK, 2015. 
Tablo 1'de 2001-2014 dönemine ilişkin Türkiye-Rusya arasındaki dış ticaretin gelişimi görülmektedir. 2001 yılında 924.107 dolar olan ihracat miktarı 2008 yılına kadar artmış ve 2008 yılında 6 milyon dolar olmuştur. Küresel krizin etkisiyle 2009 yılında ihracat miktarı azalmış 3 milyon dolar olmuştur. Daha sonra ise 2014 yılına kadar artarak 5 milyon dolar olarak gerçekleşmiştir. Diğer taraftan Türkiye ve Rusya arasındaki dış ticarete bakıldığında ithalatın 2001 yılında 3milyon dolar olarak gerçekleştiği, bu miktarın artış eğilimi içinde olduğu ve 2008 yılında 31 milyon dolar düzeyine ulaştı̆̆ görülmektedir. 2009 yılında ise tüm dünyada etkisini gösteren küresel krizin etkisiyle ithalat miktarında azalma olmuş ve ithalat 19 milyon dolar düzeyinde kalmıştır. Bu yıldan itibaren de tekrar artarak 2014 y1lında 25 milyon dolar olarak gerçekleşmiştir. İlgili tablo' da yıllar itibariyle hem ihracatın hem ithalatın artmasına rağmen ihracat istenilen düzeye ulaşamamıştır. 2001 yılında ihracatın ithalatı karşılama oranı \%75 iken 2014 yılında bu oranın \%65'e düştüğü görülmektedir.

\begin{tabular}{|c|c|}
\hline Mal Grubu Numarası & Mal Grubu Adı \\
\hline 0 & Canlı Hayvanlar ve Gıda Maddeleri \\
\hline 1 & İçki ve Tütün \\
\hline 2 & Akaryakıt Hariç Yenilmeyen Hammaddeler \\
\hline 3 & Mineral Yakıtlar, Yağlar ve Alkali Ürünler \\
\hline 4 & Hayvansal, Bitkisel Katı ve Sıvı Yağlar, Mumlar \\
\hline 5 & Başka Yerde Belirtilmeyen Kimya Sanayi ve Ürünleri \\
\hline 6 & Başlıca Sinıflara Ayrılan İşlenmiş Mallar \\
\hline 7 & Makineler ve Taşıt Araçları \\
\hline 8 & Çeşitli Mamul Eşya \\
\hline 9 & SITC'de Sınıflandırılmamış Eşyalar \\
\hline
\end{tabular}

Tablo 2. SITC - 3 'e Göre 1 Basamaklı Mal Grubu Sinıflandırma Listesi Kaynak: TÜIK, 2015.

Uluslararası Standart Ticaret Uygulaması (SITC) dış ticarette malların sınıflandırılmasını sağlayan bir sistemdir. SITC-3 siniflandirma listesi; 10 adet 1 basamaklı, 67 adet 2 basamaklı, 261 adet 3 basamaklı, 1033 adet 4 basamaklı 3121 adet 5 basamaklı koddan oluşmaktadır. Çalışmada SITC-3 1 basamaklı sınıflandırma listesi kullanılmış ve bu liste Tablo 2'de gösterilmiştir.

\begin{tabular}{|c|c|c|c|c|}
\hline & \multicolumn{2}{|c|}{$\mathbf{2 0 0 1}$} & \multicolumn{2}{c|}{$\mathbf{2 0 0 5}$} \\
\hline $\mathbf{0}$ & İhracat & İthalat & İhracat & İthalat \\
\hline $\mathbf{1}$ & 151.502 .593 & 12.667 .110 & 365.558 .164 & 41.618 .690 \\
\hline $\mathbf{2}$ & 20.409 .627 & 180.229 .193 & 39.624 .897 & 1.211 .993 .471 \\
\hline $\mathbf{3}$ & 3.251 .340 & 2.528 .608 .829 & 1.051 .762 & 8.802 .278 .079 \\
\hline $\mathbf{4}$ & 344.065 & 424.232 & 681.626 & 36.482 .222 \\
\hline $\mathbf{5}$ & 96.086 .410 & 100.978 .518 & 243.701 .590 & 475.534 .682 \\
\hline $\mathbf{6}$ & 314.547 .009 & 582.160 .561 & 748.858 .364 & 2.255 .950 .895 \\
\hline $\mathbf{7}$ & 163.898 .209 & 28.337 .267 & 603.601 .165 & 64.297 .107 \\
\hline $\mathbf{8}$ & 158.160 .481 & 2.060 .766 & 342.340 .338 & 4.733 .605 \\
\hline $\mathbf{9}$ & 168.739 & 204.271 & 9.147 .064 & 9.227 .191 \\
\hline Toplam & 924.106 .727 & 3.435 .672 .619 & 2.377 .049 .944 & 12.905 .619 .879 \\
\hline
\end{tabular}




\begin{tabular}{|c|c|c|c|c|}
\hline & \multicolumn{2}{|c|}{$\mathbf{2 0 1 0}$} & \multicolumn{2}{c|}{$\mathbf{2 0 1 4}$} \\
\hline & İhracat & İthalat & İhracat & İthalat \\
\hline $\mathbf{0}$ & 941.284 .900 & 482.479 .527 & 1.181 .253 .335 & 1.826 .808 .401 \\
\hline $\mathbf{1}$ & 16.370 .868 & 3.279 .884 & 35.831 .818 & 4.716 .589 \\
\hline $\mathbf{2}$ & 107.731 .302 & 808.941 .114 & 119.415 .239 & 1.525 .026 .182 \\
\hline $\mathbf{3}$ & 134.144 .745 & 15.952 .774 .197 & 129.646 .849 & 16.493 .399 .535 \\
\hline $\mathbf{4}$ & 1.330 .425 & 91.193 .885 & 5.767 .074 & 879.189 .040 \\
\hline $\mathbf{5}$ & 414.658 .596 & 678.236 .928 & 548.387 .059 & 964.390 .224 \\
\hline $\mathbf{6}$ & 1.309 .999 .580 & 3.465 .514 .154 & 1.584 .402 .607 & 3.530 .489 .374 \\
\hline $\mathbf{7}$ & 1.083 .961 .519 & 63.023 .083 & 1.525 .751 .831 & 52.454 .210 \\
\hline $\mathbf{8}$ & 608.160 .354 & 55.151 .766 & 796.493 .356 & 8.255 .376 \\
\hline $\mathbf{9}$ & 10.510 .674 & 46.901 & 16.240 .014 & 3.868 .340 \\
\hline Toplam & 4.628 .152 .963 & 21.600 .641 .439 & 5.943 .189 .182 & 25.288 .597 .271 \\
\hline
\end{tabular}

Tablo 3. SITC-3'e göre Türkiye-Rusya Dış Ticareti (Bin \$) Kaynak: TÜIK, 2015.

Tablo 3'te SITC-3 kapsamında 2001-2014 dönemine ait Türkiye-Rusya ihracat ve ithalat verileri yer almaktadır. İlgili tablo'da yıllar itibariyle veriler incelendiğinde Türkiye'nin Rusya'ya ihracatında en fazla paya sahip olan mal grupları Başlıca sınıflara ayrılan işlenmiş mal grupları (6) ve Makineler ve Taşıt Araçları (7) olduğu görülmektedir. Hayvansal, Bitkisel Katı ve Sıvı Yağlar, Mumlar (4) ve SITC'de Sınıflandırılmamış Eşyalar (9) mal gruplarının ise dönemsel olarak toplam içerisindeki payları oldukça düşük düzeydedir. Diğer taraftan tablo'da yer alan Türkiye'nin Rusya'dan yaptığı ithalat verilerine bakıldığında ise Mineral Yakıtlar, Yağlar ve Alkali Ürünler (3) ve Başlıca Sınıflara Ayrılan İşlenmiş Mallar (6) mal gruplarının toplam ithalat içerisinde en fazla paya sahip oldukları görülmektedir. Genel olarak ithalat içerisinde en az paya sahip olan mal grupları ise İçki ve Tütün (1) ve SITC' de Sınıflandırılmamış Eşyalar (9)'dır.

Bu bağlamda çalışmada, Türkiye'nin ve Rusya'nın karşılaştırmalı ihracat ve ithalat performanslarının belirlenmesi amacıyla karşılaştırmalı üstünlükler mikro bazda (Standart Uluslararası Ticaret Sınıflandırması SITC- 3, 1 basamaklı mal grubu) kullanılmış ve iki ülke için her bir mal grubunun ihracatı ve ithalatındaki üstünlükler açıklanmış karşılaştırmalı üstünlükler katsayısı ile belirlenmiştir. Söz konusu analiz, 2001 - 2014 yıllarına ilişskin yapılmıştır. Çalışmada Açıklanmış Karşılaştırmalı Üstünlükler indeksi (AKÜ) kullanılarak Türkiye'nin karşılaştırmalı üstünlüğe veya karşılaştırmalı dezavantaja sahip olduğu ürünler incelenmiştir.

\section{Literatür Araștırması}

Bender ve Li (2002), 1981-1997 dönemine ilişkin çeşitli Asya ve Latin Amerika bölgelerinin imalat sanayi mal grupları ihracatındaki AKÜ katsayılarını hesaplamıştır. Çalışmanın analizinde SITC 3 haneli 1981-1983 ve 19951997 dönemleri ortalama AKÜ değerleri hesaplanmıştır. Elde edilen bulgulara göre Doğu Asya ülkelerinin güçlü bir ihracat performansı olmasına rağmen Güneydoğu Asya ve Latin Amerika'daki daha düşük alt kademedeki ekonomilere karşı karşılaştırmalı üstünlüğünü kaybetmektedir.

Batra ve Khan (2005) çalışmalarında 2000-2003 dönemine ilişkin Hindistan ile Çin arasındaki ticarette rekabet gücünü açıklanmış karşılaştırmalı üstünlük yöntemi ile analiz edilmiştir. Sektörel düzeyde SITC (Rev. 3) sınıflandırılmasına göre yapılan analizde Balassa (1965) indeksi kullanılmıştır. Çalışmanın sonucuna göre 20002003 dönemi boyunca Çin ve Hindistan'ın ihracat yapılarında önemli bir değişiklik görülmemiştir. Ayrıca Hindistan organik kimyasallar, pamuk, demir ve çelik, giyim aksesuar sektörlerinde, ihraç ettiği malların \%32"esinde karş1laştırmalı üstünlüğe sahip olduğu sonucuna varılmıştır.

Erlat ve Erlat (2005) çalışmasının amacı AB-15 ülkelerine karşı rekabet avantajı sağlaması bakımından gelecekte Türkiye için lider olma potansiyeli taşıyan ihracat sektörlerini tespit etmeye yöneliktir. Çalışmada 1990-2000 döneminde Türkiye'nin SITC-3' e göre sınıflandırılmış 3 basamaklı ihracatçı sektörlerin verileri kullanılmıştır. Çalışmanın sonucunda Türkiye'de hem dağılımı hem de ihracat payları açısından geleneksel sektörlerin baskın olduğu görülmüştür. Ayrıca Türkiye'nin emek yoğun ve hammaddelerde uzmanlaştığı söylenebilir.

Eşiyok (2007) çalışmasında Türkiye'nin rekabet gücündeki gelişmeleri ve dış ticaret yapısını incelemiştir. Rekabet gücündeki gelişmeler Balassa (1965) tarafından geliştirilen açıklanmış karşılaştırmalı üstünlükler yaklaşımı ile analiz edilmiştir. Çalışmanın sonucuna göre Türkiye düşük ücretlere dayalı ihracat stratejisini emek-yoğun sektörlere dayandırmaktadır. Bu şekilde geleceğe dönük üretim yapısını teknolojik içeriği ve katma değeri yüksek olan sektörlere aktarmadıkça rekabet gücü ve ihracat gelirleri artmayacaktır. Dolayısıyla dış açık ve cari açık sorunları artarak var olmaya devam edecektir. 
Altay (2008)'e ait çalışmada 1995-2007 döneminde Türk endüstrilerinin AB-15 pazarındaki rekabet gücü düzeyi incelenmiştir. Çalışmanın rekabet gücünü ölçmeye yönelik İhracatta Benzerlik, Balassa Endeksi ve Vollrath Endeksi kullanılmıştır. Çalışmanın sonucunda Türkiye'nin Polonya, Romanya, Portekiz, Çin, Hindistan, Endonezya, İtalya, Tayland, Slovenya, Fas ve İsrail'e karşı Emek yoğun ve Hammadde yoğun endüstrilerde üstünlüğe sahip olduğu görülmüştür. Ayrıca Türkiye'nin Sermaye yoğun mallarda rekabet gücü potansiyeline sahip olduğu ve özellikle AB dışındaki pazarlarda bulunan rakiplerine karşı daha yüksek rekabet gücüne sahip olduğu sonucuna varılmıştır.

Shahab ve Mahmood (2012) çalışmalarında 2002-2009 döneminde Pakistan ile seçilen Asya ülkeleri arasındaki deri ürünlerindeki ticari uzmanlaşma analiz edilmiştir. Ölçüm için açıklanmış karşılaştırmalı üstünlükler tekniği kullanılmıştır. Analiz sonucuna göre Pakistan örneklem dönemi boyunca seçilen tüm ülkelere karşı deri ürünlerinde yüksek karşılaştırmalı üstünlüğe sahiptir.

Uluslararası iktisat teorisinde dış ticarette ülkelerin rekabet avantajına sahip oldukları ürünün tespit edilmesine yönelik çeşitli yöntemler bulunmaktadır. Teoride en çok bilinenleri Adam Smith'in mutlak üstünlük ve David Ricardo' nun karşılaştırmalı üstünlükler yaklaşımlarıdır (Parasız ve Ekren, 2013). Karşılaştırmalı üstünlükleri ortaya atan Ricardo rekabetçilik üzerine daha çok fiziksel ve doğal etkilere vurgu yaparken, ardından gelen iktisatçılar teknolojik ve beşeri faktörlere önem vermişlerdir. Bu teorinin gelişimi daha sonra Mill, Marshall, Heckscher, Ohlin ve Samuelson tarafından devam ettirilmiştir (Goldin, 1990).

Açıklanmış Karşılaştırmalı Üstünlükler (AKÜ) indeksini sayısal olarak ölçmeye yönelik olarak yapılan ilk çalışmalar Liesner (1958)'e aittir. Ardından bu konuya ilişkin çalışmalar Balassa (1965) tarafından geliştirilmiş ve literatürde Balassa indeksi olarak yerini almıştır (Sandalcılar, 2011). Bu indeks, küresel Pazar yapısındaki ihracatın ulusal yapısını karşılaştırmak ve belirli bir ürünün ihracatını analiz etmek için geliştirilmiştir (De Pablo Valenciano, vd, 2012). Balassa (1965) indeksi aşağıdaki gibi ifade edilmektedir:

$$
A K \ddot{U} i j=\frac{\frac{X i j}{X w j}}{\frac{X i}{X w}}
$$

Formüldeki;

$A K U ̈ i j:$ i ülkesinin j malı ihracatı AKÜ indeksi

$X i j$ : i ülkesinin j malı ihracatı

$X w j$ : j malının dünya ihracatı

$X i$ : i ülkesinin toplam ihracatı

$X w$ : toplam dünya ihracatını göstermektedir.

Literatürde yer alan Balassa indeksi zamanla değiştirilmiş olup ithalat düzeyleri de formüle dahil edilerek analiz geliştirilmiştir. $\mathrm{Bu}$ bağlamda çalışmada AKÜ değerleri hesaplanırken aşağıdaki Balassa indeksi kullanılacaktır:

Formüldeki;

$$
A K \ddot{U} i j=\left[\ln \frac{\frac{X i j}{X i}}{\frac{M i j}{M i}}\right]
$$

$X i j$ : i ülkesinin j malı ihracatı

$M i j:$ i ülkesinin j malı ithalatı

$X i$ : i ülkesinin toplam ihracatı

$M i$ : i ülkesinin toplam ithalatı ifade etmektedir.

Hesaplanan AKÜ' nün alacağı değerlere göre endüstri, ürün veya ürün grubu açısından karşılaştırmalı üstünlük veya rekabet gücü yorumlanmaktadır. AKÜ değeri 0.50 'den büyük olması durumunda mal grubunda karşılaştırmalı üstünlüğün yüksek, -0.50 'den küçük olması halinde karşılaştırmalı düşük olduğunu göstermektedir. Ayrıca AKÜ değerinin 0.50 ile -0.50 arasında bulunması halinde karşılaştırmalı üstünlük yüksek veya düşük olması konusunda net bir yorum yapılmamaktadır. Bu bağlamda çalışmada ithalatı da dikkate alan yukarıdaki indeks kullanılarak Türkiye'nin Rusya pazarında Açıklanmış Karşılaştırmalı Üstünlügüü, SITC- 3 bir basamaklı mal gruplarına göre analiz edilmiştir. 2001-2014 dönemine ilişkin veriler Türkiye İstatistik Kurumu (TÜIK) veri tabanından elde edilmiştir. 


\begin{tabular}{|c|c|c|c|c|c|c|c|c|c|c|}
\cline { 2 - 11 } \multicolumn{1}{c|}{} & $\mathbf{0}$ & $\mathbf{1}$ & $\mathbf{2}$ & $\mathbf{3}$ & $\mathbf{4}$ & $\mathbf{5}$ & $\mathbf{6}$ & $\mathbf{7}$ & $\mathbf{8}$ & $\mathbf{9}$ \\
\hline $\mathbf{2 0 0 1}$ & 3.79 & 1.53 & -0.86 & -5.34 & 1.11 & 1.26 & 0.69 & 3.07 & 5.65 & 1.12 \\
\hline $\mathbf{2 0 0 2}$ & 2.36 & 3.7 & -1.46 & -5.34 & 2.09 & 0.99 & 0.77 & 4.13 & 6.33 & \\
\hline $\mathbf{2 0 0 3}$ & 2.19 & 3.36 & -1.23 & -5.72 & -1.12 & 1.19 & 0.33 & 4.1 & 5.94 & 7.12 \\
\hline $\mathbf{2 0 0 4}$ & 2.87 & 3.85 & -1.61 & -7.4 & -1.2 & 0.98 & 0.29 & 3.84 & 7.02 & 2.9 \\
\hline $\mathbf{2 0 0 5}$ & 3.86 & 3.55 & -1.73 & -7.34 & -2.29 & 1.02 & 0.59 & 3.93 & 5.97 & 1.68 \\
\hline $\mathbf{2 0 0 6}$ & 4.07 & 3.59 & -1.37 & -6.56 & -3.71 & 1.16 & 0.51 & 5.11 & 5.41 & 0.99 \\
\hline $\mathbf{2 0 0 7}$ & 2.34 & 3.42 & -0.9 & -3.87 & -1.08 & 1.12 & 0.61 & 5.04 & 6.69 & -0.34 \\
\hline $\mathbf{2 0 0 8}$ & 1.79 & 2.44 & -0.3 & -3.62 & -2.57 & 0.96 & 0.51 & 5.85 & 6.74 & 3.47 \\
\hline $\mathbf{2 0 0 9}$ & 2.03 & 2.54 & -0.36 & -3.46 & -2.78 & 0.9 & 0.83 & 5.31 & 3.62 & 4.71 \\
\hline $\mathbf{2 0 1 0}$ & 2.21 & 3.15 & -0.48 & -3.24 & -2.69 & 1.05 & 0.57 & 4.39 & 3.94 & 6.95 \\
\hline $\mathbf{2 0 1 1}$ & 1.75 & 3.31 & -0.79 & -3.24 & -3.44 & 0.72 & 0.5 & 4.91 & 6.15 & 3.17 \\
\hline $\mathbf{2 0 1 2}$ & 1.17 & 3.76 & -0.86 & -3.39 & -5.42 & 0.92 & 0.89 & 4.96 & 6.39 & 2.48 \\
\hline $\mathbf{2 0 1 3}$ & 1.1 & 3 & -0.84 & -3.61 & -3.74 & 0.66 & 0.61 & 5.3 & 6.27 & \\
\hline $\mathbf{2 0 1 4}$ & 1.01 & 3.48 & -1.1 & -3.4 & -3.58 & 0.88 & 0.65 & 4.81 & 6.02 & 2.88 \\
\hline
\end{tabular}

Tablo 4: Türkiye'nin Rusya Pazarında Açıklanmış Karşılaştırmalı Üstünlüklere Sahip Olduğu Malların AKÜ Indeks Değerleri (2001-2014) Kaynak: TÜIK veri tabanından elde edilen verilerle yazarlar tarafindan hesaplanmiştır.

Tablo 4'teki veriler incelendiğinde 2001 yılında canlı hayvan ve gida maddeleri (0) mal grubuna ait AKÜ değeri 3.79 iken yıllar itibariyle azaldığı ve 2014 yılında 1.01'e düştüğü görülmektedir. Dolayısıyla ilgili mal grubunda karşılaştırmalı üstünlüğünün önemli ölçüde azaldığı tespit edilmiştir. Aksine içki ve tütün (1) mal grubunun karşılaştırmalı üstünlüğü yıllar itibariyle artmıştır. AKÜ değeri 2001 yılında 1.53 olup 2014 yılında 3.48'e yükselmiştir.

Akaryakıt hariç yenilmeyen hammaddeler (2) ve mineral yakıtlar, yağlar ve alkali ürünler (3) mal gruplarının AKÜ indeks değerlerinin tüm dönem boyunca ayrıca 4 numaralı (hayvansal, bitkisel katı ve sıvı yağlar, mumlar) mal grubunun da 2003 sonrası negatif değerler aldığı ilgili tabloda görülmektedir. Bu bağlamda AKÜ değerleri genel olarak -0.50'den küçük olduğu için Türkiye bu mal gruplarında karşılaştırmalı dezavantaja sahip bir ülke konumundadir.

Başka Yerde Belirtilmeyen Kimya Sanayi ve Ürünleri (5) mal grubunun AKÜ indeks değeri tüm dönem boyunca 0.50 'den büyük olduğu için Türkiye'nin bu mal grubunda karş1laştırmalı avantaja sahip olduğunu söylemek mümkündür.

Başlıca Sınıflara Ayrılan İşlenmiş Mallar (6) mal grubunun AKÜ indeks değerleri incelendiğinde (2003-2004 hariç) 2001 yılında 0.69 değerinin 2014 yılında 0.65 'e düşmesine rağmen Türkiye'nin görece karşılaştırmalı üstünlüğünü koruduğu yorumu yapılabilir.

Tablo 4'de Türkiye'nin tüm mal gruplarına ilişkin AKÜ indeks değerlerine bakıldığında Makineler ve Taşıt Araçları (7) ve Çeşitli Mamul Eşya (8) mal gruplarının en yüksek AKÜ indeks değerlerine sahip olduğu görülmektedir. Dolayısıyla Türkiye'nin Rusya pazarında ilgili mal gruplarına ilişkin en fazla karşılaştırmalı üstünlüğe sahip olduğu belirlenmiştir.

SITC'de Sınıflandırılmamış Eşyalar (9) mal grubuna ait AKÜ indeks değerinin en yüksek karşıllaştırmalı üstünlüğünün 7.12 ile 2003 döneminde gerçekleştiği, 2007 yılında ise -0.34 ile karşılaştırmalı dezavantaja sahip olduğu, tüm dönem boyunca ise istikrarlı bir seyir izlemediği görülmektedir.

\section{Sonuç}

1980 sonrası dönemde ihracata yönelik sanayileşme politikası izlemeye başlayan Türkiye'nin yıllar itibariyle hem ihracatı hem de ithalatı önemli ölçüde artmıştır. Gelişmekte olan ülkelerden biri olan Türkiye'nin dış ticaret hacmindeki artışa bağlı olarak dış ticaret açığı da artmaktadır. 2000 yılı sonrası dönem açısından diş ticaret açığının yüksek olmasının başlıca sebepleri arasında enerji bakımından dışa bağımlı olunmasıdır. Bu bakımdan Türkiye'nin dış ticarette ikili ilişkileri incelendiğinde Rusya ile olan ticareti göze çarpmaktadır. Çalışmanın amacı Açıklanmış karşılaştırmalı üstünlükler yaklaşımıyla Türkiye ve Rusya'nın ürün bazında dış ticaret performansını değerlendirmektir. AKÜ yaklaşımıyla SITC-3 bazında 2001 - 2014 yılları arasında yapılan analizden elde edilen bulgulara göre Türkiye, Rusya pazarında Canlı Hayvanlar ve Gıda Maddeleri (0), İçki ve Tütün (1), Hayvansal, Bitkisel Katı ve Sıvı Yağlar, Mumlar (4), Başka Yerde Belirtilmeyen Kimya Sanayi ve Ürünleri (5), Başlıca Sınıflara Ayrılan İşlenmiş Mallar (6), Makineler ve Taşıt Araçları (7), Çeşitli Mamul Eşya 
(8) ve SITC' de Sınıflandırılmamış Eşyalar (9) mal grubunda karşılaştırmalı olarak üstün konumdadır. Akaryakıt Hariç Yenilmeyen Hammaddeler (2) ve Mineral Yakıtlar, Yağlar ve Alkali Ürünler (3) mal gruplarında ise Türkiye'nin dezavantajlı konumda olduğu görülmektedir. Üretim ve nüfus artışına paralel olarak enerji ihtiyacının yoğun olarak Rusya Federasyonu'ndan karşılanması, bu mal gruplarında Rusya'nın karşılaştırmalı olarak üstün olmasına neden olmaktadır. Çalışmanın bir diğer bulgusu ise Makineler ve Taşıt Araçları (7), Çeşitli Mamul Eşya (8) mal gruplarında Rusya pazarında Türkiye'nin rekabet gücünün yüksek olduğu, 1 basamaklı mal grubu bazında hesaplanmış AKÜ değerlerinden anlaşılmaktadır. Analiz sonucundan elde edilen bulgular ışı̆̆ında, Türkiye'nin enerjide dışa bağımlılığını azaltması yönünde hem enerji tasarrufu sağlayacak yöntemler uygulamalı hem de alternatif ve yenilenebilir enerji kaynaklarına ağırlık vermelidir. İhracat yönünden de Türkiye'nin Rusya pazarında sahip olduğu rekabet gücünü sürdürebilmesi için bu alanlarda özellikle AR-GE faaliyetleri ve teknolojik gelişmelere önem vermesi, verimliliğin bu sayede arttırması gerekmektedir.

\section{Kaynakça}

- Altay, H. 2008. "Karşılaş̧ırmalı üstünlükler teorisi kapsamında Türk endüstrilerinin Avrupa Birliği (15) pazarındaki rekabet gücü düzeylerinin incelenmesi: 1995-2007”. Dumlupınar Üniversitesi Sosyal Bilimler Dergisi, 21, p. 215-239.

- Batra, A., and Khan, Z., 2005. "Revealed comparative advantage: an analysis for India and China". Indian Council for Research on International Economic Relations, Working Paper, 168, p. 1-85.

- Bender, S. and Li, K. W. 2002. "The changing trade and revealed comparative advantages of Asian and Latin American manufacture exports". Yale Economic Growth Center Discussion Paper, p.843.

- De Pablo Valenciano, J. Giancinti, M. A. and Uribe, J. 2012. "Revealed comparative advantage and competitiveness in pear". International Journal on Food System Dynamics, 3(1), p. 1-10.

- Erlat Güzin ve Erlat Haluk, 2005. "Do Turkish Exports Have Comparative Advantage With Respect to The European Union Market, 1990- 2000", Department of Economics Middle East Technical University.

- Eşiyok, B.Ali, 2007, “Türkiye Ekonomisinin Rekabet Gücündeki Gelişmeler ve Faktör Kullanım Yoğunluklarına Göre Dış Ticaretin Yapısı”, Finans Politik \& Ekonomik Yorumlar, 44,p. 514.

- Goldin, I. 1990. "Comparative advantage: Theory and application to developing country agriculture". $O E C D$.

- Parasız, İ. ve Ekren, N. 2013. Uluslararası İktisat ve Yeni Yönelimler, Ezgi Kitabevi.

- Sandalcılar, A. R. 2011. "Türkiye-Suriye Dış Ticaretinin Sektörel Analizi”. Atatürk Üniversitesi İktisadi ve İdari Bilimler Dergisi, 25, p. 3-4.

- Shahab, S. and Mahmood, M. T. 2012. "Comparative advantage of leather industry in Pakistan with selected Asian economies". International Journal of Economics and Financial Issues, 3(1), p. 133-139.

- TÜIK, 2015. Diş Ticaret İstatistikleri, http://www.tuik.gov.tr/PreTablo.do?alt_id=1046. 


\title{
Telafi Hipotezi Türkiye İçin Geçerli midir? Is the Compensation Hypothesis Valid for Turkey?
}

\author{
Asst. Prof. Dr. Murat Can Genç (Karadeniz Technical University, Turkey) \\ Asst. Prof. Dr. Osman Murat Telatar (Karadeniz Technical University, Turkey)
}

\begin{abstract}
Increases of trade openness in an economy raise the external risks in globalization. The societies demand on increases of the government expenditure in order to compensate for their risks. Hence the more trade openness may cause the more government size. This relation is named as compensation hypothesis in the literature has been comprehensively discussed by Rodrik (1998) but started by Cameron (1978). This paper attempts to analyze the cointegration and causality relationships between trade openness and government size in Turkey, utilizing annual data for the period 1980-2013. The existence of the long run relationship between trade openness and government size is investigated by applying Engle and Granger (1987) cointegration test. The empirical findings of cointegration test stated that the series are cointegrated. On the other hand the results of error correction model indicate that there is a unidirectional causality from trade openness to government size. The significance of this results state that the compensation hypothesis is valid for Turkey.
\end{abstract}

\section{Giriş}

Dünya ekonomisinde çok taraflı serbestleşme sürecinde yaşanan olumlu gelişmelerin kaynağı sanayi devrimine kadar inse de İkinci dünya Savaşı sonrası yaşanan ilerlemelerden oluşmuştur. Gelişmiş ülkelerin küresel ticareti serbestleştirme çabalarına başlangıçta gelişmekte olan ülkeler rağbet etmemişlerdir. Aksine gelişmekte olan ülkeler ithal ikameci sanayileşme politikaları vasıtasıyla ekonomik büyüme gerçekleștirmeyi amaç edinmişlerdir. 1980'li yıllarla birlikte bilgi iletişim sektöründe yaşanan gelişmeler ve 1990'lı yılların başında soğuk savaş döneminin sonlanması ekonomik küreselleşme sürecini hızlandırmıştır. Dünya ekonomisinde küresel ticaret lehinde yaşanan bu gelişmelere ülkeler gümrük tarifelerini azaltarak ve dışa açık bir kalkınma anlayışıly ayak uydurmuştur. Doğrudan yabancı sermaye yatırımlarında yaşanan olumlu gelişimler ve finansal sistemde yaşanan serbestleşmeler, küresel ticaretin serbestleşmesini hızlandırmıştır.

Ülkelerin ticari açıklıklarında oluşan pozitif yöndeki gelişmeler, araştırmacıların ülkelerin kamu büyükleri ve ticari açıklıkları arasındaki ilişkiye odaklanmasına neden olmuştur. Cameron (1978) ve Rodrick (1998), ülkelerin dış ticarete açıklıkları ile kamu harcamaları arasında bir ilişkinin olabileceğini ileri sürmüş̧ür. Cameron (1978)'e göre; ülkelerin dışa açılması sanayi yoğunlaşmasını artırarak sendikalaşmanın ve işçilerin pazarlık güçlerinin artmasına, dolayısıyla işgücü konfederasyonlarının güçlenmesine neden olur. Bu etkileşim, geçim yardımlarına yapılan harcamaların yükselmesiyle ve kamu ekonomisinin genişlemesiyle sonuçlanır. Ticari açıklık ile kamu büyüklüğü arasında pozitif bir ilişki olduğunu ileri süren Rodrick (1998)'e göre; toplumlar hükümetlerden dış riskleri üstlenmesini talep eder (ve alır). Böylece kamu harcamaları, ülkelerin dışa açılmalarından dolayı doğacak olan risklerden ötürü sosyal sigortayı sağlamak için kullanılabilir. Şöyle ki, dış risklerin artması yurtiçi gelirde ve tüketimdeki değişkenliğin büyümesine neden olur. Kamunun mal ve hizmet alımlarının GDP içindeki payının artması ise gelirdeki değişkenliği azaltır. Kamu harcamalarının dış riskleri azaltıcı rolü ise belirgin bir şekilde sosyal güvenlik ve yardım harcamalarında görülebilir. Dolayısıyla nedensellik ilişkisinin ticari açıklıktan kamu harcamalarına doğru olması beklenir. Bu yolla dış ticaretten doğacak olan riskler kamu harcamaları ile telafi (compensate) edilmeye çalışılır. Literatürde bu ilişki telafi hipotezi (compensation hypothesis) olarak ifade edilir.

Ekonomiler dışa açıldıkça dış riskler artmaktadır. Türkiye 1980 yılında ithal ikameci sanayileşme politikası terk ederek ihracata yönelik sanayileşme anlayışını kabul etmiştir. Bu çalı̧̧ma ticari açıklıktan kamu büyüklüğüne doğru nedensellik ilişkisini yansıtan telafi hipotezinin Türkiye için 1980-2013 döneminde geçerli olup olmadığını test etmeyi amaçlamaktadır. Çalışmanın geri kalan kısmı aşağıdaki şekilde organize edilmiştir. 2. bölümde telafi hipotezini test eden çalıșmaların literatür özeti verilmiș, 3. bölümde çalıșmada kullanılan veri seti sunulmuş, 4 bölümde ekonometrik yöntem ve yöntemden elde edilen ampirik bulgular ortaya konulmuş ve 5 . bölüm de ise çalışmanın sonuçları değerlendirilmiştir.

\section{Literatür Özeti}

Ticari açıklık ve kamu büyüklüğü arasındaki ilişkiler üzerine birç̧ok çalışma yapılmıştır. Garret (2001), kamu harcamaları ve tüketiminin belirleyicilerini 96 ve 103 ülkeden oluşan gruplar için yatay kesit analiz ile incelemiştir. 1985-1995 dönemi ortalamalarının kullanıldığı çalışmada, ticari açıklığın kamu harcamaları ve tüketimini pozitif olarak etkilediği tespit edilmiştir. 
Balle ve Vaidya (2002), ticari açıklık ve kamu harcamaları arasındaki ilişkiyi Amerika Birleşik Devletleri (ABD) eyaletleri için yatay kesit regresyon analizi ile incelmişlerdir. Çalışmada kamu harcamalarının, eğitim harcamalarının ve kamu hizmetlerinin kamu eyalet gelirleri içindeki payı 1995-1997, ticari açıklık ise 19871994 dönemi ortalamaları ile analize sokulmuştur. Araştırmanın sonuçlarına göre kamu hizmetleri ve sağlık harcamaları ile ticari açıklık arasında pozitif ve anlamlı bir ilişki tespit edilmiştir. Molana vd. (2004), telafi hipotezini 1948-1998 döneminde Sims ve Granger yaklaşımlarını kullanarak 23 0ECD ülkesi (Avustralya, Avusturya, Belçika, Kanada, Danimarka, Finlandiya, Fransa, Almanya, Yunanistan, İzlanda, İrlanda, İtalya, Japonya, Lüksemburg, Hollanda, Yeni Zelanda, Norveç, Portekiz, İspanya, İsveç, İsviçre, İngiltere ve ABD) üzerine uygulamıştır. Araştırmacılar elde ettikleri bulgulara göre telafi hipotezini tüm ülkeler için reddetmiştir. Islam (2004), telafi hipotezini Avustralya, Kanada, İngiltere, Norveç, İsveç ve ABD için sınır testi (ARDL) yaklaşımı ve Tam Değiştirilmiş En küçük Kareler (FMOLS) yöntemiyle incelemiştir. Modelde, kamu büyüklüğü ve ticari açıklık değişkenlerine ilaveten ticaret hadlerindeki değişkenlik, dış ticaret haddi oynaklığı ve riski ile kişi başına düşen yurtiçi gelir değişkenleri modele dahil edilmiştir. Çalışmadan elde edilen bulgular sınır testi yaklaşımına göre sadece ABD ve Kanada için değişkenler arasında uzun dönemli bir ilişki bulunduğunu ortaya koymaktadır. Buna karşın FMOLS sonuçları Avusturya ve İsveç hariç diğer tüm ülkelerde kamu büyüklüğü ile ticari açıklık arasında pozitif ve anlamlı bir ilişki bulunduğuna işaret etmektedir.

Jeanneney ve Hua (2004), 29 Çin eyaleti kamu büyüklüğünün belirleyicilerini yatay kesit analiz ile belirlemiştir. Çalışmada kamu büyüklüğü 1996-1998 dönem ortalaması, ticari açıklık ise 1992-1995 dönem ortalaması kullanılarak analize dahil edilmiştir. Elde edilen bulgular (dış risk değişkenlerinin kullanılmadığ tahminlerde) ticari açıklığın kamu harcamalarının gayri safi yurtiçi hasıla (GSYH) oranı üzerinde pozitif anlamlı ve sosyal güvenlik harcamalarının GSYH oranı üzerinde pozitif anlamsız bir etki oluşturduğunu ortaya koymuştur.

Abizadeh (2005), telafi hipotezini 1960-2000 döneminde Amerika, Kanada, Kore, Singapur, Misır ve Uruguay için iki aşamalı regresyon (2SLS) yöntemi ile test etmiştir. Ticari açıklığın Kanada, Singapur ve Uruguay için kamu harcamalarını arttırmadığı aksine azalttığı Amerika, Mısır ve Kore için ise kamu harcamalarını arttırdığı sonucuna ulaşmıştır.

Maurao (2007), 1947-2002 döneminde telafi ve ticari açıklığın kamu büyüklüğünü negatif yönde etkilemesi şeklinde kurulan etkinlik hipotezini Portekiz için Engle ve Granger eşbütünleşme yöntemi ve hata düzeltme modeli ile analiz etmiştir. Kamu harcamalarının alt kalemlerinin de analize dahil edildiği çalışmadan elde edilen bulgular sübvansiyon harcamaları, faiz harcamaları ve diğer kamu harcamaları alt kalemleri için telafi hipotezinin geçerliliğini ortaya koymaktadır.

Shelton (2007), 1970-2000 döneminde 101 ülkeden oluşan grup için kamu harcamalarının belirleyicilerini panel veri analizi ile araştırmıştır. Temel ve genişletilmiş modeller üzerinden gerçekleştirilen analizlerde ticari açıklık değişkeni de belirleyiciler arasına eklenerek dolaylı olarak telafi hipotezi de inceleme konusu yapılmıştır. Aynı zamanda kamu harcamaları merkezi ve yerel olmak üzere ikiye ayrılmış ve yerel harcamaların 8 alt kalemi ile merkezi harcamaların 11 alt kalemi analizlerde kullanılmıştır. Elde edilen bulgulara göre; ticari açıklığın yerel hükümet harcamaları üzerinde hem temel hem de genişletilmiş modellerde pozitif bir etkisi tespit edilememiştir. Diğer taraftan ticari açıklığın hem temel hem de genişletilmiş modellerde kamu harcamaları ve kamu harcamalarının alt kalemleri eğitim, sağlık hizmeti, taşımacılık, kamu tüketimi, savunma, ücret ve maaşlar üzerinde pozitif etkisi bulunmuştur. Epifani ve Gancia (2008) 1950-2000 döneminde panel veri ve 1995-2000 döneminin ortalamasında yatay kesit analizli ile 143 ülkeden oluşan grup için telafi hipotezini araştırmışlardır. Hem panel regresyon hem de yatay kesit regresyon bulguları (ihracat farklılaşmasının kullanılmadığı tahminlerde) ticari açıklığın kamu tüketimini pozitif yönde etkilediği sonucunu ortaya koymuştur.

Hui Kueh vd. (2008) 1974-2006 döneminde telafi hipotezini ASEAN-4 ülkeleri (Endonezya, Malezya, Filipinler ve Tayland) için sınır testi yaklaşımıyla analiz etmişlerdir. Çalışmada ticari açıklık ve kamu büyüklüğü arasında pozitif uzun dönemli bir ilişki tespit edilerek, telafi hipotezi ele alınan ASEAN-4 ülkeleri için doğrulanmıştır. Benarroch ve Pandey (2008) telafí hipotezini, 1970-2000 dönemini altılı 5 yıllık gruba ayırıp her beş yıllık grubun ortalaması alınarak 96 ülke için panel regresyon yöntemi ve Granger nedensellik sınaması ile incelemişlerdir. Regresyon analizinden elde edilen bulgular ticari açıklık ile kamu büyüklügü arasında pozitif bir ilişkiye işaret ederken, nedensellik analiz sonuçları telafi hipotezinin aksine kamu büyüklüğünün artmasının ticari açıklığı azalttığı sonucuna işaret etmektedir. Ram (2009), telafi hipotezini 154 ülke için 1960-2000 döneminde 1, 5 ve 10 yıllık ortalamalar ile panel En Küçük Kareler (OLS) ve sabit etkiler yöntemlerini kullanarak analiz etmiştir. Modele kamu büyüklüğü ve ticari açıklığın yanında kişi başına düşen gayri safi yurtiçi hasıla (KBDGSYH) dahil edilmiştir. Çalışmada her iki yöntem üzerinden de ticari açıklığın kamu büyüklüğünü pozitif yönde etkilediği sonucuna ulaşılmıştır.

Gadea vd. (2009), 1960-2000 ve 1960-1993 dönemlerinde İspanya için telafi hipotezini Johansen eşbütünleşme testi ve hata düzeltme modeli yardımıyla analiz etmiştir. Çalışmada 6 farklı ticari açıklık göstergesinin yanında kamu ve sosyal kamu harcamalarının GSYİH'a oranı olarak iki kamu büyüklüğü göstergesi de ele alınmıştır. Elde edilen bulgular; 1960-1993 döneminde ticari açık göstergeleri ve kamu harcamaları arasındaki uzun dönemli ilişkiyi tespit etmiş ve ticari açıklık göstergelerinin kamu harcamasını 
pozitif yönde etkilediğini ortaya koymuştur. Ayrıca hata düzeltme modeli sonuçları uzun dönem ilişkisi tespit edilen değişkeler arasında çift yönlü nedensellik ilişkisi bulunduğunu ortaya koymuştur. Dolayısıyla çalışmada 1960-1993 döneminde İspanya için telafi hipotezinin doğrulandığ1 sonucuna ulaşılmıştır.

Benarroch ve Pandey (2012), 1972-2000 döneminde 119 ülkeden oluşan grup için telefi hipotezini test etmiştir. Çalışmada kamu harcamaları, kamu harcamalarının 8 alt kalemi ve kamu tüketimi inceleme konusu yapılmıştır. Hipotezin test edilmesinde statik ve dinamik panel veri analizleri kullanılmış ve ülke grubu düşük ve yüksek gelirli olmak kaydı ile ikiye ayrılarak da analiz edilmiştir. Elde edilen bulgular telafi hipotezi yalnızca düşük gelirli ülkelerin eğitim harcamaları için doğrulamış, ticari açıklıkta meydana gelecek artışların ise eğitim harcamalarını arttıracağını ortaya koymuştur. Ayrıca yapılan nedensellik analizlerinden düşük ve yüksek gelirli ülkeler için ticari açıklık ve kamu büyüklüğü arasında nedensellik ilişkisi bulunmadığı tespit edilmiştir.

Altay ve Aysu (2013), 1974-2010 döneminde 15 AB ülkesi (Avusturya, Danimarka, Finlandiya, Fransa, Almanya, Yunanistan, İrlanda, İtalya, Lüksemburg, Malta, Hollanda, Portekiz, İspanya, İsveç ve İngiltere) ile Türkiye ve İzlanda'dan oluşan grup için panel veri analizi ile telafi hipotezini test etmişlerdir. Çalışmada uygulanan Pedroni eşbütünleşme testi kamu büyüklüğü, ticari açıklık, KBDGSYH ve nüfus artış hızının eşbütünleşik olduğunu ortaya koymaktadır. Panel Dinamik En Küçük Kareler (DOLS) sonuçları ise ticari açıklığın kamu büyüklüğü üzerinde negatif yönlü bir etki oluşturduğuna ve bu nedenle telafi hipotezinin aksine etkinlik hipotezinin geçerli olduğuna işaret etmektedir.

Aydoğuş ve Topçu (2013), 1974-2011 dönemi için Türkiye'de ticari açıklık ile kamu büyüklüğü arasındaki ilişkiyi Engle-Granger eşbütünleşme ve Granger nedensellik testleri yardımıyla incelemişlerdir. Eşbütünleşme testinden elde edilen bulgulara göre değişkenler arasında uzun dönem ilişkisi bulunmamaktadır. Granger nedensellik testi sonuçlarına göre ise telafi hipotezinin aksine kamu harcamalarından ticari açıklığa doğru tek yönlü bir ilişki tespit edilmiştir. Zeren ve Ergün (2013), 1970-2011 döneminde 15 Avrupa Birliği (AB) ülkesi için telafi hipotezinin geçerliliğini test etmişlerdir. Ekonometrik yöntem olarak Emirmahmutoglu ve Köse (2011) panel nedensellik testinin uygulandığı çalışmada ticari açıklıktan kamu büyüklüğüne doğru tek yönlü bir nedensellik ilişkisi tespit edilmiştir.

Aregbeyen ve Ibrahim (2014), 1970-2012 döneminde Nijerya için ARDL eşbütünleşme ve nedensellik analizi ile telafi hipotezini incelemişlerdir. ARDL sonuçları kamu harcamaları ve sermaye dışındaki kamu harcamaları ile ticari açıklığın eşbütünleşik olduğunu ortaya koymuştur. Diğer taraftan ARDL yönteminden elde edilen uzun ve kısa dönem katsayıları telafi hipotezini doğrulamıştır. Öte yandan nedensellik analizi sonuçlarına göre; ticari açıklıktan hem kamu harcamalarına hem de sermaye dışındaki kamu harcamalarına doğru tek yönlü nedensellik ilişkisi tespit edilmiştir.

Lin vd. (2014), 1985-2010 dönemi için 92 gelişmekte olan ülkede ticari açıklık ile kamu büyüklüğü arasındaki ilişkiyi incelemişlerdir. Panel OLS ve 2SLS yöntemlerinin uygulandığı çalışmada ticari açıklık ile kamu büyüklüğü arasında pozitif bir nedensellik ilişkisi bulunduğu tespit edilmiştir. Buna göre, ticari açıklıktaki $\% 1$ 'lik bir artış kamu harcamalarını yaklaşık olarak \%0.1-0.2 arasında artırmaktadır.

Parvizkhanlou (2014), 2000-2009 dönemi için ECO ülkeleri Azerbaycan, İran, Kazakistan, Kırgızistan, Pakistan, Tacikistan ve Türkiye'den oluşan grup panel veri analizi ile telafi hipotezini test etmiştir. Panel regresyon bulgularının ticari açıklığın kamu büyüklügü üzerindeki pozitif etkisini ortaya koyduğu çalışmada ülke grubu için telafi hipotezi doğrulanmıştır.

Farklı dönem ve ülkeler için hem zaman serisi hem de panel veri yöntemleri ile telafi hipotezini test eden çalışmalara ait literatür özeti Tablo 1'de sunulmuştur. 


\begin{tabular}{|c|c|c|c|}
\hline Yazar & Ülke ve Dönem & Yöntem & Ampirik Bulgular \\
\hline Garret (2001) & 103 Ülke (1985-1995) & $\begin{array}{l}\text { Yatay kesit regresyon } \\
\text { analizi }\end{array}$ & $\mathrm{OPN} \rightarrow \mathrm{GS}(+)^{\mathrm{a}}$ \\
\hline Balle ve Vaidya (2002) & $\begin{array}{c}\text { ABD (1987-1994 ve 1995- } \\
1997)\end{array}$ & $\begin{array}{l}\text { Yatay kesit regresyon } \\
\text { analizi }\end{array}$ & $\mathrm{OPN} \rightarrow \mathrm{GS}(+)^{\mathrm{a}}$ \\
\hline Molona vd. (2004) & $\begin{array}{c}23 \text { OECD Ülkesi } \\
(1948-1998)\end{array}$ & $\begin{array}{c}\text { Sims ve Granger } \\
\text { nedensellik }\end{array}$ & $\mathrm{OPN} \propto \mathrm{GS}^{\mathrm{b}}$ \\
\hline Islam (2004) & $\begin{array}{c}\text { Avusturya, Kanada, } \\
\text { İngiltere, Norveç, İsveç ve } \\
\text { ABD }\end{array}$ & ARDL ve FMOLS & $\begin{array}{c}\text { Eşbütünleşik (+) } \\
\text { (ARDL: ABD, Kanada) } \\
\text { (FMOLS: ABD, Kanada, } \\
\text { İngiltere, Norvec) }\end{array}$ \\
\hline Jeanneney ve Hua (2004) & $\begin{array}{c}29 \text { Çin Eyaleti (1992-1995 } \\
\text { ve 1996-1998) }\end{array}$ & $\begin{array}{l}\text { Yatay kesit regresyon } \\
\text { analizi }\end{array}$ & $\mathrm{OPN} \rightarrow \mathrm{GS}(+)^{\mathrm{a}}$ \\
\hline Abizadeh (2005) & $\begin{array}{c}\text { Kanada, ABD, Kore, } \\
\text { Singapur, Misir ve Uruguay } \\
(1960-2000)\end{array}$ & 2SLS & $\begin{array}{l}\text { OPN } \rightarrow \text { GS }(-)^{\mathrm{a}} \text { (Kanada, } \\
\text { Singapur, Uruguay) } \\
\text { OPN } \rightarrow \text { GS }(+)^{\mathrm{a}}(\mathrm{ABD}, \\
\text { Kore, Misir) }\end{array}$ \\
\hline Maurao (2007) & Portekiz (1947-2002) & $\begin{array}{l}\text { Engle-Granger } \\
\text { eşbütünleşme testi ve } \\
\text { Regresyon Analizi }\end{array}$ & $\begin{array}{l}\text { Eşbütünleşik } \\
\text { OPN } \rightarrow \text { GS }(+)^{\mathrm{a}}\end{array}$ \\
\hline Shelton (2007) & 101 ülke (1970-2000) & Panel regresyon analizi & $\begin{array}{l}\text { OPN } \propto \mathrm{GS}^{\mathrm{a}} \text { (yerel kamu } \\
\text { harcamaları için) } \\
\text { GS } \rightarrow \text { OPN }(+)^{\mathrm{a}} \text { (merkezi } \\
\text { kamu harcamaları için) }\end{array}$ \\
\hline $\begin{array}{c}\text { Benarroch ve Pandey } \\
(2008)\end{array}$ & 96 Ülke (1970-2000) & $\begin{array}{c}\text { Panel regresyon analizi ve } \\
\text { Granger nedensellik }\end{array}$ & $\begin{array}{c}\text { OPN } \rightarrow \text { GS }(+)^{\mathrm{a}} \\
\text { GS } \rightarrow \text { OPN }(-)^{\mathrm{b}}\end{array}$ \\
\hline Epifani ve Gancia (2008) & $\begin{array}{l}143 \text { Ülke }(1950-2000) \\
(1995-2000)\end{array}$ & $\begin{array}{l}\text { Panel regresyon analizi ve } \\
\text { Yatay kesit regresyon } \\
\text { analizi }\end{array}$ & $\mathrm{GS} \rightarrow \mathrm{OPN}(+)^{\mathrm{a}}$ \\
\hline Hui Kueh vd. (2008) & $\begin{array}{l}\text { Endonezya, Malezya, } \\
\text { Filipinler ve Tayland } \\
\quad(1974-2006)\end{array}$ & ARDL & $\begin{array}{l}\text { Eşbütünleşik } \\
\text { GS } \rightarrow \text { OPN }(+)^{\mathrm{a}, \mathrm{b}}\end{array}$ \\
\hline Ram (2009) & 150 Ülke (1960-2000) & Panel regresyon analizleri & $\mathrm{OPN} \rightarrow \mathrm{GS}(+)^{\mathrm{a}}$ \\
\hline Gadea vd. (2009) & $\begin{array}{l}\text { İspanya }(1960-2000 \mathrm{ve} \\
1960-1993)\end{array}$ & $\begin{array}{c}\text { Johansen eş bütünleşme } \\
\text { testi ve hata düzeltme } \\
\text { modeli }\end{array}$ & $\begin{array}{l}\text { Eşbütünleşik (+) } \\
\text { GS }^{\mathrm{b}} \leftarrow \rightarrow \mathrm{OPN}^{\mathrm{b}}\end{array}$ \\
\hline $\begin{array}{l}\text { Benarroch ve Pandey } \\
\text { (2012) }\end{array}$ & 119 Ülke (1972-2000) & $\begin{array}{l}\text { Panel regresyon ve } \\
\text { nedensellik analizleri }\end{array}$ & $\begin{array}{l}\mathrm{GS} \rightarrow \mathrm{OPN}(+)^{\mathrm{a}} \text { (düşük } \\
\text { gelirli ülkelerin eğitim } \\
\text { harcamaları için) } \\
\text { OPN } \propto \mathrm{GS}^{\mathrm{b}}\end{array}$ \\
\hline Altay ve Aysu (2013) & $\begin{array}{c}17 \text { Ülke } \\
(1974-2010)\end{array}$ & $\begin{array}{c}\text { Pedroni eşbütünleşme testi } \\
\text { ve Panel DOLS }\end{array}$ & $\begin{array}{c}\text { Eşbütünleşik } \\
\text { GS } \rightarrow \text { OPN }(-)^{\mathrm{a}}\end{array}$ \\
\hline Aydoğuş ve Topçu (2013) & Türkiye (1974-2011) & $\begin{array}{c}\text { Engle-Granger } \\
\text { eşbütünleşme testi ve } \\
\text { Granger nedensellik testi } \\
\end{array}$ & $\begin{array}{l}\text { Eşbütünleşik değil } \\
\text { GS } \rightarrow \text { OPN }^{\mathrm{b}}\end{array}$ \\
\hline Zeren ve Ergün (2013) & $\begin{array}{l}15 \text { AB Ülkesi } \\
(1970-2011)\end{array}$ & Panel nedensellik testi & $\mathrm{OPN} \rightarrow \mathrm{GS}^{\mathrm{b}}$ \\
\hline $\begin{array}{l}\text { Aregbeyen ve Ibrahim } \\
\qquad(2014)\end{array}$ & Nijerya (1970-2012) & ARDL Nedensellik analizi & $\begin{array}{c}\text { Eşbütünleşik } \\
\text { GS } \rightarrow \text { OPN }(+)^{a, b}\end{array}$ \\
\hline Lin vd. (2014) & 92 Ülke (1985-2010) & Panel regresyon analizleri & $\mathrm{OPN} \rightarrow \mathrm{GS}(+)^{\mathrm{a}}$ \\
\hline Parvizkhanlou (2014) & $\begin{array}{c}\text { Azerbaycan, İran, } \\
\text { Kazakistan, Kırgizistan, } \\
\text { Pakistan, Tacikistan ve } \\
\text { Türkiye (2000-2009) }\end{array}$ & Panel regresyon analizi & $\mathrm{OPN} \rightarrow \mathrm{GS}(+)^{\mathrm{a}}$ \\
\hline \multicolumn{4}{|c|}{ 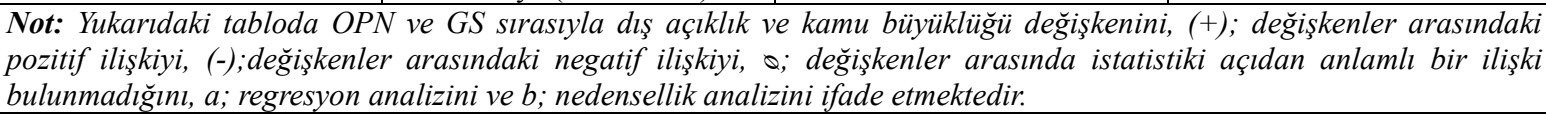 } \\
\hline
\end{tabular}

Tablo 1. Telafi Hipotezini Test Eden Çalışmalarla İlgili Literatür Özeti

\section{Veri Seti ve Yöntem}

Bu çalışmada, telafi hipotezinin Türkiye'de geçerli olup olmadığı zaman serisi analiziyle araştırılmıştır. Bu amaçla kamu büyüklüğü (GS) değişkeni için devletin nihai tüketim harcamalarının GSYH içindeki \% payı, ticari açıklık (OPN) değişkeni için ise ithalat ve ihracat toplamının GSYH içindeki \% payı kullanılmıştır. İthalat ve 
ihracat serileri Türkiye İstatistik Kurumu'ndan (TÜIK) temin edilmiştir. GSYH ve devletin nihai tüketim harcamaları serileri 1980-1997 dönemi için Kalkınma Bakanlığı Ekonomik ve Sosyal Göstergeler Tablo 1.42'den (Cari Fiyatlarla Uyumlaştırılmış Harcamalar Yoluyla GSYH) ve 1998-2013 dönemi için TÜiK'den alınmıştır. GS ve OPN serileri çalışmada logaritmik formuyla analize tabi tutulmuştur. $\Delta$ ise fark operatörünü ifade etmektedir.

\section{Ekonometrik Yöntem ve Bulgular}

Çalışmada öncelikle GS ve OPN ait tanımlayıcı istatistikler aşağıda Tablo 2'de sunulmuştur.

\begin{tabular}{|c|c|c|c|c|c|}
\hline Değișken & Gözlem Sayısı & Ortalama & Standart Hata & Minimum & Maksimum \\
\hline GS & 34 & 0.103039 & 0.005130 & 0.094672 & 0.114579 \\
\hline OPN & 34 & 0.293429 & 0.115116 & 0.123096 & 0.493349 \\
\hline
\end{tabular}

Tablo 2. Değişkenlere Ait Tanımlayıcı İstatistikler

Tablo 2'den görüldüğü üzere GS ve OPN değişkenlerinin ortalamaları sırasıyla 0.103 ve 0.293 olarak gerçekleşmiştir. Kamu harcamaları en düşük değerine 1985 yılında, en yüksek değerine ise Türkiye'de 2001 krizinin yaşandığı yıl ulaşmıştır. Ticari açıklık değişkeni ise en düşük değerini 1980 yılında en yüksek değerini de 2012 yılında gerçekleştirmiştir.

Çalışmada ayrıca değişkenler arasındaki ilişkinin yönünü belirlemede kullanılan yöntemlerden biri olan korelasyon analizine de yer verilmiştir. Korelasyon analizinden elde edilen bulgular değişkenler arasındaki nedensellik ilişkisine dair kesin bir sonuç ifade etmese de değişkenler arasındaki ilişkiye dair ön bilgiler sunmaktadır. GS ve OPN değişkenlerine ait Pearson korelasyon analizi sonuçları Tablo 3'de sunulmuştur.

\begin{tabular}{|c|c|c|}
\hline Değișken & $\operatorname{lnGS}$ & $\operatorname{lnOPN}$ \\
\hline InGS & 1 & $0.388^{\mathrm{b}}$ \\
\hline InOPN & $0.388^{\mathrm{b}}$ & 1 \\
\hline Not: Tek ve çift yanlı $t$ testine göre $b \% 5^{\prime}$ 'de \\
\hline
\end{tabular}

Tablo 3. Korelasyon Analizi Sonuçları

Korelasyon analizi sonucunda pozitif ve istatistiksel olarak anlamlı çıkan korelasyon katsayısı, değişkenler arasında doğru yönlü bir iliş̧kinin bulunduğuna işaret etmektedir.

Çalışmada ele alınan değişkenlerin birim kök taşıyıp taşımadıklarının tespitinde Genişletilmiş Dickey-Fuller (ADF) birim kök testi kullanılmış ve elde edilen bulgular Tablo 4'de sunulmuştur.

\begin{tabular}{|c|c|c|}
\hline \multirow{2}{*}{ Değişken } & \multicolumn{2}{|c|}{ ADF } \\
\hline & Sabitli-Trendli & Sabitli \\
\hline $\ln G S$ & $-3.147(8)$ & $-2.929(0)$ \\
\hline$\Delta \ln G S$ & $-6.552(0)^{\mathrm{a}}$ & $-6.629(0)^{\mathrm{a}}$ \\
\hline $\operatorname{lnOPN}$ & $-2.823(1)$ & $-1.354(0)$ \\
\hline$\Delta \ln O P N$ & $-4.741(0)^{\mathrm{a}}$ & $-4.810(0)^{\mathrm{a}}$ \\
\hline
\end{tabular}

Tablo 4. Birim Kök Testi Sonuçlarl

Tablo 4'de görüldüğü üzere GS ve OPN değişkenlerinin $\% 5$ anlamlılık seviyesinde birim kök taşıdıkları tespit edilmiş̧ir. İlgili serilerin birinci farkı alındığında serilerin \%1 anlamlılık düzeyinde birim kök taşımadıkları yani 1 farkında durağan oldukları sonucuna ulaşılmıştır. GS ve OPN serilerinin eşbütünleşik olup olmadıklarının tespitinde Engle ve Granger (1987) eşbütünleşme sınaması kullanılmıştır. İki aşamalı olarak gerçekleştirilen bu testin ilk aşamasında ilgili değişkenlerin seviye değerlerinin yer aldığı aşağıda sunulan (1) ve (2) nolu regresyon denklemleri OLS ile tahmin edilerek denklemlere ait hata terimleri elde edilir.

$\operatorname{lnGS} S_{\mathrm{t}}=\alpha_{0}+\alpha_{1} \operatorname{lnOPN} \mathrm{N}_{\mathrm{t}}+\varepsilon_{1 \mathrm{t}}$

$\operatorname{lnOPN}=\beta_{0}+\beta_{1} \operatorname{lnGS}{ }_{t}+\varepsilon_{2 t}$

İkinci aşamada eşbütünleşme ilişkine $\varepsilon_{1}$ ve $\varepsilon_{2}$ hata terimlerinin durağan olup olmadıklarına göre karar verilmektedir. Hata terimlerinin durağanlığ istatistiği Engle ve Yoo (1987) tablo kritik değeri ile karşılaştırılmaktadır. Eşbütünleşme testinde boş hipotez seriler eşbütünleşik değildir şeklinde kurulur. Eğer hata terimleri için yapılan ADF test istatistiği Engle ve Yoo tablo değerinden büyükse boş hipotez reddedilir ve seriler eşbütünleşiktir şeklinde olan alternatif hipotez kabul edilir. Dolayısıyla eşbütünleşme yönünde karar verilir. Engle-Granger eşbütünleşme testi sonuçları aşağıda Tablo 5 'de sunulmuştur. 


\begin{tabular}{|c|c|c|c|c|}
\hline \multirow{2}{*}{$\begin{array}{l}\text { Eşbütünleşme } \\
\text { Denklemi }\end{array}$} & \multirow{2}{*}{$\begin{array}{l}\text { ADF test } \\
\text { İstatistiği }\end{array}$} & \multicolumn{3}{|c|}{$\begin{array}{l}\text { Engle ve Yoo (1987) tablo kritik } \\
\text { değeri ve Anlamlılık Düzeyleri }\end{array}$} \\
\hline & & $\% 1$ & $\% 5$ & $\% 10$ \\
\hline $\begin{array}{c}\operatorname{lnGS}_{\mathrm{t}}=2.177^{\mathrm{a}}+0.047^{\mathrm{b}} \operatorname{lnOPN}_{\mathrm{t}} \\
{[0.065][0.20]}\end{array}$ & $-4.098(3)^{b}$ & \multirow{2}{*}{4.32} & \multirow{2}{*}{3.67} & \multirow{2}{*}{3.28} \\
\hline $\begin{array}{c}\operatorname{lnOPN}_{\mathrm{t}}=-4.209+3.221^{\mathrm{b}} \operatorname{lnGS} \mathrm{S}_{\mathrm{t}} \\
{[3.157][1.354]}\end{array}$ & $-2.105(0)$ & & & \\
\hline
\end{tabular}

\section{Tablo 5. Engle-Granger Eşbütünleşme Testi Sonuçları}

Tablo 5'de görüldüğü üzere (1) ve (2) numaralı denklemlerin OLS ile tahmininden elde edilen hata terimlerine sabitsiz ve trendsiz model vasıtası ile yapılan ADF birim kök sonuçlarına göre; GS ile OPN eşbütünleşiktir. Eşbütünleşmenin varlığı durumunda seviye değerlerinin yer aldığı regresyon sahte bulgular ortaya çıkarmaz. OPN değişkenin GS üzerine OLS yöntemi ile koşulmasından elde edilen OPN katsayısı 0.047'dir ve istatistiksel olarak \%5 anlamlılık seviyesinde anlamlıdır. Buna göre; OPN'deki artışlar kamu büyüklüğünü 1980-2013 dönemi için artırmaktadır. $\mathrm{Bu}$ durum beklentilerle örtüşmekte, telafi hipotezini doğrulamaktadır. Eşbütünleşmenin varlığı durumunda değişkenler arasında en az tek yönlü bir nedensellik ilişkisi beklenmektedir. Dolayısıyla değişkenler arasındaki nedensellik ilişkisi aşağıda sunulan (3) ve (4) nolu denklem üzerinden araştırılmıştır.

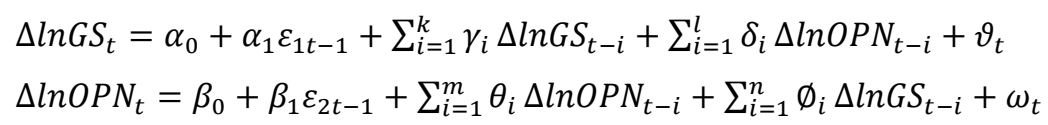

Yukarıdaki denklemlerde $\alpha_{0}$ ve $\beta_{0}$; sabit terimi, $\alpha_{1}$ ve $\beta_{1}$; hata düzeltme katsayısını (HDK), $\varepsilon_{1}$ ve $\varepsilon_{2}$; hata terimlerini, $\gamma, \delta, \theta$ ve $\phi$; katsayıları, $\mathrm{k}, 1, \mathrm{~m}$ ve $\mathrm{n}$ ise optimal gecikme uzunluklarını ifade etmektedir. Denklem (3) ve Denklem (4)'ün OLS ile tahmininden elde edilen hata düzeltme modeli sonuçları Tablo 6'da sunulmuştur.

\begin{tabular}{|c|c|c|}
\hline Model & F-Testi & HDK \\
\hline$\Delta \operatorname{lnGS} S_{\mathrm{t}}=\alpha_{0}+\alpha_{1} \varepsilon_{1 \mathrm{t}-1}+\sum_{\mathrm{i}=1}^{3} \gamma_{\mathrm{i}} \Delta \operatorname{lnGS} \mathrm{t}_{\mathrm{t}-\mathrm{i}}+\delta_{1} \Delta \operatorname{lnOPN} \mathrm{N}_{\mathrm{t}-1}+\mu_{\mathrm{t}}$ & 0.184 & $\begin{array}{l}-0.885^{\mathrm{a}} \\
(0.238)\end{array}$ \\
\hline \multicolumn{3}{|c|}{$\mathrm{R}^{2}: 0.426 \mathrm{~F}$ istatistiği: $3.565^{\mathrm{b}} \mathrm{LM}\left(\chi^{2}\right): 0.001[0.978] \mathrm{White}\left(\chi^{2}\right): 23.199[0.279]$} \\
\hline Model & F-Testi & HDK \\
\hline$\Delta \operatorname{lnOPN} N_{t}=\beta_{0}+\beta_{1} \varepsilon_{2 t-1}+\theta_{1} \Delta \ln 0 P N_{t-1}+\emptyset_{1} \Delta \operatorname{lnGS} S_{t-1}+v_{t}$ & 1.155 & $\begin{array}{c}-0.074 \\
(0.049)\end{array}$ \\
\hline \multicolumn{3}{|c|}{$\mathrm{R}^{2}: 0.160 \mathrm{~F}$ istatistiği: $1.774 \mathrm{LM}\left(\chi^{2}\right): 0.252[0.616]$ White $\left(\chi^{2}\right): 7.088[0.628]$} \\
\hline \multicolumn{3}{|c|}{$\begin{array}{l}\text { Not: Parantez ve kösseli parantez içindeki değerler sırasıyla standart hatayl ve ilgili olasılık değerin } \\
\text { göstermektedir. a ve b strastyla \%1 ve \% } 5 \text { 'de anlamlıdır. }\end{array}$} \\
\hline
\end{tabular}

Tablo 6. Hata Düzeltme Modeli Sonuçlart

Tablo 6'dan görüldü üzere GS'den OPN'ye doğru F testi sonuçları ve HDK'nın anlamsız olmasından ötürü nedensellik ilişkisi saptanamamıştır. Öte yandan GS'den OPN'ye doğru F testi sonuçları anlamsız olmasına rağmen HDK'nın \%1 anlamlılık düzeyinde anlamlı olmasından ötürü tek yönlü bir nedensellik ilişkisi tespit edilmiştir.

\section{Sonuç ve Değerlendirme}

Devletin ekonomiye müdahalesi Keynes ile gündeme gelmiş ve iktisat politikasında kendine yer edinmiştir. Özellikle 1980'li yıllarla birlikte yaşanan bilgi ve iletişim devrimi dünya genelinde ticaretin serbestleşmesi çabalarına olumlu katkılar sunmuştur. Ülkeler dışa kapalı sanayileşme politikalarını terk ederek ihracata dönük sanayileşme anlayışını Kabul etmeye başlamışlardır. Bu süreç aynı zamanda serbestleşme sürecini de hızlandırmıştır. Ancak ülkelerin dışa açılması doğacak dış riskleri de beraberinde getirmiş ve ülke vatandaşlarının refahı bu süreçten olumsuz etkilenebilmiştir. Rodrik (1988) bu sürecin kamu harcamalarını artıracağına çünkü doğabilecek refah azalışlarının devletin kamu harcamalarında yaratacağı genişleme ile giderilebileceğini ileri sürmüştür. Buna karşın yaşanan serbestleşme sürecinin kamu harcamalarını artırmayıp aksine azaltacağını ileri süren etkinlik hipotezi de literatürde inceleme konusu yapılmıştır. 
Türkiye 1980 yılında ithal ikameci sanayileşme politikalarını terk edip ihracata dönük sanayileşme anlayışını benimseyerek dünyadaki gelişmelerden uzak kalmamıştır. Dolayısıyla bu çalışmanın amacı 1980-2013 dönemi için Türkiye'de telafi hipotezinin geçerliliği araştırmaktır. Bu doğrultuda Engle ve Granger eşbütünleşme testi ile uzun dönemli ilişki, hata düzeltme modeli ile de nedensellik ilişkisi araştırılmıştır. Elde edilen bulgular göre; değişkenler eşbütünleşiktir ve ticari açıklıktan kamu büyüklüğüne doğru nedensellik ilişkisi bulunmaktadır. Aynı zamanda ticari açıklığın kamu harcamalarını pozitif etkilediği bulgusu da tespit edilmiştir. Bu bulgular, söz konusu dönem için Türkiye'de telafi hipotezinin geçerliği olduğunu ortaya koymaktadır. Elde edilen bu bulgunun önemi serbestleşme sürecinde diş risklerden dolayı oluşabilecek olan refah kayıplarında, maliye politikasının bir iktisat politikası aracı olarak değerlendirilebileceğidir. Bundan sonra yapılabilecek çalışmalar için kamu harcamalarının alt kalemleri ile telafi hipotezinin test edilmesi araştırmacılara önerilebilir.

\section{Kaynakça}

- Abizadeh, 2005. “An Analysis of Government Expenditure and Trade Liberalization”, Applied Economics, 37, pp. 1881-1884.

- $\quad$ Altay ve Aysu, 2013. "Etkinlik ve Telafi Edici Etki Hipotezi: Seçilmiş Ülkeler Üzerine Ampirik Bir İnceleme”, TISK Akademi, 8 (15), pp. 130-154.

- Aregbeyen ve Ibrahim, 2014. "Trade Openness-Government Size Nexus: Compensation Hypothesis Considered for Nigeria”, Journal of Reviews on Global Economics, 3, pp. 364-372.

- Aydoğuş ve Topçu, 2013. "An Investigation of Co-Integration and Causality between Trade Openness and Government Size in Turkey”, International Journal of Economics and Financial Issues, 3(2), pp. 319-323.

- Balle ve Vaidya, 2002. “A Regional Analysis of Openness and Government Size”, Applied Economics Letters, 9(5), pp. 289-292.

- Benarroch ve Pandey, 2008. “Trade Openness and Government Size”, Economics Letters, 101, pp. 157-159.

- Benarroch ve Pandey, 2012. "The relationship between trade openness and government size: Does disaggregating government expenditure matter?”, Journal of Macroeconomics, 34 (1), pp. 239-252.

- Cameron, 1978. "The Expansion of the Public Economy: A Comparative Analysis", The American Political Science Review, 72(4), pp. 1243-1261.

- Engle ve Granger, 1987. "Cointegration and Error Correction: Representation, Estimation and Testing”, Econometrica, 55(2), pp. 251-276.

- Emirmahmutoglu ve Kose, 2011. "Testing for Granger Causality in Heterogeneous Mixed Panels", Economic Modelling, 28(3), pp. 870-876.

- Epifani ve Gancia, 2008. “Openness, Government Size and Terms of Trade” Review of Economic Studies, 76(2), pp. 629-668.

- Garrett, 2001. "Globalization and Government Spending around the World", Studies in Comparative International Development, 35(4), pp. 3-29.

- Gadea vd., 2009. "The relationship between trade opennes and public expenditure. The Spanish case, 1960 2000”, Documento de Trabajo 2009-06 Facultad de Ciencias Económicas y Empresariales Universidad de Zaragoza, pp. 1-49. http://www.dteconz.unizar.es/DT2009-06.pdf

- Hui Kueh vd., 2008. "Bounds Estimation for Trade Openness and Government Expenditure Nexus of Asean-4 Countries", MPRA, 12351, http://mpra.ub.uni-muenchen.de/12351/1/MPRA_paper_12351.pdf.

- Jeanneney ve Hua, 2004. “Why Do More Open Chinese Provinces Have Bigger Governments?”, Review of International Economics, 12(3), pp. 525-542.

- Islam, 2004. "The long run relationship between openness and government size: evidence from bounds test”, Applied Economics, 36, pp. 995-1000.

- Lin vd., 2014. "Trade openness and government size of small developing countries: an instrumental approach", Economics of Transition, 22(4), pp. 783-808.

- Molana vd., 2004. "On the Causal Relationship between Trade Openness and Government Size: Evidence from 23 OECD Countries”, University of Dundee. Discussion Paper, 164, pp. 1-18.

- Mourao, 2007. "Has trade openness increased all Portuguese public expenditures? A detailed time-series study”, Financial Theory and Practice, 31(3), pp. 225-247.

- Parvizkhanlou, 2014. "An Impact of Trade and Financial Openness on Government Size: A Case Study for ECO”, IRC'S International Journal of Multidisciplinary Research in Social \& Management Sciences, 2(2), pp. 1-4. 
- $\quad$ Ram, 2009. “Openness, Country Size, and Government Size: Additional Evidence from a Large CrossCountry Panel”, Journal of Public Economics, 93, pp. 213-218.

- Rodrik, 1998. "Why Do More Open Economies Have Bigger Governments?”, Journal of Political economy, 106(5), pp. 997-1032.

- Shelton, 2007. "The size and composition of government expenditure", Journal of Public Economics, 91(1112), pp. 2230-2260.

- Zeren ve Ergün, (2013). “Ticari Açiklik ve Kamu Büyüklüğü İlişkisi: Panel Nedensellik Testi”, Atatürk Üniversitesi Íktisadi ve İdari Bilimler Dergisi, 27(4), pp. 229-240. 


\title{
İthalatta Haksız Rekabet ve Türkiye'de Anti-damping Uygulamaları
}

\section{Unfair Competition in Imports and Anti-damping Practices in Turkey}

\author{
Asst. Prof. Dr. Hülya Göktepe (Anadolu University, Turkey)
}

\begin{abstract}
Unfair competition in imports is done by dumping or subsidy. According to the Turkish legislation dumping; export price of a product to Turkey being less than the normal value for the like product, subsidy; a direct or indirect financial contribution by the country of origin or export, which confers a benefit or any form of income or price support within the meaning of Article XVI of GATT 1994. In the case of unfair competition in imports, General Directorate of Imports applies trade defence instruments (antidumping, antisubsidy, safeguard measures) in compliance with WTO rules and national legislation, and follows up the enforcement of those measures.

The purpose in this study is to contribute to Turkish literature related to damping and subsidy. In this study, national and international regulation on antidumping will be given. It will be explained antidumping practices in Turkey. Dumping investigations will be presented. The data from Ministry of Economy and foreign trade data will be used. This study is a descriptive study.
\end{abstract}

\section{Giriş}

Benzer veya doğrudan rakip mallar üreten yerli üreticilerin ithalat yoluyla yapılan haksız rekabete karşı korunmaları, ithalattan zarar görmelerinin önlenmeleri amacıyla ticaret politikası savunma araçlarına başvurulmaktadır. Ticaret politikası savunma araçları dampinge karşı önlemler, sübvansiyona karşı önlemler ile korunma ve gözetim önlemlerinden oluşmaktadır. Türkiye'de ithalatta haksız rekabetin önlenmesine ait düzenleme 1989 yılında İthalatta Haksız Rekabetin Önlenmesi Hakkında Kanun ile yapılmıştır. Bu kanunun uygulanmasına yönelik yönetmelik ve Karar çıkarılmıştır. İthalatta haksız rekabetin önlenmesi hakkında mevzuata göre: damping; bir malın Türkiye'ye ihraç fiyatının, benzer malın normal değerinin altında olmasını, sübvansiyon; menşe veya ihracatçı ülkenin fayda sağlayan, doğrudan veya dolaylı mali katkısını veya GATT 1994'ün XVI'ncı maddesi çerçevesinde herhangi bir gelir veya fiyat desteğini ifade etmektedir. Damping veya sübvansiyonun tespiti halinde savunma aracı olarak antidamping vergileri kullanılmaktadır.

Damping veya sübvansiyonun tespiti için damping veya sübvansiyon soruşturmaları açılmaktadır. Eskiden $\mathrm{ABD}, \mathrm{AB}$, Kanada gibi gelişmiş ülkeler tarafından kullanılan damping soruşturmaları artık gelişmekte olan ülkeler tarafından da kullanılmaktadır.

\section{Antidampingle İlgili Uluslararası ve Ulusal Düzenlemeler}

Dampingle ilgili uluslararası düzenleme Gümrük Tarifeleri ve Ticaret Genel Anlaşması 1994'ün VI. Maddesinin Uygulanmasına İlişskin Anlaşma'dır. Dampinge karşı önlemler yalnızca GATT 1994 Madde VI'da öngörülen koşullarda ve bu Anlaşma hükümlerine uygun olarak başlatılan ve yürütülen soruşturmalar gereğince uygulanacaktır. Kısaca Antidamping Anlaşması olarak anılan bu anlaşma uyarınca, bir ülkeden başka bir ülkeye ihraç edilen bir ürünün ihraç fiyatı, normal ticari işlemler içinde, ihracatçı ülkede tüketime konu benzer ürünün karşılaştırılabilir fiyatından daha düşük olduğunda, sözkonusu ürünün dampingli olduğu, yani bir başka ülkenin pazarına normal değerinden daha düşük bir fiyatla sokulduğu kabul edilir. Anlaşmaya göre, İhracat fiyatı ile normal değer arasında adil bir karşılaştırma yapılacaktır. Bu karşılaştırma aynı ticari aşamada, normal olarak fabrika çıkış aşamasında ve yapılan satışlar için mümkün olduğu ölçüde aynı zamanda yapılacaktır. Zarar tesbiti olumlu delile dayanacak ve dampingli ithal ürün hacminin ve dampingli ithal ürünlerin, iç piyasada benzer ürünlerin fiyatı üzerindeki etkisinin ve bu ithalatın sonuçta bu ürünlerin yerli üreticileri üzerindeki etkisinin nesnel bir incelemesini içerecektir. Iddia edilen dampingin mevcudiyeti, derecesi ve etkisini tesbit etmek için, üretim dalı tarafindan veya üretim dalı adına yapılan yazılı başvuru üzerine bir soruşturma başlatılacaktır. Başvuru, damping, zarar ve dampingli ithalatla iddia edilen zarar arasında nedensel bir ilişki ile ilgili delilleri içerecektir. Yetkililer bir soruşturmanın başlatılması için yeterli delil olup olmadığını belirlemek üzere başvuru beraberinde verilen delillerin doğruluğunu ve yeterliliğini inceleyeceklerdir. Yetkililer özel durumlarda, üretim dalı tarafından veya onun adına böyle bir soruşturmanın başlatılması için yazılı bir başvuru yapılmadan soruşturma başlatmaya karar verdikleri takdirde, bu soruşturmayı ancak, soruşturmanın başlatılmasını haklı kılacak olan, damping, zarar ve nedensel ilişki ile ilgili yeterli delili buldukları takdirde başlatacaklardır. Yetkililer soruşturmayla ilgili işlemlerin sürdürülmesini haklı kılacak damping veya zararla ilgili yeterince delil olmadığı kanaatine vardıklarında, yapılan başvuru reddedilecek ve soruşturma derhal kapatılacaktır. 
Soruşturmalar, özel durumlar dışında bir yıl içinde sonuçlandırılacak ve başladıktan sonra hiçbir şekilde 18 aydan daha uzun sürmeyecektir.

Verginin uygulanması için tüm koşulların yerine geldiği durumlarda dampinge karşı verginin uygulanıp uygulanmayacağına ilişkin karar ve uygulanacak dampinge karşı vergi tutarının damping marjı kadar veya daha az olmasına ilişkin karar, ithalaţ̧ı Üye yetkililerince verilecek kararlardır. Dampinge karşı vergi tutarı, belirlenen damping marjını aşmayacaktır. Dampinge karşı vergiler yalnızca, zarara neden olan dampingi önlemek için gerekli olduğu sürece ve gerekli olduğu ölçüde yürürlükte kalacaktır. Bu Anlaşma kapsamında dampinge-karşı önlemlerin uygulanması sözkonusu olduğunda, gelişmiş Üye ülkeler tarafindan gelişmekte olan Üye ülkelerin özel durumunun özellikle dikkate alınması gerektiği kabul edilmektedir. Dampinge karşı vergilerin gelişmekte olan Üye ülkelerin önemli çıkarlarını etkileyeceği durumlarda bu vergiler uygulanmadan önce Anlaşmada öngörülen yapıcı çözümler araştırılacaktır. Bu Anlaşma ile Üyelerin herbirinin temsilcilerinden oluşan bir Dampinge Karşı Uygulamalar Komitesi kurulmaktadır. Üyeler aldıkları her türlü dampingekarşı ön ve kesin önlemlerini gecikmeden Komiteye rapor edeceklerdir. Üyeler ayrıca her altı ayda bir, bir önceki altı-aylık süre içinde alınan damping karşı önlemler ile ilgili raporları da sunacaklardır.

Türkiye'de damping ve sübvansiyonla ilgili mevzuata bakıldığında; 14/6/1989 tarih ve 3577 say1lı Ithalatta Haksız Rekabetin Önlemesi Hakkında Kanun, 99-13482 Sayılı Bakanlar Kurulu Kararı ile yürürlüğe konulan Ithalatta Haksız Rekabetin Önlenmesi Hakkında Karar, 30/10/1999 tarih ve 23861 say1lı Ithalatta Haksız Rekabetin Önlemesi Hakkında Yönetmelik'ten oluştuğu görülmektedir.

Ithalatta Haksız Rekabetin Önlenmesi Hakkında Kanun, ithalatta haksız rekabet hallerinden dampinge veya sübvansiyona konu olan ithalatın sebep olduğu zarara karşı bir üretim dalının korunması amacıyla yapılacak işlemlere, alınacak önlemlere, gerekli ilke ve uygulama kararlarını verecek bir Kurul oluşturulmasına ve bunun görevlerine ilişkin usul ve esasları kapsar. Damping veya sübvansiyona karşı önlem alınmasını gerektiren haller, dampinge veya sübvansiyona konu olan ithalatın Türkiye'de bir üretim dalında maddî zarara yol açması veya maddî zarar tehdidi oluşturması veya bir üretim dalının kurulmasını fizikî olarak geciktirmesidir. Ancak, sübvansiyona konu ithalata karşı önlem alınabilmesi için, sübvansiyonun Sübvansiyonlar ve Telafi Edici Tedbirler Anlaşması'nın 2'nci Maddesi çerçevesinde bir firma/firma grubu veya bir üretim dalı/üretim dalı grubuna yönelik olduğunun da tespit edilmiş olması gerekir.

Ithalat Genel Müdürlüğü şikayet üzerine veya gerektiğinde re'sen damping veya sübvansiyon incelemesi yapabilir. Dampinge veya sübvansiyona konu olan ithalattan maddi zarar gördüğünü veya maddi zarar tehdidi altında bulunduğunu veya bu tür ithalatın bir üretim dalının kurulmasını fiziki olarak geciktirdiğini iddia eden üreticiler veya üretim dalı adına hareket eden gerçek veya tüzel kişi veya kuruluşlar İthalat Genel Müdürlügüne yazılı olarak başvuruda bulunabilirler. Re'sen veya şikayet üzerine yapılan inceleme sonucunda dampinge veya sübvansiyona konu olan ithalatın ve bu ithalattan kaynaklanan zararın varlı̆̆ konusunda yeterli delillerin bulunması durumunda soruşturma açılır. Ithalat genel müdürlüğü şikâyet üzerine veya gerektiğinde re'sen, verilen bilgi ve belgeler veya mevcut diğer bilgilerin ışığı altında ön incelemeyi yapar. Soruşturma açılıp açılmayacağı hususunda İthalatta Haksız Rekabeti Değerlendirme Kuruluna teklif sunar. Soruşturma açılması halinde, soruşturmayı yürütür ve önlemlerle ilgili olarak Kurula teklif sunar ve Kurulun sekreterlik hizmetlerini yürütür. Genel Müdürlük, şikayet üzerine veya re'sen yapacağı incelemeyi azami 45 gün içinde tamamlayarak, soruşturma açılıp açılmaması hususunda Kurula teklifte bulunur.

İthalatta Haksız Rekabeti Değerlendirme Kurulu, İthalat Genel Müdürünün veya görevlendireceği genel müdür yardımcısının başkanlığında, Tarım ve Köyişleri Bakanlığı, Sanayi ve Ticaret Bakanlığı, Devlet Planlama Teşkilatı Müsteşarlığı, Gümrük Müsteşarlığı, Türkiye Odalar ve Borsalar Birliği'nin ve Türkiye Ziraat Odaları Birliği’'nin birer yetkili temsilcisi ile İthalat Genel Müdürlüğ̈̈'nün ilgili daire başkanından teşekkül eder. Kurul, gerekirse, üniversitelerden ve diğer kurum ve kuruluşlardan bilgi alabilir. Kurulun görevleri şunlardır: a) Soruşturma açılıp açılmamasına veya açılmış bir soruşturmanın durdurulmasına karar vermek, b) Soruşturma sırasında yeterli delil olması halinde geçici önlem kararını Bakanlığın onayına sunmak, c) Soruşturma sonuçlarını değerlendirmek, bunun gerektireceği tedbirleri almak ve kesin önlem kararını Bakanlığın onayına sunmak, d) Soruşturma sırasında taahhütte bulunulmasını önermek, taahhütte bulunulması halinde, taahhüdü kabul edip etmemek hususunda karar vermek ve taahhütlerin yerine getirilmemesi durumunda gerekli önlemleri almak. Kurul, gerekli hallerde, Kurul Başkanının daveti üzerine toplanır. Toplantı gündemi, Genel Müdürlük tarafindan hazırlanır ve gündemde görüşülecek maddelere ilişkin bilgiler Kurul üyelerine önceden gönderilir. Kurul salt çoğunlukla toplanır. Kurul kararları, toplantıya katılanların oy çokluğu ile alınır. Oyların eşit olması halinde, Kurul Başkanının oy vermiş olduğu taraf çoğunluğu sağlamış kabul edilir. Kurul Başkanı, görüşülecek konuların niteliğine göre ve istişari mahiyette olmak üzere, Kurul toplantılarına üniversiteler ve ilgili kurum ve kuruluşların temsilcilerini davet edebilir. Bu kişiler oylamaya katılamazlar. Kurul üyesi meslek kuruluşu temsilcilerinin, soruşturma konusu benzer malın üreticisi, ihracatçısı veya ithalatçısı olmaması ve bu malın herhangi bir şekilde ticaretiyle iştigal etmemesi zorunludur.

Re'sen veya şikâyet üzerine yapılan inceleme sonucunda dampinge veya sübvansiyona konu olan ithalatın ve bu ithalattan kaynaklanan zararın varlığı konusunda yeterli delillerin bulunması durumunda soruşturma açılır. Soruşturma sırasında menşe ülke, ihracatçı ülke veya ihracatçı, soruşturma konusu dampingli veya 
sübvansiyonlu ithalattan kaynaklanan zararı ortadan kaldıracak şekilde kendiliğinden veya Kurulun önerisi üzerine taahhütte bulunabilir. Kurulun taahhüdü kabul etmesi halinde soruşturma, geçici veya kesin önlem alınmaksızın durdurulabilir veya sonuçlandırılabilir.

Soruşturma açılabilmesi için; şikayetin üretim dalı tarafından veya üretim dalı adına yapıldığının tespit edilmesi ve damping veya sübvansiyona konu olan ithalatın ve bu ithalattan kaynaklanan zararın varlığ konusunda yeterli delillerin bulunması gerekir. Re'sen soruşturma açılabilmesi için de, damping veya sübvansiyona konu olan ithalatın ve bu ithalattan kaynaklanan zararın varlığı konusunda yeterli delillerin bulunması gerekir. Bir şikayetin üretim dalı tarafından veya üretim dalı adına yapılmış sayılabilmesi için; şikayeti destekleyen üreticilerin toplam benzer mal üretiminin, şikayeti destekleyen üreticiler ile şikayete karş1 çıkan üreticilerin toplam benzer mal üretiminin \% 50'sinden fazla olması ve toplam Türkiye benzer mal üretiminin \%25'inden az olmaması gerekir. Üretici sayısının çok fazla olduğu küçük parçalara bölünmüş sanayiler söz konusu olduğunda, destek veya muhalefet derecesi istatistiki açıdan geçerli örnekleme yöntemleri kullanılmak suretiyle belirlenebilir.

Kurulca soruşturma açılmasına karar verilmesi halinde, konuya ilişkin olarak ilgili ülkeye bildirimde bulunulur ve Resmi Gazete'de yayımlanacak bir tebliğ ile soruşturma başlatılır. Söz konusu tebliğde; soruşturmanın başlangıç tarihi, soruşturma konusu mal, ihracatçı veya menşe ülke, dampingli veya sübvansiyonlu ithalata ve bu ithalatın zarara neden olduğu iddialarına ilişkin açıklamalar ile ilgili tarafların Genel Müdürlüğe kendilerini bildirmeleri için tanınan süreye ilişkin bilgi yer alır. Kurulun kararı soruşturma açılmaması yönünde ise, durum şikayeti yapan tarafa bildirilir. Soruşturma başlatılıncaya kadar başvuru hakkında herhangi bir bilgi ifşa edilemez. Soruşturma açılmasını takiben, soruşturma konusu malın bilinen ithalatçılarına ve ihracatçılarına soru formları gönderilir. Sübvansiyon soruşturmalarında, ihracatçı ülkeye de soru formu gönderilir. Soruşturma sırasında Genel Müdürlük, ilgili taraflar ile soruşturma konusu malın endüstriyel kullanıcılarına ve malın perakende düzeyde satıldığı hallerde, tüketici örgütleri temsilcilerine görüşlerini bildirme olanağ sağlar. Soruşturma açılmasını takiben, şikayete ilişkin gizli olmayan tüm bilgiler bilinen ihracatçılara ve ilgili ülke temsilciliğine gönderilir. İhracatçı sayısının çok fazla olması halinde, söz konusu bilgiler yalnızca ilgili ülke temsilciliğine veya ilgili meslek kuruluşuna gönderilir. Soruşturma, özel durumlar dışında 1 yıl içinde sonuçlandırılır. Bu süre, gerektiğinde, Kurulca 6 ayı geçmemek üzere uzatılabilir. Soruşturma sonucunda; soruşturma konusu ithalatın dampinge veya sübvansiyona konu olmadığının veya bu ithalattan kaynaklanan zararın bulunmadığının belirlenmesi halinde veya damping marjı, sübvansiyon miktarı ya da ithalat miktarının ihmal edilebilir düzeylerin altında olması halinde, Kurulca soruşturma kapatılır.

Bir damping veya sübvansiyon soruşturması açılması kararı ile soruşturma sırasında alınan geçici önlem, kesin önlem, taahhüt, durdurma ve kapatma kararları, Resmi Gazete'de yayımlanacak bir tebliğle ilan edilir. Bu ilanlarda; soruşturma konusu mal, ihracatçı firma, ihracatçı ülke veya menşe ülke ve gizlilik ilkesi gözetilmek kaydıyla, soruşturma ile ilgili bilgi, bulgu ve belirlemeler yer alır. Söz konusu ilanlar, ilgili ülkelere ve soruşturma konusu malın bilinen üretici ve ihracatçılarına gönderilir.

Soruşturma sonucunda dampingli veya sübvansiyonlu ithalatın varlığı ve bu ithalatın zarara neden olduğu belirlendiğinde, bu zararın önlenmesi amacıyla, Kurulca belirlenen ve Bakanlıkça onaylanarak kesinleşen damping marjı veya sübvansiyon miktarı kadar veya zararı ortadan kaldıracak daha az bir oran veya miktarda dampinge karşı vergi veya telafi edici vergi alınır. Damping konu malın ithalinde dampinge karşı vergi, sübvansiyona konu malın ithalinde ise telafi edici vergi alınır. Dampinge karşı vergi veya telafi edici vergi konulmuş olması, ilgili malın fiilî ithalatını engellemez. Bununla birlikte, dampinge veya sübvansiyona konu ithalat nedeni ile meydana gelen zararın telafisinin, tespit edilen damping marjı veya sübvansiyon miktarından daha az bir miktar veya oranda vergi konulmasıyla mümkün olabileceğinin belirlenmesi halinde bu oran veya miktarda vergi uygulanır. Bu vergilerin, ithali evvelce gerçekleştirilen mallar için, geriye dönük olarak uygulanmasına ilişkin esaslar Bakanlar Kurulu Kararı ile tespit edilir. Ancak, geriye dönük uygulamanın süresi geçici önlemlerin alındığı tarihten itibaren 90 günü geçemez.

Dampinge karşı vergi veya telafi edici vergi mükellefi; dampinge veya sübvansiyona konu malı ithal eden gerçek ve tüzelkişilerdir. Dampinge karşı vergi veya telafi edici vergi Gümrük İdarelerince, ithalde alınan diğer vergilerden ayrı olarak tahsil olunur veya teminata bağlanır.

Gümrük mevzuatının, gümrük vergisinin tesciline, tahakkukuna, tahsiline, geri verilmesine, takibine ve teminata bağlanmasına ilişkin bu Kanuna aykırı olmayan usul ve şekle müteallik hükümleri, dampinge karş1 vergi veya telafi edici verginin tescili, tahakkuku, tahsili, geri verilmesi, takibi ve teminata bağlanması işlemlerinde de uygulanır. Soruşturma sonucunda, soruşturma konusu ithalatın dampinge veya sübvansiyona konu olmadığının veya bu ithalattan kaynaklanan zararın bulunmadığının belirlenmesi halinde veya şikâyet konusunun ortadan kalkması durumunda Kurulca soruşturma kapatılır.

İthalatta Haksız Rekabetin Önlenmesi Hakkında Kanunda hüküm bulunmayan hallerde, GATT 1994'ün VI ncı Maddesinin Uygulanmasına İlişkin Anlaşma ile Sübvansiyonlar ve Telafi Edici Tedbirler Anlaşması hükümleri dikkate alınır. GATT 1994: Gümrük Tarifeleri ve Ticaret Genel Anlaşması 1994’ü, Sübvansiyonlar ve Telafi Edici Tedbirler Anlaşması: 26/1/1995 tarihli ve 4067 sayılı Kanunla onaylanması uygun bulunan ve 3/2/1995 
tarihli ve 95/6525 sayılı Bakanlar Kurulu Kararı ile onaylanan Dünya Ticaret Örgütü Kuruluş Anlaşması Ek 1'de yer alan Anlaşmayı ifade eder.

\section{Türkiye'de Antidamping Uygulamaları}

Türkiye'nin 2015 yılı Nisan ayı dış ticaret verilerine bakıldığında; 2015 yılı içinde en fazla ithalat yapılan ülke Çin Halk Cumhuriyeti olurken, bu ülkeyi Rusya Federasyonu, Almanya, ABD, Fransa ve diğerleri izlemektedir. 2015 yılı içinde en fazla ihracat yapılan ülke Almanya olurken, bu ülkeyi İngiltere, İsviçre, Irak, BAE ve diğerleri izlemektedir. Önceki yıllarda da benzer sıralama görülmektedir.

Türkiye'de en fazla ithalat yapılan ülkelerin hepsine karşı açılmış antidamping soruşturmaları vardır fakat en çok Çin Halk Cumhuriyeti menşeli ürünlere karşı antidamping soruşturması açıldığı görülmektedir (Tablo 1 ve Tablo 2). 2014-2015 yılında yaklaşık 17 soruşturma Çin Halk Cumhuriyeti menşeli ürünlere karşı açılmıştır. Çin Halk Cumhuriyetinin en fazla ithalat yapılan ülkeler arasında başlarda yer alması damping soruşturmalarının da neden en fazla Çin Halk Cumhuriyeti menşeli ürünlere karşı açıldığının bir göstergesidir. Türkiye'de damping soruşturmaları önceleri, eski Doğu Bloku ve Orta Avrupa ülkelerinde yoğunlaşırken son yıllarda özellikle Çin Halk Cumhuriyeti olmak üzere, Uzakdoğu ülkelerinde yoğunlaşmaktadır. Verilere bakıldığında 20 ülkeye yönelik damping soruşturmalarının devam ettiği görülmektedir. Bu ülkeler; Çin Halk Cumhuriyeti, Endonezya, Malezya, Tayland, Hindistan, Misır, Vietnam, Rusya Federasyonu, Polonya, Slovakya, Suudi Arabistan, Hong Kong, Bulgaristan, ABD, Fransa, İsrail, Almanya, Japonya, Ukrayna, Romanya'dır. Bazı ürünlerde birden fazla ülkeye damping soruşturması açılmıştır. Örneğin; cam kapak, kontraplaklar, sıcak haddelenmiş yassı çelik, BOPP Filmler, paslanmaz çelik borular, motosiklet iç/dış lastikleri, bisiklet iç/dış lastikleri gibi. 2012 yılı itibariyle herhangi bir önlem alınmadan sonuçlandırılan soruşturmaların sayısı 23'dür. Dış Ticaret Müsteşarlığı (DTM) yetkililerinden edinilen bilgiye göre, İthalatta Haksız Rekabetin Önlenmesi Hakkında Mevzuat hükümleri çerçevesinde, bugüne kadar toplam 144 damping soruşturması başlatılırken, bu soruşturmalardan 59'u dampinge karşı vergilerin uygulanmaya konulması ile sonuçlandırılmıştır (ntv, 2015).

\begin{tabular}{|c|c|c|c|c|}
\hline Madde ismi & Ülke & $\begin{array}{c}\text { Tebliğ } \\
\text { numarası }\end{array}$ & RG Tarih & RG No \\
\hline $\begin{array}{l}\text { Demir veya Çelikten Belirli } \\
\text { Boru Bağlantı Parçaları }\end{array}$ & Çin Halk Cumhuriyeti & $2015 / 2$ & 22.01 .2015 & 29244 \\
\hline Sıcak Haddelenmiş Yassı Çelik & $\begin{array}{l}\text { Çin Halk Cumhuriyeti, } \\
\text { Fransa, Japonya, } \\
\text { Romanya, Rusya } \\
\text { Federasyonu, Slovakya, } \\
\text { Ukrayna }\end{array}$ & $2015 / 1$ & 28.01 .2015 & 29250 \\
\hline $\begin{array}{l}\text { Mensucat - Suni veya Sentetik } \\
\text { Liflerden Belirli Mensucat } \\
\text { veya Tekstil Ürünleri }\end{array}$ & Çin Halk Cumhuriyeti & $2015 / 7$ & 10.04 .2015 & 29322 \\
\hline Sodyum formiat & Çin Halk Cumhuriyeti & $2015 / 10$ & 12.04 .2015 & 29324 \\
\hline $\begin{array}{l}\text { Belirli Salon Tipi Sıcak ve } \\
\text { Soğuk Hava Cihazları }\end{array}$ & Çin Halk Cumhuriyeti & $2015 / 13$ & 10.05 .2015 & 29351 \\
\hline $\begin{array}{l}\text { Zincirler - Muhtelif Mafsal } \\
\text { Halkalı Zincirler ve Aksamı }\end{array}$ & Çin Halk Cumhuriyeti & $2015 / 14$ & 23.05 .2015 & 29364 \\
\hline $\begin{array}{l}\text { Bebek Arabaları / Yalnız } \\
\text { Şasiler }\end{array}$ & Çin Halk Cumhuriyeti & $2015 / 15$ & 21.05 .2015 & 29362 \\
\hline Cam Kapak & $\begin{array}{l}\text { Çin Halk Cumhuriyeti } \\
\text { Endonezya, Hong Kong }\end{array}$ & $2015 / 17$ & 21.05 .2015 & 29362 \\
\hline Poliester Tekstüre İplikler & Vietnam, Tayland & $2015 / 18$ & 15.05 .2015 & 29356 \\
\hline $\begin{array}{l}\text { Demir (Dökme Demir Hariç) } \\
\text { ve Çelikten Dikişsiz Çekme } \\
\text { Borular }\end{array}$ & Çin Halk Cumhuriyeti & $2015 / 19$ & 15.05 .2015 & 29356 \\
\hline Kontraplaklar & Bulgaristan, Vietnam & $2015 / 20$ & 27.05 .2015 & 29368 \\
\hline $\begin{array}{l}\text { Kondenserleri Isı Değiştiricisi } \\
\text { Fonksiyonu Gören } \\
\text { Kompresörlü Üniteler }\end{array}$ & Çin Halk Cumhuriyeti & $2015 / 25$ & 20.06 .2015 & 29392 \\
\hline
\end{tabular}

Tablo 1. Türkiye'nin 2015 Yılında Açtı̆̆ Damping Soruşturmaları Kaynak: Ekonomi Bakanlı̆̆l, www.economy.gov.tr 


\begin{tabular}{|c|c|c|c|c|}
\hline Madde ismi & Ülke & $\begin{array}{c}\text { Tebliğ } \\
\text { numarası }\end{array}$ & RG Tarih & RG No \\
\hline Renksiz düz cam & İsrail & $2014 / 3$ & 10.01 .2014 & 28878 \\
\hline PET Filmler & Hindistan & $2014 / 6$ & 21.03 .2014 & 28948 \\
\hline Polivinil Klorür (PVC-S) & ABD, Almanya & $2014 / 18$ & 17.06 .2014 & 29033 \\
\hline $\begin{array}{l}\text { Beyazlatılmamış Kraftlayner } \\
\text { Kağıtlar }\end{array}$ & $\mathrm{ABD}$ & $2014 / 26$ & 22.07 .2014 & 29068 \\
\hline $\begin{array}{l}\text { Kapı Kilitleri - Topuzlu Kapı } \\
\text { Kilidi /Diğer Kilitler /Yalnız } \\
\text { Kapı Kilitleri için Silindir- } \\
\text { Bareller ile Kilit Kasası }\end{array}$ & Çin Halk Cumhuriyeti & $2014 / 28$ & 22.07 .2014 & 29068 \\
\hline $\begin{array}{l}\text { Lastikler - Motosiklet İç/Dış } \\
\text { Lastikleri }\end{array}$ & $\begin{array}{l}\text { Çin Halk Cumhuriyeti } \\
\text { Endonezya, Malezya } \\
\text { Tayland }\end{array}$ & $2014 / 22$ & 25.07.2014 & 29071 \\
\hline $\begin{array}{l}\text { Lastikler - Bisiklet İç/Dış } \\
\text { Lastikleri }\end{array}$ & $\begin{array}{l}\text { Çin Halk Cumhuriyeti } \\
\text { Endonezya, Malezya } \\
\text { Hindistan, Tayland }\end{array}$ & $2014 / 23$ & 25.07.2014 & 29071 \\
\hline Kaynak Makinaları & Çin Halk Cumhuriyeti & $2014 / 27$ & 25.07 .2014 & 29071 \\
\hline $\begin{array}{l}\text { Mensucat - } 5407 \text { Sentetik } \\
\text { Flamenten }\end{array}$ & Bulgaristan & $2014 / 29$ & 11.08 .2014 & 29085 \\
\hline $\begin{array}{l}\text { Mensucat - } 55 \text { Grubu Sentetik } \\
\text { ve Suni Devamsiz Liflerden } \\
\text { Dokunmuş }\end{array}$ & Bulgaristan Polonya & $2014 / 30$ & 11.08 .2014 & 29085 \\
\hline BOPP Filmler & $\begin{array}{l}\text { Çin Halk Cumhuriyeti } \\
\text { Hindistan, Misır, } \\
\text { Suudi Arabistan }\end{array}$ & $2014 / 32$ & 15.10 .2014 & 29146 \\
\hline Pamuk & $\mathrm{ABD}$ & $2014 / 33$ & 18.10 .2014 & 29149 \\
\hline $\begin{array}{l}\text { Kalemler-Plastikten } \\
\text { Mürekkepli Bilyalı Kalemler / } \\
\text { Plastikten Olanlar }\end{array}$ & Çin Halk Cumhuriyeti & $2014 / 34$ & 07.11 .2014 & 29168 \\
\hline Polisitren & Misır & $2014 / 35$ & 30.11 .2014 & 29191 \\
\hline Emniyet Camları & $\begin{array}{l}\text { Çin Halk Cumhuriyeti } \\
\text { İsrail }\end{array}$ & $2014 / 40$ & 26.12 .2014 & 29217 \\
\hline Granitler & Vietnam & $2014 / 42$ & 12.12 .2014 & 29203 \\
\hline Paslanmaz Çelik Borular & Malezya, Vietnam & $2014 / 43$ & 12.12 .2014 & 29203 \\
\hline
\end{tabular}

Tablo 2. Türkiye’nin 2014 Yllında Açtı̆̆ Damping Soruşturmaları Kaynak: Ekonomi Bakanlı̆̆l, www.economy.gov.tr

Damping soruşturmaları, sübvansiyon soruşturmaları ile karşılaştırıldığında damping soruşturmalarının sayısının daha fazla olduğu görülmektedir. Devam eden soruşturmalara bakıldığında, (2014-2015 y1lı için) sübvansiyon soruşturmalarının sayısı 1, damping soruşturmalarının sayısı ise 26'dır. Sübvansiyon soruşturması demir ve çelikten dikişsiz çekme borular konusunda Çin Halk Cumhuriyeti’ne karşı açılmıştır. Soruşturma tarihi 15 Mayıs 2015’tir. Tebliğ 29356 sayılı Resmi Gazetede yayımlanmıştır.

Damping soruşturmaları korunma önlemleri ile karşılaştırıldığında yine damping soruşturmalarının sayısının daha fazla olduğu görülmektedir. Türkiye'de yürürlükte bulunan korunma önlemlerinin sayısı 12 iken damping soruşturmalarının sayısı 26'dır. Korunma önlemleri, bir malın benzer veya doğrudan rakip mallar üreten yerli üreticiler üzerinde ciddi zarar veya ciddi zarar tehdidi oluşturacak şekilde artan miktar ve şartlarda ithal edilmesi halinde, bu zarar veya zarar tehdidini ortadan kaldırmak üzere, söz konusu zarar veya zarar tehdidiyle sınırlı ve geçici olmak kaydıyla alınabilmektedir. Korunma önlemi, bir malın ithalatında uygulanmakta olan gümrük vergilerinde artış yapılması veya miktar sınırlaması şeklinde uygulanabileceği gibi bunların kombinasyonu olarak da uygulanabilmektedir. Türkiye'de korunma önlemleri getirilen ürünler; gözlük çerçeveleri, cam eşya, bazı elektrikli aletler, seyahat çantaları, el çantaları, naylon iplik, çerçevesiz cam aynalar, kibritler, motosiklet, polyester elyaf, poli etilen tereftalat gibi ürünlerdir. Cep telefonları, kâğıt, duvar kâğıdı, porselen ve seramik mutfak eşyası, düzcam gibi ürünlerde koruma önlemleri soruşturmaları devam etmektedir. 


\begin{tabular}{|c|c|c|c|}
\hline Madde İsmi & Menşe Ülke & Önlem & Önlemin Başlangıç Tarihi \\
\hline Gözlük çerçeveleri & Tüm ülkeler & Ek mali yükümlülük & $\begin{array}{c}30.01 .2008 \\
\text { (3 Abd doları/adet) }\end{array}$ \\
\hline $\begin{array}{l}\text { Seyahat çantaları, el çantaları } \\
\text { ve benzeri mahfazalar }\end{array}$ & Tüm ülkeler & Ek mali yükümlülük & $\begin{array}{c}07.03 .2008 \\
\text { (3 Abd doları/adet) }\end{array}$ \\
\hline Cam Eşya & İran & $\begin{array}{l}\text { Ek mali yükümlülük/ } \\
\text { Miktar Kısıtlaması }\end{array}$ & $\begin{array}{c}09.05 .2002 \\
\text { (5.800.000 Adet kota) }\end{array}$ \\
\hline Bazı Elektrikli Aletler & Tüm ülkeler & Ek mali yükümlülük & $\begin{array}{c}1.11 .2008 \\
\text { (5-8 Abd doları/adet) }\end{array}$ \\
\hline Naylon iplik & İran & Ek mali yükümlülük & $\begin{array}{c}11.07 .2006 \\
(1,50 \text { ABD Dolar } 1 / \mathrm{kg})\end{array}$ \\
\hline Kibritler & Tüm ülkeler & Ek mali yükümlülük & $\begin{array}{c}06.12 .2009 \\
(3,10-1,00 \text { ABD Dolar } / \mathrm{kg})\end{array}$ \\
\hline Çerçevesiz Cam Aynalar & İran & Miktar Kisitlaması & $\begin{array}{c}03.06 .2005 \\
\left(500.000 \mathrm{Kg} / \mathrm{Y}_{1} \text { kota }\right)\end{array}$ \\
\hline Motosiklet & Tüm Ülkeler & Ek mali yükümlülük & $\begin{array}{c}01.03 .2007 \\
\text { (200-300 Abd Dolar1/ adet) }\end{array}$ \\
\hline $\begin{array}{l}\text { Poli etilen tereftalat (PET), } 78 \\
\mathrm{ml} / \mathrm{g} \text { veya daha fazla } \\
\text { viskozitesi olanlar }\end{array}$ & Tüm ülkeler & Ek mali yükümlülük & $\begin{array}{l}8.11 .2011 \\
(8 \mathrm{CIF} \%)\end{array}$ \\
\hline Polyester Elyaf & İran & Ek mali yükümlülük & 21.09 .2013 \\
\hline BOPP Film & İran & Miktar Kısıtlaması & 02.07 .2013 \\
\hline
\end{tabular}

Tablo 3. Türkiye'ye Yürürlükte Bulunan Korunma Önlemleri Kaynak: Ekonomi Bakanllğgl, www.economy.gov.tr

2015 yılı Nisan ayı dış ticaret verilerine göre; Türkiye'nin en büyük beş ihracat kalemi sırasıyla; kıymetli veya yarı kıymetli taşlar, motorlu kara taşıtları, kazanlar, makinalar, mekanik cihazlar ve aletler, örme giyim eşyası ve aksesuarı, demir ve çeliktir. Türkiye'nin en büyük beş ithalat kalemi sırasıyla; mineral yakıtlar, mineral yağlar, kazanlar, makinalar, mekanik cihazlar ve aletler, motorlu kara taşıtları, elektrikli makine ve cihazlar, demir ve çeliktir.

Türkiye'nin en büyük beş ihracat ve ithalat kalemi sıralamasında beşinci sırada yer alan demir, çelik ürünleri antidamping soruşturmalarına en çok maruz kalan ürünler olmuştur. Türkiye'de ki demir, çelik sektörü son yıllarda sayısı giderek artan antidamping ve korunma önlemleri soruşturmalarıyla uğraşmaktadır. Son dönemde demir, çelik ürünleri konusundaki davaların sayısında büyük artış yaşanmıştır.

Türkiye'de buna karşılık Çin Halk Cumhuriyeti (ÇHC), Fransa, Japonya, Romanya, Rusya, Slovakya ve Ukrayna menşeli sıcak haddelenmiş yassı çelik ithalatına karşı damping soruşturması başlatmıştır. Soruşturma karar1, 28 Ocak 2015 tarih ve 29250 sayll Resmi Gazete'de 2015/01 nolu İthalatta Haksız Rekabetin Önlenmesine İlişkin Tebliğ kapsamında yayımlanarak, 28 Ocak 2015 tarihi itibariyle yürürlüğe girmiştir. Tebliğe göre, Yerli üretici Ereğli Demir Çelik T.A.Ş., Tosçelik Profil ve Sac Endüstrisi A.Ş. ve Çolakoğlu Metalurji A.Ş. tarafından yapılan ve İskenderun Demir ve Çelik A.Ş. ile HABAŞ tarafindan desteklenen başvuruda, Çin Halk Cumhuriyeti (ÇHC), Fransa, Japonya, Romanya, Rusya, Slovakya ve Ukrayna menşeli "sıcak haddelenmiş yassıçelik"in Türkiye’ye dampingli fiyatlarla ihraç edildiği ve bu durumun yerli üretim dalında (YÜD) zarara neden olduğu iddiasıyla anılan ülkeler menşeli söz konusu ürün ithalatına karşı önlem alınması talep edilmektedir. Yapılan inceleme neticesinde; şikayete konu ülkeler için damping marjlarının ve bu ülkeler menşeli ithalatın miktar bazında ithalat içi paylarının ihmal edilebilir seviyenin üzerinde olduğu; söz konusu ülkelerden ithal edilen şikayet konusu ürünlerin ortalama birim ithal fiyatlarının YÜD tarafındanüretilen benzer ürünün ortalama birim satış fiyatları üzerinde fiyat baskısı oluşturduğu anlaşıldığından ve şikayete konuülkeler menşeli ürünlerin birbirleri arasında ve yerli sanayi tarafindan üretilen benzer ürün ile doğrudan rekabet içerisinde oldukları değerlendirildiğinden, şikayete konu ülkeler menşeli ithalat toplu olarak değerlendirilmiş, söz konusu ülkelerden yapılan ithalatın nispi olarak artış gösterdiği belirlenmiştir. YÜD'ün kapasite kullanım oranı, üretim ve yurt içi satış gibi temel ekonomik göstergelerinde özellikle 2014 y1lında bozulma görüldüğü, yurtiçi satışlardan karlılık ile toplam karlılıkta ise 2011-2014 döneminde ciddi bozulma oluştuğu, bunun ise dampingli ithalattan kaynaklanan fiyat baskısı nedeniyle YÜD'nin yurtiçi satış fiyatlarını olmasıgereken seviyede belirleyememesinden kaynaklandığı değerlendirilmiştir. Başvuru aşamasında sunulan deliller ve ithalata ilişkin resmî istatistikler esas alınarak yapılan tespitler 1şığında, dampingli olduğu iddia edilen ithalatın YÜD’ün ekonomik göstergelerinde zarara yol açtığ değerlendirilmiştir. 
Yapılan inceleme sonucunda; başvurunun yeterli bilgi, belge ve delilleri içerdiği anlaşıldığından, İthalatta Haksız Rekabeti Değerlendirme Kurulunca, ÇHC Fransa, Japonya, Romanya, Rusya, Slovakya ve Ukrayna menşeli söz konusu ürün için, Yönetmelik çerçevesinde damping soruşturması açılmasına karar verilmiştir.

Türkiye'ye yönelik antidamping soruşturmalarının en fazla ABD tarafından açıldığı tespit edilmektedir (Tablo 4). ABD, karbon kaynaklı çelik tüp ve borular, makarna (yumurta içermeyen, pişirilmemiş), kesiti dikdörtgen veya kare şeklinde olan demir/çelikten tüp ve borular, petrol boruları konusunda soruşturma açmış ve önlem uygulamaktadır, hat boruları konusundaki soruşturma devam etmektedir. Kanada, dikişli veya dikişsiz borular köşeli, profil boru, inşaat demiri, petrol boruları konusunda soruşturma açmış ve önlem uygulamaktadır. Avrupa Birliğinini önlem uyguladığı ürün, demir veya çelikten boru bağlantı parçalarıdır. Dominik Cumhuriyeti, demir ve alaşımsız çelikten köşeli çubukların Türkiye'den ithali konusunda önlem uygulamaktadır. Pakistan, hidrojen peroksit, Brezilya, pet film, Ukrayna, düz cam, Hindistan soda külü, Rusya, hafif ticari araçlar, Fas sıcak haddelenmiş sac, Filipinler buğday unu konusunda önlem uygulamaktadır. Ayrıca Endonezya buğday unu, Avustralya inşaat demiri, Mısır sslak mendil konusunda damping soruşturması açmıştır ve soruşturma devam etmektedir.

\begin{tabular}{|c|c|c|}
\hline Ülke & Madde İsmi & Son Durum \\
\hline $\mathrm{ABD}$ & $\begin{array}{l}\text { Karbon kaynaklı çelik tüp ve borular } \\
\text { (standart borular) }\end{array}$ & Önlem Yürürlükte \\
\hline $\mathrm{ABD}$ & $\begin{array}{l}\text { Makarna (Yumurta İçermeyen, } \\
\text { Pişirilmemiş) }\end{array}$ & Önlem Yürürlükte \\
\hline $\mathrm{ABD}$ & $\begin{array}{l}\text { Kesiti dikdörtgen veya kare şeklinde olan } \\
\text { demir/çelikten tüp ve borular }\end{array}$ & Önlem Yürürlükte \\
\hline $\mathrm{ABD}$ & Petrol boruları & Önlem Yürürlükte \\
\hline G.Afrika Cum. & Battaniye & Önlem Yürürlükte \\
\hline Kanada & $\begin{array}{l}\text { Dikişli veya dikişsiz borular köşeli, profil } \\
\text { boru }\end{array}$ & Önlem Yürürlükte \\
\hline $\begin{array}{l}\text { Dominik } \\
\text { Cumhuriyeti }\end{array}$ & $\begin{array}{l}\text { Demir ve alaşımsız köşeli çelikten } \\
\text { çubuklar }\end{array}$ & Önlem Yürürlükte \\
\hline Pakistan & Hidrojen peroksit & Önlem Yürürlükte \\
\hline Brezilya & Pet film & Önlem Yürürlükte \\
\hline Ukrayna & Düz cam & Önlem Yürürlükte \\
\hline Avrupa Birliği & $\begin{array}{l}\text { Demir veya çelikten boru bağlantı } \\
\text { parçaları }\end{array}$ & Önlem Yürürlükte \\
\hline Rusya (GB adına) & Hafif ticari araçlar & Önlem Yürürlükte \\
\hline Hindistan & Soda külü & Önlem Yürürlükte \\
\hline Fas & Sıcak haddelenmiş sac & Önlem Yürürlükte \\
\hline Filipinler & Buğday unu & Önlem Yürürlükte \\
\hline Kanada & İnşaat demiri & Önlem Yürürlükte \\
\hline Kanada & Petrol boruları & Önlem Yürürlükte \\
\hline Endonezya & Buğday unu & Soruşturma Devam Ediyor \\
\hline $\mathrm{ABD}$ & Hat boruları & Soruşturma Devam Ediyor \\
\hline Avustralya & İnşaat demiri & Soruşturma Devam Ediyor \\
\hline Misir & Islak mendil & Soruşturma Devam Ediyor \\
\hline
\end{tabular}

Tablo 4. Türkiye'ye Yönelik Antidamping Önlemleri/Soruşturmaları Kaynak: Ekonomi Bakanlı̆̆l, www.economy.gov.tr

Dış Ticaret Müşteşarlığı yetkililerine göre; damping mevzuatı her ülke tarafindan üreticisini korumak amacıyla kullanılabilirken, "Anti damping vergisi uygulaması, iki ucu keskin bir kılıç. Bir ülkeye karşı damping vergisi uyguladığınız zaman, o ülkenin de sizin herhangi bir malınıza karşı soruşturma başlatması riski her zaman için mevcut (ntv, 2015). Burada Türkiye'nin ABD’nin antidamping soruşturmalarından rahatsız olarak ABD menşeli pamuk ithali hakkında damping soruşturması başlatması örnek olarak verilebilir. 
ABD Uluslararası Ticaret Komisyonu, 2014 yılı Ağustos ayında Türkiye, Hindistan, Güney Kore, Tayvan, Ukrayna ve Vietnam'dan ithal edilen çelik boru ürünlerine, ithalatın yerli üreticilere zarar verdiği gerekçesiyle antidamping vergisi uygulanmasına karar vermiştir. Türkiye'de serbest piyasa ekonomisi olmadığ gerekçesiyle bu karar alınmıştır. Ekonomi Bakanı Zeybekçi, 2 Ekim 2014 tarihli açıklamasında, ABD’nin son dönemde Türk ürünlerine karşı yürüttüğü antidamping soruşturmalarından rahatsız olduklarını, ihracata konacak her engele misliyle karşılık verileceğinin resmi olarak ABD'li yetkililere iletildiğini söylemiştir. Bunun hemen sonrasında 18 Ekim 2014 tarihinde ABD menşeli pamuk ithali hakkında damping soruşturması başlatılmıştır. ABD Ulusal Pamuk Konseyi bu soruşturmanın Türkiye pamuk sektörü tarafından talep edilmediğini belirterek 'sıradışı' olarak nitelemiştir. ABD'den ithal edilen pamuk hakkında bu kadar büyük ölçekli bir soruşturma daha önce Peru tarafından başlatılmıştır. Peru 2012-2013 yılları arasında ABD'li üreticilere yapılan olası telafi ödemeleri ve damping iddialarını araştırmıştır. Damping soruşturması ile ilgili Tebliğe göre; resen yapılan inceleme sonucunda ABD menşeli ürünün ithalatının mutlak olarak 2011-2013 dönemi arasında artış eğiliminde olduğu; toplam Türkiye pazarının büyümesine rağmen yerli üretim dalında ABD menşeli ithalat nedeniyle pazar kaybı yaşandığ 1 belirtilmiştir. Yerli üretim dalının üretim, satış, karlılık, istihdam ve kapasite kullanım oranı gibi göstergelerinde 2011-2013 döneminde bozulmaların ortaya çıktığı tespit edilmiştir. ABD menşeli ithalatın yerli üretim dalının fiyatlarını 2012 yılı haricinde kırdığı belirlenmiştir. Öte yandan, yerli üretim dalının üretim maliyetlerini fiyatlarına tam olarak yansitamaması neticesinde 2011-2013 döneminde yurtiçi satış fiyatlarının dampingli ithalat nedeniyle baskı altında kaldığı, maliyet altı satışlar nedeniyle fiyatlarının bastırıldığı ve fiyatlarının enflasyon karşısında reel olarak yıprandığı tespit edilmiştir. İnceleme aşamasında elde edilen deliller ve ithalata ilişkin resmî istatistikler esas alınarak yapılan tespitler 1şığında, dampingli olduğu iddia edilen ithalatın yerli üretim dalının ekonomik göstergelerinde zarara yol açtığı değerlendirilmiştir. Yapılan inceleme sonucunda; dampingli ithalat ve bu ithalattan kaynaklanan zararın varlı̆ 1 konusunda damping soruşturması açılmasını haklı kılacak yeterlilikte bilgi, belge ve delillerin mevcut olduğu anlaşıldığından, İthalatta Haksız Rekabeti Değerlendirme Kurulunca, ABD menşeli söz konusu ürün için, Yönetmelik çerçevesinde re'sen bir damping soruşturması açılmasına karar verilmiştir

Bazı durumlarda dampinge karşı önlemler menşe saptırması yapılarak etkisiz hale getirilmeye çalışılabilir. Bunun tespit edilerek, önlemlerin uygulanması önemlidir. Bu konuda Ekonomi Bakanlığının açmış olduğu bir soruşturma bulunmaktadır. Çin Halk Cumhuriyeti menşeli kontrplaklar, Bulgaristan ve Vietnam üzerinden Türkiye'ye ithal edilmiştir. 20/10/2006 tarihli ve 26325 sayılı Resmî Gazete'de yayımlanan İthalatta Haksız Rekabetin Önlenmesine İlişkin 2006/28 sayılı Tebliğ ile Çin Halk Cumhuriyeti (ÇHC) menşeli "kontrplak" ithalatında dampinge karşı kesin önlem yürürlüğe konulmuştur. 10/07/2012 tarihli ve 28349 sayılı Resmî Gazete'de yayımlanan 2012/16 sayılı İthalatta Haksız Rekabetin Önlenmesine İlişkin Tebliğ ile tamamlanan nihai gözden geçirme soruşturması (NGGS) kapsamında anılan önlemin devamına karar verilmiştir. Kontrplak Üreticileri Derneği (KONÜDER) ÇHC menşeli kontrplakların ithalatında uygulanmakta olan dampinge karşı önlemin Bulgaristan ve Vietnam üzerinden menşe saptırması yapılarak etkisiz kılındığı iddiasıyla Ekonomi Bakanlığına başvuruda bulunmuştur. Tebliğe göre; inceleme konusu üründe toplam ithalatımız 2012 yılında $265.006 \mathrm{~m} 3$ iken, 2013 yılında bir önceki yıla göre \%8,5 oranında artarak $287.695 \mathrm{~m} 3,2014$ y1lında ise bir önceki yıla göre \%9,4 oranında artarak $314.652 \mathrm{~m} 3$ olarak gerçekleşmiştir. ÇHC menşeli kontrplak ithalatının 2012 yılında 444 m3 iken, 2013'de \%74 oranında gerileyerek 115 m3'e düştüğü; buna karşın başvuru konusu iki ülkeden yapılan toplam ithalatın aynı dönemde \% 19 oranında artarak $19.831 \mathrm{~m} 3$ 'den 23.682 m3'e çıktığı belirlenmiştir. 2014 yılında ÇHC menşeli ithalat $267 \mathrm{~m} 3$, başvuru konusu iki ülkeden yapılan toplam ithalat ise $43.656 \mathrm{~m} 3$ olarak kaydedilmiştir. Vietnam'dan önlem (NGGS) öncesinde gerçekleştirilen ithalat 2010 y1lında $3.250 \mathrm{~m} 3$ iken, 2013 y1lında $10.052 \mathrm{~m} 3$ 'e, 2014 y1lında ise $24.065 \mathrm{~m} 3$ 'e yükselmiştir. Toplam ithalat içinde Vietnam'ın payı 2010 yılında \% 2 iken 2014 yılında \%8'e ulaşmıştır. Bulgaristan'dan yapılan ithalat 2010 y1lında $13.243 \mathrm{~m} 3$ iken 2014 y1lında $19.591 \mathrm{~m} 3$ 'e yükselmiştir. Toplam ithalat içinde Bulgaristan'ın payı 20102014 yılları itibariyle yaklaşık \% 6 seviyesinde gerçekleşmiştir. Yapılan incelemeler ve ilgili ülkelerdeki Ticaret Müşavirliklerimiz aracılığıyla elde edilen bilgiler doğrultusunda, yürürlükteki dampinge karşı önlemin Bulgaristan ve Vietnam üzerinden etkisiz kılındığına dair ciddi şüphe hasıl olmuştur. Anılan başvuru sonrası yapılan incelemeler sonucunda Bulgaristan ve Vietnam menşeli/çıkışlı söz konusu eşya için İthalatta Haksız Rekabeti Değerlendirme Kurulu'nca, Yönetmelik çerçevesinde önlemlerin etkisiz kılınmasına karşı soruşturma açılmasına karar verilmiştir.

Damping veya sübvansiyona karşı önlem alınmasını gerektiren haller, dampinge veya sübvansiyona konu olan ithalatın Türkiye'de bir üretim dalında maddî zarara yol açması veya maddî zarar tehdidi oluşturması veya bir üretim dalının kurulmasını fizikî olarak geciktirmesidir. Soruşturma ithalattan kaynaklanan zararın varlığı konusunda yeterli delillerin bulunması durumunda açılır. Buna uygun davranılması çok önemlidir. Soruşturmalar ithalatı engelleme amacıyla kullanılmamalıdır. Belki piyasada ki rekabetin durumu ve haksız rekabet olup olmadığı konusunda Rekabet Kurumundan görüş alınabilir ve ona göre soruşturma açılıp açılmamasına karar verilebilir. Örneğin; özel sektörden gelen haksız rekabet şikayetleri üzerine cep telefonu, tablet ve lap-toplarla ilgili anti damping soruşturması başlatılmıştır. Ekonomi Bakanı Nihat Zeybekci "Türkiye'deki özel sektör de cep telefonu, tablet ve diz üstü bilgisayar üretiyor. Ancak ithal edilen bu tip mallar sebebiyle haksız rekabet 
yaşanıyor" demiştir. Bu soruşturmada cep telefonu, tablet ve lap-top pazarındaki rekabet konusunda Rekabet Kurumundan görüş alınabilir. Bu görüşler ışığında ithalattan kaynaklanan zararla ilgili inceleme yapılabilir.

Türkiye'de bir damping veya sübvansiyon soruşturması açılması kararı ile soruşturma sırasında alınan geçici önlem, kesin önlem, taahhüt, durdurma ve kapatma kararları, Resmi Gazete'de yayımlanacak bir tebliğgle ilan edilir. Uygulama tebliğleri olarak geçen bu tebliğlerin sayısının 2002 yılı itibariyle artmaya başladığ görülmektedir. 2002 yılı öncesi sayısı 6, 7 ve 10'nu geçmeyen uygulama tebliğleri yıllar itibariyle artış göstermiştir. Bu da Türkiye'de damping veya sübvansiyon soruşturmalarının ve önlemlerinin 2002 yılından itibaren daha fazla kullanıldığını göstermektedir. 2015 yılı haziran ayı itibariyle uygulama tebliğlerinin sayısı 25 'dir.

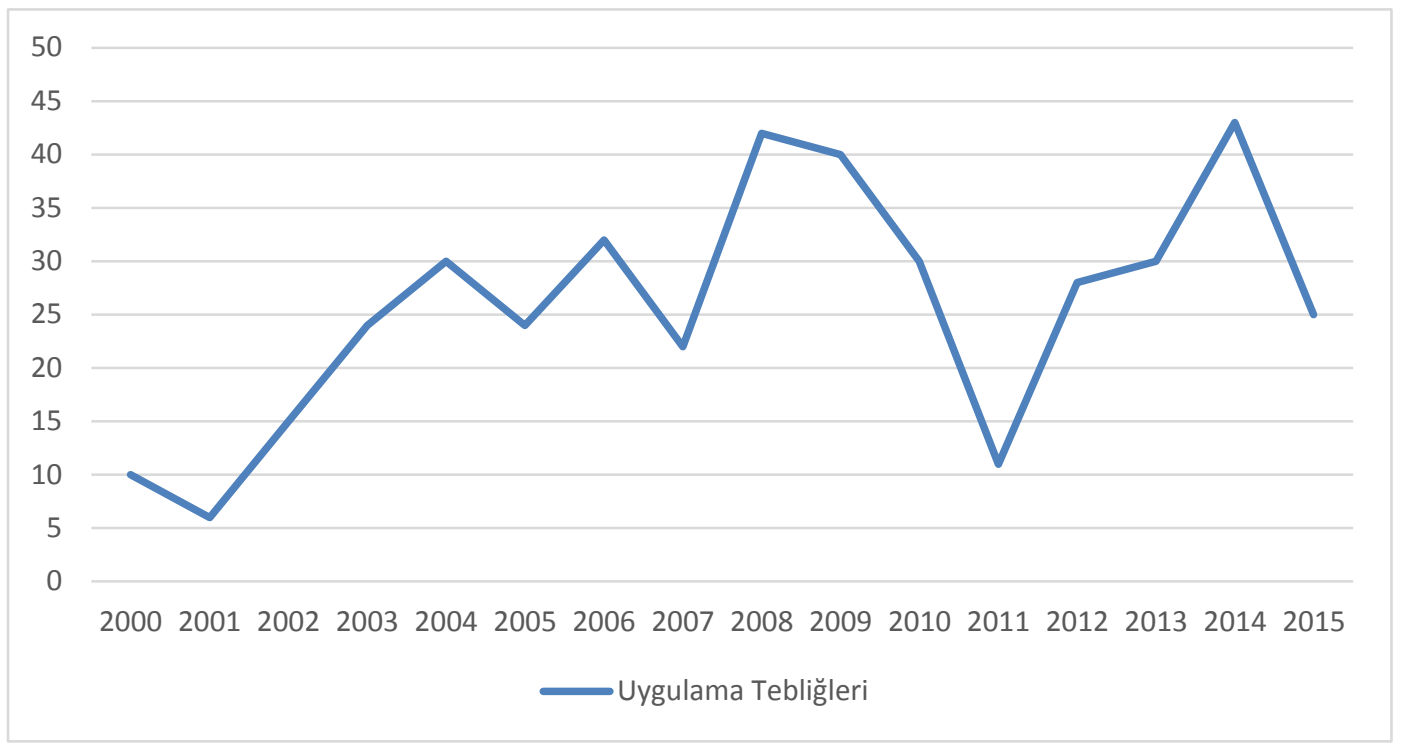

Şekil 1. Yıllar İtibariyle Damping ve Sübvansiyon Uygulama Tebliğlerinin Sayısı

\section{Sonuç}

Türkiye'de son yıllarda en fazla ithalat yapılan ülkelerin hepsine karşı açılmış antidamping soruşturmaları vardır fakat en çok Çin Halk Cumhuriyeti menşeli ürünlere karşı antidamping soruşturması açıldı ̆ 1 görülmektedir. 20 Ülkeye yönelik damping soruşturmaları devam etmektedir. Damping soruşturmaları önceleri, eski Doğu Bloku ve Orta Avrupa ülkelerinde yoğunlaşırken son yıllarda özellikle Çin Halk Cumhuriyeti olmak üzere, Uzakdoğu ülkelerinde yoğunlaşmaktadır. Damping soruşturmaları, sübvansiyon soruşturmaları ve korunma önlemleri ile karşılaştırıldığında damping soruşturmalarının sayısının daha fazla olduğu görülmektedir. 2014 ve 2015 yıllarında sübvansiyon soruşturmalarının sayısı 1, yürürlükte bulunan korunma önlemlerinin sayısı 12 iken damping soruşturmalarının sayısı 26'dır.

Demir, çelik ürünleri antidamping soruşturmalarına en çok maruz kalan ürünler olmuştur. Türkiye'de ki demir, çelik sektörü son yıllarda sayısı giderek artan antidamping ve korunma önlemleri soruşturmalarıyla uğraşmaktadır. Türkiye'de buna karşılık Çin Halk Cumhuriyeti (ÇHC), Fransa, Japonya, Romanya, Rusya, Slovakya ve Ukrayna menşeli sıcak haddelenmiş yassı çelik ithalatına karşı damping soruşturması başlatmıştır.

Türkiye'ye yönelik antidamping soruşturmalarının en fazla ABD tarafından açıldığı tespit edilmektedir. Türkiye'de ABD'nin antidamping soruşturmalarından rahatsız olarak ABD menşeli pamuk ithali hakkında damping soruşturması başlatmıştır.

Damping karşı önlemlerin menşe saptırması yapılarak etkisiz hale getirilmeye çalışılması durumunda bunun tespiti ve buna karşı önlemlerin uygulanması önemlidir. Bu konuda Ekonomi Bakanlığının açmış olduğu bir soruşturma bulunmaktadır. Kontrplak Üreticileri Derneği Çin Halk Cumhuriyeti menşeli kontrplakların ithalatında uygulanmakta olan dampinge karşı önlemin Bulgaristan ve Vietnam üzerinden menşe saptırması yapılarak etkisiz kılındığı iddiasıyla Ekonomi Bakanlığına başvuruda bulunmuştur ve incelemeler sonucunda soruşturma başlatılmıştır.

Mevzuata göre, damping ve sübvansiyon soruşturmaları ithalattan kaynaklanan zararın varlığı konusunda yeterli delillerin bulunması durumunda açılır. Buna uygun davranılması çok önemlidir. Soruşturmalar ithalatı engelleme amacıyla kullanılmamalıdır. Belki piyasada ki rekabetin durumu ve haksız rekabet olup olmadığ konusunda Rekabet Kurumundan görüş alınabilir ve ona göre soruşturma açılıp açılmamasına karar verilebilir. 
Uygulama tebliğlerinin sayısına bakılarak Türkiye'de damping veya sübvansiyon soruşturmalarının ve önlemlerinin 2002 yılından itibaren daha fazla kullanıldığı söylenilebilr. 2015 yılı haziran ayı itibariyle uygulama tebliğlerinin sayısı 25 'dir.

\section{Kaynakça}

- Anti-damping Anlaşmasi-VI Maddenin Uygulanmasına İliş̧in Anlaşma, 2015. http://www.orgtr.org/tr/antidamping-anlasmasi-vi-maddenin-uygulanmasina-iliskin-anlasma

- http://www.ekodialog.com/Makaleler/turkiyenin_ithalat_politikasi.html, 2015.

- “ABD’li pamuğa damping soruşturması”, Milliyet Gazetesi, 2015. http://www.milliyet.com.tr/abd-lipamuga-damping-sorusturmasi/ekonomi/detay/1962412/default.htm).

- Büyükşahin Taylan, "Sektörler antidamping haklarını bilmiyor”, Dünya Gazetesi, 2015. http://www.dunya.com/kobi/sektorler-antidamping-haklarini-bilmiyor-262104h.htm

- "Dampinge karş1 144 soruşturma", 2015. http://arsiv.ntv.com.tr/news/178191.asp.

- Elele Onur, 2008. Uluslararası Ticarette Damping ve Anti-damping, Yaklaşım Yayıncılık, Ankara.

- Ekonomi Bakanlığı, 2015. http://www.ekonomi.gov.tr/portal/content/conn/UCM/uuid/dDocName:EK126292

- GATT; Dünya Ticaret Örgütü ve İthalatta Haksız Rekabetin Önlenmesi, 2015. http://anti-damping.com/gattdunya-ticaret-orgutu-ve-ithalatta-haksiz-rekabetin-onlenmesi/).

- Gültekin Sadettin, 2010. "Dış Ticarette Haksız Rekabet:Damping”, Ankara Barosu Dergisi, http://www.ankarabarosu.org.tr/siteler/ankarabarosu/frmmakale/2010-1/1.pdf)

- Gümrük ve Ticaret Bakanlığı, 2015 yılı Nisan ayı veri bülteni, 2015. http://risk.gtb.gov.tr/data/55441fccf29370a90c681435/2015\%20Y\%C4\%B11\%C4\%B1\%20Nisan\%20Ay\%C 4\%B1\%20Veri\%20B\%C3\%BClteni.pdf

- Gümrük Tarifeleri Ve Ticaret Genel Anlaşmasi 1994'ün Vi Ncı Maddesinin Uygulanmasina İlişkin Anlaşma, 2015. http://www.ekonomi.gov.tr/portal/content/conn/UCM/uuid/dDocName:EK-126292

- "Ithal telefon ve tablete antidumping soruşturması", 2015. http://www.teknolojigundem.com/mobilhaberleri/ithal-telefon-ve-tablete-anti-damping-sorusturmasi-641845.htm\#ixzz3dzHioloV

- Uluslararası Antidamping Anlaşması, Ekonomi Bakanlığı, 2015. http://www.orgtr.org/antidampinganlasmasiturkce.pdf,

- World Trade Organization, Anti-dumping, subsidies, safeguards: contingencies, etc, 2015. https://www.wto.org/english/thewto_e/whatis_e/tif_e/agrm8_e.htm

- 'Zeybekçi'den ABD’ye antidumping resti”, Dünya Gazetesi, 2015. http://www.dunya.com/politika/hukumet/zeybekciden-abdye-anti-damping-resti-240615h.htm

- 14/6/1989 tarih ve 3577 sayılı Ithalatta Haksız Rekabetin Önlemesi Hakkında Kanun,

- 99-13482 Sayılı Bakanlar Kurulu Kararı ile yürürlüğü konulan Ithalatta Haksız Rekabetin Önlenmesi Hakkında Karar,

- 30/10/1999 tarih ve 23861 sayılı Ithalatta Haksız Rekabetin Önlemesi Hakkında Yönetmelik 


\title{
Kırgızistan'da Dış Ticaret ve Yurtdışından Transferlerin Gayri Safi Yurtiçi Hasılaya Etkisi: ARDL Sınır Testi Yaklaşımı The Effect of Foreign Trade and Remittances to Gross Domestic
Product of Kyrgyzstan: An ARDL Bound Testing Approach
}

Asst. Prof. Dr. Junus Ganiev (Kyrgyzstan-Turkey Manas University, Kyrgyzstan)

\begin{abstract}
The foreign trade deficit of Kyrgyzstan is increasing year by year and the import is exceeding export about twice. A significant portion of the foreign trade deficit is covered by remittances. Furthermore, the ratio of remittance to Gross Domestic Product (GDP) is reached almost 30\%. In this context, it is important to examine the effects of import, export and remittances to GDP. Empirical analysis using quarterly data covering the period 2000-2014 with ARDL Bounds Testing Approach showed that exports and imports effect GDP positively, while transfers from abroad effect negatively. So Kyrgyz Republic can further develop foreign trade in integration process with Eurasian Economic Union, but it has to involve foreign direct investments to decrease negative effects of emigration.
\end{abstract}

\section{Giriş}

Kırgızistan'da dış ticaret açığı giderek artmaktadır ve şekilden görüldüğü gibi, ihracatın ithalatı karşılama oranı 2003 'de 0,82 iken, 2014'de 0,35 'e düşmüştür, yani ithalat ihracattan yaklaşı 3 katı fazla olmaktadır (şekil 1). Bunun Gayri Safi Yurtiçi Hasılaya olan etkisinin daha çok olumlu mu veya olumsuz mu olduğu çok tartışılan konulardan biridir.

Diğer taraftan, cari transferler ile ihracatın toplamı ithalatın büyük kısmını, hatta 2003-2005 ve 2009-2011 yıllarında tamamen kapatabilmiştir. Bu durum Kırgızistan'ın yurtdışında çalışan işçiler tarafından transfer edilen dövizlerin istikrarlı olması durumunda önemli dış açık sorunuyla karşı karşıya kalmayacağını göstermektedir. Fakat yurtdışından transferlerde bir düşüş olduğunda ise dış açık sorunu artarak döviz piyasasında istikrarsızlık ortaya çıkacak ve bu da büyük ihtimalle dış borçların artması şeklinde ekonomiye yansıyacaktır.

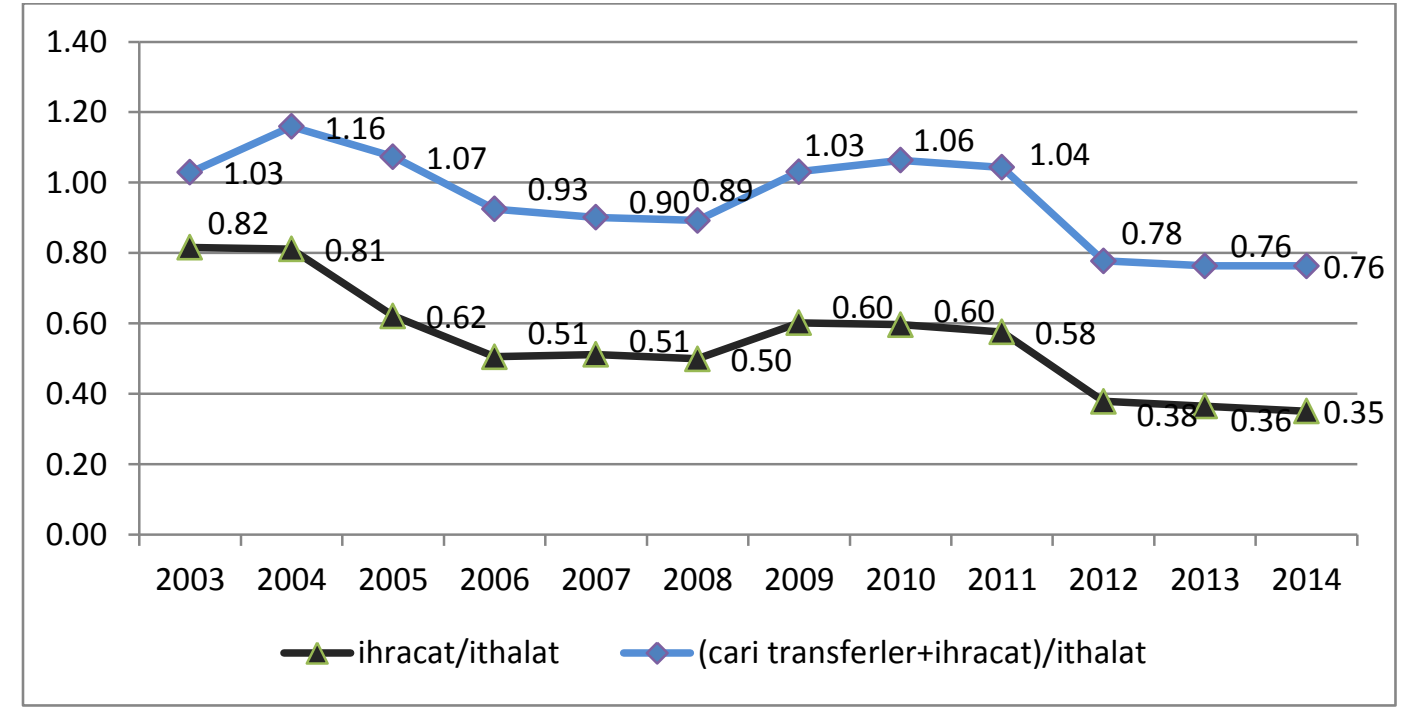

Şekil 1. Kırgızistan'da İhracatın ve Cari Transferler ile İhracatın Toplamının İthalatı Karşılama Oranları

Fakat son on senedir yurtdışından net transferlerde çok hızlı bir artış görülmekte ve ekonominin söz konusu transferlere olan bağımlılığı da gittikçe artmaktadır. Şekil 2'den görüldüğü gibi, net transferlerin, yani ülkeye gelen transferlerle ülkeden çıkan transferlerin farkının GSYIH'ya oranı 2005'de \%12'ler civarında iken 2010 'dan sonra \%25 ile \%30 arasında değişmektedir. Sadece ülkeye gelen transferlerin GSYİH'ya oranına bakıldığında ise, bu oran \%35'lere ulaşmaktadır. Bunun \%96-97'sinin Rusya'dan yapılan transferler olmasından dolayı Kırgızistan ekonomisinin Rusya'ya olan bağımlılığı gittikçe artmaktadır. Büyük bölümü Rusya'da çalışan işçi transferlerinden oluşan bu dövizlerin Kırgızistan ekonomisine olan etkisi konusunda da tartışmalı bazı çalş̧malar mevcuttur. Örneğin, Akmoldoev and Budaichieva (2012) empirik çalışma sonucunda işçi dövizlerinin yatırımlardan ziyade tüketimi ve dolayısıyla ithalatı arttırarak dış açığa yol açmakta olduğu sonucuna ulaşmıştır. 


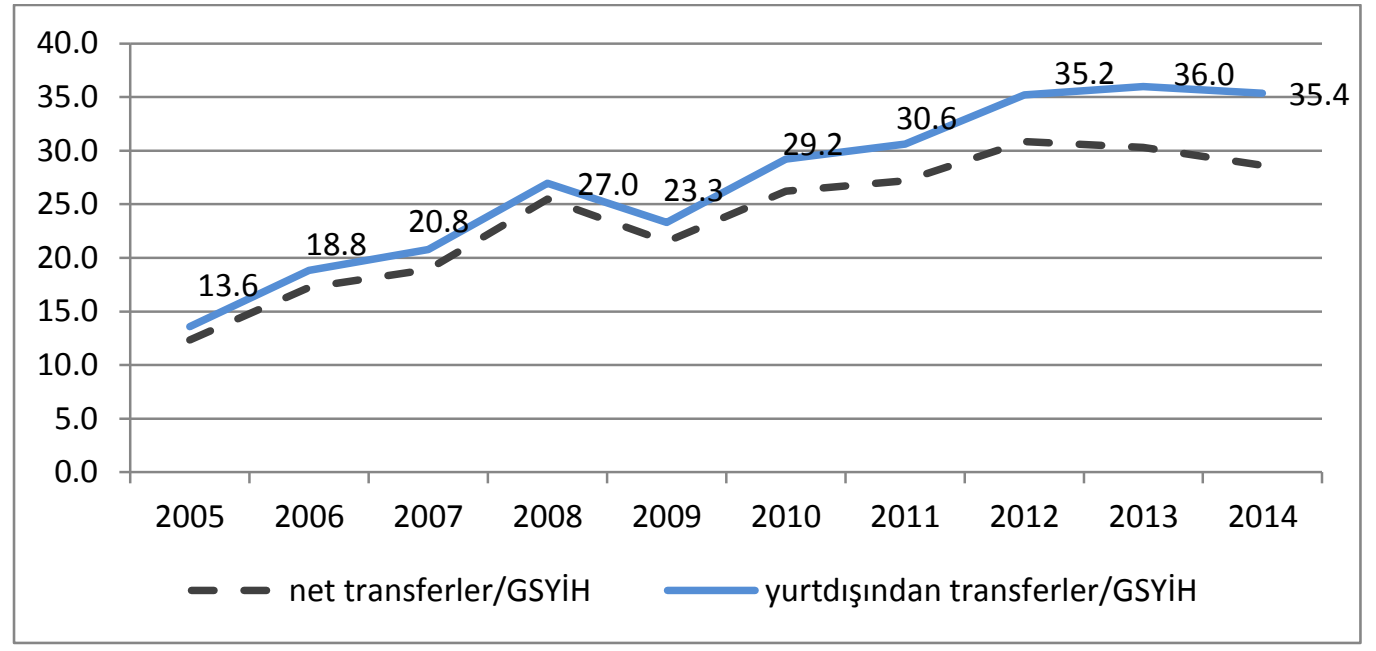

Şekil 2. Yurtdışından Transferlerin GSYİH'ya Oranı, \%

Bu doğrultuda bu çalışmada ithalat, ihracat ve yurtdışından transferlerin GSYİH'ya etkisinin incelenmesi amaçlanmıştır.

\section{Literatür Taraması}

Dış ticaretle ekonomik büyüme arasındaki ilişki uzun süredir çok tartışılan konulardan biridir. İhracatın ekonomik büyümeye olan etkisinin empirik araştırılmasında iki tip çalışmalar yapılmaktadır: ülke gruplarını inceleyen panel veri analizleri ve tek ülkeyi inceleyen zaman serisi analizleri (Abbas, 2012: 92). Fakat ülkeler arasında farklılıklar olması nedeniyle zaman serisi analizlerin daha net sonuçlar vereceği söylenebilir.

Günümüze kadar dünyada bu konuda sayısız empirik çalışmalar yapılmıştır. Belirtmek gerekirse, Thornton (1997) altı Avrupa ülkesinde ihracata dayalı büyümenin geçerliliğini araştırmış ve çalışma sonuçları; İtalya, Norveç ve İsveç'te ihracattan GSYİH'ya doğru tek yönlü, İngiltere'de GSMH'dan ihracata doğru tek yönlü ve Danimarka ve Almanya'da ikisi arasında çift yönlü nedensellik ilişkisinin olduğunu göstermiştir.

Ramos (2001) Portekiz'de ihracat, ithalat ve ekonomik büyüme arasındaki ilişkiyi inceleyerek onların arasında hiçbir istatistiki anlamlı ilişki bulamamıştır.

Hatemi-j (2002) Granger nedensellik testini kullanarak Japonya'da ihracat büyümesi ile ekonomik büyüme arasında çift yönlü ilişkinin olduğunu tespit etmiştir.

Saraç (2013) Türkiye'de ihracat ve ithalatın ekonomik büyüme üzerindeki etkisini doğrusal olmayan ekonometrik yöntem ile araştırarak hem ihracat hem de ithalatın ekonomik büyümeyi pozitif yönde etkilediğini ortaya koymuştur.

Özetlersek, genel olarak ihracatın ekonomik büyümeyi olumlu etkileyeceği kabul edilmektedir. Bu olumlu etkinin bazı önemli nedenleri şu şekilde özetlenebilir:

- Ölçek ekonomisinin avantajlarından yararlanma;

- Verimliliğin ve yeni teknolojilerin elde edilmesi (teknoloji ithali) ve bunun sonucunda ekonomik büyüme oranının artması (Grossman, 1991; Rivera-Batiz and Romer, 1991);

- Döviz gelirlerinin artması ve dış ödemeler bilançosu açığı sorununun azalması. Böylece teknoloji, ara ve yatırım malların ithalatına ve büyümeye kaynak sağlanması;

- Diş rekabet nedeniyle mal kalitesi ve verimliliğin artması;

- Çarpan etkisiyle toplam talebin gelişmesi.

Bunlar, özellikle ikinci ve üçüncü maddeler aynı zamanda ithalatın da büyümeye olumlu etkilerini göstermektedir. Özellikle gelişmekte olan ülkelerde hammadde, ara malı, yatırım malı ve teknoloji ithali ekonomik kalkınmada büyük role sahiptir. Diğer taraftan, Dordoy ve Karasuu gibi büyük toptan pazarların yer aldığı Kırgızistan’da reeksport da önemli düzeylere ulaşmaktadır.

\section{Metodoloji}

Öncelikle ARDL modelin şartlı (kısıtsız) hata düzeltme versiyonu tahmin edilir: 


$$
\begin{gathered}
\Delta \ln (G D P)_{t}=\alpha_{0}+\sum_{i=1}^{q} \beta_{i} \Delta \ln (G D P)_{t-i}+\sum_{i=0}^{q} \gamma_{i} \Delta \ln (X)_{t-i}+\sum_{i=0}^{q} \delta_{i} \Delta \ln (M)_{t-i}+ \\
+\sum_{i=0}^{q} \mu_{i} \Delta \ln (T F)_{t-i}+\sigma_{1} \ln (G D P)_{t-1}+\sigma_{2} \ln (X)_{t-1}+\sigma_{3} \ln (M)_{t-1} \\
+\sigma_{4} \ln (T F)_{t-1}+\varepsilon_{t}
\end{gathered}
$$

burada $\Delta$ işareti birinci farkı, q ise en uygun gecikme uzunluğunu gösterir.

Uzun dönemli ilişkinin olup olmadığını test etmek için burada F-test kullanılır. (1) nolu denklemdeki değişkenler arasında eşbütünleşme olmadığını gösteren $H_{0}$ hipotezi şöyledir: $\sigma_{1}=\sigma_{2}=\sigma_{3}=\sigma_{4}=0$, alternatif hipotez ise $H_{1}: \sigma_{1} \neq \sigma_{2} \neq \sigma_{3} \neq \sigma_{4} \neq 0$. Buradan bulunan F-istatistik değeri ilgili üst sinır kritik değerinden büyük ise o zaman değişkenler arasında uzun dönemli iliş̧inin olduğu sonucu çıkartılabilir. Bu sonuca ulaştıktan sonra aşağıdaki uzun dönem ilişkisini gösteren eşbütünleşme (cointegration) modeli tahmin edilir:

$$
\begin{gathered}
\Delta \ln (G D P)_{t}=\alpha_{1}+\sum_{i=1}^{q} \beta_{1 i} \ln (G D P)_{t-i}+\sum_{i=0}^{q} \gamma_{1 i} \ln (X)_{t-i}+\sum_{i=0}^{q} \delta_{1 i} \ln (M)_{t-i}+ \\
+\sum_{i=0}^{q} \mu_{1 i} \ln (T F)_{t-i}+\varepsilon_{t}
\end{gathered}
$$

ARDL modeldeki uygun gecikme sayısı Akaike (AIC) ve/veya Schwarz (SC) kriterlerine göre belirlenebilir. Kısa dönemli ilişskileri gösteren ARDL modeli aşağıdaki hata düzeltme modeli formundan türetilebilir:

$$
\begin{aligned}
\Delta \ln (G D P)_{t}=\alpha_{2}+ & \sum_{i=1}^{q} \beta_{2 i} \Delta \ln (G D P)_{t-i}+\sum_{i=0}^{q} \gamma_{2 i} \ln (X)_{t-i}+\sum_{i=0}^{q} \delta_{2 i} \Delta \ln (M)_{t-i} \\
& +\sum_{i=0}^{q} \mu_{2 i} \Delta \ln (T F)_{t-i}+\rho E C T_{t-1}+\varepsilon_{t}
\end{aligned}
$$

burada $\mathrm{ECT}_{\mathrm{t}}$ aşağıdaki gibi gösterilebilen uzun dönem modelinin artıkları olan hata düzeltme terimidir:

$$
E C T_{t}=\ln (G D P)_{t}-\alpha_{0}-\alpha_{1} \cdot \ln (\mathrm{X})_{\mathrm{t}}-\alpha_{2} \cdot \ln (\mathrm{M})_{\mathrm{t}}-\alpha_{3} \cdot \ln (\mathrm{TF})_{\mathrm{t}}
$$

\begin{tabular}{|c|c|c|c|c|}
\hline \multirow[t]{2}{*}{ Değişkenler } & \multicolumn{2}{|c|}{ Genişletilmiş Dickey-Fuller (ADF) } & \multicolumn{2}{|c|}{ Phillips-Perron (PP) } \\
\hline & Intercept & $\begin{array}{l}\text { Trend and } \\
\text { intercept }\end{array}$ & Intercept & $\begin{array}{l}\text { Trend and } \\
\text { intercept }\end{array}$ \\
\hline \multicolumn{5}{|c|}{$D \ddot{U Z E Y Y}$} \\
\hline $\ln (\mathrm{GDP})$ & -0.85 & -2.41 & -1.18 & $-4.23 * * *$ \\
\hline $\ln (\mathrm{X})$ & -0.96 & -0.89 & -1.60 & $-4.56^{* * *}$ \\
\hline $\ln (\mathrm{M})$ & -0.73 & -1.29 & -0.74 & -1.65 \\
\hline $\ln (\mathrm{TF})$ & -1.51 & -0.45 & -0.84 & -2.50 \\
\hline \multicolumn{5}{|c|}{ BIRINCI FARK } \\
\hline$\Delta \ln (\mathrm{GDP})$ & $-2.98 * *$ & $-3.53 * *$ & $-25.40 * * *$ & $-24.66 * * *$ \\
\hline$\Delta \ln (\mathrm{X})$ & $-10.17 * * *$ & $-10.15^{* * *}$ & $-15.76^{* * *}$ & $-16.43 * * *$ \\
\hline$\Delta \ln (\mathrm{M})$ & $-6.35^{* * *}$ & $-6.34 * * *$ & $-6.35 * * *$ & $-6.34 * * *$ \\
\hline$\Delta \ln (\mathrm{TF})$ & $-12.49^{* * *}$ & $-4.53 * * *$ & $-13.61 * * *$ & $-14.38 * * *$ \\
\hline
\end{tabular}

Kısa dönem denkleminin tüm katsayıları modelin kısa dönemde dengeye yakınsama dinamikleriyle ilgili katsayılardır ve $\rho$ ise düzelme hızını gösterir.

\section{Uygulama Sonuçları}

Bu çalışmada 2000:Q1-2014:Q4 dönemi arası çeyrek veriler kullanılmıştır. Çalışmaya Kırgızistan'ın Gayri Safi Yurtiçi Hasıla (GDP), ihracat (X), ithalat (M) ve yurtdışından transferler (TF) verileri milyon dolar olarak alınmışıtır. Veriler Kırgızistan Cumhuriyeti Milli İstatistik Komitesi ve Kırgızistan Cumhuriyeti Merkez Bankası'ndan temin edilmiştir.

Tablo 1. Birim Kök Testi Sonuçları 
Tablo 1'de değişkenlerin birim kök testi sonuçları verilmiştir. Bu testin sonuçlarına göre, tüm değişkenlerin düzeyde durağan olmadığı, birinci farklarının ise durağan olduğu ortaya çıkmıştır. Fakat GSYİH ve ihracat verilerinin Phillips-Perron testi sonuçlarına göre düzeyde durağan olduğu görülmektedir. Pesaran and Shin (1995, 1999), Pesaran et al. (1996) ve Pesaran (1997) tarafından geliştirilen ARDL yaklaşımının bir avantajı da farklı seviyede durağan olan, yani bazıları I(0) ve bazıları da I(1) olan verilere uygulanabilmesidir. Bu nedenden dolayı da bu çalışmada ARDL yaklaşımı tercih edilmiştir.

Öncelikle değişkenler arasındaki uzun dönemli ilişkiyi test etmek için (1) nolu denklem tahmin edilmiştir. Hem AIC hem SC'ye göre optimal gecikme uzunluğu 6 olarak bulunmuştur.

Hesaplanan F-değeri (5.4682) üst sınır kritik değerinden \%5 önem düzeyinde daha büyüktür (4.35). Dolayısıyla değişkenler arasında eşbütünleşmenin olmadığını söyleyen $\mathrm{H}_{0}$ hipotezi red edilmiştir, yani değişkenler arasında uzun dönemli ilişki vardır.

\begin{tabular}{|c|c|c|c|c|c|}
\hline \multirow{2}{*}{ Test-istatistiği } & \multirow{2}{*}{ Değeri } & \multirow{2}{*}{ Gecikme } & \multirow{2}{*}{ Önem düzeyi } & \multicolumn{2}{|c|}{ Kritik değerler* } \\
\hline & & & & Alt sinır I $(0)$ & Üst sınır I(1) \\
\hline F-istatistiği & 5.4682 & 2 & & & \\
\hline & & & $1 \%$ & 4.29 & 5.61 \\
\hline & & & $5 \%$ & 3.23 & 4.35 \\
\hline & & & $10 \%$ & 2.72 & 3.77 \\
\hline
\end{tabular}

Tablo 2. Eşbütünleşme İlişkisinin F-istatistiği

Uzun dönem modeli aşağıdaki gibi bulunmuştur. Bu modelin sonuçlarına göre, hem ihracat hem de ithalatın artması ülkenin GSYİH'sını artırmaktadır, yani dış ticaret ülke ekonomisine önemli düzeyde katkı sağlamaktadır. Uzun dönemde ihracatın \%1'e artması GSYİH'nın \%0,47'ye artmasına neden olurken, ithalatın \%1'e artması da GSYİH'nın \%0,44'e artmasına yol açar. Belki de ithalatın bir kısmının reexporta gitmesi ve hammadde ve ara mal ithalatının üretime katkı sağlaması nedeniyle uzun dönemde ithalatın GSYİH'ya etkisi pozitif kalmaktadır. Granger nedensellik testinin sonuçları da bunu destekler nitelikte bulunmuştur. Yurtdışından transferlerin katsayısı ise negatif çıkmıştır. Çünkü transferlerin önemli kısmının tüketim harcamalarına gitmesi nedeniyle tüketim mallarının ithalatını artırarak ülke ekonomisini negatif etkilemesi ihtimali yüksektir. Diğer taraftan, yurtdışından transferlerin önemli kısmı işçi gelirlerinden oluşmaktadır. Dolayısıyla transferlerin artışı işgücü göçünün de arttığına ve bunun da iç üretimin kısılmasına neden olduğuna bir işaret sayılabilir. Daha ilerideki çalışmalarda transferlerin ithalatın yapısına olan etkilerinin incelenmesi belki de bu soruya net cevap verebilecektir. Ancak transferlerin katsayısı istatistiki olarak anlamsız bulunmuştur. İhracat ile ithalatın katsayıları ise istatistiki olarak \%1 önem düzeyinde anlamlıdır.

$$
\begin{aligned}
& \operatorname{Ln}(\mathrm{GDP})=0.8302+0.4677^{*} \mathrm{Ln}(\mathrm{X})+0.4435^{*} \mathrm{Ln}(\mathrm{M})-0.0818^{*} \operatorname{Ln}(\mathrm{TF}) \\
& \text { Prob. } \quad(0.0088)(0.0013) \quad(0.0008)
\end{aligned}
$$

\begin{tabular}{|c|c|}
\hline \multicolumn{2}{|l|}{ Bağımlı değișken: $\mathrm{d}(\ln (\mathrm{GDP}))_{\mathrm{t}}$} \\
\hline Bağımsız değişkenler & Katsayı \\
\hline Constant & $0.0503 * * *(3.2280)$ \\
\hline $\mathrm{d}(\ln (\mathrm{GDP}))_{\mathrm{t}-1}$ & $0.1377(1.0094)$ \\
\hline $\mathrm{d}(\ln (\mathrm{GDP}))_{\mathrm{t}-2}$ & $-0.3569 * * *(-3.0846)$ \\
\hline $\mathrm{d}(\ln (\mathrm{GDP}))_{\mathrm{t}-3}$ & $-0.2794 * *(-2.4326)$ \\
\hline $\mathrm{d}(\ln (\mathrm{GDP}))_{\mathrm{t}-4}$ & $0.1986(1.6481)$ \\
\hline $\mathrm{d}(\ln (\mathrm{GDP}))_{\mathrm{t}-5}$ & $-0.3436 * * *(-2.8170)$ \\
\hline $\mathrm{d}(\ln (\mathrm{GDP}))_{\mathrm{t}-6}$ & $0.0033(0.0294)$ \\
\hline $\mathrm{d}(\ln (\mathrm{GDP}))_{\mathrm{t}-7}$ & $-0.2365^{*}(-2.0050)$ \\
\hline $\mathrm{d}(\ln (\mathrm{X}))_{\mathrm{t}}$ & $0.1366 * * *(3.5245)$ \\
\hline $\mathrm{d}(\ln (\mathrm{X}))_{\mathrm{t}-1}$ & $-0.0271(-0.6105)$ \\
\hline $\mathrm{d}(\ln (\mathrm{M}))_{\mathrm{t}}$ & $0.1713(1.6535)$ \\
\hline $\mathrm{d}(\ln (\mathrm{M}))_{\mathrm{t}-1}$ & $-0.0618(-0.5445)$ \\
\hline $\mathrm{d}(\ln (\mathrm{TF}))_{\mathrm{t}}$ & $0.0086(0.1889)$ \\
\hline $\mathrm{d}(\ln (\mathrm{TF}))_{\mathrm{t}-1}$ & $-0.0350(-0.7215)$ \\
\hline $\mathrm{ECT}_{\mathrm{t}-1}$ & $-0.4729 * * *(-4.2258)$ \\
\hline \multicolumn{2}{|l|}{ Ek testler: } \\
\hline Breusch-Godfrey serisel korelasyon LM testi F-istatistiği & 0.8607 \\
\hline ARCH testin F-istatistiği & 1.5108 \\
\hline Jarque-Bera Normal Dağılım Testi & 1.8706 \\
\hline 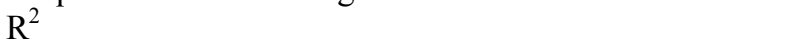 & 0.8212 \\
\hline
\end{tabular}

Tablo 3. Gayri Safi Yurtiçi Hasıla için Hata Düzeltme Modeli 
Bunun üzerine hata düzeltme modeli (error correction model) tahmin edilmiştir. Onun sonuçları Tablo 3'de gösterilmiştir. Uygun bulunan gecikme uzunluğunda model tahmin edildiğinde hata terimlerinde otokorelasyonun bulunduğu sorunu ortaya çıkmıştır. Bunu gidermek için de bağımlı değişkenin yedinci gecikmesi de modele eklenmiş ve böylece otokorelasyon sorunu giderilmiştir.

Hata düzeltme teriminin (ECT) istatistiki olarak anlamlı bulunması en azından bir tarafa doğru bir nedenselliğin olduğunu ispatlar. Bir gecikmeli hata düzeltme terimi $\left(\mathrm{ECT}_{\mathrm{t}-1}\right)$ negatif ve \%1 önem düzeyinden anlamlı bulunmuştur. Katsayının yüksek olması $(-0,4729)$ dengeye yakınsama hızının yüksek olduğuna işaret eder. Yani herhangi bir dengeden uzaklaşma olduğunda bunun \%47,29'u bir çeyreklik dönemde düzelebilecektir.

Ek testlerin sonucunda hata düzeltme modelinde serisel korelasyonun, değişen varyans (heteroskedasticity) etkisinin olmadığı ve CUSUM testi sonucunda modelin kararlı olduğu görülmüştür.
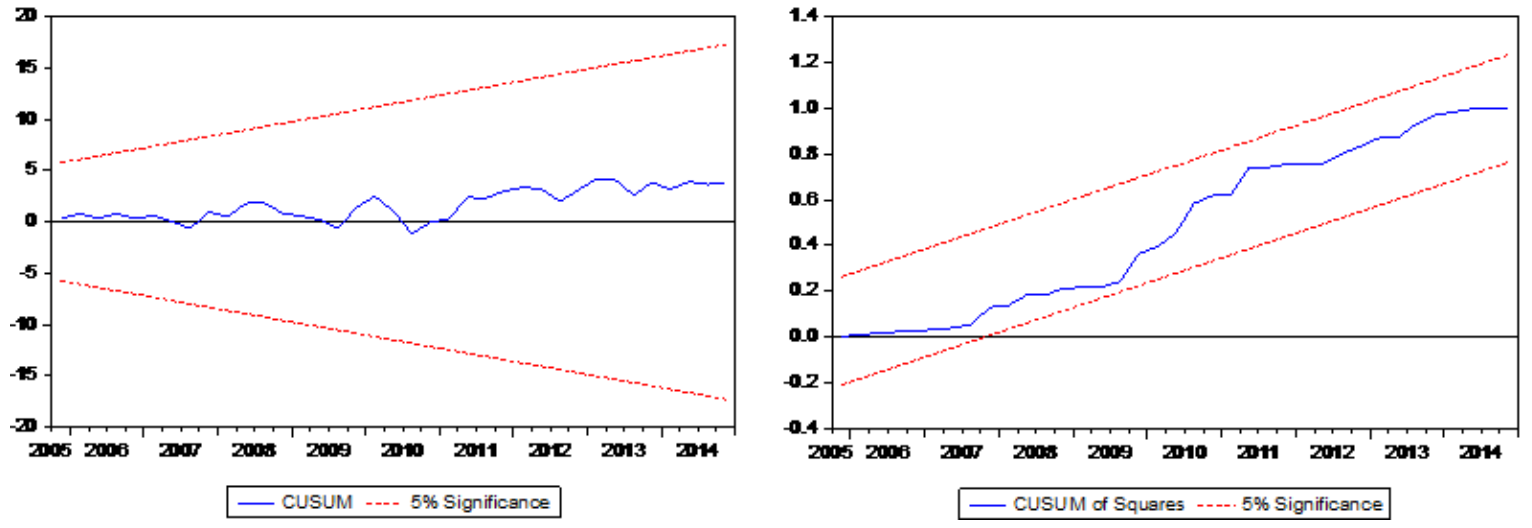

Şekil 3. CUSUM Testi Sonucu

Ayrıca modelin dinamik olarak kararlılığı da kontrol edilmiştir. Şekil 4'den görüldüğü gibi, tüm kökler birim dairenin içindedir ve burada da bir sorunun olmadığı görülmektedir. Inverse Roots of AR Characteristic Polynomial

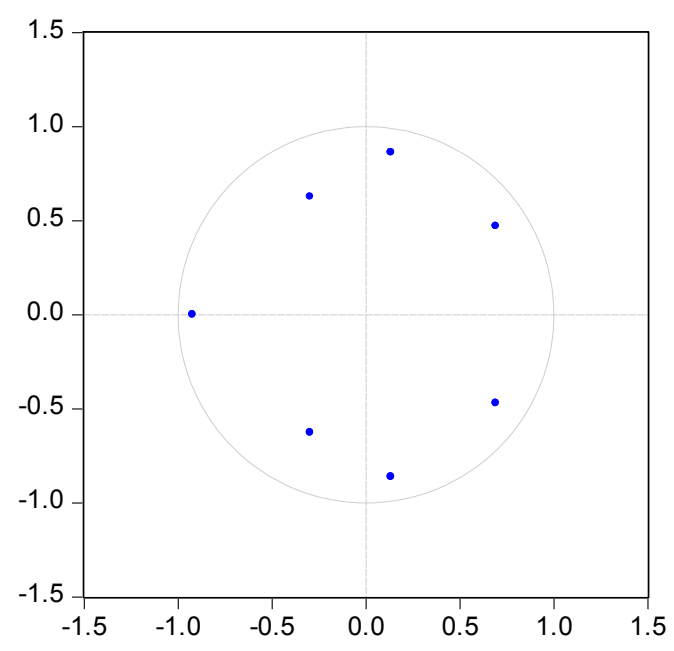

Şekil 4. Modelin Dinamik Kararlıliğg

\section{Sonuç ve Değerlendirme}

Sonuç olarak eşbütünleşme testine göre diş ticaret, GSYİH ve yurtdışından transferler arasında uzun dönemli bir ilişki söz konusudur. Uzun dönem modeline göre, dış ticaretin ülke ekonomisine katkısı pozitif olurken yurtdışından transferlerin katkısı negatif olmaktadır. Uzun dönemde ihracattaki \%1'lik bir artış GSYİH'nın \%0,47'ye artmasına neden olurken, ithalattaki \%1'lik bir artış da GSYİH'nın \%0,44'e artmasına yol açmaktadır. Ülkede çeşitli ekonomik ve siyasi nedenlerle iç yatırım ve üretimin yetersizliği, uluslararası düzeyde rekabet edebilecek üretim teknolojilerinin olmaması gibi nedenlerle genellikle tarım ürünleri ve hammaddeler ihracat edilmektedir ve diğer taraftan, Dordoy ve Karasuu gibi büyük toptan pazarların yer aldığı Kırgızistan'da reeksport da önemli düzeylere ulaşmaktadır. Ayrıca, ara malı, enerji kaynakları (yani petrol), hammadde, teknoloji gibi üretim için gerekli malların önemli kısmının dışarıdan ithal edilmekte olması ülkenin ekonomik gelişmesinin ithalata bağımlı olduğunun bir göstergesidir. 
Bunun gibi nedenlerle hem ihracat hem de ithalat toplam üretimi pozitif etkilemektedir. Bu sonuçlardan görülmektedir ki, ekonominin gelişmesi bundan sonra da büyük ölçüde dışa bağımlı bir şekilde devam edecektir. Dolayısıyla Kırgızistan Avrasya Ekonomik Birliği’ne girdikten sonra da söz konusu ülkelerle ve tüm dünya ülkeleriyle ticari ilişkileri geliştirme yönünde politikaları aktif olarak yürütmeye devam etmelidir.

Diğer taraftan, yurtdışından transferlerin GSYİH'ya etkisi ise negatif, fakat istatistiki olarak anlamsız bulunmuştur. Transferlerin negatif etkisinin temel nedenlerinden birinin yurtdışına işgücü göçünün olduğu söylenebilir. Burada bir anlamda kısır döngü gibi bir durum vardır: iç üretimin ve iş imkanlarının yetersiz olması işgücü göçünü artırmakta, işgücü göçü de iç üretimi negatif etkilemektedir. Bu bağlamda, işgücü göçünün azalması ve yurtiçi yatırımların ve üretimin artması için tüm gerekli faaliyetlerin hayata geçirilmesi gerekmektedir. Özellikle entegrasyon sonucunda oluşacak geniş piyasa avantajından yararlanmak isteyen yabancı yatırımcılara uygun yatırım ikliminin oluşturulması konusunda gerekli adımların hızlandırılması lazım. Bunun için öncelikle kayıtdışı ekonomik faaliyetlerin ve yolsuzluğun azaltılması, siyasi istikrarın sürdürülmesi, altyapı yatırımlarının tamamlanması, yabancıların haklarının çok iyi korunması ve ülke vatandaşlarının yabancılara ve genel olarak liberal ekonomik sisteme bakış açısının değişmesi gerekmektedir.

\section{Kaynakça}

- Abbas Sh. (2012). Causality between Exports and Economic Growth: Investigating Suitable Trade Policy for Pakistan. Eurasian Journal of Business and Economics 2012, 5 (10), 91-98.

- Akmoldoev K. and Budaichieva A. (2012). "The Impact of Remittances on Kyrgyzstan Economy”. Proceedings of International Conference On Eurasian Economies 2012. Pp. 6-12.

- Grossman H. (1991). Trade, innovation and growth. American Economic Review, Vol.80, 86-91.

- Hatemi-j, A. (2002). Export Performance \& Economic Growth Nexus in Japan: a Bootstrap Approach. Japan and World Economy, 14, 25-33.

- Pesaran, H. M. (1997) The role of economic theory in modelling the long-run, Economic Journal, 107, pp. 178-191.

- $\quad$ Pesaran, H. M. and Shin, Y. (1995) Autoregressive Distributed Lag Modelling Approach to Cointegration Analysis, DAE Working Paper Series No. 9514 (Cambridge: Department of Applied Economics, University of Cambridge).

- $\quad$ Pesaran, H. M. and Shin, Y. (1999) Autoregressive distributed lag modelling approach to cointegration analysis, in: S. Storm (Ed.) Econometrics and Economic Theory in the 20th Century: The Ragnar Frisch Centennial Symposium, chapter 11 (Cambridge: Cambridge University Press).

- Pesaran, H. M. et al. (1996) Testing the Existence of a Long-run Relationship, DAE Working Paper Series No. 9622 (Cambridge: Department of Applied Economics, University of Cambridge).

- Ramos, F. F. (2001). Exports, imports, and economic growth in Portugal: evidence from causality and cointegration analysis. Economic Modelling, 18, 613-623.

- Saraç, T.B. (2013). İhracat ve İthalatın Ekonomik Büyüme Üzerindeki Etkisi: Türkiye Örneği. Ege Akademik Bakış, 13(2), 181-194.

- Thornton, J. (1997). Exports and economic growth: Evidence from 19th Century Europe. Economic Letters, $55,235-240$. 
Küçük ve Orta Ölçekli İşletmelerde Dış Ticaret Politikalarının Önemi

\title{
Small and Medium Sizes Enterprises (SMEs) and Foreign Trade Policy
}

\author{
Asst. Prof. Dr. İlkay Noyan Yalman (Cumhuriyet University, Turkey) \\ $\mathrm{Ph}$. D. Candidate Mutlu Türkoğlu (Cumhuriyet University, Turkey) \\ Dr. Yalçın Yalman (Cumhuriyet University, Turkey)
}

\begin{abstract}
A high level of a country's foreign trade is related to the growth of foreign earnings, to the acceleration of investments, to increase employment and contributes significantly to the growth of the country's economy. In this context, SMEs as one of the mile stones of the economy, foreign trade and economic growth are located in the leading roles. Especially SMEs sufficiently developed oppressed against strong opponents abroad, government policies or practices in trade restrictive policies are some of the reasons for this downside.

SMEs that exports goods, or the infrastructure needed to produce goods for SMEs who import raw materials as well as the country's foreign trade policies and developments in the world economy is important. SMEs to follow the development, recognizing competitors, new markets, new products is very important in terms of growth both business and the countries.

In this study, SMEs engaged in foreign trade in Sivas Province performing an application on in terms of both the business and government policy at the local level status will be examined. Data will be obtained on issues such as ultimately foreign trade potential of existing SMEs while doing foreign trade problems they face, strengths and weaknesses, market policies at national and international levels, the opinions about the state's foreign trade policy. The results obtained from the data on SMEs engaged in foreign trade by making general inferences about the data obtained on a micro scale, will allow making inferences on the macro scale.
\end{abstract}

\section{Giriș}

Dünya piyasalarındaki küreselleşme tüm ekonomileri etkilemekte ve gerçekleşen değişimlere uyum sağlayabilmeleri ekonomilerin başarı kriterlerinden biri olmaktadır. Özellikle dış ticaret alanında dünya ekonomisindeki gelişmeler, ülke ekonomileri için etkili olmakta ve diş ticaret yapan KOBİ'leri doğrudan ilgilendirmektedir. Bir ülkede dış ticaret hacminin artmasıyla, döviz girdilerinin çoğalması, yatırımların hızlanması, istihdamın artması ve ülke ekonomisinin büyümesi gibi makroekonomik dinamikler harekete geçmektedir. Bir ülke ekonomisinde ihracat, öncelikle üretim ve istihdamda sebep olduğu etkilerle ekonominin gelişimi doğrudan etkilemektedir. Bu bağlamda ekonominin temel taşlarından olan KOBİ'ler diş ticaret ve ekonominin büyümesinde başrollerde yer almaktadır.

Bu çalışmada KOBİ'lerin diş ticaretteki öneminin vurgulanması amacıyla, Sivas’ta faaliyet gösteren ve ihracat yapan KOBI'lerle ilgili bir uygulama yer almaktadır. Bu uygulama, dış ticaret yapan KOBİ'lerin mevcut dış ticaret potansiyelleri ve dış ticaret faaliyetleri ile ilgili olarak, işletmelere uygulanan anketlerin analiz sonuçlarına yöneliktir. Elde edilen sonuçlarla dış ticaretin yöre ekonomisindeki önemi analiz edilmeye çalışılmış ve dış ticaretteki sorunların giderilmesi ve geliştirilmesi konularında çözüm önerileri geliştirilmeye çalışılmıştır. Ayrıca KOBI'lerin diş ticaret stratejileri geliştirmeleri önemine vurgu yapılmıştır.

\section{KOBİ’ler ve Dış Ticaretteki Önemleri}

KOBI'ler daha az sabit sermaye yatırımları ile kurulabilmeleri, esnek üretim imkânlarına sahip olmaları, talep değişikliklerine daha kısa sürede uyum sağlayabilmeleri gibi özellikleriyle milli gelire, istihdama, verimliliğe ve girişimci yetiştirmeye sağladıkları katkılar nedeniyle çok önemlidir. Bir ülke ekonomisinde ihracat ve KOBI'ler ekonominin temelini oluşturan unsurların başında gelmektedir. Küreselleşmenin etkisiyle artan dış ticaret ve KOBİ'lerin bu konudaki etkinlikleri de önemini artırmıştır. Özellikle 1980'lerden itibaren bir ülkenin hızlı kalkınma ve büyümesinin sağlanabilmesi için ihracatın teşvik edilmesi ve geliştirilmesinin önde gelen önemli bir faktör olduğu genel kabul gören bir görüş olmuştur. Hızlı büyüyen bir ihracat piyasası ekonomideki diğer bütün sektörleri uyararak GSYİH'nın büyümesine destek olmaktadır (Niroomand and Nissan, 1997:167). İhracattaki artış ve dış piyasalara açılma pozitif dışsallıklar sağladığı için ekonomik büyümenin anahtarı olarak ifade edilmektedir (Awokuse, 2006:299). İhracatla büyüme azgelişmiş ülkeler başta olmak üzere, hemen her ekonomide uzmanlaşmayı ve dolayısıyla ekonomik verimliliği artıran bir kaynak önem kazanmaktadır (Scott and Storper, 2003:19). 
Michaely (1977), Balassa (1978), Edwards (1998) ve Wu (2004) yaptıkları çalışmalarda ihracattaki artışın ekonomik büyümeyi hızlandırdığını tespit etmişlerdir. Çalışmalarda genel olarak ihracat performansı ile ekonomik büyüme arasında doğru orantılı ilişki tespit edilmiş ve daha dışa açık ekonomilerde, büyümenin daha hızlı gerçekleştiği ortaya konmuştur. İhracat ile birlikte artan üretim, ekonomide dışsal ölçek ekonomilerin ortaya çıkmasına yol açarak maliyetlerin düşmesine ve yeni üretim metotlarının bulunmasına sebep olmaktadır. İhracat için etkin bir şekilde üretim yapan işletmeler, ekonomideki diğer işletmeleri de bu yolda üretim yapmaya teşvik ederek rekabetin artmasını ve verimliliğin yükselmesini sağlamaktadır (Kemer, 2003: 30). Ayrıca ihracatın artması, ihracat yapan sektörün üretiminde kullanılan faktörlere olan talebi artırarak faktör gelirlerinin yükselmesini de sağlamaktadır. İhracat yapan KOBİ’ler ise bu katkılara destek olmaktadır.

Ekonomide yaşanan küreselleşmeyle birlikte, ihracat yapan firmaların birbirleriyle rekabetleri artmış, daha kaliteli mal, daha düşük fiyat ve daha bol çeşit gibi rekabet üstünlüğü sağlayacak unsurlara dikkat etmek durumunda kalmışlardır. Bu konuda hükümetler ihracat yapan firmalara yönelik özellikle ihracatı özendirici politikalar başta olmak üzere, dış ticaret politikaları geliştirmişlerdir. İhracatı teşvik politikaları, firmaların daha verimli çalışabilmesi ve yeni teknolojilere daha çabuk uyum sağlayabilmesi, piyasada daha etkin olabilmesi konusunda oldukça önemli bir araçtır (Kurt ve Berber, 2008). İhracatı teşvik politikalarıyla ihracatın artması, milli geliri artırarak kalkınmayı doğrudan olumlu etkilerken, döviz darboğazını genişleterek de ekonomik kalkınmaya destek olmaktadır (Karluk, 2005). İhracatı teşvik politikalarının temel amacı, KOBİ niteliğindeki firmalar başta olmak üzere, ihracaţ̧ı firmaların ihracata yönelik faaliyetlerini gerek üretim, gerekse pazarlama aşamalarında destekleyerek, uluslararası pazarlarda karşılaştıkları sorunların giderilmesine yardımcı olmak ve rekabet gücü kazanmalarına olanak sağlamaktır (Ersungur ve Noyan Yalman, 2009:82). KOBİ'lerin içinde bulundukları özel şartlar göz önüne alınarak teşviklerin etkinliğinin arttırılması noktasından bölgesel veya sektörel düzenlemelere gidilebilir (Aktürk ve Şenol, 2010).

KOBİ'lerin bölgesel dengesizliği azaltmada kilit rol oynadığ kabul edilse de bunun tam olarak sağlanamadığ görüşleri mevcuttur. Ertugal (2005)'a göre beş yıllık kalkınma planları, daima bölgesel dengesizlikleri azaltmaya öncelik vermelerine rağmen, bu hedefe ulaşmak tam olarak mümkün olamamış ve mekânsal boyuta göre değil, sektörel bir mantığa göre formüle edilmişlerdir. KOBİ'lerin geliştirilmesi ve desteklenmesi amacıyla kurulan Organize Sanayi Bölgeleri ve Küçük Sanayi Siteleri bazı bölgelerde yerel potansiyelin harekete geçirilmesine, sanayinin yerelleşmesine bölgenin gelişmesine katı sağlamakla birlikte, bu durum tüm bölgeler için geçerli bir model olmamıştır (Özaslan, 2005).

\section{Türkiye'de KOBİ'ler ve Dış Ticaret}

Küreselleşmeyle birlikte rekabetin de artması ülkelerde ihracatın desteklenmesi gereğini ortaya koymuştur. Gelişmiş ve gelişmekte olan tüm ülkeler vergi indirimi, vergi muafiyeti, girdi teşvikleri ve pazarlama araştırması gibi ihracatı teşvik edici uygulamalarla ihracatı artırmanın yollarını araştırmaktadırlar. Türkiye'de de ihracatın geliştirilmesi amacıyla, ar-ge yardımları, yurt dışı ve yurt içi fuar ve sergilere katılımın desteklenmesi, pazar araştırması ve istihdam yaratma desteği, marka tanıtımı faaliyetlerinin ve patent tescili harcamalarının desteklenmesi gibi benzer politikalarla devlet yardımları uygulanmaktadır (Çelik, 2008).

Türkiye'de KOBİ'ler ve dış ticaret konusunda yapılan çalışmalarda genel olarak KOBİ'lerin bu konuda karşılaşıkları sorunlara değinilmiştir. Dış pazarlarda rekabet gücünü etkileyen belli başlı sorunlar, kalite düşüklüğ̈̈, fiyatlamada yanlışlıklar, rakipleri tanıyamama, hatalı pazarlama stratejileri, ihracat konusunda nitelikli eleman ve bilgi eksikliği, üretim kapasitesi yetersizliği, psikolojik engeller ve diş ticaret organizasyonlarının yeterince yardımcı olmaması olarak sayılabilir (Akgemci, 2001). Bu sorunlarla birlikte geleneksel yönetim tarzı, iletişim sorunları, cesaretsizlik ve sabırsızlık gibi kişisel özelliklerde dış rekabet gücünü zayıflatan unsurlardır (Alpugan, 1988; Müftüoğlu, 1989).

KOBI'lerin pazar araştırması yapmadan kişisel yöntem ve gözlemler ile dış pazarlarda başarılı olabilmeleri oldukça zordur. Bunun için, ucuz maliyetle yeterli düzeyde kaliteli ürün üretebilme, modern pazarlama tekniklerini kullanabilme, yeterli sermaye, etkin bir yönetim ve organizasyon ile nitelikli eleman ve deneyim sahibi olabilmeleri gerekir (Yücel, 2004). Bunların KOBİ'ler tarafindan tek başına sağlanması oldukça güçtür. Ancak KOBI'ler üretim, tedarik, pazarlama, finansman, yönetim gibi birçok alanda yapacakları işbirliği ile birçok avantaj sağlayabilirler (Müftüoğlu, 1989). Bu işbirliği sonucu KOBI'lerin, teknolojik olarak yenilenme, pazarlama teknikleri konusunda uzmanlaşma, ürün kalitesini yükseltme, dağıtım harcamalarında azalma, bilgi birikimlerini artırma, yönetim üstünlüğü kazanma gibi avantajlar sağlayarak dünya pazarlarına daha kolay girebilecekleri düşünülmektedir. Bunun sonucunda ekonomiye dinamizm kazandırmaları, yeni iş imkânları ve istihdam yaratmaları ve bölgesel kalkınmayı güçlendirerek dengeli kalkınmayı sağlamaları açısından kalkınmada önemli roller üstlenebilirler.

Sermayesi ve tecrübesi az olan birçok KOBİ'nin uluslararası piyasada rekabet şansının yükseltilmesi için 1980’lerden sonar ihracat stratejisiyle uyumlu olarak Dış Ticaret Sermaye Şirketleri kurulmuş, ancak bu şirketler amacı dışında faaliyetlere girmiş̧lerdir. 1990'lı yıllardan sonar ise bir KOBİ örgütlenmesi olan sektörel Dış Ticaret firmaları kurulmuş, ancak bunlarda beklenen performansı gösterememişlerdir (www.ekodialog.com). 
Sektörel Dış Ticaret Şirketleri (SDŞ) KOBİ'lerin birtakım dezavantajlarını ve zayıflıklarını gidermek üzere ortaya çıkan bir oluşumdur. SDŞ aynı üretim dalındaki KOBİ'lerin ihracat sektörü içinde bir organizasyon altında toplanarak dünya pazarlarına açılmaları, dış ticarette uzmanlaşmaları ve etkin faaliyet göstermeleri amacıyla kurulmuştur. KOBİ'lerin "ihracat" hedefiyle yola çıkarak ihtiyaçlarının tespiti ve ortak bir stratejinin oluşturulması için SDŞ modelinin hayata geçmesi önem taşımaktadır (Diken,1998). Bugün itibariyle kurulu bulunan sektörel diş ticaret şirketlerinin sayısı 37 olarak tespit edilmiştir. SDŞ üyelerinin faaliyet gösterdiği sektörler tekstil ve konfeksiyon, deri, ayakkabı, gıda, tarımsal ürünler, kesme çiçek, mobilya, inşaat yan sanayi, yazılım, plastik işleme, otomotiv ve otomotiv yan sanayi, makina ve makina yan sanayiidir. SDŞ modeline devlet tarafından sağlanan destekler şu şekilde sıralanabilir: • Pazar Araştırması Yardımı, • Eğitim Yardımı, • İstihdam Yardımı, • Marka Yardımı, • Yurt Dışı Fuar ve Sergilere Katılım Yardımı, • Yurt Dışı Ofis/Mağaza Yardımı

2008 verilerine göre KOBI'ler Türkiye'de; toplam istihdamın \%78'ini, toplam katma değerin \%55'ini, toplam satışların \%65,5'ini, toplam yatırımların \%50'sini, toplam ihracatın \%56'sını oluşturmaktadır. KOBİ kredilerinin toplam krediler içindeki payı \%23'tür.

Türkiye'de KOBİ'ler en fazla ticaret ve imalat sektörlerinde ihracat yapmaktadır. Hizmet, inşaat, madencilik ve enerji sektörleri de diğer ihracat konularını oluşturmaktadır (Şekil:1).

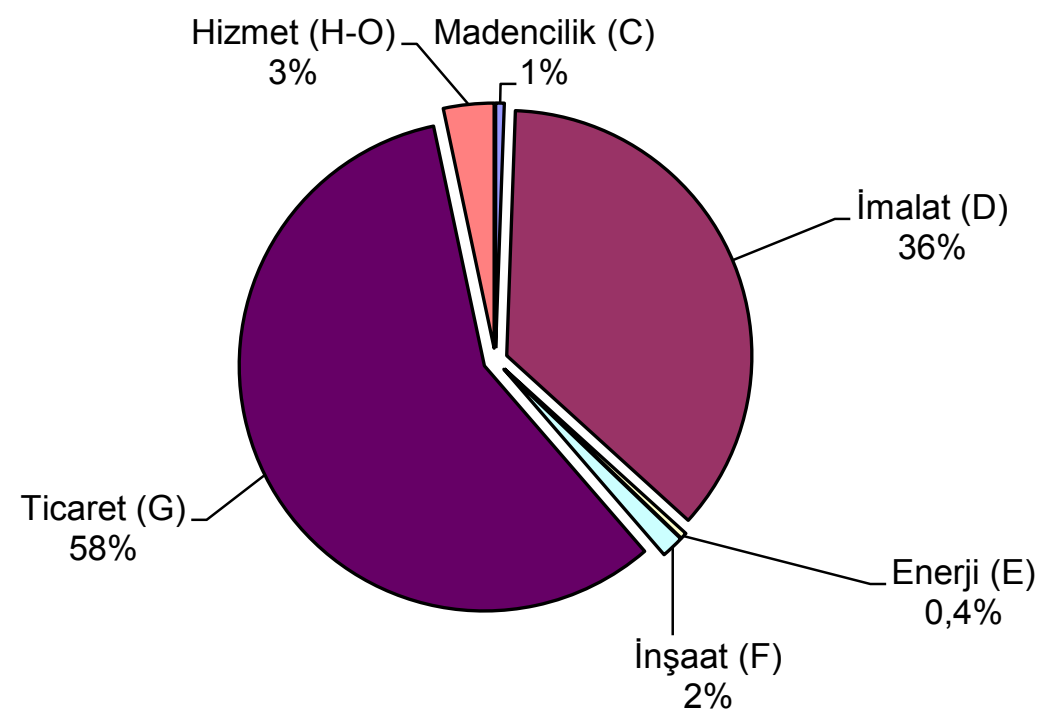

Şekil 1. KOBI'ler tarafından yapılan ihracatın sektörlere dă̆llımı Kaynak: KOSGEB 2011 - 2013 KOBI Stratejisi ve Eylem Planı, Ankara 2010 (2007 TÜIK ihracat istatistiklerine göre hesaplanmıştır)

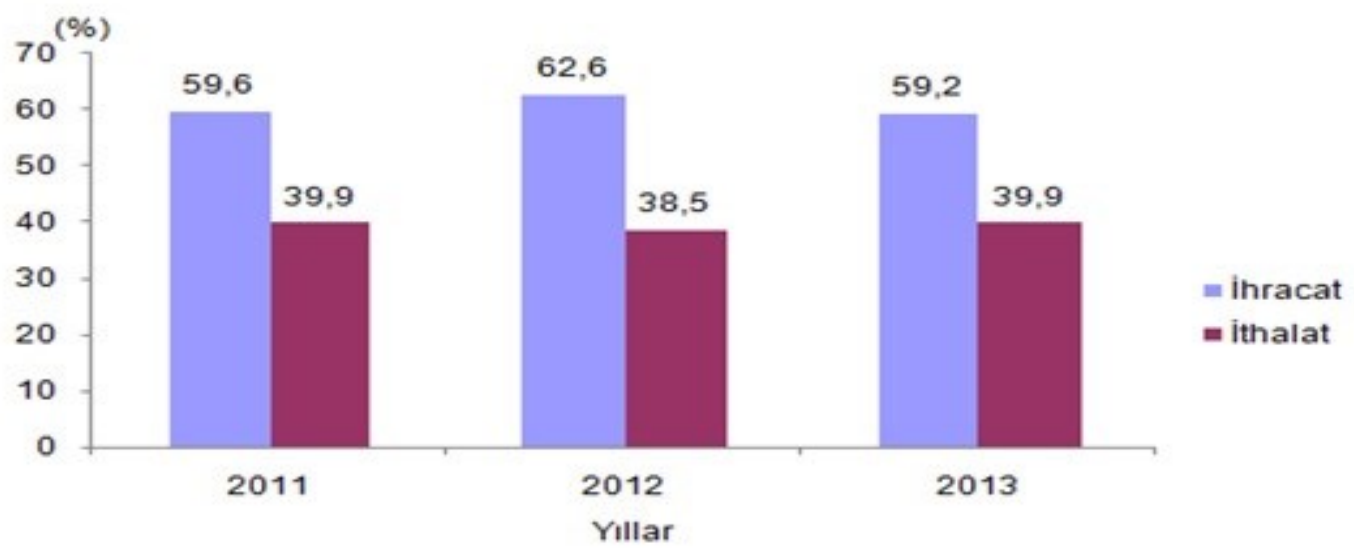

Grafik 1: KOBI'lerin Dlş Ticaretteki Payl (2011-2013) Kaynak: http://www.kobi.org.tr/index.php/tanimi/stats

Grafik 1'de 2011-2013 yılları arasında Türkiye'de KOBI'ler tarafından gerçekleştirilen ihracat ve ithalat oranları izlenmektedir. KOBİ'ler 2013 yılında ihracatın \%59,2'sini gerçekleşmiştir. İhracatta; 1-9 kişi çalışan mikro ölçekli girişimlerin payı \%17,8 iken, 10-49 kişi çalışan küçük ölçekli girişimlerin pay1 \%24,1, 50-249 kişi çalışan orta ölçekli girişimlerin payı \%17,3, 250+ kişi çalışan büyük ölçekli girişimlerin payı ise \% 40,7 olmuştur. Girişimin ana faaliyetine göre KOBİ'lerin ihracatının \%35'i sanayi, \%60,4'ü ticaret sektöründe faaliyet gösteren KOBİ'ler tarafından yapılmıştır. 
KOBI'lerin 2013 yılında ithalattaki payı ise \%39,9 olmuştur. İthalatta; 1-9 kişi çalışan mikro ölçekli girişimlerin payı \%5,7, 10-49 kişi çalışan küçük ölçekli girişimlerin payı \%16,2, 50-249 kişi çalışan orta ölçekli girişimlerin payı \%17,9, 250+ kişi çalş̧an büyük ölçekli girişimlerin payı ise $\% 60,1$ olmuştur. Girişimin ana faaliyetine göre KOBİ'lerin ithalatının \%34,9'u sanayi, \%55,9'u ticaret sektöründe faaliyet gösteren KOBİ'ler tarafindan gerçekleştirilmiştir. Ülke gruplarına göre 2013 yılında dış ticaret incelendiğinde, KOBİ’ler tarafindan yapılan ihracatın \%45,9'u Avrupa ülkelerine, \%38,7'si Asya ülkelerine gerçekleştirilmiştir. KOBİ'ler ithalatının \%51,4'ünü Avrupa ülkelerinden, \%38,9'unu Asya ülkelerinden yapmıştır. KOBİ'lerin ihracatı içinde giyim eşyası sektörünün payı $\% 14,5$, "ana metaller" in payı $\% 12,1$ ve "tekstil ürünleri”"nin pay1 $\% 10,3$ olmuștur. KOBİ'lerin ithalatında ise öne çıkan sektörler "kimyasallar ve kimyasal ürünler" $(\% 15,6)$, "ana metaller" $(\% 14,8)$ ve "başka yerde sınıflandırılmamış makine ve ekipmanlar" $(\% 12,7)$ olmuştur.

İtalya'nın Torino şehrinde düzenlenen Dünya Odalar Kongresi'nde konuşan B20 Türkiye ve TOBB Başkanı Rifat Hisarcıklığlu, "2008 küresel krizinden beri dünyada büyümeyi sağlayamadık. Dengeli büyüyemedik. Dünyanın bir bölgesi toparlansa, diğer taraflarda sıkıntı başlıyor. Büyümeyi dengelemek ve sürdürebilir kılmak için tek yol KOBİ'leri ateşlemektir" ifadelerini kullanarak, KOBİ'lerin önemini ortaya koymuştur. Hisarcıklığlu, G20'nin, 2008 krizinden bu yana küresel ekonomiyi uçurumun kenarından almak için iyi işler yaptı̆̆ını belirterek, 2015 yılının KOBİ'ler yılı olacağını ifade etmiştir.

\section{Araştırmanın Amacı ve Önemi}

Araştırmanın temel amacı, ihracatın ekonomik büyümedeki etkisine vurgu yaparak, ihracat yapan KOBİ'lerin bu konudaki önemini ortaya koymak ve bu alanda var olan sorunları tespit ederek, KOBİ'ler için ihracat paylarını artıracak dolayısıyla ekonomik gelişmeyi hızlandıracak çözüm önerilerine ulaşmaktır. Bu çalışmada elde edilecek veriler Sivas yöresinde faaliyette bulunan işletmelere ait olup, elde edilecek sonuçlar bölgeye özgü ve orijinal verilerdir. Bölge bazında elde edilen veriler, bölgeye yönelik yapısal özellikleri taşıdığından tespitler ve öneriler de genel verilere göre daha etkili olacağından önemlidir.

Grafikte Sivas'a ait ihracat verileri yer almaktadır. 2009 yılında finansal krizin etkisi olarak bir azalma izlense de Sivas'ta ihracat değerlerinde sürekli bir artış izlenmektedir.

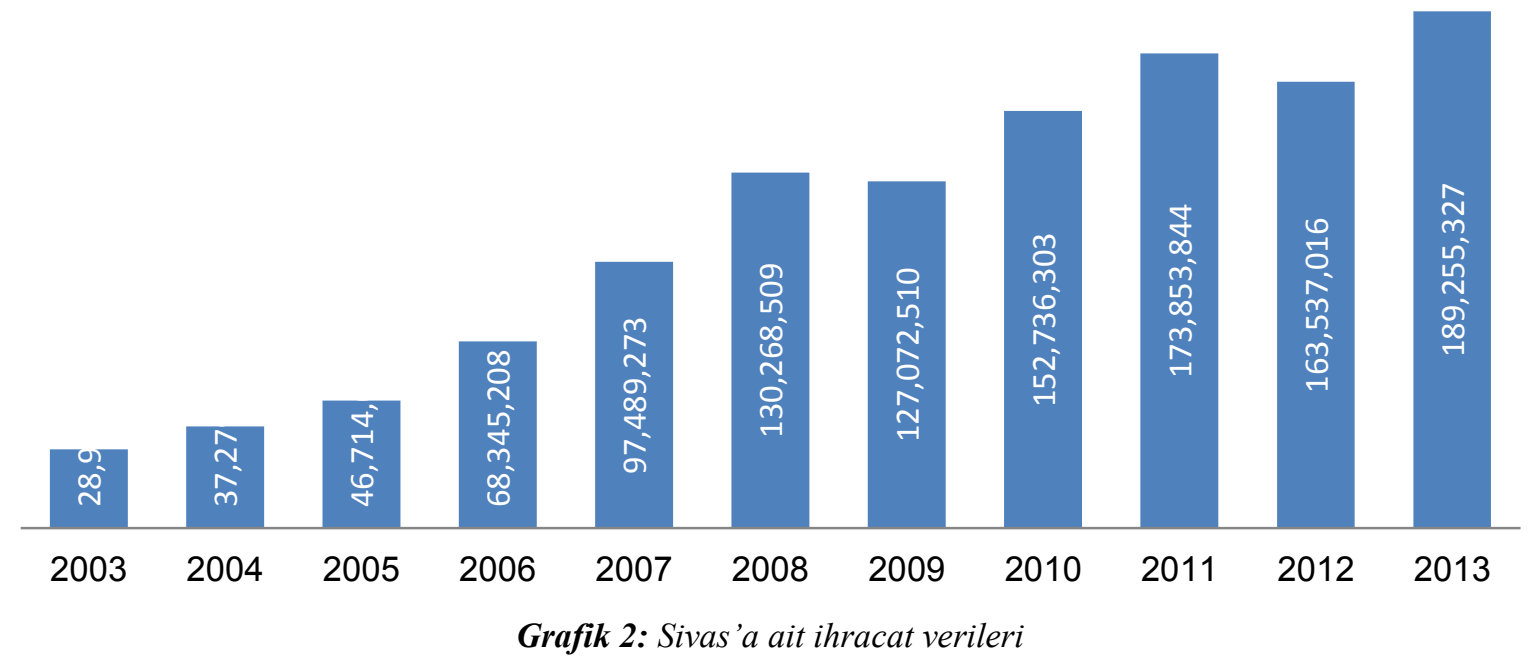

Sivas TSO'dan alınan verilere göre 2014 ihracat rakamları da 197 milyon dolar olan Sivas'tan 78 ülkeye ihracat yapılmaktadır. \%12 metal ürünleri, \%52 doğal taş ve madenler, \%24 tekstil ve hazır giyim olarak ifade edilmektedir.

\subsection{Araştırmanın Kapsamı Ve Sınırları}

Araştırma, Sivas İlinde 2013-2014 yıllarında ihracat yapan KOBI'lere yönelik yapılmıştır. Sivas'ta faaliyet gösteren ve ihracat yapan firmalar I. Organize Sanayi Bölgesinde faaliyette bulunan firmalarla sınırlandırılmıştır.

\subsection{Araştırmanın Varsayımları}

Araştırmaya kaynaklık eden firma yetkililerinin, anket sorularını doğru olarak algıladıkları ve doğru yanıtlar verdikleri varsayilmıştır.

\subsection{Araştırmanın Yöntemi}

Araştırma için veriler yüz yüze anket yöntemiyle toplanmıştır. Cevaplama oranının yüksek olması ve daha fazla soru sorabilme avantajı nedeniyle yüz yüze görüşme tekniği tercih edilmiştir. Sivas TSO verilerine göre 2013-2014 döneminde ihracat yapan 46 firma ile görüşülmüştür. Verilerin değerlendirilmesinde SPSS paket program kullanılmıştır. 


\subsection{Araştırma Verileri Ve Değerlendirilmesi}

$\mathrm{Bu}$ bölümde anket formlarında yer alan sorulara verilen cevaplarla elde edilen veriler yardımıyla çeşitli tablolar oluşturulmuş ve değerlendirmeler yapılmıştır.

\subsection{Firmaların Genel Özellikleri}

Araştırmaya katılan 46 firmanın genel özellikleri şu şekilde özetlenebilir:

- Araştırmaya katılan firmaların kuruluş süreleri; \%6,3’ü 4-10 yıl, \%69,8’i 11-20 yıl ve \%23,8’i 20 yıldan fazladır.

- Araştırmaya katılan firmaların faaliyet alanları; \%12,7'si maden,\%9,5'i medikal, \%23,8'i makine, \%25,4'ü mobilya, \%7,9'u inşaat, \%9,5'i gida, \%11,1'i hizmetlerdir.

- $\quad$ Araştırmaya katılan firmaların \%4,8'i 1-10 kişi, \%39,7’si 11-50 kişi, \%25,4'ü 51-100 kişi, \%9,5'I 101-250 kişi ve \%19,0’I 250’den fazla kişi çalıştırmaktadır.

- Araştırmaya katılan firmaların \%7,9'u hammadde, \%4,8'I yarı mamul ve \%87,3'ü mamul mal üretmektedir.

- Araştırmaya katılan firmaların \%49,2'si ithalat yapmakta, \%50,8'i se ithalat yapmamaktadır.

- Araştırmaya katılan firmaların \%20,6'sı 1-4 yıldır, \%58,7'si 5-10 yıldır ve \%20,6'sı ise 10 yıldan fazladır ihracat yapmaktadir.

- $\quad$ Araştırmaya katılan firmaların\%84,1 inde diş ticaret departmanı var, \%15,9'unda ise yoktur.

- Araştırmaya katılan firmaların\%25,4’ü e-ticaret yapmakta, \%66,7'si ise yapmamakta, \%7,9 u ise cevap vermemiştir.

- Araştırmaya katılan firmaların \%76,2'si ihracat teşviklerinden faydalanmış, \%15,9'u faydalanmamıs, $\%$ 7,9'u ise soruya cevap vermemiştir.

- Araştırmaya katılan firmalar başta Avrupa ülkeleri olmak üzere, Arap ülkeleri, Amerika, Latin Amerika ülkeleri, Türk Cumhuriyetleri, Çin ve bazı Doğu Asya ülkelerine ihracat yapmaktadır.

İşletmelerin dış ticaretlerini etkileyen gelişmelerle ilgili yöneltilen sorulara verilen cevaplar tablo 1 'de izlenmektedir. Tablo genel olarak değerlendirildiğinde, Türkiye'de yapılan diş ticaretin yurt dişındaki ekonomik ve siyasi krizlerden etkilendiği, Türkiye'deki firmaların ve ürünlerin yurt dışında tercih edildiği, dış ticarette ödemeler konusunda fazla sıkıntı yaşanmadığı söylenebilir. Tabloda dış ticaret yaparken iletişim kurma konusunda sorun yaşamadıkları konusunda kararsız ve katılmayanların oranları dikkat çekicidir. Bu konuda yapılan görüşmelerde yabancı dil bilen kalifiye eleman sıkıntısı yaşadıkları belirtilmiştir.

\begin{tabular}{|c|c|c|c|c|}
\hline & $\begin{array}{c}\text { Kesinlikle } \\
\text { katıliyorum }\end{array}$ & Katıliyorum & Kararsızım & Katılmiyorum \\
\hline $\begin{array}{l}\text { Ülkemizdeki ekonomik gelişmeler diş ticaretimizi } \\
\text { olumlu yönde etkiliyor }\end{array}$ & 20,6 & 60,3 & 14,3 & 4,8 \\
\hline $\begin{array}{l}\text { Ülkemizdeki ekonomik istikrar yurt dışında firmamızın } \\
\text { imajını olumlu etkiliyor. }\end{array}$ & 30,2 & 60,3 & 4,8 & 4,8 \\
\hline $\begin{array}{l}\text { Misır ve Suriye olayları ticaretimizi olumsuz yönde } \\
\text { etkiliyor. }\end{array}$ & 27,0 & 52,4 & 6,3 & 14,3 \\
\hline $\begin{array}{l}\text { AB ülkelerindeki kriz ticaretimizi olumsuz yönde } \\
\text { etkiliyor. }\end{array}$ & 7,9 & 63,5 & 9,5 & 19,0 \\
\hline $\begin{array}{l}\text { Yurt dişındaki firmalar Türk firmalarla ticaret yapma } \\
\text { konusunda istekli davranıyor. }\end{array}$ & 23,8 & 65,1 & 4,8 & 6,3 \\
\hline $\begin{array}{l}\text { Yurt dışındaki firmalardan alacaklarımızı genellikle } \\
\text { zamanında tahsil ediyoruz. }\end{array}$ & 28,6 & 63,5 & 6,3 & 1,6 \\
\hline $\begin{array}{l}\text { Yurt dışındaki firmalara ödemelerimizi genellikle } \\
\text { zamanında ödüyoruz. }\end{array}$ & 33,3 & 60,3 & 4,8 & - \\
\hline $\begin{array}{l}\text { Diş ticaret yaparken iletişim kurma konusunda sıkıntı } \\
\text { yaşamıyoruz. }\end{array}$ & 28,6 & 36,5 & 20,6 & 9,5 \\
\hline $\begin{array}{l}\text { Dış ticaret kazancımızı artırmak için yerli aramalı (ithal } \\
\text { olmayan) kullanmaya özen gösteriyoruz. }\end{array}$ & 28,6 & 36,5 & 19,0 & 14,3 \\
\hline $\begin{array}{l}\text { İhraç ettiğimiz ürünler yurt dışında tanınıyor ve tercih } \\
\text { ediliyor. }\end{array}$ & 24,4 & 55,6 & 14,3 & - \\
\hline
\end{tabular}

Tablo 1: Dış Ticareti Etkileyen Başlıca Faktörler

İşletmelerin yurt içi ve yurt dışı fuarlara bakışları ve katılımları ile ilgili yöneltilen soruya verilen cevaplar tablo 2'de izlenmektedir. Tablo genel olarak değerlendirildiğinde fuarların işletmeler açısından avantajları kabul edilmiş görülmektedir. Ancak fuarlara yeterince hazırlanamadıklarını belirten işletmeler özellikle sözlü görüşmelerde yine yabancı dil eksikliğini dile getirmişlerdir. 


\begin{tabular}{|l|c|c|c|c|}
\hline & $\begin{array}{c}\text { Kesinlikle } \\
\text { katılıorum }\end{array}$ & Katılıyorum & Kararsızım & Katılmıyorum \\
\hline Firmamızın tanıtımında etkili oluyor. & 44,4 & 42,9 & 1,6 & - \\
\hline Piyasa şartlarını tanımamıza yardımcı oluyor. & 33,3 & 54,0 & 1,6 & - \\
\hline Rakip firmaların ürünlerini tanıma şansı yakalıyoruz. & 33,3 & 49,2 & 4,8 & 1,6 \\
\hline $\begin{array}{l}\text { Rakip firmaların teknolojilerini tanıma firsatı } \\
\text { yakalıyoruz }\end{array}$ & 27,0 & 50,8 & 6,3 & 1,8 \\
\hline Yeni Pazar fırsatları yakalıyoruz. & 36,5 & 52,4 & & \\
\hline Satış ve siparişlerimiz artıyor & 30,2 & 41,3 & 15,9 & 1,6 \\
\hline Firmamızın vizyonuna katkı sağlıyor. & 38,1 & 46,0 & - & 4,8 \\
\hline Firma olarak fuarlara yeterince hazırlanamıyoruz. & 1,6 & 36,5 & 14,3 & 36,5 \\
\hline Fazla fayda sağlayamıyoruz. & - & 7,9 & 27,0 & 54,0 \\
\hline
\end{tabular}

Tablo 2: Yurt İçi-Yurt Dışı Fuarların işletmelere katkıları

İşletmelerin ihracat yaparken karşılaştıkları sorunlarla ilgili sorulara verilen cevaplar tablo 3'de yer almaktadır. İhracatta karşılaşılan sorunlara her işletmenin değişik oranlarda katıldıkları görülmektedir. En yoğun karşılaşılan sorunlar; dış pazarlardaki güçlü rakipler, döviz fiyatlarındaki yükseliş, dünya ekonomisindeki olumsuz gelişmeler ve Sivas ekonomisinde piyasa şartlarının olumsuzluğu olarak belirtilmiştir. Ardından girdi fiyatlarının yüksek olması, kalifiye eleman eksikliği, teşviklerin yetersizliği olarak tespit edilmiştir.

\begin{tabular}{|l|c|c|c|c|}
\hline & $\begin{array}{c}\text { Kesinlikle } \\
\text { katılıyorum }\end{array}$ & Katılıyorum & Kararsızım & Katılmıorum \\
\hline İhracattaki yoğun bürokrasi & 25,4 & 33,3 & 19,0 & 22,2 \\
\hline Döviz fiyatlarındaki yükseliş & 7,9 & 69,8 & 17,5 & 4,8 \\
\hline Hammadde girdi fiyatlarının yüksekliği & 17,5 & 50,8 & 14,3 & 17,5 \\
\hline Dış pazardaki güçlü rakipler & 3,2 & 74,6 & - & 22,2 \\
\hline Dünya ekonomisindeki olumsuz gelişmeler & 20,6 & 69,8 & 4,8 & 4,8 \\
\hline Finansman sorunları & 1,6 & 25,4 & 27,0 & 46,0 \\
\hline Pazarlara ulaşmadaki zorluklar & 1,6 & 20,6 & 14,3 & 63,5 \\
\hline Teşviklerin yetersizliği & 19,0 & 39,7 & 12,7 & 28,6 \\
\hline Gümrük sorunları & 12,7 & 36,5 & 1,6 & 49,2 \\
\hline Yabancı dil eksikliği & - & 41,3 & 22,2 & 34,9 \\
\hline Bu alanda kalifiye eleman eksikliği & 12,7 & 58,7 & 3,2 & 23,8 \\
\hline Ulaşım/taşıma sorunları & 4,8 & 34,9 & - & 58,7 \\
\hline Sivas’taki piyasa şartlarının yetersiz olması & 27,0 & 69,8 & - & 1,6 \\
\hline
\end{tabular}

Tablo 3: İhracat yaparken karşılaşılan başlıca sorunlar

Tablo 4'de işletmelerin ihracat teşviklerinden faydalandıkları ve faydalanmadıkları kalemler izlenmektedir. Tabloya göre en fazla fuar desteğinin kullanıldığı izlenmektedir. Fuarlara katılımla ilgili sorulan sorulara alınan cevaplara paralel olarak, teşviklerde de en fazla fuar desteğinden faydalanılması anlamlı bir sonuçtur. Ayrıca KOSGEB'den faizsiz ihracat kredisi kullanan işletmelerin oranı da fazladır. 


\begin{tabular}{|l|c|c|}
\hline & Faydalandım & Faydalanmadım \\
\hline Dahilde İşleme Rejimi & 47,6 & 42,9 \\
\hline İhracat Kredi Garantisi & 28,6 & 67,3 \\
\hline Fuarlar & 79,4 & 14,3 \\
\hline İhracat Seminerleri & 34,9 & 55,6 \\
\hline İhracat Finansmanı & 27,0 & 63,5 \\
\hline Yurt Dışı Ofis-Mağaza Yardımı & 9,5 & 90,5 \\
\hline İstihdam Yardımı & 28,6 & 52,4 \\
\hline Patent ve Endüstriyel Tasarım Yardımı & 38,1 & 49,2 \\
\hline Uluslararası Pazar Araştırmaları & 23,8 & 66,7 \\
\hline Yabancı Alıcılarla Tanıştırma & 33,4 & 57,1 \\
\hline Ticaret Misyonları ve Gezileri & 20,6 & 69,8 \\
\hline Firmaların Ürünlerinin Yurtdışında Tanıtımı & 41,3 & 49,2 \\
\hline Satış Geliştirme Faaliyetleri & 27,0 & 63,5 \\
\hline Türkiye'de Danışmanlık & 14,3 & 76,2 \\
\hline Birebir İhracat Danışmanlığı & 23,8 & 66,7 \\
\hline İhracat Yapılan Ülkede Danışmanlık & 14,3 & 76,2 \\
\hline Test, Analiz ve Kalibrasyon Desteği & 41,2 & 49,2 \\
\hline Çevre Yardımı, Eğitim Yardımı & 38,0 & 52,4 \\
\hline KOSGEB Faizsiz İhracat Kredisi & 60,3 & 33,3 \\
\hline
\end{tabular}

Tablo 4: İ̧sletmelerin İhracat teşviklerinden faydalandıkları alanlar

\section{Sonuç}

Dünya genelinde hemen her ekonomide ekonomik büyümenin sağlanmasında ihracatın önemi artık kabul edilmiş̧tir. KOBİ'ler ise ekonomideki pozisyonları itibarıyla değişimlere çabuk ayak uydurabilen ve bu değişimlerden çabuk etkilenen bir yapı içerisindedirler. İhracat yapan KOBİ’ler bir ekonominin gelişmesinde ve büyümesinde etkin rol oynamaktadır ve dolayısıyla ihracat yapan KOBI'lerin hükümetler tarafindan desteklemesi gereklidir.

KOBI'lerin ihracatta karşılaştıkları sorunlarla ilgili yapılan çalışmalarda ortaya çıkan temel unsurlar; finansman sorunları, bilgi yetersizliği, bürokratik sorunlar, pazar sorunları, teşvik yetersizliği, kota sorunları, hammadde sorunları, bilgi ve veri sorunları, dış talep yetersizliği, nitelikli işgücü sorunları ve üretim, kalite ve standardizasyon sorunları olarak sayılabilir (Kendirli vd.,2003:47, Akgemici, 2001:30, Keski, Koşan, Ayık, 2009, Aktürk ve Şenol; 2010).

Türkiye'de bu alanda yapılan çalışmalarda ihracat yaparken karşılaşılan sorunlar ve yoğunlukları değişim göstermektedir. Daha önceleri pazarlara ulaşım, bilgi eksikliği ya da ekonomik istikrarsızlık daha fazla sorun iken son yıllarda bunların oranlarında azalma olduğu izlenmektedir. Bürokrasi, kalifiye eleman eksikliği, rekabet edebilirlik gibi sorunların ise hala yoğun biçimde yaşandığı belirtilmektedir.

Sivas ile ilgili sonuçlar değerlendirildiğinde dış pazarlardaki güçlü rakipler, döviz fiyatlarındaki yükseliş, dünya ekonomisindeki olumsuz gelişmeler ve Sivas ekonomisinde piyasa şartlarının olumsuzluğu, girdi fiyatlarının yüksek olması, kalifiye eleman eksikliği, teşviklerin yetersizliği olarak tespit edilmiştir. Sivas ölçeğinde yapılan çalışmada ise Sivas'taki işletmelerin özellikle finansman, dış talep eksikliği ve pazarlara ulaşmada daha az yoğun sorunlar yaşaması dikkat çekicidir. Katılımcıların dışardaki işletmelerle rekabet gücünün zayıf olması üretim, maliyet, kalite, pazarlama ve iletişim gibi konularda destek almalarını gerektirmektedir.

Sivas'ta ihracat yapan firmaların dış ticaret politikaları geliştirmeleri ve uygulamaları gerekmektedir. En önemli sorunlar arasında yer alan nitelikli eleman eksikliğinin giderilebilmesi için sanayi ve eğitim kurumları arasındaki işbirliklerinin arttıılması (eğitim programlarının sanayinin ihtiyaçlarına göre düzenlenmesi, işbaşı eğitim ve staj olanaklarının çoğaltılması vb.) gerekmektedir. KOBI'lerin uyum yeteneklerinin arttırılmasına dönük projeler arttırılmalıdır. İ̧̧letmeler arası işbirlikleri (network üretim sistemleri ve dış büyüme yöntemleri) arttırılmalı risk önleyici ve azaltıcı (sigorta sistemleri, pazar çeşitlendirmesi) uygulamalar geliştirilmelidir. 


\section{Kaynakça}

- Akgemci, Tahir, (2001), KOBİ'lerin Temel Sorunları ve Sağlanan Destekler, T.C. Sanayi ve Ticaret Bakanlığı, KOSGEB

- Aktürk, Ahmet ve Hasan ŞENOL, (2010) “Kobi’ler Açısından İhracat Teşviklerinin Önemi Ve Etkinliğinin Arttırılmasına Yönelik Öneriler" Süleyman Demirel Üniversitesi İktisadi ve İdari Bilimler Fakültesi Dergisi C.15, S.2 s.375-391.

- Alpugan, Oktay. (1988). Küçük İşletmeler Kavramı, Kuruluşu ve Yönetimi. Trabzon: Karadeniz Teknik Üniversitesi.

- Awokuse, Titus O. (2007), “Casuality between Exports, Imports, and Economic Growth: Evidence From Transition Economies", Economics Letters, 94.

- Balassa, Bela (1978), "Export Incentives and Export Performance in Developing Countries: A Comparative Analysis", Review of World Economics, Vol: 114, Number:1, March.1978.

- Çelik, Doğan. (2008). Makro İktisada Giriş, (1. Baskı), Trabzon: Murathan Yayınevi.

- Diken,1998: 49

- Edward,S. (1998) “Opennes, Productivity And Growth: What Do We Really Know?”, The Economic Journal, 108:March, ss: 383-398

- Ersungur ve Noyan Yalman, "Bölgesel Kalkınmada İhracat Teşviklerinin Etkinliği: Sivas İlinde Bir Uygulama"2009:82

- Ertugal, Ebru. (2005). Strategies For Regional Development: Challenges Facing Turkey On The Road to EU Membership. Turkish Policy Quarterly, 4, 3, 63-86.

- Eryılmaz, Ünal, "Küçük ve Orta Ölçekli İşletmelerin Dış Ticaret Performansları" Gazi Üniversitesi, Sosyal Bilimler Enstitüsü Seminer Dersi Notları, Ankara 1999.

- http://kobi.tobb.org.tr/(2015)

- $h t t p: / / w w w . t o b b . o r g . t r /(2015)$

- http://www.ekodialog.com/Makaleler/ihracat-stratejisi-makale.html

- Karluk, Rıdvan; Türkiye Ekonomisinde Yapısal Dönüşüm, Beta Yayınları. 2005, İstanbul.

- Kemer, Osman Barbaros (2003), İhracat Teşvikleri, Alfa Yayınları, İstanbul.

- Kendirli, Selçuk, (2003) "Türkiye'deki Küçük Ve Orta Ölçekli İşletme (KOBİ)'lerin İhracat Durumlarına Yeni Bir Çözüm: Elektronik Ticaret Ve Çorum'da Faaliyet Gösteren KOBİ'lere Yönelik Uygulama Örneği", Üçüncü Sektör Kooperatifçilik , 36-59 pp.,

- Keskin, Gülümser, A. Kadir KOŞAN, Y. Ziya AYIK, (2009) "Bölgesel Gelişme Aracı Olarak Kobi'ler ve İhracat Sorunları (Erzurum’da Bir Araştırma)”, Atatürk Üniversitesi Sosyal Bilimler Enstitüsü Dergisi 13 (2): $279-290$

- KOSGEB 2011 - 2013 KOBİ Stratejisi ve Eylem Planı, Ankara 2010

- Kurt, Serdar ve Metin BERBER (2008), “Türkiye'de Dışa Açıklık ve Ekonomik Büyüme”, Atatürk Üniversitesi İ.İ:B.F Dergisi, Cilt:22, Sayı:2.

- Michaely, Michael (1977), "Export and Growth: An Empirical Investigation” Journal of Development Economics, Vol: 4, p:49-53.

- Müftüoğlu, Tamer, (1989) “Türkiye'de Küçük ve Orta Ölçekli İşletmeler”, A.Ü. Siyasal Bilimler Fakültesi, II Bask1, s.35

- Niroomand, Farhang and Edward Nissan (1997), “An Inquiry Into Openness in International Trade”, Journal Economics Studies, Vol:24, No:3.

- Özaslan, Metin. (2005). Recent Local Development Models in Turkey. Turkish Policy Quarterly, 4(3), 121139.

- Scott, Allen J. and Michael Storper (2003), "Regions, Globalization, Development”, Regional Studies, Vol:37, 6\&7, p: 579-593)

- Wu, Yanrui (2004), "Opennes, Productivity and Growth in the APEC Economies" Empiricial Economics, 29: 593-604.

- $\quad$ www.dtm.gov.tr (2015) 


\title{
Kırımda Rus İşgalinden Sonra Rusya'ya Karşı Yaptırımların Ekonomik Sonuçları
}

\section{The Economic Consequences of Sanctions against Russia after the Invasion of Russia in the Crimea}

\author{
Assoc. Prof. Dr. Kutluk Kağan Sümer (Istanbul University, Turkey)
}

\begin{abstract}
The US and EU have imposed economic sanctions on Russia over its annexation of Crimea from Ukraine. Russia's economy has been severely impacted not only by sanctions, which have isolated it from international business and trade, but from the falling oil price which has plummeted around 60 percent since June 2014, hurting its exports and revenues. As a consequence, Russia is expected to enter recession in 2015. The estimated impact of Russia's ban on agro-food imports from the EU imposed in August 2014 is expected to be the highest in the Baltic's. These losses are undoubtedly painful, yet manageable (a trade decline bigger than $10 \%$ would obviously lead to greater losses). Economic conditions in Russia have deteriorated at a faster rate in recent months. Capital flight from Russia has accelerated, the ruble has depreciated by more than $50 \%$, inflation has increased, and the Russian economy is projected to contract by $3.0 \%$ in 2015 . The question is whether these losses are justifiable and will achieve the desired effects - to change Russia's behavior in Ukraine, European Union, US, Turkey and beyond.
\end{abstract}

\section{Giriş:}

Son 20 yılda Doğu Blokunun çöküşüyle beraber dünya dengeleri değişmeye başladı. Sovyetler Birliği gerek Balkan gerek doğu Avrupa gerekse Orta Asya coğrafyasındaki hedeflerinden nispeten vazgeçmek zorunda kaldı. Sovyetler Birliğinden boşalan coğrafyada gerek $\mathrm{AB}$ gerekse $\mathrm{ABD}$ yoğun bir şekilde söz sahibi oldu. $\mathrm{ABD}$ öncelikle orta doğuda söz sahibi olmayı benimserken Avrupa Birliği Doğu Avrupa ve Balkanlarda etkisini arttırdı. Bu etki zaman içinde de Rusya Federasyonunun bölge üzerindeki etki ve çıkarlarını zorlayacak boyutlara ulaşmış oldu. Coğrafyada eski SSCB'den yetişen Rusya'ya bağlı liderler, Rus etnik nüfus ve Rusya'nın daha Sovyetler devrinden hazırladığı nifak tohumları bölgedeki siyasi gerginliği daha da tırmandırmıştır.

Her ne kadar Transdinyester, Abhazya, Güney Osetya, Çeçenistan, Dağlık Karabağ'da bu gerilim yer yer patlak verdiyse de genellikle "Dondurulmuş Çatışmalar (Frozen Conflicts)" sürüp gitmiştir. Bu durum hem Rusya Federasyonu içinde ve dışında birçok yerde mevcuttur. Bundan Orta Asya Türk Cumhuriyetleri, Beyaz Rusya, Baltık Cumhuriyetleri ve Ukrayna da nasibini almıştır. Geçen yirmi yılı en iyi yansıtan cümle belki de Dondurulmuş Çatışmalar (Frozen Conflicts) olmalıdır. Geçen yirmi yılın sonunda bu çatışmaların buzları yavaş yavaş erimeye başlamış dondurulmuş çatışmalar yer yer alevlenmiştir.

Petrol fiyatlarının hızla yükselmesi ile ekonomik problemlerini düzelten Rusya bölgede tekrar söz sahibi olmak istediğinde karşısında bölge kaynaklarını yönetmeye başlamış $\mathrm{AB}$ ve ABD'yi bulmuştur. Tabi ki bu da daha öncede zikrettiğimiz üzere dondurulmuş çatı̧̧maların artık buzlarının çözülmesi anlamına gelmekteydi. Gerek nüfus yoğunluğu, gerek yakın coğrafya olması, gerek kültürel yakınlıklar, gerek Karadeniz donanması gerekse $\mathrm{AB}$ ile en yakın ilişkileri kurmaya çalışan Ukrayna'da öncelikle buzlar eritilmeye başlanmıştır.

Neredeyse iç savaşa varan çatışmalar sonrasında Kiev'de bağımsızlık ve AB taraftarları "Euro Meidan" gösterileri sonrasında Rusya taraftarı Cumhurbaşkanını kaçırarak Ukrayna'da yönetimi ele geçirmiş oldular. Rusya AB ye karşı bir ileri karakolunu kaybetmek üzereydi. Tarihte Rusya'yı Rusya yapan, Avrupa ve Osmanlıya karşı ileri karakol vazifesi gören Ukrayna (Kiev Kıynazlığı) Avrupa'ya yakınlaşmaktaydı. Ukrayna'nın her yerinde etnik Ruslar ve Rusya federasyonu taraftarları çatışmalar yaratmaya başladı. Tarihin tekerrürü olsa gerekirse silahlı çatışmaya en uygun yer Kırım gibi gözükmekteydi. Kırım Harbi Avrupa'nın olduğu gibi Rusya'nın da hafizasında halen çok tazeydi. Etnik nüfus olarak da askeri güç olarak da Rusya'nın en güçlü olduğu yer Kırım'dı. Bölge yakın tarihte etnik arındırılamaya tabi tutulmuş Kırım Tatarlarından temizlenmişti. Onların yerine Rus aileler yerleştirilmiş, Sovyetler devrinde bir dağılma düşünülmediği için Ukrayna'ya bırakılmıştı. Fakat Rusya için stratejik ve romantik açıdan büyük önem arz etmekteydi. Her ne kadar bölgede Ukraynalılar ve özellikle 1987 sonrasında vatanlarına geri dönmeye çalışan Kırım Tatarları varsa da bunlar etnik ve siyasi olarak zayıftı. Kiev'de kaybedilen meydan (Euro Meidan) Kırımda kazanılabilirdi. Kırımdaki etnik Ruslar tetiklendi. Çoğunluğu Rus olan Kırım Bölge parlamentosundan bir Rusya'ya bağlanma kararı çıkarılmaya çalışılmaktaydı. Bu oldubittiye beklenmedik şekilde Kırım Tatarları parlamento önünde etten bir duvar örerek karşı durdular. Maalesef ertesi sabah ağır silahlı birlikler Akmescit (Simferepol) hava alanını ve parlamentoyu işgal ettiler. 16 Mart 2014 de silahların gölgesinde yapılan gayri demokratik oturumda sözde bir Rusya'ya bağlanma kararı çıktı. Rusya zaten fiilen başlamış olan işgali böylece meşrulaştırmak çabasına girişti. Buzlar erimeye başlamıştı Birçok batılı aydına göre bu yeni birçok kutuplu dünya düzeninin ilk habercisiydi. 
Bu kadar sert çatışmalara ve bölgesel kutuplaşmalara sebep olan Kırım’ı mercek altına yatıracak olursak yaklaşık 2 milyon kişilik nüfusunun \%58,32 sinin Rus, \%24 ünün Ukraynal1, \%12,1 inin Kırım Türkü olduğunu görebiliriz.

Kırımdaki Etnik Yapı ve Etnik Guruplar:

Kırım Yarımadası nüfusunun büyük çoğunluğu Rus olmakla birlikte, ülkede Ukraynalılar ve Kırım Tatarları oldukça büyük nüfusa sahiptir. Ruslar: \%58,32; Ukraynalılar: \%24,32; Kırım Tatarları: \%12,1; Beyaz Ruslar: \%1,44; Tatarlar: \%0,54; Ermeniler: \%0,43; ve Yahudiler: \%0,22.

Diğer azınlık grupları: Polonyalılar, Moldovalılar, Azeriler, Özbekler, Koreliler, Yunanlar ve Karadeniz Almanları, Çuvaşlar, Romanlar, Bulgarlar ve Gürcüler'dir.

Ekonomik olarak da çok büyük bir ehemmiyeti olmayan Kırım'ın işgalindeki iki ana sebebin etnik ve stratejik olduğunu söylemek mümkündür. (Sümer; 2012) Sümer aynı makalesinde 2012 yılında bölgedeki etnik ve siyasi tedirginliğin ekonomiye etkilerinden de bahsetmiştir.

\begin{tabular}{|l|l|}
\hline Sanayi & 17,6 \\
\hline Ticaret & 13,6 \\
\hline Taşıma & 10,1 \\
\hline Tarım & 9,7 \\
\hline Emlak & 9,5 \\
\hline Sağlik & 8,3 \\
\hline Kamu Yönetimi & 8,2 \\
\hline Eğitim & 6,1 \\
\hline İnșaat & 5,0 \\
\hline Oteller ve Restoranlar & 4,4 \\
\hline Finans & 3,4 \\
\hline Kamu Hizmetleri & 3,1 \\
\hline
\end{tabular}

Tablo 1: Kırım'da Sektörlerin Katma Değer Üretimi Dă̆llımı (Sümer; 2012)

\begin{tabular}{|l|c|c|}
\hline & Milyon ABD doları & \% \\
\hline Rusya Federasyonu & 298.8 & 40.5 \\
\hline Almanya & 105.4 & 14.3 \\
\hline Kibris & 94.7 & 12.8 \\
\hline Virgin Adaları & 63.1 & 8.6 \\
\hline Birleșik Krallık & 55.6 & 7.5 \\
\hline Sicilya & 31.5 & 4.3 \\
\hline Amerika Birleşik Devletleri & 26.9 & 3.6 \\
\hline Fransa & 26.3 & 3.6 \\
\hline Özbekistan & 21.8 & 3.0 \\
\hline Beyaz Rusya & 13.1 & 1.8 \\
\hline
\end{tabular}

Tablo 2: Kırım ekonomisine doğrudan yabancı yatırım girişi (ülkelerin) (Sümer; 2012)

\begin{tabular}{|l|r|}
\hline & \multicolumn{1}{|c|}{$\mathbf{2 0 1 1}$} \\
\hline Sanayi Ürünleri Satıș Hacmi (Mal ve Hizmet - Milyon Grivna) & $16,665.6$ \\
\hline Hayvansal Ürünler Üretimi (Sivastopol Dahil) & 209.2 \\
\hline Et (Bin Ton) & 329.9 \\
\hline Süt (Bin Ton) & 782.8 \\
\hline Yumurta (Milyon Adet) & $2,218.0$ \\
\hline İnşaat (Milyon Grivna) & $29,254.3$ \\
\hline Perakende Ticaret (Milyon Grivna) & $7,093.6$ \\
\hline Yük Tașıma Hacmi (Km/Ton) & 600.1 \\
\hline Mal İhracatı (Milyon Dolar) & $1,349.8$ \\
\hline Mal İthalatı (Milyon Dolar) & -749.7 \\
\hline Diș Ticaret Dengesi (Milyon Dolar) & $2,263.0$ \\
\hline Ortalama Maaș (Grivna) & $20,500.0$ \\
\hline Kayitlı İșsiz Sayısi (Kiși) & 200 \\
\hline
\end{tabular}

Tablo 3: Kırım Özerk Cumhuriyeti 2011 Yılı Temel Ekonomik Göstergeleri (Sümer; 2012)

\begin{tabular}{|c|c|c|c|c|c|}
\hline Yıllar & İhracat & Değişim \% & İthalat & Değişim \% & $\begin{array}{c}\text { Toplam Dış } \\
\text { Ticaret Hacmi }\end{array}$ \\
\hline 2011 & 55.42 & 48.7 & 34.98 & 27.9 & 90.4 \\
\hline 2010 & 37.26 & 21.5 & 27.34 & 2.2 & 64.6 \\
\hline
\end{tabular}

Tablo 4: 2011 Yılı Türkiye - Kırım Özerk Cumhuriyeti Mal Ticareti (Milyon Dolar) (Sümer; 2012) 
Kırım'ın uluslararası temayüllere uymayan işgali sonrasında AB ve ABD Rusya Federasyonuna karşı çeşitli yaptırımlara girişmiştir. Şimdi ülkeler itibariyle bu yaptırımların boyutunu ve sonuçlarını incelemeye çalışalım.

\section{ABD Açısından Ambargo ve Ekonomik Yaptırımlar}

Rusya Suriye krizi üzerinden Akdeniz ve Ortadoğu üzerinde etkili olmaya başlamıştır. Aynı şekilde Gümrük Birliği, AB komşuluk politikası, enerji kaynaklarına ulaşım konusunda Baltık-Hazar hattında da etkili hale gelmeye başlamıştır. Bütün bunlar tek kutuplu dünya düzeninin yeni hakimi ABD üzerinde uzun zamandır bir tehdit oluşturmaktayd1.

ABD'nin daha önceki Rusya'yı bölmek (Balkanlaştırma) veya kutuplaştırarak iki kutuplu bir dünya oluşturmak (Çevreleme ve Kuşatma) şeklindeki iki stratejiden hangisini seçeceği ile ilgili tereddütler de süre gelmekteydi. Bununla birlikte bu kriz sonrasında:

1- AB-Rusya yakınlaşmasına büyük ölçüde darbe vurulmuştur,

2- Rusya-Almanya yakınlaşmasıyla ABD'den uzaklaşmanın da sonu gelmiş olmuştur,

3-Avrupa'daki barışçıl dost Rusya algısı son bularak eski yayılmacı Rusya algısı güçlenmiştir

Bütün bu gelişmeler ise ABD'nin Avrupa açısından tekrar önem kazanmasına sebep olmuştur. Özellikle Çin'in Rusya'dan yana tavır alması aynı şekilde Kazakistan'ın da bu işgale destek vermesi çok kutuplu bir dünya sistemine geri dönüldüğünün bir başka göstergesidir. Bu süreçte Ukrayna'nın bu yeni dünya düzenindeki yerinin batı olduğu açıktır ki bu Rusya için çok ciddi bir kayıp manasına gelmektedir. Ekonomik olarak Rusya ABD ilişkilerine bakacak olursak:

\begin{tabular}{|l|r|}
\hline Mal Gurubu (HS Kodu) & Milyon Dolar \\
\hline Rusya'ya 5 önemli İhraç Kalemi & 2313 \\
\hline Nükleer Reaktörler, Boylerler, Makine ve Ekipman (84) & 1999 \\
\hline Demiryolu ve Tramvay Harici Araçlar ve Parçaları (87) & 1961 \\
\hline Uçak, Uzay Aracı ve Parçaları (88) & 675 \\
\hline Elektrikli Aletler, Ses ve Görüntü Sistemleri ve Parçaları (85) & 659 \\
\hline Optik, Foto, Tıbbi ve Cerrahi Sistemler (90) & 19458 \\
\hline \multicolumn{2}{|}{$\mid$} \\
\hline Rusya'dan 5 önemli İthal Kalemi & 1640 \\
\hline Ham Petrol v.s. (27) & 1354 \\
\hline Demir ve Çelik (72) & 813 \\
\hline Inorganik Kimyasallar, Radyoaktif Elementler ve Kompostoları (28) & 796 \\
\hline Değerli Madenler (71) & \\
\hline Gübreler (31) & \\
\hline
\end{tabular}

Tablo 5: ABD'nin Rusya'ya İhracat ve İthalatı (2013) Kaynak: U.S. Census Bureau- Global Trade Atlas

Tablo 5'i yakından incelediğimizde ABD'nin Rusya'dan en fazla petrol ürünleri, demir ve çelik aldığ karşılığında ise Nükleer Reaktörler, Boylerler, Makine Ekipmanları ve araç sattığı söylenebilir.

Ambargo kapsaminda ABD:

1- Önde gelen Rus iş adamlarının ve politikacılarının ABD ye girişlerini durdurmuştur

2-Önde gelen Rus firmalarının faaliyetlerini durdurmuştur (Bank Rossiya, Volga Grou v.b.)

3- Belli sektörlerdeki Rus firmalarıyla Finansal ilişkilere sınırlamalar getirmiştir (Rosneft (Petrol) Rostec (Savunma Sanayii), Sberbank (Bankacilık))

4- Petrol ile ilgili ihracat ve proje sinırlamaları

5- Sivil ve Askeri amaçlı Teknoloji (Dual-Use) ihracı sınırlamaları

6- Gıda, Hayvancılık ve Tarımsal ürün sınırlamaları

başlatmış; bu gurup içerisinde ABD, AB, Avusturalya, Kanada, Japonya, Norveç ve İsveç'in takip ettiği ekonomik yaptırımlar konusunda başı çekmiştir.

Rusya'ya verilen zarar kadar kendi ekonomisinin uğradığı zararı da Tablo-5 açıkça ortaya koymaktadır.

\section{Avrupa Birliği Açısından Ambargo ve Ekonomik Yaptırımlar}

Avrupa Birliği aslında krizin tırmanmasında büyük rol sahibidir demek mümkündür. Ukrayna ile Rusya arasındaki çatışma $\mathrm{AB}$ taraftarları ile Rusya taraftarları arasında bir sinir harbi olarak uzun süre sürmüştür. 
Kiev'de Euro Meydan sonrasında kontrolün AB taraftarlarına geçmesinin rövanşı olarak Rusya Kırım'ı işgal etmeyi seçmiştir. AB'ni enerji ihtiyacının çoğunu Rusya'dan karşıladığı düşünülecek olunursa bu AB üzerinde büyük bir risk teşkil etmektedir. Şekil-1 de Rusya'nın bölgedeki Gaz ve Transit boru hatları görülebilir. Aynı şekilde Tablo-6 da Ukrayna üzerinden gelen Rus gazının Avrupa'daki kullanım miktarlarını da görmek mümkündür.

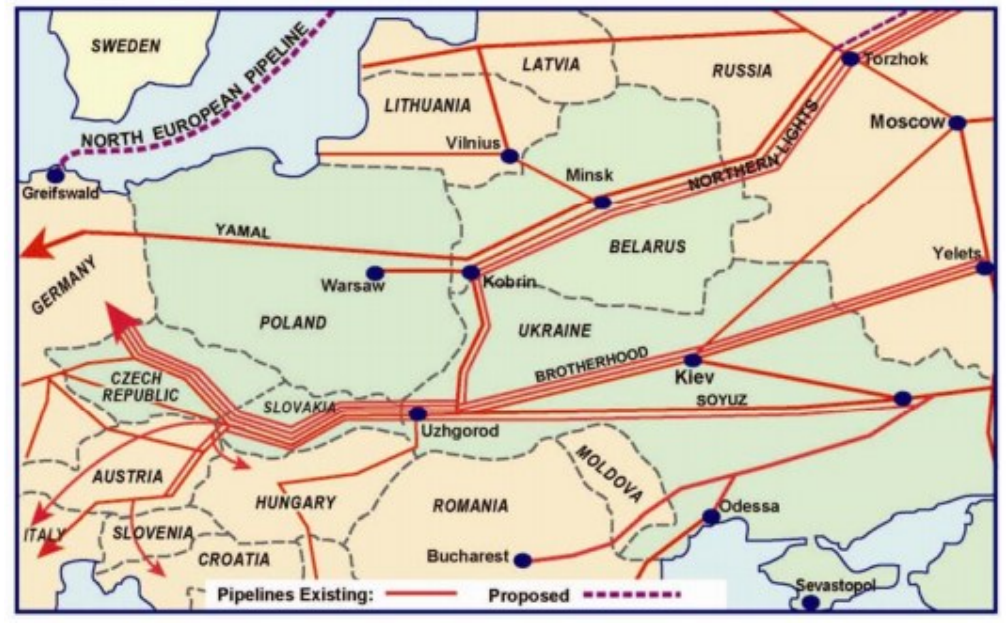

Şekil 1: Rusya'nın Avrupa'daki Gaz Transit Boru Hatları (Pirani, 2014)

\begin{tabular}{|l|c|c|}
\hline & $\mathbf{2 0 1 3}$ & $\mathbf{2 0 1 4}$ \\
\hline İtalya & 25.33 & 15.08 \\
\hline Türkiye & 13.00 & 14.02 \\
\hline Almanya & 22.71 & 21 \\
\hline Çek Cumhuriyeti & 7.32 & 7.28 \\
\hline Macaristan & 6.00 & 5.29 \\
\hline Slovakya & 5.42 & 4.19 \\
\hline Avusturya & 5.23 & 5.22 \\
\hline Fransa & 3.21 & 3.04 \\
\hline Bulgaristan & 2.76 & 2.53 \\
\hline Yunanistan & 2.63 & 2.50 \\
\hline Romanya & 1.19 & 2.17 \\
\hline Sirbistan & 1.16 & 0.74 \\
\hline Slovenya & 0.54 & 0.50 \\
\hline İsviçre & 0.37 & 0.30 \\
\hline Bosna-Hersek & 0.19 & 0.26 \\
\hline Makedonya & 0.04 & 0.08 \\
\hline Toplam & $\mathbf{8 6 . 1 0}$ & $\mathbf{8 4 . 2 0}$ \\
\hline
\end{tabular}

Tablo 6: Ukrayna Üzerinden Avrupa Ülkelerine Yollanan Gaz Miktarlarl (Pirani, 2014)

Aynı şekilde Rusya'nın gıda ihtiyacı üzerinde ise AB önemli bir paya sahipti Kırım'ın işgal edildiği Mart 2014 sonrasında $\mathrm{AB}$ de $\mathrm{ABD}$ gibi bir seri ambargo tedbirlerini seçmiştir. Bunlar:

1 - Bazı önde gelen kişilerin hesaplarının dondurulması

2- Bazı kişilere vize ve giriş çıkışlarının yasaklanması

3- Finansal ve ekonomik ambargo

Tablo-7 de Rusya Federasyonunun gıda ithalatının \% dağılımı görülmektedir. Özetle ambargoyla beraber Rusya'nın gıda piyasasında bir daralma yaşandığı gibi $\mathrm{AB}$ ülkelerinde de bir üretim ve ihraç fazlası oluşmuş oldu. Bu pazar 2013 için 11.8 milyar Avro idi. Bu miktar Avrupa tarımsal gıda ihracatının \% 10 u kadardı. Detayları Tablo-7 ve Tablo-8 de görmek mümkündür. 


\begin{tabular}{|l|r|r|r|r|r|r|r|}
\hline \multicolumn{1}{|c|}{ Ürün } & \multicolumn{1}{c|}{ Et } & \multicolumn{1}{c|}{$\begin{array}{c}\text { Domuz } \\
\text { Eti }\end{array}$} & $\begin{array}{c}\text { Kümes } \\
\text { Hayvanları }\end{array}$ & $\begin{array}{c}\text { Balık ve Deniz } \\
\text { Ürünleri }\end{array}$ & $\begin{array}{c}\text { Süt ve Süt } \\
\text { Ürünleri }\end{array}$ & \multicolumn{1}{c|}{ Sebze } & Meyve \\
\hline Avusturalya & 4.1 & 0.0 & 0.0 & 0.0 & 0.9 & 0.0 & 0.1 \\
\hline Kanada & 0.0 & 11.1 & 0.0 & 4.1 & 0.0 & 0.1 & 0.0 \\
\hline AB & 4.6 & 58.9 & 10.6 & 7.5 & 37.4 & 31.9 & 23.5 \\
\hline Norveç & 0.0 & 0.0 & 0.0 & 39.0 & 0.1 & 0.0 & 0.0 \\
\hline USA & 0.0 & 0.9 & 37.7 & 2.6 & 0.0 & 0.3 & 3.6 \\
\hline $\begin{array}{l}\text { Toplam } \\
\text { Ambargo }\end{array}$ & $\mathbf{8 . 7}$ & $\mathbf{7 0 . 9}$ & $\mathbf{4 8 . 3}$ & $\mathbf{5 3 . 2}$ & $\mathbf{3 8 . 4}$ & $\mathbf{3 2 . 3}$ & $\mathbf{2 7 . 3}$ \\
\hline Dünya & 100.0 & 100.0 & 100.0 & 100.0 & 100.0 & 100.0 & 100.0 \\
\hline
\end{tabular}

Tablo-7: Rusya'nın Toplam Gıda Ithalatından \% Paylar ve Ambargo (European Parliament, 2014)

\begin{tabular}{|l|c|c|c|}
\hline Ülke & $\begin{array}{c}\text { İhracat } \\
\text { Milyon } \\
\text { Avro }\end{array}$ & $\begin{array}{c}\text { Toplam İhracat } \\
\text { İçindeki \% Payı }\end{array}$ & $\begin{array}{c}\text { GSMH } \\
\text { Içindeki \% } \\
\text { Payı }\end{array}$ \\
\hline Litvanya & 910 & 3.7 & 2.6 \\
\hline Norveç & 838 & 0.7 & 0.2 \\
\hline Polonya & 832 & 0.5 & 0.2 \\
\hline Almanya & 554 & 0.1 & 0.0 \\
\hline ABD & 545 & 0.0 & 0.0 \\
\hline Hollanda & 525 & 0.1 & 0.1 \\
\hline Danimarka & 366 & 0.4 & 0.1 \\
\hline İspanya & 338 & 0.5 & 0.0 \\
\hline Finlandiya & 283 & 0.1 & 0.1 \\
\hline Belçika & 280 & 0.1 & 0.1 \\
\hline Fransa & 234 & 0.0 & 0.0 \\
\hline İtalya & 161 & 0.5 & 0.0 \\
\hline Yunanistan & 125 & 0.1 & 0.1 \\
\hline Avusturya & 102 & 0.1 & 0.0 \\
\hline İranda & 89 & 0.1 & 0.1 \\
\hline Macaristan & 76 & 0.1 & 0.1 \\
\hline Estonya & 72 & 0.6 & 0.4 \\
\hline Letonya & 67 & 0.6 & 0.1 \\
\hline Ingiltere & 40 & 0.0 & 0.9 \\
\hline Kıbrıs & 13 & & 0.1 \\
\hline
\end{tabular}

Tablo-8: Rusya Gıda Ambargosu ve AB ülkelerini İhracatına Etkisi (European Parliament, 2014)

$\mathrm{Bu}$ ambargo ve yaptırımların Rusya'ya verdiği zarar kadar AB için de bir tehdit haline geldiği açıktır. AB ihracatındaki daralma açıkça AB'nin üretim düzeyinde bir azalmaya yol açmış bu da AB'deki krizi biraz daha derinleştirmiştir. Üretim azalmasının yanında işsizlik oranı da giderek artmaya başlamıştır. Aynı şekilde AB turizm gelirlerinde de ciddi azalmalar başlamıştır.

Özetle AB ülkelerinin GSYIH'larında Rusya ambargosu sonrasında düşüşler yaşanmaya başlamıştır. AB'nin söz konusu ambargoyu sürdürmesi tablolarda da görüldüğü gibi $\mathrm{AB}$ ekonomisi için de mevcut ekonomik krizi daha da körükleyecek gibi görünmektedir. Üstelik henüz hiç bir gaz kesintisi yaşanmamış ve bir enerji darboğazı doğmamış durumdadır. Rusya elindeki enerji kartını henüz piyasaya sürmemiştir.

\section{Rusya Federasyonu Açısından Ambargo ve Ekonomik Yaptırımlar}

Krizin baş aktörü olan Rusya Federasyonu daha önceki bölümlerde de değindiğimiz üzere dünyanın belli başlı petrol, gaz ve enerji ihraç eden ülkeleri arasında yer almaktadır. 1990'lı yıllarda SSCB'nin yıkılmasından sonra ciddi sıkıntılar yaşamış, bölünmüş, toprak kaybetmiş fakat hali hazırda bölgenin en etkin gücü olagelmiştir. ABD ve $A B$ ile yaşadığı siyasi gerginlikleri bir yana bırakacak olursak söz konusu ekonomik krizden çıkmasında en 
önemli etken petrol ve enerji fiyatlarındaki yükselme olmuştur. (Şekil-2) 2000'li y1llara gelindiğinde petrol fiyatlarının yükselmesi ile birlikte daha da zenginleşmiş; dün bıraktığı eski SSCB ülkeleri üzerinde yeniden etki sahibi olmaya çalışmıştır.

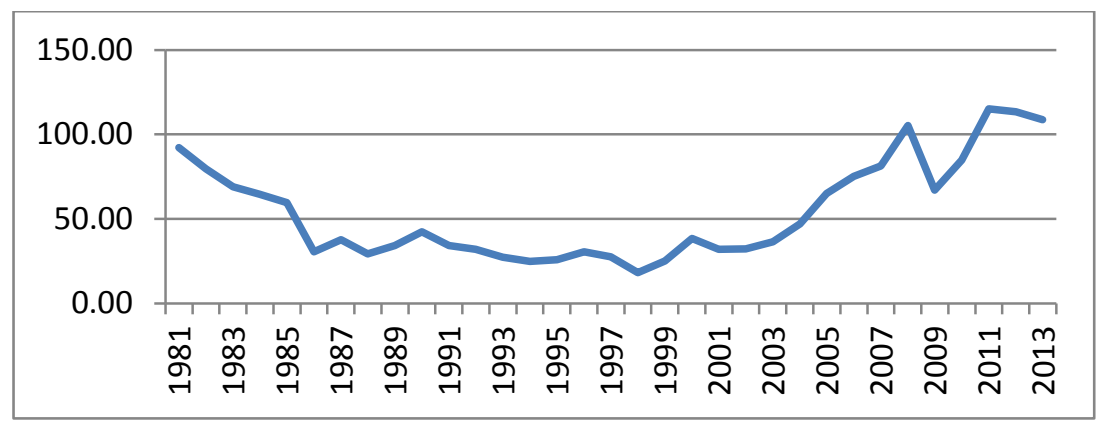

Şekil 2: Petrol Fiyatlarl (BP, 2015)

$\mathrm{Bu}$ esnada ise karşısına artık bölgede söz sahibi olmaya başlayan $\mathrm{ABD}$ ve $\mathrm{AB}$ çıkmıştır. En önemli ihraç maddesi olan enerjiyi özellikle de doğalgazı $\mathrm{AB}$ ülkeleri üzerinde uzun zaman bir tehdit unsuru olarak kullanmış olmakla beraber Ukrayna krizinde AB ile siyasi olarak çatışmayı göze almıştır.

Kırım'ın Mart 2014 tarihinde işgali sonrasında en fazla Rusya ekonomisi bu siyasi kriz ve arkasından gelen ekonomik yaptırımlardan etkilenmiştir. Bu kriz öncesinde Rusya Federasyonunun ekonomik ilişkilerini net bir şekilde Şekil-3 de görebiliriz. Buradan da görüldüğ̈̈ gibi Rusya'nın asıl etkin ticaret ortağı söz konusu kriz sürecine kadar Avrupa Birliği olmuştur. Yabancı sermaye girişleri ve bankacılık sektörü kaynaklarının büyük kısmı AB kaynaklıdır. Şimdi ekonomik yaptırımların ve ambargonun Rusya Federasyonu ekonomisindeki sonuçlarına göz atalım:

Rusya ekonomisi zaten 2009 yllındaki ekonomik krizden ileri derecede etkilenmişti; ardından gelen petrol fiyatlarındaki düşüş Rusya Federasyonu ekonomisini daha da derinden etkiledi. Üretmeyen ve petrol fiyatlarındaki artışla finanse edilen bir ekonomi için şartlar giderek daha da kötüleşmekteydi. 2020 için belli başlı ekonomik hedefler ortaya konulmaya çalışıldı. Bu hedeflerde GSYI'nın \%5-\%10 arttırılması planlanmaktaydı. Oysa 2009 yılında GSYIH \%7,8 düştü. Ardından 2010 da \%4,5 2011 de ise \%4 lük düşš̈şler geldi. 2012 GSYIH'nın yukarıya tekrar yukarıya gitmeye başladığı yıl oldu. \%2,5'luk artışla başlayan bu yavaş geri dönüş 2013 yılında \%1,3 ile devam etti. (Vercueil, 2014)

İçerideki ekonomik kriz 2014 de başlayan siyasi krizlerle birlikte iyice tırmanmaya başladı. Belki de yapılması gereken en doğru hareket popülist politikalardı ki Rusya'da tekrar Rus milliyetçiliğinin tekrar yükselmeye başladığı yıllarda bu yıllar oldu. Fakat bu milliyetçilik klasik anlamda panslavizmden farklı bir Rus milliyetçiliğiydi.

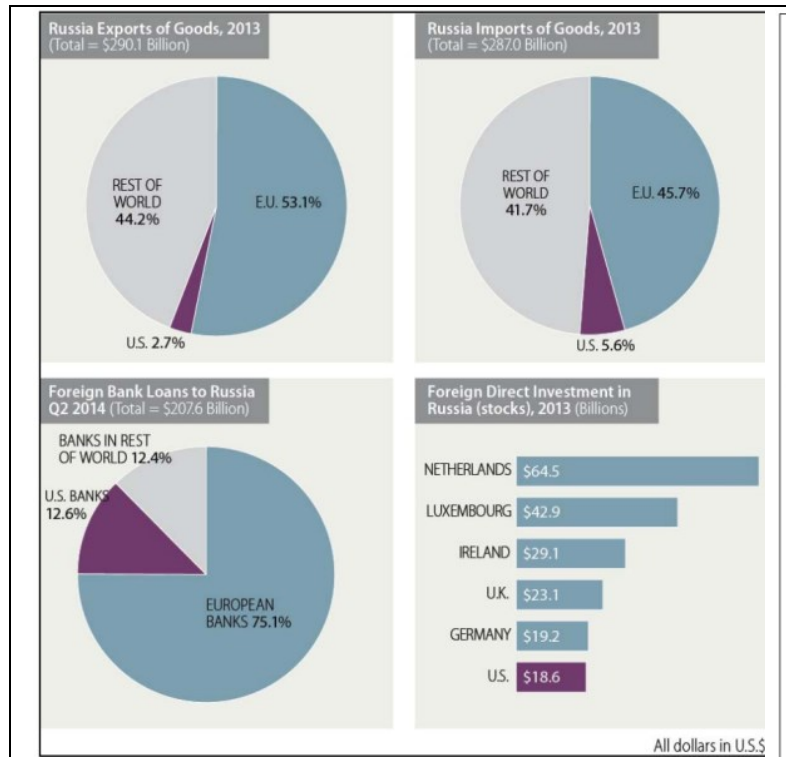

Şekil 3: Rusya'nın Ekonomik İlişkileri (Nelson, 2015)

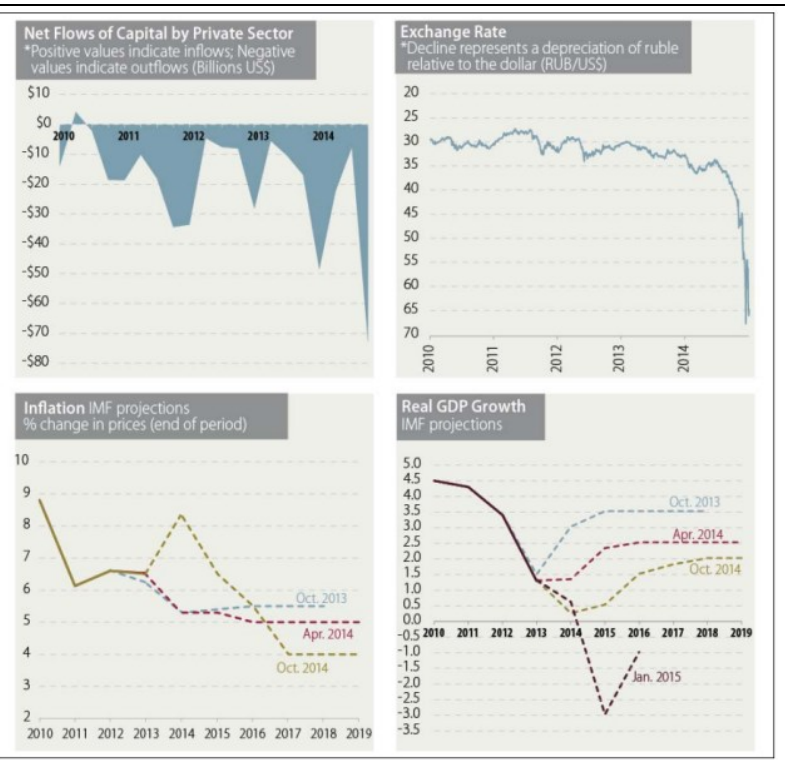

Şekil 4: Rusya'da Ekonomik Trendler (Nelson, 2015)

İlk raunt etkisi: 2014 Martında Rusya'nın Kırım'ı işgali sonrasındaki ambargo ve ekonomik yaptırımların ilk raunt etkisi sermaye girişlerinde oldu. Rusya'ya sermaye girişleri ilk ay olan Nisanda 20 milyar dolar olmak üzere 2014 de 51 milyar dolar düş̧ü (IMF, 2014). Moskova borsası bu uluslararası sermaye hareketlerinden çok 
yakından etkilendi. 3 Mart 2014 de ilk etki \%13,8'lik bir düşüşle oldu. Rusya Merkez Bankasının piyasaya sürdüğü 11.3 milyar dolar eridi (World Bank, 2014). Şekil-5 de Moskova borsası endeksi Micex'in seyrini görmek mümkündür.

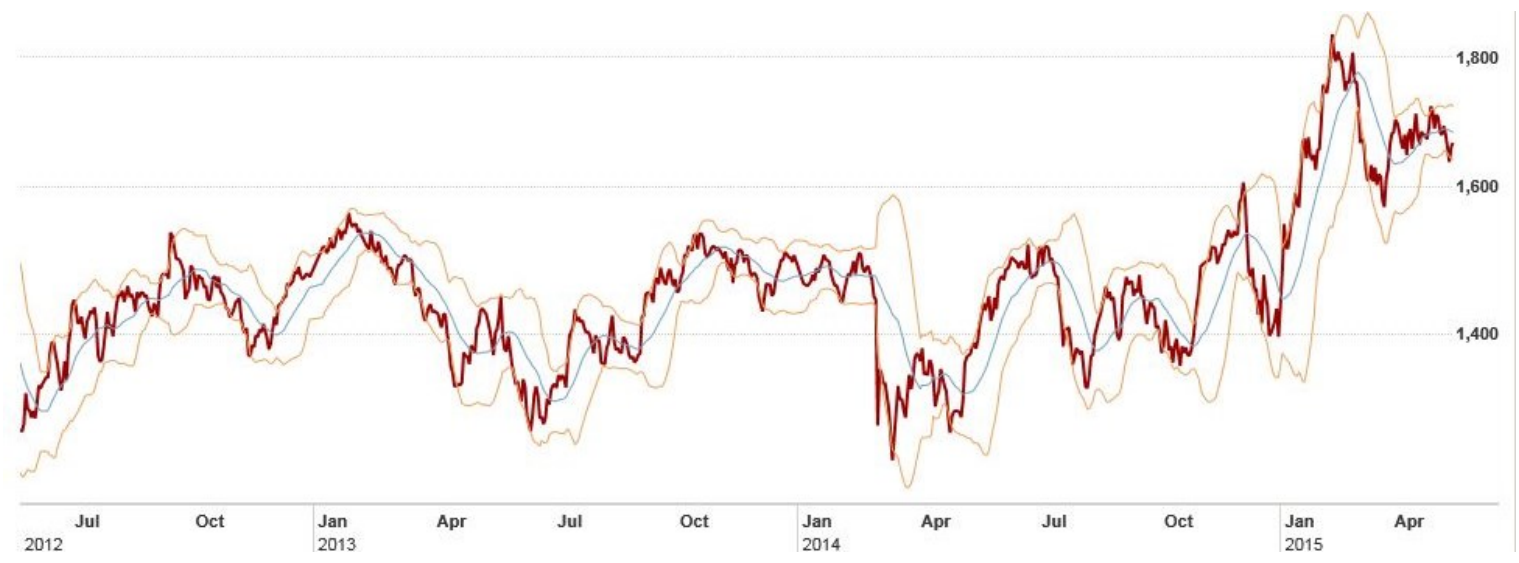

Şekil 5: Rus Borsa İndeksi Micex'in seyri (Bloomberg, 2015)

Bununla beraber 2014'ün ilk çeyreğimde Ruble \%8 değer kaybetti. Bunun \%5,5'i 3 Mart 2014 de oldu. Rusya'da faizler giderek yükselmeye başladı. (Tablo-9)

\begin{tabular}{|l|l|}
\hline & Faiz Oran1 \% \\
\hline 3 Mart 2014 öncesinde & 5.5 \\
\hline 3 Mart 2014 & 7.0 \\
\hline 28 Nisan 2014 & 7.5 \\
\hline 28 Temmuz 2014 & 8.0 \\
\hline
\end{tabular}

Tablo-9: Işgal Esansında ve Sonrasında Faiz Oranları (Central Bank of Russia, 2015)

Íkinci Raunt etkileri: Söz konusu ani düşüş ve yükselişlerin ardından ikinci gurup etkiler gelmeye başladı. Bunlar gerek gıda ambargosuyla ilgili olarak fiyatların yükselmesi gerekse yatırımların düşmesiyle gerçekleşti. İthalat ve İhracat da düşmeye devam etti. Rusya Federasyonu diplomatları ve devlet adamları gıda ambargosu ile ilgili çeşitli yeni kaynaklar bulma gayretine giriştiler. Putin'in Türkiye ziyareti de tam manasıyla bu amaçla gerçekleşti. Bu ziyaret ile ilgili detaylar çalışmanın "Türkiye Açısından Ambargo ve Ekonomik Yaptırımlar" başlığı altında incelenmiştir.

\section{Türkiye Açısından Ambargo ve Ekonomik Yaptırımlar}

Türkiye ile Rusya arasında ambargo öncesi dış ticaret hacmi 35 milyar dolar civarındaydı. Türkiye'de kullanılan doğal gazın \%60'ı da Rusya'dan alınmaktaydı. Rusya'ya ihracatın 2014 öncesi itibariyle toplam değeri yaklaşık 6 milyar dolar iken başlıca kalemleri tarım, tekstil, otomotiv ürünleridir. Ülkemize yaklaşın 4,5 milyon civarında Rusya menşeli turist gelmekteydi. Son 25 yılda Rusya'da üstlenilen inşaat projelerinin toplamı 50 milyar doları aşmıştır. Türk şirketlerinin Rusya'da gıda, içecek, cam, beyaz eşya gibi sektörlerde 10 milyar dolarlık yatırımı da bulunmaktadır.

Ambargo ve ekonomik yaptırımlar sonrasında özellikle tarım ve gıda sektöründe AB yaptırımlarından dolayı ihracatta gelişmeler beklenmiştir. Bununla birlikte gerek ambargo sebepli gerekse diğer sebeplerle çok ciddi değişiklikler olmamıştır. Yine de ambargoyu deldiği için uluslararası kamu oyunda ayıplanan Türk gemileri de mevcuttur.

\begin{tabular}{|l|c|c|}
\hline Sektör & $\mathbf{2 0 0 4}$ & $\mathbf{2 0 1 4}$ \\
\hline Tarım & 12.6 & 17.4 \\
\hline Tekstil & 16.4 & 14.5 \\
\hline Otomotiv & 10.9 & 11.9 \\
\hline B.Y.S. Makine ve Teçhizat & 3.6 & 7.7 \\
\hline Elektrikli Teçhizat & 7.6 & 6.0 \\
\hline Kimyasal Ürünler & 7.6 & 5.8 \\
\hline Giyim Eşyası & 9.8 & 5.6 \\
\hline Fabrikasyon Metal Ürünler & 5.1 & 5.5 \\
\hline Kauçuk ve Plastik & 6.2 & 5.1 \\
\hline Gida & 6.7 & 3.2 \\
\hline Diğer & 13.5 & 17.3 \\
\hline TOPLAM & $\mathbf{1 0 0}$ & $\mathbf{1 0 0}$ \\
\hline
\end{tabular}

Tablo-10: Türkiye'den Rusya'ya yapılan ihracatın sektörel Payı (DTM, 2014) 
Putin'in Ankara ziyaretinden sonra özellikle gaz projeleri ve ortak projeler bağlamında antlaşmalar yapılmıştır. Türkiye Kırım Türklerinin hakları konusunda hassasiyetini belirtmiş fakat herhangi bir yaptırım ve talepte bulunmamıştır. Rusya \%6'lık bir doğalgaz indiriminde bulunsa da Türk yetkililerce bunun \%15 olması talep edilmiş Rusya buna sıcak baktığını fakat karşılığında Akkuyu santralinin vergi oranlarının düşürülmesi gerektiğini deklare etmiştir (Erusam). Toplantıda ortak ticaret bölgelerinin oluşturulması karara bağlanmıştır. 2023'de ticaret hacminin 100 milyar dolara ulaşması temenni edilmiştir.

Bu toplantıda Rusya AB ye karşı bir ileri karakol temin etmeye çalışmıştır. Bununla birlikte bu AB ve ABD'nin ekonomik yaptırımları ve ambargo çerçevesinde pek de makul ve makbul görünmemektedir. Türkiye'nin önündeki seçeneklere gelinecek olunursa:

1- Söz konusu bir Türk-Rus iş birlikteliği

2- Rus yayılmacılığına karşı Türk-ABD iş birlikteliğinin Karadeniz'e taşınması

3- Avrupa Birliği; özellikle de Almanya'nın Rusya’yla yakın ilişki içerisindeki doğu politikasının sona ermesiyle ek bir bölgesel önem kazanılması olarak değerlendirilebilir.

\section{Sonuç:}

2015 ve sonrasındaki gelişmeleri Rusya için geri adım atma, köşeye sıkışma ve çatışma olarak üç senaryo üzerinde toplayacak olursak karşımıza aşağıdaki tablo çıkar:

\begin{tabular}{|c|c|c|c|}
\hline & Geri Adım Atma & Köşeye Sıkışma & Çatışma \\
\hline $\begin{array}{l}\text { 1. Aşama } \\
\text { Askeri ve } \\
\text { Diplomatik } \\
\text { durum }\end{array}$ & $\begin{array}{ll} & \begin{array}{l}\text { Ukrayna'yla çatışmayı } \\
\text { bitirme }\end{array} \\
> & \text { Kirım'ı bırakmak } \\
> & \text { Ukrayna Rusya } \\
\text { ilişkilerinin } & \text { normalizasyonu } \\
& \text { Rusya ve AB } \\
\text { ilişkilerinin } \\
\text { normalizasyonu }\end{array}$ & $\begin{array}{ll}\quad \text { İşgal halini } \\
\text { dondurmak } \\
>\quad \text { Ateşkesle Yetinmek }\end{array}$ & $\begin{array}{l}\text { Donbass ve diğer } \\
\text { Ukrayna şehirlerinin } \\
\text { işgali } \\
\text { Batılı güçlerin } \\
\text { Ukrayna'ya askeri } \\
\text { destek vermesi }\end{array}$ \\
\hline $\begin{array}{l}\text { 2. Aşama } \\
\text { Ambargo ve } \\
\text { Kontr önlemler }\end{array}$ & $\begin{array}{l}\text { Ambargonun kalkması } \\
\text { ve maddi yardımlar } \\
\text { Gıda girişinin } \\
\text { sağlanması }\end{array}$ & $\begin{array}{l}\text { Süren ambargo ve } \\
\text { yaptırımlar } \\
>\quad \begin{array}{l}\text { Rusya'nın yeni ithal } \\
\text { arayışları }\end{array}\end{array}$ & $\begin{array}{l}\text { Enerji sektörü ambargo } \\
\text { ve tedbirleri } \\
\text { Gasprom'un Avrupa } \\
\text { ülkelerine gaz } \\
\text { dağıtımını durdurması }\end{array}$ \\
\hline $\begin{array}{l}\text { 3. Aşama } \\
\text { Sektör spesifik } \\
\text { makro ekonomik } \\
\text { etkiler }\end{array}$ & $\begin{array}{ll}> & \text { Gida tüketiminin temini } \\
& \text { Uluslararası Rus } \\
& \text { hammaddelerine } \\
& \text { taleplerin artması } \\
> & \text { Rus firmalarına } \\
& \text { uluslararası fon temini } \\
> & \text { Yabanc1 yatırımların } \\
\text { artış1 }\end{array}$ & 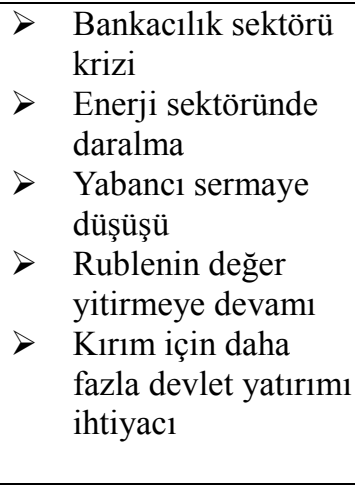 & $\begin{array}{ll}> & \begin{array}{l}\text { Rusya ve Avrupa'da } \\
\text { tüketimin azalması }\end{array} \\
> & \begin{array}{l}\text { Rusya'nın finansal } \\
\text { sisteminin çöküşü }\end{array} \\
> & \begin{array}{l}\text { Rublenin şiddetli } \\
\text { düşüşü ve }\end{array} \\
\text { konvertibilitesini } \\
\text { yitirmesi }\end{array}$ \\
\hline $\begin{array}{l}\text { 4. Aşama } \\
\text { Genel Ekonomi }\end{array}$ & $\begin{array}{ll}> & \text { Tüketim artış1 }(\% 2-\% 7) \\
& \begin{array}{l}\text { Devlet Bütçesinde } \% 5 \\
\text { daralma }\end{array} \\
> & \text { Faiz haddinin kriz } \\
& \text { öncesi } \% 5,5 \text { e dönmesi } \\
> & \text { Rublenin değer artışı } \\
& (\% 15) \\
>\quad & \text { Yatırımlar Stagflasyon } \\
& (\% 0) \\
> & \text { İthalat }(\% 4) \\
> & \text { İhracat }(\% 0) \\
> & \text { Enflasyon }(\% 8)\end{array}$ & $\begin{array}{ll}> & \begin{array}{l}\text { Tüketim erozyonu } \\
(-\% 2)\end{array} \\
> & \begin{array}{l}\text { Devlet Bütçesinde } \\
\% 15-\% 20 \text { daralma }\end{array} \\
> & \text { Faiz haddi }(\% 8-\% 9) \\
> & \text { Rublenin değer } \\
& \text { kaybı }(\% 10-\% 20) \\
> & \text { Yatırımlar }(-\% 5) \\
> & \text { İthalat }(-\% 10-\% 15) \\
> & \text { İhracat }(-\% 5) \\
> & \text { Enflasyon }(\% 8- \\
& \% 10)\end{array}$ & $\begin{array}{ll}> & \begin{array}{l}\text { Tüketim çöküşü } \\
(-\% 10)\end{array} \\
>\quad & \begin{array}{l}\text { Devlet Bütçesinde \%20- } \\
\text { \%30 daralma }\end{array} \\
>\quad & \text { Faiz haddi }(\% 10-\% 15) \\
>\quad & \text { Rublenin değer kaybı } \\
& (\% 20-\% 30) \\
>\quad & \text { Yatırımlar Keskin düşüş } \\
& (-\% 20) \\
>\quad \text { Itthalat }(-\% 20-\% 30) \\
>\quad \text { Ihracat }(-\% 20) \\
>\quad \text { Enflasyon }(\% 20-\% 25)\end{array}$ \\
\hline
\end{tabular}

Tablo-11: Gelecek Senaryoları 
Bütün bu senaryoların ekonomik sonuçlarını özetleyecek olursak Rusya ekonomisi aşağıdaki tablodaki hali alacaktır.

\begin{tabular}{|l|c|c|c|c|}
\hline & Yatırımlar & $\begin{array}{c}\text { Mali Denge } \\
(\% \text { GSYIH) }\end{array}$ & $\begin{array}{c}\text { GSYIH } \\
\text { Değişimi } \%\end{array}$ & $\begin{array}{c}\text { İhraç edilen bir varil petrolün 80 } \\
\text { doların altına düşmesi etkisi }\end{array}$ \\
\hline Geri Adım Atma & $+\% 2$ & $-\% 2$ & $+\% 3$ & -80 milyar \$ \\
\hline Köşeye Sıkışma & $+\% 0$ & $-\% 5,5$ & $+\% 1$ & -75 milyar $\$$ \\
\hline Çatışma & $-\% 6$ & $-\% 14,5$ & $-\% 3$ & -65 milyar $\$$ \\
\hline
\end{tabular}

Tablo-12: Gelecek Senaryolarl

Rusya açısından senaryolarını incelediğimiz mantıkla AB ve ABD'yi de inceleyecek olursak özellikle AB'nin gerek turizm, gerek ihracat, gerek büyüme, gerekse işsizlik açısından Rusya'yla aynı durumda olacağı ve benzer senaryoların yaşanacağı söylenebilir.

ABD ise iki kutuplu bir dünya düzeninde Avrupa Birliğine ve Rusya'ya karşı 1990 öncesi tavırlarına ve politikalarına geri dönecektir. Kırım'ın işgali dünyayı muhtemel bir ikinci Kırım harbine doğru sürüklemektedir. Türkiye'nin Kırım Türklüğüne karşı tavrı da ilk Kırım Harbindekinden çok da farklı değildir. Bu bağlamda dış politika açısından birinci Kırım harbinden farklı davranmayan Türkiye'nin karşılaşacağı muhtemel sonuçlar da birinci Kırım harbinden farklı olmayacaktır.

\section{Kaynakça}

- Central Bank of Russia. 2013. Guidelines for the Single State Monetary Policy in 2014 and for 2015 and 2016. Moscow: The Central Bank of the Russian Federation, November 2013.

- IMF. 2014. Russian Federation: IMF Country Report Nº14/175. Washington, D.C.: IMF, July 2014. www.imf.org

- Nelson Rebecca M.; U.S. Sanctions on Russia: Economic Implications; Congressional Research Service; February 4, 2015

- OCDE. 2014. "Russian Federation.” OECD Economic Surveys, January 2014. Paris: OCDE

- Pirani S. , Henderson J , Honoré A, Rogers H., and Yafimava K., " What the Ukraine crisis means for gas markets"; Oxford Energy Comment; Oxford Institute for Energy Studies; March 2014

- $\quad$ Sümer K.K., "Investment Potentials Of The Crimean Peninsula", International Conference on Eurasian Economies, KAZAKISTAN, 11-13 October 2012; http://avekon.org/papers/550.pdf

- The EU and Russia: Before and beyond the crisis in Ukraine; Hous of Lords; Europian Union Committee 6th Report of Session 2014-15; London; HL Paper 115

- The Russian Embargo: Impact on the Economic and Employment Situation in the EU; Employment And Social Affairs Breefings; Policy Department A: Economic and Scientific Policy; European Parliament; 2014

- U.S. Census Bureau- Global Trade Atlas; Çevrim İçi:https://www.census.gov/foreigntrade/reference/products/catalog/stateweb.html (26.6.2014)

- Vercueil Julien; "The impact of sanctions on the Russian economy. Assessing the consequences of the Ukrainian conflict"; L'Observatoire CCI Franco-Russe, No: 9, November 2014

- World Bank. 2014. “Confidence Risk Exposes Economic Weakness.” Russian Economic Report, n³1, March 2014. www.worldbank.org

- Zhavoronkov, S. 2014a. "Political and Economic Results of March 2014." Russian Economic Trends, no. 4, April 2014, p. 1-4. 


\title{
Rus Dış Politikasında Sibirya Faktörü: Ekonomik Araçlar ve Jeopolitik Oyunlar
}

\section{The Siberian Factor in the Russian Foreign Policy: Economic Instruments and Geopolitical Games}

\author{
Prof. Dr. Erhan Büyükakıncı (Galatasaray University, Turkey)
}

\begin{abstract}
In this paper, we try to discuss how the Siberian part of the Russian territory can present advantages and disadvantages for Russian foreign policy. Situated in the center of the Eurasian geography, Siberia offers many economic opportunities and energy reserves as well as a strategic value for Russia, whose population and interests are mostly concentrated in the western provinces. Long considered as an isolated continent for exile for political dissidents, Siberia has become nowadays a center of the economic strategies of the Russian administration, in relation with its foreign policy perspectives. As an energy source for natural gas and oil and transit corridor toward China and Kazakhstan, Siberia is now supported through governmental policies of restructuration and labour migration. This new perspective can lead to a new policy of regionalism in connection with foreign policy interests. For the federal center, there is an unavoidable correlation between the domestic and foreign policy stakes with Siberia's integration in world and regional politics.
\end{abstract}

\section{Giriș}

Dünya tarihi genel olarak Batı uygarlığının yönelimlerinin ve girişimlerinin tarihçesi olarak yazılagelmiştir; bu yayılmacı politikalar ağırlıklı olarak ekonomik ve askeri araçlarla gerçekleştirilmeye çalışılmıştır. Nasıl 19. yüzyılda Afrika kıtası Avrupalılar için ekonomik hedeflerin merkezi olmuşsa, günümüzde benzer kolektif bir "hücum süreci"ni Asya kıtası için gözlemliyoruz. İmparatorluklar çağının gözdesi Afrika kıtası artık yerini küresel siyaset ve ekonomik ilişkiler bağlamında daha farklı bir çerçeveye bırakmış durumdadır. Günümüz uluslararası ilişsilerinde "Doğu'ya Yolculuk" deyimi, eskiden olduğu gibi nostaljik ya da maceracı bir kullanımdan çok artık Batı'nın önem verdiği insan hakları ve demokratik hak ve özgürlükler gibi temel siyasal ve hukuksal değerlerin kapsam dışında bırakılarak, tamamen ekonomik çıkarlara odaklı bir içeriğe sahiptir. Bu coğrafyanın temel aktörlerinden Rusya da günümüzdeki bu sürece ayak uydurmuş durumdadır; nitekim bu yaklaşım kendi siyasal arayışları ve gereksinimleriyle de uyumlu görünmektedir. Hem Avrupalı hem Asyalı bir ülke sıfatıyla Rusya'nın dış politikasındaki bu "Doğu'ya Yolculuk" arayışı bir yandan uluslararası konjonktürdeki değişimlerle uyumludur, öte yandan da kendi ekonomik kalkınma ihtiyaçlarını tamamlamak açısından önemli bir araçtır.

Rusya'nın 2013 tarihli Dış Politika Konsepti'ne baktığımızda, "jeopolitik bir alanda büyük değişimler", "uluslararası ilişkilerde çok-merkezli bir sistemin yaratılması" ve "Asya-Pasifik bölgesi merkezli Doğu'ya kayan küresel güç ve kalkınma potansiyeli” vurgularını görmekteyiz. Birçok konuşmasında, Rusya Cumhurbaşkanı V. Putin'in ulusal ekonomide Çin rüzgârından büyük ölçekli yararlanılması, Sibirya ve Rus Uzakdoğusu'nun bu yollarla kalkındırılması ve "Yeni Asya"daki dinamik bütünleşme sürecine Rusya'nın yapısal araçlarla daha da katılım göstermesi gibi noktalar vurgulanmaktadır. Her ne kadar Rus topraklarının üçte ikisi Uralların ötesinde yer alırken, Rus kimliğinin tarihsel ve pratik merkezi hep Avrupa coğrafyası (Rusya Ana söylemi) olmuştur. 2014 Ukrayna krizinden sonra Moskova'nın Asya eksenli dış politika üzerinde yoğunlaşması, ekonomik girdabı atlatmak ve uluslararası sistemde etkin rol oynamayı sürdürmek açısından Rusya için tek çıkış yolu olmuştur. Rus dış politikasında artık açıkça dile getirilen "Povorot na Vostok" (Doğu'ya Dönüş) söyleminin ne kadar gerçekçi ve tüm araçlarıyla uygulanma şansının olabilirliği tartışılabilir, ama şu noktayı vurgulamak gerekir ki Avrasyacı bir dış politika söylemi güden bir ülke açısından bu doğal bir tartışma sürecidir (Lukyanov, 2010).

Bu çalışmamızda Rusya'nın yeni “Doğu'ya Yolculuk” politikası çerçevesinde Sibirya coğrafyasının getirdiği avantajları ve dezavantajları tartışmak istiyoruz. Ekonomik kalkınma, nüfus politikaları ve demokratik yönetim anlayışı açısından yüzyıllardır Batı'daki Rusya Ana söyleminin dışında kalan Sibirya ve Uzakdoğu toprakları, artık bir sürgün ya da tecrit bölgesi olmanın dışında yeni keşiflere açık duruma gelmektedir. Bu açıklık sadece Moskova yönetiminin burayı yeniden keşfetmesi sürecini değil aynı zamanda dış aktörlerin de bu bölgelere ilgi duymalarının sonucunu getirmektedir. İşe bu çerçevede Sibirya ve Uzakdoğu bölgeleri, Rus dış politikasında belirli firsatları doğurduğu kadar da endişe noktalarını da sunmaktadır.

\section{Rusya'dan Sibirya ve Uzakdoğu'ya Bakış}

Ruslar tarafından 17. yüzyıl itibariyle tamamen fethedilen Sibirya'ya Çarlık Rusya'sı ve Sovyetler Birliği yönetimleri uzaktaki bir "sömürge" gözüyle bakmışlardır. Merkezdeki yönetici seçkinlerin bu coğrafyaya olan bakışı zamanla bölge zenginliklerinin merkezi beslemeye yönelik bir gelir kaynağı olarak görülmesini de 
beraberinde getirmiştir. Rusya topraklarının Uralların ötesinde kalan kısmını üç coğrafi ve ekonomik bölümlendirmeyle ele alıyoruz: Batı Sibirya (Novosibirsk merkezli), Doğu Sibirya (İrkutsk merkezli) ve Uzakdoğu (Vladivostok merkezli) bölgeleri; ancak günümüz terminolojisinde Sibirya ve Uzakdoğu adları çoğunlukla birlikte kullanılıyor.

Merkez tarafından bölgeye yapılan ilk ciddi yatırım, 19. yüzyılın sonlarında ancak inşasına başlanan ve 1904 yılında tamamlanan Trans-Sibirya demiryolu hattı olmuştur. İlkin 6.000 mil uzunluğunda olarak inşa edilen ve Moskova-Vladivostok kentleri arasında işleyen bu hattın 1956 yılında güneye doğru genişlemesiyle Moskova ile Çin'in başkenti Pekin de birbirine demiryolu ile bağlanabilmiştir. Bu demiryolu, tarihsel süreçte Moskova'nın bölgeye en önemli yatırımı olmasının ötesinde, hat üzerindeki şehirlerin gelişimine sunduğu sosyo-ekonomik katkı nedeniyle de önemlidir. 20. yüzyılda bölgeye olan nüfus hareketleri gerek 1930'ların zorunlu endüstrileşme hamleleri gerekse siyasi mahkûmların aktarılması açılarından olsun ancak Trans-Sibirya demiryolu hattının varlığıyla mümkün olabilmiştir. Geçtiği şehirlerde kümelenme ve idari bağlantı sağlayan hat, Moskova açısından bölgeyi kontrol etmek ve ekonomik etkinlikleri düzenlemek açılarından oldukça işlevsel bir rol üstlenmiştir.

Günümüz Rusya’sının gündeminde Trans-Sibirya hattı 21. yüzyıl perspektifleri açısından bölgenin iktisadi kalkınmasında farklı bir rol oynayacak "sınır ötesi”" bir hat olarak da görülmektedir. Bu hattın modernleştirilerek özellikle yük taşımacılığında kapasitesinin artırılması projesi her geçen gün daha fazla tartışılmaktadır. Öyle ki Çinli üreticilerin Avrupa pazarlarına ulaşımında bu hattın kullanımı, Süveyş Kanalı üzerinden yapılan taşımacılığı iki hafta kısaltarak, hem üretici/tüketiciler hem de transit gelirleri artıracağından Rusya açısından büyük bir dinamizm sağlayacaktır (Zamyatina, 2013).

Tarih boyunca uzun süre sürgün yeri olarak görülen bu bölgenin büyük ölçekte sanayi ile ilk tanışması 1930'larda "Gulag" sistemi ve Moskova ile batısında yer alan endüstriyel tesislerin II. Dünya savaşı sırasında Alman tehlikesi nedeniyle Uralların ötesine taşınması tercihiyle yapılan zorunlu yer değiştirme politikalarıyla mümkün olmuştur. Gulag sistemi, Stalin'in SBKP Genel sekreterliği döneminde, 1930'lu yıllardan başlayarak NKVD (Sovyet İç İstihbarat Birimi) tarafından yönetilen, ağırlıkla ağır cezalılar ve politik mahkûmların buralara sürülerek ağır koşullarda zorla çalıştırıldıkları bir sürgün/tecrit ve toplama kampları politikasıydı. Yine II. Dünya savaşı sırasında Alman ordularının o zamanlar Sovyetler Birliği’nin neredeyse tüm petrol ihtiyacını karşılayan Bakü kaynaklarına ulaşma hamlesi Stalingrad Muharebesi’yle bu korku kâbusa dönüşmekten son anda kurtulmuş ve savaş sonrası tek kaynağa bağlanma riskini dağıtmak isteyen Sovyet planlamacıları ülkenin enerji güvenliği için Sibirya' daki rezervleri ön plana almışlardır.

1991 'de Sovyetlerin yıkılması bölgeyi de derinden sarsmıştır; endüstri üretiminin yaşadığı genel çöküş ve yapısal dönüşüm bölgenin demografik yapısını da derinden etkilemiştir. Öyle ki SSCB'nin dağılmasından hemen sonra 8 milyon insana ev sahipliği yapan Rus Uzakdoğu'sunun nüfusu \% 25'lik bir kayıla 2014 itibariyle 6,2 milyona kadar düşmüştür. 2002-2010 nüfus sayımlarını da karşılaştırırsak Sibirya ve Uzakdoğu federe bölgesinin nüfusunun 27,2 milyondan 25,6 milyona düştüğünü görmekteyiz (Rusya Federal Nüfus İstatistikleri Birimi, 2014).

Seneler boyunca Moskova merkezli hükümetler, Sibirya ve (Rus) Uzakdoğu (RUD) bölgelerinin zenginliklerini kendileri için bir gelir kapısı olarak görmüş, ancak buna karşın hiçbir zaman bu bölgelerin Rus ekonomisi ve siyasetinde merkezi bir konuma gelmesine izin vermemiştir. Bu bölgelerin Rus ekonomisine katkılarının istatistiksel değeri bile düşük gösterilmektedir. Devlet güdümlü Rus enerji şirketlerinin kayıtlı oldukları merkez Moskova'da gözükmesinden ötürü, bu bölgeler Rusya Federasyonu (RF) toplam ihracatının aslında \% 70'inden fazlasını yapmalarına rağmen bu oran istatistiklerde \% 10 olarak geçmektedir (Inozemtsev, 2013). Makalemiz genelinde bu iki bölgeyi tek bir kombine bölge olarak değerlendireceğiz. Bölgenin makus talihi günümüzde kısmen devam etse de 21. yüzyılla birlikte bu durum değişmeye başlamıştır. Bunun temel sebebi ise Rusya dışı bir faktördür: Dünya iktisadi ve siyasal sistemik merkezinin Atlantik’ten Asya-Pasifik'e doğru kayması olgusu (Gunder Frank, 1998).

Yeltsin'li yıllarda olan yürürlüğe konulan her türlü akım (ekonomide liberalleşme, siyasette adem-i merkezileşme, özelleştirmeler), 2000'li yıllarda tamamen tersine dönerken Sibirya kaynaklarını içeren enerji sektörü de merkezi yönetimin hedeflerinin başında gelmiştir. Putin KGB yıllarından beri ekip olarak çalıştığ İgor Seçin gibi isimleri beraberinde Kremlin'e taşırken bunlara oligarklarla aktif mücadele talimatı vermiştir. Bunun yanı sıra, ekonominin yeniden yapılandırılmasında petrol ve doğal gaz en önemli kaynaklar olarak değerlendirilmiş ve bu çerçevede Volga havzası, Yamal-Nenets, Hansi-Manti bölgeleri gibi hidrokarbür üretim merkezleri tamamen işletilmeye açılarak Rus ekonomisinin küresel piyasalar koşullarına uygun bir biçimde güçlendirilmesi sağlanmıştır. Nitekim Yeltsin'li yılların dış borçları bu vesileyle tamamen ödenmiş ve Rus ekonomisi ve savunma sanayi yeniden yapılanma firsatı bulmuştur.

Bu dönüşüme paralel olarak dünyadaki iktisadi merkezin Asya-Pasifik'e kayması ile birlikte Moskova'daki karar alıcılar açısından Sibirya ve Uzakdoğu bölgeleri farklı bir ölçekte değerlendirilmeye başlanmıştır. Bunun neticesinde Rusya tarihinde ilk defa bölgenin kalkındırılmasına yönelik geniş kapsamlı çalışmalar başlatılmış ve bölgesel kalkınmanın organizasyonun eşgüdüm altında yürütülebilmesi için 21 Mayıs 2012 tarihinde müstakil "Rusya Federasyonu Uzakdoğu Kalkındırma Bakanlığı” bile kurulmuştur. Zira Sibirya ve RUD’un artık RF için 
en önemli bölge olduğu ve bu bölge kaynakları olmadan ne Rus ekonomisinin modernleştirilebileceği ne de Asya-Pasifik pazarlarına açılmaksızın Rusya'nın dünya gücü konumunu koruyabileceği gerçeği yatmaktadır.

Öte yandan, Rus uzmanların bölge üzerinden dış politika açılımları ve bu yöndeki fikirleri 2000'li yılların başından beri büyük bir tartışma konusudur. RF'nin ancak bölge sayesinde Asya-Pasifik ve dolayısıyla dünya siyasetinde varoluşunu idame ettirebileceği saptamaları da bu kapsama dâhildir. Hatta ABD'nin Kaliforniya örneğinde olduğu gibi kendi "vahşi Batı"sı üzerinden Asya-Pasifik ekonomilerinde etkin olmasına benzer bir şekilde, RF'nin de bu bölgeler üzerinden bunu yapması gerektiği, bunun için de bölgenin öncelikle jeoekonomik açıdan ele alınması gerektiği yazılıp çizilmiş ve buranın "Yeni bir Kaliforniya" ya dönüştürülme projesi bile ortaya atılmıştır (Kudinov, 2001). Son yıllarda bölgesel kalkınma adına altyapı yatırımlarını da içeren iki strateji belgesi kabul edilmiştir: Bunlar 2011 tarihli Sibirya Federal Bölgesi (2011) ve 2010 tarihli Uzakdoğu Trans-Baykal Bölgesi Kalkınma Planları'dır (Kapsamlı bilgi için bkz. Seliverstov \& Melnikova, 2013: 96-102). Ne var ki bu strateji belgelerinde vurgu yine devlet eliyle kalkınma olmuştur ve özel sektör yatırımlarının bölge kalkınmasında yer alması firsatı henüz öncelik dahilinde değildir (Aleschenko, Nedelea, Nedelea, 2009).

\section{Bölgenin Jeo-Ekonomik Avantajları}

Batı Sibirya kalkınmışlık bakımından Doğu Sibirya ve Uzakdoğu bölgesine göre daha ileri bir konumdadır. Özellikle Yamal-Nenets bölgesini içermesiyle gelir kaynakları açısından epey zengin olan Batı Sibirya'nın gelişmişlik sorunlarının Rusya'nın St. Petersburg ve Moskova gibi merkezlerinin dışında kalan geniş kesimleriyle paralellik göstermesi bu açıdan şaşırtıcı değildir. Doğu Sibirya ve Uzakdoğu bölgelerinin kalkınma sorunları ise başlı başına bir vaka olarak üzerinde ayrıntıyla durulması gereken bir meseledir. Bugün için iktisadi açıdan bölgenin Asya-Pasifik piyasalarındaki mukayeseli üstünlüğü enerji ve maden alanlarındaki rezervlerdir (Barabanov \& Bordachev, 2012).

Sibirya gibi geniş bir coğrafyanın tamamının kalkındırılması kısa ve orta vadede mümkün olmadığından Rus yönetimin elinde önemli kozlar bulunmaktadır; bu olumlu faktörler arasında ise aşağıdaki hususları sayabiliriz:

a) Son yıllarda Moskova'nın Sibirya ve RUD'sunu kalkındırmak için ciddi emek sarf etmesi ve kaynakların kullanımını etkili hale getirebilmek için devlet yapısında ayrı bir bakanlık bile kurmuş olması;

b) Coğrafi konum olarak dünyanın iktisadi merkezinin kaydığı Asya-Pasifik Bölgesine olan yakınlık. Asya'da artan refahla beraber artacak talebi karşılamada bölgenin avantajlı bir konuma sahip olması ve bu olgu karşısında geliştirilen hem transit hem de üretim projelerinden faydalanılması;

c) Bölgenin dünyanın en önemli ve henüz keşfedilmemiş hidrokarbon kaynaklarının (doğal gaz, petrol) ve diğer madenlerine (demir, altın, nikel) sahip olması. Sanayi üretiminin enerji talebini mutlaka çekeceği iktisadi kuralı kabul edildiğinde bölgenin akıllı yönetilirse Asya pazarlarının bu talebini yüksek katma değerle karşılayabilme potansiyeli;

d) Tarımdan, madenciliğe, ağır sanayiden, ormancılığa, balıkçılıktan altyapı yatırımlarına kadar bölgenin dünya pazarlarında rekabet edebilecek birçok farklı ekonomik sektöre ev sahipliği yapıyor oluşu;

e) Bölgenin ulaştırma ve enerji naklinde transit bir merkez olma durumu. Gerek mal gerekse artan ticaretle birlikte insan ve yük taşımacıllğında ülkenin hizmet sektörüne yük sunulacak katkı potansiyeli;

f) Bölgenin verimlice kullanılamayan büyük turizm potansiyeli. Soyu tükenmekte olan hayvan çeşitlerinden dünya mirası listesine giren birçok tabiat güzelliğine ve bunlara yönelik olarak kurgulanan UNESCO programlarına kadar bölgenin harekete geçirebileceği bir alanın bulunması (Suslov, 2014).

Uzakdoğu bölgesindeki Sahalin'in sahalarında devam eden gaz ve petrol alanındaki "upstream" yatırımlarının yanı sıra bölgenin kömür yatakları da yıllardır ilgi odağıyken, dünya enerji sektörünün gözdesi Arktik sahaları ve Doğu Sibirya kaynakları olmaya başlamıştır. Bu sahalardan üretilecek petrol ve doğal gaz Batı Sibirya'ya göre daha maliyetlidir, fakat RF'nin geleneksel sahalarında azalan üretimi dengeleyecek yegâne unsur olarak ön plana çıkmaktadır. Bilhassa Arktik sahaları için uluslararası rekabetin giderek kızışmakta olduğu bilinmekteyken dünya ticaret yollarını değiştirecek bir gelişmeye de yine bu bölge tanıklık etmektedir. Küresel isınmaya paralel olarak Arktik Okyanusu'ndaki buzulların erimesiyle birlikte "Kuzey Deniz Rotası" (Northern Sea Route) üzerinden hammadde ve mal taşımacılığı buna göre tasarlanmış yeni yük taşıma gemileriyle artık mümkün olmaya başlamıştır. Bu rotanın aktif bir şekilde kullanılmasıyla Asya ekonomilerine denizden mal sevk etmek çok daha kısa ve az masraflı olacak, bu da bölge ekonomisinin dünyayla entegrasyonunu hızlandıracaktır. 


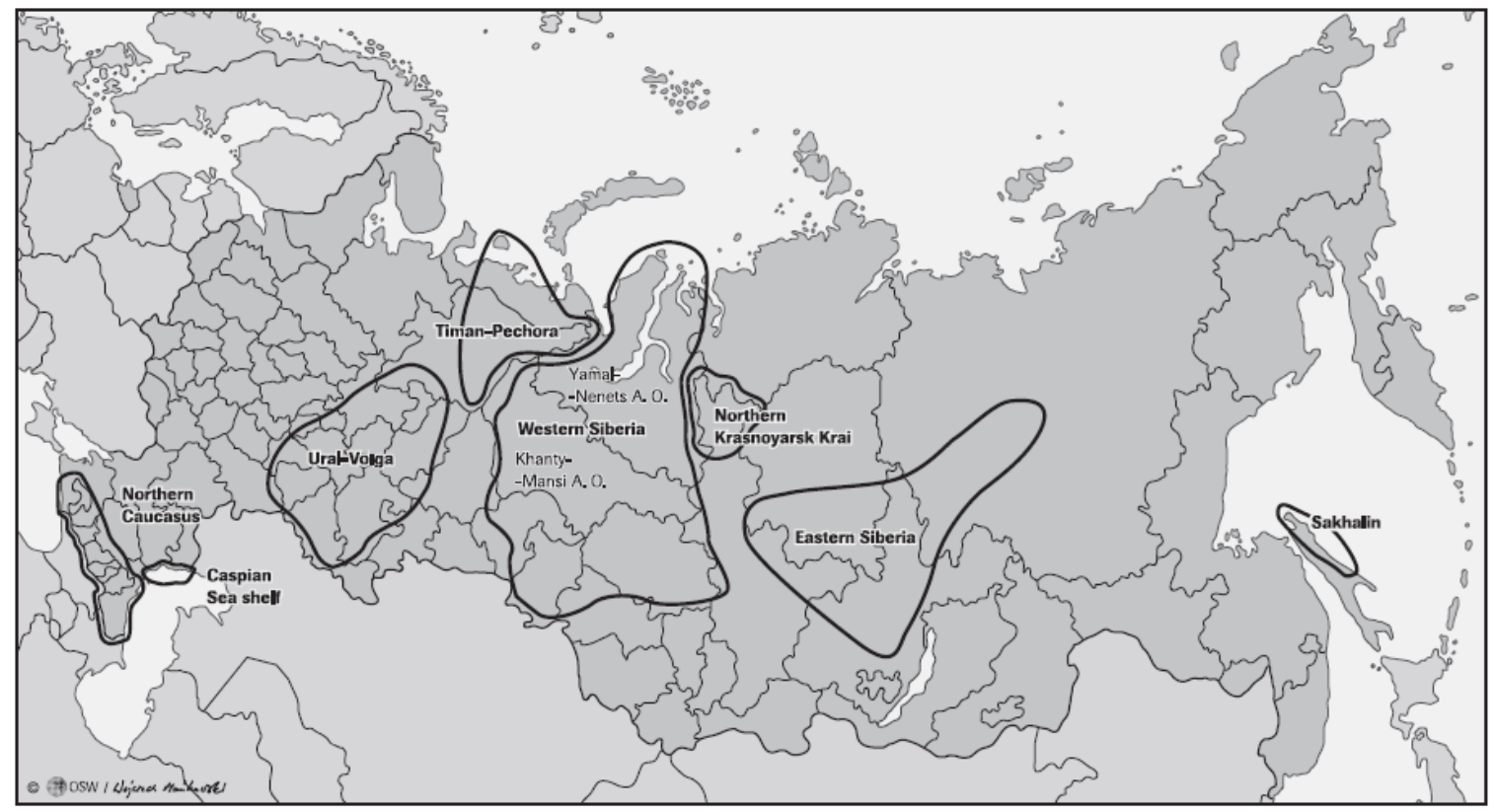

Harita 1 - Rusya Federasyonu'ndaki Petrol ve Doğal Gaz Havzaları

\section{Rus Dış Politikası Açısından Sibirya'nın Sunduğu Avantajlar ve Dezavantajlar}

Tarihsel olarak Rusya'nın nüfusu ve iktisadi gelişimi daha çok ülkenin Batı ya da başka bir deyişle Ural dağlarından başlayarak Rus Avrupa'sı (Rusya Ana) denilen kısımlarında yoğunlaşmıştır. Bunun temel nedeni de aslında son 300 yıldır Avrupa ve Batı medeniyetinin dünyada hâkim ve merkezi bir konum teşkil etmesidir. Asya ile Avrupa arasındaki devasa coğrafyada uzanan Rusya'nın da Batı ile daha yoğun ilişkiler içerisinde olması ve Batı'ya yönelmesi bu nedenle anlaşılabilir. Fakat denildiği gibi Asya'nın yükselişi RF'nin iç dinamiklerini Doğu'ya doğru yönlendirmeye başlamış ve bunun doğal bir sonucu olarak da Sibirya ve RUD, Moskova için hiç olmadığı kadar önem kazanmıştır. Bu çerçevede iç ve dış politika etkileşimini apaçık bir biçimde görmekteyiz.

Ancak tarihte Rusya'nın Asya'daki uluslararası aktörlere bakışı hep güvenlik açılarından olmuştur. Stalinli yıllardan sonra Sovyet-Çin ilişkileri yaklaşık otuz yılı aşkın bir süre için gergin ve rekabet ilişkisinde olmuş ve hiçbir Sovyet yöneticisi Asya-Pasifik eksenini uluslararası bir işbirliği alanı olarak değerlendirmemiştir. Asya kıtasının Rusya açısından öneminin yeniden değerlendirilmesi, ancak 1990'ların ortasından itibaren gündeme gelmiş ve özellikle Çin'e yönelik “stratejik ortaklık” bakışı, ABD’nin uluslararası siyasetteki rolünün dengelenmesi ve tek-taraflı eğilimlerinin dizginlenmesi amacıyla önem kazanmıştı. Bu çerçevede özellikle Şanghay İşbirliği Örgütü'nün kurulması Rus-Çin ikili ilişkilerinin örgüt üyesi Orta Asya ülkelerinin varlığıyla çok-taraflı bir diplomasiye dönüşmesi sürecini başlatmıştır. Bu çok-taraflı işbirliği süreci, hem sınır güvenliği hem ekonomik ilişkilerin artırılması hem de enerji hatlarının yaygınlaştırılması açılarından Asya kıtasında çok önemli bir çekim merkezi yaratmıştır.

Sovyetlerin dağılmasından sonra Rus dış politikasında gündeme gelen Avrasyacı söylemin Yakın Çevre ve Uzak Çevre yaklaşımları, Rus karar seçkinlerinin uluslararası sistemde Batılı güçleri dengeleyecek çok-merkezli arayışların bir ürünü olarak karşımıza çıkmıştır. Nitekim Putin'in birçok dış politika konulu konuşmasında Rusya coğrafyasının özgünlüğü ve biricikliği vurgulanırken Doğu ile Batı arasında bir köprü rolü ile ABD ile Çin arasında "dalgalanan güç" (swing power) deyimleri çok kullanılır olmuştur. Ancak uluslararası sistemde yaşanılan küresel mali krizlerin olumsuz etkileri, Moskova yönetimini farklı aktörlerle stratejik ilişkilere girerek çok-vektörlü ve çok-araçlı bir dış politika izlemesine destek vermiştir. Nitekim Batılı ülkelerin 2008 mali krizinden beri tam anlamıla toparlanamamaları, Rusya'nın daha dinamik bir ekonomik hayata ve potansiyele sahip Doğu’ya yönelme fikrini desteklemiştir. Nitekim 2000’lerin sonlarında etkililikleri yoğunlukla tartışılan yeni küresel aktörler olarak BRICS (Brezilya, Rusya, Hindistan, Çin ve Güney Afrika) ülkeleri, Batı merkezli küresel yönetişime alternatif söylemler getirmişler ve kendi coğrafyalarında yeni stratejiler ve sinerji yaratmışlardır, ancak 2010'ların ortalarına geldiğimiz bu dönemde BRICS ülkelerinin kalkınma başarılarının sürdürülebilirliği etkisini yitirmiş gibi (özellikle Rusya ve Brezilya'da görülen mali krizlerle birlikte) görünmektedir.

Rusya'nın Asya politikasına baktığımızda belirli öncelikleri söz konusudur. Bu çerçevede Sibirya ve Uzakdoğu bölgesinin konumu belirli hassasiyetleri doğurmaktadır. Bunları sıralamak ve tartışmak gerekirse; 
a) Birincil olarak, Rusların dış politikasında hep merkezi konumda olan ulusal güvenlik konusudur. Ulusal güvenlik kavramından öncelikli olarak anlamamız gereken husus, Rusya'nın çok-etnikli yapısından kaynaklanan bir istikrarsızlık düşüncesidir. Özellikle Çeçen Savaşları'ndan sonra merkezi yönetim etnik gruplarla Moskova arasındaki ilişkilere çok hassas açılardan yaklaşmakta ve her etnik bölgedeki etnik Rus nüfus varlığına özen göstermektedir. Dolayısıyla nüfusları günden güne azalan Sibirya ve Uzakdoğu bölgelerindeki etnik çeşitliliğe ve çoğulculuğa rağmen buralarda ekonomiyi güdebilecek seçkinler olarak Rusların (oligarklar) ön plana çıkarılmaları söz konusudur. Nitekim Hruşçev’li yıllarda uygulanılan Bakir Topraklar politikasıyla birçok etnik bölgede nüfus dengesinin Rusların lehine geçmesi sağlanmıştı, ancak iş göçleri ve doğurganlığın azalmasıyla günümüzdeki azalan nüfusla Moskova yönetiminin bölgedeki ağırlığını kaybetme riski söz konusudur. Bu çerçevede dış göçler konusu çok hassas bir güvenlik konusu haline gelmiştir. Özellikle Uzakdoğu bölgesine yönelik kısa vadede yaşanılan ve ilerde yaşanılması mümkün Çinli işgücü göçüne karşı sınırların kapatılması söz konusudur.

b) İkincil olarak, bölgesel kalkınma arayışlarında Sibirya ve Uzakdoğu bölgelerine yatırım desteğini çekmek ve bu bölgelerin Rusya geneliyle de bütünleşmesine de yardımcı olmaktır. Bu çerçevede yabancı sermaye desteğini çekebilmek de önemli bir siyasal tercihtir. Dış politika aracı olarak Batılı ülkeler gibi siyasal koşullar aramayan ve daha düşük maliyetli Çin ve diğer büyük Asya ülkeleri (özellikle Güney Kore) sermayelerinden daha fazla yararlanarak bu bölgeleri kalkındırma, yapılandırma ve altyapı eksiklerini gidermek gibi bir tercih söz konusudur. Bu yatırım ilişkisi, hem Asyalı firmaların bölgede "Rus ekonomisinin kurallarına uyacak şekillerde" altyapı yatırımlarında bulunmaları hem de bölge kaynaklı, üretimli ve ihtiyaçlı malların ikili ticari ilişkilerin çatısını oluşturması hususlarını kapsamaktadır. Sibirya ve Uzakdoğu bölgelerinin dış dünyayla yaptığı ticaretin, Rusya’nın başta Çin olmak üzere diğer Asya ülkeleriyle olan ticaret hacmine olumlu katkısı bulunmaktadır; bunun yanı sıra bu bölgenin aslında hali hazırdaki ülkelerle farklı oranlarda ticaret geçmişi olduğunu da belirtmek gerekmektedir. Sanıldığının aksine, bölge ekonomisi sadece Asya ülkelerine eklemlenmiş değildir, dış ticaret ilişkilerinde Büyük Britanya gibi uzak coğrafyaların da önemli bir payı bulunmaktadır (Lee, 2013). Bölgedeki alt birimler incelendiğinde, örnek olarak Saha (Yakut) Cumhuriyeti için Belçika'nın, Kamçatka için ise Güney Kore'nin birinci ticaret partneri olduğu görülecektir.

c) Üçüncü öncelik ise, Asya'nın ve küresel dinamiklerin jeopolitik avantajlarından yararlanmaktır. Bu çerçevede Trans-Sibirya hattının tekrar canlandırılarak "Büyük İpek Yolu” projesinin hayata geçirilmesi söz konusudur. Öte yandan Sibirya ve Uzakdoğu bölgeleri, komşu oldukları coğrafyalarla Orta Asya’y1, Moğolistan'1, Asya'nın Çin, Hindistan, Endonezya gibi ekonomi devlerini, Japonya, Güney Kore ve diş dünyadakiler gibi Pasifik bağlantısını devreye sokabilmektedir. Bu açılardan (özellikle 2008 Gürcistan ve 2014 Ukrayna krizleriyle) Batı'yla olan gergin siyasal ilişkileri karşısında yeni bir alternatif üretebilmek açısından Asya'nın ekonomik ilişkilerine dayanan jeopolitiğini kullanmak için Sibirya ve Uzakdoğu bölgeleri Rus yönetimine çok önemli bir avantaj sunmaktadır.

d) Dördüncü olarak, Rusya'nın ekonomik çıkarlarını ve altyapı şartlarını geliştirmek ve buna bağlı olarak devlet ve özel aktörlerin konumlarını güçlendirmek konusu söz edilebilir. Nitekim bölgeye dair bakanlığın kurulması ve özel bir kalkınma stratejisinin belirlenmesi açısından Putin yönetiminin bu konularda ciddi ve tutarlı olduğunu göstermektedir. Bu çerçevede süreci hızlandırmak adına bölgedeki federe cumhuriyetlerin ve federe bölgelerin başlarına oligarkların atanması söz konusu olmuştur. Putin döneminin ekonomik yapılanmasının en önemli aktörleri konumundaki silovikler (eski istihbaratçı ve asker kökenli yöneticiler) ve oligarklar, bu bölgeye doğrudan atanarak Moskova merkezli bir kontrol süreciyle buradaki kalkınma hamlelerini yürütmektedirler. Bu çerçevede her ne kadar Rusya'nın batısıyla doğusunu birbirine yakın kalkınma düzeylerine getirmek kısa vadede mümkün olmasa da belirli merkezler ve şehirler (özellikle Novosibirsk bu konuda pilot bölge olarak seçilmiştir) üzerinden bölgesel kalkınma hamlelerinin odak noktaları olarak seçildiğini görmekteyiz. Altay Cumhuriyeti'nin Rusya'da kumar turizmi merkezi olarak seçilmesi, hem turizmi geliştirmek hem de nüfus yoğunlaşmasını Rusların lehine çekmek adına önemli bir örnek olarak da gösterilebilir.

e) Beşinci olarak, geçmişten beri varolan hidrokarbür (petrol ve doğal gaz) boru hatlarının Sibirya ve Uzakdoğu bölgelerine komşu olan devletlere (Kazakistan, Moğolistan, Çin) doğru uzatılması ve bu bölgelerin enerji nakil hatlarının ağı olarak merkez bir alana dönüştürülmesi söz konusudur. Nitekim bu ağ sayesinde RF, Asyalı partnerlerine AB'ye sattığı petrol ve doğal gazın birçok katı büyüklükteki bir dış ticaret hacmi yaratabilecek bir stratejiyi yaratmaktadır (Boru hatları için, bkz. Harita-2). 2013 yılında imzalanan bir sözleşmeyle Rosneft'in 25 yıllık bir vadeyle Çin'e 270 milyar dolarlık petrol satışı (Times of India, 21 Haziran 2013), 2014 Ukrayna krizinin akabinde Rus-Çin Cumhurbaşkanlarının imzalarıyla kesinleşen doğal gaz anlaşmasıyla Rusya'dan Çin'e doğru 30 yıl içinde 400 milyar dolarlık bir doğal gaz satış garantisi (Reuters, 11 Ekim 2014), buna bağlı olarak yeni bir boru hattının döşenmesi ve ESPO'nun kapasitesinin arttırılması ihaleleri söz konusu olmuştur.

f) Sonuç olarak, Rusya'nın Asya'daki dış politika ve küresel ekonomi aktörü konumunu da kalıcı hale getirmektir. Tabii bu çerçevede Rus politikasının “Asyalılaşması”, küresel bir gereklilik mi yoksa Batı’yla 
siyasal ve askeri sorunlar yaşayan Moskova açısından yeni bir firsatlar odağı mıdır, bu tartışma birçok açılardan zamana dayalı bir süreci içermektedir. Eski Sovyet mirasını artık bertaraf edebilmek için kendilerine yeni bir kilit rol arayan Rus yöneticileri, Avrasyalılık ile Avro-Pasifik kimlikler arasında bir konumu tercih etmektedirler. Avro-Pasifik kimliği, Rusya'nın Asya-Pasifik coğrafyasında başat bir aktör olmasını sağlamak yanı sıra Avrasyalılığın getirdiği tarihsel ve uygarlık mirasının ağırlığın aşılacağı ve daha küresel ve ekonomik anlamda farklı araçların da devreye gireceği bir platform söz konusu olacaktır. Bu çerçevede kendi ulusal kalkınma hamlelerinde bu yeni kimlik tartışmaları da araç olacaktır.

Arktik kaynaklarının yanında yine son yıllarda gözde olan Doğu Sibirya'nın enerji zenginlikleri satış pazarı olarak Avrupa yerine coğrafi açıdan daha yakın olan Asya ekonomilerine doğru artan oranda akmaktadır. Her ne kadar bölgenin Çin'in basit bir hammadde sömürgesine dönüşeceği endişesi yaşansa da bu konuda ortaya atılan "Doğu Yönelimi” stratejisi çerçevesinden çeşitli projeler geliştirilmiştir (Poussenkova, 2009: 133). Bölgenin petrol potansiyeli Doğu Sibirya Pasifik Okyanusu (ESPO) ham petrol boru hattıyla artmaya başlamıştır. Senelik 400.000 varil/günlük kapasiteyle işletmeye alınan hattın kapasitesinin 2020’ye gelindiğinde tam kapasiteye ulaşması beklenmektedir. Hali hazırda Rus petrolü Asya pazarlarına ihracı bu zamana kadar rekor bir seviye olan 1,2 milyon varil/günlük kapasiteye ulaşmış, toplam petrol ihracatı ilk defa 2014 y1lı itibariyle \% 30'u aşmıştır (Vedomosti, 15 Ağustos 2014).

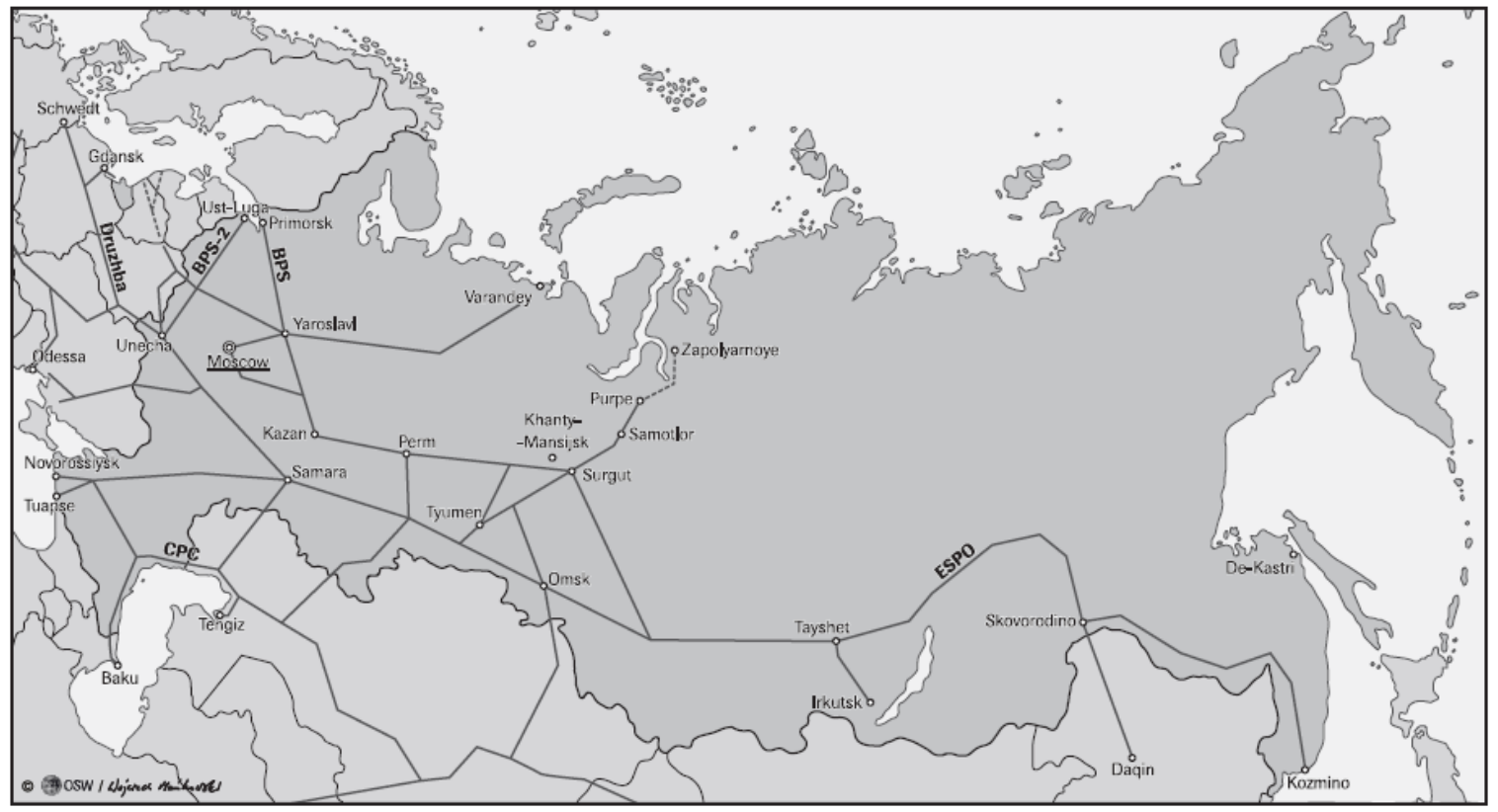

Harita 2 - Petrol ve Doğal Gaz Boru Hatlarl

Petrolden sonra Doğu Sibirya'nın doğal gaz yataklarını işleme ve ihraç etmede önemli bir eşik ise son zamanlarda atılmıştır. Buna göre, Rus Gazprom ile Çin devlet petrol şirketi CNPC arasında 10 yıldan fazla süren müzakereler 21 Mayıs 2014'te nihayete ermiş ve taraflar 2018 yılından başlamak üzere 30 sene süreli yıllık azami 38 milyar metre küplük (mmk) gaz alım-satım anlaşmasına imza atmışlardır. Anlaşma Gazprom’un Avrupa pazarlarında Amerika'daki 'shale gas' devriminden ve dünya Sıvılaştırılmış doğal gaz (LNG) piyasasının rekabetçiliğinden ötürü düştüğü sıkıntılı durumdan sonra Asya’ya açılımı olarak yorumlanmıştır. 400 milyar dolar değerindeki bu anlaşmanın Çin ekonomisine kaynak çeşitliliği açısından olumlu katkı yapması beklenmektedir. Uzun süren müzakerelerde taraflar arasındaki en hassas pazarlık konularından birisi gaz fiyatı olmuştur. Gazprom, Avrupa ortalama satış fiyatında $(1000 \mathrm{mk} / 380 \$)$ 1srar ederken Türkmenistan'dan aldığı gaz için yaklaşık 1000mk/320\$ gibi bir fiyat ödeyen Çin için Rus gazının kıymetinin de yakın bir seviyede olması gerektiği Çinliler tarafından hesaplanmıştır. Petrol ürünleri fiyatına bağlı olarak yapılan kontrattaki fiyatın başlangıçta $1000 \mathrm{mk} / 350$ \$ibi bir seviyede olduğu anlaşılmaktadır (Milov, 2014). İlk başta taraflar orta yol buldu gibi görünse de Çin'in asıl doğal gaz ithal kaleminin LNG olduğu ve bunu da Pasifik'te en az $1000 \mathrm{mk} / 550$ \$ gibi bir fiyatla satın aldığı düşünüldüğünde burada CNPC'nin önemli bir kazanım edindiği düşünülmektedir. Çin petrolden sonra doğal gazı da Rusya'nın Avrupa'ya gönderdiği uluslararası piyasalardaki fiyattan daha indirimli bir şekilde ithal edecektir. Rusya'nın buradaki kazanımı ise iktisadi olmaktan çok stratejiktir. Rusya Asya-Pasifik açılımı ve bu bağlamda Bölgenin gelişim projelerini Çin’le yaptığı anlaşmalar üzerinden somut bir hale getirmiş gözükmektedir. Çin'e satılacak doğal gaz için kaynak olarak RUD ve Doğu Sibirya'da yer alan Çayanda (Yakutistan) ve Kovykta (İrkutsk) sahalarının geliştirilmesi hedeflenmektedir.

Bu kadar ekonomik değere dayanan avantajlar tartışmasının yanı sıra Sibirya'da yaşayan halklar açısından baktığımızda küreselleşen dünya karşısında yerel kimliklerin aciz bir durumda kaldığını görüyoruz. Yerli 
halkların kendi yaşadıkları özerk bölgelerde bile çoğunluğu yıllardan beri Rusların lehine kaybetmeleri ve hiçbir zaman ekonomiyi güden aktör konumuna gelememeleri bu yerel kimliklerin ne yazık ki sadece şehir ve bölge müzelerine sıkışmış örnekler olmaya doğru gitme sonucunu da doğurmaktadır.

Sibirya ve Uzakdoğu gibi büyük ve engin bir coğrafyanın kalkındırılması Rus dış politikası açısından çok maliyetli ve zaman alacak bir projedir. Buna bir de Arktik bölgesini eklediğimizde uluslararası hukuk, egemenlik sorunları gibi Rus dış politikasına sorunlar ve yeni tartışma konuları yaratması da söz konusudur. Nitekim dış göçlerin Sibirya ve Uzakdoğu'daki nüfus dengelerini değiştirme durumu da ayrı bir dezavantaj noktası olarak karşımıza çıkmaktadır; bu çerçevede Moskova yönetiminin ulusal güvenlik hassasiyetiyle dizginleri elden bırakmayacağı aşikardır.

\section{Sonuç Değerlendirmesi}

Sonuç olarak tarihsel süreç içerisinde Rusya için Sibirya ve Uzakdoğu bölgelerinin Moskova tarafindan kaynakları sömürülen yarı koloni olduğu olgusu karşımızdadır. Bu durum 21. yüzyıla kadar böyle devam etmiş fakat dışsal etmenlerin zorlamasıyla değişen şartlarda bölge ilk defa ciddi bir şekilde makûs talihini değiştirebilecek iktisadi kalkınma tartışmalarının odağında yer almıştır. Bölgesel kalkınmanın kendi içerisinde barındırdığ zorluklara rağmen jeo-ekonomik perspektiften bölge kaynakları ve diğer sektörlerdeki gelişimin son yıllarda yapılan düzenlemelerden sonra umut verici olduğunu iddia edebiliriz. Ancak enerji sektörü bölgesel kalkınmanın tek lokomotifi olarak görülüp diğer sektörleri besleyen bir araç olarak idrak edilmezse bölgenin kötü talihini tekrarlaması şaşırtıcı olmayacaktır. Bölgenin en büyük şansı, dünya ekonomik-politik güç dengesinin komşu coğrafya olan Asya-Pasifik kıtasına kaymakta olduğu gerçeğidir. Geleceğe yönelik öngörüler yapılmak gerekirse, uluslararası konjonktürde Asya’nın yükseldiği bir dönemde Sibirya ve Uzakdoğu bölgelerinin kalkınması için yerel yönetimlere verilecek geniş yetkiler adem-i merkeziyetçiliğe ve bu da bölgenin zamanla özellikle Çin'le daha sıkı entegrasyonuna sebep olabilecektir. Bu tür bir gelişmenin doğal sonucu ise bölgenin ileride Rusya'dan koparak Çin'in bir uydusu haline gelmesi riskini de içinde barındırmaktadır. Burada temel nokta Moskova açısından bölge kalkındırılırken kontrollü entegrasyonun ne denli yönetilebileceği sorusudur. Eğer bölge tamamen ihmal edilirse bu da sonunda Çin tarafından yutulma riskini barındıracaktır. Bölgenin kaybedilmesi Rusya'ya ağır bedeller ödeteceğinden Moskova'nın bulacağı çıkış yolu ve bunun uygulama süreci hayati önemdedir.

Rus stratejist Sergey Karaganov’un hem bölgeyi kalkındırmak hem de 21. yüzyılda zamanın ruhu olan Asya yükselişinden faydalanarak Rusya'ya Sibirya üzerinden çizdiği vizyon bu çerçevede dile getirilebilir: Çar I. Petro'nun 1700'lerin başında o dönemin yükselen gücü Avrupa'ya Baltık denizi üzerinden açılarak St. Petersburg'u başkent yapmasıyla Rusya'nın kaderini olumlu yönde çizmesine benzer bir şekilde 2000'lerde Rusya'nın kaderi, yükselen Asya’ya Pasifik üzerinden çıkmak ve ikinci başkenti Vladivostok yapmaktır. Bu sayede hem bölge hem de Rusya Federasyonu kurtuluşa erecek, ancak bu yapılamazsa Rusya'yı zor yıllar bekleyecektir. Karaganov'un deyimiyle, Çar I. Petro bu yüzyılda yaşasaydı aynen böyle bir karar alır, karasal merkez Moskova'dan çıkar, fakat başkenti bu sefer Avrupa'daki St. Petersburg yerine Asya sınırı olan Vladivostok'a taşıyabilirdi (Karaganov, 2012). Bu vizyonun 21. yüzyıl gerçeklerinde Rus karar alıcılar tarafından paylaşılıp paylaşılmayacağı tartışmaya açık iken, tartışmasız olan konu bölgenin asırlar boyu süren yalıtılmışlık ve ihmal edilmişliğinin son yıllarda yaşanan gelişmeler neticesinde artık kader olmaktan çıkmakta olduğu gerçeğidir.

\section{Kaynakça}

- Aleschenko, V., Nedelea, A., Nedelea, S.O., 2009. "Economic Growth in Russia Regions: Key Factors", The Annals of The "Ştefan cel Mare" University of Suceava. Fascicle of the Faculty of Economics and Public Administration Vol. 9, No. 2/10.

- Amirov, V., 2010. "Russia's Posture in and Policy Moves in North-Eastern Asia, Derl. S. Blank, Russia’s Prospects in Asia, Strategic Studies Institute Publ, Carlisle/PA, ss. 2-28.

- $\quad$ Balcer, A. \& Petrov, N., 2012. The Future of Russia: Modernization or Decline?, Demos-Europa, Centre for European Strategy, Varşova.

- Barabanov, O. \& Bordachev, T., 2012. Toward the Great Ocean, or the New Globalization of Russia, Valdai Discussion Club analytical report, Moscow.

- Craig, R., 2010. "Russia in Eastern Asia: Aspirations and Limitations”, Derl. S. Blank, Russia’s Prospects in Asia, Strategic Studies Institute Publ,, Carlisle/PA, ss. 29-62.

- Gunder Frank, A., 1998. Re-Orient: Global Economy in the Asian Age, Berkeley: University of California Press.

- Haas, M. de, 2013. Russia-Chinese Security relations, The Netherlands Institute of IR Clingendael, Lahey.

- Inozemtsev,V., 2013. A Development Strategy for Siberia, CSIS Russia and Eurasia Program. 
- Karaganov, S. "Russia Needs One More Capital in Siberia", 21.06.2012, http://eng.globalaffairs.ru/pubcol/Russia-Needs-One-More-Capital--in-Siberia-15567

- Klein, M., 2014. Russia: a Euro-Pacific Power, SWP Research Papers, Berlin.

- Kononczuk, W., 2012. Russia's Best Ally: The situation of the Russian Oil Sector and Forecasts for its future", OSW Studies, Varşova.

- Kudinov, L.B., 2001. Geopoliticheski interesi I strategiya rossii ATR v 21 veke, Moskova.

- Lavrov, S., 2006. "The Rise of Asia and the Eastern vector of Russia's Foreign Policy", Russia in Global Affairs, Vol. 4/3, ss. 68-80.

- Lee, R., 2013. The Russian Far East and China: Thoughts on Cross-Border Intgegration, http://www.fpri.org/docs/Lee___Russia_and_China.pdf

- $\quad$ Liik, K., 2014. Russia's Pivot to Eurasia, ECFR Publ..

- Liuhto, K., 2010. Energy in Russia’s Foreign Policy, Electronic Publ. Of Pan-European Institute, C. 10, 94 s.

- Lo, B., 2014. "Russia's Eastern Direction - Distinguishing the Real from the virtual" IFRI - Russia / NIS Center, Paris.

- Lukyanov, F., 2010. “Uncertain World: Russia’s Asia Challenge”, Russia in Global Affairs, Ekim say1s1.

- Milov, K., Kitayskiy Kontrakt: Suhoy http://www.echomsk.spb.ru/blogs/milov/21426.php (erişim tarihi: 01.08.2014)

- Mohaptra, N.K., 2013. "Energy security and Russia's Foreign Policy," CRP Working Paper Series, University of Cambridge.

- Reuters, 11 Ekim 2014.

- Rusya Federal Nüfus İstatistikleri Birimi, 2014.

- Poussenkova, N., 2009. "Russia's future customers: Asia and beyond", Derl. J. Perovic, R.W. Orttung ve A.Wenger, Russian Energy Power and Foreign Relations: Implications for Conflict and Cooperation, New York: Routledge.

- Rozman, G., 2010. "Russian repositioning in North-Eastern Asia: Putin's Impact and Current Prospects", Derl. S. Blank, Russia’s Prospects in Asia, Strategic Studies Institute Publ,, Carlisle/PA, ss. 63-96.

- Salin, P., 2012. "Russia's Three Roads to Asia”, Russia in Global Affairs, Aralık sayıs1.

- $\quad$ Seliverstov, V.E., Melnikova, L.V., 2013. "Analysis of Strategic Planning in Regions of the Siberian Federal District”, Regional Research of Russia, C.3, No.1, ss.96-102.

- Suslov, V.I., 2014. "Images of Siberia: Economy and History," Journal Region: Economics and Sociology", Vol. 1.

- Zamyatina, T., 2013. "Foreign investment in Trans-Siberian may creat global economic boom," Itar-Tass, 10 Ekim, Internet: http://in.rbth.com/economics/2013/10/10/foreign investment in transsiberian_may create_global_economic boo_30045.html (erişim tarihi: 31 Ağustos 2014)

- Ziegler, C., 2006. "The Russia Diaspora in Central Asia: Russian Compatriots and Moscow's Foreign Policy”. Demokratizatsiya, C. 01, ss. 103-126. 


\title{
Türkiye'de Uygulanan AB Hibe Destekli Projelerin İncelenmesi (2000-2015)
}

\section{Investigation of EU Grant Funded Projects Implemented in Turkey (2000-2015)}

\author{
Ph. D. Candidate Hilal Abacı (Çankırı Karatekin University, Turkey) \\ $\mathrm{Ph}$. D. Candidate Gizem Saray (Çankırı Karatekin University, Turkey) \\ Prof. Dr. Hasan Akça (Çankırı Karatekin University, Turkey) \\ Asst. Prof. Dr. Levent Şahin (Çankırı Karatekin University, Turkey)
}

\begin{abstract}
Turkey has benefitted from financial assistance of the EU in order to enhance the institutional capacity and the quality of legislation in different areas since 2001. It is aimed that Turkey could integrate easily to common policies when she became a full member of the EU via projects funded by the EU. In this context, financial assistance is distributed to both public and private sectors and also non-governmental organizations via Central Finance and Contracts Unit (CFCU), National Agency, Agriculture and Rural Development Support Institution (ARDSI), and Ministries. At least $50 \%$ or all of the funds in some projects have been taken from the EU.

After recognition of Turkey as a candidate country by the EU in December 1999, accession negotiations started between Turkey and the EU in October 2005. Therefore, the study covers the period of 2000-2015. The method of STEEPLED Analysis was used in the study. EU grant projects implemented in the last 15 years were investigated various point of view (Social, Technological, Economics, Environmental, Politics, Legal, European and Demographic) and in the light of the findings, contribution of the EU grant schemes to the local/regional development, employment, environmental conservation and reduction of poverty were determined.
\end{abstract}

\section{Giriş}

Avrupa Birliği (AB)'nin amacı, ülkelerarası güçlü bir mali yapı ile ortak bir politika benimsenmesini sağlamak ve güçlü mali yapıda olan ülkelere nazaran zayıf mali yapıya sahip olan ülkelerin güçlenmesine katkı sağlamaktır. Bu amaca yönelik olarak Birliğe üye, aday ya da potansiyel aday olan ülkelere mali yardımlarda bulunmaktadır (Kösecik ve Akbaş, 2009: 2). AB mali yardımlarının bir kısmı Avrupa Yatırım Bankası (AYB) aracılığıyla $\mathrm{AB}$ 'ye üye ülkelerin bütünleşmeleri, dengeli kalkınmaları, ekonomik ve sosyal uyum sağlamaları için kullanılmaktadır. Kredi şeklinde yapılan bu yardımlar yatırımlar için uzun vadeli finansman imkânı sağlamaktadır (Karabacak, 2004: 70). AB mali yardımlarının belirli bir kısmını ise hibe şeklinde yapılan ve üye ya da aday ülkeleri kapsayan mali yardımlar oluşturmaktadır (Yıldız ve Yardımcıŏlu, 2005: 81). AB'nin aday ülkelere yönelik yaptığı yardımlar ise Avrupa Toplulukları Genel Bütçe Harcama kalemlerinden finance edilen dış yardımlara yönelik harcamalar ve katılım öncesi yardımlar dâhilinde hibe niteliğinde Afrika, Karayip ve Pasifik Ülkelerine (AKP), Bağımsız Devletler Topluluğuna (BDT), Akdeniz Ülkelerine, Asya ve Latin Amerika Ülkelerine (ALA), Merkezi ve Doğu Avrupa Ülkelerine yapılmıştır (Karabacak, 2004: 78). Ayrıca AB Balkan ülkelerine CARDS adı altında katılım öncesi mali yardımlar kapsamında yardımlarda da bulunmuştur (Karataş, 2010: 67).

Ankara anlaşması ile AB mali yardımlarından faydalanmaya başlayan Türkiye 1964-1986 döneminde dört mali protokol, bir ek protokol, özel işbirliği fonu ve idari işbirliği fonu yardımları kapsamında mali destek almıştır. 1992-1996 yılları arasında Yenileştirilmiş Akdeniz Politikası (YAB)'ndan yararlanırken, 1996 yılında ise AB ile Gümrük Birliği Anlaşması sonucunda Türkiye'nin, Yenileştirilmiş Akdeniz Politikası (YAB) kapsamındaki destekleri, 1996-1999 yılları için Avrupa-Akdeniz İşbirliği Programı (MEDA I) kapsamına alınmıştır. Helsinki Zirvesi (1999) ile AB'ye üye olmak için aday statüsüne geçen Türkiye, 2000-2006 dönemini kapsayan Katılım Öncesi Mali Yardımlar kapsamında diğer aday ülkelere verilen destek programlarından (PHARE, ISPA, SAPARD) yararlanamamıştır. Bunun yerine Türkiye 2000-2006 yılları için Avrupa Akdeniz İşbirliği (MEDA II) kapsamında destek sağlamıştır (Karataş, 2010: 69-75). Ayrıca adaylık sürecinde hibe niteliğindeki Türkiye için Avrupa Stratejisi ve deprem yardımlarından ve kredi şeklindeki Euromed II, Terra, Özel Eylem Programı, Katılım Öncesi Kolaylığı ve Avrupa-Akdeniz Ortaklığı Kolaylığı programlarından destek almıştır (Gençkol, 2003: 178-180). AB, 2007-2013 y1lları arası için aday ve potansiyel aday ülke statüsünde bulunan ülkelerinin yardım programlarını Katılım Öncesi Mali Yardımlar (IPA) adı altında birleştirmiştir. Bu kapsamda $\mathrm{AB}$, her yıl kalkınmayı ve girişimcileri destelemek adına binlerce projeye destek vermektedir. IPA kapsamında verilen bu mali desteklerden faydalanmak için AB'ye aday ya da potansiyel aday ülkelerin kurum/kuruluşlarının çeşitli konuları kapsayan projeler geliştirmesi gerekmektedir (Akça ve Albeni, 2009: 319320). 2014-2020 yılları için ise Türkiye'nin, Katılım Öncesi Mali Yardım Aracı (IPA)'nın mali yardımları 
çerçevesinde bulunan beş bileşeni korunarak IPA II oluşturulmuş ve bu bileşenlerin mali yardımları yönlendirecek beş politika alanına dönüştürülmesi kararı verilmiştir (DİAB, 2015a).

Türkiye'de AB mali yardımlarının projelendirme ve projelere destek sağlama görevi başta Avrupa Birliği Bakanlığı olmak üzere diğer Bakanlıklar, Merkezi Finans İhale Birimi (MFİB), Tarım ve Kırsal Kalkınmayı Destekleme Kurumu (TKDK), TÜBİTAK ve Ulusal Ajans gibi kurum/kuruluşlara verilmiştir. Literatürde AB mali yardımlarının analizi konusunda yazılmış bilimsel çalışma yok denecek sayıdadır.

\section{Türkiye'ye Yönelik AB Mali Yardımları}

Türkiye, Ankara Anlaşması'ndan Gümrük Birliği Anlaşması'na kadar geçen süreçte (1964- 1996) kredi ve hibe şeklinde toplamda 1005 milyon Avro tutarında AB mali yardımlarından yararlanmıştır (Yeğen, 2009: 66). Gümrük Birliği döneminde ise AB ülkeleri ile diğer üçüncü ülkeler arası farklılığın etkilerinin azaltılması için mali yardımda bulunma kararı alınmıştır (Yeğen, 2009: 70-71). Yapılan bu yardımlar ise Türkiye adına Yunanistan'ın vetoları nedeniyle tam anlamıyla kullanılan finans kaynakları olamamıştır (Atak, 2009: 149).

Türkiye 1999 yılında Helsinki Zirvesi'nde AB'ye adaylık statüsü kazanmıştır fakat bu dönemde diğer aday ülkelere mali yardım sağlanan PHARE, ISPA ve SAPARD programlarından yararlandırılmamıştır. Buna gerekçe olarak ise AB programların bütçelerinin önceden hazırlandığı gösterilmiştir (Kösecik ve Akbaş, 2009: 57). 2001 yılı sonundan itibaren ise tek bir çerçevede hibe nitelikli AB fonlarından yararlandırılmıştır (ABGS, 2015a). AB'ye adaylık döneminde Türkiye hibe şeklinde MEDA II, Deprem Yardımları ve Türkiye için Avrupa Stratejisi isimli mali yardımlardan kullanmıştır (Gençkol, 2003: 172-178). Ayrıca bu dönemde Türkiye kredi şeklinde olan mali yardım programlarından da yararlanmıştır (Özcanlı, 2006: 52-53).

2007 yılında AB'nin aday ve potansiyel aday ülkelere PHARE, ISPA, SAPARD, CARDS ve Türkiye için katılım öncesi mali yardımlar kapsamındaki mali yardımlar Katılım Öncesi Mali Yardım Aracı (IPA) olarak tek bir çatı altında birleştirilmiştir (Akça, 2010: 334). IPA 5 bölümden oluşmaktadır ve getirdiği yenilik yapısal fonlarla aynı prensiplerle yönetilen çevre, ulaştırma, bölgesel rekabet, insan kaynaklarının kalkınması ve kırsal kalkınma konularının katılım öncesi mali destek programına dâhil edilmesidir (European Commission, 2015a).

\begin{tabular}{|l|l|l|l|l|l|l|l|l|}
\hline Bileşenler & 2007 & 2008 & 2009 & 2010 & 2011 & 2012 & 2013 & Toplam \\
\hline $\begin{array}{l}\text { Geçiş Dönemi Yardımı ve } \\
\text { Kurumsal Yapılanma }\end{array}$ & 256,7 & 256,1 & 239,6 & 217,8 & 231,3 & 227,5 & 238,5 & 1667,5 \\
\hline Bölgesel ve Sınır Ötesi İşbirliği & 2,1 & 2,9 & 3,0 & 3,1 & 5,1 & 2,2 & 2,2 & 20,6 \\
\hline Bölgesel Kalkınma & 167,5 & 173,8 & 182,7 & 238,1 & 293,4 & 356,1 & 366,9 & $1.778,4$ \\
\hline İnsan Kaynakları & 50,2 & 52,9 & 55,6 & 63,4 & 77,6 & 83,2 & 91,2 & 474,1 \\
\hline Kırsal Kalkınma & 20,7 & 53,0 & 85,5 & 131,3 & 172,5 & 187,4 & 204,2 & 854,6 \\
\hline Toplam & 497,2 & 538,7 & 566,4 & 653,7 & 779,9 & 856,3 & 903,0 & 4795,2 \\
\hline
\end{tabular}

Tablo 1. IPA Dönemi Türkiye Mali Yardım Miktarları (Milyon Avro) Kaynak: ABGS, (2015a).

Türkiye’nin Katılım Öncesi Mali Yardım Aracı'ndan yararlanma durumu giderek artış göstermiştir. Örneğin, 2007 yılında toplamda 497,2 milyon Avro olan yardım miktarı 2013 yılı itibariyle 903,0 milyon Avro olarak gerçekleşmiştir. 2007 yılında en çok yardım tahsil edilen bileşeni Geçiş Dönemi ve Kurumsal Yapılanma oluştururken, 2013 yılında ise Bölgesel Kalkınma bileşeni olmuştur.

\begin{tabular}{|c|c|c|c|c|c|c|}
\hline & $\begin{array}{r}\text { Yüz ölçümü̈ } \\
\left(\mathrm{km}^{2}\right)\end{array}$ & Avro/ $\mathrm{km}^{2}$ & Nüfus (2006) & Avro / Kişi & $\begin{array}{r}\text { Toplam } \\
\text { (Milyon Avro) }\end{array}$ & $\%$ \\
\hline Hirvatistan* & 56594 & 17634 & 4443000 & 224,6 & 998 & 10,0 \\
\hline Makedonya & 25713 & 23918 & 2039000 & 301,6 & 615 & 6,2 \\
\hline Türkiye & 783562 & 6119 & 72520000 & 66,1 & 4795 & 48,2 \\
\hline Arnavutluk & 2875 & 206957 & 3149000 & 188,9 & 595 & 6,0 \\
\hline Bosna Hersek & 1209 & 12810 & 3843000 & 170,7 & 656 & 6,6 \\
\hline Karadağ & 13812 & 17087 & 624000 & 378,2 & 236 & 2,4 \\
\hline Sirbistan & 77474 & 17890 & 7425000 & 186,7 & 1386 & 13,9 \\
\hline Kosova & 10887 & 58326 & 2070000 & 306,8 & 635 & 6,4 \\
\hline İzlanda** & & & & & 30 & 0,3 \\
\hline TOPLAM & 1022126 & 9489 & 96113000 & 103,5 & 9944 & 100,0 \\
\hline
\end{tabular}

Tablo 2. IPA AB Mali Yardımının Aday ve Potansiyel Aday Ülkelere Göre Dă̆̆lımı Kaynak: ABGS, (2015a). 
Aday ve potansiyel aday ülkelerin IPA kapsamında yararlandıkları mali yardım tutarı açısından ilk sırayı Türkiye, ikinci sırayı Sırbistan ve üçüncü sırayı Hırvatistan almıştır. Aday ülkelerin IPA'nın beş bileşeninden de yararlanabilmesi, potansiyel aday ülkelere kıyasla daha çok destek almalarına fırsat vermektedir. Fonların \%48,2'si Türkiye'ye ayrılsa da 66,1 Avro ile kişi başına en az mali destek kullanan ülkedir. Sağlanan fonların \%10'unu alan Hırvatistan ve \% 6,6'sını alan Kosova kişi başına en fazla mali destekten yararlanan ilk iki ülkedir. İzlanda'nın aday ülke konumunda olmasına rağmen 2011 yılı itibariyle IPA'dan faydalanmaya başladığı için sağladığı mali destek miktarı düşük miktardadır. Hırvatistan'ın mali yardımlarını incelerken ise 1 Temmuz 2013 tarihinde AB'nin 28. üye ülkesi olması dikkate alınmalıdır.

2007-2013 yıllarını kapsayan Katılım Öncesi Mali Yardım Aracı (IPA)'nın ilk döneminde mali yardımların kapsamında yer alan beş bileşen korunarak bu yardımları yönlendirecek beş politika alanına dönüştürülmesiyle 2014-2020 yıllarını kapsayan IPA II programı uygulamaya konulmuştur (DİAB, 2015a).

\begin{tabular}{|c|c|c|c|c|c|}
\hline $\begin{array}{l}\text { Politika } \\
\text { Alanı }\end{array}$ & Sektörler & Alt- Sektörler & $\begin{array}{l}\text { Bütçe } \\
2014-2020\end{array}$ & Öncelik Alanları & Sorumlu Kurum \\
\hline \multirow{7}{*}{$\begin{array}{l}\text { Demokrasi } \\
\text { ve } \\
\text { Hukukun } \\
\text { Üstünlüğ̈ü }\end{array}$} & \multirow{4}{*}{$\begin{array}{l}\text { 1.Demokrasi } \\
\text { ve } \\
\text { Yönetişim }\end{array}$} & $\begin{array}{l}\text { 1.Tekil } \\
\text { Eylemler }\end{array}$ & 58,5 & & \multirow[t]{4}{*}{$\begin{array}{l}\text { Avrupa Birliği } \\
\text { Bakanlığ } 1\end{array}$} \\
\hline & & $\begin{array}{l}\text { 2. Müktesebata } \\
\text { Uyum Desteği }\end{array}$ & 121,7 & & \\
\hline & & $\begin{array}{l}\text { 3. Birlik } \\
\text { Programı ve } \\
\text { Ajansların } \\
\text { Katılıma Destek }\end{array}$ & 590,4 & & \\
\hline & & 4. Sivil Toplum & 186 & & \\
\hline & \multirow{3}{*}{$\begin{array}{l}\text { 2. Hukukun } \\
\text { Üstünlüğü } \\
\text { ve Temel } \\
\text { Haklar }\end{array}$} & 5. Yarg1 & 183,7 & Yarg1 & Adalet Bakanlığ \\
\hline & & 6. Temel Haklar & 33,7 & Temel Haklar & $\begin{array}{l}\text { Avrupa Birliği } \\
\text { Bakanlığ } 1\end{array}$ \\
\hline & & 7. İçişleri & $\begin{array}{l}\quad 392,6 \\
\text { (40 milyon avro } \\
\text { ekstra fon } \\
\text { kaynağ1 verildi) }\end{array}$ & $\begin{array}{l}\text { * Göç ve İltica } \\
\text { * Entegre Sınır } \\
\text { Yönetimi } \\
\text { * Organize Suçlarla } \\
\text { Mücadele }\end{array}$ & İçişleri Bakanlığ1 \\
\hline \multirow[t]{7}{*}{$\begin{array}{l}\text { Rekabet } \\
\text { ve } \\
\text { Büyüme } \\
\text { Yatırımları }\end{array}$} & 3. Çevre & 8.Çevre & 644,6 & & $\begin{array}{l}\text { Çevre ve } \\
\text { Şehircilik } \\
\text { Bakanlığı } \\
\text { Orman Bakanlığ1 }\end{array}$ \\
\hline & 4. Ulaştırma & 9.Ulaştırma & 442,8 & & $\begin{array}{l}\text { Ulaştırma, } \\
\text { Denizcilik ve } \\
\text { Haberleşme } \\
\text { Bakanlığ }\end{array}$ \\
\hline & 5. Enerji & 10.Enerji & 93,5 & & $\begin{array}{l}\text { Enerji ve Tabii } \\
\text { Kaynaklar } \\
\text { Bakanlığı } \\
\end{array}$ \\
\hline & $\begin{array}{l}\text { 6. Rekabet } \\
\text { Edilebilirlik } \\
\text { ve } \\
\text { İnovasyon }\end{array}$ & $\begin{array}{l}\text { 11.Rekabet } \\
\text { Edilebilirlik ve } \\
\text { İnovasyon }\end{array}$ & 344,4 & & $\begin{array}{l}\text { Bilim, Sanayi ve } \\
\text { Teknoloji } \\
\text { Bakanlığı }\end{array}$ \\
\hline & $\begin{array}{l}\text { 7. Eğitim, } \\
\text { İstihdam ve } \\
\text { Sosyal } \\
\text { Politikalar } \\
\end{array}$ & $\begin{array}{l}\text { 12.Eğitim, } \\
\text { İstihdam ve } \\
\text { Sosyal } \\
\text { Politikalar }\end{array}$ & 435 & $\begin{array}{l}\text { İstihdam ve İş } \\
\text { Piyasaları }\end{array}$ & $\begin{array}{l}\text { Çalışma ve Sosyal } \\
\text { Güvenlik } \\
\text { Bakanlığı }\end{array}$ \\
\hline & \multirow[t]{2}{*}{$\begin{array}{l}\text { 8. Tarım ve } \\
\text { Kirsal } \\
\text { Kalkınma }\end{array}$} & $\begin{array}{l}\text { 13. Kırsal } \\
\text { Kalkınma } \\
\text { Programı }\end{array}$ & 801 & & $\begin{array}{l}\text { TKDK (Tarım ve } \\
\text { Kırsal } \\
\text { Kalkınmayı } \\
\text { Destekleme } \\
\text { Kurumu) } \\
\end{array}$ \\
\hline & & $\begin{array}{l}\text { 14. Kurumsal } \\
\text { Kapasite } \\
\text { Geliştirme }\end{array}$ & 111,2 & & $\begin{array}{l}\text { Gida, Tarım ve } \\
\text { Hayvancılık } \\
\text { Bakanlığ } 1 \\
\end{array}$ \\
\hline
\end{tabular}

Tablo 3. 2014-2020 IPA II Dönemi (Milyon Avro) Kaynak: DİAB, (2015a). 
IPA II, 16 Mart 2014 tarihinde yürürlüğe girmiş ve 1 Ocak 2014 tarihinden itibaren geriye dönük uygulanabilir öngörülmüştür. IPA II'deki en önemli yenilik, stratejik odaklı olmasıdır. 7 yıllık süreçte Ülke Strateji Belgeleri her yararlanıcı için ayrı bir spesifik stratejik plan içerir. Bu sayede, yararlanıcılar kendi reform ve kalkınma gündemlerini $\mathrm{AB}$ standartlarına uyumlu hale getirecektir. Çoklu-Ülke Strateji Belgesi ile bölgesel işbirliği ya da bölgesel işbirliği öncelikleri incelenecektir. IPA II önceden tanımlanmış sektörlerde reform gerçekleştirmeyi amaçlar. Bu sektörler ise, demokrasi ve yönetişim, kanun veya büyüme ve rekabet üstünlüğü gibi genişleme stratejisi ile bağlantılı alanları içerir. IPA II, AB standartlarını getirecek yapısal reforma, sektörlerin değişiminin ve AB standartlarına ulaşmasının bir aracı olacaktır (European Commission, 2015b).

\section{Türkiye’ye Yapılan AB Hibe Destekli Projelerin STEEPLED Yöntemi ile Analizi}

STEEPLED Yöntemi stratejik planlama yapmaya ya da içinde yer alınan çevresel faktörleri irdelemeye yardımcı olan, bu faktörlerin etkilerinin neler olduğunu ve neler olacağını görmek için kullanılan bir analiz yöntemidir. Sosyal (Social), Teknolojik (Technology), Ekonomik (Economic), Çevresel (Environment), Politik (Political), Yasal (Legal), Avrupalılaşma (European) ve Demografik (Demographics) faktörlerinin ingilizce baş harflerinden meydana gelen bu analiz yönteminde uygulama bu faktörler dikkate alınarak yapılır. Çalışmada, STEEPLED yöntemine göre $\mathrm{AB}$ hibe destekli proje ve program türlerinin örnekleri kategorize edilerek sunulmaktadır.

\begin{tabular}{|l|l|}
\hline Faktörler & Konular \\
\hline Sosyal (Social) & Sosyal uyum sağlama, eğitim, sektörler arası işbirliği, gençlik ve spor \\
\hline Teknolojik (Technology) & Teknik destek sağlama, teknoloji geliştirme programları \\
\hline Ekonomik (Economic) & Nitelikli iş gücü, KOBİ yardımları, enerji kullanımı ve istihdam \\
\hline Çevresel (Environment) & Çevre düzenleme ve gelişimi \\
\hline Politik (Political) & Yerelde AB proje fikri oluşturma ve yerel düzeyde yapılan düzenlemeler \\
\hline Yasal (Legal) & Avrupa Birliği müktesebatının aktarımı, uygulanması ve yürütülmesi \\
\hline Avrupalılaşma (European) & Müzik, sanat, kültürel miras ve insan hakları \\
\hline Demografik (Demografic) & Nüfus yapısı, dil ve kültür çeşitliliği, ülkeler arası öğrenim farklılığ1 \\
\hline
\end{tabular}

Tablo 4. STEEPLED Yöntemi (*Yazarlar tarafindan oluşturulmuştur)

\subsection{Sosyal (Social) Faktörler}

“Hayatboyu Öğrenme Programı (2007-2013)”, AB’yi sosyal uyuma ve sürdürülebilir ekonomik kalkınmaya sahip olan bir bilgi toplumu yapmak için meydana getirilmiştir. Önceki dönem programları olan Socrates ve Leonardo da Vinci programlarının yerini alan bir uygulamadır. Program bünyesinde sektörel alt programları (Comenius, Erasmus, Leonardo da Vinci, Grundtvig ve bunlara ek olarak Ortak Konulu Program (Transversal) ve Jean Monnet Programı) kapsar (Avrupa Birliği Bakanlığı, 2015a).

2007-2013 yıllarını kapsayan Hayatboyu Öğrenme Programının yükseköğretim alanındaki hibe destekleri Avrupa Birliği Komisyonu tarafından 2014-2020 yılları için “Erasmus+ Programı” altında devam ettirilmesi kararı alınmıştır. Bu program ile eğitim, gençlik ve spor konularında oluşabilecek yeni gereksinimler için Avrupa 2020 Stratejisi hedeflerine uygun olarak çeşitli sektörler arasında işbirliğinin oluşmasına firsat verecek daha etkin araçlar kullanılması hedeflenmektedir. Ayrıca yükseköğretimde kaliteyi, kurumların birbirleri ve iş çevresi ile işbirliğini artırmayı amaçlamaktadır (Türkiye Ulusal Ajansı, 2015).

Türkiye ile AB arasında yapılan anlaşma ile “ístihdam ve Sosyal Yenilik (Employment and Social Innovation-EaSI)” programının, 1 Ocak 2014 - 31 Aralık 2020 dönemini içerecek şekilde nitelikli ve sürdürülebilir istihdam, yeterli sosyal korumanın temini, sosyal dışlanma ve yoksullukla mücadele ile çalışma şartlarının iyileştirilmesi hususlarına destek verilmesi amacıyla uygulanması ve 920 milyon Avro toplam bütçeye sahip olması kararlaştırılmıştır. Bu dönemden daha önce ki Çalışma ve Sosyal Güvenlik Bakanlığı (ÇSGB) tarafinca yürütülen Ortak Değerlendirme Belgesi (JAP) ve Ortak Sosyal İçerme ve Sosyal Koruma Belgesi (JIM), ESRP ile tek bir belgede toplanmıştır (Çalışma ve Sosyal Güvenlik Bakanlığı, 2015a).

“íçişleri Bakanlığı İnsan Hakları Yapılanmasının Geliştirilmesi için Destek Projesi (SEI) (Technical Support to Promote Human Rights Structure in Ministry of Interior)” tamamı Avrupa Birliği tarafından finanse edilecek olan 263.000 Avro bütçeli proje 13 Nisan 2015 tarihinde uygulanmaya başlamıştır. Böylece, İçişleri Bakanlığı'nın insan hakları konusundaki görevli merkez birim olması, bağlı kuruluşların ihtiyaçlarının belirlenmesi ile ihtiyaçlar göz önüne alınarak kapasite ve bilgi artışını sağlayan bir Eylem Planının meydana getirilmesi amaçlanmaktadır (DİAB, 2015b).

“Jean Monnet Burs Programı” yaklaşık 20 yıldır AB müktesebatı konusunda bilgi sahibi personel ihtiyacının giderilmesi için yürütülmektedir. 1989 yılında uygulamaya konulan program Türkiye-AB ilişkilerinin en dinamik ve renkli yönlerini açığa vurmaktadır. Jean Monnet bursları Türkiye'deki kamu/özel sektör çalışanlarına, STK üyelerine, üniversite öğrencileri ile akademik ve idari personele AB üyesi ülkelerde eğitim firsatı sunarken, AB ile ilgili konularda uzmanlar yetiştirilmesine katkı sağlar (Avrupa Birliği Bakanlığı, 2015a). 
“Katılım Öncesi Süreçte Sivil Toplumun Güçlendirilmesi: Sivil Toplum Kuruluşları (STK) Hibe Programı” katılım öncesi süreçte Türkiye'de sivil toplumu güçlendirerek, siyasal reformların ve AB'ye uyum çabalarının genişlemesini kalıcılığını sağlamayı amaçlamaktadır. Türkiye için 2005 yılı Katılım Öncesi Mali Yardım Programı kapsamında yer almakta olan program kapsamındaki sekiz farklı hibe programı için ayılan toplam bütçe 10,5 milyon Avro'dur (ABGS, 2015b). Programdan daha sonra ise "Sivil Toplum Diyaloğu'nun Geliştirilmesi-I (CSD I) projesi (2005)” oluşturulmuştur. “Avrupa Birliği ve Türkiye Arasındaki Sivil Toplum Diyaloğunun Geliştirilmesi-II (CSD II)” başlıklı proje ise IPA kapsamında 2007 programına dâhil olmuştur. Bu proje sayesinde Avrupa Birliği’nin dayandığı değerler, işlevi ve politikaları ile birlikte Türk tarihi ve kültürü de dâhil olmak üzere Avrupa Birliği içerisinde Türkiye'nin daha fazla tanınmasının yanında anlaşılmasını sağlamak ve bu sayede de gelecekteki genişlemenin firsatları ve zorlukları konusunda farkındalık oluşmasını mümkün kılmak hedeflenmiştir. Proje 5.3 milyon Avro tutarında olan ve işbirliğini, ortaklıkların desteklenmesini ve Kültür ve Sanat, Balıkçılık ve Tarım konularında Türk sivil toplumları ile AB'deki benzer örgütler arasındaki diyaloğun geliştirilmesini amaçlayan hibe programlarının uygulamasını kapsamaktadır. Avrupa Birliği Genel Sekreterliği tarafindan “AB Yolunda Genç Iletişimciler Yarışması, Iletişim Gönüllüleri Projesi (2011), Avukatlar için Yargı ve Temel Haklar Projesi” gibi sosyal içerikli çeşitli uygulamalar yürütülmüştür (ABGS, 2015c).

\subsection{Teknolojik (Technology) Faktörler}

2002 yılından itibaren kurumların proje hazırlama ve AB müktesebatına uyumu için kısa dönemli teknik destek ihtiyaçlarını karşılamak adına “AB Entegrasyon Sürecinin Desteklenmesi Faaliyetleri (Support Activities to Strengthen the European Integration Process - SEI)” adındaki finansman projesi yıllık olarak AB Katılım Öncesi Mali Yardım Programları kapsamında uygulanmaktadır (ABGS, 2015d).

1984 yılından bu yana Avrupa'nın bilim, teknoloji politika ve uygulamalarının uyumlaştırılması için Avrupa Birliği Çerçeve Programları oluşturulmuştur. Bunlar, Avrupa'nın araştırma ve teknoloji geliştirme kapasitesini güçlendirme, üniversite-sanayi işbirliğini sağlama, AB'nin üye ülkelerini, aday ülkelerini ve işbirliği yaptığ diğer ülkelerini $\mathrm{AB}$ politikalarına uygun çeşitli alanlarda işbirliğini sağlamak amacıyla uygulanmaktadırlar. Çerçeve Programlar, geniş kapsamlı bir bilimsel çerçevede araştırma ve teknoloji geliştirme faaliyetlerini güçlendirmek adına özel bir fonlama uygulaması ile yürütülmektedir. Bu amaçla 2007-2013 yılları için “ $\boldsymbol{A B} 7$. Çerçeve Programi” yürütülmüştür. 2014-2020 yıllarında ise “Horizon 2020” programı uygulamaya konmuştur (TÜBİTAK, 2015).

AB mali işbirliği kapsamında Ulaştırma Bakanlığı tarafından teknik destek sağlama adına "Karayolu Taşımacılı̆̆̆ Sektörüne Destek Projesi”, “Türk Demiryolu Sektörünün Yeniden Yapılandırılması ve Güçlendirilmesi Projesi”, “Posta Sektörünün Yeniden Yapılandırılmasına Yönelik - Farklılı Analiz Etüdü̈” (Tamamlanmıştır), “TINA (Transport Infrastructure Needs Assessment) Projesi”, “Türkiye'de Deniz Güvenliğinin Güçlendirilmesine Destek Projesi” (Denizcilik Müsteşarlığı'nca yürütülmektedir) isimlerindeki çalışmalar uygulanmaktadır (Ulaştırma Bakanlığı, 2009).

\subsection{Ekonomik (Economic) Faktörler}

Günümüz şartlarına uygun ve daha nitelikli işgücü sağlamak ve karşılaşılan zorlukların üstesinden gelebilmek için ülkelerdeki mevcut çerçeveyi oluşturmayı hedefleyen "Uluslararası Yetişkin Becerilerinin Ölçülmesi Programı (PIAAC)”, OECD Eğitim Direktörlüğü (EDU) ile İstihdam, Çalışma ve Sosyal İşler Direktörlüğü (DELSA) tarafından ortaklaşa yürütmeye konmuştur. Genel amacı, iş gücünün becerilerini daha verimli ve etkili olarak ekonomiye kazandırılmasını sağlamaya yardımcı olmaktır. OECD tarafından bir itibar projesi olarak görülen PIAAC'ın 2008-2013 yılları için düzenlenen ilk dönemine Türkiye dâhil olmamıştır. 2012-2016 yıllarını kapsayan ikinci dönemine ise katılımı sağlanmıştır. Çalışma ve Sosyal Güvenlik Bakanlığı AB Koordinasyon Dairesi Başkanlığı ve Türkiye İş Kurumu Genel Müdürlüğü programdan sorumlu kurumlardır. OECD Beceriler Stratejisi, Ulusal Hayat Boyu Öğrenme Stratejisi ve Eylem Planı, Ulusal İstihdam Stratejisi, İnsan Kaynaklarının Geliştirilmesi Operasyonel Programı PIAAC ile ilişkili Türkiye'de uygulanan program ve proje türleridir (Çalışma ve Sosyal Güvenlik Bakanlığı, 2014).

2007-2013 yılları arasında işletmelere ve küçük ve orta büyüklükteki işletmelere yönelik “Rekabet Edebilirlik ve Yenilik Çerçeve Programı (Competitiveness and Innovation Framework Programme - CIP)” uygulamaya koyulmuştur. Üç programdan oluşan bu programın ilk programı, “Girişimcilik ve Yenilik Özel Programı (Entrepreneurship and Innovation Programme)", ikinci programı “Bilgi ve İletişim Teknolojileri Politikaları Destek Programı (Policy Support Programme - ICT)” şeklindedir ve Türkiye bu iki programı uygularken; üçüncü olan “Avrupa Akıllı Enerji ve Teknoloji Programını (Intelligent Energy Europe Programme -IEE)” uygulamaya koyamamıştır (Bilim, Sanayi ve Teknoloji Bakanlığı, 2015).

Avrupa Birliği 2007-2013 yılları arasında KOBİ'ler ve işletmeler için “Rekabet Edebilirlik ve Yenilik Çerçeve Programın (Competitiveness and Innovation framework Programme - CIP)” yürütmüştür. Programın Avrupa çapındaki bütçesi 3,6 milyar avrodur ve üç bileşenden oluşur. İlki “Girişimcilik ve Yenilik Ö̈el Programı (Entrepreneurship and Innovation Programme - EIP)” iken bütçesi 2.17 milyar Avro ve yürütücü kurum Bilim, Sanayi ve Teknoloji Bakanlığı'dır. İkincisi “Bilgi ve İletişim Teknolojileri Politikaları Destek programı 
(Policy Support Programme - ICT)” ve bunun bütçesi ise 728 milyon Avro iken Kalkınma Bakanlığ - Bilgi Toplumu Dairesi tarafından uygulanmıştır. Üçüncüsü ise “Avrupa Akıllı Enerji ve Teknoloji Programı (Intelligent Energy Europe Programme - IEE)”dır ve bütçesi 727 milyon Avro olan bu bileşene Türkiye'de katılım mevcut değildir (Bilim, Sanayi ve Teknoloji Bakanlığı, 2013).

\section{4 Çevresel (Environment) Faktörler}

2007-2009 dönemini kapsaması üzere “Çevre Operasyonel Programı (ÇOP)” uygulamaya konulmuştur. Bu program Türkiye'nin çevre sektöründeki performansını, Avrupa Birliği'nin ilkeleri ve politikaları kapsamında gelişmesine katkıda bulunacak temel plan ve eylem belgelerinden biri olma özelliğini taşımaktadır. Çevre ve Orman Bakanlığı tarafından, Avrupa Komisyonu ile birlikte şekillendirilmiş ve geliştirilirken; Katılım Öncesi Yardım Aracı (IPA) Tüzüğü'nün 8 (1) maddesine göre, Komisyon Kararı ile onaylanmıştır. ÇOP'un uygulanması aynı zamanda bölgelerdeki ekonomik faaliyetleri canlandırarak geri dönüşüm, yenilikçi enerji üretimi, turizm ve eğlence sektörlerinde yeni istihdam olanakları sunmasını hedeflemiştir (Çevre ve Şehircilik Bakanlığı, 2015).

\subsection{Politik (Political) Faktörler}

Katılım Öncesi Mali Yardım Aracı kapsamında "Valiliklerde AB İşleri için Kapasite Oluşturulması Projesi (VABpro)”, katılım sürecindeki projelerin uygulanması ve takibinin yanı sıra AB'ye üyelik aşamasında halkın desteğini sağlayabilme adına oluşturulmuştur. Avrupa Birliği Bakanlığı tarafından 20 pilot şehri kapsayan ve 2 yıl sürmesi planlanan bu projenin toplam bütçesi 1950000 Avro’dur (Yereldeab, 2015a).

2010 yılının başında AB hakkında yerel düzeyde bilgi sağlanması ve kamuoyunun AB ile ilgili doğru fikir edinmesi, projelerin uygulanması, takibi ve anlaşılır hale getirilmesi fikriyle "Valiliklerin AB Sürecinde Etkinliğinin Artırılması Projesi” hayata geçirilmiştir. 26 Ocak 2010 tarih ve 2010/6 sayılı İçişleri Bakanlığı'nın Genelgesi başlatılmıştır. Ayrıca bu projeye destek olması amacıyla, valiliklerde kurulmuş olan AB birimlerinin altyapısının güçlendirilmesi, teknik kapasitelerinin ve etkinliklerinin artırılması için "İllerimiz Avrupa Birliğine Hazırlanıyor Programı” uygulamaya konmuştur (Yereldeab, 2015b). “ill Özel İdareleri AB'ye Hazırlanıyor Projesi” ise yerel yönetimlerin, Türkiye'nin AB'ye katılım sürecini destekler nitelikte hareket edebilmeleri ve Avrupa Birliği'nin bu süreçte sunduğu firsatları en iyi şekilde değerlendirmelerini başarılı bir süreç içerisinde gerçekleştirebilmeleri adına ortaya konmuştur. Proje 28 Kasım 2011 tarihinde İl Özel İdareleri'nin Avrupa Birliği ile ilgili konularda idari kapasitelerinin güçlendirilmesi ve farkındalığının artırılması amacıyla Avrupa Birliği Bakanlığı, İçişleri Bakanlığı ve Vilayetler Hizmet Birliği tarafından hayata geçirilmiştir (Yereldeab, 2015c). “Ístanbul AB'ye Hazırlantyor Projesi” 26 Nisan 2012 tarihindeki protokol imza töreninde Avrupa Birliği Bakanlığı, İstanbul Valiliği, İstanbul Büyükşehir Belediye Başkanlığı ve Türkiye Belediyeler Birliği arasında uygulamaya konulmuştur. İstanbul'daki yerel yönetimlerin Avrupa Birliği hakkındaki farkındalıklarının artırılmasını amaçlayan bu proje ayrıca ilgili birimlerin alt yapısını güçlendirmeyi, teknik kapasitelerini ve etkinliklerini artırmayı hedeflemiştir. Proje dâhilinde Şehir Eşleştirme Programı, İstanbul İli En Başarılı Proje Yarışması, AB Sürecinde Türkiye'de Yerel Yönetimler Sempozyumu, Müktesebat Eğitimleri ve Proje Sergileri düzenlenmesi ve çeşitli yayınların ortaya konulması planlanmıştır (Yereldeab, 2015d). 27 Mart 2012 tarihinde imzalanan protokol ise $\mathrm{AB}$ müktesebatına ve uyum sürecine olan bilgi ve becerilerin güçlendirilmesi ve farkındalıkların artırılması için Avrupa Birliği Bakanlığı, Ankara Valiliği ve Ankara Büyükşehir Belediyesi işbirliğinde “Ankara AB’ye Hazırlanıyor Projesi” ni ortaya koymuştur. Proje Ankara Valiliği, Ankara Büyükşehir Belediyesi, ilçe belediyeleri, kaymakamlıklar, valiliğe bağlı il müdürlükleri ve Ankara ili Avrupa Birliğine Uyum, Danışma ve Yönlendirme Kurulu (AB UDYK) üyesi kuruluşlarda uygulanmaya başlanmıştır (Yereldeab, 2015e).

\subsection{Yasal (Legal) Faktörler}

“AB Teknik Destek ve Bilgi Değişim Ofisi (TAIEX)” Avrupa Birliği müktesebatının aktarımı, uygulanması ve yürütülmesi konularında ülkelere destek sağlamak üzere uygulanan bir programdır. Yalnızca kamu kurumlarını kapsayan program, çalışma ziyaretleri, uzman talebi ve seminer/çalışma toplantıları adları altında destek vermektedir. Kamu kurumlarının talebi üzerine işleyen bu programın koordinasyonu ve takibi T.C. Çalışma ve Sosyal Güvenlik Bakanlığı'nca yürütülmektedir (Çalışma ve Sosyal Güvenlik Bakanlığı, 2015b).

\subsection{Avrupalılaşma (European) Faktörleri}

Avrupa Birliği tarafından Türkiye'de 2007-2013 yılları arasında desteklenen proje türlerinden bir diğeri ise “Kültür Programı”dır. Müzik, plastik sanatlar, görsel sanatlar, sahne sanatları ve kültürel miras alanlarındaki projelere finansman kaynağı sunmuştur. Ayrıca program kapsamında yapılan kültürel aktiviteler ile çeşitli etnik ve sosyal gruplar arasında köprüler kurulması sağlanmıştır (Avrupa Birliği Bakanlığı, 2015a).

“Demokrasi ve Insan Hakları için Avrupa Aracı (DIHAA)” dünya genelinde sivil toplum girişimlerine imkân tanıyarak demokrasi ve insan haklarını geliştirmeyi hedefleyen programdır. Türkiye'de 2002'de uygulanmaya başlayan program ile makro(küresel)/mikro(ülke) nitelikteki hibeleri desteklemek için yılda yaklaşık 2,7 milyon avroluk destekler sağlanmaktadır. Her iki proje türü de AB Türkiye Delegasyonu tarafindan yürütülmektedir. Projeler ile ifade özgürlüğü, adalete erişim, cezasızlık, işkenceyle mücadele, kültürel farklılıkların yanı sıra kadın haklarının korunması ve savunulması sağlanmaktadır (Europa, 2015). 


\subsection{Demografik (Demografic) Faktörler}

AB müktesebatının önemli kısmının belediyelerin yetki alanına girmesi nedeniyle, belediyelerin AB ile ilgili konularda yeterli bilgi ve kapasiteye sahip olması gerekmektedir. Türkiye'de belediyelerin AB ile ilgili alanlarda idari kapasitelerinin güçlenmesini ve farkındalığının artırılmasını sağlamak amacıyla Avrupa Birliği Bakanlığı Eğitim ve Kurumsal Yapılanma Başkanlığı, Proje Uygulama Başkanlığı ve Türkiye Belediyeler Birliği tarafından ortaklaşa uygulanacak olan “Belediyelerimiz AB'ye Hazırlanıyor” projesi hazırlanmıştır. Projenin hedef kitlesi nüfusu 50.000 üzerinde olan il ve ilçe belediyeleridir. Böylece nüfus açısından yeterli hacime sahip il ve ilçelerde gerekli çalışmaların yürütülmesi hedeflenmiş ve 2011 yılında uygulanmaya başlayan proje amacı doğrultusunda il ve ilçelerde çeşitli faaliyetlerde bulunmaktadır (Yereldeab, 2015f).

$\mathrm{AB}$, hedeflerine ulaşabilmek için öğrenciler ve eğitim personeli arasında kültür ve dil çeşitliliği ile birlikte bilgi ve anlayış sağlamayı hedefler. Öğrencilerin kişisel gelişimleri için temel kabiliyetlerini edindirmeyi amaçlarken bu doğrultuda “Comenius Programı” nı uygulamaya koymuştur. Böylece ülkelerarası farklılıkların meydana getirdiği dil öğrenimi gereksiniminin yerine getirilmesini sağlar (Avrupa Birliği Bakanlığı, 2015b).

\begin{tabular}{|c|c|}
\hline Faktörler & Örnekler \\
\hline $\begin{array}{l}\text { Sosyal } \\
\text { (Social) }\end{array}$ & $\begin{array}{ll}> & \text { Hayatboyu Öğrenme Programı (2007-2013) } \\
& \text { 2014-2020 yılları için Erasmus+ Programı } \\
> & \text { İçişleri Bakanlığ İnsan Hakları Yapılanmasının Geliştirilmesi İçin Destek Projesi } \\
& \text { (SEI) (Technical Support to Promote Human Rights Structure in Ministry of } \\
& \text { Interior) } \\
> & \text { İstihdam ve Sosyal Yenilik (Employment and Social Innovation - EaSI) Programı } \\
> & \text { Jean Monnet Burs Programı } \\
> & \text { Katılım Öncesi Süreçte Sivil Toplumun Güçlendirilmesi: Sivil Toplum Kuruluşları } \\
& \text { (STK) Hibe Programı } \\
> & \text { Sivil Toplum Diyaloğu'nun Geliştirilmesi-I (CSD I) projesi (2005) } \\
> & \text { Avrupa Birliği ve Türkiye arasındaki Sivil Toplum Diyaloğunun Geliştirilmesi-II } \\
& \text { (CSD II) } \\
> & \text { İletişim Gönüllüleri Projesi (2011) }\end{array}$ \\
\hline $\begin{array}{l}\text { Teknolojik } \\
\text { (Technological) }\end{array}$ & $\begin{array}{ll}> & \text { AB Entegrasyon Sürecinin Desteklenmesi Faaliyetleri (Support Activities to } \\
& \text { Strengthen the European Integration Process - SEI) } \\
> & \text { Karayolu Taşımacılığı Sektörüne Destek Projesi } \\
> & \text { Türk Demiryolu Sektörünün Yeniden Yapılandırılması ve Güçlendirilmesi Projesi } \\
> & \text { Posta Sektörünün Yeniden Yapılandırılmasına Yönelik "Farklılık Analiz Etüdü } \\
> & \text { TİNA (Transport Infrastructure Needs Assessment) Projesi” } \\
> & \text { Türkiye'de Deniz Güvenliğinin Güçlendirilmesine Destek Projesi } \\
> & \text { AB 7. Çerçeve Programı } \\
> & \text { Horizon } 2020\end{array}$ \\
\hline $\begin{array}{l}\text { Ekonomik } \\
\text { (Economic) }\end{array}$ & $\begin{array}{l}>\text { Uluslararası Yetişkin Becerilerinin Ölçülmesi Programı (PIAAC) } \\
\text { Rekabet Edebilirlik ve Yenilik Çerçeve Programı(Competitiveness and Innovation } \\
\text { Framework Programme - CIP } \\
\text { Girişimcilik ve Yenilik Özel Programı (Entrepreneurship and Innovation } \\
\text { Programme-EIP) } \\
\text { Bilgi ve İletişim Teknolojileri Politikaları Destek programı (Policy Support } \\
\text { Programme-ICT }\end{array}$ \\
\hline $\begin{array}{l}\text { Çevresel } \\
\text { (Environmental) }\end{array}$ & $>$ Çevre Operasyonel Programı (ÇOP) \\
\hline $\begin{array}{l}\text { Politik } \\
\text { (Political) }\end{array}$ & $\begin{array}{ll}\text { Daliliklerde AB İşleri İçin Kapasite Oluşturulması Projesi (VABpro) } \\
>\quad \text { Valiliklerin AB Sürecinde Etkinliğinin Artırılması Projesi } \\
>\quad \text { İl Özel İdareleri AB'ye Hazırlanıyor Projesi } \\
>\quad \text { İstanbul AB'ye Hazırlanıyor Projesi } \\
>\text { Ankara AB'ye Hazırlanıyor Projesi }\end{array}$ \\
\hline $\begin{array}{l}\text { Yasal } \\
\text { (Legal) }\end{array}$ & $>$ AB Teknik Destek ve Bilgi Değişim Ofisi (TAIEX), \\
\hline $\begin{array}{l}\text { Avrupalilaşma } \\
\text { (European) }\end{array}$ & $\begin{array}{ll}> & \text { 2007-2013 yılları arası Kültür Programı } \\
& \text { Demokrasi ve İnsan Hakları için Avrupa Aracı (DİHAA) }\end{array}$ \\
\hline $\begin{array}{l}\text { Demografik } \\
\text { (Demographic) }\end{array}$ & $\begin{array}{l}>\text { Belediyelerimiz AB'ye Hazırlanıyor Projesi } \\
>\text { Comenius Programı }\end{array}$ \\
\hline
\end{tabular}

Tablo 5. STEEPLED Özeti (*Yazarlar tarafindan oluşturulmuştur) 


\section{Sonuç}

Türkiye'de uygulanan AB hibe destekli projelerin konu ve hibe tutarları o dönemki proje program içeriklerine göre değişiklik göstermiştir. Maddi yetersizlik nedeniyle hayata geçirilemeyen projeler AB fonları yardımıyla pek çok ekonomik ve sosyal gelişime katkı sağlayacak şekilde uygulanmıştır. Fonlardan kurum/kuruluşların yanı sıra bireylerde yararlanma imkânı yakalamıştır. Bu durum ise toplumsal girişimciliğge destek vermiştir.

Bu çalışmada Türkiye'nin AB mali yardımlarından yararlanma durumu daha önce kullanılmamış olan STEEPLED Yöntemi ile ele alınmıştır. Bu analiz yöntemiyle AB hibe program ve projeleri kategorize edilmiş ve ekonomik kalkınmaya etkileri ortaya konmuştur. Türkiye'de uygulanan AB destek programlarının özellikle sosyal, ekonomik ve teknolojik boyutlarda daha aktif olduğu dikkat çekmektedir. Bu durumda AB'nin bölgesel kalkınmaya destek olan projelere öncelik verdiği görülmüştür. AB'nin amacı kendisine üye ya da aday olan ülkeler arasında ekonomik ve sosyal refah düzeyini eşit hale getirmek olması sebebiyle özellikle demografik sebeplerle herhangi bir ayrıma gidilmediği gözlemlenmiştir.

\section{Kaynakça}

- Akça and Albeni, 2009. "Turkey’s Benefits from EU Financial Asistance: Difficulties and Successes". 2nd ICES International Conference on European Studies, 06-07 November 2009, Tiran-Albania, p. 319-324.

- Akça, 2010. "Instrument for Pre-accession Assistance (IPA) to Turkey: Expectations and Results". 2nd International Symposium on Sustainable Development, 8-9 June 2010, Sarajevo, p. 334-338.

- Atak, 2009. “Avrupa Birliği’nde Yapısal Fonlar: Türkiye ile Üye Ülkelerin Karşılaştırılması Üzerine Bir İnceleme”, Trakya Üniversitesi Sosyal Bilimler Enstitüsü, Edirne.

- $\quad$ ABGS, 2015a. TR-AB Mali İşbirliğii, http://www.abgs.gov.tr/index.php?p=5

- ABGS, 2015b. Katılım Öncesi Süreçte Sivil Toplumun Güçlendirilmesi: STK Hibe Programı, http://www.abgs.gov.tr/index.php?p=41105

- $\quad$ ABGS, 2015c. AB Bakanlığ1 Projeleri, http://www.abgs.gov.tr/index.php?p=46008

- ABGS, 2015d. SEI - Avrupa Birliğine Entegrasyon Sürecini Destekleme Faaliyetleri Projesi, http://www.abgs.gov.tr/?p=45545\&l=1

- Avrupa Birliği Bakanlığı, 2015a. Kültür Programı, http://www.ab.gov.tr/index.php?p=46037\&l=1

- Avrupa Birliği Bakanlığı, 2015b. Hayat Boyu Öğrenme Programı (LLP), http://www.ab.gov.tr/index.php?p=46033\&l=1

- Bilim, Sanayi ve Teknoloji Bakanlığı, 2013. AvrupaBirliği Rekabet Edebilirlik ve Yenilik Çerçeve Programi (CIP) Kapsaminda Bakanlığımız Koordġnasyonunda Yürütülen Girişimcilik ve Yenilik Programina (EIP) İlişkin Bilgi Notu, https://www.sanayi.gov.tr/Files/Documents/eip-genel-bilgi-notu-web27122013162637.pdf

- Bilim, Sanayi ve Teknoloji Bakanlığı, 2015. Rekabet Edebilirlik ve Yenilik Çerçeve Programi, https:/www.sanayi.gov.tr/Files/Documents/cip-bilgi-notu-web-27122013162312.pdf

- Çalışma ve Sosyal Güvenlik Bakanlığı, 2014. http://www.csgb.gov.tr/csgbPortal/ShowDoc/WLP+Repository/per/dosyalar/duyurular/abdairesi

- Çalışma ve Sosyal Güvenlik Bakanlığı, 2015a. http://www.ikg.gov.tr/tr-tr/abili\%C5\%9Fkileri/easi.aspx

- Çalışma ve Sosyal Güvenlik Bakanlığı, 2015b. http://www.ikg.gov.tr/tr-tr/abili\%C5\%9Fkileri/taiex.aspx

- Çevre ve Şehircilik Bakanlığı, 2015. Avrupa Birliği Yatırımları Dairesi Başkanlığı, Çevre Operasyonel Programi (2007-2009), http://www.csb.gov.tr/gm/ab/index.php?Sayfa=sayfa\&Tur=webmenu\&Id=9362

- DİAB, 2015a. http://www.diab.gov.tr/ipa-2-donemi-2014-2020

- DİAB, 2015b. http://www.diab.gov.tr/icisleri-bakanligi-insan-haklari-yapilanmasinin-guclendirilmesi-icindestek-projesi-seii

- $\quad$ Europa, 2015. EU and Civil Society, What is The European Instrument for Democracy and Human Rights (EIDHR)?,Projects Supported, http://avrupa.info.tr/tr/ab-ve-sivil-toplum/demokrasi-ve-insan-haklari-icinavrupa-araci-dihaa-nedir/desteklenen-projeler.html

- European Commission, 2015a. Regional Policy, http://ec.europa.eu/regional_policy/archive/intro/regions5_en.htm\#1

- European Commission, 2015b. Neighbourhood - Enlargement Instrument for Pre-accession assistance (IPA) Overview, http://ec.europa.eu/enlargement/instruments/overview/index_en.htm

- Gençkol, 2003. “Avrupa Birliği Mali İşbirliği Politikaları ve Türkiye”. Devlet Planlama Teşkilatı, Uzmanlık Tezi, Yayın No: DPT: 2679. 
- Karabacak, 2004. “Avrupa Birliği Mali Yardımları ve Türkiye ile Mali İşbirliği”. Maliye Dergisi, 146: 69106.

- Karataş, 2010. Avrupa Birliği Katılım Öncesi Mali Yardımlar, Ankara.

- Kösecik ve Akbaş, 2009. AB Mali Yardımları ve Türkiye'de Desteklenen Yerel Yönetim Projeleri. Ankara: Gazi Kitabevi.

- Ö̈canlı, 2006. “Avrupa Birliği Yardımları Çerçevesinde Türkiye’ye Yapılan Yardımlar: Isparta Kilimcilik Eğitim Destek ve Pazarlama Projesi Örneği”, Süleyman Demirel Üniversitesi Sosyal Bilimler Enstitüsü, Isparta.

- TÜBİTAK, 2015. AB Çerçeve Programları, http://www.fp7.org.tr/tr/icerik/ab-cerceve-programlari

- Türkiye Ulusal Ajansı, 2015. Erasmus+ Programı: Genel Yap1, http://www.ua.gov.tr/programlar/erasmusprogram $\% \mathrm{C} 4 \% \mathrm{~B} 1$

- Ulaştırma Bakanlı̆̆ı, 2009. AB Koordinasyon Dairesi Başkanlığı, http://www.ubak.gov.tr/BLSM_WIYS/UBAK/tr/dokuman_ust_menu/bakanlik/20090610_174257_204_1_6 4.html

- Yeğen, 2009. “AB Mali Yardımları ve AB’nin Yeni Üye Ülkeleriyle Türkiye Üzerine Amprik Bir İnceleme”. Süleyman Demirel Üniversitesi Sosyal Bilimler Enstitüsü, Isparta.

- Yereldeab, 2015a. Valiliklerde AB İşleri İçin Kapasite Oluşturulması Projesi (VABpro), http://www.yereldeab.org.tr/TabId/98/ArtMID/1456/ArticleID/789/\%E2\%80\%9CValiliklerde-AB$\% \mathrm{C} 4 \% \mathrm{~B} 0 \% \mathrm{C} 5 \% 9$ Fleri- $\% \mathrm{C} 4 \% \mathrm{~B} 0231$ in-Kapasite-Olu $\% \mathrm{C} 5 \% 9$ Fturulmas $\% \mathrm{C} 4 \% \mathrm{~B} 1$-Projesi $\% \mathrm{E} \% 80 \% 9 \mathrm{D}-$ VABpro.aspx

- Yereldeab, 2015b. Valiliklerin AB Sürecinde Etkinliğinin Artırılması Projesi, http://www.yereldeab.org.tr/TabId/98/ArtMID/1456/ArticleID/790/Valiliklerin-AB-S252recindeEtkinli\%C4\%9Finin-Art\%C4\%B1r\%C4\%B1lmas\%C4\%B1-Projesi.aspx

- Yereldeab, 2015c. İl Özel İdareleri AB'ye Hazırlanıyor, http://www.yereldeab.org.tr/TabId/99/ArtMID/1480/ArticleID/734/\%C4\%B01-214zel-\%C4\%B0dareleriAB\%E2\%80\%99ye-Haz\%C4\%B1rlan\%C4\%B1yor.aspx

- Yereldeab, 2015d. İstanbul Avrupa Birliğine Hazırlanıyor Projesi, http://www.yereldeab.org.tr/TabId/98/ArtMID/1456/ArticleID/762/\%C4\%B0stanbul-AvrupaBirli\%C4\%9Fine-Haz\%C4\%B1rlan\%C4\%B1yor-Projesi.aspx

- Yereldeab, 2015e. Ankara AB'ye Hazırlanıyor Projesi, http://www.yereldeab.org.tr/TabId/99/ArtMID/1480/ArticleID/791/Ankara-AB\%E2\%80\%99ye$\mathrm{Haz} \% \mathrm{C} 4 \% \mathrm{~B} 1 \mathrm{rlan} \% \mathrm{C} 4 \% \mathrm{~B} 1$ yor-Projesi.aspx

- Yereldeab, 2015f. Belediyeler AB'ye Hazırlanıyor Projesi, http://www.yereldeab.org.tr/TabId/99/ArtMID/1480/ArticleID/697/Belediyeler-ABye$\mathrm{Haz} \% \mathrm{C} 4 \% \mathrm{~B} 1 \mathrm{rlan} \% \mathrm{C} 4 \% \mathrm{~B} 1$ yor-Projesi.aspx

- Yıldız ve Akdağ, 2006. "Avrupa Birliği Yapısal Fonları Kapsamında Bölgesel Kalkınma ile Kırsal Kalkınma Fonlarının Karşılaştırılması”. Tarım ve Köyişleri Bakanlığı Türktarım Dergisi, 167: 1-17. 


\title{
Avrupa Birliğinde Malların Serbest Dolaşımının İlkesinin Analizi Analyzing the Free Movement of Goods Principle in European Union
}

\author{
Prof. Dr. Ahmet Ay (Selçuk University, Turkey) \\ $\mathrm{Ph}$. D. Candidate Fatih Ayhan (Selçuk University, Turkey) \\ Ph. D. Candidate Mustafa Gerçeker (Selçuk University, Turkey)
}

\begin{abstract}
In this paper, it will be analyzed the free movement of goods principle's progress in European Union. This principle have special importance for all countries not only EU members. Because of globalisation's effects, all countries have to open their boundaries to all over the World. Thus the free movement of goods affects almost all countries. Free movement of goods principle is achieved a successful progress in EU case. In this paper, we will try to show this principle's success in EU agreements, regulations, settlements and peaks. Not only in EU, but also all open economies are getting extra benefit from trade. Free movement of goods is a part of international trade and also first step of EU integration process. Followings steps are consisting of free movement of capitals, services and human. In this paper, we'll show the meaning and importance of this principle and its historical progress in EU. And also it will be analyzed to basic drawback, preventions, and exceptions of this principle.
\end{abstract}

\section{Giriş}

Günümüzde hiçbir ülke dış dünyadan kayıtsız olarak ekonomi politikalarını uygulama imkânına sahip değildir. Tüm ülkeler daha çok üretim bunun yanında daha çok tüketim yapabilmek için dışa açılmak ve diş ticaret yapmak durumunda kalmışlardır. Artık korumacı politikalar yerine dış dünya ile daha çok etkileşim halinde olan politikalar tercih edilmektedir. Ülkeler dış ticarette bulunmalarına karşın tarife dışı engeller nedeniyle, zaman zaman hedeflerine ulaşamamaktadırlar. Bazı ekonomilerin yerli üretimi korumak amacıyla yabancı mallara karşın tarife dışı engeller uygulanması, ticari malların serbest dolaşımları önünde engel oluşturmaktadırlar. Bu engellemelerin önüne geçilebilmesi için Dünya Ticaret Örgütü, GATT ve Avrupa Birliği (AB) bir takım önlemler almışlardır. Bu çalışmada $\mathrm{AB}$ özelinde malların serbest dolaşımı için alınmış önlemler ve zaman içinde konuyla ilgili olarak gelinen aşamalar incelenmiş, bu önlemlerin $\mathrm{AB}$ ekonomisinin dış ticaretini nasıl etkilediğine ilişkin kısa bir analiz yapılmaya çalışılmıştır.

Malların serbest dolaşımının tam olarak sağlanabilmesi için gümrük vergisi, eş etkili vergiler ile miktar kısıtlamalarının kaldırılmasının yanı sıra ticarete konu olan ürünlere ilişkin teknik niteliklerin Birlik genelinde kabul edilecek kurallar ile belirlenmesi gerekmektedir. AB'nin ekonomik entegrasyon sürecindeki asıl hedef; malların, kişilerin, hizmetlerin ve sermayenin serbestçe dolaşabileceği bir iç pazarın oluşturulmasıdır.

Malların serbest dolaşımı(MSD), AB'nin kuruluşundan beri hedeflediği dört temel serbestisinden (malların, kişilerin, hizmetlerin ve sermayenin serbest dolaşımı) en önemlisi olanını ifade etmektedir. AB'nin kuruluşundan beri hedefi olan İç Pazar oluşumu MSD ile başlamış, diğer serbestiler ise sonrasında uygulamaya konulmuştur. MSD, üye ülkeler tarafindan iç pazara arz edilen malların belli kurallar içinde bir teknik engelle karşılaşmadan Topluluk sınırları içinde serbest dolaşımını ifade etmektedir.

\section{Malların Serbest Dolaşımının Anlamı ve Önemi}

Klasik iktisatçılardan beri tam olarak mal piyasalarında bütünleşmiş olmak, serbest ticaretin en temel unsuru olarak belirlenmiştir. Malların serbest dolaşımı, ülkelerin karşılıklı olarak ithalat/ihracat vergileri (gümrük vergileri), eş etkili vergiler ile tüm miktar kısıtlamaları ve eş etkili engellerin kaldırılmasıyla gerçekleşir. Bir ülkede üretilip, ülke içinde serbest dolaşımda olan mallar farklı bir ülkede serbest dolaşıma girmesi için; giriş yaptığı ülkede belirli oranda gümrük vergisi tahsil edilir. Dünya ticaretinin zamanla serbest hale gelmesiyle birlikte ülkeler, düzenledikleri tercihli anlaşmalar (Serbest Ticaret Anlaşmaları, Gümrük Birliği vb.) aracılığıyla karşılıklı olarak ithalat vergileri ve miktar kısıtlamalarını kaldırarak, malların serbest dolaşıma girmelerini sağlarlar.

Malların serbest dolaşımı sağlanarak ticaretin serbestleştirilmesi ile birlikte mal piyasalarının bütünleşmenin sağlayacağı avantajlar şöyle özetlenebilir (Bayraktutan,2004:57);

$\checkmark \quad$ Ülkeler karşılaştırmalı üstünlüğe sahip oldukları ürünlerin üretiminde uzmanlaşarak üretim faktörlerini en iyi şekilde tahsis ederek etkin üretim yapılabilecektir. Bu durum A.Smith'in "Mutlak Üstünlük” ve Ricardo'nun "Karşılaştırmalı Üstünlük" teorilerinin temelinde yatmaktadır.

$\checkmark \quad$ Üretim artışı ölçek ekonomilerinden faydalanmayı, rekabeti ve üretimde etkinliği artıracaktır. Bu hedefler mal piyasalarının bütünleşmesinde odağı oluşturmaktadır. 
$\checkmark \quad$ Malların serbest dolaşımının sağlanması ile ekonomik birliğe üye ülkelerin dış ticaret hadleri birlik dışındaki ülkelere nazaran iyileşecektir. Üye ülkelerin ticaret hadleri, yani ihracat fiyatlarının ithalat fiyatlarına oranı, dünyanın geri kalan bölümüne karşı iyileşecektir.

\section{Malların Serbest Dolaşımına Engel Olan Unsurlar}

Malların serbest dolaşımı çeşitli vasıtalarla engellenmekte ve dış ticaretin serbestleştirilmesinde engel olan faktörler şöyle özetlenebilecektir (Bayraktutan,2004:58-59):

$\checkmark \quad$ Gümrük tarifeleri,

$\checkmark \quad$ Tarife dişı engeller,

$\checkmark \quad$ Tarife Benzeri Engeller(Vergi, resim, harçlar, bürokratik işlem maliyetleri)

$\checkmark \quad$ Miktar Kisitlamalari(Kotalar),

$\checkmark \quad$ Kambiyo Kisitlamaları,

$\checkmark$ Görünmez Engeller-Teknik Engeller(Sağlık, çevre, güvenlik vb. gerekçelerle yapılan yasal ve idari düzenlemeler, devlet tekelleri ve teknik standart uygulamaları),

$\checkmark$ Gönüllü İhracat Kısıtlamaları(İhracat Kotaları),

$\checkmark \quad$ Diğer Tarife Dışı Engeller(sübvansiyonların bağlı ticaret, takas, clearing, karşı-satınalım, geri-satınalım, dengeleme(ofset) anlaşmaları şeklinde yabancı malların girişinin önlenmesi)

Ticaret politikaları uygulanırken bazen korumacılık ve dış ticarette serbestleşme politikaları birlikte uygulanabilmektedir. Serbest ticaret politikaları uygulanırken korumacılığın da uygulanmasının sebepleri şu şekilde açıklanmaktadır (Bayraktutan,2004:60-61).

$\checkmark \quad$ Stratejik önemi olan mallarda dışa bağımlı olmama,

$\checkmark$ Genç endüstrileri koruma,

$\checkmark$ Dampinge karşı korunma,

$\checkmark \quad$ Sosyal dampinge karşı korunma (ücretlerin, emek verimliliğinin altında kalmasını engelleme)

$\checkmark \quad$ İstihdamı artırma,

$\checkmark$ Ekonomik yapının çeşitlendirilmesi (döviz gelirinin istikrarı için ihraç ürün yelpazesinin geniş tutulması),

$\checkmark \quad$ Ödemeler bilançosunun dengelenmesi,

$\checkmark \quad$ Stratejik ticaret politikası (sanayileşmiş ülkelerin büyümelerine büyük katkı sağlayan bilgisayar ve iletişim araçları endüstrilerinde karşılaştırmalı üstünlük kurmaları).

Ticarette uygulanan teknik engeller malların serbest dolaşımını engelleyebilmektedir. Uluslararası pazarda dolaşan ürünler için konulan standartlar, teknik düzenlemeler ve uygunluk değerlendirmeleri farklı farklı biçimlerde uygulanabilmektedirler. Artan yaşam standartlarından dolayı güvenli ve kaliteli malların talebinin artması, tüketicinin korunması ve çevrenin korunmasına ilişkin hassasiyetin artması nedeniyle teknik engellerin arttığı kabul edilmektedir (TÜSİAD,2001).

AB'de malların serbest dolaşımını gümrük vergilerine ilişkin düzenlemeler, miktar kısıtlamaları ve tarife dışı engellerin kaldırılmasına ilişkin uygulamalar sağlayabilmektedir. Ortaya çıkacak ticaret sapmasına bağlı olarak oluşacak haksız rekabetin önüne geçebilmek amacıyla ticaret politikalarının da uyumlaştırılması gerekmektedir. Üye ülkeler için eşit firsatlar oluşturabilmek için iç pazardaki ülkelerin üçüncü ülkelere karşı ortak ticaret politikalarını kabul etmeleri gereklidir. Bunun yanında Gümrük Birliği’ne tabi ülkelerin teknik mevzuatlarının da birbirine paralel olmaları gereklidir. İç pazarda serbest dolaşıma tabi malların standardizasyonunun artması tarife dış1 engelleri de yok edecektir (İKV,2014:6-7).

Uluslararası ticarete ilişkin engeller, tarifeler ve tarife dışı engeller şeklinde uygulanmaktadır. Uluslararası ticareti daraltacak şekilde etkide bulunabilecek tüm yasa, kural ve vergilendirme uygulamaları tarife dişı engeller arasında sayılabilmektedir. Genellikle oluşturulan bu kurallar ülkeler arası yasal yapılar ve idari zorunlulukların farklılaştırılmasından ortaya çıkmaktadır. Bu kurallar ticareti engellemek yerine iç piyasayı korumak ve bunun yanında sağlık, güvenlik, hijyen, hayvan, bitki ve çevrenin korunması amacıyla ortaya konulmaktadır. Ülkeler bu uygulamalara başvururken başlangıçta ticareti ve malların serbest dolaşımını engellemeyi planlamasalar da, zaman zaman gizli korumacılık sağlamak için de kullanılmaktadır (TÜSİAD,2001:23).

Ülkeler arasında malların sağlık, güvenlik, çevre ve tüketiciyi korumak gibi farklı standartlar koymaları teknik engelleri oluşturmaktadır. Standartların farklılaşması firmaların seri üretimini kısıtlarken, ürünlerde farklılaşmaya gitmeyi zorunlu kılmakta ve üretim maliyetini artırmaktadır. Bu durum yabancı ülke pazarlarına açılmayı hedefleyen ihracatçı firmaların bu pazarların standartlarına yönelik üretim yapmaları için maliyetlerinin artması firmaların bu pazarlarda rekabet avantajını kaybetmelerine sebep olmakta ve yerel firmalarla rekabet edememelerine sebep olmaktadır (TÜSİAD,2001:23) 
Tüketicinin refahının, sağlığının ve güvenliğinin korunabilmesi için malların serbest dolaşımında temel kriterlere uyum sağlanması çok önemlidir. Fakat ülkelerin farklı farklı değerlendirme süreçleri belirlemeleri malların serbest dolaşımının önünde teknik engel oluşturmaktadır (TÜSİAD,2001:35).

\section{Malların Serbest Dolaşımına Engel Olan Unsurlar:}

Malların serbest dolaşımı önündeki engeller fiziki, teknik ve mali engeller şeklinde gruplandırılabilmektedir. Bu engeller özetle şöyle tanımlanmaktadır:

> Fiziki Engeller: Gümrüklerde turistlerin yanlarındaki mallara getirilen miktar kısıtlamaları, sınır kapılarındaki kontroller nedeniyle uzun süre bekletilme ve bürokrasiye ilişkin engeller fiziki engeller kapsamında değerlendirilmektedir. Özellikle bürokrasi işlerinin uzatılması malların serbest dolaşımını büyük oranda engellemektedir.

Teknik Engeller: Oluşturulan ekonomik birliklerde üye ülkelerin sağlık, standartlar, çalışma, güvenlik, tüketiciyi koruma ve çevrenin korunması gibi çeşitli nedenlerle belirledikleri yerel yasal yapılanmalardan kaynaklanan zorunluluklar nedeniyle mallar yabancı piyasalara giriş yapamamaları teknik engel kapsamında değerlendirilmektedir. Yerel standartların farklılaştırılmasından kaynaklanan üretim maliyeti artışı ülkeler arası rekabeti de engellemektedir.

Mali Engeller: Özellikle dolaylı vergilendirmelerden kaynaklanan maliyet artışları mali engeller kapsamında değerlendirilmektedir. Katma değer vergisi ve özel tüketim vergisi gibi dolaylı vergileme uygulamaları sınır kontrollerini güçlendirirken malların serbest dolaşımını engellemektedir (Karluk,2003:52).

\section{Malların Serbest Dolaşımının Engellenmesinin Yaratacağı Sakıncalar:}

Uluslararası ticarette uygulanacak teknik engellerin; gerek üreticiler gerek ihracatçılar gerekse serbest ticaretin gelişmesi açısından yaratacağı mikro ve makro sorunlar şu şekilde özetlenebilmektedir (TÜSİAD,2001:29-30);

5.1 Mikro Sorunlar:

$\checkmark$ Ölçek Ekonomisi Fırsatının Değerlendirilememesi: Uygulanan teknik engeller nedeniyle firmaların ülke ve piyasalar arasındaki standartların farklı olması nedeniyle farklı farklı üretim yapma durumunda kalmaları üretim maliyetlerini artırmaktadır. Firmaların farklı tiplerde ürünleri üretmek zorunda kalmaları ölçek ekonomisi imkanından yararlanmayı olanaksızlaştırmaktadır. Birim maliyetlerin artması özellikle KOBİ'lerin üretimlerini zorlaştırmaktadır.

$\checkmark$ Uygunluk Değerlendirme Prosedürlerinin Yüklediği İlave Maliyetler: Firmaların dış pazarlara ürünlerini satabilmek için zorunlu tutulan teknik düzenleme ve standartlara uygunluğun resmi makamlarca onaylanması zorunluluğu uygunluk değerlendirmesi, test ve belgelendirme gibi ilave maliyetler yüklemektedir.

$\checkmark$ Bilgilenme Maliyetleri: Yabancı teknik düzenlemelerin analizi, tercümesi ve uzman personelin yetiştirilmesi gibi ilave maliyetler getirmektedir.

$\checkmark$ Sürpriz Maliyetler: Teknik düzenlemelerde yapılan değişikliklere uyum sağlamaya çalışan yabancı üreticiler yerli firmalara göre rekabet avantajını kaybetmektedir.

5.2 Makro Düzeyde Sakıncalar:

$\checkmark$ Gizli Korumacılık: Ülkeler tüketici sağlığı, güvenliği ve çevrenin korunması gibi konulara ilişkin düzenlemeleri gizli korumacılı yapmak amacıyla kullanarak serbest ticareti engelleme çabalarına girebilmektedirler.

$\checkmark$ Serbest Ticaretin Aksaması: Serbest ticarete ilişkin teknik engellerin artması ülkelerin dış ticarete girişmelerini engelleyerek iç piyasaya yönelmelerine neden olabilmekte ve uluslararası ticaret zarar görmektedir.

$\checkmark$ Yeni Yatırımlardan Vazgeçilmesi: Ülkeler arasında teknik düzenleme ve standartların aşırı derecede farklılaşması farklı ülkelerde üretilen parçalar arasındaki uyumu bozmakta birim maliyetleri artırarak imalat sektörü bu durumdan olumsuz etkilenmektedir. Ayrıca firmaların etkin lojistik kanalları kurmalarını zorlaştırması da maliyetleri olumsuz etkileyecektir. İthal girdi kullanan sektörlerde dişardan alınan parçalar arasındaki uyumsuzluk imalatı olumsuz etkilemektedir. Bütün olarak değerlendirildiğinde bu olumsuz etkiler yeni yabancı yatırımlardan vazgeçilmesine sebep olacaktır.

\section{Malların Serbest Dolaşımına İlişkin AB Düzenlemeleri}

İktisadi bütünleşme örneklerinden iç pazar uygulaması, serbest ticaret anlaşması ve gümrük birliğine göre farklılıklar göstermektedir. Serbest ticaret anlaşması ile ülkeler karışlıklı olarak gümrük vergileri ile kotaları kaldırmakta ve diğer ülkelere karşı vergilendirmede inisiyatif kullanabilmektedirler. Gümrük birliğinde bunun 
yanında diğer ülkelere karşı ortak gümrük vergisi uygulanmaktadır. İç pazarda ise, gümrük birliği ile malların serbest dolaşımının yanında üretim faktörlerinin de serbest dolaşımı sağlanmaktadır (Craig,1998:548-549).

AB'deki tek pazar veya ortak pazar olarak da bilinen iç pazar $A B$ üyesi devletler arasında malların serbest dolaşımına imkan sağlamaktadır. Yani yasal olarak ticareti ve üretimi yapılan malların üye devletlerarasında sınır kontrollerinin kaldırılması anlamına gelmektedir. Böylece $\mathrm{AB}$ üyesi devletlerarasında çoğu mal vergi ödemeden, gümrük bildirimi yapmadan ve gümrük belgelerine gerek duymadan sınırlar arasında geçiş yapabilmektedir (HMRC,2014:1).

Gümrük birliği ile $\mathrm{AB}$ içinde gümrüklerin kaldırılıp üçüncü ülkelere karşı ortak gümrüklerin uygulanması, ticaret ve rekabet politikalarının uyumlaştırılması ile birlik içinde malların serbest dolaşımını sağlamaktır. AB gümrük vergileri, haksız rekabete karşı uygulamalar ve teknik engellerin uyumlaştırılarak ortak bir diş ticaret politikası ile malların serbest dolaşımını sağlamaya çalışmaktadır (IKV,2014:4). AB içinde üye ülkelerin etkisinin azaltılıp iç pazarın etkin şekilde işlemesi için gümrük birliğine ilişkin yasal düzenlemelerin yapılması malların serbest dolaşımı için tek başına yeterli olamamıştır (Şahin,2010:49).

Roma Anlaşması veya AB'yi Kuran Anlaşma olarak bilinen 1958 yılında yürürlüğe giren $\mathrm{AB}$ anlaşması AB'nin temel amacı olan bir iç pazarın oluşturulmasının temelini oluşturmakta ve malların serbest dolaşımını hedeflemektedir. 1993 yılında Maastricht Anlaşmasının imzalanması ile birlikte üye ülkeler arasında ticari engellerin tamamen kaldırılmasını amaçlayan bir İç Pazarın oluşturulması için önemli bir adım atılmıştır. Bununla birlikte, bir üye ülke tarafindan diğer üye ülkelerin ürettiği mallara uygulanan sistematik sinır kontrolleri ve diğer tüm ayrımcı işlemler (gümrük vergileri dahil) kaldırılmıştır. Üçüncü ülkeler için ise ortak bir gümrük tarifesi uygulanmaya başlamıştır(HMRC,2014:20).

Avrupa Birliğini (AB) kuran Roma Antlaşmasının 2. Maddesinde AB'nin kurulmasındaki amaç; ortak pazarın kurulması ve üye devletlerin ekonomi politikalarının yaklaştııılması ile ekonomik etkinliğin artırılması, sürekli ve dengeli biçimde yayılması, istikrarın artırılması, yaşam standartlarının hızla yükseltilmesi için sıkı bir işbirliğinin oluşturulması şeklinde özetlenmiştir (Karluk,2003:49).

$\mathrm{AB}$ içinde ticaretin serbestleştirilmesi ve malların serbest dolaşımının sağlanması ile ilgili olarak aynı anlaşmanın 9. Maddesinde yer alan "Topluluk, mal alışverişlerinin tümünü içine alan ve üye devletlerarasındaki ithalat ve ihracata uygulanan gümrük vergileri ve eş etkili resimlerinin yasaklanması ile üçüncü ülkelerle ilişkilerinde ortak gümrük tarifesinin kabulünü kapsayan bir gümrük birliği üzerine kurulur.” şeklindeki maddesi ile 12.-17. maddelerinde üye ülkeler arasında gümrük vergilerinin kaldırılması, 18.-29. maddelerinde ortak gümrük tarifesinin konulması ve 30-37. maddelerinde ise üye ülkeler arasındaki miktar kısıtlamalarının kaldırılmasına ilişkin hukuki düzenlemeler yapılmıştır (Kılıç,2002:249).

Malların serbest dolaşımı AB'nin hukuki zeminini oluşturan AB Antlaşması ile gümrük birliği çerçevesinde sağlanmaktadır. $\mathrm{AB}$ Antlaşmasının 10. Maddesine göre bir ürünün "Serbest Mal" niteliği kazanabilmesi için gümrük vergileri, eş etkili vergiler ve miktar kısıtlamalarının üye ülkeler arasında karşılıklı olarak kaldırılarak diğer ülkelere karşı da ortak bir gümrük politikası uygulanması öngörülmüştür (Yavaşi,2001:29).

$\mathrm{AB}$ Antlaşmasının 28. Maddesinde yer alan "İthalatta miktar kısıtlamaları ve eş etkili tüm önlemler üye devletlerarasında yasaktır." hükmü ile 29. maddede bulunan "İhracatta miktar kısıtlamaları ve eş etkili tüm önlemler üye devletlerarasında yasaktır." hükmü çerçevesinde malların serbest dolaşımına engel teşkil eden mali nitelikli olmayan teknik engellerin kaldırılması amaçlanmıştır. 28. Maddenin çerçevesi oldukça geniştir. Örneğin; gümrüklerde uygulanan bürokrasi işlerinden yerli ürün için yapılan hükümet propagandaları ile ürünün menşeine bakılmaksızın yiyeceklerdeki katkı maddelerinin tanımlanması gibi geniş bir inceleme alanı oluşturulmuştur (Baykal,2006:106-107).

$\mathrm{AB}$ anlaşmasının 90. Maddesinde yer alan "Hiçbir üye devlet, diğer üye devletin ürünlerine, kendi benzer ürünlerine doğrudan veya dolaylı olarak uyguladığından daha yüksek herhangi bir iç vergiyi doğrudan veya dolaylı olarak koyamaz. Ayrıca hiçbir üye devlet, diğer üye devletlerin ürünlerine diğer ürünlere dolaylı koruma sağlayacak nitelikte herhangi bir iç vergi uygulayamaz." hükmü ile malların vergilendirme ve koruma politikalarıyla serbest dolaşımı önündeki engeller yasaklanmıştır. Bu hüküm ile 23-25. Maddelerdeki gümrük vergileri veya gümrük vergilerine eş etkili yükümlülükler uygulamak suretiyle MSD'nin kısıtlanmasının engellemeye çalışılması için ayrımcı bir iç vergilendirme yoluna gidilmesi engellenmiştir (Şahin,2010:33).

$\mathrm{AB}$ Antlaşmasının üçüncü bölümündeki, 30. maddede ise malların serbest dolaşımına getirilebilecek istisnai durumlar özetlenmiştir. Bu istisnalar:

$\checkmark \quad$ Kamu düzeni, kamu güvenliği ve ahlakı,

$\checkmark \quad$ İnsan ve hayvan sağlı̆̆ı ve bitkilerin korunması,

$\checkmark \quad$ Milli, kültürel, tarihi veya arkeolojik değerlerin korunması,

$\checkmark \quad$ Ticaret ve sınai mülkiyetin korunması şeklinde sıralanmıştı (IKV,2005;46).

AB içinde malların serbest dolaşımı Roma Antlaşması ile 1 Ocak 1970'de gerçekleştirilmesi hedeflenmiştir. Fakat ulaştırma ve enerji alanlarındaki gecikmelere rağmen 1 Temmuz 1968 'de hedeflenen tarihten önce kurucu 
altı ülke üye arasında gümrük birliği oluşturulmuştur. Gümrük vergileri ve miktar kısıtlamaları üye ülkeler arasında tamamen kaldırılmış, diğer ülkelere karşı ortak gümrük tarifesi kabul edilmiştir.

Yasal olarak ticareti yapılan mallara ilişkin iç sınırların kontrolü AB üyesi ülkeler arasında kaldırıldığından, AB kendisi için bir dış sınır oluşturmaya ihtiyaç duymuştur. Bu nedenle İç Pazara giriş ve çıkış aynı oranda vergilendirilmekte ve İç Pazara girmeden önce aynı süreçlere tabi tutulmaktadır. Bu da üye devletlerin, malların AB'ye giriş ve çıkışlarında gümrük hizmetlerinde ortak bir tarife ve standartlaştırılmış gümrük süreçlerine tabi tutulmasina gerektirmektedir (HMRC,2014:6-7).

Bütün $\mathrm{AB}$ üyesi devletler $\mathrm{AB}$ gümrük birliğinin bir parçasıdır. Bunun yanında $\mathrm{AB}$ ile Türkiye, Andorra, San Marino ve Monako arasında da bir gümrük birliği tesis edilmiştir. İlaveten dört EFTA üyesi ülkeler (Norveç, İzlanda, Lichtenstein ve İsviçre) arasında da İç Pazara katılmaya ve malların serbest dolaşımından fayda sağlamalarına izin verilmiştir. Bu düzenlemeler sayesinde malların serbestçe dolaşabileceği $\mathrm{AB}$ alanı daha da genişletilmiştir (HMRC,2014:7).

Ulusal yasalardaki sapmalar nedeniyle dört özgürlüğe ilişkin engellerin kaldırılmasına için AB tarafından yasalar yapılmaktadır. Bu süreç "pozitif entegrasyon” olarak bilinmektedir. Bu yasalar, Anlaşmaya ilişkin geniş hükümlerin detayları ve iktisadi faaliyet gösterenler için faydalı olacak hukuki yolu açıklamaktadır (HMRC,2014:9).

Ticarette teknik engellerin kaldırılmasına dair AB mevzuatı, üye ülkelerarasında malların serbest dolaşımını sağlayabilmek amacıyla ürün bazında teknik özellikleri, test ve belgelendirme yöntemleri ve benzeri hususlardaki düzenlemeleri, piyasaya arz edilecek tüm ürünlerde güvenli olma şartını getiren veya $A B$ dışı ülkelerden ithalatta yapılacak kontrollerin usullerini belirleyen bazı yatay düzenlemeleri içermektedir. $A B$ mevzuatı ile düzenlenmeyen alanlarda malların üye ülkeler arasında dolaşımının önündeki teknik engelleri kaldırmak için "bir üye ülkede yasal olarak üretilmiş ve/veya yasal olarak serbest dolaşıma girmiş bir ürünün diğer üyelerde de piyasaya arzına engel getirilemeyeceği” ilkesi kabul edilmiştir (Yeşiltepe,2013:35).

MSD aynı zamanda diğer üye ülkelerin malları için eşit muamele yapılmasını gerektirmektedir. Bu nedenle ithal edilen ürünler için şart koşulan hususlar doğrudan ayırımcılık olarak incelenmelidir. Yerli malı alımlarına ilişkin kampanyalarda bu yasağa aykırıdır (Örneğin; İrlanda malı tüketilmesi kampanyası Komisyonda incelenmiş bir husustur.). Ayrıca Anlaşma dolaylı ayrımcılığı da yasaklamaktadır. Yani, ülkelere karşı tarafsızmış gibi görünmesine karşın diğer üye ülkelerin mallarına büyük etki yapan uygulamalar yasaklanmıştır. Bu sebeple, bir üye ülke, diğer üye ülkelerde malların üretilmesini ve pazarlanmasını yasal olarak yasaklayacak şekilde sonuçlanacak kısıtlamalar getirememekte ve bu prensip, "Karşılıklı Tanıma” prensibi olarak bilinmektedir (HMRC,2014:20-21).

İç pazarın oluşturulması ilk kez 1983 Stuttgart Zirvesinde ele alınmış olup, bu zirvedeki konular içinde en önemli konu olarak gündeme getirilmiştir. AB Konseyi bu kararla iç pazarın 1992 yılına kadar gerçekleştirilmesini talep etmiş ve Komisyon 18-29.06.1985 tarihleri arasında Milano’da toplanan Bakanlar Konseyinde iç pazarın tamamlanması kabul edilmiştir. Beyaz Kitap olarak bilinen raporda, AB'ye üye ülkeler arasında iç sınırlar tamamen kaldırılmış gerçek bir birlik iç pazarının, 1992 yılına kadar oluşturulabilmesi için, mal, hizmet, kişi ve sermayenin serbest dolaşımı önündeki fiziki, teknik ve mali nitelikteki engellerin kaldırılmasına yönelik yasa önerileri çalışılmaya başlanmıştır. AB Komisyonu bu hedefler için 26.05.1986, 11.05.1987, 21.03.1988, 20.06.1989 ve 28.03.1990 tarihlerinde her y1l iç pazar oluşumu sürecindeki ilerlemeleri gösteren beş rapor yayınlamıştır. 1985 tarihli Beyaz Kitap’ta öngörülen kuralların bir kısmı 01.01.1993 tarihi beklenilmeden uygulamaya konulmuştur. Örneğin sekiz üye devlet arasındaki ticari denetimler ve sermaye hareketleri üzerindeki kısıtlamalar, Temmuz 1990'dan itibaren yürürlükten kaldırılmıştır. İç pazarın oluşumu için Temmuz 1987'de yürürlüğe giren Tek Avrupa Senedi de büyük önem taşımaktadır. Tek senet Roma Antlaşmasının 236'ncı maddesini referans almakta ve bu anlaşma üzerinde kapsamlı değişiklikler yapmayı öngörmektedir. Nitekim iç pazarın 1992 yılına kadar tamamlanması ve hukuki altyapının oluşturulması için gerekli ivme Tek Senetten alınmıştır(Karluk,2003:54).

Roma Anlaşması'nın Tek Avrupa Senedi ile getirilen değişiklikler çerçevesinde düzenlenen yeni 8A, 8B ve 8Cmaddelerinde (Tek Avrupa Senedinin 13., 14. ve 15. maddeleri) iç pazarın tanımı yapılmakta ve iç pazarın kuruluşuyla ilgili prensipler düzenlenmektedir (DTM,2007:219).

AB'de pazarın ulusal piyasalara bölünmesi ve üye ülkeler arasındaki değişik ticareti engelleyici uygulamaların varlığı birlik ruhuna aykırı olacak şekilde ilave maliyet unsuru haline gelmiştir. İç pazarın etkin biçimde işlemesi, malların, hizmetlerin, kişilerin ve sermayenin serbest dolaşımının sağlanması ve bunu engelleyecek fiziki, teknik ve mali engellerin kaldırılması gerekliliği nedeniyle Tek Avrupa Senedi ile iç pazarın oluşturulmasının yasal boyutu oluşturulmuştur.

İç pazarın kazançlarının bilimsel olarak analizi için hazırlanan ve 1998'de yayınlanan Cecchini Raporuna göre, iç pazarın oluşturulması ile orta vadede, Birlik çapında 170-250 Milyar ECU tutarında kazanç sağlayacağı belirtilmiştir. Bu kazanç üye ülkelerin yarattığı toplam GSMH'nin \%4,5-6,5'ini oluşturmaktadır. Bunun yanında tek pazara gidilmesi ile 2 milyon ilave istihdam alanı oluşturulacaktır. Ayrıca tüketici fiyatlarında \%6'ya varan azalma, kamu açıklarında GSMH'ye göre \%2,2'lik, cari işlemler dengesinde ise \%1'lik düzelme görülecektir. 
Raporda piyasalar arasın sınır kontrollerinin kaldırılmasının AB'ye getirdiği maliyetlerin yanında getireceği firsatlar ve faydalarda ele alınmıştır (Karluk,2003:54).

Cechini raporuna göre Tek Pazardan beklenen olumlu gelişmeler şu şekilde özetlenebilir(DTM,2007:219) ;

$\checkmark$ Gümrük işlemlerinde, kamu alımlarında ve mali hizmetlerdeki engellerin kaldırılması maliyet tasarrufu ve kazanç artışı sağlayacak,

$\checkmark$ Ölçek ekonomileri ile irrasyonel davranışlar ve tekel kârlarının azaltılması sağlanacak,

$\checkmark$ Yoğun rekabet ortamının oluşması,

$\checkmark$ Araştırma ve geliştirme faaliyetleri için daha çok kaynak tahsisi,

$\checkmark$ Düşük fiyat sayesinde talep artışının yanında üretim ve kamu müdahaleleri için gereksiz kaynak ayrılmasının önüne geçilecektir.

İç pazarda malların serbest dolaşımı için SOLVIT ağı, Ürün Bağlantı Noktaları ve Çilek Düzenlemeleri şeklinde üç temel mekanizma oluşturulmuştur. Bu düzenlemeler özetle şu şekildedir (HMRC,2014:9);

$\checkmark$ SOLVIT (Solutions to your problems with your EU rights), AB komisyonunun bir girişimi olarak kurulmuş ve kamu otoritelerince $\mathrm{AB}$ kurallarının yanlış uygulandığına inanan vatandaş ve işletmeler için ücretsiz ve resmi olmayan bir çatışma çözüm mekanizması olarak tasarlanmıştır. İşletmeler için SOLVIT, temel olarak yanlış gümrük formaliteleri, kısıtlamaları ve aşırı teknik gerekçelerle ilgili şikâyetlerle mücadele etmektedir.

$\checkmark \quad$ Ürün Bağlantı Noktaları 764/2008 sayılı düzenleme ve 305/2011 numaralı Yapı Ürünleri Düzenleme kapsamında kurulmuştur. Bunlar $\mathrm{AB}$ piyasasında satılabilecek ürünlere uygulanabilecek ulusal düzenlemeler hakkında ücretsiz bilgiye ulaşım imkânı sağlamaktadır.

$\checkmark$ 2679/98 numaralı Çilek Düzenlemeleri (The Strawberry Regulations) malların serbest dolaşımı engellerini geçici fakat yeterli düzeyde denetleme ağı ve bilgi alanı sağlamaktadır. Üye devletler ticareti engelleyecek fakat belli üye devletin dışındaki işletmeler tarafından bilinemeyecek büyük olayların (gösteriler ve yol yapımı gibi) detayları yayımlanacaktır.

MSD’nin sağlanabilmesi için öncelikle üye ülkeler arasındaki teknik mevzuat uyumlaştırılması gereklidir. Bunun sağlanabilmesi için, gümrük vergileri, eş etkili vergiler ve miktar kısıtlamaları kaldırılmalı, bunlara ilaveten ticarete konu olan ürünlere ilişkin ortak kurallar benimsenmelidir. Buna göre "Uyumlaştırılmış" ve "uyumlaştırılmamış" alan olarak iki farklı kural benimsenmektedir. "Uyumlaştııılmamış Alan" kuralına göre, AB üyesi bir ülkede yasal olarak satılabilen bir ürün, diğer üye ülkelerde de sorunsuz şekilde piyasaya sürülebilmelidir. Malların serbest dolaşımı ile ilgili olarak"Klasik Yaklaşım" ve "Yeni Yaklaşım" şeklinde iki farklı yaklaşım kabul edilmiştir.

Teknik engellerin kaldırılmasında klasik (eski) yaklaşım Roma Antlaşmasının 100. Maddesinde yer almakta ve üye ülkeler arası farklılıklar nedeniyle serbest ticaretin engellenmesine ilişkin topluluk direktifleri düzenlenerek ülkeler arasında uyumun sağlanmasını ifade etmektedir. Bu yaklaşıma ilişkin uygulamalar her alanda ayrı ayrı direktif oluşturulması nedeniyle süreci uzatmış ve ekonomik anlamda daha maliyetli olmuştur (TÜSİAD,2001:32).

7 Mayıs 1985 tarihinde 85/136 no'lu konsey kararıyla kabul edilen Yeni Yaklaşım ile teknik engellerin kaldırılmasına ilişkin AB Konseyi tarafından en büyük adım atılmıştır. Bu yaklaşıma göre bu alandaki topluluk mevzuatı, piyasaya sürülen ürünlere ait güvenlikle ilgili tüm detayları kapsayacaktır. $\mathrm{Bu}$ detayların belirlenmesini takiben Birlik standardizasyon kurumlarınca ayrıntılı standartlar hazırlanacaktır. Sonuçta bir üye ülkede yasalara uygun olarak üretilmiş ürünler önemli sağlık ve güvenlik koşullarını sağlaması halinde, Birliğin her yerinde pazarlanabilecektir (Karluk,2003:55). Bu yaklaşım, toplu uyumlaştırmayı öngören klasik yaklaşım ile ticarette ülkelerin karşılıklı olarak yasalarını tanımalarını kapsayan ve tam liberalizasyona dayanan 'Karşılıklı Tanıma' anlayışı arasında yer almaktadır (TÜSİAD,2001:33).

Yeni yaklaşımda kabul edilen temel hedefler şunlardır:

- Uyumlaştırma işlemi sağlık ve güvenlik gerekleri içinde sınırlandırılmakta ve diğer alanlarda karşılıklı tanıma prensibi benimsenmekte,

- Ticarette Avrupa standartlarının gelişmesini sağlamak, bu standartların olmadığı alanlarda teknik engel uygulanmasına engel olmak ve böylece Avrupa standartlarının bulunmadığı alanlarda ulusal standartların karşılıklı olarak benimsenmesine imkân sağlamaktadır. Standartların ve spesifikasyonların geliştirilmesi CEN ve CENELEC'e bırakılmıştır (TÜSİAD,2001:33).

Özetle Klasik Yaklaşımda, ürünler hakkında detaylı düzenlemeler bulunurken, Yeni Yaklaşımda ürünlere ait temel gereklilikler belirlenip uygunluk değerlendirmesi, akreditasyon, standardizasyon ve piyasa gözetimi kurumsal boyut kazanmıştır.

Yeni Yaklaşım Direktifine uygun olarak üretilen ürünler CE işareti taşımak zorundadır. CE işareti ile ürünün tüm direktiflerdeki temel zorunluluklara sahip olduğu ve bütün değerlendirme süreçlerini başarıyla geçtiği sembolize edilmektedir. CE işaretinin korunmasına ilişkin önlemlerin üye ülkelerce alınmalıdır (DTM,2007:94). 
1985 yılı sonrasında uygulanmaya başlayan Yeni Yaklaşım Direktifleri doğrultusunda 21 Aralık 1989 tarihinden sonra kullanılmaya başlanan $\mathrm{CE}$ işareti, bu işareti taşıyan ürünlerin sağlık, güvenlik, çevreyi ve tüketiciyi koruma konusundaki zorunlu kriterleri taşıdığının bir göstergesi olarak kabul edilmektedir. Yani CE işareti bir kalite göstergesi olmaktan ziyade $\mathrm{AB}$ 'nin ilgili direktiflerinde belirtilen şartları taşıyarak bir ürünün, insanların, hayvanların ve bitkilerin can ve mal güvenliğini korumak için gerekli şartları taşıdığının göstergesidir (Yeşiltepe,2013:40).

$\mathrm{CE}$ işareti bulunan ürünlerde ilgili teknik düzenlemelere uygunluk ve güvenlik göstergesi olmasının yanında ticari açıdan $\mathrm{AB}$ üyesi ülkeler içinde ürünlerin dolaşımı esnasında bir tür pasaport görevi taşımaktadır. $\mathrm{AB}$ sınırları içerisinde $\mathrm{CE}$ işareti kapsamına alınan ürünlerin bu işaret olmadan pazarlanması olanaksızdır. Bu kural hem iç piyasada üretilmiş hem de üçüncü ülkelerden ithal edilen ürünler için geçerlidir. CE işaretinin işletilmesine ilişkin kurallara aykırı hareket edilmemişse AB'ye üye ülkeler sınırları içinde CE işareti taşıyan ürünlerin piyasaya arzını ve hizmete sokulmasını yasaklayamamaktadır (DTM,2007:94).

Bir diğer yaklaşım olan Küresel (Global) yaklaşımda ise farklı laboratuvar testleri ve uygunluk değerlendirmelerinin sebep olacağı engellerin önüne geçilmeye çalışılmaktadır. AB'ye üye ülkeler uygunluk değerlendirmesi yapıp CE işareti verebilecek kuruluşlar belirlenerek AB Komisyonuna rapor edilmekte ve onaylanan bu kuruluşlar Komisyon tarafından yayınlanmaktadır. Üye ülkeler resmi olarak onaylanmış kuruluşların tarafsız ve uygun altyapı ile çalıştığının sistemli olarak denetlenmesinden sorumlu bir akreditasyon kurumu oluşturmak zorundadır. Bu kurallara uygun biçimde yapılacak test ve uygunluk değerlendirmeleri tüm üye ülkeler tarafindan karşılıklı olarak kabul edilmek durumundadır (TÜSİAD,2001:35).

Modüler yaklaşımda ise ürün özellikleri ve taşıdıkları risklere bağlı olarak yapılacak uygunluk değerlendirme yöntemlerinin belirlenmesi söz konusudur. Sistem, mevzuat hazırlayıcılara yönelik olarak oluşturulmuş olup mevzuat hazırlayıcı, insan ve hayvan sağlığı ile güvenliği ve çevre korunmasını sağlamak için belli bir alanda bir modül veya modüler kombinasyonu ilgili mevzuatın kapsamına alarak uygunlukdeğerlendirme süreçleri oluşturabilmektedir. Bu yaklaşımda A'dan H’ye kadar 8 modül bulunmaktadır(TÜSİAD,2001:35).

AB içinde ortak Avrupa standartlarının hazırlanmasına ilişskin çalışmaların geçmişi 1960 yılına dayanmakta olup 1973 yılından itibaren önem taşımaya başlamıştır. Avrupa Standardizasyon Komitesi (CEN) ve Avrupa Elektronik Standardizasyon Komitesi (CENELEC) bu anlamda AB içinde standardizasyonun sağlanması açısından önem taşıyan iki farklı kuruluştur. Elektronik ve telekomünikasyon alanlarının dışındaki alanlarda faaliyet gösteren CEN, 1960'lı yıllardakurulmuş olmasına karşın 1980’li yıllarda Yeni Yaklaşım Politikası ve Yeni Yaklaşım Direktifleri’nin kabul edilmesiyle birlikte daha da önemli hale gelmiştir. CENELEC ise, AB ülkelerine yönelik elektronik standartlarını hazırlamaktan sorumlu olup, bunun yanı sıraMilletlerarası Elektronik Komitesi (IEC) ile imzaladığı protokole bağlı olarak çalışmalarının bir kısmını IEC bünyesinde yürütmektedir. $\mathrm{Bu}$ dönemde, elektronik standartlarını hazırlayan iki kuruluş alçak gerilim konusundaki direktifinçıkartılmasını takiben Avrupa Elektronik Standardizasyon Komitesi (CENELEC) adı altında birleştirilip etkinlik kazandırılmıştır.

\section{AB'nin Ticari Verilerinin İstatistiki Analizi}

\begin{tabular}{|c|c|c|c|c|c|c|c|c|c|c|c|c|}
\hline \multicolumn{13}{|c|}{ ÜRÜN GRUPLARINA GÖRE AB-28 DIŞI İTHALAT (Milyon Euro) } \\
\hline $\begin{array}{c}\text { Ürün } \\
\text { grubu/ yll }\end{array}$ & 2003 & 2004 & 2005 & 2006 & 2007 & 2008 & 2009 & 2010 & 2011 & 2012 & 2013 & 2014 \\
\hline $\begin{array}{l}\text { Tüm } \\
\text { Ürünlerin } \\
\text { Toplam }\end{array}$ & 934974 & 1027392 & 1183909 & 1364591 & 1446811 & 1585231 & 1235636 & 1532089 & 1728314 & 1795886 & 1685013 & 1680505 \\
\hline $\begin{array}{l}\text { Yiyecek, } \\
\text { İçecek ve } \\
\text { Tütün }\end{array}$ & 57260 & 58896 & 62974 & 67824 & 75656 & 80976 & 73842 & 80767 & 91478 & 93057 & 93612 & 98329 \\
\hline Hammadde & 42902 & 48247 & 52478 & 62911 & 70006 & 75315 & 47270 & 70750 & 85397 & 80714 & 76231 & 72876 \\
\hline $\begin{array}{l}\text { Mineral } \\
\text { Yakıtlar, } \\
\text { Yağlar vb. } \\
\text { Maddeler }\end{array}$ & 158727 & 184469 & 273965 & 341232 & 338346 & 460170 & 299884 & 384980 & 493358 & 548480 & 500557 & 443522 \\
\hline Kimyasallar & 80424 & 88412 & 96348 & 109145 & 120654 & 124242 & 112519 & 137329 & 155243 & 163359 & 157898 & 164807 \\
\hline $\begin{array}{l}\text { Makine ve } \\
\text { Nakliye } \\
\text { Ekipmanları }\end{array}$ & 326694 & 354307 & 385885 & 412627 & 429021 & 425845 & 352904 & 446471 & 445209 & 447732 & 434487 & 450579 \\
\hline $\begin{array}{l}\text { Diğer Sınai } \\
\text { Ürünler }\end{array}$ & 237776 & 261702 & 290335 & 341347 & 382658 & 375125 & 296498 & 362356 & 401398 & 389697 & 381884 & 407456 \\
\hline $\begin{array}{l}\text { Kategori D1ş1 } \\
\text { Ürünler }\end{array}$ & 31190 & 31358 & 21923 & 29506 & 30469 & 43558 & 52719 & 49438 & 56231 & 72847 & 40345 & 42936 \\
\hline
\end{tabular}

Tablo 1.AB-28'in Ürün Gruplarına Göre İthalatı (Milyon Euro) Kaynak: Eurostat.

Malların serbest dolaşımı prensibinin uygulanmasına ilişskin çabaların AB ticaret hacmini nasıl etkilediğinin görülebilmesi amacıyla $\mathrm{AB}$ ticaretinde meydana gelen değişimler istatistiki olarak incelenecektir. Tablo.1 incelendiğinde 2003 yılından itibaren AB-28 ithalatının yaklaşık iki kat arttığı gözlemlenirken, en çok artışın 
mineral yakıtlar, yağlar vb. maddeler grubunda olduğu dikkat çekmektedir. Takiben makine ve nakliye ekipmanları ile diğer sınai ürünlerin yer aldığı görülmektedir.

\begin{tabular}{|c|c|c|c|c|c|c|c|c|c|c|c|c|}
\hline \multicolumn{13}{|c|}{ AB ÜYESİ ÜLKELERİN AB İÇİ İHRACAT RAKAMLARI (MİLYON EURO, AB28) } \\
\hline ÜLKE/YIL & 2003 & 2004 & 2005 & 2006 & 2007 & 2008 & 2009 & 2010 & 2011 & 2012 & 2013 & 2014 \\
\hline Almanya & 433151 & 474431 & 503859 & 563919 & 626599 & 625584 & 502968 & 572949 & 629995 & 622717 & 623719 & 657311 \\
\hline Hollanda & 210692 & 229880 & 261096 & 292618 & 314168 & 342919 & 276748 & 334939 & 369526 & 386390 & 382559 & 383792 \\
\hline Fransa & 231577 & 240248 & 236905 & 259156 & 268039 & 268042 & 217730 & 240934 & 261409 & 260909 & 259827 & 264244 \\
\hline Belçika & 174605 & 190273 & 206456 & 223387 & 239486 & 246844 & 201279 & 224596 & 246042 & 243051 & 247572 & 250933 \\
\hline İtalya & 167165 & 178158 & 185992 & 205785 & 224981 & 220338 & 170323 & 195523 & 212934 & 211867 & 209829 & 217721 \\
\hline İngiltere & 160188 & 164418 & 177916 & 225146 & 186658 & 178528 & 140321 & 165678 & 182673 & 185032 & 177226 & 182353 \\
\hline İspanya & 104077 & 109364 & 112249 & 121380 & 131076 & 133435 & 113992 & 131996 & 146929 & 146324 & 150517 & 155852 \\
\hline Polonya & 39083 & 48652 & 56745 & 69945 & 81008 & 90539 & 78200 & 95580 & 106014 & 109962 & 115755 & 125663 \\
\hline Çek Cum. & 37843 & 48636 & 54036 & 65171 & 76669 & 85216 & 68960 & 84604 & 97590 & 99380 & 99119 & 107520 \\
\hline Avusturya & 65719 & 71241 & 73533 & 79758 & 88163 & 90590 & 71526 & 83149 & 90944 & 90844 & 92433 & 93591 \\
\hline İsveç & 53105 & 58638 & 62267 & 70948 & 75496 & 75021 & 54833 & 68382 & 75358 & 76644 & 72777 & 72286 \\
\hline Macaristan & 32442 & 37684 & 41646 & 48369 & 55998 & 58836 & 47718 & 56469 & 62458 & 62398 & 63004 & 66588 \\
\hline Slovakya & 16702 & 19451 & 22450 & 29106 & 37233 & 41505 & 34698 & 41329 & 48810 & 52790 & 53557 & 54986 \\
\hline Danimarka & 41395 & 43860 & 48466 & 52506 & 52879 & 55608 & 45612 & 47793 & 52549 & 52161 & 52569 & 52986 \\
\hline İrlanda & 51186 & 53007 & 56262 & 54860 & 56318 & 53739 & 50894 & 51073 & 52189 & 53577 & 48996 & 48404 \\
\hline Romanya & 11861 & 14292 & 15785 & 18286 & 21384 & 23856 & 21672 & 27111 & 32284 & 31705 & 34506 & 37309 \\
\hline Portekiz & 22775 & 23053 & 25003 & 27863 & 29540 & 28925 & 23905 & 28117 & 31888 & 32170 & 33235 & 34181 \\
\hline Finlandiya & 28346 & 28745 & 29935 & 35263 & 37380 & 36728 & 25105 & 28537 & 31738 & 30539 & 30979 & 32000 \\
\hline Slovenya & 8701 & 10088 & 11951 & 14269 & 16976 & 17720 & 14459 & 17088 & 19307 & 18776 & 19170 & 20493 \\
\hline Bulgaristan & 4251 & 5003 & 5670 & 7332 & 8346 & 9245 & 7664 & 9551 & 12689 & 12237 & 13351 & 13782 \\
\hline Litvanya & 3869 & 5030 & 6237 & 7175 & 8111 & 9703 & 7592 & 9554 & 12371 & 13955 & 13612 & 13389 \\
\hline Yunanistan & 8324 & 8828 & 9577 & 11499 & 12408 & 12963 & 10278 & 11583 & 12604 & 12236 & 12837 & 13009 \\
\hline Lüksemburg & 10505 & 11797 & 13756 & 16380 & 14694 & 15457 & 13361 & 12493 & 12025 & 11576 & 11245 & 11922 \\
\hline Estonya & 3301 & 3835 & 4849 & 5066 & 5645 & 5938 & 4511 & 5998 & 7958 & 8264 & 8725 & 8737 \\
\hline Letonya & 2032 & 2494 & 3178 & 3555 & 4397 & 4731 & 3737 & 4839 & 6227 & 6983 & 7236 & 7487 \\
\hline Hırvatistan & 3733 & 4249 & 4475 & 5307 & 5430 & 5842 & 4548 & 5439 & 5736 & 5602 & 5899 & 6464 \\
\hline Malta & 972 & 1000 & 1005 & 1156 & 1111 & 955 & 821 & 1114 & 1296 & 1293 & 1229 & 1016 \\
\hline Kıbris & 259 & 514 & 863 & 747 & 731 & 771 & 604 & \begin{tabular}{|l|}
701 \\
\end{tabular} & \begin{tabular}{|l|}
889 \\
\end{tabular} & 822 & 881 & 766 \\
\hline
\end{tabular}

Tablo 2.AB Üyesi Ülkelerin AB İçi İhracat Rakamları (Milyon Euro, AB28) Kaynak: Eurostat.

Tablo.2'de AB üyesi ülkelerin AB içindeki ihracat rakamları sunulmuştur. Tablo.2'ye göre 657,3 milyon Euro ile Almanya birlik içinde en çok ihracat yapan ülke durumundadır. Almanya'ya en yakın ülkeler ise sırasıyla, Hollanda, Fransa, Belçika, İtalya, İngiltere ve İspanya'dır. 20085 yılında yaşanan küresel krizin tüm üye ülkelerin ihracat rakamlarını önemli ölçüde daralttığı görülmektedir.

AB'nin dünya ticaretindeki ithalatının payı için Tablo.3'te sunulmuştur. Tablo.3 incelendiğinde AB'nin ABD'den sonra en büyük paya sahip olduğu görülmektedir. AB-28'i Çin, Japonya ve Güney Kore takip etmektedir.

\begin{tabular}{|c|c|c|c|c|c|c|c|c|c|c|c|}
\hline \multicolumn{8}{|c|}{ ANA TICARET ORTAKLARINA GÖRE AB'NIN ITHALAT PAYLARI (MILYON EURO) } \\
\hline Ülke Adı & $\mathbf{2 0 0 3}$ & $\mathbf{2 0 0 4}$ & $\mathbf{2 0 0 5}$ & $\mathbf{2 0 0 6}$ & $\mathbf{2 0 0 7}$ & $\mathbf{2 0 0 8}$ & $\mathbf{2 0 0 9}$ & $\mathbf{2 0 1 0}$ & $\mathbf{2 0 1 1}$ & $\mathbf{2 0 1 2}$ & $\mathbf{2 0 1 3}$ \\
\hline AB 28 & 934974 & 1027392 & 1183909 & 1364591 & 1446811 & 1585231 & 1235636 & 1532089 & 1728314 & 1795886 & 1684891 \\
\hline AB 27 & 934957 & 1027522 & 1183213 & 1367529 & 1448684 & 1582932 & 1234317 & 1531022 & 1727740 & 1795250 & 1684738 \\
\hline Kanada & 212497 & 220120 & 252749 & 278766 & 277743 & 277918 & 230304 & 295775 & 323692 & 359876 & 347714 \\
\hline ABD & 1153723 & 1226199 & 1392429 & 1528351 & 1471814 & 1471875 & 1148477 & 1483365 & 1625421 & 1816474 & 1753128 \\
\hline Çin & 364887 & 451185 & 530466 & 630345 & 697640 & 770031 & 720931 & 1051670 & 1252439 & 1415161 & 1468257 \\
\hline (Hong Kong Hariç) & 338978 & 365989 & 414650 & 461185 & 454027 & 518448 & 395745 & 523542 & 614497 & 689480 & $:$ \\
\hline Japonya & 158085 & 180449 & 209980 & 246400 & 260373 & 295941 & 231633 & 320742 & 376728 & 404402 & 388203 \\
\hline Güney Kore & 50695 & 60752 & 79340 & 109754 & 145732 & 181569 & 122474 & 172672 & 219893 & 246103 & 237140 \\
\hline Rusya & 120460 & 139546 & 160799 & 190117 & 192014 & 217419 & 176215 & 234435 & 262766 & 295550 & 280864 \\
\hline Singapur & 150765 & 158220 & 178297 & 203955 & 205711 & 209806 & 168042 & 227413 & 252042 & 288567 & 287034 \\
\hline Meksika & 64030 & 79573 & 113224 & 141934 & 159537 & 214653 & 190996 & 202632 & 332186 & 380586 & 350912 \\
\hline Hindistan & 42721 & 50515 & 59160 & 72748 & 88012 & 117757 & 91517 & 136123 & 162531 & 173684 & $:$ \\
\hline Brezilya & & & &
\end{tabular}

Tablo 3.AB'nin Dünya Ticaretindeki Payı (İthalat-Milyon Euro) Kaynak: Eurostat. 
Aynı şekilde AB'nin dünya ticaretindeki ihracat payı ise Tablo.4'te sunulmuştur. Tablo.4 incelendiğinde; AB28 'in dünyada en büyük paya sahip olduğu dikkat çekmektedir. AB'yi Çin, ABD, Japonya ve Güney Kore takip etmektedir. Küresel krizin dünya ekonomisinde ağırlığı olan ülkelerin ihracat paylarını önemli derecede daralttığı dikkat çekmektedir.

\begin{tabular}{|c|c|c|c|c|c|c|c|c|c|c|c|}
\hline \multicolumn{10}{|c|}{ ANA TICARET ORTAKLARINA GÖRE AB İHRACAT PAYLARI (MILYON EURO) } \\
\hline ÜLKE/YIL & $\mathbf{2 0 0 3}$ & $\mathbf{2 0 0 4}$ & $\mathbf{2 0 0 5}$ & $\mathbf{2 0 0 6}$ & $\mathbf{2 0 0 7}$ & $\mathbf{2 0 0 8}$ & $\mathbf{2 0 0 9}$ & $\mathbf{2 0 1 0}$ & $\mathbf{2 0 1 1}$ & $\mathbf{2 0 1 2}$ & $\mathbf{2 0 1 3}$ \\
\hline AB 28 & 861923 & 945185 & 1049477 & 1152357 & 1234321 & 1309147 & 1093961 & 1353195 & 1554252 & 1684193 & 1736589 \\
\hline AB 27 & 869229 & 952951 & 1057627 & 1161776 & 1244166 & 1319819 & 1101746 & 1360054 & 1561930 & 1691376 & 1742459 \\
\hline Kanada & 240656 & 254976 & 289810 & 309157 & 306371 & 309785 & 225966 & 291604 & 323585 & 352881 & 343645 \\
\hline ABD & 639682 & 657533 & 726903 & 825923 & 848258 & 883804 & 757608 & 963347 & 1063025 & 1202962 & 1188165 \\
\hline $\begin{array}{c}\text { Cin } \\
\text { (Hong Kong Hariç) }\end{array}$ & 387401 & 476988 & 612454 & 771691 & 890230 & 972731 & 861519 & 1190460 & 1363785 & 1594631 & 1663284 \\
\hline Japonya & 417252 & 454828 & 478210 & 515073 & 521216 & 531284 & 416346 & 580655 & 591368 & 621550 & - \\
\hline Güney Kore & 171338 & 204072 & 228614 & 259205 & 271052 & 286921 & 260633 & 351800 & 398857 & 426412 & 421368 \\
\hline Rusya & 118154 & 145993 & 194077 & 239920 & 257035 & 318190 & 216372 & 299515 & 371403 & 408442 & 397008 \\
\hline Singapur & 141410 & 159685 & 184593 & 216478 & 218386 & 229927 & 193456 & 265420 & 294184 & 317865 & 308900 \\
\hline Meksika & 145780 & 151122 & 172179 & 199077 & 198337 & 198032 & 164692 & 225017 & 251127 & 288483 & 286094 \\
\hline Hindistan & 52476 & 61021 & 80663 & 96528 & 106456 & 123648 & 126731 & 166258 & 216583 & 225377 & 253453 \\
\hline Brezilya & 64713 & 77721 & 95273 & 109753 & 117219 & 134581 & 109689 & 148870 & 183936 & 188807 & - \\
\hline
\end{tabular}

Tablo 4.AB'nin Dünya Ticaretindeki Payı (İhracat-Milyon Euro) Kaynak: Eurostat.

İstatistikî tablolarında gösterdiği gibi son 12 yıllık veriler ışı̆̆ında, AB'de malların serbest dolaşımının sağlanması ile birlikte AB'nin dünya ticaretindeki payı ihracatta 861 milyon Euro'dan 1.7 Trilyon Euro'ya yani yaklaşık iki katına çıktığı dikkat çekmektedir.

\section{Sonuç}

AB'de malların, hizmetlerin, kişilerin ve sermayenin serbest dolaşımı arasında MSD ağırlık kazanarak en önemli serbesti halini almıştır. Roma Anlaşmasından bu yana AB'de ekonomik anlamda bir birlik oluşturularak birlik içi ticaretin artırılıp ekonomik olarak güçlenmek hedeflenmiştir. Bu amaçla MSD, AB için en önemli ideal olmuştur. MSD’nin sağlanabilmesi amacıyla çok önemli anlaşmalar ve düzenlemeler yapılarak iç pazar oluşturulmaya çalışılmış, gümrük birliği uygulamaları ile AB'nin ticaret hacmi artırılmaya çalışılmıştır. Zamanla artan üye sayısı ile birlikte MSD’nin sağlanmasına yönelik çabaların da yardımıyla AB ticaret hacminde önemli artışlar kaydedilerek, AB dünya ticaretinde önemli bir ekonomik blok halini almıştır.

Zaman zaman MSD’nin uygulanmasına yönelik sıkıntılar söz konusu olsa da, MSD prensibine ilişkin karşılaşılan sorunların ortadan kaldırılmasına yönelik AB çapında önemli çabalar sarfedilmektedir. Ayrıca bu prensibin diğer ülke grupları veya ülkeler arasında uygulanması ile dünya ticaret paylarını artırabilecekleri gerçeği ortaya çıkmıştır. AB gibi önemli bir ekonomik birliğin ticari anlamdaki başarısı, buna benzer ekonomik blokların oluşması için teşvik yaratmıştır.

\section{Kaynakça}

- $\quad$ Baykal,2006. “AB’de Malların Serbest Dolaşımı ve Çevrenin Korunması: Farklı Menfaatler Arasında Denge Arayışı”, Ank.Ünv.Avrupa Çalışmaları Dergisi, 5(2), p.103-130.

- Bayrakturan, 2004. "Küresel Ekonomide Bütünleşme Trendleri Bölgeselleşme ve Küreselleşme”, 2.Basım, Nobel Yayınları, Ankara.

- $\quad$ Craig, 1998. "EU Law, Text, CasesandMaterails", 2nd Edition, OxfordUnv. Press.

- $\quad$ DTM, 2007. “Avrupa Birliği ve Türkiye”, 6. Baskı, Ankara.

- Eurostat, 2015, International Trade Data, http://ec.europa.eu/eurostat/data/database.

- $\quad$ HMRC (Revenue and Customs), the Department for Business, Innovation and Skills and the Intellectual Property Office UK., 2014. "Review of the Internal Market: Free Movement of Goods; including the EU Customs Union and Intellectual Property Rights Call for Evidence", Erişim Adresi: https://www.gov.uk/government/uploads/system/uploads/attachment_data/file/279200/Call_for_Evidence_ v_12.pdf, Erişim Tarihi:11.02.2014

- $\quad$ İKV, 2005. “AB ile Katılım Müzakereleri Rehberi”, İKV Yayınları: Yayın No:184, İstanbul.

- $\quad$ İKV, 2014. “Avrupa Birliğinin Ortak Ticaret Politikası”, Erişim Adresi:www.ikv.org.tr/pdfs/7c53b0dc.pdf, Erişim Tarihi:22.02.2014.

- Karluk, 2003. “Avrupa Birliği ve Türkiye”, 7.Baskı. Beta Yayınları, İstanbul.

- Kılıç, 2002. “Türkiye-AB İlişkileri ve Gümrük Birliği”, Siyasal Kitabevi, Ankara.

- S S Sahin, 2010. “Avrupa Birliğinde Malların Serbest Dolaşımı ve Türkiye, DPT Uzmanlık Tezi, Ankara. 
- TÜSİAD, 2001. "Avrupa Birliği’nin Malların Serbest Dolaşımı Mevzuatına Uyumda Sorunlar ve Çözüm Önerileri”, (Yay.No. TÜSİAD-T/2001-12-315), TÜSİAD Yay.:İstanbul.

- TÜSİAD, 2003. "Avrupa Birliğine Uyum Sürecinde Gümrük Birliğinin Dış Ticaretimize Etkileri”, (Yayın No. TÜSİAD-T/2003-10-364), TÜSİAD Yayınları: İstanbul.

- Yavaşi, 2001. Avrupa Birliğinde Malların Serbest Dolaşımı ve Türkiye, Ankara Barosu, Fikri Mülkiyet ve Rekabet Hukuku Dergisi, 1(4), p.25-52.

- Yeşiltepe, 2013."Bir Dış Ticaret Engeli Olarak CE İşareti Ve Avrupa Birliği İle Uyum”, Yayınlanmamış Yüksek Lisans Tezi, Marmara Ünv.Sos.Bil.Ens., İstanbul. 


\title{
Dolar Kuru’nun Borsa İstanbul-30 Endeksi Üzerindeki Etkisi ve Aralarındaki Nedensellik İlişkisinin İncelenmesi Effects of USD Exchange Rate over the Istanbul Stock Market 30
Index and Investigation of the Relationship between them
}

\begin{abstract}
It is known that financial markets have important place in today's economy. Individuals could be evaluated their saving with their own research or they could be evaluated their savings with financial experts recommendations. A large portion of those funds of individual or institutional investors managed are directed to the stock market of the country. When considered in terms of Turkey, Istanbul Stock Exchange is examples for this topic. The changes in economic data, is influenced to many variables especially the stock market. It is perceived in the market as bad data that the rising in unemployment, the reduction of industrial production, the increases in interest rates and cost of credit, the increase in foreign exchange rates. In this study, it was investigated the causality of the dollar exchange rate between Istanbul Stock Exchange National 30 Index (BIST30) with "Granger Causality Test". Monthly values are used including the period of 2009:1 (January of 2009) between period of 2014:12 (December 2014) as data set. We used the first trading day closing values in the calculation of monthly returns for the period. At the end of the study, we couldn't find any causal relationship between the dollar exchange rate and the BIST-30 Index.
\end{abstract}

\section{Giriş}

Günümüz ekonomilerinde finans piyasalarının önemli bir yer edindiği bilinmektedir. Bireyler tasarruflarını kendi yaptıkları araştırmalar veya finans uzmanlarının tavsiyeleri doğrultusunda finans piyasalarında değerlendirebilmekte ya da finansal kuruluşlardaki fon yöneticilerine bu işi devredebilmektedirler. Bireysel ya da kurumsal yatırımcıların yönlendirdiği bu fonların büyük bir kısmı da ülkelerin borsalarında işlem görmektedir. Türkiye açısından ele alındığında Borsa İstanbul bu konu için örnek olarak verilebilir.

Ekonomik verilerdeki değişmeler, borsa başta olmak üzere birçok değişkene etki etmektedir. İşsizlik rakamlarının yükselmesi, sanayi üretiminin azalması, faiz ve kredi maliyetlerindeki yükselme, döviz kurlarındaki artış, ekonomi alanında yapılan genel değerlendirmelere göre piyasada kötü veri olarak algılandığı için borsaları olumsuz yönde etkileyebilmektedir.

Bu çalışmada Dolar Kuru ve Borsa İstanbul Ulusal 30 Endeksi (BİST-30) 'ne ait 2009:1 ile 2014:12 dönemindeki aylık ve günlük kapanış verileri doğrultusunda oluşturulan seriler arasındaki ilişki ve ilişkinin yönü "Granger Nedensellik Testi” ile incelenmiş, sonuçlar doğrultusunda değerlendirmeler yapılmıştır. Bu çalışmanın Dolar Kuru ve BİST-30 değişkenleri arasındaki ilişkinin ampirik olarak araştırılması açısından literatüre katkı sağlayacağı düşünülmektedir.

\section{Dolar Kuru ve Borsa İstanbul}

Bir birim ülke parasının diğer bir ülke parası cinsinden fiyatına "döviz kuru” denilmektedir. Dolar'ın Türk Lira'sı cinsinden fiyatı ise "Dolar Kuru" olarak ifade edilmektedir.

Türkiye'de Amerikan Doları ve Euro gibi döviz'e yapılan yatırımlar önemli yatırım araçlarından biridir. Yakın zamana kadar yüksek enflasyon ortamı, devalüasyon ve Türk Lira'sının sürekli değer kaybetmesi özellikle Dolar ve Euro'yu yatırımcılar için cazip bir yatırım aracı haline getirmiştir. Dolar ve Euro'nun bu özelliğinin hala devam ettiği söylenebilir (İbicioğlu, 2012:46-47) .

Muhammad ve Rasheed (2004) çalışmasında; döviz kurunda yaşanan artışın borsada işlem gören firmaların ihracatlarında artışa yol açacağını ve firmaların karlılığını da arttırabileceğini ifade etmişlerdir (Muhammad ve Rasheed: 2004: 537). Şirketlerin karlılığının artması borsadaki itibarlarını arttıracak ve hisse senetlerine olan talepte artış gözlenecektir. Bu da firmaların hisse senedi piyasasındaki değerlerinde yükselişe yol açacaktır.

Türkiye sermaye piyasasında borsaları tek çatı altında toplayan Borsa İstanbul, esas sözleşmesinin Sermaye Piyasası Kurulu'nca hazırlanıp ilgili Bakanın onayı sonrasında 3 Nisan 2013 tarihinde doğrudan tescil ve ilan edilmesiyle faaliyet izni almıştır. Borsa İstanbul'un başlıca amacı ve faaliyet konusu; "Kanun hükümleri ve ilgili mevzuat çerçevesinde, sermaye piyasası araçlarının, kambiyo ve kıymetli madenler ile kıymetli taşların ve Sermaye Piyasası Kurulunca uygun görülen diğer sözleşmelerin, belgelerin ve kıymetlerin serbest rekabet şartları altında kolay ve güvenli bir şekilde, şeffaf, etkin rekabetçi, dürüst ve istikrarlı bir ortamda alınıp satılabilmesini sağlamak, bunlara ilişkin alım satım emirlerini sonuçlandıracak şekilde bir araya getirmek veya bu emirlerin bir araya gelmesini kolaylaştırmak ve oluşan fiyatları tespit ve ilan etmek üzere piyasalar, pazarlar, platformlar ve sistemler ile teşkilatlanmış diğer pazar yerleri oluşturmak, kurmak ve geliştirmek, bunları ve başka borsaları veyahut borsaların piyasalarını yönetmek ve/veya işletmek ve ana sözleşmesinde yazılı olan 
diğer işlerdir.” Bu bağlamda 6362 sayılı Sermaye Piyasası Kanunu'na dayanılarak kurulan Borsa İstanbul özel hukuk tüzel kişiliğine haizdir. Borsa İstanbul yetkili olduğu konu ve alanlarda kendi yasal düzenlemelerini yapabilmektedir (Taşer, 2013: 15-16).

Borsa İstanbul Pay Endeksleri Yönetmeliği’ne göre; BİST 30 Endeksi Ulusal Pazar'da işlem gören şirketlerle, Kurumsal Ürünler Pazarı'nda işlem gören gayrimenkul yatııım ortaklıları ve girişim sermayesi yatırım ortaklıkları arasından seçilen 30 paydan oluşur. Endekslerde yer alacak payların seçimi aşağıdaki gibi yapılır.

i. Paylar, değerleme dönemi sonu itibari ile fiili dolaşımda bulunan kısmının piyasa değerlerine göre büyükten küçüğe siralanır.

ii. Paylar, değerleme dönemindeki günlük ortalama işlem hacimlerine göre büyükten küçüğe doğru sıralanır.

iii. Nihai sıralama açıklandığı şekilde yapılır:

iv. Her iki listede; birinci sırada yer alan pay varsa nihai listede ilk sıraya konur.

v. Her iki listede; birinci sırada yer alan pay yoksa, ilk iki sıra içinde yer alan pay olup olmadığına bakılır. Nihai listede ilk sırada yer alacak pay belirleninceye kadar bu işlemler tekrarlanır. Nihai listede ilk sıraya konulacak payın belirlenmesinden sonra yukarıdaki işlem takip eden sıralar için tekrar edilir. Her iki listede ilk n sıra içinde olma şartını sağlayan iki payın bulunması halinde piyasa değeri büyük olan nihai listede daha üst siraya konur.

vi. Yapılan nihai sıralamada en üst sırada yer alan paylardan başlanarak ve endekslere alınmak ve çıkarılmak için gereken üst ve alt sıralar da gözetilmek suretiyle endekslere seçim yapılır.

Endeks kapsamında olmayan bir payın endekse girebilmesi için, değerleme dönemi verileri ile bir sonraki endeks dönemi için yapılan çalışma sonucunda oluşturulan nihai sıralamada belirli bir üst sıraya veya üzerine çıkması gerekmektedir. Yine endeks kapsamındaki bir payın endeksten çıkarılabilmesi için ise nihai sıralamada belirli bir alt sıranın altına düşmesi gerekir (Taşer, 2013: 18-19).

Hisse senetleri piyasasında yaşanan artış ve düşüşler piyasada oynaklık (volatility) kavramı olarak ifade edilmekte ve yatırımcılar bu oynaklıktan yararlanarak getiri sağlamak üzere borsalarda işlem yapabilmektedirler (Ayvaz, 2006: 2).

Borsa İstanbul Endeksi'ni etkileyen faktörler üzerine yapılan araştırmalarda en çok etkileyen faktörün \%55 oran ile döviz kurunda yaşanan değişimler olduğu ortaya çıkmıştır. Geriye kalan \%45'lik kısım ise; dünya ekonomisinde yaşanan değişimler, diğer yatırım araçlarının getiri oranları, fiyat kazanç oranları ve manipülasyonlardan oluşmaktadır. Yine bir çok ampirik çalışma sonrasında döviz kurundan borsa getirisine doğru tek yönlü bir nedensellik ilişkisi olduğu ortaya çıkmıştır. Türkiye borsası için örnek vermek gerekirse 17 Ocak 2013 ile 21 Şubat 2013 döneminde ABD Doları, Türk Lirası karşısında \%2,5 değer kazanırken, BíST-100 Endeksi \%12 değer kaybetmiştir. Yine 17 Mayıs 2013 ile 30 Ağustos 2013 döneminde ABD Doları, Türk Lirasına karşı $\% 9$ değer kazanırken, BİST $-100 \quad \% 30$ oranında değer kaybına uğramıştır (http://www.bigpara.com/haber-detay/bigpara-uzman/turkiyede-borsa-doviz-kuruiliskisi/956651/?bprtme $=7528184277 \& \mathrm{sTo}=1500)$.

\section{Literatür Taraması}

Döviz kurunun Türkiye'deki Borsa Endeksi üzerinde etkisi olup olmadığını, eğer bir etki var ise etkinin özelliklerini araştıran çalışmaları aşağıdaki gibi özetlemek mümkündür.

Büberkökü (1997) çalışmasında, bazı gelişmiş ve gelişmekte olan ülkelerde hisse senedi fiyatları ile döviz kurları arasındaki ilişkiyi Granger Nedensellik Analizi ile incelemiş̧ir. Çalışmada gelişmiş ülkeler Japonya, Kanada, İngiltere, İsviçre, Almanya ve Avustralya; gelişmekte olan ülkeler ise Singapur, Güney Kore ve Türkiye olarak seçilmiştir. .Çalışma sonucunda Kanada ve İsviçre'de hisse senedi fiyatlarından döviz kurlarına doğru tek yönlü bir nedensellik ilişkisine rastlanmışen, Japonya, Almanya, İngiltere ve Avustralya'da herhangi bir nedensellik ilişkisine rastlanmamıştır. Singapur ve Güney Kore'de döviz kurlarından hisse senedi fiyatlarına doğru tek yönlü bir nedensellik ilişkisine rastlanmışken Türkiye 'de hisse senedi fiyatlarından döviz kurlarına doğru bir nedensellik ilişkisine rastlanmıştır.

Özer (1999), döviz kuru ve hisse senedi fiyatları arasındaki ilişkiyi Temmuz 1993-Şubat 1999 dönemini baz alarak incelemiştir. Çalışma sonunda Özer; Döviz kuru ve hisse senedi fiyatları arasında uzun dönemli bir denge ilişsisine ulaşamamış, kısa dönemli nedensellik sorgulaması sonucunda ise hisse senedi fiyatlarındaki değişimlerin döviz kurunda değişime yol açtığını ortaya koymuştur.

Önal ve diğerleri (2002) çalışmalarında, döviz kuru riskinin özel Türk bankalarının hisse senedi fiyatlarına olan etkisini 1994-2000 dönemindeki verilerle incelemişlerdir. Beklenmedik döviz kuru değişimleri ile 11 özel bankanın hisse senedi fiyatları arasındaki uzun dönemli ilişki eş bütünleşme analizleri aracılloğıyla incelenmiş,11 bankanın 2'sinde uzun dönemli ilişki bulgusuna ulaşmışlardır. 
Kasman (2003) çalışmasında, hisse senetleri fiyatları ile döviz kuru arasındaki ilişkiyi günlük döviz kuru ve hisse senedi indekslerini kullanarak analiz etmiş, döviz kuru ile endüstri indeksi arasında uzun dönemde istikrarlı bir ilişki olduğu sonucuna ulaşmıştır.

Akkum ve Vuran (2005) çalışmalarında, İMKB-30 endeksindeki firmaların getirileri üzerinde etkili olan makroekonomik faktörleri 1999-2002 dönemini baz alarak araştırmışlardır. Çalışmada mali, sınai ve hizmet sektörleri de ayrıca analiz edilmiş, mali sektör ile döviz kuru değişkeni arasında negatif ancak zayıf ilişki olduğu sonucuna ulaşılmıştır.

Ayvaz (2006) çalışmasında, mali, sanayi ve hizmet sektörleri endeksleri ile dolar kuru arasındaki nedensellik ilişkisini incelemiş ve dolar kuru’nun mali ve sanayi sektörleri endeksleri ile iki yönlü nedensellik ilişkisi bulunmuştur. Ancak dolar kuru ile hizmet endeksi arasında nedensellik ilişkisi bulunamamıştır.

İpekten ve Aksu (2009) çalışmalarında, İMKB-100 endeksini etkileyebilecek yabancı hisse senedi piyasaları, döviz, faiz ve altın fiyatlarının kısa ve uzun dönemli etkisini sınır testi yaklaşımı ile belirlemeye çalışmıştır. Çalışmada uzun dönemde İMKB-100 endeksi üzerine Dow Jones İndeksi ve doların istatistiki olarak anlamlı etki yaptı̆̆ı, Dow Jones İndeksinin işaretinin pozitif olması, uzun dönemde İMKB-100 ile uluslararası hisse senedi piyasalarını temsilen alınan Dow Jones indeksinin birlikte hareket ettiği, diğer bir ifadeyle, Türkiye hisse senedi piyasasının yabancı piyasalarla entegre olduğu sonucuna varılmıştır.

Kapusuzoğlu ve İbicioğlu (2010), Türkiye’deki döviz kuru (dolar) ile İMKB Ulusal 100 arasındaki ilişkiyi, ekonometrik teknikler yardımıyla, 2001:7-2010:2 dönemini kapsayan günlük veriler kullanarak analiz etmişlerdir. Çalışmada, endeks ile döviz kuru arasında uzun dönemli eş-bütünleşik bir ilişkinin varlığı, vektör hata düzeltme modeli sonucunda ise endeks ile döviz kuru arasında negatif yönde kısa dönemli bir ilişki belirlenmiştir. Bunların yanında, döviz kurunun İMKB endeksinin tek yönlü Granger nedeni olduğu ortaya konulmuştur.

Savaş ve Can (2011) çalışmalarında, İstanbul Menkul Kıymetler Borsası'nda işlem gören hisse senedi fiyatları ile Euro-Dolar Paritesi ve Reel Efektif Döviz Kuru Endeksi arasındaki ilişki “Çoklu Doğrusal Regresyon” ile ilişkinin yönü ise "Granger Nedensellik Testi” ile incelenmiştir. Veri seti olarak, 2000 yılının Ocak ayından 2009 yılının Temmuz ayına kadar aylık veriler kullanılmıştır. Granger Nedensellik Testi sonucuna göre; İMKB 100 Endeksi'nden Euro-Dolar Paritesi ve Reel Efektif Döviz Kuru Endeksi'ne doğru bir nedensellik tespit edilmiştir.

\section{Dolar Kuru ile BİST-30 İlişkisi Üzerine Ekonometrik Uygulama}

İstanbul Menkul Kıymetler Borsası (İMKB), 3 Ocak 1986 tarihinde 40 şirketle faaliyete başlamıştır. Bu tarihlerde 50 bin dolarlık işlem hacmine sahip olan İMKB, yıllar itibariyle yerli ve yabancı yatırımcıların dikkatini çekmiştir. Yine İMKB yurt içinde faaliyet gösteren birçok şirketin de ilgisini çekmiş ve kendilerine yeni ortaklar edinme ve fon sağlama gibi sebeplerle şirketler hisselerini borsa'da satmışlardır. Bugün itibariyle birçok şirkete ait hisse senetleri borsada işlem görmeye başlamıştır. Borsa İstanbul (BİST), İstanbul Menkul Kıymetler Borsası'nın (İMKB) isim değişikliğine gitmesiyle 3 Nisan 2013 tarihinde ortaya çıkmıştır ve bugün itibariyle 3 milyar dolarlık günlük işlem hacmi ile faaliyetini sürdürmektedir. BİST-30 Endeksi; Ulusal Pazar'da işlem gören şirketlerle, Kurumsal Ürünler Pazarı'nda işlem gören gayrimenkul yatırım ortaklıkları ve girişim sermayesi yatırım ortaklıkları arasından seçilen 30 paydan oluşan bir endekstir.

BİST-30 Endeksi'nin Türk Lirası ve Dolar bazında toplam değeri ile şirket sayısına ait bilgiler Tablo 1'de verilmektedir.

\begin{tabular}{|l|r|}
\hline Şirket Sayısı & 30 \\
\hline Toplam Piyasa Değeri - TL & $416,576,121,406.68$ \\
\hline Ortalama Piyasa Değeri - TL & $13,885,870,713.56$ \\
\hline Toplam Piyasa Değeri - DOLAR & $182,965,619,029.64$ \\
\hline Ortalama Piyasa Değeri - DOLAR & $6,098,853,967.65$ \\
\hline \multicolumn{2}{|c|}{ Tablo 1. BİST-30 Endeksinin Dolar ve TL Cinsinden Piyasa Değeri }
\end{tabular}

*8/12/2014 tarihindeki BİST-30 endeks verileri değerlerine göre hesaplanmıştır.

BİST-30 Endeksi'nde yer alan şirketler ve bu şirketlerin ait oldukları sektör bilgileri, endeks ağırlığı ile birlikte Tablo 2'de gösterilmektedir.

\begin{tabular}{|c|c|c|c|}
\hline No & Şirket Bazlı Dağılım & Sektör & Ağırlık \\
\hline 1 & T. GARANTI BANKASI A.S. & Bankacilik & $13.64 \%$ \\
\hline 2 & AKBANK T. A.S. & Bankacilik & $10.57 \%$ \\
\hline 4 & BIM BIRLESIK MAGAZALAR A.S. & Perakende Ticaret & $6.50 \%$ \\
\hline 5 & HACI OMER SABANCI HOLDING A.S. & Holding & $6.49 \%$ \\
\hline 6 & T. IS BANKASI A.S. & Bankacılik & $6.03 \%$ \\
\hline 8 & TURK HAVA YOLLARI A.O. & Ulaştirma & $4.82 \%$ \\
\hline
\end{tabular}




\begin{tabular}{|c|c|c|c|}
\hline 9 & KOC HOLDING A.S. & Holding & $4.80 \%$ \\
\hline 10 & TUPRAS-TURKIYE PETROL RAFINELERI A.S. & Petrokimya & $4.40 \%$ \\
\hline 11 & EMLAK KONUT GAYRİMENKUL YATIRIM ORTAKLIĞI A.S.. & Gayrimenkul YO & $3.78 \%$ \\
\hline 12 & EREGLI DEMIR CELIK FABRIKLARI A.S. & Demir Celik & $3.71 \%$ \\
\hline 13 & TURK TELEKOMUNIKASYON A.S. & Telekomünikasyon & $2.36 \%$ \\
\hline 14 & VAKIFLAR BANKASI A.S. & Bankacilik & $2.27 \%$ \\
\hline 15 & YAPI VE KREDI BANKASI A.S. & Bankacilik & $1.95 \%$ \\
\hline 16 & TAV HAVALIMANLARI HOLDING A.S. & Ulaştırma & $1.92 \%$ \\
\hline 17 & ARCELIK A.S. & Dayanıklı Tüketim & $1.83 \%$ \\
\hline 18 & ENKA INSAAT VE SANAYI A.S. & İnşaat & $1.77 \%$ \\
\hline 19 & ULLKER BISKUUVI & G1da & $1.68 \%$ \\
\hline 20 & FORD OTOSAN & Otomotiv & $1.36 \%$ \\
\hline 21 & TOFAS TURK OTOMOBIL FABRIKASI A.S. & Otomotiv & $1.34 \%$ \\
\hline 22 & T. SISE VE CAM FABRIKALARI A.S. & Holding & $1.24 \%$ \\
\hline 23 & KARDEMIR KARABUK DEMIR CELIK SANAYI VE TICARET & Demir Çelik & $1.05 \%$ \\
\hline 24 & PETKIM PETROKIMYA HOLDING A.S. & Petrokimya & $0.97 \%$ \\
\hline 25 & PEGASUS HAVA TASSIMACILIGII A.Ş. & Ulaştırma & $0.85 \%$ \\
\hline 26 & TEKFEN HOLDİNG A.S. & Holding & $0.68 \%$ \\
\hline 27 & MİGROS TİCARET A.Ş. & Perakende Ticaret & $0.55 \%$ \\
\hline 28 & DOGAN SIRKETLER GRUBU HOLDING A.S. & Holding & $0.50 \%$ \\
\hline 29 & KOZA ALTIN ISLETMELERI A.S. & Demir Çelik & $0.42 \%$ \\
\hline 30 & KOZA ANADOLU METAL MADENCIILIKK İSLETMELERİ A.Ş. & Demir Çelik & $0.21 \%$ \\
\hline
\end{tabular}

Tablo 2. BIST-30 Endeks'inin Sektör ve Şirket Bazlı Dă̆ılım ve Ağırlı̆̆

*8/12/2014 tarihindeki BİST-30 endeks verileri değerlerine göre hesaplanmıştır.

BİST-30 Endeksi içinde yer alan sektörlerin endeks içindeki ağırlıkları Tablo 3'de gösterilmektedir.

\begin{tabular}{|l|c|}
\hline Sektör & Ağırlık \\
\hline Bankacıllk & $40.97 \%$ \\
\hline Holding & $13.70 \%$ \\
\hline Telekomünikasyon & $8.16 \%$ \\
\hline Ulaştırma & $7.59 \%$ \\
\hline Perakende Ticaret & $7.06 \%$ \\
\hline Demir Çelik & $5.39 \%$ \\
\hline Petrokimya & $5.37 \%$ \\
\hline Gayrimenkul Yatırım Ortaklığı & $3.78 \%$ \\
\hline Otomotiv & $2.70 \%$ \\
\hline Dayanıklı Tüketim & $1.83 \%$ \\
\hline İnşaat & $1.77 \%$ \\
\hline Gıda & $1.68 \%$ \\
\hline
\end{tabular}

Tablo 3. BIST-30 Endeksinde Yer Alan Sektörlerin Toplam içindeki Ağırlıkları

*8/12/2014 tarihindeki BİST-30 endeks verileri değerlerine göre hesaplanmıştır.

\subsection{Veri Tabanı ve Değişkenlerin Tanımı}

Çalışmada 2009:1 ile 2014:12 döneminde Dolar kuru ve BİST-30 Endeksi kapanışları aylık ve günlük kapanış değerleri ile ayrı ayrı değerlendirilmiştir. Durağanlık Testi öncesinde verilerin doğal logaritması alınmıştır. Verilerin doğal logaritmasını almak, farklı birim değerlerinde olan gözlem değerlerinin aynı türde bir anlam kazanmasını sağlamaktadır (Ekinci, 2011: 79). Analizde kullanılan değişkenler aşağıda verilmiştir:

LogBİST30= Logaritması alınan BİST 30 Endeksi

Logdolar=Logaritması alınan Dolar Kuru

\subsection{Elde Edilen Bulguların Değerlendirilmesi}

Çalışmada 2009:1-2014:12 döneminde aylık ve günlük kapanış verilerine göre Dolar Kuru ile BİST 30 Endeksi arasındaki nedensellik ilişkisi ayrı ayrı incelenmiştir. Değişkenler zaman serisine dayalı olduğu için öncelikle serilerin durağan olup olmadığı Genişletilmiş Dickey Fuller (ADF) testi ile analiz edilmiştir. Durağan olmayan seriler farkları alınarak durağan hale getirilmiştir. Genişletilmiş Dickey-Fuller (Augmented Dickey Foller) birim kök testi uygulanan serilere daha sonra VAR (Vector Auto Regression) modeli kurulmuş ve değişkenler arasındaki nedensellik ilişkisi Granger Nedensellik Analizi yardımı ile test edilmiştir. Tüm testler ekonometrik analiz programı kullanılarak gerçekleştirilmiştir.

Durağan serilerde veriler sabit bir ortalama etrafinda dalgalanmaktadır. Bu nedenle bir serinin durağan olup olmadığını anlamak için öncelikle serinin zaman içindeki değişimini gösteren grafiğini göstermek gereklidir (Yılmazer, 2010:251). Şekil 1'de Dolar Kuru aylık kapanış verilerinin logaritmalı halinin zaman içindeki 
değişimi sunulmuştur. Değişkenlerin ele alınan dönemler itibariyle durağan bir seyir izlemediği görülmektedir. ADF Testi uygulanarak Dolar Kuru serileri durağan hale getirilmiştir.

\subsubsection{Aylık Kapanış Değerleri Arasındaki Nedensellik İlişkisi}

Şekil 1'deki Dolar Kuru serilerinin durağanlığını sağlamak için verilerin birincil farkı alınmıştır. Seriler birincil farkta durağan hale gelmiştir.
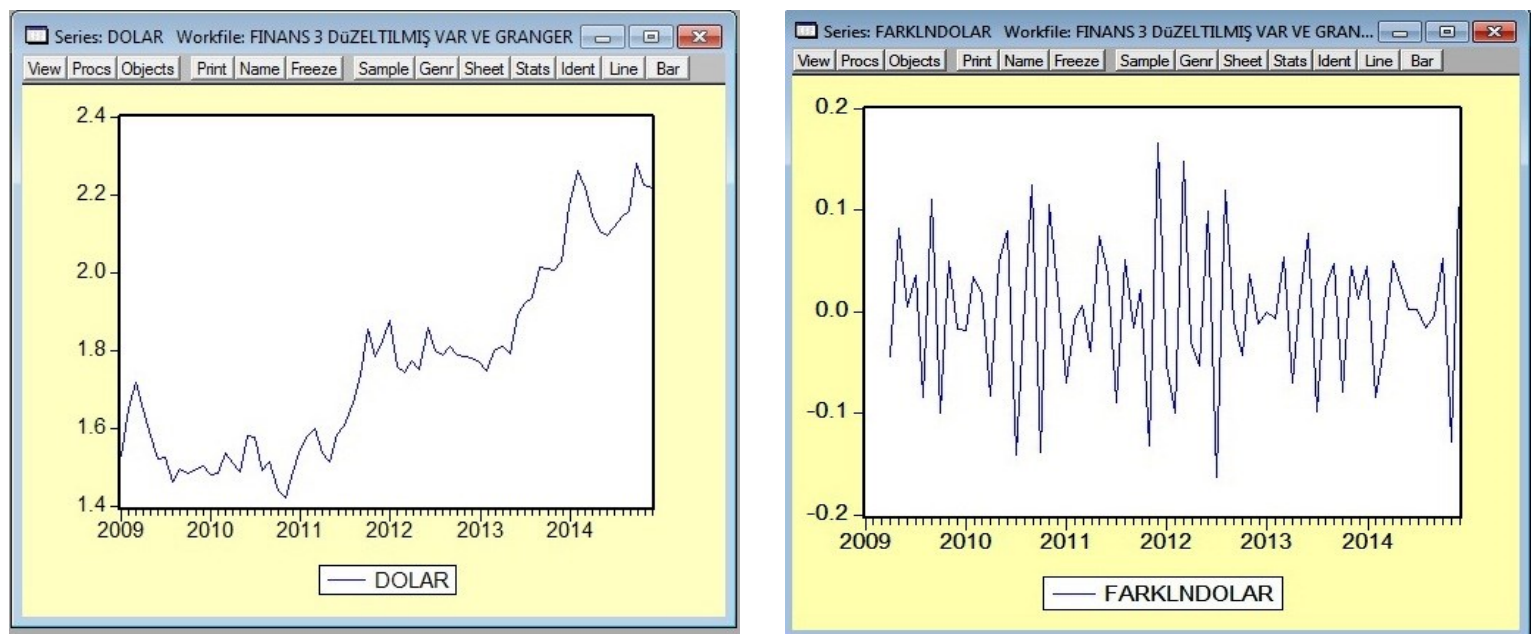

Şekil 1. Dolar Serisinin ADF Testi ile Dură̆anlaşması (Aylık Kapanışlara Göre)

Şekil 2'de BİST-30 Endeks verilerinin logaritmalı halinin zaman içindeki değişimi sunulmuştur. Değişkenlerin ele alınan dönemler itibariyle durağan bir seyir izlemediği görülmektedir. ADF Testi uygulanarak BİST-30 Endeksi serileri durağan hale getirilmiştir.
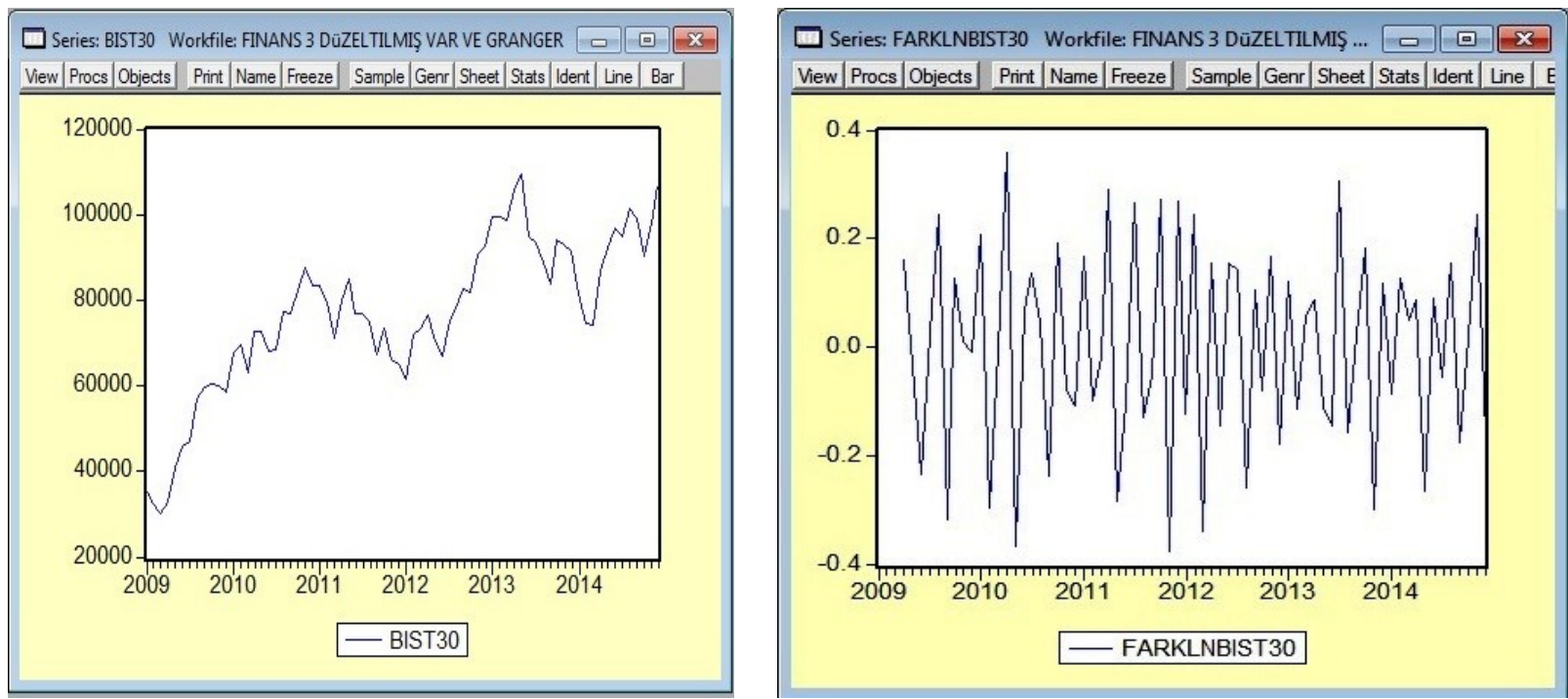

Şekil 2. BIST-30 Serisinin ADF Testi ile Durağanlaşması (Aylık Kapanışlara Göre)

Şekil 2'deki BİST-30 Endeksi serilerinin durağanlığını sağlamak için verilerin ikincil farkı alınmıştır. Seriler ikincil farkta durağan hale gelmiştir.

Dolar Serisinin durağanlığını sağlamak için verilerin öncelikle kendi düzeyine bakılmış, Genişletilmiş Dickey Fuller (Augmented Dickey Fuller) Test Değeri, McKinnon Kritik Değeri’nden mutlak değer olarak küçük olduğu için serilerin durağan olmadığı görülmüştür. Serinin birincil farkı alındığında verilerin durağanlaştığı görülmüştür (ADF testinin mutlak değeri değeri > Mc Kinnon Kritik Mutlak Değeri).

\begin{tabular}{|l|c|c|c|c|c|}
\hline \multicolumn{5}{|c|}{ ADF TEST İSTATİSTİĞİ DEĞERLERI (DOLAR) } \\
\hline & ADF DEĞERİ & Prob (F-Statistic) & MC KİNNON KRİTIK DEĞGRİ \\
\hline & & & $\%$ & $\% 1$ & $\% 10$ \\
\hline YÜZEY DEĞER & -2.451860 & 0.000000 & -3.5478 & -2.9127 & -2.5937 \\
\hline BİRİNCİL FARK & -3.805390 & 0.000000 & -3.5501 & -2.9137 & -2.5942 \\
\hline
\end{tabular}

Tablo 4. Dolar Kuru'nun ADF Test Değerleri

BİST-30 serisinin durağanlığını sağlamak için verilerin öncelikle kendi düzeyine bakılmıs, Genişletilmiş Dickey Fuller (Augmented Dickey Fuller) Test Değeri, McKinnon Kritik Değeri’nden küçük olduğu için serilerin durağan olmadığı görülmüştür. Serinin birincil farkı alındığında yine serilerin durağan olmadığı 
görülmüştür. Serilerin ikincil farkları alındığında ise serinin durağanlaştığı görülmüştür (ADF testinin mutlak değeri değeri > Mc Kinnon Kritik Mutlak Değeri).

\begin{tabular}{|c|c|c|c|c|c|}
\hline \multicolumn{6}{|c|}{ ADF TEST İSTATÍSTİĞİ DEĞERLERİ (BİST 30) } \\
\hline & ADF DEĞERI & Prob (F-Statistic) & \multicolumn{3}{|c|}{ MC KİNNON DEĞERİ } \\
\hline & & & $\% 1$ & $\% 5$ & $\% 10$ \\
\hline YÜZEY DEĞER & -2.175608 & 0.000000 & -3.5478 & -2.9127 & -2.5937 \\
\hline BİRINCİL FARK & -2.831733 & 0.000000 & -3.5501 & -2.9137 & -2.5942 \\
\hline İKINCIL FARK & -5.427262 & 0.000000 & -3.5523 & -2.9146 & -2.5947 \\
\hline
\end{tabular}

Tablo 5. BíST-30 Endeksi'nin ADF Test Değerleri

Granger nedensellik analizine başlamadan önce değişkenlere ait gecikme değerlerinin belirlenmesi gerekmektedir. Veri setinin gecikme değerinin saptanması için veri setinin yapısına bakılmalıdır. Eğer değişkenler yıllıksa 1, altı aylık dönemler halindeyse 2, üç aylık ise 4, aylık ise 12 gecikme sayısı kullanılır. İki değişken arasındaki nedensel bir ilişkinin varlığını ve yönünü test etmek için Granger Nedensellik Analizi kullanılmaktadır (Yılmazer, 2010:254). Birim kök testi ile durağanlığı saptanan veriler ile yapılan nedensellik analizinin sonuçları Tablo 6' da gösterilmektedir.

\begin{tabular}{|l|c|c|c|}
\hline \multicolumn{1}{|c|}{ Boş Hipotez } & Gözlem Sayısı & F İstatistiği & Olasılık Değerleri \\
\hline Dolar Kuru, BíST-30'un nedeni değildir & 57 & 1.51508 & 0.16977 \\
\hline BİST 30, Dolar Kuru'nun nedeni değildir & 57 & 1.02868 & 0.44769 \\
\hline
\end{tabular}

Tablo 6. Granger Nedensellik Testi Sonuçları

2009:1 ile 2014:12 döneminde aylık kapanış verilerine göre analizi yapılan Dolar Kuru ile BİST-30 Endeksi değişkenleri arasındaki nedensellik ilişkisinin varlığı ve yönü dikkate alındığında aşağıdaki değerlendirmeyi yapmak mümkündür.

- Granger Nedensellik Analizi sonuçlarına bakıldığında; Dolar Kuru ile BİST-30 Endeksi arasında \%1, $\% 5$ ve $\% 10$ düzeyde karşılıklı bir nedensellik ilişkisi bulunamamıştır.

\subsubsection{Günlük Kapanış Değerleri Arasındaki Nedensellik İlişkisi}

Şekil 3'de Dolar Kuru günlük kapanış değerlerinden oluşan serinin logaritmalı halinin zaman içindeki değişimi sunulmuştur. Serinin ele alınan dönemler itibariyle durağan bir seyir izlemediği görülmektedir. ADF Testi uygulanarak Dolar Kuru serisi durağan hale getirilmiştir.
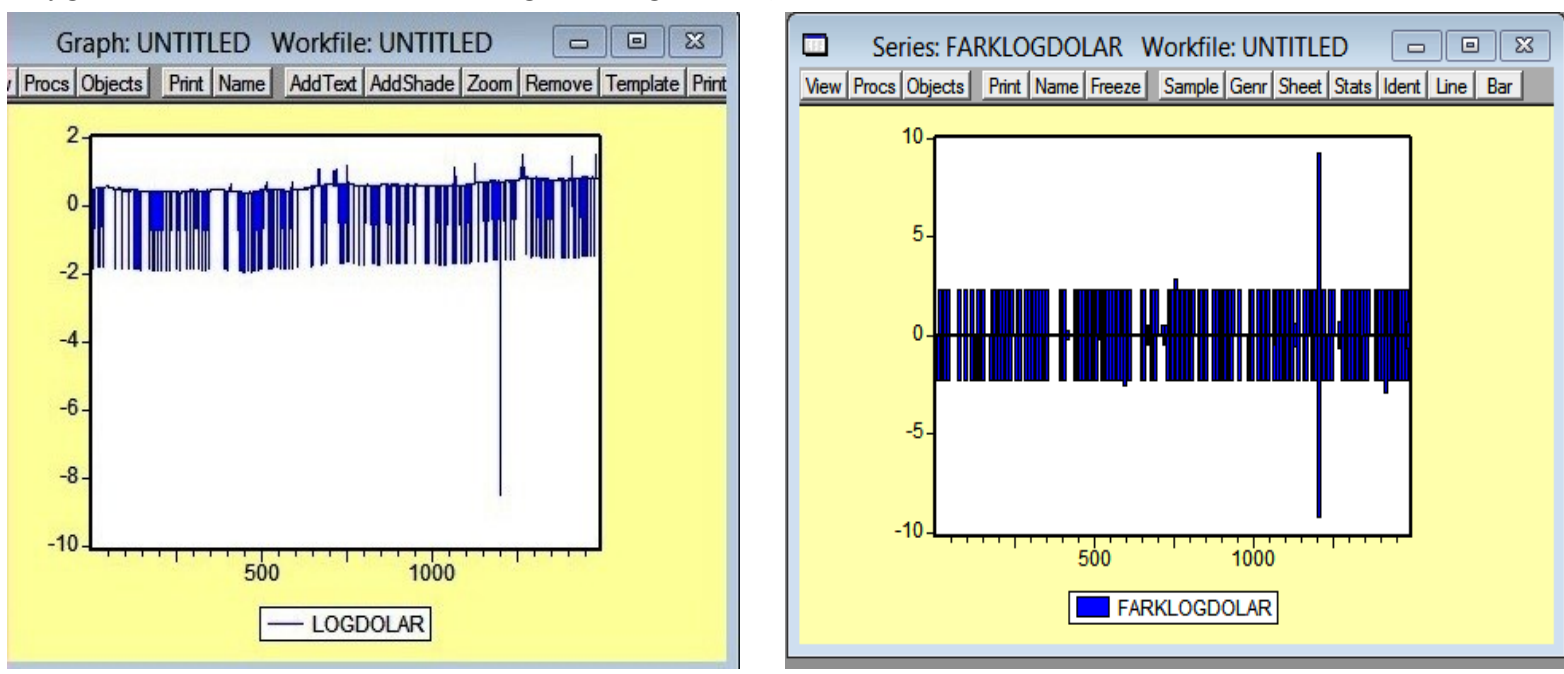

Şekil 3. Dolar Serisinin ADF Testi ile Durağanlaşması

Şekil 3'deki Dolar Kuru serilerinin durağanlığını sağlamak için ADF Testi uygulanmış ve seriler birincil farkta durağan hale gelmiştir.

Şekil 4'de BİST-30 Endeks verilerinin logaritmalı halinin zaman içindeki değişimi sunulmuştur. Değişkenlerin ele alınan dönemler itibariyle durağan bir seyir izlemediği görülmektedir. ADF Testi uygulanarak BİST-30 Endeksi serileri durağan hale getirilmiştir. 
Graph: UNTITLED Workfile: UNTITLED

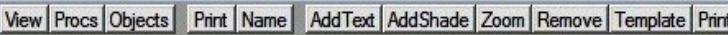

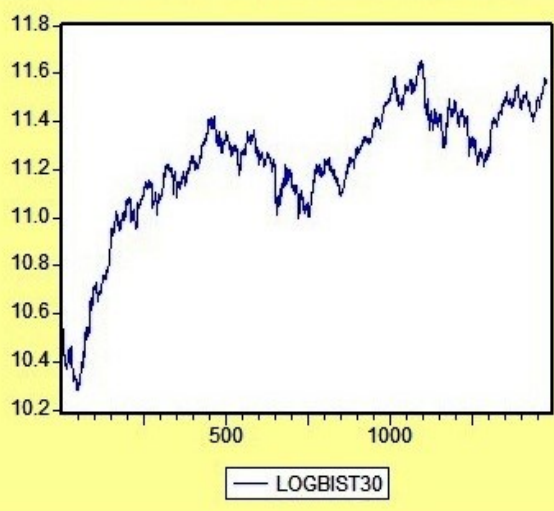

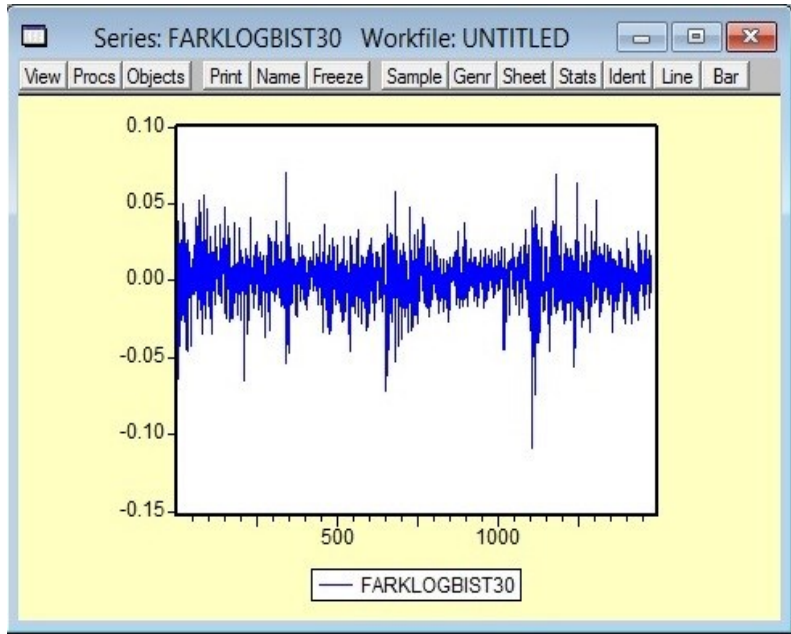

Şekil 4. BIST-30 Serisinin ADF Testi ile Dură̆anlaşması

Şekil 4'de BİST-30 Endeksi serilerinin durağanlığını sağlamak için ADF Testi uygulanmış ve seriler yüzey değerde durağan hale gelmiştir.

Dolar Serisinin durağanlığını sağlamak için verilerin öncelikle yüzey değerine bakılmıș, mutlak değerlerdeki Genişletilmiş Dickey Fuller Test Değeri (Augmented Dickey Fuller), McKinnon Kritik Değeri'nden büyük olduğu için serilerin durağan olduğu görülmüştür. (ADF test değeri > Mc Kinnon Kritik Değeri).

\begin{tabular}{|c|c|c|c|c|c|}
\hline \multicolumn{6}{|c|}{ ADF TEST İSTATİSTİĞİ DEĞERLERİ (DOLAR) } \\
\hline & ADF DEĞERİ & Prob (F-Statistic) & MC KII & N KRİTÍ & EĞERİ \\
\hline & & & $\% 1$ & $\% 5$ & $\% 10$ \\
\hline YÜZEY DEĞER & -28.48995 & 0.000000 & -3.4377 & -2.8639 & -2.5681 \\
\hline
\end{tabular}

Tablo 7. Dolar Kuru'nun ADF Test Değerleri

BİST-30 serisinin durağanlığını sağlamak için verilerin öncelikle yüzey değerine bakılmıș, mutlak değerlerdeki Genişletilmiş Dickey Fuller Test Değeri (Augmented Dickey Fuller), McKinnon Kritik Değeri'nden büyük olduğu için serilerin durağan olduğu görülmüştür. (ADF test değeri > Mc Kinnon Kritik Değeri).

\begin{tabular}{|l|c|c|c|c|c|}
\hline \multicolumn{5}{|c|}{ ADF TEST İSTATISTIĞİ DEĞERLERİ (BİST 30) } \\
\hline & ADF DEĞERİ & Prob (F-Statistic) & \multicolumn{3}{c|}{ MC KİNNON DEĞERİ } \\
\hline & & & $\% 1$ & $\% 5$ & $\% 10$ \\
\hline YÜZEY DEĞER & -15.76515 & 0.000000 & -3.4377 & -2.8640 & -2.5681 \\
\hline
\end{tabular}

Tablo 8. BISST-30 Endeksi'nin ADF Test Değgerleri

Birim kök testi ile durağanlığı saptanan veriler ile yapılan nedensellik analizinin sonuçları Tablo 9' da gösterilmektedir.

\begin{tabular}{|l|c|c|c|}
\hline \multicolumn{1}{|c|}{ Boş Hipotez } & Gözlem Sayısı & F İstatistiği & Olasılık Değerleri \\
\hline Dolar Kuru, BİST-30'un nedeni değildir & 1225 & 1.20238 & 0.03451 \\
\hline BİST 30, Dolar Kuru'nun nedeni değildir & 1225 & 0.93868 & 0.72227 \\
\hline
\end{tabular}

Tablo 9: Granger Nedensellik Testi Sonuçları

2009:1 ile 2014:12 döneminde günlük kapanış verilerine göre analizi yapılan Dolar Kuru ile BİST-30 Endeksi arasındaki nedensellik ilişkisinin varlığı ve yönü dikkate alındığında aşağıdaki değerlendirmeyi yapmak mümkündür.

- Granger Nedensellik Analizi sonuçlarına bakıldığında; Dolar Kuru'ndan BİST-30 Endeksi'ne doğru \%5 ve \%10 düzeyinde tek yönlü bir nedensellik ilişkisi bulunmuştur (Olasılık değeri <0,05). Böylece günlük kapanış değerlerine göre Dolar kuru BİST-30 Endeksi’nin nedenidir.

\section{Sonuç ve Değerlendirme}

Bu çalışmada Dolar Kuru'nun ile BİST-30 Endeksi arasındaki nedensellik ilişkisi aylık ve günlük kapanış değerleri üzerinden ayrı ayrı olarak incelenmiştir. Bağımlı değişken olarak BİST-30 endeksi, bağımsız değişken olarak ise Dolar Kuru seçilmiştir. Veri seti 2009:1 (2009 Yılı Ocak Ayı)-2014:12 (2014 Yılı Aralık Ayı) dönemini kapsamaktadır.

Baz alınan dönemlerdeki aylık kapanış verileri Granger Nedensellik Analizi ile değerlendirildiğinde; Dolar Kuru ile BİST-30 Endeksi arasında değişkenler arasında anlamlı bir nedensellik ilişkisi bulunamamıştır. Ancak 
aynı dönemler günlük kapanış verilerine göre incelendiğinde Dolar Kuru ile BİST-30 Endeksi arasında tek yönlü bir ilişki olduğu ve Dolar Kuru'nun BİST-30'un nedeni olduğu sonucuna ulaşılmıştır. Her ne kadar farklı dönemler incelenmiş olsa da bu çalışma; Kapusuzoğlu ve İbicioğlu (2010) ile Kasman (2003)'ın çalışmalarını desteklediği söylenebilir. Bundan sonraki çalışmalarda araştırmacılar farklı dönemleri ele alarak daha çok bağımsız değişken ile bunların BİST-30, BİST-50, BİST-100 veya BİST'in diğer sektör endeksleri ile olan nedensellik iliş̧isini araştırabilirler.

\section{Kaynakça}

- $\quad$ AKKUM, T. ve B. VURAN, (2005), “Türk Sermaye Piyasasındaki Hisse Senedi Getirilerini Etkileyen Makroekonomik Faktörlerin Arbitraj Fiyatlama Modeli ile Analizi”, İktisat İşletme ve Finans Dergisi, Y11.20, Ağustos: ss.28-45.

- AYVAZ, Ö, (2006), “Döviz Kuru ve Hisse Senetleri Arasındaki Nedensellik İlişkisi”, Gazi Üniversitesi İ̈BF Dergisi, C:8, S:2, ss.1-14.

- BÜBERKÖKÜ, Ö. (1997) "Hisse Senedi Fiyatları İle Döviz Kurları Arasındaki İlişkinin İncelenmesi: Gelişmiş ve Gelişmekte Olan Ülkelerden Kanttlar”, İMKB Dergisi, C:13, S:52, ss-1-18. (http://www.borsaistanbul.com/datum/imkbdergi/IMKB_Dergisi_Turkce52.pdf Erişim Tarihi: 14/12/2014).

- EKINCI, Aykut, (2011), "Doğrudan Yabancı Yatırımların Ekonomik Büyüme ve İstihdama Etkisi: Türkiye Uygulamas1 (1980-2010)." Eskişehir Osmangazi Üniversitesi İIBBF Dergisi 6.2. s.71-96.

- İBİĊOĞLU, M. (2012). Yatırım Araçlarının Getirileri Arasındaki İlişkilerin Çok Boyutlu Ölçekleme Yöntemi ile Analizi. AİBÜ-İ̈BF Ekonomik ve Sosyal Araştırmalar Dergisi.

- İPEKTEN, O. B., ve AKSU, H. (2009). Alternatif Yabancı Yatırım Araçlarının İMKB İndeksi Üzerine Etkisi/The Effect of Alternative Investment Tools on ISE, Atatürk Üniversitesi Sosyal Bilimler Enstitüsü Dergisi, 13(1), 413-423.

- KAPUSUZOĞLU, A., İBíCiOĞLU, M. (2010) “Döviz Kuru İle Hisse Senedi Fiyatları Arasındaki İlişkinin Analizi: Türkiye Uygulaması" Muhasebe Bilimi Dünyası, Cilt:12, Sayı:4, Sayfa:135-153

- KASMAN, S, (2003) "The Relationship Between Rates and Stok Prices : A Causality Analyisis", Dokuz Eylül Üniversitesi Sosyal Bilimler Dergisi, C:5, S:2, ss-70-79.

- MUHAMmAD, N. And RASHEED, A. (2004) "Stok Prices and Exchange Rates: Are They Related? Evidence From South Asian Contries”, Pakistan Development Review, Vol.10, No:4, pp-535-549.

- ÖNAL, Y. B., M. DOGANLAR ve S. CANBAS, (2002), "Döviz Kuru Riskinin Özel Türk Bankalarının Hisse Senedi Fiyatların Etkisinin Araştırılması", İMKB Dergisi, Cilt:6 (22): 17-33

- ÖZER, M. (1999). “Türkiye'de Hisse Senedi Fiyatları ile Döviz Kuru Arasındaki Etkileşimler”, Ekonomi ve Yönetim Bilimleri Dergisi, Bahçeşehir Üniversitesi, Eylül 1999: 61-72

- SAVAŞ, İ., ve İsmail, CAN, Euro-Dolar Paritesi ve Reel Döviz Kuru'nun İMKB 100 Endeksi’ne Etkisi

- TASSER, M., (2013) BİST 30 Endeksi ile Amerikan 10 ylllık tahvil faizi ve CBOE Volatilite endeksi arasındaki ilişki, TOBB Ekonomi ve Teknoloji Üniversitesi Sosyal Bilimler Enstitüsü İşletme Anabilim Dalı Yayımlanmamış Yüksek Lisans Tezi, Ankara

- YILMAZER, M., (2010), "Doğrudan Yabancı Yatırımlar, Dış Ticaret ve Ekonomik Büyüme İlişkisi: Türkiye Üzerine Bir Deneme." Celal Bayar Üniversitesi SBE, Sosyal Bilimler Dergisi 8.1 s.241-260.

- http://www.ist30.com/sayfa/ist30-BİST-30-endeks-bilgileri Erişimim Tarihi: 09/12/2014

- http://www.ist30.com/sayfa/ist30-BİST-30-endeks-kapsami Erişim Tarihi: 09/12/2014

- http://www.bigpara.com/haber-detay/bigpara-uzman/turkiyede-borsa-doviz-kuru-iliskisi/ 956651/ ?bprtme $=7528184277 \& \mathrm{sTo}=1500$ Erişim Tarihi: $14 / 12 / 2014$

- http://www.ist30.com/sayfa/ist30-BİST-30-endeks-bilgileri 


\title{
Türkiye'de Bireysel Emeklilik Fonlarının Performansı ve Temel Yatırım Araçları ile Karşılaştırılması
}

\section{Private Pension Fund Performance and Comparison with Basic Investment Instruments in Turkey}

\author{
Prof. Dr. Turgut Özkan (Beykent University, Turkey) \\ Ph. D. Candidate Özge Demirkale (Beykent University, Turkey)
}

\begin{abstract}
In 2001, after the preparation of legal infrastructure in Turkey, private pension fund system started to be complementary to the Social Security system. There are many expectations from the private pension fund system both socially and economically. Social expectation is to direct individuals to alternative investment instruments to provide additional income for retirement. Economic expectation is to provide long-term funding to support the economic development. Pension fund companies have the most important responsibility to meet these expectations. In this study, the profits of investment instruments and individual pension funds are compared in a long term perspective, using three basic portfolio performance measures. The term between January 2004 and September 2014 have been considered. Investment alternatives have been discussed in detail. BIST100, deposit, gold and currency basket (USD+EUR) are the investment instruments that are compared with individual pension funds. In addition, individual pension funds have been analyzed on company basis and the achievements of the pension fund companies have been revealed during the term mentioned above. According to our analysis, it has been concluded that personal retirement funds lost value considerably, especially due to inflation.
\end{abstract}

\section{Giriş}

Türkiye'de son yıllarda belirgin olarak düşüş sergileyen yurtiçi tasarruf oranı benzer ekonomik göstergelere sahip ülkelerin yurtiçi tasarruf oranlarının altına düşmüş̧ür. Tablo 1'den de görüldüğü gibi Türkiye'de yurtiçi tasarrufların GSMH'ya oranı 1999 yılında \%20,1 iken 2005 yılında \%15,9'a ve 2013 yllinda \%13,4'e gerilemiştir (Kalkınma Bakanlığı).

\begin{tabular}{|rrrrrrrr|}
\hline 1998 & $\mathbf{1 9 9 9}$ & $\mathbf{2 0 0 0}$ & $\mathbf{2 0 0 1}$ & $\mathbf{2 0 0 2}$ & $\mathbf{2 0 0 3}$ & $\mathbf{2 0 0 4}$ & $\mathbf{2 0 0 5}$ \\
\hline 24,3 & 20,1 & 18,4 & 18,4 & 18,6 & 15,5 & 15,9 & 15,9 \\
\hline 2006 & 2007 & $\mathbf{2 0 0 8}$ & $\mathbf{2 0 0 9}$ & $\mathbf{2 0 1 0}$ & $\mathbf{2 0 1 1}$ & $\mathbf{2 0 1 2}$ & $\mathbf{2 0 1 3}$ \\
\hline 16,6 & 15,5 & 16,8 & 13,2 & 13,9 & 13,3 & 15,1 & 13,4 \\
\hline
\end{tabular}

Tablo 1. Yurtiçi Tasarruflar / GSMH (\%) Kaynak: T.C. Kalkınma Bakanlı̆̆

Türkiye'nin tasarruf oranı uluslararası standartlarla karşılaş̧ırıldığında kişi başına düşen geliri daha az olan ülkelerin oranlarından daha düşük bir seyir izlediği görülmektedir. Malezya'nın kişi başına düşen geliri Türkiye'den az olan orta gelir grubundaki ülkelerden biri olmasına rağmen tasarruf oranı 2005-2007 döneminde oldukça yüksek seyrederek, yüzde 42,7 olmuştur. Malezya'da Personel Yardım Fonu (EPF) adı altında zorunlu tasarruf programı uygulanmakta olup katk1 payı oranları çalışanlar için yüzde 11, işverenler için yüzde 12'dir.EPF devlet tahvillerine, hisselere ve altyapı projelerine yatırım yapmaktadır (Dünya Bankası, 2012).

Tayland'da hane halkının tasarruf oranını artırabilmek için devlete bağlı tasarruf bankası kurulmuştur. Böylece kü̈cük yatırımcılar ve tasarruf edenler de sisteme dahil edilebilmişlerdir. Bunun yanısıra tasarrufların teşvik edilmesi amacıyla çalışanlardan ve işverenlerden öngörülen limite kadar olan katkı paylarının vergiden düşebileceği emeklilik yatırım fonları da mevcuttur (RMF) (Özlale ve Karakurt, 2012).

Güney Kore'nin yüksek tasarruf oranını yakalamasını sağlayan önlemlerin başında bankalar ve zorunlu tasarruf müdahaleleri gelmektedir (Öz, 2008). Güney Kore'deki bireysel emeklilik sistemi ise üç ayaklı bir sistemdir. Birinci ayağı, "Devlet Sosyal Güvenlik Sistemi" ve ikinci ayağını da "İsveren Katılımlı Güvenlik Sistemi” olup her iki sisteme de katılım zorunludur. Sistemin üçüncü ayağında ise gönüllü katılım bulunmaktadır (İlhan, 2007).

Gelişmiş ülkelere bakıldığında özel emeklilik fonu uygulamalarının hem çalışanların hem de bireylerin çabaları sonucunda başladığı görülmektedir. Özel emeklilik fonlarının zorunlu veya gönüllü olması koşulu gelişmiş ve gelişmekte olan ülkelerde farkl1lık göstermektedir. Gelişmekte olan ülkelerde genellikle özel emeklilik fonlarına ilişkin reformlar zorunlu uygulamalar şeklinde ve devlet desteğiyle başlatılmaktadır (Bayraktutan ve Şahin, 2007). Örneğin bazı OECD ülkelerinde bireysel emeklilik sisteminin zorunlu olarak uygulandığı görülmektedir. Bu tür uygulamalarda bulunan ülkelerde fon varlıklarının büyüme beklentisi gönüllü katılıma dayalı bireysel emeklilik sistemi uygulayan ülkelere kıyasla daha yüksek olmaktadır (Dağlı vd., 
2015).Türkiye'de bireysel emeklilik sistemine katılım gönüllü katılım esasına dayanmaktadır. Grafik 1'de görüldüğü gibi OECD ülkelerine kıyasla Türkiye'de emeklilik fonu varlıklarının GSYH'ya oranı oldukça düşük seviyededir.

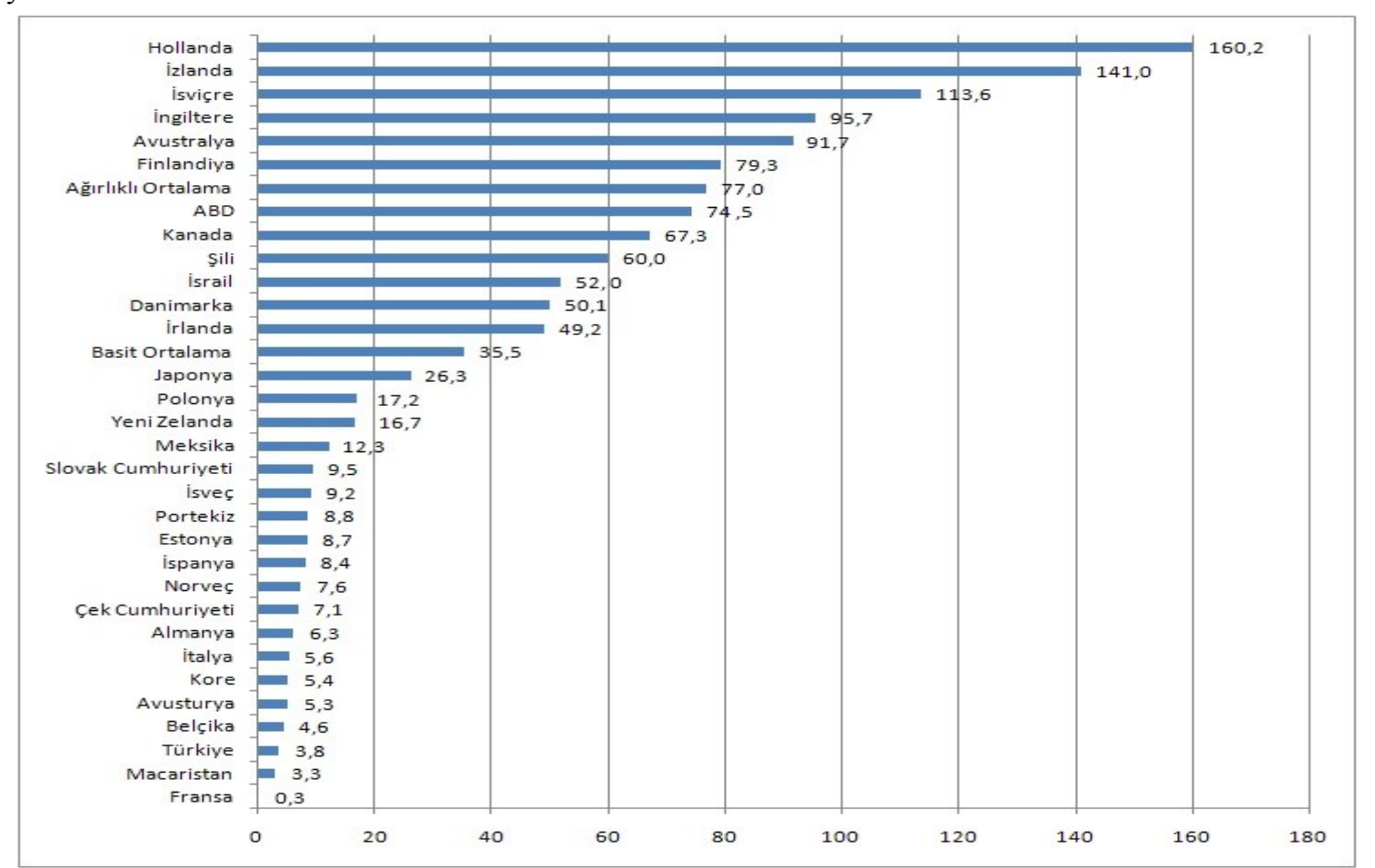

Şekil 1: Özel Emeklilik Fonlarının GSYH'ya Oranı (2012) Kaynak: OECD Pension Markets in Focus, Issue, 10

1980'li yılların başlarından itibaren dünya genelinde sosyal güvenlik alanında ortaya çıkan sorunların çözülmesine yönelik çalışmalara başlatılmıştır. Türkiye'de ise bireysel emeklilik sisteminin dahil olduğu reform çalışmaları 1999 yılından itibaren uygulanmıştır (Oktayer ve Oktayer 2007). Çalışmalar 7 Ekim 2001 tarih ve 4632 sayılı "Bireysel Emeklilik Tasarruf ve Yatırım Sistemi Kanunu” ile düzenlenmiştir. Bu kanuna göre bireysel emeklilik sistemi; kamu sosyal güvenlik sisteminin tamamlayıcısı olarak, bireylerin emekliliğe yönelik tasarruflarının yatırıma yönlendirilmesi ile emeklilik döneminde ek bir gelir sağlanarak refah düzeylerinin yükseltilmesi, ekonomiye uzun vadeli kaynak yaratarak istihdamın arttırılması ve ekonomik kalkınmaya katkıda bulunulmasını sağlamak üzere, gönüllü katılıma dayalı ve belirlenmiş katkı esasına göre oluşturulan bir sistemdir.

Bireysel emeklilik sisteminde toplanan fonlar ülkenin tasarruf hacminin artmasını sağlamaktadır. Emeklilik fonları finansal piyasalarda değerlendirilerek ekonomiye uzun vadeli kaynak yaratmakta istihdamın arttırılmasına ve ekonomik kalkınmaya katkı sağlanmasına olanak sağlamaktadır. Bu bağlamda da mali sektöre kaynak yaratarak, kamu ve özel sektörün borçlanmasını kolaylaştırıcı bir etki sağlamakta kurumsal yatırımcıların gelişmesine ve sermaye piyasalarının derinleşmesine de katkıda bulunmaktadır (Uyar, 2012).

$\mathrm{Bu}$ çalışmamızda yatırım araçlarının getirileri ile bireysel emeklilik fonlarının getirileri uzun vadeli bir perspektifle analiz edilmiştir. Çalışmada 2004 başı ile 2014 Eylül ayı arasındaki dönem ele alınmıştır. Çalışmamızda yatırım alternatifleri mümkün olduğunca geniş tutulmaya çalışılmıştır. BIST100, mevduat, altın ve döviz sepeti (USD+EUR) bireysel emeklilik fonları ile karşılaştırılan yatırım araçlarıdır. Ayrıca bireysel emeklilik fonları şirket bazında analiz edilerek ilgili dönemde emeklilik şirketlerinin başarısı da ortaya çıkartılmaya çalışılmıştır.

Çalışmamızın giriş bölümü sonrası, ikinci bölümünü analizde kullanılan veriler ve analiz yöntemi tanıtılmaktadır. Üçüncü bölümde araştırmanın bulguları tartışılmakta olup, dördüncü bölümü sonuç kısmı oluşturmaktadır.

\section{Veri ve Yöntem}

Portföy performansını ölçmeye yönelik gerçekleştirilen ilk önemli çalışmalar Treynor (1965), Sharpe (1966) ve Jensen (1968) tarafından yapılmıştır. Sharpe (1966),1954-1963 yılları arasında faaliyet gösteren 34 adet yatırım fonunun performansını Sharpe oranı ve Treynor endeksine göre değerlendirmiştir. Bu çalışmada fonların büyük bir kısmının çalışmada gösterge portföyü olarak kullanılan “Dow Jones Endeksi’nin” aynı dönem için hesaplanan değerlerinin altında bir değere sahip olduğu sonucuna ulaşmıştır. Jensen (1968), 1945-1964 y1lları arasında faaliyet gösteren 115 yatırım fonunun performansını incelemiştir. Fonların performansını 
değerlendirirken fon yöneticilerinin seçicilik kabiliyetini dikkate almıştır. Bu çalışmanın sonucunda fon yöneticilerinin düşük bir performans gösterdiği sonucuna ulaşmıştır.

Bu çalışmada Ocak 2004 ve Eylül 2014 dönemleri arasına Türkiye'deki emeklilik yatırım fonlarının risk getiri açısından değerlendirilmesi ve ilgili dönemde emeklilik şirketlerinin performanslarının karşılaştırılması amaçlanmaktadır.

Değerlendirme kapsamında dokuz emeklilik şirketi ve her şirketten üç adet aynı tür emeklilik yatırım fonu analiz kapsamına alınmıştır. Şirketlerden alınan üç adet emeklilik yatırım fonunun aylık ortalama getirileri çıkartıldıktan sonra üç fon birleştirip, her şirket için tek fon oluşturulmuş ve şirketlerin yıllık portföy ortalamalarına ulaşılmıştır. Bu fonlar; Büyüme Amaçlı Hisse Senedi, Gelir Amaçlı Kamu Borçlanma Araçları ve Esnek emeklilik yatırım fonlarıdır. Çalışma kapsamının şirket ve portföy sayısı ile sınırlandırılmasının nedeni ilgili dönemlerde diğer şirketlerin verilerinin tam olmaması ve her şirkette aynı fon türünün bulunmamasıdır. Piyasa portföyü olarak ise aylık BIST getiri endeksi değerleri dikkate alınmıștır. Değerlendirmede gözlemler enflasyon verilerinin aylık olmasından dolayı, reel getirileri karşılaştırabilmek için, aylık baz üzerinden yapılmıştır. Veri kaynağı olarak BIST aylık bültenleri ve www.fonbul.com ve Forex FX Plus internet adresinde yer alan veri bankasından yararlanılmıştır. Çalışmada risksiz faiz oranı olarak yıllık hazine bonosu aylık ortalama faiz oranları kullanılmış, veri kaynağı olarak BIST istatistiklerinden sağlanmıştır. Analizde standart sapmayı esas alan Sharpe ve betayı esas alan Treynor ve Jensen performans ölçütleri kullanılmıştır.

Çalışmamızda yatırım alternatifleri mümkün olduğunca geniş tutulmaya çalışılmıştır. Altın, döviz sepeti ve vadeli mevduat bireysel emeklilik fonları ile karş̧laştırılan yatırım araçlarıdır. Bu değişkenlere ait değerler TCMB veri bankasından alınmıştır. Altının 2006 Ocak - 2014 Eylül dönemleri içindeki aylık ortalama getirileri hesaplanarak, yıllık getirilerine ulaşılmıştır. Döviz sepetinin 2004 Ocak - 2014 Eylül dönemleri analiz kapsamına alınarak yıllık ortalama getirileri hesaplanmıştır. Vadeli mevduatın getirisinin hesaplanmasında ise 1 yıla kadar vadeli mevduat akım verileri dikkate alınmış, ilgili yılın değeri on ikiye bölünüp her ay için aylık ortalama getirilerine ulaşılarak, yıllık ortalama getirileri bulunmuştur. Ayrıca çalışmamızda emeklilik şirketlerinin Treynor ölçütleri ile altın, vadeli mevduat ve döviz sepetinin yıllık getirilerinin enflasyondan arındırılmış reel getirileri hesaplanmıştır. Enflasyon oranları için TCMB'ndan alınan aylık TÜFE oranları kullanılmıştır.

\subsection{Getirinin Hesaplanması}

Çalışmada 3 adet emeklilik yatırım fonuna ilişkin, işlem tarihindeki birim fiyatları dikkate alınmıştır. Geometrik getiri esasına göre yapılan hesaplamada $\mathrm{V}$, $\mathrm{t}$ zamanında yatırım yapılmış olan varlı̆ı̆ın fiyatını, $\mathrm{R}$ yatırımın t ve t-1 zaman dilimleri arasındaki getirisini göstermektedir. Formül aşağıdaki gibidir (Ege vd., 2011:83):

$$
\begin{aligned}
& \mathrm{R}_{\mathrm{p}}=\left(\mathrm{V}_{\mathrm{t}}-\mathrm{V}_{\mathrm{t}-1}\right) / \mathrm{V}_{\mathrm{t}-1} \\
& \mathrm{R}_{\mathrm{p}} \text { P Portföyün Getirisi } \\
& \mathrm{V}_{\mathrm{t}: \text { Portföyün Dönem Sonu Değeri }} \\
& \mathrm{V}_{\mathrm{t}-1} \text { : Portföyün Dönem Başı Değeri }
\end{aligned}
$$

\subsection{Piyasa Gösterge Endeksi}

Bu çalışmada piyasa portföyü olarak BIST100 endeksi kullanılmıştır. Piyasa portföyünün getiri oranının hesaplanmasında aşağıdaki eşitlikten yararlanılmıştır:

$\mathrm{R}_{\mathrm{e}}=\left(\mathrm{R}_{\mathrm{t}}-\mathrm{R}_{\mathrm{t}-1}\right)$

$\mathrm{Bu}$ eşitlikte $\mathrm{R}_{\mathrm{e}}$ Endeksin aylık getirisini, $\mathrm{R}_{t}$ Endeksin dönem sonu değerini, $\mathrm{R}_{\mathrm{t}-1}$ Endeksin dönem başı değerini göstermektedir.

\section{Araştırmanın Bulguları}

Çalışmada; 9 emeklilik şirketine ait 3 adet emeklilik yatırım fonu, standart sapmayı esas alan Sharpe ve betayı esas alan Treynor ve Jensen ölçütleri kullanılarak analiz edilmiştir. Çalışmamız 2004 Ocak ve 2014 yılının üçüncü çeyreğini kapsamaktadır. Ancak fonların başlangıç tarihi sistemin yeni olmasından dolayı her şirkette aynı değildir. Bu nedenle her şirket için ayrı tablolar oluşturularak ortaya çıkan sonuçlar değerlendirilmiştir.

Büyüme Amaçlı Hisse Senedi, Gelir Amaçlı Kamu Borçlanma Araçları ve Esnek Emeklilik Yatırım Fonları; Allianz Yaşam ve Emeklilik, Anadolu Hayat Emeklilik, BNP Paribas Cardif, Garanti Emeklilik ve Groupama Emeklilik şirketlerinde 2004 Ocak ve 2014 Eylül ayına kadar kesintisiz olarak devam etmiştir. Bu sonuçlara göre Tablo 2 hazırlanmıştır.

Tablo 2'de yer alan 2004:01 - 2014:09 dönemi istatistiklerine göre; emeklilik yatırım fonlarının piyasa portföyüne olan duyarlılığını ortaya koyan beta ( $\beta$ i) katsayılarının genel olarak, 1'den küçük olduğu görülmektedir. Bunun anlamı BIST100 bileşik endeksinin getirisindeki bir birimlik değişim karşısında emeklilik 
yatırım fonlarının getirilerinde bir birimden daha az bir değişikliğin söz konusu olmasıdır. Bazı fonların beta katsayılarının negatif yönlü çıkması ise bu fonların piyasa portföyüyle ters yönde hareket ettiğini göstermektedir. Emeklilik yatırım fonlarının portföy ortalamalarına baktığımızda genelde piyasa portföyü ortalamasının altında bir seyir izlediği anlaşılmaktadır. Ayrıca ilgili dönemlerde yıllık hazine faizi oranlarının da yüksek olduğu görülmektedir.

Tablo 2'de ayrıca analiz kapsamındaki emeklilik yatırım fonlarının Treynor, Sharpe ve Jensen endekslerine göre hesaplanan performans sonuçları ve altın, vadeli mevduat ve döviz sepetinin ilgili dönemlerdeki yıllık ortalama getirileri verilmiştir. Elde edilen sonuçları değerlendirdiğimizde, Treynor endeksi baz alındığında BNP Paribas Cardif'in diğer dört şirkete göre daha üstün performans gösterdiği anlaşılmaktadır. $2004-2007$ dönemlerini değerlendirdiğimizde beş emeklilik şirketinin de istenilen performansı gösteremedikleri görülmektedir.

2008 - 2014'ün üçüncü çeyreğinde ise emeklilik fonlarının getirilerinde geçen dönemlere oranla çok fazla bir değişiklik olmamıştır. Aynı dönemleri inceleyecek olursak, vadeli mevduatın yıllık getirisinin diğer yatırım araçlarına oranla daha yüksek olduğu görülmektedir. Emeklilik yatırım fonlarının Sharpe ve Jensen ölçütlerinin yüksek çıkması ve negatif eğilim göstermesinin en önemli nedenlerinin başında hazine faizi oranının büyüklüğü ve emeklilik yatırım fonlarından alınan yüksek yönetim giderleri gelmektedir.

Tablo:3 dört emeklilik şirketinin 2005:01 - 2014:9 dönemlerine ait istatistikleri ve performans sonuçlarını göstermektedir. Avivasa Emeklilik Şirketi'ne ait veriler Mart 2007 tarihinden itibaren alınmıştır. Çalışmamızda daha öncede bahsettiğimiz gibi fonların başlangıç tarihlerinin her şirkette aynı olmaması nedeni ile her şirket için fon başlangıç tarihlerini esas alarak tablolarda sonuçlar paylaşılmıştır. Emeklilik yatırım fonlarının piyasa portföyüne olan duyarlılığını ortaya koyan beta ( $\beta$ i) katsayılarına bakıldığında genel olarak diğer emeklilik şirketlerine benzer bir tablo ortaya çıkmaktadır. Emeklilik yatııı fonlarının beta katsayılarının genel olarak 1 'den küçük olması pazara duyarlı olmadığını ve negatif eğilimli olması nedeniyle pazarla ters yönde hareket ettiğini göstermektedir. Emeklilik şirketlerinin performans ölçütlerine baktığımızda Treynor ölçütüne göre Cigna Finans Emeklilik Şirketi'nin 2010 yılından itibaren diğer şirketlere oranla daha başarılı bir performans sergilediği görülmektedir.

Tablo:4 ilgili dönemlerde analiz edilen emeklilik şirketlerinin Treynor ölçütlerine göre hesaplanan enflasyondan arındırılmış yıllık getirilerini göstermektedir. Daha doğru bir karşılaştırma yapabilmek için altın, vadeli mevduat ve döviz sepetinin yıllık getirileri de enflasyondan arındırılarak hesaplanmıştır. Altının verileri 2006 yılından itibaren alındığı için 2004 ve 2005 karşılaştırmalarında tabloda ilgili verilere yer verilememiştir. Analiz kapsamında 2004 - 2014 üçüncü çeyreğine bakıldığında emeklilik yatırım fonlarının ve yatırım araçlarının yıllık getirilerinin enflasyonun altında kaldığı görülmektedir. Şirketlerin performanslarına baktığımızda, 2004 - 2014/9 dönemlerinde en düşük performansın Groupama Emeklilik Şirketi’ne ait olduğu görülmektedir. Beş emeklilik şirketi içinde en iyi performansın Garanti Emeklilik Şirketi'ne ait olduğu görülmektedir.

Tablo:5 2008 global krizinin etkilerini daha net görebilmemiz açısından emeklilik şirketlerinin Treynor ölçütlerine göre hesaplanan yıllık reel getirilerini ve diğer yatırım araçlarının reel getirilerini iki dönem ayırarak bir tablo oluşturulmuştur. 2004 - 2007 dönemlerini incelediğimizde beş emeklilik şirketlerinin yılllı reel getirilerinin enflasyonun altında kaldığı görülmektedir. Fonların reel getirileri sistemin yeni başladığı dört yıllık dönemde istenilen düzeyde bir getiri sağlamamıştır. Beş şirket içerisinden Garanti Emeklilik Şirketi daha başarılı bir performans göstermiştir. 2008 - 2014 dönemlerini incelediğimizde diğer yatırım araçlarının reel getirilerinde çok fazla bir değişiklik olmamasına rağmen bazı emeklilik fonlarının bir önceki döneme oranla daha düşük bir seyir izlediği görülmektedir. 2008 - 2014 dönemlerinde diğer şirketlere göre en iyi performansın NN Hayat ve Emeklilik Şirketi göstermiştir. 


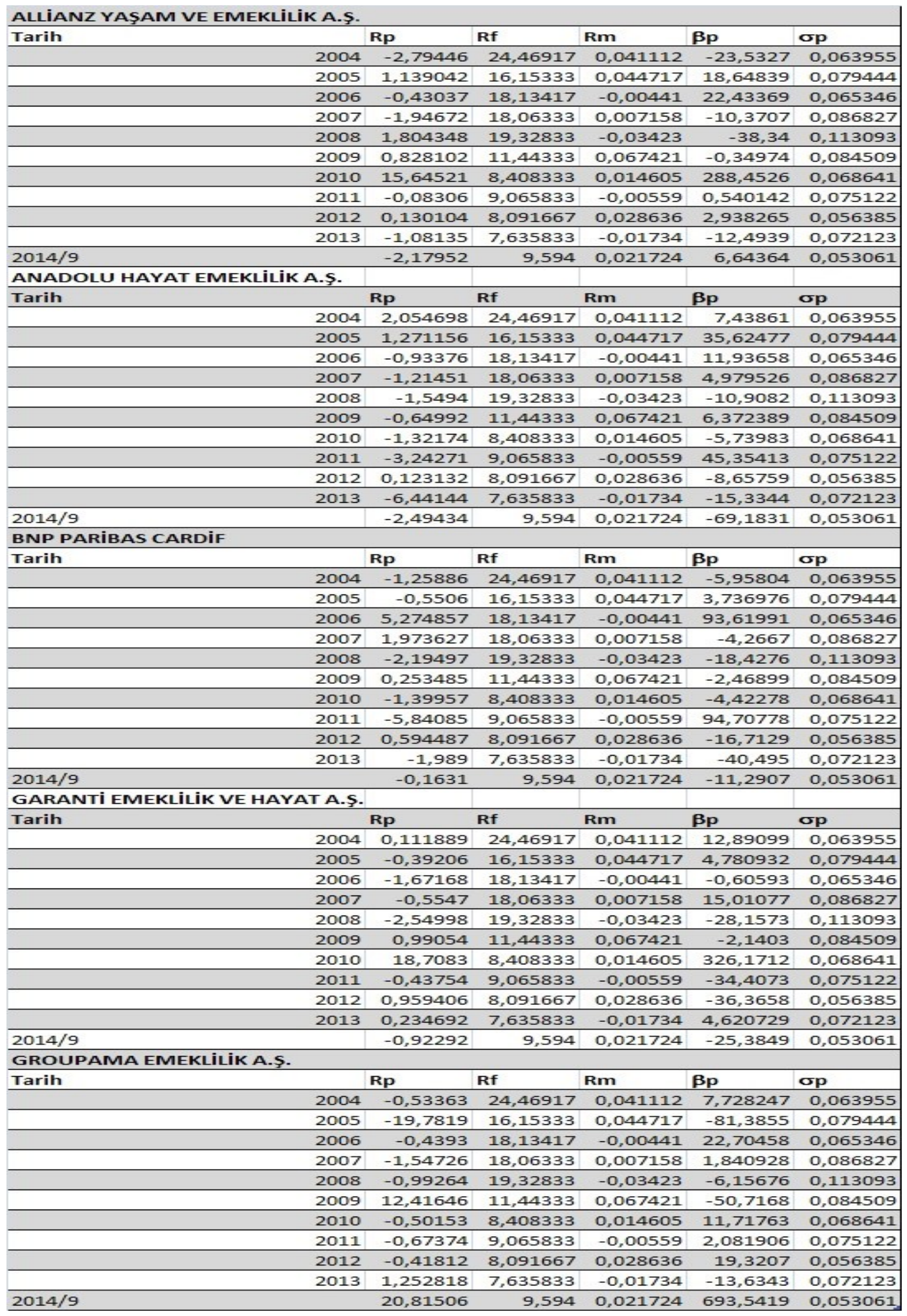




\begin{tabular}{|c|c|c|c|c|c|c|c|}
\hline Tarih & & Treynor & Sharpe & Jensen & Altın Y.O. & Döviz Sepeti Y.O. & Vadeli Mevduat Y.O \\
\hline & 2004 & 1,15854 & $-426,295$ & $-602,123$ & & 0,003761895 & 1,865902778 \\
\hline & 2005 & $-0,80513$ & $-188,992$ & 285,3854 & & $-0,003608408$ & 1,414305556 \\
\hline & 2006 & $-0,82753$ & $-284,095$ & 388,3507 & 0,02524 & 0,010586998 & 1,364305556 \\
\hline & 2007 & 1,929484 & $-230,459$ & $-207,265$ & 0,015061 & $-0,008957862$ & 1,464236111 \\
\hline & 2008 & 0,457068 & $-154,953$ & $-759,885$ & 0,03119 & 0,022810542 & 1,437777778 \\
\hline & 2009 & 30,35199 & $-125,611$ & $-14,5938$ & 0,007043 & $-0,003750384$ & 0,881041667 \\
\hline & 2010 & 0,025089 & 105,4307 & 2428,43 & 0,025066 & 0,005620976 & 0,667361111 \\
\hline & 2011 & $-16,9379$ & $-121,788$ & $-4,24903$ & 0,033033 & 0,006706115 & 0,608333333 \\
\hline & 2012 & $-2,70961$ & $-141,199$ & 15,72976 & $-0,00244$ & 0,000967804 & 0,663194444 \\
\hline & 2013 & 0,697718 & $-120,866$ & $-104,335$ & $-0,00316$ & 0,021197005 & 0,532569444 \\
\hline $2014 / 9$ & & $-1,77215$ & $-221,888$ & 51,82123 & $-0,10067$ & $-0,102684366$ & 0,740333333 \\
\hline \multicolumn{8}{|c|}{ ANADOLU HAYAT EMEKLILIK A.Ş. } \\
\hline Tarih & & Treynor & Sharpe & Jensen & Altın Y.O. & Döviz Sepeti Y.O. & Vadeli Mevduat Y.O \\
\hline & 2004 & $-3,01326$ & $-350,474$ & 159,2963 & & 0,003761895 & 1,865902778 \\
\hline & 2005 & $-0,41775$ & $-187,329$ & 558,9835 & & $-0,003608408$ & 1,414305556 \\
\hline & 2006 & $-1,59744$ & $-291,799$ & 197,4447 & 0,02524 & 0,010586998 & 1,364305556 \\
\hline & 2007 & $-3,87142$ & $-222,027$ & 70,63334 & 0,015061 & $-0,008957862$ & 1,464236111 \\
\hline & 2008 & 1,913945 & $-184,608$ & $-232,089$ & 0,03119 & 0,022810542 & 1,437777778 \\
\hline & 2009 & $-1,89776$ & $-143,1$ & 60,39849 & 0,007043 & $-0,003750384$ & 0,881041667 \\
\hline & 2010 & 1,695186 & $-141,753$ & $-57,9086$ & 0,025066 & 0,005620976 & 0,667361111 \\
\hline & 2011 & $-0,27139$ & $-163,848$ & 399,1182 & 0,033033 & 0,006706115 & 0,608333333 \\
\hline & 2012 & 0,920411 & $-141,322$ & $-77,7749$ & $-0,00244$ & 0,000967804 & 0,663194444 \\
\hline & 2013 & 0,918017 & $-195,185$ & $-131,434$ & $-0,00316$ & 0,021197005 & 0,532569444 \\
\hline $2014 / 9$ & & 0,17473 & $-227,822$ & $-674,328$ & $-0,10067$ & $-0,102684366$ & 0,740333333 \\
\hline \multicolumn{8}{|c|}{ BNP PARIBAS CARDIF } \\
\hline Tarih & & Treynor & Sharpe & Jensen & Altın Y.O. & Döviz Sepeti Y.O. & Vadeli Mevduat Y.O \\
\hline & 2004 & 4,318206 & $-402,285$ & $-171,271$ & & 0,003761895 & 1,865902778 \\
\hline & 2005 & $-4,46991$ & $-210,261$ & 43,49357 & & $-0,003608408$ & 1,414305556 \\
\hline & 2006 & $-0,13736$ & $-196,788$ & 1685,273 & 0,02524 & 0,010586998 & 1,3643055556 \\
\hline & 2007 & 3,770991 & $-185,308$ & $-93,1301$ & 0,015061 & $-0,008957862$ & 1,464236111 \\
\hline & 2008 & 1,167994 & $-190,316$ & $-378,328$ & 0,03119 & 0,022810542 & 1,437777778 \\
\hline & 2009 & 4,532154 & $-132,41$ & $-39,2769$ & 0,007043 & $-0,003750384$ & 0,881041667 \\
\hline & 2010 & 2,217587 & $-142,887$ & $-46,9315$ & 0,025066 & 0,005620976 & 0,667361111 \\
\hline & 2011 & $-0,1574$ & $-198,434$ & 844,2281 & 0,033033 & 0,006706115 & 0,608333333 \\
\hline & 2012 & 0,448585 & $-132,963$ & $-142,254$ & $-0,00244$ & 0,000967804 & 0,663194444 \\
\hline & 2013 & 0,237679 & $-133,451$ & $-319,54$ & $-0,00316$ & 0,021197005 & 0,532569444 \\
\hline $2014 / 9$ & & 0,86417 & $-183,886$ & $-117,835$ & $-0,10067$ & $-0,102684366$ & 0,740333333 \\
\hline \multicolumn{8}{|c|}{ GARANTI EMEKLiLIK VE HAYAT A.Ş. } \\
\hline Tarih & & Treynor & Sharpe & Jensen & Altın Y.O. & Döviz Sepeti Y.O. & Vadeli Mevduat Y.O \\
\hline & 2004 & $-1,88948$ & $-380,852$ & 290,5446 & & 0,003761895 & 1,865902778 \\
\hline & 2005 & $-3,4607$ & $-208,265$ & 60,46881 & & $-0,003608408$ & 1,414305556 \\
\hline & 2006 & 32,68683 & $-303,091$ & $-30,7965$ & 0,02524 & 0,010586998 & 1,364305556 \\
\hline & 2007 & $-1,24031$ & $-214,427$ & 252,4191 & 0,015061 & $-0,008957862$ & 1,464236111 \\
\hline & 2008 & 0,777003 & $-193,455$ & $-567,076$ & 0,03119 & 0,022810542 & 1,437777778 \\
\hline & 2009 & 4,883809 & $-123,688$ & $-34,8006$ & 0,007043 & $-0,003750384$ & 0,881041667 \\
\hline & 2010 & 0,031578 & 150,0555 & 2748,093 & 0,025066 & 0,005620976 & 0,667361111 \\
\hline & 2011 & 0,276202 & $-126,507$ & $-321,627$ & 0,033033 & 0,006706115 & 0,608333333 \\
\hline & 2012 & 0,196126 & $-126,491$ & $-300,35$ & $-0,00244$ & 0,000967804 & 0,663194444 \\
\hline & 2013 & $-1,60173$ & $-102,619$ & 27,9621 & $-0,00316$ & 0,021197005 & 0,532569444 \\
\hline $2014 / 9$ & & 0,414299 & $-198,206$ & $-253,508$ & $-0,10067$ & $-0,102684366$ & 0,740333333 \\
\hline \multicolumn{8}{|c|}{ GROUPAMA EMEKLILIK A.Ş. } \\
\hline Tarih & & Treynor & Sharpe & Jensen & Altın Y.O. & Döviz Sepeti Y.O. & Vadeli Mevduat Y.O \\
\hline & 2004 & $-3,23525$ & $-390,945$ & 163,7832 & & 0,003761895 & 1,865902778 \\
\hline & 2005 & 0,441544 & $-452,334$ & $-1346,94$ & & $-0,003608408$ & 1,414305556 \\
\hline & 2006 & $-0,81805$ & $-284,232$ & 393,2553 & 0,02524 & 0,010586998 & 1,364305556 \\
\hline & 2007 & $-10,6526$ & $-225,859$ & 13,62952 & 0,015061 & $-0,008957862$ & 1,464236111 \\
\hline & 2008 & 3,300593 & $-179,685$ & $-139,532$ & 0,03119 & 0,022810542 & 1,437777778 \\
\hline & 2009 & $-0,01919$ & 11,51503 & $-575,977$ & 0,007043 & $-0,003750384$ & 0,881041667 \\
\hline & 2010 & $-0,76038$ & $-129,804$ & 89,44478 & 0,025066 & 0,005620976 & 0,667361111 \\
\hline & 2011 & $-4,6782$ & $-129,651$ & 9,146292 & 0,033033 & 0,006706115 & 0,608333333 \\
\hline & 2012 & $-0,44045$ & $-150,922$ & 147,2736 & $-0,00244$ & 0,000967804 & 0,663194444 \\
\hline & 2013 & 0,468158 & $-88,5023$ & $-110,729$ & $-0,00316$ & 0,021197005 & 0,532569444 \\
\hline $14 / 9$ & & 0,016179 & 211,4765 & 6649,995 & $-0,10067$ & $-0,102684366$ & 0,740333333 \\
\hline
\end{tabular}

Tablo 2. Emeklilik Yatırım Fonlarına Ait 2004:01 - 2014:09 Dönemi İstatistikleri ve Performans Sonuçları 


\begin{tabular}{|c|c|c|c|c|c|c|}
\hline Tarih & & $\mathbf{R p}$ & Rf & $\mathbf{R m}$ & Bp & op \\
\hline & 2005 & $-0,8209$ & 16,15333 & 0,044717 & $-1,61821$ & 0,079444 \\
\hline & 2006 & $-0,39359$ & 18,13417 & $-0,00441$ & 8,76812 & 0,065346 \\
\hline & 2007 & $-0,40144$ & 18,06333 & 0,007158 & $-5,31828$ & 0,086827 \\
\hline & 2008 & 0,095456 & 19,32833 & $-0,03423$ & $-0,63149$ & 0,113093 \\
\hline & 2009 & $-0,53355$ & 11,44333 & 0,067421 & 10,87226 & 0,084509 \\
\hline & 2010 & $-0,56038$ & 8,408333 & 0,014605 & 10,55596 & 0,068641 \\
\hline & 2011 & 2,750013 & 9,065833 & $-0,00559$ & $-0,51305$ & 0,075122 \\
\hline & 2012 & 0,019202 & 8,091667 & 0,028636 & 2,436884 & 0,056385 \\
\hline & 2013 & $-1,37263$ & 7,635833 & $-0,01734$ & 1,90723 & 0,072123 \\
\hline $2014 / 9$ & & $-10,6026$ & 9,594 & 0,021724 & $-391,727$ & 0,053061 \\
\hline \multicolumn{7}{|c|}{ AVIVASA EMEKLILIK VE HAYAT A.S. } \\
\hline \multirow[t]{8}{*}{ Tarih } & & $\mathbf{R p}$ & Rf & $\mathbf{R m}$ & Bp & op \\
\hline & 2007 & 0,56786 & 18,06333 & 0,007158 & 20,28917 & 0,086827 \\
\hline & 2008 & $-19,6935$ & 19,32833 & $-0,03423$ & $-347,013$ & 0,113093 \\
\hline & 2009 & $-3,72099$ & 11,44333 & 0,067421 & 18,5048 & 0,084509 \\
\hline & 2010 & 0,199529 & 8,408333 & 0,014605 & 22,17474 & 0,068641 \\
\hline & 2011 & $-12,368$ & 9,065833 & $-0,00559$ & 249,0924 & 0,075122 \\
\hline & 2012 & 0,714878 & 8,091667 & 0,028636 & 32,6699 & 0,056385 \\
\hline & 2013 & $-1,50412$ & 7,635833 & $-0,01734$ & $-25,6356$ & 0,072123 \\
\hline $2014 / 9$ & & 0,925462 & 9,594 & 0,021724 & 54,27732 & 0,053061 \\
\hline \multicolumn{7}{|c|}{ CIGNA FINANS EMEKLILIK VE HAYAT A.S. } \\
\hline \multirow[t]{6}{*}{ Tarih } & & $\mathbf{R p}$ & Rf & $\mathbf{R m}$ & Bp & op \\
\hline & 2009 & $-1,77469$ & 11,44333 & 0,067421 & 14,49653 & 0,084509 \\
\hline & 2010 & $-0,95167$ & 8,408333 & 0,014605 & $-1,95875$ & 0,068641 \\
\hline & 2011 & $-1,41128$ & 9,065833 & $-0,00559$ & $-8,83341$ & 0,075122 \\
\hline & 2012 & 0,279871 & 8,091667 & 0,028636 & $-0,41624$ & 0,056385 \\
\hline & 2013 & $-0,57459$ & 7,635833 & $-0,01734$ & $-16,1209$ & 0,072123 \\
\hline $2014 / 9$ & & $-0,28147$ & 9,594 & 0,021724 & $-3,23199$ & 0,053061 \\
\hline \multicolumn{7}{|c|}{ MEtLife EMEKLILIK VE HAYAT A.Ş. } \\
\hline \multirow[t]{5}{*}{ Tarih } & & $\mathbf{R p}$ & Rf & $\mathbf{R m}$ & Bp & op \\
\hline & 2010 & $-3,56498$ & 8,408333 & 0,014605 & 15,87876 & 0,068641 \\
\hline & 2011 & 1,252897 & 9,065833 & $-0,00559$ & $-6,27796$ & 0,075122 \\
\hline & 2012 & 0,227233 & 8,091667 & 0,028636 & 1,133048 & 0,056385 \\
\hline & 2013 & $-2,88322$ & 7,635833 & $-0,01734$ & $-37,9083$ & 0,072123 \\
\hline $2014 / 9$ & & 0,401239 & 9,594 & 0,021724 & 56,21148 & 0,053061 \\
\hline
\end{tabular}

\section{NN HAYAT VE EMEKLILIK}

\begin{tabular}{|c|c|c|c|c|c|c|c|}
\hline Tarih & & Treynor & Sharpe & Jensen & Altın Y.O. & Döviz Sepeti Y.O. & Vadeli Mevduat Y.O. \\
\hline & 2005 & 10,48951 & $-213,663$ & $-43,0414$ & & $-0,003608408$ & 1,414305556 \\
\hline & 2006 & $-2,11308$ & $-283,533$ & 140,5135 & 0,02524 & 0,010586998 & 1,364305556 \\
\hline & 2007 & 3,471946 & $-212,662$ & $-114,493$ & 0,015061 & $-0,008957862$ & 1,464236111 \\
\hline & 2008 & 30,45625 & $-170,063$ & $-31,4602$ & 0,03119 & 0,022810542 & 1,437777778 \\
\hline & 2009 & $-1,1016$ & $-141,723$ & 111,705 & 0,007043 & $-0,003750384$ & 0,881041667 \\
\hline & 2010 & $-0,84963$ & $-130,661$ & 79,63517 & 0,025066 & 0,005620976 & 0,667361111 \\
\hline & 2011 & 12,31024 & $-84,0746$ & $-10,97$ & 0,033033 & 0,006706115 & 0,608333333 \\
\hline & 2012 & $-3,31262$ & $-143,166$ & 11,5762 & $-0,00244$ & 0,000967804 & 0,663194444 \\
\hline & 2013 & $-4,72332$ & $-124,905$ & 5,587897 & $-0,00316$ & 0,021197005 & 0,532569444 \\
\hline $2014 / 9$ & & 0,051558 & $-380,633$ & $-3769,92$ & $-0,10067$ & $-0,102684366$ & 0,740333333 \\
\hline \multicolumn{8}{|c|}{ AVIVASA EMEKLILIK VE HAYAT A.Ş. } \\
\hline \multirow[t]{8}{*}{ Tarih } & & Treynor & Sharpe & Jensen & Altın Y.O. & Döviz Sepeti Y.O. & Vadeli Mevduat Y.O. \\
\hline & 2007 & $-0,86231$ & $-201,499$ & 348,8493 & 0,015061 & $-0,008957862$ & 1,464236111 \\
\hline & 2008 & 0,112451 & $-345,044$ & $-6758,09$ & 0,03119 & 0,022810542 & 1,437777778 \\
\hline & 2009 & $-0,81948$ & $-179,44$ & 195,3447 & 0,007043 & $-0,003750384$ & 0,881041667 \\
\hline & 2010 & $-0,37019$ & $-119,59$ & 177,9199 & 0,025066 & 0,005620976 & 0,667361111 \\
\hline & 2011 & $-0,08605$ & $-285,322$ & 2238,19 & 0,033033 & 0,006706115 & 0,608333333 \\
\hline & 2012 & $-0,2258$ & $-130,828$ & 256,0416 & $-0,00244$ & 0,000967804 & 0,663194444 \\
\hline & 2013 & 0,356533 & $-126,728$ & $-205,334$ & $-0,00316$ & 0,021197005 & 0,532569444 \\
\hline $2014 / 9$ & & $-0,15971$ & $-163,371$ & 510,889 & $-0,10067$ & $-0,102684366$ & 0,740333333 \\
\hline \multicolumn{8}{|c|}{ CIGNA FINANS EMEKLILIK VE HAYAT A.Ş. } \\
\hline \multirow[t]{6}{*}{ Tarih } & & Treynor & Sharpe & Jensen & Altın Y.O. & Döviz Sepeti Y.O. & Vadeli Mevduat Y.O. \\
\hline & 2009 & $-0,91181$ & $-156,409$ & 151,6933 & 0,007043 & $-0,003750384$ & 0,881041667 \\
\hline & 2010 & 4,778548 & $-136,362$ & $-25,8012$ & 0,025066 & 0,005620976 & 0,667361111 \\
\hline & 2011 & 1,186078 & $-139,469$ & $-90,6088$ & 0,033033 & 0,006706115 & 0,608333333 \\
\hline & 2012 & 18,76732 & $-138,543$ & $-11,168$ & $-0,00244$ & 0,000967804 & 0,663194444 \\
\hline & 2013 & 0,509304 & $-113,84$ & $-131,586$ & $-0,00316$ & 0,021197005 & 0,532569444 \\
\hline $2014 / 9$ & & 3,055541 & $-186,117$ & $-40,8129$ & $-0,10067$ & $-0,102684366$ & 0,740333333 \\
\hline \multicolumn{8}{|c|}{ MetLife EMEKLiLIK VE HAYAT A.Ş. } \\
\hline \multirow[t]{5}{*}{ Tarih } & & Treynor & Sharpe & Jensen & Altın Y.O. & Döviz Sepeti Y.O. & Vadeli Mevduat Y.O. \\
\hline & 2010 & $-0,75405$ & $-174,434$ & 121,3087 & 0,025066 & 0,005620976 & 0,667361111 \\
\hline & 2011 & 1,244502 & $-104,004$ & $-64,763$ & 0,033033 & 0,006706115 & 0,608333333 \\
\hline & 2012 & $-6,94095$ & $-139,476$ & 1,271371 & $-0,00244$ & 0,000967804 & 0,663194444 \\
\hline & 2013 & 0,277487 & $-145,85$ & $-300,638$ & $-0,00316$ & 0,021197005 & 0,532569444 \\
\hline $2014 / 9$ & & $-0,16354$ & $-173,25$ & 528,8791 & $-0,10067$ & $-0,102684366$ & 0,740333333 \\
\hline
\end{tabular}

Tablo 3. Emeklilik Yatırım Fonlarına Ait 2005:01 - 2014:09 Dönemi İstatistikleri ve Performans Sonuçları 


\begin{tabular}{|c|c|c|c|c|c|}
\hline $2004-2014 / 9$ & $\mathrm{re}^{*}$ & Altın* & & Döviz Sepeti* & Vadeli Mevduat* \\
\hline Allianz Yaşam ve Emeklilik A.Ş. & $-0,86278472$ & & & $-0,989598755$ & $-0,862000655$ \\
\hline Anadolu Hayat Emeklilik A.Ş. & $-1,04855031$ & & & $-0,989598755$ & $-0,862000655$ \\
\hline BNP Paribas Cardif & $-0,84940816$ & & & $-0,989598755$ & $-0,862000655$ \\
\hline Garanti Emeklilik ve Hayat A.Ş. & $-0,64981305$ & & & $-0,989598755$ & $-0,862000655$ \\
\hline Groupama Emeklilik A.ş. & $-1,16789607$ & & & $-0,989598755$ & $-0,862000655$ \\
\hline $2005-2014 / 9$ & $\mathrm{re}^{*}$ & & & Döviz Sepeti* & Vadeli Mevduat* \\
\hline NN Hayat ve Emeklilik & $-0,44476424$ & & & $-0,988466172$ & $-0,869047546$ \\
\hline $2007-2014 / 9$ & $\mathrm{re}^{*}$ & Altın* & & Döviz Sepeti* & Vadeli Mevduat* \\
\hline Avivasa Emeklilik ve Hayat A.Ş. & $-1,01624875$ & & $-0,984512619$ & $-0,985486748$ & $-0,876812831$ \\
\hline $2009-2014 / 9$ & $\mathrm{re}^{*}$ & Altın* & & Döviz Sepeti* & Vadeli Mevduat* \\
\hline Cigna Finans Emeklilik ve Hayat A.ş. & $-0,38891319$ & & $-0,979356727$ & $-0,980020301$ & $-0,890358808$ \\
\hline $2010-2014 / 9$ & $\mathrm{re}^{*}$ & Altın* & & Döviz Sepeti* & Vadeli Mevduat* \\
\hline Metlife Emeklilik ve Hayat A.Ş. & $-1,13368103$ & & $-0,976156387$ & $-0,976658116$ & $-0,894494196$ \\
\hline
\end{tabular}

Tablo 4. 2004:01 - 2014:09 Enflasyondan arındırllmış getiriler

\begin{tabular}{|c|c|c|c|}
\hline $2004-2007$ & re & $2008-2014 / 9$ & re \\
\hline Allianz Yaşam ve Emeklilik A.ş. & $-0,93$ & Allianz Yaşam ve Emeklilik A.ş. & $-0,8$ \\
\hline Anadolu Hayat Emeklilik A.Ş. & $-1,22$ & Anadolu Hayat Emeklilik A..ş & $-0,92$ \\
\hline BNP Paribas Cardif Em. A.Ş. & $-0,87$ & Avivasa Emeklilik ve Hayat A.Ş. & -1 \\
\hline Garanti Emeklilik ve Hayat A.Ş. & $-0,25$ & BNP Paribas Cardif Em. A.Ş. & $-0,81$ \\
\hline \multirow[t]{3}{*}{ Groupama Emeklilik A.ş. } & $-1,36$ & Garanti Emeklilik ve Hayat A.Ş. & $-0,89$ \\
\hline & & Groupama Emeklilik A.Ş. & $-1,01$ \\
\hline & & NN Hayat ve Emeklilik & $-0,4$ \\
\hline \multirow[t]{2}{*}{$2004-2007$} & Döviz Sepeti & Vadeli Mevduat & \\
\hline & $-0,97$ & $-0,8$ & \\
\hline \multirow[t]{2}{*}{$2008-2014 / 9$} & Altın & Döviz Sepeti & Vadeli Mevduat \\
\hline & $-0,98$ & $-0,98$ & $-0,89$ \\
\hline
\end{tabular}

Tablo 5. 2004 - 2007 ve 2008 - 2014 Enflasyondan arındırılmış getiriler

\section{Sonuç}

Türkiye'de 2001 yılında yasal altyapısının oluşturulması ile birlikte resmi olarak 2003 yılında faaliyete geçen bireysel emeklilik sistemi gönüllük esasına ve katkı payı esasına dayalı olarak başlatılan bir sistemdir. Emeklilik fonları, katılımcıların ödediği katkı paylarının yatırıma yönlendirildiği, emeklilik şirketleri tarafından kurulan ve fon portföyü portföy yöneticileri tarafından yönetilen yatırım araçlarıdır.

Bu çalışmada Ocak 2004 ve Eylül 2014 dönemleri arasında Türkiye'deki emeklilik yatırım fonlarının risk getiri açısından değerlendirilmesi ve ilgili dönemde emeklilik şirketlerinin performanslarının karşılaştırılması amaçlanmıştır. Bu amaçla dokuz emeklilik şirketine ait üç adet emeklilik yatırım fonu, standart sapmayı esas alan Sharpe ve betayı esas alan Treynor ve Jensen ölçütleri kullanılarak analiz edilmiştir.

Yapılan analiz kapsamında emeklilik yatırım fonlarının piyasa portföyüne olan duyarlılığını ortaya koyan beta katsayılarının ( $\beta$ i) genel olarak 1'den küçük ve negatif eğilimli olduğu sonucuna ulaşılmıştır. Emeklilik yatırım fonlarının Sharpe ve Jensen ölçütlerinin yüksek çıkması ve negatif eğilim sergilemesi çalışmada kullanılan hazine faizi oranının büyüklüğü ve emeklilik yatırım fonlarından alınan yüksek yönetim giderlerinden kaynaklanmaktadır.

Çalışmada ayrıca ilgili dönemlerde emeklilik şirketlerine ait fonların Treynor ölçütlerine göre enflasyondan arındırılmış yıllık reel getirileri ile altın, vadeli mevduat ve döviz sepetinin yıllık getirileri de enflasyondan arındırılarak hesaplanmıştır. Yapılan analiz sonucunda emeklilik yatırım fonlarının ve diğer yatırım araçlarının yıllık getirilerinin enflasyonun altında kaldığ 1 sonucuna ulaşılmıştır.

Sonuç olarak 2004-2014 dönemleri arasında analize dahil edilen emeklilik şirketlerinin fon performanslarının özellikle enflasyon karşısında önemli bir kayba uğradığı anlaşılmıştır.

\section{Kaynakça}

- Bayraktutan ve Şahin 2007."Bireysel Emeklilik Sektörünün Gelişimi ve Bilgi Bilişim Teknolojilerinin Kullanımı", Bilgi Ekonomisi ve Yönetim Dergisi,2007 Cilt2, Sayı:2, s.97-109.

- $\quad$ BIST aylık bültenleri. 
- Dağlı, Karakaya ve Bulut 2015. "Emeklilik Yatırım Fonlarının Karakteristik Özellikleri ve Performansı: Türkiye Örneği”. Uluslararası İktisadi ve İdari İnceleme Dergisi,2015 Sayı:14, s.178-200.

- Dünya Bankası 2012. "Yüksek Büyümenin Sürdürülebilirliği: Yurtiçi Tasarrufların Rolü” Türkiye Ülke Raporu Ankara.

- İlhan 2007."1997 Güney Asya Finansal Krizi ve Güney Asya Ülkelerinde Emeklilik Sistemi Reformları: Türkiye ve Güney Asya Ülkeleri Bireysel Emeklilik Sistemlerinin Karşılaştırılması”, 38. ICANAS ( Uluslararası Asya ve Kuzey Afrika Çalışmaları Kongresi), Ankara, s.79-99.

- Jensen. 1968. "The Performance of Mutual Funds in the Period 1945-1964”, The Journal of Finance, Vol.23, No.2, 389-416.

- OECD 2013. Pension Markets in Focus, Issue 10, http://www.oecd.org/daf/fin/privatepensions/PensionMarketsInFocus2013.pdf Erişim Tarihi 28.05.2015.

- Oktayer, N. ve Oktayer, A. 2007.“Özel Emeklilik Fonlarının Finansal Piyasaların Gelişimine Etkileri”, Afyon Kocatepe Üniversitesi, İ.İ.B.F Dergisi,2007 Cilt:9, Sayı:2, 55-80.

- Öz,2008. "Küresel Rekabette Son Aşamaya Ulaşmak: Güney Kore”, TÜSİAD-Sabancı Üniversitesi Rekabet Forumu, No:12/475, 6, 1-84.

- Ö̈zlale ve Karakurt, 2012."Türkiye'de Tasarruf Açı̆̆ının Nedenleri ve Kapatılması İçin Politika Önerileri”, Bankac1lar Dergisi, 2012 Say1:83, s.1-33.

- Sharpe 1966. "Mutual Fund Performance”, The Journal of Business, Vol.39, No.1, Part 2: Supplement on Security Prices, 119-138.

- T.C. Kalkınma Bakanlığı.

- T.C. Yasalar (07.04.2001). 4632 Sayılı Bireysel Emeklilik Tasarruf ve Yatırım Sistemi Kanunu Ankara: Resmi Gazete (24366 Sayıl1).

- Uyar 2012.“Bireysel Emeklilik Sistemi İle Ekonomik Göstergeler Arasındaki İlişkinin İncelenmesi”,Mali Çözüm Dergisi, 2012Sayı:110, 71-93.

- $\quad$ www.fonbul.com Erişim Tarihi 20.10.2014.

- $\quad$ Foreks FXPLUS( 0.2.16.45.1) Erişim Tarihi 22.10.2014

- http://www.tcmb.gov.tr/wps/wcm/connect/TCMB+TR/TCMB+TR/Main+Menu/Istatistikler/Elektronik+Veri + Dagitim+Sistemi+EVDS1 Erişim Tarihi 29.05.2015. 


\title{
Konsolide Finansal Tabloların Finansal Kuruluşların Performansı Üzerine Etkisi: Türkiye'deki Kuruluşlar Üzerine Uygulamalı Bir Çalışma
}

\section{The Impact of Consolidated Financial Statements on Performance of Financial Institutions: A Key Study from Turkey}

\author{
Prof. Dr. Turgut Çürük (Çukurova University, Turkey) \\ Ayşe Tanyeri (Çukurova University, Turkey)
}

\begin{abstract}
Financial statements prepared by companies are the main sources of information for those who make economic decisions about the companies. As the listed companies in many countries (at least on the large European stock market) have one or more subsidiaries, they are obligated by regulations to prepare dual financial statements (individual and consolidated). Unlike the practices in developed European stock exchanges, companies listed on the stock exchange in Turkey, which used to prepare individual financial statements until 2005, have been preparing only consolidated financial statements in accordance with national accounting and financial reporting standards which were adopted from International standards since then. As of today, individual financial statements have not been prepared by Turkish companies. Only exception to this general practices are the Real Estate Investment Trusts (REITs) registered with Capital Market Board (CMB). As the discussions and results of some empirical studies in the literature indicate that impact of consolidated and individual financial statements on the performances of companies are different. In line with these arguments in literature, this study, focusing on the REITs registered with CMB in Turkey, attempts to investigate the impact of consolidated financial statements on performance of financial institutions (REITs). In this context, value relevance is used as a proxy to measure the performance. Than the impact of indicators as regards to profit and owners' equity observed from two different sets of financial statements of the same Real Estate Investment Trusts on the value relevance of companies are analyzed.
\end{abstract}

\section{Giriş}

Firmalarla ilgili ekonomik kararlara esas olan bilgilerin temel kaynağı, firmalarca düzenlenen finansal tablolardır. Türk ekonomisinde meydana gelen gelişmeler, küresel ekonomi ile uyumun artması, firmaların faaliyetlerinin uluslararası boyutlara ulaşması, karar sürecinde esas verileri sunan finansal tablolara olan ihtiyacı artırmaktadır. Bu gelişme aynı zamanda firmalarca hazırlanan finansal tabloların genel kabul görmüş ilkeler doğrultusunda standart formda hazırlanmasını zorunlu kılan bazı yasal düzenlemeleri de beraberinde getirmiştir. Uluslararası alandaki gelişmeler doğrultusunda finansal raporların hazırlanmasına yönelik Türkiye'de özellikle son 10 yılda önemli yasal düzenlemeler yapılmıştır. Türkiye'de Sermaye Piyasası Kurulu'na (SPK' ya) kayıtlı firmalar 2005 y1lına kadar bireysel (solo, konsolide olmayan) finansal tablolar düzenlerken, 2005 y1lında yapılan bir değişiklikle hisse senedi borsada işlem gören firmalar Uluslararası Muhasebe Standartları Kurulu (UMSK) tarafindan yayımlanan Uluslararası Finansal Raporlama Standartları (UFRS) ile uyumlu Türk Muhasebe Standartlarına göre konsolide finansal tablo hazırlamaya başlamışlardır.

Sermaye piyasası gelişmiş birçok ülke borsalarında (en azından büyük Avrupa borsalarında) kayıtlı firmalar bir veya daha fazla iştirak ve bağlı ortaklığa sahiptirler. Bu nedenle, sermaye piyasası ve/veya ulusal mevzuatlar bu firmaların ikili (biri bireysel bazda, diğeri ise grup bazında olmak üzere iki farklı tip) finansal tablo hazırlamalarını gerektirmektedir. Türkiye'de ise, borsaya kayıtlı firmalar 2005 yılından itibaren sadece konsolide finansal tablo hazırlayıp sunmakta, bireysel finansal tablolarını ise açıklamamaktadır. Bu uygulamanın bir istisnası ise finansal bir kurum olan Yatırım Ortaklıklarıdır. 13.06.2013 tarihli ve 28676 sayılı Resmi Gazete'de yayımlanan Sermaye Piyasası'nda Finansal Raporlamaya İlişkin Esaslar Tebliği Üçüncü bölüm 10. Madde 4. fıkrasına göre; 'konsolide finansal tablo hazırlamakla yükümlü yatırım ortaklıkları, yıllık bireysel finansal tablolarını yıllık konsolide finansal tabloları ile birlikte kamuya açıklamakla yükümlüdürler” ş̧eklinde belirtilmiştir (SPK, 2015). Son zamanlarda yapılan yasal düzenlemelerle, Borsa İstanbul (BİST)'da işlem gören firmalar 2005 sonrası yalnızca konsolide finansal tablolar düzenlemekte olup, günümüzde Gayri Menkul Yatırım Ortaklıkları (GYO) ise hem bireysel hem de konsolide finansal tablo düzenlemektedirler.

Literatürdeki tartışmalar ve bazı ampirik çalışmalar, konsolide ve bireysel finansal tabloların firma performansları üzerine etkilerinin farklı olduğunu ortaya koymaktadır (Jermakowicz, 2004; Capkun, vd, 2008; Paglietti, 2009; Türel, 2009; Armstrong, vd, 2010; Devalle, vd, 2010; Agostino, vd, 2011; Clarkson, vd, 2011; Suadiye, 2012; Kayalıdere, 2013; Kargin, 2013; Callao, vd, 2007; Paananen ve Lin, 2008; Gjerde, vd, 2008; Müller, 2014). Yerel Muhasebe Standartlarından UFRS'ye göre hazırlanan konsolide finansal raporlamaya geçişin firma performansı üzerindeki etkisini doğrudan ve dolaylı analiz etmek için finansal tablo verileri ile 
pazar değeri arasındaki ilişkileri analiz eden çalışmalarda (Jermakowicz, 2004; Capkun, vd, 2008; Paglietti, 2009; Türel, 2009; Armstrong, vd, 2010; Devalle, vd, 2010; Agostino, vd, 2011; Clarkson, vd, 2011; Suadiye, 2012; Kayalıdere, 2013; Kargın, 2013) çoğunlukla finansal bilgilerin kalitesini değerlendirmek için ölçü olarak hisse senedi fiyatı kullanılmıştır. Farklı ülkelerde yürütülen çalışma sonuçları UFRS'ye zorunlu geçiş (konsolide finansal tablo düzenleme) ile birlikte finansal tablolar tarafindan sağlanan finansal bilgiler ile piyasa değeri arasındaki ilişkide olumlu bir artış olduğuna işaret etmektedir. Diğer taraftan, literatürde UFRS'ye zorunlu uyumun dolayısı ile konsolide finansal raporlamaya geçişin firmalar üzerine etkisini konsolide finansal tablolardan elde edilen kar ve öz kaynak göstergelerinin hisse senedi ile arasındaki ilişkiyi ele alarak inceleyen bazı çalışmalarda ise konsolide finansal raporlamaya geçişin karlılık ve öz kaynak göstergeleri ile firma hisse senedi fiyatı arasındaki ilişkide bir artışa yol açmadığını gösteren çalışmalar da mevcuttur (Callao, vd, 2007; Paananen ve Lin, 2008; Gjerde, vd, 2008).

Her ne kadar konsolide finansal raporlamaya geçişin firma performansı üzerine olumlu etkisinin olması literatürdeki teorik tartışmada ağırlık kazanmış olsa da, yukarıda değinilen araştırma sonuçları konsolide finansal raporlamaya geçişin firma performansı üzerine etkisinin olumlu veya olumsuz olacağını söylemenin her zaman ve her koşulda mümkün olmadığını göstermektedir. Söz konusu farklı sonuçların birçok nedeni olabilir. Çevresel Belirleme Teorisi'ne göre (Çürük, 2001) her ülkenin kendine özgü ekonomik, kültürel, politik ve sosyal yapısının olması ve ülkelerin muhasebe ve finansal raporlama uygulamalarını etkileyen iç çevresel faktörlerin birbirinden farklı olması, bu nedenler arasında gösterilebilir. Örneğin, konsolide finansal raporlamaya geçiş bazı ülkelerdeki yatırımcılar tarafından olumlu karşılanırken, eğitim, kültürel ve sosyo-ekonomik yapısı farklı olan bir diğer ülkedeki yatırımcı tepki gösterebilir. Bu durum aynı ülke sınırları içerisinde farklı yatırımcılar için bile söz konusu olabilir. Sonuç olarak bu durum yatırımcı algılarından etkilenen firma pazar değerini ve tüm ekonomiyi etkilemektedir.

Literatürdeki mevcut çalışmaların çoğunda Ohlson (1995) tarafından geliştirilen bilanço modeli ve getiri modelinin bileşiminden oluşan fiyat modeli (hisse senedi değerlendirme modeli) kullanılmıştır. Yerel muhasebe standartlarına ve UFRS'ye göre hazırlanan finansal tabloların grup ve ana şirket bazında elde edilen muhasebe verileri ile piyasa değeri (hisse senedi fiyatı) arasındaki ilişkiyi analiz eden son zamanlarda yapılan çalışma (Müller, 2014); UFRS'ye uyumdan sonra muhasebe bilgisinin kalitesinde ve dolayısıyla da piyasa değerinde bir artış meydana geldiğini göstermektedir.

Türkiye'de finansal tabloların konsolide olarak düzenlenmesine ilişkin son yıllarda yapılan değişiklik ve özellikle, GYO'lara hem bireysel hem de konsolide finansal tablo düzenleme zorunluluğunun getirilmesine yönelik düzenlemeler literatürdeki tartışma ve araştırma bulguları çerçevesinde değerlendirildiğinde, söz konusu değişikliğin, diğer bir ifade ile konsolide finansal tabloların düzenleme zorunluluğunun firma performansı üzerine bir etkisinin olup olmadığının araştırılmasını önemli hale getirmiştir. Firma performansının ölçülmesi ve konsolide finansal raporların performansa etkisinin belirlenebilmesi için aynı dönemde hem bireysel (konsolide olmayan) hem de konsolide finansal tablo hazırlayan firmaların finansal tablolarının analize tabi tutulması önemlidir. GYO'ların hem bireysel hem de konsolide finansal tablo hazırlıyor olması nedeniyle, Türkiye'de SPK'a kayıtlı finansal kurum olan Gayri Menkul Yatırım Ortaklarını baz alan bu çalışmada, konsolide finansal tabloların finansal kurumların (GYO) performansına etkisi araştırılmıştır.

\section{Araștırma Metodolojisi}

$\mathrm{Bu}$ çalışmada, konsolide finansal tabloların firma performansı üzerine etkisi, literatürde yaygın olarak kullanılan (Suadiye, 2012; Kayalıdere, 2013; Kargın, 2013; Callao, vd, 2007; Paananen ve Lin, 2008; Gjerde, vd, 2008; Müller, 2014) firmaların konsolide muhasebe verilerinin piyasa değer ilişkisi yaklaşımı ile analiz edilmiştir. Bu yaklaşım doğrultusunda, bu çalışmada firma performans göstergesi olarak hisse senetlerinin piyasa değeri esas alınmış olup, aynı dönemde aynı firmalara ait bireysel ve konsolide finansal tablolardan elde edilen karlılık ve öz kaynak göstergeleri ile firma hisse senedi fiyatları arasındaki ilişki analiz edilmiştir.

$\mathrm{Bu}$ çalışmada, 2013 yılında yapılan yasal düzenlemeyle hem bireysel hem de konsolide finansal tablo düzenlemek zorunda olan BİST’te işlem gören 20 gayrimenkul yatırım ortaklığına ait hem bireysel hem de konsolide finansal tablolardan elde edilen veriler analize tabi tutulmuştur. BİST’te işlem gören toplam $31 \mathrm{GYO}$ olmakla birlikte, 11 GYO iştirak ve bağlı ortaklığa sahip olmadığı için (sadece konsolide olmayan (bireysel) finansal tablolara sahip oldukları için), konsolide ve bireysel finansal tabloların etkisinin karşılaştırılması mümkün olmadığından çalışmaya dahil edilmemiştir. Hisse senedi piyasa değeri “ortalama değer” olarak belirlenmiştir. Ortalama hisse senedi fiyatı, finansal tabloların yayınlandığ 1 tarihi takip eden bir aylık hisse senedi günlük kapanış fiyatı ortalaması olarak hesaplanmıştır. Herhangi bir tarihteki kapanış fiyatını kullanmak yerine, zamanın bazı periyodundaki kapanış fiyatlarını kullanmak, fiyatlarda meydana gelen günlük dalgalanmaları ortadan kaldırmaktadır. Çünkü belli bir tarihteki hisse senedi fiyatını dikkate almak, günlük dalgalanmaları bertaraf etmekte ve sağlıklı analizler yapılmasını engellemektedir (Müller, 2014).

Konsolide finansal tabloların bu çalışmada firma performans göstergesi olarak alınan hisse senedi fiyatı üzerine etkisini analiz etmek için, Ohlson (1995) tarafından geliştirilen ekonometrik değerleme modelleri 
kullanılmıştır. Bu modeller finansal tablolardan elde edilen finansal bilgi (öz kaynak ve net kar) ile hisse senedi arasındaki ilişkiyi ölçmektedir. Öz kaynak ve karın hisse senedine etkisini test etmek için birçok araştırmada temel alınan ve bu çalışmada da esas alınan Ohlson (1995) tarafından geliştirilen değerlendirme modelleri (varyans karmaşasını azaltmak için öz kaynak ve kar rakamlarının hisse başına değerleri kullanılmıştır. Suadiye, 2012):

Model 1: $\quad$ Pit $=\alpha 0+\alpha 1 * \mathrm{pBVit}+\alpha 2 * \mathrm{pEit}+\varepsilon$ it

Model 2: $\quad$ Pit $=\alpha 0+\alpha 1 * \mathrm{cBVit}+\alpha 2 * \mathrm{cEit}+\varepsilon i t$

$\mathrm{pBVit}=$ Ana firma öz kaynak $/ \mathrm{t}$ yılındaki i firmasının hisse senedi

$\mathrm{pEit}=$ Ana firma net $\mathrm{kar} / \mathrm{t}$ yılındaki i firmasının hisse senedi

$\mathrm{cBVit}=$ Grup öz kaynak / t yılındaki i firmasının hisse senedi

cEit $=$ Grup net kar $/ \mathrm{t}$ yılındaki i firmasının hisse senedi

\section{Araştırma Sonuçları}

Konsolide finansal tabloların firma performansı üzerine etkisini analiz edebilmek için performans göstergesi olarak firma hisse senedi fiyatı (piyasa değeri) esas alınarak yukarıda açıklanan iki regresyon modeli oluşturulmuştur olup, örnek olarak seçilen birer finansal kurum olan gayrimenkul yatırım ortaklıklarının hisse senedi fiyatı ile bu kurumların finansal tablolarında açıklanan hisse başı öz kaynak ve net kar arasındaki ilişki doğrusal regresyon ile analiz edilmiştir. Öncelikle, GYO konsolide finansal tablolardan elde edilen hisse başı öz kaynak ve hisse başına net karın hisse senedi fiyatı ile ilişkisi (2 no'lu model) doğrusal regresyon ile analiz edilmiş olup regresyon sonuçları Tablo1'de sunulmuştur.

\begin{tabular}{|c|c|c|c|c|c|c|}
\hline Örnek & & Model & Pit $=\alpha$ & $1 * \mathrm{cBVi}$ & $2 * \mathrm{cEit}$ & \\
\hline & & $\alpha 0$ & cBV & $\mathrm{cE}$ & $\mathrm{F}$ & Adj. $R^{2}$ \\
\hline UFRS & Alfa & 0,969 & 0,605 & $-0,077$ & \multirow{3}{*}{12,774} & \multirow{3}{*}{0,553} \\
\hline \multirow[t]{2}{*}{$\mathrm{n}=20$} & $\mathrm{t}$ & 1,060 & 3,016 & $-0,097$ & & \\
\hline & VIF & - & 2,961 & 2,961 & & \\
\hline
\end{tabular}

Tablo1: Firmaların konsolide finansal tablo verilerinin Regresyon Analizi Sonuçlart

GYO ların grup (konsolide) finansal tablolarında açıklanan verilerden oluşturulan bağımsız değişkenler ile hisse senedi fiyatı arasındaki ilişki düzeyini gösteren analiz sonuçları (Model 2'deki düzeltilmiş $\mathrm{R}^{2}$ ), grup finansal tablolarında açıklanan hisse başı öz kaynak ve net kar'ın firmaların hisse senedi fiyatını açıklama düzeyinin \%55,3 olduğunu göstermektedir.

Önceki çalışmalar dikkate alınarak, her bir açıklayıcı değişkenin her bir katsayısı için Varyans Enflasyon Faktörü (VIF değeri) hesaplanmıştır. VIF değerlerinin 5 'ten büyük olması (Jermakowicz, vd, 2007) açıklayıcı (bağımsız) değişkenler arasında oto korelasyon olduğunu göstermektedir. Bu çalışmada 2,961 olarak bulunan VIF değeri bağımsız değişkenler arasında oto korelasyon olmadığına işaret etmektedir.

Ana firma (konsolide olmayan, bireysel, solo) finansal tablolarından elde edilen finansal bilgilerin (hisse başı öz kaynak ve net kar) hisse senedi fiyatı ile ilişkisi (Model 1) de doğrusal regresyon ile analiz edilmiş olup regresyon sonuçları Tablo 2 de sunulmuştur.

\begin{tabular}{|c|c|c|c|c|c|c|}
\hline Örnek & & \multicolumn{5}{|c|}{ Model 1: $\quad$ Pit $=\alpha 0+\alpha 1 * p B V i t+\alpha 2 * p$ Eit + cit } \\
\hline & & $\alpha 0$ & pBV & $\mathrm{pE}$ & $\mathrm{F}$ & Adj. $\mathrm{R}^{2}$ \\
\hline UFRS & Alfa & 1,014 & 0,634 & $-0,142$ & \multirow{3}{*}{14,432} & \multirow{3}{*}{0,586} \\
\hline $\mathrm{n}=20$ & $\mathrm{t}$ & 1,142 & 3,123 & $-0,178$ & & \\
\hline & VIF & - & 3,259 & 3,259 & & \\
\hline
\end{tabular}

Tablo2: Firmaların bireysel finansal tablo verilerinin Regresyon Analizi Sonuçları

$\mathrm{Bu}$ çalışmada örnek olarak seçilen GYO ların konsolide olmayan (bireysel) finansal tablolardan elde edilen finansal verileri (hisse başı öz kaynak ve net kar) ile hisse senedi fiyatı arasındaki ilişkiyi gösteren Tablo 2'deki analiz sonuçları, bağımsız değişkenlerin hisse senedi fiyatını \%58,6 açıkladığı görülmektedir. Ayrıca VIF değerlerinin 5'den küçük olması (3,259) açıklayıcı değişkenler arasında oto korelasyon olmadığını göstermektedir.

\section{4 Özet ve Sonuç}

Türkiye'de, Sermaye piyasası kuruluna kayıtlı halka açık firmalar 2005 yılına kadar ulusal mevzuatlara göre bireysel (konsolide olmayan) finansal tablo hazırlayıp finansal tablo kullanıcılarına açıklarken, yasal düzenlemelerle bu firmalara 2005 sonrası UFRS ile uyumlu Türkiye Muhasebe standartlarına göre konsolide 
finansal tabloları hazırlayıp açıklama zorunluluğu getirilmiştir. Günümüzde, BİS’te işlem gören firmalar yalnızca konsolide finansal tablolar düzenleyerek halka açıklamaktadır. Bu uygulamanın bir istisnası GYO olup, Türkiye'de faaliyet gösteren GYO lar hem bireysel hem de konsolide finansal tablo hazırlamak zorundadır. Her ne kadar konsolide finansal raporlamaya geçişin firma performansı üzerine etkisinin olumlu yönde olabileceğine yönelik literatürdeki teorik tartışma mevcut ise de, konsolide finansal raporlamaya geçişin firma performansı üzerine etkisinin hem olumlu hem de olumsuz olduğunu gösteren uygulamalı araştırma sonuçları mevcuttur. Literatürdeki bu tartışmaya katkı sağlayacağı düşüncesi ile Türkiye'de faaliyet gösteren finansal kuruluş esas alınarak, konsolide finansal tabloların firma performansı üzerine etkisi analiz edilmiştir.

Konsolide finansal tabloların finansal kuruluşların performansı üzerine etkisini araştırmak için borsada işlem gören GYO ile yapılan bu çalışmada, firma performans göstergesi olarak hisse senetlerinin piyasa değeri esas alınmış olup, aynı dönemde aynı firmalara ait bireysel ve konsolide finansal tablolardan elde edilen karlılık ve öz kaynak göstergeleri ile firma hisse senedi fiyatları arasındaki ilişki oluşturulan iki regresyon modeli ile analiz edilmiştir.

Analiz sonuçları, bireysel (konsolide olmayan) finansal tablolardaki hisse başı öz kaynak ve net karın bu çalışmada firma performans göstergesi olarak kullanılan hisse senedi fiyatını açıklama düzeyinin (düzeltilmiş $\mathrm{R}$ kare) \%58,6 iken, konsolide (grup) finansal tablolardaki hisse başı öz kaynak ve net kar'ın firmaların hisse senedi fiyatını açıklama düzeyinin \%55,3 olduğunu göstermektedir. Her ne kadar iki modeldeki düzeltilmiş $\mathrm{R}$ kareler birbirine yakın ise de, bireysel finansal tablolardan elde edilen verilerin hisse senedi fiyatını açıklama gücünün konsolide finansal tablolardan elde edilen verilerin açıklama gücünden yaklaşı \%3 fazla olması dikkate çekmektedir. Her ne kadar, sınırlı sayıda finansal kuruluşa ait sabit dönem verilerinden hareketle bireysel finansal tabloların firma performansına etkisinin konsolide finansal tabloların performansa etkisinden fazla olduğunu genellemek mümkün olmasa da, bu çalışmanın kısıtları çerçevesinde araştırma sonucu konsolide finansal tabloların firma performansı üzerine pozitif etkisinin olduğunu gösterir done sunmamaktadır.

Mükemmel hiçbir çalışma yoktur ve bu çalışmada bir istisna değildir. Bu çalışmanın en önemli kısıtı, örnek sayısının sınırlı olmasıdır. Bu kısıtın temel nedeni ise, bu çalışmada aynı dönemde hem bireysel hem de konsolide finansal tablo açıklayan firmalar örnek olarak alınmış olup, Türkiye'de sadece bu koşulda finansal tablo açıklayan ve sayısı sınırlı olan GYO olmasıdır. Bu bağlamda çalışma sonucu, hem anılan örneklem sayısının kısıtı hem de araştırma örnekleminin finansal kuruluş olma özelliği dikkate alınarak değerlendirilmelidir. GYO bir finansal kuruluş olup özel konumları ve farklı muhasebe sistemleri nedeniyle finansal kuruluşlar benzer nitelikteki birçok çalışmada kapsam dışı tutulmuştur. Benzer çalışmalardan farklı olarak, bu çalışmada ise sadece finansal kuruluşlar baz alınmıştır.

\section{Kaynakça}

- Agostino, Mariarosaria, Danilo, Drago, Damiano, B., Silipo, 2011. "The value relevance of IFRS in the European banking industry", Rev Quant Finan Acc, 36, p. 437-457.

- Armstrong, Christopher S., Mary E. Barth, Alan D. Jagolinzer, Edward J. Riedl, 2010. "Market Reaction to the Adoption of IFRS in Europe", The Accounting Review, p. 1-52.

- Callao, Susana, José, I., Jarne, José, A., Laínez, 2007. "Adoption of IFRS in Spain: Effect on the comparability and relevance of financial reporting", Journal of International Accounting, Auditing and Taxation, 16, p. 148-178.

- Capkun, Vedran, Anne, Cazavan-Jeny, Thomas, Jeanjean, Weiss, Lawrence A., 2008. "Earnings Management and Value Relevance during the Mandatory Transition from Local GAAPs to IFRS in Europe", p. 1-63.

- Clarkson, Peter, J. Douglas, Hanna, Gordon, D., Richardson, Rex, Thompson, 2011. "The impact of IFRS adoption on the value relevance of book value and earnings", Journal of Contemporary Accounting \& Economics, 7, p. 1-17.

- Çürük, Turgut, 2001. An Analysis of Factors Influencing Accounting Disclosure in Turkey. İstanbul Menkul Kıymetler Borsası Yayınları, İstanbul.

- Devalle, Alain, Enrico, Onali, Riccrdo Magarini, 2010. "Assessing the Value Relevance of Accounting Data After the Introduction of IFRS in Europe", Journal of International Financial Management and Accounting, 21:2, p. 85-119.

- Gjerde, Øystein, Kjell, Knivsflå, Frode, Sættem, 2008. “The value-relevance of adopting IFRS: Evidence from 145 NGAAP restatements”, Journal of International Accounting, Auditing and Taxation, 17, p. 92-112.

- Jermakowicz, Eva K., 2004. "Effects of Adoption of International Financial reporting Standards in Belgium: The Evidence from BEL-20 Companies”, Accounting in Europe, 1, p. 51-70. 
- Jermakowicz, E. K., Prather-Kinsey, J. and Wulf, I., 2007. "The Value Relevance of Accounting Income Reported by DAX-30 German Companies”, Journal of International Financial Management \& Accounting, 18, p. 179.

- Karğın, Sibel, 2013. "The impact of IFRS on the Value Relevance of Accounting Information: Evidence from Turkish Firms", International Journal of Economics and Finance, 5, p. 71-80.

- Kayalıdere, Koray, 2013. "Hisse Senedi Piyasasında Muhasebe Bilgilerinin Rolü: İMKB- Mali Sektör Üzerine Bir Uygulama”, İşletme Araştırmaları Dergisi, 5, p. 130-151.

- Müller, Victor-Octavian, 2014. "The impact of IFRS adoption on the quality of consolidated financial reporting”, Procedia- Social and Behavioral Sciences, 109, p. 976-982.

- Ohlson, James, A., 1995. "Earnings, book Values, and Dividentds in Equity Valuation", Contemporary Accounting Research, 11, p. 661-687.

- Paananen, Mari ve Henghsiu, Lin, 2008. “The Development of Accounting Quality of IAs and IFRS Over Time: The Case of Germany", Working Paper.

- Paglietti, Paola, 2009. “Earnings management, timely loss recognition and value relevance in Europe following the IFRS mandatory adoption: evidence from Italian listed companies”, Economia Aziendale, 4, p. 97-117.

- $\quad$ Suadiye, Gulhan, 2012. "Value Relevance of Book Value \& Earnings Under the Local GAAP and IFRS: Evidence from Turkey", Ege Academic Review, 12, p. 301-310.

- Türel, Ahmet, 2009. "The Value Relevance of IFRS: The Case of Turkey”, Acta Universitatis Danubius Oeconomica, 5(1), p. 119-128.

- Sermaye Piyasası Kurulu, 2015. Mevzuat (Sermaye Piyasaında Finansal Raporlamaya İlşkin Esaslar Tebliği), http://www.spk.gov.tr/apps/Mevzuat/?submenuheader=-1 (Erişim Tarihi: 15.06.2015) 


\title{
Mali Kurallar, Yaratıcı Muhasebe ve Mali Saydamlık: Geçiş Ekonomileri Üzerine Bir Değerlendirme \\ Fiscal Rules, Creative Accounting and Fiscal Transparency: An Evaluation on the Transition Economies
}

\author{
Assoc. Prof. Dr. İlter Ünlükaplan (Çukurova University, Turkey) \\ Asst. Prof. Dr. Volkan Yurdadoğ (Çukurova University, Turkey) \\ Ph. D. Candidate Ebru Canıkalp (Çukurova University, Turkey)
}

\begin{abstract}
An anonymous idea is observed in the public finance literature that includes where fiscal rules, i.e numerical rules on the fiscal indicators, are strict and stringent, policy executives will have incentives to recourse to creative accounting implementations to overcome these numerical limits. Creative accounting is applied for demonstrating economic, especially fiscal indicators better than the originals to reach the necessary fiscal limit, even if they are primarily conducted by private firms.

Many countries applied these illusory implementations to hide their reported budget deficits especially in the last global crisis period. With this manner, creative accounting violates the basic principles of governance in public finance. In this context, governments should have to establish statistical classification structure and government accounting system that aims to prevent creative accounting. With this dimension, fiscal transparency will prevent from creative accounting implementations.

In this study, the relationship between fiscal rules and creative accounting on the public finance administration level will be determined and fiscal transparency suggestions that prevent these frauds in the economies will be evaluated. As a result, the practice of good governance in public finance should be implemented to provide financial transparency. In addition, the reforms about transparency in the legislation should be consider as an important proposal.
\end{abstract}

\section{Giriş}

1970’lerin ortalarından 1990'ların ortalarına kadar geçen süre içinde birçok ülkede gözlemlenen yüksek bütçe açıklarının nedenlerini açıklamada ve sözkonusu bütçe açıklarının kapatılmasında geleneksel ekonomik modeller ve politika önerileri yetersiz kalmıştır. Aynı dönemlerde yine birçok ülkede gözlemlenen "yönetebilirlik krizi" ve yukarıda bahsedilmiş olan açı yanlı politikalar kamu politikalarına alternatif yaklaşımlara olan ihtiyacı da beraberinde getirmiştir. Geleneksel politika reçeteleri olan aktif Keynesgil politikalar yerine ekonominin yapısında bir takım kurumsal değişiklikleri içeren "yönetişim" kavramı aktif politika uygulamalarına bir alternatif olarak gündeme gelmiştir. Temel ilkeleri saydamlık başta olmak üzere katılımcılık, hukukun üstünlügüu, çabuk cevap verebilirlik, eşitlik, etkinlik, hesap verebilirlik ve stratejik vizyon, yerindenlik, yerellik, toplam kalite, toplumu güçlendirme olan yönetişim, kamu mali yönetiminde geniş ölçüde uygulama alanı bulmaktadır. $\mathrm{Bu}$ ilkelerin özellikle saydamlık ilkesiyle çelişen yaratıcı muhasebe, mali tabloların gerçekte olduklarından, muhtemel kuralların bir bölümü ya da tamamını firma ortaklarına avantaj sağlayacak ya da söz konusu bu kuralları geçersiz kılacak bir şekle dönüşümüdür (Nasser, 1993)

Milesi-Ferretti (2003), mali kuralların etkilerini hükümetlerin kamu maliyesine ilişkin veri ve süreçleri doğru olarak raporlamama imkanlarına sahip olduğu kuramsal bir çerçevede incelemiştir. Çalışmada, ilgili mali kuralı ihlal etmenin bedeli veriyken kuraldan kaynaklanan mali uyarlamanın büyüklüğü bütçenin saydamlığı ile ilişkilendirilmiştir. Beetsma and Jensen (2003), yürütmüş oldukları kuramsal analizde mali birliklerde "ahlaki tehlike" niteliğindeki işlemlerin bütçeleme sürecinde şeffaflığın olmamasından kaynaklandığını ve bu politik bozulmaların mali disiplini zayıflattığını belirtmiştir. Von Hagen ve Wolff (2006), kamu borç stokunun birikimi ile bütçe açığının finansmanına ilişkin işlemler arasındaki ilişkileri incelemiştir. Çalışmada, analize konu olan ülkelerde borç stokundaki artışın bütçe açığından daha yüksek olduğunu belirten yazarlar yaratıcı muhasebe uygulamalarının mali kuralların sıkı ve bağlayıcı olmasıyla artacağını belirtmiştir.

Mali saydamlık özellikle Meksika ve Asya krizleri sonrası gerek akademik yazında gerekse de uluslararası kuruluşların söylem ve eylem planlarında hızla yer almaya başlamıştır. IMF'nin "Codes of Good Practices on Fiscal Transparency" (IMF, 1998) ve OECD'nin “Best Practices for Budget Transparency” (OECD, 2000) adl1 yayınları mali saydamlığın eksikliğinin yukarıda bahsedilen krizlerin oluşumunda etkili faktörlerden biri olduğunu vurgulamıştır. Bu kuruluşlar tarafından önemi vurgulanan ve geçiş ekonomileri de dahil olmak üzere birçok ülkeye tavsiye edilen yüksek ölçüde mali saydamlık, iyi yönetişim ve mali sürdürülebilirlik için bir ön şart niteliğindedir (Jarmuzek, vd, 2006). 
$\mathrm{Bu}$ çalışma yukarıda, yaratıcı muhasebe ve mali saydamlık arasında vurgulanmış olan ilişskileri geçiş ekonomileri açısından değerlendirmeyi amaçlamaktadır. Çalışmanın ilk bölümünde hükümetlerin kamu maliyesine ilişkin istatistiklerini, özellikle de bütçe açıklarını olduğundan daha iyi yansıtma amacıyla yaratıcı muhasebeyi gerçekleştirme yolu olarak stok akım uyarlamaları üzerinde durulacaktır. Sonraki bölümde mali saydamlığın farklı göstergeleri ve kavramın kamu mali yönetimi açısından önemi üzerinde durulacaktır. Sonraki aşamada ise regresyon analizi çerçevesinde geçiş ekonomileri açısından stok akım uyarlamaları ile mali saydamlık göstergelerinden açık bütçe endeksi arasındaki ilişki araştırılacaktır. Son bölüm sonuç, değerlendirme ve önerileri içermektedir.

\section{Mali Kurallar ve Yaratıcı Muhasebe: Hükümetler Bütçe Açıklarını Gizleyebilir mi?}

Son 30 yıl içerisinde birçok ülkede borç stokundaki değişme ve bütçe açıkları arasındaki fark yükselmiş ve sürekli bir nitelik kazanmıştır. Stok-akım uyarlaması olarak tanımlanan bu fark, mali saydamlığı zedeleyen önemli bir faktör olarak literatürde yer almaktadır. Kamu mali yönetiminin şeffaf olması, hükümetlerin yaratıc1 muhasebeye gitme eğilimlerinin, dolayısıyla stok-akım uyarlamalarının değerinin düşüklüğüne işaret etmektedir.

\subsection{Stok-Akım Uyarlamaları}

Stok-akım uyarlamaları gayrı safi borç stokundaki değişim ile bütçe açı̆̆ı arasındaki farka karşılık gelir. Stokakım uyarlamalarının tanımı aşağıda yer alan temel borç birikimi denkliğinden elde edilebilir (Weber, 2012):

$\frac{\text { Debt }_{t}-\text { Debt }_{t-1}}{N G D P_{t}}=\frac{\text { Deficit }_{t}}{N G D P_{t}}+\frac{S F_{t}}{N G D P_{t}}$

Yukarıdaki denklikte Debt, borç stokunu, Deficit, bütçe açı̆̆ını, GDP, Gayrısafi yurtiçi hasılayı, SF ise stokakım uyarlamalarını göstermektedir. Pozitif stok-akım uyarlamaları, t ve t-1 dönemleri arasında kamu borçlanmasındaki artışın $\mathrm{t}$ dönemindeki bütçe açığından daha yüksek olduğunu göstermektedir. Negatif stokakım uyarlamaları ise kamu borçlanmasındaki artışın bütçe açığından daha düşük olduğuna işaret eder (Ünlükaplan ve Arısoy, 2010).

Stok-akım uyarlamalarının bileşenleri, Eurostat (2015)’’n sınıflandırmasında

a. Finansal varlıkların net edinimi, b. Uyarlamalar ve, c. İstatistiksel uyuşmazlıklar olmak üzere üç ana grupta toplulaştırılmıştır. Tablo 1, bu tanıma göre yapılmış sınıflandırmadaki alt kalemleri göstermektedir.

\begin{tabular}{|c|c|}
\hline Finansal varlıkların net edinimi & $\begin{array}{l}\text {-Dolaşımdaki para ve mevduat } \\
\text {-Borçlanma senetleri } \\
\text {-Kısa ve uzun vadeli borçlar } \\
\text {-Özsermaye ve yatırım fonu payları (portföy } \\
\text { yatırımları dahil) } \\
\text {-Türev finansal araçlar } \\
\text {-Diğer alacak hesapları } \\
\text {-Diğer finansal varlıklar }\end{array}$ \\
\hline Uyarlamalar & $\begin{array}{l}\text {-Ulusal paranın değer kayıp ya da artışları } \\
\text {-Döviz cinsinden borcun değer kaybı/değer } \\
\text { artışı } \\
\text {-Başa başın altı/üstü ihraç } \\
\text {-Başa başın altı/üstü borç ödeme } \\
\text {-İstatistiksel sınıflandırma değişikliklerinden } \\
\text { kaynaklanan farklar }\end{array}$ \\
\hline İstatistiksel uyuşmazlıklar & $\begin{array}{l}\text {-Sermaye hesapları ve finansal hesaplar } \\
\text { arasındaki farklar. } \\
\text {-Diğer istatistiksel uyuşmazlıklar }\end{array}$ \\
\hline
\end{tabular}

Tablo 1. Stok-Akım Uyarlamalarının Bileşenleri Kaynak. Eurostat (2015)

Yukarıda belirtilen işlemler stok akım uyarlamalarının kalıntı değer olarak hesaplandığına işaret etmektedir. Avrupa Komisyonu (European Commision, 2003) ise bu noktada stok akım uyarlamalarının dövize endeksli kamu borçlarının döviz kurundaki dalgalanmalar nedeniyle artıp azalması, nakit esaslı ve tahakkuk esaslı bütçeleme, özelleştirme ve finansal varlıkların alım satımı gibi farklı nedenlerle yükseldiğine işaret etmektedir. Devlet muhasebesine ilişkin sorunlar stok akım uyarlamalarının artışına neden olurken yüksek ve sürekli stok akım uyarlamaları devlet bütçesi ile ilgili yaratıcı muhasebe kayıtlarının artışına, diğer bir ifade ile bu değişkenlerin stratejik politika aracı olarak kullanılmasına bağlanmaktadır. 


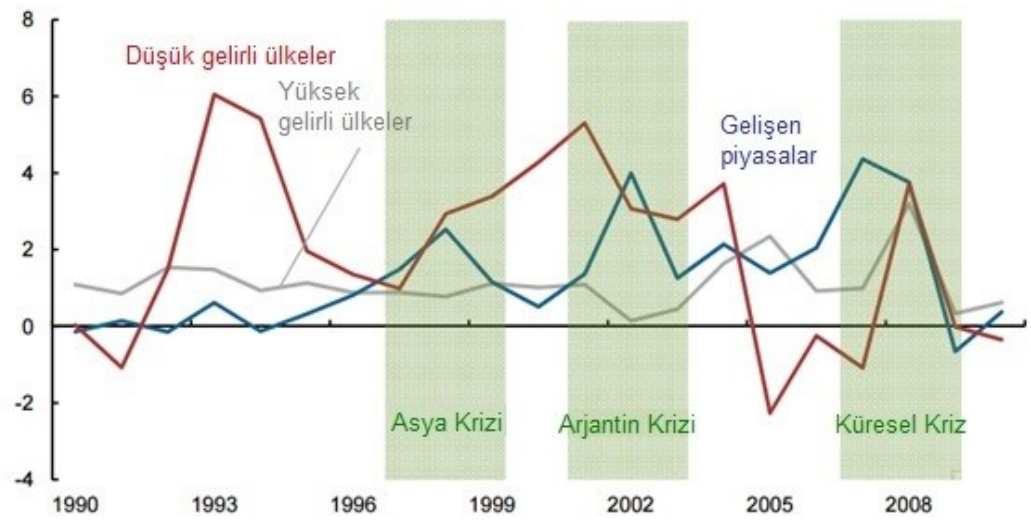

Şekil 1. Stok Akım Uyarlamaları (\% GSYIH) Kaynak. IMF World Economic Outlook (WEO), Aktaran: Weber (2012)

Weber (2012), IMF'nin World Economic Outlook (WEO) veritabanının 1980-2010 verilerinden hareketle, stok akım uyarlamalarının ortalama değerinin, yüksek değerlerin düşük gelirli ülkelere ait olmak üzere, gelişmiş ve gelişen piyasaların olduğu ekonomilerde pozitif değerlere sahip olduğunu belirtmiştir. Şekil 1'den de görüleceği üzere stok-akım uyarlamalarının ağırlıklandırılmış ortalamaları dikkate alındığında ise ciddi yükseliş ve zirvelerin kriz dönemlerine denk geldiği anlaşılmaktadır. Her üç ülke grubu için de, örneğin, 2008 Küresel Krizi döneminde stok akım uyarlamalarının ortalama değerlerinde ciddi yükseliş gözlemlenmiştir. Gelişmiş ekonomilerde bu yükselişin nedeni kriz döneminde finansal piyasalara ve bankalara verilen desteklerdir. Çalışmamız açısından bu yükselişteki diğer önemli bir faktör ise bu yükselişlerin kamu mali yönetimlerince rapor edilen bütçe açıklarını gizleme eğilimlerdir. Ayrıca düşük gelirli ülkelerde stok-akım uyarlamalarındaki oynaklık diğer ülke gruplarına göre çok daha yüksektir. Düşük gelirli ülkelerdeki stok-akım uyarlamalarının GSYİH içindeki payı -\%108,6'dan \%168,5'e kadar değişmektedir. Bu değerler düşük gelirli ülkelerin yoğun şekilde kısmen ve tamamen borç silinmesiyle karşılaştıklarını belirtmektedir (Negatif stok-akım uyarlamaları). Yine döviz kurundaki devalüasyonlar da bu ülkelerin yabancı döviz cinsinden dış borçlarının fazlalığı nedeniyle pozitif stok-akım uyarlamalarına neden olmaktadır.

\section{Hükümetlerin Yaratıcı Muhasebe Uygulamalarına Bir Önlem Olarak Mali Saydamlık}

Mali saydamlık, devletin fonksiyonları, yapısı, maliye politikası amaçları, kamu sektörü hesapları ve mali tahminler konusunda kamunun açıklığıdır (Kopits ve Craig, 1998). Kamunun bu anlamdaki açıklığı maliye politikasının oluşturulması ve uygulanmasında politika uygulayıcıların hesap verebilir olması durumunda oldukça önem kazanmaktadır. Mali saydamlık bu çerçevede daha faydalı, itibarlı maliye politikalarını, belirsizliğin daha az olduğu politik çevreyi, ortaya çıkması muhtemel ekonomik problemler karşısında maliye politikası tepkilerinin düzgün ve erken olmasını ve nihai olarak yükselen ekonomik performansı beraberinde getirecektir (Jarmuzek, vd, 2006).

Literatürde mali kurallar, yaratıcı muhasebe ve mali saydamlık arasındaki ilişkileri araştıran çalışmalarda Alesina ve Perotti'nin (1996) "bütçeyle ilgili kurumlar" tanımının oldukça baskın olduğu görülmektedir. Bu tanıma göre bütçeyle ilgili kurumlar, bütçenin tasarlanması, onaylanması ve uygulanması aşamalarına aşamalarında hakim olan tüm kural ve düzenlemelerdir. Söz konusu bu kural ve düzenlemeler bütçenin saydamlığı ile ilgili kuralları da içermektedir. Von Hagen (1992) ve Von Hagen ve Harden (1994), bütçe sürecindeki merkezileşmeyi ölçen bir endeks geliştirmiş ve merkezileşmiş bir bütçe sürecinin kamu maliyesinin performansını yükselteceğini öngörmüştür. Yazarlar bu amaçla Avrupa Birliği ülkeleri için bütçe prosedürlerinin yapısını ortaya koyan farklı endeksler oluşturmuştur. Bütçe prosedürlerinde bütçenin hazırlanması, yasama aşaması, yasama-yürütme ilişkisi, uygulama aşaması, bütçenin saydamlık derecesi, sayısal hedeflerin ve çok yıllı bütçelemenin varlığına ilişkin bilgileri derleyen yazarlar, bütçe düzenlemelerinin Avrupa Birliği ülkeleri arasında önemli ölçüde farklılaştığını ve bu durumun yine bu ülkelerde kamu borç stoku / GSYİH rakamlarının farklılaşmasıyla kuramsal olarak örtüştüğünü vurgulamıştır. Gelişmekte olan ülkelerde bütçeyle ilgili kurumların kalitesini ölçmek için ilk çalışma ise Alesina vd. (1999) tarafından gerçekleştirilmiştir. Bu çalışmada, 20 Latin Amerika ülkesindeki bütçeyle ilgili kurumlar için bir veritabanı oluşturmuş ve bu ülkelerin mali performanslarındaki farklılıklarını bütçenin formülasyonu, onaylanması ve uygulanması sürecindeki prosedürlere odaklanarak açıklamaya çalışmıştır. Yazarlar, analizlerinde bütçe sürecindeki saydam prosedürlerin mali disiplini yükselttiği sonucuna ulaşmıştır. Analiz sonuçları 1980 ve 1990’lı yılların başında Latin Amerika ülkelerinde bütçe prosedürlerinin mali çıktıları güçlü bir şekilde etkilediğini, özellikle hiyerarşik yaklaşımın ve saydam kuralların daha disiplinli bir kamu maliyesine katkı sağladığını ortaya koymuştur (Ünlükaplan, 2011). 


\subsection{Mali Saydamlığın Temel İlkeleri ve Uluslararası Mali Saydamlık Standartları}

Hemming ve Kell (2001), mali saydamlığın ilkelerini dört ana başlık altında toplamaktadır:

a. Rol ve sorumlulukların açıkça belirtilmesi: Merkezi yönetim, kamu sektörünün geri kalan kısmından açık ve net bir şekilde ayrı olup politika ve yönetime ilişkin roller belirgin ve kamusal olarak açık olmalıdır.

b. Bilgilerin kamusal bulunabilirliği: Hükümet, geçmiş, cari dönem ve tahmin edilen mali faaliyetlere ilişkin bilgileri eksiksiz bir şekilde kamuya sunmalıdır. Kamu maliyesine ilişkin bilgilerin zamanında yayınlanması için bir taahhüt verilmelidir.

c. Açık bütçenin hazırlanması, uygulanması ve raporlanması: Bütçeye ilişkin dokümantasyonun maliye politikasına ilişkin hedefleri, bütçe için politika temelini ve tanımlanabilir başlıca riskleri belirlemesi gerekmektedir. Bütçeye ilişkin bilgiler politika analizini kolaylaştıracak ve hesap verebilirliği destekleyecek şekilde sunulmalıdır. Ayrıca, onaylanmış harcamaların yürütülmesi ve denetlenmesine ve kamu gelirlerinin toplanmasına ilişkin prosedürler açıkça belirtilmelidir. Kamu maliyesine ilişkin mali raporlar yasama organına ve kamuya düzenli olarak sunulmalıdır.

d. Bütünlüğün temin edilmesi: Kamu maliyesine ilişkin veriler veri kalitesi standartlarını sağlamalıdır. Mali bilgiler bağımsız incelemeye tabi olmalıdır.

Yukarıda bahsedilen ilkeleri gerçekleştirmek amacıyla çok sayıda uluslararası mali saydamlık standart ve rehberleri geliştirilmiştir. Aşağıda bu standart ve rehberlerden başlıcaları yer almaktadır (Granickas, 2013):

a. IMF tarafindan geliştirilen "Code of Good Practices on Fiscal Transparency", "Manual on Fiscal Transparency" ve "Guide on Resource Revenue Transparency".

IMF, “Code of Good Practices on Fiscal Transparency” çerçevesinde hükümetlerin kamu sektörünün ve kamu maliyesinin yapısını açık bir şekilde ortaya koymaları için uygulanacak ilke ve uygulamaları belirlemelerine yardımcı olmayı amaçlarken "Manual on Fiscal Transparency" ile bu bahsedilen ilke ve uygulamaların uygulanmasına rehberlik etmektedir. Daha detaylı bir şekilde ilke ve uygulamaları içeren rehber, üye ülkelerin deneyimlerine yer vermekle birlikte uygulamaya yönelik yaklaşımları da içermektedir. "Guide on Resource Revenue Transparency" ile belirli kamu gelirlerinde şeffaflığı hedefleyen IMF, gelirleri ağırlıklı olarak petrol ya da mineral kaynaklardan gelen ülkeler üzerinde durmuştur.

b. OECD tarafindan geliştirilen "Best Practice Guidelines on Budget Transparency".

OECD tarafından oluşturulmuş olan hem üye hem de üye olmayan ülkelerde bütçenin saydamlığını arttırmayı amaçlayan "Best Practice Guidelines on Budget Transparency", hükümetlerin oluşturması gereken temel bütçe raporlarını ve bu raporların içeriklerini kapsar.

c. IBP tarafindan oluşturulan "International Budget Partnership's Open Budget Index"

Çalışmamızın uygulama aşamasında yararlandığımız bu endeks, ülkelerin bütçe saydamlığının, bütçeye katılımın ve bütçe gözetiminin durumunu ölçmeye çalışmaktadır. İlgili ülkelerdeki bağımsız araştırmacılar tarafindan yürütülen ve 125 soruyu içeren bu anketin 95 sorusu doğrudan doğruya hükümetlerin bütçe sürecinin farklı noktalarında bütçeyle ilgili yayınlamaları gereken temel belgelerin kamusal bulunabilirliği ve kapsayıcılı̆̆ ile ilgilidir. Kalan 30 soru ise bütçeleme sürecine kamusal katılımdan bütçenin oluşturulması ve gözetiminde yasama ve sayıştayın rolüne kadar farklı soruları içermektedir.

\section{d. GIFT - "Global Initiative for Fiscal Transparency: High Level Principles on Fiscal Transparency"}

Maliye politikası oluşturma ve uygulama sürecinde politika yapıcılara ve diğer paydaşlara mali saydamlık, katılım ve hesap verebilirliği arttırmaya yönelik çabalarını arttıracak şekilde rehberlik amaçlayan GIFT, mali saydamlık için varolan standart ve normların kapsayıcılığının, tutarlılığının ve uygunluğunun iyileştirilmesini desteklemektedir.

e. BTAP - "Global Initiative for Budget Transparency Declaration"

BTAP, 60'tan fazla ülkede 130'u aşan sivil toplum kuruluşundan derlenen verilerle yerel, ulusal ve uluslararası düzeyde kamu maliyesi ve bütçenin hesap verebilirliği sorununa eğilmektedir. Oluşumun kurulma deklarasyonunda geniş kapsamlı paydaşlar tarafından yönetilen, saydam bütçelerin oluşturulması amacıyla temel mali saydamlık ilkeleri önerilmektedir.

f. The Sunlight Foundation - "Procurement Open Data Guidelines"

Sunlight Foundation, hükümetlerin politika yürütme sürecinde yayınlayacakları verileri şekillendirmeleri konusunda ilke kümesi oluşturmuştur. Yerel, ulusal ve uluslararası ölçekte olmak üzere her aşamada uygulanabilecek olan bu ilkeler ideal veri oluşturma sürecine ilişkin ana hatları belirlemektedir.

g. International Budget Partnership - "A Government Guide to Developing Citizens Budgets"

Yine IBP kapsamında olan bu rehber, hükümetlerin kamu maliyesine ilişkin sistemlerinin daha saydam olması için uygulamaya yönelik ilkeleri kapsamaktadır. Vatandaşların mali bilgilere ulaşmasına ilişkin haklarına ve ayrıca bu bilgilerin anlaşılması ve takdir edilmesine odaklanmaktadır. 


\section{Geçiş Ekonomilerinde Yaratıcı Muhasebe Uygulamaları ve Mali Saydamlık}

Çalışmanın bu bölümü geçiş ekonomileri açısından yaratıcı muhasebe uygulamalarının büyüklüğünü temsil eden stok-akım uyarlamaları ile mali saydamlık göstergelerinin başında gelen Açık Bütçe Endeksi arasındaki ilişkiyi doğrusal regresyon analizi yardımıyla analiz etmeyi amaçlamaktadır.

Analizde kullanılan stok-akım uyarlamasına ilişkin veriler IMF Economic Outlook 2015'taki kamu borç stoku ve bütçe açığı verilerinden hareketle 1 numaralı denklikte belirtildiği üzere tarafımızca hesaplanmıştır. Açık bütçe endeksine ilişkin veriler ise IBP (2012)'den elde edilmiştir. Her iki veri de 2006, 2008, 2010 ve 2012 yıllarını kapsamaktadır. Doğrusal regresyon analizine konu olan ülkeler ise geçiş ekonomisi niteliği taşıyan Arnavutluk, Azerbaycan, Bulgaristan, Kamboçya, Çin, Hırvatistan, Çek Cumhuriyeti, Gürcistan, Kazakistan, Kırgızistan, Makedonya, Polonya, Romanya, Rusya, Slovakya, Slovenya, Tacikistan, Ukrayna ve Vietnam olmak üzere 19 ülkeyi kapsamaktadır. Analiz öncesinde gerçekleştirilmiş olan tanısal testlerde verilerde değişen varyans, normallik ve otokorelasyona ilişkin istatiksel bir sorun olmadığ 1 tespit edilmiştir.

\begin{tabular}{|l|c|c|c|c|}
\hline Ülkeler & $\mathbf{2 0 0 6}$ & $\mathbf{2 0 0 8}$ & $\mathbf{2 0 1 0}$ & $\mathbf{2 0 1 2}$ \\
\hline Arnavutluk & 25 & 37 & 33 & 47 \\
\hline Azerbaycan & 30 & 37 & 43 & 42 \\
\hline Bulgaristan & 47 & 57 & 56 & 65 \\
\hline Kamboçya & & 11 & 15 & 15 \\
\hline Çin & & 14 & 13 & 11 \\
\hline Hirvatistan & 42 & 59 & 57 & 61 \\
\hline Çek Cumhuriyeti & 61 & 62 & 62 & 75 \\
\hline Gürcistan & 34 & 53 & 55 & 55 \\
\hline Kazakistan & 43 & 35 & 38 & 48 \\
\hline Kirgizistan & & 8 & 15 & 20 \\
\hline Makedonya & & 54 & 49 & 35 \\
\hline Polonya & 74 & 67 & 64 & 59 \\
\hline Romanya & 66 & 62 & 59 & 47 \\
\hline Rusya & 47 & 58 & 60 & 74 \\
\hline Slovakya & & & 57 & 67 \\
\hline Slovenya & 82 & 74 & 70 & 74 \\
\hline Tacikistan & & & & 17 \\
\hline Ukrayna & 3 & 55 & 62 & 54 \\
\hline Vietnam & 10 & 14 & 19 \\
\hline
\end{tabular}

Tablo 2. Seçilmiş Geçiş Ekonomilerinde Açık Bütçe Endeksi (2006-2012) Kaynak. IBP (2012)

Sözkonusu 19 ülke için açık bütçe endeksi verileri Tablo 2'de yer almaktadır. Yüzde 81 ile yüzde 100 arasında puana sahip olan ülkeler “ kapsamlı bilgi” sunmakta; yüzde 61 ile yüzde 80 arasında yer alan ülkeler "önemli bilgiler" sunmakta; yüzde 41 ile yüzde 60 arasındaki ülkeler "bazı bilgi”leri sunmakta; yüzde 21 ile yüzde 40 arasındaki ülkeler "asgari düzeyde bilgi" sunmakta ve yüzde 0 ile yüzde 20 arasındaki ülkeler ise " sınırlı veya sıfır bilgi” sunmaktadır. Tablodaki değerlerin vurguladığı önemli sonuçlar arasında eski doğu bloku ülkelerinin Türk Cumhuriyetleri ve Uzak Doğu ülkelerine göre daha yüksek endeks değerlerine sahip olduğu ve neredeyse tüm ülkelerin endeks değerlerinde zaman içerisinde gözlemlenen yükseliştir.

Açık bütçe endeksi (obi) ile stok-akım uyarlaması (sfa) arasındaki ilişkiyi analiz etmek için aşağıda yer alan regresyon modeli kullanılmıştır.

$$
o b i=\alpha_{0}+\alpha_{1} s f a_{t}+\varepsilon_{t}
$$

\begin{tabular}{|c|c|c|c|c|c|}
\hline & & & & & Number of obs $=65$ \\
\hline & & & & & $F(1,63)=6.20$ \\
\hline & & & & & Prob $>\mathrm{F}=0.0154$ \\
\hline & & & & & R-squared $=0.0489$ \\
\hline & & & & & Root MSE $=20.2$ \\
\hline Obi & Coef & Robust Std. Err. & $\mathrm{T}$ & $\mathrm{P}>|\mathrm{t}|$ & [95\% Conf. Interval] \\
\hline Sfa & $\begin{array}{c}- \\
25.15126\end{array}$ & 10.09978 & -2.49 & 0.015 & $\begin{array}{c}- \\
45.33406\end{array}$ \\
\hline Cons & 48.35583 & 2.64119 & 18.31 & 0.000 & 43.07783 \\
\hline
\end{tabular}

Tablo 3. Regresyon Analizi Sonuçları 
Tablo 3'de yer alan regresyon analizi sonuçları yaratıcı muhasebeyi temsil eden stok akım uyarlamaları ve mali saydamlık göstergesi olan açık bütçe endeksi arasındaki güçlü ve ters yönlü ilişkiyi işaret etmektedir. Ayrıca olasılık değerinin 0.05 'ten düşük olması söz konusu bu ilişkinin istatistiksel olarak anlamlı olduğunu göstermektedir. $\mathrm{Bu}$ bulgular geçiş ekonomilerinde mali saydamlığın arttırılmasına yönelik önlemlerin hükümetlerin yaratıcı muhasebeye başvurma güdülerini azaltacağı yönündeki öngörüyü de desteklemektedir.

\section{Sonuç ve Öneriler}

Geçiş ekonomilerinin merkezi planlamadan piyasa mekanizmasının ağırlıklı olarak hakim olduğu bir yapıya geçiş süreci tartışılmaz şekilde birçok kurumsal reformu da beraberinde getirmiştir. Ekonominin liberalizasyon sürecine destek vermek amacıyla gerçekleştirilen reformların geçiş öncesinde Doğu Bloku olarak adlandırılan ülkelerde başarılı olduğu açıkken Türk Cumhuriyetleri başta olmak üzere Asya kıtasındaki geçiş ekonomilerinde bu başarı sağlanamamıştır.

Çalışmamız çerçevesinde geçiş ekonomisinde uygulanacak reformlardan yönetişim, özellikle de mali yönetişime yönelik reformları son derece önemli bulmaktayız. Geçiş ekonomilerinin dönüşüm sürecine başlamasıyla yönetişim kavramının akademik yazında ve politika uygulayıcılarının, aynı zamanda da uluslararası kuruluşların söylemlerinde yer almaya başlaması aynı döneme denk gelmektedir. Yönetişim ilkelerinden özellikle hesap verebilirlik ve saydamlık, maliye politikası uygulayıcılarının politika araçlarını kullanmadaki keyfi kararlarını azaltmakla birlikte kamu mali yönetimine ilişkin istatistiklerin de güvenilirliğini arttıracaktır. Çalışmamızın analiz aşamasındaki bulgular da bu öngörüyü desteklemektedir. Geçiş ekonomilerinde bütçenin açıklığı ile politika uygulayıcılarının mali kuralları etkisiz kılmak için yaratıcı muhasebe uygulamalarına başvurma eğilimleri arasında ters yönlü ve istatistiksel olarak anlamlı bir ilişki vardır.

Vurgulanması gereken diğer bir nokta, geçiş ekonomilerinin mali kurallar ve mali saydamlığa ilişkin verilerinin sınırlı düzeyde ulaşıma açık olduğudur. IMF'nin Mali Kural Veritabanında 29 geçiş ekonomisinden sadece 14'üne ilişkin (Ermenistan, Bulgaristan, Hırvatistan, Çek Cumhuriyeti, Estonya, Gürcistan, Macaristan, Litvanya, Letonya, Polonya, Romanya, Rusya, Slovenya ve Slovakya) bilgilere erişilebilmektedir. Mali saydamlık konusunda verilere erişim kısmen daha olumlu olmakla birlikte IBP'nin Açık Bütçe Endeksinde 29 ülkeden sadece 19'unun verilerinin hesaplanmış olması geçiş ekonomilerinde bu verilerin hesaplanmasına ilişkin oluşumların gerekliliğini ortaya çıkarmaktadır.

Bu bulgulardan hareketle geçiş ekonomilerine yönelik olarak mali yönetişimin sağlanmasına yönelik olarak önerilerimiz aşağıdaki şekildedir:

a) Politika uygulayıcıların hesap verebilirliğini arttıracak olan mali saydamlığın yükseltilmesi. Mali saydamlığın politika yapıcı ve uygulayıcıların hesap verebilirliğini yükseltmesi yanında yaratıcı muhasebeye başvurma konusundaki eğilimlerini de azaltacaktır.

b) Mali kural veya bağlayıcı mali taahhütlerin uygulanması. Orta vadeli mali planlarla birlikte yürütülecek ulusal ölçekli sayısal mali kurallar, mali disiplinin sağlanmasına yönelik olarak oldukça faydalı olacaktır.

c) Maliye bakanının diğer harcamacı bakanlar karşısındaki gücünün yükseltilmesi ya da yıllık bütçe görüşmelerinin başında bütçe açığının büyüklüğüne ilişkin bağlayıcı oyunun gerekliliği gibi kurumsal reformların uygulanması, diğer bir ifade ile maliye bakanının delegasyon gücünün arttırılması.

d) Bağımsız bir mali otoritenin oluşturulmasıyla radikal kurumsal reformların uygulanması. Bağımsız mali kuruluşlar maliye politikası konusunda hükümetlere öneri ve tavsiyelerde bulunacağı gibi uygulanan maliye politikasının sonuçlarına ilişkin değerlendirmelerde de bulunacaktır.

Bu çalışma Çukurova Üniversitesi Bilimsel Araştırma Projeleri Koordinasyon Birimi tarafindan desteklenmiştir. Proje No: 4936

\section{Kaynakça}

- Alesina, A. and R. Perotti, 1996. "Budget Deficits and Budget Institutions", IMF Working Papers, 96/52, International Monetary Fund.

- Alesina, A., Hausmann, R., Hommes, R., and Stein, E., 1999. "Budget Institutions and Fiscal Performance in Latin America", Journal of Development Economics, 59(2), 253-273.

- Beetsma, R. and Jensen, H., 2003. "Contingent Deficit Sanctions and Moral Hazard With a Stability Pact", Journal of International Economics, 61, 187-208.

- European Commission, Directorate General for Economic and Financial Affairs, 2003. "Public Finances in EMU 2003", Brussels: The European Commission.

- Eurostat, 2015. "Stock-Flow Adjustment (SFA) for the Member States, the Euro Area and the EU28 for the Period 2011-2014, as Reported in the April 2015 EDP Notification" http://ec.europa.eu/eurostat/documents/4187653/6797377/STOCK-FLOW-2015-APR/30508d29-19f7-4e9680b0-3d5797ab1d3a. 
- Granickas, K., 2013. Fiscal Transparency and Open Government Data, European Public Sector Platform, Topic No 2013, 11.

- Hemming, R. and Kell, M., 2001. Promoting Fiscal Responsibility: Transparency, Rules and Independent Fiscal Authorities. Available at SSRN: http://ssrn.com/abstract=2095161 or http://dx.doi.org/10.2139/ssrn.2095161

- IMF, 1998. Codes of Good Practices on Fiscal Transparency.

- Jarmuzek, M., Polgar, E. K., Matousek R., and Hölscher, J., 2006. "Fiscal Transparency in Transition Economies", Center for Social and Economic Research, Studies \& Analyses, No. 328.

- Kopits, G., and Craig, J., 1998. “Transparency in Government Operations," IMF Occasional Paper, 158, Washington: International Monetary Fund.

- $\quad$ Milesi-Ferretti, G. M., 2003. "Good, Bad or Ugly? On the Effects of Fiscal Rules with Creative Accounting”, Journal of Public Economics, 88, 377-394.

- $\quad$ Nasser, K. H. M., 1993. Creative Financial Accounting. Prentice Hall, Hemel and Hempstead.

- OECD, 2000. OECD Best Practices for Budget Transparency.PUMA/SBO(2000)6/FINAL, May.

- The International Budget Partnership, 2012, Open Budget Data Explorer, http://internationalbudget.org/opening-budgets/open-budget-initiative/open-budget-survey/open-budgetdata-explorer/

- $\quad$ Ünlükaplan, İ., 2011. AB Üyesi Ülkelerde Mali Yönetişim ve Kamu Maliyesinin Performansı İlişkisi, Seçkin Yayınevi, Ankara.

- Ünlükaplan, İ. ve Arısoy, İ., 2010. "Stok-Akım Uyarlaması, Bütçe Açığı ve Kamu Borç Stoku Arasındaki İlişkiler: Küresel Kriz Bağlamında Avrupa Birliği Üyesi Ülkeler Üzerine Bir Analiz”, Maliye Dergisi, Sayı 159, Temmuz-Aralık 2010, 376-394.

- Von Hagen, J., 1992. "Budgeting Procedures and Fiscal Performance in the European Communities", Center for German and European Studies Economic Papers, 96, University of California.

- Von Hagen, J., and Harden, I., 1994. "National Budget Processes and Fiscal Performance: European Economy", Reports and Studies, 3: 315-418.

- Von Hagen, J., and Wolff, G. B., 2006. "What Do Deficits Tell Us About Debt? Empirical Evidence on Creative Accounting with Fiscal Rules in the EU”, Journal of Banking \& Finance, 30 (1), 3259-3279.

- Weber, A., 2012. "Stock-Flow Adjustments and Fiscal Transparency: A Cross Country Comparison”, IMF Working Paper, No. 12/39. 


\title{
Toplumsal Kalkınma ve Kadın Girişimciliği Üzerine Bir Araştırma
}

\section{A Research on Community Development and Women Entrepreneurship}

\author{
Prof. Dr. Feyzullah Eroğlu (Pamukkale University, Turkey) \\ Hatice Çoban (Pamukkale University, Turkey) \\ Mustafa Koç (Pamukkale University, Turkey)
}

\begin{abstract}
Although Turkish economy system was based on a patriarchal community for a long time, Mustafa Kemal Atatürk, founder of Modern Turkish Republic, has been promoted innovative policies for female citizens to incorporate them into social and economic life. Thanks to those policies, crucial changes have emerged especially for well-educated and cultivated "urban women". In this respect, conventional social construct and economic system have been a burden for some of those "urban women". They both took care of their families and joined the economic system and raised their career expectations. In recent years, there are some entrepreneurship curriculums and financial support projects has been launched for women who would like to take an active role in business life. Those projects provide opportunity for Turkish women to create their own business instead of working as employees. First of all, literature review on "community development" and "women entrepreneurship" was conducted in this study. Those issues considered as not only an economic issue but also social and psychological behavioral processes usually by using macro-sociological analysis method. Secondly, an empirical research performed in Denizli province, in which considerable economic moves have been realized in recent years. In this context, qualifications of women entrepreneurs who set up a business afterwards of financial and educational supports of governmental and non-governmental organizations such as Denizli Chamber of Commerce, Denizli Entrepreneurial Association, Association of Eurasian Executives and Businessmen were introduced. Furthermore, women entrepreneurs evaluated by quantitative comparison according to years.
\end{abstract}

\section{Küreselleştirilen Dünya Ekonomisi ve Girişimcilik Yoluyla Toplumsal Kalkınma Gerçekliği}

Birinci sanayi devriminin başlangıcı sayılan "buhar makinesinin" icadı ve bu teknolojinin başta tekstil ve ulaştırma sektörleri olmak üzere, çeşitli üretim faaliyetleri ve alt yapı hizmetlerinde kullanılmaya başlanması sonrasında, insanlık tarihinde belki de ilk defa "kitle üretimi" çağı da başlamış olmaktadır. Sanayileşmeyi başlatan Batılı toplumları, yeni kitle üretimi döneminde, önceki zamanlara göre daha fazla hammadde ve enerji ile daha fazla insan gücüne ihtiyaç duymuşlardır. Bütün bunlara bağlı olarak, çok miktarda ürün elde etmişler ve üretilen kitle üretim stoklarına mahreçlik yapacak olan daha fazla pazar alanları ihtiyaçları gerçekliği ile karşı karşıya kalmışlardır. Aslında, İstanbul'un Türkler tarafından fethi ile Batı-Doğu arasındaki dünya ticaretinin temel ekseni, 16. Yüzyıldan itibaren yeni coğrafî keşifler sayesinde daha önceden zaten deniz aşırı sınırlara ve ülkelere doğru kaymış idi. Büyük coğrafî keşiflerin sonucunda, çevre ülkelerden Batılı ekonomilere getirilen büyük kıymetli metal birikimi, modernleşmenin yarattı̆ğ bilimsel icatlar ile birleşerek, 18.yüzyılın sonunda büyük bir sanayileşme hamlesine yol açmıştı. Bir bakıma, sanayileşmenin ortaya çıkmasında etkili rol oynayan büyük coğrafî keşifler, diğer faktörlerin de birleşimi ile sadece sanayi devriminin ve kitle üretiminin önünü açmış olmamış, aynı zamanda deniz aşırı ulaşım ve coğrafî anlamda bir küreselleşmenin de öncüsü olmak suretiyle daha sonraki zamanların her alanında yaşanacak olan "küreselleşmeye" ortam hazırlamış bulunmaktadır. Batılı toplumlar ve ekonomiler için birinci sanayileşme çağının tetiklediği, uygun fiziki ve beşeri kaynakları ile uygun pazar alanları bulma arayışları, dünya ekonomisinde yeni bir küreselleşme dalgasına sebep olmuştur. Aslında, Birinci Dünya Savaşı'nın gerçek sebebi, sanayileşen Batılı toplumların yeni kaynak transferlerini artırma ve yeni pazar alanlarını garantileme stratejilerinin, son derece kanlı gerçekleşen ve sona eren kurgularının sonucudur.

İkinci Dünya Savaşı sonrasında, biri liberal-kapitalist, diğeri kolektivist-sosyalist düşünce eksenli iki kutuplu bloklaşma, toplumlar arası kaynak mücadelesini hızlandırmıştır. 1989'dan sonraki tek merkezli Batı hegemonyasının, özellikle kendi doğal ve insan kaynaklarını yeterince kullanamayan az gelişmiş toplumların kaynaklarını, küreselleşme gerekçesi üzerinden daha fazla kontrol etmeye yönelik yeni stratejiler ve politikalar geliştirdiği görülmektedir. Öyle anlaşılıyor ki, kendi halkını yüksek bir gelir ve tüketim düzeyine sahip bir hayata alıştıran gelişmiş Batı toplumları, bütün bu olumlu şartların devamlılığı bakımından, kendi ekonomik coğrafyalarının imkânları yeterli olmadığı için dünyanın diğer ekonomik coğrafyalarının her türlü kaynaklarına, her zamankinden daha fazla ihtiyaç duymaktadırlar. Gelişmiş Batı toplumları, küreselleşme süreci adı altında, 
serbest piyasa ekonomisinin gereği olarak sermaye hareketlerini ve malların serbest dolaşımını dayatan uygulamaları, dünya ekonomisinin nispeten kapalı ve ulusal ekonomik sınırlarını, büyük ölçüde az gelişmiş ülkelerin aleyhine olacak şekilde çoğunlukla kendi lehine etkisiz hale getirmektedir.

Az gelişmiş ya da yeni bir tasnif biçimi olarak "küreselleştirilen” ülkelerin bir kısmının, dünya ekonomisine anlamlı bir katkıda bulunacak düzeyde fazla bir ekonomik kaynakları mevcut olmayabilir. Ancak, bu ülkelerin önemli bir kısmının, ekonomik ve teknik olarak işlenmesi ve işletilmesi halinde, çok önemli bir potansiyel kaynak sahipleri oldukları da bilinmektedir. Gelişmiş ya da yeni bir tasnif biçimi olarak "küreselleştiren" ülkelerin, bu tür çevre ülkelerine yönelik stratejilerinin temel hedefi, başta enerji ve endüstriyel ham madde kaynakları olmak üzere, vasıflı işgücüne sahip olmaları ile uygun fason üretim ve pazar alanları olma özelliklerine bağlı olarak, bütün bu imkân ve kaynakların kendi çıkarları doğrultusunda dönüşmelerini sağlamaktır. Refah düzeyleri yüksek olan ülkelerin etkili bir ekonomiye sahip olmalarının doğurduğu askeri, diplomatik, sosyal ve psikolojik üstünlüklerinin hiç olmazsa bir kısmı, kaynakları zengin ve yeterli olmasına rağmen bütün bunları üretken ve verimli bir şekilde kendi halklarının lehine işletemeyen az gelişmiş ülkelerin yönetim sistemlerinin çaresizliğinin sonucudur. Kendi kaynaklarını yeterince kullanma iradesini ve becerisini gösteremeyen az gelişmiş ülkelerin yönetim sistemleri, zengin ülkelere çok büyük sosyo-ekonomik rantlar sağlamaktadır. Varsayım olarak, dünya toplumlarının her biri, başka "egemen ekonomilere" rant sağlamadan, öncelikle kendi kaynaklarını kendi halklarının zenginlik ve refahı için kullanmış olsaydı, bir taraftan dünya ekonomik ve ticaret hacminin boyutları şimdikinden çok daha yüksek olacak, diğer taraftan da dünya ekonomisindeki aşırı gelir eşitsizliği belki de ortadan kalkacaktı.

Az gelişmiş ülkelerin, toplumsal kalkınma ve gelişmelerinin kısıtlılığı ya da yetersizliği, bu toplumların ekonomik coğrafyalarının her türlü üretim faktörlerinin gelirlerinin genel olarak düşüklüğüne ve gelir dağılımlarının çarpıklığına yol açmaktadır. Ayrıca, azgelişmiş ülkelerin kaynaklarının yeterince ve gereğince üretime ve gelire dönüşmemesinden dolayı bu imkân ve kaynaklar, gelişmiş ülke ekonomileri için bir ranta dönüşmekte ve onların zenginleşmesine neden olmaktadır. Bu durum, bu ülkelerin kendi kaynaklarının gelecek zamanlar içinde de yaratacağı muhtemel gelir ve refahtan da yoksun olmaları sonucunu yaratmaktadır. Varsayım olarak, eğer az gelişmiş ülkelerin yönetim sistemleri, kendi ekonomik ve beşeri kaynaklarını yeterince kullanabilecek yeterli sayı ve nitelikte "girişimci" bir kesim oluşturabilselerdi, o zaman "egemen ülkelerin" sömürülerinden kendilerini kurtarma ihtimali daha yüksek olurdu. Bu bağlamda, ulusal ve toplumsal kalkınma stratejileri bulunan ekonomiler için en stratejik ekonomik aktörler, o ulus ve toplumun "girişimcileri" olmaktadır. "Girişimciler", kendi ülke ve toplumlarını, özellikle yeni dünya düzeni denilen küreselleşme süreci içerisinde, yeni ürünler ve yeni işler yaratmak suretiyle global rekabete hazırlayan kişi ve gruplar olarak dikkat çekmektedirler (İrmiş ve Emsen, 2002).

Az gelişmiş ülke ekonomilerinin en açık sosyo-ekonomik göstergeleri arasında, aşırı bir "gelir eşitsizliği” ile güçlü bir "orta sınıfın" yokluğu dikkat çeker. Birbiriyle yakından ilişkili olan bu durumun ortaya çıkışında, büyük ölçüde üretim faktörlerinin gelirlerinin toplam milli gelir içerisindeki genel düzeyinin düşüklüğü ile bu gelirlerin oranlarındaki dağılımın aşırı dengesizliği önemli bir rol oynar. Buna göre, milli gelirin paylaşımından pay alan faktörlerin az gelişmiş ülkelerdeki genel değerlendirilmesi, genel olarak aşağıdaki bulgular çerçevesinde gerçekleşmektedir (Ülken, 1974): (1) Milli gelirin dağılımında rant ve faizler çok yüksektir ve bu da en büyük eşitsizlik kaynağıdır. Bu durumun başlıca nedenleri olarak, aşırı şehirleşme ve nüfusun şehirlerin mevcut alt yapılarının kaldırabileceğinden daha yoğun yı̆̆ılması, sanayi ve hizmet sektöründe girişimcilik yerine spekülatörlüğün ve firsatçılığın yaygınlaşması, yolsuzluk-rüşvet-nepotizm ve kayırmacılığın fazlalığı gibi etkenler sayılabilir. Böyle bir "kolay" ve "haksız" yüksek gelir elde etmenin sonucunda ise çoğunlukla, dışarıya para kaçırma eğilimi yüksek olmakta, ithalata dayalı aşırı lüks ve gösteriş tüketimi çılgınlığı oluşmakta, cari açı̆̆a bağlı olarak iç ve dış borçlanma ihtiyacının yüksekliği gibi durumlar gerçekleşmektedir. (2) Rant ve faiz hadlerinin gereğinden fazla ve çarpık bir şekilde yüksek olması ile emek verimliliğinin düşüklüğü nedeniyle, kârların dağılımındaki paylar, rant ve faizlerden sonra gelir. Zaten, az gelişmiş ülkelerde, kendi sosyo-ekonomik potansiyellerine göre girişimcilerin sayısı son derece azdır. Girişimciler, çoğu zaman spekülatörlerle karıştırılır ve bu yüzden Batı anlamında gerçek girişimcilere rastlamak zordur. (3)Ücret hadleri, çok düşük olup genellikle asgari fizyolojik düzey etrafında şekillenir. Bu durumun nedenleri arasında, tarımsal faaliyetlerin ilkel usullerle yapılması ve sanayide katma değeri düşük ürünler üretilmesi ile çalışanların marjinal verimlilik düzeylerinin düşük olması, en fazla dikkat çeken etkenlerdir.

Az gelişmiş ülkelerdeki yaygın yoksulluk ve gelir eşitsizliğinin, genel olarak çok sayıda nedeni olmakla beraber, bütün bu nedenlerin altında ise üretim faktörlerinden elde edilen gelirlerin payları arasındaki eşitsizlik yatmaktadır. Üretim faktörlerinden elde edilen gelirlerin payları arasında rant ve faizlerin aşırı yüksek olması, ülke ekonomisinde ortaya çıkacak muhtemel üretim faaliyetlerini, büyük ölçüde baltalamakta ve etkisiz hale getirmektedir. Ayrıca, teknik düzeyin zayıf olmasına bağlı olarak etkinlik ve verimliliğin düşüklüğü, emeğin vasıf düzeyinin yetersizliği ve örgütlenmemiş olması, emek arzının emek talebinden fazla olması ve aşırı bir işsizlik hâli, orta sınıfın yokluğu, özellikle lüks mal ithalatının "gösteriş etkisi” sonucu dış ticaret dengesinin bozulması, gelişmiş ekonomilerin "egemenlik etkisi” altında hem yöneticilerin hem de halkın psikolojisinin bozulması, siyasî belirsizlik ve istikrarsızlığın devamı gibi etkenler yüzünden, az gelişmiş ülke ekonomilerinde 
yeterince "girişimci” bir sınıf oluşmamaktadır (Ülken, 1974). Bu bağlamda, az gelişmiş ülkelerdeki yoksulluğun ve gelir eşitsizliğinin hafifletilmesi için üretim faktörlerinden elde edilen gelirlerin payları arasında, rant ve faiz hadlerinin nispeten azaltılıp, kâr ve ücret gelirlerinin toplam milli gelir içerisindeki nispî paylarının yükseltilmesi, o ülke ekonomisindeki toplumsal kalkınma bakımından çok önemli bir başlangıç sayılır.

Rant ve faizlerin yüksek olduğu bir ekonomik yapıdan, kâr ve ücretlerin nispeten daha yüksek olduğu bir ekonomik sisteme geçişin anahtar rolü, büyük ölçüde ülke ekonomisinde etkili ve yaygın bir "girişimci sınıfın" varlığıdır.

\section{Kadın Girişimciliği Üzerinden Toplumsal Kalkınma}

Genel olarak "girişimcilik", geleceğe yönelik olarak yeni amaç ve hedeflerin elde edilmesine aracılık edecek olan faaliyetler zincirinin başlangıcından, sonuçların elde edileceği sürecin sonuna kadar olan her aşamaya dair işlem ve etkinliklerin tümüdür. Girişimciliğin, bilinen ilk tanımına Richard Cantillon'un çalışmalarında rastlanmıştır. Cantillon (1734) girişimciliği, "belirsiz bir getiri elde etmek üzere kendi kendini istihdam etmek" olarak tanımlamıştır (Sharma ve Chrisman, 1999). Girişimcilik, yeni bir sürecin her aşamasında, başta örgütlenme olmak üzere, her türlü yönetim ve organizasyon süreçlerine dair etkinliklerin yürütülmesinde, bedeni, zihinsel ve duygusal enerji sağlayan bir güç kaynağıdır. Girişimcilik, emek, sermaye ve doğal kaynaklar başta olmak üzere mevcut üretim faktörleri ile çeşitli kaynakların birleştirilerek yepyeni bir süreç olarak bir araya getirilmesi ve yeni bir mal ve hizmetin üretilmesidir. Girişimci, emek faktöründen ayrı olarak risk yüklenir, kâr amacıyla bir takım faaliyetlerde bulunurken, aynı zamanda zarara da muhatap olur (Ertürk, 2011). Schumpeter (1934)'e göre girişimci, yeni ürünleri, süreçleri, pazarları, örgütsel yapıları ya da arz kaynaklarını birleştiren kişidir (Sharma ve Chrisman, 1999). Yani girişimci, yeni bir mal ve hizmetin üretiminin gerçekleştirilmesi, yeni pazarların bulunması, yeni üretim süreçlerinin ilâvesi, mevcut mal ve hizmetler için yeni kullanım alanlarının yaratılması doğrultusundaki temel stratejilere (Ülgen ve Mirze, 2004) dair bir takım faaliyetlerin örgütlenmesini sağlamaya çaba gösteren bir kişidir. Günümüzde, girişimci denildiğinde ilk akla gelen alt kavramlar ise risk alma, ön görebilme, firsatları değerlendirme ile yaratıcı ve farklı düşüncelere bağlı olarak yenilik yapma veya yeni değerler yaratma becerileridir (Kök, 2007). Literatüre geçmiş olan başlıca girişimci özellikleri olarak, yaratıcılık, belirsizlik ve riske karşı durabilme, yüksek bir başarı ihtiyacı ve başarısızlıktan öğrenme isteği, belirsizliğe karşı yüksek bir tolerans, yüksek bir öz güven ve içsel denetim, yüksek bir duygusal zeka, bağımsız olma arzusu ve liderlik kabiliyeti, çabaların karşılı̆̆ını alma isteği (Yurtsever vd., 2006), kendi kendini güdüleme ve olumsuz şartlar karşısında yılgınlığa düşmeden devam edebilme yeteneği (Gürol, 2006), kararlı ve azimli, firsatları öngörme ve bunları iş imkanına dönüştürme eğilimi, katma değer yaratma ve istihdam yaratma becerisi, ulusal refaha ve toplumsal kalkınmaya katkı verme heyecanı (Akpınar, 2009) gibi nitelikler dikkat çekmektedir. Ayrıca, girişimci olacak kişinin yönetim ve teknik becerilerinin bulunması da gerekmektedir. Yönetim becerileri, girişimcilik kapsamındaki faaliyet ve işlere dair strateji ve amaç oluşturma, planlama, projelendirme, örgütleme kabiliyeti, insan ilişkilerini yönetme, pazarlama ve finansman gibi etkinliklerin öğrenilmiş olmasıdır. Buna karşılık, teknik beceriler ise üretim ve bilişim süreçlerine dair teknolojiyi anlama ve edinebilme, kullanma ve yararlanma imkanı gibi etkinlikler hakkında tecrübelerdir (İrmiş vd., 2010). Bütün bunlara ilâve olarak, iyi bir girişimcinin, bedensel, zihinsel ve duygusal açıdan dayanakl1, sorumluluk bilinci yüksek bir şahsiyet sahibi olması gerekmektedir (Koç, 2011).

Erkek egemenliğine dayalı toplumsal yapılardaki "erkek-kadın" eşitsizliğine dayalı zihniyet ve kültürlerin, sürekli olarak "erkek" cinsiyeti ön plana çıkarmasına karşılık, "kadın" cinsiyetine yönelik birçok kısıtlama ve engellemeler çıkardıkları bilinmektedir. Buna karşılık, modernleşmenin ve kentleşmenin sağladığı nispeten eşitlikçi bir toplumsal cinsiyet rol dağılımına doğru bir evrilme ile birlikte "kadın girişimciliği" bağlamında yeni eğilim ve yönelimin de harekete geçtiği görülmektedir. Bu çerçevede, kadınların geleneksel olarak, çoğunlukla "erkek egemenliğine" dayalı toplumsal rol dağılımı kapsamında, "erkek sosyal aktörlerin" tasarladığı ve belirlediği çalışma şartlarında iş görmeleri ve çalışmaları, herhangi bir şekilde "girişimcilik" olarak görülmemektedir. Buna karşılık, kadınlar ev dışında bir mekânda kendi adlarına kurmuş oldukları birer işletmeleri olduğu, bir işletmede tek başına veya çalıştırdıkları diğer kişilerle birlikte çalıştıkları veya ortaklık kurdukları, sahibi veya ortağı oldukları işletmeler adına kendi işleriyle ile ilgili olarak çeşitli kamu ve özel kuruluşlarla temaslara geçtikleri, işletmelerinin geleceği ile ilgili planlar yaptıkları, işletmelerinden elde ettikleri kazancı, yatırım ve kullanım alanları üzerinde söz sahibi oldukları ve işletmeleri adına tüm riskleri üstlendikleri vakit "girişimci kadın" olma niteliğini kazanmış olurlar. Bu bağlamda, eğitimini gördükleri alanlarda kendi mesleklerini icra eden kadınlar ile erkeklerin riskleri üstlendiği çalışma alanlarında herhangi bir riske girmeksizin çalışmakta olan kadınlar için girişimcilik vasfı kabul edilmemektedir (Akt: Soysal, 2010). Aslında, "kadın girişimci denildiğinde akla sadece işveren kadınlar değil, ülke çapında bu alanda uğraş veren, çabalayan kadınların tümünün gelmesi gerekir. Yani kendi hesabına çalışan kadınlar da akla gelmelidir” (Keskin, 2014).

Az gelişmiş toplumların, mevcut kaynaklarını harekete geçirmek suretiyle üretim faktörlerinin gelirlerini artıramamış olmaları ile orta sınıfa dayalı bir toplumsal kalkınmayı gerçekleştirememiş olmalarında en önemli etkenlerden biri de, bu toplum kültürlerindeki düşük başarı ihtiyacı ve yaygın öğrenilmiş acizlik duygusudur. $\mathrm{Bu}$ bağlamda, David McClelland'ın toplumların başarı arzusunun yüksekliği ile toplumsal kalkınma arasında 
doğrusal bir ilişki olduğuna dair çok meşhur araştırmasından esinlenerek, bu tür ülkelerde çoğunlukla ihmal edilen kadın nüfusun girişimcilik gücünü harekete geçirmek maksadıyla "feminizmin teşviki" şeklindeki önerisinden yararlanılabilir (Bilgiseven, 1987). Kadınların yeteneklerinin, sadece geleneksel toplumsal rol davranışlarıyla sınırlı kalmayıp hayatın her alanında toplum hizmetine katılması anlamında "feminist" bir hamle, başta kadınlar olmak üzere çoğu bireylerin girişimcilik niteliklerini harekete geçirmek suretiyle toplumsal kalkınmaya önemli bir katkı sağlayacaktır. Erkek egemenliğine dayalı kültürlerde, normal şartlarda erkeklerin tamamının daha özgür ve bağımsız hareket ettikleri, daha cesur ve atılgan oldukları; buna karşıllık bütün kadınların ise daha kısıtlı ve bağımlı, daha ürkek ve çekingen oldukları kabul edilir. Aslında, erkek egemenliğine dayalı kültürlerde, sadece çeşitli güç kaynaklarına sahip az sayıdaki sistemin "efendisi" konumundaki erkekler ön planda olurken, toplumun diğer kesimleri (güç sahibi olmayan erkekler ve kadınlar), sürekli bir baskı ve tahakküm altında sayılırlar. Kadınlar, toplumsal cinsiyet rol davranışları bakımından "edilgen" ve "çekingen" davranışlara karşı bir anlamda alışkanlık ve bağışıklık kazanmışlardır. Oysa erkek egemenliğine dayalı kültürlerde, toplumsal cinsiyet rol davranışları bakımından kendilerine çok küçük yaşlardan itibaren "aktif" ve "atılgan" rol davranışları beklentileri yüklenmiş olan erkeklerin çoğunun, gerçek hayatta bu rolleri fiilen icra etme firsat ve imkanını bulamamış olmaları nedeniyle son derece "edilgen" ve "çekingen" davranışlara mecbur kalmalarının sonucunda, çok ciddi bir kişilik örselenmesine maruz kaldıkları gözlenmektedir. Bu yüzden, kişilik özellikleri fazlaca örselenmemiş ve belirli bir eğitim alt yapısı olan hanımların, gerekli ekonomik ve teknik alt yapı hazırlandığı vakit, benzeri erkeklere göre daha etkili ve başarılı girişimci niteliklerine sahip olacakları öngörülmektedir.

\section{Türk Ekonomisinde Kadın Girişimciliğinin Yeri ve Önemi}

Türk ekonomisinde, yeterli olmayan mevcut üretim kapasitesini ve üretim faktörleri gelirleri içerisindeki kâr ve ücretlerin payını artırmak suretiyle yaygın bir orta sınıflaşmayı daha geniş bir toplumsal tabana yaymak açısından başlatılacak en önemli hareket, kadın girişimciliğinin yaratıcı ve hamleci gücünden daha fazla yararlanmak olmalıdır. Türk kültür sisteminin geçmiş özünde, "kadın-erkek eşitliğini”" temel alan bir zihniyet kodları bulunmasına karşılık, Orta Doğu kültürlerinin etkisi ve Batı eksenli zorunlu kültür değişmelerinin ortaya çıkardığı kültür melezleşmesi nedeniyle çok ciddi bir "kadın-erkek eşitsizliği” yaşanmaktadır. Bu durum, Türk kültür sistemi çerçevesinde şekillenen her düzeydeki yönetim süreçlerinin, "erkek egemen" özelliklere sahip temel yönetici davranışlarını, son derece hiyerarşik bir ast-üst ilişkisi biçimine dönüştürmüştür. Yönetici davranışlarının, çoğunlukla tek taraflı bir güç gösterisi şeklinde tezahür etmesi ve bu yönde alışılmış yönetici şiddeti, sadece kadın astlar üzerinde değil, aynı zamanda alt kademelerde bulunan erkek yönetilenler üzerinde de yoğun bir ezilmişlik psikolojisine yol açmaktadır. Türk melez kültüründe, eğitim ve kültür düzeyi düşük hanımlarda da önemli ölçüde girişimcilik nitelikleri için gerekli olan nispeten bağımsız ve özgür hareket edebilme ile karar mekanizmalarında inisiyatif kullanma alışkanlıkları pek görülmez. Ancak, modern eğitim almış olan veya melez kültür bileşimleri ile kişilik bütünlükleri henüz bozulmamış olan "kentli kadınlarda", nispeten girişimcilik niteliklerini temsil eden bir takım değerler mevcut olabilir. Bu anlamda, Türk ekonomisinde, "kadın girişimciliğì" heyecanı içerisinde genel bir girişimcilik iklimi yaratılabilir.

Kadın girişimciliğinin yükselişinde, ekonomik anlamda üretim, iş ve istihdam ile ihracat artışı yaşanmasının yanında, başta gelir paylaşımında olmak üzere, toplumsal hayatın birçok yönünde nispeten eşitlikçi ilişskilerde de hatırı sayılır bir iyileşme beklenir. Ayrıca, kadın girişimciliğinin yükselişinde, az gelişmiş ülke siyasetçilerinin en çarpıcı tarafı olan sert ve katı siyaset yapma alışkanlıklarında, daha uzlaşmacı ve birbirini anlamaya dönük bir demokratik yumuşama da beklenmelidir. Bu bağlamda, kadın girişimciliğinin yükselişi ve hayata geçirilişi ile beklenen ekonomik refah artışı ve siyasetin demokratikleşmesi olgularıyla ardışık olarak toplumsal kalkınma ve gelişmenin, büyük bir hareketlilik kazanması öngörülmektedir. Kadınların, geleneksel toplum yapısındaki "edilgen" konumlarından sıyrılarak, modern toplumsal rol davranışlarına yönelmelerinin, modernleşme çabası içerisinde bulunan toplumlarda toplumsal kalkınma uğraşında çok kuvvetli bir toplumsal başarı motivasyonu sağlayacağı düşünülmektedir.

Türk ekonomisi, çok uzun bir süredir erkek egemen bir toplum yapısına sahip olmakla birlikte, Modern Türkiye'nin kurucusu Gazi Mustafa Kemal Atatürk'ün Türk kadınlarını sosyal ve ekonomik hayatın içine çekme yönündeki politikaları doğrultusunda yapmış olduğu yenilikler sayesinde, özellikle eğitim ve kültür düzeyi yüksek olan "kent kökenli" hanımlarda çok önemli değişimler ortaya çıkmaya başlamıştır. Bu bağlamda, "kent kökenli" Türk kadınlarının bir kısmında, geleneksel sosyal yapı ile ekonomik sistemin alışkanlıklarından kurtulmak suretiyle evde kalıp sadece ailelerine bakmak yerine, kadınlara yönelik toplumsal ve ekonomik beklentileri yükseltmeye yönelik çalışmalar ve projeler kapsamında, eğitim ya da kariyer beklentilerini artırma eğilimleri gözlenmektedir. Son yıllarda, Türk ekonomik sisteminin iş dünyasında aktif rol almak isteyen kadınlar lehine, önemli girişimcilik eğitimleri ve mali destek projeleri de başlamıştır. Bu uygulamalar, Türk kadınlarının büyük şirketlerde istihdam edilmeleri yanında, kadın girişimciliği yoluyla kendi kariyerlerine doğrudan katkı sağlamaları imkanı sunmaktadır. 


\begin{tabular}{|c|c|c|c|c|c|}
\hline Y1l & $\begin{array}{c}\text { Toplam } \\
\text { Girişimci } \\
\text { İşveren+ } \\
\text { Kendi } \\
\text { Hesabına } \\
\text { Çalışan } \\
\text { (Bin) }\end{array}$ & $\begin{array}{c}\text { Kadın } \\
\text { Girişimci } \\
\text { İşveren+Kendi } \\
\text { Hesabına } \\
\text { Çalışan } \\
\text { (Bin) }\end{array}$ & $\%$ & $\begin{array}{c}\text { Erkek } \\
\text { Girişimci } \\
\text { İşveren+Kendi } \\
\text { Hesabına } \\
\text { Çalışan } \\
\text { (Bin) }\end{array}$ & $\%$ \\
\hline 1989 & 5498 & 458 & $\% 8,3$ & 5040 & $\% 91,7$ \\
\hline 1990 & 5734 & 515 & $\% 9,0$ & 5219 & $\% 91,0$ \\
\hline 1991 & 5750 & 505 & $\% 8,8$ & 5245 & $\% 91,2$ \\
\hline 1992 & 5933 & 651 & 11,0 & 5282 & $\% 89,0$ \\
\hline 1993 & 5659 & 411 & $\% 7,3$ & 5248 & $\% 92,7$ \\
\hline 1994 & 6061 & 614 & 10,1 & 5447 & $\% 89,9$ \\
\hline 1995 & 6167 & 534 & $\% 8,7$ & 5633 & $\% 91,3$ \\
\hline 1996 & 6102 & 509 & $\% 8,3$ & 5593 & $\% 91,7$ \\
\hline 1997 & 6320 & 581 & $\% 9,2$ & 5739 & $\% 90,8$ \\
\hline 1998 & 6424 & 555 & $\% 8,6$ & 5869 & $\% 91,4$ \\
\hline 1999 & 6338 & 644 & $\% 10,2$ & 5694 & $\% 89,8$ \\
\hline 2000 & 6434 & 730 & $\% 11,3$ & 5704 & $\% 88,7$ \\
\hline 2001 & 6505 & 809 & $\% 12,4$ & 5696 & $\% 87,6$ \\
\hline 2002 & 6275 & 824 & $\% 13,1$ & 5451 & $\% 86,9$ \\
\hline 2003 & 6301 & 758 & $\% 12,0$ & 5543 & $\% 88,0$ \\
\hline 2004 & 5570 & 539 & $\% 9,7$ & 5031 & $\% 90,3$ \\
\hline 2005 & 5790 & 717 & $\% 12,4$ & 5073 & $\% 87,6$ \\
\hline 2006 & 5717 & 729 & $\% 12,8$ & 4988 & $\% 87,2$ \\
\hline 2007 & 5575 & 692 & $\% 12,4$ & 4883 & $\% 87,6$ \\
\hline 2008 & 5572 & 693 & $\% 12,4$ & 4879 & $\% 87,6$ \\
\hline 2009 & 5638 & 826 & $\% 14,7$ & 4812 & $\% 85,3$ \\
\hline 2010 & 5749 & 904 & $\% 15,7$ & 4845 & $\% 84,3$ \\
\hline 2011 & 5931 & 903 & $\% 15,2$ & 5028 & $\% 84,8$ \\
\hline 2012 & 5933 & 882 & $\% 14,9$ & 5051 & $\% 85,1$ \\
\hline
\end{tabular}

Tablo 1. Türkiye'de Toplam Girişimci İçinde Kadın ve Erkek Girişimci Sayısı Kaynak: TÜIK, 1923-2009 Ístatistik Göstergeler, s.142, TÜIK 1923-2010 Ístatistik Göstergeler, s.143, TÜIK Türkiye İstatistik Yılliğl 2011, s.171, TÜIK, Türkiye İstatistik Ylllı̆̆ 2012, s.183 (Akt: Keskin, 2014, s.82).

Türkiye'de genel nüfus yapısı içerisinde, gelişmiş ülkeler göz önüne alındığı zaman, genel olarak "girişimci”" sayısının çok fazla artış göstermediği çok bilinen bir husustur. Tablo 1'de görüldüğü gibi, "girişimci” kavramı kapsamına, "kendi işini kuran ve işleten işveren" ile "kendi hesabına çalışan" kişiler dahil olduğu vakit, 1989 yılından 2012 yılları arasındaki girişimci sayısının artışında, en dikkat çeken konu, giderek "kadın girişimci" oranında bir yükselme görülürken, "erkek girişimci”" oranının düşüyor olmasıdır. Bu bulgu, bu çalışmanın temel varsayımlarından biri olan Türk ekonomisinde "kadın girişimcilerin” yerinin ve öneminin giderek yükselmekte olduğu tezini kanıtlayacak bir sonuç olarak dikkat çekmektedir.

\begin{tabular}{|c|c|c|c|c|c|}
\hline Y1l & $\begin{array}{c}\text { Eğitim alan } \\
\text { Kişi Sayısı }\end{array}$ & Kadın & $\%$ & Erkek & $\%$ \\
\hline 2012 & 57.192 & $\sim 25736$ & $\sim 45$ & $\sim 31456$ & $\sim 55$ \\
\hline $\mathbf{2 0 1 3}$ & $\mathbf{7 9 . 9 7 7}$ & $\mathbf{3 6 . 6 9 0}$ & $\mathbf{4 6}$ & $\mathbf{4 3 . 2 8 7}$ & $\mathbf{5 4}$ \\
\hline 2014 & 83.844 & $\sim 39406$ & $\sim 47$ & $\sim 44438$ & $\sim 53$ \\
\hline
\end{tabular}

Tablo 2. Türkiye'de KOSGEB Uygulamalı Girişimcilik Ĕ̆itimi Alan Kadın Ve Erkek Kişi Sayısı Kaynak: KOSGEB Faaliyet Raporu 2012/2013/2014 / Ankara 


\begin{tabular}{|l|l|l|l|l|l|l|l|}
\hline $\begin{array}{l}\text { Girişimcilik } \\
\text { Destek } \\
\text { Programı }\end{array}$ & $\begin{array}{l}\text { Destek Tutarı } \\
\text { TL }\end{array}$ & $\begin{array}{l}\text { Kendi işini } \\
\text { kurarak Hibe } \\
\text { Desteği Alan } \\
\text { İşletme sayısı }\end{array}$ & $\begin{array}{l}\text { Kadın } \\
\text { Girişimci } \\
\text { Sayısı }\end{array}$ & $\begin{array}{l}\text { Destek Tutarı } \\
\text { TL }\end{array}$ & \% & $\begin{array}{l}\text { Erkek } \\
\text { Girişimci } \\
\text { Sayısı }\end{array}$ & $\%$ \\
\hline 2012 & 52.182 .573 & 4.984 & 2.418 & 21.744 .457 & 48,5 & 2566 & 51,5 \\
\hline 2013 & 85.618 .415 & 8.077 & 3.992 & 38.434 .661 & 49,4 & 4085 & 50,6 \\
\hline 2014 & 107.409 .093 & 10.207 & 4632 & 48.866 .158 & 45,3 & 5575 & 54,7 \\
\hline
\end{tabular}

Tablo 3. Türkiye'de KOSGEB Uygulamalı Girişimcilik Eğitimi Alan Kişi Sayısı Ve Ĕ̆itim Sonrası İs Kuran Girişimci Sayısı Kaynak: KOSGEB Faaliyet Raporu 2012/2013/2014 / Ankara

Tablo 2'ye göre, Türk ekonomisinin “girişimcilik” potansiyelini harekete geçirme konusunda, doğrudan ve çeşitli kuruluşlar aracılığıyla "girişimcilik" eğitimleri düzenleyen, ayrıca sadece eğitim vermekle kalmayıp "hibe" ve düşük faizler karşılığında "teşvikler" veren KOSGEB'in "uygulamalı girişimcilik eğitimine" başvuran kişiler arasında kadınların oranının \%50'lere yaklaşması, "kadın girişimciliği”" kavramı ve bilincinin ne kadar yükselmekte olduğunun başka bir kanıtıdır. Tablo 3'e göre ise KOSGEB'in "uygulamalı girişimcilik eğitimine" katılan kadınların, yine yaklaşık \%50 oranında fiilen işletme kurmaları ve aktif olarak girişimcilik rolleri üstlenmeleri, son derece iyi bir başlangıç gibi görünmektedir.

\section{Denizli Kent Ekonomisinde Kadın Girișimciliği Olgusu Üzerine Bir Araştırma}

Türk ekonomisinin son yıllardaki parlayan yıldızı ve “Anadolu kaplanlarından” biri olarak tanımlanan Denizli kent ekonomisinde, Denizli Ticaret Odasının 2014 yılı verilerine göre, toplam 15.367 kayıtlı iş insanından, kadın şirket sahibi ve yönetici iş insanı sayısı 1860, şirket ortağı kadın girişimci sayısı 1382 şahıs işletmesi sahibi kadın girişimci sayısı 562 olup, toplam 3804 kadın iş insanı mevcuttur. Bu durumda, Denizli'deki kadın iş insanı oranı \%24,75, Türkiye'nin Tablo 1'de görülen 2012 yılına ait ortalama kadın iş insanı oranından $(\% 14,9)$ daha fazladır. Denizli'de kadınların iş gücüne katılım oranı yalnızca girişimcilik düzeyinde değil bütün olarak da Türkiye ortalamasının üzerindedir. Türkiye Ekonomi Politikaları Araştırma Vakfi'nın kadınların iş gücüne katılımıyla ilgili raporunda Türkiye genelinde kadınların \%28,8'inin iş gücüne katılırken Denizli'de bu oranın \%37,8 olduğu belirtilmiştir (Tepav, 2012).

Denizli kent ekonomisinin gelişmesinde, çok etkili ve önemli işlevler yüklenen KOSGEB'in yürüttüğü uygulamalı girişimcilik eğitiminden yararlanan ve ayrıca bu kurslarda başarılı olduktan sonra gerekli şartlara sahip olmaları sebebiyle "hibe" ve "düşük faizli" krediler kullanmak suretiyle yeni iş kuran kişilerin yarıdan yarıya "kadın girişimciler" olması, Denizli kent ve dolayısıyla Türk ekonomisinin geleceği bakımından son derece ümit verici bir eğilimdir.

\begin{tabular}{|c|l|r|r|r|r|r|}
\hline & & Kadın & Oran & Erkek & Oran & Toplam \\
\hline \multirow{4}{*}{ Eğitim Alan Kişi Sayısı } & $\mathbf{2 0 1 2}$ & 479 & $\% 47,4$ & 532 & $\% 52,6$ & 1011 \\
\cline { 2 - 7 } & $\mathbf{2 0 1 3}$ & 182 & $\% 41,4$ & 258 & $\% 58,6$ & 440 \\
\cline { 2 - 7 } & $\mathbf{2 0 1 4}$ & 390 & $\% 50,3$ & 386 & $\% 49,7$ & 776 \\
\cline { 2 - 7 } & Toplam & $\mathbf{1 0 5 1}$ & $\mathbf{\% 4 7 , 2}$ & $\mathbf{1 1 7 6}$ & $\mathbf{\% 5 2 , 8}$ & $\mathbf{2 2 2 7}$ \\
\hline \multirow{4}{*}{$\begin{array}{c}\text { Eğitim Sonrası İş Kuran } \\
\text { Kişi Sayısı }\end{array}$} & $\mathbf{2 0 1 2}$ & 33 & $\% 48,5$ & 35 & $\% 51,5$ & 68 \\
\cline { 2 - 7 } & $\mathbf{2 0 1 3}$ & 36 & $\% 52,2$ & 33 & $\% 47,8$ & 69 \\
\cline { 2 - 7 } & $\mathbf{2 0 1 4}$ & 46 & $\% 47,9$ & 50 & $\% 52,1$ & 96 \\
\cline { 2 - 7 } & Toplam & $\mathbf{1 1 5}$ & $\mathbf{\% 4 9 , 4}$ & $\mathbf{1 1 8}$ & $\mathbf{\% 5 0 , 6}$ & $\mathbf{2 3 3}$ \\
\hline
\end{tabular}

Tablo 4. Denizli’de KOSGEB Uygulamalı Girişimcilik Eğitimi Alan Kişi Sayısı Ve Ĕ̆itim Sonrası İş Kuran Girişimci Sayısı

Denizli kent ekonomisine, yeni girişimci iş insanları yetiştirme konusunda hizmet veren sivil toplum kuruluşlarından biri de Dengider (Denizli Girişimcilik Derneği)'dir. Bu girişimcilik derneğinin, KOSGEB kapsamında yürütmekte olduğu uygulamalı girişimcilik eğitimine katılmak suretiyle kendi hesaplarına çalışmak üzere iş kuran toplam kişilerin, cinsiyet olarak yarısına yakın bir kısmının "kadın girişimci” bireyler olması, kadın girişimciliğinin yükselme eğilimi ve yönelimi bakımından oldukça dikkat çekicidir. 


\begin{tabular}{|l|c|c|c|c|c|}
\hline & Kadın & Oran & Erkek & Oran & Toplam \\
\hline $\mathbf{2 0 1 0}$ & 126 & $\% 43,9$ & 161 & $\% 56,1$ & 287 \\
\hline $\mathbf{2 0 1 1}$ & 329 & $\% 51,2$ & 313 & $\% 48,8$ & 642 \\
\hline $\mathbf{2 0 1 2}$ & 288 & $\% 47,3$ & 321 & $\% 52,7$ & 609 \\
\hline $\mathbf{2 0 1 3}$ & 80 & $\% 58,8$ & 56 & $\% 41,2$ & 136 \\
\hline $\mathbf{2 0 1 4}$ & 281 & $\% 49,3$ & 289 & $\% 50,7$ & 570 \\
\hline $\mathbf{2 0 1 5}$ & 352 & $\% 49,1$ & 365 & $\% 50,1$ & 717 \\
\hline $\mathbf{2 0 1 0 - 2 0 1 5}$ arası toplam & 1456 & $\% 49,5$ & 1505 & $\% 50,8$ & 2961 \\
\hline
\end{tabular}

Tablo 5. İ̧̧kur kapsamında Girişimcilik Ĕ̈itim Programına Katılan Kadın ve Erkek Kişi Sayısı

Türkiye'de iş piyasasını kamu adına düzenleyen ve yeni istihdam alanları yaratılması ile mevcut iş alanları için vasıflı insan gücü temin edilmesi konusunda hizmet veren Denizli İli İş Kur'un yürüttüğü "girişimcilik eğitimine" katılan kadın ve erkek girişimci aday sayılarının, yaklaşık \%50 etrafında birbirine eşit oranda olması, diğer kuruluşlardaki benzer bulgularla büyük ölçüde örtüşmektedir.

\begin{tabular}{|c|c|c|c|c|c|c|c|}
\hline \multirow[t]{2}{*}{ Yil } & \multirow{2}{*}{$\begin{array}{l}\text { Eğitim } \\
\text { alan kişi } \\
\text { Sayıs1 }\end{array}$} & \multirow{2}{*}{$\begin{array}{l}\text { İş } \\
\text { kuran } \\
\text { Sayıs1 }\end{array}$} & \multicolumn{4}{|c|}{ Kendi İşini Kuran Sayısı } & \multirow{2}{*}{ Eğitim Veren Kuruluşlar } \\
\hline & & & Kadın & $\%$ & Erkek & $\%$ & \\
\hline 2014 & 165 & 14 & 6 & 43 & 8 & 57 & Dengider \\
\hline -Mayıs 2015 & 148 & 8 & 4 & 50 & 4 & 50 & Dengider \\
\hline
\end{tabular}

Tablo 6. KOSGEB Kapsamında Dengider (Denizli Girişimcilik Derneği) Aracıllğ̆yyla Uygulamalı Girişimcilik Eğitimi Alarak Kendi Işsini Kuran Kadın Ve Erkek Kişsi Sayısı Kaynak: Dengider

Türkiye'nin en etkili "girişimci” kentlerinden biri olarak dikkat çeken Denizli'de, çok sayıdaki sivil toplum kuruluşları içerisinde önemli bir yeri bulunan Dengider (Denizli Girişimcilik Derneği) kapsamında yürütülen "girişimcilik eğitimine" katılan kişilerden, kendi işini kurmayı başaran kişiler arasında oran olarak kadın ve erkek girişimcilerin birbirine yakınlı̆ niteliktedir. Bu bağlamda, Denizli kırsalı ve açık pazarları incelendiğinde ağırlıklı olarak kadınların tarım, hayvancilık, el işleri ve dokuma vb. sektörlerde girişimcilik örneği sergiledikleri ve ürünlerini yine kendileri satarak ticaret yaptıkları gözlemlenmektedir. Bizzat, "uygulamalı girişimcilik eğitimi”" aldıkları sırada, dernek yöneticileri ile eğitmenlerin gözlemlerine göre, kursa katılan "kadın girişimci" adayların verilen bilgi ve becerileri kendi zihinlerinde sentezleyerek, eğitmenlere yeni sorular sormak suretiyle "erkek girişimci" adaylara nazaran, "girişimcilik" konusunda daha istekli ve arzulu olduklarını ortaya koymuşlardır.

Bu çalışma kapsamında, Denizli'de 2015 yılında KOSGEB Girişimcilik Eğitimi'ne katılarak kendi işletmelerini kuran yedi kadın girişimci ile konuya ilişkin mülakat tasarlanmıştır. Bu girişimcilerden iki tanesi, işyerinde bulunamadığından beşiyle yapılandırılmış mülakat yapılmıştır. Farklı eğitim durumlarında, farklı yaşlarda olan girişimci kadınlar arasındaki en önemli ortaklık ise hepsinin daha önce başka işlerde çalışmış olmalarıdır. İlkokul mezunu olan iki girişimci, 12 yaşından bu yana tekstillerde çalıştıklarını ifade etmişlerdir. Lise ve üniversite mezunu olanlar da mezuniyetlerinden itibaren çalışma hayatının içinde olduklarını belirtmişlerdir. İlkokul mezunu olan girişimcilerin daha önce yaptıkları işler ile kurdukları işletmeler arasında bir bağlantı olduğu tespit edilmiştir. İkisi de tekstil sektöründe çalışan kadınlardan biri tekstil ürünleri satan bir tuhafiyeci, diğeri ise kendi tasarımlarını dikebildiği bir moda evi açmışıı. Lise ve üniversite mezunu olan kadınlar ise daha önceki işlerinden ve eğitim aldıkları alandan başka alanlara yönelmişlerdir. Daha önce eşinin gözlükçü dükkanında çalışan kadın girişimci, aile çay bahçesi işletmeye başlamış, önceden bankacı olan girişimci hayalindeki şekerleme dükkanını açmış, turizm işletmeciliği bölümünden mezun olan genç girişimci ise hazır giyim sektöründe bir butik işletmeye başlamış̧ır. Kurdukları girişimin işletmesini bütünüyle üstlenen girişimcilerin henüz kimseyi istihdam etmedikleri ancak aile bireylerinden destek aldıkları görülmüştür. Moda evi işleten girişimci eşiyle beraber, butik işleten girişimci ise annesiyle beraber çalışıklarını belirtmiştir. Tuhafiye işleten girişimci, çalışma saatlerinin uzun olması nedeniyle çocuklarının da kendisine destek olduklarını söylemiştir. Aile çay bahçesi ve şekerleme dükkanlarında ise girişimciler yalnız çalışmaktadır ancak yanlarında bir kaç işçi çalıştırmak istediklerini belirtmişlerdir. Henüz işletmeleri oldukça yeni olduğu için yalnız çalıştıklarını, zamanla büyümek istediklerini eklemişlerdir.

Görüşülen bütün girişimciler, KOSGEB'den hibe desteği almak üzere projelerini hazırladıklarını ve teslim ettiklerini, yapılan inceleme sonucunda desteklenme kararını beklediklerini ifade etmişlerdir. KOSGEB'den aldıkları girişimcilik eğitiminin oldukça faydalı olduğunu, daha önce bilmedikleri pek çok şeyi öğrendiklerini belirten girişimciler, girişimci olmanın bireysel kararları olduğunu eklemişlerdir. Özellikle tekstilde çalıştıkları dönemlerle kıyasladıklarında şimdiki işlerinin kendilerine güven kazandırdı̆̆ını, kendi işine sahip olmanın bir rahatık ve ayrıcalık olduğunu söylemişlerdir. Moda evi ve şekerleme dükkanı açan kadınlar, Denizli'de bu alanlarda bir eksiklik olduğunu tespit ettikleri için bu işletmeleri açmaya karar verdiklerini vurgulamışlardır. Moda evinde kendi tasarımlarını yapan, müşterilerden gelen talepler doğrultusunda istediğini dikebilen özel bir çalışma yaptığını belirten girişimci, belirli başlı ürünler yapabilen terzilerden farklı olduğunu ifade etmiştir. 
Şekerleme dükkanı açan işletmeci ise dükkanında hem lokum, şekerleme gibi ürünlerini sattığını hem de bu ürünlerin tadılabileceği, oturulup bir şeyler yenilip içilebileceği bir kafe konseptiyle işletmesini kurduğunu belirtmiştir.

\section{Sonuç}

Küreselleşme sürecine bağlı olarak Dünya ekonomisinin, serbest piyasa ekonomisi kurumları ve kurallarının, zengin Batı'lı ülkeler lehine olmak üzere giderek tekelleşmesi, dünya nüfusunun çok önemli bir kısmının temel yaşama hakkını tehdit edecek bir konuma gelmiştir. Bilindiği gibi, kapitalist piyasa ekonomisinin temel amacı, ne pahasına olursa olsun, kimlerin canı yanarsa yansın, mümkün olabilen en yüksek ve dolgun kâr elde etmektir. Liberal-kapitalist sistemin, güçlü olanın zayıf olan üzerinde kendi gücü ölçüsünde bir egemenlik kurma hakkı olduğu zihniyetine dayalı bir hayat felsefesi olarak "Sosyal Darvinizm" düşüncesi ile birlikte tarih sahnesine çıkması çok manidar bir olgudur. Bu bağlamda, küresel kapitalist sistem, maliyet fiyatlarını en aza indirirken satış fiyatlarının en yükseğe çıkarılması tutkusu ile adeta her türlü insan, kaynak ve doğa istismarı yapmaktan kaçınmamaktadır. Soyut ekonomik ilke ve kurallar ile toplumsal kalkınmayı temel alan ulusal çıkar merkezli ekonomilerde, ekonomik ve işletmecilik faaliyetlerine esas yön veren düşünce, ülke kaynaklarının öncelikle o ülke toplumunun ihtiyaçlarına ve amaçlarına cevap verebilecek tarzda gerçekleştirilmesidir. Oysa küreselleştirilen kapitalist sistem, dünya ekonomisinde hegemonik bir şekilde "merkez-çevre" ikilemi oluşturmak suretiyle kontrol altındaki ülke ve bölgelerdeki ekonomik ve işletmecilik faaliyetlerini, kendilerinin bir arka bahçesi haline getirme stratejisini uygulamaya çalışmaktadır.

Dünya ekonomisindeki küreselleştirme dayatmalarının sonucunda, "sermaye hareketliliği", "malların serbest dolaşımı", "fason üretim", "şirket evlilikleri" ve "emeğin "taşeronlaşması" gibi uygulamalar soncunda, gerçekte önceki zamanlara göre daha fazla "finansal yatırımlar", daha fazla "ticaret hacmi", daha fazla "gelir imkânları" ve daha fazla "zenginleşme" gibi ekonomik göstergelerde fiziki ve rakam olarak büyük artı̧lar meydana gelmiştir. Ancak, küreselleşen dünya ekonomisindeki bütün bu artı̧̧lar ve olumlu göstergeler, zengin ülkelere yüksek bir refah sağlarken, yoksul ülkelerde belirli bir zümrenin serveti artarken, genel olarak bu ülkelerin aşırı iç ve dış borçlanmalara dayalı olarak ithalatlarında çok büyük artışlar meydana gelmiştir. Bu yoksul ülkelerdeki gelir dağılımındaki adaletsizlikler ve üretim ekonomisinin çöküşüne bağlı olarak ortaya çıkan işsizlik durumu, zaten var olan yoksul kesimlerin daha fazla yoksullaşmasına yol açmıştır. Ayrıca, bu çevre ülkelerin ekonomilerinde yolsuzluk ve hırsızlıkta adeta bir patlama meydana gelmiştir. Bu çerçevede, çevre ülkelerinin işbirlikçi siyasetçi-yönetici kesimi ile mutlu bir işveren grubunun gelir düzeylerine ve yaşama tarzlarında çok ciddi bir refah artışı ve hatta ülke gerçekleriyle büyük bir çelişki ve tutarsızlık oluşturacak şekilde vahşi bir israf ekonomisi sergilenmektedir. Küreselleşme süreci, serbest piyasa ekonomisinin yaratacağı büyük bir ekonomik sinerji ile kaynakları harekete geçirecek, sermaye hareketlerinin sayesinde fiziki yatırımları artıracak, işsizlikleri önleyecek, kayıt dışı ekonomik faaliyetleri engelleyecek, orta gelir tuzağına son verecek, yönetici hırsızlıklarını bitirecek ve sonuçta bütün dünya insanlarını ve toplumlarını çok mutlu edecekti. Fakat küreselleşme sürecinin son on yıllık uygulamalarına bakılacak olursa, özellikle küreselleşme "merkezleri" ile içli-dışlı olan "çevre ülkelerindeki" bütün toplumun büyük fedakarlık ve çabalarıyla elde edilmiş olan sermaye birikimleri ile kamu mülkiyet araçlarının, büyük ölçüde toplumun çoğunluğunun aleyhine olacak şekilde el değiştirmiş olduğu görülür. Bir takım dayatmalar sonrasında küreselleştirilen çevre ülkelerinde, ulusal ekonomiler çağında bir şekilde harekete geçmiş olan "üretim eksenli" sanayileşme duygusu yerine, son zamanlarda kolay yoldan ve hatta gayri meşru yollardan gelir elde etme tutkusuna dönüşmüştür. Bu durum, henüz toplumsal kalkınmasını tamamlayamamış ve orta sınıflaşmayı başaramamış olan çevre ülkelerinde, vahşi ve ölçüsüz bir "rant ekonomisine" yol açmıştır. Aslında, "rant ekonomisi", bir anlamda "hırsızlık" ve "hak edilmeyen gelirlerin" ekonomisidir. "Rant ekonomisi", toplumsal üretim ve meşru kazanç yollarını tıkayarak, üst gelir gruplarının çoğunun "üretmeden zenginleşmelerini" teşvik eder; alt gelir gruplarının çoğunu ise "beleşçiliğe" ve "bedavacılığa" alıştııır. Bu durum ise bir bakıma, hem sosyo-ekonomik anlamda, hem de sosyo-psikolojik anlamda bir çürümeye işarettir.

Küreselleşme sürecinin, "merkez" ülkelerine çok büyük rantlar sağlarken, aynı sürecin "çevre" ülke halkının çoğunda çok büyük hayal kırıklıklarının yaratılmış olması, bugünkü dünya ekonomisinin yaşamakta olduğu en büyük çelişki ve tutarsızlığıdır. Bu bağlamda, çevre ülkelerinin, özellikle kendi kaynaklarından, öncelikle kendi halklarının yararlanması ve bu gelişmelere bağlı olarak bu toplumlarda açık bir "orta sınıflaşmanın" gerçekleştirilmesi, büyük ölçüde yaratılacak olan "girişimci" bir sınıfın yaratılmasıdır. "Girişimci" bir sınıf, öncelikle ekonomik faaliyetlerin ve üretim ekonomisinin daha geniş bir tabana yayılmasına öncülük edecektir. Toplum nüfusunun tamamı, zorunlu olarak "tüketici" olmak durumundadır. Yaygın ve dinamik bir "girişimci" sınıf aracılığıyla toplum nüfusunun "faal nüfus" denilen kesimin çok büyük bir kısmına, "üreticilik" niteliği kazandırmak ve belirli bir gelir kazanç sahibi yapmak, toplumsal kalkınmanın ve "orta sınıflaşmanın" gerçekleştirilmesinin zorunlu şartlarından biridir. Bu çerçevede, çevre ülkelerinin "faal nüfusunun" ortalama olarak yarısını teşkil eden kadınların, öncelikle çalışma hayatına katılması ve bu sosyal ve ekonomik tecrübelerden yararlanarak, esas itibarıyla onların potansiyel "girişimcilik" yetenek ve becerilerini, toplum ve ülke hizmetine sunmak, yoksul ülkeler ile bu ülkelerdeki yoksul insanların ekonomik refah düzeylerinin global 
yükselişinde, 21. Yüzyılın ortaya koyacağı en büyük devrimlerden biri olacaktır. Bu anlamda, yeni küresel ekonomik düzende, yoksul çevre ülke ve toplumlarında, genelde "girişimcilerin" sayısının artırılması, özelde "kadın girişimciliğinin” teşviki, elbette diğer etkili faktörlerle beraber, bu toplumlar için çok açık bir kurtuluş reçetesi gibi görünmektedir.

Türkiye, mevcut coğrafi ve stratejik konumu, yer altı ve yer üstü doğal kaynakları, genç nüfus yapısı, eğitilmiş insan gücü potansiyeli ile dünya ekonomisinin en dinamik ve önemli ekonomik aktörlerinden biri olma potansiyeline sahiptir. Türkiye, Türkçe'deki, "Durgun su, pislik üretir" veya "Akan su, pislik tutmaz" özdeyişi doğrultusunda, diğer etkenlerle birlikte, özellikle yeterince "girişimci" sınıfı bulunmadığından dolayı mevcut potansiyel gücünü harekete geçirmemiş ve bu çağa uygun "yönetim sistemini” kuramamıştır. Bu yüzden de, birçok sosyo-ekonomik, siyasi ve güvenlik konularında ciddi sorunlar yaşamaktadır. Bütün bu sorunların çözümünde, özellikle "kadın girişimciliğinin” öncülüğünde, toplumda yaratılacak genel bir "girişimcilik iklimi”, yaygın bir toplumsal kalkınma ve "orta sınıflaşma” ülküsünün fiilen gerçekleşmesine katkıda bulunabilir.

Bu çalışmada, Türk ekonomisinde "girişimcilik" yönü ile Türkiye ihracatında önemli bir yere sahip olmakla bilinen Denizli kent ekonomisinin, "kadın girişimciliğinin” ciddi bir alt yapısının ve davranışsal yatkınlığının bulunduğu, çeşitli kurum ve kuruluşlar tarafından yürütülen uygulamalı girişimcilik eğitimi kapsamında, son yıllardaki "kadın girişimciliğgi" ile ilgili rakamlar ve yapılan mülakatlar üzerinden ortaya konmaya çalışılmıştır. $\mathrm{Bu}$ rakamlara göre, son yıllarda çeşitli kurum ve kuruluşlar tarafından yürütülen "uygulamalı girişimcilik eğitimlerine", Denizli'li kadınların neredeyse erkekler kadar ilgi gösterdikleri ve gerekli şartları sağlayarak kendi adlarına yeni işyerleri kurdukları açıkça görülmektedir

Sonuç olarak, Türk toplumsal kalkınma ve orta sınıflaşma ülküsünün başarıya ulaşması, dengeli ve sağlıklı bir iktisadi ve siyasi demokrasinin kurulabilmesi bağlamında, "kadın girişimciliğgi" öncülüğünde genel bir girişimcilik seferberliğinin başlatılmasının, son derece yararlı olacağı izlenimi edinilmiştir. Bu bağlamda, Denizli kent ekonomisi üzerinden Türk ekonomisine, "kadın girişimciliğinin” daha fazla yükseltilmesini sağlayacak bazı tedbirler alma zorunluluğu vardır. Bunları şu şekilde sıralamak mümkündür:

Denizli Girişimcilik Derneğinin 2014 yılında düzenlemiş olduğu girişimcilik eğitimine katılan 165 kişiyle yapılan mülakat ve gözlemden, eğitim süresinin daha uzun olması ve kurs sonrasında mutlaka sınav yapılması gereğini ortaya koymaktadır. Bundan başka, adı "girişimcilik eğitimi” olan bir kursta katılımcılara, bilgiden ziyade özellikle ve öncelikle "girişimci nitelikleri” kazandırıcı bir muhtevada eğitim verilmesi gerekmektedir.

Ticaret Odalarının üyelerinden topladığı aidatlardan oluşan ve çok büyük bir meblağa ulaşmış olduğu düşünülen bu parafiskal gelirlerin, oda yönetimlerince kadın girişimciliğinin daha fazla geliştirilmesi maksadına yönelik olarak uygulamalı girişimcilik eğitimi ve iş kurma aşamasında mali destek sağlanması şeklindeki hizmetlerinin yasal zorunluluk haline getirilmesi uygun olacaktır.

\section{Kaynakça}

- Akpınar, Selma (2009). Girişimciliğin Temel Bilgileri, Umuttepe Yayın No: 11, İzmit-Kocaeli.

- Bilgiseven, Amiran Kurtkan (1987). Eğitim Sosyolojisi, Türk Dünyası Araştırmaları Vakfı Yayını, 26.

- Ecevit, Yıldız (1993). Kadın Girişimciliğin Yaygınlaşmasına Yönelik Bir Model Önerisi, Kadın Girişimciliğe Özendirme ve Destekleme Paneli, Bildiriler ve Tartışmalar, Devlet Bakanlığı Kadın ve Sosyal Hizmetler Müsteşarlığı Kadının Statüsü ve Sorunları Genel Müdürlüğü, Eğitim Serisi, Yayın No: 74.

- Ertürk, Mümin (2011). İşletme Biliminin Temel İlkeleri, Beta Yayın No:2376, İstanbul.

- Gürol, Mehmet Ali (2006). Girişimci ve Girişimcilik, Gazi Kitabevi, Ankara.

- İrmiş, Ayşe; Emsen, Ö.Selçuk (2002). İktisadi Gelişmede Girişimcilik, Denizli ve Erzurum Örneği, Beta Yayınları No:1236, İstanbul.

- İ̀miş, Ayşe; Durak, İbrahim; Özdemir, Lütfiye (2010). Girişimcilik Kültürü, Anadolu Girişimciliğinden Örnekler, Ekin Basın Yayın, Bursa.

- Keskin, Sevtap (2014). "Türkiye'de Kadın Girişimcilerin Durumu", Girişimcilik ve Kalkınma Dergisi, 9, 1, s.77, s.81.

- Koç, Mustafa (2011). Girişimciler İçin 1001 Kârı İş Fikri, Girişimcilik ve Krizlere Karşı Stratejiler, Denizli.

- Kök, Sabahat Bayrak (2007). Küçük ve Orta Ölçekli İşletmeler ve Kadın Girişimciliği, Denizli Ticaret Odası Ekonomik Araştırma Serisi Yayın No:1, Ankara.

- Sharma, Pramodita and Chrisman, James J. (1999). "'Toward a Reconciliation of the Definitional Issues in the Field of Corporate Entrepreneurship", Entrepreneurship Theory And Practice, Spring, p.12.

- Soysal, Abdullah (2010). "Türkiye'de Kadın Girişimciler: Engeller ve Fırsatlar Bağlamında Bir Değerlendirme", Ankara Üniversitesi SBF Dergisi, 65, 1, s.85. 
- Türkiye Ekonomi Politikaları Araştırma Vakfi (2012). Türkiye'de Kadınların İşgücüne Katılımı. http://www.tepav.org.tr/upload/files/13557697899.Turkiye_de_Kadinlarin_Isgucune_Katilimi Istanbul _ve_Ankara_da_Katilim_Bingol_ve_Tunceli_ile_Ayni.pdf: Erişim Tarihi: 24/06/2015.

- $\quad$ Ülgen, Hayri; Mirze, S.Kadri (2004). İşletmelerde Stratejik Yönetim, Literatür Yayınları No: 113, İstanbul.

- $\quad$ Ülken, Yüksel (1974). 20. Yüzyılda Dünya Ekonomisi, Günümüzün İktisadi Sorunları ve Başlıca Tahlil Aletleri, İstanbul Üniversitesi İktisat Fakültesi Yayın No:326, İstanbul.

- Yurtsever, Gülçimen; Atış, Caner; Yurtsever, Şaziye (2006), Girişimcilik, Karahan Yayınları:48, Adana. 


\title{
Eğitim ve Kültürün Girişimciliğe Etkisi: Geçiş Ekonomilerinden Kırgızistan'da Üniversite Öğrencilerine Yönelik Saha Araştırması The Effect of Entrepreneurship Education and Culture, the Transition Economies of Field Research for University Students in Kyrgyzstan
}

\author{
Asst. Prof. Dr. Çağatay Karaköy (Cumhuriyet University, Turkey) \\ Asst. Prof. Dr. Necati Alp Erilli (Cumhuriyet University, Turkey) \\ Asst. Prof. Dr. Sema Babayiğit (T.C. Melikşah University, Turkey) \\ Emine Rabia Ersoy (Cumhuriyet University, Turkey)
}

\begin{abstract}
In modern production labor, capital and natural resources the fourth factor is included as an element of entrepreneurship, participation or implementation in the production as profit or loss to the performing element is faced with. According to the other production factors are dealt with more risk element of the entrepreneur, as well as entrepreneurial function with the same time in economic growth locomotive power is on. For many years, enterprise element carrying out the state interference in socialist countries, the collapse of the iron curtain in 1991 transitional recession and hyperinflation become inevitable experience. In other expression, economic developments and social life as result of the change in the importance of the concept of entrepreneurship has been further increased. Entrepreneurship is a kind of genetic element, or is it potential education and draw from revealing whether the topic of discussion is. The resulting depending on these two alternative viewpoint even equipped with higher education made the younger generation in production as well as the tendency to have more skilled labor force as reflection of education they receive visions of their enterprise ability to affect. Determination of specifications of entrepreneurship of university students, the entrepreneurial potential of development of the country's important step because on of this property is the value of interest. The main objective of this research, long time socialist system managed entrepreneurial characteristics of university students in Kyrgyzstan determinants will be examined.
\end{abstract}

\section{Giriş}

Günümüzde üniversitelere toplum tarafından yeni roller yüklenmekte ve bu yönde çalışmalar yapması beklenmektedir. Eğitimin yanı sıra ekonomik kalkınmaya destek vermeleri de beklenmektedir. Ekonomik kalkınmaya ise üniversiteler direkt olarak değil de dolaylı yollardan destek olabilirler. Birçok üniversite araştırama geliştirme çalışmalarında tekno kenti kullanarak direkt destek vermektedir bazıları ise eğitim sistemleri içerisinde girişimcilik derslerini de ekleyerek dolaylı katkı sağlamaktadırlar. Uzun süre piyasaya devletin hakim olduğu merkezi Asya ülkeleri özellikle 90’lardan sonra kendilerini geçiş süreci içerisinde bulmuşlardır. Bu süreç aynı zamanda yapısal sorunları ve ekonomik krizleri de beraberinde getirmiştir. Diğer bir ifadeyle ekonomik gelişmeler ve sosyal yaşamdaki değişimler neticesinde girişimcilik kavramının önemi daha da artar olmuştur. Girişimciliğin bir tür genetik unsur mu, yoksa eğitim ile açığa çıkartılabilecek bir potansiyel mi olup olmadığı tartışma konusudur. Üniversite öğrencilerinin girişimcilik özelliklerinin belirlenmesi, ülkelerin girişimcilik potansiyelini geliştirmenin önemli adımlarından birisini oluşturduğundan, bu özelliklerin incelenmesi ilgiye değerdir. Bu çalışmanın amacı ise, her biri potansiyel birer girişimci adayı olan üniversite öğrencilerinin girişimcilik eğilimlerini tespit etmek, bu eğilimleri etkileyen faktörleri belirlemek ve bu faktörlerin fakülteler arasında bir farklılık gösterip göstermediğini araştırmaktır. Böylece, mezun olacak üniversite öğrencilerinin, girişimcilik özellikleri yönünden ne kadar yeterli olduğu incelenerek, sorunun çözümüne yönelik öneriler geliştirilecek ve bu bölgede yaşayan insanların girişimcilik yönünün araştırılması, geliştirilmesine katkı sağlanabilecektir. Dolayısıyla Kırgızistan'ın en önemli eğitim kurumlarından biri olan Kırgızistan- Rusya Slavyanski Üniversitesinin farklı fakülteleri arasında anket çalışması yapılmış ve sonuçlar değerlendirilmiştir.

\section{Literatür Araştırması}

Ülke ekonomileri açısından girişimciliğin önemi bilinen bir gerçektir. Kalkınmayı gerçekleştirebilmek için girişimciliğin ne denli öneli olduğunu ve girişimciliğin doğuştan mı yoksa daha sonra edinilebilen bir özellik mi olduğunun merak edilmesi, bu konudaki çalışmaları da beraberinde getirmiştir. Tablo 1'de günümüzde bu konu ile ilgili çalışmaların genel bir literatür taraması verilmiştir. Birçok çalışma girişimeiliğin bireysel özelliklerden olabileceği gibi eğitim yoluyla da artırılabileceği konusunda hem fikirdir. Girişimciliğin geliştirilmesi konusunda büyük rol oynayan eğitim kurumları ve bunların başında da üniversiteler bulunmaktadır. Üniversitelerdeki ders 
programlarına girişimcilik derslerinin eklenmesi, girişimcilik ruhunu etkileyebilecek ve ortaya çıkmayan kendini gösteremeyen girişimcilerin de kendilerini bulmalarını sağlayabilecektir.

\begin{tabular}{|c|c|c|c|}
\hline Yazar (1ar) & Kapsam ve Dönem & Yöntem & Sonuç \\
\hline Aytaç (2006). & $\begin{array}{l}\text { Dumlupınar } \\
\text { Üniversitesi Sosyal } \\
\text { Bilimler Dergisi,/15: }\end{array}$ & $\begin{array}{l}\text { Girişimcilik: Sosyo- } \\
\text { Kültürel Bir Perspektif }\end{array}$ & $\begin{array}{l}\text { Girişimci olmayı etkileyen üç faktörden bahsetmiş. } \\
\text { İlki bireyin cinsiyeti eğitimi ailesi ve çevresi, ikincisi } \\
\text { çocukluk dönemi, demografik faktörler, son olarak } \\
\text { kişisel niteliklerdir. }\end{array}$ \\
\hline Çetin Murat, (2007). & $\begin{array}{l}\text { Ege Akademik } \\
\text { Bakış,7/1 }\end{array}$ & $\begin{array}{l}\text { "Bölgesel Kalkınma ve } \\
\text { Girişimci Üniversiteler", }\end{array}$ & $\begin{array}{l}\text { Akademik çevrede girişimcilik kültürü ve } \\
\text { prensiplerini yerleştirmeye çalışan girişimci } \\
\text { üniversitelerin en önemli rolü, bölgesel ve ulusal } \\
\text { refah artışını destekleyecek şekilde girişimcilik } \\
\text { üzerinde yoğunlaşmaktır }\end{array}$ \\
\hline İlter Berfu, (2008). & $\begin{array}{l}\text { Sosyal Bilimler } \\
\text { Enstitüsü, Doktora } \\
\text { Tezi, Afyonkarahisar }\end{array}$ & $\begin{array}{l}\text { Girişimcilik Sürecinde } \\
\text { Kadın Girişimcilerin } \\
\text { Karşılaştıkları Sorunların } \\
\text { Analizi: Kagider Örneği, }\end{array}$ & $\begin{array}{l}\text { Girişimciliğin gelişebilmesi için toplum tarafından } \\
\text { kabul edilmesi gerekliliği üzende durmaktadır. }\end{array}$ \\
\hline $\begin{array}{l}\text { İbicioğlu Hasan, Özmen } \\
\text { H.İbrahim, TAŞ (2010). }\end{array}$ & $\begin{array}{l}\text { Alanya İşletme } \\
\text { Fakültesi Dergisi,2/1 }\end{array}$ & $\begin{array}{l}\text { Sebahattin, "Üniversite } \\
\text { Eğitiminin Girişimcilik } \\
\text { Düşüncesinin Değişimine } \\
\text { Etkisi: Üniversite } \\
\text { Öğrencileri Üzerine Bir } \\
\text { Uygulama" }\end{array}$ & $\begin{array}{l}\text { Girişimciliğgin eğitimle geliştirilebileceği ve } \\
\text { üniversitelerin bu konuda büyük bir role sahip } \\
\text { olduğudur. }\end{array}$ \\
\hline $\begin{array}{l}\text { Yüzüak Elif, Sosyal } \\
\text { Bilimler Enstitüsü, } \\
(2010) \text {. }\end{array}$ & $\begin{array}{l}\text { Yüksek Lisans Tezi, } \\
\text { Çanakkale }\end{array}$ & $\begin{array}{l}\text { Üniversitelerde Öğrenim } \\
\text { Gören Kı̈ Öğrencilerin } \\
\text { Girişimcilik Eğilimlerini } \\
\text { Etkileyen Faktörler: } \\
\text { Çanakkale On sekiz Mart } \\
\text { Üniversitesi Biga İ.İ.B.F. } \\
\text { Örneği, }\end{array}$ & $\begin{array}{l}\text { Üniversitelerin girişimcilik eğitimi vererek } \\
\text { öğrencilerin girişimcilik özelliklerini } \\
\text { artırabileceğinden bahsetmektedir. }\end{array}$ \\
\hline Kaygin Erdoğan, (2011). & $\begin{array}{l}\text { Sosyal Bilimler } \\
\text { Enstitüsü, Doktora } \\
\text { Tezi, Erzurum }\end{array}$ & $\begin{array}{l}\text { Girişimcilik Sürecinde } \\
\text { Dönüştürücü Liderlik } \\
\text { Anlayışı-Bir Uygulama }\end{array}$ & $\begin{array}{l}\text { Girişimciliğin problemlere ve sorunlara hemen cevap } \\
\text { verebilme yeteneğinden oluştuğu, firsatları } \\
\text { değerlendirebilme ve görebilmenin önemine } \\
\text { değinilmiştir. }\end{array}$ \\
\hline $\begin{array}{l}\text { Günel Ö.Devrim ve } \\
\text { Yilmaz B.Selin, (2011). }\end{array}$ & $\begin{array}{l}\text { Akademik Bakış } \\
\text { Dergisi, 26: }\end{array}$ & $\begin{array}{l}\text { "Üniversite Eğitimi ve } \\
\text { Girişimcilik: Bireyleri } \\
\text { Girişimciliğe Yönlendiren } \\
\text { Etkenler Üzerine Bir } \\
\text { Araştırma", }\end{array}$ & $\begin{array}{l}\text { Ulusal kalkınmanın gerçekleşmesi için girişimciliğin } \\
\text { öneminden bahsetmiştir. }\end{array}$ \\
\hline Er P.Hazel, (2012). & $\begin{array}{l}\text { Sosyal Bilimler } \\
\text { Enstitüsü, Yüksek } \\
\text { Lisans Tezi, Konya }\end{array}$ & $\begin{array}{l}\text { Girişimcilik ve Yenilik } \\
\text { Kavramlarının İktisadi } \\
\text { Düşüncedeki Yeri: Joseph } \\
\text { A.Schumpeter }\end{array}$ & $\begin{array}{l}\text { Ekonomik anlamadaki büyümenin sağlanmasında } \\
\text { girişimciliğin rolü üzerinde durulmuştur. }\end{array}$ \\
\hline Cici E.Nihan, (2013). & $\begin{array}{l}\text { Sosyal Bilimler } \\
\text { Enstitüsü, Yüksek } \\
\text { Lisans Tezi, Konya }\end{array}$ & $\begin{array}{l}\text { Kadınların Girişimcilik } \\
\text { Yolunda Karşılaştıkları } \\
\text { Sorunların Öz Girişimcilik } \\
\text { Yetenekleri Üzerindeki } \\
\text { Etkisi: Konya İlinde Bir } \\
\text { Araştırma, }\end{array}$ & $\begin{array}{l}\text { Günümüz dünyasında girişimci ruha sahip kişilerin } \\
\text { çok önemli olduğu, girişimciliğin genetik özelliğinin } \\
\text { yanı sıra eğitimle de geliştirilebileceğini ortaya } \\
\text { koymuştur. }\end{array}$ \\
\hline Mungan Seylan,( 2013). & $\begin{array}{l}\text { Sosyal Bilimler } \\
\text { Enstitüsü, Yüksek } \\
\text { Lisans Tezi, İstanbul }\end{array}$ & $\begin{array}{l}\text { Kadın Girişimcilik } \\
\text { Değerleri İle Kadın } \\
\text { Girişimcilik Algısı } \\
\text { Arasındaki İlişkide } \\
\text { Girişimcilik Eğitimlerinin } \\
\text { Rolü }\end{array}$ & $\begin{array}{l}\text { Girişimciliğin kişilerin kendisinden kaynaklanan bir } \\
\text { özellik olduğu görüşünün giderek öğretilebilir olduğu } \\
\text { yönünde değiştiğinden bahsetmektedir. }\end{array}$ \\
\hline $\begin{array}{l}\text { Meriç Sağbetullah, } \\
\text { (2013). }\end{array}$ & $\begin{array}{l}\text { Sosyal Bilimler } \\
\text { Enstitüsü, Yüksek } \\
\text { Lisans Tezi, Düzce }\end{array}$ & $\begin{array}{l}\text { Girişimcilik Potansiyeli İle } \\
\text { Etik Algı Arasındaki İlişki: } \\
\text { Akçakoca Turizm } \\
\text { İşletmeciliği ve Otelcilik } \\
\text { Yüksekokulu Örneği, } \\
\end{array}$ & $\begin{array}{l}\text { Girişimciliğin bireysel anlamda öneme sahip olduğu } \\
\text { dolayısıyla bireysel özelliklerin incelemeye değer } \\
\text { olduğundan bahsetmektedir. }\end{array}$ \\
\hline $\begin{array}{l}\text { Cin Hatice ve Yumuk G } \\
\text { Gülsevim,(2013). }\end{array}$ & $\begin{array}{l}\text { Girişimcilik ve } \\
\text { Kalkınma Dergisi }\end{array}$ & $\begin{array}{l}\text { Girişimcilerin Girişimcilik } \\
\text { Tipleri İle Duygusal } \\
\text { Zekâları Arasındaki İlişki: } \\
\text { "Edirne Örneği" }\end{array}$ & $\begin{array}{l}\text { Girişimcilerin farklı özelliklerinin girişimcilikte } \\
\text { büyük rol oynadığından bahsetmektedir. }\end{array}$ \\
\hline $\begin{array}{l}\text { Alaybeyoğlu Küçük } \\
\text { Kübra, (2014). }\end{array}$ & $\begin{array}{l}\text { Sosyal Bilimler } \\
\text { Enstitüsü, Yüksek } \\
\text { Lisans Tezi, Ankara }\end{array}$ & $\begin{array}{l}\text { Kişilik Özelliklerinin } \\
\text { Girişimcilik Davranışına } \\
\text { Etkisi: "Abant İzzet Baysal } \\
\text { Üniversitesi Örneği”" }\end{array}$ & $\begin{array}{l}\text { Kişinin kendisine ait olan özelliklerin ve içinde } \\
\text { bulunduğu ortamın, düşünce tarzının, kendini ifade } \\
\text { etme özgürlüğünün girişimciliği etkilediği üzerinde } \\
\text { durmuştur. }\end{array}$ \\
\hline
\end{tabular}

Tablo 1. Literatür Özeti 


\section{Analiz ve Sonuçlar}

Uygulamada Kırgızistan- Rusya Slavyanski Üniversitesi’nde 123 öğrenciye anket tekniği uygulanmış ve sonuçlar analiz edilmiştir. Anket sonuçları SPSS.22 paket programı yardımıyla değerlendirilmiş ve yorumlanmıştır. Analizde ilk olarak ankete katılan öğrencilere ait demografik bilgiler kısaca derlenmiştir. İkinci olarak anket çalışmasının temelini oluşturan "Fakülteyi bitirdikten sonraki mesleki idealiniz nedir?" ve "Mesleki tercihlerinizin oluşumunda etkin olan faktörler nelerdir?" sorularına verilen cevaplar ile ilgili görülen bazı sorular arasında çapraz tablolar oluşturularak yorumlanmıştır. Üçüncü olarak yukarıda verilen iki soru ile ilgili görülen bazı sorular arasında ki-kare analizi yapılmış ve bu sorulara verilen cevaplar ile ilgili değişkenler arasında fark olup olmadığı araştırılmıştır. Son olarak yukarıda verilen iki soruya verilen sıralamalar arasında korelasyon analizi uygulanmış ve yorumlanmıştır.

\section{Demografik Bilgiler}

Ankete katılanların öğrencilerin \%60'sı Sosyal Bilimler fakültesinde, \%33'ü Fen fakültesinde ve \%7'si Sağlık fakültesinde öğrenim görmektedir ve \%38'i bayan, \%62'si erkektir. Öğrencilerden Kırgızca eğitim görenlerin oranı \%89, Rusça eğitim görenlerin oran1 \%8 iken diğer dillerde eğitim görenlerin oranı ise \%3'tür. Kırsal kesimde oturanların oranı \%25 iken kentsel kesimde oturanların oranı \%75 olarak bulunmuştur. Ankete katılanların dini inançlarına baktığımızda, \%68'inin Müslüman, \%20'sinin Hristiyan ve \%12'sinin de diğer dinlere ait olduklarını görülmektedir. Ankete katılan öğrencilerin uyrukları incelendiğinde, \%61 Kırgız, \%20 Rus, \%7 Çin, \%5 Kazak, \%2 Özbek kökenli öğrenciler oldukları belirlenmiştir. Bu çalışmaya katılan öğrencilerin \%45'i 3 veya daha fazla dil bilmekte ve \%79'u Çuy bölgesinde ikamet etmektedir. Ankete katılan öğrencilerin ailelerinin aylık gelirleri 15.000 Som'dan daha fazla olanların oran $\% 63$ iken 2 veya daha fazla kardeşe sahip olanların oranı ise \%49'dur. Öğrencilerin \%65'inin annesi, \%64'ünün ise babası yüksek lisans mezunudur. Öğrencilerin ebeveynlerinin meslek durumlarına baktığımızda ise, öğrencilerin babalarının \%50'si özel sektörde çalışırken annelerinin \%44’ü özel sektörde çalışmaktadır. Benzer şekilde babalarının \%29'u kamu sektöründe çalışırken annelerinin \%35'i kamu sektöründe çalışmaktadır.

\section{5 Çapraz Tablolar}

İlk olarak, öğrencilerden "Fakülteyi bitirdikten sonraki mesleki idealiniz nedir?" sorusu için verilen dört seçeneğin önem sırasına göre sıralanması istenmiştir. Bu soru ile cinsiyet, mezun olunan lise, dini inanç ve öğrencilerin okudukları fakültelere verilen cevaplar ile çapraz tablo oluşturularak, verilen cevapların yüzdeleri belirlenmiştir. "Kamu sektöründe çalışma” seçeneğini bayanların \%30’u, erkeklerin \%34'ü birinci tercih olarak ifade etmişlerdir. "Özel sektörde çalışma" seçeneğini bayanların \%25'i ilk sırada tercih ederken, erkeklerin sadece \%9'u birinci tercih olarak ifade etmişlerdir. "Kendi işini yapma” seçeneğini bayanların \%30'u, erkeklerin \%33'ü ve "Diğer iş alanlarında çalışma” seçeneğini de bayanların \%21'u, erkeklerin \%24'ü birinci tercih olarak ifade etmişlerdir. Okunulan lise türüne göre "Kamu sektöründe çalışma" seçeneğini Kırgızca eğitim alan öğrencilerin \%34'ü, Rusça eğitim alan öğrencilerin \%30’u ilk sırada tercih etmiştir. "Özel sektörde çalışma” seçeneğini Kırgızca eğitim alan öğrencilerin \%15’i, Rusça eğitim alan öğrencilerin \%20'si ilk sirada tercih etmiştir. "Kendi işini yapma” seçeneğini Kırgızca eğitim alan öğrencilerin \%30’u, Rusça eğitim alan öğrencilerin \%30'u ilk sırada tercih etmiştir. "Diğer iş alanlarında çalışma” seçeneğini Kırgızca eğitim alan öğrencilerin \%23’ü, Rusça eğitim alan öğrencilerin \%20'si ilk sırada tercih etmiştir. Öğrencilerin dinlerine göre "Kamu sektöründe çalışma" seçeneğini Müslüman olanların \%31'i, Hristiyan olanların \%36'sı ve Diğer dinlere mensup olanların \%33'ü ilk sırada tercih etmişlerdir. “Özel sektörde çalışma” seçeneğini Müslüman olanların \%13'ü, Hristiyan olanların \%20'si ve Diğer dinlere mensup olanların \%20'si ilk sırada tercih etmişlerdir. "Kendi işini yapma” seçeneğini Müslüman olanların \%36's1, Hristiyan olanların \%16'sı ve Diğer dinlere mensup olanların \%33'ü ilk sırada tercih etmişlerdir. "Diğer iş alanlarında çalışma” seçeneğini Müslüman olanların \%22'si, Hristiyan olanların \%32'si ve Diğer dinlere mensup olanların \%14'ü ilk sırada tercih etmişlerdir.

Son olarak öğrencilerin okudukları fakültelere göre meslek idealleri ise şu şekilde gerçekleşmiştir: "Kamu sektöründe çalışma" seçeneğini Sosyal bilimlerde okuyan öğrencilerin \%28'i, Fen bilimlerinde okuyan öğrencilerin \%34'ü ve Sağlık bilimlerinde okuyan öğrencilerin \%50'si ilk sırada tercih etmişlerdir. "Özel sektörde çalışma" seçeneğini Sosyal bilimlerde okuyan öğrencilerin \% 15 'i, Fen bilimlerinde okuyan öğrencilerin \%19’u ve Sağlık bilimlerinde okuyan öğrencilerin \%0’1 ilk sırada tercih etmişlerdir. "Kendi işini yapma" seçeneğini Sosyal bilimlerde okuyan öğrencilerin \%36's1, Fen bilimlerinde okuyan öğrencilerin \%27'si ve Sağlık bilimlerinde okuyan öğrencilerin \%12'si ilk sırada tercih etmişlerdir. "Diğer iş alanlarında çalışma" seçeneğini Sosyal bilimlerde okuyan öğrencilerin \%22'si, Fen bilimlerinde okuyan öğrencilerin \%22'si ve Sağlık bilimlerinde okuyan öğrencilerin \%38'i ilk sırada tercih etmişlerdir. İkinci olarak "Mesleki tercihlerinizin oluşumunda etkin olan faktörler nelerdir?” sorusu için verilen dokuz seçeneğin önem sırasına göre sıralanması istenmiştir. Bu soru ile cinsiyet, mezun olunan lise, dini inanç ve öğrencilerin okudukları fakültelere verilen cevaplar ile çapraz tablo oluşturularak, verilen cevapların yüzdeleri belirlenmiştir. "Kar elde etme isteği" seçeneğini; bayanların \%26'sı ilk sırada, \%13'ü ikinci sırada tercih ederken, erkeklerin \%41'i ilk sırada ve 
\%17'si ikinci tercih etmiştir. Ankete katılan öğrencilerin ise \%35'i birinci sırada ve \%19'u ikinci sırada tercih etmişlerdir. "Bağımsız çalışma isteğì" seçeneğini; bayanların \%8'i ilk sırada, \%21'i ikinci sırada tercih ederken, erkeklerin \%7'si ilk sırada ve \%25'i ikinci tercih etmiştir. Ankete katılan öğrencilerin ise \%7'si birinci sırada ve \%20'si ikinci sırada tercih etmişlerdir. "Kişisel tatmin sağlama isteği” seçeneğini; bayanların \%21'i ilk sırada, \%13'ü ikinci sırada tercih ederken, erkeklerin \%17'si ilk sırada ve \%11'i ikinci tercih etmiştir. Ankete katılan öğrencilerin ise \%19'u birinci sırada ve \%11'i ikinci sırada tercih etmişlerdir. "Yoğun bir tempoda çalışma isteği” seçeneğini; bayanların \%2'si ilk iki sırada tercih ederken, erkeklerin \%1'i ilk sırada ve \%4'ü ikinci tercih etmiştir. Ankete katılan öğrencilerin ise \%2'si birinci sırada ve \%3'ü ikinci sırada tercih etmişlerdir. "Sabitrisksiz gelire ulaşma isteği" seçeneğini; bayanların \%2'si ilk iki sırada tercih ederken, erkeklerin \%5'i ilk sırada ve \%3'ü ikinci tercih etmiştir. Ankete katılan öğrencilerin ise \%4'ü birinci sırada ve \%2'si ikinci sırada tercih etmişlerdir. "Grup çalışması yapma isteği”" seçeneğini; bayanların \%0'1 ilk sırada, \%6'sı ikinci sırada tercih ederken, erkeklerin \%3'ü ilk sırada ve \%5'i ikinci tercih etmiştir. Ankete katılan öğrencilerin ise \%2'si birinci sırada ve \%6'sı ikinci sırada tercih etmişlerdir. "Sermaye gerektiren ancak sermaye-siz olarak işleri yapma isteği” seçeneğini; bayanların \%15'i ilk sırada, \%17'si ikinci sırada tercih ederken, erkeklerin \%7'si ilk sırada ve \%12'si ikinci tercih etmiştir. Ankete katılan öğrencilerin ise \%10'u birinci sırada ve \%14'ü ikinci sırada tercih etmişlerdir. "Belirli ve düzenli çalışma saatine bağlı çalışma isteği”" seçeneğini; bayanların \%6'sı ilk sırada, $\% 13$ 'ü ikinci sırada tercih ederken, erkeklerin \%8'si ilk sırada ve \%12'si ikinci tercih etmiştir. Ankete katılan öğrencilerin ise \%7'si birinci sırada ve \%12'si ikinci sırada tercih etmişlerdir. "Aile baskısından kurtulma isteği”" seçeneğini; bayanların \%19'u ilk sırada, \%13'ü ikinci sırada tercih ederken, erkeklerin \%12'si ilk sırada ve $\% 12$ 'si ikinci tercih etmiştir. Ankete katılan öğrencilerin ise \%15'i birinci sırada ve \%12'si ikinci sırada tercih etmişlerdir.

Mezun olunan lise türü ile "Mesleki tercihlerinizin oluşumunda etkin olan faktörler nelerdir?" sorusuna çapraz tablo sonuçları şu şekilde oluşmuştur: "Kar elde etme isteği” seçeneğini; Kırgızca eğitim alanların \%36'sı, Rusça eğitim alanların \%40'1, diğer dillerde eğitim alanların \%33'ü ve genelde de \%35'i ilk sırada tercih etmiştir. "Bağımsız çalışma isteği” seçeneğini; Kırgızca eğitim alanların \%7'si, Rusça eğitim alanların \%10'u, diğer dillerde eğitim alanların \%0'ı ve genelde de \%7'si ilk sırada tercih etmiştir. "Kişisel tatmin sağlama isteği" seçeneğini; Kırgızca eğitim alanların \%17'si, Rusça eğitim alanların \%30'u, diğer dillerde eğitim alanların \%33'1 ve genelde de \%19'si ilk sırada tercih etmiştir. Diğer seçenekleri ilk sırada tercih etme oranları \%3'ün altında iken "Aile baskısından kurtulma isteği seçeneğini; Kırgızca eğitim alanların \%16'sı, Rusça eğitim alanların $\% 10$ 'u, diğer dillerde eğitim alanların \%0'1 ve genelde de \%14'ü ilk sırada tercih etmiştir.

Öğrencilerin okudukları fakülteler ile "Mesleki tercihlerinizin oluşumunda etkin olan faktörler nelerdir?" sorusuna çapraz tablo sonuçları şu şekilde oluşmuştur: "Kar elde etme isteği" seçeneğini; Sosyal fakültesinde okuyanların \%41'i, Fen fakültesinde okuyanların \%27'si, Sağlık fakültesinde okuyanların \%25'i ve genelde de \%35'i ilk sırada tercih etmiştir. "Bağımsız çalışma isteği” seçeneğini; Sosyal fakültesinde okuyanların \%7'si, Fen fakültesinde okuyanların \%5'i, Sağlık fakültesinde okuyanların \%25'i ve genelde de \%7'si ilk sirada tercih etmiştir. "Kişisel tatmin sağlama isteği” seçeneğini; Sosyal fakültesinde okuyanların \%2'si, Fen fakültesinde okuyanların \%3'ü, Sağlık fakültesinde okuyanların \%2'si ve genelde de \%2'si ilk sırada tercih etmiştir. "Yoğun bir tempoda çalışma isteği”" seçeneğini; Sosyal fakültesinde okuyanların \%19'u, Fen fakültesinde okuyanların \%22'si, Sağlık fakültesinde okuyanların \%0'1 ve genelde de \%19'u ilk sırada tercih etmiştir. "Sabit-risksiz gelire ulaşma isteği”" seçeneğini; Sosyal fakültesinde okuyanların \%4'ü, Fen fakültesinde okuyanların \%5'i, Sağlık fakültesinde okuyanların \%0'1 ve genelde de \%4'ü ilk sırada tercih etmiştir. "Grup çalışması yapma isteği”" seçeneğini; Sosyal fakültesinde okuyanların \%2'si, Fen fakültesinde okuyanların \%0'1, Sağlık fakültesinde okuyanların \%13'ü ve genelde de \%2'si ilk sırada tercih etmiştir. "Sermaye gerektiren ancak sermayesiz olarak işleri yapma isteği” seçeneğini; Sosyal fakültesinde okuyanların \%8'i, Fen fakültesinde okuyanların \%15'i, Sağlık fakültesinde okuyanların \%0'1 ve genelde de \%10’u ilk sırada tercih etmiştir. "Belirli ve düzenli çalışma saatine bağlı çalışma isteği” seçeneğini; Sosyal fakültesinde okuyanların \%7'si, Fen fakültesinde okuyanların $\% 5$ 'i, Sağlık fakültesinde okuyanların $\% 25$ 'i ve genelde de \%7'si ilk sırada tercih etmiştir. “Aile baskısından kurtulma isteği” seçeneğini; Sosyal fakültesinde okuyanların \%13'ü, Fen fakültesinde okuyanların \%19'u, Sağlık fakültesinde okuyanların \%13'ü ve genelde de \%15'i ilk sırada tercih etmiştir.

\section{Ki-Kare Analizi}

Sayısal olmayan değişkenler arasında herhangi bir ilişkinin araştırılmasında Ki-kare analizi kullanılmaktadır. Anket çalışmasında öğrencilere "Fakülteyi bitirdikten sonraki mesleki idealiniz nedir?" sorusuna verilecek dört farklı seçeneği ve "Mesleki tercihlerinizin oluşumunda etkin olan faktörler nelerdir?" sorusuna verilecek dokuz farklı seçeneği önem seviyesine göre sıralamaları istenmiştir. Yapılan bu sıralamalarda, cinsiyet, mezun olunan lise, doğum yeri, din, uyruk, ailenin yerleşim yeri ve aylık geliri, anne ve babanın mesleği ve öğrencinin okuduğu fakülte değişkenlerinin hangilerinin etkili olduğu araştırılmıştır. Tablo.2'de öğrencilerin, "Fakülteyi bitirdikten sonraki mesleki idealiniz nedir?" sorusuna verdikleri cevaplar ile Cinsiyet, Mezun Olunan Lise, Doğum Yeri, Din, Uyruk, Ailenin Yaşadığı Yer, Babanın Mesleği, Annenin Mesleği ve Okudukları Fakülte değişkenlerine göre Ki-kare analiz sonuçları ( $p$ değerleri) verilmiştir. 


\begin{tabular}{|l|c|c|c|c|c|c|c|c|c|c|}
\cline { 2 - 10 } \multicolumn{1}{c|}{} & Cinsiyet & $\begin{array}{c}\text { Mezun } \\
\text { Lise }\end{array}$ & $\begin{array}{c}\text { Doğum } \\
\text { Yeri }\end{array}$ & Din & Uyruk & $\begin{array}{c}\text { Aile } \\
\text { Yerleşim }\end{array}$ & Gelir & $\begin{array}{c}\text { Baba } \\
\text { Meslek }\end{array}$ & $\begin{array}{c}\text { Anne } \\
\text { Meslek }\end{array}$ & Fakülte \\
\hline Kamu & $0,000^{*}$ & 0,222 & 0,023 & $0,011^{*}$ & $0,000^{*}$ & 0,075 & $0,000^{*}$ & $0,002 *$ & $0,049 * *$ & $0,000^{*}$ \\
\hline Özel & $0,000^{*}$ & $0,000^{*}$ & $0,001 *$ & $0,000^{*}$ & $0,001 *$ & $0,003 *$ & $0,000^{*}$ & $0,005^{*}$ & $0,000^{*}$ & $0,000^{*}$ \\
\hline Kendi İși & 0,122 & 0,053 & $0,003 *$ & 0,364 & $0,000^{*}$ & 0,083 & $0,002 *$ & 0,370 & $0,000^{*}$ & 0,276 \\
\hline Diğer & $0,000 *$ & $0,000^{*}$ & $0,000^{*}$ & $0,000^{*}$ & $0,000^{*}$ & $0,000^{*}$ & $0,000^{*}$ & $0,001 *$ & $0,000^{*}$ & $0,000^{*}$ \\
\hline
\end{tabular}

Tablo.2. Meslek İdeali ile İlgili Değişkenler Arasındaki Ki-Kare p Dĕgerleri * $p<0,01 * * p<0,05$

Tablo.2'deki sonuçlara baktığımızda, cinsiyet, din, uyruk, ailenin geliri, babanın mesleği, annenin mesleği ve okudukları fakülte değişkenleri bakımından devlet memurluğu yapmayı öncelikli olarak düşünen öğrencilerin kararları arasında fark vardır. Benzer şekilde doğum yeri, aile yerleşim yeri ve mezun lise değişkenleri bakımından devlet memurluğu yapmayı öncelikli olarak düşünen öğrencilerin kararları arasında fark yoktur. Cinsiyet, mezun lise, doğum yeri, din, uyruk, ailenin yerleşim yeri, ailenin geliri, babanın mesleği, annenin mesleği ve okudukları fakülte değişkenleri bakımından özel şirketlerde çalışmayı öncelikli olarak düşünen öğrencilerin kararları arasında fark vardır. Doğum yeri, din, uyruk, ailenin geliri ve annenin mesleği değişkenleri bakımından kendi işini açmayı düşünen öğrencilerin kararları arasında fark vardır. Benzer şekilde cinsiyet, mezun olunan lise, din, aile yerleşim ve baba mesleği değişkenleri bakımından değişkenleri bakımından kendi işini açmayı düşünen öğrencilerin kararları arasında fark yoktur. Cinsiyet, mezun lise, doğum yeri, din, uyruk, ailenin yerleşim yeri, ailenin geliri, babanın mesleği, annenin mesleği ve okudukları fakülte değişkenleri bakımından diğer iş alanlarında çalışmayı öncelikli olarak düşünen öğrencilerin kararları arasında fark vardır. Tablo.3'de ise öğrencilerin, "Mesleki tercihlerinizin oluşumunda etkin olan faktörler nelerdir?" sorusuna verdikleri cevaplar ile Cinsiyet, Mezun Olunan Lise, Doğum Yeri, Din, Uyruk, Ailenin Yaşadığı Yer, Babanın Mesleği, Annenin Mesleği ve Okudukları Fakülte değişkenlerine göre Ki-kare analiz sonuçları ( $p$ değerleri) verilmiştir.

\begin{tabular}{|c|c|c|c|c|c|c|c|c|c|}
\hline & $\begin{array}{c}\text { Kâr } \\
\text { Elde } \\
\text { Etme } \\
\text { İsteği }\end{array}$ & $\begin{array}{l}\text { Bağımsız } \\
\text { Çalışma } \\
\text { İsteği }\end{array}$ & $\begin{array}{l}\text { Kişisel } \\
\text { Tatmin }\end{array}$ & $\begin{array}{l}\text { Yoğun } \\
\text { Tempo }\end{array}$ & $\begin{array}{c}\text { Risksiz } \\
\text { Gelir }\end{array}$ & $\begin{array}{c}\text { Grup } \\
\text { Çalışması } \\
\end{array}$ & $\begin{array}{c}\text { Sermayesiz } \\
\text { İş } \\
\end{array}$ & $\begin{array}{l}\text { Düzenli } \\
\text { İş } \\
\text { Saatleri }\end{array}$ & $\begin{array}{c}\text { Aile } \\
\text { Baskısından } \\
\text { Kurtulma }\end{array}$ \\
\hline Cinsiyet & $0,00^{*}$ & $0,00 *$ & $0,00^{*}$ & $0,00^{*}$ & $0,00 *$ & $0,00 *$ & $0,00 *$ & 0,382 & 0,272 \\
\hline $\begin{array}{l}\text { Mezun } \\
\text { Lise }\end{array}$ & $0,00 *$ & $0,00^{*}$ & $0,00 *$ & $0,00^{*}$ & $0,00 *$ & $0,00 *$ & $0,00^{*}$ & 0,866 & 0,65 \\
\hline $\begin{array}{l}\text { Doğum } \\
\text { Yeri }\end{array}$ & $0,00^{*}$ & $0,00 *$ & $0,00 *$ & $0,00 *$ & $0,00 *$ & $0,00 *$ & $0,00 *$ & 0,468 & 0,476 \\
\hline Din & $0,00^{*}$ & $0,00 *$ & $0,00^{*}$ & $0,00^{*}$ & $0,00 *$ & $0,00 *$ & $0,00 *$ & 0,221 & $0,00 *$ \\
\hline Uyruk & $0,00^{*}$ & $0,00 *$ & $0,00 *$ & $0,00 *$ & $0,00 *$ & $0,00 *$ & $0,00 *$ & 0,070 & $0,00 *$ \\
\hline $\begin{array}{c}\text { Aile } \\
\text { Yerleşim }\end{array}$ & $0,00^{*}$ & $0,00 *$ & $0,00 *$ & $0,00 *$ & $0,00 *$ & $0,00 *$ & $0,00 *$ & $0,00 *$ & $0,00 *$ \\
\hline Gelir & $0,00^{*}$ & $0,00 *$ & $0,00 *$ & $0,00 *$ & $0,00 *$ & $0,00 *$ & $0,00 *$ & 0,068 & $0,00 *$ \\
\hline $\begin{array}{c}\text { Baba } \\
\text { Meslek }\end{array}$ & $0,00 *$ & $0,00 *$ & $0,00^{*}$ & $0,00 *$ & $0,00^{*}$ & $0,00 *$ & $0,00 *$ & 0,202 & $0,012 * *$ \\
\hline $\begin{array}{c}\text { Anne } \\
\text { Meslek }\end{array}$ & $0,00 *$ & $0,00 *$ & $0,00 *$ & $0,00 *$ & $0,00 *$ & $0,00 *$ & $0,00 *$ & 0,313 & 0,073 \\
\hline Fakülte & $0,00^{*}$ & $0,00^{*}$ & $0,00^{*}$ & $0,00 *$ & $0,00 *$ & $0,00^{*}$ & $0,00 *$ & 0,569 & 0,13 \\
\hline
\end{tabular}

Tablo.3. Meslek Oluşumunda Etkili Faktörler ile İlgili Değişkenler Arasındaki Ki-Kare p Değerleri * $p<0,01$ $* * p<0,05$

Tablo.3'deki sonuçlara baktığımızda Düzenli iş Saatleri ve Aile Baskısından Kurtulma değişkenleri ile ilgili değişkenlerden bazıları arasında fark olduğu, diğer tüm değişkenlerin (Kar elde etme isteği, Bağımsız çalışma isteği, Kişisel tatmin, Yoğun Tempo, Risksiz gelir, Grup çalışması, Sermayesiz iş) ilgili değişkenler ile aralarında fark olmadığı görülmektedir. Buna göre, cinsiyet, mezun olunan lise, doğum yeri, din, uyruk, ailenin geliri, babanın mesleği, annenin mesleği ve okudukları fakülte değişkenleri bakımından Düzenli iş Saatlerini öncelikli olarak düşünen öğrencilerin kararları arasında fark yoktur. Benzer şekilde, cinsiyet, mezun olunan lise, doğum yeri, annenin mesleği ve okudukları fakülte değişkenleri bakımından Aile baskısından kurtulmayı öncelikli olarak düşünen öğrencilerin kararları arasında fark yoktur. 


\section{Korelasyon Analizi}

Korelasyon analizi, iki değişken arasındaki ilişkiyi ölçen bir katsayıdır. Değişkenlerden en az biri sıralı ise Spearman Sıra Korelasyonu kullanılmalıdır. Bu analizde, Spearman Sıra Korelasyonu ile "Fakülteyi bitirdikten sonraki mesleki idealiniz nedir?" ve "Mesleki tercihlerinizin oluşumunda etkin olan faktörler nelerdir?" sorularına verilen cevaplar arasında ilişki incelenmiştir. İlk olarak "Fakülteyi bitirdikten sonraki mesleki idealiniz nedir?" sorusu için verilen dört seçeneğe ait sıralamalar incelenmiştir. Buna göre; "Kamu sektöründe çalışma" seçeneği ile "Özel sektörde çalışma" seçeneği arasında ters yönde orta şiddette ve anlamlı bir korelasyon katsayısı $(r=-0,322$ ve $p=0,000)$ hesaplanmıştır. "Kamu sektöründe çalışma" seçeneği ile "Kendi İşini yapma" seçeneği arasında ters yönde orta şiddette ve anlamlı bir korelasyon katsayısı (r= -0,506 ve $\mathrm{p}=0,000)$ hesaplanmıştır. "Özel sektörde çalışma" seçeneği ile "Diğer işlerde çalışma" seçeneği arasında ters yönde orta şiddette ve anlamlı bir korelasyon katsayısı $(r=-0,453$ ve $\mathrm{p}=0,000)$ hesaplanmıştır. "Kendi İşini yapma" seçeneği ile "Diğer işlerde çalışma" seçeneği arasında ters yönde orta şiddette ve anlamlı bir korelasyon katsayısı $(r=-0,455$ ve $\mathrm{p}=0,000)$ hesaplanmıştır. Diğer ilişki katsayıları anlamsız çıkmıştır. İkinci olarak ve "Mesleki tercihlerinizin oluşumunda etkin olan faktörler nelerdir?" sorusu için verilen dokuz seçeneğe ait sıralamalar incelenmiştir. Bütün korelasyon katsayıları 0,40’ın altında (pozitif veya negatif) çıkmıştır. "Kâr elde etme isteği” seçeneği ile "Grup Çalışması", "Sermayesiz İş", "Düzenli İş Saatleri”, "Aile Baskısından Kurtulma” ve "Bağımsız çalışma isteği” seçenekleri arasındaki korelasyon katsayısı anlamlı çıkmıştır. Benzer şekilde "Bağımsız çalışma isteği” seçeneği ile "Sermayesiz İş", "Düzenli İş Saatleri”, "Aile Baskısından Kurtulma" seçenekleri arasındaki korelasyon katsayısı anlamlı çıkmıştır. "Kişisel tatmin” seçeneği ile "Grup Çalışması”, "Sermayesiz İş”, "Düzenli İş Saatleri”, “Aile Baskısından Kurtulma” seçenekleri arasındaki korelasyon katsayısı anlamlı çıkmıştır. "Yoğun tempo" seçeneği ile "Sermayesiz İş" ve "Düzenli İş Saatleri” seçenekleri arasındaki korelasyon katsayısı anlamlı çıkmıştır.

\section{Sonuç}

Kırgızistan- Rusya Slavyanski Üniversitesi'nde yapılan anket sonucunda öğrencilerin \%60'sı Sosyal Bilimler fakültesinde, \%33'ü Fen fakültesinde ve \%7'si Sağlık fakültesinde öğrenim gördüğü tespit edilmiş ve \%38'i bayan, \%62'si erkektir. Öğrencilerden Kırgızca eğitim görenlerin oran1 \%89, Rusça eğitim görenlerin oranı \%8 iken diğer dillerde eğitim görenlerin oranı ise \%3’tür. Kırsal kesimde oturanların oranı \%25 iken kentsel kesimde oturanların oranı \%75 olarak bulunmuştur. Ankete katılanların dini inançlarına baktığımızda, \%68'inin Müslüman, \%20'sinin Hristiyan ve \%12'sinin de diğer dinlere ait olduklarını görülmektedir. Ankete katılan öğrencilerin uyrukları incelendiğinde, \%61 Kırgız, \%20 Rus, \%7 Çin, \%5 Kazak, \%2 Özbek kökenli öğrenciler oldukları belirlenmiştir. Bu çalışmaya katılan öğrencilerin \%45’i 3 veya daha fazla dil bilmekte ve \%79'u Çuy bölgesinde ikamet etmektedir. Anne ve babaların eğitim düzeyleri lisans ve yüksek lisan mezunu olup, çoğunluğu özel sektörde çalışmaktadırlar. Anketi cevaplayan öğrencilerin Kırgızca eğitim alanlar, Rusça eğitim alanlar ve diğer dillerde eğitim alanlar dahil olmak üzere özel sektörde çalışma isteklerinin düşük olduğu tespit edilmiştir. Özellikle sağlık bilimlerinde okuyan öğrencilerin yüzde elliden fazlasının kamu sektörünü düşünmesi özel sağlık alanında yapılması gereken çalışmaların olduğunu göstermektedir. Rus kökenli Kırgız vatandaşlarının kar elde etme isteği birinci sırada, Özbek ve Kazak kökenli olup Kırgız vatandaşı olanların ikinci sıra ve Kırgız kökenli olanların üçüncü sırada olması, uyruğun girişimcilik üzerinde etkilerin olabileceğini göstermektedir. Lisede eğitim dili Rusça olan öğrencilerin bağımsız çalışma isteklerinin ön sıralarda olduğu da gözlenmektedir. Dolayısıyla uzun süre kapalı bir sistem ve sosyalist düzen içerisinde yaşamış toplumlarda girişimcilik kültürünün gelişmemesinin doğal olduğu düşünüldüğünde, girişimcilikte uyruğun önemli olduğu fakat eğitimle ve devletin bu konudaki teşvikleriyle bağımsız çalışma isteğinin artırılabileceği göz önündedir. Diğer bir faktör ise Kırgızistan nüfusunun karma bir yapıya sahip olması din dil uyruk anne baba mesleğinin girişimcilik konusunda etkili olduğu, devlet memurluğuna bakış acılarını etkilediği yapılan anket sonucunda tespit edilmiştir.

\section{Kaynakça}

- Alaybeyoğlu Küçük Kübra, Kişilik Özelliklerinin Girişimcilik Davranışına Etkisi: “Abant İzzet Baysal Üniversitesi Örneği”, Sosyal Bilimler Enstitüsü, Yüksek Lisans Tezi, Ankara 2014.

- Aytaç Ömer, "Girişimcilik: Sosyo-Kültürel Bir Perspektif”, Dumlupınar Üniversitesi Sosyal Bilimler Dergisi, /15: (2006).

- Aytaç Ömer ve İlhan Süleyman, “Girişimcilik ve Girişimci Kültür: Sosyolojik Bir Perspektif”, Selçuk Üniversitesi Sosyal Bilimler Dergisi,(2007).

- Cici E.Nihan, Kadınların Girişimcilik Yolunda Karşılaştıkları Sorunların Öz Girişimcilik Yetenekleri Üzerindeki Etkisi: Konya İlinde Bir Araştırma, Sosyal Bilimler Enstitüsü, Yüksek Lisans Tezi, Konya 2013.

- Cin Hatice ve Yumuk G. Gülsevim, "Girişimcilerin Girişimcilik Tipleri İle Duygusal Zekâları Arasındaki İlişki: Edirne Örneği”, Girişimcilik ve Kalkınma Dergisi,8/2: (2013).

- C Çetin Murat, "Bölgesel Kalkınma ve Girişimci Üniversiteler”, Ege Akademik Bakış, 7/1: (2007). 
- $\quad$ Er P. Hazel, Girişimcilik ve Yenilik Kavramlarının İktisadi Düşüncedeki Yeri: Joseph A.Schumpeter, Sosyal Bilimler Enstitüsü, Yüksek Lisans Tezi, Konya 2012.

- Günel Ö. Devrim ve Yılmaz B. Selin, "Üniversite Eğitimi ve Girişimcilik: Bireyleri Girişimciliğe Yönlendiren Etkenler Üzerine Bir Araştırma”, Akademik Bakış Dergisi, /26: (2011).

- İ́bicioğlu Hasan, Özmen H.İbrahim, TAŞ Sebahattin, "Üniversite Eğitiminin Girişimcilik Düşüncesinin Değişimine Etkisi: Üniversite Öğrencileri Üzerine Bir Uygulama”, Alanya İşletme Fakültesi Dergisi,2/1: (2010).

- İlter Berfu, Girişimcilik Sürecinde Kadın Girişimcilerin Karşılaştıkları Sorunların Analizi: Kagider Örneği, Sosyal Bilimler Enstitüsü, Doktora Tezi, Afyonkarahisar 2008.

- Kaygin Erdoğan, Girişimcilik Sürecinde Dönüştürücü Liderlik Anlayış1-Bir Uygulama, Sosyal Bilimler Enstitüsü, Doktora Tezi, Erzurum 2011.

- Meriç Sağbetullah, Girişimcilik Potansiyeli İle Etik Algı Arasındaki İlişki: Akçakoca Turizm İşletmeciliği ve Otelcilik Yüksekokulu Örneği, Sosyal Bilimler Enstitüsü, Yüksek Lisans Tezi, Düzce 2013.

- Mungan Seylan, Kadın Girişimcilik Değerleri İle Kadın Girişimcilik Algısı Arasındaki İlişkide Girişimcilik Eğitimlerinin Rolü, Sosyal Bilimler Enstitüsü, Yüksek Lisans Tezi, İstanbul 2013.

- Yüzüak Elif, Üniversitelerde Öğrenim Gören Kız Öğrencilerin Girişimcilik Eğilimlerini Etkileyen Faktörler: Çanakkale On sekiz Mart Üniversitesi Biga İ.İ.B.F. Örneği, Sosyal Bilimler Enstitüsü, Yüksek Lisans Tezi, Çanakkale 2010. 


\title{
Küreselleşme Sürecinde Küçük ve Orta Büyüklükteki İşletmeler ve İstihdam Yapıları: Yalova Örneği \\ Small and Medium Sized Enterprises and Their Employment Structures in the Process of Globalization: Yalova Sample
}

\author{
Assoc. Prof. Dr. Orhan Koçak (Yalova University, Turkey) \\ Prof. Dr. Eyüp Zengin (İstanbul University, Turkey) \\ Hande Oğuz Karademir (Yalova University, Turkey)
}

\begin{abstract}
Today, small and medium sized companies are briefly called SMEs, are becoming more important in order to sustain of both national and local economies under the intensive competition and in the existing global markets. SME's are making important contributions countries' economic growths by making innovations, giving responses for the economic crises, positive effects on the growing of employment and having flexibility on their productions. In this study, the current situation of SMEs in the globalized economic order, the advantages and disadvantages, economic problems, the importance of SMEs in Turkey's economy and also incentives provided for SMEs is emphasized. In the second part, with the globalization changing employment structure of SMEs and their conditions in the fight against unemployment is emphasized in Turkey. In the final part, an investigation is done and it is aimed to research employment structures, strategies for the future and approaches for the big companies of SMEs that are doing business in Yalova city. For this, survey method is used and survey results were analyzed for 158 SMEs in Yalova.
\end{abstract}

\section{Giriș}

Küreselleşme, genel olarak adeta sınırların göz ardı edilmesi ve tüm dünyanın bütünleşmesi ve bilgi, para ve mal piyasalarının entegrasyonu anlamlarına gelir. Aslında, ülkeler arasında giderek artan bir ticari hareketlilik ile yatırımının yapılabildiği uluslararası piyasa olarak yorumlanırsa, küreselleşme yeni sayılmaz (Hırst ve Thompson, 1996, 8). Bazı yazarlar, küreselleşmenin yalnızca ekonomik yönüne önem verirken; diğerleri ilave olarak siyasi ve kültürel boyutlarına da temas etmektedir. Ekonomik yaklaşıma göre küreselleşme, ticaret, finansal akımlar, teknoloji değişimi ile bilgi ve işgücünün hareketliliği yoluyla dünya ekonomisinin entegrasyonudur. Ayrıca küreselleşme dış ticaretin, emek ve sermaye hareketliğinin artması, ülkeler arasındaki farklılıkların azalması, teknolojik dönüşüm sayesinde toplumların sosyal, ekonomik, kültürel ve siyasal boyutlarla karşılıklı yakınlaşmaları olarak da görülmektedir (Yılmaz, 2009: 48).

KOBI'ler ekonomik ve sosyal kalkınmaya yaptıkları olumlu katkıları, yeni istihdam alanları açmada etkileri ve değişimlere çabuk uyum sağlayan esnek bir üretim yapılarına sahip olmaları dolayısıyla hem ülkemiz hem de dünya ekonomisinde çok önemli bir yere sahiptir. Ekonomik krizlerle sıkça karşılaşılan son yıllarda, KOBİ’ler krizlerden en az zararla çıkmam için önemli aktörler olarak değerlendirilmiștir. KOBİler hızlı karar verme yetenekleri, yenilikçi ve esnek yapıları, istihdama yaptıkları katkıları sayesinde işsizlikle mücadelede de öne çıkmalarına ve desteklenmelerine neden olmaktadır. Bir diğer etken ise, KOBİ'ler çabuk kurulmaları nedeniyle az gelişmiş ve gelişmekte olan bölgelerde de hem ekonomik kalkınma hem de göçün önlenmesi açısından önemsenmektedir.

Bu çalışma ile Türkiye ve Avrupa Birliği'ne göre KOBİ tanımları yapılmış, KOBİ'lerin avantaj ve dezavantajları vurgulanmış, KOBİ'lerin sosyo-ekonomik sisteme katkıları ve KOBI'lerin Türkiye ekonomisindeki yeri değerlendirilmiştir. Ayrıca KOBİ'lerin yaşadığı sorunlara dair çözüm önerilerine vurgu yapılmıştır. Çalışmanın son bölümünde Yalova ilinde yapılan anket çalışması ile Yalova'da bulunan KOBI'lerin istihdam yapıları tespit edilmeye çalışılmış, beklentileri ve teşviklere bakışları anlaşılmaya çalışılmıştır. Verilerden yola çıkarak gerek frekans gerekse çapraz tablolar ile değerlendirmeler yapılmıştır.

\section{Literatür Taraması}

\subsection{KOBİ'lerle İlgili Tanımlar}

AB genelinde ve Türkiye'de KOBİ'lerle ilgili netleşmiş kesin tanımlara rastlanmamakla birlikte, aşağıdaki tabloları kullanarak bir karşılaştırmada bulunabiliriz. 


\begin{tabular}{|c|c|c|c|c|c|}
\hline КОВі் (AB) & Eleman Sayısı & $\begin{array}{lr}\text { Yıllık } & \text { Ciro veya } \\
\text { Yıllık } & \text { Bilanço } \\
\text { (EURO) } & \end{array}$ & Bağımsızlık & $\begin{array}{l}\text { KOBİ (DİE'ye } \\
\text { Göre Türkiye) }\end{array}$ & Eleman Sayısı \\
\hline Orta & 250 'den az & $\begin{array}{l}27-40 \text { milyon } \\
\text { EURO aras1 }\end{array}$ & \multirow{3}{*}{$\begin{array}{l}\text { Birkaç şirkete } \\
\% 25 \text { 'in } \\
\text { üstünde ait } \\
\text { olmamas } 1\end{array}$} & Orta & 100 'den az \\
\hline Küçük & 50 'den az & $\begin{array}{c}5-7 \text { milyon } \\
\text { EURO aras1 }\end{array}$ & & Küçük & 50 'den az \\
\hline Çok Küçük & 10'dan az & - & & Çok Küçük & $\begin{array}{l}\text { İşçi istihdam } \\
\text { etmeyen }\end{array}$ \\
\hline
\end{tabular}

Tablo 1: AB ve Türkiye'de KOBİ Tanımları Kaynak: Ören, 2003:106

Bunun yanı sıra ülkemizde, KOBİ'lere yönelik faaliyetlerde bulunan kurum ve kuruluşların; görev tanımları, hedef kitleleri ve faaliyetlerine ayırdıkları kaynakları çerçevesinde, hizmet götürdükleri grupları belirleyen farklı KOBİ tanımları kullandıkları görülmektedir. KOSGEB, Halkbank, Hazine Müsteşarlığı, Dış Ticaret Müsteşarlığı ve Eximbank gerek işçi sayısına gerekse yapmış oldukları yatırım tutarlarına göre sınıflandırma yapmaktadırlar (DPT, 2004).

\subsection{KOBİ' lerin Avantajları ve Dezavantajları}

KOBİler konumları ve sahip olduğu yapıları itibariyle bir takım avantajlara ve dezavantajlara sahiptirler. Bunları aşağıdaki tabloda inceleyebiliriz.

\begin{tabular}{|c|c|}
\hline & \\
\hline $\begin{array}{l}\text { ama, üretim ve hizmet konularında esnektirler, } \\
\text { yapıları itibariyle ekonomik dalgalanmalardan } \\
\text { z etkilenirler, } \\
\text { lerarası dengeli kalkınmayı sağlarlar, } \\
\text { dağılımındaki dengesizlikleri azaltırlar, } \\
\text { el tasarrufları teşvik ederler, } \\
\text { az yatırımla daha çok üretim ve ürün çeşitliliği } \\
\text { lar, } \\
\text { değişikliklerine ve çeşitliliklerine daha kolay } \\
\text { gösterirler, } \\
\text { sanayi işletmelerinin destekleyicisi ve } \\
\text { layıcısıdır, } \\
\text { en mal veya hizmete olan talep sınırlıdır, } \\
\text { gelişmelere kısa sürede ayak uydurabilme } \\
\text { ğine sahiptirler, } \\
\text { n yapılırken daha çok kendi öz sermayelerine } \\
\text { verirler. } \\
\text { yoğun teknolojilerle çalışarak ve genelde düşük } \\
\text { eleman istihdam ederek işsizliğin aşağı } \\
\text { lesine katkıda bulunmak, }\end{array}$ & 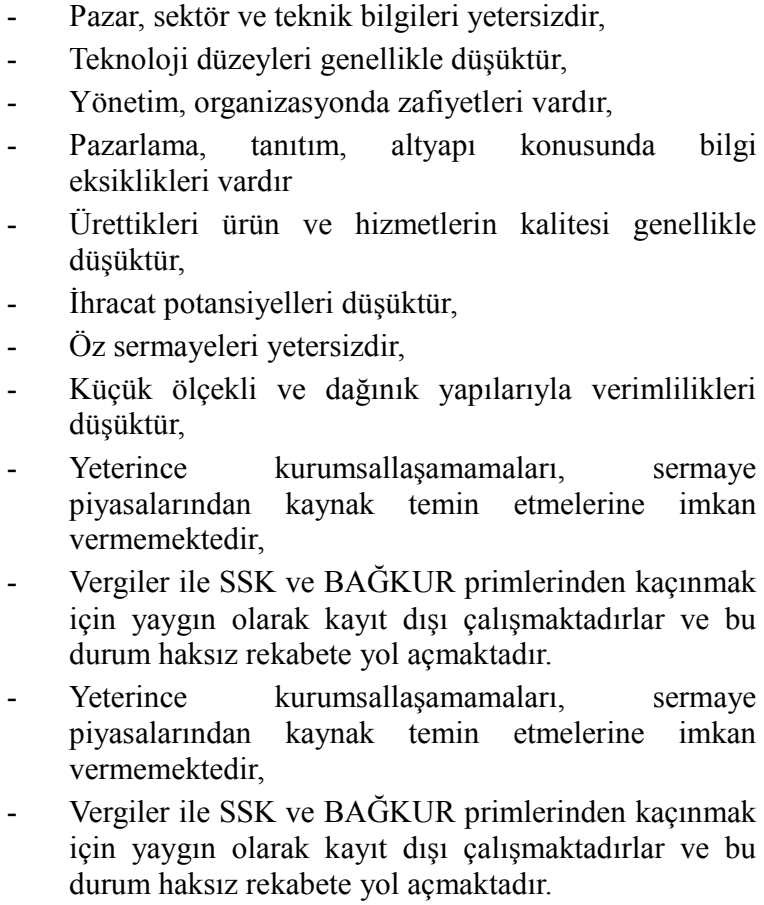 \\
\hline
\end{tabular}

Tablo 3: KOBI'lerin Avantajlarl ve Dezavantajları Kaynak: Akgemci, 2001:15; Yllmaz, 2003:4

KOBİ'ler o ülkedeki bölgesel gelişmişlik farklılıklarının giderilmesinde, istihdam artışı sağlanmasında, gelir dağılımında adaletin sağlanmasında, sosyal dışlanmanın önlenmesinde ve mülkiyetin geniş bir tabana yayılmasında ekonomide nitelikli ve deneyimli işgücünün oluşmasında vb. büyük boyutlarda katkıda bulunmaktadır. Tüm bu yararları yanında o ülkede demokrasinin geliştirilmesinde, ekonomik ve sosyal krizlerin atlatılmasında oynadığı roller de gözden uzak tutulmamalıdır (Yılmaz, 2004:3).

Ayrıca KOBİ'ler; mevzuata hakim olamama ve bürokrasi, kalifiye eleman eksikliği, Ar-ge faaliyetlerinin yetersizliği, ihale, fuar gibi bir takım etkinlikleri takip edememek, üretim ve satış arasındaki koordinasyonun tam sağlanamaması, stratejik kararların sadece işletme sahiplerinin vermesi gibi dezavantajlara da sahiptirler (Sabuncuoğlu ve Tokol, 2001: 63).

\subsection{KOBİlerin Temel Sorunları}

KOBI'lerin hemen her işletmecilik fonksiyonları olan finansman, yönetim, üretim ve pazarlama fonksiyonlarının her birinde karşılaştıkları birçok sorunları bulunmaktadır. Bunlar, genel sorunlar, yönetim sorunları, üretim sorunları, pazarlama sorunları ve diğer sorunlar olarak sınıflandırılabilir. 
Girişimcilik, fizibilite çalışmalarının yetersizliği, işletmeler arası işbirliği eksikliği, kuruluş yeri seçimi ile ilgili sorunlar, verimliliklerinin düşüklüğü, teknoloji düzeylerinin düşüklüğü, KOBİ’lerin genel sorunları olarak ifade edilebilir (Sabuncuoğlu ve Tokol, 2001:63). Yönetim ve yönetici sorunları, nitelikli personel bulunamaması, işletme sahiplerinin teknik kökenli olması, uzmanlaşma, formasyon eksikliği, danışmanlık ve rehberlik hizmetlerinden yoksun olmaları; teknolojik yetersizlik, üretim kapasitesi yetersizliği, Ar-ge faaliyetlerinin yetersizliği, hammadde tedarikindeki sorunlar, fason üretim planında karşılaşılan sorunlar ve stoklama sorunları gibi sorunlar KOBİ'lerin karşılaştığı başlıca üretim ve yönetim sorunlarındandır (Akgemici, 2001:26-29).

KOBİ' ler, yeni pazar kanallarının hazırlanamaması, dağıtım sorunları, potansiyel iç pazarların bulunması, araştırılması ve değerlendirilmesindeki güçlükler, pazar bilgisi eksikliği, ihracat pazarlama sorunları, dış pazarlardaki yoğun rekabet, dış pazarda potansiyel belirleme güçlükleri, dış pazarlama giderlerinin yüksekliği gibi pazarlama sorunlarıyla karşı karşıya kalmaktadırlar (Özgen ve Doğan, 1998, 85-87). Özsermaye yapıları yeterli olmayan işletmeler büyümede ve faaliyetlerini sürdürmede zorluklarla karşılaşmaktadırlar. Alternatif olarak kullanılan banka kredisi ise yüksek reel faiz oranlarının mevcudiyeti nedeniyle işletmelere önemli bir maliyet yüklemektedir (Aras ve Müslümov, 2002:7).

\section{Türkiye'de KOBİ'ler}

\subsection{KOBİ'lerin Türkiye'deki Gelişim Süreci}

KOBI'lerin ülkemizdeki tarihi gelişimi incelendiğinde başlangıcı 13. yüzyıla dayanan bir geçmişle karşılaşılmaktadır. 1933- 1970 dönemleri arasında KOBI'lere yardımcı olmak için Halk Bankası, Esnaf Odaları, Ticaret ve Sanayi Odaları, Etibank, Sümerbank ve KÜSGEM (Küçük Sanayi Geliştirme Merkezi) kurulmuştur. 1954 'te imalat sanayi ve diğer ekonomik faaliyet kollarında özel yabancı sermayenin teşviki için 6224 sayılı Özel Yabancı Sermayeyi Teşvik Kanunu yürürlüğe konmuştur. Küçük sanayiye teknik alanda destekler söz konusu olmuş ve büyük sanayi ile işbirliği yapması teşvik edilmiştir. Ayrıca 17 adet küçük sanayi siteleri açılmıştır.

1990-1994 yılları arasındaki dönemde KOBİ'lerin modernizasyonu ve kurumsallaşmanın aşamalı olarak sağlanması, uzmanlaşması ve büyük sanayiye entegrasyonunun özendirilmesi hedeflenmiştir. 1996 yılı KOBİ yılı olarak ilan edilmiştir. Bu konuda başta KOSGEB, TOBB, TESK ve TOSYÖV olmak üzere KOBİ'lere hizmet veren tüm kamu ve özel kuruluşlarla koordineli bu kampanya ile ihracat potansiyeli olup ihracat yapmamış KOBİ'lerin harekete geçirilmesi, bu firmalara ihracat yöntemlerinin anlatılması, özetle KOBİ'lerin diş ticarete yönlendirilmesi hedef alınmıştır.

\subsection{KOBİ'ler ve Türkiye Ekonomisindeki Önemi}

Dünyada ve Avrupa Birliği'nde KOBİ'ler istihdamın önemli bir bölümünü karşılamakta ve sanayi içinde büyük bir yer tutmaktadır. KOBİ'ler küçük, esnek yapıları sayesinde gelişmelere hızla uyum sağlayabilmektedirler. Ölçek üretim yerine butik üretim yaparak müşteri memnuniyetini daha iyi sağlayabilmektedirler. Uluslararası alanda iletişim araçlarının etkisiyle tüketici bilinci değişmiş ve üreticiler için daha esnek bir üretim yapısı sayesinde hızla tüketici isteklerine cevap verme zorunluluğu doğmuştur. Genel olarak ele alacak olursak KOBI'ler, istihdam yaratılması, esneklik sayesinde yeniliklere hızla uyum sağlama, girişimciliği teşvik, butik üretim sayesinde ürün farklılaşması, büyük işletmelere ara malı temini gibi alanlarda ekonomiye katkı sağlarlar (Oktay ve Güney,2002:2). KOBI'ler ülkelerin büyüme ve kalkınmasında önemli bir rol oynamaktadırlar. Fakirliğin çeşitli toplum kesimleri arasında azaltılmasını sağlama potansiyelini taşımaktadırlar (Cook ve Nixson, 2002:2).

Ülkemizde KOBİ'lerin sayısı hizmet sektörü de dahil olmak üzere, tüm işletmelerin sayısının \% 99,8'ini ve bu işletmeler de toplam istihdamın \% 76,7'sini oluşturmaktadır. KOBİ yatırımlarının, toplam yatırımlar içindeki payı \% 38'e ulaşmakta ve toplam katma değerin \% 26,5'i yine bu işletmelerce yaratılmaktadır. KOBI'lerin toplam ihracat içindeki payları, yıllar itibarıyla değişiklik göstermekle beraber, ortalama \% 10 oranında gerçekleşmekte ve bu kesimin toplam banka kredileri içindeki payı \% 5'in altında seyretmektedir ( DPT, 2004: 9).

Taşıdıkları önem dolayısıyla başta gelişmiş ülkeler olmak üzere bütün ülkeler KOBİ’lerin doğması, büyümesi, gelişmesi ve korunması için uygun ortamı hazırlayacak politikalar geliştirmekte ve uygulamaktadırlar. KOBİ'lerin dünyadaki artan önemine koşut olarak ülkemizde de 80'li yılların sonundan itibaren KOBİ'lere yönelik bir destek sisteminin oluşturulması çalışmaları başlatılmıştır. KOBİlere çeşitli kamu kuruluşu, özel kuruluş ve vakıflar tarafından destekler verilmektedir (Akdeniz, 2005: 11). Teknoloji tabanlı işletmelerin desteklenmesi, üniversite-sanayi işbirliğinin geliştirilmesi ve teknoloji yayımının kolaylaştırılması amacıyla, Teknoloji Geliştirme Bölgeleri Kanunu yürürlüğe girmiştir. Mevzuat ve bürokrasi politikalarında değişiklikler yapılmıştır (www.kosgeb.gov.tr). Ayrıca KOBİ'lere sağlanan finansman destekleri içindeki en önemli payı T. Halk Bankası tarafından kullandırılan uygun koşullu krediler oluşturulmaktadır. Milli Eğitim Bakanlığı tarafından öğrenci ve kursiyerlere 109 ayrı konuda meslek eğitimi verilmektedir (KOBİ Stratejisi ve Eylem Planı, 2004). 
Hem gelişmiş sosyal refah ekonomilerinde hem de ülkemizde KOBİ'lerin en önde gelen özelliklerinden birisi yeni işler ve iş alanları oluşturmak ve bu yolla istihdam sağlama gücüdür. KOBİ'lerin istihdamla ilişkisi, yalnızca KOBİ'lerin daha az sermaye ile, daha çok sayıda işgücüne istihdam olanağı sunması ve çok sayıda insana ücretli olarak çalışabilme firsatı vermesinin yanında bir gerçeği daha ifade etmektedir. O da girişimci ruhu olan çok sayıda insanın kendi işletmelerini kurarak işgücüne girişimci olarak katılmalarına olanak sağlaması ve bu yolla da bir ülkedeki istihdam seviyesini yükseltmesidir. Bir işverenin yanında ücretiyle çalışmak yerine, kendi işini kurmayı tercih eden girişimcilerin sahip oldukları ruh ve yetenekleri ile bir ekonomi için çok daha büyük öneme sahiptirler ( Gök, 2004:115).

Büyük işletmeler krize yönelik önlemler arasında çalışanlarını işten çıkartmayı çare olarak görürken; KOBI’ler bu şartlarda dahi personeline sahip çıkmakta, çok zorda kalmadıkça kriz dönemlerinde de ekonomik gücü elverdiği ölçüde onların maliyetine katlanmaktadır (Özdemir, Ersöz ve Sarıoğlu, 2006: 62). KOBİ'lerin bir diğer özelliği işsizliğin düşürülmesine olan katkılarının yanında özellikle niteliksiz işçilerin istihdamına olanak sağlayan ekonomik birimler olmalarıdır. Ülkemizde bazı bölgelerde nitelikli işçi sayısı son derece sınırlıdır. Bu kişiler KOBİ'ler tarafından istihdam edilerek çalışma yaşamına katılmaktadırlar. Büyük işletmeler vasıflı ve yarı vasıflı işçiler çalıştırmayı tercih ederken, KOBİ'ler vasıflı işçilerin yüksek ücretleri dolayısıyla ancak düşük ve orta vasıf seviyesindekileri çalıştırabilmektedirler. Vasıflı/kalifiye elemanların bu işletmelerde istihdam edilme oranları büyük ölçekli işletmelere göre oldukça düşüktür. KOBI'ler büyüdükçe ve geliştikçe vasıflı işçileri de istihdam edebilir hale gelmektedir.

\section{Yalova'da KOBİ'ler İle İlgili Uygulama}

\subsection{Araştırmanın Amacı ve Kapsamı}

Bu çalışmada Yalova bölgesindeki KOBİ'lerin istihdam özellikleri, istihdam yapı ve şekilleri, KOBİlerin işsizliği önlemedeki rol ve etkileri ile istihdam sorunlarının saptanması amaçlanmıştır. Araştırmanın kapsamı Yalova sınırları içinde faaliyette bulunan KOBİ'lerdir.

\subsection{Araştırmanın Yöntemi}

$\mathrm{Bu}$ çalışmada veri toplama aracı olarak anket yöntemi kullanılmıştır. Hazırlanan anket formu Yalova bölgesindeki 158 KOBİ'ye uygulanmıştır.

Bu araştırmanın ana kütlesi, Yalova İli’nde faaliyet gösteren KOBİ’lerdir. Anketler hazırlanan veri kodlama önergesi doğrultusunda kodlanarak bilgisayarda SPSS 17.0 programında değerlendirilmiştir. Araştırma sonucu elde edilen veriler sistematik bir şekilde değerlendirilmiş ve analiz edilmiştir. Araştırmada veri analizi sıklık dağılımı( frequencies) ve mukayese imkanı veren karşılaştırma tabloları(cross-tabulations) çerçevesinde yapılmıştır. Anket 25 sorudan oluşmaktadır. Bu sorular KOBİ'lerin işsizliği önlemesinde ve yeni istihdam alanlarının yaratılmasındaki katkılarını ölçmeye yöneliktir. Ankette işletme profili, istihdam yapısındaki değişimler ve işverenlerin kriz dönemlerindeki istihdam politikaları tespit edilmeye çalışılmıştır. Son olarak, KOBİ'lerin istihdam sorunlarına yaklaşımları ve işletmeye yönelik teşviklerden faydalanma düzeylerinin belirlenmesi amaçlanmıştır.

\subsection{Araştırmanın Hipotezleri}

KOBI’lerin işsizliği önlemedeki rol ve etkileri ile istihdam sorunlarının saptanması amacı doğrultusunda bir takım hipotezler öne sürülmüştür. Bunlar:

1. KOBI'ler esnek yapıları sayesinde işsizliğin azaltılması ve gelir dağılımının düzeltilmesinde ekonomiye katkı sağlar.

2. Son dönemlerde Yalova bölgesinde açılan alışveriş merkezleri bu bölgedeki KOBİ'leri olumsuz etkilemiştir.

3. KOBI'lerin sendikalaşma eğilimleri düşüktür.

\subsection{Verilerin Analizi}

\begin{tabular}{|l|l|l|}
\hline Kuruluş yılı & Frekans & Yüzde \\
\hline $1-3$ yıl & 21 & 13.3 \\
\hline $4-6$ y1l & 63 & 39.9 \\
\hline $7-10$ y1l & 50 & 31.6 \\
\hline 11 y1l ve üzeri & 24 & 15.2 \\
\hline Toplam & 158 & 100 \\
\hline
\end{tabular}

Tablo 4: İ̧sletmenin Kuruluş Yll

Ülkemizde köklü ve uzun bir geçmişe sahip işletmeler çok büyük sayılarda değildir. KOBİler arasında uzun yıllar faaliyet gösteren işletmeler azdır. İşletmelerin büyük çoğunluğu 2000'li y1llarda kurulmuştur. Buda KOBİ'lerin dinamik ve girişimci yapısının bir göstergesidir. Tablo 1'de görüldüğü gibi işletmelerin \%63'ünün 4- 
6 yıllık, yarısının 7 ile 10 yıllık, \%24'ünün 11 yıl ve üzeri geçmişe sahip olduğu ve en az paya ise \%21 ile daha yeni açılmış olan yani 1 ile 3 yıllık bir geçmişe sahip olan işletmeler oluşturmaktadır.

\begin{tabular}{|l|c|c|}
\hline Sektör & Frekans & Yüzde \\
\hline Gıda & 57 & 36.1 \\
\hline Tekstil & 7 & 4.4 \\
\hline Ağaç, orman, mobilya & 2 & 1.3 \\
\hline Tarım, sera & 4 & 2.5 \\
\hline İnşaat & 7 & 4.4 \\
\hline Otomotiv & 38 & 24.1 \\
\hline Eğitim & 3 & 1.9 \\
\hline Kuyumculuk, saat & 2 & 1.3 \\
\hline Hizmet & 8 & 5.1 \\
\hline Sağlık & 9 & 5.7 \\
\hline Diğer & 10 & 6.3 \\
\hline Makine, elektrik & 11 & 7.0 \\
\hline Toplam & 158 & 100 \\
\hline
\end{tabular}

Tablo 5: Firmanın Faaliyette Bulunduğu Sektör

Ankete katılan firmalar arasında neredeyse her sektörden işletme bulmak mümkündür. Bunlar arasından en yüksek pay \%24 ile otomotiv sektörüne, sonrasında ise $\% 36$ ile gida sektörüne aittir. Bunları \%7 ile makine ve elektrik, \%6 ile diğer sektörler, \%5.7 ile sağlık, \%5 ile hizmet sektörü, \%4.4 ile tekstil ve \%2.5 ile tarım ve seracılık izlemektedir. En düşük paylar ise \%1.9 ve \%1.3 ile eğitim, kuyumculuk, saat ve ağaç, orman, mobilya sektörlerine aittir.

\begin{tabular}{|l|l|l|}
\hline Bölge & Frekans & Yüzde \\
\hline Meskun Mahal & 97 & 61.4 \\
\hline Küçük Sanayi Sitesi & 61 & 38.6 \\
\hline Toplam & 158 & 100 \\
\hline
\end{tabular}

Tablo 6: Firmanın Bulunduğu Bölge

Tablo 6’te görüldüğü gibi işletmelerin \%61.4 gibi çok büyük bir kısmı meskun mahalde yer alırken \%38.6’s1 ise küçük sanayi sitesinde yer almaktadır. Bu durum KOBİ'lerin gelişimi açısından negatif bir durum olarak karşımıza çıkmaktadır. Çünkü KOBİ’lerin gelişiminde küçük sanayi siteleri ve organize sanayi sitelerinde yer almanın büyük faydaları vardır.

\begin{tabular}{|l|c|c|c|c|c|c|}
\hline \multirow{2}{*}{} & \multicolumn{9}{|c|}{ Azaldı } & \multicolumn{2}{c|}{ Aynı Kaldı } \\
\cline { 2 - 7 } & \multicolumn{2}{|c|}{ Arttı } & \multicolumn{2}{c|}{ Az̈ry } \\
\cline { 2 - 7 } & Frekans & Yüzde & Frekans & Yüzde & Frekans & Yüzde \\
\hline Mal ve Hizmet Üretimi & 99 & 62.7 & 43 & 27.2 & 16 & 10.1 \\
\hline Satışlar & 99 & 62.7 & 48 & 30.4 & 11 & 7.0 \\
\hline Kar marjı & 93 & 58.9 & 50 & 31.6 & 15 & 9.5 \\
\hline İstihdam edilen personel & 26 & 16.5 & 7 & 4.4 & 125 & 79.1 \\
\hline Kapasite kullanım oranı & 24 & 15.2 & 9 & 5.7 & 125 & 79.1 \\
\hline Yatırımlar & 87 & 55.1 & 46 & 29.1 & 25 & 15.8 \\
\hline Verimlilik & 93 & 58.9 & 51 & 32.3 & 14 & 8.9 \\
\hline Maliyetler & 108 & 68.4 & 39 & 24.7 & 11 & 7.0 \\
\hline
\end{tabular}

Tablo 7: Firmanız aşă̆ıldaki konularda geçen yıla göre "ne gibi değişimler" göstermiştir?

Firmaların bazı göstergelerinin geçen yıla göre değişimini sorduğumuz bu soruda göstergelerin 2 tanesi hariç artış eğilimi gösterdiği görülmektedir. Bunlar mal ve hizmet üretimi, satışlar, kar marjı, yatırımlar ve verimliliktir. Bunların \%62 ile 55 arasında değişen kısmı artarken, \%51 ile 39 arası değişen kısmı geçen yıla göre azalmış, \%25 ile 16 arasında değişen kısmı ise geçen yılla aynı seviyede olmuştur. Bu sonuçlardan hareketle ankete katılan işletmelerin büyük çoğunluğunun önemli düzeyde geliştikleri görülmüştür.

İstihdam edilen personel sayısı ve kapasite kullanım oranı ise \%79 oranıyla aynı kalmış, \%5.7 ile 4.4 arası değişen değerlerde azalmış ve \%16.5 ile 15.2 arası değişen değerlerde artmıştır. Buradan da anlaşılacağı üzere 
KOBI'lerin büyük bir kısmı eksik kapasiteyle çalışmaktadırlar. KOBİ'lerin eksik kapasiteyle çalışmaları, bir yandan bu işletmelerin kaynak israfına yol açarken, diğer yandan istihdama olan katkıları azaltmaktadır.

\begin{tabular}{|c|c|c|c|c|c|c|}
\hline & \multicolumn{2}{|c|}{ Artacak } & \multicolumn{2}{|c|}{ Azalacak } & \multicolumn{2}{|c|}{ Aynı Kalacak } \\
\hline & Frekans & Yüzde & Frekans & Yüzde & Frekans & Yüzde \\
\hline Mal ve Hizmet Üretimi & 95 & 60.1 & 33 & 20.9 & 30 & 19.0 \\
\hline Satışlar & 98 & 62.0 & 37 & 23.4 & 23 & 14.6 \\
\hline Kar marjı & 95 & 60.1 & 37 & 23.4 & 26 & 16.5 \\
\hline İstihdam edilen personel sayısı & 23 & 14.6 & 2 & 1.3 & 133 & 84.2 \\
\hline Kapasite kullanım oranı & 36 & 22.8 & 4 & 2.5 & 118 & 74.7 \\
\hline Yatırımlar & 96 & 60.8 & 34 & 21.5 & 28 & 17.7 \\
\hline Verimlilik & 98 & 62.0 & 37 & 23.4 & 23 & 14.6 \\
\hline Maliyetler & 105 & 66.5 & 36 & 22.8 & 17 & 10.8 \\
\hline
\end{tabular}

Tablo 8: Firmanin Gelecek Yll Beklentileri

Ankete kayılan KOBI'lerin gelecek yıl beklentilerine baktığımızda ise kapasite kullanım oranı ve istihdam edilen personel sayısı hariç bütün değerlerin artış beklentisinde olduğu görülmektedir. Kapasite kullanım oranı ve istihdam edilen personel sayısının ise aynı kalacağı beklenmektedir. Buradan mevcut durumlarını koruyabilecekleri düşünülmektedir.

\begin{tabular}{|l|c|c|}
\hline 3 yıllık ciro & Frekans & Yüzde \\
\hline$\% 0$ & 5 & 3.2 \\
\hline$\% 10$ & 56 & 35.4 \\
\hline$\% 20$ & 43 & 27.2 \\
\hline$\% 21-40$ & 39 & 24.7 \\
\hline$\% 41-50$ & 12 & 7.6 \\
\hline$\% 51-70$ & 2 & 1.3 \\
\hline$\% 71-99$ & 1 & 0.6 \\
\hline Toplam & 158 & 100 \\
\hline
\end{tabular}

Tablo 9: İşletmenin 3 Ylllk Cirosunun Yüzdesel Artışı

İşletmelerin \%35'inin 3 yıllık cirosu \%10, \%27'sinin 3 yıllık cirosu \%20, \%24.7'sinin 3 yılllk cirosu da \%21 ile 40 arasında artış göstermiştir. İşletmelerin \%3'ünün cirosu aynı kalmıştır. Bunun yanında işletmelerin yaklaşık \%10'unun cirosu \%40'in üzerinde artmıştır.

Ankete katılan KOBİ'lerden ürettikleri mal ve hizmetlerin maliyetlerini etkileyen faktörlerden 5 tanesini seçmeleri ve bunları yüzdesel olarak belirtmeleri istenmiştir. Personel giderleri maliyetleri etkileyen faktörlerin başında gelmektedir. Personel giderleri bütün işletmelerin maliyetlerini etkilemektedir. İşletmelerin \%10'unun personel giderlerinin maliyetler içindeki pay1 \%1 ile 10 arasında, işletmelerin $\% 50$ 'sinde bu oran $\% 11$ ile 25 arasındadır. Firmaların \%37'sinde ise personel giderlerinin maliyetler içindeki payı \%26 ile 40 arasındadır. En düşük oran ise işletmelerin \%1'ini kapsayan \%41 ile 60 arasındaki paydır. Hammadde/ malzeme giderleri de personel giderlerine benzer bir dağıllım göstermektedir. En yüksek oran \%54 ile maliyetlerin \%26 ile 40'llk kısmını kapsamaktadır. Bunu sırayla \%31 ile \%11-25'lik kısım; \%9.5 ile \%0'llk kısım; \%2.5 ile de \%41-60 ve \%1-10'luk kısım kapsamaktadır. Finansman giderleri genellikle maliyeti etkileyen faktörler arasında büyük bir paya sahip değildir. Enerji giderleri ise yaklaşık olarak maliyetlerin \%11-25'lik kısmını kapsamaktadır.

Nakliye giderleri maliyetlerin yaklaşık \%1-10'luk kısmını kapsamaktadır. Faaliyet giderlerine bakacak olursak, bunun maliyetler içindeki payının yaklaşık \%1 ile 10 arasında olduğunu görmekteyiz. Son olarak diğer giderlerin ise maliyetleri çok fazla etkilemediği görülmektedir. Bir sıralama yapacak olursak maliyetleri belirleyen faktörleri şu şekilde sıralayabiliriz: 1) Hammadde/malzeme giderleri, 2) Personel giderleri, 3) Kira giderleri, 4) Enerji giderleri, 5) Faaliyet giderleri, 6) Nakliye giderleri, 7) Finansman giderleri, 8) Diğer giderler.

\begin{tabular}{|l|l|l|}
\hline İhracat & Frekans & Yüzde \\
\hline Evet & 4 & 2.5 \\
\hline Hayır & 154 & 97.5 \\
\hline Toplam & 158 & 100 \\
\hline
\end{tabular}

\begin{tabular}{|l|l|l|}
\hline İthalat & Frekans & Yüzde \\
\hline Evet & 3 & 1.9 \\
\hline Hayır & 155 & 98.1 \\
\hline Toplam & 158 & 100 \\
\hline
\end{tabular}

Tablo 10: Ihracat ve Ithalat 
Ankete katılan KOBİ'lerin çok büyük bir kısmı ithalat ve ya ihracat yapmamaktadır. İşletmelerin sadece \% 2.5'i ihracat yaparken, ithalat yapanlarda \%1.9'luk kısmı oluşturmaktadır. Bu KOBİ'lerin zayıflıklarını, kendilerini çok fazla geliştiremediklerini ve dış pazarlarda kendilerine yer bulamadıklarını göstermektedir.

\begin{tabular}{|l|c|c|}
\hline AVM'lerin Etkisi & Frekans & Yüzde \\
\hline Olumlu & 7 & 4.4 \\
\hline Olumsuz & 61 & 38.6 \\
\hline Etkilemedi & 90 & 57 \\
\hline Toplam & 158 & 100 \\
\hline
\end{tabular}

Tablo 11: Yalova Bölgesinde Açılan Alışveriş Merkezlerin (Kipa- Özdilek) Etkisi

Son zamanlarda Yalova bölgesinde açılan alışveriş merkezlerinin etkisine bakıldığında işletmelerin \%38.6'sı bundan olumsuz etkilendiğini, \%4’ü olumlu etkilendiğini \%57 gibi büyük bir çoğunluğu ise olumlu ya da olumsuz bir etkisi olmadığını belirtmiştir.

\begin{tabular}{|l|l|l|}
\hline KOBİ Sınıfi & Frekans & Yüzde \\
\hline Mikro Ölçekli & 153 & 96.8 \\
\hline Küçük Ölçekli & 3 & 1.9 \\
\hline Orta Ölçekli & 2 & 1.3 \\
\hline Toplam & 158 & 100 \\
\hline
\end{tabular}

\begin{tabular}{|l|l|l|}
\hline Personel Sayısı & Frekans & Yüzde \\
\hline 1-3 kişi & 36 & 22.8 \\
\hline 4-6 kişi & 69 & 43.7 \\
\hline 7-10 kişi & 41 & 25.9 \\
\hline 11-15kişi & 9 & 5.7 \\
\hline 16-50 kişi & 2 & 1.3 \\
\hline 51 ve üzeri & 1 & 0.6 \\
\hline Toplam & 158 & 100 \\
\hline
\end{tabular}

Tablo 12: KOBİ Sinıfi ve İstihdam Edilen Personel Sayısı

Anket yapılan işletmelerin \%96.8 gibi çok büyük bir kısmı mikro ölçekli iken, \%1.9'u küçük ölçekli, \%1.3’ü ise orta ölçeklidir. İşletmelerin \%43'ünde personel sayısı 4 ile 6 arasında, \%26'sında 7 ile 10 arasında, \%23'ünde ise 1 ile 3 kişi arasındadır. 11 ile 15 kişi istihdam eden işletmeler toplam işletmelerin \%6'sını oluştururken işletmelerin \%2'sinde de personel sayısı 15'in üstündedir.

\begin{tabular}{|l|l|l|}
\hline İstihdam Şekli & Frekans & Yüzde \\
\hline Düzenli çalışan & 143 & 90.5 \\
\hline Düzenli ve esnek çalışan & 15 & 9.5 \\
\hline Toplam & 158 & 100 \\
\hline
\end{tabular}

Tablo 13: Istihdam Şekli

Araştırmaya katılan işletmelerde hakim çalışma şekli \%90 ile düzenli (tam süreli) çalışmadır. Az sayıda işletme ise \%10 gibi bir oranla hem düzenli hem de esnek çalışmayı tercih etmektedir. Sadece esnek çalışma biçimini benimseyen işletme ise bulunmamaktadır.

\begin{tabular}{|l|c|c|}
\hline & Frekans & Yüzde \\
\hline İşten Çıkarma & 84 & 53.2 \\
\hline Ücretleri Düşürme & 37 & 23.5 \\
\hline Ücretsiz İzin & 8 & 5.1 \\
\hline Esnek Çalışmaya Geçme & 29 & 18.4 \\
\hline Toplam & 158 & 100 \\
\hline
\end{tabular}

Tablo 14: Ekonomik Sorunlarla Karşılaşıldı ̆̆ında Çalışanlarla İlgili Olarak Öncelikli Olarak Başvurulacak Çözüm Yollarl

Ankete katılan işletmelere ekonomik sorunlarla karşıllaştıklarında çalışanlarla ilgili olarak öncelikli olarak başvurulacak çözüm yolları sorulmuştur. İşletmelerin \%53'ü işten çıkarma derken, \%23'ü ise ücretleri düşürme demiştir. Esnek çalışmaya geçmeyi savunan işletmelerin payı \%18 iken \%5'lik ufak bir kesim ise ücretsiz izini tercih etmektedirler. Yani KOBİ'ler genel olarak işten çıkarma ya da ücret düşürmeyi tercih etmektedirler. Bunun sebebi KOBİ'lerin daha çok aile şirketi olmaları ve çalışanlarıyla yakın ilişkiler kurmalarıdır. 


\begin{tabular}{|l|c|c|}
\hline Son 1 yıl için personel sayısı & Frekans & Yüzde \\
\hline Artt1 & 32 & 20.3 \\
\hline Azald 1 & 13 & 8.2 \\
\hline Ayn1 Kald 1 & 113 & 71.5 \\
\hline Toplam & 158 & 100 \\
\hline
\end{tabular}

Tablo 15: Son 1 Yll İçinde İstihdam Edilen Personel Sayısındaki Değişim

İşletmenin son 1 yıl içindeki personel sayısına bakacak olursak, bunun \%71.5 ile aynı kaldığı, \%20 oranında arttığı, \%8 oranında ise azaldığı görülmüştür. İstihdam edilen personel sayısındaki azalışın az bir orana sahip olması KOBİ'lerin istihdama olan katkısını göstermektedir.

İşe alınan ve işten çıkarılan personel sayısını incelediğimizde değişik bir tablo karşımıza çıkmaktadır. Bu ise, işe alınan ve işten çıkarılan personel sayılarının \%45 ve \%33 ile birbirine yakın değerlerde çıkmasıdır. Bunun nedeni mevsimlik işe alımlardır. Bölgenin yaz aylarında yoğun olması sebebiyle işe alımlar bu aylarda yoğunlaşmakta, kış aylarında ise bu işçiler işten çıkarılmaktadır. Buda bir üst tabloda gördüğümüz durumu yaratmaktadır. Tablo 17'de de görüldüğü gibi yıl içinde istihdam edilen personel sayısı büyük bir oranla aynı kalmıştır.

Ankete katılan KOBİ'lerden istihdamı artırmada önemli olarak gördükleri unsurlardan 5 tanesini önem sırasına göre sıralamaları istenmiştir. İşletmelerin \%42’si uygun koşullu krediyi çok önemli bulurken, \%35’i ise önemli bulmuştur. İstihdamı teşvik eden vergi indirimi ya da vergi istisnaları ise \%26 ile ortalama bir öneme sahip bulunmuştur. Personel kaynaklı maliyetlerin düşürülmesi ise \%31 ile önemli, \%40 ile ise ortalama öneme sahip bulunmuştur. Sendikasız işçi çalıştırmada kolaylık ve istihdam teşvikleri ise önemsiz bulunan unsurlardandır. Sıralama yapacak olursak 1. sırada uygun koşullu kredi, 2. sırada personel kaynaklı maliyetlerin düşürülmesi, 3. sırada istihdamı teşvik eden vergi indirimi ya da vergi istisnaları, 4. sırada istihdam teşvikleri ve 5. sırada sendikasız işçi çalıştırmada kolaylık yer almaktadır.

Ankete katılan işletmelere firmalarında çalışan sendikalı işçi olup olmadığı sorulmuştur. KOBİ'lerde çalışanların \%84'ü sendikalı değildir. İşçilerin sadece \%1'i sendikalı iken, işletme sahiplerinin \%13'ü çalışanlarının sendikalı olup olmadıklarını bilmemektedirler. Bu durum KOBİ'ler için olası bir durumdur. Zaten aile şirketi konumunda ya da az sayıda çalışana sahip olan KOBI'lerde sendikalaşma oranının yüksek çıması beklenmemektedir. Ayrıca KOBİ'lerde çalışanlar sorunlarını çözmek için bir aracıya gereksinim duymamaktadır. Ankete katılan işletmelere teşviklerden faydalanıp faydalanmadıkları sorulmuş ve işletmelerin \% 83.5 gibi çok büyük bir kısmının teşviklerden faydalanmadığı görülmüştür. İşletmelerin \%16.5'i ise teşviklerden faydalanmaktadır. Bu bize KOBI'lere yönelik teşvikler konusunda faaliyette bulunan kurumlar ve hizmetleri konusunda işletmelerin bilgilendirilmesi ve bu işletmelere yönelik teşvik danışmanlığı hizmetinin verilmesi gerektiğini göstermektedir.

İşletmelere teşvikler ilave personel istihdam etmede faydalımıdır diye sorulmuştur ve işletmelerin \%94'ü hayır yanıtını vermiştir. İşletmelerin \%6'sı ise teşviklerin ilave personel istihdam etmede faydalı olduğunu düşünmektedir. $\mathrm{Bu}$ durum araştırmaya katılan KOBİlerin yeteri kadar bilgiye sahip olamamasından kaynaklanmaktadır. Ayrıca teşviklerin ilave personel istihdam etmede faydalı olup olmadığını araştırmak için bu değişkenle istihdam edilen personel sayısı ve son 1 yıl içinde işe alınan personel sayıları gibi değişkenler arasında çapraz tablolar hazırlanmıştır. Fakat ankete katılan işletmelerin büyük bir bölümü teşvikleri, istihdamı arttırmaya yardımcı görmediği için bu değişkenlerin ilişkilerini incelemek anlamsız olacaktır. Araştırmaya katılan işletmelerin büyük bir kısmı KOBİ teşvik araçlarının tümünden neredeyse hiç yararlanmamıştır. Teşvikler içinde en fazla yurt içi tanıtım faaliyetleri desteğinden faydalanılmıştır. Faydalanılan diğer teşviklerin ise sayısı çok az olup bunlar; yardım desteği, üretim desteği, yurtiçi fuarlara katılım desteği ve ar-ge desteğidir.

\section{Sonuç}

Dünyadaki gelişmelere paralel bir trend izlediğini gözlediğimiz KOBİ sektörünün önemi, ülkemizde de giderek artmaktadır. Bu çalışmada, KOBİ-istihdam-işsizlik ilişkisinin ne kadar büyük bir öneme sahip olduğu üzerinde durulmuştur. Ülkemizde işsizlik sorununun çözümünde, KOBİ'lerin hali hazırda önemli bir rol oynadığı, ancak KOBİ'lerin mevcut potansiyellerinden de tam olarak yararlanılamadığına dikkat çekilmektedir. Çalışma kapsamında Yalova bölgesinde 158 KOBİ üzerinde yapılan alan araştırmasında KOBİ'lerin istihdamları ve bu konudaki problemleriyle ilgili gözlemler yapılmaya çalışılmıştır. Kısaca çalışmanın sonuçları şu şekilde özetlenebilir:

İşletmeler kuruluş yılı bakımından incelendiğinde bunların \%31.6’sının kuruluş yılının 7-10 y1l arası, \%40'ının 4-6 yıl olduğunu, \%15'inin 11 yıl ve üzeri bir geçmişe sahip olduğunu ve \%13'ünün de 1-3 yıllık bir geçmişe sahip olduğunu görmekteyiz. Hukuki statü bakımından işletmelerin \%87'si şahıs şirketi, \%5.7'si limited şirket ve adi komandit, \%1'i ise anonim şirkettir. Çalışmaya katılan KOBİ'ler sektörlere göre dağglım göstermektedir. İlk 3 sektöre bakacak olursak; \%36 ile gıda, \%24 ile otomotiv ve \%7 ile makine ve elektrik karşımıza çıkmaktadır. 
İşletmelerin üretilen mal ve hizmetlerinin maliyetlerini etkileyen faktörleri sıralayacak olursak; Hammadde/malzeme giderleri, personel giderleri, kira giderleri, enerji giderleri, faaliyet giderleri, nakliye giderleri, finansman giderleri ve diğer giderler şeklindedir.

Ankete katılan KOBİ'lerin çok büyük bir kısmı ithalat ve ya ihracat yapmamaktadır. Bu KOBİ'lerin zayıflıklarını, kendilerini çok fazla geliştiremediklerini ve dış pazarlarda kendilerine yer bulamadıklarını göstermektedir. Son zamanlarda Yalova bölgesinde açılan alışveriş merkezlerinin etkisine bakıldığında işletmelerin \%38.6'sı bundan olumsuz etkilendiğini, \%4'ü olumlu etkilendiğini $\% 57$ gibi büyük bir çoğunluğu ise olumlu ya da olumsuz bir etkisi olmadığını belirtmiştir. Ayrıca alışveriş mağazalarının etkilerinin bölgeye göre farklılık gösterip göstermediğine bakılmıştır. Buna göre alışveriş merkezlerinin kendilerini olumsuz etkilediğini söyleyen işletmelerin 52 tanesi meskun mahalde, 9'u ise küçük sanayi bölgesinde bulunmaktadır. Araştırmaya katılan işletmelerden küçük sanayi sitesinde bulunanlardan 52 tanesi, meskun mahalde bulunanlardan da 38 tanesi bu alı̧̧veriş merkezlerin kendileri üzerinde olumlu ya da olumsuz bir etkileri olduğuna katılmadıklarını belirtmişlerdir.

Anket yapılan işletmelerin \%96.8 gibi çok büyük bir kısmı mikro ölçekli iken, \%1.9’u küçük ölçekli, \%1.3'ü ise orta ölçeklidir. İşletmelerin \%43'ünde personel sayısı 4 ile 6 arasında, \%26'sında 7 ile 10 arasında, \%23'ünde ise 1 ile 3 kişi arasındadır. 11 ile 15 kişi istihdam eden işletmeler toplam işletmelerin \%6'sını oluştururken işletmelerin \%2'sinde de personel sayıs1 15'in üstündedir. Araştırmaya katılan işletmelerde hakim çalıșma şekli ise $\% 90$ ile düzenli (tam süreli) çalı̧̧madır.

Ankete katılan işletmelere ekonomik sorunlarla karşılaştıklarında çalışanlarla ilgili olarak öncelikli olarak başvurulacak çözüm yolları sorulmuştur. İşletmelerin $\% 53$ 'ü işten çıkarma derken, $\% 23$ 'ü ise ücretleri düşürme demiştir. Esnek çalışmaya geçmeyi savunan işletmelerin payı $\% 18$ iken $\% 5$ 'lik ufak bir kesim ise ücretsiz izini tercih etmektedirler. İşletmenin son 1 yll içindeki personel sayısına bakacak olursak, bunun $\% 71.5$ ile aynı kaldığı, \%20 oranında arttığı, \%8 oranında ise azaldığı görülmüştür. İstihdam edilen personel sayısındaki azalışın az bir orana sahip olması KOBİ'lerin istihdama olan katkısını göstermektedir. İşe alınan ve işten çıkarılan personel sayılarının \%45 ve 33 ile birbirine yakın değerlerde çıkmasıdır. Bunun nedeni mevsimlik işe alımlardır. Bölgenin yaz aylarında yoğun olması sebebiyle işe alımlar bu aylarda yoğunlaşmakta, kış aylarında ise bu işçiler işten çıkarılmaktadır.

Ankete katılan KOBİ'lerden istihdamı artırmada önemli olarak gördükleri unsurlardan 5 tanesini önem sırasına göre sıralamaları istenmiştir. Sıralama yapacak olursak 1. sırada uygun koşullu kredi, 2. sırada personel kaynaklı maliyetlerin düşürülmesi, 3 . sırada istihdamı teşvik eden vergi indirimi ya da vergi istisnaları, 4 . sırada istihdam teşvikleri ve 5. sırada sendikasız iş̧̧i çalıştırmada kolaylık yer almaktadır. Ankete katılan KOBI'lerde çalışanların \%84'ü sendikalı değildir. İş̧ilerin sadece \%1'i sendikalı iken, işletme sahiplerinin \%13'ü çalışanlarının sendikalı olup olmadıklarını bilmemektedirler.

İşletmelerin \% 83.5 gibi çok büyük bir kısmının teşviklerden faydalanmadığ görülmüştür. İşletmelerin $\% 16.5$ ' $\mathrm{i}$ ise teşviklerden faydalanmaktadır. İşletmelere teşvikler ilave personel istihdam etmede faydalımıdır diye sorulmuştur ve işletmelerin \%94'ü hayır yanıtını vermiş̧ir. İşletmelerin \%6's1 ise teşviklerin ilave personel istihdam etmede faydalı olduğunu düşünmektedir. Araştırmaya katılan işletmelerin büyük bir kısmı KOBİ teşvik araçlarının tümünden neredeyse hiç yararlanmamışıı. Teşvikler içinde en fazla yurt içi tanıtım faaliyetleri desteğinden faydalanılmıştır. Faydalanılan diğer teşviklerin ise sayısı çokaz olup bunlar; yardım desteği, üretim desteği, yurtiçi fuarlara katılım desteği ve ar-ge desteğidir.

\section{Kaynakça}

- AKDENIZ, M. Billur. , 2005, KOBİ'lerin Ekonomik ve Sosyal Yapı İçindeki Yerleri, Destekleyici Kurumsal Çevreleri ve Avrupa Birliği’ne Uyum Sürecinde Yeniden Yapılandırılmaları.

- Çevrimiçi: http://sbe.dpu.edu.tr/13/69-90.pdf

- Akgemici, Tahir. , 2001, KOBİ’ lerin Temel Sorunları ve Sağlanan Destekler. Ankara: KOSGEB Yayınları.

- Aras ve Müslümov. , 2001, Küreselleşme Sürecinde KOBİ’lerin Finansal ve Ekonomik Sorunları ve Çözüm Önerileri, 21. Yüzyılda KOBİ’lerin Finansman Sorunları ve Çözümleri Sempozyumu, Yayınlanmış Tebliğ.

- Bayülken, Yavuz. KOBİ'lerin Tanımı, AB Ülkelerinde KOBİ'ler ve Sanayideki Yeri, Çevrimiçi: http://www.metalmakina.com/

- Cook, Paul ve Nixson, Frederick. , 2000, Finance and Small and Medium-Sized Enterprise Development, Finance and Development Resource Programme, Working Paper Series, No: 14, University of Manchester.

- DPT, Devlet Planlama Teşkilatı, 2004, KOBİ Stratejisi ve Eylem Planı.

- Gök, Mehmet. İşgücü Piyasası ve KOBI'ler, Ankara: Roma Yayınları, 2004.

- Hırst, Paul ve Thompson, Grahame, 2000, Küreselleşme Sorgulanıyor, Dost Kitabevi, Ankara.

- KOSGEB. KOBİ Ekonomisi ( Tarihi Gelişimi), 2003, Ekonomik ve Stratejik Araştırmalar Merkez Müdürlüğü 
- Oktay, Ertan ve Güney, Alptekin, 2002, Türkiye'de KOBİ'lerin Finansman Sorunu ve Çözüm Önerileri, 21.yüzyılda KOBİ’ler: Sorunlar, Fırsatlar ve Çözüm Önerileri” Sempozyumu.

- $\quad$ ÖZDEMİ, Süleyman, ERSÖZ, Halis Yunus ve SARIOĞLU, İbrahim, 2006, İșsizlik Sorununun Çözümünde Kobi’lerin Desteklenmesi, İstanbul Ticaret Odası Yayınları, No: 2006-45, İstanbul.

- Ö̈zgen, Hüseyin ve S. Doğan, 1998, Küçük ve Orta Ölçekli İşletmelerin Uluslararası Pazarlara Açılmada Karşılaştıkları Temel Yönetim Sorunları, Dış Ticaret Dergisi. Sayı 9.

- Öztürk, Özkan. İstihdam Konusunda KOBİ’lerin Önemi ve KOBİ Alanında Eğitim İstihdam İlişkisi Açısından Kamu İstihdam Kurumunun Rolü, 2007.

- Çevrimiçi:http://statik.iskur.gov.tr/tr/rapor_bulten/uzmanlik tezleri/\%C3\%96ZKAN\%20\%C3\%96ZT\%C3\% 9CRK $\% 20(\% \mathrm{C} 4 \% \mathrm{~B} 0 \mathrm{ST} \% \mathrm{C} 4 \% \mathrm{~B} 0 \mathrm{HDAM} \% 20 \mathrm{KONUSUND} \mathrm{A} \% 20 \mathrm{KOB} \% \mathrm{C} 4 \% \mathrm{~B} 0 \% \mathrm{E} 2 \% 80 \% 9 \mathrm{LER} \% \mathrm{C} 4 \%$ B0N\%20\%C3\%96NEM\%C4\%B0\%20VE\%20KOB\%C4\%B0\%20AL.pdf

- Sabuncuoğlu, Zeyyat ve Tokol, Tuncer. İşletme. Bursa: Ezgi Kitabevi, 2001.

- Taş, Yunus, 2007, Türkiye'de KOBİ’lerin Sosyo - Ekonomik Etkileri Bütçe Dünyası Dergisi, Sayı 33.

- Türkiye Cumhuriyeti Başbakanlık Devlet Planlama Teşkilatı, 2004, KOBİ Stratejisi ve Eylem Planı.

- Yılmaz, Beytullah, Ocak 2004, KOBİ'lerin Toplumda Üstlendikler Roller Bakımından Analizi, Dış Ticaret Dergisi.

- Y1lmaz, Fatih, 2009, Küreselleşme Sürecinde Gelişmekte Olan Ülkelerde ve Türkiye’de İş Sağlığı ve Güvenliği, Uluslararası İnsan Bilimleri Dergisi, Cilt: 6, Sayı: 1.

- Y Ylmaz, Figen, 2003, Türkiye'de Küçük ve Orta Boy İşletmeler (KOBİ’ler), İş Bankası İktisadi Araştırmalar ve Planlama Müdürlüğü.

- www.kosgeb.gov.tr

- $\quad$ www.tuik.gov.tr 


\title{
Değişim Mühendisliği Temelinde Muhasebe Bürolarının Reorganizasyonu: İstanbul'daki Serbest Muhasebeci Mali Müşavirliklerde Bir Araştırma
}

\section{Reorganization of Reengineering Depending Accounting Firm: A Study in Public Accountancy in Istanbul}

\author{
Asst. Prof. Dr. Cihat Kartal (Kırıkkale University, Turkey) \\ Assoc. Prof. Dr. Recep Yücel (Kırıkkale University, Turkey) \\ Prof. Dr. Mustafa Kara (Abant İzzet Baysal University, Turkey)
}

\begin{abstract}
After globalization; living in the most profound effects of the accountancy profession dimensions of internationalization; already in an office, is considered as an occupation area of the execution of local operations. However; ACCA, XBRL, concepts such as IFRS or strategic partnerships, demonstrate the need to be addressed in the international integration process of this profession. Today, local thinking, just considering the fact that reveal the results beyond the local competence; think of the international dimension of such a formation or to be accredited, the reconsideration of the existing accountancy organizational structure and will need to run the restructuring process in this direction.
\end{abstract}

\section{Giriş}

Bir işletmenin yönetsel nitelikteki kararlarının önemli bir bölümü, sayısal nitelikli verilerden sağlanmaktadır. $\mathrm{Bu}$ anlamda, işletmenin muhasebe işlevi, yönetimin karar almasına esas teşkil edebilecek sayısal verileri sağlayan ve teknik nitelikteki tek bilgi kaynağıdır. Muhasebe örgütlerinin sağladığı bilgiler esasında, planlar ve maliyet standartları oluşturulmaktadır. Bu sayede, bütçeler hazırlanarak hedeflerde neyin yapılması ve nereye erişilmesi gerektiği ortaya konulmaktadır. Böylece, muhasebe organizasyonlarınca düzenlenen denetim ve sorumluluk raporları da, neyin ne oranda gerçekleştirilmekte olduğunu göstererek yürütme çalışmalarını yönlendiren ana unsurlardır (Lebibyalkın; 2015). Bilişim çağında bilginin ne denli önemli olduğundan hareketle, bir üretim faktörü olarak ta algılanmasının gerekliliği yadsınmayacak kadar önem göstermektedir. Aynı zamanda muhasebe meslek mensupları sayısal bilgiyi üretmenin yanı sıra, bunu yönetme becerisi gerekmektedir (Xing;2015). Bu gerekçeler 1şı̆̆ında, işletmelerin amaçları ve hedeflerine yönelik doğru karar vermelerini katkı verdiği düşünülen muhasebe ofislerinin, değişim mühendisliği yaklaşımı ile reorganizasyonu önem kazanmaktadır. Ancak, muhasebe ofislerinde değişimi gerekli kılan sebepleri ortaya konması, bunun ne yönde gerçekleşebileceğinin de ifade edilebilmesi gereklidir. Bu amaçla çalışmada; değişim mühendisliği süreç olarak incelenerek, muhasebe ofislerinin reorganizasyonu kapsamında, İstanbul'daki serbest muhasebeci mali müşavirliklerde yapılan bir uygulama ile bunun sonuçları ortaya konmaya çalışılmıştır.

\section{Değişim ve Reorganizasyon Kavramına Genel Bir Bakış}

Reorganizasyon kavramı, küreselleşmenin bir sonucu olarak ortaya çıkmıştır. Zira küreselleşme ile yönetimdeki anlayışlar değişim göstermekte ve bunun sonucunda yeni değerler ortaya çıkmaktadır. Bunlar; ürün kalitesini geliştirmek, hizmet, çevrim zamanı ve maliyetlerin azaltılmasıdır (Johansson vd.,1993, Boone ve diğ.,2011). Diğer yandan İşletmelerin içinde bulunduğu dünyadaki uyumunu sağlayabilmek için, pazarlama stratejilerini, ürün çeşitlerini, üretimini ve hatta kendi örgütsel yapısını dahi değiştirebilmesi gereklidir (Pearce II vd.,2011; DeGeus,1997). Kısaca değişim, genel olarak herhangi bir şeyi bir düzeyden başka bir düzeye getirmeyi ifade etmektedir. Günümüzde, örgütleri değişime iten en önemli faktörler; küreselleşme ve rekabet, uluslararası ve bölgesel entegrasyonların önem kazanması, bilgi teknolojilerindeki gelişmeler, insanın en önemli ve ikame edilemeyecek kaynak olduğunun anlaşılması, insanların bilinçlenmesi ve beklentilerinin değişmesi ve uluslararası ticarette standardizasyona gidilmesi olarak sıralanabilir (Robins vd.,2013; Daft, 2007;Akçakaya, 2004). Nihayetinde dış çevre faktörlerindeki değişme ve gelişmeler stratejik yönetimin karar ve uygulamalarının en belirgin öğelerden bir tanesidir. Çevre, sürekli değişen bir unsurdur. Stratejik yönetimin doğası olarak, bu değişim uzun vadelerde daha belirsiz ve karmaşık bir yapı arz eder (Güçlü,2003).

Bedeian ve Guleck (1983, s.384), değişime yönelten önemli diş değişkenler olarak sosyal değerler, hükümet, müşteriler, kaynak sağlayıcılar, rakipler ve yerel halkı ele almaktadır. Yeni yasal düzenlemelerin yeni üretim yöntemlerini gerektireceği; tüketici istemlerindeki değişimin işletmenin üretim hattında farklı seçeneklerin devreye sokulmasına yol açacağı; yeni bir rekabetin, reklamlarda artışa ve fiyat indirimlerine yol açabileceği ve benzeri gibi dış çevresel unsurlardaki değişimlerin işletmenin ona uygun tepkileri gösterecek şekilde değişimini gerektireceğini belirtmektedirler. Yazarlar, içsel etkenler olarak ise; işletmenin amaçları ve politikalarındaki; 
işletmenin çalışanlarının tutum ve davranışlarındaki; işletmenin sunduğu ürünler ve hizmetlerindeki değişimlerin, bölümler arasındaki anlaşmazlıkların örgütsel değişime yol açtığını tartışmaktadırlar (Sucu, 2000).

Günümüz işletmeleri için değişimi yönetebilmek oldukça profesyonel bir bakış açısı gerektirmektedir. Değişim mühendisliği olarak tanımlanan bu profesyonel yaklaşıma göre değişim yönetsel olduğu kadar teknik çabaları da gerektirmektedir. "Değişim mühendisliğinin işletmelere sağladığı birçok avantaj bulunmaktadır. Bunlar (Scott, 1995);

- Daha iyi müşteri hizmeti,

- Yönetim sürecinde iyileşmeler

- Yönetim etkinliği ve verimliliği

- Örgüt yapısında daha az kademe

- Ürün kalitesinin geliștirilmesi

Değişim mühendisliği her şeyden önce yaratıcı uygulamaları geliştirebilmek ile ilgilidir. Zira "Değişim mühendisliğinde başarı, tasarımın radikal olmasına bağlıdır. Başarılı tüm değişim mühendisliği projeleri radikal tasarımlarla başlamaktadır" (Kiely, 1993).

Akademik literatürde reorganizasyon ile ilgili birçok tanım bulunmaktadır. Bu kavramların temelinde, işletmelerin yapısal organizasyonlarının günü koşullarına göre yeniden biçimlendirilmesini içermektedir. Her işletme, içinde yaşadığı farklı koşullara uygun bir örgüt yapısına sahiptir. Hiyerarşik, matris, yatay, sanal ve komite gibi işletme gereklerine göre değişebilen örgüt yapılamaları bulunmaktadır. Çevresel koşulların etkisi altındaki işletmelerin, örgüt yapısı da değişmez değildir. İşletmenin büyümesi, küçülmesi veya sabit kalması, karmaşı çabaların birbirleriyle uyumlaştırılması gereği örgütlenme ihtiyacı daha da artar (Türkhukuksitesi,2015). Yeniden yapılandırmanın; günümüzde, "yönetsel reform", "yönetimin iyileştirilmesi", "yönetimin yeniden düzenlenmesi", "yönetsel reorganizasyon gibi terimlerle de ifade edildiği de görülmektedir. $\mathrm{Bu}$ bağlamda reform kavramı, genellikle, aksaklık ve hataları giderme, düzeltme, iyileştirme ve yeni bir biçim verme anlamında kullanılmaktadır. Reorganizasyon kavramı ise, kuruluşlardaki düzensizlik ve yetersizlik nedenlerinin araştırılarak optimum çözüm yollarının bulunması şeklinde tanımlanabilmektedir. Görüleceği üzere yeniden yapılandırma kapsamında ele alınan kavramlar benzer içeriklere sahip bulunmaktadır (Arem;2015).

Kısaca örgütler, onları saran çevrenin değişken koşullarına, yapı ve faaliyetlerini uydurmak zorundadırlar. Faal bir örgütün değişen, genel yakın ve örgütsel çevre koşullarına göre yeniden düzenlenmesi ve değiştirilmesi çabalarının tümü reorganizasyon kavramı ile açıklanabilir (Muhasebetürk;2015). Reorganizasyon kavramı sadece, örgütsel yapının biçimsel olarak yeniden düzenlenmesi değil, aynı zamanda, bir iş ile ilgili olarak işletmenin içyapısının yeniden revize edilmesidir. İşletmeler, maliyetleri düşürmek, verimliliği arttırmak, bir işi yeniden konumlandırmak, birleşme ya da satın alma gibi kurumsal değişiklikler gibi çeşitli nedenlerle reorganizasyon faaliyetlerine girişirler. Kısacası bu kavram; bölümler, iş birimleri ve çalışanların rolleri ve çoğunlukla işten çıkarma gibi konulardaki değişiklikleri de içermektedir. Bu bağlamda, organizasyon yapısındaki değişiklikler, genellikle bir işin ya temel yetkinlikleri üzerinde yoğunlaşılması ya da başka kaynakların kullanımının en aza indirilmesi konusunda yapılmaktadır (WhatisTechtarget;2015).

\section{1 İşletmeler Açısından Reorganizasyonun Gerekliliği}

Reorganizasyonun en temel amacı; işletmeyi en uygun organizasyon yapısına yeniden kavuşturmaktır (Özalp 1992). Zira işletmeler; maliyetlerini düşürmek, pazar paylarını, karlılıklarını ve performanslarını arttırmak gibi nedenlerden dolayı reorganizasyonu tercih etmektedirler. Organizasyon yapıları önemli bir yönetim aracıdır (Örücü, 2013, Yücel:2010). Mal veya hizmet üreten işletmelerin, varlıklarını sürdürmek için gösterdikleri performanslarının azalmasına, artmasına ve sabit kalmasına sebep olan önemli bir etmen de, şirket organizasyonunun çalışamaz hale gelmiş olmasıdır. Bu yüzden, işletmelerin devamlılıkları için, amaca uygun ve hızlı çalışan dinamik bir düzene ihtiyaçları vardır. Büyüyen bir işletmede, karmaşıklaşan işlerin birbirleriyle uyumlaştırılabilmesi için örgütlenme ihtiyacı daha da artar. Her işletme, içinde yaşadığı farklı koşullara, duruma ve ortama uygun bir örgüt yapısına sahiptir. Ayrıca, işletme çevresi ile arasındaki uzlaşmayı da ifade eden ve organizasyonu değişmeyen bir yapıya sahip değildir. Dolayısı ile organizasyonun tıkanması, işlevsiz hale gelmesi bu uzlaşmanın bozulmasına da yol açacağından, örgütün reorganizasyonu yoluyla, ihtiyaç ve beklentilere cevap verebilecek duruma getirilmesi ve yeniden dinamizm kazandırılması gerekebilir (Türkhukuksitesi;2015). Aynı zamanda; üretimde değişiklik yapılması, dış kaynaklardan yararlanma, bölümlerin birleştirilmesi ya da yeni bölümler kurulması, modern teknolojinin ve yönetim tekniklerinin uygulanması, üst yönetim kararları, eski ve biçimci sıkı kontrollerin yönetimi işlemez hale getirmesi gibi ihtiyaç ve koşullarda oluşan değişiklikler nedeniyle zamanla yetersiz kalan organizasyon yapısının reorganizasyonu nu gerektirir. Böylece, organizasyonun beklentilerini karşllayabilecek duruma getirilmesi, işletmeye yeni bir güç ve dinamizm kazandırılmasına yardım eder. Bu bağlamda yeniden yapılanma çalışmaları, işletmelerde oluşan yetersizleşmeyi gideren etkili bir araçtır ve onun devamında önemli katkısı vardır. Yeniden yapılanma çalışmaları, organizasyonun tümünde veya bir kısmı üzerinde yapılacağı gibi, iş süreçlerindeki değişikliklerle yolu ile de yapılabilir. $\mathrm{Bu}$ çalışmalarda hedef, organizasyonun performansını iyileştirmek ve optimize etmektir (Hrweb. Berkeley;2015). 


\subsection{Reorganizasyonu Yönetmenin Adımları}

$\mathrm{Bu}$ faaliyetler, sistematik biçimde yürütülmesi gereken bir dizi faaliyetleri içermektedir. Temel olarak bu faaliyetler aşağıdaki adımlardan oluşmaktadır (Umaine;2015);

- Problemi tanımlamak,

- Mevcut yapının, bölüm hedefleri ile uyumlu olup olmadığının kontrolü,

- İş ve yapının etkinliğine katkı sağlayan faktörlerin neler olduğunun tespiti,

- Veri toplama metotlarının tanımlanmasi,

- Hedefleri destekleyecek yeni yapı ya da modellerin tespit edilmesi,

- Yeniden yapılanma önerisinin geliştirilmesi,

- Her pozisyon için gerekli becerilerin belirlenmesi,

- Gerekli becerilerin karşılaştırılması,

- Eğitim ihtiyaçlarını ve kaynaklarını belirlemek,

- Tasarım ve eğitimi uygulamak,

- İnceleme ve yeniden gözden geçirme,

- Uygulama sırasında geri bildirimler alabilmek için yöntemler geliştirmek,

- Yönetimden düzenli geri bildirimler sağlayacak sistemlerin geliştirilmesi,

- Etkili bir takımın oluşturulması,

- Başarı için misyon, hedef ve standartların geliştirilmesi,

- Düzenli personel toplantılarının yapılması,

- Önerileri açık kılan iletişimin geliştirilmesi,

- Anlaşmazlıkların çözümü için gerekli sistemlerin geliştirilmesi,

- Bilgi paylaşımı konusunda tüm ekip üyelerinin teşvik edilmesi,

- Beyin firtınası ve karar vermede fikir birliği için destek vermektir.

\section{Değişim Mühendisliği Kavramına Genel Bir Bakış}

Değişim mühendisliği ile reorganizasyon kavramları tanımları açısından birbirlerinden farklılık göstermektedirler. Reorganizasyon, dar anlamda yeniden yapılanmayı içerir ve var olan bir yönetsel sistemin üzerinde değişime uyum sağlayıcı çalışmalar bütünüdür. Geniş anlam da ise; organizasyon yapısındaki ve departmanlara ayırmadaki değişikliklerin finansal yapının amaçların ve politikaların gözden geçirilerek yeniden düzenlenmesi, bu amaçlara varmak için otorite, sorumluluk ve haberleşme ilişkilerinin yeniden belirtilmesi olarak tanımlanır. "Değişim mühendisliği ise bir anlamda her şeye yeniden başlamak anlamına gelir (Efil, 2013; Can vd., 2004; Bakan vd, 2004; Ertürk,2012 )". Değişim mühendisliği bir anlamda, iki yüz yıllık endüstriyel yönetim sonucu elde edilen bilgeliğin bir yana atılarak, işin kitle üretim çağında nasıl yapıldığının unutulup, şu anda en iyi şekilde nasıl yapılabileceğini saptamaktadır (Koçel, 2014). Değişim mühendisliğinde eski iş unvanları ve organizasyon düzenlemeleri bir önem taşımaz. Bunlar artık başka bir çağın oluşumlarıdır. Önemli olan, günümüz pazarlarının ve teknolojilerinin taleplerine göre işin günümüzde ne şekilde organize edilmek istendiğidir. İnsanların ve şirketlerin geçmişte işleri nasıl yürüttükleri hiç önemli değildir (Enm;2015). Bir başka ifadeyle, değişim mühendisliği; bir atılım stratejisi ile organizasyonda performans düzeyini yükseltmek ve daha sonra bu performansın sürekliliğini sağlamak için geliştirilmiş bir tekniktir (Biraz;2015).

Kaldı ki, değişim mühendisliği, reorganizasyon kavramını da içeren geniş boyutlu ve iyileştirme kavramlarını da içeren bir reform ya da dönüşüm olarak görmekle beraber; değişimin ya da transformasyonun nasıl gerçekleştirilebileceğini açıklayan bir yönetim tekniğidir. Amacı, organizasyonda performans düzeyini yükseltmek olup, hedefi marjinal veya aşamalı geliştirmeler yapmak değil performansta önemli çarpıcı sıçramalar yapmaktır (Turgutözal;2015).

\subsection{Değişim Mühendisliğinin Esasları}

Değişim mühendisliği iki temel görüş üzerine kurulmuştur;

a. İşe beyaz bir sayfa açılarak başlanması, şirketin bütün bölüm ve operasyonlarının yeniden dizayn edilmesi,

b. Şirket organizasyonunun çok ve çeşitli fonksiyonlar olarak değil, az sayıda başı sonu belli olan ve devamlılık arz eden prosesler olarak görülmesidir. Bu iki kavramda esasında yeni olmayıp, farklılığı yaratmak için bunların detaylı olarak uygulamaya konulmasıdır. Bu görüşlerden hareketle, kavram üzerinde 9 temel ilke geliştirilmiştir (Biraz;2015);

- Pek çok iş tek bir iş halinde birleştirilir,

- Kararları elemanlar verir,

- Sürecin içindeki adımlar doğal bir sıra içinde gerçekleştirilir,

- Süreçlerin pek çok versiyonu vardır,

- İş en mantıklı yerde gerçekleştirilir, 
- Kontrol ve denetimler azalttlir,

- Mutabakat en aza indirilmiştir,

- Tek temas noktasını vaka yöneticisi oluşturur,

- Merkeziyetçi/Ademi merkeziyetçi işlemler yaygınlaşır.

\section{Genel Olarak Muhasebe Sisteminin Tasarımı}

Muhasebe sistemlerinin tasarımı ve kapasiteleri büyük farklılıklar gösterir. Bu yüzden, bu sisteminin yapısını etkileyen birçok unsur arasında en önemli ikisi; muhasebe bilgilerine duyulan gereksinim düzeyi ve bunun işletilebilmesi için kullanılabilir kaynaklar şeklinde sıralanabilmektedir. Günümüzde, muhasebe sisteminin tasarımı ve kurulması iş dünyası açısından bir uzmanlık alanı haline gelmiştir. Tasarlanacak bu sistemin kurulabilmesi için her şeyden önce sistem yapısını etkileyen çeşitli unsurlara ve özellikle de yukarıda sıralanan iki unsura yönelik analiz gereklidir. Ancak tüm bu çalışmalar, iyi organize edilmiş bir muhasebe sisteminin kurulup işletilebilmesi için yeterli değildir. Zira, muhasebe uygulamalarını yönlendiren en önemli unsurlar arasında (Nuveforum;2015);

- Ülkenin ticaret ve vergi yasaları,

- Ulusal ve uluslararası kavram, ilke ve standartlar ile

- Muhasebe işlemlerini oluşturan yasal belge düzeni yer almaktadır.

$\mathrm{Bu}$ çerçevede muhasebe sisteminin kurulması ve etkin olarak sürdürülmesine yönelik gerekli işlemler (Nuveforum;2015);

- Muhasebe bölümünün personel ve donanım yönünden organize edilmesi,

- Belge düzeninin kurulması,

- Kullanılacak defterler ve kayıt düzeni ile ilgili iş tanımlarının yapılması,

- Hesap Planının hazırlanması ve yönergeye bağlanması,

- Raporlama düzeninin kurulması şeklinde sıralanır.

\section{Araştırma}

\subsection{Araştırmanın Amacı}

Konu hakkında yapılan incelemelerde ülkemizde değişim mühendisliği kavramı, muhasebecilik mesleği açısından üzerinde durulan konular arasında değildir. Değişim mühendisliği, mesleki hizmetlerin itibarını arttırmak, kalite, maliyet ve zaman konularında köklü süreçleri ve bunu destekleyen bilgi akış sistemlerinde yeniden yapılanmayı amaçlamaktadır. Başka bir ifade ile değişim mühendisliği; organizasyon yapısından çok, hizmet üretimindeki süreçlerin yeniden tasarlanmasıdır ve iş süreçlerinin yürütülmesinde yeni bir sayfa açılması ile tanımlanabilir. $\mathrm{Bu}$ bakış açısı altında çalışma da; değişim mühendisliği kavramının içinde reorganizasyon kavramını da entegre ederek, bu mesleğin örgütsel yapısına ilişkin olarak değiştirilmesi ve geliştirilmesine ilişkin tavsiyelerin tartışılması amaçlamıştır.

\subsection{Araştırmanın Sorunsalı}

Muhasebecilerin ofislerinin örgütsel yapısı; her ne kadar klasik yapı temelli olsa da, aslında mali boyuttaki işlemlerin tamamına yakın kısmı, meslekte yeterliliği olmayanlar tarafından yapıldığı ve böylece örgütsel yapının farklılaştığı düşünülmektedir. Bu yüzden; muhasebeciler, asli görevleri olan mali görevlerinin önemli bir bölümünü, yardımcı çalışanlarına devretmek suretiyle, mesleğin örgütsel yapısının sorumluluklarını kurumsallaştırmaktan uzak ve keyfileştirdikleri değerlendirilmektedir. Ayrıca, bu hususu yürütenlerinde denetlenmemesi zafiyeti ile birlikte, bu meslekteki riski arttırdığı düşünülmektedir. Bu anlamda, benzeri akademik çalışmalarda da, mükelleflerin memnuniyetsizliklerine yönelik verilerin bu sıkıntıları desteklediği görülmektedir. Bu nedenlere dayanılarak, muhasebecilik ofislerinde değişim mühendisliği yaklaşımı ile yeniden örgütsel yapılanmanın sorununun gerekliliği ön plana çıkmaktadır.

\subsection{Metodoloji}

Araştırmanın evrenini, İstanbul'da faaliyet gösteren muhasebe bürolarındaki meslek mensupları ile yardımcı çalı̧̧anlar; örneklemini ise, İstanbul Serbest Muhasebeci ve Mali Müşavirler Odası'nın kayıtlarından, rassal yöntemle seçilen 500 meslek mensubu ve yardımcı çalışanlardan oluşmaktadır. Büroların tespitinde en az iki çalışanın varlığına özen gösterilmiş olup, verilerin elde edilmesinde görüşülen kişilerin sertifikalı meslek mensubu olmasına dikkat edilmiştir. Araştırmaya ilişkin veriler; a) Reorganizasyon ve b) Reorganizasyona etki eden Kurumsal Performans olmak üzere iki ayrı grupta değerlendirilmiştir. Her iki gruba ait güvenirliliğinin sınanmasında Kaiser-Meyer-Oklin, geçerliliğin ortaya konmasında ise faktör analizine başvurulmuştur. Kullanılan performans ölçeğinde (Goodman ve Svyantek, 1999) aidiyete ait 4, memnuniyete ait 6 soru kullanılmıştır. Ölçeklere SPSS'de varimax döndürmesi ile keşifsel faktör ve iç tutarlılık analizleri uygulanmıştır.

Araştırmada, nicel araştırma yöntemi kullanılmış ve veriler anketle elde edilmiştir. Anket ile elde edilen verilerin analizinde ayrıca yüz yüze görüşme yöntemi de kullanılmıştır. $\mathrm{Bu}$ araştırmada uygulanan anketlerin 
cevaplandırılmasında 5'li likert ölçeği kullanılmıştır. Ölçekteki değerlendirme seçenekleri ise şu şekildedir: 1Kesinlikle Katılmıyorum, 2-Katılmıyorum, 3- Kararsızım, 4- Katılıyorum ve 5- Kesinlikle Katılıyorum şeklinde düzenlenmiştir. Veriler SPSS programı ile analiz edilmiş olup, geliştirilen bazı hipotezlerin sınanması ve bulguların değerlendirmesi verilere ait değişkenlerin ortalamaları ve standart sapmaları dikkate alınarak yapılmıştır.

\subsection{Araştırma Bulguları}

\section{a) Mali Müssavirlik Bürolarının Reorganizasyonuna Yönelik Veriler}

Mali müşavirlik bürolarının reorganizasyonuna yönelik olarak 35 soru sorulmuş olup Kaiser-Meyer-Oklin güvenirlilik oranı \%73,4 olarak tespit edilmiştir. Sorulara ilişkin kodların dağılımları aşağıda verilmiştir;

A1- Büroda mali konulardaki yasal değişimlere kolayca uyum sağlanabilmektedir.

A2- Hangi işlem olursa olsun çözüm önerilerine birlikte karar veririz.

A3- Mali müşavirimiz, mükelleflerin ticari hukuksal sorunlarının çözümüne yönlendirici olabilmektedir.

A4- Personelin iş bırakma sebebi doğrudan mali müşavirin kendi davranışları ile ilgilidir.

A5- Tüm işlemler mali müşavir tarafından kontrol edilmektedir.

A6- Bizler mükelleflerimizi iyi tanır ve taleplerini biliriz.

A7- Büroda genellikle ciddi sorunlar görülmez.

A8- Mükellefler ile hemen hemen hiç tartışma ortamı olmaz.

A9- Mali müşavirimiz vergi mevzuatına çok hakimdir.

A10- Mükelleflerimiz ne yapmak istediğimizi iyi bilirler.

A11- Büroda mevzuat kitaplığı bulunmaktadır.

A12- Büroda çalışanların birbirlerinin işlemlerini kontrol ettiği bir çalışma biçimi vardır.

A13- Mükelleflerin bilgi güvenliğine yönelik her türlü önlem alınmıştır.

A14- Mali danışmanlık hizmetleri için ayrı ücret talep edilmektedir.

A15- Büroda personel ile mali müşavir arasında sıkı bir iş birliği vardır.

A16- Dosyalarımız büroya personel dışında gelen kişiler tarafından görülemeyecek biçimde arşivlenmiştir.

A17- Çoğu zaman mükelleflerimiz bürodan kaynaklanan vergi cezalarının farkında olmadan ödeme yaparlar.

A18- Mali müşavirimiz sosyal güvenlik mevzuatına çok hakimdir.

A19- Büroda, defter ve vergi işlemleri dışında mali danışmanlık hizmeti verilebilmektedir.

A20- Elemanların hiç biri mükellefler ile iş dışı ilişkilere girmezler.

A21- Mali müşavirimiz adliyede bilirkişilik hizmeti vermektedir.

A22- Hataların önlenmesine yönelik yeterli önlemler alınmıştır.

A23- Birlikte iş paylaşımını yaptığımız bir avukatımız vardır.

A24- Bilgisayarlarımızda ayrı bir şifreleme sistemi bulunmaktadır.

A25- Mükellef dosyalarının sırtında mükellef adını göstermeyen işaretler bulunmaktadır (Numara gibi).

A26- Mali müşavirimizin başka ticari faaliyetleri de bulunmaktadır.

A27- Sorunlara çözüm bulabilecek her tür ilişkiyi kurabilmiş durumdayız.

A28- Hatalarımız mükelleflerimize vergi / işlem cezası olarak yansımaz.

A29- Vergi dairesi ve defterdarlık personeli ile yakın ilişkilerimiz bulunmaktadır.

A30- Mükelleflerin bilgi taleplerine aynı gün vakit geçirmeden cevap verilebilmektedir.

A31- Mükellefin uğradığı zararı mali müşavirimiz mükellefe bilgi vermeden giderir.

A32- Mükellef işlemlerinin takibinde personel arasında dosya paylaşımı yapılmıştır.

A33- Büroda mali müşavir ile personel arasında yönetim sorunu bulunmamaktadır.

A34- Yapılan tüm hatalar personelle yapılan ortak toplantıda açıklanır.

A35- Yasal mevzuatlar konusunda çalışanlara sürekli bilgi verilmektedir.

Tablo-1'de yer alan veriler incelendiğinde, frekans dağılımlarına dikkat edilecek olursa ankete katılanların önemli bir bölümünün katılıyorum seçimini destekler nitelikte yanıtlar verdiği görülmektedir. Ayrıca sorulara ilişkin olarak, Varimax yöntemi ile faktör analizi aşağıdaki gibi tespit edilmiştir (Faktör yüklerinin 0,50'nin üzerinde olması beklenir ve 0,50'nin altında yer alan değişkenler faktör analizinden çıkarılmış ve analiz yeniden yapılmıştır. İfadelerin faktör yükleri 0,40 eşik değerinin çok üzerinde çıkmıştır.). 


\begin{tabular}{|c|c|c|c|c|c|c|c|c|c|c|c|c|c|}
\hline & \multicolumn{2}{|c|}{$\begin{array}{l}\text { Kesinlikle } \\
\text { Katılmiyorum }\end{array}$} & \multicolumn{2}{|c|}{ Kat1lmiyorum } & \multicolumn{2}{|c|}{ Kararsızım } & \multicolumn{2}{|c|}{ Kat1liyorum } & \multicolumn{2}{|c|}{\begin{tabular}{|l} 
Kesinlikle \\
Kat1liyorum \\
\end{tabular}} & \multicolumn{2}{|c|}{$\begin{array}{l}\text { Cevap } \\
\text { Yok } \\
\end{array}$} & \multirow{2}{*}{ 吾言 } \\
\hline & $\mathrm{N}$ & $\%$ & $\mathrm{~N}$ & $\%$ & $\mathrm{~N}$ & $\%$ & $\mathrm{~N}$ & $\%$ & $\mathrm{~N}$ & $\%$ & $\mathrm{~N}$ & $\%$ & \\
\hline A1 & 0 &, 0 & 50 & 10,0 & 135 & 27,0 & 291 & 58,2 & 24 & 4,8 & 0 & ,0 & 0,74 \\
\hline A2 (Fak.-1/0,755) & 1 & 2 & 26 & 5,2 & 142 & 28,4 & 292 & 58,4 & 39 & 7,8 & 0 & ,0 & 0,70 \\
\hline A3 (Fak.-5/0,737) & 0 & ,0 & 0 & , 0 & 8 & 1,6 & 439 & 87,8 & 53 & 10,6 & 0 & ,0 & 0,34 \\
\hline A4 & 6 & 1,2 & 9 & 1,8 & 47 & 9,4 & 312 & 62,4 & 126 & 25,2 & 0 & ,0 & 0,72 \\
\hline A5 (Fak.-5/0,664) & 2 &, 4 & 19 & 3,8 & 86 & 17,2 & 316 & 63,2 & 77 & 15,4 & 0 & ,0 & 0,71 \\
\hline A6 & 0 & ,0 & 3 & 6 & 19 & 3,8 & 431 & 86,2 & 47 & 9,4 & 0 & , 0 & 0,39 \\
\hline A7 (Fak.-3/0,705) & 2 & 4 & 56 & 11,2 & 265 & 53,0 & 162 & 32,4 & 15 & 3,0 & 0 & ,0 & 0,71 \\
\hline A8 (Fak.-3/0,723) & 12 & 2,4 & 95 & 19,0 & 231 & 46,2 & 138 & 27,6 & 24 & 4,8 & 0 & ,0 & 0,86 \\
\hline A9 (Fak.-2/0,718) & 0 & ,0 & 2 &, 4 & 12 & 2,4 & 300 & 60,0 & 186 & 37,2 & 0 & ,0 & 0,54 \\
\hline A10 (Fak.-3/0,683) & 18 & 3,6 & 137 & 27,4 & 212 & 42,4 & 126 & 25,2 & 7 & 1,4 & 0 & ,0 & 0,85 \\
\hline A11 & 1 & ,2 & 36 & 7,2 & 12 & 2,4 & 345 & 69,0 & 106 & 21,2 & 0 & ,0 & 0,74 \\
\hline A12 (Fak.-4/0,467) & 6 & 1,2 & 48 & 9,6 & 53 & 10,6 & 370 & 74,0 & 23 & 4,6 & 0 & , 0 & 0,75 \\
\hline A13 (Fak.-4/0,773) & 0 &, 0 & 6 & 1,2 & 39 & 7,8 & 412 & 82,4 & 43 & 8,6 & 0 & ,0 & 0,46 \\
\hline A14 & 22 & 4,4 & 198 & 39,6 & 178 & 35,6 & 94 & 18,8 & 8 & 1,6 & 0 & ,0 & 0,87 \\
\hline A15 (Fak.-1/0,799) & 7 & 1,4 & 19 & 3,8 & 35 & 7,0 & 416 & 83,2 & 23 & 4,6 & 0 & ,0 & 0,61 \\
\hline A16 (Fak.-4/0,626) & 0 & ,0 & 48 & 9,6 & 27 & 5,4 & 359 & 71,8 & 66 & 13,2 & 0 & ,0 & 0,75 \\
\hline A17 & 0 & ,0 & 2 &, 4 & 20 & 4,0 & 327 & 65,4 & 151 & 30,2 & 0 & ,0 & 0,54 \\
\hline A18 (Fak.-2/0,799) & 0 & ,0 & 2 & 4 & 8 & 1,6 & 290 & 58,0 & 200 & 40,0 & 0 & ,0 & 0,54 \\
\hline A19 & 5 & 1,0 & 37 & 7,4 & 146 & 29,2 & 293 & 58,6 & 19 & 3,8 & 0 & ,0 & 0,73 \\
\hline A20 & 14 & 2,8 & 44 & 8,8 & 74 & 14,8 & 316 & 63,2 & 52 & 10,4 & 0 & ,0 & 0,87 \\
\hline A21 & 54 & 10,8 & 325 & 65,0 & 2 & 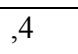 & 108 & 21,6 & \begin{tabular}{|l|}
11 \\
\end{tabular} & 2,2 & 0 & 0 & 1 \\
\hline A22 (Fak.-4/0,601) & 2 & 4 & 0 & ,0 & 34 & 6,8 & 437 & 87,4 & 27 & 5,4 & 0 &, 0 & 0,40 \\
\hline A23 (Fak.-6/0,845) & 16 & 3,2 & 218 & 43,6 & 32 & 6,4 & 218 & 43,6 & 15 & 3,0 & 1 & 2 & 1 \\
\hline A24 (Fak.-6/0,817) & 10 & 2,0 & 122 & 24,4 & 10 & 2,0 & 321 & 64,2 & 37 & 7,4 & 0 & , 0 & 1 \\
\hline A25 (Fak.-6/0,786) & 28 & 5,6 & 207 & 41,4 & 14 & 2,8 & 236 & 47,2 & 15 & 3,0 & 0 & 0 & 1 \\
\hline A26 & 106 & 21,2 & 369 & 73,8 & 7 & 1,4 & 17 & 3,4 & 1 & ,2 & 0 & ,0 & 0,60 \\
\hline A27 (Fak.-1/0,777) & 2 & 4 & 14 & 2,8 & 82 & 16,4 & 378 & 75,6 & 24 & 4,8 & 0 & ,0 & 0,57 \\
\hline A28 & 2 & 4 & 6 & 1,2 & 153 & 30,6 & 302 & 60,4 & 36 & 7,2 & 1 & 2 & 0,62 \\
\hline A29 & 9 & 1,8 & 194 & 38,8 & 186 & 37,2 & 96 & 19,2 & 15 & 3,0 & 0 & ,0 & 0,86 \\
\hline A30 (Fak.-2/0,500) & 0 &, 0 & 17 & 3,4 & 214 & 42,8 & 238 & 47,6 & 31 & 6,2 & 0 & ,0 & 0,66 \\
\hline A31 & 75 & 15,0 & 217 & 43,4 & 125 & 25,0 & 83 & 16,6 & 0 & ,0 & 0 & ,0 & 0,94 \\
\hline A32 & 6 & 1,2 & 52 & 10,4 & 37 & 7,4 & 385 & 77,0 & 20 & 4,0 & 0 & ,0 & 0,75 \\
\hline A33 (Fak.-5/0,438) & 0 &, 0 & 2 &, 4 & 24 & 4,8 & 445 & 89 , & 29 & 5,8 & 0 & ,0 & 0,35 \\
\hline A34 & 3 & ,6 & 32 & 6,4 & 91 & 18,2 & 350 & 70,0 & 24 & 4,8 & 0 & , 0 & 0,68 \\
\hline A35 & 1 & ,2 & 21 & 4,2 & 56 & 11,2 & 368 & 73,6 & 54 & 10,8 & 0 & ,0 & 0,63 \\
\hline
\end{tabular}

Tablo-1. Mali Müşavirlik Bürolarının Reorganizasyonuna Yönelik Frekans Dă̆ılımları Kaynak: Yazarlar Tarafından Geliştirilmiştir.

Yasal mevzuatlara hakimiyet konusundaki A1, A3, A9, A11, A18, A35 numaralı sorulara \%58 üstünde kat1lım gösterilmiştir. Bu duruma özellikle son zamanlardaki Türk Ticaret Kanununa yönelik yeni düzenlemelerin sıkı biçimde takip edilmesinin sebep olduğu düşünülmektedir. Mevzuat takibi mali müşavirlik bürolarında ruhsat sahibi meslek mensubu tarafından yapılırken, diğer personelin bu anlamda uygulayıcı rol oynadığı görülmektedir.

Veri ve işlem güvenliğine yönelik olarak A5, A12, A13, A16, A20, A22, A24, A25 ve A26 numaralı sorulara \%63'ün üstünde katılıyorum yanıtı verilmiştir. Konu ile ilgili olarak dosya kodlama konusunda farklı uygulamalara rastlanmıştır. Veri güvenliği konusu mali müşavirler için hayati önem taşımaktadır. Bu nedenle, çoğu mali müşavirin bilgisayar kullanımı konusundaki yetersiz uygulamalarına rağmen önemle dikkat edilen bir 
konu olduğu tespit edilmiştir. A26 ya verilen yanıt veri güvenliği açısından oldukça önemli bir sorundur. Mükelleflerin yanı sıra meslek mensuplarının önemli bir bölümü, bir mali müşavirin ticari faaliyetler ile uğraşmasının meslek etiği açısından olumsuz etkiler doğuracağını savunmaktadır.

Mükellefler ile olan ilişkiler açısından A6, A8, A10, A17, A28, A30, A31 ve A32 kodlu sorulara verilen cevaplardaki dağılımlar dikkat çekicidir. Mali müşavirlerin \%86'sı mükelleflerini \%42'si ise mükelleflerin mali müşavirlerini iyi tanıdıklarını ifade etmişlerdir. Bununla birlikte $\% 46$ ya yakın bölümü çeşitli sebeplerle bazı çatışma ortamlarına girebildiklerini ve çoğu zaman bu çatışma ortamlarından uzaklaşabilmek için bazı hatalardan mükelleflerin haberdar edilmeden, olası cezaların $\% 60$ oranında mali müşavirlerin bütçelerinden karşılandığı ifade edilirken \%43'lük bölümün bu konuda mükelleflere bilgi vermeyi tercih ettiklerini açıklamışlardır. İşlemlerin düzgün ve doğru yapılabilmesi için genellikle (\%77 oranında) personel arasında dosya paylaşımı yapılmaktadır. Bu grupta özellikle A17 kodlu soruya verilen yanıtta çelişki tespit edilmiştir. Ancak bu çelişkinin mükelleflerin vergi ödemelerinin içeriğini tam olarak anlamadığı yönünde değerlendirilmiştir.

Yönetsel açıdan değerlendirmeye konu A2, A4, A7, A15, A27, A33 ve A34 kodlu sorulara \%58 ile \%89 arasında katılıyorum cevabı verilmiştir. Genel olarak mali müşavirlik bürolarında temel iş ve işlemleri yapan personel ile sorunlara olan çözümlerin birlikte geliştirildiği, bu anlamda mali müşavirler ile işbirliği sağlanabildiği ve hataların birlikte değerlendirildiği görülmektedir. Ancak mali iş ve işlemlerin getirmiş olduğu yüksek sorumluluk bu iş birliğine rağmen, personelin ayrılma kararına etki eden en önemli faktörün yine mali müşavirin kendisi olduğu \%62 oranında görülmüştür.

D1ş ilişkilere yönelik olarak sorulan A14, A19, A21, A23 ve A29 kodlu sorulara verilen yanıtlar dağılım göstermiştir. Mali müşavirlik bürolarında mevcut işlemlerin dışında \%60 oranında danışmanlık hizmetleri verilmektedir. Çoğu mali müşavir bu anlamda ticari davalar konusunda uzmanlaşmış bir avukat ile de işbirliği yapmaktadır. Bununla birlikte danışmanlık hizmetlerinin ücretlendirilmesine yönelik farklı uygulamalar bulunmaktadır. Kimi mali müşavirler bu konuda ayrı ücret alırlarken kimileri de bunu bir reklam unsuru olarak görmektedirler. Cevaplayıcıların yaklaşık \%65'i adil bir dağılımın yapılmaması düşüncesi ile bilirkişilik hizmeti veremediğini öne sürmüştür. Maliye ve defterdarlıklar ile olan ilişkilerin güçlendirilmesinde kurumsal dışı faaliyetlerinde kullanılabildiği tespit edilmiştir. Özellikle bu yöndeki ilişkilerin geliştirilmesinde muhasebe meslek mensupları tarafından hemen her türlü firsatın değerlendirildiği açıklanmıştır.

\section{b) Mali Müşavirlik Bürolarında Performansa Yönelik Veriler}

Performans ya da performansa yönelik sorunlar, reorganizasyona yönelik girişimlerin en önemli sebepleridir. Sadece çalışan personele olmak üzere, araştırmada bu gruba yönelik 10 soru sorulmuş olup Kaiser-Meyer-Oklin güvenirlilik oranı \% 79,5 olarak tespit edilmiştir. Sorulara ilişkin kodların dağılımları aşağıda verilmiştir.

B1- Faaliyetlerimizden dolayı ödüllendirme sistemimiz bulunmaktadır.

B2- Hatalarımızın mali sorumluluğu bize aittir.

B3- Aldığımız ücretten memnunuz.

B4- Ücretlerimiz bölgedeki diğer muhasebe personellerinin ücretleri ile hemen hemen aynıdır.

B5- Hata yapmazsak ücretimin artacağından eminim.

B6- Personele ait değerleme sistemi açık biçimde herkes tarafından bilinir.

B7- Maaşlarımız iş başarımıza göre düzenlenmiştir.

B8- Adil bir ücret dağılımının yapıldığını düşünüyorum.

B9- Kişisel gelişmemize sürekli destek olunmaktadır.

B10- Çalışmamıza göre ücret dışında da ayrı bir ödüllendirme sistemimiz bulunmaktadır.

Sorulara verilen cevapların frekans dağılımları ve standart sapmaları aşağıdaki gibidir;

\begin{tabular}{|c|c|c|c|c|c|c|c|c|c|c|c|c|c|}
\hline & \multicolumn{2}{|c|}{$\begin{array}{l}\text { Kesinlikle } \\
\text { Katılmiyorum }\end{array}$} & \multicolumn{2}{|c|}{ Katılmiyorum } & \multicolumn{2}{|c|}{ Kararsızım } & \multicolumn{2}{|c|}{ Katıliyorum } & \multicolumn{2}{|c|}{\begin{tabular}{|l} 
Kesinlikle \\
Kat1liyorum \\
\end{tabular}} & \multicolumn{2}{|c|}{$\begin{array}{l}\text { Cevap } \\
\text { Yok }\end{array}$} & \multirow{2}{*}{ 劳 } \\
\hline & $\mathrm{N}$ & $\%$ & $\mathrm{~N}$ & $\%$ & $\mathrm{~N}$ & $\%$ & $\mathrm{~N}$ & $\%$ & $\mathrm{~N}$ & $\%$ & $\mathrm{~N}$ & $\%$ & \\
\hline B1 (Fak.-1/0,873) & 31 & 6,2 & 248 & 49,6 & 132 & 26,4 & 85 & 17,0 & 3 & ,6 & 1 & ,2 & 0,87 \\
\hline B2 (Fak.-3/0,590) & 20 & 4,0 & 270 & 54,0 & 93 & 18,6 & 96 & 19,2 & 21 & 4,2 & 0 & 0 & 0,97 \\
\hline B3 (Fak.-2/0,797) & 20 & 4,0 & 99 & 19,8 & 169 & 33,8 & 178 & 35,6 & 33 & 6,6 & 1 & ,2 & 0,97 \\
\hline B4 (Fak.-2/0,797) & 4 &, 8 & 47 & 9,4 & 197 & 39,4 & 220 & 44,0 & 30 & 6,0 & 2 & 4 & ,078 \\
\hline B5 (Fak.-1/0,713) & 43 & 8,6 & 258 & 51,6 & 110 & 22,0 & 60 & 12,0 & 28 & 5,6 & 1 & ,2 & 1 \\
\hline B6 (Fak.-2/0,570) & 15 & 3,0 & 155 & 31,0 & 163 & 32,6 & 151 & 30,2 & 15 & 3,0 & 1 & ,2 & 0,92 \\
\hline B7 (Fak.-1/0,738) & 45 & 9,0 & 211 & 42,2 & 135 & 27,0 & 90 & 18,0 & 18 & 3,6 & 1 & 2 & 0,99 \\
\hline B8 (Fak.-2/0,082) & 20 & 4,0 & 88 & 17,6 & 138 & 27,6 & 235 & 47,0 & 19 & 3,8 & 0 & , 0 & 0,94 \\
\hline B9 (Fak.-2/0,522) & 1 &, 2 & 22 & 4,4 & 62 & 12,4 & 352 & 70,4 & 63 & 12,6 & 0 & , 0 & 0,66 \\
\hline B10 (Fak.-1/0,812) & 39 & 7,8 & 304 & 60,8 & 78 & 15,6 & 66 & 13,2 & 13 & 2,6 & 0 &, 0 & 0,91 \\
\hline
\end{tabular}


Tablo-2. Mali Müşavirlik Bürolarında Performansa Yönelik Frekans Dağıllmları Kaynak: Yazarlar Tarafindan Geliştirilmiştir.

Muhasebe bürolarında rutin faaliyetler bulunmakta ve çoğu zaman çalışan personel için sıkıcı bir durum yaratmaktadır. Buna rağmen bu durumun giderilmesine yönelik parasal bir ödüllendirme ya da teşvik sistemi büyük ölçüde bürolarda bulunmamaktadır. Yapılan hatalardan dolayı kurum içinde bir sorumluluk sistemi geliştiriliyor olsa da yasal anlamda sorumluluk ruhsat sahibi mali müşavire aittir.

Personel ücreti konusunda ilginç bir sonuç elde edilmiştir. İstanbul piyasasında ortalama ücret 900.-TL ile 1.500.-TL arasında değiştiği görülmüştür. Bununla birlikte alınan ücret memnuniyeti konusunda $\% 33$ kararsız kalırken yaklaşık \%36'sı ücretlerini düşük bulmuşlardır. Cevaplayıcıların \%44'ü ücretlerinin bölgedeki diğer çalışanlar ile aynı olduğunu paylaşırken, \%39'u kararsız kalmıştır. Cevaplayıcıların yaklaşık \%52'si işlerinde ne kadar düzenli olurlarsa olsun ücretlerinin artmayacağını, \%42'si ücretleri ile çalışma performansı arasında ilişki bulunmadığını beyan etmişlerdir. Ancak buna rağmen mevcut sistem içinde cevaplayıcıların \%47'si ücretlerinin adil dağılldığını ifade etmişlerdir. Bu konudaki diğer bir tespit ise birçok muhasebe bürosunun teşvik konusunda paranın dışında ki ödüllendirme sistemlerini kullandıkları yönündedir. Personel gelişimi konusunda, meslek mensupları tarafından \%70,4 oranında destek sistemi bulunurken, personel değerlendirme sisteminin bilinirliliği konusunda muhasebe büroların arasında farklılıklar bulunmaktadır.

\section{Sonuç ve Öneriler}

Küresel değişimler, işletmelerin birçok faaliyetlerindeki uygulama biçimlerini, hizmetin verilme şeklini, örgütsel yapının temel elemanlarını etkilemektedir. Bu değişimler; rekabetin ciddi etkilerinin ortaya konduğu ticari hayatın kendisinde olduğu kadar, ekonomik, siyasi, hukuksal ve sosyal yaşamın içeriğinde meydana gelmektedir. Değişim; işletmeler açısından olumlu yararlar sağlayabildiği gibi işletmeyi negatif yönde etkileyen sonuçlar da ortaya koyabilmektedir. İş dünyası değişime direnç göstermenin anlamlı bir yaklaşım olmadığını keşfetmiş durumdadır. Bu durumda değişime uyum sağlayabilmek kadar, gelecek değişimleri de öngörebilmek suretiyle gerekli önlemleri alabilmek işletmeler açısından yarar sağlayacaktır. Kısaca değişim işletmelerin varoluşları üzerinde önemli etkilere sahiptir.

Değişim kavramı, reorganizasyon olarak adlandırılan yeniden yapılanma ve reengineering olarak adlandırılan değişim mühendisliği kavramlarını ortaya çıkartmıştır. Reorganizasyon yumuşak geçişleri ifade ederken, reengineering köklü değişimlerden bahsetmektedir. Özellikle finansal dünyadaki değişimler, muhasebe bürolarının yeniden tasarımını gerekli kılmıştır. Sadece bir ruhsat sahibi mali müşavirin yönetimindeki büroların, Amerika'daki paydaşlarında olduğu gibi örgütlü bürolar şeklinde tasarlandığı ve yeni modellerin uygulamaya konduğu, ancak ülkemizde pek alışık olunmayan örgütsel modellerin varlığından bahsedilmektedir.

Yukarıda yer alan durumlara dayalı olarak bu araştırmada; İstanbul ilinde faaliyet gösteren muhasebe bürolarında yeniden yapılanmaya gidilip gidilmemesi konusunda bir değerlendirme yapılmaya çalışılmıştır. İstanbul, finansal anlamda Türkiye'nin en büyük şehridir. İthalat ve ihracat verileri ve maliye bakanlı̆̆ının vergi gelirleri konusundaki çalışmaları incelendiğinde İstanbul'un mali açıdan önemi görülecektir. Diğer yandan mali müşavirlik bürolarının modernizasyon ve yapılanma modellerinin belirtilerine bu ilde rastlanmıştır. Araştırmada hem anket hem de yüzyüze görüşme modelleri kullanılarak 45 soru sorulmuş, bu sorulara verilen yanıtlar, belirlenen ölçek çerçevesinde hem frekans dağılımları itibarıyla hem de faktör grupları itibarılya ayrı ayrı değerlendirilmiş ve cevaplar arasındaki ilişkiler ortaya konmaya çalışılmıştır. Bu çerçevede aşağıdaki bulgular elde edilmiştir;

- Mükellefler ile mali müşavirler arasındaki ilişkilerin olumsuz boyutunda kısmen de olsa bir artış gözlemlenmiş olup bu ilişkilerin bir kısmı da değişim göstermiştir.

- Mükellefler ile muhasebe ofisinde çalışanlar arasındaki ilişkilerin de negatif boyutunda artış gözlemlenmiş, bilhassa mali müşavirlik staj müessesesinde bazı sorunlar tespit edilmiştir..

- Muhasebe ofislerinde, mesleğe yönelik olarak teknik anlamda olmasa da önemli ölçüde bir yeniden yapılanma ihtiyacı olduğu gözlemlenmiştir. Bu durum, bilhassa muhasebe bürosunda çalışan elemanlar ile meslek mensubu ile ilişkilerin yeniden biçimlendirilmesi açısından gerekli olduğu sonucu ortaya çıkmıştır.

- Gerek uluslararasılaşma, gerekse yerelleşme sürecinde meslekte "stratejik ortakllk" kavramının gündeme getirilmesi inancının kuvvetle yaygınlaştı̆̆ ancak ortaklık kavramına karşı olan negatif düşüncenin bir paradox yarattığı gözlemlenmiştir.

- Mali müşavirlerin meslekte tek adam olma olgusunun, kısa zamanda yeniden değerlendirilerek, sahada örgütsel yapıya ilişkin modellerin geliştirilmesinin gerekli olduğu anlaşılmıştır.

Sonuç olarak, araştırmamızdan elde edilen bulgulara göre muhasebe bürolarının örgütsel yapısının, uluslararası rekabetin biçimlendirdiği koşullara göre yeniden yapılandırma süreci içinde incelenmeleri, yönetsel sürecin ise değişim mühendisliği ilkelerine göre baştan sona doğru gözden geçirilmesi gerektiği değerlendirilmektedir. 


\section{Kaynakça}

- De Geus (1997), “The Living Company”, Harvard Business Review, Marc-April 1997.USA, p.97

- E.ÖRÜCÜ (2013), Modern İşletmecilik, Dora Yayınları, Bursa.

- George SCOTT, "Downsizing, Business Process Reengineering, and Quality Improvement Plans: How Are They Related?", Information Strategy:The Executive's Journal, Vol.11, Issue:3,1995, s.18-34 (http://core.coll.mpg.de/Record/129201146)

- H.CAN vd.(2004), Genel İşletmecilik Bilgileri, Siyasal Kitapevi, Ankara.

- H.JOHANSSON vd.(1993), Business Process Reenigineering: Breakpoint Strategies For Market Dominance, John Wiley and Sons., Chichester, USA

- İ. ÖZALP (1992), "Reorganizasyonun İşletmenin Devamlılığını Sağlayıcı Bir Süreç Olarak Kullanılması ve Eskişehir'de Faaliyet Gösteren İșletmelerde Reorganizasyon İle İlgili Yapılan Çalışma ve Uygulama Sonuçları", Eskişehir Anadolu Üniversitesi, İktisadi ve İdari Bilimler Fakültesi Dergisi C: X, S: 1 -2.,s.132

- İ.EFIL(2013), İşletmelerde Yönetim ve Organizasyon, Dora Yayınları, Bursa.

- İ.BAKAN (2004), Çağdaş yönetim Yaklaşımları, Beta Basım, İstanbul.

- J.A.PEARCE vd. (2015), Stratejik Yönetim, Nobel Yayınları, Ankara.

- L.E. BOONE vd. (2013), Çağdaş İşletme, Nobel Yayınevi, Ankara.

- M.AKÇAKAYA (2004), "Değişim Mühendisliği ve Türk Kamu Yönetiminde Uygulanabilirliliği”, Sayıştay Dergisi, Sayı:66-67.,s.3

- M.ERTÜRK (2012), İşletmelerde yönetim ve Organizasyon, Beta Yayıncılık, İstanbul.

- $\quad$ N. GÜÇLÜ (2003), "Stratejik Yönetim”, G.Ü. Gazi Eğitim Fakültesi Dergisi Cilt: 23, Sayl: 2.,s.76

- R. YÜCEL (2010), Merkez ve Çevre İlişsisine Bağlı Örgütsel Yapı ve Performans, Nobel Yayınevi, Ankara.

- R.YÜCEL ve C.KARTAL(2014), "Muhasebecilerin Mesleki Uygulamalarındaki Etik Algılarına İlişkin Bir Araştırma”, Kırıkkale Üniversitesi, Sosyal Bilimler Enstitüsü Dergisi, Cilt:4, Sayı:2, Temmuz 2014, Kırıkkale

- R.L.DAFT (2015), Örgüt Kuramları ve Tasarımını Anlamak, Nobel Yayınları, Ankara.

- S.P.ROBBINS vd.(2013), Yönetimin Esasları, Nobel Yayınları, Ankara.

- T.KOÇEL (2014), İşletme Yöneticiliği, Beta Basım, İstanbul.

- T. KIELY (1993), “The Burdened Boss”, CIO,March, s.28-32. (https://books.google.com.tr/books?....)

- Y. SUCU (2000), Örgütsel Değişim, Güncellenmemiş Kitap, Elit Yayıncılık, Ankara, (www.yasarsucu.net)

- http://www.nuveforum.net/716-iktisat-bolumu/252864-hizmet-uretimi-bulunan-ticaret-isletmelerindemuhasebe-organizasyonu-uygulama-onerileri

- http://www.biraz.gen.tr/ekonomi/degisim-muhendisligi

- http://www.turgutozal.edu.tr/lvurgun/ contents/lvurgun/files/3\%20Degsm\%20Muhendisligi.pdf

- http://enm.blogcu.com/degisim-muhendisliginin-tanimi-nedenleri-kapsami-ve-ogeleri-2/2841533

- https://umaine.edu/hr/managers-tools/reorganization-guidelines/

- http://hrweb.berkeley.edu/guides/managing-hr/managing-successfully/reorganizations/steps

- Http://www.turkhukuksitesi.com/makale1449.htm

- http://whatis.techtarget.com/definition/reorganization-reorg

- http://muhasebeturk.org/ecopedia/402-r/17513-reorganizasyon-nedir-ne-demek-tanimi-anlaminedemek.html

- http://www.arem. gov.tr/ortakicerik/arem/Projeler/Yonetim/Koyhizmetleri/Bl_4.pdf

- https://www.xing.com/communities/posts/muhasebe-mesleginde-neler-yapilmali-1005423083

- http://www.lebibyalkin.com.tr/dergiicerikp.asp? dicerik_id=13\&dergi_id=22 


\title{
Fiyatları Etkileme Suçu Crime of Manipulation on Prices
}

\author{
Prof. Dr. Çetin Arslan (Hacettepe University, Turkey) \\ Ph. D. Candidate Didar Özdemir (Hacettepe University, Turkey)
}

\begin{abstract}
In a regular free market economy, the prices of goods and services occur at the point where the quantities of supply and demand get up with one another. On the other hand, it can be in question the distortion of this equilibration by various purposes and practices. In this case, optimal goods and services cannot be received under optimum conditions. As a conclusion of "ultima ratio" principle in the criminal law, every illegal conduct in this context does not constitute a crime but some fraudulent ones are imposed a sanction. The crimes of "fraud" in articles 157-158, "fraudulent bankruptcy" in article 161, "bid rigging" in article 235, "rigging during the discharge of contractual obligation" in article 236 and "manipulation on prices" in article 237 of Turkish Penal Code are some of the examples which can be given in this context. In this study, "crime of manipulation on prices" which is not dwelled on adequately in the doctrine is examined by featuring the controversial points.
\end{abstract}

\section{Giriş}

Serbest piyasa ekonomisi kurallarının tam olarak işlediği bir ortamda mal ve hizmet fiyatları arz ve talep miktarlarının birbirleriyle eşitlendiği noktada oluşmaktadır. Bununla birlikte çeşitli amaç ve yöntemlerle bu dengenin bozulması söz konusu olabilmektedir. Bu durumda en iyi mal veya hizmetin en uygun koşullarda edinilmesi veya alınması mümkün olamamaktadır. Ceza hukuku yaptırımlarının son çare olmasının doğal sonucu olarak anılan kapsamda ortaya çıkan her hukuka aykırı davranış suç teşkil etmemekle birlikte, hileli şekilde gerçekleştirilen bazıları cezai yaptırıma bağlanmıştır. Türk Ceza Kanunu'nun 157-158. maddelerindeki "dolandırıcılık suçu", 161. maddesindeki "hileli iflas suçu", 235. maddesindeki "ihaleye fesat karıştırma suçu", 236. maddesindeki "edimin ifasına fesat karıştırma suçu" ve 237. maddesindeki "fiyatları etkileme suçu" bu çerçevede örnek olarak gösterebileceğimiz düzenlemelerden bazılarıdır. Çalışmamızda bu suçlardan doktrinde üzerinde yeterince durulmayan "fiyatları etkileme suçu” özellikle tartışmalı noktalara ağırlık verilmek suretiyle genel olarak değerlendirilecektir.

\section{Sayılı Türk Ceza Kanunu Düzenlemesi}

"Fiyatları etkileme suçu” 765 sayılı mülga Türk Ceza Kanunu (765 sayılı TCK)'nun 358 ve 359. maddelerde düzenlenmekteydi. 358. madde "Her kim yalan havadis neşir ve işaasiyle veya sair hileli vasıtalar ile umumi pazarlar yahut ticaret borsalarında amele ücretlerinin veya erzak veya emtia yahut umumi pazarlarda alınıp verilen veya esham borsalarına kabul edilen evrak ve senedat piyasasının artıp eksilmesine sebebiyet verirse üç aydan üç seneye kadar hapis ve yüz liradan beş yüz liraya kadar ağır cezayı nakdi ile cezalandırılır." hükmünü getirmekte ve böylece 5237 sayılı Türk Ceza Kanunu (TCK)'nda nitelikli hal olarak düzenlenen "işçi ücretlerinin ya da besin veya malların değerinin artıp eksilmesine sebep olma” fiili suçun temel hali olarak düzenlemekteydi. Dolayısıyla 765 sayılı TCK döneminde zarar suçu olarak düzenlenen bu suç yeni TCK'ye alınırken "fiyatların değişmiş olması" hali unsur olmaktan çıkarıldığı için zarar suçu olmaktan çıkmıştır. Benzer şekilde, 765 sayılı TCK'nın 359. maddesinde "Bundan evvelki maddede yazılı cürüm, resmi ruhsatı haiz simsar yahut borsa tellalları tarafindan irtikap olunursa failin göreceği ceza bir seneden beş seneye kadar hapis ve meslek ve sanattan muvakkaten memnuiyet ve elli liradan az olmamak üzere ağır cezayı nakdidir.” şeklinde yer alan nitelikli hal, TCK md. 237'nin üçüncü fikrasında düzenlenmektedir (Aslan ve Azizağaoğlu, 2004).

765 sayılı TCK’nın 358. maddesi 28.07.1981 tarihli ve 2499 sayılı Sermaye Piyasası Kanunu (2499 sayılı SPK)'nun 47. maddesi ile kısmen yürürlükten kaldırılmış ve 358. madde düzenlemesinde yer alan "esham borsalarına kabul edilen evrak ve senedat” hakkında 2499 sayılı SPK uygulama alanı yer bulmuştu (Erdağ, 2015; Evik, 2004; Tepe, 2010). 06.12.2012 tarihli ve 6362 sayılı Sermaye Piyasası Kanunu (2499 sayıl1 SPK) ile 2499 sayılı SPK yürürlükten kaldırılmış, eski 47. maddenin ilk fikrasının A bendinin 2. ve 3. alt bentlerindeki işleme ve bilgiye dayalı manipülasyon fiilleri 6362 sayılı SPK'nın 107. maddesinde "piyasa dolandırıcılı̆̆ı" başlığı altında düzenlenmiştir. 6362 sayılı SPK, 30.12.2012 tarihli ve 28513 sayılı Resmi Gazete (RG)'de yayınlanarak aynı gün yürürlüğe girdiğinden 30.12.2012'den sonraki fiiller açısından 6362 sayılı SPK m. 107 uygulama alanı bulmuştur. Gerçekten TCK'nın 237. maddesinde “esham borsalarına kabul edilen evrak ve senedat" ibaresine yer verilmeyerek 2499 sayılı SPK'nın sermaye piyasalarında işlem gören belgeler ve senetler hakkında uygulanmaya devam edilmesi zımnen kabul edilmiş olmaktadır. 2012 değişikliğinden sonra ise, 6362 sayılı SPK söz konusu belge ve senetler hakkında uygulama alanı bulacaktır. Diğer bir ifadeyle, TCK'nın 237. maddesi sermaye piyasalarında işlem gören belge ve senetler hakkında uygulanmayacaktır. 


\section{Korunan Hukuki Değer}

765 sayıl1 Kanun'un 358. ve 359. maddeleri "Ticaret ve sanayie ve müzayedeye hile ve fesat karlştırmak cürümleri”, 5237 sayılı TCK'nın 237. maddesi ise “Ekonomi, Sanayi ve Ticarete İlişkin Suçlar” bölümünde yer almaktadır. Düzenlendiği bölümden hareketle fiyatları etkileme suçunun ekonomik suçlar arasında yer aldığı, genel anlamda kamu ekonomisini ve kamu güvenini koruduğu, özelde ise fiyatların ve değerlerin serbest piyasa koşulları içerisinde piyasa koşullarına uygun olarak tespit edilmesinin korunduğu ve piyasa istikrarının bozulmasının önüne geçilmeye çalışıldığı söylenebilir. Nitekim madde gerekçesinde de bu husus, “...maddenin esasta korumak istediği hukukî yarar, serbest rekabet koşulları çerçevesinde fiyatların belirlenmesini ihlâl edici hareketleri engellemektir." ifadesiyle ortaya konmuştur (Arslan ve Azizağaoğlu, 2004; Artuk, vd, 2014; Parlar ve Hatipoğlu, 2010; Akbulut, 2015).

\section{Kanunilik Unsuru}

Fiyatları etkileme suçu, uygulamada pek sık karşılaşılmamakla birlikte ihtiyaç duyulduğu takdirde uygulanmak üzere düzenlenmiş, Dönmezer'in ifadesiyle "devletin silahhanesinde bulunmasl gereken”, koruduğu hukuki değer itibariyle büyük öneme sahip, ekonomik suçlar kategorisinde yer alan bir suç tipidir (Dönmezer, 1987). Suç, TCK'nın “Özel Hükümler” başlıklı ikinci kitabının, “Topluma Karşı Suçlar” başlıklı üçüncü kısmının “Ekonomi, Sanayi ve Ticarete İlişkin Suçlar” başlıklı dokuzuncu bölümünde yer almaktadır. Buna göre,

“(1) Işçi ücretlerinin veya besin veya malların değerlerinin artıp eksilmesi sonucunu doğurabilecek bir şekilde ve bu maksatla yalan haber veya havadis yayan veya sair hileli yollara başvuran kimseye üç aydan iki ylla kadar hapis ve adli para cezasl verilir.

(2) Fïl sonucu besin veya malların değerleri veya işçi ücretleri artıp eksildiği takdirde ceza üçte biri oranında artırllır.

(3) Fail, ruhsatl simsar veya borsa tellalı ise ceza ayrıca sekizde bir oranında artırllır.”

Madde metninden anlaşılacağı üzere, ilk fikrada suçun temel hali tehlike suçu olarak düzenlenmekte, ikinci fıkrada neticenin ortaya çıkması hali, üçüncü fikrada ise failin belli nitelikleri taşıması hali nitelikli hal olarak gösterilmektedir.

6362 sayılı SPK'nın 107. maddesinde de benzer bir düzenleme sermaye piyasası araçlarının değerinin etkilenmesi durumu için yer almaktadır. İşleme dayalı manipülasyon olarak adlandırılan ilk fikrasına göre, "Sermaye piyasası araçlarının fiyatlarına, fiyat değişimlerine, arz ve taleplerine ilişkin olarak yanlış veya yanıltıcı izlenim uyandırmak amacıyla alım veya satım yapanlar, emir verenler, emir iptal edenler, emir değiştirenler veya hesap hareketleri gerçekleştirenler iki ylldan beş yıla kadar hapis ve beş bin günden on bin güne kadar adli para cezası ile cezalandırllırlar. Ancak, bu suçtan dolayı verilecek olan adli para cezasının miktarl, suçun işlenmesi ile elde edilen menfaatten az olamaz.” (Yüce, 2012). Bilgiye dayalı manipülasyon ya da finansal bilgi manipülasyonu olarak da adlandırılan ikinci fikrasına göre ise, "Sermaye piyasası araçlarının fiyatlarını, değerlerini veya yatırımcıların kararlarını etkilemek amacıyla yalan, yanlış veya yanıltıcı bilgi veren, söylenti çıkaran, haber veren, yorum yapan veya rapor hazırlayan ya da bunlarl yayan ve bu suretle menfaat sağlayanlar iki yıldan beş yıla kadar hapis ve beş bin güne kadar adli para cezası ile cezalandırılırlar."(Yüce, 2012).

Görüldüğü üzere, SPK md. 107 sermaye piyasası araçlarını koruma altına alırken TCK md. 237 sermaye piyasası araçları dışında kalan işçi ücretleri veya besin veya malların değerlerini korumaktadır.

\section{Maddi Unsurlar}

\subsection{Konu}

Fiyatları etkileme suçunun konusu, işçi ücretleri veya besin veya malların değeridir. İşçi ücretleri ile kastedilen aslında hizmet niteliğindeki edimin değeridir. Diğer bir ifadeyle, suçun maddi konusu hizmet veya malın değeridir. Sermaye piyasasında işlem gören belge ve senetlerin değeri ise SPK md. 107 ile korunmaktadır. Dolayısıyla sermaye piyasasında işlem gören kıymetli evrak ve senetler TCK'nin 237.maddesi kapsamında değildir (Parlar ve Hatipoğlu, 2010; Yaşar, vd, 2010; Akbulut, 2015).

Maddede geçen kavramları kısaca tanımlayacak olursak, ücret "iş gücünün karşılığı olan para veya mal”; mal "bir kimsenin, bir tüzel kişinin mülkiyeti altında bulunan, taşınır veya taşınmaz varlıkların bütünü”; besin "yenilebilir, beslenmeye elverişli her tür madde, azık, gıda"; haber "bir olay, bir olgu üzerine edinilen bilgi, salık"; havadis "ilgi ile karşılanabilecek haber"; hile ise "birini aldatmak, yanıltmak için yapılan düzen, dolap, oyun, ayak oyunu, alavere dalavere, desise, entrika” olarak tanımlanmaktadır (TDK, 2015).

İlk olarak belirtmek isteriz ki, maddede haber ve havadis terimlerinin her ikisinin de kullanılması gereksizdir çünkü havadis kelime anlamı itibariyle zaten ilgi uyandırabilecek haber anlamı taşımaktadır. Kanımızca daha 
genel bir kavram olan "haber" ifadesi tercih edilmeli ve madde metninden tekrardan öteye geçmeyen havadis ibaresi çıkarılmalıdır.

Tanımlardan çıkarılabileceği üzere, söz konusu malların taşınır ya da taşınmaz mal olması mümkündür. Besin kavramı ile beslenmeye elverişli her türlü madde kastedilirken sadece yiyecekler değil içecekler de bu kapsamda ele alınmalıdır. Fakat kanaatimizce ilaçlar besin niteliği taşımadıklarından dolayı madde kapsamında değerlendirilmemelidir. Kanımızca, paraların da mal kapsamı içinde değerlendirilmesi gerekir. Zira para piyasalarında paraların da değeri artıp azalabilmekte ve bu artış ve azalışlar dış faktörlerden etkilenebilmektedir (Akbulut, 2015).

Doktrinde "işçi ücretleri" ifadesinden ne anlaşılması gerektiği konusunda farklı görüşler mevcuttur. İşçi ücretleri ifadesinin bireysel iş görüşmeleri neticesinde belirlenen ücret ile toplu iş görüşmeleri ile belirlenen ücreti kapsayıp kapsamayacağı ve asgari ücret belirlemesinin bu kapsamda değerlendirilip değerlendirilemeyeceği hususları tartışılmalıdır. Dönmezer'e göre, toplu iş sözleşmeleri ile belirlenen ücretlerin ve sendikalı işçilerin ücretlerinin bu şekilde etkilenmesi pek mümkün görünmese de bireysel iş sözleşmesi yapmış sendikasız işçiler için maddenin uygulanması mümkündür (Dönmezer, 1987).

TCK md. 237'nin düzenlenme şekli açısından tüm işçi ücretlerini kapsadığı görülse de toplu iş görüşmeleri ile belirlenen ücretlerin ve sendikalı işçi ücretlerinin etkilenmesinin uygulamada etkilenme ihtimalinin oldukça düşük olduğu kanaatindeyiz. Bu sebeple, maddenin daha çok bireysel iş sözleşmesi ile ücreti belirlenen sendikasız işçilerin ücretlerinin artıp azalması bakımından cezai koruma sağladığını düşünüyoruz. Asgari ücretin tespiti konusunda ise, birçok parametre dikkate alınarak ciddi hesaplamalar yapıldığından herhangi bir yalan haber ya da havadis ile etkilenmesinin imkânsız olduğunu, dolayısıyla asgari ücretin TCK md. 237'ye konu olamayacağını düşünüyoruz (Akbulut, 2015).

Doktrinde bir görüşe göre, genel pazarlarda ve ticaret borsalarında işlem görmeyen ücret ve değerler bu madde kapsamında değerlendirilmemektedir (Parlar ve Hatipoğlu, 2010; Yaşar, vd, 2010). 765 sayılı TCK'nın 358. maddesinde yer alan bu ibarenin TCK'nın 237. maddesine alınmamış olmasından dolayı günümüzde genel pazarlarda ve ticaret borsalarında işlem görmek şartının aranmaması gerektiği kanaatindeyiz (Akbulut, 2015).

Madde metninde geçen "ve sair hileli yollar" ifadesi ile kastedilen ise yalan haber yaymanın haricinde herhangi bir yöntem olabilecektir. Doktrinde bu hileli yolların daha çok işleme dayalı yöntemler olacağı ifade edilmektedir (Tepe, 2010). Kanaatimizce anılan ibarenin içeriği son derece geniş ve belirsiz olup, esasen kanunilik ilkesi gözetildiğinde AY md. 38'e aykırıdır.

\subsection{Fail}

TCK md. 237'de fail açısından herhangi bir özellik aranmamaktadır. Bu sebeple, herkesin bu suçun faili olması mümkündür. Dikkat edilmesi gereken husus, maddenin üçüncü fikrasında düzenlenen failin belli özellikleri haiz olması durumunda uygulanacak nitelikli haldir. Bu hükme göre, failin ruhsatlı simsar ya da borsa tellalı olması halinde verilecek ceza sekizde bir oranında artırılacaktır (Arslan ve Azizağaoğlu, 2004).

SPK md. 107/1'de “alım veya satım yapmak, emir vermek, emir iptal etmek, emir değiştirmek veya hesap hareketleri gerçekleştirmek” fiilleri; SPK md 107/2'de ise, "bilgi vermek, söylenti çıkarmak, haber vermek, yorum yapmak veya rapor hazırlamak ya da bunlarl yaymak ve bu suretle menfaat sağlamak” fiilleri açısından maddede herhangi bir sınırlama öngörülmediğinden herkesin bu suçların faili olması mümkündür.

\subsection{Mağdur}

$\mathrm{Bu}$ suçun mağduru toplumu oluşturan herkestir. İşçi ücretlerinin veya besin veya malların fiyatlarının etkilenmesi neticesinde bazı gerçek kişiler doğrudan mağdur olabilirler. Bununla birlikte, fiyatların artıp azalmasından etkilenen tüzel kişiler suçun mağduru olmayıp ancak suçtan zarar gören olarak nitelenebilirler.

\subsection{Fiil}

Fiyatları etkileme suçunun maddi unsuru, işçi ücretlerinin veya besin veya malların değerlerinin artıp eksilmesi sonucunu doğurabilecek bir şekilde ve bu maksatla "yalan haber" veya "havadis yaymak" veya "sair hileli yollara başvurmak"tır.

Madde metninde anlaşılacağı üzere, bu suç tipi hareketin sayısı bakımından seçimlik hareketli suç olarak düzenlenmektedir. Seçimlik hareketlerden ilki "yalan haber veya havadis yaymak”, diğeri ise "sair hileli yollara başvurmak” "tır. Yukarıda da değindiğimiz üzere "sair hileli yollara başvurmak” seçimlik hareketi niteliği gereği belirlilik ilkesine ihlal edecek nitelikte geniş ve muğlâk olup, bu şekliyle işçi ücretlerini veya besin veya malların değerini etkileyebilecek herhangi hileli bir yola başvurmak bu suçu oluşturabilecektir. Doktrinde ise, "sair hileli yollar" ifadesinden daha çok işleme dayalı manipülatif hareketlerin anlaşılması gerektiği ileri sürülmektedir (Tepe, 2010).

Bu hareketlerden herhangi birinin gerçekleştirilmesi halinde suç oluşur; birden fazlasının gerçekleştirilmesi ise suç tekliğini etkilemez. Anılan hareketler neticesinde işçi ücretlerinin veya besin veya malların değerlerinin etkilenmesi öngörülmediğinden suçu tehlike suç niteliğindedir. Bununla birlikte, maddenin 2. fikrasında düzenlenen nitelikli hal uyarınca yalan haber veya havadis yayılarak ya da herhangi bir hileli yol kullanılarak işçi ücretlerinin ya da fiyatların etkilenmesi halinde ceza üçte bir oranında artırılır. 
"Yalan haber veya havadis yaymak"; "klsmen veya tamamen gerçek dışı olan veya belirli bir konuda, herkesin veya çok sayıda kişinin bilgi sahibi olacă̆ şekilde duyurulması”" şeklinde tanımlanabilir (Erman ve Özek, 1992). Yaymak ifadesi, bu haber veya havadisin aleniyet kazanmasını gerektirmektedir. Diğer bir ifadeyle, bu yalan haber ya da havadis belirli bir kişiye, gruba ya da sayılabilir nitelikte birkaç kişiye iletilmişse bu durumda yaymadan bahsedilemez. Yayılmaya çalışılan yalan haber ya da havadisin veyahut sair hileli davranışların doğru olmadığı herkes tarafindan rahatça ve kolaylıkla anlaşılabilir olması durumunda suçun oluşması mümkün değildir (Erdağ, 2015). Nitekim madde metninde bu husus "Isş̧i ücretlerinin veya besin veya malların değerlerinin artıp eksilmesi sonucunu doğurabilecek bir şekilde...” açıç̧a ifade edilmiştir.

SPK md. 107/1 açısından, sermaye piyasası araçlarının fiyatlarına, fiyat değişimlerine, arz ve taleplerine ilişkin olarak yanlış veya yanıltıcı izlenim uyandırmak amacıyla alım veya satım yapmak, emir vermek, emir iptal etmek, emir değiştirmek veya hesap hareketleri gerçekleştirmek tipik fiili teşkil eder. İşleme dayalı manipülasyon suçu, seçimlik hareketli bir suç olarak düzenlenmektedir. Alım-satım yapmak, emir vermekdeğiştirmek-iptal etmek veya hesap hareketleri gerçekleştirmek seçimlik hareketleri oluşturur.

SPK md. 107/2 açısından ise, bilgi vermek, söylenti çıkarmak, haber vermek, yorum yapmak veya rapor hazırlamak ya da bunları yaymak ve bu suretle menfaat sağlamak tipik fiildir. Madde metninden anlaşılacağ üzere, bu suç tipi bağlı ve seçimlik hareketli olarak düzenlenmektedir. Maddede sayılan bağlı hareketlerden birinin yapılarak menfaat temin edilmesi suçun meydana gelmesi açısından yeterli olacağından, bağlı hareketlerden birden fazlasının ya da tamamının gerçekleştirilmesi suretiyle menfaat temini suç tekliğini etkilemez. Ancak dikkat edilmesi gereken, bilgi vermek, söylenti çıkarmak, haber vermek, yorum yapmak veya rapor hazırlamak ya da bunları yaymak bağlı hareketler olup, suçu oluşturan fiil "bu suretle menfaat sağlamak” tır. Burada önemli olan bir başka husus, gerçekleştirilen hareketin sermaye piyasası araçlarının değerini, fiyatını ya da yatırımcıların kararını etkileyebilecek nitelikte ve her halükarda yalan, yanlış veya yanıltıcı olmasıdır. Bilginin, söylentinin, haberin, yorumun ya da raporun içeriği ile ilgili bir sınırlandırma getirilmemiştir. Sermaye piyasası araçlarının değerini etkileyebilecek herhangi bir yalan, yanlış veya yanıltıcı bilgi, söylenti, haber, yorum ya da rapor suçun meydana gelmesine sebep olabilir.

\subsection{Netice}

Suçun temel şekli açısından gerçekleştirilen hareketler neticesinde işçi ücretlerinin veya besin veya malların değerlerinin etkilenmesi gerekmez çünkü fiyatları etkileme suçu tehlike suçu olarak düzenlenmektedir. Bununla birlikte, yalan haber veya havadis yayılarak ya da herhangi bir hileli yol kullanılarak işçi ücretlerinin ya da fiyatların etkilenmesi durumunda TCK md. 237/2 uyarınca ceza üçte bir oranında artırılır çünkü neticenin meydana gelmesi yani fiyatların etkilenmesi hali nitelikli hal olarak düzenlenmektedir.

SPK md. 107'de "piyasa dolandırıcılı̆̆ ’” başlığı altında düzenlenen işleme ve bilgiye dayalı manipülasyon suçları bakımından ise, maddede sayılan hareketlerin yapılması suçun meydana gelmesi açısından yeterli olup suçun tamamlanması için mutlaka sermaye piyasası araçlarının değerinin, fiyatının ya da yatırımcıların kararlarının etkilenmesine gerek bulunmamaktadır.

\subsection{Nedensellik Băğ}

Fiyatları etkileme suçunun temel şekli ile işleme ve bilgiye dayalı manipülasyon suçları, neticesi harekete bitişik suç özelliği gösterdiğinden ayrıca nedensellik bağı tartışmasına gerek bulunmamaktadır. Ancak TCK md. 237/2'deki nitelikli halin oluşması için "Fiil sonucu besin veya malların değerleri veya işçi ücretleri artıp eksil(mesi)...” arandığından, bu halle sınırlı olmak üzere, meydana gelen neticenin failin fiilinden kaynaklanmış olması gerekir.

\subsection{Nitelikli Haller}

Yukarıda da değindiğimiz üzere fiyatları etkileme suçunun temel şeklinin oluşması için işçi ücretlerinin veya besin veya malların değerinin artıp eksilmesi zorunlu değildir. Fakat yayılan yalan haber veya havadis ya da kullanılan diğer hileli yöntemler neticesinde işçi ücretleri ya da besin veya malların değerleri etkileniyor ise bu durumda verilecek ceza üçte bir oranında artırılacaktır. Diğer bir ifadeyle, suçun temel halinin oluşması için fiyatların etkilenebilir olması yeterli iken ve bu tehlike cezalandırılırken, ikinci fikrada fiyatların etkilenmesi hali nitelikli hal olarak öngörülmekte ve zarar suçu olarak cezası artırılmaktadır.

Belirtmek gerekir ki doktrinde ikinci fikranın niteliği tartışmalıdır. Bir görüşe göre bu hüküm "neticesi sebebiyle ağırlaşmış suç" teşkil ederken (Yaşar, vd, 2010; Erdağ, 2015; Akbulut, 2015), diğer bir görüş bu hükmün nitelikli hal olduğunu savunmaktadır (Tepe, 2010). Neticesi sebebiyle ağırlaşmış hali olması için kastedilenden daha ağır ya da başka bir neticenin ortaya çıkması gerekir. Fakat ikinci fikrada düzenlenen aslında birinci fıkrada kastedilen netice ile aynıdır. Dolayısıyla TCK md. 23 hükmü netice sebebiyle ağırlaşmış hal değil, nitelikli hal teşkil ettiği kanaatini paylaşmaktayız.

Öte yandan, failin bu nitelikli halden sorumlu tutulabilmesi için işçi ücretleri ya da besin veya malların fiyatının artıp azalması ile yayılan yalan haber veya havadis ya da kullanılan diğer hileli yollar arasında bir neden-sonuç ilişkisi bulunmalıdır. 
Üçüncü fikrada ise, failin belli nitelikleri haiz olması hali suçun temel halinden daha tehlikeli görülmüş ve daha ağır cezayı gerektiren nitelikli hal olarak düzenlenmiştir. Buna göre failin ruhsatlı simsar ya da borsa tellalı olması halinde verilecek ceza sekizde bir oranında artırılacaktır. Burada dikkat edilmesi gereken husus, madde gerekçesinin son paragrafında da belirtildiği üzere, fikrada geçen "borsa tellalı" ifadesinin 06.12.2012 tarihli ve 6362 sayılı SPK'nın kapsamı dışında kalan borsa tellallığını ifade ettiğidir. “Borsa tellalı" ise, ticaret borsalarında komisyonculuk yapan kişiler ile menkul kıymetler borsalarında aracılık faaliyeti gerçekleştiren kurumları kapsayan bir kavram olarak kullanılmaktadır (Akbulut, 2015). "Ruhsatl simsar" ise, "sebze ve meyve hallerinde komisyonculuk yapan, belediyelerin gösterdiği kapall mahallerde, müstahsilden gelen malların tüketiciye veya tüccara satılmasina aracılık ederek komisyon geliri elde eden ticaret erbabl" olarak tanımlanmaktadır (Parlar ve Hatipoğlu, 2010). Failin bu iki sıfattan birini taşıması halinde kendisine verilecek ceza sekizde bir oranında artırılacaktır.

TCK md. 237'nin ikinci ve üçüncü fikralarında düzenlenen nitelikli haller ile ilgili özellik arz eden diğer bir husus ise, cezanın ağırlaştırılması konusunda hâkime takdir hakkı tanınmamasıdır. İkinci ve üçüncü fikralarda, alt sınır ve üst sınır verilerek hâkime artırım yapacağı oranı bu sınırlar arasından seçme hakkı vermek yerine doğrudan belli bir oran belirtilmiştir.

\section{Manevi Unsur}

TCK md. 237'de öngörüldüğü üzere, suçun oluşması için, işçi ücretlerinin veya besin veya malların değerlerinin artıp eksilmesi sonucunu doğurabilecek bir şekilde "ve bu maksatla" yalan haber veya havadis yaymak veya sair hileli yollara başvurmak gerekmektedir. Bu ifadeden hareketle suçun oluşması için özel kast arandığı ve bu nedenle olası kastla işlenmeyeceği söylenebilir. Keza suçun taksirli halinin cezalandırılması öngörülmediğinden TCK md. 22/1 gereğince taksirle işlenmesi mümkün değildir.

SPK md. 107/1'de failin "sermaye piyasası araçlarının fiyatlarına, fiyat değişimlerine, arz ve taleplerine ilişkin olarak yanlış veya yanıltıcı izlenim uyandırmak amacıyla”; SPK md. 107/2'de ise "sermaye piyasası araçlarının fiyatlarını, değerlerini veya yatırımcıların kararlarını etkilemek amacıyla" hareket etmesi aranmaktadır. Suçun oluşması için her iki fikrada da failin kasten ve belli bir amaç taşıyarak/özel bir amaçla hareket edilmesi arandığından suçun olası kastla işlenmesi mümkün değildir. Ayrıca taksirli hali öngörülmediğinden TCK md. 22/1 gereğince taksirle işlenmesi de mümkün değildir (Evik, 2004).

\section{Hukuka Aykırılık Unsuru}

Fiyatları etkileme suçu hukuka aykırılık unsuru açısından bir özellik göstermemektedir. Diğer taraftan teorik olarak bir engel bulunmamakla birlikte suçun işleniş şekli gözetildiğinde TCK'daki genel hukuka uygunluk nedenlerinin uygulanması pek olası gözükmemektedir.

\section{Suçun Özel Görünüş Şekilleri}

\subsection{Teşebbüs}

Suçun temel şeklinde bir netice öngörülmediğinden kural olarak teşebbüse elverişli değildir. Fakat icra hareketlerinin kısımlara bölünebildiği hallerde teşebbüs aşamasında kalması mümkündür. Diğer taraftan, TCK md. 237/2'de düzenlenen suça teşebbüs mümkün değildir. Zira yalan haber veya havadis yayıldıktan ya da diğer hileli yöntemlere başvurulduktan sonra failin elinde olmayan sebeplerle fiyatlar etkilenmese dahi bu durumda, birinci fikrada öngörülen durum gerçekleştiğinden suçun temel hali meydana gelmiş olur (Yaşar, vd, 2010).

\section{2 İştirak}

Maddede iştirak ile ilgili özel bir düzenleme getirilmediğinden genel hükümlerin iştirak ile ilgili olanları fiyatları etkileme suçu açısından da uygulama alanı bulacaktır. Ancak bu konuda, borsa tellalı ya da ruhsatlı simsar ile bu sıfatları taşımayan biri tarafından suçun iştirak iradesi ile işlenmesi durumunda ortaya çıkacak durum özellik arz etmektedir. Bu durumda, borsa tellalı ya da ruhsatlı simsar olan kişi TCK m. 237/3'ten sorumlu olurken, bu sıfatları taşımayan kişi -TCK $\mathrm{md}$. 40 gereği azmettirme veya yardım etme halleri bir tarafa bırakıldiğında- TCK md. 237/1'den sorumlu tutulacaktır (Akbulut, 2015).

\section{3 İçtima}

TCK md. 237'de içtima açısından özel bir hüküm öngörülmemektedir. Bu sebeple, suçların içtimaı konusunda genel hükümler bu suç açısından da uygulama alanı bulacaktır. Yukarıda yeri geldikçe değinildiği üzere fiyatları etkileme suçuna benzer bir düzenleme SPK md. 107'de yer almaktadır. Bu hükümde sadece sermaye piyasası araçları konu edilirken TCK md. 237 bunlar dişında kalan işçi ücretleri veya besin veya malların değerini kapsadığından TCK md. 237'ye kıyasla özel hüküm niteliği taşımaktadır. Diğger bir deyişle, sermaye piyasası araçları, menkul kıymetler borsasında işlem gören belge veya senetler söz konusu olduğunda SPK md. 107 özel hüküm olarak uygulama alanı bulurken, bunlar dışında işçi ücretleri, besin veya mal değerleri söz konusu olduğunda özel düzenleme bulunmadığından TCK md. 237 genel hüküm olarak uygulanır. 
Failin tek bir eylemi ile birden fazla işçi ücreti veya besin veya malın değeri artmış ya da eksilmiş ise ya da bu değerlerin değişmesi tehlikesi doğmuş ise bu durumda zincirleme suç hükümleri uygulanacak, fail tek bir fiyatları etkileme suçundan sorumlu olacaktır (Yaşar, vd, 2010).

\section{Yaptırım}

TCK md. 237 uyarınca bu suçun yaptırımı üç aydan iki yıla kadar hapis cezası ve buna ek olarak adli para cezasıdır. TCK md. 52/1, bu adli para cezası en az 5, en fazla 730 gün olarak belirlenebilecektir. Sermaye piyasası araçları söz konusu olduğunda ise suçun yaptırımı, iki yıldan beş yıla kadar hapis ve beş bin güne kadar adlî para cezası olarak öngörülmektedir. Yaptırımdan yola çıkarak kanun koyucunun sermaye piyasalarının korunması konusuna daha çok önem verdiği, sermaye piyasası araçlarının değerlerinin etkilenmesi durumunda ortaya çıkacak haksızlığın daha büyük olduğunu düşündüğü sonucuna varılabilir. Ekonomik suçlarda failin kazanç elde ettiği bilinmekle beraber çoğu zaman bu kazancın miktarı belirlenmediği için, suçun bir kazanç elde etme yöntemi olarak görülmesinin önüne geçmek amacıyla hapis cezasının yanında adli para cezası da öngörülmektedir (Özgenç, 2005).

Bununla yanında, TCK md. 242 uyarınca, fiyatları etkileme suçunun da aralarında bulunduğu ekonomi, sanayi ve ticarete ilişkin suçlar neticesinde tüzel kişiler yararına haksız bir menfaat sağlanması durumunda TCK md. 60 gereğince tüzel kişilere özgü güvenlik tedbirlerine de hükmolunacaktır.

\section{Sonuç}

TCK md. 237'de yer alan fiyatları etkileme suçu, uygulamada pek rastlanmasa da piyasa istikrarını çeşitli manipülatif hareketlere karşı koruyan bir ekonomik suç normudur. Maddede işçi ücretleri ile besin ve mal fiyatlarını koruma altına alırken, sermaye piyasası araçlarının değerini işleme veya bilgiye dayalı manipülasyona karşı SPK md. 107 korumaktadır. Çalışmamızın "suçun maddi konusu” bölümünde belge ve senetlerin de aslında mal kavramı içerisinde kabul edilebileceğine değinmiştik. Bu sebeple, kanaatimizce SPK'da yalnızca manipülatif hareketlerin sayılarak yaptırım konusunda TCK'daki "fiyatları etkileme suçu”na atıf yapılması ve sermaye piyasalarında işlem gören belge ve senetler açısından arz ettikleri önemden dolayı nitelikli hal düzenlenerek bu iki hüküm arasında bütünlük kurulması faydalı olacaktır.

\section{Kaynakça}

- $\quad$ AKBULUT, 2015. "Fiyatları Etkileme Suçu (TCK m. 237), Türkiye Adalet Akademisi Dergisi (TAAD), 20.

- $\quad$ ARSLAN ve AZİZAĞAOĞLU, 2004. Yeni Türk Ceza Kanunu Şerhi, Asil, Ankara.

- $\quad$ ARTUK, vd, 2014. Türk Ceza Kanunu Şerhi, 5. Cilt (m. 234-345), Adalet, Ankara.

- $\quad$ OÖNMEZER, 1987. Ekonomik Suçlar ve Ceza Kanunu Öntasarısı Sempozyumu (17-18 Nisan 1987), İTO Yayınları, İstanbul.

- ERDAĞ, 2015. “Ekonomi, Sanayi ve Ticarete İlişkin Suçlar ve Bilişim Alanında Suçlar”, www.cezabb.adalet.gov.tr/makale/100.doc

- $\quad$ ERMAN ve ÖZEK, 1992. Ceza Hukuku Özel Bölüm- Kamu İdaresine Karşı İşlenen Suçlar (TCK m. 202-281), Işık, İstanbul.

- $\quad$ EVİK, 2004. Sermaye Piyasası Araçlarının Değerini Etkileyebilecek Aldatıcı Hareketler Yapma (Manipülasyon) Suçları, Seçkin, Ankara.

- ÖZGENÇ, 2005. "Yeni Türk Ceza Kanunu'ndaki Ekonomi, Sanayi ve Ticarete İlişkin Suçlar”, in Ekonomik Suç ve Ceza Sempozyumu (30 Nisan- 1 Mayıs 2005), TOBB Yayınları, Ankara.

- $\quad$ PARlar ve HatíPOĞLU, 2010. Türk Ceza Kanunu Yorumu, 4. Cilt (230- 345. Maddeler), Seçkin, Ankara.

- $\quad$ TEPE, 2010. “Fiyatları Etkileme Suçu (TCK m. 237)”, Ceza Hukuku Dergisi (CHD), 14, Seçkin, Ankara.

- TÜRK DİL KURUMU, 2015. "Büyük Türkçe Sözlük", http://www.tdk.gov.tr/index.php?option=com_bts\&view=bts

- YAŞAR, vd, 2010. Yorumlu- Uygulamalı Türk Ceza Kanunu, Cilt V (m. 205-256), Adalet, Ankara.

- YÜCE, 2012. “Sermaye Piyasasında Manipülasyon”, Türkiye Barolar Birliği Dergisi, 98. 


\title{
Türkiye’de Devletin Vergilerle Ekonomiye Müdahalesinin Sinırları
}

\section{The Limits of State Intervention in Economy by Taxation in Turkey}

\author{
Prof. Dr. Sabahat Binnur Çelik (Beykent University, Turkey)
}

\begin{abstract}
People, mostly and directly affected from the state's decision about taxation. State, in order to realize public services, while using its taxation authority depending to its power of sovereignty, intervenes in the economy in different ways. While using taxation authority, state is subject to various limitations. The most important limitation about taxation is the necessity of obeying the laws.

The basic principles about taxation are indicated on the Universal Declaration of Human Rights and Constitutions. Nowadays, nearly in every country, advanced tax payer rights, public pressure and the ruling parties' intent about remaining in power or the opposition parties' intent about coming in power also determines the limits of taxation.

Proceedings of the independent judicial bodies are very important about the limitation of taxation. Because independent judicial bodies can control the power of sovereignty of the state about taxation. In the judging process, they judge the tax rules and tax applications' harmony to the basic principles of taxation. If there are no fair limits about taxation in a country, this means that there is no democracy in that country.
\end{abstract}

\section{Giriş}

Devlet sektörünün 19. Yüzyıldan itibaren öneminin artığı, devlet faaliyetlerinin, ekonominin bütününün işleyişi üzerinde önemli etkiler yapacak seviyeye ulaştığı, bilhassa kamu gelir ve harcamalarında ayarlamalar yaparak ekonomik dengeyi etkilediği bilinmektedir (John F. Due, 1967).

Devlet, belirli bir ülke üzerinde yaşayan insan topluluğunun, üstün bir iktidara tabi olmak suretiyle oluşturduğu, hukuki kişiliğe sahip, devamlı bir teşkilattır (Gözler, 2013). Devlet, müeyyidelerle donatılmış genel ve bağlayıcı kamusal kurallar koyabilir ve bunları uygulama yetkisine sahiptir (Erdoğan, 2005). Devletin sahip olduğu bu yetki, millete ait olan egemenlik yetkisinin kullanımıla ilgilidir ve kamu gücü olarak adlandırılır. Bir ülkede egemenlik yetkisinin kullanımı sadece devlet tüzel kişiliğine ait bir güç olarak görülür (Yayla, 2009).

Günümüzde, her ülkede, devletin gerçekleştirdiği kamu giderlerinin giderek büyüdüğü bilinmektedir. Adolph Wagner, kamu giderlerindeki artı̧s nedeni olarak, devletin ekonomik ve sosyal yapı içindeki rolünün fazlalaşmasını, devlet faaliyetlerindeki büyümeyi belirtmektedir (Akdoğan, 2011). Gerçekten günümüz devleti, zaman içinde daha fazla kamu hizmeti gerçekleştirmeye çalışmakta ve bu nedenle daha fazla kamu gelirine ihtiyaç duymaktadır.

Demokratik ülkelerde, seçimle iktidara gelmek isteyen tüm partilerin parti programlarında halka vaat edilen hizmetlerin yıllar içinde fazlalaştığı ve halkın nabzını yakalama noktasında hizmet çeşitlerinde yaratıcılığın oy sağladığı görülmektedir. Halkın ise giderek devletten daha fazla hizmet talep ettiği de göz önünde bulundurulması gereken bir gerçektir. Devlet, ihtiyaç duyduğu kamu gelirinin büyük kısmını, egemenlik gücünü kullanarak halktan topladığı vergilerle sağlamaktadır.

Devletin vergilendirme yetkisini kullanması, ülkenin ekonomik, mali ve sosyal yapısı üzerinde önemli etkiler yaratır. Vergilemenin, ekonomiye müdahalenin en önemli araçlarından birisi olduğu görülmektedir. Devletin vergileme yapması, ülkedeki üretim ve tüketime doğrudan müdahalede bulunarak yönlendirmesi anlamına gelir. Günümüzde devlet, ülke milli gelirinin üçte birine yakın bir bölümünü ekonomiden kamu geliri olarak çeker ve bu gelirleri kamu hizmetini gerçekleştirirken geri ekonomiye aktarır (Akdoğan, 2011).

Toplum mühendisliği, yönetenlerin toplumu şekillendirme çabası olarak tanımlandığında, bunun gerçekleştirilebilmesini sağlayan araçlardan en önemlisi vergilendirme olarak karşımıza çıkmaktadır. Devlet, gelir elde etmek amacıyla, vergiler eliyle, vergi mükelleflerinin bazı davranışlarını özendirir veya ödüllendirir, bazı davranışlarını ise caydırır veya cezalandırır, başka ifade ile devlet, vergileme ile doğrudan bireylerin tercihlerine müdahale ederek iktisadi, sosyal, kültürel sonuçlar yaratır (Göker, 2011).

Devlet, toplum mühendisliği faaliyetleri kapsamında ekonomiye vergileme ile müdahale eder ve belli sonuçlara ulaşmayı hedefler. Bunlardan bir tanesi, ekonomik dengeyi sağlamaktır. Örneğin enflasyonist ortamda vergileri artırarak mükelleflerin talep düzeyini kısmayı hedefler, deflasyonist ortamda ise, vergileri düşürerek talep artırıcı sonuçlar hedefler. Devletin bir diğer hedefi, ekonomik kalkınma ya da büyümeyi gerçekleştirmektir. Bunun için de devlet, vergiler yoluyla tasarrufları teşvik etmek yönünde müdahalelerde bulunur. Devletin, 
ekonomiye, gelir dağılımı ile ilgili tercihleri doğrultusunda da müdahalesi önemli sonuçlar yaratır. Bu doğrultuda devlet bilhassa vergi istisnaları ve vergi muafiyetleri düzenleyerek etkin olabilir.

Devletin ekonomiye vergileme yoluyla müdahalesi, bazı uygulamalarda çok hızlı ve önceden öngörülebilir sonuçlar yaratır. Örnek olarak gümrük vergisi gösterilebilir. Devletin, gümrük vergisinin oranını artırması halinde ithalat miktarının düşeceği, gümrük vergisinin oranını düşürmesi halinde ise ithalat miktarının artacağı bilinir. Devletin, belirtilen uygulamalarla, dış ticaret dengesine doğrudan müdahalesi açıkça görülebilmektedir. Ayrıca, ithalat vergilerinin düşürülmesinin, ülkede herhangi bir üretim alanında tekelleşme olduğunda ithalat yoluna gidilerek tekelleşme ile mücadele edilebileceği ve olumlu sonuçlara kısa sürede ulaşılabileceği günümüz taşımacılı̆̆ındaki hız göz önünde bulundurulduğunda - açıktır. Bu sayılanlar gibi devletin vergilerle ekonomiye müdahalesinin ve dolayısıyla bireylerin tercihlerini etkilemesinin birçok örneği bulunmaktadır.

Kamu sektörünün toplam büyüklüğünü, toplumu oluşturan bireylerin vergi seviyesi hakkındaki kararlarının ya da ortak bilinçlerinin belirlemesi en ideal yaklaşımdır (Hayek, 1997). Ancak, bu ideale henüz yaklaşılamadığı da bilinmektedir. Devlet, bir toplumda, ihtiyaç duyduğu gelirleri, halkın gönüllü katkısından veya sunduğu hizmetlerin bedelinden değil de, sahip olduğu egemenlik kullanma yetkisine dayalı cebir yoluyla elde eden tek örgüttür (Erdoğan, 2005). Bu noktada, devletin ekonomiye vergilerle müdahalesinin sınırları önem kazanmaktadır.

Devletin sahip olduğu vergilendirme yetkisi, günümüz demokratik ülkelerinde birçok sınırlamaya sahip bulunmaktadır. Bu sınırlamaların başında devletin hukuk devleti ve sosyal devlet olması zorunluluğu gelmektedir. Bunların dışında ekonomik gerçeklerden ve siyasi nedenlerden doğan sinırlamalar da olduğu bilinmektedir.

Çalışmamızda devletin vergilerle ekonomiye müdahalesinin sınırları, mali hukuk kapsamında kalınarak, hukuk devleti olmak zorunluluğundan doğan sınırlar (bunlar yasal sınırlar olarak da isimlendirilebilir), sosyal devlet olmak zorunluluğundan doğan sınırlar, siyasi sınırlar ve ekonomik sınırlar olarak ayrıştırılarak incelenecektir.

\section{Devletin Vergilerle Ekonomiye Müdahalesinin Hukuk Devleti Olmak Zorunluluğundan Doğan Sınırları/ Yasal Sınırlar}

Hukuk devleti, en genel ifade ile aynı toplumda yaşayan bireylerin, hukukun egemenliği altında yaşamak zorunda olduğu ve devlet ile devlet çalışanlarının bazı sınırlara tabi olduğu devlet tipi olarak tanımlanabilir (Fallon, 2014). Hukuk devleti olgusu, devlet yetkililerinin hiç bir kurala uymaksızın yönetim faaliyetini sürdürmelerine engel olarak bireyleri korur.

Hukuk devletinin genel şartları; yasama, yürütme ve yargı organlarının hukuka bağlı olmasıdır. Hukuk devletinin özel şartları ise; idarenin bütün eylem ve işlemlerinin yargı denetimine tabi olması gereği, hakimlerin bağımsız ve teminatlı olması gereği, idarenin faaliyetlerinin önceden bilinebilir olması gereği, idarenin mali sorumluluğunun olması gereği ve bireylerin kendilerine uygulanacak hukuk kurallarının neler olduğunu önceden bilme olanağının varlığı olarak tanımlanabilecek hukuki güvenlik ilkesi ve geçmişe etki yasağı gereğidir (Gözler ve Kaplan, 2011).

Devletin vergilerle ekonomiye müdahalesinin hukuk devleti olmak zorunluluğundan doğan sınırları, uluslararası hukuk kurallarından doğan sınırlar, Anayasadan doğan sınırlar ve vergilendirmenin yargısal denetiminden doğan sınırlar başlıkları altında incelenecektir.

\subsection{Uluslararası Hukuk Kurallarından Doğan Sınırlar}

Uluslararası hukuk kurallarının başında İnsan Hakları Evrensel Beyannamesi gelir.

İnsan Hakları Evrensel Beyannamesi, Birleşmiş Milletler Genel Kurulu'nun 10 Aralık 1948 tarih ve 217 A (III) sayılı Kararıyla ilan edilmiştir. Ülkemizde, 6 Nisan 1949 tarih ve 9119 Sayılı Bakanlar Kurulu ile "İnsan Hakları Evrensel Beyannamesi'nin Resmi Gazete ile yayınlanması, yayımdan sonra okullarda ve diğer eğitim müesseselerinde okutulması ve yorumlanması ve bu Beyanname hakkında radyo ve gazetelerde münasip neşriyatta bulunulması" kararlaştırılmış ve Bakanlar Kurulu Kararı ile 27 Mayıs 1949 tarih ve 7217 Sayılı Resmi Gazete'de yayınlanarak yürürlüğe girmiştir.

İnsan Hakları Evrensel Beyannamesinin 17. maddesinin birinci fikrasında "Herkesin tek başına veya başkalarıyla ortaklaşa mülkiyet hakkı vardır" ilkesi yer alır. Bu madde ile devletin, kişilerin mülkiyet hakkına mutlak saygı duyması gereği ilkeye bağlanmıştır. Aynı ilke, 1952 yılında Paris'te imzalanan İnsan Hakları ve Temel Özgürlüklerin Korunmasına İlişkin Sözleşme'ye Ek Protokol'ün 1. maddesinde de mülkiyeti korumaya dair "Her gerçek ve tüzel kişinin mal ve mülk dokunulmazlığına saygı gösterilmesini isteme hakkı vardır" ifadesi ile vurgulanmaktadır.

İnsan Hakları Evrensel Beyannamesinin 17. maddesinin ikinci fikrasında, "Hiç kimse keyfi olarak mülkiyetinden yoksun birakılamaz" ilkesi yer alır. Bu ilke, bizlere, devletin keyfi yollarla vergilendirme yaparak kişileri mülkiyetinden yoksun bırakamayacağını ifade etmektedir. Başka ifade ile vergilendirmenin asla mülkiyetten yoksun bırakacak düzeyde olamayacağını ifade ederek vergilendirmenin düzeyine yönelik temel 
sınırlamayı belirtmektedir. Anılan 17. maddenin üçüncü fikrasında ise, "Herkesin kendisi ve ailesi için insan onuruna yaraşır ve gerekirse her türlü sosyal koruma önlemleriyle desteklenmiş bir yaşam sağlayacak adil ve elverişli bir ücrete hakkı vardır" ilkesi yer alır. Bu ilke, bizlere, ücret hakkı tutarının alt sınırını açıklar. Buna göre ücret, herkesin kendisi ve ailesi için insan onuruna yaraşır bir yaşam sağlayacak adil ve elverişli bir düzeyde olmak zorundadır. Bu ilkede, açıkça ücret tutarının vergilendirilmesine sınır getirildiği, ücret tutarının vergilendirme yoluyla belirtilen düzeyin altına inemeyeceği belirlenmektedir.

İnsan Hakları Evrensel Beyannamesinin 30. maddesinde "Bu bildirgenin hiçbir kuralı, herhangi bir devlet, topluluk veya kişiye, burada açıklanan hak ve özgürlüklerden herhangi birinin yok edilmesini amaçlayan bir girişimde veya eylemde bulunma hakkını verir biçimde yorumlanamaz" hükmü yer almaktadır. Bu maddeyi devletin vergileme yetkisi açısından irdelersek, yasama ve yürütme organlarının vergileme sırasında ve yargı organlarının da verginin yargısal denetimi sırasında, yukarıda belirtilmiş bulunan ilkeleri yorumlayarak değiştiremeyeceklerine dair güvence getirildiğini görmekteyiz.

\subsection{Anayasadan Doğan Sınırlar}

İnsan Hakları Evrensel Beyannamesi 29. maddesinde "Herkesin, kişiliğinin serbestçe ve tam gelişmesine olanak veren topluma karşı ödevleri vardır" ifadesi yer almaktadır. Topluma karşı ödevlerden birisi de vergi ödevidir. Bu doğrultuda T.C. Anayasasının 73. maddesi vergi ödevini düzenlemekte ve vergi ile ilgili temel prensipleri belirtmektedir.

T.C. Anayasasının 73. maddesi 1. fikrası "Herkes, kamu giderlerini karşılamak üzere, malî gücüne göre, vergi ödemekle yükümlüdür" hükmüne yer verir. $\mathrm{Bu}$ hükümde belirtilen mali gücün göstergeleri gelir, servet ve tüketimdir (Budak, 2010). Mali güç ifadesi bize vergi ödeme gücünün kaynağını ifade eder ve vergi mükellefinin mülkiyet hakkına vergi aracılığıyla getirilebilecek sınırı açıklar.

T.C. Anayasasının 73. maddesi 3. fikrası "Vergi, resim, harç ve benzeri malî yükümlülükler kanunla konulur, değiştirilir veya kaldırılır" hükmüne yer verir. Bu hüküm bize, kanunilik ilkesini ifade eder ve vergilemenin ancak kanunla yapılabileceğini başka ifade ile vergileme konusunda sadece yasama organının yetkili olduğunu belirterek vergiyi koyan organ olarak sınırlama getirir ve keyfi ve sınırsız ölçülere dayalı bir uygulamanın önlenmesi amacını taşır (Güneş, 2011). Kanunilik ilkesi, devletin vergilendirme yetkisinin, genel, soyut, kişisel olmayan, Anayasa Mahkememizin vurguladığı gibi verginin temel unsurlarını belirten ve yasama organı tarafindan anayasal usullere uygun olarak çıkartılan kanunlarla kullanılması anlamına gelir (Öztürk, 2014) ve bireyin devlete karşı sahip olması gereken hukuki güvenliğini sağlar.

Anayasamızın 73. maddesinde yer alan kanunilik ilkesi, vergileme konusunda kıyas yasağı ilkesini de beraberinde getirmektedir. Hukukta kıyas, bir olay hakkında kanunda yer alan kuralın, nitelikleri ve şartları ona benzeyen fakat kanunda düzenlenmemiş diğer bir olaya uygulanmasıdır (Öncel, Kumrulu ve Çağan, 1992). Vergilemede kıyas yoluna başvurulması halinde, vergilemeye yönelik kanun olmasa da vergileme yapılması sonucunu yaratarak hukuk devletinin hukuki güvenlik ilkesini ortadan kaldırır. Bu ilke ile devletin, ekonomik, sosyal, politik ve pratik gerekçelerle kıyas yaparak vergileme yoluna gitmesi engellenmektedir (Saygılığlu, 1987).

Kanunilik ilkesine uygun olarak T.C. Anayasası, Bakanlar Kurulunun vergi konusunda yetkilerini sınırlamıştır. T.C. Anayasanın 73. maddesi 4. fikrası "Vergi, resim, harç ve benzeri malî yükümlülüklerin muaflık, istisnalar ve indirimleriyle oranlarına ilişkin hükümlerinde kanunun belirttiği yukarı ve aşağı sınırlar içinde değişiklik yapmak yetkisi Bakanlar Kuruluna verilebilir" ifadesine yer verir. Her ne kadar bu fikra kanunilik ilkesinin yumuşatıldığını gösterse de, Bakanlar Kurulunun vergi ile ilgili yetkilerinin iki önemli açıdan sınırlandırıldığını belirtir. Bu sınırlardan birisi, Bakanlar Kurulunun verginin temel unsurlarına yönelik değişiklik yapamayacağını göstermesidir, çünkü Bakanlar Kurulu vergilerle ilgili olarak sadece muaflık, istisna, indirim ve oranlarına yönelik değişiklik yapabilecektir, ikinci sınırlama ise, bu yetkisini kanunda belirtilen yukarı ve aşağı sınırlar içinde kullanabilecek olmasıdır. Bakanlar Kuruluna vergilendirme konusunda sınırlı da olsa takdir yetkisinin tanınmış olmasının sebebi, parlamentonun işleyiş usulüne bağlı olarak kanun çıkarmanın zaman alması gerçeğinden hareketle (Gerçek, 2006), ekonomideki değişme ve gelişmelere paralel olarak vergi önlemlerinin hızlı bir şekilde alınması zorunluluğundandır. Bu yetkinin belirtildiği şekilde sınırlandırılmış olmasının nedeni ise, kanunilik ilkesi ve kişilerin hukuki güvenliklerini sağlamaktır (Üstün, 2007). Yasama organı, Bakanlar Kuruluna, mali yükümlülüklerin muaflık, istisna ve indirimlerine yönelik değişiklik yapma yetkisini devrederken, mükellefler arasında negatif ayırımcılık yapılmasına neden olmamalı, mali yükümlülüklerin oranlarına ilişkin hükümlerinde değişiklik yapmak yetkisini devrederken de geniş marjlı yetki devretmemelidir, aksi halde, yasama organının kanun yapma yetkisi bir anlamda Bakanlar Kuruluna devredilmiş olur (Erol, 2011).

Vergilemeyle ilgili bir başka sınırlama T.C. Anayasasının 90. maddesinde yer almaktadır. Bu maddenin 1. fikrasında " Türkiye Cumhuriyeti adına yabancı devletlerle ve milletlerarası kuruluşlarla yapılacak antlaşmaların onaylanması, Türkiye Büyük Millet Meclisinin onaylamayı bir kanunla uygun bulmasına bağlıdır" hükmü yer almakta, 4. fikrasında ise, " Türk kanunlarına değişiklik getiren her türlü antlaşmaların yapılmasında birinci fikra hükmü uygulanır" hükmü yer almaktadır. Bu iki fikra hükmü birlikte değerlendirildiğinde, Anayasamızın, 
uluslararası anlaşmalarla, vergileme ile ilgili kanunlarımızda değişiklik yapılması halinde, tek yetkilinin yasama organı olduğunu belirttiği, diğer devlet organları açısından yetki konusunda sınırlama getirdiği görülmektedir.

Anayasamızda yer alan vergilemeyle ilgili bir başka sınırlama, Bakanlar Kurulunun Kanun Hükmünde Kararname çıkarma yetkisinde yer alır. T.C. Anayasasının 91. maddesinde Kanun Hükmünde Kararname yetkisi verme başlı̆̆ı altında "Türkiye Büyük Millet Meclisi, Bakanlar Kuruluna kanun hükmünde kararname çıkarma yetkisi verebilir. Ancak sıkıyönetim ve olağanüstü haller saklı kalmak üzere, Anayasanın ikinci kısmının birinci ve ikinci bölümlerinde yer alan temel haklar, kişi hakları ve ödevleri ile dördüncü bölümünde yer alan siyasî haklar ve ödevler kanun hükmünde kararnamelerle düzenlenemez" hükmü yer almaktadır.

Anayasamızın dördüncü bölümünde yer alan siyasî haklar ve ödevler başlığı altında düzenlenmiş olduğuna göre, Anayasamızın 91. maddesine göre, sıkıyönetim ve olağanüstü haller dışında Bakanlar Kurulu, Kanun Hükmünde Kararname çıkarma yetkisine sahip değildir. Görüldüğü gibi Anayasamız, vergileme konusunda yürütme organının yetkisini sınırlandırmıştır.

\subsection{Yargısal Denetimden Doğan Sınırlar}

Devletin vergilendirme yetkisinin, kişi haklarına uygun olarak, uluslararası hukuk kuralları ile veya anayasa ve kanunlarla sınırlandırılmış olması yeterli değildir, hukuk kuralları ile sınırlamanın yanında bu kuralların doğru uygulandığının denetlenmesi gereklidir. Belirtilen denetimin bağımsız yarg1 organları tarafindan gerçekleştirilmesi gereği açıktır. Bu doğrultuda, ülkemizde Anayasa Mahkemesine ve Danıştay'a çok önemli bir görev yüklenmiş bulunmaktadır.

Vergilendirmenin yasallı̆ının yargısal denetimi konusunu öncelikle Anayasa Mahkemesinin fonksiyonuna bakarak incelemek gerekir. Anayasamızın 148. maddesinin birinci fikrasında "Anayasa Mahkemesi, kanunların, kanun hükmünde kararnamelerin ve Türkiye Büyük Millet Meclisi İçtüzüğünün Anayasaya şekil ve esas bakımlarından uygunluğunu denetler ve bireysel başvuruları karara bağlar. Anayasa değişikliklerini ise sadece şekil bakımından inceler ve denetler. Ancak, olağanüstü hallerde, sıkıyönetim ve savaş hallerinde çıkarılan kanun hükmünde kararnamelerin şekil ve esas bakımından Anayasaya aykırılığı iddiasıyla, Anayasa Mahkemesinde dava açılamaz" hükmü yer almaktadır. Olağan dönemde Kanun Hükmünde Kararnamelerle vergi düzenlemesi yapılamayacaktır, olağanüstü dönemlerde yapılabilecek olsa dahi Anayasa Mahkemesine bu konuda denetim görevi düşmeyecektir ve Türkiye Büyük Millet Meclisi İçtüzüğü ile vergi düzenlemesi yapılamayacaktır. Sayılan nedenlerle, bu maddede konumuzla ilgili olarak Anayasa Mahkemesinin, vergi kanunlarının Anayasaya uygun olup olmadığını denetleyen yargı organı olduğu görülmektedir.

Ülkemizde Anayasa Mahkemesinin, vergi kanunlarının Anayasada belirlenen ilkelere uygun olup olmadığını denetlerken, bağlayıcı ve temel kaynak yaratma özelliğinin hakkını verdiği görülmektedir. Bu nedenle, Anayasa Mahkemesinin, yasama organını, vergi kanunu çıkartmasında temel ilkelerle sınırlayıcı bir yargısal denetim fonksiyonu gördüğ̈̈ bilinmektedir.

12 Eylül 2010 tarihli halkoylaması sonucunda yapılan Anayasa değişikliği ile Anayasamıza eklenen 148. maddenin üçüncü fikrasında, "Herkes, Anayasada güvence altına alınmış temel hak ve özgürlüklerinden, Avrupa İnsan Hakları Sözleşmesi kapsamındaki herhangi birinin kamu gücü tarafından ihlal edildiği iddiasıyla Anayasa Mahkemesine başvurabilir. Başvuruda bulunabilmek için olağan kanun yollarının tüketilmiş olması şarttır" ifadesi yer almaktadır. Maddeden görüldüğü gibi, bireysel başvuru, bireyin temel hak ve özgürlüklerinin yasama, yürütme ve yargı organlarının işlemlerine karşı ulusal düzeyde korunması amacıyla başvurulabilecek son hukuksal çaredir (Karaman, 2013). Hukuk sistemimize 2010 yllında dahil edilen Anayasa Mahkemesine bireysel başvuru hakkının, bireyin temel hak ve özgürlüklerine yönelik, örneğin vergileme ile mülkiyet hakkının zedelenmesine yönelik olan devletin keyfi veya yanlış uygulamalarını sınırlama ve dolayısıyla hukuk düzenini koruma noktasında çok önemli ve fonksiyonel olduğu açıktır.

Vergilendirmenin yasallı̆ının yargısal denetimi konusunda Anayasa Mahkemesinin fonksiyonundan sonra Danıştay'ın fonksiyonuna da bakmak gerekir. Anayasamızın 155. maddesinin birinci fikrasında, "Danıştay, idari mahkemelerce verilen ve kanunun başka bir idari yargı merciine bırakmadı̆̆ karar ve hükümlerin son inceleme merciidir. Kanunla gösterilen belli davalara da ilk ve son derece mahkemesi olarak bakar" ifadesi yer almakta ve Anayasamızın 155. maddesinin ikinci fikrasında, "Danıştay, davaları görmek, Başbakan ve Bakanlar Kurulunca gönderilen kanun tasarıları, kamu hizmetleri ile ilgili imtiyaz şartlaşma ve sözleşmeleri hakkında iki ay içinde düşüncesini bildirmek, tüzük tasarılarını incelemek, idari uyuşmazlıkları çözmek ve kanunla gösterilen diğer işleri yapmakla görevlidir" ifadesi yer almaktadır.

Danıştay'ın vergileme konusundaki yargılama fonksiyonuna, Anayasada sıralanmış olan görevleri açısından baktığımızda, idari/vergi mahkemelerince verilen karar ve hükümlerin son inceleme mercii olduğu, vergiye yönelik kanun tasarıları hakkında iki ay içinde düşüncesini bildirdiği, vergi ile ilgili tüzük tasarılarını inceleyip istişari nitelikte olan görüşünü bildirdiği anlaşılmaktadır. Danıştay Kanunu'nun 24. maddesinde de Danıştay'ın ilk derece mahkemesi olarak; Bakanlar Kurulu Kararlarına, Bakanlıklar ile kamu kuruluşları veya kamu kurumu niteliğindeki meslek kuruluşlarınca çıkarılan ve ülke çapında uygulanacak düzenleyici işlemlere ve birden çok idare veya vergi mahkemesinin yetki alanına giren işlere karşı açılacak iptal ve tam yargı davalarını karara bağlamakla görevli olduğu belirlenmiştir. Danıştay Kanunu'nun 25. maddesinde ise, temyiz yoluyla Danıştay'da 
görülecek davalar sıralanmıştır. Bu hükme göre, idare mahkemeleri ile vergi mahkemelerince verilen nihai kararlar ve ilk derece mahkemesi olarak Danıştay'da görülen davalarla ilgili nihai kararlar Danıştay'da temyiz yoluyla incelenecek ve karara bağlanacaktır.

Danıştay'ın vergileme ile ilgili yargısal denetim görevlerine yukarıdaki hükümler doğrultusunda baktığımızda, Danıştay'ın vergi ile ilgili Bakanlar Kurulu Kararlarının, tüzüklerin, yönetmeliklerin ve Genel Tebliğlerin, Anayasaya ve kendilerinden önce gelen kurallara uygun olup olmadığının yargısal denetimlerini yaptığı anlaşılmaktadır.

Danıştay'ın vergileme ile ilgili çok önemli bir başka fonksiyonu da İçtihadı Birleştirme Kararları verebilmesidir. Danıştay Kanunu'nun 39. maddesinde içtihatları birleştirme kurulunun görevleri "İçtihatları Birleştirme Kurulu, dava dairelerinin veya idari ve vergi dava daireleri genel kurullarının kendi kararları veya ayrı ayrı verdikleri kararlar arasında aykırılık veya uyuşmazlık görüldügü veyahut birleştirilmiş içtihatların değiştirilmesi gerekli görüldüğü takdirde, Danıştay Başkanının havalesi üzerine, Başsavcının düşüncesi alındıktan sonra işi inceler ve lüzumlu görürse, içtihadın birleştirilmesi veya değiştirilmesi hakkında karar verir" şeklinde düzenlenmiştir. İçtihadı Birleştirme Kararları, vergi hukuklunun temel ve uyulması zorunlu kaynaklarındandır ve hukuka aykırı kararların uygulanmasını engelleyerek, vergi uygulamaları konusunda idari tasarrufları sinırlandırmaktadır.

Danıştay vergilemeye yönelik yargılama yaparken vergi ilkelerini de göz önünde tutmaktadır. Bu ilkelerden birisi "vergilerin geriye yürümezliği ilkesi" dir. Vergilerin geriye yürümezliği ilkesi, vergi kanunlarının geçmişe etkili olarak değiştirilemeyeceğini ifade eder. Vergi mükellefinin, kendisine, Resmi Gazetede yayınlanmış bir kanun hükmünün uygulanmasını beklemesi doğaldır (Lang ve Marchgraber, 2011). Buna göre, devlet, vergiyi doğuran olayın ortaya çıkmasından sonra Resmi Gazetede yayınladığı bir kanun hükmünü, o vergiyi doğuran olaya uygulayamaz, ancak yayım tarihinden sonra ortaya çıkan vergiyi doğuran olayla ilgili olarak yeni hükmü uygulayabilir, aksi takdirde, devlet, hukuk devletinin güvenilirliğini zedeleyecektir. Anayasamızda ve Vergi Usul Kanununda yer almayan bu ilkeye ters uygulamalara zaman zaman rastlanılmaktadır, bu uygulamaların Danıştay tarafından iptal edilmesi, hukuk devletinin güvenilirliğini sağlamaktadır.

\section{Devletin Vergilerle Ekonomiye Müdahalesinin Sosyal Devlet Olmak Zorunluluğundan Doğan Sınırları}

Anayasamızda, devletin, vergilerle ekonomiye müdahalesinin sosyal devlet olmak zorunluluğundan doğan sınırlarına yönelik temel prensipleri belirleyen çok önemli iki madde bulunmaktadır. Bunlardan birisi Anayasamızın 2. maddesinde, diğeri ise, 73. maddede yer almaktadır.

Anayasamızın 2. maddesinde, Türkiye Cumhuriyetinin sosyal bir devlet olduğu ifade edilmektedir. Bir devletin sosyal devlet sayılabilmesi için, vergilerle ilgili bazı önlemleri alması gereklidir. Bu önlemler; herkese insan onuruna yakışan asgari bir yaşam düzeyi sağlamaya yönelik olanlar, gelir ve servet farklılıklarının azaltılmasına yönelik olanlar ve toplumdaki bazı bireylerin özel olarak korunmasına yönelik olanlardır.

Anayasamızın 73/1. maddesinde, vergi ödevi ile ilgili olarak, herkesin, kamu giderlerini karşılamak üzere, malî gücüne göre, vergi ödemekle yükümlü olduğu ifade edilmekte, 73/3. maddesinde ise, vergi yükünün adaletli ve dengeli dağılımının, maliye politikasının sosyal amacı olduğu belirtilmektedir.

Yukarıdaki anayasal hükümler birlikte değerlendirildiğinde, karşımıza sosyal devletin vergileme ile ilgili sınırları açıkça ortaya çıkmaktadır. Bu sınırlardan birisi, herkese insan onuruna yakışan asgari bir yaşam düzeyi sağlamaya yönelik olarak asgari ücretin vergileme dışında bırakılması gereğidir. Asgari ücret, kişinin kendisini ve ailesini asgari düzeyde geçindirmeye yeterli tutardır ve bu tutardan vergi alınması halinde kişinin, insan onuruna yakışan asgari bir yaşam düzeyini sürdüremeyeceği açıktır. Anayasamız, açık bir şekilde mali güce göre vergi ödeneceğini ifade etmiştir, bu hükümden hareketle mali gücü olmayanın vergi ödememesi gerektiği ortaya çıkmaktadır. Ülkemizde, devletin bu ilke doğrultusunda sosyal devlet olma görevini henüz gerçekleştiremediği dolayısıyla devletin, "vergilendirme gücünün aşırı kullanımı" ya da "mali zorlama" (Akdoğan, 2011) olarak isimlendirebileceğimiz bir uygulama içinde olduğunu ifade edebiliriz.

Sosyal devletin vergileme ile ilgili bir başka sınırı, gelir ve servet farklılıklarının azaltılmasına yönelik görevinden doğar. Devlet, bu görevini gerçekleştirmek için, ayırma ilkesine uygun vergileme yapmalı ve vergi tarifelerini artan oranlılığa göre düzenlemelidir. Ayırma ilkesi, emek gelirleri ile servet gelirlerini birbirlerinden ayırıp, emek gelirlerinden daha az vergi almayı amaçlar. Devlet, vergileme yaparken, emekten elde edilen gelirin vergi oranını, servetten elde edilen gelire oranla daha az belirlediği takdirde, vergi yükünün adaletli dağıtımını sağlamış olacaktır. Ülkemizde ayırma ilkesi doğrultusunda, "asgari geçim indirimi" adı ile ücretlilere yönelik bir uygulama vardır. Buna göre, ücretlinin maaşının asgari ücretin \%50'sine denk gelen kısmı vergi matrahından düşülmekte ve ücretli diğer gelir elde eden bireylere karşı korunmaktadır. Vergi tarifelerinin artan oranlı bir yapıda düzenlenmesi ise, vergi adaletini etkin bir şekilde gerçekleştirmeye yönelik bir başka önlemdir. $\mathrm{Bu}$ uygulamada, daha fazla geliri olanın daha fazla vergi ödeme gücü olduğundan hareketle, gelir tutarı artıkça vergi oranı da artırılarak vergileme yapılır, sonuç olarak az kazanan, çok kazanana göre daha az vergi öder. 
Sosyal devletin vergileme ile ilgili bir diğer sınırı ise, özel olarak korunması gereken bireylerin, vergi kanunlarında çeşitli vergi istisnaları veya muafiyetleri getirilerek korunmasıdır. Ülkemiz uygulamalarından, bir tek eve sahip olan bireylerden emlak vergisi alınmaması, sakatların kullanabileceği motorlu araçların, motorlu araçlar vergisi ve gümrük vergisi dışında bırakılması, sadece emekli maaşı ile geçimini sürdüren bireylerden gelir vergisi alınmaması, doğal afetlerden etkilenenlere vergi kolaylıkları getirilmesi örnek gösterilebilir.

Kamu maliyesinin temel kaygısı, en fazla vergiyi en az direnişle toplamak olmalıdır (Hayek, 1997). Devlet vergileme yaparken sosyal devlet olma özelliğini dikkate almaz ise, vergiye yönelik tepkinin artmasını beklemek yanlış olmayacaktır. Egemenlik gücüne sahip olan Devletin, vergileme yaparken kamu yararı ile birey çıkarları arasında var olan çelişme ve çatışmayı gözeterek, vergilendirmeyi duyarlı bir dengeye oturtması gereklidir (Kaneti, 1986/1987).

\section{Devletin Vergilerle Ekonomiye Müdahalesinin Siyasi Sınırları}

Tarihteki ilk demokrasi mücadelelerinin, yönetenlerin sınırsız vergileme yetkisine karşı geliştiği bilinmektedir. Demokratik yönetimlerin gelişmesi ile birlikte, vergileme yetkisi yasama organına geçmiştir. Zaman içinde halkın devletten beklediği hizmetler artıkça, devletin gereksinim duyduğu kamu gelirleri artmış ve vergiler konuları bakımından çeşitlendiği gibi oranlarında da artış ortaya çıkmıştır. İktidara gelmek isteyen veya iktidarda kalmak isteyen siyasi partiler, parti programlarında bir taraftan daha fazla kamu hizmeti vaat etmek zorunda kalırken başka taraftan vergileme konusunda halkın tepkisini çekmemeye çalışır hale gelmişlerdir.

Vergileme konusundaki siyasal sınırın başında oy kaybı korkusu gelir (Nadaroğlu1983). Ülkemizde, giderin, Katma Değer Vergisi ile vergilendirilebilir hale gelmesinin ihtilal dönemine rastlaması tesadüf olmayıp, oy kaybının söz konusu olmadığı bir dönem olduğu gözlemlenebilir.

Günümüz demokratik toplumlarında, çeşitli sivil toplum örgütlerinin ve basının iktidarı yönlendirebildiği bilinmektedir. Mükellef haklarının gelişmesiyle birlikte, bir zor alım olan verginin gönüllü ödenmesini gerçekleştirecek politikaların uygulanması zorunlu hale gelmiştir. Bir toplumda az sayıda mükellefin vergisini ödememesi büyük sorunlara neden olmaz ama toplumun büyük kısmı vergiye tepki gösterir hale gelirse, sosyal direnişler ortaya çıkar ve devlet vergi toplayamaz hale gelir. Buna göre, devlet vergileme konusunda halktan destek almak zorundadır.

Devlet, vergileme yaparken işlemlerinde saydamlığa önem vermeli ve halkta vergi tedirginliğine yol açmamalıdır. Aksi takdirde, halk, vergi idaresine giderek vergi sorunlarını çözmekten kaçınacak ve kayıt dışına itilecektir.

Devlet, vergilemeyi asla politik baskı olarak kullanmamalıdır. İktidar partisine yakın olmayan mükellefleri bezdirmek amacıyla, örneğin gereksiz, vakitsiz vergi incelemesine alarak otoritesini sağlamaya çalışmamalıdır.

Halk, devlete karşı kendisini güçsüz hisseder. Devletin bu konuya duyarlı politikalar gerçekleştirmesi gereklidir. Örnek olarak vergi uyuşmazlıklarının adil yargılanma sürecinde kısa zamanda karara bağlanmasını sağlayacak yargı reformları gerekiyorsa, zaman kaybetmeden bu reformlar yapılmalıdır.

İktidar partileri, olumsuz politikalarla, mükellefler üzerinde vergi baskısı yaratmamalıdır. Vergi baskısı, vergi ödemenin bireylerin davranışları üzerine meydana getirdiği psikolojik etkidir (Pehlivan, 2002). Eğer devlet, bireyler üzerine aşırı vergi baskısı yaratırsa, bireyler vergi kaçakçılığına yönelirler. Bu sonuç ise, toplumda vergi ahlakı ve vergi bilincinin gelişmesini engeller.

İktidar partilerinin oy kazanma hırsı ile çok sık vergi af kanunları çıkartmaları da, vergisini zamanında ödeyen mükelleflere karşı bir haksız rekabet yaratacaktır. Sürekli af kanununun çıkacağı beklentisi, verginin zamanında yatırılmasının önünde caydırıcı bir sebeptir ve bu uygulama da sonuçta vergi ahlakı ve vergi bilincinin gelişmesini engeller.

Vergileme ile ilgili çok önemli bir siyasi sınır ise, halkın kamu harcamalarına duyduğu güven ile ilgilidir. Halk, yapılan kamu harcamalarını yerinde buluyorsa, bu harcamaların toplum yararına olduğunu düşünüyorsa ve harcama tutarlarını makul buluyorsa vergi ödeme isteği artacaktır. Örneğin istihdam yaratıcı kamu harcamalarında veya tekel piyasası ile mücadelede ya da ulaşımı rahatlatan bayındırlık hizmetlerinde harcanan tutarlara halkın tepkisi olmadığı gibi, bu harcamaları yapan iktidar partisine desteği de devamlı olacaktır.

\section{Devletin Vergilerle Ekonomiye Müdahalesinin Ekonomik Sınırları}

Vergilemenin ekonomik sınırlarından birisi vergi rekabetinin varlığıdır. Eğer bir ülke, vergi oranlarını diğer birçok ülkeye göre daha düşük oranda belirlerse veya vergi konularını diğer ülkelere göre azaltırsa, bireyler ve bilhassa günümüzde sayıca artmakta olan çok uluslu şirketler, o ülkenin vergi rejimine tabi olmayı tercih ederler. Vergi rekabetini göz önünde bulundurmadan vergileme yapan bir ülke, vergilendirilebilir geliri olan bireylerin ve şirketlerin başka ülkelere kaçmasına neden olur. Buna göre, ülkeler arasındaki vergi rekabeti de vergilemeyi hem konu hem de oranı bakımından sınırlamaktadır. 
Vergilemenin bir başka ekonomik sınırları, verginin devlete olan maliyetidir. Bu maliyet, gelir örgütünün vergi toplarken katlandığı giderlerdir. Eğer vergi toplama amacıyla yapılan gider, toplanan vergi tutarına eşitse ya da daha fazla ise, vergi toplamanın anlamı kalmaz. Ülkemizde Amme Alacaklarının Tahsil Usulü Hakkında Kanun'un 106. maddesinde "Yapılacak takip sonunda tahsili imkansız veya tahsili için yapılacak giderlerin alacaktan fazla bulunduğu anlaşılan ve 213 sayılı Kanun kapsamına giren amme alacaklarında 10 Türk Lirasına (10 Türk Lirası dahil), diğer amme alacaklarında 20 Türk Lirasına (20 Türk Lirası dahil) kadar amme alacakları, amme idarelerinde terkin yetkisini haiz olanlar tarafindan tahsil zamanaşımı süresi beklenilmeksizin terkin olunabilir" hükmü yer almaktadır. Yine benzer mantıkla, Vergi Usul Kanunu'nun Mükerrer 115. maddesinde de "İkmalen, re'sen veya idarece tarh edilen vergi ve bunlara ilişkin cezaların toplam miktarı 23 TL aşmaması ve tahakkukları için yapılacak giderlerin bu miktardan fazla olacağının tespiti halinde, Maliye Bakanlığınca belirlenecek usul ve esaslar dahilinde tahakkuklarından vazgeçilebilir" hükmüne yer verilmiştir. Bu iki hükmü birlikte değerlendirecek olursak, ülkemizde 23 TL sına kadar vergileme yapılmayabileceğini söyleyebiliriz.

Vergi kapasitesi de vergilendirme sınırını belirleyen kavramlardan birisidir. Vergi kapasitesi, ülkenin vergilenebilir ekonomik potansiyelini ifade eder (Bilici, 2015), başka ifade ile ülkedeki asgari geçimi sağlayan gelir düzeyinin üzerinde kalan gayrisafi milli gelirin büyüklüğüdür (Pehlivan, 2002). Vergilemenin son noktası, ülkenin vergi kapasitesidir. Günümüzde hiç bir ülkede bu sınıra ulaşılamadığı bilinen bir gerçektir. Bu noktada, vergi gayreti kavramı önem kazanmaktadır. Vergi gayreti, bir ülkede fiilen toplanan verginin o ülkenin toplam vergi kapasitesine oranını ifade eder (Bilici, 2015). Buna göre, bir ülkede verginin sınırı, vergi gayreti ile de bağlantılıdır. Vergilemenin sınırı üzerinde çalışan bilim insanlarından Colin Clark, vergilemenin sınırını, milli gelirin \%25'i olarak belirlemektedir (Nadaroğlu1983), Laffer ise, vergi oranlarındaki artışın bir yere kadar vergi gelirlerini artırdığına, bu yerin optimal nokta olduğuna dikkat çeker ve devletin, vergileme yaparken, verginin en fazla optimal noktaya kadar gelmesi gerektiğini ileri sürer. Laffer'e göre, optimal noktaya kadar vergi artarsa, verginin gelir etkisi ortaya çıkar, daha açık ifade ile vergide artış sonucu geliri azalan bireyler, eksilen kısmı geri kazanmak amacıyla daha fazla çalışırlar, ama vergilemede optimal nokta aşılırsa, vergi hasılatı düşer, üretim zarar görür ve vergilemenin ikame etkisi ortaya çıkar ki bu da vergi nedeniyle geliri azalan mükellefin çalışmaktan vazgeçmesidir (Bilici, 2015).

\section{Sonuc}

Devlet, çeşitli amaçlarla vergileme yaparak ekonomiye müdahale etmekte ve toplum açısından çok önemli ekonomik etkiler yaratmaktadır. Günümüzde, hiç bir demokratik ülkede, devlet, kişilerin temel haklarını zedeleyici, keyfi ve sınırsız vergileme yapamayacaktır. Devlet, hukuk devleti olmak zorundadır. Hukuk devleti, uluslararası ve ulusal hukuk kurallarına uymak zorundadır. Bu bağlamda, devlet, İnsan Hakları Evrensel Beyannamesinde ve Avrupa İnsan Hakları Sözleşmesinde yer alan ilkelerle, Anayasal kurallarla ve yargısal denetimle sahip çıkılan vergi ilkeleriyle sınırlıdır.

Devlet, vergileme yaparken, sadece hukuki sınırlamalara değil, sosyal devlet olmak zorunluluğundan kaynaklanan sınırlara da tabidir. Sosyal devlet, vergileme yoluyla, herkese insan onuruna yakışan asgari bir yaşam düzeyi sağlamak, gelir ve servet farklılıklarını azaltmak, toplumdaki bazı bireyleri özel olarak korumak ve vergi yükünü adil ve dengeli dağıtmak zorundadır.

Demokratik ülkelerde yasama organı seçimle işbaşına gelir. Vergileme politikalarını yaratacak ve uygulayacak olan yasama organı ve bilhassa yürütme organı, çeşitli siyasi baskılar altında görevlerini sürdürürler. Günümüzde, teknolojik gelişmeye dayalı olarak, halkı, devlet uygulamalarından kısa sürede haberdar edebilen medyanın gücü ve oluşturabildiği kamuoyu baskısı, devlet açısından önemli siyasal sınırlar getirmektedir ve devlet vergilemeyi istediği gibi bir baskı aracı olarak kullanamamaktadır, aksi takdirde kamu vicdanı harekete geçmekte ve oy kaybına neden olmaktadır. Bu nedenle, iktidar olmak isteyen partiler halkın kabul edebileceği vergi politikaları üretmeye çalışmakta, iktidarda kalmak isteyen partiler ise, vergileme nedeniyle oy kaybetmemek için gayret göstermektedirler. Vergileme ile ilgili çok önemli bir siyasi sınır ise, halkın kamu harcamalarını makul bulması noktasında olduğu açıktır.

Vergilemenin önemli ekonomik sınırları, ülkeler arasında var olan vergi rekabeti, verginin maliyeti ve vergi kapasitesidir.

Günümüzde devlet, bir yandan kamu hizmetleri yapmak amacıyla kamu geliri elde etmeye çalışırken, diğer yandan çalışmaya konu olan tüm vergileme sınırlarına da uymak zorundadır.

\section{Kaynakça}

- Akdoğan, 2011. Kamu Maliyesi. Gazi Kitabevi, Ankara.

- Amme Alacaklarının Tahsil Usulü Hakkında Kanun.

- $\quad$ Bilici, 2015. Kamu Maliyesi. Savaş Yayınevi, Ankara.

- Budak, 2010, Türk Vergi Hukukunda Anayasal Ölçüt: Mali Güç. XII Levha Yayıncılık, İstanbul.

- Erdoğan, 2005, Anayasa Hukuku. Orion Yayınevi, Ankara. 
- $\quad$ Erol, 2011. Vergi Felsefesi. İstanbul Serbest Muhasebeci Mali Müşavirler Odası, İstanbul.

- $\quad$ Fallon, 2014. "Hukuk Devleti", Adalet ve Hukuk Devleti, Uluslararasi Sempozyum, p. 49.

- Gerçek, 2006. Türk Vergi Hukukunda İdarenin Takdir Yetkisi. Yaklaşım Yayıncılık, Ankara.

- Göker, 2011, Yönlendirici Vergilendirme. Turhan Kitabevi, Ankara.

- Gözler ve Kaplan, 2011, İdare Hukuku Dersleri. Ekin Basın, Yayın Dağıtım, Bursa.

- Gözler, 2011. Türk Anayasa Hukuku Dersleri. Ekin Basım, Yayın, Dağıtım, Bursa.

- Gözler, 2013. Anayasa Hukukunun Genel Esasları. Ekin Basım Yayın Dağıtım, Bursa.

- Güneş, 2011. Verginin Yasallığı İlkesi. XII Levha Yayıncılık, İstanbul.

- Hayek, 1997. Hukuk, Yasama ve Özgürlük, Türkiye İş Bankası Kültür Yayınları.

- Insan Hakları Evrensel Beyannamesi.

- İnsan Hakları Evrensel Beyannamesi İnsan Hakları ve Temel Özgürlüklerin Korunmasına İlişkin Sözleşme'ye Ek Protokol.

- John F. Due. (Çevirenler, Sevim Görgün ve İzzettin Önder), 1967, Maliye. Fakülteler Matbaası, İstanbul.

- Kaneti, 1986/1987. Vergi Hukuku. Özdem Kardeşler Matbaası, İstanbul.

- Karaman, 2013. Karşılaştırmalı Anayasa Yargısında Bireysel Başvuru Yolu. XII Levha Yayıncılık, İstanbul.

- Lang ve Marchgraber, 2011. "Avusturya Vergi Hukukunda Geriye Yürüme ve Haklı Beklentiler", Vergi Hukukunda Geriye Yürümezlik Esası, s. 2.

- Nadaroğlu,1983. Kamu Maliyesi Teorisi. Okan Yayıncılık, İstanbul.

- Öncel, Kumrulu ve Çağan, 1992. Vergi Hukuku. Turhan Kitabevi, Ankara.

- $\quad$ Öztürk, 2014. "Vergilerin Kanuniliği İlkesinin Tarihi Gelişimi". Dokuz Eylül Üniversitesi Hukuk Fakültesi Dergisi Prof. Dr. Hakan Pekcanıtez'e Armă̆an,16,s.4836.

- Pehlivan,2002. Kamu Maliyesi. Derya Kitabevi, Trabzon.

- Saygılığlu, 1987. Vergi Hukukunda Yorum. Maliye ve Gümrük Bakanlığı Araştırma, Planlama ve Koordinasyon Kurulu Başkanlığı, 1987/288,Ankara

- T.C. Anayasasi

- Üstün, 2007. Türk Vergi Hukukunda İdarenin Takdir Yetkisi. Turhan Kitabevi, Ankara.

- Vergi Usul Kanunu.

- Yayla, 2009. İdare Hukuku, Beta Yayıncılık, İstanbul. 


\title{
Türkiye'de Kadına Karşı Şiddetin Önlenmesinde Devletin Sorumluluğu
}

\section{Government's Responsibility to Prevent the Violence against Women in Turkey}

\author{
Asst. Prof. Dr. Ebru Karaman (Beykent University, Turkey)
}

\begin{abstract}
Violence against women, which is accepted as a violation of human right in Turkey and in whole world for many years, causes physical and mental harms by practicing all kind of personal and collective behavior including force and pressure. Femicides have increased $1400 \%$ in the last seven years and one of every three women is subjected to violence.

It is doubtful that in international law; Convention on the Elimination of All Forms of Discrimination against Women and Council of Europe Convention and in additional to this in national law; The 1982 Constitution and The Law to Protect Family and Prevent Violence Against Women can provide effective guarantee to protect the place of woman in Turkish Society or not? Despite all of the legislative regulations, the violence against women in Turkey increasingly goes on. For this reason it is crucial to evaluate the articles no $5^{\text {th }}, 10^{\text {th }}, 17^{\text {th }}, 41^{\text {st }}$ and $90^{\text {th }}$ of Constitution which compose the legal basis for preventing violence against women.

Republic of Turkey's founding philosophy bases on equality of women and men, which means equal rights for every single citizen. To end this violence against women; can be achieve only through provide this equality legally and defacto, and also, apply social state's principles in real life. Because in social states, struggling against this violence should be accepted as government's policy. The state should be in cooperation with all women's organizations and provide training for related trade bodies.
\end{abstract}

\section{Giriş}

Kadına yönelik şiddet, güncelliğini yitirmeden hayatımızda olmaya ve bir şekilde bizi etkilemeye devam etmektedir. Son yıllarda kadına yönelik şiddetin giderek daha fazla göz önünde olması, kadına yönelik şiddetin eskiye nazaran artıp artmadığı tartışmalarını da birlikte getirmektedir. Kısa vadede sona erecek gibi gözükmeyen bu tartışmalar, aslında kadına yönelik şiddetin Türkiye'de de ne kadar yaygın olduğu gerçeğini bir kere daha gözler önüne sermektedir. Kadına yönelik şiddetin varlığının, kadın hareketleri ve konuya duyarlı grupların çabalarıyla görünür hale gelmesi, aslında kadına karşı şiddetle mücadelede önemli bir yer tutmaktadır.

Bu mücadelede unutulmaması gereken ise, kadına yönelik şiddetin bir "insan hakkı ihlali” olduğudur. Kadına yönelik şiddetin ne olduğu ve hangi durumları kapsadığının ayrıntılı şekilde ulusal ve uluslararası mevzuatta yer alması, devletlerin bu konuya gösterdikleri hassasiyetle paraleldir. Ancak kadına yönelik şiddetle ilgili veriler, hukuk kurallarını değiştirmenin ya da yeni kurallar yaratmanın tek başına sorunları çözmeye yetmediğini göstermektedir. Kadına karşı şiddetin önlenmesine yönelik uluslararası düzeyde pek çok sözleşme, bildirge, tavsiye kararı vs. kabul edilmiş olmasına rağmen, kadına yönelik şiddetin azaldığı yönünde emareler bulunmamaktadır. Uluslararası belgelerde, kadına yönelik şiddet, kadına yönelik ayrımcılığın şekillerinden biri olarak tanımlanmakta ve böylelikle, kadınların diğer faktörlerin yanında yalnızca kadın oldukları için bazı şiddet türlerine maruz kaldıkları kabul edilmektedir (Kuyucu, 2014).

Kadına yönelik şiddet toplumda her yerdedir; ancak en acısı, kadınlar için güvenilirliği en fazla olması gereken "aile içinde" de olmasıdır. Kadına karşı şiddet sorunu çözülmedikçe, toplumda kadın erkek eşitliğinin sağlanması da mümkün olamayacaktır. Kadınların karar verme mercilerinde bulunamaması, şiddetin önlenerek mağdurun korunmasına çözüm getirilememesine neden olmaktadır (Moroğlu, 2012).

Kadına yönelik şiddet bireysel bir sorun değil, bir çok faktörden oluşan toplumsal bir sorundur. Tüm dünyada ciddi bir toplumsal sorun olarak varlığını sürdüren kadına karşı şiddetin tarih boyunca yok sayılması ve görünür olduğu zamanda da meşrulaştırılmaya çalışılmasının sebebi; kadına yönelik şiddetle kadınlar üzerinde hakimiyet kurularak onları kontrol edebilmekti. Günümüzde ise, şiddete karşı koruyucu ve önleyici yasalar çıkartılmakta, uluslararası sözleşmeler yapılmaktadır. Türkiye'de de kadına yönelik mevcut olan şiddetin önlenebilmesi için ulusal ve uluslararası alanlardaki hukuki düzenlemelere, uygulamada da uyulması zorunludur. Nitekim kadına karş1 şiddetin önlenmesinde devletin sorumluluğunun tespiti için yasal çerçevenin önceden çizilmiş olması gerekmektedir. Şiddetle mücadele konusunda, devlet ve tüm kurumlar üzerlerine düşen yükümlülükleri yerine getirmediği ve toplumsal bakış açısı değiştirilmediği sürece, maalesef kadınların toplumda erkeklerle "eşit haklara" sahip olduğu anlayışı da yerleşemeyecektir. 


\section{Türkiye'de Kadına Karşı Şiddetin Varlığı}

\subsection{Kadına Karșı Șiddet Kavramı ve Türleri}

Şiddet, insanın maddi ve manevi varlığına zarar veren her çeşit davranıştır. Farklı fikirde olanlara kaba kuvvet kullanma olarak tanımlanan şiddet, aslında insanlık tarihi kadar eski bir sorundur. Şiddet kavramı, toplumların insan hakları çerçevesinde gösterdikleri gelişime bağlı olarak yeniden tanımlanmakla birlikte, tarihsel, sosyal ve kültürel bakımdan da zamanla değişmektedir (Uluocak, vd., 2014).

Günlük hayatta şiddet, mağdurlara baskı, eziyet, korkutma, sindirme, cezalandırma, öldürme şeklinde kendini gösterebilmekte ve bireylerin kendi istekleri dışında maruz kaldıkları eylemler sonucunda ortaya çıkabilmektedir. Nitekim bu maruz kalma, bireyleri bir şey yapmaktan alıkoyabileceği gibi, bireylere zorla bir şey yaptırtan bir durum da olabilmektedir (Kocacık, 2001). Şiddet kavramı, "kanunlara uymamak, kişilere zarar vermek, hakaret etmek, onurunu kırmak, huzurunu bozmak, hakkını ihlal etmek, hırpalamak ve canını acıtmak için zor kullanmak, aşırı derecede yıkıcı ve öfkeli davranmak" olarak tanımlanmaktadır (Erten ve Ardalı, 1996).

Nitekim benzer bir şiddet tanımı 6284 sayılı Ailenin Korunması ve Kadına Karşı Şiddetin Önlenmesine Dair Kanun'da görülmektedir. Söz konusu Kanun'un 2. maddesi uyarınca şiddet, “Kişinin fiziksel, cinsel, psikolojik veya ekonomik açıdan zarar görmesiyle veya acı çekmesiyle sonuçlanan veya sonuçlanması muhtemel hareketleri, buna yönelik tehdit ve baskıyı ya da özgürlüğün keyfî engellenmesini de içeren, toplumsal, kamusal veya özel alanda meydana gelen fiziksel, cinsel, psikolojik, sözlü veya ekonomik her türlü tutum ve davranışı" kapsamaktadir.

Böylelikle, 6284 sayılı Kanun'un ilgili hükmünün, şiddet eylemini geniş bir şekilde ele alan yorumu kabul ettiği anlaşılmaktadır. Diğer bir ifadeyle, sadece fiziksel şiddet eylemleri değil, psikolojik, cinsel ve ekonomik açıdan zarar vermeyi hedefleyen davranışların da şiddet kapsamına girdiği yönünde bir eğilim bulunmaktadır. (Gökulu, 2005).

Kadına yönelik şiddet kavramı ise, kadına yapılan fiziksel şiddetle örtüştürülmesine rağmen; yapılan çalışmalar, kadına yönelik şiddet olgusunun sadece fiziksel eylemler üzerinden değil, şiddetin diğer boyutlarıyla birlikte değerlendirilmesi gerektiğini göstermektedir. Doktrin fiziksel şiddeti, ilk olarak göze çarpan ve verdiği zararlar objektif olarak değerlendirilebilen bir şiddet türü olduğu için ön plana çıkarsa da, psikolojik, cinsel ve ekonomik şiddet türlerini de kadına yönelik şiddetin kapsamına dahil etmektedir. Ancak kadına yönelik şiddet, teoride farklı sınıflandırmalara tabi tutulsa da genellikle toplumda birlikte görülebilmektedir. Diğer bir ifadeyle, fiziksel şiddete maruz kalmış bir kadın, aynı zamanda cinsel şiddete de maruz kalabilmektedir (Uluocak, vd., 2014).

Kadına yönelik fiziksel şiddet, kadına zorla bir şey yaptırma ya da bir şey yapmaktan alıkoyma amacıyla, kadının iradesi dışında gerçekleşen fiziksel zarar verici eylemleri içermektedir. Fiziksel şiddet; vurma, bedene zarar verme, tokat atma, tekmeleme, bükme, boğaz sıkma vb. eylemleri içermektedir. Şiddetin en çok bilinen çeşidi olan fiziksel şiddet, ceza kanunlarında suç olarak düzenlenmektedir (Karınca, 2011).

Kadına yönelik cinsel şiddet, kadına yönelik gerçekleştirilen ve kadının iradesi dışında ilişki kurma, tecavüz, sözlü ya da fiili gerçekleştirilen taciz vb. eylemleri kapsamaktadır. Kimin gerçekleştirdiğinin önemi olmaksızın, kadına istemi dışında yöneltilen her türlü cinsel amaçlı söz veya eylemler cinsel şiddet olarak tanımlanmaktadır (Karınca, 2011).

Kadına yönelik psikolojik şiddet, tanımlanması ve kanıtlanması en zor şiddet türüdür. Nitekim bu tarz şiddet eylemlerinin ilk etapta fark edilebilmesi de zordur. Kadını aşağılayan, kadının özsaygısına ve kişiliğine zarar veren ifadeler bu kapsamda değerlendirilmektedir. Kadını küçük görerek fikirlerini önemsememek, yaptıklarını sürekli kontrol etmek, kadının iş ve sosyal yaşamını engellemek, bağırmak, korkutmak, küfretmek, tehdit etmek ve hakaret etmek gibi pek çok davranış biçimi kadına yönelik psikolojik şiddet tanımı içerisinde yer almaktadır (Uluocak, vd., 2014).

Kadına yönelik ekonomik şiddet, kadının mallarını ve diğer gelirlerini elinden almak, kadının iradesi dışında onu çalışmaya zorlamak ya da çalışmaktan alıkoymak, ekonomik konulardaki kararlarda kadını saf dışı bırakmak gibi çeşitli eylemleri kapsamaktadır. Ayrıca, kadının ev içerisindeki iş bölümüne dayalı eşitsiz görev dağılımı nedeniyle iş hayatında kariyer yapamaması da ekonomik şiddet olarak değerlendirilmektedir.

Doktrindeki bu farklı şiddet tanımlarına rağmen, 6284 sayılı Kanun’un 2. maddesi, kadına yönelik şiddeti; "Kadınlara, yalnızca kadın oldukları için uygulanan veya kadınları etkileyen cinsiyete dayalı bir ayrımcılık ile kadının insan hakları ihlaline yol açan ve Kanun'da şiddet olarak tanımlanan her türlü tutum ve davranış” olarak geniş bir biçimde tanımlamaktadır.

Sonuç olarak; kadına yönelik şiddet, kadının fiziksel, ruhsal, sosyal, cinsel ve ekonomik açıdan zarar görmesine, acı çekmesine neden olan, onurunu zedeleyen, temel hak ve özgürlüklerini kullanmasını engelleyerek, kadına yönelik ayrımcılığın sürmesine yol açan bir eylemdir. 


\subsection{Türkiye'de Kadına Karşı Şiddetin Boyutları}

Kadına karşı şiddet, evrensel bir sorundur. 1970'lerden önce genelde yabancıların ya da uzak tanıdıkların saldırısı ve tecavüzüyle sınırlı olarak görülen kadına yönelik şiddet, ülkemizde, ancak 1980'lerin ortalarından itibaren tartışılmaya başlanmıştır (Yıldırım, 1998). Maalesef, Türkiye'de erkeğin eşini ya da kızını dövmesi, onun hakkı olarak kabul edilmektedir. Kadına yönelik şiddetin nedenlerinin belirlenmesi, soruna çözüm getirilmesi için gereklidir. Araştırmalar göstermektedir ki, eşine şiddet uygulayan erkeklerin büyük çoğunluğu, şiddetin nedenini "söz dinlememe" olarak ifade etmektedir. Bununla birlikte, kadınların genellikle geleneksel işlerini yerine getirmedikleri ve bir yere giderken de izin almadıkları için şiddete maruz kaldıkları anlaşılmaktadır (Kalaycıoğlu ve Kılıç, 2001).

Ülkemizde şiddetin var olduğu ve her geçen gün de arttığı bir gerçektir. Türkiye'de her beş kadından ikisinin fiziksel şiddete, her iki kadından birinin de duygusal şiddete maruz kalmaktadır. Kadınlar ilk yıllarda eşlerinin değişeceğine inanmakta; ancak daha sonra da çevre baskısı, ekonomik nedenler, korku, meslek sahibi olmama gibi gerekçeler yüzünden eşlerini terk edememektedir. Ancak şiddet çocuklarına yöneldiği zaman yardım aramaya karar verdikleri belirlenmiştir (Gümüşoğlu, 1998). Kadına yönelik şiddetin oldukça yaygın olduğu; şiddetin yoğunluğunun yaş, cinsiyet, eğitim düzeyi gibi faktörlerden etkilendiği belirtilmektedir. Kadınların insan hakları kapsamındaki birçok hakkını kullanamamasına neden olan "cinsiyet sorunsalı", toplumun kadına biçtiği rol ve dayatmalarıyla daha fazla genişlemektedir.

Türkiye'de aile içinde yaşanan sorunlar mahrem kabul edildiğinden yakın kişilere bile anlatılamamaktadır. Nitekim şiddete maruz kalan kadın, uğradığı şiddeti başkasına anlatmaktan utanmaktadır. Şiddet gördüğünün bilinmesini istememektedir. Maalesef Türkiye'de kadına biçilen bu geleneksel rol, şiddetin giderek yaygınlaşmasına ve normal kabul edilmesine neden olmaktadır. Kadınlar üzerindeki meşrulaştırılmış bu baskı da, şiddete maruz kalan kadınların yardım alabilmelerini zorlaştırmaktadır.

\section{Türkiye’de Kadına Karşı Şiddeti Önlemeye Yönelik Hukuki Düzenlemeler}

Kadına karşı şiddetle mücadele, başlangıçta büyük ölçüde hükümet dışı kuruluşlar tarafından yürütülmektedir. Ancak kadına karşı şiddeti önlemekte devlet kurumlarının tutumu değişmedikçe mücadelenin başarıya ulaşması zordur. Bu nedenle, devletin bu konudaki sorumluluğunu yerine getirmesi ve buna ilişkin çalışmalar yürütmesi gerekmektedir. Kadına yönelik şiddetin tüm dünyada bu kadar yaygın olması, uluslararası sivil toplum örgütlerini de harekete geçirmiştir. Diğer bir ifadeyle, feminist hareketlerin de etkisiyle uluslararası toplumda konunun yoğun biçimde ele alınması; soruna insan haklarına ilişkin evrensel bir boyut kazandırmıştır. Dolayısıyla bu durum, Türkiye'de kadına karşı şiddeti önlemeye yönelik ulusal düzenlemelerin yanı sıra uluslararası alandaki düzenlemelerin de dikkate alınmasına neden olmaktadır.

\subsection{Uluslararası Alandaki Hukuki Düzenlemeler}

Kadın haklarına ilişkin ilk uluslararası sözleşme, Birleşmiş Milletler tarafından kabul edilen 1979 tarihli “Kadınlara Karşı Her Türlü Ayrımcılığın Önlenmesi Sözleşmesi (CEDAW)”dir. Türkiye'nin de 1985 y1lında taraf olduğu bu Sözleşme, taraf devlet sayısının çokluğu ve kadınlara karşı ayrımcılığı ortadan kaldırmak için devletlere getirdiği önemli yükümlülüklerle bu konudaki en önemli sözleşmelerden biridir. Sözleşme, 19 Ocak 1986 tarihinde yürürlüğe girmiştir. Sözleşme'de kadına karşı şiddet, kadınların erkeklerle eşit hak ve özgürlüklerden faydalanabilmelerini engelleyen bir ayrımcılık türü olarak düzenlenmesine rağmen, kadına yönelik aile içi şiddeti düzenlememiştir. Söz konusu Sözleşme'nin temel hedefi, toplumsal yaşamın her alanında kadın erkek eşitliğini sağlamak amacıyla, kalıplaşmış kadın erkek rollerine dayalı önyargıların yanı sıra geleneksel ve benzer tüm ayrıcalık içeren uygulamaların ortadan kaldırılmasını sağlamaktır.

Sözleşme'nin 18. maddesi uyarınca; taraf devletler, her dört yılda bir dönemsel ülke raporlarını CEDAW Komitesine sunmak zorundadırlar. Türkiye bu zorunluluk kapsamında 7. Ülke Raporunu tamamlayarak Ekim 2014’te CEDAW Komitesi’ne iletmiştir (Kadının Statüsü Genel Müdürlüğü, 2015).

1993 yılında Birleşmiş Milletler Genel Kurulu tarafından hazırlanan "Kadınlara Karşı Şiddetin Ortadan Kaldırılması Hakkında Bildirge" yayınlanmıştır. Söz konusu Bildirge ile aile içi şiddetin kapsamı ilk defa uluslararası bir belgede tanımlanmıştır. Bildirge'de, kadınlara karşı şiddetin tanımı yapıldıktan sonra, şiddete ilişkin örnekler verilmektedir. Bildirge'nin 4. maddesinde, şiddetin önlenmesi, failin cezalandırılması ve şiddete uğrayanın korunması konularında devletlere düşen sorumluluklar düzenlenmiştir. Devletlerin iç hukuklarında bu konuya ilişkin düzenleme yaparak farklı kuruluşlarla işbirliği yapması gerektiği belirtilmiştir. Bildirge'deki ilke ve kuralların hukuki bağlayıcılığı yoktur; ancak kadınlara karşı şiddetin önlenmesi açısından devletlere örnek teşkil etmektedir. Kadınlara yönelik şiddeti, fiziksel şiddet ile sınırlamayan Bildirge, şiddet korkusuyla kadınları sindiren her türlü eylemi "şiddet" kapsamında değerlendirmektedir. Devletler kadınlara yönelik şiddeti kınamalı ve önlenmesine yönelik yükümlülüklerinden kaçınmak için hiçbir geleneği veya dinsel düşünceyi ileri sürmemelidir. Devletler imkanlarını kullanarak ve gecikmeksizin kadınlara karşı şiddeti önlemeye yönelik bir politika izlemek ve bu amacı gerçekleştirecek gerekli tedbirleri almak zorundadır.

Avrupa İnsan Hakları Sözleşmesi’nde kadına karşı şiddeti önlemeye yönelik ayrı bir düzenleme yoktur. Bu nedenle Mahkeme, Sözleşme'de yer alan işkence ve zorla çalıştırma yasaklarından hareketle Bildirge'deki 
ilkelere uyumlu kararlara hükmetmiştir. Avrupa Konseyi Bakanlar Komitesi, 2002'de verdiği tavsiye kararında, aile içi ve kadına karşı şiddetin önlenebilmesi için ayrıntılı düzenlemelere yer vermiştir: sosyal hizmetler çalışanları ve yargı mensuplarına konuyla ilgili meslek içi eğitim verilmesi; şiddet mağdurunun korunması için sığınma evleri açılması; çocuk yaşta evliliklerin önlenmesi ve medyanın desteğinin gerektiği gibi. CEDAW'a ilişkin olarak hazırlanan İhtiyari Protokol Türkiye tarafından 30 Temmuz 2002 tarihinde onaylanmış, 29 Ocak 2003 tarihinde yürürlüğe girmiştir (Kadının Statüsü Genel Müdürlüğü, 2015).

Avrupa İnsan Hakları Mahkemesi, Türkiye’ye karşı açılan davada, aile içi şiddet konusunda gerekli tedbirlerin alınmaması ve kadın mağdurun korunamaması nedeniyle tazminata hükmetti. Söz konusu kararda; Devletin, kişileri aile içi şiddete karşı korumak için öngörülen yasal önlemleri şiddete uğrayan kadınlara gereğince uygulamaması da Sözleşme'nin ihlali olarak kabul edildi. Mahkeme, Sözleşmesi'nin yaşam hakkını güvence atına alan 2. maddesinin, işkence ve insanlık dışı ve kötü muamele yasağını düzenleyen 3. maddesinin ve her türlü ayrımcılığı yasaklayan 14. maddesinin ihlal edildiğine karar verdi (Opuz - Türkiye kararı, 9.6.2009).

Avrupa Konseyi Bakanlar Komitesi tarafından 11 Mayıs 2011'de imzaya açılan "Kadına Yönelik Şiddetin ve Aile İçi Şiddetin Önlenmesi ve Bunlarla Mücadeleye Dair Sözleşme” uluslararası hukukta kadına karşı şiddet ve aile içi şiddet konusunda yaptırım gücü olan ilk sözleşmedir. İstanbul'da imzaya açıldığından İstanbul Sözleşmesi olarak anılan Sözleşme, kadına yönelik şiddetin insan hakları ihlali olduğunun vurgulanması açısından da ilktir. Sözleşme, bağlayıcı olmasının yanı sıra bağımsız bir denetim mekanizması kurulmasını da öngörmektedir. CEDAW'ın güçlenmesine destek olacak nitelikte olan Sözleşme, şiddetin kadın erkek eşitsizliğinin bir sonucu olduğunu belirtmektedir (Moroğlu, 2012).

Türkiye, Sözleşme’yi çekincesiz olarak onaylayan ve yürürlüğe koyan ilk ülke olmuştur. 20 Mart 2012 itibarıyla Sözleşme’yi onaylayan Türkiye, onay belgesini de Avrupa Konseyi Genel Sekreterliği’ne iletmiştir. Sözleşme 1 Ağustos 2014 tarihinde yürürlüğe girmiş; Mayıs 2015 itibarıyla da Sözleşme'yi 18 ülke onaylamıştır. Uluslararası bağlayıcılığa sahip ilk hukuki belge olan Sözleşme, Avrupa Konseyi üyeleri dışındaki ülkelerin de imzasına ve onayına açılmıştır.

Sözleşme'nin amacı; kadına ve aile içi şiddete son verilmiş, bir Avrupa'nın hukuki çerçevesini çizmektir. Bunun için şiddeti önleme, kadını koruma, şiddeti kovuşturma ve mağdura destek mekanizmaları öngörmektedir. Sözleşme, ayrımcılık yapmadan tüm kadınların şiddetten korunması gerektiğini, haklarıyla birlikte düzenlemektedir. Kadına yönelik şiddeti, kadınlara fiziksel, cinsel, psikolojik ve ekonomik acı ve istırap veren veya verebilecek olan cinsiyete dayalı her türlü eylemdir. Söz konusu eylemler, insan haklarını ihlal etmekte ve kadınlara yönelik ayrımcılık oluşturmaktadır. Kadının mağdur olduğu durumların ayrıntılı bir şekilde düzenlenmesi, farkındalık yaratmak açısından önemlidir. (Uluocak, vd., 2014).

Sözleşme, taraf devletlere ayrımcılık yapmama, devlet kurumları ile şiddetin aktörü olmama, toplumsal cinsiyetle ilgili hassasiyet gerektiren kapsamlı politikalar düzenleme, finansal kaynakları bulma, sivil toplum kuruluşları ile ortak çalışmalar yürütme, koordinasyon kurumu kurup veri toplama gibi genel yükümlülüklerin yanı sıra şiddeti önleme, mağduru koruyup destekleme ve faile hukuki/cezai yaptırım uygulama yükümlülüklerini de yüklemektedir (Demirkır Ünlü, 2012).

Sözleşme hükümleri devletlere “özen yükümlülüğü” çerçevesinde hareket etme zorunluluğu getirmektedir. Bu kapsamda devlet önleyemediği her türlü kadına yönelik şiddet ve aile içi şiddet vakasından sorumlu tutulacak ve tazminat ödemekle yükümlü olacaktır (md.5). Şiddet sonucu doğan maddi veya manevi zararın saldırgan tarafından karşılanamaması halinde, zarara uğrayana devlet tarafından tazminat ödenecektir (md.30).

\subsection{Türkiye'deki Hukuki Düzenlemeler}

1982 Anayasası'nda devlete, kadınları aile içi şiddete karşı koruma konusunda doğrudan ödev yükleyen açık bir düzenleme yoktur. Ancak Anayasa'nın yaşam hakkını düzenleyen 17. maddesi, kanun önünde eşitliğe ilişkin 10. maddesi ve "ailenin korunması" başlıklı 41. maddesi, aile içi şiddetle ilişkilendirilebilecek hükümlerdir.

Anayasa'nın 41. maddesi uyarınca; “Aile, Türk toplumunun temelidir ve eşler arasında eşitliğe dayanır. Devlet, ailenin huzur ve refahı ile özellikle ananın ve çocukların korunması ve aile planlamasının öğretimi ile uygulanmasını sağlamak için gerekli tedbirleri alır, teşkilâtı kurar." Maddenin gerekçesinde ise, "ananın, bu sıfatla korunması" gerektiği belirtilmektedir. Anayasa'nın 41. maddesine, 2010 yılında eklenen son fikraya göre; devlet, her türlü istismara ve şiddete karşı çocukları koruyucu tedbirler almakla yükümlüdür. Söz konusu değişiklik, kadınların aile içi şiddete karşı korunmasında, çocuklarla sınırlı olsa da bir katkı sağlamıştır (Öden, 2014).

Doktrinde, devletin kadınları aile içi şiddete karşı koruma konusundaki ödevinin “ananın korunması”na ilişkin bu hükme dayandırılmasının iki önemli sonucu olduğu vurgulanmaktadır. Kadınları koruma ödevinin somutlaştırılması ve yerine getirilmesi, Anayasa'nın 65. maddesi uyarınca, büyük ölçüde yasama organının takdirine kalmaktadır. Bununla birlikte, şiddet karşısında kadınları "birey" olarak değil, "aile" dolayısıyla "ana" sıfatıyla korumaya değer gören bir anlayış ortaya konulmaktadır. Kadınları "birey” olduğu için korumaya değer gören ve bu nedenle devlete kadınları koruma ödevi yükleyen Anayasa'nın diğer hükümlerinin de değerlendirilmesi gerekmektedir. 
Temel hak ve özgürlüklerin niteliğini düzenleyen Anayasa'nın 12. maddesinin ilk fikrası uyarınca; "Herkes, kişiliğine bağlı, dokunulmaz, devredilmez, vazgeçilmez temel hak ve hürriyetlere sahiptir.” Anayasa'nın 17. maddesi ise; kişinin dokunulmazlığı ile maddî ve manevî varlığını düzenlemektedir. Söz konusu maddeye göre; herkes, yaşama, maddî ve manevî varlığını koruma ve geliştirme hakkına sahiptir. Tıbbî zorunluluklar ve kanunda yazılı haller dışında, kişinin vücut bütünlüğüne dokunulamaz; rızası olmadan bilimsel ve tıbbî deneylere tâbi tutulamaz. Kimseye işkence ve eziyet yapılamaz; kimse insan haysiyetiyle bağdaşmayan bir cezaya veya muameleye tâbi tutulamaz..."

Kişilerinin yaşama hakkının ve maddi ve manevi varlığının yalnızca devletin değil; diğer kişilerin müdahalelerine karşı da korunması zorunludur. Bu hakların diğer kişilere karşı korunması ise, devletin katkısı olmadan gerçekleşemez. Dolayısıyla, kişinin yaşama hakkı ve maddi ve manevi varlığını koruma ve geliştirme hakkı, devlete yalnızca bu haklarla korunan özel alana müdahaleden kaçınma gibi olumsuz değil; aynı zamanda kişiye ayrılmış özel alanı diğer kişilere karşı koruma gibi olumlu bir ödev de yüklemektedir (Öden, 2014).

Kadınlara karşı şiddetin, onların maddi ve manevi varlığını ve bütünlüğünü, hatta yaşam haklarını ihlal ettiği açıktır. Bu nedenle, kadınlara karşı aile içi şiddetin önlenmesi, devletin sosyal alandaki ödevlerinden önce, kişinin yaşama ve maddi ve manevi bütünlüğünü koruma ve geliştirme haklarından doğan olumlu ödevlerinin bir gereği sayılmalıdır. Bunun sonucu olarak, devlet, kadınları şiddete karşı koruyucu önlemleri almak, diğer bir ifadeyle kanunlar çıkararak idari ve yargısal koruma sistemlerini kurmak ve öngördüğü önlemleri somut olaylarda gerçekleştirmekle yükümlüdür (Öden, 2014).

Devletin, kadınları aile içi şiddete karşı koruma ödevinin bir diğer anayasal dayanağı olarak 1982 Anayasası'nın eşitlik ilkesini düzenleyen hükmüne de değinmek gerekmektedir. Nitekim "Kanun önünde eşitlik" başlıklı Anayasa'nın 10. maddesi uyarınca; "herkes, dil, ırk, renk, cinsiyet, siyasî düşünce, felsefî inanç, din, mezhep ve benzeri sebeplerle ayırım gözetilmeksizin kanun önünde eşittir. Kadınlar ve erkekler eşit haklara sahiptir. Devlet, bu eşitliğin yaşama geçmesini sağlamakla yükümlüdür. Bu maksatla alınacak tedbirler eşitlik ilkesine aykırı olarak yorumlanamaz..."

Anayasa'nın ilgili maddesi, Devlete açıkça iki ödev de yüklemektedir. Bunlardan ilki, Devlet organları ve idare makamlarının bütün işlemlerinde kanun önünde eşitlik ilkesine uygun olarak hareket etme zorunluluğudur. İkincisi ise, Devletin kadın erkek eşitliğinin yaşama geçmesini sağlama yükümlülüğüdür. Konuya kadınların temel hak ve özgürlüklerden eşit yararlanmalarını sağlamak amacı açısından yaklaşıldığında ise, Anayasa'nın 10. maddesinin devletin yükümlülüklerini somutlaştırdığı anlaşılmaktadır. Kadınların içinde bulunduğu durumlar temel hak ve özgürlüklerden eşit olarak yararlanmalarını engelleyen ölçüde farklılık gösterdiğinde, Devletin kadınların durumlarındaki bu farklılığı göz önünde tutarak onlara farklı davranması gerekmektedir. Bu bağlamda şiddete karşı savunmasız durumdaki kadınların özel olarak korunması da, Devletin yükümlülüğüdür (Karınca, 2008).

Devleti kadınlar ile erkeklerin haklardaki eşitliğini yaşama geçirmekle yükümlü kılan 10. madde, hem devletin kadınlara karşı ayrım yasağından doğan olumlu yükümlülüklerini desteklemekte, hem de Devleti kadınların hak ve özgürlüklerini sınırlandıran sosyal ve ekonomik engelleri kaldırmakla yükümlü kılmaktadır. Bu maksatla alınacak tedbirlerin eşitlik ilkesine de aykırı sayılmaması, kadınlara karşı şiddetin onların içinde bulunduğu sosyal ve ekonomik koşulların elverişsizliğinden kaynaklandığı durumlarda Devlet, söz konusu fiili eşitsizliği gidermek amacıyla kadınlar lehine önlemler almakla da yükümlüdür. Sonuç olarak, devletin kadınları şiddete karşı koruma ödevinin anayasal dayanağının 10, 12 ve 17. maddelerde aranması; Türkiye'de kadınları da korunmaya değer bir "birey” olarak kabul eden bir anlayışın temelini oluşturma çabasıdır.

Normlar hiyerarşisinin en üst basamağında olan Anayasalar, temel ilkeleri belirleyerek ülkenin hukuksal çerçevesini çizer. Anayasal hükümler genellikle doğrudan uygulanabilir nitelikte değildir. Asıl uygulamayı belirleyecek olan yasaların içeriğidir. Dolayısıyla bu konuya ilişkin Türkiye'nin taraf olduğu uluslararası antlaşmalarla 1982 Anayasası'nın ilgili hükümlerinin yanı sıra konuya ilişkin detaylı yasalara da ihtiyaç vardır. Ancak maalesef, yakın zamana kadar, Türkiye'de kadına karşı şiddetin önlenmesine hukuk yeterince ilgi göstermemekteydi.

8 Mart 2012 tarih ve 6284 sayılı Ailenin Korunması ve Kadına Karşı Şiddetin Önlenmesine Dair Kanun ile birlikte, kadınlara karşı şiddetin önlenmesi konusunda daha iyi bir yasal çerçeveye kavuşulmuştur. Söz konusu Kanun'da düzenlenen tedbirler, doğru uygulandığı takdirde kadına karşı şiddetle başa çıkılabilecektir. 6284 sayılı Kanun'dan önce yürürlükte olan 4320 sayılı Ailenin Korunmasına Dair Kanun'un hükümleri gibi adında da "Kadına Karşı Şiddetin Önlenmesi”" ifadesi yer almamaktaydı. Bu nedenle kanun koyucunun önceliğinin, "ailenin korunması”ndan "kadınların şiddete karşı korunması”na doğru kaydığı söylenebilmektedir.

6284 sayılı Kanun'un amacı, şiddete uğrayan ve şiddete uğrama tehlikesi bulunan, herhangi bir ayrım yapılmaksızın tüm kadınların, çocukların ve aile bireylerinin korunması (md.1/1) ve bu kişilere yönelik şiddetin önlenmesi amacıyla alınacak tedbirlere ilişkin usul ve esasları düzenlemektir. Söz konusu Kanun'un gerekçesinde de, kişilere yönelik şiddetin bir insan hakkı ihlali olduğu ifade edilmektedir. Bu nedenle günümüzde bu sorun, özel alan sorunu olmaktan çıkarak toplumsal alanda tartışılmakta ve mücadeleci bir devlet 
politikası olarak kabul edilmektedir. Kadın erkek eşitliğinin sağlanması, kadının insan haklarının teminat altına alınması devletin sorumluluğundadır (Uluocak, vd., 2014).

6284 sayılı Kanun, kadına yönelik şiddetin bildirilmesi, açığa çıkarılması, önlenmesi, mağdurların korunması ve cezalandırılması süreçlerinde iyileşmeler hedeflemektedir. Kanun'da şiddet, aile içi şiddet ve kadına yönelik şiddet ayrıntılı olarak tanımlanmaktadır. Söz konusu düzenleme, kadına yönelik şiddeti, cinsiyete dayalı bir ayrımcılık ve kadının insan haklarını ihlal eden bir tutum olarak tanımlamaktadır (md.2/1-ç). Anayasa, uluslararası sözleşmeler ve özellikle İstanbul Sözleşmesi, Kanun'un uygulanmasında dikkate alınmak zorundadir.

4320 sayılı eski Kanun'da düzenlenmiş koruma tedbirleri, 6284 sayılı yeni Kanun'da da mevcuttur. Yeni Kanun, şiddeti önleyici tedbir kararı verilmesi, koruma kararı verilmesi, kurumlar arası iş birliği sağlanması, şiddet mağduruna geçici maddi yardım sağlanmasına ilişkin düzenlemeler içermektedir.

Tedbir kararları korunan kişiye yönelik "koruyucu tedbir", şiddet uygulayanlara yönelik "önleyici tedbir" olarak ikiye ayrılmaktadır. Koruyucu tedbir kararı verilmesi için, şiddetin uygulandığı hususunda delil veya belge aranmaması yine bu Kanun'la düzenlenmektedir. Ayrıca söz konusu Kanun, barınma, geçici maddi yardım, rehberlik ve danışmanlık hizmeti, korunma, kreş yardımı, iş yerinin değiştirilmesi, eşinden ayrı yerleşim yeri belirlenmesi, tapu kütüğüne aile konutu şerhi konulması, tanık koruma gibi koruyucu tedbir kararları alınmasına da imkan tanımaktadır (Sertkaya, 2014).

Şiddet veya şiddet uygulanma tehlikesinin varlığı hâlinde, herkes bu durumu resmi makamlara ihbar edebilmektedir (md.7). Gecikmesinde sakınca olan durumlarda ise, şiddeti önleyici tedbirlerin aile mahkemesi hakimince verilmesinin yanında kolluk amirine yasada yazılı tedbirleri alma yetkisi de verilmektedir (md.5). Kolluk kuvveti veya mülki amirin koruyucu tedbir kararı verebilmesi, yine gecikmesinde sakınca bulunan hallerde mümkündür (md.3). Hayati tehlike olması halinde, Tanık Koruma Kanunu çerçevesinde kimlik ve belgelerinin değiştirilmesi de mümkün hale getirilmiştir (md.4/1-ç). Özellikle, şiddeti önleme ve izleme merkezlerinin kurulmasına yönelik düzenleme son derece ileri bir adım olmakla birlikte, bunların kurulması ve işleyişine ilişkin detayların ve kurumsal alt yapısının tam olarak netleşmemiş olması düşündürücüdür (Sözüer vd., 2014).

Hatırlatmak gerekir ki, sorunların çözümü için yasalar tek başına yeterli değildir; yasaların öngördüğü tüm düzenlemelerin aynı zamanda etkin bir şekilde uygulanabiliyor olması da gerekmektedir. Aksi halde yasanın yürürlüğe girmesiyle kısa sürede sonuç alınması mümkün olmayacaktır (Sözüer vd., 2014).

\section{Sonuc}

Türkiye'de kadına yönelik şiddetle mücadele, ancak devlet kurumları ile kadın kuruluşlarının deneyimlerinin bir araya getirilmesiyle başarıya ulaşabilir. Devlet, tüm kadın örgütleriyle işbirliği içinde olmalı; sivil toplum kuruluşlarının çalışmalarını kolaylaştırıp güçlendirmelidir. Nitekim devletin sadece yasal düzenlemeler getirerek bu konuya ilişkin önlemler alması, mevcut şiddeti tamamen ortandan kaldırmayacaktır.

Devlet, kadınlara yönelik şiddeti kınamalı, şiddetin önlenmesine yönelik yükümlülüklerden kaçmak için hiçbir geleneği veya dinsel düşünceyi ileri sürmemelidir. Diğer bir ifadeyle devlet, kadın ve erkeklerin sosyal ve kültürel davranış, biçimlerini değiştirmek ve cinslerden birinin üstünlüğü veya aşağı olması fikrine, kadın ve erkekler için basmakalıp rollere dayanan önyargıları, geleneksel uygulamaları silmek üzere, özellikle eğitim alanında tüm tedbirleri almalıdır.

Devlet, kadınlara yönelik şiddete ilişkin erkeklerin eğitimi konusunda farkındalık yaratmalıdır. Bu eğitim aileden başlayarak toplumsal yaşamın her alanında (eğitim, çalışma yaşamı ve siyaset) olmalıdır.

Devlet, şiddete maruz kalmış, kadınlara adalet mekanizmasına başvuru imkânını ve uğradıkları zararın ulusal hukuk uyarınca adil bicimde tazmin edilmesini sağlamalıdır. Kadınlar, bu mekanizmalara başvurarak hakları konusunda bilgilendirilmelidir. Elbette bunun için de sorumluluk yerel yönetimler bazında devlete aittir ve kadınlara yönelik şiddetin önlenmesine ilişkin tüm bu faaliyetler için de bütçeden yeterli kaynak ayrılmalıdır. Dolayısıyla, Türkiye'de kadına yönelik şiddeti önlemek ve şiddetin olumsuz etkilerini ortadan kaldırmak için en başta devlete, daha sonra ilgili her kuruma ve kadın erkek herkese görev düşmektedir.

Son olarak tekrar tekrar söylemekte fayda vardır ki, "kadına yönelik şiddet, insan hakları ihlalidir" ve ne yazık ki, "Türkiye eğitimli ve konularında yetkin kadın potansiyelinden yararlanmamakta ya da yararlanamamaktadır. Türkiye'nin çağdaşlaşması ve kalkınması için kadınların katkısına ve bakış açısına ihtiyaç vardır. İşte sırf bu nedenle, kadınların eşitlik mücadelesine devam etmesi gerekmektedir. Nitekim kadına şiddet yönelterek ezen sadece erkek değildir. Kadın kendi hayatından sorumlu olmaktan vazgeçerek, kendi kendini de mağdur etmekte ve bu eşitlik mücadelesinde kendisini güçsüz bırakmaktadır.

\section{Kaynakça}

- Davaz, 2014. Eşitsiz Kız Kardeşlik. İş Bankası Kültür Yayınları, İstanbul.

- Demirkır Ünlü, 2012. Kadına Yönelik Şiddet ve Aile İçi Şiddet. Legal Yayıncılık, İstanbul. 
- Dişsiz ve Şahin, 2008. "Evrensel Bir Kadın Sağlığı Sorunu: Kadına Yönelik Şiddet”, Maltepe Üniversitesi Hemşirelik Bilim ve Sanatı Dergisi, C.1, S.1, s.50.

- Erten ve Ardal1, 1996. "Saldırganlık, Şiddet ve Terörün Psikososyal Yapıları”, Cotigo, S.6-7, s.143.

- Gökulu, 2005. Terör Eylemlerinin Medyaya Yansıması. Polis Akademisi Güvenlik Birimleri Enstitüsü Yüksek Lisans Tezi.

- Karınca, 2011. Sorularla Kadına Yönelik Aile İçi Şiddet. Ankara Barosu Yayını, Ankara.

- Kartal, 2008. “Kadına Yönelik Şiddetin Önlenmesinde Sağlık Teşkilatının Rolü”, Kadına Yönelik Şiddet Kongresi, Ankara, s.91.

- Kocacık, 2001. "Şiddet Olgusu Üzerine”, Cumhuriyet Üniversitesi İ̈BF Dergisi, S.2, s.1.

- Kuyucu, 2014. Kadına Yönelik Şiddet. Seçkin Yayıncılık, Ankara.

- Levinson, 1990. Family Violence in Cross-Culturel Perspective. CA: Sage Publication.

- Moroğlu, 2009. Kadınların İnsan Hakları Sözleşmesi. On İki Levha Yayıncılık, İstanbul.

- Moroğlu, 2012. "Kadına Yönelik Şiddetin Önlenmesi - 6284 sayılı Yasa ve İstanbul Sözleşmesi”, Türkiye Barolar Birliği Dergisi, Ankara, s.357.

- Ö̈den, 2014. “Türk Anayasa Hukukunsa Kadınları Ev-İçi Şiddete Karşı Koruma Ödevi”, Kadına Yönelik Şiddet ve Ev-İ̧i Şiddet, Savaş Yayınevi, Ankara, s.77.

- Rubio-Marin, 2015. “Türkiye’de Kadının Anayasal Statüsü Yol Ayrımında”, Güncel Hukuk Dergisi, Ankara, s. 40

- Sertkaya, 2014. Kadına Yönelik Şiddet. Aile ve Sosyal Politikalar Bakanlığı, Ankara.

- Sever, 2012. "Kadına Karşı Eviçi Şiddette Devletin Sorumluluğu ve Avrupa İnsan Hakları Mahkemesi’nin Opuz v. Türkiye Kararı”, Atılım Sosyal Bilimler Dergisi, 1-2, s.19.

- Sözüer, 2014. Kadına Yönelik Şiddet ve Ayrımcılık. Adalet Yayıncılık, Ankara.

- Uluocak, vd., 2014. Toplumsal Cinsiyet Eşitsizliği ve Kadına Yönelik Şiddet. Paradigma Akademi Yayınları, Edirne.

- Vatandaş, 2003. Aile ve Şiddet: Türkiye'de Eşler Arası Şiddet. Uyum Ajans, Ankara.

- Yıldırım, 1998. Sıradan Şiddet. Boyat Kitapları, İstanbul.

- http://www.anayasa.gov.tr

- http://conventions.coe.int

- $\quad$ http://kadininstatusu.aile.gov.tr 


\title{
Uluslararası Ekonomi Hukuku Kavramı ve Uluslararası Ekonomi Hukukunun Kaynakları
}

\section{International Economy Law Concept and the Source of International Economy Law}

\author{
Prof. Dr. Şaban Kayıhan (T.C. Hasan Kalyoncu University, Turkey) \\ Mehmet Eski (İstanbul Ticaret University, Turkey)
}

\begin{abstract}
Depending on the justification of the domination promulgates Law principles which is related with the multiareas of the social life and assures implementation of Law rules due to its judicial power. However, nowadays implementation of State's Law principles has been gradually damaged. In fact, not only markets transformed into the world bazaar with the globalization but also the participants of the markets acts global. As a result of the findings of the economic facts, one State's cross-border trade and beside the national law which regulates the economic actions, normative arrangements increase which adjust identical subjects and receive the sources from different fields and in order for the operation of the current adjustment they create novice establishments with the view point of showing action in different types of areas. As a parallel of these improvements "international economy law" which arranges the international economical actions in the western countries and examines the law principles as a whole which is usually founded dispersedly is developed. Cross border economical actions constitute the subject of a lots of diversified law arrangement. While some of them are the characters of public law and private law, the others originate from international law. Fractionally, nonbinding rules are also inclusive here. At this point the whole law regulations which are about the international rules, determines the scope of international law relations. So in this research, in accordance with the globalization, our purpose is to examine the source and term of the international economy law.
\end{abstract}

\section{Giriş}

Devlet özellikle iç hukukunda, egemenlik haklarına dayanarak, toplumsal hayatın çeşitli alanlarına ilişkin hukuk kurallarını yürürlüğe koymakta ve yasama, yürütme yargı saç ayağında yargı gücü sayesinde hukuk kurallarının uygulanmasını temin etmektedir. Ancak günümüzde devletin hukuk kurallarının ihdası ve uygulanmasındaki tekeli giderek erozyona uğramaktadır. Nitekim küreselleşme olgusu ile birlikte sadece pazarlar dünya pazarına dönüşmemiş, aynı zamanda pazar katılımcıları da küresel hareket etmektedirler. $\mathrm{Bu}$ ekonomik olguların sonucu olarak, bir devletin sınır ötesi ticaretini ve ekonomik faaliyetlerini düzenleyen milli hukuk kuralları yanında, aynı konuları düzenleyen kaynağını çok farklı alanlardan alan normatif düzenlemeler artış göstermekte ve kurulan yeni düzenin işleyişini teminen çok farklı alanlarda faaliyet göstermek üzere yeni uluslararası kuruluşlar ihdas olunmaktadır. İşte bu gelişmelere paralel olarak batılı ülkelerde uluslararası ekonomik faaliyetleri düzenleyen ve dağınık halde bulunan hukuk kurallarını bir bütün olarak inceleyen hukuk dalı olarak uluslararası ekonomi hukuku gelişmiştir. Sınırlar ötesi ekonomik faaliyetler birçok farklı hukuki düzenlemenin konusunu teşkil etmektedir. Bunların bir kısmı milli kamu hukuku ve özel hukuk karakterli, bir kısmı da uluslararası hukuk kaynaklıdır. Kısmi olarak bağlayıcı olmayan kurallar da buraya dâhil olmaktadır. Bu anlamda uluslararası ekonomik ilişskileri konu alan bütün hukuki düzenlemeler, uluslararası ekonomi hukukunun kapsamını belirlemektedir. Belirtelim ki, küreselleşme olgusunun en önemli etkilerinden biri olarak sınır ötesi ekonomi ve ticaret modern dünyanın olmazsa olmazı haline gelmiştir. Bu gelişmeler de elbette hukuki zemine ihtiyaç duymaktadır. İşte sözünü ettiğimiz uluslararası ekonomi hukuku bütün bu ihtiyaçların sonucudur. Biz bu tebliğimizde uluslararası ekonomi hukukunu bir bütün olarak ele alabilme imkanına sahip olmamakla birlikte, bu hukuk dalını ilgili konuları ile birlikte hem kavram olarak açıklamayı hem de kaynaklarını incelemeyi amaçladık. Bu doğrultuda incelememizi giriş dışında iki paragraf halinde ele almayı hedefledik. Birinci paragrafta uluslararası ekonomi hukuku kavramını ilgili konuları ile birlikte ele aldıktan sonra, ikinci paragrafta ise bu hukuk dalının küresel düzlemde kabul edilen kaynaklarını inceledik ve bu hukuk dalı hakkında özellikle ekonomistlerde ve hukukçularda farkındalık oluşturmayı amaçladık. Tebliğimizi sonuç kısmı ile de nihayete erdirdik.

\section{Uluslararası Ekonomi Hukuku Kavramı}

\subsection{Kavram}

Geleneksel anlayışta hukuk ve devlet, birlikte düşünülen kavramlardır. Devlet egemenlik haklarına dayanarak, toplumsal hayatın çeşitli alanlarına ilişkin hukuk kurallarını yürürlüğe koymakta ve yargı gücü sayesinde hukuk kurallarının uygulanmasını temin etmektedir. Yine devletler, karşılıklı menfaatlerin uyuşması durumunda antlaşmalar yoluyla uluslararası hukuk ihdas ederek, bu hukuk kurallarını iç hukuklarının bir parçası haline 
getirmektedirler. Ancak günümüzde devletin hukuk kurallarının ihdası ve uygulanmasındaki tekeli giderek erozyona uğramaktadır. Küreselleşme ile birlikte sadece pazarlar dünya pazarına dönüşmemiş, aynı zamanda pazar katılımcıları da (müşteriler, sermayedarlar ve üreticiler) küresel hareket etmektedirler. Bu ekonomik olguların sonucu olarak, bir devletin sınır ötesi ticaretini ve ekonomik faaliyetlerini düzenleyen milli hukuk kuralları yanında, aynı konuları düzenleyen kaynağını çok farklı alanlardan alan normatif düzenlemeler artış göstermekte ve kurulan yeni düzenin işleyişini teminen çok farklı alanlarda faaliyet göstermek üzere yeni uluslararası kuruluşlar ihdas olunmaktadır.

Bundan böyle devletler giderek artan oranda egemenlik haklarını uluslararası ve supranasyonal (uluslarüstü) aktörlerle paylaşma durumundadır. Uluslararası ekonomik ilişkileri düzenleyen hukuk kurallarının ihdası ve uygulanması, sadece bir devletin kendi organlarıyla veya devletlerin kendi aralarında oluşturduğu bir olgu olmaktan çıkmış ve başkaca aktörlerle paylaşılan alana dönüşmüştür.

İşte bu gelişmelere paralel olarak batılı ülkelerde uluslararası ekonomik faaliyetleri düzenleyen ve dağınık halde bulunan hukuk kurallarını bir bütün olarak inceleyen hukuk dalı olarak uluslararası ekonomi hukuku (International Economic Law) gelişmiştir. Bu bakış açısıyla uluslararası ekonomi hukuku, uluslararası ekonomik faaliyetleri bütünsel olarak dikkate almakta ve bu oluşuma uygulanan veya uygulanabilir hukuk kurallarını toplu bir şekilde değerlendirmektedir. Bu hukuk dalının baş döndürücü hızla gelişmesi, öğretide uluslararası ekonomi hukuku ihtilali tabirine sebep olmuştur (Trachtman, 2015).

Anglo-Sakson hukuk düzeninde hâkim olan görüşe göre, uluslararası ekonomi hukuku, sadece uluslararası hukuk kaynaklı normları inceleme konusu yapmaktadır ve bu haliyle de devletler ekonomi hukuku (Wirtschaftsvölkerrecht) kavramıyla eş anlamlıdır. Bu anlamda uluslararası ekonomi hukuku, sadece veya en azından öncelikli olarak devletlere odaklanan ve onların uluslararası ekonomik ilişkilerindeki davranışlarını yönlendiren uluslararası kamu hukuku kuralları ile sınırlıdır (Hoffman, 2015).

Buna karşın Kıta Avrupası'nda hâkim olan ve bizim de katıldığımız görüşe göre, uluslararası ekonomi hukuku uluslararası ekonomik ilişkileri düzenleyen kuralları açıklamaktadır (Hoffmann, 2009). Konu bu bakış açısıyla ele alındığında, Anglo Sakson hukuk düzenindeki hakim anlayışın aksine, uluslararası ekonomi hukuku, sadece "ekonominin uluslararası hukuku" ile sinırlı olmayıp bunun ötesinde "uluslararası ekonominin hukuku"dur. Her şeyden önce klasik, kamu hukuku - özel hukuk ayrımı, ekonomi alanında keskin sınırlarla ayrışmamakta, kesiştikleri ve iç içe girdikleri hususlar ziyadesiyle bulunmaktadır. Örneğin, ülkemizde 1980’lerden sonra ekonominin çeşitli sektörlerine ilişkin kurulmuş olan BDDK, SPK ve EPDK gibi kurumları dikkate aldığımızda, bu kurumlar kamusal yetkiler kullanmakla birlikte yetki alanlarına giren aktiviteler özel hukukun bir parçasıdır (bankacılık). Uluslararası ekonomi hukuku, hem kamu hukuku hem de özel hukuk karakterlidir ve milli, supranasyonal ve uluslararası hukukun farklı kurallar hiyerarşisinden de normlar ihtiva etmektedir (Rainer 2015).

Uluslararası ekonomik ilişkilere ilişkin düzenlemeler inceleme konusu yapılırken, bütüncül bakış açısı Matthias Herdegen tarafından şu şekilde özetlenmektedir; "Bugünün devletler toplumundaki ekonomik yaşamın hakkını vererek incelenmesi yukarıdan resmin bütününe bakmayı gerektirmektedir. Böylece uluslararası ekonomi hukuku, özellikle uluslararası hukuk, dış ticaret hukuku ve milli ekonomi hukukunun özel hukuk unsurlarını bir araya getirmektedir. Bu anlayış sistematik olarak, hukuk kaynakları çıkış noktasından hareket ederek belirlenen ve sadece uluslararası hukuk düzenleme sahasındaki unsurları inceleme konusu yapan, uluslararası ekonomi hukuku kavramını ret etmektedir. Devletlerarasındaki kurallara dayalı bir perspektif yerine böylece, hukukun düzen sağlama fonksiyonuna odaklanma devreye girmektedir; uluslararası ekonomi hukuku bu sayede uluslararası ekonomik ilişkiler için normatif düzen çerçevesi olarak ortaya çıkmaktadır (Herdegen, 2014).

Uluslararası ekonomi özel hukuku olarak da adlandırabileceğimiz uluslararası ticaret hukuku ise; özel hukuk kişilerinin birbirleriyle veya kamu tüzel kişileriyle uluslararası alanda olan ticari ilişkilerini incelemektedir. Genel olarak uluslararası ticaret hukuku, uluslararası ticari sözleşmeleri, bunlara uygulanacak özel hukuku birleştiren antlaşmaları (CISG), kendine özgü kuralları (Incoterms), uluslararası eşya taşımacılığı ve uluslararası ticari tahkim gibi konuları inceleme konusu yapmaktadır.

Diğer taraftan uluslararası ekonomi hukukunun başlıca inceleme konularından olan DTÖ antlaşmaları, tek başına inceleme konusu yapıldığı hallerde, literatürde bu alanı ifade etmek üzere dünya ticaret hukuku (World Trade Law Welthandelsrecht) kavramına yer verilmektedir.

Uluslararası ekonomi hukukunun tam olarak kapsamına giren unsurlar arasında da çok belirgin sınırlar bulunmamaktadır. Daha ziyade birçok durumda karşılıklı bağımlılık, kesişmeler ve iç içe girmeler söz konusu olduğunu ifade etmek gerekir (Krajewski, 2012).

$\mathrm{Bu}$ bağlamda son yıllarda yaygınlaşan "transnasyonal(ulus ötesi) hukuk" kavramına da değinmek gerekir. Transnasyonal hukuk kavramı, ilk kez 1956 yılında Philip C. Jessup tarafından ortaya atılmıştır. Ona göre, milli hukuk ile uluslararası hukuk arasında yapılan klasik ayırım, artık sınır ötesi gelişmelerin hepsini düzenleme kapsamına alma yönünden yetersiz kalmaktadır. Zira giderek artan oranda uluslararası hukukun ötesinde farklı devletlerin hukukları arasında bağımlılık ilişkisi oluşmakta ve hukuk düzenleri birbirlerine etki etmektedirler( Farahat, 2013). Bu görüş, özellikle sınırlar ötesi ekonomik ilişkileri düzenlemeye çalışan hukuk kurallarının (çok 
taraflı ve bölgesel) artışıyla birlikte de zamanla hukuk literatürüne girmiştir. Belirtelim ki günümüzde halen 'transnasyonal ekonomi hukuku' kavramı üzerinden "Lex Mercatoria” kavramı gibi, teorik tartışmalar yürütülmektedir (Rost, 2007). Genel olarak "transnasyonal ekonomi hukuku", uluslararası hukuk ve milli hukuklardan sonra üçüncü kategori olarak değerlendirilmektedir. Bu anlamda 'transnasyonal' kavramı, farklı ülke vatandaşları olan özel hukuk kişilerinin birbirleriyle veya bir devletle olan ilişkilerinden yola çıkmaktadır ve bu ilişkileri, devletlerin birbiriyle olan ilişkilerini ifade eden 'uluslararası' kavramından ayrıştırmak üzere kullanılmaktadır (Emmerich, 2015). Dolayısı ile transnasyonal hukuk; devletler, milli ve uluslararası hukuk ötesinde otonom hukuk sistemlerini ifade etmektedir (Callies, 2006). Transnasyonal ekonomi hukuku, devletler ekonomi hukuku veya milletlerarası özel hukuk gibi hukuk ayrımlarının yedeği veya aynı şekilde bu kategorileri ortadan kaldıran nitelikte değildir ve olmamalıdır. Bu hukuk alanlarının küresel ekonomik ilişkileri düzenlenmesindeki etkileri halen çok büyüktür ve tartışılmamaktadır. Transnasyonal ekonomi hukuku teorisi daha ziyade bizim var olan bakış açımızı genişletmeli ve transnasyonal ekonomi sisteminin nesnel olarak birbiriyle bağlantılı sorularını açıklayabilmemizi sağlamalıdır (Rost, 2007).

\section{Uluslararası Ekonomi Hukukuna Hâkim Olan Temel İlkeler}

Devletlerin Egemen Eşitliği İlkesi: Uluslararası hukukun mihenk taşlarından biri olan devletlerin egemen eşitliği ilkesi gereğince devletler, ülke, nüfus, doğal kaynaklar, ekonomik ve askeri güç ve başka açılardan birbirlerinden farklı olsalar da, birbirleri arasında ayrım yapılamaz ve aralarında astlık - üstlük ilişkisi bulunmamaktadır (Ünal, 2005).

Konuyu ekonomi ilişkiler bağlamında ele aldığımızda 1974 yılında BM Genel Kurulu tarafından kabul edilmiş olan Devletlerin Ekonomik Haklarına ve Görevlerine Dair Şart somut düzenlemeler içermektedir. Genel Kurul oylamasında kimi devletler karşı oy kullandığından (ör. ABD, Almanya ve Birleşik Krallık) ve kimi devletler de çekimser kaldığından Şart'ın doğrudan bağlayıcılığı bulunmamaktadır. Şart'la getirilen düzenlemelerin bağlayıcılığı için, uluslararası hukukun kaynaklarınca da (ör. uluslararası örf ve adet hukuku) bu düzenlemelerin kabul görmesi gerekir (Schöbener, 2010).

Birleşmiş Milletler Antlaşması m. 2/1;

1. Örgüt, tüm üyelerinin egemen eşitliği ilkesi üzerine kurulmuştur.

Devletlerin Ekonomik Haklarına ve Görevlerine Dair Şart;

Madde 2- 1. Her Devletin, bütün zenginliği, doğal kaynakları ve ekonomik faaliyetleri üzerinde, zilliyetlik, kullanma ve tasarruf etme de dahil, tam ve daimi egemenliği vardır ve onu serbestçe kullanacaktır.

Madde 10- Bütün Devletler, hukuken eşittir, ve milletlerarası toplumun üyeleri olarak, dünyanın ekonomik, mali ve parasal problemlerini, diğerleri yanında, uygun milletlerarası örgütler aracılı̆̆ ile onların mevcut ve inkişaf eden kurallarına uygun şekilde çözme hususlarında milletlerarası karar alma sürecine tamamıyla ve etkin bir şekilde iştirak etme ve ondan doğan nimetleri hakça bir şekilde paylaşma hakkına sahiptirler.

$\mathrm{Bu}$ ilke, müdahale yasağını da (içişlerine karışmama) içinde barındırmaktadır.

Devletlerin egemen eşitliği ilkesi, devletlerin dışarıdan baskı görmeden ve bağımsız olarak politik, ekonomik, sosyal ve kültürel sistemi ile kararlar verebilmesine imkân tanımaktadır. Yabancı bir devletin bu yöndeki iç meselelerine meşru olmayan karışması, müdahale yasağını ihlal eder (Herdegen, 2014a).

Devletlerin Ekonomik Haklarına ve Görevlerine Dair Şart;

Madde 1- Her Devletin, kalkınma iradesine uygun şekilde, dışarıdan herhangi bir şekilde müdahale, zorlama veya tehdit olmadan, siyasi, sosyal veya kültürel sistemlerini olduğu kadar ekonomik sistemlerini de seçme hususunda egemen ve devredilmez hakkı vardır.

Bu bağlamda, Dünya Bankası veya IMF'nin kalkınmakta olan devletlere sağladıkları kredi ve diğer mali olanaklarla ilgili olarak, bir devlette gerekli reformların yapılması yönünde o devletin içişlerine karışmaları, tartışma konusu olmaktadır. Ancak bir devletin bu tür mali olanaklar ve kredilerden yararlanması, baştan itibaren somut olarak mevcudiyeti var olan bir hakka dayanmadığından, bu kuruluşların içişlerine karışması, müdahale yasağı kapsamında değerlendirilmemektedir (Herdegen, 2014b).

İşbirliği ve Dayanışma İlkesi

Uluslararası ekonomi hukukun tarihsel gelişim sürecinde az gelişmişliği temsil eden ve daha ziyade dünyanın güney yarım küresinde yer alan ülkelerle, daha ziyade kuzey yarım küresinde yer alan gelişmiş ülkeler arasındaki menfaat çatışmalarını ifade eden Kuzey-Güney İhtilafı önemli bir aşamayı temsil etmektedir. Gelişmekte olan ülkeler, ikinci dünya savaşından sonra oluşturulan yeni dünya düzeninde giderek artan oranda, gelişmiş ülkelerle aralarındaki eşitsizliklerin giderilmesi noktasında taleplerde bulunmaya başlamışlardır.

1945 ’te kabul edilmiş olan BM Antlaşması m. 55, bu yönde ilkesel düzenleme içermektedir.

Birleşmiş Milletler Antlaşması m. 55; 
Uluslararasında halkların hak eşitliği ve kendi yazgılarını kendilerinin belirlemesi ilkesine saygı üzerine kurulmuş barışçı ve dostça ilişkiler sağlanması için gerekli istikrar ve refah koşullarını yaratmak üzere Birleşmiş Milletler:

a. yaşam düzeylerinin yükseltilmesini tam istihdamı, ekonomik ve sosyal alanlarda ilerleme ve gelişme koşullarını,

b. ekonomik, sosyal alanlarla sağlık alanındaki uluslararası sorunların ve bunlara bağlı başka sorunların çözümünü, kültür ve eğitim alanlarında Uluslararası işbirliğini ve ırk, cinsiyet, dil ya da din ayrımı gözetmeksizin herkesin insan haklarına ve temel özgürlüklerine bütün dünyada etkin bir biçimde sayg1 gösterilmesini, kolaylaştıracaktır.

Devletlerin Ekonomik Haklarına ve Görevlerine Dair Şart;

Madde 8- Devletler, daha akılı daha hakça milletlerarası ekonomik ilişkileri kolaylaştırmakta ve bütün Devletlerin, özellikle kalkınmakta olan ülkelerin ihtiyaç ve menfaatleriyle uyum halinde olan dengeli bir dünya ekonomisi çerçevesinde yapısal değişiklikleri teşvik etmekte işbirliği yapmalıdır ve bu amaçla uygun tedbirleri almalidir.

Madde 9- Bütün Devletler, dünyada, özellikle kalkınmakta olan ,ülkelerde ekonomik ve sosyal gelişmeyi iyileştirmek için ekonomik, sosyal, kültürel, bilimsel ve teknolojik sahalarda işbirliği yapma sorumluluğunu taşır.

Özellikle devletlerin ekonomik alandaki menfaat çatışmalarının ve küresel sorunların aşılmasına yönelik işbirliği sağlanması noktasında, ekonomik kuruluşlar da önemli rol üstlenmektedirler.

İyi Yönetişim (Good Governance) Standartları

İyi yönetişim kavramı ilk kez 1989 yılında Dünya Gelişme Raporu'nun takdiminde Dünya Bankası Başkanı tarafından zikredilmiş ve o tarihten bu yana da uluslararası ekonomi hukukunda yerini almıştır (Tietje, 2009).

Çatı bir kavram olarak iyi yönetişim, devletler bakımından daha fazla şeffaflığın sağlanması, sorumluluk, etkinlik, tarafsızlık ve katılım gibi konuları kapsamaktadır(Öztürk 2015). Demokrasi ve hukuk devleti standartlarının gerçekleştirilmesine yönelik konsept teşkil eden iyi yönetişim, günümüzde parasal, mali ve kalkınma alanlarındaki uluslararası kuruluşların faaliyetlerine ilişkin, hukuki ve toplumsal politikalarının merkezi bağlanma noktasını teşkil etmektedir (Tietje, 2009a).

Ayrımcılık Yapmama İlkesi

Uluslararası ekonomi hukukunda merkezi ilkelerden biri olan ayrımcılık yapmama ilkesi, karşılaştırılabilir obje ve olaylara farklı muamele yapılarak ilgililerinde dezavantaja yol açılmasını yasaklamaktadır (ayrımcılık yasağ1).

Ayrımcılık yasağının uluslararası ekonomik ilişkilere etkisi iki yönlüdür. Ayrımcılık yasağı, hem devletlerin birbirleriyle olan ilişkilerini hem de devletlerin bireylerle olan ilişkilerini etkilemektedir (Tietje, 2009b).

Devletlerin Ekonomik Haklarına ve Görevlerine Dair Şart m. 4;

Siyasi, ekonomik ve sosyal sistemlerine bakmaksızın, her Devletin milletlerarası ticaret ve diğer ekonomik işbirliği şekillerine girmek hakkı vardır. Hiçbir Devlet münhasıran bu farklılıklara dayalı herhangi bir ayırıma tabi tutulamaz. Milletlerarası ticaret ve diğer ekonomik işbirliği şekilleri ararken, her Devlet diş ekonomik ilişkiler örgütünü istediği şekilde seçmekte ve milletlerarası yükümlülük ve milletlerarası ekonomik işbirliği ihtiyaçları ile tutarlı olan iki taraflı ve çok taraflı antlaşmalara girmekte serbesttir.

Ayrımcılık yasağı günümüzde uluslararası hukuk ve supranasyonal hukukun birçok alanında öne çıkarılan bir kavramdır. Bunlara örnek olarak DTÖ Antlaşmalarını, uluslararası insan hakları, AB hukuku ve tüm uluslararası ekonomi hukukunu verebiliriz (Tietje, 2009c).

Ayrımcılık yasağı devletler düzeyindeki ekonomik ilişkilerde bir devlet açısından ele alındığında, dışarıya yönelik olarak en çok gözetilen ülke kuralı (en ziyade müsaadeye mazhar millet kaydı) ile ifade olunmaktadır.

En çok gözetilen ülke kuralı, belli bir yabancı devletin veya bu devletin vatandaşlarının ekonomik faaliyetlerinin bir başka devlete tanınan daha lehteki bir işleme tabi tutulması gerekliliğini ifade etmektedir

Örnek;

(A) devleti, (B) devletine en çok gözetilen ulus kuralını tanır ve daha sonra (C) ülkesinden gerçekleştirilecek ithalat için daha düşük tarife uygularsa, bu tarifeyi (B) ülkesine ve vatandaşlarına tanımakla mükelleftir (Telli 1991).

Günümüzde uluslararası hukuka ilişkin ticari antlaşmaların önemli bir unsuru olan en çok gözetilen ülke kuralı, uluslararası örf ve adet kuralı niteliğinde değildir. Yani bir antlaşmada bu yönde bir düzenleme bulunmadığı takdirde, eşit muamele zorunluluğu da bulunmayacaktır. Haklı bir neden bulunmadan bir devletin diğer devlete bu ilkeyi tanımaması, uluslararası hukuk açısından genel olarak sadece dostane olmayan muamele olarak nitelendirilebilecektir ( Bender, 239).

Mütekabiliyet İlkesi 
Genel olarak mütekabiliyet (karşılıklılık) ilkesi; bir devletin, başka bir devlette hem kendi işlemlerini de kapsayan düzenleme ve uygulamaları hem de vatandaşlarının yararlandığı hakları ve tabi olduğu uygulamaları dikkate alarak, o devletin işlemlerine veya vatandaşlarına hâkimiyet alanında aynı kapsamda düzenlemeler öngörmesini ve uygulamada bulunmasını ifade etmektedir.

Uluslararası ticarette mütekabiliyet ilkesi, sağlanan ticari kolaylıkların devletler arasında dengeli dağılmasını, yani örneğin tanınacak tavizlerin karşı tarafın aynı ölçüde tavizler tanımasına bağımlı hale getirilebileceğini ifade etmektedir (Göttsche, 2010). Mütekabiliyet, DTÖ antlaşmalarının hiç birinde doğrudan normatif düzenleme olarak yer almasa da içerik olarak belli düzenlemelerde yer almaktadır (Göttsche, 2010a).

GATT Antlaşması Önsöz; Mütekabiliyet ve karşılıklı menfaat esası üzerinden, gümrük resimlerinin ve mübadeleleri daraltan diğer mânilerin esaslı surette azaltılması ve milletlerarası ticaret alanında fark gözetici muamelelerin bertaraf edilmesini istidaf eden anlaşmalar yaparak yukarda zikredilen gayelerin tahakkukuna yardım etmek arzusuyla

GATT Antlaşması Mükerrer XXVIII inci madde;

Tarife müzakereleri

- Akit Taraflar, Gümrük vergilerinin, ekseriyetle, ticarete ciddi manialar teşkil eylediklerini, bundan dolayı, Gümrük vergilerinin ve ithalât ve ihracatta tahsil olunan diğer mükellefiyetlerin umumi seviyelerinin ve hususiyle, asgari miktarlarda emtia ithalâtına mâni teşkil eden yüksek nispetli vergilerin tenziline matuf mütekabiliyet ve karşılıklı menfaat esasına müstenit müzakerelerin, işbu Anlaşmanın hedefleri ve her Akit Tarafın çeşitli ihtiyaçları gereği veçhile nazarı itibara alınmak suretiyle yürütülmeleri halinde, milletlerarası ticaretin gelişmesi bakımından büyük ehemmiyet arz ettiklerini kabul ederler, Binnetice, Akit Taraflar muayyen devreler zarfinda bu kabil müzakereler tertipleyebilirler.

Günümüzde mütekabiliyet ilkesi daha ziyade, yabancılar hukuku ve milletlerarası usul hukuku alanlarında doğrudan normatif düzenleme olarak karşımıza çıkmaktadır.

Milletlerarası Özel Hukuk ve Usul Hukuku Hakkında Kanunu m. 54;

- Yetkili mahkeme tenfiz kararını aşağıdaki şartlar dâhilinde verir:

a) Türkiye Cumhuriyeti ile ilâmın verildiği devlet arasında karşılıklılık esasına dayanan bir antlaşma yahut o devlette Türk mahkemelerinden verilmiş ilâmların tenfizini mümkün kılan bir kanun hükmünün veya fiilî uygulamanın bulunmasi....

- Uluslararası Ekonomi Hukukunun Kaynakları

- Genel Olarak

Sınırlar ötesi ekonomik faaliyetler birçok farklı hukuki düzenlemenin konusunu teşkil etmektedir. Bunların bir kısmı milli kamu hukuku ve özel hukuk karakterli, bir kısmı da uluslararası hukuk kaynaklıdır.

$\mathrm{Bu}$ doğrultuda uluslararası ekonomi hukukunun içeriğini belirleyen hukuk branşları şunlardır:

- Uluslararası Hukuk,

- Supranasyonal Hukuk,

- Milli Hukuk,

- Diğer Normatif Yönlendirme Mekanizmaları.

- Uluslararası Hukuk

- Uluslararası Antlaşmalar

Uluslararası hukukun, ekonomik faaliyetleri düzenleyen ve antlaşmalar neticesinde oluşan kuralları, uluslararası ekonomi hukukunun başlıca kaynağını teşkil etmektedir. Antlaşmalar, devletlerarasında iki veya çok taraflı olarak yapılabilmektedir.

Uluslararası antlaşmalar, iki veya daha fazla devlet ya da antlaşma yapma ehliyetine sahip uluslararası hukuk kuruluşları arasında, hukuken bağlayıcı şekilde antlaşma taraflarının hak ve yükümlülüklerini ihdas eden, değiştiren veya kaldıran ve taraflarca uluslararası hukuka tabi kılınan anlaşmalardır.

\section{A. Devletlerin Ekonomik İlişkilerini Düzenleyen Antlaşmalar}

Devletlerin ekonomik ilişkilerini düzenleyen antlaşmalar ile uluslararası ekonomi alanında devletlerin birbirleriyle yahut devletlerin özel hukuk kişileriyle olan ilişkilerini konu alan kamu hukuku karakterli hukuk kuralları ihdas olunmaktadır,. Bunlar, düzenledikleri alana ilişkin temel ilkeleri koyarlar ve dolayısıyla üye ülkelerin düzenlenen alandaki milli mevzuatlarının da çerçevesini çizmiş olurlar. Bu tür antlaşmalar çok veya iki taraflı yapılmaktadır.

B. Özel Hukuk İlişkilerini Düzenleyen Antlaşmalar

$\mathrm{Bu}$ tür antlaşmalar, uluslararası alanda özel hukuk kişilerinin kendi aralarında ve kamu tüzel kişileriyle gerçekleştirdikleri özel hukuk karakterli ekonomik ilişkileri düzenlemektedir. Özel hukuk ilişkilerini düzenleyen antlaşmaların temel amacı, milli hukuklarda yer alan farklı düzenlemelerin tekdüze hale getirilmesidir. 
Antlaşmayla getirilen kural, kanunlar çatışması ve milletlerarası usul hukukuna ilişkin olabileceği gibi, kişiler arasındaki çeşitli ilişkileri düzenleyen maddi hukuka da ilişkin olabilmektedir.

- Uluslararası Örf ve Adet Hukuku

Uluslararası hukukun kaynaklarından olan uluslararası örf ve adet hukuku, uluslararası ekonomi hukuku alanında da önemli bir kaynak olarak karşımıza çıkmaktadır.

Uluslararası örf ve adet hukuku, devletler pratiğinde sürekli ve fiili olarak uygulanan ve hakkında devletler tarafindan uyulması hususunda zorunluluk atıf olunan kuralları kapsamaktadır (Krajewski 2012a).

Diplomatik koruma hakkı; bir devlette bulunan yabancı bir devletin vatandaşının, bulunduğu devlete atfolunabilecek bir fiil veya ihmalden dolayı zarara uğradığı hallerde vatandaşı bulunduğu devletin kendisini koruma altına almasını ifade etmektedir. Tabiiyetinde bulunulan devlet koruma kapsamında, uluslararası hukukun tüm imkânlarından yararlanabilecektir. Koruma hakkının kullanılabilmesi için, zarar görenle korumaya alacak ülke arasında uyrukluk bağının bulunması ve yabancı tarafından bulunulan ülkede tüm iç hukuk yollarının tüketilmiş olması gerekir (Gündüz, 2014). Geçmişte önemli bir fonksiyon icra eden bu kurum, zamanla yabancı yatırımcılara ev sahibi devleti doğrudan dava edebilme imkânı tanınmış olması nedeniyle günümüzde önemini kaybetmiştir.

Devlet bağışıklığı ise, bir devletin başka bir devletin mahkemeleri önünde yargılanamamasını ve kendisine karşı cebri icra işlemlerinin uygulanamamasını ifade etmektedir (Gündüz, 2014a).

Günümüzde devlet bağışıklığı, hâkimiyet tasarrufu niteliğinde olmayan özel hukuk ilişkilerinden doğan uyuşmazlıklar yönünden kabul olunmamaktadır.

Milletlerarası Özel Hukuk ve Usul Hukuku Hakkında Kanun m. 49;

(1) Yabancı devlete, özel hukuk ilişkilerinden doğan hukukî uyuşmazlıklarda yargı muafiyeti tanınmaz.

(2) Bu gibi uyuşmazlıklarda yabancı devletin diplomatik temsilcilerine tebligat yapılabilir.

Cebri icra yönünden de hâkimiyet tasarrufları çerçevesinde malvarlığının söz konusu olup olmadığı devlet bağışıklığını belirlemektedir (Herdegen, 2014b).

- Hukukun Genel İlkeleri

Uluslararası Adalet Divanı Statüsü'nün 38. maddesinde hukukun genel ilkeleri de uluslararası hukukun üçüncü kaynağı olarak belirtilmiştir.

Hukukun genel ilkelerinin boşluk doldurucu fonksiyonları olup, dünyadaki önemli hukuk sistemlerinin birbirleriyle karşılaştırması neticesinde kazanılmaktadırlar. Bu nevi ilkelere örnek olarak, hakkın kötüye kullanımı yasağı, sebepsiz zenginleşme ilkeleri ve hakların kazanılmasında iyi niyeti gösterebiliriz (Krajewski, 2012b).

\section{Supranasyonal Hukuk}

Ulusları bağlayan ve onlarında üzerinde olan kuralları ihtiva eden supranasyonal hukuk, hali hazırda dünyada sadece entegrasyon örgütlenmesi Avrupa Birliği'nde ehemmiyete sahiptir. Bu bağlamda supranasyonal hukuk, uluslararası antlaşmalar neticesinde kendilerine verilen yasa koyma gücü sayesinde $A B$ 'nin organları tarafindan ihdas olunan ve milli hukuk kurallarının üstünde olan hukuk normlarını ifade etmektedir. Diğer ekonomik ve hukuki entegrasyon örgütlenmelerinde kıyaslama yapılacak düzeyde bir seviyeye halen ulaşılamamıştır (Schöbener, 2010) AB hukuki düzenlemelerinin bu güce kavuşabilmesi için, üye devletler egemenliklerini sınırlayarak yetkilerinin bir kısmını AB organlarına devretmişlerdir.

Avrupa Birliğinde hedeflenen birlikteliğe ulaşmak için kurucu metinlerin içeriği zamanla değişikliğe uğramış veya yeni antlaşmayla yürürlükten kaldırılmıştır. Günümüzde Avrupa Birliği Antlaşması (ABA), Avrupa Birliğinin İşleyişi Hakkında Antlaşma (ABİA) ve Avrupa Atom Enerjisi Topluluğu'nu Kuran Antlaşma AB'nin temellerini teşkil etmekte ve bu antlaşmalardaki kurallar asli düzenleme niteliğine sahiptir.

Supranasyonal niteliği olan ve dayanağını kurucu metinlerden alan $\mathrm{AB}$ ikincil düzenlemeleri ise, tüzük, yönerge, karar, tavsiye ve görüşten ibarettir;

- Tüzükler (ABİA m. 288/II), tüm içeriğiyle bağlayıcıdırlar ve doğrudan uygulanırlar. Genel nitelikte düzenlemeler içeren tüzüklerin muhatapları (kişiler, üye devletler ve birlik organları) bu türden düzenlemelere uymakla mükelleftirler. Tüzükler ayrıca uygulanması noktasında, $\mathrm{AB}$ üyesi devletlerce iç hukuka aktarılmaya ihtiyaç duymamaktadır. $\mathrm{Bu}$ nevi düzenlemeler, tüm $\mathrm{AB}$ üyesi devletlerde $\mathrm{AB}$ hukukunun yeknesak olarak uygulanmasına imkân sağlamaktadır.

- Yönergeler (ABİA m. 288/III), AB üyesi devletlere yönelik olup, üye devletler yönergede öngörülen sürede getirilen düzenlemeleri iç hukuklarına aktarmakla mükelleftirler. Yönergelerin hedefi kural olarak üye devletlerdir ve kişilere doğrudan etkisi yoktur. $\mathrm{AB}$ üyesi bir devletin bir yönergeyi öngörülen sürede hiç veya gereği gibi iç hukukuna aktarmaması halinde AB Adalet Divanı, vermiş olduğu ilke kararlarla belli koşullarda yönergelerin de kişiler yönünden doğrudan uygulanabilirliğine hükmetmiştir (Bozkurt, 2012). 
- Kararlar (ABİA m. 288/IV), normal haliyle somut bir olaya ilişkin olup, belli muhatabı (gerçek kişi, teşebbüs veya üye devlet) hedef alırlar ve bütün olarak ilgilileri bakımından bağlayıcıdırlar. Bu tür somut olay kararları $\mathrm{AB}$ komisyonu tarafından alınmaktadır (ör. rekabet sınırlamalarına ilişkin). Somut olay kararları dışında, bir de AB Konseyi'nin ortak dış ve güvenlik politikalarına ilişkin genel düzenleyici işlem olarak, karar alma yetkisi vardır (ABA m.25-26).

- Tavsiye ve Görüşler (ABİA m. 288/V), bağlayıcı olmasalar da politik etki gösterirler. Tavsiye ve görüşlerin amaç ve hedefleri muhataplarını zorlayıcı bir özellik olmadan belli bir davranışa yöneltmektir (Kotzur, 2015).

\section{Milli Hukuk}

\subsection{Genel Olarak}

Milli hukukun, uluslararası ekonomik faaliyetleri düzenleyen kuralları da uluslararası ekonomi hukukunun kaynağını teşkil etmektedir. Özellikle dış ticaret hukuku, milletlerarası özel hukuk (kanunlar çatışması) uluslararası ekonomi hukuku açısından önem arz etmektedirler. Dış ticareti düzenleyen milli hukuk kuralları, bir devlete, malların ve hizmetlerin sınır ötesi değişimini çeşitli araçlarla (ör. gümrük vergisi) yönlendirme ve kontrol imkanı tanımaktadır. Ancak günümüzde dünya ticaretin liberalleştirilmesine yönelik antlaşmalar ve dünya genelinde oluşturulan bölgesel entegrasyonlar, bu alanda giderek artan oranda devletlerin düzenleme tekeline sınırlamalar getirmektedir. Türkiye de bu alanı DTÖ antlaşmaları ve AB ile oluşturduğu gümrük birliği kuralları çerçevesinde düzenlemiştir. Bu alandaki temel düzenlemelerimiz İhracat Rejim Kararı ve İthalat Rejim Kararı'dır.

İhracat Rejim Kararı m. 2;

İhracatla ilgili her türlü işlem, bu Karar, ihracatla ilgili sair mevzuat ile ikili ve çok taraflı antlaşmalar ve bunlara istinaden çıkarılacak yönetmelik, tebliğ ve talimatlar çerçevesinde yürütülür.

İthalat Rejim Karar1 m. 1;

$\mathrm{Bu}$ Kararın amacı, ithalatın ülke ekonomisi yararına ve uluslararası ticaretin gereklerine uygun olarak düzenlenmesini sağlamaktır. İthalat, bu Karar ile bu Karara dayanılarak çıkarılacak yönetmelik, tebliğler, ilgili kuruluşlara verilecek talimatlar, çok taraflı veya iki taraflı antlaşmalar hükümleri çerçevesinde yürütülür.

\subsection{Milli Hukukların Düzenleme Sınırları}

Devletler tarafından kullanılan egemenlik yetkisi (jurisdiction), bir devletin kendi egemenlik hakkına (kanun koyma, yürütme ve yargılama) dayanarak kişiler ve eşyalarla ilişkileri hukuki bağlayıcı şekilde düzenlenmesini ifade etmektedir (Schöbener, 2010).

Devletler, uluslararası örf ve adet hukuku gereğince, yabancı unsurlu olguları düzenlerken tam bir serbestiye sahip değildirler (Herdegen, 2014c). Kişilerin veya olayların milli hukuka tabi kılınabilmesi için kural olarak bağlanma noktası olarak ülkesellik veya kişisellik ilkesine göre, o devletle bir irtibatın kurulması gerekir.

Ülkesellik ilkesine göre, bir devletin egemenlik haklarını uygulayabilmesi için, kişilerin o devletin sınırları içinde bulunuyor veya ikametgâh sahibi olması yeterli irtibat sağlamaktadır. Aynı şekilde yurt içinde bulunan eşyalar ve işlenen fiiller yönünden de irtibat kabul olunmaktadır.

Kişisellik ilkesi ise bağlanma noktası olarak devlet vatandaşlığını dikkate almakta ve yurt dışında gelişen bir olguyu da bu nevi irtibatın bulunması halinde milli hukuka tabi kılmaktadır.

Ancak ülkesellik ve kişisellik ilkesine göre irtibat kurulamasa bile, ülkesellik ilkesinin genişletilmesi sonucunda, tamamen bir devletin sınırları dışında gelişen bir ekonomik olgu etkilerini devlet içinde de gösteriyor ve devlet vatandaşlarının haklarının zedelenmesine yol açıyorsa, bu hallerde de devletin milli hukuk kurallarının uygulanması söz konusu olabilmektedir (etki ilkesi) (Tietje, 2010a).

Rekabetin Korunması Hakkındaki Kanun m. 2;

Türkiye Cumhuriyeti sınırları içinde mal ve hizmet piyasalarında faaliyet gösteren ya da bu piyasaları etkileyen her türlü teşebbüsün aralarında yaptığı rekabeti engelleyici, bozucu ve kısıtlayıcı antlaşma, uygulama ve kararlar ile piyasaya hakim olan teşebbüslerin bu hakimiyetlerini kötüye kullanmaları ve rekabeti önemli ölçüde azaltacak birleşme ve devralma niteliğindeki her türlü hukuki işlem ve davranışlar, rekabetin korunmasına yönelik önlem, tespit, düzenleme ve denetlemeye ilişkin işlemler bu Kanun kapsamına girer.

Selüloz Uyuşmazlığı;

Bir çok selüloz üreticisi ki aralarında $\mathrm{ABD}$ ve Kanada'dan teşebbüslerde bulunmaktadır, AB pazarını da kapsayacak şekilde fiyatlandırma konusunda birlikte hareket etme konusunda antlaşmalara varmışlardır.

AB Komisyonu, bu antlaşmaları ABİA m. 101 (eski-m.81) hükmü çerçevesinde yasak kartel oluşumu olarak vasıflandırmış ve buna bağlı olarak para cezaları kesmiştir. Amerikan ve Kanada teşebbüsleri Komisyonun kararına karşı AB Adalet Divanı'nda iptal davası açmışlardır. Teşebbüsler, Komisyon'un AB dışında ikametgahı 
olan teşebbüslere ilişkin para cezası kesmeye yetkisi bulunmadığını, zira bu teşebbüslerin onun yargılama gücü dışında olduğunu iddia etmişlerdir.

Adalet Divanı, bu teşebbüslerin itirazlarını ret ederek, kartelin oluşumu ile uygulanması aşamasını birbirinden ayırmış ve nazarı itibara alınması gereken yerin kartelin uygulandığı yer olduğunu belirtmiştir.

ABD Helms Burton Uyuşmazlı̆̆ı;

ABD, 1996 yılında çıkarmış olduğu 'Helms-Burton Act' olarak anılan kanun ile uzun zamandan beri Küba'ya karşı uyguladığı ekonomik yaptırımları genişletmiş ve Küba ile ticaret yapan üçüncü devlet teşebbüslerini de kapsama alanına almasıyla, uluslararası alanda yoğun şekilde eleştirilere maruz kalmıştır. Eleştirilerin odağı şu noktalardadır; üçüncü devlet teşebbüsleri bakımından, ne ülkesellik ne de kişisellik ilkesi, ABD ile bir irtibat kurmamaktadır. Üçüncü devlet teşebbüslerinin Küba ile ticaretinin, ABD hakimiyet alanında, doğrudan, önemli ve öngörülebilir bir etkisi olmadığı için, etki ilkesine dayanılarak düzenleme yapılmasının da hukuki mesnedi bulunmamaktadir.

AB, 03.05.1996 tarihinde Helms-Burton Act düzenlemelerinin GATT ve GATS hükümlerine aykırılı̆g 1 iddiasıyla DTÖ uyuşmazlık mekanizmasını işleterek istişare talebinde bulunmuştur. İstişarelerden bir sonuç alınmayınca panel sürecine geçilmiştir.

ABD, GATT ve GATS hükümlerine aykırılığı kabul etmiş, ancak kanunun GATT m. XXI'de yer alan milli güvenliğin sağlanmasına yönelik istisnai hüküm kapsamında yer aldığını ve bu nedenle de bir panelin bu konuyla ilgili yargılama yapma yetkisinin bulunmadığını iddia etmiştir.

Panel, tarafların AHMM m. 12/12 kapsamında süre talep etmeleri nedeniyle, bu talep doğrultusunda çalışmalarını sona erdirmiştir.

\section{Diğer Normatif Yönlendirme Mekanizmaları}

Yumuşak Hukuk (Soft Law)

Uluslararası antlaşmaların gerek hazırlanmasında yaşanan zorluklar ve antlaşmalara devletlerin geniş düzeyde katılımının her zaman sağlanamaması, gerek ise uluslararası ekonomik faaliyetlere pratik çözümler bulma gayreti nedeniyle zamanla uluslararası ekonomi hukuku alanında yumuşak hukuk gelişmiştir. Yumuşak hukukta uluslararası ekonomi hukukunun önemli kaynaklarındandır.

Yumuşak hukukun en önemli özelliği, antlaşmalarda olduğu gibi mutlak bağlayıcılıklarının olmayışlarıdır.

Yumuşak hukuku da, kendi içinde alt kategorilere ayırabiliriz;

Her şeyden önce yumuşak hukuk, özel hukuk ilişkilerine yönelik uygulama alanı bulmaktadır: Özel hukuka ilişkin bir dizi kural, tarafların sözleşmeleri hazırlamalarını ve sözleşmenin kapsamına bu kuralları almalarıyla hukuki ilişkilerini etkilemektedir. Bu tür kurallara örnek olarak, Unidroit tarafindan hazırlanan uluslararası ticari sözleşmelere ilişkin temel kurallar, çeşitli kuruluşlar tarafindan hazırlanan sözleşme örnekleri (ör. FIDIC ve ICC’nin sözleşme örnekleri), ICC tarafından hazırlanan yeknesak kurallar (ör. akreditife ilişkin) ve uluslararası ticari tahkime ilişkin çeşitli kuruluşlarca hazırlanan kurallar (ör. Uncitral tahkim kuralları) verilebilir.

Diğer bir grup yumuşak hukuk türünde ise belli alanlara ilişkin dünya çapında standartlar getirilmektedir. Bu tür yumuşak hukuka örneğin, OECD tarafından hazırlanan transnasyonal teşebbüsler için davranış kurallarını sayabiliriz.

\section{Lex Mercatoria}

Lex Mercatoria, zamanla uluslararası ekonomik faaliyetlerde yerleşmiş ve kökleri çok eskiye dayanan kendine özgü, ticari teamül kurallarıdır(Lex, 2015). Niteliği ve kapsamı çok tartışmalı olan, bu kuralların, bir kısmı çeşitli uluslararası kuruluşlar tarafından yazılı kurallar haline getirilmiştir. Bu tür kurallara ör. olarak ICC tarafindan yazılı hale getirilmiş olan ve uluslararası ticarette yaygın uygulamaya sahip Incotermsi belirtebiliriz.

Bu kuralların tek başına bağlayıcılığı olmayıp, tarafların bu kuralları sözleşme kapsamına alması yanında, milli hukukun da bunu tanıması gerekir. Bu kuralların bağlayıcı hale gelmesine ilişkin diğer bir ihtimal de uluslararası örf ve adet hukuku kuralı niteliğine kavuşmasıdır(Gramlich 2004).

Ayrıca belirtmek gerekir ki literatürde, lex mercatoria kavramının içerisine kökleri Roma hukukuna kadar dayanan özel hukuk ilkeleri ve günümüzün özel hukuka ilişkin yumuşak hukuk uygulamaları da dahil edilerek genişletilmesiyle, kavramın "transnasyol hukuk" kavramı ile örtüşür şekilde anlaşıldığı da görülmektedir.

Lex Mercotaria belirsizliklerine rağmen, özellikle uluslararası ticari tahkimde uygulama alanı bulabilmektedir. Bir kısım kurumsal tahkim düzenlemelerinde olaya uygulanacak maddi hukuk yönünden bizatihi Lex Mercatoria'ya atıfta bulunulmaktadır.

Uluslararası Ticaret Odası Tahkim Kuralları m. 21;

- Taraflar, hakem kurulu tarafindan uyuşmazlı̆ğın esasına uygulanacak hukuku belirlemekte serbesttirler. Bu hususta bir antlaşma yoksa hakem kurulu uygun gördüğü hukuku uygular. 
- Hakem Kurulu, taraflar arasında yapılmış esas sözleşme hükümlerini ve varsa, ilgili ticari örf ve adetleri göz önünde bulundurur.

- Hakem Kurulu, ancak taraflar yetki vermişse, bir dostane aracı yetkisine sahip olacak veya hakkaniyet ve nesafet kurallarına göre karar verebilecektir.

Model Kanunlar

Özel hukuk alanında devletlerin bir sözleşmeyi veya kurumu düzenlerken model alabilecekleri ve çeşitli kuruluşlarca (ör. Uncitral) hazırlanan model kanunlarda, uluslararası ekonomi hukukunda ayrı bir normatif yönlendirme mekanizması olarak karşımıza çıkmaktadır.

Uyuşmazlık Çözümüne İlişkin Kararlar

Uluslararası ekonomik ilişkilerde çıkan uyuşmazlıkların önüne götürüldüğü mahkemelerin, mahkeme benzeri kurumların veya tahkimin yargılama neticesinde verdiği kararlar, uluslararası ekonomi hukukunda da yardımcı kaynak niteliğindedir.

Devletler düzeyindeki ekonomik uyuşmazlıkların önüne götürüldüğü kurumlara örnek olarak, Uluslararası Adalet Divanı'nı ve DTÖ uyuşmazlık çözüm mekanizmasını verebiliriz. Devletler düzeyindeki ekonomik uyuşmazlıklarda çözüm mekanizması olarak ayrıca, ad hoc (geçici) tahkim de başvurulan yollardandır.

Örnek Olay;

Merkezi Almanya'da olan Alman şirketi (A), Türkiye'de merkezi bulunan (B) isimli Türk şirketiyle satış sözleşmesi yaparak mal satın almıştır.

$\mathrm{Bu}$ satış sözleşmesi, uluslararası nitelikte olduğundan ulusal nitelikte satış sözleşmelerine kıyasla, daha karmaşık bir yapıya sahiptir ve bu ticari ilişki farklı alanlarda olan hukuk kurallarının düzenleme alanına girmektedir.

Milli dış ticaret hukuku, kamu hukuku karakterli: -Örnek olayda, satılan malların Türkiye gümrük sahasında gümrük çıkış işlemleri yapılmasından itibaren Türkiye açısından ihracat, Almanya gümrük sahasında gümrük giriş işlemleri yapıldığı andan itibaren de Almanya açısından ithalat söz konusudur. Dolayısıyla bu aşamalarda Türkiye ve Almanya'nın dış ticaret kuralları devreye girmektedir.

Supranasyonal Hukuk (Avrupa diş ticaret hukuku), kamu hukuku karakterli: -Devletler günümüzde dış ticaret kurallarını düzenlerken çok büyük serbestiye sahip değillerdir. Almanya, Avrupa Birliği üyesidir ve dış ticaret kurallarını düzenlerken bu alandaki Avrupa Birliği normlarını dikkate almak durumundadır. Türkiye'de, Avrupa Birliği ile Gümrük Birliğinin kurulmasına ilişkin karar çerçevesinde dış ticaret kurallarını düzenleyecektir.

Uluslararası hukuk, kamu hukuku karakterli: -Almanya, Avrupa Birliği ve Türkiye aynı zamanda Dünya Ticaret Örgütü üyesidir. Bu itibarla Dünya Ticaret Örgütü’nün Mal Ticaretine İlişkin Antlaşmaları da dış ticaret kuralları düzenlenirken dikkate alınmak zorundadır.

Uluslararası ekonomi hukukunun kendine özgü kuralları (lex mercatoria): $\quad$ Yine örnek olaydaki satış sözleşmesine dönecek olursak, taraflar satış sözleşmesine karşılıklı mutabakatla malın teslimine ilişkin uluslararası ticarete özgü teslim koşulları (Incoterms) koyabilirler.

Milletlerarası Usul Hukuku uygulaması: -Örnek olayda, taraflar arasında uyuşmazlık çıktığını düşünürsek, uyuşmazlığın hangi yer mahkemesinde görüleceği sorusu gündeme gelecektir. Taraflar satış sözleşmesinde tahkim şartı da kabul etmiş olabilirler, bu sefer uyuşmazlığın yargılaması sözleşmede öngörülen hakemler tarafindan yapilacaktır.

Milletlerarası özel hukuk (Kanunlar Çatışması) kuralları ve milli özel hukuk: -Uyuşmazlık açısından diğer bir konu da, mahkeme veya hakemler olayı hangi ülkenin maddi hukuk kurallarını uygulayarak çözeceklerdir? Taraflar yaptıkları sözleşmede bu konuda seçim yapmamışlarsa, bu sefer kanunlar çatışması kurallarının gösterdiği ülkenin maddi hukukunun somut olaya uygulanması söz konusu olabilecektir.

Uluslararası hukuk, özel hukuk karakterli: -Ancak uluslararası satım sözleşmeleri için maddi hukuk kuralları öngören CISG'i Türkiye ve Almanya onaylamış devletler arasındadır. Taraflar yaptıkları sözleşmede milli hukuk seçimi yapmamış iseler ve satış konusu mal da CISG kapsamana girmekteyse, olaya maddi hukuk olarak CISG'te yer alan kurallar uygulanacaktır.

\section{Sonuç}

Uluslararası ekonominin hukuku olarak da ifade edebileceğimiz uluslararası ekonomi hukuku hem kamu hukuku ve hem de özel hukuk karakterli, bu doğrultuda karma hukuk altında ele alabileceğimiz nispeten yeni bir hukuk dalıdır. Bu alan küresel düzlemdeki gelişmelere koşut olarak hızla gelişecek bir alandır. İç hukukta olduğu şekliyle, uluslararası ticari ve ekonomik faaliyetleri kendisine konu olan uluslararası ekonomi hukuku, bütün devletleri bağlayıcı uluslarüstü yeknesak kurallara sahip değildir. Bununla birlikte bu alandaki faaliyetlerin hukuki zeminin yeknesaklaştırılmaya çalışıldığı da ortadadır. 
Süreç içerisinde küresel düzlemde rol almak isteyen bütün ülkeler uluslararası ekonomi hukuku dalının önemini anlayacak ve özellikle bütün ülkelerce benimsenmesi kaçınılmaz olan kaynakları çerçevesinde kendilerine hukuk oluşturacaklardır.

\section{Kaynakça}

- $\quad$ Bender Tobias, in Hilf Oeter, s. 239.

- Bozkurt Enver Özcan, Mehmet Köktaş Arif; Avrupa Birliği Hukuku, Ankara 2012.

- Callies Gralf Peter; Grenzüberschreitende Verbrauchervertraege, Tübingen 2006.

- Emmerich http://www.nwir.de/archiv/NWiR17/emmerichfritsche1121.pdf, (21.04.2015).

- Emmerich Fritsche, Angelika; Die lex mercatoria als durchsetzbares transnationales Handelsrecht und Weltgesellschaftsrecht, http:/www.nwir.de/archiv/NWiR17/emmerichfritsche1121.pdf, (21.04.2015).

- $\quad$ Farahat Anuschech; Progressive Inklusion, Heidelberg 2013.

- Göttsche Götz J, in; Hilf, Meinhard Oeter, Stefan (Hrsg.); WTO-Recht, 2. Bası, Baden-Baden 2010.

- Gündüz Aslan; Milletlerarası Hukuk, 7. Bası, İstanbul 2014.

- Herdegen Matthias; Internationales Wirtschaftsrecht, 10. Bas1, München 2014.

- Herrmann Christoph Weiss, Wolfgang Ohler, Christoph; Welthandelsrecht, 2. Bas1, München 2007.

- Hoffman, Rainer; Skript Internationales Wirtschaftsrecht, http://www.jura.uni-frankfurt.de/47.971.065/ 1 Begriff-und Bedeutung_Internationales-Wirtschaftsrecht WiSe-2012 13.pdf (21.04.2015).

- Hoffmann Jochen; Theorie des internationalen Wirtschaftsrechts, Tübingen 2009.

- Kotzur Markus; leoEuroparecht;http://www.unileipzig.de/ eurlaw/eurlaw/images/stories/materialien/leoeuroparecht 2011 skript 20leo 20europarecht 20sose 202011.pdf, s. 21, (21.04.2015).

- $\quad$ Krajewski Markus; Wirtschaftsvölkerrecht, 3. Bas1, Heidelberg 2012.

- Namık Kemal Öztürk; Bürokratik Devletten Etkin Yönetime Geçiş: İyi Yönetişim, www.deu.edu.tr/userweb/hilmi.coban/bürokratik\%20devletten.doc, (21.04.2015).

- Özdemir Didem; Milletlerarası Ticarî Tahkimde Esasa Uygulanacak Hukuk Olarak Lex Mercatorıa, http://webftp.gazi.edu.tr/hukuk/dergi/7_4.pdf, (21.04.2015).

- Pazarcı Hüseyin; Uluslararası Hukuk, 12. Bası, Ankara 2013.

- Rainer, http://www.jura.uni-frankfurt.de/47971065/-1-Begriff-und Bedeutung_InternationalesWirtschaftsrecht_WiSe-2012 13.pdf(21.04.2015).

- Rost Birgit; Die Herausbildung des transnationalen Wirtschaftsrechts auf dem Gebiet der internationalalen Finanz und Kapitalmaerkte, Berlin 2007.

- Schöbener, Burkhard Herbst, Jochen Perkams; Markus, Internationales Wirtschaftsrecht, Heidelberg, 2010.

- Telli Serap; Devletler Hukuku Açısından Uluslararası Ticaret ve Kurumlaşması, Ankara 1991.

- $\quad$ Tietje Christian, in Tietje Christian (Hrsg.) Internationales Wirtschaftsrecht, Berlin 2009.

- Trachtman Joel P.The International Economic Law Revolution http://www.worldtradelaw.net/ articles/trachtmanrevolution.pdf (21.04.2015).

- $\quad$ Ünal Şeref, Uluslararası Hukuk, Ankara 2005. 


\title{
Maden İşyerlerinde İş Sağlığı ve Güvenliği Önlemleri ve Zorunlu Sendikalaşma
}

\section{Occupational Health, Safety and Unionization in Mining Businesses}

\author{
Prof. Dr. Faruk Andaç (Çağ University, Turkey)
}

\begin{abstract}
Turkey has had two major mine accidents recently. In 2014, three hundred and one (301) miners died in the Soma coal mine accident and about five months later, in October 2014, eighteen miners lost their lives in Ermenek. In June 2012, a new Occupational Health and Safety Law entered into force. Although this law brought serious clauses for the organizations to take precautions to prevent such accidents, it was not applied properly for some reasons. First, it was ignored by the businesses as it brought financial burden for them. Second, workers could not express their views individually because they did not have a union to do it for them. The third and most important reason was that; businesses were not inspected properly. As a result of these accidents, The Turkish Grand National Assembly approved the ILO Mine Workers' Health and Safety Agreement No. 176 in December 2014. Before Turkey, this agreement had been approved by 29 countries among 185 ILO members including Zambia, USA, Finland, Albania and Germany. These frequent mine accidents get serious reactions from the public. Therefore, unionization must be compulsory in mine businesses and inspections must be more effective.
\end{abstract}

\section{GíRiş}

6331 sayılı İş Sağlığı ve Güvenliği kanunu yürürlüğe girdiği 30 Haziran 2012 tarihinden itibaren henüz 2 yıl geçmeden 13 Mayıs 2014 tarihinde Manisa'nın Soma Bölgesindeki Kömür Madeni İşletmesinde yeraltında çıkan yangın sonucu 301 işçi hayatını kaybetti. 5 ay sonra Karaman'ın Ermenek Bölgesindeki Kömür Maden ocağını su basması sonucu 18 madenci boğularak 28 Ekim 2014 tarihinde feci şekilde vefat etmişlerdir. Yapılan araştırmaya göre ölümlerin tamamen ihmal ve güvenlik önlemlerinin basite alınmasından kaynaklandığı anlaşılmaktadır. TBMM bu olaylar sonucu hemen apar topar Uluslararası Çalışma Örgütü'nün 1995 yılında kabul ettiği 176 sayılı Maden İşyerlerinde Güvenlik ve Sağlık Sözleşmesi'ni 4 Aralık 2014 tarihinde 2015/7213 sayılı kararıyla onayladı. Halbuki bu sözleşme daha önce ILO üyesi 185 ülkeden içlerinde Arnavutluk, Zambiya, Finlandiya, ABD, Almanya, Belçika, Bosna Hersek gibi ülkelerin bulunduğu 29 ülke tarafından onaylanmıştır.

SGK 2013 yılı istatistiklerine göre 2012 yılında 74.871 iş kazası meydana gelirken, 2013 yılında 191.389 iş kazası meydana geldi. 2013 yılında meydana gelen iş kazası sayısı 2012 yılına göre \% 291 oranında artmıştır. 2013 yılı itibariyle 15.699 kadar en çok iş kazası metal ürünleri imalatında olmuştur. Kömür ve linyit çıkarma işlerinde ise 11.289 iş kazası meydana gelmiştir (SGK, 2013).

İşçi Sağlığ 1 ve İş Güvenliği (İSIG) Meclisi Raporu'na göre 2014 yılında 1.886 çalışan iş kazalarında hayatını kaybetti. 2013'te iş kazasında ölen işçi sayısı ise 1.235 olarak açıklanmıştır. 2014 yılında iş kazalarında ölen işçi sayısı, 2013 yılına göre \% 50 artış göstermiş̧tir. 2013 yılında İş kazası sonucu ölüm, 2012 yılına göre (745 ölen işçi) $\% 83$ oranında artış göstermiştir.

Rapora göre 2014 yılında yaşamını yitiren 1.886 işçiden $29^{\prime}$ u meslek hastalığı nedeniyle can vermiştir. Ölen işçilerin 423'ü inşaatta çalışırken, 386'sı maden çıkarma esnasında, 309'u ise tarım işkolunda çalışırken hayatını kaybetmiştir. Trafik ve servis kazası nedeniyle iş kazasında ölen iş̧̧i sayısı 421 iken, zehirlenme ve boğulma nedeniyle 395, düşme nedeniyle 298 işçi can vermiş̧ir.

İşçiler, kamu çalışanları, doktorlar, mühendisler, iş güvenliği uzmanları, akademisyenlerden oluşan İSíG Meclisi'nin raporunda 2014 yılında ölen işçilerin 54'ünün çocuk olması dikkat çekmektedir. Emekli ya da emeklilik çağında çalışırken hayatını kaybeden işçi sayısı 331 dir. Ölen işçilerin 132'si kadın, 53'ü ise göçmen işçidir. 2013 yılı itibarıyla Manisa'da 343 işçi, İstanbul'da 198 işçi, Kocaeli'nde 67 işçi iş kazası nedeniyle can vermiştir. Raporda sadece Aralık 2014 ayında ülkenin bütününde 127 işçinin hayatını yitirdiği açıklandı (Guvenlicalisma, 2014).

Çalışma ve Sosyal Güvenlik Bakanı Faruk Çelik'in 13 Kasım 2014 tarihinde TV'de yaptı̆̆ konuşmasında "Ekim ayında denetlenen 2.079 inşaat alanının 1.610'unda çalışmaların iş sağlığı güvenliği açısından tehlike arz ettiği için durdurulduğu ve Türkiye genelinde 1.1.2014 tarihi itibarıyla Tehlikeli ve Çok tehlikeli 680.000 civarında işyeri için aylı iş güvenliği uzmanı ve işyeri hekimi hizmeti alma zorunluluğunun bulunduğunu, bunlardan sadece 205.000 işyeri ile iş güvenliği sözleşmesi yapıldığını" açıklamıştı ( NTV 2014). Buna göre 475.000 işyeri halen iş sağlığı ve güvenliği kapsamı dışında faaliyet göstermektedirler. Özellikle maden çıkarılan işyerlerinde iş sağlı̆̆ı ve güvenliği ile ilgili önlemler alınmasının önemi fazladır. 
Maden çıkarılması ile ilgili işyerlerinde meydana gelen ölümcül iş kazalarının önlenmesi için her şeyden önce nedenlerinin bilinmesi gerekir. Çünkü maden çıkarılan işyerlerinde ölümcül iş kazası olma ihtimali çok kapsamlı ve çok özel nedenlere dayanır.

\section{Maden Çıkarma İşyerlerinde İş Kazasi Riskinin Fazla Olmasının Nedenleri}

Manisa'nın Soma ilçesinde 301 işçinin hayatını kaybettiği 13 Mayıs 2014 tarihinde meydana gelen maden kazalarını araştıran TBMM Soma Maden Kazalarını Araştırma Komisyonu Başkanı Ali Rıza Alaboyun, Soma'da yaşanan maden kazasının yetki çatışması ve yetki boşluğundan kaynaklandığını vurguladı. Soma'da, 600 milyon ton çıkarılabilir bir kömür bulunduğunu dile getiren Alaboyun, çok kıymetli bir kömür olduğunu ve Türkiye'nin bundan vazgeçmesinin düşünülemeyeceğini ifade etti. Ancak, bu işyerlerinde Madencilik Sektörüne yön verecek kalıcı ve günün koşullarına uygun bir madencilik politikasının oluşturulmuş olmaması, Türk Madenciliğinin gelişmesini sağlayacak bilimsel araştırma kapasitesi eksikliği nedenleriyle iş kazası olma ihtimalini artırmaktadır.

Komisyon Başkanına göre; kamuda görev ve yetki dağılımından kaynaklı denetim sorunlarının bulunması, can ve mal güvenliği bakımından İşletme Projesi, inceleme ve projeye uygun faaliyetler yürütülüp yürütülmediğinin Denetimi, yeterli ve yetenekli denetim elemanı kadrosu olmaması, denetim yapan personelin «denetim nosyonu» eğitiminin bulunmaması, iş kazalarının oluşmasının başlıca nedenleridir. Maden işletmesi faaliyete başladıktan sonra faaliyetlerin İSG yönünden müfettişlerce denetimi, teftiş sürelerinin yetersizliği, ifade alımında yaşanan sorunlar, aldatmaya yönelik faaliyetler, ulaşım vb. sorunlar iş kazalarının oluşumunu daha da kolaylaştırmaktadır.

Ayrıca işverenin üretim zorlaması, yatırımlardan kaçınması, İSG tedbirlerine önem vermemesi, üretim yöntemi, ocak tasarımı ve işletmecilikten kaynaklanan sorunlar, risk değerlendirme ve yönetim sisteminin yetersiz olması, mevzuattan kaynaklanan sorunlar, eğitimsizlik, taşeron uygulaması, ISSG kültürünün olmaması, madenciliği bilmeyen arama kurtarma ekiplerinden kaynaklı sorunlar, erken uyarı sistemi sorunu, yeraltında bilgisiz ve yetersiz kişilerin olmasından dolayı oluşan kaos ve hayati risk, geri hizmetlerin eksikliği gibi sorunlar maden çıkarma işyerlerinde işkazasının başlıca sorunları ve nedenleri olarak belirlenmiştir (Bugün,2014).

Çalışma ve Sosyal Güvenlik Bakanlığı İş Teftiş Kurulu Başkanlığı’nca bir maden iş kazası için hazırlanan bir rapora göre;

- Sistemdeki hava kapılarının güvenli olmadı̆̆

- Kullanılmakta olan pervanelerin gücünün ana havalandırmadan gelen hava miktarına göre uygun olmadığ1,

- Kontrol ve Degaj sodajlarının güvenliğinin yeterli düzeyde yapılmadığı, kontrol sondajlarının sonuçları değerlendirilerek gerekli önlemlerin alınmadığı,

- Kullanılan elektrikli ekipmanların kablolarda ekler yapıldığı ve gazlı ortama uygun özelliklerinin uygun olmadığı,

- Ocak içerisinde metan gazı oranının \% 1,5'u geçmesine rağmen kesicilerin enerjiyi kesmediği,

- İrtibat lağımları ile su havuzlarında yapılan çalışmalarda düzenli olarak gaz ölçümlerinin yapılmadığı ve ölçüm sonuçlarının düzenli olarak kayıt altına alınmadığı,

- Metan gazı tehlikeli düzeye çıkmasına rağmen, gerekli ve yetkili kişilere haber verilmediği, izleme merkezi ve ocak arasında seri bir düzenek oluşturulmadığı ocağın zamanında tahliye edilmediği,

- Çalışma alanlarına yerleştirilen sensörlerin yerlerinin değiştirildiği, ayarlarının değiştirildiği ve donanımlarının amaçları dışında kullanıldı̆̆ı,

- $\quad$ İşyerinde çalışan yetkili kişilere yeterli sayıda gaz ölçüm cihazı verilmediği ve gerekli yerlere otomatik gaz ölçüm cihazının yerleştirilmediği,

- Çalışan alt işveren işçilerine CO veya ferdi kurtarıcı maske verilmediği, maskelerin kullanılması yönünde denetimler yapılmadığ 1 ve çalışanların sadece belirli bir kısmına CO maske kullanma eğitimi verildiği,

- Noterce onaylı Teknik nezaretçi rapor defteri oluşturulmadığı ve teknik nezaretçi tarafindan gerekli denetimler yapılmadiğ

- Asıl işveren tarafindan risk analizi yapılmadığı ve risk analizinin olmadığ, Alt işverenin sağlık ve güvenlik dökümanı ve acil durum planı olmadığı,

- Asıl işverenin işçilerinden 23 işçinin mesleki eğitim belgesinin bulunmadığı, tespit edilmiştir (TMMOB,48).

- $\quad$ TMMOB Maden Mühendisleri Odası Madencilikte Yaşanan İş Kazaları ile ilgili Raporuna göre Kazalarda Belirlenen Ortak Noktalar şöyle belirlenmiştir;

- Metan kaynaklı maden kazalarının tümü, aynı anda birden çok ölü, birden çok yaralı ile sonuçlanabilecek kazaların oluşabileceği çok riskli bölgelerde meydana gelmiştir.

- Kazaların öncesinde veya kaza sırasında dinamit atımı yapılmıştır.

- Elektrikli teçhizat, kablolar ve motorlar alev sızdırmaz (ALSz) özellikte olmayıp, bu özellikte olan motorlar da arıza yaptığında yerüstünde tamiratı sonrası özelliğini koruyup korumadığı kontrol edilmeden tekrar yeraltında kullanılmaktadır. 
- Havalandırma planları yok veya yetersizdir. Ocak içersinde özellikle kör bacalarda yeterli ve etkin havalandırma yapılmamaktadır.

- Sağlıklı hava ve gaz ölçümleri yapılmamakta, kayıt altına alınmamaktadır. Uzaktan izleme yapılan ocakta var olan sensörler, sayısal olarak yetersiz, bulundukları yerler itibariyle de seyrelmiş gaz ölçümleri yapmaktadırlar.

- Sigara içildiği tespit edilen ocakta, mevcut mevzuata göre çalışan sayısı ölçüsünde iş güvenliği mühendisi, işyeri hekimi çalıştırma ve iş sağlığı güvenliği kurulu oluşturma yükümlülüğü yoktur.

- İçsel denetim yapılmamaktadır.

- Çalışanlarda kişisel koruyucu bulunmamaktadır.

- Çalışanlar yeterli uzmanlığa, sertifikaya ve mesleki eğitime sahip değildirler (TMMOB,51).

Raporlardan anlaşıldığına göre maden çıkarma işyerlerinde meydana gelen ölümcül iş kazalarının başlıca nedeni mevzuat eksikliği değil, özellikle işverenin sorumsuzluğudur.

İş Güvenliği Genel Müdürü Kasım Özer'e göre: “Müfettiş, sorar. Uzman, önerir. Sorumluluk işyerinindir! Mevzuatta hiç eksiğimiz yok. AB'de ne varsa bizde de o var. ILO'ya göre Türkiye'deki müfettiş sayısı yeterli. Madenleri yılda iki kez denetleriz ama her şeyi göremeyiz bilemeyiz. İşyeri sahibi ahlaklı davranmalı"dır (Star,2014).

\section{Maden Çıkarma İşyerleri ile İlgili Yasal Düzenlemeler}

İş Sağlığı ve Güvenliği konusunda ülkemizde 4857 sayılı İş Kanunu'nda koruyucu hükümler yer almaktaydı. Ancak bugün için işyerlerinde iş sağlı̆̆ 1 ve güvenliğinin sağlanması ve mevcut sağlık ve güvenlik şartlarının iyileştirilmesi için işveren ve çalş̧anların görev, yetki, sorumluluk, hak ve yükümlülüklerini düzenlemek amacıyla 20.6.2012 tarih ve 6331 sayılı İş Sağlı̆ğ ve Güvenliği Kanun ile başlı başına bir yasa çıkarılmış bulunmaktadır.

6331 sayılı Kanun, kamu ve özel sektöre ait bütün işlere ve işyerlerine, bu işyerlerinin işverenleri ile işveren vekillerine, çırak ve stajyerler de dâhil olmak üzere tüm çalışanlarına faaliyet konularına bakılmaksızın uygulanacaktır. $\mathrm{Bu}$ yasaya bağlı olarak "Maden İșyerlerinde İş Sağlığ ve Güvenliği Yönetmeliğì" (R.G.;T:19.09.2013-S:28770) çıkarılmıştır (Andaç, 249).

Maden İşyerlerinde İş Sağlığı ve Güvenliği Yönetmeliği işverenlerin ve çalışanların yükümlülüklerini belirlemekte olup, patlama ve yangın çıkmasını ve bunların olumsuz etkilerini önlemek üzere, patlayıcı ve sağlığa zararlı ortam havasının oluşmasını önlemek, yapılan işlemlerin doğası gereği patlayıcı ortam oluşmasının önlenmesi mümkün değilse patlayıcı ortamın tutuşmasını önlemek, patlama ve yangın başlangıçlarını tespit etmek, yayılmasını önlemek ve mücadele etmek için yapılan işe uygun tedbirler almak üzere işvereni zorunlu kılmaktadır (Yön. md.7).

Diğer taraftan İşveren, bir tehlike anında çalışanların çalışma yerlerini en kısa zamanda ve güvenli bir şekilde terk edebilmeleri için uygun kaçış ve kurtarma araçlarını sağlar ve kullanıma hazır bulunduracak (Yön. md.8) ve işyerinin bütününde gerekli haberleşme ve iletişim sistemini kuracak ve ihtiyaç halinde yardım, kaçış ve kurtarma işlemlerinin derhal uygulamaya konulabilmesi için gerekli uyarı ve diğer iletişim sistemlerini hazır bulunduracaktır (Yön. md.9). Ayrıca erişilebilir ve anlaşılır şekilde çalışanlar bu bilgiler hakkında bilgilendirilecektir (Yön. md.10).

2012 tarihli ve 6331 sayılı İş Sağlığ ve Güvenliği kanunu ile 2013 tarihli Yönetmelik bulunmasına rağmen yine de Soma ve Ermenek’te ölümcül iş kazaları önlenememiş̧ir. TBMM maden çıkarılan işyerlerinde ölümcül iş kazalarının artması sonucu ILO'nun 1995 yılında kabul ettiği 176 sayılı "Maden İş̧ilerinin Güvenliği Ve Sağlığı Sözleşmesini”, Aralık 2014 tarihinde hemen onayladı (R.G.;T:12.12.2014-S:29203). Bu sözleşmeyi daha önce 185 ILO üyesi ülke içinden aralarında Zambiya, ABD, Finlandiya, Arnavutluk, Almanya gibi 29 ülke onaylamıştır.

ILO'nun 176 sayılı Maden İşyerlerinde Güvenlik ve Sağlık Sözleşmesi ile işverenlere, devlete ve hatta işçiye büyük oranda sorumluluk yüklemektedir.

İşverenler, iş kazalarını önlemek için işçilere, herhangi bir maliyet getirmeksizin her türlü önlemi alma, işçileri bilgilendirme ve eğitme yükümlülüğü altında olacaklardır.

İşverenler ayrıca, denetimleri altındaki maden işyerlerinde güvenlik ve sağlık risklerini ortadan kaldırmak ya da asgari düzeye indirmek için gerekli bütün önlemleri alacaklar ve özellikle aşağıdaki hususları gözeteceklerdir.

- Güvenli çalışma ve sağlıklı bir çalışma ortamı koşulları sağlanması için, maden işyerinin iletişim sistemi dahil olmak üzere, madenin biçimine göre tasarlanması, inşa edilmesi, elektrik, mekanik ve diğer gerekli cihazlarla donatılmasi;

- Madende işçilerin, kendilerine verilen işleri kendilerinin ya da başkalarının güvenlik ve sağlığını tehlikeye atmadan yapabilecekleri şekilde çalışmaya başlatılması, işletilmesi, sürdürülmesi ve faaliyetinin durdurulmasi; 
- Kişilerin kendi yaptıkları işler çerçevesinde bulunabilecekleri alanlarda zeminin sağlamlığını koruyacak önlemlerin alınması,

- Mümkünse yer altındaki her çalışma mahallinde her biri ayrı bir yolla yeryüzüne çıkan iki çıkış bulundurulmasi;

- İş̧̧ilerin karşılaşacakları çeşitli tehlikelerin ve seviyelerinin belirlenmesi ve değerlendirilmesi için çalışma ortamlarının izlenmesi, değerlendirilmesi ve düzenli olarak denetlenmesi;

- Girilmesine izin verilen yeraltındaki tüm çalışma mahallerinde yeterli havalandırmanın sağlanması;

- Bazı tehlikelere açık bölgeler için güvenli bir çalışma sistemi ve işçilerin korunmasını sağlamak üzere bir işletme planı ve usulleri hazırlanarak bunların uygulanması;

- Yangın ve patlamaların başlamasını ve yayılmasını önlemek, tespit etmek ve gerekli müdahalelerde bulunmak için maden işlerine uygun önlemlerin ve tedbirlerin alınması,

- İş̧̧ilerin güvenliği ve sağlı̆̆ açısından ciddi bir tehlike ortaya çıktığında faaliyetlerin durdurulmasını ve iş̧̧ilerin güvenli bir yere tahliyesinin sağlanması (Sözleşme md.7) gerekir.

İşveren, riski kaynağında bertaraf etmek, güvenli çalışma sistemleri tasarlamak, kaza riskleriyle ilgili işçileri bilgilendirmek ve kaza olduğunda gerekli tıbbi yardıma ulaşmaların sağlamak zorundadır. Ayrıca işçilere ücretsiz olarak uygun koruyucu donanımı, gerekli giysileri ve diğer olanakları sunmak ve bunların bakımını sağlamak zorundadır. Sözleşmeye göre işverenler, kaza sonrasındaki sağlık ve kurtarma etkinliklerinden de sorumludurlar (Sözleşme md.8,9,10,11,12).

Sözleşmeye göre işçilerin ve temsilcilerinin de kazaları, riskli durumları bildirmek, güvenlik ve sağlıklarına ilişkin koşullara dair bilgi edinmek, güvenlik ve sağlı önlemlerinin karar süreçlerine katılmak gibi hakları ve yükümlülükleri vardır (Sözleşme md.13,14) (Datassist ,2014).

Sözleşme, üye devletlere de yükümlülük getirmektedir. Şöyle ki; üye devlet, sözleşme hükümlerinin fiilen uygulanmasını sağlamak için uygun cezalar ve iyileştirici önlemler dâhil olmak üzere gerekli tüm önlemleri alacaktır ve sözleşme uyarınca alınacak önlemlerin yaşama geçirilmesini denetlemek için gerekli denetim hizmetlerini sağlayacak ve bu hizmetlerin yerine getirilmeleri için gerekli kaynakları oluşturacaktır (Sözleşme md.16).

Raporlarda ve mevcut yasal düzenlemelerde görüldüğü üzere maden çıkarma işyerlerinde, işverenlerin ihmal, ilgisizlik ve önlem maliyetlerinden kaçınması, çalışııran ve çalışanların bilgisiz ve eğitimsizliği, devletin denetim olanaklarının yetersizliği ve özel itina gösterilmesine ihtiyaç duyulan maden çıkarma işyerlerinde sendikalaşma zorunluluğunun olmaması iş kazalarının önlenmesini engelleyememektedir.

\section{Maden Çıkarma İşyerlerinde Zorunlu Sendikacilik}

Maden çıkarma işyerlerinde sendikalaşma zorunluluğu ortaya çıkmaktadır. Devletin yapamadığı denetimi sendikalar yapabilecektir. Çalışma ve Sosyal Güvenlik Bakanı Faruk Çelik'in ifade ettiği gibi "Türkiye genelinde 1.1.2014 tarihinden sonra Tehlikeli ve Çok tehlikeli 680.000 civarında işyeri için aylık iş güvenliği uzmanı ve işyeri hekimi hizmeti alma zorunluluğunun bulunduğu, sadece 205.000 işyeri ile iş güvenliği sözleşmesi yapıldığı" görülmektedir. 475.000 işyeri henüz iş güvenliği ile ilgili bir önlem almayı taahhüt etmemiştir.

İş Güvenliği Genel Müdürü Kasım Özer “ ILO standartlarına göre gelişmiş bir ülkede 10 bin işçiye 1 müfettiş olması normaldir. Türkiye'de 12 milyon çalışan var, bin tane müfettiş var. Yani Türkiye'de durum ILO standartlarına uygun. İşverenleri harekete geçirmek, ikaz etmek, hatırlatmak için yapılacak teftişler için gerekli eleman bulunmaktadır. Mevzuatta da hiç eksik bulunmamaktadır. ILO'ya göre Türkiye'deki müfettiş sayısı yeterlidir. Madenler yılda iki kez denetlenmektedir. Fakat her şeyi görmek ve bilmek mümkün olmamaktadır. İşyeri sahibi ahlaklı davranmalıdır. 6331 sayılı iş sağlığı ve güvenliği yasası 1.1.2013 tarihinde yürürlüğe girdi. Yazık ki Soma'daki faciada kaybettiğimiz 301 canla birlikte aslında bu yasanın onları koruyamadığı görülmüştür. Müfettiş altı ayda, yılda bir gidip denetleme yapıyor. İşyeri sahibi 'müfettiş gelsin, yanlışlarımı o zaman düzelteyim' diye düşünüyor”, şeklinde maden işyerlerinde meydana gelen ölümcül iş kazalarının nedenlerini açıklamaya çalışmaktadır (Star,2014).

Buna göre 12 milyon çalışan için bin müfettiş hangi birini denetleyebilecektir? Bu nedenle denetim eksikliği bulunmaktadır.

Denetim eksikliğini sendikaların gidermesi gerekir. Sendikaların işverene ve işvereni denetleyecek olan devlete karşı, iş sağlığının güvenceye alınması için yeterince baskı yapması gerekir. Halbuki İş Güvenliği Genel Müdürü, hiçbir iş̧̧i sendikasının iş sağlığı ve güvenliği noksanlarından veya tedbirsizliğinden dolayı bugüne kadar greve gitmediğini, işverenlerle ücret pazarlığı yaptığı gibi iş sağlığı ve güvenliği konusunda pazarlık yapmadığını ifade etmektedir (Star, 2014).

Anayasanın 51. Maddesine göre sendikalar üyelerinin çalışma ilişkilerinde, ekonomik ve sosyal hak ve menfaatlerini korumak ve geliştirmek için kurulmuşlardır. Diğer taraftan 52. Maddesine göre işçiler ve işverenler, karşılıklı olarak ekonomik ve sosyal durumlarını ve çalışma şartlarını düzenlemek amacıyla toplu iş sözleşmesi yapma hakkına sahiptirler. Buna göre sendikaların üyelerinin ekonomik ve sosyal hak ve 
menfaatlerini korumak anayasal görev ve yetkileri bulunmaktadır. Ancak adı geçen maden işyerlerinde bazı ocaklarda sendika üyelerinin bulunmadığı veya sendikal faaliyetlerin çok zayıf olduğu görülmüştür. Bunun başlıca nedeni çalışanlar üzerinde sendikal faaliyetlere karşı işverenlerce büyük baskı uygulandığı ve çalışanın da bu baskılara tepki gösterememeleridir.

Gerçi bu baskılara karşı gerek 6356 sayılı Sendikalar ve Toplu İş Sözleşmesi kanunun sendika özgürlügünün güvencesi ile ilgili 25. maddesinde ve gerekse Türk Ceza kanununun sendikal hakların kullanılmasının engellenmesi konusu ile ilgili 118. maddesi hem idari para cezası ve hem de hapis cezası öngörmek ise de, bu hükümler uygulamada etkili olamamaktadırlar.

$\mathrm{Bu}$ nedenle bu işyerlerinde sendika üyeliğinin zorunlu olması zarurettir. Bunun için yapılacak yasal düzenlemenin başında Anayasanın 51. maddesinde yer alan "Çalışanlar ve işverenler... sendikalar... kurmaya... bunlara serbestçe üye olma ve üyelikten serbestçe çekilme haklarına sahiptir. Hiç kimse bir sendikaya üye olmaya ya da üyelikten ayrılmaya zorlanamaz." hükmünün yeniden düzenlenmesi gerekir. Uluslararası Çalışma Örgütünün 98 sayılı Sözleşmesinin 1. Maddesinde yer alan "Bir iş̧̧inin çalıştırılmasını, bir sendikaya girmemesi veya bir sendikadan çıkması şartına tabi kılmak" cümlesinin iyi yorumlanması da gerekir. Burada "sendikaya girmemesi" himaye edilmelidir. "Girmesi” nin himayeye ihtiyacı yoktur. İşçi belirlediği bir sendikaya serbestçe üye olmaya karar verebilmeli fakat tıpkı Sosyal Güvenlik Sigortası gibi zorunlu olmalı.

Zorunlu sendika üyeliği tıpkı Avukatlık Yasasında olduğu gibi avukat olacakların Baro’ ya üye olmaları gibidir. Bu sistemde işçi sendika seçmekte serbesttir. İstediği sendikaya üye olabilir. Avukatlık yasası tek olan Baro' ya üyeliği zorlamaktadır. İşçinin ise kendi tercih ettiği sendikaya üye olması onun sendikal özgürlüğünü kısıtlamamakta, aksine iş̧̧iyi işverene karşı korumakta ve işveren karşısında özgürlüğüne kavuşmaktadır. Bu tür uygulama Anglo-Sakson ülkelerinde özellikle ABD’de uygulanmıştır (Esener-Gümrükçüoğlu,169) (Sur,42).

\section{Sonuç}

Ülkemizde devamlı olarak meydana gelen maden çıkarma işyerlerindeki ölümcül iş kazalarının önüne geçilmesi için gerekli yasal düzenlemeler bulunmasına rağmen kazaların devam etmesi denetim yetersizliğinden, işverenin ilgisiz kalmasından, işçi ve işverenlerin bilgisiz ve bilinçsiz olmasından, işverenin önlem almak için gerekli yatırımları maliyet artırıcı unsur olarak kabul etmesinden kaynaklandığı anlaşılmaktadır. Bunun en etkin denetimi sendikalaşmaktır. Çünkü sendikalar, işverenin baskısı altında kalmadan, işçisinin ekonomik ve sosyal hak ve menfaatlerini korumak ve geliştirmek zorundadır.

\section{KAYNAKÇA}

- $\quad$ SGK. İş kazası istatistikleri 2013.

- http://www.guvenlicalisma.org/icerik/haber/dosyalar/2014.pdf(13.11.2014)

- $\quad$ http://www.ntv.com.tr/arsiv/id/25549906/\#storyContinued (13.11.2014)

- http://www.bugun.com.tr/son-dakika/-somadaki-maden-kazasinin-nedeni-- haberi/1377286(4.12.2014)

- TMMOB Maden Mühendisleri Odası Madencilikte Yaşanan İş Kazaları Raporu Haziran/2010

- http://haber.star.com.tr/yazar/is-guvenligi-genel-muduru-kasim-ozer-mufettis-sorar-uzman-onerir sorumlulukisyerinindir/yazi-884826. (19.05.2014)

- Andaç Faruk; İş Hukuku, Detay Yayıncılık, Ank.2014

- http://iskanunu.com/haberler/2316-176-sayili-maden-isyerleri-ile-ilgili-ilo-sozlesmesi-yasalasti. İş Kanunu Datassist, (15.11.2014)

- Esener, Turhan-Bozkurt Gümrükçüoğlu, Yeliz; Sendika Hukuku, Vedat Yayıncılık,İst.2014

- Sur Melda; İş Hukuku Toplu İlişkiler; Turhan Kitabevi, Ank.2008 


\title{
Milletlerarası Mal Satımına İlişkin Sözleşmeler Hakkında Birleșmiş Milletler Antlaşmasının (CISG) Uygulama Alanı Field of Application of United Nations Convention on Contracts for the International Sale of Goods
}

\author{
Prof. Dr. Adnan Deynekli (Bahçeşehir University, Turkey)
}

\begin{abstract}
United Nations Convention on Contracts for the International Sale of Goods (CISG) entered into force on the 1st August 2011 in Turkey. CISG is accepted with the purpose of development and encouragement of international trade and application of uniform rules for resolution of disputes arising from the contracts for the international sale of goods. CISG applies to contracts of sale of goods between parties whose places of business are in different states when the states are contracting states; or when the rules of private international law lead to the application of the law of a contracting state. Neither the nationality of the parties nor the civil or commercial character of the parties or of the contract is to be taken into consideration in determining the application of CISG. In order to apply CISG, there has to be a contract about international sale of goods and the parties shall be from different contracting states or the rules of private international law shall lead to the application of the law of a contracting state. The parties may totally or partially exclude the application of this CISG. CISG does not apply in terms of third party rights and the validity of the contract or of any of its provisions or of any usage.
\end{abstract}

\section{Giriş}

6098 sayılı Türk Borçlar Kanunu satıma ilişkin hükümleri düzenlenirken Milletlerarası Mal Satımına İlişkin Viyana Sözleşmesinden yararlanılmıştır. Milletlerarası Mal Satımına İlişkin Sözleşme’ye Türkiye 2011 yılında katılmıştır. Sözleşmenin uygulama alanı önemli hale gelmiş̧ir. Bu nedenle sözleşmenin uygulama alanının incelenmesi gereği hissedilerek çalışma konusu yapılmıştır.

\section{Zaman Bakımından Uygulanma Alanı}

Viyana Satım Sözleşmesi'nin "Son Hükümler" başlıklı dördüncü kısmında, Sözleşme'nin zaman bakımından uygulama alanına ilişkin düzenlemelere yer verilmiştir. Sözleşme'nin 99'uncu maddesi yürürlüğe gireceği tarihi, 100'üncü maddesi taraflar arasındaki satım sözleşmesi bakımından Viyana Satım Sözleşmesi'nin geçerli olacağı tarihi, 101'inci maddesi ise Sözleşme'den çekilme usulünü ve çekilmek için gerekli bildirimin hüküm doğuracağı tarihi düzenlemektedir.

Sözleşme'nin yürürlüğe girdiği tarihten sonra Sözleşme'yi onaylayan veya Sözleşme'ye katılan ülkeler bakımından Sözleşme, 99'uncu maddenin 2'nci fikrasına göre, "Bir Devletin, onuncu onay, kabul, uygun bulma veya katılma belgesinin tevdi edilmesinden sonra bu Antlaşmayı onaylaması, kabul etmesi, uygun bulması veya Antlaşmaya katılması halinde, bu Antlaşma, hariç bırakılan Kısım dışında, bu maddenin 6. fikrası saklı kalmak kaydıyla, o Devlet bakımından, onay, kabul, uygun bulma veya katılma belgesinin tevdi edildiği tarihten itibaren on iki ayın tamamlanmasını izleyen ayın ilk gününde yürürlüğe girer”.

Viyana Satım Sözleşmesi’nin 100'üncü maddesinde, “(1) Bu Antlaşma bir sözleşmenin kurulmasına ancak, o sözleşmenin akdi konusundaki icabın, 1. maddenin 1. fikrasının (a) bendinde anılan taraf Devletler veya 1. fikrasının (b) bendinde anılan taraf Devlet bakımından bu Antlaşmanın, yürürlüğe girdiği tarihte veya bu tarihten sonra yapılması halinde uygulanır. (2) Bu Antlaşma, sadece 1. maddenin 1. fikrasının (a) bendinde anılan taraf Devletler veya 1. fikrasının (b) bendinde anılan taraf Devlet bakımından Antlaşmanın yürürlüğe girdiği tarihte veya bu tarihten sonra akdedilen sözleşmelere uygulanır" denmektedir. Viyana Satım Sözleşmesi’nin bu maddesinden anlaşılacağı üzere, satım sözleşmesinin kuruluşunda Viyana Satım Sözleşmesi’nin uygulanabilmesi için, icabın Sözleşme'nin yürürlüğünden sonra yapılması gerekirken; satım sözleşmesinin ifasında uygulanabilmesi için ise icabın yürürlükten sonra yapılması gerekmemekte, satım sözleşmesinin, Viyana Satım Sözleşmesi'nin yürürlüğünden sonra yapılmış olması yeterli olmaktadır. O halde, Sözleşme'nin hükümleri geriye yürümez. İcabın yapılmasından kastedilen ise icabın gönderildiği andır, icabın vardığı anın bir önemi yoktur.

\section{Yer Bakımından Uygulama Alanı}

\section{1 İşyerlerinin Farklı Ülkelerde Bulunması}

Viyana Satım Sözleşmesi'nin 1'inci maddesinin ilk fikrasına göre, Sözleşme'nin yer bakımından uygulanabilmesi için, satım sözleşmesi taraflarının işyerlerinin farklı ülkelerde bulunması gerekmektedir.

Viyana Satım Sözleşmesi'nin yer bakımından uygulama alanı, satım sözleşmesi taraflarının işyerlerinin nerede olduğu ile belirlenir, sözleşmenin kurulduğu yer veya ifa yeri dikkate alınmaz. 
Viyana Satım Sözleşmesi'nde, işyeri kavramından ne anlaşılması gerektiği hakkında bir tanım yoktur. Birleşmiş Milletler Milletlerarası Ticaret Odası Temsilcisi işyeri kavramını, "mal veya hizmet satmak amacıyla memurlardan ve bürolardan oluşan sürekli bir ticarî organizasyon" şeklinde tanımlamıştır. Doktrinde bazı yazarlar ise işyeri kavramını, merkez gibi katı kurallara tâbi olmayan, sürekli ve düzenli iş yapılan yer şeklinde tanımlamaktadır. Bazı yazarlarca da işyeri, sözleşme tarafının meslekî faaliyetini fiilen ve ağırlıklı olarak yürüttüğü yer olarak ifade edilmiştir. Bir başka yazar ise işyerini, millî ve milletlerarası planda ticarî işlemlerde bulunmak amacıyla oluşturulan, devamlı ve düzenli bir organizasyonun bulunduğu yer olarak tanımlamaktadır. Satım sözleşmesi taraflarının farklı ülkelerde birden fazla işyerinin bulunması halinde, tarafların hangi işyerinin esas alınacağı Viyana Satım Sözleşmesi'nin 10'uncu maddesine göre belirlenecektir. Sözleşme'nin 10'uncu maddesi, "taraflardan birinin birden fazla işyerinin olması halinde, sözleşmenin akdi sırasında veya öncesinde taraflarca bilinen veya dikkate alınan koşullar değerlendirilerek sözleşme ve sözleşmenin ifası ile en yakın irtibat içinde olan işyeri esas alınır, taraflardan birinin hiçbir işyerinin olmaması halinde mutat meskeni esas alınır" demektedir. O halde sözleşme ve sözleşmenin ifası ile en sıkı ilişkili olan işyeri esas alınacaktır. En sıkı ilişkili işyerinin tespitinde, yeknesaklığı sağlamak açısından, Viyana Satım Sözleşmesi'nin uygulanabilmesini sağlayacak işyeri hangisi ise daha çok o tercih edilmelidir. Burada tarafların, sözleşmenin kuruluşu sırasında dikkate aldıkları ve bildikleri hususlar da değerlendirilmelidir.

Taraflardan birinin işyerinin bulunmaması durumu da, Viyana Satım Sözleşmesi'nin 10’uncu maddesiyle, tarafın mutat meskeni esas alınır denilerek çözüme kavuşturulmuştur. Satım sözleşmesinin temsilci aracılığı ile yapıldığı durumlarda, temsil doğrudan temsil ise temsil edilenin işyeri, dolaylı temsil ise temsilcinin işyeri Viyana Satım Sözleşmesi’nin uygulama alanında belirleyicidir.

Viyana Satım Sözleşmesi'nin uygulanabilmesi için tarafların işyerlerinin farklı ülkelerde bulunması gerekir. İşyerlerinin farklı ülkelerde bulunup bulunmadığı değerlendirilirken, sözleşmenin kurulması anındaki durum dikkate alınır. Ancak işyerlerinin farklı ülkelerde bulunması, Sözleşme'nin uygulanabilmesi için yeterli değildir. Sözleşme'nin 1'inci maddesine göre, “(a) bu devletlerin âkit devletlerden olması veya (b) milletlerarası özel hukuk kurallarının âkit bir devletin hukukuna atıf yapması” da gerekmektedir.

Viyana Satım Sözleşmesi'nin uygulanabilmesi için, Sözleşme'nin 1'inci maddesine göre ilk seçenek, tarafların işyerlerinin bulunduğu farklı ülkelerin Sözleşme'nin tarafı olmasıdır. Bir başka ifadeyle, satım sözleşmesi taraflarının işyerleri, Viyana Satım Sözleşmesi’nin tarafı olan farklı ülkelerde bulunmalıdır. O halde, Viyana Satım Sözleşmesi'ne taraf ülkelerde, bu ülkelerin kanunlar ihtilâfı kuralları uygulanmayacak, doğrudan Viyana Satım Sözleşmesi hükümleri uygulanacaktır. Ancak bu şart, sadece Sözleşme’ye taraf olan ülkelerin mahkemelerini bağlar. Viyana Satım Sözleşmesi'ne taraf olmayan bir ülkenin mahkemesinde davanın açılmış olması halinde, bu şart gerçekleşse bile, hâkim, Sözleşme'yi uygulamak zorunda değildir.

Viyana Satım Sözleşmesi'nin uygulama alanı bulabilmesi için, Sözleşme'nin 1'inci maddesine göre ikinci seçenek, ülkenin kanunlar ihtilâfı kurallarının Sözleşme'ye taraf bir ülke hukukuna atıfta bulunmasıdır. Bu kurala göre, yine satım sözleşmesi taraflarının işyerlerinin farklı ülkelerde olması gerekirken, işyerlerinin bulunduğu ülkelerin Viyana Satım Sözleşmesi'ne taraf olması gerekmez43. Burada hâkim, kanunlar ihtilâfı kurallarına göre yetkili hukuku Sözleşme’ye taraf olan bir ülkenin hukuku olarak tespit ederse, Viyana Satım Sözleşmesi’nin hükümleri o ülkenin iç maddî hukuku sıfatıyla uygulama alanı bulur.

\section{2 İşyerlerinin Farklı Ülkelerde Bulunduğunun Anlaşılır Olması}

Viyana Satım Sözleşmesi'nin uygulanabilmesi için, Sözleşme'nin 1'inci maddesinin 2'nci fikrasına göre, "tarafların işyerlerinin ayrı devletlerde bulunması olgusu sözleşmeden veya sözleşmenin akdi sırasında veya öncesinde gerçekleşmiş olan görüşmelerden veya verilmiş olan bilgilerden..." anlaşılır olmalıdır. Aksi durumda işyerlerinin farklı ülkelerde olması olgusu dikkate alınmaz. Bir başka ifadeyle, Viyana Satım Sözleşmesi uygulama alanı bulmaz. Bunun sebebi, bu durumda işlemin milletlerarası niteliğinin açık olmamasıdır. Satım sözleşmesinin milletlerarası niteliğinin objektif olarak anlaşılır olması yeterlidir; taraflar işyerlerinin farklı ülkelerde bulunduğunu bilmeseler de, objektif olarak bunun farkına varabileceklerse, Viyana Satım Sözleşmesi uygulama alanı bulacaktır. Bunun yanı sıra tarafların, işyerlerinin farklı ülkelerde olduğunu bilmeleri yeterli olup, Viyana Satım Sözleşmesi'nin tarafı olan bir ülkede olduğunun bilinmesinin önemi yoktur. Satım sözleşmesinin, Viyana Satım Sözleşmesi’nin kapsamına giren bir sözleşme olduğunun da taraflarca bilinmesi gerekmez.

\section{Viyana Satım Sözleşmesi'nin Uygulanmasında Dikkate Alınmayacak Durumlar}

Viyana Satım Sözleşmesi'nin 1'inci maddesinin 3'üncü fikrasına göre, “bu Antlaşmanın uygulanmasında ne tarafların vatandaşlığı, ne tacir olup olmadıkları, ne de sözleşmenin adî veya ticarî nitelikte olması dikkate alınır”. O halde, Viyana Satım Sözleşmesi’nin uygulanması bakımından maddede sayılan durumlar önemli değildir. Satım sözleşmesinin taraflarının aynı ülke vatandaşı olması veya Viyana Satım Sözleşmesi'ne üye olmayan ülkenin vatandaşı olması, Sözleşme'nin uygulama alanı bakımından önem taşımaz. Önemli olan işyerlerinin farklı ülkelerde bulunmasıdır. Tarafların tacir sıfatı veya sözleşmenin ticarî niteliği ise, Viyana Satım Sözleşmesi’nin tüm hükümleri bakımından değil, sadece Sözleşme'nin yer bakımından uygulama alanının 
belirlenmesinde dikkate alınmamaktadır. Tarafların tacir sıfatı, örneğin satıcının malı teslim etmesi gereken sürenin belirlenmesi gibi başka konularda göz önüne alınabilir.

\section{Konu Bakımından Uygulama Alanı}

\subsection{Sözleşme Kapsamındaki Satımlar}

Sözleşme'nin 1. maddesinin 1. fikrasına göre Viyana Satım Sözleşmesi, taşınır mal satımı akitlerine uygulanacaktır. Ancak mal satım akitlerinin Sözleşme hükümlerinden hiçbirinde tanımlanmaması nedeniyle pratikte bazı sorunlarla karşılaşılabilir. Bu nedenle Sözleşme'nin kapsamı belirlenirken öncelikle hem satım akdi, hem mal kavramları tanımlanmalıdır. Satım akdi kavramı, bir hukuki ilişki türü olarak Sözleşme içerisinde açıkça tanımlanmamakla birlikte Sözleşme'de satım akdinin tanımlanmasına hizmet edecek pek çok maddi norm bulunmaktadır. Satıcının malı teslim ederek malın mülkiyetini alıcıya teslim etmekle yükümlü olduğunun düzenlendiği $\mathrm{m}$. 30 ile alıcının semeni ödemek ve malları teslim almakla yükümlü olduğunun belirtildiği $\mathrm{m}$. 53 birlikte değerlendirildiğinde, satım akdi şu şekilde tanımlanabilir: Satım akdi, satıcının alıcıya malları teslim etmek ve malların mülkiyetini geçirmek, alıcının ise bu edimin karşılığı olarak semeni ödemek ve malları teslim almakla yükümlü olduğu bir akittir. Sözleşme kapsamındaki satım türleri, Sözleşme'nin 1. maddesinde belirtildiği üzere yalnızca mal satımlarıdır. Sözleşme'nin getirdiği mal kavramının, Sözleşme metninde açıkça belirtilmemekle birlikte yalnızca taşınır malları kapsadığı, taşınmazların mal kavramına dâhil olmadığı şüphesizdir. Doktrinde görüş birliğine varıldığı üzere, gayri maddi ve cisimleşmiş olmayan şeyler, mal kapsamında değerlendirilmez.

Viyana Satım Sözleşmesi, Sözleşme'ye tâbi bir satım sözleşmesine ilişkin ön sözleşmeye ve bir dizi satım sözleşmesi akdetmenin yükümlenildiği çerçeve sözleşmelere uygulanmazken; alım, önalım ve geri alım haklarının kullanılması sonucu meydana gelen satım sözleşmelerinde uygulama alanı bulmaktadır.

\subsection{Sözleşme Kapsamı Dışında Bırakılan Satımlar}

Sözleşme'nin uygulama alanı dışına çıkarılan satım türlerinden ilki, Sözleşmede kişisel kullanım için mal temini olarak tanımlanan tüketici satımlarıdır. Sözleşme'nin ikinci maddesinin a bendinde yapılan tüketici satımlarına ilişkin bir tanımla söz konusu tanımın kapsamına giren satımlar, Sözleşme'nin uygulama alanı dışına çıkarılmıştır. Dolayısıyla Sözleşme'nin uygulama alanı belirlenirken somut hukukî ilişkide mevcut olan satım türünün m. 2/(a)'da yapılan tanımın kapsamı dışında kalıp kalmadığına bakılacak; satım türü, tanımı verilen bir tüketici satımı ise Sözleşme uygulanmayacaktır. Sözleşme'ye göre tüketici satımı, kişisel kullanım ya da aile veya ev ihtiyaçlarında kullanılmak amacıyla malların satımını konu edinen satımlardır. Ancak, satıcının Sözleşme'nin kuruluş anında veya kuruluş anından önce malların böyle bir kullanım için alıcı tarafından satın alındığını bilmemesi ya da bilmek zorunda olmaması durumunda satım, tüketici satımı olmayacak ve dolayısıyla Sözleşme'nin uygulama alanına girecektir.

Sözleşme'nin uygulama alanı dışında bırakılan bir diğer satım türü, açık artırmayla yapılan satımlardır. Tüketici satımlarında olduğu gibi açık artırma yoluyla yapılan satımların kapsam dışı bırakılmasının nedeni de pek çok ülkede bu konuya ilişkin özel kurallar getirilmiş bulunmasıdır. Bunun yanında açık artırma yoluyla yapılan satımlarda açık artırma sonuna kadar alıcının kimliğinin bilinmemesi nedeniyle Sözleşme'nin uygulanmasını bir olasııık hesabına dayandırmamak için bu satımlar, kapsam dışı bırakılmıştır. Açık artırmanın kapsam dışı bırakılması lehinde bir diğer gerekçe olarak doktrinde açık artırmalarda maldaki ayıptan doğan sorumluluğun daha sıkı sınırlamalara tâbi tutulmuş olması da ifade edilmektedir.

\subsection{Sözleşme Kapsamında Satım Sözleşmesi Olarak Değerlendirilen Sözleşme Türleri}

İmal Edilmek veya Üretilmek Üzere Mal Temini Akitleri; Hükmün ilk fikrasında satım akdi ile istisna akdi arasında bir ayırım yapılarak yeni mal imal etmeye veya üretmeye yönelik akitler ele alınmıştır. Buna göre, imal edilmek veya üretilmek üzere mal teminini konu edinen akitler, imalat veya üretimde bulunmak için siparişte bulunan tarafin, imalat veya üretim esnasında gerekli olan maddelerin esaslı bir bölümünü karşılamayı taahhüt etmediği hallerde satım akdi olarak kabul edilecek ve Viyana Sözleşmesi'nin kapsamına girecektir. Ancak siparişi veren tarafın imalât veya üretim için gerekli olan maddelerin asli kısmını karşılamayı taahhüt ettiği hallerde taraflar arasindaki akit, istisna akdi olarak kabul edilecektir.

Satıcı Tarafından İfa Edilecek Bir Hizmet Edimini İçeren Satım Akitleri; Üçüncü maddenin ikinci fıkrasında ise satım akdi ile hizmet akdi arasında bir ayrıma gidilerek satıcının borçlarının ağırlıklı olarak kendisi tarafindan ifa edilecek bir hizmet veya çalışma edimini gerektirmediği hallerde taraflar arasındaki akit, satım akdi olarak nitelendirilmiş ve Sözleşme kapsamında değerlendirilmiştir. Buna karşılık, satıcının borçlarının önemli kısmının hizmet veya çalışma edimini gerektirdiği akitler, hizmet akdi olarak kabul edilerek Sözleşme kapsamı dışında bırakılmıştır.

\subsection{Sözleşme Kapsamı Dışında Bırakılan Mallar}

Sözleşme, 2. maddesinin d, e ve f bentlerinde bazı malların satımını kapsama alanı dışında bırakmıștır. Anılan maddenin d bendinde menkul kıymet, kambiyo senedi ve para satımını konu edinen akitler; e bendinde gemi, tekne, hovercraft (hava yastıklı tekne) ve uçak satımını konu edinen akitler ve $\mathrm{f}$ bendinde elektrik satımları, Sözleşme'nin kapsamı dışında bırakılmışıır. 
Mala ilişkin belgelerin teslimi ile yapılan satımlar, bir başka ifadeyle senedin doğrudan malı temsil ettiği, örneğin konişmento, emtia senedi gibi belgelerle yapılan satımlar, Viyana Satım Sözleşmesi'nin uygulama alanına girmektedir. Sözleşme'nin kapsamına girmeyen para ise, bir ülke içinde tedavülde bulunan paradır; tedavülü olmayan, örneğin antika bir para, Sözleşme'nin uygulama alanına girer. Gemi veya teknelerin motorlu yahut yelkenli olması ya da denizlerde veya iç sularda kullanılıyor olması önemli değildir. Elektrik satımı Sözleşme'nin uygulama alanı dışında tutulmuşken, diğer enerji kaynakları ise, doğal gaz, petrol gibi, Sözleşme'nin uygulama alanına dâhildir. Bu tür malların satımında daha çok, ülkelerin emredici iç hukuk kuralları mevcuttur. Bu sebeple Viyana Satım Sözleşmesi'nin emredici iç hukuk kuralları ile çatışmasını ve Sözleşme'nin uygulanmasında çıkabilecek farklılıkları önlemek; bunun yanı sıra Sözleşme'nin daha fazla ülke tarafından imzalanmasını sağlamak amacıyla bu şekilde bir düzenleme getirilmiştir.

\section{Viyana Satım Sözleşmesinin Uygulandığı ve Uygulama Alanı Dışında Kalan Konular}

Viyana Satım Sözleşmesi’nin 4'üncü maddesinde, “bu Antlaşma, sadece satım sözleşmesinin kurulmasını ve alıcı ile satıcının böylesi bir sözleşmeden doğan hak ve borçlarını düzenler. Antlaşmada aksine bir düzenleme bulunmadığı sürece, özellikle; (a) sözleşmenin veya sözleşmenin hükümlerinin veya teamüllerin geçerliliği; (b) sözleşmenin, satılan malların mülkiyeti üzerindeki olası etkileri düzenlenmemiştir” denmektedir. O halde bu maddeye göre, Viyana Satım Sözleşmesi’nin uygulama alanı içinde kalan satım sözleşmesine ilişkin konular, satım sözleşmesinin kurulması ve satım sözleşmesinin tarafları arasında doğurduğu haklar ve borçlardır.

Viyana Satım Sözleşmesi'nin uygulama alanı dışında kalan satım sözleşmesine ilişkin konular, 4'üncü madde dışında, 5'inci ve 6'ncı maddelerde de düzenleme alanı bulmuştur. Sözleşme'nin 5'inci maddesine göre, "bu Antlaşma satıcının, malların bir kimsenin ölümüne veya yaralanmasına sebep olmasından kaynaklanan sorumluluğuna uygulanmaz". 6'ncı maddeye göre ise, “taraflar, bu Antlaşmanın uygulanmamasını kararlaştırabilecekleri gibi, 12. madde saklı kalmak şartıyla, hükümlerine istisna getirebilir veya hükümlerinin doğurabileceği etkileri değiştirebilirler".

Satım sözleşmesinin kurulması ve sözleşmenin tarafları arasında doğurduğu hak ve borçlar dışında kalan konular hakkında, satım konusu malın sebep olduğu cismanî zararlardan veya ölümden doğan zararlardan dolayı satıcının sorumluluğu hakkında ve satım sözleşmesinin taraflarının Viyana Satım Sözleşmesi'nin uygulanmamasını kararlaştırdıkları durumlarda, Viyana Satım Sözleşmesi uygulama alanı bulmaz. Üçüncü kişilerin hakları da Viyana Satım Sözleşmesi’nin uygulama alanı dışındadır.

\section{Sonuç}

Milletlerarası Mal Satımına İlişkin Viyana Sözleşmesinin iç hukukumuzun bir parçası haline getirilmesinden sonra sözleşmenin zaman bakımından uygulanması konusunda 99. Maddeye göre işlem yapılacaktır. Sözleşmenin yer bakımından uygulama alanı konusunda sözleşmenin taraflarının iş yerinin farklı ülkelerde bulunması gerekmektedir.

Sözleşmenin konu bakımından uygulama alanı sözleşmenin birinci maddesinde düzenlenmiştir. Sözleşme taşınır mal satımı akitlerine uygulanacaktır. Bazı satımlar sözleşmenin kapsamı dışında bırakılmıştır. Bazı sözleşme türleri de sözleşme kapsamında satım sözleşmesi olarak değerlendirilmiştir. Sözleşmenin uygulama alanı dışında kalan satım sözleşmesine ilişkin konular 4. Maddenin dışında 5. ve 6. Maddelerde de düzenleme alanı bulmuştur. Sözleşmenin uygulanabilmesi için uygulama alanının belirlenmesi önemli olduğundan konu ile ilgili düzenlemelerin daha açık ve net olarak yapılması çıkacak tereddütleri giderir.

\section{Kaynakça}

- Bettina, 2012. CISG’ın Uygulama Alanı: Konu Bakımından, Milletlerarası Satım Hukuku, On İki Levha Yayınevi.

- $\quad$ Erdem, 2008. Viyana Satım Anlaşmasına Genel Bakış ve Uygulama Alanı, Yeni Türk Borçlar Kanunu ve CISG’e Göre Satış Sözleşmeleri, Milletlerarası Mal Satım Hukuku, , On İki Levha Yayınevi.

- Mistelis, 2012. CISG’ın Uygulama Alanı: Yer, Zaman ve Kişi Bakımından, Milletlerarası Satım Hukuku, On İki Levha Yayınevi.

- Sağlam, 2013. Milletlerarası Mal Satımına İlişkin Sözleşmeler Hakkında Birleşmiş Milletler Anlaşması Uyarınca Sözleşmenin Kurulması (CISG m. 14-24), On İki Levha Yayınevi.

- Yalçıntaş, 2011. "Viyana Satım Sözleşmesi’nin Kapsamı ve Sözleşme ile Türk Milletlerarası Satım Hukukunda Yaşanacak Değişiklikler”, Banka ve Ticaret Hukuku Dergisi, C. XXVII, s. 281- 308.

- Yıldırım, 2013. "Milletlerarası Mal Satımına İlişkin Birleşmiş Milletler Sözleşmesi'nin (Viyana Satım Sözleşmesi) Uygulama Alanı”, Gazi Üniversitesi Hukuk Fakültesi Dergisi, C. XVII, s. 1061-1094.

- Yılmaz, 2013. Milletlerarası Mal Satımına İlişkin Sözleşmeler Hakkında Birleşmiş Milletler Antlaşması (CİSG) Uyarınca Sözleşmenin İhlalinde Alıcının Hakları, Yetkin Yayınları. 


\title{
Milletlerarası Mal Satımına İlişsin Sözleşmeler Hakkında Birleşmiş Milletler Antlaşması Çerçevesinde Satıcının Kötü İfadan Doğan Sorumluluğu The Liability of Seller for the Conformity of the Goods in Contracts of Sale According to United Nations Convention on Contracts for the International Sale of Goods
}

\author{
Prof. Dr. Çağlar Özel (Hacettepe University, Turkey) \\ Ph. D. Candidate Dila Okyar (Hacettepe University Law School, Turkey)
}

\begin{abstract}
In practice, breach of contract cases mostly involve controversies over the failure of the seller to deliver conforming goods in accordance with the contract. Article 35 CISG defines the obligation of the seller to deliver conforming goods in a very broad and uniformed manner as it states that, the seller must deliver goods which are of the quantity, quality and description required by the contract and which are contained or packaged in the manner required by the contract. CISG provides two criteria for the assessment of the non-conformity of goods. One of them is called "subjective" criterion of non-conformity. It goes without saying that the goods delivered shall be in conformity with all specifications agreed upon by the parties whether explicitly or implicitly. The other one is called "objective" criterion. If the agreement of the parties does not involve any specifications at alllike in the case of routine and quick orders of purchase, or if the agreement of the parties is insufficient in this respect, conformity of the goods will be decided according to the objective criterion. In accordance with Article 35 CISG, Article 36 CISG establishes the responsibility of the seller for any lack of conformity which exists at the time when the risk passes to the buyer, even though the lack of conformity becomes apparent only after that time. Regarding this, Article 67 CISG defines the moment at which the risk passes to the buyer and thus, divides the responsibility between the seller and the buyer.
\end{abstract}

\section{Giriş}

Nisan 1980 tarihli Milletlerarası Mal Satımına İlişkin Sözleşmeler Hakkında Birleşmiş Milletler Antlaşması (kısaca CISG), uluslararası satım sözleşmelerine uygulanacak olan maddi hukuk kurallarının yeknesaklaştırılmasına ilişkin uluslararası düzeydeki çalışmalar arasında büyük bir başarı örneği olarak karşımıza çıkmaktadır. Antlaşmanın giriş kısmında, "farklı sosyal, ekonomik ve hukuki sistemleri dikkate alan yeknesak kuralların kabul edilmesinin milletlerarası ticarette hukuki engellerin kaldırılmasına yardımcı olacağı ve milletlerarası ticaretin gelişmesini teşvik edeceği inancı" ile hareket edildiği belirtilmiştir. Bugün itibariyle, taraf Devlet sayısı 83'e ulaşmış olup, küresel boyutta uluslararası ticaretin 2/3'ünü kapsadığı tahmin edilmektedir (Castellani, 208, 3). 14 Nisan 2015 itibariyle CISG'e ilişkin rapor edilmiş mahkeme ve hakem kararı toplam sayısı ise 3,115 'tir.

Türkiye, 07.07.2010 tarihinde katılım belgesini Birleşmiş Milletler'e tevdi etmiş ve CISG, 1 Ağustos 2011 tarihinden itibaren yürürlüğe girerek Anayasa m.90 uyarınca Türk Hukukunun bir parçası haline gelmiştir. CISG, Türk dış ticareti bakımından büyük önem arz etmektedir zira taraflarca aksi kararlaştırılmadıkça, uluslararası satım sözleşmesine kendiliğinden uygulanma kabiliyetini haizdir (CISG m.6).

CISG'in Türk Hukukundaki uygulama alanını, sözleşmesel ilişkinin taraflarının niteliğine göre şu şekilde tespit edebiliriz (Atamer 2012,188):

- Her iki tarafın da tacir olduğu ulusal satımlarda Türk Ticaret Kanunu (TTK) ve Türk Borçlar Kanunu (TBK) hükümleri

- Her iki tarafın da tüketici olduğu ulusal satımlarda TBK hükümleri

- Tacir ile tüketici arasında ulusal satımlarda Tüketicinin Korunması Hakkında Kanun (TKHK) hükümleri

- Her iki tarafın da tacir olduğu uluslararası satımlarda ise CISG hükümleri uygulama alanı bulacaktır.

Bu genel bilgilerden sonra, tebliğimizin konusunu oluşturan "kötü ifa" kavramını incelemek istiyoruz:

\section{Kötü İfa Kavramı}

Her borç ilişkisinde amaç; bu ilişkiden doğan borçların ifa edilmesi ile tarafların yüklendikleri edimlerden kurtulmaları, böylelikle borç ilişkisinin çözülmesidir. Roma Hukukunda ifa anlamında "hukuki zincirin çözülmesi" olarak kullanılan "solutio" kavramı da bu durumu ifade etmektedir. Ancak, ifanın bu sonucu doğurabilmesi için her şeyden önce borç ilişkisinde aranan niteliklere uygun, edimle her yönden örtüşen, tam ve 
doğru bir ifanın söz konusu olması gerekir (Serozan 2010, 1049). Diğer bir ifadeyle ifa, edimin borç ilişkisinde kararlaştırılmış olan ifa modalitelerine uygun olmalıdır. Bu modaliteler, konu, tutar, yer, zaman ve kişi olarak karşımıza çıkar. Bunlara aykırılık durumunda ise borcun "hiç ya da gereği gibi ifa edilmemesi"nden bahsedilir.

Alman Hukukunda "ifa engelleri" olarak ifade edilen "borcun ifa edilmemesi", borcun hiç ifa edilmemesi ve kötü ifa edilmesi olmak üzere iki başlığa ayrılır. Hiç ifa etmeme, ifa imkânsızlığı ile gecikmiş ifayı kapsamaktadır. Nitelikli gecikme hali ise "temerrüt” olarak adlandırılır. İmkânsızlık ve gecikmiş ifa dışındaki tüm haller ise, "kötü ifa" başlığı altında incelenir. Kötü ifa ile gecikmiş ifa arasındaki en temel farklılık; gecikmiş ifa durumunda alacaklının kural olarak ifayı kabul mecburiyeti olmasına karşılık, kötü ifa hallerinde alacaklının ifayı reddedebilmesidir (Oğuzman ve Öz, 2014, 313).

Türk Hukukunda da ifa etmeme ve temerrüt olarak değerlendirilemeyen ifa olgularını kapsamak üzere gereği gibi ifa etmemenin bir görünümü olarak ele alınan kötü ifa, ayıplı ifa, zapt ve yan borçlara aykırılık olarak çeşitli şekillerde karşımıza çıkar (Oğuzman ve Öz, 2014, 373 vd). Eren ise, "kötü ifa” üst başlı̆ğ yerine "gereği gibi ifa etmeme" kavramını üst başlık olarak kullanılmakta ve "kötü ifa” ile " yan yükümlülüklerin ihlali"ni, gereği gibi ifa etmemenin türleri olarak incelenmektedir (Eren, 2014). Kötü ifa hallerini ifade etmek üzere, doktrinde "akdin müspet ihlali” kavramı da kullanılmaktadır. (Bu kavram hakkında ayrıntılı bilgi için bkz. Kocayusufpaşaoğlu vd. 2010). Öte yandan, kötü ifa hallerinin kapsamına giren durumlarda mutlaka müspet bir fiilin olması gerekmediği, yapılması gereken bir şeyin yapılmaması şeklinde menfi olarak da ortaya çıkabileceği gerekçesiyle bu kavram eleştirilmektedir (Oğuzman ve Öz, 2014, 405).

Kötü ifa kavramı, yanlış ifa kavramı ile karıştırılmamalıdır. Sözleşmede kararlaştırılmış olandan başka bir şeyin ifa edilmesi durumunda "aliud"dan bahsedilir. Böyle bir durumda alacaklı ifayı reddederek borçluyu temerrüde düşürebileceği gibi dilerse hiç ifa etmememe hükümlerine de başvurabilir (Eren 2014, 1048; Gümüş 2013, 72).

Kötü ifa, yanlış ifadan farklı olduğu gibi, ifa imkânsızlığından da farklıdır zira kötü ifa durumunda, borç ilişkisine uygun olmasa bile ifaya "teşebbüs" hali söz konusudur (Eren 2014, 1048).

Türk ve İsviçre doktrininde tartışmalı olan konulardan biri de; özel hüküm öngörülmüş olan ayıplı ifa hallerinde karşımıza çıkar. Örneğin; satım, kira ve eser sözleşmelerine ilişkin olarak Türk Borçlar Kanununda, tüketici işlemlerine ilişsin olarak da Tüketicinin Korunması Hakkında Kanunda ayıplı ifaya ilişkin özel hükümler mevcuttur. Bu durumda acaba, bu özel hükümler yerine, Borçlar Kanununun Genel Hükümleri arasında düzenlenmiş olan gereği gibi ifa edilmemesine ilişkin hükümlere (TBK m.112 vd.) dayanılması mümkün müdür? Bu konuda, hem İsviçre Federal Mahkemesi hem de Türk Yargıtayı, özel hükümler yerine genel hükümlere başvurulabileceğini kabul etmektedir (Oğuzman ve Öz 2014, 147; Eren 2014, 1048).

Görüldüğü üzere, Türk Borçlar Hukuku sisteminde ifa engelleri; "imkânsızlık", "temerrüt” ve "kötü ifa” olmak üzere üç temel yapı üzerine kuruludur. Bu noktada, 2014 yılında yürürlüğe giren yeni Tüketicinin Korunması Hakkında Kanun'da, bu geleneksel yapıdan ayrılarak benimsenen farklı yaklaşıma da dikkat çekmek istiyoruz. Söz konusu kanunun 8. maddesine göre, "sözleşmeye konu olan malın, sözleşmede kararlaştırılan süre içinde teslim edilmemesi veya montajının satıcı tarafından veya onun sorumluluğu altında gerçekleştirildiği durumlarda gereği gibi monte edilmemesi” hali de ayıplı ifa kapsamında değerlendirilmiştir. Böylelikle tüketici işlemlerinde, sözleşmeye konu malın süresi içinde teslim edilmemiş olması durumunda da, ayıplı ifa hükümlerinin uygulanması söz konusu olacaktır.

\section{CISG Çerçevesinde Satıcının Kötü İfadan Sorumluluğu}

CISG'e göre, sözleşmeye uygun mal teslim etmek satıcının asli borcudur. Bu borcun ihlali, sözleşmeye aykırılık teşkil eder. Bu kapsamda bir ifanın ayıplı olup olmadığının tespiti CISG m.35'e göre yapılır. Ancak üçüncü kişilerin mala ilişkin ayni-şahsi hak talepleri ile fikri mülkiyet hukukundan kaynaklanan hak ve talepleri, CISG m.35 kapsamında değildir; bu hususlar CISG m.41 ve 42'de düzenlenmiştir. İstatistiklere göre ayıplı ifa; uluslararası nitelikteki satım sözleşmelerinden kaynaklanan uyuşmazlıklarda en sık rastlanan nedenler arasında baş sıralarda yer almaktadır (Kröll/Mistelis/Perales Viscasillas 2011, N.1).

CISG m.35, ifanın ayıplı olup olmadığına ilişkin değerlendirmede oldukça geniş kapsamlı bir yaklaşım benimseyerek, ayıplı ifa kavramını yeknesaklaştırmayı amaçlamıştır. Bu noktada, kapsam bakımından tür, kalite, miktar ve paketleme ölçütlerinin temel alındığı görülmektedir. Taraflar, bunlara ek olarak malların taşıması gereken başkaca özellikleri de aralarındaki sözleşmede kararlaştırabilirler.

CISG m.35 bakımından en önemli konulardan biri, bu maddede geniş bir şekilde düzenlenmiş olan sözleşmeye uygun olmayan mal kavramının yorumlanması meselesidir. Bilindiği üzere Antlaşmanın temel amacı, uluslararası ticareti geliştirme ve uluslararası nitelikteki satım sözleşmelerine uygulanacak hukukun yeknesaklaştırılmasıdır. Bu amaca uygun olarak Antlaşmanın yorumlanmasına ilişskin CISG m.7/(1)'e göre; "bu Antlaşmanın yorumunda, Antlaşmanın milletlerarası niteliği dikkate alınacağı gibi yeknesak uygulanmasının teşviki ve milletlerarası ticarette dürüstlük kuralının korunması gereği de gözetilir". Bu açıdan, "sözleşmeye uygun olmayan mal" kavramı da, ulusal hukuklardaki yaklaşımlardan bağımsız olarak yorumlanmalıdır. 
Dolayısıyla, Türk, İsviçre ve Avusturya Hukuklarında mevcut olan yukarıda sözü edilen ayıplı ifa ile yanlış ifa (aliud) arasındaki fark, CISG bakımından söz konusu değildir (Kröll/Mistelis/Perales Viscasillas 2011; Schlechtriem ve Schwenzer 2010).

Ayrıca CISG m.35, sözleşme taraflarının menfaatlerinin dengelenmesi bakımından da isabetli bir düzenlemedir. Aşağıda ele alınacağ 1 üzere, CISG m.35 bir yandan ilk fikrada tarafların iradesine itibar ederken, diğer yandan da ikinci fikradaki düzenleme ile sözleşmedeki düzenlemelerin yetersiz olması durumunda tarafların makul beklentilerini de dikkate almaktadır (Kröll/Mistelis/Perales Viscasillas 2011).

Tarafların iradesinin üstünlüğü prensibinin bir yansıması olarak, CISG m.35(1) malların ilk olarak sözleşmeye uygunluğunu aramaktadır. Böylelikle, malların uygunluğu bakımından temel kaynak sözleşme olup, birçok ulusal hukuk sistemindeki yaklaşıma paralel olarak sübjektif bir yaklaşım benimsenmiş̧ir. Malların sözleşmesel tanımına ilişkin olarak belirtilmiş olan hususlar, malın miktarı, kalitesi, türü ve paketleme/muhafaza şeklidir. Bunlar arasında özellikle kalite, malın fiziksel özellikleri yanında, malın çevre ile ilişkisini etkileyen maddi ve hukuki şartları da kapsar (Schlechtriem ve Schwenzer 2010). Örneğin; kamu hukukundan kaynaklanan kurallar, üretiminde çocuk iş̧̧i kullanılmamış olması, üretimde belli standartlara uygunluk gibi fiziksel olmayan özellikler bunlara örnek olarak gösterilebilir (Kröll/Mistelis/Perales Viscasillas 2011). Sözleşmenin içeriğinin belirlenmesi gereken bu aşamada, tarafların beyan ve davranışlarının nasıl yorumlanacağını düzenleyen CISG m.8 ve tarafların yükümlülüklerin kapsamının belirlenmesinde örf ve âdetin rolünü düzenleyen CISG m.9 uygulama alanı bulacaktır.

Hükmün ikinci fikrasında ise, taraflar aksini kararlaştırmış olmadıkça, malların taşıması beklenen ve sözleşmenin bir parçası olduğu kabul edilen birtakım özelliklere yer verilmiştir. Diğer bir ifadeyle, bu tür özelliklere sözleşmede açıkça yer verilmemiş olsa bile, CISG m.35/2 gereği var olduğu ve dolayısıyla satıcının yükümlülüğünün kapsamına dâhil olduğu kabul edilmiştir. Bunlar, aynı türden malların mutat olarak tahsis edildiği kullanım amacına uygunluk, sözleşmenin kurulması esnasında satıcıya bildirilen özel kullanım amacına uygunluk, örnek veya model üzerinden yapılan satımlarda örnek ya da modele uygunluk ve malın muhafazası ve korunmasına uygun şekilde paketlenmiş olma biçiminde belirlenmiştir.

Önemle belirtmek gerekir ki, bu dört ölçüte ilişkin düzenleme emredici nitelikte değildir; taraflar bu standartların uygulanmasını istemezse, aksini kararlaştırabilirler. Ancak bu noktada karşımıza çıkan en önemli sorun, tarafların, sözleşmelerinde yaptıkları düzenlemeler ile CISG m.35(2)'yi uygulama dışı bırakmak isteyip istemedikleridir ki bu sözleşmenin yorumu meselesidir.

Ayrıca, sözleşmenin kurulması anında alıcı tarafından bilinen ya da bilinmemesinin mümkün olmadığı sözleşmeye aykırılıklar bakımından satıcının bu dört ölçüt bakımından sorumluluğunun ortadan kalkacağı düzenlenmiştir (CISG m.35/3).

Mutat olarak tahsis edilen kullanım amacına uygunluk bağlamında ilk olarak, mallara ticari amaca uygun olması, diğer bir ifadeyle, yeniden satımın mümkün olması gerekmektedir. CISG m.35/2 bakımından en popüler sorunlardan biri; malların alıcının ülkesindeki kamu hukuku kaynaklı kurallara/standartlara uygunluğu konusunda satıcının yükümlülüğü olup olmadığıdır. Bu soruna ilişkin CISG uygulamasına yön veren Alman Federal Mahkemesi'nin 1995 tarihli midye kararına kısaca değinmek gerekir. İsviçreli satıcı ile Alman alıcı arasındaki davaya konu olayda, sözleşme konusu midyelerin Alman mevzuatına göre olması gereken miktarın üzerinde kadminyum içerdiği tespit edilir ve bunun üzerine alıcı, malların geri alınmasını satıcıdan talep ederek bedel ödemeyi reddeder.

Alman Federal Mahkemesi kararında, kural olarak, satıcının, alıcının ülkesindeki kamu hukuku kökenli kuralları bilmek ve buna uygun mal teslim etmek zorunda olmadığına hükmeder. Mahkeme, böyle bir yükümlülüğün gündeme gelebileceği üç istisnai durumları da şu şekilde belirtir:

1. Satıcının kendi ülkesinde de aynı standartların olması.

2. Alıcının, söz konusu standartlar konusunda satıcıyı bilgilendirmiş olması.

3. Somut olayın özelliklerine göre, örneğin, uzun süredir alıcının ülkesine mal ihracatı yapmak gibi, satıcının söz konusu standartları biliyor ya da bilmesinin gerekiyor olması.

Özel kullanım amacına uygunluk ölçütünün kullanılabilmesi için ise, CISG birtakım şartlar aramaktadır. Bunlardan ilki, özel kullanım amacının sözleşmenin kurulması esnasında satıcıya açıkça ya da örtülü olarak bildirilmiş olmasıdır. İkinci olarak da; alııının, satıcının bilgisine ve değerlendirmesine güvenmesi veya güvenmesinin makul olması gerekmektedir. Dolayısıyla, alıcının da mallar hakkında en az satıcı kadar ya da satıcidan daha fazla bilgi sahibi olması durumunda, CISG m.35(2)(b) uygulama alanı bulmayacaktır. Malların karmaşık yapıda olduğu ve satıcının da sadece aracı olarak hareket ettiği ya da örneğin, satıcının mallarla ilgili yerli uzman bilgisine başvurulmasını tavsiye etmesinde olduğu gibi satıcının mallara ilişkin bilgi eksikliğini açıkladığı durumlarda, alıcının satıcının bilgi ve değerlendirmesine güvenmesinin makul olmasından bahsedilemez (Kröll/Mistelis/Perales Viscasillas 2011).

Örnek ya da modele uygunluk ölçütünün öngörülmesinin amacı, örnek ya da model gösterilmesinin, malların ayrıntılı bir şekilde tarif edilmesi ile eşdeğer olmasıdır. Ancak bu ölçütün uygulanabilmesi için, söz konusu örnek 
ya da modelin satıcı tarafından sağlanmış olması gerekir. Örnek ya da modelin alıcı tarafından sağlanmış olması durumu ise, ancak, sözleşmesel tanımın bir parçası haline gelmiş ise CISG m.35(1) ya da CISG m.35(2)(b) kapsamında özel kullanım amacına uygunluk kapsamında değerlendirilebilir (Kröll/Mistelis/Perales Viscasillas 2011). Bunların haricinde, alıcı tarafından sağlanmış olan örnek ya da modele uygunluk bakımından satıcının sorumluluğu doğmaz.

Örnek ya da model üzerine yapılan satımlarda tespiti gereken hususlardan biri de, örnek ya da model olarak gösterilen malın hangi özelliklerinin dikkate alınacağıdır. Malların birçok özelliği olduğu için acaba satıcı tarafından teslim edilecek olan, örnek ya da modelin taşıması gereken tüm özellikleri taşımadıkça sözleşmeye aykırı mı olacaktır? Bunu tespit edebilmek için somut olayın özelliklerini değerlendirmek gerekir. Satıcı, söz konusu örnek ya da modeli, malın sadece belirli birtakım özelliklerini göstermek için sağlamış olabileceği gibi, yaklaşık bir tasvir amacıyla da hareket etmiş olabilir.

Malın muhafazası ve korunması ilişkin bir kararda (CLOUT no.202, Cour d'appel, Grenoble, Fransa, 13 Eylül 1995) ise, alıcının ülkesinde yeniden satılacağını bile satıcının, sözleşmeye konu peynirler o ülkenin gıda etiketleme kurallarına uygun olarak paketlememiş olması, 'd' bendinin ihlali olarak değerlendirilmiştir.

CISG m.35, malların sözleşmeye uygunluğunun kapsamını belirlerken, önemli-önemsiz aykırılıklar ayrımına yer vermemiştir. Ancak CISG sisteminde alıcının satıcının sorumluluğuna başvurabilmesi için aykırılığın belirli bir derecede olması arandığından, önemsiz bir aykırılık durumunda satıcının sorumluluğuna gidilmesi pek mümkün gözükmemektedir. Şöyle ki; CISG m.46(2)’ye göre alıcının ikame mal teslimini talep edebilmesi için "bu uygunsuzluğun sözleşmeye esaslı bir aykırılık oluşturması" gerekmektedir. Benzer şekilde CISG m.46(3)'e göre, alıcını onarım talebinde bulunabilmesi için "tüm koşullar göz önüne alındığında bu, makul bir talep" olmalıdır. Keza, sözleşmeye aykırı mal teslimi durumunda alıcının sözleşmeyi tek taraflı irade beyanı ile ortadan kaldırabilmesi için CISG m.49(1)(a) uyarınca "sözleşmeye esaslı bir aykırılığın" söz konusu olması gerekir.

CISG m.35, malların sözleşmeye uygunluğunun tespitinin nasıl yapılacağını ve kapsamını belirlerken, m.36 ise, sözleşmeye aykırılıktan dolayı satıcının sorumlu tutulabilmesi için aykırılığın, sözleşmeye aykırılık bu andan sonra ortaya çıkmış olsa bile, hasarın geçişi anında var olması gerektiğini belirtmektedir. Hasarın geçişi ise, Antlaşmanın "Hasarın Geçişiı” başlıklı Dördüncü Bölümünde ayrıntılı bir şekilde düzenlenmiştir.

Satıcının sözleşmeye uygun mal teslim etme yükümlülüğünün karşılığı olarak, alıcının da malları muayene etme ve bu muayene sonucunda aykırılık tespit etmesi durumunda da aykırılığı satıcıya bildirme külfeti getirilmiştir. CISG m.39'a göre, alıcının makul bir süre içerisinde ayıp ihbarında bulunması gerekmektedir. Bu süre, alıcının aykırılığı saptadığı ya da saptaması gereken süre andan itibaren işlemeye başlar. Öte yandan, alıcının kendisine tanınan hukuki imkânlardan faydalanabilmesi için, malların fiilen kendisine teslim edildiği tarihten itibaren en geç iki yıl içerisinde sözleşmeye aykırılığı satıcıya bildirmesi gerekir. Aksi halde, bu sözleşmeye aykırılığa dayanma hakkını kaybeder; meğerki bu süre sözleşmesel bir garanti süresiyle bağdaşmıyor olsun [(CISG m.39(2)].

1 Temmuz 2012 tarihinde yürürlüğe girmiş olan Türk Borçlar Kanununda da satım sözleşmesinde ayıptan sorumluluğa iliş̧in zamanaşımı süresi, önceki Kanunda düzenlenmiş olan bir yıl yerine, iki yıl olarak düzenlenmiştir. TBK m.231(1)’e göre, “Satıcı daha uzun bir süre için üstlenmiş olmadıkça, satılanın ayıbından doğan sorumluluğa ilişkin her türlü dava, satılandaki ayıp daha sonra ortaya çıksa bile, satılanın alıcıya devrinden başlayarak iki yıl geçmekle zamanaşımına uğrar". Ancak, "Satıcı, satılanı ayıplı olarak devretmekte ağır kusurlu ise, iki yıllık zamanaşımı süresinden yararlanamaz". Bu durumda satıcının sorumluluğu, genel zamanaşımı süresi olan 10 yıllık süreye tabi olacaktır. Tacirler arası satımlar bakımından Türk Ticaret Kanununda öngörülmüş olan altı aylık zamanaşımı süresine yeni Kanunda yer verilmemiş olduğundan, ulusal nitelikteki tacirler arası satımlarda da iki yıllık süre öngören TBK m.231 uygulama alanı bulacaktır (Gümüş 2013, 115).

Hiç veya gereği gibi ayıp ihbarında bulunmamış ise alıcı, kural olarak, sözleşmeye aykırılığa dayanma hakkını kaybeder. Ancak, bu kuralın birtakım istisnaları yer almaktadır. CISG m.40’a göre satıcının bildiği ya da bilmesi gereken bir ayıp söz konusu ise ya da CISG m.44'e göre alıcının zamanında ayıp ihbarında bulunmamış olması makul bir sebebe dayanıyorsa veya satıcı zamanında ihbarda bulunulmamasına ilişkin itiraz hakkından feragat etmiş ise, bu durumda alıcı sözleşmeye aykırılığa dayanma hakkından yararlanmaya devam edecektir (Schlechtriem ve Schwenzer 2010).

Satıcıya, malların sözleşmeye aykırılığını bildiren ihbarda bulunma, alıcı bakımından teknik anlamda bir borç (yükümlülük) olarak değil, bir külfet (yük) olarak karşımıza çıkar zira muayene ve ihbar külfetini yerine getirmediği takdirde olumsuz sonuçlara katlanacak olan alıcıdır; CISG'nin kendisine sunduğu haklar yelpazesinden yararlanamayacaktır.

Sözleşmeye uygun olmayan mal teslimi durumunda CISG alıcıya çeşitli imkânlardan oluşan bir yelpaze sunmaktadır. Bunlar, aynen ifa talebi, eksik ifa durumunda eksik kısmın ifasını talep (CISG m.51), malların onarımı üsteme, bedelde indirim (CISG m.50), sözleşmeden dönme (CISG m.49(1)(a)) ve tazminat talep etme hakkı (CISG m.74). 
Son olarak, sözleşmeye uygun olmayan mal teslim edilmesi durumunda CISG'nin alıcıya tanıdığı hakların, ulusal hukuk sistemlerinde öngörülmüş olan hukuki çareler ile ilişkisine de kısaca değinmek gerekir. Bu bağlamda özellikle, ulusal hukuk sistemlerinde düzenlenmiş olan hata, hile kurumları ile sözleşmeye aykırı malın alıcının diğer malvarlığı değerlerine de zarar vermesi durumunda haksız fiil sorumluluğu akla gelmektedir. CISG'de öngörülen hukuki çarelerin ulusal hukukta öngörülen imkânlar ile ilişkisi konusunda çeşitli görüşler ileri sürülmekte olan, baskın görüş Antlaşmanın yeknesaklaştırma amacına da uygun olarak, CISG'de öngörülen hukuki çarelerin tüketici nitelikte olup, ulusal hukuka başvurulmasını engellediği yönündedir.

\section{Sonuç}

1980 tarihli Milletlerarası Mal Satımına İlişkin Sözleşmeler Hakkında Birleşmiş Milletler Antlaşması, hukukun yeknesaklaştırılması bakımından büyük bir başarı örneğidir. 1 Ağustos 2011 tarihinde Türk hukukunda yürürlüğe giren Antlaşma, şartları gerçekleştiğginde kendiliğinden uygulama alanı bulmaktadır.

Her borç ilişkisinde beklenen, borcun gereği gibi ifa edilmesidir. Borcun ifa edilmediği durumlar ise çeşitli şekillerde karşımıza çıkar. "İfa Engelleri” üst başlığı altında incelenen bu durumlar, Türk Hukukunda hiç ifa etmeme ve kötü ifa olmak üzere temel olarak ikiye ayrılmaktadır. Hiç ifa etmeme, gecikmiş ifa ve ifa imkânsızlığını, kötü ifa ise, ayıplı ifa, zapt ve yan borçlara aykırılık hallerini kapsamaktadır.

Satıcı tarafından teslim edilen malların sözleşmeye uygun olup olmadığının, diğer bir ifadeyle ayıplı olup olmadığının tespiti CISG m.35'e göre yapılır. CISG m.35, satım sözleşmesi taraflarının menfaatlerini isabetli bir şekilde dengeleyen bir düzenlemedir. Söz konusu hüküm, önceliği taraf iradelerine tanıyarak sübjektif bir yaklaşımla malın sözleşmesel tanımını esas almış ve bununla birlikte, sözleşmesel tanımın yetersiz olması ihtimaline karşı da, tarafların makul beklentilerini de dikkate alarak sözleşmeyi tamamlayıcı nitelikte birtakım ek ölçütlere de yer vermiştir. Böylelikle, sözleşmeye uygun olmayan mal kavramının oldukça geniş bir şekilde ele alındığı görülmektedir. Bu kavram, CISG m.7 gereğince, Antlaşmanın yeknesaklaştırma amacına uygun olarak ulusal hukuklardaki yaklaşımlardan bağımsız olarak yorumlanmalıdır.

Satıcının bu şekilde kapsamı oldukça geniş olarak düzenlenmiş sözleşmeye uygun mal teslim etme yükümlülüğüne karşılık olarak, alıcıya da malları şartlara göre uygun olan en kısa sürede muayene etme (CISG m.38) ve makul sürede bu durumu satıcıya bildirme külfeti (CISG m.39) yüklenmiştir. Aksi takdirde alıcı kendisine tanınan geniş hak yelpazesinden yararlanma imkânından mahrum olacaktır. CISG ile ulusal hukukta tanınan hukuki çareler arasındaki ilişki bakımından farklı görüşler ileri sürülmekle birlikte baskın görüş, ulusal hukuktaki hukuki çarelere başvurulamayacağı yönündedir.

\section{Kaynakça}

- Atamer, 2012. Taşınır Satımı Sözleşmesi, Türk Borçlar Kanunu Sempozyumu: Makaleler-Tebliğler, Derleyen: Murat İnceoğlu, On İki Levha Yayınları, İstanbul.

- Castellani, 2008. Türkiye'nin CISG’a Taraf Olmasına İlişkin Çerçeve, Milletlerarası Satım Hukuku, Ed. Yeşim Atamer, On İki Levha Yayınları, İstanbul.

- $\quad$ Eren, 2014, Borçlar Hukuku Genel Hükümler, Ankkara.

- Gümüş, 2013. Borçlar Hukuku Özel Hükümler, Cilt.1, İstanbul.

- Kocayusufpaşaoğlu ve diğerleri. 2010, Borçlar Hukuku Genel Bölüm, İstanbul.

- Kröll/Mistelis/Perales Viscasillas, 2011. UN Convention on Contracts for the International Sale of Goods (CISG), Baden-Baden.

- Oğuzman ve Öz, 2014. Borçlar Hukuku Genel Hükümler, C.1, İstanbul,

- Schlechtriem ve Schwenzer, 2010. Commentary on the UN Convention on the International Sale of Goods: CISG, 3rd edition, Oxford University Press, UK.

- UNCITRAL Digest of Case Law on the United Nations Convention on Contracts for the International Sale of Goods, 2012, The Journal of Law and Commerce, Special Issue, Volume 30, 2012, madde 35, para.5.Baden-Baden. 


\title{
Milletlerarası Mal Satımlarında Sözleșmeden Dönme Avoidance of the Contract at International Sales of Goods
}

\author{
Prof. Dr. Mustafa Topaloğlu (Beykent University, Turkey)
}

\begin{abstract}
Avoidance the Contract is a kind of legal system arrangement which is adopted as a private law enforcement applied effortlessly, in the context of not to be performed delivery of goods in accordance with the contract. Merely, International Tendency in 20th century have fronted that avoidance of the contract is the "ultimum remedium" in the case of any breach of the contract. In several of modern sale law systems, for instance in German Law and Scandinavian Law systems, avoidance of the contract is a process which should be applied in the case of other enforcements are inadequate. The "Convention on International Sale of Goods (CISG)" which has stipulated the same solution way, has an important role in the formation of this modern tendency mentioned below. In accordance with the CISG enforcement of avoidance of the contract shall be exercised in the case of essential breach of the contract. Besides, In case of insubstantial breaches, the buyer is enabled to refer a possibility "the avoidance of the contract" as if the breach is a kind of material breach of the contract by giving additional period to the seller who the party in breach. Despite the additional period of time fixed him, in the case of the seller does not perform delivery of the goods the buyer shall have the right to avoidance of the contract.
\end{abstract}

\section{Giriş}

Sözleşmeyle tarafların yarattığı hukuk olan "lex contractus" un ancak tarafların ortak iradesiyle ortadan kaldırılabileceği, buna karşılık bir tarafın tek başına sözleşme ilişkisini sonlandıramayacağı Roma Hukukunda kabul edilmekteydi. XIX.Yüzyıl kodifikasyonlarında bir tarafa sözleşmeden dönme hakkı tanınmaya başlanmıştır. Ancak bu kodifikasyonlarda sözleşmeden dönmenin yarattığı malın iadesi gibi birtakım sorunlardan dolayı bu hakkın sınırlandırılması yoluna gidilmiştir (Atamer, 2005; Erkan 2013).

Milletlerarası Mal Satımına İlişkin Viyana Konvansiyonu (CISG) da sözleşmeden dönme hakkının sınırlandırılmasında hukuk sistemlerini etkileyici bir rol oynamıştır. CISG uyarınca sözleşmeden dönmeye son çare olarak başvurulabilir. Bu bağlamda CISG, sözleşmeden dönebilmek için ihlalin esaslı olması veya esaslı olmayan hallerde de satıcıya süre verilerek ihlalin esaslı hale getirilmesini aramaktadır.

Konvansiyonda öngörülen sözleşmeden dönme hali dört türlüdür. Bunlar: satıcının sözleşmeyi ihlali (CISG m.49), alıcının sözleşmeyi ihlali (CISG, m.64), satıcı veya alıcının sözleşmeyi esaslı ihlal edeceğinin açık olması (CISG m.72), art arda teslimli sözleşmelerde taraflardan birinin münferit edimlerden birini ifa etmemesidir (CISG, m.73). (Y1lmaz, 2013).

Aşağıda öncelikle alıcının sözleşmeden dönmesi hallerini ve inleyeceğiz. Daha sonra da esas itibariyle satıcının sözleşmeden dönme hallerine paralel olarak düzenlemiş bulunan satıcının sözleşmeden dönmesinin şartları ve sonuçlarına değineceğiz.

\section{Alıcının Sözleşmeden Dönmesi}

Alıcının sözleşmeden dönmesi genel şartlar itibariyle CISG m.49'da düzenlenmiştir. CISG m.49 (1), sözleşmeden dönmek için satıcıya iki imkan sunmakta, CISG m.49 (2) ise dönmenin tabi olduğu komplike bir süre sınırlaması getirmektedir. Sözleşmeden dönmenin hukuki sonuçları ise CISG m.81'de düzenlenmektedir (Huber, 2008).

CISG m.49 (1) "Alıcı aşă̆ıdaki durumlarda sözleşmenin ortadan kalktı̆̆ını beyan edebilir:(a) Satıcının sözleşmeden veya bu Antlaşmadan doğan yükümlülüklerinden herhangi birini yerine getirmeme sözleşmeye esasl bir aykırllı oluşturuyorsa veya (b) Teslim etmeme durumunda satıcl, alıcı tarafindan 47. maddenin 1. fikrası uyarınca verilmiş ek süre içinde malları teslim etmez veya verilmiş süre içinde bunları teslim etmeyeceğini açılklarsa" hükmünü öngörmektedir.

Kural olarak CISG m.49 (1) uyarınca alıcının sözleşmeden dönebilmesi için sözleşme ihlalinin esaslı olması gerekir. Anglo-Amerikan hukuk sistemi ülkelerinden İngiltere'de sözleşmeden dönmek için "condition" denilen bir yükümlülük ihlali aranarak CISG'de öngörülen esaslı ihlal şartına yakın bir şart öngörülmüştür. Yine aynı hukuk ailesine mensup ABD’de sözleşmeden dönme hakkının kullanımı bakımından esaslı ihlal kurumuna benzer bir sistem benimsenmiştir (Erkan, 2013).

Kara Avrupası (Continental) hukuk sistemlerinde satış sözleşmelerine ilişkin hükümlere bakıldığında genellikle CISG m.49 anlamında esaslı ihlal şartı aranmadan satıcıya sözleşmeden dönme hakkı tanınmaktadır (Yılmaz, 2013). Avusturya Medeni Kanununda (ABGB) de alıcın satım sözleşmesinden dönebilmesi, malın tamirinin mümkün olmaması, ikame mal tesliminin aşırı masraf gerektirmesi gibi birtakım şartlara bağlanmıştır. Alman 
Medeni Kanunu (BGB)'nin 2002 değişikliklerinden sonra satış sözleşmesinden her türlü dönme halleri ancak süre tayininden sonra mümkün hale getirilmiştir (Erkan 2013).

Türk Borçlar Kanunu (TBK) m.227'de hakime ayıba karşı tekeffül nedeniyle dönme hakkını kullanan alıcıya durumun haklı göstermesi halinde satılanın onarılması veya satış bedelinin indirilmesi konusunda takdir hakkı tanınmıştır. Yine satıcının temerrüdü halinde uygulanacak TBK m.212'nin atfı dolayısıyla uygulanacak 123.maddesine göre temerrüt nedeniyle alıcının satış sözleşmesinden dönebilmesi için satıcıya uygun bir süre tanıması gerekir. TBK'da yer alan bu hükümler aslında farklı tipte bir dönme hakkının sınırlandırılması olarak kabul edilebilir (Erkan, 2013).

\section{Alıcının Sözleşmeden Dönmesinin Şartları}

Alıcının sözleşmeden dönebilmesi için öngörülen ilk alternatif, sözleşmenin satıcı tarafından esaslı surette ihlal edilmesidir. Esasl1 ihlal, CISG m.25'e göre belirlenir. CISG m.25'te esasl1 ihlal, "Taraflardan birinin sözleşme ihlâli, diğer tarafi, sözleşme uyarınca beklemekte haklı olduğu şeyden önemli ölçüde yoksun bırakacak bir olumsuzluğa sebep oluyorsa, esaslıdır; meğer ki, böyle bir sonucu sözleşmeyi ihlâl eden taraf öngörmemiş ve aynı konum ve koşullar içindeki makul bir kişi de öngöremeyecek olsun." şeklinde tanımlanmıştır. Buna göre esaslı ihlal, sözleşmenin ihlal edilmiş olması, sözleşmenin ihlali sonucu sözleşmenin karşı tarafının bu sözleşme uyarınca beklemekte olduğu şeyden önemli ölçüde yoksun kalması ve bu ihlalin ihlali yapan tarafından ve aynı konum ve şartlarda bulunan üçüncü kişi tarafından öngörülebilir olması halinde söz konusu olur (Goode, 2004). İhlal edilmiş sözleşmesel yükümlülüğün asli veya tali olması önemli değildir.

$\mathrm{Bu}$ ihlalin alıcının sözleşmeden haklı olarak beklediği menfaatten önemli ölçüde yoksun bırakacak bir olumsuzluğa (detriment) neden olması gerekir. Sözleşmenin esaslı ihlali sonucunu doğuracak olumsuzluğun mevcut olup olmadığı her somut olayda yargısal yorumla belirlenir (Dayıŏglu, 2011).

Ayrıca, CISG m.25'te olumsuzluğa neden olan ihlalin böyle bir sonuca doğuracağının satıcı tarafından veya aynı şartlar altında bulunan makul bir kişi tarafından da öngörülebilir olmasını şart koşmaktadır. Sözleşmenin yorumu sonucunda ihlalin olumsuz olduğu öngörülebiliyorsa ihlal esaslı sayılır. Eğer taraflar sözleşmede bir ihlalin açıkça esaslı ihlal sayılacağını kararlaştırmışlarsa yoruma gerek kalmadan satıcının ihlalin sonuçlarını öngörmüş olduğu varsayılır (Dayığlu, 2011).

CISG m.25 olumsuzluğun ne zaman öngörüleceği konusunda sessiz kalmıştır. Acaba satıcının öngörüsü sözleşmenin kurulduğu anda mı yoksa ihlalin gerçekleştiği anda mı aranacaktır? Bu husus tartışmalı olmakla birlikte bu zamanın ihlalin gerçekleştiği tarih değil de, sözleşmenin kurulduğu tarih olarak kabul edilmesi uygun olur (Goode, 2004).

Sözleşmenin esaslı ihlali, vaktinde ifa etmeme, kalıcı olarak ifa etmeme, sözleşmeye aykırı mal teslim etme, sözleşmeyle ilgili belgeleri hiç ya da gereği gibi teslim etmeme hallerinde ortaya çıkar. Bu dört halin gerçekleşmesi tek başına esaslı ihlal sayılmayıp, ayrıca alıcı açısından sözleşmeden beklediği menfaati önemli ölçüde azaltan bir olumsuzluğa neden olması ve bu olumsuzluğun öngörülebilir olması gerekir. Örneğin, bir sergi kataloğundaki küçük bir basım hatası esaslı ihlalin kabulü için yeterli değildir. Buna karşılık, alıcıya gösterilen cihazdan daha fazla elektrik çeken bir soğutma cihazının tesliminde esaslı ihlal hali yaratan olumsuzluk vardır (Atamer, 2005). Alıcı, ortaya çıkan bu olumsuzluk nedeniyle tazminat, semenin tenzili veya tamirat seçenekleri beklediği menfaati karşılayamıyorsa başvuracağı son çare sözleşmeden dönme olmalıdır.

Eğer satıcı, teslim borcunu hiç yerine getirmemişse ve alıcının CISG m.47 uyarınca tanımış olduğu makul ek süreden de yararlanmamışsa, alıcı artık sözleşmenin esaslı ihlal edildiğini ispat etmeden sözleşmeden dönebilir. Esaslı ihlal sayılmayan bir hal, bu suretle alıcının tanımış olduğu ek sürede satıcı tarafından ifada bulunulmaması nedeniyle esaslı ihlal haline gelmektedir. Kural olarak, ek süre tanıyarak sözleşmeden dönme, sadece teslim etmeme hallerinde söz konusu olur. Buna karşılık, sözleşmeye aykırı mal teslim edilmişse, bazı istisnalar dışında, ek süre tanımak, tek başına bu ihlali esaslı ihlal haline getirmez. Ayıca yukarıda belirtilen esaslı ihlal halinin mevcut olduğunun ispatı gerekir (Atamer, 2005).

\section{Alıcının Sözleșmeden Dönme Beyanı}

CISG m.26, alıcının sözleşmeden dönme hakkını kullandığını satıcıya bildirmesi gerektiğini öngörmektedir. $\mathrm{Bu}$ husus, CISG, m.26'da "Sözleşmenin ortadan kaldırılması beyanı, ancak diğer tarafa bildirimle yapılması halinde hüküm ifade eder." şeklinde ifade edilmektedir.

Esaslı ihlal hali mevcut olsa bile, alıcının dönme beyanı satıcıya bildirilmediği sürece kendiliğinden (ipso facto) sözleşme sona ermez. Hatta satıcıya verilen sürenin dolmuş olması dahi sözleşmenin kendiliğinden sona ermesi sonucunu doğurmaz. Her hâlükârda dönme beyanında bulunulması şarttır. Bu suretle sözleşmenin sona ermesi dönme beyanına bağlanarak, sözleşmenin devam edip etmediği konusundaki belirsizlik önlenmek istenmiştir (Yılmaz, 2013).

Dönme beyanına uygulanacak CISG m.27 uyarınca dönme beyanı gönderilmekle hüküm ve sonuçlarını doğurur. Gerçekten de CISG m.27 "Antlaşmanın bu Kısmında açıkça aksi düzenlenmedikçe, sözleşme taraflarından birinin bu Kısma uygun bildirim, talep veya diğer bir açıklaması koşullara uygun araçlarla yapılmışsa, bu açıklamanın iletimindeki bir gecikme veya hata veya ulaşmamış olması açıklamada bulunan 
tarafi ona dayanmak hakkından yoksun bırakmaz." hükmünü içermektedir. Buna göre uygun araçlarla gönderilen dönme beyanın yolda kaybolması veya geç gitmesi rizikolarına muhatap satıcı katlanacaktır. Aynı şekilde gönderme teorisi kabul edildiğinden dönme beyanı muhataba yöneltildiği anda hüküm ifade etmeye başlar (Y1lmaz, 2013).

Sözleşmeden dönme beyanı herhangi bir şekil şartına tabi değildir. Bu nedenle yazılı ve sözlü yapılabileceği gibi, elektronik iletişim tekniği kullanılarak da yapılabilir. Hatta dönme sebebine açıkça yer vermek şartıyla ayıp ihbarı ile ya da ek süre ile birlikte dönme beyanının da gönderilmesi mümkündür (Erkan, 2013).

Zımni davranışlarla da sözleșmeden dönülebilir. Bunun için zımni davranıştan sözleşmeden dönüldüğü sonucunun açıkça çıkarılması gerekir. Örneğin, alıcının belirlediği ek süreye rağmen satıcı mal tesliminde bulunulmamış ve bunun üzerine alıcı aynı türden bir malı başka satıcıdan almış ve eski satıcıya karşı mahkemede dava açmışsa, artık satıcıdan ayrı bir dönme beyanı beklenmesine gerek yoktur (Yılmaz, 2013; Erkan, 2013).

Konvansiyon, sözleșmeden dönme beyanın yapılabileceği süre hakkında herhangi bir hüküm ifade etmemektedir. Mal teslim edilmemişse, satıcı, kural olarak, herhangi bir süre sınırlaması söz konusu olmadan dönme beyanında bulunabilir. Doğal olarak bu durumda iç hukukta geçerli olan zamanaşımı süresini dikkate almak gerekir. Eğer mal teslimi yapılmışsa dönme beyanı makul süre içinde satıcıya gönderilmelidir. Ayıplı mal tesliminde ise, makul süre, ayıp ihbarının satıcıya gönderildiği andan itibaren başlar (Yılmaz, 2013).

\section{Satım Konusu Malın İadesi Zorunluğu}

Genel olarak, mal teslim edildiği durumlarda alıcının dönme hakkını kullanabilmesi için malın iadesinin

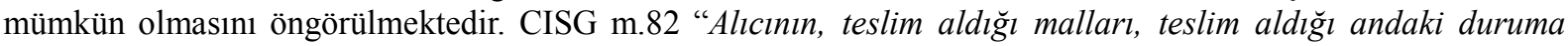
esaslı surette yakın bir durumda iade etmesi imkansızlaşmışsa, sözleşmeyi ortadan kaldırma veya satıcıdan ikame mal talep etme hakkı düşer." hükmünü içermektedir. Buna göre, alıcı, teslim aldığı malı teslim aldığı andaki durumunda esaslı değişiklik olmadan iade etme imkanına sahip değilse dönme hakkını kullanamaz.

Satıcıya iade edilecek malların mutlaka teslim anındaki durumuyla birebir aynı olması gerekli değildir. Önemli olan söz konusu malların teslim anındaki durumlarına objektif olarak yakın olmasıdır. Bu anlamda maldaki önemsiz değişiklikler dikkate alınmaz. Alıcının dönmeyi beyan ettiği anda, iade edilecek malın teslim edilen andaki durumuna yakın olması gerekli ve yeterlidir.

CISG m.82.(2) hükmünde iade edilecek malın iade zorunluluğunun istisnalar düzenlenmiştir: “ Önceki fikra hükmü aşağıdaki hallerde uygulanmaz: (a) malların iade edilmesinin veya teslim alındı $\breve{l}$ andaki duruma esaslı surette yakın bir durumda iade edilmesinin imkansızlaşması alıcının bir eyleminden veya eylemsizliğinden kaynaklanmıyorsa; (b) mallar veya malların bir bölümü 38. maddeye dayalı olarak yapılan muayene sonucunda ziya'a veya hasara uğramışsa; veya (c) mallar veya malların bir bölümü sözleşmeye aykırılı̆̆ın tespit edildiği veya tespit edilmesi gerektiği tarihten önce ticarî faaliyetin olă̆an seyri içinde satılmıs veya olağan kullanım kapsamında alıcı tarafından tüketilmiş veya şekil değiştirmişse. ”. Birinci olarak, alıcının teslim aldığı malı teslim aldığı andaki durumuna esaslı surette yakın şekilde iade malı iade edememesi alıcının eylem veya eylemsizliğinden kaynaklanmıyorsa, dönme hakkı kaybolmaz. İkinci olarak, satım konusu malın tamamı veya bir kısmı, alıcının CİSG m.38 kapsamında yaptığı inceleme sonucu yok olması veya hasara uğraması, dönme hakkını etkilemez. Son olarak da alıcı, satım konusu malı iade etmesi gerektiğinden habersiz olduğu dönemde malı satmış veya tüketmiş olsa da dönme hakkını kullanabilir (Yılmaz, 2013; Erkan 2013).

\section{Alıcının Sözleșmeden Dönmesinin Hüküm ve Sonuçları}

Dönme beyanıyla birlikte sözleşme sona erer. CISG, dönme halinde sözleşmenin tamamen sona ermeyip tasfiye sözleşmesine dönüşeceği yönünde hükümler sevk ederek, Türk-İ́sviçre hukukunda hakim olan dönüşüm teorisini desteklemektedir.

CISG m.81 (1) "Sözleşmenin ortadan kaldırılması, tazminat yükümlülüğü saklı kalmak kaydıyla her iki tarafi da sözleşme ile üstlendikleri yükümlülüklerden kurtarır. Sözleşmenin ortadan kaldırılması, uyuşmazlıkların çözümüne ilişkin sözleşme hükümlerini veya sözleşmenin ortadan kaldırllması sonrasında tarafların haklarını ve borçlarını düzenleyen diğer sözleşme hükümlerini etkilemez." hükmünü içermektedir. Buna göre, taraflar dönmeyle birlikte asli edim ve yan edim yükümlülüklerinden kurtulurlar. Artık, alıcı, satış bedelini, satıcı da, mal teslimi, bakım ve servis gibi yan yükümlülükleri yerine getirmek zorunda kalmazlar.

CISG m.81 (2) hükmü bunun dışında dönmeyle sözleşmenin bazı hükümleri ile tasfiyeye yönelik maddelerinin yürürlükte kalacağını öngörmektedir. Başta sözleşmede yer alan tali yüküm olan tazminat ödeme yükümlülüğü devam etmektedir. Yine, sözleşmenin sona ermesi halinde tarafların hak ve yükümlülüklerini düzenleyen, tahkim, yetkili mahkeme, uygulanacak hukuk, cezai şart ve dönme cezaları, sorumluluk kayıtları ve gizlilik kayıtları gibi hükümler tasfiyeye yönelik olarak geçerliliklerini devam ettirirler (Yılmaz, 2013; Erkan 2013).

Taraflar arasında sözleşme ilişkisi ortadan kalktığı için taraflar tamamen veya kısmen ifa ettikleri edimleri iade etmekle yükümlüdürler. CISG m.82 uyarınca her iki taraf da iade borcu altında iseler, edimlerin aynı anda iade edilmesi kuralı burada da geçerlidir. CISG'de kabul edilen dönme teorisi gereği iade borcunun hukuki dayanağı, 
iç hukuktaki sebepsiz zenginleşme hükümleri değil, tasfiye sözleşmesine dönüşen taraflar arasındaki sözleşmedir (Dayığlu, 2011).

CISG m.84 uyarınca taraflar birbirlerinden aldıkları mal ve semenden elde ettikleri yararları da ide etme yükümlülüğü altındadırlar. Bu kapsamda özellikle satıcı semeni tahsil ettiği tarihten itibaren işleyecek faizi alıcıya ödeyecektir. Alıcı da malı bizzat kullanmışsa bunun karşılığını alıcıya ödemek zorundadır. Bunun dışında alıcının maldan elde etmeyi ihmal ettiği ürün ve semere bedelini satıcıya ödeme zorunluluğu yoktur (Yılmaz, 2013; Dayığlu, 2011).

\section{Satıcının Sözleşmeden Dönmesi}

CISG m.64'te satıcının sözleşmeden dönmesi, alıcının sözleşmeden dönmesine ilişkin CISG m.49 hükmüne paralel olarak düzenlenmiştir. CISG m.64 hükmü şu şekildedir:” (1) Satıcı aşağıdaki durumlarda sözleşmenin ortadan kalktığını beyan edebilir: (a) Alıcının sözleşmeden veya bu Antlaşmadan doğan yükü̈mlülüklerinden herhangi birini yerine getirmemesi sözleşmeye esasl bir aykırılık oluşturuyorsa veya (b) Alıcı, satıcı tarafindan 63. maddenin 1. fikrası uyarınca verilmiş ek süre içinde semeni ödeme borcunu yerine getirmez veya malları teslim almaz veya verilmiş süre içinde bunu yapmayacă̆ını açıklarsa. (2) Ancak, alıcının semeni ödediği hallerde, satıcl, sözleşmenin ortadan kalkttğın beyan etme hakkın yitirir; meğerki (a) alıcının gecikmiş ifası halinde, ifanın gerçekleşmiş olduğunu öğrenmeden önce sözleşmenin ortadan kalktı̆ı̆n beyan etmiş olsun veya(b) alıcının gecikmiş ifa dışındaki bir sözleşmeye aykirllığı halinde, i) bu aykirllığı bildiği veya bilmesi gerektiği andan itibaren makul bir süre içinde veya (ii) satıcı tarafindan 63. maddenin 1. fikrası uyarınca verilmiş herhangi bir ek sürenin geçmesinden sonra veya alıcının bu ek süre içinde yükümlülüklerini yerine getirmeyeceğini açılklamasından sonra makul bir süre içinde sözleşmenin ortadan kalktığını beyan etmiş olsun.”. Buna göre, satıcının dönme hakkı, alıcının sözleşmeyi esaslı ihlal halinde mevcuttur. Ayrıca, sözleşmenin ihlali esaslı ihlal niteliğinde olmasa da, satıcı, ek süre tanıyarak, bu süre sonunda semen ödenmezse veya mal teslim alınmazsa ya da bunları açıkça reddedilmişse, sözleşmeden dönme hakkı vardır (Chuah, 2013).

Temerrüde düşen alıcı, satıcının henüz dönme hakkını kullanmadan önce semeni öderse, dönme hakkı düşer. Ancak satıcı, ödemenin yapıldığını bilmeden bulunmuş olduğu dönme beyanı geçerlidir. Yine geç ödeme dışındaki diğer alıcının temerrüdü hallerinde de semen ödenmesine rağmen temerrüt devam ettiği sürece satıcı dönme hakkını kullanabilir (Zeytin, 2011).

Satıcı, sözleşmeden dönme hakkını alıcıya beyanda bulunarak kullanmalıdır. CISG m.26 ve 27 uyarınca şartlara uygun araçlarla yapılan dönme beyanı, alıcıya geç ulaşmışsa dahi satıcıyı dönme hakkından yoksun bırakmaz. Beyanın yazılı yapılması şart olmayıp, dava açama gibi başka suretlerle de ispatlanabilir (Mohs, 2015).

\section{Sonuç}

CISG, sözleşmeden dönme konusunda modern eğilimlere uygun bir sistem öngörmüştür. Bu dönme sistemi, tarafların hak ve yükümlülüklerini adil şekilde dengelemeye çalışmıştır. Sözleşmeden dönmenin şartları, dönmede uygulanacak süreç ve dönme sonrası tasfiyeye ait hususlar net ve açık bir şekilde ortaya konulmuştur.

Bunun ötesinde dünyada farklı iki hukuk sistem olan Kıta Avrupası sistemi ile Anglo-Amerikan sistemi açısından da kabul edilebilir ve uygulanabilir bir dönme sisteminin ortaya konulması da bu Konvansiyonun dikkate değer başarısıdır.

Özellikle dönmeyi son çare olarak öngören CISG hükümleri başta Almanya dair birçok ülkenin borçlar kanuna alınmıştır. Ne var ki, 2012 yılında değiştirilen 6098 sayılı Türk Borçlar Kanunundan bu Konvansiyondan yeterince yararlanılmamıştır.

\section{Kaynakça}

- Atamer, 2005. Uluslararası Satım Sözleşmelerine İlişskin Birleşmiş Milletler Anlaşması (CISG) Uyarınca Satıcının Yükümlüllükleri ve Sözleşmeye Aykırılığın Sonuçları, Beta Yayınevi.

- Chuah, 2013. Law of International Trade: Cross-Border Commercial Transactions, 5ThEdition, Sweet\&Maxwell.

- Dayığlu, 2011. CISG Uygulamasında Sözleşmenin İhlali Halinde Alıcının Hakları ve Özellikle Alıcının Tazminat Talep Etme Hakkı, On İki Levha Yayıncılık, İstanbul

- Erkan, 2013. CISG Gereğince Alıcının Sözleşmeden Dönmesi, On İki Levha Yayıncılık, İstanbul

- Goode, 2004. Commercial Law, 3rd Edition, Penguin Books, United Kingdom

- Huber, 2008. CISG - Sözleşemeye Aykırılık Halinde Alıcının Hakları", Milletlerarası Satım Hukuku, Editör: Atamer, On İki Levha Yayıncılık, İstanbul 
- Mohs, 2015. "Sözleşmenin Alıcı Tarafından İhlali Halinde Satıcının Sahip Olduğu Hukuki Imkanlar" in Milletlerarası Mal Satımına İlişkin Birleşmiş Milletler Antlaşması (Viyana Satım Sözleşmesi) Şerhi, Editörler: Schwenzer, Çağlayan Aksoy, s.1056.

- Yılmaz, 2013. Milletlerarası Mal Satımına İlişkin Sözleşmeler Hakkında Birleşmiş Milletler Antlaşması (CISG) Uyarınca Sözleşmenin İhlali Halinde Alıcının Hakları, Yetkin Yayınları, Ankara

- Zeytin, 2011. Milletlerarası Mal Satım Sözleşmeleri (CISG), Seçkin Yayıncılık, Ankara 


\title{
Küresel İklim Değişikliği Sorununun Çözümü İçin Yeni Bir Sürdürülebilir Kalkınma Anlayışı
}

\section{A New Approach to Sustainable Development Solution for Global Climate Change Problem}

\author{
Prof. Dr. Serdar Altınok (Gazi University, Turkey) \\ Asst. Prof. Dr. Emine Frrat (Aksaray University, Turkey) \\ Esra Soyu (Aksaray University, Turkey)
}

\begin{abstract}
Globalization notion is encountered not only economically, but also politically, culturally, technologically and ecologically. Environmental problems seen national at first glance can cause regional and subsequently global problems. Climate changes create regional, social and economic problems in terms of effects thereof. Many factors such as continuation of rapid population growth, proliferation of water problems, increase of global warming and irrevocable habits of countries can lead to world pollution and impairment of environment.

Industrialization, population growth and excessive consumption tendency on the one hand and need for balanced use of natural sources such that energy can meet needs of future generations on the other hand has rendered "environment" and "development" subjects substitute for each other. While increase of welfare and happiness of people are aimed with economic development, socio-economical costs caused by global climate change threaten this welfare cycle. A variety of sources extinct due to global warming and some of them cannot be effectively used in a desirable level. This situation prevents economic productivity. Global climate change problem should be reevaluated with not only conventional sustainable development approach but also in a global plane containing new political ecology notions such as "environmental justice" and "climate justice". For this purpose, each of us has a role to play and also, novel law and policies are required that will lead global-scale solutions. In this study, relationship between global climate change and sustainable development approach will be handled within the scope of a new tendency.
\end{abstract}

\section{Giriș}

Dünya jeologlar tarafindan hesaplanan yaklaşık 4.6 milyar yıllık tarihi süreç boyunca her zaman ayakta kalmayı başararak bugünlere gelmiştir. Ancak günümüzde uygarlık ile ekolojik sistem çatışma halindedir. Hızlı nüfus artışının devam etmesi, su sorunlarının yaygınlaşması, küresel ısınmanın ve kirlenmenin artması özellikle ülkelerdeki vazgeçilemeyen alışkanlıklar, dünyanın kirlenmesine ve çevrenin bozulmasına yol açmışır. Sıcak hava tarlaları kurutup, ekinleri yok etmekte, firtınalar daha yıkıcı olmakta ve daha yoğun kuraklıklar yaşanmaktadır. Artan sıcaklık buzulların erimesine yol açmakta, değişen mevsimler, dengesiz hava şartları okyanuslardaki su seviyelerinin artması, ormanların azalması, çöllerin genişlemesi, yeraltı su seviyelerinin düşmesi, balık tarlalarının çökmesi, canlı türlerinin yok olması gibi sonuçlar küresel ısınmayla özetlenmektedir. Günümüzde toplumların çoğunda tüketicilik doğal hale gelmiştir. Tüketim her sene agresif bir şekilde yayılmaya devam etmektedir. Bu kadar yüksek seviyede tüketmek dünyanın yaşamsal ekosistem hizmetlerini verme kapasitesini azaltmaktadır. İnsanlık doğal kaynakları kendilerini yenilenebilmelerine izin vermeyen bir hızda tüketmektedir. Artık pek çok kişi GSYIH' nin ötesine geçmenin ve ekonomik kalkınmanın ne olduğuna dair daha zengin bir kavramsallaştırma oluşturmanın zamanının geldiğinin farkına varmıştır. Bütün dünya ülkelerinin küresel sürdürülebilirlik anlaşması uyarınca, insani kalkınmayı ön planda tutan yepyeni kalkınma stratejilerine ihtiyacı vardır.

İklim değişimleri, etkileri bakımından dünyada çevresel, sosyal ve ekonomik sorun oluşturmaktadır. Küresel ısınma nedeniyle küresel kaynakların birçoğu yok olmakta bir kısmı ise istenilen etkinlikte kullanılamamaktadır. $\mathrm{Bu}$ durum ekonomik verimliliği engellemektedir. Ekonomik kalkınma ile insanların refah ve mutluluğunun arttırılması hedeflenirken, küresel iklim değişikliğinin ortaya çıkardığı sosyo-ekonomik maliyetler bu refah döngüsünü tehdit etmektedir. Küresel iklim değişikliği sorununun sadece klasik sürdürülebilir kalkınma yaklaşımı ile değil, "çevresel adalet", "iklim adaleti” gibi yeni politik ekoloji kavramlarını içeren sürdürülebilir kalkınma stratejilerinin küresel bir düzlem içerisinde yeniden değerlendirilmesi gerekmektir.

İnsanların teknoloji ve bilim alanındaki hızlanan gelişimi sadece 100-150 yılda hayal edilemeyecek hayat şartlarını oluşturmuştur. Günümüzde dünya, enerji ekonomisini yeniden yapılandırmayı ve iklimi istikrara kavuşturmayı sağlayacak teknolojilere sahiptir. Ekolojik dengeler daha fazla bozulmadan ve tehlikeli bir küresel 1sınmayla karşılaşılmadan güvenlik, ekonomi ve iklim krizleri çözülmelidir. Dünyayı kurtarmak için iklimi istikrara kavuşturmak, nüfusa istikrar kazandırmak, yoksulluğu ortadan kaldırmak ve yerkürenin ekosistemlerini iyileştirmek gerekmektedir. 2008 'de ortaya çıkan büyük küresel krizin ülkeleri derinden etkilediği ve hemen 
hemen tüm dengeleri değiştirdiği günümüzde, kuşkusuz birey olarak her birimizin oynayacağı bir rol olduğu gibi küresel ölçekli çözümlere götürecek yeni yasa ve politikalara ihtiyaç vardır.

$\mathrm{Bu}$ çalışmada, küresel iklim değişikliği ve sürdürülebilir kalkınma yaklaşımı arasındaki ilişki bu yeni eğilim çerçevesinde ele alınacaktır.

\section{Küreselleşme ve Çevre Sorunları}

Özellikle ikinci dünya savaşı sonrası bağımsızlığını kazanan ülkelerin bağımlı devletler haline getirilme çabası içerisinde olan kalkınma iktisadı Sovyetler Birliği' nin dağılması ile yeni bir boyut kazanmıştır. İki kutuplu dünyada bir tarafın yanında yer alma gereksinimi ortadan kalkmıştır. Sovyetlerin dağılması ile artan Amerikan yayılmacılığı küreselleşme sürecinin hâkimiyet dönemini başlatmıştır.

Yeni dünya düzeni Doğu bloğunun ve iki kutupluluğun sona ermesinden sonra konuşulmaya başlanmıştır. Yeni dünya düzeniyle soğuk savaş döneminde varolan ancak siyasal sorunların çıkmaması için üstü kapatılan ekonomik sorunlar ülkeler ve siyaset arenasında su yüzüne çıkmıştır. Bu durum dünyanın farklı inanç, düşünce ve ekonomik bloklara bölünmesine neden olmuştur (Binay, 1997). Küreselleşme kavramı son yıllarda sadece ekonomik olarak değil, siyasal, kültürel, teknolojik ve ekolojik olarak da karşımıza çıkmıştır. Küreselleşme sadece ulus devletlerden ziyade ulus ötesi aktörlerin yön verdiği bir süreçle birlikte politik-ideolojik- sosyolojik bir oluşumu ortaya koyan bir dünya yaratmıştır (Kongar, 1997) Küreselleşme sonucu devletlerin yapıları ve IMF (International Monetary Fund), WB (World Bank), WTO (World Trade Organization) gibi uluslararas1 kurumların aracılığı ile bilinen ekonomi modelleri de değişime uğramıştır. Küreselleşme ile mevcut modeller herhangi birinin kazanabileceği bir yarış olmaktan çıkmış, yerini kapitalizmin yeni tiplerine bırakmıştır (Yalçınkaya, 2001).

Yeni dünya düzeniyle ABD, soğuk savaş dönemi ve bunun etrafında şekillenen uluslararası siyaset anlayışının sona ermesinden sonra yeni bir uluslararası işbirliği dönemi başlatmıştır (Bergstresser, 2003). Küreselleşen dünya ile birlikte sınırların ortadan kalkması, gelirlerin uluslararası pazarda paylaşılması beraberinde bir takım sorunlar getirmiştir. Geçmişte kaynak ve sermaye yetersizliği ile yüzleşen ve azgelişmişliğe mahkûm olan ülkeler, yeni dünya düzeninde gelirlerin adaletsiz dağılımı ve kaynakların sermaye sahiplerine akışına engel olamayışından ötürü azgelişmişlik statüsünden kurtulamamaktadır. Belirli ülkeler ekonomik anlamda ilerleme kaydetse de bu ilerleme salt parasal olgularla sınırlı kalmakta toplumun tamamına fayda sağlayacak bileşenler ile buluşamamaktadır. Küreselleşme bir taraftan ülkelerin dünya nimetlerinden daha fazla yararlanmalarını sağlarken, bu ülkelerin dünya konjonktüründe meydana gelen krizlerden etkilenmesine neden olmaktadır.

Çevre; insan ve insanın etrafındaki her şeyi kapsayan ve yaşamın devamı için en önemli koşullardan birisidir. Günümüzde çevresel sıkıntılardan en çok etkilenen varlık insandır. Yine aynı şekilde çevresel yıkımlara neden olan da insandır. Bu karşılıklı etkileşimin ortaya çıkardığı en önemli sonuç; insanın bundan en çok etkilenen varlık olmasına rağmen, bu yıkımın yeniden inşa edilmesinin de yine insana bağlı olmasıdır. Doğal yollarla çevre kendi kendini yenileyebilmesine rağmen, insan eliyle yapılan yıkımlarda çevrenin kendini onarması imkânsız hale gelmektedir. Kendi ihtiyaçlarını karşılamak için her türlü yeteneğe sahip olan ve kendi ihtiyaçlarını karşılamak için her yolu deneyen insan çevreyi korumada yetersiz kalabilmektedir. Bu yetersizlik, kabiliyet eksikliğinden ziyade çalışmamaktan ve sorumsuzluktan kaynaklanmaktadır. Çevresel problemlerin kendini hissettirmesinin insan ömrünün ortalama yaşam süresinden daha uzun olması, "ben yaşarken bir şey olmaz benden sonrakiler için ben niye rahatsız olayım" düşüncesini doğurabilmektedir (Yılmaz vd.,2010). Dünyada ve ülkemizde çevre sorunlarının zaman geçtikçe çok daha ciddi boyutlara ulaştığı; doğayı ve insanlığı tehdit eder hâle geldiği kaçınılmaz bir gerçektir. Küresel ısınmanın yok edici sonuçları ile birebir karşı karşıya geldiğimiz günümüzde, esas problem, çevre sorunlarının önlenmesi, en azından yıkıcı etkilerinin asgariye indirilmesi için şimdiye kadar yapılan çalışmaların ve harcanan çabaların çevrenin mevcut hâliyle korunmasında bile çok da etkili olamadığıdır (Yücel Işsldar, 2008). İlk bakışta ulusal düzeyde görülen çevre sorunları, önce bölgesel, sonrasında da küresel sorunlara neden olabilmektedir. Bu yönüyle geniş anlamda çevre politikasının insan ve doğa arasındaki ilişkileri düzenleme amacı taşıdığı belirtilebilir. Ancak bunun bir politika haline gelmesi için gerekli olan toplumsal iradenin sağlanmasında devlet en önemli aktördür. Küreselleşme süreci ile birlikte devletin yanısıra uluslararası devlet örgütleri, sivil toplum örgütleri ve ulusaşırı şirketlerin de birer önemli aktör haline gelmiş olduğu görülmektedir. Dolayısıyla hem çevre sorunlarının doğasından kaynaklanan ulusaşırı olma hem de küreselleşme sürecinin de etkisiyle çevre politikalarının oluşturulması ve uygulanması çok aktörlü bir yapının karşılıklı işbirliği ve müzakeresi ile olanaklı hale gelmektedir. Bu politikaların başarıya ulaşması ise belirlenmiş olan ilkelerin uygulanabilir olmasına bağlıdır. Bu ilkeler arasında uygulama olanağı bulan ve kabul gören ve belki de en yaygın olan ilkelerden biri sürdürülebilir gelişmedir. Böylece sürdürülebilir gelişme kavramı uluslararası çevre politikalarının ekonomik araçlarından birine dönüşmüştür (Kaplan, 1999). Kavramın büyüme, kalkınma, eşitlik ve çevreciliğin en acil ve ihtilaflı sorunları arasında bir uzlaşmayı temsil ettiği belirtilmektedir (Hayırsever Topçu, 2008). 


\section{Küresel İklim Değişiklikleri ve Dünya}

Kalkınma açısından bakıldığından dünya hükümetlerinin 2015 yılı için belirlediği Binyıl Kalkınma Hedeflerinden birine 2000 yılında ulaşmış durumdadır. Dünyada temiz su kaynaklarına erişimi olmayan insan sayısı 2010 yılında 1990 rakamlarına göre yarı yarıya azalmıştır. Geçtiğimiz on yıl küresel fakirliğin de ciddi şekilde azaldığı bir dönem olmuştur. Bu da diğer bir kalkınma hedefi açısından önemlidir. Öyle ki Londra merkezli ODI dış yardım ile ilgilenen kurum ve kuruluşların önümüzdeki 13 yıl boyunca yardım stratejilerini çoğunlukla Sahraaltı Afrika'daki sayısı giderek azalan çok dar gelirli ülkelere yönlendirmeleriyle ilgili çalışmalar arttırılmıştır. Bazı ölçütlere göre ekonomik zenginliğin ve dünyanın pek çok yerinde temel ihtiyaçların karşılanma oranının arttığı söylenebilir (Worlwatch Enstitüsü, 2013). Ancak küresel iklim değişiklikleri bu olumlu gelişmelere rağmen dünyanın dengesine ciddi bir biçimde zarar vermektedir.

Küresel ısınmanın en büyük nedeni karbondioksit, iklim krizine yol açmaktadır. Küresel 1sınmaya Karbondioksit(CO2) \% 43.1, metan (CH4) \%26.7, gazdaki kurum (Kara Karbon) \%11.9, sülfürheksaflorid (SF6) \%7.8, tetrafloretan (CH2FCF3), karbonmonoksit (CO) \% 6.7, bütan (CH3CH2CH2CH39), azotoksit ( $\mathrm{N} 2 \mathrm{O}$ ) \% 3.8 oranında neden olmaktadır. Güneşin 1sıttığı dünya kendisine ulaşan 1şınları atmosfere geri yansıtarak dengeyi sağlamaktadır. Ancak su buharı, karbondioksit ve metan gazının dünyanın üzerinde oluşturduğu tabii bir örtü, insanlar tarafından atmosfere salınan gazları engellemesi sera etkisi oluşturmasına sebep olmaktadır. Kirliliğin kaynağ1 fosil yakıtlardan sonra insan elinden çıkan karbondioksit olup, her gün atmosfere 90 milyon ton CO2 salınmaktadır (Algore, 2009). Son yıllarda hızlı ve çoğunlukla beklenmedik iklim değişiklikleri yaşanmaktadır. Amerikan Ulusal Havacılık ve Uzay Dairesi'ndeki (NASA) Goddard Enstitüsü'nde görev yapan bilim adamlarına göre 1970'den bu yana yerkürenin ortalama sıcaklığının 0,6 derece yükseldiğini en sıcak havaların son yıllarda yaşandığını belirtmişlerdir. Hükümetlerarası İklim Değişikliği Paneli( IPCC) ise bulunduğumuz yüzyılda 1,1-6,4 derece artacağına ilişkin tahminlerde bulunmakta ve öngörülen 1sı artışının dünyada eşit bir şekilde dağılmayacağını belirtmişlerdir. 2007 IPCC raporunda 1 derecelik artışın toplam canlı türlerinin yüzde 30’unu tükenme tehlikesiyle karşı karşıya bırakacağı konusu incelenmiş ve yüksek sıcaklıklardan ekosistemin etkileneceği vurgulanmıştır (Brown, 2008). Bu gelişmelerin sonucu, gelecekte istikrarlı bir iklimden bahsetmek mümkün gibi gözükmemekte olup, yaşayan canlılar için ölüm kalım savaşı anlamına gelmektedir. İnsanlar için artan gıda fiyatları, kıtlık ve büyük göçlere yol açarak yıkıcı sonuçlar doğuracaktır (Kurtoğlu, 2013). Çevre bilimciler tarafından yüksek sıcaklıklar sonucu özellikle pirinç, mısır, buğday gibi temel besin maddeleri olumsuz etkilenerek verimliliklerinin düştüğü gözlenmiştir. Artan sıcaklıklarla birlikte dağlardaki kar ve buz kütleleri olumsuz etkilenerek, kar yağışı ve yağmur önemli ölçüde azalmaktadır. Dünyadaki Himalaya Dağları, Gangotri Buzulu, Tibet-Qinghai Platosu, Hindistan ve Pakistan Havzası, And Dağları, ABD’nin güneyindeki dağlar, Orta Asya'da Hindikuş, Pamir Dağları gibi birçok kar ve buz kütleleri oluşturacak rezervuarlar, yerkürenin ısınmasından olumsuz olarak etkilenmektedir. Dağlardaki buzların erimesinin yanında Antarktika ve Grönland'ın erimesi deniz seviyelerini yükseltmektedir. Kuzey Kutbu İklim Etkisi Değerlendirme grubu (ACIA) tarafından yapılan araştırmada Kuzey Kutbunun kış mevsimi sıcaklıklarının geçtiğimiz 50 yıl içinde 3-4 derece yükseldiğini göstermektedir. ACIA raporu denizlerdeki buzulların erimesinden o bölgedeki yaşayan tüm canlıların etkileneceğini göstermiştir (Brown, 2008).Örneğin küresel 1sınma sebebiyle buzların erimesi sonucu fok avlamak için uygun alan bulamayan kutup ayılarının birbirini yemeye başlamaları durumun ne kadar ciddi olduğunun sadece bir örneği olarak basına yansımıştır (Kurtoğlu, 2013). Uluslararası Çevre ve Kalkınma Enstitüsü deniz seviyesindeki yükselişin sebebinin buz tabakalarındaki erimeden kaynaklı olduğunu belirterek, bu bölgede yaşayan insan topluluklarının göç etmek zorunda kalacaklarını bildirmişlerdir. Küresel ısınmanın diğer bir olumsuz etkisi de güçlü firtınalar ve kasırgalardır. Örneğin 2004 yılımda Japonya'da ard arda yaşanan 10 tayfun, 2005 yılında New Orleans yakınlarındaki ortaya çıkan Katrina Kasırgası dünyanın en yıkıcı kasırgaları olarak tarihe geçmiştir. Dünyada güçlü kasırgalara karşı çok hassas olan bölgeler bulunmaktadır. ABD’nin Atlas Okyanus'undan Karayip ülkelerine, Doğu ve Güney Doğu Asya Ülkelerinden Pasifik ülkelerine kadar iklim değişmeleri sonucu büyük fırtınalar yaşanabilir. Almanya merkezli Germanwatch, 200 iklim uzmanıyla yaptığı yıllık İklim Değişikliği Performans Endeksi’ni açıklamıştır. 58 ülkenin iklim değişikliği hususundaki politikaları saldıkları karbondioksit oranları ve emisyonlarına göre hesaplanmıştır. Bu endekse göre hiçbir ülke çok iyi performans göstermemiştir. İngiltere, İsveç, Almanya iyi kategoriye giren üç ülke olmuştur. Türkiye ise en kötü performans gösteren ülkeler arasında yer almaktadır. Türkiye'den sonra gelen en kötü performansa sahip ülkeler; Kazakistan, İran ve Suudi Arabistan'dır. Ayrıca Türk Hükümeti iklim değişikliği politikaları başlı̆̆ı altındaki ülkeler arasında Suudi Arabistan, Kanada, İran, İtalya'dan sonra beşinci sırada yer almaktadır. Yeryüzünde nüfusun devamlı arttığı şehirleşmenin giderek hızlandığ 1 ve küresel iklim değişikliğinin bütün tatlı su kaynaklarını olumsuz yönde etkilediği dünyamızda, tatlı su kaynaklarının uzak olmayan bir gelecekte, talebi karşılayamama durumu söz konusu olacaktır. Dünyadaki iklim değişiklikleri bir yandan da sıkıntısını arttırmaktadır. Su sıkıntısı nehirlerin kuruması, göllerin yok olması yeraltı su seviyelerinin düşmesi gibi durumlarda daha net ortaya çıkmaktadır. Dünyadaki pek çok ülke artan su ihtiyaçlarını yeraltı sularından karşılamaktadır. Bugün dünyanın her köşesinde Çin'den Hindistan'a ABD'den Suudi Arabistan'a kadar yeraltı su seviyelerinde düşme nedeniyle su sıkıntısı yaşanmaktadır. Sulama sıkıntısı tarım alanlarının azalmasına ve gıda tüketimindeki sorunların artmasına neden olmaktadır. Günümüzde su sadece kentlerin değil ulusların sorunu 
haline gelmiş durumdadır. Çin, Hindistan, Pakistan, Orta Doğu ile Kuzey Afrika'daki ülkelerin çoğu su sıkıntısı çekmektedir (Brown, 2008). Gelecekte savaşların su yüzünden çıkacağı söylenmektedir. Son yıllarda özellikle Çin, Hindistan, Yemen gibi ülkelerde kentler ile çiftçiler arasında su rekabetleri yaşanmaktadır. Kenya'da kabileler arasında, İsrail ve Filistinliler arasında, Irak, Türkiye ve Suriye'de Fırat nehri üzerindeki barajların yetersiz olması dolayısıyla bu bölgede su sıkıntısının baskısı giderek artmaktadır. Türkiye ve Yunanistan arasında Meriç Nehri, Türkiye ve Bulgaristan arasında Meriç ve Tuna Nehri, Türkiye ve Gürcistan, Ermenistan arasında ayrı ayrı Çoruh, Posof Çayı, Kura Nehri, Arpaçay, Aras Nehri, Türkiye ve İran arasında Aras, Sarısu ve Karasu, Türkiye ve Irak arasında Fırat ve Dicle, Türkiye ve Suriye arasında Fırat, Dicle, Asi Nehri, Afrin, Çağçay ve Küvelik Suyu gibi nehirleri nispeten bol olan ülkemiz, Fırat ve Dicle Nehirleri’nin suyu için, İsrail, ABD ve AB kıskacındadır. Küresel iklim değişiklerinin bölgede doğuracağı kuraklığa bağlı kullanılabilir su kaynaklarımızdaki azalma büyük bir tehlike olarak karşımıza çıkmaktadır (Kurtoğlu, 2013).

İnsanların artan tüketimleri, ormanları, çiftlikleri ve balık tarlalarını büyük bir baskı altına almaktadır. Küresel ısınmadan dolayı tükenen balık türleri aşırı avlanmanın da bir sonucu olarak görülmektedir. Tükenme ve yok olma sadece denizlerde değil her türden canlıda görülmektedir. Artan sıcaklık, kimyasal kirlilik bitki ve hayvan türlerini yok eden başlıca tehlikeler arasında gelmektedir. Özellikle kuşlar, arılar, şempanzeler, kaplumbağalar, balıklar, büyük kediler ve nice hayvan türleri yok olma tehlikesiyle mücadele etmektedir (Brown, 2008).

\section{Sürdürülebilir Kalkınma ve Küresel Isınma}

Sürdürülebilirlik kavramı üç unsuru barındırmaktadır. Bunlar, sosyal, ekonomik ve çevresel sürdürülebilirliktir. Sosyal sürdürülebilirlik, toplumun 'ahlaki sermaye' sinin, toplumsal, dinsel ve kültürel etkileşimlerle sürdürülmesi ve yenilenmesidir. Ekonomik sürdürülebilirlik ise, fiziki sermayenin (malzeme, enerji ve doğal kaynaklar) devamlılığıdır. Çevresel sürdürülebilirlik kavramının yeterli bir içerik kazanması için sosyal ve ekonomik sürdürülebilirlikle birlikte gerçekleşmesi gerekmektedir. Sosyal ve ekonomik sürdürülebilirlikle birlikte ekosistemin sağlığını bozmadan insan ihtiyaçlarının karşılanması gerekmektedir. Bu yüzden iklim değişikliğinin sürdürülebilir kalkınma çerçevesinde ele alınması gerekmektedir (Goodland, 1995).

Dünyadaki "sürdürülemez" kalkınmanın önündeki engellerin başında yoksulluk, nüfus artışı ve etkin olmayan kaynak kullanımı ve zengin ülkelerdeki israfa kaçan tüketim gelmektedir. Yeşil alanların azalması, besin gereksinimini karşılayan arazinin giderek küçülmesi, hava kirliliğinin artışı, ozon tabakasının delinmesi, iklim değişikliği ve ekolojik dengenin bozulması gibi sorunlar, uluslararası ortaklaşa önlem almayı kaçınılmaz hale getirmiştir (Ögütçü, 2004). Bu süreçte gerçekleşen "tüketim toplumu” eleştirisi ekolojik krizin en önemli baş aktörünün sanayileşmiş ülkeler olduğu ve bu yüzden öncelikle bedel ödemesi gereken ülkelerin bu ülkeler olması gerektiği şeklinde var olan düşünce "sürdürülebilir kalkınmaya yönelik üçüncü dünyacı eleştirel tutumu" kuvvetlendirmiştir. $\mathrm{Bu}$ yaklaşıma göre; sürdürülebilir kalkınma ile ilgili politikaları üçüncü dünyanın yoksul ülkelerinin kalkınma sorununun çözümünü engelleyici boyutta olmaması; dünyasal eşitsizliğin ve yoksulluğun ortadan kaldırılması durumunda bu politikaların dünyada geçerli olabileceği vurgulanmıştır. Dünya'nın etkin sözcülerinden olan Hindistan Başbakanı İndira Gandhi'nin 1972'deki Stockholm Çevre Konferansı'nda yer alan şu sözleri bu eleştirel tutumu çarpıcı bir şekilde özetlemektedir: "Yoksulluk ve karşılanmayan insan gereksinimleri, en önemli kirlenme biçimleri değil midir? Köylerimizde ve gecekondularımızda yaşayan kitlelere, yaşamlarının kaynağında mikroplar içerisinde bulunurken havayı, denizleri ve akarsuları temiz tutmanın zorunluluğunu nasıl anlatabiliriz? Çevreyi, yoksulluk koşulları içerisinde iyileştirmek imkânsızdır" (Keleş, vd. 2009)

Sürdürülebilir Kalkınma (SK) kavramının ardında önemli bir fikir bulunmaktadır: "Günümüzde ve gelecekteki kuşaklar da dâhil olmak üzere herkes için çok daha yüksek bir yaşam kalitesine erişmek felsefesi”. Kavram, ilk kez 1987 Brundtland Raporu'nda "bugünün ihtiyaçlarının, gelecek kuşakların kendi ihtiyaçlarını karşılama kabiliyetlerinden ödün vermeden karşılanması" olarak tanımlanmış, 1997 yılında Amsterdam Antlaşmasıyla Avrupa Birliği' nin (AB) temel hedefi haline gelmiştir. Düşük ya da yüksek gelir grubunda olanlar, 'herkesin yaptığını yaparak kendi payını arttırmaya çalışınca' dünya çevresel olarak sürdürülebilir olmayan bir alana doğru ilerlemiştir. Bir yandan sanayileşme, nüfusta meydana gelen artış ve aşırı tüketim eğilimi diğer yandan doğal kaynakların, enerjinin gelecek nesillerin ihtiyacını karşılayabilecek şekilde dengeli kullanılması ihtiyacı 'çevre' ve 'kalkınma' kavramlarını birbirlerinin yerine kullanılabilecek duruma getirmiştir. Bu yüzden biyosferle uyum içinde küresel bir sürdürülebilirliğe ihtiyaç duyulmuştur (European Commission, 2013)

Birleşmiş Milletler Çevre Konferansı, ekoloji ve kalkınma arasındaki dengeyi ön plana çıkaran "eko kalkınma" politikası çerçevesinde sürdürülebilir kalkınmanın iki temel öğesi olan "insan merkezlilik" ve "gelecek nesillerin kaynaklarının korunması" konularını gündeme getirmiştir. Ancak sürdürülebilir kalkınmanın küresel boyutta aktif bir politika olarak kullanılması 1992 Rio Zirve'sinden sonra mümkün olabilmiştir (Dulupçu, 2010).

Bu konu 1997 Kyoto Protokolü ile desteklenmiştir. Protokol ancak 2005 yılı Şubat ayında 55 ülkenin protokole onay vermesi ile yürürlüğe girebilmiştir. Türkiye de 6 Şubat 2009'da Kyoto protokolünü imzalamıştır (Worldwatch Enstitüsü, 2013). 2001 Gothenburg Avrupa Konseyinde, AB Ülkeleri, "Daha İyi Bir Dünya İçin Sürdürülebilir Bir Avrupa ve Sürdürülebilir Kalkınma için ise Avrupa Stratejisi” adında 2010 yılı hedefiyle 
Sürdürülebilir Kalkınmanın bir sorun olduğu ifade etmişlerdir. Stratejide SK konusunda odak nokta olarak sayılabilecek öncelikli alanlar; İklim Değişikliği ve Temiz Enerji, Sürdürülebilir Ulaşım, Sürdürülebilir Tüketim ve Üretim, Doğal Kaynakların Korunması, Halk Sağlığı ve Sosyal Refah, Nüfus ve Göç ile Küresel Yoksulluk temaları olmuştur (European Commission, 2013) 2007 yılında ortaya konulan Sürdürülebilir Kalkınma Stratejisi ile ilgili raporda, küresel ısınma ve enerjinin de içinde bulunduğu öncelikli alanlarda, bu konuda ilerlemenin somut bir eyleme dönüşmediği de ifade edilmiştir (AB-Türkiye Görünüm, 2000). 2012'de Güney Afrika'da gerçekleştirilen Dünya Sürdürülebilir Kalkınma Zirvesi’ nde iklim değişikliği konusunda beklenen ve istenilen sonuca ulaşılamamıştır (Dulupçu, 2010)

Yoksullukla savaş, doğal kaynakları adaletli bir şekilde kullanma, nüfus denetiminin yapılması ve çevre dostu teknolojilerin üretilmesi, bu teknolojilerin geliştirilmesi ve küresel ısınma sürdürülebilir kalkınma ile doğrudan ilişkilidir. Küresel ısınma nedeniyle küresel kaynakların birçoğu yok olmakta bir kısmı ise istenilen etkinlikte kullanılamamaktadır. Bu durum ekonomik verimliliği engellemektedir. Sürdürülebilir kalkınmanın bir değişim süreci olması nedeniyle, iklim değişikliği ve çevre sorunu değerlendirme sistemleri içerisinde niceliksel olarak ifade edilebilmektedir (Keleş, Hamamcı, 1998). Mevcut durumun tespiti ve izlenmesi konusunda yapılan ölçüm sistemlerinin başında sürdürülebilir kalkınma endeksleri, ekolojik ayak izi, Çevresel Performans Endeksi (ÇPE), Çevresel Sürdürülebilirlik Endeksi (ÇSE), Gerçek İlerleme Göstergesi yer almaktadır (Nükhet, 2013). 2010 yılında yapılan Çevresel Performans Endeksi sonucunda kaynakların yeterince etkin kullanılmadığı hatta küresel boyutta çevresel tahribatın şiddetlendiği, iklimin küresel boyutta değiştiği sonucu çıkmıştır (Satır ve Reyhan, 2013). Çevresel Sürdürülebilirlik Endeksi (ÇSE)'nde ise az gelişmiş ülkelerin kısa sürede kalkınma sorununu çözmek zorunda olduklarından dolayı dünya ekosistemine yeni baskılar oluşturmaması için gelişmiş ülkelerin önemli ölçüde yükümlülükler üstlenmesi gerektiği sonucu çıkmıştır (Yıkmaz, 2011). Ekolojik ayakizi ise; tabiatın taşıma kapasitesini ölçmek için geliştirilmiş olan bir yöntemdir ve sonuçları bir ülkenin sürdürülebilir kalkınma derecesinin göstergesi olarak kullanılmaktadır. 1980 li y1llardan itibaren ekolojik ayakizi ile biyolojik kapasite arasındaki fark sürekli açılmaktadır. Bu durum ülkelerin tüketim düzeylerinin yüksek olmasını ve dünya kaynaklarını aşırı derecede baskı altında tuttuklarını göstermektedir (Günsoy, 2006)

Son 20 yılda dünyada yaşanan gelişmeler ve değişimler bu gündemin daha da güçlendirilmesi ve desteklenmesine olan ihtiyacı artırmıştır (Kalkınma Bakanlığı, 2012). Gerçekte Sürdürülebilir kalkınmanın küresel ısınma ile ilgili olduğu gerçeği ortadadır. Çünkü küresel ısınma nedeniyle küresel kaynakların çoğu yok olma tehlikesiyle karşı karıya kalmakta bir kısmı iste istenilen etkinlikte kullanılmamaktadır. Bu durum ise ekonomik verimliliği büyük ölçüde engellenmektedir. İklim değişikliği' nin doğrudan ve parasal olarak ölçülebilen zararları UNEP tarafından Johannesburg Zirvesinde yayınlanmıştır. Zirve sonrasındaki değerlendirme raporunda 20. Yüzyıl'daki iklimsel afetlerin yılda \%10 hızla şiddetlenip sıklaştı̆̆ belirtilerek 1987-2002 döneminde ödenen hasar tazminatlarının 1 trilyon \$ düzeyine eriştiği ve 2002 zararının 150 milyar \$ olduğu ifade edilmektedir. İklim değişikliği ile ilgili gerekli önlemler alınmadığı sürece, küresel 1sınmanın dünya ekonomisine 2100 yılına kadar birikimli maliyetinin 2 katrilyon \$ civarında olacağı öngörülmektedir. Bu büyüklük dünya üretiminde yetinin 2 katrilyon $\$$ civarında olacağı öngörülmektedir. Bu büyüklük dünya üretiminde yıllık \% 6-8 oranında bir küçülmeyi göstermektedir. Ortalama 4 derecelik bir ısı artışının yiyecek sektöründe 9.9 milyar $€$, akaryakıt sektöründe 5.9 milyar $€$ ve bankacılık sektöründe 8.9 milyar $€$ sermayeyi riske atacağı ve olumsuz sonuçlara sebep olacağı tahmin edilmektedir. Ayrıca küresel 1sınma doğrudan insan sağlığını da tehdit edeceğinden dolayı artan sayıda ölümlere de yol açacağı düşünülmektedir (United Nations Environment Programme, 2002). Dünyanın görünümü dikkate alındığında küresel iklim değişikliğinin getirdiği sosyoekonomik maliyetler göz önünde bulundurulduğunda; "sürdürülebilir kalkınma" stratejilerinin, yeni çevre sorunları dikkate alınarak, "iklim adaleti”, "çevresel adalet" vs. gibi kavramlarla birlikte yeniden değerlendirilmesi gerekmektedir (Reyhan, 2013).

Dünyada bir yandan hizlı ekonomik büyümeden kaynaklanan diğer bir yandan ise yoksulluktan kaynaklanan sorunlar vardır. Yeşil alanların azalması, hava kirliliğinin artışı, ozon tabakasının delinmesi, iklim değişikliği ve ekolojik dengenin bozulması gibi sorunlar, uluslararası ortaklaşa önlem almayı kaçınılmaz hale getirmiştir.

\section{Küresel İklim Değişikliği Sorunu Çözmek İçin Yeni Bir Sürdürülebilir Kalkınma Yaklaşımı}

Küresel iklim değişikliği/küresel ısınma sorununa klasik sürdürülebilir kalkınma yaklaşımı ile çözüm bulunabileceği yönündeki yaklaşımların geçici çözümler getireceği düşünülmektedir.

Yeni sürdürülebilir kalkınma yaklaşımı; çevre dostu bir ekonomik sistem için gereken yapılandırma üzerinde durmaktadır. Çevresel adalet fikrinde ekolojik krizin nedenleri üzerine odaklanılarak, ekolojik krizin oluşmasında en büyük pay sahibi olan sanayileşmiş ülkelerin çözüm sürecinde en fazla yükümlülüğü alması gerektiği temel alınmış, sürdürülebilir kalkınmanın içerdiği 'sosyal adalet'in daha iyi hissedilmesi hedeflenmiştir (Dobson, 2003). İklim adaleti kavramında iklim değişikliğinde en büyük paya sahip olan sanayileşmiş/zengin Kuzey ülkelerinin azgelişmiş/gelişmekte olan Güney ülkelerine 'ekolojik borç' yükümlülüğünün olduğu belirtilmektedir (Roberts ve Parks, 2007). Kuzey'den Güney’e iklim borçlarının tazminatı, zenginlerin aşırı 
tüketimlerine sınırlamaların getirilmesi bu hareketin temel hedefi olmuştu (Benlisoy, 2009). İklim değişikliklerinin en acımasız bedelini, hem zengin hem de yoksul ülkelerde yaşayan yoksullar ödemektedir. Uluslararası raporlara göre saatte 300 çocuk yetersiz beslenme sebebiyle ölmektedir.

Sanayileşmiş ülkelerdeki sağlık sorunlarının başında kalp hastalıkları, kanser, obezite ve sigaranın etkisi yoğun biçimde görülmekte olup, gelişmekte olan ülkelerde bulaşıcı hastalıklar (AIDS, ishal, solunum yolu, verem, sıtma, kızamık gibi) daha yaygındır. Yoksullukla mücadele etmek ve nüfusun istikrarlı bir şekilde devam etmesini sağlamak için en önemli yollardan birisi herkese eğitim imkanı sunabilmektir. UNICEF, WHO (Dünya Sağlık Örgütü), BM gibi birçok uluslararası kuruluşun faaliyetleri, çoğu ülkede başarılı sonuçlar vermiştir. Toprak tabakasını korumak amacıyla toprak sürme yöntemleri, uzun ömürlü bitkilerin ekilmesi, kuraklığga ve soğuğa daha dayanıklı ürünler yetiştirme, aşırı otlatmayı ortadan kaldıran yöntemler, deniz rezervleri ya da deniz parklarının oluşturulması, daha verimli sulama teknolojileri kullanma, gelişmekte olan ülkelere maddi destek sağlayan ülkelerdeki tarım sübvansiyonlarında reformlar, suyun israf edilmesine neden olan su ve enerji sübvansiyonları kaldırma uygulamaları, az trafik, temiz hava imkanı sunan ulaşım sistemleri yeniden yapılandırılmaktadır. Dünyanın bir çok yerinde otopark için verilen dolaylı desteklerin kaldırılması, metronun kullanışlı daha uygun fiyatlarda olması, vergi sisteminin değiştirilerek toplu ulaşım araçlarını kullananların ücretsiz otopark hakkı kazanmaları, kentte otomobillerin girmesinin yasak olduğu alanlar oluşturmaları yenilikçi uygulamalardır. Fosil yakıtlar enerji ekonomisini küreselleştirirken, yenilenebilir kaynaklar ekonomiyi yerelleştirecektir. Yenilebilir altyapı kurulduğunda yakıt maliyeti sıfıra düşecektir. Yenilebilir enerji verimliliği arttıracak, maliyeti düşürecek, inovasyon sürecini hızlandıracak, araştırma ve geliştirme teşviklerini arttıracak, enerji arzı sağlanacak, sürdürülebilirlik kazandırılacaktır. Hemen hemen her sektörde verimli üretim sistemlerinden ve geri dönüşümden yararlanılarak enerji tüketimi azaltılabilecektir. Avrupa Birliği ve UNESCO tarafından çevre dostu oluşu nedeniyle desteklenen küçük ve orta ölçekli işletmeler olan nehir tipi hidroelektrik santraller özellikle kırsal kesimde istihdam olanakları yaratması ve o kırsal bölgenin kalkınması üzerine olumlu etkileri olmasından dolayı önemlidir. İklime zarar vermeyen, havayı kirletmeyen yeni bir enerji ekonomisi için gerekli teknolojilere sahip olunan dünyada harekete geçmek için acele edilmesi gerekmektedir (Brown, 2008). İklim krizinin çözümü için kapitalizmin güçlü yönlerinden yararlanmanın yeni yolları bulunmak zorundadır. Daha uzun vadeli ve sorumluluk taşıyan bir sürdürülebilir kapitalizm biçimine ihtiyaç duyulmaktadır. Bunun için günümüzdeki kapitalist sistem anlayışının yeniden ele alınması, ekonomiye bilimsel metotların eklenmesi gerekmektedir. Bir yandan ekoloji genel olarak ekonominin bir kolu haline gelmeli diğer yandan da davranışsal ekonomi, biyofiziksel ekonomi ve benzeri alanlarla geliştirilmelidir (Algore, 2009).

\begin{tabular}{|c|c|c|c|}
\hline & Mevcut Ekonomik Model & Yeşil Ekonomi Modeli & Ekolojik Ekonomi Modeli \\
\hline $\begin{array}{l}\text { Birincil } \\
\text { politika hedefi }\end{array}$ & $\begin{array}{l}\text { Daha fazla: Klasik anlamda } \\
\text { GSYİH ile ölçülen ekonomik } \\
\text { büyüme. Varsayımları büyümenin } \\
\text { eninde sonunda diğer bütün } \\
\text { sorunlara deva olacağına dayanır. } \\
\text { Daha çok her zaman daha iyidir. }\end{array}$ & $\begin{array}{l}\text { Daha fazla ama daha düşük bir } \\
\text { çevresel etki ile: karbon salımı } \\
\text { ve diğer materyal ve enerji } \\
\text { etkisiyle bağlaşığı kesilmiş bir } \\
\text { GSYİH büyümesi. }\end{array}$ & $\begin{array}{l}\text { Daha iyi: Odak noktasında sadece büyüme } \\
\text { değil gerçek anlamında sürdürülebilir insan } \\
\text { refahının iyileştirilmesi anlamına gelen } \\
\text { 'Kalkınma' var. Büyümenin çok önemli } \\
\text { olumsuz yan etkilerinin olduğunun kabulü }\end{array}$ \\
\hline $\begin{array}{l}\text { Gelişmenin } \\
\text { temel ölçüitü }\end{array}$ & GSYİH & $\begin{array}{l}\text { Hala GSYİH, fakat doğal } \\
\text { sermaye üzerindeki etkileri göz } \\
\text { önünde bulundurularak }\end{array}$ & $\begin{array}{l}\text { Sürdürülebilir Ekonomik Refah Endeksi, } \\
\text { Gerçek İlerleme Göstergesi (GİG) ya da } \\
\text { gerçek refahın diğer iyileştirilmiş gösterge. }\end{array}$ \\
\hline $\begin{array}{l}\text { Ölçek/taşıma } \\
\text { kapasitesi/ } \\
\text { çevrenin rolü }\end{array}$ & 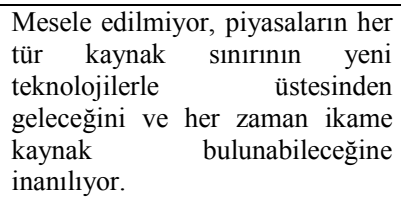 & $\begin{array}{lcr}\text { Dikkate } & \text { alınıyor, fakat } \\
\text { bağlaşımın } & \text { kesilmesiyle } \\
\text { çözülebileceği düşünülüyor. }\end{array}$ & $\begin{array}{l}\text { Ekolojik sürdürülebilirliğin temel } \\
\text { belirleyicilerinden biri olarak görülüyor. } \\
\text { Doğal sermaye ve ekosistem hizmetlerinin } \\
\text { sonsuz bir şekilde ikame edilemez olduğu ve } \\
\text { gerçek sınırların olduğu düşünülüyor. }\end{array}$ \\
\hline $\begin{array}{l}\text { Bölüşüm/ } \\
\text { yoksulluk }\end{array}$ & $\begin{array}{l}\text { Bahsi geçse de politikacılara } \\
\text { havale ediliyor: 'Yükselen' suyun } \\
\text { bütün gemileri yukarı kaldıracağı } \\
\text { varsayılıyor. }\end{array}$ & $\begin{array}{l}\text { Önemli bir sorun olarak } \\
\text { addediliyor. } \\
\text { yeşillendirmenin yoksulluğu da } \\
\text { azaltacağı } \\
\text { Tarımın iyileşmënülülyor. } \\
\text { yeşil işler sayesinde. }\end{array}$ & $\begin{array}{l}\text { Temel endişelerinden biri. Yaşam kalitesini } \\
\text { ve sosyal sermayeyi doğrudan etkiliyor ve } \\
\text { ekonomik büyüme yoksulluğu genellikle } \\
\text { artırıyor: Hızla yükselen sular sadece yatları } \\
\text { yukarı kaldırırken yalpalayan küçük } \\
\text { kayıkları alabora eder. }\end{array}$ \\
\hline $\begin{array}{l}\text { Ekonomik } \\
\text { verimlilik ve } \\
\text { kaynak } \\
\text { paylaşımı }\end{array}$ & $\begin{array}{l}\text { Temel mesele ama sadece piyasa } \\
\text { ürünleri ve hizmetlerine (GSYİH) } \\
\text { ve piyasa kurumlarına dair. }\end{array}$ & $\begin{array}{l}\text { Doğal sermayenin de verimli } \\
\text { kullanılması gerektiği ve piyasa } \\
\text { kararlarına dâhil edilmesi } \\
\text { gerektiği düşünülüyor. }\end{array}$ & $\begin{array}{l}\text { Temel mesele ama hem piyasa mallarını hem } \\
\text { de piyasa dışı mal ve hizmetlerle onların } \\
\text { etkilerini içeriyor. Gerçek verimlilik ve } \\
\text { kaynakların doğru dağılımı için doğal ve } \\
\text { sosyal sermeyenin değerine vurgu yapılması } \\
\text { gerekir. }\end{array}$ \\
\hline $\begin{array}{l}\text { Mülkiyet } \\
\text { hakları }\end{array}$ & $\begin{array}{l}\text { Özel mülke ve klasik piyasalara } \\
\text { vurgu var. }\end{array}$ & $\begin{array}{lcr}\text { Piyasanın } & \text { ötesinde } & \text { araçlara } \\
\text { gereksinim } & \text { duyulduğu kabul } \\
\text { ediliyor. } & & \end{array}$ & $\begin{array}{l}\text { Sistemin doğasına ve ölçeğine uygun şekilde } \\
\text { bir özel mülkiyet rejimi ve hakların } \\
\text { sorumluluklarla ilişkilendirilmesi arasında } \\
\text { bir denge kurulması gerektiğine vurgu. Ortak } \\
\text { mülkiyet kurumlarına daha büyük bir rol } \\
\text { biçiyor. }\end{array}$ \\
\hline Hükümetin & $\begin{array}{l}\text { Hükümet } \quad \text { müdahalesinin } \\
\text { minimize edilmesi ve özel ve }\end{array}$ & $\begin{array}{l}\text { Doğal sermaye dışsallıklarının } \\
\text { içerilmesi } \quad \text { için } \quad \text { hükümet }\end{array}$ & $\begin{array}{l}\text { Hükümet merkezi rol oynuyor. Hatta hakem, } \\
\text { kolaylaştırıcı ve brokerlik gibi ortak varlık }\end{array}$ \\
\hline
\end{tabular}




\begin{tabular}{|l|l|l|l|l|}
\hline rolü & $\begin{array}{l}\text { piyasa kurumlarıyla ikame } \\
\text { edilmesi. }\end{array}$ & $\begin{array}{l}\text { müdahalesinin gerektiği kabul } \\
\text { ediliyor. }\end{array}$ & $\begin{array}{l}\text { kurumlarının sahip olması gereken yeni } \\
\text { fonksiyonlarla birlikte. }\end{array}$ \\
\hline $\begin{array}{l}\text { Yönetim } \\
\text { prensipleri }\end{array}$ & $\begin{array}{l}\text { 'Bırakınız yapsınlar' piyasa } \\
\text { kapitalizmi. }\end{array}$ & $\begin{array}{l}\text { Hükümete } \\
\text { duyulduğunun kabulü. }\end{array}$ & $\begin{array}{l}\text { Sürdürülebilir yönetişime dair Lizbon } \\
\text { prensipleri. }\end{array}$ \\
\hline
\end{tabular}

Tablo 1. Mevcut, Yeşil ve Ekolojik Ekonomi Modellerinin Temel Özellikler Kaynak: (2014) Worldwatch Enstitüsü Dünyanın Durumu 2013 Sürdürülebilirlik Hala Mümkün mü? Editör: Linda Starke Türkiye Işs Bankası Kültür Yayınları e Çev. Cana Ulutaş Ekiz- Çă̆rı Ekiz, s.183.

\section{Sonuç}

Bu yeni dünya düzenine küreselleşmeyle birlikte öyle hızlı girildi ki çevresel bozulmalara engel olunamadı. Geriye dönüş mümkün olamadığı için günümüz ve geleceğimiz kurtarılmak zorundadır. Bunun için hatalardan geri dönülmesi ve küresel bozulmanın hızla tersine döndürülmesi gerekmektedir. Karşı karşıya olduğumuz sorunun büyüklüğü ve aciliyeti için dünya sürdürülebilir bir ekonomik gelişme yoluna girmek zorundadır. Sürdürülebilir kalkınma için şu anda mevcut olan etkin çözümlerin yanında uluslararası katılımın sağlandığ kapsamlı stratejiler izlenmelidir. Bireysel çabalarında önemli olduğu bu konunun yenilikçi hükümet politikaları ile desteklenmesi de gerekmektedir. Ekonomik kalkınmayı sürdürülebilen bir küresel ekonomi haline getirmek için gerçekleri yansıtan bir piyasa oluşturmak gerekmektedir. Vergilerin yeniden yapılandırılması ve dışsallıkların hesaba katılması, dışsallıkların kurumsal olarak raporlanması, gelir dağılımındaki adaletsizliğin azaltılması, ekolojik hizmetler için iyi bir fiyatlandırma sistemi oluşturulması gerekmektedir. Kömür ve petrolün gerçek çevresel maliyetini yansıtacak şekilde karbona vergi koymak, emisyon üst sınır ve ticaret sistemi kullanılarak CO2 miktarını sınırlamak, CO2 emisyonlarını Temiz Hava Anlaşması gibi yasalarla düzenleme altına almak seçenekler arasındadır. Finansal kurumların kaldıracını denetlemek için zorunlu karşılık ve sermaye yeterlilik oranının kullanılması, beyan zorunluluklarının artırılması, konsorsiyum bankacılığının arttırılması, faizin vergiden düşülebilmesinin ortadan kaldırılması, çevresel vergi değişiklikleri gibi uygulamalar çevreye zararlı davranışların engellenmesini sağlarken ekonomik kalkınma için de bir firsat olabilecektir. Bozulan çevresel destek sistemlerinin iyileştirilmesi ve yoksulluğun önlenmesi için, küresel ve ulusal güvenliğin sağlanması, etkin bir kriz yönetiminin sağlanması, zayıf ve çökmekte olan devletler için harekete geçilmesi, tehlikeli bir dünyada esneklik kavramının geliştirilmesi, sürdürülebilir bir makroekonominin inşa edilmesi gerekmektedir. Bu noktada ekonomik planlar ekolojik duruma göre değiştirebilir, sürdürülebilir olan "kalkınma politikası" ile herkese yüksek bir yaşam kalitesi sağlayabilir hale getirilmelidir. Dünya nüfusu, temiz bir şekilde sağlıklı bir dünyada yüksek kaliteli ve sürdürülebilir bir yaşamdan vazgeçmeden yaşama şansı elde etmeyi ümit etmelidir. Zengin ve canlı bir permakültür oluşturmak için önümüzde fiziksel ve teknik imkanlar kullanılmalıdır. $\mathrm{Bu}$ imkânı gören insanlık bu permakültürü sorumluluk projesi haline getirebilmelidir. İslam dini başta olmak üzere dünyanın büyük inançları çevremizin sağlığını koruma, bize sunulan bolluğun kıymetini bilme değerine ilişkin önemli ve büyük esaslar içermektedir. İnsan hayatında bu inanç, etik yaşam sürdürmek isteyenler için önemli bir yol göstericidir.

$\mathrm{Bu}$ anlayışın yol göstericiliğinde yaklaşılan çevre konusu; bizim için rolümüzü yerine getirmede, gerekli olan değişiklikleri nesillerce sürecek bir bağlılıkla devam ettirme ve pekiştirmede önemli bir rol oynayacaktır.

\section{Kaynakça}

- AB-Türkiye Görünüm, 2000. “Avrupa Komisyonu Türkiye Delegasyonu, AB Türkiye Görünüm, Sürdürülebilir Kalkınma”, Sayı:12, 2000, s. 2-3.

- Algore, 2009. “Tercih Sizin İklim Krizinin Çözümü İçin Bir Plan”, Optimistik Yayınları, Hazırlayan: Mutlu Dinçer, s. 304-316

- Barlas, N., 2013. “Küresel Krizlerden Sürdürülebilir Topluma Çağımızın Çevre Sorunları”, Boğaziçi Üniversitesi Yayınları, Bask1: 1, s.185-190, İstanbul.

- Benlisoy, Stefo., 2009. “Çözüm İklim Adaleti Hareketi”, www.ekolojistler.org, Erişim Tarihi: 19.12.2009

- Bergstresser, H., 2003. “Ufuktaki yeni dünya düzeni”,http://www.dwelle.de/turkish/yorum/332731.html

- Binay, M., 1997. “1997'de Yeni Dünya Düzeni” http://www.turkiye.net/mbinay/review96/1997.htm,

- Dobson, Andrew, 2003. "Introduction, Fairness and Futurity/Essays on Environmental Sustainability and Social Justice”, (Ed.Andrew Dobson), Oxford Press, s. 3-4.

- Dulupçu, A., 2010. "Sürdürülebilir Kalkınma Politikasına Yönelik Gelişmeler", Başbakanlık Dış Ticaret Müsteşarlığ1, http://sosyalbilimler.sdu.edu.tr/PDF/yil2_sayi4_08.pdf, Erişim Tarihi: 22.10.2012

- $\quad$ European Commission, 2013.

http://www.oxfordscholarship.com/view/10.1093/0198294891.001.0001/acprof-9780198294894chapter-2,Erişim Tarihi: 22.07.2013 
- Goodland, Robert. 1995. "The Concept of Environmental Sustainability" Annual Review of Ecology and Systematics Thesis: 26, ss: 1-24.

- Günsoy, B., 2006. "Piyasa Dostu Sürdürülebilir Kalkınma Politikaları: Eleştirel Bir Yaklaşım”, Mevzuat Dergisi, Sayı: 101.

- Yalçınkaya, T., 2001. "Sanayi ve Bilgi Toplumlarında Rekabet Ekonomisi” Rekabet Bülteni Dergisi, ESC Consulting Yayın1, Y11: 2001, Say1:5, .s.10.

- Hayırsever Topçu, F., 2008. “Küreselleşme ve Uluslararası Çevre Politikaları: Yönetimden 'Yönetişim'e Geçiş Sorunu”, Turhan Kitabevi, Ankara.

- Kalkınma Bakanlığı, 2012. “Türkiye’ nin Sürdürülebilir Kalkınma Raporu: Geleceği Sahiplenmek, En Iyi Uygulama Örnekleri”, ISBN: 978-605-466701-7, s.1 Ankara.

- Kaplan, A., 1999. “Küresel Çevre Sorunları ve Politikaları”, Mülkiyeliler Birliği Vakfı Yayınları, Ankara.

- Keleş, R., Hamamcı, C. 1998. Çevrebilim, İmge Kitabevi, Ankara, 1998, s:158.

- Keleş, R., Keleş, R., Hamamcı, C., Çoban., A., 2009. “Çevre Politikaları”, İmge Kitabevi, s.59-62, Ankara.

- Kongar, E., 1997. “Küreselleşme Ve Kültürel Farklıllklar Çerçevesinde Ulusal Kültür”, http://www.kongar.org/makaleler/mak_ku.php

- Kurtoğlu, R., 2013. “Küresel Hegemonya Savaşları İklim Su Gıda”, Karma Kitaplar, İstanbul.

- Brown, Lester R., 2008. "Plan Bb.3.0 Uygarlığını Kurtarmak İçin Harekete Geçmek” Çeviri: Ayşe Başcı, Tema Vakfı Yayını, İstanbul.

• Öğütçü, M., 2004. “Küreselleşmede Nereye Gidiyoruz”, Finans Dünyası, Sayı:170, s.14

- $\quad$ Roberts, Timmons, Parks, Bradley, 2007. “A Climate of Injustice: Global Inequality/North-South Politics and Climate Policy”, The MIT Press, s.21, London

- Satır, A., Reyhan, H., 2013. “Küresel İklim Değişikliği Sorununa Çözüm İçin Nasıl Bir Sürdürülebilir Kalkınma Anlayışına İhtiyacımız Var?” 2013 INTERNATIOAL EUROS.. COGRESS s.962-964.

- Worldwatch Enstitüsü, 2014. Dünyanın Durumu 2013 Sürdürülebilirlik Hala Mümkün mü? Editör: Linda Starke Türkiye İş Bankası Kültür Yayınları e Çev. Cana Ulutaş Ekiz- Çağrı Ekiz, s. 9-183.

- (United Nations Environment Programme, 2002

- Y1kmaz, R. F., 2011. "Sürdürülebilir Kalkınmanın Ölçülmesi ve Türkiye için Yöntem Geliştirilmesi ”, Devlet Planlama Teşkilatı, Sosyal Sektörler ve Koordinasyon Genel Müdürlüğü, Ankara, s. 72-73

- Yılmaz, V., vd., 2010. "Enerji Çeşitleri ve Geri Dönüşüme Karşı Tutumların Çevresel Davranışa Etkisi”, Frrat Üniversitesi Sosyal Bilimler Dergisi, Cilt: 20, Sayı:2, s. 323-342.

- Yücel Iş1ldar, G. 2008. “Meslek Yüksekokulları Boyutunda Çevre Eğitiminin Çevreci Yaklaşımlar ve Davranışlar Üzerindeki Etkilerinin Değerlendirilmesi” Türk Eğitim Bilimleri Dergisi, Sayı: 6/4, 2008, ss. 759-778. 


\title{
Yenilenebilir Enerji Tüketimi, İktisadi Büyüme ve Karbondioksit Emisyonu Arasındaki Nedensel İliş̧ki: Orta Doğu ve Kuzey Afrika Ülkeleri Örneği
}

\section{The Causal Relationship between Renewable Energy Consumption, Economic Growth and Carbon Dioxide Emissions: Evidence from Middle East and North Africa Countries}

\author{
Prof. Dr. Ebru Çağlayan Akay (Marmara University, Turkey) \\ Asst. Prof. Dr. Raziiakhan Abdieva (Kyrgyzstan-Turkey Manas University, Kyrgyzstan) \\ Dr. Zamira Oskonbaeva (Kyrgyzstan-Turkey Manas University, Kyrgyzstan)
}

\begin{abstract}
Renewable energy plays a crucial role in increasing economic growth while reducing carbon dioxide emissions. The aim of this study is to examine the interaction between renewable energy consumption, economic growth and carbon dioxide emissions for selected Middle East and North Africa countries. For this aim, panel vector autoregression approach is used in the study. The annual data used in this study cover the period from 1988 to 2010 for Middle East and North Africa countries. Firstly, second generation unit root test are used to investigate stationarity properties of the variables and second generation panel cointegration test is applied to the data under consideration because of the cross-sectional dependence. Then a panel causality approach is proposed to examine the causal relationship between the variables. Finally, panel vector autoregression model, impulseresponse and variance decomposition analysis are applied using generalized moment methods. The finding of this study shows that there is a bi-directional causality between growth and renewable energy consumption, which is consistent with the feedback hypothesis in terms of the energy consumption-growth nexus. It is found the evidence of unidirectional causality from carbon dioxide emissions to renewable energy consumption and from growth to carbon dioxide emissions. It is also found that the responses of growth to a shock of energy consumption are positive and the impact of renewable energy consumption on carbon dioxide emissions is negative.
\end{abstract}

\section{Giriş}

Ekonomik büyümeyi hedefleyen ülkeler, bu hedeflerine ulaşırken aynı zamanda çevreye de önem vermek zorundadır. "Düşük karbon ve yeşil büyüme" kavramına olan ilgi yıldan yıla önemli bir artış göstermektedir (Hwang ve Yoo 2014). Mevcut enerji kaynaklarının daha fazla kullanımı iklim değişikliğine neden olan sera gazlarının daha da artması anlamına gelmektedir. Bunun nedeni, fosil yakıtlarının yanma sırasında bol miktarda karbondioksit $\left(\mathrm{CO}_{2}\right)$ açığa çıkarmasıdır. Dünyadaki, sera gazlarının \% 76'sını oluşturan $\mathrm{CO}_{2}$ en önemli kirletici gaz olarak bilinmektedir (International Energy Agency IEA; 2012). Özellikle, 1997 y1lında Kyoto Protokolü imzalandıktan sonra fosil yakıtlarının yerine yenilenebilir enerji kaynaklarının kullanılmasına güçlü bir vurgu yapılmıştır. Bu Protokol gelişmiş ülkeleri karbon dioksit emisyonunu sınırlama konusunda yükümlü kılmıştır (Silva, 2011). 2002'de yapılan Johannesburg zirvesinde ise enerjinin çevreye olan olumsuz etkilerine işaret edilmiştir. Kirletici emisyonlarının ana sorumlusu olarak $\mathrm{CO}_{2}$ emisyonu kabul edilmiştir (Farhani ve Rejeb, 2012). Bu sorunun üstesinden gelebilmek için tüm dünya ülkeleri yenilenebilir enerji kaynaklarına daha fazla önem vermeye başlamışlardır. Araştırmacıların da yenilenebilir enerji tüketimi, iktisadi büyüme ve $\mathrm{CO}_{2}$ arasındaki nedensel ilişkiyi ampirik olarak inceleyen çalışmalar üzerinde yoğunlaştıkları görülmektedir (Örneğin; Omri vd. 2015; Jebli ve Youssef 2015; Jaforullah ve King 2015; Apergis ve Payne 2014; Sebri ve BenSalha 2014; Shafiei ve Salim 2014; Lin ve Moubarak 2014; Bölük ve Mert 2014; Zeb vd. 2014; Al-Mulali vd. 2013). Bu çalışmalarda kullanılan verilerin, ülke sayısının, dönemin ve ekonometrik yöntemin değişik olmasından dolayı elde edilen bulgular da farklılık göstermektedir.

Orta Doğu ve Kuzey Afrika (MENA) ülkeleri gelişmekte olan ülkeler olduğundan Kyoto protokolüne imza atmamışlardır. Fakat, bu ülkeler de gelişmiş ülkelerin karşılaştıkları kirletici emisyonları azaltma, enerji kullanımını geliştirme ve bunun yanında ekonomik gelişmeyi sağlama gibi sorunlarla karşı karşıya kalmışlardır. MENA bölgesi dünyadaki petrol üretiminin ve ihracatının büyük payına sahiptir. Dünyanın bilinen ham petrol rezervlerinin yaklaşık üçte ikisi MENA bölgesindedir. Dünyanın toplam doğal gaz rezervlerinin \% 15'i ise İran İslam Cumhuriyeti'nde bulunmaktadır. Cezayir, Fas, Tunus, Ürdün ve Suriye Arap Cumhuriyeti ise dünyanın fosfat üretiminin yaklaşık üçte birini oluşturmaktadır (Al-Iriani, 2006).

MENA bölgesi yenilenebilir enerji potansiyeli yönünden oldukça zengin bir bölgedir. MENA ülkelerinin güçlü yenilenebilir enerji kaynak tabanına sahip olması nedeniyle var olan potansiyel pazar büyüklügü yenilenebilir enerji üretimini finanse eden uluslararası yatırımcı ve kuruluşların ilgisini çekmekte ve bu bölgede enerji 
talebinin artmasına ve böylece müşteri tabanı gelişmektedir (Hamilton, 2011). MENA bölgesinde sürdürülebilir enerji arzı için enerji üretiminin çeşitli kaynaklardan sağlanması gerekir. Örneğin, doğal gaz ve özellikle yenilenebilir enerji kaynaklarına önem verilmeli ve böylelikle yenilenebilir enerji kaynaklarının enerji üretiminin maliyetini azaltması ve çevrenin kirlenmemesi sağlanmalıdır (Griffiths, 2012).

$\mathrm{Bu}$ çalışmanın amacı, 1988-2010 dönemine ait yıllık verileri kullanarak, seçilmiş MENA ülkeleri için yenilenebilir enerji tüketimi, iktisadi büyüme ve karbondioksit emisyonu arasındaki ilişkiyi incelemektir. Bu amaç için Panel Vektörotoregresyon (PVAR) yöntemi kullanılarak 3 değişkenli PVAR modeli tahmin edilmiştir. Ayrıca değişkenler arasındaki şokların etkisini belirlemek amacı ile etki tepki fonksiyonları ve varyans ayrıştırması analizleri yapılmıştır.

Çalışmanın bundan sonraki bölümünde MENA ülkelerinde yenilenebilir enerjiye yer verilmiştir. Üçüncü bölüm konuyla ilgili literatürün incelendiği bölümdür. Dördüncü bölümde veri ve değişkenler hakkında açıklamalar yapılmıştır. Beşinci bölümde ise ekonometrik metodoloji ve tahmin sonuçları özetlenmiştir. Çalışma sonuç bölümüyle sona ermektedir.

\section{MENA Bölgesinde Yenilenebilir Enerji}

1990'larda dünya çapında artış gösteren yenilenebilir enerji 2000'li yıllara doğru hız kazanmaya başlamıştır. 2012 yılında yenilenebilir enerji küresel enerji tüketiminin \%19'unu karşılamıştır. Yenilenebilir enerji küresel enerji üretim kapasitesinin \%26,4'ünü oluşturmaktadır. Bunun yanı sıra küresel elektriğin \% 22,1'i yenilenebilir kaynaklardan sağlanmıştır. 2014 yılında ise yenilenebilir enerji sektörüne 270 milyar dolar civarında yatırım yapılmıştır. 2004 yılında yenilenebilir enerji hedefini benimseyen ülke sayısı 48 iken 2014 yılında bu rakam 164 'ü bulmuştur (Global Status Report, GSR 2015).

MENA bölgesi yenilenebilir enerji potansiyeli yönünden oldukça zengin bir bölgedir. Küresel yenilenebilir kaynak potansiyelinin \% 45'i söz konusu bölgede bulunmaktadır (Jalilvand 2012). Dünya Bankası verilerine (International Finance Corparation, IFC, 2015) göre toplam güneş enerjisinin \% 22-26 kadarlık kısmı MENA bölgesindedir. Sözkonusu bu oran yılda 1-2 milyon varil petrolden üretilen enerjiye eşdeğerdir. MENA bölgesinin güneş enerjisinin şimdiki elektriğe olan küresel talebi karşılamaya yetecek düzeyde olduğu düşünülmektedir (IFC, 2015).

2012 yılı sonu itibariyle bu bölgede kurulu enerji kapasitesi 185000 MW civarında gerçekleşmiştir. Bunun 19000 MW'1 (ya da \%10’u) yenilenebilir kaynaklara aittir (IFC 2015; MENA Renewables Status Report, RSR 2013). Orta Doğu'da toplam enerji üretiminde yenilenebilir kaynakların oranı 2010' da \% 2 civarında iken 2035 yılına doğru bu oranın \% 12'ye çıkartılması tahmin edilmektedir (World Energy Outlook, WEO, 2012). Söz konusu bölgede yenilenebilir enerji sektörüne 2012 yılında 2,9 milyar dolar yatırım yapılmış ve bu rakam 2011 ile kıyaslandığında yatırımın \% 40 oranında ve 2004 yılına göre de 6,5 kat arttığını göstermektedir. Bunun yanısıra, 2007 yılında MENA ülkelerinin ancak 5'inde yenilenebilir enerji hedefi benimsemiş, 2013 yılında ise bu rakam 21'i bulmuştur (MENA RSR, 2013). Bu gelişmeler MENA bölgesinde yenilenebilir kaynaklara olan ilginin yıldan yıla artmakta olduğunu göstermektedir.

Çalışmamızda MENA ülkeleri için yenilenebilir enerji tüketimi, iktisadi büyüme ve $\mathrm{CO}_{2}$ arasındaki ilişkiye odaklanacağımızdan, 1988-2010 yılları arasında bu değişkenlerdeki değişim incelenmiştir. Şekil 1.'de seçilmiş MENA ülkeleri için GSYİH değerleri ele alınmıştır.

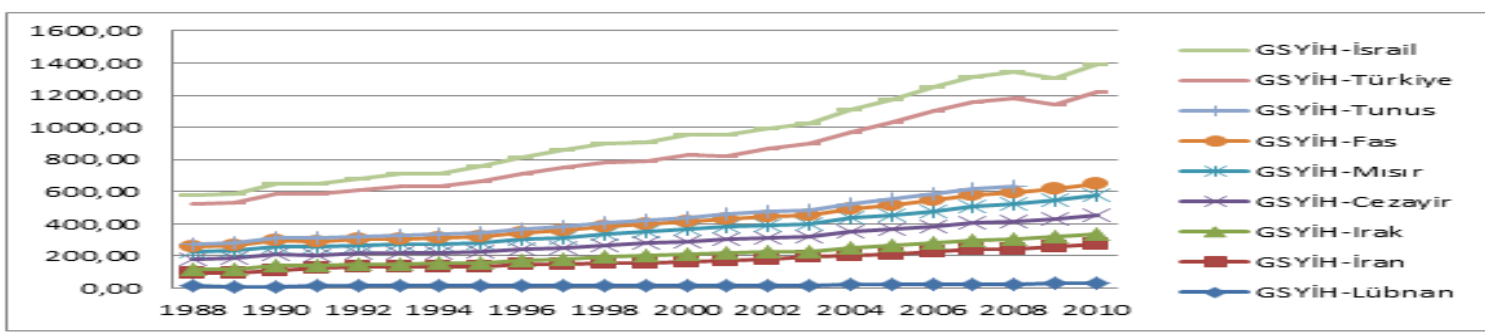

Şekil 1. MENA ülkelerinde GSYİH. Kaynak: Dünya Bankası 2015 Verileri

Şekil 1'e göre ele ülkeler içinde GSYİH'nın büyüklüğüne göre Türkiye, İran ve İsrail'in 1988-2010 yıllarında GSYİH ölçek ve hız açısından da daha büyük olduğu görülmektedir. İkinci grupta ise Cezayir ve Mısır ülkeleri gelmektedir. Diğer ülkelerin ise GSYİH büyüme hızının daha yavaş olduğu görülmektedir. Bu ülkeler için yenilenebilir enerji tüketimleri ise Şekil 2.'de görülmektedir.

Şekil 2.'ye göre, Türkiye, Mısır ve İran diğer ülkeler ile karşılaştırıldığında yenilenebilir enerji tüketiminin en yüksek olduğu ülkelerdir. Irak'ta 2005'ten ve Fas'ta 2008'den itibaren yenilenebilir enerji tüketimi artmaya başlamıştır. Diğer ülkelerde ise yenilenebilir enerji tüketiminin düşük seviyede olduğu görülmektedir. Bu ülkeler için iklim değişikliğine neden olan sera gazları içinde en büyük çevre kirleticisi olarak kabul edilen $\mathrm{CO}_{2}$ emisyonu oranları Şekil 3.'te ele alınmıştır. 


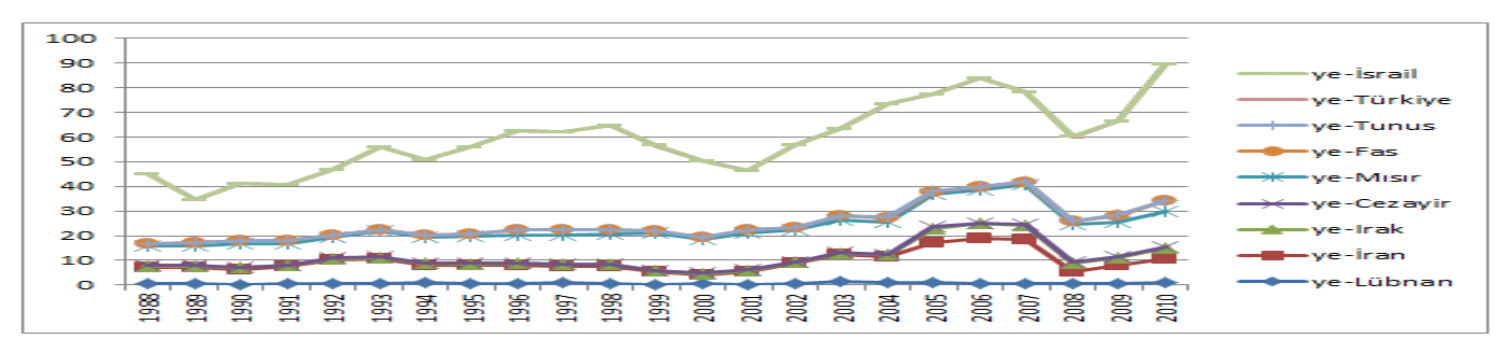

Şekil 2. MENA Ülkelerinde Yenilenebilir Enerji. Kaynak: US Energy Information Administration 2015

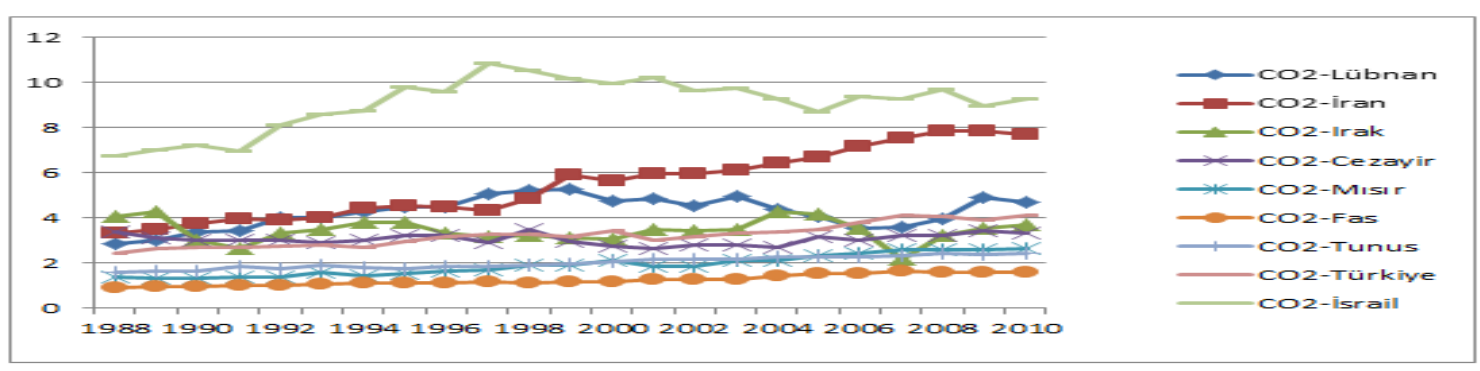

Şekil 3. MENA Ülkelerinde CO2 emisyonu Kaynak: Dünya Bankası 2015 Verileri

Şekil 3.'e göre, İsrail ve İran $\mathrm{CO}_{2}$ emisyonunun en yüksek olduğu ülkelerdir. İkinci grupta Lübnan, Türkiye, Cezayir ve Irak ülkeleri yer almaktadır. Bu ülkelerde $\mathrm{CO}_{2}$ emisyonu seviyesi ilgili dönemde hemen hemen aynı derecede olmasına rağmen, diğer ülkelere göre nispeten daha yüksektir. Türkiye'de GSYİH hızlı bir şekilde büyümesine rağmen, $\mathrm{CO}_{2}$ emisyonunun aynı seviyede kaldığ görülmektedir. Buna rağmen, diğer ülkeler ile karşılaştırıldığında, GSYİH İsrail ve İran'da hızla büyümekte olduğu, fakat bu ülkelerin aynı zamanda en çok $\mathrm{CO}_{2}$ yayan ülkeler arasında olduğu görülmektedir.

\section{Literatür}

Enerji tüketimi ile ekonomik büyüme arasındaki ilişkiler araştırmacıların ilgisini çeken cazip konulardan biri olmaktadır. Enerji tüketimi ile ekonomik büyüme arasındaki ilişkiyi ilk defa Kraft ve Kraft (1978) Granger nedensellik testini kullanarak incelemişlerdir. Bu konu ile yapılan sonraki ampirik çalışmaları bulgularına göre dört gruba ayırmak mümkündür. Birinci gruptaki araştırmaların sonuçları enerji tüketiminin ekonomik büyümeyi arttıracağını göstermiştir. Diğer bir değişle enerji tüketiminden ekonomik büyümeye doğru tek yönlü ilişki bulmuşlardır (Nerayah ve Smyth, 2005; Al-Iriani, 2006; Mehrara, 2007; Apergis ve Payne, 2010). Büyüme hipotezi olarak adlandırılan bu durumda incelenen ülkenin enerjiye bağımlı bir ülke olduğunu göstermektedir. $\mathrm{Bu}$ durumda enerji koruma politikalarının iktisadi büyümeyi olumsuz etkileyeceği vurgulanmaktadır. İkinci gruptaki çalışmalar ise ekonomik büyümeden enerji tüketimine doğru tek yönlü ilişki tespit etmiştir (Stern, 2000; Oh ve Lee, 2004; Yuan v.d., 2008; Apergis ve Payne, 2009). Koruma hipotezi olarak adlandırılan bu durumda incelenen ülkenin ekonomik büyümeyi devam ettirebilmek için enerjiye bağımlı olmadığı sonucu ortaya çıkmakta ve enerji koruma politikalarının ekonomik büyümeyi olumsuz etkilemeyeceğini göstermektedir. Üçüncü grup araştırmalarının sonuçları ekonomik büyüme ile enerji tüketimi arasında iki yönlü ilişki tespit etmişlerdir (Masih ve Masih, 1997; Paul ve Bhattacharya, 2004; Lee v.d, 2008). Feedback hipotezi (Geri besleme) hipotezi olarak adlandırılan bu durumda ise, enerji tüketimiyle GSYİH arasında iki yönlü bir nedensellik mevcuttur ve bu iki değişken birlikte belirlenmekte ve aynı anda etkilenmektedir. Dördüncü gruptaki çalışmalar ise ekonomik büyüme ile enerji tüketimi arasında ilişkinin olmadığını açıklamışlardır (Cheng, 1995; Fatai v.d., 1995; Jobert ve Karanfil, 2007). Bu ise Nötralite hipotezi (Yansızlık) olarak ifade edilir. Bu enerji koruma ya da genişletici politikaların büyüme üzerinde etkisinin olmadığını göstermektedir.

Son zamanlarda enerji tüketimi, özellikle yenilebilir enerji tüketimi, ekonomik büyüme ve $\mathrm{CO}_{2}$ emisyonu arasındaki ilişkiyi incelemek büyük önem kazanmıştır. Bunun nedeni, enerji kullanımının sürdürülebilir kalkınmaya ulaşmada en iyi araç olarak görülmesidir (Farhani ve Rejeb, 2012). Literatürde MENA bölgesi için yapılmış enerji tüketimi ve büyüme ilişkisini inceleyen çalışmalar da bulunmaktadır. Örneğin, Farhani ve Rejeb (2012), Mbarek v.d. (2014), Arouri v.d. (2012), Shahateet (2014), Mehrara (2007), Saidi ve Hammami (2015) ve Omri (2013). Yapılan çalışmalar sonucunda enerji tüketimi ve büyüme arasındaki nedensellik ilişkisinin farklı sonuçlar verdiğini görülmüştür. Farhani (2015) ise 12 MENA ülkesinde 1975-2008 yıllar arasında yenilenebilir enerji tüketimi, ekonomik büyüme ve $\mathrm{CO}_{2}$ arasında nedensellik ilişsisini panel eşbütünleşme tekniği ile incelemiştir. Granger nedensellik testi bu değişkenler arasında kısa vadede sadece yenilenebilir enerji tüketiminden $\mathrm{CO}_{2}$ 'ye doğru tek yönlü ilişkinin bulunduğunu açıklamıştır. Uzun vadede ise ekonomik büyüme ve $\mathrm{CO}_{2}$ 'den yenilenebilir enerji tüketimine doğru tek yönlü nedensellik ilişkisi tespit edilmiştir. Panel FMOLS ve 
DOLS hesaplamaları sadece $\mathrm{CO}_{2}$ emisyonunun yenilenebilir enerji tüketimi üzerinde etkili olduğunu göstermiştir.

\section{Veri}

Bu çalıșmada 1988-2010 dönemine ait y1llık veriler kullanılarak MENA bölgesinde bulunan 9 ülke (Lübnan, İran, Irak, Cezayir, Mısır, Tunus, Fas, İsrail ve Türkiye) için yenilenebilir enerji tüketimi, iktisadi büyüme ve karbondioksit emisyonu arasındaki ilişki incelenmiştir. Uygulamada kullanılan verilere ilişkin bilgiler Tablo 1'de özetlenmiştir. Ayrıca çalışmada değişkenlerin logaritmik formları incelenmiştir.

\begin{tabular}{llll}
\hline Değişken & Kısaltma & Tanımlama & Kaynak \\
\hline Yenilenebilir enerji & REC & Milyar kilovat saat & ABD Enerji Enformasyon İdaresi Veri \\
İktisadi büyüme & GDP & Sabit 2005 ABD\$ & Dünya Bankası Veri tabanı \\
Karbondioksit emisyonu & CO2 & Kişi başına metrik ton & Dünya Bankası Veri tabanı \\
\hline
\end{tabular}

Tablo 1. Veriler

\section{Ekonometrik Metodoloji ve Sonuçları}

Çalışmada ekonomik büyüme, yenilebilir enerji tüketimi ve $\mathrm{CO}_{2}$ emisyonu arasındaki dinamik nedensellik ilişkisine odaklanılmış ve Panel VAR (PVAR) modeli kullanılmıştır. PVAR modeli Genelleştirilmiş Momentler Yöntemi (GMM) ile tahmin edilerek, etki tepki ve varyans ayrıştırması analizleri yapılmıştır. Burada ilk önce panel birim kök ve panel eş bütünleme analizleri ile incelenen seriler için durağanlık durumları ve bütünleme mertebeleri belirlenmiş ve değişkenler arasında uzun dönem ilişkinin varlığ 1 araştırılmıştır.

\subsection{Yatay Kesit Bağımlılık ve Birim Kök Analizi}

Panel veriler kullanıldığında birim kök analizi iki farklı test yapısı ile incelenmektedir. Bunlar, birinci nesil (Levin, Lin ve Chu (LLC, 2002); Breitung (2000), Hadri (2000); Im, Pesaran ve Shin (IPS,1997); Harris ve Tzavalis (1999) ve ikinci nesil (Pesaran (2007); Moon ve Perron (2004); Bai ve Ng (2004) birim kök testleri olarak iki gruba ayrılmaktadır. Bu iki grup arasındaki temel fark, yatay kesit bağımlılık yani birimler arası korelasyonun varlığı ile ilgilidir. Yatay kesit bağımlılık olmadığında birinci nesil testler, yatay kesit bağımlılık olduğunda ise ikinci nesil testler kullanılmaktadır. Hangi nesil birim kök testleri ile inceleme yapılacağına karar verebilmek için ilk olarak yatay kesit bağımlılık olup olmadığının incelenmesi gerekir. Seriler arasındaki yatay kesit bağımlılığının dikkate alınıp alınmaması elde edilecek sonuçları önemli ölçüde etkilemektedir (Breusch ve Pagan, 1980; Pesaran, 2004). Pesaran (2004) tarafindan önerilen CD (Cross-Section Dependence ) Testi yatay kesit bağımlılı̆̆ının analizinde yaygın olarak kullanılan testlerden biridir. Test istatistiği, $C D=\sqrt{\frac{1}{N(N-1)}} \sum_{i=j}^{N-1} \sum_{i=j+1}^{N}\left(T \hat{\rho}_{i j}^{2}-1\right) \sim N(0,1)$

şeklinde hesaplanmaktadır. Burada $\rho_{i j}$ herbir denklemin en küçük kareler yöntemi ile tahmininden elde edilen artıklar arasındaki basit korelasyon katsayısıdır. Pesaran (2004) CD testi sonuçları Tablo 2.'de özetlenmiştir.

\begin{tabular}{lcc}
\hline Değişkenler & Test İstatistiği & Olasılık \\
\hline LGDP & 26.77 & 0,000 \\
LREC & 10.82 & 0,000 \\
LCO2 & 11.25 & 0,000 \\
\hline Temel hipotez, & $H_{0}: \rho_{i j}=\operatorname{cor}\left(u_{i t}, u_{j t}\right)=0$ & $i \neq j$ şeklindedir ve yatay kesit bağımlılık olmadı̆̆ını gösterir. \\
\hline
\end{tabular}

Tablo 2. Pesaran (2004) CD Testi Sonuçları

Tablo 2.'de özetlenen sonuçlara göre, tüm değişkenler için \%1 anlamlılık düzeyinde temel hipotezin reddedildiği görülmektedir. Buna göre yatay kesit bağımlılık olduğuna karar verilmiştir. Bu durumda serilerin birim kök analizleri yatay kesit bağımlılığı dikkate alan ikinci nesil testlerden Pesaran (2007) tarafindan geliştirilen CADF (Cross-Sectionally Augmented Dickey Fuller) testi ile incelenecektir. CADF testi, bilindik ADF regresyonunun gecikmeli yatay kesit ortalamaları ile genişletilmiş şeklini kullanmaktadır. Pesaran (2007) yaptığı Monte Carlo çalışmaları sonucunda CADF testinin hem $\mathrm{T}>\mathrm{N}$ hem de $\mathrm{N}>\mathrm{T}$ durumlarında geçerli olduğunu ortaya koymuştur. CADF regresyon denklemi, $\Delta Y_{i t}=a_{i}+b_{i} Y_{i, t-1}+c_{i} \bar{Y}_{t-1}+d_{i} \Delta \bar{Y}_{t}+\varepsilon_{i t}$ olarak yazılabilir. Burada $\Delta Y_{i t}=Y_{i t}-Y_{i, t-1} ; \bar{Y}_{t}=N^{-1} \sum_{i=1}^{N} Y_{i t}$ ve $\Delta \bar{Y}_{t}=N^{-1} \sum_{i=1}^{N} \Delta Y_{i t}$ 'dir. $\bar{Y}_{t}$, tüm yatay kesit gözlemlerin $(\mathrm{N})$ zamana $(\mathrm{T})$ göre ortalamasını ifade etmektedir. Klasik ADF testinde olduğu gibi otokorelasyonun varlığı durumunda denklem genişletilmektedir. Bu testte CADF regresyon modelindeki $b_{i}$ 'nin tahmin edilen t oranına bağlı olarak birim kök hipotezi test edilmektedir. t oranı $t_{i}(N, T)$ şeklinde gösterilir ve panelin her bir i. birimi için her bir CADF modelinden elde edilir. Test istatistiği, $\operatorname{CIPS}(N, T)=N^{-1} \sum_{i=1}^{N} t_{i}(N, T)$ olarak hesaplanır. Ele aldığımız değişkenler için Pesaran (2007) CADF birim kök testi sonuçları Tablo 3.'de özetlenmiştir. 


\begin{tabular}{|c|c|c|c|}
\hline & t bar istatistiği & $\mathrm{z}$ bar istatistiği & Olasılık \\
\hline \multicolumn{4}{|c|}{ Düzey Seviyeleri (sabit+ trend ) } \\
\hline LGDP & $-2.843 * *$ & $-4.710 * *$ & 0.043 \\
\hline LREC & -2.585 & -0.887 & 0.188 \\
\hline $\mathrm{LCO} 2$ & -2.383 & -0.236 & 0.407 \\
\hline \multicolumn{4}{|c|}{ İlk Farklar (sabit+ trend) } \\
\hline$\Delta \mathrm{LGDP}$ & $-3.770 * * *$ & $-4.710 * * *$ & 0.000 \\
\hline$\triangle \mathrm{LREC}$ & $-3.706 * * *$ & $-4.505 * * *$ & 0.000 \\
\hline$\triangle \mathrm{LCO} 2$ & $-3.028 * * *$ & $-2.316 * * *$ & 0.010 \\
\hline \multicolumn{4}{|c|}{$\begin{array}{l}\text { (i) Testlerin deterministik spesikasyonu sabit ve trendi içermektedir. } \\
\text { (ii) Temel hipotez birim kök vardır, seri durağan değildir şeklindedir. } \\
\text { (iii)*** ve ** sırasıyla \% } 1 \text { ve \% } 5 \text { kritik değerlerine göre anlamlılığı göstermektedir. } \\
\text { (iv) Kritik değerler Pesaran (2007) çalışmasından alınmıştır. }\end{array}$} \\
\hline
\end{tabular}

\section{Tablo 3. Pesaran (2007) Birim Kök Testi Sonuçları}

Tablo 3 'teki sonuçlara göre, incelenen tüm serilerin birim kök içerdiği (\% 1 anlamlılık düzeyine göre) düzeyde durağan olmadığı görülmektedir. Serilerin tümü birinci mertebeden durağandır, yani I(1)'dir. Bütünleme mertebeleri belirlenen değişkenler arasında uzun dönem ilişkisinin varlığını incelemek için eşbütünleme analizi yapılmıştır. Çalışmada yatay kesit bağımlılığa izin veren ikinci nesil eşbütünleme testi Westerlund (2007) tarafından geliştirilen panel eşbütünleme testleri kullanılmıştır. Testin uygulanmasında yatay kesit bağımlılık olması durumunda bootstrap olasılıkların hesaplanması gerekir.

\subsection{Panel Eșbütünleme Analizi}

Westerlund (2007) tarafından önerilen panel eşbütünleme testi dört adet test istatistiğinden oluşmaktadır. Bunlardan ikisi grup ortalamalarına dayalı $\left(G_{\tau}\right.$ ve $\left.G_{\alpha}\right)$ ve diğer ikisi ise panele $\left(P_{\tau}\right.$ ve $\left.P_{\alpha}\right)$ dayalı test istatistiklerdir. Test için gecikme (lags) ve öncül (leads) değerlerin belirlenmesi gerekir. Westerlund (2007) orjinal makalesinde bu değerlerin belirlenmesinde Newey-West (1994) yönteminden yararlanmıştır Testlerin amacı, her bir birimin kendi hata düzeltmesine sahip olup olmadığına karar vererek eşbütünlemenin varlığııı araştırmaktır. Westerlund (2007) Testi sonuçları Tablo 4 'te verilmiştir.

\begin{tabular}{llll}
\hline İstatistikler & & Test istatistikleri & Olasılıklar \\
\hline \multirow{2}{*}{ Grup Ortalaması } & $G_{\tau}$ & -2.585 & 0.420 \\
& $G_{\alpha}$ & -3.326 & 1.000 \\
\hline \multirow{2}{*}{ Panel } & $P_{\tau}$ & -5.488 & 0.936 \\
& $P_{\alpha}$ & -7.479 & 0.909 \\
\hline (i)Temel hipotez eşbütünleme yoktur şeklindedir. & & \\
(ii) Regresyon sabit ve trendi içermektedir. & \\
(iii) gecikme ve öncül değerler 4*(T/100) ${ }^{2 / 9}$ ile hesaplanmıştır. & \\
\hline
\end{tabular}

\section{Tablo 4. Westerlund (2007) Testi Sonuçları}

Tabloda özetlenen sonuçlar incelendiğinde, her dört test istatistiği tarafından da eşbütünleme yoktur temel hipotezinin reddedilemediği görülmektedir. $\mathrm{Bu}$ sonuçlara göre paneli oluşturan yatay kesit birimler arasında eşbütünleme olmadığına karar verilmiştir. Dolayısıyla, Westerlund (2007) testi sonuçlarına göre incelenen değişkenlerin uzun dönemde birlikte hareket etmedikleri söylenebilir.

Değişkenler arasındaki nedensellik ilişkisini incelemek amacı ile Panel Granger nedensellik analizi yapılmıştır. Analiz sonuçları Tablo 5'te özetlenmiştir.

\begin{tabular}{llll}
\hline Nedenselliğin Yönü & $\boldsymbol{\chi}$ test istatistiği & Olasılık & Sonuç \\
\hline$\Delta \mathrm{LGDP} \rightarrow \Delta \mathrm{LCO} 2$ & 11.78696 & 0.0028 & Granger nedeni \\
$\Delta \mathrm{LREC} \rightarrow \Delta \mathrm{LCO} 2$ & 2.151386 & 0.3411 & Granger nedeni değil \\
$\Delta \mathrm{LCO} 2 \rightarrow \Delta \mathrm{LGDP}$ & 2.265676 & 0.3221 & Granger nedeni değil \\
$\Delta \mathrm{LREC} \rightarrow \Delta \mathrm{LGDP}$ & 8.500187 & 0.0143 & Granger nedeni \\
$\Delta \mathrm{LCO} 2 \rightarrow \Delta \mathrm{LREC}$ & 42.27921 & 0.0000 & Granger nedeni \\
$\Delta \mathrm{LGDP} \rightarrow \Delta \mathrm{LREC}$ & 13.42195 & 0.0012 & Granger nedeni \\
\hline Temel hipotez Granger nedeni değildir şeklindedir. & & \\
\hline
\end{tabular}

Tablo 5. Nedensellik Testi Sonuçları

Tablo 5. incelendiğinde, büyüme ile yenilenebilir enerji tüketimi arasında çift yönlü ilişkinin (Büyüme $\leftrightarrow$ Yenilenebilir Enerji) mevcut olduğu görülmektedir. Bu durum karşısında yenilenebilir enerji tüketimi ile büyüme arasında geri besleme hipotezinin geçerli olduğu kanısına varılabilir. Ayrıca (Karbondioksit Emisyonu $\rightarrow$ Yenilenebilir Enerji) karbondioksit emisyonundan yenilenebilir enerjiye 
doğru ve büyümeden karbondioksit emisyonuna doğru tek yönlü (Büyüme $\rightarrow$ Karbondioksit Emisyonu) nedensellik bulunmuştur.

\subsection{Panel VAR Modeli}

Büyüme, yenilebilir enerji tüketimi ve karbondioksit emisyonu arasındaki ilişkiyi görmek amacı ile PVAR modeli tahmin edilmiştir. Çalışmamızda PVAR analizi üç kısımda ele alınmıştır. Birinci kısımda PVAR modeli değişkenler arasındaki iliş̧iyi açıklamak amacı ile GMM ile tahmin edilmiştir. Daha sonra değişkenler arasındaki şokların etkisini belirlemek amacı ile etki tepki fonksiyonları ve varyans ayrıştırması analizleri yapılmıştır. Bir makro ekonomik büyüklüğün üzerinde en etkili değişkenin hangisi olduğu varyans ayrıştırması analizi ile etkili bulunan değişkenin politika aracı olarak kullanılabilir olup olmadığı ise, etki-tepki fonksiyonları ile belirlenmektedir (Lütkepohl, 2009).

Arellano ve Bover (1995) ortalamadan arındırma yoluyla sabit etkilerin modelden silinmesini önermektedir. $\mathrm{Bu}$ işlem tahmincilerin gecikmeli değerleri ile dönüştürülmüş değişkenler arasındaki dışsallık ilişkisine zarar vermediğinden, PVAR modelin tahmini, tahmincilerin gecikmelerini araç değişken olarak kullanan GMM yaklaşımı ile yapılmaktadır (Love ve Zicchino, 2006). Çalışmamızda tahmin edilecek iki gecikmeli PVAR modeli, $Y_{i t}=\Gamma_{0}+\Gamma_{1} Y_{i t-1}+\Gamma_{2} Y_{i t-2}+\mu_{i}+\varepsilon_{i t}$ olarak tanımlanmıştır. Burada $\mu_{i}$ birim etki, $Y_{i t}$ ise değişkenler vektörüdür. Modelimizde kullanılacak değişkenler; büyüme, yenilebilir enerji tüketimi ve karbondioksit emisyonu değişkenleri olduğundan üç değişkenli PVAR modeli tahmin edilecektir. Yukarıda açıklamalar doğrultusunda, tahminler modelde sabit etkileri ortadan kaldıran GMM ile tahmin edilmiş ve sonuçlar Tablo 6'da özetlenmiştir. Bu modeller Inessa Love tarafından yazılmış STATA kodları kullanılarak tahmin yapılmıştır.

\begin{tabular}{lllllll}
\hline & $\Delta \mathrm{LGDP}_{\mathrm{t}-1}$ & $\Delta \mathrm{LREC}_{\mathrm{t}-1}$ & $\Delta \mathrm{LCO}_{\mathrm{t}-1}$ & $\Delta \mathrm{LGDP}_{\mathrm{t}-2}$ & $\Delta \mathrm{LREC}_{\mathrm{t}-2}$ & $\Delta \mathrm{LCO}_{\mathrm{t}-2}$ \\
\hline \multirow{2}{*}{$\Delta \mathrm{LGDP}_{\mathrm{t}}$} & -0.3785 & 0.0106 & 0.3335 & -0.1404 & 0.0145 & -0.0256 \\
& $(-1.5361)$ & $(1.0286)$ & $(1.2207)$ & $(-1.6268)$ & $(1.4860)$ & $(-0.2019)$ \\
$\Delta \mathrm{LREC}_{\mathrm{t}}$ & -0.3793 & -0.0364 & 0.2438 & -0.4204 & 0.0488 & 0.0275 \\
& $(-0.7556)$ & $(-0.5576)$ & $(0.5546)$ & $(-1.0279)$ & $(0.6406)$ & $(0.0709)$ \\
$\Delta \mathrm{LCO} 2_{\mathrm{t}}$ & -0.1628 & -0.0219 & -0.0152 & -0.0006 & -0.0431 & 0.0368 \\
& $(-2.0097)$ & $(-1.2725)$ & $(-0.1172)$ & $(-0.0097)$ & $(-1.1956)$ & $(0.4503)$ \\
\hline
\end{tabular}

(i) Ü̧̧ değiş̧enli PVAR modeli GMM yöntemi ile tahmin edilmiştir. Verilen değerler sütundaki

değişkenlerin gecikmeleri ile satırda yer alan değişkenin regresyonu sonucu elde edilen katsayılardır.

(ii)Parantezin içindeki değerler t istatistikleridir.

(iii) Gecikme uzunluğu AIC kriterine göre 2'dir.

Tablo 6. Üç Değişkenli PVAR Modeli Tahminleri

PVAR sonuçları modelde kullanılan değişkenler arasındaki ilişkinin yönü hakkında bir bilgi sunmaktadır. Tablo 6'daki sonuçlara göre, büyüme değişkeni bağımlı değişken olarak ele alındığında yenilenebilir enerji değişkeni farklı gecikme uzunluklarında pozitif değer almaktadır. Diğer bir deyişle iki gecikmenin katsayıları 0.0106 ve 0.0145 sırasıyla yenilenebilir enerjide meydana gelecek bir şokun büyüme üzerindeki etkisinin pozitif yönde olduğunu göstermektedir. Bu sonuç yenilenebilir enerji tüketiminin büyümeyi tetikleyeceği şeklinde yorumlanabilir. Karbondioksit emisyonu bağımlı değişken olarak ele alındığında ise, yenilenebilir enerjinin karbondioksit emisyonu üzerindeki etkisi iki gecikmede de negatif yönde olduğu gözlemlenmektedir. Yani 0.0219 ve -0.0431 katsayıları sırasıyla yenilenebilir enerjideki artışın karbondioksit emisyonu üzerinde azaltıcı yönde etki yapacağı söylenebilir.

VAR yaklaşımı etki-tepki fonksiyonlarının kullanımına da izin vermektedir. Etki tepki fonksiyonları hata terimlerinde zaman içinde meydana gelen değişmelerin içsel değişkenler üzerindeki etkilerini göstermektedir. Bu fonksiyonlar, rassal hata terimlerinden birindeki \%1'lik standart hatalık şokun, içsel değişkenlerin şimdiki ve gelecekteki değerlerine olan etkisini yansıtır (Lütkepohl, 2009). Tahmin edilen etki - tepki fonksiyonları Şekil 4 'te yer almaktadır. Etki tepki fonksiyonları ele alınan serilerin şoklar karşısındaki davranışlarını görebilmemiz açısından pratik bir yoldur. Şekil 4'teki sonuçlara göre büyüme değişkeninin hata teriminde meydana gelen bir birimlik şoka karşı yenilenebilir enerjinin verdiği tepki negatifken, karbondioksit emisyonunun tepkisi ilk dönemlerde negatif, ilerleyen dönemlerde ise pozitiftir. Karbondioksit emisyonundaki bir şoka karşı hem yenilenebilir enerjinin hem de büyümenin tepkisi ilk dönemlerde pozitif daha sonra ise negatiftir. Yenilenebilir enerjideki bir birimlik şoka karşı büyümenin gösterdiği tepki ilk başta negatif, ilerleyen dönemlerde ise pozitiftir ve karbondioksit emisyonunun tepkisi ise negatif yöndedir. Diğer bir deyişle yenilenebilir enerji tüketiminin artmasının karbondioksit emisyonu üzerinde azaltıcı etki yapacağı söylenebilir.

Son olarak PVAR modelinde ele aldığımız değişkenlerin varyansındaki değişmelerim kaynaklarını belirleyebilmek için varyans ayrıştırması analizi yapılmıştır. VAR modelinin hareketli ortalamalar bölümünden elde edilen varyans ayrıştırması, değişkenlerin kendilerinde ve diğer değişkenlerde meydana gelen şokların kaynaklarını yüzde olarak ifade eder. İncelenen değişkenlerde meydana gelecek bir değişimin yüzde kaçının kendisinden, yüzde kaçının diğer değişkenlerden kaynaklandığını gösterir. Bir değişkende meydana gelen değişmelerin büyük bölümü kendisindeki şoklardan kaynaklanıyorsa, bu değişkenin dişsal olarak hareket ettiğini gösterir (Enders, 1995). Varyans ayrıştırması analizi sonuçları Tablo 7’de özetlenmiştir. 

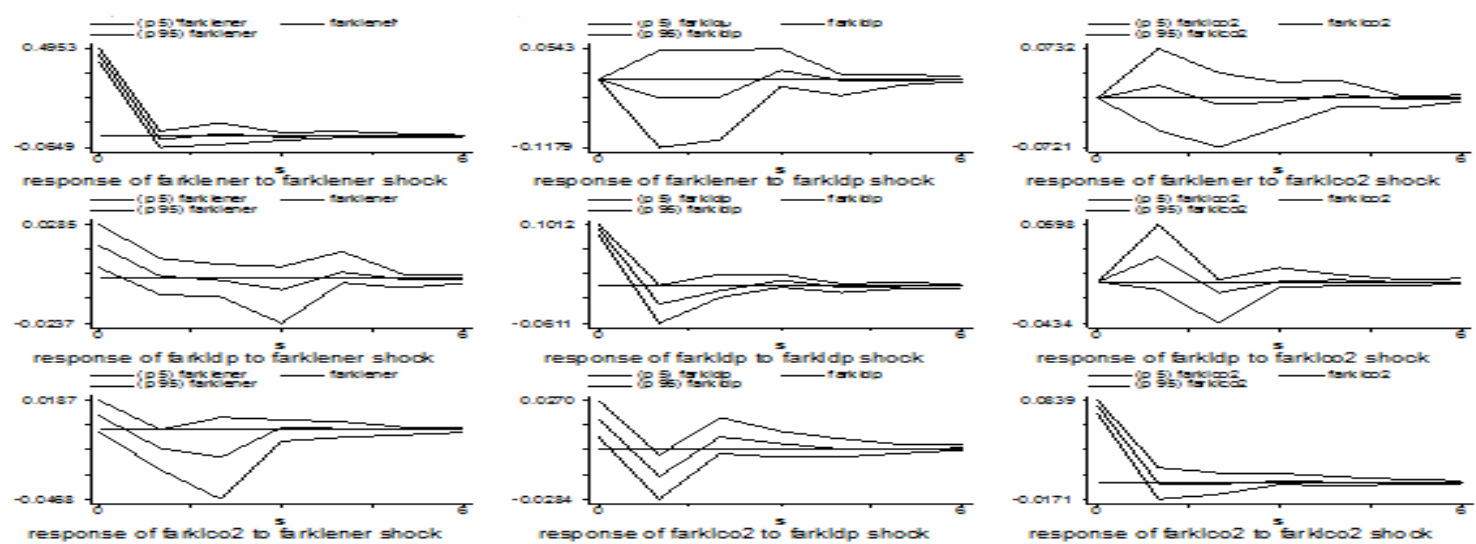

Şekil 4. Etki-Tepki Fonksiyonları

\begin{tabular}{llll}
\hline Değişken & Y.Enerji & Büyüme & CO2 Emisyonu \\
\hline Y.Enerji & 0.9875 & 0.0101 & 0.0023 \\
\hline Büyüme & 0.0313 & 0.8933 & 0.0752 \\
\hline CO2 Emis. & 0.0831 & 0.0775 & 0.8393 \\
\hline $\begin{array}{l}\text { Elde edilen varyans ayristtrmast sonuçları etki-tepki sonuçlartna dayanmaktadır. Sattrda yeralan } \\
\text { değiskenlerdeki değișimlerin yüzdesi sütunlarda açılklanmaktadir. Sonuçlar } 10 \text { period ilerisi içindir }\end{array}$ \\
\hline
\end{tabular}

Tablo 7. Varyans Ayrıştırması Sonuçları

Varyans ayrıştırması sonuçlarına göre, yenilenebilir enerjide meydana gelen değişmenin yaklaşık \% 99'u kendi geçmiş değerleri tarafından açıklanırken, yaklaşık \%1'i büyüme tarafından açıklanmaktadır. Büyümede meydana gelen değişmelerin \%89'u kendisi, \%3'ü yenilenebilir enerji ve \%7'si karbondioksit emisyonu tarafindan açıklanmaktadır. Son olarak karbondioksit emisyonunda meydana gelen değişmelerin yaklaşık \%84'ü kendi geçmiş değerleri tarafından, \%7'si büyüme ve \%8'si ise yenilebilir enerji tarafından açıklanmaktadır. Kendisinden sonra büyümeyi etkileyen ikinci değişken karbondioksit emisyonu olarak belirlenmiş, bu değişkeni yenilebilir enerji izlemiştir.

\section{Sonuç}

Bu çalışmada MENA bölgesinde bulunan 9 ülke (Lübnan, İran, Irak, Cezayir, Mısır, Tunus, Fas, İsrail ve Türkiye) için 1988-2010 dönemine ait yıllık verileri kullanarak yenilenebilir enerji tüketimi, büyüme ve karbondioksit emisyonu arasındaki dinamik ve nedensel ilişkinin varlığı incelenmiştir. Çalışmada panel veriler için uygulanan zaman serisi yöntemleri kullanılmışırı. Yatay kesit bağımlılı̆̆ın bulunması nedeni ile ikinci nesil birim kök ve eş bütünleme testleri kullanılmıştır. Panel nedensellik ve panel VAR analizleri yapılarak değişkenler arasındaki ilişki incelenmiştir.

Nedensellik analizi sonuçlarına göre, büyüme ile yenilenebilir enerji tüketimi arasında çift yönlü nedensellik ilişkisi bulunmuştur. Bu sonuç, yenilenebilir enerji tüketimi ile büyüme arasında geri besleme hipotezinin geçerli olduğunu gösterebilmektedir. Ayrıca karbondioksit emisyonundan yenilenebilir enerjiye doğru ve büyümeden karbondioksit emisyonuna doğru ise tek yönlü nedensellik olduğu görülmüștür.

Sonuçlar genel olarak değerlendirildiğinde, ele alınan dönem ve ülkeler açısından bakıldığında büyümenin en önemli belirleyicisinin kendisi olduğu görülmektedir. Yenilenebilir enerjide meydana gelecek bir şokun büyüme üzerindeki etkisinin artırıcı yönde, karbondioksit emisyonu üzerinde ise azaltıcı yönde olduğu bulunmuştur. $\mathrm{Bu}$ sonuç yenilenebilir enerji tüketiminin büyümeyi tetikleyeceği şeklinde yorumlanabilir. Bunun yanında yenilenebilir enerji tüketiminin artmasının karbondioksit emisyonu üzerinde azaltıcı etki yapacağı söylenebilir.

Elde edilen ekonometrik bulgular, ele alınan ülkelere ait incelenen değişkenlerin zaman içerisinde birbirlerine gösterdikleri tepkiler araştırmacılar ve politika yapıcılar için uygun alternatif enerji ve çevre politikalarının uygulanması açısından bilgi sağlayabilir.

\section{Kaynakça}

- Al-mulali, U., Fereidouni, H.G., Lee, J.M., Che Sab, N.B., 2013. "Examining the bi-directional long run relationship between renewable energy consumption and GDP growth", Renewable and Sustainable Energy Reviews, 22, p. 209-222.

- Apergis N, ve Payne J.E. 2009. "Energy consumption and economic growth in Central America: evidence from a panel cointegration and error correction model". Energy Econ, 31, p.211-216 
- Apergis N. ve Payne J.E., 2010. "A panel study of nuclear energy consumption and economic growth". Energy Econ 32, p. 545-549

- Apergis, N. ve Payne, J.E., 2014. "Renewable energy, output, CO2 emissions, and fossil fuel prices in Central America: Evidence from a nonlinear panel smooth transition vector error correction model", Energy Economics, 42, p. 226-232.

- Al-Iriani, M.A., 2006.”Energy-GDP Relationship Revisited: An Example from GCC Countries Using Panel Causality”. Energy Policy, 34(17), p.3342-3350.

- Arellano, M., O. Bover. 1995. "Another Look at the Instrumental Variable Estimation of Error-Components Models”. Journal of Econometrics, 68 p. 29-51.

- $\quad$ Arouri, M. E. H., Youssef, A. B., M'Henni, H. ve Rault, Ch. 2012. "Energy consumption, economic growth and CO2 emissions in Middle East and North African countries". Energy Policy, 45, pp.342-349.

- Bai, J., Ng, S., 2004. “A PANIC attack on unit roots and cointegration,” Econometrica, 72(4), p. 1127-117.

- Breitung, J., 2000. The local power of some unit root tests for panel data, In: nonstationary panels, panels cointegration and dynamic panels, Baltagi B.H. (ed). Elsevier Amsterdam, p.161-177.

- Bölük, G. ve Mert, M., 2014. "Fossil \& renewable energy consumption, GHGs (greenhouse gases) and economic growth: Evidence from a panel of EU (European Union) countries”, Energy, 74,(1) p. 439-446.

- Breusch, T. S., Pagan, A. R., 1980. "The Lagrange Multiplier Test And Its Applications To Model Specification In Econometrics", Review Of Economic Studies, Blackwell Publishing, 47(1), p. 239-253.

- Cheng, B. 1995. "An investigation of cointegration and causality between energy consumption and economic growth". Energy Dev, 21, p.73-84

- $\quad$ Enders, W., 1995. Applied Econometric Time Series, John Wiley and Sons Inc., New York.

- Farhani, S., 2015. "Renewable energy consumption, economic growth and CO2 emissions: Evidence from selected MENA countries” IPAG Working Paper Series, 2015-612.

- Fatai K, Oxley L, Scrimgeour, F. 2002.’Energy consumption and employment in New Zealand: searching for causality". Paper presented at NZAE conference, Wellington

- Griffiths, S., 2012. "MENA Renewable Energy Challenges of Meeting Future Regional Power Targets", http:/www.mesia.com/wp-content/uploads/2012/11/11.30-Sreve-Grifiths-Masdar-Institute.pdf

- Hamilton, K., 2011. Investing in Renewable Energy in the MENA Region: Financier Perspectives, EEDP Working Paper

- Harris, R.D., Tzavalis, E., 1999. "Inference for unit roots in dynamic panels where the time dimension is fixed," Journal of econometrics, 91(2), p. 201-226.

- Hwang, Jo-Hee ve Yoo, Seung-Hoon, 2014. "Energy consumption, $\mathrm{CO}_{2}$ emissions, and economic growth: evidence from Indonesia", Quality \& Quantity 48, (1), pp. 63-73.

- Hadri, K., 2000. "Testing for unit roots in heterogeneous panel data", Econometrics Journal, 3, pp. 148161.

- International Energy Agency, 2011. http://www.iea.org/index info.asp?id=1959

- International Energy Agency, 2012. $\mathrm{CO}_{2}$ Emissions From Fuel Combustion

- International Finanace Corporation, 2015. Knowledge series in MENA Issue 5

- Im, K.S., Pesaran, M.H., Shin, Y., 2003. "Testing for unit roots in heterogeneous panel”, Journal of Econometrics, 115, pp. 53-74.

- Jaforullah, M. ve King, A., 2015. "Does the use of renewable energy sources mitigate CO2 emissions? A reassessment of the US evidence", Energy Economics, 49, p. 711-717.

- Jalilvand, D.R., 2012. Renewable Energy for the Middle East and North Africa/ Policies for a Successful Transition

- Jebli, M.B. ve Youssef, S.B., 2015. "The environmental Kuznets curve, economic growth, renewable and non-renewable energy, and trade in Tunisia", Renewable and Sustainable Energy Reviews, 47, p. 173-185.

- Jobert, T. ve Karanfil, F. 2007. "Sectoral energy consumption by source and economic growth in Turkey". Energy Policy, 35, p.5447-5456

- Kraft, J. ve Kraft, A., 1978. “On the relationship between energy and GNP”. J Energy Dev, 3:401-403

- Lee, C.C., Chang, C.P. ve Chen, P.F. 2008. "Energy-income causality in OECD countries revisited: the key role of capital stock". Energy Econ, 30, p.2359-2373

- Levin, A., Lin, C.F., Chu, C.S.J., 2002. "Unit Root Test in Panel Data: Asymptotic and Finite Sample Properties", Journal of Econometrics, 108, pp. 1-24.

- Lin, B. ve Moubarak, M., 2014. "Renewable energy consumption - Economic growth nexus for China", Renewable and Sustainable Energy Reviews, 40, p. 111-117.

- Love, I., Zicchino, L., 2006. "Financial development and dynamic investment behavior: Evidence from a panel VAR", The Quarterly Review of Economics and Finance, 46, pp. 190-210. 
- Lütkepohl, H., 2009. "Econometric Analysis with Vector Autoregressive Models", Handbook of Computational Econometrics içinde, Der: D.A. Belsley ve E.J. Kontoghiorghes, John Wiley \& Sons, Ltd., UK.

- Masih A.M,M, ve Masih, R., 1997. “On temporal causal relationship between energy consumption, real income and prices; some new evidence from Asian energy dependent nics based on a multivariate cointegration/vector error correction approach". Policy Model, 19, p. 417-440

- Mbarek, M. B., Ali N. B. ve Feki, R., 2014. "Causality relationship between $\mathrm{CO}_{2}$ emissions, GDP and energy intensity in Tunisia", Environment, Development and Sustainability, Volume 16, Issue 6, pp 12531262

- Mehrara M., 2007. "Energy consumption and economic growth: The case of oil exporting countries". Energy

- $\quad$ Policy, 35, 2939-2945

- Moon, H.R., Perron, P., 2003. Panel evidence on units root in exchange rate interest rates with crosssectional dependence. Manuscript, USC.

- Narayan P.K. ve Smyth R, 2005. "Electricity consumption, employment and real income in Australia evidence from multivariate Granger causality tests". Energy Policy, 33:1109-1116

- Newey, W.K. ve K.D. West, 1994. "Automatic lag selection in covariance matrix estimation”. Review of Economic Studies 61, 631-653.

- Ocal, O. ve Aslan, A., 2013. "Renewable energy consumption-economic growth nexus in Turkey", Renewable and Sustainable Energy Reviews, 28, p. 494-499.

- $\quad$ Oh W. ve Lee K, 2004. "Causal relationship between energy consumption and GDP: the case of Korea 1970-1999”. Energy Econ, 26 (1), p. 51-59

- Omri, A., 2013. " $\mathrm{CO}_{2}$ emissions, energy consumption and economic growth nexus in MENA countries: Evidence from simultaneous equations models". Energy Economics, 40, p. 657-664

- Omri, A., Mabrouk, N. B., Sassi-Tmar, A., 2015. "Modeling the causal linkages between nuclear energy, renewable energy and economic growth in developed and developing countries", Renewable and Sustainable Energy Reviews, 42, p. 1012-1022.

- Paul, S. ve Bhattacharya, R.N., 2004. "Causality between energy consumption and economic growth in India: a note on conflicting results". Energy Econ, 26, (6), p.977-983.

- Pesaran, H., 2004. “General Diagnostic Tests For Cross Section Dependence In Panels”, Working Paper, No: 0435 University of Cambridge.

- Pesaran, M. H. 2007. "A Simple Panel Unit Root Test In The Presence Of Cross-section Dependence," Journal Of Applied Econometrics, 22, p. 265-312.

- Saidi, K. ve Hammami, S. 2015. "The impact of $\mathrm{CO}_{2}$ emissions and economic growth on energy consumption in 58 countries". Energy Reports. _1, November, p. 62-70

- Sebri, M. ve Ben-Salha, O., 2014. "On the causal dynamics between economic growth, renewable energy consumption, $\mathrm{CO} 2$ emissions and trade openness: Fresh evidence from BRICS countries". Renewable and Sustainable Energy Reviews, 39, p. 14-23.

- Shafiei, R. ve A. Salim, 2014. "Non-renewable and renewable energy consumption and CO2 emissions in OECD countries: A comparative analysis". Energy Policy, 66, p. 547-556.

- Shahateet, M. I., 2014. "Modeling Economic Growth and Energy Consumption in Arab Countries: Cointegration and Causality Analysis". International Journal of Energy Economics and Policy, Vol. 4, No. 3, pp.349-359

- Silva, S., I. Soares and C. Pinho 2011. "The impact of renewable energy sources on economic growth and CO2 emissions - a SVAR approach”. FEP Working Papers N. 407

- Stern, D.I., 2000. "A multivariate cointegration analysis of the role of energy in the US macroeconomy". Energy Econ, 22, p. 267-283.

- US Energy Information Administration 2015 http://www.eia.gov

- Worldbank 2015 http://www.worldbank.org/

- Westerlund, J., 2007. "Testing for Error Correction in Panel Data", Oxford Bulletin of Economics and Statistics, 69(6), p. 709-748.

- Yuan, J., Kang, J-G, Zhao, C., Hu, Z, 2008. "Energy consumption and economic growth: evidence from China at both aggregated and disaggregated levels". Energy Econ, 30, p.3077-3094

- Zeb, R., Salar L., Awan, U., Zaman, K. ve Shahbaz, M., 2014. "Causal links between renewable energy, environmental degradation and economic growth in selected SAARC countries: Progress towards green economy", Renewable Energy, 71, p.123-132. 


\title{
İnşaat Endüstrisinde Geri Dönüşüm Çalışmalarının Geliştirilmesi ve Ekonomi Üzerine Etkileri \\ The Development of Recycling in the Construction Industry and Its Effect on the Economy
}

\author{
Asst. Prof. Dr. Fatih Kürşat Fırat (Aksaray University, Turkey) \\ Mr. Fahri Akbaş (Aksaray University, Turkey)
}

\begin{abstract}
The growth in world population, global climate change, consumption habits of people, and the excessive use of prime materials, causes natural resources to decline rapidly. We waste more energy during the process of production, operation and transportation of materials than ever. Perhaps one of the most important challenges that our generation faces is to create an economy that prevents waste. Considering limited resources, countries are searching for new methods of recycling and reusing waste material.

Recycling is one primary way to reduce the consumption of natural resources. Waste material can go through a reproduction process with various physical and chemical transformation methods. The recycling of petrochemicals used in the automotive industry, electrical appliances, steel and cement industries, and the improvement of the transportation sector can reduce energy consumption and raw material significantly. Investment in recycling facilities can maximize profits by turning waste back into the economy.

In Turkey, the improvements on the subject of recycling of materials such as plastics and paper are observed. However, we almost see no recycling in the construction industry, except iron and steel sector. Demolition materials in other countries are included in the reproduction processes through recycling. Thus both the benefits of reducing energy consumption and carbon emissions are at a minimum. Therefore, this study focuses on the recycling in the Turkey construction industry. The research also investigates the impact of recycling of construction materials to the economy and the environment based on the data and knowledge obtained from some European countries.
\end{abstract}

\section{Giriş}

İnsanın etrafındaki her şeyi kapsayan ve hayatın devamı için gerekli ortamlardan birisi olan çevre ile ilgili problemler giderek artmakta hem doğayı hem de tüm insanlığı tehdit eder hale gelmektedir. Son yıllarda doğal kaynakların hızla azalmasıyla birlikte küresel iklim değişikliklerinden dolayı çevre sorunlarına verilen önem hızla artmaktadır. Çevresel problemlerle birlikte çevresel tahribatlar da hızla artmaktadır ve bu yıkımlarda insan baş sorumlu olarak karşımıza çıkmaktadır. Küreselleşmeyle birlikte teknolojik ve bilimsel olarak da hızlı bir değişim süreci yaşanmaktadır. Çevresel tahribattan en çok etkilenen insan olmasına rağmen bu yıkımlara neden olan da çevrenin yeniden eski haline getirilmesi için kullanılacak bilimsel ve teknolojik altyapıya sahip olan da insanoğludur. Doğal çevre kendini yenileyebilen bir özelliğe sahip olmasına rağmen insan eliyle sonradan bozulmuş olan çevrenin kendini eski hale getirmesi her geçen gün daha da zorlaşmaktadır. Her ne kadar çevre sorunları ile ilgili çok fazla eğitim ve bilinçlendirme çabaları yapılmakta, bazı yasa ve yönetmelikler çıkarılmakta ve uluslararası anlamda bir takım anlaşmalar imzalanmakta olsa bile; en büyük sorun, bu çalışmaların küresel ısınma başta olmak üzere çevre sorunlarının yıkıcı etkilerinin azaltılması açısından çok fazla etkili ve yeterli olmadığı gerçeğidir.

Günümüzde Asya ve Latin Amerika'nın yükselen ekonomileri daha kaynak yoğun bir sanayileşmeye geçerek binalar, su ve kanalizasyon sistemleri, havaalanları, elektrik şebekeleri sulama kanalları, demiryolları ve diğer altyapı unsurları gibi büyük boyutta enerji, metal, mineral ve diğer yenilenemez kaynaklara ihtiyaç duyan yapılar ve sistemler inşa etmektedirler. Bu yapıların inşası ve sonrasında toprak, hava ve su ortamları belirli oranda etkilenmektedir. Sanayileşmiş ülkelerin bitmeyen malzeme talebi, büyümekte olan ekonomilerin gelişme hızı ve modern yaşamın malzemeleri kullanıp atma alışkanlığı sorunları da beraberinde getirmektedir (Worldwatch Enstitüsü, 2013). Dünyada yaşanan küresel ısınma gibi iklimsel değişimler ve hızla nüfus artış1 etkisiyle doğal kaynakların tükenmeye başlaması, atıkların daha verimli kullanılması gerçeğini ortaya koymuş, son zamanla hükümetlerin çevre bilincini arttırma çabaları ile birlikte geri dönüşüm kavramı hızla yayılma başlamıştır. Sınırlı olan doğal kaynaklardan üretilen ürünlerin tam ve etkin kullanımı ile olduğu şekliyle kullanılamaz hale gelen ürün ve kaynakların bir takım kimyasal ve fiziksel işlemlerden geçmesi ile yeniden kullanımına veya daha farklı bir amaçla tüketilmelerine yönelik çalışmalara olan ilgi hızla artmaktadır. Üreticilerin daha düşük maliyet ile piyasanın ihtiyaçlarını giderme ve daha kaliteli ürün pazarlama istekleri, tüketicilerin de daha düşük fiyata daha kaliteli ürüne sahip olma arzuları geri dönüşüm uygulamalarıyla ürünlerin yeniden kullanılmasını ön plana çıkarmıştır. 
Modern kullan-at ekonomisi malzemelerin üretim, işletim ve boşaltım süreçlerinde sadece malzemelerin kendisini değil bu malzemeleri kullanılacak hale getiren enerjiyi de israf etmektedir. Plastik, suni gübre, çelik, çimento ve kağıt üretimi de dahil olmak üzere sanayi üretimi, küresel enerji tüketiminin \% 30' undan fazlasını oluşturmaktadır. Otomotiv, elektrikli ev aletleri, inşaat, petrokimya, çelik sanayinde, çimento ve ulaştırma sektöründe, en verimli üretim sistemlerinin yanında geri dönüşümden yararlanılarak enerji tüketimi azaltılabilmektedir. Örneğin petrokimya sanayindeki fosil yakıt tüketiminin büyük bölümü hammaddeler için kullanıldığından, plastik gibi malzemelerin üretiminde verimli üretim sistemlerine geçilerek geri dönüşümden daha fazla yararlanılması, petrokimya sanayindeki enerji tüketimini azaltmaktadır. Kağıt ürünleri, cam, plastik, inşaat malzemeleri, otomobiller, elektrikli ev aletleri, evsel atıklar, ofis malzemeleri, uçak, dizel motor, bilgisayar, kıyafetler ve diğer ürünlerin yeniden kullanım ya da geri dönüşüm için kullanılmak üzere kolayca parçalara ayrılabilmesini sağlayacak tasarımların yapılması dünyayı atmosferdeki $\mathrm{CO} 2$ düzeyinin istikrarlı olduğu döneme geri döndürmek açısından önemli rol oynamaktadır (Brown, 2008). Geri dönüşümün literatürde yeni bir kavram gibi görünmesine rağmen, geçmişinin 1900'lü yıllara kadar dayandığı bilinmektedir. Kavram, II. Dünya Savaşı'nın ardından kaynakların azalması ve çevrenin kirlenmesiyle birlikte yavaş da olsa anlaşılmaya başlanmış̧ır.

1970'lerden beri dünya çapında tüm bu atıkların oluşumunu önlemek veya azaltmayla beraber geri kazanım veya geri dönüşüm yoluyla yeniden kullanma ile ilgili birçok çalışma yapılmaktadır. İnşaat sektörünün ekonomi açısından önemli bir itici sektör olduğundan inşaat atıklarının doğru değerlendirilememesinin ekonomiye verdiği zararın boyutunun büyük olacağı tahmin edilmektedir. Katı atıkların hepsinde olduğu gibi inşaat sanayinde ortaya çıkan atıklar geri dönüştürülmediği takdirde ekonomik zararlara ilaveten ekolojik yıkımlarda hızlanacaktır. Geri dönüşümde malzemelerin toplanması, ayrılması, geri dönüştürülmesi ve tekrar kullanılması için profesyonel şirketler kullanılmaktadır. Kaynak israfını ve ortaya çıkan enerji krizini önlemek için gelişmiş ülkeler atıkların geri kazanılması ve tekrar kullanılması için çeşitli yöntemler aramış ve geliştirmişlerdir. $\mathrm{Ne}$ yazık ki ülkemizde diğer gelişmiş ülkelere nazaran demir-çelik ürünleri hariç inşaat endüstrisinde geri dönüşüm miktarı yok denecek kadar azdır.

İnşaat sektörü Avrupa Birliğinin ekonomisine \% 9,8 katkı sağlamakla birlikte, inşaat ve yıkıntı atıkları ekonomiye ve çevresel zarar vermektedir. İnşaat ve yıkıntı atıkları evsel olarak nitelendirilen atıklardan hacim olarak daha büyük bir yer işgal etmektedir. Avrupa'da II. Dünya Savaşı'ndan sonra inşaat ve yıkıntı atıklarıyla ilgili faaliyetler başlamış olup, küreselleşme süreci ile birlikte hızlanmıştır. Hollanda ve Almanya başta olmak üzere hemen hemen tüm Avrupa Ülkeleri geri dönüşümle ilgili olarak Atık Yönetim Kurumu düzenlemelerine dayalı olup, bu düzenlemeler teknolojik ve çevresel faktörleri içeren yöntem ve düzenlemeler içermektedir (Altındağ, 2011). Avrupa ülkelerinde inşaat/yıkıntı ve rehabilitasyon çalışmaları esnasında yıllık 175-370 milyon ton veya $0.5-1$ ton/kişi/yıl inşaat/yıkıntı atı̆̆ oluştuğu tahmin edilmektedir (Ölmez ve Yıldız, 2008). Avrupa'daki geri dönüşüm çalışmalarının A.B.D’ye oranla daha hızlı geliştiği söylenebilir. Ancak küreselleşmenin getirmiş olduğu değişimle A.B.D. ninde geri dönüşüm uygulamalarını arttırdığı görülmektedir.

ABD'de geri dönüşümü yapılıp, tekrar kazanılan inşaat ve yıkıntı atıklarından metaller ve ahşap malzemeler ilk sırada yer almaktadır. Çin, Hindistan, Hong Kong gibi çoğu ülkenin inşaat sektörlerindeki büyümeyle birlikte artan inşaat ve yıkıntı atıklarını değerlendirdikleri büyük oranda geri kazandıkları tespit edilmiştir (Altındağ, 2011). Dünyadaki diğer ülkelerde Avrupa ve A.B.D.'nin geri dönüşümle ilgili sorumluluk duygularını ciddiye alarak sürdürülebilir bir dünya için yeni stratejiler geliştirmiştir.

Türkiye'de meydana gelen 1992 Erzincan, 1995 Dinar, 1998 Adana-Ceyhan, 17 Ağustos 1999 Marmara, 12 Kasım 1999 Düzce, 2002 Afyon-Sultandağı, 2003 Bingöl depremleri ve en son 2011 yılında meydana gelen Kütahya-Simav ve Van depremlerinden sonra ciddi anlamda bir inşaat yıkıntısı meydana gelmiş olup ayrıca depremde yıkılmayan ama çok ciddi oranda hasar gören binalar ortaya çıkmıştır. Aşağıdaki resimlerde (Şekil 1) en son yaşanan büyük depremlerden olan Simav ve Van depremlerinde hasar gören ve yıkılması gereken iki bina görülmektedir. Depremler sonrasında elde edilen veri ve bilgiler Türkiye'nin mevcut yapı stokunun beklenen depremlere karşı yetersiz olduğunu ortaya çıkarmıştır (Fırat ve Yücemen, 2014; Fırat ve Yücemen, 2015). Bahsedilen bu depremlerden sonra yapı dayanımının arttırılması için çeşitli bilimsel çalışmalar yapılmış, yapı tasarım kriterleri değiştirilmiş, çeşitli yönetmelik ve standartlarda revizyona gidilmiştir. Hâlihazırda var olan yapılar, yenilenen standart ve yönetmeliklerde bulunan tasarım kriterlerine uygun hale getirilme çalışmaları ülke ekonomisi göz önünde bulundurularak devam etmektedir. Ülkemizde genellikle kritik ekonomik faaliyetlerin bulunduğu, nüfus yoğunluğunun fazla olduğu ve ciddi oranda enerji yatırımlarının bulunduğu bölgeler aynı zamanda deprem kuşağında yer almaktadır. Geçmişte bu bölgelerde meydana gelen depremler ülkede birçok can ve mal kayıplarına neden olmuş hatta ekonomik krizlerin meydana gelmesinde önemli bir parametre olarak kendini göstermiştir ( Fırat, 2009; Fırat ve Soyu, 2014). Bu nedenle, şu anda kullanılan ama deprem tehlikesine karşın zayıf olduğu aşikâr ilgili standartlara uymayan binaların depreme karşı dayanımının arttırılması amacıyla güçlendirilmesi ya da yıkılıp yeniden inşa edilmesi gerekmektedir. Bunun da ciddi anlamda inşaat atığı ortaya çıkaracağı görünen bir gerçektir. 


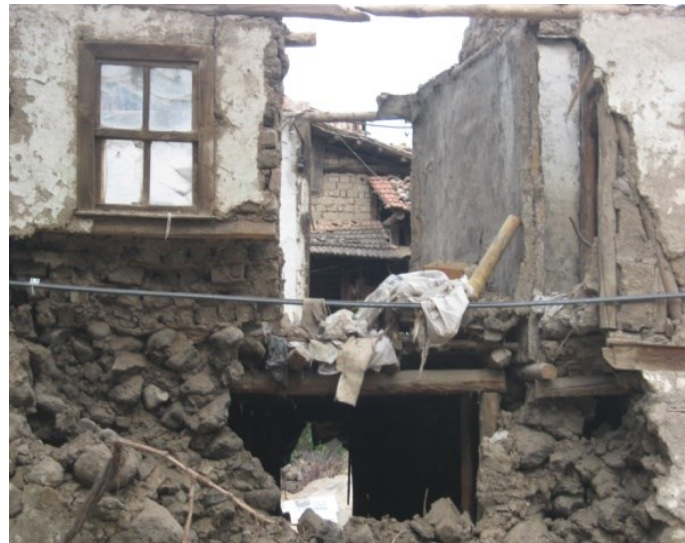

a) Simav depremi sonrası yığma bir yapı

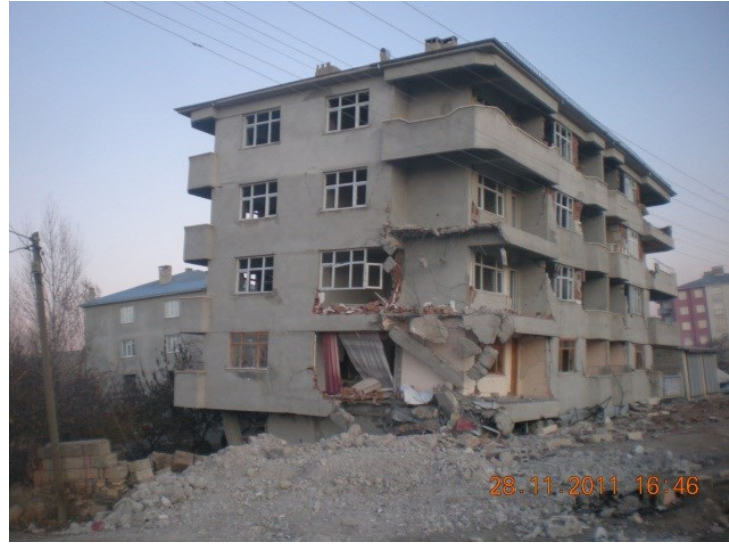

b) Van depremi sonrası betonarme bir yap1

\section{Şekil 1. Depremlerden sonra hasar gören yapılar}

Ülkemizde son zamanlarda kentsel dönüşüm maksadıyla birçok proje uygulanmaya başlamaktadır. Kentsel Dönüşüm; eskiyen veya bozulmaya uğrayan veya yakın bir gelecekte uğrayacağı tahmin edilen problemli kentsel alanın ekonomik, toplumsal, fiziksel ve çevresel koşullarının iyileştirilmesine yönelik olarak uygulanan strateji ve eylemlerin tümü olarak tanımlanabilir. Yerleşim alanının kullanım maksadını yitirmiş veya gecekondu bölgelerinde herhangi bir doğal afette şehrin hasar görmesi olası bölgelerinde yenileme, iyileştirme, sağlıklılaştırma amacıyla yapılan faaliyetleri kapsar. Ayrıca Şekil 2'de örnek olarak verilen zamanla şehrin merkezinde kalan sanayi ve pazar bölgelerinin (oto pazarı, hayvan pazarı) taşınması maksadıyla kentsel dönüşüm uygulanabilir (Altuntepe ve Firat, 2013). Kentsel dönüşüm, ülkemizde son yıllarda çok önemli oranda yaşanan köyden şehire göç sonucu meydana gelen plansız şehirleşme sonucu ortaya çıkan birçok fiziksel ve toplumsal olumsuzluklardan kurtulmak için önemli bir aşamadır. Fakat kentsel dönüşümden sonra ortaya çok ciddi bir miktarda inşaat atığı ortaya çıkacaktır. Ülkemizde, inşaat atıklarının doğal çevreye zarar verecek şekilde biriktirilmesinin ya da gelişigüzel atılmasının önüne geçilmesi, bu malzemelerin geri dönüşümünün sağlanması amacıyla, 18 Mart 2004 tarih ve 406 Sayılı Resmi Gazetede "Hafriyat Toprağı, İnşaat ve Yıkıntı Atıklarının Kontrolü Yönetmeliği” yayımlanmıştır. Örnek olarak, Çevre ve Şehircilik Bakanlığı birçok kentsel dönüşüm planlanan İstanbul'da yıkılacak yapıların atıklarından elde edilen malzemelerin, Arnavutköy-Göktürk-Çatalca yollarının kesiştiği alanda bulunan 3 bin 500 hektarlık bölgeye yapılacak üçüncü havaalanında kullandırmayı planlamaktadır.

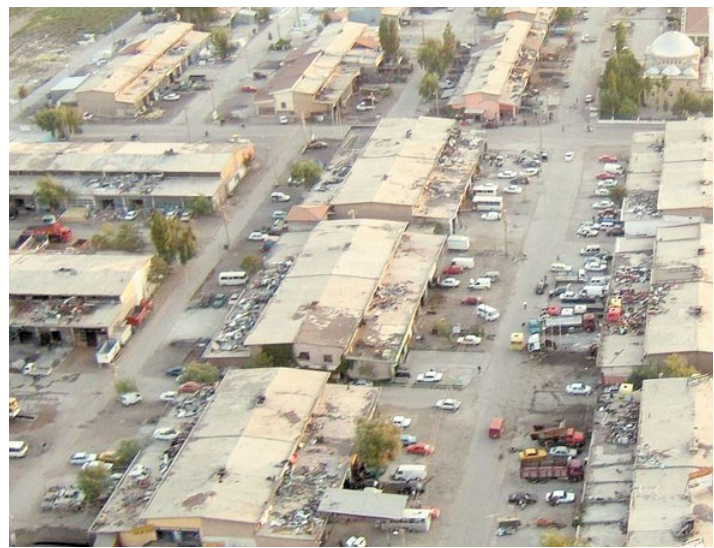

a) Kentsel dönüşüm öncesi mevcut hal

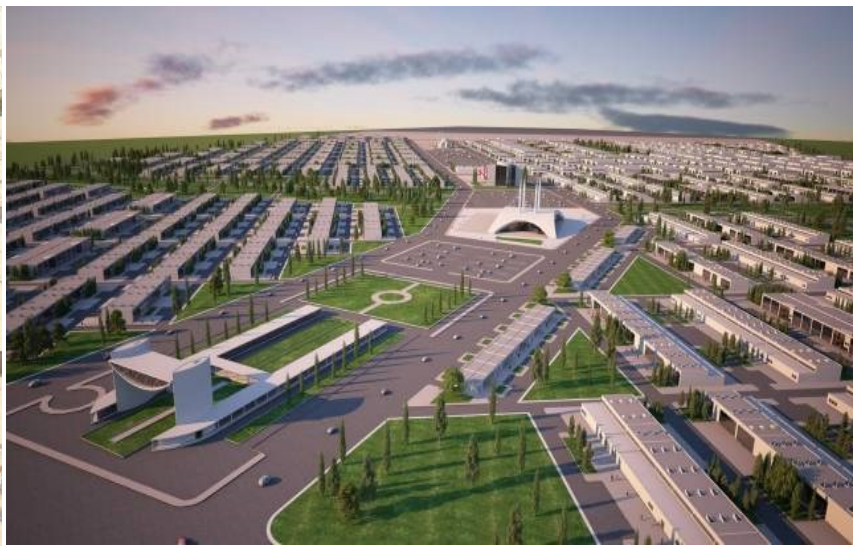

b) Kentsel dönüşüm sonrasına planlanan

Şekil 2. Aksaray sanayi sitesi kentsel dönüşüm planı

\section{Geri Dönüşüm Kavramı ve İnşaat Endüstrisi Açısından Geri Dönüşüm}

İktisatın genel tanımı olan kıt kaynaklarla sınırsız ihtiyaçların karşılanması olgusu, günümüzde yetersiz olan dünya kaynaklarının verimli bir şekilde kullanılması açısından önemli bir sorun haline gelmiştir. Kıtlık sorununun kaynaklar tükenmeden çözülmesi gerekmektedir. Kıtlık sorunu arz yetersizliğine anlamına gelmekte olup arz sorununun en önemli faktörü maliyet olarak karşımıza çıkmaktadır.

Bir kaynağı çıkarmak için gereken enerji miktarı fazla ise, çevresel düzenlemeler basit çıkarma yöntemlerini yasaklarlarsa veya düşük kalite kaynakların ekonomik olarak işe yarar hale getirilmek için yoğun bir şekilde işlenmesi gerekiyorsa o zaman o kaynağı çıkarmak çok pahalıya mal olmaktadır. Teknolojik gelişmeler kaynak 
çıkarma maliyetini düşürerek arzı arttırabileceği gibi geri dönüşüm de kaynak arzını arttırarak piyasalarda yaşanan kıtlı̆̆ azaltabilecektir.

Doğada var olan kaynakların günden güne azalmasıyla birlikte, mevcut atıkların yeniden bir hammadde kaynağı haline dönüştürülmesi, değerlendirilmesi, işlenmiş hammaddelerin yeniden kullanılması, geri dönüşüm ve bu atıkların azaltılması ve yönetimi konusunu gündeme getirmiştir. Metal hurda toplama, atık kağıt dönüşümü, cam şişeler için depozito uygulamaları uzun zamandır yapılmaktadır. Aslında geçmiş zamanlarda kullanılmış ürünler ve malzemeler tekrar kullanılmaktaydı. Ancak teknolojinin günümüzdeki kadar gelişmediği o dönemlerde kullanılan ürünlerin yeniden kullanılması kısıtlı olanaklarla yapılabilmekteydi. Küreselleşmeyle birlikte teknolojik yenilikler hızla artmış, geri dönüşüm imkanları çok geniş bir alana yayılmıştır.

Atık, doğayı olumsuz yönde etkileyecek miktarda çevreye boşaltılan, sıvı, katı, gaz ya da radyoaktif istenmeyen her türden maddeler olarak ifade edilebilir (Bayramoğlu, 1995). Atıklar çevreye olan etkileri bakımından zararlı ve zararsız atıklar; yapılarına göre sıvı, katı, gaz atıkları; kaynaklarına göre ise, evsel, endüstriyel, ticari, kurumsal, tarımsal (zirai) ve özel atıklar olarak sınıflandırılabilir (Tenikler, 2007). 2 Nisan 2015 tarihli 29314 sayılı resmi gazetede yayınlanan Çevre ve Şehircilik Bakanlığı Atık Yönetimi yönetmeliğinde geri dönüşüm ve geri kazanım kavramları tanımlanmıştır. Bu yönetmeliğe göre: "Geri Dönüşüm: Enerji geri kazanımı ve yakıt olarak kullanımı ya da dolgu yapmak üzere atıkların tekrar işlenmesi hariç olmak üzere, organik maddelerin tekrar işlenmesi dâhil atıkların işlenerek asıl kullanım amacı ya da diğer amaçlar doğrultusunda ürünlere, malzemelere ya da maddelere dönüştürüldüğü herhangi bir geri kazanım işlemini; Geri kazanım: Piyasada ya da bir tesiste kullanılan maddelerin yerine ikame edilmek üzere atıkların faydalı bir amaç için kullanıma hazır hale getirilmesidir." Geri dönüşüm de ürünler özelliklerini tamamen kaybetmekte olup, ürün yenileştirme, ürün tamiri, ürünü yeniden kullanma, ürünün yeniden üretimi gibi faaliyetler, kullanılmış ürünlerin özelliklerinin ve fonksiyonlarının korunmasını sağlamaktadır (Acar ve Köseoğlu, 2014).

Atık yönetimi, atık ürünlerin meydana geldiği kaynakta oluşumunun önlenmesi, önlenilemeyen durumlarda atıkların azaltılması, yine aynı kaynakta kullanılabilirliğinin sağlanması, toplanması, türüne göre ayrılması, geçici olarak toplanması, toplanan bu atıkların ilgili yerlere taşınması, geri dönüştürerek yeniden kullanılması, geri kazanılması, yok edilmesi, yok edilme işlemi sonrası denetim faaliyetlerini kapsamaktadır. Geri dönüşülebilir atıklar öncelikle kaynaktan ayrıştırılmakta ve ürün geri alımı sürecinde ürünlerin ya da ambalajların kullanılabilen kısımları toplanmaktadır. Ürünlerin bileşenlerini oluşturan parçalar sökme işlemi ile gruplandırılmakta ve atıklar arasında sınıflandırma (cam, plastik ve kağıt gibi) yapılmaktadır. Geri dönen ürünlerde stok kontrolü yapılmakta ve geri dönüştürülecek malzemeler kimyasal ve fiziksel değişime uğratılarak yeni bir malzeme üretilmektedir. Böylece geri dönüştürülen ürünler kullanılarak ekonomik kazanım sağlanmaktadır (Guide vd., 1999).

Doğal kaynakların korunması ve verimli kullanılması için geri dönüşüm oldukça önemlidir. Aynı zamanda malzeme üretiminde endüstriyel işlem sayısının azalması ile enerji tasarrufu da sağlanmaktadır. Hedeflerin sonuca ulaşmasıyla birlikte geri dönüşüm sayesinde hem geleceğe hem de ekonomiye yatırım yapılmaktadır. Geri dönüşüm sayesinde arz arttırılacak, maliyetlerin düşecek, maliyetlerin düşmesiyle fiyatların düşecek, toplumsal baskılar ortadan kalkacak, yasal zorunluluklar yerine getirilecek ve en önemlisi de çevre kirliliği azaltılacaktır. Sonuçta hem yaşayan toplumların hem de gelecek nesillerin doğal kaynaklardan daha fazla yararlanmasına ve daha kaliteli bir hayat yaşamasına imkân sağlayacaktır. Tablo 1'de birincil kaynaklara kıyasla geri kazanımın sağladığı enerji tasarrufu oranları verilmektedir. Buna göre alüminyumda en yüksek enerji tasarrufu sağlanırken çinko en düşük enerji tasarrufu sağlayan metal olarak görülmektedir.

\begin{tabular}{|c|c|}
\hline Metal/Malzeme & Enerji Tasarrufu \\
\hline Alüminyum & 95 \\
\hline Bakır & 85 \\
\hline Demir-Çelik & 74 \\
\hline Kurşun & 65 \\
\hline Çinko & 60 \\
\hline Kağıt & 64 \\
\hline Plastik & $>80$ \\
\hline
\end{tabular}

Tablo 1: Birincil Kaynaklara Kıyasla Geri Kazanımın Să̆ladı̆̆ı Enerji Tasarrufu Kaynak:(Yazıcı, Deveci, 2009).

Ekonomik kalkınma ve sürdürülebilir istihdamın sağlanmasında inşaat sektörünün önemli bir yeri olup, bir ülkenin ekonomisinde büyümenin lokomotifi niteliğinde bir sektördür. Bu yüzden bir ülkedeki inşaat sektörü ne kadar gelişmişse ekonomik büyümeye katkısı o kadar fazla olacaktır. Özellikle gelişmekte olan bir ülkedeki konjonktürel dalgalanmalardan başta inşaat malzemesi sanayi olmak üzere tüm inşaat sektörü önemli oranda etkilenecektir. İnşaat sektörü ve uygulamaları ülkedeki makro ekonomik politika değişikliklerinden de doğrudan etkilenecektir. Ayrıca, inşaat sektörü ağır sanayi yönünden çeşitli yatırım olanaklarına sahiptir. İnşaat malzemeleri de neredeyse tüm sanayiyi doğrudan etkilemektedir. Hammaddenin en çok tüketildiği sektörlerden 
birisi de inşaat sektörüdür. İnşaat sektörü de diğer sektörler gibi ekonomik olarak imalat süreçlerindeki girdilerin maliyetini minimum seviyeye indirmeye, hammadde kullanımını ve enerji tüketimini mümkün olduğu kadar azaltmaya çalışmaktadır. Bu sektörde en çok kullanılan malzemelerin başında beton, asfalt, ahşap, alüminyum, demir gibi malzemeler gelmektedir. Bu malzemeler inşaat sektöründe yaygın olarak kullanılan başlıca malzemeler olup geri dönüşüm ve geri kazanım miktarları yüksektir. Bu açıdan bakıldığında, talep ve tüketim ilişkisi içerisinde geri dönüşümün özellikle inşaat alanında yaygın bir şekilde uygulanmasının kayda değer ölçüde ekonomik kaynak sağlayacağı görülmektedir. Barajlar, hidro elektrik santraller, nükleer enerji tesisleri, limanlar, deniz dolguları, kanallar, binalar, yollar, köprüler, tüneller, metrolar, gibi her türlü inşaat faaliyetleri ülkenin ekonomisini olumlu yönde etkilemesine rağmen doğal çevreye ciddi oranda zarar vermektedirler.

Son zamanlarda özellikle çevresel etkilerin artmasıyla özellikle katı atıkların kontrolü tüm toplumların üzerinde durdukları önemli bir sorun olmuştur. Kentsel katı atıkların yaklaşık \%13-30 luk gibi önemli bir kısmını oluşturan inşaat ve yıkıntı atıkları, kontrol altına alınmadığı sürece hem uygarlığa hem de çevreye büyük zarar verecektir (Ölmez ve Yıldız, 2008). Tüm katı atıkların içinde beton, çelik, tuğla, alçı, ahşap, cam, metaller, plastikler ve hafriyat toprağı gibi maddelerin önemli bir yüzdeye sahip olduğu açıkça görünmektedir (Coşkun ve Öztürk, 2012). İnşaat ve yıkıntı atıkları, konut, köprü, yol ve benzeri yapıların yapımı, tamiratı, tadilatı, yenilenmesi, yıkımı veya deprem gibi doğal afetler sonucu oluşmaktadır. Bu atıklar, inşaat sanayinin çok yönlü olmasından dolayı teknik ve malzeme açısından çok çeşitlidir. Genellikle inşaat sektöründe en çok betonarme, beton, sıva, tuğla, briket, tahta, cam, metal parçası (çelik alüminyum, bakır, pirinç) alçı kartonpiyer, kiremit, plastik, borular ve asfalt gibi malzemeler kullanılmaktadır. Sağlıklı bir geri dönüşüm sistemi için iyi bir kazanım sisteminin oluşturulması gerekmektedir. Bunun için belirli süreçler izlenmelidir. Konut, bina, köprü, yol gibi, alt ve üst yapıların yıkımı öncesinde ve sırasında içindeki yabancı ve geri kazanımı mümkün olmayan maddelerin geri dönüşümü mümkün olan maddelerden ayıklanması gerekmektedir. Çünkü bu ayıklama işlemi yapılmadığında geri dönüşümü mümkün olan maddelerde işleme karışacak uygulama daha zahmetli bir hal alacaktır. Enkaz ve yıkımın belirli ölçülerde ve kontrollü olarak (seçici yıkım) yapılmasıyla, hafriyat toprağı ile inşaat/yıkıntı atıklarının karıştırılması önlenmektedir. Hafriyat toprağının geri kazanılması ise öncelikle dolgu, rekreasyon, katı atık depolama alanında günlük örtü şeklinde kullanılarak olmaktadır. Geri kazanımı mümkün olmayan maddelerin ise düzenli depolama sahalarına gönderilerek işlemin tamamlanması gerekmektedir (Bilim, Sanayi ve Teknoloji Bakanlığı, 2012). Beton hacimsel olarak dünyada sudan sonra en çok kullanılan malzemedir. Beton güç ve performans olarak çok az kayba uğramakta olup, geri dönüşüm oranı yüksek bir malzemedir. Betonun, yol döşemesi yada inşaat dolgu malzemesi olarak yeniden kullanılmasını sağlayan sistemler de vardır. Üretimi ve işlenmesi esnasında meydana gelen atık miktarı \% 60'lara ulaşan mermer sektöründe de yeniden kullanım için önemli miktarlarda hammadde açığa çıkmaktadır. Meydana gelen atıklar toz ve parça atıklar olmak üzere ikiye ayrılmaktadır. Bu atıklardan inşaat sektöründe değişik alanlarda yararlanılmaktadır. Mermer toz atıkları asfalt betonu karışımında filler malzemesi olarak değerlendirilmekte, bozuk zemin özelliklerinin iyileştirilmesinde katkı maddesi olarak kullanılabilmektedir. Beton, beton ve asfalt karışımlarda agrega, yol zemini ve baraj inşaatlarında dolgu malzemesi, suni mermer plağı, karosıman ve süsleme sanatı olarak da antik taş yapımında kullanılmaktadır. Geri dönüşüm uygulamalarından birisi de asfalt geri dönüşümüdür. Genellikle asfalt geri dönüşüm santrallerinde \% 70 oranında geri dönüştürülmüş malzeme kullanılmaktadır (Gürer vd., 2004).

İnşaat sektörünün geri dönüşüm açısından en verimli malzemelerinden biri de çelik olarak karşımıza çıkmaktadır. Türkiye Demir Çelik Üreticileri Derneği’nin verilerine göre Türkiye yıllık 12 milyar dolar civarında çelik hammaddesi ithal etmekte olup bunun 9 milyar doları demir çelik hurdası 3 milyar doları ise demir cevheridir. Türkiye demir-çelik sektörü hammadde olarak kullandığ hurdanın \%70'ini ithal etmekte ve \%30'unu yerli kaynaklardan temin etmektedir. Yine aynı şekilde hammadde olarak kullanılacak demir cevherinin \% 60’1 ithalat \% 40’ 1 yerlidir. Bu oranda sadece demir çelik endüstrisindeki geri dönüşümün Türkiye sektör ihtiyacının ortalama \%72'isini karşıladığını göstermektedir. Üretilen çeliğin yaklaşık yarısı da ihraç edilmektedir (17 milyar dolar).

\section{Dünya'da ve Türkiye'de Geri Dönüşümle İlgili Gelişmeler}

Ülkeler enerji ve hammaddenin korumasıyla ilgili olarak sürdürülebilir kalkınma içinde katı atık yasaları ve yönetmelikleri üzerinde önemle durmaktadır. Bu düzenlemeler arasında inşaat sonrası ortaya çıkan moloz atıklarının da değerlendirilmesi konusu da yer almaktadır. Geri kazanılan bu atıklar tekrar inşaatlarda kullanılarak hem çevre korunacak hem de ülke ekonomisine olumlu bir katkı söz konusu olacaktır (Erdin, vd., ty.). Son zamanlarda gerek gelişmiş ülkelerde gerekse gelişmekte olan ülkelerde atık yönetimi konusunda farklı uygulamalar bulunmaktadır. Avrupa Birliği'nde geri dönüşüm ile ilgili birçok politika uygulanmaya çalışılmıştır ve bu uygulamalar diğer ülkeler tarafından da desteklenmiştir.

2001 Gothenburg Avrupa Konseyinde, AB Ülkeleri, "Daha İyi Bir Dünya İçin Sürdürülebilir Bir Avrupa ve Sürdürülebilir Kalkınma için ise Avrupa Stratejisi” hedeflemişlerdir. "AB Sürdürülebilir Kalkınma Stratejisi” uzun dönemli hedefi, “Avrupa'nın hatta dünyanın geri dönüştüren, atığı önleyen ve atıkları tekrar kullanan bir toplum olmasının sağlanması” olarak belirlenmiştir (Bilim, Sanayi ve Teknoloji Bakanlığı, 2014). 


\begin{tabular}{|c|c|c|c|c|}
\hline Ülke & $\begin{array}{c}\text { İnşaat/Yıkıntı } \\
\text { Atığı } \\
\text { (milyon ton) }\end{array}$ & $\begin{array}{c}\text { İnşaat/Yıkıntı } \\
\text { Atı̆̆ } \\
\text { (kg/kişi/yıl) }\end{array}$ & $\begin{array}{c}\text { Geri Dönüştürülen } \\
\text { veya Tekrar } \\
\text { Kullanılan (\%) }\end{array}$ & $\begin{array}{c}\text { Yakma veya } \\
\text { Depolama(\%) }\end{array}$ \\
\hline Almanya & 59 & 750 & 17 & 83 \\
\hline İngiltere & 30 & 530 & 45 & 55 \\
\hline Fransa & 24 & 420 & 15 & 85 \\
\hline İtalya & 20 & 350 & 9 & 91 \\
\hline İspanya & 13 & 340 & $<5$ & $>95$ \\
\hline Hollanda & 4 & 270 & 90 & 10 \\
\hline Belçika & 7 & 700 & 87 & 13 \\
\hline Avusturya & 5 & 650 & 41 & 59 \\
\hline Portekiz & 3 & 300 & $<5$ & $>95$ \\
\hline Danimarka & 3 & 575 & 81 & 19 \\
\hline Yunanistan & 2 & 200 & $<5$ & $>95$ \\
\hline İsviçre & 2 & 240 & 21 & 79 \\
\hline Finlandiya & 1 & 200 & 45 & 55 \\
\hline İrlanda & 1 & 285 & $<5$ & $>95$ \\
\hline Lüksemburg & 0 & - & $\mathrm{n} / \mathrm{a}$ & $\mathrm{n} / \mathrm{a}$ \\
\hline AT & 180 & 28 & & 72 \\
\hline
\end{tabular}

Tablo 2: AB Ülkelerinde Üretilen İnşaat ve Yıkıntı Atığı Miktarl, Kaynak: (Ölmez ve Yıldız, 2008.)

Tablo 2'ye göre geri dönüşüm konusunda Hollanda \%90 ile başı çekerken Norveç, Belçika ve Almanya yüksek geri dönüşüm oranlarıyla dikkat çekmiş olup, Portekiz, Yunanistan, İrlanda ve İspanya gibi ülkeler \% 5'in altında bir geri dönüşüm ve tekrar kullanım oranına sahip olmuşlardır.

Ülkemiz açısından bakıldığı zaman artarda yaşanan finansal krizlerin ardından son yıllarda ekonomik, teknolojik ve sosyal olarak birtakım değişmeler küreselleşmeyle birlikte hız kazanmıştır. Türkiye'de yeni bir ekonomik büyüme modeli uygulamasına geçilmiş, yeni kavramlar önem kazanmaya başlamıştır. Bu kavramlardan bir tanesi de geri dönüşümdür. Ülkemizde nüfusun artmasıyla birlikte sanayileşme ve kentleşme faaliyetlerinin yükselmesi neticesinde atık sorunu gündem maddesi oluşturmuştur. Ülkemizde çöplerin ve atıkların giderek yaygınlaşması bu konuyla ilgili olarak Avrupa ve Amerika'yı örnek almayı gerektirmiştir. Avrupa ve Amerika'daki gibi başarılı bir geri dönüşüm geçmişi olmayan Türkiye'nin son yıllarda geri dönüşüm yoluyla kazanılan atıkların miktarında artış yaşanmıştır. Artan atık miktarıyla ilgili olarak "atık yönetimi yaklaşımı" önemli bir konu haline gelmiştir. Halen Türkiye açısından atık yönetimi ile ilgili düzenlemeler yapılmakta olup son yıllarda hız kazanmıştır.

$\mathrm{Bu}$ faaliyetlerin paralelinde ülkemizde atıkların toplanması, kontrolü ve bertarafı ile ilgili "Atık Pil ve Akümülatörlerin Kontrolü Yönetmeliği, Ömrünü Tamamlamış Lastiklerin Kontrolü Hakkında Yönetmelik, Ömrünü Tamamlamış Araçların Kontrolü Hakkında Yönetmelik, Elektrikli ve Elektronik Eşyalarda Bazı Zararlı Maddelerin Kullanımının Sınırlandırılmasına Dair Yönetmelik, Ambalaj Atıklarının Kontrolü Yönetmeliği, Atıkların Düzenli Depolanmasına Dair Yönetmelik, Tıbbi Atıkların Kontrolü Yönetmeliği, Atık Yağların Kontrolü Yönetmeliği, Bitkisel Atık Yağların Kontrolü Yönetmeliği, PCB ve PCT’lerin Kontrolü Hakkında Yönetmelik, Bazı Tehlikesiz Atıkların Geri Kazanımı Tebliği, Tehlikeli Atıkların Kontrolü Yönetmeliği, Atıkların Yakılmasına İlişkin Yönetmelik ve Madencilik Faaliyetleri ile Bozulan Arazilerin Doğaya Yeniden Kazandırılması Yönetmeliği” düzenlenmiştir. Örneğin ülkemizde 2010 yılı verilerine göre yaklaşık 2,5 milyon ton ambalaj piyasaya sürülmüş ve bu ambalajların 1,9 milyon tonunun (\% 76), Ambalaj Atıklarının Kontrolü Yönetmeliği kapsamında geri kazanımı sağlanmıştır (Çevre ve Şehircilik Bakanlığı, 2014).

İnşaat sanayi ile ilgili olarak da Hafriyat Toprağı İnşaat ve Yıkıntı Atıklarının Kontrolü Yönetmeliği 18.03.2004 tarihli ve 25406 sayılı Resmi Gazete'de yayımlanarak yürürlüğe girmiştir. 2014-2018 yıllarını kapsayan 10'uncu Kalkınma Planı'nda geri dönüşüme ilişkin olarak, sanayi sektöründe geri dönüşüm ve geri kazanım gibi uygulamalara yer verilmiştir. Bu gelişmelere rağmen geri dönüşüm çalışmalarında istenilen hız yakalanamamıştır.

AB'nin Atık Çerçeve Direktifi kapsamında ise 2020 yılına kadar inşaat atıklarının \%70'inin geri dönüşüme kazandırılması hedeflenmektedir. Türkiye'de her yıl 125 milyon hafriyat toprağı yeniden kazanım çalışmaları kapsamında değerlendirilmektedir. Mevcut durumda inşaat ve yıkıntı atıkları miktarının 4-5 milyon ton/yıl olduğu tahmin edilmektedir. 6306 sayılı “Afet Riski Altındaki Alanların Dönüştürülmesi Hakkında Kanun”un yürürlüğe girmesiyle birlikte sayıları artacak olan kentsel dönüşüm uygulamaları ile birlikte inşaat ve yıkıntı atıkları miktarının ilk 3 yıl boyunca yıllık hedefin \%40'ı esas alınarak 10 milyon ton/yıl ve geri kazanılacak malzeme miktarının 6 milyon ton/yıl civarında oluşacağı öngörülmektedir (Bilim, Sanayi ve Teknoloji Bakanlığı, 2014). Ülkemizde Çevre ve Şehircilik Bakanlığı verilerine göre 2002 yılında toplama ve geri dönüşüm alanının 5 bin çalışan ile ekonomiye kattığı katma değer 60 Milyon TL iken, 2013 yılında bu alanda 60 bin çalışan ile 2.1 
Milyar TL'lik ekonomiye katma değer sağlanmıştır (Pektaş, 2015). Son yıllarda küresel dalgalanmalardan etkilenmekle birlikte, ülkemizde inşaat sektörünün GSMH içindeki payının yaklaşık yüzde 30 seviyesinde olduğu görülmektedir (İntes, 2014).

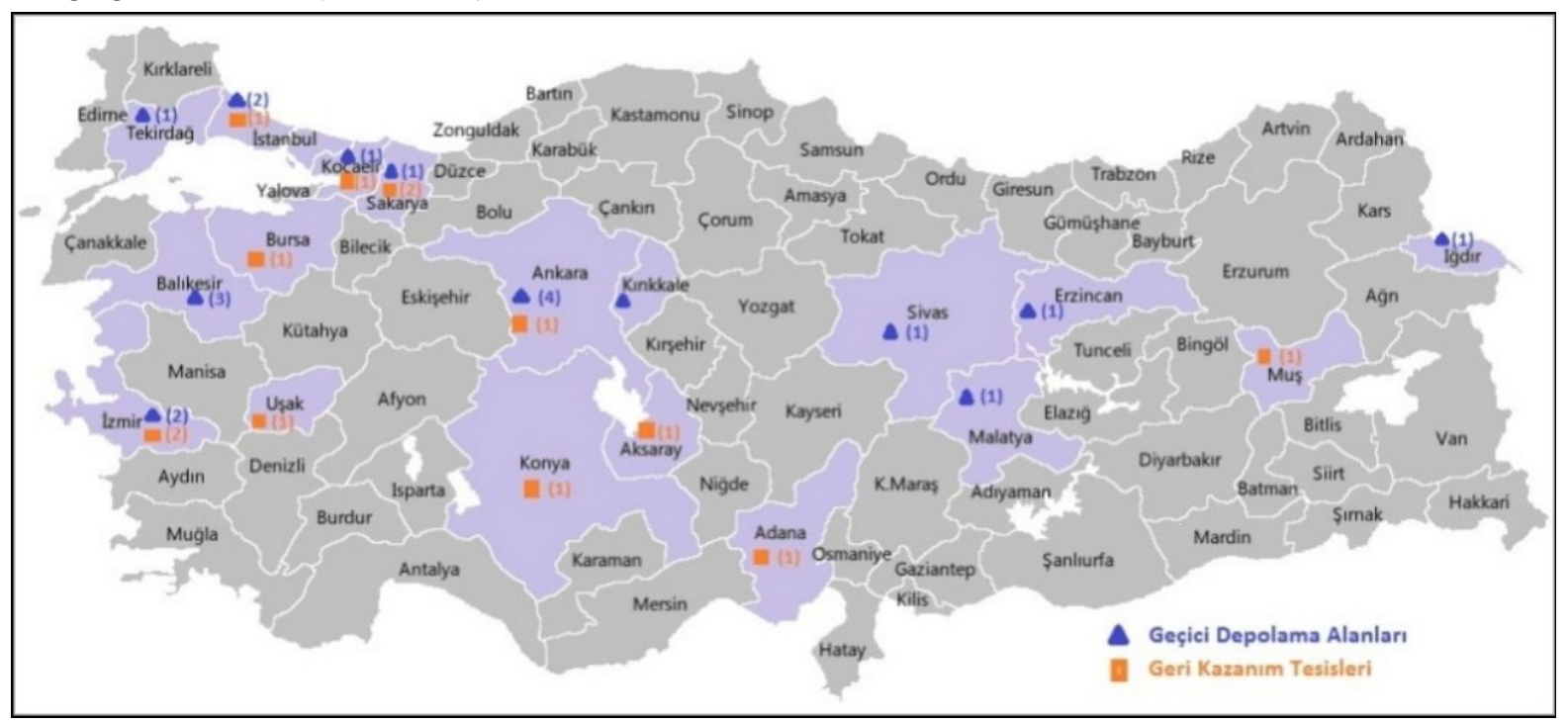

Şekil 3: Lisanslı ÖTL geri kazanım tesisleri ve geçici depolama alanlarl Kaynak: (Bilim, Sanayi ve Teknoloji Bakanlı̆̆l, 2014).

Şekil 3'de Türkiye'de Çevre ve Şehircilik Bakanlığından Çevre İzin ve Lisans Belgesi alınma alanları gösterilmektedir. Lisanslı ÖTL geri kazanım tesisleri ve geçici depolama alanlarının yetersiz olduğu dikkat çekmekte olup, Çevre ve Şehircilik Bakanlığınca geri kazanılan ürün kullanım süreçlerinin izlenmesi ve kamusal kullanımın geliştirilmesi konularında düzenlemeler yapılması gerektiği düşünülmektedir.

\section{Sonuç}

Kaynakların giderek kısıtlı olduğu günümüzde nüfus artışının devam etmesi, küresel ısınmanın ve kirlenmenin artması, geri dönüşüm faaliyetlerinin hızlanmasına yol açmıştır. Kaynakların daha etkin ve verimli bir şekilde kullanılması için, herşeyi yeniden kullanan ve geri dönüştüren bir ekonomi gerekmektedir. Meydana gelen atıkların azaltılması, mevcut atıkların potansiyel bir hammadde kaynağı olarak değerlendirilmesi, kullanılmış hammaddelerin yeniden kullanılması gibi geri dönüşüm konularının giderek önem kazanmıştır. Gelişmiş olan ülkelerde geri dönüşüm uygulamaları artmış, mevzuat ve yönetmeliklerle geri dönüşümün kontrol altına alınmasıyla ilgili düzenleme ve revizyonlar yapılmıştır. Avrupa ülkelerinin çoğunda geri dönüşümü sağlayıcı, verimli çalışan ve kaliteli malzeme elde edilen tesisler kurulmuştur. Ülkemizde yaygın olarak uygulanmayan geri dönüşüm dünyada hızla artmaktadır. Bu bakımdan ülkemiz açısından ulusal ve uluslararası düzeyde etkin bir geri dönüşüm politikası izlenmelidir. Sözkonusu politikaların uygulanması yürürlükteki yönetmeliklerin ekonomik hayatta karşılığını bulmasına ve herkesin sorumluluğunu bilmesine dayalıdır. Bu yüzden geri dönüşüm konusuyla ilgili çalışmalar arttırılmalı, bu konuya ilişkin ekonomik birimler gerekli hassasiyeti göstermelidir.

İnşaat sektörünün ekonominin lokomotifi olarak ülkelerin kalkınmasında payı büyüktür. İnşaat endüstrisi içinde pek çok alt sektörler bulundurmasından dolayı gelişmekte olan ekonomilerin lokomotifi durumundadır. İnşaat atıklarının geri dönüşümü ve kazanımı da ülke ekonomisini yakından ilgilendirmektedir. Geri dönüşümde inşaat endüstrisinin büyük önem arz ettiği görülmektedir. İnşaat sektöründe geri dönüşümle potansiyel bir hammadde kaynağı oluşturularak, enerji, hammadde tasarrufu sağlanmaktadır. İnşaat sektöründe inşaat ve yıkımlar sırasında geri dönüştürülebilecek birçok inşaat malzemesi ortaya çıkmaktadır. İnşaat sanayindeki atık konuları iyi değerlendirilmeli ve bunların verdiği ekonomik ve çevresel kayıplar en aza indirilmeye çalışılmalıdır. Geri dönüştürülmüş maddelerin üretim sistemine kazandırılması esnasında yeni iş imkanları yaratılmakta ve ekonomiye istihdamı arttırıcı etkisi de görülmektedir. Doğal kaynakların kıt olduğu dünyada sürdürülebilir kalkınma yaklaşımıyla geri dönüşümün sosyal, çevresel ve ekonomik etkileri ön plana çıkmaktadır. Atık yönetiminin en önemli kollarından olan geri dönüşüm değerlendirilebilir atıkların çeşitli yöntemlerle tekrar üretim sürecine dahil edilmesiyle verimli bir ekonomik yatırım olarak görülmektedir. Bu nedenle geri dönüşüm makro düzeyde çevresel ve ekonomik olarak, mikro olarak da işletmeler ve tüketiciler açısından önem taşımaktadır. Sonuç olarak geri dönüşümün bir yandan çevrenin korunması bir yandan da ekonomiye sağladığı katma değer bakımından, ekonomik kalkınma ve refahın arttırılmasında büyük bir paya sahip olduğu unutulmamalıdır. 


\section{Kaynakça}

- $\quad$ Altuntepe, S., Fırat, F.K., 2013. “Kentsel Dönüşümle Yapı Stoğunun Yenilenmesi Yapı Denetiminin Bu Süreçteki Önemi”: Aksaray Örneği, 3. Yapı Denetimi Sempozyumu, 5-6 Ekim, Diyarbakır, Türkiye.

- Acar, A. Z., Köseoğlu, A., Lojistik Yaklaşımıyla Tedarik Zinciri Yönetimi, Nobel Akademik Yayıncılık, Ekim 2014.S.361.

- Altındağ, S., 2011. “İstanbul'da Hafriyat Toprağı, İnşaat ve Yı1kıntı Atıklarının Tersine Lojistik Yöntemiyle Alternatif Yönetim Planı”, İstanbul Teknik Üniversitesi Yüksek Lisans Tezi, ss.20-22.

- Bayramoğlu, Y. F., 1995. Çevre Terimleri Sözlüğü, IULA Çevre Kitapları Serisi, İstanbul, s.5

- Bilim, Sanayi ve Teknoloji Bakanlığı (Sanayi Genel Müdürlüğü), “Ulusal Geri Dönüşüm Strateji Belgesi ve Eylem Planı" ss.1-113. (http://www.resmigazete.gov.tr/eskiler/2014/12/20141230M1-12-1.pdf ) Erişim Tarihi: 14.03.2015

- Brown, Lester R. 2008. "Plan Bb.3.0 Uygarlığı Kurtarmak İçin Harekete Geçmek”, Çeviri: Ayşe Başcı, Tema Vakfi Yayını, İstanbul, ss.254-264.

- Coşkun, H. Öztürk, M., 2012. “Katı Atık Yönetimi Konusunda İnşaat Sektörü Paydaşlarının Algılamaları: Hatay İli Örneği”, e-Journal of New World Sciences Academy, Volume:7, Number:1 Article Number: $1 \mathrm{~A} 0302$.

- $\quad$ Çevre ve Şehircilik Bakanlığı, Strateji ve Geliştirme Başkanlığı, 2014. 2014 Yılı Faaliyet Raporu.

- CÇevre ve Şehircilik Bakanlığı, 2015. “Atık Yönetimi Yönetmeliğ̈’”, 2 Nisan 2015 tarih 29314 Sayılı Resmi Gazete.

- $\quad$ Erdin, E. vd., 1980. “İşaat Atıklarının Değerlendirilmesi”, Dokuz Eylül Üniversitesi, ss: 2-20.

- Frrat, F.K. and Yücemen, M.S., 2015. Comparison of loads in Turkish earthquake code with those computed statistically, Earthquakes and Structures, Volume. 8, No.5, pp.977-994, DOI: http://dx.doi.org/10.12989/eas.2015.8.5.977.

- $\quad$ Firat, F.K. and Yucemen, M.S. 2014. "Determination of Reliability Based New Load and Resistance Factors for Reinforced Concrete Structural Members", Teknik Dergi, Digest 2014, 1785-1808.

- $\quad$ Firat, E. 2009. "The Effects of 17 August Marmara Earthquake on the Turkish Economic Crisis of 2000 November", International Earthquake Symposium, Kocaeli, Turkey.

- $\quad$ Fırat, F.K., Soyu, E. 2014, “Küresel Krizin Türkiye’deki İnşaat Sektörü Üzerindeki Etkileri”, International Conference on Eurasian Economies, 1-3 Temmuz, Üsküp, Mekadonya.s..

- Gürer, C. vd. 2004. “İşaat Endüstrisinde Geri Dönüşüm ve Bir Hammadde Kaynă̆ı Olarak Farklı Yapı Malzemelerinin Yeniden Değerlendirilmesi”, 5 Endüstriyel Hammaddeler Sempozyumu, İzmir, ss: 28-36

- $\quad$ Guide Jr. V.D.R. Jayaraman, V., Srivastava, R., 1999. "The Effect Of Lead Time Variation On The Performance Of Dsassembly Release Mechanisms", Computers \& Industrial Engineering, 36, ss. 320-3345.

- $\quad$ İntes, Türkiye İnşaat Sanayicileri İşveren Sendikası, 2014. İnşaat Sektörü Raporu, Mart 2014, s.2.

- Ö̈lmez, E. Yıldız, Ş. 2008. “Inşaat ve Yıkıntı Atıklarının Yönetimi ve Planlanan İstanbul Modeli”, Kent Yönetimi, İnsan ve Çevre Sorunları 08 Sempozyumu.

- Pektaş, Ö. 2015. “Atıkların Ekonomik Değeri 2,1 Milyar TL’yi Buluyor”, ekoiq.

- Tenikler G., 2007. “Türkiye’de Tehlikeli Atık Yönetimi ve Avrupa Birliği Ülkeleri İle Karşılaştırmalı Bir Analiz", Doktora Tezi, s. 3-6.

- Worldwatch Enstitüsü, 2014. “Dünyanın Durumu 2013 Sürdürülebilirlik Hala Mümkün mü?” Editör: Linda Starke Türkiye İş Bankası Kültür Yayınları e Çev. Cana Ulutaş Ekiz- Çağrı Ekiz, s.145, 146.

- Yazıcı, E.Y., Deveci, H., 2009. “E-Atıklardan Metallerin Geri Kazanımı”, Madencilik, Cilt.48, Sayı: 3, s.5. 


\title{
Nükleer Enerji Türkiye İçin Doğru Bir Tercih mi? Is Nuclear Energy the Right Choice for Turkey?
}

\author{
Asst. Prof. Dr. İsmail Güneş (Çukurova University, Turkey)
}

\begin{abstract}
Developing countries need energy supply. Turkish economy is one of the most dynamic in the region. The consumption of electric power in the country is growing rapidly. But the price of electric energy in Turkey is one of the detrimental factors. Of all the neighboring countries, Turkey has one of the highest prices for electric energy. While some academicians and non-governmental organizations supported the Turkish government's plans for establishment of nuclear power plants in Turkey, some others opposed it. Due to increased energy demand, Turkey is continuing to explore the possibilities of introducing nuclear power. Gaining acceptance from local populations, however, may be problematic because nuclear power has a negative image and risk perceptions are complicated by a range of psychological and cultural factors. The main aim of this work is to investigate Turkey's nuclear preferences is it right. We will discusses the Akkuyu nuclear energy projects, market trends and analysis. In addition we will look at Turkey's nuclear energy policies.
\end{abstract}

\section{Giriș}

Gelişmekte olan ülkeler açısından en önemli konulardan birisi enerji konusudur. Türkiye bölgesinde dinamik bir ekonomiye ve nüfus yapısına sahip bir ülke olarak yıllık ortalama \%5.5 düzeyinde enerji talebi artan bir ülkedir. Yüksek enerji fiyatları yatırımcılar ve hanehalkı açısından ciddi sorunlar yaratmaktadır. \%0 yılı aşkın süredir nükleer enerji konusuyla ilgilenmesine rağmen Türkiye'nin bugüne kadar sahip olduğu bir nükleer reaktör yoktur. 2010 Yılında Rusya ve Türkiye hükümetleri arasında imzalanan anlaşma ile Akkuyu nükleer santralinin inşasına karar verilmiştir. Türkiye'de bilim ve Sivil Toplum örgütleri nükleer enerjiye sahip olma konusunda ikiye ayrılmış durumdadır. Bu çalışmada nükleer enerji'nin gerekli olup olmaması tartışılmayacaktır. Çalışmanın asıl amacı Türkiye'nin Akkkuyu projesi ile başlattığı nükleer yolculuğunda projenin ekonomik, siyasal, teknik açılardan ele alınarak Türkiye'nin tercihinin doğru olup olmadığının analizidir. Bu kapsamda önce Türkiye'nin nükleer tarihçesi, ardından Dünya'da nükleer enerjinin mevcut durumu ve son olarak Türkiye'nin Akkuyu santrali konusundaki argümanları ve geçerlilikleri ele alınacaktır.

\section{Akkuyu Nükleer Santralinin Tarihsel Gelişimi}

Son dönemlerde gündemimize giren ve kamuoyunda yoğun tartışmalar yaratan nükleer enerji ile ilgili çalışmalar sanıldığının aksine son yıllarda ortaya çıkmamıştır. Ülkemizde nükleer enerji ile ilgili çalışmalar 1950'li yıllara dayanmaktadır.

ABD’nin "Barış için Atom" söylemiyle başlattığı işbirliği anlaşmasını 5 mayıs 1955'de imzalayan ilk ülkelerden biri Türkiye olmuştur. Bunun sonucunda İstanbul Üniversitesi (İ̈̈) ile İstanbul Teknik Üniversitesi (İTÜ) (Çekmece Nükleer Araştırma ve Eğitim Merkezi, ÇNAEM) kurmuştur. 1956 tarihinde de Atom Enerjisi Komisyonu (AEK) yasası yürürlüğe girmiştir. 1957'de 7015 sayılı yasayla Uluslararası Atom Enerjisi Ajansına (IAEA) üye olmuştur. 9 Temmuz 1982 yılında çıkartılan 2690 sayılı yasayla da Türkiye Atom Enerjisi Kurumu (TAEK) kurulmuştur (Bayülgen: 171-172). 1965 yılından itibaren Elektrik İşleri Etüd İdaresi (EİEİ) ve İstanbul Teknik Üniversitesi (İTÜ) Nükleer Enerji Enstitüsü işbirliği sonucu ilk ön fizibilite etüdü çalışması yapıldı (Şahin, 1985:10-11).

Nükleer santrallerle ilgili ilk etütler 1967-70 yılları arasında yapılmıştır. TEK'e bağlı olarak kurulan Nükleer Enerji Dairesi 1972'de çalışmaya başlamıştır. II. Beş Yıllık Kalkınma Planında, 1977 yılında işletmeye alınmak üzere 300-400MW gücünde bir nükleer santral kurulması öngörülmüş, ancak yer seçiminde karşılaşılan güçlükler ve diğer gelişmeler nedeniyle proje gerçekleşmemiştir. Ardından 1983 yılında işletmeye alınmak üzere $600 \mathrm{MW}$ bir santral planlanmış ve kuruluş yeri olarak Akkuyu belirlenmiştir. Ancak firmalarla yapılan görüşmeler karara bağlanamamıştır (Belen, 2007). 1982 yılında 2690 sayılı yasayla Türkiye Atom Enerjisi Kurumu (TAEK) kurulmuştur (Resmi Gazete 9 /7/1982).

1965 yılında başlayan nükleer santral projesi çalışmalarında, 1977'de tamamlanmak üzere 300-400 mw gücünde tabii uranyumla çalışan "ağır su” tipi bir santral kurulması öngörülse de bu gerçekleştirilemedi. 1970 yılı sonunda Türkiye Elektrik Kurumu (TEK) yasasının kabul edilmesi sonucu nükleer santralle ilgili çalışmalar TEK'e devredilmiştir. 1971yılında ise TEK'e bağlı olarak Nükleer Santraller Daire Başkanlığı oluşturulmuştur (Bozkurt,1994:14-15). Bu dönemi takip eden günlerde yoğun olarak santral yerinin belirlenmesine çalışılmıştır.

1976 yılında Silifke-Akkuyu mevkiinde yapılan etüt çalışmaları sonucunda, burada bir nükleer santral kurulması için yer lisansı alındı Asea-Atom/Stal-Laval adlı İsveç firma grubuna ihale edildi ancak sözleşme görüşmeleri firmanın kredi getirememesi nedeniyle sonuçlandırılamadı. 1980 yılında İsveç hükümetinin kredi 
garantisini kaldırmasının ardından, Akkuyu'da KWU firmasına 986 MW, AECL firmasına da 685 MW gücünde iki ayrı santral, General Electric firmasına da Sinop'ta 1,185MW gücünde bir veya iki nükleer santral kurulmas1 için niyet mektubu verildi. 1984 yılında yapımcı firmalara, nükleer santralları 15 yıl işletmeleri ve sonra TEK'e devretmeleri (yap-işlet-devret) modeli önerildi. Diğer firmalar çekilirken AECL bu öneriyi Kabul etti ve 1985yılında TEK ile firma arasında ön anlaşma imzalandı. Ancak projenin YIDD modeline dönüştürülmesi ve getirilecek krediye devlet garantisi verilmemesi üzerine KWU vazgeçti, GE de Sinop’ta yer lisansı olmadığı için teklif veremedi (NTV).

Nisan 1986'da Chernobly de meydana gelen nükleer kaza nedeniyle görüşmeler kesilmiş ve bekleme dönemine girilmiştir ( Bozkurt, 1994:15-16). 1993'de TEAŞ nükleer programı yeniden uygulamaya koydu. Akkuyu Nükleer Güç Santralı, yeniden Devlet Yatırım Programına alınarak, Kore danışmanlık firması KAERI tarafından hazırlanan ihale şartnameleri, TEAŞ Santraller ve Ticaret/Hukuk Dairelerince 1995 ve 1996'da geliştirilerek, 17 Aralık 1996'da yeniden uluslararası ihaleye çıkarılmıştır (Ekşi, 2014:78).

4 Aralık 1992'de Enerji ve Tabii Kaynaklar Bakanının Bakanlar Kurulu'na sunduğu bir raporda ülkenin başka enerji kaynakları ihdas etmediği taktirde 2010 yılında büyük bir enerji krizine düşeceğine ve bunun için de mutlaka nükleer enerjiden yararlanılması gerektiğini söylemesini takiben 1993 yılında toplanan Bilim ve Teknoloji Yüksek Kurulu nükleer enerjiden elektrik tüketimini ülkenin öncelikli meseleleri arasında 3. sıraya koymuştur. . 17 Ekim 1996'da Resmi Gazete'de Akkuyu Nükleer Santrali için ihale açılmış olduğu ilan edilmiştir. 15 Ekim 1997'de AECL (Atomic Energy of Canada Limited), NPI (Nuclear Power International/Siemens ve Framatome konsorsiyumu) ve WESTINGHOUSE (Mitsubishi ile birlikte) tekliflerini sundu. Bu teklifler TEAŞ Nükleer Santraller Dairesi, danışman firma Empresarios Agrupados Internacional S.A. ve Enerji Bakanlığ danışmanları tarafından incelenmiştir. 25 Temmuz 2000'de Bakanlar Kurulu bu ihaleyi önce ertelemiş daha sonrada 2000 yılın da nükleer santral kurulmasından vazgeçilmiştir (Akkaya,2002).

12.05.2010 tarihinde Rusya Federasyonu Hükümeti ile Türkiye Cumhuriyeti Hükümeti Arasında Türkiye Cumhuriyeti'nde 'Akkuyu Sahası'nda Bir Nükleer Güç Santralin Tesisine ve İşletimine Dair İşbirliği Anlaşması'nın imzalandı. 21.07.2010 tarihinde Türkiye'de Hükümetlerarası Anlaşma’nın Uygun Bulunduğuna Dair Kanun'un Resmi Gazete'de yayımlanarak yürürlüğe girdi.(21.07.2010 tarihli Kanun 27648 sayılı Resmi Gazete) . Ardından Rusya Hükümeti proje katılımcılarını tespit etti ve 03.12.2010 tarihinde Rusya Federasyonu'nda Hükümetlerarası Anlaşma'nın Uygun Bulunduğuna Dair Kanun yürürlüğe girdi. 13.12.2010 tarihinde Türkiye Cumhuriyetinde 'AKKUYU' NGS ELEKTRIK ÜRETIMM A.Ş. tescil edildi (Akkuyu NGS, 2015).

\section{Dünya'da Nükleer Enerji}

20. yüzyılın ortalarında “Her maddenin atom adı verilen ve bölünemeyen parçacıklardan oluştuğu' kabulünün yıkılması bilimsel açıdan 2000 yıl süren bir anlayışta da önemli bir değişiklik yarattı. 1938'de Otto Hahn, Fritz Strassman, Lise Meitnerve, Otto Frisch adlı Alman fizikçiler Uranyum üzerinde yaptıkları denemelerle atom çekirdeğini parçalamayı başardılar (Erbaşı Cuhadar, 2015:6).

Fisyon adı verilen bu çekirdek bölünmesi sırasında zincirleme bir reaksiyon oluyor ve sonuçta çok büyük bir enerji açığa çıkıyordu. 1942 yılında İtalyan asıllı Amerikan fizikçi Enrico Fermi bu zincirleme reaksiyonu kontrol altına almayı başararak nükleer enerjinin üretilmesine olanak sağladı. Ancak bu bilimsel ilerleme kısa sürede yönetenlerin dünya hâkimiyeti savaşında önemli bir caydırıcılık aracı halini aldı. İkinci dünya savaşında Nazi Almanya'sının bu teknolojiyi barışçıl olmayan amaçlar için kullanabileceği kaygısı vardı ve bu kaygı dünyanın en saygın bilim insanlarından Albert Einstein tarafından Amerika Birleşik Devletleri Başkanı Roosevelt'e yazdığı bir mektupla dile getirildi. Herkes Almanya'dan korka dursun ABD 2.Dünya savaş1 sonlarında Atom bombasını yapmakla kalmadı Amerika Birleşik Devletleri Başkanı Henry Truman'ın emriyle Japonya üzerinde denedi. 6 Ağustos 1945 'de Hiroşima'da 1.5 km'lik alanda 140 bine yakın insan ve tüm canlılar kömüre dönüştü. Atom bombasının o güne kadar kullanılan tüm silahların ötesinde ne denli öldürücü ve yok edici olduğu görülmesine rağmen ABD 9 Ağustos 1945'de bu kez 60 bin kişinin ölümüyle sonuçlanacak olan Nagazaki atom bombası saldırısını gerçekleştirdi (Özgür, 2006, 6-7).

Savaş sonrası 1946' da Amerika Atomik Enerji Komisyonunu kurarken 1951' de Arco' da ilk elektrik üreten reaktör açıldı. 1957' de ise finansal elektrik üreten ilk santral tam üretime geçti. Ancak bu adımlar Amerika Birleşik Devletlerinin askeri alanda nükleer teknolojiden vazgeçtiği anlamı taşımamaktadır. 1954'de Nautilus nükleer denizaltısını ve yine aynı yıl ilk termonükleer bomba'yı denediler. Aynı yıl soğuk savaşın diğer önemli aktörü Sovyet Sosyalist Cumhuriyetler Birliği Obninsk' de küçük bir nükleer santral çalıştırmaya başladı. Bir yandan ABD ve SSCB arasında soğuk savaş ve nükleer silahlanma devam ederken diğer yandan ekonomik rekabette avantaj sağlamak amaçlı olarak nükleer enerjinin kullanımı yaygınlaştı. 1973 yılında petrol krizi ile başlayan enerji sıkıntısından sonra nükleer enerjiden yararlanmaya daha çok önem verilmiştir.1979 yılında yaşanan ikinci petrol kriziyle nükleer enerji dünya platformunda önemini daha da artmıştır (Muradov, 2012:2).

Başlangıçta oldukça güvenli olduğu inanışı yaygın olan nükleer enerji reaktörlerine karşı şüpheler yaşanan kazalar sonucu arttı ve 1986 'da Ukrayna'nın Çernobil Nükleer Santralinde meydana gelen kaza sonrası adeta 
zirveye çıktı. Özellikle Avrupa'da çevreci örgütlerin başarılı kampanyaları ve siyasal güce tesir etmeleri neticesinde nükleer karşıtllğının arttığı görüldü.

22 Nisan 2002 tarihinde Alman hükümeti Atom santralleri ile ilgili kararını açıkladı. 2002 yılında Almanya genelinde 19 adet atom santrali elektrik üretimi yapıyordu. Alınan karara göre 2022 yılına kadar atom santralleri kapatılacaktı. 2010 yilında Hrıstiyan Demokrat Parti ve Hür Demokrat Parti'den oluşan Angela Merkel hükümetinin Almanya'da kullanımda olan 17 nükleer enerji santralinin işletme süresinin uzatılmasını öngören tasarıs1 Federal Mecliste kabul edildi. Buna göre 1980'den önce devreye giren yedi santral 8, kalan on santral de 14 yıl daha işletilecekti. Söz konusu düzenlemeyle Almanya'da nükleer santrallerin kapatılması 2036 yılını bulacaktı. Japonya'da Fukuşima santralında tsunami sonrası meydana gelen patlamalar, nükleer santralların güvenliğiyle ilgili tartışmalara ivme kazandırdı. Tepkiler üzerine oluşturulan komisyon Almanya'da nükleer santrallerin tümünün gelecek 10 yıl içinde kapatılmasını önerdi. Böylece Almanya nükleer santrallerin en geç 2022 yılı sonuna kadar tümüyle kapatılmasını kararlaştırdı (Muradov, 2012:106-107).

2015 Yılının Haziran ayı verilerine göre nükleer enerjinin dünyadaki genel durumuna baktığımızda

\begin{tabular}{|l|r|r|}
\hline BÖLGE & \multicolumn{1}{|l|}{ REAKTÖR } & KAPASITE (MWE) \\
\hline AFRIKA & 2 & 1860 \\
\hline AMERIKA-LATIN & 7 & 4841 \\
\hline KUZEY AMERIKA & 118 & 112139 \\
\hline ASYA - UZAK DOGU & 100 & 90014 \\
\hline ASYA- ORTA DOGU VEGÜNEY & 25 & 6913 \\
\hline AVRUPA - ORTA VE DOGU & 69 & 49657 \\
\hline AVRUPA - BATI & 117 & 113837 \\
\hline TOPLAM & 438 & 379261 \\
\hline
\end{tabular}

Tablo -1: Reaktörlerin Bölgelere Göre Dağıllımı: Kaynak: International Atomic Energy Agency (IAEA) Power Reactor Information System (PRIS)

2015 Yı1ı Haziran ayı itibariyle çalışan 438 santralin en yoğun olduğu bölgeler Batı Avrupa ve Kuzey Amerika'dır. Onları uzak Doğu Asya ve Orta ve Doğu Avrupa takip etmektedir. Reaktörlerin net üretim kapasitelerine bakıldığında ise Batı Avrupa ve Kuzey Amerika doğru orantılı olarak ön plana çıkmaktadır.

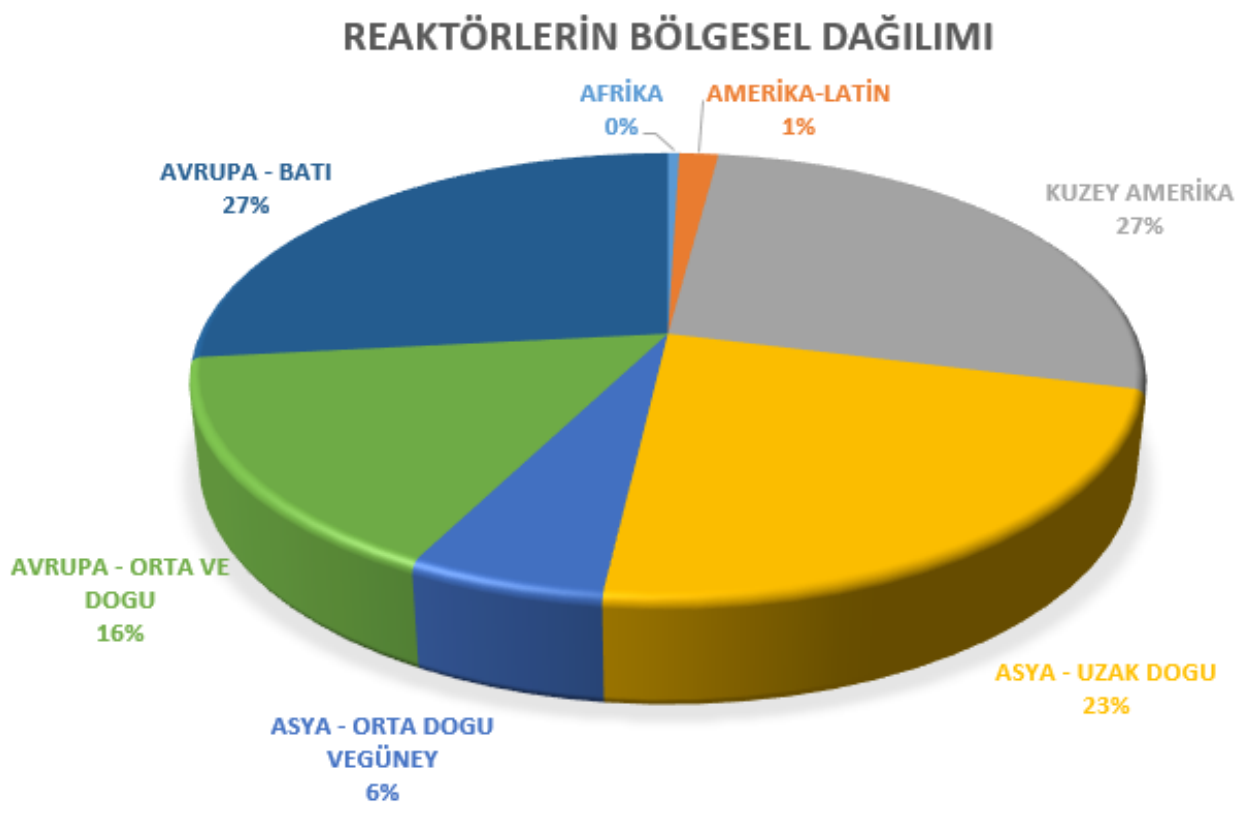

Grafik 1: Reaktörlerin Bölgesel Dă̆glımı 


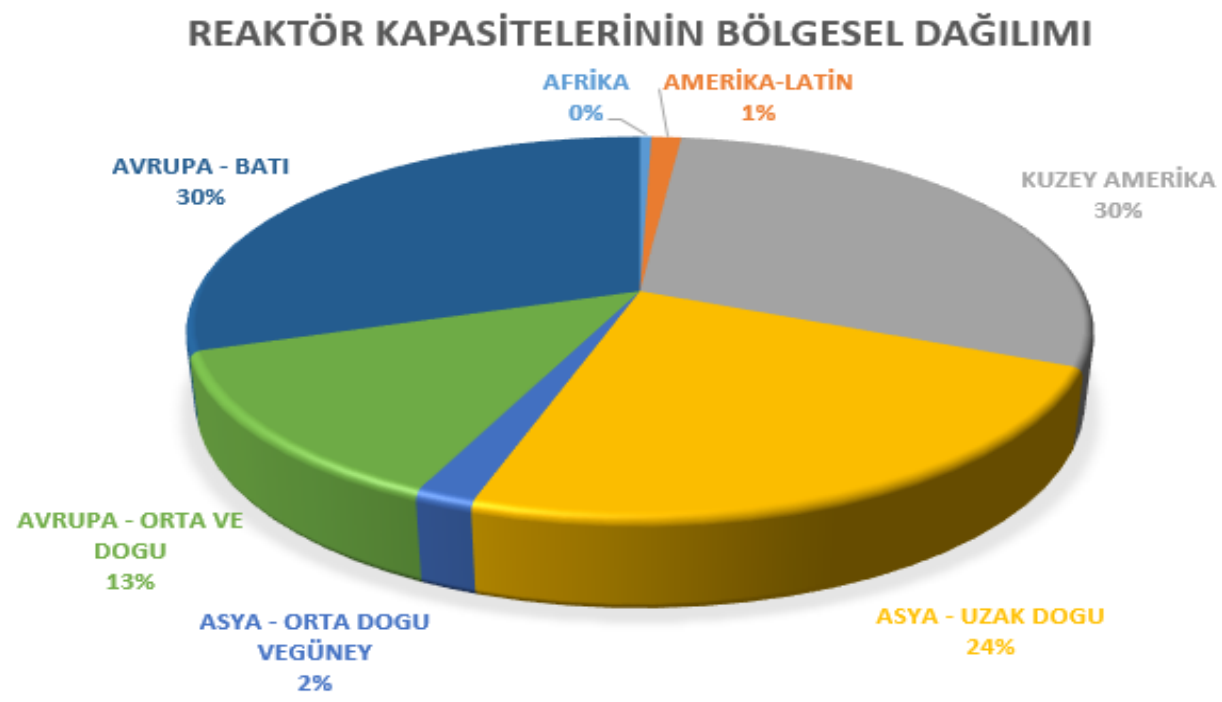

Grafik: 2 Reaktör Kapasitesinin Bölgesel Dă̆glımı

ABD 100 reaktörle Dünya'da en fazla nükleer enerji reaktörüne sahip ülkedir. Buna karşın Toplam elektrik üretimi içerisindeki payı \%19 düzeyindedir. Bu ise ABD'nin farklı enerji kaynaklarını dağıtarak kullanmasının bir sonucudur. Toplam elektrik üretimi içerisinde nükleer enerjinin en yüksek olduğu ülke \%76.9 oranı ile Fransa'dır. Slovakya $(\% 56.8)$, Macaristan $(\% 53,6)$ Ukrayna(\%49.4) Belçika (\%47.5) ile Fransa'yı takip etmektedir.

\begin{tabular}{|c|c|c|c|c|}
\hline ÜLKE & REAKTÖR & $\begin{array}{l}\text { NET ELEKTRİK } \\
\text { KAPASITTESİ (MW) }\end{array}$ & $\begin{array}{c}\text { NÜKLEER } \\
\text { ELEKTRÍK ARZI } \\
\text { (GW.h) }\end{array}$ & $\begin{array}{l}\text { ELEKTRİK } \\
\text { ÜRETIMMINDE } \\
\text { PAYI }\end{array}$ \\
\hline ARJANTİN & 3 & 1627 & 5258.17 & 4.0 \\
\hline ERMENISTAN & 1 & 375 & 2265.64 & 30.7 \\
\hline BELÇİKA & 7 & 5927 & 32093.74 & 47.5 \\
\hline BREZILYA & 2 & 1884 & 14463.39 & 2.9 \\
\hline BULGARİSTAN & 2 & 1926 & 15013.99 & 33.6 \\
\hline KANADA & 19 & 13500 & 98588.12 & 16.8 \\
\hline ÇİN & 23 & 19007 & 123807.69 & 2.4 \\
\hline ÇEK CUMH & 6 & 3904 & 28636.78 & 35.8 \\
\hline FINLANDIYA & 4 & 2752 & 22645.96 & 34.6 \\
\hline FRANSA & 58 & 63130 & 418001.40 & 76.9 \\
\hline ALMANYA & 9 & 12074 & 91783.70 & 15.8 \\
\hline MACARISTAN & 4 & 1889 & 14777.73 & 53.6 \\
\hline HİNDİSTAN & 21 & 5308 & 33231.87 & 3.5 \\
\hline İRAN & 1 & 915 & 3723.60 & 1.5 \\
\hline JAPONYA & 48 & 42388 & 0.00 & 0.0 \\
\hline KORE & 23 & 20717 & 149199.22 & 30.4 \\
\hline MEKSIKKA & 2 & 1330 & 9311.60 & 5.6 \\
\hline HOLLANDA & 1 & 482 & 3873.51 & 4.0 \\
\hline PAKİSTAN & 3 & 690 & 4577.53 & 4.3 \\
\hline ROMANYA & 2 & 1300 & 10753.68 & 18.5 \\
\hline RUSYA & 34 & 24654 & 169064.84 & 18.6 \\
\hline SLOVAKYA & 4 & 1814 & 14420.34 & 56.8 \\
\hline SLOVENYA & 1 & 688 & 6060.82 & 37.2 \\
\hline G.AFRİKA & 2 & 1860 & 14762.70 & 6.2 \\
\hline İSPANYA & 7 & 7121 & 54860.38 & 20.4 \\
\hline İSVEÇ & 10 & 9470 & 62270.05 & 41.5 \\
\hline İSVİÇRE & 5 & 3333 & 26467.90 & 37.9 \\
\hline UKRAYNA & 15 & 13107 & 83122.79 & 49.4 \\
\hline İNGİLTERE & 16 & 9373 & 57918.48 & 17.2 \\
\hline AMERIKKA & 100 & 99244 & 798616.26 & 19.5 \\
\hline TOPLAM & 439 & 376821 & 2410372.94 & NA \\
\hline
\end{tabular}

Tablo-2: Ülkelere Göre Reaktör Sayısı ve Elektrik Üretimi içinde Payı Kaynak: International Atomic Energy Agency (IAEA), Power Reactor Information System (PRIS) 
Kullanılan reaktör tiplerine baktığımızda ise Dünya'da kullanılan reaktörlerin \%64'ü Basınçlı Su Reaktörü (PWR) iken, \%18'i kaynar Sulu Reaktör tipindedir. 3. nesil reaktörler kamuoyu gündeminde daha yoğun yer almasına rağmen sayısal olarak faal durumda olanların sayısı düşüktür.

\begin{tabular}{|l|c|c|c|r|}
\hline \multicolumn{1}{|c|}{ REAKTÖR } & TÜRÜ & SAYI & YÜZDE & \multicolumn{2}{|c|}{ KET } \\
\hline Kaynar Sulu Reaktör BWR & BWR & 78 & 18 & 74686 \\
\hline Hızı̈ Üretken Reaktör FBR & FBR & 2 & 1 & 580 \\
\hline Gaz Soğutmalı Reaktör GCR & GCR & 15 & 3 & 10219 \\
\hline $\begin{array}{l}\text { Grafit Yavaşlatıcılı Su } \\
\text { Soğutmalı Reaktörler LWGR }\end{array}$ & LWGR & 15 & 3 & 24549 \\
\hline $\begin{array}{l}\text { Basınçlı Ağır Su Reaktörü } \\
\text { PHWR }\end{array}$ & PWHR & 49 & 11 & 261052 \\
\hline Basınçlı Su Reaktörü PWR & PWR & 279 & 64 & 379261 \\
\hline TOPLAM & TOPLAM & 438 & 100 & \\
\hline
\end{tabular}

Tablo-3: Reaktörlerin Türlerine Göre Dă̆llımı Kaynak: International Atomic Energy Agency (IAEA), Power Reactor Information System (PRIS)

Özellikle Son 20 yılda nükleer enerji çok tartışılan bir enerji türü olmasına karşın, dünya genelinde nükleer enerji kullanım kapasitesine bakıldığında 1995-2014 arasında grafikler yardımıyla görüleceği üzere kapasite konusunda dikkat çekici bir değişme olmamıştır.

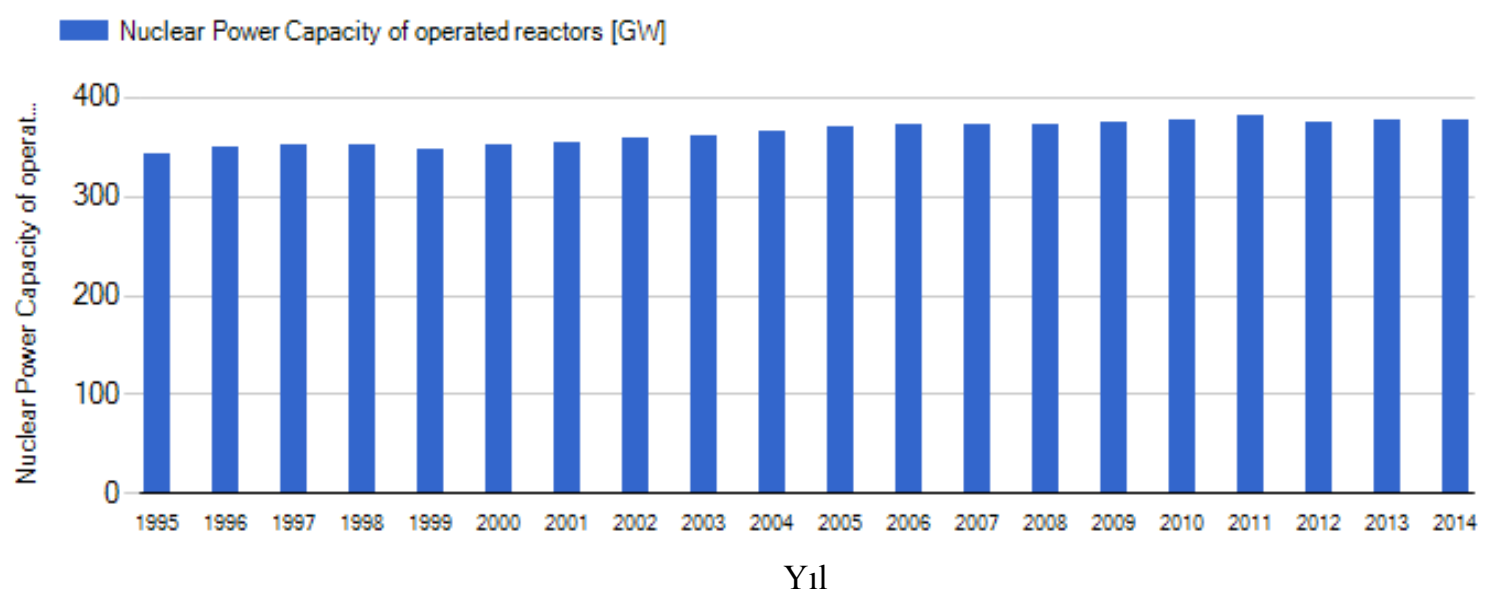

Grafik: 3 Nükleer Enerji Kapasitesi 1995-2014

En dikkat çekici konu nükleer santrallerin yaşları konusunda karşımıza çıkmaktadır. Günümüzde aktif olarak varlıkları devam eden santrallerin yaşlarının 28-35 yaş aralığında yoğunlaştığımı görüyoruz. Özellikle eski tip santrallerin ekonomik ömrü 40 yıl öngörülmekteydi. Bu durumda 2019-2025 arasında nükleer santral ve kapasitelerde ciddi bir azalma söz konusu olabilecektir. 2022 Y1lında uygulandı̆̆ 1 taktirde Almanya'nın da nükleer santrallere son vermesi durumunda nükleer enerjiden faydalanma oranında düşme beklenebilir. Ortaya çıkan açı̆̆ı kapatma konusunda Çin, Hindistan ve Rusya önde gelen ülkeler olarak görünmektedir

Yeni nesil santrallerde ekonomik ömür 60 yıl öngörülürken eski nükleer santrallerin lisansları yenilenerek işletilmeleri 60 yıla çıkarılması sıkça önümüzdeki dönemlerde tartışma konusu olacaktır. 60 yıla çıkarılmaları büyük ölçüde gerçekleşse bile tamamının verimli çalışması mümkün olmayacaktır. Lisansların uzatılması durumunda bile 2035 sonrası Nükleer endüstri ciddi sıkıntılar yaşayacaktır. Ancak yeni yönelimlere baktığımızda özellikle 3 ülkenin dünya enerji gereksinimi karşılama, nükleer riskleri üstlenme ve dünya adına üretimi yapmaya aday olduğunu görüyoruz. Bunlar Çin, Hindistan ve Rusya'dır. 


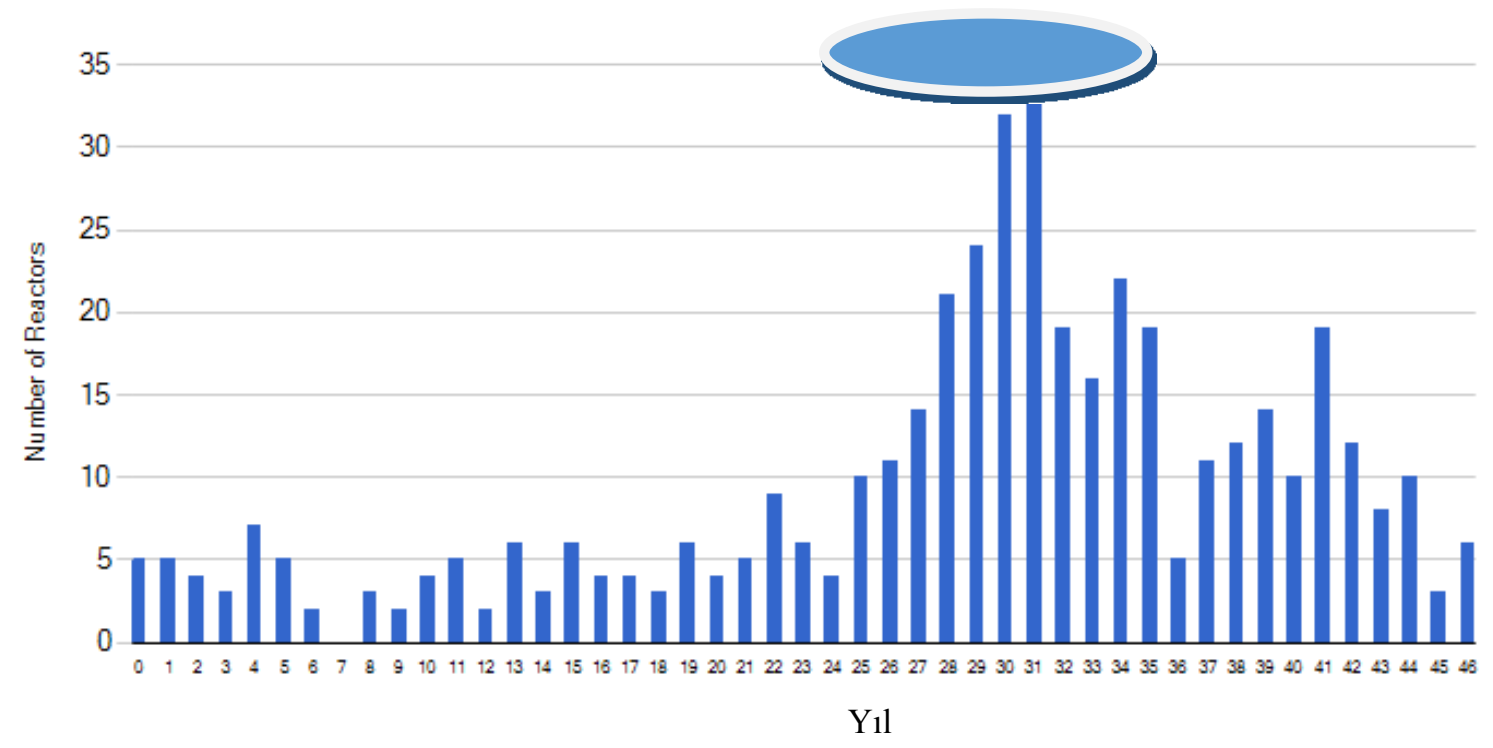

Grafik: 4 Yaşlarına Göre Nükleer Santraller

\begin{tabular}{|c|c|c|c|c|c|}
\hline Yaş & Sayı & Yas & Sayı & Yaş & Sayı \\
\hline $\mathbf{0}$ & 5 & $\mathbf{1 7}$ & 4 & $\mathbf{3 4}$ & 22 \\
\hline $\mathbf{1}$ & 5 & $\mathbf{1 8}$ & 3 & $\mathbf{3 5}$ & 19 \\
\hline $\mathbf{2}$ & 4 & $\mathbf{1 9}$ & 6 & $\mathbf{3 6}$ & 5 \\
\hline $\mathbf{3}$ & 3 & $\mathbf{2 0}$ & 4 & $\mathbf{3 7}$ & 11 \\
\hline $\mathbf{4}$ & 7 & $\mathbf{2 1}$ & 5 & $\mathbf{3 8}$ & 12 \\
\hline $\mathbf{5}$ & 5 & $\mathbf{2 2}$ & 9 & $\mathbf{3 9}$ & 14 \\
\hline $\mathbf{6}$ & 2 & $\mathbf{2 3}$ & 6 & $\mathbf{4 0}$ & 10 \\
\hline $\mathbf{7}$ & 0 & $\mathbf{2 4}$ & 4 & $\mathbf{4 1}$ & 19 \\
\hline $\mathbf{8}$ & 3 & $\mathbf{2 5}$ & 10 & $\mathbf{4 2}$ & 12 \\
\hline $\mathbf{9}$ & 2 & $\mathbf{2 6}$ & 11 & $\mathbf{4 3}$ & 8 \\
\hline $\mathbf{1 0}$ & 4 & $\mathbf{2 7}$ & 14 & $\mathbf{4 4}$ & 10 \\
\hline $\mathbf{1 1}$ & 5 & $\mathbf{2 8}$ & 21 & $\mathbf{4 5}$ & 3 \\
\hline $\mathbf{1 2}$ & 2 & $\mathbf{2 9}$ & 24 & $\mathbf{4 6}$ & 6 \\
\hline $\mathbf{1 3}$ & 6 & $\mathbf{3 0}$ & 32 & TOPLAM & 438 \\
\hline $\mathbf{1 4}$ & 3 & $\mathbf{3 1}$ & 33 & & \\
\hline $\mathbf{1 5}$ & 6 & $\mathbf{3 2}$ & 19 & & \\
\hline
\end{tabular}

Tablo:-4 Reaktörlerin Yaşlarına Göre Dă̆llımı Kaynak: International Atomic Energy Agency (IAEA), Power Reactor Information System (PRIS)

Devam eden santral inşaatlarına baktığımızda Arjantin(2), Belarus (2), Çin (24) Finlandiya (1) Fransa(1), Hindistan (6), Japonya(3), Kore (4), Pakistan (2), Slovakya (2) Birleşik Arap Emirlikleri(3), ABD(5) santral kurmaktadır. Özellikle planlananlar da dikkate alınınca Çin 44, Rusya 31, Hindistan 22 santralle gelecekte nükleer enerji alanında öncü olacaklardır. Bu 3 ülkenin dünya ekonomisinde üretici olarak oynamak istedikleri roller özellikle günümüz Avrupa'sının ithal ettiği kirli endüstrilere ev sahipliği yapma olasılığının yüksek olduğunu ve enerji gereksinimlerinin artacağını öngörmek yanlış olmayacaktır. Türkiye ise Akkuyu'da inşa etmeyi düşündüğü 4 ünite ile nükleer dünyasına katılmayı planlamaktadır (World Nucleer Association, 2015).

\section{Türkiye'nin Nükleer Tercihi Doğru mu?}

Türkiye'nin 50 yıla yaklaşan bir nükleer enerjiye sahip olma arzusu var. Kesintilere uğrayan bu istek 2010 yılında Rusya Cumhuriyeti ve Türkiye arasında imzalanan anlaşma ile bambaşka bir yola girdi. O güne kadar adı geçen teknolojiler ve ülkeler arasında adı geçmeyen Rusya ile hükümetin ani kararla anlaşma ile Akkuyu sahasında 4 ünite 1200 MWe anlaşması imzalaması tüm dikkatleri Rusya nükleer teknolojisi üzerinde yoğunlaştırd1.

Çalışmamız nükleer enerjinin gerekli olup olmadığı tartışması üzerinde durmamaktadır. Tüm Dünya'da nükleer enerji taraftarları ve karşıtları mevcuttur ve tarafların ortaya koydukları bilimsel savlar vardır İki tarafında kendine has savları ve ciddiye alınması gereken gerekçeleri vardır. Yazının ana konusu seçilen nükleer yolculuğunda Türkiye'nin doğru bir seçim yapıp yapamadığının analiz edilmesidir. Bu amaçla çalışmamız 
teknik, ekonomik, politik ve diğer açılardan Akkuyu Nükleer santralini incelemek ve yatırımın bu açılardan uygunluğunu analiz etmektir

Türkiye Devletinin nükleer enerji hamlesini kamuoyuna anlatırken iki temel savı bulunmaktadır. Bu savlardan birincisi nükleer enerji güneş, rüzgar gibi doğa koşullarına bağlı olmayan ucuz bir enerji kaynağıdır. Bu ucuz enerjinin kullanılması Türkiye'nin cari açığını düşürecek ve enerjide \%72 düzeyinde olan dışa bağımlılığı düşürecektir. "Güçlü Türkiye'nin Enerjisi “ sloganı ile de 2013 yılında dünyanın ilk 10 ekonomisi arasında yer alma hedefi konulmuştur. Bu hedeflere ulaşmak içinde nükleer enerjinin zorunlu olduğu konusunda kamuoyu iknaya çalışılmıştır.

Daha önceki yıllarda nükleer santral gündeme geldiğinde genellikle güvenlik konuları, alternatif enerji kaynaklarının kullanılması, yer seçimi daha ön plana çıkarken özellikle Türkiye ve Rusya arasında enerji alanındaki işbirliğine gidilerek Rus teknolojisinin Akkuyu'da seçilmesi bir anda tartışmaların yönünü değiştirdi. Bunun temel nedeni nükleer enerji tarihinde Rusya'nın olumsuz imajıdır. Firma olumsuz imajını iyileştirmek amacıyla hedef pazarları olan Bulgaristan, Arjantin, Türkiye, Vietnam, Macaristan, Hindistan, Slovakya, Güney Afrika, Macaristan ve benzeri ülkelerde halkla ilişkiler uzmanları ile çalışıyor. Benzer çalışmayı Türkiye'de de yürütürken bu kez farklı bir yöntem izlendi. Seçim kozu olarak nükleer enerji projesi kullanıldı. Akkuyu projesi konusunda halkı ika etmek, bilgilendirmek yerine mevcut iktidara destek niteliği taşıyan söylemler ön plana çıkarıldı. Nükleer enerji santralleri güçlü Türkiye sloganı ile birleşerek şirket desteği ile siyasal sonuç almak için kullanıldı. Nükleer santral konusunda bu tür kampanya ve reklam çok rastlanan bir olay olmamasına rağmen konunun asıl konuşulması gereken boyutları kamuoyunda sağlıklı bir biçimde tartışılamadı.

Akkuyu'da inşa edilmesi planlanan VVER-1200 reaktörleri, Rusya Federasyonu'nun düzenleyici kurumu Rostechnadzor'dan inşaat lisansı almış durumda ancak Avrupa ülkelerinden henüz onay alamamış durumda. Çernobil kazası sonrası bu onayları almaları da oldukça güç görünüyor. Santrali yapacak olan şirket Rosatam Rusya'nın yarı devlet kuruluşu niteliğindedir. Akkuyu'ya yapacakları santralden Rusya'daki Novovoronezh ve Leningrad sahalarında toplam 4 adet inşa ediyorlar. Dünyada çalışan ve test edilmiş bir VVER-1200 reaktör bulunmuyor. Bir anlamda Türkiye'de bu teknoloji teste çıkmaktadır. Bu da kaygılanılması gereken bir durumdur (TMMOB, 2013:15).

İnsanların nükleer teknolojiden ciddi kaygılarını anlamak gerekir. Bu kaygıların dünyada ki en büyük nedeni 26 Nisan 1986'da Sovyetler Birliği sınırları içerisinde yer alan bugünkü Ukrayna'nın başkenti Kiev yakınlarındaki Çernobil nükleer santralinde meydana gelen kazadır. Dünya nükleer tarihinin en büyük kazasının nedeni ise santralin dördüncü ünitesi bakıma alınmadan önce olası bir elektrik kesintisi durumunda güvenlik işlemlerinin nasıl ilerleyeceği üzerine yapılan bir deneydi. Bu kaza günlerce dünyadan gizlendi. İsveçliler sudaki radyasyon ölçümlerinde anormal düzeyde radyasyon tespit ederek Rusya'dan resmi açıllama isteyince ortaya çıtı. Kurtarılabilecek insanları bile ölüme atan, komşu ülkelerde milyonlarca insanı riske eden Sovyet firması tüm dünyadan olayı gizlemeye çalıştı. O dönemde de Rus teknolojisinin güvenli olup olmadığı tartışma konusuydu. Firma ise teknolojisinin güvenli olduğunu iddia ediyordu. Kaza sonrası Birleşmiş Milletler raporu bu kazanın binlerce insanın kansere yakalandığı, binlerce kilometre ötesinde bile doğayı tahrip ettiğini ortaya koydu. Kaza esnasında 31 kişi ölse de etkiler nedeniyle tam olarak kaç kişinin öldüğü bilinemiyor. Karadeniz bölgesinde lösemi vakasında artış oldu. Çernobil reaktörlerindeki radyoaktif maddenin 10 binlerce yıl daha varlığını sürdüreceği tahmin ediliyor. Nükleer tarihinin en ölümcül kazasına neden olan Çernobil santralini yapan Rosatam firmasının Akkuyu'yu inşa edecek olması Türkiye kamuoyunda ciddi kaygı ve korku nedenidir.

Türkiye kamuoyunda kaygıları artıran bir başka konuda sürecin şeffaflık içerisinde yürütülmemesidir. Tüm Dünya'da nükleer enerji faaliyetleri Birleşmiş Milletlere bağlı olarak 1957'den bu yana çalışan “ Uluslararası Atom Enerjisi Ajansı tarafından kontrol edilir. Bu kurum güvenlik standartlarını hazırlar ve sürekli olarak ülkelerin taahhütlerini yerine getirip getirmediğine bakar. 20 Şubat 2014 tarihinde hazırladığı "Entegre Nükleer Altyapı Gözden Geçirme” Akkuyu raporu ile Türkiye'ye 24 Tavsiye ve 15 öneride bulundu. Türkiye bu raporu kamuoyuna açıklamadı ve konuya dair bir bilgilendirme de bulunmadı. Akkuyu ile ilgili ÇED raporu mahkemelik olunca Mersin 1. İdare Mahkemesi bu raporu talep etti. Ancak belgeler mahkemeye "İstenen bilgi ve belgeler Devletin güvenliğine veya yüksek menfaatlerine veya Devletin güvenliği ve yüksek menfaatleriyle birlikte yabancı devletlere de ilişsin ise, Başbakan veya ilgili bakan, gerekçesini bildirmek suretiyle, söz konusu bilgi ve belgeleri vermeyebilir." Gerekçesi ile sunulmadı. Milyonlarca insanın hayatını ilgilendiren konuda devlet sırrı demek, devlet güvenliği zırhına sığınmak çok da samimi bir yaklaşım olarak görülmemektedir. Bu tür projeler üst düzeyde güven ve açıklık içerisinde yürütülmesi gerekir. Bu konuda gerek Rusya gerek se Türkiye'nin Uluslararası alanda şeffaflık raporlarında durumu pek parlak değildir. Her iki ülkede yönetimsel anlayışlardaki sorunlar kaygıları daha da artırmaktadır.

Benzer şekilde ÇED raporu incelendiğinde ciddi eksikleri olduğu ve önemli konuların detaylı ve objektif ele alınmadığı görülmektedir. Özellikle geçmişte yapılan çok sayıda rapor ve bulgu var iken özellikle ÇED raporu önceki tüm çalışmaları yok sayar bir şekilde hazırlandığı görülmektedir. Özellikle turizm ve tarım sektörü üzerindeki etkilerin adeta yok sayıldığı görülmektedir. Bu tür çalışmalar yasal zorunluluk olduğu için değil, tüm kamuoyunu bilgilendirmek, bilimsel gerçekleri ortaya çıkarmak ve olası olumlu durumları avantaja çevirmek, olumsuz durumlara karşı önlem almak için özenle yapılır. Tüm bunlar yapılırken de objektif ve önyargılardan 
uzak olmak gerekir. Ancak rapor tek yönlü ve bir yasal zorunluluğun aşılması için düzenlenmiş izlenimini güçlü şekilde vermektedir.

\section{Akkuyu Türkiye'nin Enerji Bağımlılığını Sona Erdir mi?}

Türkiye Hükümetinin ikinci savı nükleer enerji santrali kurulmaz ise Türkiye'nin dışa bağımlı enerji politikası izlemek zorunda kalacağı nükleer enerjinin bu bağımlılığı ortadan kaldıracağıdır. Akkuyu nükleer Santrali enerjide dışa bağımlılığı azaltacak mı sorusuna analiz etmeye çalışırsak Türkiye'nin 2013 Yılı sonunda ürettiği elektrik üretimi 241 milyar Kwh dolayındadır. Bunun \% 43'ü doğal gazdan elde edilirken, \%26,6’sı kömürden yaklaşık $\% 25$ 'ide hidroelektrikten sağlanmıştır. Herhangi bir ülkede enerji sistemi yüzde yirmilerin üzerinde bir tek kaynağa bağlı hale gelirse bağımlılıktan bahsedilebilir. Genel ilke olarak tüm enerji kaynakları belirli oranlarda ulusal sisteme katkı yapmalıdır. Bu tabloda göz ardı edilenin yenilenebilir enerji kaynakları olduğu açık ve nettir. Üretilen enerjinin çeşitliliği ne kadar fazla ise ülke açısından "ikame" etme gücü o denli yüksektir. Aksi takdirde tek kaynağa bağımlılık zaman zaman ciddi sorunlar yaşatır. $\mathrm{Bu}$ anlamda Türkiye'de elektrik üretimi içinde doğal gaza bağımlılı̆̆ı $\% 43$ gibi üst düzeyde olduğu görülmektedir. Türkiye doğal gazın yaklaşık üçte ikisini Rusya'dan sağlamaktadır. Diğer önemli satıcı ise İran'dır. Kömür santrallerinde kullanılan yakıtın $\% 30$ 'u da aynı zamanda ithalata dayanmaktadır.

Şimdi tabloya başka bir gözle bakarsak nükleer enerji santralini de Rusya'nın inşa ettiği düşünülürse sanıldığının aksine nükleer enerji bağımlılığını azaltmayacak aksine Türkiye'nin Rusya'ya doğal gaz açısından olan bağımlılığına bir de nükleer bağımlılık eklenecektir. Bu ise mevcutta var olan enerji bağımlılığını daha da artıracaktır. Türkiye ve Rusya arasındaki yapılan anlaşma gereğince Akkuyu santralinin sahibi, işleticisi başlangıçta \%100 hisse ile Rusya'dır ve anlaşma gereğince de ilerleyen yıllarda şirket hisse satışı yapabilir ama Rusya'nın payı $\% 51$ 'in altına düşmemesi garanti altına alınmıştır. Rusya 15 yıl sonunda yatırım kendini finanse ettikten sonra oluşan karın sadece \%20'sini Türkiye'ye verecektir. İnşaat esnasında tesis kurmak, yardımcı sistemler, ekipmanlar Rus firmalarınca tedarik edilecektir (Resmi Gazete, 6-Ekim-2010).

Yine aynı şekilde yakıt temin ve tasarımı Rusya tarafından yapılacaktır. Peki, Türkiye bu süreçte ne yapacaktır? Türkiye'ye düşen görev yatırımın önünde oluşabilecek engelleri kaldırmak ve öncelikle her bir ünitenin işletmeye alınmasından sonra ilk iki ünitede üretilen enerjinin \%70'ni sonraki iki ünitede \%30'unu 15 yıl boyunca satın almayı garanti etmektir. Geri kalanını Rusya serbest şekilde elektrik piyasasında satabilecektir. Bunun dışında yasal düzenleme, kamulaştırma gibi işlemleri yapmakta Türkiye'ye düşmektedir. Anlaşmadaki bedeller dolar üzerinden hesaplanmıştır. Bu anlaşma kabul etmek gerekir ki Rusya açısından başarılı bir ticari anlaşmadır. Alınacak elektrik fiyatları da anlaşma ile belirlenmiştir. Türkiye Cumhuriyeti Devleti, Türkiye Elektrik Ticaret ve Taahhüt A.Ş. (TETAŞ) aracıllığıyla satın alma garantisi verilen miktardaki elektriğin her bir kilovatsaatini 12,35 dolar sent fiyatla alacaktır. Ayrıca TETAŞ ile Proje Şirketi arasında mutabaka edilen tarife kademelerinde, elektrik fiyatlarındaki artış, Akkuyu projesinin geri ödemesinin sağlanması amacıyla fiyat 15,33 dolar sent $\mathrm{kWh}$ tavan fiyatına kadar proje şirketi tarafindan belirlenecektir (Resmi Gazete, 6 Ekim 2010). Sinop'da düşünülen santral için ise düşünülen fiyat 11.80 sent civarındadır.

Akkuyu'da her biri 1200 MW kapasiteli 4 reaktör inşa edilecektir. İlk ünitenin 2019 yıllnda devreye girmesi planlanmaktadır (Enerji ve Tabi Kaynaklar Bakanlığı:2014). Diğer üniteler birer yıl arayla devreye girecek ve 2022 'de tüm üniteler hizmete girmiş olacaktır. Y1llık elektrik talep artı̧ı ülkemizde ortalama yüzde $\% 5,5$ düzeyinde artmaktadır. 2022 yılında üretime geçecek Akkuyu'nun tam olarak faaliyete geçmesinden 8 yıl sonra enerji tüketiminin \%5,5'ini karşılayacağı tahmin edilmektedir. Alım garantisi süresinin dolacağı 2036 yllında Akkuyu Nükleer Santrali ülke tüketiminin ancak \%4'ünü karşılayabilecektir. Proje tahmini ekonomik yaşamının sonu olan 2082 yılında ise Türkiye tüketiminin sadece yüzde 1,8'ini karşllayacaktır. Tabi bunlar tahmini ve belli varsayımlarla hesaplanan rakamlardır.(Enerji Ajansı:2015) Ancak bu rakamlar bize şunu gösteriyor Akkuyu bir enerji bağımlığını ortadan kaldırma projesi değildir. Bu proje bir Türkiye projesi de değildir. Özellikle teknik ve finansal açıdan Türkiye hükümetinin kaynak sorunu nedeniyle proje tamamıyla Rusya tarafına ihale edilmiştir. Rusya'nın Türkiye'de bir santral işletmesi, ürettiği enerjiyi garanti fiyatla sattı̆̆ı, hisseleri elinde bulundurduğu bir projedir. Proje özünde Rusya'nın kendi topraklarında kendi finansal ve insan gücü ve teknolojisi ile yaptığı bir projeyi Türkiye'den izin alarak Akkuyu'da yapması anlamı taşımaktadır. İddia edildiği gibi Türkiye'nin özkaynakları ile yaptığı santraller aracılığı ile ürettiği enerjiyi kullanarak ve satarak bağımlıllğı düşürecek bir proje değildir. Alıcının, satıcının ve fiyatın önceden belirlendiği bir opsiyonel işlem niteliğindedir. Bu durum Türkiye açısından enerji bağımlılığını azaltmaktan çok Rusya'ya olan bağımlılı̆̆ı artıracaktır.

Ekonomik açıdan maliyetli, teknik açıdan henüz yeterli düzeyde test edilmemiş bir teknolojinin kullanımı konusunda Türkiye'nin tercihte bulunmasının üçüncü nedeni Türkiye ile Rusya arasında Stratejik bir işbirliği olabilir mi sorusu sorulmalıdır. İki ülke arasında iç sorunlara dışarıdan bakış konusunda ciddi farklılıklar vardır. Türkiye'nin Kürt sorununa Rusya'nın bakışı, Çeçenistan olayına Türkiye'nin yaklaşımı tarafları mutlu etmemektedir. Bunu yanında özellikle son 3 yıldır Suriye sorununda taraflar adeta farklı görüşleri temsil etmektedir. Ortadoğu politikalarında bariz farklılıklar görülmektedir. Boğazlar konusu iki ülke arasında tarihsel 
bir konu olarak durmaktadır. Genel olarak bakıldığında iki ülkenin siyasi arenada benzer söylem ve davranışlar sergilediğini ve uyum içinde olduklarını söylemek oldukça güç görünüyor

\section{Kaynakça}

- $\quad$ Ahmet Bayülgen Türkiye'de Nükleer enerji Online Erişim http://www.iaea.org/inis/collection/NCLCollectionStore/_Public/41/103/41103131.pdf [29.06.2015]

- Harun Akkaya, 18 Kasım 2002, 5.Akkuyu Nükleer Savaşı Aksiyon Dergisi Online Erişim: http://www.aksiyon.com.tr/kapak/5akkuyu-nukleer-savasi_511148 [29.06.2015]

- Akkuyu NGS, (2015) Online Erişim: http://www.akkunpp.com/ [20/06/205]

- Belen Tuncay (2007) Türkiye'de Nükleer Enerjinin Politiği ESAM Stratejik Araştırma Dergisi, Yıl:1 Sayı 1 Şubat 2007 Online Erişim: http://www.nukte.org/node/185 [28.06.2015]

- Bozkurt, Güngör (1994) "Elektrik Sektöründe Nükleer Santrallerin Yeri, Alternatifleri ile Ekonomik ve Çevre Açısından Karşılaştırılması” Dünya Enerji Konseyi Türk Milli Komitesi, Türkiye 6.Enerji Kongresi, Sayfa 7-17, 17-22 Ekim İzmir

- Ekşi Muharrem (2014) Türkiye’nin Nükleer Enerji Stratejisi, Büyük Güç Olma İdeali, 23 - 24 Eylül 2014 Kocaeli Üniversitesi “Uluslararası Enerji ve Güvenlik Kongresi” Bildirisi Online Erişim http://www.bilgesam.org/Images/Dokumanlar/0-355-2014121621guvenlik_kongresi_bildirileri-7.pdf [28/06/2015]

- Enerji ve Tabi Kaynaklar Bakanlığı (2014) "Nükleer Güç Santralleri ve Türkiye, Nükleer Enerji Proje Uygulama Daire Başkanlığı Yayın No:2) Online Erişim:

http://enerji.gov.tr/File/?path=ROOT\%2F1\%2FDocuments\%2FSayfalar\%2FNukleer_Guc_Santralleri_ve_T urkiye.pdf [12/06/205]

- Erbaşı Çuhadar, Aslıhan Ayşe (2015) “Uluslararası Nükleer Sorumluluk Rejimi Çerçevesinde Sivil Amaçlı Nükleer Santral İşletenin Hukuksal Sorumluluğu “ İnönü Üniversitesi Hukuk Fakültesi Dergisi Cilt:6 Özel Sayı Online Erişim:

https://www.inonu.edu.tr/uploads/contentfile/173/files/ay $\% \mathrm{C} 5 \% 9 \mathrm{Fe} \% 20 \mathrm{asl} \% \mathrm{C} 4 \% \mathrm{~B} 1 \mathrm{han} \% 20 \mathrm{erba} \% \mathrm{C} 5 \% 9 \mathrm{~F}$. pdf [13/06/2015]

- International Atomic Energy Agency (IAEA), Power Reactor Information System (PRIS) (2015) Online Erişim: https://www.iaea.org/pris/

- World Statistic: https://www.iaea.org/PRIS/WorldStatistics/OperationalReactorsByCountry.aspx

- Country Statistic: https://www.iaea.org/PRIS/CountryStatistics/CountryStatisticsLandingPage.aspx

- Trend Report: https://www.iaea.org/PRIS/WorldStatistics/WorldTrendNuclearPowerCapacity.aspx

- Nucleer Share: https://www.iaea.org/PRIS/WorldStatistics/NuclearShareofElectricityGeneration.aspx

- $\quad$ NTV Nükleer santral inşası yine gündemde Online Erişim : http://arsiv.ntv.com.tr/news/188224.asp?cp1=1\#BODY [28/06/2015]

- Under Constraction: https://www.iaea.org/PRIS/WorldStatistics/UnderConstructionReactorsByCountry.aspx [21/06/205]

- Muradov, Elman (2012) " Almanya'nın Nükller Enerji Poltikasını Etkileyen Faktörler” Marmara Üniversitesi e-dergi Öneri.C.10.S.38.Temmuz 2012.105 Online Erişim: http://e dergi.marmara.edu.tr/maruoneri/article/ viewFile/1012000212/pdf_115 [24/06/205]

- SSahin, Sümer (1985) Nükleer Enerji ve Nükleer Santraller, Türkiye Elektrik Kurumu, Eğitim Dairesi Başkanlığı Yayını

- Özgür, Salih (2006) "Soğuk Savaş ve Sonrası DÖnemde Kitle İmha Silahları ve Silahlanma Çabaları, Süleyman Demirel Üniversitesi, Sosyal Bilimler Fakültesi Uluslararası İlşkiler Anabilim Dalı Yüksek Lisans Çalışması

- TC Resmi Gazete (6 Ekim 2010) Türkiye Cumhuriyeti ile Rusya Federasyonı Hükümeti arasında Türkiye Cumhuriyetinde Akkuyu Sahası'nda Bir Nükller Güç Santralinin Tesisine ve İşletmesine İlişkin Anlaşma Online Erişim http://www.resmigazete.gov.tr/eskiler/2010/10/20101006-6.htm [20/06/2015]

- TC Resmi Gazete (9-07-1982) Türkiye Atom Enerjisi Kurumu Kanunu Online Erişim http://www.mevzuat.gov.tr/MevzuatMetin/1.5.2690.pdf

- $\quad$ TMMOB (2013) Türkiye Nükleer Enerji Raporu, TMMOB Elektrik Mühendisleri Odası Online Erişim http://www.emo.org.tr/ekler/d28ac2cf3783f23_ek.pdf [20/06/205]

- World Nucleer Association (2015) “World Nuclear Power Reactors \& Uranium Requirements" Online Erişim: http://www.world-nuclear.org/info/Facts-and-Figures/World-Nuclear-Power-Reactors-and-UraniumRequirements/ [24/06/205] 


\title{
Çevre Ekonomisi ve Sürdürülebilir Kalkınma Açısından E-Atık Yönetiminin Önemi
}

\author{
The Importance of E-Waste Management In Terms of \\ Environmental Economics and Sustainability
}

\author{
Prof. Dr. Mehmet Marangoz (Muğla Sitkı Koçman University, Turkey) \\ Prof. Dr. Asım Günal Önce (Dokuz Eylül University, Turkey) \\ Ph. D. Candidate Ali Emre Aydın (Muğla Sıtkı Koçman University, Turkey)
}

\begin{abstract}
Today, environmental economics examining the economic contribution of protecting the environment and natural resources and preventing the environmental pollution has become an important issue like energy. In this context the relationship between economy and environment is analyzed. In this relationship process of economy management change the environment and environmental qualifications take part in success of economy. Sustainable development, as an another important concept, explains realization of the efforts for economic growth and enhancing the welfare level in the meantime protecting the environment and people's quality of life. Sustainable development has great importance for managing environmental, economic and social resources accurately.

E-waste (electronic waste) management comes to the forefront in the context of environmental economics and sustainable development. Along with technological advancements and changing consumption habits e-waste management and e-waste recycling become crucial. While there are several related studies focus on waste management and recycling and their relationship between environmental economics and sustainable development few study deal with e-waste management. This study aims to fill this gap and make a contribution with emphasizing the importance of e-waste management for environmental economics and sustainable development.

In this study e-waste practices in the World are evaluated, recycle ratios and their economic impact are examined, e-waste management's importance as a financial trigger is emphasized, not only short term but also long term effects of e-waste management are elaborated from the point of sustainability and suggestions are discussed for improving the recycling processes for practitioners and law-makers.
\end{abstract}

\section{Giriş}

Çevre ve ekonomi arasındaki ilişki kaçınılmazdır ve döngüsel olarak ortaya çıkmaktadır. Tüketim ve üretimin meydana getirdiği ekonomik sistemlerde kaynakların tükenmesi, atıkların çevre alanlarına bırakılması, estetiğin işlevinin değişmesi ve global yaşamın yeni bir şekil alması gibi süreçlerde ekonomi ve çevrenin karşılıklı etkileşimi görülmektedir. $\mathrm{Bu}$ etkileşimde ekonominin yönetilme süreci ve biçimi çevreyi değiştirmekte ve çevresel nitelikler ise ekonominin başarıya ulaşmasında rol almaktadır (Ertürk, 1998). Bu ilişki günümüzde giderek daha büyük bir önem kazanmaktadır ve tartışmalar genel itibariyle kaynakların dikkatli kullanımı ve verilen zararın karşılığında ortaya çıkan bedelin karşılanması üzerine yoğunlaşmaktadır. Bu bağlamda çevre ile ekonomi arasındaki ilişki temelde iki noktada şekillenmektedir. İlk olarak çevre ve çevre değerlerinin korunması için yapılan harcamalar, ikincisi ise çevreye verilen zararın ortadan kaldırılması için ekonominin üstlenmesi ve katlanması gereken harcamalardır (Keleş ve Hamamcı, 2005).

Günümüzde teknoloji hızla gelişmekte, hem tüketim hem de üretim boyutunda ekonomik faaliyetler çeşitlenmektedir. Bu süreçte çevrenin korunması, ekonomik kalkınmanın sürdürülebilir nitelik kazanmasında son derece önemlidir. Kaynakların etkin ve uzun vadeli kullanımı ile doğrudan ilişkisi göz önüne alındığında sürdürülebilir faaliyetlerin ve yönetim süreçlerinin desteklenmesi gerekmektedir. Bu kapsamda atık yönetimi, çevrenin korunması, kaynakların israf edilmemesi ve sürdürülebilirlik açısından stratejik bir öneme sahiptir. Bu konuda yatırım kararları alan işletmeler, politika üreten kurum ve kuruluşlar, işletmelerin bu konudaki tutumlarını değerlendirerek satın alma kararlarını şekillendiren tüketiciler, atık yönetimi teknolojisinin gerektirdiği alt yapının sağlanması için üreticiler, geri dönüşüm sürecinde ortaya çıkan madde ve bileşenlerin ekonomik değeri ve atıkların geri dönüştürülmesi ile sağlanan ekonomik kazanım, atık yönetiminin ekonomik boyutunun ne kadar geniş olduğunun göstergeleri olarak değerlendirilebilir.

Değişen tüketim davranışları ile ortaya çıkan bir atık şekli de elektronik atıklardır. Elektronik ve elektrikli atıkların geri dönüşüme kazandırılması, bu ürünlerin bileşeninde bulunan maddelerin ekonomik değeri dikkate alındığında oldukça önemlidir. E-atık kapasitesinin artmasıyla birlikte başta $\mathrm{AB}$ ve gelişmiş ülkeler olmak üzere tüm dünyada konuya ilgi yoğunlaşmıştır. Hem doğal çevrenin korunması hem de sürdürülebilir kalkınma ilkelerinin hayata geçirilmesi için e-atıkların yönetilmesi sürecinde belirlenen adımlar ve uygulanan politikalar 
ile birlikte bu atıkların ekonomiye geri kazandırılması sağlanmalıdır. Bu bağlamda bu çalışmanın amacı, e-atık yönetimi uygulamalarının çevre ekonomisi ve sürdürülebilir kalkınma için önemini vurgulamaktır.

\section{2 Çevre Ekonomisi ve Sürdürülebilir Kalkınma}

İnsanların üretim ve tüketim faaliyetleri beraberinde çevre ile ilgili sorunları ortaya çıkarmış, ancak doğanın kendini yenileyebilme özelliği bu sorunların fark edilmesini geciktirmiştir. Zaman içerisinde çevre kirliliğinin hem nicel hem de nitel olarak artış göstermesi doğanın kendini yenileyebilme özelliğinin önüne geçmiş ve sonuç olarak çevre hızla bozulmaya başlamıştır (Keleş ve Hamamcı, 2005). Bu bağlamda çevre ekonomisi kavramı ön plana çıkmaktadır. Çevre ekonomisi uygulamalı ekonomi alanı olarak nispeten yeni bir yaklaşım olarak değerlendirilebilir. 50 yıllık geçmişine bakıldığında klasik ekonomi anlayışına bir alternatif olarak dinamik bir süreç geçirmektedir. Bu süreç içerisinde, çevresel bozulmalara ve yıkımlara farklı devlet düzenlemeleri ve çözümler sunulmaktadır (Slavikova, 2012). Burada amaç, çevrenin hıla bozulmasının önüne geçmek, yani çevresel sürdürülebilirliği sağlamaktır.

1960'lı yıllarda çevre kirliliğinin artması ile birlikte ortaya çıkan çevre ekonomisi kavramı o dönemde ekonomistler tarafından daha fazla ciddiye alınmaya başlamıştır. Kaynak ve çevre ekonomisi ile ilgili çalışmaları olan ekonomistler, çevreyi ekonomik modellere dahil etmeye çalışmışlardır. Bu araştırmacılar için doğal çevre ekonomik sistemin önemli bir bileşenidir ve tıpkı işçi ve sermaye gibi bir varlık ve kaynak olarak değerlendirilmelidir. Bu bakış açısıyla çevre bileşenleri, ekonomik aktiviteler için bir kısıtlayıcı değil diğer bileşenler ile dönüşüm yapılabilecek önemli bir unsurdur (Beder, 2011).

Keleş vd. (2009), ekonomi ile çevre arasındaki ilişkiyi açıklamak amacıyla mikro ve makro ekonomi boyutlarından çevrenin önemi üzerinde durmuştur. Yazarlar, mikro ekonomi boyutunda fiyat kuramı çerçevesinde tek tek firmaların faktör fiyatları üzerinde çevre harcamalarının etkili olduğunu, yine çevre harcamalarının satış fiyatını etkilediğini belirtmektedir. Ayrıca çevre harcamalarının ortaya çıkardığı yükün dağıtılmasında firmaların yükünün hesaplamasının mikro ekonomik çözümlemeler gerektirdiğini ifade etmişlerdir. Makro boyutta ise dört boyutlu bir değerlendirme söz konusudur. İlk olarak, çevre harcamalarının maliyeti yükselterek satış fiyatına etki etmesinin yalnızca ülke içinde değil ülkeler arasında da rekabeti etkilediğini öne süren yazarlar, çevre ekonomisinin uluslararası ekonomi yönünden de önemini vurgulamışlardır. İkinci olarak, ulusal gelir ve büyümenin çevre harcamalarından etkilenmesi ve yavaşlaması sorunudur. Bu nedenle harcamaların planlı bir şekilde yürütülmesi önem kazanmaktadır. Üçüncü olarak istihdam açısından değerlendirme yapan yazarlar, çevreyi koruma ile ilgili düzenlemelerin yeni istihdam alanı açabileceğini öte yandan çevre için konulan harcama yükümlülükleri ile baş edebilmek için sanayi kuruluşlarını eksik kapasiteyle çalışmaya zorlayabileceğini belirtmektedirler. Son olarak çevrenin korunması amacıyla ortaya çıkan vergi yükünün adaletli dağılımı da ekonomi ile ilişkilidir.

Çevre ekonomisi kavramı ile ilişkili olarak değerlendirilebilecek bir diğer kavram ise sürdürülebilir kalkınma kavramıdır. Birleşmiş Milletler Çevre ve Kalkınma Komisyonu (1987) tarafından insanlığın, gelecek kuşakların gereksinimlerine cevap verme yeteneğini tehlikeye atmadan, günlük ihtiyaçlarını temin ederek kalkınmayı sürdürülebilir kılma yeteneği olarak tanımlanan sürdürülebilir kalkınmanın başarılı olabilmesi ekonomik, sosyal ve çevresel boyutlar kapsamında değerlendirilmektedir. Ekonomik boyutuyla, kıt kaynakların etkin kullanımı ile ilgili bir sistem olarak sürdürülebilir kalkınma, mal ve hizmetleri devamlılık odaklı üretebilen, tarımsal ve endüstriyel üretime zarar veren dengesizliklerden sakınan, iç ve dış borçların yönetilebilir düzeyde olmasını ifade eder. Sosyal boyutuyla, insan odaklı bir yaklaşımı ve eğitim, sağlık gibi sosyal himetlerin yeterliliği ve eşitliği, politik sorumluluğu ve katılımı sağlayabilen bir sistemi ifade eder. Çevresel boyutuyla ise biyolojik ve fiziksel sistemlerin dengeli olmasını ve ekosistemlerin değişen koşullara adaptasyonunu merkeze alır. Çevresel olarak sürdürülebilir sistem, kaynak temelini sabit tutarak, yenilenebilir kaynakların ve çevresel yatırımların istismarından kaçmalı ve yenilenemeyen kaynaklardan yalnızca yatırımlarla yerine konulmuş olanların tüketilmesini öngörür (Tıraş, 2012).

Sürdürülebilir kalkınma yaklaşımı her üç boyutuyla da hem çevre ekonomisinin odak noktasında yer alan kavram ve varsayımlara hem de atık yönetimi sürecinin amaçlarıyla örtüşmektedir. Atık yönetimi açısından ele aındığında sürdürülebilirlik yaklaşımı, müşteri açısından kullanım ömrü biten ürünleri bir kaynak olarak ele alır ve bu ürünleri düşük maliyetli ve etkin geri kazanım yöntemleri ile ekonomiye yeniden kazandırmayı hedefler. $\mathrm{Bu}$ ürünler arasında yeniden kaynak olarak değerlendirilemeyecek kısımları da doğaya en az zararla bertaraf etmek amacıdır. Bu durum hem hammadde hem de üretim maliyetlerinde önemli derecede tasarruf elde edilmesine ve kaynakların sürdürülebilir bir yaklaşım içerisinde değerlendirilmesini sağlamaktadır (Ergülen ve Büyükkeklik, 2008). Atık yönetimi ve geri dönüştürülme süreçlerinin hem çevre ile ekonomik açıdan ilişki içerisinde bulunduğu hem de sürdürülebilir kalkınma açısından önem taşıdığı ifade edilebilir. Bu bağlamda hem doğal çevre hem de süreç içerisinde yer alan paydaşların kazanımları açısından atık yönetimi sürecinin iyi planlanması gerekmektedir. 


\section{E-Atık Kavramı ve Yönetimi}

Hızlı ekonomik büyüme, teknolojik ilerlemeler, sanayileşme ve nüfus artışı gibi olgulara paralel bir şekilde atık miktarında da artış yaşanmıştır. $\mathrm{Bu}$ nedenle atıksız veya olabildiğince az atıklı üretimi ve tüketimi hedefleyen atık yönetimi yaklaşımı önem kazanmaktadır. Atık yönetimi kapsamında evsel, tıbbi, tehlikeli ve tehlikesiz atıkların mümkün olduğunca azaltılması, ayrı toplanması, ara depolanması, atıkların taşınması, geri kazanımı, geri dönüştürülmesi ve bertarafı yer almaktadır. Doğal kaynakların tüketilmesini engellemek ve üretilen atıkların çevre ve insan sağlığını tehdit etmesinin önüne geçip ekonomik bir değere dönüştürülmesini amaçlayan atık yönetim stratejileri, sürdürülebilir kalkınma yaklaşımının temelini oluşturmaktadır (Bilim, Sanayi ve Teknoloji Bakanlığg Sanayi Genel Müdürlüğü, 2014).

Atık yönetimi süreçlerinin iyileştirilmesi için tüm dünyada ulusal ve uluslararası düzeyde çalışmalar devam etmektedir. Temel olarak Avrupa Birliği tarafından belirlenen WEEE ve RoHS direktiflerinin üye ve üyelik sürecindeki ülkeler için bağlayıcılığı bulunmaktadır. ABD'de ise bu konudaki etkin kurum Environmental Protection Agency (Çevre Koruma Örgütü-EPA)'dır. EPA'nın katı atık yönetimi ile ilgili olarak oluşturduğu hiyerarşi, katı atık yönetiminde en etkili çevreci yöntemleri sıralamaktadır.

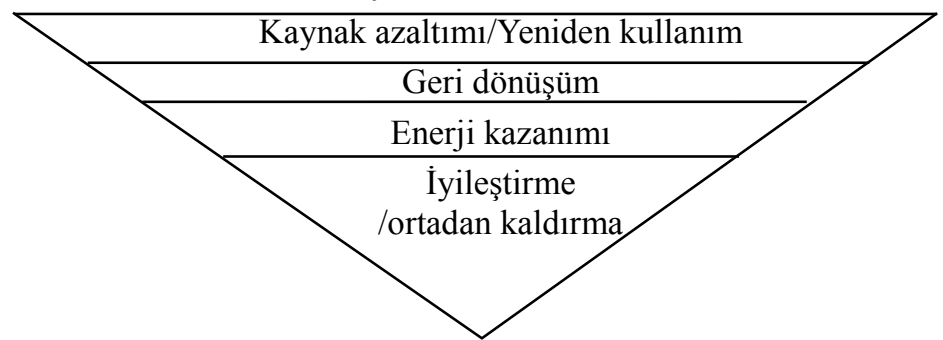

Şekil 1. Katı Atık Yönetim Hiyerarşisi Kaynak: U.S. Environmental Protection Agency, 2013

$\mathrm{Bu}$ hiyerarşik modele göre; yeniden kullanımı da kapsayan kaynak azaltımı, en çok tercih edilen yöntemdir. Sırasıyla geri dönüşüm, enerji geri kazanımı ve son olarak da iyileştirme ve ortadan kaldırma tercih edilmektedir. EPA'nın bu hiyerarşi ile amacı atılan elektronik ürünler ile ilgili olarak çevre odaklı çözümler üretebilmektir. Bu hiyerarşi kapsamında EPA düzenlemeler sunmakta, atıklar için gönüllü katılım programlarını teşvik etmekte ve geri dönüşüm konusunda çalışan sertifikalı işletmeler ile işbirliği yapmaktadır (EPA, 2013).

Genel olarak atıklar, ömrü ve kullanım süresi dolmuş pillerden, tarımsal ve evsel kalıntılara kadar çok çeşitli ürün ve atıkları kapsamaktadır. Bu ürünler de kendi içlerinde farklı atık yönetimi ve geri dönüşüm süreçlerini gerektirmektedir. Atık sınıflandırmasında ayrı bir yeri olan elektronik ve elektrikli ekipmanlardan kaynaklanan atıklar ise kendilerine has yönetim ve geri dönüşüm süreçlerini, bu kapsamda da farklı altyapı ve teknolojilerin kullanılmasını gerektirmektedir.

Çevrenin hızla bozulmasına neden olan atık tipleri günümüzün koşulları ile farklılaşmaktadır. Teknolojinin ve tüketim alışkanlıklarının hızla değişmesi atık tiplerinin değişmesine katkı sağlamış ve bu bağlamda ortaya çıkan yeni tür atık tiplerinden bir tanesi de elektronik atıklar (E-Atık) olarak nitelendirilmektedir. Günümüzde tüketicilerin eğilimleri ve pazarlama çabaları ile birlikte kullanımı artan elektronik cihazlar, kullanım amaçları kapsamında değişmekle birlikte, ortalama 1 ile 6 yıllık süre içerisinde işlevselliklerini yitirmekte ya da tamiri yenisini almaktan daha pahalı bir hale gelmektedir. Bu durumda yüksek maliyetlerle edinilen elektronik cihazlar çok fazla değer yitirerek ya hurdacılara satılmakta ya da çöpe gitmektedir. E-atık adı verilen atıklar bu şekilde ortaya çıkmaktadır (Çiftlik vd., 2009).

E-atıklar ile ilgili olarak Avrupa Birliği kriterlerini tamamlamak amacıyla elektrik ve elektronik ekipmanlardan kaynaklanan atıklar ile ilgili olarak direktifler yayınlanmaktadır. Belirli tehlikeli maddelerin elektrik ve elektronik ekipmanların kullanımına sınırlamalar getiren Ocak 2003 tarihli 20002/95/EC direktifi (RoHS/Restriction of Hazardous Substances-Zararlı Maddelerin Kullanımının Sınırlandırılması) ve elektrik ve elektronik ekipman atıkları konusundaki 27 Ocak 2003 tarihli 2002/96/EC direktifi (WEEE/Waste Electrical and Electronic Equipment-Elektrikli ve Elektronik Ekipman Atıkları Direktifi), hızla artan elektrik ve elektronik ekipmanlardan kaynaklanan atık akımlarını çözümlemek ve atık depolama ve yakma konusunda AB kriterlerini tamamlamak amacıyla tasarlanmışlardır. Elektrik ve elektronik ekipmanlarının geri kazanımının arttırılması ile son aşamada bertarafa giden toplam atık miktarı sınırlandırılacaktır. Üreticiler geri alımdan ve elektrik ve elektronik ekipmanların geri kazanımından sorumlu olacaklardır. Bu da elektrik ve elektronik ekipmanların, atık yönetimi bakış açısını tamamen dikkate alan, çevresel anlamda daha etkin tasarlanmasına özendirecektir. Tüketiciler de ekipmanlarını para ödemeden geri verebileceklerdir.

Elektrikli ve elektronik ekipmanlar kategorisinde çok sayıda eşya ve ürün yer almaktadır. Bu kapsamda WEEE direktifi atık yönetimi süreçlerinin verimli bir şekilde işlemesi, uygun altyapı ve teknolojilerin oluşturulması için elektrikli ve elektronik ekipmanları Tablo 1'deki gibi sınıflandırmaktadır: 


\begin{tabular}{|l|l|l|}
\hline \multicolumn{3}{|c|}{ Elektrikli ve Elektronik Eşya Kategorileri ve Ayrıntılı Listede Yer Alan Ürünlerden Bazıları } \\
\hline 1 & Büyük ev aletleri & $\begin{array}{l}\text { Buzdolapları, çamaşır makineleri, bulaşık makineleri, elektrikli } \\
\text { sitıcılar, iklimlendirme cihazları vb. }\end{array}$ \\
\hline 2 & Küçük ev aletleri & $\begin{array}{l}\text { Elektrikli süpürgeler, ütü makineleri, dikiş makineleri, tost } \\
\text { makineleri, tartılar vb. }\end{array}$ \\
\hline 3 & $\begin{array}{l}\text { Bilişim ve telekomünikasyon } \\
\text { ekipmanları }\end{array}$ & $\begin{array}{l}\text { Ana bilgisayarlar, kişisel bilgsayarlar, yazıcılar, kopyalama } \\
\text { ekipmanı, cep telefonları, faks makineleri vb. }\end{array}$ \\
\hline 4 & Tüketici ekipmanları & $\begin{array}{l}\text { Radyo alıcıları, televizyon alıcıları, video kameraları, müzik } \\
\text { enstirümanları vb. }\end{array}$ \\
\hline 5 & Aydınlatma ekipmanları & $\begin{array}{l}\text { Evsel kullanım hariç floresan ampuller, düz floresan lambalar, } \\
\text { düşük basınçlı sodyum lambalar vb. }\end{array}$ \\
\hline 6 & Elektrik ve elektronik aletler & Matkaplar, testereler, dikiş makineleri, kaynak makineleri vb. \\
\hline 7 & $\begin{array}{l}\text { Oyuncaklar, eğlence ve spor } \\
\text { ekipmanları }\end{array}$ & $\begin{array}{l}\text { Elektrikli tren ve yarıs arabası takımları, video oyunları, elektrikli } \\
\text { veya elektronik spor aletleri, jetonlu makineler vb. }\end{array}$ \\
\hline 8 & $\begin{array}{l}\text { Tıbbi cihazlar (tüm nakledilmiş } \\
\text { ve enfekte edilmiş ürünler hariç) }\end{array}$ & $\begin{array}{l}\text { Radyoterapi ekipmanı, diyaliz, sun'i teneffüs tertibatı, nükleer tıp } \\
\text { ekipmanı, analiz ekipmanı vb. }\end{array}$ \\
\hline 9 & İzleme ve kontrol enstrümanları & Duman dedektörü, ısı ayarlayıcıları, termostatlar vb. \\
\hline 10 & Otomatik dağıtıcılar & $\begin{array}{l}\text { Sicak içecek otomatları, katı ürünler için otomatlar, para otomatları } \\
\text { vb. }\end{array}$ \\
\hline
\end{tabular}

Tablo 1: Elektrikli ve Elektronik Eşya Kategorileri ve Ayrıntılı Listede Yer Alan Ürünlerden Bazıları Kaynak: T.C. Çevre ve Orman Bakanlı̆̆l, Tehlikeli Atıkların Sınıflandırılması Kılavuzu, Cilt 1, 2012

E-atık olarak değerlendirilebilecek ürünler ve eşyaların kapsamı yukarıdaki tabloda görüldüğü gibi oldukça geniştir. Söz konusu ürünlerin ekonomik ömrünü tamamladıktan ve işlevlerini yitirdikten sonra nasıl değerlendirildiği ve değerlendirileceği son derece önemlidir.

Elektronik atıkların yönetimi, elektrikli ve elektronik eşyaların içeriğinde yer alan metal, plastik, cam vb. ürünler ile bileşenlerinde bulunan kurşun, kadmiyum, cıva, krom gibi maddeler çevre ve insan sağlı̆̆ına zarar verme ihtimaline sahip pek çok zehiri barındırması nedeniyle önemlidir. Bu bağlamda e-atıkların geri dönüşüme kazandırılmak yerine gelişigüzel bir şekilde doğaya bırakılması uzun vadede hem insan hem de çevre sağlığına ciddi zararlar verebilir. Bununla birlikte sebep olduğu hammadde ve enerji kaybı göz önüne alındığında ekonomik olarak da sorun yaratmaktadır (Nur ve Karınca, 2014). Özellikle gelişmiş ülkeler, AB ve ABD’de bu e-atıkların bertaraf edilmesi ve geri dönüştürülmesi üzerine önemli çalışmalar yürütülmektedir.

ABD'de ne kadar elektronik atık üretildiğine ve bu atıkların bertaraf olma ya da geri dönüşüme kazandırılmasına ilişkin EPA (United States Environmental Protection Agency) tarafından hazırlanan 2010 verileri Tablo 2'de yer almaktadır:

\begin{tabular}{|c|c|c|c|c|}
\hline Ürünler & $\begin{array}{c}\text { Toplam hazır } \\
\text { e-atık (birim) }\end{array}$ & $\begin{array}{c}\text { Bertaraf olan } \\
\text { (birim) }\end{array}$ & $\begin{array}{c}\text { Geri } \\
\text { dönüştürülen } \\
\text { (birim) }\end{array}$ & $\begin{array}{c}\text { Geri } \\
\text { dönüşsürülme } \\
\text { oranı (yüzde) }\end{array}$ \\
\hline Bilgisayarlar & $51,900.000$ & $31,300.000$ & $20,600.000$ & $\% 40$ \\
\hline Monitörler & $35,800.000$ & $24,100.000$ & $11,700.000$ & $\% 33$ \\
\hline Yazıc1 ve tarayıcılar & $33,600.000$ & $22,400.000$ & $11,200.000$ & $\% 33$ \\
\hline Klavye ve Mouse & $82,200.000$ & $74,400.000$ & $7,830.000$ & $\% 10$ \\
\hline Televizyonlar & $28,500.000$ & $23,600.000$ & $4,940.000$ & $\% 17$ \\
\hline Mobil cihazlar & $152,000.000$ & $135,000.000$ & $17,400.000$ & $\% 11$ \\
\hline TV aksesuarları & Dahil edilmemiş & Dahil edilmemiş & Dahil edilmemiş & Dahil edilmemiş \\
\hline Toplam (birim) & $\mathbf{3 8 4 , 0 0 0 . 0 0 0}$ & $\mathbf{3 1 0 , 0 0 0 . 0 0 0}$ & $\mathbf{7 3 , 7 0 0 . 0 0 0}$ & $\mathbf{\% ~ 1 9}$ \\
\hline
\end{tabular}

Tablo 2: ABD’de Elektronik Atıklara ve Dönüşüm Oranlarına Iliş̧kin Veriler Kaynak: Electronic Waste Management in the United States Through 2009, U.S. EPA May, 2011

Yukarıdaki tablo, işleme hazır toplam e-atık'lardan oldukça düşük bir orandaki kısmının geri dönüştürüldügünü ortaya koymaktadır. Bilgisayar başlığı altında kişisel bilgisayarlar, masaüstü bilgisayarlar ve taşınabilir bilgisayarlar yer almaktadır. Yazıcı ve tarayıcılar, yazıcıları, dijital fotokopi makinelerini, tarayıcıları, çok işlevli cihazları ve faks makinelerini kapsamaktadır. Mobil cihazlar içerisinde cep telefonları, elektronik ajandalar, akıllı telefonlar ve çağrı cihazları yer almaktadır. Toplam hazır e-atık kavramı çöpe ve geri dönüşüme 
giden ürünleri kapsamaktadır. Toplam sayı, evde ve iş yerlerinde duran ancak kullanılmayan cihazları kapsamamaktadır.

Elektronik atıkların yönetilme sürecinde karşılaşılan en büyük sıkıntılardan biri tüm dünyada elektronik atıklar ile ilgili verilerin elde edilmesidir. Bu konudaki en güncel araştırmalardan bir tanesi Birleşmiş Milletler Üniversitesi (UNU) tarafından yapılmıştır. "2014 Global E-Atık İzleme Raporu” verileri, tüm dünyayı dikkate alan ve elektronik atık ile ilgili diğer çalışma ve raporlardan derlenen kapsamlı bir rapordur. Bu verilere göre 2013 yılında dünya genelinde 41,8 milyon e-atık ortaya çıkmıştır.

\begin{tabular}{|c|c|c|c|}
\hline \multicolumn{4}{|c|}{ Dünyada Üretilen Elektronik Atı Miktarı } \\
\hline Y11 & $\begin{array}{c}\text { Ortaya çıkan E-Atık Miktarı } \\
\text { (Metrik ton) }\end{array}$ & $\begin{array}{c}\text { Nüfus } \\
\text { (milyar) }\end{array}$ & $\begin{array}{c}\text { Ortaya çıkan E-Atık Miktarı } \\
\text { (kg/kiși) }\end{array}$ \\
\hline 2010 & 33.8 & 6.8 & 5.0 \\
\hline 2011 & 35.8 & 6.9 & 5.2 \\
\hline 2012 & 37.8 & 6.9 & 5.4 \\
\hline 2013 & 39.8 & 7.0 & 5.7 \\
\hline 2014 & 41.8 & 7.1 & 5.9 \\
\hline 2015 & 43.8 & 7.2 & 6.1 \\
\hline 2016 & 45.7 & 7.3 & 6.3 \\
\hline 2017 & 47.8 & 7.4 & 6.5 \\
\hline 2018 & 49.8 & 7.4 & 6.7 \\
\hline
\end{tabular}

Tablo 3: Dünyada Üretilen Elektronik Atık Miktarı Kaynak: Birleşmiş Milletler Üniversitesi, Global E-Atık İleme Raporu 2014

*2015 ve sonrast veriler tahminidir.

Dünya çapında ortaya çıkan elektronik atık miktarı 1 metrik ton lamba, 3 metrik ton küçük bilgi teknolojisi cihazları, 6.3 metrik ton ekran ve monitör, 7.0 metrik ton sıcaklık değişim ekipmanları (soğutucu ve dondurucu ekipman), 11.8 metrik ton büyük ekipman ve 12.8 metrik ton küçük ekipman. E-atık miktarının 2018'e kadar, yıllık \%4 ya da \%5 civarında artarak 49.8 metrik tona kadar yükselmesi beklenmektedir.

Genel olarak, atık yönetimi süreçlerinde izlenebilecek adımların dışında e-atıkların yönetilmesinde izlenebilecek farklı yöntemler mevcuttur. Son zamanlarda konu ile ilgili olarak başta Genişletilmiş Üretici Sorumluluğu (Extended Producer Responsibility-EPR) olmakla birlikte e-atıkların yönetilmesi sürecinde aşağıdaki yöntemler de yer almaktadır (Mansfield, 2013):

Atık yı̆̆ını/Çöpe atma: Bu yönteme göre e-atıklar özel tehlikeli atık alanlarında bertaraf edilebilir. Ancak bu durumun gerçekleşmesinin önünde üç engel bulunmaktadır:

- Tehlikeli atık alanları yaygın olarak kullanılmamaktadır.

- Fazla maliyetli ve tehlikeli atık arazileri için yeterli alan bulmak zordur.

- Bu bağlamda e-atıklar ağırlıkla oluşturulan atık arazilerinde ve yakılarak bertaraf edilmektedir.

$\mathrm{Bu}$ engellerin üstesinden gelip elektronik ve elektrikli ürünlerin özel tehlikeli atık alanlarında bertaraf edilmesi son derece önemlidir.

Geri Dönüştürme: Son zamanlarda bertaraf edilen e-atıkların sayısındaki artış ve Avrupa Birliği Komisyonunun direktifleri doğrultusunda, geri dönüşüm amacıyla elektronik cihazları parçalarına ayırmak için kullanılan teknolojiler ortaya çıkmaktadır. Bu durum geri dönüşüm sürecinde görev yapan işçileri, e-atıkların içerisinde bulunan zehirli maddelerin olumsuz etkisinden korumak için önemlidir. Geri dönüştürme sürecinde karşılaşılan problemlerden biri de "arka bahçe geri dönüşümü" (backyard recycling) olarak adlandırılabilecek süreçtir. Bu noktada bazı firmalar ya da şahıslar düzensiz ve sağlıksız koşullarda elektronik atıkları parçalarına ayırmakta ve bu durumda ortaya çıan zehrin kullanım alanları denetlenememektedir.

Yenileme/Yeniden Üretim: Yenileme, bir elektronik cihazı tam anlamıyla yeniden üretmeden önemli sayıda parçasını yeniden inşa etmek anlamında kullanılmaktadır. Yenilenen ürünler, yeni ürünlerin daha düşük kalitede biçimlenmiş hali olarak nitelendirilebilir. Yeniden üretilen ürünler ise yeni bir ürün kadar veya ondan daha iyi kalitede olabilir. Yeniden üretilen ürünler yeni ürünlere verilen kadar garanti süreleri verilebilmektedir; bu durum yeniden üretilen ürünlerin yeni ürünler kadar kaliteli olduğu sonucuna varılabilir.

Onarım: Bu yöntem yalnızca üretilen ürün üzerinde gerçekleştiği ve geri dönüşüm süreci için fazladan bir üretim gerektirmediğinden, e-atıklarla başa çıabilmek için ideal bir yöntem olarak ifade edilmektedir. Bir ürün sonsuza dek kullanılabilir halde kalırsa hiçbir zaman atık olarak değerlendirilmeyecek anlamına gelir. Ancak bu durum ile ilgili bazı problemler söz konusudur. Bir ürün tam anlamıyla bozulmasa ve kullanımına devam edilse 
de zaman içerisinde kullanıcı için maliyeti artacaktır. Bir diğer problem ise tamir ettirme maliyetinin zamanla artmasıdır. Bu durumda tüketiciler için tamir ettirmek yerine yeni bir ürün satın almak ekonomik açıdan daha mantıklı olabilir.

Genişletilmiş Üretici Sorumluluğu: Bu yöntemde işletmeler kendi ürünlerinden yaşam döngüsü boyunca sorumludurlar. $\mathrm{Bu}$ bağlamda bir işletme ürünlerinin bertaraf edilme sürecini dışsal bir süreç olarak değil, kendileri için yasal bir maliyet olarak değerlendirmelidir. $\mathrm{Bu}$ durum üreticilerin, ürünlerin kullanım süresi dışında kalan hayat evresindeki her aşamada ürünlerinden sorumlu olmasına imkan tanır. Genişletilmiş üretici sorumluluğu, işletmeleri kolay geri dönüşüm ve parçalara ayırma süreci için teknolojik yenilik tasarlamaya teşvik etmektedir. Aynı zamanda bu yöntem, işletmelerin geri dönüşüm ve yeniden üretime uygun ürünler üretmelerini sağlarken, planlı eskitme uygulamaları için de bir caydırıcıdır.

\section{4 Çevre Ekonomisi, Sürdürülebilir Kalkınma ve E-Atık Yönetimi İlişkisi}

Çevre sorunları birçok açıdan ekonomi ile doğrudan bir ilişkiye sahiptir. Hem mikro boyutta işletmeler hem de makro boyutta ülke ekonomisi çevrenin ve atıkların yönetiminden etkilenmektedir ve çevreyi bu boyutlardan soyutlamak mümkün değildir (Keleş ve Hamamcı, 2005). Bu konu ile ilgili olarak, e-atıkların geri kazanımının genelde birincil kaynakların tüketim hızını azaltmasının yanısıra, katı atık miktarının azalması, metal dışında kalan malzemelerin kazanılması, demir, demir dışı ve değerli madenlerin kazanılması bağlamında fayda sağlamaktadır. Bununla birlikte e-atık geri kazanım işlemi ikincil kaynak ortaya çıkarma olarak ifade edildiğinde metal elde edilmesi sırasında harcanan enerji, cevherden metal elde edilmesinde harcanan enerji miktarından daha düşük olması nedeniyle önemli bir enerji tasarrufu sağlamaktadır. Bu bağlamda e-atıkların geri dönüşümü ve işlenmesi aracılığıyla elde edilen metal hem enerji tasarrufu hem de ulusal kaynakların etkin kullanımına katkıda bulunmaktadır (Yazıcı ve Deveci, 2009).

$\mathrm{Bu}$ durum yalnızca metal açısından değil elektronik ve elektrikli ürünlerin içeriğinde ve bileşiminde bulunan diğer maddeler de göz önüne alındığında daha dikkat çekici olmaktadır. E-atıkların bileşimlerindeki birçok malzemenin çevreye olumsuz etkileri olmasına karşın, bu atıkların ekonomik değerleri göz ardı edilemeyecek seviyededir. Değerli madenler olarak sınıflandırılabilecek altın, bakır ve demir gibi metaller sayesinde bir ton eatığın getirisi 9193.46 dolara kadar yükselebilmektedir. Bunun yanısıra bu metallerin geri dönüşümleri ile sağlanan enerji tasarrufları da son derece önemlidir. Bu durum aşağıdaki gibi örneklendirilmektedir (Ergülen ve Büyükkeklik, 2008):

- Geri kazanılmış maddeden 1 ton alüminyum elde etmek için gereken enerji, cevherden çıkarılacak alüminyum için harcanan enerjinin \%4'ünü,

- Bakır bileşenlerin geri kazanılması için gereken enerji, bakırın madenden çıkarılması için gereken enerjinin $\% 13$ '̈̈,

- Demir/çelik bileşenlerin geri kazanılması için gereken enerji, madenden çıkarılması için gereken enerjinin $\% 19$ 'u kadar olmaktadır.

Atıkların geri dönüşümü iktisadi açıdan karın maksimize edilmesinde oldukça önemlidir. Sürdürülebilir ekonomik kalkınma ile geri dönüşüm arasında akıcı ve sistematik bir ilişki söz konusudur ve bu ilişkinin sürekliliği için ilk olarak gereksiz atıkların önüne geçilmesi ve üretimlerin optimal atık çıkarma oranları dahilinde çıktı almaları gerekmektedir. Bundan sonraki aşamada geri dönüşüm yatırımlarıyla kurulan tesislerde atıkların dönüştürülerek ekonomik bir varlık halinde girdi yaratması gerekmektedir. E-atıkların geri kazanım oranı özellikle gelir düzeyi yüksek toplumlarda yüksektir (Hobıkoğlu, 2013).

Çevre sorunları dikkate alındığında ülkelerin gelişmişlik seviyesi, konuya yaklaşımda ve uygulamalarda dikkat çekici bir ayrım olarak değerlendirilmektedir. Gelişmiş ülke hükümetleri, doğal çevrenin korunması ile ilgili yaptırımları koymada ve uygulamada daha dikkatli davranmaktadır. Gelişmekte olan ülkelerdeki hükümetler ise arıtma tesisleri kurulmasının büyük çapta yatırım gerektirdiğini ve bu durumun da ekonomik büyümeyi yavaşlatacağı görüşünü savunmaktadırlar. Buna karşın tam aksi yöndeki görüşler yaygınlaşmaktadır. Örneğin, Birleşmiş Milletler Çevre Programı eski İcra direktörü Mustafa Tolba, çevre korumanın bir lüks değil gereksinim olduğunu belirtmiş ve dahası çevrenin karlı bir yatırım olduğunu vurgulamıştır. Bu görüşe göre çevre yatırımı maliyetinden daha karlıdır. Bu yaklaşım çerçevesinde ülkelerin gelişmişlik seviyeleri doğrultusunda GSMH değerinin uygun bir kısmının çevre politikalarına ayrılmasının büyümeyi durdurmayacağı belirtilmektedir (Keleş vd. 2009).

E-atıkların etkili yönetimi -yeniden kullanım, müşterilerden toplama, düşük maliyetler geri kazanma ve bertaraf etme-, elektronik ve elektrikli malzemelerin içeriğinde yer alan bileşenlerin ekonomik değerleri de dikkate alındığında son derece önemlidir. Çevre ekonomisi bağlamında düşünüldüğünde doğru ve etkin yönetilemediğinde e-atıklar, çevre unsurları ve doğal kaynaklar için potansiyel bir tehditken; e-atıkların doğru süreçlerle ve etkin bir şekilde değerlendirilmesi ile ortaya çıkacak ekonomik değer yeni pazarlar yaratabilecek kapasitededir. Bu kapsamda gelişmiş ülkeler tarafından hazırlanan Avrupa Birliği elektrik ve elektronik ürün atıkları ile ilgili yönetmeliğinde (WEEE Directive) elektrik elektronik ürün üreticilerini ürünleri tasarlarken ve 
üretirken, tamirini, yeniden kullanımlarını, demonte edilebilmelerini ve geri dönüştürülme sürecini dikkate almaya; tüketicileri de elektronik ürün atıklarının toplanmasına katkıda bulunmaya zorlamaktadır. Aynı direktifle işletmeler için yeniden kullanım, geri dönüşüm ve geri kazanım oranları için bir alt sınır belirlenmiş, bu sayede kaynakların tükenmesi ve çevre kirliliğinin azalması yolunda adımlar atılmıştır. (Ergülen ve Büyükkeklik, 2008). Bu kapsamda Mansfield (2013)'e göre e-atıklar, hem bazı bileşenleri değerli olduğu hem de bertaraf edilmesi süreci ekonomik anlamda firsat yarattığı için e-atık toplayıcıları tarafından satın alınmaktadır.

Elektronik ve elektrikli ürünlerin tüm dünyada sahip olduğu pazar payının ve hem üretim hem de tüketim miktarlarının artması beraberinde üretilen e-atık miktarını da artırmaktadır. Ülkelerin e-atık yönetimi konusundaki çabaları artıyor olsa da henüz yeterli seviyeye ulaşmamıştır (Ergülen ve Büyükkeklik, 2008).

Bu konuda dünyadaki ilgili kuruluşların bakış açıları değişmektedir. Çevre ekonomisi kapsamında önemli bir konu olarak görülen atık yönetimi ile ilgili olarak Türkiye Bilim, Sanayi ve Teknoloji Bakanlığı'nın 2014 yılında yayınladığı Ulusal Geri Dönüşüm Strateji Belgesi ve Eylem Planında, atıkların çevreye zarar vermeden bertaraf edilmesinin önemi vurgulanmış, geri dönüşümün uzun vadede verimli bir ekonomik yatırım olduğu ifade edilmiştir. Rapora göre (Bilim, Sanayi ve Teknoloji Bakanlığı Sanayi Genel Müdürlüğü, 2014):

"Doğal kaynakların hızla tükenmesine bağlı olarak üretim sürecinde kullanılan hammadde arzının azalması ve buna bağlı olarak maliyetinin artması sonucunda ekonomik problemler ortaya çıkmaktadır. Sektörlerin hammadde ihtiyacının bir bölümünün geri dönüş̧rülebilen ve ekonomik değeri bulunan atıklardan karşılanması sürdürülebilirliğin sağlanması adına büyük önem taşımaktadır. Etkin bir geri dönüşüm sistemi, hammadde ve ara malı ithalat bağımlılığı yüksek olan sektörlerde bu bağımlılı̆g azaltıcı yönde yapacağı etkiyle de sürdürülebilir ekonomik büyümeye katkı sağlayacaktır.”.

\section{Sonuçlar ve Tartışma}

Tüm dünyada sanayileşme, kentleşme, nüfus artışı, tüketim alışkanlıklarının değişmesi gibi gelişmeler çevrenin kirlenmesine yol açmanın yanısıra enerji, hammadde gibi kaynakların kıtllğı rasyonel kulllanımı zorunlu hale getirmektedir. Endüstriyel üretim süreçleri ve nüfusa oranla daha fazla artan atık miktarının bu kirlilikte önemli bir paya sahip olduğu ifade edilebilir. Atık maddelerin değişen üretim ve tüketim süreçleri ile çeşitlenmesi ve çevreye olan etkileri tehlikeli boyutlara ulaşmaktadır (Akdoğan ve Güleç, 2007). Bu bağlamda işletmeler, ilgili kurum ve kuruluşlar ve diğer paydaşlar için e-atık yönetimi ile ilgili olarak aşağıdaki öneriler getirebilir:

- E-atık bileşenlerinin taşıdığı zararlı ve zehirli maddelerin doğal çevreyi tahrip etmemesi için geri dönüşüm teknolojisi ve süreçlerinin uygun bir şekilde planlanması ve uygulanması gerekmektedir. Bu konuda üreticilerin sorumluluğu üzerinde durulmalıdır. Üreticiler, üretim ve tasarım süreçlerinde tüketicinin kullanımı, bertaraf etme ve geri dönüştürme aşamalarını dikkate alarak daha çevreci teknolojiler ve çevreci ürünler kullanmalı ve sürdürülebilirlik ilkesi odak noktası olmalıdır. Bu durum, yalnızca üreticilerin inisiyatifine bırakılmamalı, ilgili Bakanlık ya da diğer denetleme yetkisi verilen/olan kurumlar tarafindan kontrol edilmelidir.

- E-atıkların geri dönüşüm sürecinde kullanılacak altyapı ve teknoloji işletmeler tarafından kısa vadede maliyetli yatırımlar olarak değerlendirilebilecektir. Bu durum orta ve uzun vadede geri dönüş̧ürülen madde ve bileşenlerin sağlayacağı ekonomik değerlerin göz ardı edilmesine neden olabilir. Bu nedenle, işletmeler için geri dönüşüm ve atık yönetimi için yapılacak altyapı ve teknoloji yatırımları ilgili Bakanlık ve kurumlar tarafından desteklenmeli ve teşvik edilmelidir. Bu teşvikler yalnızca finansal yardımlar kapsamında değil çeşitli projeler ve yarışmalarla da gerçekleştirilebilir.

- E-atıklar, genel olarak katı atıklardan bileşenleri, yapıları ve yönetim süreçleri itibariyle farklılık göstermektedir. Bu bağlamda elektronik ve elektrikli ürünler üreten ya da bu ürünlerle ilgili sektörlerde faaliyetlerine devam eden işletmeler özellikle e-atıkların yapısının gerektirdiği teknoloji ve altyapıya sahip olmal1, bu konuda uzman personel ile atık sürecini yönetmelidir.

- Elektronik ve elektrikli ürünlerin oluşturduğu pazar payı ve tüketicilerin bu ürünlere olan ilgisi her geçen gün artmaktadır. Bu ürünleri oluşturan parçalar ve bileşenler ekonomik değeri olan maddelerdir. Altın, bakır ve demir gibi metallerin geri kazanımları, yüksek getirileri nedeniyle son derece önemlidir. Yine bu maddelerin geri kazanımı ile sağlanacak enerji tasarrufu da e-atık geri dönüşümünün değerini göstermektedir. Bu kapsamda e-atıkların ve elektronik ve elektrikli ürünleri oluşturan, geri dönüşüme müsait tüm parçaların/bileşenlerin geri dönüşüm sürecine dahil edilmeleri çevrenin korunmasının yanısıra değerli maddelerin ve enerjinin de israf edilmesinin önüne geçecektir.

- E-atıkların geri dönüşüm sürecindeki en önemli konulardan bir tanesi de bu sürecin başlangıç aşaması olarak değerlendirilebilecek toplama aşamasıdır. E-atıkların bertaraf edilmesi ve geri dönüştürülmesinde hem işletmeler hem de ilgili kuruluşlar ilkel olarak ifade edilebilecek alanları değil, modern yatırımlar ve uygun teknolojilerle oluşturulmuş alanları kullanmalıdır. Kullanılan uygunsuz atık alanları ya da 
elektronik ve elektrikli ürünlerin yakılması, e-atıkların çevreye verdiği zararı arttırmakta ve bu ürünlerin parçalarının sağlayacağı ekonomik değer yok edilmektedir. Bunun yerine işletmeler, belediyeler ve diğer ilgili kurumların katkısıyla tehlikeli atık alanları oluşturulmalı, geri dönüşüm sürecinin henüz ilk aşamada sona ermesinin önüne geçilmelidir.

- Günümüzde tüketicilerin sosyal sorumlu ve çevre odaklı üretim yapan ve ürün/hizmet sunan işletmelere ilişkin olumlu tutumları dikkate alındığında atık yönetimi ve geri dönüşüm süreçlerini benimsemek işletmelere bu açıdan da faydalı olabilecektir. Küreselleşme ile birlikte ürün ve hizmetlerin standartlaşması, benzer kalite ve fiyatlar ile tüketicilere sunulması işletmelerin farklılaşma ihtiyacı duymasına neden olmuştur. Bu durumda işletmeler hem çevre odaklı olmayı benimserken hem de bu durumdan bir farklılaştırma stratejisi olarak fayda sağlayabileceklerdir. İşletmelerin sürdürülebilir ilkelerle faaliyetlerine devam etmesi ve bunu yansıtması işletmelerin firma ve marka imajı sağlamasında önemli bir alternatif olarak değerlendirilebilir.

- Elektronik ve elektrikli ürün pazar payının artması ile doğru orantılı olarak, bu ürünlerin faydalı ekonomik ömrünü tamamlaması ile birlikte ortaya çıkan atık miktarı da artış gösterecektir. Bu artış ile birlikte e-atık geri dönüşüm sürecinin başarıya ulaşması için gerekli altyapı ve teknolojinin yanısra sürecin her aşamasında yer alması gereken personele olan ihtiyaç da artmaktadır. İşletmelerin kendi bünyesinde atık yönetiminden sorumlu personele olan ihtiyaç, e-atık toplama ve geri dönüşüm tesislerinde çalışacak personele olan ihtiyaç, yine ilgili kurumlarda geri dönüşüm konusunda uzmanlaşmış kişilere olan ihtiyaç dikkate alındığında bu alanda çalışmak için gerekli ve yeterli donanıma sahip personelin yetiştirilmesi ve istihdam edilmesi son derece önemlidir.

- E-atıklarla ilgili olarak çalışacak gerekli ve yeterli donanıma sahip personelin yetiştirilmesinin yanısıra işletmeler kendi organizasyon yapıları içinde bu konunun önemine dikkat çekmeli ve bir örgüt kültürü olarak çevre odaklı olmaya ve atık yönetiminin önemine odaklanmalıdırlar. Bu durum, personele uzmanlar tarafından verilecek eğitim ve bilgilendirme toplantılarıyla gerçekleştirilebilir. Aynı zamanda tüm iş süreçlerinin çevreyi koruma odaklı ve geri dönüşüm sürecinin farkında olan personelle ve teknolojiyle geliştirilmesi, personelin bu konuda bilinçlendirilmesi için çaba gösterilmesi de oldukça önemlidir.

- E-atıklarla ilgili olarak uygulayıcıların ve karar alıcıların karşılaştıkları problemlerden bir tanesi de verilerin elde edilmesi ile ilgilidir. Toplanan, bertaraf edilen, geri dönüştürülen e-atıklarla ilgili bilgilerin elde edilmesi, sistematik bir şekilde sınıflandırılması ve analizi yapılacak araştırmalar ve çalışmalar için büyük önem taşımaktadır. Bu konuda e-atıkların geri dönüşüm sürecinde rol alan tüm paydaşların (üreticiler, işletmeler, atık toplama tesisleri, belediyeler, devlet ve diğer ilgili kurumlar) üzerine düşeni yapması gerekmektedir. $\mathrm{Bu}$ sayede ülkelerin istatistik kurumları ya da bakanlıklardaki ilgili birimler verileri düzenli, gerçekçi ve doğru bir şekilde paylaşabilir, bu durum yapılacak çalışmaların ve hazırlanacak raporların önünü açabilir.

- E-atıkların geri dönüşüm sürecindeki önemli paydaşlardan bir tanesi olarak toplum dikkate alındığında, konu ile ilgili olarak insanların bilinçlendirilmesi gerekmektedir. E-atıkların toplanması ve geri dönüştürülmesi ile ilgili olarak insanların üzerine düşen sorumluluklar konusunda oluşturulacak bir kamuoyu bilinci, sürecin işlemesi ve geri kazanılan ekonomik değerin artmasına yardımcı olacaktır. Bu konuda da kitlesel medya araçları, her seviyede eğitim-öğretim veren kurumlar ve internet üzerinden çeşitli kampanyalar, dersler ve mesajlar ile konunun önemi aktarılabilir.

Özetle, e-atık yönetimi sürecinde başta üreticiler olmak üzere, tüketiciler, devlet tarafindan gerekli şartları sağladıktan sonra yetki alan atık toplama tesisleri, belediyeler ve diğer ilgili kurumların sorumluluğu bulunmaktadır. İlk olarak mevcut durumun ortaya konması, geri dönüşüm sürecinin sağlıklı bir şekilde işleyebilmesi için gerekli altyapı ve teknolojinin tesis edilmesi ve bu konuda teşvik ve yatırım firsatlarının sağlanması, atık yönetimi konusunda personel yetiştirilmesi ve mevcut personelin bilinçlendirilmesi, kullanılan yöntem ve teknikler için karşılıklı bir denetim mekanizmasının oluşturulması ve verilerin çeşitli araştırma ve raporlar aracılığıyla ilgili paydaşlara aktarılması son derece önemlidir. Bu bağlamda e-atık yönetimi konusundaki çalışmaların ve çabaların artması ile birlikte doğal çevre korunacak, kaynaklar daha etkin kullanımı ile ekonomik değer sağlanacak, sürdürülebilir kalkınma ilkeleri hayata geçirilmiş olacaktır.

\section{Kaynakça}

- Akdoğan ve Güleç, 2007. "Sürdürülebilir Katı Atık Yönetimi ve Belediyelerde Yöneticilerin Katı Atık Yönetimiyle İlgili Tutum ve Düşüncelerinin Analizine Yönelik Bir Araştırma”, Hacettepe Üniversitesi Íktisadi ve İdari Bilimler Fakültesi Dergisi, 25 (1), p. 39-69.

- Beder, 2011. "Environmental Economics and Ecological Economics: The Contribution of Interdisciplinary to Understanding, Influence and Effectiveness”, Environmental Conservation, 28 (2), p. 140-150. 
- Bilim, Sanayi ve Teknoloji Bakanlığı Sanayi Genel Müdürlüğü, 2014. Ulusal Geri Dönüşüm Raporu,

- Birleşmiş Milletler Enstitüsü, 2014. Global E-Atık İzleme Raporu, http://i.unu.edu/media/unu.edu/news/52624/UNU-1stGlobal-E-Waste-Monitor-2014-small.pdf

- Birleşmiş Milletler Çevre ve Kalkınma Komisyonu, 1987. http://www.mfa.gov.tr/dunya-surdurulebilirkalkinma-zirvesi_johannesburg_-26-agustos---4-eylul-2002_.tr.mfa

- Çiftlik, Handırı, Beyhan, Akçil, Ilgar ve Gönüllü, 2009. "Elektrikli ve Elektronik Atıkların (E-Atık) Yönetimi, Ekonomisi ve Metal Geri Kazanım Potansiyeli Bakımından Değerlendirilmesi”, in Proceedings Türkiye'de Katı Atık Yönetim Sempozyumu, p. 1-8.

- Ergülen ve Büyükkeklik, 2008. "Sürdürülebilir Kalkınmanın Ekonomik ve Çevre Boyutları Açısından Atık Yönetimi ve E-Atıklar”, Niğde Üniversitesi İktisadi ve İdari Bilimler Fakültesi Dergisi, 1 (2), p. 19-30.

- $\quad$ Ertürk, 1998. Çevre Bilimlerine Giriş. Uludağ Üniversitesi Güçlendirme Vakfı Yayınları, Bursa.

- Hobıkoğlu, 2013. "Davranışsal Finans Çerçevesinde E-Atık Geri Dönüşüm Yatırım Risk Algılamasında Tüketici Tercih ve Davranış Düzeyinin Sosyo-Ekonomik Analizi: İstanbul Örneği”, Finansal Araştırmalar ve Çalışmalar Dergisi, 4 (8), p. 55-70.

- Tıraş, 2012. "Sürdürülebilir Kalkınma ve Çevre: Teorik Bir İnceleme”, Kahramanmaraş Sütçü İmam Üniversitesi İktisadi ve İdari Bilimler Fakültesi Dergisi, 2 (2), p. 57-73.

- Yazıcı ve Deveci, 2009, “E-Atıklardan Metallerin Geri Kazanımı”, Madencilik, 48 (3), p.3-18.

- Keleş, Hamamcı ve Çoban, 2009. Çevre Politikası. İmge Kitabevi, Ankara.

- Keleş ve Hamamcı, 2005. Çevre Politikası. İmge Kitabevi, Ankara.

- Mansfield, 2013. "Electronic Waste Disposal in the European Union: Avoiding the Once-ler's Dilemma", Unpublished Research Thesis, Environmental Studies Program at the University of Vermont.

- Nur ve Varınca, 2014. "Electronic Waste Management in Turkey in the Process of Adaptation with EU”, in Proceedings of 2. International Symposium on Environment and Morality, p. 670-682.

- Slavikova, 2013. "From Cost-Benefit to Institutional Analysis in the Economics of the Environment", Contemporary Economics, 7 (2), p. 67-75.

- T.C. Bilim, Sanayi ve Teknoloji Bakanlığı, 2014. Ulusal Geri Dönüşüm Strateji Belgesi ve Eylem Planı, http://www.resmigazete.gov.tr/eskiler/2014/12/20141230M1-12-1.pdf

- T.C. Çevre ve Orman Bakanlığı, 2012. Tehlikeli Atıkların Sınıflandırılması Kılavuzu, http://www.csb.gov.tr/dosyalar/images/file/TR_Vol_1-03_04_2012.pdf

- U.S. Environmental Protection Agency, 2011. Electronic Waste Management in the United States Through 2009, http:/www.epa.gov/epawaste/conserve/materials/ecycling/docs/fullbaselinereport2011.pdf

- U.S. Environmental Protection Agency, 2013. Improved Information Could Better Enable EPA to Manage Electronic Waste and Enforce Regulations, http://www.epa.gov/oig/reports/2013/20130621-13-P-0298.pdf 


\title{
Security Perceptions of the Tourists Visiting Alanya According to Their Home Country
}

\section{Alanya'yı Ziyaret Eden Yabancı Turistlerin Ülke Gruplarına Göre Güvenlik Algılarının Analizi}

\author{
Asst. Prof. Dr. Muharrem Aksu (Alanya Alaaddin Keykubat University, Turkey) \\ Asst. Prof. Dr. Ali Rıza Aktaş (Alanya Alaaddin Keykubat University, Turkey) \\ Asst. Prof. Dr. Mehmet Özer Demir (Alanya Alaaddin Keykubat University, Turkey) \\ Asst. Prof. Dr. Faruk Kerem Şentürk (Düzce University, Turkey)
}

\begin{abstract}
In today's world there exists severe competition in all sectors, in tourism sector as well. That's why countries with successful destinations consider tourism security concept as part of the tourism concept in order to maximize tourist demand. On the other hand, tourism security and risk perception of a destination is one of the principal components of destination image. Tourism security seems to be the most important appealing factor of the demand. The aim of the study is to research the risk perception differences between the tourists' home countries when grouped (North European, East European, Middle European, West European and the others). According to Data set from 500 respondents different countries visiting Alanya is analyzed, findings suggest that there exits differences among the places (beach, recreation center, public transportation etc.) and factors (traffic, terror, day and night treks, mugging, theft etc.) effecting respondents' risk perceptions.
\end{abstract}

\section{Giriş}

Günümüzde her geçen gün uluslararası turistlerin sayısının artması turizm sektörüne yönelik yatırımların önemini ortaya koymaktadır. Turizm talebinin yaratılmasına yönelik sektöre ciddi yatırımlar yapılmakta; bu yatırımların değer yaratabilmesi ise turistlerin destinasyon bölgesini ziyaret etmesi ile mümkün olabilmektedir. Turistlerin destinasyonu ziyaret etme kararı, karmaşık bir karar-alma sürecinden sonra olgunlaşmaktadır. Kararalma sürecinde destinasyon seçimi ise belirli değişkenlerin etkisi altında gerçekleşmektedir. Bu değişkenlerinden biri de güvenliktir. Özellikle destinasyonun güvenliği uluslararası turistlerin en çok hassas oldukları faktörlerden biri olarak karşımıza çıkmaktadır. Destinasyonun imajı, güvenlik açısından olumsuz ise turistler genellikle o bölge hakkında olumsuz algıya sahip olmakta ve tatil tercihlerini genellikle değiştirebilmektedirler. Gerçekten de turizm sektörünün en küçük risk faktörlerinden kolaylıkla etkilenebilen kırılgan bir sektör olması, emniyet ve güvenliğin önemini daha da arttırmaktadır. Kabul edilebilir risk seviyesinin üstünde bir risk algılaması, yani emniyetsizlik ya da güvensizlik durumu, ilgili destinasyona talebi düşürebilmektedir. Turistlerde oluşan olumsuz destinasyon imajı, turizm yatırımlarının atıl kalmasına neden olmaktadır. Özellikle ekonomik ve politik ve ekonomik istikrarsızlık, suç, hastalık, doğal felaketler gibi turistin seyahat tatminini engelleyebilecek problemlerin ilgili destinasyonlarda var olması, turizm talebini etkileyebilmektedir. Bahsedilen riskler turistler tarafından farklı düzeylerde algılanabilmektedir. Farklı düzeylerde oluşan alg1 ise, çoğunlukla turistlerin çeşitli sosyo-demografik özelliklerinden kaynaklanabilmektedir. Sosyo-demografik özellikler içerisinde milliyet faktörü de literatürde önemli bir değişken olarak görülmektedir. Bu bağlamda turistlerin tatil esnasında ya da öncesinde ne hissettiğini anlamak, ziyaretçilerin kişisel güvenlik algılarını tespit etmek açısından şarttır. Yabancı turistlerin riskten kaynaklı güvenlik algısı, onların kendi içsel güvenlik ihtiyaçlarını anlama ve tatmin etme açısından da kritik öneme sahiptir.

Araştırmamızda Alanya'yı ziyaret eden yabancı turistlerin özellikle ülke gruplarına göre güvenlik algı düzeylerinin farklı olup olmadığı sorgulanmıştır. Çalışmada öncelikle turizm güvenlik ilişkisi, bu ilişkide belirleyici unsur olan risk algısı ve milliyetlere göre güvenlik algı düzeylerinin farklılığı teorik olarak incelenmiş ve bulgular kısmında ise Alanya'nın güvenlik algısının milliyetlere göre farklılı̆̆ irdelenmiştir.

\section{Turizm ve Güvenlik}

Turizmde politik güvenlik, ekonomik istikrar, sağlık, hijyen, turist mahremiyeti, suç ve yasal koruma gibi birbirine bağlı faktörleri kapsayan emniyet ve güvenlik, karmaşık ve çok boyutlu kavramlardır. Emniyet ve güvenlik, konaklama sektöründe huzurlu bir tatilin ve turizm destinasyonuna talebin en temel unsuru olarak görülmektedir (Kovari ve Zimanyi, 2011). Ziyaretçilerin seyahat kararlarını alırken güvenlik ve emniyet algısı, önemli bir belirleyici olduğu çalışmalarda vurgulanmaktadır (Rittichainuwat ve Chakraborty, 2009; Çetinsöz ve Ege, 2013). Araştırmalarda doğal afetler, bulaşıcı hastalıklar, güvenli olmayan seyahat olanakları, suç, şiddet ve siyasi istikrarsılık gibi kişisel güvenlikle doğrudan ilgili olan güvenlik risklerinden etkilenen birçok turizm aktivitesi tanımlanmıştır. Turistlerin bahsedilen risklerden kaynaklı tatil bölgesini güvensiz ve tehdit edici 
hissettiğinde, o yere yönelik olumsuz bir izlenim geliştireceğini yani o bölgenin tehlikeli bir yer olarak algılanacağını ve dolaylı olarak da o bölgede turistlerin sayısını azalacağını göstermektedir (Flicker ve Gardner, 2002; Anuar ve diğ., 2010; Amir ve diğ., 2015:124,126). Bu nedenle emniyet ve güvenliğin tüm turizm destinasyonlarının gelişimi için oldukça önemli boyutları olduğu ortadadır (Amir ve diğg., 2015:124). Özellikle destinasyonda turistlere yönelik suçların artması, hatta arttığı algısının ortaya çıkması turist sayısında ciddi düşüşlere neden olabilmektedir (Elliot ve Ryan, 1993; Kelly, 1993; Prideaux ve Dunn, 1995; Pizam ve Mansfeld, 1996:1; Dimanche ve Lepetic, 1999; Pelfrey, 1998; Tarlow, 2000; Levantis ve Gani, 2000; Cavlek, 2002). Ryan'a göre (1993) suç, destinasyonun emniyetli imajının kırılgan doğasına önemli bir darbe vurarak turizm talebini engelleyebilmektedir. Bu durum turizm sektörüne ciddi zararlar verebileceği gibi bölgede turizmin düşüşüne de sebep olabilmektedir. Dahası, potansiyel turistler, yüksek bir suç oranı ününe sahip bir destinasyonu ziyaret etmeme yönünde karar verebildikleri gibi; onların konaklama tesisi dışında etkinliklere katılmaları, başkalarına destinasyonu tavsiye etmeleri, aynı destinasyona tekrar gelmeleri de olası değildir (George, 2003:577; Pizam ve Mansfeld, 2006; Batra, 2008:92,93). Bu da bir turizm destinasyonun başarısında emniyet ve güvenliğin mutlak öncelikler arasında olduğunu göstermektedir

Güvenlik ve emniyet algısı, destinasyon hakkında karar-alma süreci boyunca belirleyici faktörlerin başında gelmektedir (Sönmez ve Graefe, 1998a, 1998b; Mawby, 2000; George, 2003; Rittichainuwat ve Chakraborty, 2009; Çetinsöz ve Ege, 2013). Karar-alma süreci, belirli eylemler tarafindan şekillenen ve farklı aşamalardan oluşan, bir dizi psikolojik (içsel) ve psikolojik olmayan (dışsal) değiş̧kenler tarafından etkilenmektedir (Sırakaya ve Woodside, 2005). İ̧sel unsurlar pozitif olsa bile dışsal etkenlerin algılanmasında önemli bir belirleyici olan emniyet ve güvenlik olgusu, algıyı ve motivasyonu etkileyerek karar-alma sürecinde merkezi bir rol oynamaktadır (Ferreira ve Harmse, 2000; Mawby, 2000; Amir ve diğ., 2015:124).

Kısacası, turistin karar-alma sürecinin en başından seyahatinin sonuna kadar güvenlik ve emniyet öncelikli bir konu olarak görünmektedir. Gerçekten de turistin olumsuz güvenlik algısı, öncelikle tatil planlarını değiştirmelerine, tatil esnasında yaşadığı olumsuz deneyimlerden kaynaklı güvenlik endişesi ya da tehdidi ise, tekrar bölgeyi ziyaret etmeme veya başkalarına tavsiye etmeme gibi davranışlara neden olabilecek bir dizi olumsuz sonuçlara neden olabilmektedir.

\section{Risk ve Algılanan Risk}

Son zamanlarda uluslararası seyahatle ilgili önemli bir endişe olarak kabul edilen "risk", uluslararası seyahatin değerlendirilmesinde önemli bir faktör olarak vurgulanmaktadır (Yavaş, 1987; Sönmez ve Graefe, 1998a, 1998b; Lepp ve Gibson, 2003; Reisinger ve Mavondo, 2005; Qi ve diğ., 2009). Kitlesel ve küresel turizmin artmasiyla birlikte emniyet ve güvenlik bağlamında "algılanan risk"in seyahat kararlarını etkileyen önemli bir faktör olduğu ortaya konmuştur (Surakaya ve diğ., 1997; Sönmez ve Graefe, 1998b). Özellikle 90'lardan sonra turizm güvenliğine ilişkin çalışmaların çoğu, turizmde riski tartışmakla birlikte, önemli bir kısmı ise gerçek riskten ziyade "algılanan risk" üzerine odaklanmıştır (Roehl ve Fesenmaier, 1992; Maser ve Weiermair, 1998; Sönmez ve Graefe, 1998a, 1998b).

Turistin karar-alma sürecinde önemli bir rol oynayan risk, tüketicinin davranışı üzerinde olası olumsuz sonuçlara yol açacak istenmeyen olayların olasılığı olarak tanımlanmıştır (Laws ve Prideaux, 2005). Diğer yandan algılanan risk mutlak risk ya da gerçek riskten oldukça farklı olduğu vurgulanmıştır (Haddock, 1993). Haddock (1993) riski üçe ayırarak incelemiştir; Mutlak/Kesin Risk (hiçbir güvenlik önleminin olmadığı) herhangi bir durumun doğasında var olan riskin en üst seviyesidir. Gerçek Risk; belirli bir zamandaki gerçekte olan risk miktarıdır (güvenlik tedbirleri alınmış mutlak risktir). Algılanan risk ise; bir bireyin belirli bir zamanda gerçek riskle ilgili öznel değerlendirmesidir. Reisinger ve Mavondo'ya (2005) göre algılanan risk, tehdit ve tehlikeye maruz kalınacağının bilişsel olasılığı olarak tanımlanıştır. Genelde, turistler seyahat kararlarını gerçeklerden ziyade algılar üzerine temellendirerek yaptıkları literatürde belirtilmektedir (Irvine ve Anderson, 2006). Turistler tehlikeli bir durumda, kendilerini riske istekli olmayacakları ve herhangi bir belirsizlikten kaçınma isteyecekleri için önleyici bir karar olarak algılarını kullanma eğilimdedirler (Roehl ve Fesenmaier, 1992). Seyahat karar-alma sürecinde belirgin bir isteksizlik ve kaçınmayı ortaya çıkaran bu algı, mutlak ya da gerçek riskten daha fazla etkin olabilmektedir. Yapılan çalışmalar turistlerin seyahat niyetlerinin ve destinasyon tercihinin algılanan riskten etkilendiğini göstermektedir (Sönmez ve Graefe, 1998b). Algılanan bir risk yanlış bir seyahat kararına dönüşeceğinden, turist böyle bir riskin yüksek olduğunu hissettiğinde rezervasyon iptali, yaptırmama, erteleme ya da destinasyondan kaçış yönünde tatil planlarını ve davranışlarını değiştirebilmektedir (Maser ve Weiermair, 1998; George, 2003: 577; Sasso, 2005; Pizam ve Mansfeld, 2006; Irvine ve Anderson, 2006). Kısacası araştırmalar, turistlerin belirli bir destinasyona seyahatini iptal etmesi ya da değiştirmesi gerçek risklerden ziyade algılanan risklerden kaynaklandığını (Mitchell ve Vasso, 1997; Irvine ve Anderson, 2006) ve gerçeklerden ziyade algılara göre seyahat kararlarını verdikleri görülmektedir.

Turistlerin risk algılarının, özellikle heyecan aramaya eğilimli kişilere özgü kişilik tipi, sosyal sınıf, eğitim, seyahat bilgi kaynakları, kültür/milliyet, yaş ya da yaşam evresi, kalış süresi, cinsiyet, motivasyon, seyahatin amacı ve geçmiş seyahat deneyimleri gibi sosyo-ekonomik faktörlerden etkilendiğini ve bu faktörlere göre 
değişiklik gösterdiği tespit edilmiştir (Roehl ve Fesenmaier, 1992; Sönmez ve Graefe, 1998a, 1998b; Pizam ve diğ., 2002; Lepp ve Gibson, 2003; Reisinger ve Mavondo, 2005; George, 2010:809). Gerçekte turistler her zaman riski eşit düzeyde algılamazlar. Risklerin bazısı çekiciyken bazıları iticidir (Pizam ve diğ., 2002; Lepp ve Gibson, 2003). Risk algısını etkileyen faktörlerin belirlenmesi, seyahat niyeti ile destinasyon imajı arasındaki ilişsinin daha iyi anlaşılmasına katkıda bulunur (Qi ve diğ, 2009:46).

Turistler bahsedilen riskleri, hiç ya da en az satın alabilecekleri tercihleri yapmak isterler. Zira riski satın almak turizmin amacına çok kez ters düşebilmektedir. Turistlerin en az tehlikeli olarak algılanan bir destinasyonu tercih etmeleri, çok daha büyük bir olasılık olarak görünmektedir. Olumsuz algılara yol açmayacak destinasyonun pozitif imajı, sürdürülebilir ziyaretçi talebini ve bir destinasyonun geleceğini çok derin etkileyebileceği bilinmektedir (Donaldson ve Ferreira 2009). Gerçekten de algılanan risk, destinasyon imajıyla doğrudan ilgilidir (Lepp ve Gibson, 2003).

\section{Milliyetlere/Ülkelere Göre Güvenlik Algı Düzeylerinin Farklılığı}

Turizm güvenliği konusunda yapılan çalışmalarda, turistlerin seyahat motivasyonu, tutum, algı, beklenti ve davranışlarının kültürel farklılıklar ya da milliyetlerinden etkilendiğini ve güvenlik algılarının farklı olduğu görülmüştür. Richardson ve Crompton'un (1988) ifade ettiği gibi, farklı milletlerden turistlerin aynı riski, farklı düzeylerde algılayabilmektedirler. Örneğin Seddighi ve diğ. (2001), uluslararası turizmle ilişkili olarak risk algısının milliyetlere göre farklılık gösterdiğini tespit etmişlerdir. 6 Batı Avrupa ülkesinden gelen turistlerin risk algı düzeylerinin birbirlerinden farklı olduklarını ortaya koymuşlardır.

Guam'1 ziyaret eden turistlerin tipik tatil faaliyetlerine odaklanarak güvenlik endişelerini araştıran Pinhey ve Iverson (1994:92) Guam'a gelen Japon ziyaretçilerin diğer ülkelerden gelen ziyaretçilere göre güvenlik konusunda daha hassas olduklarını ve boş zaman aktiviteleri esnasında daha genç ve daha zengin Japon turistlerin kendilerini daha az güvende hissettiklerini ortaya koymuşlardır (George, 2003:57; Batra, 2008:91).

Benzer şekilde George (2003), ziyaretçilerin geldikleri ülke ile karanlık çöktükten sonra Cape Town sokaklarında yürümekten korkma seviyesi arasında istatistiksel olarak anlamlı bir ilişki bulmuştur. İngiltere ve Almanya'dan gelen katılımcılar, karanlık çöktükten sonra Cape Town'un sokaklarında yürümeyi güvensiz veya emniyetsiz olarak gördüklerini belirtmiştir. Amerikalılar karanlık çöktükten sonra Cape Town sokaklarında yürümeyi makul derecede güvenli bulurken ve Cape Town'u güvenli olarak tavsiye etmeye eğilimli iken, Almanlar Cape Town'u sadece makul derecede ziyaret edilebilecek güvenli bir yer olarak tavsiye etmekte ve karanlık çöktükten sonraki güvenlik konusunda ise emin olmadıkları gözlemlenmiştir (George, 2003: 583).

Chang’ın (2011) Tayvan'da yapmış olduğu araştırmada, farklı kültür ve ülkelerden gelen turistlerin, konaklama, ulaşım, tıbbi destek ve yasal düzen konularında anlamlı istatistiksel farklılar bulunmuştur. Araştırmaya göre, Asya'dan gelen turistlerin ulaşım ve tıbbi destek konusunda Amerika, Avrupa ve Okyanusya bölgesinden gelen turistlere nazaran daha fazla risk algıladıkları; Okyanusya'dan gelen turistler konaklama faktörü açısından Asya ve Amerika bölgesinden gelen turistlere göre daha az risk algıladıkları; Okyanusya'dan gelen turistler yasal düzen faktörü açısından Asya ve Avrupa bölgesinden gelen turistlere göre daha fazla risk algıladıkları görülmüştür (Chang, 2011:35).

Barker ve Page (2002:277), Yeni Zelanda Aucland'daki Amerika Kupası 2000 müsabakasına giden uluslararası turistlerden Japonların, saldırı ve soygun konusuna, diğer ülkelerden gelen turistlerden daha fazla önem verdiklerini tespit etmişlerdir. Yapılan başak bir araştırmada ise Amerikalı turistlerin gündüz şehir turu yaparken kendilerini Hollandalı ve Güney Afrikalı turistlerden daha güvenli hissettiklerini tespit edilmiştir (George ve Booyens, 2014:461)

Batra (2008:97) tarafından yapılan bir çalışmada ise Amerikalı ve Afrikalı turistler gündüz vakti gezerken Bangkok'u “çok güvenli” bulurken; Asyalı ve Avrupalı turistler ise, "oldukça güvenli” bulmuşlardır. Afrikalı turistlerin saldırı ya da soyulma konusunda neredeyse hiç endişeli değilken; Avrupalı ve Amerikalı turistlerin biraz, Asyalı turistlerin ise orta düzeyde endişeli oldukları tespit edilmiştir. Aynı şeklide Sönmez (1998) Amerikalı turistlerin, diğer ülkelerden gelen turistlerle uluslararası seyahat ile ilgili risk algıları karşılaştırıldığında, daha yüksek risk algılama eğiliminde olduklarını vurgulamıştır. George ve Swart (2012:27), 2010 FIFA Dünya Kupası müsabakalarına gelen turistlerin suç-risk algılarını inceledikleri çalışmada, Avustralya ve İngiltere'den gelen turistlerin Asya'dan gelen turistlere göre geceleri daha güvenli hissettiklerini ortaya koymuşlardır.

Yukarıda bahsedilen çalışmaların sonucu, turistler arasındaki farklılıkların tespit edilerek, farklı ülkelerden gelen turistlerin memnuniyetini artırmak amacıyla farklı pazarlama stratejilerinin uygulanması gerekliliğini ortaya koymaktadır (Chang, 2011:26). Diğer yandan ülkelere göre risk algılamalarının farklılığının tespit edilmesi, farklı uyruktan olan turistlerin tatil memnuniyetini maksimize etmek bakımından da önemlidir. 


\section{Metodoloji}

Araştırmanın evreni 2012 yılında farklı ülkelerden Alanya'ya tatile gelen yabancı turistlerden oluşmaktadır. Araştırmanın örneklemini ise Alanya kent merkezine gelen yabancı turistlerden rastgele seçilen 500 yabancı kişiden oluşmuştur. Örneklem yöntemi olarak "Kolayda Örneklem Yöntemi” kullanılmıştır. Örneklem büyüklügünün hesaplanmasında kabul edilebilir hata payı 0.05 (\%5) olarak kabul edilmiş, \%95'lik güven seviyesine göre minimum örneklem büyüklüğü, örneklem belirleme çizelgesinden yararlanılarak 384 olarak hesaplanmıştır. Ancak anketlerin hatalar ya da eksik veri gibi nedenlerle yeterli sayıda geri dönmeyebileceği düşünülerek turistlere 550 anket uygulanmış; geri dönen anketlerden eksik/hatalı doldurulanlar çıkarıldıktan sonra 500 anket araştırma için kullanılmıştır.

Araştırmada literatür taraması ve alan araştırması yöntemi kullanılmıştır. Literatür taramasında ikincil kaynaklardan yararlanılırken, alan araştırmasında çalışmanın amacını ortaya koyacak nitelikte bir anket formu kullanılmıştır. Söz konusu anket formu, deneklerin demografik özelliklerini ve araştırma alanıyla ilgili güvenlik/risk algılarını belirlemeye yönelik sorulardan oluşmaktadır. Araştırma bölgesine çok farklı ülke/milletlerden turist gelmesi ve gelen turistlerin çok farklı dilleri konuşuyor olmasından dolayı anket formları İngilizce, Almanca ve Rusça dillerinde hazırlanmıştır. Anket, 2012'de sezonun en yoğun olduğu TemmuzAğustos aylarında kent merkezindeki turistlerin risk altında kalabilecekleri ve yoğun olarak zaman geçirdikleri bar, restoran, kafe, plaj ve otellerde uygulanmıştır. Ayrıca verilerin analizinde ülkelerin sınıflandırılmasında coğrafi bölümleme esas alınmıştır.

Anket uygulaması sonucu elde edilen veriler SPSS paket programında analiz edilmiştir. Verilerin işlenmesi konusunda yapılan analiz iki aşamadan oluşmaktadır. Birinci aşamada deneklerin tüm sorulara verdikleri cevapları frekans çizelgeleri ile gösterilerek, cevapların düzeylere göre dağılımı belirlenmiştir. İkinci aşamada ise gelinen ülke grupları ile taşıma araçlarında, gece ve gündüz yaya olarak dışarı çıktıklarında, plajlarda, eğlence mekânlarında, hırsızlık, kap-kaç, cinsel taciz, suç ve trafik durumunda güvenlik algılarını incelemek için ki-kare testi yapılmıştır. Gelinen ülke grupları ile cinsel taciz, hırsızlık, kap-kaç ve trafik kazasına maruz kalmaları durumundaki risk algıları arasında bir ilişkileri belirmek için ise ANOVA testi yapılmıştır. Ki-kare testinde boş hipotez yani $\mathrm{H}_{0}$ hipotezi sorulara verilen cevaplar arasında "ilişki yoktur/fark yoktur" $\left(\mathrm{H}_{0}\right.$ : değişkenler arasında ilişki yoktur) ve alternatif hipotez yani $\mathrm{H}_{\mathrm{A}}$ hipotezi ise sorulara verilen cevaplar arasında "ilişki vardır/en az biri farklıdır” ( $\mathrm{H}_{\mathrm{A}}$ : değişkenler arasında ilişki vardır) şeklinde oluşturulmuştur. Ki-kare ve ANOVA testi yardımıyla aşağıdaki hipotezler test edilmiştir.

$\mathbf{H}_{\mathbf{0}}$ : Turistlerin geldikleri ülke grupları ile toplu taşıma araçlarında, gece ve gündüz yaya olarak dışarı çıktıklarında, plajlarda ve eğlence mekânlarında güvenlik algıları arasında bir ilişki yoktur.

$\mathbf{H}_{\mathbf{A}}$ : Turistlerin geldikleri ülke grupları ile toplu taşıma araçlarında, gece ve gündüz yaya olarak dışarı çıktıklarında, plajlarda ve eğlence mekânlarında güvenlik algıları arasında bir ilişki vardır.

$\mathbf{H}_{\mathbf{0}}$ : Turistlerin geldikleri ülke grupları arasında turistlerin cinsel tacize, hırsızlığa, suça, kap-kaça ve trafik kazasına maruz kalmaları durumunda risk algıları bakımından bir fark yoktur.

$\mathbf{H}_{\mathbf{A}}$ : Turistlerin geldikleri ülke grupları arasında turistlerin cinsel tacize, hırsızlı̆̆a, suça, kap-kaça ve trafik kazasına maruz kalmaları durumunda risk algıları bakımından en az biri farklıdır.

\section{Araştırma Bulguları ve Değerlendirmesi}

\begin{tabular}{|c|c|c|c|c|c|c|c|c|c|c|c|c|c|}
\hline \multirow{2}{*}{\multicolumn{2}{|c|}{$\begin{array}{c}\text { Ülke Grupları } \\
\text { Demografik Değișkenler }\end{array}$}} & \multicolumn{2}{|c|}{$\begin{array}{c}\text { Batı } \\
\text { Avrupa } \\
\end{array}$} & \multicolumn{2}{|c|}{$\begin{array}{l}\text { Kuzey } \\
\text { Avrupa } \\
\end{array}$} & \multicolumn{2}{|c|}{$\begin{array}{c}\text { Orta } \\
\text { Avrupa } \\
\end{array}$} & \multicolumn{2}{|c|}{$\begin{array}{c}\text { Doğu } \\
\text { Avrupa } \\
\end{array}$} & \multicolumn{2}{|c|}{$\begin{array}{c}\text { Diğer } \\
\text { ülkeler }\end{array}$} & \multicolumn{2}{|c|}{ Toplam } \\
\hline & & f & $\%$ & f & $\%$ & $\mathbf{f}$ & $\%$ & f & $\%$ & f & $\%$ & $\mathbf{f}$ & $\%$ \\
\hline \multirow{2}{*}{ Cinsiyet } & Erkek & 49 & 24,7 & 79 & 39,9 & 20 & 10,1 & 42 & 21,2 & 8 & 4 & 198 & 39,6 \\
\hline & Kadın & 53 & 17,5 & 120 & 39,7 & 34 & 11,3 & 76 & 25,2 & 18 & 6,3 & 302 & 60,4 \\
\hline \multirow{5}{*}{ Yaş } & 20 yaş altı & 22 & 22,2 & 49 & 49,5 & 14 & 14,1 & 11 & 11,1 & 3 & 3,0 & 99 & 19,8 \\
\hline & 21-30 yaş & 45 & 23,0 & 84 & 42,9 & 18 & 9,2 & 35 & 17,9 & 14 & 7,1 & 196 & 39,2 \\
\hline & $31-40$ yaş & 13 & 18,1 & 22 & 30,6 & 5 & 6,9 & 27 & 37,5 & 5 & 6,9 & 72 & 14,4 \\
\hline & 41-50 yaş & 11 & 17,2 & 19 & 29,7 & 11 & 17,2 & 22 & 34,4 & 1 & 1,6 & 64 & 12,8 \\
\hline & 61 ve üstü & 11 & 15,9 & 25 & 36,2 & 6 & 8,7 & 23 & 33,3 & 4 & 5,8 & 69 & 13,8 \\
\hline \multirow{3}{*}{$\begin{array}{l}\text { Medeni } \\
\text { durum }\end{array}$} & Evli & 36 & 18,1 & 64 & 32,2 & 19 & 9,5 & 69 & 34,7 & 11 & 5,5 & 199 & 39,8 \\
\hline & Bekâr & 57 & 23,4 & 115 & 47,1 & 28 & 11,5 & 29 & 11,9 & 15 & 6,1 & 244 & 48,8 \\
\hline & Boşanmış & 9 & 15,8 & 20 & 35,1 & 7 & 12,3 & 20 & 35,1 & 1 & 1,8 & 57 & 11,4 \\
\hline \multirow{5}{*}{ Eğitim } & İlköğretim & 12 & 38,7 & 11 & 35,5 & 4 & 12,9 & 2 & 6,5 & 2 & 6,5 & 31 & 6,2 \\
\hline & Lise & 40 & 23,5 & 93 & 54,7 & 22 & 12,9 & 13 & 7,6 & 2 & 1,2 & 170 & 34,0 \\
\hline & Ön lisans & 19 & 18,6 & 36 & 35,3 & 14 & 13,7 & 31 & 30,4 & 2 & 2,0 & 102 & 20,4 \\
\hline & Lisans & 11 & 8,5 & 33 & 25,4 & 10 & 7,7 & 63 & 48,5 & 13 & 10,0 & 130 & 26,0 \\
\hline & Lisansüstü & 20 & 29,9 & 26 & 38,8 & 4 & 6,0 & 9 & 13,4 & 8 & 11,9 & 67 & 13,4 \\
\hline \multirow{4}{*}{$\begin{array}{l}\text { Kalıș } \\
\text { Süresi }\end{array}$} & $\begin{array}{ll}\text { Bir } & \text { haftaya } \\
\text { kadar } & \\
\end{array}$ & 41 & 18,0 & 107 & 46,9 & 28 & 12,3 & 37 & 16,2 & 15 & 6,6 & 228 & 45,6 \\
\hline & İki hafta & 45 & 21,8 & 65 & 31,6 & 26 & 12,6 & 62 & 30,1 & 8 & 3,9 & 206 & 41,2 \\
\hline & Üç hafta & 13 & 37,1 & 11 & 31,4 & --- & --- & 10 & 28,6 & 1 & 2,9 & 35 & 7,0 \\
\hline & Dört hafta ve + & 3 & 9,7 & 16 & 51,6 & --- & --- & 9 & 29,0 & 3 & 9,7 & 31 & 6,2 \\
\hline
\end{tabular}




\begin{tabular}{|c|c|c|c|c|c|c|c|c|c|c|c|c|c|}
\hline \multirow{5}{*}{$\begin{array}{c}\text { Kiminle } \\
\text { Tatile } \\
\text { Çıktığı }\end{array}$} & Yalnız & 4 & 12,5 & 11 & 34,4 & --- & --- & 12 & 37,5 & 5 & 15,6 & 32 & 6,4 \\
\hline & Kar1/Koca & 32 & 19,4 & 52 & 31,5 & 18 & 10,9 & 54 & 32,7 & 9 & 5,5 & 165 & 33,0 \\
\hline & Arkadaşlarla & 39 & 22,4 & 85 & 48,9 & 18 & 10,3 & 25 & 14,4 & 7 & 4,0 & 174 & 34,8 \\
\hline & Aile & 8 & 17,8 & 16 & 35,6 & 7 & 15,6 & 12 & 26,7 & 2 & 4,4 & 45 & 9,0 \\
\hline & Diğer & 19 & 22,6 & 35 & 41,7 & 11 & 13,1 & 15 & 17,9 & 4 & 4,8 & 84 & 16,8 \\
\hline
\end{tabular}

Tablo. 1 Demografik Değişkenler Tablosu

Araştırma kapsamında Tablo 1'e göre, Alanya'ya gelen turistlerin \%39.6'nın erkek ve \%60,4'ünü ise kadın olduğu tespit edilmiştir. Ülke gruplarına göre incelendiğinde ise Batı Avrupa ülkeleri dışından Alanya'ya gelen turistler cinsiyetleri bakından benzerlik gösterdiği görülmektedir. Batı Avrupa ülkelerinden erkeklerin (\%24.7) kadınlara (\%17.5) oranla daha fazla araştırma bölgesini tercih ettiği tespit edilmiştir. Araştırma bölgesine gelen turistlerin çoğunluğunun (\%59) 30 ve altı yaş grubundan oluştuğu Tablo 1'de görülmektedir. Ülke gruplarına göre araştırma bölgesine gelen turistlerin yaş dağılımı incelendiğinde, 30 ve altı yaş gruplarında Kuzey Avrupa'dan gelenlerin oranı (daha fazla iken 30 ve üstü yaş gruplarında) Doğru Avrupa'dan gelen turistlerin oranından daha fazla olduğu görülmektedir. Araştırma gölgesine gelen turistlerin \% 49'unun bekar ve \%40'1nın evli olduğu tespit edilmiştir. Tatil amaciyla araştırma bölgesine gelen evli turistlerin büyük çoğunluğunu Doğu Avrupalı turistler oluşturuyorken bekar turistlerin büyük çoğunluğunu ise Kuzey Avrupa ülkelerinden gelen turistlerden oluştuğu görülmektedir.

Araştırma bölgesine gelen turistlerin büyük bir çoğunluğunun lisans ve lisans-üstü eğitim (\%59.8) düzeyine sahip olduğu görülmekte olup lise ve altı eğitime sahip olanların oranı $\% 40.2$ düzeyinde olduğu tespit edilmiştir. Tablo 1 incelendiğinde, lisans-üstü eğitim düzeyine sahip olan ülkeler içerisinde ilk sırada Kuzey Avrupa ülkeleri (\%38.8), lisans eğitim düzeyinde Doğu Avrupa ülkeleri (\%48.5) ve lise düzeyinde ise Kuzey Avrupa ülkeleri (\%54.7) ilk sirada görülmektedir.

Araştırma bölgesine gelen yabancı turistlerin büyük bir çoğunluğu bir hafta ve daha kısa süreli tatil için Alanya'da bulunduğunu beyan etmiş olup iki hafta ve daha uzun süre araştırma bölgesinde kalanların oranı oldukça düşük düzeyde kalmıştır (\%13.2). Araştırma bölgesine gelen turistlerden iki hafta ve daha kısa süreli tatil için gelenlerin içerisinde ilk sırayı Kuzey Avrupa ülkeleri, üç hafta için gelenlerin içerisinde Batı Avrupa ülkeleri ve dört hafta ve daha fazla süre Alanya'da bulunanlar içerisinde ise yine Kuzey Avrupa ülkelerinden gelenler ilk sırada yer almaktadırlar.

Araştırma bölgesine gelen turistlerin büyük bir çoğunluğu eşleriyle (\%33) veya arkadaşlarıyla (\%34.8) tatile gelmekteyken yalnız (\%6.4) veya ailesi (\%9) ile birlikte tatile gelenlerin oranı oldukça düşük düzeyde kaldığı gözlemlenmiştir. Doğu Avrupa ülkelerinden gelenlerin \%37.5'i Alanya'ya yalnız gelmeyi tercih ederken Kuzey Avrupa ülkelerinden gelenlerin ise arkadaşları ile birlikte gelmeyi tercih ettikleri tespit edilmiştir.

Tablo 2'ye göre ise, Alanya kent merkezine tatile gelen yabancı turistlerin \%90,6'sı Alanya kent merkezini güvenli bulduklarını ifade ederken güvensiz olduğunu belirtenlerin oranı ise $\% 9.4$ olarak tespit edilmiştir. Alanya kent merkezini güvenli bulanların ülke gruplarına göre dağılımı incelendiğinde; ilk sırada Kuzey Avrupa ülkelerinden gelenler yer alırken (\%40,0); bunu sırasıyla Doğu Avrupa (\%23) ve Batı Avrupa ülkelerinden $(\% 20,8)$ gelenler takip etmektedir. Araştırma kapsamında Alanya'nın güvenli bir kent olup olmaması bakımından kendi yaşadığı kent/ülke ile mukayese etmesi istenen turistlerin \%55.8'i kendi kentlerinin daha güvenli olduğunu belirtirken, Alanya'yı kendi kentlerinden daha güvenli bulanların oranı ise \% 14.8 ve her iki kent arasında güvende hissetme bakımından fark yok diyenlerin oranı ise \%29.4 düzeyinde olduğu görülmektedir. Kuzey Avrupa ülkelerinden gelen turistler kendi yaşadıkları kentin Alanya'dan daha güvenli (\%48) bir kent olduğunu beyan ederken Doğu Avrupa ülkelerinden gelenler ise Alanya'nın daha güvenli bir kent olduğunu ifade etmişlerdir $(\% 47,3)$.

Alanya’ya gelmeden önce Alanya’yı güvenli bir kent bulmayanların oranın \%22.4 gibi düşük bir seviyede kalması, Alanya'nın destinasyon imajının genel olarak güvenli bir kent olarak algılandığını göstermektedir. Dolayısıyla Alanya'nın güvenli bulunma oranın yükselmesi, Alanya'ya gelen turistlerin daha sonradan güvenli olduğu yönünde bir alg1 değişiminin (Alanya'ya gelmeden önce Alanya hakkında güvenlik algısı olumsuz olanlardan \%34.6'sının olumlu olarak değişmesi) katkısı da göz önüne alındığında güvenli kent imajı pekişmektedir. Diğer bir ifade ile Alanya'ya gelmeden Alanya'yı güvenli bulup; geldikten sonra olumsuz olduğu yönde değişimin \%5.8 (29 kişi) gibi oldukça az bir oranda kalması, gerek verilen güvenlik hizmetlerine gerekse destinasyon imajına gerekse de risk algısının düşüklügüne bağlanabilir. İnsanların elbette kendilerini yabancısı oldukları bir ülkeye göre kendi ülkelerinde güvende hissetmeleri doğal bir durum olmakla birlikte, Alanya'yı kendi ülkesinden daha güvenli bulanlar ile kendi ülkesiyle fark yok diyenlerin toplam oranının \% 44.2 olması, Alanya’nın güvenli bir kent olduğunu gösteren diğer bir veridir. Turistlerin Alanya’yı kendi kentlerinden daha güvenli bulma oran1, \%14,8'dir. Tablo 2'deki veriler değerlendirildiğinde, Kuzey Avrupa ülkelerinden gelen turistlerin kendi ülkelerine göre Alanya'da kendilerini daha az (\%6.5) güvende hissetmekteyken, Doğu Avrupa ülkelerinden gelen turistler kendi ülkeleri ile karşılaştırdıklarında Alanya'da kendilerini daha güvende (\%29.7) hissettikleri ifade etmişlerdir. 
Bir kente verilen güvenlik hizmetlerinin kalitesinin yüksekliği o kentin güvenlik algısı üzerinde olumlu etki yapacağı kesindir. Araştırma kapsamında Alanya'ya gelen turistlerden Türk güvenlik görevlilerine güven düzeyi ve alınan güvenlik hizmetinin kalitesini değerlendirmesi istendiğinde, Türk güvenlik görevlilerine güvenenlerin oranı \%36.7 ve güvenmeyenlerin oranının ise \%5.6 düzeyinde olduğu tespit edilmiştir. Alanya'daki güvenlik görevlilerinin hizmetlerinden memnuniyet düzeylerini değerlendirilmesi istendiğinde ise \%13.8'i mükemmel olarak değerlendirirken, $\% 40.8$ ' $\mathrm{i}$ iyi, $\% 21^{\prime} \mathrm{i}$ ise orta olarak değerlendirmekte ve $\% 21.8$ ' $\mathrm{i}$ ise fikirlerinin olmadığını beyan etmişlerdir. Alınan güvenlik hizmetinin kalitesinin mükemmel olduğunu belirten 69 kişi içerisinde Doğu Avrupa ülkelerinden gelenler (\%40.6) ve iyi bulan 204 kişi içerisinde \%42,0 ile Kuzey Avrupa ülkelerinden gelenler ilk sırada yer almaktadırlar. Araştırma sonucu dikkate alındığında Alanya kent merkezine gelen turistlerin yaklaşık 3/4’ü güvenlik hizmetlerini kötü bulmamaktadır. Bu durum, güvenlik hizmet kalitesinin iyi olmasının aynı zamanda Alanya'yı güvenli bulmasında da etkin bir faktör olduğu söylenebilir. Diğer yandan farklı bir ülkede tatil yapan bir turistin güvenlik gibi hassas bir konuda, münferit bir olay yaşamadıkça bulunduğu ülkenin güvenlik gücüne ve hizmetlerine karşı olumsuz bir tutum takınması da pek olası değildir.

\begin{tabular}{|c|c|c|c|c|c|c|c|c|c|c|c|c|c|}
\hline \multirow{2}{*}{\multicolumn{2}{|c|}{$\begin{array}{c}\text { Ülke Grupları } \\
\text { Demografik değişkenler } \\
\end{array}$}} & \multicolumn{2}{|c|}{$\begin{array}{c}\text { Batı } \\
\text { Avrupa } \\
\end{array}$} & \multicolumn{2}{|c|}{$\begin{array}{l}\text { Kuzey } \\
\text { Avrupa } \\
\end{array}$} & \multicolumn{2}{|c|}{$\begin{array}{c}\text { Orta } \\
\text { Avrupa } \\
\end{array}$} & \multicolumn{2}{|c|}{$\begin{array}{c}\text { Doğu } \\
\text { Avrupa } \\
\end{array}$} & \multicolumn{2}{|c|}{$\begin{array}{c}\text { Diğer } \\
\text { ülkeler }\end{array}$} & \multicolumn{2}{|c|}{ Toplam } \\
\hline & & f & $\%$ & f & $\%$ & $\mathbf{f}$ & $\%$ & f & $\%$ & f & $\%$ & f & $\%$ \\
\hline \multirow{2}{*}{$\begin{array}{l}\text { Alanya'da kendinizi } \\
\text { güvende hissediyor } \\
\text { musunuz? }\end{array}$} & Evet & 94 & 20.8 & 181 & 40,0 & 49 & 10,8 & 104 & 23,0 & 25 & 5,5 & 453 & 90,6 \\
\hline & Hayır & 8 & 17,0 & 18 & 38,3 & 5 & 10,6 & 14 & 29,8 & 2 & 4,3 & 47 & 9,4 \\
\hline \multirow{3}{*}{$\begin{array}{lr}\text { Hangi } & \text { ülkede } \\
\text { /şehirde } & \text { kendinizi } \\
\text { daha } & \text { güvende } \\
\text { hissediyorsunuz? }\end{array}$} & Kendi ülkemde & 64 & 22,9 & 134 & 48,0 & 25 & 9,0 & 43 & 15,4 & 13 & 4,7 & 279 & 55,8 \\
\hline & Alanya'da & 14 & 18,9 & 13 & 17,6 & 5 & 6,8 & 35 & 47,3 & 7 & 9,5 & 74 & 14,8 \\
\hline & Fark yok & 24 & 16,3 & 52 & 35,4 & 24 & 16,3 & 40 & 27,2 & 7 & 4,8 & 147 & 29,4 \\
\hline \multirow{2}{*}{$\begin{array}{lr}\text { Alanya'ya } & \text { gelmeden } \\
\text { önce } & \text { Alanya } \\
\text { hakkında güvenlik } \\
\text { algınız nasıldı? }\end{array}$} & $\begin{array}{l}\text { Alanya } \\
\text { güvenlidir }\end{array}$ & 83 & 21,4 & 148 & 38,1 & 46 & 11,9 & 93 & 24,0 & 18 & 4,6 & 388 & 77,6 \\
\hline & $\begin{array}{l}\text { Alanya güvenli } \\
\text { değildir }\end{array}$ & 19 & 17,0 & 51 & 45,5 & 8 & 7,1 & 25 & 22,3 & 9 & 8,0 & 112 & 22,4 \\
\hline \multirow{3}{*}{$\begin{array}{l}\text { Alanya'ya geldikten } \\
\text { sonra Alanya ile } \\
\text { ilgili güvenlik } \\
\text { algınızda nasıl bir } \\
\text { değişme oldu? }\end{array}$} & $\begin{array}{l}\text { Olumlu olarak } \\
\text { değişti }\end{array}$ & 26 & 15,0 & 68 & 39,3 & 19 & 11,0 & 49 & 28,3 & 11 & 6,4 & 173 & 34,6 \\
\hline & $\begin{array}{l}\text { Olumsuz olarak } \\
\text { değişti }\end{array}$ & 6 & 20,7 & 9 & 31,0 & 1 & 3,4 & 12 & 41,4 & 1 & 3,4 & 29 & 5,8 \\
\hline & Değişmedi & 70 & 23,5 & 122 & 40,9 & 34 & 11,4 & 57 & 19,1 & 15 & 5,0 & 298 & 59,6 \\
\hline \multirow{2}{*}{$\begin{array}{l}\text { Alanya'nın güvenli } \\
\text { bir kent olduğunu } \\
\text { tavsiye eder misiniz? }\end{array}$} & Tavsiye ederim & 92 & 20,5 & 174 & 38,8 & 50 & 11,1 & 110 & 24,5 & 23 & 5,1 & 449 & 89,8 \\
\hline & Tavsiye etmem & 10 & 19,6 & 25 & 49,0 & 4 & 7,8 & 8 & 15,7 & 4 & 7,8 & 51 & 10,2 \\
\hline \multirow{4}{*}{$\begin{array}{l}\text { Türk güvenlik } \\
\text { görevlilerine } \\
\text { güveniyor musunuz? }\end{array}$} & Evet & 32 & 17,0 & 62 & 33,0 & 24 & 12,8 & 55 & 29,3 & 15 & 8,0 & 188 & 37,6 \\
\hline & Kismen & 27 & 20,0 & 60 & 44,4 & 9 & 6,7 & 32 & 23,7 & 7 & 5,2 & 135 & 27,0 \\
\hline & Hayır & 8 & 28,6 & 10 & 35,7 & 2 & 7,1 & 7 & 25,0 & 1 & 3,6 & 28 & 5,6 \\
\hline & Fikrim yok & 35 & 23,5 & 67 & 45,0 & 19 & 12,8 & 24 & 16,1 & 4 & 2,7 & 149 & 29,8 \\
\hline \multirow{6}{*}{$\begin{array}{l}\text { Alanya'daki } \\
\text { güvenlik } \\
\text { görevlilerinin } \\
\text { hizmetlerinden } \\
\text { memnuniyet } \\
\text { dereceniz nedir? }\end{array}$} & Mükemmel & 7 & 10,1 & 21 & 30,4 & 5 & 7,2 & 28 & 40,6 & 8 & 11,6 & 69 & 13,8 \\
\hline & İyi & 42 & 21,0 & 86 & 42,0 & 22 & 11,0 & 43 & 21,0 & 11 & 5,4 & 204 & 41,0 \\
\hline & Orta & 33 & 31,0 & 40 & 38,0 & 14 & 13,0 & 12 & 11,0 & 6 & 5,7 & 105 & 21,0 \\
\hline & Kötü & 1 & 12,5 & 3 & 37,5 & --- & --- & 4 & 50,0 & --- & --- & 8 & 1,6 \\
\hline & Çok kötü & 1 & 20,0 & 2 & 40,0 & --- & --- & 2 & 40,0 & --- & --- & 5 & 1,0 \\
\hline & Fikrim yok & 18 & 16,5 & 47 & 43,1 & 13 & 11,9 & 29 & 26,6 & 2 & 1,8 & 109 & 21,8 \\
\hline
\end{tabular}

Tablo. 2 Algı Değişkenleri Tablosu

\section{Hipotezlerin Test Edilmesi}

Araştırma bölgesine gelen turistlerin kendilerini en fazla güvende hissettikleri durumunun "gündüz yaya olarak dişarı çıkma" durumu olup bu oran \%80.0 olarak tespit edilmiş olup en düşük güvende hissettikleri durumun ise cinsel taciz durumu olduğu saptanmıştır (\%32.8). Araştırma bölgesine gelen turistlerin geldikleri ülke grupları ile toplu taşıma araçlarında, gece ve gündüz yaya olarak dışarı çıktıklarında, plajlarda ve eğlence mekanlarında, güvenlik algıları arasında bir ilişkinin varlığını araştırmak amacıyla ki-kare testi yapıılmıştır. "Toplu Taşıma Araçlarında", "Gece Yaya Olarak Dışarı Çıktığınızda" ve "Gündüz Yaya Olarak Dışarı Çıktığınızda" durumlarında gelinen ülke grubu ile güvenlik algıları arasındaki ilişkiyi belirlemeye yönelik yapılan ki kare testi sonucunda elde edilen ki kare değerleri sırasıyla 0.000, 0.028 ve 0,000 olarak hesaplanmıştır. Buna göre $\mathrm{P}<0,05$ olduğundan \%5 anlamlılık düzeyinde HA hipotezi kabul edilmiştir.

Tablo 3'e göre araştırma bölgesine gelen yabancı turistlerin kendilerini en fazla güvende hissettikleri durumunun "gündüz yaya olarak dışarı çıkma" durumu olup bu oran \%80.0 olarak tespit edilmiştir. Alanya'ya gelen yabancı turistlerin \%50.4'ü toplu taşıma araçlarında kendilerini güvende hissettiklerini ifade ederken benzer sonuçlar gece yaya olarak dişarı çıktıklarında (\%48.6) da gözlemlenmiştir. Araştırma bölgesine gelen yabancı turistlerin plajlarda ve eğlence mekanlarında da kendilerini güvende hissettiklerini görülmekte olup bu oranların sırasıyla \%45.8 ve \%42'dir. Toplu taşıma araçlarında kendilerini güvende hissettiklerini belirten 252 kişi içerisinde Kuzey Avrupa ülkelerinden gelenler (\%34,5) ilk sırada yer alırken bunu sırasıyla Doğu Avrupa ülkelerinden gelenler $(\% 25,8)$ ve Batı Avrupa ülkelerinden $(\% 17,1)$ gelenler takip etmektedir. Tablo 3 
incelendiğinde, gece ve gündüz yaya olarak dışarı çıkma durumunda, plajda ve eğlence mekanlarında kendini güvende hissetme durumlarında da ülke gruplarına göre benzer bir dağılım söz konusu olduğu görülmektedir.

$\boldsymbol{H}_{\boldsymbol{A}}$ Turistlerin geldikleri ülke grupları ile toplu taşıma araçlarında, gece ve gündüz yaya olarak dişarı çıktıklarında, plajlarda ve eğlence mekânlarında güvenlik algıları arasında bir iliş̧ki vardır.

\begin{tabular}{|c|c|c|c|c|c|c|c|c|c|c|c|c|c|c|c|c|}
\hline \multirow{2}{*}{\multicolumn{2}{|c|}{$\begin{array}{l}\text { Ülke Grupları } \\
\text { Değişkenler }\end{array}$}} & \multicolumn{2}{|c|}{$\begin{array}{c}\text { Batı } \\
\text { Avrupa }\end{array}$} & \multicolumn{2}{|c|}{$\begin{array}{c}\text { Kuzey } \\
\text { Avrupa }\end{array}$} & \multicolumn{2}{|c|}{$\begin{array}{c}\text { Orta } \\
\text { Avrupa }\end{array}$} & \multicolumn{2}{|c|}{$\begin{array}{c}\text { Doğu } \\
\text { Avrupa }\end{array}$} & \multicolumn{2}{|c|}{$\begin{array}{l}\text { Diğer } \\
\text { ülkeler }\end{array}$} & \multicolumn{2}{|c|}{ Toplam } & \multirow[b]{2}{*}{ क } & \multirow{2}{*}{ 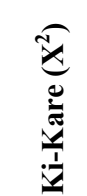 } & \multirow{2}{*}{$\mathbf{P}$} \\
\hline & & $\mathbf{f}$ & $\%$ & f & $\%$ & f & $\%$ & f & $\%$ & $\mathbf{f}$ & $\%$ & f & $\%$ & & & \\
\hline \multirow{3}{*}{$\begin{array}{l}\text { Toplu } \\
\text { taşıma } \\
\text { araçlarında }\end{array}$} & Evet & 43 & 17,1 & 88 & 34,9 & 35 & 13,9 & 65 & 25,8 & 21 & 8,3 & 252 & 50,4 & \multirow[t]{3}{*}{8} & \multirow[t]{3}{*}{28,544} & \multirow[t]{3}{*}{$0,000^{*}$} \\
\hline & Kismen & 45 & 24,3 & 91 & 49,2 & 10 & 5,4 & 36 & 19,5 & 3 & 1,6 & 185 & 37,0 & & & \\
\hline & Hayır & 14 & 22,2 & 20 & 31,7 & 9 & 14,3 & 17 & 27,0 & 3 & 4,8 & 63 & 12,6 & & & \\
\hline \multirow{3}{*}{$\begin{array}{l}\text { Gece yaya } \\
\text { olarak dışarı } \\
\text { çıktığınızda }\end{array}$} & Evet & 50 & 20,6 & 87 & 35,8 & 39 & 16,0 & 51 & 21,0 & 16 & 6,6 & 243 & 48,6 & \multirow[t]{3}{*}{8} & \multirow[t]{3}{*}{17,226} & \multirow[t]{3}{*}{$0,028^{*}$} \\
\hline & Kismen & 37 & 20,8 & 75 & 42,1 & 10 & 5,6 & 48 & 27,0 & 8 & 4,5 & 178 & 35,6 & & & \\
\hline & Hayır & 15 & 19,0 & 37 & 46,8 & 5 & 6,3 & 19 & 24,1 & 3 & 3,8 & 79 & 15,8 & & & \\
\hline \multirow{3}{*}{$\begin{array}{l}\text { Gündüz } \\
\text { yaya olarak } \\
\text { dışarı } \\
\text { çıktığınızda }\end{array}$} & Evet & 84 & 21,0 & 158 & 39,5 & 50 & 12,5 & 83 & 20,8 & 25 & 6,3 & 400 & 80,0 & \multirow[t]{3}{*}{8} & \multirow[t]{3}{*}{29,317} & \multirow[t]{3}{*}{$0,000^{*}$} \\
\hline & Kismen & 11 & 18,0 & 31 & 50,8 & 3 & 4,9 & 14 & 23,0 & 2 & 3,3 & 61 & 12,2 & & & \\
\hline & Hayır & 7 & 17,9 & 10 & 25,6 & 1 & 2,6 & 21 & 53,8 & --- & --- & 39 & 7,8 & & & \\
\hline \multirow{3}{*}{ Plajlarda } & $\overline{\text { Evet }}$ & 42 & $\overline{18,3}$ & 81 & 35,4 & 27 & 11,8 & $\overline{61}$ & 26,6 & 18 & $\overline{7,6}$ & 229 & 45,8 & \multirow[t]{3}{*}{8} & \multirow[t]{3}{*}{13,731} & \multirow[t]{3}{*}{0,089} \\
\hline & Kismen & 33 & 23,2 & 65 & 45,8 & 16 & 11,3 & 23 & 16,2 & 5 & 3,5 & 142 & 28,4 & & & \\
\hline & Hayır & 27 & 20,9 & 53 & 41,1 & 11 & 8,5 & 34 & 26,4 & 4 & 3,1 & 129 & 25,8 & & & \\
\hline \multirow{3}{*}{$\begin{array}{l}\text { Eğlence } \\
\text { yerlerinde }\end{array}$} & Evet & 46 & 21,9 & 83 & 39,5 & 23 & 11,0 & 42 & 20,0 & 16 & 7,6 & 210 & 42,0 & & \multirow[t]{3}{*}{6,938} & \multirow[t]{3}{*}{0,543} \\
\hline & Kismen & 30 & 18,1 & 67 & $\begin{array}{l}40,4 \\
\end{array}$ & 20 & 12,0 & 42 & 25,3 & 7 & 4,2 & 166 & 33,2 & & & \\
\hline & Hayır & 26 & 21,0 & 49 & 39,5 & 11 & 8,9 & 34 & 27,4 & 4 & 3,2 & 124 & 24,8 & & & \\
\hline
\end{tabular}

Tablo. 3 Alanya'da Turistlerin Ülke Grupları İle Çeşitli Ortamlarda Kendilerini Güvenli Hissetme Durumlarının Dă̆glımı

Tablo 4'e göre, araştırma bölgesine gelen turistlerin hırsızlık olayı ile karşılaşma durumlarının dağılımında $\% 30,8$ 'i az riskli \%27'si orta riskli olarak algılarken risk yok diyenlerin oranı \%17.4 olarak gerçekleşmiştir. Benzer bir durum kapkaç olayında karşılaşmaları durumundaki risk algılarının dağılımında da görülmektedir. Nitekim araştırma bölgesine gelen turistlerin kap-kaç olayının gerçekleşme risk algılarının dağılımında ilk sırada orta riskli bulanlar (\%34) oluştururken bunu az riskli bulanlar \%26,4 ile takip ettiği tespit edilmiştir. Cinsel tacize uğrama riskinin dağılımı incelendiğinde ise turistlerin \%11,4'ü yüksek riskli, \%22,2'si orta riskli, \%29,4 düşük riskli bulduklarını ifade ederken, cinsel tacize uğrama riskinin olmadığını belirtenlerin oranı $\% 22,2$ düzeyinde olduğu tespit edilmiştir. Araştırma kapsamında görüşme yapılan yabancı turistlerin yaklaşık $\% 55^{\prime} \mathrm{i}$ kriminal suçlarla (saldırı, yaralama ya da öldürmeye teşebbüs) karşılaşma riskinin olduğunu ifade ederken \% 26'si böyle bir risk algılarının olmadığını beyan etmişlerdir. Turistlerin en yüksek risk algıladıkları durumun ise trafik kazası durumu olduğu tespit edilmiştir (\%80). Trafik kazası durumuyla karşılaşma riskini yüksek risk algısı olarak algılayanların oranı \%29.1; orta riskli algılayanların oranı $\% 28.9$ ve az riskli olarak algılayanların oranı \%21.6 iken risksiz olduğunu ifade edenlerin oranı ise oldukça düşük düzeyde kaldığı tespit edilmiştir $(\% 8,4)$. Alanya'ya gelen yabancı turistlerin yaklaşık $\% 35$ 'i terör olayı ile karşılaşma riskinin olmadığını ifade eder iken yüksek risk olarak algıladıklarını belirtenlerin oranı ise \%4 düzeyinde kalmıştır.

ANOVA tablosuna göre turistlerin geldikleri ülke grupları algılanan hırsızlık, kap-kaç, cinsel taciz, kriminal suçlar ve terör risklerinde farklılığa neden olmaktadır. Diğer bir ifade ile farklı durumlarda ülke grupları farklı seviyelerde risk algılamaktadır. "Hırsızlık", "kap-kaç", "cinsel taciz", "kriminal suçlar" ve "terör" riskleri için $\mathrm{H}_{\mathrm{A}}$ hipotezi kabul edilirken "trafik" için ise istatistiksel olarak anlamlı bir fark bulunamamıştır. Söz konusu bu farklılı̆ıın hangi ülke gruplarının bu farklılığa neden olduğunu tespit etmek amacıyla Post-Hoc testlerden Benforini testi uygulanmıştır.

Benforini testi sonucunda; "Hırsızlık" riski algısı konusunda Doğu Avrupa ülkelerinden gelen turistlerin Kuzey Avrupa ülkelerinden gelen turistlerden ayrıştığı görülmektedir. Ülke gruplarının risk algılarının ortalamaları incelendiğinde Doğu Avrupa'dan gelen turistlerin daha yüksek "hırsızlık" riski algıladıkları görülmektedir $(\mathrm{p}<0,05)$. Diğer ülke grupları istatistiksel olarak anlamlı bir farklılığa yol açmamaktadırlar.

"Kap-kaç" güvenlik riski algısı konusunda Post-Hoc testleri bir farklılık yakalamakta başarısız olmuşlardır. Bu nedenle hangi ülke grubunun farklılaştı̆̆ını tespit etmek için ülke gruplarına ikişerli olarak Bağımsız Örneklemler t-testi uygulanmıştır. Bağımsız Örneklemler t-testi sonuçlarına göre Orta Avrupa, Batı Avrupa ve Kuzey Avrupa ülkelerinden gelen turistlerden farklılaşmaktadır ve daha yüksek "kap-kaç" riski algılamaktadırlar $(\mathrm{p}<0,05)$. Diğer ülke gruplarından gelen turistler, Batı Avrupa'dan ve Kuzey Avrupa'dan gelen turistlerden daha yüksek "kap-kaç" riski algılamaktadır. 
“Cinsel taciz" risk algısı konusunda yine Doğu Avrupa ülkelerinden gelen turistlerin Kuzey Avrupa ülkelerinden gelen turistlerden ayrıştığı görülmektedir. Ülke gruplarının risk algılarının ortalamaları incelendiğinde Doğu Avrupa'dan gelen turistlerin daha yüksek "cinsel taciz" riski algıladıkları görülmektedir. Diğer ülke grupları istatistiksel olarak anlamlı bir farklılığa yol açmamaktadırlar.

"Kriminal suçlar" risk algısı konusunda Orta Avrupa ülkeleri grubundan gelen turistler, Kuzey Avrupa, Orta Avrupa ve Batı Avrupa ülkelerinden farklılaşmaktadır, Orta Avrupa ülkelerinden gelen turistler risk algısı değişkeninin aritmetik ortalamaları baz alındığında Kuzey Avrupa, Orta Avrupa ve Batı Avrupa ülkelerinden daha yüksek "kriminal suçlar" riski algılamaktadır.

“Terör” güvenlik riski algısı konusunda kriminal suçlar değişkenine oldukça benzer şekilde Orta Avrupa ülkeleri grubundan gelen turistler, Kuzey Avrupa, Orta Avrupa ve Batı Avrupa ülkelerinden farklılaşmaktadır. Orta Avrupa ülkelerinden gelen turistler risk algısı değişkeninin aritmetik ortalamaları baz alındığında Kuzey Avrupa, Orta Avrupa ve Batı Avrupa ülkelerinden daha yüksek “terör” riski algıladıkları tespit edilmiştir.

$\boldsymbol{H}_{A}$. Turistlerin geldikleri ülke grupları arasında cinsel tacize, hırsızlı̆̆a, suça, kap-kaça ve trafik kazasına maruz kalmaları durumunda risk algıları bakımından en az biri farklıdır.

\begin{tabular}{|c|c|c|c|c|c|c|c|c|c|c|c|c|c|c|c|c|}
\hline \multirow{2}{*}{\multicolumn{2}{|c|}{$\begin{array}{l}\text { Ülke Grupları } \\
\text { Değişkenler }\end{array}$}} & \multicolumn{2}{|c|}{$\begin{array}{c}\text { Batı } \\
\text { Avrupa }\end{array}$} & \multicolumn{2}{|c|}{$\begin{array}{c}\text { Kuzey } \\
\text { Avrupa }\end{array}$} & \multicolumn{2}{|c|}{$\begin{array}{c}\text { Orta } \\
\text { Avrupa }\end{array}$} & \multicolumn{2}{|c|}{$\begin{array}{c}\text { Doğu } \\
\text { Avrupa }\end{array}$} & \multicolumn{2}{|c|}{$\begin{array}{c}\text { Diğer } \\
\text { ülkeler }\end{array}$} & \multicolumn{2}{|c|}{ Toplam } & \multicolumn{3}{|c|}{$\begin{array}{c}\text { ANOVA Test } \\
\text { Değerleri }\end{array}$} \\
\hline & & $\mathbf{f}$ & $\%$ & $\mathbf{f}$ & $\%$ & f & $\%$ & f & $\%$ & $\mathbf{f}$ & $\%$ & f & $\%$ & SD & $\mathbf{F}$ & Sig \\
\hline \multirow{5}{*}{ Hirsızlık } & En fazla riskli & 5 & 14,3 & 20 & 57,1 & -- & - & 7 & 20,0 & 3 & 8,6 & 35 & 7,0 & \multirow{5}{*}{4} & \multirow{5}{*}{3,828} & \multirow{5}{*}{$0,004 *$} \\
\hline & Orta riskli & 26 & 19,3 & 65 & 48,1 & 21 & 15,6 & 17 & 12,6 & 6 & 4,4 & 135 & 27,0 & & & \\
\hline & Az riskli & 40 & 26,0 & 50 & 32,5 & 16 & 10,4 & 47 & 30,5 & 1 & 0,6 & 154 & 30,8 & & & \\
\hline & Risk yok & 8 & 9,2 & 26 & 29,9 & 16 & 18,4 & 27 & 31,0 & 10 & 11,5 & 87 & 17,4 & & & \\
\hline & Fikrim yok & 23 & 25,8 & 38 & 42,7 & 1 & 1,1 & 20 & 22,5 & 7 & 7,9 & 89 & 17,8 & & & \\
\hline \multirow{5}{*}{ Kap-kaç } & En fazla riskli & 13 & 20,6 & 36 & 57,1 & 1 & 1,6 & 12 & 19,0 & 1 & 1,6 & 63 & 12,6 & \multirow{5}{*}{4} & \multirow{5}{*}{2,944} & \multirow{5}{*}{$0,020^{*}$} \\
\hline & Orta riskli & 41 & 24,1 & 63 & 37,1 & 18 & 10,6 & 38 & 22,4 & 10 & 5,9 & 170 & 34,0 & & & \\
\hline & Az riskli & 26 & 19,7 & 45 & 34,1 & 18 & 13,6 & 38 & 28,8 & 5 & 3,8 & 132 & 26,4 & & & \\
\hline & Risk yok & 13 & 15,9 & 27 & 32,9 & 15 & 18,3 & 18 & 22,0 & 9 & 11,0 & 82 & 16,4 & & & \\
\hline & Fikrim yok & 9 & 17,0 & 28 & 52,8 & 2 & 3,8 & 12 & 22,6 & 2 & 3,8 & 53 & 10,6 & & & \\
\hline \multirow{5}{*}{$\begin{array}{l}\text { Cinsel } \\
\text { Taciz, } \\
\text { (fiili- sözlü) }\end{array}$} & En fazla riskli & 9 & 15,8 & 35 & 61,4 & 1 & 1,8 & 9 & 15,8 & 3 & 5,3 & 57 & 11,4 & \multirow{5}{*}{4} & \multirow{5}{*}{5,119} & \multirow{5}{*}{$0,000^{*}$} \\
\hline & Orta riskli & 27 & 24,3 & 42 & 37,8 & 9 & 8,1 & 28 & 25,2 & 5 & 4,5 & 111 & 22,2 & & & \\
\hline & Az riskli & 28 & 19,0 & 59 & 40,1 & 17 & 11,6 & 40 & 27,2 & 3 & 2,0 & 147 & 29,4 & & & \\
\hline & Risk yok & 22 & 19,8 & 31 & 27,9 & 23 & 20,7 & 25 & 22,5 & 10 & 9,0 & 111 & 22,2 & & & \\
\hline & Fikrim yok & 16 & 21,6 & 32 & 43,2 & 4 & 5,4 & 16 & 21,6 & 6 & 8,1 & 74 & 14,8 & & & \\
\hline \multirow{5}{*}{$\begin{array}{l}\text { Kriminal } \\
\text { suçlar, } \\
\text { (öldürmeye } \\
\text { teşebbüs, } \\
\text { yaralama }\end{array}$} & En fazla riskli & 3 & 15,8 & 12 & 63,2 & $\overline{---}$ & $\overline{---}$ & 4 & 21,1 & $\overline{---}$ & $\overline{---}$ & 19 & 3,8 & \multirow{5}{*}{4} & \multirow{5}{*}{4,403} & \multirow{5}{*}{$0,002 *$} \\
\hline & Orta riskli & 17 & 22,7 & 33 & 44,0 & 3 & 4,0 & 17 & 22,7 & 5 & 6,7 & 75 & 15,0 & & & \\
\hline & Az riskli & 34 & 19,0 & 75 & 41,9 & 20 & 11,2 & 45 & 25,1 & 5 & 2,8 & 179 & 35,8 & & & \\
\hline & Risk yok & 24 & 18,2 & 42 & 31,8 & 27 & 20,5 & 31 & 23,5 & 8 & 6,1 & 132 & 26,4 & & & \\
\hline & Fikrim yok & 24 & 25,3 & 37 & 38,9 & 4 & 4,2 & 21 & 22,1 & 9 & 9,5 & 95 & 19,0 & & & \\
\hline \multirow{5}{*}{ Trafik } & En fazla riskli & 34 & 23,4 & 54 & 37,2 & 15 & 10,3 & 36 & 24,8 & 6 & 4,1 & 145 & 29,1 & & & \\
\hline & Orta riskli & 43 & 29,7 & 55 & 37,9 & 14 & 9,7 & 25 & 17,2 & 8 & 5,5 & 145 & 28,9 & & & \\
\hline & Az riskli & 13 & 12,0 & 47 & 43,5 & 17 & 15,7 & 26 & 24,1 & 5 & 4,6 & 108 & 21,6 & 4 & 2,379 & 0,051 \\
\hline & Risk yok & 8 & 13,3 & 25 & 41,7 & 8 & 13,3 & 16 & 26,7 & 3 & 5,0 & 60 & 12,0 & & & \\
\hline & Fikrim yok & 4 & 9,5 & 18 & 42,0 & --- & --- & 15 & 35,7 & 5 & 11,9 & 42 & 8,4 & & & \\
\hline & En fazla riskli & 3 & 16,7 & 5 & 27,8 & 1 & 5,6 & 9 & 50,0 & --- & --- & 18 & 3,6 & & & \\
\hline & Orta riskli & 25 & 37,3 & 24 & 35,8 & 2 & 3,0 & 11 & 16,4 & 5 & 7,5 & 67 & $\begin{array}{l}13,4 \\
13,4\end{array}$ & & & \\
\hline Terör & Az riskli & 18 & 14,2 & 63 & 49,6 & 13 & 10,2 & 30 & 23,6 & 3 & 2,4 & 127 & 25,4 & 4 & 3,891 & $0,004 *$ \\
\hline & Risk yok & 34 & 19,5 & 66 & 37,9 & 35 & 20,1 & 31 & 17,8 & 8 & 4,6 & 174 & 34,8 & & & \\
\hline & Fikrim yok & 22 & 19,3 & 41 & 36,0 & 3 & 2,6 & 37 & 32,5 & 11 & 9,6 & 114 & 22,8 & & & \\
\hline
\end{tabular}

Tablo. 4 Turistlerin Cinsel Tacize, Hırsızlı̆̆a, Suça, Kap-Kaç, Trafik ve Terör Olaylarına Maruz Kalmaları Durumunda Risk Algılarının Dă̆ılımı

\section{Sonuç}

Çalışmanın bulgularına göre, farklı ülkelerden Alanya'yı ziyarete gelen turistlerin çok büyük bir oranının $(\% 90,6)$ Alanya'yı güvenli buldukları görülmektedir. Ülke gruplarına göre incelendiğinde Alanya’yı diğer ülke gruplarına göre en güvenli bulanlar Kuzey Avrupa ülkelerinden gelen turistlerdir. Ancak Kuzey Avrupa ülkelerinden gelen turistlerin kendi yaşadıkları kentin Alanya'dan daha güvenli olduklarını vurgulamaktadırlar. Doğu Avrupa ülkelerinden gelen turistler kendi kent/ülkeleriyle karşılaştırmaları istendiğinde ise diğer ülke gruplarına göre Alanya'nın daha güvenli bir kent olduğunu ifade etmişlerdir (\%47,3). Yine belirgin bir farklılık, güvenlik hizmetlerinden duyulan memnuniyete ilişkindir. Doğu Avrupa ülkelerinden gelen turistler diğer ülke gruplarına göre yüksek bir oranda güvenlik hizmetlerinden (\%40.6) memnun oldukları görülmektedir.

Turistlerin toplu taşıma araçlarında ve gece ve gündüz yaya olarak dışarı çıktıkları durumlarda gelinen ülke grubu ile güvenlik algıları arasında bir ilişki olduğu belirlenmiştir. Kuzey Avrupa ülkelerinden gelen turistler, toplu taşıma araçlarında diğer ülke gruplarına göre kendilerini daha güvende $(\% 34,5)$ hissetmektedirler. Diğer durumlarda da ülke gruplarına göre benzer bir dağılım söz konusu olduğu görülmektedir.

Genel olarak turistlerin en yüksek risk algıladıkları durumun trafik sorunu (\%80) olduğu diğer bulgular arasındadır. Ülke gruplarına göre turistlerin hırsızlık, kap-kaç, cinsel taciz, kriminal suçlar ve terör gibi risk 
algısını etkileyen faktörler bakımından farklı seviyelerde risk algılarının olduğu göze çarpmaktadır. Örneğin hırsızlık konusunda Doğu Avrupa'dan gelen turistlerin daha yüksek düzeyde risk algılarının olduğu tespit edilmiştir. t-testi sonuçlarına göre kap-kaç riski konusunda Orta Avrupa, Batı Avrupa ve Kuzey Avrupa ülkelerinden gelen turistlerden farklılaşmaktadır ve daha yüksek kap-kaç riski algılamaktadırlar. Ülke gruplarının risk algılarının ortalamaları incelendiğinde Doğu Avrupa'dan gelen turistlerin cinsel taciz konusunda daha yüksek risk algısına sahip oldukları görülmektedir. Kriminal suç ve terör riski açısından ise Kuzey Avrupa, Orta Avrupa ve Batı Avrupa ülkelerinden daha yüksek daha yüksek risk algılamaktadırlar.

Uluslararası literatürde daha önce yapılan çalışmaları teyit eden bulgulara ulaşan araştırma, gelinen ülke grubu ile algılanan risk arasındaki ilişkiyi ortaya koymuştur. Gerçekten de risk algısını etkileyen faktörler açısından ve Alanya'da günlük yaşamın devam ettiği ortamlar bakımından ülke gruplarına göre farklı seviyelerde göze çarpan bir farklılık söz konusudur. Bu bağlamda, ülke gruplarına göre farklı düzeylerde ortaya çıkan algı farklılığının nedenlerinin belirlenmesi; özel ve kamusal güvenlik hizmeti sağlayıcılarının, destinasyon yönetiminin ve diğer paydaşların risk algılarını minimize edecek nitelikte turizm planlama, pazarlama ve reklam stratejilerini oluşturması, destinasyon imajı açısından hayati bir öneme sahiptir.

\section{Kaynakça}

- Anuar, A.N.A., S. N. Bookhari ve N. A. Aziz, 2010. "The effectiveness of Safe City Programme as Safety Basic in the Tourism Industry: Case Study in Putrajaya", Procedia-Social and Behavioral Sciences, 42, 477 485.

- Barker, M. ve S. J. Page, 2002. "Visitor Safety in Urban Tourism Environments: The Case of Auckland, New Zealand", Cities, 19(4), 273-282.

- $\quad$ Batra, A., 2008. "Foreign Tourists' Perception towards Personal Safety and Potential Crime While Visiting Bangkok", Anatolia: An International Journal of Tourism and Hospitality Research, 19(1), 89-101.

- Cavlek, N., 2002. "Tour Operators and Destination Safety”, Annals of Tourism Research, 29(2), 478-496.

- Çetinsöz, B. C. ve Z. Ege, 2013. "Impacts of Perceived Risks on Tourists' Revisit Intentions”, Anatolia: An International Journal of Tourism and Hospitality Research, 24(2), 173-187

- Chang, H. H., 2011. "Nationality's Differences in Youth Tourists' Travelling Risk Perceptions and Satisfactions within Taiwan", Journal of Tourism, XI (2), 19-50.

- Dimanche, F. ve A. Lepetic, 1999. "New Orleans Tourism and Crime: A Case Study", Journal of Travel Research, August, 38, 19-23.

- Donaldson, R. ve S. Ferreira, 2009. “(Re-) Creating Urban Destination Image: Opinions of Foreign Visitors to South Africa on Safety and Security", Urban Forum, 20(1), 1-18.

- Elliot, L. ve C. Ryan, 1993. "The Impact of Crime on Corsican Tourism: A Descriptive Assessment", World Travel and Tourism Review, 3, 287-293.

- Ferreira, S. ve A. Harmse, 2000. "Crime and Tourism in South Africa: International Tourists' Perceptions and Risk”, South Africa Geographical Journal, 82(2), 80-85.

- Flicker, M. H. ve M. P. Gardner, 2002. "Which is Scarier: the Mall of the Mail?", Paper Presented at the Direct Marketing Education Foundation Annual Conference, San Francisco, CA.

- George, R. ve I. Booyens, 2014. "Township Tourism Demand: Tourists' Perceptions of Safety and Security", Urban Forum, 25(4), December, 449-467.

- George, R., 2003. "Tourists' Perceptions of Safety and Security While Visiting Cape Town", Tourism Management, 24(5), 575-585.

- Glaesser, D., 2003. "Crises' Spheres of Activity. Crisis Management in the Tourism Industry", Burlington, MA: Elsevier Butterworth-Heinemann.

- Irvine, W. ve A. R. Anderson, 2006. "The Effect of Disaster on Peripheral Tourism Places and the Disaffection of Prospective Visitors", in Y. Mansfeld ve A. Pizam (Eds.), Tourism, Security \& Safety: From Theory to Practice, Oxford: Butterworth-Heinemann, 169-186.

- Iverson, T. J., 1997. "Decision Timing: A Comparison of Korean and Japanese Travelers", International Journal of Hospitality Management, 16(2), 209-219.

- Kelly, I., 1993. "Tourist Destination Crime Rates: An Examination of Cairns and the Gold Coast, Australia", Journal of Tourism Studies, 4(2), 2-11.

- Kovari, I., ve K. Zimanyi, 2011. "Safety and Security in the Age of Global Tourism (The Changing Role and Conception of Safety and Security in Tourism)", APSTRACT: Applied Studies in Agribusiness and Commerce, 5, 59-61.

- Laws, E. ve B. Prideaux, 2005. "Crisis Management: A Suggested Typology", Journal of Travel and Tourism Marketing, 19(2/3), 1-8.

- $\quad$ Lepp, A. ve H. Gibson, 2003. "Tourist Roles, Perceived Risk and International Tourism”, Annals of Tourism Research, 30(3), 606-624.

- Levantis, T. ve A. Gani, 2000. "Tourism Demand and the Nuisance of Crime", International Journal of Social Economics, 27(7/8/9/10), 959-967. 
- March, R. ve A. G. Woodside, 2005. "Tourism Behavior: Travellers' Decisions and Actions, Oxon, UK: CABI.

- Maser, B. ve K. Weiermair, 1998. "Travel Decision-Making: From the Vantage Point of Perceived Risk and Information Preferences, Journal of Travel \& Tourism Marketing, 7 (4), 107-121.

- Mawby, R. L., 2000. "Tourists' Perceptions of Security: The Risk-Fear Paradox", Tourism Economics, 6(2), 109-121.

- Mitchell, V. W. ve V. Vasso, 1997. "Perceived Risk and Risk Reductions in Holiday Purchase: A CrossCultural and Gender Analysis, Journal of Euromarketing, 6(3), 47-97.

- Moutinho, L., 2000. "Consumer Behavior in Tourism", in L. Moutinho (Ed.), Strategic Management in Tourism, New York: CABI.

- Pelfrey, W. V., 1998. "Tourism and Crime: A Preliminary Assessment of the Relationship of Crime to the Number of Visitors at Selected Sites", International Journal of Comparative and Applied Criminal Justice, 22(2), 293-304.

- Pinhey, T. K. ve T. J. Iverson, 1994. "Safety Concerns of Japanese Visitors to Guam”, Journal of Travel and Tourism Marketing, 3(2), 87-94.

- Pizam, A. ve Y. Mansfeld, 2006. "Toward A Theory of Tourism Security", in Y. Mansfeld ve A. Pizam (Eds.), Tourism, security \& Safety: From Theory to Practice, Oxford: Butterworth-Heinemann, 1-27.

- Pizam, A., A. Reichel ve N. Uriely, 2002. "Sensation Seeking and Tourist Behavior", Journal of Hospitality \& Leisure Marketing, 9(2), 17-33.

- Pizam, A. ve Y. Mansfeld, 1996. "Introduction”, in A. Pizam ve Y. Mansfeld (Eds.), Tourism, Crime and International Security Issues, Chichester: John Wiley \& Sons, 1-7.

- Prideaux, B. ve A. Dunn, 1995. "Tourism and Crime: How Can the Tourism Industry Respond? The Gold Coast Experience", Australian Journal of Hospitality Management, 2 (1), 7-15.

- Qi, C. X., H. J. Gibson ve J. J. Zhang, 2009. "Perceptions of Risk and Travel Intentions: The Case of China and the Beijing Olympic Games", Journal of Sport and Tourism, 14 (1), 43-67.

- Reisinger Y. ve F. Mavondo, 2005. "Travel Anxiety and Intentions to Travel Internationally: Implications of Travel Risk Perception", Journal of Travel Research, 43 (3), 212-225.

- Richardson, S. ve J. Crompton, 1988. "Vacation Patterns of French and English Canadians", Annals of Tourism Research, 15(3), 430-545.

- Rittichainuwat B. N. ve G. Chakraborty, 2009. "Perceived Travel Risks Regarding Terrorism and Disease: The Case of Thailand", Tourism Management, 30(3), 410-418.

- Roehl, W. S., ve D. R. Fesenmaier, 1992. "Risk Perceptions and Pleasure Travel: An Exploratory Analysis", Journal of Travel Research, 30(4), 17-26.

- Ryan, C., 1993. “Crime, Violence, Terrorism and Tourism, An Accidental or Intrinsic Relationship?”, Tourism Management, 14, 173-183.

- Sirakaya, E. ve A. G. Woodside, 2005. "Building and Testing Theories of Decision Making by Travelers", Tour Manage, 26(6): 815-832.

- Sirakaya, E., A. G. Sheppard ve R. W. McLellan, 1997. “Assessment of the Relationship Between Perceived Safety at A Vacation Site and Destination Choice Decisions: Extending the Behavioral Decision-Making Model", Journal of Hospitality \& Tourism Research, 21(2), 1-10.

- Sönmez, S. F. ve A. R. Graefe, 1998a. "Influence of Terrorism Risk on Foreign Tourism Decisions", Annals of Tourism Research, 25 (1), 112-144.

- Sönmez, S. F. ve A. R. Graefe, 1998b. "Determining Future Travel Behavior from Past Travel Experience and Perceptions of Risk and Safety", Journal of Travel Research, 37(2), 171-177.

- Tarlow, P., 2000. "Creating Safe and Secure Communities in Economically Challenging Times", Tourism Economics, 6(2), 139-149.

- Yavaş, U., 1987. "Foreign Travel Behavior in A Growing Vacation Market: Implications for Tourism Marketers”, European Journal of Marketing, 21(5), 57-69. 


\title{
Yükselen Bir Değer Olan Medikal Turizmin; Türkiye Ekonomisine Katkısı
}

\section{Rising Medical Tourism with a Value; Contribution to Turkey's Economy}

\author{
Ph. D. Candidate Vedat Moloğlu (Istanbul Aydın University, Turkey)
}

\begin{abstract}
In today's globalising world, with the developing of countries, trying new income opportunities has been inevitable. Tourism, which is one of the biggest alternative income sources for countries, has been one of the sectors that getting more and more important for countries in terms of social and economic aspects. At first, doing tourism mostly refers to holiday and tours. However, recently this concept expanded with the added health tourism. The main purpose of this study, investigating the medical tourism that is a type of health tourism and getting more and more important in Turkey. The study firstly begins with the giving information about concept definition of medical tourism, and historical background of it. Then, with the investigating medical tourism in the world and Turkey setting, it was aimed that reaching a holistic point of view about it in terms of macro and micro profits to our economy. Lastly, to execute existing state of medical tourism in Turkey, the opportunities and weakness of medical tourism in Turkey was defined. Managerial and further research implications are also provided.
\end{abstract}

\section{Giriş}

Dünyada önemli gelir kaynağı olan sektörlerden bir tanesi de turizmdir. Turizm insan istek ve ihtiyaçları, artan iletişim, teknoloji ve ulaşım imkanlarıyla vb. faktörler nedeniyle sürekli bir değişim ve gelişsim içerisindedir. 1970 yıllara kadar turistlerin yaptıkları gezilerin ana amacını denize girmek, yeni yerleri keşfetmek, doğal güzellikleri gezmek gibi nedenler oluştururken, özellikle 21 yüzylla beraber bu klasik turizm olarak ifade ettiğimiz turizmle beraber insanlar, hastalarını tedavi etme ve o ülkenin yeraltı ve yerüstü zenginliklerinden faydalanarak iyileşmek, daha sağlıklı ve zinde hayat sürdürmek için de farklı ülkelere gitmesi, Sağlık turizminin doğmasına yol açmıştır. Sağlık turizminin başlamasındaki ana amaç artan ileri yaş ve bazı hastalıkların iyileşme ve tedavi sürecinde, bazı ülkelerin çözüm olması gelmektedir. Medikal turizm, Sağlı turizmini oluşturan ve ülke ekonomisine katkı sağlayan sağlık turizimin çeşitlerden en önemlisidir. Ülkemiz özellikle son yıllarda medikal turizmin en önemli merkezlerinden olmuştur. Ülkemiz maliyet, teknoloji ve hizmet kalitesi aynı zamanda doğal ve tarihi güzellikleri ile medikal turistlerin ilgisini çeken bir ülkedir.

$\mathrm{Bu}$ çalışmada öncelikle medikal turizmin kavramı ve gelişimini sonra medikal tarizimin özellikleri ve nedenleri ile medikal turizmin mikro ve makro iktisadi özelliklerini daha sonra Dünyada ve Türkiye'de Medikal turizm hakkında bilgi verdikten sonra sonuç bölümünde medikal turizmin Türkiye için önemi ifade edilmiştir.

\section{Medikal Turizm ve Gelişimi}

İnsanların sağlıklarına kavuşma yollarını kendi ülkesi dışarısında farklı ülkelerde araması sonucu Sağlık turizmi ortaya çıkarmıştır. "Sağlık turizmi”" literatürüne baktığımızda sağlık amaçlı seyahatleri üç başlık altında toplayabiliriz (Aydın, vd, 2011).

Termal ve Spa-Wellness Turizm

İleri yaş Ve Engelli Turizm

Medikal Turizm

\begin{tabular}{|c|c|c|}
\hline Termal ve Spa-Wellness & Medikal & İleri yaş ve Engelli \\
\hline $\begin{array}{ll}\text { - } & \text { SPA } \\
\text { - } & \text { Doğal Turizm } \\
\text { - } & \text { Ekoturizm } \\
\text { - } & \text { Kitle Turizmi } \\
\text { - } & \text { Bitkisel Tedaviler } \\
\end{array}$ & $\begin{array}{ll}\text { - } & \text { Elektif Cerrahi } \\
\text { - } & \text { Plastik Cerrahi } \\
\text { - } & \text { Eklem Replasmanı } \\
\text { - } & \text { Kardiotorasik Servisler } \\
\text { - } & \text { Diagnostik Servisler } \\
\text { - } & \text { Kanser Tedavisi } \\
\text { - } & \text { Infertilite Tedavisi } \\
\end{array}$ & $\begin{array}{ll} & \text { Diyaliz } \\
\text { - } & \text { İlave Programlar } \\
\text { - } & \text { Yaşlı Bakımı Programları } \\
\text { - } & \text { Bağımlılık Tedavileri }\end{array}$ \\
\hline
\end{tabular}

Tablo 1. Sağlık Turizmi Çeşitleri Kaynak: Aydın ve diğerleri; 2011:19

Medikal turizm veya diğer bir adıyla Tıp turizmi, insanların kendi ülkelerinde tedavi ücretlerinin yüksek olması nedeniyle farklı ülkelere giderek bu ülkelerdeki kendi ülkelerine göre düşük tedavi ücretlerinden 
faydalanarak tıbbı olarak tedavi ve operasyonların farklı ülkelerde gerçekleşmesiyle oluşan turizm hareketleri olarak tanımlanmaktadır (İçöz,2009). "Medikal turizm" insanların uzak ülkelere tıbbı tedavi alabilmek bununla beraber tatil yapmasını ifade eden bir kavramdır. Daha genel bir tanım olarak sağlık ve medikal turizmi, "Sağlık turizmi insanların bedenlerini ve ruhlarını iyileştirme ve bireysel refah düzeyini artırmak için bir yerel ortamın dışına çıkılarak yapılan organize geziler" olarak tanımlamaktadır (Carrera ve Bridges, 2006).

Kendi ülkelerinden ayrılarak acil olmayan tıbbı tedavi ve operasyonlar için farklı ülkede sağlık hizmetlerine erişme düşüncesin yaygınlaşmasıyla başta araştırmacılar, hükümetler ve medya bu alana önem vermeye başladı (Corera ve Bridge, 2006).

Medikal turizm bir niş pazar olarak ortaya çıkmış, insanların tıbbı tedavi almakla beraber tatil yapmak için farklı ülkelere gidilen hatta uzun mesafeler kat edilerek deniz aşırı ülkelere seyahatlerin yapıldığı hızla gelişen ve büyüyen bir endüstri haline gelmiştir. Medikal turizm ülke ekonomilerin iki hizmet türü olan tıp ile turizm arsındaki ortakları kapsar (Bookman ve Bookman 2007; Jones ve Mc Culloungh 2007; Medhekar, 2013).

Medikal turizm eğilimi geleneksel ekonomik modelden farklılık gösterir. Genelsek modelde hastalar daha iyi kaliteli tıbbı hizmeti alabilmek için az gelişmiş ülkelerden gelişmiş ülkelere giderken medikal turizmde tam tersi bir durum geçerli olup, gelişmiş ülkelerden gelişmekte olan ülkelere gidilmektedir. En önemli nedenin fiyat avantaj1 olduğudur (Gill ve Singh, 2011).

Medikal Turizm her ne kadar 20 yüzyılda ikinci yarısında gelişen bir endüstri olsa da insanlar bilinen tarih boyunca tedavi olmak ve iyileşmek için yüzylllar boyunca seyahat etmişlerdir (Jagyasi, 2010).

- MÖ 4200 yıllarda ilk Sümerlerde şifalı suların bulunduğu banyolar ve termal kaynakların bulunduğu tapınaklar yapmışlar,

- MÖ 1500 yıllarda Antik Yunanlar şifa Tanrısı Onuruna Asclepha tapınağı yapmış, tapınağa birçok farklı ülkelerden hastalar şifa bulmak için gelmişlerdir.

- 12-13 yüzyıllarda sıcak mineralli sular Japon savaşçılar tarafından mucizevi olduğuna inanılmış, tedavi olmak ve iyileşmek için kullanılmıştır.

- 14-15 yüzyılda "Salude Per Agua" (SPA) Fransa da demir yönünden yoğun kaynak suyu dünya çapında ilgi görerek Sağlık turizmi çeşitlerinden olan SPA turizm gelişmesini sağlamıştır.

- 18-19 Yüzy1llarda Sanatoryum hastaneleri kurularak Karaciğer Tüberküloz ve bronşit gibi hastalıklar tedavi edilmeye başlanmış ve farklı ülkelerden birçok hasta bu hastanelere tedavi olmaya gelmiştir.

- 20 yüzyılda ise özellikle Küba göz cerrahisinde; Tayland plastik cerrahi ve Orta Amerika ülkeleri diş tedavilerinde ün kazanmışlardır.

- 21 Yüzyılda Özellikle teknolojinin önemli kısıtlayıcı olmamasıyla beraber rekabet başlamış ve modern medikal turizm doğmuştur.

- Günümüzde 50 in üzerinde ülke medikal turizm bir parçası olmuştur. Özellikle de Asya, Latin Amerika, Uzak Doğu ülkeleri önemli bir konum elde etmekle beraber rekabet hızlanmıştır.

- Yakın gelecek medikal turizm bölge ve ülke ekonomileri arasında büyük avantajlara sebep olması beklenmektedir. Ülkeler arası rekabette sağlık hizmetlerinde kalite önemli bir ölçüt haline gelecektir

\section{Medikal Turizminin Özellikleri}

Medikal turizmin etkili bir şekilde uygulanabilmesi için turizm sektörünü oluşturulan işletmelerin; ulaşım, konaklama, yiyecek-içecek hizmetlerinin ayrıca sağlık sektörü oluşturan işletmelerin, modern donanımlı hastaneler ve sağlık kuruluşları ile yasal düzenlemeler yapacak devlet kurumları ayrıca profesyonel hizmet veren aracı işletmelerinin tam bir uyum içinde çalışmaları ile hastanın istek ve ihtiyaçlarını en üst düzeyde karşılanmalıdır.

Medikal Turizmin Özellikleri ise (Yalçın, 2006);

- Medikal Turizm teknik ve donanım iş gücü gerektiren bir turizm çeşididir.

- Medikal turizminde hizmet sunan işletmelerin uluslararası standartlara sahip olması gerekmektedir (Joint Comissions International / Uluslararası Birleşik Komisyonu, JCI vb.)

- Sağlık hizmeti sunan kuruluşlarda mutlaka hasta ile iletişimi kurabilecek yabancı dil bilen personel bulundurulmalidir.

- Hasta ve refakatçileri için farklı turizm türlerini gelişmesini sağlayan katma değeri yüksek bir turizm seçidir.

- Kıyı ve Sahil turizmi gibi mevsimsel değildir.

- Seçilmiş hedef pazarlara (ülkelere) o ülkenin dilinde reklam ve tanıtım yapılması gerekmektedir ve yapılan bu tanıtımla hastaları yurt dışında tedavi hizmetlerini alabilmesini kolaylaştırmak için sigorta, sağlık ve acente kuruluşlarıyla ortak hareket edilmelidir. 


\section{Medikal Turizm Nedenleri}

Hastalar, yüksek maliyet ve ücretler, uzun bekleme süreleri ve daha kaliteli hizmet alabilmek için hastalar farklı ülkelere seyahat etmektedirler. Mckinsey\& Campany tarafindan yapılan bir araştırmaya göre (Ehrbeck, vd, 2008) medikal turizm nedenlerini oranlarına göre sıralamıştır.

Tedavi amacı seyahat eden hastaların $\% 40$ en yüksek teknolojiyi tercih ettiğini ve bu hastaların dünyadaki yüksek kalitedeki tıbbı tedavi hizmetlerini araştırmakta ülkenin yakınlığı ise ulaşım imkânlarının artmasıyla daha az dikkate alınmaktadır.

Tedavi amaçlı seyahat eden hastaların \%32 bir grup ise tedavi için kendi ülkelerinden daha gelişmiş ülkelere gitmeyi tercih ediyorlar. Özellikle bu gruba Ortadoğu ülkeleri olan Irak, Suriye ve İran gibi ülkelerden ülkemize tedavi olmaya gelen hastaları örnek verebiliriz. Bu gruptaki hastalar ülke seçerken maliyetleri ile kalite ve kültür ve uzaklık arsında değerlendirme yaparlar. Bu gruptaki hastaların bir kısmı maliyeti dikkate almazken diğer bir kısmı daha az maliyetle daha kaliteli hizmet almak isterler. Bu gruptaki hastalar daha çok kardiyoloji ve beyin cerrahi alanında tedavi hizmeti alan kişilerdir.

Üçüncü en büyük grubu \%15 hastalar ise kendi ülkelerinde ortopedi ve Genel Cerrahi gibi tedavileri uzun bekleme süreleri olan hastalar, tedavi hizmetlerine daha kısa zamanda ulaşabilmek için farlı ülkeler seyahat ederler.

Tedavi amaçlı yurt dışına giden hastaların \%9 tedavi ücretlerinin yüksek olması nedeniyle farklı ülkelere gitmektedirler. Örneğin, Amerika'da saç Ekimi 30.000 Dolar iken ülkemizde 5.000 Türk Lirasıdır.

Medikal turizm üzerine 2010 yılında yapmış olduğu bir çalışmaya göre kişiler yurt dışından sağlık hizmetleri almasının 4 ana nedenini sıralamıştır.( Jagyasi, 2010)

- Tedavi ücretlerinin kendi ülkelerinde daha yüksek olması

- $\quad$ Ülkelerinde tedaviye ulaşması zor olması (Uzun bekleme sırası)

- $\quad$ Ülkelerinden daha iyi hizmet alma beklentisi

- Yaşadıkları ülkede kişiler için yeterli bakım / tedavi hizmetlerinin olmaması

Ana nedenlerle beraber diğer nedenlere baktığımızda (Sağlık.gov, 2015)

- Hastanın kendi ülkesinde herhangi bir nedenden dolayı tedavisinin ya da operasyonunu bilinmesini istememesi (Plastik cerrahi operasyonu, İnfertilite tedavisi vb.)

- Kronik hasta ve yaşlıların başka ülkeleri görme ve tedavi olma istekleri.

- Kişinin yaşama tutunması ve hayat isteği.

- Hastalanın bir yakının tedavi görüp memnun kalarak bir yakına tavsiye etmesi (Yalçın, 2006).

Etkili bir medikal turizmim olmazsa olmazlarını şöyle ifade etmiştir (Jagyasi, 2010).

- Hizmette standart ve kalite

- Hizmet verene erişebilme

- Teknoloji tesis ve uzmanlaşma

\section{Medikal Turizimin Makro ve Micro Iktisadi Özellikleri}

Medikal turizm; doğrudan insan sağlığını kendine özgü özelliklerinden dolayı hem klasik turizm ve hem tıp ve iktisat gibi bilimler bileşeninden oluşan bir kombine turizm sektörüdür. Bu karşılıklı etkileşim boyutlarına bağlı olarak medikal turizm makro ve mikro iktisat özellikleri taşımaktadır (Özkurt, 2007).

\subsection{Medikal Turizm Mikro özellikleri}

- $\quad$ Medikal turizm bir piyasadır. Güçlü Arz ve talep dengesine göre şekillenir.

- Medikal turizm piyasası oligopolostik bir yapıdan tam rekabetçi bir yapıya doğru gelişmektedir. Nedenine baktığımızda bu sektörden hizmet alan ve sektöre hizmet veren kurum ve kuruluşlar artmaktadır. Buda hizmetlerde fiyatın düşmesi ve kalitenin artmasına neden olmaktadır.

- Medikal turizm başka turizm çeşitleriyle yer değiştiremez ikamesi olmayan bir turizm sektörüdür.

- Medikal turizm piyasa fiyatları karşısında oldukça kırılgan olması nedeniyle fiyatlara esnektir.

\subsection{Medikal Turizm Makro özellikleri}

- $\quad$ Medikal turizm sektörü birçok sektörü bünyesinde alt sektörleri beslerken (otelcilik, lokantacılık ulaşım vb.) aynı zamanda onlar tarafından beslenir.

- Medikal turizme yapılan yatırımlar genellikle kamusal güvencelere ve özel sektördeki girişimcilere dayanmaktadir.

- Medikal turizmin ülkenin tanınması kalkınmasında önemli bir yere sahiptir. 


\section{Dünyada ve Türkiye'de Medikal Turizm}

Dünyada medikal turizmin ana bölgesi Asya’dır. Asya'daki ülkeler özellikle ortopedi ve kardiyak cerrahinde ün kazanmışlardır. Medikal turizm konusunda alt yapısını geliştirmiş olan Hindistan, Singapur ve Tayland büyük ve modern tıbbı imkânlara sahip sağlık hizmetleri karmaşık prosedürleri yerine getirebilen iyi eğitim almış doktorlar ile sağlık hizmeti almak isteyen hastaları ülkelerine çekmekte ve verdikleri sağlık hizmetleri karşılığında yüksek bir gelir elde etmektedirler.(Horowitz ve Rosenweing, 2007)

Özellikle Asya ülkelerinden Tayland cinsiyet değiştirme konusunda daha sonra estettik alanda uzmanlaşmaya giderek bu alanda hizmet farklılaştırması yapmıştır. Malezya ise bu gruba Asya krizinde sonra Taylan'daki yerli hastaların fiyatları ödeyemez durum gelmesiyle 1998 yılında katılmış daha sonra Singapur girdiği bu alanda Tayland ile rekabet edebilmek için sağlık hizmet fiyatlarını düşürmüş hava limanlarına medikal turizm seçenekleri ile ilgi bilgi stantları açmıştır. 19901 yıllardan sonra medikal turizm, Sağlık turizminin bir dalı olarak sektörleşmiştir (Çetinkaya, 2010).

Farklı ülkelere giden Medikal turistler dünyanın popüler turizm yerlerinde kalmanı keyfini çıkartırken aynı zamanda tedavi ve cerrahi operasyonu olma avantajı elde ederler. Tıbbı operasyonlar yalnız plastik cerrahi ve diş operasyonları gibi efektif cerrahi değil aynı zamanda bilgi ve teknoloji gerektiren kompleks operasyonları da kapsamaktadır. Aynı zamanda koruyucu sağlık hizmetleri olan Chek-up ve sağlık taraması hizmetleri de medikal turizm kapsamına girmektedir.

Medikal turizm sektörü Dünya ve ülkeler ekonomisine büyük bir katkı yapmaktadır. Medikal turizm endüstrisi dünyada yaklaşık 60 milyar ABD doları dolarlık bir Pazar payını oluşturmaktadır (Heung, vd, 2010). Dünya Ticaret Örgütü verilerine göre 2014 yılında 100 milyar Amerikan doları geçmiş bir sektördür (Haberler.com,2015).

Ülkemiz medikal turizm hizmetinde diğer ülkelerle karşılaştırıldığında; alt yapı, teknoloji, eğitimli sağlık personeli ve özelliklede fiyat avantajlarıyla medikal turizmin gelişmesi için önemli bir potansiyele sahiptir.

\begin{tabular}{|l|l|l|l|l|l|l|l|}
\hline \multicolumn{1}{|c|}{ Ülke } & \multicolumn{1}{c|}{ Anjio } & \multicolumn{1}{c|}{ Bypass } & $\begin{array}{c}\text { Kalp } \\
\text { Kapakçı̆̆ }\end{array}$ & $\begin{array}{c}\text { Kalça } \\
\text { Ameliyat1 }\end{array}$ & $\begin{array}{c}\text { Diz } \\
\text { Ameliyat1 }\end{array}$ & \multicolumn{1}{c|}{ Omurga } & Mastektomi \\
\hline Amerika* & 98.618 & 210.000 & 274.395 & 75.399 & 69.000 & 108.127 & 40.832 \\
\hline Hindistan* & 11.000 & 10.000 & 9.500 & 9.000 & 8.500 & 5.500 & 7.500 \\
\hline Tayland* & 13.000 & 12.000 & 10.500 & 12.000 & 10.000 & 7.000 & 6.000 \\
\hline Singapur* & 13.000 & 20.000 & 13.000 & 12.000 & 13.000 & 9.000 & 12.400 \\
\hline Türkiye** & 3.500 & 12.000 & 12.000 & 13.000 & 15.000 & 15.000 & 9.000 \\
\hline
\end{tabular}

Tablo 2: Seçilmiş Ameliyatlar için Maliyet Karşılaştırması Kaynak: Devon M. Herrick National Center for Policy Analysis, 2015. ** TÜIK, 2015. Verileri (Karşılaştırmak Iç̧in ortak para birimi olarak Amerikan Doları baz alınmıştır.)

Dünyada bu pazardan en büyük payları alan ülkelere sıraladığımızda Tayland, Hindistan, Malezya, Almanya, Meksika, Güney Afrika, Brezilya, Kosta Rica ilk 10 da yer alırken, daha sonra gelen ülkeler ise, Polonya, Saudi Arabistan, İsviçre, Arjantin, Birleşik Arap Emirlikleri, Türkiye, Çin, İspanya, İngiltere, Avusturalya, Küba, Fransa, Panama, Filipinler, Belçika, Macaristan, İsrail, Japonya, Monako, Yeni Zelanda, Güney Kore, Tayvan, Tunus ülkelerini sıralayabiliriz (Jagyasi,2010). Sağlık Bakanlığımız 2013 Verilerine göre Türkiye 10 uncu sıraya yükselmiştir. Sağlık Bakanlığımızın 2023 hedefi ilk 5'in içerisinde olmak ve 20-25 milyar Amerikan dolar gelir elde etmektir (Sağlikturizm.org, 2015).

Hastalar medikal turist olarak gideceği ülkeler hakkında bilgi edinmek için araştırma seçenekleri şu şekilde sıralamıştır. En fazla \%73 oranda internet üzerinden, \%10 kendi aile hekimlerin tavsiyesi, \%8 arkadaşlarının ve aile mensuplarını önerisi, \%6 hastanenin referansları, \%1 ise basılı broşür tur videoları ve televizyon haberleri ile sağlık hizmeti alacağı ülkeyi tespit etmektedir (Gill ve Singh, 2011).

Türkiye Sağlık turizmin sadece medikal değil tüm türlerinde oldukça gelişmiş ve ileri bir alt yapısı vardır. Özellikle 2000 yıllarda sonra gerek kamu ve gerekse özel hastane ve sağlık kuruluşları fiziki şartların yansıra yetişmiş doktor ve sağlık personeli ile gelişmiş ülkeler seviyesine ulaşmış ve hatta bazı medikal turizm alanlında daha ileri gitmiştir (Aydın ve Yılmaz, 2010).

Ülkemizde kısa bir geçmişi olmasına rağmen sağlık sektörünün dikkatini çeken medikal turizm ülkemize yeni fırsatlar sunmuştur. Bu firsatları değerlendirmek ve ülke ekonomisine katkı sağlamak için gerek akademik ve kamu-özel sağlık kuruluşların ilgisini canlı tutmak medikal turizm sektörünün ülkemizde gelişmesi için çok önemlidir (Aydın, vd, 2011).

Türkiye'de medikal turizminde son yıllarda yaşanan pozitif gelişmeler ve özel sağlık işletmelerinin payının artması. Sağlık hizmet alanlarında önemli yatırımlar yapılması ayrıca sağlık hizmetlerinde kalitenin artması medikal turizm pazarında Türkiye’ye önemli katkılar sağlamaktadır. Diğer sektörlere göre kıyasladığımızda yatırım maliyeti yüksek olan bir turizm sektörüdür (Şahin ve Tuzlukaya, 2013). 
Şu anki durumdan Türkiye istenilen kadar olmasa da medikal turizmden önemli gelir elde etmektetir. Ülkemize gelen medikal türistler 4 ana sınıfta incelebilir (Genç, 2007).

- Değişik nedenlerden dolayı, bünyesinde büyük Türk nüfusu bulunduran ülkeler (Almanya, Hollanda, Fransa, Belçika)

- $\quad$ Altyapı eksikliği ve hekim sayısı eksikliği nedeniyle hizmet sunma sıkıntısı çeken gelişme olan ülkeler (Balkan Ülkeleri ve Orta Asya'daki Türki Cumhuriyet Ülkeleri)

- Sağlık hizmet ücretlerinin yüksek olması ve sağlık sigortası alanına girmeyen (Estetik cerrahi operasyonlar) hizmetleri talep eden bazı gelişmiş ülkeler (Almanya. Amerika ve Kanada)

- Arz Talep dengesindeki noksanlıklar sebebiyle uzun bekleme sırası olan ülkeler (Kanada, Hollanda, İngiltere)

Ülkemizi dünyanın farklı ülkelerinden tedavi olmak üzere çok sayıda hasta tercih etmektedir. Bunun en önemli etki orijin ülkelerde çağdaş yöntemlerle yapılan tıbbı operasyonlar ülkemizde daha uygun yapılmasıdır. Başta Plastik ve estetik operasyon, saç ektirme, göz ameliyatları, tüp bebek, açık kalp ameliyatları, deri hastalıkları, chek up, kanser tedavileri, kulak-burun-boğaz diyaliz, kalp damar cerrahisi, beyin cerrahisi, ortopedi diş, fizik tedavi rehabilitasyon gibi hemen her dalda gelen hastalar hem düşük maliyet hem de yüksek kalite ve teknoloji sahipbir ülke olmamız nedeniyle yabancı hastalar ülkemize sağlık hizmeti alabilmek için gelmektelerdir (İçöz, 2009).

Ülkemizin tercih edilme nedenleri arasında sadece Avrupa ülkelerine göre ücretlerin ucuz olması değildir. Ülkemizdeki sağlık hizmetindeki kalitete çok önemli bir yere sahiptir. Örneğin Çocuk sahibi olabilmek için Türkiye'yi tüp bebek tedavisi olmaya gelen hastaların ilk denemelerinde çocuk sahibi olmasıdır. Ortadoğu ve doğu Avrupa'dan gelen hastalar kanser tedavisi içi özellikle ülkemizi tercih etmektedir ( Aktepe, vd, 2007).

Dünya Ticaret Örgütü 2014 verilerine göre ülkemizde tercih edilen ilk 5 branşın sırasıyla iç hastalıkları, göz hastalıkları, ortopedi, doğum ve kadın hastalıkları, kulak-burun-boğaz(KBB) gelmektedir (Haberler.com, 2015).

Aynı zamanda ülkemiz özellikle kozmetik ve diş tedavi ve operasyonlarında başarılı ülkelerin arasında yer almaktadır. Örneğin gelişmiş ülkeler olan İngiltere ve Kannadada özelikle kozmetik ameliyatların ücretlerinin yüksek olması ve uzun bekleme süresi gerekmesidir. Aynı zamanda Türkiye'nin mevsimsel özellikleri nedeniyle hastanın güneşli ve sıcak bir iklimde iyileşme ve uygun fiyatlarla tedavi konaklama ve tatil yapma firsatı sunulmaktadır (Tengilimoğlu ve Kahraman, 2013).

Dünya Ticaret Örgütünün verilerine göre 2014 yılında ülkemize gelen hastaların \%71 oranında özel sağlık kuruluşlarını tercih ederken \%29 oranda kamu kuruluşlarını tercih etmişlerdir (Haberler.com, 2015).

\begin{tabular}{|c|c|}
\hline Yıl & Hasta Sayısı \\
\hline 2008 & 74.093 \\
\hline 2009 & 91.961 \\
\hline 2010 & 109.878 \\
\hline 2011 & 176.000 \\
\hline 2012 & 261.999 \\
\hline 2013 & 300.000 \\
\hline $2014^{*}$ & $496.324^{*}$ \\
\hline
\end{tabular}

Tablo 3: Yıllara Göre Ülkemize Gelen Hasta Sayısı Kaynak: Sağlık Bakanlı̆̆ 2013 verileri (* 2014 verilerini Sağlık Bakanlığı henüz açıklamadığı için Dünya Ticaret Örgütü verilerinden alınmıştır.)

Türkiye Medikal turizme yatırımın milyarlarca dolar olmasına rağmen talebin istenilen düzeye ulaşmamıştır. En büyük nedeni ise konuyla ilgili yeteri kadar tanıtım olmaması ayrıca pazarlama ile satış ağının oluşturulmamasıdır (İçöz, 2009).

Ülkemizde medikal turizmin geliştirilmesi ve bu alanda rekabette etkili olabilmek için;

- Sağlık Bakanlığı bünyesinde “medikal turizm ”sektörün hizmetleri yürütecek uzmanlarda oluşacak bir birim oluşturulması,

- Kültür Bakanlığı İçerisinde “medikal turizm ” sektörün hizmetleri yürütecek uzmanlarda oluşacak bir birim oluşturulmas1,

- Medikal turizm ile ilgili hedef olarak belirlenen pazarlarda medikal turizm de Türkiye'nin üstün özelliklerini vurgulayacak tanıtım ve kampanyaların yapılmalıdır.

- Medikal turizmde kapsayan paket turlar hazırlanırken alternatif turizm diğer çeşitleri de pazarlanmalıdır.

- Kamu ve özel sektörler uyum içerinde çalışarak hem medikal turizmi tanımı sağlamsına yardımcı olmalı hem de ülkemizin imajını güçlendirmelidir.

- Hasta ve hasta arasında iletişimi sağlayan aracı kurumların hizmetleri uluslararası satandalar sahip olmalı ve sertifika aldırılıp sürekli ve etkili bir denetim sağlanmalıdır. 
- Medikal turizm alanında uluslararası fuarlara katılarak, seminerlere ve kongrelere katılarak Türkiye'nin

kaliteli ve düşük Medikal turizm hizmetlerini tanıtıp pazarlanması sağlanmalıdır.

Özelikle Türkiye medikal turizmdeki pazar payını artırabilmek için başta soydaşlarımız olan Türki Cumhuriyetlerine, AB ülkelerine, Orta Doğu pazarına, Arap ülkeleri ve Amerika’ya karşı farklı pazarlama karması oluşturmalıdır.

\subsection{Türkiye'de Medikal Turizmin Avantajları ve Eksik Kalan Yönleri}

Türkiye mevcut coğrafi yapısı ve stratejik konumu itibariyle başta medikal turizm olmak üzere sağlık turizmde birçok avantaja sahiptir. Bu avantajları şu şekilde sıralayabiliriz (İçöz, 2009):

- Türkiye'de medikal sağlık hizmeti veren hastanelerin alt yapı ve donanımlarının yüksek olması.

- Türkiye'deki doktorlar ve sağlı personelinin dünya standartlarında eğitime ve deneyime sahip olması.

- Diğer ülkelere göre sunduğu düşük fiyat avantaj1.

- Türkiye'nin doğası ve tarihi ile geleneksel turizm çekiciliğin olması ve iklim koşulların uygun olması.

- Yüksek standartlara ulaşmış turizm tesisleri ve iyi eğitim almış yabancı dil bilen personeli olması.

- Medikal turizm diğer turizmlerle birleşebilmesi ve ortak bile paket bir programın yapılabilmesi.

Ülkemizin Sağlık turizminde eksik kalan yönlerini ifade etmek gerekirse (İçöz, 2009):

- Medikal Turizm ülkemizde yeni bir sektör olması nedeniyle henüz tam olarak organize olamaması

- Sağlık Kuruluşlarında yetişmiş yeteri kadar uzman personel olmaması.

- Konuyu ilişkin aracı kuruluşların henüz bu alana yeteri derecede önem vermemesi ve bu konuda özellikle yurt dışında tanıtım ve pazarlama faaliyetlerinin yeteri kadar yapılmaması.

- Sağlık Kuruluşlarının genellikle büyük şehirlerde olması ve bu nedenle klasik turizm bölgeleriyle yeteri kadar bütünleşmemesi

- Yüksek standartlara ulaşmış turizm tesisleri ve iyi eğitim almış yabancı dil bilen personeli yetersiz olması.

\subsection{Medikal turizmde akreditasyonun önemi}

Akreditasyonunu, sağlık hizmeti veren kuruluşların hizmetteki kalitesini geliştirmek ve yükseltmek için planlanmış bir takım koşulları sağlayıp sağlamadığını belirlenmesi amacıyla gerçekleştirilen bir değerleme süreci olarak ifade edebiliriz. Hastanelerdeki akreditasyon ise hizmet sunumu konusundaki belirlenmiş olan standartlara uygun olduğunu, dış denetçiler tarafindan değerlendirilen bir süreçtir (Kalite. Saglık, 2015).

Medikal turizm hizmeti veren pazarından pay almayı hedefleyen sağlık kuruluşlarının öncelikle uluslararası akreditasyon sahibi olması gerekmektedir. Özellikle gelişmiş ülkelere hizmet sunmayı hedefleyen sağlık kuruluşlarının, tedavi amaçlı turizminde, bu hasta grubunun kalite arayışına ancak akredite olmuş servis sağlayıcılar ile hizmet verilebilir.

Günümüzde dünyada çeşitli akreditasyon kuruluşları olmasına rağmen sağlık kuruluşlarının akreditasyonu ile ilgili olarak en saygın kuruluş Amerika Birleşik Devletleri merkezli bir organizasyon olan Joint Commission International (JCI), Uluslararası Birleşik Komisyon'un Avrupa'daki benzeri ise European Foundation for Quality Management (EFQM)'dır. JCI akreditasyonuna sahip olan sağlık kuruluşları uluslararası arenadan hasta akışının daha kolay sağlaya bilmesi anlamını taşır.

JCI akreditasyonuna sahip toplam 43 sağlık kuruluşumuz vardır. Bu kuruluşların 38 adedi hastane, 3 adedi klinik laboratuvar, 1 adedi ayakta tedavi merkezi, 1 adedi tıbbi nakil merkezidir (ahd.org, 2015).

\section{Sonuç}

Türkiye ve Dünya genelinde Sağlı turizminin, özellikle de medikal turizmin ülkenin kalkınması ve tanıtılmasında önemli bir turizm çeşididir. Medikal turizm, Türkiye kıyı turizmden ortalama kişiden yaklaşık 3000 dolar kazanırken Medikal turizminden 12000 Amerikan doları gelir elde edilmektedir. Üstelik Sağlık turizminde sezon kavramı olmadı̆̆ için yılın 12 ayı hizmet verilmesi avantajı vardır. Dünya 100 milyar dolarlık ve her yıl daha fazla büyüyen bir pazar olunca medikal turizmin önemi ülkemizin ekonomisindeki değeri her geçen gün artmaktadır. Dünya sıralamasında Tayland birinci Türkiye yaklaşık 2,5 milyar dolarlık gelirle ise 10 uncu sırada yer almaktadır. Türkiye 2023 hedeflediği gelirini 2,5 milyar Amerikan dolarından 25-30 milyar Amerikan dolarına çıkarmak ve 10 uncu sıradan ilk 5 in içine girebilmeği amaçlamaktadır. Yüksek gelişme potansiyeline sahip medikal turizmin geliştirilmesi ve ülke ekonomisine katkısı için aşağıda belirtilen öneri ve uygulamalar yararlı olacaktır;

- Başta Turizm Bakanlığımız olmak üzere bu alanda faaliyet gösteren sağlık kuruluşlarının bu konuda uzman tur operatörleri ve uzman acenteler ile beraber en etkin pazarla yöntemleri nelerdir sorunun cevabı aranmalıdır.

- Medikal turizmde satış ve pazarlamanın yöntemlerinden bir tanesi olan sağlık tanıtım fuarlarına etkin bir şekilde ülkemizde faaliyet gösteren sağlık kuruluşlarının katılımı sağlanmalıdır. 
- Başta Ortadoğu olmak üzere Avrupa'nın ve gelişmiş ülkelerin sağlık ve sigorta sistemlerinin araştırılmalı, tanı, tedavi ve teknolojileri araştırılarak ülkemiz için hedef ülkeler (pazarlar) seçilmelidir.

- Medikal turizmle beraber Türkiye'nin tarihi ve doğal güzelliklerini avantajlarını kullanarak medikal turizmimde içine alacak paket turları oluşturulmalıdır.

- Medikal turizm hizmeti sunan sağlık kuruluşlarının da hizmet veren sağlık personelinin eğitim çalışmaları yapılmalı ve yabancı dil bilen sağlık personeli sayısı artırılmalıdır.

- Medikal turizm hizmeti veren sağlık kuruluşlarının mutlaka akreditasyonları almalıdırlar.

- Özellikle medikal hizmeti sunan ülkemizde sağlık kuruluşların internet üzerindeki tanıtım ve reklam faaliyetlerini artırmalıdır.

Yukarıdaki şartlar sağlandığı takdirde Sağlık Bakanlığımızın belirlediği hedef olan yıllık 25-30 milyar Amerikan dolarlık geliri sağlayabiliriz. Medikal turizm ülkemizdeki sağlık kuruluşları ve akademik çevre bakımından hem yeni hem de araştırmalara açık bir alandır. Bu konu ile ilgili daha ileri çalışmalar için; medikal turizmde bölgeler ve ülkeler arası stratejiler, medikal turistlerin ülke seçimi kriterleri, medikal turizmde arz ve talebi etkileyen faktörler, medikal turizmde sanal(internet) tanıtım ve pazarlamanın önemi, vb. konularda araştırmalar yapılabilir.

\section{Kaynakça}

- Aydın, Enginer, Aypek, Aktepe, Şahpazr, 2011. Türkiye’de Turizm Sağlık Bakanlığı Hizmetleri, Genel Müdürlüğü, 836, 2011, Ankara.

- Aydın, Yılmaz, 2010. Medikal Turizm Araştırması, Birinci Bölüm) Temel Sağlık Hizmetleri Genel Müdürlüğü, Ankara

- Bookman, Bookman, 2007. Medical Torrism in Developing Countries, Palgrave Macmillan, New York.

- Corera, Bridge, 2006. “ Globalization and Healthcare :'Understanding Helath and Medical Tourism. Export Review of Pharmacoeconomicsand Outcames Reaschrs". Future Drugs, 7 (1), 445-447,

- Çetinkaya, 2010. “Sağlık Turizmi Açısından Sağlık Turizminin Pazarlanabilirliği Konusunda Sağlık Çalışanlarının Görüşlerinin Değerlendirmesi Üzerine Bir Araştırma ”, Yayınlanmamış Yüksek Lisans Tezi, Sakarya Üniversitesi Sosyal Bilimler Enstitüsü. Sakarya.

- Eyrbeck, Guevac, Mnango, 2008 Mapping The Market For The Medical Travel, Mckinsey \& Company,

- Genç, 2007. Sağlıklı Bir Dönüşüm, Türkiye’de Sağlık Turizmi Çerceve Dergisi

- Sayı:43, 96-97,

- Gill, Singh, 2011. “ Exploring the Factors That Effect the Choice of Destination fo Madical Tourism”, USA.

- Heung, Kucukust, Song, 2010. “Medical Tourism Development in Hong Kong”, An Assessment of The Barrers, Hong Kong.

- Horowitz, Rosensweig, 2007. Medical Tourism- Health Care in The Global Economy. 2007

- İçöz, 2009. “Sağlık Turizm Kapsamında Medikal(Tıbbi) Turizm Ve Türkiye’ nin Olanakları”, JournaL of Yasar Üniversty, 4-14, 2009, İzmir

- İçöz O. ' 'Sağlık Turizmi Konusunda Medikal (Tıbbi) Turizm ve Türkiyenin Olanakları '”. Journal of Yaşar University. 2257-2279

- Jagyasi, 2010. Medical Tourism Research \& Survey Reports.

- Jones, Mc Cullough, 2007 ' What to do when Patient's International Medical Care goes South", Journal of Vascular Surgery "5) :1077-1-79

- Medhekar, 2013. “ İndian Government Policy to Support Trade in Medical Tourism Services ”, Seventy International Conference on Healthy and Global Business Issues January, 3-6,

- Jaipur, İndian.

- Şahin, Tuzlukaya, 2013. “ Turizm Türleri ve Turizm Politikaları”, Dünyada ve Türkiye'de Medikal Turizm. Sağlık Turizmi Kitabı (2 Bölüm) Siyasal Kitap Evi, Ankara

- Özkut, 2007. “ Sağlık Turizmi Tahvilleri”, Maliye DergisiSayı:152, Ankara.

- Yalçın, 2007. “Türkiye’de Sağlık Turizminde Altyapı Oluşturulma Gereği ve Sağlık Kurumlarına Yönelik Bir Araştırma”. Ankara Gazi Üniversitesi Sosyal Bilimler Enstitüsü İşletme Ana Bilim Dalı Hastane İşletmeciliği Bilim Dalı (Yüksek Lisan Tezi), Ankara.

- Tengilimoğlu, Kahraman, 2013. “Dünyada ve Türkiye’de Medikal Turizm”, Sağlık Turizmi Kitabı (4 Bölüm) Siyasal Kitap Evi, Ankara 
- Özel hasataneler.org, 20015 Medikal Turizm Nedenleri, http://www.ozelhastaneler.org.tr /images/Documents/sanal\%20kütüphane/DÜNYA\%\%20DA\%20VE\%20TÜRKIYYE\%\%20DE\%20SAĞLIK\%2 0TURİZMİ-2010.pdf.

- Akredite Hastaneler Derneği, 2015 Akredite Edilmiş Hastane Sayısı, http://www.ahd.org.tr/ akreditasyon. aspx,

- Sağlık Bakanlığı, 2015. http://www.saglik.gov.tr/SaglikTurizmi/dosya/1-91778/h/turkiye-medikal-turizmdegerlendirme-raporu.

- Haberler.com, 2015. Dünya Ticaret Örgütü 2014 Medikal Turizm Verileri http://www.haberler.com/turkiyeye-tedavi-amaciyla-gelen-hasta-sayisi-2014-7252984-haberi/;

- $\quad$ Ülkelere Göre Tıbbı ücretlerin Dağılımı, 2015. http:/w.medretreat.com/templates/UserFiles/Documents/Medical\%20Tourism\%20\%20NCPA\%20Report.pdf.

- TÜİK Verileri, 2015. http://www.tuik.gov.tr/basinOdasi/duyuru/36.pdf 


\title{
Bişkek’te Faaliyet Gösteren Türk İșletmelerinde İnsan Kaynakları Yönetimi Sorunları
}

\section{Human Resource Management Problems in Turkish Business in Bishkek}

\author{
Ömer Faruk Karaman (Kırgızistan-Türkiye Manas University, Kyrgyzstan)
}

\begin{abstract}
Human Resource Management of the basic concepts of this study, applications, functions, International Human Resources Development of management, the impact of globalization, showing the current location and activities in Kyrgyzstan aimed to determine international firms HRM issues. These problems have been introduced as a result of business manager one to one meeting with. Selected businesses are based in Turkey. The reason are Turkish companies seeking to operate in Kyrgyzstan. Especially in recent years, bilateral relations between Kyrgyzstan and Turkey are developing. Proliferation of Turkish investors in Bishkek also increases the importance of this research. This study may guide the Turkish businessmen in Bishkek.
\end{abstract}

\section{Giriş}

1980'li yıllarda ortaya çıkan küreselleşme, tüm dünyayı etkisi altına alan bir olgudur. Küreselleşme süreci; politik, ekonomik, kültürel ve sosyal sınırların ortadan kalktığı bir süreç olarak tanımlanabilir. Bu süreçte dünya ticaretinden daha fazla pay alabilmek için yeni pazarlar oluşturulmuş, ürün çeşitliliği, kalitesi, üretim hızı ve verimliliği artmıştır. Bunun yanında çok uluslu örgütler ve uluslararası örgütlerin sayısı artmış ve bu artışla birlikte, örgütler arası rekabet de artarak devam etmiştir. Yaşanan bu süreç, sürekli deşişim içinde olan dinamik bir süreç olarak tanımlanabilir (Baykal, 2007).

Ulusal ve uluslararası arenada faaliyet gösteren her işletme insan gücü ihtiyaçlarını tespit etmek, bu ihtiyaçlarını karşılayacak nitelikteki personeli istihdam etmek, rekabet üstünlüğü sağlamak, verimliliklerini arttırabilmek için çalışanları motive etmek, değişen teknoloji ve çevre şartlarına göre eğitmek ve onlara ücret ödemek durumundadır (Dereli, 2005). Bu ise insan kaynakları yönetiminin işletmeler için ne kadar önemli olduğunu göstermektedir.

“Uluslararası İşletmelerde İnsan Kaynakları Yönetimi Sorunlarının Belirlenmesi: Bişkek’teki Türk İşletmeleri Örneği” konulu yüksek lisans bitirme tezinden yararlanılarak hazırlanan bu çalışmada İnsan Kaynakları Yönetimi (IKY) temel kavramları, uygulamaları ve Bişkek’te faaliyet gösteren Türk işletmelerinin İKY sorunlarını saptamak amaçlanmışıtır. Aynı zamanda bu çalışmanın Kırgızistan'daki uluslararası anlamda faaliyet gösteren veya faaliyet göstermeyi planlayan şirket yöneticilerine İKY konusunda ışık tutması ve rehberlik etmesi planlanmaktadir.

Çalışmada uluslararası işletmelerle ilgili temel kavramlar, İKY uygulamaları, uluslararası İKY, araştırmanın yöntemi, bulgular ve son olarak sonuç, değerlendirme ve önerilere yer verilmiştir.

\section{Araştırmanın Amaç ve Önemi}

Çalışmanın amacı Kırgızistan'da faaliyet gösteren Türk işletmelerinde İnsan Kaynakları sorunlarını saptamaktır. Ayrıca bu çalışmanın Kırgızistan'da yatırım yapmayı planlayan yatırımcılara rehber olması öngörülmektedir. Çalışma sonunda konu ile ilgili önceden yapılmış çalışmalardaki boşlukları tamamlama, günümüz koşullarına uyarlama ve eksiklikleri giderme amacı güdülmektedir. Özellikle son yıllarda Türkiye ile Kırgızistan arasındaki ikili ilişkilerin gelişmesine paralel olarak Kırgızistan'da Türk yatırımcıların çoğalması da bu araştırmanın önemini artırmaktadır.

\subsection{Araştırmanın Kapsam ve Sınırılıkları}

Kırgızistan'da faaliyet gösteren tüm işletmeler arasından Türk işletmeler örneği irdelenmiş ve bu işletmelerin insan kaynakları bölümü ele alınarak kapsamda sınırlandırma yapılmıştır. Ayrıca örneğin Bişkek’ten seçilmesi kapsamı minimize etmede faydalı olmuştur. Çalışmada kullanılacak yöntemlerde ise kütüphane araştırması, mülakat ve anket verilerinden yararlanılmak üzere sınırlandırma yapılmıştır.

\subsection{Araştırma Soruları}

- Bişkek'te faaliyet gösteren işletmelerde IKKY ve çalışan sorunları hangi düzeydedir?

- İK planlaması, arama, bulma, seçme, yerleştirme sorunları hangi düzeydedir?

- Eğitim ve geliştirme, performans değerlendirme, ücretlendirme, ödüllendirme, motivasyon ve kariyer geliştirme sorunları hangi düzeydedir?

- Kariyer geliştirme, iş sağlı̆̆ ve güvenliği, çalışma ilişkileri sorunları hangi düzeydedir? 
- Kalifiye eleman bulma ve işletmede tutma, çalışanın işi sahiplenmesi, disiplin, işe geç gelme ve devamsızlık ile ilgili sorunlar hangi düzeydedir?

\section{Uluslararası İşletmelerle İlgili Temel Kavramlar}

Uluslararası kavramı sözlükte, "çeşitli milletlerin arasında yapılan, milletlerin arasında çok yönlü ilişkilerle ilgili olan, milletlerarası, beynelmilel"; uluslararasılaşma ise, "sömürgeci imparatorluklar çağından beri bilinen bir olgu olup iktisadi etkinliklerin ülke sınırlarını aşan coğrafi yayılımı" olarak tanımlanmaktadır (www.tdk.gov.tr). Bu tanımlamalara uygun olarak, etkinlikleri ülke sınırlarını aşan ve uluslararasılaşmada etkin bir araç olarak kabul edilen işletmeleri şu şekilde sıralamak ve kategorize etmek mümkündür: (1) sermayenin hangi alanlara yöneltileceği kaynak ülke tarafından belirlenen ve yerli işletmeler gibi benzer politikalarla yönetilen işletmeler, (2) yatırım politikası kaynak ülke tarafından belirlenmekle birlikte uluslararası piyasalara girebilmek için esnek ve global stratejiler takip eden işletmeler, (3) Herhangi bir ülkeye bağlı olmayan farklı uluslara mensup, sermaye sahiplerinin oluşturdukları işletmeler, (4) Uluslararası bir kuruluş tarafından kontrol edilen işletmeler (Pinnington, 2004: 3).

Uluslararası işletmeler günümüzde uluslararası ticaretin önemli bir aktörü haline gelmiştir. Dünyanın çeşitli bölgelerine yayılmış faaliyetleri ile dünya ticaretinde önemli bir yer tutmaktadırlar (Tağraf, 2002: 35). Uluslararası işletmelerin pek çok tanımları yapılmıştır. Bir tanımda "Uluslararası işletme/ şirket iki ya da daha fazla ülkede faaliyet gösteren, karının bir kısmını yabancı ülkedeki faaliyetlerden kazanan ve mal varlıklarının bir kısmı diğer ülkelerde olan şirkettir. Uluslararası şirketin karakteristik özelliği büyüklügüüür.” denilmektedir (Dereli, 2005: 61). Uluslararası işletme ikiden fazla ülkede faaliyet gösteren ve doğrudan yabancı yatırımı tanımlayan örgütlenme biçimi olan bir iş örgütü olarak da tanımlanabilmektedir (Smelser ve Baltes, 2001: 10197). Uluslararası işletmeleri ulusal işletmelerden ayıran en önemli üstünlük, global maksimizasyonu sağlayacak bir örgütlenme oluşturarak kaynaklarını sınır dışına transfer etmekteki esneklikleridir. Bununla birlikte uluslararası işletmeler sadece büyük işletmeler değildir. Küçük işletmeler de uluslararası alanda faaliyet göstermektedir (Dereli, 2005: 61). Uluslararası işletmeler farklı isimlerle altında çeşitli şekillerde tanımlanabilir.

Uluslararası (International) İ̧sletme; "Bir ülkede kuvvetli şekilde yerleştikten sonra merkezi bir yönetimden yararlanarak diğer ülkelere girmeye ve oralarda yerleşmeye çalışan firmadır"(Keser, 2003: 2). Genellikle kendi ülkesi dışında bir veya daha fazla ülkede faaliyet gösteren işletmeler olarak da birçok kaynakta gösterilmektedir (İnal Zorel, 2013: 123).

Çokuluslu (Multinational) Işsletme; "Bir ülkeden yönetilmeye başlanan ve yabancı ülkelerdeki faaliyetin sanki asıl ülkede cereyan etmiş gibi kabul edildiği firmalardır". Bir diğer tanıma göre Çokuluslu Şirket; "Genel merkezi belli bir ülkede olduğu halde, etkinliklerini bir veya birden fazla ülkelerde kendisi tarafından koordine edilen şubeler, yavru şirketler aracılığıyla ve genel merkez tarafından kararlaştırılan bir işletme politikasına uygun olarak yürütülen büyük şirketlerdir (Keser, 2003: 3). Çokuluslu şirketler, küresel ekonomik kalkınma, teknoloji transferi ve derinleşen küreselleşmede etkin rol oynamaktadırlar (Hunya, 2012: 1).

Uluslarötesi (Transnational) İşletme; "Çokuluslu bir şirket gibi kabul edilen ve yönetimi çeşitli uluslardan gelen kişilerden olan kuruluş tarafindan geliştirilen firmadır" (Keser, 2003: 2). Diğer bir deyişle uluslararası ya da ülkeler arası sınırların ötesine geçebilen, politik, ekonomik, ideolojik sınır tanımayan işletmelerdir (İnal Zorel, 2013: 123).

Uluslarüstü (Supranational) İşletme; "Halen mevcut olmayan ve hiçbir ülkeye mensup olmayan, uluslararası bir anlaşma ile kurulan, uluslararası bir kuruluş nezdinde tescil edilmiş ve bu kuruluşa bağlı olan, bu kuruluş tarafindan denetlenen, bu kuruluşlara vergi ödeyen ve böylece milletini hukuken kaybeden şirkettir"(Keser, 2003: 3).

\section{4 İnsan Kaynakları Yönetimi Uygulamaları}

Insan Kaynakları Planlaması: İnsan kaynakları planlaması ne kadar sayıda ve hangi nitelikte personele gerek duyulacağını, bu talebin hangi dereceye kadar karşılanmasının olası olduğunu tahmin etmektir. İnsan kaynakları planlaması işletmede çalışacak işgücünü nitelik ve nicelik yönünden belirli bir düzen içinde sağlamaktır. Bu kapsamda insan kaynakları planlaması organizasyonda beceri düzeylerinin belirlenmesini ve emeklilik, işten uzaklaştırma, nakil, terfi, hastalık gibi ayrılmalarla, devamsızlık ya da diğer nedenlere ilişkin şimdiki ve beklenen ayrılmalar, şimdi ve gelecekte beklenen işletmenin genişlemesi ya da daralması ile ilgili bir öngörüyü içermektedir (Uysal, 2007: 13). Aynı zamanda İnsan Kaynakları planlaması hedeflerinin belirlenmesi, mevcut ve gelecekteki yeterli insan gücü ile iş görevleri sağlamak için düzenlemeleri gerçekleştirerek, kalkınma tahmini ile örgütün hedeflerine ulaşmak için hizmet vermektedir (Koltnerova vd., 2012: 62).

Personel Temini ve Seçimi: İnsan kaynakları temini ve seçimi sürecinde, ilk olarak çalışan işgücü ihtiyacı sayısal olarak belirlenir sonra iş ilanları ve internet aracılığı ile işin niteliğine uygun adaylar bulunur. Burada önemli olan aranan niteliklerin tam olarak belirlenip, işe en uygun adayın alınmasıdır. Ayrıca İnsan kaynakları, işletmede boşalan ya da boşalacak görevlere iç ve dış kaynaklardan başvuran adaylar arasından işin gereklerine 
en uygun kişi ya da kişileri seçmelidir. İşletmenin gerek kendi personeline gerekse dışarıya karşı izlediği insan kaynakları politikasının olumlu görüntüsü, sağlam temellere ve ilkelere dayalı bir iş gören seçim sistemiyle sağlanabilir. Objektif ilkelere dayalı bir iş gören seçim süreci işletmeye karşı güven oluşturduğu gibi, adaylar arasından en iyisini seçmekle işletmeye daha verimli bir çalışma olanağ 1 verir (Yurdatapan, 2011: 39).

Ĕ̆itim, Geliştirme ve Yetiştirme: Eğitimin en genel tanımı, yeteneklerin gelişmesinde bir araç olmasıdır. İşletme için, eğitimler iş gücünün daha verimli olması için çeşitli eğitim programları vasıtasıyla çalışanın bilgi, beceri ve davranışlarında olumlu gelişme sağlanması amaçlanır. Aslında bir çalışanın işe başlamasından işten ayrılıncaya kadar performanslarının yükseltilmesi için işletme tarafından yapılan çabaların tümü, eğitim ve geliştirme faaliyetlerinin içinde yer alır. Yani şirketlerde verilen eğitim ve geliştirme faaliyetleri çalışana sadece belli dönemlerde değil, tüm iş yaşamı boyunca uygulanmalıdır (Deringöl, 2010: 49).

Geliştirme, organizasyonun uzun vadede rekabet edebilme potansiyelini iyileştirebilmek için kişilerin ve grupların performansını arttırıcı strateji ve planları geliştirmeyi ve uygulamayı; performans planı ve gözden geçirme süreçlerini uygulamayı; bireylerin kapasitelerini arttırmak için eğitime, uzun vadeli kişisel gelişmeye ve takım gelişmesine önayak olmayı içermektedir (Bayraç, 2008: 127).

Yetiştirme ve geliştirme kavramları birbiriyle yakın kavramlardır. Yetiştirme, kişinin işinde yapabildikleriyle yapması gerekenler arasındaki boşluğu dolduran eylemlerden oluşmaktadır. İşgörenlerin çalıştığı işte gereksinim duyduğu bilgi ve beceriyi sağlamaya ilişkin bir eylemdir. Genellikle yeni işe başlayan işgörenin işinde yetişmesini sağlayan bir faaliyettir (Ertürk, 2011: 118).

Performans Dĕ̆erlendirme: Başarı değerlendirmesi bir yöneticinin önceden belirlenmiş standartlarla karşılaştırma ve ölçme yoluyla personelin iş başarımını değerlendirmesi sürecidir. Kısaca başarı değerlendirmesi personelin kendisinden beklenen görevleri ne derece iyi gerçekleştirdiğini belirlemeye yönelik bir süreçtir. Başarı değerlendirmesinin amaçları genel olarak değerleme ve geliştirme amaçları şeklinde iki ana grupta toplanabilir. Değerleme amaçları, ücretlendirme, ödüllendirme, yükseltme, rütbe düşürümü, işten uzaklaştırma gibi konularla ilgilidir. Geliştirme amaçları ise yönetici geliştirme, başarının geliştirilmesi insan gücü planlaması gibi süreçlerle ilgilidir (Bingöl, 2013).

Performans yönetimi sadece performans değerlendirme amacıyla değil aynı zamanda bilgi ve liyakat değerlendirmesi olarak örgüt yönetiminin olumsuz yönlerine tepki olarak 1980'lerin sonlarına doğru ortaya çıktığı görülebilmektedir (Itika, 2011: 94).

Ücretlendirme: Personelin örgüte yaptığı katkılar karşılığı aldığı ücret onların yaşamlarını devam ettirmesini sağlaması yanında personele örgüt içinde bir statü ve saygınlık da kazandırmaktadır. Bireyler paraya onun değişim gücünün gerektirdiğinden daha fazla önem vermektedir. Çünkü para toplumda statü elde etmek için gerekli olan önemli bir faktördür. Yüksek statü daha çok saygı daha çok ilgi topladığından bireyler için değerlidir. Yapıla ücret ödemeleri artıp birey çevresindekilerden daha fazla kazanç elde ettiğinde ise bu bireyde başarı veya başarılı olma duygusu gelişir. Ücret kavramı örgüt açısından da büyük önem taşır (Bingöl, 2013: 123).

Ödüllendirme ve Motivasyon: Ödüllendirme, geçmiş çabaları için çalışana bir teşekkür ve gelecek performansı teşvik etmede etkili bir araçtır. Performansa bağlı ödüllendirme, çalışanların davranış ve performansını etkiler. Ücret, terfi ve örgütte kalma gibi ödüllendirme kararları performansa bağlı olursa, bu çalışanların performans ve iş tatminini artırır. Ödüllendirmeyi de içeren bütünleştirilmiş insan kaynakları uygulamaları yetenekli insanları örgütte tutar, örgütsel bağlılığı artırır, beceri geliştirmeye teşvik eder ve yüksek performans ile sonuçlanacak davranışlar göstermeye çalışanları motive eder. $\mathrm{Bu}$ nedenle çalışanların tutumlarını etkilemek ve örgütsel amaçlara ulaşmalarını sağlamak için, ödüllendirme uygulaması yalnızca ücret ve yan ödemeleri değil, başarılı çalışanın tanınması, kariyer ve çalışan yaşamına ait ödül programlarını da içermelidir. Çok değişkenli ödüllendirme paketi bu sayede, çalışanı başarılı olma yönünde güdülemek ve çalışanlara değer kazandırması amacıyla örgüt stratejilerine sıkıca bağlanmalıdır. Yönetim bu noktada ödüllendirme yöntemlerinin çalışan tutum ve davranışlarını etkileyip etkilemediğini gözlemelidir (Uysal, 2013).

\section{Uluslararası İnsan Kaynakları Yönetimi}

Üretimin küreselleşmesiyle, tüketim kalıpları ile zevklerin giderek ayrışmasının, üretim yapılarını ülkelerin farklı yapısal ve ekonomik şartlarına uydurma gereğini beraberinde getirmesi insan unsurunun önemi üzerinde dikkatlerin yoğunlaşmasına yol açmıştır. Bu da, Çokuluslu şirketlerin, uluslararası üst düzey yönetici seçiminde, geleneksel personel yönetim uygulamasından uluslararası insan kaynaklarına yönelmelerine yol açmıştır. UİKY, insan kaynakları yönetimi disiplininde bir araştırma alanı olarak kısa bir süre önce ortaya çıkmıştır (Parlak, 2000: 199). Aynı zamanda uluslararası bir ortamda çalıştırmak için bir insan kaynakları departmanı uluslararası ilişkiler ve yönelim, konuk işletme için idari hizmetler, konuk ve devlet ilişkileri ve dil tercüme hizmetleri alanlarında faaliyet gösterebilmektedir (Dowling vd., 2008).

Yerel ve uluslararası insan kaynaklarını uygulamalarını birbirinden ayıran en temel özellik, uluslararası alanda farklı ülkelerdeki uygulamaları yürütmekten ve farklı ulusları çalıştırmaktan kaynaklanan karmaşıklıklardır. Bu 
iki uygulamayı ayırıcı diğer önemli özelikle ise, insan kaynakları yönetimi ile çokuluslu işletmelerin stratejik ve organizasyonel seviye unsurlarının bir araya getirilmesidir (Ünal, 2008: 77).

Ayrıca uluslararası İnsan kaynakları yönetimini yerel İKY'den ayıran etmenler şu şekilde de siralanabilmektedir (Helm, 2014: 3):

- Daha fazla İK faaliyetleri

- Geniş bir perspektif ve ihtiyaçlar kümesi

- Çalışanların kişisel yaşamları (sorunlar)

- Gurbetçiler ve yerli işgücünün farklılıkları

- İşletmenin riskleri

- Geniş diş etkiler

\subsection{Uluslararası İşletmelerde İnsan Kaynakları Yönetim Fonksiyonları}

Çokuluslu işletmelerin yatırım yaparak üretime geçirdikleri yavru işletmelerini nasıl yönettikleri çeşitli açılardan incelenmiştir. En çok üzerinde durulan noktalardan biri de çokuluslu işletmelerde organizasyon yapısına verilen önemdir. Her ülkenin ve işletmenin yapısına göre seçilen organizasyon tipleri bu işletmelerin başarılı olmasını sağlamıştır. İnsan kaynakları yönetiminde yapıya önem verilmesinin bir diğer nedeni de çokuluslu ilişkilerin karmaşıklığını azaltıp, ilişkileri daha fazla netleştirmektir (Dereli, 2005: 63).

Planlama: Uluslararası planlama, çokuluslu ortamın değerlemesi, gelecekteki dünya çapında olanak ve tehlikelerin tahmin edilmesi, bu çevresel değerleme ışı̆̆ında işletmenin global amaç ve stratejilerinin saptanması, güçlü ve zayıf yönlerinin ortaya çıkarılması ile ilgilidir. Çokuluslu işletmelerin çoğunda personel stratejileri planlanmasına, çeşitli ülkelerde ihtiyaç duyulacak yöneticiler, bilim adamları, mühendisler, teknik elemanlar ve işgören tiplerinin tasarlanması ile başlanmaktadır. İnsan kaynakları yönetiminde personel işleri incelenirken, planlamanın niteliği, personel programlarının hedefleri, personel politikası planlamada önemli yer tutacaktır. Planlama düzenli bir yönetim biçimidir. İsgörenlerin çoğu, az ya da hiç yetişmemiş ve eğitilmemiştir. Çokuluslu işletmeler için gelişmekte olan ülkeler sahip olduğu işgörenlerini gereksinim duyulduğunda yetiştirip, geliştirip, hazırlamak zorundadır (Dereli, 2005: 64).

Uluslararası bir organizasyonda yönetim tarzı çalışanları etkilemektedir. Bu bağlamda etnisite merkezli yönetim yaklaşımında olan bir işletmede genelde önemli pozisyonlara ana ülke vatandaşları yerleştirilmektedir. Oysa ki evrensel yaklaşımda olan yani jeosantrik bir işletme yönetiminde ise bir pozisyona en uygun olan kişi seçilir (Treven, 2001: 181)

Organizasyon: Organizasyon görev, yetki ve sorumlulukları belirleme, bölüştürme ve dağıtma işlevidir. Eğer yönetim kademesi birçok ülkede yapılacak yönetimi işletebilecek beceri kazandırılmış işgücüne sahip değilse, teknik personel yetersizse organizasyonel yapı ve planlamanın gerçekleştirilmesi mümkün değildir. Çokuluslu işletmelerin özel organizasyonel ihtiyaçları vardır, çünkü firmaların yönetimi, girişimleri, tüm ihtiyaçları uluslararası ölçek üzerindedir. Bu gereksinmelerden en önemlisi firmanın sistem yaklaşımına olan ihtiyacıdır. $\mathrm{Bu}$ yaklaşımda organizasyonun birbirinden ayrı parçaları tamamıyla birleşik olarak düşünülmüştür. Her bir kısım birbirleriyle ilgili olarak bağımsız fonksiyon görebilir. Ancak her bölüm diğer bölümlerle bir koordinasyon ve birliktelik içinde olmalıdır (Hays vd., 1972: 267).

Kontrol: Kontrol işlevi genellikle, faaliyetlerin verilen talimatlara ve kurallara uygun biçimde yerine getirilip getirilmediğini gözetmek olarak tanımlanabilir. Kontrol sürecinde dört ana unsur vardır (Sherman ve Bohlander, 1992: 27):

1) Performansın ölçülebilmesi için standartların belirlenmesi.

2) Kişisel ya da organizasyonel performansı izlemek için tekniklerin ve yöntemlerin geliştirilmesi.

3) Gerçeklesen performansın planlanan performansla karşılaştırılması.

4) Planlanandan ciddi performans sapmalarını ortadan kaldırmak için düzeltici önlemler alınmasıdır.

\section{Araştırmanın Yöntemi}

Araştırmanın yöntem bölümünde araştırmanın modeli, evreni, örneklemi, verilerin toplanması ve verilerin analiz edilmesine ilişkin hususlar bulunmaktadır.

\subsection{Araştırmanın Modeli}

Araştırmada, Bişkek'te faaliyet gösteren Türk işletmelerindeki sorunları belirlemek amacıyla İKY fonksiyonları ve işgören sorunları ile demografik sorulara verilen cevaplara göre farklılaşan grupları birbiriyle karşılaştırarak ilişkisel karşılaştırma modeli kullanılmıştır.

\subsection{Araştırmanın Evreni ve Örneklemi}

Araştırmanın evrenini Bişkek'te faaliyet gösteren Türk işletmeleri oluşturmaktadır. Bu işletmeler için KITİAD (Kırgız Türk İşadamları Derneği) üyesi olan 95 Türk işletmesi örneklem grubu olarak incelenmiştir. Söz konusu üyeler içinden 52 Türk işletmesi seçilmiştir. 


\subsection{Veri Toplama}

Araştırmayla ilgili yapılan çalışmalara ilişkin incelenen literatür ve araştırmaya pilot çalışma olarak hazırlanan mülakat sonucunda elde edilen bulgular doğrultusunda anket hazırlanmış ve Bişkek’te bulunan 52 Türk işletmesi sahibi/IKK çalışanı veya üst düzey yöneticisi tarafından doldurulan anketler aracılığıyla veri toplama işlemi gerçekleştirilmiştir. Anket tekniği ile hazırlanan çalışmada Sezer ve Karaman (2014) tarafından hazırlanan "Ülke Dışında Faaliyet Gösteren Türk İşletmelerinin IKKY Fonksiyonlarına İlişsin Sorun Algıları: Bişkek’te Bir Araştırma" makalesinden yararlanılmıştır.

Ankette yer alan işletmenin demografik özellikleri ile İKY fonksiyonları sorunlarına ilişkin ifadelere verilen cevaplar "Çok yüksek", "Yüksek", "Orta”, "Düşük” ve "Çok düşük” olarak 5'li Likert tipinde hazırlanmıştır. Söz konusu ankette işletmenin demografik özelliklerine bağlı olarak işletme türü, faaliyet alanı, merkez ülke, faaliyet gösterdiği ülke, hukuki yapı, işletme yaşı, çalışan sayısı, yönetici ülkesi soruları yer alırken bağımlı değişkenler bölümünde İKY fonksiyonları ve işgören sorunlarına ilişkin sorular yer almıştır. [Puan Aralığ1 = (En yüksek değer - En düşük değer) $/ 5=4 / 5=0,80$ ] formülü ile aritmetik ortalamalar için puan aralığı katsayısı 0.80 olarak hesaplanmıştır. Aralıkların eşit olduğu varsayılmış ve bu değer cevap kodlarının en düşüğü olan 1,00'den başlayarak ardışık olarak sonraki değerlere eklenmek suretiyle değerlendirme aralıkları elde edilmiştir.

\subsection{Verilerin Analizi}

Anketlerden elde edilen veriler SPSS 16.0 programına aktarılmak suretiyle işletmenin demografik bilgileriyle İKY ve işgören sorunlarının frekans ve yüzdeleri verilmiştir. Elde edilen sonuçlara göre İKY ve işgören sorunlarına ilişkin verilen cevaplar doğrultusunda sorun düzeyleri (aritmetik ortalamaları) belirtilmiştir. Cronbach's Alpha değerinin $0.80 \leq \alpha<1$ aralığında olması ölçeğin yüksek düzeyde güvenilir olduğu anlamına gelirken (Sevim, 2014: 953) yapılan çalışmada bu değer 0.92 olarak belirlenmiştir.

\section{Bulgular}

Yapılan mülakat sonuçlarına göre Kırgızistan’da faaliyet gösteren uluslararası işletmelerde İnsan Kaynakları Yönetiminde sıkça rastlanan sorunların başında vasıflı, tecrübeli, sorumluluk sahibi, işi sahiplenen işgörenlerin bulunmasının zor olduğu saptanmıştır. Bunun nedeni ise çalışanlara verilmekte olan ücretlerin az olması çalışma esnasında işletme sahibi, İK yöneticisi ve çalışanlar ile yapılan anket ve mülakat sonucunda belirlenmiştir. Söz konusu işletmelerde uygulanan İK uygulamalarının da profesyonelce yapılmadığı saptanmıştır. Böylece yapılan mülakatlardan elde edilen verilere göre hazırlanmış olan anket bulguları ve değerlendirme aşağıda belirlenmiştir.

Yapılan çalışmada ele alınan işletmelerin demografik özellikleri şu şekildedir;

İşletmelerin \% 75'i kendisini uluslararası, \% 25'i ise kendisini uluslararası olmayan (yerel/ulusal) işletme olarak tanımlamaktadır. Bu işletmelerin \% 36,5'i hizmet ve üretim alanında faaliyet gösterirken, \% 27 'si ticaret alanında faaliyet göstermektedir. Merkezi Türkiye olan işletmelerin oranı \% 71,2 iken Kırgızistan merkezli işletmelerin oranı \% 28,8 olarak kaydedilmiştir. Söz konusu işletmelerin faaliyet gösterdiği ülkeler arasında Kırgızistan \% 100'lük bir orana sahip iken Türkiye \% 42,3, Kazakistan \% 28,8, Rusya \% 11,5 ve diğer ülkeler \% 17,3 oranındadır.

$\begin{array}{clc} & \text { Sorunlar } & \text { Ortalama } \\ \mathbf{1} & \text { İnsan Kaynakları planlaması sorunları } & 2,69 \\ \mathbf{2} & \text { İnsan kaynakları arama sorunları } & 2,77 \\ \mathbf{3} & \text { İnsan kaynakları bulma sorunları } & 2,90 \\ \mathbf{4} & \text { İnsan kaynakları seçme sorunları } & 2,80 \\ \mathbf{5} & \text { İnsan kaynakları yerleştirme sorunları } & 2,74 \\ \mathbf{6} & \text { Eğitim ve geliştirme sorunları } & 2,80 \\ \mathbf{7} & \text { Performans değerlendirme sorunları } & 2,76 \\ \mathbf{8} & \text { Ücretlendirme sorunları } & 2,74 \\ \mathbf{9} & \text { Ödüllendirme sorunları } & 2,85 \\ \mathbf{1 0} & \text { İK motivasyon sorunları } & 2,85 \\ \mathbf{1 1} & \text { Kariyer geliştirme sorunları } & 2,98 \\ \mathbf{1 2} & \text { İş sağlığı ve güvenliği sorunları } & 3,19 \\ \mathbf{1 3} & \text { Çalışma ilişkileri sorunları } & 3,36\end{array}$

Tablo 1 İşletmelerdeki IK Fonksiyonları sorunlarının aritmetik ortalaması

Hukuki yapısına göre bu işletmelerin \% 46,2 sini limitet şirketleri oluşturmakla beraber \% 38,5'ini anonim şirketleri oluşturmaktadır. Bahse konu işletmelerin yaş dağılımına bakıldığında 11-15 yaş aralığında olan işletmeler \% 32,7 oranla çoğunluğu oluştururken, 0-5 ile 16-20 yaşları arasındaki işletmelerin oranı \% 19,2'dir. 6-10 yaşları arasındaki işletmelerin oranı \% 15,4, 21 ve üstü yaşlardaki işletmelerin oranı ise \% 13,5'tir. Çalışan sayısına göre işletmelerin dağılımında 10-49 arası çalışana sahip olanların oranı \% 30,5, 50-99 arası çalışanı bulunanların oranı ise \% 28,8'dir. $\mathrm{Bu}$ ise işletmelerin çoğunluğunun orta ölçekli olduğunu göstermektedir. 
Bununla birlikte söz konusu işletmelerin \% 50'sinde İK departmanı, \% 51,9'unda İK yöneticisi ve \% 55,8'inde İK danışmanı bulunmaktadır.

Araştırma anketine katılan işletmelerde insan kaynakları planlaması sorun düzeyinin aritmetik ortalaması 2,69, insan kaynakları arama sorunları 2,77, insan kaynakları bulma sorunları 2,90, insan kaynakları seçme sorunları 2,80, insan kaynakları yerleştirme sorunları 2,74 düzeyinde belirlenmiştir. Eğitim ve geliştirme sorunlarında 2,80, performans değerlendirme sorunlarında 2,76, ücretlendirme sorunlarında 2,74, ödüllendirme sorunlarında ise 2,85 ortalama çıkmıştır. İnsan kaynakları motivasyon sorunlarına ilişkin 2,85, kariyer geliştirme sorunlarına ilişkin 2,98, iş sağlığ 1 ve güvenliği sorunlarına ilişkin 3,19 ve son olarak çalışma ilişkileri sorunlarına ilişkin 3,36 ortalama elde edilmiştir.

\begin{tabular}{|l|l|l|}
\hline & Sorunlar & Ortalama \\
\hline $\mathbf{1}$ & Kalifiye (vasıflı) eleman bulma sorunları & 3,48 \\
\hline $\mathbf{2}$ & Yerleştirilen elemanın işletmede tutulması & 3,51 \\
\hline $\mathbf{3}$ & Çalışanın işi sahiplenmesi ile ilgili sorunlar & 3,61 \\
\hline $\mathbf{4}$ & Çalışanların disiplin ile ilgili sorunlar & 3,50 \\
\hline $\mathbf{5}$ & İşe geç gelme ile ilgili sorunlar & 3,60 \\
\hline $\mathbf{6}$ & Devamsızlık sorunları & 3,05 \\
\hline
\end{tabular}

Tablo 2 Işsletmelerdeki çalışanlar ile ilgili sorunların aritmetik ortalaması

Anket çalışmasına katılan ve pilot çalışma olarak yapılan mülakat verilerine göre hazırlanan işletmedeki çalışanlara ilişkin sorulara verilen cevaplar doğrultusunda kalifiye (vasıflı) eleman bulma sorunlarına ilişkin 5'li puanlamaya göre 3,48 sorun düzeyi ortalaması çıkmıştır. Yetiştirilen vasıflı elemanın işletmede tutulmasıyla ilgili 3,51 oranında sorun düzeyi saptanırken, çalışanın işi sahiplenmesi ile ilgili sorun düzeyi 3,61 olarak en yüksek değeri vermiştir. Çalışanların disiplin ile ilgili sorun düzeyi 3,50, çalışanların işe geç gelmesi ile ilgili sorun düzeyi 3,60 ve çalışanların devamsızlıkları ile ilgili sorun düzeyi ortalaması 3,05 olarak belirlenmiştir.

\begin{tabular}{|l|l|l|l|l|l|}
\hline \multicolumn{5}{|c|}{ Disiplin ile ilgili sorunlar } \\
\hline & Çok düşük & Düşük & Orta & Yüksek & Çok Yüksek \\
\hline A.Ș. & $\% 16,7$ & $\% 5,6$ & $\% 5,6$ & $\% 55,6$ & $\% 16,7$ \\
\hline Ltd. & $\% 0$ & $\% 10$ & $\% 40$ & $\% 35$ & $\% 15$ \\
\hline
\end{tabular}

Tablo 3 Hukuki yapısına göre işletmelerdeki çalışan sorunları (Yüzde)

Çapraz tablolama sistemiyle yapılan yukarıdaki tabloda görüldüğü üzere işletmelerin hukuki yapısına göre çalışanlara ilişkin sorunlar bölümünde yalnız "disiplin ile ilgili sorunlar" bölümünde en fazla işaretlenen seçenek farklı çıkmıştır. Anonim şirketlerinde en fazla \% 55,6 oran ile "yüksek" seçeneği işaretlenirken limitet şirketlerinde en fazla \% 40 oran ile "orta" seçeneği işaretlenmiştir. Bununla birlikte kalifiye eleman bulma konusunda her iki işletme türünde en fazla "yüksek", kalifiye elemanın işletmede tutulması ile ilgili sorunlarda "yüksek", çalışanın işi sahiplenmesi konusunda iki işletme türünde "yüksek", işe geç gelme konusunda "yüksek" ve devamsızlık konusunda "orta" seçeneği işaretlenmiştir.

\begin{tabular}{|c|c|c|c|c|c|c|c|c|c|c|c|}
\hline & 1 & 2 & 3 & 4 & 5 & 6 & 7 & 8 & 9 & 10 & 11 \\
\hline İnsan kaynakları & 1 & & & & & & & & & & \\
\hline İnsan kaynakları & 852 & 1 & & & & & & & & & \\
\hline İnsan kaynakları &, 670 & ,655 & 1 & & & & & & & & \\
\hline İnsan kaynakları &, 591 &, 644 &, 727 & 1 & & & & & & & \\
\hline Ĕgitim ve geliștirme (5) & .546 & .549 & .647 & 891 & 1 & & & & & & \\
\hline Performans &, 575 &, 634 &, 504 &, 673 & ,734 & 1 & & & & & \\
\hline Ücretlendirme (7) &, 463 & 546 &, 362 & .655 &, 716 & ,806 & 1 & & & & \\
\hline Ödüllendirme (8) &, 346 &, 396 &, 370 &, 575 & 467 &, 595 &, 641 & 1 & & & \\
\hline Motivasyon (9) &, 316 &, 431 &, 340 & .514 &, 385 &, 430 &, 412 & .789 & 1 & & \\
\hline Kariyer geliștirme (10) &, 440 & .592 & .507 &, 718 & 465 &, 424 &, 384 & .749 & ,731 & 1 & \\
\hline Çalıșan ilișkileri (11) & 310 & 412 & .540 & .540 & 409 & 331 &, 337 & 436 & 360 & .639 & 1 \\
\hline
\end{tabular}

Tablo 4 IKKY fonksiyonları sorunları arasındaki ilişki (Korelasyon Analizi)

Tablo 4'te belirtilen Korelasyon analizine göre bütün sorun algıları arasında (İK planlamasının motivasyon ve çalışma ilişkileri hariç) birçoğu güçlü olmak suretiyle anlamlı ilişki olduğu saptanmıştır.

\section{Sonuç ve Değerlendirme}

İK fonksiyonları ve işletmedeki çalışan sorunlarına ilişkin verilen cevaplar ise aşağıdaki gibi belirlenmiştir;

İnsan Kaynakları planlaması, arama, bulma, seçme ve yerleştirme sorunlarına ilişkin verilen cevapların çoğunluğu "orta" düzeydedir. Eğitim ve geliştirme, performans değerlendirme ve ücretlendirme sorunlarına 
ilişkin sorun düzeyi yine "orta" düzeydedir. Ödüllendirme, motivasyon ve kariyer geliştirme sorunlarında ise yine değerler birbirine yakın olmakla beraber "orta" düzeyde sorun olduğu tespit edilmiştir.

İş sağlı̆̆ ve güvenliği sorunlarına ilişkin en fazla işaretlenen seçeneğin “yüksek” olması Kırgızistan'ın sağlık koşulları ve ülke iş kanunlarının yetersiz olmasına bağlanabilir.

Çalışma ilişkileri konusunda "yüksek" derecede sorun algısının belirlenmesinde farklı ülke mensubu olan çalışanlar arasında kültür çatışmasının neden olduğu söylenebilir. Aynı zamanda kalifiye eleman bulma ve yetiştirilen kalifiye elemanın işletmede tutulmasına ilişkin sorun düzeyinin "yüksek" olarak tespit edilmesi Bişkek’te yeterli düzeyde mesleki eğitim verilmemesine bağlanabilir.

Çalışanın işi sahiplenmesi ve disiplin konusunda işletmelerden alınan cevaplar doğrultusunda çıkan "yüksek" düzeydeki sorun algısının sebebinin ise bu işletmelerde örgüt kültürü, kurumsallaşma, örgüt ahlakı ve çalışma ahlakı konusunda eksikliklerin olduğu söylenebilir. Aynı zamanda işe geç gelme sorunlarına ilişkin çıkan "yüksek" derecede sorun düzeyinin sebebi de bu nedenlere bağlı olabilir.

Devamsızlık ile ilgili sorunlar sorusuna ise işletmelerden ağırlıklı olarak "orta" düzeyde cevap alınmasıyla beraber "yüksek" oranı da ikinci en çok işaretlenen seçenekler arasındadır.

İşletmelerdeki çalışan sayısının İK departmanı, yöneticisi ve danışmanı durumuna göre dağılımına bakıldığında oran olarak farklılıklar görülmektedir. Çalışan sayısının arttığı işletmelerde İK Departmanı, yöneticisi veya danışmanı da paralel olarak artış göstermektedir. Çalışan sayısı açısından mikro ve küçük ölçekli işletmelerde İK departmanı veya çalışanı sayısında en az oran görülmektedir. Orta ve büyük ölçekli işletmelerde bu oran artı̧̧ göstermektedir. Oran olarak en fazla İK departmanı, yöneticisi ve danışmanı bulunduran işletme 100-149 arasında işçi çalıştıran işletmeler olarak belirlenmiştir.

İşletmelerin türlerine göre İKY fonksiyonlarına verilen cevaplar doğrultusunda ise uluslararası olmayan (yerel/ulusal) işletmelere göre uluslararası işletmelerdeki İKY fonksiyonlarının sorun düzeyi daha yüksek çıkmıştır. Bunun nedeni ise uluslararası işletmelerin ülkedeki işgücü piyasasından yeteri kadar faydalanamadığı olabilmektedir. Ayrıca her iki işletme türünde de kalifiye eleman bulunması, kalifiye elemanın tutulması, çalışanın işi sahiplenmesi, disiplin, işe geç gelme ve devamsızlık sorunlarına ilişkin verilen cevaplarda sorun düzeyinin yüksek olduğu ve değerlerin birbirine yakın olduğu tespit edilmiştir. Bunun nedeni ise uluslararası işletmelerde İK fonksiyonlarının daha iyi düzeyde gerçekleştiği olabilir.

İşletmelerde İK çalışanının durumuna göre İK fonksiyonlarına verilen cevaplar incelendiğinde İK çalışanı olan işletmelerde verilen cevaplar arasında keskin ayrımlar varken İK çalışanı olmayan işletmelerde verilen cevaplar doğrultusunda genelde birbirine yakın değerler olduğu görülmektedir. Bu ise İK çalışanı olan işletmelerdeki sorunların kesin olarak belirlenmiş olmasına bağlanabilir. Bu durum İK personeli olmayan işletmelerde ise tam tersi durumundadir.

Faaliyet alanlarına göre işletmelerdeki çalışan sorunlarına bakıldığında kalifiye eleman bulma konusunda oranlar birbirine yakın olmakla beraber en fazla sorunu yaşayan üretim işletmeleri tespit edilmiştir. Bunun nedeni ise üretim açısından mesleki yeterliliğe sahip olan çalışanların bulunamamasına bağlanabilir.

Yetiştirilen kalifiye elemanın işletmede tutulmasına ilişkin yaşanan sorunlar düzeyi en fazla ticaret işletmelerinde gerçekleşmektedir. Bunun nedeni de mesleğinde yetişen vasıflı çalışanın daha yüksek geliri olan farklı işletmelere yönelmesi olabilir.

Çalışanın işi sahiplenmesi konusunda hizmet, üretim ve ticaret işletmelerinde sorun düzeyi birbirine yakın oranlar ile yüksek olarak belirlenirken disiplin konusunda üretim işletmelerinde diğerlerine göre daha yüksek düzeyde sorun olduğu belirlenmiştir. Bunun yanında işe geç gelme konusunda hizmet işletmeleri diğerlerine göre daha fazla yüksek derecede sorun yaşadığını belirtmiştir.

İşletmelerin hukuki yapısına göre çalışanlara ilişkin sorunlar bölümünde yalnız "disiplin ile ilgili sorunlar" bölümünde en fazla işaretlenen seçenek farklı çıkmıştır. Anonim şirketlerinde disiplin konusunda yüksek sorun olduğu belirtilirken limitet şirketlerinde orta düzeyde sorun yaşandığı tespit edilmiştir. Bununla birlikte kalifiye eleman bulma, işletmede tutma, çalışanın işi sahiplenmesi ve işe geç gelme konusunda anonim ve limitet şirketlerinde yüksek düzeyde sorun belirlenmiştir.

Sonuç olarak Bişkek'te faaliyet gösteren Türk işletmelerinde İnsan Kaynakları Yönetimi fonksiyonları konusunda genel olarak orta düzeyde sorun yaşanırken işletme çalışanları konusunda yüksek düzeyde sorun yaşandığı belirlenmiştir. Aynı zamanda işletmenin türü, faaliyet alanı, işletmede çalışan sayısı gibi değişkenler arasında bu sorunlar sınırlı da olsa farklılaşma gösterebilmektedir. Genel olarak işletme demografilerine göre İKY sorunlarında farklılığa rastlanmamıştır. Dolayısıyla İKY sorunlarının tüm işletmelerde genel olduğu söylenebilir.

\section{9 Öneriler}

- Bişkek’te faaliyet gösteren işletmelerde IKKY fonksiyonlarının daha iyi düzeyde gerçekleştirilmesi için işletmeler tarafından çalışmalar yapılmalıdır. 
- İşletmelerde İKY fonksiyonları daha profesyonelce gerçekleştirilmelidir.

- İşletmeler için İKY konusunda hizmet verecek danışmanlık merkezleri kurulmalıdır.

- İşletmelerde kurumsallaşma, örgütsel ahlak, çalışan ilişkileri olgularına gereken önem verilmelidir.

- İşletmeler tarafından insan kaynakları planlaması yapılırken çevresel faktörler dikkate alınmalıdır.

- Çalışmada yapılan analizlerde çıkan ilişki ve farklılaşma nedenleri daha sonra yapılacak olan çalışmalarla belirlenmelidir.

\section{Kaynakça}

- Baykal, B., (2007) Uluslararası İnsan Kaynakları Yönetimi: Yönelim, Felsefe ve Uygulamalar Bakımından Karşılaş̧ırmalı Bir İnceleme, Yüksek Lisans Tezi, Gazi Üniversitesi Sosyal Bilimler Enstitüsü, Ankara.

- Bayraç, A. (2008) İşletmelerde Stratejik İnsan Kaynakları Yönetiminde Eğitim ve Geliştirme, Yüksek Lisans Tezi, Selçuk Üniversitesi, Sosyal Bilimler Enstitüsü, Konya.

- Bingöl, D., (2013) İnsan Kaynakları Yönetimi,8. Baskı, Beta Yayınları, İstanbul.

- Dereli, B. (2005) Çokuluslu İşletmelerde İnsan Kaynakları Yönetimi, İstanbul Ticaret Üniversitesi Sosyal Bilimler Dergisi, 4(5):59-81.

- Deringöl, H., (2010) Trihsel Gelişimi İçinde İnsan Kaynakları Yönetimi Anlayışı, Amaçları ve Fonksiyonları Üzerine Çukurova Bölgesinde Faaliyet Gösteren İşletmelerde Bir Araştırma, Yayımlanmamış Yüksek Lisans Tezi, Çukurova Üniversitesi Sosyal Bilimler Enstitüsü. Adana.

- Dowling, P. J. vd. (2008) International Human Resource Management, Fifth Edition.

- Ertürk, M. (2011) İnsan Kaynakları Yönetimi, Beta Yayıncılık, İstanbul.

- Hays R., ve Korth C., (1972) International Business and Introduction to the World of the Multinational Firm, New York, Printice-Hall.Inc.

- Helm, K. (2014) International Human Resource Management, South-Western Cencage Learning.

- Hunya, G. (2012) The Role of Multinational Companies in International Business Integration, Research Reports.

- İnal Zorel, F. (2013) Uluslararası İşletme Çalışanlarının Sahip Olması Gereken Niteliklerden Biri Olarak Kültürlerarası Yetkinlik, Uluslararası Sosyal Araştırmalar Dergisi, 7 (30), ss.122-135.

- Itika, J. S. (2011) Fundamentals of Human Resource Management, University of Groningen.

- Keser, A. (2003) Çokuluslu Şirketlerde İK Yönetimi, Uludağ Üniversitesi, İktisadi ve İdari Bilimler Fakültesi, Çalışma Ekonomisi ve Endüstri İliş̧kileri Bölümü.

- Koltnerova, K., Chlpekova, A. ve Samakova. J. (2012) The Importance Of Human Resource Planning in Industrial Enterprises, Faculty Of Materials Science And Technology in Trnava Slovak University Of Technology in Bratslava, Special Number, pp. 62-67.

- Parlak, N.K. (2000) Uluslararası İnsan Kaynakları Yönetiminin Gelişimi, İstanbul Üniversitesi İktisat Fakültesi, İstanbul.

- Pinnington, A. (2004) The Internatıonal Company, UQ Business School The University of Queensland Brisbane Queensland 4072 Australia.

- Sevim, O. (2014) Akademik Etik Değerler Ölçeğinin Geliştirilmesi: Güvenirlik Ve Geçerlilik Çalışması, Turkish Studies - International Periodical for The Languages, Literature and History of Turkish or Turkic, 9 (6), pp. 943-957.

- Sherman, A., ve Bohlander, G., (1992) Managing Human Resources, Cincinnati, College Division South Western Publishing Co.

- Smelser, N. J. ve Baltes, P.B., (2001) Multinational Corporations, International Encyclopedia of the Social and Behavioral Sciences, (2), Stanford, USA.

- Tağraf, H., (2002) Küreselleşme Süreci Ve Çokuluslu İşletmelerin Küreselleşme Sürecine Etkisi, C.Ü. İktisadi ve İdari Bilimler Dergisi, 3 (2), ss.33-47.

- Treven, S., (2001) Human Resource Management In Internatıonal Organızatıons, Management, 6 (1-2), pp.177-189.

- Uysal, G., (2007) İnsan Kaynakları Yönetimi, Ders Notları, Ondokuz Mayıs Üniversitesi, İ̈BF, İşletme Bölümü, Samsun.

- Ünal, P. (2008) Uluslararası İnsan Kaynakları Yönetimi, Yüksek Lisans Tezi, İstanbul Teknik Üniversitesi Fen Bilimleri Enstitüsü, İstanbul.

- Yurdatapan, S. (2011) Türk Bankacılık Sektöründe İnsan Kaynakları Yönetimi Uygulamalarını Belirlemeye Yönelik Bir Araştırma, Yayımlanmamış Yüksek Lisans Tezi, Trakya Üniversitesi, Sosyal Bilimler Enstitüsü, Edirne.

- $\quad$ http://www.tdk.gov.tr/index.php?option=com_gts\&arama=gts\&guid=TDK.GTS.5551a512b7bb97.45395212 (Erişim tarihi 08.03.2015) 


\title{
Bir Kırsal Kalkınma Modeli Olarak Geleneksel Üretimi Yeniden Canlandırma Örneği: Yeşilyuva Ayakkabı Üretimi Revitalization of Traditional Manufacturing as Rural Development Model: Yeşilyuva Shoe Manufacturing Case
}

\author{
Prof. Dr. Ayşe İrmiş (Pamukkale University, Turkey) \\ Dr. Şeyma Gün Eroğlu (Pamukkale University, Turkey)
}

\begin{abstract}
Research field of study is formed Yeşilyuva Town in Denizli is a rural area which provides its income via shoe manufacturing. The aim of the study is to discover the contribution, the exchange and the development of traditional manufacturing at the development process in a rural area. As a research method in the first phase of historical background of shoe manufacturing in Yeşilyuva was researched, and then were interviewed about the shoe manufacturing in Yeşilyuva. According to the research findings, the background of Yeşilyuva's contemporary production consists of Akhi production culture. In Yeşilyuva, production of leather-related goods has been improving over time since those days. In 1970's, the people of Yeşilyuva founded a cooperative and a leather factory through consolidating their savings. However, the cooperative could not maintain the factory and it is rented to private sector for operation. Nowadays, in Yeşilyuva, at least one member of each family are producing shoes in small plants. Some of the products are sold to specific brands as a result of contract manufacturing; and some of them are taken to nearby cities by the sellers and sold there. While the presence of women in production used to be perceived negatively; women are entrepreneurs and employees in shoe manufacturing for the last thirty years. In Yeşilyuva, a developing place; the shoes, which had been produced only by hand crafts before; now are produced in still small plants, but through modern techniques; with the contribution of both men and women.
\end{abstract}

\section{Kırsal Kalkınma}

Kırsal alanla ilgili çok sayıda araştırma yapılmış olmasına rağmen, uluslararası alanda kırsal kavramıyla ilgili kabul görmüş tek tanım mevcut değildir. Ülkelerin mevcut yapıları, yaşam şekilleri, coğrafyaları vb. pek çok sebebin varlığı ortak bir tanımın oluşturulmasını güçleştirmektedir. Tek bir tanımın oluşturulmasındaki güçlüklerin sebebi temelde, üç unsurla ifade edilmektedir. Bunlardan ilki, kırsalın ve kırsallığı karakterize eden doğal, ekonomik ve kültürel unsurların ne olup olmadığıyla ilgili algı farklılıklarıdır. İkincisi, kırsallıkla ilgili incelenen konudaki oluşmuş politikalara göre şekil alan tanımların mevcudiyetidir. Üçüncüsü ise temel coğrafik birimler düzeyinde veri toplama güçlügüüür. Çünkü ilgili birim, idari açıdan, içerisinde yer aldığı sistem açısından, arsa temeli açısından vb. farklı bakış değerlendirmeleri gerektirebilmektedir (Rural Development in the EU Statical and Economic Information Report, 2013).

Kırsal alanla ilgili ortak bir tanımın oluşturulmasındaki güçlüklere rağmen, ülkeleri bir arada değerlendirebilmek ve karşılaştırmalarda aynı kriterleri kullanabilmek için uluslararası kuruluşlarca ortak tanımlar oluşturulmuştur. Bu tanımlardan en yaygın kullanılanları OECD tarafından geliştirilen ve AB tarafından kullanılan kırsal alan tanımıdır. Bu tanıma göre idari sınırlar açısından nüfus yoğunluğu km. başına 150 kişiden az olan yerler kırsal alan olarak belirlenmiştir (Kırsal Kalkınma Planı, 2010-2013). Ülkemizde ise kırsal alan tanımı, TÜİK kırsal alan istatistikleri esas alınarak yapılmaktadır. TÜİK'in son tanımında temel kriter nüfus eşiği olarak alınmıştır. 1982 yılında sonuçlanan Kent Eşiği Araştırmasına göre "asgari kentsel fonksiyonları gösteren yerleşimlerin nüfusu 20 bin” olarak kabul edilmiş, diğer yerleşimler ise kır alan olarak dikkate alınmıştır. Ulusal Kırsal Kalkınma Stratejisi I belgesinde nüfusu 20 binden düşük il ve ilçe merkezleri, beldeler ve köyler kırsal yerleşim alanı kapsamına girmektedir. Ancak, 6360 sayılı 14 ilde Büyük Şehir Belediyesi ve 27 ilçe kurulmasıyla ilgili bazı kanun ve kanun hükmündeki kararnamelerde yapılan değişiklilerle Büyük Şehir Belediyesi sınırları kırsal alanları kapsayacak şekilde il sınırlarına genişletilmiştir. Bu sebeple ülkemizde kırsal alan kapsamının ve tanımının yeniden belirlenmesi ve değerlendirilmesi gerekmektedir (Ulusal Kırsal Kalkınma Stratejisi, 20142020).

Kalkınma kavramı, toplumun daha iyi yaşamasını sağlamak üzere yapılan faaliyetleri kapsamına alır. Bunun için, bir bütün olarak toplumun ve o toplumda yaşayan insanların ihtiyaçlarının belirlenmesi, tartışılması ve planlaması yapılarak toplumun her bir aktörüyle birlikte çözümlerin oluşturulması gereklidir. Süreç içerisinde devletin halkla el ele vermesi büyük önem taşır. Bunun yanı sıra dernek, kooperatif gibi örgütlerin kurulması ve devletin, halkın ve bu kurumların işbirliğiyle sinerji oluşturulması öngörülmektedir. Etkili, verimli ve uzun dönemli bir kalkınmanın gerçekleşmesi için, halkın kendi ihtiyaçlarını ve sorunlarını ortaya koymalarında ve onlara çözüm aramalarında demokratik bir atmosfer oluşturulmalı ve hatta onlara gerekli olan bilgi aktarılmalıdır (Türkdoğan, 1977). 
Kalkınma süreci genel olarak üç boyut dikkate alınarak tanımlanmaktadır. Bunlar ekonomik kalkınma, sosyal kalkınma ve insan kalkınmasıdır. Ekonomik kalkınma insanların refahını ve mutluluğunu artırmak üzere insan ihtiyaçlarını karşılayan mal ve hizmetlerin gelişmiş bir ekonomik yapı içerisinde üretilmesiyle ilgilidir. Sosyal yaşamın iyileştirilmesi için yapılan sağlık, eğitim, altyapı, şehirleşme ve çevre sorunları gibi hizmet yönü ağır basan kalkınma, sosyal kalkınma olarak ifade edilmektedir. İnsan kalkınması ise insanların bireysel ve toplumsal olarak sahip oldukları potansiyellerini kalkınmaya yönelik kullanmaları ve ülkenin gelişmesinde yapıcı rol oynanmalarıyla ilgilidir. $\mathrm{Bu}$ doğrultuda eğitim, özellikle insan kalkınmasında ve dolaylı olarak sosyal ve ekonomik kalkınmada ana rolü oynamaktadır. Ayrıca her üç kalkınmayla da ilgili iki temel soruya cevap aranması gereklidir. Birinci soru kalkınmayı gerçekleştirecek faktörlerin neler olduğuyla ilgilidir. İkinci soru ise mevcut üretim faktörleriyle en yüksek kalkınma hızına nasıl ulaşılacağıdır. Böylece üretim faktörlerinin sektörler arasında nasıl dağıtılacağı, hangi projelerin faaliyete geçirileceği ve nerede hangi teknolojinin kullanılacağıyla ilgili kararlar da verilmiş olacaktır (Tolunay ve Akyol, 2006).

Kalkınma çabalarının mekânsal açıdan ele alınması ve kentli kesime göre daha geri kaldığı düşünülen kırsal alanlarda ekonomik ve sosyal imkânların geliştirilmesi gayesiyle kırsal kalkınma kavramı pek çok araştırmanın ve kalkınma planının konusunu teşkil etmektedir. Kırsal kalkınma, "kentsel alanların dışında bulunan dezavantajlı yaşam ve çalı̧̧ma ortamlarında, mevcut doğal kaynakların istismarına neden olmadan, uygulanabilirlik ve sürdürülebilirlik açısından değerlendirilmek yoluyla, hayat standartlarının ve gelir düzeylerinin yükseltilmesi ve refahın artırılmasıdır”. Kimi zaman kır alanı özelliği sebebiyle sadece tarımsal yapının iyileştirilmesi ve tarımda kalitenin artııılması olarak düşünülen kırsal kalkınma olgusu, çok daha geniş kapsamda değerlendirilmekte ve kırsal alanda her ölçekten işletme sanayinin kurulması ve tarımsal üretimin sanayi ile entegre edilmesini de ifade etmektedir (Can ve Esengül, 2007). Bu bağlamda, kırsal kalkınma tarımda verimliliği artıracak yöntemlerin yaygınlaştırılmasını, alt yapının iyileştirilmesini ve ekonomik çeşitlendirmenin yapılmasını gerektirmektedir. Kırsal alan turizminin geliştirilmesi, organik tarımın teşvik edilmesi, halıcılık, el sanatları, geleneksel üretim konuları gibi kültürel ve sanatsal üretimin ve bu alandaki istihdamın teşvik edilmesi, eğitimin ve sağlığın iyileştirilmesi kırsal alan kalkınması için oldukça önemli kabul edilmektedir (Işık ve Baysal, 2011).

2000'li yıllarda kırsal kalkınma yaklaşımında yoksulluğun azaltılması ve kırsal alanlarda yaşayanlar ile kent alanlarında yaşayanların eşit ekonomik firsatlara sahip olmasıyla ilgili düşünce daha etkili olmaya başlamıştır. Gaye kırsal alanların yaşamak ve çalışmak için sürdürülebilir ve çekici hale getirilmesidir. Sürdürülebilir kırsal kalkınma ise pek çok hususun yanı sıra, çok disiplinli ve çoğulcu yaklaşımları ve kırsal alt yapıya önem verilmesini gerektirmektedir. Kırsal alandaki böyle bir kalkınma sadece tarımı değil yerel ekonomileri de etkileyecek ve geliştirecektir (Giray vd., 2004). Bu bakımdan, kırsal alanda girişimciliğin geliştirilmesi kaçınılmaz olmaktadır. Kırsal alanda girişimciliğin teşvik edilmesi, aynı alan içerisinde hem tarım alanlarının korunmasını ve işlenmesine firsat verecek hem de ekonomik kalkınmayı sağlayarak ve yeni istihdam imkânları sunarak işsizliği azaltacak böylece kente göçü düşük düzeye indirecektir (Öztürk, 2009). Özellikle küçük meta üretiminin yapılması ve küçük işletmecilik anlayışının geliştirilmesi kırsal alanın, kentlerdeki büyük sanayiler için de dolaylı katkısını artıracaktır. Keza, Kırsal Kalkınma Planı 2010-2013'de bu konunun önemi "Türkiye'de kırsal kesimin genel gelişmişlik düzeyi; kırsal kalkınma için ekonomik ve sosyal alandaki diğer sektörlerde de birtakım tedbirlerin alınmasını zorunlu kılmaktadır. Bu yönüyle Türkiye'de "kırsal kalkınma" sadece tarım ve bölgesel gelişmeye yönelik uygulamalar kapsamında değil, diğer sektörel uygulamalarda da "çapraz uyum" adına gözetilmesi gereken öncelikli bir konudur" (2011) şeklinde vurgulanmaktadır. Benzer şekilde, 2014-2018 yılları için hazırlanan Onuncu Kalkınma Planı'nda (2013) da; kırsal alanda tarım dışı istihdam imkânlarının artması ve kırsal işgücünün tarım dışı sektörlerdeki istihdam edilebilirliğinin önemi vurgulanarak, kırsal kesimin sorun çözme kapasitesini geliştirebilecek yerel nitelikteki kalkınma girişimleri desteklenmesi öngörülmektedir.

Kırsal kalkınmayla ilgili olarak, kırsal alanda girişimciliğin teşvik edilmesinde genel olarak ekonomik ve sosyal olmak üzere iki hedef söz konusudur (Soysal, 2013). Ekonomik hedefler; gelirin yükseltilmesi, sermayenin dönüşümünün hızlandırılması, finans kaynaklarından yararlanma yeteneğinin geliştirilmesi, yatırımın yaygınlaştırılması ve kolaylaştırılması, verimliliğin artırılması, satış imkânlarının geliş̧tirilmesi, yönetimin ve örgütlenmenin rasyonel halde gerçekleştirilmesi, sermayenin tabana yayılması vb. Sosyal hedefler ise iş yapma becerisinin kazanılması, boş zamanın gereğince değerlendirilmesi, sosyal güvenlikle ilgili önlemlerin alınması, zor koşulların iyileştirilmesi, kadınların ve gençlerin sosyal haklarının korunarak üretime katılmalarının sağlanması vb.

Kırsal kalkınmayla ilgili hedeflerin gerçekleşmesi kırsal yerleşim alanındaki taşınmaz kaynak olarak ifade edilen, sosyal sermaye, kültürel sermaye, çevresel sermaye ve yerel bilgi sermayesiyle de yakından ilgilidir. İçsel Kırsal Kalkınma yaklaşımlarından biri olan "Yaratıcı Topluluk Kalkınması Teorisi'nde, kalkınma sürecinde kırsal mirasın kullanılması üzerinde durulmaktadır (Çekiç ve Ökten, 2009). Kırsal alandaki girişimciliğin geliştirilmesinde en etkili faktörlerden biri yerel bilgi sermayesini de içine alan kültürel sermayedir. Diğer etkili faktör ise sosyal sermaye ve sosyal sermaye bağlamıyla kurulan birliklerdir. Bu faktörlerin varlı̆̆ kırsal kalkınmanın hızlandırılmasında etkin rol oynamaktadır. Kültürel sermaye bir nesilden diğerine aktarılan genel kültürel birikim, bilgi ve becerinin toplamıdır. Kültürel sermaye ile birey içerisinde bulunduğu sosyal yapının 
gelir, meslek, yaşam tarzı ve tüketim alışkanlıklarını kazanır ve bunu diğer nesillere aktarabilir (Abdioğlu ve Yavuz, 2013).Yerel bilginin birikimiyle tarihsel süreç içerisinde oluşan kültürel sermaye, nesiller arasında üretimin ve üretim becerisinin yaygınlaşmasını da sağlayarak kırsal ve kentsel alanlarda hayatın devamlılı̆̆ını sağlar ve kalkınmanın sürdürülebilirliğine katkı verir. Sosyal sermaye ise özünde sosyal ağları bulunduran, bireylerin ve grupların verimliliğini etkileyen değerler ve sosyal bağlantılar bütünüdür. İki veya daha fazla birey arasında işbirliğini destekleyen sosyal sermaye, enformasyon, güven ve davranış normlarını kapsamaktadır (Çekiç ve Ökten, 2009). Sosyal sermayenin varlığı ile hem daha kısa sürede hem de daha az fiziksel sermayeye ihtiyaç duyularak sinerji yaratılacaktır. Meselâ Pakistan kırsal bölgelerinde yapılan bir araştırmada sosyal sermaye ile mikro finans programları arasında karşılıklı pozitif ve güçlü bir ilişki olduğu görülmüştür. Benzer şekilde Grup kredilerinde de sosyal sermayenin önemi nicel ve nitel araştırmalarla desteklenmiştir (Akram ve Routray, 2013).Ancak sosyal sermayenin oluşması ve etkinliği için güven ana unsurdur. Yapılan çalışmalarda da görülmektedir ki, yüksek güvene sahip toplumlar, sosyal sermaye açısından da zengin toplumlardır (Başak ve Öztaş, 2010:35). Sosyal sermayenin temel belirleyicisi olan "kişiler arası güven”, 1995-1996 yılları arasında yürütülen "Dünya Değerler Anketi” ile pek çok ülkede ölçülmüştür. Araştırmanın Türkiye açısından sonuçları, sosyal sermayenin yapısı açısından olumsuz bir durumu ortaya koymaktadır. Türkiye'de "insanlara güvenirim" diyenlerin oranı sadece \%6.5 olarak ortaya çıkmıştır. Güven unsurunun yükssek oranda çıktığı ülkelerin ise gelişmiş ülkeler olduğu görülmüştür (Çekiç ve Ökten, 2009).

Sosyal sermayenin kırsal kalkınma açısından bir diğer önemli etkisi ise kırsal kooperatif toplumlarının oluşumuna firsat vermesidir. Kırsal alanda ortaya çıkan kooperatifler toplumun refahını artırmak üzere işbirliğini tesis ederek, kırsal kitlenin, üreticilerin ve bir bütün olarak kırsal toplumun ekonomik standartlarını yükseltirler. Kırsal alanda nicel ve nitel değişimler sağlayan kırsal alan kooperatifleri, kalkınmaya uygun bir alt yapıyı tesis eder. Batı Bengal'deki Burdwan yerleşim alanında, kırsal kalkınma ile kooperatif toplumunun finans durumu arasındaki ilişkiyi göstermek amacıyla yapılan araştırmada, söz konusu kooperatiflerin kırsal nüfusun maddi ve finansal refahını sağlayacak şekilde yaşam standartlarını değiştirmede başarılı olduğu görülmüştür. Araştırma sonucunda, kooperatiflerin üretime katılan kitleler için daha konforlu bir hayat sağladığı, işbirliği ruhunu artırdığg ve bütün bu vasıflarıyla da kırsal toplumun kalkınmasında önemli rol oynadığı sonucuna varılmıştır (Chakrabarty ve Krishnamay, 2009). Ancak, özellikle kırsal alanda tanıdıklık, yakınlık, arkadaşlık akrabalık bağlarıyla oluşan sosyal sermayenin (Yıldız ve Topuz, 2011:206) devamlılığında olduğu gibi, onun somut ürünü olan kooperatiflerin kurulmasında ve devamlılığında da güven olmazsa olmaz unsurdur.

\section{Yeşilyuva Kasabası ve Üretim Geçmişi}

Yeşilyuva Denizli’nin Acıpayam ilçesine bağlı, nüfusu 5106 olan, tarihsel süreç içerisinde geçimini deri, deri işleme ve ayakkabıcılıkla sürdüren bir kasabasıdır (www.mebk12.meb.gov.tr). Yeşilyuva'nın büyük bir bölümü geçimini ayakkabıcılık üzerinden sağladığı için, tarım ve hayvancılık genellikle ek geçim kaynağı olarak yapılmaktadır. Kasabanın çeşitli bölgelerinde meyve ve sebze yetiştirilen bahçeler bulunmakta ve daha ziyade üzüm bağlarına rastlanmaktadır. Küçükbaş hayvancılığın ve kümes hayvancılığının da görüldüğü kasabada büyükbaş hayvancılık yapılmamaktadır. Tarım ve hayvancılık konusunda uygun olmayan coğrafik yapısı ve karasal iklim etkisinden dolayı Yeşilyuva'nın kısıtlı imkâna sahip olduğu görülmektedir (yesilyuvam.tr.gg).

Yeşilyuva'nın eski adı Kayser (Gayser)'dir. 1908 yılına kadar köy olan Kayser bu yıldan itibaren kasaba olmuş ve 1925 yılından itibaren de adı Yeşilyuva olarak değiştirilmiştir (yesilyuvam.tr.gg).Türk hâkimiyeti döneminde Kayser ismi ile anılan bugünün Yeşilyuvası'na Kaisaria adı, ilk defa İmparator Octavianus Augustus tarafından Romalı devlet adamı Sezar'ın (Caesar) onuruna bir unvan olarak verilmiştir. Kaisareia bu dönemde, dericilik sektöründe etrafındaki yerleşim bölgelerinin de ihtiyaçlarını karşılayabilecek kapasitede üretim yapan, bölgenin en önemli kenti olarak ün yapmıştır (Kılıç, 2014).1200'lü yıllarda Türklerin eline geçen Yeşilyuva'da dericilik zanaatı başarılı bir şekilde devam etmiştir. Bunun iki önemli sebebi vardır. Yeşilyuva'nın etrafındaki köylerde hayvancılığın yaygın olması ve yeterli su kaynağının bulunması birinci sebeptir (Türktaş. 2014). Bu sebepledir ki antik çağdan itibaren bu yerleşim bölgesinde dericilik üzerine üretim yapılmaktadır. İkinci sebep ise, buraya yerleşen Türklerin deri üretimini ve işleyişini Orta Asya'dan beri biliyor olmalarıdır. Bu üretimi bilen oba halkı, yerleşim yeri olarak bu gün Yeşilyuva diye bilinen alanı seçmiştir.

Denizli ili aynı zamanda Ahi birlikleri ve Ahi’lerin uğrak yeri olması sebebiyle de üretim geleneğini kazanmış ve devam ettirmektedir. Ahi Sinan, Ahi Kıran, Ahi Ali, Ahi Kaysar gibi Ahi'ler Denizli'de üretim konusunda önderlik yapmışlar (Tok, 2012), Ahi birliklerinde usta-çırak ilişkisi içerisinde üretimin devamlılığını sağlamışlardır. Özellikle deri ve deri işleme ve ilgili üretimin devamlılığının sağlanmasında Ahi Evran Denizli’yi Ahilik konusunda önemli bir konuma oturtmuştur (Gökçe, 2012). Keza, Ahi Kayser'in dericilik ve deri işlenmesi konusunda Yeşilyuva'ya gelip burada yerleşerek bir müddet zanaatın etkin öğretiminde ve yeni çırak ve ustaların yetiştirilmesinde önemli payı olduğu bilinmektedir (Kallimci, 2007). Ancak hakkında yeterli bilgi edinilemeyen Ahi Kayser'in gerçek adının daha farklı olduğu bu adın kendisine yöre halkı tarafından verildiği düşünülmektedir (yesilyuvam.tr.gg). 
XIX. yüzyılın ortalarındaki kayıtlara göre de o dönemki adıyla Kaysar'ın sosyo-ekonomik durumunu dericilik iş kolu şekillendirmiştir. Elde edilen kayıtlara göre dericilik iş koluna giren mesleklerle uğraşan hane reisleri, köy toplam haneleri içerisinde \%40'l1k bir oranı teşkil etmektedir. Benzer şekilde dericilikle ilgili bir meslek adı olan "dikici" mesleği de toplam hane sayısının \%28,7 gibi bir oranını oluşturmaktadır. Ayakkabıcılık mesleği, dede-baba-torun şeklinde devam etmiştir (Özçelik, 2014).

Ayakkabıcılık zanaatı Cumhuriyet döneminde de varlığını devam ettirmiştir. Cumhuriyet Arşivinde yer alan 1946 tarihli bir belgeye göre Yeşilyuva'da 30 yıl süreliğine, 1000 Türk Lirası sermaye ile ayakkabı üretimi yapan esnafi korumaya ve ayakkabıcılığ 1 geliştirmeye yönelik bir kooperatif kurulmuştur. Mahdut Sorumlu Yeşilyuva Umumi Ayakkabıcı Sanatkârları Küçük Sanat Kooperatif Ortaklığı adıyla kurulan kooperatif ile ayakkabıcı esnafın hammaddelerini daha ucuza almaları ve ürettikleri ayakkabıları satacakları pazarları oluşturmaları amaçlanmıştır (Haykıran ve Çetin, 2014).

Beldedeki ayakkabıcılığın yakın tarihine kadar ayakkabıcılar genellikle camız köselesinden elle ayakkabı dikmişler, daha sonraki dönemlerde kendi ürettikleri derileri ayakkabıların üst kısımlarında kullanmışlardır. Daha sonraki dönemde deri-kösele tabanlardan lastik tabanlı ayakkabılara geçilmiştir. O dönemde şimdiki dönemlerde kullanılan hazır plastik tabanlar kullanılmadığı için, kamyon lastiklerinin dış kısımlarından yararlanılmıştır. Maliyeti oldukça düşük olan ve daha ziyade köyde ve kasabada yaşayan alıcıları olan bu ayakkabılar hemen hemen 1980'li yıllara kadar devam etmiştir. Kamyon lastiğinden yapılan ayakkabılardan sonra yemeni türü, yemeniden sonra ise yöre halkının deyimiyle "gıcırdaklı ayakkabı" yapımına geçilmiştir. Tabanı kösele olan fakat ince koyun derisinin gazyağı ile iyice yağlandıktan sonra kösele ile ayakkabı arasına geçirilmesi neticesinde yürüdükçe gıcırtılar çıkaran bu ayakkabı daha ziyade gençler, memurlar ve üst düzey devlet yetkilileri tarafından tercih edilirmiştir. Bu gün ise hem Yeşilyuva'daki üreticiler tarafından hem de Yeşilyuva'dan Denizli'ye göç eden Yeşilyuvalı üreticiler tarafından kösele ayakkabı tabanı yaygın olarak yapılmakla beraber modern teknolojinin getirdiği, sıcak ve soğuğu fazla geçirmeyen, hafif poli tabanlar ya da yarısı poli, altı termo olan iki kısımlı tabanlar tercih edilmektedir (Türktaş 2014).

Ayakkabıcıllk mesleğinin günümüze kadar devam etmesindeki en önemli unsurlardan biri Ahi kültürünün bir devamlılığı olarak bu yörede mesleğin usta-çırak ilişkisi içerisinde gelişmesidir. Genellikle ilkokulu bitiren çocuklar bir ustanın yanında çalışmaya başlayarak 3-4 yıl çıraklık yaptıktan sonra, usta çırağın yetiştiğine kanaat getirirse peştamal bağlama töreni yapılmaktaydı (Çot vd., 2014). Peştamal bağlama törenlerinin 1960’lı yıllara kadar devam ettiği bilinmektedir (Kallimci, 2012).

Halihazırda Yeşilyuva'da 40.000 metrekare alanda 7 blok ve 1 hizmet binasından oluşan 254 dükkânın yer aldığı "Yeşilyuva Ayakkabıcılar Küçük Sanayi Sitesi”" bulunmaktadır. Eskiden tamamen el yapımı olan ayakkabı üretimi artık yerini makineyle üretime bırakmıştır. Bununla beraber, hâlâ ayakkabıların sadece belirli bir kısmı elle yapılmaktadır. Ayrıca alınan siparişe göre ustası tarafından tamamen el yapımı ayakkabılar da üretilmektedir. Kasabadaki kadınların da ayakkabının saya denilen ön yüzünü işleyerek üretime katkı verdikleri Yeşilyuva'dan artık, ülke içerisindeki büyük ayakkabı firmalarına ve 42 ülkeye (İtalya da dahil) üretim yapılmaktadır. Türk tarihindeki deri ve deri işlemeciliğinde yaklaşı 850 senelik bir kültürel birikimin devamı olan Yeşilyuva bu gün Türkiye için ekonomik katkı veren bir ayakkabı imal ve dericilik üretim alanı haline gelmiştir (Başkan, 2014). Bununla beraber, Yeşilyuva ayakkabı üreticilerinin gelişen teknolojiye yeterince ayak uydurdukları söylenememektedir. M Türktaş'ın yaptığı çalışmaya (2014) göre Yeşilyuva ayakkabı üreticileri, bu durumun kendilerinin birleşip güçlenememesinden kaynaklandığını ifade etmektedirler.

\section{Yeşilyuva Ayakkabı Üretimiyle İlgili Alan Araştırması}

Çalışmanın araştırma alanını oluşturan Denizli Yeşilyuva Beldesi, verimli tarım yapılmasına imkân vermeyen coğrafyasında gelirini ve geçimini ayakkabı üretiminden sağlayan kırsal bir alandır. Araştırmanın amacı; kırsal bir alanın kalkınma sürecinde geleneksel hale gelen üretimin katkısını, değişimini ve gelişimini keşfetmektir. Bu doğrultuda hazırlanan araştırma soruları şunlardır;

1. Yeşilyuva'daki üretim geleneksel hale nasıl gelmiştir?

2. Yeşilyuva'da üretim nasıl gerçekleşmektedir?

3. Kadınların üretime katkısı ve bundan elde ettiği gelir var mıdır?

4. Yeşilyuva'da üretilen ayakkabıların hammaddesi ve ara mamulü nasıl tedarik edilmektedir?

5. Yeşilyuva'da üretilen ayakkabıların pazarı nasıl oluşmaktadır?

6. Yeşilyuva'da bu üretimle ilgili halkın oluşturduğu birlikler, örgütler var mıdır?

Araştırmada bahsi geçen sorulara cevap aramak ve incelemek üzere ilk aşamada Yeşilyuva'daki ayakkabı üretiminin tarihsel geçmişi araştırılmış, daha sonra araştırmacılar tarafından bizzat Yeşilyuva'ya gidilerek yarı biçimsel mülakatlar yapılmıştır. Mülakata katılan kişiler şunlardır:

Mehmet Ali Kaya (M.A.K), 89 yaşında, eski kooperatif başkanı ve Yeşilyuva'daki deri fabrikasının kurucusu; Mehmet Erdal Çevik (M.E.Ç), Yeşilyuva Ayakkabıcılar Küçük Sanayi Sitesi’nde ayakkabı üretim atölyesi bulunan girişimci; Osman Ceman (O.C), Yeşilyuva'daki ayakkabıları satın alıp, onları Denizli’nin diğer beldelerinde ve Denizli çevresindeki illerde pazarlayan tüccar; Arif Alagöz (A.A), şimdiki kooperatifin başkanı 
(daha önceden kooperatifte müdür olarak çalışmış), Şükran Kepe (Ş.K); Yeşilyuva'daki ilk kadın saya dikicisi ve kadın girişimci; Hacı Durmuş Özyurt (H.D.Ö), 90 yaşında, yaşayan en eski ayakkabı ustalarından; Abdurrahman Karadağ (A.K), 72 yaşında hâlâ çalışmasını devam ettiren ayakkabı ustası; Tahir Özsoy (T.Ö), 75 yaşında, eski ayakkabı ustası. Elde edilen araştırma bulguları dört ana başlık altında incelenmektedir.

\subsection{Kırsal Bir Alan Olan Yeşilyuva'da Deri ve Ayakkabı Üretiminin Tarihi}

Daha önceden de ifade edildiği gibi, Yeşilyuva'daki dericilik ve ayakkabıcılık yüzyıllar öncesine dayanmaktadır. M.A.K, tarihçeyi anlatırken “Ahi Kayser Yeşilyuva'ya gelmiş o zaman için. Yüzden fazla tabakhane kumuş, basit tabakhaneler, evlerin altında. Çıraklar yetiştirmiş. Kayser gölü diye ün yapmış, yani derinin kösele olmadan önceki hali. Yeşilyuva'dan imal ettikleri derileri hayvanlarla Fethiye'ye taşırlarmış. Fethiye'den Girit adasına, Meis adasına kayıklarla pazarlarlarmış" diye bilgi veriyor. Yeni kooperatif başkanı A.A ise bu bölgenin Selçuklulardan beri sistematik şekilde kurulduğunu, Osmanlı kayıtlarında Yeşilyuva'nın Dikici olarak kayda geçtiğini, tabakhanelerin burada bolca bulunduğunu, Ahi Kayser'in dericiliğin yaygınlaşmasında önemli bir isim olduğunu söyleyip, Yeşilyuva'da bu tarihlerde yoğun bir eğitim ve öğretimin varlığından bahsetmiştir.

Yakın çağla ilgili bilgiler ise daha ziyade ayakkabı yapımındaki gelişimle ve ayakkabıcılığın işleyiş sistemiyle ilgilidir. H.D.Ö, söze "ata ne yapmışsa evlat da onu yağmış diye başlıyor ve şöyle devam ediyor: "10-12 yaşında çırak olarak uzak-yakın akrabam bir ustanın yanında çalışmaya başladım. O zamanlar 5-6 usta vardı. Herkes bu ustalara çocuklarını vermek isterdi. Her ustanın yanında 5-6 çocuk olurdu. 5-6 yıl çalışılırdı onlar. Usta çırağın yetiştiğine karar verirse, mevlidini okutur, önlüğünü giydirir, bağımsız çalışmasına izin verirdi. Ondan sonra, biriktirdiğimiz sermayeyle kendi dükkanımızı açardık, usta izin verirse giderdik, vermezse gitmezdik”. H.D.Ö, A.K ve T.Ö'den elde edilen bilgilere göre, o dönem ayakkabı üretimi için gereken malzeme ve özellikle deri, Kayser'e (eski adıyla) gelen tacirler tarafından tedarik edilmektedir. Ustalar tacirlerden veresiye aldıkları derilerden ayakkabı üreterek, pazara götürür orada satar ve daha sonra tacire borçlarını öderlermiş. Kimi zaman ayakkabıların bir kısmını kendilerine deri temin eden tacirlere de sattıkları olurmuş. H.D.Ö, ayakkabıyla ilgili gelişmeyi anlatırken. "Ayakkabı bütün olarak üretilirdi. Sayanın dikişleri singer makineyle dikilirdi. Diğer üretim elle yapılırdı. Ustada makine vardı. Haftalık 15-20 çift ayakkabı dikilirdi. Bunlar 1950'den önce. O zaman ayakkabıcılık işi kösele ayakkabı işi zor işti. Daha sonra, otomobil lastiklerden ayakkabı yaptık. 1955 'te başladı, 10 sene devam etti, sonrasında hazır tabanlar çıktı. Şimdi daha güzel alt tabanlar çıktı" diye ifade ediyor. H.D.Ö usta olduktan sonra, bir müddet evin içerisinde üretim yapıp geçimini temin ederken, daha sonra yanında A.K'de olmak üzere 2-3 işçi çalıştırdığı dükkanını açıyor. Oğlu ve torunu hâlâ ayakkabı üretimini gerçekleştirmektedirler.

İki sene çıraklık yaptıktan sonra ustalığa geçen T.Ö ise o dönemle ilgili "O dönem çok para kazanıldı. Sayası deri, sadece alt taban kamyon tekeri ayakkabılar yaptık. Hiç eskimezdi. Bizim dedelerimiz bir odanın içinde mutfak, yatak odası hepsi bir yerde üretim yapardık. Ben usta olduktan sonra dükkân açtım” diye belirtiyor.

M.A.K ve diğer üç eski ustayla yapılan mülakatlar neticesinde görülmektedir ki Yeşilyuva tarihten gelen yerel bir bilgi birikimine ve bunun birikimiyle oluşan bir kültür sermayesine sahiptir. Yeşilyuva'da hâlâ ayakkabı üretiminin devam etmesinde ve bunun gelire dönüşmesinde böyle bir birikimin varlığ 1 oldukça etkilidir.

\subsection{Yeşilyuva'da Deri ve Ayakkabı Üretiminde Örgütlenme}

Yeşilyuva'daki ilk örgüt modeli Ahi Kayser tarafından kurulan Ahi örgütüdür. Yakın çağda dericilik üzerine gerçekleşen ilk örgütlenme ise o dönemki kooperatif adına kooperatif başkanı, Köy İşleri ve Kooperatifler Bakanlığı, Özel İdare ve bizzat Denizli Valisi Münir Güney'in iş birliği ve birbirlerine destek vermeleri neticesinde gerçekleşmiştir. Bu işbirliği Yeşilyuva'da Türkiye'nin en büyük ve modern deri fabrikası YDSAN'ın (Yeşilyuva Deri Sanayi) kurulmasını ve kısa bir müddet de olsa üretim yapmasını sağlamıştır. Deri üretimini tabakhanesi olan dayısının yanında öğrenen, daha sonra da ayakkabı üretim atölyesini açan M.A.K bu konudaki çabalarını ve oluşan işbirliğini şöyle dile getiriyor; "Yeşilyuva'da 1965'de Tarımsal Köy Kalkınma Kooperatifi kurulmuş. Bu kooperatif esasen Isparta tipi halıcılık yaparak, 1973 tarihine kadar gelmiş. 1973 yılında yapılan kooperatif kongresinde beni yönetime getirdiler. 37 kooperatif tezgahını (Isparta tipi) teslim aldım. Bizim Yeşilyuva'nın kuruluşundan bu yana, ayakkabıcılık mesleği olduğu için halkın \%90’1 da ayakkabıcıdır. Her evde ayakkabı imal eden kişi vardır. Ayakkabının malzemesi deriye bağlı olduğu için ortaklarımızdan bana ayakkabı mamulünün hammaddesi olarak bir deri fabrikası kurulsun diye teklif ettiler. Ben o zaman 1974'de Denizli valisi Münir Güney’le görüştüm. Allah razı olsun. Bana destek olan O'dur. Bunu yapmamın sebebi de O'dur yani. Denizli'nin valisi Münir Güney’e Yeşilyuvanın tarihçesini, Kayser'in tarihçesini mektup yazdım. Vali, bu mektubu alınca, sekreteri bana telefon etti "Vali Bey görüşmek istiyor sizinle" dedi. Sen devam et ben sana yardımcı olacağım dedi Vali Bey ve o tarihte kooperatife 700.000 lira para verdi. Yani projenin gerçekleşmesi için destek verdi...... Köy İşleri ve Kooperatifler Bakanlığı Kararıyla böyle proje yapanlara \%70 devlet destek verir, \%30'unu kooperatif üyeleri karşılar kararı vardı. Hep beraber projenin gerçekleşmesi için çalıştık”. M.A.K'nın aktardığı bilgilere göre Devlet Planlama Teşkilatı ile İstanbul Pendik Dericilik Araştırma Enstitüsünün Ortak çabaları neticesinde proje hazırlanmıştır. Proje hazırlanırken, adı geçen Enstitüde, bir İngiliz “deri profesörü” (M.A.K’nın ifadesiyle), makinelerle ilgili raporu doğrultusunda kooperatif başkanı M.A.K ve 
yönetimdeki bir kaç kişi İngiltere'ye gidip orada, deri üretiminde kullanılan makinelerin satın alınması için anlaşma yapmıştır. Aynı zamanda kooperatifin proje sermayesi için koyacağı \%30'luk payı temin etmek üzere M.A.K ve yönetimdeki ilgili kişiler Almanya, Hollanda ve benzeri Avrupa ülkelerine giderek orada çalş̧an Türk işçilerini kooperatife üye etmiş ve deri fabrikasının kurulması için gerekli olan kooperatife ait yatırım sermayesi payını tamamlamışlardır. Açıktır ki, böyle bir fiziki sermayenin oluşturulmasının ardındaki ana unsur, devletin desteği ve sosyal sermayenin etkin kullanımıdır (yurt dışında çalışan iş̧̧ilerle kurulan bağ ve kooperatif üyelerinin işbirliği).

1981 yılında üretime geçen YDSAN deri fabrikası işletme sermayesinin yetersizliği sebebiyle üç yıl boyunca \%50 kapasiteyle çalışmıştır. Oldukça kaliteli deri üreten işletmenin ürünlerinin pazarının çok büyük bir kısmını İstanbul pazarı oluştururken, çok az bir kısmını da Yeşilyuva'daki ayakkabı ustaları oluşturmaktadır. Bunun sebebini M.A.K, "YDSAN'da üretilen derinin çok kaliteli olması nedeniyle pahalı olması, Yeşilyuva ayakkabı ustalarının bu deriyi almak için güçlerinin yetmemesi" olarak açıklamaktadır. Yeşilyuva ayakkabı ustaları, üretimlerinde kullandıkları ayakkabı derilerini Gerede ve Antep’ten temin etmişlerdir. Ayrıca M.A.K, işgörenin nasıl temin edildiğiyle ilgili soruya, Yeşilyuva'daki pek çok ayakkabı ustasının ve onların yanında çalışan kişilerin işlerini bırakıp, fabrikada işçi olarak çalışmaya başladıkları, şeklinde cevap vermiş̧i (Fabrikada 45 işgören çalışmıştır).

Bütün bu çabalara rağmen Devlet ve 1500 ortaklı kooperatifin işbirliği ve sinerjisiyle kurulan YDSAN, sadece üç-dört yıl fiilen çalışabilmiş daha sonra aşağıda anlatılacak olan sebeplerle kapatılmışıtır. M.A.K'ın aktarımına göre Bu gün Yeşilyuva Üretim ve Pazarlama Şirketi adıyla özel sermayeye kiralanan fabrikadaki kooperatifin ortaklığ dahilinde 1500 kişiden sadece 150 kişi kalmıştır.

Yeşilyuva'da 1985 yılında yeni bir kooperatif daha kurulmuştur. Ancak, bugünkü kooperatif başkanı A.A, bu kooperatifin "daha iyi bir üretim ve pazarlama gayesiyle çalışmadığını söyleyerek şöyle devam etmektedir: "Adı Yeşilyuva Ayakkabıcılar Küçük Sanayi Sitesi. Yani ayakkabıcılar daha iyi şartlarda üretim yapsınlar diye 85 yılında fiziki binalar üretmek üzere kurulmuş bir kooperatif. Bugün binalar üretilmiş durumda. Şu anda binaların tapuları çıkacak işte buna benzer birkaç işlem var. Bizim yürüttüğümüz faaliyet bu ama biz binaları teslim ettik başka işe karışmayız diyemiyoruz. Fuarlara katılıp, üretimimizi tanıtmaya çalışıyoruz. İki hafta sonra, ayakkabı yan sanayi fuarı var. Bu tür fuarlara biz esnaflarımızı organize edip, otobüslerle ziyarete götürüyoruz, buna benzer faaliyetler yapıyoruz. Ayrıca, Tarım ve Kırsal Kalkınmayı Destekleme Kurumu'ndan, Güney Ege Kalkınma Ajansı'ndan görevlileri çağırıyoruz. Ustalarımız nasıl destek alabilirler diye onlardan bilgi alıyoruz. Kendi özel çabalarımızla bunlarla uğraşıyoruz".

Yeşilyuva'daki ilk kadın saya ustası Ş.K'nin hayali ise Yeşilyuva'da kadın saya dikicilerinin bir araya gelip beraber işletecekleri bir atölyeyi kurmaktır. Ş.K bu hayalini "Bayanlarla beraber bir iş yeri kurmak isterim. Benim yetiştirdiğim 8 tane elemanım var, her türlü makineyi kullanabilirler, bu gün gelin desem gelirler. Bayan olarak iş biliyoruz ama bunu yapabilecek cesaret yok. Bankadan kredi almamız için deftere tabi olmamız lazım, o yok bizde, esnaf belgem olmadığı için yapamıyorum. Ustalık belgesini alsam başlasam.... Deftere tabii olmak için ustalık belgesi almam lazım. Ama nasıl alacağım..." ş̧eklinde dile getirmektedir.

Mülakatlardan da görüleceği üzere Yeşilyuva'da üretim yapan kişilerin biraraya gelmesi ve örgütlenmesi eskiden beri var olan ve günümüze kadar süregelen bir durumdur. Hem devlet kurumlarıly hem de birbirleriyle olan ilişki ve iletişim kurabilme konusundaki tutumları yatırım yapma konusunda onları faaliyete geçirebilmektedir. $\mathrm{Bu}$ durum Yeşilyuvada kültürel sermayenin de desteklediği bir sosyal sermayenin var olduğunu ve bu sermayenin yatırıma dönüşebildiğini de göstermektedir. Bu tecrübenin, belirli bir yönetim ve organizasyon üst yapısı şeklinde, dengeli bir kurumsallaşmaya dönüşememesinin en önemli sebebi; girişimci kişi ve gruplar arasında zaman içinde "karşılıklı güven duygusunun" kaybedilmesidir. Bu durum, yönetim açısından da asıl önemli olanın, işletmeyi kurmanın ötesinde kurulanı devam ettirme bağlamında kurumsallaşma olduğu gerçeğini ortaya koymaktadır. Yönetimde kurumsallaşma, çok ortaklı işletme ve girişimler için nimet-külfet dengesini belirli bir esasa ve kurallara bağlaması sebebiyle muhtemel suistimalleri ve dedikoduları önleyecektir. Hukuki sistemle desteklenen ve şeffaflık ilkesine dayalı ilke ve kuralların oluşturulması ve bunlara uyulması, "karşılıklı güven duygusunun sürekliliğine, dolayısıyla sosyal sermayenin birikimiyle işletmelerin gelişerek ve büyüyerek devamlılığının sağlanmasına katkıda bulunacaktır. Yeşilyuva'da güven konusunda yaşanan zaaflar ve bunun işletmelerin ve birliklerin devamlığını ortadan kaldırması, yapılan mülakatlarda sıklıkla dile getirilmektedir:

A.K, Yeşilyuva'nın emsallerine göre geride kalmasının sebebini şöyle açıklamaktadır: "Kendimizi yenileyemedik, piyasaya ayak uyduramadık. Şimdi biraz iyileşmeye başladı ama geç kaldık. Konya geldi bizi geçti. Birleşip şirket kurmayı da yapamadık. Millet birbirine itimatsız, birleşilemedi, bu sebepten geri kaldık”. Keza, T.Ö bu konuda, A.K ile hemfikir olduğunu söylüyor; Birlik beraberlik kuramadık, teknolojiye ayak uyduramadık. Burada 60-65'lerde kooperatif kuruldu, ayakkabılar bir elden yapılsın, bir elden satılsın diye, şöyle olsun böyle olsun diye, o da yürümedi. Daha sonraki süreçte gücü olan teknolojiye uydu, gerisi elendi. Kısa vadeli çalışıldı, hap yapıp para kapılıyor (Kısa sürede para kazanılmak isteniliyor anlamında kullanılmıştır)". 
Güven eksikliğinin bedelini Yeşilyuva halkı YDSAN fabrikasının kuruluşundaki ana aktörlerden biri olan M.A.K'nın kooperatif başkanlığı sırasında ortaya çıkan güvensizlik zaafiyetiyle yaşamıştır. Yeşilyuva'da kooperatifleşme gücünü ortaya çıkaran, yurt dışındaki Türk işçilerinin dahi kooperatife üye olmaları sağlanarak fiziki sermayeyi bir araya getiren ve devlet kurumlarının yönetici ve çalışanları ile halk önderleri arasında bağların kurulmasını sağlayan sosyal sermaye, işleyiş sürecinde yaşanan güvensizlik problemiyle verimli kullanılamamıştır. M.A.K ilgili konu hakkında "15.06.1986 tarihinde kooperatifin genel kurulu yapıldı. Bu genel kurulda, biz ibra edilmedik. \%100 kapasite ile çalıştırılmak için o günkü Belediye Başkanı ibra etmediler. Benim için kooperatiften bir kaç kişi onu çaldı, bunu yedi falan demiş. Yeni yöneticilere 500.000 desi mamul derisi bırakıp, başkanlıktan ayrıldım, sonra da Denizli’ye gelip ayakkabı atölyesi açtım. \% 50 kapasite olarak çalışan fabrikayı gelen yeni yöneticilere teslim ettim. Ertesi gün bu 500.000 desiyi, 91 liraya mal olan bir derinin desisini \%50- \%60 düşük sattılar. Ertesi gün de fabrikaya kilit vurdular” şeklinde bilgi vermektedir. M.A.K ile yapılan mülakatta; Kooperatif tarafından Bakanlıktan hesapların kontrol edilmesi için talep edilen müfettişlerin, yapılan incelemenin ardından hiçbir noksanlık, yolsuzluk ve hata bulamadıklarını beyan ettikleri, ifade edilmiştir. M.A.K aynı belediye ve aynı kooperatif üyeleri zamanında yaptığı ikinci kooperatif başkanlığı dönemiyle ilgili şunları anlatmaktadır: "İkinci safhaya geliyorum şimdi. Fabrikaya kilit vurdular kapattılar. 500.000 desi deriyi maliyetinin altında sattılar. 1990 yılına kadar fabrika kilitli kald1. 90 yılında bir genel kurul yapılmış Yeşilyuva'da. Ben genel kurula katılmadım. Katılmadığım halde orada beni tekrar seçmişler. 4 sene sonra". M.A.K kendisinin olmadığı bir genel kurulda kooperatif bakanı seçilmiş olmasını kabul edemeyeceğini söylemiş olmasına rağmen Denizli Valisi’nin ricasıyla tekrar görevi devralmıştır. Ancak 3-4 yıldır üretim yapılmayan fabrikada makineler çalışamaz vaziyete geldiği için, alınan kararla fabrika özel sermayeye kooperatif adına kiraya verilmiştir. Bir kaç kez kiracı değiştiren fabrika, hâlâ özel sermayenin işletimindedir. 1500 ortağı bulunan kooperatifin üye sayısının ise 150 kişiye düştüğü ifade edilmektedir.

\subsection{Günümüzde Yeşilyuva Ayakkabı Üretimi}

Yapılan gözlem ve mülakatlardan elde edilen bilgilere göre Yeşilyuva'da ayakkabı üretiminin bir kısmı evlerin altındaki, halkın da genellikle dükkân diye bahsettiği küçük atölyelerde gerçekleşmektedir. Ayakkabı üretiminin diğer önemli bir kısmı ise kooperatifleşilerek yapılan, yakın zamanda da tapuları dağıtılacak olan, Yeşilyuva Ayakkabıcılar Küçük Sanayi Sitesi'nde gerçekleşmektedir. Yeşilyuva'daki evlerin altında bulunan küçük atölyelerde ağırlıklı olarak ve Yeşilyuva Ayakkabıcılar Küçük Sanayi Sitesi’nde bir miktar ayakkabının üst derisinin dikimi ve işlenmesi anlamına gelen "saya dikimi” gerçekleşmektedir. Saya dikim ustaları ayakkabı üreten işletmeler için fason üretim yapmaktadırlar. Aynı zamanda Yeşilyuva'da bütün olarak ayakkabı üretimi de gerçekleşmektedir. Yapılan mülakatlarda, özellikle Yeşilyuva Ayakkabıcılar Küçük Sanayi Sitesi'nde üretilen ayakkabı derilerinin Bursa, Gazi Antep ve Bolu Gerede'den temin edildiği öğrenilmiştir. Ayakkabı alt tabanları ise çoğunlukla Denizli'de üretim yapan firmalardan temin edilmektedir. Üretilen ayakkabıların satışı ise iki şekilde gerçekleşmektedir. Bunlardan ilki Türkiye'deki markalı ayakkabı firmalarına yapılan fason üretimdir. Ancak bu konuda katıldıkları fuarlar haricinde (kendilerini tanıtmaktan ziyade öğrenmek için gittiklerini ifade etmişlerdir) internet de dahil hiçbir kanaldan tanıtım yapmamaktadırlar. Müşteriler ya mağazalardan (süper market gibi) ve markalı ayakkabı firmalarından gelip, üretilen ayakkabıları satın almaktadır ya da markalı firmalara satış yapan toptancılar Yeşilyuvaya gelip buradan temin ettikleri ayakkabıları İzmir, İstanbul, Bursa gibi illerde perakende satış yapan mağazalara pazarlamaktadırlar. İkinci satış yöntemi ise Denizli’nin diğer kasabalarından gelen ve ürünlerini çevre illerde ve Denizli'ye yakın tatil beldelerinde pazarlayan toptancılara yapılan satıştır. Sanayi Sitesinde Ayakkabı atölyesi bulunan M.E.Ç tedarik ve pazarlamayla ilgili faaliyetleri şu şekilde anlatmaktadır: "Deriyi Bursa'dan, Bolu Gerede'den getirtiyoruz. Ayakkabı tabanını, Denizli'de hazır taban yapan arkadaşlar var onlardan alıyor, burada imalatını yapıyoruz. Ürünlerimizi genelde dükkâncı, pazarcı gibi küçük esnafa satıyoruz. Bizim ayakkabı kalitesi öyle tam dört dörtlük değil. Orta kesime hitap ediyoruz. Biz ilk önce malı dikiyoruz, hazırlıyoruz, Bursa'dan, İzmir'den İstanbul'dan herhangi bir toptancı geliyor, buradan malını beğeniyor, hoşuna gidenleri kargoya veriyor ya da kendisi götürüyor".

M.E.Ç ile mülakat yaparken ayakkabı örneklerini inceleyen O.C, "ben aldım meselâ, Tavas’tan geldim" diyerek söze giriyor. Kendi mağazasının olmadığını, kendi deyimiyle pazarcı olduğunu söyleyen O.C, "M.E.Ç ile tesadüfen tanıştım. Malını gördüm beğendim. 5-10 senedir buradan da mal alırım, yazın yazlık, kışın kışlık. Bunları götürüp Tavas’taki mağazalara satıyorum. Muğla'daki Fethiye'deki turistik mağazalara satıyorum”. M.E.Ç Muğla, Fethiye, Antalya, İstanbul, İzmir gibi yerlerden de mal almak için pazarcıların geldiğini ilave ediyor. M.E.Ç Yeşilyuva'da kadın işgörenlerin de istihdam edildiğini, özellikle saya dikiminde ve bez yapıştırmada çalıştıklarını söylerken Ş.K ile yapılan mülakatta, kadın işgörenlerin erkek işgörenler kadar çalıştığı fakat daha düşük ücret aldıkları konusunda vurgu yapılmıştır.

Mülakatlar sırasında ayakkabı tasarımlarının nasıl yapıldığı sorulmuştur. Elde edilen bilgiye göre, Denizli vb. yerlerde görülen ayakkabı modelleri üzerinde çalışıldığı, ya da müşteri tarafından sipariş verilirken tarif edildiği anlatılıyor. En çok kullanılan yöntemlerden birisi ise ayakkabı üretimi ve pazarlaması konusunda kendilerinden daha ileri aşamada olduklarını söyledikleri Konya ilindeki tanıdıkları ayakkabı tasarımcılarına tasarım konusunda sipariş vermeleridir. Genel olarak mülakatlarda denilenler A.A'nın söylediklerinde özetleniyor: "burada bizim sıkıntımız şu; sektörde, üreticinin de işçinin de eğitim düzeyi düşük. Üretim de pazarlama da bilgi 
kapasitesiyle oluyor Aslında üniversite bunun işletmesini, pazarlamasını, modellemesini çok daha profesyonel şekilde ortaya koysa insanların önüne bıraksa... mesleğimiz çok yüksek katma değer sağlayabilir. Yüksek istihdam sağlayabilir. Bu şekilde dış pazara da açılırız. Özellikle de bize modelist lazım. Şimdi biz şu modeli yaptırmak için İstanbul'dan İzmir'den Konya'dan modelist bulup çizim yaptırıyoruz. Numuneyi gönderiyor. Çizim işte numune kesim yapılıyor, kalıbı oluyor olmuyor tekrar gidiyor. Hepsi zaman kaybı. Halbuki burada bir modelist olsa, bir hafta içinde bu sistem otursa, sezona çok rahat yetişebiliriz. Modelist ve üniversite imkanları şart".

\subsection{Kırsal Kalkınma Açısından Yeşilyuva'da Kadın Çalışan ve Kadın Girişimci}

Yeşilyuva'da kadınların evin dışında ayakkabı üretimine katılmaları 1990-91 yılında gerçekleşmeye başlamıştır. H.D.Ö, A.K ve T.Ö (eski ustalar) ile yapılan mülakatlarda eskiden Yeşilyuva'da kadınların dükkanlarda çalışmasının ayıp karşılandığı bu sebeple çok eskiden sadece evde eşlerine yardım ettikleri anlatılmıştır. Ş.K Yeşilyuva'daki ilk kadın saya ustası ve hatta girişimcisidir, "bayanların dükkana girmesi ayıp bir şeydi Yeşilyuva'da, hani köy yeri ama ailede birimizin ayakta durması lazımdı" diyerek sözlerine başlıyor. Eşi, bir başkasına ait atölyede ayakkabı üretiminde işçi olarak çalışan Ş.K geçirdikleri bir takım sıkıntıların üstesinden saya dikimiyle kalkacağını düşünerek işe başlamıştır. Ş.K dantel ören kadınların saya da dikebileceklerini düşünerek, elindeki ayakkabıyı tamamen söküp sayanın nasıl dikilebileceğini kendi başına öğrenmeye çalışmıştır. Bu arada kendisini çok desteklediklerini söylediği erkek kardeşleri ve eşine de diktiği sayaları göstererek yardım alan Ş.K ilk dönem saya üretimlerini evde yapmaya başlıyor. Ş.K Saya üretiminden kazandığı parayla, ailesiyle beraber çalıştığı ve halihazırda işçi istihdam ettiği atölyesini açıyor. Hayatındaki değişiklikleri anlatırken, "sigortalı oldum, Yeşilyuva'daki ilk çamaşır makinesini, bulaşık makinesini ben aldım. Şimdi de emeklilik zamanım geldi, kendi paramla emekli olmaktan çok gurur duyuyorum" diyor. Daha önceden saya ayakkabı ürettiği için saya dikimini yapmamış olan eşinin artık kendi atölyelerinde yardım ettiğini söyleyen Ş.K atölyesine de gelişen teknolojiye göre bilgisayarlı yeni makineler satın alıp, üretimi daha hızlı ve kaliteli yaptığını, üstelik makineleri satın alırken kredi kullanmadığını söylüyor. Ş.K aynı zamanda diğer kadınlara da saya dikimini öğreterek onların da üretime ücretli ve doğrudan katılımını sağlıyor. Beldedeki diğer kadınlar Ş.K'yı görüp cesaretlenerek ayakkabı üretiminde yer almaya başlıyorlar. Fason üretim yaptıkları için yeterince kazanamadıklarını söyleyen Ş.K'nın bu günkü hayali Yeşilyuva'daki 8-9 kadınla birleşerek daha modern, daha iyi çalışan bir atölye kurmaktır.

S..K'ya kadın işgörenlerin ve bizzat kendisinin yaşadığı sıkıntıların neler olduğu sorulduğunda; "burada kadınlar da erkekler de aynı işi yapıyor ama kadınlar daha düşük ücret alıyorlar, bu bir haksızlık" cevabını veriyor. Kendisinin halihazırdaki sıkıntısını ise şöyle ifade ediyor: "Herşeyi kredi çekmeden, destek almadan yaptık. O hakkı kullanamıyoruz, ben buna karşıyım, İş-Kur'un bir sürü teşvikleri vardı. Ben o teşvikten yararlanmak isterdim ama ustalık belgesi istiyor. Ben bu yaştan sonra kendi kendimi bu hale getirdim. Nereden alacağım ki ustalık belgesini? Ben o teşvikten hiçbir zaman yaralanmadım. Bu teşviklerden yararlanmak istiyoruz doğrusu. Mesela lafa gelince böyle şey ediyorlar. KOSGEB'e gittim, İŞ-KUR a da gittim. Kendimi de anlattım ama olmadı. Deftere kayıtlı olmamız lazımmış, ustalık belgemin olması lazımmış".

\section{Sonuç}

Açıktır ki, Yeşilyuva kırsal bir alandır. Bununla beraber, tarım dışı sektörde tarihsel süreç içerisinde devam eden bir üretim uzmanlığına da sahiptir. Bu durum Yeşilyuva'nın önemli bir avantajını oluşturmaktadır. Çünkü kırsal alanda ikamet eden Yeşilyuva halkı hem ayakkabı üretimi ile kendine önemli bir geçim kaynağı sağlamakta hem de en azından kendi ihtiyacını karşılayacak kadar tarım ve hayvancılı̆̆ı yapabilmektedirler. Bu durum sadece Yeşilyuva halkına sağladığı faydayla sınırlı değildir. Aynı zamanda bir bütün olarak Denizli ve Türkiye açısından da, tabandan tavana toplumsal kalkınmaya katkı vermektedir. Bu katkılardan birincisi, Yeşilyuva'nın özellikle Türkiye'nin farklı yerlerinde nispeten kırsal alanda yaşayan nihai tüketicinin ayakkabı ihtiyacına cevap vermesidir. İkincisi, Yeşilyuva halkının kendi yerleşim alanında üretim yaparak ikamet etmeleri neticesinde köyden kente göçün önemli ölçüde azalmasıdır. Üçüncüsü, Yeşilyuva'dan Denizli’ye göç ederek deri ve ayakkabı üretiminde daha büyük tesisler kuran sanayici için fason üretim ve yan sanayi sağlamaktadır. Dördüncüsü, fason üretim Türkiye'deki diğer ayakkabı markaları için de gerçekleşmektedir. Böylece Yeşilyuva'daki tarım dışı üretimle gerçekleşen kalkınma, kent kalkınmasına ve bir bütün olarak ülke kalkınmasına destek verebilmektedir. Yerelden ve çevreden gelen güç, merkezi yapının da güçlenmesine vesile olacak şekilde dalga halinde yayılmaktadır.

Yeşilyuva'daki atadan evlada geçerek artık geleneksel hale gelen ayakkabı üretiminin bu zamana kadarki devamlılı̆̆ beldedeki kültürel sermaye ve sosyal sermaye ile yakından ilgilidir. Ancak Yeşilyuva'daki ayakkabı üretiminin geleceğe aktarılmasında ve daha etkin ve verimli şekilde devam ettirilmesinde iki temel problemin varlığı görülmektedir. Bunlardan ilki eğitimin yetersizliğidir. Yukarıdaki mülakat aktarımlarında da görüleceği üzere beldede ayakkabı üretimi iş başındaki eğitimle öğrenilmektedir. Hâlbuki, tüketici istek ve ihtiyaçları çok farklılaşmıştır ve teknoloji her geçen gün hızla gelişmektedir. Bu bağlamda liselerde ve üniversitede ayakkabı tasarımı, üretimi ve pazarlanmasını uzmanlık oluşturacak şekilde ele alan bölümlerin olması önemli 
görülmektedir. Yöre halkının talebi de bu yöndedir. Diğer taraftan gençlerin lise ve üniversite tercihlerinde bu mesleği tercih edip, bu konuda uzmanlaşmaları için teşvik edilmeleri ve bir takım unsurlarla ayakkabı uğraşının ve mesleğinin cazip hale getirilmesi önemlidir. Çünkü yapılan mülakatlarda meslek lisesinde kunduracılıkla ilgili bir kol bulunduğu fakat öğrenciler tarafından tercih edilmediği için kapatıldığı ifade edilmiştir. Ayrıca yöre halkı için ayakkabı dizaynı, ayakkabı üretimi ve pazarlanmasıyla ilgili eğitimler alabilecekleri şartlar oluşturulmalıdır.

Bir diğer öneri, kırsal alandaki kadınların çalışma hayatına erkeklerle eşit haklarla katılmalarının ve girişimde bulunmalarının özendirilmesidir. Böylece kırsal kalkınma hiç bir ayrıma gidilmeksizin yöre halkının topluca katılımıyla, bu sinerjinin getirdiği güçle ve bireylerin kendilerini ve karşılıklı dayanışmaları neticesinde birbirlerini güçlendirmeleriyle gerçekleşecektir. Kalkınan ve güçlenen kırsal alanlar, kentsel alanların, sanayi ve turizm bölgelerinin kalkınmasına ve güçlenmesine katkıda bulunacak, bir bütün olarak ülkenin kalkınması ve güçlenmesi sağlanacaktır.

Üçüncü öneri Yeşilyuva'da kırsal kalkınma için proje yönetimi usulüyle çalışılmasına yöneliktir. Yeşilyuva'da yapılan alan araştırmasında dikkat çeken en önemli unsurlardan biri, biraraya gelip örgütlenmek isteyen halkın birbirine karşı güvensizlik yaşadığının gözlenmesidir. Sosyal sermayenin uzun döneme yansıtılabilmesi ve daha etkin ve verimli olabilmesi için gereken güven unsuru yatırıma gidilirken nispeten daha fazla olduğu halde, işin devamlılığı sürecinde kaybedilmekte, devamlılığı sağlanamamaktadır. Elbette ki, toplumun kendi tarihi ve kültür mirası içerisinde öğrendiği ve edindiği bir takım zihniyet yapıları ve davranış şekilleri vardır. Dolayısıyla özellikle sosyal bilimlerde geliştirilen her bir tekniğin ve modelin bütün toplumlarda uygulanabilirliğinin olduğunu ve aynı sonuçları doğuracağını düşünmek bilimi dogmatik hale getirecektir. Bu açıdan yapılan bu çalışmada kırsal kalkınma açısından getirilecek önerinin de bir kırsal kalkınma alanı olan Denizli Yeşilyuva beldesinin tarihsel süreci ve mevcut durumu dikkate alınarak yapılması gereklidir. Açıktır ki, tarihsel olarak Yeşilyuva'da bir üretim uzmanlık alanı ve bunu işletebilmek gayesine yönelik örgütlenme cesareti ve tecrübesi mevcuttur. Ancak yöre halkı tarafından üretim alanındaki bilgi ve becerinin katma değeri yüksek bir yatırım ve işleyişe dönüştürülmesinde, ayrıca üretimin sonucunun pazarlamaya dönük hale getirilmesinde ve sonuç olarak işletme zihniyetlerinde, yönetim ve organizasyon faaliyetlerinde önemli eksiklikler söz konusudur.

Yeşilyuva halkı, tarım dışı bir üretim faaliyeti açısından kırsal kalkınmada tabandan gelen bir güce ve itme kuvvetine sahiptir. Yukarıda anlatılan unsurlar da dikkate alınarak, proje örgütleri şeklinde çalışan danışmanlık şirketlerinin, devlet kurumları ile Yeşilyuva üreticileri arasında bir bağ oluşturacak şekilde yer alması öneri olarak getirilebilir. Çünkü Yeşilyuva halkının, daha ucuza daha kaliteli tedarik malzemelerini temin etmesi, işletmelerinin finansmanını gerçekleştirmesi, daha bilimsel, etkili ve verimli yönetim ve organizasyon faaliyetlerini gerçekleştirmesi ve ürününü pazarlayabilmesi için gerekli olan bilgi ve becerisi henüz çok düşük düzeydedir. Devletin bütün bu konularda doğrudan müdahale etmesi ise hem devlet açısından büyük bir maliyeti doğuracak hem de Yeşilyuva halkının esnek ve bağımsız hareket etme isteğine ve gücüne, girişimcilik potansiyeline ve motivasyonuna ket vuracaktır. Bunun yerine işletme ve yönetim danışmanlık firmalarından profesyonel yönetim desteğinin sağlanacağı kanalın açılması gereklidir. Bu firmalar, gerektiğinde o bölgedeki üniversitede bulunan bilim adamlarından da yardım alıp, onlarla işbirliği yaparak, ilgili yörenin meselâ Yeşilyuva'nın kalkınması için projeler oluşturarak, bu projeleri ilgili devlet kurumlarına sunmalıdırlar. Firmaların sundukları bu projelerle, yöre halkına (bu çalışmada Yeşilyuva ayakkabı üreticilerine) İş-Kur, KOSGEB, Kalkınma Ajansları, Ticaret odaları vb. kurumlarla nasıl bağlantı kuracaklarına, finans kaynaklarından nasıl yararlanacaklarına, daha etkili ve verimli üretimin nasıl yapılacağına, nasıl bir yönetim ve örgütlenmeye gidileceğine dair bilgi eğitim yoluyla aktarılmalıdır. Ancak böyle bir bilgi aktarımı sürecin sadece başlangıcını oluşturacaktır. Danışmanlık firmaları proje kapsamında, yöre halkını ve girişimcileri kooperatifler ve YDSAN örneğinde olduğu gibi örgütleyerek, bizzat finans kaynaklarıyla, pazar kanallarıyla bağlantıları sağlanmalı, danışmanlık firmasının kendi yönetim ve teknik kadrosuyla destek verilmelidir. Yöre halkı için ilk aşamanın uygulamalı öğretilmesi, sürecin başlatılması oldukça önemli bir safha olacaktır. Proje, yöre halkının bütün bu faaliyetleri kendi başına yapabilme becerisine kavuşmasıyla sonlandırılmalıdır. Yöre halkı tarafından kazanılan bu bilgi ve beceri daha sonraki nesillere kendiliğinden aktarılacak ve gelecek neslin o yörede kalıp, mevcut iş ve uzmanlığı devam ettirmesinde, yeni girişimler yapmasında motive edecektir. Diğer taraftan, yapılan daha profesyonelce ve uzun dönemli örgütlenmelerle milli sermayenin birikerek çoğalmasına katkıda bulunulacaktır. Böylece, kısa vadede proje maliyetinden dolayı masraflı gibi görülen danışmanlık firmalarının proje yöntemi, uzun dönemdeki kırsal kalkınmayı yüksek değerli bir toplumsal kalkınmaya dönüştürecektir.

$\mathrm{Bu}$ doğrultuda devlete danışmanlık firmalarının projelerine kırsal kalkınma için maddi kaynaklar vermesinin haricinde önemli bir görev daha düşmektedir. Devletin ilgili kurumları, hem proje yapan danışmanlık firmasının projeyle ilgili faaliyetlerini hem de projenin kapsamına giren işletmelerin (küçük büyük demeden bütün işletmelerin), ortaklıkların ve kişilerin faaliyetlerini zamanında ve titizlikle denetlemeli, herhangi bir yolsuzluk durumunda ya da vaadedilen şeylerin yerine getirilmemesi durumunda hiçbir tolerans gösterilmeden gerekli olan hukuki işlemi yapmalıdırlar. Güvenilir bir hukuki sistem, bireylerin de birbirlerine güven duymalarında ve bu güveni sürdürmelerinde etkili olarak sosyal sermayeyi artıracaktır. Tabandan tavana doğru gelen bir kuvvetle güç kazanan ülkenin uluslararası alandaki konumu, saygınlığı ve dolayısıyla gücü de kendiliğinden artmış olacaktır. 


\section{Kaynakça}

- Abdioğlu Hasan, Seren Yavuz (2013), "İşletmelerde Sosyal Sermayenin Ölçümlenmesi ve Raporlanmasına Yönelik Bir Araştırma”, Afyon Kocatepe Üniversitesi IIIBF Dergisi, 15 (1), s. 28.

- Akram Sohail, Jayant Kumar Routray, (2013),"Investigating Causal Relationship Between Social Capital And Microfinance", International Journal of Social Economics, 40 (9), p. 773.

- Başak Suna, Nail Öztaş (2010), "Güven Ağbağları, Sosyal Sermaye ve Toplumsal Cinsiyet”, Gazi Üniversitesi İktisadi ve İdari Bilimler Fakültesi Dergisi, 12 (1), s.35.

- Başkan Ayşe Esin (2014),Bir Denizli Seyahati, T.C. Güney Ege Kalkınma Ajansı, Denizli Yatırım Destek Ofisi, Denizli.

- Can Metin, Kemal Esengün (2007), Avrupa Birliği Kırsal Kalkınma Programlarının Türkiye'nin Kırsal Kalkınması Açısından İncelenmesi: SAPARD ve IPARD Örneği”, GOÜ Ziraat Fakültesi Dergisi, 24 (2), s.44.

- Chakrabarty Amit K., Krishnamay Ghosh (2009), "Appraisal of a rural co-operative with the thrust on rural development: an empirical study", International Journal of Social Economics, 36 (1-2), p. 209-210.

- Çekiç İnal Tuba, Ayşe Nur Ökten (2009), "Sosyal Sermaye Perspektifinden Kırsal Kalkınma Sorunsalına Yeniden Bakış", Megaron, 4 (3), s. 205, 207, 210.

- Çot Döner, Mustafa Nerkız, Hüseyin Karakaya (2014), Yeşilyuva Halk Kültürü, Yeşilyuva, Editörler: Turgut Tok, Mehmet Tolga Bakırtaş, Pamukkale Üniversitesi, Yeşilyuva Belediye Başkanlığı, Denizli, s. 210.

- Giray F.H, Akın A, Gün S, 2004, “Kırsal Kalkınmada Yeni Perspektifler”, Türkiye VI. Tarım Ekonomisi Kongresi, ss.161-168, http://www.agri.ankara.edu.tr/economy/1189_1205572781.pdf (Erişim tarihi:11.06.2015)

- Gökçe Turan (2012), Ahilik ve Denizli: Türk Kültür Tarihinde Ahilik ve Denizli Ahiliği, Denizli Belediyesi Kültür Yayınları, Denizli, s. 36.

- Haykıran Sarıbey Aysun, Muzaffer Çetin (2014), “Osmanlı Arşiv Belgelerinde Yeşilyuva:Kaysar'dan Yeşilyuva'ya Bir Beldenin Tarihi”, Yeşilyuva Bildiriler Metinleri, Editörler: Turgut Tok, Mehmet Tolga Bakırtaş, Pamukkale Üniversitesi, Yeşilyuva Belediye Başkanlığı, Denizli, s. 29.

- Işık Nihat, Duygu Baysal (2011), “Avrupa Birliği’ne Uyum Sürecinde Türkiye'de Kırsal Kalkınma Politikaları: Genel Bir Değerlendirme”, C. Ü. İktisadi ve İdari Bilimler Dergisi, 12 (1), s. 183.

- Kallimci Hasan (2007), Denizli Ahileri, Tornacı Hüseyin, Denizli Ticaret Odası Kültür Yayınları-3, Ankara.

- Kallimci Hasan (2012), Denizli Ahileri, Türk Kültür Tarihinde Ahilik ve Denizli Ahiliği, Denizli Belediyesi Kültür Yayınları, Denizli, s. 66.

- K1lı̧ Yusuf (2014), "Eskiçağda Yeşilyuva (Kaisareia/Kaysa/er)", Yeşilyuva Bildiriler Metinleri, Editörler: Turgut Tok, Mehmet Tolga Bakırtaş, Pamukkale Üniversitesi, Yeşilyuva Belediye Başkanlığı, Denizli, s. 1719.

- Kırsal Kalkınma Planı (2010-2013), T.C. Tarım ve Köyişleri Bakanlığı, Ankara, s.14.

- Onuncu Kalkınma Planı 2014-2018, T.C. Kalkınma Bakanlı̆̆ı, Ankara, 2013, s.135-136.

- Özçelik Selahittin (2014), "XIX Yüzyıl Ortalarında (1844-1845) Kaysar'da Sosyo-Ekonomik Hayat", Yeşilyuva, Editörler: Turgut Tok, Mehmet Tolga Bakırtaş, Pamukkale Üniversitesi, Yeşilyuva Belediye Başkanlığı, Denizli, s. 68-70.

- Öztürk Şinasi (2009), "Kırsal Kalkınma Yaklaşımları Ve Küçük Meta Üretimi”, Anadolu Üniversitesi Sosyal Bilimler Dergisi, 9 (2), s. 180-183.

- Soysal Abdullah (2013), "Kırsal Alanda Kadın Girişimciliği: Türkiye İçin Durum Değerlendirmesi" Eskişehir Osman Gazi Üniversitesi İ̈BF Dergisi, 8 (1), ss. 163-189.

- Tok Turgut (2012), Türk Kültür Tarihinde Ahilik ve Denizli Yöresi’nde İzleri, Denizlili Bir Önder: Ahi Sinan, Türk Kültür Tarihinde Ahilik ve Denizli Ahiliği, Denizli Belediyesi Kültür Yayınları, Denizli, s. 21.

- Tolunay Ahmet, Ayhan Akyol (2006), "Kalkınma ve Kırsal Kalkınma: Temel Kavramlar ve Tanımlar", Süleyman Demirel Üniversitesi Orman Fakültesi Dergisi, Seri: A, Sayı: 2, s 119-120.

- Türkdoğan Orhan (1977), Toplum Kalkınması, 2. Baskı, Dede Korkut Yayınları, İstanbul.

- Türktaş Metin (2014), Yeşilyuva'da Ayakkabıcılık, Yeşilyuva, Editörler: Turgut Tok, Mehmet Tolga Bakırtaş, Pamukkale Üniversitesi, Yeşilyuva Belediye Başkanlığı, Denizli, s. 180, 181, 183.

- Ulusal Kırsal Kalkınma Stratejisi 2014-2020, Ankara 2014.,http://dap.gov.tr/yeniDosyalar/Kaynaklar/ulusal_kirsal.pdf, (Erişim Tarihi: 15.06.2015)

- Yıldız Zafer, Hüseyin Topuz (2011), "Sosyal Sermaye ve Ekonomik Kalkınma İlişkisi Açısından Türkiye Üzerine Bir Değerlendirme", Sosyal Siyaset Konferansları, 61(2), s. 206.

- http://mebk12.meb.gov.tr/meb_iys_dosyalar/20/02/736412/icerikler/yesilyuva-kasabasi_204924.html (Erişim Tarihi: 24.06.2015)

- http://yesilyuvam.tr.gg/Ana-Sayfa.htm (Erişim Tarihi: 24.06.2015) 


\title{
Türk İmalat Sanayinde Performans, İnovasyon ve Rekabet Arasındaki İlişski
}

\section{The Relationship between Performance, Innovation and Competition in Turkish Manufacturing Industry}

\author{
Asst. Prof. Dr. Aykut Karakaya (Recep Tayyip Erdogan University, Turkey) \\ Assoc. Prof. Dr. Seymur Ağazade (Recep Tayyip Erdogan University, Turkey) \\ Prof. Dr. Selçuk Perçin (Karadeniz Technical University, Turkey)
}

\begin{abstract}
The relationship between performance and innovation is covered most extensively in neoclassical economic theory and Schumpeterian approach. These two approaches explain the relationship between innovation and performance in different ways. The neoclassical theory predicts that innovation emerges in competitive markets while Schumpeterian approach predicts it will emerge in imperfect competitive markets. Using data for the period 2008-2013, this study investigates the relationship between innovation and competition level in the Turkish Manufacturing Industry. Data analyzing method is Two-Step System Generalized Moments of Method. Performance variables of the study are net profit margin, return on assets and return on equity. R\&D intensity is innovation indicator. Industrial competition level is measured by Herfindahl-Hirsckman Index. The results of Two-Step System Generalized Method of Moments analysis show that R\&D intensity affects positively performance variables in contrast one lag of R\&D effects negatively. Furthermore, competition intensity also improves performance. Positive coefficient of R\&D variable supports the view of innovation has the characteristics of providing competitive advantage. The negative coefficient of R\&D lag indicates the problems related to the protection of intellectual property right. This finding can be interpreted that innovation operations are imitated approximately after a period. The positive effect of competition intensity supports the prediction of Schumpeterian approach.
\end{abstract}

\section{Giriş}

Firmalar küreselleşmeyle birlikte artan rekabetin olduğu ulusal ve uluslararası piyasalarda, faaliyetlerini kesintisiz ve performanslarını iyileştirerek sürdürmeleri için daha yoğun şekilde inovasyon yapmaktadır. Literatürde inovasyonun performansa etkisini açıklamaya çalışan araştırmalarda son yirmi yılda önemli artış olmuştur. Bu araştırmalar amaçları açısından üç grupta sınıflanabilir. İlkinde, inovasyonun içeriği ve firma performansı arasındaki bağlar karşılaştırılmıştır. İkincisinde, inovasyon türleri ile performans arasındaki bağlar incelenmiştir. İnovasyon ve performans arasındaki ilişki araştırmaların bazısında pozitif, bazısında negatif ve bazısında da anlamsız bulunmuştur (Heunks, 1998; Freel, 2000; Avlonitis ve Salavou, 2007; Rochina-Barrachina vd., 2010). Son grupta, inovasyon ve performans arasındaki ilişkide finansmanın büyüklüğü, finansman riski, talep gibi ekonomik koşullar dikkatte alınmıştır. Bu çalışmalarda ekonomik koşulların inovasyon ve performansı etkilediği ortaya konmuştur (Cainelli vd., 2006). İnovasyon performansı etkileyen önemli bir faktör olması ile birlikte performansı birçok başka değişkenin de etkilemektedir. Bunlar arasında rekabet ve teknoloji yoğunluğu ön plana çıkmaktadır (Bessen ve Maskin, 2009; Kim ve Lee 2009; Oh vd., 2015).

Piyasa rekabeti ile firma performansı arasındaki ilişkiye yönelik literatürde farklı görüşler mevcuttur. Söz konusu görüşlerde ilişkinin yönü ile ilgili farklılıklar olmasına rağmen, uzlaşılan husus rekabetin performans üzerindeki belirleyici rolünün olduğudur. Rekabet firmaların stratejik kararlarında göz önünde bulundurdukları kuşkusuz en önemli piyasa bilgileri arasındadır. Performans, inovasyon ve rekabet arasındaki ilişki literatürde yaygın biçimde Neoklasik iktisat teorisi ve Schumpeteryen görüşle açıklanmaktadır. Neoklasik teori inovasyonun rekabetçi piyasalarda, Schumpeteryen görüş ise daha çok aksak rekabet piyasalarında ortaya çıkacağını öngörür.

Firmalar açısından rekabetin yanında faaliyette bulundukları endüstrilerdeki teknoloji yoğunluğu da önemlidir. Teknoloji firma açısından ölçek ekonomisi oluşturduğundan üretim maliyetlerinin azaltılmasına olanak sağlamaktadır (Oh vd., 2015). Rekabet gibi teknoloji de firma performansında, maliyetleri azaltıp verimliliğin artırılması açısından, belirleyici ekonomik sonuçlar doğurmaktadır. İnovasyon, rekabet ve teknoloji firma performansında önemli etkiye sahip olan ve etkisi uzun süre devam eden stratejik faktörlerdir.

Türk İmalat Sanayiinde inovasyon, rekabet ve performans arasındaki ilişki üzerine yapılmış çalışmalar sınırlı sayıdadır. Hatta NACE Rev.2 endüstri sınıflamasına göre bu konuda yapılmış çalışmalara rastlanamamıştır. Bu çalışmada Türk İmalat Sanayiinde inovasyon, rekabet ve performansın ne düzeyde olduğuna ilaveten rekabet yoğunluğu, inovasyon ve teknolojik yoğunluğun performansa etkisinin nasıl olduğu soruları cevaplanmaya çalışılmıştır. Söz konusu soruların cevaplanmasında, firmaların bilanço ve gelir tablolarının ilgili endüstri kolları itibariyle toplulaştırıldığı endüstri bilanço ve gelir tablolarından elde edilen finansal bilgilerden yararlanılmıştır. 
Bu doğrultuda endüstri kolları düzeyinde 2008-20013 yılları bilanço ve gelir tablolarından elde edilen verilerle panel veri analiz yöntemlerinden dinamik panel analizi tahmincilerinden içselliği dikkate alan İki Aşamalı Sistem Genelleştirilmiş Momentler Yöntemi aracılı̆̆ılyla analiz gerçekleştirilmiştir.

Çalışma altı bölümden oluşmaktadır. İkinci bölümde performans, inovasyon ve rekabet arasındaki ilişki teorik olarak ele alınmıştır. Üçüncü bölümde, çalışmanın veri seti ve değiş̧kenleri hakkında bilgiler verilmiştir. Dördüncü bölümde çalışmanın analiz yöntemi tanıtılmış ve performans modeli sunulmuştur. Beşinci bölümde araştırma sorularının cevaplandığı araştırma bulguları yer almıştır. Son olarak altıncı bölünde sonuç ve öneriler sunulmuştur.

\section{Firma Performansı, İnovasyon ve Rekabet Arasındaki İlişki}

Firmaların faaliyet gösterdikleri piyasalarda mevcut rekabet yoğunluğunun firma performansına etkisi konusunda farklı görüşler vardır. Neoklasik iktisat teorisi piyasaların daha etkin şekilde çalışması için rekabetin önemli olduğunu varsayar. Etkin piyasalarda faaliyet gösteren firmaların varlıklarını sürdürebilmelerini rekabet edebilmelerine bağlar, rekabetin firmalar için maliyetlerini düşürme ve üretimlerini geliştirme yönünde güçlü teşvikler sağlayacağı belirtilir. Böylece Neoklasik iktisat teorisindeki görüş, rekabetin yenilik için yatırım yapma yönünde firmalara teşvik sağladığı yönündedir. Yenilik veya yeni ürünlerin geliştirilmesinde, ürün farklılaştırılmasında firmaların amacı kendilerini rekabet yoğunluğuna karşı korumak veya piyasa gücü elde etmektir. Bu görüşe göre rekabetçi piyasalarda firmalar sahip oldukları kaynakları etkin şekilde kullanma yönünde daha güçlü güdülere sahip olduklarından firma performanslarının da yüksek olması beklenir. Monopolistik piyasa ya da düşük rekabet düzeyi ise firmalara tekniklerini geliştirme yönünde güçlü bir güdü sağlamadığından firma performanslarının da nispeten düşük olması beklenir.

Arrow'un (1962) argümanları da rekabet yoğunluğunun olduğu piyasalarda maliyetleri azaltmaya yönelik daha güçlü teşvikler olduğunu desteklemektedir. Şöyle ki Arrow (1962), buluşların uygun telif hakkı ödenerek ticarileştirilmesi ve fikri mülkiyet haklarıın korunması varsayımıyla rekabetçi piyasaların monopolistik özellikler taşıyan piyasalara oranla maliyetleri düşürmeye yönelik yenilik yapma yönünde daha güçlü bir güdü sağladığını ileri sürer. Buna göre düşük rekabetin olduğu piyasalarda maliyetli yenilikleri yapmak veya yeni ürünler geliştirmek için daha az teşvik vardır. Buluş öncesi monopolistik güç daha ileri buluşlar için güçlü engelleyici, caydırıc faktör olmaktadır.

Rekabet ve firma performansı arasındaki ilişki Holmstrom (1982), Nalebuff ve Stiglitz (1983), Hart (1983) gibi çalışmalarda ise vekâlet (asıl-vekil) modelleri çerçevesinde ele alınmaktadır. Rekabetin firma performansını pozitif yönde etkilediğini öngören bu modeller monopolistik rantların yöneticilere kaytarma olanağı verdiği düşüncesine dayanmaktadır (Nickell, Nicolitsas ve Dryden, 1997). Buna göre firma yöneticileri ve sahipleri arasında bilgi asimetrisi ve sübjektif risk mevcuttur. Firma performansını etkilediği düşünülen yeniliğe yönelik yatırımların da düşük efor harcama eğilimine sahip firma yöneticilerinin kararlarına bağlı olduğu varsayılmaktadır. Rekabet düzeyinin yönetici eforunu ve dolayısıyla firma performansını etkileyeceği düşünülmektedir. Şöyle ki yoğun rekabet yöneticilerin daha fazla efor göstermelerine ve dolayısıyla daha yüksek firma performansına neden olurken, rekabet baskısının düşük olduğu monopolistik piyasalar firma yöneticilerinin daha az efor göstermelerine, daha fazla kaytarmalarına ve dolayısıyla daha düşük firma performansina neden olmaktadır.

Vekâlet modelleri rekabet ve firma performansı ilişkisini rakip firma sayısının neden olduğu izleme kolaylığının yanı sıra iflas riskinin ve talep esnekliğinin rekabetçi ve monopolistik piyasalardaki farklılaşmasından hareketle de açıklamaktalar. Rekabet göstergesi olarak rakip firma sayısının dikkate alındığı modellerde, bu sayıdaki artışın hissedarlara firma veya yönetici performanslarını izleme ve değerlendirme konusunda daha fazla olanak sağladığı ve bilgi asimetrisini azatllğı düşünülür. Ayrıca rakip firma sayısının daha fazla olması cari performanslarına bağlı olduğu düşünülen gelecekteki ücret ödemeleri konusunda firma yöneticilerinin daha fazla endişe duymalarına neden olur. Bu durumun yöneticileri daha yüksek efor harcamaya zorlayacağı ve kaytarmayı azaltacağı düşünülür. Yönetici efor artışının da firma performansını artıracağı varsayılır. Bu nedenle rakip firma sayısı ile firma performansı arasında pozitif bir ilişki öngörülür (Rogers, 2004).

Daha yoğun rekabetin olduğu piyasalarda firmaların daha yüksek iflas riski taşımaları da beklenir. Bu nedenle rekabetçi piyasalarda yöneticilerin iflastan kaçınma için de daha yoğun efor göstermeleri gerekir ve bu piyasalarda kaytarmanın daha düşük oranlarda gerçekleşmesi beklenir. Bunun yanı sıra monopolistik özelliklerin yüksek olduğu piyasalarda talebin fiyat esnekliğinin daha düşük olması gerekir. Bunun sonucu olarak monopolistik özelliklerin yüksek olduğu piyasalarda fiyatların azalması satış gelirlerinin azalmasına neden olabilecektir. Dolayısıyla bu piyasalarda maliyetlerin azaltılması için yöneticiler güçlü güdülere sahip değildir. Talep esnekliğinin yüksek olduğu rekabetçi piyasalarda ise fiyat düşüşleri satı̧̧ gelirlerini artırabileceğinden dolayı maliyetlerin azaltılmansa neden olacak üretkenlik artışı için yöneticilerin daha güçlü güdüleri vardır (Souare, 2013). 
Schumpeteryen görüş ise rekabet yoğunluğu ve firma performans arasında daha farklı bir öngörüde bulunmaktadır. Buna göre üretkenliği ve firma performansını artıracak yatırımlar için gerekli kaynağın oluşturulması, kredi piyasası aksaklıkları dikkate alındığında önemli ölçüde firmaların geçmiş ve cari dönem karlarına bağlı olmaktadır. Bunun yanı sıra, gelecek dönemlere ilişkin kar beklentisi de bu tür yatırımlar için güçlü bir güdü sağlamaktadır. Daha fazla rekabet firma karlarını ve kar beklentilerini azalttığından yeniliği ortaya çıkartacak araştırmalar için ayrılması gereken kaynakların ve yenilik için gerekli teşviklerin azalmasına neden olmaktadır. Rekabet düşüklüğünün sunacağı monopolistik karların ise yenilik yaratmak için daha büyük kaynaklar ve teşvikler sunacağı düşünülmektedir (Rogers, 2004).

Schumpeteryen görüşe göre faaliyette bulundukları piyasada belirsizliğin düşük olmasından ve daha istikrarlı kaynaklara sahip olmalarından dolayı rekabet düzeyinin düşük olduğu endüstrilerde faaliyet gösteren firmalar daha istekli olabilirler. Bu noktada Schumpeteryen hipotez farklı şekillerde ifade edilebilmektedir. Bunlardan ilki 'yenilikçi faaliyetlerin büyük firmalarca desteklendiği' şeklinde ifade edilirken, diğeri 'yenilikçi faaliyetlerin daha çok piyasa yapısından yani aksak rekabet tarafından teşvik edildiğidir' (Kamien ve Schwartz, 1975; Levin, Cohen ve Mowery, 1985). Aghion, Bloom, Blundell, Griffith ve Howitt (2002) konuya ilişkin katkıları ise rekabet artışının yenilik ve üretkenliği pozitif ve negatif yönde etkileyebileceği, dolayısıyla ilişkinin ters ' $U$ ' biçiminde olabileceği şeklindedir. Buna göre tam rekabetçi veya monopol piyasa yapısına oranla orta düzeyde rekabetçi özellikler taşıyan piyasa yapısı yeniliğin ortaya çıkması için daha uygun koşullar sunmakta ve Schumpeteryen etki düşük rekabet düzeyinde değil yüksek rekabet düzeyinde ortaya çıkmaktadır.

Ar-ge faaliyetlerinin de ürün geliştirme, teknolojik ilerleme ve böylelikle firma performansı üzerinde belirleyici etkisinin olduğu düşünülebilir. Maliyetlerin azalmasına neden olacak yeni üretim tekniklerinin, tüketici zevk ve tercihlerine daha fazla hitap eden ürünlerin geliştirilmesi veya ürünlerin farklılaştırılması bu yönde bir efor gösterilmesini gerektirir. Başarılı bir şekilde sonuçlanan Ar-ge faaliyeti maliyet düşürücü gelişmenin yanı sıra ürün geliştirme veya ürün farklılaştırmasına, firmanın önemli bir piyasa pozisyonuna sahip olmasına veya pazar payını genişletmesine, rekabet üstünlüğü veya monopol gücü kazanmasına ve bu nedenle firma performansının artmasına neden olabilir. Düşük ar-ge yatırımları ise yeniliğin veya bilgi üretiminin azalmasına neden olur ki bu da nihayetinde üretkenlikte düşüşün yanı sıra fiziki ve beşeri sermaye yatırımlarında da azalmaya neden olur.

Ar-ge harcamalarının firma performansı üzerindeki pozitif etkisini vurgulayan Branch (1974), Tassey (1983), Jaffe (1986), Erickson ve Jacobson (1992) gibi çok sayıda çalışma olmasına karşın firmalar için ar-ge faaliyetlerini gerçekleştirmek nihayetinde maliyetli bir süreçtir. Bunun yanı sıra ar-ge faaliyetlerine yönelik harcamanın firma performansı üzerinde potansiyel pozitif etkisinin ortaya çıkması başarılı şekilde inovasyona dönüşmesine bağlıdır. Bu nedenle ar-ge harcamaları firma performans artışını garanti etmez. Fikri mülkiyet haklarının iyi şekilde korunmaması ve inovasyonun taklit edilmesi de ar-ge harcamalarının potansiyel faydasını azaltır. Bunun yanı sıra ar-ge harcamalarının firma performansı üzerindeki etkisi genellikle Hartmann, Myers ve Rosenbloom'ın (2006) ifade ettikleri gibi gecikmeli ve orantılı olmayan şekildedir. Şöyle ki, ar-ge harcamalarının gerçekleşmesi ile nihai gelirlerin veya karların gerçekleşmesi arasındaki gecikme mevcuttur. Ayrıca, ar-ge harcamalarındaki artış orantılı kazanımlar sağlamaz. Buradan da anlaşıldığı gibi, Hartmann ve diğerlerinin (2006) ifade ettiği gecikme nedeniyle firma performansının başlangıçta olumsuz yönde etkilenmesi mümkündür. Kazanımların orantılı olmaması, azalan getiri ilkesinin yansıması olup daha yüksek ar-ge harcamalarının firma performansına aynı derecede yansımayacağını ifade eder.

Ar-ge harcamalarının aşırı derecede yüksek oranını ifade etmek için risk sermayedarları tarafından kullanılan bir kavram da batık oranıdır (burn rate) (McCutchen ve Swamidass, 1996). Batık oran ile aşırı derecede ar-ge harcamalarına katlanan firmaların bile piyasada rakiplerinin güçlü rekabeti ile karşılaşabilecekleri ifade edilmektedir. Rekabet üstünlüğünü rakiplere kaybetme ile karşı karşıya olan firmalar ar-ge faaliyetlerine kaynak harcayabilirler. Fakat rekabet yoğunluğu bu harcamaların performanslarına yansımasını engelleyebilmektedir.

\section{Araştırma Verisi ve Değişkenler}

Çalışmada Türk İmalat Sanayi NACE Rev.2 endüstri kollarının performans, inovasyon ve rekabet arasındaki ilişki ele alınmıştır. Analiz, yıllık verilerle gerçekleştirilmiş ve veriler Türkiye İstatistik Kurumu'nun www.tuik.gov.tr adresli internet sitesinden derlenmiştir. Çalışma veri seti inceleme dönemi olarak 2008-2013 dönemlerini kapsayan 6 yıldaki 24 imalat sanayii endüstri kolu için 144 gözlemden oluşmuştur. Türk İmalat Sanayi’nde firmaların dağılımlarına bakıldığında gıda, tekstil, metalik olamayan mineraller, giyim ve fabrikasyon metal ürünleri endüstrilerinde faaliyet gösteren firmaların toplam imalat sanayii firmalarının yarısından fazlasını oluşturmaktadır. Türk İmalat Sanayi’nde teknolojinin görece daha düşük düzeyde kullanıldığı ve daha geleneksel sanayi hâkimdir.

İnovasyonla işletme performansı arasındaki bağlantıyı ele alan çalışmalarda performans büyüme oranları (Freel, 2000; Verhees vd.,2010; Oh vd., 2015), karlılık oranları (Heunks, 1998; Freel, 2000; Forsman ve Temel, 2011) ve verimlilikle ifade edilmiştir (Huergo ve Jaumandreu, 2004; Kannebley vd., 2010; Forsman ve Temel, 
2011). Çalışmada performans net kar marjı, öz sermaye karlılık oranı ve aktif karlılık oranı olarak performans karlılık yönünden ele alınmıştır.

İnovasyonu Schumpeter yeni veya geliştirilmiş ürünler, üretim teknikleri, organizasyon yapıları, yeni pazarların keşfi ve yeni girdi faktörleri olarak geniş biçimde tanımlamıştır. İnovasyon faaliyetlerinin ortak özelliği yeni ve farklı olmaktır (Forsman ve Temel, 2011). İnovasyon literatürde üç şekilde ölçülür. Bunlar; inovasyon girdi göstergeleri (ar-ge harcamaları, ar-ge personeli gibi), inovasyon ara çıktı göstergeleri (patentler, ticari markalar gibi) ve inovasyon çıktı göstergeleri (yenilik sayısı, yenilik türü, yenilik devir hızı gibi). Bu inovasyon göstergelerinden literatürde daha yoğun kullanılanları, girdi ve çıktı göstergeleridir. Literatürde inovasyonu girdi göstergeleriyle ölçen çalışmalar arasında Nassimbeni (2001), Özçelik ve Taymar (2004), Lopez, Rodriguez ve Garcia Rodriguez (2005), Wignaraja (2007), Harris ve Li (2009), D'Angelo (2012) ile Tsao ve Chen (2015) tarafında yapılan çalışmalar gösterilebilir. İnovasyonu çıktı göstergeleriyle ölçenler arasında ise, Hitt vd. (1991), Pegels ve Thirumurthy (1996) ve Tsao ve Chen (2015) sayılabilir. Bu çalışmada inovasyon, bir girdi göstergesi olan ar-ge harcamalarıyla ölçülmüş̧ür.

Piyasa yoğunluğu piyasa performansının bir parametresi veya göstergesi olarak kullanılmaktadır. Özellikle, Herfindahl-Hirsckman Endeksi (HHI) piyasa rekabetinin değerlendirilmesinde bir dönüm noktası olarak kabul edilir (Sung, 2014). HHI, hem piyasadaki tüm firmaları hesaba katmasından, hem de firma sayısındaki azlık ve firma büyüklükleri arasındaki değişikliklere hassas olmasından dolayı daha yoğun biçimde kullanılmaktadır. HHI 0 ile 1 arasında değerler alabilmektedir. HHI piyasada tek bir firma varsa en yüksek değer olan 1'e ulaşır. Piyasada çok sayıda ve küçük ölçekli firmalar olduğunda indeks sıfıra yakın bir değer almaktadır. HHI 0-0,20 arası ise düşük yoğunluklu ve tam rekabetçi bir piyasa; $0,20-0,40$ arası ise orta yoğunluklu ve monopolcü rekabetçi bir piyasa; $0,40-1$ arası ise yoğun ve rekabetçi olmayan oligopolcü bir piyasadan söz edilmektedir. $\mathrm{Bu}$ çalışmada rekabet göstergesi olarak HHI modele katılmıştır.

Farklı endüstri kollarındaki firmaların farklı inovasyon stratejilerinin olabileceği ve bu farklı inovasyon stratejilerinin de performansa etkilerinin farklı düzeylerde olabileceğinden (Oh vd., 2015) hareketle performans modeline endüstri teknoloji yoğunluğu kukla değişkenleri dâhil edilmiştir. Endüstri teknoloji yoğunluğu NACE Rev.2 temelinde düşük, orta-düşük, orta-yüksek ve ileri teknoloji kukla değişkenleriyle belirlenmiştir. Böylece, endüstrilerdeki teknoloji seviyelerinin performansa etkileri ortaya konmuştur. Ayrıca, modelde sermaye ve emek faktörlerini temsilen kontrol değişkenleri olarak iki bağımsız değişken yer almıştır.

\section{Araştırma Tahmin Yöntemi}

Panel veri analizi temel tahmin yöntemi Havuzlanmış En Küçük Kareler (HEKK) olmasına rağmen hata terimi ve bağımsız değişkenler arasında ilişkinin varlığında ve zaman içinde hata teriminde ardışık bağımlılık olduğunda HEKK ile tutarlı tahminler elde edilemez (Wooldrige, 2002: 256). Söz konusu bu sakıncaların giderilmesi amaciyla statik ve dinamik olan panel veri analizi için özel tahminciler geliştirilmiş̧ir.

Statik panel veri yöntemlerinde, esasen cari dönemde oluşan iktisadi ve ticari davranışların geçmiş deneyim ve davranışlardan bağımsız olduğu fikri yatmaktadır. Bu geçmiş deneyim ve davranışları dikkate alındığında analize dinamik bir nitelik kazandırılmaktadır. Bunu dikkate alan panel veri yöntemleri dinamik panel veri modellerdir. Bu yönüyle dinamik panel veri analizi, yatay kesit veya zaman serisi yöntemlerinin ortaya koyamadı̆̆ı, mikro ve makro dinamikleri ortaya koyabilmektedir (Bond, 2002: 1).

Dinamik panel veri analizi, ekonometri literatüründe, ilk olarak Hansen (1982) tarafindan geliştirilmiş olan Genelleştirilmiş Momentler Metodunu (GMM) temel almaktadır. Anderson ve Hsiao (1981 ve 1982) GMM'yi panel veriye uyarlamışlardır. Daha sonradan Arellano ve Bond (1991), Arellano ve Bover (1995) ve Blundell ve Bond (1998) tarafından bu yöntem geliştirilmiş ve panel veri yazınında yazarların isimleriyle birlikte anılan GMM ve Sistem Genelleştirilmiş Momentler Metodu (SGMM) olarak geçmiştir.

GMM tahmin yönteminde öncelikle modelin birinci fark1 alınıp, fark modelin araç değişken matrisi kullanılarak dönüştürülmektedir. Daha sonra dönüştürülmüş model Genelleştirilmiş En Küçük Kareler (GEKK) ile tahmin edilmektedir. Veri seti dengeli olmayan panel veri ya da birim sayısının zamandan az olduğu panel verilerde birinci fark dönüşümü zayıf kalmaktadır. Bu durumda doğrusal (orthogonal) sapmaları kullanan SGMM kullanılmaktadır. Böylece SGMM ile etkin araç değişken tahmincisi elde edilebilmektedir (Baltagi, 2005: 148). SGMM'de GMM deki cari dönemden bir önceki dönemin farkının alınması yerine, değişkenlerin tüm olası gelecek değerlerinin ortalamalarının farkı alınmaktadır. Böylece, birinci farklar yönteminden kaynaklanan veri kaybı en aza indirilmektedir (Blundell ve Bond, 2000).

GMM tahmin yöntemi zamanın birim sayısından daha fazla olduğu panel veri setindeki değişkenler arası ilişkilerin tahmininde tercih edilmektedir. Dolayısıyla, birimin zamandan büyük olduğu panel veri setlerinde değişkenler arasındaki doğrusal ilişkinin ortaya konmasında da SGMM tahmin yöntemi tercih edilir. GMM ve SGMM'nin iki aşamalı tahmincileri de mevcuttur. Bağımsız değişkenlerin içsel değişken olduğu durumda iki aşamalı tahminlerden elde edilen bulgular daha tutarlı ve sapmasızdır. Bu çalışmanın veri setinde birim sayısı zamandan büyük olduğundan Arellano ve Bover (1995) ve Blundell ve Bond (1998) tarafindan önerilen İki Aşamalı SGMM tahmin yöntemi ile tahminler gerçekleştirilmiştir. Ayrıca küçük örneklem tahminlerindeki 
standart hataların sapmasız olması için Windmeijer'in (2005) tarafından önerilen dirençli standart hatalar kullanılmıştır. Söz konusu dirençli standart hataların hesaplanmasında Roodman (2009) tarafından yazılan kod kullanılmıştır.

Çalışmada performans modelleri dinamik panel veri analiz yaklaşımıyla tahmin edilmiştir. İlgili ilişki aşağıdaki denklemde gösterilmiştir:

$$
\begin{aligned}
& \sum_{j=1}^{k} \text { PERFORMANS } S_{i t}=\beta_{1} \sum_{j=1}^{k} \text { PERFORMANS }{ }_{i t-1}+\beta_{2} S E R M A Y E_{\mathrm{i} t}+\beta_{3} E M E K_{\mathrm{I} t} \\
& +\beta_{4} A R G E Y O \breve{G} U N L U \breve{\mathrm{G}} U_{\mathrm{i} t}+\beta_{5} A R G E Y O \breve{G} U N L U \breve{\mathrm{G}} U_{\mathrm{I} t-1}+\beta_{6} H H I_{\mathrm{I} t}+\beta_{7} \sum_{l=1}^{m} K T E K N O L O J \dot{\mathrm{I}}_{i t}+\varepsilon_{i t} \\
& i=1,2, \ldots, 24 \quad j=1,2 \text { ve } 3 \quad l=1,2 \text { ve } 3 \quad t=2008, \ldots, 2013
\end{aligned}
$$

Burada, $i, t$, $j$ ve $l$ sırasıyla endüstri kolu, zaman, performans göstergesi ve teknoloji düzeyini ifade etmektedir.

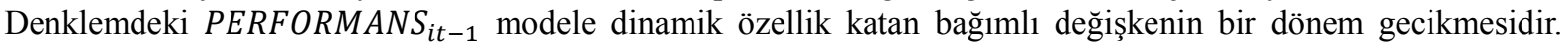
$\sum_{j=1}^{k}$ PERFORMANS it $_{\mathrm{t}} \mathrm{t}$ dönemi endüstri kolu performansı olan öz sermaye karlılık oranı, aktif karlılık oranı ve net kar marjını, $\sum_{j=1}^{k} P E R F O R M A N S_{i t} \mathrm{t}-1$ dönemi endüstri kolu performansı olan öz sermaye karlılık oranı, aktif karlılık oranı ve net kar marjını, $S E R M A Y E_{i t} \mathrm{t}$ dönemi endüstri kolu maddi duran varlık toplam aktif oranını, $E M E K_{t} \mathrm{t}$ endüstri kolu çalışan sayısını, $A R G E Y O \breve{G} U N L U \breve{G} U_{\mathrm{I} t} \mathrm{t}$ dönemi endüstri kolu ar-ge yatırımının toplam aktife oranını, $A R G E Y O \breve{G} U N L U \breve{G} U_{\mathrm{I} t-1} \mathrm{t}-1$ dönemi endüstri kolu ar-ge yatırımının toplam aktife oranını $\sum_{l=1}^{m} K T E K N O L O J \dot{\mathrm{I}}_{i t} \mathrm{t}$ dönemi endüstri kolu teknoloji yoğunluk düzeyi kukla değişkenlerini, $H H I_{\mathrm{I} t} \mathrm{t}$ dönemi endüstri rekabet yoğunluğu değişkeni ve $\varepsilon_{i t}$ denklemin hata terimini göstermektedir.

\section{Araştırma Bulguları}

Araştırmanın bulguları endüstrilerin genel özellikleri ve model değişkenleri arasındaki ilişkilerin sunulduğu tanımlayıcı istatistikler, korelasyonlar, eğilimler ve panel veri analiz tahmin sonuçları aşağıda sunulmuştur.

\subsection{Tanımlayıcı İstatistikler ve Korelasyonlar}

Aşağıdaki Tablo 1-3'de araştırmanın değişkenlerin ortalama ve standart sapmaları olarak tanımlayıcı istatistikleri yer almaktadır. Tablo 1'de çalışmanın bağımlı ve bağımsız değişkenlerinin ortalama ve standart sapma değerleri sunulmuştur. İnceleme döneminde Türkiye'deki imalat sanayiinde performans göstergeleri olan net kar marjı, aktif karlılık oranı ve öz sermaye karlılık oranının $\% 3$ ile $\% 9$ arasında düşük düzeyde gerçekleşmiştir. İktisadi açıdan sermaye olan maddi duran varlıkların toplam aktif içerisindeki payı imalat sanayiinde ortalama \%27'dir. Bu bulgu toplam aktifin yaklaşık \%27'si düzeyinde fiili üretim kapasitesine sahip olunduğunu göstermektedir. Buna ilave olarak, endüstrilerin ortalama istihdamının 40.000'inin üzerinde, ar-ge yatırımının aktifin sadece \%1'i civarında ve orta yoğunlukta monopolcü rekabetçi bir piyasadır. Dolayısıyla, imalat sanayinde sermayenin ve rekabetin orta düzeyde, buna rağmen performansın, ar-ge yoğunluğunun ve istihdamın görece düşük olduğu ortaya çıkmaktadır.

\begin{tabular}{|l|l|l|l|l|l|}
\hline Değişkenler & Ortalama & Std. Sapma & Değişkenler & Ortalama & Std. Sapma \\
\hline Net Kar Marjı (\%) & 3,69 & 4,80 & Emek (Kişi) & 41.573 & 40.634 \\
\hline Aktif Karlılık Oranı (\%) & 3,65 & 4,04 & Sermaye (\%) & 26,89 & 8,32 \\
\hline Öz Sermaye Karlılık Oranı (\%) & 8,49 & 9,49 & HHI $(0 \leq$ HHI $\leq 1)$ & 0,2259 & 0,2135 \\
\hline Ar-ge Yoğunluğu (\%) & 1,16 & 3,48 & & & \\
\hline
\end{tabular}

\section{Tablo 1: Değişkenlerin Tanımlayıcı İstatistikleri}

Tablo 2'ye göre imalat sanayinde aslında düşük ve orta-düşük teknolojilerin hakimiyeti söz konusudur. Teknoloji yoğunluğunun yüzde dağılımı incelendiğinde imalat sanayii içinde yüksek teknoloji endüstrileri sadece \%8'dir. Teknoloji yoğunluğu firma dağılımına göre irdelendiğinde yüksek teknoloji firma yüzdesi daha da düşüktür. Bu bilgiler Türk İmalat Sanayi’nde düşük ve orta düzey teknoloji yoğunluğunun egemen olduğunu göstermektedir. Dolayısıyla, imalat sanayiinde görece katma değeri ve rekabet gücü daha düşük olan endüstriler ağırlıktadır. Teknoloji yoğunluğundaki yüksek teknoloji lehine politikalar geliştirilirken firma dağılımının iyileştirilmesi gerekliliği ön plana çıkmaktadır. Bu iyileşmelerin ardından imalat sanayiinde katma değeri daha yüksek çıktılarla birlikte endüstri performanslarında artışlar sağlanabilecektir.

\begin{tabular}{|l|l|l|l|l|}
\hline Teknoloji Yoğunluk Düzeyleri & Endüstri Sayıs1 & Endüstri \% & Firma Sayıs1 & Firma \% \\
\hline Düşük Teknoloji & 11 & 45.9 & 10.081 & 49.3 \\
\hline Orta-Düşük Teknoloji & 6 & 25 & 5.852 & 28.7 \\
\hline Orta-Yüksek teknoloji & 5 & 20.8 & 4.059 & 19.9 \\
\hline Yüksek Teknoloji & 2 & 8.3 & 438 & 2.1 \\
\hline Toplam & 24 & 100 & 20.430 & 100 \\
\hline
\end{tabular}


Tablo 2: Endüstrilerin Teknoloji Yoğunluk Düzeyi Frekansları

Tablo 3'de değişkenlerin korelasyonları sunulmuştur. Performans değişkenleri arasındaki korelasyon beklendiği üzere yüksektir. Performans ile sermaye dışındaki bağımsız değişkenler arasındaki korelasyon pozitiftir. Sermaye değişkeni olan maddi duran varlıkların toplam aktife oranı ile performans değişkenleri arasındaki korelasyonun negatif olması maddi duran varlıklara yatırımın karlılığı azalttığı anlamına gelmektedir. $\mathrm{Bu}$, beklenen bir bulgudur çünkü maddi duran varlıklara yapılan yatırım karın azalmasına neden olur. Bu azalma iç finansmana başvurulduğunda karın doğrudan maddi duran varlıklara yatırılmasıyla, dış finansmana başvurulduğunda ise borcun anapara ve faiz ödemesiyle gerçekleşecektir. Emeğin performansla pozitif korelasyonu emekteki verimlilik artışından kaynaklanmaktadır. Ar-ge yoğunluğunun performansla pozitif korelasyonu, yeniliğin verimlilik artışına neden olduğu biçiminde yorumlanabilir. Endüstri rekabet düzeyi ile performans arasındaki pozitif korelasyon rekabet yoğunluklu ile performansın doğrusal yönde ilişkide olduğunu ifade etmektedir. Dolayısıyla imalat sanayinde rekabetin düşük olduğu yoğunlaşmış endüstrilerde daha yüksek performansın varlığından söz edilebilir.

\begin{tabular}{|l|l|l|l|l|l|l|}
\hline Değişkenler & NKM & AKO & ÖSKO & Sermaye & Emek & Ar-ge \\
\hline NKM & 1 & & & & & \\
\hline AKO & $0,8804^{* * *}$ & 1 & & & & \\
\hline ÖSKO & $0,8271^{* * *}$ & $0,9514^{* * *}$ & 1 & & & \\
\hline Sermaye & $-0,2153^{* *}$ & $-0,2151^{* * *}$ & $-0,2539^{* *}$ & 1 & & \\
\hline Emek & 0,0520 & $0,0993^{*}$ & 0,0563 & $0,1179^{*}$ & 1 & \\
\hline Ar-ge & $0,1460^{* *}$ & 0,0286 & $0,1176^{*}$ & $-0,4657^{* * *}$ & $-0,1098^{*}$ & 1 \\
\hline HHI & 0,0258 & 0,1003 & $0,1437^{* *}$ & 0,0208 & $-0,1563^{*}$ & $-0,0827$ \\
\hline${ }^{* * *}{ }^{* * * *}$ ve & 0,21 asiyla $0.10,0.05$ ve 0.01 düzeyinde istatistiksel anlamll11kları göstermektedir.
\end{tabular}

Tablo 3: Korelasyon Katsayllarl

\subsection{Değişkenlerin Ĕgilimleri}

Grafik 1-3'de çalışma değişkenlerinin inceleme döneminde gösterdiği eğilimler sunulmuştur. Grafik 1'de Türk İmalat Sanayi’nin yıllar itibariyle performansı verilmiştir. Tüm performans göstergelerinin benzer seyir izlediği tespit edilmektedir. Bu seyir "ters W" şekline benzetilebilir. Performans göstergeleri sırasıyla 2009, 2010 ve 2012 yıllarında yükselmiş, buna karşın 2008 ve 2011 yıllarında düşmüştür. Dolayısıyla performansta dalgalanmalar olmuş, yıllar itibariyle inişler ve çıkışlar birbirini izlemiştir. Bu bulgu, inceleme döneminde Türkiye'deki İmalat Sanayii'nin istikrasız, yani değişken bir performansa sahip olduğunu gösterir. Bunun daha çok, küresel ekonomide yaşanan finansal krizden kaynaklandığını söylemek yanlış olmayacaktır.

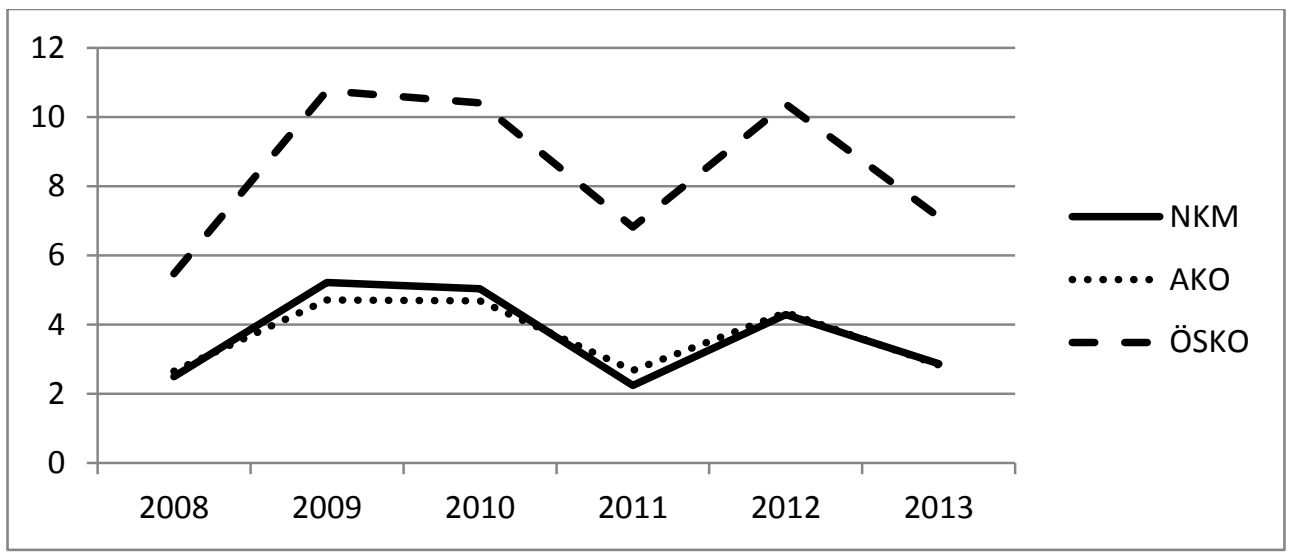

Grafik 1: Performans Göstergeleri \%

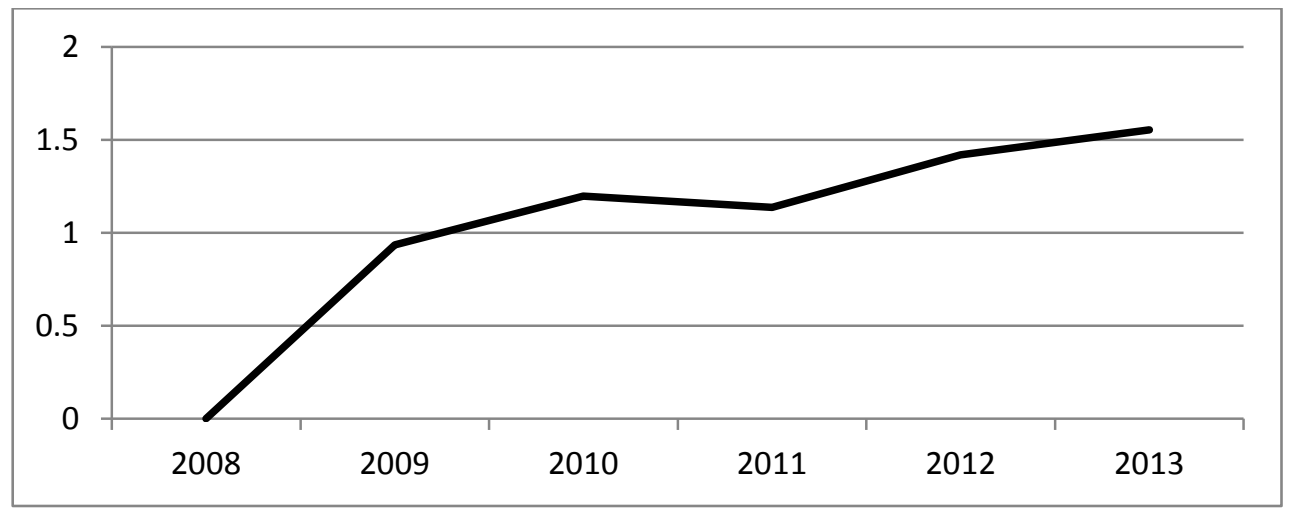




\section{Grafik 2: Ar-ge Yoğunluğu (\%)}

Grafik 2'de ifade edildiği gibi Türk İmalat Sanayi'nin ar-ge yoğunluğunda aynı düzeyde olmasa bile sürekli bir artış vardır. 2008 yılında ar-ge yoğunluğu neredeyse sıfırdır. Bunu takip eden yıllarda ar-ge yoğunluğu artarak yaklaşık \%1,6 seviyesine gelmiştir. Gelinen seviye düşük olmasına rağmen, bu hızlı artış hükümetin sektörel ve bölgesel kalkınma politikalarının yanında teknoloji yatırımlarına verdiği teşviklerin sonucu olduğu söylenebilir.

Grafik 3'de Herfindahl-Hirsckman Endeksi (HHI) ile hesaplanmış endüstri rekabet yoğunluğunun 2009-2012 yılları için ortalamaları sunulmuştur. HHI belirtilen yıllarda 0,20-0,40 arası değer aldığı ve orta yoğunluğa sahip olduğu görülmektedir. HHI'deki düzenli düşusş ise, imalat sanayiinde yoğunluğun azaldığını yani rekabetin gittikçe arttığını göstermektedir. Türk İmalat Sanayii 2009'da düşük rekabetçi bir yapıya sahipken, 2012'de nispeten daha rekabetçi bir görünüm kazanmıştır.

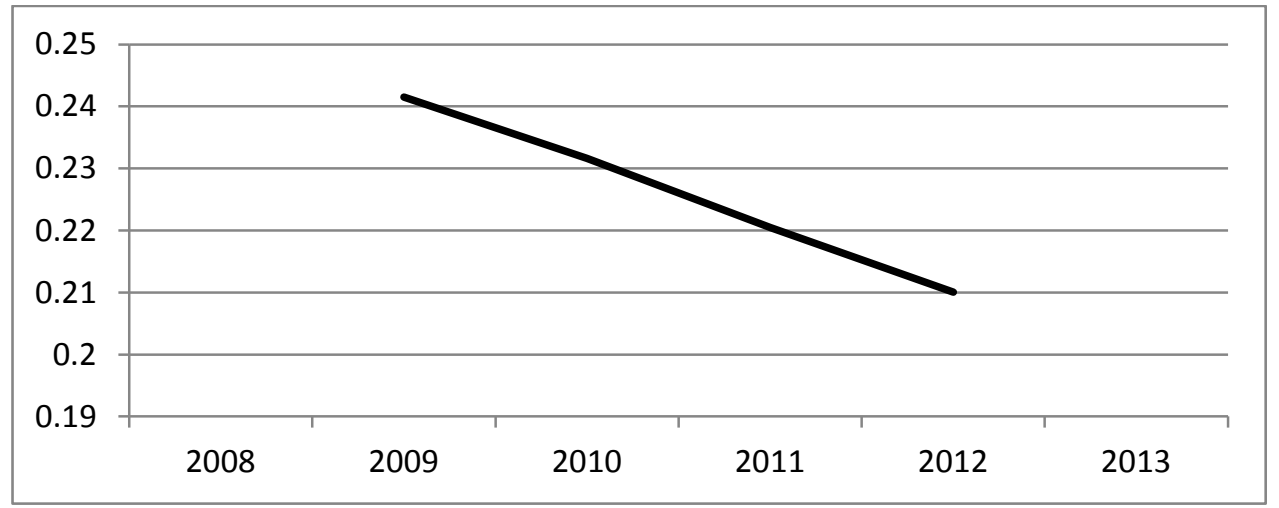

Grafik 3: Endüstri Rekabet Yoğunluğu (HHI)

\subsection{Performans Modeli Bulguları}

Performans modellerinde elde edilen bulgular aşağıdaki Tablo 4'de sunulmuştur. Modellerin genel anlamlılı̆̆ını sınamak için yapılan Wald İstatistikleri'ne göre modeller anlamlıdır. Modellerle ilgili, birinci mertebe otokorelasyonun varlığının testinde Arellano ve Bond'un otokorelasyon (AR1) testi anlamlı ve ikinci mertebe otokorelasyon (AR2) testi anlamsızdır. Bu testlere göre, modellerde birinci mertebe otokorelasyonun olduğu buna karşın, ikinci mertebe otokorelasyonun olmadığı bulunmuştur. Bu bulgu, modellerdeki bağımsız değişkenlerin ikinci gecikmeleri olan araç değişkenlerin doğru tespit edildiği anlamına gelmektedir. Ardından, modellerden elde edilen araç değişkenlerin geçerliliği için yapılan dirençsiz Sargan Testi anlamlı iken, dirençli Hansen Testi ve dirençli Fark Hansen Testi anlamsızdır. Dirençsiz Sargan Testi dışındaki dirençli testler, performans modellerinin tahmininde kullanılan araç değişkenler regresyonunda kullanılan araç değişkenlerin geçerli ve modellerin uygun olduğunu göstermektedir. Sonuçta, modellerin genel anlamlılık, otokorelasyon ve araç değişkenler regresyonu ile ilgili koşulları sağladığı söylenebilir.

\begin{tabular}{|c|c|c|c|}
\hline & \multicolumn{3}{|l|}{ Bağımlı Değişkenler } \\
\hline & ÖSKO & $\mathrm{AKO}_{\mathrm{t}}$ & $\mathrm{NKM}_{\mathrm{t}}$ \\
\hline ÖSKO $_{\mathrm{t}-1}$ & $0.21768^{* * *}[0.05927]$ & & \\
\hline $\mathrm{AKO}_{\mathrm{t}-1}$ & & $0.09468^{* * *}[0.02192]$ & \\
\hline $\mathrm{NKM}_{\mathrm{t}-1}$ & & & $0.28359^{* * *}[0.00831]$ \\
\hline Sermaye $_{t}$ & $-0.01989[0.05926]$ & $0.01841[0.02017]$ & $0.03566^{* * *}[0.01018]$ \\
\hline Emek $_{\mathrm{t}}$ & $0.00004^{* * * *}[0.00001]$ & $0.00003^{* * *}[0.00001]$ & $0.00002^{* *}[0.00001]$ \\
\hline Ar-ge Yoğunluğ $u_{t}$ & $1.35320^{* * *}[0.23812]$ & $0.36558^{* * *}[0.01385]$ & $0.61683^{* * *}[0.01028]$ \\
\hline Ar-ge Yoğunluğ $\mathrm{u}_{\mathrm{t}-1}$ & $-0.81427^{* * * *}[0.24267]$ & $-0.15851^{* * * *}[0.01299]$ & $-0.30295^{* * *}[0.00779]$ \\
\hline $\mathrm{HHI}_{\mathrm{t}}$ & $8.92872^{* *}[4.23284]$ & $4.47346^{* * *}[1.21160]$ & $2.04443^{* * *}[0.61091]$ \\
\hline Orta-Düşük Teknoloji $i_{t}$ & $4.22161^{* * * *}[2.11688]$ & $0.73995^{* *}[0.31512]$ & $0.17779 \quad[0.80563]$ \\
\hline Orta-Yüksek Teknoloji $\mathrm{i}_{\mathrm{t}}$ & $6.24778^{* * *}[0.86290]$ & $2.55037^{* * *}[0.26926]$ & $1.38183^{* * *}[0.24478]$ \\
\hline Yüksek Teknoloji $i_{t}$ & $-2.79958[2.16741]$ & $-0.67932[0.40843]$ & $-2.11308^{* * *}[0.23368]$ \\
\hline Wald İstatistiği & $18853.52^{* * *}$ & $18898.45^{* * *}$ & $81800.00^{* * *}$ \\
\hline AR1 Testi & $-2.11^{* *}$ & $-2.14^{* * *}$ & $-2.03^{* * *}$ \\
\hline AR2 Testi & 0.56 & 1.14 & 0.61 \\
\hline Sargan Testi & $25.32^{* * *}$ & $25.96^{* *}$ & $38.73^{* * *}$ \\
\hline Hansen Testi & 16.95 & 17.25 & 16.91 \\
\hline Fark Hansen Testi & 2.65 & 2.68 & 2.50 \\
\hline
\end{tabular}

${ }^{*},{ }^{* *}$ ve ${ }^{* * *}$ sirasıyla $0.10,0.05$ ve 0.01 düzeyinde istatistiksel anlamlılıkları gösterirrmektedir. Köşeli parantez içinde standart hatalar sunulmaktadır. 


\section{Tablo 4: Performans Modelleri Çözüm Sonuçları}

Tablo 4'deki performans modellerinin tamamında endüstri performansına endüstri performansının bir dönem gecikmesinin pozitif ve anlamlı etkisi vardır. Bu etki öğrenmenin ve deneyimin olum katkısının incelenen dönemde çalıştığı anlamına gelir. Tablodan sermayenin performans göstergelerinden sadece net kar marjına pozitif ve anlamlı etkisinin olduğu, diğer performans göstergeleri olan aktif karlılık oranı ve öz sermaye karlılık oranına etkisinin ise anlamlı olmadığı tespit edilmiştir. Bununla birlikte, Emeğin performans göstergelerinin tamamına etkisi pozitif ve anlamlıdır. Emek ve sermayenin performans üzerindeki bu etkileri, emeğin sermayeye kıyasla veriminin yüksek olduğu ve maliyetlerdeki göreli azaltılmayla performansı artırdığı anlamına gelebilir.

Ar-ge yoğunluğunun performansa etkisi pozitif, ar-ge yoğunluğunun bir dönem gecikmesinin performansa etkisi ise negatiftir. Cari dönem yeniliği cari dönem performansını artırmasına rağmen, ar-genin bir dönem gecikmesi azaltmaktadır. Söz konusu ar-ge yatırımları endüstri performansını yükselttiği, bir dönem önceki ar-ge yatırımları dolayısıyla ortaya çıkan ticari faydanın ise rakipler tarafindan taklit edilip rekabet avantajının yani farklılığın ortadan kalktığı görülmektedir.

Endüstri kolu rekabet düzeyini gösteren rekabet yoğunluğu (HHI) değişkeninin performansa etkisi pozitiftir. Endüstri rekabetinin daha düşük olduğu aksak rekabete sahip endüstrilerde performans daha yüksek gerçekleşmiştir. Dolayısıyla, Türkiye İmalat Sanayinde endüstrilerde tam rekabetçi piyasadan rekabetçi monopolcü piyasaya oradan da rekabetçi oligopolcü piyasaya geçildikçe performansı arttığı ortaya konmuştur. Türkiye İmalat Sanayinde rekabetin performansa etkisi Schumpeteryen görüş öngörüsünü destekleyici niteliktedir.

Son olarak endüstrilerin teknolojik yoğunluk düzeylerini gösteren üç teknoloji kukla değişkeninin performans göstergelerine etkilerinin hem pozitif hem de negatiftir. Orta-düşük düzey teknolojiyi gösteren teknoloji kukla değişkeninin öz sermaye karlılık oranı ve aktif karlılık oranına etkisi pozitif ve anlamlıdır. Orta-yüksek düzey teknolojiyi gösteren teknoloji kukla değişkeninin performans göstergelerinin tamamına pozitif ve anlamlı etkisi vardır. Yüksek yoğunlukta teknolojiyi ifade eden teknoloji kukla değişkenin ise, sadece net kar marjına etkisi anlamlı ve negatiftir. Teknoloji yoğunluklarının performansa etkisi Oh vd. (2015) tarafından Kore firmaları bulguları ile örtüşmektedir. Firma sayısının çoğunlukta olduğu düşük ve orta düzey teknoloji yoğunluğuna sahip endüstrilerde teknoloji performansı artırırken, buna karşın ileri teknoloji endüstrilerinde azaltmıştır.

\section{Sonuç ve Öneriler}

İktisat teorisinde inovasyon ve rekabetin performans üzerinde etkisini açıklayan yaklaşımlar birbirileri ile farklılık gösterir. Neo-klasik iktisadi görüşe göre, rekabetçi piyasalarda firmalar sahip oldukları kaynakları etkin şekilde kullanma yönünde güçlü güdülere sahip olduklarından bu piyasalarda firma performansı karşılaştırmalı olarak daha yüksektir. Schumpeteryen görüş ise rekabet firma karını veya kar beklentisini azalttığı için inovasyonu ortaya çıkartacak faaliyetler için ayrılması gereken kaynakları ortadan kaldırma yönünde etki eder. Bu nedenle rekabet yoğunluğu inovasyonu ortaya çıkarmak için gerekli teşviklerin azalmasına neden olur. Düşük rekabetten kaynaklanan monopolistik karların ise inovasyon yaratmak için daha büyük kaynaklar sağlayacağı ve teşvikler sunacağı düşünülmektedir.

Çalışmada, Türk İmalat Sanayi'nin dalgalı bir performansa, düşük seviyede olmasına rağmen giderek yükselen ar-ge yatırımlarına, düşük fakat giderek artan rekabet bir rekabet yapısına, üretim teknolojisinin ise çoğunlukla düşük ve orta yoğunluk düzeyine sahip olduğu tespit edilmiştir.

Panel veri analizi sonuçlarına göre emek endüstri performansı artırıcı yönde etkilemektedir. Ar-ge yoğunluğunun performansı artırdığı, bir dönem önceki ar-ge'nin ise Hartmann vd., (2006)'nin belirtiği gibi azalttığı görülmüştür. Gecikmeli etkinin negatif olması inovasyonun rakipler tarafından taklit edilmesi elde edilen rekabet avantajının ortadan kalkmasından kaynaklanabilir. Bu bulgu Arrow'un (1962), buluşların uygun telif hakkı ödenerek ticarileştirilmesi ve fikri mülkiyet haklarının korunması uyarısının Türkiye İmalat Sanayiinde tam olarak sağlamadığını göstermektedir. Sonuç olarak, yüksek maliyet gerektiren inovasyon yatırımlarının radikal ve sürekli şekilde cesaretlendirilmesi amacıyla merdiven altı veya taklit üretimin etkin biçimde önlenmesi gerekliliği ortaya çıkmaktadır.

Rekabetinin daha düşük olduğu endüstrilerde performans daha yüksek gerçekleşmiştir. Bu bulgu, Türk İmalat Sanayii için Schumpeteryen görüşü destekleyici niteliktedir. Schumpeteryen görüşe göre rekabet düzeyinin düşük olduğu piyasalarda faaliyette bulunan firmalar daha istikrarlı kaynaklara sahip olduklarından dolayı daha başarılı olabilirler. Daha fazla rekabet firma karlarını ve kar beklentilerini azalttığından inovasyonu ortaya çıkartacak araştırmalar için ayrılması gereken kaynakların ve inovasyon için gerekli teşviklerin azalmasına neden olmaktadır.

Teknoloji yoğunluğunun performansa etkisi ise tek düze değildir. Çalışma bulguları orta düzey teknolojinin performansı pozitif, yüksek teknolojinin ise negatif yönde etkilediğini gösterir. Teknoloji yoğunluklarının performansa etkisi Oh vd. (2015) tarafından Kore firmalarına ilişkin yapılan çalışmanın bulguları ile örtüşmektedir. Firma sayısının çok olduğu düşük ve orta düzey teknoloji yoğunluğuna sahip endüstrilerde 
teknoloji performansı artırırken, buna karşın yüksek teknoloji endüstrilerinde azalttığı görülmüştür. Burada kritik olan, ileri teknoloji endüstrilerinin ve bu endüstrilerde faaliyette bulunan firmaların ağırlığının son derece düşük olmasıdır. Bunun için, inovatif, yarışmacı rekabete sahip, katma değeri yüksek olan yüksek teknolojinin sanayide ağırlık kazanacağı yapısal dönüşümün sağlanması gerekmektedir. Bu dönüşümle, teknolojinin çarpan etkisinden yararlanılabilir. Bu değişimin hayata geçirilmesinde öncelikle ortak bir strateji çerçevesinde üniversite-sanayidevlet iş birliği sağlanmalıdır. $\mathrm{Bu}$ iş birliği sonucunda, üretilen bilimsel bilgi ekonomik gelecek vadeden inovasyonlara objektif ve tarafsız biçimde yönlendirilmelidir. Türkiye'de yeni uygulanmaya konan teknoloji yoğunluklu alanlara verilen destekler, bu dönüşümü sağlama potansiyeline sahiptir. Ancak yine de kurumsal bir iş birliği ve koordinasyon eksikliği hala mevcuttur. Ayrıca, inovasyon içeriği ve türleri açısından hem firma hem de endüstri düzeyinde yapılacak gelecekteki çalışmalarla inovasyon, rekabet ve performans arasındaki ilişkilerin doğası daha iyi anlaşılabilecektir.

\section{Kaynakça}

- $\quad$ Aghion, P., N. Bloom, R. Blundell, R. Griffith ve P. Howitt, 2002. Competition and Innovation: An InvertedU Relationship", The Institute For Fiscal Studies, Wp02/04.

- Anderson, T. W., ve Hsiao, C., 1981, "Estimation of Dynamic Models with Error Components", Journal of the American Statistical Association, 76, 375, 598-606.

- Anderson, T. W., ve Hsiao, C., 1982, "Formulation and Estimation of Dynamic Models Using Panel Data", Journal of Econometrics, 18, 47-82.

- Arellano M., ve Bond, S., 1991, "Some Tests of Specification for Panel: Monte Carlo Evidence and An Application to Employment Equations", Review of Economic Studies, 58, 277-297.

- Arellano M., ve Bover, O., 1995, "Another Look at the Instrumental Variable Estimation of ErrorComponents Models", Journal of Econometrics, 68, 29-51.

- Arrow, K., ,1962, "Economic Welfare and the Allocation of Resources for Invention." In The Rate and Direction of Inventive Activity: Economic and Social Factors, A Report of the National Bureau of Economic Research, ss.609-25.

- $\quad$ Avlonitis, GJ., ve H. Salavou, 2007, "Entrepreneurial Orientation of SMEs, Product Innovativeness, and Performance", Journal of Business Research, 60(5), 566-575.

- Baltagi, B. H., 2005, Econometric Analysis of Panel Data, Third Edition, John Wiley\&Sons, Ltd., England.

- Bessen, J., ve E. Maskin, 2009, “Sequential Innovation, Patents, and Imitation”, The RAND Journal of Economics 40(4), 611-35.

- $\quad$ Blundell R., ve Bond S., 1998, "Initial Conditions and Moment Restrictions in Dynamic Panel Data Models", Journal of Econometrics, 87, 115-143.

- Blundell, R. ve S. Bond, 2000, “GMM Estimation with Persistent Panel Data: An Application to Production Functions”, Econometric Reviews 19, 321-340.

- Bond, S., 2002, "Dynamic Panel Data Models: A Guide to Micro Data Methods and Practice", CEMMAP Working Paper, No: Cwp0209, 1-36.

- Branch, B., 1974, "Research and Development Activity and Profitability: A Distributed Log Analysis", Journal of Political Economy, 82(5), 999-1011.

- Cainelli, G., R. Evangelista ve M. Savona, 2006, "Innovation and Economic Performance in Services: A Firm-Level Analysis", Cambridge Journal of Economics, 30(3), 435-458.

- D'Angelo, A., 2012, “Innovation and Export Performance: A Study of Italian High-Tech SMEs", Journal of Management and Governance 16, 393-423

- Erickson, G. ve R. Jacobson, 1992, “Gaining Comparative Advantage Through Discretionary Experience: The Returns to R\&D and Advertising”, Management Science, 38(9), 1264-1279.

- Forsman, H., ve S. Temel, 2011 "Innovation and Business Performance in Small Enterprises, An EnterpriseLevel Analysis”, International Journal of Innovation Management 15(3), 641-665.

- Freel, MS., 2000, "Do Small Innovating Firms Outperform Non-innovators?", Small Business Economics, 14(3), 195-210.

- Hansen, L.P., 2002 “Large Sample Properties of Generalized Method of Moments Estimators”, Econometrica,50, 1029-1054.

- Harris, R., ve Q. C. Li, 2009, “Exporting, R\&D, and Absorptive Capacity in UK Establishments”, Oxford Economic Papers, 61(1), 74-103.

- Hart, O. D., 1983, “The Market Mechanism as An Incentive Scheme”, Bell Journal of Economics14(2), 366-82.

- Hartmann, G. C., M. B. Myers ve R. S. Rosenbloom, 2006, "Planning Your Firm's R\&D Investment", Research Technology Management, 49(2), 25-36.

- Heunks, FJ, 1998, “Innovation, Creativity and Success”, Small Business Economics, 10(3): $263-272$.

- Hitt, M. A., Hoskisson, R. E., Ireland, R. D., ve Harrison, J. S., 1991 "Effects of Acquisitions on R\&D Inputs and Outputs”, Academy of Management Journal, 34(3): 693-706. 
- Holmstrom, B. ,1982,. "Moral Hazard in Teams”, Bell Journal of Economics, 13(2): 392-415.

- Hsiao, C., 2003, Analysis of Panel Data, Second Edition, Cambridge University Press, United Kingdom.

- Huergo, E ve J. Jaumandreu, 2004, "Firms' Age, Processes Innovation and Productivity Growth", International Journal of Industrial Organization, 22(4), 541-559.

- Jaffe, A.B., 1986, “Technological Opportunity and Spillovers of R\&D”, American Economic Review, 76(5), 984-1001.

- Kamien, M. I. ve N. L. Schwartz, 1975, "Market Structure and Innovation: A Survey”, Journal of Economic Literature, 13(1), 1-37.

- Kannebley, S Jr., JV Sekkel ve BC Araujo, 2010, "Economic Performance of Brazilian Manufacturing Firms: A Counterfactual Analysis of Innovation Impacts”, Small Business Economy, 34(3), 339-353.

- Kim,W.J., ve J.D. Lee, 2009, "Measuring The Role of Technology-Push and Demand-Pull in The Dynamic Development of Semiconductor Industry: The Case of The Global DRAM Market”, Journal of Applied Economics 7(1), 83-108.

- $\quad$ Levin, R. C., W. M. Cohen ve D. C. Mowery, 1985, "R \& D Appropriability, Opportunity, and Market Structure: New Evidence on Some Schumpeterian Hypotheses", The American Economic Review,75(2), 20-24.

- $\quad$ Lopez Rodriguez, J., ve Garcia Rodriguez, R. M., 2005, “Technology and Export Behaviour: A Resourcebased View Approach”, International Business Review, 14(5), 539-557.

- Nassimbeni, G., 2001, "Technology, Innovation Capacity, and The Export Attitude of Small Manufacturing Firms: A Logit/Tobit Model”, Research Policy, 30(2), 245-262.

- Nickell, S., D. Nicolitsas ve N. Dryden, 1997, "What Makes Firms Perform Well”, European Economic Review 41(3-5), 783-796.

- McCutchen Jr, W. W. ve Swamidass, P. M. 1996, "Effect of R\&D Expenditures and Funding Strategies on the Market Value of Biotech Firms", Journal of Engineering and Technology Management, 12(4), 28799.

- $\quad$ Oh, C., Y. Cho ve W. Kim, 2015, “The Effect of A Firm's Strategic Innovation Decisions on Its Market Performance", Technology Analysis \& Strategic Management, 27(11), 39-53.

- $\quad$ Özçelik, E., ve Taymar, E., 2004, "Does Innovativeness Matter for International Competitiveness in Developing Countries”, Research Policy, 33(3), 409-424.

- Pegels, C. C., ve Thirumurthy, M. V., 1996 “The Impact of Technology Strategy on Firm Performance", IEEE Transactions on Engineering Management, 43(4): 246-249.

- Rochina-Barrachina, ME., JA. Mañez ve JA. Llopis, 2010, "Process Innovations and Firm Productivity Growth", Small Business Economics, 34(2), 147-166.

- Rogers, M., 2004, "Competition, Agency and Productivity", International Journal of the Economics of Business, 11:3, 349-367.

- Roodman, D., 2009, "How to Do xtabond2: An Introduction to "Difference" and "System" GMM in Stata," The Stata Journal , 9(1), 86-136.

- Souare, M., 2013, "Canada-US Productivity Gap: The Role of Competition Intensity Differential”, International Review of Applied Economics, 27 (3), 404-428.

- Sung, N., 2014, "Market Concentration and Competition in OECD Mobile Telecommunications Markets", Applied Economics, 46(25), 3037-3048.

- Tassey, G., 1983, “Competitive Strategies and Performance in Technology-Based Industries”, Journal of Economic Business, 35 (1), 21-40.

- Tsao, S-M. ve G-Z, Chen, 2015, “The Impact of Internationalization on Performance and Innovation: The Moderating Effects of Ownership Concentration”, Asia Pacific Journal of Management 29, 617-642.

- Verhees, F, M Meulenberg ve J Pennings, 2010, "Performance Expectations of Small Firms Considering Radical Product Innovation", Journal of Business Research, 63(7), 772-777.

- Wignaraja, G,. 2007, "Foreign Ownership, Technological Capabilities and Clothing Exports in Sri Lanka", Journal of Asian Economics, 19(1), 29-39.

- Windmeijer F., 2005, “A Finite Sample Correction for The Variance of Linear Efficient Two-Step GMM Estimator”, Journal of Econometrics, 126(1), 25-51.

- Wooldridge, J. M., 2002, Econometric Analysis of Cross Section and Panel Data, The MIT Press, England. 


\title{
Kalite Kontrol Çemberleri Üzerine Kavramsal Bir Araştırma The Conceptual Research on the Quality Control Circles
}

\author{
Dr. Gülçin Özbay (Sakarya University, Turkey) \\ Prof. Dr. Mehmet Sarışık (Sakarya University, Turkey)
}

\begin{abstract}
Quality circles occurred in Japan after the Second World War, and the forefront of the competition today, has an important role in improving the quality and efficiency. The main philosophy of the quality circle is to achieve quality with a participative management approach. Quality circles, only to find not only identify problems also suggests a variety of solutions. It is settled principle that the employees can do the best work by themselves and, according to this it is tried to provide more opportunities for employees. This situation motivates the staff, and thus prepares the ground to increase the quality of goods or services. Customer satisfaction and management objectives are carried out. Considering all these factors, quality circles has emerged as a concept that should be investigated. In this study, it was examined quality circles that considered as a factor of enhancing success in the operations and having an important role inquality management. The study carries a descriptive qualification that is prepared literature review. In the first section of the study was investigated the purpose of the quality control that the steps followed and the methods used in this process. The second section was focused on quality circles. In this section, it has tried to explain shortly the definition of quality circles, history, characteristics, comparison with other groups and objectives. Benefits of quality circles were examined separately for businesses and employees, and determined the business sectors. The organizational structure of quality circles and organization members' tasks was explained.
\end{abstract}

\section{Giriş}

Kalite (Qualite) Latince "nasıl oluştuğu” anlamına gelen "qualis” kelimesinden gelmektedir. Kalite, genel olarak günlük konuşmalarda üstünlüğü ve iyiliği, diğer bir deyişle kaliteye konu olan ürün ve hizmetin iyi niteliklerinin olduğunu belirtmektedir. Bu bakımdan kalite sübjektif (kişisel) bir kavramdır. Sübjektif değerlendirmelerden oluşan kalite anlayışı; ülkeden ülkeye, yaşam düzeyi, zevk, gelenekler, toplumsal yapı, eğitim gibi çok sayıda faktörün etkisi altında değişik bir yapı göstermektedir (Şimşek, 2001: 5). Barutçugil (1998: 275) çalışmasında kaliteyi, tüketici gereksinimlerini en iyi şekilde karşılayan, yeterli ve doyurucu kullanım olanağı sağlayan ürün özelliklerini ifade eden bir kavram olarak açıklarken, Feigenbaum (1991: 7) müşterinin belirttiği yada belirtmediği, teknik olarak kullanılmaya hazır ya da tamamen sübjektif olan gereksinimlerine karşı ortaya konan ürün ya da hizmetle ilgili gerçek deneyimlerine dayanan ve rekabet ortamında devamlı değişen bir kavram olarak ifade etmektedir.

Kalite, müşterinin mükemmellikle ilgili algılamasına kuruluşun verdiği cevaptır. Kalite, müşterinin, ürünün veya hizmetin total değerini, rakiplerine göre nasıl algılandığına bağlıdır. Algılanan kalitenin yüksekliği, müşterinin sadakatini, tekrar eden alımları, fiyat savaşlarından daha az etkilenmeyi, pazar payını azaltmadan makul bir kar marjını korumayı sağlamaktadır (Akdemir, 2001: 298). Genellikle müşteriler mal ve hizmeti altı boyutta ele almaktadır (Gümüşoğlu, 2000: 1): Mal ve hizmetin işlevsel performansı, güvenilirliği, konforu, servis alabilme kolaylığı, görüntüsü ve fark edilen kalitesidir. Kalite en genel anlamıyla "amaca uygunluk derecesi” şeklinde tanımlanabilir. Burada amaç, ürünü veya hizmeti kullanacak olan kişinin ihtiyacına ve ödeme olanaklarına göre belirlenmektedir (Kobu, 1998: 471).

Kalite kontrol kavramını açıklamak için kontrol kavramı tanımlanmalıdır. Kontrol, genel olarak; bir yöneticinin sorumluluklarından bir kısmını astlarına devrettikten sonra, uygulama sonuçlarının istediği gibi olup olmadığını tespit etmesi şeklinde tanımlanabilir (Kobu, 1998: 478). Kalite kontrol, bir ürünün tüketilmesi sonucu müşterinin tatmin edilmesi ve müşteri beklentilerinin en iyi biçimde karşılanması amacıyla üretimin her aşamasında sürdürülen denetim işlemleridir. Kalite kontrolü, üretimin planlama aşamasında belirlenen kalite standartlarına üretim işlemleri boyunca, öncesinde ve sonrasında ne ölçüde uyulduğunun incelenmesi olarak da açıklanabilir (Barutçugil, 1988: 275). Toplam Kalite Kontrolü her şeyden önce çeşitli düzeydeki yöneticilere yol gösteren ve daha isabetli karar vermelerine yardımcı olan bir araçtır. Bu aracın işe yarayacak biçimde dizaynı ve etkin kullanılabilmesi için;

- Tüketici isteklerinin titizlikle incelenerek değerlendirilmesi,

- Gerekli teknolojik olanakların sağlanması,

- İşletme organizasyonu içinde olumlu beşeri ilişkilerin sürdürülmesi,

- Kalite ve onunla ilgili kavramların tüm personel tarafından eksiksiz ve doğru olarak anlaşılması gerekmektedir (Kobu, 1998: 478). 


\section{Kalite Kontrolünün Amaçları ve Aşamaları}

Kalite kontrolünün maliyetten karlılık politikasına, müşteri memnuniyetinden insan kaynakları alanına kadar birçok önemli amacı bulunmaktadır. Bir işletmede etkili bir kalite kontrol uygulaması sonucunda ulaşılmak istenen amaçlar şu şekilde sıralanabilir (Kobu, 1998: 481):

- $\quad$ Mamul kalite düzeyinin yükseltilmesi

- Mamul dizaynının geliştirilmesi

- İşletme maliyetlerinin azalması

- $\quad$ Üretim hattındaki dar boğazların giderilmesi

- Personel moralinin yükseltilmesi

- Tüketicinin parasının karşılığını aldığını görerek memnun olması

- $\quad$ Ülke ekonomisine olumlu katkılar sağlaması

- İşletmenin prestijinin artması

- İşçi-işveren ilişkilerinin düzelmesi

Kalite kontrol yalnızca bir defada ve belirli bir yerde gerçekleştirilecek tek aşamalı bir fonksiyon değildir. Kalite kontrol işlemlerinin genellikle dört aşamada tamamlanabildiği kabul edilmektedir. Bu aşamalar kısaca şöyledir (Barutçugil, 1988: 275):

- Kaliteye ilişkin standartların ve ana ilkelerin üst yönetim düzeyinde belirlenmesi

- Belirlenen kalite düzeyi doğrultusunda ürün tasarlama ve maliyet hesabı

- Üst yönetim ve üretim mühendisliği tarafından belirlenen ilkelere uygunluğun sağlanması amacıyla hammadde ve malzeme alımında, üretim sürecinin tüm aşamalarında sürdürülen kontrol işlemleri

- Ürünün dayanıklılığı ve güvenilirliğini kanıtlayan ve satış-kullanım başarısını artırmayı amaçlayan kalite kontrol çalışmaları

\section{Kalite Kontrolünü Etkileyen Faktörler}

Bir işletmede kalite kontrol geniş kapsamlı faaliyetlerden oluşan bir fonksiyondur. Diğer işletme departmanlarının kararları ve uygulama yöntemleri -başta üretim araç ve yöntemleri olmak üzere- az veya çok kalite kontrolüne de yansımaktadır. Etkin bir kalite kontrol sistemi tüketicinin isteklerinden, depolama ve sevkiyata kadar olan faaliyetler zincirinin her halkasından etkilenmektedir. Kalite kontrolünü etkileyen bu faktörleri şöyle sıralamak mümkündür (Kobu, 1998: 482):

- Pazar ve tüketici özellikleri

- Parasal olanaklar

- IInsan gücü (yönetici, teknik eleman, işçi)

- Malzeme

- $\quad$ Tesis, makine ve üretim yöntemleri

- $\quad$ Teknolojik ve kültürel düzey

- Eğitim

- $\quad$ Ülkenin yasaları

\section{Kalite Çemberleri, Özellikleri ve Gelişim Süreci}

İşletmeler ürün ve hizmetlerinin kalitesi geliştirmek ve verimliliklerini arttırmak için birçok kalite programına başvurmaktadır ve bunlardan biri de kalite çemberleridir. Rekabet avantajı sağlayarak yüksek organizasyon performansı, katılımın olduğu karar verme sistemi ve karlılık artışına olan etkileri bilinen kalite çemberleri (Pereira ve Osburn, 2007: 145) Toplam Kalite Yönetimi içinde sürekli gelişmeyi sağlamak için öncelikle Japonya'da kullanılmıştır. Tüm dünyaya yayılan kalite çemberleri, örgütlerde takım çalışmasından yararlanarak başarılı olmuştur. Terminolojide kalite kontrol çemberi, kalite çevrimi, kalite kontrol halkası, kalite geliştirme grupları, kalite iyileştirme çemberleri, sorun çözme grupları, yaratıcı ekipler, inisiyatif sahibi çemberler gibi terimler kullanılmaktadır (Başer, 2000: 39; Dağl1, 2003).

Kalite çemberlerinin bu kadar çok değişik isimlerle anılmasının nedeni, bu çemberlerin yalnızca kalitenin iyileştirilmesiyle değil, iş ve iş süreçlerinin iyileştirilmesi, bunlara ilişskin sorunların çözümü, maliyetlerin düşürülmesi, verimliliğin artırılması, grup çalışmalarının desteklenmesi gibi konularla da ilgili olmasından kaynaklanmaktadır. Genellikle kalite çemberlerinin çalışma konularının \%50’sini kalite, \%40'ını verimlilik ve kalan \%10'unu da diğer konuların oluşturduğu tespit edilmiştir (Bolat, 2000: 52). Japon Bilimadamları ve Mühendisleri Derneği (JUSE), kalite çemberlerini şöyle tanımlamaktadır: "Bir kalite çemberi, aynı yerde çalışan, 
kalite yönetimi faaliyetlerini gönüllü olarak yerine getirmeyi üstlenen iş görenlerden oluşmuş küçük bir çalışma grubudur" (Düren, 1990: 40; Çetin, 2007: 46).

Kalite çemberleri toplam kalite için temel köktür. Deming ile birlikte Juran ve Crosby de bu yönetimin önemli teorisyenleridir (Gökçen, 2006: 62). Kalite çemberlerinin gelişmesinde büyük emeği olan Ishıkawa ise kalite çemberleri için, kalite kontrol etkinliklerini gönüllü olarak aynı iş yerinde yürüten küçük grup tanımlamasını yapmaktadır (Dinç, 2001: 68). Kalite çemberlerinin temelinde, çalışanların yaptıkları işleri en iyi kendilerinin yapabileceği prensibi yerleştiği için çalışanlara daha fazla imkan sağlamaya çalışılmaktadır (Katzan, 1991: 22).

Kalite çemberleri, aynı mesleki faaliyet içinde olan veya aynı üniteye bağlı olarak çalışan (atölye, büro, hizmet, laboratuar, satış örgütü gibi) sayıları beş ile on kişi arasında değişen gönüllü kişilerin oluşturduğu küçük gruplardır. Kalite çemberleri çalışanların işlerinden gurur duymaları ve katkılarının daha çok olduğunu görmeleri açısından bir motivasyon kaynağıdır (Efil, 1997: 4). Bu gruplarda; çalışanlar yaptıkları iş ile ilgili çeşitli sorunların kaynaklarını ve nedenlerini, birlikte çalışarak ve periyodik toplantılar yaparak araştırmakta, çözmekte ve üst kademe yönetimine rapor etmektedir (Köksal, 2011: 66).

Kalite çemberleri gönüllü olarak biraraya gelen, benzer işlerde çalışan küçük bir çalışanlar grubudur. Bu küçük grup düzenli olarak toplanarak sorunları saptar, inceler ve çözer (Gökçen, 2006: 68; İnand1, 2001: 139; Oxley, 1984: 15). Biraraya gelme amacı eğer mal ve hizmetin kalitesini arttırmaksa kalite çemberleri "verimlilik çemberleri” veya "problem çözme grupları" adını alır. Eğer amaç etkin bir yönetim kurmaksa kalite çemberleri "katılım çemberleri" olarak adlandırılır (Gökçen, 2006: 68).

Kalite çemberlerinin çıkış yeri Japonya'dır. İkinci Dünya Savaşı'ndan sonra Japonya kendini toparlama dönemine girmiş ve bu dönemde ilk önce ekonomisini düzeltebilmek için dünyada ucuz ve kalitesiz ürünleri ile tanınan (Japon malı) imajını silmeye çalışmıştır (Dinç, 2001: 72). Kalite çemberleri Japon üretim endüstrisinde kullanılmak üzere geliştirilmiştir. Çalışan motivasyonunu arttırdığı ve örgütsel performansı geliştirdiği düşüncesinden hareket edilmiştir (Nahai ve Österberg, 2012: 388).

Japonya'da faaliyetlerine başladıklarında kalite çemberleri sadece bu ülkeye veya Budist ülkelere özgü birşey olarak görülmüştür. Bunların bireyin insan olma özelliğine saygı gösteren işyeri faaliyetlerine bir katılım biçimi olduğu sonraları daha fazla kişi tarafından kavranmıştır. Bu anlayışın gelişmesiyle kalite çemberleri hareketi Asya dışına taşmıştır (Kondo, 1999: 69). 1960'lı yıllarda Japonya'da, 1970'li yıllarda ABD (Oxley, 1984: 15) ve diğer batı ülkelerinde, 1980'li yıllarda da ülkemizde uygulanmaya başlanan kalite çemberleri, sadece gelişmekte olan ülkelerin değil, gelişmiş ülkelerin de dikkatle inceleyip uyguladıkları ve çalışanların kendi yaptıkları işlerle ilgili kararlara katılmalarını sağlayan bir yaklaşımdır (Paşaoğlu, 2011: 17).

Toplam kalite yönetiminin; müşteri odaklılık, sürekli gelişme, takım çalışması ve süreç anlayışı olmak üzere dört temel değeri olduğu bilinmektedir. Bu değerlerden biri olan takım çalışması ise kalite çemberleri ile gerçekleştirilmektedir (Gökçen, 2006: 63-64). Bilgi toplumunda örgüt yöneticilerinin çalışanı güçlendirme, fikir ve görüşlerine başvurma yöntemlerinden biri olarak değerlendirilmektedir (Alpaslan ve Kutaniş, 2007: 60).

\subsection{Kalite Çemberlerinin Diğer Gruplarla Karşılaştırılması}

Uygulamada öneri geliştirme grupları, sorun çözme grupları gibi kalite çemberlerine benzer pek çok grup çalışması vardır. Ancak kalite çemberlerini diğer gruplardan ayıran bazı özellikler Dinç'in çalışmasında (2001: 71-72) karşılaştırılmalı olarak aşağıdaki şekilde özetlenmektedir:

Yaşam Süreci Farklılıkları: Kalite çemberlerinde sürekli çalışma esastır. Diğer gruplarda bir sorunun çözüme ulaştırılması ile sınırlı zaman vardır.

Grupların Oluşumu: Kalite çemberleri 4 ile 12 kişilik çekirdek gruptan oluşmaktadır. Diğer gruplar üst ve orta kademe yöneticilerin veya ilgili çalışanların oluşturduğu çeşitli servis temsilcilerini bir araya getiren gruplardır.

Yönlendirme: Kalite çemberlerinde yönlendirme üyelere hiyerarşide en yakın olan şef, ustabaşı gibi kişiler tarafından yapılmaktadır. Diğer gruplarda bir grup üyesi, dışarıdan gelen bir danışman, bir uzman yönetici veya liderdir.

Çalışma Yöntemleri: Kalite çemberleri, düzenli olarak haftada bir saat toplanırlar. Diğer gruplar değişik düzen ve şekillerde toplanırlar ve belirli bir sorunu çözmek üzere bir araya gelinen toplantılar yaparlar.

Çalışma Konuları: Kalite çemberlerinde üyelerin işleri ile ilgili ve yetkili oldukları tüm konular çalışma alanı kapsamı içindedir. Diğer gruplarda, gruptakilerin görüş açısını geliştirecek işletme düzeyindeki sorunlar ele alınmaktadır.

Çalışma Metotları: Kalite çemberlerinde sorun analizi, çözümü, yaratıcılık, istatistikle ilgili belirli teknikler kullanılmaktadır. Diğer gruplar soruna veya konuya göre değişen metotlar uygulamaktadır.

Yönetim Kademelerinin Tutumu ve Katkısı: Kalite çemberlerinde, yeni bir yönetim tarzı olan kalite çemberleri için yöneticiler özel olarak eğitilmektedirler. Çember kararlarının uygulanmasından da sorumludurlar. Diğer gruplarda yöneticiler sadece grubun çalışmalarını kolaylaştırmaktadır. 


\subsection{Kalite Cemberlerinin Amaçları}

Kalite çemberlerinin temel amacı, gruplar oluşturarak çalışanların kendi işleriyle ilgili kararlara katılımını sağlamak, işle ilgili problemlerin çözümünde bilgi ve yeteneklerinden faydalanmaktır. Bu temel amaca ilave olarak aşağıdaki amaçlara da ulaşılmaya çalışılmaktadır (Bolat, 2000: 52-53):

- Hata ve defoları önleyerek daha kaliteli mal ve hizmet sunmak

- İş ve iş süreçlerine ilişkin maliyetleri düşürmek

- Verimliliği yükseltmek

- Çalışanların kararlara katılımını sağlamak

- Haberleşmeyi (özellikle alt kademe ile yönetim arasındaki haberleşmeyi) sağlamak

- Çalışanların sorun belirleme ve problem çözme yeteneklerini geliştirmek

- Müşterilerin mal ve hizmetlere ilişkin beklentilerini en üst düzeyde karşılayarak şikayetleri en aza indirmek

- Çalışanların motivasyonlarını artırarak işe ve işyerlerine ilişkin tatmin düzeylerini yükseltmek

- İşi bizzat yapan kişinin, o işi ve o işe ilişskin sorunları en iyi bilen kişi olduğundan hareketle, var olan ancak yöneticiler tarafından görülemeyen iyileştirme alanlarının ortaya çıkarılmasını sağlamak (Vargün, 2009: 254)

- Toplam Kalite Yönetiminin tüm örgüt üyeleri tarafından benimsenmesini ve Toplam Kalite Yönetimi uygulamalarının işlerlik kazanması için gerekli olan örgüt kültürünün yaratılmasına zemin sağlamak.

\subsection{Kalite Çemberlerinin Yararları}

Kalite çemberi uygulamaları sonucunda örgütün kaliteli üretim ve hizmet giderlerinde azalma, verimlilik artışı gibi amaçlarının gerçekleşmesi sağlanırken, çalışanın bireysel amaçları ve örgüt içi ilişskiler bakımından da bir dizi yararlar sağlamaktadır. Kalite çemberlerinin yararlarını, çalışanlara ve kuruluşa yararları olmak üzere iki gruba ayırmak mümkündür (Başer, 2000: 47). Kalite çemberlerinin bu iki gruba olan yararları alt başlıklar halinde aşağıda açıklanmaktadır.

Kalite çemberlerinin temelini oluşturan işletme çalışanlarına yararları aşağıdaki gibi sıralanabilir (Başer, 2000: 47):

- Kişi teknik düşünebilmeyi öğrenmekte, problem çözme tekniklerini uygulayarak tüm yaşamında bilek gücüne, beyin gücünü katabilme becerisi edinmektedir.

- Çalışanların başındaki kişiler belli bir süre sonunda, toplantılarda konuşmayı, fikir üretmeyi, fikre saygı göstermeyi, toplantıyı yönetmeyi ve topluluk önünde konuşabilen insanlar olmayı öğrenmektedirler.

- İnsanları bireysellikten uzaklaştırarak "ben" kavramı yerini "bize" bırakmakta, üyeler güçlerini ve bilgilerini aynı hedef doğrultusunda birleştirerek çözüme ulaşabileceklerini görmektedirler.

- Düşüncelerine değer verilmiş olması, çalışanların şirket sorunlarına daha kolay çözüm bulabilmesine neden olmakta, bu da kişiyi, kuruluşu ile bütünleştirmekte, aidiyet duygusunu geliştirerek işletmeyi sahiplenmesini sağlamaktadır.

- Çalışanlara, yeteneklerini sergileme ve geliştirebilme, liderlik özelliklerini gösterebilme ve sivrilebilme imkanı verilmektedir.

- Birim sorunları hakkında çok kısa zamanda fikir elde edilebilmektedir.

- Önderlik, sorun çözme, sorunları görebilme, sorunlara karşı tarafın gözü ile bakabilme, hayal gücü, karar verme ve değerlendirme gibi yetenekler büyük ölçüde gelişmektedir (Dale ve Lees, 1987: 748).

Kalite çemberlerinin, uygulandığı işletmeye sağladığı yararlar aşağıda yer almaktadır (Başer, 2000: 49):

- Elemanların bilek gücünün yanında beyin gücü ve gönül gücünden de faydalanarak sınırsız bir potansiyeli olan insan gücünü en iyi şekilde değerlendirebilme şansı vermektedir.

- Birden fazla kişinin gücünü, bilgisini, yeteneklerini ve tecrübelerini belli bir hedef doğrultusunda birleştirmesini sağlamakta, kolektif çalışma bilincini ve ruhunu yerleştirmektedir.

- Bilinen ancak ele alınmayan sorunlar çözüme kavuşmaktadır.

- Sürekli eğitim ve gelişme imkanı sağlanmaktadır (Nahai ve Österberg, 2012: 389).

- Fire ve masraflar azalmakta ve işgücünün bilinçli kullanılması sonucu verimlilik artmaktadır.

- Devamsızlıklarda azalma görülmektedir.

- İçinde bulunduğu süreci daha iyi anlayan çalışanlar işletmenin gelişimine katkıda bulunmaktadır (Dale ve Lees, 1987: 748).

Kalite çemberleri, işletme içindeki dikey-yatay haberleşmeyi kolaylaştırmak ve yönetim ile çalışanlar arasında dayanışma sağlamak gibi hem işletmeye hem de çalışanlara ortak yararlar sağlamaktadır. Böylece daha önce iki 
zıt kutup olan yönetim ile çalışanlar arasında birbirlerini daha iyi anlama ve kolayca anlaşma sağlama ortamı oluşmaktadır (Söğütlü, 1998: 57).

Kalite çemberlerinin yararları Paşaoğlu'nun çalışmasında (2011: 17) ise farklı iki yarar grubuna ayrılmıştır. Birincisi, sosyal düzeyle ilgilidir. Çemberler, kişiye fikirlerini ifade edebilme ve kendi işiyle ilgili sorunları bizzat çözme olanağını vererek personelin işletme yaşamına katılmasını kolaylaştırmaktadır. İkincisi, ekonomik düzeyle ilgilidir. Çemberler işletmedeki tüm beyinleri harekete geçirmeye olanak vererek performansın da iyileştirilmesini kolaylaştırırlar. Böylece kalitesizliğin azalmasına katkıda bulunurlar.

Her ne kadar kalite kontrol çemberlerinin esasen başlaması ve gelişmesi, üretim ve kalite yöneticilerinin kaliteyi geliştirmek ve maliyetleri düşürmek amacıyla olmuş olsa da yayılmasının ve kökleşmesinin nedeni, çalışma hayatının kalitesinin yarattığı dikkate değer faydalardır. Bu faydalar aşağıda sıralanmaktadır (Nakamura ve Nitta, 1995):

- $\quad$ İşyerinde işçilerin küçük grup faaliyetleri yoluyla aralarında daha iyi iletişim kurmaları

- Kalite kontrol çemberlerinin yayılması ile işçilerin işyerinde bazı üretim kontrol görevlerini üstlenmeleri nedeniyle kendiliğinden oluşan iş genişleme ve iş zenginleştirme

- $\quad$ Üretim ve kalite kontrol tekniklerinde ve ustalıkların paylaşılması yoluyla özel üretim bilgi konularında çalışma esnasında eğitim için firsat oluşması

- $\quad$ İşçilerin işlerini daha kolay ve daha az sıkııı olarak yapabilmeleri firsatı sunulması

\subsection{Kalite Çemberlerinin Faaliyet Alanları}

Kalite çemberleri genellikle şu alanlarda kullanılabilir (Sögütlü, 1998: 56).

- Genel olarak işletmenin faaliyetlerinin kalite kontrolü

- Eğitim

- $\quad$ İstatistik metotların uygulanması

- Satış faaliyetleri

- Müşteri tatmini

- Güvenlik sağlama

- $\quad$ İşe olan devamsızlığı azaltma

- $\quad$ Ast-üst ilişkilerinin düzenleme

- Personelin becerisini artırma

- $\quad$ Kalitede sürekliliği sağlama (Ece ve Abdioğlu, 2005: 80)

Kalite çemberlerinin hangi konular üzerinde çalışıp çalışmayacakları, çember faaliyetlerine başlamadan önce belirlenmeli ve tüm çalışanlara bildirilmelidir. Lider ve çember üyelerinin eğitimlerinde, üzerinde çalışmayacakları konular, toplantı tarihi ve yeri açıkça belirtilmelidir (Nahai ve Österberg, 2012: 394). Çemberlerin üzerinde çalışmaması gereken konular şu şekilde sıralanabilir (Düren, 1990:48):

- $\quad$ Ücret ve maaşlar

- Disiplin ve politikalar

- $\quad$ Eleman alımı

- Şikayetler

- Kișisel ve sendikal sorunlar

- Çalışma düzenleri

- Yönetimce sonuçları sakıncalı görülen öneriler

- Bir başka servisin faaliyet alanına giren konular

- Büyük kutuplaşma ve ikiliklere neden olan sorunlar

\subsection{Kalite Çemberlerinin Organizasyon Yapısı}

Kalite çemberlerinin organizasyonu temel çatı aynı olmak üzere, işletmeler arasında farklılıklar bulunabilmektedir. Bu değişiklikler, şirketin büyüklüğüne, kurulacak çember sayısına, hazırlık çalışmalarına, verilen önem derecesine, eldeki kaynak ve olanaklara bağlıdır (Başer, 2000: 52).

Kalite çemberleri organizasyondan bağımsız bir örgüt yapısı değildir. Kişiler işletme içinde kendi görevlerini yaparken diğer taraftan iyileştirme çalışmalarına gönüllü olarak katılmaktadırlar. Kalite çemberleri; organizasyon komitesi, rehber, lider ve çember üyelerinden oluşmaktadır (Dinç, 2001: 81). Kalite çemberinin lideri üst yönetim ile arabuluculuk rolünü üstlenmektedir. Gruptaki bireysel farklılıkları dikkate alarak grup etkileşimi sağlamakta kurumsal değişkenleri etkilemektedir (Pereira ve Osburn, 2007: 146).

Kalite çemberlerinin organizasyon yapısını değerlendirirken işletmedeki diğer birimlerle ilişkisi ele alınmalıdır. Kalite çemberlerinin başarısı için üst yönetimin yüksek derecede desteği gerekmektedir. Ancak böylelikle kalite çemberlerinin bir organizasyonun gelişimine katkı sağlayabileceği kabul edilir. Ayrıca üretim ve diğer departmanyöneticileri tarafından da kalite çemberlerine karşı pozitif yönlü bir farkındalık olmalı ve karşılıklı destekleyici bir tavır takınılmalıdır (Oxley, 1984: 15-16). 


\subsection{Kalite Çemberlerinin İşleyişi}

Kalite çemberinin oluşturulması konusunda öncelikle bir brifing verilmesi, brifing yoluyla herkesin kalite çemberlerinden haberdar olmasının sağlanması, örgütün bir fizibilite analizine tabi tutulması gerekmektedir. Üyeler ve denetleyiciler eğitime tabi tutulmalıdır (İnandı, 2001: 142). Bu şekilde kurulan çemberlerin sorun inceleme yöntemi ise beş aşamadan oluşmakta ve bu aşamalar aşağıda incelenmektedir (Efil, 1997: 98-100):

\section{Birinci Aşama: Problemleri Teşhis Etme ve Onlardan Birini Seçme}

Kalite çemberi üzerinde çalışacağı bir problemi seçer. Bu seçime yardımcı olmak için en etkili araçlar olarak oylama, çoklu kriter veya pareto analizinden yararlanılmaktadır. Temel amaç, kalite çemberlerinin mümkün olduğunca çözebileceği problemi seçmektir.

\section{İkinci Aşama: Problemin Nedenlerini Araştırma ve Analiz Etme}

$\mathrm{Bu}$ aşamanın amacı, ele alınan problemin inandırıcı olması ve net bir şekilde açıklanabilmesini sağlamaktır. Problemin özüne ve genel duruma bağlı unsurlar olarak gözlenebilir unsurları bir araya toplamak gerekmektedir. Problemin mümkün olabilecek tüm nedenlerini tespit etmek için beyin firtınası, soru dizini ve neden/sonuç diyagramı önemli bir rol oynamaktadır.

\section{Üçüncü Aşama: Bir Çözüm Arama ve Seçme}

Bir problemin birden çok nedeni olabileceği gibi neden bir tane nedeni olsa da birden çok çözüm mümkün olabilir. Beyin firtınası bu çözümlerin belirlemesine yardımcı olmaktadır.

\section{Dördüncü Aşama: Seçilen Çözümün Denenmesi}

Kalite çemberleri ulaşılan gerçekleştirilebilir çözümü doğrulamak için denemek ve incelemek, sonuçları kontrol etmeye yardımcı olacak bir prosedür oluşturmak zorundadır. Sonuçların kontrolünde pareto diyagramı, puantaj föyleri, uzman personelin düşünceleri, deneyler ve gerçekleştirme testlerinden yararlanılmaktadır. Eğer seçilen çözümün sonuçları olumlu ise çember üyeleri bu sorunla ilgili olarak amaca ulaşmış demektir. Tersine çözüm belli bir iyileşme ve gelişmeyi sağlamıyorsa, çok büyük bir ihtimalle problemin ana nedeni yanlış teşhis edilmiş olabilir. Bu durumda analiz ikinci aşamadan itibaren tekrar ele alınmalıdır.

\section{Beşinci Așama: Yönetime Sunma}

İstenilen çözüme ulaştıktan sonraki son aşama elde edilen sonuçların yönetime sunulmasıdır. Yönetim önerilen çözümün uygulanıp uygulanmaması konusunda kalite çemberi ile birlikte karar verecektir. Burada dikkat edilmesi gereken nokta üst yönetimin bu konuda karar verirken tek başına davranmaması, çember üyelerini dikkate almasıdır. Çözüm kabul edilirse sonuçlar standart hale getirilerek hayata geçirilir. Ancak çözüm çeşitli nedenlerle uygulanamıyorsa bu durumda, bu, nedenleriyle birlikte açıklanmalıdır.

\section{7 İşletmenin Kalite Çemberleri Çalışmasına Uygunluğunun İncelenmesi}

Bir işletmenin içinde bulunduğu koşulları ciddi olarak analiz etmeden ve bu koşulların eylemin muhtemel başarısı üzerine etkisi incelenmeden girişilmemelidir. Bulunduğu koşullar açısından kalite çemberlerine uygun olmayan bir işletmenin başarısızlığa uğraması kaçınılmaz olmaktadır. Bulunduğu koşulların kalite çemberlerine uygunluğunu araştırmadan bu işe girişen işletme başarısız olacağ gibi, belli bir zaman, emek ve para kaybına da uğrayacaktır. İşletmelerde yapılan yenilikler bir değişim olarak algılanabilir. Gerek yapısal gerek iş yöntemleri ve diğer konularda yapılmak istenen değişime bazı bireyler karşı çıkabilir. Böyle bir değişime bireylerin karşı koymasında pek çok neden olabilir (Efil, 1997:162).

Kalite çemberlerinin yalnızca basit bir yönetimsel taktik değişikliği olmadığı açıktır. Kalite çemberlerinin işletmeye girişi, aynı zamanda yeni bir sosyal ilişkiler düzenini de beraberinde getirmektedir. Bu nedenle kalite çemberlerine geçişle sağlanan sosyal, ekonomik ve teknik gelişmeler, beraberinde çözümlenmesi gereken sosyalbeşeri sorunlar ve zorluklar da getirmektedir (Dinç, 2001: 127-128).

Kalite çemberlerini uygulamak isteyen işletmelerde her şeyden önce yönetici kadronun kalite çemberleri konusunda gerekli desteği vermeye hazır olup olmadığı incelenmelidir. Bunun yanında tüm yönetim kademesi üzerine düşen görevi yerine getirip, desteğini sürekli tutmalıdır. Ancak, sadece yöneticilerin desteği ve istekli olması yeterli değildir. Bunun yanında çalışanların da kalite çemberlerinin başarısı için yeterince motive edilmiş ve yetişmiş olması gerekmektedir (Efil, 1997: 16).

Kalite çemberleri yöneticiler ve çalışanların bireysel çaba ve çalışmalarına dayalı olmaktan çok, karmaşık problemler ve görevler üzerine odaklanmış bölümlerarası yönetim ve takım çalışmalarına dayanmaktadır. İşletmede etkili bir kalite kültürü oluşturabilmek için işletmenin tüm düzeylerine takım çalışması sistemi kurulmalı, karar verme ve problem çözme aşamalarında etkili şekilde kullanılabilmelidir. Kalite çemberlerinin istenilen sonuçları verebilmesi için işletmenin bütün bölümlerine yaygınlaştırılması ve personelin tümünü kapsaması şarttır (Paşaoğlu, 2011: 17).

İşletmesinde kalite çemberlerini kurmak isteyen yöneticiler içinde bulunulan sosyal iklimi çok iyi analiz etmek zorundadır. Sosyal iklimin iyi olmadığı ve çeşitli çatışmaların varlığg halinde bu çeşit bir faaliyetin başarı şansı olmayacaktır. Çünkü kalite çemberlerinin kurulacağı işletmede çalışanların kendi içinde, çalışanlarla yönetim 
arasında uyumlu bir işbirliği ve güven olmalıdır. Kalite çemberlerinin kurulmasına uygun olmayan faktörler aşağıda siralanmaktadır (Efil, 1997: 167):

- Yönetimin amaçları ile yönetilenlerin amaçlarının farklı olması

- Yönetimin çok kısa zamanda sonuç elde etme arzusunda olması

- Gruplar arası ilişkilerin bozukluğu

- $\quad$ Kalite çemberlerinin faaliyetini yansıtacak düzenli bir planın olmaması

- Belli bir grubun çalışmasını kolaylaştıran eğitim ve enformasyon kaynağının olmaması

- $\quad$ İşletmede güvensiz bir ortamın varlı̆̆ 1

- $\quad$ Yönetimin kontrolü kaybedeceği gibi bir düşünce içinde olması

- Otokratik veya teknokratik yönetim stili

- Yeterli zamanı ayırmayı reddetme

- $\quad$ Gerekli eğitime yeterli bir bütçe ayırmayı reddetme

Bir işletmede kalite çemberlerinin başarılı olabilmesi için, yöneticilerin her şeyden önce çemberlere geçiş zamanlamasını belirlemeleri gerekmektedir. Kalite çemberleri uygulamasına doğru zamanda başlanmalıdır. Kriz anlarında geçişlerden sakınılmalıdır (Düren, 1990: 99-100). Ülkenin ve kuruluşun ekonomik durumu kalite çemberlerinde başarıyı etkileyen unsurlardan biridir. Kalite çemberleri ekonominin dengeli bir büyüme içinde ve işgücü devrinin düşük olduğu ekonomik ortamlarda daha başarılı olmaktadır. Bunun nedeni çemberlerde devamlılığın önemli olması ve ülke ile kuruluşların ancak olumlu ekonomik ortamlarda bu iş için gerekli kaynak (insan, işgücü) ayırmaya istekli olmalarıdır (Dinç, 2001: 130).

Kalite çemberlerinde başarılı olabilmek için uyum, bağlılık ve benzeri özellikler kadar geri besleme (feedback) de çok önemlidir. Ancak bu yetenek kalite çemberlerini geliştirebilir. Eğer yapılan çalışmalar dikkate alınmaz, uygulamaya geçirilmesinde ağırdan alınır ise çember faaliyetleri bozulabilir (Dinç, 2001: 131). Temel başarı koşullarını tamamlayıcı başka bir unsur da kalite çemberlerinin işletme içinde marjinal uygulama olarak kalmaması için, yetkililerin çember toplantılarının düzenli yapılmasına, çember metodolojisine bağlı kalınmasına ve çemberlerdeki üye sayılarının küçük grup özelliğini bozacak şekilde kabartılmamasına özen göstermeleridir (Düren,1990:101).

\section{Sonuç}

Toplam Kalite Yönetimi içinde sürekli gelişmeyi sağlamak için öncelikle Japonya'da başarılı olup tüm dünyaya yayılan kalite çemberleri, son yıllarda işletmelerin büyük önem verdiği bir kavram haline gelmiştir. Kalite çemberleri aynı amaç doğrultusunda çalışan, sayıları 8 ile 12 kişi arasında değişen, gönüllü kişilerin oluşturduğu küçük gruplardır. Bu gruplar düzenli olarak haftada bir saatlik toplantılar yapmaktadır. Kalite çemberlerinin asıl amacı gruplar oluşturarak çalışanların kendi işleriyle ilgili kararlara katılımını sağlamak ve böylece genel anlamda kaliteyi artırmaktır.

Kalite çemberleri genel olarak işletme faaliyetlerinin kalite kontrol, eğitim, satış faaliyetleri, müşteri memnuniyeti, ast-üst ilişkilerini düzenleme, personelin becerisini artırma gibi alanlarda faaliyet göstermektedirler. Kalite çemberlerinin faaliyet alanlarının önceden belirlenmesi ve çember üyelerine bildirilmesi etkinliği artırması açısından önemlidir. Kalite çemberleri koordinasyon komitesi, rehber, lider ve çember üyelerinden oluşmaktadır. Çember üyeleri, kalite çemberlerinin en önemli unsurudur ve çember çalışmalarının başarısı için grup davranışları, temel kavramlar, çeşitli teknikler hakkında yeterli eğitimi almış olmaları gerekmektedir.

Kalite çemberlerinin işleyişi seçilen bir problemin nedenlerini araştırma, bu nedenleri ortadan kaldıracak çözüm önerileri geliştirme, en geçerli olduğuna inanılan çözümün denenmesi ve çözüm olumluysa yönetime sunulması şeklinde gerçekleşmektedir. Bu aşamalarda genellikle problem çözme teknikleri kullanılmaktadır. Kalite çemberlerinin en çok kullandığı teknikler; beyin fırtınası, neden/sonuç diyagramı, pareto analizi, histogram, grafikler ve gant diyagramıdır.

Kalite çemberleri, katılımcı yönetim anlayışının benimsendiği günümüzde personelin motive olmasını sağlayarak verimliliği ve kaliteyi artırmaktadır. İşletmede yaşanan sorunların kısa sürede tespiti ve çözümlenmesi, hataların azalması, ast-üst ilişkilerinin düzelmesi ve benzeri birçok yarar sağlayan kalite çemberleri, işletmelerde başarı artırıcı bir unsur olarak değerlendirilmektedir.

\section{Kaynakça}

- $\quad$ Akdemir, Ali, 2001. İşletme Bilimine Giriş. Eskişehir: Birlik Ofset-Yayıncılık.

- Alpaslan, Sümeyra ve Kutaniş, Rana Özen, 2007. "Sanayi ve Bilgi Toplumu Yönetim Metaforlarının Karşılaştırılması”, Akademik İncelemeler, Cilt: 2, Sayı: 2, 49-71.

- Barutçugil, İsmet, 1998. Üretim Sistemi ve Yönetim Teknikleri. Genişletilmiş 2. Baskı. Bursa: Uludağ Üniversitesi Yayınları.

- Başer, Erol, 2000. “Kalite, Toplam Kalite Yönetimi ve Kalite Çemberleri”. Basılmamış Yüksek Lisans Tezi. Selçuk Üniversitesi Sosyal Bilimler Enstitüsü. Konya. 
- Bolat, Tamer, 2000. Toplam Kalite Yönetimi (Konaklama İşletmelerinde Uygulanması. 1. Baskı. İstanbul: Beta Basım Yayım.

- Burnak, Nimetullah, 1997. Toplam Kalite Yönetimi -İstatistiksel Süreç Kontrolü-, Eskişehir: Osmangazi Üniversitesi TEKAM Yayın No: TS-97-008-NB.

- CÇetin, Kadir, 2007. Eğitimde Kalite Ödülü El Kitabı, Ankara: Milli Eğitim Bakanlığg Personel Genel Müdürlüğü.

- Dağl1, Abidin, 2003. Toplam Kalite Yönetimi Ve Eğitim Sistemine Uygulanabilirliği.

- Dale, B.G. and LEES J., 1987. “A Snapshot ofthe Profile of A Quality Circle Programme atthe Eighteenth Monthstage”, IEEE PROCEEDINGS, Vol. 134, Pt. A, No. 9, NOVEMBER, 747-751.

- Dinç, Erdinç, 2000. "Kalite Çemberleri ve Brisa Örneği”, Basılmamış Yükssek Lisans Tezi. Kocaeli Üniversitesi Sosyal Bilimler Enstitüsü. Kocaeli.

- Düren, Zeynep, 1990. İşletmelerde Kalite Çemberleri. İstanbul: Evrim Basım Yayım Dağıtım.

- Ece, Oğuzhan ve Abdioglu, Hasan, 2005. "Toplam Kalite Yönetimin Muhasebe Meslek Elemanları Üzerinde Uygulanmasına Yönelik Bir Model Önerisi”, Ekonomik ve Sosyal Araştırmalar Dergisi, 1: 67-96.

- $\quad$ Efil, İsmail, 1997. Yönetimde Kalite Çemberleri ve Uygulama Örnekleri. 4. Baskı. Bursa:Uludağ Üniversitesi İİBF Yayınları.

- $\quad$ Feigenbaum, V.Armond, 1991. Total Quality Control. NewYork: McGraw-Hill International Editions.

- Gökçen, Eylem, 2006. "Halkla İlişkilerdeki Toplam Kalite Yönetimi Çerçevesinde ISO 9000:9001 Kalite Güvence Sistemleri”, Basılmamış Yüksek Lisans Tezi, Marmara Üniversitesi Sosyal Bilimler Enstitüsü, İstanbul.

- Gümüşoğlu, Şevkinaz, 2000. İstatistiksel Kalite Kontrolü ve Toplam Kalite Yönetimi Araçları, 2. Bask1. İstanbul: Beta Basım A.Ş.

- İ̀nand, Yusuf, 2001. “Kalite Halkaları Eğitim Örgütlerine Nasıl Uyarlanabilir?”, İstanbul Üniversitesi Tecrübi Psikoloji Dergisi, Cilt 22, 135-153.

- Katzan, Harry, 1991. Quality Circle Management, 1st Published, NewYork: TAB Professional and Reference Books.

- Kobu, Bülent, 1998. Üretim Yönetimi, 10. Bask1. İstanbul: İstanbul Üniversitesi Yayınları.

- Kondo, Yoshio, 1999. İşletmelerde Bütünsel Kalite. Çev: Ayşe Bilge Dicleli. İstanbul.

- Köksal, Onur, 2011. “Organizasyonel Etkinliği Sağlamanın Yeni Yolu: Simbiyotik Liderlik”, C.Ü. İktisadi ve İdari Bilimler Dergisi, Cilt 12, Sayı 1, 55-71.

- Nahai, Rebekah and Österberg, Sophie, 2012. "Higher Education in A State Of Crisis: A Perspective from A Students’ Quality Circle”, AI \& Soc, 27: 387-398.

- Oxley, Michael, 1984. "Quality Circles Benefit Foundries”, The Production Engineer, p. 15-16.

- Paşaoğlu, Pakize, 2011. "Hizmet İşletmelerinde Toplam Kalite Yönetim” Basılmamış Yüksek Lisans Bitirme Projesi. Süleyman Demirel Üniversitesi Sosyal Bilimler Enstitüsü. Isparta.

- $\quad$ Pereira, $Æ$ H. and Osburn, G., 2007. "Effects of Participation in Decision Making on Performance and Employee Attitudes: A Quality Circles Meta-analysis”, J BusPsychol, 22: 145-153.

- Nakamura, Keisuke and Nitta, Michio, 1995. "Developments in Industrial Relations and Human Resource Practices in Japan", Employment Relations in a Changing World Economy, The MIT Press, 325-358, Çeviren: Selamoğlu, Ahmet, 1998. “Japonya'da Endüstri İlişkileri Ve İnsan Kaynakları Uygulamalarında Gelişmeler”, Sosyal Siyaset Konferansları Dergisi, Sayı: 41-42, 253-288.

- Seyidoğlu, Halil, 2000. Bilimsel Araştırma ve Yazma El Kitabı. Geliştirilmiş 8. Baskı. İstanbul:Güzem Yayınları.

- Söğütlü, Vahdettin, 1998. "İşletmelerde Başarı Artırmada Bir Faktör Olarak Kalite Çemberleri - Beksa Çelik Kord Sanayi ve Ticaret A.Ş. Uygulaması”. Basılmamış Yüksek Lisans Tezi. Anadolu Üniversitesi Sosyal Bilimler Enstitüsü. Eskişehir.

- Ş̧imşek, Muhittin, 2001. Toplam Kalite Yönetimi. Gözden Geçirilmiş 3. Baskı. Alfa Yayınevi.

- Vargün, Hakan, 2009. “Tam Zamanında Üretim Modeline Göre Maliyetlerin İzlenebilirliği”, The Journal of Accounting and Finance (MUFAD), Ekim, Sayı: 44, 251-263. 


\title{
Türk İmalat Sanayinde İhracat ve İnovasyon Arasındaki İlişki The Relationship between Export and Innovation in Turkish Manufacturing Industry
}

\author{
Prof. Dr. Selçuk Perçin (Karadeniz Technical University, Turkey) \\ Asst. Prof. Dr. Aykut Karakaya (Recep Tayyip Erdogan University, Turkey) \\ Assoc. Prof. Dr. Seymur Ağazade (Recep Tayyip Erdogan University, Turkey)
}

\begin{abstract}
Posner's (1961) “technological gap theory" and Vernon's (1966) "product life cycle theory" predicts that innovation causes market power and facilitates export. In other side export encourages firms and provides more affirmative environment for innovative processes. These theoretical approaches have different predictions regarding the direction of causality between export and innovation. Using Two-Step System Generalized Moments of Method this study investigates causality relationship between export intensity and R\&D intensity for the period 2008-2013 in Turkish Manufacturing Industry. Causality relationship was modeled within two different equations and analyzed by Wald Test. First equation models export intensity as function of R\&D intensity and real exchange rate. In the second equation R\&D intensity estimated as a function of export intensity and Herfindahl-Hirschman Index as competition variable. Causality test results show that there is unidirectional causal relationship from R\&D intensity to export intensity. This finding supports the predictions of Posner's (1961) "technological gap theory" and Vernon's (1966) "product life cycle theory" related to the innovation and export relationship in Turkish Manufacturing Industry.
\end{abstract}

\section{Giriş}

İnovasyon ve ihracat arasındaki ilişkinin yönü konusunda dış ticaret literatüründe farklı yaklaşımlar mevcuttur. İnovasyon daha önce var olmayan ve dış ticarete de konu olabilecek yeni malların, bunun yanı sıra teknolojik ürün veya bilginin ortaya çıkması biçiminde ifade edilebilir. Mevcut malların tüketici tercihlerine daha iyi hitap edecek tarzda, şekil ya da kalite bakımından farklılaştırılması da inovasyona ilişkindir. Aynı zamanda inovasyon, malların daha düşük maliyetle üretilmesine neden olacak üretim tekniklerinin geliştirilmesi, daha etkin yönetim, satış ve pazarlama anlayışının kullanılmasını da kapsar. İster yeni ürünlerin ortaya çıkması veya ürün farklılaştırması şeklinde, isterse de düşük maliyetli yöntemlerin kullanılması şeklinde olsun inovasyonun ihracatı artırıcı yönde etkilemesi beklenir. Posner (1961) tarafından geliştirilen “teknoloji açığı teorisi” ve Vernon (1966) tarafından geliştirilen "ürün dönemleri teorisi” de inovasyonun ihracatı artırıcı etkisini vurgular. Bu iki teori inovasyonun piyasa gücüne neden olduğunu ve ihracatı kolaylaştırdığını öngörür.

Posner (1961) dış ticareti ülkeler arasındaki teknoloji farkı ile açıklamakta ve bu görüş literatürde "teknoloji açığı teorisi” olarak bilinmektedir. Posner'in (1961) çalışmasında sunduğu teorik tartışma benzer ekonomik koşullara sahip gelişmiş ekonomiler arasında sanayi ürünleri ticaretine ilişkindir. Bu ticaretin büyük kısmı genellikle gelişmiş ülkelerin yenilikçi firmaları tarafından gerçekleştirilen inovasyona dayandırılır. Burada patent ve fikri mülkiyet haklarına ilişkin yasaların yenilikçi firmalara daha fazla teşvik ve bu firmaların monopolistik özellikleri için koruma sağladığı da kabul edilir. Böylelikle teknik değişim veya bazı endüstrilerdeki gelişmelerin ticaret artışına neden olduğu düşünülür. Çünkü Posner'e göre bir ülkede meydana gelen belirli bir teknik değişimden kaynaklanan karşılaştırmalı maliyet farklılıkları, inovasyonun diğer ülkelerce taklit edilmesine yetecek kadar bir öğrenme döneminde belirli malların ticaretini teşvik eder.

Vernon (1966) tarafindan geliştirilen "ürün dönemleri teorisi” de inovasyon ve ihracat ilişkisini teknolojik açık teorisine benzer bir yaklaşımla açıklar. Fakat bu yaklaşım karşılaştırmalı maliyet farklılıklarına değil de inovasyon zamanlamasının, ölçek ekonomilerinin, bilgi eksikliğinin ve belirsizliğin dış ticaret üzerindeki etkisine vurgu yapar. "Ürün dönemleri teorisi", dış ticareti nitelikli emek ve ar-ge harcamalarının yüksek olduğu sanayileşmiş ülkelerde yeni ürünün ortaya çıktığı ilk aşama ve takip eden aşamalar yardımıyla açıklar. Başlangıç aşamasında ürünün standartlaştırılmadığı ve girdilerin, imalat sürecinin ve ürünün nihai şeklinin belirlenmesi geniş bir zaman aralığı gerektirdiğinden üretim ve ihracat düşük düzeydedir. Olgunlaşmış ürün olarak adlandırılan ikinci aşamada ise üretim ve ihracat artış gösterir. Standartlaşmış ürün safhasında ise, üretim düşük girdi maliyetleri nedeniyle az gelişmiş ülkelere kaydırılır ve ihracat da önemli ölçüde bu ülkeler tarafindan gerçekleştirilir. Krugman'ın (1979) “kuzey-güney modeli” de Vernon’un (1966) "ürün dönemleri teorisi” ile benzer bir sonuca ulaşır. Şöyle ki, inovasyonun yapıldığı yenilikçi kuzey ülkesi başlarda yeni ürünleri güney ülkesine ihraç eder. Sonraları söz konusu üretim teknolojisinin güney ülkesinde de mevcut olmasıyla düşük ücret rekabetinden dolayı kuzey ülkesi artık eski olan bu ürünleri güney ülkeden ithal edecektir. "Kuzey-güney modeli"nde, inovasyon mevcut malların üretiminde verimlilik artışı sağlanması şeklinde değil, yeni malların geliştirilmesi şeklinde ele alınır. Bu yeni mallarda monopol rantına neden olduğundan, modelde teknolojik gecikme ülkeler arasında ticaretin nedeni olarak ifade edilir. 
Dış ticaretin endüstri içi etkilerini bir heterojen firma modeli çerçevesinde inceleyen Meltiz (2003) çalışmasında nedensellik ilişkisinin inovasyondan ihracata doğru olduğunu ima eder. Bu durum sadece verimlilikleri yüksek olan firmaların ihracat piyasasına girmelerine, düşük verimliliğge sahip firmaların ise bu piyasadan çıkmalarına ve sadece iç piyasaya yönelik üretim yapmalarına neden olur. Çünkü ihracat piyasasına yönelme taşıma, dağıtım, pazarlama gibi ilave maliyetlerin yüklenilmesini gerektirmektedir ki bunlara ancak yüksek verimliliğe sahip olan firmalar katlanabilir. Bernard ve Jensen (1999) de ihracatçı firmalarda ücret, verimlilik, sermaye yoğunluğu gibi değişkenlerin daha yüksek olduğunu ve dolayısıyla bu firmaların ihracat yaptıklarını ifade etmiştir.

İhracatın inovasyona veya ar-ge harcamalarına neden olduğu ise, Arrow'un (1962) “öğrenme teorisi”nden uyarlanmış olan ihraç ederek öğrenme (learning by exporting) fikrine dayanan inovasyon ve ar-ge'nin içselleştirildiği içsel büyüme modellerine dayanır (Romer, 1990; Grossman ve Helpman, 1991; Aghion ve Howitt, 1992). Buna göre firmaların uluslararası yapıda faaliyet göstermeleri veya dış ticarete açılmaları daha güçlü rekabetle karşılaşmalarına neden olur. Bu yapı yurtiçi piyasalardan daha farklı genellikle üst düzey standartlar gerektirir. Firmaların uluslararası ticarete açılmaları mevcut gelişmiş teknoloji ve bilgiye ulaşmalarını mümkün kılar. Yoğun rekabette ayakta kalmak, etkilerini hafifletmek veya rekabet üstünlüğü sağlamak ihraç ederek öğrenme etkisine neden olur ve firmaları inovasyona ve ar-ge faaliyetlerine yönlendirir. Bunun yanı sıra Blalock ve Gertler'in (2004) de belirttiği gibi uluslararası piyasada yer almanın sağladığı öğrenme, bilgi, teknoloji, operasyonel etkinlik artışına neden olur ki bu da üretkenliği artırır. Yurtdışındaki bilgi birikiminin ihracat kanalıyla transfer edilmesi firmalara inovasyon veya üretim tekniklerini geliştirmeleri için daha geniş bir zemin hazırlar. Çünkü ihracaţ̧ı firmalar mallarına ilişkin daha geniş bir tüketici kitlesinin tercihlerini izleme olanağına sahip olurlar. Greenaway ve Kneller (2007) ise öğrenme ve rekabetin daha ileri verimlilik artışına neden olmasının ihracatçı firmanın maruz kaldığı rekabete bağlı olduğunu ve endüstriler arasındaki farklılıkların öğrenme etkisinin ortaya çıkması için önemli bir belirleyici olduğunu ifade eder. İnovasyonun ihracatı desteklemesi veya öğrenme etkisinin geçerli olmasının yanı sıra inovasyon ve ihracat ilişkisinin karşlıklı olması da muhtemeldir. Aw, Roberts ve Xu (2011) da belirtildiği gibi ar-ge yatırımları firmanın ihracattan beklenen karlılığını artırır. Aynı zamanda ihracat da ar-ge yatırımlarının getirisine pozitif katkıda bulunur.

Yukarıda ifade edildiği üzere, inovasyon ve ihracat ülkeler, endüstriler ve firmalar açısından uluslararası pazarlara açılıp yeni talepler oluşturma ve bunu sürekli kılmak yeni yetenekler kazanmayı gerektirmektedir. Bu açıdan Türk İmalat Sanayi’nde endüstrilerin inovasyon ve ihracat kabiliyeti ne düzeyde, gelişim ne yönde ve aralarındaki bağın nasıl olduğu soruları bu çalışmayla cevaplanmaktadır. Bu çalışma, Türk İmalat Sanayi endüstrilerinin 2008-2013 dönemleri y1llık verileriyle inovasyon yani ar-ge yoğunluğu ile ihracat yoğunluğu arasındaki nedensellik ilişkisini ortaya koymayı amaçlamaktadır. Araştırma analiz yöntemi içselliği dikkate alan İki Aşamalı Sistem Genelleştirilmiş Momentler Metodu ve nedensellik ilişkisi Wald Testiyle gerçekleştirilmiştir. Ar-ge yoğunluğu ve ihracat yoğunluğu arasındaki nedensellik ilişkisiyle Posner'in (1961) "teknoloji açığı teorisi”, Vernon'un (1966) "ürün dönemleri teorisi” veya Arrow’un (1962) "öğrenme teorisi”nden hangilerinin Türk İmalat Sanayi'nde geçerli olduğu ortaya çıkacaktır. Çalışmanın takip eden bölümleri şu şekilde düzenlenmiştir. İkinci bölümde araştırma veri ve değişkenleri, üçüncü bölümde araştırma tahmin yöntemi, dördüncü bölümde araştırma bulguları ve son bölümde sonuç ve öneriler yer almıştır.

\section{Araştırma Veri ve Değişkenleri}

Çalışmada Türk İmalat Sanayi NACE Rev.2 iki basamak endüstri sınıflamasına göre 24 endüstri kolunun ihracat ve inovasyon arasındaki nedensellik bağın ortaya konması amaçlanmıştır. Çalışmanın veri setini 24 imalat endüstri kolunun yıllık bilanço ve gelir tablosundan elde edilen bilgiler oluşturmuştur. Söz konusu veriler Türkiye İstatistik Kurumu'nun www.tuik.gov.tr ve TC Merkez Bankası'nın www.tcmb.gov.tr adresli internet sitelerinden derlenmiştir. Çalışma veri seti inceleme dönemi olarak 2008-2013 dönemlerini kapsayan 6 yıl için 24 imalat sanayii endüstri kolundan oluşan 144 gözlemden meydana gelmiştir. Aşağıdaki Tablo 1'de NACE Rev. 2 iki haneli sınıflama esasına göre Türkiye'deki İmalat Sanayii endüstrilerinde yer alan firmaların inceleme dönemindeki dağılımı sunulmuştur.

Tablo 1'deki firma dağılımlarına bakıldığında gıda, tekstil, metalik olamayan mineraller, giyim ve fabrikasyon metal ürünleri endüstrilerinde faaliyet gösteren firmaların toplam imalat sanayii firmalarının yarısından fazlasını oluşturduğu görülmektedir. Söz konusu bu endüstriler daha ziyade teknolojinin görece daha düşük düzeyde kullanıldığı daha geleneksel sanayii temsil etmektedir. Dolayısıyla, Türk İmalat Sanayi'nde üretim teknolojisinin ağırlıklı biçimde düşük ve orta yoğunlukta olduğu söylenebilir. Bu özelliğinden ötürü imalat sanayiinin dönüşümünde hayati rol oynayabilecek faktörler arasında inovasyon öne çıkmaktadır. Söz konusu dönüşümün etkin biçimde gerçekleşebilmesinde yeni pazarların önemi yadsınamaz. $\mathrm{Bu}$ ise, ya var olan pazarların geliştirilmesine ya da yeni pazarlara ulaşılmasıyla mümkün olacaktır. Bu yönüyle firmalar ve endüstriler açısından en etkili yeni pazarlara ulaşma yolu ihracat olarak karşımıza çıkmaktadır. Bu öneminden dolayı da, bu çalışmada inovasyon ve ihracat arasındaki nedensellik bağı incelenmiştir. İnovasyon ve ihracat arasındaki nedensellik ilişkisi modellerinde yer alan değişkenlerle ilgili açılamalar aşağıda sunulmuştur. 
İhracat firmaların uluslararası aktivitelere girişte çok sık başvurduğu bir stratejidir (Wolff ve Peet, 2000). İhracatın ölçümü literatürde genelde üç boyutta ele alınmaktadır. İlki, firmaların ihracat yaptığı ülke sayısıyla ihracatın coğrafi bir alan olarak ölçümü, diğeri yurt dışı satışlardaki hız ve büyümedir. Üçüncüsü ise, ihracat yoğunluğudur (Leonidou vd. (2002); Zucchella vd., 2007). Bu çalışmada, ihracat Cavuşgil (1980), Ramaswamy vd. (1996), Wakelin (1998), Rasiah (2003), Özçelik ve Taymar (2004), Kirbach ve Schmiedeberg (2008) ve D’Angelo (2012) tarafından yapılan çalışmalarda olduğu gibi ihracatın toplam satışlara oranı olan ihracat yoğunluğu şeklinde ölçülmüştür.

\begin{tabular}{|l|l|l|l|}
\hline $\begin{array}{l}\text { Endüstri } \\
\text { Kodu }\end{array}$ & Endüstri Kolu & Sayı & \% \\
\hline 10 & Gıda Ürünlerinin İmalatı & 2.682 & 13,13 \\
\hline 11 & İçeceklerin İmalatı & 159 & 0,78 \\
\hline 12 & Tütün Ürünlerinin İmalatı & 66 & 0,32 \\
\hline 13 & Tekstil Ürünlerinin İmalatı & 2.778 & 13,59 \\
\hline 14 & Giyim Eşyalarının İmalatı & 1.719 & 8,41 \\
\hline 15 & Deri ve İlgili Ürünlerin İmalatı & 303 & 1,48 \\
\hline 16 & Ağaç, Ağaç Ürünleri ve Mantar Ürünleri İmalatı (Mobilya Hariç) & 378 & 1,85 \\
\hline 17 & Kağıt ve Kağı Ürünleri İmalatı & 561 & 2,74 \\
\hline 18 & Kayıtlı Medyanın Basılması ve Çoğaltılması & 231 & 1,13 \\
\hline 19 & Kok Kömürü ve Rafine Edilmiş Petrol Ürünleri İmalatı & 87 & 0,42 \\
\hline 20 & Kimyasalların ve Kimyasal Ürünlerin İmalatı & 894 & 4,37 \\
\hline 21 & Temel Eczacılı Ürünleri ve Eczacıllğa İlişkin Malzemelerin İmalatı & 237 & 1,16 \\
\hline 22 & Kauçuk ve Plastik Ürünlerin İmalatı & 1.257 & 6,15 \\
\hline 23 & Diğer Metalik Olmayan Mineral Ürünlerin İmalat & 1.773 & 8,67 \\
\hline 24 & Ana Metal Sanayii & 1.230 & 6,02 \\
\hline 25 & Fabrikasyon Metal Ürünleri İmalatı (Makine ve Teçhizat Hariç) & 1.467 & 7,18 \\
\hline 26 & Bilgisayarların, Elektronik ve Optik Ürünlerin İmalatı & 201 & 0,98 \\
\hline 27 & Elektrikli Teçhizat İmalatı & 723 & 3,54 \\
\hline 28 & Başka Yerde Sınıflandırılmış Makine ve Ekipman İmalatı & 1.254 & 6,14 \\
\hline 29 & Motorlu Kara Taşıtı, Treyler ve Yarı Treyler İmalatı & 900 & 4,40 \\
\hline 30 & Diğer Ulaşım Araçlarının İmalatı & 288 & 1,41 \\
\hline 31 & Mobilya İmalatı & 570 & 2,79 \\
\hline 32 & Diğer İmalatlar & 534 & 2,61 \\
\hline 33 & Makine Ekipmanların Kurulumu ve Onarımı & 138 & 0,67 \\
\hline & İmalat Sanayii & $\mathbf{2 0 . 4 3 0}$ & 100 \\
\hline
\end{tabular}

\section{Tablo 1: Endüstri Kollarındaki Firma Dă̆glımları}

İnovasyon doğası gereği çok boyutlu ve karmaşık olduğundan ölçümünde bir uzlaşı bulunmamaktadır. Literatürde inovasyon genelde üç biçimde ölçülmektedir. Bunlar; girdi göstergeleri (ar-ge harcamaları, ar-ge personeli gibi), ara çıktı göstergeleri (patentler, ticari markalar gibi) ve çıktı göstergeleridir (inovasyon sayısı, inovasyon türü, inovasyon devir hızı gibi). Bunlardan daha çok girdi ve çıktı göstergeleri kullanılmaktadır. Literatürde inovasyonu girdi göstergeleriyle ölçen çalışmalar arasında Wakelin (1998), Nassimbeni (2001), Özçelik ve Taymar (2004), Lopez Rodriguez ve Garcia Rodriguez (2005), Wignaraja (2007), Kirbach ve Schmiedeberg (2008), Harris ve Li (2009) ve D’Angelo (2012) tarafında yapılan çalışmalar gösterilebilir. Bu çalışmada inovasyon girdi göstergelerinden, ar-ge yatırımının toplam aktiflere oranı olarak hesaplanan, ar-ge yoğunluğuyla ölçülmüştür.

İhracat modeline, ihracat döviz kurundan etkilendiğinden, Reel Döviz Kuru Endeksi (RDKE) ve inovasyon modeline inovasyon faaliyetleri yurt içi piyasa rekabetinden etkilendiğinden endüstri rekabet yoğunluğunu temsilen Herfindahl-Hirsckman Endeksi (HHI) dâhil edilmiştir.

\section{Araștırma Tahmin Yöntemi}

Panel veri analizi temel tahmin yöntemi Havuzlanmış En Küçük Kareler (HEKK) olmasına rağmen hata terimi ve bağımsız değişkenler arasında ilişkinin varlığı ile zaman içinde hata teriminin ardışık bağımlılığını göz ardı ettiğinden HEKK ile tutarlı tahminler elde edilememektedir (Wooldrige, 2002: 256). Söz konusu bu sakıncaların giderilmesi amacıyla statik ve dinamik olmak üzere iki grupta sinıflanan panel veri analiz tahmincileri geliştirilmiştir.

Statik panel veri yöntemlerinde, cari dönemde oluşan iktisadi ve ticari davranışlar geçmiş dönemlerdeki deneyimlerden ve davranış biçimlerinden bağımsız kabul edilir. Hâlbuki iktisadi ve ticari davranışlarda, geçmiş deneyim ve davranışların etkisi oldukça önemlidir. Bu geçmiş deneyim ve davranışlar dikkate alındığında 
analize dinamik bir nitelik kazandırılmaktadır. Bunu dikkate alan panel veri yöntemleri dinamik panel veri modellerdir. Dinamik panel veri modellerinde ise, bağımlı değişkeni etkileyen faktörler arasında, bağımsız değişken veya değişkenlerin gecikmeli değerleri olabileceği gibi, bağımlı değişkenin gecikmeli değerleri de yer alabilmektedir. Bu yönüyle dinamik panel veri analizi, yatay kesit veya zaman serisi yöntemlerinin ortaya koyamadığı, mikro ve makro dinamikleri ortaya koyabilmektedir (Bond, 2002: 1).

Dinamik panel veri analizi, ekonometri literatüründe, ilk olarak Hansen (1982) tarafindan geliştirilmiş olan Genelleştirilmiş Momentler Metodunu (GMM) temel almaktadır. Anderson ve Hsiao (1981 ve 1982) GMM'yi panel veriye uyarlamışlardır. Daha sonradan Arellano ve Bond (1991), Arellano ve Bover (1995) ve Blundell ve Bond (1998) tarafindan bu yöntem geliştirilmiş ve panel veri yazınında yazarların isimleriyle birlikte anılan GMM ve Sistem Genelleştirilmiş Momentler Metodu (SGMM) olarak geçmiştir.

GMM tahmin yönteminde öncelikle modelin birinci farkı alınıp, fark modelin araç değişken matrisi kullanılarak dönüştürülmektedir. Daha sonra dönüştürülmüş model Genelleştirilmiş En Küçük Kareler (GEKK) ile tahmin edilmektedir. Veri seti dengeli olmayan panel veri ya da birim sayısının zamandan az olduğu panel verilerde birinci fark dönüşümü zayıf kalmaktadır. Bu durumda doğrusal (orthogonal) sapmaları kullanan SGMM kullanılmaktadır. Böylece SGMM ile etkin araç değişken tahmincisi elde edilebilmektedir (Baltagi, 2005: 148). SGMM'de GMM deki cari dönemden bir önceki dönemin farkının alınması yerine, değişkenlerin tüm olası gelecek değerlerinin ortalamalarının farkı alınmaktadır. Böylece, birinci farklar yönteminden kaynaklanan veri kaybının önüne geçilmektedir (Blundell ve Bond, 2000). Dolayısıyla, birimin zamandan büyük olduğu panel veri setlerinde değişkenler arasındaki doğrusal ilişkinin ortaya konmasında da SGMM tahmin yöntemi tercih edilir. Eğer bağımsız değişkenler içsel değişkense, bu durumda içsellik problemini çözen İki Aşamalı SGMM'nin tahmincileri daha tutarlı ve sapmasız olacaktır. Çalışmada, Arellano ve Bover (1995) ve Blundell ve Bond (1998) tarafından önerilen iki Aşamalı SGMM tahmin yöntemi ile analizler gerçekleştirilmiştir. Ayrıca küçük örneklem tahminlerindeki standart hataların sapmasız olması için Windmeijer'in (2005) tarafından önerilen dirençli standart hatalar kullanılmıştır. Söz konusu dirençli standart hataların hesaplanmasında Roodman (2009) tarafından yazılan kod kullanılmıştır. Nedensellik için Walt Testi yapılmıştır.

Çalışmanın ihracat modeli ve inovasyon modeli dinamik panel veri analiz yaklaşımıyla tahmin edilmiştir. İlgili ilişki aşağıdaki denklemlerde gösterilmiştir:

$$
\begin{aligned}
& \text { İhracat Yoğunluğ } u_{i t} \\
& =\beta_{1} \text { İhracat Yoğunluğ } u_{i t-1}+\beta_{2} \text { Arge Yoğunluğ } u_{i t}+\beta_{3} \text { Arge Yoğunluğ } u_{i t-1} \\
& +\beta_{4} \text { Arge Yoğunluğ } u_{i t-2}+\beta_{5} R D K E_{i t}+\varepsilon_{i t} \\
& \text { Arge Yoğunluğ } u_{i t} \\
& =\beta_{1} \text { Arge Yoğunluğ } u_{i t-1}+\beta_{2} \dot{\mathrm{I}} \text { hracat Yoğunluğ } u_{i t}+\beta_{3} \dot{\mathrm{I}} \text { hracat Yoğunluğ } u_{i t-1} \\
& +\beta_{4} \dot{\mathrm{I} h r a c a t} Y \text { oğunluğ } u_{i t-2}+\beta_{5} H H I_{i t}+v_{i t} \\
& i=1,2, \ldots, 24 \quad t=2008, \ldots, 2013
\end{aligned}
$$

Burada, $i$ ve $t$ sırasıly endüstri kolu ve zamanı göstermektedir. İhracat ve ar-ge modellerindeki $t-1$ ve $t-2$ dönemlerini temsil eden değişkenler modellere dinamik özellik katan bağımlı ve bağımsız değişkenlerin gecikmeleridir. İhracat Yoğunluğ $u_{i t}$ endüstrilerin t dönemi ihracatını, İhracat Yoğunluğ $u_{i t-1}$ t-1 dönemi ihracatını ve İhracat Yoğunluğ $u_{i t-2}$ t-2 dönemi ihracatıdır. Arge Yoğunluğ $u_{i t}$ endüstrilerin t dönemi ar-ge yatırımını, Arge Yoğunluğ $u_{i t-1}$ t-1 dönemi ar-ge yatırımını ve Arge Yoğunluğ $u_{i t-2}$ t-3 dönemi ar-ge yatırımıdır. $R D K E_{i t} \mathrm{t}$ dönemi Türkiye'nin dış ticaretinde önemli paya sahip olan 38 ülkenin para biriminden oluşan sepete göre, Türk Lirasının nispi fiyat (ÜFE) etkilerinden arındırılarak elde edilen ağırlıklı ortalama değeridir. $H H I_{i t}$ endüstrilerin $\mathrm{t}$ dönemi rekabet yoğunluğu düzeyidir. $\varepsilon_{i t}$ ve $v_{i t}$ denklemlerin hata terimini göstermektedir.

\section{Araştırma Bulguları}

Araştırmanın bulguları endüstrilerin genel özellikleri ve değişkenler arasındaki ilişkilerin sunulduğu tanımlayıcı istatistikler ve model tahmin sonuçlarının verildiği performans modelleri olmak üzere iki alt başlıkta aşağıda yer almaktadır.

\subsection{Tanımlayıcı İstatistikler}

Tablo 2'de değişkenlerin inceleme dönemindeki ortalama, standart sapma, minimum ve maksimum değerleri görülmektedir. Ortalamalardan yola çıkarak, endüstrilerde toplam satışların yaklaşık \%30'unun ihraç edildiği ve toplam varlıkların \%1'i dolayında ar-ge yatırımı yapılan piyasanın orta düzey rekabete sahip olduğu ifade edilebilir. TC Merkez Bankasının döviz politikasını belirlemek için kullandığı RDKE’nin ortalaması Türk Lirasının (TL) aşırı değerli olmadığını gösterir. Değişkenlerin minimum ve maksimum değerleri arasındaki farkın olması inceleme birimi olan endüstrilerin yaptıkları işlerdeki farklılıkların doğal bir sonucudur. RDKE'sinin minimum ve maksimum değerleri arasındaki fark TL'nin değerinin aşırı değerli olduğunu ifade 
etmez. Buradan, 2008-2013 dönemlerinde TL'nin düşük değerli, ar-ge yarımlarının yetersiz, yurt içi piyasada rekabetin orta düzeyde ve ihracatın orta yoğunlukta olduğu söylenebilir.

Tablo 2'de değişkenlerle ilgili sunulan bilgileri yıllar itibariyle gösteren aşağıdaki Grafik 1-4 bakıldığında, değişkenlerin yıllar itibariyle izlediği seyirler görülmektedir. Grafik 1 endüstrilerin yıllar itibariyle ihracat yoğunluğunun eğiminde 2008'den 2011'e kadar düşüş ardından 2011'den sonra 2013'e kadar yükseliş kaydettiğini göstermektedir. İhracat yoğunluğu 2008'de yaklaşık \%30' seviyesinden düşerek 2011'de yaklaşık $\% 27$ 'ye inmiş ve ardından artarak 2013'de \%28'e gelmiştir. İhracat yoğunluğunun biçimi 'V' şeklindedir. İhracat yoğunluğundaki bu azalışın küresel finansal krizin ardından geldiği ve sonrasında bu etkinin 2012 ve 2013 yıllarında nispeten attığı görülmektedir. Ancak, ihracat yoğunluğu seviyesi küresel finansal krizden önceki seviyesine ulaşamamıştır. Buradan, Türk İmalat Sanayi'nin ihracatta krizle birlikte küresel piyasalardaki daralmanın etkisini tam olarak atlatamadığını söylemek yanlış olmaz.

\begin{tabular}{|l|l|l|l|l|}
\hline Değişkenler & Ortalama & Std. Sapma & Minimum & Maksimum \\
\hline İhracat Yoğunluğu (\%) & 28,245 & 15,077 & 3,967 & 61,358 \\
\hline Ar-ge Yoğunluğu (\%) & 1,164 & 3,477 & 0 & 20,439 \\
\hline Reel Döviz Kuru Endeksi (RDKE) & 111,875 & 5,603 & 104,15 & 122,21 \\
\hline HHI $(0<$ HHI $\leq 1)$ & 0,226 & 0,213 & 0,007 & 0,809 \\
\hline
\end{tabular}

Tablo 2: Değişkenlerin Tanımlayıcı İstatistikleri

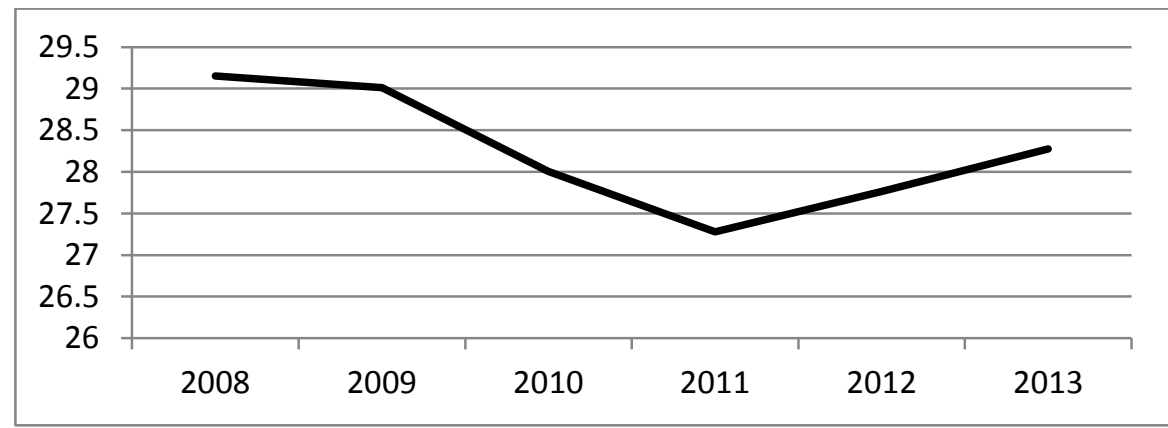

Grafik 1: Ihracat Yoğunluğu (\%)

Grafik 2 incelendiğinde Türk İmalat Sanayi’nin ar-ge yoğunluğunda sabit olmasa da sürekli bir artış vardır. 2008 yılında ar-ge yoğunluğu neredeyse sıfırdır. Bunu takip eden yıllarda ar-ge yoğunluğu artarak süreklilik arz etmiş ve yaklaşı \% 1,6'seviyesine gelmiştir. Gelinen seviye düşük olmasına rağmen, bu hızlı artış hükümetin sektörel ve bölgesel kalkınma politikalarının yanında teknoloji yatırımlarına verdiği teşviklerin bir sonucu olduğu söylenebilir.

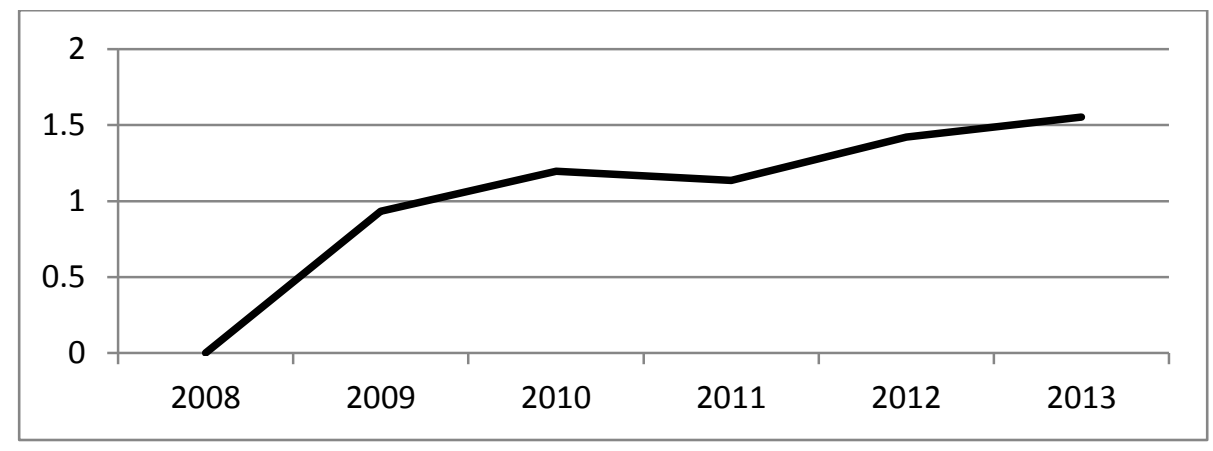

Grafik 2: Ar-ge Yoğunluğu (\%)

Grafik 3'de TC Merkez Bankasının döviz kuru politikası aracı olan reel döviz kuru endeksinin yıllar itibariyle nasıl bir eğilime sahip olduğunu göstermektedir. TC Merkez Bankası reel döviz kuru endeksinin 120'nin üzerinde olmasını TL'nin aşırı değerli olduğunu kabul etmektedir. Reel döviz kuru endeksinin biçimi ters 'W' şeklindedir. Grafiğe bakıldığında sadece 2010 yılında TL'nin aşırı değerli diğer yıllara ise nispeten düşük değerlendiği görülmektedir. Dolayısıyla, TL'nin değeri firmaların ihracatını zorlaştırmayıp, aksine ihracatı daha yapılabilir kılmıştır. Sonuç olarak, TC Merkez Bankası kur politikasının küresel finansal krizle birlikte firmaların ihracatını teşvik edici yönde seyrettiğini söylemek yanlış olmayacaktır. 


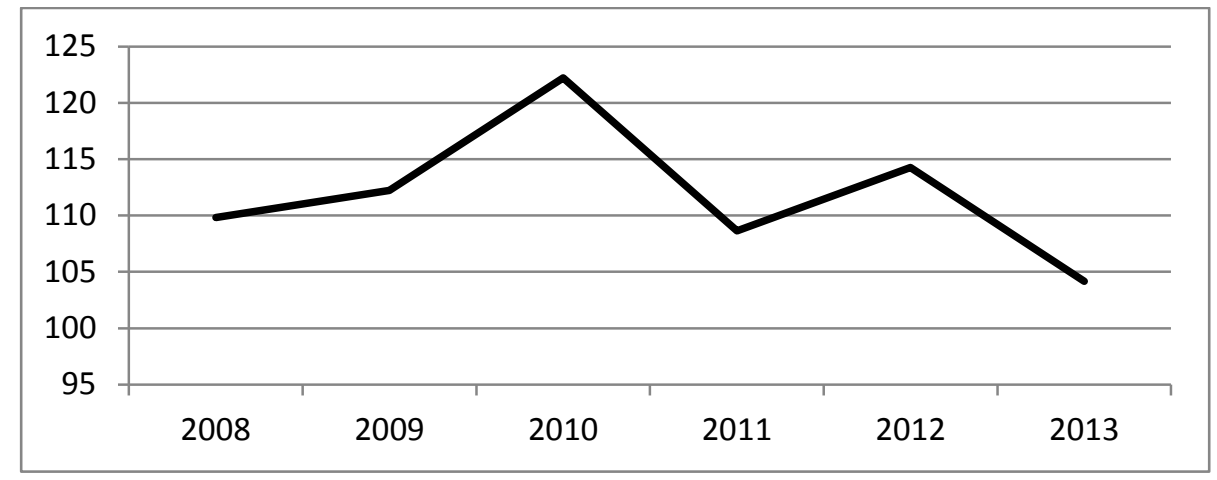

Grafik 3: Reel Döviz Kuru Endeksi

Grafik 4'de endüstrilerin rekabet yoğunluğu Herfindahl-Hirsckman Endeksi (HHI) ile hesaplanmış ve 20092012 yılları itibariyle ortalamaları sunulmuştur. HHI 2009'dan 2012'ye kadar düzenli olarak düşüş olmuştur. HHI'daki bu düşüş piyasa yoğunluğunun azaldığını yani rekabette artış olduğunu ortaya koymaktadır. Yıllar itibariyle rekabette bu artış, 2012 yılında Türk İmalat Sanayi’nde piyasa rekabetini rekabetçi monopol ile tam rekabet piyasası sınırına taşımıştır. Yukarıdaki bulgular 1şı̆̆ında, Türk İmalat Sanayi’nde ihracat yoğunluğunun azaldığı, ar-ge yoğunluğunun arttığı, yurt içi piyasa rekabetinin arttığı ve TL'nin düşük değerlendiği söylenebilir.

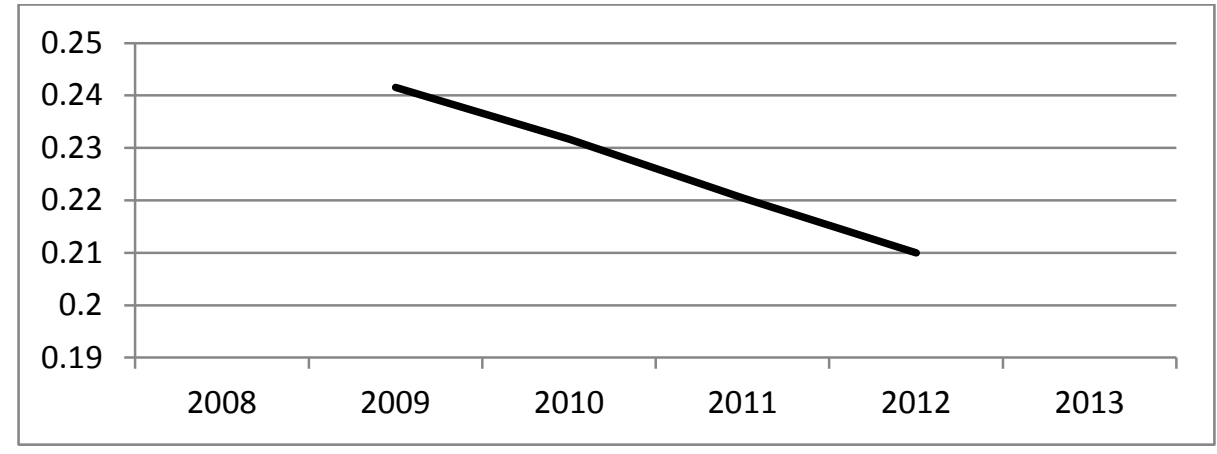

Grafik 4: Endüstrilerin Rekabet Yoğunluğu (HHI)

Tablo 3'de değişkenlerin korelasyonları yer almaktadır. Bu ilişkiler incelendiğinde, ihracat yoğunluğu ile ar-ge yoğunluğu arasında pozitif bir ilişki vardır. İlaveten, rekabet yoğunluğu ile ihracat ve ar-ge arasında negatif bir ilişki hesaplanmıştır. Diğer değişkenler arası ilişkiler istatistiksel olarak anlamlı değildir. İhracat ve ar-ge arasında pozitif ilişki ar-ge'nin yüksek olduğu endüstrilerde ihracatın da yüksek olduğunu gösterir, bunun tersi de geçerlidir. Rekabet yoğunluğu ile ihracat ve ar-ge arasında ise negatif ilişki vardır. Rekabet yoğunluğunun artması daha az sayıda firmanın piyasaya hakim olduğunu ve rekabetin düşük olduğunu göstermektedir. Dolayısıyla, yurt içi piyasada rekabetin yüksek olduğu endüstrilerde ihracat ve ar-ge yüksek, yurt içi piyasada rekabetin düşük olduğu endüstrilerde ise ihracat ve ar-ge düşüktür. Böylece, Türk İmalat Sanayi’nde ihracat, arge ve piyasa rekabeti arasındaki ilişkinin pozitif olduğu ortaya çıkmaktadır.

\begin{tabular}{|l|l|l|c|}
\hline Değişkenler & İhracat Yoğunluğu & Ar-ge Yoğunluğu & RDKE \\
\hline İhracat Yoğunluğu & 1 & & \\
\hline Ar-ge Yoğunluğu & $0,265^{* * *}$ & 1 & \\
\hline Reel Döviz Kuru Endeksi & 0,007 & 0,013 & 1 \\
\hline HHI & $-0,429^{* * *}$ & $-0,079^{*}$ & 0,011 \\
\hline
\end{tabular}

Tablo 3: Değişkenlerin Korelasyonları

\section{2 İhracat Yoğunluğu ve Ar-ge Yoğunluğu Arasındaki Nedensellik İlişkisi}

Aşağıdaki Tablo 4-5'de sunulan İki Aşamalı SGMM tahmincisinden elde edilen bulgularda, modellerin genel anlamlılığını gösteren Wald İstatistikleri sonuçlarına bakıldığında, tüm modeller anlamlıdır. Modellerle ilgili, birinci mertebe otokorelasyonun varlığının testinde Arellano ve Bond'un otokorelasyon (AR1) testi anlamlı ve ikinci mertebe otokorelasyon (AR2) testi anlamsızdır. $\mathrm{Bu}$ testlere göre, modellerde birinci mertebe otokorelasyonun olduğu buna karşın, ikinci mertebe otokorelasyonun olmadığı bulunmuştur. Bu bulgu, modellerdeki bağımsız değişkenlerin ikinci gecikmeleri olan araç değişkenlerin doğru tespit edildiği anlamına gelmektedir. Ardından, modellerden elde edilen araç değişkenlerin geçerliliği için yapılan dirençsiz Sargan Testi anlamlı iken, dirençli Hansen Testi ve dirençli Fark Hansen Testi anlamsızdır. Dirençsiz Sargan Testi dışındaki 
dirençli testler, İki Aşamalı Sistem GMM yöntemiyle yapılan performans modellerinin tahmininde kullanılan araç değişkenler regresyonunda kullanılan araç değişkenlerin geçerli ve modellerin uygun olduğunu göstermektedir. İhracat ve inovasyon (ar-ge) modelleri genel anlamlılık, otokorelasyon ve araç değişkenler regresyonu ile ilgili koşulların tamamını sağlamaktadır.

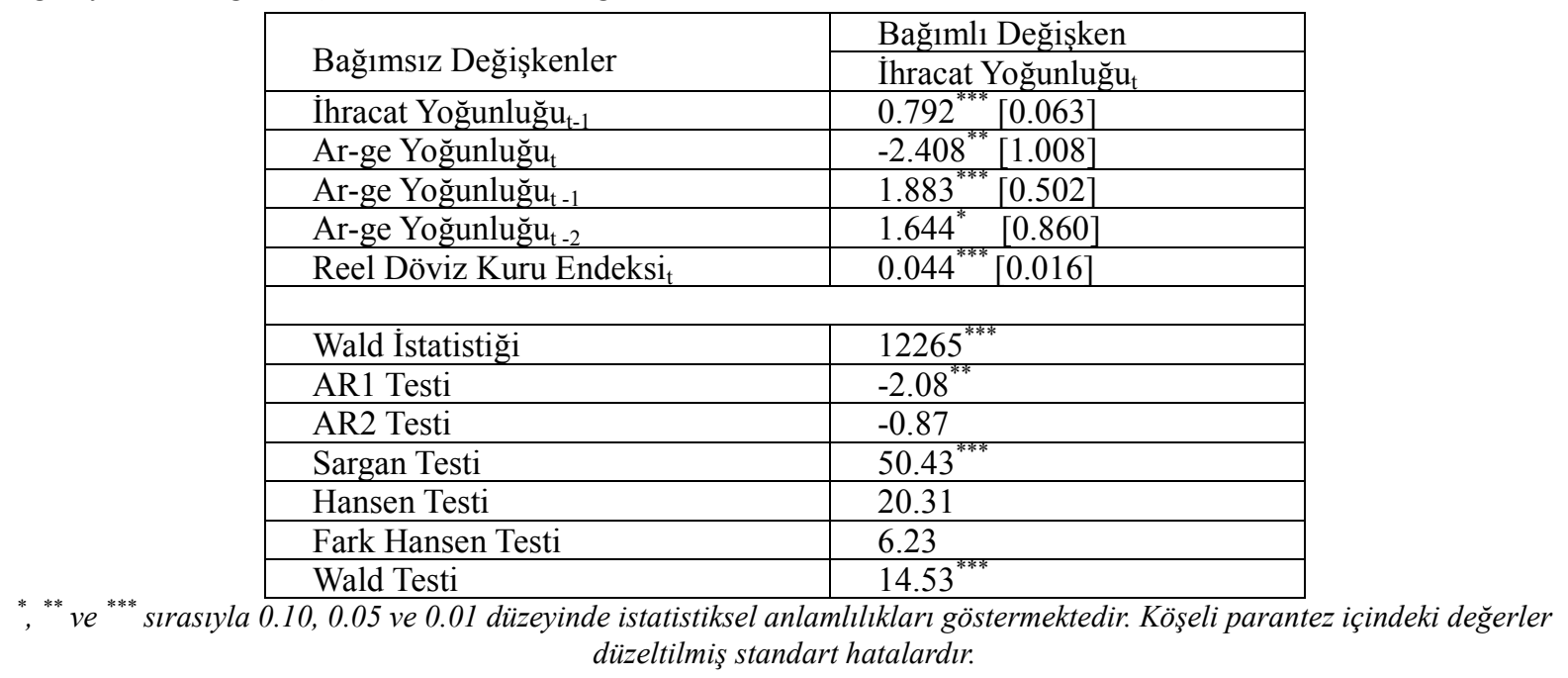

Tablo 4: İhracat Modeli Tahmin Sonuçları

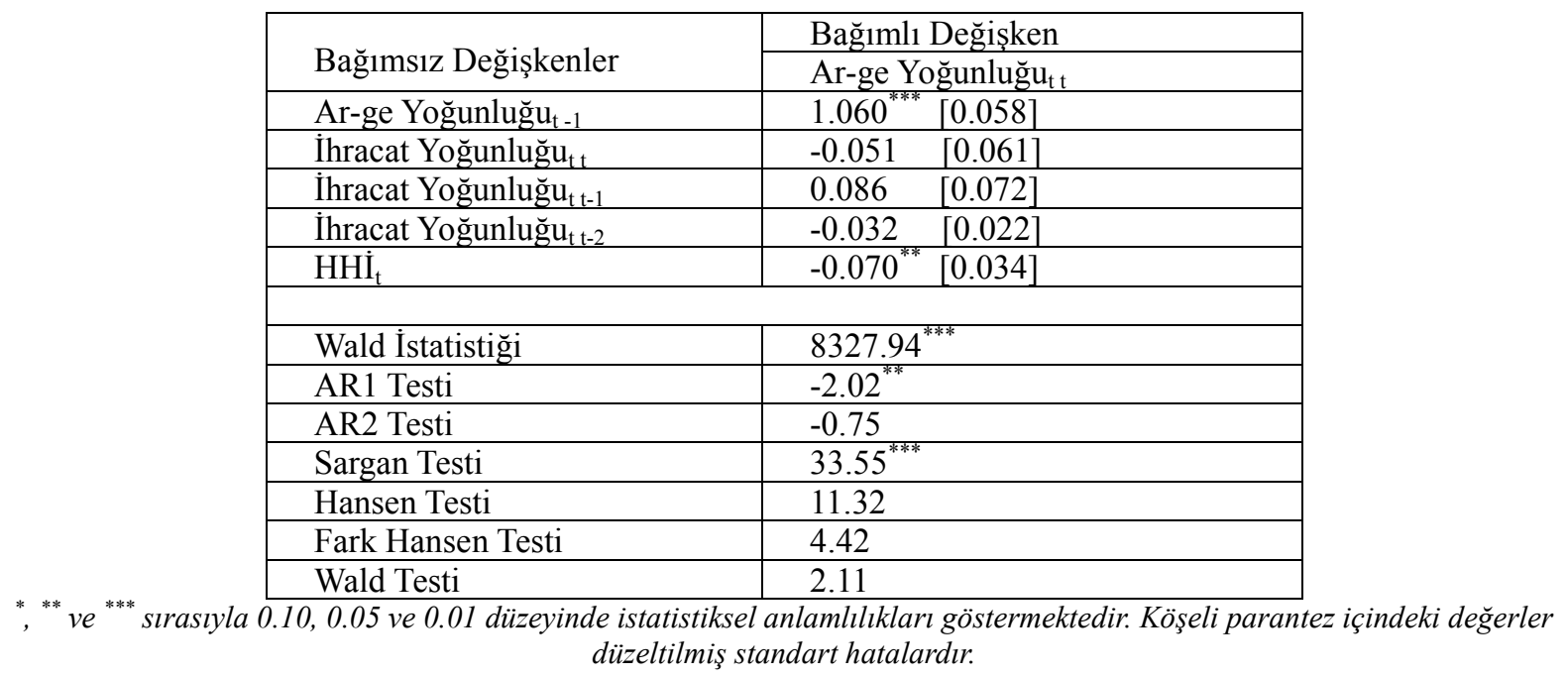

Tablo 5: Ar-ge Modeli Tahmin Sonuçlarl

Tablo 4'deki ihracat modelinde tüm bağımsız değişkenlerin anlamlı olduğu görülmektedir. Bağımsız değişken ihracat yoğunluğunun bir dönem gecikmesinin bağımlı değişken ihracat yoğunluğuna pozitif yönlü etkisi, kazanılan ihracat deneyiminin daha sonraki ihracatı desteklediği anlamına gelebilir. Dolayısıyla, Türk İmalat Sanayi firmalarının, yurt dışında kazandığı ihracat deneyiminden öğrendikleriyle takip eden dönem ihracatlarını daha da artırabildiği söylenebilir. İhracat yoğunluğuna reel döviz kuru endeksinin pozitif yöndeki etkisi ise, TC Merkez Bankası tarafından belirlenen düşük değerlenen TL’nin cari dönem ihracatını teşvik ettiği anlamına gelir. Bağımsız değişkenlerden ar-ge yoğunluğunun bir ve iki dönem gecikmesinin ihracat yoğunluğuna etkisi pozitif, cari dönem ar-ge yoğunluğunun ise negatiftir. Önceki dönemlerde yapılan ar-ge harcamalarının ticarileşmesiyle ihracatın arttığı, buna karşın cari dönem ar-ge harcamalarının ticarileşmesi için yeterli zaman geçmediğinden ihracatı azalttı̆̆ı görülmüştür.

Ar-genin yani inovasyonun ihracatın nedeni olup olmadığıyla ilgili ar-ge yoğunluğu değişkenlerinin önündeki katsayılar Walt Testiyle sınanmıştır. Test sonucunda \%1 anlamlılık düzeyinde boş hipotez ret edilmiştir. Bu sonuç, ar-ge yoğunluğunun yani inovasyonun ihracatın nedeni olduğu anlamına gelmektedir. Türk İmalat Sanayi'nde inovasyonun ihracatın nedeni olduğu bulgusu, bu ilişsiyi ele alan öncü araştırmalardan Hirsch ve Bijaoui (1985)'nin İsrail, Brouwer ve Kleinknecht (1996)'in Hollanda, Zhao ve Li (1997)'nin Çin ve Gourlay ve Seaton (2004)'nın Büyük Britanya için elde ettikleri sonuçları destekleyici niteliktedir.

Tablo 5'deki ar-ge (inovasyon) modelindeki bağımsız değişkenlerden ihracat yoğunluğu değişkenleri haricindeki diğer değişkenler anlamlıdır. Bağımlı değişken ar-ge yoğunluğunu bağımsız değişkenlerden ar-ge yoğunluğunun bir dönem gecikmesi pozitif ve HHI endüstri rekabet yoğunluğu değişkeni negatif yönde 
etkilemiştir. Bu bulgu, daha önce yapılan ar-ge deneyiminin sonraki dönem ar-geyi artırdığını göstermektedir. Bu durumda bir dönem önceki ar-ge harcamalarının ticarileşip firmaları yeni ar-ge yatırımlarını teşvik ettiği söylenebilir. Rekabet yoğunluğunun ar-ge yoğunluğunu negatif yönde etkilemesi ise, piyasadaki rekabet düzeyindeki artışın ar-ge harcamalarını arttığı anlamına gelmektedir.

İhracatın ar-genin yani inovasyonun nedeni olup olmadığıyla ilgili ihracat yoğunluğu değişkenlerinin önündeki katsayılara Walt Testi uygulanmıştır. Test sonucunda $\% 5$ anlamlılık düzeyinde boş hipotez ret edilememiştir. $\mathrm{Bu}$ sonuç, ihracatın ar-genin yani inovasyonun nedeni olmadığı anlamına gelmektedir.

\section{Sonuç ve Öneriler}

İnovasyon ve ihracat arasındaki ilişkinin yönü konusunda dış ticaret literatüründe farklı yaklaşımlar mevcuttur. Posner (1961) tarafindan geliştirilen "teknoloji açığı teorisi" ve Vernon (1966) tarafından geliştirilen "ürün dönemleri teorisi” inovasyonun ihracatı artırıcı etkisini vurgular. Bu iki teori inovasyonun piyasa gücüne neden olduğunu ve ihracatı kolaylaştırdığını öngörür. İhracatın inovasyona veya ar-ge harcamalarına neden olduğu ise, Arrow'un (1962) "yaparak öğrenme" görüşünün ihraç ederek öğrenmeye uyarlandığı içsel büyüme modellerine dayanır. Bazı çalışmalar ise, ihracat ve inovasyon arasındaki ilişkinin çift yönlü olduğu yönünde teorik temeller sunmaktadır. Uygulamalı çalı̧̧malar ise firma düzeyinde olduğu gibi endüstri ve ülke düzeyinde de yapılmaktadır. Bu çalışmada, Türk İmalat Sanayi endüstrilerinin 2008-2013 dönemleri yıllık verileriyle inovasyon ile ihracat arasındaki nedensellik ilişkisi araştırılmıştır. Analiz yöntemi içselliği dikkate alan İki Aşamalı Sistem Genelleştirilmiş Momentler Metodu ve Wald Testidir.

Çalışmadan elde edilen tanımlayıcı bulgulara göre; Türk İmalat Sanayi’nde, ar-ge yarımları yetersiz, yurt içi piyasa rekabetçi monopolistik karakterde ve ihracat görece düşük düzeydedir. Buna karşın, yıllar itibariyle ihracatın, ar-genin, yurt içi piyasa rekabetinin giderek arttı̆̆ görülmektedir. Küresel finansal krize rağmen, bu olumlu gelişmelerde sektörün dinamizminin yanında uygulanan ekonomi ve teşvik politikaları etkili olduğu düşünülmektedir.

İhracat modeli için tahmin sonuçlarına göre; kazanılan ihracat deneyiminin sonraki ihracatı desteklediği, dolayısıyla bilgi sağlayarak ihracatı motive ettiği görülmüştür. İhracatın önceki dönemlerde yapılan inovasyonun ticarileşmesiyle arttığı, buna karşın ilgili dönemde azaldığı görülmüsstür. Aynı döneme ait inovasyonun negatif etkisi ticarileşme veya yeni ürünün piyasaya tanıtılması ve kabul edilmesi için gerekli süreden kaynaklanabilir. Ayrıca, düşük değerli TL ile ihracat desteklenmiştir.

İnovasyon modelinde; bir dönem önceki inovasyonun firmaları yeni ar-ge yatırımlarına teşvik ettiği ve rekabetin inovasyonu desteklediği tespit edilmiştir. Bu durum, rekabetin firmaları inovasyon yatırımı yapmaya yönlendirdiği anlamına gelir. Firmaların inovasyona yönelmesindeki amaç rekabetten korunmak veya piyasa gücü elde etmektir. Artan yurt içi piyasa rekabetinin üstesinden gelmenin bir aracı olarak, Türk İmalat Sanayi'nde firmaların inovasyona yöneldikleri, dolayısıyla Neoklasik iktisadın rekabet ve inovasyon ilişkisine dair görüşüne uyan davranış şekli gösterdikleri söylenebilir.

Nedensellik testi bulgularına göre, inovasyon ihracatın nedeni, buna karşın ihracat inovasyonun nedeni değildir. Nedenselliğin yönü tek taraflı ve inovasyondan ihracata doğrudur. Türk İmalat Sanayi’nde inovasyon faaliyetleriyle ihracatın artırılabildiği tespit edilmiş̧ir. Dolayısıyla çalışma bulguları, Posner'in (1961) "teknoloji açığı teorisi” ile Vernon'un (1966) “ürün dönemleri teori”lerindeki inovasyon ve ihracata ilişkin öngörülerinin Türk İmalat Sanayi içinde geçerli olduğunu destekleyici niteliktedir. Buna karşın çalışma sonuçları ihracatın inovasyonu artırdığını öneren, Arrow'dan (1962) uyarlanmış ihracat yaparak öğrenme görüşünü destekleyici nitelikte değildir. Böylece, hayata geçirilecek etkin inovasyon politikalarıyla Türk İmalat Sanayi'nde ihracatın artırılabileceği buna karşın, uygulanacak ihracat politikalarıyla Türk İmalat Sanayi'nde inovasyonun artırılamayacağını ileri sürmek yanlış olmayacaktır.

Ar-ge politikasıyla teknolojinin sürekli olarak iyileştirilmesi ve yenilenmesi benimsendiğinde Türkiye'nin yurt dışı piyasalarda rekabet üstünlüğü sağlamayı sürdürecektir. Rekabet üstünlügünün elde edilmesi ve güçlendirilmesi kur politikalarından ziyade inovasyona daha fazla ağıllık verilmesi ile mümkündür. Bu nedenle yüksek teknolojiye dayalı üretime ve ihracata geçilmesi desteklenmelidir. Uygulanacak ar-ge faaliyetleri sonucunda geliştirilen ürün ve süreçlerle Türkiye'nin uluslararası rekabet gücü artacaktır. Böylece, ihracat muhtemelen döviz kurlarındaki dalgalanmalardan daha az etkilenecektir. Dolayısıyla, Türkiye'nin uluslararası rekabetteki maliyet avantajı kur politikaları değil, inovasyon ve teknoloji politikaları temelinde olmalıdır.

Çalışma inovasyonun ihracatı artırdığını göstermektedir. İsabetli politikaların kurgulanması ve uygulanabilmesi amacıyla hangi endüstrilerde inovasyonun etkili olacağının bilinmesi büyük önem taşımaktadır. Bu doğrultuda, inovasyon ve ihracat arasındaki bağın daha iyi anlaşılabilmesi amacıyla inovasyonun içeriği, inovasyonun türü ve teknoloji yoğunluğunu dikkate alan araştırmalar yapılabilir.

\section{Kaynaklar}

- Aghion, Philippe ve Peter Howitt ,1992, "A Model of Growth Through Creative Destruction”, Econometrica, 60 (2), 323-351. 
- Anderson, T. W., ve Hsiao, C., 1981, "Estimation of Dynamic Models with Error Components", Journal of the American Statistical Association, 76, 375, 598-606.

- Anderson, T. W., ve Hsiao, C., 1982, "Formulation and Estimation of Dynamic Models Using Panel Data", Journal of Econometrics, 18, 47-82.

- $\quad$ Arellano M., ve Bond, S., 1991 "Some Tests of Specification for Panel: Monte Carlo Evidence and An Application to Employment Equations”, Review of Economic Studies, 58, 277-297.

- Arellano M., ve Bover, O., (1995) “Another Look at the Instrumental Variable Estimation of ErrorComponents Models", Journal of Econometrics, 68, 29-51.

- Arrow, K. J., 1962, “The Economic Implications of Learning by Doing”, The Review of Economic Studies, 29 (3), 155-173.

- Aw, B. Y., M. J. Roberts, ve D. Yi Xu, 2011, "R\&D Investment, Exporting, and Productivity Dynamics", American Economic Review, 101(4), 1312-44.

- Baltagi, B. H., 2005, Econometric Analysis of Panel Data, Third Edition, John Wiley\&Sons, Ltd., England.

- Bernard, A. B. ve B. Jensen, J., 1999, “Exceptional Exporter Performance: Cause, Effect, or Both?”, Journal of International Economics, 47, 1-25.

- Blalock, G.,_ve P. J. Gertler, 2004, “Learning from Exporting Revisited in A Less Developed Setting”, Journal of Development Economics 75 (2), 397-416.

- Blundell R., and Bond S., 1998 "Initial Conditions and Moment Restrictions in Dynamic Panel Data Models”, Journal of Econometrics, 87, 115-143.

- $\quad$ Blundell, R. and S. Bond, 2000, “GMM Estimation with Persistent Panel Data: An Application to Production Functions", Econometric Reviews 19, 321-340.

- Bond, S., 2002, "Dynamic Panel Data Models: A Guide to Micro Data Methods and Practice", CEMMAP Working Paper, No: Cwp0209, 1-36.

- Brouwer, E. ve Kleinknecht, A., 1996, "Determinants of Innovation: A Microeconometric Analysis of Three Alternative Innovation Output Indicators”, In: Kleinknecht, A. (ed.). Determinants of Innovation. London: Macmillan Press Ltd., 99-125.

- Çavuşgil, S. T., 1980, “On the Internationalisation Process of Firms”, European Research, 8(6), $273-281$.

- D'Angelo, A., 2012, “Innovation and export performance: a study of Italian high-tech SMEs”, Journal of Management and Governance 16, 393-423.

- Greenaway, D., ve R. Kneller, 2007, “Industry Differences in the Effect of Export Market Entry: Learning by Exporting?", Review of World Economics/Weltwirtschaftliches Archiv, 143(3), 416-432.

- Grossman, G. M. ve E. Helpman, 1991, “Endogenous Product Cycles”, The Economic Journal, 101 (408), 1214-1229.

- Gourlay, A.R. ve Seaton, J.S., 2004, “UK Export Behaviour at the Firm Level”, Economic Issues, 9(2), 319.

- Hansen, L.P., 2002 “Large Sample Properties of Generalized Method of Moments Estimators”, Econometrica,50, 1029-1054.

- Harris, R., ve Li, Q. C., 2009, "Exporting, R\&D, and absorptive capacity in UK establishments", Oxford Economic Papers, 61(1), 74-103.

- Hirsch, S., ve Bijaoui, I., 1985, “R\&DIntensity and Export Performance:AMicroView”, Review ofWorld Economics, 121, 238-251.

- Hsiao, C., 2003, Analysis of Panel Data, Second Edition, Cambridge University Press, United Kingdom.

- Kirbach, M., ve C. Schmiedeberg, 2008, "Innovation and Expert Performance: Adjustment and Remaining Differences in East and West German Manufacturing”, Economics of Innovation and New Technology, $17: 5,435-457$

- Krugman, P., 1979, “A Model of Innovation, Technology Transfer, and the World Distribution of Income”, Journal of Political Economy, 87 (2), 253-266.

- $\quad$ Leonidou, L. C., Katsikeas, C. S., ve Samieec, S., 2002 "Marketing Strategy Determinants of Export Performance: A Meta-Analysis”. Journal of Business Research, 55(1), 51-67.

- Lopez Rodriguez, J., ve Garcia Rodriguez, R. M., 2005, “Technology and Export Behaviour: A Resourcebased View Approach”, International Business Review, 14(5), 539-557.

- Melitz, M. J., 2003, “The Impact of Trade on Intra-Industry Reallocations and Aggregate Industry Productivity”, Econometrica,. 71 (6), 1695-1725. 
- Nassimbeni, G., 2001, “Technology, Innovation Capacity, and the Export Attitude of Small Manufacturing Firms: A Logit/Tobit Model”, Research Policy, 30(2), 245-262.

- $\quad$ Özçelik, E., ve Taymar, E., 2004, "Does Innovativeness Matter for International Competitiveness in Developing Countries", Research Policy, 33(3), 409-424.

- Posner, M. V., 1961, "International Trade and Technical Change”, Oxford Economic Papers, New Series, 13 (3), 323-341.

- $\quad$ Ramaswamy, K., Kroeck, K. G., ve Renforth, W., 1996 "Measuring the Degree of Internationalisation of A Firm: A Comment”, Journal of International Business Studies, 27(1), 167-177.

- Rasiah, R., 2003, "Foreign Ownership, Technology and Electronics Exports from Malaysia and Thailand", Journal of Asian Economics, 14(5), 785-811.

- $\quad$ Romer, P. M., 1990, “Endogenous Technological Change”, Journal of Political Economy, 98 (5), Part 2, S71-S102.

- Roodman, D., 2009, "How to Do xtabond2: An Introduction to "Difference" and "System" GMM in Stata," The Stata Journal, 9, Number 1, pp. 86-136.

- Vernon, R., 1966, "International Investment and International Trade in the Product Cycle”, The Quarterly Journal of Economics, 80, 190-207.

- Walkelin, K., (1998) “Innovation and Export Behaviour at The Firm Level”, Research Policy 26, 829-841

- Wignaraja, G,. 2007, "Foreign Ownership, Technological Capabilities and Clothing Exports in Sri Lanka", Journal of Asian Economics, 19(1), 29-39.

- Windmeijer F., 2005, “A Finite Sample Correction for The Variance of Linear Efficient Two-Step GMM Estimator", Journal of Econometrics, 126(1), 25-51.

- Wolff, J. A., ve Pett, T. L., 2000, “Internationalisation of Small Firms: An Examination of Export Competitive Patterns, Firm Size, and Export Performance”. Journal of Small Business Management, 38(2), 34-47.

- Wooldridge, J. M., 2002, Econometric Analysis of Cross Section and Panel Data, The MIT Press, England.

- Zhao, H., ve Li, H., 1997, "R\&D and Export: An Empirical Analysis of Chinese Manufacturing Firms", Journal of High Technology Management Research,.8(1), 89-106.

- Zucchella, A., Palamara, G., ve Denicolai, S., 2007, “The Drivers of The Early Internationalisation of The Firm”, Journal of Word Business, 42(3), 268-280. 


\title{
İş Görenlerin İş Yaşam Dengesine Yönelik Tutumlarının Örgütsel Bağlılık Üzerindeki Etkisi
}

\section{Impact on Organizational Commitment of Attitudes towards Work-Life Balance of Employees}

\author{
Prof. Dr. Ufuk Durna (Akdeniz University, Turkey) \\ Ali Babayiğit (Akdeniz University, Turkey)
}

\begin{abstract}
Work and family environment is the areas that individuals spend most of their time and gives the most importance comparatively. Despite the rules, different and perceived thoughts and behavior patterns they have, these fields represent the area continually interacting with each other. Work and family is two most important elements in every person's life. For this reason, individuals have certain roles in their work and family life. These roles are the most significant roles undertaken in their lives. They have to strike a balance to play the roles in their work and family life and to get the expected yield. Work and life balance is the most important aim for individuals and family members interacting each other in work and family life. Having a balance in work and life is significant not only for working individual but also for the society he lives. Today, the subject how the expectations on work and private life can be balanced has become a specific discipline because of the radical changes on the responsibilities related to work and family. Examining the previous studies, it is seen that workers can't achieve a healthy balance between work and private life and as a result they can't work efficiently and can't allow time to their families. Therefore, they face individually organizational and environmental problems. In this paper, the significance of the balance from the point of individuals and organizations and the extent of influence on work and family balance to employee's organizational commitment will be studied.
\end{abstract}

\section{Giriş}

Günümüz dünyasında ekonomik, sosyal ve kültürel alanda yaşanan değişimler çalışma yaşamı açısından da yeni oluşumları ve yaklaşımları beraberinde getirmektedir. Bireylerin hayatlarında işin öneminin giderek artması ve merkezileşmesi, yaşam standartlarının artması, aile varlığının vazgeçilmezliği, iş, aile ve bireyin talepleri arasındaki rekabeti artırmaktadır. Bu bakımdan bireylerin iş ve aile ortamında gereken rolleri gerçekleştirmeleri için iki alan arasında belirli bir dengenin sağlanmış olması gerekmektedir. Bu çalışmamızda iş yaşam dengesinin bireyler açısından önemi ve algılanan iş yaşam dengesi tutumlarının çalışmış oldukları kurumlarına karşı örgütsel bağl1lıklarına etkisi incelenecektir.

\section{2 İş Yaşam Dengesi}

Değişen teknoloji koşulları ile birlikte iş hayatında önemli değişimler meydana gelmiş, bu değişimler ile birlikte işletmeler arasında rekabet ortamında artışlar yaşanmıştır. Yaşanan değişimler ile birlikte kişilerin iş ve aile yaşamları arasında dengenin sağlanması önemli bir konu olarak literatürde yerini almıştır (Smith ve Gardner, 2007). İş hayatında rekabet ortamının artması, çalışanlar üzerinde daha fazla baskı kurmakta ve bu baskı çalışanlar ve şirketler için olumsuz bazı sorunları beraberinde getirmektedir. Bu bakımdan iş ve yaşam dengesine yönelik daha fazla araştırma yapılmalı ve bireylere ve örgütlere bu konuda yol gösterilmelidir (Narayanan ve Narayanan, 2012).

İş yaşam dengesi, sanayi ve endüstri sonrası topluma geçişte kadın çalışanların iş hayatına katılmaları sonucu iş hayatında meydana gelen taleplerin artması ile ön plana çıkmıştır (Duxbury ve Higgins, 2001). Ekonomi dünyasında meydana gelen değişimler toplumsal yapıyı önemli ölçüde etkilemekte ve bunun sonucunda da toplum ve birey bazında mutluluğun sağlanabilmesi açısından iş ve yaşam dengesi önem arz etmektedir. İş ve yaşam dengesinin sağlanabilmiş olması, bireylerin yaşam kalitesini artırmakta, iş ve aile hayatındaki rollerin sağlanmasının getirmiş olduğu mutlulukla toplum huzuruna katkı sağlamakta, iş hayatında verimlilikleri artırmakta ve bireylerin işe devamsızlık oranlarını azaltmaktadır (Hogarth vd. 2001).

Hayatımızda çok önemli bir yere sahip olan iş yaşam dengesi ile ilgili literatürde çok sayıda tanımlama bulunmaktadir.

- $\quad$ Lockwood (2003)'e göre iş yaşam dengesi; kişinin iş ve aile yaşamındaki taleplerini dengede tutmasıdır.

- Barnett (1999)'a göre iş yaşam dengesi; bireylerin iş hayatında insiyatif sahibi olması nedeniyle, iş ve aile hayatına yönelik esneklik sosyallik ve bireyselliğini kapsamaktadır.

- Marks ve MacMermid (1996)' e göre iş yaşam dengesi; rol dengesi olarak isimlendirilmektedir. Bu bakımdan bireylerin rol sisteminde sahip olduğu tüm rolleri ile meşgul olma eğilimi olarak ifade edilmektedir. 
- Smith ve Gardner (2007)' e göre iş yaşam dengesi; bireyin iş ve iş dışındaki sorumluklarını dengede tutması olarak ifade edilmektedir.

- Clark (2001)'a göre iş yaşam dengesi; bireyin iş ve aile hayatında minimum sevide rol çatışması ile iş ve aile hayatında faal ve tatmin olması olarak ifade edilmektedir.

- Allen (2001)'e göre iş yaşam dengesi; bireyin ne zaman, nerede ve nasıl çalıştığına yönelik kontrol sahibi olması olarak ifade edilmektedir.

İş yaşam dengesi, aynı zamanda insan kaynakları yönetimi açısından da önem arz etmekledir. İş yaşam dengesine yönelik yapılan çalışmalar, iş görenlerin taleplerinde meydana gelen değişimlerin örgütler tarafindan fark edilmesine ve buna yönelik örgütlerin esnek çalışma stratejileri oluşturmasına olanak sağlamıştır (Küçükusta, 2007). İş yaşam dengesinin sağlanmış olması, bireylerin işinden memnun olmaları ve işinde başarı sağlamaları ve bunun yanında özel yaşamlarının da mutlu olmaları anlamına gelmektedir (Noor, 2011). Bu bakımda iş yaşam dengesin sağlanabilmesi için çalışma saatleri önem arz etmektedir. Uzun çalışma saatleri bireylerin iş ve yaşam dengelerini olumsuz yönde etkilemektedir. İş yaşam dengesinin sağlanamamasının asıl nedenine bakıldığında ise bireylerin işlerinde geçirmiş oldukları uzun çalışma saatlerinin sosyal hayatlarında güzel vakit geçirme olanaklarını engellemesi olarak ifade edilmektedir (Marafi, 2013). İş ve yaşam dengesinin bozulması ile birlikte, iş ve aile alanlarındaki rollerin ve isteklerin yerine getirilmesinde sorunlar yaşanmakta ve iki alan arasında çatışmaya neden olmaktadır (Tremblay, 2011). Bireyler ise iş ve aile alanlarında mutlu olmak istemekte ve iş hayatında kendine zaman ayırma noktasında esnekliğe sahip olmak istemektedir. Bu bakımdan iş yaşam dengesinin sağlanabilmesi için bireylerin her iki alana da eşit miktarda zaman ayırması gerekmektedir. Dolayısıyla, iş yaşam dengesinin sağlanması noktasında en önemli unsur "zaman" olarak ifade edilmektedir (Kumar, Chakraborty, 2013).

İş ve yaşam dengesini birey ve örgütlere yönelik dar bir biçimde düşünmemek gerekmektedir. İş ve aile hayatında gerçekleşen sorunlar, bireylerin aile yaşamını olumsuz yönde etkilediği gibi, çalışmış oldukları örgütleri ve hatta içinde bulunduğu sosyal yapıyı da olumsuz yönde etkilemektedir. Bu nedenle iş ve yaşam dengesi birey, örgüt ve toplum açısından önem arz eden bir konu olarak literatürde yerini almaktadır.

\section{3 Örgütsel Bağlılık}

Bireylerin örgütlerine olan bağlılık derecelerini belirten (Gruksy, 1966), ve kişilerin işine yönelik tutumlarından biri olan örgütsel bağlılık; kişilerin örgütte kalmak ve örgütte çalışmaya devam etmek için, örgütün amaç ve hedeflerine inanması ve kabul etmesi ve bu amaç ve hedefler için çaba ve gayret sarf etmesi olarak ifade edilmektedir (Mowday vd., 1979). Çalışma hayatında örgütsel bağlılıkla ilgili yapılan tanımlar yazarlara göre farklı anlamlar taşımaktadır. Bazı yazarlar bağlılık kavramını çalışanların örgütlerine yönelik duygusal bir yönelim olarak tanımlarken, bazı yazarlar ise çalışanların işten ayrılmaları sonucu meydana gelebilecek sonuçları göze alamaması sonucunda örgüte karşı hissedilen sorumluluk veya zorunluluk olarak ifade etmektedirler ( Buchanan, 1974).

Örgütlerin temel amaçları ve nihai hedeflerinden biri de örgütsel bağl1lıktır. Örgüte karşı bağlılık duyan çalışanlar işlerinde uyumlu, üretken oldukları görülmekte ve örgütlerine karşı sadakat ve sorumluluk bilincinde çalışmakta ve bunun neticesi olarak da örgüt maliyetlerini azaltmaktadırlar (Bayram, 2009). Örgütsel bağl1lık, örgüte güven duygusunu artırmakta, çalışanların işe tam katılımı ve ekip çalışması geliştirmekte, örgüt içerisinde iletişimi artırmakta, problemlerin çözümü noktasında kolaylık sağlamaktadır. Aynı zamanda yeniliğe açık olma ve örgüt içerisindeki bilgilerin paylaşılması noktasında kolaylıklar sağladığından dolayı örgüt içerişinde çalışanlar arasındaki ilişkileri geliştirmekte ve örgütün hizmet kalitesini artırmaktadır (Demirel, 2009).

Örgütsel bağlılık, literatürde duygusal, devamlılık ve normatif olmak üzere üç boyutta incelenmektedir. Bu yaklaşımlar örgütte çalışanlar arasında bir bağ oluştursa da bu bağın farklı olduğu ifade edilmektedir (Allen ve Meyer, 1990). Üç boyutta ele alınan örgütsel bağlılık boyutlarının dört ortak özelliği bulunmaktadır (Meyer ve Allen, 1997; AKT: Uyguç ve Çimrin, 2004).

- Psikolojik durumları yansıtır.

- $\quad$ Birey ile örgüt arasında ilişkileri gösterir.

- Örgüt üyeliğini sürdürme kararı ile ilgilidir.

- Isş gücü devrini azaltıcı yönde etkileri vardır.

Duygusal bağlılık; çalışanların örgütün amaç ve hedefleri doğrultusunda örgütüne karşı duygusal olarak bağlanmasını ifade etmektedir. Örgütüne karşı duygusal bağlılık hisseden çalışan, örgütün bir üyesi olmaktan gurur duyar ve örgütüne karşı olumlu duygular sergiler. Örgütüne karşı bağlılığı yüksek olan çalışan kendi isteği ile örgütte kalmayı devam ettirmektedir (Meyer ve Allen, 1991).

Devam bağlılığı; çalışanların örgütüne karşı yapmış oldukları kişisel yatırımlar sebebiyle örgütte kalma isteğinden kaynaklanmaktadır. Bu yatırımlar; kişinin örgütte uzun yıllar çalışması sonucu elde ettiği özel yetenekler, kıdem hakları, emeklilik hakları, mesai arkadaşları ile sosyal ilişkilerdir (Durna ve Eren, 2005).

Normatif bağlılık; çalışanların örgütte çalışmaya devam etme zorunluluğunun getirdiği ve örgüte karşı hissedilen sorumluluk bilincinin olduğu bağlılık türüdür. Normatif bağlılığı yüksek olan çalışanlar, örgütte kalma 
gerekliliğini hissetmektedirler. Normatif bağllık, bireylerin, örgüt içeresindeki sosyalleşme süreci, örgüte duyulan sadakat ve bireyin deneyimleri le ilişkilidir (Meyer ve Allen, 1991).

Örgütsel bağl1lık üç farklı boyutta incelense de her bir bağlllık türü çalışanın örgütüne karşı bağlılık duymasını sağlamaktadır. Duygusal bağlılığı olan çalışanlar istedikleri için, devam bağlılığı güçlü olan çalışanlar, ihtiyaç duydukları için, normatif bağl1lığı yüksek olan çalışanlar zorunlu oldukları için örgüte karşı bağl1lık duymaktalar ve işlerine devam etmektedirler. Her bağllık türünün nedenleri farklı olduğu için, etki ve sonuçları bakımından da farkl1lık göstermektedir (Bayram, 2009).

\section{Metodoloji}

İş görenlerin iş yaşam dengesine yönelik tutumlarının örgütsel bağlılık üzerindeki etkisine yönelik olan bu çalı̧̧ma, Afyon ili sınırları içerisinde ikamet eden ve çeşitli taşeron firmalarla çalışan iş görenler üzerinde yapılmıştır. Çalışma kapsamında ilk olarak iş görenlerin demografik özelikleri verilmekte ve daha sonra elde edilen verilere yönelik regresyon analiz tekniği kullanılarak iş yaşam dengesinin örgütsel bağllık üzerindeki etkisi ölçülmektedir. Çalışmanın son kısmında ise araştırmaya yönelik sonuç ve öneriler kısmına yer verilmektedir.

\subsection{Katılımeıların Demografik Özellikleri}

Tablo 1'de görüldüğü üzere, katılımcıların tamamı erkek katılımcılardan oluşmaktadır. Katılımcıların \%57'si evli, \% 43'ü bekâr çalışanlardır. Katılımcıların \% 57,3 18-30 yaş aralığında, \%31,7'si 31-45 yaş aralığında ve $\% 11$ 'i, 46 ve üzeri yaş aralığındadır. Katılımcıların \%23'ü 1000 TL ve altı gelire sahip iken, \% 43,7'si 1001 2000 TL ve \% 33,3'ü 2001 TL ve üzeri gelire sahiptir. Katılımcıların \%55,7'si işçi pozisyonunda, \%37,7'si usta ve \%6,7'si de ustabaşı pozisyonunda çalışmaktadır. Katılımcıların \%46,7'si ilköğretim ve \%53,3'ü lise düzeyinde eğitime sahiptir. Katılımcıların \%6,3'ü 8 saatten az, \%72,3’ü 8-11 saat ve \%21,3’ü 12 saat ve üzeri çalışmaktadır. Katılımcıların \%23,7'si 1 yıldan az, \%25,3'ü 1-3 yıl arası, \%27'si 4-5 yıl aralığında ve \%24'ü 6 yıl ve üzeri çalışmaktadır. Katılımcıların \%57,3'ü geçici olarak çalışmakta iken, \%42,7'si devamlı olarak çalışmaktadır.

\begin{tabular}{|c|c|c|c|c|c|}
\hline Cinsiyet & $\mathbf{n}$ & $\%$ & Medeni Durum & $\mathbf{n}$ & $\%$ \\
\hline Erkek & 300 & 100 & Evli & 171 & 57,0 \\
\hline Kadın & 0 & 0 & Bekâr & 129 & 43,0 \\
\hline Toplam & 300 & 100 & Toplam & 300 & 100 \\
\hline Yaş & $\mathbf{n}$ & $\%$ & Gelir & $\bar{n}$ & $\%$ \\
\hline $18-30$ & 172 & 57,3 & 1000 TL ve alt1 & 69 & 23,0 \\
\hline $31-45$ & 95 & 31,7 & $1001-2000 \mathrm{TL}$ & 131 & 43,7 \\
\hline 46 ve üzeri & 33 & 11,0 & 2001 ve üzeri & 100 & 33,3 \\
\hline Toplam & 300 & 100 & Toplam & 300 & 100 \\
\hline İş Pozisyonu & $\mathbf{n}$ & $\%$ & Ĕgitim & $\mathbf{n}$ & $\%$ \\
\hline İşçi & 167 & 55,7 & İlköğretim & 140 & 46,7 \\
\hline Usta & 113 & 37,7 & Lise & 160 & 53,3 \\
\hline Ustabaşı & 20 & 6,7 & & & \\
\hline Toplam & 300 & 100 & Toplam & 363 & 100 \\
\hline Çalışma Saatleri & $\mathbf{n}$ & $\%$ & Çalışma Yılı & $\mathbf{n}$ & $\%$ \\
\hline 8 saatten az & 19 & 6,3 & Bir y1ldan az & 71 & 23,7 \\
\hline $8-11$ saat & 217 & 72,3 & 1-3 Y1l & 76 & 25,3 \\
\hline 12 saat ve üzeri & 64 & 21,3 & 4-5 Yil & 81 & 27,0 \\
\hline Toplam & 300 & 100 & 6 Y1l ve üzeri & 72 & 24,0 \\
\hline Çalışma Şekli & $\bar{n}$ & $\%$ & Toplam & 300 & 100 \\
\hline Geçici & 172 & 57,3 & & & \\
\hline Devamlı & 128 & 42,7 & & & \\
\hline Toplam & 300 & 100 & & & \\
\hline
\end{tabular}

Tablo 1: Katılımcıların Demografik Özellikleri

\subsection{Regresyon Analizi}

Çalışmanın bu bölümünde iş yaşam dengesinin boyutlarının hangisinin örgütsel bağlılık üzerinde etkili olduğunu incelemek adına regresyon analiz bulguları yer almaktadır. 


\begin{tabular}{cccccc}
$\mathrm{R}$ & $\mathrm{R}^{2}$ & Düzeltilmiş $\mathrm{R}^{2}$ & Durbin-Watson & $\mathrm{F}$ & Sig. \\
\hline 0,812 & 0,659 & 0,654 & 1,785 & 142,335 & 0,000 \\
\hline
\end{tabular}

Bağımsız Değişkenler:

İş Yaşam Uyumu, Yaşamı İhmal Etme, Kendine Zaman Ayıramama, Yaşamın İşten İbaretliği

Tablo 2: İş Yaşam Dengesinin Boyutlarının Örgütsel Bağglılık Üzerindeki Etkisi

Tablo 2'de görüldüğü üzere, iş yaşam dengesi boyutlarının örgütsel bağlllık üzerindeki etkisi istatistiksel olarak anlamlıdır ( $\mathrm{F}=142,335 ; \mathrm{p}=0,000)$. Düzeltilmiş $\mathrm{R}^{2}$ değeri 0,659 düzeyinde hesaplanmıştır. Bu bağlamda, iş yaşam dengesi ölçeğinin boyutları olan, iş yaşam uyumu, yaşamı ihmal etme, kendine zaman ayıramama ve yaşamın işten ibaretliği boyutları, örgütsel bağlılık üzerindeki değişimin $\% 65,9$ 'unu açıklamaktadır. DurbinWatson katsayısı ise, değişkenler arasında otokorelasyon olmadığını açıklamaktadır (Anderson, Sweeney ve Williams, 2011: 751-753).

\begin{tabular}{|c|c|c|c|c|c|}
\hline & \multicolumn{2}{|c|}{$\begin{array}{c}\text { Standartlaşmamış } \\
\text { Katsayılar }\end{array}$} & \multirow{2}{*}{$\begin{array}{c}\begin{array}{c}\text { Standartlaşmış } \\
\text { Katsayılar }\end{array} \\
\beta\end{array}$} & \multirow[t]{2}{*}{$\mathbf{t}$} & \multirow[t]{2}{*}{$\mathbf{p}$} \\
\hline & $\boldsymbol{\beta}$ & S.S & & & \\
\hline Sabit Değer & 3.104 & ,383 & & 8,109 &, 000 \\
\hline Yaşamı İhmal Etme &,- 513 & 102 &,- 485 & $-5,033$ & 000 \\
\hline Kendine Zaman Ayıramama &,- 411 & ,093 &,- 391 & $-4,394$ & 000 \\
\hline Yaşamın İşten İbaretliği &,- 669 & 103 &,- 384 & $-6,476$ & 000 \\
\hline İş Yaşam Uyumu &, 256 & 064 & 253 & 4.016 &, 000 \\
\hline
\end{tabular}

Bağımlı Değişken: Örgütsel Bağlılık

Tablo 3: İş Yaşam Dengesi Boyutlarının Örgütsel Bağlllık Değişkeni Arasındaki Regresyon Katsayıları

Tablo 3'de iş yaşam dengesi boyutları ile örgütsel bağlılık arasındaki regresyon analiz katsayılar yer almaktadır. Yapılan regresyon analizi sonucuna göre, iş yaşam dengesi ölçeği boyutlarının tümünün örgütsel bağllık üzerinde etkili olduğu belirlenmiş̧tir $(\mathrm{p}<0,050)$. Bağımsız değişkenler üzerindeki önem sırasını gösteren Beta $(\beta)$ değerine göre örgütsel bağll1ık üzerinde iş yaşam uyumu $(\beta=, 253)$ pozitif yönde etki ederken, yaşamı ihmal etme $(\beta=-, 485)$, kendine zaman ayıramama $(\beta=-.391)$ ve yaşamın işten ibaretliği $(\beta=, 384)$ değişkenleri de negatif yönde etkili olduğu saptanmıştır. Aynı zamanda bağımsız değişkenlerden yaşamı ihmal boyutu, örgütsel bağlilık üzerinde en fazla etkiye sahip olan boyuttur.

\section{Sonuç ve Öneriler}

Ekonomi dünyasının küreselleşmesi ile birlikte işletmeler arasında rekabet ortamları artmakta ve işletmelerde bu rekabet ortamında ayakta kalmaya çalışmaktadır. Bu rekabet ortamında örgütlerin başarısının en önemli unsurlarından biriside çalışanları olabilmektedir. Örgüt çalışanların bağlılıkları küreselleşen ekonomi dünyasında önem arz ettiğinden dolayı, işletmeler çalışanlarını işletmede tutmaya çalışmakta ve çalışanlarında bu noktada bağlılıklarını artırmaya çalışmaktadır. Çalışanlar açısından bakıldığında ise, iş ve aile alanları arasındaki rollerin gerçekleşmesi ve bu rollerin gerçekleşmesi sonrası tatmin olma duygusu önem arz etmektedir. Çalışanlar bu iki alan arasında belirli bir denge kurmaya çalışmakta ve hayatlarını bu düzen içerisinde sürdürmeye çalışmaktadırlar.

İş görenlerin iş yaşam dengesine yönelik tutumlarının örgütsel bağlllık üzerindeki etkisine yönelik bu çalı̧̧ada iş yaşam dengesi dört boyutta incelenmiş ve her bir boyutun örgütsel bağl1lığa yönelik etkisi incelenmiştir. Yapılan analiz sonucunda, iş yaşam dengesinin, örgütsel bağl1lığı etkilediği görülmektedir. Çalışanların iş yaşam uyumunu sağlandığı takdirde örgüte olan bağllıkları artmakta, yaşamlarını ihmal ettiklerinde, kendilerine zaman ayıramadıklarında ve yaşamlarını işten ibaret olarak gördüklerinde örgüte olan bağllıkları azalmaktadır. Bu bakımdan çalışanlar için iş yaşam uyumu önem arz etmektedir. Çünkü iş görenler için önem arz eden iki alan arasında dengenin sağlanmış olması, iki alan arasındaki rollerin gerçekleşmesi noktasında önemli bir etkiye sahiptir. Bireyler, iki alandaki rollerini yerine getirdiği takdirde, yaşamsal olarak tatmin olmakta ve buda örgütsel ve bireysel verimliliği olumlu bir şekilde etkilemektedir.

Sonuç olarak, işletmelerin ekonomi dünyasındaki rekabet ortamında başarılı olabilmek ve işletmenin verimliliğini artırmak adına, başarının önemli bir unsuru olan çalışanların örgüte olan bağlılıkları artırmalı ve bu noktada çalışanların iş ve yaşam alanlarında denge kurmasına yardımcı olmalıdır. 


\section{Kaynakça}

- Allen, T.D. 2001. "Family-Supportive Work Environments: The Role of Organizational Perceptions", Journal of Vocational Behavior, 58, p.414-435.

- Allen, N.J. \& Meyer, J.P. 1990. "The measurement and antecedents of affective, continuance and normative commitment to the organization", Journal of Occupational Psychology, 63, 1-18.

- Anderson, David R., Sweeney, Dennis J. and Williams, Thomas A., 2011. Statistics for Business and Economics (11th Ed.). Mason, OH: South-Western Cengage Learning.

- Barnett, R. C., 1999. “A New Work-Life Model for the Twenty First Century”, Academy of Political and Social Science.

- Bayram, L. 2009. "Yönetimde Yeni Bir Paradigma: Örgütsel Bağlllık", Ankara Üniversitesi Eğitim Bilimleri Bölümü, Sayıştay Dergisi, Sayı 59.

- Buchanan, Bruce, 1974. "Building organizational commitment: the socialization of managers in work organizations", Administrative Science Quarterly, 19, N. 4, pp.533-546.

- C. S. Bruck, T. D. Allen ve P. E. Spector, 2002. "The Relation between Work-Family Conflict and Job Satisfaction: A Finer-Grained Analysis", Journal of Vocational Behavior, 60, ss. 336-353.

- Clark, S.C. 2001. "Work cultures and work-family balance”. Journal of Vocational Behavior, 58, 348-365.

- Demirel, Y. 2009. “Örgütsel Bağllı̆̆ı̆ İç Hizmet Kalitesi Üzerine Etkisi: kamu ve Özel Sektör Çalışanlrı Üzerine Bir Araştırma", Dumlupınar Üniversitesi Sosyal Bilimler Dergisi ", 23, (2009), s.269-281.

- Durna, U. ve Eren, V., 2005. "Üç Bağll1ık Unsuru Ekseninde Örgütsel Bağll1ık” Doğuş Üniversitesi Dergisi, 6, No 2 (s. 201-219.

- Duxbury, L. and Higgins, C. 2001. "Work-Life balance in the New Millennium: Where Are We? Where Do We Need to Go?" Canadian Policy Research Betworks.

- Grusky. O. 1966. "Career Mobility and Organizational Commitment". Administrative Science Quarterly. 10, No.4, pp.488-503.

- Hogarth, T., Hasluck, C., Pierre, G., Winterbotham, M., and Vivian, D. 2001. "Work-life balance 2000: baseline study of work-life balance practices in Great Britain", Summary Report, Institute for Employment Research.

- Küçükusta, D., 2007. “Konaklama İşletmelerinde İş-Yaşam Dengesi Sorunları ve Çözüme Yönelik Yaklaşımlar” Dokuz Eylül Üniversitesi Sosyal Bilimler Enstitüsü Dergisi, Cilt 9, Sayı:3.

- Kumar, Harish, Sudeep Kumar Chakraborty, 2013. "Work-Life Balance (WLB): A Key to Organizational Efficacy”, Aweshkar Research Journal, 15, (1), 62-70.

- Lockwood, R., Nancy, 2003. "Work/Life Balance: Challenges and Solutions", Society For Human Resource Management,

- MarafI, Hama, 2013. "Perception of Work-Life Balance-An Investigation of Education Sector of East and West", Asian Journal of Business Management, 5, (1), 174-180.

- Stephen R. Marks and Shelley M. MacDermid, 1996. "Multiple Roles and the Self: A Theory of Role Balance", Journal of Marriage and Family, 58, No. 2, pp. 417-432.

- Meyer, John P. ve Allen, Natalie J., 1991. "A three-component conceptualization of organizational commitment". Human Resource Management Review, 1, S.1, ss.61-89.

- Mowday, R., Steers, R. and Porter, L. 1979. "The Measurement of Organizational Commitment", Journal of Vocational Behavior, 14, pp. 224-247.

- Narayanan, A.G.V. ve Narayanan, R.L. 2012. “An Emprical Study on Factors Affecting Work-Life Balance of IT Professionals". European Journal of Social Sciences, 31, (3): 302-313.

- Noor, Khairunneezam Mohd, (2011), "Work-Life Balance and Intention to Leave Among Academics in Malaysian Public Higher Education Institutions", International Journal of Business and Social Science, 2, (11), 240-248.

- Uyguç, N. ve Çimrin, D. 2004. "Deü Araştırma Ve Uygulama Hastanesi Merkez Laboratuvarı Çalışanlarının Örgüte Bağlılıklarını Ve İşten Ayrılma Niyetlerini Etkileyen Faktörler” Dokuz Eylül Üniversitesi I.I.I.B.F. Dergisi, 19, Say1 1, s. 91-99.

- Smith, J. ve Gardner, D. 2007. "Factors Affecting Employee Use of Work-Life Balance Initiatives", New Zeland Journal of Psychology. 36, (1): 3-12.

- Tremblay, Diane-Gabrielle, Émilie Genin, Martine di Loreto, 2011. "Advances and Ambivalences: Organisational Support to Work- Life Balance in A Police Service", Employment Relations Record, 11, (2), 75-93 


\title{
Hasta Yatış Süreleri Açısından Cerrahpaşa Tıp Fakültesi Hastanesi Çocuk Nefroloji Servisi'nin 2012 Yılı Analizi Analysis of Cerrrahpaşa Medical School Hospital's Children Nephrology Service in Terms of Length of Stay in 2012
}

\author{
Asst. Prof. Dr. Volkan Öngel (Beykent University, Turkey) \\ Emel Duran (Beykent University, Turkey)
}

\begin{abstract}
It is known that operational costs of health care organizations constitute an important part of health expenditure in the world. Careful examination of all kinds affecting costs is inevitable in order to provide more effective and efficient health care services. For this reason, in the study, impact of factors affecting hospitalization period on costs is mentioned. The purpose of the study is to measure the effects of these factors on costs by identifying the factors prolonging the duration of patients' hospital stay. It is regarded that the factors extending the duration of patients' hospital stay increase the costs. In the scope of the study, 405 patients who are discharged from Cerrahpaşa Faculty of Medicine Hospital Pediatric Nephrology Service in 2012 are discussed. Variables of the study, the average hospitalization days, number of patients, the maximum number of patients, bed occupancy rate, bed turnover and bed units are used in the rev range. The data of the patients included in our study has been gathered with the help of retrospective study area, retrospective method, scanning archives, and financial epicrisis in the system of hospital automation. The obtained data have been studied on standard deviation, maximum and minimum value by making use of the excel programme. As a result of studies based on these reviews, it has been found out that the factors extending the period of patients' hospital stay increase the costs.
\end{abstract}

\section{Giriş}

Sağlık Bakanlığının geçmiş yıllardaki bütçelerine bakıldığında hastanelere ayrılan payın bütçenin en büyük kısmını oluşturduğu görülmektedir. Sınırlı olan kaynakların etkin kullanılarak verimli sağlık hizmetinin sağlanması maliyet unsurlarının iyi analiz edilmesi ve maliyetlerin düşürülmesiyle mümkün olabilir. Çalışmanın amacı hasta yatış sürelerini ele alarak Cerrahpaşa Tıp Fakültesi Hastanesi Çocuk Nefroloji Servisinin 2012 yılı verilerini analiz etmektir. 2012 yılında çocuk nefroloji servisine yatan 405 hastanın temel bulguları, yatış sürelerini etkileyen faktörler, yatış sürelerinin maliyetlere etkisi hastane otomasyon sisteminden geriye dönük arşiv taraması yapılarak analizi edilmiştir. Çalışmanın sınırlılıkları olarak Cerrahpaşa Tıp Fakültesi Hastanesi Çocuk Nefroloji Servisine 2012 yılında yatan hastalar ele alınmıştır.

Çalışmaya ait iki adet hipotez ortaya koyulmaktadır;

$\mathbf{H}_{1}$ : Hastaların SGK kapsam türlerine göre ortalama yatış süreleri diğer sağlık hizmeti kapsam türlerine göre farklılık göstermektedir.

$\mathbf{H}_{2}$ : Hastaların servise tekrar başvuru durumları ortalama yatış sürelerini uzatmaktadır.

\section{Hasta ve Hasta Yatış Süresine İlişkin Kavramlar}

Sağlık hizmetinden faydalanma ihtiyacı bulunan kimse olarak tanımlanan hastalar; ayakta, yatarak ve günübirlik tedavi alanlar olarak üçe ayrılmaktadır. Sağlık hizmetlerinden sağlık kurumlarında yatırılmaksızın faydalanan hastalar ayakta tedavi alan hasta olarak ifade edilmektedir. Hastanede yatmadan kemoterapi, radyoterapi, hemodiyaliz gibi günübirlik hizmet alanlar günü birlik tedavi alan; sağlık hizmetinden hastanede yatarak yararlananlar ise yatarak tedavi alan hasta olarak tanımlanmaktadır. Hasta sağlık kurumuna yattıktan taburcu olana kadar uygulanan tedavilere yatarak tedavi denilmektedir.

Hastanın hastaneye kabul edilmesinden taburculuğuna kadar geçen gün sayısı hasta yatış süresi olarak tanımlanmaktadır. Hasta yatış günü hesaplamasına yatılan gün dahil olup; hastanın taburcu edildiği, sevk edildiği veya öldüğü gün dahil değildir. Aynı gün içinde sağlık kuruluşuna yatıp çıkan hastaların hasta yatış günü sayıları bir gün olarak hesaplanmaktadır (Sümbüloğlu 1990,166) Hasta yatış süresinin maliyetler açısından oldukça önemli olduğu iddia edilebilir. Hastanede yatış süresinin uzaması komplikasyonların artmasına sebep olabilmekte, komplikasyonlar arttıkça hastane de yatış süresi uzamaktadır (Gogas Yavuz, et. al 2013, 71). Bu nedenle hastaların yatış sürelerini uzatan faktörlerin doğru tespit edilerek ortadan kaldırılması, yatış süresinin kısaltılmasına ve buna bağlı olarak maliyetlerin azaltılmasına yardımcı olabilir. Ayrıca hasta yatış süresinin kısaltılmasıyla birlikte mevcut yatak sayısı ile daha fazla sayı da hastaya hizmet verme (yatak devir hızının artmasıyla) şansı ortaya çıkmaktadır (Aksaraylı, et. al. 2009, 4). Kısıtlı kaynakların verimli kullanılması açısından değerlendirildiğinde de hasta yatış sürelerinin kısalmasının özellikle üst basamaklardaki sağlık 
hizmetlerinin etkinliğini arttırabilir. Hastaneden çıkan bir hastanın ortalama kaç gün kaldığını gösteren ortalama yatış süresi, sağlık hizmetlerinin değerlendirilmesinde, verimliliğin ölçülmesinde ve yatak gereksinmelerinin hesaplanmasında kullanılabilen bir göstergedir. Ortalama yatış süresi; toplam yatılan gün sayısının çıkan hasta sayısına bölünmesiyle bulunur. Hesaplama içerisine ölen ve sevk edilen hastalarda dahil edilmektedir. Ortalama yatış süresinin düşük olması hastane performansı açısından olumlu olarak değerlendirilmektedir.

Ortalama yatış süresinin ülkelerin sağlık ve finansman sistemlerinden etkilendiği gözlemlenmektedir. Bazı ülkeler, en azından bakım kalitesini yükselterek ve toplum bakım hizmetlerini geliştirerek ortalama yatış sürelerini azaltmanın yollarını aramaktadır. Diğer değişkenlerin sabit olduğu düşünüldüğünde ortalama yatış süresinin kısa tutulması hastane maliyetlerini azaltmaktadır. Fakat gözden kaçırılmaması gereken nokta; hastanın kısa kaldığı dönemlerde de yoğun hizmet alma gereksinimi olduğunda maliyetlerin yükselmesinin söz konusu olabileceğidir (OECD Indicators 2013, 82).

Hastanede kapasite kullanım oranını en iyi yansıtan ölçütün hasta günü sayısı olduğu şeklinde bir kabul söz konusudur. Hasta günü sayısı, yatan hasta sayısının bir hastanın ortalama yatış günü ile çarpılması sonucu elde edilir. Hasta günü sayısı, maksimum hasta günü sayısına ne kadar yakınsa hastanenin kapasitesinin o oranda büyük kısmını kullandığını gösterir. Maksimum hasta günü sayısı fiili yatak sayısının belirli bir dönem içerisinde (üç ay, bir yıl) belirli bir serviste yatılabilecek gün sayısının çarpımıyla bulunur ve bir hastanenin teorik kapasitesini ifade eder (Somunoğlu 2012,29).

Sağlık sektöründe hastane verimlilik ve etkinliğinin değerlendirilmesinde yaygın bir şekilde kullanılan bir diğer kriterde yatak doluluk oranıdır (Akbolat 2009, 133). Yatak doluluk oranının yüksek olması mevcut hasta yataklarının etkili ve verimli kullanıldığını gösterir. Genellikle yüzde olarak ifade edilen yatak doluluk oranı; (belirli bir dönemde bir serviste yatılan gün sayıs1*100) / (belirli bir dönemde serviste yatılabilecek gün sayısı* fiili yatak sayısı) formülü ile hesaplanmaktadır. Hastaneler açısından yatak kullanım oranı değeri, kapasite kullanım oranını göstermektedir. Hastanelerin hasta yatağı sayısını arttırmaktan daha çok mevcut hasta yataklarının daha etkili ve verimli kullanılabilmesi için yatak doluluk oranını arttırmaları gerekmektedir (Top ve Şahin 2004, 102).

Hastanelerde yatak kullanım oranı değeri kapasite kullanım oranını göstermektedir (T.C. Sağlık Bakanlığı Tedavi Hizmetleri Genel Müdürlüğü 2001, 4). Kapasite kullanım oranı da hasta yataklarının ve hastane hizmet potansiyelinin ne oranda kullanıldığını göstemektedir. Yatak sayısı baz alındığında kapasite kullanım oranı, belirli bir dönemde ( üç ay ya da bir yıl) belirli bir servisin fiili hasta günü sayısının teorik hasta günü sayısına oranıdır (Yiğit ve Ağırbaş 2004, 144). Hastanelerde yatak gereksinimlerinin saptanabilmesi için kapasite kullanım oranının bilinmesi gerekmektedir (Sözbir 1986, 5).

Bir yatağın bir yıl içerisinde kaç kez kullanıldığını gösteren yatak devir hızı ve bir yatağın ortalama kaç gün boş kaldığını gösteren yatak devir aralığı verileri de hastane servislerinin performans değerlendirilmelerinde ele alınması gereken kriterlerdir. Hastaneler de çıkan hasta sayısının fiili yatak sayısına bölünmesiyle elde edilen yatak devir hızı değerinin yüksek olması istenmektedir. Yatak devir hızının arttırılabilmesi için servisin yatak sayısı sabitken, servise yatan hasta sayısının artması gereklidir. Hasta sayısını arttırmak için kullanılabilecek verimli yöntem hastaların ortalama yatış sürelerinin kısaltılmasıdır. Yatak devir hızının düşük olması hastane maliyetlerinin yükselmesi ve gelirlerinin azalması açısından sorun olurken, yüksek bulunması hastanelerin kapasitelerinin arttırılması için bir göstergedir. Örneğin; fizik tedavi ve rehabilitasyon klinikleri gibi hastaların uzun süre kaldığı klinikler, düşük yatak devir hızları sebebi ile yüksek maliyet-düşük gelir sıkıntısıyla karşılaşabilmektedirler (Ağırbaş, Gök, et. al. 2012, 108).

Bir yatağın ortalama kaç gün boş kaldığını ifade eden yatak devir aralığı ((fiili yatak sayısı* 365 gün) - yatılan gün sayısı)) / çıkan hasta sayısı formülü ile elde edilebilmekte ve olabildiğince düşük olması istenmektedir. Çünkü yatak devir aralığı boş kapasiteyi göstermektedir. "Hastanenin büyüklügüu ile kapasite kullanım oranı ve yatak devir hızı arasında bir ilişki bulunmaktadır. Şöyle ki; büyük hastaneler genellikle daha yüksek kapasite kullanım oranı ile çalışırlar. Ancak bunlar tedavisi zor ve ağır hastalıkları kabul ettiklerinden tedavi süresi uzar ve böylece yatak devir hızı düşer. Diğer taraftan küçük hastanelerde ise kapasite kullanım oranı düşük olduğundan hastanın yatış süresi düşük olsa bile, az sayıda hasta yatırıldığı için devir hızı düşük olacaktır." Küçük hastanelerde yatak devir hızının yüksek çıkması, boş yatak sayısının azaltılması ve yatan hasta sayısının arttırılması ile mümkün olabilmektedir (A ğırbaş ve Yiğit 2004, 144).

\section{Bulgular ve Değerlendirme}

Türkiye Sağlık Bakanlığı'nın 2012 Sağlık İstatistikleri Yıllı̆̆g verilerine göre, Türkiye'de üniversite hastanelerinde hastaların ortalama yatış süresi 6,1 gün; tüm sağlık bakım hizmeti veren sektörlerde ise 4 gündür. 2002 yılında 5,8 gün olan ortalama yatış süresi zaman içerisinde azalmıştır. OECD ülkelerine bakıldı̆̆ında ortalama yatış süresi 7,5 gündür (Başara; et. al. 2013, 105). Hastane verimliliğini gösteren diğer kriterler açısından Türkiye'de 2002-2011 yılı verileri karşılaştırıldığında, yatak doluluk oranı \%59,4'den \%64,9'a; yatak devir hızı hasta bazında \%37,1'den \%60,8'e yükselmiştir. Türkiye'de hastane yataklarının yıllar içerisinde giderek daha verimli kullanıldığı gözlemlenmektedir. Fakat yatak doluluk oranı 2011 yılı OECD ortalaması olan 
\%78,2'den hala önemli oranda düşüktür. Yatak devir aralığı da 2002 yılında 4 gün iken, 2011 yılında 2,1 güne düşmüştür. Hastaneler için boş kalan yatak kaynak israfına sebep olacağından mümkün olduğunca düşük çıkması istenen yatak devir hızının düşmekte olduğu ve bir yatağın yıl içerisinde boş kaldığı gün sayısının azaldığı görülmektedir.

Çalışmamız kapsamındaki 405 hastanın hastanede yattıkları toplam gün sayısı 3829'dur. İlgili verilere göre hastaların ortalama yatış süreleri 9,45 gün olarak hesaplanmıştır. Bu hastalardan en kısa kalan hastanın yatış süresi 1 gün, en uzun kalan hastanın yatış süresinin 170 gün olduğu görülmüştür. 9,45 gün Türkiye ve OECD ortalamalarının üzerinde bir ortalama yatış süresidir. Ortalama yatış süresinin uzunluğu servisin performansının düşük olduğu şeklinde yorumlanabilmektedir. Uzun yatış süreleri hem maliyetleri yükseltmekte hem de yatak devir hızını azaltmakta ve verimliliği olumsuz etkilemektedir.

Çalışma kapsamındaki 13 yataklı çocuk nefroloji servisinin maksimum hasta günü sayısı (13*365 gün) 4745 gündür. Bu rakam tam kapasiteyi göstermekte olduğundan hastanelerin genellikle bu oranda hizmet vermeleri mümkün olmamaktadır. Çalışmamızda hasta günü sayısı ortalama 9,45 gün kalan 405 hasta ile 3827,25 gün olarak hesaplanmıştır. Maksimum yatılabilecek gün sayısı, yatılan gün sayısından 918 gün fazladır. Bu veriler 1şığında 2012 yılında servisin \% 80,65 kapasite ile çalıştığı, kapasitenin \% 19,35'inin atıl kapasite olarak kullanılamadığ1 görülmektedir. Çalışmamızda hesaplanmış olan \% 80,65'lik kapasite kullanımı hastaneler açısından bakıldığında bir miktar daha arttırılma şansı olmasına rağmen olumlu olarak değerlendirilebilir.

13 yataklı servisin yatak devir hızı (405/13) 31,15’tir. Sağlık bakanlığı 2012 Sağlık istatistikleri yıllığına göre, Türkiye'de üniversite hastanelerinin yatak devir hızı 45,6; tüm sektörlerin yatak devir hızı 59,5'tir. Çalışmamızda ki devir hızı bu verilerle kıyaslandığında düşüktür. Çalışmanın yapıldığı servisin tedavisi zor ve ağır hastalıkları olan hastalara hizmet vermesi sebebi ile tedavi sürelerinin uzamasına bağlı olarak yatak devir hızının düşük çıktığg düşünülebilir.

Çalışmamızda hesaplanan yatak devir aralığı ise 2,27 gündür. Sağlık bakanlığı 2012 Sağlık istatistikleri yıllığına göre, Türkiye'de üniversite hastanelerinin yatak devir aralığı 1,9; tüm sektörlerin yatak devir aralığ1 2,1'dir. Bir yatağın ortalama kaç gün boş kaldığını göstermesi bakımından yatak devir aralığı değerinin yüksek çıkması istenen bir durum değildir. Özellikle hastane gelirlerinin bu durumdan olumsuz etkilendiği söylenebilir.

Yatan hastaların sosyal güvenlik durumlarına ilişkin veriler incelendiğinde yaklaşık \%96'sının çeşitli alt başlıklarla (Bağ-Kur, isteğe bağlı sigorta, Emekli Sandığı, 18 yaş altı vb.) SGK kapsamında hizmet aldı̆̆ görülmektedir. Yeşilkartlı hastaların oranı \%3'tür. Ücretli hasta oranı \%1'in altındadır. İlgili hastaların ortalama yatış süreleri ele alındığında toplam sayı içerisinde ihmal edilebilir oranda olan ücretsiz ve ücretli sağlık hizmeti alan hastaların süreleri yüksek çıkmaktadır. Bunlar dışında ortalama yatış sürelerinin birbirine yakın olduğu ve sosyal güvenlik durumlarına göre ortalama yatış süreleri arasında önemli bir fark olmadığı görülmektedir.

\begin{tabular}{|l|c|c|c|c|c|}
\hline DURUM & EN AZ & EN ÇOK & TOPLAM & ORTALAMA & STANDART SAPMA \\
\hline SGK-SB & 1 & 76 & 1992 & 8,83 & 8,68 \\
\hline SGK-Bağ-Kur & 1 & 39 & 424 & 8,00 & 7,48 \\
\hline SGK-İsteğe Bağl1 Sigorta & 1 & 25 & 165 & 8,09 & 6,69 \\
\hline SGK-Emekli Sandığ 1 & 1 & 22 & 136 & 6,18 & 4,53 \\
\hline Yeşil Kart & 1 & 29 & 109 & 9,91 & 9,24 \\
\hline SGK-18 Yaş Altı & 2 & 30 & 78 & 9,75 & 9,16 \\
\hline Ücretli & 16 & 23 & 39 & 19,50 & 4,95 \\
\hline Ücretsiz Sağlık Hizmeti Alanlar & 9 & 15 & 24 & 21,00 & 4,24 \\
\hline
\end{tabular}

Tablo 1. Yatan Hastaların Sosyal Güvenlik Durumlarına Göre Hasta Yatış Süreleri Kaynak: Hastane Otomasyon Sistemi verilerinden derlenmiştir.

\begin{tabular}{|l|c|c|c|c|c|}
\hline & EN AZ & EN ÇOK & TOPLAM & ORTALAMA & STANDART SAPMA \\
\hline TEKRAR BAŞVURU & 2 & 10 & 135 & 3,29 & 1,78 \\
\hline TOPLAM YATIŞ GÜNLERİ & 2 & 113 & 1153 & 28,12 & 23,02 \\
\hline AMELIYYAT SAYILARI & 0 & 6 & 77 & 0,71 & 1,33 \\
\hline GENEL MÜDAHALE SAYILARI & 0 & 257 & 2371 & 57,83 & 58,94 \\
\hline RADYOLOJIK TETKIK SAYILARI & 0 & 17 & 179 & 4,48 & 4,41 \\
\hline
\end{tabular}

Tablo 2. Yatan Hastaların Servise Tekrar Başvuru Durumları Kaynak: Hastane otomasyon Sistemi verilerinden derlenmiştir.

Yukarıda yer alan tablo 2'de servise birden fazla kez başvuran hastalar ele alınmaktadır. Servise tekrar başvuran hasta sayısı 41 'dir. 41 hastadan en az başvuru yapan 2, en fazla başvuru yapan 10 kez yeniden servise gelmiştir. Bu hastaların ortalama başvuru sayıları 3,29; ortalama yatış günleri 28,12 olarak hesaplanmıştır. 
Servise birden fazla başvuruda bulunmuş hastaların oranı yaklaşık \%10'iken bu hastaların toplam yatış günleri, tüm hastaların toplam yatış günlerinin yaklaşık 1/3'ü kadardır.

\section{Sonuç}

Hastane maliyetleri içerisinde önemli bir paya sahip olan yatan hasta maliyetlerinin azaltılmasının ortalama yatış sürelerinin kısaltılması ile önemli ölçüde ilişkili olduğu söylenebilmektedir. Ortalama yatış sürelerinin kısaltılması ise kaliteli ve koordinasyonlu sağlı hizmeti verilmesi yanında yatan hastalarda oluşabilecek komplikasyonları en aza indirecek sağlık bakım hizmeti verilmesi ile sağlanabilir. Maliyetlerin azalması için yatarak tedavi alacak hastaların planlamalarının en doğru şekilde yapılarak; genel hizmetleri kapsayan operasyonların, radyolojik tetkik incelemelerinin ve genel müdahalelerin gerekliliğine uygun şekilde karar verilmelidir.

Çalışmamızda hastaların SGK kapsamına göre ortalama yatış süreleri diğer sağlık hizmeti kapsam türlerine göre farklılık göstermektedir şeklinde ileri sürülen $\mathrm{H}_{1}$ hipotezi kabul edilmemiştir. Düşünülenin aksine sosyal güvenlik durumlarına göre ortalama yatış sürelerinde önemli bir farklılık bulunmamıştır. Hastaların servise tekrar başvuru durumları ortalama yatış sürelerini uzatmaktadır şeklinde ileri sürülen $\mathrm{H}_{2}$ hipotezi kabul edilmiştir. Servise tekrar başvuran hastaların ortalama yatış günleri tüm hastaların ortalama yatış günlerinin üç katından daha fazladır. Servise tekrar başvuran hastaların yatış sürelerini azaltabilmek ve tekrar başvuruları engelleyebilmek için yatış-çıkış işlemleri, genel müdahaleler, radyolojik tetkik ve ameliyat gereksinimleri için birimler arası koordinasyon ve işbirliğinin sağlanması faydalı olabilir. Hastaların şifa ile taburcu edilmiş olmaları tekrar başvuruları en aza indirebilecektir.

\section{Kaynakça}

- Ağırbaş ve diğerleri, 2012. "Hastanelerde Maliyet Analizi ve Tıbbi Rehabilitasyon Hizmetlerinde Birim Maliyet Hesaplanması", Türkiye Fiziksel Tıp Rehabilitasyon Dergisi, ss. 103-108.

- Ağırbaş ve Yiğit, 2004. "Hastane İşletmelerinde Kapasite Kullanım Oranının Maliyete Etkisi: Sağlı Bakkanlığı Tokat Doğumevi ve Çocuk Bakımevi Hastanesinde Bir Uygulama" Hacettepe Sağlık İdaresi Dergisi, Cilt: 7, Say1: 2, ss. 141-162.

- $\quad$ Akbolat, 2009. "Türk Sağlık Sektöründe Miles Ve Snow'un Stratejik Tipolojisi: Hastaneler Üzerinde Bir Araştırma", Gazi Üniversitesi İktisadi ve İdari Bilimler Fakültesi Dergisi, Cilt: 11, Sayı: 3, ss. 127-146.

- Aksaraylı ve diğerleri, 2009. "Sağlık İşletmelerinde Yatak Kullanım Etkinliğinin Benzetim Yoluyla Optimizasyonu: Bir Eğitim ve Araştırma Hastanesi Uygulaması", Gazi Üniversitesi İkdisadi ve İdari Bilimler Dergisi (Gazi Üniversitesi), Cilt: 11, Say1: 1, ss. 1-22.

- $\quad$ Aktaş ve diğerleri, 2012. "Yatarak Fizyoterapi Alan Hastaların Yaşam Kaliteleri ve Maliyet Analizi", Marmara Medical Journal, Cilt: 26, ss. 34-38.

- Bora Başara ve diğerleri, 2013. Sağlık İstatistikleri Yıllığı 2012, T. C. Sağlık Bakanı̆̆ı Sağlık Araştırmaları Genel Müdürlüğ̈ Yayınları, Ankara.

- Gogas ve diğerleri, 2013. "Hastanede Yatan Hastalarda Hiperglisemi Sıklığı" Marmara Medical Journal (Marmara Üniversitesi Tıp Fakültesi), Cilt: 26, ss. 68-71.

- OECD İndicators, 2013. Average Length of Stay in Hospitals, www.oecd-ilibrary.org, 21 November 2013 , http://www.oecd-ilibrary.org/social-issues-migration-health/health-at-a-glance 19991312 Erişim: (28.12.2013).

- Somunoğlu, 2012. "Sağlık-Sağlık Hizmetleri ve Türk Sağlık Sistemi" Sağlık Kurumları Yönetimi 1 içinde yazan, Tatar, Mehtap, Anadolu Üniversitesi Web-Ofset Yayınları, Eskişehir.

- Sözbir, 1986. Hastanelerde Etkinliği Artırmada Yönetime Yardımcı Bir Araç Olarak Maliyet Bilgilerinin Kullanılması ve Afyonda Bir Örnek Olay Çalışması, T.C. Anadolu Üniversitesi Yayınları, Eskişehir.

- Sümbüloğlu, 1990. Sağlık Alanına Özel İstatistiksel Yöntemler, (3. Basım) Hatipoğlu Yayınları, Ankara.

- $\quad$ Top ve Şahin, 2004. "Hastane Endüstrisinde Değişen Sınırlar: Avrupa Ülkelerinde Yaşanan Son Yirmi Yıllık Süreç", Hacettepe Sağlık İdaresi Dergisi, Cilt: 7, Sayı: 102, ss. 86-106.

- T.C. Sağlık Bakanlığı, 2001. İstatistik Formları (Form 056) Hakkında Genelge, www.istanbulsaglik.gov.tr, Tedavi Hizmetleri Genel Müdürlüğ̈̈, http://www.istanbulsaglik.gov.tr/w/mev/mev_gen/tedavi_hiz/istatistik_formlari_(Form_056)_hakkinda_gen elge.pdf Erişim: (28.12.2013). 


\title{
Neoliberal Politikalar Sonucunda Medya Alanında Tekelleşme Eğilimleri ve Türkiye Örneğinde Son Yarım Yüzyıla Bakış Monopolization Tendencies as a Result of the Neoliberal Policies in the Media Industry and a Look to the Last Half Century in the Example of Turkey
}

\author{
Assoc. Prof. Dr. Hüseyin Çelik (İstanbul Arel University, Turkey)
}

\begin{abstract}
Economy politics that were formed with neoliberalism affected media industry like it affected all the other spheres of economy. The concentration of media structures in the world, the companies which work in the media industry being worked in the other spheres of economy, the struggle of these companies against the regulations about the media and their emphasis on the cancellation of these regulations; and the international activities of media companies attract the attention of the public for the last 50 years approximately. These developments in the media industry have been experienced in Turkey and these continued to be experienced. Neoliberal politics that were applied after 1980s caused important changes in the media industry. Another important point that attracts the attention is that even though the media actors have changed; the number of the structures that are active in media is limited and this number has not been changed for years. This paper aims to put forward the changes in the media industry in Turkey and the structures that have been shaped around these changes in the framework of neoliberal policies which were started in 1980s. In this paper a qualitative research design is used and ownership structures are analysed to investigate the changes in Turkey's media industry since 1980s. Consequently it is seen that media actors have been changed but their numbers stayed the same. Furthermore the ownership structure of the media that is formed as a result of these developments and the organic bond between the government is underlined.
\end{abstract}

\section{Giriş}

Teknolojik gelişmeler kitle iletişim araçlarının kullanım amaçlarını, şekillerini, boyutlarını genişletmiş ve devasa bir kültürel endüstri meydana getirmiştir. 1980'lerde olgunlaşan neoliberal politikalar ile birlikte kamu tekelleri yıkılmış, serbestleştirmeler yoluyla dev medya yapıları ortaya çıkmıştır. Günümüzde kamu medya oluşumları sözde tek başına ayakta durmaktadır ve sermaye ile eklemlenmiştir. Sermaye ile birlikte hareket etmeleri söz konusudur. Neoliberal oluşumlar kamusal medya aktörlerini de biçimlendirmiş ve şimdiye kadar medya dünyasında var olmayan bir yapı ortaya çıkmıştır.

Bu bildiri, 1980'li yıllardan yola çıkan neoliberal politikalar çerçevesinde Türkiye'de medya sektöründeki değişmeleri ve bu değişmeler etrafında şekillenen medya yapılarını ortaya koymayı amaçlamaktadır. Bu bildiride niteliksel bir araştırma dizaynı kullanılmış ve Türkiye'de medya sektöründeki değişmeleri incelemek için 1980'li yıllardan itibaren mülkiyet yapılarına bakılmıştır.

Günümüzde enformasyon sektörü ile büyük sermayenin buluşması yeni bir sermaye birikim modelini oluşturmuş, bu model kapitalizmin ideolojik, sembolik ve siyasal yeniden yapılanmasıyla tam bir entegrasyon kurmuştur (Kaya, 2009:18). Günümüzde medya, hem sermaye birikimine hem de ideolojiyi tekrar üreten bir aygıt kaline dönüşmüştür (Kaya, 2009:18). Gerçekliği yeniden kurgulanmış şekliyle aktarma biçimi ve dolayımlanmış olarak aktarma şekli ile medyanın gerçekliği yapay olarak "yeniden inşası" söz konusudur. İktidarlar ve sermaye çevreleri medyanın bu özelliğinden istifade etmek amacıyla girişimlerde bulunmaktadır. Günümüzde medyanın gerçekliği nasıl aktaracağı önem taşımaktadır. Medyanın aktörlerinin ve medya profesyonellerinin kurguladığı ve ne/nasıl aktardığının üzerinde durmak gerekmektedir. Profesyonel medya aktörleri, gerçeği aktarmada profosyonellik ilkeleri mi, yoksa aldığı talimatları mı veya otokontrol biçimlerini mi kullanmaktadırlar? Haber ilk üretildiği aşamada kişinin izlerini taşımaktadır. Haberi üretenin niyeti ve içinde bulunduğu koşullar önemlidir. Batı'daki medya etik ilkeleri bunu bir standard hale getirmek amacıyla üretilmiştir. Sembolik seçkinlerin baskısı, doğru duruş olarak herhangi bir görüşün dayatılması, toplumsal ilişkilerin korunması, haberi tüketenlerin iletileri nasıl açacaklarının benimsetilmesi, yaygın ortak duyu (common sense), normal ve anormalin ne olduğu konusunda ön fikirler haberin üretilmesi sürecinde belirleyici olmaktadır. Aynı zamanda bir ticari etkinlik olan medya faaliyetleri, diğer sektörlerdeki ekonomik mantığa gore işleyen yapısıyla onu aynı zamanda bir ticari ve sanayi etkinliği haline getirmektedir (Kaya, 2009:18 ).

Medya iletilerinin nasıl tüketildiği bu aşamada önem taşımaktadır. Çünkü okuyucuların bir gazeteyi okuyacak yeterlilikte bir kültür birikimine ulaşmış olmaları gerekmektedir. Medyanın öneminin giderek daha çok artması aynı zamanda okuryazarlığın gelişimiyle ilgilidir. Bu nedenle kitle iletişimi kapitalizmin bir ürünüdür (Kaya, 2009:56) denilebilir. Ancak kapitalizmin muhatab olduğu kitleler daha çok okuryazar hale gelmekte ve bu kitleleri kontrol etmek için daha fazla kontrol mekanizmaları kurmak gerekmektedir. Toplumsal doku değişirken 
siyasal ekomomik kurumlaşmalar üretilmesine neden olmakta ve medya bu yönde yapılandırılmaktadır. 16 ncı yüzyıldan sonra gazetenin ve telgrafın ortaya çıkması insanların haber alması, enformasyon ihtiyaçlarının karşılanmasından ziyade kapitalist ticari yapının gelişmesi ve devam etmesi içindir. 20 nci yüzyılda radyo ve televizyonun, aynı yüzyılın sonunda da internetin eklenmesiyle birlikte medya alanı genişlemiştir. Bu genişleme ticari alana doğru olmuştur. Fakat bu alan enformasyon üretmekten ve kamusal araç olmaktan ziyade her zaman bir ticari alan olarak görülmüştür. Medyanın enformasyon, eğitme işlevleri hep geri planda kalmış, eğlence işlevi ise ön planda tutulmuştur.

Medyayı denetleme girişimleri ön-izin alınmasıyla başlamakta, lisans ücretleri ile devam etmekte ve iktidarların medyayı kontrol etmek, ellerinde tutmak için reklam ve ilan verme konusunda bir tutum içerisine girmektedirler. $\mathrm{Bu}$ nedenle ticari baskı ve vergi denetlemeleri yapmaktadırlar. Düzenleme adına yapılan girişimler ile düzenleyici kuruluşların iktidar ile kurdukları organik bağ oluşmakta ve bu nedenle çeşitli normatif düzenlemeler yapılmaktadır.

1789 yılında Fransız İnsan ve Yurttaş Hakları Bildirgesi’nde “düşünce ve iletişim özgürlüğünün temeli atılmıştır. Bu bildirgeye göre "insan görüşlerinden dolayı suçlanamaz (madde 10), düşünce ve görüşlerinin serbestçe iletme insanın en doğal en değerli haklarından biridir Her yurttaş yaşanan yaşam hakkını kötüye kullanılması olarak belirlediği haller dışında serbestçe konuşabilmeli, yazabilmeli ve yayında bulunabilmelidir" (madde 11). 1791 ABD Anayasasında yapılan ilk değişiklik (First Amentment) kongrenin söz ya da basın özgürlüğünü kısıtlayan hiçbir yasa yapamayacağını hükme bağlamıştır. Liberal öğretimin temeli olan yayın ve ifade özgürlüğü temel hak ve özgürlüklerin anlam kazanmasında ön koşuldur. Liberalizmin temellerinin atıldığı dönemde her şeyi akılcılıktan öte doğal durum olarak kabul eden ve bir toplu sözleşmesine dayanan yap1 oluşturulmuştur. Liberalizmin temeli aslında Adam Smith ile atılmıştır. Adam Smith aklı ön planda tutmuş, böylece gerçekliği bulmak için çalışmıştır, Ama sonuçta gerçekliğin ancak piyasa mekanizmasını serbest bırakarak doğal bir yoldan elde edilebileceğini işaret etmiştir. Aydınlanmadan hareket eden bu görüş, aydınlanma düşüncesinin ateist olmadığı yaratılış ile son arasındaki yaşam evresinde başına gelebilecek tüm şeylerin başka bir irade tarafından gerçekleştiğini savunur. İnsan aklı sadece bu irade tarafından inşalara dayatılan bu dünyayı biçimlendirir ve şekillendirir. Böylece sadece gerçekliğin bir boyutunu görüp yansıtabilir. Böylece serbest piyasa koşulları iyinin kötüden, yararlının zararlıdan yanlışın doğrudan gerçek olmayanın gerçekten ayrışmasını sağlamaktadır (Kaya, 2009:95). Bu şekilde oluşan liberal öğretiye dayalı bir iletişim düzeninin "bırakınız yapsınlar bırakınız geçsinler” anlayışı üzerine kurulması ilk bakışta güzel bir fikir olarak görülmektedir. Liberal düşüncenin tekelleşmeyi beraberinde getirdiği savını liberaller kesinlikle reddederler (Kaya, 2009:133).

Liberal düşünceye dayalı iletişim düzeni bilgi başta olmak üzere her şeyi serbestçe dolaşabildiği ve hiçbir engelin yasağın olmadığı bir düzendir. Eğer bu düzende engel ve yasak olursa, bilgi birilerinin tekelinde kaldığından haksız güç elde edilmesine yol açacaktır. Bilginin serbestçe dolaşması, insanların bu bilgiye her an serbestçe ulaşabilmeleri ve bunların serbestçe aktarılabilmesi, paylaşılabilmesi öngörülmektedir Oysa dünyada bütün bu şeyler diğer özgürlük alanlarında olduğu gibi kısıtlıdır ve serbest değildir. Liberal düşüncenin temeli olan girişimcilik dahi tekelci yapı tarafından engellenmektedir İktisadi bir etkinlik olan medya endüstrisi önce para kazanmayı düşünmek zorundadır. Ortak fayda (common good) ve kamusal yarar (public interest) gibi sosyal devlet anlayışının gerekliliklerini düşünmek zorunda değildir. Medyanın endüstri olmasının nedeni para kazandırma özelliğinin olması, yani iktisadi olmasıdır. Böylece içerikte eğlendirmenin, haber ve bilginin önüne geçtiği görülmektedir. Sansasyona dayalı, sarı basın olarak adlandırılan ve eğlendirmeyi amaçlayan tabloidleşmenin önem kazanması medyanın magazinleşmesini beraberinde getirmiştir. Bu yolla kitlesel üretim yapan gazeteler ve geniş kitlelere ulaşan radyo ve televizyon işletmeciliği bir iş kolu ve "business" bir faaliyet alanı haline dönüşmüştür. Böylece bir iş kolu haline dönüşen medya, dolaylı ve dolaysız karlarını artırdıkça tekelleşmeye doğru gitmektedir.

ABD'de yapılan ilk anayasa değişikliği ile birlikte ruhsat alma zorunluğu basında kaldırılmıştır. Fakat radyo televizyonların çıkışı ile birlikte bu değişiklik uygulanmamıştır Böylece doğal hakkın önüne engel olarak çıkan devlet bu alana müdahale etmiştir. Amerikan Anayasa Mahkemesi tarafından kabul edilen FCC (Federal Communication Commision) ruhsat başvurusu değişikliğini uygun bulması ile radyo ve televizyonları basından ayırmıştır.

Günümüzde özgürlüklerin kısıtlanmayacağı, kısıtlanacaksa sınırların nasıl belirleneceği üzerinde tartışmalar yaşanmaktadır. 20 nci yüzyıl ve öncesinde özgürlüklerin kısıtlanması konusunda yaşanan acı tecrübenin tekrar yaşanması korkusu liberal çevrelerde hâkimdir (Kaya, 60).

Bir medya endüstrisinin oluşması ve kar ile paranın bilgiyi oluşturma ve yaymada önemli hale gelmesi, medya endüstrisini şekillendirmiştir. Bunun paralelinde reklam gelirleri önem kazanmış ve izleyicilerin reklamverenlere satılması (Dallas Symthe), izleyicilerin reklam aralarından programları izlemesi hali hasıl olmuştur. Bu nedenle izleyicileri tüketiciliğe indirgeyen bir yaklaşım benimsenmesi ile program içeriğinde değişiklikler yapılmıştır. Medya iletileri izleyici, dinleyici ve okurlara ulaşırken asıl hedefleri reklamverenler ve sponsorlardır. İkinci hedefi ise izlerkitleler oluşturmaktadır. 
Radikal ve marjinal yanları törpülenmiş eğlence unsuru artırılmış bir program içeriği ile daha fazla izleyici edinme arayışları meydana gelmiştir. Basını sistemi içerisine alma girişimleri ile önce basın dördüncü güç olarak nitelendirilmiş, daha sonra ona bekçi köpeği görevi verilmiştir (Kaya, 2009:144).

Liberal öğretide "sözde" medyanın görevleri vardır. Bu görevler piyasa mekanizmasının var olması ve işlemesi için yapılmaktadır Oluşturulan rekabet koşulları bu sistemi daha çok iyileştirmeye yaramaktadır Fakat radyo ve televizyon kuruluşlarını açmak, onları ulusal ve uluslararası çapta büyütmek için önemli miktarda sermaye birikimine ihtiyaç vardır. Bunu küçük kuruluşların karşılaması mümkün değildir. Böylece çoğulculuğuna yaslanan bir yapının oluşması çok zordur, yani para olmaz ise medya yapılarının oluşturulması mümkün değildir. Sonuçta önemli miktarlarda sermaye birikimini elde eden kişi ve gruplar bu imkânı yakalamaktadırlar. Böylece küçük gruplar ve kişilerin yayın içeriklerine tikel çıkarları için müdahaleleri söz konusu olmaktadır. Bu durum tekelleşmeyi daha çok artırmaktadır.

\section{Medya Yapılarının Dönüştürülmesi Süreci}

1990'larla birlikte soğuk savaşın bitmesi, kapitalizmde yeni bir yapılanmaya neden olmuştur. 1973 petrol krizinden sonra Keynes'in sosyal politikaları terk edilmeye başlanmış ve 1980'lerde Avrupa ve ABD'de "Yeni Sağ" düşünceyi savunan politikacılar iş başına geçmiştir. Örneğin ABD'de Reagan, İngiltere'de Thatcher ve Türkiye'de Özal bu yapısal dönüşümün önemli figürleri olmuşlardır. Sosyal politikalar terk edilmiş ve özelleştirmeler yapılmıştır. Medya alanında Thompson ilkeleri yani Yoğunlaşma (Concentration), Kuralların Kaldırılması (Deregulation), Çeşitlenme (Diversification) ve Küreselleşme (Globalisation) politikaları uygulanmaya başlanmıştır. Medya endüstrisinin yoğunlaşması, medyan sahiplerinin giderek sayısının azalmasıdır. Medya sektöründe birleşmeler ve evlilikler yoluyla yoğunlaşma yaşanmaktadır. Çeşitlenmenin büyümesi, medya alanında faaliyet gösteren şirketlerin başka alanlarda da faaliyet göstermeleri ve medyayı bu alanların gelişmesi için araç olarak kullanmalarıdır. Medya alanında küreselleşmenin artması, dev medya şirketlerinin dünyanın birçok ülkesinde yayına başlamalarıdır. Kuralsızlaştırma yönünde eğilimler, neoliberal ekonomi düşüncesi doğrultusunda oluşturulmuştur. Bu eğilimler kuralların, gümrük ve tarifelerin olmadığı, mal ve hizmetlerin dünyada serbestçe dolaşabileceği bir alan yaratılabilmesini hedeflemektedir. Bu düşünceye göre dünya çapında uluslararası medya yapılanmasının önündeki tüm engeller kaldırılmalıdır. Böylece tek bir medya yapılanması ve tek yönlü bir iletişim akışı meydana gelecektir.

Tek yönlü iletişim akışı, hem donanımın hem de yazılım olarak ifade edilen yayın içeriğinin ABD tarafından üretilmesine dayalıdır. Dünyada Dünya Ticaret Örgütü, Uluslararası Para Fonu ve Dünya Bankası tarafından sevk ve idare edilen düzende medya alanı "Yeni Sağ" politikalarının savunucusu, öğreticisi ve uygulatıcı görevini üstlenmiştir. Bu modelde para ve hizmetlerin serbest dolaşımı ilkesi çerçevesinde medya içeriği her ülkeye kısıtlama olmadan girebilmesinin mümkün hale gelmesi gerekmektedir. Bunun temini için mümkünse ulus devlet yapılarının ortadan kalkması, daha çok küçük gruplardan oluşan toplulukların devletin yerine geçmesi gerekmektedir. Tam rekabet koşulları elde edilecek, mal ve hizmetler serbestçe dünyada dolaşabilecektir. Böylece tek bir pazarın hâkim olduğu bir dünyada oyun kurucularının oyun kurallarını her topluluğa dayatmaları daha kolay hale gelecektir. Bu sistem ancak tekelleşme ile mümkün hale gelecektir.

Medya alanında tekelleşme iki biçimde gerçekleştirilmiştir: Birincisi sektörde yalnızca bir alanda faaliyette bulunan firmalar faaliyetlerini diğer alanlara yayarak etkinlik yelpazelerini genişletmişlerdir. İkincisi birleşmeler ve satın almalar yoluyla bütünleşerek büyümüşlerdir. Böylece karlarını maksimize etmişlerdir (Kaya, 2009:152).

Marks’ın Alman İdeolojisi’nde vurguladığı gibi “maddi üretim araçlarına sahip olanlar aynı zamanda düşünsel üretim araçlarını da kontrol ederler" düşüncesi uygulama alanı bulmuştur. Bu tekelleşme süreci sonunda "yoğunlaşma" ilkesi çerçevesinde dünyada medyayı kontrol edenlerin sayısı giderek azalmış ve tek haneli rakamlara kadar düşmüştür. Örneğin Dünyada Time Warner, Disney, Viacom, New Corporation, Sony, Seagram, Westinghouse, Garett ve General Electric önemli miktarda medya yatırımlarını ellerinde bulundurmaktadırlar.

Medya sektöründeki yoğunlaşmalar ve tekelleşmelerin devlet yapısına karşı bir bağımsızlık ve böylece dördüncü güç olma yoluna güç katacağı değerlendirilmektedir. Oysa medya devleri devlet ile beraber hareket etmekte, hak ve özgürlükler konusunda sadece ticari oluşumların lehine düzenlemeleri desteklemektedirler.

\section{Türkiye'de Medyada Tekelleşme}

Türkiye'de ekonomik gelişmelerle birlikte 1950'li yıllardan itibaren basın sektörü oluşmaya başlamıştır. İlk kez Simavi ailesi tarafından başlatılan ticari gazetecilik faaliyetleri reklam, ilan ve satış gelirleri sayesine basından para kazanmanın yolunu açmıştır. Basın kökeninden gelen Milliyet gazetesinin sahibi Karacan Ailesi, Tercüman gazetesinin sahibi Ilıcak ailesi bu gelişmelere ayak uydurarak basın sektöründe büyümeye başlamışlardır. Medyanın bu şekilde büyüyerek holdingleşmesi bu alanda faaliyet göstermeyen diğer holdinglerin ilgisini çekmiştir. Özellikle 1980'li yıllarda basın bir sektör haline dönüşmeye başlamıştır. 1980 askeri darbesinden yara alan basın sektörü siyaset gibi konularla daha az ilgilenmeye başlamış, siyaset yerine ekonomi, spor ve magazin haberlerine daha fazla yer vermeye başlamıştır. Özal döneminde İzmir'de çıkan Yeni Asır gazetesinin sahibi olan Bilgin ailesi Sabah gazetesini çıkararak iktidara destek olmaya başlamıştır. Bu 
yıllarda çeşitli sektör dışı kuruluşlar basın sektörüne el atarak basını bu sektörleri geliştirmenin, karlarını maksimize etmenin aracısı haline getirmişlerdir. Asil Nadir Gelişim grubu ve Günaydını satın alarak basını uluslararası faaliyetler ile Kıbrıs davası için yararlanmayı planlamıştır. 1980'li yıllarda basın sektörünün ekonomik alanlarda bu kadar önem kazanması değişik sektörleri bu alana yatırım yapmalarına neden olmuştur. Bunun nedenleri; basını dördüncü güç olarak paylaşma isteği, siyasi kişilikleri etkileyerek yatırımların etkinliğini artırmayı amaçlama, devlet teşviklerinden ve rantlarından öncelik kapma düşüncesi, medyayı sahibi olduğu kuruluşların reklamını yapma isteği, medyayı pazarlama faaliyetlerini artırmak amacıyla kullanma düşüncesidir.

1990’lı yıllarda Türkiye'de radyo ve televizyon alanında medya tekelinin kalktığı görülmektedir. Bu dönemde medya sektöründe Türkiye'de o yıllara dek görülmemiş gelişmeler yaşanmıştır. Kitle iletişimde yeni teknolojik araçlar kullanılmaya başlandı. Kitle iletişimin örgüt yapılarında önemdi değişiklikler oldu. Kitle iletişimi pazarı global bir duruma geldi ve Türkiye bu global pazarın önemli bir parçası haline gelmiştir (Erdoğan ve Korkmaz, 2002:497).

1990’lı yıllarda Türkiye'de ortaya çıkan krizler "Yeni sağ” düşüncesini reddeden Cumhuriyetçi ve geleneksel yapının düzenlemelere direnmesi sonucu ortaya çıkmıştır. Cumhuriyetin kazanımı olarak değerlendirilen 70 yıllık ticari, iktisadi ve kültürel miras kamu ve özel girişimler arasında bir dengenin oluşturulması sonucunda oluşturulmuştur (Sönmez, 1996:76). Oysa neoliberalizm devletin her alandan çekilmesini ve özelleştirmelerin hızlanmasını hedeflemiştir. Buna direnen Türkiye bürokrasisi ve diğer kuruluşlar ekonomik krizlerle karşı karşıya kalmışlar ve sonunda direnememişlerdir.

90’lı yılların sonunda 16 ulusal gazete olmak üzere toplam 3500 gazete ve dergi vardı. Kamu tekellerinin yık1lmasıyla birlikte 30 ulusal olmak üzere 1150 radyo, 16's1 ulusal, 15'i bölgesel 230 yerel olmak üzere 261 televizyon kanalı bulunuyordu (Kaya, 2009:247).

Türkiye'de son olarak Sabah grubunun sahibi Dinç Bilgin'in iflası sonrasında gazeteci kökenli medya patronu kalmamıştır. 2013 yılına kadar Doğan ve Çukurova grubunun medya alanında zayıfladıkları görülmektedir. Bunun yerine AKP iktidarını savunan Merkez medya adıyla bilinen bir destekçi medya yapısı oluşturulmuştur.

\section{Sonuç}

Günümüzde Doğan ve Çukurova grubunun elinde bulunan televizyon ve gazete sayısının azaldığı görülmektedir. Ciner grubunun iki televizyona sahip olduğu, fakat basın alanından çekildiği dikkat çekmektedir. Buna karşılık geçmişteki önemli medya sahiplerinden Erol Aksoy, Tuncay Özkan ve Zafer Mutlu'nun medya sektöründen çekildikleri görülmektedir.

Türkiye'de medya sektöründeki en önemli büyümeler Çalık ve Doğuş grubuna aittir. Ak Parti lehinde yayın yapan bu medya grupları enerji, inşaat, turizm, madencilik alanlarında da faaliyet göstermektedirler. Doğuş grubu ayrıca Garanti bankasını elinde tutmaktadır. Ak Parti döneminde faaliyetlerini artıran diğer gruplar şunlardır: Koza İpek grubu, İhlas Holding, Samanyolu Yayıncılık ve News Corporation. Rubert Murdock'un sahip olduğu ve uluslararası boyutta medya şirketleri olan News Corporation'ın en önemli televizyon kanalı Fox TV'dir.

2000'li yıllardan sonra Merkez Grubu olarak tarif edilen Çalık ve Doğuş grupları hükümete yakın durmaları ve bu doğrultuda yayın yapmaları ekonomi alanında büyümelerine neden olmuştur.

Türkiye'de 2015 yılındaki medya manzarası şu şekildedir: İktidar ile iyi ilişkiler kuran, bu yolla ekonomi alanında hâkimiyetini genişleten medya yatırımlarını karlı olmamasına rağmen sürdürmek istemeleridir. Medya liberal ilkeler çerçevesinde eğitme, eğlendirme ve enformasyon verme faaliyetlerinin yanında kapitalist ekonomiyi destekleme doğrultusunda yayın yapmaları dikkat çekmektedir. $\mathrm{Bu}$ nedenle medya sektöründe yaşanan el değiştirmeler ve yeni oluşumları siyasal ekonomi doğrultusunda değerlendirmek ve anlamlandırmak gerekmektedir.

\section{Kaynakça}

- Akarcalı, Sezer (1997) Türkiye'de Kamusal Radyodan Özel Radyo ve Televizyon'a Geçiş Süreci, Ankara: Punto.

- Erdoğan, İrfan ve Korkmaz Alemdar (2002) Öteki Kuram: Kitle İletişimine Yaklaşımların Tarihsel ve Eleştirel Bir Değerlendirilmesi, Ankara: Erk.

- Kaya, A. Raşit (2009) İktidar Yumağı: Medya Sermaye Devlet, Anakara: İmge.

- Mc Luhan, Marshall. (2001). Gutenberg Galaksisi: Tipografik İnsanın Olusumu. Çev.: Gül Çağalı Güven. İstanbul: YKY.

- Marcuse, Herbert. (2010) Tek Boyutlu İnsan: İleri İşleyim Toplumunun İdeolojisi Üzerine İncelemeler, İstanbul: Idea.

- Sönmez, Mustafa (1996) “Türk Medya Sektöründe Yoğunlaşma ve Sonuçları”, Birikim Dergisi, Sayı:92, Aralık 1996, ss.76-86, İstanbul Birikim.

- Wallerstein, Immanuel. (2011) Dünya Sistemleri Analizi, İstanbul: BGST. 


\title{
Türk Spor Sektöründe Kurumsallaşma: Futbol Kulüpleri Örneği Institutionalization of Turkish Sport Sector: Example of Football Clubs
}

\author{
Asst. Prof. Dr. Yeter Aytül Dağlı Ekmekçi (Pamukkale University, Turkey) \\ Prof. Dr. Ayşe İrmiş (Pamukkale University, Turkey)
}

\begin{abstract}
Sport is an enormous growing sector day after day with its sub-sectors like food, textile, technology, communication, health, tourism etc. Besides it is providing an important source of income in the economy. One part of this sector is sport clubs and most of them are running as companies nowadays. Therefore they need to be managed professional and to get an institutional structure to survive in the economic system. Thus the aim of this study is to examine the institutionalization of Turkish sport clubs, how the managers and workers evaluate their clubs. The data was collected from 178 managers/workers from Super League and PTT 1. League clubs, which are the top level organizations of Turkish football system. The obtained data from the questionnaires are analyzed through the SPSS statistical packaged software. Analysis results revealed that high level educated managers/workers are evaluating both sub-dimensions of institutionalization (professionalization and cultural element) at a lower level than the others. Similarly the managers/workers who indicated that clubs doesn't have mission and vision, they evaluated the institutionalization of clubs in a lower level. But on the other side there has been found any differences between managers/workers who are educated in sport sciences area, than who are not educated in this area.
\end{abstract}

\section{Giriş}

Kurumsallaşmanın ülkemizde ve dünyadaki önemine yapılan vurgu farklı sektörleri de içine alarak her geçen gün artmaktadır. Çünkü kurumsallaşma örgütlerin kendilerini geleceğe taşımalarında ve yer aldıkları sistem içerisinde kendilerini kabul ettirmede önemli bir rol oynamaktadır. Örgütler kurumsallaşarak meşruluk, tahmin edilebilirlik ve istikrar kazanmakta, ayrıca işletme kaynaklarını artırarak çevreye uyum sağlamaktadırlar.

Örgütlerin kurumsallaşma sürecinin temelinde, 'biçimsel faaliyet yapısı', 'biçimsel organizasyon yapısı', 'profesyonelleşme', 'yetki devri', 'kültürel güç', 'kurumsal çevreye uyum', 'kurumsal sosyal sorumluluk', 'toplumsal değer ve normlara uyum', 'şeffaflık ve hesap verebilirlik' ve 'biçimsel yapıya uyum' esasları bulunmaktadır. Tarım, sanayi, hizmet vb. sektörlerdeki örgütlerde çıktı; ürün, performans göstergesi; kâr ya da bir buluş, varlıklar; entelektüel sermaye, know-how, şerefiye gibi değerler olurken, spor sektöründe bu unsurlar nispeten farklılaşmaktadır. Sporda çıktı sportif başarıdır. Sportif başarı içinse finansal güç, varlığın sürdürülmesinde gerekli kaynakları elde etmek için faaliyetlerin kârlılıkla sonuçlanması, örgüte bağlı ve uzmanlık sahibi çalışan/yönetici ve sporcuların varlığı gereklidir.

Ülkemizde, 1980'li yıllardan itibaren hıla büyüyen spor sektörünün, günümüzde geldiği nokta itibariyle kurumsallaşma çalışmalarından henüz tam olarak nasibini almamış olduğu görünmektedir. Uluslararası yazında ise spor örgütlerinde kurumsallaşma konusunu araştıran birçok çalışma bulunmaktadır. Uluslararası alan yazınındaki alan araştırmaları bir taraftan spor kulüplerine kurumsallaşma konusunda yön verme gayesi taşırken, diğer taraftan bu kulüplerin kurumsallaşma etkenlerini ve süreçlerini incelemektedir.

Örneğin futbol endüstrisi hakkında veriye dayalı uluslararası çalışmalar yapan danışmanlık şirketi Deloitte'un çalışmasına göre 15 milyar Euro'ya yakın olan Avrupa futbol gelirinden elde edecekleri payı artırmak amacıyla başta İngiliz kulüpleri olmak üzere diğer üst düzey Avrupa kulüpleri yeniden yapılanma çalışmalarına ağırlık vermeye başlamışlarıdır. Bu amaçla başta beş büyük ligin (İngiltere, İspanya, İtalya, Almanya, Fransa) kulüpleri olmak üzere üst düzey futbol kulüpleri, ülkelerinde "kurumsal yönetim" uygulamalarını iyileştirme arayışı içindedirler" (TKYD, 2010: 40-42).

Spor endüstrisinin Dünya'da 1,6 trilyon dolar ile sağlık sektörü ve Hollywood sektöründen daha büyük olduğu belirtilmektedir. Sportif giyim, eğitim, bahis endüstrisi, spor turizmi başta olmak üzere birçok yan endüstrisi bulunan spor endüstrisinde, spor kulüplerinin sporcu transferi için yaptığı ödemelerin toplamı yılda 500 milyar doları bulmaktadır. Bu sektörde maç biletlerine yıllık 52 milyar dolar harcandığı göz önüne alındığında spor kulüplerinin sektördeki önemi ortaya çıkmaktadır (Eurosport).

Futbol kulüplerinin uluslararası faaliyet göstermesi onların kendi ülkelerini uluslararası alanda temsil etmesi sonucunu da doğurmaktadır. Bu bakımdan, futbol kulüpleri uluslararası alanda bir taraftan kendi varlıklarını göstermeye ve sürdürmeye çalışırken, diğer taraftan da bu arenada ülkelerinin temsilciliğini yapmaktadırlar. Aynı zamanda, futbol kulüpleri yukarıda ifade edildiği gibi şirketleşme yoluna da gitmektedirler. Bütün bu unsurların varlığ 1 , futbol kulüpleri açısından kurumsallaşmayı zorunlu hale getirmektedir. 
Bu çalışmanın amacı Türkiye'deki futbol kulüplerinin kurumsallaşma süreçlerini bilimsel olarak incelemek ve bir takım öneriler getirmektir. Ayrıca, ülkemizde doğrudan kurumsallaşma kuramlarını içine alan spora yönelik bir çalışma, hâlihazırda bulunmamaktadır.

\section{Kurumsallaşmanın Tanımı ve Önemi}

En genel tanımıyla kurum; "evlilik, aile, ortaklık, mülkiyet gibi köklü bir yapıyı içeren, genellikle devletle ilişkisi olan yapı veya birlik, müessese" şeklinde tanımlanmaktadır (www.tdk.gov.tr). Ayrıca sigorta, askerlik, akademik çalışma, oy kullanma, eğitim alma, başkanlık gibi farklı ancak kurum olarak nitelendirilen kavramlar mevcuttur. Bu terimlerin ortak özellikleri bulunmakla birlikte bazılarında örgütsel, bazılarında kültürel ya da yapısal bir içerik ön plana çıkmaktadır (Jepperson, 1991:144-145).

Kurumlaşma, sosyal, ekonomik ve politik nitelikteki olayların incelenmesinde kullanılan bir yaklaşımdır. Kurumların oluşumu, toplumsal özellikler ile ilişkileri ve örgütlerin yapı ve işleyişi konularını inceleyen bu yaklaşımda net olarak görüş birliğine varıldığı söylenemez. Kurumlaşma sosyolojik bir yaklaşımdır ve bu anlamda kurum; toplumda organize olmuş, yerleşmiş, kabul edilmiş, prosedürleri belli sosyal ilişkiler düzeni ve topluluğunu ifade etmektedir. Herhangi bir olayın, davranışın kurum sayılabilmesi, bu olayın geçtiği çevreye, kişilerin amaçlarına, ilişkilerin özelliğine ve analiz edilecek soruna büyük ölçüde bağlı bulunmaktadır (Koçel, 1998: 259).

Klasik kurum tanımı, kurumların kararlı sistemler olduğunu ve yavaş değişim gösterdiğini belirten Hughes’a (1936) uzanmaktadır. Commons'un tanımına göre kurumlar, özel bir zamanda ortaya çıkan, geçmiş çatışmaları uzlaştırmak için kusurlu ve pragmatik (faydacı) çözümlerden daha fazlasını temsil etmemektedirler. Hak ve görevler setini, bunları dayatan bir otoriteyi ve tedbirli ve makul davranışlardan oluşan ortak normlara uymayı içerirler (Van de Ven, 1993: 142). Selznick (1949) kurumsallaşmayı değerlerin etkileri ve rolleri ile açıklamıştır. Diğer bir deyişle kurumsallaşmayı; örgütlerin veya sosyal kuruluşların görevlerinin teknik gerekliliklerin ötesinde değerler ile aşılanmış olduğu bir süreç olarak tanımlamıştır (Farashahi vd., 2005: 3).

Türkiye'de "kurumsallaşma" mevcut örgütleri; sürekliliği ön planda tutan, işlerin yürütülmesinde ve sorumlulukların belirlenmesinde kişisellikten uzaklaşmış örgütlere dönüştürmeye yönelik yönetsel çabalar olarak algılanmaktadır. Kurumsallaşan örgütlerin belirsizlik ortamlarından kurtulacağı, etkin ve verimli faaliyet göstereceği, yönetimin devamlılığının sağlanacağı, işlerin ve eylemlerin sistematik bir şekilde yürüyeceği varsayılmaktadır. Ancak kurumsallaşma konusunu inceleyen yayınlarda kavrama ve içeriğine yönelik bir belirsizlik bulunmaktadır. Kurumsallaşma konusuna aile örgütlerine ve küçük ve orta ölçekli örgütlere danışmanlık yapanlar tarafından daha fazla ilgi gösterilmekte ve Türkiye'ye özgü anlayış uluslararası yazının kastettiği kurumsallaşma (institutionalization) kavramından oldukça uzak kalmaktadır (Ulukan, 2005: 31 -32).

Sosyolojik açıdan spor, köklü bir sosyal kurumdur ve bu kurumun içindeki kişiler, kurumun fonksiyonel unsurlarıdır. Kurumun oluşma sebebi ve varlığını devam ettirmesi bu kişilerin varlığına bağlıdır. Bu kişilerin fikirleri, duyguları ve beklentileri bir taraftan sporla ilgili talebi oluştururken diğer taraftan da, yönetici ve politikacıların karar, mevzuat, resmi işlemler, politikalar ve çözüm yapılarında temel alınan rehber olmaktadır. Sporda bürokratikleşme ve kurumsallaşmadaki artış (Guttmann, 1978) 19. y.y.'da gerçekleşirken, spor hukuku ve politikaları alanındaki yükselme (Malatos, 1996) 20. y.y.'ın son üç on y1llık döneminde görülmektedir. Spor modern toplumlarda sosyal bir kurumdur ve bu durum sporun politika, ekonomi, eğitim ve aile gibi kurumlarla sık etkileşiminin büyüklüğü ve yaygınlığı ile açıklanabilir. MacPherson ve arkadaşlarına göre kurumsallaşma; sosyal birim ve aktivitelerin kalıcı ve sürekli ilişkili şekilde organize olduğu küresel bir süreçtir. Bu bakış açısında spor, oyun unsurlarının ve aktivitelerinin kurumsallaştığı ve sonradan örneğin aslında eğlence için tasarlanmış spordan türetilen ticarileşmiş spor ligleri gibi faydacı aktivitelere dönüştürülmüş bir rasyonelleşme süreci geçirmiştir (Yetim, 2006:9).

\section{3 İșletmelerin Kurumsallaşma Amaçları}

İşletmelerin kurumsallaşma amaçlarını "meşrulaşma", "tahmin edilebilirlik kazanma", "istikrar kazanma", "işletme kaynaklarını artırma" ve "uyumlu olma" olarak tanımlanmaktadır.

Boddewyn ve Brewer (1994) ve Milne ve Patten (2002)'ye göre meşrulaşma, örgütlerin kaynaklara ulaşmasını ve yaşamını devam ettirmesini sağlamaktadır. Bu da örgütlerin performansını etkilemektedir. Örgütler kaynak sağlayıcıların güvenini meşrulaşarak kazanıp daha fazla finans ve insan kaynağına ulaşabilmektedir. Kaynak bağımlısı örgütler, davranışlarını başkalarının taleplerine uydurma ve örgütün eylemlerine kısıtlar yaratan bağımlılıkları yönetme çabası içerisindedir. Örgütlerin kaynakları kıt oldukça ya da kaynağın örgütler için önemi arttıkça bu kaynaklara sahip olan tarafların örgütler üzerinde kontrolü artmaktadır. Daha büyük sistemden gelen kaynakları kullanabilmeleri ve eylemlerini çevrelerine kabul ettirebilmeleri için örgütlerin meşru olması gerekmektedir (Apaydın, 2007: 32).

Kişilerin ve örgütlerin ilişki içinde bulundukları örgütlere güven duymaları, toplumsal norm ve değerlere uyan bu örgütlerin gelecek faaliyetlerini öngörebilmeleri ile mümkün olabilmektedir. Özellikle de küreselleşmenin 
getirdiği sayı ve çeşitlilik açısından farklılık gösteren birçok örgütün bulunduğu, yoğun rekabetin yaşandığı pazarlarda daha önceki faaliyetleri ile gelecek faaliyetlerinin tahmin edilebileceği izlenimini paydaşlarına hissettirebilen örgütler bunu, tercih edilme konusunda avantaj olarak kullanabileceklerdir.

Hannan ve Freeman (1977) örgütlerin yapısal ataletsizliklerinin büyük değişiklikler yapmalarını zorlaştıran tipik özellikleri olduğunu öne sürmektedirler. Yüksek derecede güvenilirliğe ve hesap verilebilirliğe sahip örgütler, örgütsel çevre tarafindan tercih edilen örgütlerdir. Yüksek güvenilirlik ve hesap verebilirlik zaman içerisinde tekrarlanabilmeyi ve istikrarı sağlamaktadır. Örgütler yaş olarak büyüdükçe örgüt üyelerinin birbirlerine olan güven duygusu ve işbirliği artacağından ve örgüte özgü yetenek ve rutinler öğrenileceğinden, yapıların tekrarlanabilirliği de artmaktadır. Diğer bir deyişle yaşlı örgütler daha yüksek yapısal durgunluğa ve düşük yok olma oranına sahiptirler. Her ne kadar tekrarlanabilirlik zamanla iç örgütsel süreçlerden yükseliyorsa da, bazı önemli örgütler dış süreçlere bağlı yenilik eğilimindedirler (Singh vd., 1996: 171-173).

Ruerkert vd. (1985)'e göre kaynakları düzenleyen kişi ve kurumlar, meşru, uygun ve tahmin edilebilirliği yüksek olan örgütlere güven duyacağından, bu örgütlere yatırım yapma ve onlarla uzun süreli ilişkiler yürütme konusunda istekli olmaktadırlar. Eğitimli insanların da çalışacakları kurumları seçme kriterleri arasında bu özellikler bulunmaktadır (Apaydın, 2009: 10). Örgütler hem örgütsel işlevlerin gerçekleştirilmesinde hem de gerekli yönetsel becerilerin sağlanmasında nitelikli insan kaynağına gereksinim duymaktadırlar. Aynı zamanda hızlı örgütsel büyümeye katkı sağlayacak uygun finansal kaynaklar da önemlidir. Mal ve hizmet üretiminde kullanılmak üzere elde edilecek diğer kaynaklara ulaşımda güçlükler yaşandığı dönemlerde, kurumsallaşma düzeyi, çevredeki diğer örgütlere göre daha yüksek olan örgütler, bu özelliklerinin sağlayacă̆g faydalardan yararlanabilirler (Can, 1999: 49).

Meyer ve Rowan (1977) örgütlerin; ihtiyaçları olan kaynaklara ulaşarak varlıklarını sürdürebilmek ve bu sürdürülebilirlik sırasında çevresel unsurlar tarafindan kabul edilebilir olmak (meşrulaşmak) için pozisyonları, politikaları, program ve prosedürleri ile modern toplumlardaki kurumsallaşma kurallarına uymak zorunda olduklarını savunmaktadır (Scott, 2004: 6). Bu sayede örgütler teknik açıdan yeterli düzeyde olmasalar bile kurumsallaşmanın gerektirdiği dışsal değerlendirme kriterleri (sertifikalar, belgeler, ödüller gibi) ile meşruluklarını ve hayatta kalma çabalarını güçlendirmektedirler (Özen, 2007: 255-256).

\section{Sporun Tanımı}

Jay J. Coakley'in anlatımıyla, en geleneksel tanımlarda ve birçok kültürde spor, bireylerin katılımlarının içsel (bireysel zevk) ve dışsal (dışsal ödül) faktörlerin birleşimiyle motive edildiği, yoğun fiziksel çaba ya da görece karmaşık fiziksel yeteneklerin kullanımını içeren kurumsallaşmış rekabet faaliyetleri olarak tanımlanabilir. Sosyal yaşamın diğer alanlarından giderek ayrılan ve farklı ve ayrı bir sosyal alan oluşturan, sosyal aktivitenin kurumsallaşmış ve özelleşmiş bir alanıdır (Mukharji, 2009: 1874).

Serbest zaman değerlendirmede alternatif olarak kabul edilen spor, teknolojinin gelişmesine paralel olarak geniş kitlelere yayılmış ve bu sektör içinde yer alan kişi ve kuruluşlar zaman içinde değişime uğrayarak kulüpler birer işletmeye, taraftar ve izleyiciler ise birer tüketiciye dönüşmüştür. 1990'lı yılların başından bu yana profesyonel spor kulüplerinin şirketleşmesi ve halka arzı, aşırı yüksek bilet fiyatları ve yayın hakları spor endüstrisinin şeklini değiştirmiş ve diğer endüstrilerce de kârlı bir alan olarak görülmeye başlanmıştır (Alkibay, 2005: 84).

\section{Spor Yönetimine Genel Bir Bakış}

Yönetim biliminin kavram, ilke ve yöntemleri çeşitli faaliyet alanlarına uyarlanarak eğitim yönetimi, kamu yönetimi, sağlık yönetimi, işletme yönetimi ve spor yönetimi şeklinde uzmanlık alanlarına indirgenerek genel yönetimin özel uygulama alanları oluşturulmuştur. Yönetim biliminin bir alt dalı olarak spor yönetimi; yönetim bilimiyle birçok ortak noktayı paylaşırken, aynı zamanda spor alanının özelliklerini de dikkate alarak, sporcuyönetici, sporcu-spor örgütü ve spor örgütü-toplum ilişkilerini barındıran bir yapı oluşturmaktadır. Spor yönetimi de kendi içinde spor tesisleri yönetimi, spor kulüpleri yönetimi, spor örgütleri yönetimi gibi alt dallara ayrılmaktadır. Sonuç olarak çalışma alanları ve örgüt türü farlılık gösterse de etkin ve verimli bir yönetim için yönetim biliminin ilke ve yöntemlerinin esas alınması gereği geçerlidir (Ekenci ve İmamoğlu, 2002: 20-21).

Sporun küreselleşmesinde ve dünya pazarlarına ulaşmasında hızı bir büyümenin yanı sıra yerel tarih, yerel politika ve spor kültürü, yerel ekonomik koşulların özelliklerini taşıyan ürünlerin spor işletmeciliğindeki modellerinin çeşitliliği de söz konusudur (Amara vd., 2005: 189). Hoye ve Auld (2001)'a göre hızla değişen bir çevrede yönetişim, spor örgütlerinin etkin ve verimli yönetiminde merkezde kalmaya devam etmektedir. Örgütlerin işleyişleri ve genel yönleri ile sorumluluğu kapsayan "yönetişim”, kulüp seviyesinden ulusal yapılara, kamu kurumları, spor hizmet örgütleri ve dünya çapındaki profesyonel takımlara kadar sporla ilgili tüm kodlar için gerekli ve kurumsallaşmış bir bileşendir (Ferkins vd., 2005: 196). 
Spor kulüpleri dünyanın her yerinde sporun çekirdek teşkilatı ve onun temel birimi olarak görev yapmaktadırlar. Bu bağlamda sporcuların ve teknik heyetin bir amaç etrafında bir araya geldiği, sporculara sporu bilimsel olarak öğreten ve uygulatan tüzel kişiler olarak tanımlanabilirler (Devecioğlu ve Çoban, 2003: 3).

\section{Spor Kulüplerinde Kurumsallaşmanın Unsurları}

Washington ve Patterson (2011:1) çalışmalarında ilk olarak kurumsal teorinin hâkim kavramlarını gözden geçirerek kurumsal yönetimin spor yönetimi alan yazınında nasıl kullanıldı̆̆ını incelemişlerdir. Böylece spor yönetimi araştırmalarında kurumsal teorinin kullanımı ile ilgili iki ana tartışma noktası belirlemişlerdir. İlk nokta kurumsal değişim ve örgütsel alan dinamikleri konuları incelenerek spor yönetiminde kurumsal teorinin daha da ayrıntılandırılması üzerinedir. İkinci nokta ise kurumsal teorinin, spor yönetimi konularında farklı şekillerde kullanımının araştırmacılar tarafından sunulmasının önerilmesidir.

Spor kulüplerinde kurumsallaşmanın unsurları değerlendirilirken, genel olarak alan yazında kurumsallaşmanın unsurları olarak belirlenen on alt boyut aynı başlıklarla değerlendirilmiştir. Çalışmanın alan araştırması kısmında da temel oluşturan bu boyutlar spor kulüpleri temelinde incelenmeye çalışılmıştır.

\subsection{Spor Kulüplerinde Biçimsel Faaliyet Yapısı}

Shilbury (2001), spor örgütlerinde amatör yönetimden profesyonel yönetime geçişte yaşanan gerginliklerin, yönetim kurulu üyelerinin rollerinin incelenmesine katkı sağlayacağı sonucunu desteklemektedir. Slack (1985) spordaki bürokratikleşme ve profesyonelleşmeyle ilgili olarak, spor örgütlerindeki bürokratik özelliklerin aynı anda ortaya çıkmadığını belirtmektedir. Örgütler büyüdükçe karmaşıklık düzeyi artmaktadır (Ferkins vd.,2005:202).

Spor örgütleri, işletmelere göre işlevlerinin çeşitliliğinden ziyade farklı düzey ve özelliklerde kurum ve paydaşlarla ilişkili olduklarından, biçimsel faaliyet yapısının belirlenmesinde zorluklar ortaya çıkmaktadır. Bu nedenle biçimsel faaliyet yapısı, spor örgütlerinin sporun kendine has yanlarından etkilenerek faaliyet gösterdiği göz önüne alınarak değerlendirilmelidir.

\subsection{Spor Kulüplerinde Biçimsel Organizasyon Yapısı}

Biçimsel organizasyon yapısının oluşturulması ve bu yapıya uyum sağlanması spor örgütleri için diğer örgütlere göre daha fazla önem arz etmektedir. Çünkü spor örgütleri spor çevresinin birçok öğe içermesi ve bu öğeler arası ilişkilerde çeşitliliğin çok olması nedeniyle karmaşık bir yapıya sahiptir. Bu karmaşık yapılar içinde iletişimin, farklı durumlarda standart uygulamalara gidilerek tutarlılığın, çevre tarafından kabul görmüş değer ve normların sürekli yansıtılmasının sağlanması biçimsel yapıya uyumla gerçekleşecektir. Aksi takdirde taraftarlık özelliği nedeniyle duygusal bağlılığın diğer örgütlere nispeten yoğun olduğu spor örgütlerinde çatışma, uyumsuzluk, tatminsizlik ve verimsizlik orta çıkacaktır.

\subsection{Spor Kulüplerinde Profesyonelleşme}

Amatör düzeyden profesyonel düzeye geçişle birlikte yaşanan profesyonelleşme süreci, örgütsel değişim sürecinde aktivitelerin ve prosedürlerin biçimselleşmesi ve gönüllü çalışanların ücretli çalışanlara dönüşmesi şeklinde sporculardan yönetim organlarına kadar tüm birimlerde önemli etkiler yaratmıştır. Spor örgütlerinin yapısına etki eden bir diğer unsur da özellikle örgütleri yeni pazarlama stratejileri geliştirmeye iten ticarileşmedir (Gomez vd., 2008:13-14).

\subsection{Spor Kulüplerinde Yetki Devri}

Sporun etkilediği gruplar sporcular, toplum, iş dünyası, taraftarlar ve medya gibi birbirleriyle çıkarları çatışan gruplar olduğundan, spor örgütlerinde karar alma da karmaşık bir özellik göstermektedir. Karar almada bu çıkar gruplarının ağırlıklı etkilerinin dikkate alınmasının yanı sıra spor yöneticileri finansal maliyetleri, takıma etkilerini, liglerdeki düzenlemeleri, hukuki yapıyı ve oyunu kazanmanın etkisini de göz önünde bulundurmalidirlar (Sherry vd, 2007: 268).

Spor örgütlerinde biçimsel faaliyet ve organizasyon yapısının tam olarak olmasa da belli bir düzeyde oluştuğu ifade edilmektedir. Ancak henüz bu yapıya uyum tam olarak gerçekleşmemektedir. Bu uyumun istenilen düzeyde olması profesyonelleşmeyle birlikte olacaktır. Yetki devri de profesyonelleşmenin olduğu diğer örgütlerdeki gibi, ast üst ilişkisinin gerektiği gibi yaşanması, yöneticilerin sorumlu oldukları birimle ilgili kararlarda söz sahibi olmasıyla gerçekleşecektir.

\subsection{Spor Kulüplerinde Kültürel Güç}

Smith ve Shilbury (2004: 133-134), ulusların kültürlerinin bireyleri etkilediği gibi örgütlerin kültürlerinin de üyelerinin davranışlarını şekillendirdiği ve spor kültürünün benzersiz ve kendine özgü ekonomik yapısından etkilendiğini belirtmektedirler. Örgüt kültürü, çalışanların davranışlarını ve motivasyonlarını etkileyerek sonuçta örgütsel değişim ve başarıyı etkilemektedir. Başka bir deyişle kültür; yenilik, yaratıcılık, performans, işgören katılımı, dayanışma, etkinlik ve karar vermeyle ilişkilidir. Kültür, çalışanların davranışlarını belirlemek için değerlerin, normların, varsayımların ve beklentilerin şekillendirilmesinde kullanılabilir ve kültürün uygunluğu, açıkça örgütsel başarı ile bağlantılıdır. 
Ülkemizde spor kulüplerinin kültürel yapıları değerlendirilirken şehir takımlarında hemşehri olmanın, kulüp yönetiminde yaşanan sorunlara çalışanların duygusal yaklaşmalarına ve eleştirel bakış açısı yerine örgütsel bağlılık olarak algılamayı sürdürmelerine sebep olduğu şeklindeki örnekler mevcuttur. Ayrıca spor kulüplerinin birçoğunun ortak ve sabit bir çalışma ortamının olmayışı, bireylerin kültürel değerlerini paylaşmalarına yeterince olanak vermemektedir.

\subsection{Spor Kulüplerinde Kurumsal Çevreye Uyum}

Slack ve Hinings (1994), örgütlerin kurumsal çevrelerindeki kuralcı, taklitçi ve zorlayıcı baskıların, spor örgütlerinin daha profesyonel olmalarına ve yaptıkları işi bir meslek gibi algılamalarına katkı sağladığını öne sürmektedirler. Profesyonelleşmeye bağlı normatif (kuralc1) standartlar, uygun yönetim ve karar verme yapısıyla ilgili inanç ve değerleri tanımlayan ve kâr amacı olmayan sportif topluluklar tarafından belirlenmiştir (Kikulis, 2000: 301).

\subsection{Spor Kulüplerinde Kurumsal Sosyal Sorumluluk}

Futbol kulüplerinin işletmeler olarak faaliyet göstermeleri, toplumlara kulüplerin sosyal sorumluluk faaliyetlerini de artıracaklarını düşündürmektedir. Futbol kulüpleri topluma yayılmış ve paydaşlarıyla güçlü ilişkilere sahip olmaları nedeniyle kurumsal sosyal sorumluluk faaliyetleri için oldukça uygun araçlardır. Kurumsal sosyal sorumluluğun sağlayacağı ekonomik yararlar, toplumda gündem yaratabilmesi ve yönetici ve paydaşların beklentilerinin bu yönde olması bu faaliyetlerinin gerçekleştirilmesi için itici güç olmalıdır. Çünkü kurumsal sosyal sorumluluk faaliyetlerinin pekiştirdiği iletişim, kurumsal yönetim yapısı içinde paydaşlara karşı hesap verebilirliğin gelişmesi için firsat sağlamakta ve ilişkisel ortaklıklar ve ağların oluşturulmasını kolaylaştırmaktadır (Hamil ve Morrow, 2011: 143).

\subsection{Spor Kulüplerinde Toplumsal Değer ve Normlara Uyum}

Spor örgütlerinin faaliyetlerindeki çeşitlilik, farklı özelliklerde birçok sosyal yapıyla ilişkili olmalarını da beraberinde getirmektedir. İlişkili olunan bu kurumların da toplumsal olarak kabul görmüş olmaları, yani meşruiyetlerinin sağlanmış olması, spor örgütlerinin bu kurumlar tarafindan benimsenmiş değer ve normlara uygun davranmasını gerektirmektedir. Ayrıca bu çalışmanın alan araştırmasını dikkate aldığımızda spor kulüpleri için süreklilik, karlılık ve kültürel gücü artırmada önemli role sahip olan paydaşlardan biri taraftardır. Spor örgütleri taraftarların beklediği yönde davranışlar sergileyerek onların değer ve normlarına uygunluk gösterdiklerinde, taraftarlar tarafindan benimsenme ve bağlılı̆̆ın artması da kolaylaşacaktır.

\subsection{Spor Kulüplerinde Şeffaflaşma ve Hesap Verebilirlik}

Spor örgütlerin bulundukları çevre içinde varlıklarını sürdürebilmek ve faaliyetlerinde etkinlik sağlayabilmek için iyi yönetilmeleri gerektiğinden bahsedilmektedir. Bu iyi yönetim kavramının içine örgütsel yapı, profesyonelleşme, kurumsal çevreye uyum, kültürel güç başta olmak üzere kurumsallaşmanın alt boyutlarından biri olan şeffaflaşma ve hesap verebilirlik de girmektedir. Örgütlerin hukuka ve etik kurallara uygun olarak yaptıkları faaliyetleri açıklayarak meşrulaşma, istikrar ve tahmin edilebilirlik kazanma, işletme kaynaklarını artırma ve uyumlu olma amaçlarına ulaşmaları için de faaliyetlerinde açık olmaları ve gerekçeli nedenlere sahip olmaları gerekmektedir.

\subsection{Spor Kulüplerinde Biçimsel Yapıya Uyum}

McKelvey (1975) örgütlerin gelişimlere için bilimsel bir yapıya kavuşmalarında en temel unsurlardan birinin sınıflandırma şeması ya da bölümleme olduğunu vurgulamaktadır. Bu bakış açısı, uzmanlaşma, standardizasyon ve merkezileşme olarak üç temel unsurla tanımlanmıştır. Bu kavramlar spor örgütlerinin giderek bürokratik ve profesyonelleşmiş hale geldiklerini göstermektedir (Kikulis vd., 1989: 146).

Resmi yönetim deneyiminin eksikliği ve yöneticiler tarafindan geçmiş oyunculuk (sporcu olarak) deneyimlerinin yönetim için yeterli hazırlık olarak görülmesi hatası bazı Avrupa ülkelerinde açık bir şekilde görülmektedir. Taraftarlar açısından memnuniyet verici ve heyecan yaratan ünlü sporcuların transfer edilmesi, etkin yöneticilerin atanması için iyi bir yol değildir. Göreve uygun olmayan ve atanmaması gereken yöneticilerin işlerini kaybetmeleri kaçınılmaz olmaktadır. Son yıllarda gerçekleşen yabancı yatırımcıların katılımı ve onların atadığı yabanc1 yöneticilerin göreve gelmesi eğiliminin zaman içinde yerli yöneticilerin eğitim ve nitelikleri açısından yaratacağı etkiler henüz bilinmemektedir (Kelly, 2008: 416).

\section{Araştırmanın Amacı, Kapsamı, Önemi ve Yöntemi}

Çalışmanın ana amacı Türkiye profesyonel futbol kulüplerinin kurumsallaşma düzeylerinin (ya da kurumsallaşma faaliyetlerinin) belirlenmesidir. Bu doğrultuda anket uygulanarak Türkiye'deki spor kulüplerinde kurumsallaşma düzeyi belirlenmeye çalışılmıştır. Çalışmanın kuramsal kısmında kurumsallaşmanın düzeyini oluşturan unsurlar ve sporun özgüllüğü çerçevesinde spor kulüplerinin yönetim yapıları ele alınmıştır. Uygulama kısmında ise, spor kulüplerini yönetsel açıdan kurumsal yönetim ilkeleri temelinde değerlendiren çalışmalar bulunmasına karşın, belirtilen on alt boyutun bir arada incelendiği ve kulüplerin kurumsallaşma düzeylerinin belirlenmesine iliş̧kin önceden yapılmış çalışmaların sınırlı olması nedeniyle, bu araştırma keşifsel olarak öncü bir çalışma olarak değerlendirilebilir (Özeren, 2011: 82). Çalışmada kullanılan ve Tavşancı (2009)'nın 
geliştirmiş olduğu ölçeğin faktörlerinin spor kulüpleri için uyarlanması sürecinde spor yönetimi alanından araştırmacıların ve spor örgütü çalışanlarının görüşleri dikkate alınmıştır.

Araştırma evreninin tanımı, problem tanımının örnekte kimlerin yer alması ya da olmaması gerektiği şeklindeki kesin ifadeler haline çevrilmesini kapsamaktadır (Altunışık vd., 2012:135). Kulüplerin hukuki yapıları, mücadele ettikleri lig seviyesi ve bazı diğer unsurlara göre değişmekle birlikte, ortalama olarak her kulüpte 20 yönetici/çalışanın bulunduğu bilgisine kulüplerle iletişim kurulmak amacıyla yapılan telefon görüşmelerinden ulaşılmıştır. Buradan yola çıkılarak araştırmanın evreni 18'er kulüpten oluşan Süper Lig ve 1. Lig takımlarında görevli yaklaşık 720 yönetici/çalışan olarak belirtilebilir.

Örnek kütleden elde edilen verilerden yola çıkılarak evren hakkında genellemeler yapıldığından, örnek kütle büyüdükçe evren hakkında yapılan genellemelerde yanılma olasılığı artar. Bu nedenle araştırmacının hem temsil yeteneğini sağlayan örnek büyüklüğünü, hem de maliyet, zaman ve veri analizi şartlarını dikkate alarak bir dengeye ulaşması gerekir (Altunışık vd., 2012:136). Araştırmanın örnek büyüklügünü analize uygun olarak elde edilen 178 adet veri seti oluşturmaktadır.

Türkiye'de Spor Toto Süper Ligi'nde 2014-2015 sezonunda mücadele eden 18 takım şöyledir: Akhisar Belediye Gençlik ve Spor, Balıkesirspor, Beşiktaş A.Ş., Bursaspor, Çaykur Rizespor A.Ş., Eskişehirspor, Fenerbahçe A.Ş., Galatasaray A.Ş., Gaziantespor, Gençlerbirliği, İstanbul Başakşehir A.Ş., Kardemir Karabükspor, Kasımpaşa A.Ş., Mersin İdmanyurdu, Sivasspor, Suat Altın İnşaat Kayseri Erciyesspor, Torku Konyaspor, Trabzonspor A.Ş.. PTT 1. Lig'de mücadele eden 18 takım ise şöyledir: Adana Demirspor, Adanaspor A.Ş., Albimo Alanyaspor, Altınordu A.Ş., Antalyaspor A.Ş., Boluspor, Bucaspor, Denizlispor, Elazığspor, Gaziantep Büyükşehir Belediyespor, Giresunspor, Karşıyaka, Kayserispor, Manisaspor, Orduspor, Osmanlıspor Futbol Kulübü, Samsunspor, Şanlıurfaspor.

Araştırmada Tavşancı'nın 2009 yılında tamamladığı doktora çalışmasında kullandığ ölçek, spor kulüpleri için adaptasyon yapılarak kullanılmıştır. İçerik geçerliliğini test etmede yaşanan zaman, uygulama imkânı, bütçe gibi bazı sınırlılıklar olmasına karşın, bu araştırmada soru formundaki ifadelerin spor kulüplerine yöneltilmesinin uygun olup olmadığı konusunda spor bilimleri alanında çalışan ve spor kulüplerinde yöneticilik deneyimi olan üç akademisyenden görüş alınarak ölçek maddelerinin yargılarını ve amaçlarını değiştirmeden spor alanına adaptasyonu yapılmıştır.

Araştırma anketi 01.09.2013 - 01.11.2014 tarihleri arasında uygulanmıştır. Anket formunun ilk bölümünde araştırmanın amacı ve kapsamı hakkında bilgiler verilmiştir. İkinci bölümde kulüplerin kurumsallaşma düzeylerini ölçmek amacıyla Tavşancı'dan (2009) uyarlanan 5'li likert (5; Tamamen katılıyorum, 4; Çok katılıyorum, 3; Orta derecede katılıyorum, 2; Biraz katılıyorum, 1; Hiç katılmıyorum) ölçeğe yer verilmiştir. Son bölümünde ise demografik özelliklere ve kulüplerle ilgili sorulara yer verilmiştir. Ölçekte yer alan ifadelerin spor kulüplerine adaptasyonunda spor yönetimi alanında çalışan bazı öğretim üyelerinin de görüşü alınmış, aynı zamanda ankette yer alan ifadelerin anlaşılırlığı, kapsamı, uzunluğu, akıcılığı gibi özellikler bir spor kulübü yöneticisinin değerlendirmelerine tabi tutulmuştur.

\section{Verilerin Analizi}

Veri toplama sürecinin sonunda toplam 178 adet kullanılabilir soru formuna ulaşılmıştır. Ölçek uygulamasından elde edilen bilgilerin çözümlenmesi istatistiksel hesaplamalarla gerçekleştirilmiştir. Güvenilirlik için alfa katsayısı kullanılmış, tanımlayıcı özelliklerin özetlenmesinde frekans ve yüzde istatistiklerinden yararlanılmıştır. Faktörlerin demografik özelliklerine göre farklılaşma durumunun belirlenmesinde ise normal ya da normal olmayan dağılım durumuna göre t-testi, tek yönlü varyans analizi, Mann-Whitney U ve Kuruskal Wallis tekniklerinden faydalanılmıştır.

Ölçeğin cevaplandırıcılar tarafından anlaşılabilir olduğunun görülmesi amacıyla ön araştırma yapılmıştır. Ölçeğin maddelerinin tutum dereceleri "hiç katılmıyorum (1 puan), biraz katılıyorum (2 puan), orta düzeyde katılıyorum (3 puan), katılıyorum (4 puan), tamamen katılıyorum (5 puan)" şeklinde değerlendirmeye alınmıştır. Ardından, elde edilen verilerle, araştırma ölçeğinin güvenilirlik analizi yapılmış ve alfa katsayısı 0,9438 olarak sonuçlandığı için "yüksek derecede güvenilir” olarak yorumlanmıştır. Güvenilirlik analizine göre, çıkarıldı̆̆ zaman genel güvenilirlikte büyük artış yaratmadığı için kurumsallaşma ile ilgili herhangi bir ifade ölçekten çıkarılmamıştır.

Yapılan ön araştırma ile nihai araştırmanın güvenilirlik sonuçları karşılaştırıldığında, her iki ölçekte de artışın olduğu görülmüştür ve veri sayısının artmasına rağmen güvenilirlik oranlarında artışın olması, ölçeğin içsel tutarlılığının yüksek olduğunu göstermiştir.

Spor Örgütleri İçin Elde Edilen Verilerle Yapılan Doğrulayıcı Faktör Analizine Yönelik Bulgular: Doğrulayıcı faktör analizinde daha önceden edinilen bilgilerden hareketle oluşturulan bir modelin eldeki veriler tarafindan doğrulanıp doğrulanmadığı sınanır. Doğrulayıcı faktör analizinde örtük değişkenler teorik bir yapıyı temsil ederken, gözlenen ölçümler ise bu yapının göstergeleri olarak tasarlanır (Jöreskog ve Sörbom, 1993). 
Doğrulayıcı faktör analizi, 10 örtük değişkenin (açımlayıcı faktör analizinde belirlenen 10 faktörün), 50 gözlenen değişkeni doğru bir şekilde yordayabildiğine dair bir eşitlik üzerine kurulmuştur. 10 örtük değişken daha önce açımlayıcı faktör analizinde, biçimsel faaliyet yapısı, biçimsel organizasyon yapısı, profesyonelleşme, yetki devri kültürel güç, kurumsal çevreye uyum, kurumsal sosyal sorumluluk, toplumsal değer ve normlara uyum, şeffaflaşma ve hesap verebilirlik ve biçimsel yapıya uyum olarak adlandırılan alt boyutlardır. Doğrulayıcı faktör analizinde, yapının uygunluğu için model uygunluk ölçütlerinden $\chi 2 / d f$, RMSEA (Root Mean Square Error of Approximation), CFI (Comparative Fit Index), GFI (Goodness of Fit Index), AGFI (Adjusted Goodness of Fit Index) ve NFI (Normed Fit Index) değerleri dikkate alınmıştır. $\chi 2 / d f$ için söz konusu değerin 5 'ten küçük olması iyi bir uyumu (Schumacker \& Lomax, 2004), RMSEA için söz konusu değerin 0,1'den küçük olması kabul edilebilir bir uyumu göstermektedir (Browne \& Gudeck, 1993; MacCallum, Browne, \& Sugawara, 1996). Yine iyi bir model-veri uyumu için CFI, GFI, AGFI ve NFI değerlerinin de 0.95 'in üzerinde olması beklenmektedir (Hu \& Bentler, 1999). Yürütülen analiz sonucu elde edilen sonuçlar $(\chi 2 / \mathrm{df}=2.30, \mathrm{RMSEA}=.09$, $\mathrm{CFI}=.96, \mathrm{GFI}=.96, \mathrm{AGFI}=.96, \mathrm{NFI}=.95)$ modelin veri tarafindan doğrulandığını, yani hesaplanan uyum indekslerinin 10 faktörlü model ile veri seti arasında kabul edilebilir bir uyum sergilediğini göstermiştir.

Ölçü aracının uygulanması ve puanlanması, değerlendiricinin yorumunu gerektirdiği için, güvenirliğin hesaplanması gerekir. Ölçme aracının güvenirliğini analiz etmede kullanılan en yaygın yöntem cronbach alfa katsayısı yöntemidir. Bu çalışmada kurumsallaşma ölçeğinin alfa katsayısı 0,968 olarak sonuçlandığı için "yüksek derecede güvenilir" olarak yorumlanmıştır.

Araştırmada spor örgütlerinde kurumsallaşmanın değerlendirilmesinde örgüt çalışan ve yöneticilerinin eğitim düzeylerine ve eğitim şekillerine göre fark olacağı tahmin edilmiştir. Bunu açıklamak amacıyla oluşturulan hipotezler şöyledir:

Yönetici/çalışanların eğitim düzeylerine göre; Spor örgütlerinin kurumsallaşmasında biçimsel faaliyet yapısı alt boyutunun değerlendirilmesinde $(\mathrm{H} 1)$; biçimsel organizasyon yapısı alt boyutunun değerlendirilmesinde $(\mathrm{H} 2)$; profesyonelleşme alt boyutunun değerlendirilmesinde (H3); yetki devri alt boyutunun değerlendirilmesinde (H4); kültürel güç alt boyutunun değerlendirilmesinde (H5); şeffaflaşma ve hesap verebilirlik alt boyutunun değerlendirilmesinde (H6); kurumsal çevreye uyum alt boyutunun değerlendirilmesinde (H7); toplumsal değer ve normlara uyum alt boyutunun değerlendirilmesinde (H8); kurumsal sosyal sorumluluk alt boyutunun değerlendirilmesinde (H9) biçimsel yapıya uyum alt boyutunun değerlendirilmesinde (H10) anlamlı fark vardır.

Yönetici/çalışanların spor yönetimi ya da yönetim eğitimi almış olma durumuna göre; Spor örgütlerinin kurumsallaşmasında biçimsel faaliyet yapısı alt boyutunun değerlendirilmesinde (H11); biçimsel organizasyon yapısı alt boyutunun değerlendirilmesinde (H12); profesyonelleşme alt boyutunun değerlendirilmesinde (H13); yetki devri alt boyutunun değerlendirilmesinde (H14); kültürel güç alt boyutunun değerlendirilmesinde (H15); şeffaflaşma ve hesap verebilirlik alt boyutunun değerlendirilmesinde (H16); kurumsal çevreye uyum alt boyutunun değerlendirilmesinde (H17); toplumsal değer ve normlara uyum alt boyutunun değerlendirilmesinde (H18); kurumsal sosyal sorumluluk alt boyutunun değerlendirilmesinde (H19) biçimsel yapıya uyum alt boyutunun değerlendirilmesinde (H20) anlamlı fark vardır.

\section{Bulgular}

\subsection{Demografik Özellikler}

Araştırma kapsamındaki yönetici ve çalışanların yüzde 13,5'i (24 kişi) kadın, 84,3'ü (150) erkektir. Soru formuna yanıt verenlerin \%19,7'si " $20-30$ ” yaş grubunda, $\% 42,1$ ' $\mathrm{i}$ " $31-40$ ” yaş grubunda, $\% 27$ 'si " $41-50$ ” yaş grubunda ve \%11,2'si “51 ve üzeri” yaş grubundadır. Yanıtlayıcıların genel olarak yaş ortalaması 38,5'tir. Eğitim durumları açısından bakıldığında, lisans ve lisansüstü eğitim düzeyine sahip kişilerin \% 53,9 ile lise ve ön lisans mezunlarına göre daha fazla yüzdeye sahip oldukları görülmektedir. Kulüpte çalı̧̧ma pozisyonlarına bakıldığında soru formunu yanıtlayanların $\% 25,3$ 'ü üst düzey, $\% 10,1$ 'i orta düzey, $\% 32,6$ 'sı alt düzey yöneticidir. Ayrıca teknik ekip kadrosunda görev yaptığını belirtenlerin oranı $\% 12,4$, danışmanların oranı $\% 6,7$, çalışanların oranı $\% 5,6$, asistanların oranı ise $\% 3,4^{\prime}$ tür. Belirtilen pozisyonların çeşitliliğine bakıldığında görev tanımlarının ve pozisyon adlarının kulüplerde birçok farklı şekilde ifade edildiği anlaşılmaktadır. Bu durum kulüplerde ortak bir tanım olmadığı şeklinde yorumlanabilir. Kulüp yöneticileri ve çalışanlarının oldukça büyük kısmının $(\% 60,1)$ çalışma sürelerinin 1-5 yıl arasında, \%23,6'sının 6-10 yıl arasında, \%9,6'sının 11-15 yıl arasında, \%3,9'unun 1620 yıl arasında ve 21 ve üzeri yıl aralığında sadece \%1,1'i bulunmaktadır. Soru formuna yanıt verenlerin kulüplerde ortalama çalışma süresi 5,6 yıldır. Yönetici ve çalışanların sadece \%36'sı işletme/iktisat, spor yönetimi lisans, yüksek lisans, doktora ya da sertifika programları gibi çalıştıkları alanda yöneticilik yapmalarına doğrudan katkı sağlayacak şekilde eğitim almışlardır. Araştırmaya katılan çalışan ve yöneticilerden spor yönetimi konusunda eğitim aldığını belirtenlerin \%31,3'ü spor yönetimi lisansı, \%21,9'u işletme/iktisat lisansı, $\% 12,5^{\prime}$ i spor yönetimi yüksek lisansı, $\% 6,3$ 'ü spor yönetimi doktorası derecelerine sahiptir. $\% 25$ 'i ise spor yöneticiliği sertifika programlarına katılmıştır. 
Araştırmaya verilen yanıtlara göre kulüp çalışanları ve yöneticilerinin \%50'si kulüplerinde yazılı misyon ve vizyon ifadelerinin bulunduğunu, \%34,3’ü ise organizasyonel el kitaplarının bulunduğunu belirtmiştir. Ancak yazılı misyon/vizyon ifadelerinin ve organizasyonel el kitabının bulunmadığını belirtenlerin oranı sırasıyla $\% 22,5, \% 21,9$ ve \%30,3'tür. Ayrıca bu sorulara "bilmiyorum" yanıtını verenlerin oranı sırasıyla \%27,5, \%28,1 ve $\% 35,4$ 'tür.

\subsection{Kurumsallaşma Unsurlarına Verilen Yanıtlar ve Hipotezlerin Testi}

Araştırmaya katılan 178 spor kulübü yöneticisi ve çalışanlarının Türkiye Spor Toto Süper Ligi ve PTT 1. Lig'de faaliyet gösteren kulüpleri adına verdikleri yanıtların faktörler bazında ortalamalarına bakıldığında kurumsallaşma derecelerini ölçen soru formuna göre ortalama değerlerinin 3,256 ile 4,093 arasında olduğu görülmektedir. Tüm maddelere verilen yanıtların genel ortalaması ise 3,81'dir. Bu değerlere bakıldığında genel olarak kulüplerin kurumsallaşma düzeylerinin (1 - düşük, 5 - yüksek) ortanın üzerinde hatta iyi olduğu sonucuna varılabilir.

\begin{tabular}{|l|c|c|c|}
\hline FAKTÖRLER & $\begin{array}{c}\text { İÇ TUTARLILIK } \\
\text { ORANI }\end{array}$ & $\begin{array}{c}\text { ORTALAMA } \\
\text { DEGER }\end{array}$ & $\begin{array}{c}\text { STANDART } \\
\text { SAPMA }\end{array}$ \\
\hline Bi்çiMSEL FAALIYYT YAPISI & 0,811 & 3,576 & 0,94024 \\
\hline Bi்çiMSEL ORGANİZASYON YAPISI & 0,812 & 3,749 & 0,81613 \\
\hline PROFESYONELLEŞME & 0,827 & 3,256 & 1,02157 \\
\hline YETKİ DEVRİ & 0,785 & 3,75 & 1,04185 \\
\hline KÜLTÜREL GÜÇ & 0,903 & 3,854 & 0,74139 \\
\hline KURUMSAL ÇEVREYE UYUM & 0,851 & 3,868 & 0,83623 \\
\hline KURUMSAL SOSYAL SORUMLULUK & 0,787 & 4,031 & 0,73292 \\
\hline TOPLUMSAL DEĞER VE NORMLARA UYUM & 0,853 & 4,093 & 0,68574 \\
\hline ŞEFFAFLAŞMA VE HESAP VEREBİLİRLİ & 0,857 & 3,961 & 0,79764 \\
\hline Bi்çiMSEL YAPIYA UYUM & 0,88 & 3,876 & 0,90361 \\
\hline
\end{tabular}

Tablo 1. Kurumsallaşmanın Alt Boyutlarına İlişkin Tanımlayıcı Analiz Sonuçları

Kurumsallaşmanın alt boyutlarına verilen yanıtların ortalama değerlerine bakıldığında; 5'li likert ölçeğinde $\overline{\mathrm{x}}=1,00-2,59$;Düşük, $\overline{\mathrm{x}}=2,60-3,39 ;$ Orta, $\overline{\mathrm{x}}=3,40-5,00$;Yüksek olan düzey belirleme kriterlerine göre spor kulüplerinde "profesyonelleşme" alt boyutunda orta düzeyde, diğer tüm boyutlarda ise yüksek düzeyde kurumsallaşma olduğu belirtilmiştir. Benzer şekilde genel olarak ölçeğin ortalama değeri de 3,801 ile yüksek düzeyde kurumsallık olarak belirlenmiştir. Ancak alan yazında spor örgütlerinin kurumsallaşmaları gerekliliği ve bu süreçte yaşanılan zorluklara değinilmiş olması bu konunun daha derin analiz edilmesi gerekliliğini sürdürmektedir.

Örnekleme dahil olan yönetici/çalışanların kurumsallaşma ölçeğini değerlendirmeleri sonucunda faktörler bazında iç tutarlılık ve ortalama değerlerini belirttikten sonra, bu faktörlerle ilgili değerlendirmelerin demografik özelliklere göre (cinsiyet, yaş, eğitim durumu, kulüpteki görev, kulüpte çalışma süresi, spor/kulüp yönetimi konusunda eğitim almış olup/olmama, eğitim alınmış ise eğitim düzeyi, kulüpte aralarında kan/aile bağı olan çalışanların bulunup bulunmaması, varsa bu çalışanların kulüpteki görevleri ve çalışanların kulüp misyon, vizyon, organizasyonel el kitabı hakkındaki bilgi durumları) kurumsallaşma ölçeğini değerlendirmelerinde anlamlı fark yaratıp yaratmadığı test edilmiştir.

Bir örneklemde yığılımlı frekans dağılımı ile belirli ya da herhangi bir yığglımlı olasılık dağılımının uygunluğu Kolmogorov-Smirnov testi ile belirlenebilmektedir (Yazıcıŏglu ve Erdoğan, 2011: 294). Verilerin normal dağılım gösterip göstermediğini test etmek, seçilecek olan analiz tekniği açısından önem taşımaktadır. Araştırma örnekleminin normal dağılım gösterip göstermediğini ölçmek için yapılan Kolmogorov-Smirnov testi sonuçlarına göre örnekleme dahil olan 178 kişinin verdikleri yanıtlardan "biçimsel organizasyon yapısı", "profesyonelleşme" ve "toplumsal değer ve normlara uyum" alt boyutları (p>0,05) normal dağılım göstermektedir. Diğer alt boyutlar $(\mathrm{p}<0,05)$ normal dağılım göstermemektedir. Normal dağılmış olan alt boyutların yanıtlayıcılar tarafından değerlendirilmesinde demografik özelliklere göre bağımsız iki grup arasında (cinsiyet ve spor yönetimi eğitimi alıp almama durumu) anlamlı fark olup olmadığına bakmak için t testi, bağımsız ikiden fazla grup arasında anlamlı fark olup olmadığına bakmak için ANOVA testi uygulanmıştır. ANOVA testi sonucu anlamlı fark var ise bu farkın hangi gruplar arasında olduğunu görmek içinse Tukey testi uygulanmıştır. Normal dağılım göstermeyen alt boyutlarda ise bağımsız iki grup arasında anlamlı fark olup olmadığına bakmak için Mann-Whitney U testi, bağımsız ikiden fazla grup arasında anlamlı fark olup olmadığına bakmak için ( $\mathrm{K}$ independent samples) Kruskal-Wallis testi uygulanmıştır.

Örnekleme dahil olan spor kulübü çalışan/yöneticilerinin kulüplerin kurumsallaşmalarıyla ilgili değerlendirmelerinde eğitim düzeylerine göre "profesyonelleşme" ve "kültürel güç" alt boyutlarında $p<0,05$ anlamlılık düzeyinde anlamlı fark bulunmuştur. Bu fark "profesyonelleşme" faktöründe genel ortalama 3,256 iken, doktora ve yüksek lisans eğitimi almış kişilerin yanıtlarının ortalamalarının sırasıyla 2,416 ve 3,009 olmasından kaynaklanmaktadır. Aynı zamanda Tukey testi sonuçlarına göre, bu fark yüksek lisans ve doktora 
eğitimi almış kişilerin değerlendirmelerinin lise ve ön lisans eğitimi almış kişilerin değerlendirmelerinden farklı olmasından kaynaklanmaktadır. Başka bir deyişle spor kulüplerinin profesyonel olup olmamasıyla ilgili spor kulüplerinde çalışanlardan yüksek lisans ve doktora eğitimi almış kişilerin değerlendirmeleri eleştirel bir tarzdadır.

"Kültürel güç" faktöründe de benzer şekilde doktora eğitimi almış kişilerin değerlendirmelerinin ortalamaları diğer eğitim seviyelerine göre en düşük değerdedir. Bunu yine yüksek lisans mezunlarının değerlendirmeleri takip etmektedir. Bu sonuçlar doğrultusunda araştırmaya katılan örneklem düzeyinde doktora ve yüksek lisans mezunlarının kulüpleri, profesyonelleşme ve kültürel güç sahibi olma açısından diğer eğitim seviyelerinde olan çalışan/yöneticilere göre daha başarısız gördükleri söylenebilir.

$\mathrm{Bu}$ sonuçlara göre "spor örgütlerinin kurumsallaşmasında profesyonelleşme alt boyutunun değerlendirilmesinde, yönetici/çalışanların eğitim düzeylerine göre anlamlı fark vardır” şeklinde tanımlanan hipotez 3 ile "spor örgütlerinin kurumsallaşmasında kültürel güç alt boyutunun değerlendirilmesinde, yönetici/çalışanların eğitim düzeylerine göre anlamlı fark vardır” şeklinde tanımlanan hipotez 5 kabul edilmiştir. Örnekleme dahil olan spor kulübü çalışan/yöneticilerinin kulüplerin kurumsallaşmaya ait "profesyonelleşme" ve "yetki devri" alt boyutlarını değerlendirmelerinde $\mathrm{p}<0,05$ anlamlılık düzeyinde cinsiyete göre anlamlı fark bulunmuştur. Kadın çalışan / yöneticilerin erkeklere göre kurumsallaşma unsurlarını tanımlayan sorulara verdikleri yanıtların ortalamaları daha yüksektir. Buradan yola çıkarak kadınların erkeklere göre profesyonelleşme ve yetki devri alt boyutlarında kulüplerini daha olumlu değerlendirdiklerini söylenebilir.

Çalışan/yöneticilerinin kulüplerin kurumsallaşmaya ait "biçimsel organizasyon yapısı" alt boyutu için kulüplerinde misyon ifadesinin bulunduğunu belirten yanıtlayıcıların değerlendirmelerinde $p<0,05$ anlamlılık düzeyinde anlamlı fark bulunmuştur. Bu fark kulüpte misyon ifadesinin olmadığını belirtenler ile olduğunu belirtenlerin kulüplerinin kurumsallaşma düzeyini değerlendirmelerinde ortaya çıkmıştır. Misyon ifadesinin olmadığını belirten kişilerin biçimsel organizasyon yapısını ölçmek için sorulan sorulara verdikleri yanıtların ortalamaları "evet" ya da "bilmiyorum" şeklinde yanıt verenlere göre düşüktür. Spor kulübü çalışan/yöneticilerinin kulüplerin kurumsallaşmaya ait "biçimsel organizasyon yapısı" ve "yetki devri” alt boyutları için kulüplerinde vizyon ifadesinin bulunduğunu belirten yanıtlayıcıların değerlendirmelerinde $p<0,05$ anlamlılık düzeyinde anlamlı fark bulunmuştur. Bu farklar kulüpte vizyon ifadesinin olmadığını belirtenler ile olduğunu belirtenlerin kulüplerinin kurumsallaşma düzeyini değerlendirmelerinde ortaya çıkmıştır. Misyon ifadesi ile benzer olarak; vizyon ifadesinin olmadığını belirten kişilerin biçimsel organizasyon yapısını ve yetki devrini ölçmek için sorulan sorulara verdikleri yanıtların ortalamaları "evet" ya da "bilmiyorum" şeklinde yanıt verenlere göre düşüktür.

\section{Sonuç}

Anket sonuçlarına bakıldığında 5'li likert tipi ölçek derecelerine göre alt boyutların aritmetik ortalamaları spor örgütlerinin profesyonelleşme alt boyutunda orta derece, diğer alt boyutlarda yüksek derece kurumsal olduğu yönündedir. Benzer şekilde anketin genel ortalaması da yüksek düzey kurumsallaşmanın olduğu yönündedir.

Spor örgütlerindeki karmaşıklık ve potansiyel belirsizlikler, dikey farklılaşma ve profesyonel rollere ihtiyaç olduğunu, genel anlamda işletmelere göre nispeten daha fazla olan faaliyet programlarının politika ve prosedürlerle gerçekleştirilmesi gerektiğini ve program ve faaliyetlerin yönetim tarafindan koordine edilmesi gerektiğini göstermektedir. Bu düzeyde gönüllü katılımının azalması ve ademi merkeziyetçi karar verme sisteminin olması spor örgütlerinde program ve faaliyetlerin profesyonel personel tarafindan yapılmasını zorunlu kılmaktadır (Kikulis vd., 1989: 140).

Profesyonelleşme konusunda Dünya genelinde kulüpleri değerlendirdiğimizde ulusal ve uluslararası alanda elde edilen başarılar, alınan stratejik kararlar ve bu kararlardan elde edilen sonuçlar, kulüplerin kârlılıkları, sportif ürün üretme ve satma becerileri gibi sonuçlar gösterge olarak kabul edilebilir. Bu göstergeler dikkate alındığında Avrupa kulüplerinin birçok başarısı bulunmaktadır. Bu başarılarında aynı yönetici/teknik direktörle uzun yıllar çalışmaları, alt yapıdan gelen sporcularının bulunması, mesleki normlara uyma konusunda hassas olmaları etkilidir. Ülkemizde profesyonelleşmenin önündeki en önemli engel eğitim olarak görülmektedir. Alanında uzman kişilerin karar verici olmasının profesyonelleşmeyi sağlamada olmazsa olmaz bir şart olduğu sürekli belirtilmektedir. Eğitimin teknik ekiplerin ve yöneticilerin değişim hızını yavaşlatacağı, bu sayede psikolojik uyumun da önemli olduğu spor kulüplerinde farklı çalışma prensibi, kültürel ortam, medyanın etkin olması nedeniyle haklarında yargılar oluşmuş kişilerle uyum sağlama gibi sorunların azaltacağı ve bunun da performansa olumlu şekilde yansıyacağı bilinmektedir.

Kurumsallaşmanın gereklerinden bir tanesi de aynı konuyu aynı dille ifade edebilmektedir. Yani genel kabul görmüş ortak bir dilin varlığından bahsetmek gerekir. Anket formunda çalışan ve yöneticilerin görev alanlarını belirtmeleri istendiğinde karşımıza oldukça fazla görev tanımı çıkmıştır.

Futbolun büyüyen mali yapısından ve gün geçtikçe birçok yan sektörle artan ilişkisinden bahsederken, hâlâ taraftarlık ve gönüllülük esasıyla asıl işleri başka sektörlerde olan kişilerin yeterince zaman ve emek veremedikleri halde spor kulübü yöneticiliğine devam etmek istemeleri çelişki yaratmaktadır. Spor kulüplerinin 
"business-iş" olarak kabul gördüğü günümüzde hobi olarak bu işi yapan kişiler tarafından yönetilmeleri de mümkün değildir.

Bu araştırma doktora tezinden üretilmişstir.

\section{Kaynakça}

- Alkibay, S. (2005) "Profesyonel Futbol Kulüplerinin Taraftar İlişkileri Yoluyla Marka Değeri Yaratmaları Üzerine Bir Araşıırma", Hacettepe Üniversitesi, İ̈BF Dergisi, Cilt 23, Sayı 1, s. 83-108.

- Amara M. vd. (2005) “The Governance of Professional Soccer: Five Case Studies Algeria, China, England, (2004France and Japan”, European Journal of Sport Science, December 2005; 5(4), p. 189-206.

- Apaydın F. (2009) "Kurumsal Teori ve Isşletmelerin Kurumsallaşması”, C.Ü. İktisadi ve İdari Bilimler Dergisi, Cilt 10, Say1 1, s. 1-22.

- Farashahi M., Hafzi T., Molz R. (2005) "Institutionalized Norms of Conducting Research and Social Realities: A Research Synthesis of Empirical Works From 1983 to 2002”, International Journal of Management Reviews, 7, Issue 1, pp. 1-24.

- Ferkins L., Shilbury D., McDonald G. (2005) "The Role of the Board in Building Strategic Capability: Towards an Intagrated Model of Sport Governance Research", Sport Management Review, p. 195-225.

- Gomez S., Opazo M., Marti C. (2008) "Structural Characteristics of Sport Organizations: Main Trends in the Academic Discussion", IESE Business School, Working Paper, p. 1-22. Jepperson R. L.,(1991)

Institutions, Institutional Effects, and Institutionalization Der: Walter W. Powell ve Paul J. DiMaggio, The University of Chicago Press, 1991, s. 143-163.

- Hamil S., Morrow S. (2011) "Corporate Social Responsibility in the Scottish Premier League: Context and Motivation”, European Sport Management Quarterly, Vol. 11, No 2, p. 143-170 April.

- Kelly S. (2008) "Understanding the Role of Football Manager in Britain and Ireland: A Weberian Approach”, European Sport Management Quarterly, Vol. 8, No. 4, 399-419.

- Kikulis L., Slack T., Hinings B. (1989) “A Structural Taxonomy of Amateur Sport Organizations”, Journal of Sport Management. 1989 (3). P. 129-150.

- Mukharji M. (2009) "Metaphors of Sport in Baul Songs: Towards an Alternate Definition of Sports", The International Journal of the History of Sport, Vol. 26, No. 12, September 2009, p. 1874-1888.

- Özen Ş., (2007) Yeni Kurumsal Kuram: Örgütleri Çözümlemede Yeni Ufuklar ve Yeni Sorunlar, Der. Sargut S., Özen Ş. Örgüt Kuramları, İmge Kitabevi, Ankara.

- Scott W. R. (2004) Institutional Theory: Contributing to a Theoretical Research Program, (Chapter preparred for Great Minds in Management: the Process of Theory Development, Ken G. Smith and Micheal A. Hitt, eds. Oxford UK: Oxford University Press.

- Sherry E., Shilbury D., Wood G. (2007) "Wrestling with "Conflict of Interest" in Sport Management", Corporate Governance, Vol. 7 No. 3 p. 267-277.Singh J. V., Tucker D. J., House R. J. (1996) "Organizational Legitimacy and the Liability of Newness", Administrative Science Quarterly, 31, s. 171-193

- Smith A.C.T., Shilbury D) "Mapping Cultural Dimensions in Australian Sporting Organisations", Sport Management Review, Vol. 7, p. 133-165.

- Van De Ven A. H. (1993) "The Institutional Theory of John R. Commons: A Review and Commentary", Academy of Management Review, 18 s. 139-152.

- Washington M., Patterson K. (2011) "Hostile Takeover or Joint Venture: Conenctions Between Instituonal Theory and Sport Management Research", Sport Management Review, 14, p. 1-12. 


\title{
İnternet'ten Alışverişte Tüketiciler Tarafından Algılanan Riskler ve Risk Azaltma Çabaları
}

\section{Consumers' Perceived Risks and Risk Reduction Efforts in Internet Shopping}

\author{
$\mathrm{Ph}$. D. Candidate Çetin Kalburan (Pamukkale University, Turkey) \\ Assoc. Prof. Dr. Selçuk Burak Haşıloğlu (Pamukkale University, Turkey)
}

\begin{abstract}
Becoming widespread of Internet increases share of electronic commerce (E-commerce) in the economy each passing day. Therefore, analysis of the behaviors of consumers who are shopping on the Internet has become more important for companies. Consumers have more or less risk perception because of possible problems they may face in the post-shopping. Usually, consumers make an effort to reduce this risk. These efforts to reduce risk play a key role between perceived risk and perceived benefit. On the other hand, perceived risk and risk reduction methods vary on the Internet in comparison to traditional commerce. From this point of view, in this study, for online shopping, the relationships between perceived risk and risk reduction variables were investigated on the basis of the different products.
\end{abstract}

\section{Giriş}

Tüketiciler alışveriş sonrasında karşılaşabilecekleri muhtemel olumsuzluklar nedeniyle az ya da çok bir risk algısına sahiptirler. Bu nedenle tüketiciler algıladıkları riskleri azaltmak amacıyla genellikle çaba gösterme eğilimindedirler. Ancak risk azaltma çabaları her ürün grubu için aynı düzeyde ortaya çıkmayabilir. Örneğin, tüketiciler bir çift ayakkabı ve televizyon satın almadan önce risk azaltmak amacıyla her iki ürün için aynı düzeyde çaba göstermeyebilirler. Öte yandan İnternet'ten alışveriş de kendi başına bir risk algısına sebep olabilir. Bu durumda risk üründen değil İnternet’ten alışveriş yapmanın kendisinden kaynaklanacaktır. Bunun sonucunda İnternet'ten alışverişte algılanan riskin ve risk azaltma çabalarının geleneksel alışverişe göre daha karmaşık bir yapıya büründüğü söylenebilir. Bu noktadan hareketle çalışmamızda, İnternet’ten alışverişte algılanan risk farklı boyutlarıyla irdelenerek risk azaltma değişkenlerinin farklı ürünler temelinde incelenmesi amaçlanmıştır.

\section{Algilanan Risk}

Algılanan risk kavramı pazarlama literatürüne Bauer'in (1960) tüketici davranışını risk alma teorisi çerçevesi üzerinde değerlendirmesi ile girmiş ve sonraki yıllarda bu konuda birçok araştırma literatürdeki yerini almıştır. Cox ve Rich (1964) algılanan riskin, belirli bir satın alma kararı üzerinde düşünen tüketicinin algıladığı "riskin niteliğini ve miktarını" ifade ettiğini belirtirken Peter ve Ryan (1976) satın almayı önleyici bir işlev gördüğünü vurgulayarak algılanan riski marka düzeyinde satın alma ile ilgili kayıpların beklentisi olarak tanımlamıştır. Featherman ve Pavlou ise (2003) algılanan riskin yaygın olarak bir ürün veya hizmeti kullanmanın olası negatif sonuçları ile ilgili belirsizlik hissi olarak değerlendirildiğini vurgulamıştır.

Risk alma kuramı, birçok tüketicinin bir marka hakkında bir takım belirsizlikler altında satın alma kararı verdiğini ileri sürmektedir. Algılanan risk bilindiğinde tüketici riski azaltmak için adımlar atabilir ve bu da bazı fikir ya da kişilere güvenmesiyle kendini gösterir (Sheth ve Venkatesan, 1968). Risk unsurunun genellikle mevcut olmasının nedeni tüketicinin alışveriş yapmadan önce planladığı satın almanın onu satın alma hedeflerine ulaştıracağından her zaman emin olamayışıdır (Cox ve Rich, 1964).

Roselius (1971) tüketicilerin alışveriş sonucu karşılaşabileceği riskleri zaman kaybı, tehlike (ürün kaynaklı), ego kaybı ve para kaybı olarak 4 kategoriye ayırmıştır. Bu sınıflandırmaya paralel olarak Brown ve Gentry (1975) her alışverişte tüketicinin bir derecede ve tipte riskle karşılaştığını ve bu riskin ekonomik, psikolojik veya sosyal kaynaklı olabilecek çıktıların ve beklentilerin bir fonksiyonu olduğunu belirtmişlerdir.

İnternet'ten alışverişte ise algılanan risk, online satın alma düşüncesindeki İnternet müşterisi tarafindan öznel olarak belirlenmiş kayıp beklentisi olarak tanımlanabilir. Online alışveriş yaparken, tüketiciler her bir risk türü için birden fazla endişe ifade etmektedirler. Örneğin tüketiciler, online sipariş vermenin zor olduğu veya online sipariş sonucu malların kendisine ulaşmasında potansiyel gecikmeler olacağı algısında olabilir. Her iki endişe de zaman/kolaylık kaybı ilgili algılanan endişelerdir (Forsythe ve Shi, 2003). Hizmet ve ürünlerin online satın alınmasında işlem güvenliği ve müşteri veri (bilgileri) güvenliği de başlıca endişe kaynaklarıdır (Constantinides, 2004). Gelişen teknoloji online firmalara web sitelerini ziyaret eden tüketicilerin büyük miktarda bilgilerini toplama, analiz etme gibi olanakların artışını sağlamış, bu da, İnternet'in gelişmesi ve popülerliği ile birlikte, tüketicilerin ve devletin online gizliliğin korunmasına ilişkin endişelerini artırmıştır (Miyazaki ve Krishnamurthy, 2002). 
Flavian ve Guinaliu (2006) online işlemlerde tüketici de risk algısı yaratabilecek bazı unsurları aşağıdaki şekilde sıralamıştır.

- Tüketici satıcı ile fiziksel iletişime girmez ve bu nedenle sunulan ürünü etkin bir şekilde değerlendirmesi ve satıcının kimliğini kontrol etmesi mümkün değildir.

- Genellikle ürünün ödemesi kredi kartı ile mal ve hizmetlerin tesliminden önce yapılır, bu da tüketicinin finansal verilerinin bir takım sahtekârlıklar için kullanılma olasılığını ortaya çıkarır.

- Alınan ürünün sipariş edilen ile aynı olmama olasılığı vardır.

- Fiziksel varlığa sahip olmayan ya da merkezi başka bir ülkede bulunan firmalar için şikâyette bulunmanın zorluğu söz konusu olabilir.

- Tüketiciler spam (istenmeyen e-posta), korsan saldırılar ve virüslerle karşılaşabilir.

\section{Risk Azaltma}

Risk algısı tüketici davranışının çok önemli bir yönüdür, çünkü risk genellikle acı vericidir ve anksiyeteye neden olabilir ve bu durumda tüketici tarafından bir şekilde üstesinden gelinmesi gereken bir hal alır (Taylor, 1974). Bir ürün sınıfındaki çeşitli markaların satın alınması sonucu ortaya çıkacaklar hakkındaki belirsizliği azaltmak amacıyla izlenecek 3 ana yol vardır: 1) Arkadaşlar referans grupları, aile gibi kişisel, resmi olmayan kaynaklardan bilginin aranması, 2) Alışveriş öncesi alternatif markalar arasında karşılaştırma yapmak, 3) Markaya güvenmek. Eğer marka imajı yoksa satın alma deneyimleriyle belirsizliği azaltmak (Sheth ve Venkatesan, 1968). Bir tüketicinin algılanan riski azaltması için bilgi arayışı en uygun ve muhtemelen en verimli yöntemdir. Tüketici bilgi arayışında üç ana kaynaktan faydalanabilir (Brown ve Gentry, 1975):

- Pazarlamacının egemenliğinde olan kanallar (reklamlar, satış elemanları ve diğer tutundurma (iletişim) kanalları.

- Tüketici egemenliğinde olan kanallar (ağızdan ağza iletişim).

- Tarafsız kanallar (tüketici raporları).

Roselius (1971) ise riski azaltmaya yönelik olarak 11 yöntem ortaya koymuştur:

- Marka sadakati: Daha önce kullanılmış ve tatmin etmiş bir markanın satın alınması.

- $\quad$ Büyük marka imajı: Markanın itibarına güvenerek iyi bilinen büyük bir markanın satın alınması.

- Özel test: Özel bir şirket tarafından test edilmiş ve onaylanmış markanın satın alınması.

- Mağaza imajı: Mağazanın itibarına dayalı olarak duyulan güven sonucu markanın satın alınması.

- $\quad$ Ücretsiz numune: Satın almadan önce deneme amaçlı olarak ürünün ücretsiz bir numunesinin kullanılması.

- $\quad$ Ürünün geri verilmesi ile para iade garantisinin sunan markanın satın alınması.

- Resmi (Devlet) Test: Devletin resmi kurumları tarafından test edilmiş ve onaylanmış markanın satın alınmas1.

- $\quad$ Alışveriş: Mağazaları dolaşmak ve birçok mağazadaki birçok markanın ürün özelliklerini karşılaştırmak.

- $\quad$ Pahalı model: Ürünün ene pahalı ve gösterişli modelini satın almak.

- $\quad$ Ağızdan ağza: Ürün hakkında bilgi edinmek için arkadaşlara veya aileye danışmak.

- Cirolar: Büyük reklam bütçelerine sahip, bir ünlüden, ürünün uzmanından ya da başka birinden referans alınan markanın satın alınması.

Genellikle alışveriş öncesi algılanan risk daha fazla olduğunda hizmet hakkında bilgi arayışına yönelik tüketici eğilimi daha fazla olur ve çevrimiçi ortamda gezinmek bu arayışta başlıca yöntem olarak kendini gösterir (Chen ve He, 2003). Ayrıca tüketiciler ürünler ve markalar hakkındaki duygu ve bilgilerini online olarak çeşitli şekillerde birbirleriyle paylaşırlar (Goldsmith ve Horowitz, 2006).

\section{Araştırmanın Amacı ve Yöntemi}

$\mathrm{Bu}$ çalışmada, İnternet’ten alışverişte "algılanan risk" ve "risk azaltma” değişkenlerinin farklı ürünler temelinde incelenmesi amaçlanmıştır. Bu doğrultuda İnternet’ten alışverişte; risk azaltma çabalarının cinsiyete ve ürünlere göre farklılık gösterip göstermediği, her bir boyutuna göre algılanan riskin cinsiyete göre farklılık gösterip göstermediği incelenmiştir.

Araştırmanın evreni, Pamukkale Üniversitesi İktisadi ve İdari Bilimler Fakültesi’nde 3. ve 4. sınıflarda öğrenim gören öğrencilerdir. Elde edilen 206 sağlıklı anketle analiz aşamasına geçilmiştir. Kolayda örnekleme yönteminin kullanıldığı araştırmanın cevaplayıcılarına ait demografik bilgiler Tablo 1 'de sunulmuştur. 


\begin{tabular}{|c|c|c|c|}
\hline Değişken & & Say1 (n) & Yüzde (\%) \\
\hline \multirow{2}{*}{ Cinsiyet } & Kadın & 127 & 61,7 \\
\hline & Erkek & 79 & 38,3 \\
\hline \multirow{6}{*}{ Yaş } & 20 & 13 & 6,3 \\
\hline & 21 & 32 & 15,5 \\
\hline & 22 & 60 & 29,1 \\
\hline & 23 & 60 & 29,1 \\
\hline & 24 ve üzeri & 41 & 19,9 \\
\hline & Toplam & 206 & 100 \\
\hline
\end{tabular}

Tablo 1. Araştırmanın Örneklemine ait Demografik Bilgilerin Frekans Dă̆ılımı

Tablo 1'de görülebileceği üzere, yapılan araştırmadaki katılımcıların \%61,7'si bayan, \%38,3'ü bay'dır. Örneklemdeki yaş sıklığı ise 22 ve 23 yaşlar üzerinde yoğunlaşmakta, bu iki yaş grubunun toplamı örneklem içerisinde \%58,2'lik bir orana karşılık gelmektedir. Üçüncü sırada \%19,9'luk oranla 24 yaş ve üzeri, dördüncü sirada $\% 15,5$ ile 21 ve son sırada $\% 6,3$ ile 20 yaş bulunmaktadır.

Araştırmada veri toplama aracı olarak, "Genel Bilgi Formu” ile “İnternet’ten Alışverişte Algılanan Risk Ölçeği” ve "Risk Azaltma Ölçeği” kullanılmıştır. "İnternet'te Alışverişte Algılanan Risk Ölçeği” Crespo ve arkadaşlarının (2009), "Risk Azaltma Ölçeği” Cases’in (2002) çalışmalarından Türkçe’ye uyarlanmıştır.

Araştırmada kullanılan ölçekler uygulandıktan sonra verilerin girilmesi ve analizlerin gerçekleştirilmesi için SPSS 15.0 istatistik paket programı kullanılmıştır. Öncelikle güvenirlik analizi gerçekleştirilmiş daha sonra incelenen değişkenler üzerinden varyans analizi ve t-testleri gerçekleştirilmiştir.

\section{Bulgular}

Güvenirlik analizleri sonuçlarına göre “İnternet’te Alışverişte Algılanan Risk Ölçeği”nin ölçeğin Cronbach Alfa $(\alpha)$ değeri .823 bulunmuştur. "Risk Azaltma Ölçeği” ise 3 farklı ürün için uygulanmış olup Cronbach Alfa ( $\alpha$ ) değeri; tişört için .738, parfüm için .805 ve cep telefonu için .741 olarak tespit edilmiştir.

\begin{tabular}{lccc}
\hline Değişken & Madde Sayısı & Ortalama & Standart Sapma \\
\hline Algılanan Risk & & & \\
\hline Finansal Risk & 3 & 2.95 & .827 \\
\hline Performans Riski & 3 & 3.51 & .906 \\
\hline Sosyal Risk & 3 & 1.92 & .942 \\
\hline Zaman Riski & 3 & 2.72 & .788 \\
\hline Psikolojik Risk & 3 & 2.68 & .973 \\
\hline Gizlilik Riski & 3 & 3.71 & .915 \\
\hline Risk Azaltma & & & \\
\hline Tişört & 11 & 3.99 & .591 \\
\hline Parfüm & 11 & 4.12 & .651 \\
\hline Cep Telefonu & 11 & 4.69 & .428 \\
\hline
\end{tabular}

\section{Tablo 2. Değişkenlere Ait Tanımlayıcı İstatistikler}

Tablo 2 incelendiğinde, cevaplayıcıların İnternet’ten alışverişte en fazla gizlilik riskinden endişe ettikleri görülmektedir. İkinci sırada yer alan endişe kaynağı ise satın alınacak ürünün performansına ilişkin beklentilerin karşılanmama ihtimalidir. Göze çarpan bir diğer önemli nokta ise sosyal risk algısının en son sırada ve düşük seviyede kalmasıdır. Bu sonuç İnternet’ten yapılan alı̧̧veriş hakkında sosyal çevrenin olası negatif bakış açısının tüketicilerce fazla önemsenmediğini göstermektedir.

Risk azaltma çabalarına ilişkin ortalamalar da ürünlere göre farklılık göstermektedir (Tablo 2.). Farklılığın anlamlılığını test etmek için varyans analizi gerçekleştirilmiştir. Gerçekleştirilen analiz sonucunda, değişkenlerin ortalamaları arasındaki farkın anlamlı olduğu bulunmuştur $(\mathrm{p}<0.05)$. Diğer bir ifadeyle üç farklı ürüne ilişkin risk azaltma çabaları arasında anlamlı bir farklılık bulunmaktadır.

Ürünler arasındaki farklılığın hangi ürün ya da ürünlerden kaynaklandığını ortaya çıkarmak amacıyla gerçekleştirilen Bonferroni testi sonuçları Tablo 3'teki gibidir. Bu sonuçlara göre, her üç ürünün de kendi aralarında risk azaltma çabaları açısından anlamlı bir farklılık bulunduğu anlaşılmaktadır $(\mathrm{p}<0.05)$. Elde edilen sonuçlardan yola çıkarak, cep telefonu için risk azaltma çabasının en yüksek seviyede olduğu söylenebilir. Cep telefonunu sırasıyla parfüm ve tişört takip etmektedir. Ortaya çıkan sonuç ile alışverişte ödenecek bedelin risk 
azaltmaya etki ettiği düşünülebilir. Bununla birlikte cevaplayıcıların algıladıkları risk olarak performansı ilk sıralara koyması nedeniyle risk azaltma çabalarının yüksekliği cep telefonunun beklenen performansı karşılamaması riskinden kaynaklanabilir.

\begin{tabular}{|c|c|c|c|c|c|}
\hline Risk Azaltma & Ortalama & \multicolumn{2}{|c|}{ İkili Karşılaştırmalar } & Ortalama Farkı & p \\
\hline Tişört & 3.99 & \multirow{2}{*}{ Tişört } & \multirow{2}{*}{$\begin{array}{l}\text { Parfüm } \\
\text { Cep Telefonu }\end{array}$} & -.13 & .003 \\
\hline & & & & -.70 & .000 \\
\hline \multirow[t]{2}{*}{ Parfüm } & 4.12 & \multirow{2}{*}{ Parfüm } & \multirow{2}{*}{$\begin{array}{l}\text { Tişört } \\
\text { Cep Telefonu }\end{array}$} & .13 & 003 \\
\hline & & & & -.57 & .000 \\
\hline \multirow[t]{2}{*}{ Cep Telefonu } & 4.69 & \multirow[t]{2}{*}{ Cep Telefonu } & \multirow{2}{*}{$\begin{array}{l}\text { Tişört } \\
\text { Parfüm }\end{array}$} & .70 & .000 \\
\hline & & & & .57 & .000 \\
\hline
\end{tabular}

Tablo 3. Ürünlere göre risk azaltma çabalarının karşılaştırılması

İnternet’ten alışverişe ilişkin algılanan riskin cinsiyete göre farklılık gösterip göstermediğini analiz etmek için bağımsız örneklem t-testi gerçekleştirilmiştir. Test sonuçları "finansal risk", "performans riski” ve "psikolojik risk" boyutlarında cinsiyete göre anlamlı bir farklılık olduğunu ortaya koymaktadır (Tablo 4.). Bu sonuçlara göre her üç boyutta da bayanların daha fazla risk algısına sahip olduğu söylenebilir.

\begin{tabular}{|c|c|c|c|c|c|}
\hline Değișken & Cinsiyet & Sayı (n) & Ort. & Standart Sapma & $\mathbf{p}$ \\
\hline \multirow{2}{*}{ Finansal Risk } & Kadın & 127 & 3.10 & 0.760 & \multirow{2}{*}{.001} \\
\hline & Erkek & 79 & 2.70 & 0.877 & \\
\hline \multirow{2}{*}{ Performans Riski } & Kadın & 127 & 3.70 & 0.801 & \multirow{2}{*}{.000} \\
\hline & Erkek & 79 & 3.19 & 0.984 & \\
\hline \multirow{2}{*}{ Sosyal Risk } & Kadın & 127 & 1.84 & 0.760 & \multirow{2}{*}{.138} \\
\hline & Erkek & 79 & 2.04 & 1.075 & \\
\hline \multirow{2}{*}{ Zaman Riski } & Kadın & 127 & 2.71 & 0.762 & \multirow{2}{*}{.804} \\
\hline & Erkek & 79 & 2.73 & 0.834 & \\
\hline \multirow{2}{*}{ Psikolojik Risk } & Kadın & 127 & 2.80 & 0.912 & \multirow{2}{*}{.017} \\
\hline & Erkek & 79 & 2.47 & 1.039 & \\
\hline \multirow{2}{*}{ Gizlilik Riski } & Kadın & 127 & 3.77 & 0.831 & \multirow{2}{*}{.258} \\
\hline & Erkek & 79 & 3.62 & 1.036 & \\
\hline
\end{tabular}

Tablo 4. Cinsiyete göre algılanan risk faktörlerinin karşılaştırılması

Bir sonraki aşamada farklı ürünlere ilişkin risk azaltma çabalarının cinsiyete göre farklılık gösterip göstermediği analiz edilmiştir. Yapılan bağımsız örneklem t-testi sonuçları Tablo 5'teki gibidir. Elde edilen sonuçlara göre tişört ve parfüm ürünleri için risk azaltma çabaları farklılık göstermezken, cep telefonu için ortalamalar yakın olsa da bayanların daha fazla risk azaltma çabası gösterdiği söylenebilir.

\begin{tabular}{|l|l|l|c|c|c|}
\hline \multicolumn{1}{|c|}{ Değişken } & Cinsiyet & Sayı (n) & Ort. & Standart Sapma & \multirow{2}{*}{ p } \\
\hline \multirow{2}{*}{ Tişört } & Kadın & 127 & 3.99 & 0.557 & \multirow{2}{*}{.912} \\
\cline { 2 - 5 } & Erkek & 79 & 3.98 & 0.646 & \multirow{2}{*}{.250} \\
\hline \multirow{2}{*}{ Parfüm } & Kadın & 127 & 4.16 & 0.654 & 0.647 \\
\cline { 2 - 5 } & Erkek & 79 & 4.05 & 0.336 & \multirow{2}{*}{.044} \\
\hline \multirow{2}{*}{ Cep Telefonu } & Kadın & 127 & 4.74 & 0.540 & \\
\cline { 2 - 5 } & Erkek & 79 & 4.61 & \\
\hline
\end{tabular}

Tablo 5. Cinsiyete göre risk azaltma çabalarının karşılaştırılması

\section{Sonuç}

Bu çalışmada, 206 üniversite öğrencisinden elde edilen verilere dayalı olarak İnternet’ten alışverişte "algılanan risk" ve "risk azaltma" değişkenlerinin farklı ürünler temelinde incelenmesi amaçlanmıştır. Bu doğrultuda İnternet'ten alışverişte; risk azaltma çabalarının cinsiyete ve ürünlere göre farklılık gösterip göstermediği, her bir boyutuna göre algılanan riskin cinsiyete göre farklılık gösterip göstermediği incelenmiştir. Çalışmadan elde edilen veriler, literatüre girdiği günden bugüne "algılanan risk"in boyutlarından biri olarak kabul edilen "Sosyal Risk”in İnternet’ten alışverişte algılanan riski açıklamakta zayıf kaldığı görülmektedir. Gerek anakütle seçimi, gerekse örneklem seçim yöntemi genelleme yapılmasına olanak vermese de araştırmaya katılan cevaplayıcıların tamamının genç olması İnternet’ten alışveriş için "Sosyal Risk”in gelecekte etkisini yitireceği konusunda 
ipuçları vermektedir. Öte yandan bu bulgu ile ilgili dikkat edilmesi gereken önemli bir husus, sosyal riskin İnternet'ten alışveriş yaparak bir ürünün alınması sonucu mu yoksa İnternet'ten bağımsız olarak herhangi bir ürün satın alınması sonucu olarak mı ortaya çıktığıdır. İlk durumda sosyal risk "İnternet’ten alışveriş" için algılanacakken, ikinci durumda ise bir ürün satın alındığında ürün odaklı bir sosyal risk algılanacaktır.

Çalışmada ortaya çıkan bir diğer sonuç, İnternet'ten alışverişte risk azaltmaya yönelik çabaların ürünler arasında farklılık gösterdiğidir. Bu sonuca göre cep telefonu için sarfedilen risk azaltma çabası parfüm ve tişörte göre daha fazladır. Riskin azaltılması açısından ele alınan üç ürün karşılaştıııldığında ürünün fiyatındaki artışla beraber riski azaltmaya yönelik girişimlerin de arttığı düşünülebilir.

Son olarak, elde edilen bulgular, hem İnternet'ten alışverişe ilişkin algılanan riskin hem de risk azaltma çabalarının farklı ürün ve boyutlarda cinsiyete göre farklılık gösterdiğini ortaya koymaktadır. Bu sonuçlara göre İnternet'ten alışverişe ilişkin olarak, kadınların erkeklerden daha fazla finansal, performans ve psikolojik risk algısına sahip oldukları anlaşılmaktadır. İnternet'ten alışverişte risk azaltma çabaları ürünler açısından incelendiğinde ise, tişört ve parfüm için erkekler ve kadınlar arasında bir farklılığa rastlanmamıştır. Öte yandan cep telefonu satın alırken kadınların erkeklerden daha fazla risk azaltma çabası gösterdikleri anlaşılmıı̧tır.

\section{Teşekkür}

Bu çalışma Pamukkale Üniversitesi BAP Koord. Birimi tarafından Kongre Katılım Destek Projesi kapsamında desteklenmiştir.

\section{Kaynakça}

- Bauer, R. A. (1960). Consumer Behavior as Risk Taking, Chicago: American Marketing Association, 389398.

- Brown, T. L. ve Gentry, J. W. (1975). "Analysis of Risk and Risk-Reduction Strategies- A Multiple Product Case", Journal of the Academy of Marketing Science, 3(2), 148-160.

- Cases, A. S. (2002). "Perceived Risk and Risk-Reduction Strategies in Internet Shopping", The International Review of Retail, Distribution and Consumer Research, 12(4), 375-394.

- Chen, R. ve He, F. (2003). "Examination of Brand Knowledge, Perceived Risk and Consumers' Intention to Adopt An Online Retailer", TQM \& Business Excellence, 14(6), 677-693.

- Constantinides, E. (2004). "Influencing The Online Consumer's Behavior: The Web Experience", Internet Research, 14(2), 111-126.

- Cox, D. F. ve Rich, S. U. (1964). "Perceived Risk and Consumer Decision-Making, The Case of Telephone Shopping", Journal of Marketing Research, 1(4), 32-39.

- Crespo, A. H., Bosque, I. R. ve Salmanos Sanchez, M. M. G. (2009). The Influence of Perceived Risk on Internet Shopping Behavior: A Multidimensional Perspective", Journal of Risk Research, 12(2), 259-277.

- Featherman, M. S. ve Pavlou, P. A. (2003). "Predicting E-Services Adoption: A Perceived Risk Facets Perspective", International Journal of Human-Computer Studies, 59, 451-474.

- Flavian, C. ve Guinaliu, M. (2006). "Consumer Trust, Perceived Security and Privacy Policy - Three Basic Elements of Loyalty to A Web Site", Industrial Management \& Data Systems, 106(5), 601-620.

- Forsythe, S. M. ve Shi, B. (2003). "Consumer Patronage and Risk Perceptions in Internet Shopping", Journal of Business Research, 56, 867-875.

- Goldsmith, R. E. ve Horowitz, D. (2006). "Measuring Motivations for Online Opinion Seeking", Journal of Interactive Advertising, 6(2), 3-14.

- Miyazaki, A. D. ve Krishnamurthy, S. (2002). "Internet Seals of Approval: Effects on Online Privacy Policies and Consumer Perceptions", The Journal of Consumer Affairs, 36(1), 28-49.

- Peter, J. P. ve Ryan, M. J. (1976). "An Investigation of Perceived Risk at the Brand Level", Journal of Marketing Research, 13(2), 184-188.

- Roselius, T. (1971). "Consumer Rankings of Risk Reduction Methods", Journal of Marketing, 35(1), 56-61.

- Sheth, J. N. ve Venkatesan, M. (1968). "Risk-Reduction Processes in Repetitive Consumer Behavior", Journal of Marketing Research, 5(3), 307-310.

- Taylor, J. W. (1974). “The Role of Risk in Consumer Behavior”, Journal of Marketing, 38(2), 54-60. 


\title{
Предпосылки вхождения Кыргызстана в Евразийский экономический союз \\ Preconditions of Entering of Kyrgyzstan into the Eurasian Economic Union
}

\author{
Prof. Dr. Jusup Pirimbaev (Kyrgyzstan-Turkey Manas University, Kyrgyzstan)
}

\begin{abstract}
In May 2015, Kyrgyzstan became a member of the Eurasian Economic Union, participation in which requires regulation of the economy, taking into account the goals and objectives of the Union. Today Kyrgyzstan is interested in the future of its membership in the EAEU: can we radically change the economic situation in the country and the structure of the economy. Kyrgyzstan's economy requires coordination with external actors in terms of domestic consumption and increasing export potential. To achieve this it is necessary: first, to develop a reasonable program of development of the industry, including the formation of large enterprises and their balanced arrangement in accordance with the level of productive forces; secondly, to make adjustments to the work of the construction sector in the building of not only housing complex, but also the development of infrastructure in all regions of the country and, thirdly, to follow the path of consolidation of the agricultural enterprises based on specialization, taking into account the export interests of Kyrgyzstan.
\end{abstract}

В мае 2015 г. Кыргызстан стал членом Евразийского экономического союза, участие в котором предполагает регулирование экономики с учетом задач и целей союза. Многие предрекали невозможность вступления Кыргызской Республики в данный союз из-за неравномерного развития экономик предполагаемых членов союза. Хотя было известно, что различные международные союзы и организации в мире допускают такую неравномерность.

Главной причиной сопротивления против членства в ЕАЭС было мнение об угрозе потери суверенитета республики и ее независимости. Об этом очень много говорили и писали. Однако анализ экономического положения КР за время обретения независимости показал, что зависимости стала больше, чем в советский период.

ЕАЭС явился результатом логического решения в условиях изменения экономических взимоотношений в мире, основанных на либеральных ценностях, имеющих склонность к манипуляции и спекуляции, допускающих обнищание большинства и бесчинства крупных компаний и транснациональных корпораций. В мире явно проявляется агрессия в борьбе за ресурсы, на глазах теряется доверие государств друг к другу. Информационная зона все больше идеологизируется и становится зависимой от капиталов и собственников. Международное право не соблюдается и становится не-управляемым, чаще стали говорить о необходимости реформирования $\mathrm{OOH}$, то есть стремлении к изменению миропорядка. В таких условиях говорить о свободном и независимом проведении экономической политики, особенно маленьких государств, не приходится.

ЕАЭС для Кыргызстана является площадкой, где можно осуществить равноправные экономические отношения со всеми его членами и проявить свой голос на международной арене, опираясь на возможности и патенциал всего союза.

На сегоднашний день Кыргызстан интересует будущее его членства в ЕАЭС: сможем ли мы кардинально изменить экономическую ситуацию в республике и структуру экономики, ускорить интеграцию отраслей с другими членами союза, ставшую традиционной еще при Советском Союзе, обеспечить удовлетворительный уровень дохода на душу населения, который является самым низким среди всех других стран-членов. В этой связи от нас требуется тщательный анализ базового состояния экономики страны для обеспечения реальной оценки ее состояния в будущем. Состояние промышленности, строительства и сельского хозяйства страны на сегодняшний день характеризует уровень развития реальной экономики. ВВП Кыргызстана за последние пять лет располагает следующими данными (табл. 1).

\begin{tabular}{|l|c|c|c|c|c|}
\hline & 2010 & 2011 & 2012 & 2013 & 2014 \\
\hline ВВП, млрд. сом. & 220,4 & 273,1 & 310,5 & 350,0 & 397,3 \\
\hline Реальный ВВП & $-0,5$ & 5,7 & $-0,9$ & 10,5 & 3.6 \\
\hline
\end{tabular}

Таблица 1. ВВП Кыргызской Республики за 2010-2014 г2 (млн. сом.) Источник: НСК КР.

Как показывают данные табл. 1, несмотря на тенденцию роста ВВП республики, в абсолютной величине он является весьма незначительным, а в сравнении с ВВП членов ЕАЭС - некорректным. Проблема роста заключается не в том, что республика является маленькой и ресурсы недостаточны, а в 
том, что отсутствует реальная оценка ресурсного потенциала страны и не хватает усилий для решения организационных проблем. К сожалению, до сих пор все экономические проблемы находятся в политической плоскости и все отраслевые министерства и ведомства привязаны руководствоваться политическими мотивациями, а функциональная значимость отодвигается на второй план. В выполнении показателей ВВП доля промышленности, строительства и сельского хозяйства, согласно данным Нацстаткома КР, приведена в табл. 2.

\begin{tabular}{|l|c|c|c|c|c|}
\hline & 2010 & 2011 & 2012 & 2013 & 2014 \\
\hline ВВП & 100 & 100 & 100 & 100 & 100 \\
\hline Строительство & 5,7 & 4,9 & 5,7 & 2,0 & 6,3 \\
\hline Промышленность & 19,3 & 16,28 & 16,8 & 16,1 & 18,5 \\
\hline Сельское хозяйство & 18,5 & 18 & 17,5 & 15,2 & 14,6 \\
\hline
\end{tabular}

Таблица 2. Доля реального сектора экономики КР в ВВП (\%) Источник: НСК КР, НБКР.

Как видим, в 2014 г. доля промышленности в ВВП составила всего 18,5\%, хотя она выше в строительстве и сельском хозяйстве. Если напомнить, что в свое время более половины ВВП создавалось промышленностью и она являлась основным бюджетообразующим источником, то многие вопросы, касающиеся этого сектора, еще ждут своего решения. Да, тогда была мощная интеграция промышленности по всей территории Советского Союза, были созданы необходимые научноисследовательские комплексы по совершенствованию промышленной технологии и разработке новой промышленной продукции. Но была мощная и вполне конкурентоспособная промышленность республики, со 100\%-ным обеспечением местным сырьем, местной технологией горнодобывающей, легкой и пищевой отраслей. Для восстановления их потенциала имеются все необходимые условия и производительные силы, а машиностроительный комплекс ждет своего часа интеграции с заинтересованными сторонами, что предполагает привлечение необходимых средств извне. Значит, можно без ложного представления обеспечить долю промышленности в ВВП в ближайший период до 3040\%. Причем это можно реализовать на базе остатков крупных предприятий в различных регионах республики.

Сейчас в стране действуют 1854 промышленных предприятия, структура которых характеризует масштаб охвата различных производств (табл. 3). Из них 180 расположены в Джалал-Абадской, 186 в Ошской, 464 в Чуйской областях, а в г. Бишкеке 617 промышленных предприятий и остальные 407 расположены в четырех областях - Иссык-Кульской, Нарынской, Таласской и Баткенской. Причем определяющая часть трудовых ресурсов страны находится в южных областях - Джалал-Абадской, Ошской и Баткенской, с соответствующим ресурсным потенциалом.

Нужно отметить, что если в ближайшем будущем мы не решим вопрос о размещении производственного сектора в соответствии с уровнем производительных сил, то можем получить реальную угрозу социальных волнений, которые могут отбросить страну в экономическом отношении на много лет назад. К этому еще нужно добавить, исходя из данных табл. 3, наличие мелких предприятий горнодобывающей промышленности в секторе добычи топливно-энергетических полезных ископаемых, где невозможно использовать современные технологии и достичь соответствующего эффекта по рациональной добыче, поэтому есть риски самовольного закрытия из-за отсутствия средств на социальную поддержку местного населения, что постоянно вызывает протестное настроение против политики освоения полезных ископаемых.

Наличие этих непростых проблем экономики страны должно подтолкнуть нас к разработке научно обоснованной программы развития промышленности в целом в условиях членства в ЕАЭС, рассчитанной на несколько лет вперед. Ведь именно на площадке этого союза можно реально влиять на инвестиционный и интеграционный климат страны исходя из обоснованности и привлекательности разработанной программы.

Строительный сектор с долей в ВВП 6,3\% и объемом выполненных подрядных работ 36604,3 млн. сом. представляют 800 организаций (табл. 4). 


\begin{tabular}{|l|c|c|c|c|c|c|}
\hline & 2009 & 2010 & 2011 & 2012 & 2013 & \% к общ. \\
\hline Всего & 2092 & 2039 & 1931 & 1883 & 1854 & \\
\hline $\begin{array}{l}\text { Горнодобывающая } \\
\text { промышленность }\end{array}$ & 133 & 140 & 142 & 151 & 158 & 8,5 \\
\hline $\begin{array}{l}\text { Добыча топливно-энергетических } \\
\text { полезных ископаемых }\end{array}$ & 76 & 79 & 75 & 77 & 82 & \\
\hline $\begin{array}{l}\text { Добыча полезных ископаемых, кроме } \\
\text { топливно-энергетических }\end{array}$ & 57 & 61 & 67 & 74 & 76 & \\
\hline $\begin{array}{l}\text { Обрабатывающая } \\
\text { промышленность }\end{array}$ & 1660 & 1591 & 1455 & 1399 & 1364 & 73,6 \\
\hline $\begin{array}{l}\text { Производство пищевых продуктов, } \\
\text { включая напитки, и табака }\end{array}$ & 412 & 392 & 372 & 354 & 339 & \\
\hline Текстильное и швейное производство & 132 & 131 & 128 & 124 & 118 & \\
\hline $\begin{array}{l}\text { Производство кожи, изделий из кожи } \\
\text { и производство обуви }\end{array}$ & 17 & 16 & 13 & 13 & 12 & \\
\hline $\begin{array}{l}\text { Обработка древесины и производство } \\
\text { изделий из дерева }\end{array}$ & 62 & 58 & 51 & 55 & 54 & \\
\hline $\begin{array}{l}\text { Целлюлозно-бумажное производство, } \\
\text { издательская деятельность }\end{array}$ & 253 & 259 & 142 & 136 & 130 & \\
\hline $\begin{array}{l}\text { Производство нефтепродуктов и } \\
\text { ядерных материалов }\end{array}$ & 7 & 8 & 8 & 8 & 7 & \\
\hline Химическое производство & 65 & 61 & 57 & 55 & 53 & \\
\hline Производство резиновых и & 154 & 133 & 152 & 125 & 112 & \\
\hline Производство прочих & 194 & 195 & 189 & 198 & 220 & \\
\hline Металлургическое производство и & 118 & 103 & 101 & 101 & 103 & \\
\hline Производство машин и оборудования & 110 & 103 & 99 & 93 & 84 & \\
\hline $\begin{array}{l}\text { Производство электрооборудования, } \\
\text { электронного и оптического }\end{array}$ & 64 & 57 & 56 & 60 & 59 & \\
\hline $\begin{array}{l}\text { Производство транспортных средств } \\
\text { и оборудования }\end{array}$ & 6 & 8 & 7 & 10 & 7 & \\
\hline Прочие отрасли производств & 66 & 67 & 80 & 67 & 66 & \\
\hline $\begin{array}{l}\text { Производство и распределение } \\
\text { электроэнергии, газа и воды }\end{array}$ & 299 & 308 & 334 & 333 & 332 & 17,9 \\
\hline
\end{tabular}

Таблица 3. Число промышленных предприятий и производств по видам экономической деятельности (единиц) Источник: НСК КР.

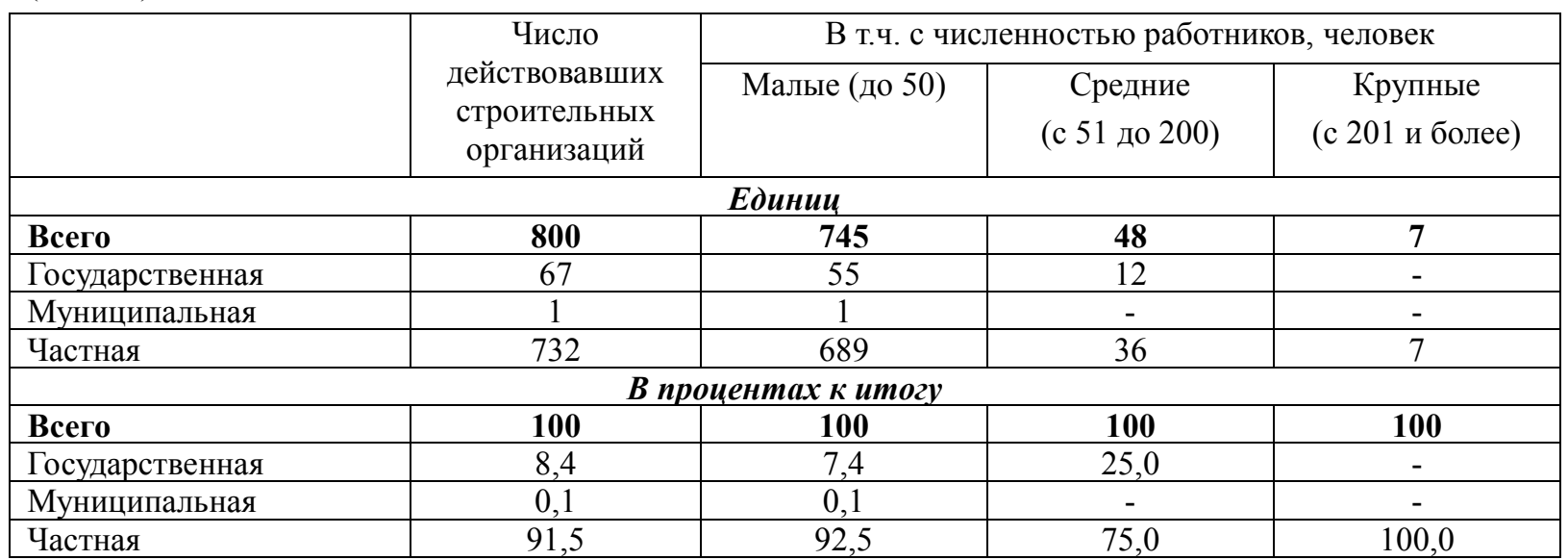

Таблица 4. Распределение строительных организаций по численности работников и формам собственности на 2014 г. Источник: НСК КР.

Как показывают данные табл. 4, особенность структуры строительного сектора заключается в том, что 91,5\% приходится на частную собственность, 8,4\% государственную и $0,1 \%$ муниципальную собственность; из всех строительных организаций 745 являются малыми. Это к тому, что более $93 \%$ всех строительных организаций являются мобильными и эффективными в строительстве жилищного комплекса и мелких подрядных работ и малоэффективными в строительстве промышленных комплексов и инфраструктурных объектов, которые требуют укомплектования отдельными специалистами. В строительном секторе тоже наблюдается дисбаланс как в размещении, так и в объемах выполненных строительных работ. Так, более 70\% выполненных работ приходится на долю г. Бишкека и в основном в 
строительстве жилья. Строительство же в других городах и областях в основном связано с индивидуальным жилищным строительством. Предстоит строительство северного Нарынского каскада ГЭС, железной дороги Север-Юг с выходом в зарубежные страны и крупных объектов социального значения, а также решение проблем туристического комплекса по всем регионам страны, что требует особого подхода к дальнейшему развитию строительной индустрии.

Сельское хозяйство с долей ВВП 64,6\% представляет 603,6 тыс. хозяйствующих субъектов (табл. 5).

\begin{tabular}{|c|c|c|c|c|c|c|c|}
\hline & \multirow[t]{2}{*}{ Всего } & \multicolumn{6}{|c|}{ В том числе } \\
\hline & & малые & средние & крупные & $\begin{array}{l}\text { Крестьянские } \\
\text { (фермерские) } \\
\text { хозяйства }\end{array}$ & $\begin{array}{l}\text { Индивидуальные } \\
\text { предприниматели }\end{array}$ & $\begin{array}{l}\text { Прочие } \\
\text { обособленные } \\
\text { подразделения }\end{array}$ \\
\hline $\begin{array}{l}\text { Кыргызская } \\
\text { Республика }\end{array}$ & 603,6 & 20,8 & 3,8 & 1,8 & 287,3 & 283,6 & 6,4 \\
\hline $\begin{array}{l}\text { Баткенская } \\
\text { область }\end{array}$ & 54,8 & 1,0 & 0,3 & 0,1 & 29,1 & 24,0 & 0,4 \\
\hline $\begin{array}{l}\text { Джалал- } \\
\text { Абадская } \\
\text { область }\end{array}$ & 116,4 & 2,0 & 0,6 & 0,2 & 72,3 & 40,3 & 1,0 \\
\hline $\begin{array}{l}\text { Иссык- } \\
\text { Кульская } \\
\text { область }\end{array}$ & 56,7 & 1,4 & 0,4 & 0,1 & 20,0 & 33,9 & 0,9 \\
\hline $\begin{array}{l}\text { Нарынская } \\
\text { область }\end{array}$ & 49,8 & 0,9 & 0,2 & 0,1 & 28,1 & 20,0 & 0,6 \\
\hline Ошская область & 132,3 & 1,8 & 0,6 & 0,2 & 69,7 & 59,1 & 1,0 \\
\hline $\begin{array}{l}\text { Таласская } \\
\text { область }\end{array}$ & 30,7 & 0,9 & 0,2 & 0,1 & 18,1 & 11,1 & 0,4 \\
\hline $\begin{array}{l}\text { Чуйская } \\
\text { область }\end{array}$ & 110,1 & 2,4 & 0,6 & 0,2 & 47,9 & 57,9 & 1,1 \\
\hline г.Бишкек & 27,8 & 9,3 & 0,8 & 0,6 & 0,0 & 16,2 & 0,8 \\
\hline г.Ош & 24,9 & 1,1 & 0,2 & 0,1 & 2,2 & 21,1 & 0,2 \\
\hline
\end{tabular}

Таблица 5. Действующче хозяйствующче субъекты по типам и территории на 1 января 2015 г. (тыс. единии) Источник: НСК КР.

Главный проблемой сельского хозяйтва является его разрозненность на мелкие и индивидуальные хозяйства. Если вспомнить, что в советский период сельское хозяйство производило больше, чем сейчас, и это обеспечивали всего около 400 сельхоз-предприятий, то можно представить масштаб разрушений его инфраструктуры. Несмотря на то, что именно сельское хозяйство получило прерогативное направление в сотруничестве с ЕАЭС, выполнить ожидаемые результаты будет очень трудно без интеграции с крупными сельхозпредприятиями. При наличии огромных запасов воды, особенно в горных местностях, их неиспользование в целях развития лесного хозяйства и искусственных лесопосадок более чем странно.

\begin{tabular}{|l|c|c|c|c|c|}
\hline \multirow{2}{*}{} & \multicolumn{5}{|c|}{2013 г. } \\
\cline { 2 - 6 } & $\begin{array}{c}\text { Структура } \\
\text { ВВП }\end{array}$ & $\begin{array}{c}\text { в \% к } \\
\text { итогу }\end{array}$ & $\begin{array}{c}\text { Налоговые } \\
\text { поступления }\end{array}$ & $\begin{array}{c}\text { в \% к общим } \\
\text { налогам }\end{array}$ & $\begin{array}{c}\text { Налоговая } \\
\text { нагрузка, \% }\end{array}$ \\
\hline Всего & $\mathbf{3 5 0 ~ 0 2 8 , 4}$ & & $\mathbf{3 5 8 8 5 , 3}$ & & 21,8 \\
\hline Промышленность & 56323,6 & 16,1 & 12299.8 & 34,3 & 1,2 \\
\hline Сельское хозяйство & 53156,5 & 15,2 & 653,7 & 1,8 & 7,7 \\
\hline Строительство & 23644,5 & 6,8 & 1820,2 & 5,1 & 12,7 \\
\hline Услуги & 166666,9 & 47,6 & 21111,6 & 58,8 & \\
\hline Налоги на продукты и импорт & 50236,9 & 14,4 & & & \\
\hline
\end{tabular}

(*) не включает налоги на импорт и социчальные отчисления

Таблица 6. Налоговая нагрузка по отраслям экономики Источник: НСК КР, НБКР.

В контексте состояния промышленности, строительства и сельского хозяйства вызывает интерес налоговая нагрузка, приходящаяся на их доли. Согласно проекту «Концепции фискальной политики КР на 2015-2020 годы» налоговая нагрузка по отраслям экономики на 2013 г. приведена в табл. 6. Если исходить из этих данных, то можно задаться непростым вопросом: сколько нужно трудиться, чтобы реальный сектор экономики стал основной налогооблагаемой базой? Ведь, не имея соответствующей стабильной налоговой базы, вести разговоры вокруг налогового администрирования, совершенства налогового законодательства остается благим намерением. Налоговая нагрузка в секторе услуг всегда 
будет зависеть от потребительского отношения к экономике, и оно очень изменчиво и зависит от уровня развития экономики.

Для наглядности о состоянии экономики Кыргызстана на фоне стран-участниц ЕАЭС приведем данные по производству некоторых видов продукции в абсолютной величине (табл. 7). Приведенные цифры показывают, насколько несравнимы потенциалы стран при производстве этой продукции. Вместе с тем они служат ориенитиром для дальнейшего развития этих производств и нереализованной части потенциала Кыргызстана.

\begin{tabular}{|c|c|c|c|}
\hline & \multicolumn{2}{|c|}{2014 г. } & \multirow{2}{*}{$\begin{array}{c}2013 \text { г. по отношению к } \\
2012 \text { г. }\end{array}$} \\
\hline & Всего & по отношению к 2013 г. & \\
\hline \multicolumn{4}{|c|}{ Мясные продукты } \\
\hline Беларусь & 613,9 & 89,5 & 110,3 \\
\hline Казахстан & 217,0 & 103,2 & 111,8 \\
\hline Россия & 5811,4 & 109,6 & 111,3 \\
\hline ТС и ЕАЭС & 6642,3 & 107,2 & 111,2 \\
\hline Армения & 82,3 & 113,7 & 109,7 \\
\hline Кыргызстан & 8,4 & 110,6 & 117,0 \\
\hline \multicolumn{4}{|c|}{ Растительное масло } \\
\hline Беларусь & 192,5 & 106,5 & 138,0 \\
\hline Казахстан & 329,5 & 117,3 & 96,0 \\
\hline Россия & 4772,8 & 121,3 & 94,2 \\
\hline ТС и ЕАЭС & 5294,8 & 120,4 & 95,7 \\
\hline Армения & 4,0 & 85,3 & 175,1 \\
\hline Кыргызстан & 13,5 & 95,8 & 100,9 \\
\hline \multicolumn{4}{|c|}{ Молочные продукты } \\
\hline Беларусь & 1900,1 & 104,5 & 104,8 \\
\hline Казахстан & 466,3 & 105,9 & 118,2 \\
\hline Россия & 11445,3 & 99,1 & 102,7 \\
\hline ТС и ЕАЭС & 13811,7 & 100,0 & 103,4 \\
\hline Армения & 386,5 & 106,6 & 113,4 \\
\hline Кыргызстан & 30,6 & 146,2 & 80,7 \\
\hline \multicolumn{4}{|c|}{ Животные жиры } \\
\hline Беларусь & 106,4 & 107,4 & 87,9 \\
\hline Казахстан & 15,7 & 111,6 & 114,9 \\
\hline Россия & 253,2 & 111,8 & 102,8 \\
\hline ТС и ЕАЭС & 375,3 & 110,5 & 98,3 \\
\hline Армения & 1,1 & 210,9 & 93,7 \\
\hline Кыргызстан & 2,2 & 110,7 & 92,0 \\
\hline \multicolumn{4}{|c|}{ Мука } \\
\hline Беларусь & 626,9 & 85,0 & 95,8 \\
\hline Казахстан & 3848,5 & 99,2 & 96,8 \\
\hline Россия & 9672,2 & 98,6 & 102,6 \\
\hline ТС и ЕАЭС & 14147,6 & 98,1 & 100,6 \\
\hline Армения & 219,6 & 129,6 & 72,0 \\
\hline Кыргызстан & 319,0 & 114,5 & 80,3 \\
\hline \multicolumn{4}{|c|}{ Caxap } \\
\hline Беларусь & 743,6 & 87,2 & 98,8 \\
\hline Казахстан & 400,2 & 112,1 & 206,3 \\
\hline Россия & 5212,7 & 106,5 & 92,1 \\
\hline ТС и ЕАЭС & 6356,5 & 104,2 & 96,1 \\
\hline Армения & 89,2 & 128,1 & 100,5 \\
\hline Кыргызстан & 20,1 & 79,9 & 189,7 \\
\hline
\end{tabular}

Таблица 7. Промышленное производство в странах ЕАЭС и в Кыргызстане (тыс. т) Источник: Евразийская экономическая комиссия. Стр. 7-9.

Исходя из вышеизложенного, экономика Кыргызстана требует координации с внешними игроками в плане обеспечения внутреннего потребления и повышения экспортного потенциала. Для реализации этого необходимо: во-первых, разработать обоснованную программу развития промышленности, включая создание крупных предприятий и сбалансированное их размещение в соответствии с уровнем производительных сил; во-вторых, внести коррективы в деятельность строительного сектора в создании не только жилищного комплекса, но и освоении инфраструктуры по всему региону страны и, в-третьих, 
идти по пути укрупнения сельскохозяйственных предприятий с необходимостью их специализации с учетом экспортного интереса Кыргызстана.

\section{Литература}

- Евразийская экономическая комиссия, 2015. «Об основных социально-экономических показателях государств - членов Таможенного союза и Единого экономического пространства» Январь-декабрь 2014 г. (аналитический обзор).

- Концепции фискальной политики КР на 2015-2020 годы (проект).

- Национальный статистический комитет Кыргызской Республики, www.stat.kg

- Национальный Банк Кыргызской Республики, www.nbkr.kg. 


\title{
Региональный анализ российской внешней торговли в целях содействия развитию международной кооперации и импортозамещения
}

\author{
Regional Analysis of Russian Foreign Trade for Promoting \\ International Cooperation and Import Substitution
}

\author{
Assoc. Prof. Dr. Rinas Kashbrasiev (Kazan Federal University, Russia) \\ Assoc. Prof. Dr. Anatoly Stepin (Kazan Federal University, Russia)
}

\begin{abstract}
This research is a continuation of the comprehensive study of foreign economic activity of the Russian Federation, conducted by the authors over the past several years. The article is devoted to the typology of Russian regions on import statistics, taking into account their sectoral characteristics. At the same time the main direction of the article is focused on solving problems of rationalization of import substitution, which became urgent after the geopolitical fallout of 2014. The methodology presented in this study is the author's uniquely designed method of typology of regions based on import statistics. The method includes a combination of integrated assessments of homogeneity/heterogeneity of regional import's structure by seven commodity groupings used in Russian state statistics, and the graphical visualization of their results. The results of the typology are the following: the identification of several groups of regions, unequal in size, but relatively homogeneous in imported goods. The most representative group includes regions with predominant expenditures on imports of machine-building products ( 57 of 82 regions of the Russian Federation). This group of regions and the machine-building sector of the national economy were the basis for recommendations on the development of international cooperation and import substitution. Other groups of imports were not left without analysis.
\end{abstract}

\section{1 Введение}

Данная работа является продолжением исследования авторов по внешнеэкономической деятельности Российской Федерации. Если предшествующая работа авторов была посвящена типизации субъектов России по показателям экспорта с позиции определения структурных особенностей региональной специализации (Kashbrasiev etc., 2014), то цель данной статьи - анализ региональной структуры импорта. Естественной предпосылкой для изучения импорта явилось предположение о сбалансированности использования средств, полученных от реализации экспортируемой продукции, для решения насущных задач рационализации импортозамещения. Проблема импортозамещения за счет интенсификации собственного производства неявно начала прослеживаться с периода глобального финансового кризиса 2008-2010 годов. Именно в этот период в России было провозглашено направление, связанное с модернизацией национальных производительных сил (Connolly, 2011; Aleksashenko, 2012). В настоящее время эта проблема стала явной, осязаемой и злободневной (Fal'tsman, 2015).

В нашей работе, упомянутой выше, использовались традиционные приемы выделения типов по принятым в государственной статистике товарным группам. Последовательность групп сохранена и при исследовании российского импорта. Вместе с тем, для типизации посубъектного импорта была использована модель, которую условно назовем «паутинообразной», так как в ее основе заложен специфический вид диаграмм. Эта модель является модификацией модели, использованной на заре проникновения математических методов в географические исследования применительно к классификации городских поселений (Блажко и др., 1970). Новым, по сравнению с нашей предыдущей работой, явился и показатель меры однородности структуры импорта, используемой как в разрезе отдельных субъектов, так и их товарных групп, образующих типы и подтипы.

\section{2 Теоретические вопросы типологии региональных экономических систем}

С теоретической точки зрения типология и классификация экономических объектов относятся к задаче дифференциации совокупности признаков, принадлежащих к двум и более генеральным совокупностям. По мнению Кендалла М. Дж. и Стюарта А. существуют три принципиальных типа задач статистической дифференциации: дискриминация, классификация и разбиение (Кендалл и Стюарт, 1976, стр.437). В первом случае по наличию и свойствам выборок, полученных из двух и более генеральных совокупностей, подчиненных собственным, не обязательно совпадающим статистическим распределениям, осуществляется процедура принадлежности одного из элементов одному из данных распределений. Во втором случае задача заключается в выделении групп (классов, типов) элементов, при одном условии, что группы будут насколько это возможно различны между собой. Вместе с тем, 
определенные два направления являются антиподами, так как в первом случае количество групп задано, тогда как во втором случае их количество и состав следует определить. В третьем типе задач естественность и детерминированность границ не является фиксированными (заданными).

Любая задача классификации, по мнению Кендала М. Дж. и Стюарта А., может быть разбита на два принципиальных типа, первый из которых может условно быть назван классификационным анализом, а второй - классификацией по компонентам. В первом случае нас интересует функция «близости» элементов группы, составленной из объектов, которая определяется в виде функции от их значений, тогда как во втором нас интересует группировка признаков, а не объектов. И в том, и в другом случае первоначальная трудность состоит в определении того, что понимается под «классом», «группой», «типом». Преодоление этой «трудности» осуществляется несколькими способами, которые, в свою очередь, основываются на метриках «близости» или «расстояния» между объектами или между признаками. Требования ко всем мерам «близости» одинаковы - безразмерность и достаточная простота вычисления. Для этого, как известно, используются такие метрики как коэффициент корреляции, косинус угла между векторами, разного типа расстояния (Евклидово, Хемминговое и пр.). Применительно к совокупности качественных (количественно неизмеримых) признаков используется процедура ранжирования.

\section{3 Методика исследования}

Анализ сложившихся отраслевых и территориальных характеристик внешнеторговой деятельности России предлагается проводить путем использования типологии субъектов по товарным группам. При этом типология (классификация) является естественной основой для определения путей рационализации импортозамещения, наиболее рельефно проявляющая в сложных социально-экономических условиях современного периода. Далее рассмотрим основные теоретические положения, которые можно рассматривать в качестве авторского метода научного исследования в заданном направлении.

Допустим, что структурная организация внешнеторговой деятельности представлена $n$ товарными группами и $m$ регионами (субъектами). Тогда для каждого территориального субъекта с номером $k$, где $k$ определяется в виде последовательности чисел натурального ряда от 1 до $m$, что символически записывается в виде $(k=1,2, \ldots, m)$, экономический результат по внешнеторговой деятельности (в данной работе - импорт) для $i$-ой товарной группы $(i=1,2, \ldots, n)$ для $k$-го субъекта определим в размере $a_{i}^{(k)}$. Суммарный результат внешнеторговой деятельности $k$ - го субъекта в этом случае составит:

$$
A^{(k)}=\sum_{i=1}^{n} a_{i}^{(k)} \quad(k=1,2, \ldots, m) .
$$

Рассчитаем удельный вес $i$ - ой товарной группы по формуле:

$$
d_{i}^{(k)}=\frac{a_{i}^{(k)} \cdot 100}{A^{(k)}} \quad(k=1,2, \ldots, m ; i=1,2, \ldots, n) .
$$

Для конкретного $k(k=1,2, \ldots m)$ определим максимальное значение, которое мы обозначим через $d_{i}^{\left(k_{0}\right)}$. Поделим каждое из значений весового коэффициента $i$ - ой товарной группы на величину соответствующего максимального значения. Получим безразмерный вектор (записанный для экономии места в виде вектора-строки $\left(\beta^{(k)}\right)$, который составлен из величин $\beta_{i}^{(k)}$ :

$$
\beta^{(k)}=\left(\beta_{1}^{(k)}, \beta_{2}^{(k)}, \ldots, \beta_{n}^{(k)}\right),
$$

где $\beta_{i}^{(k)}=\frac{d_{i}^{(k)}}{d_{i}^{\left(k_{0}\right)}}(k=1,2, \ldots, m ; i=1,2, \ldots, n)$. Следует отметить, что любая из величин $\beta_{i}^{(k)}$ удовлетворяет неравенству $0 \leq \beta_{i}^{(k)} \leq 1$.

Для осуществления процедуры типологии используем паутинообразную диаграмму, которая визуализирует структуру импорта соответствующих товарных групп для каждого из субъектов. На основании визуального совпадения и рассчитанной меры однородности (меры полиструктурности) каждого из векторов $\beta^{(k)}$ производится отбор типов всей совокупности товарных групп. В качестве $M е p b l$ однородности структурного вектора $\beta^{(k)}$ предлагается показатель:

$$
q^{(k)}=\sqrt{\frac{\sum_{i=1}^{n}\left(\beta_{i}^{(k)}-1\right)^{2}}{n-1}},
$$

которую можно назвать $q$ - мерой однородности (неоднородности) структуры импорта $k$-го субъекта. Для случая, при котором наблюдается равенство весов в структуре импорта $\left(\beta_{1}^{(k)}=\beta_{2}^{(k)}=\cdots=\beta_{n}^{(k)}\right)$, что характерно для абсолютной однородности структуры (абсолютной полиструктурности) величина $q^{(k)}=0$. В случае же полной моноструктуры (в нашем случае эта ситуация может быть названа «абсолютно чистым» типом) величина меры однородности $q^{(k)}=1$. 
Паутинообразная диаграмма, соответствующая равновесовой структуре импорта (абсолютная однородность) представляется многогранной фигурой соединяющей номера признаков (внешней огибающей). Случай же крайней неоднородности представляется паутинообразной моделью в виде «стрелки», направленной из середины «паутины» по радиусу, совпадающему с номером превалирующей товарной группы $i_{0}$ в величине валового импорта для субъекта.

Сравнение площадей фигур, получаемых в паутинообразной типологии, позволяет сделать вывод о том, что чем больше визуализированная площадь фигуры, определяющей конкретную структуру товарного импорта, представленной на «паутине», то тем ближе к полиструктурной организации исследуемая структура субъекта по товарным группам. Вместе с тем, чем ближе конфигурация к «часовому виду» с двумя или одной «стрелкой», то тем ближе структура к моноструктурному типу.

В качестве итога следует отметить, что физическая основа признака в данной процедуре визуализации не играет какой-либо роли, тогда как на первый план выходит соотношение признаков. Таким образом, предложенная процедура «сетевой» типологии может быть использована для признаков любой природы. При этом, относительные признаки сложной размерности, используемых в осуществлении сравнения могут быть применены со значительной эффективностью, по сравнению с процедурами, требующей усреднения и определения расстояний в классическом смысле слова. В последнем случае методики, основанные на усреднении, приводят, как правило, к искажению существующей объективной реальности.

Согласно Федеральной службы государственной статистики (Росстату), в статистике внешней торговли принято объединение показателей внешнеторговой деятельности в семь групп, т.е. в нашем случае $n=7$. В данном исследовании товарные группы представлены в следующей последовательности:

1. продовольственные поставки,

2. поставки топливно-энергетических компонентов,

3. продукции нефтехимии,

4. поставки леса и продуктов из него,

5. поставки продукции металлургической

6. поставки машиностроительной продукции,

7. прочие виды продукции.

Для расчетов использованы данные Росстата в разрезе отдельных субъектов Российской Федерации, осуществлявших внешнеторговые операции за период с 2000 по 2010 гг, а по некоторым показателям и за 2012 (Россия в цифрах и картах, 2015). Общее число субъектов равно 82, т.е. $m=82$. В данной работе типология субъектов проведена по данным 2010 г.

\section{4 Результаты исследования}

В отраслевой структуре импорта всей совокупности субъектов выделены 6 типов:

- машиностроительный,

- продовольственный,

- нефтехимический,

- «прочие товары»,

- топливно-энергетический.

- $\quad$ металлургический,

Следует отметить, что распределение регионов по типам неравномерно, т.к. в подавляющем большинстве регионов в структуре импорта явно выделяются доли машиностроительной, продовольственной и нефтехимической продукции.

Качественный состав выделенных типов регионов рассмотрим по превалирующей импортной специализации, определяемой согласно авторской методике.

Машиностроительный тип в разной степени прослеживается в 57 субъектах, что составляет более $2 / 3$ субъектов РФ, включая такие экономически развитые субъекты как Москва, Санкт-Петербург, Республика Татарстан, Калининградская, Калужская, Московская и Ленинградская области. На долю этого типа в валовом импорте приходится 90,23\%. Анализ показывает, что практически вся совокупность субъектов, формирующих топливно-энергетический тип экспортных поступлений, относится к данному типу импортных расходов. Это предполагает, что часть полученных от экспорта энергоносителей возвращается в виде «российских нефтедолларов» в отрасли топливно-энергетического комплекса, в виде новейшей техники и технологий.

Для этого типа характерно превалирование доли импорта продукции машиностроения над остальными товарными составляющими (средний для машиностроительного типа коэффициент однородности составляет величину $q=0,825)$. При этом 35 субъектов образуют так называемый «чистый» машиностроительный тип, для которого характерно значительное явное превалирование 
машиностроительной продукции $(q=0,845)$. В паутинообразной модели эти субъекты имеют явно выраженное «стрелочное» изображение, напоминающее минутную стрелку на часах.

Паутинообразную модель структуры импорта для данного типа импорта представим в графической форме (рис.1):

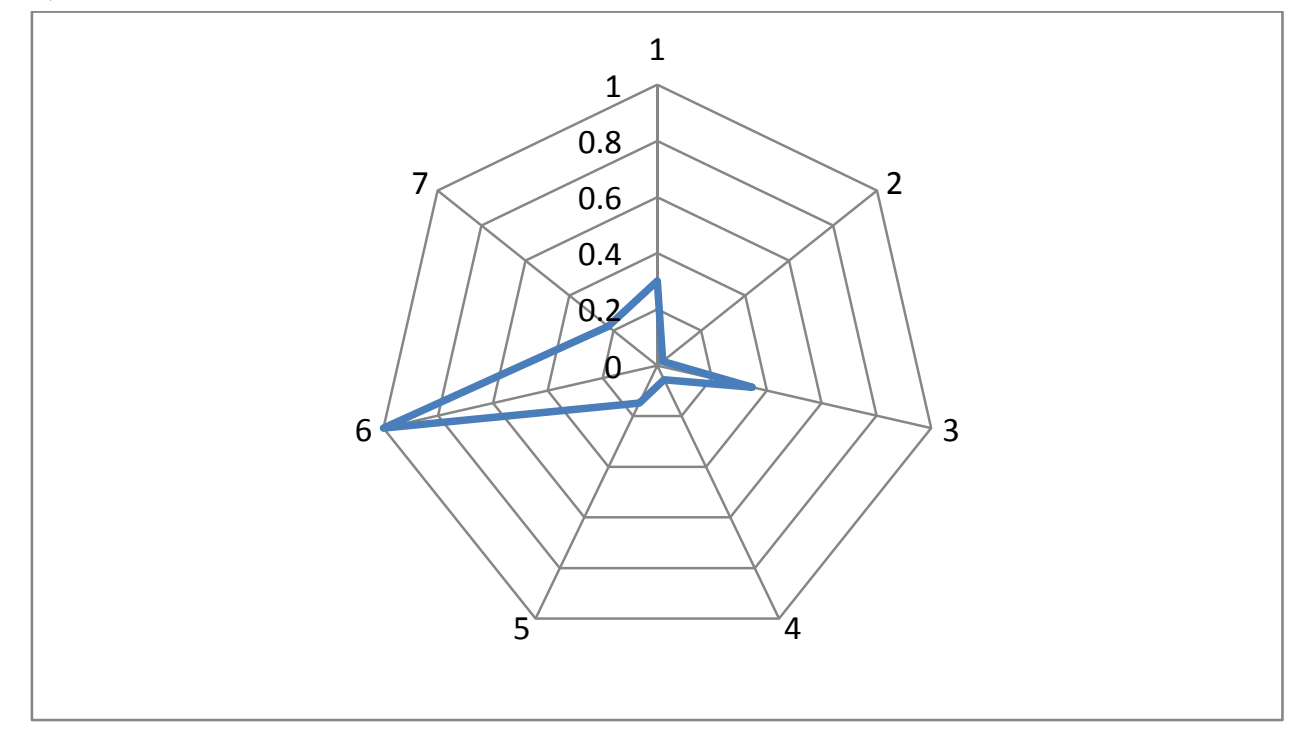

Pис.1. Профиль регионов, импортирующих машиностроительную продукцию. (Цифры в вершинах многоугольника - номера товарной группы, используемые в статистике внешней торговли)

Машиностроительный тип импорта является ярким выражением сочетания двух принципиальных направлений использования ввозимой продукции - производственным и личным потреблением. Производственное потребление ориентировано на ввоз новейших видов техники и технологий в целях технического перевооружения производства. Личное потребление связано со ввозом, в значительной степени, бытовой и автомобильной техники, удовлетворяющих потребности населения, способствующих повышению качества жизни. Если первое требует локализации производства, в тоже время развития международной промышленной кооперации, а также интеграции российских компаний в глобальные производственные цепочки, то последнее направление является темой для стимулирования использования отечественных товаров вместо импортируемых иностранных (не нарушая норм ВТО). Определенное импортозамещение возможно в обоих направлениях. Вместе с тем, существует и «пограничный» аспект изучения машиностроительной части российского импорта - определение эффективности инвестирования в отрасли машиностроительного комплекса, которые могли быть стать отраслями международной специализации России - тяжелое, транспортное и арктическое машиностроение.

Второй по численности тип субъектов - продовольственный формируется 10 субъектами $(4,27 \%$ валового импорта). Среди них республика Алтай, республика Дагестан, Алтайский, Забайкальский, Краснодарский край, Астраханская, Брянская, Владимирская, Псковская и Тамбовская области $(q=0,797)$. Для данного типа структуры импорта четыре субъекта являются базовыми субъектами национального аграрно-промышленного комплекса (Республика Алтай, Алтайский и Краснодарский края, Тамбовская область). По всей видимости, значительная доля ввозимой продукции является, либо дополняющим ассортиментом, либо продукцией (сырьём) более конкурентоспособной по сравнению с местными видами продовольствия. Кроме того, значительность доля продовольственного импорта могло быть связана с крайне неблагоприятными природно-климатическими условиями периода исследования. Тем не менее, именно эти 4 субъекта должны быть рассмотрены на предмет импортозамещения.

Нефтехимический тип импорта характерен для субъектов $(1,63 \%)$, среди которых республики Хакасия и Калмыкия, Иркутская, Мурманская, Рязанская, Томская, Тульская области $(q=0,840)$. Судя по последнему показателю данный тип обладает наивысшим признаком структурной неоднородности среди всех выделяемых типов, т.е. своеобразной специализацией по импорту продукции нефтехимического цикла.

Группу субъектов с превалированием в структуре валового посубъектного импорта товаров $(2,92 \%)$, не вошедших в наиболее принятые составляющие импорта (названных прочими), составляют 5 субъектов: Приморский край, Еврейская автономная область, Амурская, Ивановская и Новгородская области $(q=0,771)$. Анклавное положение регионов и специфика их отраслевой структуры показывает, что основные виды импортируемой продукции относится к отраслям легкой промышленности, включая ввоз сырья. Для первых трех регионов это, в первую очередь, связано с географической близостью к Китаю. 
Остальные два типа формируют три оставшихся субъекта (0,44\% и 0,52\%, соответственно). Два их них - республика Ингушетия и Оренбургская область - образуют топливно-энергетический тип импорта $(q=0,766)$, а Волгоградская область $(q=0,732)$ представляет тип с превалированием импорта изделий металлургического профиля.

Таким образом, отраслевая структура импорта имеет большую неоднородность, чем подобная структура экспорта, которая определяется как специфическим сочетанием хозяйственных и социальных условий, так и природной основой. В случае импорта природная основа отодвигается на второй план, тогда как на первый план выходят сложившиеся производственно-хозяйственные и социальные факторы, напрямую связанные с проблемами импортозамещения.

\section{5 Выводы}

В результате исследования отраслевой структуры импорта каждого российского региона удалось выделить 6 типов субъектов РФ, которые наиболее точно отражают особенности регионального импорта: машиностроительный, продовольственный, нефтехимический, «прочие товары», топливноэнергетический, металлургический.

Перечисленные типы субъектов РФ по отраслевой структуре импорта позволяют сделать вывод, что в настоящее время импорт представляет собой достаточно компактную систему, связанную, в первую очередь, с ввозом в страну продукции машиностроения. У 70\% регионов (57 из 82 субъектов РФ) профильной статьей импорта является машиностроение. Импорт продовольствия также составляет весомую часть импорта.

По результатам проведенного исследования могут быть составлены рекомендации в следующих направлениях:

1. Развитие собственного машиностроения.

2. Стимулирование импортозамещения.

Как показывает наш эмпирический анализ, существует огромный спрос на машиностроительную продукцию, удовлетворяемый за счет импорта $(45,4 \%$ в валовом импорте). Эти же цифры свидетельствуют о том, что преждевременным и неправильным был отказ от проведения промышленной политики, от развития отечественного машиностроения. Необходимо развивать «арктическое машиностроение», авиастроение и транспортное машиностроение, являющиеся актуальными для жизнедеятельности страны. А с учетом разнообразия и большого количества регионов-импортеров с их налаженными и устойчивыми международными кооперационными связями, а также достаточного количества регионов-экспортеров машиностроительной продукции, эти и другие отрасли машиностроения России могли бы стать отраслями специализации. Сказанное означает активизацию участия страны в системе международной производственной кооперации, поставляя за рубеж и приобретая готовые изделия, детали и компоненты.

Что касается импортозамещения, важно формировать условия для роста производства в базовых отраслях экономики и для стимулирования производства в тех отраслях и регионах страны, где имеются конкурентные преимущества. С другой стороны, визуализация результатов нашего исследования показывают на существование регионов и отраслей, напрашивающихся на «явное» импортозамещение. Например, трудно объяснить топливную импортную ориентацию Республики Ингушетия и Оренбургской области или продовольственный импортный профиль Краснодарского края и Тамбовской области. Данные виды продукции могли бы определить их экспортную специализацию.

В завершение следует отметить, что развитие машиностроения и поддержка аграрнопродовольственного комплекса страны должны оставаться приоритетными в стратегическом развитии страны, базой для решения инновационных задач современной экономики (развитие нанотехнологии, биотехнологии, ИТ, новых материалов и т.д.).

\section{Литература}

- Aleksashenko, S., 2012. "Russia's economic agenda to 2020" International Affairs, Vol. 88, No 1, P. 31-48.

- Connolly, R., 2011. "Financial constraints on the modernization of the Russian economy" Eurasian Geography and Economics, Vol.52, No 3, P. 428-459.

- Fal'tsman, V. K., 2015. "Forcing import substitutions in a new geopolitical situation" Studies on Russian Economic Development, Vol. 26, No 1, P. 15-21.

- $\quad$ Kashbrasiev, R.V., Stepin, A.G., Shtanchaeva, M.R., Maklakova, N.V., 2014. "Typology of Export Specialization of the Russian Regions” Mediterranean Journal of Social Sciences, Vol. 5, No 24, P. 453-457.

- Блажко, Н.И., Григорьев, С.В., Заботин, Я.И., 1970. Математико-географические методы исследования городских поселений. Казань, Изд-во Казанского университета.

- Кендалл, М., Стюарт, А., 1976. Многомерный статистический анализ и временные ряды. М.: Наука, Т. 3

- Россия в цифрах и картах, 2015. URL: http://www.sci.aha.ru/map/rus/index.htm 


\title{
Торгово-экономические связи раннесредневекового Кыргызского государства
}

\section{Trade and Economic Relations of Early Medieval Kyrgyz State}

\author{
Assoc. Prof. Dr. Muratbek Kozhobekov (Kyrgyz-Turkish Manas University, Kyrgyzstan)
}

\begin{abstract}
According to written sources of trade with neighboring countries occupied an important place in the economy of the Kyrgyz State. That would create a successful economy, as well as to meet the needs of consumers the Kyrgyz State established extensive trade links in the Central Asian region. Trading partners of the Kyrgyz in the early middle ages were economic developed countries East and Central Asia. This reflects the fact that the degree of development of the Kyrgyz people related to trading partners. In general terms, the characteristics of the Kyrgyz State trade relations with neighboring countries in the period VII-X centuries. Thus, definition and comparison of different time in bars allow you to re-evaluate the economic and political aspects of the problem components.
\end{abstract}

По свидетельству письменных источников торговля с соседними странами занимала значительное место в экономике Кыргызского государства. Что бы создать успешную экономику, а также для удовлетворения нужды народного потребления Кыргызское государство наладило обширные торговые связи в центрально-азиатском регионе. Торговыми партнерами кыргызов в период раннего средневековья были экономические развитые государства Востока и Средней Азии. Данный факт свидетельствует тому что, степень развития производства кыргызов соответствовала потребностям торговых партнеров. Перефразируя классиков марксизма можно констатировать, что сотрудничество между разными народами зависит от того, насколько каждая из них развила свои развила свои производительные силы и от степени углубления разделение труда (Маркс, Энгельс, 1966: 24).

Несмотря на отдаленность страны кыргызов от основной магистрали Великого шелкового пути, они активно участвовали в ее функционировании. Согласно восточных авторов, для этого у них имелись свои пути сообщения. Торговые пути которые выходили от страны кыргызов соответствовали географическому месторасположению основных экономических партнеров. Одна дорога которая вела на северо-восток связывала государство кыргызов с Дальним Востоком. Другая шла на запад к верховьям Иртыша, таким образом соприкасаясь с древним «Степным путем». Кроме вышеперечисленных путей, имелись дороги идущие на юг - к уйгурам и на юго-восток, соединяющие ставку кыргызского кагана с «уйгурской дорогой».

Оживленные торговые отношения складываются в период образования Кыргызского государства, когда внешняя граница каганата «простиралась до Гулигани (район оз. Байкал-М.К.), на юг до Тибета (т.е. до Восточного Туркестана-М.К.), на юго-запад до Гэлолу (район Семиречья-М.К.) (Бичурин, 1950: 351-355). Именно в этот период политического могущества кыргызы устанавливают дипломатические и торговые связи с Китаем. Факт отправки в 632 г. в государство Кыргыз китайского посланника Ван и-хуна (Супруненко, 1963: 63, 67-81), а также ответное посольство кыргызов в 643 году, когда они «отправили посланника пинести в дань китайскому двору соболиные шубы и соболиные шкуры» (Кюнер, 1961: 56), следует рассматривать первым актом установления отношений между двумя государствами. Судя по письменным источникам, 643 по 747 гг. кыргызы в Срединное государство отправили одиннадцать «посольств» (Супруненко, 1963: 67-81). По авторитетному мнению академика В. В. Бартольда, прибытие торгового каравана рассматривалось китайцами, как прибытие посольства (Бартольд, 1963: 253), а приношение «дани» послами следует понимать как доставление купцами различных товаров, производимых в стране кыргызов.

Судя по характеру письменных источников, виды товаров ввозимых купцами в Китай, были продукции кочевого животноводства, охотничьего помысла, а также изделия кузнечного ремесла.

В Китае особо ценились меха пушных зверей, а также знаменитые кыргызские лошади. Краткое перечисление летописцами домашних животных кыргызов возможно говорить, о значительном интересе ими китайской стороной. Поэтому следует предполагать, о том что кыргызские купцы на китайский рынок поставляли «верблюдов, но более коров и овец» (Киселев, 1947: 94). Свидетельством тому является тот факт, что за 13 лет торговли с тюрками в начале VIII века поголовье скота в Китае выросло почти в два раза, если к 713 г. лошадей насчитывалось 240 тыс., а быков 35 тыс., баранов - 112 тыс., то к 726 году оно соответственно выросло: лошадей - 430 тыс., а быков - 50 тыс., баранов - 286 тыс. (Зуев, 1960: 95). 
При торговле кыргызов с Китаем приоритет отдавался обмену лошадей на шелк. Если в благоприятные годы эквивалентной стоимостью одной лошади было 15-20 кусков шелка, то в начале IX в., в годы джутов за каждую лошадь платили 40-50 кусков шелка (Кызласов, 1969: 120).

Кроме домашнего скота кыргызы продавали в Китай лесоматериалы, ценные ископаемые и продукцию из них, искусно изготовленное кыргызскими ремесленниками и высоко ценимые китайцами оружие, рог хуту или же ручки ножей из рога хуту (Бартольд, 1963a: 493).

В письменных источниках, ввиду установившейся традиции китайских хронистов, отсутствуют данные взамен получаемых товаров кыргызскими купцами. Но археологические материалы ярко свидетельствуют, что кыргызские товары обменивались на шелковые ткани - традиционный предмет китайского экспорта, ввозились металлические изделия - плуги с отваломя, сбруйные принадлежности (Киселев, 1947: 94), а таже ювелирные изделия и зеркала, изделия из фарфора (Кызласов, 1969: 120).

В результате интенсивных торговых отношений в период VI-X вв., енисейским кыргызам поступали в больших количествах ханьские зеркала (Лубо-Лесниченко, 1975: 13-25), а также монеты. Среди множества находок отличается уникальная, и не имеющая аналогов в мире, позолоченная монета «цяньюнь чжунбао», свидетельствующая о богатстве и мощи кыргызского государства (Лубо-Лесниченко, 1975a: 162-164). Поступления китайских монет наиболее велики в период кыргызского великодержавия (Киселев, 1951: 120). Видимо китайские монеты не только служили эквивалентом товаров при торговле между двумя государствами, но и выполняли в кыргызском государстве функции обмена. Свидетельством тому может послужить тот факт, что на монете кайюань вырезана руническая надпись «бир чиким акча» одна расходная монета (Щербак, 1960: 139-141).

Помимо торговли с китайцами, кыргызы вели экономические отношения с восточными соседями китайцев - с чжурчженями. Подтверждением тому являются найденные в Минусинской котловине монеты тайхэ тунбао (Лубо-Лесниченко, 1975a: 162-164).

Письменные источники и материальные памятники свидетельствуют о тесных связях кыргызов с государством Ляо. А последние даже принимают из государства Кыргыз людей, «стремившихся к просвещению» (Кюнер, 1954: 12).

Несомненный интерес вызывают торговые отношения кыргызов с юго-западными и западными соседями, в будущем объект военной экспансии против уйгур и массового переселения их с Енисея на Тянь-Шань По характеру письменных источников кыргызы были хорошо знакомы с этими странами и «сие государство (т.е. Кыргыз - М.К.) было в дружественных связах с Даши (Средняя Азия - М.К.), Туфанью (Тибет и Восточный Туркестан - М.К.) и Гэлолу (Бичурин, 1950: 351-355).

Там же сообщается, что «женщины (кыргызов - М.К.) носят платье из шерстяных и шелковых тканей, которые получают из Аньси (Куча - М.К.), Бэйтина (Бешбалык - М.К.) и Дася». Возможно, здесь торговые пункты Аньси и Бэйтин служили для переправы транзитных товаров, поступавших из Средней Азии и персии, в том числе узорчатых шелковых тканей «занденечи», хорошо известных даже на родине шелка в Китае (Беленицкий, Бентович, 1991: 70). О регулярной поставке этого товараговорит тот факт, что «их невозможно было уместить всего, то раскладывали на двадцать четыре верблюда. Такой караван отправляли один раз в каждые три года (Бичурин, 1950: 351-355).

Несмотря на многие вонные столкновения между кыргызскими и уйгурскими гсударствами, они не стали помехой существования торговых связей кыргызов с уйгурами.

Упомянутые в источнике получаемые кыргызами шерстяные ткани производились в Принаньшане (Малявкин, 1983: 234). И возможно эти товары поставлялись в государство Кыргыз через столицу Уйгурского государства Бешбалык.

В рассматриваемы период особо дружественные связи наблюдаются между кыргызами и Тибетом. Помимо политической близости между ними устанавливаются интенсивные торговые отношения. При перевозке товаров из Тибета, туфаньцы, опасаясь грабителей со стороны уйгуров, непременно отправлялись к карлукам, чтобы подаждать охраны из кыргызов. Кыргызы из Тибета получали предметы роскоши, дорогие ткани, посуду и богато украшенные оружия (Худяков, 1988: 130). Подтверждением дружественных связей между кыргызами Тибетом послужат сыглынские фрагменты тибетских рукописей на бересте, датируемых IX-X вв. (Грач, 1980:: 103-121).

Такова в общих чертах характеристика торговых отношений Кыргызского государства с соседними странами в период VII-X вв. Таким образом, определение и сравнение товарооборота в различные временные отрезки позволяют по новому оценить экономический и политические составляющие аспекты данной проблемы.

\section{Литература}

- Бартольд В. В. (1963а). История культурной жизни Туркестан.//Соч., - Т.ІІ. Ч. 1.

- Бартольд В.В. (1963б).Киргизы: Исторический очерк. //Соч. - М., 1963. - Т.2, ч.1. 
- Беленицкий А.М., Бентович И.Б. Из истории среднеазиатского шелкоткачества. (К идентификации средне-азиатского шелкоткачества) //Сов. археология. - 1961. - N2.

- Бичурин Н.Я. Собрание сведений о народах, обитавших в Средней Азии в древние времена. Т. 1-3 М.;-Л., 1950-1953. - Т.1.

- Грач А.Д. Древнекыргызские курганы у северной границы котловины Больших озер и находки тибетских надписей на бересте. //Страны и народы. Вып. XXII, 1980.

- Зуев Ю.А. Тамги лошадей из вассальных княжеств //Новые материалы по древней и средневековой истории Казахстана. - Алма-Ата, 1960.

- К Киселев С.В. Из истории торговли енисейских кыргызов //Крат.сообщ.о докл.и полевых исслед.Ин-та истории матер. культуры АН СССР.- 1947.-Вып.16.

- Киселев С.В. Древняя история Южной Сибири. -М., 1951.

- Кызласов Л.Р. История Тувы в средние века. -М., 1969.

- Кюнер Н.В. Новые китайские материалы по этнографии кыргызов (хакасов) VII-VIII вв. н.э. //Учен. зап. Хакас. НИИ яз., лит. и истории. - 1951. - Вып. 2.

- Кюнер Н.В. Китайские известия о народах Южной Сибири, Центральной Азии и Дальнего Востока. M., 1961.

- Маркс К., Энгельс Ф. Фейербах. Противоположность материалистического и идеалистического воззрений. М., 1966.

- Лубо-Лесниченко Е.И. (1975) Привозные зеркала Минусинской котловины. - Новосибирск, 1975.

- Лубо-Лесниченко Е.И. (1975а)Дальневосточные монеты из Минусинской котловины //История и культура Востока Азии. - 1975. - Т.3.

- Малявкин А.Г. Уйгурские государства в IX-XII вв. - Новосибирск, 1983.

- Худяков Ю.С. Кыргызы и Тибет/Эпоха камня и палеометалла Азиатской части СССР. Новосибирск, 1988.

- Щербак А.М. Еще раз о монетах с руническими надписями из Минусинска //Вестн. древ. истории. 1960. - N2 


\title{
Внешнеторговая деятельность индивидуального предпринимательства в Кыргызской Республике и общие проблемы его развития Foreign trade activities of individual enterprise in Kyrgyz Republic and issues of its development
}

\begin{abstract}
This article is dedicated to a complex evaluation of individual enterprise in Kyrgyz Republic. In general, this field determines the solution of many social and economic issues in the country. Among them are the organizations of population self-employment, development of business initiatives promoted by citizens, efficient use of population funds and strengthening of financial ground of local budgets. All mentioned above gives an opportunity to move to a more advanced level of business entrepreneurship. Based on the statistical data analysis it was possible to discuss the major development trends in individual enterprise and its impact on the economic progress of the country. One of the peculiar branches of individual enterprise is "shuttle trading" which has a very special feature in the economic development of Kyrgyz Republic. Possible ways are shown both for the development of individual enterprise and the "shuttle trading" in particular for near future. In addition, the restricting factors of individual enterprise are defined. There are several ways to support individual enterprise by means of dedicated tax policy, mainly through the system of tax allowance consisting of support individual enterprise. Determination of the development plan is very crucial, especially through the perspective of joining the Eurasian Customs Union.
\end{abstract}

\section{1 Введение}

Экономический рост общества традиционно характеризует показатель роста ВВП, но конкретно реализуется в процессе увеличения факторов производства и материальных благ, которые непосредственно связаны с трудом человека в производство. Именно этот фактор привносится предпринимателем на основе инициативы и собственников материальных ценностей.

В Кыргызской Республике в настоящее время действуют около 330 тысяч индивидуальных предпринимателей. Для сравнения: малых предприятий в 2013 г. насчитывалось около 12 тысяч, а средних предприятий - около 800. Таким образом индивидуальные предприниматели без организации юридического лица - самая многочисленная организационно-правовая форма ведения бизнеса в Кыргызской Республике. Это 45,5\% от общего числа предпринимателей, включая фермеров и крестьянских хозяйств и $96 \%$ без учёта последних. Однако и вклад индивидуальных предпринимателей в ВВП также значителен. Доля ВДС в ВВП в 2013 г. составила 17,3\%, на остальные формы предпринимательства - средние, малые предприятия и крестьянско-фермерские хозяйства - приходится соответственно: 7,6; 4,4 и 9,5\%.

Более $38 \%$ из общего числа индивидуальных предпринимателей работают в сфере оптовой и розничной торговли и обслуживании населения по ремонту автомобилей и мотоциклов. Этот сектор индивидуального предпринимательства (ИП) даёт более $43 \%$ от объема торговли, ремонта автомобилей, бытовых изделий и предметов личного пользования республики. То есть в этой сфере индивидуальные предприниматели занимают ведущую позицию в отличие от промышленности, где доля ИП в 2013 г. составила всего $8,4 \%$.

В целом эта сфера ИП определяет решение многих социальных и экономических вопросов страны. Если их ранжировать, то первое место следует определить организации самозанятости населения и развитию предпринимательских инициатив граждан, что в условиях развивающейся экономики очень важно. Далее ИП - это производительное использование средств населения и укрепление финансовой базы местных бюджетов муниципальных образований Кыргызской Республики. И, наконец, ИП - это стартовая площадка для перехода на более высокий уровень предпринимательской деятельности. Всё это обуславливает исследование торгового аспекта ИП, как наиболее представительной сферы этого сектора ведения бизнеса, и проблем его развития.

\section{2 Индивидуальное предпринимательство в сфере внешнеэкономической деятельности}

Индивидуальные предприниматели вносят определённый вклад в развитие внешнеэкономической деятельности. Если их значение в экспорте небольшое (от 3,0\% в 2008 г. до 5,7\% от общего объёма Кыргызской Республики в 2012 г.), то в импорте товаров массового потребления доля их весьма заметна более $20 \%$ в 2012 г. (табл. 1). И в целом за весь период внешнеторговый оборот ИП постоянно возрастал. Неопределённость и смутные ожидания вступления Кыргызской Республики в Таможенный союз 
отрицательно повлияли на развитие внешнеэкономической деятельности, экспортные и импортные операции заметно сократились - по ИП их доля уменьшилась в 2013 г. до 1,3\% и 14,9\% соответственно.

\begin{tabular}{|l|l|l|l|l|l|l|l|l|}
\hline \multicolumn{1}{|c|}{ Показатели } & 2006 & 2007 & 2008 & 2009 & 2010 & 2011 & 2012 & 2013 \\
\hline Экспорт МСБ & 36,0 & 29,3 & 41,7 & 25,7 & 25,9 & 27,9 & 35,0 & 28,7 \\
\hline $\begin{array}{l}\text { в том числе } \\
\text { индивидуальные } \\
\text { предприниматели }\end{array}$ & 3,0 & 4,0 & 4,6 & 3,6 & 4,7 & 4,7 & 5,7 & 1,3 \\
\hline Импорт МСБ & 52,6 & 40,8 & 69,7 & 65,8 & 63,5 & 60,5 & 57,3 & 52,1 \\
\hline $\begin{array}{l}\text { в том числе } \\
\text { индивидуальные } \\
\text { предприниматели }\end{array}$ & 5,3 & 5,3 & 23,4 & 17,6 & 15,9 & 18,8 & 20,5 & 14,9 \\
\hline
\end{tabular}

Таблица 1. Показатели внешнеэкономической деятельности МСБ КР (процент к общему объему).

Если проанализировать пострановую структуру внешнеэкономической деятельности (рис. 1) и за исходную точку взять кризисный 1998 год, то можно отметить: основную долю импорта вначале развития составляют страны вне СНГ (пик преобладания отмечен в 2008 г. на уровне 89,2\%), в экспорте большую долю занимают страны СНГ (87,7\% в 2011 г.). Обратные тенденции развития наблюдаются также в 2013 г.: если в завозе товаров индивидуальными предпринимателями соотношение стран СНГ и вне СНГ почти уравнялось (51,8 и 48,2 процентов), то в экспорте впервые стали преобладать страны вне СНГ (35,2 и 64,8 процентов).

Странами-лидерами в импорте товаров в 90-х годах были Китай, Германия, Объединённые Арабские Эмираты, Япония, Турция. В последние годы выстраивается несколько другой ряд: Китай (неизменно все годы), Япония, Германия, Турция, Корея. В экспорте основное место занимают фрукты и овощи, в импорте - все потребительские товары, в том числе предметы одежды и одежные принадлежности, а также бывшие в употреблении автомобили (в основном из Германии, Японии и Литвы).

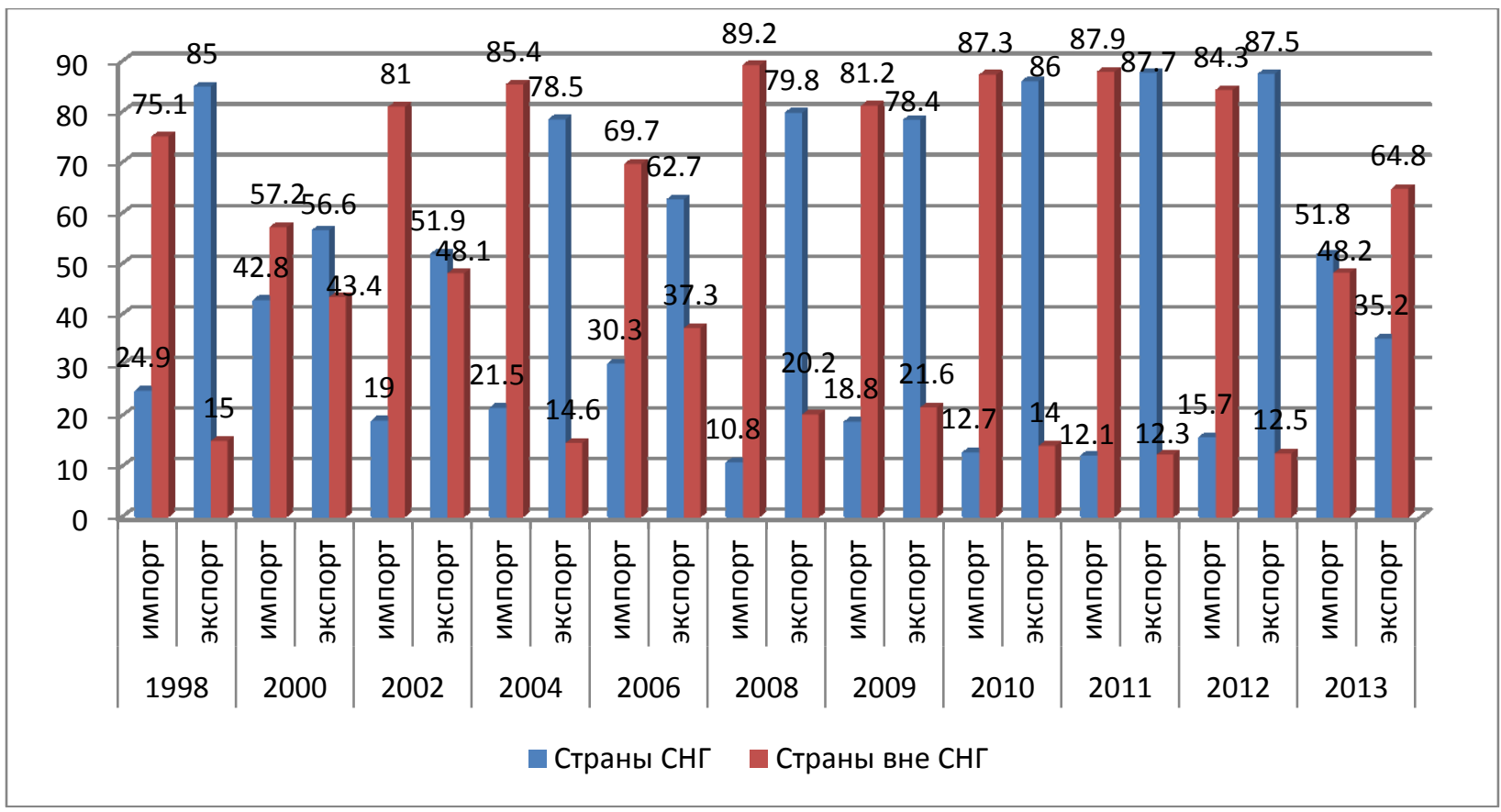

Puc. 1. Структура внешнеэкономической деятельности ИП по странам (процент к итогу).

Интересен анализ внешнеэкономической деятельности ИП в части закупки и реализации бывших в употреблении автомобилей, являющейся выгодной по причине низких ввозных таможенных пошлин в Кыргызской Республике. Так ещё в 2006-2007 гг. экспорт этих товаров преобладал над импортом в 27-30 раз (за счёт продажи завоза прошлых лет), но уже в 2008 г. картина кардинально переменилась: отмечено превышение импорта более чем в 75 раз. В 2012 этот разрыв превысил 300 раз: импорт ИП бывших в употреблении автомобилей составил 76088 штук, а экспорт - 251. Эти изменения вызваны изменениями в таможенном законодательстве в странах-членах Таможенного союза (ТC), в основном Казахстана и России. Таким образом, в настоящее время бизнес поддержанных автомобилей ориентирован в основном на внутренний рынок. С одной стороны это говорит о проблемах в развитии внешнеэкономической деятельности ИП в этом сегменте торговли в связи с условиями функционирования ТС, с другой стороны 
- это свидетельство роста среднего класса и в целом благосостояния населения в Кыргызской Республике.

Изучение отраслевой структуры индивидуального предпринимательства в Кыргызской Республике и внешнеэкономической деятельности ИП по странам позволяет сделать заключение, что в основном субъектами в этой сфере являются представители так называемого «челночного» бизнеса - формы международной торговли, начало развития которой было положено в 90-х годах XX в. в России и странах СНГ. «Челночная» торговля заключалась в импорте потребительских товаров физическими лицами с целью их продажи в розницу или мелким оптом в основном на внутреннем рынке. Кыргызская Республика в силу географического положения получила ещё и статус реэкспортёра: импортированные товары, в основном из Китая, вывозились затем такими же «челноками» в сопредельные районы России, Казахстана, Узбекистана и др. Возникновение «челночной» торговли в условиях товарного дефицита было связано, с одной стороны, с альтернативными возможностями для заработка, с другой - с появившейся возможностью свободного выезда за рубеж, а также таможенными льготами в отношении внешнеторговых операций физических лиц, что создавало челнокам конкурентные преимущества по сравнению с традиционными формами ведения торговли (Капралова Н.Л., Карасева Л.А., 2013).

«Челночная» торговля относится к ненаблюдаемой экономике, по которой нет полной и объективной информации: в соответствии с Постановлением Правительства Кыргызской Республики № 976 от 31 декабря 2004 г. таможенное оформление товаров и автотранспорта, перемещаемых через границу республики физическими лицами, ведется в упрощенном порядке по таможенному приходному ордеру. Однако в большей степени это связано с трудностями таможенного контроля за импортными товародвижениями, так как в этой сфере внешнеэкономической деятельности в связи с большими расходами при легальном оформлении груза бытует практика неформального урегулирования таможенных отношений, или оформление грузов с занижением таможенной стоимости, а также путем перекодировки товаров в пределах одной товарной группы, но с более низкой тарифной ставкой, что приводит к искажению данных об объемах импорта.

Всё же собранные статистические данные с учётом досчётов по принятой в статистике методике позволяют в определённой степени представить картину развития «челночной» торговли. В таблице 2 представлены данные по импорту физических лиц, не оформленные по грузовым таможенным декларациям (в 2007 г. - объёмы, не учтённые по грузовым таможенным декларациям).

\begin{tabular}{|c|c|c|c|c|c|}
\hline Годы & Импорт & Экспорт & Годы & Импорт & Экспорт \\
\hline 1994 & $\ldots$ & $\ldots$ & 2004 & 5,8 & 2,3 \\
\hline 1995 & 36.6 & $\ldots$ & 2005 & 87,4 & 2 \\
\hline 1996 & 54,2 & $\ldots$ & 2006 & 213,0 & 1,9 \\
\hline 1997 & 23,0 & 26,9 & 2007 & 376,4 & 186,9 \\
\hline 1998 & 27,8 & 21,4 & 2008 & 848,1 & 65,7 \\
\hline 1999 & 13,5 & 8,7 & 2009 & 417,0 & 43,6 \\
\hline 2000 & 3,9 & 6,4 & 2010 & 440,5 & 68,6 \\
\hline 2001 & 4,3 & 3,9 & 2011 & 672,8 & 87,4 \\
\hline 2002 & 2,9 & 1,8 & 2012 & 930,3 & 92,1 \\
\hline 2003 & 4,8 & 1 & 2013 & 892,5 & 25,3 \\
\hline
\end{tabular}

Таблица 2. Объёмы внешней торговли товарами физических лиц КР («челночная» торговля), млн. долл. Источник: Статсборник Внешняя торговля в Кыргызской Республике и данные Нацстаткомтета КР.

Определённо с начала появления в начале 90-х годов до кризисного 1998 г. наблюдалось интенсивное развитие этой сферы деятельности индивидуальных предпринимателей, что было вызвано имевшимся в Кыргызской Республике и других странах СНГ большим дефицитом потребительских товаров и представившейся возможностью закупки их в других странах. При этом ИП, как физические лица, имели таможенные льготы, что позволяло им существенно сокращать расходы на перевозку и успешно конкурировать с другими организационными субъектами экономической деятельности.

В кризисный период сумели выжить не все занятые в «челночном» бизнесе, а только самые крупные из них. Несмотря на введённые в этот период ужесточения, связанные с таможенным оформлением, повысившие налоговые тяготы, и снижение в связи с этим уровня рентабельности, положение начало выправляться уже в 2005 г. Объёмы импорта по «челночной» торговле в 2012 г. составили 81,6\% от общего объема импорта индивидуальных предпринимателей, экспорта - соответственно 83,7\%. 


\section{3 Перспективы развития индивидуального предпринимательства и налоговая политика}

Значение «челночной» торговли в развитии индивидуального предпринимательства и социальноэкономической жизни Кыргызской Республики столь велико, что интересы занятых в этой сфере стали одним из главных аргументов против вступления в Таможенный союз (ТС). В настоящее время в Кыргызской Республике функционируют крупнейшие в Центральноазиатском регионе вещевые рынки «Дордой», «Кара-Суу», «Мадина», имеющие многочисленные филиалы. Противники вхождения Кыргызстана в евразийский таможенный альянс предвещают социальный взрыв в случае, если занятие реэкспортом станет невыгодным бизнесом.

Невступление в ТС даёт возможность без особых усилий продержаться Кыргызской Республике ещё некоторое время, которое будет безвозвратно потеряно, чтобы не отстать от соседей и других стран ТС в своём развитии. Поэтому ТС представляется неким рубежом, переход которого позволит во главу угла поставить развитие производства (всякого, но, прежде всего, потребительских товаров массового потребления) и, соответственно, экспорта произведённой на территории Кыргызской Республики продукции, пусть и на импортируемом сырье из того же Китая. ТС даст необходимые импульсы Кыргызской Республике для возрождения своей индустрии, которая единственно является критерием развитости состоявшегося независимого государства. В то же время, это будет способствовать развитию внешнеторговой деятельности Кыргызской Республики, что будет оправдано для вхождения её в международное экономическое пространство в рамках ТС. Между тем уже сейчас по условиям деятельности ТС становится весьма проблематичными перепродажи за границу (в части автомобилей, бывших в употреблении, см. выше), о снижении деловой активности «челночного» бизнеса говорят сами торговцы (Tushtuk.kg, 2014). Поэтому в любом случае необходимо принятие срочных комплексных мер, способных мотивировать ИП на производственную деятельность уже в ближайшее время.

Для частичного перепрофилирования торговых рынков «Дордой» и «Кара-Суу» нужно на государственном уровне разработать разновекторные программы (по предоставлению кредитов, по подготовке кадров, инвестиционные, технологические и пр.), но важным и действенным представляется для целей развития индивидуального предпринимательства в сфере производства проведение целенаправленной налоговой политики, состоящей в поддержке малого бизнеса через систему налоговых льгот вплоть до полного освобождения от уплаты налога на прибыль и доходы в первые, например, три года деятельности.

Необходимость оказания государственной финансовой поддержки ИП вызвана неравными возможностями конкуренции с другими экономическими субъектами по разным проблемам хозяйствования, начиная от вопросов доступности к финансовым ресурсам и государственным инвестициям, и заканчивая вопросами переоснащения, приобретения новых технологий, а также исследования конъюнктуры рынков, обучения и пр.

Следует отметить, что в соответствии с налоговым законодательством 2008 г. упорядочена система налоговых проверок в отношении субъектов экономики, в том числе и предпринимателей. Относительное снижение налоговой нагрузки произошло через упрощение механизма уплаты налога на прибыль (предварительные ежеквартальные платежи). Однако для индивидуальных предпринимателей не предусмотрено никаких налоговых льгот ни по одному из подходов налогообложения (считается, что льготой является сама возможность уплаты налога по упрощённой схеме и патентам). Применяемая же ИП основная форма налогообложения на патентной основе содержит активно используемые соответствующими административными и контролирующими органами коррупционные схемы, которые, между тем, вполне могут быть устранены при проведении должных мер налогового администрирования.

Стимулирующая роль налогов в настоящее время в Кыргызской Республике используется недостаточно. Налогообложение ИП в основном, как упоминалось, осуществляется на основе разных форм патентов: добровольных и обязательных. Причём при уплате добровольного патента имеется альтернатива: избрать форму налогообложения по общеустановленной схеме (налог на прибыль). Однако ведение налогового и бухгалтерского учёта в соответствии с международными стандартами, действующими в Кыргызской Республике, в некоторой степени усиливает налоговую нагрузку, что изначально предопределяет выбор ИП в пользу патентов, которые имеют определенные достоинства, вопреки мнению отдельных исследователей о неэффективности и постепенном их изживании. Упрощённые формы налогообложения имеют место и в условиях развитой западной экономики, например, так называемое паушальное налогообложение (Lump sum), означающее замену нескольким налогам суммарной платой (Бектенова Д.Ч. и др., 2011).

Вместе с тем патентная форма налогообложения ИП имеет некоторое отступление от основных принципов налогообложения, в частности, справедливости и равномерности: фактические доходы налогоплательщиков отклоняются от вменённых (средних) как в сторону увеличения, так и уменьшения. Соответственно, налоговая нагрузка одних будет занижена, других - завышена. Кроме того, 
налогообложение индивидуальной предпринимательской деятельности на основе патентов может быть использовано (и используется в условиях высокой коррумпированности общества в Кыргызской Республике) в развитии теневого сектора экономики. И это перечеркивает все имеющиеся достоинства патентного налогообложения.

В этой ситуации лучше обеспечивать реализацию основных принципов налогообложения через совершенствование общей схемы налогообложения (налога на прибыль), которая в современной редакции (Налоговый кодекс Кыргызской Республики, раздел VIII) не популярна среди ИП в виду отсутствия каких бы то ни было налоговых льгот. Так, в отличие от физических лиц, уплачивающих подоходный налог с доходов от занятости, ИП не имеют вычетов: ни стандартных, ни социальных, ни имущественных, не говоря уже о вычетах расходов по предпринимательской деятельности, если они не подтверждены документально на основании ведения бухгалтерской отчётности.

Следует признать, что реформирование системы налогообложения в 2008 г. в части ИП проведено несколько половинчато. Те же вычеты, например, о которых упоминалось выше, переняты из российской практики налогообложения. Однако в соответствии с Налоговым кодексом РФ они распространены и на ИП (здесь они платят налог на доходы физических лиц), более того - они и трактуются шире, то есть эти льготы более значимы. Так, социальные вычеты включают не только расходы на образование, но и на пожертвования и медицинские услуги (Налоговый кодекс Российской Федерации, статья 219). Так же и по имущественным вычетам, предоставляемым не только в связи с уплатой ипотечного кредита (как по Налоговому кодексу Кыргызской Республики).

Существенной поддержкой ИП в Кыргызской Республике было бы использование российского опыта налогообложения доходов субъектов этой категории МСБ. Общая схема предусматривает предоставление индивидуальным предпринимателям без организации юридического лица профессиональных налоговых вычетов на суммы фактически произведённых расходов, непосредственно связанных с извлечением доходов от предпринимательской деятельности (Налоговый кодекс Российской Федерации, статья 221) при определении налоговой базы по налогу на доходы физических лиц. При невозможности документального подтверждения своих расходов, связанных с предпринимательской деятельностью, зачастую имеющих место, вычет производится в размере $20 \%$ общей суммы доходов, полученной ИП.

Вполне справедливым будет применение к ИП также стандартных, социальных и имущественных вычетов, прописанных налоговым законодательством для физических лиц по подоходному налогу (Налоговый кодекс Кыргызской Республики, статьи 170, 171, 172). В самом деле, почему чиновник (или другой работник), получающий определённую заработную плату и имеющий гарантию в виде социального пакета, имеет право на эти вычеты, а индивидуальный предприниматель, получающий доход от самозанятости, сопряженной практическими сложностями, и рискующий по определению всем своим имуществом в случае банкротства, их не имеет?!

\section{4 Выводы}

Исследование вопроса состояния и деятельности предпринимателей без образования юридического лица в Кыргызской Республике позволяет заключить:

1. ИП БОЮЛ в КР являются ведущей формой ведения бизнеса как по численности, так и по вкладу в ВВП страны.

2. Роль ИП в развитии внешнеэкономической деятельности характеризуется относительно заметной долей в импорте товаров массового потребления - более $20 \%$ от общего объёма КР в 2012 г. И в целом за весь период внешнеторговый оборот ИП постоянно возрастал. Неопределённость и смутные ожидания вступления КР в ТС отрицательно повлияли на развитие внешнеэкономической деятельности, экспортные и импортные операции заметно сократились.

3. Анализ пострановой структуры ВЭД позволяет отметить: основную долю импорта в начале развития составляли страны вне СНГ, в экспорте большую долю занимали страны СНГ. Обратные тенденции развития наблюдаются также в 2013 г. в связи с функционированием ТС: если в завозе товаров индивидуальными предпринимателями соотношение стран СНГ и вне СНГ почти уравнялось, то в экспорте впервые стали преобладать страны вне СНГ.

4. Анализ отраслевой структуры ИП в и ВЭД ИП по странам позволяет сделать заключение, что в основном субъектами в этой сфере являются представители «челночного» бизнеса - импорта потребительских товаров физическими лицами с целью их продажи в розницу или мелким оптом на внутреннем и внешнем рынках (сопредельные районы России, Казахстана, Узбекистана и др.).

5. Значимость «челночной» торговли в развитии ИП и социально-экономической жизни Кыргызской Республики определяет защиту интересов занятых в этой сфере при вступления в ТС, который даст необходимые импульсы для возрождения промышленности, являющейся критерием развитости состоявшегося независимого государства. 
6. Для эффективного развития ИП КР в условиях ТС в рамках Евразийского экономического сообщества требуется активная поддержка государства, направленная на цели скорейшей переориентации основной массы ИП с торговой сферы на производственную путём использования стимулирующей роли налогов.

7. В силу незначительности налоговых льгот в этой сфере (не считая различных форм упрощённого налогообложения, нагрузка по которым также велика), то государственная финансовая поддержка должна быть оказана, прежде всего, посредством предоставления существенных налоговых преференций, например, в виде инвестиционного налогового кредита или других льгот по налогу на прибыль, способствующих развитию предпринимательства в регионах (вплоть до полного освобождения от налога на доходы от производственной деятельности ИП в первые три года функционирования), а также предоставления всех вычетов, в том числе и профессиональных, при определении базы налога на прибыль ИП по общей схеме (декларации), что и предполагается при использовании российского опыта налогообложения доходов субъектов этой категории МСБ.

\section{Литература}

- Бектенова Д.Ч., Фынчина, Х.А., Кененбаева Г.А., 2011. «Налоговое регулирование предпринимательской деятельности». Материалы международного конгресса «Предпринимательство». Бишкек: КТУ «Манас». С. 198-203.

- Гражданский кодекс Кыргызской Республики от 8 мая 1999 г. (с изменениями и дополнениями по состоянию на 30.05.2013).

- Долоталиева Д. «Кыргызстан рискует потерять рынок «Дордой», 18.03.2014. http://www.tushtuk.kg/econom/14878.

- З Закон Кыргызской Республики «О защите прав предпринимателей» от 1.02 .2001 г. (с изменениями и дополнениями по состоянию на 30.07.2013).

- Капралова Н.Л., Карасева Л.А. «Феномен челночной торговли в российской экономике и его эволюция», www.hse.ru/data/209/669/1234/Капралова.doc.

- Налоговый кодекс Кыргызской Республики от 17 октября 2008 г. (с изменениями и дополнениями по состоянию на 15.03.2014 г.).

- Налоговый кодекс Российской Федерации от 19.07.2000 (действующая редакция от 30.01.2014).

- Статистические сборники «Кыргызстан в цифрах», Малое и среднее предпринимательство в Кыргызской Республике за периоды с 1992 по 2013 гг. и Внешняя торговля в Кыргызской Республике 1995-1999, 2000-2004, 2005-2009 гг., 2007-2013 гг. 


\title{
Государственный маркетинг как фактор, влияющий на укрепление макроэкономических показателей страны State Marketing as a Factor in the Strengthening of
Macroeconomic Indicators
}

\author{
Prof. Dr. Anara Kamalova (Academy of Management, Kyrgyzstan)
}

\begin{abstract}
This article deals with the state of marketing and its role in strengthening macroeconomic indicators of the Kyrgyz Republic, but it does not apply in the country properly. The need for the use of state marketing is intensifying with the entering of Kyrgyzstan to EEU as a member. To improve the structure of foreign trade, it is proposed marketing initiatives and research on the study of the external market, the internal potential of the country, specialization of production, the creation of "umbrella brand" for the country, the best way of satisfying consumers of public services, effective control of the quality and safety of products, regulation of the relevant parameters, that meet international standards, the fight against counterfeit, creating a positive image of Kyrgyzstan in the world and others.
\end{abstract}

В современных условиях развития экономики Кыргызской Республики, когда рыночная экономика набирает все большую силу, удовлетворение потребности народа на товары и услуги является одним из главных задач всех субъектов рынка: государства, предприятий и организаций, так как от этого зависит общее состояния развития экономики страны в целом. В этих условиях резко возрастает значение применения достижений различных областей науки к практическому решению государственных задач, что в свою очередь значительно усиливает роль внедрения государственного маркетинга на практике.

Маркетинг в тесном взаимодействии с другими научными направлениями выявляет потребности субъектов рыночных отношений, дает оценку ситуации на рынке и анализирует тенденции его развития, обеспечивая продвижение товаров и услуг до потребителя и организуя реализацию товаров. Это следует из понимания сущности маркетинга как понятия предусматривающее постулат - «...производите и продавайте только те товары, которые, безусловно, будут куплены...».

Специфика государственного маркетинга наиболее четко просматривается при сравнении его с политическим и экономическим маркетингом. В условиях рыночных конкурентных отношений основные характеристики государственного, экономического и политического маркетинга существенно различаются (Фоканова Л. К., 2012).

В политическом маркетинге субъектами выступают политические партии и движения, объектами являются избиратели, активные социальные слои и общественные организации. Целью этого маркетинга является получение поддержки общества для достижения и удержания власти. Предлагаемые продуктыполитические программы, политические лидеры и организации, идеология. Особенностями рынка являются сильная конкуренция, множество соперников и значительное влияние внешних факторов (например, состояние экономики, вмешательства государства в избирательные процедуры и т.д.) (Окландер М., 2003).

В экономическом маркетинге субъектами выступают фирмы, пред-приятия, промышленные и финансовые группы, объектами являются обладающее покупательной способностью население, предприятия, конкуренты, выпускающие продукцию с аналогичными потребительскими характеристиками. Целью экономического маркетинга является получение максимальной прибыли.

В государственном маркетинге субъектами выступают государственные органы и учреждения управления на всех уровнях, при этом объектами являются граждане, социальные группы, государственные и частные организации. Товаром выступают государственные услуги, товары и социальные программы. Целью маркетинговой деятельности является их реализация и распределение. Особенности рынка определяются высокой степенью монополизации всех процессов, а также безусловным доминирующим влиянием бюрократии и правовых норм, устанавливаемых самим же государством. Деятельность государства «перекрывает» почти все известные виды маркетинга:

- маркетинг товаров массового спроса;

- $\quad$ маркетинг товаров производственного назначения;

- социальный маркетинг ;

- некоммерческий маркетинг;

- $\quad$ макромаркетинг . 
- $\quad$ маркетинг услуг;

Сфера государственного обслуживания даже в условиях развития частной собственности очень широка. К государственному сектору в любом случае будут относиться судебная система и армия, силовые министерства, система образования, институты социального обеспечения, биржи занятости, пожарная охрана и т.д. Государство обширно представлено в сферах производства (например, оборонного) и социальных услуг (Котляров И. Д., 2012) .

Маркетинг в государственном управлении имеет свою специфику, которая определяется следующими основными чертами:

1. Не вполне рыночный характер отношений.

2. Маркетинговая деятельность весьма масштабна по сфере действия, рассчитывается на длительные периоды, происходит в сравнительно стабильных условиях и привлекательна для предпринимателей.

3. Значительная часть активности протекает в форме участия в конкурсных процедурах (открытых аукционах, тендерных торгах).

4. Маркетинг реализуется в условиях более высокой, чем в коммерческой сфере, открытости и контролируемости со стороны общества. В этой связи важнейшую роль приобретают коммуникационные инструменты маркетинга, в частности, PR-технологии.

5. Высокая зависимость рынка государственных заказчиков от положений нормативных актов, решений, принятых органами власти, политической конъюнктуры.

Поэтому повысить эффективность государственного управления без активного использования маркетинга представляется для нас достаточно проблематичным, а сложность рыночных процессов и особенности участие в них государства требуют в настоящее время выделение в системе маркетинга такой его разновидности как государственный маркетинг (Сафрин А.А, 2013) .

Государство как субъект маркетинга рядом с продавцами и потребителями выполняет на рынке специфическую роль. Не удовлетворяя непосредственно потребности потребителей, оно должно регулировать этот процесс и оказывать содействие эффективному достижению компромисса интересов с минимальными затратами общества. Это обусловлено необходимостью рассматривать экономические и социальные процессы в единстве и взаимодействии. При этом государство в отличие от отдельного предприятия заинтересовано в эффективном функционировании экономики в целом. С другой стороны, государство можно рассматривать с точки зрения предоставления гражданам важных социальных услуг (здравоохранение, просвещение, безопасность, охрана окружающей среды и т.п.). Вышеприведенные обстоятельства указывают на необходимость обеспечения маркетингового подхода к государственному управлению, как в целом, так и при проведении отдельных экономических реформ.

В научной литературе сегодня ряд авторов делают акцент на необходимости более широкого использования маркетинга для усовершенствования государственного управления. На необходимости широкого применения государственного маркетинга настаивает М. Окландер. Он указывает, что «национальный, региональный и муниципальный маркетинг есть формы проявления, разновидности территориального (государственного) маркетинга» (Окландер М., 2003).

Так, Н. Куденко указывает, что необходимо различать такие разновидности маркетинга, как макромаркетинг и микромаркетинг: макромаркетинг применяют на уровне государства, т. е. экономики страны в целом, а микромаркетинг - на уровне фирмы (Бендриков А.М., 2014).

Государственное управление можно рассматривать как деятельность органов и учреждений всех ветвей государственной власти, направленной на определение целей развития, разработку и осуществление регулирующих, организующих и координирующих влияний на все сферы общества для удовлетворения потребностей граждан, которые постоянно изменяются, и достижение поставленных общественных целей развития (Ильясов Ф.Н., 2010). Целью государственного маркетинга должно быть в первую очередь максимальное удовлетворение потребностей граждан (материальных и духовных) в рамках выделенных общественных затрат. Государственный маркетинг должен изучать потребности и интересы, т. е. их суть, структуру, приоритетность, факторы и тенденции развития. Достижение поставленной общественной цели предусматривает поэтапное выполнение определенных задач и удовлетворение потребностей членов общества в зависимости от их приоритетности и важности. Эффективная разработка «дерева целей» без применения маркетинга сегодня достаточно проблематична.

Усовершенствование государственного управления должно предусматривать использование маркетинга как важного средства поступательного развития всей социально-экономической системы и отдельных ее подсистем, обеспечение ее сбалансированного развития и формирования оптимальных макроэкономических пропорций между ее элементами. Актуальность этих проблем возрастает, поскольку просчеты в государственном управлении, в значительной мере связанные, по мнению В.В. Цветкова, с тем, что властные структуры во многих случаях действуют эмпирически, весьма 
нерациональным способом проб и ошибок, не учитывают интересов многих социальных групп населения (Ильясов Ф.Н., 2010).

Как отмечает Сафрин А.А. «Маркетинг в исполнении государственных органов имеет определенные особенности, из-за того что эти органы не всегда непосредственно удовлетворяют эти потребности, а лишь опосредствованно оказывают содействие этому. В сравнении с задачами, которые решает маркетинг на уровне отдельного предприятия, цели государственного маркетинга намного масштабнее и более сложные. Так, если на предприятии маркетинг обеспечивает продвижение узкого ассортимента товаров, то на уровне государства он разносторонний, что требует комплексного и сбалансированного подхода к удовлетворению потребностей потребителей на основе формирования и развития соответствующих логистических систем как на уровне отдельных регионов и в разрезе товаров, так и на уровне государства. Кроме того, необходимо учитывать и такие факторы, как экологические, политические и пр. Это означает, что государственный маркетинг должен быть социально ориентирован (Сафрин А,А., 2013).

Таким образом, мнение всех авторов сводится к тому, что настоящее время без применение государственного маркетинга решить государственно важные проблемы по укреплению макроэкономических показателей, удовлетворении потребности потребителей на высоком уровне и т.д не получиться. Необходимость использования маркетинга органами государственной власти связана также и со сложной экономической ситуацией в стране и процессами глобализации в мире.

Основным направлением государственной политики в рыночной экономике является поддержка и развитие конкуренции, и обеспечение высокого уровня конкурентоспособности национальных производителей. Для решения этих проблем отдельное предприятие имеет ограниченные возможности и ресурсы, поэтому именно государство должно взять на себя решение сложных и масштабных задач. Для обеспечения необходимого уровня конкуренции в распоряжении государства есть довольно действенные инструменты регулирования, которые можно разделить на прямые и косвенные, и которые направлены на регулирование объемов производства, экспорта и импорта конкретных групп товаров. В этой связи именно маркетинговая концепция государственного управления должна обеспечить более эффективное и качественное выявление, формирование и удовлетворение потребностей потребителей.

Государственный маркетинг должен использоваться в первую очередь для решения следующих основных задач:

- обеспечение стабильности в государстве;

- $\quad$ анализ рынка, его структуризация, анализ и прогнозирование общественного спроса на товары и услуги;

- $\quad$ регулирование экспорта и импорта в зависимости от состояния внутреннего и внешнего рынков с помощью маркетинговых инструментов;

- повышение конкурентоспособности собственных производителей и защита внутреннего рынка;

- формирование положительного имиджа государства;

- $\quad$ всесторонняя помощь отечественным предприятиям для выхода на внешние рынки;

- проведение рекламных мероприятий на государственном уровне, использование государственных структур для продвижения товаров на внешних рынках (через дипломатические представительства);

- $\quad$ содействие формированию оптимальных межотраслевых и региональных пропорций, развития конкуренции, обеспечение равных условий бизнеса для всех субъектов рынка;

- законодательное обеспечение и создание соответствующих условий для реализации законов;

- стабилизация рынка товаров и услуг.

Кыргызская Республика выбрала себе рыночный путь развития, где минимизируется роль государства. В таких условиях социально-экономические процессы в обществе достаточно сложны и противоречивы. Решения, которые принимаются государственными органами без объективной и достоверной информации, широкого обсуждения и консультаций в обществе, часто вызывают недовольство отдельных социальных групп. Необходимость активного использования маркетинга видна и в активном влиянии государства на потребителей. Анализ структуры потребления населения Кыргызстана показывает, что ни количественно, ни качественно она не отвечает научно обоснованным нормам. Контроль над качеством и безопасностью продукции, регламентирование соответствующих параметров, которые отвечают международным стандартам, борьба с фальсифицированной продукцией и информирование населения о таких фактах должно стать одними из задач государственного маркетинга. С одной стороны, государство должно влиять на формирование правильного потребительского поведения граждан, а с другой стимулировать производителей на удовлетворение рационального спроса с помощью комплекса государственных маркетинговых мероприятий и инструментов. 
Отрадным моментом является вступление Кыргызской республики в 2015 году в состав ЕАЭС, что открывает кыргызским товаропроизводителям новые рынки сбыта и тем самым дает большие возможности в создании условий для экономического роста. В этих условиях важной составной частью государственного маркетинга должна быть поддержка кыргызских производителей на внешних рынках, так как во многих случаях без политической поддержки выход на внешние рынки становится проблематичным. Как показывал недавняя ситуация сложившаяся в России, когда основные Европейские страны объявили экономические санкции, некоторые дружелюбные к России страны рассчитав свои возможности сразу предложили свои товары, а Кыргызстан не смог этого делать. Это говорить о том, что на государственном уровне не применяется маркетинг, не ведется маркетинговые исследования внутреннего потенциала страны и не знают продовольственный рынок России. Поэтому не медлительно необходимо решить эти проблемы и в первую очередь на Правительственном уровне необходимо создать рабочую маркетинговую группу, из числа грамотных маркетологов умеющий организовать государственный маркетинг. Государственный маркетинг должен обеспечить возможность более оперативного реагирования на изменения и колебания ситуации на рынке, более полно учитывать не только экономические, но и социально-психологические факторы. Для принятия качественных управленческих решений и обеспечения эффективного функционирования экономики органам государственного управления нужна не только обобщенная информация о состоянии товарных рынков, но и конкретные данные о региональных рынках и особенно информации о пустых сегментах рынка стран членов ЕАЭС.

Формирование положительного имиджа государства в мире - эта также важная задача государственного маркетинга. После нескольких беспорядков в республике (революций) и ситуации на золоторудном комбинате «Кумтор», Кыргызстан потерял в некотором роде свой положительный имидж в мировом сообществе. В этих условиях создание положительного имиджа для страны - первостепенная задача государственного маркетинга. Необходимо на наш взгляд, разработать соответствующую маркетинговую программу активного, правдивого и привлекательного «государственного пиара» для страны.

Являясь членом стран ЕАЭС и применяя основные стратегии государственного маркетинга, Правительство Кыргызстана должно оказывать содействие усовершенствованию региональной специализации производства. Особенно актуально это в сельском хозяйстве, где эффективность производства во многом зависит от правильного выбора специализации в зависимости от природноклиматических условий, наличия путей сообщения и мобильности предприятий, рыночной инфраструктуры, способных обеспечить эффективный обмен продукцией между регионами, особенно экспортируя в другие страны ЕАЭС.

Необходимо отметить, что для облегчения продвижения отечественного продукта на внешнем рынке и для экономии финансовых средств необходимо, на наш взгляд, разработать для Кыргызстана так называемый «зонтичный» бренд. Это такой единый для товаров республики бренд, под которым будет представляться все экспортируемые товары Кыргызстана. (например можно было бы разработать такие простые, быстро запоминающие бренды как «Страна KG», «+996 KG» и т.д.)

Одной из функций государственного маркетинга может быть и законодательное регулирование внешнеторговой, маркетинговой (рекламной) и др. деятельности в целях недопущения отрицательного влияния на потребителей, создания условий для равноправной конкуренции на рынке. Маркетинговые средства должны эффективно использоваться на всех этапах подготовки, принятия и реализации управленческих решений, в том числе и при принятии действенных законов. В частности, следует обратить внимание на необходимость использования инструментов маркетинговой коммуникации, что позволит сделать более открытой и демократичной систему государственного управления.

Маркетинговые исследования должны определить ориентиры на будущее, которые позволят сформулировать задачи социальной и экономической политики государства на перспективу. Такая информация будет способствовать принятию правильных и объективных управленческих решений с учетом особенностей развития ситуации во времени и пространстве, позволит предотвратить или уменьшить негативные последствия экономических и социальных кризисов. Особое внимание следует обратить на роль средств массовой информации. В условиях информационного общества эти средства становятся активными участниками влияния на сознание людей и экономическую ситуацию на рынке. Представленные в них материалы и сюжеты способны в очень короткий срок спровоцировать определенный ажиотаж и вызвать социальное напряжение. В то же время информация, по признанию самих журналистов, часто подается необъективно и односторонне. Учитывая то, что не все СМИ всегда объективно освещают события, информационная работа органов государственного управления (можно сказать, «государственный пиар») должна быть активной, правдивой и своевременной. Как мы уже отмечали, в условиях рынка возможности административных методов управления уменьшаются, поэтому актуальным становится повышение авторитета власти через рекламу ее достижений, организации презентаций, широкое и открытое обсуждение планов и программ деятельности. 
Таким образом, государственный маркетинг должен стать неотъемлемой частью системы государственного управления в стране в условиях рынка, а его основной задачей является максимальное удовлетворение разумных потребностей населения за счет собственных производителей, для которых государство должно создать наиболее благоприятные условия развития. С этой целью должна быть разработана стратегия и тактика поддержки национального производителя на внутреннем и особенно на внешнем рынках, тем самым государственный маркетинг, безусловно, будет важным фактором, влияющим на укрепление макроэкономических показателей страны.

\section{Литература}

- Фоканова Л. К. (2012). «Развитие кадрового потенциала сферы предоставления населению государственных и муниципальных услуг» // Корпоративное управление и инновационное развитие экономики- с. 12.

- Окландер М. (2003). «О государственном маркетинговом регулировании» // Экономика Украины. №4. - с. 80-81.

- Котляров И. Д.(2012). «Сущность услуги как экономического блага» // Вестник Омского университета. Серия «Экономика». № 3. - с. 79-86.

- Сафрин А.А. (2013). Маркетинг в органах государственной власти: анализ: Москва. - с. 179.

- Бендриков А.М. (2014). Позитивный политический директ-маркетинг на выборах. - Н. Новг.,-с. 162.

- Ильясов Ф.Н. (2010). Политический маркетинг. Искусство и наука побеждать на выборах. - М.: ИМА-Пресс, с.13.

- Багиев Г.Л. (2011). Маркетинг взаимодействия: учебник для вузов. - СПб.: Астерион.

- Гоулд Ф. (2003). Стратегическое планирование избирательных кампаний. Политические исследования. - №4.

- Камалова А.К. (2008). Маркетинг - Бишкек.

- Мирзов А.К. (2012). Политический рынок и политический маркетинг: концепции, модели, технологии. - М.: РОССПЭН.

- Крылов И. (2008). Маркетинг: Политическая теория: тенденции и проблемы., М.

- Морозов М.М. (2012). Политический маркетинг в государственно-политическом управлении // Политическое управление. М.

- Нежданов Д.В. (2013). Политический маркетинг: Вчера, сегодня, завтра. - СПб.: Питер.

- Политический маркетинг. / Под ред. С. Горбатова. - M.: BCI Marketing, 2003. 


\title{
Аудит и его влияние на формирование национального капитала
}

\section{Audit and its Influence on the Formation of National Capital}

\author{
Asst. Prof. Dr. Kylychbek Supataev (Kyrgyz-Russian Slavyan University, Kyrgyzstan)
}

\begin{abstract}
This article is about the objective requirement in audit for acceptance of the well-founded economic decision by users of the financial reporting to exclude or lower information risk, and also are dealt with the reasons of occurrence of information risk and ways of their decrease. And also are researched market of auditing services, the location of the audit entities and their influence on ensuring timely auditing businesses. Financial reporting transparency are studied and their impact on the financial issue of the managing subject. Recommended actions aimed at ensuring transparency of financial statement of an entity and the rights of owner. And explored the current state and prospects of development of independent audit, it is influense on the formation of national capital.
\end{abstract}

В Кыргызской Республике до приобретения независимости, т.е. в составе бывшей социалистической страны, аудит, как таковой, отсутствовал. Многие годы и десятилетия административно-командная система осуществляла контрольно-ревизионную проверку за деятельностью любых хозяйствующих субъектов. Аудиторская деятельность в Кыргызской Республике появилась после преобразования экономики страны и перехода к рыночным отношениям.

Переход к рыночной экономике и экономические реформы в Кыргызской Республике начались без соответствующей законодательной базы, без развитого и авторитетного отечественного института, защищающих интересы собственников. В процессе переходного периода произошёл массовый обман незажиточного населения, секвестром его накопленного дохода и сбережений были с одной стороны государство, с другой стороны им же легализованные финансовые пирамиды, а также банкротство ряда финансовых институтов, использующих преимущественно средства населения. Негативный опыт банкротств затронул интересы миллионов людей и десятков предприятий. Таким образом, к началу XXI века в нашей стране уже произошел подрыв доверия вкладчиков и акционеров ко всем существующим финансовым структурам.

Рыночные преобразования экономики продолжались, хотя и весьма противоречиво, да к тому же в условиях отсутствия гражданского общества, правового государства. Так, например, о том, что аудитор защищает интересы собственника, знала совершенно мизерная доля населения Кыргызстана, вернее говоря, об этом знали единичные люди. И только в начале XXI века, когда сотни тысячи предприятий и граждан вложили свои купоны, полученные от приватизации государственной собственности в акции акционерных предприятий, коммерческих банков, экономически активное население страны ощутило насущную потребность в аудиторских заключениях относительно результатов деятельности этих структур. В те времена, нужно признать, что в нашей республике был, слаб реальный спрос на аудиторские услуги.

Собственники, и прежде всего акционеры, инвесторы, - а также кредиторы лишены возможности самостоятельно убедиться в том, что все многочисленные и зачастую очень сложные операции предприятия законны и правильно отражены в отчетности, так как обычно не имеют ни доступа к учетным записям, ни соответствующего опыта, и поэтому нуждаются в услугах аудиторов.

Современный аудит - это особая организационная форма контроля. Он неплохо зарекомендовал себя в условиях развитой рыночной экономики, даже экономики условно-рыночной, переходного типа, которая сложилась в Кыргызской Республике. Говоря другими словами, современный аудит - это неотъемлемый элемент инфраструктуры рыночной экономики. В этом и состоит его особенность. Практический аудит неуклонно развивался, исходя из внутренней логики экономических преобразований, на естественном фундаменте соотношения спроса и предложения.

Стихийное зарождение и развитие отечественного аудита помогало преодолеть нездоровые настроения, которые начинали появляться у наиболее квалифицированных в этом плане специалистов и свидетельствовали об их неверии в значимость и эффективность выполнения столь важных и скрупулезных работ. Это позволяло принимать срочные и актуальные меры для ликвидации источников, углублявшейся диспропорции между трудной ответственной работой, требующей особых бухгалтерских и аудиторских познаний и неадекватным вознаграждением, общественной роли аудиторов. 
Начало функционирования аудиторских организаций, фирм, товариществ, таким образом, явилось хотя и слабыми, но в целом действенными и повсеместными шагами наиболее квалифицированных специалистов в области управления, учета, анализа и финансового менеджмента, направленными на создание правовой экономики и на строительство гражданского общества.

Соответственно, на разных уровнях и срезах экономики стал более - менее проявляться и спрос на функцию засвидетельствования аудиторов. Усилия аудиторов уже способствовали решению определенных проблем, например, при создании совместных и стопроцентно иностранных предприятий, формировании принципиально новой кредитно-банковской системы и т.д. Они шли на защиту прав и свобод тех экономических субъектов, которые более успешно вписывались в новые, более жестокие условия капитализирующегося Кыргызстана.

За последние годы немало сделано Правительством Кыргызской Республики по развитию аудиторской деятельности, принят закон «Об аудиторской деятельности» от 30.07 .2002 г. № 134. А также 22 апреля 2002 года постановлением Правительства Кыргызской Республики № 235 в качестве стандартов аудита в Кыргызской Республике утверждены Международные стандарты аудита. Принятие нового закона и стандартов подтвердило окончательное становление аудита в Кыргызской Республике, позволило принять ряд нормативных правовых актов по регулированию аудиторской деятельности в нашей стране, сделать шаг по пути интеграции отечественного аудита в международную аудиторскую систему.

В настоящее время на рынке аудиторских услуг республики работают более 300 аудиторов в 94 аудиторских организациях и 24 индивидуальных аудиторов. На рынке аудиторских услуг Кыргызской Республики осуществляют аудиторскую деятельность представители 4-х международных аудиторских компаний, входящих в состав так называемой «Большой четверки» ОcОО «Делойт и Туш», ОсОО «КПМГ-Бишкек», ОсОО «Прайсуотерхаус Куперс» и ОсОО «Эрнст энд Янг Аудит». В 2011 году на рынке аудиторских услуг Кыргызской Республики начали осуществлять аудиторскую деятельность ОсОО «BDO Казахстанаудит - Бишкек» и ОcОО «Baker Tilly Bishkek», входящие в 10-ку ведущих международных аудиторских компаний, что показывает поступательное развитие рынка аудиторских услуг в Кыргызской Республике.

Засвидетельствование об относительно удовлетворительном функционировании экономических субъектов - важнейшая задача аудитора. Выполнение этой задачи основано на результатах проверки и способности аудитора к профессиональным суждениям. Аудитор определяет, правильно ли отражены учетная информация тех экономических событий, которые произошли за проверяемый период и важнейшие финансовые результаты которых отражены в финансовой отчетности. А завершается выполнение этой задачи выражением его мнения о соответствии деятельности проверяемых экономических субъектов определенным критериям, т.е. составлением аудиторского заключения.

Наличие достоверной информации позволяет повысить эффективность функционирования рынка капитала и дает возможность оценивать и прогнозировать последствия различных экономических решений. Проведение аудиторской проверки даже в тех случаях, когда она не является обязательной, несомненно, имеет важное значение.

В условиях рынка предприятия, кредитные учреждения, другие хозяйствующие субъекты вступают в договорные отношения по использованию имущества, денежных средств, проведению коммерческих операций и инвестиций. Доверительность этих отношений должна подкрепляться возможностью для всех участников сделок получать и использовать финансовую информацию. Достоверность информации подтверждается независимым аудитором.

Как известно независимая аудиторская проверка главным образом направлена на защиту прав собственников, наряду с этим, такая деятельность необходима обществу и государству для развития экономики страны. Чтобы поднять экономику страны необходимо соответствующие источники финансирования, таким источником могут быть только вложенные капиталы в экономику или заработанный капитал, в виде реинвестированной прибыли. Собственники, акционеры и инвесторы не будут вкладывать свои средства в экономику, пока у них не будут доверия, прозрачности, открытости, объективности и достоверности информации о хозяйственной деятельности экономических субъектов. Заслужить такое доверие общественности и собственников способствует аудиторская проверка и публикация финансовой отчетности в средствах массовой информации.

В последние годы Национальный банк Кыргызской Республики строго контролирует проведение ежегодной аудиторской проверки коммерческих банков и кредитных учреждений, по результатам проверки они регулярно публикуют финансовые отчетности в средствах массовой информации. Их информация размещена на интернет-сайтах и доступна каждому заинтересованному лицу. Таким образом, коммерческие банки страны заслужили определенное доверие населения и хозяйствующих субъектов, этому способствовало в определенной мере и проводимые аудиторами аудиторские проверки этих банков. Об этом свидетельствуют статистические данные Национального статистического комитета Кыргызской Республики. 


\begin{tabular}{|l|r|r|c|c|c|c|}
\hline \multicolumn{1}{|c|}{ Показатели } & \multicolumn{5}{|c|}{ Годы } & Рост в 2013 г. к 2009 \\
\cline { 2 - 7 } & 2009 & 2010 & 2011 & 2012 & \multicolumn{1}{c|}{2013} & \multicolumn{1}{c|}{ в } \\
\hline Активы & 67904 & 55181 & 66022 & 85996 & 109091 & 213,4 \\
\hline $\begin{array}{l}\text { В т.ч. кредиты } \\
\text { клиентам }\end{array}$ & 25288 & 24380 & 31143 & 40004 & 53958 & 168,6 \\
\hline Обязательства & 53361 & 46152 & 52238 & 69745 & 89961 & \\
\hline $\begin{array}{l}\text { В т.ч. расчетные } \\
\text { счета и депозиты } \\
\text { клиентов }\end{array}$ & 21029 & 15794 & 14216 & 19834 & 22148 & 105,3 \\
\hline $\begin{array}{l}\text { депозиты } \\
\text { физических лиц }\end{array}$ & 9566 & 11645 & 15790 & 21427 & 28682 & 299,8 \\
\hline $\begin{array}{l}\text { срочные депо- } \\
\text { зиты клиентов }\end{array}$ & 2050 & 1474 & 2216 & 2199 & 7134 & 348,0 \\
\hline Капитал & 14543 & 9029 & 13784 & 16251 & 19130 & 131,5 \\
\hline
\end{tabular}

Таблица 1. Динамика активов, обязательств и капитал коммерческих банков Кыргызской Республики (млн. сомов)

Как показывают данные таблицы, вложенные средства физическими лицами за последние пять лет утроились, а срочные депозиты выросли почти в 3,5 раза. Это свидетельствует о росте доверия вкладчиков. Депозиты клиентов увеличиваются быстрыми темпами по сравнению с ростом суммы представленного кредита клиентам, говоря другими словами, общая сумма депозитов клиентов полностью покрывает сумму выданных кредитов. Хотя для банков депозиты считаются обязательствами, в экономической сущности они являются капиталом, вложенным собственниками в банки. В этом отношении, физические и юридические лица сделали весомый вклад в формирование капитала и кредитных ресурсов коммерческих банков.

Однако, нельзя сказать о том, что банки полностью владеют доверием общественности, об этом свидетельствует недавно прошедший факт совершения кражи денежных средств у известного певца, народного артистка Кыргызской Республики С. Садыковой. У неё дома воры украли более 30 тыс. долларов США, в сомовом эквиваленте по сегодняшнему курсу около 2-х миллионов сомов. До сих пор, некоторые физические лица предпочитают, хранить деньги дома, т.е. пока еще полностью не доверяют финансовым структурам.

Хотя, достигнуты определенные успехи по формированию капиталов коммерческих банков республики, не так хорошо обстоят дела по формированию капитала предприятий реального сектора экономики, особенно крупных предприятий. В настоящее время в нашей стране из 1329 зарегистрированных открытых акционерных обществ, фактически функционируют 541, то есть меньше половины. Из-за финансовых затруднений и не имея финансовых ресурсов, т.е. недостаточности собственного капитала, простаивает 788 зарегистрированных обществ. Все эти компании организованы на базе предприятий, оставшихся в наследство от бывшей социалистической страны.

Кроме того, за последние 10-15 лет, в практической жизни нашей республики не было случаев, когда за счет средств собственников были организованы и введены в действие новые крупные компании. Здесь причин много, на наш взгляд, главная причина - это вопрос открытости, доступности, прозрачности деятельности этих компаний, которые отсутствуют в практической деятельности действующих компаний. Законодательством нашей республики предусмотрено, что эти компании подлежат ежегодному обязательному аудиту и согласно статьи 14 закона «О бухгалтерском учете» они обязаны публиковать свои финансовые отчеты в средствах массовой информации не позднее 1 июня текущего года, после подтверждения независимыми аудиторами. В реальности ни одна компания не выполняет требования закона, а со стороны государственных органов отсутствует контроль над их выполнением. Отсюда возникает сомнение, что управляющий и бухгалтер какой-либо коммерческой структуры могут быть заинтересованы в том, чтобы скрыть от акционеров, собственников этого предприятия свои просчеты или даже возможные злоупотребления.

С такими проблемами часто сталкиваются научные работники и исследователи при получении информации о финансово-хозяйственной деятельности хозяйствующих субъектов. Мы, при необходимости информации финансовой отчетности экономического субъекта с трудом добиваемся их, уговаривая и обещая соблюдать тайну полученной информации. Ссылаясь на конфиденциальность информации, руководители предприятия считают, что все их экономические показатели содержат конфиденциальную информацию, и они не должны их предоставлять пользователям, хотя они знают, что финансовая отчетность предназначена для использования широкого круга общественности. В таких обстоятельствах, естественно собственники, акционеры, инвесторы, кредиторы не в полной мере доверяют той финансовой информации, которую предоставляют администрация, менеджеры, управляющие и подчиненные им бухгалтеры предприятий. $\quad$ В результате общественность не доверяет, и 
они не желают вкладывать свои средства в деятельность таких коммерческих структур. Таким образом, оказывается отрицательное влияние на формирование национального капитала предприятий реального сектора экономики.

Анализ формирования капитала предприятий экономики показывает что, он за последние пять лет почти удвоился, если в конце 2009 года его сумма составляла 60569,8 млн. сомов, а в конец 2013 года составил 124066,8 млн. сомов или прирост составил 104,8 процента. Этот рост в основном обеспечен за счет не прямых вложений 55178 млн. сом или 91,1 процент от общего роста. В том числе, за счет дополнительно оплаченного капитала 1257 млн. сом, корректировки по переоценке активов 18992 млн. сом, аванса собственников 6468 млн. сом, нераспределенной прибыли 27214 млн. сом и резервного фонда 1247 млн. сом. За счет прямых вложений рост составил 8390 млн. сом или 8,9 процента. В основном эти капиталы вложены в малый и средний бизнес, бесспорно, они имеют весомый удельный вес в экономике страны, почти более 65 процентов ВВП страны, производится именно в этих предприятиях. Однако, необходимо учесть, что «локомотивом» экономики являются крупные компании, созданная инфраструктура вокруг этих компаний, также будет способствовать развитию малого и среднего бизнеса.

\begin{tabular}{|c|c|c|c|c|c|c|}
\hline \multirow[t]{2}{*}{ Показатели } & \multicolumn{5}{|c|}{ Годы } & \multirow{2}{*}{$\begin{array}{c}\text { Рост в } 2013 \text { г. к } \\
2009 \text { г, в \% } \\
\end{array}$} \\
\hline & 2009 & 2010 & 2011 & 2012 & 2013 & \\
\hline Собственный капитал & 60570 & 136341 & 140117 & 118417 & 124067 & 204,8 \\
\hline В т.ч. уставный капитал & 31750 & 34249 & 36289 & 36788 & 40140 & 126,4 \\
\hline $\begin{array}{l}\text { дополнительно оплачен- } \\
\text { ный капитал }\end{array}$ & 5924 & 6659 & 6788 & 7007 & 7181 & 121,2 \\
\hline $\begin{array}{l}\text { корректировки по } \\
\text { переоценке }\end{array}$ & 9795 & 60840 & 50451 & 21625 & 28716 & 293,2 \\
\hline $\begin{array}{l}\text { капитал, авансирован- } \\
\text { ный собственниками }\end{array}$ & 2907 & 20250 & 22834 & 23447 & 9375 & 322,5 \\
\hline $\begin{array}{l}\text { нераспределенная } \\
\text { прибыль }\end{array}$ & 5689 & 9822 & 18947 & 24241 & 32903 & 578,4 \\
\hline резервный капитал & 4505 & 4521 & 4808 & 5309 & 5752 & 127,7 \\
\hline
\end{tabular}

Таблица 2. Динамика состава капитала предприятий реальной экономики Кыргызской Республики (млн. сомов)

К росту капитала предприятий оказывает большое влияние привлечение иностранных инвестиций. В 2013 году на территории Кыргызской Республики функционировало 2,7 тысячи предприятий с иностранными инвестициями, из них более 50 процентов - с полным участием иностранного капитала. Доля иностранного капитала в общей сумме капитала предприятий в 2013 году составила 52083 млн. сом или 42,0 процента, за последний пять лет его рост составил более 2,5 раза и приближается к половине общего объема. Валовая добавленная стоимость, произведенная предприятиями с иностранными инвестициями, в 2013 г. составила 80,5 млрд. сомов, или 23 процента к ВВП республики. В 2013 г. балансовая прибыль предприятий с иностранными инвестициями составила 18,5 млрд. сомов, в общереспубликанском объеме её доля составляла 57,3 процента.

За последние годы немало сделано в этом деле, например, на Китайские инвестиции построены и введены в эксплуатацию крупная электрическая подстанция «Датка» в Базар-Курганском районе, нефтеперерабатывающий завод в г. Карабалте, прокладывается электролиния, соединяющая север с югом республики «Датка-Кемин». На инвестиции России строится Камбар-Атинская ГЭС и малые гидроэлектрические станции на Нарынском каскаде, и много другое. Состояние экономики нашей страны в настоящее время нуждается в иностранных инвестициях, однако одновременно с этим необходимо направить усилие на формирование национального капитала.

Необходимо учесть, что имеем горький опыт привлечения иностранных инвестиций, например, золотодобывающее предприятие «Кумтор оперейтинг компани» организовано на средства инвесторов из Канады и Правительства Кыргызской Республики. В начале создания компании контрольный пакет акции находился у Правительства Кыргызской Республики. Из-за недоступности и непрозрачности информации для общественности о деятельности компании, пакет акций перешел путем мошенничества на сторону канадских инвесторов, в этом было замешано руководство республики, и акции нашего правительства в настоящее время составляют всего лишь 33 процента. По поводу деятельности этой компании уже более десяти лет идут скандальные разбирательства на уровне Правительства Кыргызской Республики и Жогорку Кенеша Кыргызской Республики. В результате несколько председателей правительства досрочно ушли в отставку, и этот скандал продолжается до сегодняшнего дня. Главный вопрос скандала в том, что большая часть заработанной прибыли выплачивается иностранным инвесторам виде дивидендов. Естественно целью иностранных инвесторов является больше извлечь выгоду от вложенного капитала, 
такое положение дел способствует оттоку заработанного капитала из нашей страны, а что касается, реинвестирования полученной прибыли, то это зависит от их решений.

Отсюда вывод, одной из важных проблем развития экономики нашей страны является формирование национального капитала, однако этому вопросу Правительство и руководство республики достаточного внимания не уделяют, т.е. в этом направлении действенные меры не принимаются, в основном их деятельность направлена на привлечение иностранных инвестиций. Как указано выше, соотношение между национальным и иностранным капиталом достигло критической точки. Если по такому сценарию будет развиваться экономика нашей республики, то в ближайшие сроки она станет полностью зависима от иностранного капитала. Перспективы развития экономики будут затруднены, потому что большая часть заработанной прибыли, являющейся основным источником накопления капитала, будет уходить иностранным инвесторам.

Если собственники половины своих депозитных средств, вкладывали бы прямо в деятельность коммерческих структур, это был бы ощутимый вклад в формирование национального капитала предприятий. По нашим расчетам, это было бы выгодно собственникам и хозяйствующему субъекту. В настоящее время коммерческие банки выдают кредиты клиентам под 25-30 процентов годовой ставки, а на депозиты клиентам выплачивают максимум 12 процентов годовых. Например, половина депозитных средств физических лиц на конец 2013 года составляла 13341 млн. сомов. Если эти средства прямо вложили бы в акционерные общества и они хотя бы выплачивали 15 процентов дивидендов, то физические лица дополнительно получали бы процентный доход в более чем на 400 миллионов сомов, по сравнению с получаемого процентного дохода от банков, а компания почти в два раза меньше выплачивала бы процентов за использование финансовых ресурсов кредиторов.

Поэтому необходимо прилагать усилия по формированию национального капитала предприятия реального сектора экономики. Может возникнуть вопрос, откуда взять средства? Средства имеются, только они вложены в банки и определенная часть хранится в домах собственников. В условиях рыночной экономики собственники сами принимают решение, куда вкладывать свои капиталы. Поэтому необходимо проводить целенаправленную работу с тем, чтобы убедить их, войти в их доверие. Для этого необходимо осуществлять контроль за проведением ежегодной обязательной аудиторской проверки, выполнением требований закона и публикации финансовой отчетности хозяйствующих субъектов, и добиваться открытости, доступности, прозрачности и достоверности их отчетности.

В экономически развитых странах периодически информируют общественность о достижениях ведущих национальных компаний, о сумме полученной прибыли и размере выплачиваемых дивидендов. Как известно, это делается для того, чтобы собственники и инвесторы использовали эту информацию, когда они принимают решение о вложении своих капиталов в ту или иную коммерческую структуру. Нам тоже можно перенять этот положительный опыт, периодически информировать о финансовых результатах деятельности ведущих компаний, это тоже имеет немаловажное значение для формирования национального капитала реального сектора экономики.

И наконец, необходимо оказывать поддержку действующим аудиторским организациям, они переживают трудное время, у многих из них финансовое положение неустойчивое и они борются за самовыживание, потому что наша экономика пока еще не встала на ноги.

В связи с этим, со стороны государства могут быть представлены льготы аудиторским организациям по определенным видам налогов. Кроме того, больше внимания необходимо уделять проблемам бухгалтерского учета (как у нас в народе говорят «не бывает богатства без учета»). Только с помощью точного учета происходящих процессов в экономике мы можем двигаться вперед. Без сильного отечественного аудита при всей сложности экономической и политической ситуации значительно снижается эффективность проводимых реформ. Аудит обеспечивает демократизацию экономики. Посредством аудита можно решать глобальные проблемы перехода к рыночным методам хозяйствования, снижения количества экономических преступлений в сфере экономики, формирования национального капитала в необходимом объеме и экономического роста.

\section{Литература:}

- Абдыкаиров Т., Супатаев К. Теория аудита. Учебное пособие. - Б.: типография Кыргызского национального университета, 2015.

- Аренс Э.А. и Лоббек Дж.К. Аудит: Пер. с англ. - М.: Финансы и статистика, 2012.

- Робертсон Дж. Аудит: Пер. с англ. - М.: KPMG, Аудиторская фирма «Контакт», 1993.

- Деятельность предприятий с иностранными инвестициями в Кыргызской Республике: 2009-2013. Б.: Нацстатком КР, 2014.

- Финансы предприятий Кыргызской Республики: 2009-2013. - Б.: Нацстатком КР, 2014.

- Материалы Госфиннадзора КР. www. fsa. kg 


\title{
Особенности Российской Безработицы и Безработных: 2000- 2014гг
}

\section{Features of Russian Unemployment and Unemployed: 2000-2014}

\author{
Alexandra Salatova (Kazan Federal University, Russia)
}

\begin{abstract}
The study of unemployment and the unemployed in Russia began in the 1990s. The three periods can be distinguished in the unemployment study: 1. 1992-1998 - Post-reform period of heightened public attention. 2. 1999-2008 Post-transformation recovery period - attempts to explore the correlations between unemployment and the main socio-economic trends. 3. 2009 - present. Period of protracted economic and financial crisis - the themes of unemployment losing its actuality, despite the fact that Russians still fear of firing and the job-hunting difficulties. However, there are the lack of articles, which are analyzed the present features of the unemployment and unemployed in Russia. The paper based on the results of analysis of socio-economic development indicators and the statistical data by the Federal State Statistical Service for 2000-2014 for the Central, Volga and NorthCaucasian Federal Districts (with lowest, medium and highest levels of unemployment respectively). Findings: Russian unemployed do not form a particular social stratum. The large number of unemployed people live in cities; the number of rural unemployed is almost constant and does not fluctuate in crisis. The number of unemployed as men as women is reducing. Data on gender structure of the unemployed allow mention the labor market is becoming more civilized: a female unemployment rate lower than male; there is no trend to the preferential exclusion of women from labor market. The average age of the unemployed is increasing, possibly due to the innovation economy needs in new skills, and professional inertia of older people.
\end{abstract}

\section{1 Введение}

Реформирование российского общества в начале 1990-х годов, с одной стороны, было направленно на развитие рыночных принципов и отношений в социально-экономической сфере в результате чего появились новые для нашей действительности социальные явления (например, безработица), а с другой на наполнение актуальным содержанием уже имеющихся процессов и отношений. Значительная дифференциация между уровнем развития различных регионов страны, меры «шоковой терапии», кризис политической системы повлияли на формирующиеся рыночные отношения в сфере труда и отразились в ряде специфических черт российской безработицы. Экономические кризисы 1998г. и 2008-2009гг. довершили процесс их формирования. К настоящему моменту, можно говорить о российской безработице, как об относительно оформившемся социально-экономическом явлении со своими особенностями, отличающимися от любой другой, в том числе и постсоветской страны.

Понимание специфики безработицы позволит не просто переносить зарубежный опыт ее регулирования в российскую действительность (чем часто грешат государственные деятели), а адекватно его корректировать с учетом российских реалий. При этом, изучение отличительных черт российской безработицы должно осуществляться в общем контексте исторического развития нашей страны. Особый интерес, представляет временной период 2000-2014г. Если для поколения 1990-х годов безработица была чем-то абстрактным и новым (в СССР безработица официильно была ликвидирована $в$ 1930-x и с тех пор не существовала), то к середине 2000-х годов на рынок труда вышло поколение «выросшее» с безработицей. Это поколение не только осознало, но и на себе прочувствовало существующую конкуренцию на рынке труда, что позволило сформировать особое отношение к данной проблеме, отличное от ментальности предыдущих поколений. Если на безработицу и на рынок труда 1990-х годов существенное влияние оказывала общая ломка социалистических ценностей и переход к капиталистическому рынку. В 2000-х годах определенные итоги этого перехода уже могут быть подведены и обобщены. В двухтысячных, российская экономика, восстановившаяся после кризиса 1998г., испытала на себе мировой финансово-экономический кризис 2008-2009гг., который затем, по официальной позиции Правительства Российской Федерации перерос в структурный кризис, продолжающийся до настоящего времени. (Interfax, 2015)

Изучение особенных черт безработицы в России должно осуществляться как с позиции экономической, так и социологической наук. Более того, на наш взгляд, наиболее целесообразным является использование социоэкономического подхода. Исключительно социологическая интерпретация представляет определенную сложность теоретического анализа в силу своей социо-экономической природы. Кроме того, безработица как явление, тесно связана с исторической динамикой, с общим ходом развития экономики, со сменой советских стереотипов деятельности, поведения и сознания. И наконец, безработица прямо или косвенно затрагивает широкий спектр общественных явлений, жизненные интересы различных субъектов социального действия, что, в свою очередь порождает многоплановость 
толкований, оценок и мнений касательно данного явления. В связи с этим характеристика особенностей безработицы в России будет даваться в историческом контексте и в тесной связи с экономическими и политическими процессами.

\section{2 Особенности безработицы: теоретические аспекты изучения}

После кризиса 1998г., а именно в 2000-2008гг., исследователями анализировались тенденции развития безработицы как явления, возможности управления ее динамикой; предпринимались попытки соотнести данные о синхронных с ним социально-экономических процессах. (Морозова, 2000; Шабаева, 2000; Шатсков ve Радонцев 2000; Юсупов, 2000) На современном этапе научных исследований явления безработицы (с 2009г.) наблюдается рост числа работ, стремящихся использовать междисциплинарные, социоэкономические подходы. Использование социоэкономического подхода к анализу проблемы позволяет рассматривать работника как субъекта, имеющего свои потребности и интересы. В этом случае, по мнению Комлева А.Л., «основные компоненты рынка труда рассматриваются в контексте их включенности в систему широких социальных связей и отношений, обусловливающих наряду с экономическими, политическими, демографическими и социально-психологическими условиями и факторами детерминацию состояния и тенденции развития рынка труда». (Комлев, 2006) Однако, несмотря на то, что социоэкономический и социологический подходы позволяют взглянуть на проблему занятости более широко, в отечественной науке они находятся в стадии формирования. (Горина, 2011) Анализ диссертаций (кандидатских и докторских), размещенных в Открытой электронной библиотеке диссертаций Российской государственной библиотеки с 2003 по 2013гг. показал, что безработица в первую очередь становится предметом исследования в рамках экономических наук и только потом в рамках социологического направления (30 экономических работ простив 9 социологических).

В общем массиве исследований особенностей российской безработицы можно выделить ряд основных блоков:

1. исследование особенностей региональной безработицы. В рамках этого направления учеными предпринимаются попытки обобщить и проанализировать обобщённости безработицы как социальноэкономического явления, а также специфические черты региональных механизмов ее регулирования (Беркович, vd, 2010; Вайс, 2014). При этом, в качестве объекта исследования может выступать не только безработица субъекта Российской Федерации, но и отдельно взятого города (Яковлева, 2010) или группы городов (Грищенко, 1999), а также сельской местности. Так, Ермакова А.М. и Кириллова О.В. выделили специфику сельской безработицы на примере Тюменской области (Ермакова ve Кириллова, 2006).

2. исследование гендерных особенностей российской безработицы: гендерного равенства при устройстве на работу, отраслевой сегрегации, вытеснения женщин с рынка труда в кризисные периоды и др. (Дадаева, 2005; Бутарева, 2009; Шаожева, 2010; Котоманова vе Осинский, 2015).

3. исследование особенностей безработицы среди различных слоев и групп населения. Например, безработицы среди молодежи (Бабичева vе Яркова, 2012; Брусянина, 2010; Якушкина, 2011), среди выпускников вузов (Ивлева, 2012; Малин, 2013) безработицы среди экономически активного населения (Дунакин vе Деева, 2012).

4. Исследование особенностей переживания и преодоления ситуации безработицы безработными (Бендюков, vd, 2007; Ивлева, 2007).

5. Изучение особенностей безработицы как явления. В рамках данного направления рассматриваются сложности в трактовке различных опредедлений и видов безработицы, проблемы проведения многофакторного анализа данного явления. (Яковлева, 2007).

Однако существует определенный недостаток комплексных, обзорных исследований, посвященных особенностям российской безработицы в целом, как современного социально-экономического явления. В связи с этим, наша статья посвящена выделению на основании имеющегося массива исследований, а также на основе статистических данных Росстата и результатов опросов ВЦИОМ наиболее общих, ключевых особенностей российской безработицы в страновом масштабе за период 2000-2014г. с точки зрения социологической науки.

\section{3 Динамика безработицы в России: 2000-2014}

Общей тенденцией в динамике российской безработицы за 2000-2014гг. является снижение численности незанятого населения по всем федеральным округам. (График 1.)

Особенно резко уровень безработицы снижается в последние 5 лет, причем происходи это в условиях замедления экономического роста. Причиной такого, на первый взгляд парадоксального явления, являются более быстрые темпы старение экономически активного населения в сравнении с темпами сокращения рабочих мест. Общее снижение безработицы характерно для всех федеральных округов. Однако, картина динамики уровня безработицы в период кризиса 2008-2009гг. не является такой же 
однозначной. Наиболее резкий скачок в численности безработных в 2008-2009г. произошел в СевероКавказском федеральном округе. По остальным округам показатели численности безработных в 2009г. достиг показателей 2003-2004гг. (ILO, 2014).

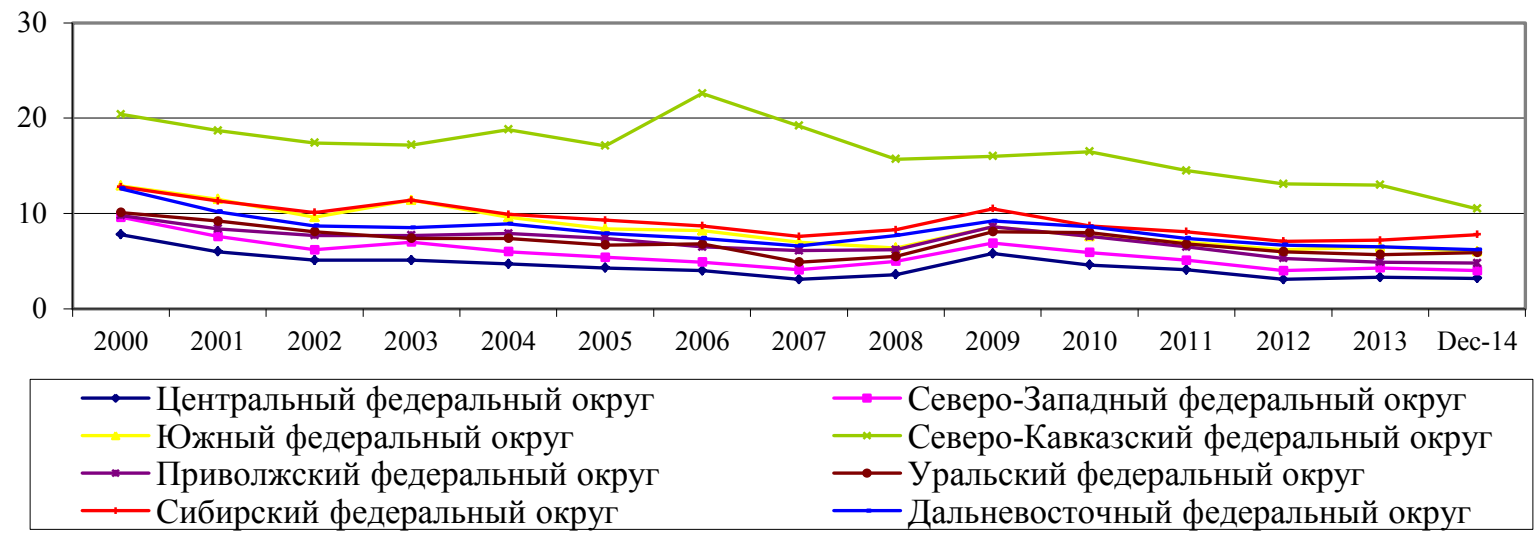

График 1. Уровень безработииь населения по федеральньмм округам Российской Федерации, в среднем за год (Poccmam)

Для не вполне «типичного» отсутствия резкого увеличения количества незанятого населения в кризис, есть ряд причин: увеличение неполной занятости, сокращение объемов найма рабочей силы, неформальное давление на предприятия.

\section{4 Особенности российской безработицы}

\section{1 Общественная реакция: тема безработицы теряет свою актуальность}

Для начала рассмотрим общественную реакцию на кризис 1998г., что позволит понять реакцию населения на кризис 2008-2009гг. На уровне массового сознания в вопросах восприятия безработицы к концу 1998г. обозначились тревожные тенденции. По данным опросов ВЦИОМ к ноябрю 1998г. четверо из десяти опрошенных не имели представления о собственных ближайших перспективах в занятости, оплате труда и сохранении своего предприятия в целом. (Куприянова, 1999) Под воздействием кризисной ситуации, население страны все интенсивнее испытывает на себе давление реальных жизненных обстоятельств (потеря работы, падение уровня благосостояния, рост цен, инфляция) и начинает больше и больше осуждать безработицу. Число респондентов, считающих, что безработица в России вообще недопустима возросло в 1998г. до 54\%, против с 47\% в 1995г. (Куприянова, 1999) Однако, с преодолением острой фазы кризиса, общественный интерес к теме безработицы год от года начал падать. И к 2006 году проблема безработицы в массовом сознании отошла на второй план. По итогам обследования ВЦИОМ, поведенного в октябре 2006г. среди проблем, наиболее значимых для россиян безработица занимала третье место после роста цен и пенсионного обеспечения. (Wciom, 2015)

В масштабах общественного мнения, по данным опросов ВЦИОМ на 2014г. «тема безработица является для россиян значительно менее актуальной, нежели во время экономического кризиса 20082009гг». (Wciom, 2014) Анализ специфики общественного восприятия проблемы безработицы возможно провести, используя индикаторы общественного отношения к ее различным аспектам, разработанные ВЦИОМ. Однако, подобный анализ можно провести только за период расчета этих данных, а именно за 2008-2014гг. (График 2.) Данные различных индикаторов общественного отношения к теме занятости и безработицы свидетельствуют о том, что общественная оценка вероятности увольнения остается примерно на одинаковом уровне, испытывая незначительные колебания под воздействием кризисных явлений в экономике. В аналогичных пределах наблюдается колебание индекса вероятности трудоустройства, с той лишь разницей, что его значения находятся на более пессимистичном уровне. Воздействие объективной экономической ситуации в стране и мире испытывает на себе только индекс актуальности проблемы безработицы, показавший максимальный прирост на 46 пунктов в начале 2009г. Также данный показатель, отражающий наличие/отсутствие в окружении респондентов лиц, потерявших работу за последние 2-3 месяца, наиболее подвержен сезонным колебаниям. В целом, с 2008 по 2014 гг. россияне стали меньше обсуждать проблему безработицы, но не перестали бояться увольнений, достаточно пессимистично оценивая свои возможности для трудоустройства на равноценную работу. Сохранение на протяжении 6 лет опасений россиян может быть связано, с одной стороны, со вступлением с 2009г. экономики страны в затяжной структурный кризис. А с другой стороны, может быть объяснено «привычкой», воспитанной на потрясениях 1990-х годов держаться за постоянное место работы, страшась потерять основной источник дохода. 


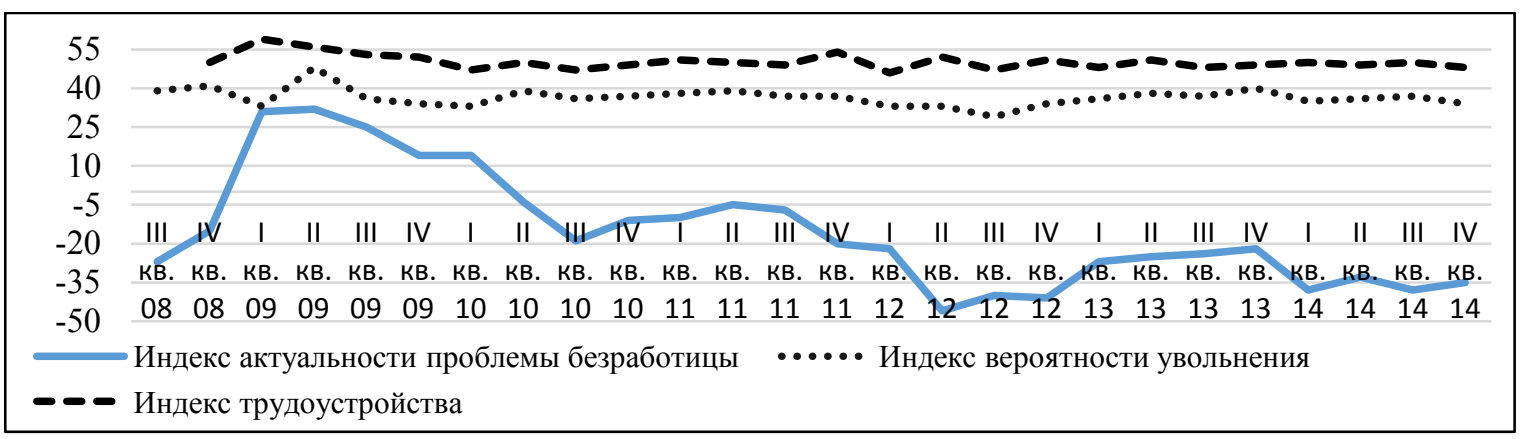

График 2. Динамика индексов общественного восприятия проблемы безработищы (III кв. 2008г. - IV кв. 20142., по данным опросов ВЦИОМ)

Общественное восприятие явления безработицы прошло с времен кризиса 1998г. естественные этапы от негативного до спокойного и даже будничного. Однако, в массовом общественном сознании на протяжении последних восьми лет страх потери работы сохраняется практически на одном и том же уровне. Более того, по данным опросов ВЦИОМ население продолжает опасаться за возможность трудоустройства, после потери работы, на аналогичную должность. Несмотря на ухудшения социальноэкономической обстановки в стране после введения антироссийских санкций в 2014 году, ситуация на рынке труда, согласно Прогнозу Министерства экономического развития Российской Федерации, на 2015 год, ожидается более спокойная в сравнении с кризисом 2008-2009гг. Связано это, с одной стороны, с существенным сокращением в течении последних лет численности населения в трудоспособном возрасте, а, следовательно, и с сокращением предложения рабочей силы. С другой стороны, в результате проведенной оптимизации численности персонала в 2009г. на предприятиях, на настоящий момент, отсутствует избыточная занятость. Тем не менее, опасения россиян за собственные трудовые перспективы, скорее всего, останутся на прежнем уровне.

\section{2 Российские безработные не образуют гомогенного слоя, имеющего маргинальное положение}

В настоящее время в ряде западных стран безработица все чаще приобретает затяжной характер. По данным Евростата, уровень длительной (long-term) безработицы в странах Евросоюза возрос с 33,5\% от общего числа безработных в 2009г. до 47,5\% в 2013г. (Harris, 2014; Eurostat news release, 2014) Наибольший процент безработных $(74,9 \%)$, находящихся в данном статусе более 1 года был зафиксирован в регионе Východné Slovensko (Словакия), а наименьший (12.4\%) - в Övre Norrland (Швеция). Около половины всех длительно безработных находились в этом статусе более 2-х лет.

Одним из результатов повышения уровня застойной безработицы является формирование относительно гомогенного социального слоя безработных. Его характерными чертами являются: недоверие к власти, депрессивные настроение, потенциальная агрессивность поведения, риск быть вовлеченными в криминальную деятельность. Кроме того, в виду наличия социальных гарантий и значительных материальных выплат безработным гражданам в рамках складывающегося слоя выделяется отдельная группа «профессиональных безработных» - лиц, осознанно отказавшихся от дальнейших поисков работы и существующих за счет пособий и дотаций государства. Представители данной группы зачастую ведут подобный образ жизни на протяжении поколений и формируют некое подобие общин, занимая целые кварталы в городах. В январе 2014г. в Великобритании на Canal 4 вышел пяти серийный документальный фильм «Улица пособий» («Benefits Street»), повествующий о буднях жителей нескольких улиц г. Бирмингема, 95\% населения которых являются безработными и получают государственные субсидии. (Canal, 2014) Герои фильма заняты своими будничными делами: совершают мелкие кражи и мошенничества, ведут антисоциальный образ жизни, нарушают общественный порядок. Районы, аналогичные показанным в «Улице пособий», существуют и в других городах Европы. Например, во Франции 30-40\% жителей районов социального жилья HLM являются безработными. (Canal 4, 2014) Население подобных кварталов, помимо занятости в неформальном секторе, часто оказывают организованное сопротивление представителям властей и полиции, а также активно участвуют в волнениях и массовых беспорядках. Правительства различных стран, с целью сокращения количества «профессиональных» безработных, вынуждены вводить специальные контрольно-регулятивные меры. Так, например, в Израиле с 2004г. службами занятости населения используется практика фиксирования отказов безработных от предлагаемых вакансий с последующим лишением права получать государственные пособия по безработице. (Еврейский интернет-клуб, 2014) Безработица, особенно застойная, представляет реальную угрозу социальной стабильности в обществе. По данным панельного исследования, проведенного в 33 европейских странах, даже однопроцентное повышение уровня безработицы на 2\% увеличивает количество преступлений против собственности (краж, угонов, случаев вандализма и т.п.). (Altindag, 2012) 
В России, в сравнении с другими странами, не происходит формирования однородного слоя безработных, занимающих маргинальное положение по следующим причинам. Во-первых, уровень застойной безработицы в нашей стране колеблется в пределах 30\%, что ниже среднеевропейских показателей. (График 3). По данным Росстата, в декабре 2014г. количество граждан, ищущих работу один год и более составило $27,1 \%$ от общей численности безработных (в июне 2014 их численность была $28,5 \%$, а в октябре $2014-26,1 \%$ ).

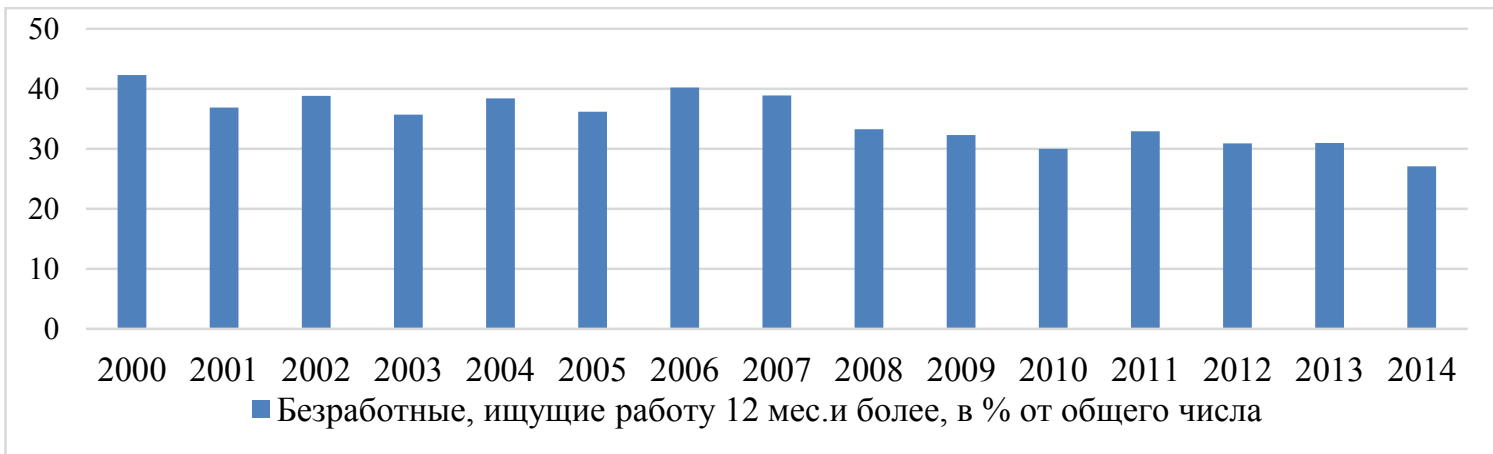

График 3. Уровень «застойной» безработищь по данных РОССТАТ (в \% от общего числа безработных, имеющих опыт трудовой деятельности)

Кроме этого, в России явление «профессиональной безработицы», в виду относительно невысокого уровня государственных субсидий лицам, потерявшим работу, фактически отсутствует.

Во-вторых, однозначно определить социальное положение российских безработных как маргинальное достаточно сложно в силу того, что они представляют собой различные социальные слои: от среднего и ниже. В этом отношении, отличие безработных от работающих, по мнению З.Т. Голенковой и Е.Д. Игитханян, проявляется только в том, что у последних разброс занимаемых позиций гораздо больший начиная с высшего слоя. (Голенкова vе Игитханян, 2001) Иными словами, российские безработные по своей слоевой самоидентификации достаточно интегрированы в различные социальные слои.

В-третьих, слой безработных достаточно разнороден и состоит, по мнению К.А. Феофанова, как минимум из трех категорий: лиц, которые остались без работы и не находят ее по объективным (экономическим) обстоятельствам; тех, кто не может выбраться из ситуации в силу особенностей характера или здоровья; лиц, для которых безработица является осознанным выбором. (Феофанов, 1995) Среди безработных имеются как приспособившиеся (или надеющиеся приспособиться) к сложившейся ситуации, так и те, кто по разным причинам надеется исключительно на помощь государства. Подобная разнородность проявляется, в частности, в соотношении показателей фактической и «официальной» безработицы. В-четвертых, согласно данным социологических исследований, проведенных как в 1990-х, так и в 2000-х годах (Гордон ve Клопов, 2000; Зудина, 2011), российские безработные, оценивают свое материальное положение, ситуацию в экономике и обществе, причины социального неравенства в целом так же, как большинство занятых.

Российские безработные, фактически не образуя особого однородного социального слоя, занимающего маргинальное положении, составляют скорее промежуточную, текучую часть экономически активного населения, отличительной чертой которой является отсутствие постоянного места работы.

\section{3 Правительство Российской Федерации фактически сняло с себя политическую ответственность за уровень занятости населения}

Официальную концепцию, выработанную Российским правительством с начала 1990-х годов на основании опыта ряда зарубежных стран можно озаглавить как «содействие занятости населения». (Сулакшин, 2008). В рамках данной концепции, правительство придерживается официальной позиции невмешательства в регулирование системы рабочих мест и уровня занятости. Эти аспекты являются зоной ответственности бизнеса. «Содействие» занятости не означает ее обеспечения для населения страны и фактически означает, что правительство не гарантирует рабочие места для своих граждан и реализацию их права на труд. Снятие с правительства политической ответственности за рост безработицы было «подкреплено изъятием из Конституции Российской Федерации (1993г.) и Трудового кодекса Российской Федерации (декабрь 20001г.) прямых формулировок о праве на труд». (Сулак шин, 2008) Задача поддержания занятости на уровне Правительства России принципиально не ставиться, эти вопросы отданы в ведение Федеральной службы занятости. Попытка глобального решения проблем безработицы на федеральном уровне фактически предпринималась один раз по инициативе Министерства труда и закончилась выработкой «Комплексной программы мер по созданию и сохранению рабочих мест на 1996 -2000гг.» Однако, в силу недостаточного финансирования, данная программа не оказала значительного влияния на общую ситуацию в стране. 
После кризиса 2008-2009гг. в каждом субъекте действовали региональные программы по снижению напряженности на рынке труда и преодолению последствий мирового финансового кризиса. В настоящее время, в субъектах Российской Федерации, отнесенных к территориям с напряженной ситуацией на рынке труда действуют программы дополнительных мероприятия, направленные на снижение напряженности на рынке труда. Финансирование мероприятий, предусмотренных программами, осуществляется за счет средств региональных бюджетов и субсидий из федерального бюджета. Согласно оценкам Всемирного банка, «программы могут оказывать положительное, хотя и небольшое воздействие, однако, их реализация может быть целесообразна даже в случаях, когда они не влияют на чистую занятость». (Алессио, vd, 2012)

В связи с введением санкций относительно России в 2014г. в начале 2015г. Правительство Российской Федерации утвердило План первоочередных мероприятий по обеспечению устойчивого развития экономики и социальной стабильности. В качестве мероприятий, содействующих изменению структуры занятости предусмотрены следующие: обеспечение выплаты пособия по безработице, содействие опережающему профессиональному обучению и организация общественных работ. Подобные мероприятия по оценкам специалистов Всемирного банка не являются в достаточной степени результативными: «общественные работы неэффективны с точки зрения затрат: дорогостоящие и не оказывающие долгосрочного положительного воздействия на занятость». (World Bank, 2015) Кроме этого, из правительственного плана не совсем ясно на кого будут рассчитаны программы опережающего профессионального обучения. В любом случае, результативность этих программ рассчитана, как правило, на долгосрочную перспективу. С точки зрения реального роста занятости населения, наиболее эффективными являются государственные мероприятия, направленные на обеспечение населения рабочими местами путем ускорения экономического подъема, роста реального сектора экономики. В рассматриваемом плане на мероприятия по активизации экономического роста путем поддержки предпринимательства, несырьевого сектора и предприятий, выполняющих импортозамещение предусмотрено порядка 234 млрд. руб., на реализацию заявленных мероприятий по изменению структуры занятости - 52,2 млрд. Наибольшему финансированию подвергнется финансовый сектор 1550 млрд. руб. будут выделены на докапитализацию банков, как это уже было сделано в 2008-2009гг. Такое распределение бюджетных средств может свидетельствовать о том, что основной упор в программе антикризисных мероприятий направлен на стабилизацию финансовой системы, а не реформирование социально-экономического сектора, чтобы могло привести к росту занятости.

4.4 Российская безработица фактически представляет собой комплекс «региональных безработиц»

Россия, в первую очередь в силу своих географических и территориальных характеристик, значительно отличается от большинства Западных стран, на опыт которых принято ориентироваться при конструировании рыночных отношений. Огромная протяженность территории при недостаточном уровне развития систем связи, транспорта, коммуникаций создает значительные сложности для развития рынка. В силу этого российский рынок труда фактически состоит из множества самостоятельных, региональных рынков рабочей силы. Отечественными учеными (Ахмадинуров, 2003; Базарсадаева, 2009; Караханов, 1999; Кондратьева, 2003; Кузнецова, 2004) исследующими специфику региональных рынков труда было установлено следующее:

- становление и развитие региональных рынков труда значительно отличается друг от друга. Для экономически слаборазвитых регионов характерно наличие всех форм безработицы с преобладанием в структуре работников физического труда, молодежи и женщин. (Кузьминова, 2003) В то время как в регионах Центрального федерального округа (в частности в Москве и Московской области) безработица сокращается, регионах Северного Кавказа безработица начинает носить затяжной, застойный характер.

- одни и те же факторы оказывают различное воздействие на рынки труда различных регионов. Например, если для слаборазвитых регионов миграция рабочей силы является фактором, осложняющим развитие рынка труда, то для активно развивающихся регионов, напротив, - стабилизирующим.

- единая государственная политика занятости не всегда учитывает региональную специфику. Так, проведенный А.Д. Базарсадаевой анализ нормативно-правовых и организационно-управленческих механизмов, обеспечивающих реализацию государственного регулирования безработицы (в частности молодежной безработицы) на региональном уровне, выявил следующие противоречия: правовые нормы государственного регулирования не соответствуют в достаточной степени реалиям социальной действительности, а конкретные механизмы государственной политики на уровне региона четко не определены. (Базарсадаева, 2009)

- мероприятия по борьбе с безработицей должны носить вариативный характер, учитывающий региональные особенности рынков труда. Для одних регионов оправдано применение мероприятий, разработанных в рамках кейнсианско-фордистской теории (увеличение спроса на рабочую силу без предъявления требований к ее квалификации), то для других оптимальное будет применение адаптированных для России либеральных преобразований. (Караханов, 1999) 


\section{5 Особенности российских безработных}

Общую разнородность динамики безработицы в зависимости от региона России, в частности по федеральным округам, можно проследить на графике 1. В связи с этим, анализ особенностей российских безработных целесообразно проводить также с учетом региональной специфики. Нами были выбраны 3 федеральных округа: Северо-Кавказский, Приволжский и Центральный - с высокими, средними и низкими показателями безработицы за последние 14 лет. Рассмотрим подробнее основные выявленные особенности.

- Безработные не обращаются в службу занятости населения. Анализ динамики уровня зарегистрированной безработицы к уровню безработицы, рассчитанной по методологии МОТ, показал, что большинство безработных граждан не склонны обращаться в службу занятости населения по вопросам поиска работы. Такая ситуация характера как для России в целом, так и для трех рассматриваемых федеральных округов. (График 3.) Разрыв в уровнях между регистрированной и общей безработицей может достигать до 10 раз. Такое расхождение впервые было впервые зафиксировано в 1992 году и к настоящему моменту приобрело системный характер. Не стоит полагать, что подобная ситуация является уникальной только для российского рынка труда. Исследователи выделяют целый ряд факторов, от институциональных и общеэкономических до социально-психологических, оказывающих воздействие на сложившуюся практику. Так, Р.И. Капелюшников выделяет ряд фоновых и общих характеристик, оказывающих влияние на стимулы к регистрации в службах занятости населения. К общим характеристикам он относит: не большой размер пособий по безработице, ограничение круга безработных, имеющих право на пособия; продолжительность выплаты пособий, «отсечение» от системы регистрации длительно безработных (более 18 месяцев). Фоновые характеристики, оказывающие косвенное воздействие на уровень регистрируемой безработицы: бюрократические сложности в регистрации, слабая информированность о деятельности служб занятости населения, фактор стигматизации (боязнь общественного осуждения), территориальная удаленность служб занятости населения. (Капелюшников, 2002) За последние 14 лет наметилась тенденция к сокращению разрыва между рассчитываемым по методике МОТ и регистрируемым уровнями безработицы. Так, по России в целом произошло снижение с 7,5 раз в 2000г. до 4,5 раз в январе 2015г. Аналогичная ситуация наблюдается во всех рассматриваемых федеральных округах: в Центральном округе произошло снижение с 7-ми кратного разрыва в показателях в 2000г. до пятикратного в январе 2015г., в СевероКавказском - с 7-ми до 3-х кратного разрыва, в Приволжском - с 6 до 5 кратного разрыва. Это может быть связано как с общим снижением уровня безработицы, так и с улучшениями в работе служб занятости населения.

- Городские безработные. Ввиду глобальной тенденции к урбанизации, набравшей силу в XXI веке, анализ динамики численности безработных по виду поселения показал, что подавляющее большинство безработных проживает в городах. Однако это не может быть связано с более благоприятной ситуацией на «негородских» рынках труда. Такая ситуация отражает общее пропорциональное соотношение городского и сельского населения в России, около 70\% которого проживает в городах. Только в СевероКавказском федеральном округе соотношение городского/сельского населения является примерно одинаковым и составляет 49,1\% / 50,9\%. Значительной общей численностью сельского населения, а также наличием большего числа вакансий в городах можно объяснить высокие показатели сельской безработицы в округе. С одной стороны, ситуация в Северо-Кавказском округе является нетипичной для России в целом и заслуживает разработки отдельных программ, способствующих росту занятости именно сельского населения. С другой стороны, в связи с тем, что городские агломерации часто не способны обеспечить рабочими местами постоянно растущее население, программы содействия занятости на селе могут быть применены и в остальных регионах России. Еще одной особенностью сельской безработицы является ее относительная стабильность, проявляющаяся во время кризисов. Так, если численность городских безработных в период экономического кризиса 2009 года увеличилась практически в двое, на селе рост уровня безработицы носил более сдержанный характер.

- Мужская безработица преобладает над женской. В период с 2000 по 2014 годы основным трендом по всем рассматриваемым федеральным округам являлось уменьшение количества как безработных мужчин, так и женщин, что может быть связано со снижением уровня безработицы в целом. Во всем мире уровень женской безработицы превышает уровень мужской. Однако, в России наблюдается противоположная ситуация, когда численность безработных мужчины превышает численность безработных женщин. Такая ситуация может быть обусловлена ставшей традиционной, после Великой отечественной войны ролью женщины, как основной трудовой силы государства. Более того, возрастающее количество разводов налагает на женщин роль основного кормильца семьи, в следствие чего женщины склонны всеми силами «держаться» за рабочие места соглашаясь на переработки и получение меньшей, в сравнении с мужчинами, заработной платы. Гипотеза о традиционно сильных гендерных стереотипах в отношении занятости женщины в южных регионах не подтверждается статистическими данными. Роль женщины, как хранительницы домашнего очага, несущей основную 
нагрузку по воспитанию детей, постепенно отходит на второй план и женщина превращается в полноправного участника рынка труда. С 2009г. в Северо-Кавказском федеральном округе наблюдается тенденция к выравниванию численности безработных женщин и мужчин. Другой положительной тенденцией в динамике мужской и женской безработицы является ее равное увеличение в периоды экономических кризисов.

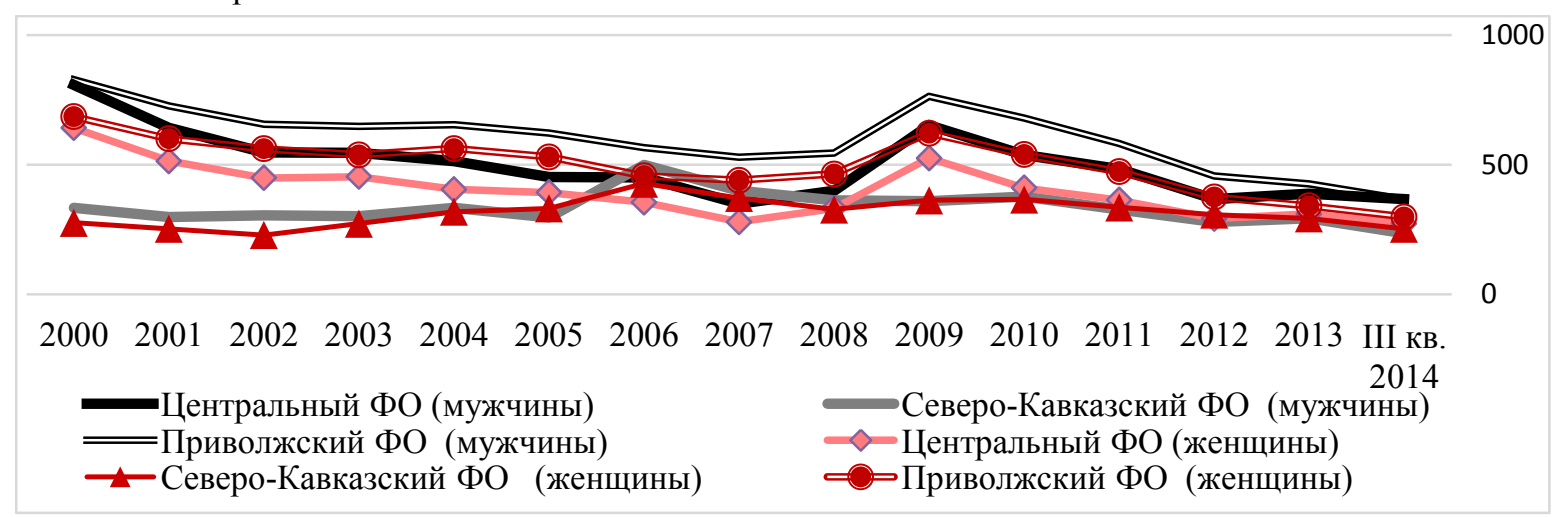

График 4. Динамика численности мужской и женской безработищы за 2000-2014гz. (тыс. чел; по данным Росстат)

Как показано на графике 4, Спад занятости в результате Мирового финансово-экономического кризиса 2008-2009г. одинаково коснулся и мужчин, и женщин. Это может свидетельствовать об изживании стереотипа о преобладающей ценности мужской профессиональной компетентности над женской. Помимо дискриминации в оплате труда, другим следствием этого стереотипа являлось массовое увольнение (добровольное и принудительное) женщин в периоды экономических кризисов.

- Безработные в расцвете лет. Средний возраст безработного колеблется в пределах 32-37 лет, что приходиться на самый расцвет карьеры. С преобладанием в половозрастной структуре населения численности данной возрастной группы это не связано, т.к. по данным всероссийской переписи населения 2010г. большая часть россиян находятся в возрасте 50-55 лет, следующая многочисленная группа 23-27 лет. Показатели молодежной безработицы по всем федеральным округам на протяжении 13 лет остаются стабильно высокими. Так, среди общего количества безработных каждый третий находиться в возрасте от 20 до 29 лет, каждый пятый - 30-39 лет. Наименьшее количество безработных составляют возрастную категорию 60-72 года. Настораживает наметившаяся тенденция постепенного увеличения среднего возраста безработного, что может свидетельствовать о постепенном вытеснении с рынка труда лиц более старшего возраста. В качестве основной причины «старения» среднестатистического безработного можно выдвинуть растущие потребности инновационной экономики в новых специальностях и навыках, и инертность в вопросах профессиональной компетенции лиц более старшего возраста. Отсюда - устаревание профессий, навыков и профессиональных компетенций.

- Чем выше уровень образования, тем меньше шансов оказаться безработным. Анализ состава безработных по уровню образования за 2001-2013гг. подтверждает, что значительную роль в положении на рынке труда играет уровень образования. Так за 14 рассматриваемых лет, доля безработных, имеющих высшее профессиональное образование оставалась ниже 20-22\%. В то время как доля безработных, получивших только среднее общее образование (11 классов школы) в Центральном и Приволжском составляла порядка 30\%, а в Северо-Кавказском округе в 2012-2013г. превышала 50\%. Общий уровень безработицы также чувствителен к уровню образования. По данным Росстата, среди лиц с высшим образованием безработных лишь 3,6\%, тогда как среди лиц, не имеющих основного общего этот показатель достигает 20\%. Это может быть объяснено воздействием следующих факторов: повышенной конкурентоспособностью высококвалифицированных работников на рынке труда; их гибкостью и способностью к адаптации в изменяющихся экономических условиях, возможностью осваивать новые виды трудовой активности; общемировой тенденцией к инновационному развитию экономики и повышающейся роли человеческого капитала. Вместе с тем напряженность на рынке труда для лиц с более высоким уровнем образования может оказывать давление на рынок труда для лиц с более низким уровнем образования, что во многом объясняет тот факт, что уровень безработицы среди специалистов со средним профессиональным образованием превышает эту величину для лиц с высшим профессиональным образованием, т.е. специалист, имеющий высшее профессиональное образование может занимать должность, требующую лишь среднего профессионального образования. Аналогично по среднему и начальному профессиональному образованию. 


\section{6 Заключение}

Безработица в России в 2000-2014 годах демонстрировала динамику постоянного снижения численности незанятого населения. Более того, даже кризисные показатели 2008-2009 годов не достигли пиковых значений 1998г. Однако, не смотря на невысокие показатели уровня безработицы, ряд ее отличительных черт вызывает серьезные опасения. Так, несмотря на снижение «обсуждаемости» темы безработицы после кризиса 2008г., население продолжает опасаться потери работы, негативно оценивая шансы своего трудоустройства на аналогичные позиции. Это подтверждает продолжающийся экономический спад и сокращение объемов найма рабочей силы. Кроме того, в обществе еще достаточно сильны советские установки о полном недопустимости безработицы, которые в кризис приобретают особую популярность. Однако, в настоящий момент правительство фактически сложило с себя обязанности по обеспечению рабочими местами населения и перешло к политике «содействия занятости», выражающейся в выплате пособий, организации общественных работ и опережающему профессиональному обучению, т.е. мероприятиям, не гарантирующим занятость и достойный заработок. Такая политика может войти в конфронтацию с общественными настроениями в случае осложнения экономической обстановки в стране. Более того, традиционно применяемые государственными деятелями меры борьбы с безработицей, хотя и обеспечивают номинальное снижение статистических показателей, но приводят к падению уровня благосостояния населения всей страны в целом. Все это, в случае обострения проблемы безработицы может привести к серьезной социальной напряженности в стране.

\section{Литература}

- Altindag, 2012. "Crime and unemployment: evidence from Europe”.International Review of Law and Economics. 32. p.145-157.

- Canal 4, 2014. Benefits Street http://www.channel4.com/programmes/benefits-street

- $\quad$ Eurostat, 2014. Unemployment in the EU28 regions in 2013. http://epp.eurostat.ec.europa.eu/cache/ITY_PUBLIC/1-15042014-BP/EN/1-15042014-BP-EN.PDF

- Harris, 2014. Record unemployment with nearly half of EU's jobless out of work for over a year. http://www.euronews.com/2014/04/15/record-long-term-unemployment-with-nearly-half-of-eus-jobless-outof-work-for-/

- ILO, 2014. The Russian Federation's Response to Crisis. Meeting of Labour and Employment Ministers, http://www.ilo.org/public/libdoc/jobcrisis/download/g20_russia_countrybrief.pdf

- Interfax, 2015. Россия и кризис встретились в Давосе, http://www.interfax.ru/business/419940

- World Bank, 2015. Алессио Дж.Г. Браун и Йоханнес Коэттл. Программы реализации активной политики на рынке труда: при каких условиях, почему, когда и в какой степени они являются эффективными? http://www-wds.worldbank.org/external/default/WDSConte.pdf

- Ахмадинуров, 2003. Регионалыныйрыноктруда и социальные механизмы его регулирования. Уфа.

- Базарсадаева, 2009. Молодежная безработица: основные направления государственного регулирования. Чита

- Беркович, Папина, Сущикова, 2010. “Безработица в современныхусловиях: региональные особенности и формы поддержки.” Сборник научных трудов вузов России "Проблемы экономики, финансов и управления производством". С. 107-111.

- Брусянина, 2010. Особенности молодежной безработицы в России. Томский государственный университет. Томск.

- Бушмарин, 1998. “Аномалии российского рынка труда” Мировая экономика и международные отночения. 2. С. 12.

- Вайс 2014. Особенности безработицы на региональном рынке труда на примере Омской области. Материалы Международной научно-практической конференции. г.Уфа, С. 52-54.

- ВЦИОМ, 2014. Безработица и разговоры о ней. Пресс-выпуск № 2568 http://wciom.ru/index.php?id=459\&uid=114804.

- ВЦИОМ, 2015. Россияне опровергают министров. http://wciom.ru/index.php?id=269\&uid=3406 -

- Гимпельсон, Капелюшников, 2010. Рынок труда: «пейзаж после кризиса». Материалы доклада на заседании Экспертного совета при Правительственной комиссии по экономическому развитию и интеграции, 6 июля 2010г.

- Голенкова, Игитханян, 2001. “Безработные: особенности российского бытия” Сочиологические исследования, 5, С.67-76. 
- Гордон, Клопов. 2000. "Социальные эффекты и структура безработицы в России". Экономическая сочиология. 1. С. 37-47.

- Горина, 2011. “Исследование рынка труда: междисциплинарный подход”. Современная экономика: проблемы, тенденции, перспективы, 5. С. 1-7.

- Грищенко, 1999. Особенности региональной безработицы и пути ее регулирования (На примере городов Самарской области). Москва.

- Дадаева, 2005. “Динамика гендерной структуры рынка труда и занятости в Мордовии”. Регионология. 3. С. $125-141$.

- Ермакова ve Кирилова, 2006. “Сельская безработица, особенности ее проявления и регулирования”. Вестник Тюменского государственного университета. Социально-экономические и правовые исследования. 4. С. 245-247.

- Зудина, 2011. "Представления россиян о причинах экономических достижений и неравенства: Россия и мир". Материалы XI международной научной конференции по проблемам развития экономики и общества: В 3 кн. - Кн. 3.

- Ивлева, 2007. “Особенности переживания ситуации безработицы у людей с различными смысложизненными ориентациями”. Известия Российского государственного педагогического университета им. А.И. Гериена. Т. 16. 40. С. 416-419.

- Ивлева, 2012. “Выявление особенностей безработицы среди выпускников вузов”. Bonpocbl современной науки и практики, 2-40, С. 96-100.

- Капелюшников, 2002. Обшая и регистрируемая безрабопица: в чем причины разрыва? ГУВШЭ, Москва

- Капелюшников, 2006. Конец российской модели рынка труда? Изд. дом Государственного университета - Высшей школы экономики. Москва.

- Комлев, 2006. Региональный рынок труда (проблемы и перспективы). Издательство Волгоградского института экономики, социологии и права. Волгоград.

- Костикова, 2005. Введение в гендерные исследования: Учеб. Пособие для студентов вузов. Аспект Пресс, Москва.

- Котоманова, Осинский, 2015. “Социальное самочувствие мужчин и женщин в ситуации безработицы (На примере г. Улан-Уде)” Вестник Бурятского государственного университета. 5. С. 139-144.

- Кузнецова, 2004. Регулирование занятости и безработицы как социальных явлений на региональном рынке труда: на материалах Подмосковья. Москва.

- Кузьминова, 2003. “Исследование феномена безработицы отечественной наукой: По материалам фондов диссертационного отдела РГБ”. Социологические исследования. 7. С.145-149.

- Куприянова, 1999. “Безработица и безработные” Мониторинг общественного мнения: экономические и соичильные перемены. 1 (39). С. 28-31.

- Малин, 2013. “Особенности безработицы выпускников вузов в современной России”. Научноисследовательские публикацุии. 3. С. 21-26

- Маслов, 2014. “Проверка на цивилизованность”. Центр деловой информации Капитал. 25.06.2014.

- Морозова, 2000. Взаимодействие рынка труда и потенциал потребительского рынка. Материалы конференции Актуальные проблемы регионального и муниципального управления. Москва. С. 41-47.

- Нечитайло, Гнутова, 2010. Особенности Российской экономики в переходный период: учеб. пособие. Изд-во СГАУ, Самара.

- Сулакшин, 2008. Государственная экономическая политика - экономическая доктрина России. К умной и нравственной экономике. Научный эксперт, Москва.

- Феофанов, 1995. “Ценностно-нормативный аспект безработицы в России”. СОЦИС. 9. С.69-74.

- Шабаева, 2000. “Проблема занятости и демографическая ситуация в Росси в период трансформации (Обзор)”. Экономические и социальные проблемы России. 4. С. 89-106.

- Шаожева, 2010. “Региональные особенности женской безработицы в Кабардино-Балкарии на современном этапе”. Вестник Северо-Осетинского государственного университета имени Коста Левановича Хетагурова.4. С. 101-104.

- Яковлева, 2007. “Особенности безработицы в РФ” Российский экономический интернет-журнал. 2. С. 77.

- Яковлева, 2010. Особенности безработицы в крупном городе: тенденции и направления регулирования. Научно-исследовательский институт труда и социального страхования, Москва. 


\title{
Легализация платных услуг - источник повышения заработной платы медицинских работников
}

\section{Legalization of Paid Services - The Source of Increasing Salaries of Medical Workers}

\author{
Assoc. Prof. Dr. Damira Japarova (Kyrgyzstan-Turkey Manas University, Kyrgyzstan)
}

\begin{abstract}
The main reason for the existence of informal payments in health care in Kyrgyzstan is low wages. On preferential treatment of patients is used $94 \%$ of funds allocated by the state. The financing of medical services largely transferred to the citizens themselves. Replacement free assistance paid services, in the absence of government regulation, acts as a natural addition to the market price, it is impossible to cancel or destroy. Promote the quality of work does not go beyond payroll. Kyrgyzstan should be legalized paid medical services. The source of the additional accrual of wages may become fund clinics, hospitals generated by paid services.
\end{abstract}

\section{1 Введение}

В Кыргызско-Турецком университете «Манас» в 2013-2014 годах осуществлялся проект «Экономический анализ системы здравоохранения в Кыргызстане», в рамках которого были определены проблемы, сдерживающие прогрессивные процессы в сфере здравоохранения. Одна из них - низкий уровень заработной платы. Вследствие именно этой причины в государственных учреждениях Кыргызстана широко распространено такое явление, как неформальные платежи. Во время опроса, проведенного среди врачей государственных учреждений, 93\% выразили свое неудовлетворение размерами заработной платы. Степень неудовлетворенности столь велика, что многие врачи и медсестры отправляются в ближнее и дальнее зарубежье в поисках более высокой платы за свой труд, и число эмигрирующих растет. Единственным источником оплаты труда в медицинских учреждениях в Кыргызстане является фонд оплаты труда, а его экономия позволяет накопить средства для стимулирования работников системы здравоохранения в виде премиальных выплат. Платные же услуги оказались вне сферы управляющего воздействия со стороны государства. И этот процесс, т.е. замена бесплатных медицинских услуг на платные, носит стихийный и бессистемный характер. Отсутствует механизм, с помощью которого можно было бы регулировать этот процесс, поэтому данная плата выступает как нерегулируемое государством прибавление к рыночной цене, что не поддается ни отмене, ни уничтожению. Единственный способ приведения их в какие-то рамки и реальный путь к повышению уровня заработной платы - это легализация неформальных платежей.

\section{2 Проблемы миграции работников системы здравоохранения}

Правительство КР предпринимает меры для повышения заработной платы медицинских работников. В 2013 году она увеличилась в 3,9 раза, если сравнивать с 2007 годом. По данным Министерства здравоохранения КР, она со всеми надбавками составила 11915 сом. (Минздрав КР, 2009-2013). В целом же, в рамках социальной сферы, у медиков заработная плата самая низкая. Только 6 тыс. сом. получает молодой специалист, окончивший медицинский вуз, медицинская сестра после окончания медучилища и того меньше - 4 тыс. сом. Этим объясняется стремление молодых специалистов устроиться в частное медицинское учреждение, где и условия лучше, и заработная плата выше.

Медработники: медсестры и врачи всех профилей мигрируют в Россию, Казахстан и даже в дальнее зарубежье. И чаще всего это специалисты со стажем, превышающим 10 лет. Таким образом, они способствуют росту сектора здравоохранения других стран, повышая его экономическую эффективность. Помогают им в этом хорошее знание русского языка и подготовка в КГМИ, который во времена Советского союза украшал десятку самых сильных вузов страны. Усуглубляет проблему и внутренняя миграция. Причина та же - низкая заработная плата и слабая, а то и отсутствующая инфраструктура. Конечно, это касается села и отдаленных регионов, куда с неохотой едут молодые специалисты. И там наблюдается острая нехватка медицинских кадров специальной и высшей квалификации. Это касается таких районов, как Чон-Алайский, Сузакский, Аксуйский. Положение с медицинскими кадрами здесь катастрофическое -8-9 медработников на 10 тысяч населения (Эту страну уже не вылечить?, 2013).

Труд медицинских работников должен быть мотивирован. Однако предпосылки для этого отсутствуют: не разработан механизм экономического стимулирования за наилучшие показатели оказываемой помощи, не установлены показатели результативности, не решаются жилищные проблемы, отсутствует социальная защищенность большинства медработников. Особенно это касается сельской местности. 
Поэтому следует говорить о поиске реальных источников мотивации к оказанию качественной медицинской помощи как актуальной проблеме в Кыргызстане.

\section{3 Формы и методы оплаты труда в здравоохранении Кыргызстана}

В Кыргызстане единственным источником вознаграждения за труд в системе здравоохранения являются средства фонда оплаты труда. Фонд оплаты труда медицинских работников здравоохранения Кыргызстана формируют четыре источника:

1) бюджетные начисления в соответствии со сметой расходов по статьям бюджетной классификации «Заработная плата» и «Отчисления» в Социальный фонд;

2) средства обязательного медицинского страхования - определяются ФОМС как процент от суммы, выделяемой в расчете на душу населения (35\% для ПСМ), или за пролеченный случай $(25 \%$ - для стационаров;

3) специальные средства - какой объем направлять на заработную плату решает руководитель лечебного учреждения;

4) средства сооплаты устанавливаются в Минздраве КР - 20\% от поступлений общей суммы поступлений сооплаты.

Выплаты гарантированной и дополнительной заработной платы осуществляются из консолидированного бюжета Единого плательщика в соответствии с положением об оплате труда и законодательной системой КР. Для того чтобы определить размер фонда оплаты труда в стационарных условиях, берутся затраты прошлого года за пролеченный случай. Лечение регламентируется твердыми нормативами, из нескольких альтернатив выбираются минимальные затраты на лечение.

Из этого фонда оплаты труда начисляется заработная плата и осуществляются премиальные выплаты за счет экономии фонда. По мнению Гульгун Мурзалиевой (Г. Мурзалиева «Оценка существующего механизма распределения дополнительной заработной платы...», Бишкек, 2010), эта система оплаты труда в организациях здравоохранения не лишена недостатков: в ней нет ясности и самое главное - она не учитывает вклада конкретного сотрудника. Ссылаясь на Брайнс Трейси (БрайанТрейси. Искусственный отбор, 2008), мы констатируем, что тарифная ставка - это фиксированная сумма, которую работник получает в виде заработной платы за тот объем работы разной сложности, который он выполняет в течение часа, дня или месяца. При этом учитываются профессионализм и квалификация сотрудника, степень сложности его работы, но не оцениваются очень важные особенности труда конкретного работника: напряженность (нагрузка на эмоциональную сферу), опыт работы, особые условия выполнения работы и др.).

Итак, в обмен на свой труд работник получает заработную плату, размер которой исчисляется по следующей формуле:

$$
\text { ЗП= ГЗП + ИВ +ДЗП, }
$$

где ЗП - заработная плата;

ГЗП - гарантированная заработная плата;

ИВ - индивидуальные выплаты;

ДЗП - дополнительная заработная плата.

Составляющей гарантированной заработной платы являются должностной оклад, в соответствии с ЕТС (единая тарифная ставка), и надбавки к окладу, устанавливаемые в зависимости от наличия: ученой степени и звания, категории квалификации (это касается руководителей и замов); особых условий, связанных с угрозой здоровью и тяжестью труда; для должности руководителя какого-либо подразделения в структуре организации и для медицинских работников сельской местности.

Индивидуальные выплаты включают вознаграждение за занятость в ночные часы и в дни праздников; за дополнительную работу по другой профессии; за превышение объема работы и увеличение зоны обслуживания; выплаты за отпускной период, в случае болезни (при оформленном больничном листе); единовременное пособие в связи с сокращением и увольнением.

Дополнительная заработная плата определяется по формуле:

ДЗП = ГЗП х КДЗ х КТУ,

где ДЗП - дополнительная заработная плата;

ГЗП - гарантированная заработная плата;

КДЗ - коэффициент дополнительной заработной платы;

КТУ - коффициент трудового участия.

Есть расчетная формула и для коэффициента дополнительной заработной платы (КДЗ):

КДЗ = ФДЗП + КПОПР, 
где ФДЗП - фонд дополнительной заработной платы;

КПОПР - поправочный коэффициент (зависит от фонда оплаты труда, его определяет сама медицинская организация, (Гульгун Мурзалиева «Оценка существующего механизма распределения дополнительной заработной платы...», Бишкек, 2010).

Трудовое участие всей структуры медицинской организации определяется специальным коэффициентом КТУ ежемесячно экспертной комиссией, в которую входят сотрудники организации и ее структурных подразделений. Основанием при этом служат трудовые паспорта, заполняемые от имени подразделения и каждого работника (Положение об оплате труда работников здравоохранения Кыргызской Республики 2011 года).

В процессе реформирования системы здравоохранения были выявлены новые источники финансирования, что определило повышение заработной платы медицинских работников. Это средства OMC, сооплаты и специальные средства бюджетных организаций. Согласно утвержденным нормативным документам, часть финансовых средств из указанных выше трех источников направляются на дополнительные выплаты медицинским работникам.

Формирование ФДЗП осуществляется согласно КТУ как показатель работы отдельного подразделения, так и медицинской организации. Данный механизм внедрен с 2002 года и призван оказывать стимулирующее влияние на работающий персонал. Однако, несмотря на фактическое наличие премий и надбавок, распределяются они, скорее всего, механически и уравнительно и потому не играют стимулирующей роли. Это связано с тем, что источник стимулирования качества работы находится в пределах фонда оплаты труда, и размер дополнительной заработной платы зависит от суммы гарантированной заработной платы, размер которой остается неизменным. Увеличение дополнительной заработной платы для какого-либо работника требует экономии суммы дополнительной заработной платы за счет других работников. Иной альтернативы нет.

При анкетировании из 514 врачей на вопрос «Влияет ли администрация на размер заработной платы?» $18,9 \%$ ответили, что оказывает большое влияние, $29 \%$ - среднее влияние и $52 \%$ - отсутствует влияние. И на вопрос «Есть ли мотивация хорошей работы? » 61,8\% отметили, что мотивация отсутствует. Все это свидетельствует о необходимости пересмотра источников стимулирования и принципов установления коэффициента трудового участия. Дополнительная выплата врачам в размере 1 тыс. сом. от мэрии Бишкека должна была доукомплектовать первичное звено медицинским персоналом и послужить стимулирующим фактором доступности и улучшения качества медицинских услуг. В реальной ситуации руководство ЛПУ не имеет никакого влияния на размер данной выплаты, т.е. она оказывается фиксированной, что собственно говоря, лишает эту выплату ее главной функции - стимулирования.

На производстве формирование фонда материального поощрения осуществляется за счет прибыли. Таким образом, задаемся вопросом: «Где найти истинный источник материального стимулирования качественной работы медицинского работника? ». Отсутствие прибыли в медицине вынуждает в качестве мотивации использовать средства, поступившие от предоставления платных услуг. В связи с этим рассмотрим состояние платных услуг в медицине Кыргызстана.

\section{4 Платные услуги и неформальные платежи в системе здравоохранения КР}

В Кыргызской Республике повышение заработной платы медицинским работникам не решило проблемы формальных платежей. Они в этой сфере услуг по-прежнему широко распространены, что создает материальные трудности для пациентов, нуждающихся и в стационарной, и амбулаторной помощи. Больной человек испытывает многократные материальные затраты. Несмотря на оплату налогов, медицинского страхования, он вынужден еще и покупать дорогие лекарства, оплачивать услуги по прейскуранту и осуществлять неформальные платежи. И снова на первый план как главная причина незаконных выплат выступает относительно низкий уровень заработной платы. Мы уже отмечали, что по результатам опроса не удовлетворены размером получаемого вознаграждения за свою работу $93 \%$ врачей. При этом степень удовлетворенности работой у многих медицинских работников обусловлена не столько материальными, сколько моральными факторами. Это прежде всего осознание правильности выбора профессии и чувство удовлетворения от своей полезности обществу.

Из числа опрошенных врачей 96\% отметили, что любят свою профессию и 91,3\% признали взаимоотношения, сложившиеся с товарищами по работе, хорошими и доброжелательными. Профессиональная деятельность абсолютного большинства врачей осуществляется в коллективе и придается большое значение оценкам коллег по работе и оценкам результатов индивидуального труда. Однако 89,9\% врачей хотят получить больше самостоятельности в своей профессиональной деятельности.

В сфере оказания медицинских услуг в государственных медицинских учреждениях отсутствуют цивилизованные рыночные экономические отношения. В здравоохранении республики по-прежнему 
доминируют преимущественно административные методы управления. Органы госуправления регламентируют деятельность каждого лечебно-профилактического учреждения различного рода нормативами. В условиях волевых рычагов воздействия невозможно оценить объективные результаты труда, обеспечить и создать экономические стимулы.

По результатам опроса 75\% врачей убеждены, что оплата медицинского труда не зависит или зависит в малой степени от объема и качества их работы. По оценкам большинства опрошенных (78\%), незначительны и такие факторы, как премии и надбавки. Выплаты из фонда дополнительной оплаты труда производятся скорее механически, с элементом уравниловки, поэтому не имеют стимулирующего значения.

В основе оплаты труда в здравоохранении КР лежит Единая сетка с учетом соответствующей доплаты. Однако повременная система имеет существенные недостатки: считается как фиксированная и независящая от качественных показателей работы. Она предусматривает выплаты вознаграждения даже при условии невыполнения необходимого объема работы. Медицинские работники, согласно этой системе, несмотря на отличие показателей качества работы и результатов труда, имеют одинаковую заработную плату. Ни длинная очередь у кабинета врача, ни отсутствие таковой, не влияют на размер заработной платы, она у них одинаковая. Поэтому здесь не приходится говорить о стимулирующей функции и присутствии фактора мотивации к труду. Наоборот, снижается показатель качества медицинских услуг, у работника не возникает желания затрачивать большие усилия.

Средства, затрачиваемые на лечение льготных пациентов, составляют 94\%. Остальные граждане вынуждены самостоятельно финансировать оказываемую им медицинскую помощь. Таким образом, возник разрыв между декларациями и реальным положением в области оказания медицинских услуг. Сумма расходов населения на препараты и услуги здравоохранения неуклонно повышается. Растет доля платных услуг. Государственные расходы замещаются частными, и процесс этот не регулируется. Снижается качество в государственных медучреждениях. Эти негативные последствия в большей степени испытывают наиболее уязвимые слои населения. Различные социальные группы имеют неравные возможности доступа к медицинским услугам.

Источником расходов здравоохранения являются также спецсредства, которые поступают от платных медицинских услуг. Это и услуги стоматологии, и плата, вносимая за аренду помещения и повышенную комфортность в стационарах. Кроме того, это и прямая покупка лекарственных препаратов, и неформальные платежи за оказанные медицинские услуги. Минуя государственное перераспределение, эти средства напрямую попадают в медицинские учреждения как прямая оплата медицинских услуг.

Есть определенный экономический эффект от использования платных медицинских услуг. Во-первых, внедряются новые медицинские технологии; во-вторых, идет интенсивное освоение материальнотехнической базы; в-третьих, шире привлекаются кадровые ресурсы. Эти положительные моменты при переходе к рыночным отношениям позволяют смягчить проблему дефицита бюджета. Однако платные услуги оказались за пределами сферы управления государства. Замечен и такой фактор, как оказание платных медицинских услуг тем же медперсоналом и с помощью того же оборудования, что при условии бесплатной помощи. Увеличиваются нагрузки на ресурсы больниц, их приходится делить на большее количество госпитализаций, отсюда ниже стоимость одного пролеченного случая и, как следствие, снижение качества медицинских услуг. Это прямой путь к различного рода злоупотреблениям. Растет теневая экономика. И этот процесс носит стихийный характер.

И хотя фактор замещения бесплатной медицинской помощи на платную ни в каких стратегических документах и нормативных актах не формулируется, это не мешает ему существовать в реальности. Причина кроется в установленных прейскурантах. Они существуют с 2008 года и не способствуют окупаемости затрат на такие, например, процедуры, как рентген, общий анализ крови и др. Так, в городе Таласе рентген работает только для стационара и стоит 50 сом. Цены на анализы не покрывают затраты. Технология старая, томографии нет. Ультразвук стоит 25 сомов, обследование желчного пузыря и печени - 38 сомов, прокол гайморовой пазухи - 64 сома и вскрытие паратонзилярного абцесса - 47 сомов. А в частной клинике только общий анализ крови стоит 160-300 сомов.

Во время анкетирования пациенты (26,9\%) отметили, что помимо сооплаты вносили плату за хирургическое вмешательство. Видимо, этим объясняется, что 70,2\% пациентов больниц выступают за легализацию оплаты оказанных им врачебных услуг. Чуть больше половины опрошенных больных (58\%) убеждены, что качественное лечение может быть только платным. В процессе опроса пациентов 28,6\% пациентов признались, что платят за медицинские услуги непосредственно в руки врача. При этом удельный вес поступлений от частных выплат в виде сооплаты и официальной платы за лечение, поступающих в распоряжение Единого плательщика, составляет лишь 6,3\%. Получается, что реальная плата за услуги имеет неофициальную форму. Отсутствие механизма регулирования приводят к тому, что неформальный платеж является не регулируемым государством дополнением к рыночной цене. И его необходимо легализовать, учитывая, что наблюдается тенденция выхода платных услуг из тени. 
Специальные средства, или поступления от платных услуг должны стать источником собственного дохода поликлиники и больницы, используемого в первую очередь для повышения заработной платы медицинских работников.

\begin{tabular}{|c|c|c|c|c|c|c|}
\hline & 2009 год & 2010 год & 2011 год & 2012 год & 2013 год & $\begin{array}{c}\text { Темпы роста к } \\
2009 \text { г., \% } \\
\end{array}$ \\
\hline \multicolumn{7}{|l|}{ Стационары: } \\
\hline Зарплата +социальный & 16,6 & 16.2 & 19.0 & 23.1 & 49,6 & 298,8 \\
\hline Коммунальные услуги & 3,6 & 4.1 & 4.1 & 5.8 & 10,8 & 300,0 \\
\hline Медикаменты & 2,0 & 1.3 & 3.6 & 35.5 & 6,1 & 305,0 \\
\hline Питание & 0,4 & 0.9 & 0.6 & 18.8 & 1,3 & 325,0 \\
\hline Другие статьи & 25,4 & 40.2 & 56.5 & 38.9 & 76,1 & 299,6 \\
\hline Итого & 48,0 & 62.7 & 83.8 & 121.9 & 143,9 & 299,8 \\
\hline \multicolumn{7}{|l|}{ ПМСП } \\
\hline $\begin{array}{l}\text { Заработная плата с } \\
\text { отчислениями }\end{array}$ & 11,4 & 15.1 & 17.1 & 19.8 & 37,4 & 328,0 \\
\hline Коммунальные услуги & 1,0 & 0.7 & 1.0 & 1.2 & 3,3 & 330,0 \\
\hline Медикаменты & 2,5 & 3.7 & 4.2 & 7.4 & 8,2 & 328,0 \\
\hline Питание & 0,3 & 0.3 & 0.5 & 1.1 & 0,9 & 300,0 \\
\hline Другие статьи & 9,7 & 12,5 & 16.8 & 16.5 & 31,7 & 326,8 \\
\hline Итого & 24,9 & 32.3 & 39.5 & 46.1 & 81,5 & 327,3 \\
\hline \multicolumn{7}{|l|}{ Всего ЕП } \\
\hline $\begin{array}{l}\text { Заработная плата с } \\
\text { отчислениями }\end{array}$ & 28,0 & 31.3 & 36.1 & 42.9 & 87,0 & 310,7 \\
\hline Коммунальные услуги & 4,6 & 4.8 & 5.0 & 7.0 & 14,1 & 306,5 \\
\hline Медикаменты & 4,5 & 5.0 & 7.8 & 42.9 & 14,3 & 317,8 \\
\hline Питание & 0,7 & 1.2 & 1.1 & 19.9 & 2,2 & 314,3 \\
\hline Другие статьи & 35,5 & 52.7 & 73.4 & 55.4 & 107,8 & 303,7 \\
\hline Итого & 73,3 & 95.0 & 123.3 & 168.0 & 225,4 & $\mathbf{3 0 7 , 5}$ \\
\hline
\end{tabular}

Таблица 1. Специильные средства в разрезе статей расходов по видам медиичнских услуг за 2009-2013 годы, млн. сом. Источник: Данные Министерства здравоохранения КР за 2009-2013 годы.

По данным таблицы, наблюдается увеличение спецсредств медучреждений более чем в 3,1 раза. При этом финансирование медико-санитарной помощи - в 3,3 раза, стационаров - в 3,0 раза. Преимущественно эти средства используются на повышение заработной платы медицинских работников, оплату услуг коммунальных служб и др. Тем не менее, как было отмечено выше, платные услуги в общем объеме финансирования государственного здравоохранения не превышают 6,3\%. Это говорит о том, что платные услуги в медицине КР приобрели форму «неформальных платежей». Поэтому мы предлагаем легализировать платные медицинские услуги и использовать их для повышения заработной платы.

\section{5 Оборотный капитал в медучреждениях}

Для мотивации труда работников здравоохранения, помимо повременной оплаты труда по тарифной сетке, следует активно использовать различные формы сдельной оплаты труда, т.е. вводить дифференцированную оплату труда. В качестве источника стимулирования необходимо использовать средства лечебного учреждения, образованные за счет платных услуг (Опыт Турции). (DÖNER SERMAYE..AFYON 2014).

Цель создания «оборотного капитала» в медицинских учреждениях Турции: получение дополнительного дохода, что уменьшает груз на государственный бюджет; позволяет использовать простаивающие мощности государственных медицинских учреждений; обеспечивает общественную пользу медицинских учреждений.

Оборотные средства или возобновляемые фонды в государственных лечебных учреждениях Турции создаются за счет платных услуг. Это плата за диагностику, лечение, хирургические операции и другие виды услуг. В поликлиниках, согласно специальным тарифам, осуществляются платные услуги застрахованным туристам и иностранным пациентам. Полученные доходы распределяются между работниками медицинского учреждения в виде дополнительной заработной платы. Она может намного превышать размер основной заработной платы. Кроме расходов на заработную плату, средства фонда используются для покупки медицинского оборудования и идут на обучение медицинского персонала.

Такой опыт можно использовать в Кыргызской Республике. Легализация платных услуг может стать источником роста зарплаты в медицинских учреждениях. Однако для реальной мотивации труда следует пересмотреть принципы материальной заинтересованности в качественном выполнении трудовых 
обязанностей медработников. Необходимо разработать новые принципы премирования врачей и медицинских сестер, а также мотивировать непрерывное повышение квалификации медперсонала.

\section{6 Выводы:}

- Неформальные платежи в системе здравоохранения КР обусловлены низким уровнем оплаты труда .

- Увеличилось количество медицинских работников, уезжающих в страны ближнего и дальнего зарубежья.

- Единственным источником начисления заработной платы в системе здравоохранения КР является фонд оплаты труда.

- Работники системы КР премируются за счет экономии фонда оплаты труда. Однако это не является стимулирующим фактором.

- З Замена бесплатной помощи платными услугами происходит стихийно и бессистемно.

- Неформальные платежи в медицине не следует считать «взяткой», они выступают как нерегулируемое государством дополнение к рыночной цене.

- В качестве источника мотивации труда необходимо использовать фонд лечебного учреждения, образуемого за счет платных услуг

- Следует мотивировать непрерывное повышение квалификации медицинских работников.

\section{Литература}

- Гульгун Мурзалиева и др. «Оценка существующего механизма распределения дополнительной заработной платы в организациях здравоохранения КР»Бишкек 2010.

- DÖNER SERMAYE BÜTÇE BİRIMİ AFYON 2014 www.tkhk.gov.tr/../b6388c566cc4491ea2dc56.

- Материальное вознаграждение медицинского персонала http://www.medicinarf.ru/public/12488/ 2014

- Брайан Трейси Искусственный отбор. 21 способ решения кадрового вопроса

- 2008,Альпина Бизнес Букс. http://www.ippnou.ru/book.php?idbook=000405

- Данные Министерства здравоохранения КР за 2009-2013 годы

- Положение об оплате труда работников здравоохранения Кыргызской Республики Утверждено постановлением Правительства Кыргызской Республики от 26»мая 2011 года

- Чернышев В.М., Стрельченко О.В. Дифференцированная оплата труда в здравоохранении.Новосибирск, 2011. http://www.somc-nsk.ru/Documents/books/7.pdf

- Эту страну уже не вылечить? Из Киргизии уезжают врачи и медсестры HTTP:/NEWS.TJ/RU/NEWS/ETUSTRANU-UZHE-NE-VYLECHIT-IZ-KIRGIZII-UEZZHAYUT-VRACHI-I-MEDSESTRY 


\title{
Факторы, Определяющие Роста Микрокредитного Сектора в Кыргызстане
}

\section{Determinants of Growth of Microcredit Sector in Kyrgyzstan}

\author{
Assoc. Prof. Dr. Turusbek Asanov (Kyrgyzstan-Turkey Manas University, Kyrgyzstan) \\ Ph. D. Candidate Kadyrbek Sultakeev (Kyrgyzstan-Turkey Manas University, Kyrgyzstan)
}

\begin{abstract}
Microcredit has developed extremely rapidly since its beginning in the late 1970, however which main factors determine the growth of the microcredit is a subject for debate. The primary purpose of this study was to determine the key factors that determine the growth of the microcredit sector. The target population was the 307 borrowers of microfinance institutions selected from Isyk-Kul region, Chuy region and Bishkek city. Data collection methods such as questionnaires, observation and interviews were used. Sampling technique was used and results analyzed qualitatively and quantitatively in terms of descriptive statistics. The main factor for developing microcredit was the excessive demand for microcredit product in Kyrgyzstan due to the structure of the economy and employment.
\end{abstract}

\section{1 Введение}

Микрофинансовая система начала развиваться в Кыргызстане с 1994 года с помощью проектов Всемирного банка, ПРООН, Азиатского банка развития, Международного корпуса милосердия, ACDI/VOCA, Швейцарской НПО «Каритас». Были созданы и начали свою работу первые институты ФИНКА, Кыргызская сельскохозяйственная финансовая корпорация (ныне Айыл банк), Финансовая компания по поддержке и развитию кредитных союзов. Период 1994 - 2000 года можно считать первым этапом развития, в этот период были апробированы отдельные кредитные схемы, организованы пилотные проекты, разработаны первичные нормативные правовые документы, принят первый Закон КР «О кредитных союзах». По состоянию на конец 2000 года совокупный кредитный портфель небанковских финансово-кредитных учреждений составил 586 млн. сом, количество заемщиков - 19 тыс. человек (NBKR, 2011).

В период 2000-2005 годы создавались экономические и правовые условия для микрофинансовых институтов, к примеру, в 2002 году был принят закон «О микрофинансовых организациях», увеличивалась их ресурсная база, расширялась филиальная сеть с проникновением, преимущественно, в сельские местности. Микрофинансовый сектор демонстрировал динамичный, устойчивый рост и доходность, и все больше привлекал внимание доноров и международных организаций. Так, за период с 2002 г. по 2015 г. количество МФО выросло с 18 до 175, кредитный портфель вырос с 1 млрд. сом. до 30 млрд. сом., количество заемщиков - с 80 тыс. до 456 тыс. человек. В этой сфере уже действовали проекты практически всех донорских организаций, включая Департамент Сельского Хозяйства США, Правительство Швейцарии, USAID, Правительство Германии, Правительство Голландии, Европейский союз, KFW и другие.

Усилия государственных органов, международных доноров и организаций микрофинансового сектора привели к тому, что к концу 2015 году объем кредитного портфеля небанковских финансово-кредитных учреждений составил 30 млрд. сом, количество заемщиков - 456 тыс. человек. Уровень возвратности микрокредитов составил 94,4\% за 2014 год. Учитывая динамичный рост сектора, в 2011 году Национальный банк инициировал разработку Среднесрочной стратегии развития микрофинансирования в Кыргызской Республике на 2011-2015 годы.

В переходном периоде в Кыргызстане начались серьезные социально-экономические проблемы, процесс становления и развития рыночных отношений сопровождался появлением ряда негативных тенденций, препятствующих дальнейшему позитивному экономическому развитию страны. К их числу относятся: неравное распределение доходов, высокий уровень бедности, безработица, низкая предпринимательская способность, неразвитость финансовой системы, высокие процентные ставки. Несмотря на политические потрясения, феномен микрокредитования в Кыргызстане продолжает укореняться и развиваться. Практика оказалась настолько успешной, что вместе с ней все активнее начинают развиваться и другие коммерческие структуры.

Сектор микрофинансирования в настоящее время является одним из важнейших в экономике Кыргызской Республики, обеспечивающим занятость 444 тыс. чел. (около 12\% населения страны трудоспособного возраста) и занимает второе место после трудовой миграции, составляющей около 900 тыс. чел. (24\% трудоспособного населения) (Davlesov and Ibraev, 2014). 
Наличие значительного спроса на кредитные ресурсы в особенности в сельских регионах КР привели к значительному росту основных показателей микрофинансовых организаций. Вместе с тем, в последние годы в секторе микрофинансирования наблюдаются высокие процентные ставки по кредитам МФО, что вызвали большой общественный резонанс. С целью снижения процентной ставки кредитов и защиты прав потребителей - заемщиков посредством обеспечения справедливого определения размера процентных ставок при выдаче займов был принять в 24 июля 2013 году Закон КР «Об ограничении ростовщической деятельности в Кыргызской Республике».

Основной целью данного исследования было определение ключевых факторов, определяющих развитие микрокредитного сектора в Кыргызстане.

Для достижения цели исследования были исспользованы первичные и вторичные данные. Первичные данные были получены на основе анкетирования работающих и взявщих кредит для развития дела в торговли, промышленности, сельской хозяйстве, швейном производстве и др. Итоги анкетирования были обработаны на основе факторного анализа и были определены причины, влиящие на спрос микрокредитования. Результаты факторного анализа показывают что, главный фактор влиющий на развития микрокредитования является высокий спрос на получение микрокредитов. Поэтому основная задача правительства состоит в том, чтобы способствовать увеличения предложения и снижению совокупного спроса на микрокредитование.

\section{2 Факторный Анализ Развития Микрокредитного Сектора в Кыргызстане}

Мы использовали факторный анализ, чтобы найти факторы, влияющие на развитие микрокредитования услуг в Кыргызстане.

\begin{tabular}{|c|c|c|c|c|}
\hline \multicolumn{4}{|c|}{ Kaiser-Meyer-Olkin Measure of Sampling Adequacy. } & ,743 \\
\hline \multirow{3}{*}{$\begin{array}{l}\text { Bartlett's } \\
\text { Sphericity }\end{array}$} & Test & of & Approx. Chi-Square & $1,708 \mathrm{E} 3$ \\
\hline & & & $\mathrm{df}$ & 136 \\
\hline & & & Sig. &, 000 \\
\hline
\end{tabular}

Таблица 1. КМО и тест Бартлетта

Целесообразность выполнения факторного анализа определяется наличием корреляций между переменными. Критерий сферичности Бартлетта (Bartlett's Test of Sphericity) проверяет нулевую гипотезу об отсутствии корреляций между переменными в генеральной совокупности. Критерий адекватности выборки Кайзера-Мейера-Олкина (Kaiser-Meyer-Olkin Measure of Sampling Adequaсу) позволяет проверить, насколько корреляцию между парами переменных можно объяснить другими переменными (факторами). Нулевую гипотезу о том, что корреляционная матрица является единичной, отклоняем в соответствии с критерием сферичности Бартлетта. Приближенное значение статистики равно 1,70 с 136 степенью свободы, она является значимой на уровне 0,05 . Значение статистики КМО $(0,74)$ большое $(>0,5)$. Вывод: факторный анализ является приемлемым методом для анализа корреляционной матрицы.

Главными целями факторного анализа являются: (1) сокращение числа переменных (редукция данных) и (2) определение структуры взаимосвязей между переменными, т.е. классификация переменных. Поэтому факторный анализ используется или как метод сокращения данных или как метод классификации.

\begin{tabular}{|c|c|c|c|c|c|c|c|}
\hline \multirow[b]{2}{*}{ Component } & \multicolumn{2}{|c|}{ Initial Eigenvalues } & \multirow[b]{2}{*}{$\begin{array}{c}\text { Cumulative } \\
\%\end{array}$} & \multicolumn{3}{|c|}{ Rotation Sums of Squared Loadings } & \multirow[b]{2}{*}{$\begin{array}{c}\text { Cumulative } \\
\%\end{array}$} \\
\hline & Total & $\begin{array}{c}\% \text { of } \\
\text { Variance }\end{array}$ & & Total & Total & $\begin{array}{c}\% \text { of } \\
\text { Variance }\end{array}$ & \\
\hline 1 & 4,068 & 23,927 & 23,927 & 4,068 & 2,806 & 16,507 & 16,507 \\
\hline 2 & 2,561 & 15,066 & 38,993 & 2,561 & 2,374 & 13,964 & 30,472 \\
\hline 3 & 1,587 & 9,338 & 48,331 & 1,587 & 2,042 & 12,013 & 42,485 \\
\hline 4 & 1,243 & 7,311 & 55,642 & 1,243 & 1,732 & 10,191 & 52,676 \\
\hline 5 & 1,117 & 6,573 & 62,215 & 1,117 & 1,535 & 9,028 & 61,703 \\
\hline 6 & 1,017 & 5,985 & 68,201 & 1,017 & 1,105 & 6,497 & 68,201 \\
\hline
\end{tabular}

Таблица 2. Определение Количества Факторов

Анализ главных компонентов (Principal Components Analysis) основан на определении минимального числа факторов, которые вносят наибольший вклад в дисперсию данных. Они называются главными компонентами. Таблица 2 показывает, какую часть дисперсии каждой из включенных в анализ переменных объясняет предлагаемая факторная модель. Первый главный компонент объясняет 16,5\% 
общей дисперсии, второй $13,9 \%$. Всего в модели отобрано шесть факторов, которые объясняют 68,2\% общей дисперсии.

\begin{tabular}{|c|c|c|c|c|c|c|}
\hline & 1 & 2 & 3 & 4 & 5 & 6 \\
\hline A16 & .850 & .182 & -.072 & .164 & -.027 & -.003 \\
\hline A 14 & 838 &, 053 & 278 &,- 070 &, 127 & ,072 \\
\hline A 15 & 821 & ,145 & ,228 & ,002 & ,096 & ,133 \\
\hline A 17 & 680 & .072 &,- 060 & 252 & 085 &,- 004 \\
\hline A 6 & ,098 & 853 &,- 025 & .034 &,- 043 & ,026 \\
\hline A 5 & 165 & 805 &,- 032 &, 094 & 154 & ,026 \\
\hline A 2 & .053 &, 761 & 047 &,- 048 & 078 &, 162 \\
\hline A 13 & 040 & ,016 &, 863 & ,122 &,- 065 & 033 \\
\hline A 12 & 199 &,- 090 & 842 & 047 &,- 125 &, 040 \\
\hline A 9 & 143 & ,002 &, 131 & 814 &,- 103 & 087 \\
\hline A 8 & ,001 &, 058 & .578 & .582 & ,082 &,- 104 \\
\hline A 11 & ,114 &,- 045 & ,225 & ,542 &,- 016 &, 503 \\
\hline A 7 & 206 & .356 &,- 101 &, 503 &, 326 &,- 110 \\
\hline A 1 & 062 &,- 005 &, 033 &,- 151 &, 763 & 207 \\
\hline A 3 & 054 &, 115 &,- 117 & 090 &, 736 &,- 053 \\
\hline A 4 & 274 & 417 &,- 136 &, 167 & &,- 130 \\
\hline A 10 &, 078 &, 172 &,- 041 & .018 & 083 & 840 \\
\hline
\end{tabular}

Таблица 3. Матрица факторных нагрузок

В Таблица 3 указана матрица факторных нагрузок и она служит для интерпретации полученных факторов. Первый фактор имеет высокие корреляции с А16, А14, A15, А17. «Социальное и Экономическое Воздействие Микрокредитов». Второй фактор имеет высокие корреляции с А6, А5, А2. «Удобное условие выдачи микрокредитов». Третий фактор имеет высокие корреляции с А13, А12. «Обеспечивать открытие своего собственного бизнеса». Четвертый фактор имеет высокие корреляции с A9, A8, A11 и A7. «Поддержка бизнеса». Пятый фактор имеет высокие корреляции с A1, A3. «Огромный спрос на получение микрокредитов не смотря на большие процентные ставки». Шестой фактор имеет высокие корреляции с А10. «Микрокредит как альтернативный источник заимствования».

\section{3 Заключение}

Микрофинансирование является одной из самых динамичных и быстроразвивающихся финансовых отраслей. Быстрому развитию микрофинансирования в Кыргызстане способствовал либеральные условия в секторе микрокредитования. Надзорный орган- Национальный Банк КР не предьявлял требования по периодичному регулятивному отчету и плановых мероприятий по оптимизации процентных ставок. Не было законодательства против растовщичества. Такие либеральные условия в секторе микрокредитовании привели к его мощному развитию. Второй причиной роста данного сектора явилось превышение спроса над предложением в сфере микрофинансирования. Высокому спросу на микрокредитование повлияло и то, что $65 \%$ населения Кыргызстана живут в сельской местности. Часть спроса является «вынужденным, так, как в селах нет банковского представительства. В селах большая часть населения не имеет постоянной работы и вынуждена вести предпринимательскую деятельность для удовлетворения своих жизненных потребностей. Ведение предпринимательской деятельности в условиях отсутствия основных и оборотных средств требует внешнего финансирования - кредитования. Также по данным анкетирования заемщиков, результаты факторного анализа показывают что, главный фактор, влиющий на развитие микрокредитования является высокий спрос на получение микрокредитов. Поэтому основная задача правительства состоит в том, чтобы способствовать увеличения предложения и снижению совокупного спроса на микрокредитование.

Для сокращения совокупного спроса необходимо:

1. Привлекать в регионы инвестиции с целью создания рабочих мест

2. Развивать Государственное-Частное Партнерство (ГЧП)

3. Оказать государственную поддержку реальному сектору в виде льготного кредитования Для увеличения совокупного предложения необходимо:

1. Способствовать увеличению число крупных микрокредитных организации

2. Расширение ресурсной базы микрофинансирования за счет государства

3. Улучшение финансовой инфраструктуры страны 
4. Применение новых технологии и повышение квалификации работников сферы микрофинансирования

5. Для защиты заемщиков нельзя использовать механизм ограничения процентных ставок

6. Повышение финансовой граматности заемщиков

\section{Литература}

- Закон Кыргызской Республики «О внесении изменений и дополнений в некоторые законодательные акты Кыргызской Республики» от 26 апреля 2013 года № 60

- Национальная Стратегия Устойчивого Развития Кыргызской Республики на период 2013-2017 годы

- Методика расчета средневзвешенной процентной ставки по кредитам финансо кредитных учреждений для цели исполнения Закона Кыргызской Республики «Об ограничении ростовщической деятельности в Кыргызской Республике»

- Каликова энд Ассошиэйтс, 2013. О микрофинансировании в Кыргызстане: правовые барьеры в развитии

- НБКР, 2011. «Стратегия развития микрофинансирования на 2011-2015 гг.»

- А. Давлесов, Н. Ибраев, 2014. Отчет «Роль микрофинансового рынка в Кыргызской Республике: перспективы и угрозы», Национальный институт стратегических исследований Кыргызской Республики», г.Бишкек, от 24 июля 2013 года N 163 


\title{
Интеграционные инициативы в Каспийском регионе: тенденции и перспективы
}

\section{Caspian Region Integration Initiatives: Trends and Prospects}

\author{
Lidiya Parkhomchik (Eurasian Research Institute, Kazakhstan)
}

\begin{abstract}
Nowadays, along with the fast-developing processes of globalization there is an active dissemination of the regionalization process, which allows the nation-states to reach a higher level of cooperation and, in most cases, leads to the creation of supranational organizations. Although the level of integrity and interdependence in particular interstate regional organizations considerably differs from one part of the word to another, nevertheless, each state is aware of the need to achieve a higher level of economic and, in some cases, political integration.

The basic tendency marked above can be fully applicable to characterize the current trends, which, to some extent, are fixed in the dialogue between the countries of Caspian Five. It becomes more and more obvious that the Caspian states feel the need for improving multilateral economic relations, so as strengthening security, cultural and environmental cooperation. Therefore, the article is devoted to identifying promising political and economic initiatives that could form the basis for future regional integration.
\end{abstract}

\section{1 Введение}

На современном этапе важность Каспийского региона для формирования энергетической стратегии как региональных, так и внерегиональных акторов не вызывает сомнений. Располагая значительными запасами нефтегазовых ресурсов, которые, по различным оценкам, могут достигать до 4\% от общемировых запасов углеводородного сырья, Каспийский регион притягивает к себе внимание все большего количества игроков, заинтересованных в расширении масштабов своего участия в сферах добычи и транспортировки энергоносителей. Именно это обстоятельство долгое время определяло положение Каспийского региона в качестве объекта мировой геополитики. И хотя обозначенный процент не позволяет региону претендовать на роль полноценного альтернативного источника нефти и газа для мирового энергетического рынка, это не помешало странам ближнего и дальнего зарубежья в демонстративном порядке наращивать свое присутствие в нефтегазодобывающем секторе прикаспийских государств.

Столь ярко выраженный тренд сохранялся вплоть до начала 2000-х гг. и в итоге привел к формированию каспийского рынка компаний добывающего сектора, которые спустя два десятилетия с момента появления каспийского вопроса смогли наладить разработку энергоресурсов, выведя их производство на уровень коммерческой добычи. Начав получать стабильную прибыль в государственный бюджет от продажи каспийских углеводородов, страны «каспийской пятерки», в особенности бывшие страны-члены СССР, вошли в фазу некоторого пересмотра национальных стратегий в отношении развития региона. К прежней ориентированности на развитие добывающей промышленности стали добавляться элементы более глубокого политико-экономического регулирования, которые, в перспективе, способны подготовить условия для достижения более высокого уровня экономической, а в некоторых случаях, и политической интеграции.

\section{2 Особенности внутрирегионального взаимодействия}

\section{1 Правовой статус Каспийского моря}

Говоря о потенциальных возможностях для интеграционного взаимодействия в Каспийском регионе, следует принимать во внимание ключевую особенность взаимоотношений государств региона, а именно, незавершенные переговоры по определению международно-правового статуса каспийского водоема. С момента возникновения необходимости обозначить новые положения правового режима на Каспии, а именно, с 1992 г., страны «каспийской пятерки» провели 41 заседаний Специальной рабочей группы (СРГ) по разработке Конвенции о правовом статусе Каспия, последнее из которых прошло 8 сентября 2015 г. в Москве. Само создание СРГ стало возможным после того как в 1996 г. в Ашхабаде состоялось первое совещание министров иностранных дел прикаспийских государств. Именно на этой встрече были достигнуты политические договоренности активизировать переговорный процесс по разрешению вопроса о правовом режиме на Каспии в пятистороннем формате. Нужно отметить, что до недавнего времени результативность проводимых консультаций оставалась на довольно низком уровне. Однако, определенные подвижки в данном вопросе наметились у принимающих участие в работе СРГ делегаций после того, как главы прикаспийских государств активизировали региональный диалог по каспийской 
проблематике. Речь, в частности, идет о подписанной в рамках IV Саммита глав прикаспийских государств Декларации, в которой закреплены основополагающие принципы определения правового статуса Каспия. Эти принципы и должны в итоге лечь в основу будущей Конвенции. Речь, в первую очередь, идет о вопросах обеспечения безопасности и определения вопроса о ширине национальных зон, включая зону под национальным суверенитетом и рыболовную зону.

На данный момент текст будущей Конвенции все еще находится в стадии разработки и согласования. По оптимистичным прогнозам, завершенный проект Конвенции о правовом статусе Каспийского моря будет представлен на очередном Саммите глав прикаспийских государств, который пройдет в Астане в 2016 г. Именно с таким заявлением выступил специальный представитель Президента Российской Федерации по вопросам Каспийского моря И. Братчиков по итогам прошедших консультаций СРГ в Тегеране (Tass, 2015). Вместе с этим, нужно отметить, что международные эксперты по-разному оценивают вероятность осуществления подобного сценария. Отмечая безусловную успешность проведенного 29 сентября 2014 г. в Астрахани IV Каспийского Саммита, в рамках которого было заключено 3 пятисторонних соглашения преимущественно по вопросам экологии и охраны биологических ресурсов водоема, а также достигнуто соглашение относительно регулирования ширины территориального моря и рыболовной зоны - 25 морских миль - остается открытым вопрос о готовности Ирана пойти на согласование своего подхода в отношении принципа разграничения каспийского водоема. Вплоть до настоящего момента иранские власти продолжают настаивать на том, что до согласования Конвенции по статусу Каспийского моря правовой режим водоема должен определяться советскоиранскими договоренностями, а именно, Договором между РСФСР и Персией от 1921 г. и Договор о торговле и мореплавании между СССР и Ираном от 1940 г. Более того, официальный Тегеран продолжает настаивать на разделе Каспия на 5 равных частей, по 20\% каждому из прикаспийских государств. Подобный подход не находит поддержки среди остальных государств «каспийской пятерки», которые сконцентрировали свое внимание на варианте раздела Каспия по методу модифицированной срединной линии.

Данный метод раздела Каспийского моря был успешно применен Казахстаном, Россией и Азербайджаном в период с 1998 г. по 2003 г., которые завершили процесс разграничения северного Каспия, подписав Соглашение о точке стыка линий разграничения сопредельных участков дна Каспийского моря, которое стало финальным аккордом в деле определения национальных донных секторов с исключительным правом недропользования. После заключения ряда соглашений Россия, Азербайджан и Казахстан разделили 64\% акватории Каспия на три неравные части в соответствии с протяженностью береговой линии, при этом Казахстану досталось 27\%, России - 19\%, Азербайджану $18 \%$. Следует отметить, что де-факто официальное использование термина сектор Каспийского моря относится еще к периоду существования СССР. В 1970 г. Министерство нефтедобывающей промышленности СССР приняло решение о разделении советской части моря на национальные секторы между четырьмя прикаспийскими союзными республиками. При этом линии раздела зафиксировались и как административно-территориальные границы прикаспийских государств. И хотя права собственности подобное разделение не предусматривало, именно данное обстоятельство и стало основанием для последующих конфликтов (Сыроежкин, 2000).

До недавнего времени вопрос о присоединении Туркменистана к разработанному Казахстаном, Россией и Азербайджаном формату делимитации национальных секторов оставался открытым. Однако 7 ноября 2014 г. Астана и Ашгабат подписали Соглашения между Республикой Казахстан и Туркменистаном о разграничении дна Каспийского моря между Республикой Казахстан и Туркменистаном, которое было ратифицировано в Парламентах двух государств в мае 2015 г. Исходя из этого, можно констатировать, что переговорный процесс вокруг проблемы определения правового статуса каспийского водоема вступил в новую стадию. Возможное формирование альянса МоскваАстана-Баку-Ашгабат, который не только будет придерживаться идентичных подходов к проблеме раздела каспийской акватории, но и будет выступать единым фронтом «продавливая» свою точку зрения на переговорах с Исламской Республикой Иран (ИРИ), имеет шансы вынудить Тегеран внести изменения в декларируемый подход в отношении разграничения Каспия. И хотя, иранское руководство пока не дает поводов для оптимизма, а скорее наоборот, в своих заявлениях, адресованных соседям по Каспийскому региону, подчеркивает сохранение изначального намерения добиться раздела водоема на 5 равных частей, не следует полагать, что подобная позиция не может быть изменена в сторону некоторого послабления.

Следует отметить, что заключенные между Россией, Азербайджаном, Туркменистаном и Казахстаном двух- и трехсторонние соглашения представляют собой временную меру правового регулирования на Каспии. Однако, именно обозначенные договоренности, представленные в Таблице 1, могут послужить основой для дальнейшей разработки пятистороннего соглашения о разделе дна каспийского водоема. 


\begin{tabular}{|c|c|c|}
\hline Год & Страны & Соглачение \\
\hline 1998 & Казахстан и Россия & $\begin{array}{l}\text { Соглашение о разграничении дна северной части } \\
\text { Каспийского моря в целях осуществления } \\
\text { суверенных прав на недропользование }\end{array}$ \\
\hline 2001 & Казахстан и Азербайджан & Соглашение о разграничении дна Каспийского моря \\
\hline 2002 & и Россия & $\begin{array}{l}\text { Соглашение о разграничении дна северной части } \\
\text { Каспийского моря }\end{array}$ \\
\hline 2002 & Россия и Азербайджан & $\begin{array}{l}\text { Соглашение о разграничении сопредельных } \\
\text { участков дна северной части Каспийского моря }\end{array}$ \\
\hline 2003 & $\begin{array}{l}\text { Казахстан, } \\
\text { Азербайджан }\end{array}$ & $\begin{array}{l}\text { Соглашение о точке стыка линий разграничения } \\
\text { сопредельных участков дна Каспийского моря }\end{array}$ \\
\hline 2014 & Казахстан и Туркменистан & Соглашение о разграничении дна Каспийского моря \\
\hline
\end{tabular}

Таблица 1. Делимитаџионные соглашения Источник: авторская таблица.

\section{2 Динамика каспийского диалога}

Нужно отметить, что проводимые переговоры на всегда имели устойчивую динамику, что также является одной из ключевых особенностей каспийского межгосударственного взаимодействия. Несмотря на то, что ряд прибрежных государств достиг некоторых успехов в процессе делимитации водоема, обозначенные действия сложно рассматривать в качестве полноценного многостороннего диалога регионального формата. Только после того, как к обсуждению региональных проблем подключились главы прикаспийских государств в рамках регулярных пятисторонних встреч, произошло переформатирование каспийского диалога. Проводимые странами «каспийской пятерки» консультации с течением времени наполнялись новым содержанием и, постепенно, из переговоров исключительно о юридических аспектах правового статуса Каспийского моря трансформировались в многоплановое обсуждение целого комплекса проблем, связанного с организацией межгосударственного диалога на Каспии. И хотя первый опыт Каспийского Саммита, проведенного в 2002 г. в Ашгабате, был не слишком удачен, сам факт проведения подобного мероприятия с участием глав всех прикаспийских стран имел большую политическую значимость для дальнейшего развития переговорного процесса и положил начало традиции проведения Саммитов «каспийской пятерки» (Casfactor, 2014).

Проведенный в 2007 г. в Тегеране II Каспийский Саммит оказался более успешным. Стороны смогли подписать итоговую декларацию, которая закрепляла права прибрежных стран в отношении моря и его ресурсов, обеспечения режимов судоходства и рыболовства. Однако, по-настоящему прорывным оказался именно III Каспийский Саммит, проведенный в 2010 г. в Баку. По его итогам было подписано Соглашение о сотрудничестве в сфере безопасности на Каспийском море, которое регулирует вопросы борьбы с терроризмом, организованной преступностью, контрабандой оружия, наркотиков и ядерных технологий, захватом судов, нелегальной миграции, незаконной добычи биоресурсов и т.д. Данное Соглашение стало вторым по счету документом после Рамочной Конвенции по защите морской среды Каспийского моря от 2003 г. подписанным в пятистороннем формате. Однако, именно после его подписания, процесс подготовки и согласования других пятисторонних документов значительно ускорился. За последующие 4 года были подписаны 3 Протокола к Рамочной Конвенции по защите морской среды Каспийского моря, а также 3 пятисторонних Соглашения преимущественно по вопросам экологии и охраны биологических ресурсов водоема. Обозначенные документы легли в основу так называемой «новой» нормативнодоговорной базы правового режима на Каспии.

Следует отметить, что несмотря на малое количество проведенных в рамках данного формата встреч, прослеживается прямая зависимость между повышением интенсивности консультаций по каспийской проблематике и проведение очередной встречи на высшем уровне. В данных обстоятельствах Саммиты глав прикаспийских государств являются наиболее действенным инструментом продвижения тех или иных политических и экономических инициатив в рамках каспийского диалога.

\section{3 Каспийские интеграционные инициативы}

\section{1 Экономическое взаимодействие}

Одной и первых интеграционных инициатив, выдвинутых на рассмотрение среди стран «каспийской пятерки», стала идея создания такой региональной структуры как Организация каспийского экономического сотрудничества (ОКЭС). Предложение создать подобную структуру было озвучено бывшим президентом ИРИ А. Рафсанджани в ходе организованной иранской стороной в 1992 г. межправительственной конференции (Салыгин vе Сафарян, 2005). И хотя, несколькими месяцами позже стороны все же собрались на специальной конференции в Тегеране для обсуждения возможности создания обозначенной организации, достичь итоговых договоренностей странам региона так и не удалось. Спустя 2 года идея создания специализированной межгосударственной организации по 
сотрудничеству на Каспийском море была выдвинута уже российской стороной в рамках представленного на Московской встрече с участием представителей «каспийской пятерки» проекта Соглашения о региональном сотрудничестве между прикаспийскими странами от 1994 г. Однако и в рамках обозначенного периода страны региона только приступили к формированию своих национальных Концепций по определению международно-правового статуса каспийского водоема, что в значительной мере препятствовало концентрации внимания прибрежных государств на возможности совместными усилиями развивать экономический потенциал региона. Помимо этого, руководство стран Прикаспия в большей степени было заинтересовано в урегулировании вопроса с привлечением иностранных инвестиций в добывающий сектор экономики, в некоторых аспектах даже конкурируя друг с другом.

Несмотря на то, что на современном этапе вопрос о привлечении иностранных инвестиций в нефтегазодобывающую промышленность нашел свое разрешение, форсированного сближения экономических интересов стран Каспийского бассейна так и не произошло. Вместе с тем, Россия последовательно продолжает поддерживать идею создания ОКЭС, основной целью которой является консолидация потенциала прикаспийских государств, а также достижение нового уровня экономического развития на базе многосторонних проектов. Если говорить об отношении к данной инициативе со стороны остальных членов «каспийской пятерки», то можно отметить, что союзниками России в реализации этой идеи выступают Азербайджан и Казахстан, позиция Туркменистана четко не определена, что же касается иранской стороны, которая, как было сказано выше, выступила инициатором создания организации, то Иран, при всей своей заинтересованности в региональном экономическом сотрудничестве, выражает беспокойство относительно того, что в подобной структуре будет доминировать именно Россия. В первоначальном варианте ИРИ предлагала создать ОКЭС со штабквартирой в Тегеране (Webeconomy, 2010). Однако, на современном этапе подобное предложение несколько потеряло свою актуальность ввиду особенностей геополитического положения ИРИ, связанного с проблемой развития ядерной программы страны. И хотя в ходе последних двухнедельных переговоров Тегерана и стран «шестерки», прошедших в Вене в начале июля 2015 г., сторонам все же удалось достичь компромиса и в конечном итоге подписать Всеобъемлющий план совместных действий по иранской ядерной программе, практические шаги по выходу страны из геополитической и экономической изоляции будут проходить постепенно, что говорит о том, что шансы Ирана разместить у себя штаб-квартиру потенциальной региональной структуры все еще недостаточно высоки.

Если говорить о перспективах реализации обозначенной инициативы, то, безусловно, опыт подобных региональных организаций, как организации Балтийского региона, Черноморского экономического сотрудничества показывает, что создание Организация каспийского экономического сотрудничества действительно может стимулировать взаимную торговлю. Однако, в случае со странами Каспийского региона, необходимо принимать во внимание тот факт, что «каспийская пятерка» пока находится на стадии формирования стратегии региональной экономической интеграции. Отсутствие четко обозначенных приоритетов регионального экономического развития не позволяет говорить о наличии устойчивой и уникальной социально-экономической системы регионального межгосударственного сотрудничества. Вместе с этим, создание организационной структуры, интегрирующей экономики стран региона могло бы существенно снизить напряженность в некоторых вопросах регионального взаимодействия, в том числе и в вопросе соперничества трубопроводных проектов.

В данных обстоятельствах особое значение приобретает инициатива проведения Каспийских бизнесфорумов. Впервые подобное мероприятие было проведено в Астрахани в 2014 г. в рамках IV Каспийского Саммита. Создание постоянно действующей платформы поддержки бизнес-инициатив предпринимателей стран Каспийского региона в перспективе будет способствовать росту пятистороннего экономического взаимодействия, что позволит сформировать приемлемые условия необходимые для перехода на более высокий уровень кооперации в рамках ОКЭС.

Одним из альтернативных вариантов усиления экономических взаимосвязей между государствами региона может стать реализация предложения Президента Казахстана Н. Назарбаева создать Каспийскую зону свободной торговли, которое он озвучил в рамках Астраханского Саммита глав прикаспийских государств. Нужно отметить, что в регионе уже имеется позитивный опыт по созданию специальных экономических зон (СЭ3). Так, например, в Казахстане на Каспии функционирует СЭЗ «Морской порт Актау», в рамках которой осуществляются 5 проектов, обеспечивших выпуск продукции на сумму в 220 миллиардов тенге, а в течении 2015 г. совместно с азербайджанской стороной планируется приступить к реализации очередного проекта - логистического терминала. В Иране успешно действует специальная экономическая зона «Бендер-Энзели», проект «Национальная туристическая зона «Аваза» функционирует в Туркменистане. Азербайджан рассматривает возможность размещения СЭЗ в поселке Алят, где ведется строительство дополнительных мощностей Бакинского порта, о создании свободной экономической зоны в Астрахани заявила и Россия. В перспективе у прикаспийских государств есть возможность объединить созданные СЭЗ в единую региональную систему, которая бы «опоясывала» Каспийское море, и в дальнейшем перейти к формату зоны свободной торговли (ЗСТ). 
Не исключен также вариант создания ЗТС посредством использования механизмов такой интеграционной структуры как Евразийский экономический союз (ЕАЭС). В частности, инициатива о создании зоны свободной торговли была высказана иранской стороной, которая неоднократно выражала свою заинтересованность в ЗСТ. В 2015 г. Тегеран надеется запустить процесс переговоров о подписании меморандума о взаимопонимании с ЕАЭС, а также инициировать консультации с Евразийской экономической комиссией о подготовке необходимых документов для создания ЗСТ по примеру Вьетнама.

\section{2 Транспортно-логистическое взаимодействие}

Одной из характерных особенностей Каспийского региона в советский период являлось то обстоятельство, что большинство транспортных магистралей функционировали по направлению к центральным районам России. Однако, после распада СССР транспортные связи между РФ и бывшими союзными республиками существенно ослабла, что вынудило страны региона приступить заполнению образовавшихся транспортных «пробелов». Примечательно, что именно российская сторона выдвинула инициативу, в которую постепенно были вовлечены все без исключения страны «каспийской пятерки». Речь идет о таком инфраструктурном проекте как Международный транспортный коридор «Север-Юг», соглашение о создании которого было подписано между Россией, Ираном и Индией в 2000 г. О намерении присоединиться к проекту позднее заявляли ряд и других государств, в числе которых были Казахстан, Азербайджан и Туркменистан. Нужно отметить, что реализовать проект в его первоначальном варианте, а именно, транспортировать контейнерные грузы из Индии через Иран в Россию, оказалось непростой задачей. После выявления ряда технических сложностей перевозки контейнеров из Индии через Астрахань были заморожены. Однако данное обстоятельство позволило участникам проекта сконцентрироваться на развитии транспортных потоков вокруг/через Каспийское море. Наиболее интенсивное движение грузопотока в настоящий момент осуществляется по так называемому транскаспийскому маршруту, который проходит через такие порты на Каспии, как Астрахань, Оля, Махачкала - с российской стороны, и Энзели, Амирабад и Ноушехр - с иранской. В настоящее время именно данный маршрут обеспечивает российско-иранскую двухстороннюю торговлю, которая в 2014 г. составила 2,8 миллиарда долларов. После завершения строительства и пуска в эксплуатацию железнодорожной ветки Узень-Берекет-Этрек-Горган (Казахстан-Туркменистан-Иран) в $2014 \quad$ г. оживились грузоперевозки и по восточному маршруту проекта «Север-Юг». Лишь западный маршрут, основой которого должна выступить железнодорожная линия Астара-Решт-Казвин (Азербайджан-Иран), все еще испытывает значительные сложности с реализацией.

Несмотря на значительные объемы проделанной работы темпы реализации обозначенной инициативы значительно отличаются от запланированных. В данных обстоятельствах вполне закономерно, что страны региона рассматривают и другие возможности активизировать транспортно-логистическое взаимодействие. Речь, в первую очередь, идет об инициативе Президента Туркменистана Г. Бердымухамедова разработать проект Соглашения о сотрудничестве в области транспорта на Каспийском море, в рамках которого станет возможно создание Регионального транспортно-логистического центра, а также предложении Президента России В. Путина приступить к формированию железнодорожного кольца вокруг Каспия.

\section{3 Военно-политическое взаимодействие}

В ходе одной из первых встреч по обсуждению проблемы определения статуса Каспийского моря, которая состоялась в Алма-Ате в 1995 г., новые независимые государства в лице Казахстана, Азербайджана и Туркменистана высказались за демилитаризацию водоема и последующее его использование в исключительно мирных целях. Однако, с течением времени, Астана, Баку и Ашгабат пересмотрели свой подход к данной проблеме и теперь рассматривают наличие ВМС на Каспии как неотьемлемую часть политики страны по обеспечению безопасности нефтегазодобывающих работ на каспийском шельфе.

На сегодняшний момент самой значительной военно-морской группировкой на Каспии обладает Россия, при этом Иран занимает второе место по количеству дислоцируемых на Каспии кораблей. Исходя из этого, вполне очевидно, что именно политика обозначенных держав во многом определяет современную ситуацию в сфере обеспечения безопасности в регионе. Неудивительно, что именно Россия в 2003 г. выдвинула идею создания группировки «Касфор», объединяющей военно-морские силы прикаспийских государств. Согласно предложению РФ, оперативное военное соединение «Касфор», создаваемое по аналогии с военно-морской группой оперативного взаимодействия на Черном море «Blackseafor», могла бы взять на себя функции ряда военных структур, в частности, подразделений пограничных войск и войск специального назначения, а также могла бы вести борьбу против реальных угроз региональной безопасности на Каспии (Мамедов, 2006). Нужно отметить, что в отличие от американского проекта «Каспийский страж» (Caspian Guard Initiative), выдвинутого Вашингтоном в том же году и нацеленного на модернизацию военно-морских сил Азербайджана и Казахстана, а также их координацию с центральным командованием США, российский проект не противоречил принятому 
странами «каспийской пятерки» принципу невмешательства третьих государств в вопросы обеспечения региональной безопасности. Однако, данного обстоятельства оказалось недостаточно, чтобы прикаспийские страны выразили свою абсолютную поддержку выдвинутому проекту и подписали соответствующее межгосударственное соглашение.

Вместе с этим, неудача проекта не означает прекращения сотрудничества прибрежных государств по вопросам охраны государственных границ на Каспии. В рамках региона активно развивалось двухстороннее взаимодействие по линиям Россия-Казахстан и Россия-Азербайджан и лишь в 2015 г. страны северного Каспия вышли на новый уровень кооперации и провели первые трехсторонние военные учения. Подписание Соглашения об обеспечении безопасности в Каспийском море в 2010 г. открыло новые перспективы для военного взаимодействия «каспийской пятерки». В частности, в октябре 2015 г. главнокомандующие ВМФ России, Казахстана, Азербайджана и Ирана планируют провести консультации по созданию на Каспийском море системы коллективной безопасности. В ходе предстоящей встречи стороны обсудят возможность учреждения многостороннего консультативносовещательного органа - Комитета командующих ВМС прикаспийских государств и подписания Соглашения о предотвращении инцидентов на Каспийском море.

\section{4 Социокультурное взаимодействие}

Поддержание должного уровня социально-культурного взаимодействия между народами, проживающими на прикаспийских территориях, остается важной составляющей обеспечения социетальной безопасности в регионе. Одним из наиболее показательных примеров формирования регионального единения является ежегодное празднование 12 августа Дня Каспия. Решение о праздновании Дня Каспия было принято всеми прикаспийскими странами на Первой конференции сторон Тегеранской конвенции в мае 2007 г. в Баку. Целью данной инициативы было вовлечение общественности в процесс реализации Рамочной конвенции по защите морской среды Каспийского моря, подписанной в 2003 г. и вступившей в силу 12 августа 2006 г. Инициатива получила признание не только со стороны руководства стран «каспийской пятерки», но и жителей прикаспийских областей и провинций. Так как традиционно празднование включает в себя широкий спектр событий от культурномассовых мероприятий до конференций, круглых столов и региональных встреч с участием представителей государственных органов, неправительственных и общественных организаций и научных институтов, то в рамках Дня Каспия нередко выдвигаются общественные инициативы, способные оказать положительное воздействие на региональное развитие. К числу подобных предложений следует отнести предложение установить «Зеленый стандарт Каспия», в рамках которого будет выработан комплекс повышенных экологических требований для их добровольного применения субъектами хозяйственной деятельности на территории всего Каспийского региона, а также предложение создать Каспийскую межпарламентскую ассамблею.

Следует также отметить инициативы в таком немаловажном сегменте национальной политики, как работа с молодежью. В 2014 г. на площадке IV Каспийского Саммита в Астрахани прошла Первая встреча молодых лидеров Каспийского региона. Вторая встреча была организована по инициативе иранской стороны в мае 2015 г. Начало работы было положено в Тегеране, затем встреч продолжилась на берегу Каспийского моря в провинции Мазандаран. В рамках программы прошла презентация работы с молодежью в странах Каспийского региона, представители государств рассказали о состоянии молодежной политики и ее трендах (Gazetazm, 2015). Отдельно внимания заслуживает информация о проведенном в сентябре 2015 г. в Астрахани Первом прикаспийском медиафоруме. Создание единого информационного пространства в рамках региона уже давно стоит на повестке дня среди других вопросов каспийской проблематики. Актуальность налаживания обмена информационными материалами, организации взаимных стажировок, реализации совместных проектов в сфере экономики, экологии, образования, культуры и туризма возрастает год от года. В данных обстоятельствах проведение подобного мероприятия может стать первым шагом в сторону разрешения обозначенных проблем.

Следует также отметить, что каждое прикаспийское государство ежегодно проводит серию научнопрактических и научно-технических конференций, посвященных обсуждению современного ситуации в Каспийском регионе. Так, например, Россия с 2008 г. ежегодно проводится Каспийский энергетический форум, с 2009 г. - Каспийский инновационный форум, с 2011 г. - Экономический форум Каспийский диалог. Целью подобных мероприятий является не только практическое накопление научнотеоретических знаний, но и активное их использование в выработке национального стратегического курса в отношении Прикаспия.

В целом, нужно отметить, что, хотя каспийское социокультурное сотрудничество пока не достигло того уровня интенсивности, при котором полностью раскрылся бы его позитивный потенциал, на современном этапе можно наблюдать формирование весьма перспективных в данном отношении инициатив. 


\section{4 Заключение}

Несмотря на то, что в настоящее время прикаспийские страны в силу причин объективного и субъективного характера еще не достигли достаточного уровня взаимного доверия, необходимого для формирования полноценного интеграционного объединения, тем не менее ряд выдвинутых странами региона инициатив свидетельствуют об их намерении развивать свое сотрудничество в обозначенном направлении.

Анализируя последние встречи лидеров прибрежных стран в рамках Саммитов глав прикаспийских государств, можно заключить, что ряд озвученных предложений направлены именно на формирование тесных экономических взаимосвязей, которые в перспективе будут способствовать формированию региональных интеграционных образований. Безусловно, проблема неопределенности статуса Каспийского водоема в значительной мере затрудняет любые переговоры, связанные с расширением взаимовыгодных партнерских отношений, однако, в условиях изменения геополитической конъюнктуры, что, в частности, связано с выходом Ирана из международной изоляции, прогноз относительно успешности усиления региональной интеграции становится более оптимистичным.

\section{Литература}

- Мамедов Д., 2006. "Каспийский страж взял верх", Военно-промышиленныий курьер, 36, С. 28.

- Салыгин В.И. ve Сафарян А.В., 2005. Современные международные экономические отношения в Каспийском регионе. МГИМО-Университет, Москва.

- Сыроежкин К.Л., 2000. "Как будем делить Каспий", Континент, 20, С. 15.

- Casfactor, 2010. Проблемы региона накануне IV Каспийского Саммита. Экспертный доклад, http://www.casfactor.com/ru/editor/57.html

- Gazetazm, 2015. Молодые лидеры 5 стран принимают участие во Втором Каспийском молодежном саммите, http://gazetazm.ru/?p=37333

- Tass, 2015. Соглашение о правовом статусе Каспия подготовят к саммиту в Астане, http://tass.ru/politika/2010637

- Webeconomy, 2010. Экономическое сотрудничество в Каспийским регионе, http://www.webeconomy.ru/index.php?page=cat\&newsid=1593\&type=news 


\title{
Экономика мусульманской повседневности: религиозные и экономические практики мусульман Республики Татарстан Economics of the Muslim Everyday Life: Religious and Economic Practices of Muslims in the Republic of Tatarstan
}

\author{
Alsou Garaeva (Kazan Federal University, Russia)
}

\begin{abstract}
The change of the economic model in Russia in the beginning of the 1990's has laid basis for the public institutionalization of religious associations. The sphere of commercial religious services has appeared and a diversification of the religious practices has begun. In the regions of Russian Federation Muslims make up about $10 \%$, including Tatarstan with a Muslim majority of about $50 \%$. This creates a fertile soil for the business targeted for satisfying Muslims' needs. The research that we have carried out as a part of the quality strategy, and particularly, the depth interview, the expert survey and the overt observation, shows that there are some barriers to introduction and successful development of such elements of the Islamic economics as Islamic banking and Islamic insurance. And the explanation for this fact lies in everyday, microcosociological practices. The services of "Muslim" taxi or messages informing about the prayers time didn't "survive" in Tatarstan. Nevertheless, there are 29 prosperous catering enterprises which specialize in "halal" meals, 34 Muslim clothes and accompanying goods shops, 6 Islamic bookstores, 3 large travel agencies organizing pilgrimage tours, and two beauty parlors using "halal" standard cosmetics in the Tatar capital. Thus a successful business is usually connected to the Muslims' everyday needs. The results of investigations indicate that introduction of new religious services require a careful preliminary study of the market and of the needs of the religious people, the exact forecast of the demand of the specific services and goods.
\end{abstract}

\section{1 Введение}

Смена экономической системы в России в начале 1990-х заложила начало процесса публичной институционализации религиозных объединений. Они обрели правовой статус, а верующие, в частности мусульмане, обрели возможность свободно отправлять свои религиозные обряды. Появилась сфера платных религиозных услуг, началась диверсификация религиозных практик.

\section{2 Исламская экономика}

Исламская экономика - это, с одной стороны, теория, с другой стороны конкретные практики взаимодействия людей. Можно говорить о том, что практика исламской экономики намного более развита, чем теория, т.к. практики повседневного взаимодействия людей в экономической сфере по религиозным исламских нормам существуют давно, но не всем даны объяснения с теоретических позиций.

Практики исламской экономики оцениваются по-разному, например, сингапурские ученые рассматривают их, с одной стороны, как препятствие на пути развития рыночной экономики, с другой, как новые возможности развития (Bianchi, 2013). Подобный дуализм в оценке роли исламских экономических механизмов является доминирующим и оправданным, потому что есть объективные показатели эффективного их применения в рыночных условиях, например, «халяль»-индустрия в Республике Татарстан, в то же время в странах, где мусульманские экономические принципы являются основными в предпринимательской деятельности, невозможна работа таких рыночных структур, как банки в традиционной форме.

\section{3 Халяль-индустрия}

В последнее десятилетие в России халяль-продукция оценивается как важный элемент как региональной, так и федеральной экономики в виду стабильного спроса на данную продукцию и услуги. Сфера «халяль» стала новым брендом и сформировалась в самостоятельный сектор экономики. Халяльпродукция сочетает в себе два элемента - религиозный и экономический. Во-первых, это определенные религиозные нормы и предписания, которые регламентируют качество, методики изготовления с позиций норм ислама, в то же время пользование подобными товарами и услуги несет в себе определенный религиозный смысл и «демонстрацию» приверженности к конфессии. Во-вторых, это реальный рыночный продукт и фирмы, производящие его, подчиняются законам рыночной экономики. И настоящее время «халяль» становится символом качества и определённого образа жизни.

Халяль-продукты должны соответствовать шариату, то есть не предполагают «харам» (запрещенного): использование вредных компонентов, эксплуатации труда и нанесения вреда окружающей среде, 
предназначенного для использования «вредного». Нормы халяль могут распространяться на все используемые материалы, на косметические и фармацевтические препараты, на услуги, включая финансовые.

В Казани на 2015 год предприятия, оказывающие услуги или торгующие продуктами стандарта «халяль» составляют около половины официально зарегистрированных предприятий, оказывающих платные мусульманские услуги (29 из 75).

Возникает вопрос о месте «халяль» продуктов и услуг в региональной рыночной экономике. Дает ли преимущество их выделение в отдельную отрасль? Исследователи этого вопроса в странах с преобладающей исламской экономикой полагают, что необходимо объединение исламского финансирования и халяль-индустрии в одну отрасль экономики для унификации соответствия предлагаемых услуг и продукции нормам шариата (Muhamed, vd, 2014).

\section{4 Исламский банкинг}

Сферой услуг, регулярно подвергающаяся процессу диверсификации, является сфера «исламского финансирования» или «исламский банкинг». Этим объясняется расхождения исследователей в вопросе выделения перечня используемых в работе конкретных механизмов финансирования, т.к. в разных регионах распространены разные механизмы, оптимизирующиеся под конкретное законодательство, местные традиции и нормы. Например, Абдулла Саид, исследователь особенностей исламского банкинга, выделяет три основные схемы практик исламского «кредитования». Первая схема, «мудараба», в рамках которой банк финансирует заемщика для торговой сделки, т.е. заемщику необходимы деньги для покупки товара и последующей его перепродажи. В данном случае деньги будут переданы не заемщику, а непосредственно продавцу товара и в результате банк получает вложенную сумму и часть прибыли со сделки. Вторая схема, «мушарака» или «партнерство», где банк и заемщик являются партнерами в определенном коммерческом проекте, со временем партнер просто выкупает долю банка. И третья схема, «мурабаха» сводится к тому, что банк выкупает требуемый товар для клиента ( Saeed, 2001).

Помимо этих трех схем, на интернет-сайте takaful-kz.narod.ru, посвященном хахалному страхованию, подробно описываются еще шесть исламских финансовых инструментов. «Иджара» или «лизинг», банк приобретает некий актив и сдает её в аренду. Для долгосрочных проектов существует «истисна», при использовании этого финансового инструмента, выплаты как правило осуществляются по окончании проекта. «Вакала» - договор найма агента с фиксированным вознаграждением за его услуги. «Кард-ульХасан» - по сути это беспроцентная ссуда, однако заемщик имеет право в добровольном порядке выплатить премиальные. «Сукук» или «облигация», дающая право получать определённую часть прибыли. И, наконец, «такафул» - аналог страхование, отличие которого заключается в том, что риск несет не только страховщик, но все участники фонда такафул (Такафул, 2010).

Можно сделать вывод, что исламская финансовая система владеет множеством экономических инструментов, способна удовлетворить все финансовые потребности мусульман, и, главное, гибко реагирует на условия применения этих инструментов.

Отдельно стоит сказать о возможностях внедрения исламских экономических практик на территорию Российской Федерации, в том числе и в Республику Татарстан. Заместитель директора российского центра исламской экономики и финансов Исхаков И.Р. полагает, что годы советской власти снизили уровень самосознания российских мусульман, они адаптировались к современной экономической системе и могут вкладывать свои средства и сбережения в «обычные» банки, что, в целом, снижает их потенциальную потребность в специализированных религиозных экономических услугах. Однако, по его мнению все же есть потенциал, если рассматривать опыт друг стран постсоциалистического пространства, где довольно успешно развиваются элементы исламской экономики, например, в Киргизии. (Исхаков, 2010) В пользу этой же точки зрения выступает Зарубина Н.Н., полагая, что хозяйственная деятельность мусульман не выходит за рамки традиционной экономической системы, в то же время существуют условия для её успешного включения в капиталистическую экономику (Зарубина, 1998).

В Республике Татарстан, по официальным заявлениям, планируют открыть исламский финансовый институт. Но исследований, посвященных анализу спроса на специфические продукты исламских банков на территории республики, не проводилось. Между тем, подобные исследования в других регионах показывают, как минимум, целесообразность их проведения, потому что, например, на основании проведенного исследования в Курской области методом анкетного опроса, Подрогный Б.Б. приходит к заключению, что религиозные традиции оказывают сильное влияние на развитие и функционирование национального рынка. Были получены данные, что только около 30 \% населения Курской области, которые причисляют себя к верующим мусульманам, негативно относятся к операциям на фондовом рынке, считая, что это нарушает основы их веры, в то время как остальные 70\% считают их приемлемыми для себя (Podgornyi, 2012). 


\section{5 Конфессиональный состав России и Республики Татарстан}

Если говорить о конфессиональном составе населения России, то достоверной информации о сложившейся ситуации на сегодняшний день нет. Согласно исследованию «Религия в жизни россиян», которое было проведено ВЦИОМ в декабре 2008 года (опрошено 1600 человек), мусульмане составляют 6 \% от населения России (примерно 9 млн. человек). Этот показатель остался неизменным с 2006 года.( Религия в жизни россиян, 2008) Совет муфтиев России называет цифру 20 миллионов мусульман (Ильичев и Клин,2006), опираясь на данные посещаемости мечетей. По результатам упомянутого исследования ВЦИОМ, большинство россиян относят себя к последователям православия - это 73\% опрошенных, и с 2006 года доля православных выросла на 10\%. (Опрос Левада-Центра, 2010) По данным опросов Левада-центра, численность мусульман уменьшилась с 6\% (2007г.) до 4\% (2010г.), а численность православных возросла с 69\% до 76\% (Опрос Левада-Центра, 2010).

Представителей татарской национальности в республике Татарстан (по данным последней переписи населения 2010 года) - 2 млн. 13 тыс. человек, что составляет 53,2 \% от общей численности населения (3 млн. 786 тыс. чел). Число лиц русской национальности насчитывает 1 млн. 501 тыс. человек, это 39,7 \% от всего населения региона (Перепись населения РФ, 2010).

Данные о количестве мечетей в Республике Татарстан представляют собой довольно четкую картину. В Управлении Министерства Юстиции Республики Татарстан на 1 января 2012 года зарегистрировано 1505 религиозных организаций, из которых 1128 мусульманских. Второе место занимает Русская православная церковь, к которой относятся 290 религиозных организаций (Религия, 2013).

Согласно данным опроса населения, проведённого кафедрой социологии КФУ в 2012 г., мусульманами себя назвали 50,5\% опрошенных, православными - 39\% и к другим конфессиям себя отнесли $0,5 \%$ (Низамова, 2013).

Таким образом, если в регионах Российской Федерации мусульмане в среднем составляют около $10 \%$ от населения, то в Республике Татарстан согласно статистическим данным мусульман большинство около 50\%. Это создает благоприятную почву для развития предпринимательства, направленного на удовлетворение нужд верующих. Проведенные нами исследования в рамках качественной стратегии, а именно глубинное интервью, экспертный опрос и включенное наблюдение показывают, что существуют препятствия по внедрению и успешному развитию элементов исламской экономики, таких как исламский банкинг и мусульманское страхование. И объяснения причин подобных явлений лежит в области повседневных, микросоциологических практик.

\section{6 Мусульманские услуги в Республике Татарстан}

В республике не «выжили» такие услуги как мусульманское такси, услуга операторов мобильной связи - сообщения со временем намаза. Услуга «мусульманское такси» предоставляется как временная благотворительная акция, призванная поддержать инвалидов и помочь им с комфортом добираться до мечетей. Сейчас ни одна из представленных компаний сотовой связи не предоставляет специальные религиозные услуги, такие как смс со временем намаза. Последние упоминания о подобном встречаются в статьях за 2009 год, данную услугу предоставлял своим абонентам Мегафон (в том числе и в Татарстане).

В то же время столице процветает 29 заведений, специализирующихся на продуктах питания «халяль», 34 магазина мусульманской одежды и сопутствующих товаров, 6 книжных магазина религиозной мусульманской литературы, три крупных туристических кампании, организующих паломнические туры и два салона, специализирующихся на косметике, произведенной по стандартам «халяль». Таким образом, успешный бизнес связан в основном с повседневными потребностями верующих.

Существуют различны объяснения причин непопулярности некоторых услуг в республике. В частности, одно из объяснений кроется в таком понятии как социоэкономичексий генотип, под которым понимается механизм социального наследования и социальных изменений, который обеспечивает воспроизводство структур, принципов работы, и процессов регулирования в определенной социальной системе. Таким образом, в нашем обществе уже есть объективные предпосылки «оригинального» развития, в том числе и отстающего экономического. Получается, что республиканское общество просто может не принять не существовавшие ранее структуры, а воспроизводить привычные механизмы, например, коммерческие услуги банковского кредитования.

\section{7 Заключение}

Результаты исследований показывают, что внедрение любых новых форм религиозных услуг требует тщательного предварительного изучения рынка, потребностей верующих, и точных прогнозов спроса на определённые услуги и товары. Исламская экономика привлекла внимание исследователей, как социологов, так и экономистов, сравнительно недавно. Исламские страны играют значительную роль в 
современной политики и экономике. Для понимания основ происходящих процессов необходимо изучение исламских экономических практик и в религиозном, и в социальном контекстах. Также для формирования адекватного восприятия исламской экономической модели важно учитывать мусульманскую специфику. На данный момент процветают общеизвестные практики, такие как продажа халяль-продукции, специализированной одежды и туры паломничества в святые места. Однако, услуги требующие более глубоко ознакомления с религиозными нормами, такие как, например, использование специальных косметических и фармацептических средств, пользуются меньшей популярностью. Рабочей гипотезой дольнейших исследований по данной тематике может служить предположение, что республиканские мусульмане недостаточно осведомлены о всех религиозных канонах своей религии и их полностью устраивают существующие экономические практики.

\section{Литература}

- Зарубина Н.Н. Социально-культурные основы хозяйства и предпринимательства: учеб. пособие для студентов и аспирантов. М.: Магистр, 1998. 360 с.

- Ильичев, Г. и Клин, Б. В России можно только верить? 2006 г. $<$ http://wciom.ru/index.php?id=266\&uid=3769> (10.04.2013)

- Исхаков И.Р. Привлечение инвестиционных ресурсов посредством развития исламских финансовых механизмов // Современные тенденции конкурентоспособности Республики Татарстан: инновации, кластерный подход. 2010. С. 86-89.

- Национальный состав населения Республики Татарстан по результатам Всероссийской переписи населения 2010 года < http://www.tatstat.ru/VPN2010/DocLib8/Forms/AllItems.aspx> (10.04.2013)

- Опрос Левада-Центра 2010 г. <http://www.levada.ru/archive/religiya/kakuyu-religiyu-vy-ispoveduete> (10.04.2013)

- Официальный Татарстан, Религия <http://tatarstan.ru/about/religion.htm> (10.04.2013)

- Религия в жизни россиян, 2008 г. $<$ http://wciom.ru/index.php?id=268\&uid=11099> (10.04.2013)

- Такафул: халалное страхование [Электронный ресурс] // Исламские Финансы: [сайт]. [2010]. URL: http://takaful-kz.narod.ru/index/0-11 (дата обращения: 12.10.2014).

- $\quad$ Этничность, религиозность и миграции в современном Татарстане / под ред. Р.Г. Минзарипова, С.А. Ахметовой, Л.Р. Низамовой. - Казань: Казан. ун-т, 2013. С. 57.

- Saeed A. Islamic Banking and Interest. A study of the prohibition of Riba and its contemporary interpretation. EJ Brill, 2001.

- Bianchi R.R. Islamic Globalization: Pilgrimage, Capitalism, Democracy, and Diplomacy. Singapore, SGP: World Scientific Publishing Company, 2013.

- Muhamed N.A., Ramli N.M., Aziz S.A., Yaakub N.A. Integrating Islamic Financing and Halal Industry: A Survey on Current Practices of the Selected Malaysian Authority Bodies // Asian Social Science. 2014. T.10, № 17. C. 120-127.

- Podgornyi B.B. Economic Behavior and the Influence of Religious Traditions // Russian Social Science Review. 2012. T.53, № 6. C. 43-61. 


\title{
Rekabet Gücü ve Ekonomik Büyüme İlişkisi: Seçilmiş Ülkeler Üzerine Panel Veri Analizi \\ The Relationship between Competitiveness and Economic Growth: A Panel Data Analysis on Selected Countries
}

\author{
Asst. Prof. Dr. Ziya Çağlar Yurttançıkmaz (Atatürk University, Turkey) \\ Prof. Dr. Ömer Selçuk Emsen (Atatürk University, Turkey) \\ Asst. Prof. Dr. Ahmet Fatih Aydemir (Atatürk University, Turkey) \\ Asst. Prof. Dr. Ahmet Alkan Çelik (Beykent University, Turkey)
}

\begin{abstract}
As economic growth is very important for the development of individuals and the society, the importance of capital stocks and labor force for the economic growth of countries cannot be neglected. Additionally, the human capital component and especially the role of competitiveness increases on the growth process have been extensively discussed over the last two decades. This paper examines the impact of competitiveness increases on economic growth of selected middle-income countries including Turkey for the period of 1997-2012 using a balanced panel data analysis, which was relatively less studied in the literature. According to analysis results, an increase on the competitiveness index of countries in the panel, which were obtained from the data set of the International Institute for Management Development (IMD), positively increases per capita income level. This result may be interpreted as several factors that increase competitiveness including infrastructure, economic structure, business world and regulations and investments that ensure public efficiency may have a positive impact on economic growth. Therefore, this study suggests that future policies that concentrate on extensive growth instead of intensive dimension may contribute to efficient and sustainable growth.
\end{abstract}

\section{Giriş}

İlk çağlarda ekonomik büyüme ve toplumsal refah artışı sağlamak için su kenarları ve verimli ovaların denetimini silah gücü ile ele geçirmek şeklinde gerçekleşen rekabet anlayışı (Childe, 1992), daha sonra paranın icadı ve artan ticari faaliyetler sonucunda önemli ticaret yollarının denetimini elde tutma şeklinde evrim geçirmiştir. Rekabet sonucu elde edilen bu kazançlar ekonomik açıdan zenginliğin ve dolayısıyla refahın temel dayanağı olmuştur. Büyüme-rekabet gücü-refah artışı ilişkilerine bakış açıları iktisat ekollerinde tartışma konusu olmuştur. Bu çerçevede Smith, Ricardo, Malthus ve Marx, ekonomik büyüme için temel aynı olmakla birlikte farklı öneriler sunmuşlardır. Tümünde büyüme ve refahın artırılmasının ortak paydasını emek ve sermaye artışı oluşturur. Büyüme ve refahı etkileyen temel unsurlardan üretim faktörlerinin artması ve dışa açılık ise ülkenin rekabet gücünü artırmaktadır. Klasiklerin anti-sentezi olan Keynesyen modele göre ise ülkelerin ekonomik büyümeleri ve rekabet gücü kazanmaları açısından toplam talebi yüksek tutmak en önemli etkendir. Toplam talebin yüksekliği kaynakların etkin kullanımını beraberinde getirerek ekonomiye dinamizm kazandırmakta ve ekonominin rekabet gücünün yükselmesine katkıda bulunmaktadır. Harrod ve Domar'da ekonomik büyüme için önemli olan tasarruf düzeyi ve sermayenin verimlilik artışlarına paralel olarak rekabet gücünün artacağı belirtilir. Neo-klasik iktisatçılar ise ekonomik büyüme ve rekabet gücünün kazanılması için teknolojik gelişmelere önem verirken, Schumpeter emek ve sermaye artışının bir noktaya kadar ekonomiyi sürükleyebileceğini; asıl önemli olanın yeni bir ürün veya üretim teknolojisi meydana getirme olduğunu vurgulamıştır. Yeni büyüme teorisyenlerinden Romer, Lucas, Rebelo ve Barro ise Ar-Ge çalışmalarının, beşeri sermaye yatırımlarının, birikimli sermayenin ve kamu harcamalarının üretim kaynaklarının verimliliklerini artırarak firmalara ve ülkelere dış rekabette avantaj sağlayacağını ve ekonomik büyümeye yardımcı olacağını belirtmişlerdir.

Rekabet kavramının sıklıkla kullanılmasında ve ekonomik büyüme sürecindeki öneminin artmasında ise özellikle 1980'lerden sonra gelişen bilgi-iletişim teknolojilerine paralel olarak küreselleşme olgusunun yeri büyüktür. Küreselleşmeyle birlikte dünya genelinde bir rekabet olgusu oluşmuş ve ekonomik büyümeyi sağlamak için ülkeleri yoğun bir rekabetle karşı karşıya bırakmıştır (Çivi vd. 2008). İlerleyen zaman ve gelişen ilişkiler ağı bu kavramın sadece ekonomik değil, sosyal, kültürel ve siyasal alanları da kapsamış ve dünya ülkelerinin ekonomik bağımlılıklarının ötesinde, zaman ve mekânsal olarak bir dönüşümü ifade eden bir kavram olmuştur. Özellikle kamu kuruluşlarının özelleştirilmesi, küreselleşme, ticari ve finansal serbestleşme, dünya genelinde bazı bölgelerde yüksek refah artışı; buna karşılık bazı bölgelerde yüksek oranlı refah düşüşleri ve sermayenin hızlı hareket etmesi içinde bulunulan dönemin ekonomik özellikleri arasında yer almaktadır. Siyasal açıdan çok kutupluluk sonucu artan istikrarsızlık; teknolojik açıdan gelişmiş ürün ve hizmetlerde artış, yenilikçi ürünlerde ve süreçlerdeki gelişim ile bilgi ve iletişim teknolojilerindeki gelişim; sosyo-kültürel düzeyde kentleşmedeki artış ve insanların bireyselleşmesi; ekolojik bakımdan küresel iklim değişiklikleri, çevresel kirlenme, kuraklık problemleri; demografik yapıda hızlı nüfus artışı ve değişen nüfus yapısı; organizasyon 
bakımından artan küresel rekabet, yeni açılan pazarlar, bilinçli müşteriler, yenilikler, düşük maliyetle hammadde elde etme mücadelesi dünya düzeninde oluşan temel değişikliklerdendir (Yeldan, 2001: 14).

Küreseleşme-rekabet gücü-büyüme ve dolayısıyla refah artışı ilişkilerinin irdeleneceği bu çalışma iki temel alt başlıktan oluşturulmuştur. Birinci alt başlıkta literatür araştırması yapılarak rekabet gücü ve ekonomik büyüme ilişkileri üzerine yapılmış çalışmalar incelenmesi yoluna gidilmiştir. İkinci alt başlıkta ise literatür araştırmalarından hareketle oluşturulan model çerçevesinde, rekabet gücünün orta gelir gurubunda yer alan ülkelerde ekonomik büyüme üzerindeki etkileri araştırılmıştır. Sonuç kısmında da Türkiye'nin de dahil olduğu bu araştırma gurubunda yer alan ülkeler için politik çıkarıma gidilmiştir.

\section{Literatür Araştırması}

Rekabet gücü ülkelerin ekonomik ve sosyal olarak gelişimlerinde tarihin her döneminde büyük önem taşımıştır. Bu durum özellikle küreselleşmeyle rekabet olgusu dünya ölçeğinde önem kazandırmış ve ülkeler küresel mal ve hizmet piyasalarından daha fazla pay almak için büyük çaba sarf etmelerine yol açmıştır. Rekabet gücünün ekonomik büyüme üzerindeki etkisi konusunda literatürde sınırlı çalışma olmakla birlikte rekabet gücüne doğrudan değinilmesi de rekabet gücünün belirleyicileri ve ekonomik büyüme ilişkisini ele alan çok sayıda çalışma bulunmaktadır. Bu kapsamda yapılan bir kısım çalışmaları aşağıdaki tabloda özet olarak göstermek mümkündür.

Uluslararası rekabet gücünü etkileyen faktörlerin çeşitliliği göz önüne alındığında, rekabet gücünü artırmak için çok yönlü olarak politika ve uygulamaların devamlı bir şekilde geliştirilmesi gerekli olmaktadır. Bu kapsamda "Rekabet gücünün geliştirilmesi, bir sürat koşusu olmayıp maraton yarışı gibidir" (Porter, 2004: 32). Rekabet gücünün belirleyicileri olarak kullanılan değişkenler çok fazla olmakla birlikte literatürde yaygın olarak kullanılan ve yukarıda sayılanlar toplulaştırarak şu şekilde sıralayabilmek mümkündür;

(i) Makroekonomik Göstergeler (Yatırım ve Tasarruflar, Enflasyon Düzeyi, Kur ve Faiz Politikası)

(ii) Kamu Ekonomisinin Yapısı, büyüklüğü, kalite ve etkinliği

(iii) Dış Ticaret Politikası, Dışa Açıklık Düzeyi ve Dış Ticaret Göstergeleri

(iv) Üretim Maliyetleri, Uluslararası Rekabet Gücünde Fiyat-Maliyet İlişkisi

(v) Kalitenin Artırılması, Çevrenin Korunması, Kentsel Altyapının Geliştirilmesi, İş Ortamının ve Tarımsal Altyapının İyileştirilmesi

(vi) Verimlilik

(vii) Ekonomide Kayıtdışılığın Azaltılması

(viii) Finansal Sistemin Geliştirilmesi

(ix) Enerji, Ulaştırma ve Üretim Altyapısının Geliştirilmesi

(x) Eğitim-Sağlık gibi Beşeri Sermaye Göstergelerinin İyileştirilmesi

(xi) Coğrafi Konum, Demografik ve Sosyo-Kültürel Yap1

(xii) AR-GE, Yenilik ve Teknolojik Gelişme

(xiii) Doğrudan Yabancı Sermaye Yatırımları ve Ticari-Finansal Alanda Liberalizasyon

Bu değişkenlerdeki iyileşmelerin ülkelerin rekabet gücünü artırarak ekonomik büyüme sürecine katkı sağladığı yapılan uygulamalı çalışmalarda da ifade edilmiştir.

\begin{tabular}{|c|c|c|c|}
\hline Alexandar (1997) & $\begin{array}{l}20 \text { OECD ülkesi, 1974- } \\
1991\end{array}$ & Panel Veri Analizi & $\begin{array}{llll}\begin{array}{l}\text { Enflasyon ekonomik } \\
\text { etkilemektedir. }\end{array} & \text { büyümeyi negatif } & \text { olarak } \\
\end{array}$ \\
\hline $\begin{array}{ll}\text { Hanson } & \text { ve } \\
\text { Jonung (1997) }\end{array}$ & İsveç'in 1834-1991 & Zaman serisi analizi & $\begin{array}{l}\text { Finansal gelişme sonucu ekonomik büyüme pozitif } \\
\text { yönlü etkilenmektedir. }\end{array}$ \\
\hline $\begin{array}{l}\text { Nelson ve Singh } \\
(1998)\end{array}$ & $\begin{array}{l}67 \text { gelişmekte olan ülke } \\
\text { için 1970-89 dönemi }\end{array}$ & Ortalamalı EKK & $\begin{array}{l}\text { Ekonomik özgürlükler, ekonomik büyümeyi pozitif } \\
\text { etkilemektedir. }\end{array}$ \\
\hline $\begin{array}{l}\text { Rajan ve Zingales } \\
\text { (1998) }\end{array}$ & 41 ülke, 1980-1990 & Regresyon analizi & $\begin{array}{l}\text { Finansal geliş̧menin, ekonomik büyümeyi oldukça } \\
\text { yüksek düzeyli etkilediği görülmüşşur. }\end{array}$ \\
\hline $\begin{array}{ll}\text { Bosworth } & \text { ve } \\
\text { Collins (1999) }\end{array}$ & $\begin{array}{l}\text { 23'ü GÜ ve } 62 \text { 'si GOÜ } \\
\text { toplam } 85 \text { ülke }\end{array}$ & Panel Veri Analizi & $\begin{array}{l}\text { DYY girişlerinin ekonomik büyümeyi pozitif yönlü } \\
\text { etkilemektedir. }\end{array}$ \\
\hline $\begin{array}{l}\text { Pereira ve Sagales } \\
\text { (1999) }\end{array}$ & İspanya, 1970-1989 & VAR analizi & $\begin{array}{l}\text { Kamunun ulaştırma ve haberleşme yatırımları } \\
\text { ekonomik büyümeyi olumlu yönde etkilemektedir. }\end{array}$ \\
\hline Heshmati (2001) & $\begin{array}{l}\text { OECD ülkeleri, } \\
\text { 1970-1992 }\end{array}$ & $\begin{array}{l}\text { Mankiw, Romer ve Weil } \\
\text { modeli ve regresyon } \\
\text { analizi }\end{array}$ & $\begin{array}{l}\text { Sağlık harcamalarının ekonomik büyümeyi pozitif } \\
\text { olarak etkilemektedir. }\end{array}$ \\
\hline Vedder (2001) & ABD, 1957-1997 & Zaman serisi analizi & $\begin{array}{l}\text { Vergi oranlarındaki artışı ekonomik büyümeyi negatif } \\
\text { etkilediği görülmüştür. }\end{array}$ \\
\hline Were (2001) & Kenya, 1970-1995 & Regresyon analizi & $\begin{array}{l}\text { Dış borç birikiminin ekonomik büyümeyi ve negatif } \\
\text { etkilediği görülmüştür. }\end{array}$ \\
\hline $\begin{array}{l}\text { Chowdhury } \\
(2002)\end{array}$ & Endonezya, 1950-1997 & $\begin{array}{ll}\text { Ortalama ve } & \text { serpilme } \\
\text { diyagramları } & \end{array}$ & $\begin{array}{l}\text { Enflasyonla ekonomik büyüme arasında pozitif yönlü } \\
\text { bir ilişsi bulunmuştur. }\end{array}$ \\
\hline $\begin{array}{ll}\text { Holtz-Eakin } & \text { ve } \\
\text { Kao (2003) } & \end{array}$ & $\begin{array}{l}50 \text { ABD eyaleti, 1986- } \\
1998\end{array}$ & Panel veri analizi & $\begin{array}{l}\text { Girişimciliğin verimlilik artışı üzerinde pozitif bir } \\
\text { etkisi olduğu vurgulanmıştır. }\end{array}$ \\
\hline
\end{tabular}




\begin{tabular}{|c|c|c|c|}
\hline $\begin{array}{l}\text { Karabegovic vd. } \\
(2003)\end{array}$ & $\begin{array}{l}\text { Kanada } \begin{array}{l}\text { ve } \\
\text { eyaletleri, }\end{array} \text { 1994-1999 }\end{array}$ & Panel Veri Analizi & $\begin{array}{l}\text { Ekonomik özgürlük düzeyi ile ekonomik büyüme } \\
\text { arasında pozitif yönlü bir ilişki var. }\end{array}$ \\
\hline $\begin{array}{l}\text { Asheghian } \\
(2004) \text {, }\end{array}$ & $\mathrm{ABD}, 1960-2000$ & Zaman serisi analizi & $\begin{array}{l}\text { DYY'nin ekonomik büyüme üzerinde pozitif bir etkisi } \\
\text { olduğu görülmüştür. }\end{array}$ \\
\hline $\begin{array}{l}\text { Berber ve Artan } \\
(2004)\end{array}$ & Türkiye, 1987-2003 & Zaman serisi analizi & $\begin{array}{l}\text { Enflasyonun ekonomik büyüme üzerinde negatif etkiye } \\
\text { sahip olduğu görülmüştür. }\end{array}$ \\
\hline $\begin{array}{l}\text { Datta ve Agarwal } \\
(2004)\end{array}$ & $\begin{array}{l}22 \text { OECD ülkesi için } \\
1980-1992\end{array}$ & Panel veri analizi & $\begin{array}{l}\text { Telekom alanında ki yatırımlar arttığında ekonomik } \\
\text { büyüme de pozitif yönlü değişmektedir. }\end{array}$ \\
\hline Benos (2004) & $\begin{array}{l}16 \text { OECD ülkesi, } 1970- \\
1997\end{array}$ & Panel Veri Analizi & $\begin{array}{l}\text { Bütçe fazlalarının ekonomik büyümeye pozitif katkı } \\
\text { yaptığı görülmüştür. }\end{array}$ \\
\hline $\begin{array}{l}\text { Musila ve Belassi } \\
\text { (2004) }\end{array}$ & Uganda, 1965-1999 & Zaman serisi analizi & $\begin{array}{l}\text { Kamu eğitim harcamalarındaki artışın kısa ve uzun } \\
\text { dönemde ekonomik büyümeyi pozitif etkilediği } \\
\text { görülmüştür. }\end{array}$ \\
\hline Onur (2005) & Türkiye, 1980-2003 & Zaman serisi analizi & $\begin{array}{l}\text { Finansal kalkınma ve açıklığın ekonomik büyümeyi } \\
\text { pozitif etkilediği görülmüştür. }\end{array}$ \\
\hline Acs vd. (2006) & $\begin{array}{l}18 \text { gelişmiş ülke, 1981- } \\
1998\end{array}$ & $\begin{array}{l}\text { Birleştirilmiş kesitlerarası } \\
\text { veri yöntemi }\end{array}$ & $\begin{array}{l}\text { Yüksek girişimcilik düzeyine sahip ülkeler daha iyi } \\
\text { ekonomik büyüme performansı göstermektedirler. }\end{array}$ \\
\hline $\begin{array}{l}\text { Değer ve Emsen } \\
(2006)\end{array}$ & $\begin{array}{lr}27 & \text { geçiş } \\
1990-2002 & \text { ekonomisi, } \\
\end{array}$ & Panel veri analizi & $\begin{array}{l}\text { DYY'lar ekonomik büyüme performansı üzerinde } \\
\text { pozitif etkilidir. }\end{array}$ \\
\hline $\begin{array}{l}\text { Shan ve Jianhong } \\
\text { (2006) }\end{array}$ & Çin, 1978-2001 & $\begin{array}{l}\text { VAR yöntemi ve Granger } \\
\text { nedensellik testi }\end{array}$ & $\begin{array}{l}\text { Finansal gelişme ve ekonomik büyüme arasında çift } \\
\text { yönlü nedensel ilişki tespit edilmiştir. }\end{array}$ \\
\hline Tsen (2006) & Çin, 1952-1999 & Zaman serisi analizleri & $\begin{array}{l}\text { Dışa açıklık, beşeri sermaye ve ekonomik büyüme } \\
\text { arasında karşılıklı nedensellik ilişkisi görülmüştür. }\end{array}$ \\
\hline $\begin{array}{lll}\text { Kurt ve } & \text { Terzi } \\
(2007) & \end{array}$ & Türkiye, 1989-2003 & VAR analizi & $\begin{array}{l}\text { Ekonomik büyümeyle verimlilik düzeyi arasında çift } \\
\text { yönlü bir ilişki vardır. }\end{array}$ \\
\hline $\begin{array}{l}\text { Temiz ve } \\
\text { Korkmaz (2007) }\end{array}$ & Türkiye, 1965-2005 & Zaman serisi analizi & $\begin{array}{l}\text { Sağl1k göstergelerindeki iyileşmenin } \\
\text { büyümeyi pozitif etkilediği görülmüştür. }\end{array}$ \\
\hline $\begin{array}{ll}\text { Bilginoğlu } & \text { ve } \\
\text { Aysu (2008) } & \\
\end{array}$ & Türkiye, 1968-2005 & Zaman serisi analizi & $\begin{array}{l}\text { D1ş borçların ekonomik büyümeyi negatif etkilediği } \\
\text { görülmüştür. }\end{array}$ \\
\hline $\begin{array}{l}\text { Zahra, Azim ve } \\
\text { Mahmood (2008) }\end{array}$ & $\begin{array}{l}24 \text { düşük, orta ve yüksek } \\
\text { gelirli ülke, 1985-2003 }\end{array}$ & Panel Veri Analizi & $\begin{array}{l}\text { Kişi başına düşen altyapı yatırımları arttıkça, ekonomik } \\
\text { büyüme de pozitif etkilenir. }\end{array}$ \\
\hline $\begin{array}{l}\text { Omisakin vd. } \\
(2009)\end{array}$ & Nijerya, 1970-2006 & $\begin{array}{l}\text { Toda-Yamamoto } \\
\text { nedensellik ve ARDL } \\
\text { yöntemi }\end{array}$ & $\begin{array}{l}\text { Ticari açıklığın rekabet gücünü artırdığı bunun ise } \\
\text { büyümeyi pozitif etkilediği sonucuna ulaşılmıştır. }\end{array}$ \\
\hline $\begin{array}{l}\text { Wang ve Wong } \\
(2009)\end{array}$ & $\begin{array}{lrr}69 & \text { gelişmiş } & \text { ve } \\
\text { gelişmekte } & \text { olan } & \text { ülke, }\end{array}$ & Panel Veri Analizi & $\begin{array}{l}\text { DYY'ın belli koşullarda ekonomik büyümeyi pozitif } \\
\text { etkilediği görülmüştür. }\end{array}$ \\
\hline $\begin{array}{l}\text { Genç ve Atasoy } \\
(2010)\end{array}$ & $\begin{array}{lrr}34 & \text { gelişmiş } & \text { ve } \\
\text { gelişmekte } & \text { olan } & \text { ülke, } \\
\end{array}$ & Panel Veri Analizi & $\begin{array}{l}\text { Ar-Ge harcamaları ekonomik büyümeyi pozitif } \\
\text { etkilemektedir. }\end{array}$ \\
\hline $\begin{array}{l}\text { Compton vd. } \\
(2011)\end{array}$ & $\begin{array}{lll}\text { ABD'nin } 50 \quad \text { eyalet, } \\
\text { 1981-2004 }\end{array}$ & Panel Veri Analizi & $\begin{array}{l}\text { Büyüme ve ekonomik özgürlükler arasında pozitif ve } \\
\text { anlamlı ilişki bulunmuştur. }\end{array}$ \\
\hline Jangili (2011) & Hindistan, 1950-2008 & Zaman serisi analizi & $\begin{array}{l}\text { Yüksek tasarruf ve yatırımlar, yüksek ekonomik } \\
\text { büyümeyi sağlamaktadır }\end{array}$ \\
\hline $\begin{array}{l}\text { Umutlu } \\
(2011)\end{array}$ & $\begin{array}{l}29 \text { OECD ülkesi, 2000- } \\
2007\end{array}$ & Panel veri analizi & $\begin{array}{l}\text { Eğitimin ve mülkiyet hakkı değişkenlerindeki } \\
\text { iyileşmenin ekonomik büyümeyi pozitif yönde } \\
\text { etkilediği sonucuna ulaşılmıştır. }\end{array}$ \\
\hline $\begin{array}{l}\text { Güloğlu ve Tekin } \\
\text { (2012) }\end{array}$ & $\begin{array}{l}\text { OECD ülkeleri, } 1991- \\
2007\end{array}$ & Panel Veri Analizi & $\begin{array}{l}\text { Ar-Ge harcamalarının teknoloji düzeyini, teknolojideki } \\
\text { değişimin ise ekonomik büyümeyi olumlu olarak } \\
\text { etkilediği belirtilmiştir. }\end{array}$ \\
\hline $\begin{array}{lll}\text { Kara } & \text { ve } & \text { Taş } \\
(2012) & & \\
\end{array}$ & Türkiye, 2004-2008 & Panel veri analizi & $\begin{array}{l}\text { Altyapı harcamalarının bölgesel gelirin artmasında } \\
\text { pozitif katkısı olduğu görülmüştür. }\end{array}$ \\
\hline Çetin (2013) & $\begin{array}{l}81 \underset{\text { gelişmiş }}{\text { ve }} \\
\text { gelişmekte olan }\end{array}$ & Panel Veri Analizi & $\begin{array}{l}\text { Ekonomik özgürlük düzeyi yükseldikçe, kişi başına } \\
\text { gelirde artış göstermektedir. }\end{array}$ \\
\hline
\end{tabular}

Tablo 1. Literatür Çalışmalarının Özeti

\section{Ekonometrik Analiz}

\subsection{Veri Seti ve Ekonometrik Uygulama}

Rekabet gücünün ülkelerin ekonomik performansları üzerindeki etkisi ile ilgili olarak yapılan bu çalışmada Türkiye'nin de yer aldığı ve IMF sınıflamasına göre orta gelirli ülkeler grubunda yer alan (Brezilya, Çin, Kolombiya, Hindistan, Endonezya, Malezya, Meksika, Filipinler, Güney Afrika Cumhuriyeti, Tayland ve Venezuela) ülkeler ele alınmıştır. Bu 12 ülke için zaman boyutu 1997-2012 dönemini kapsamış, dolayısıyla dengeli panel veri analizi yapılmıştır. Uygulamada kullanılan veriler, IMD (International Management Development) Uluslararası Yönetim Geliştirme Merkezi, Dünya Bankası (World Bank) World Development Indicators (WDI)/Global Development Finance(GDF) ve IMF'in "World Economic Outlook" (WEO) veri setlerinden derlenmiştir. Çalışmada yapılan tüm analizlerde Eviews-7, Stata-12 ve Gauss-9 ekonometri programından faydalanılmıştır. 
Çalışmada totolojiye düşmeme adına ve hem teorik hem de uygulamalı literatürden hareketle IMF (Uluslararası Para Fonu) ve WB (Dünya bankası) veri setlerinden yararlanılarak rekabet gücüne etki eden değişkenler bağımsız olarak belirlenmiştir. Böylece IMD rekabet gücü alt endeksleri üzerinde bu faktörlerin etkilerinin daha iyi bir şekilde analiz edilmesi hedeflenmiştir. Çalışmanın uygulama bölümünde Barro (1997), Easterly ve Levine (1997), Stel vd. (2005), Escosura vd.(2011), Amar ve Hamdi (2012) ile Baranova (2013) tarafından yapılan çalışmalarda ekonomik büyüme üzerinde rekabet gücünün veya belirleyicilerinin etkileri tahmin edilmiştir. Uygulamada bu çalışmalar referans alınarak modeller oluşturulup analizler yapılmıştır.

Rekabet gücü ve ekonomik büyüme ilişkisi kapsamında IMD endeksi, sermaye stoku ve işgücü değişkenleri ile ekonomik büyüme üzerinde rekabet gücünün, sermayenin ve emeğin etkileri analiz edilmiştir. Bu kapsamda ekonomik büyüme göstergesini temsilen kişi başına gelir [gdpc; 2005 yılı sabit fiyatlarla kişi başı gelir (USD)], rekabet gücü göstergesi olarak IMD rekabet gücü genel endeks değeri, işgücü (L) olarak işgücüne katılım oranı, sermaye stoku $(\mathrm{K})$ değişkeni olarak sabit sermaye birikiminin GSYİH'ya oranı (gfc) verilmiştir. Model i aşağıdaki gibi tanımlamak mümkündür:

$$
\mathrm{Gdpc}_{\mathrm{i}, \mathrm{t}}=\mathrm{ex}_{\mathrm{i}, \mathrm{t}}+\mathrm{lab}_{\mathrm{i}, \mathrm{t}}+\mathrm{gfc}_{\mathrm{i}, \mathrm{t}}
$$

\begin{tabular}{|c|c|c|c|c|}
\hline Değişken & Ortalama & St. Hata & Min. & Max. \\
\hline gdpc & 3938.489 & 2351.651 & 506.978 & 8545.382 \\
\hline ex & 51.592 & 13.658 & 18.270 & 87.230 \\
\hline lab & 58.431 & 8.826 & 38.600 & 74.600 \\
\hline gfc & 22.507 & 6.746 & 9.550 & 51.982 \\
\hline
\end{tabular}

Tablo 2. Rekabet Gücü ve Ekonomik Büyüme Modeli Tanımlayıcı İstatistikleri

Yukarıdaki tablodan da görülebileceği gibi paneli oluşturan ülkelerde ortalama kişi başına gelir (gdpc) 3938 dolar, ortalama genel rekabet gücü (ex) endeks değeri 51.59 (100 üzerinden değerlendirilmiştir), ortalama işgücüne katılım oranı (lab) \%58.43 ve ortalama sabit sermaye birikimi/GSYİH (gfc) oranı \%22.5 ’tir.

\subsection{Rekabet Gücü-Büyüme İlișkileri Panel ARDL Modeli}

Zaman ve kesit veriler uyarlamasında tahmin yöntemi olarak havuzlanmış regresyon ile tahmini iki yöntem siklıkla kullanılır;

1. Sabit Etkiler Yöntemi (Fixed Effects Model-FEM)

2. Tesadüfi (Rassal) Etkiler Yöntemi (Random Effects Model-REM)

İki yöntem arasındaki temel fark sabit terimlerden kaynaklanmaktadır. Sabit etki tahmini yönteminde panelde yer alan her bir yatay kesit (ülke) arasındaki fark her bir yatay kesit için ayrı ayrı sabitler eklenmek suretiyle elde edilmekte iken, tesadüfi etkiler yönteminde ise yatay kesitlerin özellikleri gözlemlenemez ve tesadüfi olarak dağılmış olması sebebiyle bu tesadüfi etkiler hata terimlerinden elde edilebilmektedir. Sabit ve tesadüfi etkili modelden hangisinin kullanılacağına Hausman (1978) testi ile karar verilir. Hausman (1978) testinin Ki-kare değerinin olasılığı \%1'den küçük çıkması halinde sabit etkiler modelinin doğru olduğu sonucuna varılacaktır (Çetin, 2013: 42-43).

Modelde kişi başı gelir üzerinde rekabet gücü endeksinin, işgücünün ve sabit sermaye birikiminin etkileri analiz edilmiştir. Bu kapsamda kullanılan değişkenler gdpc; 2005 yılı sabit fiyatlarla kişi başı gelir (USD), ex; IMD rekabet gücü genel endeks değeri, lab; işgücüne katılım oranı, gfc; sabit sermaye birikiminin GSYİH'ya oranı şeklinde verilmiştir.

\begin{tabular}{|l|c|c|c|c|}
\hline Bağımlı Değişken: & Katsayı & St. Hata & t-değeri & Olasılık Değeri \\
\hline $\mathrm{EX}$ & 24.28 & 3.40 & 7.14 & 0.00 \\
\hline $\mathrm{LAB}$ & -26.28 & 17.05 & -1.54 & 0.125 \\
\hline $\mathrm{GFC}$ & -43.72 & 5.58 & -7.82 & 0.00 \\
\hline $\mathrm{C}$ & 5205.79 & 988.73 & 5.27 & 0.00 \\
\hline $\mathrm{F}(11,177)=495.64$, Prob $>\mathrm{F}=0.000$ & \multicolumn{5}{|l|}{} \\
\hline
\end{tabular}

Tablo 3. Sabit Etkili Model

\begin{tabular}{|l|c|c|c|c|}
\hline Bağımlı değişken: GDPC & Katsay1 & St. Hata & z-değeri & Olasılık Değeri \\
\hline EX & 24.13 & 3.38 & 7.12 & 0.00 \\
\hline LAB & -30.64 & 16.65 & -1.84 & 0.06 \\
\hline GFC & -43.67 & 5.56 & -7.84 & 0.00 \\
\hline C & 5467.32 & 1181.92 & 4.63 & 0.00 \\
\hline Wald $\chi^{2}(3)=229.16$, Prob $>\chi^{2}=0.000$
\end{tabular}

Tablo 4. Tesadüfi Etkili Model

Sabit etkili modelde regresyon katsayıları incelendiğinde rekabet gücündeki bir birimlik değişimin kişi başına gelir üzerinde 24.28 birimlik değişime yol açtığı görülmektedir. İşgücü ve sabit sermaye birikimindeki birer birimlik değişimler ise kişi başı gelir üzerinde sırasıyla -26.28 birim ve -43.72 birimlik etki oluşturmaktadır. 
Sabit etkili modeldeki bu katsayılardan işgücü dışındakiler istatistiksel olarak da anlamlı bulunmuştur. Sabit etkili model incelendiğinde $\mathrm{F}$ testi anlamlı bulunmuştur.

Tesadüfi etkili modeldeki regresyon katsayıları ise rekabet gücündeki bir birimlik değişimin kişi başına gelir üzerinde 24.13 birimlik değişime yol açtığ 1 görülmektedir. İşgücü ve sabit sermaye birikimindeki birer birimlik değişimler ise kişi başı gelir üzerinde sırasıyla -30.64 birim ve -43.67 birimlik etki oluşturmaktadır. Sabit etkili modeldeki bu katsayıların tamamı \%10 önem düzeyinde istatistiksel olarak da anlamlı bulunmuştur. Tesadüfi etkili model incelendiğinde Wald testi anlamlı bulunmuştur.

Hausman test istatistiği: $\chi^{2}=1.61$, prob $>\chi^{2}=0.6578$ şeklindedir.

Hausman test istatistiği kapsamında $\mathrm{H}_{0}$ hipotezi kabul edilirse tesadüfi etkili model uygundur; $\mathrm{H}_{0}$ red edilirse, sabit etkili model uygundur şeklindeki hipoteze göre çalışmada tesadüfi etkili modelin kullanılması uygun olacaktır.

\subsection{Yatay Kesit Bağımlılık Testleri}

Birim kök testlerine geçmeden önce modelde kullanılan değişkenler arasında yatay kesit bağımlılığının olup olmadığını araştırılması Pesaran (2004) $\mathrm{CD}_{\mathrm{LM} 2}$ testi ile sınanmıştır.

\begin{tabular}{|l|l|l|}
\hline & Test İstatistiği & Olas1lik Değeri (Prob.) \\
\hline Pesaran $\mathrm{CD}_{\mathrm{LM} 2}(2004)$ & 6.780 & 0.000 \\
\hline
\end{tabular}

Tablo 5. Yatay Kesit Bă̆ımlılı̆̆ı Test Sonuçları

$\mathrm{H}_{0}$ : Yatay kesit bağımsızdır.

$\mathrm{H}_{1}$ : Yatay kesit bağımlılı̆̆ı vardır şeklindedir.

Yukarıda verilen yatay kesit bağımlılı̆̆ı testiyle, birimlerin bağımsız olduğunu ileri süren $\mathrm{H}_{0}$ hipotezi \%1 önem düzeyinde reddedilmiş ve söz konusu serilerde yatay kesit bağımlılı̆̆ı olduğu sonucuna ulaşılmıştır (Pesaran, 2004; Göçer, 2013: 5093).

\subsection{Panel Birim Kök Testleri}

Yukarıda verilen analizi sonuçlarına göre çalışmamızda yatay kesit bağımlılı̆̆ı bulunmaktadır. Bu nedenle yatay kesit bağımlılığını dikkate alan ikinci nesil birim kök testlerinden CADF-CIPS birim kök testi ile serilerin durağanlıkları araştırılmıştır (Göçer, 2013: 5094).

Gfc seviyeden durağan diğer değişkenler I(1) düzeyinde durağan oldukları sonucuna ulaşılmıştır. Bu kapsamda değişkenlerin bir kısmı seviyeden, bir kısmı ise farktan durağan olduklarından, ARDL yöntemiyle çalışmaya devam edilmesine karar verilmiştir. Bu kapsamda önce Westerlund (2008) panel eş-bütünleşme analizi yapılmış ve daha sonra ise gecikme uzunluğu belirlemesinde ulaşılan en küçük AIC ve BIC değeri dikkate alınarak ARDL model uygulamasına geçilmiştir.

\begin{tabular}{|l|l|l|l|}
\hline \multirow{2}{*}{ Değişkenler } & \multicolumn{3}{|l|}{ Model: Sabitli } \\
\cline { 2 - 4 } & CIPS değeri / t-bar & z-bar & P-değeri \\
\hline Gdpc & -1.388 & 1.228 & 0.890 \\
\hline Ex & -1.292 & 1.556 & 0.940 \\
\hline Lab & -1.542 & 0.706 & 0.760 \\
\hline Gfc & $-2.852^{\mathrm{a}}$ & -3.743 & $0.000^{\mathrm{a}}$ \\
\hline Kritik değerler & $\% 10$ & $\% 55$ & $\% 1$ \\
& -2.140 & -2.260 & -2.470 \\
\hline \multirow{2}{*}{ Değişkenler } & Model: Sabitli ve Trendli \\
\cline { 2 - 4 } & CIPS değeri / t-bar & z-bar & P-değeri \\
\hline Gdpc & -2.016 & 0.916 & 0.820 \\
\hline Ex & -1.938 & 1.184 & 0.882 \\
\hline Lab & -1.607 & 2.330 & 0.990 \\
\hline Gfc & $-2.914^{\mathrm{a}}$ & -2.196 & $0.014^{\mathrm{b}}$ \\
\hline Kritik değerler & $\% 10$ & $\% 5$ & $\% 1$ \\
& -2.670 & -2.780 & -3.010 \\
\hline
\end{tabular}

Not: Gecikme uzunluğu otomatik belirlenmiştir. a: \%1, b: \%5 ve c: \%10 önem düzeyi için serinin durağan olduğunu göstermektedir.

Tablo 6. CADF-CIPS Panel Veri Birim Kök Sonuçları (Seviye) 


\begin{tabular}{|c|c|c|c|}
\hline \multirow{2}{*}{ Değişkenler } & \multicolumn{3}{|l|}{ Sabitli } \\
\hline & CIPS değeri / t-bar & z-bar & P-değeri \\
\hline$\Delta \mathrm{Gdpc}$ & -3.943 & -7.034 & $0.000^{\mathrm{a}}$ \\
\hline$\Delta \mathrm{Ex}$ & -3.723 & -6.334 & $0.000^{\mathrm{a}}$ \\
\hline$\Delta \mathrm{Lab}$ & -3.236 & -4.788 & $0.000^{\mathrm{a}}$ \\
\hline$\Delta \mathrm{Gfc}$ & -3.833 & -6.685 & $0.000^{\mathrm{a}}$ \\
\hline Kritik değerler & $\begin{array}{l}\% 10 \\
-2.160\end{array}$ & $\begin{array}{l}\% 5 \\
-2.280\end{array}$ & $\begin{array}{l}\% 1 \\
-2.520\end{array}$ \\
\hline \multirow{2}{*}{ Değişkenler } & \multicolumn{3}{|l|}{ Sabitli ve Trendli } \\
\hline & CIPS değeri / t-bar & z-bar & P-değeri \\
\hline$\Delta \mathrm{Gdpc}$ & -4.288 & -6.330 & $0.000^{\mathrm{a}}$ \\
\hline$\Delta \mathrm{Ex}$ & -3.869 & -5.021 & $0.000^{\mathrm{a}}$ \\
\hline$\Delta \mathrm{Lab}$ & -3.429 & -3.648 & $0.000^{\mathrm{a}}$ \\
\hline$\Delta \mathrm{Gfc}$ & -3.844 & -4.944 & $0.000^{\mathrm{a}}$ \\
\hline Kritik değerler & $\begin{array}{c}\% 10 \\
-2.680 \\
\end{array}$ & $\begin{array}{c}\% 5 \\
-2.820 \\
\end{array}$ & $\begin{array}{c}\% 1 \\
-3.070\end{array}$ \\
\hline
\end{tabular}

Not: Gecikme uzunluğu otomatik belirlenmiştir. $\Delta$ işareti değişkenlerin fark dĕgerini göstermektedir. a: \%1, b: \%5 ve c: \%10 önem düzeyi için serinin dură̆an olduğunu göstermektedir.

Tablo 7. CADF-CIPS Panel Veri Birim Kök Sonuçları (Birinci Fark)

\subsection{Westerlund (2008) Panel Eş-bütünleşme Testi}

Çalışmada yatay kesit bağımlılığı analiz sonuçlarına göre seriler arasında yatay kesit bağımlılığ bulunmaktadır. Dolayısıyla bu aşamadan sonra yapılacak panel veri analizinde yatay kesit bağımlılığı dikkate alan ve bağımlı değişkenin I(1) olması şartıyla, bağımsız değişkenlerin I(1) veya I(0) olmasına izin veren eşbütünleşme testlerinden Westerlund (2008) Durbin-H testi kullanılmıştır. Bu testin hipotezleri şu şekildedir:

$\mathrm{H}_{0}$ : Panelde eşbütünleşme ilişkisi yok.

$\mathrm{H}_{1}$ : Panelde eşbütünleşme ilişkisi var.

Yapılan eş-bütünleşme testi sonucunda hesaplanan Durbin $\mathrm{H}$ değerleri tablo değerleri ile karşılaştırılarak $\mathrm{H}_{0}$ hipotezlerine bakılır. Buna göre, elde edilen test istatistiği tablodaki kritik değerden büyük olduğunda, $\mathrm{H}_{0}$ hipotezi \%1-5-10 anlamlılık düzeylerinde reddedilir ve eş-bütünleşme ilişkisinin varlığı kabul edilir (Westerlund, 2008).

\begin{tabular}{|l|c|c|}
\hline Durbin-H Testleri & Durbin-H Hes.Değer & Olas1lık Değeri (Prob.) \\
\hline Durbin-H Grup İstatistiği & 2.305 & 0.011 \\
\hline Durbin-H Panel İstatistiği & 5.097 & 0.000 \\
\hline
\end{tabular}

Tablo 8. Westerlund (2008) Durbin-H Testi Sonuçları

Test sonucu elde edilen grup ve panel istatistik olasılık değerleri \%1'den küçük olduğu için $\mathrm{H}_{0}$ hipotezi reddedilmiş ve paneldeki bütün ülkelerde ekonomik büyüme ile bu endeks üzerindeki etkili olan IMD rekabet gücü genel endeks değeri, işgücüne katılım oranı, sabit sermaye birikiminin GSYİH'ya oranı değişkenleri arasında eşbütünleşme ilişkisi olduğu sonucuna ulaşılmıştır.

\subsection{Model Panel Ardl Tahmini}

Çalışmada kullanılan temel model panel ARDL modelidir. Modelde bağımlı ve bağımsız değişkenlerin yanında $\Delta$ serinin fark değerini ve $\mathrm{e}_{\text {it }}$ de hata terimini ifade etmektedir. Ortalama grup tahmincisi (mean group, MGE) katsayıların bireysel yatay kesitlerine göre ağırlıklandırılmamış ortalamasını alırken, havuzlanmış ortalama grup tahmincisi (pooled mean group, PMGE) ise katsayıları hesaplar ve ağırlıklandırılmış tahminde bulunur (Blackburne ve Frank, 2007). Aşağıda temel matematiksel model verilmiştir. Bu model oluşturulurken, Pesaran vd. (1999) ile Erdem vd. (2010) çalışmasından faydalanılmıştır.

$$
\begin{gathered}
\Delta G D P C_{t i}=\alpha_{i}+\emptyset_{i} G D P C_{t-1, i}+\delta_{i} E X_{t i}+\vartheta_{i} L A B_{t i}+\gamma_{i} G F C_{t i} \\
+\sum_{j=1}^{p i-1} \beta_{i j} \Delta G D P C_{t-j, i}+\sum_{j=0}^{q i} \delta_{i j} \Delta E X_{t-j, i}+\sum_{j=0}^{k i} \vartheta_{i j} \Delta L A B_{t-j, i}+\sum_{j=0}^{l i} \gamma_{i j} \Delta G F C_{t-j, i}+\varepsilon_{t i} \\
\mathrm{t}=1997, \ldots, 2012 \text { ve } \mathrm{i}=1,2,3, \ldots, 12 \text { şeklindedir. }
\end{gathered}
$$

Modelde bağımlı değişken gdpc; 2005 yılı sabit fiyatlarla kişi başı geliri, bağımsız değişkenler ex; IMD rekabet gücü genel endeks değeri, lab; işgücüne katılım oranı, gfc; sabit sermaye birikiminin GSYİH'ya oranını göstermektedir. 


\begin{tabular}{|c|c|c|c|c|c|c|}
\hline & \multicolumn{3}{|c|}{ MGE } & \multicolumn{3}{|c|}{ PMGE } \\
\hline & Katsayı & St. Hata & P-değeri & Katsayı & St. Hata & P-değeri \\
\hline \multicolumn{7}{|c|}{ Uzun Dönem Katsayılar } \\
\hline Ex & 81.212 & 36.08 & $0.02^{\mathrm{b}}$ & 11.92 & 3.79 & $0.00^{\mathrm{a}}$ \\
\hline $\mathrm{Lab}$ & 818.84 & 883.55 & 0.32 & 252.41 & 30.35 & $0.00^{\mathrm{a}}$ \\
\hline Gfc & -292.68 & 187.67 & 0.12 & -170.47 & 11.02 & $0.00^{\mathrm{a}}$ \\
\hline \multicolumn{7}{|c|}{ Hata Düzeltme Katsayısı } \\
\hline $\mathrm{EC}$ & -0.51 & 0.29 & $0.08^{\mathrm{c}}$ & -0.13 & 0.07 & $0.05^{\mathrm{b}}$ \\
\hline \multicolumn{7}{|c|}{ Kısa Dönem Katsayılar } \\
\hline$\Delta \operatorname{Gdpc}(-1)$ & 0.07 & 0.19 & 0.72 & 0.22 & 0.15 & 0.14 \\
\hline$\Delta \mathrm{Ex}$ & -9.21 & 7.86 & 0.24 & 0.975 & 2.06 & 0.63 \\
\hline$\Delta \mathrm{Lab}(-1)$ & 44.54. & 65.88 & 0.49 & -19.51 & 22.26 & 0.38 \\
\hline$\Delta \mathrm{Gfc}(-1)$ & 9.49 & 5.06 & $0.06^{\mathrm{c}}$ & 5.41 & 6.17 & 0.38 \\
\hline $\mathrm{C}$ & -2933.38 & 4272.12 & 0.49 & -667.55 & 299.08 & $0.02^{b}$ \\
\hline \multicolumn{7}{|c|}{ Hausman test istatistiği: $\chi^{2}=0.55$, prob $>\chi^{2}=0.9076$} \\
\hline
\end{tabular}

\section{Tablo 9. Ekonomik Büyüme Üzerinde Etkili Olan Değ. Panel ARDL Sonuçları}

Hausman testinde yokluk hipotezi "uzun dönemde parametreler homojendir" önermesi ve alternatif hipotez ise "uzun dönemde parametreler heterojendir" önermesi sınanmaktadır. Bu doğrultuda yokluk hipotezi kabul edilirse, PMGE ve yokluk hipotezi ret edilirse, MGE tercih edilir. Uzun dönem homojenlik varsayımı altında MGE tutarl, PMGE tutarlı ve etkin tahmincidir (Erdem vd., 2010: 375-376).

Model kapsamında yapılan analiz sonuçlarına göre Hausman test istatistiğinin değeri ki-kare değerinden büyük çıkmıştır ve "uzun dönemde parametreler homojendir" şeklindeki sıfır hipotezi kabul edilmiştir. Bu kapsamda Havuzlanmış Ortalama Grup Tahmincisinin (PMGE) geçerli olduğuna karar verilir. Uzun dönem parametreleri homojendir ve birimden birime değişmemektedir.

PMGE tahmincisinin geçerli olduğu sonucuna ulaştıktan sonra bu tahminciden elde edilen sonuçlar incelendiğinde, uzun dönemde rekabet gücü endeksinin ve işgücünün istatistiksel olarak anlamlı ve pozitif bir şekilde kişi başı gelir düzeyini etkilediği görülür. Sabit sermaye birikiminin kişi başı gelir üzerinde istatistiksel olarak anlamlı ve negatif bir şekilde etkili olduğu görülmüştür. Uzun dönemde rekabet gücündeki bir birimlik artış kişi başına gelir üzerinde 11.9 birimlik bir artış meydana getirmektedir. İşgücü ve sabit sermaye birikimi değişkenlerindeki bir birimlik artış ise sırasıyla 252 birim artış ve 170 birim azalış şeklinde bir etki ortaya çıkarmaktadır. Elde edilen bu sonuçlar istatistiksel olarak anlamlı bulunmuştur. Modelin kısa dönemli katsayıları incelendiğinde ise, ekonomik büyümenin göstergesi olarak alınan kişi başına gelir üzerinde kişi başına gelirin bir dönem gecikmeli değerinin pozitif, rekabet gücünün pozitif, işgücünün negatif ve sabit sermaye birikiminin pozitif yönlü etkide bulunduğu görülmüştür. Ancak, söz konusu katsayılar istatistiksel olarak anlamlı bulunmamıştır. Hata düzeltme katsayısının negatif ve istatistiksel olarak anlamlı olması da modeldeki sapmaların ve değişimlerin bir dönem içinde \%13 oranında dengeye ulaşacağını göstermektedir.

\section{Sonuç}

Model genel olarak değerlendirildiğinde, sermaye birikimi, rekabet gücü ve işgücündeki artışların ekonomik büyümeyi pozitif etkilemesi beklenmektedir. Beklenenin aksine sabit sermaye birikiminin uzun dönemde ekonomik büyüme performansı üzerinde negatif yönlü bir etki ortaya çıkardığı tespit edilmiştir. Bu durum ise ülkenin faktör donatımına/yapısına uygun olmayan (sermaye) yatırımların ekonomik büyüme süreci üzerinde olumsuz etkiler oluşturduğu şeklinde yorumlanabilir. Paneli oluşturan ülkelerin büyük kısmının emek-yoğun ülkeler olduğu göz önüne alındığında, bu sonuç söz konusu ülkelerde yapılan sermaye-yoğun yatırımların istenilen ekonomik faydayı ya da verimliliği getirmediği şeklinde yorumlanabilir. Fizibil olmayan sermaye yatırımlara ilaveten bu ülkelerde sermaye yatırımları için gerekli kaynağa ulaşmada ihtiyaç duyulan tasarrufların tüketim düzeyini düşürmesi ve bunun da ekonomik büyüme süreci üzerinde oluşturduğu daralmadan bahsedilebilir. Bu sava örnek olarak Sovyet-tipi büyüme modeli verilebilir. Sovyet modelinde sermaye malı üretimine ağırlık verilmesi ve halkın ihtiyaçlarını/refah düzeyini dikkate almayan büyük sermaye yatırımlarına yoğunlaşılmasının paralelinde, ekonomi belli bir düzeyden sonra büyüme yerine küçülmeye gitmiş ve bu durum da Sovyetler Birliğinin çöküş nedenlerinden biri olmuştur.

\section{Kaynakça}

- $\quad$ Acs, Z., Audretsch, D., Braunerhjelm, P. and Carlsson, B. (2006). Growth and Entrepreneurship: An Empirical Assessment. Centre for Economic Policy Research, Discussion Paper 5409.

- Alexander, W. R. (1997). "Inflation and Economic Growth: Evidence From A Growth Equation". Applied Economics, 29, 233-238. 
- Amar, M. and Hamdi, M. T. (2012). "Global Competitiveness and Economic Growth: Empirical Verification for African Countries". International Journal of Economics and Finance, 4(6), 125-131.

- Asheghian, P. (2004). "Determinants of economic growth in the United States: The role of foreign investments" The International Trade Journal, 18(1), 63-83.

- Barro, R.J. (1997). Determinants of Economic Growth: A Cross-Country Empirical Study, Cambridge, MA: MIT Press.

- Baranová, V., (2013). "The Impact of Price-Cost Competitiveness Factors on Economic Growth". Review of Economic Perspectives, De Gruyter Open, 13(2), 63-76.

- Benos, N. (2004). "Fiscal Policy and Economic Growth: Empirical Evidence from OECD Countries," University of Cyprus, Munich Personal RePEc Archive.

- Berber, M. (2006). İktisadi Büyüme ve Kalkınma. Trabzon: Derya Kitabevi.

- Berber, M. ve Artan, S. (2004). “Türkiye'de Enflasyon-Ekonomik Büyüme İlişkisi: (Teori-Literatür ve Uygulama)". Atatürk Üniversitesi IIIBF Dergisi, 18(3-4), 103-117.

- Bilginoğlu, M. A. ve Aysu, A. (2008). "Dış Borçların Ekonomik Büyüme üzerindeki Etkisi: Türkiye Örneği”. Erciyes Üniversitesi İktisadi ve İdari Bilimler Fakültesi Dergisi, 31, 1-23.

- Bosworth, B. and Collins, S. M. (1999). "Capital Inflows, Investment and Growth". Tokyo Club Papers, 12, 35-74.

- Childe, G. (1992). Kendini Yaratan İnsan, Çev.: Filiz Ofluoğlu, Varlık Yayınları, İstanbul.

- Chowdhury, A. (2002). "Does Inflation Affect Economic Growth? The Relevance of the Debate for Indonesia" Journal of Asia Pacific Economy, 7(1), 20-34.

- Compton, R.A., Giedeman, D.C. and Hoover, G. A. (2011). "Panel Evidence on Economic Freedom and Growth in the United States". European Journal of Political Economy, 27, 423-435.

- Çetin, R. (2013). “Ekonomik Özgürlüğün Gelir Düzeyi Üzerindeki Etkisinin Panel Veri Analizi Yöntemiyle İncelenmesi” Eskişehir Osmangazi Üniversitesi İIBF Dergisi, 8(2), 37- 47.

- Çivi, E., Erol, İ., İnanlı,T. ve Erol, E. D. (2008). "Uluslararası Rekabet Gücüne Farklı Bakışlar”. Ekonomik ve Sosyal Araştırmalar Dergisi, 4(1), 1-22.

- Datta, A. and Agarwal, S. (2004). "Telecommunications and Economic Growth: A Panel Data Approach" Applied Economics, 36(15), 1649-1654

- Değer, K. M. ve Emsen, S. Ö. (2006). "Geçiş Ekonomilerinde Doğrudan Yabancı Sermaye Yatırımları ve Ekonomik Büyüme İlişkileri: Panel Veri Analizleri (1990-2002)”. C.Ü. İktisadi ve İdari Bilimler Dergisi, 7(2), 121-137.

- Easterly, W. and Levine, R. (1997). “Africa's growth tragedy: politics and ethnic divisions" Quarterly Journal of Economics, 112, 1203-1250.

- $\quad$ Erdem, E., Güloğlu, B., Nazlığlu, S. (2010). "The Macroeconomy and Turkish Agricultural Trade Balance with the EU Countries: Panel ARDL Analysis". International Journal of Economic Perspectives, 4(1), 371379 .

- Escosura, P., Rosés, L., Joan R. and Sanz-Villarroya, I. (2011). "Economic reforms and growth in Franco's Spain". Revista de Historia Económica/Journal of Iberian and Latin American Economic History.

- Genç, M. C. ve Atasoy, Y. (2010). "Ar-Ge Harcamaları ve Ekonomik Büyüme İlişkisi: Panel Veri Analizi” The Journal of Knowledge Economy and Knowledge Management, 5(2), 27-34.

- Göçer, İ. (2013). "Seçilmiş OECD Ülkelerinde Bütçe Açıklarının Sürdürülebilirliği: Yatay Kesit Bağımlılığı Altında Panel Eş-Bütünleşme Analizi". Journal of Yasar University, 30(8), 5086-5104.

- Güloğlu, B. ve Tekin, R.B. (2012). “A Panel Causality Analysis of the Relationship among Research and Development, Innovation and Economic Growth in High-Income OECD Countries”. Eurasian Economic Review, 2(1), 32-47.

- Hansson, P. and Jonung, L. (1997). "Finance and Economic Growth: the Case of Sweden, 1834- 1991". Research in Economics, $\mathbf{5 1}$.

- Heshmati, A. (2001). "On the Causality between GDP and Health Care Expenditure in Augmented Solow Growth Model". SSE/EFI Working Paper Series in Economics and Finance, 423, 1-19.

- Holtz-Eakin, Douglas and Kao, Chihwa (2003). "Entrepreneurship and Economic Growth: The Proof is in the Productivity". Syracuse University Center for Policy Research.

- Jangili, R. (2011). "Causal relationship between saving, investment and economic growth for India-what does the relation imply?" Reserve Bank of India Occasional Papers, 32(1), 25-39.

- Kara, M. A. ve Taş, S. (2012). "Ulaştırma ve Haberleşme Altyapısının Bölgesel Kalkınmaya Katkısı ve Türkiye Üzerine Bir Uygulama". Maliye Dergisi, 163, 468-480.

- Karabegovic, A., Samida, D., Schlegel, C. M. ve McMahon, F. (2003). "North American Economic Freedom: An Index of 10 Canadian Provinces and 50 US States". European Journal of Political Economy, 19, 431-452. 
- Kurt, S. ve Terzi, H. (2007). "İmalat Sanayi ve Dış Ticaret i Verimlilik ve Ekonomik Büyüme İlişkisi”, Atatürk Üniversitesi IIIBF Dergisi, 21(1), 25-46.

- Musila, J. and Belassi, W. (2004). "The Impact of Education Expenditures on Economic Growth in Uganda: Evidence from Time Series Data" The Journal of Developing Areas, 38(1), 123-133

- Nelson, M. and Singh, R. D. (1998). "Democracy, Economic Freedom, Fiscal Policy and Growth in LDCs: A Fresh Look" Economic Development and Cultural Change Univ. of Chicago Press, 46(4), 677-696.

- Omisakin, O., Adenyiyi, O., ve Omojolaibi, A. (2009). "Foreign Direct Investment, Trade Openness and Growth in Nigeria". Journal of Economic Theory, 3(2), 13-18.

- Onur, S. (2005). "Finansal Liberalizasyon ve GSMH Büyümesi Arasındaki İlişki”. ZKÜ Sosyal Bilimler Dergisi, 1(1), 127-152

- Pereira, A.M. and Sagales, O.R. (1999), "Public Capital Formation and Regional Development in Spain". Review of Development Economics, 3(3), 281-294.

- Pesaran, M. H., (2004), "General Diagnostic Tests for Cross Section Dependence in Panels". CEsifo Working Paper Series, 1229, Munich.

- Rajan, R. R. and Zingales, L.(1998). "Financial Dependence and Growth". The American Economic Review, 88(3), 559-586.

- Shan, J. ve Jianhong, Q. (2006). 'Does Financial Development 'Lead' Economic Growth? The Case of China", Annals of Economics and Finance, 1, 231-250.

- Stel, A. V., Carree, M. and Thurik, R. (2005). "The effect of entrepreneurial activity on national economic growth" Small Business Economics, 24(3). 311-321

- Tsen, W. H. (2006) "Granger Causality Tests Among Openness to International Trade, Human Capital Accumulation and Economic Growth in China: 1952-1999," International Economic Journal, 20(3), $285-$ 302 .

- Tatoğlu Yerdelen, F. (2012). İleri Panel Veri Analizi: Stata Uygulamalı. İstanbul: Beta Basım, Yayım, Dağıtım.

- Temiz, D. ve Korkmaz, S. (2007). "Türkiye'de Sağlık ve Ekonomik büyüme İlişkisi: 1965-2005 Dönemi” TÜIK, 16. Istatistik Araştırma Sempozyumu Bildiriler Kitabı, 266-278.

- Umutlu, G., Yılmaz, F. A. ve Günel, S. (2011). "Ekonomik Büyüme Farklılıklarının İncelenmesi: OECD Ülkeleri İçin Bir Uygulama”. SÜ İIBF Sosyal ve Ekonomik Araştırmalar Dergisi, 16(22), Konya, 351-372.

- Vedder, R. (2001) Taxes and Economic Growth, Ohio University.

- Wang, M. and Wong, S. (2009). "Foreign Direct Investment and Economic Growth: the Growth Accounting Perspective". Economic Inquiry, 47(4), 701-710

- Were, M. (2001) "The impact of external debt on economic growth and private investment in Kenya: An empirical assessment" A paper presented at the Wider Development Conference, Helsinki, 2001.

- Westerlund, J. (2008). "Panel cointegration tests of the Fisher effect" Journal of Applied Econometrics, 23(2). 193-233.

- Yeldan, E. (2001). Küreselleşme Sürecinde Türkiye Ekonomisi, Bölüşüm, Birikim ve Büyüme, İletişim Yayınc1lı, İstanbul. 


\title{
Seçilmiş Bazı Geçiş Ekonomilerinde İktisadi Özgürlükler ve İktisadi Büyüme İlişkisi: Bir Panel Veri Analizi
}

\section{Relationship between Economic Freedom and Economic Growth in Some Selected Transition Economies: A Panel Data Analysis}

\author{
Asst. Prof. Dr. Hakan Türkay (Cumhuriyet University, Turkey)
}

\begin{abstract}
This study estimated the influence of economic freedom in transition economies between the years 2000-2012 on economic growth by using panel data analysis. Economic freedom index developed by Fraser Institute was used in the study. The index values prepared by this institute do not cover all economies in transition. In addition, there is missing data for the periods that the study covers in terms of some countries. Thus, the analysis uses the data about 15 economies in transition. The study was conducted within the scope of two different models. In one of these models, the global economic crisis of 2009 was also included. As a conclusion, a negative relationship was found between economic freedom and economic growth when the crisis was not included; however, there was a positive but statistically insignificant relationship when the crisis was taken into consideration.
\end{abstract}

\section{Giriş}

İktisat biliminin ortaya çıkışından bu tarafa en önemli konularından biri iktisadi büyümenin sağlanması ve bu büyümenin kaynaklarının belirlenmesidir. Neoklasik iktisat büyümeyi, sermaye, işgücü, beşeri sermaye ve teknoloji faktörlerinin bir fonksiyonu olarak kabul etmektedir (Romer, 1990). Ancak, burada akla gelen soru şudur: Büyüme için uygun iktisat politikaları nelerdir? 1776 yılında yayınlanan ünlü Milletlerin zenginliği kitabında Adam Smith özel mülkiyet haklarının korunması ve ekonomide devletin varlığının olabildiğince küçük olmasının zenginliği sağlayacağı görüşünü savunmaktadır. Bir başka deyişle, ekonomik özgürlüğün ekonomik büyümeye yol açacağını iddia etmektedir.

Smith'in bu görüşü iktisatçıların çoğu tarafından kabul görmekle birlikte, sonraki dönemlerde, bu iddianın aksine görüşler de iktisat biliminde sıkça dile getirilmiştir. 20. yüzyılın başlarından itibaren bazı iktisatçılar ekonomide merkezi planlamanın büyüme ve zenginleşme için özellikle az gelişmiş ülkeler için daha iyi bir yol olduğunu savunmuşlardır. Ancak, 20. Yüzyılın sonlarında planlı ekonomilerin çöküşünden sonra Smith'in görüşlerine geri dönüş söz konusu olmuştur. Smith rekabetçi piyasada kaynak tahsisatını desteklemek için düşük vergiler ve düşük kamu harcamaları gerekliliğini, özel mülkiyet haklarının korunmasını, ayrıca uluslararası ticareti desteklemek içinde düşük tarifeleri savunmuştur. Özetle, sağlıklı bir piyasa ortamı oluşturulur ve sürdürülürse büyümenin ve zenginleşmenin gerçekleşeceğini düşüncesindedir. Benzer bir görüş, 1817'de Ricardo'nun Politik İktisadın ilkeleri adlı ünlü eserinde yer almıştır. Ricardo, düşük tarifeler belirlenerek serbest ticaretin teşvik edilmesinin refaha giden yol olduğunu savunmuştur. (Holcombe:1998)

Özetle, "iktisadi özgürlük" isteğe bağlı mübadele, serbest rekabet, bireylerin ve mülkiyetin korunduğu piyasa ekonomisini ifade eder. (Berggren,2003:193) Bu tanımdan anlaşılacağı üzere, bireylerin isteğe bağlı olarak iktisadi faaliyetlerini yürüttüğü, devletin ise bireylerin bu faaliyetlerinden elde ettikleri kazanımları koruyucu ve destekleyici olduğu piyasa ekonomileri iktisaden özgür olarak değerlendirilmektedir. Bu yönüyle, teoride iktisadi özgürlüklerin iktisadi büyümeyi sağlayacağına dair yaygın bir kanı söz konusudur. Bu çalışmada, merkezi planlamadan serbest piyasa ekonomisine geçen ülkelerde iktisadi özgürlük düzeylerindeki artışın büyüme üzerindeki etkisi araştırılmıştır.

\section{2 İlgili Literatür}

İktisadi özgürlük ve büyüme ilişkisini araştıran çok sayıda çalışma bulunmaktadır. İktisadi özgürlüğün indeksler aracılığıyla ölçülebilir hale gelmesi bu konudaki ilgiyi hızla artırmıştır. Berggren (2003) ile De Haan, Lundstrom ve Sturm (2006) makalelerinde konuyla ilgili oldukça kapsamlı literatür taraması mevcuttur. Bu çalışmaların önemli bir kısmında büyümenin iktisadi özgürlük ile pozitif ve istatistiksel olarak anlamlı bir ilişki bulunmuştur. Çalışmalarda farklı ülke grupları kullanılmışır, ayrıca yapıldıkları dönem itibariyle farklı zaman dilimlerini kapsamaktadırlar. Bazı çalışmalar ülkeler yerine belli ülkelerin eyaletlerini kullanmayı tercih etmiştir. Ali (1997), Easton ve Walker (1997), Goldsmith (1997), Dawson (1998), Wu and Davis (1999), Hanson (2000), Ali ve Crain (2001 ve 2002), Pitlik (2002), Scully (2002), Weede ve Kampf (2002), Carlsson ve Lundstrom (2002), Karabegovic vd. (2003), Chheng (2005), Compton, Giedeman ve Hoover (2011) bu çalışmaların başlıcalarıdır.

Bazı çalışmalarda, iktisadi özgürlük indeksinin düzey değerleri yerine indeksteki değişim kullanılmıştır. Dawson (1998), Gwartney, Lawson ve Holcombe (1999), De Haan ve Sturm (2000 ve 2001), Adkins, Moomaw 
ve Savvides (2002), Pitlik (2002), Weede ve Kampf (2002), De Haan, Lundstrom ve Sturm (2006), Ashby ve Sobel (2008) bu çalışmalar arasındadır. Yine bu eserlerin tamamında iktisadi özgürlük indeksindeki değişim ile büyüme arasında pozitif ve anlamlı ilişki bulunmuştur.

Gwartney, Lawson ve Holcombe (1999), De Haan ve Sturm (2000 ve 2001), Heckelman ve Stroup (2000); Adkins, Moomaw ve Savvides (2002), Ashby ve Sobel (2008) çalışmalarında ise iktisadi özgürlük ile büyüme arasında anlamlı bir ilişki bulunamamıştır. Dikkat edilirse, bu çalışmaların bazılarında iktisadi özgürlük indeksinin düzey değerleri kullanıldığında büyüme ile arasında ilişki bulunamamakla birlikte iktisadi özgürlük endeksinin değişim değerlerinin kullanıldığı durumda ilişki bulunmuştur.

İktisadi özgürlük ile iktisadi büyüme ilişkisine dair Türkiye de gerçekleştirilen çalışmalarda ulaşılan sonuçlar ise şöyledir: Sarıbaş(2009), 49 ülkenin Heritage Vakfı ve Penn Dünya Tabloları veri tabanından alınan 19952004 yılları arasındaki yıllık verilerine panel regresyon uygulamış olup, ekonomik özgürlüklerin iktisadi büyümeyle negatif bir ilişki içerisinde olduğu sonucuna ulaşmıştır.

Beşkaya ve Manan (2009), Türkiye için 1970-2005 arası zaman serilerini kullanarak yaptıkları araştırmada ekonomik özgürlüklerle ekonomik performans arasında pozitif bir ilişki bulmuşlardır.

Yalman v.d.(2011) iktisadi özgürlüğün bileşenlerinin büyüme ile ayrı ayrı ilişkisini araştırmıştır. Sonuçta, ticari özgürlüğün, mülk edinme özgürlüğünün ve rüşvet vermemek özgürlüğünün ekonomik büyümeyi pozitif yönde etkilediği ve sermaye özgürlüğü ve yatırım özgürlüğünün ise büyümeyi negatif yönde etkilediği sonucuna ulaşmışlardır. Bununla birlikte, iktisadi özgürlüğün bileşenlerinin eşit biçimde büyümeyi etkilemediğini de belirtmektedirler.

Çetin (2013), panel regresyon yöntemiyle ekonomik özgürlüğün düzey ve değişim değerlerindeki artışların gelir düzeyine pozitif ve anlamlı etki ettiğini göstermiştir. Bu çalışmada 81 ülkenin 2000-2010 dönemi yıllık verileri kullanılmış olup, iktisadi özgürlük ölçütü olarak ise Heritage vakfı tarafından geliştirilen genel indeks tercih edilmiştir.

\section{Veri ve Yöntem}

Çalışmada Fraser Institute için Gwartney and Lawson 2002, tarafından oluşturulan ekonomik özgürlük indeksinin özet değerleri kullanılmıştır. Bu indeks 1970 yılından 2000 yılına kadar beşer yıllık periyotlarda, 2000 yılından sonrası için yıllık periyotlarda hesaplanarak ilgili kuruluşa ait web sitesi üzerinden yayınlanmaktadır. 1970 yılında indekse dâhil edilen ülke sayısı 54 iken 2012 yılında 153 ülkeye ulaşılmıştır. Bu enstitü tarafindan hazırlanan indeks değerleri tüm geçiş ekonomilerini kapsamamaktadır. Yine, bazı ülkelere ait veriler de, çalışmanın kapsadığ 1 dönem için eksiklikler vardır. Bu nedenlerle analizde 15 geçiş ekonomisine ait veriler kullanılmıştır. Bu ülkeler, Arnavutluk, Bulgaristan, Çin, Çek Cumhuriyeti, Hırvatistan, Estonya, Macaristan, Letonya, Litvanya, Polonya, Romanya, Rusya, Slovak Cumhuriyeti, Slovenya ve Ukrayna'dır. Söz konusu ülkelere ait iktisadi büyüme verileri Dünya Bankası web sitesinden elde edilmiştir.

Verilerin analizinde panel regresyon yöntemi kullanılmıştır. Panel veriler, zaman serisi verilerinin kısa olduğu ya da yatay kesit gözleminin yetersiz olduğu durumlar da analiz yapılmasına imkân vermektedir. Panel veri analizi daha fazla veri kullanma imkânı sağlamaktadır, buna bağlı olarak panel verilerle tahmin edilen modellerde serbestlik derecesi artmakta ve daha etkin sonuçlar elde edilmektedir. Ayrıca panel veriler, birimlere ait heterojenliğin kontrolüne imkân sağlaması, değişkenler arasında var olabilecek çoklu doğrusal bağlantıyı azaltmas1 gibi avantajlara sahiptirler. (Baltagi,2005: 4-6). Panel regresyon uygulamalarında temel ayrım olan rassal etki ile sabit etki modelleri arasındaki seçim Hausman (1978) testi yardımıyla gerçekleştirilmiştir.

\section{Uygulama ve Bulgular}

İktisadi özgürlük ve iktisadi büyüme değişkenleri arasındaki ilişkinin analizine geçilmeden önce, muhtemel bir sahte regresyon olgusundan kaçınmak için değişkenlerin durağanlığının araştırılması gerekmektedir. Tablo1.de değişkenlere uygulanan panel birim kök testlerinin sonuçları görülmektedir.

\begin{tabular}{|l|c|c|c|c|c|c|}
\hline \multicolumn{2}{|c|}{} & \multicolumn{4}{c|}{ Değişken } \\
\cline { 3 - 7 } & Yatay-Kesit & Gözlem & İstatistik & Olas1l1k & İstatistik & Olas1lk \\
\hline Yöntem & 15 & 165 & -3.42993 & 0.0003 & -8.60686 & 0.0000 \\
\hline Levin, Lin \& Chu t & 15 & 165 & 57.2423 & 0.0020 & 68.4666 & 0.0001 \\
\hline ADF - Fisher Chi-square & 15 & 180 & 67.8244 & 0.0001 & 79.9765 & 0.0000 \\
\hline PP - Fisher Chi-square & 15 &
\end{tabular}

Tablo 1. İktisadi özgürlük indeksi(EFI) ve Büyüme(BYM) değişkenleri için Birim Kök testi sonuçları

Sonuçlar incelendiğinde iktisadi özgürlük indeksi ve büyüme değişkenlerinin her ikisinin de durağan oldukları görülmektedir. Buna bağlı olarak, bu iki değişken arasındaki ilişki panel regresyon yöntemiyle araştırılmıştır. Ele alınan dönemin 2009 küresel krizini de kapsaması nedeniyle büyüme ve iktisadi özgürlük arasında ilişki iki ayrı model çerçevesinde incelenmiştir. Bunlardan ilki krizin dikkate alınmadığı durum, ikincisi ise krizin bir gölge 
değişken yardımıyla modele dâhil edildiği durumdur. Öncelikle krizin modelde yer alamadığı durum analiz edilmiştir.

\begin{tabular}{|c|c|c|c|}
\hline Test Summary & Chi-Sq. Statistic & Chi-Sq. d.f. & Prob. \\
\hline Cross-section random & 0.133948 & 1 & 0.7144 \\
\hline
\end{tabular}

Tablo 2. Hausman testi sonuçlart

Tablo 2'te yer alan Hausman testi sonucuna göre, Rassal etki modelinin uygun model olduğu savını içeren sıfır hipotezi reddedilememektedir. Bu durumda uygun modelin Rassal etki modeli olduğu görülmektedir. Rassal etki modelinin tahmin sonuçları Tablo 3'verilmiştir.

\begin{tabular}{|c|c|c|c|c|c|}
\hline \multicolumn{6}{|c|}{ Bağımlı Değișken: Büyüme } \\
\hline \multicolumn{6}{|c|}{ Method: Panel EGLS (Cross-section random effects) } \\
\hline \multicolumn{2}{|c|}{ Sample: 20002012} & \multicolumn{4}{|c|}{ Periods included: 13} \\
\hline \multicolumn{2}{|c|}{ Cross-sections included: 15} & \multicolumn{4}{|c|}{ Total panel (balanced) observations: 195} \\
\hline \multicolumn{6}{|c|}{ Swamy and Arora estimator of component variances } \\
\hline Değişkenler & Katsayı & & Std. Hata & t-istatistiği & Olasılık \\
\hline $\mathrm{C}$ & 15.0602 & & 4.170449 & 3.611183 & 0.0004 \\
\hline EFI & -1.6040 & & 0.611130 & -2.624673 & 0.0094 \\
\hline \multicolumn{6}{|c|}{ Ağırlıklandırılmış İstatistikler } \\
\hline $\mathrm{R}^{2}$ & \multicolumn{2}{|c|}{0.034614} & \multicolumn{2}{|c|}{ Düzeltilmiş $\mathrm{R}^{2}$} & 0.029612 \\
\hline Std. Hata & \multicolumn{2}{|c|}{4.599067} & \multicolumn{2}{|c|}{ Durbin-Watson istatistiği } & 1.283674 \\
\hline F-istatistiği & \multicolumn{2}{|c|}{6.919960} & \multicolumn{2}{|c|}{ Olasılık(F-istatistiği) } & 0.009212 \\
\hline
\end{tabular}

Tablo 3. Büyüme ile İktisadi Özgürlük indeksi ilişkisinin Tahmini

Tablo 3 'te verilen iktisadi büyüme ilişkisi ile iktisadi özgürlük değişkenleri arasındaki regresyon modelinin tahminine göre, geçiş ekonomilerinde 2000-2012 dönemi için iktisadi özgürlüklerin büyümeyi negatif yönde etkilediği ve tahminin istatistiksel olarak anlamlı olduğu bulunmuştur.

\begin{tabular}{|c|c|c|c|}
\hline Test Summary & Chi-Sq. Statistic & Chi-Sq. d.f. & Prob. \\
\hline Cross-section random & 4.901603 & 2 & 0.0862 \\
\hline
\end{tabular}

\section{Tablo 4. Hausmann testi sonuçları}

Tablo 4'de kriz değişkenin eklendiği durum için gerçekleştirilen Hausmann testi sonuçları görülmektedir. Bu testin sonuçlarına göre rassal etki modelinin uygun model olduğu tespit edilmiş ve aşağıda bu modelin tahminine dair sonuçlar verilmiştir.

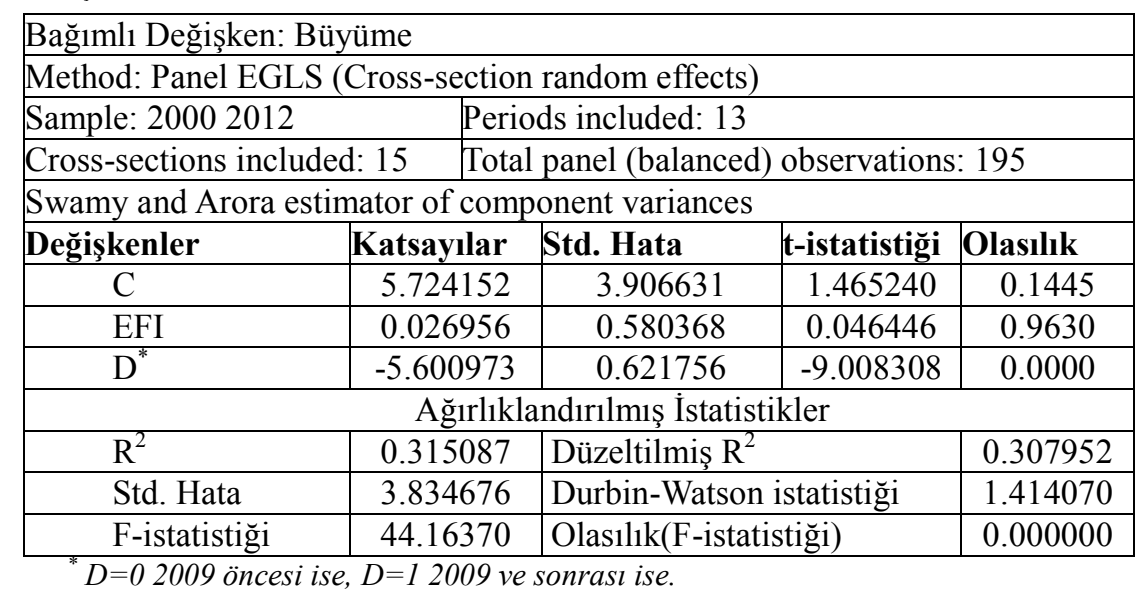

Tablo 5. Büyüme ile İktisadi Özgürlük indeksi ilişkisinin Tahmini ( 2009 Krizi için Gölge değişken Kullanılmıştır.)

Tablo 5'te yer alan sonuçlar incelendiğinde iktisadi özgürlük ile büyüme arasında pozitif ilişsi bulunduğu, ancak istatistiksel olarak anlamsız olduğu görülmektedir. 2009 Krizini temsilen modele dâhil edilen gölge değişken negatif ve istatistiksel olarak anlamlı bulunmuştur.

\section{Sonuç}

15 geçiş ekonomisine ait verilerin kullanıldığı bu çalışma, iki ayrı model çerçevesinde yürütülmüştür. Bu modellerin ilkinde panel regresyon yöntemiyle büyüme ile iktisadi özgürlükler arasında ilişki araştırılmıştır. İktisadi özgürlük ölçütü olarak Fraser Institute tarafından yayınlanan iktisadi özgürlük indeksinin özet değerleri 
kullanılmıştır. Sonuçta, iktisadi özgürlükler ile büyüme arasında negatif ve anlamlı bir ilişki bulunmuştur. Bu modellerden ikincisinde, kullanılan verilerin kapsadığı dönemde yaşanan 2009 küresel ekonomik krizinin sonuçları etkilemiş olabileceği kanaatiyle, kriz gölge değişken yardımıyla modele dâhil edilmiştir. Bu modelin tahmininden ise, iktisadi özgürlükler ile büyüme arasındaki ilişki pozitif, ancak istatistiksel olarak anlamsız bulunmuştur. Ele alınan ülke ekonomilerinin çok farklı büyüklükte olmaları ve serbest piyasa ekonomisine geçişte farklı düzeylerde yer almaları gibi hususların bulunan sonuçları etkileyebileceği açıktır. Bununla birlikte, elde edilen sonuçlar, iktisadi büyümenin sağlanmasında tek başına iktisadi özgürlügü̆n önemli bir etken olamayacağını göstermektedir.

\section{Kaynakça}

- $\quad$ Adkins, Lee C., Ronald L. Moomaw, and Andreas Savvides. 2002. "Institutions, Freedom, and Technical Efficiency", Southern Economic Journal 69 (July): 92-108.

- Ali, A., 1997. "Economic Freedom, Democracy, and Growth", Journal of Private Enterprise 13 (fall): 1-20.

- Ali, A., W. M. Crain, 2001. "Political Regimes, Economic Freedom, Institutions, and Growth", Journal of Public Finance and Public Choice 19, no. 1: 3-22.

- Ali, A., W. M. Crain, 2002. "Institutional Distortions, Economic Freedom, and Growth", Cato Journal 21(3), 415-426.

- Ashby, N. J., R. S. Sobel, 2008. "Income Inequality and Economic Freedom in the U.S. States", Public Choice, 134, 329-346.

- Baltagi, B. H., 2005. Econometric Analysis of Panel Data, Third Edition, England: John Wiley\&Sons Ltd.

- Berggren, Niclas, 2003. "The Benefits of Economic Freedom: A Survey", The Indepent Review, Vol:8, N:2.

- Beşkaya Ahmet, Ömer Manan, 2009. "Ekonomik Özgürlükler ve Demokrasi İle Ekonomik Performans Arasındaki İlişkinin Zaman Serileri İle Analizi: Türkiye Örneği”, ZKÜ Sosyal Bilimler Dergisi, Cilt 5, Sayı 10, 2009, ss. 47-76.

- Carlsson, Fredrik, and Susanna Lundström, 2002. "Economic Freedom and Growth: Decomposing the Effects", Public Choice 112, no. 3-4: 335-44.

- Chheng, K., 2005. “How Do Economic Freedom and Investment Affect Economic Growth?” EconWPA, Macroeconomics, No. 0509021.

- Compton, R. A., D. C. Giedeman, G. A. Hoover, 2011. "Panel Evidence on Economic Freedom and Growth in the United States", European Journal of Political Economy, 27, 423-435.

- Çetin Rahmi, 2013. "Ekonomik Özgürlüğün Gelir Düzeyi Üzerindeki Etkisinin Panel Veri Analizi Yöntemiyle İncelenmesi”, Eskişehir Osmangazi Üniversitesi İ̈BF Dergisi, 8(2), 37- 47.

- Dawson, John W, 1998. "Causality in the Freedom-Growth Relationship", European Journal of Political Economy. Vol. 19 (2003) 479 - 495.

- De Haan, J., J. E. Sturm, 2000. “On the Relationship between Economic Freedom and Economic Growth”, European Journal of Political Economy, 16, 215-241.

- De Haan, J., J. E. Sturm, 2001. "How Robust Is the Relationship Between Economic Freedom and Economic Growth?” Applied Economics 33, no. 7: 839-44.

- De Haan, J., S. Lundstrom ve J. Sturm, 2006. "Market-oriented Institutions and Policies and Economic Growth: A Critical Survey", Journal of Economic Surveys, 20, 157-191.

- Heckelman, Jac C., and Michael D. Stroup, 2000. "Which Economic Freedoms Contribute to Growth?" Kyklos 53, no. 4: 527-44.

- Easton, Steven T., and Michael A. Walker, 1997. "Income, Growth, and Economic Freedom”, American Economic Review 87, no. 2: 328-32.

- Goldsmith, Arthur A. 1995. Democracy, Property Rights, and Economic Growth. Journal of Development Studies 32, no. 2: 157-74.

- Gwartney, James G., Robert A. Lawson, and Randall G. Holcombe. 1999. Economic Freedom and the Environment for Economic Growth. Journal of Institutional and Theoretical Economics 155, no. 4: 1-21.

- Hanson, John R., II. 2000. Prosperity and Economic Freedom. The Independent Review 4, no. 4: 525-31.

- Hausman, J. A., 1978. "Specification Tests in Econometrics”, Econometrica, 46, 1251-1272.

- Holcombe Randall G., 1998. "Economic Freedom and Economic Growth”, February, http://fee.org/freeman/ detail/economic-freedom-and-economic-growth.

- Karabegovic, A., D. Samida, C. M. Schlegel, F. McMahon, 2003. "North American Economic Freedom: An Index of 10 Canadian Provinces and 50 US States", European Journal of Political Economy, 19, 431-452. 
- Pitlik, Hans. 2002. The Path of Liberalization and Economic Growth. Kyklos 55, no. 1: 57-80.

- $\quad$ Romer, Paul M., 1990. "Endogenous Technological Change”, Journal of Political Economy 98, no. 5: S71S102.

- Sarıbaş Hakan, 2009. "Ekonomik Özgürlükler ve Ekonomik Büyüme İlişkisi: Bir Panel Veri Analizi”, Finans Politik \& Ekonomik Yorumlar, Cilt: 46 Sayı:538, Syf.7-15.

- Scully, Gerald. 2002. Economic Freedom, Government Policy, and the Trade-Off between Equity and Economic Growth. Public Choice 113, nos. 1-2: 77-96.

- Yalman, İlkay; Ali Rıza Sandalcılar, Ferhan Demirkoparan, 2011. “Özgürlükler Ve Ekonomik Kalkınma: Latin Amerika Ve Türkiye”, Atatürk Ü. İIBF Dergisi, 10. Ekonometri ve İstatistik Sempozyumu Özel Sayısı, 431-444.

- Weede, Erich, and Sebastian Kämpf. 2002. “The Impact of Intelligence and Institutional Improvements on Economic Growth”. Kyklos 55, no. 3: 361-80.

- Wu, Wenbo, and Otto A. Davis. 1999. "The Two Freedoms, Economic Growth and Development: An Empirical Study”, Public Choice 100, nos. 1-2: 39-64.

- (http://www.freetheworld.com, 2015)

- (http://data.worldbank.org, 2015) 


\title{
Türkiye Ekonomisinde Orta Gelir Tuzağı ve Ödemeler Bilançosu Kisıtı
}

\section{Middle Income Trap and Balance of Payments Constraint in the Turkish Economy}

\author{
Asst. Prof. Dr. Zekayi Kaya (Çankırı Karatekin University, Turkey) \\ Assoc. Prof. Dr. Erkan Tokucu (Kafkas University, Turkey) \\ Murat Aykırı (Kafkas University, Turkey) \\ Cahit Durmuş (General Directorate of Laws and Regulations, Office of the Prime Ministery, \\ Turkey)
}

\begin{abstract}
Since the 1980's, the growth rates have been continuously fluctuating because of internal and external economic and politic developments. These fluctuating - low growth rates led to a discussion on the middle income trap which is an outcome of low growth rates in Turkey.

According to the some indicators, there is a middle income trap in the Turkish economy and the competitiveness of the economy has been decreasing in the international area because of the trap. It is seen that especially technology and innovations are the prominents factors that the governments have to take into account.

This study is on the middle income trap in Turkey. In this context, firstly, the definitions of income traps, income grups, and the middle income trap will be given. Second, the causes of the middle income trap and the exit strategies from the trap will be expressed. Third, some indicators of the economy will be examined and compared with the high middle income and the high income countries. Fourth, the rank of the Turkish economy in the global competitiveness indeks will be shown and compared with the other countries. Fifth, the relationship between the middle income trap and the balance of payments will be investigated in context of the Thirlwall Rule. Finally, in order to escape from the trap, some policy proposals of the authors will be asserted.
\end{abstract}

\section{Giriş}

Türkiye ekonomisinde, 1980 sonrası süreçte daha önceki dönemde takip edilen ithal ikameci büyüme modeli terk edilerek ihracata dayalı büyüme modeline geçilmiştir. 1980 sonrası dönem Türkiye'de ayrıca liberal piyasa ekonomisine geçildiği dönemdir ki 1980-1990 döneminde serbest piyasa ekonomisinin hakim kılınması için bir taraftan yasal düzenlemeler yapılırken diğer taraftan devletin ekonomi içerisindeki payı her geçen gün azaltılmıştır. 1989 yılında kabul edilen 32 Sayılı Kanun hükmünde kararname ile kambiyo mevzuatı liberal hale gelmiş ve bunun sonucu olarak da tam konvertibiliteye geçilerek serbest piyasa ekonomisinin gerektirdiği birçok adım atılmıştır.

1990’lı yıllar krizlerin yaşandığı ve reel büyüme oranlarında dalgalanmaların görüldüğü yıllardır. 1990'lar boyunca biriken yapısal problemler Kasım 2000 ve Şubat 2001 tarihlerinde iki büyük krizin daha yaşanmasına neden olmuş, yapısal düzenlemeler kaçınılmaz bir hal almıştır. Krizlerinden sonra Güçlü Ekonomiye Geçiş Programılla birlikte gerçekleştirilen yapısal ve yasal düzenlemelerden sonra ekonomide istikrar ortamı oluşmuş ve son finansal krize kadar büyüme devamlı artı̧ kaydetmiştir. Son finansal krizin Türkiye ekonomisini olumsuz yönde etkilemesi büyüme oranının 2008 yılında \% 0.6 ve 2009 yılında \% -4.8 olmasına yol açmıştır. 2010 yılı ile birlikte hızlı bir toparlanma süreci ile büyüme oranı 2010 yılında \%9, 2011 yılında \%8'ler civarında gerçekleşmiştir. 2012, 2013 ve 2014 yıllarındaki büyüme oranları ise yaklaşı \%2, \%4 ve \%3 olarak gerçekleşmiştir. 2000'li yıllarda genel olarak iktisadi büyüme süreci olumlu olmasına rağmen net ihracat devamlı açık vermiş ve cari açık problemi büyüme sürecinin önündeki temel engellerden birisi haline gelmiştir. Hızlı büyüme süreciyle birlikte cari açığın milli gelire oranı da hızlı bir şekilde artmış, aynı süreçte özel kesimin dış borç stokunda da önemli artışlar kaydedilmiştir.

Son yıllarda Türkiye'deki temel tartışmalardan birisi büyüme oranlarına yöneliktir. İleri sürülen bazı görüşlere göre Türkiye ekonomisi orta gelir tuzağına yakalanmıştır ve bundan dolayı büyüme oranlarında hedeflenen rakamlara ulaşılamamaktadır. Ekonomide Thirlwall Yasası hâkim olmaya başlamıştır yani ödemeler bilançosunun büyüme üzerinde yarattığı kısıt dolayısıyla ekonomi büyüyememektedir. İthalatın artması, ihracatın ithalatı karşılama oranının azalması ve ithal girdiye bağlı ihracattan dolayı cari açık sorunu ortaya çıkmıştır. Bu da büyümeyi engelleyici bir unsur olmuştur. Bazılarına göre ise 2000'li yıllardan sonra yaşanan hızlı büyüme sürecinin temel nedeni borçlanarak gerçekleştirilen yatırımlardır. Ancak devamlı borç kullanarak yapılan yatırımlarla elde edilen büyüme sürdürülebilir bir büyüme değildir ve bu sürecin sonuna gelinmiştir.

Bu çalışmada Türkiye ekonomisinin son yıllarda karşı karşıya kaldığı hızlı büyüyememe sorunu birkaç açıdan irdelenecektir. İlk olarak, ekonomideki büyüyememe sorunu orta gelir tuzağı kavramı çerçevesinde 
incelenecektir. Bu çerçevede literatürde orta gelir tuzağına yol açan temel faktörlerden olan bütçe içerisinde eğitim için ayrılan payın milli gelir içerisindeki oranına; şirketlerin araştırma geliştirme (Ar-Ge) için yaptıkları harcamaların milli gelir içerisindeki oranına; son olarak da patent başvurularının 16-65 yaş grubu içerisindeki oranına bakılarak Türkiye ile yüksek orta gelir grubunda yer alan diğer bazı ülkeler ve Türkiye ile yüksek gelir grubunda yer alan ülkelerin karşılaştırması yapılacaktır. İkinci olarak, Türkiye'nin uluslar arası rekabetçiliği, Dünya Ekonomik Forumu tarafından her yıl yayınlanan Dünya Rekabetçilik Endeksi baz alınarak incelenecek ve Sabancı Üniversitesi ile TÜSİAD tarafından oluşturulan rekabetçilik veri tabanından elde edilen verilerle ihraç edilen ürünlerin teknolojik yoğunluğu hakkında bilgiler verilecektir. Üçüncü olarak, literatürde Thirlwall Yasası olarak da bilinen ödemeler bilançosu kısıtlı büyüme sürecinin Türkiye'de işlemesine yol açan unsurlar hakkında bilgiler verilecektir.

\section{Gelir Tuzakları, Gelir Grupları ve Orta Gelir Tuzağı}

Gelir tuzakları denildiği zaman son yıllarda genellikle orta gelir tuzağı kavramı akla gelse de, "gelir tuzağı" ifadesi bütün gelir gurupları için geçerli olan bir durumdur. Ülkelerde kişi başına düşen milli geliri veri alan ve ağırlıklı olarak Satın Alma Gücü Paritesi 'ne (SGP) göre kişi başı geliri dolar cinsinden ölçen bu kavram, genel olarak bir ülkenin belli bir gelir seviyesinde patinaja tutulması yani içine girdiği kısır döngüden uzun bir süre kurtulamaması durumunu ifade etmektedir. Dolayısıyla gelir tuzakları, orta gelir seviyesinde ortaya çıkabileceği gibi, düşük ve yüksek gelir gruplarında da karşımıza çıkabilir. Gelir tuzağına düşmüş ülkeler, çok uzun süre bu seviyede kalmakta ve bir üst gelir grubuna geçememektedirler (Karahan, 2012).

“Orta Gelir Tuzağı (OGT)" kavramı, iktisadi büyüme ve kalkınma konuları arasına yeni katılmış bir konu olmakla birlikte, geniş bir "Gelişmekte olan ülkeler" grubunu ilgilendirdiği için iktisat literatüründe ve iktisatçılar arasında önemi hızla artan güncel bir kavramdır. Orta gelir tuzağı, büyüme süreci içerisinde bazı ülkelerin gelir düzeyinin orta gelir düzeyi olarak adlandırılan belirli bir gelir düzeyine ulaştıktan sonra uzun süre o düzeyde kalmaları ve yüksek gelir düzeyine geçememelerini tarif eden bir olgudur. Orta gelir tuzağına düşmüş ülkeler olarak Latin Amerika ülkeleri literatürde sıkça verilen örneklerdendir. Güney Kore ve Tayvan gibi bazı Güney Doğu Asya ülkelerinin içinde bulunduğu bir gurup ülke ise orta gelir düzeyine ulaştıktan sonra hılı bir şekilde yüksek gelir gurubuna geçebilmeyi başarmış ülkeler olarak ön plana çıkmaktadır (Aiyar, vd, 2013).

OGT konusu ele alınırken hangi gelir düzeyinin orta gelir düzeyi olarak kabul edileceğinin belirlenmesi gerekiyor. Dünya Bankası (World Bank(WB)) günümüz ekonomilerini gelişmişlik düzeyleri bakımından üç grupta toplamaktadır. Dünya bankası bu sınıflandırmayı yaparken ülkelerin kişi başına gayrisafi milli hasıla (GSMH) düzeylerini dikkate almakta ve hesaplamalarını "Atlas Metodunu" kullanarak yapmaktadır. Bu metot, ulusal para birimi cinsinden hesaplanan kişi başı GSMH rakamlarının son üç yılın döviz kuru ortalamaları kullanılarak Amerikan doları cinsinden ifade edilmesi esasına dayanmaktadır. Dolayısıyla döviz kurlarında meydana gelen dalgalanmaların kişi başı GSMH düzeyleri üzerindeki etkileri belirli ölçülerde azaltılmaya çalışılmaktadır. Dünya Bankasının Atlas metodu hesaplamalarıyla ulaştığı 2013 yılı kişi başına GSMH değerlerine göre; kişi başı GSMH düzeyi 1,045\$'dan az olan ülkeler düşük gelirli ülkeler, 1,045\$ -12,745\$ aralığında olan ülkeler orta gelirli ülkeler $(1,045 \$-4,125 \$$ gelir aralığında olanlar alt-orta gelirli, $4,125 \$-12,746 \$$ gelir aralığında olanla üst-orta gelirli ülkeler) ve kişi başı GSMH'sı 12,746\$'dan daha fazla olan ülkeler yüksek gelirli ülkeler olarak sınıflandırılmaktadır (World Bank, 2013a).

\begin{tabular}{|c|c|c|c|}
\hline Kaynaklar & $\begin{array}{c}\text { Alt-Orta Gelirli } \\
\text { Ekonomiler }\end{array}$ & $\begin{array}{c}\text { Üst-Orta Gelirli } \\
\text { Ekonomiler }\end{array}$ & Notlar \\
\hline Dünya Bankası & $1,026 \$-4,035 \$$ & $4,036 \$-12,475 \$$ & $\begin{array}{l}\text { ABD Doları cinsinden } \\
\text { Cari Fiyatlarla }\end{array}$ \\
\hline Felipe v.d. (2012) & $2,000 \$-7,250 \$$ & $7,251 \$-11,750 \$$ & $\begin{array}{l}1990 \text { Yılı Satın Alma } \\
\text { Gücü Paritesine Göre }\end{array}$ \\
\hline Eichengreen v.d. (2012) & \multicolumn{2}{|c|}{ Kişi Başı GSYH < 17000\$ } & $\begin{array}{l}2005 \text { Yılı Satın Alma } \\
\text { Gücü Paritesine Göre }\end{array}$ \\
\hline Woo (2012) & \multicolumn{2}{|c|}{ Kişi Başı GSYH= ABD’nin \%20-55 } & $\begin{array}{l}1990 \text { Yılı Satın Alma } \\
\text { Gücü Paritesine Göre }\end{array}$ \\
\hline Robertson and Ye (2013) & \multicolumn{2}{|c|}{ Kişi Başı GSYH= ABD’nin \%8-36 } & $\begin{array}{l}2005 \text { Yılı Satın Alma } \\
\text { Gücü Paritesine Göre }\end{array}$ \\
\hline Gill ve Kharas (2009) & \multicolumn{2}{|c|}{$\begin{array}{l}\text { Kişi Başı GSYH'sı 1000\$ ile 10000\$ aralığında } \\
\text { buluna ülkeler }\end{array}$} & \\
\hline
\end{tabular}

Tablo 1. Gelir Grupları Sinıflandırmasında Kullanılan Farklı Görüşler

Dünya bankasının Atlas Metoduna göre yapmış olduğu sınıflandırmada 2013 yılı verilerine göre Dünyadaki 214 ülkeden 34'ünün düşük gelir grubunda, 50'sinin alt-orta gelir grubunda, 55'inin üst-orta gelir grubunda ve 75'inin ise yüksek gelir grubunda yer aldığı görülmektedir (World Bank, 2013b). Bu metoda göre Türkiye 
10,970\$'lık (satın alma gücü paritesine göre 18,570\$) kişi başı GSMH'sı ile üst-orta gelir grubunda yer alan bir ülkedir.

Dünya bankasının gelir grupları sınıflandırmasında kullandığı genel kabul görmüş ölçütlerin yanı sıra gelir guruplarının tespitinde başka sınıflandırma ölçütlerinin de kullanıldı̆̆ı görülmektedir. Tablo 1, bu anlamda yapılmış çalışmaların bir özeti sunmaktadır.

OGT kavramı ilk olarak Dünya Bankası tarafından 2007 yılında yayınlanan “An East Asian Renaissance: Ideas for Economic Growth (Bir Doğu Asya Rönesansı: Ekonomik Büyüme İçin Fikirler)” isimli raporda Dünya Bankası uzmanları Gill ve Kaharas tarafindan gündeme getirilmiştir. Bu raporda genel olarak; "Orta gelirli ülkelerin, günümüz dünyasında meydana gelen ekonomik değişim ve dönüşümlere ayak uydurmakta zorlandıkları ve bu nedenle zengin ülkelere göre daha yavaş bir büyüme performansı sergiledikleri ifade edilmektedir. Diğer bir ifadeyle orta gelir tuzağına yakalanan ülkeler, fakir ülkelere karşı düşük ücretli standart imalat sanayi ürünlerinde rekabet edemeyen, öte yandan yenilikçilik temelli büyüyen zengin ülkelere yakınsamakta ise zorlanan ülkeler şeklinde tanımlanmaktadır (Gill ve Kaharas, 2007). Rapor bu açıdan bahsedilen nedenlerden dolayı orta gelirli ülkelerin, yüksek gelirli ülkelerle düşük gelirli ülkeler arasında sıkışıp kalmalarına işaret etmektedir (Bozkurt, vd, 2014).

Benzer şekilde 2012 yılında yine Dünya Bankası tarafından yayınlanan “Avoiding Middle-Income Growth Trap (Orta Gelirli Büyüme Tuzaklarından Kaçınma)” adlı diğer bir raporda; 1950’den bu yana sergiledikleri hızlı büyüme performansı sayesinde çok sayıda ülkenin düşük gelirli ülke düzeyinden orta gelirli ülke düzeyine ulaşma imkanı elde ettiği vurgulanmaktadır. Ancak bu düzeyden sonra az sayıda ülkenin yüksek gelirli ülkeler gurubuna geçmeyi başarabildiği, diğerlerinin ise orta gelir tuzağı diye adlandırılan gelir düzeyinde sıkışıp kaldıkları ifade edilmiştir (Agenor, vd, 2012).

Dünya bankası tarafından yayınlanan bu raporların ardından OGT olgusu iktisatçılar arasında ilgi odağı haline dönüşmeye başlamış ve farklı ülke ve ülke grupları üzerinde yapılan araştırmalar hız kazanmaya başlamıştır. Orta gelir tuzağı yaklaşımı ilk kez ortaya atıldığında ABD'de kişi başına düşen yıllık gelirin yüzde 20'si ekonomiler açısından orta gelir düzeyi olarak kabul edilmekteydi. ABD'de kişi başına düşen milli gelirin yaklaşık olarak 50.000 dolar olduğunu düşünürsek orta gelir düzeyi sınırı yaklaşık 10.000 dolara tekabül etmektedir.

Dünya Bankası'nın gelir sınıflaması daha çok ülkeleri gelir gruplarına ayırmak için kullanılmaktadır. Dünya Bankası ülkeleri kişi başına düşen GSMH'lalarına bağlı olarak düşük gelirli, alt orta gelirli, üst orta gelirli, yüksek gelirli ülkeler diye sınıflamaktadır. Dünya Bankası değişik gelir grupları için orijinal kişi başına gelir basamaklarını yoksulluk oranı, bebek ölüm oranı ve kişi başına GSMH'yı içeren refah ölçütleri arasındaki ilişkiye bakarak oluşturmuştur. Orijinal basamaklar oluşturulduğunda refahın gelir dışı yönü göz önünde tutularak hazırlanan Dünya Bankası'nın her bir gelir sınıflama kategorisi bir grup ülkenin (sadece geliri kapsamayan) refah seviyesini yansitmaktadır.

Dünya Bankası orijinal basamakları; Euro Bölgesi, Japonya, Birleşik Krallık (BK) ve Birleşik Devletler (ABD) 'in ortalama enflasyonunu ifade eden uluslararası enflasyona göre ayarlayarak güncellemiştir. Enflasyona göre ayarlandığında basamaklar zaman içinde reel olarak sabit kalmaktadır (Felipe, 2012).

\section{3 Ülkelerin Orta Gelir Tuzağına Yakalanma Sebepleri ve Tuzaktan Çıkış Yolları}

Yapılan çalışmalar irdelendiğinde Gelir Tuzağı veya özelde Orta Gelir Tuzağı olgusunun aslında sürdürülebilir bir ekonomik büyüme sorunu olduğu ortaya çıkmaktadır. Orta gelir düzeyi ele alındığında, bu gurupta yer alan çoğu ülkenin sergiledikleri yüksek büyüme hızları sayesinde düşük gelir grubundan hızla kurtulup orta gelir grubuna girebildikleri fakat bu gelir grubuna dahil olduktan sonra büyüme hızlarını koruyamadıkları görülmektedir (Öztürk, vd, 2012). Bu durumu ortaya çıkaran sebepler incelendiğinde bu ülkelerde "orta gelir" düzeyine ulaşıldıktan sonra kırsal kesimlerde eksik istihdamın giderek azalması, ücret düzeylerinde meydana gelen artışlar ve buna bağlı olarak uluslararası rekabet avantajlarının kaybolmaya başlaması gibi nedenlerin ön plana çıktığı görülmektedir. Böylesi bir durumda bu tür dezavantajları ortadan kaldırmaya yönelik adımların (örneğin; teknolojinin geliştirilmesi ve kaynak verimliliğinin artırılması, inovasyon vs...) atılamaması halinde mütevazı oranlarda sürüp giden büyüme oranları ile bu ülkelerin bir üst gelir grubuna terfi etmeleri çok uzun yıllar almaktadır. Böylece bu ülkeler, kendini, orta gelir tuzağının içinde bulmaktadırlar (Öz, 2012).

Bir başka sebep olarak ise ülkelerin ithalata dayalı teknolojik yatırımlarının yerel bazda yenilikçi faaliyetlerle ikame edilememesi gösterilmektedir. Düşük gelir grubundan orta gelir grubuna çıkan ülkelerde ekonomik büyüme daha fazla sermaye ve daha vasıflı işgücüne ihtiyaç duymaktadır. Fakat iç pazardaki genişleme ve vasıflı işgücündeki artışlar işgücü maliyetlerininide artırmaktadır (Eichengreen, vd, 2012). Bu durum bir taraftan işgücü verimliliğinindeki artışlara bağlı olarak ülkelerin kişi başı hasılasını artırmakta fakat diğer taraftan artan işgücü maliyetleri ülkenin ulslararası rekabet gücünü yavaş yavaş ortadan kaldırmaya başlamaktadır. Rekabet şansını kaybeden ülkeler yukarıda da değinildiği üzere teknolojik atılımlarla, bilgi ağırlıklı yatırımlarla, reformlarla ve beşeri sermayeyi hissedilir ölçülerde artırıcı bir takım önlemlerle bu tür dezavantajları ortadan 
kaldırmamadıklarında kaçınılmaz olarak kendilerini orta gelir tuzağı diye adlandırılan tuzağın içinde bulmaktadırlar (Spence, 2011 ve Flaen, vd., 2013)

Bir başka görüşe göre ise orta gelir tuzağının temel sebeplerinden biri ise ekonomilerin günümüz bilgi yoğun üretim yapılarına uyum sağlayamamaları ve teknoloji yoğun üretim süreçlerine geçememeleri olarak gösterilmektedir (Paus, 2012).

Orta gelir tuzağından kurtulabilmenin temel yollarından birisi verimliliğin artırılması ve buna bağlı olarak katmadeğeri yüksek ürünlerin ve hizmetlein hayata geçirilmesi olarak ifade edilmektedir. Ülkelerin özellikle ArGe faailyetlerine yoğunlaşmak suretiyle teknoloji konusunda dışa bağımlılıklarını azaltmaları bu aşamada hayati öneme sahip bulunmaktadır. Kalkınma yolunda yeni stratejilerin belirlenmesi ve özellikle dış ticarette ürün çeşitliliğinin artırılması bir diğer unsur olarak karşımıza çıkmaktadır. Bu aşamada özellikle ucuz işçiliğe dayalı büyüme stratejilerinden beşeri sermaye unusurunu daha fazla barındıran, katma değeri yüksek ve inovasyona dayalı stratejilerin takip edilmesi oldukça önemlidir. Son olarak üretimin, eğitimin, nitelikli işgücünün, girilşimciliğin ve yenilikçiliğin önünü açacak kurumsal altyapının oluşturulması ve yapısal dönüşümü sağlalayacak politikaların uygulanması bu konu üzerine kafa yoran bütün araştırmacıların ortak kanaatleri olarak karşımıza çıkmaktadır (Agenor ve Canuto, 2012 , Kritayanavaj, vd, 2012 ve Ghani, vd, 2013)

\section{Orta Gelir Tuzağının Türkiye'deki Bazı Göstergeleri}

Aşağıdaki iki grafik yüksek gelir gurubundaki ülkelerle yüksek orta gelir gurubundaki ülkelerin kişi başına gelirlerinin Amerika Birleşik Devletleri (ABD)'ndeki kişi başına gelirine oranlarını vermektedir. İlk grafik yüksek gelir gurubundaki ülkelere ait verileri göstermektedir. Yüksek gelir gurubunda yer alan ülkelerden Norveç'in ABD'den daha yüksek kişi başına gelire sahip olduğu ve 1980'lerden itibaren bu farkı arttırdığı ve \% 140'ın üzerine çıkardığı görülmektedir. İsveç, Hollanda ve İngiltere'deki kişi başına gelirlerin ABD'deki kişi başına gelirlerin \%80-100’üne denk geldiği ve bunu 1960'lardan beri devam ettirdikleri görülmektedir.

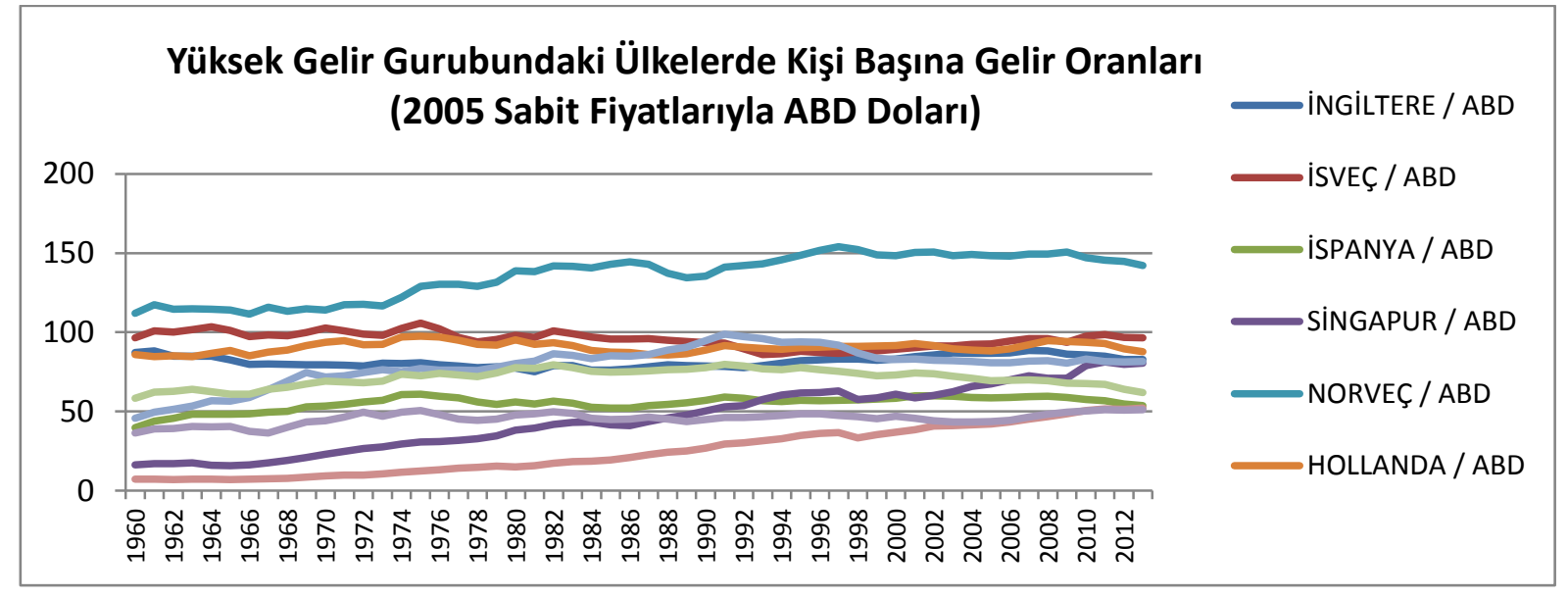

Şekil 1. Kiş̧i Başına Düşen Milli Gelir Karşılaştırmaları Kaynak: WB Database. World Development Indicators.

İtalya \%60-80 bandında, İspanya ve İsrail ise \%40-60 bandında yer almakta ve bu ülkelerin durumu 1960'lardan beri bu şekilde devam etmektedir. Japonya 1960'ların başında hızlı bir gelişme göstermiş 1990'larda ABD'deki kişi başına gelir düzeyine ulaşmış ancak 1990'lardan sonra bir azalma ortaya çıkmış ve \%80 oranına gerilemiştir. Tabloda Singapur ve Güney Kore'ye ait veriler orta gelir tuzağından kurtulan ülke örnekleri olarak verilebilir. 1960'ların başında her iki ülkede de kişi başına gelirler ABD'deki kişi başına gelirlerin \%20'sinden daha azken kişi başına gelirlerde hızlı bir artış sağlanmış ve bu artış hiç durmadan son yıllara kadar devam etmiştir. Singapur ABD kişi başı gelirinin \%80’ine Güney Kore ise yaklaşık \%50’sine yaklaşmıştır.

Aşağıdaki grafik orta gelir tuzağına yakalanan ülkelerdeki kişi başına gelirlerin ABD'deki kişi başına gelire oranını göstermektedir. Arjantin ve Güney Afrika 1960'ların başında görece iyi durumlarını süreç içerisinde kaybederek 1990'larda \%10-15 bandına inmişler ancak Arjantin 2000'lerin başından itibaren durumunu düzelterek \%15-20 bandına girmiştir. Macaristan 1960-1980 arasında kişi başına milli gelirini istikrarlı bir şekilde artırmış, 1980'lerde düşüşe geçerek \%20-25 bandına yerleşmiştir. Brezilya 1960'tan beri \%10-15 bandında kalarak bir iyileşme gösterememiştir. Çin 1990’lı yıllara kadar \%5'in altında kalmış, 1990’ların ortalarından itibaren yakaladığı ivmeyle \%5'in üzerine çıkabilmiştir. Türkiye ise 2000'li yıllara kadar \%15 çizgisinde kalmış 2000'lerden sonra \%15-20 bandına geçmiştir. Orta gelir tuzağına yakalanan ülkelerden hiçbirinin kişi başına düşen gelir ABD kişi başına gelirinin \%25'inin üzerinde değildir. 


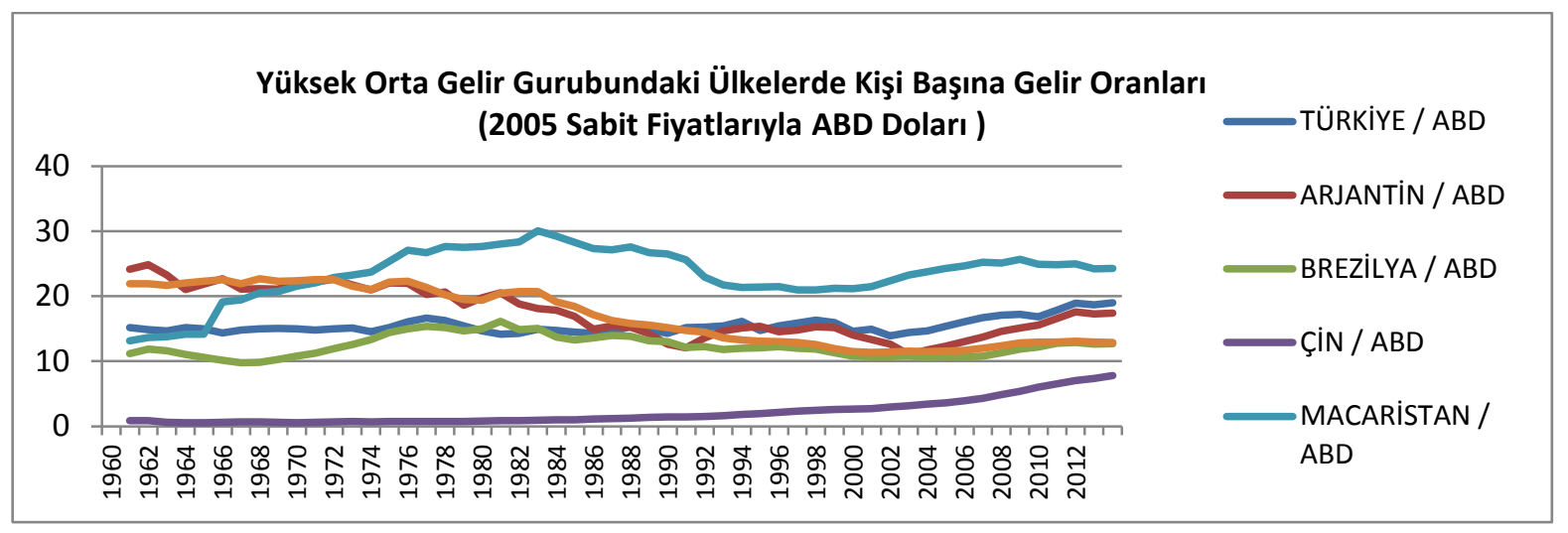

Şekil 2. Yüksek Orta Gelir Gurubundaki Ülkelerde Kişi Başına Gelir Oranları Kaynak: WB Database

Türkiye açısından bakıldığında 1960-2015 döneminde yaklaşık 55 yıldır kişi başına düşen gelirin ABD kişi başına düşen gelirine oran olarak hep \%20’nin altında kaldığı görülmektedir. Son 15 yıldır nispi bir iyileşme söz konusudur ancak bu iyileşme yeterli değildir.

Ülkelerin orta gelir tuzağına yakalanmaları ile büyüme performansları arasında yakın ilişki söz konusudur ve büyümenin kaynakları açısından bakıldığında büyümenin tek kaynağı artık basit bir şekilde sermaye birikimi değildir. İçsel büyüme modellerinin de üzerinde durduğu üzere, eğitim ve araştırma geliştirme faaliyetleri (ArGe) ile hem teknoloji gelişmekte hem de emeğin de dahil olduğu beşeri sermaye gelişmekte ve aynı miktar emek ve sermaye ile daha fazla üretimde bulunmak mümkün olmaktadır (Yeldan, vd, 2012). Eğitim ve Ar-Ge harcamaları ülkenin yenilikçilik kapasitesini de geliştirmekte ve aşağıda da üzerinde durulacağı üzere ülkeleri yenilikçi odaklı ekonomiler haline getirmektedir. Dolayısıyla eğitime ayrılan pay ve Ar-Ge harcamalarının milli gelir içerisindeki oranının düzeyi orta gelir tuzağındaki ülkelerin nasıl bir kalkınma modeli izlemeleri gerektiği hakkında da bilgi vermektedir.

1980 sonrası süreçte hem yüksek gelir gurubundaki hem de yüksek orta gelir grubundaki ülkelerin bütçeden eğitim harcamaları için ayırdıkları kaynaklara bakıldığında yüksek gelir grubundaki ülkelerde bu oranın Türkiye'deki orandan iki, üç ya da dört kat daha fazla olduğu görülmektedir. Örneğin yüksek gelir grubunda yer alan Danimarka'da bu oran 1980'lerin başlarında \%5'ler düzeyinde iken 1990'lardan itibaren \%8 düzeyine çıkmış ve günümüze kadar devam etmiştir. Bu oran Japonya'da \%7'ler, Fransa ve ABD'de \%5'ler düzeyindedir. Türkiye'de ise bu oran 1980'ler boyunda \%2'ler civarında iken 1990'lardan günümüze \%2-\%3 bandında seyretmiştir. Türkiye ile beraber yüksek orta gelir grubunda yer alan Arjantin, 1980'lerin başında bütçeden eğitime \%3 oranında pay ayırırken 1990'lardan itibaren oran sürekli artmış ve günümüzdee \%6 düzeyine yükselmiştir. Güney Afrika 1980'den 2010 yılına kadar istikrarlı bir şekilde bütçeden eğitime ayırdığı payı \%5 düzeyinde sürdürmüş 2010 yılından sonra ise \%6'nın üzerine çıkarmayı başarmıştır. Benzer şekilde Brezilya da bütçeden eğitime ayırdığı kaynakları 2000'lerin başından itibaren artırarak \%6'lar düzeyine yükseltmiştir (Worldbank Database, 2015).

Oranlardan da görüleceği üzere yüksek gelir gurubundaki ülkelerin hepsi milli gelirden eğitime önemli oranda kaynak ayırmaktadır. Bu durum, aşağıda da görüleceği üzere, bu ülkelerin uluslar arası alanda rekabetçi avantajlar elde etmelerine neden olmaktadır. Yüksek orta gelir gurubundaki ülkelerin eğitimin önemini kavradıkları ve bundan dolayı milli gelirden eğitime daha fazla kaynak ayırdıkları görülmektedir. Türkiye'de ise eğitime ayrılan payın yüksek orta gelir gurundaki ülkelerin tamamından daha düşük olduğunu göstermektedir. Elbette kişi başına düşen gelirlerin artışında eğitim harcamaları tek başına belirleyici değildir ancak en önemli göstergelerden birisidir. Eğitime ayrılan payın giderek artması beşeri sermayenin ve beşeri sermayeye bağlı olarak da girişimcilik ve yenilikçiliğin düzeyini doğrudan belirleyecektir.

Ülkelerin hızlı bir şekilde gelişmelerine, uluslararası ticarette rekabetçi bir avantaj elde etmelerine ve orta gelir tuzağından kurtulmalarına neden olacak bir diğer önemli unsur Ar-Ge harcamalarıdır. Aşağıdaki grafikler yüksek gelir ve yüksek orta gelir gurubunda yer alan ülkelerdeki Ar-Ge harcamalarının milli gelire oranlarını vermektedir.

Çin'in son yıllarda önemli bir atılım yaptığı görülmektedir. 1990'larda milli gelirinden Ar-Ge için ayrılan pay $\% 0,5$ oranında iken süreç içerisinde bu oran istikrarlı bir şekilde artırmış ve \%2 düzeyine çıkmıştır. Macaristan ve Brezilya son yıllarda milli gelirden daha fazla kaynağı Ar-Ge harcamaları için ayırmalarına rağmen oran \%1,5'un altındadır. Güney Afrika ve Arjantin Ar-Ge için ayırdıkları kaynakları artırsalar da oran \%1'in altındadır ki Arjantin ve Güney Afrika, eğitim harcamalarında gösterdikleri atılımı Ar-Ge harcamalarında gösterememiştir. Türkiye son yıllarda milli gelirden Ar-Ge için ayırdığı kaynakları iki katına çıkarmasına rağmen bu oran hala $\% 1$ 'in altındadır.

Yüksek gelir gurubunda bulunan ülkelerde Ar-Ge harcamalarının milli gelir içerisindeki oranına bakıldı ğında bu oranının devamlı bir şekilde \%2'nin üzerinde seyrettiği görülmektedir. En düşük orana sahip olan 
Singapur'da bile bu oran Türkiye'deki oranın iki katıdır. İsrail'in Ar-Ge için milli gelirden ayırdığı pay \%4-4,5 bandında, Japonya'nın ayırdığı pay \%3,5'lar civarında, Almanya, ABD ve Tayvan'da ise \%3'ler civarındadır.

Yüksek orta gelir gurubunda yer alan ülkelerde Ar-Ge harcamalarının düşük olması bu ülkelerin üretip ihraç ettikleri ürünlerde çok fazla değişiklik olmadığını ve bu ürünlerin düşük teknolojili ve katma değeri düşük ürünler olduğunu ifade eder. Bu durum uluslararası piyasalarda bu ülkelerin yüksek gelir gurubundaki ülkelerle rekabet edememesinin temel nedenlerinden birisidir.

Milli gelirinden her yıl önemli bir oranı Ar-Ge harcamaları için ayıran yüksek gelir gurubundaki ülkeler tarafindan üretilen ürünlerin neden dünya piyasalarında aranan ürünler olduğu bu sonuçlardan ortaya çıkmaktadır. İsrail tarafından tarım, sanayi ve bilişim alanında üretilen ürünlerin önemli bir çoğunluğu dünya piyasalarına hâkimdir. Aynı şekilde Almanya, Japonya, Singapur ve Tayvan tarafından üretilen ürünlerin birçoğu yüksek teknolojili ve katma değeri yüksek olan ürünlerdir ki bu durum bu ülkelerde ihracatın büyümeye önemli katkılar sunacağı anlamına gelir.

Ar-Ge harcamalarıyla ilintili bir diğer gösterge ülkelerdeki patent başvuru sayısıdır. Yüksek gelir gurubundaki ve yüksek orta gelir gurubundaki ülkelerde patent başvurusu sayısı tek başına anlamlı olmayabilir çünkü her bir ülkenin nüfusu birbirinden farklıdır. $\mathrm{Bu}$ noktada patent başvuru sayısını ülke nüfusuna oranlamak daha gerçekçidir. Bu açıdan bakıldığında Japonya'nın lider konumunda olduğu görüşmektedir. Japonya'da 15-65 yaş gurubundaki her bin kişiden yaklaşık 4'ü patent başvurusunda bulunmaktadır. Japonya'yı Singapur, ABD, Almanya, İsrail, İngiltere ve Fransa takip etmektedir. Türkiye'de ise oran maalesef çok düşüktür: 2012 yllında her yüz binde yaklaşık bir kişi patent başvurusunda bulunmuştur ve bu oran değişmemiştir. Türkiye'nin nüfus olarak kendisinden daha az olan ülkelere göre patent başvuru oranlarında bu kadar geri olması orta gelir tuzağından çıkış stratejisi belirlenirken bu konuya çok dikkat etmesini gerekli kılmaktadır. 2013 yılında İsrail'in nüfusu yaklaşık 8 milyon iken Singapur'un nüfusu yaklaşık 5,5 milyon ve Türkiye'nin nüfusu yaklaşık 75 milyondur. Singapur ve İsrail'de patent başvurularının yüksek olmasının nedenlerinden birisi yukarıda da değinildiği üzere bu ülkelerdeki Ar-Ge harcamalarının yüksekliğidir. İsrail'de Ar-Ge harcamalarının milli gelire oranı $\% 4$, Singapur'da ise $\% 2-2,5$ arasında iken Türkiye'de $\% 1$ oranına yeni yeni yaklaşılmaktadır.

Ülkelerin sürdürülebilir bir büyüme patikasına sahip olmaları açısından eğitim, Ar-Ge harcamaları ve patent başvuruları kuşkusuz önde gelen faktörlerdir. Ancak küreselleşen dünyada artan uluslararası rekabet ortamında bunlar da yeterli değildir. Bunlarla beraber, bu unsurları tamamlayan diğer unsurlarda da ülkelerin iyi durumda olmaları gerekir. $\mathrm{Bu}$ amaçla Dünya Ekonomik Forumu tarafından periyodik olarak yayınlanan Küresel Rekabetçilik Raporu kullanılacaktır.

\section{Dünya Ekonomik Forumu Tarafından Hazırlanan Küresel Rekabetçilik Endeksi}

Ülkelerin sürdürülebilir bir büyüme yolunu takip etmeleri ve yüksek büyüme oranına sahip olabilmeleri için birbiriyle tamamlayıcılık ilişkisi bulunan çok sayıda faktör vardır ve bu faktörlerin tamamı bir araya geldiğinde hem ülkelerin rekabetçi yapıları güçlenmekte hem de kişi başına düşen gelir rakamları artmaktadır. Bundan dolayı Arjantin ve yüksek orta gelir gurubunda yer alan diğer ülkelerde, Türkiye ve Çin hariç, eğitime ayrılan pay \%4-5 civarında olmasına rağmen orta gelir gurubundan kurtulmaları için yeterli değildir çünkü rekabetçiliklerini artıran diğer unsurlarda gereken yerde değillerdir.

Dünya Ekonomik Forumu (DEF) her yıl ülkelerin rekabetçilik durumunu geliştirmiş olduğu bir teknikle ölçmekte ve ülkeleri sınıflandırmaktadır. Buna göre 3 temel kategori ve 12 adet alt başlık (alt kategori) oluşturulmakta ve bu başlıklar kendi içlerinde sınıflandırılarak ülkeler taşıdıkları özelliklere uygun olarak belirli bir kategori içerisine yerleştirilmektedir. Bu çerçevede ülkeler faktör odaklı, etkinlik odaklı ve yenilikçilik odaklı olmak üzere üç temel kategori içerisinde yer almaktadır. Birinci kategorinin alt endeksleri kurumlar, alt yapl, makroekonomik ortam, sağllk - ilkögretim'den oluşmaktadır. İkinci kategorinin alt endeksleri yükseköğretim ve eğitim, mal piyasasının etkinliği, emek piyasasının etkinliği, finansal piyasaların gelişmişliği, teknolojik hazırlık ve piyasa ölçeğidir. Son kategorinin alt endeksleri ise işletmelerin gelişmişliği ve yenilikçilik inovasyondur.

İlk kategori içerisinde yer alan ilk dört alt endekste iyi olan ekonomiler faktör odaklı ekonomiler olarak adlandırılmaktadır. Faktör odaklı ekonomilerden etkinlik odaklı ekonomilere geçiş için ikinci kategoride yer alan alt endekslerin geçilmesi gerekir. Gelişmiş ve uzmanlaşmış işletmelere sahip ve yenilikçi uygulamaların iktisadi faaliyetlerde baskın olduğu ekonomiler yenilikçilik odaklı ekonomiler olarak adlandırılmaktadır (World Economic Forum, “Global Competitiveness Report: 2013-2014”).

Aşağıdaki tablo alt endekslere göre ülkelerin hangi kategoride olduklarını göstermektedir. Ülke isimlerinin hemen yanında yer alan parantez içindeki rakamlar ülkelerin genel rekabetçilik endeksinde kaçıncı sırada yer aldığını ifade etmektedir. Türkiye ekonomisi genel rekabetçilik sıralamasında 44. sırada yer almakta ve etkinlik odaklı ekonomiden yenilikçi odaklı ekonomiye geçiş aşamasındaki ekonomi olarak adlandırılmaktadır. Türkiye ile birlikte üst orta gelir gurubunda yer alan ülkelerden genel rekabetçilik sıralamasında Arjantin 104. sirada, Brezilya 56. sırada yer almaktadır ve her iki ekonomi de etkinlik odaklı ekonomiden yenilikçilik odaklı ekonomiye geçiş aşamasındaki ülkeler gurubu içerisinde yer almaktadır. Yüksek gelir gurubunda yer alan 
ülkelerden Singapur, Hong Kong Sar, Amerika Birleşik Devletleri, Japonya, Norveç, Kanada, İngiltere ve Japonya ise yenilikçilik odaklı ekonomiler olarak kategorize edilmiştir. Bu ülkeler aynı zamanda genel rekabetçilik sıralamasında da ön sıralarda yer almaktadır (Tablo 2).

\begin{tabular}{|l|c|c|c|c|c|c|c|c|c|c|c|c|}
\hline \multicolumn{1}{|c|}{ Alt Endeksler } & 1 & 2 & 3 & 4 & 5 & 6 & 7 & 8 & 9 & 10 & 11 & 12 \\
\hline ABD (5) & 35 & 15 & 117 & 34 & 7 & 20 & 4 & 10 & 15 & 1 & 6 & 7 \\
\hline Almanya (4) & 15 & 3 & 27 & 21 & 3 & 21 & 41 & 29 & 14 & 5 & 3 & 4 \\
\hline İsrail (27) & 40 & 35 & 72 & 38 & 34 & 68 & 57 & 22 & 23 & 49 & 23 & 3 \\
\hline Singapur (2) & 3 & 2 & 18 & 2 & 2 & 1 & 1 & 2 & 7 & 34 & 17 & 9 \\
\hline Güney Kore (25) & 74 & 11 & 9 & 18 & 19 & 33 & 78 & 81 & 22 & 12 & 24 & 17 \\
\hline Japonya (9) & 17 & 9 & 127 & 10 & 21 & 16 & 23 & 23 & 19 & 4 & 1 & 5 \\
\hline Norveç (11) & 6 & 33 & 2 & 14 & 10 & 22 & 14 & 9 & 3 & 51 & 13 & 13 \\
\hline Türkiye (44) & $\mathbf{5 6}$ & $\mathbf{4 9}$ & $\mathbf{7 6}$ & $\mathbf{5 9}$ & $\mathbf{6 5}$ & $\mathbf{4 3}$ & $\mathbf{1 3 0}$ & $\mathbf{5 1}$ & $\mathbf{5 8}$ & $\mathbf{1 6}$ & $\mathbf{4 3}$ & $\mathbf{5 0}$ \\
\hline Arjantin (104) & 143 & 89 & 111 & 61 & 49 & 145 & 144 & 133 & 88 & 24 & 143 & 147 \\
\hline Brezilya (56) & 80 & 71 & 75 & 89 & 72 & 123 & 92 & 50 & 55 & 9 & 39 & 55 \\
\hline Cin (29) & 47 & 48 & 10 & 40 & 70 & 61 & 34 & 54 & 85 & 2 & 45 & 32 \\
\hline Hong Kong SAR (7) & 9 & 1 & 12 & 31 & 22 & 2 & 3 & 1 & 6 & 27 & 14 & 23 \\
\hline
\end{tabular}

Tablo 2. Genel Rekabetçilik Stralaması Kaynak: World Economic Forum, “World Competitiveness Report 20132014”, ss.15-22 arasinda yer alan tablolardan derlenmiştir.

Etkinlik odaklı ekonomiden yenilikçi odaklı ekonomiye geçiş aşamasında yer alan ve genel rekabetçilik endeksinde 44. sırada yer alan Türkiye, yenilikçi odaklı ekonominin alt endeksleri olan işletmelerin gelişmişliğinde 43. sırada, yenilikçilik sıralamasında da 50. sırada yer almaktadır. Aşağıdaki Tablo ise Türkiye'nin yenilikçiliğin alt endeksleri açısından hangi durumda olduğunu göstermektedir. Tablonun ilk sütunu yenilikçiliğin alt endekslerini göstermektedir. Buna göre şirketlerin Ar-Ge harcamaları ve bilim adamları ve mühendislerin varlığı alt indekslerinde geriye gidiş söz konusu iken diğer alt indekslerde bir iyileşmenin olduğu görülmektedir. Türkiye bir yıl içerisinde, yenilikçilik kapasitesinde 3 basamak, bilimsel araştırma kurumlarının kalitesinde 25 basamak, Ar-Ge çalışmalarında üniversite sanayi işbirliğinde 18 basamak, hükümetlerin ileri düzey teknoloji temininde 9 basamak ilerleme kaydetmiştir.

\begin{tabular}{|l|c|c|c|c|}
\hline \multirow{2}{*}{ Yenilikçiliğin (İnovasyonun) Alt Göstergeleri } & \multicolumn{2}{|c|}{$2012-2013$ Raporu } & \multicolumn{2}{c|}{$2013-2014$ Raporu } \\
\cline { 2 - 5 } & Puan & Sıra & Puan & Sıra \\
\hline Yenilikçilik Kapasitesi & 3,4 & $\mathbf{4 8}$ & 3,8 & $\mathbf{4 5}$ \\
\hline Bilimsel Araştırma Kurumlarının Kalitesi & 3,4 & $\mathbf{8 8}$ & 3,7 & $\mathbf{6 3}$ \\
\hline Şirketlerin Ar-Ge Harcamaları & 3,2 & $\mathbf{5 6}$ & 3,1 & $\mathbf{6 8}$ \\
\hline Ar-Ge Çalışmalarında Üniversite Sanayi İşbirliği & 3,6 & $\mathbf{7 0}$ & 3,9 & $\mathbf{5 2}$ \\
\hline Hükümetlerin İleri Düzey Teknoloji Temini & 4,0 & $\mathbf{3 2}$ & 4,1 & $\mathbf{2 3}$ \\
\hline Bilim Adamı ve Mühendislerin Varlığı & 4,5 & $\mathbf{4 1}$ & 4,4 & $\mathbf{5 3}$ \\
\hline Patentler & 5,8 & $\mathbf{4 2}$ & 6,6 & $\mathbf{4 1}$ \\
\hline
\end{tabular}

Tablo 3. Yenilikçiliğin (İnovasyonun) Alt Göstergeleri Kaynak: World Economic Forum, "World Competitiveness Report 2012-2013" ve "World Competitiveness Report 2013-2014".

Türkiye ekonomisinin karşı karşıya olduğu bu sonucu Ohno (2009)'nun endüstrileşme sürecinde firmaların nasıl öğrendikleri ve geliştiklerine yönelik açıklamasında da bulmak mümkündür. Ohno'ya göre firmalar 4 aşamalı bir öğrenme süreci geçirerek gelişirler. Buna göre endüstrileşmenin ilk aşamasında firmalar yabancılardan elde ettikleri bilgileri kullanarak bir anlamda yabancıların rehberliğinde basit imalatta bulunurlar. İkinci aşamada, destekleyici endüstriler gelişir ve teknoloji transferi teknoloji ithal edilerek, lisans anlaşmaları yapılarak ve doğrudan yabancı yatırımlarla gerçekleştirilir. Üçüncü aşamada, firmalar yüksek kaliteli ürünleri üretebilmek için teknoloji ve yönetime hakim olmaya başlarlar. Dördüncü aşamada firmalar yenilikçilik (inovation) aşamasına geçerler. Orta gelir tuzağına yakalanan ülkeler genellikle ikinci aşamadan üçüncü aşamaya geçemeyen şirketlerin olduğu ekonomilerde görülmektedir.

\section{Thirlwall Yasası}

Gelişmekte olan ülkeler gelişmiş ülkelere göre sermaye birikimi veya teknolojik ilerlemeler yoluyla daha fazla gelişme potansiyeline sahiptirler (Kostakoğlu, 2011). Tasarrufları yetersiz olan ya da tasarrufları yeterli olduğu halde teknolojik altyapıları yeterli olmayan ülkelerin ihracatları büyük oranda yatırım ve aramalı ithalatına bağımlı kalmaktadır. İthalat giderlerinin ihracat gelirlerini aşmasından dolayı dış ticaret açıkları oluşmaktadır (Sever, 2009). Dış ticaret açıkları cari açıkların temel sebebi olmaktadır. Ödemeler bilançosunda meydana gelen cari açıklar sermaye girişleri tarafindan dengelenmektedir. Bir başka deyişle ülkeler bu açığı borçlanarak 
kapatmaktadırlar. Küresel ekonomiye entegre olmuş liberal ekonomilerde borçlanma daha kolay hale gelmekte ve daha yüksek cari açıklar oluşmaktadır. Büyümenin ithalata dayalı olduğu bu ülkelerde cari açıkla doğru orantılı bir büyüme ortaya çıkmaktadır (Kostakoğlu, 2011).

Thirlwall Kanunu, ABD ekonomisinde İkinci Dünya Savaşı sonrasında yaşanan dönemsel duraklamaların nedenlerini açıklamak için kullanılmıştır. Bu yasaya göre ekonomik büyümedeki yavaşlamanın temel nedeni ithalatta meydana gelen talep değişikliğidir. İthalat talebindeki değişiklikten dolayı cari işlemler dengesi toplam talebi ve ekonominin büyümesini kısıtlayıcı bir faktör olmaktadır. Cari açık ile ekonomik büyüme arasındaki ilişki üzerine yapılan araştırmalarda ekonomik büyümenin cari açığa neden olduğu bulunmuştur. Büyümede meydana gelen \%1'lik bir artışın cari açıkta \%0.21 artışa yol açmaktadır. Cari açıktan büyümeye doğru bir nedensellik bağı bulunamasa da sanayileşmiş ülkelerde cari işlemler açığı vermenin büyümeyi olumlu etkilediği sanayileşmemiş ülkelerde ise büyümeye katkı sağlamadığı sonucuna varılmıştır. Sanayileşmemiş ülkelerde aksine cari açığı azaltmanın ya da cari fazla vermenin büyümeyi olumlu etkilediği bulunmuştur (Kostakoğlu, 2011).

Yamak ve Abdioğlu (2010)'nun 1982-2008 dönemi için Türkiye'de Thirlwall Yasası'nın geçerliliğinin araştırıldığ çalışmasında ekonominin liberalleşme seviyesinin artmasıyla birlikte ithalatın gelir esnekliğinin yükselmesinden dolayı büyüme oranlarının ödemeler dengesi tarafından kısıtlandığı sonucu ortaya çıkmıştır (Kostakoğlu, 2011).

Türkiye ekonomisinde kişi başına düşen milli gelirin düşük olmasının nedenlerinden birisi de dış ticaret açısından Türkiye'nin karşı karşıya kaldığı kısır döngüdür. Kısır döngü, ihracata dönük sektörlerin de dahil olduğu yurt içi reel üretimin büyük oranda ara malı ithalatına bağımlı hale gelmesidir. Hem yurt içi hem de yurt dışı talebi karşılamak amacıyla üretim yapmak için ara malı ithalatını artırmak gerekiyor. Kısaca büyümeyi ve ihracatı artırmak için ithalat yapma zorunluluğu, rekabetçi olmayan ihracat ile bir araya geldiğinde cari açığın artmasına ve ödemeler bilançosunun dengelenmesinde kısa vadeli sermaye girişine bağımlılığın artmasına neden olmaktadır. Dolayısıyla ödemeler bilançosu dengesizliği büyüme üzerinde bir baskı oluşturmakta, bu baskıdan dolayı da büyüme oranlarını düşürmek için daraltıcı para ve maliye politikalarını uygulamak kaçınılmaz olmaktadır. Merkez Bankası’nın 2011 yılındaki yüksek büyüme ve yüksek cari açıktan dolayı büyüme oranlarını düşürmek için uyguladığı daraltıcı para politikasını bu çerçevede okumak gerekir.

Thirlwall Yasasında ileri sürülen temel teze göre eğer bir ülkede büyüme ödemeler bilançosu dengesi ile uyumlu olmayacak şekilde artıyorsa ödemeler bilançosundaki dengesizlik eninde sonunda büyüme oranları üzerinde bir baskı yaratacaktır. Ödemeler bilançosu açıklarının kapatılmasında her ne kadar kısa vadeli sermaye girişleri kullanılıyor ise de dış açığın kapatılması için devamlı bir şekilde kısa vadeli sermaye girişine bel bağlamak rasyonel bir davranış olmayacaktır çünkü dış borç giderek artacaktır. Yüksek büyüme oranları dış açığı giderek artıracak, artan dış açık giderek diş borçları artıracaktır. Bu durumla karşı karşıya kalmak istemeyen ülkeler ise büyüme oranlarını düşük tutmak zorunda kalacak dolayısıyla büyüme oranları düşecek, işsizlik artacak ve enflasyon yükselecektir. Dış açığı kapatmak için devalüasyonlara başvurmak da çare olmayacaktır çünkü bu politika uzun dönemde yurt içi enflasyon oranlarını artırarak bir taraftan ülkenin rekabetçiliğini olumsuz yönde etkilerken diğer taraftan dış açı̆̆ın giderek artmasına neden olacaktır (Halıcıoğlu, 2012). Bu yüzden hammadde ve aramalın ülke içinde üretimine önem verilmesi gerekiyor.

\section{1 İhracatın Durumu}

İhracattaki mevcut durumun ortaya çıkmasındaki temel nedenler yukarıda detaylı bir şekilde verilen düşük eğitim harcamaları, milli gelirden Ar-Ge için ayrılan payın düşük olması ve düşük patent başvurularıdır. Eğitim harcamalarının yüksek, Ar-Ge harcamalarının milli gelir içerisinde çok yer kapladığı ve patent başvurularının yüksek olduğu ekonomilerde ise ihraç edilen ürünlerin yüksek teknolojili, katma değeri yüksek ve nadir ürünler olduğu fark edilecektir.

Ülkelerin dış ticaretteki durumları hakkında daha detaylı bilgiler, Sabancı Üniversitesi ile TÜSİAD tarafından hazırlanan rekabet veri tabanından elde edilen bilgilerdir. Bu verilere göre, yüksek orta gelir gurubunda yer alan orta gelir tuzağına yakalanan Türkiye, Arjantin ve Brezilya tarafından ihraç edilen ürünler sıradan ürünlerdir ve o ürünleri ihraç eden ülkelere bir rekabet avantajı sağlamazlar. Yüksek gelir gurubunda yer alan Singapur ve Almanya ise sıradanlık endeksinde alt sıralarda yer almaktadır ki bu ülkelerin ihraç ettikleri ürünler genellikle nadir (sıradan olmayan, çok talep edilen) ürünlerdir ve o ülkelere dış ticarette önemli bir avantaj sağlar.

Ar-Ge, eğitim harcamaları ve patent başvuruları açısından bir diğer sonuç ise ihraç edilen ürünlerin düşük ya da yüksek teknolojiye dayanıp dayanmadığıdır. İleri teknoloji ve düşük teknoloji indeksine göre Singapur ve Almaya tarafından ihraç edilen ürünler önemli oranda yüksek teknolojiye dayanmaktadır. Ancak orta gelir tuzağına yakalanan Brezilya, Arjantin ve Türkiye tarafından ihraç edilen ürünler ise yüksek teknolojiye dayalı ürünler değildir. Sıradanlık endeksi ile ileri teknoloji endeksi bir arada düşünüldüğünde yüksek teknolojili ürünleri ihraç eden ülkeler tarafından ihraç edilen ürünlerin sıradan ürünler olmadıkları; buna karşılık üst orta gelir gurubunda bulunan ülkelerin ihraç ettikleri ürünlerin yüksek teknolojiye dayanmadığı ve sıradan ürünler oldukları ortaya çıkmaktadır. 
Türkiye İstatistik Enstitüsü’nün 30 Ocak 2015 tarihinde yayınladığı ve 2014 yılı 01 Ocak - 31 Aralık dönemini kapsayan diş ticaret verilerine göre (TÜİK, 2014) ihraç edilen imalat sanayi ürünleri içerisinde yüksek teknolojili ürünlerin payı $\% 3.4$, orta yüksek teknolojili ürünlerin payı \%31.6, orta düşük teknolojili ürünlerin pay1 \%29.2 ve düşük teknolojili ürünleri payı \%35.8' dir. Orta düşük ve düşük teknolojili ürünlerin oranı toplandığında yaklaşık $\%$ gibi bir oran etmektedir ve Türkiye'nin dış pazarlarda neden çok fazla rekabetçi olamadığını açıklamaktadır.

\section{2 İthalatın Durumu}

Türkiye'de ithalatın yüksek düzeylerde seyretmesinin temel nedenleri enerji dahil ara malı ithalatının \% 75 'lere varan oranlarda olmasıdır. TUİK tarafından yayınlanan dış ticaret istatistiklerindeki Geniş Ekonomik Grupların Sınıflamasına (BEC) göre 2014 yılında yapılan 242 milyar dolarlık ithalatın 176 milyar doları ara mallarından, 35 milyar doları yatırım mallarından, 29 milyar doları tüketim mallarından oluşmaktadır. Oransal olarak bakıldığında toplam ithalat içerisinde ara malı ithalatının yaklaşık \% 72'lik bir orana tekabül ettiği görülmektedir. $\mathrm{Bu}$ durum büyük oranda önceki yıllarda da geçerlidir. Yine dış ticaret istatistiklerindeki Uluslararası Standart Sanayi Sınıflaması (ISIC, Rev.3)'e göre 2014 yılında yapılan toplam 242 milyar dolarlık ithalat içerisinde imalat sanayi ürünlerinin 187 milyar dolarla (\%77'lik bir orana denk gelmektedir) en yüksek paya sahip olduğu ve bu değer içerisinde de 34.8 milyar dolarlık kimyasal madde ve ürünlerin; 18 milyar dolarlık kok kömürü, rafine edilmiş petrol ürünleri ve nükleer yakıtların; 26.4 milyar dolarlık ana metal sanayi ürünlerinin ilk sıralarda yer aldığı görülmektedir (TUİK, 2014).

İhracatın ve ithalatın ara malları üzerinde yoğunlaşması, Yükseler ve Türkan (2008)’ın da dikkat çektikleri üzere endüstri içi ticaretin arttığı anlamına gelir. Endüstri içi ticaretin artması üretim sürecinde yaratılacak katma değerden ülkenin daha az yararlanacağı anlamına gelir. Ayrıca artan endüstri içi ticaret ihracatın kur değişimlerine vereceği tepkiyi de azaltacaktır (Saygılı, vd, 2010).

İthal edilen ürünlerin teknolojik yoğunluklarına bakıldığında ise TUİK verilerine göre 2014 yılında ithal edilen toplam imalat sanayi ürünlerinin \%14'ünün yüksek teknolojili, \%42.1'inin orta yüksek teknolojili, \%30.3'ünün orta düşük teknolojili ve \%13.5'inin düşük teknolojili ürünler olduğu görülmektedir (TÜİK, 2014). Bu durum ithal edilen imalat sanayi ürünlerinde yüksek teknolojili ürünlerden ziyade orta yüksek, orta düşük ve düşük teknolojili ürünlerin daha fazla yer tuttuğunu göstermektedir.

Geniş Ekonomik Grupların Sınıflamasına göre ihracat ve ithalat içerisinde en yüksek paya ara malları sahiptir. Yani Türkiye dış ticareti büyük oranda ara malı ihracatı ve ithalatı üzerinde yoğunlaşmıştır. Uluslararası Standart Sanayi Sınıflamasına (TUIK) göre ise imalat sanayi ürünleri hem ihracat hem de ithalat içerisinde en yüksek paya sahiptir. Ancak imalat sanayi ürünlerinin hem ihracatı hem de ithalatı büyük oranda düşük, orta düşük ve orta yüksek teknolojili ürünlerde yoğunlaşmaktadır. Bu durum dış ticarette rekabet kaybı anlamına geldiği gibi dış ticaretin yapısal olarak sorunlu olduğunu da ortaya koymaktadır. Ara malı ihracatı ve ithalatı üzerine yoğunlaşan bir dış ticaret yapısı içerisinde döviz kuru düzenlemeleriyle ihracatta ve ithalatta kalıcı bir iyileşme sağlamak mümkün değildir. İhracata dayalı bir büyüme modelindeki temel handikap budur ve bu durum düzeltilmediği müddetçe Türkiye'de ödemeler bilançosu dengesizlikleri büyüme üzerinde önemli bir kısıtlayıcı olmaya devam edecektir.

Ekonomi Bakanlığı'na (2012) göre ara malı ithalatının bu kadar yüksek olması;

$\checkmark$ Yurt içerisindeki üretimi, girdi fiyatlarındaki ve kaynaklarındaki belirsizliklere açık hale getirmektedir.

$\checkmark \quad$ Yurt içi katma değerin istenilen düzeye çıkarılmasına engel olmaktadır.

$\checkmark$ Cari açı̆̆a neden olmaktadır

$\checkmark \quad$ İhracatta sürdürülebilir bir rekabet avantajı elde etmeyi engellemektedir.

Dolayısıyla Amerika Birleşik Devletleri, Japonya, Singapur ve diğer önde gelen ülkelerin yaptı̆̆ı gibi girdi tedarikini güvence altına alacak ve girdi temininde ithalata olan bağımlılığı azaltacak politikaların izlenmesi kaçınılmazdır.

Buraya kadar yapılan analizden orta gelir tuză̆ına yakalanan ülkeler ve elbette Türkiye ekonomisi için iktisat politikaları açısından bazı sonuçlar ortaya çıkmaktadır.

$\checkmark$ Her şeyden önce orta gelir tuzağına yakalanan ülkelerde kamunun eğitim için ayırdığı pay oldukça düşüktür.

$\checkmark \quad$ Bu ülkelerde Ar-Ge harcamalarının milli gelir içerisindeki payı oldukça düşüktür.

$\checkmark$ Patent başvuruları oldukça düşüktür.

Yukarıda ilgili yerlerde de değinildiği üzere, tek başına eğitim harcamaları, tek başına Ar-Ge harcamaları ya da patent başvuruları bir ülkenin orta gelir tuzağından kurtulması için yeterli değildir. Dünya Ekonomik Forumu tarafından hazırlanan ve ülkelerin rekabetçiliği ölçen raporlar bunu çok güzel bir şekilde ortaya koymaktadır. Orta gelir tuzağından kurtulabilmesi için bir ülkenin politikalar seti oluşturarak sorunu çözmesi gerekir. Özellikle Türkiye'de kamunun eğitim ve teknoloji alanında yaptığı harcamaları niceliksel ve niteliksel olarak artırması gerekir ki orta gelir tuzağından kurtulmak mümkün olsun. 


\section{Orta Gelir Tuzağından Kurtulmak İçin Yapılması Gerekenler}

Türkiye ekonomisine ilişkin olarak ortaya konulan veriler, Türkiye'de orta gelir tuzağına yol açan faktörlerin genellikle yapısal olduğunu ortaya koymaktadır. Dolayısıyla tuzaktan kurtulmanın yolu da yapısal önlemler almaktan geçmektedir. Yapısal yaklaşım çerçevesinde büyüme süreci basit bir emek - sermaye bileşimiyle açıklanabilecek bir süreç değildir. Emek ve sermayenin yanı sıra eğitim, alt yapı, mal ve hizmet piyasaları ile emek piyasasının durumu, teknolojik kapasite, yenilikçilik kapasitesi ve bu kapasitelerdeki artış vb. çok sayıda unsur bir ülkenin büyüme hızını ve ülkedeki kişi başına düşen gelir düzeyini belirler. Dolayısıyla orta gelir tuzağına yakalanan ülkelerin bu tuzaktan kurtulmaları için üretimde yapısal dönüşümleri gerçekleştirerek yüksek teknolojili ve yenilikçi ürünlere geçmeleri gerekmektedir. Bu yapısal dönüşüm özellikle küreselleşmenin bütün boyutlarıyla uluslararası rekabeti artırdığı günümüz dünyası için kaçınılmaz bir zorunluluktur (Paus, 2014).

Türkiye'nin orta gelir tuzağından kurtulabilmesi için sürdürülebilir bir büyüme patikasına girmesi gerekir. Ayrıca 1980 sonrası süreçte dışa açık kalkınma modeli benimsendiği için dış ticaretin büyümeye net katkısının pozitif olması bunun için de ihracatın artırılması ve özellikle ara malı ithalatına olan bağımlılığın azaltılması gerekir. Bu bağlamda;

$>$ Devletin eğitime ayırdığı kaynakları artırması, eğitimde hem nicelik hem de niteliksel ilerlemelerin kaydedilmesi gerekir. Eğitimdeki niteliksel gelişmeler, yeni buluşları gerçekleştirecek beyin gücünü artıracağı için patent başvurularını doğrudan etkileyecektir.

> Ekonomi Bakanlığı tarafından geliştirilen Girdi Tedarik Stratejisinin etkin bir şekilde hayata geçirilerek ara malı ithalatı bağımlılığının azaltılması gerekir. Bu gerçekleştirildiği takdirde üretilen katma değerin önemli bir kısmı yurt içerisinde kalacağı için toplumun paylaşılabileceği pasta giderek büyüyecek ve kişi başına düşen gelir hızla artacaktır.

> İhracatçı sektörlerde yüksek teknolojili - yüksek katma değerli ürünlerin üretilmesi ve bu sektörlerde yenilikçilik faaliyetlerinin teşvik edilmesi gerekir.

$>$ Ar-Ge faaliyetlerinde özel kesim kamu işbirliğinin geliştirilmeli, Ar-Ge için ayrılan kaynakların milli gelir içerisindeki oranı artırılmalıdır.

$>$ Teknolojiye yatırım yapan şirketlere yönelik kamu teşvikleri artırılmalıdır.

$>$ Bilimsel araştırma yapan kurumların kalitesinin artırılması için bu kurumlara yönelik devlet teşvikleri artırılmalı.

> Daha gerçekçi kur politikası takip edilerek ihracattan elde edilen gelirlerin artırılmasına gayret edilmelidir.

\section{Kaynakça}

- Agenor ve Canuto, 2012. "Middle İncome Growth Traps", World Bank Policy Research, (6210), 1-40.

- Agenor, vd, 2012. "Avoiding Middle-Income Growth Traps", Economic Premise, 98, The World Bank, Washington, s. 1.

- $\quad$ Aiyar, vd, 2013. "Growth Slowdowns and the Middle-Income Trap", IMF Working Paper, No: WP/13/71, p. 3.

- Bozkurt, vd, 2014. "Orta Gelir Tuzağı ve Türkiye Örneği”, Maliye Dergisi, Sayı 167, Temmuz-Aralık, ss. 24.

- Eğilmez, 2012. Orta Gelir Tuzağı ve Türkiye, http:/www.mahfiegilmez.com/2012/12/orta-gelir-tuzag-veturkiye.html

- Eichengreen, vd, 2012. "When Fast-Growing Economies Slow Down: International Evidence and Implications for China", Asian Economic Papers, 11:1, 42-46.

- Ekonomi Bakanlığı, 2012. Girdi Tedarik Stratejisi (GíTES) ve Eylem Planı $2013 \quad$ - 2015, www.ekonomi.gov.tr., s. 13.

- Felipe, 2012. Tracking the Middle-Income Trap: What is It, Who is in It, and Why?, Asian Development Bank Working Paper Series, No. 306, March.

- Flaen, vd, 2013. "How to Avoid Middle İncome Traps? Evidence From Malaysia", The World Bank, I (6427), 1-53.

- Ghani, vd, 2013. "How to Avoid Middle Income Traps?”, blogs.

- Gill, vd, 2007. “An East Asian Renaissance: Ideas for Economic Growht.”, World Bank Publications, The World Bank, Washington, ss.4-5.

- Gill ve Kharas, 2009. "Gravity and Friction in Growing East Asia" Oxford Review of Economic Politic, Special Issue, April 25: 190-204.

- Halıcıoğlu, 2012. "Balance of Payments - Constrained Growth: The Case of Turkey“, Journal of Post Keynesian Economics, Vol. 35, No. 165, Fall, pp. 64-77.

- Karahan, 2012. "Kalkınma Yolunda Yeni Eşik: Orta Gelir Tuzağı (Rapor No: 79)”, Türkiye Ekonomisi Raporu, İstanbul: MÜSİAD, s. 97. 
- Kostakoğlu, 2011. “Türkiye'de Cari Açık ve Ekonomik Büyüme İlişkisinin Var Yöntemi İle Analizi”, EconAnadolu 2011: Anadolu İnternational Conference in Economics II, June 15-17, Eskişehir.

- Kritayanavaj, vd, 2012. “ Breaking Out of Middle Income Trap”, Asia- Pasific Housing Journal, 6(20), 9096.

- Ohno, 2009, "The Middle Income Trap. Implications for Industrialization Strategies in East Asia and Africa", GRIPS Development Forum, National Graduate Institute for Policy Studies, Japan.

- Öz, 2012. "Orta Gelir Tuzağı”, Ekonomik Araştırma Formu (EAF) Politika Notu 12-06, Ağustos, 1-4.

- Öztürk, vd, 2012. Kalkınma Yolunda Yeni Eşik: Orta Gelir Tuzağı, İstanbul: Mavi Ofset, s. 96.

- Paus, 2012. "Confronting the Middle Income Trap: Insights from Small Latecomers", Springer Science, 115-139.

- Paus, 2014. "Latin America and Middle Income Trap", Financing for Development Series No:250, United Nations Publications, ISSN: 1564-4197, pp. 13-14.

- Robertson ve Ye, 2013. "On The Existence Of A Middle Income Trap”, The University of Western Australia, Economics Discussion Paper 13.12, February 2013: 7.

- Saygılı, vd, 2010. “Türkiye İmalat Sanayiin İthalat Yapısı”, TCMB Çalışma Tebliği, No:10/02, s. 9.

- Sever, 2009. Finans, Dış Ticaret ve Büyüme İlişkisi: Türkiye Analizi. Konya: Çizgi Kitabevi, Nisan.

- Spence, 2011. The Next Convergence: The Future Of Economic Growth in a Multispeed World, New York: Farrar Straus Grioux.

- $\quad$ TUİK, 2014. D1ş Ticaret İstatistikleri Haber Bülteni, www.tuik.gov.tr/PreHaberBultenleri.do?id=18575.

- TÜSIAD - Sabanci Üniversitesi Rekabet Forumu Veri Taban1, http://ref.sabanciuniv.edu/tr/veritabanlari/disticarette-rekabet-kiyaslamasi

- Woo, 2012. "China Meets the Middle-Income Trap: The Large Potholes in the Road to Catching-up", Journal of Chines Economic and Business Studies, 10(4), 314-336

- World Bank, 2013a. "Country and Lending Groups", data.worldbank.org: http://data.worldbank.org/about/country-classifications.

- World Bank, 2013b. "How We Classify Countries?", data.worldbank.org: http://data.worldbank.org/about/country-classifications.

- Worldbank.org, 2015. htttp:// blogs. Worldbank.org/developmenttalk/how-avoid-middle-income-traps

- World Economic Forum, http.//www3.weforum.org/docs/WEF_GlobalCompetitivenessReport 2013-14.pdf.

- Yeldan, vd, 2012. Orta Gelir Tuzağından Çıkış: Hangi Türkiye. Makro/Bölgesel/Sektörel Analiz, Türk Girişim ve İş Dünyası Konfederasyonu Yayını, Cilt 1, ISBN: 978-9944-0172-7-5, Sis Matbaacılık, İstanbul.

- Yükseler ve Türkan, 2008. Türkiye'nin Üretim ve Dış Ticaret Yapısında Dönüşüm: Küresel Yönelimler ve Yansımalar. TÜSİAD Yayınları, No: TÜSİAD-T/2008-02/453, İstanbul. 


\title{
Kazakistan Ekonomisinde Ekonomik Büyümenin Kaynakları: Girdi-Çıktı Analizi Yaklaşımıyla Bir İnceleme \\ The Sources of Economic Growth in Kazakhstan Economy: An Input-Output Analysis Approach
}

\author{
Assoc. Prof. Dr. Tuncer Özdil (Celal Bayar University, Turkey) \\ Asst. Prof. Dr. Aynura Turdalieva (Kyrgyzstan-Turkey Manas University, Kyrgyzstan)
}

\begin{abstract}
The input - output analysis reflects the production-consumption relationship between the economic production sector in a country's economy and widely applied as an analytical technique of economic analysis in both developed and developing countries. At the same time, this technique is the macroeconomic analysis tool for identifying sectoral economic relations in the industry by production and consumption dimensions.

For this study, input-output tables for Kazakhstan for the period of 2006-2013 were used. Tables consist of the same content and number of sectors and the sources of economic growth for the given period was calculated by Syrquin Decomposition model. Syrquin Model is a demand-side approach, which decomposes economic growth into four main sources: domestic demand expansion, export expansion, import substitution and technological change. Also, the study investigates the source of production increase occurred in any economic production sectors.

Within this framework, the results will be obtained for aggregated main 8 sectors and whole the economy. Admittedly, the results will give insight into the effectiveness of macroeconomic policies implemented in Kazakhstan. This aspect of the research results is expected to contribute to the creation of a more rational economic policy.
\end{abstract}

\section{Giriș}

Bir ekonomide sektörel üretim artışlarının kaynaklarının belirlenmesi hem geçmişte uygulanan iktisadi politikaların etkinliğinin değerlendirilmesi hem de gelecekte uygulanacak makroekonomik politikaların daha rasyonel şekillendirilmesi bakımından büyük önem taşımaktadır. Bunun yanısıra bu analiz; ekonomide yapısal dönüşüme neden olan endüstrilerin belirlenmesine yolaçarak kaynakların daha rasyonel kullanımına da imkan vermekte bu yolla ekonomik sorunların çözümüne de katkı sağlamaktadır.

Çalışmamızda, Girdi-Çıktı Analizi yaklaşımıyla Kazakistan ekonomisindeki ekonomik büyümenin kaynakları araştırılmaktadır. Sözkonusu araştırma; sektör sayısı ve kapsam bakımından birbirinin aynı, yayınlanmış son tablolar olan 2010-2013 yılı girdi-çıktı tabloları yardımıyla Syrquin yapısal ayrıştırma modeli kullanılarak yapılmıştır. Talep yönlü bir yaklaşım olan Syrquin Yapısal Ayrıştırma Modeli, ekonomik büyümeyi dört ana kaynağa ayrıştırmaktadır. Bunlar; yurt içi nihai talep, ihracat, ithal ikamesi ve girdi katsayılarındaki değişmeyle tanımlanan teknolojik gelişmedir. Burada herhangi bir ekonomik üretim sektöründe meydana gelen üretim artışının ne kadarının hangi kaynaktan kaynaklandığı araştırılmaktadır.

Makroekonomik anlamda elde edilen verilerin daha kolay yorumlanarak daha çarpıcı sonuçların elde edilebilmesi bakımından ayrıştırma işlemi sekiz ana sektör üzerinden yapılmıştır. $\mathrm{Bu}$ nedenle Kazakistan ekonomisine ait olan girdi-çıktı sonuç tabloları sekiz ana sektör üzerinden toplulaştırılarak dönem içinde bu sektörlerdeki üretim artışlarının kaynakları belirlenmiştir. Araştırmayla ulaşılan sonuçların Kazakistan'da uygulanan makro-ekonomik politikaların etkinliği hakkında fikir vereceği ve bu yönüyle daha rasyonel ekonomik politikaların oluşturulmasına katkı sağlayacağı düşünülmektedir.

\section{Kazakistan Ekonomisi}

1991 yılında bağımsızlığını kazanarak eski Sovyetler Birliği'nden ayrılan Kazakistan Cumhuriyeti günümüze kadar geçen yaklaşık 20 yıllık süreçte bağımsızlığını koruyarak kendi ayakları üzerinde durabilecek şekilde ekonomisini geliştirme çabasında olmuştur. Eski Sovyet sistemindeki diğer cumhuriyetlere bağımlılığı zorunlu kılan tüm cumhuriyetlerin tek merkeze bağlı olduğu ekonomik sistemden çıkarak kendi kendine yeten bir ekonomik yapıya kavuşmak hiç de kolay değildir. Buna bir de merkezden planlı ekonomiden serbest piyasa ekonomisine geçişin sancıları da eklendiğinde tüm geçiş ekonomilerinde olduğu gibi Kazakistan ekonomisi için de ekonomiyi güçlendirme çabalarıyla geçen bu süreç; hiç kolay olmamış tam tersi krizlerle dolu sıkıntılı bir dönem yaşanmıştır.

Bu geçen 20 yıllık süreçte Kazakistan ekonomisi 3 ayrı ekonomik kriz yaşamıştır. Birinci kriz 1990’lı yılların başlarında ortaya çıkan "(glasnost-perestroyka) şeffaflık ve yeniden yapılanma” kavramlarıyla açıklanan, SSCB’nin dağılmasını sağlayan krizdir. Kazakistan ekonomisi bu krizi ancak 1997-1998 yıllarında 
atlatabilmiştir. Bu dönemde arzu edilen ekonomik hedeflere ulaşılamamış, ekonomik büyüme ve gelişme gerçekleştirilememiştir. İkinci kriz 1998 yılında yaşanan Asya krizi olmuştur; üçüncü kriz ise 2007-2008 yılların ortaya çıkan batı kaynaklı küresel mali kriz olmuştur. Bu krizler tüm geçiş ekonomilerini olduğu gibi Kazakistan'1 da olumsuz yönde etkilemiş ekonomik büyümenin yavaşlamasına neden olmuştur (Алшанов Р., 2012).

Ancak bu arada belirtmek gerekir ki, bu krizlerin olumsuz etkilerinin giderilerek ekonomik büyümenin sağlanması ekonomide ihracatın arttırılmasıyla gerçekleşmiştir. Özellikle hammadde ihracatındaki artışlar ve dışa açılma çabaları bu sürecin en önemli unsurlarıdır. Dışa açılma çabalarının doğal sonucu olarak ülke ekonomisi dış dünyayla bütünleşebiliyorsa kuşkusuz bu Kazakistan için olumlu bir sonuçtur. Ama bu bütünleşmenin katma değeri düşük ürünlerin ihracatı yoluyla dışa bağımlılığı arttırıyor olması ve ülkeyi dış şoklara daha açık hale getirerek ekonomik kırılganlığı arttırıyor olması da ülke ekonomisi için bir olumsuzluktur (О. Сабден, 2008). Ancak tüm bunlara rağmen sürekli ve yüksek ekonomik büyüme hıları, uluslararası piyasalarda iyi bir konumda olma, ekonomide uygun yapısal değişimin gerçekleşmesi, yenilikçi ve toplumsal yönü kuvvetli ekonominin varlığı ülkedeki temel sorunların çözümüne imkan vermektedir (О. Сабден, 2008).

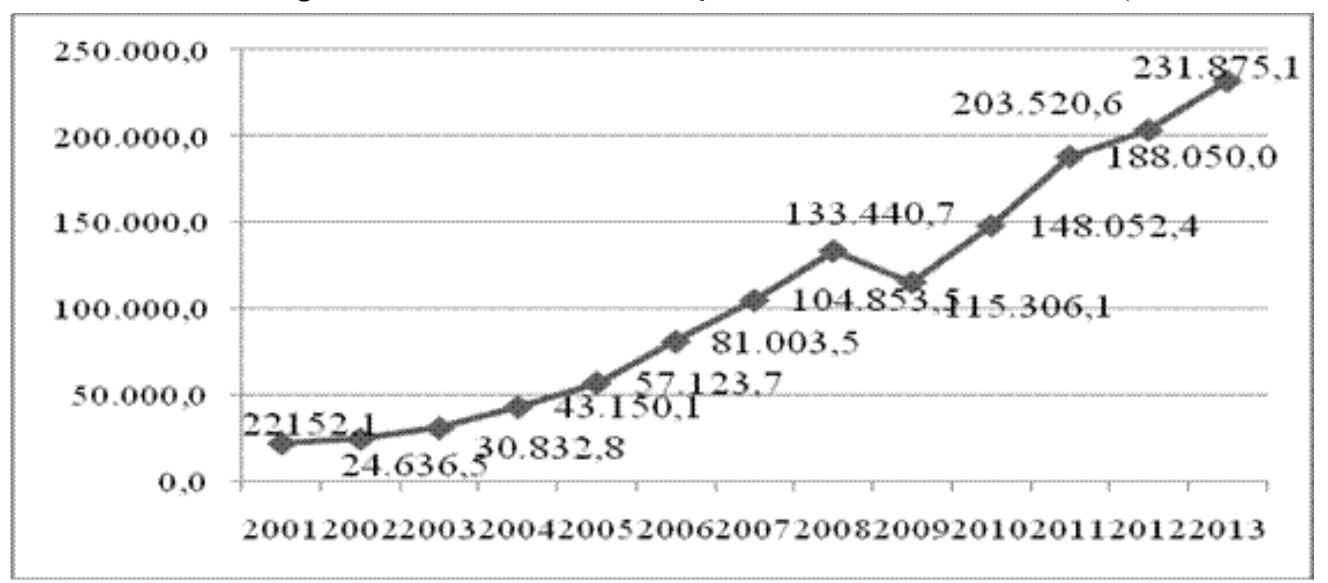

Grafik 1. 2010-13 Dönemi Kazakistan Ekonomisi Gayrisafi Yurtiçi Hasılası (mln US). Kaynak: Kazakistan Cumhuriyeti Istatistik Komitesi, www.stat.gov.kz

Grafikten de anlaşılacağı gibi, 2001-13 döneminde Kazakistan Ekonomisi’nde GSYİH genel olarak artış göstermektedir. 2009 yılındaki küresel kriz nedeniyle gerçekleşen azalmayı saymazsak dönem içinde GSYİH yaklaşık olarak 22 milyar dolardan 231 milyar dolara çıkmıştır.

GSYIH'nın sektörel dağılımına bakıldığında; İstatistik Komitesi verilerine göre, 2010-13 döneminde hizmet sektörü yaklaşık \%50'lik paylarla ençok paya sahip sektördür. 2010 yılında hizmet sektörünün milli gelirdeki pay1 \%51,7 iken 2013’te bu oran \% 54,2 olmuştur. İkinci sırada Sanayi sektörleri yeralmaktadır. Sanayinin payı 2010 yılında \% 45,1 iken 2013 yılında azalarak \%39,1 olmuştur. Üçüncü sırada ise tarım sektörü bulunmaktadır. Tarım'ın milli gelirdeki payı 2010'da \% 4,5 iken 2013'te \%4,6'dır. Sanayi sektöründe en büyük pay madencilik

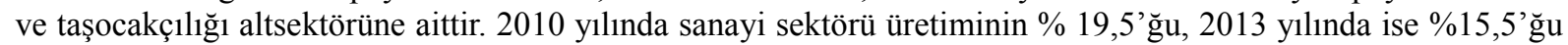
bu sektöre aittir. Sanayi'de ikinci sırada ise imalat altsektörü yer almaktadır. 2010 yılında imalat sanayilerinin pay1 \%11,3 iken, 2013'te \% 10,9'dur.

Kazakistan ekonomisinde hizmet sektörü incelendiğinde, ilk sırayı 2010'da \%13 ve 2013'te \% 15,4 paylarla toptan ve perakende ticaret ve motorlu taşıtlar ve motosiklet onarımı almakta. İkinci sırayı ise, \% 8,6 payla gayrimenkul alım-satım işlemleri almakta, Üçüncü sırada da, sırasıyla \% 8 ve \% 7,8 paylarla ulaştırma, taşıma ve depolama faaliyetleri alt hizmet sektörleri yeralmaktadır.

Toplam yatırımların sektörel dağılımında, ülkede hammadde ihracatına dayalı bir ekonomik sistemin bulunuyor olmasına paralel olarak, yaklaşık \%33'lük payla madencilik ve taşocakçılığı sektörü en yüksek paya sahiptir. Buna paralel olarak 2012 yılında toplam ihracatın \% 77.9, 2014'te ise, \% 83.5'ini maden ürünleri ihracatı oluşturmaktadır. Kazakistan ithalatına bakıldığında ise, söz konusu dönemde 2012'de toplam ithalatın \% 39.4'ü ve 2014'te ise \% 43.2'i makine-teçhizat, araç ve cihazlar ürünleri oluşturmaktadır. Tüm geçiş ekonomilerinde olduğu gibi, Kazakistan'da hammadde ihraç edip karşılığında katma değeri yüksek çeşitli makinaları ithal eden ülke konumunda yeralmaktadır.

Kazakistan ekonomik politikası son 21 yıl içinde ekonominin içinde bulunduğu doğal koşullara göre serbest piyasa ekonomisini oluşturma amacına yönelik olarak 'Kazakistan-2030' stratejisi çerçevesinde oluşturulmaktayd1. Ancak bu stratejinin kabul edilmesinden sonra ekonomik konjonktürde ortaya çıan değişme ve gelişmelerle 'Kazakistan-2050' stratejisinin kabul edilmesi ihtiyacı ortaya çıkmış ve bu strateji kabul edilmiştir. $\mathrm{Bu}$ stratejinin amacı; yabancı yatırım ve yüksek iç tasarruflarla finanse edilen serbest piyasa ekonomisine dayalı sürekli bir ekonomik büyümenin sağlanmasıdır. Bu amaç doğrultusunda; 2050 yılına kadar 
devletin makroekonomik politikalarının revizyonu, altyapı yatırımlarına önem vererek planlama, kamu kaynaklarının etkin yönetimi, doğal kaynaklar yönetimi, endüstrileşmenin gelecekteki seyrinin planlanması, tarım sektörünün modernizasyonu ve su kaynaklarının korunması ve arttırılmasına yönelik yeni strateji, politika ve planların geliştirilmesi hedeflenmektedir. Böyle bir süreçte ekonomide endüstriyel büyümenin kaynaklarının belirlenerek daha etkin makroekonomik politikaların hazırlaması çok daha önemli hale gelmektedir.

\section{Girdi-Çıktı Analizi Yaklaşımıyla Ekonomik Büyümenin Kaynakları}

Bir ekonomide sektörel üretim artışlarının kaynaklarının belirlenmesinde girdi-çıktı modelleri çerçevesinde farklı teknikler kullanılmaktadır. Girdi-çıktı modelleri çerçevesinde büyümenin kaynaklarının belirlenmesinde en sık kullanılan yöntemlerin başında ayrıştırma (decomposition) çözümlemesi gelmektedir. Ayrıştırma tekniğinin değişik şekilleri olmakla birlikte, sektörel üretim düzeylerindeki değişmeler genellikle dört unsurun etkisine ayrıştırılır: (1) yurtiçi nihai talepteki değişmelerin etkisi, (2) ihracat talebindeki değişmenin etkisi, (3) ithal ikamesinin etkisi ve (4) teknolojik değişmenin etkisi. İthal ikamesinin ölçülmesindeki farklılıklara bağlı olarak, değişik ayrıştırma modelleri elde edilebilmektedir (Aydoğuş, 2010, s.144).

Bu tür ayrıştırma çalışmalarında M.Syrquin tarafından geliştirilen ayrıştırma modeli kullanılmaktadır. Söz konusu modelin iki versiyonu bulunmaktadır. Birincisi, sapmalar versiyonu, ikincisi de toplam paylar versiyonu olmaktadır. Bu çalışmada toplam paylar yöntemi kullanılmaktadır. Bu yöntemin hareket noktası açık ekonomi için temel Leontief Girdi-çıktı modelinin denge üretim denklemleridir. i sektörü için denge üretim denklemi,

$$
X_{i}=d_{i}\left(V_{i}+Y_{i}\right)+E_{i}
$$

(1) numaralı denklemde, $X_{i}-i$ sektörünün yurtiçi üretimi, $d_{i}$ - i sektörünün aragirdi talebi, $V_{i}-$ yurtiçi nihai talep ve $\mathrm{E}_{\mathrm{i}}$ - ihracat talebini göstermektedir. $\mathrm{d}_{\mathrm{i}}$ katsayısı ithal ikame etkisini ölçmek için geliştirilmiş̧tir,

$$
d_{i}=\left(X_{i}-E_{i}\right) /\left(V_{i}+Y_{i}\right)
$$

(2) numaralı denklemde paydadaki terim i malına olan toplam yurtiçi talebi, paydaki terim ise yurtiçi üretime olan yurtiçi talebi göstermektedir. $\mathrm{d}_{\mathrm{i}}$ katsayısının paydasındaki terim net arzı;

$$
\left(\mathrm{V}_{\mathrm{i}}+\mathrm{Y}_{\mathrm{i}}=\mathrm{X}_{\mathrm{i}}+\mathrm{M}_{\mathrm{i}}-\mathrm{E}_{\mathrm{i}}\right)
$$

göstermektedir. Dolayısıyla, i malı ithalatındaki bir artış, paydanın büyümesine ve böylece $d_{i}$ katsayısının küçülmesine yol açacaktır. Buna bağlı olarak, pozitif ithal ikamesi olduğunda katsayı büyüyecektir ya da tersi. $\mathrm{d}_{\mathrm{i}}$ katsayıları bu anlamda yurtiçi arz katsayıları olarak yorumlanabilir (Aydoğuş, 2010, s.145).

$\mathrm{Bu}$ sistem matris notasyonu ile yeniden yazılır ve yurtiçi üretim vektörü $\left(\mathrm{X}_{\mathrm{i}}\right)$ için çözülürse, denge çözüm denklemi,

$$
X=(I-D A)^{-1}(D Y+E)
$$

(3) numaralı denklemde $\mathrm{D}$ anaköşegen üzerindeki elemanları $\mathrm{d}_{\mathrm{i}}$ katsayılarından oluşan bir köşegen matristir.

(3) denkleminden $\mathrm{R}=(\mathrm{I}-\mathrm{DA})^{-1}$ kısaltması yapılır ve denklemin birinci farkı alınırsa,

$$
\begin{gathered}
\Delta X=R(t) D(t) \Delta Y+R(t) \Delta E+ \\
R(t) \Delta D[Y(t+1)+V(t+1)]+R(t) D(t) \Delta A X(t)
\end{gathered}
$$

(4) numaralı denklemde gösterildiği gibi, fark denklemi elde edilir, burada $\Delta$ simgesi ilgili değişkende $t$ dönemi ile $(t+1)$ dönemi arasında ortaya çıkan değişmeyi göstermektedir(Aydoğuş, 2010, s.146). Temel ayrıştırma denkleminin sol yanındaki terim, ele alınan dönemde sektörel üretimde ortaya çıkan değişmeleri; sağ yanındaki $R(t) D(t) \Delta Y$ - sektörel üretimlerdeki değişmelerin yurtiçi nihai taleplerde ilgili dönemde ortaya çıkan değişmelerden, $R(t) \Delta E$ - ihracat değişmelerinden, $R(t) \Delta D[Y(t+1)+V(t+1)]$ - ithal ikamesinden, $R(t) D(t) \triangle A X(t)$ girdi katsayılarındaki değişmelerden kaynaklanan kısımlarını, değerlerini vermektedir. Denklemin her iki yanındaki terimler $\Delta \mathrm{X}_{\mathrm{i}}$ 'e bölündüğünde, üretim değişmelerinin kaynakları göreli olarak elde edilmiş olacaktır (Aydoğuş, 2010, s. 146).

\section{Kazakistan Ekonomisi’nde Sektörel Büyümenin Kaynakları}

Kazakistan ekonomisi için 2010 ve 2013 yıllarına ait ekonomik büyümenin kaynaklarının incelenmesi girdiçıktı analizi yaklaşımıyla yapılmaktadır. Bu amaçla Kazakistan Cumhuriyeti Ekonomi Bakanlığı İstatistik Komitesi tarafından hazırlanan; sektör sayısı, kapsam ve içerik bakımından birbirinin aynı son yayınlanmış tablolar olan 2010 ve 2013 yıllarına ait girdi-çıktı tabloları kullanılmıştır. 68 sektörden oluşan tablolar genel olarak ekonomiyi temsil eden sekiz ana sektör üzerinden toplulaştırılmış̧ır. Bu toplulaştırma işleminde Tarım sektörü orijinal tablolarda yeralan 01-03 numaralar arasında kalan alt sektörlerin, Madencilik, 04-08 numaralar arasında kalan alt sektörlerin, Genellikle Tüketim Malı Üreten Sanayiler 09-15 arasındaki alt sektörlerle 30 numaralı Mobilya üretimi altsektörünün, Genellikle Aramalı Üreten Sanayiler 15-22 arasındaki alt sektörlerin, 
Genellikle Yatırım Malı Üreten Sanayiler 23-29 arası alt sektörlerle 31 ve 32 numaralı altsektörlerin, Enerji 33 , 34 numaralı alt sektörlerin, İnşaat 35 numaralı alt sektörün ve Hizmetler kalan 36-68 numaralar arasında kalan alt sektörlerin toplulaştırılmalarıyla oluşturulmuşlardır. Döneme ait ekonomik büyümenin kaynakları Syrquin yapısal ayrıştırma modeli ile belirlenmeye çalışılmıştır. Çalışmada herhangi bir ekonomik üretim sektöründe meydana gelen üretim artışının ne kadarının hangi kaynaktan kaynaklandığı belirlenerek elde edilen sonuçlar tablo 1'de gösterilmiştir.

\begin{tabular}{|l|r|r|r|r|}
\hline $\begin{array}{l}\text { Ekonomik Üretim } \\
\text { Sektörleri }\end{array}$ & $\begin{array}{c}\text { Yurtiçi talep } \\
\text { artışı pay1 }\end{array}$ & \multicolumn{1}{|c|}{$\begin{array}{c}\text { İhracat artış } \\
\text { pay1 }\end{array}$} & \multicolumn{1}{c|}{$\begin{array}{c}\text { İthal ikamesi } \\
\text { pay1 }\end{array}$} & \multicolumn{1}{c|}{$\begin{array}{c}\text { Teknolojik } \\
\text { değişme payı }\end{array}$} \\
\hline Toplam & $\mathbf{7 2 . 0 1}$ & $\mathbf{3 8 . 4 8}$ & $\mathbf{- 1 2 . 0 8}$ & $\mathbf{1 . 6 0}$ \\
\hline Tarım & 219.13 & 25.86 & -70.02 & -74.97 \\
\hline Madencilik & 9.71 & 107.22 & 1.97 & -18.90 \\
\hline $\begin{array}{l}\text { Genellikle Tüketim } \\
\text { Malı Üreten Sanayiler }\end{array}$ & 92.94 & 11.03 & -9.64 & 5.67 \\
\hline $\begin{array}{l}\text { Genellikle Aramalı } \\
\text { Üreten Sanayiler }\end{array}$ & 25.19 & 38.79 & 15.32 & 20.70 \\
\hline $\begin{array}{l}\text { Genellikle Yatırım } \\
\text { Malı Üreten Sanayiler }\end{array}$ & 108.06 & 53.15 & -16.75 & -44.45 \\
\hline Enerji & 79.29 & 26.77 & 6.02 & -12.08 \\
\hline İnşaat & 73.37 & 11.81 & -91.22 & 106.03 \\
\hline Hizmetler & 88.80 & 20.03 & 0.82 & -9.65 \\
\hline
\end{tabular}

Tablo 1. Sektörel Üretim Artışlarının Kaynakları (\%Pay, 2010-2013). Kaynak: K.C. Ekonomi Bakanlı̆ğ İstatistik Komitesi 2010 ve 2013 Yılı Girdi-Çıktı Sonuç Tabloları kullanılarak hesaplanmıştır.

Elde edilen sonuçlara göre, ekonomi genelinde ortaya çıkan toplam üretim artışının ana kaynağını yurtiçi talep artışı oluşturmaktadır. Toplam üretim artışının \% 72,01'i yurtiçi talep artışından kaynaklanmaktadır. İkinci sırada \% 38,48 oranında payla ihracat artışı yer almaktadır. Teknolojik değişmenin büyümeye katkısı \% 1,60`tır. İthal ikamesinden kaynaklanan etki ise \% -12,08 oranında olmuştur. İthal ikamesinin ekonomik büyümeye etkisi toplam ithalatı arttırıcı negatif ithal ikamesi yönündedir. Genel olarak Kazakistan'ın hammadde ihracına ve makine teçhizat gibi yatırım malları ithalatına dayalı dış ticaret yapısı burada ulaşılan sonucu bir başka yönden de desteklemektedir.

Sektörel düzeyde incelendiğinde ise, üretim artışına yurtiçi talep artışı katkısının yüksek olduğu sektörler \% 219,13 payla tarım, \% 108,06 payla Genellikle Yatırım Malı Üreten Sanayiler ve \% 92,94 payla Genellikle Tüketim Malları Üreten Sanayiler olmaktadır. Aynı zamanda bu sektörlerin hepsinde ithal ikamesinin ve teknolojik değişmenin büyümeye katkısı negatiftir. İhracat artışının katkısı yüksek olan sektörler arasında \% 107,22 payla madencilik, \% 53,15 payla Genellikle Yatırım Malları Üreten Sanayiler dikkat çekmektedir (Tablo 1).

Ekonomik üretim sektörlerinin çoğunda negatif ithal ikame etkisi hesaplanmıştır. Pozitif ithal ikamesinin hesaplandığı sektörler Genellikle Aramalı Üreten Sanayiler, Enerji ve Madencilik sektörleri olmuştur. Teknolojik değişmenin katkısı da sektörlerin çoğunluğu için negatif çıkmıştır. Katkının pozitif olduğu sektörler; inşaat ve tarım sektörleridir.

\section{Sonuç}

Dönem içinde ekonomik büyümenin ana kaynağı yurtiçi talep genişlemesi olmuştur. Bunu ikinci sırada ihracat talebi izlemiştir. Teknolojik değişmenin katkısı ise ekonomi genelinde çok düşük kalmakla birlikte sektörel bazda çoğu sektörde negatif yönlü olmuştur. Sadece Tüketim ve aramalı üreten sanayilerle inşaatta düşük paylarla da olsa pozitif etki sözkonusuyken, diğer tarım, madencilik, yatırım malı üreten sanayiler, enerji ve hizmetlerde negatif yönde girdi kullanımını arttırarak teknolojik gerileme yönlü bir etkileşim ortaya çıkmıştır. Negatif ithal ikame etkisi elde edilmiştir. Yani bu durum; dönem içinde tüketim ve yatırım malı üreten sektörlerle inşaat ve tarımda sektörel aragirdi ithalatının artarak dışa bağımlılığın arttığı anlamında yorumlanabilir.

Tüketim malları sanayinde en büyük katkıyı yurtiçi piyasalardaki talep artışları sağlamıştır. İhracat talebindeki artışların ekonomik büyümeye etkisinin göreli en fazla olduğu sektörler madencilik ara ve yatırım malı üreten imalat sektörleri olmuştur.

Tüm geçiş ekonomilerinde olduğu gibi merkezden planlı ekonomiden serbest piyasa ekonomisine geçişin sıkıntılarını yaşayan Kazakistan ekonomisi içinde dış piyasalara entegrasyon, genelde düşük katma değerli hammadde ihracına dayalı dış ticaret yapısı, tüketim ve aramalı ithalatına dayalı ekonomik yapının varlığı, katma değeri yüksek ürünlerin üretilemiyor olması, teknolojik gelişmeleri yeterince takip edememe, dişa bağımlılık gibi temel sorunlar burada elde edilen araştırma sonuçlarında da bir kez daha ortaya çıkmıştır. Bu yönüyle uygulanacak makroekonomik politikalarda bu olumsuzlukları giderecek önlemlerin 2050 strateji planına uygun şekilde hızla uygulanması gerekmektedir. Bu kapsamda; yabancı sermaye ve daha fazla iç tasarrufla finanse 
edilen serbest piyasa ekonomisine dayalı ileri teknolojilerin kullanılarak katma değeri yüksek ürünlerin üretildiği bir ekonomik sistemin kurulması gerekmektedir.

\section{Kaynakça}

- Алшанов, Р. А. (2012). Экономика независимого Казахстана: достижения и пути развития / Р. А. Алшанов. - Алматы : Ассоциация вузов РК, с .5

- Ответ. Ред.д.э.н., профессор, академик НИА РК О. Сабден, д.э.н., проф. Н.К.Нурланова. (2008). Устойчивое развитие Казахстана в условиях глобализации: модели, стратегии, приоритеты и механизмы реализации. В 3-х кн./- Алматы: ИЭ МОНРК,-Кн.2 - 272 с 5, 19

- Aydoğuş, O., (2010), Girdi-Çıktı Modellerine Giriş, Efil Yayınevi, Ankara.

- Bocutoğlu, E. (1985). Girdi - Çıktı Analizine Giriş, Karadeniz Üniversitesi İktisadi ve İdari Bilimler Fakültesi Ders Notları, Yayın No:23, Trabzon

- $\quad$ Korum, U., (1963). Input Output Analizi, Sevinç Matbaası, Ankara.

- Öney, E., (1983), İktisadi Planlama, 3. Bask1, A.Ü.S.B.F. Yayın No:526, Ankara.

- CÇalışkan E.T., Aydoğuş O. (2011). 'Türkiye Ekonomisinde Endüstriyel Büyümenin Kaynakları: Girdi-Çıktı Modeli ile Ampirik Bir Analiz (1985-2002)’. Ege Akademik Bakış. Cilt 11, Sayı 4, ss. 499-510.

- Комитет по статистике Министерства национальной экономики РК. Таблицы «Затраты-Выпуск» Республики Казахстан за 2010 год. www.stat.gov.kz

- Комитет по статистике Министерства национальной экономики РК. Таблицы «Затраты-Выпуск» Республики Казахстан за 2013 год. www.stat.gov.kz 


\title{
Ülkelerin İnsani Gelişmişlik Endeksi Değişsenlerine Göre Etkinliklerinin İncelenmesi
}

\section{An Investigation of Country Efficiencies as to Human Development Index Variables}

\author{
Prof. Dr. Selim Başar (Atatürk University, Turkey) \\ $\mathrm{Ph}$. D. Candidate Murat Eren (Atatürk University, Turkey) \\ Dr. Miraç Eren (Atatürk University, Turkey)
}

\begin{abstract}
Inability to resolve a number of social problems in the developed countries has brought forward the relationship between economic growth and human development in the research agenda. One of the important research carried out in this context has been the calculation of the Human Development Index (HDI). The aim of this study is to measure the relative efficiencies of each country in each group of countries ranked as to their HDI Index values by evaluating each group in itself and to recommend policies for effective utilization of their resources. Non-input radial-based Data Envelopment Analysis (DEA) models, in which the efficiency measured only by utilizing output variables, was employed for this aim. Life expectancy, education and GDP indices used in calculation of HDI were used as output variables for the estimations.
\end{abstract}

\section{Giriş}

Kalkınma ve gelişme ile ilgili çalışmalar özellikle II. Dünya Savaşı sonra artış göstermiştir. 1950- 1970 döneminde ülkelerin kalkınmışlık dereceleri büyük ölçüde, ulusal gelirdeki artışla eşit görülmekteydi. Bu dönemde kalkınmanın temel amacı üretim ve istihdam yapısını, tarım yerine sanayi ve hizmet sektörleri için artırmak olmuştur. Bu amaca uygun olarak ülke refahındaki değişimlerin temel göstergesi olarak "kişi başına düşen millî gelir" ölçütü kullanılmıştır. 1970 yılından sonra gelişmeyi, insani, sosyal, kültürel, çevresel ve mekânsal boyutlarıyla tanımlama amacı taşıyan yeni yaklaşımlar ortaya çıkmıştır. Bu dönemde iktisadi büyüme kavramı yanında; yoksulluk, işsizlik, gelir dağılımı ve bölgesel eşitsizlik, kalkınma tanımlamalarının içinde yer almaya başlamıştır (DPT, 2007).

Ülkelerin gelişmişlik düzeyini tek bir ölçütle ifade etmek, ülkelerin ekonomik, sosyal ve siyasal yapılarındaki farklılık nedeniyle oldukça zordur. Bu doğrultuda, ülkeler arası sosyoekonomik gelişmişlik düzeylerinin de ortaya konduğu İnsani Gelişme Endeksi (Human Development Index-HDI), Birleşmiş Milletler Kalkınma Programı (United Nations Development Programme-UNDP) tarafindan 1990 yılında İnsani Gelişme Raporu (Human Development Report-HDR) ile yayınlanmaya başlamıştır. Bu raporda uzun ve sağlıklı bir yaşam, sosyal ve siyasi özgürlükler, insan hakları gibi faktörlerden hareketle yaşam beklentisi, eğitim ve GSYH endeksleri oluşturularak elde edilen ortalama ile HDI endeksi ortaya çıkarılmıştır.

$\mathrm{Bu}$ endeks sonucunda bir ülkenin gelişmiş, gelişmekte olan ya da gelişmemiş bir ülke olduğu; bunun yanı sıra ekonomisindeki etkinin yaşam niteliğini ne düzeyde etkilediği ile ilgili bilgiler ortaya koyulmaktadır. HDI ilk olarak 1990 yılında Pakistanlı ekonomist Mahbubul Haq tarafından geliştirilmiş ve 1993 yılından bu yana Birleşmiş Milletler Gelişme Programı tarafından yıllık Gelişme Raporu'nda sunulmuştur.

İnsani Gelişme Göstergesi ülkelerde başlica üç gelişmeyi göz önünde tutar:

- Uzun ve sağlıklı bir yaşam: Bu göstergenin ölçümü ortalama yaşam süresi ile yapılır.

- Bilgi: Bilgi okuryazar oranı (2/3'ü) ve ilkokul, lise ve üniversite kayıtları yüzdesi (1/3'ü) ile hesaplanır.

- Kaliteli yaşam standardı: Bu göstergenin ölçümü kişi başına düşen gelir ve alım gücünün Amerikan Doları üzerinden hesaplanmasıyla yapılır.

Yukarıdaki bilgiler ışığında HDI, yıllar itibarıyla geçirdiği değişiklikler neticesinde Şekil 1'de verildiği gibi hesaplanmaktadır. 
Uzun ve sağglıklı yașam

Doğumdaki yaşam beklentisi

GÖSTERGELER

KRİTERLER

ALT ENDEKSLER Yaşam beklentisi endeksi $\underline{\text { Bilgi }}$

$\underline{\text { Kaliteli yașam standardı }}$

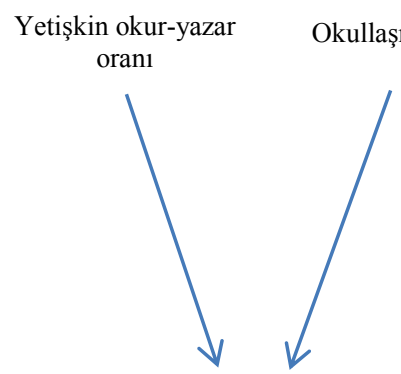

Eğitim endeksi
Kişi başı GSYH

(SGP), \$

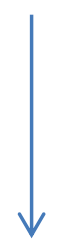

Kişi başı GSYH endeksi

Şekil 1: Insani Gelişme Endeksi Kaynak: UNDP, Human Development Report, 2005.

HDI endeksi daha önce de belirtildiği üzere 3 endeksin hesaplanması ile elde edilmektedir. Bu üç endeks aşağıdaki gibi hesaplanmaktadır:

-Yaşam Beklentisi Endeksi'nin Hesaplanması:

En yüksek ve en düşük yaş sınırları sırasıyla 25 ve 85 olarak belirlenmiştir. Bu aralık dikkate alınarak yaşam beklentisi endeksi 0 ile 1 arasında bir değer alacak şekilde hesaplanmaktadır.

Ülkenin doğumdaki yaşam beklentisi: $\mathrm{n}$ y1l ise,

Yaşam Beklentisi Endeksi $=(\mathrm{n}-25) /(85-25)$

\section{-Ĕ̌itim Endeksi’nin Hesaplanması}

Eğitim endeksine ulaşmak için yetişkin okur-yazar endeksi (15 yaş ve üstü) ve okullaşma endeksi için 0-100 Aralığı kullanılarak, 0 ile 1 arasında bir değer bulunmaktadır.

Ülkenin yetişkin okuryazar oranı- $\mathrm{m}(\%)$,

Ülkenin okullaşma oranı- $r(\%)$ ise,

Yetişkin Okur-Yazar Endeksi= $(\mathrm{m}-0) / 100-0$

Okullaşma Endeksi $=(\mathrm{r}-0) /(100-0)$

Eğitim Endeksi= $2 / 3 *$ (Yetişkin Okur-Yazar Endeksi) $+1 / 3 *$ (Okullaşma Endeksi)

\section{-GSYH Endeksi’nin Hesaplanması}

GSYH Endeksi Satınalma Gücü Paritesi SGP'ye göre düzenlenmiş kişi başı GSYH değeriyle ölçülür. Endeksin kullanılmasında 100 dolar alt düzey kişi başına gelir olarak alınırken, üst düzey olarak 40.000 dolar kullanılmıştır. Bu aralıktan hareketle GSYH Endeksi 0 ile 1 arasında bir değer olarak hesaplanmaktadır.

Ülkenin kişi başı GSYH'si y ise,

GSYH Endeksi $=[\log (\mathrm{y})-\log (100)] /[\log (40.000)-\log (100)]$

Yukarıdaki bilgiler 1şı̆̆ında HDI hesaplanırken Yaşam Beklentisi Endeksi, Eğitim Endeksi ve GSYH Endeksi'nin aritmetik ortalaması alınmaktadır:

$\mathrm{HDI}=1 / 3 *($ Yaşam Beklentisi Endeksi $)+1 / 3 *($ Eğitim Endeksi $)+1 / 3 *$ (GSYH Endeksi)

Birleşmiş milletler de ülkeleri HDI değerlerine göre çok gelişmiş, gelişmiş, orta düzey gelişmiş ve az gelişmiş olacak şekilde gruplara ayırmıştır.

İnsani gelişmişliği ölçmeye çalışan endekslerin tümü içinde HDI, çok boyutlu refah ölçümümün yansıra şeffaflık ve sadeliğinden dolayı yaklaşık 20 yıllık geçmişinde refah karşılaştırmaları için en yaygın kullanılan göstergelerden biri olmuştur (Harttgen ve Klasen, 2012). Ancak oluşturulduğu günden bu yana HDI, oluşumu ve bileşiminden genişletilmesi ve daha fazla boyut içerilmesine kadar büyük eleştiriler almıştır.

Eleştirilerin bazıları HDI'nin göstergeleri ve boyutları ile ilişkili olup (Bhanojirao, 1991; Sen ve Sudhir, 1994; Neumayer, 2001; Morse, 2003; Ranis, Stewart ve Samman, 2005; Dias, Mattos ve Balestieri, 2006; Sanusi, 2008) bazıları ise ülkelerin eşitsizliklerinin hesaba katılmamasından kaynaklıdır (Hicks, 1997; Sagar ve Najam, 1998; Grimm ve diğ., 2008; Harttgen ve Klasen, 2012). Bir de teknik yönden eleştiriler vardır ki onlar da HDI'nin analitik çerçevesi ve metodolojisi ile ilgilidir. 
(Kelley, 1991; Srinivasan, 1994; Ravallion, 1997), HDI'nin hesaplanmasında kullanılan üç bileşenin keyfi olarak eşit ağırlıklandırma düzeninin kullanılmasını eleştirmişlerdir.

(Noorbakhsh, 1998), endeksin bileşenleri ile ilgili olanlardan endeksin yapısı ile ilgili olanlara kadar iki kategoriye ayrılmış bir takım değişiklikler önermiştir. Bu da endeksin değiştirilmiş bir sürümü sonuçlanmıştır.

(Herrero, Martínez ve Villar, 2012), HDI metodolojisinde teknik konuların bazılarında bir takım göreceli değişiklikler önermişlerdir. Gelir değişkeni için logaritma alınması ve bazı uygulanan normalleştirme tipleri, önerilen değişikliklerden bazılarıdır.

Teknik olarak endeks üzerine yapılan eleştirilerin yanısıra bir de ülkelerin sıralanması ile ilgili olarak bulanık mantık temelli (Baliamoune-Lutz ve McGillivray, 2006) ve çok kriterli karar tekniklerini kullanan çalışmalar (Safari ve Ebrahimi, 2014) da mevcuttur.

$\mathrm{Bu}$ çalışmanın amacı da, HDI endeksine göre sıralanan her bir gruptaki ülkeleri kendi grubu içerisinde değerlendirerek birbirlerine göre nispi etkinliklerini ölçmek ve ülkelerin kendi kaynaklarını etkin bir şekilde kullanabilmeleri için politikalar önermektir.

\section{Metodoloji}

Ülkelerin kendi grupları içindeki etkinliklerinin araştırtılmasında veri zarflama analizi (Data Envelopment Analysis-DEA) seçilmiştir.

Ortak ölçü birimine ihtiyaç duymaksızın birden fazla girdi ve çıktıyı tek bir değerde birleştirmeyi sağlayarak karar birimlerinin etkinliklerini maksimize ederek ağırlıklar kümesini belirleyen DEA, doğrusal programlamaya dayanan matematiksel bir prosedürdür (William W Cooper, Seiford ve Tone, 2007). Bu prensip altında, insani gelişme üzerine araştırmalarda kullanılan çok sayıda model ve uzantıları geliştirilmiştir (Mahlberg ve Obersteiner, 2001; D. K. Despotis, 2004, 2005; Bollou, Ngwenyama ve Morawczynski, 2006; Lee, Lin ve Fang, 2006; Bougnol ve diğ., 2010; Dimitris K. Despotis, Stamati ve Smirlis, 2010; Shetty ve Pakkala, 2010; Zhou, Ang ve Zhou, 2010; Ülengin ve diğ., 2011; Reig-Martínez, 2013; Tofallis, 2013).

Burada HDI endeksine göre sıralanan ülkelerin kendi grubu ile ele alınarak etkinliklerinin ölçülmesinin sebebi, homojen bir yapı oluşturmaktır. Etkinlik ölçümü için kullanılacak değişkenler ise HDI hesabında kullanılan yaşam beklentisi, eğitim ve GSYH endekslerinin hesabında kullanılan değişkenler olup DEA analizi için çıktı değişkenlerini ifade etmektedir. Girdi değişkenlerinin olmadığı ve sadece çıktı değişkenleri üzerinden etkinlik ölçümün yapılacağı bir durum için (Lovell ve Pastor, 1999) tarafından geliştirilen girdisiz radyal temelli DEA modelleri kullanılmıştır.

DEA, üretim sınırlarının tahmini için ekonometri ve yöneylemde sıkça kullanılan parametrik olmayan ve karar birimleri (Decision - Making Units - DMU) için göreli etkinlik kıyaslaması yapan bir metottur (Førsund ve Sarafoglou, 2002). İlk olarak, 1978 yılında Charnes, Cooper ve Rhodes tarafından ölçeğe göre sabit getirili olan CRS (Constant Returns to Scale) modeli ortaya çıkarılmış ardından 1984 yılında Banker, Charnes ve Cooper tarafından ölçeğe göre değişken getirili VRS (Variable Returns to Scale) modeli geliştirilmiştir (WILLIAM W. COOPER, SEIFORD ve TONE). Sonraki yıllarda The Additive Model, A Slacks-Based Measure of Efficiency (SBM) gibi modeller ile farklılaşmalar ortaya çıkmıştır (WILLIAM W. COOPER ve diğ.).

Kullanım alanlarına ve varsayımlara göre pek çok DEA modeli kurulabilir. Bu modeller temel olarak girdiye ve çıktıya yönelik olmak üzere iki ana gruba ayrılabilirler. Girdiye yönelik olanlar, herhangi bir çıktı düzeyi için etkin olmayan karar birimlerinin girdilerini ne derece azaltmaları gerektiğini araştırırlar. Benzer şekilde, çıktıya yönelik etkinlik ölçütleri ise herhangi bir girdi bileşimi için etkin olmayan karar birimlerinin etkin duruma getirilebilmesi amacıyla çıktılarını ne kadar artırabilecekleri üzerinde dururlar. Eğer modeller girdi ya da çıktı yönelimli kurulamıyorsa, toplamsal modeller kullanılır. Öyleyse "Girdi odaklı modeller, sabit çıktı düzeyinde girdi kullanımını oransal olarak azaltarak teknik etkinsizliği ölçmeye çalışır. Çıktı odaklı modeller ise sabit girdi düzeyinde çıktı kullanımını oransal olarak artırarak teknik etkinsizliği ölçer" denir. Bu iki ölçek değerinin ölçeğe göre sabit getiri (Constant Return to Scale- CRS) altında aynı değeri verdiği ve ölçeğe göre değişken getiri (Variable Return to Scale-VRS) altında biraz farklı olduğu görülür. Literatürdeki çalışmaların büyük çoğunluğunda girdi miktarı öncelikli karar değişkeni olarak ortaya çıktığı için genellikle girdi odaklı modeller seçilmiştir. Fakat kaynak miktarının sabit tutulup çıktı miktarının mümkün olduğu kadar artırılmasının söz konusu olduğu durumlar da olabilir. Böyle bir durumda da çıktı odaklı model daha uygundur. Ayrıca, yönelimin seçimi, elde edilen skor değerleri üzerinde küçük bir etkiye sahiptir (Coelli ve Perelman, 2000).

Buna göre; CRS ve VRS modellerinin matematiksel ifadeleri Tablo 1'deki gibidir. 


\begin{tabular}{|c|c|c|}
\hline & Primal & Dual \\
\hline Girdi odaklı & $\begin{array}{l}\text { mak } \quad z_{o}=\sum_{r=1}^{s} u_{i} y_{i o}-\left(u_{o}\right)^{*} \\
\text { Kisitlar: } \\
\sum_{i=1}^{m} v_{i} x_{i o}=1 \\
-\sum_{i=1}^{m} v_{i} x_{i j}+\sum_{r=1}^{s} u_{r} y_{r j}-\left(u_{o}\right)^{*} \leq 0 \\
v_{i} \geq 0 \quad u_{r} \geq 0 \quad u_{o} \quad \text { Sinirsiz }\end{array}$ & $\begin{array}{l}\min \theta_{o} \\
\text { Kısıtlar: } \\
\sum_{j=1}^{n} \lambda_{j} x_{i j}-\theta_{o} x_{i o} \leq 0 \quad i=1, \ldots, m \\
y_{r o}-\sum_{r=1}^{s} \lambda_{j} y_{i j} \leq 0 \quad r=1, \ldots, \mathrm{s} \\
\left(\sum_{j=1}^{n} \lambda_{j}=1\right)^{*}\end{array}$ \\
\hline Çıktı odaklı & $\begin{array}{l}\min \quad z_{o}=\sum_{i=1}^{m} v_{i} x_{i o}-\left(v_{o}\right)^{*} \\
\text { Kisıtlar: } \\
\sum_{r=1}^{s} u_{r} y_{i j}=1 \\
\sum_{i=1}^{m} v_{i} x_{i j}-\sum_{r=1}^{s} u_{r} y_{r j}-\left(v_{o}\right)^{*} \leq 0 \\
v_{i} \geq 0 \quad u_{r} \geq 0 \quad v_{o} \text { Sinırsiz }\end{array}$ & $\begin{array}{l}\operatorname{mak} \quad \phi_{o} \\
\text { Kisıtlar: } \\
\sum_{j=1}^{n} \lambda_{j} x_{i j}-x_{i o} \leq 0 \quad i=1, \ldots, m \\
\phi_{o} y_{r o}-\sum_{r=1}^{s} \lambda_{j} y_{i r} \leq 0 \quad r=1, \ldots, \mathrm{s} \\
\left(\sum_{j=1}^{n} \lambda_{j}=1\right)^{*}\end{array}$ \\
\hline
\end{tabular}

Tablo 1: Ölçeğe Göre Sabit Getiri ve Ölçeğe Göre Değişken Getiri Modellerinin Matematiksel İfadeleri

Burada $x_{i j} \subseteq X$ ve $\mathrm{X}, \mathrm{n} \times \mathrm{m}$ boyutunda tüm karar birimleri için girdileri veren matris ve $y_{r j} \subseteq Y$ ve $\mathrm{Y}, \mathrm{n} \times \mathrm{s}$ boyutunda tüm karar birimleri için çıktıları veren matristir. $x_{i 0}$ ve $y_{r 0}$, o karar biriminin girdi ve çıktılarını veren sırasıyla $\mathrm{m} \times 1$ ve $\mathrm{s} \times 1$ boyutlu vektörler; $u_{r}$ ve $v_{i}$ sırasıyla çıktı ve girdi ağırlık vektörleridir. Yine bir skaler değer olan $\theta_{0}$ ve $\emptyset_{0}$, o karar biriminin etkinlik skorudur. Varsayılan bu kısıtlar altında model $n$ tane karar birimi için ayrı ayrı çözülerek her karar biriminin skor değerleri elde edilir. Primal doğrusal modelin kısıt sayısı dualine göre fazla olduğu için genellikle işlem kolaylığı açısından dual model tercih edilir.

Bu çalışmada da etkinlik ölçümü için kullanılacak değişkenler, HDI hesabında kullanılan yaşam beklentisi, eğitim ve GSYH endeksleri olup bu endeksler DEA analizi için çıktı değişkenlerini ifade etmektedir. Girdi değişkenlerinin olmadığı ve sadece çıktı değişkenleri üzerinden etkinlik ölçümün yapılacağı bir durum için (Lovell ve Pastor, 1999) tarafından geliştirilen girdisiz radyal temelli DEA modelleri önerilmektedir.

Lovell ve Pastor (1999) söz konusu modeller ile ilgili olarak aşağıdaki özellikleri ispatlamışlardır:

I) Girdisiz (ya da çıktısız) CRS modelleri etkin ve etkinsiz birimler arasında ayrım yapamamaktadır.

II) Tek sabit girdili çıktı odaklı ve tek sabit çıktılı girdi odaklı CRS modelleri, ilgili VRS modelleri ile çakışmaktadır.

III) Tek sabit girdili çıktı odaklı (ya da tek sabit çıktılı girdi odaklı) VRS modelleri, girdisiz (ya da çıktısız) VRS modellerine eşdeğerdir.

IV) Girdisiz (ya da çıktısız) tüm VRS modelleri bir eksik değişken ve bir eksik kısıta sahip olan modellerle özetlenebilir.

\section{Bulgular}

Analizde Etkinlik ölçümü için kullanılacak değişkenler; yaşam beklentisi, eğitim ve GSYH endekslerinin hesabında kullanılan doğumda yaşam beklentisi, ortalama eğitim yılı, okullaşma oranı ve satın alma gücü paritesine göre belirlenmiş kişi başına GSYH değişkenleri olarak belirlenmiş olup bu değişkenler DEA analizi için çıktıları ifade etmektedir. Girdi değişkenlerinin olmadığı ve sadece çıktı değişkenleri üzerinden etkinlik ölçümün yapılacağı durum için (Lovell ve Pastor, 1999) tarafından önerilen girdisiz radyal temelli DEA modellerinden yararlanılarak homojen bir yapıda değerlendirme yapabilmek için karar birimi olan ülkelerin kendi grupları içerisinde etkinliklerinin ölçümü sağlanmıştır. Bunun için girdisiz çıktı odaklı VRS modelinin uygun olduğu (Lovell ve Pastor, 1999) tarafından ortaya konulmuştur. Bu da zaten tek sabit girdili çıktı odaklı VRS modeline denk gelmektedir. Çıktı odaklı modelde amaç fonksiyonunun çıktıyı maksimize etmesi ve getiriyi 
sağlaması söz konusudur. Çünkü bu model mevcut girdi ile en fazla çıktıyı üretme amacına yöneliktir. Yani kaynak miktarının sabit olduğu ve buna karşın çıktı miktarının mümkün olduğu kadar artırılması genel olarak ülke yöneticileri tarafından istenen ve kontrolü daha kolay olan bir durumdur. Birleşmiş milletler tarafindan dört gruba ayrılan ülkelerin her biri kendi grubu içerisinde değerlendirilerek elde edilen etkinlik skorları, aşağıdaki gibidir;

\begin{tabular}{|c|c|c|c|c|c|}
\hline Suralama & $\begin{array}{c}\text { Çok Gelişmiş } \\
\text { Grubundaki Ülkeler }\end{array}$ & $\begin{array}{c}\text { Çıktı Odaklı VRS } \\
\text { Etkinliği Skorları }\end{array}$ & Sıralama & $\begin{array}{c}\text { Çok Gelişmiş } \\
\text { Grubundaki Ülkeler }\end{array}$ & $\begin{array}{c}\text { Çıktı Odaklı } \\
\text { VRS Etkinliği }\end{array}$ \\
\hline $\mathbf{1}$ & Norveç & 1,00 & $\mathbf{2 6}$ & İtalya & 1,01 \\
\hline $\mathbf{2}$ & Avustralya & 1,00 & $\mathbf{2 7}$ & İspanya & 1,01 \\
\hline $\mathbf{3}$ & İsviçre & 1,00 & $\mathbf{2 8}$ & Çek Cumhuriyeti & 1,05 \\
\hline $\mathbf{4}$ & Hollanda & 1,02 & $\mathbf{2 9}$ & Yunanistan & 1,03 \\
\hline $\mathbf{5}$ & Birleşik Devletler & 1,00 & $\mathbf{3 0}$ & Bruney & 1,05 \\
\hline $\mathbf{6}$ & Almanya & 1,00 & $\mathbf{3 1}$ & Katar & 1,00 \\
\hline $\mathbf{7}$ & Yeni Zelanda & 1,02 & $\mathbf{3 2}$ & Kibrıs & 1,04 \\
\hline $\mathbf{8}$ & Kanada & 1,02 & $\mathbf{3 3}$ & Estonya & 1,07 \\
\hline $\mathbf{9}$ & Singapur & 1,00 & $\mathbf{3 4}$ & Suudi Arabistan & 1,09 \\
\hline $\mathbf{1 0}$ & Danimarka & 1,04 & $\mathbf{3 5}$ & Litvanya & 1,04 \\
\hline $\mathbf{1 1}$ & İlanda & 1,02 & $\mathbf{3 6}$ & Polonya & 1,08 \\
\hline $\mathbf{1 2}$ & İsveç & 1,02 & $\mathbf{3 7}$ & Andorra & 1,03 \\
\hline $\mathbf{1 3}$ & İzlanda & 1,01 & $\mathbf{3 8}$ & Slovakya & 1,10 \\
\hline $\mathbf{1 4}$ & Büyük Britanya & 1,03 & $\mathbf{3 9}$ & Malta & 1,05 \\
\hline $\mathbf{1 5}$ & Hong Kong, Çin & 1,00 & $\mathbf{4 0}$ & Birleşik Arap Emirlikleri & 1,08 \\
\hline $\mathbf{1 6}$ & Kore & 1,02 & $\mathbf{4 1}$ & Şili & 1,04 \\
\hline $\mathbf{1 7}$ & Japonya & 1,00 & $\mathbf{4 2}$ & Portekiz & 1,04 \\
\hline $\mathbf{1 8}$ & Lihtenştayn & 1,01 & $\mathbf{4 3}$ & Macaristan & 1,11 \\
\hline $\mathbf{1 9}$ & İsrail & 1,01 & $\mathbf{4 4}$ & Bahreyn & 1,09 \\
\hline $\mathbf{2 0}$ & Fransa & 1,02 & $\mathbf{4 5}$ & Küba & 1,05 \\
\hline $\mathbf{2 1}$ & Avusturya & 1,03 & $\mathbf{4 6}$ & Kuveyt & 1,08 \\
\hline $\mathbf{2 2}$ & Belçika & 1,03 & $\mathbf{4 7}$ & Hırvatistan & 1,08 \\
\hline $\mathbf{2 3}$ & Lüksemburg & 1,02 & $\mathbf{4 8}$ & Letonya & 1,12 \\
\hline $\mathbf{2 4}$ & Finlandiya & 1,03 & $\mathbf{4 9}$ & Arjantin & 1,09 \\
\hline $\mathbf{2 5}$ & Slovenya & 1,04 & & & \\
\hline & & & & \\
\hline
\end{tabular}

Tablo 2: Çok Gelişmiş Grubundaki Ülkelerin Etkinlik Skorları

\begin{tabular}{|c|c|c|c|c|c|}
\hline Sıralama & $\begin{array}{c}\text { Gelişmiş Grubundaki } \\
\text { Ülkeler }\end{array}$ & $\begin{array}{c}\text { Çıktı Odaklı VRS } \\
\text { Etkinliği Skorları }\end{array}$ & Sıralama & $\begin{array}{c}\text { Gelişmiş Grubundaki } \\
\text { Ülkeler }\end{array}$ & $\begin{array}{c}\text { Çıtı Odaklı VRS } \\
\text { Etkinliği Skorları }\end{array}$ \\
\hline $\mathbf{1}$ & Uruguay & 1,00 & $\mathbf{2 6}$ & Ürdün & 1,04 \\
\hline $\mathbf{2}$ & Bahamalar & 1,00 & $\mathbf{2 7}$ & Sırbistan & 1,04 \\
\hline $\mathbf{3}$ & Karadağ & 1,00 & $\mathbf{2 8}$ & Brezilya & 1,03 \\
\hline $\mathbf{4}$ & Beyaz Rusya & 1,00 & $\mathbf{2 9}$ & Gürcistan & 1,00 \\
\hline $\mathbf{5}$ & Romanya & 1,01 & $\mathbf{3 0}$ & Grenada & 1,01 \\
\hline $\mathbf{6}$ & Libya & 1,00 & $\mathbf{3 1}$ & Peru & 1,04 \\
\hline $\mathbf{7}$ & Umman & 1,00 & $\mathbf{3 2}$ & Ukrayna & 1,03 \\
\hline $\mathbf{8}$ & Rusya Federasyonu & 1,00 & $\mathbf{3 3}$ & Belize & 1,04 \\
\hline $\mathbf{9}$ & Bulgaristan & 1,02 & $\mathbf{3 4}$ & Makedonya Cumhuriyeti & 1,05 \\
\hline $\mathbf{1 0}$ & Barbados & 1,00 & $\mathbf{3 5}$ & Bosna Hersek & 1,03 \\
\hline $\mathbf{1 1}$ & Palau & 1,00 & $\mathbf{3 6}$ & Ermenistan & 1,02 \\
\hline $\mathbf{1 2}$ & Antigua ve Barbuda & 1,02 & $\mathbf{3 7}$ & Fiji & 1,01 \\
\hline $\mathbf{1 3}$ & Malezya & 1,02 & $\mathbf{3 8}$ & Tayland & 1,07 \\
\hline $\mathbf{1 4}$ & Mauritius & 1,01 & $\mathbf{3 9}$ & Tunus & 1,03 \\
\hline $\mathbf{1 5}$ & Trinidad ve Tobago & 1,01 & $\mathbf{4 0}$ & Çin & 1,06 \\
\hline $\mathbf{1 6}$ & Lübnan & 1,00 & $\mathbf{4 1}$ & Saint Vincent ve Grenadinler & 1,07 \\
\hline $\mathbf{1 7}$ & Panama & 1,01 & $\mathbf{4 2}$ & Cezayir & 1,09 \\
\hline $\mathbf{1 8}$ & Venezuela (Bolivarc1 & 1,03 & $\mathbf{4 3}$ & Dominika & 1,03 \\
\hline $\mathbf{1 9}$ & Kosta Rika & 1,00 & $\mathbf{4 4}$ & Arnavutluk & 1,01 \\
\hline $\mathbf{2 0}$ & Türkiye & 1,03 & $\mathbf{4 5}$ & Jamaika & 1,05 \\
\hline $\mathbf{2 1}$ & Kazakistan & 1,03 & $\mathbf{4 6}$ & Lucia & 1,06 \\
\hline $\mathbf{2 2}$ & Meksika & 1,02 & $\mathbf{4 7}$ & Kolombiya & 1,07 \\
\hline $\mathbf{2 3}$ & Seyșeller & 1,04 & $\mathbf{4 8}$ & Ekvador & 1,05 \\
\hline $\mathbf{2 4}$ & Saint Kitts ve Nevis & 1,05 & $\mathbf{4 9}$ & Surinam & 1,11 \\
\hline $\mathbf{2 5}$ & Sri Lanka & 1,02 & $\mathbf{5 0}$ & Tonga & 1,04 \\
\hline $\mathbf{2 6}$ & İan & 1,03 & $\mathbf{5 1}$ & Dominik Cumhuriyeti & 1,09 \\
\hline $\mathbf{2 7}$ & Azerbaycan & 1,04 & & & \\
\hline & & & & \\
\hline
\end{tabular}


Tablo 3: Gelişmiş Grubundaki Ülkelerin Etkinlik Skorları

\begin{tabular}{|c|c|c|c|c|c|}
\hline Sıralama & $\begin{array}{c}\text { Gelişmekte Olan } \\
\text { Grubundaki Ülkeler }\end{array}$ & $\begin{array}{c}\text { Çıktı Odaklı } \\
\text { VRS Etkinliği } \\
\text { Skorları }\end{array}$ & Sıralama & $\begin{array}{c}\text { Gelişmekte Olan } \\
\text { Grubundaki Ülkeler }\end{array}$ & $\begin{array}{c}\text { Çıtı Odaklı } \\
\text { VRS Etkinliği } \\
\text { Skorları }\end{array}$ \\
\hline $\mathbf{1}$ & Maldivler & 1,00 & $\mathbf{2 2}$ & Mikronezya & 1,07 \\
\hline $\mathbf{2}$ & Moğolistan & 1,00 & $\mathbf{2 3}$ & Guatemala & 1,08 \\
\hline $\mathbf{3}$ & Türkmenistan & 1,00 & $\mathbf{2 4}$ & Kırgızistan & 1,07 \\
\hline $\mathbf{4}$ & Samoa & 1,00 & $\mathbf{2 5}$ & Namibya & 1,14 \\
\hline $\mathbf{5}$ & Filistin & 1,00 & $\mathbf{2 6}$ & Doğu Timor & 1,11 \\
\hline $\mathbf{6}$ & Endonezya & 1,03 & $\mathbf{2 7}$ & Honduras & 1,06 \\
\hline $\mathbf{7}$ & Botsvana & 1,00 & $\mathbf{2 8}$ & Fas & 1,10 \\
\hline $\mathbf{8}$ & Misır & 1,02 & $\mathbf{2 9}$ & Vanuatu & 1,04 \\
\hline $\mathbf{9}$ & Paraguay & 1,04 & $\mathbf{3 0}$ & Nikaragua & 1,04 \\
\hline $\mathbf{1 0}$ & Gabon & 1,00 & $\mathbf{3 1}$ & Kiribati & 1,07 \\
\hline $\mathbf{1 1}$ & Bolivya & 1,04 & $\mathbf{3 2}$ & Tacikistan & 1,05 \\
\hline $\mathbf{1 2}$ & Moldova & 1,05 & $\mathbf{3 3}$ & Hindistan & 1,13 \\
\hline $\mathbf{1 3}$ & El Salvador & 1,06 & $\mathbf{3 4}$ & Butan & 1,09 \\
\hline $\mathbf{1 4}$ & Özbekistan & 1,03 & $\mathbf{3 5}$ & Kamboçya & 1,08 \\
\hline $\mathbf{1 5}$ & Filipinler & 1,06 & $\mathbf{3 6}$ & Gana & 1,18 \\
\hline $\mathbf{1 6}$ & Güney Afrika & 1,00 & $\mathbf{3 7}$ & Lao & 1,14 \\
\hline $\mathbf{1 7}$ & Suriye & 1,03 & $\mathbf{3 8}$ & Kongo & 1,24 \\
\hline $\mathbf{1 8}$ & Irak & 1,00 & $\mathbf{3 9}$ & Zambiya & 1,11 \\
\hline $\mathbf{1 9}$ & Guyana & 1,10 & $\mathbf{4 0}$ & Bangladeş & 1,10 \\
\hline $\mathbf{2 0}$ & Vietnam & 1,03 & $\mathbf{4 1}$ & Sao Tome ve Principe & 1,15 \\
\hline $\mathbf{2 1}$ & Cape Verde & 1,00 & $\mathbf{4 2}$ & Ekvator Ginesi & 1,00 \\
\hline
\end{tabular}

Tablo 4: Gelişmekte Olan Grubundaki Ülkelerin Etkinlik Skorları

\begin{tabular}{|c|c|c|c|c|c|}
\hline Siralama & $\begin{array}{c}\text { Az Gelişmiş } \\
\text { Grubundaki Ülkeler }\end{array}$ & $\begin{array}{l}\text { Çıktı Odaklı VRS } \\
\text { Etkinliği Skorları }\end{array}$ & Siralama & $\begin{array}{c}\text { Az Gelişmiş } \\
\text { Grubundaki Ülkeler }\end{array}$ & $\begin{array}{c}\text { Çıktı Odaklı VRS } \\
\text { Etkinliği Skorları }\end{array}$ \\
\hline 1 & Nepal & 1,00 & 23 & Gitmek & 1,00 \\
\hline 2 & Pakistan & 1,00 & 24 & Haiti & 1,04 \\
\hline 3 & Kenya & 1,00 & 25 & Afganistan & 1,12 \\
\hline 4 & Svaziland & 1,00 & 26 & Cibuti & 1,09 \\
\hline 5 & Angora & 1,00 & 27 & Fildişi Sahili & 1,22 \\
\hline 6 & Myanmar & 1,03 & 28 & Gambiya & 1,16 \\
\hline 7 & Ruanda & 1,00 & 29 & Etiyopya & 1,08 \\
\hline 8 & Kamerun & 1,07 & 30 & Malawi & 1,13 \\
\hline 9 & Nijerya & 1,05 & 31 & Liberya & 1,12 \\
\hline 10 & Yemen & 1,04 & 32 & Mali & 1,24 \\
\hline 11 & Madagaskar & 1,00 & 33 & Gine-Bissau & 1,26 \\
\hline 12 & Zimbabve & 1,00 & 34 & Mozambik & 1,29 \\
\hline 13 & Papua Yeni Gine & 1,08 & 35 & Gine & 1,22 \\
\hline 14 & Solomon Adaları & 1,00 & 36 & Burundi & 1,24 \\
\hline 15 & Komorlar & 1,03 & 37 & Burkina Faso & 1,21 \\
\hline 16 & Tanzanya & 1,05 & 38 & Eritre & 1,08 \\
\hline 17 & Moritanya & 1,10 & 39 & Sierra Leone & 1,46 \\
\hline 18 & Lesotho & 1,06 & 40 & Çad & 1,34 \\
\hline 19 & Senegal & 1,06 & 41 & Orta Afrika & 1,33 \\
\hline 20 & Uganda & 1,06 & 42 & $\begin{array}{l}\text { Kongo (Demokratik } \\
\text { Cumhuriyeti) }\end{array}$ & 1,29 \\
\hline 21 & Benin & 1,12 & 43 & Nijer & 1,17 \\
\hline 22 & Sudan & 1,08 & & & \\
\hline
\end{tabular}

Tablo 5: Az Gelişmiş Grubundaki Ülkelerin Etkinlik Skorları

Çalışmadan elde edilen bulgular şu şekilde özetlenebilir:

Çok gelişmiş grubundaki ülkelere bakıldığında, elde edilen VRS skorları BM tarafından yapılan endeks sıralamasıyla benzer sonuçlar göstermiştir. Yani HDI endeksine göre kendi grupları içinde ilk sıralarda yer alan ülkeler, VRS skorlarına göre de etkin çıkmıştır. Ancak bazı istisnalar bulunmaktadır. Örneğin HDI endeksine göre 4. sırada yer alan Hollanda, değerlendirildiği gruptaki ülkelere göre sabit girdi altında optimal çıktıyı 
verememiştir. Buna karşın HDI endeksinde 9. Sırada yer alan Singapur, 15. sırada yer alan Hong Kong, Çin, 17. sırada yer alan Japonya ve 31. sırada yer alan Katar, HDI endekslerine göre alt sıralarda olmalarına karşın VRS skorlarında gruplarındaki ülkelere göre sabit girdi altında optimal çıktıyı verebilmişlerdir.

Gelişmiş grubundaki ülkelerde de çok gelişmiş ülkeler grubundakine benzer sonuçlar elde edilmiş, elde edilen VRS skorları HDI endeksi sıralamasına benzer sonuçlar göstermiştir. Çok gelişmiş ülkeler grubunda olduğu gibi bu gurupta da bazı istisnalar bulunmaktadır. Örneğin, HDI endeksine göre 5. ve 9. Sirada yer alan Romanya ve Bulgaristan, değerlendirildiği gruptaki ülkelere göre sabit girdi altında optimal çıktıyı verememiştir. Buna karşın, HDI endeksine göre 16. sirada yer alan Lübnan, 19. sirada yer alan Kosta Rika ve 29. sirada yer alan Gürcistan HDI endekslerine göre alt sıralarda olmalarına karşın VRS skorlarında gruplarındaki ülkelere göre sabit girdi altında optimal çıktıyı verebilmişlerdir.

Gelişmekte olan grubundaki ülkeler diğer gruplardan farklı bir görünüm sergilemektedir. HDI endeksine göre alt sıralarda olan ülkelerin Tümünün VRS etkinliklerinin de düşük olduğu görülmüştür. HDI endeksine göre 6 . Ve 8. Sırada yer alan Endonezya ve Mısır, gruplarındaki ülkelere göre sabit girdi altında optimal çıktıyı verememişlerdir. Ancak sırasıyla, 10. 16. 18. ve 21. Sirada yer alan Gabon, Güney Afrika, Irak ve Cape Verde VRS skorlarında sabit girdi altında optimal çıktıyı verebilmişlerdir.

Az gelişmiş grubundaki ülkelerde de, diğer gruplara benzer olarak, elde edilen VRS skorları ile HDI endeksi verileri ilk sıralarda benzerlik göstermektedir. Bu grubun istisnalarını ise HDI endeksinde 6. Sırada olmasına karşın VRS skorlarında sabit girdi altında optimal çıktıyı veremeyen Myanmar ve HDI endeksinde 11. 12. 14. ve 23. sırada olan, sirasıyla Madagaskar, Zimbabve, Solomon Adaları ve Gitmek, VRS skorlarında sabit girdi altında optimal çıktıyı verebilmişlerdir.

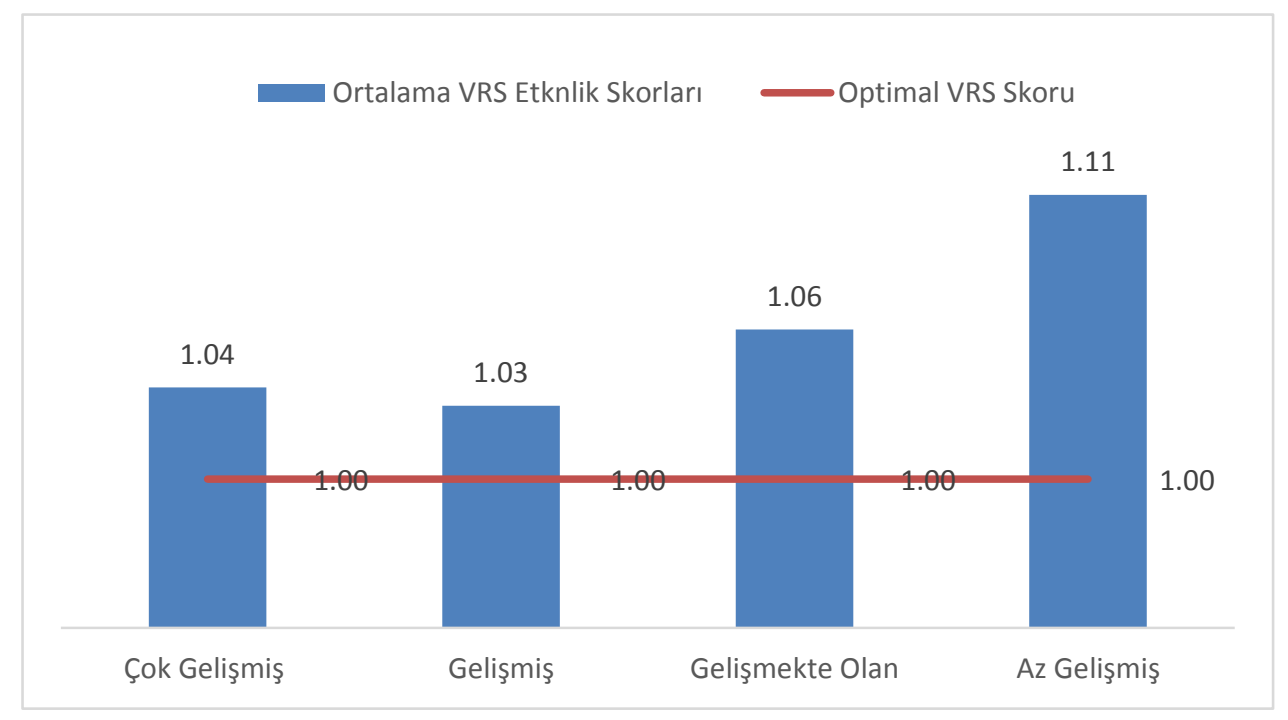

Grafik 1: Ülke Gruplarının Ortalama VRS Etkinlik Skorları

Elde edilen grafiğe göre gelişmiş olan ülke grubunun ortalama olarak optimal düzeye çok gelişmiş ülke grubunun ortalamasından daha yakın olduğu gözlenmiştir. Ayrıca, ülkelerin gelişmişlik sıralaması düştükçe ortalama etkinlik skoru da optimal düzeyden uzaklaşmaya başlamıştır.

\section{Sonuç}

İnsani gelişme endekslerine göre, çok gelişmiş, gelişmiş, gelişmekte olan ve az gelişmiş olarak gruplara ayrılan ülkelerin her birinin, kendi grubu içinde değerlendirilerek birbirlerine göre nisbi etkinliklerinin ölçüldüğü bu çalışmada, veri zarflama analizi kullanılmıştır. Böylece HDI endeksine göre gruplandırılan ülkelerin, kendi grupları içerisindeki diğer ülkelere göre nispi çıktısında optimal seviyeye ulaşıp ulaşmadığına yönelik politikalar sunulmuştur. Çalışmada, HDI endeksine göre sıralanan ülkelerin kendi grubu içinde etkinliklerinin incelenmesinin sebebi, homojen bir yapı oluşturmaktır. Etkinlik ölçümü için, HDI hesabında kullanılan yaşam beklentisi, eğitim ve kişi başına düşen GSYH endeksi verileri ile. Çıktı değişkenleri üzerinden etkinlik ölçümünün yapıldığı durum için girdisiz radyal temelli DEA modelleri kullanılmıştır.

Tablolarda verilen çıktı odaklı skor değerleri 1,00 değeri ve bu değerin üzerindedir. 1,00 değerine sahip olan ülkenin mevcut kaynaklarıyla elde ettiği çıktılarının, o ülkenin değerlendirildiği grup içerisindeki diğer ülkelerinkine göre maksimum seviyede olduğunu göstermektedir. Bu değerden uzaklaşmak ise etkinsizliğin artması anlamına gelmektedir. Buna göre, öncelikle elde edilen VRS skorları, BM tarafından yapılan endeks sıralamasıyla benzer sonuçlar izlediği gözlemlenmiştir. Yani HDI endeksine göre kendi gruplarının ilk sıralarında 
yer alan ülkeler, genellikle VRS skorlarına göre etkin çıkmış olup buna karşın bazı istisnai ülkeler vardır. Örneğin; çok gelişmiş grubunda ilk 5 'te yer alan olan Hollanda, değerlendirildiği gruptaki ülkelere göre sabit girdi altında optimal çıktıyı verememiştir.

Çalışmanın son bölümünde, ülke gruplarının ortalama VRS etkinlik skorları grafik üzerinde gösterilmiştir. Elde edilen grafiğe göre, gelişmiş grubundaki ülkelerin VRS skorları ortalamalarının, çok gelişmiş grubundaki ülkelerin VRS skorları ortalamalarından optimal düzeye daha yakın olduğu gözlemlenmiştir. Bunun yanında, ülkelerin gelişmişlik sıralaması düştükçe ortalama etkinlik skorunun da, optimal düzeyden uzaklaşmaya başladığı gözlemlenmiştir.

Bulgulara paralel olarak, ülkelerin gelişmişlik sıralamasının bir adım ötesinde DEA analizi ile politik karar alıcılara, ülke kaynaklarının diğer muadili ülkelere göre ne kadar etkin kullanıldığının gösterilmesinin dışında daha sonraki çalı̧̧malarda süper etkinlik DEA modeli ile de HDI endeksine alternatif olarak yeniden ülke sıralaması yapılabilir.

\section{Kaynakça}

- Baliamoune-Lutz, M, McGillivray, M. (2006). "Fuzzy well-being achievement in Pacific Asia". Journal of the asia Pacific Economy, 11(2), 168-177.

- Bhanojirao, V. (1991). "Human development report 1990: review and assessment". World Development, 19(10), 1451-1460.

- Bollou, F, Ngwenyama, O K, Morawczynski, O. (2006). The impact of investments in ICT, health and education on development: a DEA analysis of five African countries from 1993-1999. Paper presented at the ECIS

- Bougnol, M L, Dulá, J H, Estellita Lins, M P, Moreira da Silva, A C. (2010). "Enhancing standard performance practices with DEA". Omega, 38(1-2), 33-45. doi: http://dx.doi.org/10.1016/j.omega.2009.02.002

- Coelli, T, Perelman, S. (2000). "Technical efficiency of European railways: a distance function approach". Applied Economics, 32(15), 1967-1976.

- Cooper, W W, Seiford, L M, Tone, K. (2007). Data envelopment analysis: a comprehensive text with models, applications, references and DEA-solver software: Springer Science \& Business Media.

- Despotis, D K. (2004). "A reassessment of the human development index via data envelopment analysis". J Oper Res Soc, 56(8), 969-980.

- $\quad$ Despotis, D K. (2005). "Measuring human development via data envelopment analysis: the case of Asia and the Pacific". Omega, 33(5), 385-390. doi: http://dx.doi.org/10.1016/j.omega.2004.07.002

- $\quad$ Despotis, D K, Stamati, L V, Smirlis, Y G. (2010). "Data envelopment analysis with nonlinear virtual inputs and outputs". European Journal of Operational Research, 202(2), 604-613. doi: http://dx.doi.org/10.1016/j.ejor.2009.06.036

- $\quad$ Dias, R A, Mattos, C R, Balestieri, J A. (2006). "The limits of human development and the use of energy and natural resources". Energy Policy, 34(9), 1026-1031.

- $\quad$ DPT, D P T. (2007). "Dokuzuncu Beş Yıllık Kalkınma Planı". İsgücü Piyasası Özel İhtisas Komisyonu Raporu.

- $\quad$ Førsund, F R, Sarafoglou, N. (2002). "On the origins of data envelopment analysis". Journal of Productivity Analysis, 17(1-2), 23-40.

- $\quad$ Grimm, M, Harttgen, K, Klasen, S, Misselhorn, M. (2008). "A human development index by income groups". World Development, 36(12), 2527-2546.

- Harttgen, K, Klasen, S. (2012). "A household-based human development index". World Development, 40(5), 878-899.

- Herrero, C, Martínez, R, Villar, A. (2012). "A newer human development index". Journal of Human Development and Capabilities, 13(2), 247-268.

- $\quad$ Hicks, D A. (1997). "The inequality-adjusted human development index: a constructive proposal". World development, 25(8), 1283-1298.

- $\quad$ Kelley, A C. (1991). "The Human Development Index:" Handle with Care"'. Population and Development Review, 315-324.

- $\quad$ Lee, H-S, Lin, K, Fang, H-H. (2006). A fuzzy multiple objective DEA for the human development index. Paper presented at the Knowledge-Based Intelligent Information and Engineering Systems.

- $\quad$ Lovell, C K, Pastor, J T. (1999). "Radial DEA models without inputs or without outputs". European Journal of operational research, 118(1), 46-51. 
- $\quad$ Mahlberg, B, Obersteiner, M. (2001). "Remeasuring the HDI by data envelopement analysis". Available at SSRN 1999372.

- $\quad$ Morse, S. (2003). "Greening the United Nations' human development index?". Sustainable Development, 11(4), 183-198.

- $\quad$ Neumayer, E. (2001). "The human development index and sustainability-a constructive proposal". Ecological Economics, 39(1), 101-114.

- $\quad$ Noorbakhsh, F. (1998). "A modified human development index". World Development, 26(3), 517-528.

- $\quad$ Ranis, G, Stewart, F, Samman, E. (2005). "Human development: Beyond the HDI". Yale University Economic Growth Center Discussion Paper(916).

- $\quad$ Ravallion, M. (1997). "Good and bad growth: the human development reports". World Development, 25(5), 631-638.

- $\quad$ Reig-Martínez, E. (2013). "Social and Economic Wellbeing in Europe and the Mediterranean Basin: Building an Enlarged Human Development Indicator". Social Indicators Research, 111(2), 527-547. doi: 10.1007/s11205-012-0018-8

- $\quad$ Safari, H, Ebrahimi, E. (2014). "Using Modified Similarity Multiple criteria Decision Making technique to rank countries in terms of Human Development Index".

- $\quad$ Sagar, A D, Najam, A. (1998). "The human development index: a critical review". Ecological economics, 25(3), 249-264.

- $\quad$ Sanusi, Y A. (2008). "Application of human development index to measurement of deprivations among urban households in Minna, Nigeria". Habitat International, 32(3), 384-398.

- $\quad$ Sen, A, Sudhir, A. (1994). "Human Developmnet Index: Methodology and Measurement, human Development Report Office Occasional Paper 12". UNDP, New York.

- $\quad$ Shetty, U, Pakkala, T P M. (2010). "Multistage method of measuring human development through improved directional distance formulation of data envelopment analysis: application to Indian States". OPSEARCH, 47(3), 177-194. doi: 10.1007/s12597-011-0033-6

- $\quad$ Srinivasan, T N. (1994). "Human development: a new paradigm or reinvention of the wheel?". The American Economic Review, 238-243.

- Tofallis, C. (2013). "An automatic-democratic approach to weight setting for the new human development index". Journal of Population Economics, 26(4), 1325-1345. doi: 10.1007/s00148-012-0432-x

- $\quad$ Ülengin, F, Kabak, Ö, Önsel, S, Aktas, E, Parker, B R. (2011). "The competitiveness of nations and implications for human development". Socio-Economic Planning Sciences, 45(1), 16-27. doi: http://dx.doi.org/10.1016/j.seps.2010.10.001

- Zhou, P, Ang, B W, Zhou, D Q. (2010). "Weighting and Aggregation in Composite Indicator Construction: a Multiplicative Optimization Approach". Social Indicators Research, 96(1), 169-181. doi: 10.1007/s11205009-9472-3 


\title{
Beşeri Sermaye Harcamaları: Türkiye’de Yaşanan Gelişmeler ve Sonuçlar Üzerine Bir İnceleme
}

\section{Human Capital Spending: A Review on the Developments and the Results in Turkey}

\author{
Assoc. Prof. Dr. Haşim Akça (Çukurova University, Turkey)
}

\begin{abstract}
Human capital is defined as values like knowledge, capability, experiment and dynamism that labour contributed to production holds and enables more productive usage of other factors of production. According to this definition that includes properties of individuals in the production process like knowledge, capability, experiment and dynamism, with the definition of human capital, all capabilities devoted to the increasing production is incorporated. Developing and efficient usage of human capital and is very crucial especially in less developed and developing countries. In this countries, not only selecting the optimal combination but also acquisition and the way to use these factors of production in order to increase production exhibits an important dimension. However, this will not be sufficient to catch the developed countries. In order to achieve this goal, beyond transmitting new technologies, constructing knowledge and technology that fosters this technological development is required. Developing and efficient usage of human capital, one of the important dynamics of the economic growth is very crucial in less developed and developing countries comparing to developed countries. In order to develop human capital educated and healthy society is needed. Efficient assessment of the associated capital requires satisfaction of individuals by the means of tangible facilities social relations. In this study, the evolution of human capital will be investigated under human capital indicators and findings will be revealed. Therewithal, several suggestions will be powered for developing human capital.
\end{abstract}

\section{Giriş}

Beşeri sermaye diğer üretim faktörlerinin daha verimli şekilde kullanılmasını sağlayacak olan işgücünün bilgi, beceri, deneyim gibi etkenlerinden oluşur. Bu etkenler üretimi daha kolay hale getirerek daha fazla üretimin gerçekleştirilmesine yol açacak yeni tekniklerin ve yeni teknolojilerin bulunup, bunların etkin bir şekilde kullanılmasına yol açarak ekonomik büyüme sürecine katkı sağlamaktadır.

1960'lı yıllara kadar pek fazla fark edilemeyen bu etkenlerin yarattığı etkiler bu tarihten sonra daha fazla anlaşılmaya başlamıştır. Beşeri sermaye kavramı bu tarihten sonra oldukça fazla araştırmaya konu olmuştur. Ekonomik büyüme üzerinde klasik üretim faktörlerinin -emek, sermaye, doğal kaynaklar ve girişimci- yarattığı etki yanında hiç hesaba katılmayan bireylerin bilgi, beceri deneyim gibi nitelikleriyle yarattığı etkinin fark edilmesi beşeri sermayenin önem kazanmasına yol açmıştır.

$\mathrm{Bu}$ çalışmada öncelikle beşeri sermaye kavramının tanımlanmasıyla birlikte literatürde yer alan çalışmalar hakkında bilgi verilerek, beşeri sermaye oluşumunu belirleyen etkenler incelenecektir. Sonraki bölümde ise Türkiye'de beşeri sermayenin gelişimi değerlendirilecektir.

\section{Beşeri Sermayenin Tanımı}

Sermaye ve doğal kaynaklar gibi üretim faktörlerinin daha etkin bir şekilde kullanılmasını sağlayarak hem verimliliği hem de ekonomik büyümeyi olumlu şekilde etkileyen beşeri sermaye bireylerin sahip olduğu bilgi, beceri, deneyim gibi donanımlarının tamamını kapsamaktadır. (Atik, 2006). Bireylerin sahip olduğu bu donanımlar üretimi kolaylaştıracak ve arttıracak yeni tekniklerin ve yeni teknolojilerin bulunmasını sağlayacaktır. $\mathrm{Bu}$ yeni tekniklerin/teknolojilerin kullanılmasıyla birlikte beşeri sermaye ekonomik gelişme sürecini olumlu etkileyecektir.

Yukarıdaki ifadelere bakıldığında beşeri sermaye kavramının bireylerin bilgi, beceri, deneyim gibi niteliklerini içerdiği ve bu niteliklerin de iktisadi faaliyetlerde bireyler üzerinde olumlu etki yarattığı anlaşılmaktadır. Günümüzde beşeri sermaye tüm ülkeler için hayati öneme sahiptir. Ancak az gelişmiş ve gelişmekte olan ülkeler için beşeri sermaye daha fazla önemlidir. Zira bu ülkelerin mevcut durumlarını daha ileriye taşıyabilmeleri yani, gelişmiş ülke sınıfına dahil olabilmeleri için oldukça donanımlı bir insan kaynağına sahip olmaları gerekir. Böyle bir kaynağın oluşturulabilmesi için kuşkusuz hem sağlık hem de eğitim alanında oldukça sağlam bir altyapının olması gerekir. Bir ekonomide üretimin gerçekleştirilebilmesi eldeki mevcut teknolojinin de sürece dahil edilerek emek, sermaye ve doğal kaynakların girişimciler tarafından bir araya getirilmesi ile gerçekleşebilir. Bu noktada sermaye denilince fiziki sermaye, emek ile de beşeri sermaye olarak vasıflı işgücünün yanında vasıfsız işgücü ifade edilmektedir. Fiziki sermaye olarak belirtilen üretim faktörü işletmelerin sahip olduğu tesisler, makinalar, üretim sürecinde kullanılacak olan değişik araç ve gereçler, hammaddeler ve dayanıklı diğer üretim faktörlerinin 
stoklarından oluşur. Belli bir dönemde sermaye stokuna yapılan eklemeler yatırım olarak ifade edilir. Emek arzı ise nüfusun artması ve artan nüfusun bir kısmının emek arzına katılması ile artar. Emeğin özellikle okullarda ve işyerlerinde almış olduğu eğitimler beşeri sermayenin artmasına neden olur. Bu noktada beşeri sermayeyi işgücünün sahip olduğu bilgi ve beceriler toplamı olarak tanımlamak mümkündür (Kibritçioğlu, 1998).

Bir ekonominin gelişip büyüyebilmesi, verimliliğinin ve karlılığının arttırılabilmesi için tek başına fiziki yatırımlar yeterli değildir. Fiziki yatırımlarla ortaya çıkan fiziki sermayeyi kullanacak onu üretim sürecine sokacak olan nitelikli insan kaynaklarının olması zorunluluk arz eder. Bir başka ifadeyle, bir ekonominin uzun dönemde başarılı olabilmesi sahip olduğu insan gücü kaynaklarının niteliklerine bağlıdır. Emek dışında kalan üretim faktörleri ne kadar fazla olursa olsun bir ekonomi nitelikli beşeri sermayeye sahip değilse ekonomik büyüme ve gelişmenin uzun dönemde kalıcı olması pek mümkün değildir (Gökçen 2006).

Beşeri sermaye ile ilgili olarak yapılan çeşitli tanımlara bakılacak olursa; bireylerin sahip oldukları donanımlarıyla işgücü piyasasındaki değerlerini arttırmak yani daha yüksek gelir elde edebilecek düzeye ulaşabilmek için kazandıkları donanım beşeri sermaye olarak ifade edilir (Saxton, 2000). Beşeri sermaye kavramı, geniş anlamda bireylerin üretkenliğini arttıracak tüm nitelikleri içerecek şekilde ekonomik faaliyetlerle ilgili olarak bireylerin sahip olduğu bilgi, beceri ve diğer nitelikleri kapsamaktadır (Yumuşak ve Bilen 2000).

Eğitim ve sağlık alanlarındaki harcamalar sermaye yatırımı olarak düşünülebilir. Bu harcamalar sadece beşeri sermayeyi geliştirir. Bu ise bireylerin bilgi, beceri, sağlık ve diğer değerleriyle birlikte, diğer bireylere göre sahip olduğu bilgi birikimi ve donanımlarıyla ayrılmalarını sağlayarak onlara göre kendisine bir üstünlük sağlamasına neden olur (Becker 1993).

Beşeri sermaye ile ilgili çalışmalar oldukça geriye gitmesine rağmen, beşeri sermayenin 1960'lı yıllarda yoğun bir şekilde kavram olarak incelenmeye başlandığını söylemek mümkündür. Bu yıllarda bazı iktisatçılar (Schultz 1961; Becker 1964; Kiker 1966) tarafından yapılan çalışmalarda beşeri sermaye iş gücü piyasasında bireyin verimliliğini arttıracak olan eğitim, sağlık, iş eğitimi ve göç gibi faaliyetlerdeki yatırımların toplanması olarak tanımlanmıştır (Yu, 2001).

Yu'nun da belirttiği gibi bu tanım piyasa dışı faaliyetleri içerecek şekilde genişletilmiştir. OECD (1996)'nin tanımına göre beşeri sermaye; piyasa ve piyasa dışı koşullarda bireylerin yaşamları boyunca mal ve hizmet üretmek için edindikleri bilgi veya fikirler olarak tanımlanırken yine OECD tarafından 1998 yılında yapılan tanımda ise ekonomik faaliyetle ilgili bireylerde somutlaşan yetenek, bilgi birikimi ve diğer nitelikler beşeri sermaye olarak tanımlanmıştır (OECD 1998). Bu tanımlarda ortak nokta ekonomik faaliyetlerde yarar sağlayacak niteliklerdir. Bu nitelikler tanımlardan da anlaşılacağı gibi bilgi, beceri ve diğer niteliklerdir.

Beşeri sermaye bireylerin yapmış oldukları çabalarla ve dışsal etkilerle elde ettikleri bilgi, beceri gibi nitelikleri içerirken aynı zamanda bireylerin usta çırak ilişkisinde olduğu gibi diğer bireylerden yararlanarak elde ettikleri birikimin bir göstergesi olmaktadır (Saygılı ve Cihan, 2006).

\section{Literatür Taraması}

Schultz, beşeri sermaye yatırımlarının sınıflandırmasını yaptığı çalışmada eğitime büyük önem vermiştir. Schultz, çıraklıktan başlayarak kalfalıkla devam eden ve ustalık aşaması ile son bulan süreçte iş eğitimi olarak nitelendirilen informel eğitim; ilk, orta ve yükseköğretimi kapsayan formel eğitim ve yetişkin çalışma programlarını, eğitime ilişkin beşeri sermaye yatırımları olarak nitelendirmiştir (Schultz, 1961).

Beşeri sermaye birikiminin değişik şekillerde gerçekleştirilebileceğini savundukları çalışmada Harbison ve Myers ilk, orta ve yükseköğretim olarak alınan eğitimi formel eğitim olarak nitelendirirlerken iş eğitimi ya da iş başında eğitimi ise informel eğitim olarak nitelendirmektedirler. Bu eğitimlerin alınması çeşitli kuruluşlarda istihdam edilme şeklinde olabileceği gibi, yetişkin eğitim programlarına katılma ve çeşitli gruplara üye olma suretiyle de alınabilir. Beşeri sermayenin gelişmesiyle ilgili bir diğer yöntemde kişinin kendi kendini yetiştirmesidir. $\mathrm{Bu}$ yöntemde bireylerin bilgi birikimini arttırabilmeleri yani daha çok bilgi ve becerilerini geliştirmeleri ancak bireysel bir çaba sarf etmeleriyle mümkün olabilir (Harbison ve Myers, 1964).

Lucas beşeri sermayenin çift yönlü bir etkisinin olacağını vurguladığı çalışmada sürdürülebilir büyümenin gerçekleştirilebilmesinin beşeri sermaye birikimiyle mümkün olabileceğini belirterek eğitimi beşeri sermaye birikimini belirleyen temel unsur olarak ele almıştır. Lucas’a göre beşeri sermaye öncelikle iş gücünün verimliliğinin artmasını sağlayarak mevcut üretim faktörleri ile daha fazla üretimin gerçekleştirilmesini sağlamaktadır. Mevcut üretim faktörleriyle daha fazla üretimin gerçekleştirilmesi durumunu Lucas beşeri sermayenin dişsallığı olarak nitelendirmektedir (Lucas, 1988).

Romer 1986 ve 1990 yıllarında yapmış olduğu çalışmalarda ekonomik büyümenin gerçekleşebilmesi için nitelikli beşeri sermayenin zorunluluğuna dikkat çekmiştir. Bu çalışmalarda dikkat çeken nokta, bahsedilen beşeri sermayenin yeniliklere açık ve aynı zamanda yenilik yaratıcı niteliklere sahip olması ve bu niteliklere sahip beşeri sermaye ile gerçekleştirilen yeniliklerin de teknolojik ilerleme ve ekonomik büyümeyi sağlayacağının kabul edilmesidir (Romer, 1986; Romer, 1990). 
Psacharopoulos sermayenin bir türü olarak görülen beşeri sermayenin getirisinin ne olacağını sorguladığ çalışmada, farklı düzeylerde alınan eğitimlerin bireysel ve sosyal getirilerini hesaplamıştır. 61 ülkeyi kapsayan bu çalışmada eğitimin rekabetçi özel sektördeki getirisinin kamu sektöründeki getirisine göre daha yüksek olduğu sonucuna ulaşırken aynı zamanda ilköğretim, ortaöğretim ve yükseköğretimin bireysel getirilerinin sosyal getirilerinden daha yüksek olduğu sonucuna ulaşmıştır (Psacharopoulosi, 1985).

Psacharopoulos ve Patrinos yaptıkları çalışmada, eğitimin bireysel getirisinin sosyal getirisinden daha yüksek olduğunu belirterek, düşük ve orta gelirli ülkelerde yükseköğretimin getirisinin, gelişmiş ülkelere göre daha yüksek olduğu sonucunu elde etmişlerdir (Psacharopoulos ve Patrinos, 2002).

Barro 98 ülkenin 1960-1985 yıllarına ait verilerini kullanarak yaptığı çalışmada beşeri sermaye stokundaki artışla birlikte uluslararası teknoloji transferinin teknoloji üreten ülkeden üretilen teknolojiyi taklit eden ülkeye daha kolay yapılmasının sağlandığını ve bunun sonucunda her iki ülke arasındaki gelir farklılıklarının daha kolay kapanabileceğini öne sürmüştür (Barro, 1991).

Barro'nun yine aynı dönem verilerini kullanarak ülke sayısını 100'e çıkardı̆̆ı bir diğer çalışmada ise erkeklerin almış oldukları orta ve lise düzeylerindeki eğitim düzeyleriyle ekonomik büyüme arasında pozitif bir ilişki bulunurken, bayanlarla ilgili olarak herhangi bir ilişki tespit edilememiştir (Baro, 1998).

Barro ve Lee,1993 yılında 129 ülkeye ait 1960-1985 yıllarını kapsayan 25 yaş ve üzeri nüfusun mezun olduğu okul yılı verilerini kullandıkları çalışmada, eğitimle ekonomik büyüme arasındaki ilişkiyi incelemişlerdir. İlgili çalışmada, ilkokul düzeyinde erkek ve bayanların ekonomik büyüme ile okula gitme yılları arasında anlamlı ve pozitif bir ilişki elde edilirken, ortaokul ve yükseköğretim düzeyinde bayanların ekonomik büyümeye olumlu katkı sağlamalarına karşın erkeklerin ekonomik büyümeye katkıları anlamsız çıkmıştır (Barro ve Lee, 1993).

Barro ve Lee 2001 yılında güncelleştirdikleri çalışmada, 129 ülkeye ait 1960-1985 dönemi için kullandıkları verileri, 142 ülkeye kapsayacak şekilde ve dönemi de uzatarak 1960-2000 dönemine ait verilerle genişleterek 15 ve 25 yaş üzeri nüfusun eğitime katılma oranlarını gösterge olarak kullanmışlardır. Eğitimin ekonomik büyüme üzerindeki etkisini genel eğitim seviyeleri ve özel eğitim seviyeleri için araştırmışlardır. Elde edilen sonuçlar 1993 yılındaki çalışmada elde edilen sonuçlara benzer şekilde ortaya çıkmıştır (Barro ve Lee, 2001).

Mulligian ve Salai-Martin ABD’ye ait 1940-1990 dönemi verilerini kullandıkları çalışmada, beşeri sermayeyi ölçmek amacıyla çeşitli indeksler oluşturmaya çalışmışlardır ve oluşturdukları indekslerin sonuçlarının da birbirinden farklı olduğu sonucuna ulaşmışlardır (Mulligian ve Sala-i Martin, 2000).

Nelson ve Phelps, teknoloji taklitçisi ülkelerin beşeri sermayelerinin yeterli olması halinde teknoloji üreticisi ülkelerdeki teknolojik gelişmeleri çok kolay bir şekilde taklit ederek teknoloji üreticisi ülke ile teknolojiyi taklit eden ülke arasındaki ekonomik gelişmenin teknoloji taklitçisi ülke lehine olabileceğini ileri sürmüşlerdir (Nelson ve Phelps, 1966).

Kim ve Lee teknoloji ile eğitim arasındaki ilişkiyi araştırdıkları çalışmada eğitim ve teknolojinin birbirlerini tamamlayıcı bir yapıda oldukları sonucuna ulaşmışlardır. Çalışmada teknolojik gelişmenin ekonomik büyüme üzerinde olumlu etki yaratabilmesinin teknolojik gelişmeyle uyumlu bir beşeri sermaye stoku ile mümkün olabileceğini belirtmişlerdir (Kim ve Lee, 1999).

Becker v.d., beşeri sermaye ile ilgili yaptıkları çalışmada nüfus artış oranının etkisi üzerinde durmuşlardır. Bu çalışmada yapılan önceki çalışmalarda sabit ve dışsal olarak kabul edilen nüfus artış oranının içsel olduğu ortaya konulmuştur. Buna göre, bireylerin beşeri sermaye düzeyi arttığında, gelir düzeyleri de artacağından, çocuk bakmanın firsat maliyeti artacaktır. Bu durumun doğal sonucu olarak doğurganlık azalacaktır. Nüfus artış hızındaki bu yavaşlama ise büyümeye olumlu katkıda bulunacaktır. Becker ve arkadaşları beşeri sermaye stokunun artmasının ücretleri arttıracağını ve ücret artışı nedeniyle ortaya çıkan gelir artışının çocuk bakmanın ve yetiştirmenin fırsat maliyetini arttıracağını belirtmişlerdir. Sonuçta doğurganlığın azalacağını ancak artan beşeri sermayenin çocuk başına yapılan beşeri sermaye yatırımlarını da arttıracağını ve böylece meydana gelen büyük oranda beşeri sermaye stokunun varlığının yüksek oranlı ekonomik büyümeyi beraberinde getireceğini belirtmişlerdir (Becker,v.d., 1990).

Mankiw, v.d., Solow’un 1956 yılında kurduğu modele beşeri sermayeyide ekleyip genişlettikleri çalışmada beşeri sermayenin de an az fiziki sermaye kadar büyüme üzerinde etkisi olduğunu göstermişlerdir. Mankiw v.d.'nin 1960-1985 döneminde 98 ülkeyi kapsayan çalışmalarında, beşeri sermayenin ekonomik büyüme üzerindeki doğrudan anlamlı etkisiyle birlikte, sermaye stokunun etkisinin de, Solow’un belirttiğinden daha fazla olduğunu ortaya koymuşlardır (Mankiw, v.d.,1992).

Asteriou ve Agiomirgianakis'in Yunanistan için yaptıkları çalışmada, beşeri sermaye ile ekonomik büyüme arasındaki ilişki incelenmiştir. Bu çalışmada ilköğretim, orta öğretim ve yükseköğretim düzeylerini beşeri sermaye değişkeni olarak modele ilave etmişler ve bu değişkenlerle ekonomik büyüme arasında uzun dönemli pozitif bir iliş̧inin olduğu sonucunu elde etmişlerdir (Asteriou ve Agiomirgianakis, 2001).

Mosino (2002) 15 ülkeye ait 1960-1990 dönemi verileriyle yaptığı çalışmada beşeri sermayenin ekonomik büyümeyle olan ilişkisini araştırmıştır. Mosino beşeri sermayenin ekonomik büyüme üzerinde olumlu etki yarattığı sonucuna ulaşmıştır. 
Çoban uzun dönemde ekonomik büyüme ile beşeri sermaye arasındaki ilişkiyi incelediği çalışmada Türkiye'de 1980-1997 dönemine ait verileri kullanarak, eğitimle ilgili değişkenlerle ekonomik büyüme arasındaki ilişkileri araştırmıştır. Değişkenler arasında uzun dönemli bir iliş̧kinin yanı sıra, değişkenler arasında bir nedensellik ilişkisinin olup olmadığının belirlenmeye çalışıldığı çalışmada yapılan analizler, ekonomik büyüme üzerinde ilkokul okullaşma oranındaki artışın olumlu etkisinin olduğu, bu durumun ise lise düzeyindeki okullaşma oranını arttırdığı belirlenmiştir. Ayrıca, üniversite okullaşma oranındaki artışın nedeninin lise okullaşma oranındaki artış olduğu ve lise okullaşma oranındaki artışın ise eğitim harcamalarındaki artış sonucu ortaya çıktığı sonucu elde edilmiştir (Çoban, 2004).

Canpolat Türkiye'de beşeri sermayenin büyümeye etkisini araştırdığı çalışmada 1950-1990 yılları dönemine ait oluşturduğu beşeri sermaye birikimine ait dizi ile ekonomik büyümenin kaynaklarını analiz etmeye çalışmıştır. Canpolat, ilgili dönemde Türkiye'de teknolojik yıllık ortalama \%2,3 oranında gerçekleştiğini aynı zamanda Türkiye'de fiziki sermaye tarafından gerçekleştirilen üretime katkının $\% 53$, işgücü tarafından gerçekleştirilen katkının $\% 7$ ve beşeri sermaye tarafından gerçekleştirilen katkının ise $\% 40$ olarak gerçekleştiği sonucuna ulaşmıştır (Canpolat, 2000).

Kar ve Ağır beşeri sermaye ile büyüme arasındaki pozitif ilişkiyi araştırdıkları çalışmada, ekonomik büyüme ile beşeri sermaye arasındaki ilişkiyi nedensellik bağlamında değerlendirmeye çalışmışlardır. Çalışmanın sonucunda ekonomik büyüme ile beşeri sermaye arasındaki nedensellik ilişkisinin yönünün seçilen beşeri sermaye ölçütüne duyarlı olduğu bulgusu elde edilmiştir (Kar ve Ağır, 2003).

Taban ve Kar ekonomik büyüme ile beşeri sermaye arasındaki nedensellik ilişkisini araştırmışlardır. 19692001 dönemine ait beşeri sermaye göstergeleri olarak, Birleşmiş Milletler’in hazırladığı yıllık İnsani Gelişme Raporu'ndan derledikleri verilerle indeks oluşturmuşlardır. Bu indeksler: Beşeri sermaye indeksi, birleşik okullaşma oranı, eğitim ve yaşam süresi indeksidir. Oluşturulan bu indekslerin kullanıldığı çalışmada beşeri sermaye ile ekonomik büyüme arasındaki nedensellik ilişkisinin yönünün seçilen beşeri sermaye göstergesine göre farklılık gösterdiğini belirtmişlerdir. Ekonomik büyüme ile beşeri sermaye arasındaki nedensellik analizine göre, bir taraftan ekonomik büyüme beşeri sermayeyi belirlerken diğer taraftan beşeri sermaye göstergelerinin ekonomik büyümeyi belirlediği sonucuna ulaşmışlardır (Taban ve Kar, 2006).

Beşeri sermayenin kalkınma endeksiyle ölçüldüğü çalışmada; Uzun ve sağlıklı bir ömür, bilgi edinme ve asgari geçim standardı için gerekli kaynaklara erişme gibi üç boyutlu beşeri kalkınma endeksi kullanılmıştır. Yapılan çalışmada elde edilen bulgulara bakıldığında orta derece beşeri kalkınma düzeyindeki ülkeler arasında yer alan Türkiye'nin sıralamadaki durumunu koruyamadığı, aynı düzeydeki ülkelerle karşılaştırıldığında ise sağlık ve eğitim göstergelerinin daha düşük olduğu sonucuna ulaşılmıştır (Tuna ve Yumuşak, 2002).

\section{Beșeri Sermayenin Önemi}

Genel anlamda bilinen sermayeden ayrı bir üretim faktörü olarak ortaya çıkan beşeri sermaye (Atik, 2006: 24) bilginin temel üretim faktörlerinden birisi olarak kabul edildiği günümüz bilgi toplumunda fiziki sermaye ve doğal kaynaklara göre daha çok önem kazanmaya başlamıştır (Eser ve Ekiz-Gökmen, 2009).

Beşeri sermaye; gelişmiş ülkelerde görülen ekonomik büyüme üzerinde alışılmış sermayeden daha büyük etki yaratabilecek niteliğe sahiptir. Beşeri sermayedeki artışlar gelişmiş ülkelerin ekonomik büyümelerinin önemli bir kısmını gerçekleştirmektedirler. Bu durum ise beşeri sermayenin önemini gözler önüne sermektedir. Eğitim, sağlık, beslenme gibi bireylerin mal ve hizmet üretimindeki etkinliğini arttıran beşeri sermayeye yapılan her türlü yatırımlar üretim üzerinde beşeri sermayenin alışılmış sermayeden daha etkili olmasını sağlamaktadır (Gökçen, 2006).

Beşeri sermayenin gelişmesi ve beraberinde ortaya çıkan teknolojik değişimlerin ülkelerin sanayi toplumunu da geçtiği bir aşama olarak kabul edilen günümüz bilgi toplumunda, alışılmış sermaye ve doğal kaynaklar önemini sürekli yitirmektedir. Fiziki sermaye ve doğal kaynaklardaki azalışın yeri ise beşeri sermaye ile doldurulmaktadır (Yumuşak ve Tuna, 2002).

\section{Beşeri Sermaye Göstergeleri}

Beşeri sermaye göstergeleri içerisinde en çok kullanılanları eğitim, sağlık ve beyin göçü olarak nitelendirilen göstergelerdir. Eğitim bu göstergeler içerisinde özel bir öneme sahiptir. Çünkü eğitimin beşeri sermayenin gelişimi üzerinde doğrudan etkisi yanında beşeri sermayeyi oluşturan diğer bileşenlerin ölçülmesindeki zorluklar eğitimi diğer göstergelere daha önemli hale getirmiştir. Bununla birlikte eğitime yapılan yatırımlar ve harcamalar sonucu daha donanımlı hale gelen işgücü, beşeri sermaye stokunun ölçülmesinde kullanılabilecek en gerçekçi göstergelerin başında gelmektedir (Gökçen, 2006).

Beşeri sermayenin ölçümünde kullanılabilecek göstergelerle ilgili olarak kullanılan bir diğer yaklaşım ise yatırım göstergeleri ve stok göstergeleri olarak beşeri sermayenin iki grupta toplanarak ölçülmesidir. İşgücünü oluşturan bireylerin sahip olduğu bilgi ve becerilerin en önemli kaynağının eğitim olarak kabul edilmesi, beşeri sermayenin genellikle eğitim göstergeleri olarak gösterilmesine yol açmıştır (Eser ve Ekiz-Gökmen, 2009). Bu 
noktadan hareketle stok göstergelerinin beşeri sermayenin eğitim düzeyi, okuryazarlık göstergeleriyle gösterildiği söylenebilir.

Parasal göstergeler ve parasal olmayan göstergeler olarak iki grupta toplanan beşeri sermaye ile ilgili yatırım göstergeleri ise, eğitim harcamalarının GSYİH içerisindeki payı, öğrenci başına düşen eğitim harcamaları ve işletmelerin eğitim harcamaları gibi parasal göstergelerden meydana gelmektedir. Parasal olmayan göstergeler ise; hizmet içi eğitim ya da iş üzerinde çıraklıktan ustalık dönemine kadar geçen süre içerisinde alınan eğitim, eğitime ayrılan toplam süre gibi değişik göstergelerden oluşmaktadır (Atik, 2006).

\section{Beşeri Sermaye Oluşumuna Etki Etki Eden Faktörler}

Yukarıda yapılan açıklamalar ışığında beşeri sermayenin birikiminde, eğitimle birlikte toplumun sağlık düzeyinin yanında, genç ve dinamik bir nüfus yapısı ile beyin göçü de önemli bir role sahiptir (Gökçen, 2006). $\mathrm{Bu}$ bağlamda beşeri sermayenin oluşumunu etkileyen ve aynı zamanda beşeri sermaye stokunu arttıran faktörler üç başlık altında incelenebilir. Bunlar: Eğitim, sağlık ve işgücü transferidir (Eser ve Ekiz-Gökmen, 2009).

\subsection{Eğitim ve Beşeri Sermaye}

Eğitim, eğitim alan bireyler üzerinde doğrudan bir etki yaratırken aynı zamanda toplum üzerinde de dolaylı bir etki yaratabilecek nitelikte bir olgudur. Bireylerin nitelikli hale gelmesinde önemli bir işleve sahip olan eğitim, aynı zamanda bilgi birikimi artmış bireylerle ülkenin gelişmesine de katkı yaparak bir diğer işlevi de yerine getirmiş olur. Bundan dolayı beşeri sermaye ile ilgili çalışmalarda eğitim ile beşeri sermaye kavramlarının birlikte kullanılması yaygınlaşmıştır (Atik, 2006).

Bir ekonomideki potansiyelin harekete geçirilebilmesi ve sürdürülebilir ekonomik gelişme için beşeri sermaye olarak bireyin performansını arttıracak bilgi ile donatılması gereklidir. Bunun gerçekleştirilmesinin yegane yolu da eğitimden geçmektedir. Bu nedenle, eğitimin beşeri sermayenin oluşumunda en önemli faktör olduğunu söylemek mümkündür (Durusoy, 2007).

Eğitim kayıtları, mali göstergeler, fiziki göstergeler ve okuryazarlık göstergeleri eğitim düzeyini belirleyen temel kriterlerdir. Eğitim kayıtları, nüfusun ilköğretim, orta öğretim ve yükseköğretim gibi farklı eğitim düzeyleri arasındaki dağılımını gösterir. Mali göstergeler, GSYİH içerisinde eğitim harcamalarının payı ve kişi başına düşen eğitim harcamalarından oluşmaktadır. Fiziki göstergeler ise öğrenci ve öğretmen sayıları, öğretmen başına düşen öğrenci sayısı, okul sayısı, laboratuar v.b. diğer göstergelerden oluşmaktadır. Okuryazarlık oranı ise, eğitim düzeyi ve beşeri sermaye stokunun ölçülmesinde kullanılan en basit göstergedir (Atik, 2006).

\subsection{Sağlık ve Beşeri Sermaye}

Sağlık eğitimle birlikte beşeri sermayenin önemli bir unsuru olarak kabul edilmektedir. Zira bireylerin hem eğitim alabilmeleri hem de almış oldukları eğitimi uygulamaya geçirerek ekonomik faaliyete katılabilmeleri ancak sağlıklı olmaları halinde mümkün olacaktır. Dolayısıyla nüfusun sağlıklı bir yapıda olması beşeri sermayenin oluşumunu etkileyen başlıca etkenlerdendir (Eser ve Ekiz-Gökmen, 2009).

Toplumun sağlık düzeyi beşeri sermayenin oluşumu ve gelişiminde önemli rol oynamaktadır. Gelişmiş ülkelerde sağlık için ayrılan kaynakların artması ve bu ülkelerde yaşayan bireylerin sağlı bilincinin yükselmesi sağlıklı bireylerin sayısının artışında önemli rol oynayacaktır. Sağlıklı bireylerin sayısının artışı da ekonomik büyüme ve gelişmeyi olumlu etkileyecektir (Mazgit, 2002).

Taban tarafından yapılan 1980-2000 dönemine ait yıllık verilerin kullanıldığ çalışmada ekonomik büyüme ile sağlı harcamaları arasında nedensellik ilişkisi bulunmamakla beraber doğuşta yaşam beklentisi ile ekonomik büyüme arasında çift yönlü bir nedensellik ilişkisi görülmüştür. Taban sağlık harcamaları ile ekonomik büyüme arasında nedensellik ilişkisi kurulamamasını bu alanda yapılan harcamaların verimsizliğine ve yetersizliğine bağlamıştır (Taban, 2004).

Ortalama yaşam süresinin uzaması bir toplumdaki sağlık düzeyinin gelişmesinin sonucudur. Gelişmiş ülkelerdeki ortalama yaşam süresi diğer ülkelere göre daha uzundur. Ortalama yaşam süresi beşeri sermaye stokunun önemli belirleyicisidir. Ortalama yaşam süresinin artması aktif olarak çalışılacak sürenin artışını sağlayacaktır. Sağlık, beşeri sermaye yatırımı olarak kabul edildiğinden aktif olarak çalışma süresinin artışı yatırımın verimliliğinin artı̧ı olarak ortaya çıkacaktır. Sağlıklı bir toplum, bir taraftan eğitimin verimliliğini arttırırken diğer taraftan beşeri sermayeden daha uzun süre yararlanılabilmesine önemli katkı sağlayacaktır. (Gökçen, 2006)

\subsection{Beyin Göçü ve Beşeri Sermaye}

Eğitim ve toplumun sağlı düzeyinin beşeri sermaye oluşumuna yaptığı katkı yanında dikkate alınması gereken bir diğer etken de genç ve dinamik bir nüfus yapısı ile beyin göçü olarak isimlendirilen beşeri sermaye göçüdür. Nüfusun genç ve dinamik yapıda olması ile birlikte eğitim verilebilecek ve verilen eğitimin getirisinin geri dönüşünün uzun yıllar sonra gerçekleşmesi, beşeri sermayenin oluşumu için önemli bir kaynak aktarımı anlamına gelmektedir. Bireylerin ülkeler arasında çalışmak veya eğitim amacıyla gidip gelmeleri beşeri 
sermayenin göçünde oldukça etkilidir. Gelişmiş ülkelerin sıkça başvurdukları önemli beşeri sermaye kaynaklarından birisi beşeri sermaye göçü veya genel kullanılan haliyle beyin göçüdür (Gökçen, 2006).

Özellikle gelişmiş ülkelerin beşeri sermaye stoklarını arttıran bir faktör beşeri sermaye göçüdür. Beşeri sermaye transferi belli konularda uzmanlık düzeyinde bilgiye sahip olan bireylerin kendilerine daha iyi hayat standardı sağlayacağını düşündükleri yerlere gitmesi şeklinde gerçekleşen beyin göçü ve vasıfsız bireylerin özellikle az gelişmiş ülkelerden emek talebi yüksek emek arzı düşük olan ülkelere gitmesi şeklinde gerçekleşen işgücü göçü olmak üzere iki şekilde gerçekleşir (Eser ve Ekiz-Gökmen, 2009).

\section{Türkiye'de Beşeri Sermayenin Gelişimi}

Türkiye'de beşeri sermayenin gelişimi incelendiğinde 1930'lu yıllarda \% 18,7 olan okuryazarlık oranı günümüzde \% 95'leri bulmuştur (TÜİK, 2014). Bu gelişmelerde özellikle eğitim alanında geçmişten günümüze yapılan yatırımların oldukça önemli katkıları olduğunu söylemek mümkündür. 2000 sonrası yıllara ait verilerle oluşturulan Tablo 1 incelendiğinde okullaşma oranının ilköğretimde \% 100' e ulaşmanın eşiğinde olduğu, ortaöğretimde ise okullaşma oranının giderek artan bir seyirle \% 76'ya ulaştığı görülmektedir. Özellikle ilköğretimde öğretmen başına düşen öğrenci sayısındaki gelişmeler gelecek için oldukça umut vericidir. Orta öğretimde öğretmen başına düşen öğrenci sayısı incelendiğinde durağan bir gelişme görülmektedir. Bu durumun ise ilköğretimin ilk ve orta öğretim olarak ayrılmasından kaynaklandığını söylemek mümkündür. GSYİH içindeki eğitim ve sağlık harcamalarının payları incelendiğinde, eğitim harcamaları bir buçuk kattan daha fazla bir atış göstermiştir. Burada gösterilen eğitim harcamaları ilköğretimden başlayıp yükseköğretimi de içine alacak şekilde bütçe içerisinde yer alan toplam eğitim harcamalarının GSYİH içindeki payını oluşturmaktadır. Yani bu sütunda gösterilen eğitim harcamaları kamu sektörünün yapmış olduğu toplam eğitim harcamalarının GSYIHH içindeki payını içermektedir. Bütçe harcamaları içerisinde eğitime ayrılan payın GSYİH içindeki payı sürekli bir artış trendi göstermektedir.

\begin{tabular}{|c|c|c|c|c|c|c|}
\hline & \multicolumn{2}{|c|}{ İlköğretim } & \multicolumn{2}{c|}{ Ortä̈retim } & \multicolumn{2}{c|}{ Harcamalar } \\
\hline Yıllar & $\begin{array}{c}\text { Net } \\
\text { Okullaşma } \\
\text { Oranı (\%) }\end{array}$ & $\begin{array}{c}\text { Öğretmen } \\
\text { Başına Düşen } \\
\text { Öğrenci Sayısı }\end{array}$ & $\begin{array}{c}\text { Net } \\
\text { Okullaşma } \\
\text { Oranı (\%) }\end{array}$ & $\begin{array}{c}\text { Öğretmen } \\
\text { Başına Düşen } \\
\text { Öğrenci Sayısı }\end{array}$ & $\begin{array}{c}\text { GSYİH İçinde } \\
\text { Ĕgitim } \\
\text { Harcamaları } \\
\text { (\%) }\end{array}$ & $\begin{array}{c}\text { GSYİH } \\
\text { Icçinde Sağlık } \\
\text { Harcamaları } \\
\text { (\%) }\end{array}$ \\
\hline $\mathbf{2 0 0 0}$ & 95,28 & 30 & 43,95 & 15 & 2,6 & 4,9 \\
\hline $\mathbf{2 0 0 1}$ & 92,40 & 28 & 48,11 & 18 & 2,3 & 5,2 \\
\hline $\mathbf{2 0 0 2}$ & 90,98 & 28 & 50,57 & 18 & 2,8 & 5,4 \\
\hline $\mathbf{2 0 0 3}$ & 90,21 & 27 & 53,37 & 18 & 3,0 & 5,3 \\
\hline $\mathbf{2 0 0 4}$ & 89,66 & 26 & 54,87 & 16 & 3,0 & 5,4 \\
\hline $\mathbf{2 0 0 5}$ & 89,77 & 27 & 56,63 & 16 & 3,1 & 5,4 \\
\hline $\mathbf{2 0 0 6}$ & 90,13 & 26 & 56,51 & 16 & 3,0 & 5,8 \\
\hline $\mathbf{2 0 0 7}$ & 97,37 & 24 & 58,56 & 15 & 3,3 & 6,0 \\
\hline $\mathbf{2 0 0 8}$ & 96,49 & 23 & 58,52 & 17 & 3,2 & 6,1 \\
\hline $\mathbf{2 0 0 9}$ & 98,17 & 22 & 64,95 & 18 & 3,8 & 6,1 \\
\hline $\mathbf{2 0 1 0}$ & 98,41 & 21 & 66,07 & 18 & 3,4 & 5,6 \\
\hline $\mathbf{2 0 1 1}$ & 98,67 & 20 & 67,37 & 16 & 3,8 & 5,3 \\
\hline $\mathbf{2 0 1 2}$ & 98,86 & 20 & 70,06 & 16 & 4,0 & 5,2 \\
\hline $\mathbf{2 0 1 3}$ & 99,57 & 19 & 76,65 & 15 & 4,1 & 5,4 \\
\hline
\end{tabular}

Tablo 1. Beşeri Sermayenin Belirlenmesine İlişkin Çeşitli Göstergeler Kaynak: T.C. Maliye Bakanlı̆̆ (2014), T.C. Kalkınma Bakanlı̆̆ (2015) ve TÜIK (2015).

Sağlık harcamalarının GSYİH içindeki payı incelendiğinde, dalgalı bir seyir izlediği görülmektedir. Bu sütunu oluştururken kullanılan veriler TÜ̇KK tarafından yayınlanan verilerdir. Bu veriler içerisinde kamu ve özel sektör sağlık harcamalarının tamamı yer almaktadır. Tablo 2'de Türkiye'nin beşeri sermaye indeksi gösterilmektedir. Tablo 2 UNDP Birleşmiş Milletler Kalkınma Teşkilatı Beşeri Gelişme Raporlarından yararlanılarak oluşturulmuştur. 


\begin{tabular}{|c|c|c|c|}
\hline Yıllar & Ĕ̆itim indeksi & Sağlık İndeksi & Beșeri Gelișme İndeksi \\
\hline 1980 & 0,304 & 0.595 & 0.496 \\
\hline 1990 & 0,398 & 0.681 & 0.576 \\
\hline 2000 & 0,493 & 0.769 & 0.653 \\
\hline 2005 & 0,531 & 0.807 & 0.687 \\
\hline 2006 & 0,545 & 0.813 & 0.698 \\
\hline 2007 & 0,557 & 0.819 & 0.706 \\
\hline 2008 & 0,563 & 0.824 & 0.710 \\
\hline 2009 & 0,582 & 0.830 & 0.716 \\
\hline 2010 & 0,625 & 0.835 & 0.738 \\
\hline 2011 & 0,648 & 0.840 & 0.752 \\
\hline 2012 & 0,652 & 0.845 & 0.756 \\
\hline 2013 & 0,652 & 0.850 & 0.759 \\
\hline
\end{tabular}

Tablo 2: Türkiye için Beşeri Sermaye İndeksleri Kaynak: UNDP (2013), Human Development Reports,

Türkiye'ye ait beşeri sermaye indekslerinin gelişimi Tablo 2'de incelendiğinde, eğitim indeksindeki gelişmenin iki kat daha fazla arttığı, sağlık indeksinin bir buçuk kat arttığ 1 ve beşeri gelişme indeksinin de bir buçuk kat arttığı görülmektedir. Tablo 2 oluşturulurken yararlanılan UNDP Beşeri Gelişme Raporlarındaki ülkeler arası sıralamalarda Türkiye 69. sırada yer almaktadır. Benzer durum Dünya Ekonomik Forumu'nun 2013 ve 2015 yıllarında Beşeri Sermaye Raporlarında da görülmektedir. 2013 Beşeri Sermaye raporunda Türkiye ülke sıralamasında 60. sırada yer alırken 2015 yılında yayınlanan raporda 68. sıraya gerilemiştir (WEF, 2013; 2015). Sıralamadaki değişikliklerin her iki kuruluşun değerlendirmede dikkate aldığı kıstaslardan kaynaklandığı söylenebilir.

Türkiye ekonomisinin dünyanın ilk 20 büyük ekonomisi arasında olduğu düşünüldüğünde beşeri sermaye göstergeleri sıralamasında 69. sırada olması, beşeri sermayedeki gelişmelerin ekonomik büyümedeki gelişmelere göre daha düşük düzeyde gerçekleştiği, ekonomik büyümenin beşeri sermayenin gelişim üzerinde yeterli bir etki yaratmadığı düşüncesini uyandırmaktadır.

\section{Sonuç}

İşgücünün sahip olduğu ve diğer üretim faktörlerinin de verimliliklerini arttırmaya katkı sağlayacak olan bilgi birikimi, deneyim ve beceri gibi etkenlerin oluşturduğu beşeri sermaye 1960'lı yıllardan sonra yaygın bir şekilde inceleme konusu olmuştur. Diğer üretim faktörlerinde herhangi bir değişiklik olmadan sadece emek faktörünün donanımında meydana gelen değişimin üretim kapasitesi üzerinde yarattı̆ğ olumlu katkı, beşeri sermayenin önemini arttırmaya devam etmektedir.

Beşeri sermayenin gelişmesindeki önemli göstergeler olarak eğitim ve sağlik göstergeleri kabul edilmektedir. Eğitim bireylerin bilgi birikimini arttırıp bireylerin belirli konularda uzmanlaşmasını sağlarken, sağlıkta bireylerin yaşam süreleri başta olmak üzere diğer göstergelerle birlikte beşeri sermayeye yapılan yatırımın geri dönüşü beşeri sermaye üzerindeki olumlu etkilerdir.

Türkiye'de beşeri sermaye göstergeleri zaman içerisinde oldukça önemli sayılabilecek gelişmeler göstermiştir. Ancak Türkiye'nin dünya sıralamasındaki yerine bakıldığında beşeri sermaye göstergelerinin iyileştirilmesine yönelik olarak yapılacak yatırımların arttırılması gerekmektedir. Çünkü beşeri sermaye yatırımlarının getirisi uzun bir süre sonra ortaya çıkmaktadır. Bu açıdan hareketle beşeri sermayenin gelişimine yönelik yapılacak yatırımlar ilerleyen yıllarda Türkiye’nin gelişmesinde önemli katkılar yapacaktır.

Bu çalışma Çukurova Üniversitesi Bilimsel Araştırma Projeleri Koordinasyon Birimi tarafindan 4925 no'lu proje kodu ile desteklenmektedir.

\section{Kaynakça}

- $\quad$ Asteriou, D. ve Agiomirgianakis, G. M. (2001), "Human Capital and Economic Growth: Time Series Evidence from Greece", Journal of Policy Modelling, vol. 23, ss: 481-489.

- $\quad$ Atik, H. (2006), Beşeri Sermaye, Dış Ticaret ve Ekonomik Büyüme, Bursa: Ekin Kitabevi.

- Barro, R.J. (1991), "Economic Growth in a Cross Section of Countries," Quarterly Journal of Economics, 56, ss: 407443.

- Barro, R.J. (1998), "Human Capital and Growth in Cross-Country Regressions", Harvard University Press, $1-46$.

- Barro, R.J. ve Lee, J.-W. (1993), “International Comparisons of Educational Attainment”, NBER Working Paper Series, working paper no: 4349,1-31.

- Barro, R.J. ve Lee J.-W. (2001), "International Data on Educational Attainment Updates and Implications", Oxford Economic Papers, July, 53(3), 541-563. 
- $\quad$ Becker, G. Murphy, K. ve Tamura, R. (1990), "Human Capital, Fertility and Economic Growth,” Journal of Political Economy, 98(5), Part.2, ss: S12-S37.

- $\quad$ Becker, G., S. (1993) Human Capital: A Theoretical and Empirical Analysis with Special Reference to Education. Chicago: The University of Chicago Press, Third Edition

- Canpolat, N. (2000), “Türkiye’de Beşeri Sermaye Birikimi ve Ekonomik Büyüme,” Hacettepe Üniversitesi İIBF Dergisi, Cilt 18, Sayı 2, ss: 265-281.

- C Çoban, O. (2004), “Beşeri Sermayenin Büyüme Üzerine Etkisi: Türkiye Örneği,”.̇̇.Ü. SBF Dergisi, Cilt: 30, ss:133 142 .

- Durusoy, S. (2007) "Sanayi Toplumundan Bilgi toplumuna: Beşeri Sermayeye ihtiyaç Artarken” İçinde:“Avrupa Birliği Yolunda Türkiye’de Eğitim ve Beşeri Sermaye”, (Ed.: Oğuz Karadeniz), Ankara, Gazi Kitabevi.

- $\quad$ Eser, K. ve Ekiz-Gökmen, G. (2009) “Beşeri Sermayenin Ekonomik Gelişme Üzerindeki Etkileri: Dünya Deneyimi ve Türkiye Üzerine Gözlemler”, Sosyal ve Beşeri Bilimler Dergisi, 1(2), ss:41-56.

- Gökçen, B. (2006), "Beşeri Sermayenin İktisadi Gelişmedeki Rolü ve Önemi: Adana İline İlişkin Bir Uygulama” Ç. Ü. Sosyal Bilimler Enstitüsü Yayınlanmamış Yüksek Lisans Tezi, Adana.

- Harbison, F. ve. Myers, C.A. (1964) "Education, Manpower, and Economic Growth: Strategies of Human Resource Development.”, McGraw-Hill, New York.

- Kar, M. ve Ağır, H. (2003), “Türkiye’de Beşeri Sermaye ve Ekonomik Büyüme: Nedensellik Testi,” II. Ulusal Bilgi, Ekonomi ve Yönetim Kongresi Bildiriler Kitabı, İzmit, ss.181 190.

- Kibritçioğlu, A. (1998), "İktisadi Büyümenin Belirleyicileri ve Yeni Büyüme Modellerinde Beşeri Sermayenin Yeri”, Ankara Üniversitesi Siyasal Bilgiler Fakültesi Dergisi, Cilt 53, No.1 -4, 207-230.

- Kim, Y.,J. ve Lee J.,W. (1999), “Technological Change, Investment in Human Capital, and Economic Growth,” CID Working Papers, 29, ss. 140.

- $\quad$ Lucas, R.E. (1988), “On the Mechanics of the Economic Development”, Journal of Monetary Economics vol. 22(1), ss: 3-42.

- Mankiw, G., Romer, D. ve Weil, D.N. (1992), “A Contribution to the Empirics of Economic Growth,” The Quarterly Journal of Economics. May, Vol. 107 Issue 2, pp: 407437.

- Mazgit, İ. (2002) “Bilgi Toplumu ve Sağlığın Artan Önemi”, I. Ulusal Bilgi, Ekonomi ve Yönetim Kongresi, (Hereke-Kocaeli), ss. 405-415.

- Mosino, A. (2002), "Education, Human Capital Accumulation and Economic Growth”, University of Lousanne Department of Econometrics and Political Economics”, (Erişim Tarihi: 18.05.2015), http://www.hec.unil.ch/modmacro/recueil/Mosino.pdf

- Mulligan, C.B. ve Sala-I-Martin, X. (2000), "Measuring Aggregate Human Capital” Journal of Economic Growth, vol. 5(3), September, ss: 215-52.

- Nelson, R. ve Phelps, E. (1966), “Invesment in Humans, Techonological Diffusion and Economic Growth", The American Economic Review, Vol. 56, No. 1/2. (Mar., 1966), ss: 69-75.

- OECD, (1996),"Measuring What People Know; Human Capital Accounting for the Knowledge Economy”, OECD, Paris.

- OECD, (1998), "Human Capital Investment; An Internatioanl Comparison”, OECD, Paris.

- Psacharopoulos, G. (1985), "Returns of Education: A Further International Update and Implications" The Journal of Human Resources, 20/4, ss. 583-604.

- Psacharopoulos, G. ve Patrinos H. A. (2002), "Returns to Investment in Education: A Further Update", World Bank Policy Research Working Paper 2881, September.

- $\quad$ Romer, P. M. (1986), “Increasing Returns and Long-Run Growth”, Journal of Political Economy, 94, pp. 1002-1037.

- $\quad$ Romer, P. M. (1990), “Endogenous Technological Change”, Journal of Political Economy, vol. 98, pp. 71102.

- Saxton, J.(2000), "Invesment In Education: Private and Public Retuns”, Joint Economic Committee United States Congress,January, Washington.

- Saygılı, Ş. ve Cihan, C. (2006), “Türkiye Ekonomisinde Beşeri Sermaye- Verimlilik İlişkisi”, İşletme ve FinansDergisi: Türkiye’ de Büyüme Sorunsalı ve Gelecek, sayı:240, Y11 21, ss: 18 -35.

- Schultz, T. W, (1961), "Investment in human Capital", The American Economic Review, 51(1), March, ss: $1-17$. 
- T.C. Kalkınma Bakanlığı (2015), "Ekonomik ve Sosyal Göstergeler”, Tablo 30. (Erişim Tarihi: 12.06.2015), http://www.kalkinma.gov.tr/Pages/EkonomikSosyalGostergeler.aspx,

- T.C. Maliye bakanlığı (2014), 2015 Yılı Bütçe gerekçesi, Ekim, Ankara.

- Taban, S. (2004), “Türkiye’de Sağlık ve Ekonomik Büyüme İlişkisi: Nedensellik Testi”, 3. Ulusal Bilgi, Ekonomi ve Yönetim Kongresi: Bildiriler Kitabı, Eskişehir, ss:1-10.

- Taban, S. ve Kar, M. (2006) "Beşeri Sermaye ve Ekonomik Büyüme Nedensellik Analizi 1969- 2001”, Anadolu Üniversitesi Sosyal Bilimler Dergisi, Sayı: 6(1), ss: 159-181.

- Tunç, M. (1993), “Türkiye'de Eğitimin Ekonomik Kalkınmaya Etkisi”, 9 Eylül Üniversitesi İIBF Dergisi, Cilt:8, Say1:2, ss:1-32.

- TÜİK (2015), “Sağlık harcamaları ile ilgili Göstergeler”, (Erişim Tarihi: 12.06.2015) http://www.tuik.gov.tr/PreIstatistikTablo.do?istab_id=1614,

- TÜİK, (2014), “İstatistik Göstergeler 1923-2013”, TÜİK Matbaası, Ankara.

- UNDP (2013), “Human Development Reports”, (Erişim Tarihi: 12.06.2015), http://hdr.undp.org/en/data,

- WEF (2013), “Human Development Report 2013”, (Erişim Tarihi: 14.06.2015), http://www3.weforum.org/docs/WEF_HumanCapitalReport_2013.pdf,

- WEF (2015), “Human Development Report 2015”, (Erişim Tarihi: 14.06.2015), http://www3.weforum.org/docs/WEF_Human_Capital_Report_2015.pdf,

- Yu W. (2001), “A Survey of Existing Indicators for Human Capital” (Erişim Tarihi: 18.05.2015), http://warming.apps01.yorku.ca/library/wp-content/uploads/2013/03/NRTEE-2001-A-Survey-of-ExistingIndicators-for-Human-Capital.pdf

- Yumuşak, İ. G. ve Bilen, M. (2000), “Gelir Dağılımı - Beşeri Sermaye İlişkisi ve Türkiye Üzerine Bir Değerlendirme” K. Ü. Sosyal Bilimler Dergisi, 1(1), ss: 77-96.

- Yumuşak, İ. G. ve Tuna, Y. (2002), "Kalkınmışlık Göstergesi Olarak Beşeri Kalkınma İndeksi ve Türkiye Üzerine Bir Değerlendirme” İktisat Fakültesi Mecmuas1, 52(1), ss: 1-26. 


\title{
Bilgi Ekonomisi Sendikal Hareketin Sonu Mu? Is Knowledge Economy the End of Union Action?
}

\author{
Prof. Dr. Adem Kalça (Karadeniz Technical University, Turkey)
}

\begin{abstract}
Production methods transform social structures, including the economy. In the societies that are shaped by old production methods, the existence of those people who earn their living working through these methods will be destroyed altogether and their lives will be harder than they used to be, which will lead to conflicts. It is true that changes make transformations inevitable. Labor in the agriculture society was a very important production factor. In the industrial society, on the other hand, workers will serve their labor for the needs of people with a huge capital rather than serving their own ends, which make union action all the same very important. It is true that the potential role of labor as a vital component of the production has been weakened in the industrial societies. The reason for this is that there are now millions of people who can easily replace others in industrial societies. For this reason, the laborers who have faced huge challenges against the capital in this framework started to initiate union action in order to protect their rights. The function or the roles of union actions to have appeared in the industrial societies have changed when faced with information society in the 21 .century. Information society forced unions towards change in union actions. Today, there is need for unionists to agree on a new road map in the 21.century for union organizations and activities.
\end{abstract}

\section{Giriş}

Üretim biçimleri, toplumların bütün kurumlarını değiştirmekte ve dönüştürmektedir. Üretim biçimlerinin değişime uğramasıyla birlikte toplumsal kurumlarda dönüşümler yaşanması yanında, yeni kurumsal yapılanmalara da rastlamak mümkündür. Üretim biçimlerinin toplumu dönüştürme süreçleri sancılı olmaktadır. Eski üretim biçimleri ile şekillenen toplumlarda, yaşamlarını idame ettirenlerin çoğu ya da bazıları, ama muhakkak bir kısmının, var olma nedenleri ortadan kalkacak ve yaşamları zorlaşacağından, ortaya çıkacak olan bu sancıları, hatta çatışmaları doğal karşılamak gerekmektedir. Sonuçta istense de istenmese de değişimler dönüşümleri gerekli kılmaktadır. Her değişim olumlu ve olumsuz yanlarıyla, kazanımlarıyla ve kayıplarıyla değerlendirilmesi gereken bir dönüşüm sürecidir aynı zamanda.

Çeşitli ayrımlara tabi tutulan toplumlar, geçmişten günümüze bilimsel disiplinler çerçevesinde de ayırımlara tabi tutulmaktadır. Tarihsel, hukuksal, sosyolojik vb. bakış açılarına göre bu ayırımları çeşitlendirmek mümkündür. $\mathrm{Bu}$ bakış tarzıyla toplumlar ekonomik olarak sınıflandırıldığında şu tabloyu ortaya koymak mümkündür: Tarım Toplumu, Sanayi Toplumu ve Bilgi Toplumu.

Üretim biçimlerinin değişmesiyle meydana gelen dönüşümlerden birisi de sendikal hareketlerde görülmektedir. Tarım toplumunda en önemli meta toprak iken, sanayi toplumunda makine, bilgi toplumunda ise bilgi ön plana çıkmıştır. Tarım toplumunda en önemli üretim faktörleri toprak ve emek iken, sanayi toplumunda emek, toprak ve sermayedir. 21.yy bilgi toplumu çerçevesinde ise artık bilgiyi dördüncü bir üretim faktörü olarak dikkatlere almak gerekmektedir. Tarım toplumunda ekonomik yaşamda yer alan emek daha çok kendi işinde çalışan, fiziksel gücünü hayvan ya da sonraları makineyle birleştiren ve üretimi gerçekleştiren olmazsa olmaz çok önemli bir üretim faktörüydü. Sanayi toplumunda ise üretim sürecinde yer alacak olan emek artık kendi işini değil, sermayeye sahip kişinin yanında sadece emeğini satarak geçinen kişi olacaktır. Yani emeğin olmazsa olmaz derecesine varan önemi zayıflamıştır. Ve bu çerçevede tek başına sermaye karşısında zayıf düşen, haklarını müdafaa edemeyen emekçi kesim, haklarının mücadele adresi olarak sendikal hareketin ilk tohumlarını atacaklardır. Çok sancılı bir süreçten sonra sanayi toplumuyla birlikte sendikal hareket ekonomik dönüşüm sürecindeki yerini almıştır.

Sanayi toplumu çerçevesinde ortaya çıkan, gelişip büyüyen ve epeyce yol kat eden sendikal hareketler, 21.yy'da bilgi toplumuyla karşı karşıya kalınca birden bire bir anlam kaymasına uğramış gibi oldular, ya da değişen toplumsal yapı sendikacılık hareketlerini de diğer kurumlar gibi dönüşmeye zorladı ve zorlamaktadır. Çünkü artık toplumsal yapıda bir daha geri dönmemek üzere değişimler yaşanmaktadır. Bu değişimlerden ekonomik yapıda nasibini aldığı için, sendikacılık faaliyetlerinin bu değişim dışında kalmasını düşünmek mümkün değildir. Bu çerçevede sendikacıların artık 21.yy bilgi toplumu çerçevesinde sendikal örgütlenme faaliyetleri için kendilerine yeni bir yol haritası çizmeleri gerekmektedir.

$\mathrm{Bu}$ çalışmada 21.yy’ da teknolojik, ekonomik ve diğer birçok nedenden dolayı değişime uğrayan ve bu değişime ayak uydur(a)mayan sendikal hareketlerin teknolojik gelişmeler karşısındaki duruşları ve sonuçları irdelenecektir. 


\section{Eski Ekonomiden Yeni Ekonomiye}

The Work of Nations adlı kitabında Roberts Reich “yeni ekonomi” için şöyle demektedir: "Bu tamamen bilmediğimiz bir alandır. Ekonominin pilotları daha önce bu uzayda hiç uçmadılar. Eskiden bildiğimiz kurallar bütünüyle aşınmış görünüyor ve bize yolumuzu gösterecek yeni haritalar ve rehberler de henüz mevcut değil" (Ulagay, 2001). Dolayısıyla yeni ekonomiyi de içine alan teknolojik değişim, insan ile birlikte "politikada, devlette, eğitimde, ekonomide" de "eski anlayışları" yıkıp atıyor (Altan, 2001). Yeni ekonomi birçok çalışmada bilgi ekonomisi terimiyle de anılmaktadır. Ya da yeni ekonomiyle kastedilen şey bilgi ve iletişim teknolojisinde meydana gelen hızlı artışın ekonomiyi, toplumu dönüştürmesidir. Yeni ekonomiyi tanımlarken "new economics" değil de, "new economy" kullanılmasının nedeni; temel ekonomik yasaların değişmediğini, ama buna karşılık, yöntemlerin, ilkelerin, stratejilerinin ve kurumların değiştiğinin öne sürülmesidir (Söylemez, 2001). Son yıllarda dünya ve ABD ekonomisindeki gelişmelere bakıldığında, yeni ekonominin verimliliği, yeniden yapılanmaya yönelik baskıları, küreselliği, yol açtığı krizleri ile birlikte sistemi nasıl kökünden değiştirip sarstığı açıkça görülmektedir (Nas, 2000).

Tarihsel süreç içerisinde teknolojiyi kapsayan bir yolculuk yapıldığında görülen şudur: Dokuma tezgâhındaki baş döndürücü teknolojik gelişmeler 1730'larda başlamış, bunları demiryolları (1820'ler) ve buhar gücüne dayalı okyanus ötesi gemi taşımacılığı (1840’lar) izlemiştir. Söz konusu yıllarda işgücünün kompozisyonu süratle nitelik değiştirmiş ve örneğin İngiltere'de sanayi sektörlerinde çalışan işgücünün oranı 1800'lerin başında \%30'a, 1840'ta \%47'ye, 1870'de \%49'a ulaşmıştır (Yeldan, 2001). Günümüzde de teknolojik değiş̧iklik ve ilerlemeler geçmişteki gibi aynı izleri bırakmaktadır.

Mavi yakalı olarak tabir edilen ve sanayide çalışan işçiler 1950'li yılların ortalarına kadar İngiltere, Batı Almanya, Japonya ve ABD'de çalışan nüfusun çoğunluğunu teşkil ediyorlardı. Günümüzde ise artık küçük gruplar durumuna düşmüşlerdir. Çünkü sosyal yapıyı, toplumu, devleti, ekonomi ve siyaseti derinden etkileyen bilgi işçileri grubu hızla yükselmektedir. Bilgi işçileri bilgi toplumunun yönetici sınıfı değil, ama öncü sınıfı olmayı çoktan başardılar (Drucker, 1994).

İşçilerin niteliksel kompozisyonları değişmekte ve gitgide artan biçimde yetenekleri etrafında farklılaşmaktadırlar. Bu kompozisyonun en üst noktasında yer alan işçilerde, sınıf çıkarları ve dayanışmaya giderek azalan bir ilgiyle birlikte, daha iyi eğitimli, kariyer yönelimli ve bireyselci olmak eğilimi gözlenmektedir. Öte yandan bu kompozisyonun alt noktalarında, hizmetler sektörü ve mesleklerinde bir işçi yoğunlaşması gözlenmektedir. Bu işçiler gitgide daha fazla kadın ve göçmenlerden oluşmaktadır (Jose, 2002).

1950’lerin ortalarından beri işgücünün yüzdesi olarak sendika üyeliği hemen her yıl azalmıştır. Bu süre içinde ücretler artmış, haftalık çalışma süresi kısalmıştır. Üstelik bir sürüde yenilik ortaya çıkmıştır: Esnek çalışma saatleri, telefonla iş görme, iş yerinde çocuk bakımı, işyerinde spor salonları ve aklınıza ne gelirse (Roberts, 2002).

Sendikal kurumlar sanayi devrimi sonrasında ortaya çıkmış bir yapılanmadır. Sendikacılık, sanayi toplumunda sanayi işçisinin var olduğu ortamda gelişir ve güçlenir. Sanayi sektöründeki sanayi işçisinin toplu davranış biçiminin aksine hizmetler sektöründe daha bireyci davranışlar ağır basar. Sanayi sektöründe işin niteliği gereği işçilerin bir arada, dayanışma halinde, kader birliği söz konusu iken, hizmetler sektöründe işin niteliği böyle bir düşünce ve duyguyu gerekli kılmaz. Sanayi işçisinde hakların korunması ve savunulması için bir örgüt arayışı varken, hizmetler sektöründeki beyaz yakalı işçi kendi hakkını arayabileceğine inanır ve bir örgüt gereksinimi içinde değildir. Bu yaklaşımlar da sendikalaşma önündeki engellerden biridir (Öke, 1995). Sonuçta denilebilir ki yeni ekonomide yeni sendikalara ve yeni sendikal anlayışlara ihtiyaç duyulmaktadır.

"Mikroçip" sayesinde üretimin yapısı değişiyor. Sanayide "mikroçip" kullanılmasıyla birlikte işçiye, enerjiye, hammaddeye duyulan ihtiyaç azalmaktadır. İşsizlik artmaktadır. İşçi sınıfı gerilemektedir. Bazı sektörlerde işçiler önemini kaybetmektedir. Üretim biçimi, üretim ilişkileri, sınıfsal yapılar bir depremden geçmektedir; bütün kurumlar değişmektedir (Altan, 2001). İşçi sermaye ilişkileri, biçim değiştiriyor. İşgücünün çok yönlü niteliği, yani bir işçinin birçok işi yapabilme becerisi, esnek üretim süreçlerinin bir gereği sayılıyor (Kepenek, 1999).

21.yy Bilgi toplumu dünyasında "milli devletler, partiler, kurumlar, meslekler ve tarihsel gelenekler tarafindan temsil edilen eski, cazibe kutupları şimdilerde cazibelerini kaybetmektedirler" (Okutan, 2006). Ve yine 1990'larda, ekonomiye ilişkin pek çok varsayım, kavram, oluşum ve süreç yeniden tanımlanmaktadır (Kepenek, 1999). Ekonomiyi tanımlamakta kullandığımız terimler ise artık küresel gerçekleri yansıtmamaktadır (Carthy, 1995). Dolayısıyla sanayi toplumunun ürünü olan temel kurumlar son derece ciddi bir sarsıntı geçirmektedirler. Fabrika üretiminin egemenliğindeki sanayi toplumunun sosyo-kültürel ve sosyo-politik yapısını oluşturan ulus devlet, kitle örgütleri, akıl ve bilim gibi kavram ve kurumlar yeniden sorgulanmakta ve kriz yaşamaktadırlar (Kutlu, 2000).

Geleneksel ekonomide işçiler çoğunlukla homojen bir yapıya sahiptirler. Homojen yapıya sahip olan bu işçiler arasında sendikalaşma söz konusudur. Yeni ekonomide istihdam yapısı tam anlamıly heterojen yapıya sahip zihin işçilerinden oluşmaktadır. Dolayısıyla sendika kavramı mevcut haliyle varlığını sürdürmede zorluklar yaşayabilir ve nitekim de yaşamaktadır. 
Tablo 1'den görüldüğü üzere dünyada bazı seçilmiş ülkelerde ikibinli yıllardan günümüze değin sendikalar üye ve kan kaybına uğramaktadırlar. Aşağıdaki tabloda görülen ülkelerdeki yıllar itibariyle azalan sendikalaşma oranları açıklanmaya muhtaçtır.

\begin{tabular}{|l|l|l|l|l|l|l|l|l|l|l|l|l|l|}
\hline Ülke & $\mathbf{2 0 0 0}$ & $\mathbf{2 0 0 1}$ & $\mathbf{2 0 0 2}$ & $\mathbf{2 0 0 3}$ & $\mathbf{2 0 0 4}$ & $\mathbf{2 0 0 5}$ & $\mathbf{2 0 0 6}$ & $\mathbf{2 0 0 7}$ & $\mathbf{2 0 0 8}$ & $\mathbf{2 0 0 9}$ & $\mathbf{2 0 1 0}$ & $\mathbf{2 0 1 1}$ & $\mathbf{2 0 1 2}$ \\
\hline Avustralya & 24.5 & 24.2 & 22.9 & 22.7 & 21.9 & 21.9 & 19.8 & 18.2 & 18.2 & 19.0 & 18.0 & 18.0 & 17.9 \\
\hline Avusturya & 36.6 & 35.7 & 35.2 & 34.4 & 34.1 & 33.3 & 31.0 & 29.9 & 29.1 & 28.6 & 28.1 & $\ldots$ & $\ldots$ \\
\hline Kanada & 30.2 & 30.3 & 30.3 & 30.5 & 29.9 & 29.9 & 29.5 & 29.4 & 29.2 & 29.4 & 29.5 & 29.8 & $\ldots$ \\
\hline Finlandiya & 75.0 & 74.5 & 73.5 & 72.9 & 73.3 & 72.4 & 71.7 & 70.3 & 67.5 & 69.2 & 70.0 & $\ldots$ & $\ldots$ \\
\hline Fransa & 8.0 & 7.9 & 8.1 & 8.0 & 7.8 & 7.7 & 7.6 & 7.6 & 7.6 & $\ldots$ & $\ldots$ & $\ldots$ & $\ldots$ \\
\hline Almanya & 24.6 & 23.7 & 23.5 & 23.0 & 22.2 & 21.7 & 20.7 & 19.9 & 19.1 & 18.8 & 18.5 & $\ldots$ & $\ldots$ \\
\hline İtalya & 34.8 & 34.2 & 33.8 & 33.7 & 34.1 & 33.6 & 33.2 & 33.5 & 33.4 & 34.7 & 35.1 & $\ldots$ & 31.2 \\
\hline Japonya & 21.5 & 20.9 & 20.3 & 19.7 & 19.3 & 18.8 & 18.3 & 18.3 & 18.2 & 18.5 & 18.4 & 19.0 & 18.0 \\
\hline Meksika & 13.7 & 14.0 & 13.9 & 14.9 & 15.5 & 15.1 & 14.8 & 15.2 & 14.3 & 13.9 & 13.0 & 13.2 & 13.6 \\
\hline İsveç & 79.1 & 77.3 & 77.3 & 77.2 & 77.3 & 76.0 & 74.2 & 70.8 & 68.3 & 68.4 & 68.4 & 67.7 & $\ldots$ \\
\hline Türkiye & 9.9 & 10.0 & 9.5 & 8.9 & 8.6 & 8.2 & 7.5 & 6.6 & 5.8 & 5.9 & 5.9 & 5.4 & $\ldots$ \\
\hline İngiltere & 30.2 & 29.6 & 29.3 & 29.6 & 29.4 & 28.4 & 28.1 & 27.9 & 27.1 & 27.2 & 26.5 & 25.8 & 25.8 \\
\hline ABD & 12.9 & 12.9 & 12.8 & 12.4 & 12.0 & 12.0 & 11.5 & 11.6 & 11.9 & 11.8 & 11.4 & 11.3 & 11.1 \\
\hline $\begin{array}{l}\text { OECD } \\
\text { Ortalaması }\end{array}$ & 20.2 & 19.9 & 19.6 & 19.4 & 19.0 & 18.7 & 18.1 & 17.9 & 17.8 & 17.9 & 17.5 & 17.5 & 17.0 \\
\hline
\end{tabular}

Tablo 1. Seçilmiş Ülkelerde Sendika Yoğunluk Oranları Kaynak: Şenkal, 2015.

Giderek “entelektüel emek” fizik emeğin önüne geçince, kol gücü’nü temel alan bütün siyasi oluşumlar, örgütlenme biçimlerinde bir yeni yapılanma oldu. Sanayi Devrimi'nin 'fabrika-odaklı' gerilemenin 'ofis' ve 'firma’ bağımlılığını kırdığı 'örgüt adamı’ dönemini kapattığı hususunda görüşler ağırlık kazanmaya başladı. Kol gücü temelinde tanımlanan tüm gruplar, siyasi projeler emek gücünün marjinalleştiğini ileri sürmeye başladı. Bu gelişmenin sendikal örgütlenme ve ücret mücadelesi üzerinde etkileri oldu (Bozkurt, 2002). Bu analizin sonuçlarını tablo 1'deki ülkelerde yıllar itibariyle sendika üyeliği oranlarındaki azalışta görmek mümkündür.

Yeni ekonomide niteliksiz işçilere ihtiyaç duyulmamaktadır. İleri elektronik teknolojiyi kullanan esnek üretim, esnek, iyi eğitimli işçilere gerek duymaktadır, "beyin işçileri”" (Yates, 2002). Bu yeni nitelikli işgücü patronlar tarafından saygılı muamele görmekte, iş ortağı olarak algılanmakta veya ortak bir takımın üyeleri, işletme yönetimine katılmaktadır ki bu anlayış sendikal hareketin yaygınlık kazandığı sanayi ekonomisinde görülmemektedir.

Sendikalaşmanın önündeki en önemli engellerden birisi de robotik ve bilgisayar destekli teknolojidir. Emek yoğun teknolojiden sermaye yoğun teknolojiye geçiş bir yandan işçinin yerini makinenin almasını diğer yandan da çalışan işçinin niteliğinin değişmesi sonucunu doğurmaktadır. Vasıfsız kol işçisi yerine mavi yakalı işçiler ağırlık kazanmaktadır. Bu nitelikli emeğin kendini koruyabilecek özelliklere ve silahlara sahip olması, toplu pazarlık yerine bireysel pazarlığı öne çıkarıyor ve örgütlenme gereksinimini ortadan kaldırıyor (Öke, 1995).

Bilgi toplumunun taleplerine endüstri toplumunun örgütleri yeterince cevap veremez hale gelmektedir. Farklı paradigmalara dayanan yeni toplumda fabrika ve maddi üretim toplumun temel özelliği olma niteliğini yitirmektedir (Kutlu, 2000).

Bilgi toplumunun temellerini oluşturan internet, e-posta ve yeni teknolojiler, üyelerin, temsilcilerin ve görevli kadroların hızlı ve etkin bir biçimde iletişim kurmasını sağlayarak, çağrı merkezleri verimliliği arttırma olanağı yaratarak, web siteleri ise kampanya olanaklarını artırarak sendikal büyümeyi kolaylaştıracak olanaklarda sunmaktadır (Petrol-İş, 2001b). Ama bu görüşün yanında bilgi ekonomisinin özellikle sendikacıların beyninde çok yeni soru işaretleri oluşturduğunu söylemekte mümkündür.

\section{Bilgi Ekonomisi ve Sendikacılık}

19. yy’da sanayileşme süreci içindeki mücadelelerde geliştirilmiş sendikal yapılar, finans ve teknoloji alanındaki oluşumların yönlendirdiği 21.yy ekonomisinde işe yaramayacaktır.

Sendikalar, işçilerin değişimin üstesinden gelmesine yardımcı olan önemli araçlar (Petrol-İş, 2001c) olmasına rağmen, sendikal örgütler, toplumdaki köklü değişikliklere ayak uydurmakta zorlanmaktadırlar. Bilgi gibi bir üretim faktörünün emek ve sermayenin üretime katkısının çok ama çok önüne geçmesinin çağımızda çok önemli dönüşümlere neden olacağı kuşkusuz (Karakaş, 2006). 
Eski sendikal yapı ile mevcut ekonomi ve istihdam yapısı ve buna bağlı olarak modern çalışanın yeni talepleri ve beklentileri arasındaki uçurum gittikçe genişlemektedir (Mückenberger vd, 2001). Yeni bir küresel sendikacılığın oluşmasının gerektiği Yenidünya düzeninde meydana gelen değişikliklerden birisi olan teknolojik gelişmeler, üretim tekniği, iş örgütlenmesi ve işgücü piyasaları üzerinde radikal etkiler doğurmuştur (Öke ve Kurt, 2003) Robotların iş sürecine girmesiyle belli sayıda işgücü üretim ağının dışında kalmıştır. AT\&T 1973'ten 1992'ye istihdamını \%40 azaltırken, üretimini \%43 arttırmıştır. AT\&T 1996 Ocağında 40.000 çalışanı, IBM 1993 Temmuzunda 60.000 çalışanı, Delta Airlines 1994 Nisanında 15.000 çalışanı, General Motors 1991 Aralığında 74.000 çalışanı ve iki yıl sonrada 50.000 çalışanını işten çıkarmıştır (Öke ve Kurt, 2003). İşü̈cünü robotlar ikame ettikçe niteliksiz işgücü toplumda giderek güçsüzleşmekte, bununla birlikte, yaratıcı işgücü toplumun üst katlarına tırmanmaktadır. Karlılık için emekten tasarruf edip işsizlik baskısı yaratarak ücret artışlarını bastırmak, sendikaları güçsüzleştirip sosyal hakları kısıtlamak gibi bir amaç dışında robotlaşmanın başka bir nedeni olabilir mi? (Kazgan, 2006)

Görüldüğ̈̈ gibi yukarıdaki örnekten yola çıkılırsa, bu teknolojik devrimin işgücü piyasasında meydana getirdiği değişikliklerden sadece birisidir. Bunun yanında da teknolojik devrim emek dünyasında ve istihdamın yapısında köklü değişimler yaratmaktadır. Örneğin bütün dünyada çalışma birimlerinin boyutları küçülmektedir (Petrol-İş, 2001a). Sonucunda birçok şirket sendikalarla toplu pazarlıktan kaçınmakta ve bireysel istihdam sözleşmeleri yapmaya çalışmaktadır.

Teknolojik gelişmelerin istihdam açısından bir diğer yüzü ise işyerlerinde sendikaların rolünü ve önemini azaltmasıdır. Teknolojide meydana gelen bu devasa gelişmeler, emeğe olan ihtiyacın azalmasını gündeme getirmiştir. Emeği tasarruf eden makinelerin iş sürecine sokulmasıyla, niteliksiz emeğe olan ihtiyaç azalmış, işsizlik artmıştır. İşte bu teknolojik gelişmeler sonucunda işin ve işçinin niteliğinin artması sendikal hareket için olumsuzluklar getirmiştir. Çalışanların bilgi edinimleriyle niteliği arttıkça iş sektöründen hizmet sektörüne kaymaktadırlar. Ve böylece mavi yakalı ve beyaz yakalı işçiler, yönetenler ve yönetilenler arasındaki sınır belirsizleşmektedir. Sonuçta, teknolojik gelişmeler sonucunda ortaya çıkan meslekler son derece değişken nitelikler taşımakta ve bu nedenle çalışanlar ortak çıkarlarda buluşup kolektif hareket etmekte zorlanmaktadırlar. Çünkü, iş kavramı geçmişe oranla günümüzde köklü bir değişim geçirmektedir. 20.yy’ın son 10 yılına kadar, standart çalışma biçimi, bir işe, bir patrona ve belirli bir işyerine sahip olmaktı. Bugün, on milyonlarca kişi için durum tamamıyla değişmiştir. Çünkü son on yılda, en ilgisiz gözlemci bile, dijital çağla birlikte çalışma yaşamına giren teknolojik değişikliklerden habersiz olamaz.

Toplam kalite modeli ve Just in time üretim süreciyle gündeme gelen post-fordist üretim tekniğinde yer alan işgücü çok değişik işleri yapacak vasıftadır. Böylece yeni üretim süreciyle birlikte çok nitelikli, kendine güvenen, görece yüksek ücret alan ve sendikaya gereksinim duymayan kitle (merkez işgücü); öte yandan da niteliksiz ya da yarı nitelikli, iş güvencesi olmayan, sendikaların bünyesinde yer alan işçi kitlesi ortaya çıkmıştır (çevre işgücü) (Öke ve Kurt, 2003). Sürecin bu şekilde devam etmesi halinde sendikalar işletmelerde ikincil derecede önemi olan çevre işgücünün örgütü olarak, ikincil rollere, ikincil misyona sahip örgütler haline gelecektir.

Küresel dünyada artık kol gücü olan vasıfsız işçiye çok fazla ihtiyaç yoktur. Eğer hala varlarsa toplumsal yaşamda önemli yerleri olmayacak. Küreselleşme dünyasından dışlanacaklardır. Dolayısıyla bireyler artık üstün teknolojik becerilerle ve çok iyi eğitimle donatılmalıdır. Bu niteliklerle donatılmış emek nasıl olsa sendika gibi örgütlerde yer almayacaktır. Sendikalar kitlesel üretim çağının getirdiği oluşumlardır. Fordizm sonrası çağlarda bunlara gerek kalmamıştır (Kazgan, 2004)

Robert Kuttner sanayi sonrası şirketin en son vardığı noktanın "artık istikrarlı bir misyonu ya da sabit bir yeri olan fiziki bir varlık değil, bilgisayar ağı, telefon ve faks cihazıyla bağlı, değişken bir geçici ilişkiler kümesi oluşturan sanal kuruluş” olduğunu bildirmektedir (Barber, 2001). Sanal şirket, işçi piyasasında, gerçek değil "sanal" işçilerin işverenidir. İdeal sanal işçi bir robottur: Beslenmesi gerekmeyen, asgari bir bakımla 24 saat çalışma kapasitesine sahip, interaktif ve tam programlanmış “zeki” bir işçi (Barber, 2001). Eğer bu bakış açısı geçerliyse sanayi devriminin bir çıktısı olan ve sabit bir yeri olan, fiziki bir varlık olan fabrikalardaki çalışan işçilerin çıkarlarını sermayedara karşı toplu olarak savunan sendikacılık ve sendikacılığın geleceği sorgulanacaktır ve de sorgulanmaktadır.

Nitelikli işgücü yetiştirilmesine, yeni tekniklerin istihdam dışı bıraktığı niteliksiz işgücünün yeniden istihdamını sağlayıcı eğitim programlarına, birbiriyle koordineli eğitim ve istihdam politikalarına gereksinim duyulmaktadır (Gürel, 2001).

\section{Bilgi Ekonomisi Sonun Başlangıcı mı?}

Standart istihdam modeli içinde tamgün çalışan geleneksel işçi tipi ağırlığını kaybediyor. Öte yandan part-time istihdam, eve iş verme gibi "atipik" istihdam biçimleri yaygınlık kazanıyor. Bir zamanlar sınıfın çekirdeğini oluşturan kesimler çepere doğru çekiliyor ve yerini beyaz yakalılar gibi, özel önem ve işlev kazanmaya başlayan yeni kesimlere bırakıyor. 
Birçok sendikal hareket değişen istihdam modelleri yüzünden üye kaybetmektedir. 19 ve 20 . yy'da kömür madenciliği, metal, tekstil, gemi yapımı ve demiryolları gibi kol gücüne dayalı sektörler sendikaların kaleleri iken, 21.yy geleneksel işkollarının gerileme sürecine girdiği ve yeni işkollarının öneminin arttığı bir yy'la tekabül etmektedir. Artık hizmetler sektörü ve küçük işletmeler yaygındır. Ağırlık mavi yakalılardan beyaz yakalılara doğru kaymıştır ki, beyaz yakalılarda sendikalaşma oranı düşüktür. Sendikaların gücündeki azalmaların nedenlerinden biri sendikaların ortaya çıkan bilgi ekonomisinin taleplerine yeterince cevap verememesidir (Şenkal, 2015).

Bilgi işçilerinin yükselişi ve bilgi toplumunun doğuşu bizi, on yıllar boyunca meşgul edebilecek yeni sosyal problemlere ve tehditlere maruz bırakabilecektir. Fakat bilgi toplumunun doğuşu ile birlikte görünür olan temel gerçek onun bizleri maruz bırakacağı problemler değil, ortaya çıkardığı eşi görülmemiş sosyal firsatlardır. Sanayi toplumlarındaki iş̧̧i hareketlerinin ve grevlerinin yerini, bilgi toplumlarında sivil vatandaş hareketleri alacaktır (Kutlu, 2000).

İşçi sınıfı artık toplumun en büyük bölümü ve değiştirici gücü değil. Orta sınıflar proleteryanın yerini alıyor. Sermaye Billy Gates'in ortaya çıkışı ile iktidarını yitirmeye koyuldu. İnsanların çalışma aletlerini kullanırken örnek aldığı teknoloji kol gücünü değil, beyni model almaktadır (Altan, 2002).

Teknoloji aletlerle ilgili değildir, insanın çalışma biçimiyle ilgilidir (Altan, 2001). Teknoloji değiştikçe insanların çalışma şekilleri de değişmektedir. Emek yeni teknolojiler karşısında çok büyük fatura ödeyecek (Minibaş, 2006). Çünkü sanayi sonrası dönemin dinamizmi kimi meslekleri hızlıca tasfiye ederken, yaşayabilen mesleklerin de içeriğini sürekli değişime uğratıyor. Teknolojinin doğası hem iyileştirmeyi, hem de yıkımı içerir.

Kimi meslekler yok olup giderken yenileri doğuyor. Bunun sonucu, insanların iş garantisi yok olurken, meslek eğitimi de sürekli hale geliyor (Altan, 2000). Sonuçta üretimde emeğin yerinin değişmez, ama "emekçinin" kolayca değiştirilir hale gelmesi oldu (Belge, 2001).

Düz emeği robotlar ikame ettikçe vasıfsız emek toplumda giderek güçsüzleşiyor; oysa yaratıcı emek, yüksek vasıflı emek toplumun üst katlarına tırmanıyor (Kazgan, 2006). Bilgi sektörün büyümesiyle bilgi ekonomisinde istihdam edilecek olan bilgi iş̧̧ilerine talep de artacaktır. Böylece sanayi toplumu her anlamda yerini bilgi ekonomisinin gerçekliklerine bırakmak zorunda kalacaktır. Sonuçta emeğin mobilitesi, sermayenin ve bilginin mobilitesinin gerisinde kaldığı için emekçi kesim kayıplara uğrayabilir (Ulugay, 2001)

Sermayedar/girişimci sınıf sanayileşme sürecinde kendi karşııını, işçi sınıfı olarak yaratmış̧ı. Sermaye karşısında zayıf kalan işçi sınıfı sendika çatısı altında örgütleşmiştir. 21.yy Bilgi Çağı, sanayi çağından farklıdır. Artık girişimci sermayenin değil, bilgi üretme yeteneğine ulaşmış bireylerin yarattığı bir çağdır. Sermaye işçi çelişkisi tarihe karışmıştır. Öyleyse belki de ne sendikaları, ne işçileri korumaya yönelik düzenlemelere ihtiyaç vardır.

Bilgi ekonomisinde başarılı olabilmek işçilerin niteliklerini geliştirmeye, onları arttırmaya hazır olmalarına ve ömürleri boyunca yeni şeyler öğrenmeye kesin kararlı olmalarına bağlıdır. Kariyerlerinde uzun dönem iş güvenliği reddedilecek. Çünkü işlerin iyi gitmesi için, işçiler yeni bilgiler kazanmaya ihtiyaç duyacaklar ve daima kendilerini yenilemeye hazırlıklı olmalıdırlar. Sonuçta emek örgütleri değişime uyum sağladıkları ve çalışma düzenini çalışanlar lehine yönetmek için etkin taraf olma kimliğini kazandıkları ölçüde işlevsel olabilirler (Uçkan, 2006).

Mavi yakalı işçiler 1950 'lerin ortalarına kadar sanayileşmiş ülkelerde çalışanların çoğunluğunu temsil ediyordu. 1980'lerden sonra mavi yakalıların sayısında çok hızlı azalmalar yaşandı. Gelecekte ise toplam çalışanlar arasında \%20'lik bir paya düşmeleri beklenmektedir. Bu arada bilgi iş̧̧ilerinin sayısı yükselişe geçmiştir. Bu çalışanlar grubu tarihin geleneksel gruplarının yerlerini hızla ters yüz ediyor. Aynı hızla, çalışan nüfusun çekim merkezi oluyor ve her gelişmiş ülkede ve sanayi sonrası toplumlarda en büyük grup halini alıyor. Sosyal yapıyı, toplumu, ekonomi ve siyaseti derinden etkileyen bu gelişmeler tarihin geleneksel gruplarının yerlerini yerle bir etmektedirler.

\section{Sonuç ve Değerlendirme}

Tarımın ve sanayinin egemen olduğu ekonomilerde maddi unsurlar önem kazanmışken artık 21.yy da bilginin egemenliği söz konusudur. Tarım toplumu olmanın bütün izleri yeryüzünden siliniyor. Sirada ise sanayi devriminin kalıntıları var. Onlarda yavaş yavaş sahneyi terk etmektedirler (Altan, 2001). Büyük fabrikalar ve o fabrikalarda çalışan yüzlerce işçi artık yerlerini daha kü̧̈ük ve daha az çalışan organizasyonlara bırakmaktadırlar. Çünkü artık insanların kas gücü değil beyin gücü işletmeler için daha önemli hale gelmiştir. Ekonomik yönden gelişmiş ülkelerin çıktılarına bakıldığında yaratılan değerin çoğunun bilgi ekonomisi tabanlı olduğunu görmek mümkündür. Yine aynı ülkelerde bilgi sektörlerinin toplam istihdam içinde yer aldıkları paylara bakıldığında "bilgi işçileri"nin ağırlığı kendini hissettirmektedir. Dolayısıyla Avrupa'da işsizliğin artmasının nedeni de emeğin "üretim süreciyle" olan ilişkisidir. Çünkü köylülük gibi iş̧̧ilikte sona eriyor. Emek en yüce değer olmaktan hızla uzaklaşıyor (Altan, 2001). Niteliksiz işgücü ve teknoloji üretimi, sırasıyla küreselleşemiyor ve küreselleşmiyor (Kepenek, 1999). Bilgi yoğun ve yüksek teknolojili sanayiler küresel ekonomi içinde en tutarlı 
biçimde büyüyen sektörler (Hasdemir, 2004) olarak ortaya çıkıyor. Bilgi artık, yalnızca modern ekonominin temel karakteristiği olmayıp, aynı zamanda toplumun organizasyon tarzını oluşturuyor (Birinci, 2002).

20.yy'ın "yığınsal" sendikaları kalelerini büyük ölçekli sanayinin "çekirdek" işgücü arasında bulmuştur. İşçi sınıfindaki farklılaşmanın "bireyselleşme" süreciyle bağıntılı olarak artması dayanışmayı çözen etkenlerdendir. Çünkü sendikalar sanayi toplumunu en önemli kurumları olup, iş̧̧i hareketlerinden doğmuştur. Günümüzde mikroelektronikler zaman ve mekân sınııını kaldırmakta, insanların aynı yerde birlikte çalışmasına gerek duyulmamakta, işin bu şekilde parçalanması, geleneksel sendikal örgütlenme yaklaşımlarını etkisiz kılmaktadır (Şen, 2004).

Rekabette ve verimlilikteki artışlar karşısında çaresiz kalan sendikalar, teknolojik gelişmeden olumsuz olarak etkilenmekte, ayrıca teknolojinin yan etkilerinde de söz sahibi olamamaktadırlar. Sendikal hareketin sürekliliğini ve hayatiyetini koruyabilmesi için kendisini yeniden oluşturması ve yeni paradigmalar geliştirmesi gerekmektedir (Petrol-İș, 2001b). Yine sendikalar iş̧̧ilerin refahını artıracak somut programlar geliştirmelidirler; eğitim programları gibi.

Yeni teknoloji karşısında sendika ve işverenlerin yeni çalışma koşulları yaratmak üzere işbirliğine gitmekte, sendikaların yeni teknolojilerin talep ettiği nitelikli işgücü-iş sistemlerini olanaklı kılmak için işgücünün eğitimi konusuna ağırlık verdiğini, toplu sözleşmelerde yeni teknoloji kullanımına ilişkin modeller yer almaya başlamaktadır (Özkaplan, 1994). Artık sendikalar ekonomik, teknolojik ve politik olarak yapısal dönüşüm geçirmek zorundadırlar. Çok vasıflılığı özendiren yeni işverenlere destek verebilirler. Sözleşmelerde yıllık verim artı̧̧ını garanti edebilirler. Sendikalar özel olarak müzakereler ve beceri eğitimleri sağlayan sözleşme şartları finansmanına yardımcı olabilir ve personele yönelik bir dizi hizmeti sunmaya başlayabilirler. Bunlara ilaveten;

Yeni teknolojlerin istihdam yapısı ve hacmi, istihdam koşulları, mesleki eğitim gibi konulara etkisini araştıracak güçlü bir alt yapı kurulmalı.

Teknolojik değiş̧iklikleri iş̧̧iler üzerindeki olumsuz etkilerinin önlenmesi ve en düşük düzeyde kalması için araştırmalar yapılmalı.

İstihdam artışı sağlayacak teknolojik yatırımlar için işveren cesaretlendirilmeli.

Türdeş yeteneklere sahip daha az sayıda iş̧̧i istihdam eden bu yeni üretim birimleri, kentsel emek piyasasının sınırlarının dışında da, coğrafi olarak yayılma eğilimindedir (Jose, 2002).

Enformasyon teknolojilerinin başarılı olarak kullanabilmesi için, iş sürecinde, organizasyon yapısında, hünerli işgücünde, ürün yeniliklerinde ve hizmetlerin ulaştırılmasında "esaslı" değişiklikler yapılması gerektiğini (Söylemez, 2001) söylemekte mümkündür.

Teknolojik gelişmeler karşısında sendikaların önleyici (Önleyici politikalar; sendikaların grev ve direnişlerle işvereni yeni teknoloji uygulamalarından caydırma girişimleridir.), rekabet edici (Rekabet edici politikalar; sendikaların daha az ücret talep ederek işgücünü yeni teknoloji kullanımı karşısında cazip hale getirmeyi amaçlayan politikalardır.) ve kontrol edici politikalar uygulamaları söz konusu olup, sendikalar için uygulanması en rasyonel olanı kontrol edici politikalardır. Bu politikaya göre sendikalar yeni teknoloji kullanımını kabul etmekte ancak, bu teknolojinin kullanımı için en uygun zamanı ve koşulları oluşturmaya öncelik vermektedirler. Ücret, istihdam güvencesi ve işgücünün yeni teknoloji kullanımında eğitilmesini toplu sözleşmelerle işverene kabul ettirmeyi amaçlamaktadırlar (Terzi, 1995).

Avrupa sendikal hareketi teknolojide, ekonomide ve sosyo-kültürel çevredeki değişimlerin bir sonucu olarak büyük bir çalkantı yaşamaktadır. Özellikle toplumda bireyselleşme eğilimin artması da sendikal işçilerin hedeflerinde değişime yol açmaktadır. $\mathrm{Bu}$ ise sendikaların ortak ve etkin seferberliğinin temeli olarak dayanışmanın eski biçimiyle artık uygulanamayacağı anlamına gelmektedir.

Son yıllarda Batıda yaygınlık kazanan kısmi çalışma sanayi sektöründen daha çok hizmetler sektörüne uygun bir çalışma şeklidir. Atipik bir çalışma şekli olan kısmi çalışma da bireyselcilik ön plandadır. Toplu davranış ve sendikal kültürden uzak bir istihdam çeşididir. Hizmet ve bilgisayar sanayilerinde bütünüyle yeni iş alanlarının ortaya çıkmasıyla işçiler ekonomik yönden uzmanlaşıp kültürel yönden farklılaşmakta, sendikaların tabanı değişmektedir. Eski sanayi dalları ve meslekleri ölürken beyaz yakalı işçilerin sayısı mavi yakalı işçilerin sayısını aşmaktadır. $\mathrm{Bu}$ değişimlere rağmen eski sendikal örgüt yapısı olduğu gibi yerinde durmaktadır.

İhtiyacımız olan şey, yeni gelişmeleri harekete geçirecek olan yaratıcı ütopyalardır (Hyman, 2001).

\section{Kaynakça}

- Altan, 2001. Köylüler Ne Zaman Manşet Olur. Zaman Kitap, İstanbul.

- Altan, 2002. "Sinırlar mı İnsanlar mı?”, Cogito, Ağustos, s.10-12.

- Barber, 2001. "McWorld'e Karşı Cihat", Varlık, Mayıs, 1124, s.64.

- Belge, 2001. "Bilgi Toplumu”, Radikal, 21.08.2001.

- Birinci, 2002. “'Yeni Ekonomi’ ve İktisat Politikası”, Marmara üniversitesi İ̈BF Dergisi, Cilt: XVII, Sayı: 1, s.51-66. 
- Bozkurt, 2002. "Dünya Çalışma Hayatında Değişim ve Türkiye”, İşveren, Nisan, 7, Ek.

- Carthy, 1995. "Yeni Küresel Gerçek ve Finansal Karar Süreci”, Görüş, Kasım, s.44-45.

- Drucker, 1994. Bilgi İşi ve Bilgi Toplumu; Bu yüzyılın Sosyal Dönüşümleri, http://www.harvard.edu/ksgpress/kgs_news/transcripts/drucklec.htm.

- Gürel, 2001. “Teknolojik Gelişmelerin İstihdam Üzerindeki Etkileri”. Banka ve Ekonomik Yorumlar, 6, s.81-94.

- Hasdemir, 2004. “Küreselleşmenin Etkileri”, Sendikal Notlar, 22, s.104-127. Sendikal Notlar, 9, s.138-154.

- Hyman, 2001. "Sendikalar İçin Yeni Bir Gündem mi?"

- Jose, 2002. “İşçi Hareketlerinin Geleceği: Gelişmekte Olan Ülkeler Üzerine Bazı Düşünceler”, Sendikal Notlar, 13, s.83-109

- Kazgan, 2006. Tanzimat'tan 21. Yüzyıla Türkiye Ekonomisi, İstanbul Bilgi Üniversitesi Yayınları, İstanbul.

- Karakaş, 2006. “Bilgi Ekonomisi ve Sendikalar”, :Referans Gazetesi, 27 Nisan 2006.

- Kepenek, 1999. "Ulus devletten Gelişmeci Devlete”, ODTU Gelişim, 304, s.309-336.

- Kutlu, 2000. Bilgi Toplumunda alkınma Stratejileri. Anadolu Üniversitesi İIBF Yayını, Eskişehir.

- Minibaş, 2006. “İMF, Dünya Bankası ve Küresel Gelir Dağılımı”, İktisat, 472-478, s.55-84.

- Mückenberger vd., 2001. 21.Yüzyılda Sendikalar. Petrol-İş, İstanbul.

- $\quad$ Nas, 2000. “İstikrar Programı ve Yol Ayırımındaki Türkiye”, Banka ve Ekonomik Yorumlar, Sayı:9, Y11:37, s.5-15.

- Okutan, 2006, "Bilgi Toplumunda Sivil Toplum ve Demokrasi”, Bilgi Ekonomisi, Ed. Nikal Karg1, Ekin Yayınevi, Bursa.

- Öke, 1995. "Sendikal Hareket Nereye Gidiyor”, Ekonomik Yaklaşım, 17, 21-37.

- $\quad$ Öke ve Kurt, 2003. "Yeni Süreç ve Sendikaların Temsil Sorunu”, Sendikal Notlar, 20, s.33-55.

- Özkaplan, 1994. "Yeni Teknoloji, Sendikalaşmanın Sonu mu?", Ekonomik Yaklaşım, 12, s.79-100.

- $\quad$ Petrol- İş, 2001a. 21. Yüzyılda Sendikalar. Nisan, s.34-43.

- Petrol-İş, 2001b. Sendikal Örgütlenme. Petrol-İş, Kasım, İstanbul.

- Petrol-İş, 2001c, 21.YüzyıldaSendikal Politika Arayışları. Petrol-İş Yayını, Temmuz, İstanbul.

- $\quad$ Roberts, 2002. Görünmez Kalp. Liberte, Ankara.

- Sendikal Notlar, 2001. “Enformal Toplumunda İşin Niteliği”, Haziran, s.113-136.

- Söylemez, 2001. Yeni Ekonomi. Boyut Kitapları, İstanbul.

- Şen, 2004. "Sendikaların Güç Kaybetmesinin Objektif Nedenleri”, Sendikal Notlar, 21, s.92-125.

- SSenkal, 2015. Bilgi Ekonomisi ve Emek. Umuttepe Yayınları, Kocaeli.

- Terzi, 1995. "Teknolojik Değişiklikler ve Sendikacılıkta Yeni Oluşumlar: Türkiye Açısından Bir Değerlendirme", Marmara Üniversitesi IIBBF Dergisi, Cilt:XI, sayı:1-2, s.1-14.

- Uçkan, 2006. “Emek Örgütleri Ne Yapmiyor*”, BT Haber, 10-16 Temmuz, s.6.

- Ulagay, 2001. Küreselleşme Korkusu ve 2001 Krizi. TİMAŞ, İstanbul.

- Yates, 2002. “”Yeni” Ekonomi ve İşçi Hareketi”, Sendikal Notlar, 14, s.110-123.

- Yeldan, 2001. Küreselleşme Sürecinde Türkiye Ekonomisi. İletişim, İstanbul. 


\title{
Kuznet Eğrisi Bağlamında Türkiye’de Finansal Gelişme ve Gelir Eşitsizliği İlişkisinin Analizi
}

\section{Analysing the Relationships between Financial Development and Income Inequality in Turkey as a Parallel of Kuznet Curve}

\author{
Asst. Prof. Dr. Utku Altunöz (Sinop University, Turkey)
}

\begin{abstract}
Analysing the relationship between development and Gross Domestic Products (GDP) is one of the most important issue for economics. Kuznet claims that mentioned relationships between developing and GDP resemble as upside down U. In this paper, GINI, GDP, credit and trade variables were analysed by using ARDL bounding test for the period covering by 1991-2014. Obtained results of econometric model shows that credit in private sector, GDP per capita and trade variables play an important role to be eliminated of income inequality. Effect of trade variable is less compare with other variables. For Turkish Economy, $1 \%$ increase in private credits causes to a $0,044 \%$ fall in income inequality for the estimated period. Alike, $1 \%$ increase in income causes to a $0.055 \%$ fall in income inequality.
\end{abstract}

\section{Giriş}

İktisat biliminin uzun yıllardır uğraş verdiği konuların başında kalkınma ve gelir arasındaki ilişki gelmektedir. Simon Kuznets, bu tartışmanın başlamasına neden olmuştur. Kuznets'e göre sözkonusu iliş̧i ters U şeklindedir. Çeşitli iktisat ekolleri ekonomik kalkınma ile gelir eşitsizliği konusunda çeşitli görüşler beyan etmiş olsalar da Simon Kuznets tarafindan geliştirilen ve literatüre Kuznet hipotezi olarak giren görüşler, İngiltere, ABD ve Almanya için kısıtlı data seti geliştirilen bir hipotez olmakla birlikte üzerinde en çok çalışılan konulardan biri olmuştur.

\section{Kuznets Hipotezi'nin Teorik Altyapısı}

Kuznet gelişmekte olan ülkelerde gelirin gelişmiş ülkelere göre daha dengesiz dağılım gösterdiğini iddia etmiştir. Bu durumun sonucu olarak ekonomik kalkınmaların başlangıcında büyüyen gelir eşitsizliği, kalkınma aşamasının ileri aşamalarını olumsuz yönde etkilenecektir (Kuznets, 1955: 1-15).

Gelir düzeyinin yükselmesine paralel olarak demokrasinin gelişimi gibi etmenler gelir dağılımında meydana gelen aksaklıkların kalıcı şekilde düzelmesini sağlayacaktır (Tsai, 1995:471).Büyüme sürecinin ilk evrelerinde eşitsizliğin artması, büyüme süreci fakirliği azaltıcı bir düzene girene kadar katlanılması gereken bir maliyet olarak kabul edilmektedir.

Kuznet eğrisinin geçerliliği konusunda Kalkınma aşamasını uzun zaman önce tamamlamış ülkelerde bu yöndeki bir eğilim tam olarak kanıtlanamaması nedeniyle görüş ayrılıkları bulunmaktadır. Kuznets'in gelir artışına paralel olarak gelir dağılımının bozulacağını iddia eden hipotezi bugün belli akademisyenler tarafından red edilmektedir. Tam tersine kalkınma sürecinde adil gelir dağılımının büyümeyi arttıracağını gösteren çalışmalardaki artış dikkat çekmektedir.

\section{Türkiye'de Gelir Dağılımındaki Gelişmeler}

Türkiye'de milli gelirin 10000 doların üzerine çıkmasına rağmen en büyük sorun gelir dağılımındaki adaletsizliktir. Nobelli Amartya SEN "gelir dağılımında eşitliğin" gelirin hak edişe göre dağılmasıyla sağlanabileceğini ama adil bir gelir dağılımı kavramının insanın eğitime, sağlık hizmetlerine, politik temsile vs... ulaşmadaki eşitlik olduğuna vurgu yapar. 1980 li yıllardan sonra Türkiye ihracata dayalı bir kalkınma stratejisi uygulamaya başlamışıtır. Türkiye'de istihdam oranını belirleyen önemli bir faktör ise net ücret gelirinin iş gücü maliyetine oran`n〉n oldukça düşük olması, bir başka deyişle emek kesimine yapılan ödemelerin yüksek kamusal kesintilere uğraması nedeniyle ele geçen net tutarın düşük olmasıdır. Özellikle 1990 lı yıllardan sonra artan sermaye hareketleri olumsuz ekonomik göstergelerin en önemli sorumlulukları olarak görülmüştür. 1987'den 2001 'e sabit sermaye yatırımların GSMH'ye oranı yüzde 24,6'dan yüzde 18,4'e düşerken buna karşın toplam borç stokunun GSMH'ye oranı aynı yıllarda yüzde 69,1'den yüzde 146,4'e yükseldiği gözlenmektedir ( Bilen ve Yumuşak, 2006:51).

Türkiye ekonomisi son yıllarda gelir dağılımı konusunda önemli aşamalar kaydetmesine rağmen, sorun tam olarak çözüme kavuşturulamamıştır. OECD nin 2014 yılı raporunda gini katsayısı gelişimini inceleyen raporda, Türkiye'nin 0,41 ile Meksika'nın ardından en yüksek -yani en kötü- ikinci orana sahip olduğu dile getirilmektedir. 


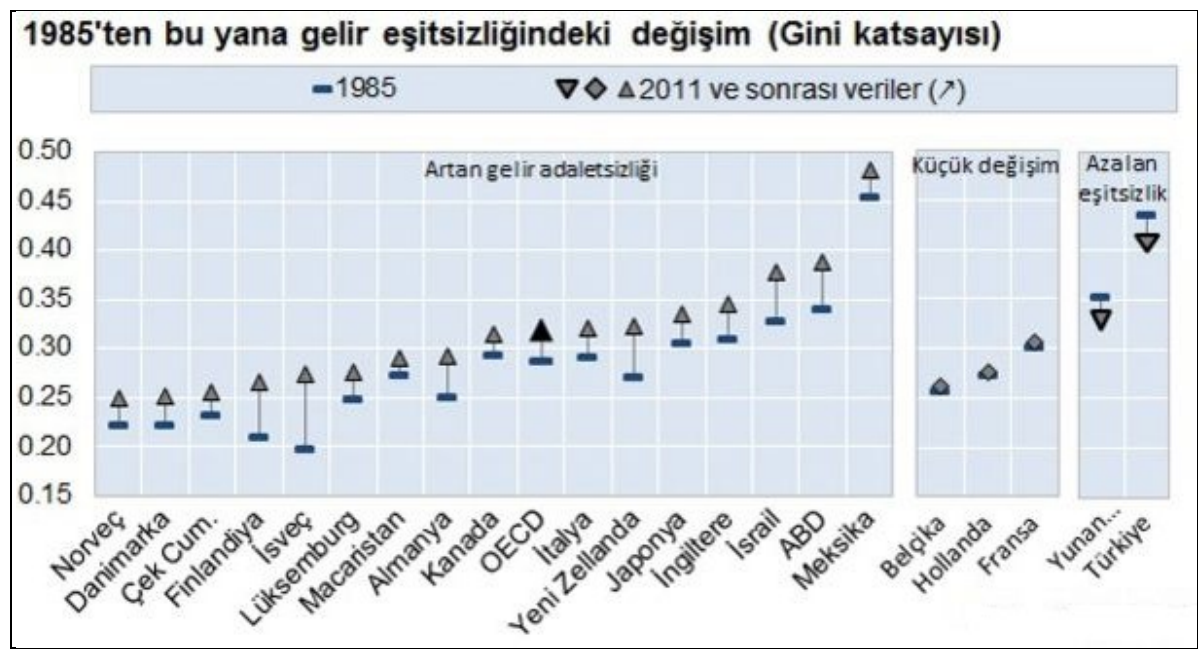

Grafik 1: Ülkelerin 1985-2014 Yılları Arası Gini katsayısı Gelişimleri Kaynak: OECD

Gelir eşitsizliğinin ekonomik büyümeye olumsuz etkisinin belirtildiği raporda 1985-2010 yılları arasında Türkiye'nin büyümesinin \% 4,6'sını gelir adaletsizliği nedeniyle kaybettiğini gösteriyor. Aynı dönemde Meksika'nın yüzde 10, Yeni Zellanda'nın ise \% 9'luk büyüme kaybı yaşadığı vurgulanıyor.

Türkiye İstatistik Kurumu'nun 2013 y1llı raporuna göre Yüzde 20'lik gruplarda, en yüksek gelire sahip son gruptakilerin toplam gelirden aldığı pay \%46,6 iken, en düşük gelire sahip ilk gruptakilerin toplam gelirden aldığ 1 pay $\% 6,1$ olmuştur.

Yüzde 20 'lik fert grupları

Türkiye

2012

\begin{tabular}{lcc} 
Toplam & 100 & 100 \\
İlk \% 20 & 5.9 & 6.1. \\
İkinci \%20 & 10.6 & 10.7 \\
Üçüncü \%20 & 15.3 & 15.2 \\
Dördüncü \%20 & 21.7 & 21.5 \\
Son \% 20 & 46.6 & 46.6 \\
\hline Gini katsayis1 & 0.402 & 0.400 \\
\hline
\end{tabular}

Tablo 1: Eşdeğer hanehalkı kullanılabilir gelire göre sıralı yüzde 20'lik gruplar, 2012-2013 Kaynak: TUİK

Sözkonusu veriler Tablo 1 den izlenebilmektedir. Gelir dağılımı eşitsizlik ölçütlerinden gini katsayısı bir önceki yıla göre 0,002 puan düşüş ile 0,400 olarak tahmin edilmiştir.

\section{Kuznet Ĕgriğsi ile İlgili Literatür}

Finansal kalkınma ve gelir eşitsizliği konusunda yapılan yerli ve yabancı çalışmalarda gerek Kuznet hipotezini destekler gerekse, gerekse red eder sonuçlara rastlanmaktadır.

\subsection{Kuznet Eğrisinin Geçerliliğini Red Eden Çalıșmalar}

Law ve Tan(2009) Malezya'da Kuznet hipotezini test ettikleri çalışmalarında 1980-200 yıları için sınır testi yaklaşımını kullanmışlar ve güçsüz de olsa finansal kalkınmadaki artışa paralel olarak gelir eşitsizliğinin azaldığını tespit etmişlerdir. Bununla birlikte söz konusu azalma istatistiki olarak Kuznet hipotezini doğrulamamıştır.

Deininger ve Squire (1998)'de gelişmiş ve gelişen 48 ülke için yaptığı çalışmada 44 ülke için gelir ve eşitsizlik arasında istatistiki anlamda ilişki bulamamıştır. Diğer 4 ülkede de ise Kuznets'in iddia ettiği ters dönmüş $U$ ilişkisi yerine U seklinde bir gelişme görülmüştür.

Huang(2004), yapmış olduğu çalışmada kuznet eğrisinin varlığını gini katsayısı, GSYİH, transfer harcamaları / GSYİH ve çalışanlar / işgücü değişkenleri ile test etmiştir. Söz konusu çalışma sonucunda gini değişkeni ile büyüme arasında kuvvetli fakat doğrusal olmayan bir ilişki saptanmıştır. Bununla birlikte Kuznet varsayımı doğrulanamamıştır.

\subsection{Kuznet Eğrisinin Geçerliliğini Destekleyen Çalışmalar}

Chen (2003) yapmış olduğu çalışmada kuznet eğrisinin geçerliliğini panel data yöntemi ile analiz etmiş ve çalışma sonucuna göre 43 ülkede Kuznet'in savunduğu ters U şeklindeki kuznet eğrisi kanıtlanmıştır. 
Ahluwalia (1976) 56 ülke için yapmış olduğu çalışmada çoklu regresyon yöntemini kullanarak Kuznet Eğrisi'ni test etmiştir. Ekonometrik analiz sonucuna göre kişi başına gelir ile çeşitli gelir gruplarının gelirden aldığı paylar arasında istatistiksel olarak anamlı ilişki olduğunu tesbit etmiştir. Kuznets'in ters-U hipotezine uygun biçimde, nüfusun düşük gelirli yüzde 40'ının ve yüzde 60' ının gelir payı, kişi başına GSMH'ın artışı ile önce azalmakta ve sonra artmaktadır.

\section{Kuznet Eğrisinin Türkiye için Geçerliliğinin Sınanması: Ekonometrik Analiz}

Kuznet'in iddia ettiği gibi gelir dağılımı ve kalkınma ile büyüme arasında ters U ilişkisinin var olup olmadığı sınır testi yaklaşımı ile test edilecektir. 1991-2014 yılları kullanılarak hem geniş bir dönemin çalışmaya dâhil edilmesi, he de güncel verilerin kullanılması amaçlanmıştır. Çalışmamızda Arvas (2014) çalışmasındaki modelden yararlanılmıştır.

\subsection{Veri ve Yöntem}

İktisat biliminde gelir dağılımı hakkında bizlere bilgi veren gini katsayısı kullanılmıştır. Türkiye'nin finansal gelişim makro göstergesi olarak ise özel sektör yurt içi kredi kullanımının GSYH' ya oranı kullanılmıştır. Mikro anlamda kişi başına GSYİH ve ihracatın ithalatı karşılama oranları kullanılmıştır. GSYH, veri seti Türkiye'de kişi başına düşen gelirin 1987 yılı fiyatları ile sabit değerlerin logaritması alınarak elde edilmiştir. Çalışmada kullanılan bütün veriler yıllık olarak modele dâhil edilmiş olup değişkenlerin logaritmik değerleri kullanılmıştır. Çalışmamızda Kanberoğlu ve Arvas'ın (2014) kullandığı modelden ve değişskenlerden yararlanılmıştır. Modelin çalışmamıza uyarlanmış hali denklem (1 ) deki gibidir.

Log gini $=\varphi+\alpha_{1} \log _{\text {gelir }}+\alpha_{2} \operatorname{logkredi}_{t}+\alpha_{3} \log _{\mathrm{lc}} \mathrm{f}_{t}+\varepsilon_{t}$

\begin{tabular}{|c|c|c|}
\hline Sembol & Değişken & Kaynağı \\
\hline loggini & Gini Endeksi & OECD ve Dünya Bankası \\
\hline loggelir & Cari fiyatlarla kişi başı gayri safi yurtiçi hasıla & TUİK ve Dünya bankası \\
\hline logkredi & Özel sektör kredisi / GSYH & Bankalar Birliği ve TUIKK \\
\hline logtcr & İhracatın ithalatı karşılama oranı & TUİK \\
\hline
\end{tabular}

Tablo 2: Ekonometrik Modele Konu Olan Değişkenler, Sembolleri ve Kaynakları

Ekonometrik modellerde değişkenler arasındaki uzun dönem ilişkisinin varlığının araştırılması temel amaçtır. Bununla birlikte çoğuz zaman zaman serileri arasında sahte ilişkiler de gözlenebilmektedir. Bu nedenle zaman serileri arasındaki ilişkilerin sahte olup olmadığı durağanlık testleri ile analiz edilmektedir. Çünkü değişkenlerin durağan olup olmaması ile sahte ilişki arasında güçlü bir bağ bulunmaktadır. Çalışmamızda söz konusu ilişkinin varlığının araştırılması için Philips-perron birim kök testi kullanılmıştır. Genişletilmiş Dickey-fuller birim kök testi yerine PP birim kök testini tercih etmemizin sebebi, Dickey-Fuller Testi hata terimlerinin istatistiki olarak bağımsız olduklarını ve sabit varyansa sahip olduklarını varsayar. Bu metodoloji kullanılırken hata terimleri arasında korelasyon olmadığına ve sabit varyansa sahip olduklarına emin olmak gerekir. Phillips ve Perron (1988) Dickey-Fuller'ın hata terimleri ile ilgili olan bu varsayımı genişletmişlerdir (Altunöz, :187).

\begin{tabular}{|c|c|c|c|c|}
\hline \multirow{2}{*}{ Seri } & \multicolumn{4}{|c|}{ Philips Perron Birimkök Testi } \\
\cline { 2 - 5 } & \multicolumn{2}{|c|}{ Düzeyde } & \multicolumn{2}{c|}{ Birinci Farkı Alındığında } \\
\cline { 2 - 5 } & Trendsiz & Trendli & Trendsiz & Trendli \\
\hline Loggini & $-1.031(0)$ & $-1.932(0)$ & $-5.121(1)^{*}$ & $-6.211(1)^{*}$ \\
\hline loggelir & $-0.009(0)$ & $-3.121(0)$ & $-5087(1)^{*}$ & $-6.121(1)^{*}$ \\
\hline logkredi & $1.121(0)$ & $-0.211(0)$ & $-6.213(1)^{*}$ & $-5.274(1)^{*}$ \\
\hline logtcr & $-0.451(0)$ & $-1.972 * * *$ & $-6.312(1)^{*}$ & $-5.786(1)^{*}$ \\
\hline
\end{tabular}

Tablo 3: Philips Perron Birim Kök Test Sonuçlarl

Not: *,**ve *** strasıyla \%1, \%5 ve \%10 anlam düzeyinde durağanlı̆̆ ifade etmektedir.

Tablo 2 de görüldüğü gibi ticaret değişkeni düzeyde \% 10 anlam seviyesinde durağanken tüm değişkenler birinci farkları alındığında trendli ve trendsiz \%1 anlam düzeyinde durağandır. Farklı durağanlık seviyelerinde kısa ve uzun dönemli ilişkilere izin veren sınır testi yaklaşımı, çalışmamız için en uygun yaklaşımdır.

$$
\begin{gathered}
\Delta \text { gini }_{t}=\alpha_{0}+\sum_{i=1}^{n} \alpha_{1} \Delta \text { gini }_{t-1}+\sum_{i=0}^{n} \alpha_{2} \Delta \text { gelir }_{t-1}+\sum_{i=0}^{n} \alpha_{3} \Delta \text { kredi }_{t-1}+\sum_{i=0}^{n} \alpha_{4} \Delta \text { tcr }_{t-1}+\beta_{1} \text { gini }_{t-1} \\
+\beta_{2} \text { gelir }_{t-1}+\beta_{3} \text { kredi }_{t-1}+\beta_{4} t c r_{t-1}+\varepsilon_{t}
\end{gathered}
$$


Çalışmamızda gecikme uzunluklarının belirlenme aşamasında Akaike Bilgi Kriteri (AIC) kullanılmıştır. Gecikme uzunluğumuz 6 olarak belirlenmiştir.

\begin{tabular}{|c|c|c|c|}
\hline Değişken & Katsayı & t Değeri & P Değeri \\
\hline Loggini (-1) & 0.3012 & 1.88 & 0.08 \\
\hline loggelir & -1.8721 & -2.12 & 0.02 \\
\hline Loggelir(-1) & -0.0321 & 3.18 & .00 \\
\hline logkredi & 0.2112 & 2.80 & .00 \\
\hline Logtcr & -0.0421 & -4.21 & 0.02 \\
\hline sabit & 5.321 & 3.21 & 0.03 \\
\hline ECM $(-1)$ & $-0,6809$ & -4.42 & .00 \\
\hline
\end{tabular}

Tablo 4: Sinır Testi için Düzeltme Modeli

Not: Bă̆ımlı Değişken Gini

Tablo 3 teki sonuçlara göre tüm değişkenler istatistiki olarak anlamlıdır. Hata Düzeltme Katsayısı (ECM(-1)) istatistiksel olarak \%1 düzeyinde anlamlıdır ve katsayı değeri yüksektir. Bu durum uyarlanma sürecinin çok hızlı olduğunu ifade etmektedir. ECM(-1) katsayısının negatif ve anlamlı olması gelir dağılımı modelindeki eşbütünleşme ilişkisini de desteklemektedir.

Gecikme uzunluğunun ardından değişkenler arasındaki eş bütünleşme ilişkisi test edilmektedir. Bu ilişkinin testinde sıfır hipotezinin testi $\mathrm{F}$ istatistik değerinin bulunması ile yapılmaktadır. Sınır testi yaklaşımı için hesaplanan f değerleri, Peseran vd.(2001) tablosunun üst ve alt değerleri ile karşılaştırılır. Hesaplanan değer alt değerin altında ise değişkenler arasında herhangi bir eşbütünleşme ilişkisinden söz edilemez. Alt ve üst sınır arasında ise kesin bir yorum yapılamamaktadır. Eğer hesaplanan değer üst değerin üzerinde ise eş bütünleşme ilişkisinin olduğu sonucuna varılmaktadır.

\begin{tabular}{|c|c|c|c|}
\hline \multicolumn{4}{|c|}{$\% 10$ Anlam Seviyesinde kritik Değerler } \\
\hline k (bağımsız Değişken sayısı) & F İstatistiği & Alt sınır I(0) & Üst sınır (I) \\
\hline 4 & 10.02 & 2.45 & 3.52 \\
\hline
\end{tabular}

Tablo 5: Wald Testi

Tablo 4 de Wald testi sonuçlarına göre f istatistiğinin üst sınırın üzerinde olduğu izlenmektedir. Bu durumda değişkenlerimiz arasında uzun dönemli bir eş bütünleşme ilişkisi olduğunu söyleyebiliriz. Maksimum gecikme uzunluğunun 7 olarak alındığı çalışmada ARDL sonuçları Tablo 5 de verilmiştir.

\begin{tabular}{|l|c|c|c|}
\hline Değişken & Katsayı & t istatistiği & p Dĕ̆. \\
\hline C & -0.0012 & -0.661 & 0.5 \\
\hline dloggini(-1) & -0.0311 & -0.231 & 0.6 \\
\hline dloggelir & -0.0711 & -6.211 & 0 \\
\hline dloggelir(-1) & 0.003 & 0.211 & 0.6 \\
\hline dlogkredi & -0.031 & -1.412 & 0.11 \\
\hline dlogkredi(-1) & 0.022 & 2.121 & 0.11 \\
\hline dlogkredi(-2) & 0.016 & 1.912 & 0.15 \\
\hline dlogkredi(-3) & 0.014 & 0.871 & 0.41 \\
\hline dlogtcr & -0.007 & -0.213 & 0.99 \\
\hline dlogtic(-1) & -0.0011 & -0.161 & .082 \\
\hline \multicolumn{2}{|c|}{ ARDL Uzun Dönem Hesaplanan Katsay1lar } \\
\hline Loggelir - & $\begin{array}{c}\text { Logkredi - } \\
0.044^{* *}\end{array}$ & $\begin{array}{c}\text { Logtcr } \\
0.006 * *\end{array}$ \\
\hline
\end{tabular}

Tablo 6: $A R D L(1,1,1,3,1$,$) Modeli Tahmin Sonuçları$

Tablo 5 teki ARDL testimizin uzun dönemli katsayıları istatistiki olarak anlamlıdır. Ekonometrik modelimizin sonucuna göre kişi başına GSYİH, özel sektör tarafından kullanılan krediler ve ticaret değişkenlerinin gelir adaletsizliğinin giderilmesinde olumlu bir etkiye sahip olduğu anlaşılmaktadır. Ticaret değişkeninin etkisinin diğer değişkenlere göre daha az olduğu da söylenebilmektedir. Uzun dönem katsayı sonuçlarına göre Türkiye'de kredilerde \%1 artış gelir eşitsizliğini \% 0.044 oranında azaltırken gelirdeki \%1'lik artış ise gelir eşitsizliğini 0.055 oranında azaltmaktadır. Ticaret değişkenimizin gelir eşitliğini azaltma gücü yok denecek kadar azdır. 


\section{Sonuç}

Ekonomik kalkınma ile gelir eşitsizliği konusunda çeşitli görüşler beyan edilmiş olsa da Simon Kuznets tarafından geliştirilen ve literatüre Kuznet hipotezi olarak giren görüş, oldukça geniş bir inceleme alanı bulmuştur. Ekonomik aktörlerin önemli görevlerinden biri, gelir dağglımındaki adaleti sağlamaktır. Türkiye İstatistik Kurumu'nun 2013 y1llı raporuna göre Yüzde 20'lik gruplarda, en yüksek gelire sahip son gruptakilerin toplam gelirden aldığı pay \%46,6 iken, en düşük gelire sahip ilk gruptakilerin toplam gelirden aldığ pay $\% 6,1$ olmuştur. Çalışmamızda 1991-2014 yılları için kalkınma ile gelir arasındaki ilişki sınır testi yaklaşımı ile incelenmiştir. Modelimizin sayısal sonuçlarına göre uzun dönem katsayı sonuçları Türkiye'de kredilerde \%1 artış gelir eşitsizliğini \% 0.044 oranında azaltırken gelirdeki \%1'lik artış ise gelir eşitsizliğini 0.055 oranında azaltmaktadır. Ticaret değişkenimizin gelir eşitliğini azaltma gücü yok denecek kadar azdır.

Ekonometrik model sonucuna göre sonucuna göre kişi başına GSYİH, özel sektör tarafından kullanılan krediler ve ticaret değişkenlerinin gelir adaletsizliğinin giderilmesinde olumlu bir etkiye sahip olduğu anlaşılmaktadır. Ticaret değişkeninin etkisinin diğer değişkenlere göre daha az olduğu da söylenebilmektedir.

$\mathrm{Bu}$ çalışma bizlere gösterdi ki her ne kadar Kuznet gelişmekte olan ülkelerde gelirin gelişmiş ülkelere göre daha dengesiz dağılım gösterdiğini iddia ederek ekonomik kalkınmaların başlangıcında büyüyen gelir eşitsizliği, kalkınma aşamasının ileri aşamalarını olumsuz yönde etkileneceğini iddia etse de ilgili dönemler için bu iddia Türkiye'de doğrulanamamıştır.

\section{Kaynakça}

- Altunöz, Utku (2013). Türkiye'de Enflasyon, Büyüme ve Finansal Derinleşme İlişkisinin Ampirik Analizi, Sütçüimam Üniversitesi İİBF dergisi sayı 2: 175-194.

- Arvas, Mehmet Akif (2014). Finansal kalkınma ve Gelir Eşitsizliği: Türkiye Örneği,19802012,Sosyoekonomi, 2014-1.

- Bilen, Mahmut ve İbrahim Güran Yumuşak (2006). Türkiye'de Gelir Dağılımı ve Yoksulluk Sorunu, Stratejik

- Chen, B., (2003), “An Inverted-U Relationship between Inequality and long run Growth”, Economic Letters, 78, 205-212.

- Deininger, L. Squire, (1998),'New Ways of Looking at old Issues: Asset Inequality and Growth', Journal of Development Economics Vol.57, 259-287.

- Dickey, David and Fuller, Wayne, 1981. "Distribution of the estimators for autoregressive time series with a unit root", Econometrica 49, ss.57-72.

- İbrahim Güran Yumuşak ve Mahmut Bilen, "Gelir Dağılımı-Beşeri Sermaye İlişkisi ve Türkiye Üzerine Bir Değerlendirme", Kocaeli üniversitesi Sosyal Bilimler Dergisi, Y11 1, Say1 1, 2000.ss. 77-96

- Kanberoğlu Ve Arvas (2014). Finansal Kalkınma ve Gelir Eşitsizliği: Türkiye Örneği, 1980-2012, Sosyo Ekonomi Dergisi, Haziran -Temmuz, 106-122.

- Kuznets, S. (1955), "Economic Growth and Ineome Inequality", American Economic Review, 45-1, 1-28.

- Law, S.H ve HY.B Tan (2009). The role of Financial Development on Income Inequality in Malaysia, journal of economic development 34(2), 153-168.

- $\quad$ OECD 2014 Türkiye Raporu

- Peseran, H, Yongcheol S. ve Richard J. S. (2001). "Bound Testing Approaches to the Analysis of Long Run Relationships", Journal of Applied Econometrics, 16(3), pp.289-326.

- $\quad$ Phillips, P. C. B.; Perron, P. (1988). "Testing for a Unit Root in Time Series Regression". Biometrika 75 (2): 335-346

- Tsai Pan-Long (1995), "Foreign Direct Investment And Income Inequality: Futrher Evidence", World Development, Vol:23, Issue:3, pp:469-483.

- TUİK Gelir ve Yaşam Koşulları Araştırması, 2013

- Ahluwalia, M. S. (1976), " Ineome Distribution and Development: Some Stylized Facts", The American Econoliiic Review, 66-2, 128-135. 


\title{
Kalkınma ve Eğitim İliş̧kisi: İnsani Gelişme Endeksine Göre Türkiye'nin Eğitim Düzeyinin Değerlendirilmesi
}

\section{The Relationship of Development and Education: An Evaluation of Turkey's Education Level by Human Development Index}

\author{
Asst. Prof. Dr. Emine Furat (Aksaray University, Turkey) \\ Emre Ürün (Aksaray University, Turkey) \\ Aytaç Aydın (Aksaray University, Turkey)
}

\begin{abstract}
The unfair distribution of income in underdeveloped countries causes the capital to be gathered in the hands of a certain party and thus preventing it from spreading to the society and although national income in these countries is high, the level of development being low creates problems. Education directly relates to issues related to the concept of development such as developing individuals' social points of view, obtaining the individual's skills and abilities, shaping the socio-cultural structure, environment, healthy life and guaranteeing rights and freedom.

The fact that frontiers disappeared together with the globalizing world and sharing the incomes in international markets have brought about some problems. The emergence of human-centered approach in development in 1970 and after has been an important opportunity for all societies. Human development has led the way to investigate concepts such as poverty, income equality, health and education and to take action to remove the deficiencies in the aforementioned area.

Education is inevitable for development. In this context, Turkey's education level will be evaluated in terms of the relationship of human development and education for development. In this study the indicators of Human Development Index (HDI) prepared by UDP annually and Education Index (EI), the sub-index of HDI, for Turkey have been taken into consideration and it has been aimed to determine Turkey's level of development in education. It was determined in the study that Turkey's level of human development is not satisfactory and that indicators for education were low.
\end{abstract}

\section{Giriş}

Küreselleşen dünya ile birlikte dünya üzerinde aşırı bolluk ile aşırı kıtlığın bir arada yaşandığı bir süreç yaşanmaktadır. Dünya içerinde mevcudiyetini koruyan ülkelerin az bir bölümü aşırı lüks ve zenginlik içerisinde yaşarken dünyanın büyük bir bölümünü oluşturan ülkeler yoksulluk içerisinde yaşamlarını sürdürmektedirler. Bu durum aynı ülke içerisinde yaşayan insanların arasında da var olup, insanlar arasında yaşam standartları açısından büyük farklılıklar görülmektedir. Özellikle azgelişmiş ülkelerde sermayenin az, emeğin çok olması dolayısıyla sermaye belirli bir grubun elinde toplanmıştır. Bu kesimin elindeki servetin lüks harcamaların giderek büyümesi, yoksul olan kesimin daha çok yoksullukla yüzleşmesine sebep olmaktadır.

Ülkelerde bulunan kaynakların doğru yönetilmemesi ve sermaye sahiplerinin de bu konuda baş aktör olması sebebiyle, toplumun özgürlükleri kısıtlanmıştır. Burada kastedilen özgürlük felsefi açıdan salt siyasal hakların elde edilmesi ile sınırlı değildir. Özgürlük bireylerin erişebildikleri sağlık, eğitim olanakları, beslenme, barınma gibi temel ihtiyaçlar, sosyo-kültürel yapının korunması ve geliştirilmesi, siyasal haklar, ifade edebilirlik gibi hakların tamamını içerisine alan bir kavrama karşılık gelmektedir. Özgürlüklerin elde edilmesi sürecinin kavramsal karşılığı ise kalkınma olarak karşımıza çıkmaktadır. Bu nedenle kalkınma ekonominin doğduğu günden itibaren insan hayatına giren bir kavramdır.

Kalkınma kavramı tarihsel açıdan çok eskiye dayansa da kavramının önemli bir konuma gelmesi İkinci Dünya Savaşı sonrasına tekabül etmektedir. Kalkınma, İkinci Dünya Savaşından sonra iktisadi literatürde sıkça kullanılmaya başlanmış ve dünyanın tamamını etkisi altına almıştır. Kalkınma gelişmiş ülkelerde korunması ve iyileştirilmesi gereken bir süreç olarak ele alınırken, azgelişmiş ülkelerde elde edilmesi zor olan bir güç olarak karşılık görmüştür. Kalkınma kavramı farklı iktisadi bakış açılarına göre farklı şekillerde yorumlanmıştır.

Kalkınma; ekonomik, sosyal ve kültürel yönleri ele alan geniş bir kavram olmakla birlikte 1970'lere kadar salt ekonomik olgular üzerinden değerlendirilmiştir. Kalkınma; gelir, sanayileşme, yatırım, sermaye birikimi ve pazar genişliği kavramları üzerinde yoğunlaşmış ve birçok iktisatçı tarafından kavram, kişi başına düşen milli gelir ile ölçülmeye çalışılmıştır. 1970'lerden sonra kalkınmışlık seviyesi, ekonomik ölçütlerin yanında beşeri sermaye, eğitim, sağlık, yaşam standartları, yoksulluk, eşitlik vb. kavramlarla birlikte ele alınmaya başlanmış, kavram insani kalkınmışlık düzeyi ile değerlendirilmeye çalışılmıştır. İnsani kalkınma kavramı salt parasal olgulardan uzak toplumun tamamının refahını amaç edinen bir yaklaşımı ele almaktadır. İnsani kalkınmanın gerçekleşmesi için öncelikle ekonomik ölçütlerin kullanılması gerekmektedir. Dünyanın büyük çoğunluğunu 
oluşturan ve azgelişmiş olarak atfedilen ülkelerin önemli bir bölümünün sorunu gelir dağılımındaki adaletsizlik ve kaynakların etkin ve verimli kullanımının gerçekleştirilememesidir.

Azgelişmiş ülkelerde gelir dağılımındaki adaletsizlik, sermayenin belirli bir zümrenin elinde toplanarak toplumun geneline yayılmamasına sebebiyet vermekte ve buna bağlı bu ülkelerde milli gelir yüksek olmasına karşın kalkınma seviyesinin düşük olması sorun teşkil etmektedir. Aynı ekonomik büyüklüğe sahip ülkelerden biri kalkınmış ülke iken bir diğeri geri kalmış ülke konumunda yer alabilmektedir. Kalkınmanın gelir dışındaki önemli unsurları içerisinde sağlık ve eğitim yer almaktadır. Eğitim bireylerin toplumsal bakış açılarının gelişmesi, bireyin bilgi ve becerilerinin elde edilmesi, sosyo-kültürel yapının şekillenmesi, çevre, sağlıklı yaşam, hak ve hürriyetlerin garanti altına alınması gibi kalkınma kavramının doğrudan ilgi alanına giren konuların bütünüyle direkt temas kurmaktadır.

Kalkınmanın 1970'li yıllardan sonra insan odaklı dönüşümü kavramın bu eksende ölçülmesine olanak sağlamıştır. İnsani kalkınma kavramı ve kalkınmanın temel göstergeleri içerisinde eğitim önemli bir yer tutmaktadır. Eğitim kavramı özgürlüklerin elde edilmesindeki en önemli araçlardan birini oluşturmaktadır. Bu nedenle kalkınmanın sağlanabilmesi için eğitim süreci önemli bir unsur oluşturmaktadır. 1990 yılı itibariyle Birleşmiş Milletler Kalkınma Programı (UNDP) tarafından İnsani Gelişme Endeksi (Human Development İndeks) hazırlanarak kalkınma kavramı insan odaklı ölçülmeye çalışılmıştır. Endeks içerisinde; gelir, sağlık ve eğitim göstergeleri kullanılarak ülkelerin insani kalkınmışlık seviyeleri belirlenmeye çalışılmıştır. Bu ölçüm her yıl UNDP tarafından yayınlanan İnsani Gelişme Raporu (İGR) ile sunulmaktadır. Bu doğrultuda 2008 yılında Fransız devlet başkanının talebi üzerine Joseph Stiglitz, Amartya Sen ve Jean Paul Fitoussi tarafından Ekonomik Performans Ölçümü ve Sosyal İlerleme Komisyonu oluşturulmuştur.

\section{Kalkınma Teorileri}

Kalkınma İkinci Dünya Savaşından sonra kendinden çok bahsedilen bir kavram olmasına rağmen XV. yüzyılda merkantilist sistem içindeki serbest pazar anlayışının gelişmesi ile kendini göstermiştir.

Kalkınma kavramı tarihsel süreçte farklı iktisadi görüşler tarafından yorumlanmıştır. Bu durum kalkınma kavramının tek bir teorik bakış açısıyla ve kesin bir ifade ile açıklanmasını engellemiştir. Kavram bir yandan GSMH'daki artış olarak görülürken, farklı bir bakış açısıyla; teknolojiye erişebilirlik, teknik bilgi, eğitim seviyesindeki artış ve buna bağlı olarak beşeri sermayedeki artış (Arndt, 1989), yani tamamı ile insani kaynaklardaki yükseliş olarak görülmüştür (Franko, 1992). Kalkınma, dar anlamıyla ekonomik koşullarda gerçekleşen değişimleri, bu değişimlerin ne şekilde gerçekleştiğini göstermektedir (Gönel, 2013). Kalkınma sadece üretimin ve kişi başına gelirin artırılması, yani GSMH'daki artış ile sınırlı görülmemeli, az gelişmiş toplumlarda iktisadi ve sosyo-kültürel yapının da değiştirilmesini içermelidir (Han ve Kaya, 2013). Azgelişmiş ülkelerde kalkınmanın gerçekleşmemesinin yoksulluk ve ekonomik durgunluğun birbirine bağımlı olmasından kaynaklı olduğunu (Ofori, 1980) belirten RagnarNurkse'e göre; gelir seviyesinin yeterli düzeyde olmaması, tasarrufların gerçekleşememesine ve sermaye birikiminin oluşmamasına neden olmaktadır. Bu tanımlardan farklı olarak Amartya Sen, Özgürlükle Kalkınma adlı eserinde, kalkınmayı, insanların yararlandığı gerçek özgürlükleri genişletme süreci olarak ifade etmektedir (Sen, 2004).

Kalkınma kavramı, İkinci Dünya Savaşı sonrasında daha farklı tartışmalara yol açarak çeşitli yaklaşımlarla ifade edilmeye çalışılmıştır. Rostow, aşamalar modelinde, toplumları tarihsel olarak sınıflandırmaktadır (Cavalcanti, 2000). Dengeli kalkınma modeli ise, ilk olarak yerel sanayinin dış ekonomik faaliyetlere karş1 korunması gerekliliğini belirten Friedrich List tarafından ortaya atılmıştır. Friedrich List (1841) Smith'in (1776) bilim ve teknolojinin önemine yeterince değer vermediğini vurgulamış, kültürel sermayenin önemli olduğuna inanmıştır. Solow öncesi Neo-Klasik iktisadi düşüncede de denge kuramı hakim olmuştur. Marx (1867), artı değer kuramı ile Schumpeter'in 'yaratıcı yıkım' tezine kaynaklık etmiştir (Tiryakioğlu, 2011). Marx toplumun tarihsel gelişimini inceleyerek, altyapı ile üstyapı arasındaki ilişkinin dinamiklerini yakalamaya çalışmıştır (Füredi, 1990). Dengeli kalkınma modeli daha geniş çerçevede ise Rosenstein-Rodan ve Nurkse gibi iktisatçılar tarafından incelenmiştir (Han ve Kaya, 2013). Rosenstein-Rodan'ın (1943), "BigPush" (Büyük İtiş) teorisine göre kalkınmanın sağlanabilmesi için emek ile sermaye bütünleşmesi önemlidir (Yavilioğlu, 2002). Nurkse'ın kısır döngü kuramına göre, kalkınmanın sağlanabilmesi için ilk olarak finansal sorunların giderilmesi gerekmektedir (Kattel ve Diğ., 2009). Dengesiz kalkınma modelinde, dengeli kalkınma modelinde yer alan piyasa dengesizliklerinin resesyona sebep olacağı algısına karşı, dengesiz kalkınmanın sağlanabileceği öne sürülmüştür (Solmaz, 2008). Hirschman'ın (1958), dengesiz kalkınma modeline göre azgelişmiş ülkelerde "Big Push" ile kalkınma sağlanabilmektedir. Kalkınma üzerine farklı bir perspektif ise Neo- Marksist iktisatçılar tarafından getirilmiştir. Paul Baran'a (1955), göre tekelci kapitalizm azgelişmiş ülkelerde kalkınmanın önünde engel teşkil etmektedir (Baran, 1974). Neo-Marksist iktisatçı olan Ernest Mandel'e (1960) göre, ülkelerin kalkınmasının ön şartı emperyalist yaptırımların ortadan kaldırılmasıdır (Mandel, 2008). Maurice Dobb'a (1958), göre gelişmekte olan ülkelerin kalkınması için planlı bir ekonomi modelinin belirlenmesi gerekmektedir (Dobb, 1973). Tarihsel açıdan ortaya atılan kalkınma modellerinin temelinde ekonomik olgular ve gelir odaklı bir yöntem bulunmaktadır. 
Kalkınma kavramı Amartya Sen (1979) tarafından farkıı bir bakış açısı ile yorumlanmış, kalkınmanın ekonomik olgularla belirlenmesinin yeterli olmadığı tespit edilerek, kavram ekonomik, sosyo-kültürel, sağlı, eğitim gibi kavramlar ele alınarak temelinde insanın olduğu bir yaklaşım ile değerlendirilmiştir (Sam, 2008). İnsani gelişme kavramının ortaya çıkması ile kalkınma kavramı farklı bir boyut kazanmış ve kalkınmanın ölçülmesinde endeksler hazırlanmaya başlanmıştır. Kalkınmanın göstergeleri arasında insani faktörleri içeren İnsani Gelişme Endeksi'nin yanı sıra bazı endeksler geliştirilmiştir. Temel İhtiyaçları Karşılama Endeksi, Fiziki Yaşam Kalitesi Endeksi, İnsani Yoksulluk Endeksi, Cinsiyete Bağlı Gelişme Endeksi, Cinsiyet Yetkinlik Ölçümü, İnsani Özgürlükler Endeksi ve Siyasi Özgürlükler Endeksi bunlardan bazılarıdır (Taban ve Kar, 2014). 1990 yılı itibariyle Birleşmiş Milletler Kalkınma Programı tarafından İnsani Gelişme Endeksleri hazırlanmakta ve endeks yıllık olarak yayınlanarak kalkınma düzeyinin değerlendirilmesi için kaynak teşkil etmektedir (Tüylüoğlu ve Karalı, 2006). Son yıllarda Stiglitz, vd. (2009)'a göre refahı tanımlamak ve ölçmek için GSYH 'nın dışında birçok kritere ihtiyaç olduğu belirtilmiştir. 2008 yılında Joseph Stiglitz, Amartya Sen ve Jean Paul Fitoussi'nin kurduğu Ekonomik Performans ve Sosyal İlerleme Ölçüm Komisyonu, (The Commission on the Measurement of Economic Performance and Social Progress) Yaşam Standardı İçin Gereken Materyaller (gelir, tüketim ve zenginlik), Sağlık, Eğitim, İş Hayatıyla İlgili Kişisel Faaliyetler, Politika ve Yönetim, Sosyal İlişkiler ve İletişimler, Çevre ve Güven olarak adlandırdıkları sekiz kriterden oluşmuştur (Stiglitz, vd, 2009). OECD tarafından 2011 yılında geliştirilen "Daha İyi Yaşam Endeksi” (Better Life Index), olarak adlandırılan endeks ülkelerin GSYİH'sı gibi ölçütlerin yanında pek çok kriteri de dikkate almaktadır. Kasparian ve Rolland (2012)'ye göre endekste yer alan 11 kriter şunlardır: Konut (konut harcamaları), Gelir (hane halkı net harcanabilir gelir, hane halkı finansal zenginlik), İş (istihdam oranı, uzun dönem işsizlik oranı, kişisel kazanç), Toplum (iletişimin kalitesi), Eğitim (eğitim düzeyi, eğitim-öğrenim yılları), Çevre (hava kirliliği, su kalitesi), Yönetim (seçmen katılımı, politika), Sağlık (yaşam beklentisi), Yaşam Memnuniyeti, Güvenlik (suçluluk oranı) ve İş Yaşam Dengesi (çalışma saatleri)'dir. Her bir kriter için ülkeler, 0 ile 10 arasında değişen bir ölçekle değerlendirilmektedir. Kulesza ve Ucieklak Jez, (2012)'ye göre, birçok kriterden oluşan bu endeks ülkeler arasındaki karşılaştırmayı kolaylaştırmakta, ülkelerin eksik olduğu alanlarda daha iyi stratejiler geliştirmesini sağlamaktadır (Akar, 2014:4-5).

\section{Kalkınma ve Eğitim İlişkisi}

Kalkınmanın sağlanmasında temel göstergelerden biri eğitim seviyesinin iyileştirilmesidir. Büyüme ve sosyal kalkınmanın sağlanması için gerekli olan eğitim, toplumların ekonomi, sağlık ve kültürel anlamda gelişmelerini sağlayan temel unsurlardan biridir. Eğitim aynı zamanda çevresel faktörleri etkilemekte ve kalkınmada sürdürülebilirliğin sağlanmasında etkili olmaktadır (Kopnina, 2014).

Eğitim bireyin kendi tercihlerine bağlı bir faaliyet gibi görülse de sonuçları geniş anlamda bütün toplumu ilgilendirir (Akgül ve Koç, 2011). OECD yetişkin becerileri anketine göre bilgiye daha fazla erişim sağlanması halinde ekonomik büyüme ve sosyal kalkınma sağlanacağı görülmektedir (OECD,2014). Beşeri sermaye ile doğru orantılı olan eğitim seviyesi üzerinde görülen artış, emeğin verimliliğini artıracak ve iş gücü verimliliği oluşturacaktır. Uzun vadeli büyümenin sağlanabilmesi için eğitim seviyesinin artırılması önemlidir (OECD,2014).

Ülkelerin eğitim alanına yapılan harcamaları kalkınmışlık düzeyleri ile doğru orantılıdır. Şekil 1'de Norveç'te eğitime yapılan toplam kamu harcamalarının GSYİH içerisindeki oranı \%8,7, Yeni Zelanda'nın \%7,4, Türkiye'nin \%4,1, Arjantin \%6,3 'dür. İnsani kalkınmışlık seviyesinde Norveç 1. sırada, Yeni Zelanda 7. sırada, Türkiye 69. sirada ve Arjantin 49. sırada yer almaktadır (UNDP, 2014).

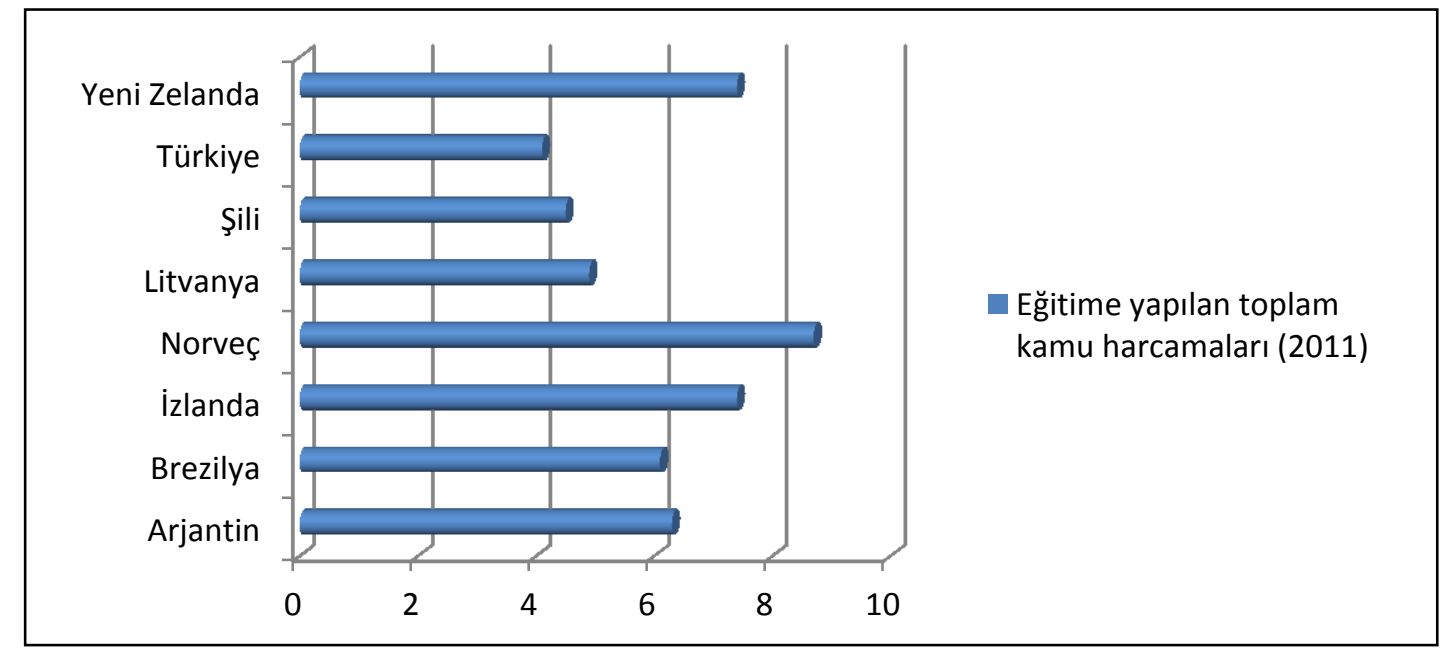

Şekil 1: Seçilmiş Ülkelerde Eğitime Yapılan Toplam Kamu Harcamalarl, 2011. Kaynak: OECD, (2014) 
Eğitim, kalkınmanın temel göstergeleri olan ekonomi, sağlık ve sosyo-kültürel gelişmişliği doğrudan etkiler. İnsani gelişme endeksinin alt endeksi olan eğitim endeksinin incelenmesi ve sonuçlarının değerlendirilmesi bu sebeple önem teşkil eder.

\section{4 İnsani Kalkınma ve Eğitim İlişkisi}

Kavramın insani olgulara dayandırılması 1970 sonrasında görülmekte olup, özellikle Amartya Sen'in toplumdaki bireylerin yetkinliklerinin artırılmasının kalkınmanın sağlanmasında temel kriter olarak göstermesi ve 1990 yılı itibariyle UNDP'nin İnsani Gelişme Endeksleri'ni oluşturması ile "İnsani Kalkınma" kavramı önemi ortaya konmuştur. Amartya Sen'e göre; kalkınma kavramı bireyin elinden alınan veya kısıtlı olarak sahip olduğu özgürlüklerin elde edilmesi için yapılan faaliyetler bütününü içerir. Sen'in özgürlük kavramı klasik anlamı dışında, demokrasi, eğitim ve sağlık vd olguların bütününü içerir. Özgürlüğün kısıtlanması sadece siyasi boyutlarla ifade edilmemektedir. Bu kısıtlanma bireyin iktisadi seviyesinin düşük olması ve bunun reel sonucu olarak sağlık, beslenme, bilgiye erişim gibi insani olgulardan yoksun kalması ile gerçekleşebilir. İnsani kalkınmayla kavram kişi başına düşen gelir artışı çerçevesinden çıkmış insani değerler, kişilik, toplumda bireylerin rolü, özgürlük gibi felsefi konuları da içerisine almıştır (Doğan ve Tatlı, 2014). Toplumda bireyin yaşam standartları bütün toplumu doğrudan etkilemektedir. Maddi refah, sağlık, siyasi istikrar, aile hayatı, toplum hayatı, iklim, iş güvenliği, siyasi özgürlükler, cinsiyet eşitliği (Pavol ve Diğ, 2014), sosyal konum, azınlık hakları, göçmen durumu, sosyal eşitsizlik (Bentley ve Huston, 2010) insani kalkınmanın temelini oluşturmaktadır. Eğitim sağlıklı toplumların oluşması ve eşitlik, adalet gibi temel hakların elde edilmesini ve korunmasını sağlar (Bilir ve Peran, 2007). Bilgi toplumunun oluşması ile son dönemde bilgi ekonomisinde sürekli bir artış görülmüştür. $\mathrm{Bu}$ artış bireylerin eğitim düzeylerini artırarak yeni bilgi sahibi olmaları ve toplumun genelinin bilgiye erişiminin sağlanması için faaliyet yürüten ülkelerin çalışmaları sonucu ortaya çıkmaktadır. Ülkelerin eğitim alanında gerçekleştirdikleri teşvikler bireylerin eğitim olanaklarını artırmakta ve küresel ölçekte yetenekli insan topluluklarını ortaya çıkarmaktadır. Eğitim insanların ekonomik koşullarında iyileşme sağlamakta ve istihdam alanında eğitimli kişilerin firsatlarını arttırmaktadır (OECD, 2012). Ülkelerin kalkınma seviyelerinin belirlenmesi ve insani gelişmişlik düzeyinin önemli göstergelerinden biri beşeri sermayedir. Beşeri sermaye içerisinde birçok öğe barındırmaktadır. Bunlardan iki temel unsur ise eğitim ve sağlıktır. Bir ülkede; eğitim seviyesinin yüksek olması, kalifiye işgücü doğuracağı için ekonomik ve sosyal sonuçlar bakımından kalkınmayı pozitif eğilimle etkilemektedir.

Ekonomik büyümenin de en temel öğesi insandır. Bu noktada insana yapılan her yatırım aynı zamanda büyümeye de fayda sağlamaktadır. İnsana yapılan yatırımın somut hali eğitimdir (Afşar, 2009). Kalkınmada önemli sorunlardan biride aynı gelişmişlik seviyesinde ya da aynı ekonomik büyüklükte yer alan iki farklı ülkenin eğitim seviyelerinde farklılıkların olmasıdır. Bu durum insani kalkınmışlık düzeyinde belirleyici etkenler arasındadır. Bu kapsamda İGE alt kategorisinde yer alan eğitim endeksinin tek başına değerlendirilmesi, eğitim seviye düzeyinin ortaya konulabilmesi farklı ülkeler ile karşılaştırılmasına imkân sağlanması ve eğitim seviyesi düşük olan ülkelerde alınacak önlemlerin ve geliştirici politikaların belirlenmesi açısından önem arz etmektedir.

İnsani Gelişme Endeksi, ülkelerin kalkınma seviyelerini ölçmede salt ekonomik olgular dışında insani olguları da içerisine alarak sayısal yöntemle ölçer ve analizini yapar. Endeksin temel ölçütleri, insani yaşam standard1, uzun ve sağlıklı yaşam, bilgiye erişim olarak kabul edilmiştir. UNDP tarafından 1990 yılından itibaren her yıl düzenli olarak yapılan İGE, bu üç göstergeyi birleştirerek tekbir bileşik endeks ile insani gelişmeyi değerlendiren bir yöntemdir (Nafziger, 2006). Endeks içerisinde yer alan insani yaşam standardı, kişi başına düşen Gayri Safi Milli Hasıla (GSMH) baz alınarak, uzun ve sağlıklı yaşam, doğumdan sonra ortalama yaşam beklentisiyle, bilgiye erişim; 25 yaş ve üstü bireylerin yaşamları süresince eğitim alabildikleri süreyle ve okula başlama çağındaki çocuklar için beklenen okula devam süresi ile hesaplanmaktadır (UNDP, 2014a). Bu üç farklı hesaplamanın bileşik endeks sonucu ile insani kalkınmışlık düzeyi belirlenmeye çalışılır. İnsani Gelişme Endeksi iki aşama kullanılarak hesaplanmaktadır. Birinci aşama boyut endekslerinin oluşturulması, ikinci aşama boyut endeks değerlerinin birleştirilmesidir. Boyut endeksi oluşturmada sağlık, okullaşma ve yaşam standardı baz alınır. Endeks değeri 0,00 ile 1,00 arasında belirlenmekte ve 0,00 değeri minimum gelişmişliği, 1,00 değeri ise maksimum gelişme düzeyini ifade eder (UNDP, 2014c:2).

Tablo 1'de yer alan seçilmiş ülke sıralamasında İGE değeri en yüksek olan ülke 0,944'lük değeri ile Norveç'tir. Norveç'i sırasıyla Avustralya, İsviçre, Hollanda, Amerika, Almanya takip etmektedir. İlk 49 ülke çok yüksek insani gelişmişlik kategorisinde yer almaktadır. 50. sırada 0,790 değeri ile Uruguay yüksek insani geliş̧̧ş̧ik kategorisinde yer almaktadır. Uruguay'ı sirasıyla Bahamalar (51), Karadağ (52), Beyaz Rusya (53), Romanya(54) ve Libya(55) takip etmektedir. Maldivler 103. sırada ve orta insani gelişmişlik kategorisinde yer almaktadır. Maldivler'i, Moğolistan (104), Türkmenistan (105) takip etmektedir. İGR'unun son 3 sirasında Orta Afrika Cumhuriyeti (185), Kongo (186) ve Nijer (187) yer almaktadır. Kişi başına GSMH en yüksek Norveç'te 63909 dolar seviyesinde, en düşük 444 dolar seviyesi ile Kongo'dadır. Norveç ve Kongo arasında yaklaşık 144 kat kişi başına düşen GSMH değeri söz konusudur. Bu durum listenin ilk sırasında yer alan gelişmiş ülkelerin tamamında bulunmaktadır. Norveç ve İsviçre' nin kişi başına düşen GSMH toplam değeri (117671\$), düşük insani kalkınma seviyesinde yer alan 40 ülkenin toplam GSMH (89342\$) değerinden 28329 dolar fazladır. Tablo 
1'de de görüldüğü üzere dünya üzerindeki ekonomik kaynakların gelişmiş ülkelerde toplandığ1, azgelişmiş ülkelerin ise açlık ve sefaletle yüzleşmek durumunda kaldığı ortadadır. Ortalama eğitim süresi Almanya ve Amerika'da 12,9 yıl değeri ile en yüksek düzeyde iken, aynı kategoride Nijer'de 1,4 yıl ortalama eğitim süresi görülmektedir. Okullaşma beklenen yıl 19,9 yıl ile Avustralya'da en yüksek seviyede iken aynı değer Nijer'de 5,4 yıl ile sınırlıdır. Tablo 1 verileri yaşam standardı, gelir ve eğitim açısından gelişmiş ülkelerin yeterli düzeye ulaştığını fakat azgelişmiş ülkelerde insani yaşam koşullarının yeterli olmadığını ortaya koymaktadır.

\begin{tabular}{|c|c|c|c|c|c|}
\hline İGE Kategori & $\begin{array}{c}\text { Yaşam } \\
\text { Beklentisi(yıl) }\end{array}$ & $\begin{array}{c}\text { Ortalama } \\
\text { Eğitim Süresi }\end{array}$ & $\begin{array}{c}\text { Okullaşma } \\
\text { Beklenen Yıl }\end{array}$ & $\begin{array}{c}\text { Kişi Başına } \\
\text { Düşen GSMH \$ }\end{array}$ & $\begin{array}{c}\text { İGE } \\
\text { Değer }\end{array}$ \\
\hline \multicolumn{6}{|l|}{ Çok Yüksek İnsani Kalkınma } \\
\hline 2. Avustralya & 82.5 & 12.8 & 19.9 & 41,524 & 0.933 \\
\hline 3. İsviçre & 82.6 & 12.2 & 15.7 & 53,762 & 0.917 \\
\hline 4. Hollanda & 81.0 & 11.9 & 17.9 & 42,397 & 0.915 \\
\hline 5. Amerika & 78.9 & 12.9 & 16.5 & 52,308 & 0.914 \\
\hline 6. Almanya & 80.7 & 12.9 & 16.3 & 43,049 & 0.911 \\
\hline 7. Yeni Zelanda & 81.1 & 12.5 & 19.4 & 32,569 & 0.910 \\
\hline 8. Kanada & 81.5 & 12.3 & 15.9 & 41,887 & 0.902 \\
\hline 9. Singapur & 82.3 & $10.2 \mathrm{~b}$ & $15.4 \mathrm{c}$ & 72,371 & 0.901 \\
\hline 10. Danimarka & 79.4 & 12.1 & 16.9 & 42,880 & 0.900 \\
\hline \multicolumn{6}{|l|}{ Yüksek İnsani Kalkınma } \\
\hline 50. Uruguay & 77.2 & 8.5 & 15.5 & 18,108 & 0.790 \\
\hline 51. Bahamalar & 75.2 & 10.9 & $12.6 \mathrm{n}$ & 21,414 & 0.789 \\
\hline 52. Karadağ & 74.8 & $10.5 \mathrm{o}$ & 15.2 & 14,710 & 0.789 \\
\hline 53. Beyaz Rusya & 69.9 & $11.5 \mathrm{o}$ & 15.7 & 16,403 & 0.786 \\
\hline 54. Romanya & 73.8 & 10.7 & 14.1 & 17,433 & 0.785 \\
\hline 55. Libya & 75.3 & 7.5 & 16.1 & 21,666 & 0.784 \\
\hline 56. Umman & 76.6 & 6.8 & 13.6 & 42,191 & 0.783 \\
\hline 57. Rusya & 68.0 & 11.7 & 14.0 & 22,617 & 0.778 \\
\hline 58. Bulgaristan & 73.5 & $10.6 \mathrm{~b}$ & 14.3 & 15,402 & 0.777 \\
\hline 59. Barbados & 75.4 & 9.4 & 15.4 & 13,604 & 0.776 \\
\hline 60. Palau & $72.4 \mathrm{~d}$ & $12.2 \mathrm{p}$ & 13.7 & 12,823 & 0.775 \\
\hline \multicolumn{6}{|l|}{ Orta İnsani Kalkınma } \\
\hline 103. Maldivler & 77.9 & $5.8 \mathrm{~b}$ & 12.7 & 10,074 & 0.698 \\
\hline 104. Moğolistan & 67.5 & 8.3 & 15.0 & 8,466 & 0.698 \\
\hline 105. Türkmenistan & 65.5 & $9.9 \mathrm{~s}$ & $12.6 \mathrm{p}$ & 11,533 & 0.698 \\
\hline 106. Samoa & 73.2 & 10.3 & $12.9 \mathrm{t}$ & 4,708 & 0.694 \\
\hline 107.Filistin & 73.2 & $8.9 \mathrm{o}$ & 13.2 & 5,168 & 0.686 \\
\hline 108.Endonezya & 70.8 & 7.5 & 12.7 & 8,970 & 0.684 \\
\hline 109.Botsvana & $64.4 \mathrm{v}$ & 8.8 & 11.7 & 14,792 & 0.683 \\
\hline 110.Misir & 71.2 & 6.4 & 13.0 & 10,400 & 0.682 \\
\hline 111. Paraguay & 72.3 & 7.7 & 11.9 & 7,580 & 0.676 \\
\hline 112. Gabon & 63.5 & 7.4 & 12.3 & 16,977 & 0.674 \\
\hline \multicolumn{6}{|l|}{ Düșük İnsani Kalkınma } \\
\hline 145. Nepal & 68.4 & 3.2 & 12.4 & 2,194 & 0.540 \\
\hline 146. Pakistan & 66.6 & 4.7 & 7.7 & 4,652 & 0.537 \\
\hline 147. Kenya & 61.7 & 6.3 & 11.0 & 2,158 & 0.535 \\
\hline 148.Svaziland & 49.0 & 7.1 & 11.3 & 5,536 & 0.530 \\
\hline 149. Angola & 51.9 & $4.7 \mathrm{w}$ & 11.4 & 6,323 & 0.526 \\
\hline 150. Myanmar & 65.2 & 4.0 & 8.6 & 3,998 & 0.524 \\
\hline 185.Orta Afrika Cumhuriyeti & 50.2 & 3.5 & 7.2 & 588 & 0.341 \\
\hline 186. Kongo & 50.0 & 3.1 & 9.7 & 444 & 0.338 \\
\hline 187.Nijer & 58.4 & 1.4 & 5.4 & 873 & 0.337 \\
\hline
\end{tabular}

Tablo 1: Seçilmiş Ülkelerin IGE Sıralaması (2013) Kaynak: UNDP, (2014). 


\begin{tabular}{cccccc}
\hline & $\begin{array}{c}\text { Doğumda Ortalama } \\
\text { Yaşam Beklentisi }\end{array}$ & $\begin{array}{c}\text { Öğrenim Görme } \\
\text { Süresi Beklentisi }\end{array}$ & $\begin{array}{c}\text { Ortalama Öğrenim } \\
\text { Görme Süresi }\end{array}$ & $\begin{array}{c}\text { Kişi Başına Düşen } \\
\text { GSMG } \\
\text { (2005 SGP \$) }\end{array}$ & $\begin{array}{c}\text { İGE } \\
\text { Değeri }\end{array}$ \\
\hline $\mathbf{1 9 9 0}$ & 64,3 & 8,9 & 4,5 & 10.546 & 0,576 \\
$\mathbf{1 9 9 5}$ & 67,0 & 9,6 & 4,8 & 11.372 & 0,604 \\
$\mathbf{2 0 0 0}$ & 70,0 & 11,1 & 5,5 & 12.890 & 0,653 \\
$\mathbf{2 0 0 5}$ & 72,5 & 11,9 & 6,0 & 15.060 & 0,687 \\
$\mathbf{2 0 1 0}$ & 74,3 & 13,9 & 7,2 & 16.587 & 0,738 \\
$\mathbf{2 0 1 1}$ & 74,6 & 14,4 & 7,4 & 17.814 & 0,752 \\
$\mathbf{2 0 1 2}$ & 74,9 & 14,4 & 7,6 & 18.011 & 0,756 \\
$\mathbf{2 0 1 3}$ & 75,3 & 14,4 & 7,6 & 18.391 & 0,759 \\
\hline
\end{tabular}

Tablo:2 Türkiyenin istikrarlı zaman dizisi verileri, yeni göstergeler ve yöntemler ışı̆̆ında İGE ĕgilimleri (19902013) Kaynak: UNDP,(2014c).

Türkiye, 0,759 değeri ile 69. sırada yüksek insani gelişme kategorisinde yer almaktadır. Sürekli bir iyileşme içerisinde olmasına rağmen dünyanın 17. büyük ekonomisi(WB, 2013) olan Türkiye, insani gelişme düzeyinde yeterli seviyeye ulaşamamıştır.

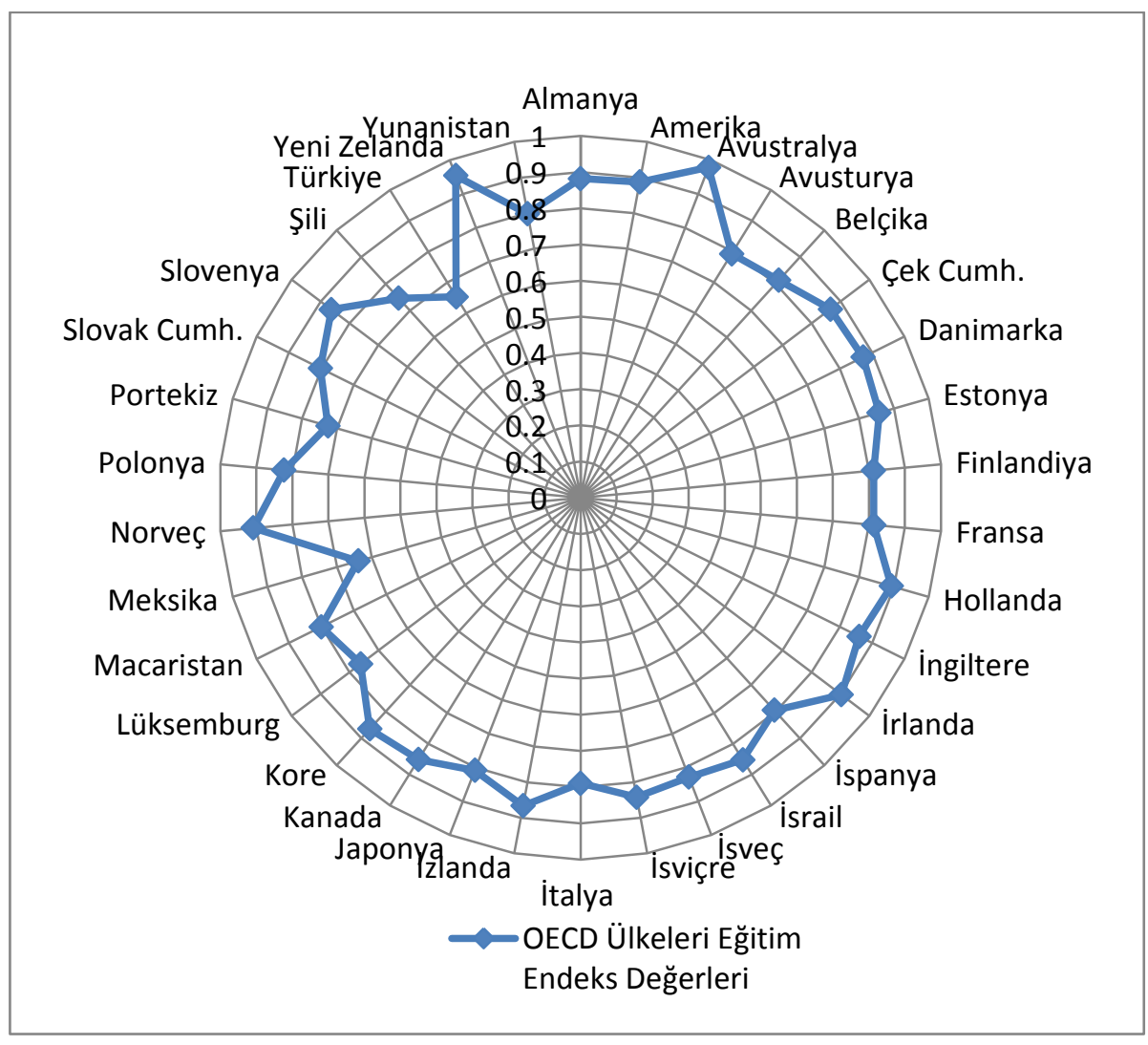

Şekil2: OECD ülkeleri ĕgitim endeks değerleri (2012-2013). Kaynak: UNDP,(2014).İnsani gelişme raporu, 2014,. Veriler boyut endeksine uygulanması ile elde edilen sonuçlar ile hazırlanmıştır.

İnsani Gelişme Endeksi alt endeksi olan "Eğitim Endeksi" 25 yaş ve üstü bireylerin yaşam süreleri boyunca ortalama eğitim gördükleri süre ve okula başlama çağındaki çocukların okula kayıt alanında hakim olan oranların okul çağındaki çocuğun yaşam süresi içerisinde aynı kalması varsayımı ele alınarak, çocuğun öğrenim görme süre beklentisinin toplamı üzerinden elde edilen sonuçların aritmetik ortalamasıdır (UNDP, 2014a). Eğitim alanında kalkınmışlığı ölçmek için OECD ülkeleri ile karşılaştırma yapıldığında, Şekil 2'de Türkiye 0,653 endeks değeri ile 34 OECD ülkesi içerisinde 0,638 endeks değerine sahip olan Meksika'dan sonra en düşük değere sahiptir. En yüksek değere sahip ülkeler sırasıyla 0,979 değeriyle Avustralya, 0,955 değeriyle Yeni Zelanda, 0,908 değeriyle Norveç ve 0,903 değeriyle İrlanda'dır. 


\section{Sonuç}

Kalkınma merkantilist dönemden 1970'lere kadar gelir odaklı, ekonomik büyümeye yönelik yapılan faaliyetlerin bütünü olarak görülmüştür. Küreselleşen dünya ile birlikte sınırların ortadan kalkması, gelirlerin uluslararası pazarda paylaşılması beraberinde bir takım sorunlar getirmiştir. Geçmişte kaynak ve sermaye yetersizliğinden dolayı azgelişmişliğe mahkûm olan ülkeler, yeni dünya düzeninde azgelişmişlik statüsünden kurtulamamıştır. Belirli ülkeler ekonomik anlamda ilerleme kaydetse de bu ilerleme salt parasal olgularla sınırlı kalmıştır. Mevcut veriler göstermektedir ki gelişmiş ülkeler kalkınmalarını sağlayacak yeterli sermaye birikimine sahip iken aynı durum azgelişmiş ülkelerde görülmemektedir. Kalkınmanın sağlanabilmesi ve azgelişmişlikten kurtulabilmek için yeterli sermayeye sahip olmayan ülkelerin ellerindeki kaynakları maksimum verimlilikle değerlendirmeleri önemlidir. Mevcut kaynakların etkin kullanımı toplumda bulunan eğitimli bireylerin sayısı ile doğru orantılıdır. Eğitim, kalkınmanın sağlanmasında motor görevi üstlenmektedir.

1970 ve sonrası dönemde kalkınmada insan odaklı yaklaşımın ortaya çıkması dünya üzerinde yaşayan bütün toplumlar için önemli bir firsat olmuştur. İnsan odaklı kalkınma yoksulluk, gelir eşitliği, sağlık, eğitim vd kavramların mercek altına alınarak araştırılmasına ve bu alanda oluşan eksikliklerin giderilmesine yönelik adımlar atılmasında öncü olmuştur. UNDP tarafından her yıl hazırlanan İnsani Gelişme Endeksi(İGE) ve alt endeksler olan eğitim, sağlık, yaşam standardı endeksleri ülkelerin insani kalkınma seviyelerinin belirlenmesinde ölçüt rapor konumunda yer almaktadır. Endeks değerleri ülkelerin değerlerinin karşılaştırılmasını sağlamakta ve ülkeler arasındaki farklılıkların giderilmesi yönünde yapılacak faaliyetlerin yönlendirilmesinde rol oynamaktadır. Endeks ayrıca ülkelerin ekonomik büyüklüklere erişim seviyelerinin yüksekliği ile kalkınmanın aynı doğrultuda gerçekleşmediğini ortaya koymaktadır. İGE alt endeksi olan eğitim endeksi kalkınma açısından, ülkelerin eğitim seviyelerinin ölçülmesinde son derece önemlidir. Türkiye'nin eğitim endeks değerleri sürekli iyileşme içerisinde yer almasına rağmen bu iyileşme eğitim seviyesini yeterli düzeye ulaştıramamıştır. Türkiye'nin değeri OECD ülkeleri ortalaması olan 0,805'inde altında kalmıştır. Bu durum Türkiye'nin kalkınma politikalarında gelir odaklı yaklaşımdan yeterince uzaklaşamadığı ve genelde insani gelişmişlik, özelde ise eğitim alanında doğru ve yeterli adımlar atamadığını göstermektedir. Bu kapsamda kalkınma ve toplumsal refahın sağlanması için Türkiye'de eğitim alanında uygulanacak faaliyetlere önem verilmesi, politika yapıcılar tarafından geçerli eğitim faaliyetlerine ek uygulamalar getirilerek eğitim seviyesinde artış sağlanması ve eğitim sektöründe yeniliklere olanak sağlayacak devlet teşvikleri hazırlanması önerilerinin kalkınmanın sağlanmasına katkı sunacağı düşünülmektedir.

\section{Kaynakça}

- Afşar, M. (2009). “Türkiye'de Eğitim Yatırımları ve Ekonomik Büyüme İlişkisi”, Anadolu Üniversitesi Sosyal Bilimler Dergisi, Sayı: 9(1), s.85-98.

- Akar., Bingül, A., B. 2014. "Eğitim-Büyüme İlişkisi Yazını Üzerine Bir Değerlendirme”. http://fdeyneli.pamukkale.edu.tr/1.pdf, Erişim Tarihi: 01.11.2014.

- $\quad$ Akgül, I., Koç, S, Ö., (2011). “Türkiye Cumhuriyeti Tarihinde Eğitim ve Büyüme İlişkisi: Eşik Otoregresif Yaklaşım”, Trakya Üniversitesi Sosyal Bilimler Dergisi, 13(2), 1-36

- Arndt, H. W. (1989). Economic Development: The History of an Idea, (1 rd ed.). Chicago: University.

- Baran, P. (1974). Büyümenin Ekonomi Politiği, (1. Bask1). çev, Ergin Günçe, İstanbul: May yayınları.

- Bentley, C, B.,Huston, C. (2010). "Human Development in Societal Context, Annual Review of Psychology", Sayı: 61, s.411-437.

- Bilir,Y.,Peran T. (2007). “Kalkınmada İtici Bir Güç: Eğitim”, Trakya Üniversitesi Sosyal Bilimler Dergisi, Sayı: 9(1), s.132-141.

- Cavalcanti, C. 2002. “Celso Furtado and The Persistence Of Underdevelopment”, Erişim adresi:http://www.redcelsofurtado.edu.mx/archivosPDF/clovis1.pdf Erişim tarihi: 14.09.2014

- Dobb, M. (1973). Kapitalizm Sosyalizm Azgelişmiş Ülkeler ve İktisadi Kalkınma, (1. Baskı). çev, Mehmet Selik, Ankara: Doğan Yayınevi.

- Doğan, E., M., Tatlı, H. (2014). “İnsani Gelişme ve Insani Yoksulluk Bağlamında Türkiye'nin Dünyadaki Yeri”,Atatürk Üniversitesi İktisadi ve İdari Bilimler Dergisi, Sayı: 28, s.99-124.

- Franko,P. M. ( 1992). The Puzzle of Latin American Economic Development, (3rd ed.). Maryland: Rowman\&LittlefieldPublishers

- Gönel, F. D. (2013). Kalkınma Ekonomisi, (2. Baskı). Ankara: Efil Yayınevi.

- Füredi, F., “Tarihsel Materyalizmde İdeoloji ve Üst Yapıya Önsöz”, Praksis 1, 2001, 224-46.

- Han, Ergül ve Kaya, A. A., (2013). Kalkınma Ekonomisi Teori ve Politika, (8. Bask1). Ankara: Nobel yayınevi. 
- $\quad$ Kattel, R.,Kregel, Jan. A.,Reinert, S. E., "TheRelevance of RagnarNurkseandClassical Development Economics”, March 2009, Erişim adresi:

http://technologygovernance.eu/files/main/2009070708560303.pdf Erişim tarihi: 14.09.2014

- Kopnina, H. (2014). "Revisiting Education for Sustainable Development (ESD): Examining Anthropocentric Bias Through the Transition of Environmental Education to ESD Sustainable Development, Sustainable Development”, Sayı: 22, s.73-83.

- Mandel, E. (2008). Marksist Ekonomi Eı Kitabı, (3. Baskı). çev, Orhan Suda, Ankara: Özgür Üniversite Kitaplı̆̆ı.

- Nafziger, W. E. (2006) “Economic Development, Cambridge UniversityPress” . Erişim adresi: www.cambridge.org/9780521829663, Erişim tarihi: 30.08.2014

- OECD, (2012). “Education at a Glance 2012Summaries” Erişim adresi:http://www.oecd.org/edu/EAG\%202012_e-book_EN_200912.pdf, Erişim tarihi: 03.11.2014.

- Ofori, G. (1980). "The Construction Industries of DevelopingCountries: The Applicability of Existing Theories and Strategies for Their Improvement and Lessons for the Future the Case of Ghana”, Erişim adresi: discovery.ucl.ac.uk/1317715/1/279216. Erişim tarihi: 30.08.2014.

- Pavol, A.,Stela, B., Zuzana, H.,(2014). “Development of Quality of Life Economic Indicators With Regard to the Environment, Procedia - Social and Behavioral Sciences”, Sayı: 110, s.747 - 754.

- Sam, N., (2008). “Yoksulluğa Bir Yaklaşım Biçimi: Kapasite Yaklaşımı”, Uludağ Üniversitesi İktisadi ve İdari Bilimler Fakültesi Dergisi, 27, 59-70

- Sen, A. (2004). Özgürlükle Kalkınma (çev.: Y. Alogan), İstanbul: Ayrıntı.

- Solmaz, E. (2008) “, İktisadi Kalkınma Kuramlarının Yoksulluk Konusuna Yaklaşımlarına Eleştirel Bir Bakış”, Mevzuat Dergisi, Sayı: 132 (11). Erişim adresi:http://www.mevzuatdergisi.com erişim tarihi: 17.08.2014.

- $\quad$ Stiglitz, J. E., Sen, A., ve Fitoussi, J.-P., (2009). "Report by the Commission on the Measurement of Economic Performance and Social Progress", Paris. Erişim adresi: http://www.stiglitz-senfitoussi.fr/documents/rapport anglais.pdf. Erişim tarihi: 01.02.2015.

- Taban, Sami ve Kar, Muhsin (2008). Kalkınma Ekonomisi, (1. Baskı). İstanbul: Seçkin Yayıncılık.

- Tiryakioğlu M., (2011). “Teknoloji Transferi, Teknoloji Yoksulluğu mu?”, Ankara Üniversitesi SBF Dergisi, 66, ss.169-199.

- Tüylüoğlu Ş., Karalı, B., (2006). “İnsani Kalkınma Endeksi ve Türkiye Iç̧in Değerlendirilmesi”. SÜ İ̈BF Sosyal ve Ekonomik Araştırmalar Dergisi, Sayı: 12, s.53-88.

- UNDP, (2014a). 2014 “İnsani Gelişme Raporu'ndaki Insani Gelişme Endeksi (IGGE) Değerleri ve Sıralamadaki Değişiklikler”, Erişim adresi:http://www.tr.undp.org, Erişim tarihi: 15.10.2014.

- UNDP,(2014c). “Techinal Note 1 Human Development Index”, Erişim adresi:http://hdr.undp.org/sites/default/files/hdr_2013_en_technotes.pdf. Erişim tarihi: 15.10.2014.

- WB, (2013). “Gross Domestic Product 2013”, PPP, Erişim adresi: http://databank.worldbank.org/data/download/GDP_PPP.pdf, Erişim tarihi: 15.10.2014.

- Yavilioğlu, C. (2002). “Geri Kalmışlık Olgusu ve Ekonomistik Kalkınma Teorileri Eleştirel Bir Yaklaşım”, Cumhuriyet Üniversitesi İktisadi ve İdari Bilimler Dergisi, Sayı: 3 (1), s.49-70. 


\title{
Ekonomik Özgürlükler ve Ekonomik Büyüme: Yükselen Piyasa Ekonomileri Üzerine Bir İnceleme
}

\section{Economic Freedoms and Economic Growth: An Investigation on Emerging Market Economies}

\author{
Prof. Dr. Bedriye Tunçsiper (Balıkesir University, Turkey) \\ Ph. D. Candidate Ömer Faruk Biçen (Balıkesir University, Turkey)
}

\begin{abstract}
The common view in the economics theory relating to the fact that economic freedom will raise labor productivity and it will provide effective use of scarce resources becomes a current issue with the increase in the number of papers investigating the effect of economic freedom on economic growth. One of the main reasons of the increasing number of those papers is that economic freedom can be measured quantitatively (numerically) through the indexes calculated by various institutions. In this paper, the relationship between economic freedoms and economic growth for some emerging market economies is investigated. In estimating of the relationship between economic freedoms and economic growth, overall economic freedom index, property right index, business freedom index, trade freedom index and investment freedom index, which was created by the Heritage Foundation was used. Investment/GDP ratio and population dependency ratio are also control variables in the model. In the paper, in which panel fixed effect model was used, property right index, investment freedom index and population dependency ratio affect economic growth negatively, but business freedom index, trade freedom index and investment/GDP ratio affect economic growth positively. It isn't found that there is a significantly relationship between overall economic freedom index and economic growth.
\end{abstract}

\section{Giriş}

Özgürlük kavramı tarihsel süreç içerisinde çeşitli şekillerde tanımlanmış olmakla birlikte temel anlamda ekonomik, politik ve sivil alana yönelik haklar bütününü ifade etmektedir. Günümüz koşullarında bu kavram kısaca; "ülke vatandaşlarının, diğer vatandaşların ve devletin baskılarına, yönlendirmelerine ve müdahalelerine maruz kalmadan yaşaması” şeklinde tanımlanabilmektedir. Ekonomik özgürlük ise, bireylerin hiçbir kısıtlamaya tabi olmadan çeşitli ekonomik faaliyetlerde bulunabilmesi ve sahip oldukları kaynaklara serbest bir biçimde yön verebilme imkanına sahip olabilmesidir (Acar, 2010). Özgürlüklerin düzeyi ülkeler arasında farklılıklar göstermekte ve özgürlüklerin boyutu diğerlerine göre geniş olan ülkelerin refah açısından da daha ileride olduklarına yönelik bazı kanıtlar sunulmaktadır. Ancak, özgürlüklerin mi refaha yol açtığı, yoksa refah düzeyinin yüksek olmasının mı özgürlükleri ilerlettiği günümüzde de tartışılan önemli bir konudur.

Hem özgürlüklerin ülkelerin gelişmesindeki rolünün belirlenmesi hem de ülkelerin özgürlük düzeylerinin karşılaştırmalı olarak analiz edilebilmesi için özgürlüklerin nicel olarak hesaplanabilmesi gerekmektedir. 1990 sonrasında Heritage Vakfı ve Fraser Enstitüsü gibi uluslararası kurum ve kuruluşlar tarafından yapılan hesaplamalar, ekonomik özgürlüklerin nicel olarak ölçülebilir hale gelmesinde önemli bir rol oynamıştır. Bu sayede, kısmen de olsa ekonomik özgürlük düzeyindeki değişmelerin ekonomik performansı ne yönde etkilediği tahmin edilebilmektedir. Aynı zamanda yapılan bu tahminlere göre; ekonomik açıdan diğer ülkelere göre daha özgür olan ülkelerin daha hızlı bir büyüme, daha yüksek kişi başına düşen gelir seviyesi, daha düşük işsizlik oranları, daha geniş kapsamda siyasi ve sivil özgürlükler ve daha düşük yolsuzluk düzeyini yakaladıkları görülmektedir (Acar, 2010). Fakat son dönemde yapılan ve belirli ülkeleri kapsayan ampirik çalışmaların elde ettiği tahminler, ekonomik özgürlüklerin ekonomik büyümeyi hiç etkilemediği veya negatif yönde etkilediğini de göstermektedir.

Çalışmanın amacı, Brezilya, Çin, Güney Kore, Hindistan, Hong Kong, Malezya, Rusya, Tayland ve Türkiye'den oluşan dokuz yükselen piyasa ekonomisinde 2000-2012 yılları arasında ekonomik özgürlük düzeyindeki ilerlemelerin ekonomik büyümeyi ne yönde etkilediğini tahmin etmektir. Çalışmada bu ilişkiye yönelik tahminde bulunabilmek için panel sabit etkiler modelinden yararlanılmıştır. Ekonomik özgürlüğe ilişkin veriler 2000-2012 dönemi için Heritage Vakfı ve Wall Street Journal tarafından ortaklaşa hazırlanan Ekonomik Özgürlükler Endeksi (IEF)'nden derlenmiştir.

Çalışma üç bölümden oluşmaktadır. Giriş bölümünü izleyen ikinci bölümde, ekonomik özgürlükler ve ekonomik büyüme arasındaki ilişki değerlendirilmiş ve ampirik kısımda ulaşılabilecek sonuçlara yönelik bir ön bilgi sağlanmıştır. Üçüncü bölümde ise, panel sabit etkiler modeli çerçevesinde çalışmaya dahil edilen dokuz yükselen piyasa ekonomisine yönelik olarak ekonomik özgürlükler ve ekonomik büyüme arasındaki ilişki incelenmiş ve elde edilen bulgular değerlendirilmiştir. 


\section{Ekonomik Özgürlükler ve Ekonomik Büyüme İlişkisi}

Ekonomik özgürlükler, siyasi ve sivil özgürlükler ile birlikte genel anlamdaki özgürlüğün temel unsurlarından biri iken, aynı zamanda büyümenin, etkinliğin ve refah artışının da önemli bir belirleyicisidir. Son 30 yıllık dönemde ekonomik büyümeyi konu alan teorik ve ampirik çalışmalar, ülkeler arasındaki büyüme, etkinlik ve refah düzeyindeki farklılaşmanın yalnızca fiziki sermaye oluşumu, nitelikli emek ve teknoloji düzeyindeki ilerleme ile açıklanamayacağını ifade etmekte ve kurumsal yapıdaki gelişmelerin de ekonomik büyüme, etkinlik ve refah düzeyindeki ilerlemelerin temel bir belirleyicisi olduğunu ortaya koymaktadırlar.

Teorik alanda ortaya çıkan yeni görüşler ampirik çalışmalarla da desteklenmektedir. Bu ampirik çalışmalar, ekonomik özgürlüklerin ülkeler arasındaki ekonomik performans düzeylerindeki farklılıkların açıklanmasında önemli bir rolü bulunduğunu göstermektedir (Sturm ve De Haan, 2001). 1990 sonrasında Heritage Vakfı ve Fraser Enstitüsü tarafından yapılan çalışmalar ve ekonomik özgürlüğe ilişkin endekslerin hesaplanması, ekonomik özgürlükleri sayısal olarak ölçülebilir hale getirmiştir. Bu sayede, ekonomik özgürlükler ve ekonomik büyüme arasındaki ilişkinin test edilmesi mümkün hale gelmiştir.

Bu iki değişken arasındaki ilişkiyi inceleyen ampirik literatür 1990'lı yıllarla birlikte oluşmaya başlamıştır (Doucouliagos ve Ulubaşoğlu, 2006). Bu durumun ortaya çıkmasındaki ana neden, daha önce de üzerinde durulduğu gibi ekonomik özgürlüklerin 1990’lı yıllardan itibaren endeksler yardımıyla ölçülebilir şekilde hesaplanmasidir.

$\mathrm{Bu}$ alana ilişkin olarak, hem yurtiçinde hem de yurtdışında çok sayıda ampirik çalışma yapılmıştır. Bu çalışmalardan bazıları; Easton ve Walker (1997), Ayal ve Karras (1998), De Haan ve Sierman (1998), Gwartney, Lawson ve Holcombe (1999), De Haan ve Sturm (2000), Heckelman (2000), Carlsson ve Lundström (2002), Doucouliagos ve Ulubaşoğlu (2006), Justesen (2008), Paakkönen (2010), Başkaya ve Manan (2009), Yenipazarlı (2009) ve Yalman, Sandalcılar ve Demirkoparan (2011)'dır.

Çalışmalar genel olarak ekonomik özgürlük ile ekonomik büyüme arasındaki ilişkiyi analiz ederken, yapılan çalışmalardan bazıları ekonomik özgürlüğe ilişkin genel endeksin yanında, ekonomik özgürlügün alt bileşenleri ile ekonomik büyüme arasındaki ilişkileri de incelemiştir. Buna göre, Easton ve Walker (1997), Gwartney, Lawson ve Holcombe (1999), Doucouliagos ve Ulubaşoğlu (2006), Justesen (2008), Başkaya ve Manan (2009) ve Yenipazarlı (2009) tarafından yapılan çalışmalar incelendiğinde, bu çalışmaların tümünde de ekonomik özgürlükler ile ekonomik büyümeyi arasında pozitif ve anlamlı bir ilişki olduğu sonucuna ulaşılmıştır.

Ayal ve Karras (1998), De Haan ve Sierman (1998) ve Yalman, Sandalc1lar ve Demirkoparan (2011) tarafindan yapılan çalışmalar yukarıda bahsedilen çalışmalardan farklı olarak, ekonomik özgürlükler ile ekonomik büyüme arasındaki ilişkiyi alt endeksler bazında incelemiştir. Ekonomik özgürlüğe ilişkin bazı alt endeksler ekonomik büyümeyi pozitif yönde etkilerken, diğerleri ise negatif yönde etkilemektedir. Carlsson ve Lundström (2002) tarafından yapılan çalışmada ise Ayal ve Karras (1998), De Haan ve Sierman (1998) ve Yalman, Sandalcılar ve Demirkoparan (2011) tarafindan yapılan çalışmaların sonuçlarına ek olarak bazı alt endeksler ile ekonomik büyüme arasında anlamlı bir ilişki bulunamamıştır. Benzer bir sonuca De Haan ve Sturm (2000) de ulaşmıştır. De Haan ve Sturm (2000)'e göre ekonomik özgürlükler ile ekonomik büyüme arasında anlamlı bir ilişki yoktur.

Ekonomik özgürlükler ile ekonomik büyüme arasında regresyon ilişkisinin haricinde nedensellik ilişkisini inceleyen çalışmalar da yapılmıştır. Heckelman (2000)'a göre, ekonomik özgürlüğe ilişkin bazı alt bileşenler ile ekonomik büyüme arasında nedensellik ilişkisi bulunurken, diğerleri ile ekonomik büyüme arasında nedensellik ilişkisine ulaşılamamıştır. Son olarak Paakkönen (2010) ise ekonomik özgürlük düzeyi düşük iken, ekonomik özgürlük düzeyindeki gelişmelerin ekonomik büyümeyi pozitif etkileyeceği sonucuna ulaşmıştır. Ancak, ekonomik özgürlükler belirli bir seviyeye ulaştığında ise negatif etkiler ortaya çıkmaktadır.

Literatürdeki yerli ve yabancı çalışmalar be bu çalışmaların sonuçları incelendiğinde de, teoriye paralel olarak ekonomik özgürlükler ile ekonomik büyüme arasında pozitif ve anlamlı bir ilişki bulunduğu sonucuna ulaşan çalışmalar çoğunluktadır. Ancak, belirli yılları ve belirli ülkeleri analiz eden bazı çalışmalarda ekonomik özgürlüklere ait alt endeksler bazında ulaşılmış olan sonuçlar istatistiksel olarak anlamsız veya negatif yönde bulunmuştur. $\mathrm{Bu}$ durumun ortaya çıkmasındaki nedenlerden biri, gelişmekte olan ülkelerde kurumsal yapının yeterli düzeyde ilerleme gösterememiş olması iken, ikincisi ise ekonomik özgürlüklerdeki gelişmelerin ülkelerin sahip olduğu yurtiçi ve yurtdışı fonları risk düzeyi daha düşük olan yurtdışındaki yatırımlarına kanalize etmesidir.

\section{Ekonomik Özgürlükler ve Ekonomik Büyüme İlişkisi: Panel Veri Analizi}

Ampirik kısımda, Brezilya, Çin, Güney Kore, Hindistan, Hong Kong, Malezya, Rusya, Tayland ve Türkiye'nin dahil olduğu dokuz yükselen piyasa ekonomisi için 2000-2012 yılları arasında ekonomik özgürlüklere ilişkin bazı alt kriterler ile ekonomik büyüme arasındaki ilişkinin boyutu analiz edilmektedir. Ülkelerin tümünün ortak özelliği; "yükselen piyasa ekonomileri” olarak değerlendirilmeleridir. Literatürde yer alan çalışmaların bir kısmında yükselen piyasa ekonomileri de bulunmaktadır. Ancak, özel olarak bu ülkeleri analiz eden çalışmaların yeterli düzeyde olmaması, çalışmada yükselen piyasa ekonomileri üzerine odaklanılması tercihinin ortaya 
çıkmasına yol açmıştır. Yine, bu konuya ilişkin olarak literatürde yer alan çalışmaların büyük bir bölümünde çok sayıda ülkenin yer alması ve ülkelerin bir kısmının gelişmiş, diğer bölümünün ise gelişmekte olan ülkeler olması, ekonomik özgürlükler ile ekonomik büyüme arasındaki ilişkiye yönelik sonuçların gelişmekte olan ülkeleri de içine alacak şekilde değerlendirilmesine yol açmaktadır. Bu durum ise, gelişmekte olan ülkeler için ters sonuçlara ve etkin olmayan politika önerilerine yol açabilmektedir.

\subsection{Yöntem ve Veri Seti}

Bu kısımda dokuz yükselen piyasa ekonomisinde 2000-2012 döneminde ekonomik özgürlüğe ilişkin bazı alt endeks değerleri ile ekonomik büyüme arasındaki ilişkinin tahmini için Denklem 1 kullanılmıştır. Çok sayıda ülkeyi ve dönemi içeren bu çalışmada değişkenler arasındaki ilişkinin tahmini için panel veri modelinden ve bu modelin tahmininde ise Stata 11 paket programından yararlanılmıştır. Oluşturulan panel veri modeli aşağıdaki gibidir.

$$
\mathrm{LNRGDP}_{\mathrm{it}}=\beta_{0}+\beta_{1} \mathrm{GEFI}_{\mathrm{it}}+\beta_{2} \mathrm{PRI}_{\mathrm{it}}+\beta_{3} \mathrm{BFI}_{\mathrm{it}}+\beta_{4} \mathrm{TFI}_{\mathrm{it}}+\beta_{5} \mathrm{IFI}_{\mathrm{it}}+\beta_{6} \mathrm{INV}_{\mathrm{it}}+\beta_{7} \mathrm{DEP}_{\mathrm{it}}+\varepsilon_{\mathrm{it}}
$$

$$
(\mathrm{i}=1, \ldots \ldots, \mathrm{N} ; \mathrm{t}=1
$$

Panel veri modelinde i ülkesinin $\mathrm{t}$ dönemindeki Reel Gayrisafi Yurtiçi Hasıla düzeyinin logaritmalı değeri (LNRGDP ${ }_{\text {it }}$ ) modelin bağımlı değişkenidir. Modeldeki bağımsız değişkenler ise; ekonomik özgürlüğe ilişkin genel endeks $\left(\mathrm{GEFI}_{\mathrm{it}}\right)$, ekonomik özgürlüğe ilişkin alt kriterlerden mülkiyet hakları endeksi (PRI $\mathrm{it}_{\mathrm{it}}$ ), çalışma/iş kurma özgürlüğü endeksi $\left(\mathrm{BFI}_{\mathrm{it}}\right)$, ticaret özgürlüğü endeksi $\left(\mathrm{TFI}_{\mathrm{it}}\right)$ ve yatırım yapma özgürlüğü endeksi $\left(\mathrm{IFI}_{\mathrm{it}}\right)^{\prime}$ dir. Ekonomik özgürlüğün alt kriterleri dışına modelde yer alan bağımsız değişkenlerden Yatırımlar/GSYİH oranı $\left(\mathrm{INV}_{\mathrm{it}}\right)$ ve nüfusun bağımlılık oranı $\left(\mathrm{DEP}_{\mathrm{it}}\right)$ da modelin kontrol değişkenleridir. $\varepsilon_{\mathrm{it}}$ ise hata terimidir.

Ekonomik özgürlüğe ilişkin yukarıdaki denklemde yer alan her bir endeks Heritage Vakfı ve Wall Street Journal tarafından ortaklaşa hazırlanan Ekonomik Özgürlükler Endeksi (IEF) veri tabanı yardımıyla oluşturulmuştur (The Heritage Foundation, 2015). Reel GSYİH, Yatırımlar/GSYİH ve Nüfusun Bağımlılık Oranına verileri ise Dünya Bankası veri tabanından derlenmiştir (The World Bank, 2015). Yatırımlar/GSYİH oranı, yatırımlar yerine Dünya Bankası veri tabanında yer alan tasarruflardan yararlanılarak hesaplanmıştır.

Verilerin hazırlanması kadar çalışmada kullanılacak yöntemin belirlenmesi de etkin sonuçlara ulaşılması için önemli bir husustur. Panel veri modelleri belirli koşullara uygun olmak kaydıyla üç farklı yönteme göre oluşturulabilmektedirler. Bu yöntemlerden birincisi panel en küçük kareler (EKK) yöntemidir. Panel EKK yöntemi, birime özel etkileri dikkate almamakta ve sabit etkiler veya tesadüfi etkiler yöntemlerine göre sınırlayıcı bir yaklaşım olduğu kabul edilmektedir. İkinci yaklaşım olan Sabit etkiler yönteminde ise, modelde yer alan her bir birimin gözlemlenemeyen ve zaman içinde değişmeyen özellikleri olduğu kabul edilmektedir. Üçüncü yaklaşım olan tesadüfi etkiler yönteminde de, belirli bir ihtimal dağılımına uygun olmak kaydıyla zaman içinde sabit olmayan etkilerin olduğu ve modeldeki bağımsız değişkenlerle sabit olmayan etkiler arasında ilişki olmadığı varsayılmaktadır. Fakat ilişkisinin olmadığı varsayımı geçerli değilse, bu yöntem tutarsız ve sapmalı çıkarsamalara yol açacaktır (Baltagi, 2005).

Panel veri analizine yönelik uygulamalarda, sabit ve tesadüfi etkiler yöntemleri arasında seçim yapmada Hausman Testinden yararlanılmaktadır (Baltagi vd, 2003; Frondel ve Vance, 2010). Bu test, tesadüfi etkiler tahmincisi olarak kabul edilen genelleştirilmiş en küçük kareler tahmincisi ve sabit etkiler tahmincisi olarak kabul edilen grup içi tahmincinin varyans kovaryans matrislerinin arasındaki farka bağlı olarak hesaplanan $\mathrm{H}$ istatistiğine dayanmaktadır. Bu testte $\mathrm{H}$ istatistiğinin sıfıra eşit olup olmadığı test edilmektedir. Uygulama sonucunda parametreler arasındaki farkın sıfırdan farklı olmadığı durumda tesadüfi etkiler yöntemi uygun bir yöntemdir. Bunun yanında, parametreler arasındaki farkın sıfırdan farklı olduğu durumda ise sabit etkiler yöntemi uygun bir yöntem olarak kabul edilmektedir (Baltagil, 2005; Yerdelen Tatoğlu, 2012).

\subsection{Ampirik Sonuçlar ve Değerlendirme}

Modelin tahmininden önce, Tablo 1'de modele dahil edilen değişkenlere ait ortalama, standart sapma, minimum ve maksimum değerler ile gözlem sayısına ilişkin özet istatistikler yer almaktadır.

\begin{tabular}{lc|ccccc|cc}
\hline & LNRGDP & GEFI & PRI & BFI & TFI & IFI & INV & DEP \\
\hline Ortalama & 27,003 & 62,246 & 53,504 & 66,882 & 68,221 & 50,401 & 31,142 & 45,639 \\
Standart Sap. & 0,932 & 11,518 & 19,600 & 15,424 & 15,874 & 20,109 & 9,570 & 7,914 \\
Minimum & 25,458 & 47,400 & 20,000 & 35,500 & 19,600 & 20,000 & 13,832 & 33,405 \\
Maksimum & 29,140 & 90,000 & 90,000 & 100,00 & 95,000 & 90,000 & 52,653 & 62,822 \\
Gözlem Sayısı & 117 & 117 & 117 & 117 & 117 & 117 & 117 & 117 \\
\hline
\end{tabular}

Tablo 1. Değişkenlere Ait Özet Istatistikler

Özet istatistiki bilgilerden sonra panel veri modelinin panel EKK yani klasik model, sabit etkiler modeli ve tesadüfi etkiler modelinden hangisine göre oluşturulacağının saptanması gerekmektedir. Bunun için başlangıçta modelin klasik modele uygun olup olmadığının belirlenebilmesi amacıyla Olabilirlik Oranı testi yapılmıştır. Bunun için, En Çok Olabilirlik modeli yardımıyla hesaplanan LR istatistikleri $\chi^{2}$ tablo değerleriyle 
karşılaştırılmış ve modelde birim ve/veya zaman etkilerinin bulunup bulunmadığ incelenmiştir. İnceleme sonucuna göre modelde birim etkilerin bulunduğu, ancak zaman etkileri bulunmadığı belirlenmiştir (Bkz. Tablo 2). Bu durumda klasik modelin geçerli olmadığı anlaşılmıştır. Daha sonrasında, Hausman Testi yardımıyla sabit etkiler modeli ve tesadüfi etkiler modelinden hangisinin geçerli olduğu incelenmiştir. Hausman Testinde $\mathrm{H}_{0}$ hipotezi; "bağımsız değişkenler ve birim etki birbiriyle korelasyonlu değildir" şeklinde ifade edilmekte iken, $\mathrm{H}_{1}$ hipotezi ise; "bağımsız değişkenler ve birim etki arasında korelasyon bulunmaktadır" şeklinde ifade edilmektedir. $\mathrm{H}_{0}$ hipotezinin reddedilemediği durumda, sabit etkiler ve tesadüfi etkiler tahmincilerinin her ikisi de tutarlıdır. Fakat tesadüfi etkiler tahmincisi diğerine göre daha etkindir. Bununla birlikte, $\mathrm{H}_{0}$ hipotezinin reddedildiği durumda ise tesadüfi etkiler tahmincisi sapmalıdır. Etkin sonuçlara ulaşılabilmesi için bunun yerine tesadüfi etkiler tahmincisine göre tutarlı olan sabit etkiler tahmincisinin kullanılması daha uygundur (Yerdelen Tatoğlu, 2012).

Hausman Testi sonucunda modelde $\mathrm{H}_{0}$ hipotezi reddedilmiştir (Bkz. Tablo 2). Sonuç olarak, tutarlı olan sabit etkiler tahmincisinin kullanılması daha uygundur. Aşağıda yer alan Tablo 2'de de sabit etkiler tahmincisi olarak kabul edilen Grup İçi Tahmin Yöntemi baz alınarak elde edilen sonuçlar özetlenmiştir.

\begin{tabular}{|c|c|c|c|c|}
\hline LNRGDP & Katsayı & Z-İstatistiği & \multicolumn{2}{|c|}{ İstatistikler } \\
\hline GEFI & $-0,0023$ & $-0,51$ & \multirow{2}{*}{$\mathbf{R}^{2}$} & \multirow{2}{*}{0,9082} \\
\hline PRI & $-0,0358$ & $-2,38 * *$ & & \\
\hline BFI & 0,0040 & $2,67^{*}$ & \multirow{2}{*}{ LR (Birim Etk.) } & \multirow{2}{*}{$\begin{array}{l}426,16 \\
{[0,000]}\end{array}$} \\
\hline TFI & 0,0046 & $3,17 *$ & & \\
\hline IFI & $-0,0018$ & $-1,73 * * *$ & \multirow{2}{*}{ LR (Zaman Etk.) } & \multirow{2}{*}{$\begin{array}{c}1,4 \mathrm{e}-13 \\
{[1,000]}\end{array}$} \\
\hline INV & 0,0068 & $2,56 * *$ & & \\
\hline DEP & $-0,0594$ & $-15,4^{*}$ & \multirow{2}{*}{ Hausman } & \multirow{2}{*}{$\begin{array}{c}30,54 \\
{[0,0001]}\end{array}$} \\
\hline C & 29,3400 & $96,57 *$ & & \\
\hline
\end{tabular}

Tablo 2. Panel Sabit Etkiler Modeline İlişkin Tahmin Sonuçları

göstermektedir.

Not: Köşeli parantez içerisindeki değerler olasılık (prob.) değerlerini ifade etmektedir.

Tablo 2'de yer alan sonuçlar değerlendirildiğinde, özellikle kontrol değişkenlerin katsayıları daha önce literatürde yapılan çalışmaların sonuçlarıyla uyumludur. Literatürde yer alan çalışmalarda yatırım oranı ile ekonomik büyüme arasında pozitif bir ilişki olduğu görülmektedir. Bu duruma paralel olarak INV değişkeninin katsayısı da pozitif ve anlamlı bulunmuştur. INV değişkeninin aksine, DEP değişkeninin katsayısı ise anlamlı olmasına rağmen işareti negatiftir. Kısaca, nüfusun bağımlılık oranı azaldığında ekonomik büyüme ise artmaktadır. Bengoa ve Sanchez-Robles (2003), yatırımlar ve büyüme arasındaki ilişkiyi doğrudan yabancı yatırımlar çerçevesinde incelemiş ve iki değişken arasında pozitif bir ilişki olduğu görülmüştür. Yabancı yatırımlar ile yurt içi yatırımlar arasında yalnızca mülkiyet açısından var olan farklılık bu çalışmada ortaya konulan sonucun literatüre uygun olduğunu göstermektedir. Gwartney vd. (1999)'e göre ise, nüfusun bağımlılık oranı ile ekonomik büyüme arasında negatif ve anlamlı bir ilişki söz konusudur. Bir ülkede nüfusun bağımlılık oranının yüksek olması, o ülkedeki üretime doğrudan katkı sağlayacak verimli girdilerin payının düşük olmasına yol açmaktadır. Bu durum uzun vadede büyüme hızının yavaşlamasına sebep olmaktadır.

Kontrol değişkenlerin dışında modelin temelini oluşturan ekonomik özgürlüklere ilişkin değişkenler incelendiğinde, sonuçların kısmen literatürle örtüşmediği görülmüştür. İlk olarak ekonomik özgürlüğü ifade eden genel endeks (GEFI)'in katsayısı incelendiğinde bu katsayının anlamsız çıktığı görülmektedir. Yani, analize dahil edilen ülkelerde 2000-2012 yılları arasında ekonomik özgürlükler ile ekonomik büyüme arasında anlamlı bir ilişki bulunmamaktadır. Diğer yandan, mülkiyet hakları endeksi (PRI)'nin katsayısı genel endeksin aksine anlamlı olmasına rağmen, bu endeks değerindeki artışların ekonomik büyümeyi azalttığı sonucuna ulaşılmıştır. Çalışma/İş kurma özgürlüğü endeksi (BFI)'nin katsayısı ise pozitif ve anlamlıdır. Bu sonucun teorik beklentilerle uyumludur. Bunun temel sebebi ise, ekonomide çalışma ve iş kurma konusundaki daha serbest uygulamalar bireylerin teşebbüs gücünü yükselterek ekonomik büyümeye olumlu katkılar sağlayacaktır. Ticaret özgürlüğü endeksi (TFI)'nin katsayısı da Çalışma/İş kurma özgürlüğü endeksi (BFI)'nin katsayısı gibi pozitif ve anlamlıdır. $\mathrm{Bu}$ durum da teorik beklentilerle uyumludur. Son olarak yatırım yapma özgürlüğü endeksi (IFI)'nin katsayısı incelendiğinde, bu endeksin katsayısı anlamlı olmasına rağmen ekonomik büyümeyi negatif yönde etkilediği görülmektedir. Yatırım yapma özgürlüğü ve ticaret özgürlüğü endeksine yönelik elde edilen sonuçlar, Yalman, Sandalcılar ve Demirkoparan tarafından 2011 yılında yapılan çalışmanın sonuçlarıyla örtüşmektedir. Buna göre bu çalışmada elde edilen sonuçlar, ticaretin hem ulusal hem de uluslararası düzeyde daha serbest hale gelmesi ekonomik faaliyet düzeyinin yükselmesine ve ekonominin büyümesine yol açacaktır. Yatırım yapma özgürlüğü düzeyindeki ilerlemelerin ekonomik büyümeyi olumsuz etkilemesinin ana sebebi ise, risk düzeyi yüksek olan 
ülkelerde yatırım yapma konusunda ortaya çıkan daha serbest uygulamaların, belirli dönemlerde yatırımların risk konusundaki olumsuz algılamalar nedeniyle bu ülkeleri terk etme eğiliminde olmasıdır.

Literatürde yer alan çalışmalar analiz edildiğinde, ekonomik özgürlüğe ilişkin genel endeks ve mülkiyet hakları endeksine ilişkin bulguların literatürdeki bulgularla paralellik göstermediği görülmektedir. Bu durumun ortaya çıkmasındaki temel sebeplerden bir tanesi, literatürde yer alan çalışmaların ciddi bir kısmının 1970-2000 arasındaki belirli dönemleri ele alan ve çok sayıda ülkeyi kapsayan çalışmalar olmasıdır. Bu çok sayıda ülkenin bir kısmı gelişmiş iken bazıları ise az gelişmiş olup, ülkeler arasında bulunan ciddi gelişmişlik farkları ekonomik özgürlükler ve mülkiyet hakları konusunda doğru olmayan sonuçlara ulaşılmasına yol açabilmektedir. Bir diğer sebep ise, çalışmaya dahil edilen ülkelerden Çin haricindekilerin tamamı 1990'lı yıllarda ciddi düzeyde ekonomik krizlerle ve finansal sarsıntılarla karşı karşıya kalmışlardır. Bu durum ise, ekonomik aktörlerin ve özellikle yatırımcıların çalışmaya dahil edilen ülkelere yönelik risk değerlendirmelerini değiştirdiği ve kriz sonrası dönemde kurumsal yapıdaki gelişmeler ve yatırım ortamındaki iyileşmelere rağmen ekonomik büyümeye olumlu bir etki sağlamadığı kabul edilmektedir.

\section{Sonuç}

Çalışmada, Brezilya, Çin, Güney Kore, Hindistan, Hong Kong, Malezya, Rusya, Tayland ve Türkiye'de 20002012 döneminde ekonomik özgürlükler (ekonomik özgürlüğe ilişkin alt endeksler) ve ekonomik büyüme arasındaki iliş̧i panel sabit etkiler modeli çerçevesinde incelenmiş̧tir. Modelden elde edilen katsayılar literatürle kısmen örtüşmeyen, ancak literatürde yer alan çalışmaların bir kısmında da yer alan önemli sonuçlar ortaya koymaktadır. Öncelikle ekonomik özgürlüğe ilişkin genel endeks (GEFI)'in katsayısı anlamsız olarak bulunmuştur. Yani, çalışmada yer alan dokuz yükselen piyasa ekonomisinde 2000-2012 döneminde genel endeks bazında özgürlük düzeyindeki ilerlemeler büyümeyi etkilememektedir. Alt kriterler bazında incelendiğinde, mülkiyet hakları endeksi (PRI)'nin katsayısı da beklentinin aksi yönünde olup, negatif ve anlamlıdır. Bulgular, mülkiyet hakları endeksi değerindeki yükselme ekonomik büyümeyi azaltmaktadır.

Çalışma/İs kurma özgürlüğü endeksi (BFI) ve Ticaret özgürlüğü endeksi (TFI)'nin katsayıları ise, pozitif ve anlamlı olarak bulunmuştur. Bu durumun teoriyle uyumlu olduğu ifade edilebilir. Çünkü ekonomide çalışma ve iş kurma konusundaki daha serbest uygulamalar bireylerin girişim gücünü yükselterek ekonomik büyümeye olumlu katkılar sağlayacaktır. Bunun yanında, ulusal ve uluslararası ticaretin daha serbest hale gelmesi de ekonomideki faaliyetlerin artmasına ve bu da ekonomik büyümeye yol açmaktadır.

Son olarak, yatırım yapma özgürlüğü endeksi (IFI)'nin katsayısı negatif ve anlamlıdır. Bunun nedeni ise, yatırım yapma serbestisindeki ilerlemelerin yatırım yapan kişilerin özellikle Brezilya, Çin, Güney Kore, Hindistan, Hong Kong, Malezya, Rusya, Tayland ve Türkiye gibi yükselen piyasalar olarak tanımlanan ülkelere yönelik yatırım kararlarını risk düzeyinin yüksek olduğu ekonomik kriz vb. dönemlerde yeniden gözden geçirmeleridir.

Özellikle bu çalışmada, ekonomik özgürlüğe ilişkin genel endeks ve mülkiyet hakları endeksinin literatürdeki sonuçlara göre farklılık göstermesindeki temel sebep, çalışmanın literatürde yer alan çalışmalara göre farklı bir örneklem grubunu ve zaman dilimini kapsamasıdır. Literatürde yer alan çalışmalar incelendiğinde, bu çalışmaların önemli bir kısmında çok sayıda ülkenin yer aldığı görülmektedir. Bu tür çalışmalarda da ana problem, çalışmaya dahil edilen ülkelerin bir bölümünün gelişmiş, diğerlerinin ise gelişmekte olan veya az gelişmiş ülkeler olmalarıdır. Böylece ulaşılan genel sonuçlar, ülkelere has sonuçların yeterli düzeyde analiz edilememesine sebep olmakta ve yapılan politika tavsiyeleri kurumsal yapıları yeterli seviyeye ulaşamamış gelişmekte olan ülkeleri de gerçekçi olmamasına rağmen kapsamış olmaktadır. Bu durumdan kaçınmak için, aynı gelişme seviyesinde bulunan ülke veya ülke gruplarına yönelik çalışmaların sayıca artması gerekmektedir. Bu çalışmada da bahsedilen yöntem izlenerek, literatürdeki çalışmaların genel sonuçlarından kaçınılmış olunmaktadır. İlerleyen dönemlerde bu konuyla ilgili yapılacak olan çalışmalarda da, belirtilen yöntemin izlenmesi ekonomik özgürlükler ve ekonomik büyüme arasında daha doğru sonuçların elde edilmesine yol açacaktır.

\section{Kaynakça}

- Acar, M., 2010. “Serbest Ticaret, Ekonomik Özgürlükler ve Refah”, Bilig, 53, s. 1-28.

- Ayal, E. B. and G. Karras, 1998. "Components of Economic Freedom and Growth: An Empirical Study", The Journal of Developing Areas, 32(3), p. 327-338.

- Baltagi, B. H., 2005. Econometric Analysis of Panel Data, John Wiley and Sons.

- Baltagi, B. H., G. Bresson and A. Pirotte, 2003, "Fixed Effects, Random Effects or Hausman-Taylor? A Pretest Estimator", Economic Letters, 79, p. 361-369.

- Bengoa, M. and B. Sanchez-Robles, 2003, "Foreign Direct Investment, Economic Freedom and Growth: New Evidence From Latin America”, European Journal of Political Economy, 19, p. 529-545. 
- Beşkaya, A. ve Ö. Manan, 2009, "Ekonomik Özgürlükler ve Demokrasi ile Ekonomik Performans Arasındaki İlişkinin Zaman Serileri ile Analizi: Türkiye Örneği”, 5(10), s. 47-76.

- Carlsson, F. and S. Lundström, 2002, "Economic Freedom and Growth: Decomposing The Effect", Public Choice, 112, p. 335-344.

- De Haan, J. and C. L. J. Sierman, 1998, "Further Evidence on the Relationship Between Economic Freedom and Economic Growth", Public Choice, 95, p. 363-380.

- De Haan, J. and J. E. Sturm, 2000, "On the Relationship Between Economic Freedom and Economic Growth", European Journal of Political Economy, 16, p. 215-241.

- Doucouliagos, C. and M. A. Ulubaşoğlu, 2006, "Economic Freedom and Economic Growth: Does Specification Make A Difference?", European Journal of Political Economy, 22, p. 60-81.

- Easton, S. T. and M. A. Walker, 1997, "Income, Growth and Economic Freedom", The American Economic Review, 87(2), p. 328-332.

- Frondel, M. and C. Vance, 2010, "Fixed, Random or Something in Between? A Variant of Hausman's Spesification Test for Panel Data Estimation", Economic Letters, 107, p. 327-329.

- Gwartney, J. D., R. A. Lawson and R. G. Holcombe, 1999, "Economic Freedom and The Environment for Economic Growth", Journal of Institutional and Theoretical Economics (JITE), 155(4), p. 643-663.

- Heckelman, J. C., 2000, "Economic Freedom and Economic Growth: A Short-Run Causal Investigation", 3(1), p. 71-91.

- Justesen, M. K., 2008, "The Effect of Economic Freedom on Growth Revisited: New Evidence on Causality From A Panel of Countries 1970-1999”, European Journal of Political Economy, 24, p. 642-660.

- Kazgan, G., 2009, Küreselleşme ve Ulus Devlet: Yeni Ekonomik Düzen, İstanbul Bilgi Üniversitesi Yayınlar1: İstanbul.

- Noyan Yalman, İ., A. R. Sandalcılar ve F. Demirkoparan, 2011, “Özgürlükler ve Ekonomik Kalkınma: Latin Amerika ve Türkiye”, Atatürk Üniversitesi İ̈B Dergisi 10. Ekonometri ve Ístatistik Sempozyumu Özel Saylsl, s. 431-444.

- Paakkönen, J., 2010, "Economic Freedom as Driver of Growth in Transition”, Economic System, 34, p. 469479.

- Sturm, J. E. and J. De Haan, 2001, "How Robust is the Relationship Between Economic Freedom and Economic Growth?", Applied Economics, 33(7), p. 839-844.

- The Heritage Foundation, 2015 Index of Economic Freedom, All Index Data, http://www.heritage.org/index/explore?view=by-region-country-year, (Erişim: 09.05.2015).

- The World Bank, 2015, http://data.worldbank.org/, (Erişim: 09.05.2015).

- Yenipazarlı, A., 2009, Ekonomik Özgürlükler ve Ekonomik Büyüme Üzerine Etkisi: Türkiye Üzerine Bir Zaman Serisi Analizi, Yayınlanmamış Doktora Tezi, Adnan Menderes Üniversitesi Sosyal Bilimler Enstitüsü İktisat Anabilim Dalı, Aydın.

- Yerdelen Tatoğlu, F., 2012, Panel Veri Ekonometrisi, Beta Yayınları: İstanbul. 


\title{
Kalkınma Ajansları Aracılığıyla Dağıtılan Hibelerin PESTLE Yöntemi İle Analizi: Türkiye'de KUZKA Örneği Analysis of Grants Distributed by Development Agencies via
Method of PESTLE: Case of KUZKA in Turkey
}

\author{
Ph. D. Candidate Gizem Saray (Çankırı Karatekin University, Turkey) \\ $\mathrm{Ph}$. D. Candidate Hilal Abacı (Çankırı Karatekin University, Turkey) \\ Prof. Dr. Hasan Akça (Çankırı Karatekin University, Turkey) \\ Asst. Prof. Dr. Levent Şahin (Çankırı Karatekin University, Turkey)
}

\begin{abstract}
Major scale projects have been implemented in Turkey in the context of FYDPs to reduce interregional disparities. Funds for these projects were provided from either WB and EU or Turkey's internal resources. A new application was started in 2006 as parallel to the establishment of Development Agencies in the context of harmonisation process to the EU. There are 26 Development Agencies in Turkey. In this study, KUZKA was selected as research area. Secondary data (call for projects, reports, data of the Ministry of Development, statistics, etc) were used and grants distributed by the KUZKA were examined via PESTLE Analysis. In substance, effects of grants were handled point schemes of politics, economics, social, technological, legal and environmental point of view and also contribution of the KUZKA to regional development in Turkey have been determined.
\end{abstract}

\section{Giriş}

Bölgesel eşitsizlik sorunları uzun zamandır tüm dünya ülkelerinde çözülmeye çalışılan bir problem olarak varlığını sürdürmektedir. İşte bu kapsamda bazı gelişmiş ve gelişmekte olan ülkelerde bölgelerarası ve hatta aynı bölge içerisinde gelişmişlik farklarının en aza indirilmesi için kalkınma ajansları bir araç olarak kullanılmaktadır.

Türkiye'de ilk Bölgesel Kalkınma Ajansı (BKA) 2006 yılında kurulmasına rağmen; dünyadaki ilk örneği 1933 yılında ABD'de “Tennessee Valley Authority” (Hasanoğlu ve Aliyey, 2006: 87-88; Eroğlu ve Kum, 2010: Özer, 2012: 40) isimli ajans olarak ortaya çıkmıştır. Daha sonra birçok Avrupa ülkesinde bölgesel kalkınma ajansları kurulmuştur. Türkiye'de 1963 yılında uygulanmaya başlayan kalkınma planlarında yer alan bölgesel gelişme politikasının merkezi düzeyde etkinleştirilmesi, yerel dinamiklere ve içsel potansiyele dayalı gelişmenin sağlanması gibi bölgelerarası gelişmişlik farklarının en aza indirilmesine yönelik hedefler son 10 yılda kalkınma ajansları ile sağlanmaktadır (Kalkınma Bakanlığı, 2015). Kalkınma ajanslarının kuruluş, koordinasyon ve görevleri hakkında kanun, 25 Ocak 2006 yılında kabul edilerek yürürlüğe girmiş ve iktisadi ve yerel kalkınmayı sağlamak amaciyla 26 adet BKA kurulmuştur (Soyak, 2005: 3).

Bu çalışmada, öncelikle "kalkınma" ve "bölgesel kalkınma” kavramları ele alınarak, Türkiye'de bölgesel kalkınma sorunları ve bölgelerarası dengesizlik nedenleri irdelenmiş, daha sonra Türkiye ve Dünya'da bölgesel kalkınma aktörü olarak BKA'lar üzerinde durulmuştur. Çalışmanın analiz bölümünde TR 82 Bölgesinde yer alan Kastamonu, Sinop, Çankırı illerini kapsayan Kuzey Anadolu Kalkınma Ajansı (KUZKA) tarafından sağlanan fonlar ve teknik destekler PESTLE yöntemi ile incelenmiştir.

\section{Kalkınma ve Bölgesel Kalkınma Kavramlarına Genel Bakış}

Kalkınma sorunu dünya genelinde en çok ilgi gören bir konu olması nedeniyle her geçen gün farklı yöntemler ve çözümler ile üzerinde düşünülen bir kavram haline gelmiştir. Han ve Kaya (2008)'e göre kalkınma kavramı sadece kişi başına gelirin artması demek olmayıp, az gelişmiş bir toplumda iktisadi ve sosyo-kültürel yapının da değişmesi, yenileşmesi gibi yapısal değişiklikleri içeren bir konudur.

Son zamanlarda kalkınma sorunlarını ülke bazında değil bölge bazında ele alan, bölgenin gelişimi endeksli hareket eden ve böylece daha kolay çözüm üreten bölgesel kalkınma biçimi tüm dünyada ses getirmiştir. (Clower, 2004: 1)'e göre bölgesel kalkınma ile bölgenin kendine has kaynaklarının işlenmesi sonucu bölgedeki gelir artışına bağlı olarak sosyo-ekonomik yapıda da iyileşmeler meydana gelmektedir. Bu durumda ülkeler bölgesel kalkınmaya yönlenerek tabandan tavana büyüme yöntemi ile bölgeler arasındaki dengesizliği ortadan kaldırmayı hedeflemektedir.

1970’lerden sonra hızlanan küreselleşme, bölgesel kalkınma anlayışında oluşan sistem değişimlerinin ana sebebi olarak kabul edilmektedir. 1950'li yıllardan sonra büyümenin sağlanmasında büyük altyapı yatırımları önerilirken şuan ki durumda bölgesel kalkınma anlayışı; yenilik, yenilikçi çevre, bilgiye dayalı kalkınma anlayışı, beşeri sermaye, kolektif öğrenme, karşılıklı bağımlılık, yerel kültür gibi kavramlardan oluşmaktadır 
(Akpınar, 2012). Küreselleşme sürecinin başlamasıyla ortaya çıkan politika değişiklikleri ile geleneksel merkeziyetçi politikalardan yeni bölgesel politika anlayışına geçiş sağlanmıştır (Tablo 1).

\begin{tabular}{|c|c|}
\hline Geleneksel Bölge Politikaları & Yeni Bölge Politikaları \\
\hline $\begin{array}{l}\text { - } \quad \text { Ulus devletin denetiminde, sınırları } \\
\text { çizilmiş ve ulus devlet dışına kapalı bir } \\
\text { birim (merkezi hükümet baskın) } \\
\text { - Temel hedef "ulusal ekonomik büyüme" } \\
\text { - } \quad \text { Temel kaynak olarak "bölgeler arası } \\
\text { yeniden dağıtım" } \\
\text { - Ulusal transferlerle ekonomik büyüme } \\
\text { - } \quad \text { Altyapı geliştirme odaklı çalışmalar }\end{array}$ & $\begin{array}{l}\text { - Yerellerin oluşturduğu ve uluslararası ilişkilere } \\
\text { doğrudan açlan bir birim (merkezi hükümet } \\
\text { daha az baskın, kolektif yaklaşım) } \\
\text { - Temel hedef "bölgesel rekabet gücünü ve bölge } \\
\text { ekonomik kapasiteni artırma" } \\
\text { - Temel kaynak olarak "yerel ve bölgesel } \\
\text { kaynakları harekete geçirme" } \\
\text { - Bölgesel yenilik ve bölgelerarası dengesizliği } \\
\text { giderme ve sürdürülebilirliği sağlama } \\
\text { - İçsel büyüme dinamikleri ile yenilikçi kalkınma } \\
\text { anlayıșı }\end{array}$ \\
\hline
\end{tabular}

Tablo 1. Geleneksel Bölge ve Yeni Bölge Politikaları Kaynak: Keskin ve Sungur (2010)'dan yazarlarca uyarlanmiştır.

\section{Türkiye'de Bölgesel Kalkınma Farkları}

Türkiye'de var olan kalkınma farklarında özellikle Doğu- Batı ayrımı dikkat çekmektedir. Bölgesel farklılığı ortaya koyan değişkenlerden biri Gayri Safi Katma Değer (GSKD) oranıdır. Gelir eşitsizliğinin göstergesi olan bu ölçümde Türkiye'de gelir dağılımında doğu batı yönünde farklılıklar görülmektedir. Özellikle TR10 (İstanbul), TR21 (Tekirdağ, Edirne, Kırklareli), TR 31(İzmir), TR41 (Bursa, Eskişehir, Bilecik), TR42 (Kocaeli, Sakarya, Düzce, Bolu, Yalova), TR51(Ankara) ve TR61(Antalya, Isparta, Burdur) Bölgelerinde GSKD ortalamanın üzerinde seyretmektedir (Şekil 1).

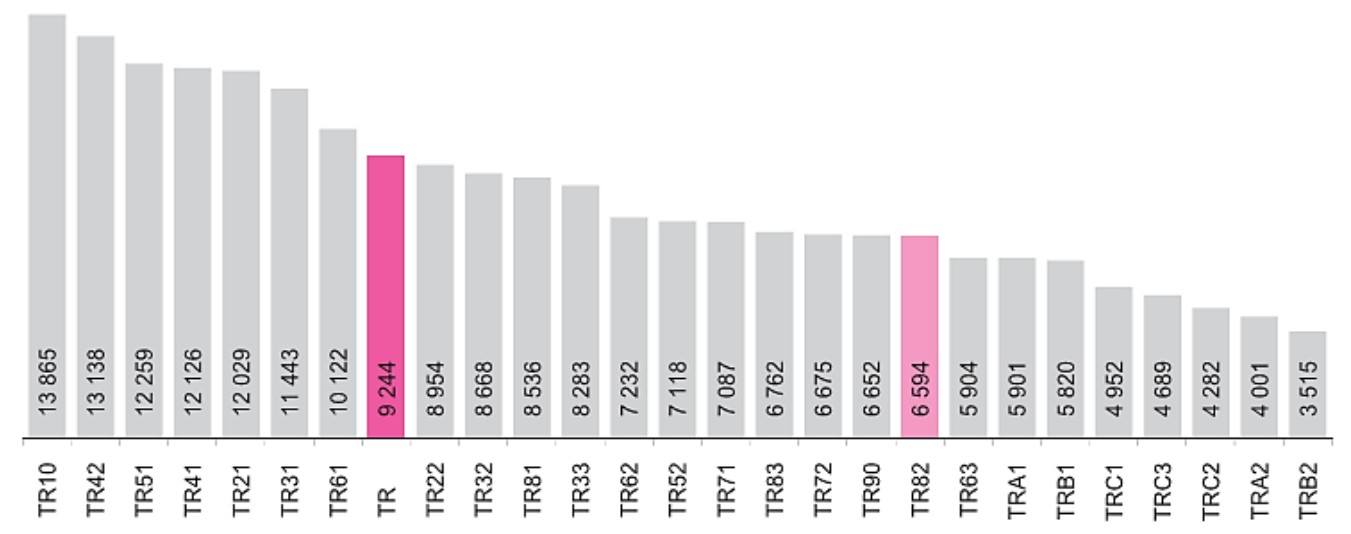

Şekil 1. Türkiye'de Bölgesel Gayri Safi Katma Değer (GSKD), Düzey 2, (2011) Kaynak: TÜIK, (2013).

Bölgesel farklılıkların ekonomik göstergelerinden biri de işgücü istatistikleridir. Düzey 2 Bölgelerinde işgücü göstergelerinin yer aldığı Tablo 2'de işsizlik ve istihdam oranlarındaki farklılıklar ile sektörel işgücü dağılımları bölgelerarası farklılığı açık bir şekilde ortaya koymaktadır. İstihdam ve iş gücü verilerinin düşük olduğu TRC2TRC3 gibi doğu bölgelerinde batıya nazaran yüksek işsizlik ve daha düşük istihdam gözlenmektedir. Genel çerçeveden bakıldığında ise Türkiye'de coğrafi, tarihi, sosyo-ekonomik ve kültürel farklılar Tablo 2'de kendini göstermektedir. $\mathrm{Bu}$ farklılıkların giderilmesi ise bölgelere yönelik özel istihdam politikaları ile mümkün olmaktadır. 


\begin{tabular}{|l|l|l|l|l|l|}
\hline 2. Düzey & $\begin{array}{l}\text { Tarım } \\
(\%)\end{array}$ & $\begin{array}{l}\text { Sanayi } \\
(\%)\end{array}$ & $\begin{array}{l}\text { Hizmet } \\
(\%)\end{array}$ & $\begin{array}{l}\text { İstihdam } \\
\text { Oranı } \\
(\%)\end{array}$ & $\begin{array}{l}\text { İşsizlik } \\
\text { Oranı } \\
(\%)\end{array}$ \\
\hline Türkiye & 21,1 & 27,9 & 51,0 & 45,5 & 9,9 \\
\hline TR10 (İstanbul) & 0,5 & 36,7 & 62,8 & 46,4 & 11,9 \\
\hline TR21 (Tekirdağ, Edirne, Kırklareli) & 19,6 & 39,9 & 40,4 & 52,0 & 7,6 \\
\hline TR22 (Balıkesir, Çanakkale) & 30,9 & 21,3 & 47,8 & 45,3 & 5,6 \\
\hline TR31 (İzmir) & 10,5 & 31,7 & 57,8 & 46,1 & 13,9 \\
\hline TR32 (Aydın, Denizli, Muğla) & 29,4 & 24,2 & 46,4 & 50,0 & 7,2 \\
\hline TR33 (Manisa, Afyonkarahisar, Kütahya, Uşak) & 39,2 & 22,6 & 38,1 & 50,3 & 3,9 \\
\hline TR41 (Bursa, Eskişehir, Bilecik) & 10,8 & 43,3 & 45,9 & 46,3 & 6,2 \\
\hline TR42 (Kocaeli, Sakarya, Düzce, Bolu, Yalova) & 18,3 & 36,5 & 45,3 & 49,0 & 10,0 \\
\hline TR51 (Ankara) & 3,0 & 25,7 & 71,3 & 45,6 & 11,5 \\
\hline TR52 (Konya, Karaman) & 25,6 & 29,0 & 45,3 & 46,4 & 5,6 \\
\hline TR61 (Antalya, Isparta, Burdur) & 27,7 & 14,6 & 57,7 & 51,4 & 8,3 \\
\hline TR62 (Adana, Mersin) & 21,1 & 23,8 & 55,1 & 43,9 & 10,7 \\
\hline TR63 (Hatay, Kahramanmaraş, Osmaniye) & 21,6 & 29,6 & 48,8 & 36,7 & 15,4 \\
\hline TR71 (Kırıkkale, Aksaray, Niğde, Nevşehir, Kırşehir) & 34,3 & 17,8 & 47,9 & 44,7 & 7,7 \\
\hline TR72 (Kayseri, Sivas, Yozgat) & 26,4 & 25,7 & 47,9 & 43,3 & 9,6 \\
\hline TR81 (Zonguldak, Karabük, Bartın) & 38,5 & 23,7 & 37,8 & 49,5 & 6,0 \\
\hline TR82 (Kastamonu, Çankırı, Sinop) & 46,6 & 15,7 & 37,6 & 49,8 & 6,5 \\
\hline TR83 (Samsun, Tokat, Çorum, Amasya) & 40,1 & 20,6 & 39,3 & 46,7 & 6,2 \\
\hline TR90 (Trabzon, Ordu, Giresun, Rize, Artvin, Gümüşhane) & 44,7 & 17,5 & 37,8 & 49,6 & 6,2 \\
\hline TRA1 (Erzurum, Erzincan, Bayburt) & 50,8 & 11,9 & 37,3 & 46,7 & 7,4 \\
\hline TRA2 (Ağrı, Kars, Iğdır, Ardahan) & 59,6 & 14,0 & 26,4 & 53,0 & 3,4 \\
\hline TRB1 (Malatya, Elazı̆g, Bingöl, Tunceli) & 31,5 & 18,1 & 50,4 & 43,2 & 7,5 \\
\hline TRB2 (Van, Muş, Bitlis, Hakkâri) & 46,9 & 19,2 & 34,0 & 42,0 & 13,5 \\
\hline TRC1 (Gaziantep, Adıaman, Kilis) & 18,7 & 33,4 & 47,9 & 39,7 & 8,0 \\
\hline TRC2 (Şanlıurfa, Diyarbakır) & 39,0 & 19,9 & 41,1 & 35,0 & 17,4 \\
\hline TRC3 (Mardin, Batman, Şırnak, Siirt) & 24,4 & 20,2 & 55,4 & 28,2 & 24,0 \\
\hline
\end{tabular}

Tablo 2. Düzey 2 Bölgeleri İşgücü İstatistikleri, 2014 Kaynak: TÜIK (2015).

\section{Dünyada ve Türkiye'de BKA Oluşumları}

BKA'lar bölgelerin çok yönlü gelişimini sağlamak amacıyla alternatif politikalar üreten, bölgenin sosyokültürel gelişimine katkıda bulunan, bölgesel girişimciliğin önünü açan yerel/bölgesel dinamikler ile merkezi hükümet arasında köprü vazifesi gören yapılar olarak değerlendirilmektedir (Engin, 2011: 68).

1929 bunalımından sonra oluşan kriz ortamından diğer bölgelere göre en çok etkilenen Tennessee Vadisi Bölgesini canlandırmak için kurulan kalkınma idaresi ile büyük baraj projeleri hayata geçirilerek göç veren konumundan göç alan konumuna geçiş sağlanmış ve bir süre sonra en önemli tarım merkezlerinden biri haline gelen bölgede istenilen kalkınma hedefine ulaşıılmıştır (Filiztekin, 2008: 97). Yeni kalkınmacılık anlayışının örgütsel bir biçimi olarak BKA'lar 1980'lerde yaygınlaşan kamu işletmeciliği ve 1990'larda yaygınlaşan yönetişim anlayışının bir ürünü olarak özel sektörün ve yerel aktörlerin bölgesel kalkınma sürecine aktif katılımını sağlamakla görevlendirilmişlerdir. 1990'lardan itibaren AB'nin rekabete dayalı fon sağlamaya başlaması ile AB üye ülkelerinde BKA sayıları ve etkinlileri oldukça artış göstermiștir. Yaklaşık 20.000 kuruluş bulunan dünyada ortak bir kalkınma ajansı modeli tanımlamak ise oldukça güçtür (TEPAV, 2005). AB'nin artan fon etkinliği ile beraber sadece Orta ve Doğu Avrupa ülkelerindeki BKA sayısı 150'ye ulaşmıştır. 1991 yılında bu ajansları ortak platformda bir araya getirme ihtiyacıyla esas görevi dünyadaki BKA'lar ile AB'deki BKA'lar arasında ortak projeler yürütmek olan ve $\mathrm{AB}$ adına danışmanlık hizmeti veren Avrupa Bölgesel Kalkınma Ajansları Birliği (EURODA) kurulmuştur (Özmen'den Akt. Cankorkmaz, 2011).

Türkiye'de 22 Eylül 2002'de kısa vadede istatistiksel bölge olarak bilinen NUTS sistemi kabul edilerek, 2003 yılı Katılım Ortaklığı Belgesinde, katılım öncesi mali yardım programından yararlanabilmek amaçlı Bölgesel Kalkınma Ajanslarının kurulması öngörülmüştür. Kalkınma Ajanslarının Kuruluşu, Koordinasyonu ve Görevleri Hakkında Kanun 25 Ocak 2006 tarihinde kabul edilerek, 08 Şubat 2006 tarihinde resmi gazetede yayınlanarak yürürlüğe girmiştir (Soyak, 2005). Kararname ile mevcut 81 İl Düzey III, komşu illerin gruplandırılması ile 26 Düzey II, Düzey II İstatistiki Bölge Birimlerinin gruplandırılması sonucu da 12 Düzey I bölgesi oluşturulmuştur 
(Sarıhan, 2011: 87). Bu sinıflandırma kapsamında Türkiye'de BKA'lar Düzey II kademesinde 26 bölgede kurulacak birimlerdir (Tablo 3).

\begin{tabular}{|l|l|l|}
\hline 1 & TR31 & İzmir Kalkınma Ajansı (İzmir) \\
\hline 2 & TR62 & Çukurova Kalkınma Ajansı (Adana, Mersin) \\
\hline 3 & TRB1 & İstanbul Kalkınma Ajansı (İstanbul) \\
\hline 4 & TR52 & Mevlana Kalkınma Ajansı (Konya, Karaman) \\
\hline 5 & TR83 & Orta Karadeniz Kalkınma Ajansı (Amasya, Çorum, Samsun, Tokat) \\
\hline 6 & TRA1 & Kuzeydoğu Kalkınma Ajansı (Erzurum, Erzincan Bayburt) \\
\hline 7 & TRB2 & Doğu Anadolu Kalkınma Ajansı (Muş, Hakkâri, Bitlis, Van) \\
\hline 8 & TRC1 & İpekyolu Kalkınma Ajansı (Adıyaman, Gaziantep, Kilis ) \\
\hline 9 & TRC2 & Karacadağ Kalkınma Ajansı (Diyarbakır, Şanlıurfa) \\
\hline 10 & TRC3 & Dicle Kalkınma Ajansı (Batman, Mardin, Siirt, Şırnak) \\
\hline 11 & TR21 & Trakya Kalkınma Ajansı (Edirne, Kırklaraeli, Tekirdağ) \\
\hline 12 & TR22 & Güney Marmara Kalkınma Ajansı (Balıkesir, Çanakkale) \\
\hline 13 & TR32 & Güney Ege Kalkınma Ajansı (Aydın, Denizli, Muğla) \\
\hline 14 & TR33 & Zafer Kalkınma Ajansı (Afyonkarahisar, Kütahya, Manisa, Uşak) \\
\hline 15 & TR41 & Bursa Eskişehir Bilecik Kalkınma Ajansı (Bursa, Eskişehir, Bilecik) \\
\hline 16 & TR42 & Doğu Marmara Kalkınma Ajansı (Kocaeli, Sakarya, Bolu, Düzce, Yalova) \\
\hline 17 & TR51 & Ankara Kalkınma Ajansı (Ankara) \\
\hline 18 & TR61 & Batı Akdeniz Kalkınma Ajansı (Antalya, Isparta, Burdur) \\
\hline 19 & TR63 & Doğu Akdeniz Kalkınma Ajansı (Hatay, Kahramanmaraş, Osmaniye) \\
\hline 20 & TR71 & Ahiler Kalkınma Ajansı (Aksaray, Kırıkkale, Kırşehir, Nevşehir, Niğde) \\
\hline 21 & TR72 & Orta Anadolu Kalkınma Ajansı (Kayseri, Sivas, Yozgat) \\
\hline 22 & TR81 & Batı Karadeniz Kalkınma Ajansı (Bartın, Karabük, Zonguldak) \\
\hline 23 & TR82 & Kuzey Anadolu Kalkınma Ajansı (Kastamonu, Çankırı, Sinop) \\
\hline 24 & TR90 & Doğu Karadeniz Kalkınma Ajansı(Artvin, Giresun, Gümüşane, Ordu, Rize, Trabzon) \\
\hline 25 & TRA2 & Serhat Kalkınma Ajansı (Ağrı, Ardahan, Iğdır, Kars) \\
\hline 26 & TRB1 & Fırat Kalkınma Ajansı (Bingö1, Elazı̆g, Tunceli, Malatya) \\
\hline
\end{tabular}

Tablo 3.Türkiye'de Bulunan Kalkınma Ajansları ve Kapsadı̆̆ı İller Kaynak: Kobi Danışmanlık (2015).

\section{PESTLE Yönteminin Teorik Yapısı}

PESTLE bir dış çevre analizi olup, Political (Politik), Economical (Ekonomik), Social (Sosyal), Technological (Teknolojik), Legal (Yasal), Environmental (Çevresel) faktörlerin İngilizce baş harflerinin birleşiminden oluşmaktadır (Dcosta, 2011). Bu yöntemin amacı konuyu farklı açılardan kategorize ederek kuş bakışı bir incelemeyi sağlamak ve incelenen faktörlerin konu üzerindeki etkinliğini tespit etmeye çalışmaktır. PESTLE Yönteminde kullanılacak unsurlar Tablo4'de yer almaktadır.

\begin{tabular}{|c|c|c|c|c|c|}
\hline $\begin{array}{l}\text { Political } \\
\text { (Politik) }\end{array}$ & $\begin{array}{l}\text { Economical } \\
\text { (Ekonomik) }\end{array}$ & $\begin{array}{c}\text { Social } \\
\text { (Sosyal) }\end{array}$ & $\begin{array}{l}\text { Technological } \\
\text { (Teknolojik) }\end{array}$ & $\begin{array}{c}\text { Legal } \\
\text { (Yasal) }\end{array}$ & $\begin{array}{l}\text { Environmental } \\
\text { (Çevresel) }\end{array}$ \\
\hline $\begin{array}{l}\text {-Siyasi etkiler } \\
\text {-Politik kararlar } \\
\text {-Hükümet } \\
\text { tutum ve } \\
\text { davranışları }\end{array}$ & $\begin{array}{l}\text {-Ekonomik } \\
\text { kalkınma bazlı } \\
\text { destekler } \\
\text {-Altyapı } \\
\text { geliştirme } \\
\text { programları } \\
\text {-İstihdam } \\
\text { olanakları }\end{array}$ & $\begin{array}{l}\text {-Sosyal refahı } \\
\text { artırmaya } \\
\text { yönelik eğitim, } \\
\text { sağlık, kültür, } \\
\text { sanat ve turizm } \\
\text { amaçlı } \\
\text { destekler }\end{array}$ & $\begin{array}{l}\text {-Bölgesel } \\
\text { kalkınmaya } \\
\text { yönelik teknik } \\
\text { destekler } \\
\text {-Teknoloji } \\
\text { transferleri }\end{array}$ & $\begin{array}{l}\text {-Dağıtılan } \\
\text { hibeleri } \\
\text { düzenlemeye } \\
\text { yönelik } \\
\text { alınan } \\
\text { kararlar, } \\
\text { kanun ve } \\
\text { tasarılar }\end{array}$ & $\begin{array}{l}\text {-Çevre koruma ve } \\
\text { sürdürülebilirliği } \\
\text { sağlamaya } \\
\text { yönelik destekler }\end{array}$ \\
\hline
\end{tabular}

Tablo 4. PESTLE Unsurlarl *Yazarlar tarafindan oluşturulmuştur

\section{PESTLE Yöntemi İle Kuzey Anadolu Kalkınma Ajansı (KUZKA) İncelemesi}

Değişim ve gelişim planlarının yapıldığı dünyada ve özellikle gelişmekte olan ülkelerde bölgelerin ve şehirlerin farklı özelliklere sahip olması bu alanlara özel bir bakış açısını gerektirmektedir. Bölge merkezli bakış açısı ile ihtiyaçların daha net görülebilirliği ve karşılanabilirliği söz konusudur. Türkiye'nin AB'ye uyum sürecinde geldiği aşamada Düzey II olarak adlandırılan 26 bölgeye ayrılması da özelden genele giden bu sistemin bir sonucudur. 


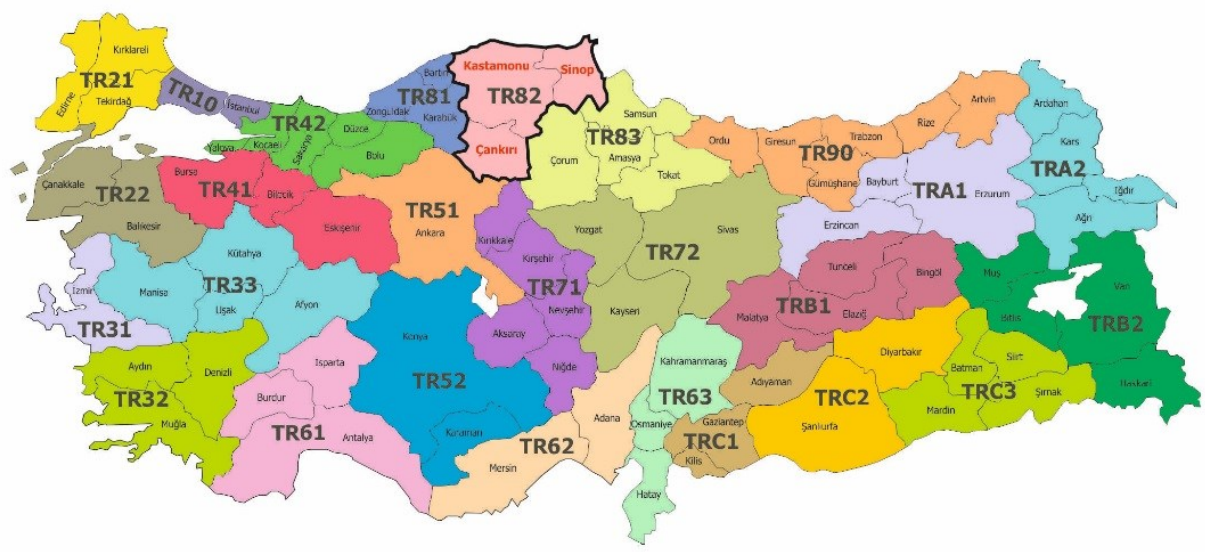

Şekil 2. İstatistikî Bölge Birimleri Düzey 2 Kaynak: KUZKA (2013a).

TR82 Düzey II Bölgesinde yer alan ve Çankırı, Kastamonu ve Sinop illerini çalışma alanı olarak kapsayan KUZKA (Şekil 2) Kuzey Anadolu Kalkınma Ajansı'nın kısaca ifade edilmiş şeklidir. 25.07.2009 tarihinde 15236 sayılı kanun ile kurulan KUZKA "Bölgenin sahip olduğu yetenekleri geliştirmek ve bilgi birikimini artırarak sürdürülebilir bölgesel kalkınmayı hızlandırmak" amacını taşımaktadır (KUZKA, 2015a). Bölge yapısal olarak incelendiğinde; nüfusu 1 milyonun altında olan tek düzey II bölgesidir, okullaşma oranı Türkiye ortalamasından iyi görünen, oransal olarak en yaşlı nüfusa sahip ve GSKD bakımından da ortalamanın altında bir durum sergilediği görülmektedir. TR82 Bölgesi'nde istihdam, sektörel dağılımında, \%15,7 sanayi, \%36,6 hizmet ve $\%$ 47,7'lik pay ise tarım sektöründe yoğunlaşmıştır (KUZKA, 2014).

KUZKA 2010-2013 yılları arasında kamu ve özel sektörlere yönelik toplamda 49 milyon TL ile 8 mali ve teknik hibe desteği sağlamıştır. Ayrıca 2015 yılında İktisadi Kalkınma (İKAP2) ve Bölgesel Altyapı Geliştirme (BAP2) mali destek programları kapsamında 20,5 milyon TL'lik proje desteği açılmıştır. TR82 Bölgesine 5 yılda toplamda 70 milyon TL'lik hibe desteğinde bulunmuştur (Tablo 5)

\begin{tabular}{|l|l|}
\hline Y1llar & Miktar (TL) \\
\hline 2010 & 200 bin \\
\hline 2011 & 15,6 milyon \\
\hline 2012 & 12,5 milyon \\
\hline 2013 & 20,9 milyon \\
\hline 2015 & 20,5 milyon \\
\hline
\end{tabular}

Tablo 5. KUZKA aracılı̆̆ ile dă̆ltılan hibeler (2010-2015) Kaynak: KUZKA (2015b).

Çankırı, Kastamonu, Sinop, bölgelerini kapsayan KUZKA’nın sağladığı destekler PESTLE analizi kullanılarak incelenmektedir. Çalışmada, KUZKA faaliyet raporları, Kalkınma Bakanlığı ve TÜİK verileri ile daha önce yapılmış lisansüstü tezler ve hazırlanmış raporlar ikincil veriler olarak kullanılmıştır.

Bölgesel kalkınma farklılıklarının giderilmesine yönelik; rekabetin ve istihdamın artırılması, beşeri gelişme ve sosyal dayanışmanın güçlenmesi, kamu hizmetlerindeki kalite ve etkinliğin artırılması ve bölgesel gelişmeye yönelik çalışmalar 9. Kalkınma Planı (2007-2013) ve 10. Kalkınma Planının (2014-2018) temel amaçlarındandır (Kalkınma Bakanlığı, 2015). KUZKA'da kalkınma planlarının gerçekleşmesinde yardımcı aktörlerden biri olarak karşımıza çıkmaktadır.

TR82 Bölgesinde yer alan Çankırı, Kastamonu, Sinop illerinde 2011 yılında 6594 dolar olarak ölçülen GSKD, 9244 dolarlık Türkiye ortalamasından düşüktür. 2013 yılında ölçülen ve bir önceki yıla göre alınan TÜFE değişim oranı ise \%7,33 olup bu değer \%7,40 olan Türkiye değerinin altındadır (KUZKA, 2013a). KUZKA bu değerleri yükseltme adına bölgenin gelişimine yönelik istihdam ve işgücü olanağı yaratan pek çok proje ve faaliyet gerçekleştirmektedir. Nitekim "Potansiyelini Değere Dönüştüren Ekonomi” vizyonu ile İktisadi Kalkınma Mali Destek Programı (İKAP2) ve Bölge Altyapısını geliştirmeye yönelik mali destek programları (BAP2) kapsamında proje ve faaliyetler gerçekleştirilmektedir. Bu faaliyetlere örnek olarak Çankırı'da ilk tuz oteli, Japon lastik üretim tesisi yatırımı, Kaya Tuzu Mağarasının Çankırı turizm ve ekonomisine kazandırılması, Kastamonu'da mesafeleri daraltan Tünel Projesi ile bölgeye talebin artması vb. verilebilir (KUZKA, 2015c).

Sosyal refahı sağlama hedefi çerçevesinde oluşturulan sosyal projeler ile sosyal ve kültürel alanların topluma kazandırılması amaçlanmaktadır. Taşköprü Belediyesi'nin Cumhuriyet Meydanı park düzenlemesinin tarihi mekânlarla birleştirilmesi, Sinop mezbaha projesi kapsamında büyük ve küçük hayvanların kesim ihtiyacının karşılanması, engelsiz okul projesi kapsamında Çankırı'da okullarda engellilere yönelik asansörlerin kurulması, 
rampaların yapılması, tuvalet ve lavaboların engellilerin kullanıma uygun hale getirilmesine yönelik planlamalar vb. projeler ile sosyal ortamlar temin edilmektedir (KUZKA, 2015c).

Bölge ekonomisinde teknolojik gelişme faktörünün kullanımı ile istihdam ve bölgesel kalkınmaya etki eden projeler bulunmaktadır. Örneğin Kastamonu Üniversitesi teknoloji geliştirme bölgesi kapsamında Kastamonu Organize Sanayi Bölgesi Endüstriyel Arıtma Tesisinin kurulumu projesi onaylanmıştır (KUZKA, 2013b). Kastamonu'da Üniversite ve KUZKA aracılığı ile Teknokent projesinin imzalanması da bölgede yeni işgücü olanakları yaratarak küçük ölçekli altyapının geliştirilmesine olanak sağlayacak projelerdendir (Kastamonu Beyaz Haber, 2014). Ayrıca yatırımcıya ihtiyacı olan bilgiyi online ve offline ortamlarda sağlayarak Kastamonu, Çankırı ve Sinop illerine yatırımı kolaylaştıran "Invest in TR82" projesi kapsamında teknik destek işbirliğinin sağlanmasını kolaylaştıracak ilk ödüllü projenin imzaları atılmıştır (KUZKA, 2015c).

Çevre koruma, düzenleme ve sürdürülebilirliği sağlamaya yönelik "yeşil doğa ve yaşanabilirlik" vizyonu çerçevesinde Boyabat Belediyesi işbirliğinde Gazidere Islahı ve Kanalizasyon Hattı kurulum Projesi (KUZKA, 2011), Çankırı'da KUZKA aracılığı ile bakım onarım ve çevre düzenlemeleri kapsamında Alpsarı Göleti ve Mesire alanı vb. girişimlerinde girişimlerinde bulunulmuştur (TC. Çankırı Valiliği, 2015).

KUZKA'nın kurulum kanunu kapsamında oluşturulan proje ve faaliyetler özelden genele gelişim ve kalkınmayı sağlayarak bölgesel eşitsizliği giderme amacı taşımaktadır.

\begin{tabular}{|c|c|}
\hline Faktörler & Örnekler ve Açıklamalar \\
\hline Politik (Political) & $\begin{array}{l}\text { Helsinki Zirvesi (1999) ile AB’ye uyum süreci } \\
\text { 9. Kalkınma Planı (2007-2013) } \\
\text { 10. Kalkınma Planı (2014-2018) }\end{array}$ \\
\hline Ekonomik (Economic) & $\begin{array}{l}\text { “Potansiyelini Değere Dönüştüren Ekonomi” Vizyonu } \\
\text { İktisadi Kalkınma (IKKAP2) Mali Destek Programı ve } \\
\text { Bölge Altyapısını (BAP2) geliştirmeye yönelik mali destek } \\
\text { programları } \\
\text { Çankırı da ilk tuz oteli } \\
\text { Çankırı'da Japon lastik firmasını için yatırım } \\
\text { Çankırı Kaya tuzu mağarasının turizme kazandırılması } \\
\text { Kastamonu'da mesafeleri daraltan Tünel projesi }\end{array}$ \\
\hline Sosyal (Social) & $\begin{array}{l}\text { "Sosyal Refah" Vizyonu } \\
\text { Taşköprü Belediyesi'nin Cumhuriyet Meydanı park düzenlemesinin } \\
\text { tarihi mekânlarla birleştirilmesi } \\
\text { Kültür, Sanat, Turizm ve Sağlıklı Yaşam Projesi } \\
\text { Engelsiz Okullar Projesi }\end{array}$ \\
\hline Teknolojik (Technological) & $\begin{array}{l}\text { "Invest in TR82" projesi kapsamında teknik destek işbirliği } \\
\text { Kastamonu Organize Sanayi Bölgesi Endüstriyel Arıtma Tesisi } \\
\text { Kastamonu'da Üniversite İşbirliğinde Teknokent Projesi }\end{array}$ \\
\hline Yasal (Legal) & $\begin{array}{l}\text { 25.1.2006 tarihli ve } 5449 \text { sayılı Kalkınma Ajanslarının Kuruluşu, } \\
\text { Koordinasyonu ve Görevleri Hakkında Kanun } \\
\text { 25.07.2009 tarihinde } 15236 \text { sayılı kanun ile KUZKA'nın kurulum } \\
\text { Kanunu }\end{array}$ \\
\hline Çevresel (Environmental) & $\begin{array}{l}\text { "Yeşil Doğa ve Yaşanabilir Mekânlar" vizyonu Boyabat Belediyesi } \\
\text { işbirliğinde Gazidere Islahı } \\
\text { Çankırı'da KUZKA aracılığı ile bakım onarım ve çevre } \\
\text { düzenlemeleri kapsamında Alpsarı Göleti ve Mesire alanı yapımı }\end{array}$ \\
\hline
\end{tabular}

Tablo 6. PESTLE Özeti *Yazarlar tarafindan oluşturulmuştur

AB'ye uyum sürecinde gerçekleşen proje ve faaliyetler TR82 bölgesinde politik, ekonomik, sosyal, teknolojik, yasal ve çevresel boyutlarda kategorize edilmiş ve incelenen bu proje ve faaliyetler ile halkın katılımı sağlanarak bölge ekonomisine ciddi oranlı katkıları görülmüştür.

Özellikle iktisadi kalkınma çerçevesinde bölge altyapısını geliştirmeye yönelik ekonomik faktörlü projeler ile sosyal refahı artıracak kültür, turizm ve sağlıklı yaşam kapsamında sosyal faktörlü projelerin daha çok desteklendiği gözlenmiştir.

Üniversiteler ile oluşturulan teknik işbirliği sonucu istihdam olanakları yaratılmıştır.

Çevresel restorasyon ve sslah projeleri ile daha yaşanabilir ortamlar oluşturulmuştur. 


\section{Sonuç}

2009 yılında faaliyete başlayan KUZKA, kurulumundan bu zamana kadar bölgesel faaliyetlerini sürdürerek ekonomik gelişimi desteklemiştir. Faaliyetlerin Politik, Ekonomik, Sosyal, Teknolojik, Yasal ve Çevresel boyutlarının incelendiği çalışmada KUZKA'nın aracı olduğu proje faaliyetlerin bölgesel değişim ve gelişimde ciddi etkileri görülmüştür. Özellikle geri kalmış bölgelerde altyapı, tarım, ticaret gibi konularda yaratıcı projeler topluma kazandırılmıştır.

Halkı girişimciliğe yönlendiren, isteklerini gerçekleştirmek için adım atan, daha katılımcı bir toplumun oluşması sağlanmıştır. Böylece gelecekte toplum içerisinde var olan halkın kendi ihtiyaçlarına cevap verebileceği bir düzen oluşacaktır.

KUZKA hibelerinin özellikle ekonomik yönlü mali destek programları sayesinde TR82 bölgesinde potansiyeller değere dönüşmüştür. Ekonomik destekler ile kapasiteleri genişleyen pek çok işletme istihdam oranında da artışları beraberinde getirmiş ve iktisadi kalınma zinciri oluşmuştur.

Eğitim, kültür, sağlık, turizm yönlü projeler ile sosyal refah artmış ve TR82 Bölgesinde 1slah projeleri ile yeşil doğa ve yaşanabilir mekânların oluşumu da artış göstermiştir.

PESTLE yöntemi ile incelenen KUZKA proje ve faaliyetlerinin özellikle ekonomik, sosyal ve çevresel faktörlerde daha etkin olduğu gözlemlenmiştir.

Sonuç olarak KUZKA potansiyeli değere dönüştüren, sosyal refah, yeşil doğa ve yaşanabilir mekânlar çerçevesinde oluşturduğu faaliyet vizyonu ile bölgesel ekonominin gelişim ve değişimini sağlamıştır. Bu durum Türkiye'de KUZKA'nın bölgesel kalkınmadaki yüksek katkısını da ortaya koymaktadır.

\section{Kaynakça}

- Akpınar, 2012. “Türkiye'de Değişen Bölgesel Kalkınma Politikaları”, Karadeniz Sosyal Bilimler Dergisi s.6, s.29.

- Cankorkmaz, 2008. “Türkiye'de Bölgesel Kalkınma Ajansları ve Bu Ajanslara Yönelik Eleştiriler” Dokuz Eylül Üniversitesi İktisadi ve İdari Bilimler Fakültesi Dergisi, 26, s. 113-138.

- Clower, 2004. "Multinational Lessons From Local and Regional Economic Development Agencies", Presented to The Annual Meeting of The European Regional Science Association, Portugal.

- $\quad$ Cankorkmaz, (2008). Dokuz Eylül Üniversitesi İktisadi ve İdari Bilimler Fakültesi Dergisi, 26, s, 113-138.

- TC. Çankırı Valiliği (2015). http://www.cankiri.gov.tr/index.php/post/view?id=3069

- Dcosta, 2011. http://www.brighthubpm.com/project-planning/51754-components-of-a-pestle-analysis/

- Engin, 2011. “Kalkınma Ajansları: Türkiye ve İngiltere Ülke Örnekleri”, Sosyal Ve Beşeri Bilimler Dergisi, 3, s. 65-77.

- Eroğlu ve Kum, 2010. “Türkiye’de Kalkınma Ajanslarının İdari Teşkilat İçindeki Yeri”, Erciyes Üniversitesi Íktisadi ve İdari Bilimler Fakültesi Dergisi, 35, s. 175-198.

- Filiztekin, 2008. “Türkiye'de Bölgesel Farklar ve Politikalar”, İstanbul.

- Han ve Kaya, 2008. "Kalkınma Ekonomisi Teori ve Politika”, Ankara.

- Hasanoğlu ve Aliyev, 2006. “Avrupa Birliği ile Bütünleşme Sürecinde Türkiye’de Bölgesel Kalkınma Ajansları”, Sayıştay Dergisi, s. 60.

- Kalkınma Bakanlığı, 2015. Dokuzuncu Kalkınma Planı (2007-2013), http://www.kalkinma.gov.tr/Lists/Kalknma\%20Planlar/Attachments/1/plan9.pdf

- Keskin ve Sungur 2010. "Bölgesel Politika Ekseninde Yaşanan Döngü”, SDÜ Fen Edebiyat Fakültesi Sosyal Bilimler Dergisi s. 271-293.

- KobiDanışmanlık, 2015. http://www.kobidanismanlik.com.tr/site/35657/uploads/o/2015/19/dc5344b456215b5e8d4f090148b47da7.jp $\mathrm{g}$

- $\quad$ KUZKA, 2011.

http://www.kuzka.org.tr/Haber/Dosya/II8E42011_YILI_CEVRE_VE_TURIZM_ALTYAPISI_MALI_DES TEK_PROGRAMI_ASIL_VE_YEDEK_LISTELEER.pdf.

- KUSKA, 2013a. Tr82 Düzey 2 Bölgesi (Kastamonu, Çankırı Ve Sinop İlleri) Bölge Planı 2014-2023.

- $\quad$ KUZKA, 2013b.

- http://www.kuzka.gov.tr/Icerik/Dosya/www.kuzka.gov.tr_70_EF5N17GK_TR82_2013_BAP_(basarili_proj eler_listesi_asil).pdf.

- KUZKA, 2014. http://www.kuzka.org.tr/Icerik/Dosya/www.kuzka.gov.tr_37_VP7W46OE_01-kurumsalstratejik-plan.pdf. 
- KUZKA 2015a. http://www.kuzka.org.tr/kurumsal.asp?K=1\&Kurumsal=hakkimizda.

- KUZKA 2015b. http://www.kuzka.org.tr/basinda-detay.asp?H=743\&Haber=kuzkadan-tr82-bolgesine-98milyon-avroluk-dev-ab-fonu .

- KUZKA 2015c. http://www.kuzka.org.tr/basinda.asp?BH=1\&Basinda=haberler

• Özer, 2012. “Türkiye'de Bölgesel Kalkınma Ajanslarının Sosyal Ekonomik İşlevleri”, Kamu-İş, 12/2, s. 37 74.

- Sarıhan, 2011. "Yerel İktisadi Kalkınma Bağlamında Kalkınma Ajanslarının Rolü ve Türkiye Uygulamaları”, Karamanoğlu Mehmet Bey Üniversitesi Sosyal Bilimler Enstitüsü.

- Soyak, 2005. "Ertelenen 9. Kalkınma Planı ve Türkiye’de Planlamanın Geleceği Üzerine Bir Not”, Bilim ve Ütopya Dergisi, s. 3-4.

- TEPAV, 2005. Bölgesel Kalkınma Ajansları, http://www.tepav.org.tr/upload/files/1271245092r8246.Bolgesel_Kalkinma_Ajanslari.pdf

- TÜİK, 2013. Seçilmiş Göstergelerle Çankırı 2013, http://www.tuik.gov.tr/ilGostergeleri/iller/CANKIRI.pdf

- TÜİK, 2015. İşücü İstatistikleri, 2014, http://www.tuik.gov.tr/PreHaberBultenleri.do?id=18645. 


\title{
Üniversite Öğrencilerinin Başarılarını Etkileyen Demografik Faktörler
}

\section{Demographic Factors Affecting the Success of University Students}

\author{
Asst. Prof. Dr. Raziiakhan Abdieva (Kyrgyzstan-Turkey Manas University, Kyrgyzstan)
}

\begin{abstract}
Having qualified and educated people is very important for the sustainable development of the country. Having well-educated, qualified and employed people will contribute to the economic growth. In the paper we analyzed demographic factors that affect the performance of students. Results of ordered probit analyze showed that the performance of those students whose parents are living together are for 4,9\% higher than students whose parents are divorced. Also, the performance of students whose mother is working is higher for $2.7 \%$. The surprising results related the level of the income of the family. The performance of the students from highest income level is lower for $12.2 \%$.
\end{abstract}

\section{Giris}

Ülkenin en önemli kaynağı beşeri sermayesidir. Ülke insanlarının eğitim seviyesi ve kalitesi ülkenin gelecekte gelişmesine önemli derecede katkı sağlayabilecektir. Eğitimli ve kalifiyeli elemanların var olması ekonominin kalkınması için bir zemin oluşturmaktadır. Geçiş dönemini yaşamakta olan Kırgızistan ekonomisinin kalkınması için kaliteli ve kalifiyeli elemanlara ihtiyacı daha da yüksektir.

Üniversite öğrencileri bağımsız yaşamaya başlamış olan fakat ailenin desteğine ihtiyacı olan ve bu eğitimden sonra kendi hayatını kurmaya başlayacak olan kişilerdir. Öğrencilerin kalifiyeli eleman olmaları ve hayatta başarılı olmaları onların üniversitede gösterdikleri performansına bağlıdır. Bu çalışmada öğrencilerin akademik performansını etkileyen bazı demografik faktörler incelenmiştir.

Girişi izleyen ikinci bölümde genel olarak öğrencilerin başarılarını etkileyen ailevi, sosyal ve ekonomik etkenler araştırılmıştır. Üçüncü bölümde Kırgızistan'da genel sosyal-demografik durum incelenmiştir. Dördüncü bölümde sıralı probit modeli ve sonuçları verilecek, beşinci bölümde ise sonuç ve değerlendirmeler sunulacaktır.

\section{2 Öğrencilerin Başarılarını Etkileyen Sosyal ve Ekonomik Faktörler}

Öğrencilerin üniversitede akademik yönden başarılı olmalarına onları aileleri ve ailedeki psikolojik ve ekonomik durum etkileyebilmektedir. Öğrencilerin öğrenmeye hazır durumda olup olmadıkları anlamına gelen, psikolojik, sosyal ve çevresel faktörler açısından aile ortamının sağlamakta olduğu psikolojik ve sosyal desteğin merkezi bir değer arz ettiğini ifade edebiliriz. Öğrencilerin ihtiyaç duydukları psikolojik ve sosyal destek için ailelerin duyarlılıklarına gereksinim duyarlar. Bu konuda yapılan araştırmalar, ailelerinden yeterli düzeyde bu desteği alan öğrencilerin daha başarılı olduklarını ortaya koymuştur (Engin v.d., 2009).

Ailede üyeleri arasındaki ilişki, anne ve babalarının ilişkisi ve onların çocuklarla olan ilişkisi çocukların psikolojik gelişimini ve öğrenmeye olan güdüsünü etkilemektedir. Bununla birlikte anne ve babasının iş hayatında ulaştıkları başarıları ve kendilerinin mutlu hissetmeleri çocukları ile olan ilişkilerini etkileyebilmektedir. Diğer bir değişle, ailedeki sosyal, kültürel ve ekonomik yapı çocuğun hayattaki başarısını önemli ölçüde belirlemektedir.

Öğrencilerin anne ve babasının mesleği ve eğitim seviyesi onların okuma becerilerini etkilemektedir. PISA değerlendirmelerinde OECD ülkelerinde aile çevresi okul öğrencilerinin okuma becerilerindeki farklılığa etki eden en güçlü faktörlerden biri olarak bu farklılığın \% 22'ni açıklamıştır. Kırgızistan'da aile çevresi okul öğrencilerinin okuma becerisinde \% 14,5 oran ölçeğindeki farklılığa neden olmaktadır. Fakat tek ebeveynlerin olumlu aile çevresini oluşturmada görev sayısının çok olmasından dolayı zorluk çekmektedir. OECD ülkelerinde 15 yaşındaki öğrencilerin \% 17'si tek ebedenler yaşamaktadırlar. Tek ebeveynlerin çoğunlukla sosyal ve ekonomik durumu daha düşüktür. Fakat Kırgızistan, Kazakistan ve Peru'da tek ebeveynle yaşayan öğrencilerin performansı daha yüksektir (Центр оценки образования и и методов обучения, 2011:128).

Ural ve Çınar (2014) anne ve babanın eğitim düzeyleri ile çocuğun matematik başarısı arasında bir ilişkiyi incelemek amacıyla 2012-2013 eğitim-öğretim yılında Burdur il merkezinde bulunan ve rastgele belirlenmiş iki yedinci sınıftan toplam 55 öğrenciye anket yapmışlardır ve araştırma sonucunda her ne kadar istatistiksel olarak anlamlı olmasa da anne ve babanın özellikle de daha net olarak annenin eğitim düzeyi artıkça, öğrencilerin matematik karne notlarının da arttı̆̆ı görülmüştür.

Engin v.d. (2009) ilköğretim öğrencilerinin öğrenme başarısını olumsuz etkileyen faktörlerden aile, psikolojik faktörler, fiziksel ortam ve öğrencinin fizyolojik durumunu incelemişlerdir. Araştırma 2006-2007 öğretim yılında Kars ili merkezdeki ilköğretim okullarının beşinci sınıflarında öğrenim gören öğrenciler üzerine yapılmıştır. 
Araştırma sonucuna eğitim ve öğretim etkinliklerinde istenmeyen durumların ortadan kaldırılması ve daha başarılı sonuçların elde edilmesi için, okul aile işbirliğinin geliştirilmesi gerektiği açıklanmıştır.

Ailelerin ekonomik durumu da öğrencilerin performansını etkilemektedir. Çeşitli yaşlardaki çocukların kelime hazinesinin analizi ekonomik ve sosyal durumu farklı olan ailelerde çok erken yaşlarda fark ortaya çıkmaya başladığını ve okula girecek yaşta çocuğun davranışı ve bilişsel yeteneğinde önemli ölçüde etkilediğini göstermiştir. Ayrıca ilkokul ve ortaokulda anne ve babalarının geliri düşük, işsiz veya prestijli olmayan yerlerde çalışan çocuklar anne ve babalarının sosyal ve ekonomik durumu daha yüksek olanlara nispeten yüksek akademik göstergelere erişme şansı daha düşüktür (Центр оценки образования и и методов обучения, 2011: 129).

PISA araştırmalarına göre ailenin sosyal ve ekonomik durumu okul öğrencilerinin başarılarını etkilemektedir. Genel olarak sosyal ve ekonomik durumu daha iyi olan öğrencilerin okuma becerilerinin de yüksek olduğu görülmüştür. Fakat aynı zamanda bu etken öğrencilerin okuma becerilerini etkileyen en önemli belirleyici değildir. Örneğin ailesinin ekonomik durumu iyi olmayan çok sayıdaki öğrenciler yüksek puanlar almışlardır (örneğin, Şanhai ve Singapur ) (Центр оценки образования и и методов обучения, 2011).

\section{Kurgızistan'da Sosyal ve Ekonomik Durum}

Kırgızistan bağımsızlığını kazandığı 1991 yılından itibaren piyasa ekonomisine geçmek amacıyla sosyal ve ekonomik düzenlemeler gerçekleştirmiştir. SSCB'nin dağılması üye ülkeler arasında ticari bağların kopmasına, çoğu sanayide faaliyetlerin durdurulmasına neden olmuştur. Kırgızistan'da reformların ilk beş yılında (19911995) fiyatlarda hızlı ve düzensiz artışlar yaşanmış; özelleştirme uygulaması mülkiyetin tabana yayılmasında başarı sağlayamamış ve gelir ve servetin belirli ellerde toplanmasına yol açmıştır. Kırgızistan'da gelir eşitsizliğinin göstergesi olan Gini katsayısı 1987-88 de 26 iken; 1993- 95 döneminde bozularak 55 olmuştur (Sakınç, 2004). Bu süreç çok sayıda işletmenin kapanmasına, üretimi durdurmasına, işsizliğin artmasına ve halkın fakirleşmesine neden olmuştur (Sarıbayev, 2002: 185).

\begin{tabular}{|l|c|c|c|c|}
\hline & $\mathbf{2 0 1 0}$ & $\mathbf{2 0 1 1}$ & $\mathbf{2 0 1 2}$ & $\mathbf{2 0 1 3}$ \\
\hline Reel GSYİH, \% & $-0,5$ & 5,7 & -0.9 & 10.5 \\
\hline $\begin{array}{l}\text { Kişi Başına } \\
\text { Düşen GSYİH, \$ }\end{array}$ & 875 & 1182 & 1280 & 1299 \\
\hline Ortalama Ücret & 7189 & 9304 & 10726 & 11341 \\
\hline Asgari Ücret & 500 & 690 & 760 & 840 \\
\hline $\begin{array}{l}\text { Asgari Tüketici } \\
\text { Bütçesi }\end{array}$ & 3502,65 & 4390,02 & 4341,15 & 4599,2 \\
\hline Fakirlik Oran1 & 33,7 & 36,8 & 38 & 38 \\
\hline Cini Katsayıs1 & 0,37 & 33,4 & & 53,578 \\
\hline Evlilik sayıs1 & 50,362 & 56,509 & 55,176 & 9,052 \\
\hline Boşanma sayıs1 & 8,155 & 8,705 & 8,698 & 16,9 \\
\hline $\begin{array}{l}\text { Boşanma say1s1/ } \\
\text { Evlilik sayıs1, \% }\end{array}$ & 16,1 & 15,4 & 15,8 & \\
\hline
\end{tabular}

Tablo 1. Kırgızistan'da Genel Sosyal ve Ekonomik Durum Kaynak: International Monetary Fund, Kırgızistan Istatistik Komitesi

Son yıllardaki gelişmelere bakıldığında, ekonomik büyüme istikrarlı olmadığını, kişi başına düşen GSYİH artış gösterdiğini fakat son iki yılda yükselme hızının düşük olduğunu görüyoruz. Asgari tüketici bütçesi 2013 yılında 4599,2 som iken asgari ücretin 840 somdur. Fakirlik oranı ise 2010 yılında \% 33,7 iken 2013 yılında \% 38'e ulaşmıştır. Bu oran kırsal kesimde daha da yüksektir. Örneğin 2010 yılında fakirlik oranı kırsal kesimde \% 39,5'e ulaşmıştır (İMF, 2012). İstatistik verilere göre Kırgızistan'da evlenenlerin \% 16'sı boşanmaktadırlar (Tablo:1).

\section{Betimleyici İstatistikler}

$\mathrm{Bu}$ çalışmada Kırgızistan-Türkiye Manas Üniversitesinde öğrencilerin problemlerini inceleme amacıyla yapılan anket verileri kullanılmıştır. Anket 3133 öğrenciye yapılmış ve bunların \% 64,1’’i kız, \% 35,3’ü erkektir. 


\begin{tabular}{|l|r|r|}
\hline Cinsiyeti & Frekans & Oranı \\
\hline K1z & 2007 & 64.1 \\
\hline Erkek & 1105 & 35.3 \\
\hline Toplam & 3112 & 99.3 \\
\hline Cevapsız & 21 & 0.7 \\
\hline Toplam & 3133 & 100.0 \\
\hline
\end{tabular}

Tablo.2 Katılımcıların Cinsiyetine Göre Dağılımı

Katılımcıların \% 44'ü 19 yaş ve altındadır, \% 19'u 20 yaşında ve 21 ve 22 yaşında olanlar her biri \% 16'sını oluşturmuşlardır.

\begin{tabular}{|l|r|r|}
\hline Yaşı & Frekans & Oranı \\
\hline 18 ve altı & 401 & 12.8 \\
\hline 19 & 1028 & 32.8 \\
\hline 20 & 600 & 19.2 \\
\hline 21 & 518 & 16.5 \\
\hline 22 ve üstü & 527 & 16.8 \\
\hline Cevapsız & 59 & 1.9 \\
\hline Toplam & 3133 & 100 \\
\hline
\end{tabular}

Tablo.3 Katılımcıların Yaşına Göre Dağılımı

Katılımcıların \% 42,2'sinin ailesinin aylık ortalama geliri 10000 soma kadar, \% 30'unun ailevi aylık ortalama geliri 10001 ile 20000 ve \% 13,4'ünün ailevi aylık ortalama geliri 20001 - 30000 som arasındadır. Genel olarak Manas Üniversitesi öğrencileri daha çok geliri az olan ailelerden olduğu söylenebilir.

\begin{tabular}{|l|r|r|}
\hline Ailevi Aylık Ortalama Geliri & Frekans & \multicolumn{1}{c|}{ Oranı } \\
\hline 1- 0- 10.000 som & 1324 & 42,2 \\
\hline 2- 10.001-20.000 som & 944 & 30,1 \\
\hline 3- 20.001- 30.000 som & 420 & 13,4 \\
\hline 4- 30.001- 50.000 som & 194 & 6,2 \\
\hline 5- 50.001- 70.000 som & 69 & 2,2 \\
\hline 6- 70.001 ve yukarı & 52 & 1,7 \\
\hline Cevaps1z & 130 & 4.1 \\
\hline Total & 3133 & 100,0 \\
\hline
\end{tabular}

Tablo.4 Katılımcıların Ortalama Ailevi Aylık Gelirlerine Göre Dă̆ılımı

\section{Ampirik Sonuçlar}

Üniversite öğrencilerinin başarılarını etkileyen demografik faktörleri incelemek amacıyla sıralı probit modeli uygulanmıştır. Bu modelde bağımlı değişken olarak ankete katılan öğrencilerin not ortalamaları alınmıştır (0 ile 4 arası). Dil öğrenmek amacıyla hazırlık sınıfında okuyan öğrencilerin not ortalamaları sıfır olarak işaretlenmiştir. Aşağıdaki tabloda modelde yer alan bağımsız değişkenlerin açıklamaları verilmiştir.

\begin{tabular}{|l|l|}
\hline Değişkenler & Açıklama \\
\hline Aylık ortalama ailevi gelir & Aylık ortalama ailevi geliri 70 000 som ve yukarı olursa 1, değilse 0 \\
\hline Anne ve babasının birlikte & Anne ve babası birlikte yaşıorsa 1, boşanmışlar ise 0 \\
\hline Anne çalışıyor & Annesi çalışıorsa 1, çalışmıyorsa 0 \\
\hline
\end{tabular}

Tablo 5. Bă̆ımsız Değişkenler

\begin{tabular}{|l|l|l|}
\hline Değişkenler & Katsayı & Marjinal Etkileri \\
\hline Aylık ortalama ailevi gelir & $-0.5333^{* *}$ & $-.1227^{* *}$ \\
\hline Anne ve babasının birlikte yaşaması & $0.2152^{* * *}$ & $0.0495^{* * *}$ \\
\hline Anne çalıșıyor & $0.1158^{* *}$ & $0.0266^{* *}$ \\
\hline Cut1 & -2.257752 & \\
\hline Cut2 & .1142334 & \\
\hline Cut3 & -1.00495 & \\
\hline
\end{tabular}

Tablo 6. Siralı Probit Modelinin Sonuçları

LR chi2 (3) $=18.10(0.0004) \quad$ Pseudo R2 $=0.0043 \quad$ Log likelihood $=-2080.8709$

Marjinal etki not ortalaması değişkeninin en yüksek değerine göre hesaplanmıştır (veya 4'e göre). Not: *, ** ve *** 10\%, $5 \%$ ve $1 \%$ düzeyinde anlamlıllk derecesini göstermektedir. 
Model sonuçlarına göre anne ve babası birlikte yaşayan öğrencilerin performansı anne ve babası boşanmış öğrencilere göre \% 4.5'e daha yüksektir. Anne ve babasının ilişkileri ve birlikte yaşaması çocukların için çok önemli destek verici faktör olduğu görülmektedir. Anne ve babasının boşanması çocuğun akademik başarısını negatif etkilemektedir.

Annesi çalışan öğrencilerin performansı annesi çalışmayan öğrencilere göre \% 2.6’ya daha yüksektir. Çoğunlukla eğitimli kadının çalıştığını kabul edersek, bu sonuca göre ailede annenin çalışması ve eğitimli olması çocuğun performansını olumlu etkilediğini söyleyebiliriz. Dolayısıyla ülkede kızların eğitim almaları gelecekte ülkenin gelişimine pozitif katkı sağlayacaktır.

Aylık ortalama ailevi geliri ankete katılanlar arasında en yüksek olan veya 70000 somdan daha yüksek olan öğrencilerin performansı diğerlerine göre \% 12'ye daha düşüktür. Gelir seviyesinin diğerlerine göre en üst kısımda olmasına rağmen, performansının düşük olduğunu göstermiştir. Öğrencinin gelir ve kaynak sıkıntısının olmadığı halde akademik başarısının daha düşük olmasının nedeni zaten yeterli gelir ve yaşam seviyesine sahip olduğu için daha çok çalışarak kendini zorlamak istememesi olabilir. Bu sonuç şaşırtıcı ve gelecekte daha geniş bir şekilde araştırılması gereken faktördür.

\section{Sonuç ve Değerlendirme}

Çalışmada Kırgızistan'da üniversite öğrencilerinin başarılarını etkileyen bazı demografik faktörler incelenmiştir. Uygulanan sıralı probit modelinin sonuçları anne ve babası birlikte yaşayan öğrencilerin akademik performansı daha yüksek olduğunu göstermiştir. Bu çerçevede gençlere evlenme kararını alırken daha bilinçli ve bağımsız olarak almaları gerektiği, evlenme ile ortaya çıkacak sorumluluklar ile ilgili seminerler gerekirse okul veya üniversitelerde verilebilir.

Öğrencilerin performansını annesinin çalışıp çalışmadığı da etkilemektedir. Annenin eğitimli olması ve çalışması özellikle çocukların çeşitli yönden gelişmesine ve performansına olumlu etki etmektedir. Bu yüzden kızların kaliteli eğitim almaları ülke açısından da önemlidir.

Gelir seviyesi daha yüksek ailelerden gelen öğrencilerin performansı diğer öğrencilerden önemli derecede düşük olduğu açıklanmıştır. $\mathrm{Bu}$ öğrencinin imkanlarının yüksek olmasına rağmen bu olanakları iyi kullanamamaktadırlar ve diğer geliri daha düşük olanlara göre performansı daha düşüktür. Bunun nedeni bu ögrencilerin akademik yönden başarılı olma motivasyonunun düşük olması olabilir.

\section{Kaynakça}

- $\quad$ Engin, A.O., Özen, Ş. ve Bayoğlu, V. 2009. ‘Öğrencilerin Okul Öğrenme Başarılarını Etkileyen Bazı Temel Değişkenler’, Sosyal Bilimler Enstitüsü Dergisi Sayı 3, Bahar s. 125-156

- International Monetary Fund, 2012. IMF Country Report, No 12/329, IMF, Washington

- International Monetary Fund, 2014. IMF Country Report, No 14/200, IMF, Washington

- Kirgizistan İstatistik Komitesi, http://stat.kg/index.php?option=com_content\&task=view\&id=24\&Itemid=101 (10.06.2015)

- Rençber, B.A., 2012. "Üniversite Öğrencilerinin Akademik Başarılarını Etkileyen Faktörler”. Çankırı Karatekin Üniversitesi Sosyal Bilimler Enstitüsü Dergisi 3(1), p.191-198, http://sbedergi.karatekin.edu.tr/Makaleler/571764929_191-198.pdf

- Sakınç, S. 2004. 'Geçiş Ekonomilerinde Kriz ve Bütçe Yönetimi: Kırgızistan Deneyimi', Proceedings of the First International Conference on the Fiscal Policies in Transition Economies, Kyrgyz Turkish Manas University Publication No: 56. Conference Series No:5, pp. 431-39

- Sarıbayev, A. 2002. Gosudarstvennıye finansı v Kırgızskoy Respubliki. Nauka obrazovaniye, Bişkek (Государственные финансы в экономике Кыргызской Республики. Наука и образование. Бишкек)

- Ural, A. ve Çınar, F.N. 2014. ‘Anne ve Babanın Eğitim Düzeyinin Öğrencinin Matematik Başarısına Etkisi’, Eğitim Bilimleri Enstitüsü Dergisi, Sayı 3, Bahar, s.41-56

- Центр оценки образования и и методов обучения, 2011. Отчет, Учимся для жизни: что знаю и умеют учащиеся, PISA 2009. Результаты международного исследования функциональной грамотности 15-летних учащихся, Бишкек 


\title{
Ekonomik Kriz Döneminde Turizm Pazarlaması Tourism Marketing In Crisis Era
}

\author{
Prof. Dr. Süleyman Karaçor (Selçuk University, Turkey) \\ Asst. Prof. Dr. Betül Garda (Selçuk University, Turkey)
}

\begin{abstract}
The tourism industry is a sector that growing very rapidly and it affects the economy substantially. At a time of crisis, tourism marketing should become a higher priority for tourism industry. Despite economic crisis has horrible effects, different positive results are seen over some sectors like tourism industry. In general, economic crisis is disorganazing the balances of the world. Apportionable costs should be reviewed in crisis periods. Luxury spendings must be reduced. But the tourism companies that have sufficient capital can create opportunity for growth with taking their competitors market shares. In tourism industry a strategy which has been established before must be applied implemented over the period of crisis without any modifications. But it is nearly impossible to go beyond crisis periods with simple measures. Being more careful, making quick decisions and being flexible are required. In this study, the interaction of economic crisis in tourism marketing and its positive aspects have been discussed and an approach about the precautions to be taken has been presented.
\end{abstract}

\section{Giriş}

Sosyal ve ekonomik açıdan ülkelerin kalkınmasına yoğun katkı sağlayan turizm sektörü, dünyanın en hızlı gelişen sektörleri arasındadır. Turizm sektörü, savaş, terör, salgın hastalık, doğal afet ve seyahat harcamalarının kısılmasına neden olan ekonomik krizler gibi beklenmedik bir zamanda ortaya çıkan durumlardan yoğun bir şekilde etkilenmektedir. Kriz bir mal veya hizmetin kıt hale gelmesi, bir ülkenin resmi parasının değer kaybetmesi, borsa endeksinin aniden düşmesi, enflasyon olarak bilinen fiyatlar genel düzeyinin sürekli yükselme eğiliminde olması vb. olayları ifade etmektedir. Ayrıca kriz; ülkede aniden gelişen, siyasi dengeleri sarsan ve istikrarsızlık oluşturan "her durum" olarak düşünülebilir. Turizm faaliyetleri, kitleleri etkileyen her krizden etkilenir ve turistlerin rotalarını değiştirmeleri olasıdır.

Dünyadaki turizm sektörlerini olumsuz yönde etkileyen uluslararası krizlerden bazıları; 2000 yılındaki İkiz Kulelere yönelik terör saldırısı, 2004 Hint Okyanusu Depremi ve Tsunami, 2005 yılındaki Katrina Kasırgası, ABD'nin en büyük enerji şirketlerinden olan Enron'un iflasıdır.

11 Eylül 2000 tarihinde Amerika'da meydana gelen İkiz Kulelere Yönelik terör saldırısı dünyada turizm sektörü açısından bir dönüm noktası olmuştur. Bu olayın ABD turizmine verdiği zararı saptamaya yönelik olarak Hawaii Üniversitesi Ekonomi Profesörü Carl Bonham başkanlığında hazırlanan bir raporda; 2000 yılında Amerika'da 51 milyon olan uluslararası ziyaretçi sayısının 46 milyona düştügü, 2004 yılına kadar 27 milyon ziyaretçi kaybı yaşandığı ABD’nin bu süreçte turizm kaybının milyar dolarları bulduğu belirtilmiştir. Ayrıca, Hint Okyanusu Depremi ve Tsunami sırasında en çok can kaybı yaşanan ülkelerden birisi Tayland'da felaket sonrasında ülkenin turizm endüstrisinin de büyük zarar gördügünü belirtmek mümkündür. Aynı şekilde İngiltere'de FMD isimli bulaşıcı hastalık krizi, Sars krizi vb. de uluslararası alanda oluşup ülkelerin turizm faaliyetlerini etkilemiştir (Sarıçay ve Ünal, 2014).

Türkiye'deki krizlere ise, 1990 Körfez Savaşı, 1999 Kocaeli Depremi, Mavi Çarşı'nın bombalaması, Güneydoğuda yaşanan terör olayları, Domuz gribi ve 1929 ekonomik krizinden sonra en büyük ekonomik kriz olarak adlandırılan 2009 ekonomik krizi ve son dönemde bütün dünyayı etkileyen Küresel boyutta finans piyasalarında yaşanan ekonomik kriz örnek olarak gösterilebilir.

Türkiye'de 1990 yılında Ağustos ayında turizm sezonunun bittiği dönemde gerçekleşen Körfez Savaşı savaş bölgesine yakın olan ülkemizin imajını da kötü yönde etkilemiştir.1990 yılında 3,2 milyon \$ olan turizm gelirleri 1991 yılında 2,6 milyon \$'a düşmüştür. Ülkemize 1990 yılında AB ülkelerinden gelen ziyaretçi sayısı 2,7 milyon iken 1991 yılında 1,7 milyona, OECD ülkelerinden gelen ziyaretçi sayısı da 1990 yılında 3,3 milyon iken 1991 yılında 2,4 milyona düşmüştür. Günümüzde küresel boyutta finans piyasalarında yaşanan ekonomik krizin dünya ve Türkiye turizmini etkilemesinin nedeni ise, turizm harcamalarının zorunlu bir harcama olmaması nedeniyle hükümetler tarafından ilk kısılan harcama olmasıdır. Turizm sektörü küreselleşmeden önemli ölçüde etkilendiği için, yaşanan krizlerin en fazla etkilediği sektörlerin başında gelmektedir. (Sarıçay ve Ünal, 2014).

Turistik tüketimin zorunlu bir tüketim olmaması, turizm sektörünün kriz dönemlerindeki en büyük dezavantajlarından biridir. Turizm krizi; turizm faaliyetlerinin etkilenmesine yol açan herhangi bir doğal ve insan kaynaklı felaket olarak tanımlanmaktadır (Henderson, 1999). Kriz dönemlerinde normal zamanlardaki stratejilerden farklı bir yol izlenmesi gerekir. Bu dönemde pazarlama stratejileri her zaman olduğu gibi, yine, tüketici istek ve ihtiyaçlarına uygun şekilde yeniden düzenlenmelidir. Turizm işletmeleri bunun bilincinde 
olurlarsa, pazarlama karmalarında gerekli düzenlemeleri yaparak satışlarını ve karlarını artırabilirler. Bu başarının sağlanabilmesi, tüketici davranışlarının iyi incelenmesiyle mümkündür.

Ekonomik kriz dönemlerinde turizm işletmeleri çeşitli olumsuzluklarla karşılaşırlar: bu olumsuzluk işletmenin gelirlerinin toplam maliyetlerinden az olmasıdır (Erol, 2008). Bu durum karşısında yapılan en önemli hata maliyetleri düşürmek için ilk olarak pazarlama ve reklam bütçelerinde kesinti yapmaktır. Maliyetleri şirket içinde azaltmak yerine, yükü yan sanayi kuruluşlarına ve bayilere aktarmak da yanlıştır ( Türkoğlu 2008).

Turizm sektörü açısından krizle mücadele etmenin en sağlıklı yolu, sadık müşteri potansiyeli olan turizm türlerini geliştirip, pazarlamada bu türlere odaklanarak, turizm potansiyellerini korumalarıdır. Sadık müşteri potansiyeli olan turizm türleri; alternatif turizm olarak tanımlanan; sağlık, termal, inanç, kültür, spor, kongre ve iş amaçlı turizmi olarak kabul edilebilir. Bu amaçla; kriz mücadelesinde örneğin Türkiye'nin kıyı turizmi yanı sıra, yukarıda bahsedilen turizm türleri açısından da eşsiz imkânlara sahip olduğu göz önüne alınmalı ve bu olanaklar turizme gelir olarak kaydedilmelidir.

\section{Krizi Oluşturan Faktörler}

Turizm sektöründe kriz oluşturan faktörler ikiye ayrılır: Bunlardan birincisi, işletme içindeki faktörlerden oluşan iç çevredir. Firmanın kaynakları, bütçesi, yapısı vb. İkincisi ise, firmanın kontrolü dışında oluşan faktörleri içeren dış çevredir. Makro çevre faktörleri, işletmenin kontrolü dışındadır. Dış çevrede meydana gelen beklenmedik değişiklikler işletmeler için bazı firsatlar veya tehlikeler oluşturabilir (Ataman, 2001). Yönetici, öncelikle, dış çevre faktörlerinin satış organizasyonunu nasıl etkilediğini anlamalı, daha sonra bu faktörlerle baş etmek için taktikler geliştirmeli ve uygulamalıdır. Başlıca dış çevre faktörleri şunlardır: Sosyal ve kültürel çevre, teknolojik gelişmeler, ekonomik çevre, rekabet, yasal ve politik çevre.

Ekonomik çevre faktörleri değerlendirilirken, pek çok alt faktör değerlendirilmelidir. Gelir düzeyi ve satın alma gücü, enflasyon, işsizlik, tasarruf ya da borçlanma eğilimi, üretim ve satış maliyeti gibi. Ekonomik çevre faktörlerinde meydana gelen değişiklikler belirsizliği ve karmaşıklığı arttırır (Doğan, 1995).

Ekonomik krizler turizm etkinliğini ve turizm talebini düşürmektedir. Ekonomik kriz döneminde gelir dağılımı dengesizliği nedeniyle seyahat çıkan yerli turist sayısı azalmakta fakat dış kaynaklı turizm talebi azaldığı için, ülkeler ise iç turizmi canlandırıcı turistik etkinliklere ağırlık verebilir. Özetle, ekonomik kriz sebebiyle turizm sektöründe yatırımlar kısılır, işgücü istihdamı azaltılır ve düşük maliyetli turistik ürün üretimi artar. Bunun sonucunda artan sektörel işsizlik, düşen doluluk oranı ve karlılık daha büyük bir darboğazın sinyallerini verir (Özkul, 2001)

İkinci dış çevre faktörü teknolojik çevreden oluşur. Hızlı gelişen teknoloji, ürünlerin çabuk eskimesine neden olmaktadır. Çünkü teknolojik devrimin en önemli özelliği değişim hızının çok yüksek olmasıdır. İşletmelerin teknolojideki değişime ayak uydurabilmeleri kuşkusuz çok önemlidir. Teknolojik gelişmelerin gerisinde kalan işletmeler kriz ya da bunalımlardan daha çabuk etkileneceklerdir.

Dış çevre faktörlerinden bir diğeri olan sosyal ve kültürel çevre koşullarındaki değişimi yakından izlemek gerekir. İşletmeleri etkileyen çeşitli firsat ve tehditler sosyal ve kültürel çevre faktörlerinden kaynaklanabilir. Toplumun modaya düşkünlüğü, kalite ya da gösterişe önem vermesi, toplumsal ve kültürel değer yargıları zaman içinde önemli değişiklikler gösterir. Bu değişimin en önemli nedenleri; bilişim teknolojisindeki değişmeler, eğitim sistemindeki değişmeler ve tüketici toplumu olma özelliğidir (Mucuk, 2006).

Politik ve yasal çevre faktörleri özellikle ülkelerdeki ticari ve yasal ilişkilerin gelişmesine paralel olarak yasal düzenlemeler de gelişmekte ve zaman içinde değişebilmektedir. Özellikle politik istikrarın bulunmadığı ve yönetim geleneğinin yerleşmediği pazarlar açısından çeşitli tehdit unsurları ile karşılaşma olasılığı artabilir. Gelişmekte olan ya da azgelişmiş ülkelerde yaşanan politik istikrarsızlık, bu anlamda pazarlama yönetiminin ileriye dönük stratejiler ve tahminlerde en fazla uğraştıran konulardandır. Vergi, tüketicinin korunması konusundaki yasalar, rekabetin korunmasıyla ilgili yasal düzenlemeler, marka ve patent hakları, çevre kirliliği, ürün güvenliği vb konular işletmelere yükümlülükler getirmektedir (Altunışık vd 2006).

Turistik ürünün temel unsurlarından biri olan doğal kaynaklar korunmalı ve tüketiciler bilinçlendirilerek sürdürülebilirliği sağlanmalıdır. Ancak tüm bu çevresel faktörlere ek olarak doğal koşulların meydana getirdiği risk ve tehlikeler ile değişme ve iniş çıkışların etkilerini tüm organizasyonlarda görmek mümkündür. Krize sebep olabilecek en önemli etkiler deprem, sel, yangın, kuraklık gibi doğal afetlerdir(Erol, 2010). Kontrol edilemeyen, belirsiz ve aniden gerçekleşen doğal afetlerin oluşturduğu krizlerle mücadelede sigorta şirketleriyle anlaşma yoluna gitmek alınan önlemlerden biridir.

Krize neden olan faktörlerin ikincisi işletme içi faktörlerdir. Bunlar da işletmeyi krize sürükleyebilir. İşletmenin rakipleri ve piyasadaki rekabet koşulları da kriz nedeni olarak sayılabilir. İşletmenin varlığını sürdürebilmesi, büyümesi ve gelişmesi içinde bulunduğu pazardaki rekabet koşullarıyla yakından ilgilidir. Pazara yeni ve güçlü rakiplerin girmesi, yeni teknolojiyi kullanarak turistik ürün sunumunda farklılık yaratmaları yönetimsel bir krize neden olabilir. Bu bağlamda başlıca işletme içi faktörlerden biri tepe yöneticilerinin krizi 
görememesi ya da işletmeyi krizden kurtarma yönünde yetersiz olmalarıdır. Yöneticilerden kaynaklanan kriz nedenleri şunlardır(Dinçer, 1998):

- Küreselleşmenin etkilerini göz ardı etme

- Artan rekabetle mücadelede zayıf kalma

- Teknolojik değişimi takip edememe

- Yöneticinin tahmin etme ve sezgi gücünün zayıf olması

- Yeni problemlerin farklılığını kavrayamama ve onlara eski çözümleri uygulama eğilimi

- Hızlı çevre değişimlerinde yavaş kalma

- Çevredeki potansiyel tüketici grupları hakkında bilgi toplama yetersizliği

- Artan ve çeşitlenen talepleri dikkate almama

İşletmenin hayat safhası doğuş, gelişme, olgunlaşma, gerileme ve çöküş olmak üzere beş aşamadan oluşur. İşletmelerin büyüme dönemlerinde önlem alınmadan belli bir sınırın aşılması, yetki, sorumluluk, karar verme ve denetim alanı konularında çatışmalar yaratarak örgüt dengesini bozucu özellik gösterir. Öte yandan işletmenin Pazar talebinden daha hızlı bir büyüme hızı göstermesi de krize neden oluşturabilir. İşletmenin satışlarının ve karlarının azalma gösterdiği gerileme dönemleri de krize uygun zemin hazırlar (Daft, 1998).

İşletmenin örgüt yapısında görülen sorunlar da krize neden olabilir. Karar verme ve uygulamada yavaşlık, sık sık yapılan önemli hatalar, işveren-işgören iletişim kopukluğu, aşırı merkezcil yönetim, yenilik ve yaratıcılık yönünden yetersizlik, çatışmalar, koordinasyon sorunları, denetim alanının aşırı geniş ya da dar olması, amaçların belirgin olmaması, işgören devir hızı ve devamsızlıkların yüksek olması, aşırı iş yükü, sinirsel gerilim, iş ortamından hoşnutsuzluk vb. faktörler sıralanabilir (Vergiliel, 2001).

\section{Turizm İșletmelerinde Kriz Dönemi Pazarlama Tedbirleri}

Kriz yönetimi, krizi tanımlayıp analiz etmeyi, çözüm önerileri geliştirip uygulamaya koymayı ve sonuçları gözlemlemeyi içeren bir planlamayı gerektirir. Kriz yönetiminin amacı, her şeyden önce olası bir krizi engellemektir. Kriz için uyarı olabilecek noktalar dikkatlice gözlenmelidir. Koruyucu önlemlerin alınması önceliklidir. Kriz gerçekleştikten sonra alınacak önlemler işletmeyi krizin zararlarından en az hasarla kurtarmaya yönelik olmalıdır. Her zaman en kötü olasılıklar hesaplanmalıdır.

Turizm işletmeleri için kriz yönetim planının temel amacı; bir krizle etkin bir şekilde başa çıkıp, işletmenin faaliyetlerini hızlı bir şekilde normal seyrine döndürmek olmalıdır. Bu bağlamda: işletme çalışanlarının kriz durumları ile ilgili özel eğitime tabi tutulması, aktif bir işletme içi iletişim sistemi geliştirilmesi, çalışanlara karar acil durumlarda karar verme opsiyonu tanınması kriz mücadelesinde güç kazandıran önlemler arasındadır (Bilgin,1998).

Kriz yönetimin en büyük faydası herhangi bir sebeple ortaya çıkan bir krizin en az zararla atlatılmasını sağlamaktır. Bilinçli bir kriz yönetimiyle tehlike en kısa zamanda bertaraf edilip işletmenin istikrarlı durumuna döndürülmesi sağlanırken, zarar minimize edilmeye çalışılır. Bu sebeple öncelikle kriz sebepleri incelenerek veriler toplanır ve kriz tanımlaması yapılır. Daha sonra çeşitli araştırma teknikleri kullanılarak öngörüler yapılır. Son olarak ise geçmiş deneyim ve hatalardan göz önüne alınarak bir önlem veri bankası oluşturulur.

Örneğin ekonomik kriz döneminde şirket üst yönetimleri hızla harcamaları kısma kararı alır. Harcama kısıntısı, pazarlama kapsamında reklam harcamalarından başlar. Üst düzey yönetimde görev alan ve çoğunluğu finans kökenli olan kişiler, pazarlamayı ve reklamı, kar yaratan bir faaliyet olarak değil; rakiplere karşı bir savunma önlemi olarak görmektedirler. Bu zihniyete göre, pazarlama bütçesinin beklenen satış gelirine oranı konusunda sabit bir beklenti bulunur ama esasında pazarlama bütçesini hedeflenen satış gelirine göre belirlemek doğru değildir. Çünkü pazarlama bütçesini tespit etmeden beklenen gelirin düzeyi de tahmin edilemez. Pazarlama bütçesi, sonuç değil nedendir. Açıkça para harcamadan para kazanılmayacağı kuralı, ekonomik kriz dönemlerinde daha da önem kazanır. Kotler'e (2003) göre ekonomik kriz döneminde yapılacak en doğru iş, çok işlevli bir komite kurmak ve tüm maliyetleri gözden geçirmektir. Komite, şirketin promosyon faaliyetlerini, dağıtım kanallarını, pazar segmentlerini, müşteri kitlesini ve coğrafi yayılımını tek tek inceleyip maliyetleri düşürülecek alanları belirlemelidir. Her işletmenin, zarar ettiği veya zayıf olduğu bir promosyonu, bir dağıtım kanalı, müşteri kitlesi ve coğrafi bölgesi vardır. İşletmenin karşı karşıya kaldı̆̆ı kriz ekonomik krizse, bu dönemde tasfiyeye bu zaaf noktalarından başlamak gerekir(Türkoğlu, 2008).

İşlerin durgunlaştığı dönemler, işletmelerin gelişme döneminde elde ettiği ekstra kaynakları kullanması için iyi bir firsattır. Lüks harcamaların ve gereksiz savurganlıkların azaltılması şirketi daha sağlıklı bir duruma getirir. Müşterilere normal zamanlarda sunulan kalite ve hizmet düzeyini, durgunluk döneminde düşürmek ise rakipleri güçlendirir. Maliyetleri şirket içinde azaltmak yerine, yükü yan sanayi kuruluşlarına ve bayilere aktarmak da yanlıştır (Kotler, 1998).

Yeterli sermayesi olan turizm işletmeleri, ekonomik kriz dönemlerinde geri adım atmak yerine, rakiplerinin pazar paylarına göz dikebilir. Bu şirketler için zor günler yeni bir büyüme fırsatı yaratır. Finansal gücü yeterli 
olmayan işletmeler ise, pazarlama harcamalarında genel bir kısıtlamaya gitmek yerine, doğru bir analiz ile eksik ve verimsiz faaliyetlerinde kesinti yaparak rahatlayabilirler.

Türkoğlu (2008), ekonomik kriz döneminde yaptılan üç ana hatadan bahsetmektedir. Bunlardan ilki maliyetleri düşürmek için ilk adım olarak pazarlama ve reklam bütçelerinde kesinti yapılır. İkincisi, ekonomiler durakladığında, iç ve dış talep ile satışların aynı oranda düşeceği varsayılır. Sonuncusu ise; zor günler için belirlenen strateji, dönem boyunca hiçbir değişiklik yapılmadan aynen uygulanır.

$\mathrm{Bu}$ önlemlerle savunmaya ağırlık verilmektedir. Oysa farklı düşünce tarzı, yaklaşım ve önlemlerle, ekonomik durgunluk dönemlerinde bile işin geliştirilmesi veya en düşük zararla çıkılması olasıdır. İşlerin durgunlaştığı dönemleri basmakalıp düşüncelerle ve üstünkörü önlemlerle geçiştirmek zordur. Böylesi dönemlerde aşağıdaki durumları dikkate alanlar ekonomik krize karşı direnme imkânı bulabilir(Kotler, 1998; Türkoğlu, 2008):

- Tüketicilerin gelir kaymalarının incelenmesi: Yeni dönemde gelir gruplarının tercihlerinde aşağıya doğru kaymalar ortaya çıkabilir. Durgunluk dönemlerinde ortanın üstü gelir grubundaki tercihlerin niteliği, orta sınıfa doğru yaklaşır. Orta sınıftakilerde ortanın altı gelir grubunun satın aldığı ürün ve hizmetlere ilgi duyabilir. Girişimciler bu kaymaları iyi etüt ederek turistik ürün farklılaştırmasına gidebilir ve satışlarını artırabilir.

- Geçici indirimler: Müşteri kaybetmemek için bazı turistik ürünlerin fiyatında, kaliteyi düşürmeksizin geçici olarak indirim yapılabilir. Bu uygulama bir süre için kar marjlarını düşürse de müşterinin orta vadedeki sadakatini güçlendirir.

- Yeni turistik ürün konseptleri: Yeni dönemde ekonominin genel seyrinin, ailelerin geçimleri üzerindeki etkilerini analiz edip, yeni ürün konseptleri geliştirmek satışları artırabilir.

- Kompakt ürünler: Durgunluk dönemlerinde fiyatı makul, ancak kalite seviyesi yüksek 'kompakt' ürünler geliştirmek, düşen talebi canlandıracak, karları düşse de markaların gelir düzenini koruyacaktır."

Shama ise (1978); işletmelerin kriz zamanlarında ürünlerinin çeşitliliğini azaltmasını ve spesifik turistik ürünlere ağırlık vermesini, fiyatı mümkün olduğu kadar düşürüp işletmede fiyatlandırma kararını merkezileştirmesini, yeni pazarlar için düşük maliyetli bir promosyon paketi hazırlamasını, sabit müşteri sayısı yüksek aracılarla(tur operatörleri) kontak kurmayı tercih etmelerini öngörmektedir.

Muhtemel kriz durumlarında turizm işletmelerinin dikkate alması gereken unsurlar şunlardır:

- Odaklanma: İçinde bulunduğumuz çağda rekabet zorlu ve piyasalar acımasızdır. Küreselleşme küçük şirketlerin, dev kuruluşları küresel düzeyde geçebilmesine imkân vermektedirler. Müşteriler ürünlere, hizmetlere ve bilgiye sınırsızca ulaşabilmektedir. Bilişim ağları, uluslardan daha önemli konuma gelmiştir ve bu çağda işletmeler ya gerçek zamanda iş yapmaktadır ya da yok olmaktadır. Kısacası kriz sessiz ve sürekli bir hale gelmiştir. Gibson'a göre(1998); endüstriyel toplumların büyük problem yaşayacağı bu 'kaosun kıyısı' eski düzenin yerini en sonunda yeni düzene bıraktığı vahşi bir geçiş dönemidir. Ancak bu dönem olağanüstü firsatlar da sağlayabilmektedir. Yirmi birinci yüzyılda pazar stratejilerini etkileyen en önemli eğilim, küresel ticarettir. Rekabetin küresel ölçekte yayılmasının sonucunda yaşanan sektör kayması ile işletmeler birbirlerinin alanlarında iş yapmaya başlamış ve saldırgan bir yaklaşım ortaya çıkmıştır. Pazarın boyutu tüm dünyayı kapsayacak şekilde genişlediğinde, firmalar dünyaya hizmet sunmak için daha geniş bir ürün hattına ihtiyaç olduğunu düşünebilirler. Oysa bunun tam tersi olmalıdır. Pazar ne kadar büyürse, başarı için o derece uzmanlaşmak gerekmektedir. Kriz döneminde iş dünyasında odak, küresel pazarın belli bir parçası üzerinde yoğunlaşacak şekilde daraltılmalıdır. Pazarlamanın gücü uzmanlaşmadır (Ries and Trout, 1998).

- Konumlandırma: Firmalar müşterilerin zihninde kazanır ya da kaybederler. Zihinlerde yer edinmek ise zorlu bir iştir. Aşırı derecede iletişimin olduğu bu dünyada değişim oldukça büyük bir mücadele kaynağıdır. Ries ve Trout'a (1998) göre: firmaların değişimle mücadele edebilmesi 'konumlandırma' ile mümkün olacaktır. Şirketler yani aşırı yayılma nedeniyle marka özelliklerini kaybetmişlerdir. Sonuçta şirketlerini en iyi yaptıkları işe, çıkış noktalarına, yeniden konumlandırmak zorunda kaldılar. Yeniden konumlandırmanın zorlu bir süreç olmasının nedeni insanların algılarını değiştirmeye çalışmanın güç olmasından kaynaklanmaktadır. Eğer insanların zihninde güçlü bir konuma sahipseniz, bu konumdan sonsuza dek yararlanabilirsiniz.

- Hız: Ekonomik kriz döneminde beklenmeyeni beklemeliyiz. Bu dönemde hız hayati önem taşımaktadır. Rakipler hızla ilerlemesi, pazardaki firsatların azalması ve müşterilerin her şeyi hızlı istemesinin sonucunda; şirketler turbo pazarlamacı olmalıdırlar. Ürün geliştirmede, sunumda, dağıtımda ve hizmette daha hızlı olmak büyük bir rekabet avantajı sağlayacaktır. Ayrıca karar verme süreci de uzman sistem ve yazılımlardan faydalanarak hızlandırılmalıdır. (Kotler, 1998)

- Fiyatlandırma: 21. yüzyılda müşteriler daha ayırt edici ve talepkardırlar ve sunulan ürünün değerini saptama konusunda daha akıllı davranmaktadır. Bu nedenle, sadece firma imajı yerine fiyatları makul düzeye çekmeli ve anlamlı fikirler kullanmalıdır. İyi fiyatlamanın anahtarı, pazar bölümlendirmesini net bir şekilde yapmak, bu pazar bölümündeki müşterilerin ürün ve ürün değeri hakkında ne düşündüklerini 
bulmak ve ürünü ve hizmet paketini buna göre fiyatlandırabilecek şekilde tasarlamaktır. Tüm ürünler belli bir müşteri grubu ve ödeyebilecekleri fiyat akılda tutularak ve pazar hücresi oluşturarak tasarlanmalıdır (Kotler, 1998).

- Satış güçleri: Satış güçleri en pahalı pazarlama araçlarından biridir. İşletmeler kriz dönemlerinde daha düşük maliyetli alternatifler aramaktadırlar. Yani bu dönemde düşük fiyat pahalı satış güçlerinin alternatifi olmaktadır. Ayrıca telefonla satış ve online rezervasyonlar da satış güçlerinin alternatifleri arasındadır (Kotler, 1998).

- Gelir düzeyi düşük pazarlar: Gelir düzeyi düşük pazarlarda da karlı hizmetler sunulabilir. Bunun için gerekli olan dikkatli bir hedefleme, ürün geliştirimi ve maliyetin düşürülmesidir (Kotler, 1998).

\section{Sonuç}

Kriz sonucunda turizm işletmelerinin karşı karşıya kalacağı sorun; yüksek enflasyon, fiyat değişmeleri ile ilgili beklentilerin paniğe yol açması, geleceğe dönük belirsizlik, denetimsiz rekabet, döviz piyasalarındaki istikrarsızlıklar, müşteri talebindeki değişiklikler, doğal afetler, savaşlar gibi nedenlerle ortaya çıkan belirsiz ortamında faaliyet göstermektedir(Akdiş, 2001).

Krizler turizm işletmeleri için endişe, panik gibi olumsuzluklar doğurabilir. Krizler birbirinden oldukça farklı yapılar içerebilir. Her krizin başlangıç, gelişme ve sonuç aşamaları bir diğeri ile karıştırılmamalıdır. Bazı krizlerin çözümü sanıldığından çok daha fazla zaman alabilir. Krize yönelik bir çözüm, ilerde gündeme gelebilecek başka bir krizde geçerlilik taşımayabilir. Dolayısıyla kriz ortamlarının tümünde geçerli olabilecek ortak bir çözüm modeli geliştirmek güçtür. Bazı koşullarda (endüstri türü, rekabet, teknolojik gelişme, risk stratejileri, vb.) krizin gelişim olasılığı yükselebilmektedir. Çözülemeyen bir kriz örgütün yok olmasın hızlandırırken, etkin olarak yönetilen başka bir kriz ortamı ise hiç hesaptı olmayan çeşitli firsatlar doğurabilmektedir ( Çelik, 2010).

Krizlerin organizasyonun kendi içyapısından ve yönetiminden kaynaklanan nedenleri de olabilir. Optimal büyüklükten uzaklaşmış, merkeziyetçi ve hiyerarşik bir organizasyon yapısı, etkin olmayan liderlik, etkin olmayan mali yönetim, organizasyonda çağdaş yönetim tekniklerinin uygulanmaması ve benzeri faktörler krizlere neden olabilir. Bu belirttiğimiz faktörlerin bulunması, organizasyonun krize karşı koyabilme gücünü de sinırlandirır (Aktan, 2003).

Turizm sektöründeki esnek talep, iç ve diş işletme çevresinde gerçekleşebilecek ani değişiklikler; krizin turizm işletmelerini daha fazla etkilemesine yol açmaktadır. Günümüzün hızlı değişim süreci, küreselleşmenin baskısı ve teknolojik gelişmeler turizm talebinde ani eğilim farklılıklarına neden olabilmektedir. Bu nedenle, kriz tam olarak ortaya çıkmadan yapılacak öngörüler hayati önem taşımaktadır. Alınan tüm önlemlere rağmen krizden kaçılamazsa makro seviyede kriz yönetimi gerçekleştirmek için bütünleşik pazarlama iletişimi kapsamında uygulanacak taktik ve stratejilere başvurulması gerekmektedir.

\section{Kaynakça}

- $\quad$ Akdiş, 2001. Türkiye'de ekonomik İstikrar Programlarının Dünü ve Bugünü. http://Makdis.pamukkale.edu.tr//Tavas.ppt.

- Aktan ve Şen 2001. “Ekonomik Kriz: Nedenler ve Çözüm Önerileri” Yeni Türkiye Dergisi, 2001/.1.

- Altunışık, Özdemir ve Torlak, 2006. Modern Pazarlama, (4. Baskı). Değişim Yayınları, İstanbul.

- Ataman, 2001. İşletme Yönetimi. Türkmen Kitabevi, İstanbul.

- Bilgin, 1998. Turizmde Risk ve Kriz. T.C. Turizm Bakanlığ 1. Turizm Şurası, Ankara.

- Çelik, 2010. Kriz ve Stres Yönetimi.Gazi Kitabevi, Ankara

- Daft, 1998. Organization Theory \&Design. Sou, Cincinati/ Ohio.

- Dinçer, 1998. Stratejik Yönetim ve İşletme Politikası. Beta Basım, İstanbul

- Doğan, 1995. İşletme Ekonomisi ve Yönetimi. Anadolu Matbaacılık, İzmir.

- Erol, 2010. "Ekonomik Kriz ve Kobiler", Journal of Entrepreneurship and Development, Vol.5 No.1 165-181.

- Gibson, 1998. "Rethinking Business". ( Edited by Rowan Gibson). Rethinking Business, Principles, Competition, Control, Leadership, Markets and the World. UK: Nicholas Brealey Publishing Ltd, 1-15.

- Henderson, 1999. "Managing the Asian Financial Crisis: Tourists Attractions in Singapore". Journal of Travel Research. 38(2). 
- Kotler, 1998. "Mapping The Future Marketplace". ( Edited by Rowan Gibson). Rethinking Business, Principles, Competition, Control, Leadership, Markets and the World. UK: Nicholas Brealey Publishing Ltd, 197-210.

- Mucuk, 2006. Pazarlama İlkeleri (15th Edition). Türkmen Kitabevi, İstanbul.

- Özkul, 2001. "Krizlerin Turizm Üzerine Etkileri Turizm Kriz İlişkisi”. 2. Ulusal Türkiye Turizm Sempozyumu Tebliğler. Türkiye Turizm Araştırmaları Enstitüsü. İzmir

- $\quad$ Ries and Trout, 1998. "Focused In A Fuzzy World”. ( Edited by Rowan Gibson). Rethinking Business, Principles, Competition, Control, Leadership, Markets and the World. UK: Nicholas Brealey Publishing Ltd, 181-196.

- Sarıçay ve Ünal, 2014.” Krizlerin Turizm Sektörü Üzerindeki Etkileri”. İzmir Ticaret Odası AR\&GE Bülteni, İzmir.

- Shama, 1978. "Management and Consumers In An Era Of Stagflation”. Journal of Marketing, 45-53.

- Türkoğlu, 2008a. “Resesyon Döneminde Pazarlama Daha da Önem Kazanacak”. Referans Gazetesi, 14.

- Türkoğlu, 2008b. “Kotler’den Durgunluk Dönemi Önerileri”, Referans Gazetesi, 6.

- Vergiliel Tüz, 2001. Kriz ve İşletme Yönetimi (1. Baskı), Alfa Basım Yayım Dağıtım, İstanbul. 


\section{Author Index}

Abacı, Hilal (Çankırı Karatekin University, Turkey)

Abdieva, Raziiakhan (Kyrgyzstan-Turkey Manas University, Kyrgyzstan)

Abishev, Ali (Kazakh Economics University, Kazakhstan)

Acar, Fusun Tekin (Erciyes University, Turkey)

Ağazade, Seymur (Recep Tayyip Erdogan University, Turkey).

Akbaş, Fahri (Aksaray University, Turkey)

Akbulut, Gizem (Gümüşhane University, Turkey)

Akça, Hasan (Çankırı Karatekin University, Turkey)

Akça, Haşim (Çukurova University, Turkey)

360,855

Aksu, Muharrem (Alanya Alaaddin Keykubat University, Turkey) ..............................................................663

Aktaş, Ali Rıza (Alanya Alaaddin Keykubat University, Turkey) ................................................................663

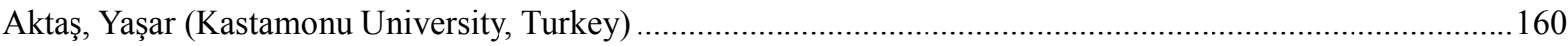

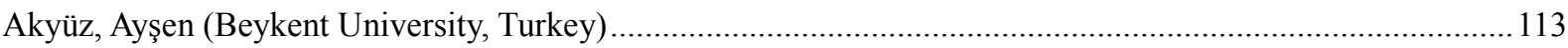

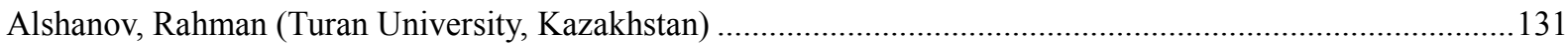

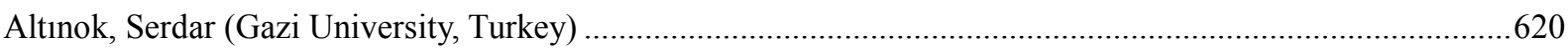

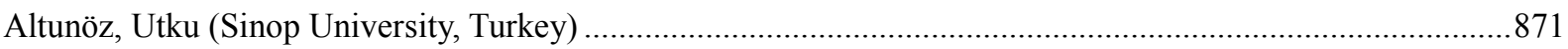

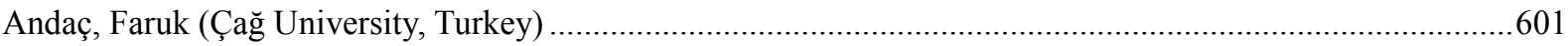

Apak, Sudi (Beykent University, Turkey) ….............................................................................24, 352

Arslan, Çetin (Hacettepe University, Turkey) ....................................................................................5

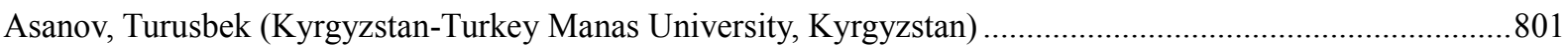

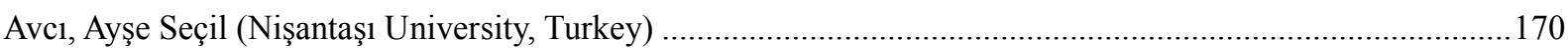

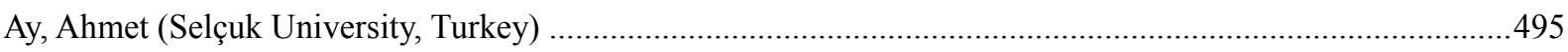

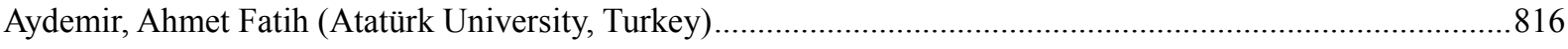

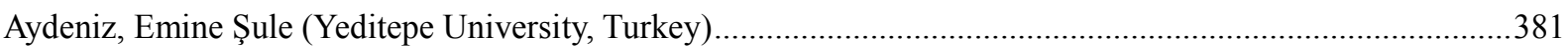

Aydın, Ali Emre (Muğla Sitkı Koçman University, Turkey) ......................................................................654

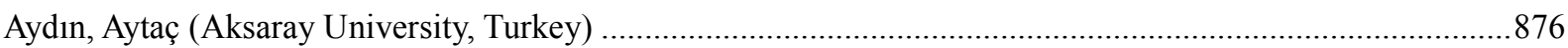

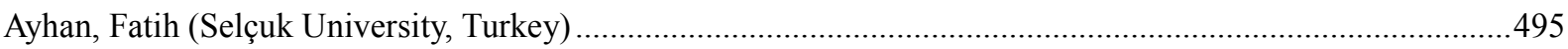

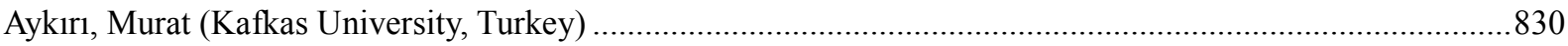

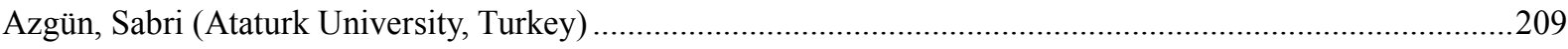

Azhykulova, Asel (International Ataturk Alatoo University, Kyrgyzstan) .................................................71

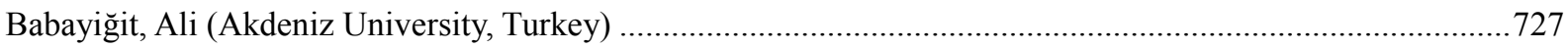

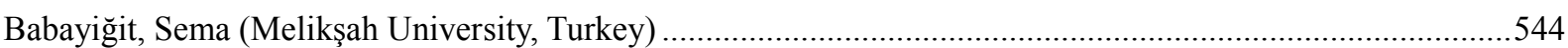

Baigonushova, Damira (Kyrgyzstan-Turkey Manas University, Kyrgyzstan) ............................................22

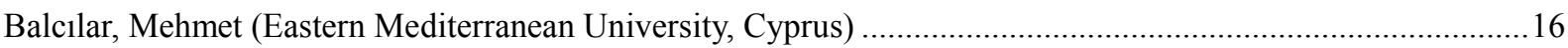

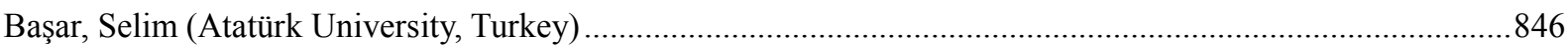

Basaran, Murat Alper (Alanya Alaaddin Keykubat University, Turkey) ........................................................... 192

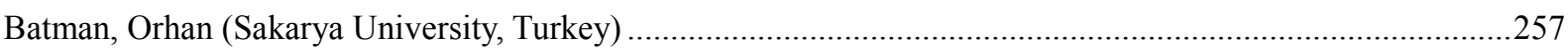

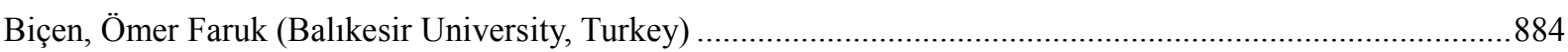

Bocutoğlu, Ersan (Karadeniz Technical University, Turkey) ....................................................................28

Burke, Ronald J (York University, Canada) .............................................................................150, 182

Büyükakıncı, Erhan (Galatasaray University, Turkey) ............................................................................478

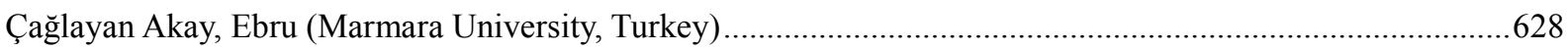

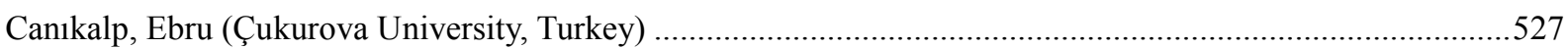

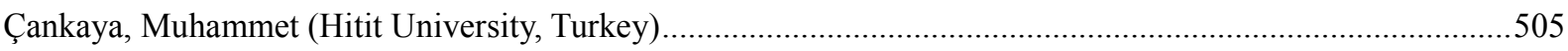

Çelik, Ahmet Alkan (Beykent University, Turkey) …........................................................................... 816

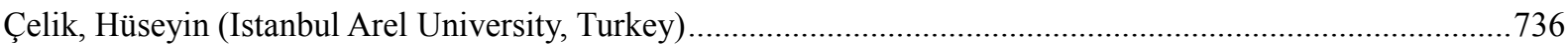

Çelik, Sabahat Binnur (Beykent University, Turkey) ….......................................................................5

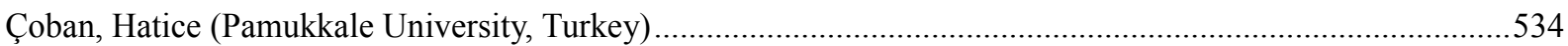


Çobanoğlu, Cihan (University of South Florida, United States of America) ……...............................................5

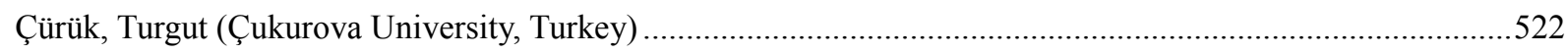

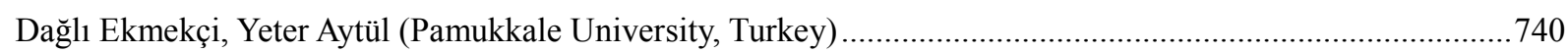

Değer, Mustafa Kemal (Karadeniz Technical University, Turkey) ……………………...................................423

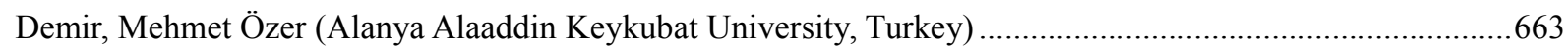

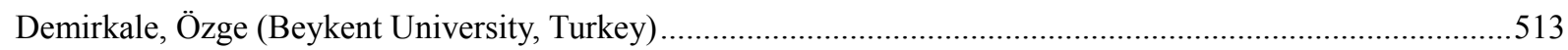

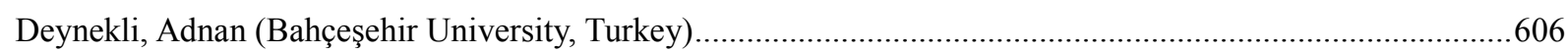

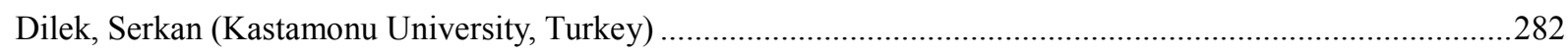

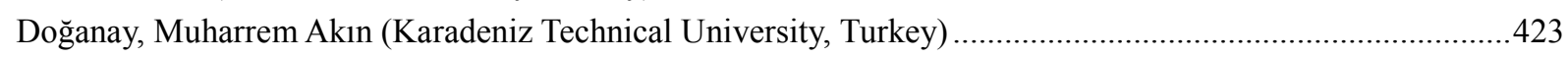

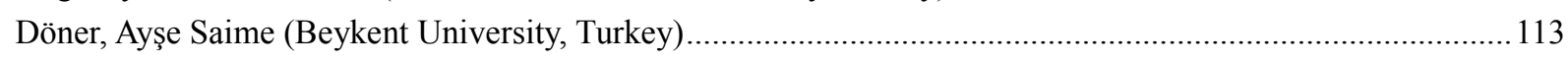

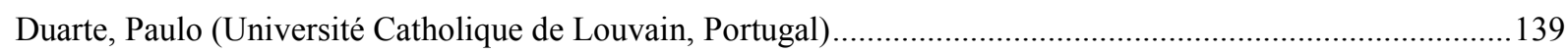

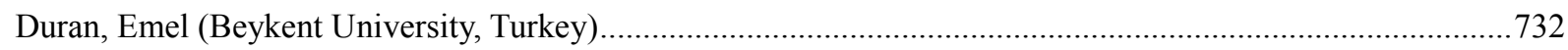

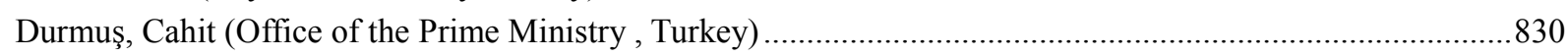

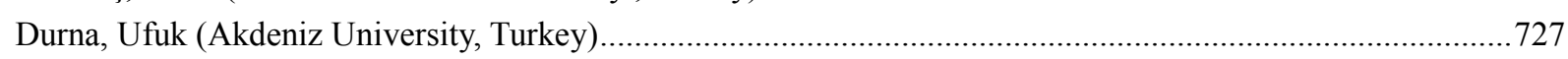

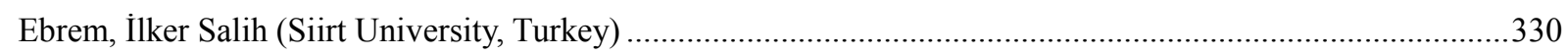

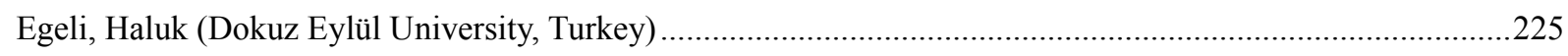

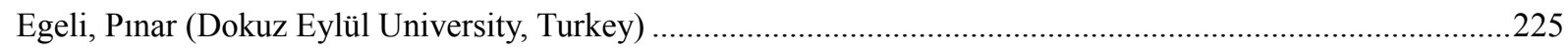

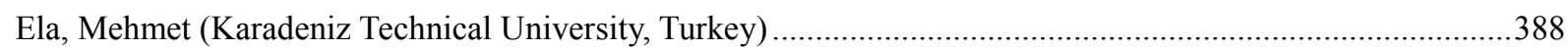

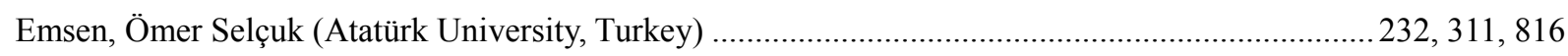

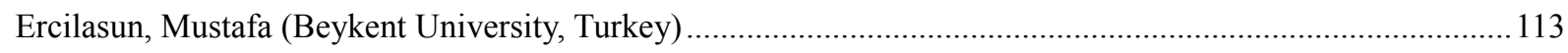

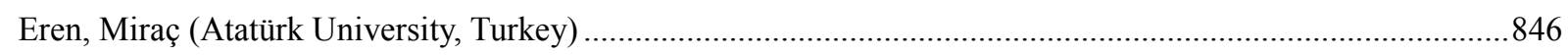

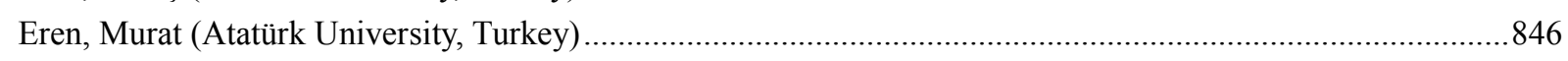

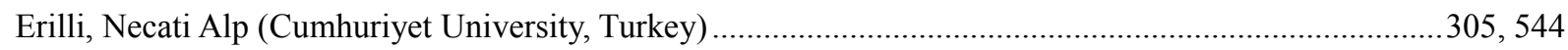

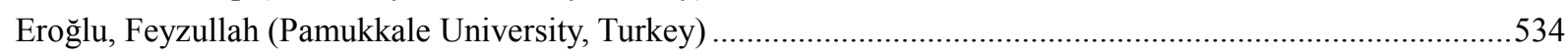

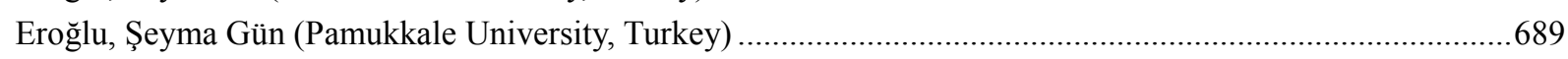

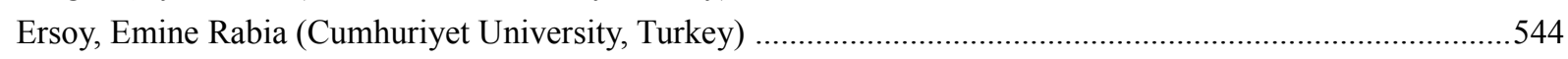

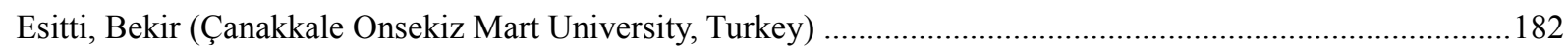

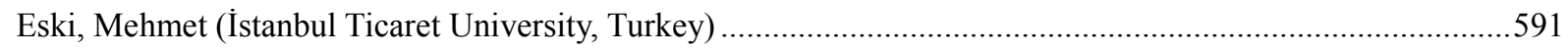

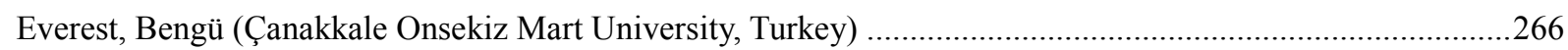

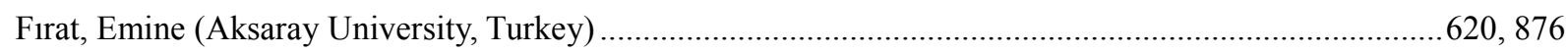

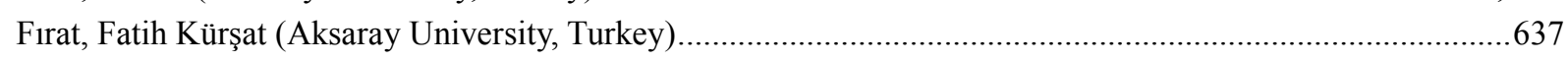

Fynchina, Khicheza (Kyrgyz-Russian Slavic University, Kyrgyzstan) ……………………………………...... 769

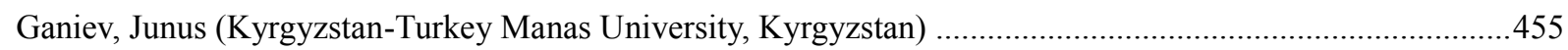

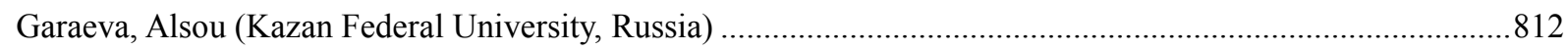

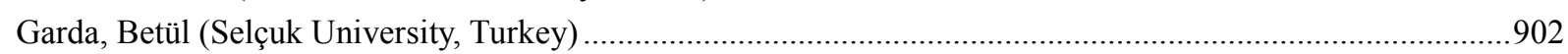

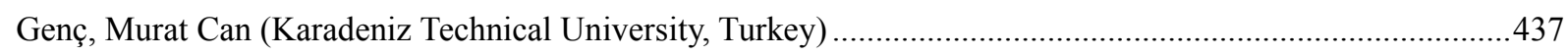

Gerasimenko, Valentina (Moscow State Lomonosov University, Russia) ........................................................131

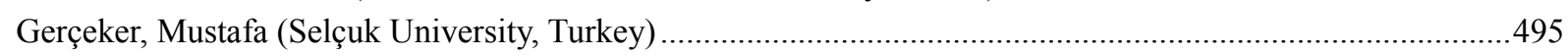

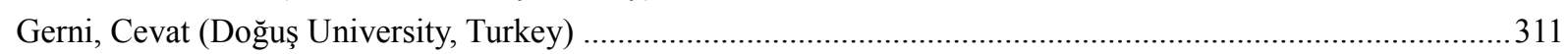

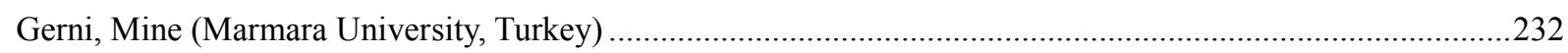

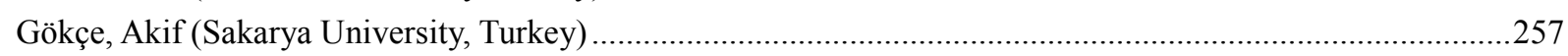

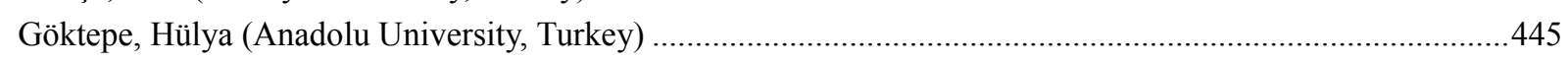

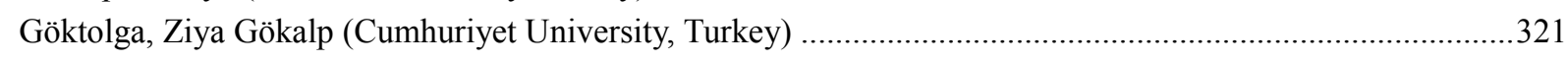

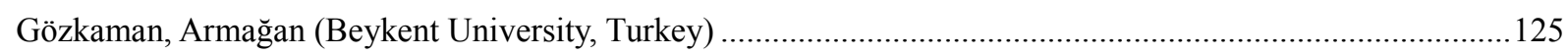

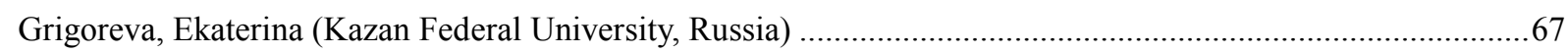

Gül Yavuz, Gonca (Agricultural Economy and Policy Development Institute, Turkey)........................................243

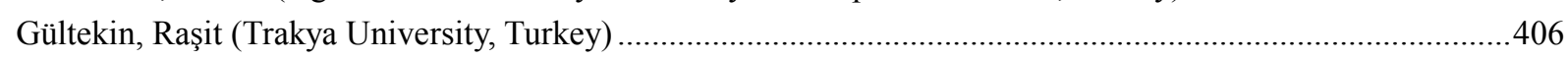

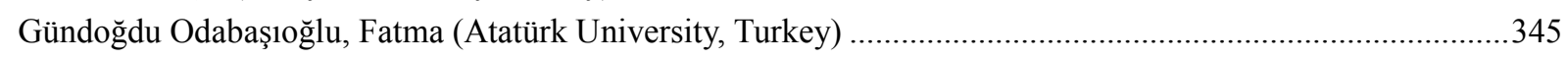

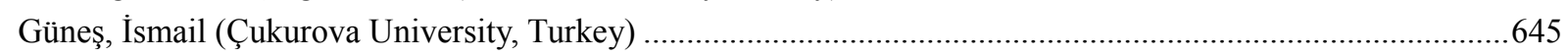


Hacıŏlu Deniz, Müjgan (Istanbul University, Turkey)

Hasdemir, Mehmet (Ministry of Food, Agriculture and Livestock, Turkey) .....

250,266

Hasdemir, Mine (Agricultural Economy and Policy Development Institute, Turkey) .......................................250

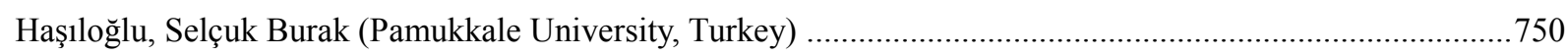

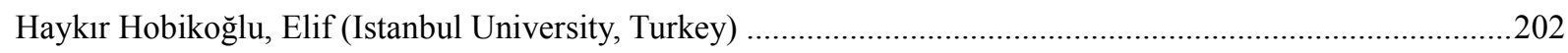

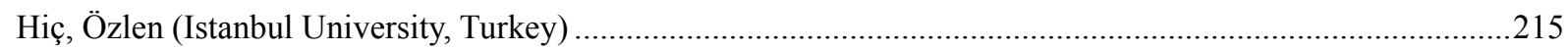

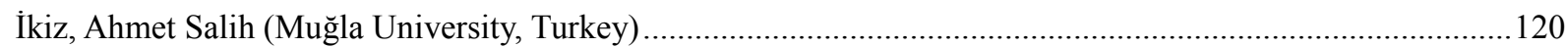

Ildırar, Mustafa (Çukurova University, Turkey) ...........................................................................4 41,81

Incekara, Ahmet (Istanbul University, Turkey) ...................................................................... 88, 202

İrmiş, Ayşe (Pamukkale University, Turkey) ..................................................................................689, 740

İşcan, Erhan (Çukurova University, Turkey) ....................................................................................41, 81

Japarova, Damira (Kyrgyzstan-Turkey Manas University, Kyrgyzstan) ......................................................795

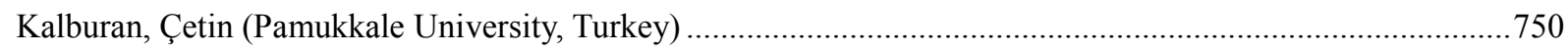

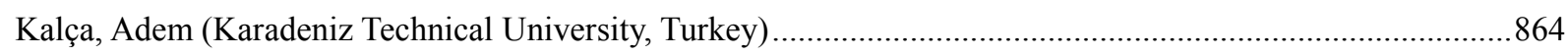

Kalenova, Saulesh (Turan University, Kazakhstan) ..................................................................................... 131

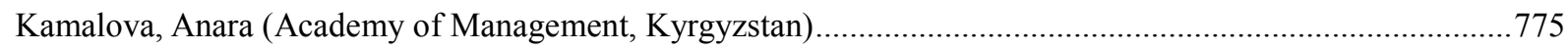

Kantarcı, Kemal (Alanya Alaaddin Keykubat University, Turkey) …......................................................192

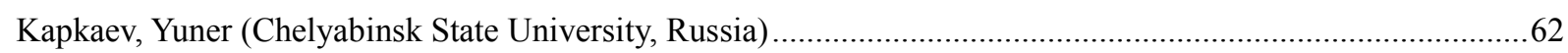

Kara, Mustafa (Abant İzzet Baysal University, Turkey) .................................................................................561

Karaçor, Süleyman (Selçuk University, Turkey) ....................................................................................902

Karakaya, Aykut (Recep Tayyip Erdogan University, Turkey) …..................................................699, 717

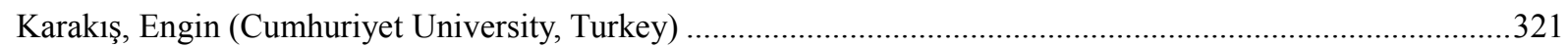

Karaköy, Çăgatay (Cumhuriyet University, Turkey) .....................................................................305, 544

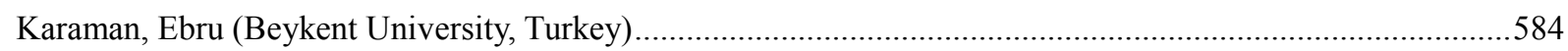

Karaman, Ömer Faruk (Kyrgyzstan-Turkey Manas University, Kyrgyzstan) ................................................681

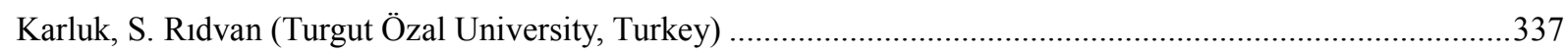

Kartal, Cihat (Kırıkkale University, Turkey)....................................................................................561

Karymshakov, Kamalbek (Kyrgyzstan-Turkey Manas University, Kyrgyzstan) ............................................176

Kashbrasiev, Rinas (Kazan Federal University, Russia) ..............................................................................761

Kaya, Zekayi (Çankırı Karatekin University, Turkey) ..............................................................................8 830

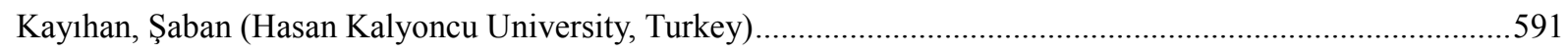

Kendirli, Selçuk (Hitit University, Turkey) ...........................................................................................505

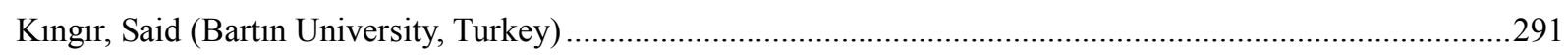

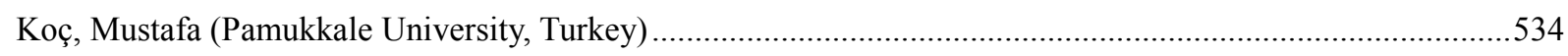

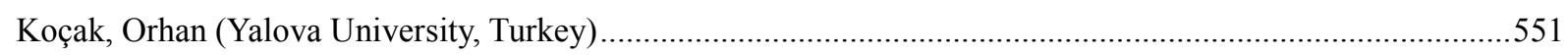

Koichueva, Merim (Kyrgyz-Russian Slavic University, Kyrgyzstan) ...............................................................2

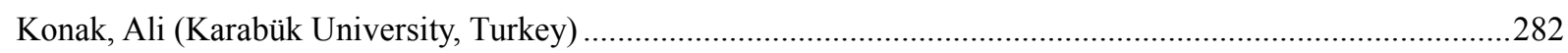

Koşan, Naime İrem (Beykent University, Turkey) ....................................................................................24

Koychuev, Turar (National Academy of Sciences, Kyrgyzstan) ..................................................................2

Koyuncu, Kadife (Çanakkale Onsekiz Mart University, Turkey) ......................................................150, 182

Koyuncu, Mustafa (Çanakkale Onsekiz Mart University, Turkey) .....................................................150, 182

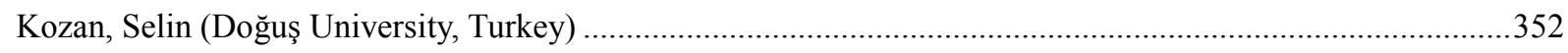

Kozhobekov, Muratbek (Kyrgyzstan-Turkey Manas University, Kyrgyzstan) .............................................766

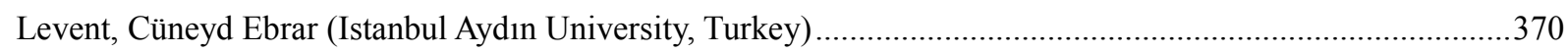

Marangoz, Mehmet (Muğla Sitkı Koçman University, Turkey) ...................................................................654

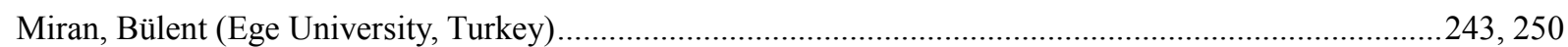

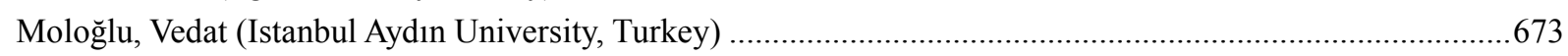

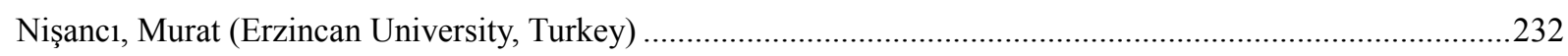

Noyan Yalman, İlkay (Cumhuriyet University, Turkey) ......................................................................461 
Oğuz Karademir, Hande (Yalova University, Turkey) ..............................................................................551

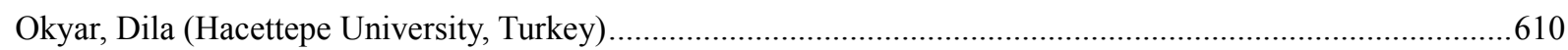

Önce, Asım Günal (Dokuz Eylül University, Turkey) ...................................................................................654

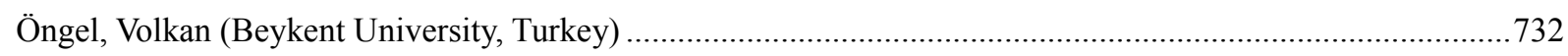

Oskonbaeva, Zamira (Kyrgyzstan-Turkey Manas University, Kyrgyzstan)................................................628

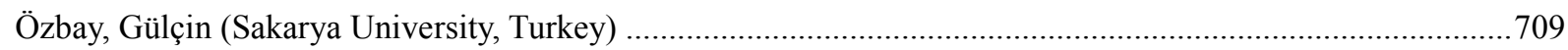

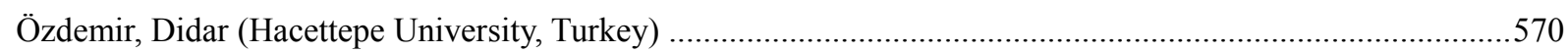

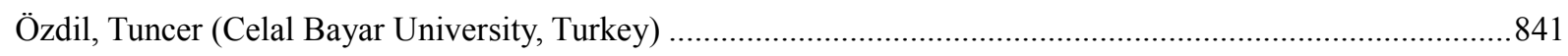

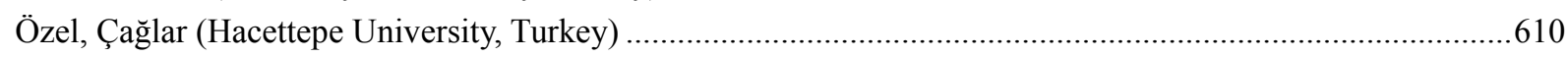

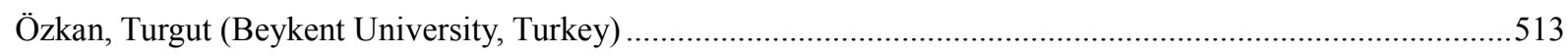

Özüdoğru, Tijen (Agricultural Economy and Policy Development Institute, Turkey).............................243, 250

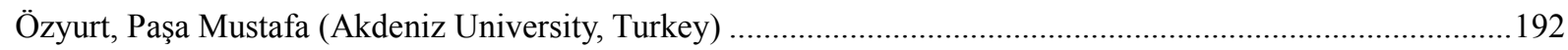

Parkhomchik, Lidiya (Eurasian Research Institute, Kazakhstan) ...............................................................805

Perçin, Selçuk (Karadeniz Technical University, Turkey) ..................................................................699, 717

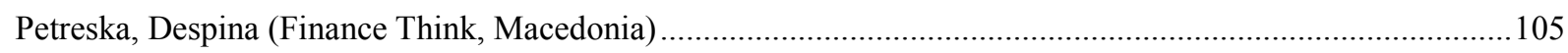

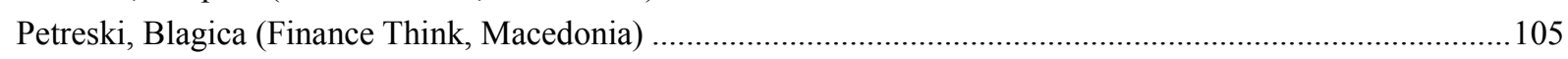

Petreski, Marjan (University American College, Macedonia) ...................................................................... 105

Pirimbaev, Jusup (Kyrgyzstan-Turkey Manas University, Kyrgyzstan) .........................................................755

Poliduts, Aleksey (Chelyabinsk State University, Russia) .............................................................................62

Şahin, Levent (Çankırı Karatekin University, Turkey) ........................................................................486, 890

Sakız, Burcu (Istanbul Aydın University, Turkey) .................................................................................95

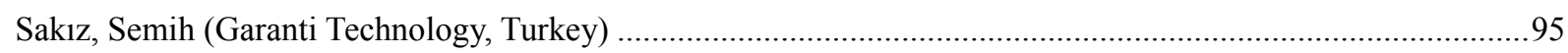

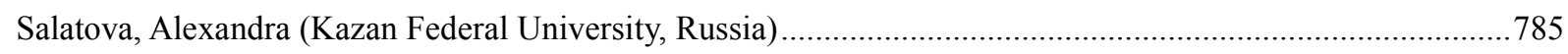

Sancar, Muhammet Fatih (Siirt University, Turkey) ..................................................................................291

Saray, Gizem (Çankırı Karatekin University, Turkey) ...................................................................486, 890

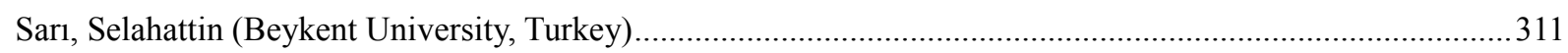

Sarışık, Mehmet (Sakarya University, Turkey) .........................................................................257, 709

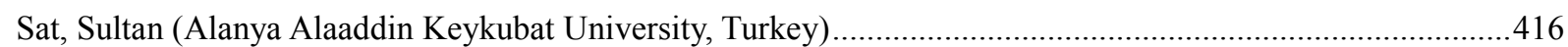

Savrul, Mesut (Çanakkale Onsekiz Mart University, Turkey) ........................................................................8

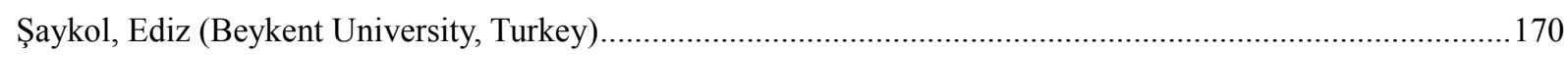

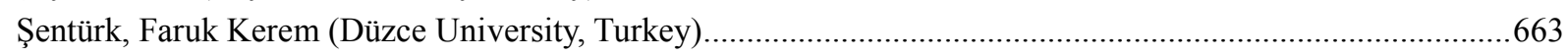

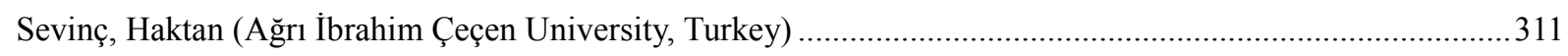

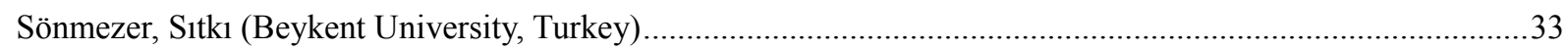

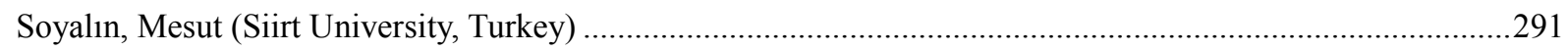

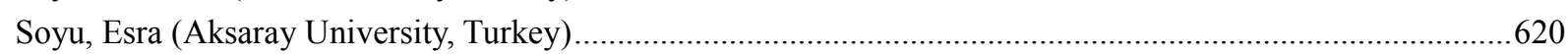

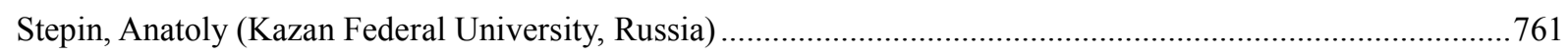

Suhendra, Euphrasia Susy (Gunadarma University, Indonesia) ......................................................................5

Sulaimanova, Burulcha (Kyrgyzstan-Turkey Manas University, Kyrgyzstan) ...................................48, 176

Sultakeev, Kadyrbek (Kyrgyzstan-Turkey Manas University, Kyrgyzstan)........................................176, 801

Sümer, Kutluk Kağan (Istanbul University, Turkey) ..................................................................298, 469

Supataev, Kylychbek (Kyrgyz-Russian Slavyan University, Kyrgyzstan) .....................................................780

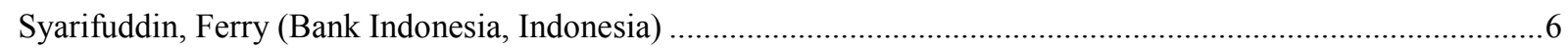

Tan, Sibel (Çanakkale Onsekiz Mart University, Turkey)..........................................................................266

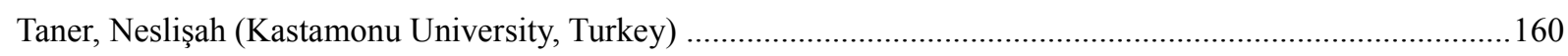

Tanyeri, Ayşe (Çukurova University, Turkey) ...........................................................................................522

Telatar, Osman Murat (Karadeniz Technical University, Turkey) .........................................................423, 437

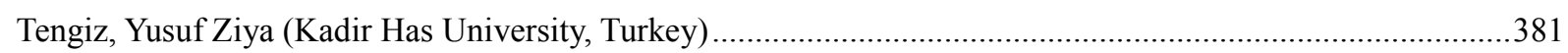

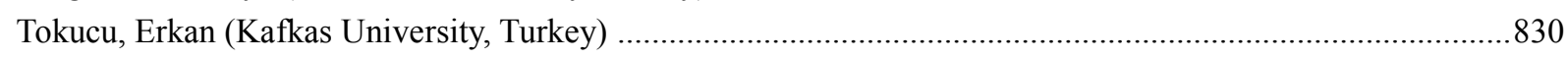

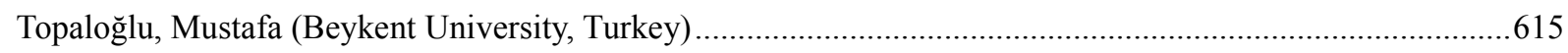


Tören, Evrim (Eastern Mediterranean University, Cyprus) .......................................................................... 16

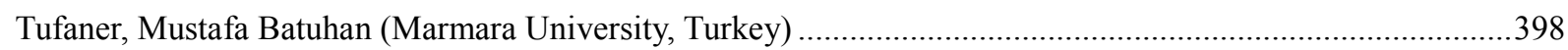

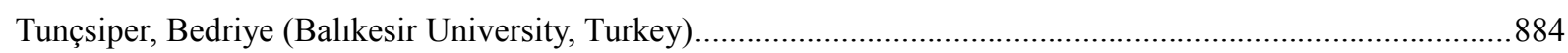

Turdalieva, Aynura (Kyrgyzstan-Turkey Manas University, Kyrgyzstan) ..................................................8. 841

Türkay, Hakan (Cumhuriyet University, Turkey)........................................................................ 321,825

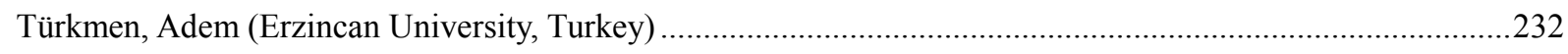

Türkoğlu , Mutlu (Cumhuriyet University, Turkey) ......................................................................................461

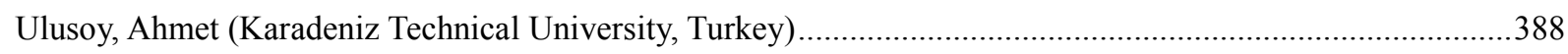

Ünlükaplan, İlter (Çukurova University, Turkey) .............................................................................360, 527

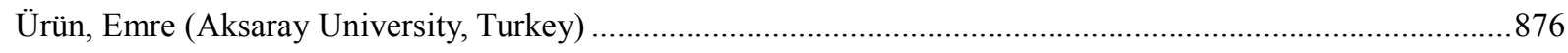

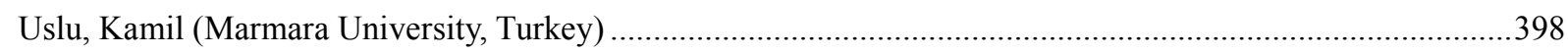

Uygur, Ercan (Turkish Economic Association, Turkey) ............................................................................. 1

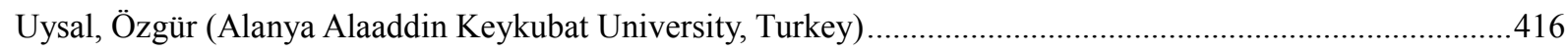

Üyümez, Mustafa Erkan (Anadolu University, Turkey) ................................................................................406

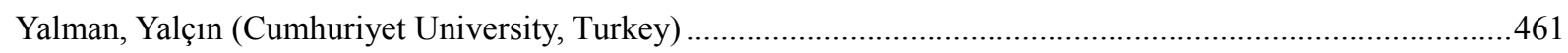

Yamaltdinova, Adilya (Kyrgyzstan-Turkey Manas University, Kyrgyzstan) ................................................48

Yılmaz, Candan (Gümüşhane University, Turkey) ..................................................................................431

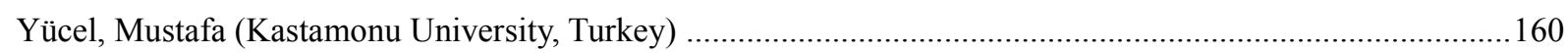

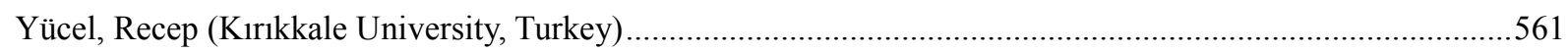

Yurdadoğ, Volkan (Çukurova University, Turkey) ........................................................................360, 527

Yurttançıkmaz, Ziya Çağlar (Atatürk University, Turkey) ….................................................................8

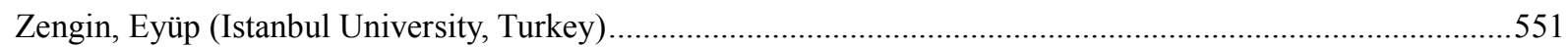


